\title{
Jornadas de Innovación Educativa y Docencia en Red de la Universitat Politècnica de València
}

Editores

Vicente Botti Navarro

Miguel Ángel Fernández Prada

José Simó Ten

Fernando Fargueta Cerdá

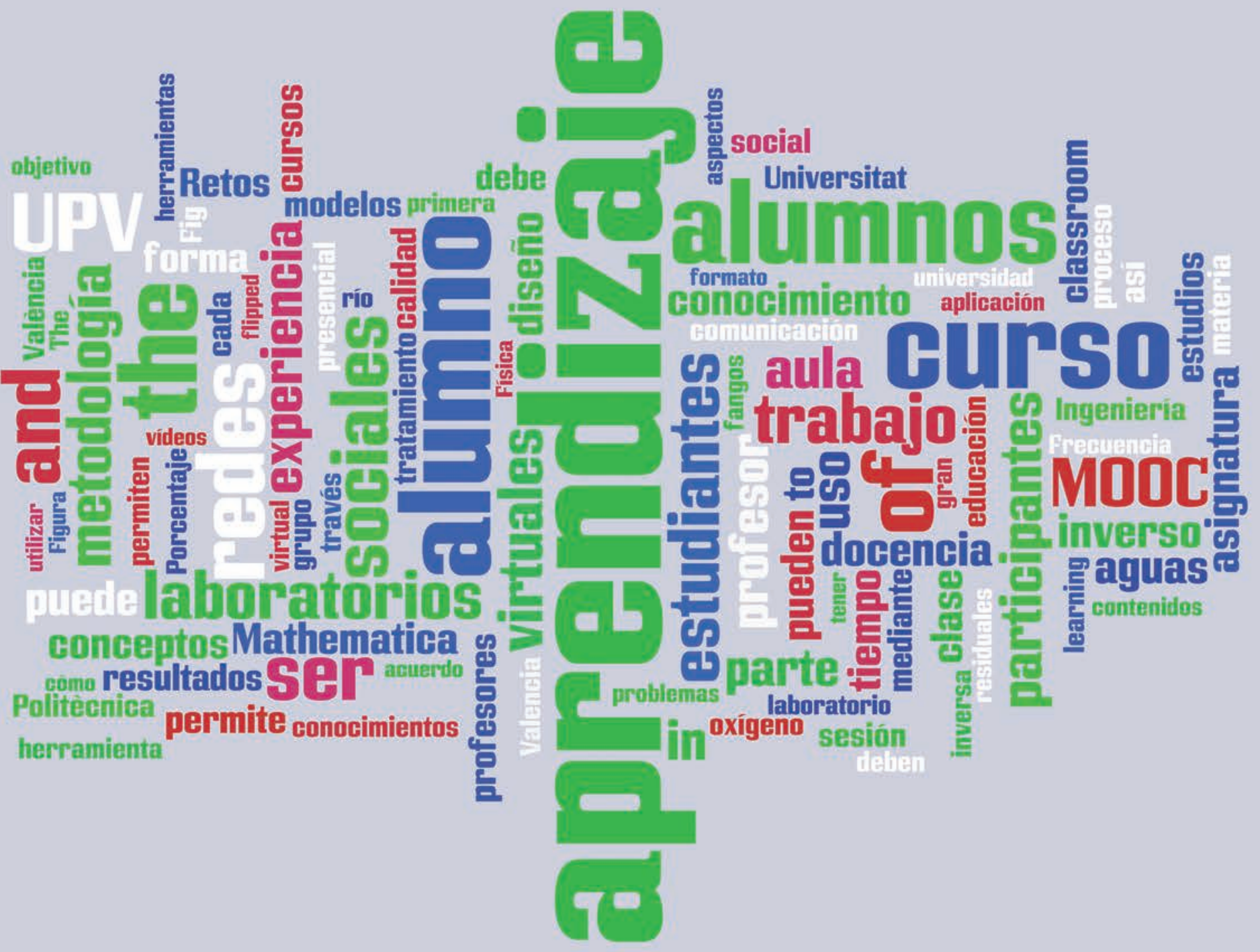

IZN-TEN

Jornadas dellnnovación Educativay deDocencia enRed delauniversitat PolitècnicađeValència
Valencia

15 y 16 de julio

de 2014
UNIVERSITAT

POLITĖCNICA DE VALĖNCIA 



\title{
Jornadas de Innovación Educativa y Docencia en Red de la Universitat Politècnica de València
}

\author{
Editores \\ Vicente Botti Navarro \\ Miguel Ángel Fernández Prada \\ J osé Simó Ten \\ Fernando Fargueta Cerdá
}

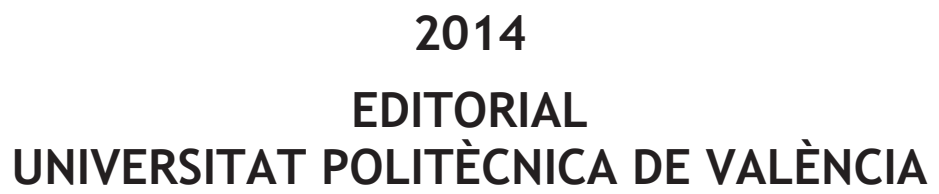




\title{
Colección Congresos
}

Los contenidos de esta publicación han sido evaluados por el Comité Científico que en ella se relaciona y según el procedimiento que se recoge en http://inred2014.blogs.upv.es/comites/

\author{
(c) Vicente Botti Navarro (editor) \\ Miguel Ángel Fernández Prada (editor) \\ J osé Simó Ten (editor) \\ Fernando Fargueta Cerdá (editor)
}

(c) 2014, de la presente edición: Editorial Universitat Politècnica de València

www.lalibreria.upv.es / Ref.: 6183_01_01_01

DOI: http://dx.doi.org/10.4995/INRED.2014.84

ISBN: 978-84-9048-271-1 (versión cd)

Queda prohibida la reproducción, la distribución, la comercialización, la transformación y, en general, cualquier otra forma de explotación, por cualquier procedimiento, de la totalidad o de cualquier parte de esta obra sin autorización expresa y por escrito de los autores. 


\title{
Comité Ejecutivo
}

Presidente: Prof. Dr. Francisco Mora Más

Rector Magnífico de la Universitat Politècnica de València

Prof. Dr. Vicente Botti Navarro

Vicerrector de las Tecnologías de la Información y las Comunicaciones

Prof. Dr. Miguel Ángel Fernández Prada

Vicerrector de Estudios, Calidad y Acreditación.

Prof. Dr. Fernando Fargueta Cerdá

Director del Instituto de Ciencias de la Educación.

\section{Comité Científico}

\author{
Simó Ten, José (Presidente) \\ Alba Fernández, Jesús \\ Benlloch Dualde, José Vicente \\ Leiva Brondo, Miguel \\ López Patiño, $M^{\mathrm{a}}$ Gracia \\ López Santiago, Mercedes \\ Martínez De Juan, José Luís \\ Monreal Mengual, Llucia \\ Monserrat del Río, José Francisco \\ Monsoriu Serra, Juan Antonio \\ Moraño Fernández, José Antonio \\ Morera Bertomeu, Isabel \\ Mula Bru, Josefa \\ Oliver Villarroya, Javier \\ Palomares Chust, Alberto \\ Pardo Vicente, Teresa \\ Pérez Pascual, $\mathrm{M}^{\mathrm{a}}$ Asunción \\ Quintanilla García, Israel \\ Rebollo Pedruelo, Miguel \\ Ribes Greus, Amparo \\ Sentieri Omarrementeria, Carla \\ Terrasa Barrena, Silvia \\ Vargas Colás, $\mathrm{M}^{\mathrm{a}}$ Desamparados \\ Watts Hooge, Frances Irene \\ Yepes Piqueras, Víctor
}

\section{Comité Organizador}

Bonet Espinosa, Ma Pilar (Secretaría Técnica)

Cáceres González, Pilar Aurora (Secretaría Técnica)

Maiques March, José $\mathrm{M}^{\mathrm{a}}$

Martínez Naharro, Susana (Secretaría Técnica)

Morales Sánchez, Juan Carlos 



\section{Presentación}

Las Jornadas de Innovación Educativa y Docencia en Red (IN-RED 2014) ofrecen un foro de intercambio de experiencias, debate y reflexión dirigido a docentes con motivación e interés por la mejora de la educación a través de la tecnología aplicada a la enseñanza. Muchos vosotros ya habéis participado durante los últimos cursos en los programas académicos de Docencia en Red y en los de Innovación Educativa (EICEs y PIMEs).

Las Jornadas IN-RED 2014 están vinculadas a dos objetivos estratégicos concretos del primer Eje (Formación y Aprendizaje) del Plan Estratégico de la UPV: los objetivos orientados a la implementación y actualización de las metodologías docentes y al desarrollo de una oferta formativa con metodologías específicas TIC.

Las iniciativas como cursos on-line, foros, blogs, MOOC, así como las experiencias innovadoras en metodologías de enseñanza y de evaluación del aprendizaje han sido numerosas a lo largo de los últimos años. La calidad obtenida, el trabajo y el esfuerzo del profesorado comprometido en su realización, demandan un foro para ser divulgadas y conocidas por la comunidad universitaria; y a la vez, para proporcionar el análisis que cuantifique la contribución al aprendizaje de los estudiantes y a la mejora de la calidad de la enseñanza.

Con estas líneas os animamos a participar activamente en próximas Jornadas y confiamos en que esta iniciativa propicie un debate fructífero y enriquecedor que nos ayude a seguir avanzando.

Cordialmente.

Vicent Botti Navarro

Vicerrector de las Tecnologías de la Información y de las Comunicaciones.

Miguel Ángel Fernández Prada

Vicerrector de Estudios, Calidad y Acreditación. 



\section{Objetivos}

- Favorecer el intercambio de experiencias tecnológicas e innovaciones entre el profesorado que imparte su docencia en las enseñanzas tanto de grado como de master en las distintas Escuelas y Facultades de la UPV.

- Abrir nuevas posibilidades y campos de acción en el proceso de renovación que actualmente es demandado a la docencia universitaria.

- Animar la reflexión y el debate ante los retos que se le plantean a las enseñanzas científico-técnicas y artísticas en el contexto actual.

- Fomentar el desarrollo de redes de innovación y de investigación educativa capaces de crear sinergias ante el cambio que supone la creación del EEES y otros cambios educativos de nuestro contexto particular.

- Contribuir a la mejora de la actividad docente, focalizando el papel esencial de una docencia de calidad.

- Contribuir al progreso del conocimiento científico sobre la enseñanza en contextos científico tecnológicos y artísticos. 



\section{Índice de sesiones}

1. Aplicación y evaluación de recursos tecnológicos de apoyo al aprendizaje

2. Metodologías activas para el aprendizaje en la Universidad 623

3. Actividades de aprendizaje y evaluación para el desarrollo de competencias genéricas ....... 1027

4. Otro tipo de innovación educativa 1275 



\section{Sesión 1}

Aplicación y evaluación de recursos 


\title{
Curso de Doctorado con Tecnologías Masivas Online (MOC)
}

\author{
Miguel Ferrando Bataller, Marta Cabedo Fabrés y Eva Antonino Daviu
}

Departamento de Comunicaciones.

mferrand@dcom.upv.es, marcafab@dcom.upv.es, evanda@upvnet.upv.es

\begin{abstract}
The Communication objectives are to present the results of the implementation of the Massive Online Course of the Doctoral School of UPV called "Career Research" considerig planning, development and results.

It is a course of 2 ECT, taught in the year 2014 with 91 students. The course has been designed using the tools provided by the UPV, especially PoliformaT and Polimedia. It has been an important task of planning and preparation of contents.

The course is structured in 7 teaching units, each unit has 5 Polimedia, supplementary material and multiple-choice test. The pace of delivery has been of one unit per week.

There have been self-assessments of each unit, a discussion forum, work and final exam. The results of the evaluation and follow-up surveys give good indicators.

This is a new experience for an official doctoral level course with online methodologies. The experience could serve as a real case and implement a model for other courses and Masters degree with similar methodologies.
\end{abstract}

Keywords: Online, PhD, polimedia, poliformaT, mass, distance, multimedia. 


\section{Resumen}

Los Objetivos de la comunicación son presentar los resultados obtenidos en la puesta en marcha del Curso Online de la Escuela de Doctorado de la UPV denominado "Carrera Investigadora", desde el punto de vista de planificación, desarrollo y resultados.

Se trata de un curso de 2 créditos ECTS, impartido en el año 2014 a 91 alumnos. El curso se ha realizado utilizando las herramientas facilitadas por la UPV, especialmente PoliformaT y Polimedia. Ha supuesto una tarea importante de planificación y preparación del material.

El curso está estructurado en 7 unidades didácticas, cada unidad cuenta con 5 videos en formato polimedia, material complementario de consulta y un examen. El ritmo de impartición ha sido de una unidad por semana.

Se han realizado autoevaluaciones de cada unidad, un foro de debate, trabajo y examen final. Los resultados de la evaluación y las encuestas indican un alto seguimiento del curso.

Se trata de un experiencia innovadora para un curso oficial de nivel de doctorado con metodologías online. La experiencia podría servir como un caso real y un modelo para implementar otras asignaturas de grado y máster con metodologías similares.

Palabras clave: Online, doctorado, polimedia, poliformat, masivo, distancia, multimedia. 


\section{Introducción}

La Universitat Politècnica de València ha impulsado durante los últimos años, dentro de su plan estratégico, la iniciativa "Docencia en Red", (Martínez Rubio, 2010). Dentro de la iniciativa se ha impulsado la creación de material multimedia de alta calidad (Turró, 2009) y la integración con la Plataforma de colaboración y aprendizaje de la UPV denominada PoliformaT (Roldán, 2006). Destaca también la definición de los Objetos Digitales de Aprendizaje (Martínez Naharro, 2007)

La Escuela de Doctorado de la UPV, como estructura responsable de los estudios de doctorado de la Universitat, ha ofertado en el curso 2013-14 un total de 14 cursos de formación transversal, de carácter obligatorio para los alumnos matriculados en los nuevos programas, según la normativa establecida en el RD 99/2011.

La Universitat Politècnica de València impulsa la creación de cursos MOOC (Massive Online Open Courses), siguiendo los desarrollos previos del Programa "Docencia en Red". Existen diversas inicitativas a nivel mundial (Pappano, 2012), aunque con una cierta controversia sobre el futuro de los cursos masivos y abiertos (Kolowich,2012).

Revistas científicas como Nature se han sumado a la inciativa, dando recomendaciones para elaborar cursos con dicha metodología (Kellogg, 2013).

\section{Objetivos}

Los objetivos de la presente comunicación son presentar la planificación, desarrollo y resultados del curso transversal de doctorado "Carrera Investigadora", con metodología online. Dicho curso se ha impartido durante los meses de Febrero y Marzo de 2014, y ha contado con una matrícula de 91 alumnos. El curso se podría clasificar como MOC (curso masivo online), pero no podemos calificarlo como MOOC, dado que no es abierto.

Los Objetivos del curso son dotar al alumno de una visión general del Sistema español de Ciencia e Innovación, darle a conocer las posibilidades de seguir una carrera investigadora y orientarle hacia los procesos de acreditación de la calidad previstos para la carrera académica.

El perfil de los estudiantes es el de alumnos en la fase inicial de realización de su Tesis Doctoral, con una gran motivación por la investigación y por la realización de una Carrera académica.

El reto planteado era combinar unos contenidos de interés junto con una metodología adecuada para su seguimiento a distancia. 


\section{Desarrollo de la Innovación}

El curso se planteó desde el origen con las siguientes condiciones

- Metodología online

- Curso previsto para un mínimo de 50 estudiantes de doctorado

- Examen final presencial

- Utilización de las plataformas y herramientas de producción de contenidos de la UPV: PoliformaT y Polimedia.

- Aprovechamiento de las experiencias previas de los cursos MOOC de la UPV.

- 2 créditos ECTS

- Tiempo de impartición: 8 semanas

Una vez realizado el encargo del curso por parte de la Escuela de Doctorado, a partir de una propuesta inicial, se seleccionaron un total de 7 unidades didácticas..

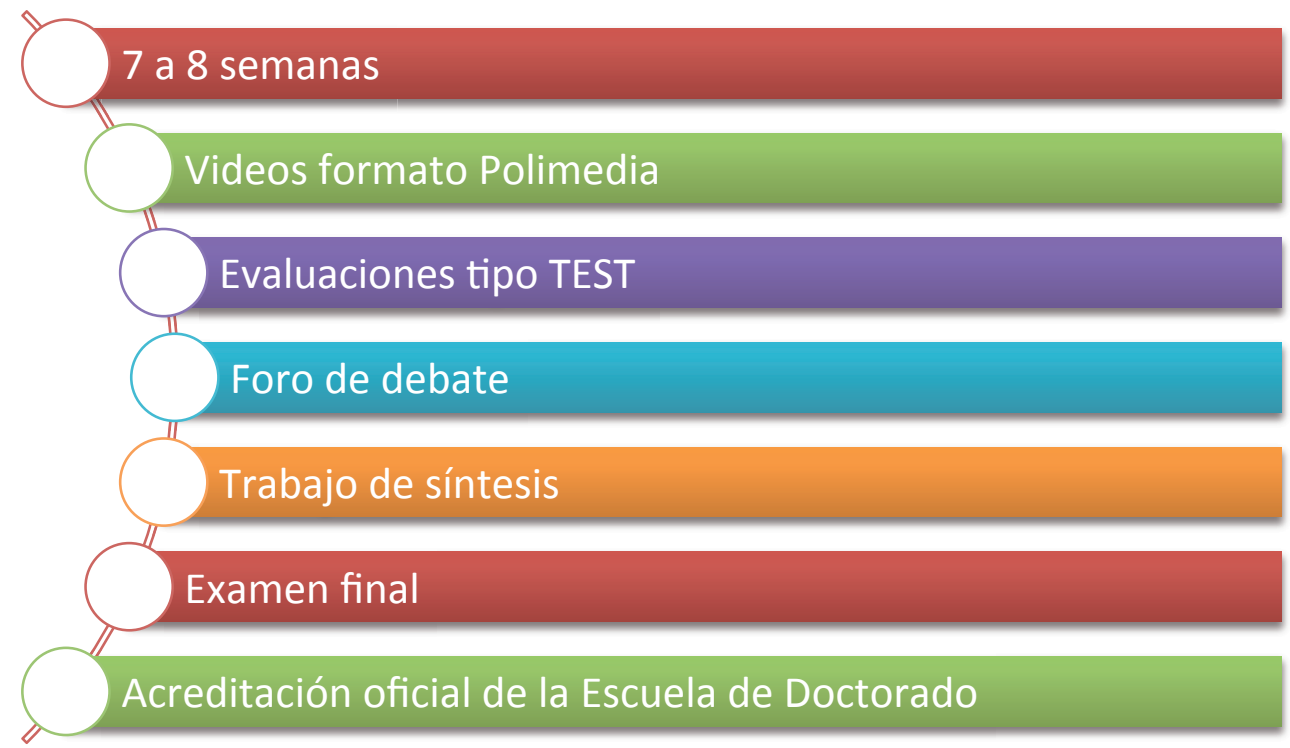

Fig. 1 Características generales del curso 


\section{La ley de la Ciencia}

- Sistema Español de Ciencia, Tecnología e Innovación

- Plan Estatal de Investigación Científica y Técnica

- Estatuto del Personal Investigador en formación

- Programa de Promoción del Talento y Empleabilidad

\section{Contratos de Investigación pre-doctorales y post-doctorales}

- Contratos pre-doctorales

- Contratos de investigador

- Carrera profesional del personal investigador funcionario

\section{El doctorado: Normativa y realización}

- Normativa sobre doctorado y doctorado europeo

- Realización de la Tesis Doctoral

- Evaluación y defensa de la Tesis Doctoral

\section{Movilidad y estancias internacionales}

- Programas de movilidad internacional

- Oportunidades de Investigación en Europa

- Programas de formación internacionales y Programa Marco de la Unión Europea Horizonte 2020

La carrera universitaria y categorías de profesorado

- Personal docente e investigador contratado

- Profesorado de los cuerpos docentes universitarios

- Personal docente e investigador de Universidades Privadas

Agencias de Evaluación y Acreditación

-Agencia Nacional de Evaluación y Prospectiva

-Agencias Autonómicas de Evaluación

- Comisión Nacional de Evaluación de la Actividad Investigadora

- Valoración de la Actividad Académica en la UPV

\section{Procesos de Acreditación}

-Acreditación para Ayudante Doctor

- Acreditación para Contratado Doctor y Profesor de Universidad Privada

- Acreditación para Profesor Titular de Universidad

-Acreditación para Catedrático de Universidad

\section{Tabla 1. Temario del Curso}

(c) EY-NC-ND 2014, Universitat Politècnica de València

I Jornadas IN-RED (2014) 
El curso online de doctorado se ha estructurado en 7 unidades didácticas, cada una de ellas consta de los elementos indicados en la figura 2.

Las guías de aprendizaje son videos en formato Polimedia, en los que se indican los objetivos de la unidad, la estructura de los contenidos, el material recomendado y la evaluación de la unidad, realizada a través de un test de respuestas múltiples.

\section{Guía de aprendizaje}

\section{Videos}

\section{Lectura de material complementario}

\section{Autoevaluación (test repuestas múltiples)}

Fig. 2 Composición de las Unidades Didácticas

Las unidades didácticas están disponibles en Contenidos de PoliformaT, donde se marca la secuencia de aprendizaje y se puede acceder directamente a través de videos en formato Polimedia, considerados como objetos digitales de aprendizaje, desde la misma aplicación de contenidos. Se van recomendado la lectura de material complementario, como normativas, informes, leyes o documentos de consulta a través de enlaces en formato HTML.

Las presentaciones realizadas en polimedia, las normativas, los documentos de consulta y el resto de material complementario están disponibles en Recursos de PoliformaT.

La autoevaluación se realiza a través de Exámenes de PoliformaT.

Para formentar la interacción y la comunicación entre los alumnos se han realizado una serie de discusiones a través de los Foros, en los que se ha valorado el número de contribuciones, la calidad de la misma y los comentarios sobre otras contribuciones. La participación en los foros se planteó como una alternativa a la realización de un trabajo 
final, que se presentó siguiendo los estándares de comunicaciones a Congresos, a través de

Tareas de PoliformaT.

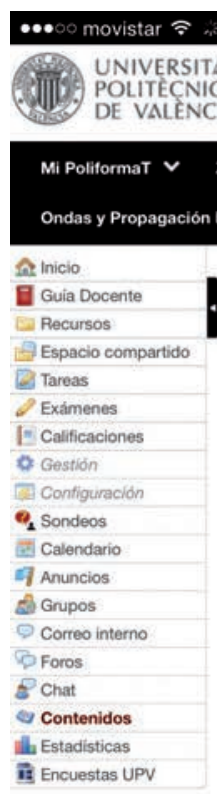

TAT

$\begin{array}{ll}A T & \text { poli [formaT] }\end{array}$

Zona de Ayuda $\vee$ Carrera Investigadora $\vee$

8 Salir

Electromagnética $\vee$ Eac $\vee$ Mis sitios activos $\approx$

Carrera Investigadora: Contenidos

Taqiendo la parte del estudiante.

Visor Autor

Anterior I Tabla de Contenidos I Siguiente

La Ley de la Ciencia * Introducción

\section{La Ley de la Ciencia}

Introducción

Bienvenido a la Unidad Didáctica 1: LEY DE LA CIENCIA.

Los objetivos de aprendizaje previstos para esta unidad son los siguientes:

- Analizar el Sistema Español de Ciencia, y realizar un diagnóstico del mismo en base a indicadores objetivos.

-Identificar la novedades que introduce la nueva Ley de la Ciencia, y su repercusión sobre el personal investigador.

-Conocer los diferentes tipos de Proyectos de $\mathrm{I}+\mathrm{D}+\mathrm{i}$ financiados dentro del Plan Estatal, y las diferentes ayudas destinadas al personal investigador.

-Conocer los centros de investigación que hay en España, y los derechos y deberes del personal investigador que trabaja en ellos.

A continuación tienes un video de introducción a esta unidad:

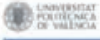

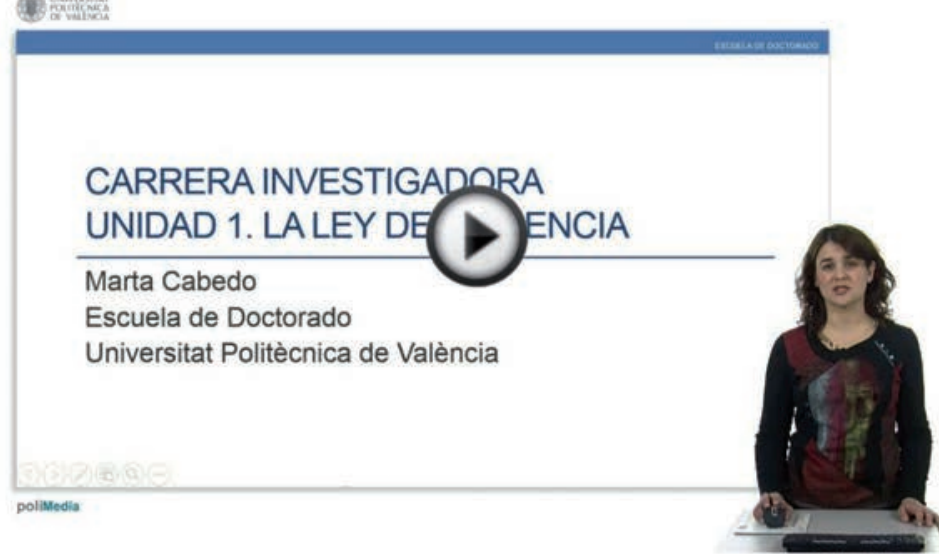

IMPORTANTE: Recuerda que cuando finalices esta unidad, deberás realizar el examen de autoevaluación correspondiente a la Unidad Didáctica 1 a través de la sección de Exámenes de Poliformat. La nota de este examen constituirá un $5 \%$ de la nota final. Ten en cuenta, que en caso que realices este examen en repetidas ocasiones, sólo quedará grabada la nota correspondiente al primer envio.

Anterior I Tabla de Contenidos | Siquiente

Fig. 3 Ejemplo de Unidad Didáctica en Contenidos de PoliformaT

(c) EY-NC-ND 2014, Universitat Politècnica de València

I Jornadas IN-RED (2014) 
En total se han realizado un total de 30 videos, entre 4 y 5 por unidad, se han planteado 7 exámenes online con 10 preguntas por examen, 5 foros de discusión, un trabajo final y una sesión presencial con expertos de ANECA en los distintos campos, coincidiendo con la fecha el examen final y a continuación del mismo.

\section{Resultados}

Mostraron interés en el curso más de 100 alumnos, aunque la matrícula final, después de las anulaciones y renuncias acabó siendo de 91 alumnos.

El curso fue superado por 57 alumnos, 10 empezaron el mismo, aunque no lo completaron y 24 estaban matriculados, pero no consta ninguna actividad. Hay que tener en cuenta que se trata de un curso online, en el que es necesario tener una cierta disciplina en el seguimiento del mismo.

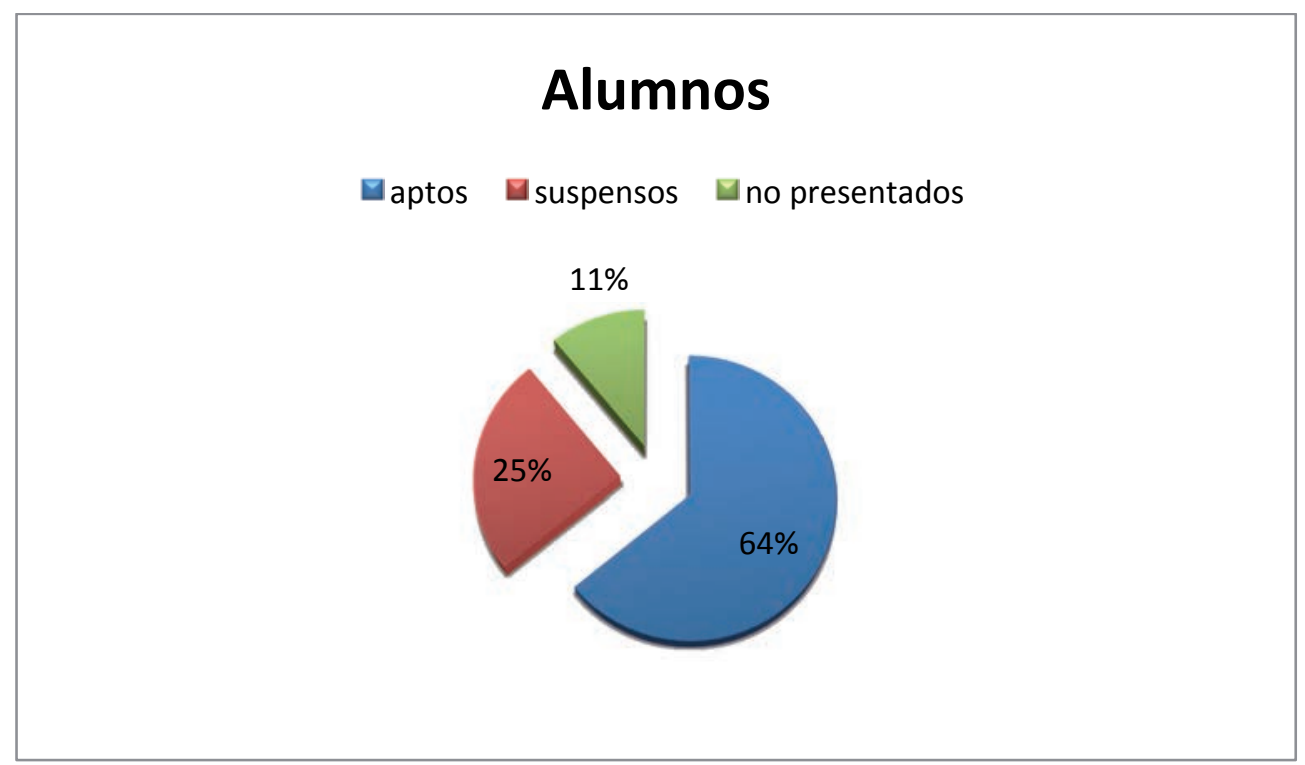

Fig. 4 Resultados del Curso "Carrera Investigadora” 2013-14

Se han realizado distintas estadísticas sobre el seguimiento de los alumnos. PoliformaT facilita muchos datos sobre la participación en foros, la fecha de lectura de los distintos documentos, la fecha de entrega de los trabajos o exámenes, etc. En general se ha observado que sólo siguen el ritmo del curso un $30 \%$ de los matriculados, en el resto de casos puede haber un retraso de varias semanas. 


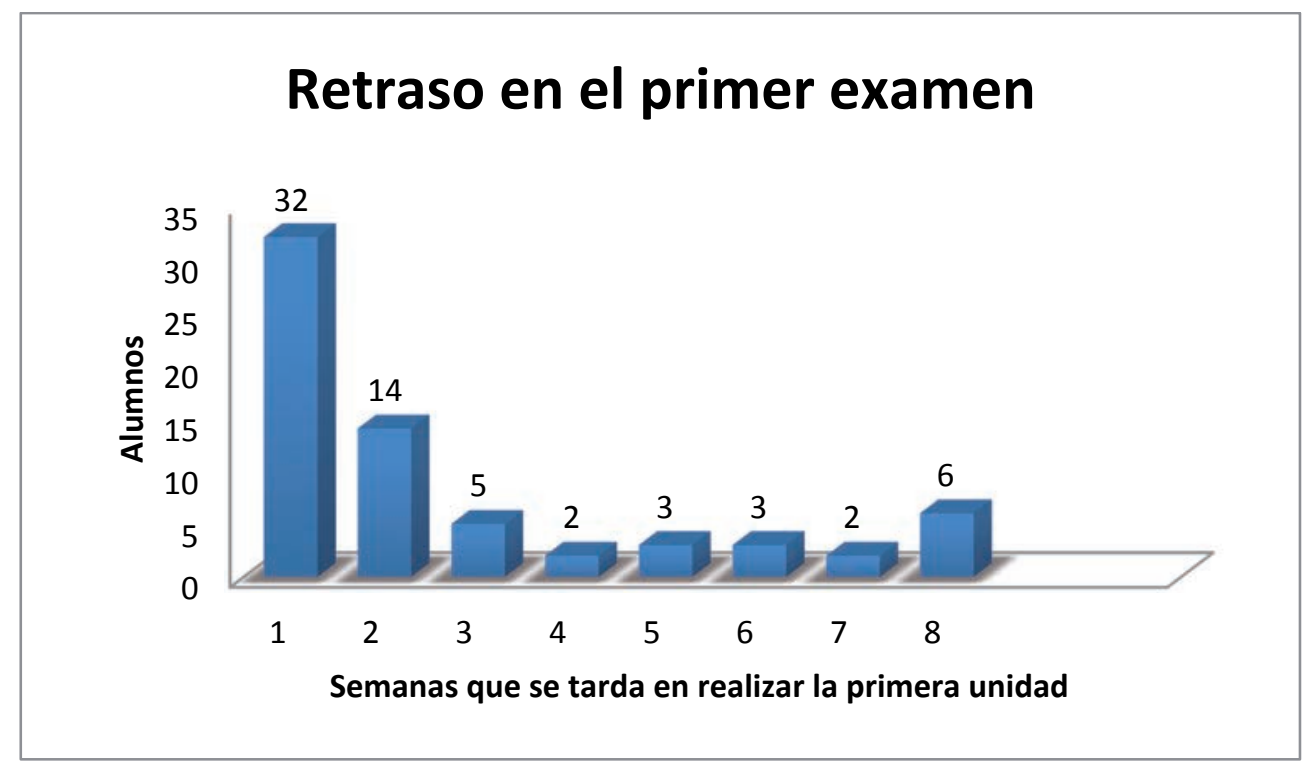

Fig. 5 Retraso en el seguimiento del curso "Carrera Investigadora" 2013-14

Se ha realizado una encuesta específica para analizar los aspectos positivos y negativos del curso, la metodología, los contenidos y sugerencias de mejora. Sobre el total de 57 alumnos que han seguido el curso se han obtenido 48 respuestas. La respuesta más unánime se tiene en la consideración de la utilidad de los contenidos, con un $92 \%$ de respuestas afirmativas.

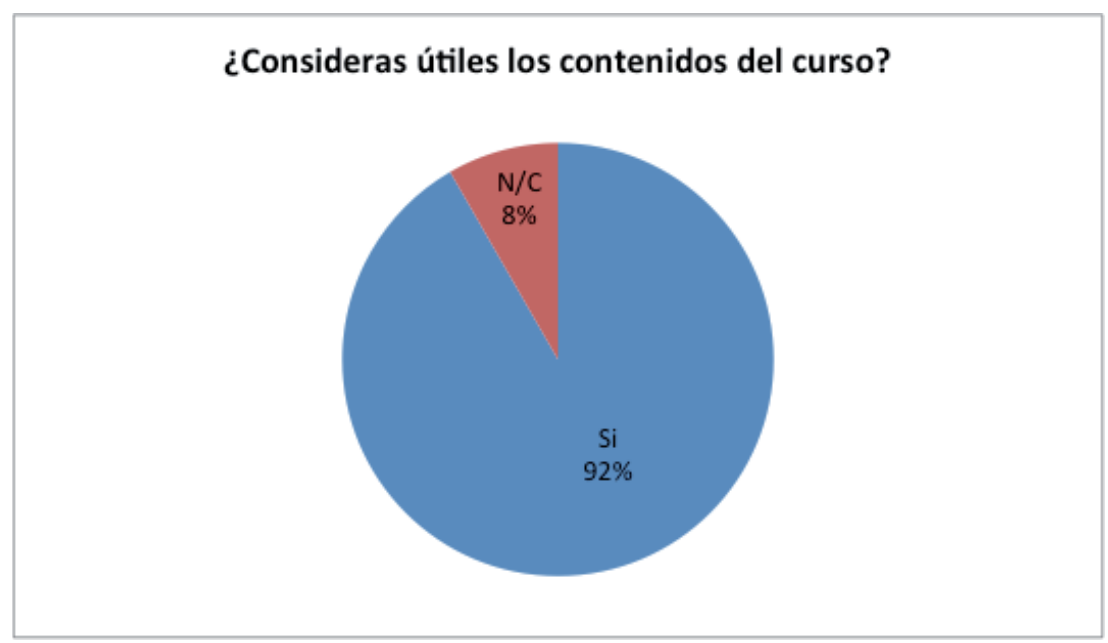

Fig. 6 Utilidad de los contenidos del curso.

(c)) EY-NC-ND 2014, Universitat Politècnica de València

I Jornadas IN-RED (2014) 
Tal como se muestra en la figura 7, los alumnos destacan los siguientes aspectos positivos: el contenido interesante y útil, la organización, y la calidad del material.

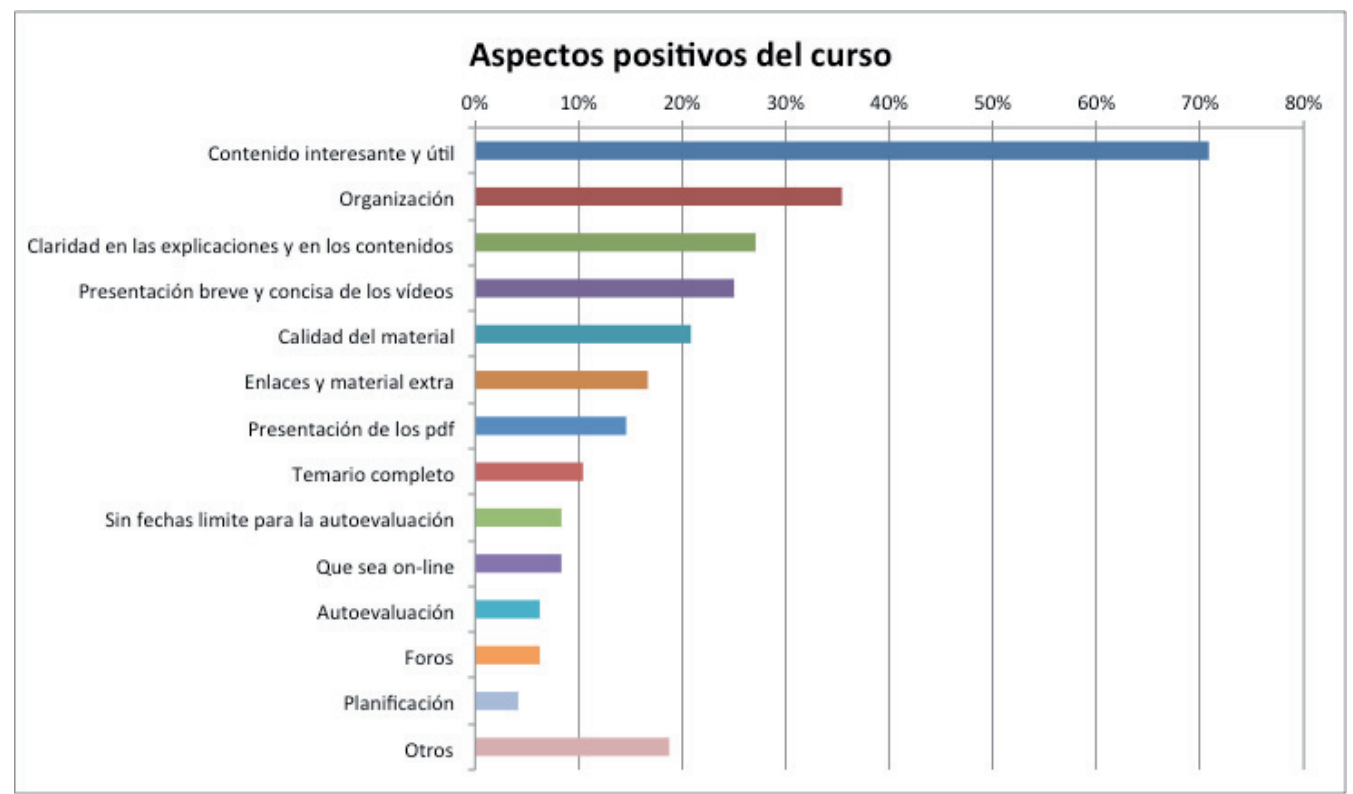

Fig. 7 Encuesta sobre aspectos positivos del curso "Carrera Investigadora” 2013-14

En la encuesta a los alumnos se preguntó por la metodología de evaluación empleada.

\section{Metodología de evaluación empleada}

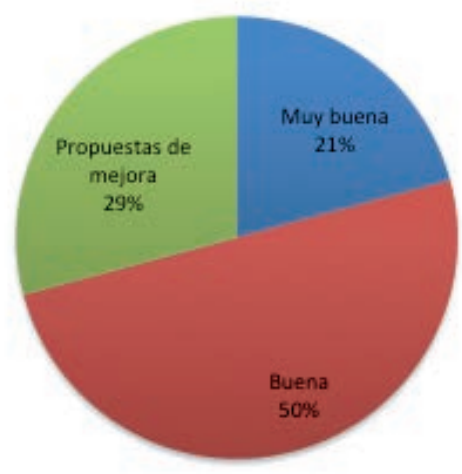

Fig. 8 Datos de la encuesta sobre la evaluación del curso “Carrera Investigadora” 2013-14 
En las sugerencias de mejora de la evaluación, hay una gran dispersión, pero se sigue insistiendo en el replanteamiento del examen final y de la evaluación continua. En algunos casos se propone aumentar las actividades presenciales y en otros casos reducirlas. En general se considera que la evaluación es buena o muy buena.

En aspectos negativos destaca la realización de un examen presencial que consideran innecesario y demasiado material para estudiar de memoria.

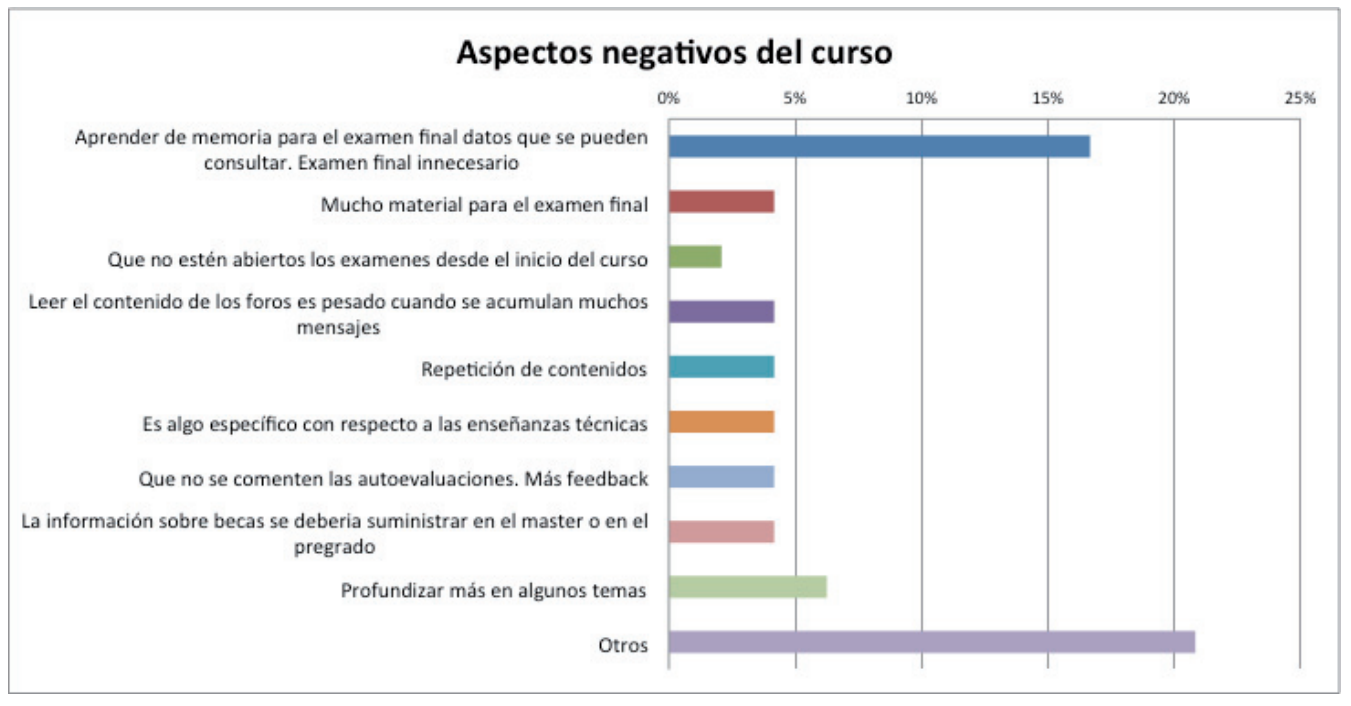

Fig. 9 Encuesta sobre aspectos negativos del curso "Carrera Investigadora” 2013-14

En resumen, los alumnos valoran muy positivamente los contenidos, y la metodología, y la evaluación. Las sugerencias de mejora son diversas y apuntan en diversas direcciones, pero destacan especialmente las que proponen evitar el examen final presencial.

\section{Conclusiones}

La experiencia de la primera edición del curso "Carrera Investigadora", en formato online, para un gran número de alumnos de doctorado ha sido muy positiva.

Los alumnos han valorado positivamente los contenidos, la organización y la calidad. Consideran que un cambio de la metodología tiene que ir asociado a un cambio en la evaluación, evitando los examenes finales presenciales.

Se ha conseguido una comunicación fluída entre los alumnos a partir de los foros, que han registrado un elevado volumen de actividad.

(c)) EY-NC-ND 2014, Universitat Politècnica de València

I Jornadas IN-RED (2014) 
Desde el punto de vista de los profesores ha supuesto un cierto esfuerzo de preparación y coordinación. Se considera que la experiencia podría extenderse, pero sería necesario un mayor reconocimiento en la nueva normativa de ordenación académica.

\section{Referencias}

MARTÍNEZ RUBIO, Juan Miguel; RAMÍREZ BLANCO, Manuel Jesús; FERRANDO BATALLER, Miguel. "Docencia en Red, una apuesta estratégica en la Universidad Politécnica de Valencia". 2010. En Virtual Educa 2010

TURRÓ, Carlos, et al. "Polimedia: a system for successful video e-learning". En Eunis 2009 international conference. 2009.

ROLDÁN, David, et al. "Software libre en la Educación Superior: PoliformaT, la plataforma de e-learning de la UPV". En Conocimiento Abierto, Sociedad Libre. III Congreso Online del OCS. 2006.

MARTÍNEZ NAHARRO, Susana, et al. "Los objetos de aprendizaje como recurso de calidad para la docencia: criterios de validación de objetos en la Universidad Politécnica de Valencia". En IV Simposio Pluridisciplinar sobre Diseño y Evaluación de Contenidos Educativos Reutilizables (SPDECE 2007). 2007

PAPPANO, Laura. The Year of the MOOC. The New York Times, 2012, vol. 2, no 12, p. 2012.

KOLOWICH, Steve. The MOOC Survivors. Insider Higher Ed, 2012.

KELLOGG, Sarah. Online learning: How to make a MOOC. Nature, 2013, vol. 499, no 7458, p. 369-371. 


\title{
Mejora de la competencia comunicativa de los estudiantes de la ETSID a través de Clilstore
}

Ana Gimeno Sanz ${ }^{a}$, David Perry ${ }^{b}$

Grupo de Investigación CAMILLE, Departamento de Lingüística Aplicada, Universitat Politècnica de

València, agimeno, bdaper @upvnet.upv.es

\begin{abstract}
The article is based on the results of a teaching innovation project conducted at the Universitat Politècnica de València during the 2013-14 school year to aid undergraduate learners at the School of Design Engineering to improve their communicative competences in English as a Foreign Language (EFL). The authors created EFL learning materials using an innovative authoring tool, which has recently been launched, developed within the Tools for CLIL Teachers EU-funded project. The materials development was based on two well-established approaches to foreign language learning, i.e. Content and Language Integrated Learning (CLIL) and Computer-Assisted Language Learning (CALL). Evaluation and validation of the materials will take place during 2014-15.
\end{abstract}

Keywords: communicative competence, English as a Foreign Language (EFL), Content and Language Integrated Learning (CLIL), ComputerAssisted Language Learning (CALL), Clilstore.

\begin{abstract}
Resumen
El artículo se centra en los resultados de un proyecto de mejora educativa llevado a cabo en la Universitat Politècnica de València durante el curso académico 2013-14 para ayudar a los estudiantes a mejorar sus competencias lingüísticas en inglés. El proceso que se ha seguido es el de crear materiales didácticois específicos para los diversos grados que se imparten en la Escuela Técnica Superior de Ingeniería del Diseño (ETSID) utilizando una nueva herramienta de autor que ha sido desarrollada dentro del proyecto europeo "Tools for CLIL Teachers" en el que han participado los autores. La utilización de dichos materiales, así como la evaluación y
\end{abstract}

(cc) EY-NC-ND 2014, Universitat Politècnica de València

I Jornadas In-Red (2014) 
validación de los mismos, se realizará a lo largo del curso 2014-15. El diseño de estos materiales se ha apoyado en dos aproximaciones a la docencia de lenguas extranjeras; por una parte, el denominado Aprendizaje Integrado de Contenido y Lenguas Extranjeras (AICLE) y, por otra, la Enseñanza de Lenguas Asistida por Ordenador (ELAO).

Palabras clave: competencia comunicativa, inglés, Aprendizaje Integrado de Contenido y Lenguas Extranjeras (AICLE), Enseñanza de Lenguas Asistida por Ordenador (ELAO), Clilstore.

\section{Introducción}

Este artículo se centra en los resultados del proyecto de mejora educativa denominado "Mejora de la competencia comunicativa de los estudiantes de la ETSID a través de Clilstore" (Ref. PIME 022-B-2013) llevado a cabo durante el curso 2013-14. El proyecto ha tenido como objetivo ayudar a los estudiantes de la ETS de Ingeniería del Diseño a mejorar sus competencias lingüísticas en inglés, francés y valenciano. Aquí nos limitaremos, sin embargo, a la parte que se refiere al aprendizaje de inglés. El proyecto se ha apoyado en dos aproximaciones a la docencia de lenguas extranjeras; por una parte, el denominado Aprendizaje Integrado de Contenido y Lenguas Extranjeras (AICLE) -método muy relacionado con la enseñanza de lenguas para fines específicos, que pretende fomentar el aprendizaje de una materia a través de una lengua extranjera- y, por otra, la Enseñanza de Lenguas Asistida por Ordenador (ELAO). Para ello se han desarrollado contenidos didácticos utilizando la herramienta de autor "Clilstore" (http://multidict.net/clilstore), desarrollada dentro del proyecto europeo "Tools for CLIL Teachers" (http://www.languages.dk/tools). En los apartados que siguen se hará referencia a las mencionadas metodologías didácticas y se ejemplificarán con la descripición de una de las unidades didácticas desarrolladas.

\section{Objetivos y contexto}

El objetivo del proyecto de mejora educativa ha sido el de crear materiales didácticos para ayudar a los estudiantes de las nuevas titulaciones de grado de la ETSID a que mejoren, en términos generales, su competencia lingüística en inglés pero, fundamentalmente a que mejoren su competencia comunicativa sobre temas relacionados con sus carreras universitarias. Los autores, con la finalidad de dar cabida a todas las ramas de la ingeniería 
que se imparten en la ETSID, hicieron en primer lugar una selección de aquellos temas comunes a los diversos grados para, posteriormente fijar los contenidos específicos de cada una de las unidades didácticas creadas. Esto se realizó mediante un estudio comparativo de los programas de las asignaturas de cada grado. Tras este primer proceso de selección, y teniendo en cuenta los niveles de conocimiento de la lengua extranjera objeto de los materiales a desarrollar, se predefinieron los siguientes temas comunes:

- Innovaciones tecnológicas aplicadas a la industria

- Desarrollo tecnológico sostenible

- Nuevos materiales utilizados en las industrias automovilísticas y aeroespaciales

- Automatización de procesos en la industria

- Desarrollo y gestión de proyectos de ingeniería

- Necesidades reales de comunicación en inglés de las pequeñas y medianas empresas

- Nuevos procesos de fabricación (reducir el impacto en el medioambiente)

- Reciclaje y re-utilización de materiales (cradle-to-grave OR life-cycle assessment)

- La importancia del trabajo colaborativo en pequeños equipos

Dado que se imparten dos asignaturas optativas en cada uno de los grados ofrecidos en la ETSID, se decidió crear el 50\% de los materiales para cada una de éstas. Por regla general, ambas asignaturas suman entre 9 y 10,5 créditos ECTS y se dividen, tradicionalmente, en créditos de teoría de aula y créditos de pácticas en aula informática. Por esta razón se decidió destinar el nuevo material didáctico a la parte práctica de las asignaturas. Las asignaturas para las que se crearon los materiales son ambas de carácter semestral; por un lado Inglés Técnico, que se imparte en el primer año de carrera, e Inglés Nivel B2 que, como su nombre indica, pretende preparar al alumnado para que alcance una competencia lingüista del nivel B2 según los descriptores del Marco común europeo de referencia para las lenguas (MCERL). Esta última se puede cursar en cualquiera de los sucesivos tres cursos a elección del alumnado. Dado que se les presupone a los estudiantes un nivel equivalente al B1 del MCERL al incorporarse a la Universidad, la asignatura denominada Inglés Técnico se situa en este nivel, con la salvedad de que ya en primer año de carrera, el estudiante tiene la oportunidad de adentrarse en lo que viene llamándose "lenguas de especialidad"; es decir, el estudio de la lengua con el fin específico de poder desenvolverse utilizando las cuatro destrezas lingüísticas en el lenguaje propio de su carrera. Puede así contextualizar su aprendizaje a las necesidades de su ámbito de estudio. Esta es una práctica docente que viene implantándose desde finales de los años 60 y comienzos de los 70 y que se conoce como "inglés para fines específicos",ii , aunque hoy en día ha cobrado matices muy distintos gracias a la incorporación de las tecnologías de la información y de las comunicaciones (TIC). La asignatura de Inglés Nivel B2 también se compone íntegramente de contenidos específicos relacionados con los estudios cursados, según el grado en el que

\section{(c) EY-NC-ND 2014, Universitat Politècnica de València}


se imparta. Es decir, cada titulación disfruta de sus propias asignaturas de inglés enfocadas hacia las materias propias del grado en el que se incluyan. Por otra parte, tampoco hemos de perder de vista que una de las competencias transversales en todos los grados de la ETSID es la "capacidad de comunicación en una lengua extranjera". Otra consideración a tener en cuentas es la obligatoriedad por parte de los estudiantes de acreditar un conocimiento equivalente al nivel B2 de la lengua extranjera cursada como requisito para poderse graduar. Estos condicionantes determinaron tanto los contenidos como el nivel lingüístico de las unidades didácticas a ser creadas con la herramienta Clilstore.

\section{Desarrollo de la innovación con Clilstore}

Clilstore es una herramienta de autor que ha sido creada fundamentalmente (aunque no de forma exclusiva) para crear y publicar materiales didácticos para el aprendizaje de contenidos pertenecientes a una materia de especialidad de forma integrada con una lengua extranjera. Como hemos mencionado arriba, esta metodología se conoce como Aprendizaje Integrado de Contenido y Lenguas Extranjeras y se conforma a unos parámetros de aplicación muy concretos. El AICLE fue reconocido como metodología docente por parte de la Comisión de las Comunidades Europeas en su Comunicación No 449, "Promover el aprendizaje de idiomas y la diversidad lingüística: Un Plan de acción 2004 - 2006", publicada en $2003^{\mathrm{iii}}$. En este documento se afirma que:

El aprendizaje integrado de contenidos e idiomas (CLIL en sus siglas inglesas), por el que los alumnos estudian una asignatura en una lengua extranjera, puede contribuir considerablemente a los objetivos de aprendizaje de la Unión. En efecto, este sistema ofrece a los alumnos oportunidades reales de utilizar inmediatamente los nuevos conocimientoslingüísticos, en lugar de adquirirlos para un uso posterior. También da acceso a los idiomas a una mayor diversidad de alumnos, lo que aumenta la confianza en sí mismos de los más jóvenes y de aquéllos que no han tenido una buena experiencia en la enseñanza de idiomas en la educación general. Permite estar en contacto con las lenguas sin necesidad de ampliar el plan de estudios, aspecto que puede tener especial interés para los centros de formación profesional. La presencia de profesores formados que sean hablantes nativos de la lengua vehicular puede facilitar la introducción de planteamientos CLIL en un centro escolar. (p.9)

Según el profesor David Marsh, precursor de esta metodología en el año 1994, CLIL incorpora un factor de motivación para el estudiante muy importante ya que les ayuda a percibir que la lengua extranjera cumple para ellos una función real a la vez que adquieren conocimientos sobre la materia objeto de estudio (Marsh 2000). De hecho, con esta 
metodología los estudiantes desempeñan un papel activo y participan de dos canales de aprendizaje con unos objetivos, contenidos y métodos de aprendizaje muy distintos; es decir, el aprendizaje simultáneo de una lengua extranjera y alguna otra materia curricular.

Como decimos, uno de los elementos implícitos en esta metodología es el de la motivación del alumnado ya que la enseñanza de la lengua siempre estará en función de una materia relacionada con sus estudios universitarios y, por ende, a la profesión a la que pretenden dedicarse en el futuro.

Los profesores que trabajan en el marco del AICLE suelen ser especialistas en su propia disciplina, más que profesores de una lengua extranjera en el sentido tradicional. Normalmente son hablantes que dominan la lengua meta con soltura, bilingües o hablantes nativos de la misma. En muchas instituciones, los profesores de lengua extranjera trabajan en colaboración con otros departamentos para ofertar el AICLE en diversas asignaturas. La cuestión fundamental es que el estudiante adquiera nuevos conocimientos inherentes a la materia curricular y, al mismo tiempo, tome contacto con la lengua extranjera, la use y la aprenda. Las metodologías y los enfoques utilizados a menudo están relacionados con el área de conocimiento de la asignatura y es el contenido de ésta el que condiciona las actividades a realizar. Hay que señalar, sin embargo, que en el proyecto PIME aquí descrito, son profesores de lengua inglesa los que están formando a sus alumnos en contenidos curriculares relacionados con sus carreras universitarias. Esto es posible gracias al carácter polifacético del AICLE que puede ofrecer los siguientes beneficios:

- contribuye al conocimiento y el entendimiento intercultural

- desarrolla destrezas comunicativas interculturales

- mejora la competencia lingüística y las destrezas comunicativas orales

- desarrolla intereses y actitudes multilingües

- proporciona oportunidades para estudiar el contenido según diversas perspectivas

- permite que los aprendices tengan un mayor contacto con la lengua meta

- no requiere horas de docencia extra

- complementa otras asignaturas, en lugar de competir con ellas

- diversifica las metodologías didácticas utilizadas en el aula

- aumenta la motivación y la confianza del estudiante tanto en la lengua como en la asignatura objeto de aprendizaje

El AICLE está también esterchamente relacionado con la enseñanza de lenguas asistida por ordenador (ELAO) ya que hoy en día no hay mejor medio para englobar una enseñanza multidisciplinar que las tecnologías de la información y de las comunicaciones (TIC). Las TIC nos permiten utilizar una gran cantidad de recursos online para poder satisfacer las necesidades curriculares tanto del aprendizaje de una lengua extranjera como las de la materia curricular en cuestión y nos permiten casar los objetivos de ambas de forma

\section{(cc) EY-NC-ND 2014, Universitat Politècnica de València}

I Jornadas IN-RED (2014) 
integrada. También caracteriza la ELAO el carácter autónomo de los materiales ya que se les suele dotar de una serie de elementos que favorecen el aprendizaje autoguiado. Clilstore, en tanto que herramienta de autor, repositorio de unidades didácticas online, intefaz de acceso a diccionarios online en más de 100 lenguas y un sistema que integra cualquier página web y enlaza todas y cada una de las palabras en ella contenidas a los mejores diccionarios online gratuitos mediante enlaces hipertextuales. Dado lo novedoso e innovaor del sistema, a continuación pasaremos a decribirlo someramente.

Clilstore es una web multifuncional que (i) permite a profesores crear unidades didácticas multimedia para la enseñanza de lenguas (o cualquier otra materia curricular) y utilizar las ya creadas por otros profesores, y (ii) ofrece un repositorio de unidades didácticas en múltiples idiomas, al cual pueden acceder los estudiantes directamente y que se puede usar de forma independiente. El repositorio de unidades disponibles es de acceso libre, por lo que los profesores y los estudiantes que quieran utilizar las unidades existentes no necesitan registrarse en el servicio para visualizar o usar los materiales. En las unidades de Clilstore destaca el aspecto multimedia, es decir, el uso de combinaciones de vídeo, audio, imágenes, texto e hipervínculos, y el apoyo de tecnologías secundarias que permiten crear y compartir ejercicios interactivos, etc. Sin embargo, para garantizar la máxima eficacia de las unidades didácticas de Clilstore, éstas deben contener una cantidad significativa de texto. Esto se debe a que un elemento fundamental que hace de Clilstore un servicio único en el aprendizaje de lenguas es el modo en que el software trata los textos introducidos. Con un solo clic, todas las palabras enlazan automáticamente con la interfaz de diccionario Multidict, que pone a disposición de los estudiantes diccionarios online en más de 100 idiomas, permitiéndoles así consultar los textos, siguiendo su propio ritmo y de acuerdo con sus propias necesidades de aprendizaje. A continuación se muestra en la Figura 1 la página de entrada a la web y sus tres elementos integrados: Multidict, Wordlink y Clilstore.

\section{Clilstere}

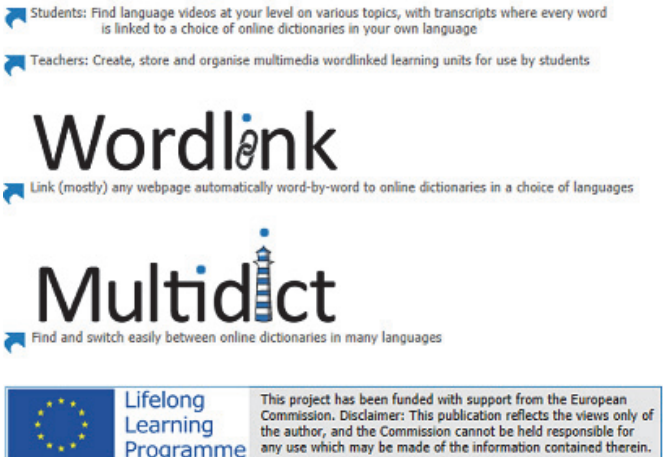

Figura 1. Página de inicio de Clilstore, accesible desde http://multidict.net. 


\subsection{Multidict}

Empezando por el nivel más bajo, Multidict es el nombre que recibe la interfaz de acceso a los diccionarios gratuitos online en más de 100 idiomas. En la Figura 2 resaltamos los elementos más importantes:

1. Campo de entrada de palabras.

2. Pares de idiomas: idioma fuente y meta.

3. Selección de diccionarios online. Selección por menú desplegable y selección por icono.

4. Interfaz del diccionario seleccionado con la traducción.

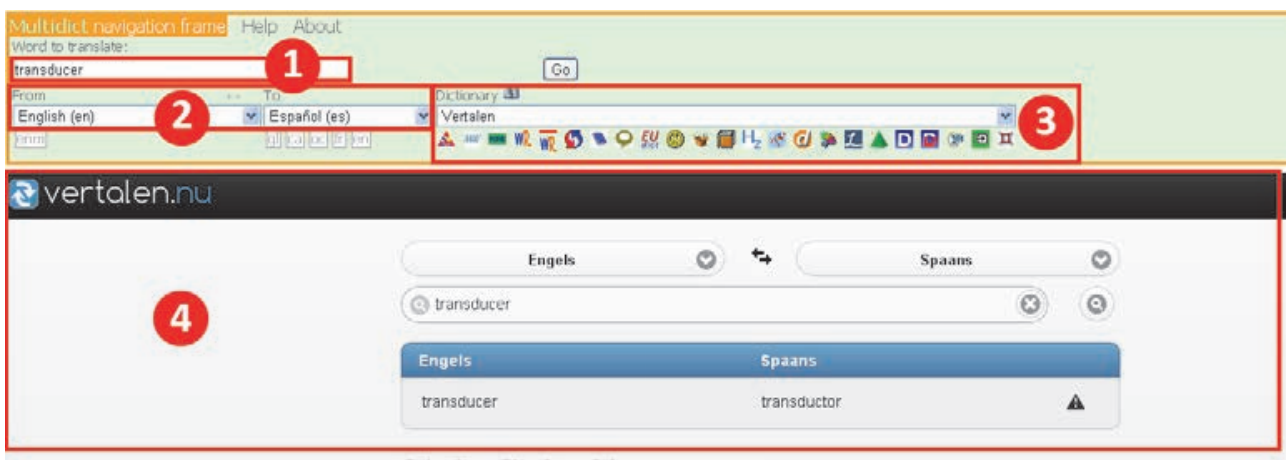

Fig. 2. Interfaz autónoma de Multidict.

Este potente motor de búsqueda de vocablos facilita que los estudiantes puedan cambiar de diccionario según las necesidades de lectura del texto que estén trabajando sin necesidad de tener que acudir a fuentes externas ya que el programa selecciona los mejores diccionarios, aplicando un algoritmo interno en función de la evaluación emitida por los propios usuarios del sistema.

Por otra parte, cuando se utiliza dentro de Clilstore, la interfaz de Multidict enlaza con el texto que el estudiante está leyendo. Esto significa que el estudiante ya no tiene la necesidad de escribir la palabra para encontrar su significado. Los estudiantes sólo han de seleccionar cualquier palabra y la traducción aparecerá en la parte derecha de la pantalla. Si la palabra no aparece, sólo se ha de elegir un nuevo diccionario de la lista desplegable. Esto, sin lugar a dudas, supone un considerable ahorro de tiempo en búsquedas y convierte la lectura en una experiencia más sencilla y fluida, tanto si se trabaja en un ordenador como en un dispositivo móvil.

\section{(c) EY-NC-ND 2014, Universitat Politècnica de València}

I Jornadas IN-RED (2014) 


\subsection{Wordlink}

Wordlink puede enlazar casi cualquier página web, palabra a palabra, con cualquier diccionario online gratuito. Es el software que facilita el vínculo automático de cada una de las palabras de los textos incrustados en las unidades didácticas de Clilstore y puede también usarse como herramienta autónoma si los estudiantes quieren consultar con facilidad diccionarios online cuando leen páginas web. En la figura 3 se ilustra la ventana principal de navegación de Wordlink.

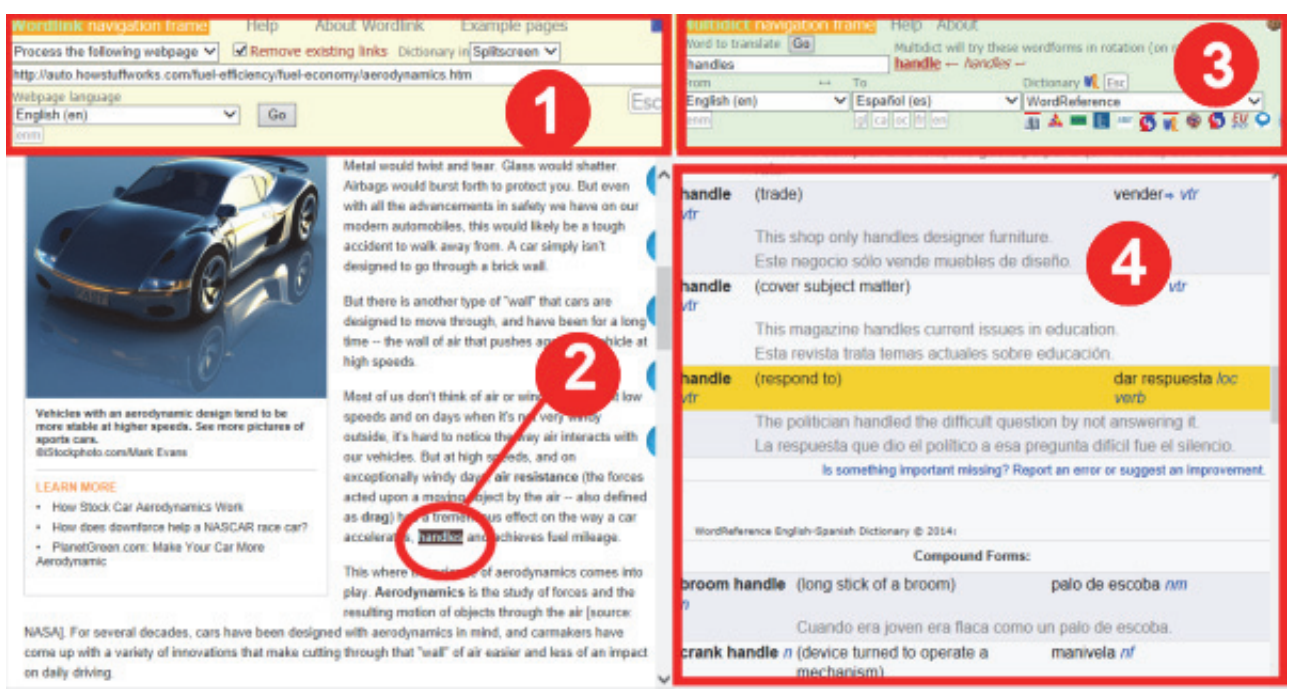

Figura 3. Página de muestra sobre aerodinámica enlazada a Wordlink.

Cuando se utiliza Wordlink como herramienta autónoma para enlazar todas las palabras de una página web determinada con los diccionarios online disponibles a través de Multidict, lo primero que debe hacer el estudiante es seleccionar el idioma del texto de la página web. A continuación, tras copiar y pegar la URL de la página web a enlazar dentro del campo correspondiente y pulsar sobre "Go" (véase la sección resaltada 1 en la Figura 3), podrá seleccionar cualquiera de las palabras del texto y buscarla en Multidict (véase la sección resaltada 3 en la Figura 3). Como se puede ver en el ejemplo de la Figura 3, la palabra que se ha señalado en el texto es "handles". Esta información enlaza automáticamente con la ventana de navegación de Multidict, como se muestra en la sección 3 de la Figura 3. Finalmente, las entradas traducidas aparecen en la interfaz nativa del diccionario seleccionado. En el ejemplo que se muestra abajo (sección resaltada 4), el diccionario desplegado es WordReference. 


\subsection{Clilstore}

Como hemos mencionado antes, Clilstore es el nombre que recibe tanto la herramienta de autor para crear unidades didácticas incorporando las funcionalidades de Multidict y Wordlink, pero también el repositorio de unidades existentes a las que pueden acceder los estudiantes para reforzar su aprendizaje. En este repositorio es donde aparecen las unidades creadas en el proyecto de innovación y mejora educativa objeto de este artículo. Los estudiantes seleccionan, mediante una serie de filtros (como son el nivel de conocimiento de la lengua meta, la temática de la unidad, el medio audiovisual incorporado, el autor, etc. o introduciendo palabras clave en el campo de búquedas), los materiales deseados. Una vez seleccionada la unidad didáctica aparece una interfaz como la siguiente:

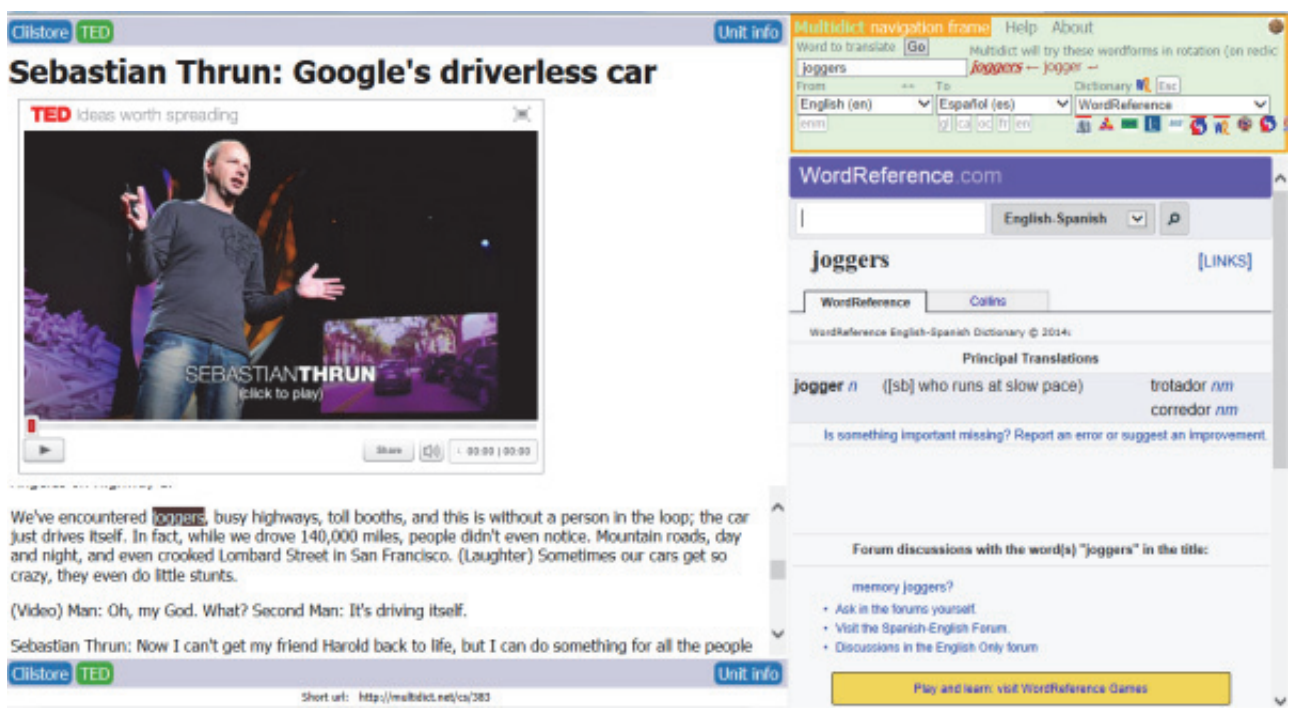

Figura 4. Ejemplo de unidad en Clilstore.

Nos referimos a estas unidades como unidades didácticas y no como ejercicios únicamente porque cada unidad incorpora una serie de actividades adicionales. Estas actividades pueden comprender ejercicios alojados en la propia plataforma en cualquiera de los formatos habituales como Word, PDF, Excel, etc., o enlaces a materiales externos disponibles en otras páginas web; también pueden consistir en lecturas adicionales para seguir profundizando en un tema, o incluso enlaces a ejercicios creados ad hoc con otras herramientas como por ejemplo Hot Potatos $^{i v}$ que permiten crear ejercicios a base de unas plantillas predefinidas.

Aunque no hay ninguna recomendación específica por parte de los creadores de Clilstore, la gran mayoría de las unidades ahí alojadas incorporan un vídeo y su transcripción completa. Serán las palabras de la transcripción del vídeo las que aparezcan

\section{(c) EY-NC-ND 2014, Universitat Politècnica de València}

I Jornadas IN-RED (2014) 
automáticamente enlazadas a la funcionalidad de Wordlink. Hay un creciente número de proveedores de vídeo streaming como YouTube, TED Talks, Kahn Academy , o el propio Politube de la UPV o los vídeos Polimedia creados a través del programa "Docencia en red"vi de la UPV, y disponibles en el repositoria institucional, Riunet, que proporcionan el código de incrustación, tanto del vídeo como de su transcripción, por lo que Clilstore no requiere la descarga de ningún vídeo ni se ve limitado por las restricciones de los derechos de autor ya que en ningún momento se apropia de los contenidos; únicamente es un vehículo para acceder a vídeos o archivos de sonido ya existentes en la red. A continuación describiremos una de las unidades creadas dentro del proyecto de innovación docente para la enseñanza de inglés, haciendo hincapié en cómo se da apoyo a las destrezas lingüísticas en general, y a la habilidad comunicativa en particular.

\section{Resultados}

Se describe en este apartado una de las unidades didácticas creadas para la asignatura de Inglés Técnico. La unidad está disponible en http://multidict.net/cs/2120 y lleva por título Design Methods. Tiene dos objetivos específicos. Por una parte, provocar la reflexión sobre distintos métodos creativos que se utilizan en el diseño industrial y, por otra, darles a conocer tres métodos para llevar a cabo sondeos entre grupos de población. Para ajustarse a la metodología propuesta -es decir, AICLE- las actividades de la unidad cumplen una doble función. Por una parte, apoyar el desarrollo de contenidos curriculares (la importancia de la validación de un nuevo diseño) y, por otra, estimular el inglés hablado. La unidad comienza con una serie de ejercicios de calentamiento en los que los estudiantes han de imaginar que tienen que diseñar una bolsa apta para el transporte en bicicleta. El enfoque de la unidad no es el diseño en sí de la bolsa, sino cómo averiguar las necesidades de los potenciales usuarios. Estas actividades iniciales están pensadas para provocar ideas por parte de los alumnos, impulsar el debate entre ellos y presentarles una serie de funciones del lenguaje, entre ellas: cómo expresar ideas propias y dar una opinión personal, y cómo motrar desacuerdo con la opinión de otros.

A continuación se les presenta a los alumnos 6 fragmentos de un texto para que lo reordenen. El texto está extraído de una página web donde se describen someramente los distintos métodos que utilizan los diseñadores para sus nuevas creaciones. La actividad tiene como finalidad, desde la perspectiva lingüística, que los estudiantes se fijen en la secuenciación discursiva y en los conectores que se utilizan para enlazar unas ideas con otras; y, desde la perspectiva curricular, la importancia que tiene en el proceso de diseño acertar en la muestra para llevar a cabo un sondeo representativo de una población determinada. Tras comentar las ideas principales del texto con la clase, acceso a la página web les permite comprobar por sí mismos si han acertado en la colocación de los 
fragmentos. Dado que el texto constituye un fragmento de un texto mayor sobre los métodos utilizados en el diseño de productos, a los estudiantes se les invita a continuación, a que lean el texto completo como preludio a un debate entre ellos (guiado) sobre la importancia de centrarse en la necesidades reales de los usuarios a la hora de diseñar un producto. Naturalmente, esta parta se centra de nuevo en la práctica y mejora del inglés oral. Para concluir esta parte de la unidad, se les pide que, en grupo, escriban una serie de cosas relacionadas con el planteamiento del inicio de la unidad (el diseño de la bolsa para personas que se desplazan al trabajo en bicicleta). En esta ocasión han de escribir. Se les pide que anoten a) las personas a las que enrevistarían, b) dónde y cuándo realizarían las entrevistas y c) las preguntas que les formularían. Desde el punto de vista del contenido curricular, los estudiantes siguen centrándose en la importancia de plantear bien un sondeo con el fin de recabar información de utilidad sobre las necesidades reales de un sector de la población que será el potencial usuario del producto a diseñar. Desde el punto de vista lingüístico, se repasa la formación de frases interrogativas en inglés.

La segunda parte de la unidad se basa en dos vídeos de YouTube y una serie de preguntas de comprensión oral. El primero de ellos describe, en menos de 5 minutos y de forma muy didáctica, tres formas de crear una muestra para llevar a cabo un sondeo. El segundo, que dura tan solo cuatro minutos, describe cuatro métodos para crear un grupo de muestra. Por último, y para concluir la unidad, se les pide a los alumnos que retomen la idea de diseñar una bolsa para personas que van a trabajar en bicicleta y que justifiquen qué método creen que es más adecuado para crear la muestra para llevar a cabo un sondeo con el fin de validar el diseño del producto en cuestión.

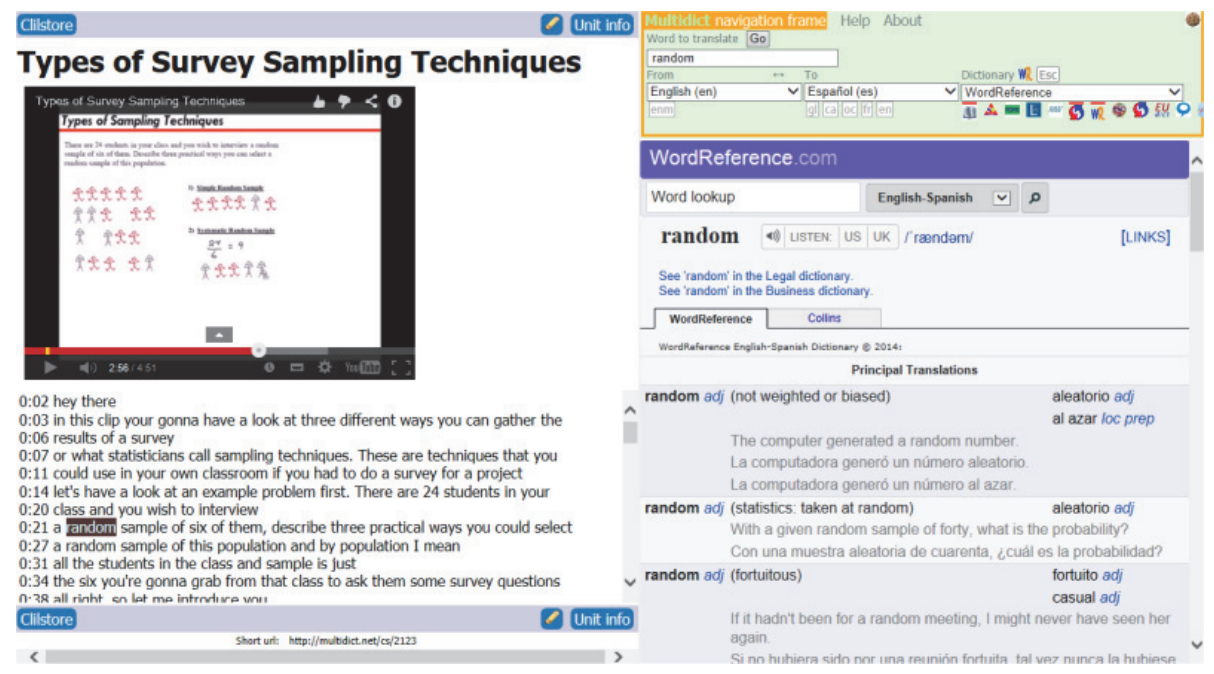

Figura 5. Unidad denominada "Design Methods".

\section{(c) EY-NC-ND 2014, Universitat Politècnica de València}

I Jornadas IN-RED (2014) 
Uno de los elementos innovadores de las actividades descritas es que, al haber sido creadas en Clilstore, todas las palabras están enlazadas a los diccionararios monolingües y bilingües que ofrece Multidict. En estos momentos, por ejemplo, hay 25 diccionarios para la combinación inglés-español-inglés y otros 21 monolingües en inglés, incluyendo el diccionario de pronunciación inglesa howjsay.com. Además, como los diccionarios de los que se nutre Multidict aceptan la lematitazión de las palabras, los estudiantes pueden consultar incluso el significado de un verbo conjugado.

El hecho de integrar los contenidos de la unidad didáctica en Clilstore significa que los estudiantes no han tenido, en ningún momento, que salir del entrono de aprendizaje para consultar un diccionario, conocer la traducción de una palabra o escuchar su pronunciación. Todo esto supone un enorme beneficio para los estudiantes ya que implica un ahorro de tiempo, además de evitar la innecesaria frustración que puede acarrear el hecho de no encontrar la definición o la traducción de una palabra desconocida a la primera y tener que ir buscando en diversas fuentes para resolver una duda. La optimización del tiempo y del esfuerzo es también, creemos, fundamental para favorecer un contexto de aprendizaje sólido.

\section{Conclusiones}

Como hemos visto, Clilstore es una herramienta sencilla pero, a la vez, muy potente por las funcionalidades que incorpora y que están diseñadas para ayudar a los estudiantes universitarios a enfrentarse a lecturas de textos y visionados de vídeos sobre temas relacionados con las asignaturas que están cursando en sus carreras sin las frustraciones propias de tropezarse con palabras o expresiones desconocidas que les obligue a paralizar la actividad para buscar ese léxico en un diccionario externo, ahorrando también así considerable tiempo que podrán invertir en la realización de las actividades. Es de destacar, asimsimso, la versatilidad del sistema ya que, en tanto que basado en código HTML, permite al autor de contenidos manipularlos según sus necesidades mediante un editor de texto incorporado.

Como las unidades pueden ser enlazadas también unas con otras, el sistema permite crear los contenidos completos de la programación de una asignatura para ofrecer al alumnado un material de apoyo que puede utilizar de forma autónoma a través de PoliformaT. ${ }^{\text {vii }}$

Dado que el proyecto se ha llevado a cabo durante el $2^{\circ}$ semestre del curso 2013-14, las fases de evaluación y de validación de los recursos didácticos desarrollados se llevarán a cabo a lo largo del curso 2014-15. 
Ana Gimeno y David Perry

\section{Referencias}

CONSEJO DE EUROPA (2001). Common European Framework of Reference for Languages. Cambridge: Cambridge University Press. Disponible en castellano a través de la web del Instituto Cervantes en http://cvc.cervantes.es/ensenanza/biblioteca_ele/marco.

DESIGN COUNCIL (2014). Introducing Design Methods. Disponible en http://www.designcouncil.org.uk/news-opinion/introducing-design-methods.

MARSH D. y LANGÉ G. (eds.) (2000). Using Languages to Learn and Learning to Use Languages, Jyväskylä, University of Jyväskylä.

\section{Agradecimientos}

Los autores quisieran agradecer a la Comisión Europea la subvención recibida para realizar el proyecto Tools for CLIL Teachers (Ref.: 517543-LLP-2011-DK-KA2-KA2MP) y al Vicerrectorado de Estudios, Calidad y Acreditación por la ayuda recibida para llevar a cabo el Proyecto de Innovación y Mejora Educativa descrito en este artículo (Ref.: B22/13).

\footnotetext{
${ }^{\mathrm{i}}$ Los cinco grados que se imparten en la ETSID son: Grado en Ingeniería Aeroespacial; Grado en Ingeniería en Diseño Industrial y Desarrollo de Productos; Grado en Ingeniería Eléctrica; Grado en Ingeniería Electrónica Industrial y Automática, y Grado en Ingeniería Mecánica.

ii Para más información sobre los inicios del "inglés para fines específicos" véase Strevens, P. (1977). New Orientations in the Teaching of English. Oxford: Oxford University Press.

iii Comisión de las Comunidades Europeas (2003). Comunicación No 449, Promover el aprendizaje de idiomas y la diversidad lingüística: Un Plan de acción 2004 - 2006.

Disponible en http://eur-lex.europa.eu/LexUriServ/LexUriServ.do?uri=COM:2003:0449:FIN:ES:PDF. [Fecha de consulta 3/6/2014]

${ }^{\text {iv }}$ Para más información sobre el programa Hot Potatoes, véase http://hotpot.uvic.ca.

v YouTube (http://www.youtube.com); TED Ideas worth spreading (http://www.ted.com); Kahn Academy (http://www.khanacademy.org).

vi Programa de apoyo a docencia utilizando medios digitales de la UPV, "Docencia en red": http://www.upv.es/contenidos/DOCENRED/indexc.html.

vii PoliformaT es la plataforma de gestión de contenidos (aula virtual) basada en Sakai, desarrollado por el MIT en EE.UU.
} 


\title{
El uso del blog y las redes sociales en la asignatura de Procedimientos de Construcción
}

\section{Víctor Yepes}

ICITECH. Equipo de Innovación y Calidad Educativa EXCELCON. Departamento de Ingeniería de la Construcción y Proyectos de Ingeniería Civil. Universitat Politècnica de València. vyepesp@cst.upv.es

\begin{abstract}
New technologies, social networks and blogs have changed the communication between people. The purpose of this paper is to describe the experience in the use of blogs and social media as a teaching tool in the subject of Construction Methods as well as to show the students' perception of using the blog as a learning tool. To know the students' perception regarding the launch of the blog, a survey was designed using a Likert Scale. The results show a positive assessment of the tool and the concern of the professor for the student learning as well as to serve students to better understand the construction methods and machinery. Moreover, in opinion of the students, the blog does not reduce the study time; additionaly, it would be of interest that the information of the blog were expanded by the professor. After a multiple regression analysis, the assessment of blog is reinforced by the fact that the professors of the subject continue to expande sharing information. To conclude, it is very important to include videos in order to improve the understanding of this subject.
\end{abstract}

Keywords: blog, social networks, construction methods, teaching innovation, new technologies, multivariate analysis.

\section{Resumen}

Las nuevas tecnologías, las redes sociales y los blogs han transformado la forma de comunicación entre las personas. El objetivo de esta comunicación es explicar la experiencia del autor en el uso de los blogs y las redes sociales como herramienta didáctica en las clases de Procedimientos de Construcción y presentar la percepción de los estudiantes del uso del blog como instrumento de aprendizaje. Para conocer la percepción de los

(cc) EY-NC-ND 2014, Universitat Politècnica de València

I Jornadas In-Red (2014) 
alumnos respecto a la puesta en marcha del blog, se ha diseñado un cuestionario utilizando una escala Likert. Los resultados muestran una valoración positiva de la herramienta, que representa para los alumnos una preocupación del profesor por el aprendizaje de los alumnos y que les sirve para mejorar la comprensión de los procedimientos constructivos y la maquinaria. Por otra parte, los alumnos opinan que el blog no les resta tiempo de estudio y que sería de interés que se ampliara la información contenida en él. Tras un análisis de regresión múltiple, la valoración del blog se refuerza por el hecho de que el profesor o los profesores de la asignatura sigan ampliando la información. Es muy importante la inclusión de vídeos explicativos, pues mejora la comprensión de la asignatura.

Palabras clave: blog, redes sociales, procedimientos de construcción, innovación docente, nuevas tecnologías, análisis multivariante.

\section{Introducción}

Las nuevas tecnologías, las redes sociales y los blogs han transformado la forma de comunicación entre las personas. Cualquier noticia o acontecimiento en cualquier parte del mundo se conoce prácticamente de forma instantánea. El uso de las redes sociales en el desarrollo de la Educación Superior es una muestra evidente de las formas de interacción que permite una comunicación fluida y dinámica entre los profesores y los alumnos.

Los blogs constituyen una de las herramientas más representativas de esta filosofía, pues ofrecen flexibilidad, adaptabilidad e integración con otras herramientas. Una página web actúa como un registro, se actualiza de forma fácil y frecuente. Los usuarios pueden aportar fácilmente información en sus blogs usando un browser, un software especializado en blogs, vía teléfono móvil o por correo electrónico. Por otra parte, las tecnologías no cambian por sí solas la enseñanza y el aprendizaje, pero pueden ayudarnos a introducir nuevas metodologías y nuevos entornos para aprender. Los blogs constituyen una nueva frontera para muchos profesores, siendo la investigación del uso de los blogs en la enseñanza escaso. Pero, ¿pueden estas herramientas usarse para mejorar la enseñanza y el aprendizaje?

Por otra parte, las obras y las construcciones que el hombre realiza para satisfacer necesidades básicas como la seguridad, la vivienda o los transportes, deben ejecutarse siguiendo cierto orden o plan preestablecido según un conjunto de normas o reglas capaces de asegurar su éxito. Pues bien, los procedimientos de construcción constituyen "los distintos procesos, sistemas y métodos disponibles para hacer realidad una obra siguiendo para ello un conjunto ordenado de reglas o prácticas constructivas basadas en la 
experiencia y en los conocimientos técnicos y científicos disponibles en ese momento, todo ello para conseguir construcciones útiles, seguras, económicas, estéticas, medioambientalmente aceptables y, a ser posible, perdurables en el tiempo" (Yepes, 2008).

En Valencia, la asignatura en el Plan anterior se denominó "Procedimientos Generales de Construcción y Organización de Obras" para pasa al nombre más corto de "Procedimientos de Construcción", y su versión reducida para algunas especialidades de ingeniero de obras públicas, "Maquinaria y Medios Auxiliares". En el actual plan de estudios, la asignatura se ha dividido en dos partes. En el grado de ingeniería civil, las asignaturas se denominan "Procedimientos de Construcción I y II", mientras que en el grado de ingeniería de obras públicas, reciben el nombre de "Tipologías y Procedimientos de las Construcciones Civiles I y II'. Estas asignaturas se ubican en el segundo curso y cada una de ellas tiene 4,5 créditos en cada cuatrimestre. En el propio blog quedan descritos los programas y la bibliografía asociada.

Procedimientos de Construcción es una asignatura donde la visualización de un vídeo (por ejemplo, procedente de Youtube), constituye una herramienta relevante para entender cómo se construye una estructura o cómo trabaja una máquina. Hasta hace bien poco, las únicas facilidades disponibles pasaban por la visualización de fotografías, catálogos, transparencias o presentaciones en Power Point (González et al., 2003), o bien libros sobre la materia (Pellicer et al., 2014). Sin embargo, en ocasiones se hace complicado explicar y entender un procedimiento, salvo que nos desplacemos a una obra. Por esta razón, creamos un blog específico para la docencia de la asignatura, que además, sirviese de repositorio de información y actuase como banderín en enganche en la motivación e interés de los alumnos. Todo el contenido se basa en libros, apuntes o información extraída de internet. Además, las redes sociales tales como Facebook, LinkedIn o Twitter se instrumentan para difundir el contenido y llegar de forma más directa a los estudiantes. Un foro o cualquier clase de red social permiten a los estudiantes encontrarse con muchos otros como él. Estas tecnologías facilitan la comunicación, la colaboración y la construcción de comunidades virtuales. Además, permite a los estudiantes aprender y aprovechar el conocimiento generado por terceros.

\section{Objetivos}

El objetivo de esta comunicación es explicar la experiencia del autor en el uso de los blogs como herramienta de enseñanza en las clases de Procedimientos de Construcción y presentar la percepción de los estudiantes del uso del blog como instrumento de aprendizaje. Esta posibilidad, tal y como se puede ver en la Tabla 1, forma parte de un entramado de comunicación interconectado con entornos y herramientas de elevada potencia de comunicación.

\section{(cc) EY-NC-ND 2014, Universitat Politècnica de València}


El uso del blog y las redes sociales en la asignatura Procedimientos de Construcción

Tabla 1. Entornos y enlaces sobre Procedimientos de Construccion

\begin{tabular}{ll}
\hline Entorno & Enlace \\
\hline Facebook & https://www.facebook.com/groups/procedimientosconstruccion/ \\
Linkedin & http://www.linkedin.com/groups/Procedimientos-generales-construcci\%C3\%B3n- \\
& organizaci\%C3\%B3n-obras-3699503?trk=hb_side_g\&gid=3699503 \\
Paper.li & $\underline{\text { http://paper.li/f-1358587409 }}$ \\
Scoop.it! & $\underline{\text { http://www.scoop.it/t/procedimientos-de-construccion }}$ \\
Wikispaces & $\underline{\text { http://procedimientosconstruccion.wikispaces.com/ }}$ \\
Wordpress & $\underline{\text { http://procedimientosconstruccion.blogs.upv.es/ }}$ \\
Youtube & $\underline{\mathrm{http}: / / \text { www.youtube.com/playlist?list=PL7E56CF86A0BF2288 }}$ \\
\hline
\end{tabular}

\section{Desarrollo de la innovación}

La fecha de nacimiento del blog (http://procedimientosconstruccion.blogs.upv.es/) es el 15 de septiembre de 2012, es decir, se inicia con el comienzo del curso académico 2012-2013. En mayo de 2014, el blog ya cuenta con más de 350 posts de contenido. Una de las necesidades que pretendía cubrir el blog era la de organizar toda la información adicional que, de forma habitual se venía utilizando en clase, pero que se encontraba dispersa y poco accesible al alumno. Así por ejemplo, a veces se recogían noticias de prensa, fotografías o vídeos sobre maquinaria y técnicas constructivas que, de un curso para otro, en ocasiones se perdía o no podía recuperarse por parte del alumno como material para otras asignaturas. Sobre estos post los alumnos realizan tareas complementarias y grupales, de forma que el blog se convierte en una herramienta viva, cuyos contenidos se actualizan y amplían constantemente. Además, pretende de servir de referencia a los alumnos en su futuro académico y profesional. Un aspecto interesante es la posibilidad que brinda el blog de insertar objetos docentes (vídeos educativos o laboratorios virtuales) procedentes del programa Docencia en Red de la Universitat Politècnica de València, así como su vinculación a la página de la asignatura alojada en la plataforma PoliformaT.

En la Figura 1 se puede observar el aspecto del blog. Se trata de ir colgando, sin solución de continuidad, y año tras año, información relevante al alumno que le permita conocer mejor, por sus propios medios, un aspecto concreto. Además, se incluye información sobre el programa de la asignatura, los apuntes docentes, un tesauro con más de 2500 términos (muchos traducidos al inglés, con hipervínculos a información adicional) y una lista de ingenieros eminentes.

Además, para aumentar la difusión de los contenidos del blog en las redes sociales, de forma que la información sea útil al mayor número de usuarios, cada contenido del blog se replica automáticamente en los grupos de Facebook, Linkedin o Twitter, con herramientas como dlrv.it o paper.li. Además, el contenido se puede colgar adicionalmente en PoliformaT, lo cual garantiza su difusión entre el alumnado de la asignatura. 


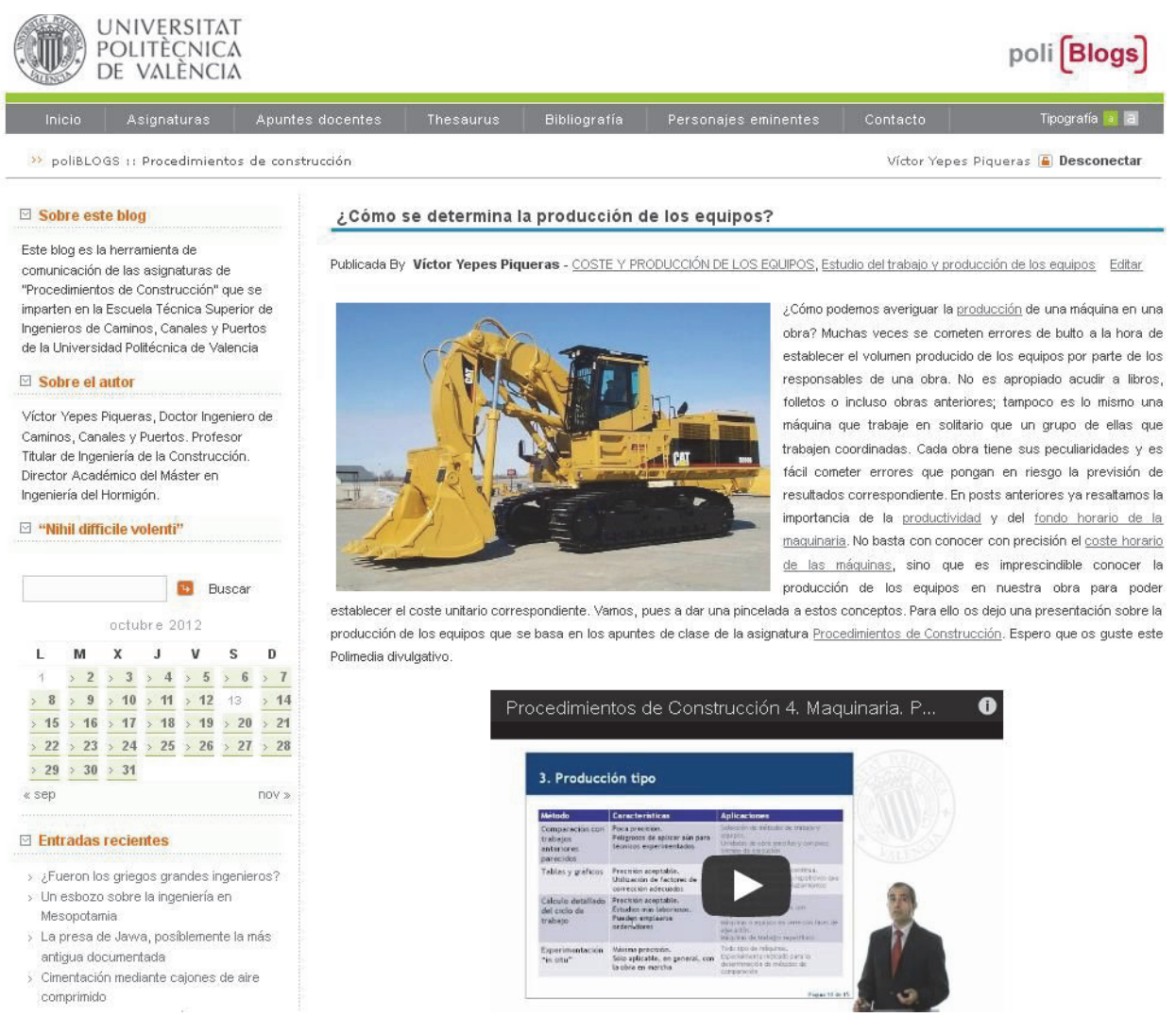

Fig. 1 Aspecto del blog de la asignatura de Procedimientos de Construcción

\section{Resultados}

Para conocer la percepción de los alumnos respecto a la puesta en marcha del blog de la asignatura, se ha diseñado un cuestionario para realizar una encuesta anónima. Con el objeto de obtener la información necesaria para realizar la investigación, el cuestionario se ha dividido en dos partes: la primera trata de caracterizar al individuo, preguntando el grupo al que pertenece, el sexo, la edad, la calificación obtenida en la asignatura y la dedicación prestada (horas de estudio semanales); en la segunda se plantearon 18 preguntas para conocer la opinión del encuestado respecto al blog utilizando una escala Likert de 5 opciones para las respuestas: 1) muy de acuerdo, 2) de acuerdo, 3) a medias, 4) en desacuerdo, 5) muy en desacuerdo.

\section{(cc) EY-NC-ND 2014, Universitat Politècnica de València}

I Jornadas IN-RED (2014) 


\subsection{Caracterización de la encuesta realizada}

Se ha realizado una muestra de conveniencia no probabilística a los alumnos de la asignatura Procedimientos de Construcción I, tras haberla cursado. El total de matriculados es de 148 , de los cuales 80 pertenecen al grupo $\mathrm{F}$ y 68 al grupo $\mathrm{G}$. El tamaño de la muestra ha sido $N=122$. El nivel de confianza utilizado es del $95 \%$, con $p=q=0,5$, lo cual implica un error muestral del $3,7 \%$.

Las respuestas recibidas al cuestionario fueron de 63 para el grupo $\mathrm{F}$ (78,75\% de los alumnos de este grupo) y de 59 para el grupo G (86,76\% de los posibles). Los alumnos encuestados fueron $89(72,95 \%)$, mientras que las alumnas fueron $33(27,05 \%)$. En cuanto a grupos de edades, entre 18 y 19 años respondieron 69 (56,55\%), entre 20 y 21 años respondieron $33(27,05 \%)$ y con 22 o más contestaron 19 (15,57\%), no contestando a esta pregunta un alumno $(0,82 \%)$.

También se preguntó sobre la nota obtenida en la asignatura: 5 alumnos con sobresaliente (4,10\%), 36 con notable (29,51\%), 69 aprobados (56,55\%), 11 suspensos $(9,02 \%)$ y un alumno no presentado $(0,82 \%)$. En cuanto a las horas de estudio, 34 alumnos $(27,87 \%)$ manifestaron que estudiaban menos de 1 hora a la semana, 74 (60,66\%) dedicaban entre una y tres horas y 14 alumnos $(11,47 \%)$ más de tres semanales. En la Figura 2 se ha representado la caracterización de la muestra analizada.

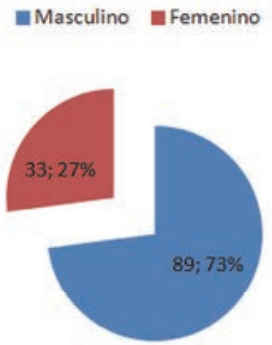

sexo

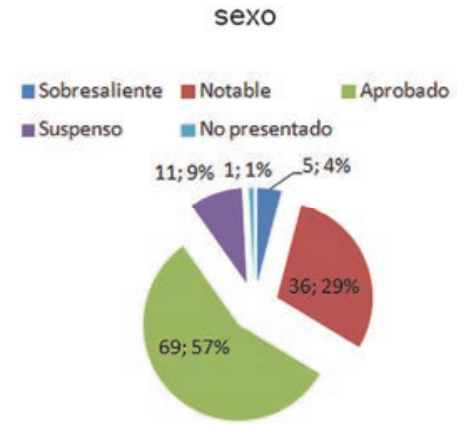

calificación obtenida

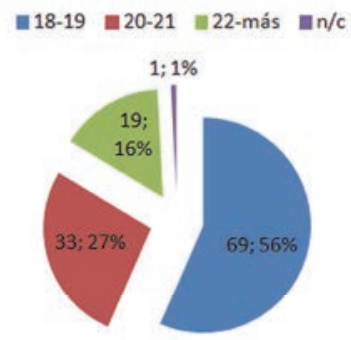

edad

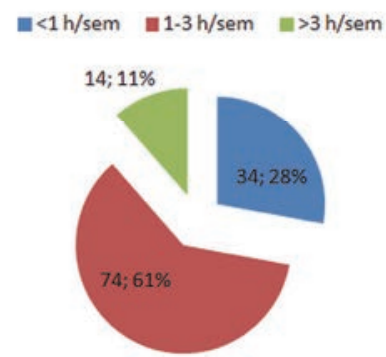

horas semanales de estudio

Fig. 2 Caracterización de la muestra analizada 
La herramienta de tratamiento de datos y análisis estadístico ha sido SPSS 17. A continuación se examinan las variables y se aplica un análisis multivariante para interpretar los resultados.

\subsection{Análisis estadístico descriptivo}

La Tabla 1 recoge la media y la desviación típica obtenidas para cada una de las 18 preguntas realizadas a los encuestados. Se comprueba que, aquello en lo que están más de acuerdo los encuestados, es que: (1) el blog muestra el interés del profesor por el aprendizaje de los alumnos, (2) que los vídeos mejoran la comprensión de los procedimientos constructivos y la maquinaria y (3) la valoración positiva de la realización de un blog de procedimientos de construcción. Se puede apreciar que la pregunta 12 no sólo es la mejor valorada, sino la que menor desviación típica presenta. En cambio, la que mayor desviación presenta es la pregunta 10 en la que el alumno manifiesta si ha visto la totalidad de los vídeos.

La valoración que más en desacuerdo están los alumnos es aquella en la que se pregunta si creen que el blog les hace perder un tiempo valioso de estudio, así como aquella otra en la que se plantea la preferencia de no ampliar la información de la asignatura con blogs. Estas preguntas están plantadas en sentido negativo, lo cual significa un fuerte acuerdo en que los blogs no hacen perder tiempo de estudio y que sería conveniente seguir ampliando la información de los blogs.

Tras realizar un análisis de correlaciones entre las preguntas realizadas, la más fuerte (correlación de Pearson de 0,654, con significación bilateral al nivel 0,01) corresponde a la valoración positiva del blog (pregunta 18) y a la voluntad de que el profesor siguiera ampliando el blog (pregunta 13). Esto presenta un gran interés en el estudio, pues parece indicar que los alumnos valoran del blog la posibilidad de que éste pueda recoger a largo plazo mucha información que, en un futuro, pueda serles de utilidad.

Se ha querido comprobar qué características influyen significativamente en la valoración positiva del blog. Para ello se ha realizado un ANOVA en el que se ha comprobado que el grupo, la edad, las horas de estudio o las calificaciones obtenidas no inciden significativamente en la valoración sobre el blog. Sin embargo, y esto resulta muy interesante, el sexo sí que influye de forma significativa. Se ha encontrado que las alumnas valoran menos el blog (2,03 de media) que los alumnos (1,69 de media), con un $p$-valor $=$ 0,029 . Para entender el motivo de esta diferencia, se han realizado tablas de contingencia que han mostrado (prueba chi-cuadrado) que no hay depedencia entre el sexo con las calificaciones obtenidas, con el grupo, con la edad o con las horas de estudio. Si aceptamos que el blog tiene como objetivo acercar la realidad de la obra por medio de vídeos y

\section{(c)) EY-NC-ND 2014, Universitat Politècnica de València}

I Jornadas IN-RED (2014) 
explicar el funcionamiento de la maquinaria y las técnicas constructivas, parece ser que las alumnas valoran esta parcela de la ingeniería civil menos que los alumnos. Se podría decir que las tareas trabajo a pie de obra serían menos atractivas para las chicas que aquellas otras de cálculo o de gabinete, aunque para afirmar esto deberíamos hacer estudios adicionales.

Tabla 1. Media y desviación típica de las respuestas al cuestionario

\begin{tabular}{|c|c|c|c|}
\hline $\mathbf{N}^{\mathbf{0}}$ & Pregunta & Media & D. Típ. \\
\hline 12 & Creo que el Blog muestra el interés del profesor por nuestro aprendizaje & 1,70 & 0,715 \\
\hline 4 & $\begin{array}{l}\text { Los vídeos del Blog han mejorado mi comprensión de los procedimientos } \\
\text { constructivos y de la maquinaria }\end{array}$ & 1,75 & 0,788 \\
\hline 18 & $\begin{array}{l}\text { Valoro positivamente la realización de un Blog de Procedimientos de } \\
\text { Construcción }\end{array}$ & 1,78 & 0,777 \\
\hline 3 & Considero que el Blog mejora mi formación como futuro ingeniero & 1,93 & 0,773 \\
\hline 14 & Creo que el Blog me servirá en un futuro para consultar cosas & 1,98 & 0,749 \\
\hline 1 & Considero que el Blog mejora la comprensión de la asignatura & 2,05 & 0,822 \\
\hline 13 & Aconsejaría al profesor seguir ampliando el Blog con más contenidos & 2,14 & 0,956 \\
\hline 15 & $\begin{array}{l}\text { Me gustaría que todos los profesores de la asignatura contribuyesen a } \\
\text { completar el Blog }\end{array}$ & 2,24 & 0,900 \\
\hline 5 & El texto explicativo del Blog es completo y suficiente para entenderlo & 2,46 & 0,740 \\
\hline 2 & Considero que el Blog aporta información necesaria para aprobar & 2,52 & 0,883 \\
\hline 9 & Siendo honestos, no me he leído todos los posts colgados por el profesor & 2,53 & 1,319 \\
\hline 6 & El Blog necesita de la explicación del profesor para entenderlo mejor & 2,64 & 0,996 \\
\hline 17 & $\begin{array}{l}\text { Todos los profesores de Ingeniería Civil deberían hacer un blog con su } \\
\text { asignatura }\end{array}$ & 2,81 & 1,039 \\
\hline 10 & Siendo honestos, no me he visto todos los vídeos colgados por el profesor & 2,90 & 1,468 \\
\hline 7 & Los posts del Blog son demasiado largos & 3,04 & 0,885 \\
\hline 8 & El Blog me ha servido para aprobar la asignatura & 3,23 & 0,994 \\
\hline 16 & Preferiría no ampliar la información de la asignatura con Blogs & 3,46 & 1,005 \\
\hline 11 & Creo que el Blog nos hace perder tiempo valioso de estudio & 3,82 & 0,927 \\
\hline
\end{tabular}




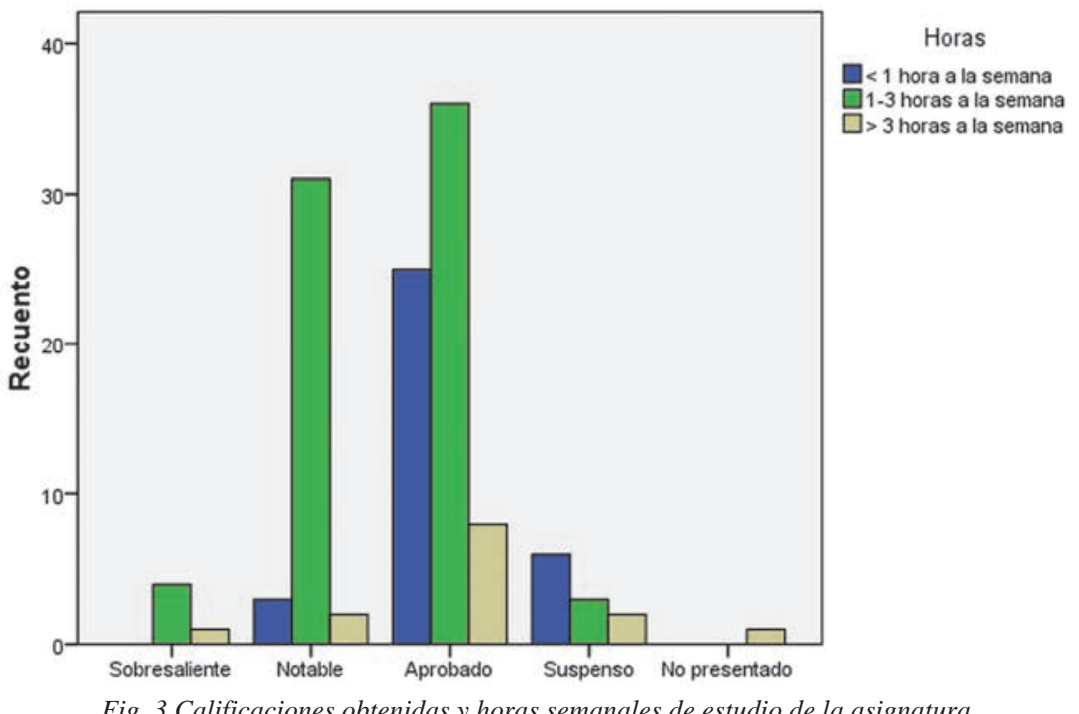

Otra conclusión de gran interés, no relacionada directamente con el estudio de la percepción del blog, ha sido ver si existe relación entre las horas de estudio y las calificaciones obtenidas. Para ello se ha realizado la prueba chi-cuadrado sobre la tabla de contingencia y se comprueba estadísticamente dicha relación, con un $p$-valor de 0,001 para la significación asintótica bilateral. Este resultado, que muestra lo que el sentido común predice, puede comprobarse de forma cualitativa en la Figura 3.

\subsection{Aplicación del análisis multivariante}

A continuación se realiza un análisis factorial mediante el método de componentes principales (Yepes et al., 2009) para identificar las variables subyacentes o factores que expliquen la configuración de las correlaciones dentro del conjunto de variables observadas. En definitiva, se quiere averiguar los "constructos" o variables subyacentes que permitan explicar la mayoría de la varianza observada. Además, se va a realizar un análisis de regresión lineal múltiple para intentar explicar al máximo la valoración positiva del blog, que se considerará como variable dependiente.

\subsubsection{Análisis de componentes principales}

$\mathrm{El}$ análisis de componentes principales examina la interdependencia entre variables para reducir la dimensión de un conjunto original de variables a un nuevo subconjunto formado

\section{(cc) EY-NC-ND 2014, Universitat Politècnica de València}

I Jornadas IN-RED (2014) 
por variables no observables. En síntesis, calcula unos factores que sean combinación lineal de las variables originales y que, además, sean independientes entre sí. La primera componente principal se escoge de forma que explique la mayor parte de la varianza posible de las variables originales, y así sucesivamente. Esta técnica no presupone una dependencia a priori entre las variables, y por tanto, se aplica antes de iniciar una regresión múltiple (Shaw, 2003).

Para evitar que la unidad de medida influya en los resultados, se ha empleado la matriz de correlaciones en lugar de la de covarianzas. De este modo, el valor medio de los componentes principales es 0 y su desviación típica, 1. Además, se ha tomado como criterio para determinar el número de componentes principales el que su autovalor sea superior a la unidad. Asimismo, para facilitar la interpretación, se ha empleado el método Varimax, que supone una rotación ortogonal que minimiza el número de variables que tienen saturaciones altas en cada factor (Kaiser, 1958).

Antes de realizar la extracción de los componentes principales, cada una de las variables queda explicada al $100 \%$ por ella misma. Sin embargo, una vez extraídas las componentes principales, éstas no explican toda la variabilidad de cada variable, pues se pierde información. En la Tabla 2 queda reflejada la desviacion estandarizada tras la extracción, es decir, las comunalidades, que miden el grado de información que tenemos tras dicha extracción. Lo que mejor explica el modelo es la pregunta 10 (no ha visto los alumnos todos los vídeos), y la que menos la pregunta 14 (el blog servirá en un futuro para consultar cosas).

Con los criterios expuestos, subyacen 6 componentes principales que son capaces de explicar el $66,669 \%$ de la varianza de las 18 preguntas de la encuesta realizada (ver Tabla 3). Los componentes tienen que ver con los siguientes aspectos subyacentes:

- Componente 1: Mejora de la comprensión

- Componente 2: Extensión del blog a otros profesores y asignaturas

- Componente 3: Uso del blog

- Componente 4: Necesidad de explicación adicional

- Componente 5: Interés del profesor por el blog

- Componente 6:Relacionado con aprobar la asignatura

La Tabla 4 recoge la matriz factorial de los componentes rotados, que indica la correlación existente entre cada uno de los componentes principales y las variables originales. Lo que representa son los pesos de cada variable en la relación lineal de cada componente principal con las distintas variables. 
Tabla 2. Comunalidades

\begin{tabular}{|c|c|c|}
\hline $\mathbf{N}^{0}$ & Pregunta & Extracción \\
\hline 10 & $\begin{array}{l}\text { Siendo honestos, no me he visto todos los vídeos colgados por el } \\
\text { profesor }\end{array}$ & 0,901 \\
\hline 9 & Siendo honestos, no me he leído todos los posts colgados por el profesor & 0,865 \\
\hline 5 & El texto explicativo del Blog es completo y suficiente para entenderlo & 0,773 \\
\hline 17 & $\begin{array}{l}\text { Todos los profesores de Ingeniería Civil deberían hacer un blog con su } \\
\text { asignatura }\end{array}$ & 0,738 \\
\hline 2 & Considero que el Blog aporta información necesaria para aprobar & 0,737 \\
\hline 13 & Aconsejaría al profesor seguir ampliando el Blog con más contenidos & 0,722 \\
\hline 4 & $\begin{array}{l}\text { Los vídeos del Blog han mejorado mi comprensión de los } \\
\text { procedimientos constructivos y de la maquinaria }\end{array}$ & 0,679 \\
\hline 18 & $\begin{array}{l}\text { Valoro positivamente la realización de un Blog de Procedimientos de } \\
\text { Construcción }\end{array}$ & 0,667 \\
\hline 8 & El Blog me ha servido para aprobar la asignatura & 0,665 \\
\hline 6 & El Blog necesita de la explicación del profesor para entenderlo mejor & 0,615 \\
\hline 16 & Preferiría no ampliar la información de la asignatura con Blogs & 0,612 \\
\hline 1 & Considero que el Blog mejora la comprensión de la asignatura & 0,611 \\
\hline 11 & Creo que el Blog nos hace perder tiempo valioso de estudio & 0,602 \\
\hline 12 & Creo que el Blog muestra el interés del profesor por nuestro aprendizaje & 0,596 \\
\hline 15 & $\begin{array}{l}\text { Me gustaría que todos los profesores de la asignatura contribuyesen a } \\
\text { completar el Blog }\end{array}$ & 0,582 \\
\hline 3 & Considero que el Blog mejora mi formación como futuro ingeniero & 0,560 \\
\hline 7 & Los posts del Blog son demasiado largos & 0,550 \\
\hline 14 & Creo que el Blog me servirá en un futuro para consultar cosas & 0,524 \\
\hline
\end{tabular}

\subsection{2. $\quad$ Modelos de regresión múltiple}

En este apartado realizamos un análisis de regresión de todas las variables para intentar establecer modelos que expliquen la variable dependiente (pregunta 18): valoro positivamente la realización de un blog de Procedimientos de Construcción. Para ello se realizan inferencias acerca de modelos lineales simples o múltiples y se obtienen medidas cuantitativas del grado de relación de las variables a través del coeficiente de correlación $R$. Los modelos lineales se ajustan por mínimos cuadrados de forma que la variable dependiente se encuentre explicada lo máximo posible por un conjunto de variables independientes. La bondad del ajuste se evalúa mediante el coeficiente de determinación $R^{2}$, que se interpreta como la proporción de variación de la variable de respuesta explicada mediante el modelo de regresión lineal (Draper y Smith, 1999).

\section{(cc) EY-NC-ND 2014, Universitat Politècnica de València}

I Jornadas IN-RED (2014) 
El uso del blog y las redes sociales en la asignatura Procedimientos de Construcción

Tabla 3. Varianza total explicada

\begin{tabular}{cccc}
\hline & \multicolumn{3}{c}{ Autovalores iniciales } \\
\hline Componente & Total & \% de la varianza & \% acumulado \\
\hline 1 & 5,512 & 30,623 & 30,623 \\
2 & 1,669 & 9,272 & 39,896 \\
3 & 1,513 & 8,404 & 48,300 \\
4 & 1,227 & 6,817 & 55,116 \\
5 & 1,065 & 5,916 & 61,032 \\
6 & 1,015 & 5,637 & 66,669 \\
7 & 0,977 & 5,429 & 72,098 \\
8 & 0,885 & 4,914 & 77,012 \\
9 & 0,649 & 3,607 & 80,619 \\
10 & 0,630 & 3,498 & 84,117 \\
11 & 0,545 & 3,025 & 87,143 \\
12 & 0,463 & 2,571 & 89,714 \\
13 & 0,440 & 2,445 & 92,158 \\
14 & 0,391 & 2,175 & 94,333 \\
15 & 0,354 & 1,968 & 96,300 \\
16 & 0,278 & 1,547 & 97,847 \\
17 & 0,224 & 1,244 & 99,091 \\
18 & 0,164 & 0,909 & 100,000 \\
\hline
\end{tabular}

En primer lugar, se intenta explicar cada variable de respuesta en función de aquella variable independiente con la cual se encuentra más correlacionada. Se trata de aumentar el coeficiente de regresión incorporando variables independientes explicativas. Para ello se procede mediante el método stepwise de pasos sucesivos (Hocking, 1976), consistente en introducir las variables una por una y comprobar si la variable permanece o sale del modelo. Se toma como criterio de inclusión un incremento en la varianza explicada significativo al $5 \%(F=0,05)$, mientras que para excluir una variable se considera un decremento del $10 \%(F=0,10)$. La primera variable introducida es la que presenta un coeficiente de correlación $R$ más alto. A continuación se vuelven a calcular todas las correlaciones eliminando la influencia de aquella que ya ha entrado en el modelo, y se introduce la siguiente con mayor $R$; de esta forma se consigue que las variables que entren no sean dependientes de las que ya figuran en el modelo. Como resultado de la regresión múltiple realizada (ver Tabla 5), se puede comprobar cómo la valoración positiva del blog se ve reforzada por el hecho de que el profesor y otros profesores continúen ampliando los contenidos. Además, esta valoración positiva se ve influenciada por la inclusión de vídeos explicativos. Por último, parece claro que los alumnos no consideran que esta herramienta les haga perder tiempo de estudio. Con el modelo 4 queda explicada el 57,3\% de toda la variabilidad de la variable dependiente.

(c)) EY-NC-ND 2014, Universitat Politècnica de València 
Tabla 4. Matriz de componentes rotados

\begin{tabular}{|c|c|c|c|c|c|c|c|}
\hline & & & & Compon & ntes & & \\
\hline $\mathbf{N}^{\mathbf{0}}$ & Pregunta & 1 & 2 & 3 & 4 & 5 & 6 \\
\hline 4 & $\begin{array}{l}\text { Los vídeos del Blog han mejorado mi } \\
\text { comprensión de los procedimientos } \\
\text { constructivos y de la maquinaria }\end{array}$ & 0,780 & & & & & \\
\hline 13 & $\begin{array}{l}\text { Aconsejaría al profesor seguir ampliando } \\
\text { el Blog con más contenidos }\end{array}$ & 0,663 & & & & & \\
\hline 1 & $\begin{array}{l}\text { Considero que el Blog mejora la } \\
\text { comprensión de la asignatura }\end{array}$ & 0,649 & & & & & \\
\hline 3 & $\begin{array}{l}\text { Considero que el Blog mejora mi } \\
\text { formación como futuro ingeniero }\end{array}$ & 0,589 & & & & & \\
\hline 18 & $\begin{array}{l}\text { Valoro positivamente la realización de un } \\
\text { Blog de Procedimientos de Construcción }\end{array}$ & 0,579 & 0,501 & & & & \\
\hline 11 & $\begin{array}{l}\text { Creo que el Blog nos hace perder tiempo } \\
\text { valioso de estudio }\end{array}$ & $-0,561$ & & & & & \\
\hline 17 & $\begin{array}{l}\text { Todos los profesores de Ingeniería Civil } \\
\text { deberían hacer un blog con su asignatura }\end{array}$ & & 0,815 & & & & \\
\hline 16 & $\begin{array}{l}\text { Preferiría no ampliar la información de la } \\
\text { asignatura con Blogs }\end{array}$ & & $\begin{array}{l}- \\
0,709\end{array}$ & & & & \\
\hline 15 & $\begin{array}{l}\text { Me gustaría que todos los profesores de la } \\
\text { asignatura contribuyesen a completar el } \\
\text { Blog }\end{array}$ & & 0,661 & & & & \\
\hline 14 & $\begin{array}{l}\text { Creo que el Blog me servirá en un futuro } \\
\text { para consultar cosas }\end{array}$ & & & & & & \\
\hline 10 & $\begin{array}{l}\text { Siendo honestos, no me he visto todos los } \\
\text { vídeos colgados por el profesor }\end{array}$ & & & 0,923 & & & \\
\hline 9 & $\begin{array}{l}\text { Siendo honestos, no me he leído todos los } \\
\text { posts colgados por el profesor }\end{array}$ & & & 0,905 & & & \\
\hline 6 & $\begin{array}{l}\text { El Blog necesita de la explicación del } \\
\text { profesor para entenderlo mejor }\end{array}$ & & & & 0,746 & & \\
\hline 7 & Los posts del Blog son demasiado largos & & & & 0,584 & & \\
\hline 5 & $\begin{array}{l}\text { El texto explicativo del Blog es completo } \\
\text { y suficiente para entenderlo }\end{array}$ & & & & & 0,837 & \\
\hline 12 & $\begin{array}{l}\text { Creo que el Blog muestra el interés del } \\
\text { profesor por nuestro aprendizaje }\end{array}$ & & & & & 0,528 & \\
\hline 2 & $\begin{array}{l}\text { Considero que el Blog aporta información } \\
\text { necesaria para aprobar }\end{array}$ & & & & & & 0,789 \\
\hline 8 & $\begin{array}{l}\text { El Blog me ha servido para aprobar la } \\
\text { asignatura }\end{array}$ & & & & & & 0,734 \\
\hline
\end{tabular}

(cc)) EY-NC-ND 2014, Universitat Politècnica de València

I Jornadas IN-RED (2014) 
El uso del blog y las redes sociales en la asignatura Procedimientos de Construcción

Tabla 5. Modelos de regresión múltiple. Variable dependiente: Valoro positivamente la realización de un blog de Procedimientos de Construcción

\begin{tabular}{|c|c|c|c|}
\hline \multicolumn{2}{|c|}{ Modelo } & \multirow{2}{*}{$\begin{array}{l}\text { Coef. } \\
0,642\end{array}$} & \multirow{3}{*}{$\begin{array}{l}\boldsymbol{R}^{2} \\
0,423\end{array}$} \\
\hline 1 & (Constante) & & \\
\hline & Aconsejaría al profesor seguir ampliando el Blog con más contenidos & 0,531 & \\
\hline \multirow[t]{3}{*}{2} & (Constante) & 0,219 & \multirow{3}{*}{0,487} \\
\hline & Aconsejaría al profesor seguir ampliando el Blog con más contenidos & 0,458 & \\
\hline & $\begin{array}{l}\text { Todos los profesores de Ingeniería Civil deberían hacer un blog con su } \\
\text { asignatura }\end{array}$ & 0,206 & \\
\hline \multirow[t]{4}{*}{3} & (Constante) & 1,335 & \multirow{4}{*}{0,539} \\
\hline & Aconsejaría al profesor seguir ampliando el Blog con más contenidos & 0,357 & \\
\hline & $\begin{array}{l}\text { Todos los profesores de Ingeniería Civil deberían hacer un blog con su } \\
\text { asignatura }\end{array}$ & 0,193 & \\
\hline & Creo que el Blog nos hace perder tiempo valioso de estudio & $-0,226$ & \\
\hline \multirow[t]{5}{*}{4} & (Constante) & 1,006 & \multirow{5}{*}{0,573} \\
\hline & Aconsejaría al profesor seguir ampliando el Blog con más contenidos & 0,288 & \\
\hline & $\begin{array}{l}\text { Todos los profesores de Ingeniería Civil deberían hacer un blog con su } \\
\text { asignatura }\end{array}$ & 0,197 & \\
\hline & Creo que el Blog nos hace perder tiempo valioso de estudio & $-0,201$ & \\
\hline & $\begin{array}{l}\text { Los vídeos del Blog han mejorado mi comprensión de los procedimientos } \\
\text { constructivos y de la maquinaria }\end{array}$ & 0,212 & \\
\hline
\end{tabular}

\section{Conclusiones}

El uso de las nuevas tecnologías y de las redes sociales en el aprendizaje de asignaturas de alto contenido tecnológico y visual resulta una herramienta de gran valor en la enseñanza universitaria. Los resultados de la percepción de los alumnos respecto al blog de la asignatura de Procedimientos de Construcción muestran una valoración positiva de la herramienta, que representa para los alumnos una preocupación del profesor por el aprendizaje de los alumnos y que les sirve para mejorar la comprensión de los procedimientos constructivos y la maquinaria. Por otra parte, los alumnos opinan que el blog no les resta tiempo de estudio y que sería de interés que se ampliara la información contenida en él. Tras un análisis de regresión múltiple, la valoración del blog se refuerza por el hecho de que el profesor o los profesores de la asignatura sigan ampliando la información. Es muy importante la inclusión de vídeos explicativos, pues mejora la comprensión de la asignatura.

Como información adicional, se ha verificado que las calificaciones obtenidas por los alumnos están relacionadas con las horas semanales de estudio. Como curiosidad, la valoración del blog es significativamente menor en las alumnas que en los alumnos, lo cual

(c) EY-NC-ND 2014, Universitat Politècnica de València

I Jornadas IN-RED (2014) 
implicaría una mayor apreciación por parte de los alumnos de los aspectos prácticos relacionados con la obra y los procedimientos constructivos reales, frente a una vocación más de gabinete u oficina técnica de las alumnas, aunque este extremo habría que comprobarlo con estudios posteriores.

\section{Agradecimientos}

El autor agradece la financiación recibida por el Ministerio de Ciencia e Innovación (Proyecto de Investigación BIA2011-23602) y por la Universitat Politècnica de València (Proyecto de Innovación y Mejora Educativa PIME B01).

\section{Referencias}

DRAPER, N.; SMITH, H. (1999). Applied regression analysis. New York: Wiley.

GONZÁLEZ, F.; MARTÍ, J.V.; YEPES, V.; DOMINGO, A. (2003). Imágenes de construcción de pasos superiores, puentes de vigas y cajones hincados. Valencia: Editorial UPV.

HOCKING, R. (1976). "The analysis and selection of variables in linear regression" en Biometrics, vol. 32, p. 1-49.

KAISER, H.F. (1958). "The Varimax criterion for analytic rotation in factor analysis" en Psychometrika, vol. 23, issue 3, p. 187-200.

PELLICER, E.; YEPES, V.; TEIXEIRA, J.C.; MOURA, H.P.; CATALÁ, J. (2014). Construction Management. New York: Wiley Blackwell.

SHAW, P.J.A. (2003). Multivariate statistics for the environmental science. London: Hoddeer-Arnold.

YEPES, V. (2008). Proyecto académico y programa razonado de la asignatura Procedimientos de Construcción. Concurso de acceso al cuerpo de profesores titulares de universidad. Universitat Politècnica de València.

YEPES, V. ; DÍAZ, J., GONZÁLEZ-VIDOSA, F.; ALCALÁ, J. (2009). "Caracterización estadística de tableros pretensados para carreteras" en Revista de la Construcción, vol. 8 , issue 2, p. 95-109.

(c)) EY-NC-ND 2014, Universitat Politècnica de València

I Jornadas IN-RED (2014) 


\title{
Experiencias Tecnológicas de Soporte al Blended Learning en un Contexto Multidisciplinar
}

\author{
Germán Moltóa $^{\text {, José F. Monserrat }}{ }^{\mathrm{b}}$, I.C. Fita ${ }^{\mathrm{c}}$ y Ana M. Fita
}

a Departamento de Sistemas Informáticos y Computación - gmolto@dsic.upv.es, ${ }^{b}$ Departamento de Comunicaciones - jomondel@dcom.upv.es, ${ }^{\mathrm{c}}$ Departamento de Física Aplicada - infifer@fis.upv.es y ${ }^{\mathrm{d}}$ Departamento de Biotecnología - anfifer@btc.upv.es.

\begin{abstract}
Blended Learning has been leveraged in the last years due to the widespread usage of ICTs and the increase of distant activities in the new degrees. This paper describes several experiences of introducing Blended Learning in subjects from different fields (Computer Science, Telecommunications, and Biotechnology). The common aspect is the usage of computer tools that enable to perform activities that range from performing practical activities in remote labs provisioned from Cloud environments to the live recording of lessons and its broadcast. This paper summarises the experiences carried out, introducing the required technologies, tools and devices. It is also described the impact for both the students and the involved professors. The goal of this paper is to describe the experiences in a way that encourages other professors from related fields to integrate these techniques and activities in their teaching methodologies.
\end{abstract}

Keywords: blended learning, video-lectures, distant learning, virtualised environments,

\footnotetext{
Resumen

El Blended Learning (o aprendizaje semipresencial) está siendo impulsado en los últimos años por el auge de las TIC y el aumento de las actividades no presenciales en los nuevos títulos de Grado. En este artículo se describen experiencias de introducción del Blended Learning en asignaturas de diferentes ámbitos (Informática, Telecomunicaciones y Biotecnología). El tronco común es el uso de herramientas y tecnologías informáticas de uso cotidiano que posibilitan y facilitan la realización de actividades que
}

(c) EY-NC-ND 2014, Universitat Politècnica de València

I Jornadas In-Red (2014) 


\begin{abstract}
abarcan desde la realización remota de prácticas de laboratorios en entornos Cloud, pasando por el uso de herramientas que fomentan la interacción en clase hasta la grabación directa de las clases y su posterior difusión. En este artículo se resumen las experiencias realizadas introduciendo las herramientas tecnológicas necesarias, tanto los dispositivos electrónicos como los programas necesarios para su aplicación concreta a los diferentes escenarios. También se describe su impacto tanto para el alumno como para los profesores involucrados. La finalidad de este trabajo es presentar estas experiencias de modo que sirvan de catalizador para que otros profesores de áreas afines decidan utilizar este tipo de técnicas y actividades en su práctica docente.
\end{abstract}

Palabras clave: blended learning, aprendizaje semi-presencial, vídeolecciones, entornos virtualizados

\title{
1. Introducción
}

Actualmente, el grado de participación presencial en el que puede manifestarse la educación va desde una aproximación completamente presencial, como es el caso de una lección magistral tradicional hasta una aproximación completamente no presencial, como la que se ve en los cursos de tipo MOOC (Massively Online Open Courses), donde miles de alumnos siguen un curso por medio de plataformas tecnológicas que les evitan tener que acudir a un sitio físico a recibir las clases.

A mitad camino entre el aprendizaje presencial y el online aparece el aprendizaje semipresencial, también conocido como Blended Learning o B-learning. Mediante esta aproximación se persigue conseguir el aprendizaje por medio de la combinación e integración de técnicas de enseñanza presencial y de herramientas y tecnologías orientadas al aprendizaje no presencial u online (Garrison, 2004). El objetivo, por tanto, es aunar las ventajas de ambos tipos de aproximaciones en el proceso de enseñanza-aprendizaje.

Dar soporte a la docencia online requiere el uso de herramientas específicas que faciliten la interacción de los alumnos tanto con el material educativo como entre ellos mismos y con el profesor para conseguir el propósito educativo de una acción formativa. Actualmente, existen numerosas herramientas online, cuyo propósito no es específicamente educativo pero que ciertamente pueden ser incorporadas como herramientas de apoyo a la docencia no presencial. Por lo tanto, es importante analizar algunas de estas herramientas para detectar casos de uso en docencia semipresencial, de manera que la tecnología se convierta en un aliado del profesor y que facilite a los alumnos la consecución de los resultados de aprendizaje que pretende el profesor.

(cc) EY-NC-ND 2014, Universitat Politècnica de València

I Jornadas IN-RED (2014) 
La Universitat Politècnica de València (UPV) ofrece a sus profesores herramientas tecnológicas que facilitan la realización de actividades no presenciales. Por ejemplo, PoliformaT es el LMS (Learning Management System) basado en Sakai que se utiliza para la interacción con los alumnos, permitiendo la compartición de material de la asignatura así como la comunicación, principalmente asíncrona. Por otra parte, PoliReunióN es una herramienta basada en Adobe Connect que permite la creación de salas virtuales para la comunicación síncrona entre alumnos y profesores, pudiendo mantener audio y videoconferencias. Por último, PoliTube [4] es la plataforma de difusión de vídeos educativos que pueden ser accedidos por medio de un navegador web por streaming.

Sin embargo, las herramientas corporativas de la UPV no cubren todos los escenarios posibles que se pueden dar en situaciones de Blended Learning, de ahí que sea interesante explorar las ventajas de incorporar otras herramientas existentes para poder mejorar la práctica docente. Concretamente, en este artículo se aborda la siguiente problemática: i) ofrecer acceso a laboratorios de prácticas remotos, para las asignaturas técnicas; ii) ofrecer vídeo-lecciones como complemento y/o refuerzo de las sesiones presenciales y iii) usar herramientas colaborativas que permitan la interacción profesor-alumno de forma remota.

En este sentido, el artículo está estructurado como sigue. En primer lugar, la sección 2 presenta los objetivos de esta comunicación. A continuación, la sección 3 desarrolla las diferentes innovaciones llevadas a cabo, describiendo las herramientas y aproximaciones consideradas. Luego, la sección 4 analiza los resultados de las innovaciones y discute las implicaciones tanto para el profesorados como para los alumnos involucrados. Finalmente, la sección 5 describe las principales conclusiones del artículo.

\section{Objetivos}

La finalidad de este artículo es definir y evaluar diferentes casos de uso de integración de herramientas tecnológicas para dar soporte a escenarios de aprendizaje semipresencial. Cada escenario detallará la herramienta elegida así como su incorporación a la práctica docente en el contexto de una asignatura, para evaluar el impacto derivado del uso de la nueva herramienta por parte tanto del profesor como de los alumnos. Esto permite recopilar una colección de escenarios de uso de blended learning.

En primer lugar, se describe el uso de técnicas de virtualización y de Cloud Computing para que los alumnos realicen de forma autónoma prácticas de programación informática en un entorno similar al laboratorio de prácticas desde sus propios equipos de trabajo. Esto permite acceso ubicuo y a cualquier hora de día al entorno proporcionado por los laboratorios de prácticas. En segundo lugar se cubre la experiencia con el servicio "vídeoapuntes" que permite la grabación automática, programada e ininterrumpida de sesiones en

\section{(cc) EY-NC-ND 2014, Universitat Politècnica de València}

I Jornadas IN-RED (2014) 
el aula, puesta a disposición de los alumnos a través de Internet. Esto permite que los alumnos accedan a las clases grabadas, mediante una interfaz configurable que permite destacar la presentación, el profesor o la pizarra, de acuerdo a las preferencial del alumno. En tercer lugar, se tratan herramientas informáticas online que pueden usarse como apoyo docente y que han sido específicamente usadas en experiencias de Blended Learning, como es el caso de Edmodo y TodaysMeet, que permiten la creación de salas virtuales de trabajo a las que los alumnos se conectan. Estas herramientas fomentan la interacción y participación de los alumnos tanto dentro como fuera del aula.

\section{Desarrollo de la innovación}

Esta sección se encarga de resumir las tres áreas de innovación docente llevadas a cabo en el contexto del aprendizaje semi-presencial. Para cada una de ellas, se describe el ámbito de aplicación, las herramientas involucradas y al menos un ejemplo de aplicación de la experiencia a una asignatura concreta de una titulación de la UPV.

\subsection{Laboratorios de Prácticas Remotos}

\subsubsection{Mediante Máquinas Virtuales}

En el primer curso del Grado en Informática en la Escola Tècnica Superior d'Enginyeria Informàtica (ETSINF) los alumnos se enfrentan a dos asignaturas cuatrimestrales de programación, Introducción a la Informática y a la Programación (IIP) y Programación (PRG). En ellas el alumno empieza a adquirir las destrezas de programación necesarias para la construcción de programas informáticos, utilizando Java como lenguaje de programación y GNU/Linux como Sistema Operativo (SO) en los laboratorios de prácticas. Este sistema operativo, aunque muy utilizado en entornos académicos y científicos, no es la opción habitual de los alumnos, tal y como se constató en una encuesta a los alumnos (Moltó y Sapena, 2013), donde únicamente el $6 \%$ de los alumnos usaba de forma habitual GNU/Linux.

Los alumnos a menudo necesitan disponer de acceso a los laboratorios de prácticas para avanzar y/o terminar con algunas prácticas propuestas de la asignatura o para implementar y codificar sus propios programas para ejercicios de asignaturas. Sin embargo, el acceso a los laboratorios, al ser un recurso compartido con otras asignaturas, es limitado. Es cierto que algunos departamentos, como es el caso del Departamento de Sistemas Informáticos y Computación (DSIC) ofrece la posibilidad de conexión remota a escritorios virtuales, mediante el servicio EVIR. Esto permite a los alumnos conectarse a través de Internet al mismo entorno que disponen en prácticas. Esta aproximación requiere que los alumnos dispongan de una conexión a Internet de banda ancha. Sin embargo, algunos alumnos 
carecen de ese tipo de conectividad, por lo que se decidió ofrecer una solución complementaria a EVIR.

Por ello, desde el curso 2012/2013 se optó por crear una máquina virtual que ofreciera al alumno un entorno similar al disponible en los laboratorios de prácticas pero pudiendo usar el mismo desde su propio ordenador y sin necesidad de acceso a Internet. Una máquina virtual es una forma de encapsular un sistema operativo y unas aplicaciones de manera que puede ejecutarse sobre otro sistema operativo, con la ayuda de un hipervisor. Esto permite, como ha sido el caso, construir una máquina virtual basada en CentOS (la distribución GNU/Linux que se utiliza en los laboratorios de prácticas que usan los alumnos) con las aplicaciones necesarias para que los alumnos puedan desarrollar las prácticas que son Java Development Kit (JDK), entorno de desarrollo BlueJ, navegador web, procesador de textos, etc.

Los alumnos pueden descargarse dicha máquina virtual y ejecutarla independientemente del sistema operativo que tengan en sus equipos. Esto permite que cualquier alumno que tenga un equipo con suficiente memoria RAM pueda ejecutar la máquina virtual y tener a su disposición un entorno similar configurado con las mismas herramientas que tendría en el laboratorio de prácticas. Para ello, únicamente debe instalarse en su equipo el hipervisor (en nuestro caso se usa VirtualBox) y descargar la máquina virtual que, dependiendo de la versión, oscila entre 2-4 GBytes. La descarga únicamente se debe hacer una vez.

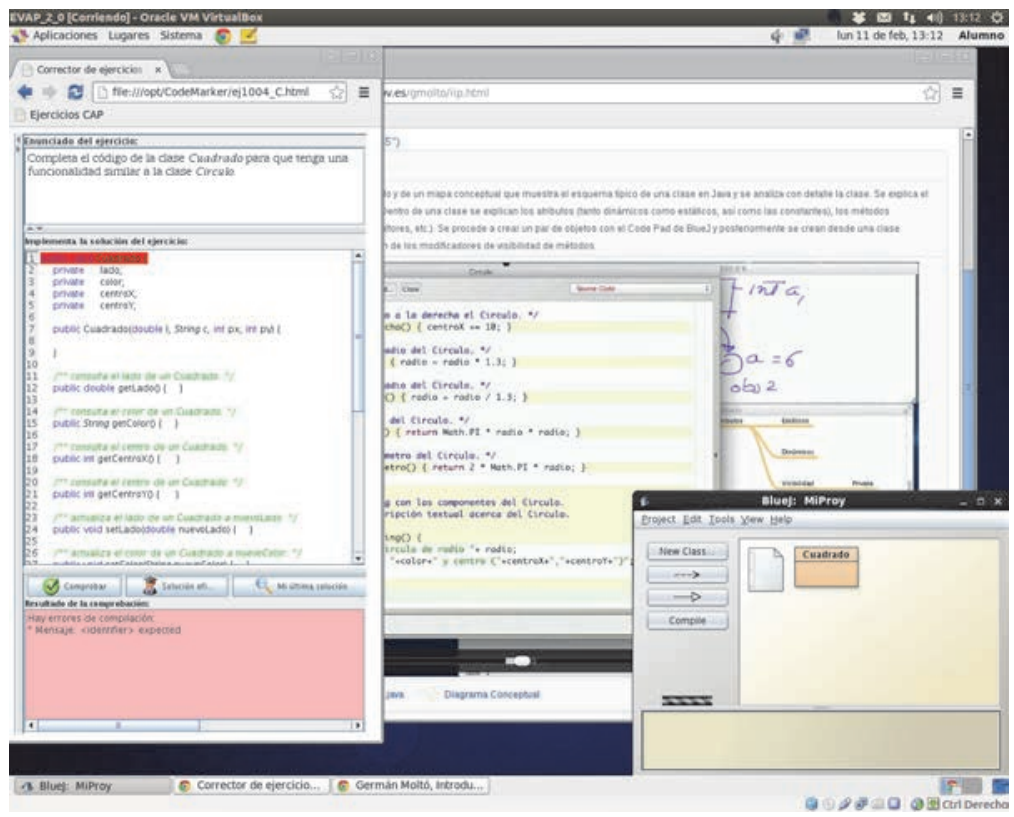

Figura 1. Aspecto del EVAP en ejecución con las principales herramientas.

\section{(c)) EY-NC-ND 2014, Universitat Politècnica de València}

I Jornadas IN-RED (2014) 
Este entorno se llamó EVAP (Entorno Virtualizado para el Aprendizaje de la Programación $)^{1}$ ya que se integró en dicha máquina virtual dos innovaciones más llevadas a cabo. Por un lado, se incorporó un Corrector Automático de Programas (CAP) que permite a los alumnos la realización guiada de ejercicios de programación, donde el sistema orienta al alumno sobre la solución que va implementando. Por otro lado, se incorporaron vídeoejercicios didácticos de las asignaturas IIP y PRG. Esto permitió disponer de un entorno integrado para el aprendizaje, desarrollo y verificación de programas de mediana envergadura, apto para facilitar el aprendizaje de competencias de programación.

La Figura 1 muestra el aspecto del EVAP en ejecución, con el CAP, el entorno de desarrollo BlueJ y un vídeo-ejercicio en segundo plano. Todo ello, ejecutado sobre un entorno GNU/Linux en la máquina de un estudiante (que puede tener Windows o cualquier otro sistema operativo instalado).

\subsubsection{Desplegados en el Cloud}

El Curso Online de Cloud Computing con Amazon Web Services (AWS) es un curso de formación permanente completamente online donde los alumnos usan herramientas basadas en web y en línea de comandos para interactuar con los principales servicios de AWS para crear arquitecturas de aplicaciones elásticas en la nube de Amazon. Por ello, necesitan laboratorios remotos a los que conectarte específicamente configurados con las herramientas y credenciales de acceso necesarias para usar los servicios de AWS.

En este caso, el laboratorio remoto consiste de nuevo en una máquina virtual, pero en lugar de tener que descargarla el alumno para ejecutarla en su propio equipo, se ejecuta en la nube de AWS de manera que los alumnos únicamente deben conectarse a ella bien mediante línea de comandos a través de SSH o mediante escritorio remoto. Esta aproximación es lo que se conoce como Cloud Computing, donde los recursos de cómputo (del laboratorio remoto) se aprovisionan de forma dinámica de un proveedor de Cloud público mediante un modelo de pago por uso, ya que el proveedor cobra según las capacidades de la máquina virtual y las horas de ejecución.

Para su despliegue se utilizó una herramienta llamada Infrastructure Manager (IM) ${ }^{2}$, creada por el Grupo de Grid y Computación de Altas Prestaciones (GRyCAP) de la UPV. Esta herramienta permite que el instructor cree una receta de alto nivel en la que se expresan los requisitos hardware, software y de configuración necesarios para una máquina virtual. En nuestro caso, para el laboratorio remoto es necesario:

\footnotetext{
${ }^{1}$ Es posible acceder al EVAP en http://www.grycap.upv.es/gmolto/evap.php

${ }^{2}$ Es posible acceder al IM en http://www.grycap.upv.es/im
} 
- Una máquina virtual con al menos 512 MB de RAM, con sistema operativo Ubuntu Linux, con la herramienta AWS CLI instalada y 50 cuentas de usuario con una determinada configuración de credenciales de usuario.

Esta herramienta, disponible bajo licencia de código abierto para toda la comunidad académica y científica, realiza el despliegue automático del laboratorio remoto justo antes del comienzo de cada edición del curso.

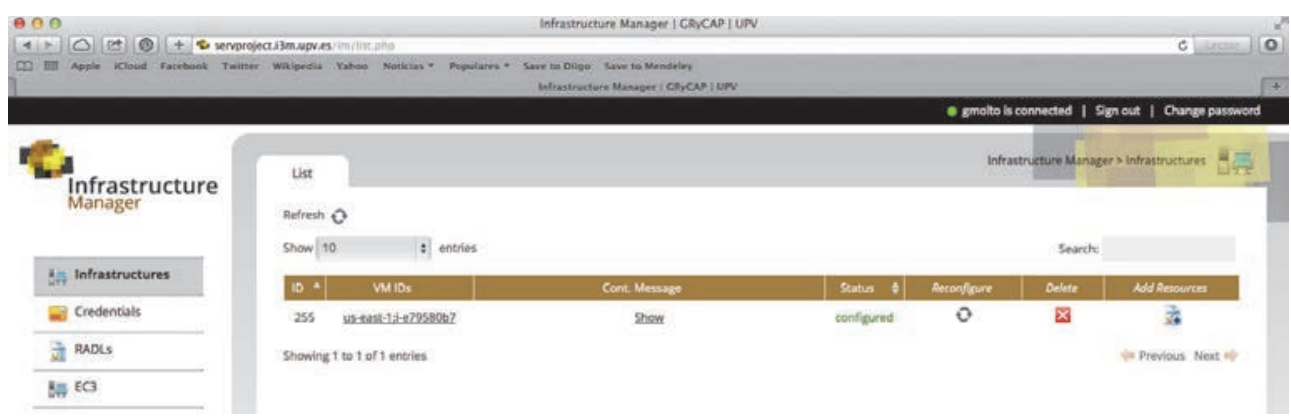

\subsection{Vídeo-apuntes para la formación no presencial.}

El servicio de vídeo-apuntes online, es una iniciativa de la Universitat Politècnica de València para facilitar a los alumnos el seguimiento de las distintas asignaturas mediante la grabación de todas las clases (Turró et al., 2014). Se trata de grabaciones multimedia que incluyen la información proyectada, un vídeo del profesor y la posibilidad de enfocar hacia el contenido de la pizarra. Son grabaciones en alta definición a las que el alumno puede acceder utilizando la misma plataforma de teleformación que se usa dentro de la UPV, poliformaT.

El servicio de videoapuntes online es un producto del proyecto Opencast, en el que muchos profesores, tanto de la UPV como de otras universidades del mundo, están colaborando. Dentro de la UPV, cada centro está dotado con, al menos, un aula preparada para realizar estas grabaciones. El equipamiento, que incluye cámaras de vídeo, micrófonos y un PC específico con una tarjeta de captura de vídeo y otra de captura de señal del proyector, permite automatizar las grabaciones. De esta manera, el profesor realiza de antemano la reserva de todas las sesiones de grabación y se despreocupa de todo el proceso de captura. Tras la misma, y sólo un par de días después, el profesor recibe la notificación de que el material multimedia está disponible y puede proceder a su edición. Una vez editado, el profesor puede decidir publicar o no el material, momento en el que los alumnos pueden proceder al visionado.

\section{(c) EY-NC-ND 2014, Universitat Politècnica de València}


Los alumnos pueden acceder a los videos tantas veces como quieran. Durante la reproducción, los alumnos pueden seleccionar distintas vistas, centrado la atención más en el profesor y en la pizarra o en los contenidos proyectados (Figura 2).
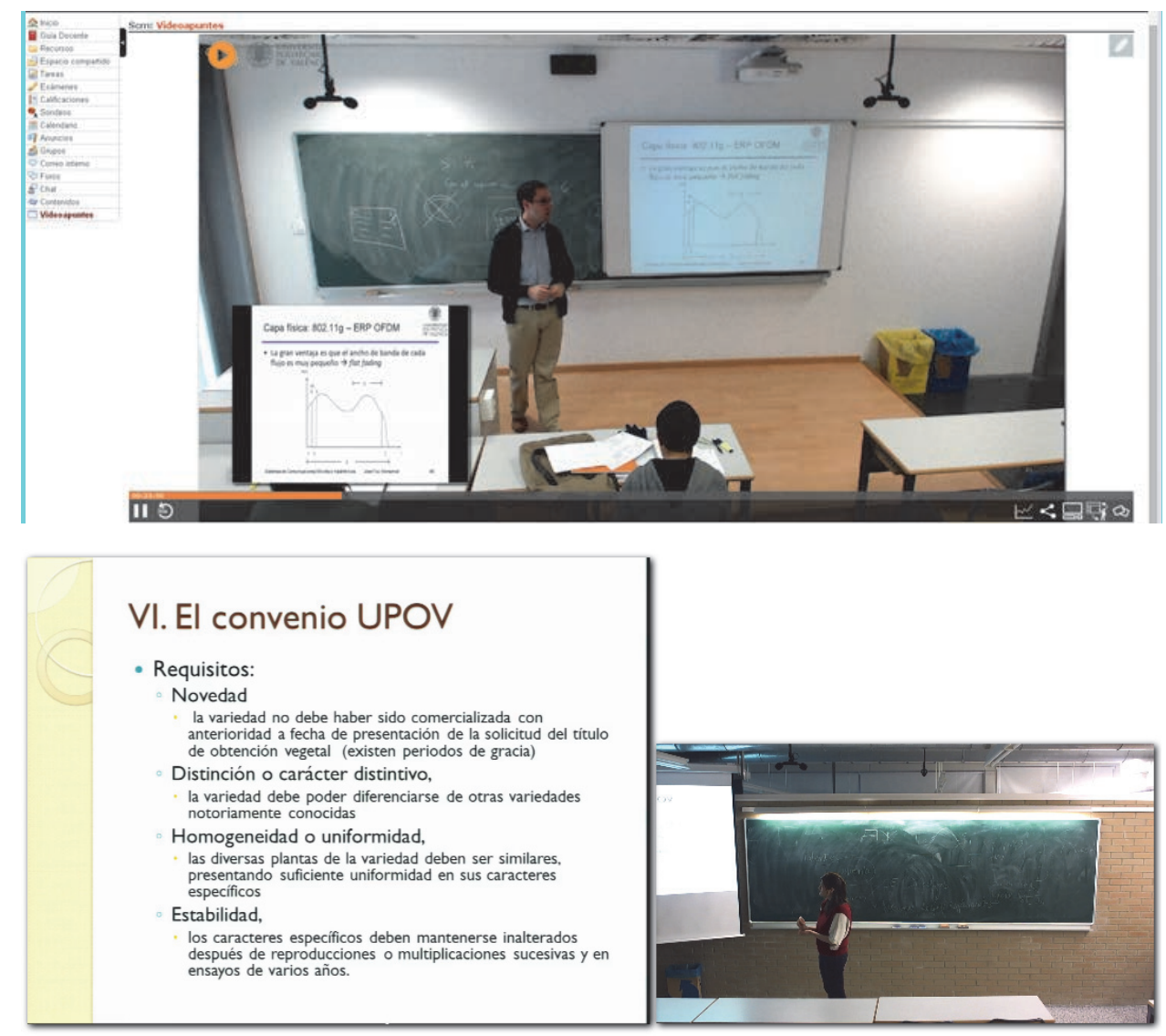

Figura 2. Captura de la herramienta de vídeo-apuntes con diferentes vistas. Arriba: con el profesor en primer plano. Abajo: profesor y diapositiva al mismo nivel.

Durante este curso, se han llevado a cabo varias experiencias sobre el impacto que tiene el uso de esta herramienta sobre el desarrollo de las clases.

En el ámbito de las telecomunicaciones, se realizó la grabación de toda una asignatura, la asignatura de máster de sistemas de comunicaciones móviles e inalámbricas. La docencia en esta asignatura es presencial de asistencia no obligatoria, aunque sí que es cierto que se califica mediante evaluación continua con pruebas en el aula, lo que siempre incentiva la mayor participación en las clases. 
En el Master Interuniversitario de Mejora Vegetal hay alumnos que siguen las clases de forma presencial y alumnos que siguen las clases a distancia (on-line). Por este motivo la herramienta de video-apuntes se utiliza con regularidad en diversas asignaturas dentro de este Master. En concreto se utilizó en la asignatura 'Derechos de las obtenciones vegetales y producción comercial de material de propagación'. En esta asignatura había 7 alumnos presenciales y 10 alumnos on-line.

\subsection{Herramientas Colaborativas}

Sin duda alguna, la colaboración entre las entidades implicadas en el proceso de aprendizaje es un factor clave para garantizar el éxito del mismo. El profesor tiene la obligación de motivar a los alumnos no sólo a que colaboren con él en las tareas encomendadas, sino a que también colaboren entre ellos para mejorar su aprendizaje y aprender de los problemas derivados del trabajo en grupo.

En la actualidad las tecnologías de la información facilitan en gran medida la articulación sencilla de la colaboración tanto fuera como dentro del aula. Herramientas como los foros, los blogs, las wikis o las mismas redes sociales, permiten gran colaboración entre los alumnos y el profesor de manera asíncrona, es decir, sin necesidad de que esa comunicación ocurra en el mismo instante temporal. Sin embargo, existen tecnologías más actuales que permiten incluso que dicha colaboración ocurra síncronamente, bien dentro del aula o bien desde ubicaciones distintas, lo que aumenta la sensación de pertenencia al grupo y facilita la vida social de la clase.

Entre las herramientas que permiten esta colaboración en tiempo real con los alumnos, cabe destacar Edmodo. Edmodo pretende conectar a estudiantes y profesores mediante una red social educativa, intuitiva y organizada a través de clases virtuales. La plataforma es gratuita, siendo posible registrarse con rol de profesor, estudiante o padre de familia. Como profesor puedes crear grupos de trabajo, asignar tareas, proponer pruebas o preguntas cortas, evaluar, publicar notas, etc. Y, además, permite hacerlo desde distintas plataformas tecnológicas, incluidas las plataformas móviles.

En el ámbito de las telecomunicaciones, se creó una clase asociada al grupo de sistemas de comunicaciones móviles e inalámbricas. El objetivo era lanzar preguntas de último minuto y sondeos a los alumnos y permitirles que se conectaran con su dispositivo móvil para responder a esas preguntas, si bien estas preguntas también podrían contestarse desde fuera de la clase como complemento a la sesión presencialLa experiencia se repitió en cinco ocasiones, en cinco diferentes sesiones, donde se probaron preguntas de respuesta múltiple, cuestiones de contenido abierto y preguntas de verdadero y falso (Figura 3 ).

(c) EY-NC-ND 2014, Universitat Politècnica de València

I Jornadas IN-RED (2014) 


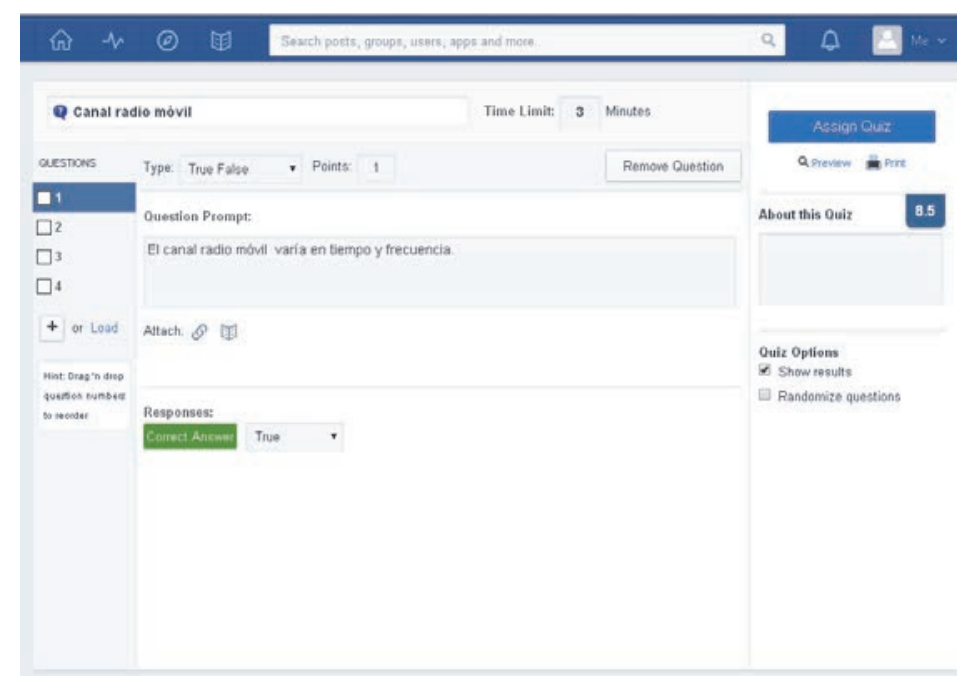

Figura 3. Aspecto de la herramienta Edmodo.

En el grado de Biotecnología se ha utilizado TodaysMeet a diversas aplicaciones, tanto en las clases presenciales como en las no presenciales. TodaysMeet es una aplicación en red sencilla en la cual se puede crear una sala virtual donde hay un panel de texto dónde todo aquel que acceda puede expresar su opinión.

Para usarlo cómodamente es interesante que el profesor cree una sala virtual con un nombre característico y la duración de la sala (desde un día hasta un año). Una vez creada la sala se puede acceder a ella mediante la dirección URL asignada, y se puede participar con tan sólo darse de alta con un nombre o pseudónimo.

Para que los alumnos accedan a la sala de TodaysMeet de forma rápida y usando sus dispositivos móviles es interesante crear un código QR asociado a la dirección URL. Una página que permite la generación automática de estos códigos es: http://qrcode.kaywa.com/ (Figura 4).

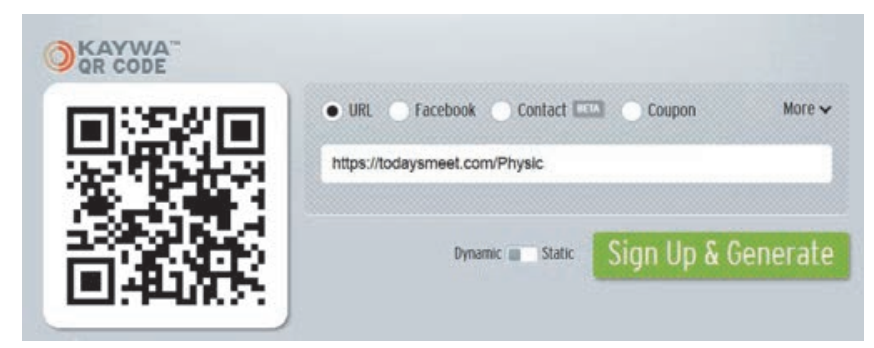

Figura 4. Generación de código QR a partir de una URL.

(cc) EY-NC-ND 2014, Universitat Politècnica de València

I Jornadas IN-RED (2014) 
TodaysMeet (Figura 5) es una aplicación interesante para retar a los alumnos en clases prácticas a proyectar en clase los resultados que van obteniendo, de forma que los compañeros van viendo lo que otros grupos ya han conseguido y permitiendo al profesor hacer comentarios al respecto. La motivación a participar, como siempre, se consigue con la valoración positiva en la evaluación de la actividad, premiando a aquellos grupos que son pioneros en aportar información al grupo. TodaysMeet también es útil como herramienta de trabajo colaborativo en actividades no presenciales. Concretamente, en ocasiones las prácticas duran más de una sesión presencial y antes de empezar la última sesión presencial es necesario determinar datos que resultan de hacer cálculos estadísticos de los resultados obtenidos por el conjunto de los grupos de trabajo en las sesiones previas. En estos casos los alumnos comparten la información requerida en TodaysMeet, pudiendo acceder a esta información de forma ubicua y en cualquier momento.

\section{TodaysMeet}

Listen

\begin{tabular}{|c|c|}
\hline 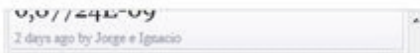 & \\
\hline 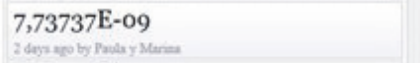 & \\
\hline 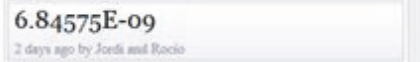 & \\
\hline 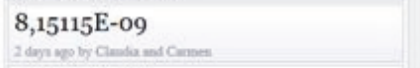 & \\
\hline $\begin{array}{l}\text { 7,90153E-09 } \\
\text { 2dersup by Antrey y lowe }\end{array}$ & \\
\hline 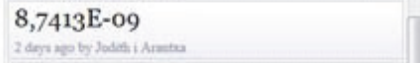 & \\
\hline 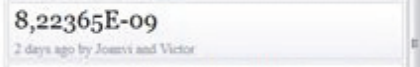 & \\
\hline $\begin{array}{l}\text { Send me the value of the } \mathrm{K} \text { of your } \\
\text { device }\end{array}$ & \\
\hline 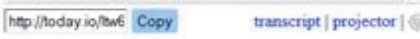 & \\
\hline
\end{tabular}

\section{Talk}

What's your name?

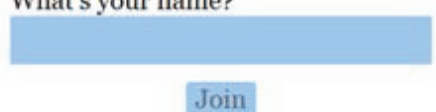

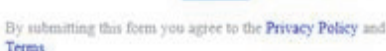

Figura 5. Aspecto de la herramienta TodaysMeet.

TodaysMeet es una herramienta facilitadora de la comunicación y del debate. El profesor puede lanzar una pregunta que a veces los alumnos pueden querer responder de forma anónima (pseudónimo), como puede ser por ejemplo: su opinión acerca de la marcha de las clases, u otros temas de interés.

\section{Resultados}

En esta sección se analizan los principales resultados de las diferentes experiencias llevadas a cabo.

\section{(c)) EY-NC-ND 2014, Universitat Politècnica de València}

I Jornadas IN-RED (2014) 
En primer lugar, Con respecto al EVAP, ésta se ha descargado hasta la fecha más de 244 veces por alumnos de diferentes perfiles. Tanto de las propias asignaturas para las que fue diseñada (IIP y PRG) como por alumnos de otras asignaturas afines e incluso por estudiantes de otras universidades, al estar ofrecida bajo licencia de código abierto. La valoración ha sido razonablemente buena donde más del $80 \%$ de los alumnos que contestaron la encuesta de satisfacción (30 personas) indicaron que el sistema es útil para mejorar su aprendizaje en las asignaturas para las que fue diseñada. El despliegue de los laboratorios remotos en el Cloud ha supuesto para los alumnos la posibilidad de realizar prácticas de laboratorio (informático) en cualquier momento y desde cualquier lugar sin más que una conexión a Internet, un terminal y un navegador web, lo que facilita en gran medida la realización de las actividades prácticas para los alumnos.

En segundo lugar, con respecto al uso de los vídeo-apuntes en el ámbito de las Telecomunicaciones, según las encuestas realizadas a los alumnos, el 100\% de los alumnos hizo uso más o menos intensivo del servicio, reconociendo el $92 \%$ de los alumnos que les pareció útil o muy útil dicho servicio. El número de visualizaciones, sobre un total de 15 clases y 25 alumnos, fue de 1282, lo que supone una media de 3.4 visualizaciones por clase y alumno. Además, gracias a la funcionalidad de estadística del visionado (Figura 6), el profesor puede detectar qué partes de la clase han generado más dudas o han sido más interesantes para el alumno, lo que permite preparar con mayor dedicación estas partes. Asimismo, cabe destacar la utilidad del servicio de vídeo-apuntes para poder reengancharse a la asignatura en el caso de no haber podido asistir algún día, llevarla más al día y repasar aquello en lo que el alumnado pueda tener mayores dificultades.

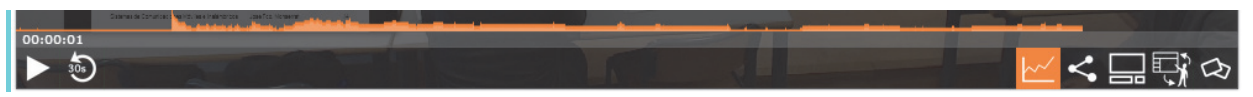

Figura 6. Funcionalidad de estadística en el vísionado del vídeo.

Respecto al impacto general tras el uso, cabe destacar que la asistencia a clase no se vio mermada. Por el contrario, los alumnos continuaron asistiendo a las clases presenciales hasta el final del curso, siendo esto un hecho que ahonda en que para el alumno este servicio no puede reemplazar la relación física y la atmósfera de aprendizaje del aula.

Finalmente, cabe destacar que la nota media de la asignatura apenas tuvo variación con respecto al año anterior (6.76 respecto a 6.73 del año anterior). Lo que sí fue significativo es la disminución de la desviación estándar de esas notas, que pasó de 2.3 a 1.53. Esto significa, que esta herramienta viene a apoyar principalmente a aquellos que tienen problemas en seguir la docencia y completar un aprendizaje satisfactorio. 
En la asignatura del Master de Mejora, el 100\% de los alumnos utilizó en algún momento los vídeos. En el caso de los alumnos presenciales su uso se limitó a reforzar conceptos o a recuperar alguna clase a la que faltaron, mientras que los alumnos a distancia utilizaron los vídeos de forma rutinaria. No existieron diferencias significativas entre las notas de los alumnos presenciales frente a los alumnos a distancia. En las encuestas realizadas ambos grupos valoraron positivamente la herramienta. Algunos alumnos a distancia destacaron la mejora cualitativa al poder seguir las clases gracias a los vídeos comparado con seguir la asignatura sólo mediante recursos convencionales. El hecho de poder seguir las clases a distancia y el poder recuperar clases perdidas hace que los alumnos tengan una mayor filiación a la asignatura y hayan menos abandonos. Este mismo efecto ha sido descrito por otros autores utilizando Blended learning (Hoic-Bozic et al 2009)

La ventaja de los vídeo-apuntes es que es una herramienta muy cómoda para el profesor que no tiene que realizar ningún esfuerzo extra de preparación de material. Por otro lado para el alumno también resulta fácil de utilizar pues no tiene que descargarse ningún programa ni utilizar ningún dispositivo extra, simplemente puede acceder a través de su asignatura en PoliformaT.La principal desventaja actual es la limitada capacidad de edición de la herramienta. Por el momento sólo se pueden eliminar los extremos del video (el principio y el final de la clase). Esto hace que si hay una parte de la clase donde los alumnos presenciales están trabajando y no hay explicación, o si por cualquier motivo hay un descanso en la explicación, queda un hueco sin contenido que no se puede eliminar. Este inconveniente se supera parcialmente con la selección por diapositivas que se puede hacer en la visualización (Figura 7)

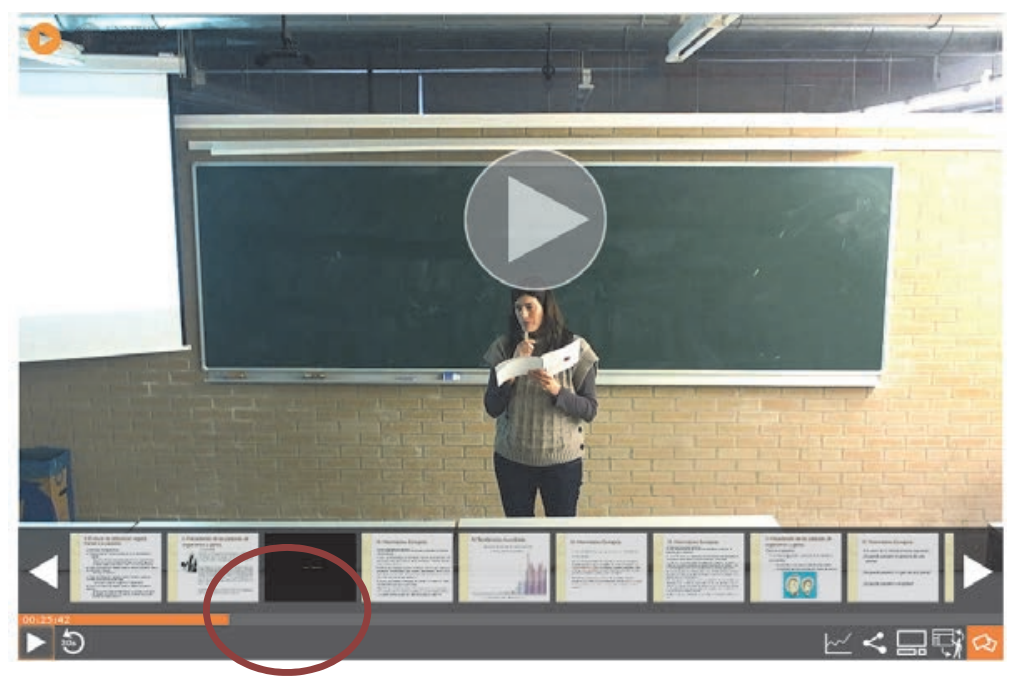

Figura 7. Visualización de diapositivas. Marcado con un círculo rojo se observa una parte de la grabación donde no se visualizaron diapositivas. Esta parte puede corresponder con periodos de explicación en pizarra o actividades de los alumnos presenciales.

\section{(cc) EY-NC-ND 2014, Universitat Politècnica de València}

I Jornadas IN-RED (2014) 
En tercer lugar, el uso de la herramienta Edmodo en Telecomunicaciones no fue tan exitoso, aunque cabe destacar que el poder hacer uso de sus dispositivos móviles fue muy gratificante para los alumnos. De hecho, el sistema no estaba disponible para todas las plataformas móviles (no existía para Windows Mobile, por ejemplo) lo que hizo que algunos alumnos no pudieran participar. Además, no todos los tipos de pregunta se podían contestar desde la plataforma móvil. Este fue el caso de las preguntas de respuesta múltiple para las cuales algunos dispositivos no permitían la selección. En cualquier caso, el tiempo requerido en la clase para responder a la pregunta resultó excesivo, lo que podría mejorarse con ciertas actualizaciones de la interfaz. Desde el punto de vista del profesor, la herramienta no resulta intuitiva, y requiere de mucho tiempo para configurar adecuadamente un sondeo (o quiz). Además, la reedición es muy costosa de gestionar, lo que dificulta el mantenimiento para futuros cursos académicos.

Finalmente, la aplicación de TodaysMeet es muy intuitiva, tanto para el profesor como para los alumnos. Sin embargo dado que no todos los alumnos disponen de smartphones, su aplicación se debe reducir a aquellos ámbitos en los que sabemos que también disponen de ordenadores (sala informática, laboratorio de prácticas o en casa).

En esta experiencia prácticamente el 100\% de los alumnos han publicado sus resultados aun no siendo los primeros en aportar la información. Esto significa que por su afán de participación, el tiempo de cada actividad se alarga más de la cuenta, circunstancia que hay que considerar si queremos aplicarla en sesiones presenciales.

Por todo lo expuesto, TodaysMeet es una herramienta muy recomendable cuando se quiere dinamizar una actividad (presencial o no presencial), fomentando la participación del alumnado.

\section{Conclusiones}

Este artículo ha resumido diferentes experiencias de introducción de herramientas y técnicas para soportar actividades Blended Learning en diferentes asignaturas de múltiples campos. Se han ofrecido laboratorios remotos tanto en la forma de máquinas virtuales descargables como desplegados en la nube, para asignaturas y cursos relacionados con la informática. Se han usado vídeo-lecciones grabadas automáticamente en asignaturas de telecomunicaciones y biotecnología usando el sistema corporativo de la UPV. Finalmente, se han usado herramientas colaborativas para facilitar la interacción profesor-alumno aplicadas en biotecnología.

Los resultados obtenidos muestran la buena receptividad de los alumnos a este tipo de herramientas con el objetivo de mejorar su aprendizaje. Este tipo de herramientas puede suponer un apoyo y un complemento a determinadas sesiones en el aula y su correcto 
dominio por parte del profesor es determinante para que los alumnos puedan percibir sus ventajas en la formación semi-presencial.

\section{Referencias}

Edmodo. http://www.edmodo.com

EVIR. http://evir.dsic.upv.es

Garrison, D. R., \& Kanuka, H. (2004). Blended learning: Uncovering its transformative potential in higher education. The Internet and Higher Education, 7(2), 95-105. doi:10.1016/j.iheduc.2004.02.001

Hoic-Bozic, N.; Mornar, V.; Boticki, I., 2009. A Blended Learning Approach to Course Design and Implementation. IEEE Transactions on doi: 10.1109/TE.2007.914945

Infrastructure Manager (IM). http://www.grycap.upv.es/im

Moltó, Germán, and Oscar Sapena. 2013. "Entorno Virtualizado de Aprendizaje Para Facilitar El Desarrollo de Destrezas de Programación.” In XIX Jornadas Sobre La Enseñanza Universitaria de La Informática (JENUI 2013), 327-334. doi:10.6035/e-TIiT.2013.13.

PoliformaT. http://poliformat.upv.es

PoliReunión. https://polireunion2.upv.es

PoliTube. http://politube.upv.es

TodaysMeet. https://todaysmeet.com/

Turró C, Despujol I., Busquets J. 2014. Grabación automatizada de clases magistrales: el proyecto Videoapuntes de la UPV. Revista de Educación a Distancia, 40. http://www.um.es/ead/red/40/ 


\title{
Socrative, una aplicación web 2.0 para evaluar la comprensión de los estudiantes
}

José Manuel Navarro Jover ${ }^{\mathrm{a}}$, Olmo Cazevieille, Françoise ${ }^{\mathrm{b}}$

${ }^{a}$ Universitat Politècnica de València, GRUPO DE INNOVACIÓN E INVESTIGACIÓN EN METODOLOGÍAS ACTIVAS (GIIMA). Dpto. de Ingeniería Gráfica jnavar@ dig.upv.es,

${ }^{b}$ Universitat Politècnica de València, GRUPO DE INNOVACIÓN E INVESTIGACIÓN EN METODOLOGÍAS ACTIVAS (GIIMA). Dpto. de Lingüística Aplicada folmo@idm.upv.es.

\begin{abstract}
The aim of this study is to actively engage students and increase their level of participation, motivation and understanding in the classroom. For this purpose, instantly-displayed rapid response questionnaires are incorporated in the teaching-learning process in the course of the classes by means of the Socrative application. Our hypothesis is that with this immediate interaction between teacher and students, the latter will be more attentive to the explanations whilst constructing knowledge in an active way since they are being asked to participate and become more involved. Learning becomes more "significant" (Ausubel, 1973) due to the fact that the answer is given immediately, thus, the learner will understand what he or she is learning. Also, this type of learning develops student autonomy as he or she is "learning to learn"..
\end{abstract}

Keywords: student, teacher, participation, motivation, interaction, questions 


\begin{abstract}
Resumen
El objetivo de este estudio es involucrar activamente al alumnado y aumentar así su grado de participación, su motivación y su comprensión en las clases presenciales. Con este fin se han incorporado en el proceso de enseñanza-aprendizaje, en el transcurso de las clases, y a través de la aplicación Socrative, unos cuestionarios de respuestas rápidas y de visualización inmediata en el aula. Nuestra hipótesis de partida es que mediante esta interacción inmediata entre profesor y estudiantes, éstos estarán más atentos a las explicaciones y construirán de forma activa su conocimiento al estar solicitados para participar. El aprendizaje se vuelve más "significativo" (Ausubel, 1973) ya que al contestar de forma inmediata, el discente debe entender lo que está aprendiendo. Asimismo, este tipo de aprendizaje desarrolla la autonomía del alumno ya que este "aprende a aprender".
\end{abstract}

Palabras clave:, alumno, profesor, participación, motivación, interacción, preguntas.

\title{
1. Introducción
}

Aunque Tim O'Reilly, creador del concepto web 2.0, apuntara en la V edición del Foro Internacional de los Contenidos Digitales (2011) que esa expresión que fue un éxito y que creó mucho entusiasmo ya había envejecido puesto que hoy en día se imponían la movilidad y la computación en la nube, en este artículo, nos referimos a ella para hacer referencia a un tipo de aplicaciones que permiten compartir, participar en grupo e interactuar para generar conocimiento. A este propósito, De Haro (2008), entre otros, señala las características de estas aplicaciones 2.0: "admiten la participación colectiva (compartir información entre los usuarios, interactuar unas personas con otras), la colaboración entre usuarios (la información compartida unido a la interacción entre los usuarios debe permitir la creación conjunta de contenidos), el uso del recurso es gratuito (al menos en parte)". El número de aplicaciones que ofrece la web no cesa de aumentar. La que hemos incorporado en el proceso de enseñanza-aprendizaje, objeto de este estudio, es la aplicación Socrative. Permite elaborar unos cuestionarios de respuestas rápidas con el fin de involucrar activamente al alumnado y aumentar así su grado de participación, su motivación y su comprensión. Pedagógica y psicológicamente, se relaciona directamente con la Teoría de la Instrucción de Bruner (1969) en donde el aprendiz es el autor principal y activo en el proceso de aprendizaje y, el aprendizaje significativo de Ausubel (1983) en el que el alumno debe realizar un esfuerzo deliberado para relacionar la nueva información solicitada con los conocimientos que posee.

(c)) EY-NC-ND 2014, Universitat Politècnica de València

I Jornadas IN-RED (2014) 
León et al. (2002) realizaron un amplio estudio sobre la importancia de generar preguntas en el ámbito educativo siguiendo a Hyman (1979), propusieron una clasificación de los tipos de preguntas que se suelen formular adaptada de Graesser et al. (1993) y expusieron una serie de sugerencias o recomendaciones al respecto. Realizar preguntas en el aula por parte del profesor, por un lado estimula los procesos de pensamiento y de construcción del aprendizaje de los estudiantes, y por otro lado pueden resultar muy útiles como instrumento de medida de la comprensión.

En este estudio, tras haber detallado los objetivos perseguidos, se describirán las actividades llevadas a cabo en dos asignaturas universitarias y su repercusión en la participación del alumnado, su comprensión y sobre todo en el conocimiento adquirido. Para investigar el grado de consecución de estos objetivos, así como el grado de satisfacción experimentado por los alumnos, se expondrán los resultados de unas encuestas distribuidas mediante la plataforma educativa de la Universitat Politècnica de València, PoliformaT. En las conclusiones, se tratarán las ventajas y los inconvenientes de este tipo de aplicación.

\section{Objetivos}

El objetivo principal de este trabajo es facilitar a través del uso de la aplicación Socrative, la comprensión y por ende, el aprendizaje de los alumnos. Los objetivos específicos son:

- involucrar activamente al alumnado y aumentar así su grado de participación, su motivación y su comprensión en las clases presenciales

- controlar la atención del alumnado

- recordar la información

- insistir en los puntos más importantes

- evaluar el nivel de comprensión

- dar retroalimentación

- desarrollar las competencias digitales

\section{Desarrollo de la innovación}

Para llevar a cabo el objetivo de participación activa y dinámica de los alumnos en clases presenciales se ha utilizado el software Socrative. Es una aplicación que permite crear cuestionarios para interactuar de forma inmediata con los estudiantes. Existe en versión web y teléfono inteligente o smartphone (IPhone y Android). Se probarán ambas modalidades. La utilización es sencilla en los dos casos.

\section{(cc) EY-NC-ND 2014, Universitat Politècnica de València}

I Jornadas IN-RED (2014) 
En primer lugar se expondrán las diferentes herramientas ofrecidas por la aplicación, y luego se explicitarán las actividades desarrolladas en dos asignaturas universitarias.

\subsection{La herramienta Socrative}

El software Socrative es una aplicación que permite al docente plantear preguntas sobre el tema que se está tratando en la clase, o sobre conocimientos previos necesarios, bien oralmente o bien a través de cuestionarios prediseñados; los alumnos contestan de forma individual o grupal, y de forma anónima o identificada, según se decida; y el profesor recoge los resultados de las mismas en el momento, pudiendo analizarlos, comentarlos y/o almacenarlos.

Para poner en comunicación a alumnos y profesor en la clase, y poder contestar a las preguntas planteadas por éste, ambos deben ejecutar la herramienta Socrative. Se puede lanzar:

- desde el navegador (socrative.com), si se dispone de ordenadores en clase, sin necesidad de instalación de software

- desde el móvil, previa descarga de la aplicación (para Android o para iPhone), o también desde el navegador del móvil. Esto permite su utilización en clases de teoría, en las cuales no se dispone de ordenador, y donde el número de alumnos suele ser más elevado

Sólo el profesor necesita registrarse en el sistema. Los alumnos deben abrir la aplicación y entrar en la sala o room del profesor (identificada por un número, según se puede observar en la Figura 1). En este momento el profesor ya puede plantear cuestiones y los alumnos responder a las mismas desde sus dispositivos.

Existen herramientas y tecnologías alternativas a Socrative.com. Una de las más extendidas es la de Peinado-Miguel et al. (2013). La utilizaron con la intención de dinamizar y generar mayor interacción de los alumnos en la clase. Mediante un software, unos mandos a distancia y una base emisora-receptora, los alumnos realizan votaciones como respuestas a cuestiones planteadas por el profesor. La ventaja que ofrece Socrative.com es la no necesidad de software ni de mandos a distancia o demás elementos. Únicamente se debe disponer de teléfonos móviles con conexión a internet, o de ordenadores.

Se pueden realizar dos tipos de actividades con la herramienta Socrative: cuestiones individuales y actividades basadas en cuestionarios o quizzes.

Las cuestiones individuales pueden ser: 
- De elección múltiple con hasta 5 opciones (A, B, C, D, E): el profesor plantea oralmente en el aula tanto la pregunta como las opciones posibles de respuesta, y los alumnos contestan una de ellas.

- Verdadero/Falso: igual que la anterior pero con estas dos posibilidades solo.

- De respuesta corta: los alumnos deben contestar escribiendo su respuesta. Cada alumno puede emitir una respuesta o varias (según se elija). Este tipo de cuestión permite también después de ver los resultados (en un proyector), realizar una votación sobre las respuestas, en la que los alumnos eligen, de todas las respuestas vertidas por la clase, la que creen que es la más correcta o adecuada.

Todas las cuestiones pueden realizarse en modo anónimo o identificado.

En la Figura 1 se muestra un ejemplo del resultado de una cuestión de respuesta múltiple, y en la Figura 2, de respuesta corta (a la izquierda el resultado en el ordenador y a la derecha el informe generado por el programa en Excel).

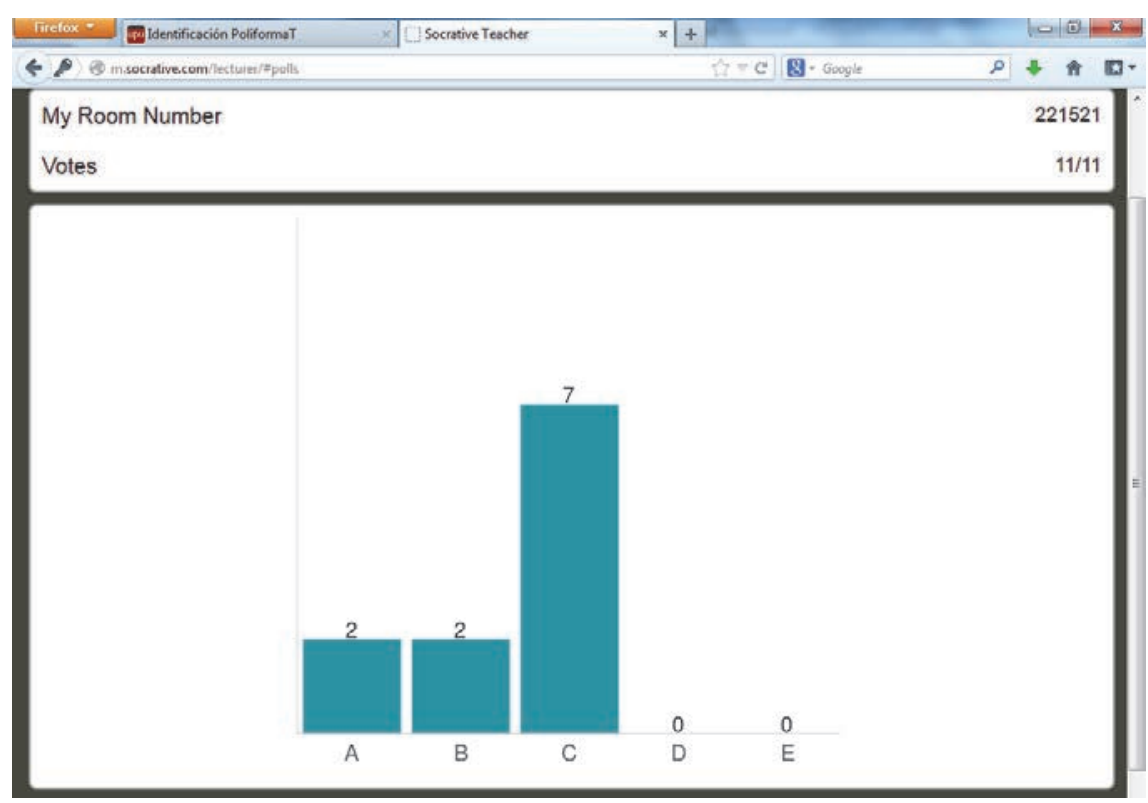

Figura 1. Vista del resultado de una cuestión de respuesta múltiple 


\begin{tabular}{l}
\hline Archivo Edición Ver Favoritos Herramientas Ayuda \\
Tip: Ask a question orally, students answer via Socrative. Learn more \\
My Room Number \\
Responses \\
\hline Student responses: \\
\hline 3.4 \\
\hline $2,89 \mathrm{~mm}$ \\
\hline 34.6 \\
\hline 3,4 \\
\hline 0,09 \\
\hline 2.88 \\
\hline $0.0865 \mathrm{~mm}$ \\
\hline $0 ' 865$ \\
\hline
\end{tabular}

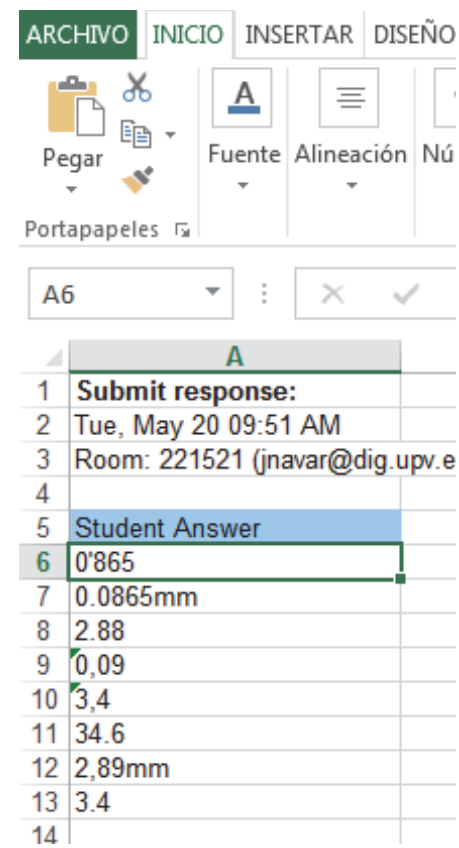

Figura 2. Vista del resultado de una cuestión de respuesta corta (izquierda) e informe generado por el programa en Excel (derecha).

Las actividades basadas en cuestionarios pueden consistir en:

- Pasar un cuestionario, previamente preparado y diseñado, configurado por varias preguntas.

- Pasar un cuestionario de salida, al final de la clase, para comprobar el grado en que los alumnos han asimilado los conocimientos o logrado los objetivos propuestos en la clase.

- Carrera: es como una competición en la que los alumnos participan, por grupos diferenciados por colores (a los que ellos se agregan o bien el profesor les asigna), los cuales van avanzando conforme miembros del grupo van acertando respuestas de un cuestionario previamente diseñado.

\subsection{Diseño de actividades}

Se ha probado la herramienta en dos asignaturas distintas de la Escuela Técnica Superior de Ingeniería Agronómica y del Medio Natural (ETSIAMN) de la Universitat Politècnica de València, en el curso académico 2013/14. Las actividades diseñadas y desarrolladas en cada 
una se describen a continuación por separado, si bien después se ponen en común los análisis y resultados.

\subsubsection{Actividad en la asignatura Representación gráfica en la Ingeniería}

Asignatura: Representación Gráfica en la Ingeniería, 6 créditos ECTS, troncal de primer curso, titulación Graduado en Ingeniería Agroalimentaria y del Medio Rural. 33 alumnos.

Las cuestiones que se han planteado en esta asignatura han sido todas de tipo simple:

- En clase de teoría, a través del móvil:

- 4 preguntas de tipo respuesta breve en las que tienen que hacer un cálculo numérico sencillo y responder el resultado

- 2 preguntas de respuesta múltiple (A, B, C, D, E) sobre conceptos teóricos importantes

- En clase de prácticas, a través del navegador del ordenador:

○ 4 preguntas de respuesta múltiple (A, B, C, D, E) sobre opinión acerca de exámenes (duraciones, tiempos, notas)

- 2 preguntas de respuesta múltiple sobre conceptos teóricos importantes

\subsubsection{Activiad en la asignatura Francés aplicado a la ingeniería agroalimentaria}

Asignatura: Francés aplicado a la ingeniería agroalimentaria, 6 créditos ECTS, complemento de formación de segundo, titulación Graduado en Ingeniería Agroalimentaria y del Medio Rural. 23 alumnos.

En esta asignatura, se han realizado diversas actividades utilizando las cuestiones simples, pudiendo los alumnos contestar mediante el móvil o el ordenador. La primera actividad para desarrollar la comprensión escrita, consistió en repartir a los alumnos tres documentos cortos. Tras su lectura, se les formulaba una pregunta y estos, tenían que elegir la repuesta A, B, C, D o E que les parecía adecuada (véase figura 1).

El mismo tipo de actividad se realizó para trabajar la comprensión oral. Pero en ese caso, el documento soporte fue una grabación.

También se utilizaron dos tests o quizzes para comprobar, al final del tema, si los puntos gramaticales vistos habían sido entendidos y retenidos.

Uno de ellos, sobre el imperativo, constaba de siete preguntas siendo siempre la primera de identificación para que el profesor tenga constancia de quién ha realizado el test y pueda ver también quién cometió errores. Las dos siguientes eran de elección múltiple (A, B, C, D

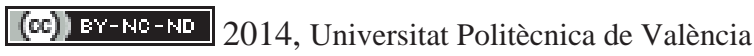

I Jornadas IN-RED (2014) 
o E) y las cuatro restantes pedían una respuesta corta. Vemos en la figura 3 el informe de Socrative con el resultado de la actividad.

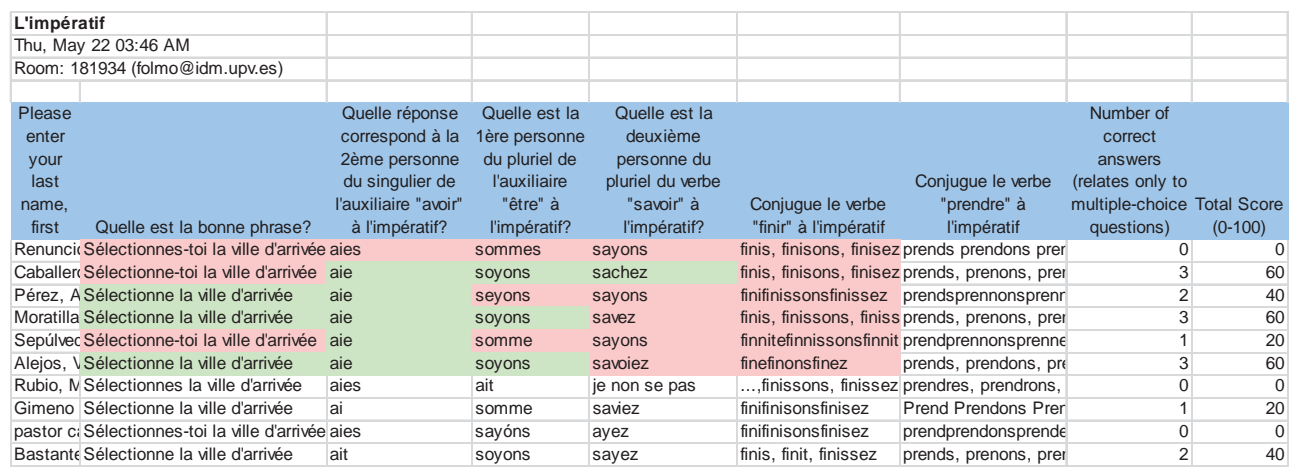

Figura 3. Informe de salida de un quiz.

\section{Resultados}

La encuesta elaborada para recoger los resultados consta de once preguntas: diez de tipo Likert con cinco niveles de respuesta y una de respuesta abierta con el fin de recoger comentarios o sugerencias sobre las actividades planteadas. La encuesta fue repartida a los alumnos de las asignaturas señaladas anteriormente mediante la plataforma educativa PoliformaT y 30 alumnos la respondieron.

Preguntados en la asignatura de ingeniería gráfica sobre en qué tipo de clase, teórica o práctica, la herramienta Socrative resulta más interesante y útil, un $60 \%$ contesta que en clase de teoría. En general, en ambas asignaturas, un $70 \%$ prefiere utilizarla a través de su teléfono móvil y un 93, 33 \% opina que es una herramienta fácil de manejar (Figura 4).
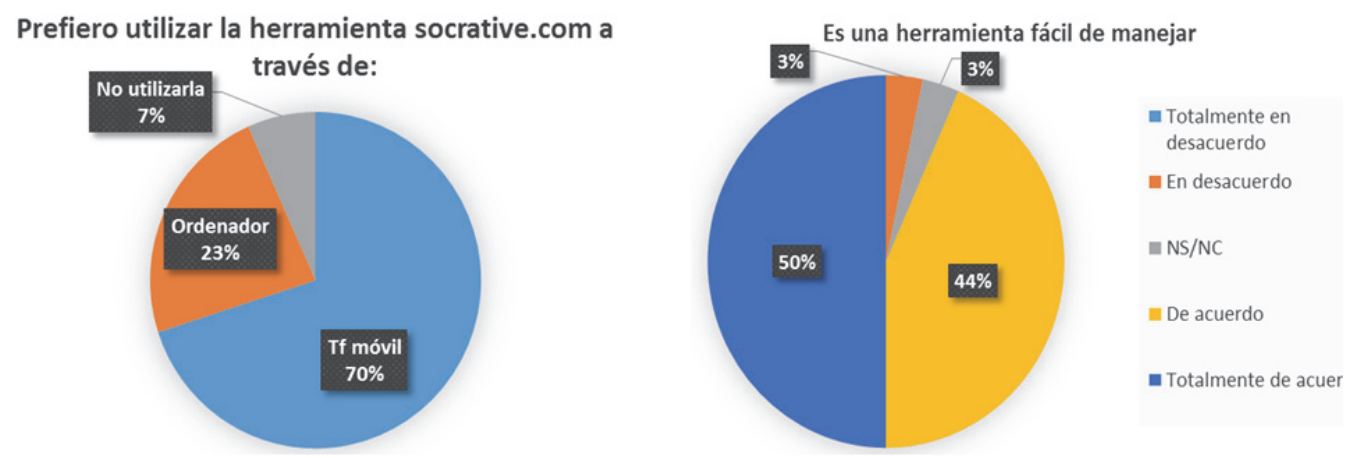

Figura 4.

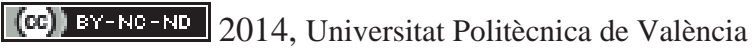

I Jornadas IN-RED (2014) 
Los alumnos (el 66,66 \%) afirman que esta aplicación les permite entender la teoría de manera más práctica (véase la Figura 5).

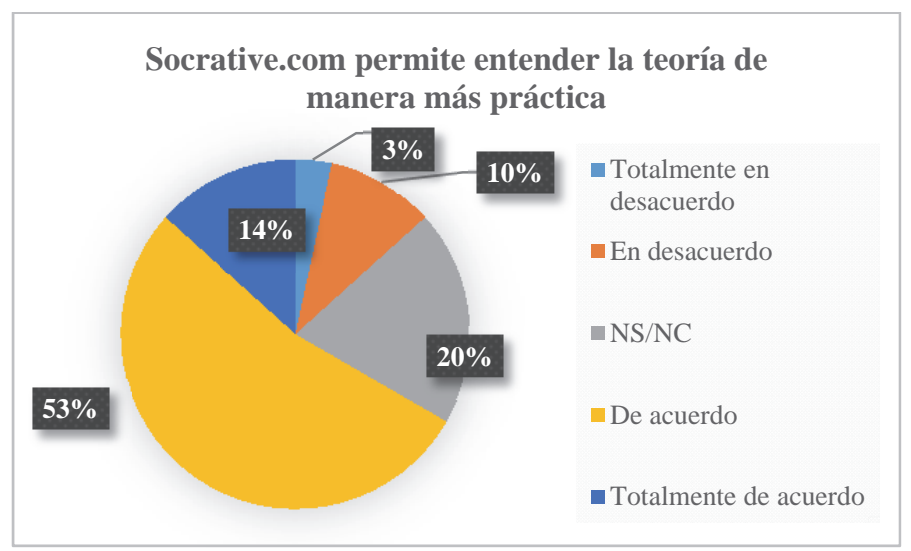

Figura 5.

En lo referente al aprendizaje y a la adquisición de conocimiento, los discentes manifiestan que la aplicación les ayuda a participar activamente (un 83,34\%), que es una herramienta interesante (un $86.66 \%$ ) porque toda la clase puede contestar a la vez la(s) pregunta(s) del profesor y que les ha gustado porque permite visualizar los resultados de toda la clase guardando el anonimato $(83,33 \%)$. Un $90 \%$ piensa que Socrative.com es una buena herramienta para repasar aspectos de la teoría y a un $93,33 \%$ le parece una herramienta útil para evaluar sus conocimientos (Figura 6). Un poco más de la mitad de los encuestados $(53.33 \%)$ recomendaría el uso de la herramienta socrative.com en otras asignaturas

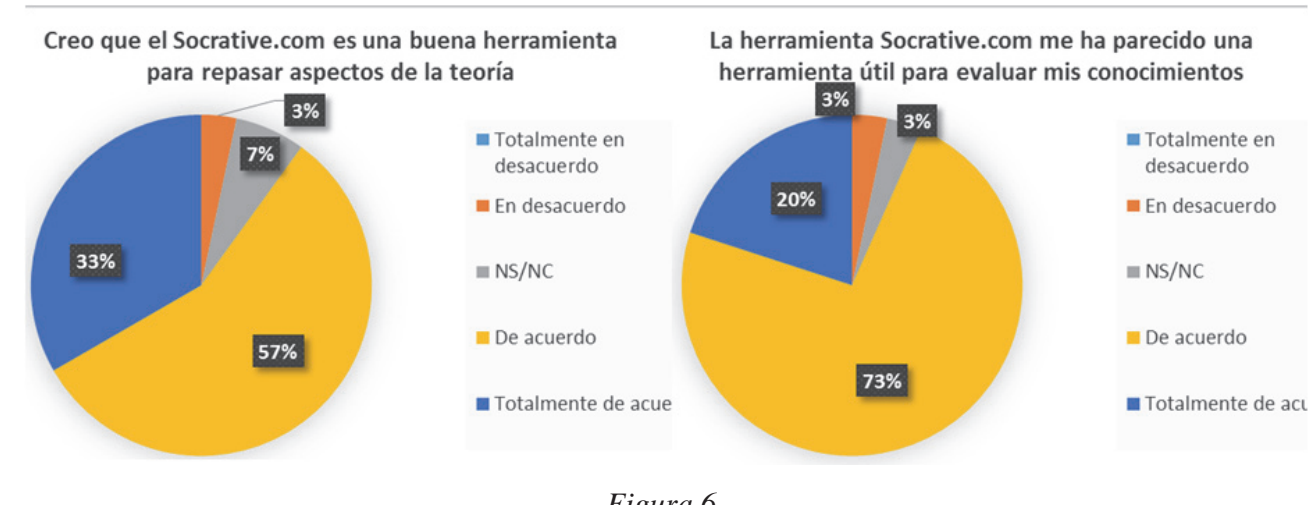

Figura 6.

En cuanto a los comentarios y sugerencias, los alumnos apuntan que la distinta rapidez de respuesta entre ellos conlleva pérdida de tiempo en clase.

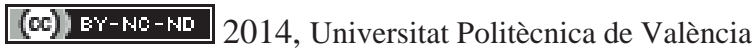

I Jornadas IN-RED (2014) 
Para comprobar los resultados del aprendizaje mediante el uso de la herramienta Socrative, se compararon dos grupos de francés del mismo nivel: uno de la Escuela Técnica Superior de Informática (ETSINF) y otro de la Escuela Técnica Superior de Ingeniería Agroalimentaria y del Medio Natural (ETSIAMN) . El primer grupo sirvió de grupo control y el segundo, de grupo experimental. Ambos grupos recibieron las mismas explicaciones sobre los mismos temas pero solo los alumnos integrantes del segundo grupo experimentaron la aplicación. Se evaluó ambos grupos mediante una prueba escrita en la que se insertaron dos ejercicios directamente relacionados con dos de los quizzes citados anteriormente. El grupo experimental obtuvo mejores resultados que el grupo control. Concretamente, todos los alumnos de este grupo (15/15) resolvieron sin problema los ejercicios propuestos y un solo alumno (1/13) lo consiguió en el grupo testigo. Por consiguiente, podemos afirmar que esta aplicación permitió mejorar el rendimiento de los alumnos con respecto a la metodología tradicional.

Los pocos inconvenientes de la aplicación Socrative están relacionados con el idioma, ya que sólo existe de momento en inglés, y con el número de alumnos, puesto que la clase está limitada a 50 estudiantes. Cabe señalar que en la asignatura Representación gráfica en la ingeniería, de primer curso, en clase de teoría no todos los alumnos disponían de teléfono inteligente (el 85 \% sí), mientras que en la asignatura de Francés aplicado a la ingeniería agroalimentaria la totalidad de los alumnos disponían de él.

El poder proyectar las contestaciones bajo forma de gráfico, de manera instantánea y de forma anónima, tiene muchas ventajas tanto para el docente como para el discente.

El profesor:

- Se asegura que todos los alumnos han entendido

- Se da cuenta si tiene que volver a explicar

- Puede hacer razonar a los alumnos respecto a las respuestas que se están visualizando

El alumno:

- Se siente solicitado y activo

- Quiere hacerlo bien, está motivado

- No se siente mal si no lo sabe porque no aparece su nombre

- le permite recibir retroalimentación directa del profesor

- Mejora su comprensión 


\section{Conclusiones}

La aplicación Socrative es uno de los recursos tecnológicos a disposición del profesorado que permite transformar la actitud de los discentes en el aula, así como la actuación de los docentes en las clases magistrales ya que su uso implica la participación activa de todos. Como acabamos de ver, da interacción inmediata, es de fácil uso, permite exportar los resultados, los resultados visionados por el alumnado son anónimos, capta el interés y permite una discusión constructiva con visualización de los errores. En resumidas cuentas, podemos decir que la aplicación Socrative permite trabajar las competencias digitales, estimular a los alumnos y ayudarles a adquirir conocimiento de la materia tratada.

\section{Referencias}

AUSUBEL, D.; NOVAK, J.D.; HANESIAN, H. (1983). Psicología Educativa: Un punto de vista cognoscitivo. $2^{\circ}$ Ed.TRILLAS México.

BRUNER, J. S. (1969). Hacia una teoría de la instrucción. México: UTEHA

DE HARO, J. J. (2008, Enero 4). Aplicaciones 2.0. EDUCATIVA. Recuperado Julio 11, 2009 < http://jjdeharo.blogspot.com.es > [ Consulta: 16/06/2014]

ELESPECTADOR.COM (Miér, 23/11/2011). Tim O'Reilly: "el concepto web 2.0 está obsoleto". 〈http://tecno.americaeconomia.com/noticias/tim-oreilly-el-concepto-web-20-esta-obsoleto $>$ [Consulta: 16/06/2014]

GRAESSER, A.C., PERSON, N.K.; HUBER, J. (1993). "Question asking during tutoring and in the design of educational software“. En M. Rabinowitz (Ed.), Cognitive science foundations of instruction. Hillsdale, NJ: Erlbaum. 149-172.

HYMAN, R.T. (1979). Strategic questioning. Englewood Cliffs, N.J.: Prentice-Hall.

LEÓN, J.A., PEÑALBA, G., ESCUDERO, I. (2002). "Profe, ¿puedo preguntar? Una breve introducción a la interacción de preguntas y respuestas entre profesor y alumno“. Psicología Educativa, 8, 2. 107-126.

PEINADO-MIGUEL, F; FERNÁNDEZ-SANDE, M; RODRÍGUEZ-BARBA, D; ORTIZ-SOBRINO, M.A. (2013). “Aprendizaje e innovación: una propuesta metodológica desde la Empresa Informativa“. Revista Latina de Comunicación Social, núm. 68. 119-144.

(cc) EY-NC-ND 2014, Universitat Politècnica de València

I Jornadas IN-RED (2014) 


\title{
Pruebas de diagnóstico del Centro de Lenguas para la formación lingüística de alumnos universitarios: Análisis comparativo
}

\author{
Asunción Jaime $^{\mathrm{a}}$ y Cristina Pérez-Guillot ${ }^{\mathrm{b}}$
}

acentro de Lenguas -UPV, ajaime@pv.es y ${ }^{\mathrm{b}}$ Centro de Lenguas- UPV, mcperez@upv.es

\section{Resumen}

Como objetivos prioritarios del Espacio Europeo de Educación Superior se encuentran la de facilitar la inserción laboral de los egresados en el mercado internacional a través de la internacionalización de las universidades y la creación de la Europa del conocimiento. Para ello es necesario que los estudiantes posean un nivel de competencia lingüística que les permita el acceso a esta Europa del conocimiento que se está forjando.

La Universidad Politécnica de Valencia, consciente de la importancia de ofrecer una formación sólida y competitiva, ha desarrollado líneas de actuación de carácter formativo y orientativo, como la inclusión de asignaturas de idiomas conducentes a un B2 en todos los grados y la elaboración de una prueba de nivel orientativa que ayude a los alumnos a planificar su formación lingüística durante los estudios universitario.

En este trabajo comparamos los resultados obtenidos en las pruebas de diagnóstico durante los años 2012-13 y 2013-14 antes y después de que los alumnos hayan completado su periodo formativo.

Los resultados servirán no sólo para concienciar al alumno de la necesidad de formación sino también como indicador de la competencia lingüística de los estudiantes y, así, poder ofrecer cursos de formación complementaria ajustados a sus necesidades reales.

Palabras clave: competencia lingüística, pruebas de diagnóstico, , orientación formativa, espacio europeo de educación superior, centro de lenguas 
Pruebas de diagnóstico del Centro de Lenguas para la formación lingüística de alumnos universitarios: Análisis comparativo

\section{Introducción}

La implementación del proceso de Boloña ha supuesto una nueva orientación de la enseñanza en las universidades ya que entre sus metas se encuentra la de facilitar la inserción laboral de los egresados en el mercado internacional a través de la internacionalización de las universidades y la creación de la Europa del conocimiento: 'A Europe of Knowledge is now widely recognised as an irreplaceable factor for social and human growth and as an indispensable component to consolidate and enrich the European citizenship, capable of giving its citizens the necessary competences to face the challenges of the new millennium, together with an awareness of shared values and belonging to a common social and cultural space' (The Bologna Declaration of 19 June 1999).

Así, en la reunión del Consejo de Europa celebrada en Lisboa en 2000 se estableció como objetivo prioritario 'to become the most competitive and dynamic knowledge-based economy in the world, capable of sustainable economic growth with more and better jobs and greater social cohesion' (Lisbon European Council, 2000: 2). El Consejo de Europa reconoció la importancia de la educación para llevar a cabo las acciones y estrategias económicas y sociales de la Unión Europea.

Según la página oficial del proceso de Bolonia, 'employability is the ability to gain initial employment, to maintain employment, and to be able to move around within the labour market' (The Official Bologna Process Website July 2007). De hecho, uno de los papeles fundamentales de las instituciones de educación superior es la de dotar a los alumnos de los recursos necesarios para aumentar su competitividad internacional: 'The role of higher education in this context is to equip students with skills and attributes (knowledge, attitudes and behaviours) that individuals need in the workplace and that employers require' (The Official Bologna Process Website July 2007).

Como acciones prioritarias en todos los comunicados posteriores se ha destacado la importancia de fomentar la movilidad y la internacionalización de las universidades como elementos clave para lograr una Europa del Conocimiento y fomentar la empleabilidad (London Communiqué 2007; Communiqué of the Conference of European Ministers Responsible For Higher Education, Leuven and Louvain-la-Neuve, 2009). Esta misma visión es la que recoge el Ministerio de Educación, Cultura y Deportes en su Plan de acción para el apoyo y la modernización de la universidad pública española en el marco de la estrategia universidad 2015: 'El Sistema Universitario es consciente de que la internacionalización constituye una condición y una garantía de calidad a la vez que un objetivo de desarrollo' (Ministerio De Educación, Cultura y Deportes, 2011).

Pero para lograr dichos objetivos es necesario que los participantes en este proceso posean un nivel adecuado de competencia lingüística en, al menos, una o dos lenguas extranjeras,

(c)) EY-NC-ND 2014, Universitat Politècnica de València

I Jornadas IN-RED (2014) 
por lo que el conocimiento de idiomas se ha convertido en pieza clave de integración en el espacio europeo de educación superior: 'La globalización del empleo y la internacionalización de los nuevos puestos de trabajo derivados de la incorporación de nuestro país en la Sociedad basada en el Conocimiento ha provocado que en el momento de adecuación de nuestros estudios al EEES se consideraran de forma especial la adquisición de conocimientos, habilidades y competencias de internacionalización con el fin de preparar a nuestros futuros egresados para un mundo cada vez más globalizado a nivel de empleo' (EIU, 2011).

Aunque desde el principio de esta reforma educativa se reconoció la importancia de los idiomas, fue en la Declaración de Belín (Berlin Declaration, 2001) donde su relevancia se evidenció de forma explícita, al destacar la necesidad de mejorar la competencia lingüística de los estudiantes universitarios. Ello llevó a que en 2003, el Consejo Europeo para las Lenguas lanzase el proyecto ENLU (European Network for the Promotion of Language Learning Among All Undergraduates) instando a las instituciones de educación superior a que elaborasen políticas lingüísticas encaminadas a promover la formación en lenguas extranjeras (European Language Council, 2005). Actualmente, nadie duda de la necesidad de fomentar el conocimiento de idiomas en la formación del estudiante universitario ya que, como reconocen Haug y Vilalta (2011), 'Se deben promover además competencias internacionales como la lingüística y la intercultural'.

La Universidad Politécnica de Valencia (UPV), comprometida con el Proceso de Bolonia y consciente de la importancia de ofrecer a sus egresados una formación sólida y competitiva que les permita abordar los difíciles retos del nuevo mercado laboral que se está gestando como consecuencia de los cambios económicos actuales, ha considerado conveniente exigir un nivel B2 de competencia lingüística en sus nuevos grados: 'para la obtención del título de Grado el alumno deberá acreditar el conocimiento de una lengua extranjera, preferentemente el inglés, con un nivel correspondiente a B2' (Documento Marco UPV, 2008).

El Centro de Lenguas de la UPV, a instancias de los Vicerrectorados de Estudios y Convergencia Europea y Alumnado y Cultura, ha elaborado una prueba on-line de diagnóstico de nivel de conocimientos lingüísticos voluntaria que se ha ofrecido tanto a los alumnos de nuevo ingreso como a alumnos de $2^{\circ}$ y 3 er año de carrera. La prueba tiene una doble finalidad, por una parte, es una prueba informativa que sirve para orientar a los estudiantes desde su entrada en la Universidad y a lo largo de sus estudios, en la planificación de su aprendizaje en lenguas extrajeras, permitiéndoles poder diseñar un plan estratégico para lograr el Nivel B2 requerido para la obtención del título de grado al finalizar el $4^{\circ}$ curso.

Por otra parte, el análisis comparativo de los resultados de la prueba en años sucesivos ha servido para corroborar la necesidad de incorporar una oferta formativa de idiomas más

\section{(c)) EY-NC-ND 2014, Universitat Politècnica de València}

I Jornadas IN-RED (2014) 
Pruebas de diagnóstico del Centro de Lenguas para la formación lingüística de alumnos universitarios: Análisis comparativo

amplia en el diseño curricular de los grados universitarios de la UPV si se quieren lograr los objetivos establecidos en su Documento marco.

\section{Descripción de la prueba de diagnóstico}

La prueba de diagnóstico on-line elaborada por el Centro de Lenguas tiene carácter informativo en la que el alumno recibe una orientación sobre su nivel de competencia lingüística y le permite actuar sobre sus deficiencias antes de finalizar sus estudios universitarios.

Entre los aspectos que se tuvieron en cuenta a la hora de seleccionar la plataforma para diseñar el test se encuentran el tiempo de realización, amigabilidad de la plataforma, respuesta inmediata de resultados y flexibilidad de la herramienta.

La prueba consta de dos partes, una sección que se centra en el uso de la lengua y que abarca aspectos gramaticales y léxicos, y una segunda sección que evalúa la comprensión auditiva. Puesto que el objetivo de la prueba es informativo y no evaluativo, se optó por no incluir otras destrezas que serían indispensables en el caso de pruebas de evaluación de otro tipo, como las de certificación de competencia o de maestría.

La duración de la prueba es de aproximadamente una hora, 20 minutos para la Sección de Uso de la lengua y 35 minutos para la Sección de Comprensión auditiva. La Sección de Uso de la lengua consta de 50 preguntas de elección múltiple, que se extraen de una base de datos de aproximadamente 2000 ítems y que cubren todos los niveles establecidos en el Marco Común Europeo de Referencia (MCER). La sección de Comprensión auditiva consta de 3 audiciones de distinto nivel y duración, correspondientes a los niveles B1, B2 y C1 del MCER. La prueba de comprensión oral se utiliza para definir de forma más precisa el nivel obtenido en la sección de Uso de la lengua. Una descripción más detallada de la prueba se puede consultar en trabajos anteriores de las autoras (Jaime y Perez-Guillot, 2012; Jaime et al., 2012).

Los alumnos tienen la información sobre la disponibilidad de la prueba en el sobre virtual de matrícula; una vez matriculados, reciben una carta informativa con la explicación del funcionamiento de la prueba on-line orientativa que tienen a su disposición a través de Poliformat, la plataforma propia de la universidad. Cuando finalizan la prueba y a efectos exclusivamente informativos, pueden consultar los resultados en 'Consulta tu calificación'.

El objetivo primordial de la prueba es poder ayudar a los alumnos a orientar su formación en lenguas extranjeras y a planificar con suficiente antelación la estrategia a seguir para lograr la adquisición del nivel B2 antes de finalizar sus estudios de Grado. 


\section{Análisis de Resultados}

En un trabajo anterior (Jaime y Perez-Guillot, 2012) las autoras analizaron los datos obtenidos en las pruebas de diagnóstico realizadas por estudiantes de nuevo ingreso y cuyos resultados se utilizaron tanto para concienciar a los alumnos de la necesidad de planificar su formación lingüística a lo largo de sus estudios como para influir en los órganos de gobierno sobre la necesidad de incluir estrategias formativas en los curricula de los grados universitarios.

En el presente trabajo presentamos los resultados de las pruebas de diagnóstico realizadas por el mismo colectivo de alumnos durante los cursos 2012-2013, o sea, alumnos que están en segundo año de grado y que aún no han cursado las asignaturas de idiomas incluidas en sus grados, y 2013-2014 correspondiente a alumnos de tercer año que ya han completado parte de la formación lingüística incluida en sus planes de estudio (véase Tabla 1)

Tabla 1. Resultados de la prueba de diagnóstico en 2012 y 2013

\begin{tabular}{|c|c|c|}
\hline & $\begin{array}{c}12-13 \\
\left(2^{\circ} \text { curso }\right)\end{array}$ & $\begin{array}{c}13-14 \\
\text { (3r curso) }\end{array}$ \\
\hline INGLES A1 & $8,80 \%$ & $6,99 \%$ \\
\hline INGLES A2 & $17,74 \%$ & $17,17 \%$ \\
\hline INGLES B1 & $33,29 \%$ & $33,73 \%$ \\
\hline INGLES B1+ & $23,80 \%$ & $24,55 \%$ \\
\hline INGLES B2 & $13,89 \%$ & $15,27 \%$ \\
\hline INGLES C1 & $2,48 \%$ & $2,30 \%$ \\
\hline $\mathrm{N}^{0}$ TOTAL & 727 & 1002 \\
\hline
\end{tabular}

Como primer dato relevante podemos destacar el mayor número de alumnos de $3 \mathrm{r}$ año que ha realizado la prueba voluntaria este curso académico (1002) frente a los alumnos de $2^{\circ}$ que la realizaron el curso académico 2012 (727), lo que indica que el interés de los alumnos por conocer su nivel de competencia lingüística es mayor a medida que avanzan en sus estudios universitarios y se aproximan a la finalización de su carrera.

Asimismo, como se puede ver en el siguiente gráfico (Gráfico 1), tras la realización de algunos cursos de formación de inglés, se aprecia una progresiva mejoría en el nivel de competencia lingüística de los alumnos, observándose como aumentan los porcentajes de los alumnos correspondientes a los niveles B1, B1+ y B2 del MCER mientras que disminuye el número de alumnos con niveles bajos (A1 y A2).

(c)) EY-NC-ND 2014, Universitat Politècnica de València

I Jornadas IN-RED (2014) 
Pruebas de diagnóstico del Centro de Lenguas para la formación lingüística de alumnos universitarios: Análisis comparativo

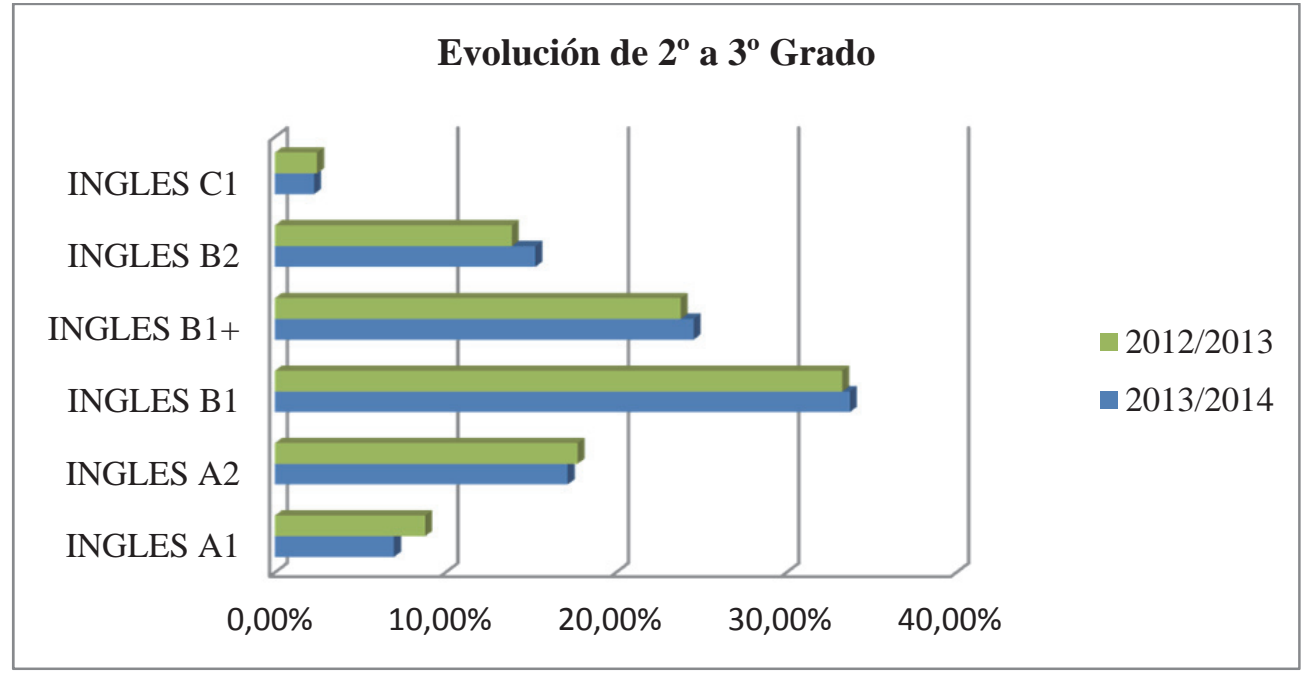

Gráfico 1. Evolución de los alumnos de $2^{\circ}$ a $3^{\circ}$ de grado

Aunque más de la mitad de los alumnos en ambos años analizados (57,09\% en 2012 y $58,28 \%$ en 2013) tiene un nivel de competencia equivalente al nivel B1 del MCER, es decir B1 y B1+, se observa una pequeña disminución en el porcentaje de alumnos con niveles A1 y A2 en el curso académico $2013(24,15 \%)$ con respecto al mismo colectivo el curso académico anterior $(26,55 \%)$, dato positivo ya que revela incremento en el nivel general de competencia lingüística.

El mayor incremento se aprecia en los datos correspondientes al Nivel B2, aumentando de un $13,89 \%$ en 2012 a un 15,27\% en 2013, lo que indica que los cursos de formación están dando sus frutos, aunque son claramente insuficientes ya que, de acuerdo con los resultados obtenidos, todavía el $82,44 \%$ de alumnos tiene un nivel de conocimientos de inglés inferior al B2 necesario para la obtención del título de grado tras haber finalizado los cursos de idiomas de sus respectivos grados.

Por tanto, sería necesario incorporar una mayor y mejor oferta formativa si pretendemos que los egresados de la UPV puedan ser competitivos en el mercado social, político y laboral no solo sino también a nivel internacional.

\section{Conclusiones}

Los conceptos de la Europa del Conocimiento y la Internacionalización de las universidades llevan implícitos la necesidad de poseer un buen nivel de competencia lingüística, como queda reflejado en las prioridades del proceso de Bolonia desde sus 
inicios en 1999 y que ha sido una constante prioridad en todos los comunicados y declaraciones posteriores.

La Universidad Politécnica de Valencia, comprometida con el EEES y para garantizar la empleabilidad de sus egresados en el nuevo mercado laboral que se está gestando como consecuencia de la crisis económica que afecta a todos los países miembro de la UE, ha considerado oportuno exigir a los graduados un nivel de competencia equivalente al B2 del MCER para la obtención del título de grado.

Entre sus acciones para obtener dicho objetivo, los órganos directivos de la UPV solicitaron al Centro del Lenguas la elaboración de una prueba de diagnóstico on-line, que se empezó a ofrecer en el curso académico 2011-12.

Los resultados de dichas pruebas pusieron de manifiesto la necesidad incorporar asignaturas de idiomas conducentes a un B2 en todos los grados.

Para hacer un mejor seguimiento de la formación lingüística de los alumnos, en los siguientes cursos académicos la prueba también se ofreció a alumnos de $2^{\circ}$ y $3 e r$ curso y así poder comprobar si la oferta formativa permite cumplir los objetivos lingüísticos marcados por la UPV.

Si bien el análisis de datos muestra una mejora en la competencia lingüística de los alumnos tras realizar los cursos de idiomas, los resultados evidencian que dicha formación es insuficiente y, por tanto, que los alumnos deberían completar su aprendizaje de idiomas con la oferta de cursos que ofrece el Centro de Lenguas.

\section{Referencias}

BERLIN DECLARATION (30 June 2001). Language Studies in Higher Education: A Key Contribution to European Integration. http://userpage.fu-berlin.de/elc/docs/ BDeclEN.pdf [Consulta: 10 de marzo de 2012].

COMMUNIQUE OF THE CONFERENCE OF EUROPEAN MINISTERS RESPONSIBLE FOR HIGHER EDUCATION, LEUVEN AND LOUVAIN-LA-NEUVE 28-29 April 2009 (2009). The Bologna Process 2020 - The European Higher Education Area in the new decade. <http://www.ehea.info/Uploads/Declarations/Leuven_Louvain-la-Neuve_Communiqu\%C3\%A9 _April_2009.pdf > [Consulta: 10 de marzo de 2012]

DOCUMENTO MARCO UPV (2008). Documento de Diseño de titulaciones. Documento marco UPV, fecha febrero 2008.

EIU (2011). Estrategia de internacionalización del sistema universitario español - Estrategia universidad 2015,EIU septiembre 2011. <http://cms.ual.es/idc/groups/public/@vic/@ vinternacional/ documents/documento/relintinter3.pdf> [Consulta: 2 febrero de 2014]

EUROPEAN LANGUAGE COUNCIL - ENLU (2005). European Network for the Promotion of Language Learning Among All Undergraduates. Doc (2005/01 - Final). 
Pruebas de diagnóstico del Centro de Lenguas para la formación lingüística de alumnos universitarios: Análisis comparativo

<http://www.celelc.org/archive/conference/Conference_documents/english_0.pdf?1370253481>

[Consulta: 2 de febrero de 2014].

HAUG G. y VILALTA J. M. (2011). La internacionalización de las universidades, una estrategia necesaria. Madrid: Studia XXI. Fundación Europea Sociedad y Educación.

JAIME, A. PEREZ-GUILLOT, C. (2012). "Prueba de Diagnóstico de Competencia Lingüística" en Jornadas de Innovación Educativa 2012 (ISSN 978-84-8363-926-9), Universidad Politécnica de Valencia, pp. $161-163$.

JAIME, A., PEREZ-GUILLOT, C. y CANDEL, M.Á. (2012). "A Comprehensive placement test tool for language centres" en Learning in Higher Education. Journal of the European Confederation of Languages Centres in Higher education. De Gruyter. pp 325-331.

LISBON EUROPEAN COUNCIL 23 AND 24 MARCH 2000 (2000). Presidency Conclusions. <http://www.europarl.europa.eu/summits/lis1_en.htm\#1> [Consulta: 4 de enero de 2011].

LONDON COMMUNIQUE 18 MAY 2007 (2007). Towards the European Higher Education Area: responding to challenges in a globalised world <http://www.ond.vlaanderen.be/ hogeronderwijs/bologna/documents/MDC/London_Communique18May2007.pdf> [Consulta: 9 de marzo de 2012]

MINISTERIO DE EDUCACION, CULTURA Y DEPORTES (2011). Estrategia universidad 2015 <http://www.mecd.gob.es/dctm/boloniaees/documentos/planaccionmodernizacion.pdf?documentId= 0901e72b8004aa5f> [Consulta: 10 de marzo de 2012]

THE BOLOGNA DECLARATION OF 19 JUNE 1999 (1999). The European Higher Education Area <http://www.ond.vlaanderen.be/hogeronderwijs/bologna/documents/ MDC/ BOLOGNA _DECLARATION1.pdf> [Consulta: 8 de marzo de 2012]

THE OFFICIAL BOLOGNA PROCESS WEBSITE JULY 2007 - JUNE 2010 <http://www.ond.vlaanderen.be /hogeronderwijs/bologna/actionlines/employability.htm> [Consulta: 8 de marzo de 2012] 


\title{
Diseño y Desarrollo de un MOOC como Estrategia para el Aprendizaje Propedéutico de la Química
}

\author{
Carmen Gómez, Juan Antonio Llorens, Isabel Morera Bertomeu y Teresa Pardo \\ mcgomez@qim.upv.es, juallom2@qim.upv.es, imorera@upvnet.upv.es, tpardo@qim.upv \\ Departamento de Química. Universitat Politècnica de València. \\ Camino de Vera s/n. 46071-València
}

\begin{abstract}
The design and development of a chemistry propedeutic course based on the Massive Online Open Course (MOOC) model as educational innovation, is shown in this work. Its aim is to help students to overcome well known shortcomings in prior knowledge and reach a suitable level to access to Higher Education. This course has been launched at the UPV[X] platform of the Universitat Politècnica de València. Its essential structure consists of alternating videotape records using the Polimedia format, application and reinforcement activities, the same way that formative and summative assessment tasks. The forum is the way for providing feed-back, academic guidance and student support. At the end of the course, data from surveys and information concerning achievement level of students expectations the same way that their opinion about its usefulness have been analyzed. This way, a useful feed-back is obtained in order to improve each one of the successive edition
\end{abstract}

Keywords: $M O O C$, chemistry, prerequisite, learning platforms, poliformaT, online.

\section{Resumen}

En esta comunicación se presenta el diseño y desarrollo de un curso propedéutico de Química, en formato Massive Online Open Course (MOOC) como innovación educativa, con el fin de nivelar a los estudiantes que acceden a los estudios universitarios, ayudándoles a superar las deficiencias 


\begin{abstract}
detectadas en sus conocimientos. El objetivo del trabajo ha sido la implementación de un modelo de curso de preparación para el aprendizaje de la Química con las características de ser principalmente masivo, gratuito $y$ con posibilidades de aprendizaje cooperativo, en el entorno de la plataforma UPV[X] de la Universitat Politècnica de València. Se usa como eje vertebrador la alternancia de grabaciones en video, actividades de aplicación, de refuerzo y de evaluación. El foro es el canal de comunicación que proporciona retroalimentación y permite la actividad tutorial. Se han analizado los datos recogidos en encuestas y se dispone de información sobre el logro de las expectativas de los estudiantes y de la satisfacción y utilidad al finalizar el curso. De este modo, se ha obtenido información que nos ha permitido mejorar en cada una de las ediciones realizadas.
\end{abstract}

Palabras clave: $M O O C$, química, propedéutico, aprendizaje, teleformación, plataforma UPV[X]

\title{
1. Introducción
}

Un modelo educativo de creciente popularidad en el ámbito universitario es el basado en la oferta de cursos masivos y abiertos a través de plataformas de teleformación. Son conocidos por MOOCs (acrónimo en inglés de Massive Online Open Course). A grandes rasgos, y partiendo de las palabras que lo definen, se trata de cursos: actividades convenientemente estructuradas y orientadas al aprendizaje, con una evaluación planificada que da lugar a una acreditación. Son abiertos, en general gratuitos y no presenciales, desarrollándose principalmente online, en el marco de plataformas educativas en la web. Su carácter masivo viene dado por la ausencia de limitaciones en cuanto al número de participantes o, al menos, por ser mucho más elevado que en los cursos presenciales. Dichas características son ampliamente descritas en la bibliografía, con diversos grados y matizaciones a la hora de valorar las características que los definen (Durall, 2012; Gea, 2013 y Ambriz, 2014)

Estos cursos constituyen un fenómeno educativo relativamente reciente. Aunque su denominación fue introducida en el año 2008 por Dave Cormier en su curso Connectivisme and Connective Knowledge, fue en el año 2102 cuando se produjo la consolidación de este modelo educativo a través de plataformas tales como Coursera, Canvas, Audacity, etc. o la española MiriadaX, con un notable incremento de la oferta de cursos en una gran variedad de campos del conocimiento.

Esta eclosión inicial puede comprenderse como una respuesta a las elevadas expectativas que la extensión de las nuevas tecnologías suscitó frente a muchos de los principales retos

(c)) EY-NC-ND 2014, Universitat Politècnica de València

I Jornadas IN-RED (2014) 
actuales de la educación, principalmente la universitaria. En este sentido, uno de los principales desafíos es la creciente demanda de un acceso universal y gratuito al conocimiento por amplios sectores sociales, de muy diferentes ámbitos geográficos y socioculturales, con intereses y motivaciones también dispares. Por otra parte, para las propias universidades, los MOOCs constituyen una alternativa eficaz para mejorar su visibilidad y reputación ante la sociedad, al presentarse como fuente y referencia de conocimientos innovadores y de calidad. Al mismo tiempo, las comunidades de aprendizaje originadas en su seno, por su elevada diversidad, constituyen un marco novedoso y de gran interés para una investigación educativa basada en una concepción del aprendizaje donde la interacción social en la red adquiere un papel esencial (Vázquez, 2013; Barbozat, 2014).

No obstante, pese a esta rápida expansión de los MOOCs como modelo educativo, no faltan autores como Poy (2014) que afirman la existencia de un cierto punto de inflexión en su crecimiento, planteando la necesidad de una reflexión crítica sobre aspectos tales como la interactividad o la viabilidad económica.

Al margen de estas consideraciones y centrándonos en los objetivos de esta comunicación, es importante, describir brevemente desde el punto de vista educativo el origen, la evolución y las diferentes orientaciones de este modelo educativo, con objeto de situar adecuadamente en su contexto nuestra propuesta.

Los MOOCs pueden considerarse como el resultado de la confluencia de dos fenómenos, uno educativo y otro social, caracterizados ambos por ser resultado de la emergencia de las nuevas tecnologías (Méndez, 2013). Por una parte, tenemos la evolución del e-learning y su progresiva integración en plataformas educativas como Sakai, dando lugar a los denominados LMS (Learning Management System), donde la aportación de recursos y contenidos educativos va asociada a la incorporación de herramientas interactivas y participativas que permiten al profesorado un mayor seguimiento del aprendizaje de sus alumnos. Al mismo tiempo, dichas herramientas permiten a los estudiantes la adquisición de competencias como la comunicación y el trabajo colaborativo.

Por otra parte, el fenómeno de las redes sociales proporciona una nueva dimensión a la interactividad. Así como el modelo LMS se caracteriza por el carácter lineal y jerárquico de la relación profesorado-alumnado, con un elevado grado de sincronización entre la tarea del profesorado y la de sus estudiantes, los MOOCs, van más allá, e implican una transformación del espacio social, rompiendo las barreras tradicionales de espacio y tiempo. De este modo, el proceso de aprendizaje adquiere un carácter no lineal y asíncrono, en el que coexisten diferentes estilos y ritmos de aprendizaje y donde la autonomía del estudiante adquiere un protagonismo esencial.

Desde el punto de vista docente, este modelo educativo no es fácilmente compatible con la mera transmisión de recursos basados en contenidos estáticos y externos, por diversa que

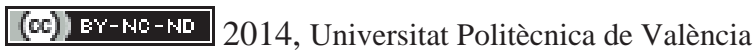

I Jornadas IN-RED (2014) 
sea su procedencia. En los MOOCs, tal como afirma Méndez (2013) existe, en mayor o menor grado, una convergencia entre el papel del profesor y el de creador de contenidos. Esta confluencia de roles se acentúa en la medida en que el desarrollo del curso se ve influenciado por la participación de los estudiantes, o en la mayor o menor especificidad de sus perfiles.

De hecho, aunque el contenido inicial de un curso sea aportado por el profesorado, va enriqueciéndose progresivamente a través de las contribuciones de los estudiantes mediante su actividad en las redes sociales, configurando así comunidades de aprendizaje. Otra importante fuente de conocimiento es, además, la que procede de las herramientas de agregación de contenidos como RSS (Really Simple Syndication), que los estudiantes pueden utilizar para compartir, ampliar o contrastar información permanentemente actualizada procedente de la web.

Puede afirmarse, en definitiva, que uno de los rasgos que definen la evolución desde la enseñanza online a los MOOCs es el progresivo reparto de responsabilidades. En los años 80 ya se afirmaba, como una cualidad definitoria de la pedagogía constructivista, que "el alumno es responsable de su propio aprendizaje". Así, si revisamos los diferentes modelos educativos que han ido surgiendo en las últimas décadas, este tipo de cursos podrían ser valorados como un contexto idóneo para que las orientaciones socioconstructivistas del aprendizaje, basadas principalmente en la obra Vygotsky (1991) y frecuentemente consideradas hasta hace pocos años como utópicas, puedan llevarse a la práctica. Podemos pensar, a modo de ejemplo, en las limitaciones que la presencialidad ha impuesto al trabajo colaborativo o en la posibilidad de proporcionar una evaluación formativa de calidad a través de un feed-back rápido y fácilmente accesible.

En este proceso de evolución pueden distinguirse dos tendencias cuya distinción es importante a la hora de caracterizar nuestra propuesta. Por una parte tenemos los cMOOCs, basados en el aprendizaje conectivo (Downes, 2008). En ellos la propuesta inicial tiene el papel de elemento dinamizador cuyo objetivo es promover la interacción entre los participantes, cuyo protagonismo en la elaboración de los contenidos es fundamental por medio de diferentes recursos: blogs, redes sociales, wikis, etc. En estos cursos, los objetivos no vienen establecidos y delimitados principalmente por criterios externos al curso, sino que tienen un carácter mucho más dinámico y van ligados a las necesidades e intereses de formación de los propios estudiantes, siendo también, consecuentemente, menos susceptibles de una evaluación objetiva.

Por el contrario, en los xMOOCs los contenidos tienden a ser establecidos y organizados desde la perspectiva de unos objetivos externos, otorgándose al papel del profesorado un mayor control en el seguimiento del trabajo y rendimiento del estudiante (tal como en los LMS) y donde las herramientas participativas, manteniendo su importancia, están más 
orientadas a la colaboración entre los estudiantes y a la acción tutorial del profesorado, y no tanto a la creación de los propios contenidos. El curso al que se refiere esta comunicación sería un ejemplo de xMOOC, ya que su carácter propedéutico implica la existencia de unos contenidos y objetivos de aprendizaje cuya referencia es externa (acceso a la Universidad). Consecuentemente, la adaptación de los contenidos vendría dada más por la necesidad de atender a la gran diversidad de los estudiantes en cuanto a sus conocimiento previos, que por sus intereses o expectativas personales.

La corta pero intensa trayectoria de los MOOCs permite identificar también un conjunto de debilidades y obstáculos que deben tenerse en cuenta en su diseño y gestión. Sin ánimo de ser exhaustivos podemos citar algunos de los que consideramos más relevantes. En primer lugar, es importante definir el papel de la tecnología: admitiendo la necesaria subordinación de la tecnología a los objetivos educativos y a los principios del aprendizaje, debe considerarse que no es un simple envoltorio o modo de transmitir el contenido, sino que, por ser la interfaz entre el estudiante y el diseñador del aprendizaje, ejerce una función esencial. Por ejemplo, la diferencia, desde el punto de vista del aprendizaje del estudiante, entre mostrar un proceso experimental mediante una secuencia estática de fotografías, mediante la grabación en vídeo o utilizando una animación; de ahí el gran impacto que posee una adecuada selección y actualización del software educativo.

También puede citarse la diversidad del alumnado en cuanto a formación previa y motivación, consecuencia del carácter abierto de los cursos. En el caso de nuestra propuesta, este hecho es de gran importancia, ya que cuestiona la consideración del curso como una unidad al responder cada una de sus partes a las necesidades específicas de determinados colectivos.

Por último, haremos referencia a la adaptación del profesorado a este modelo educativo. En general, el docente universitario ha pasado en pocos años de gestionar el aprendizaje en un espacio físico y temporal definido (aula y horario), a la semipresencialidad propia de los entornos LMS como PoliformaT. La incorporación de los MOOCs plantea la necesidad de adaptarse a un tipo de interacción con los estudiantes caracterizada por:

- La menor posibilidad de control de los procesos de enseñanza-aprendizaje (principalmente, por su carácter asíncrono).

- La incorporación de las redes sociales donde el grado de presencia de los estudiantes puede además ser desigual.

- La creciente importancia de la participación del alumnado en la creación de los propios contenidos.

Estos y otros obstáculos descritos en la literatura (Méndez, 2013) deben ser objeto de una profunda reflexión a la hora de extender la aplicación de los MOOCs como modelo educativo. Si bien no puede afirmarse que constituyan una alternativa global a la Educación

\section{(cc) EY-NC-ND 2014, Universitat Politècnica de València}

I Jornadas IN-RED (2014) 
Universitaria es evidente que constituyen un recurso valioso y de gran potencialidad en cuanto a su influencia social. En este sentido, tal como afirma Méndez (2013) citando una reciente intervención de Downes, uno de los impulsores de estos cursos, la docencia online puede evolucionar hacia los denominados PLE (Personal Learning Environments), con un papel creciente del estudiante en la toma de decisiones acerca de su propio aprendizaje (Taraghi, 2010).

\section{Objetivos}

El objetivo general de la comunicación es divulgar la experiencia del diseño e implementación de un MOOC propedéutico de Química en la plataforma UPV $[X]$ y dinamizar la participación de otros profesores universitarios en este tipo de iniciativas. Otros objetivos a señalar son: analizar su desarrollo y evaluar los resultados obtenidos.

\section{Desarrollo y resultados de la innovación}

La Universitat Politècnica de València (UPV) tiene una notoria trayectoria en las diferentes modalidades de formación online (Despujol, 2013). En este contexto surge la plataforma UPV $[\mathrm{X}]$ creada para la oferta de cursos en formato MOOC. Por iniciativa del Vicerrectorado de las Tecnologías de la Información y de la Comunicación (VTIC) de la UPV, en el curso 2012-13, se lanza la propuesta de ofertar cursos propedéuticos de Química, Física y Matemáticas en este formato, especialmente dirigido a los alumnos de nuevo ingreso. Un equipo de profesores del departamento de Química comenzamos la andadura de la puesta a punto y desarrollo del curso denominado "Introducción a la Química", con la finalidad de proporcionar a los estudiantes que acceden a la Universidad una formación básica de Química que les permita subsanar las deficiencias detectadas en sus conocimientos.

En el transcurso del diseño de este MOOC surge, a finales de 2012, la iniciativa de la plataforma MiriadaX, promovida por Telefónica Learning Services y Universia (red de universidades de habla hispana y portuguesa) con el fin de difundir el conocimiento en abierto en el espacio iberoamericano de Educación Superior. En este contexto, los profesores implicados decidimos participar en MiriadaX con el curso "El enlace y la nomenclatura de los compuestos químicos" para el que se prepararon los materiales de dos unidades didácticas.

Con este punto de partida y siguiendo el compromiso adquirido con el VTIC, se completaron posteriormente todas las unidades didácticas del MOOC "Introducción a la Química” para ofertarlo a los alumnos de nuevo ingreso en la UPV. La primera edición se 
realizó entre julio y septiembre de 2013. Iniciado el curso académico 2013-14 se volvieron a lanzar dos ediciones más.

El diseño de estos cursos responde a las características de un xMOOC y están organizados en unidades didácticas. Cada unidad didáctica se compone de varias lecciones con objetivos concretos, cada lección incluye una grabación de un video explicativo (en nuestro caso una grabación Polimedia) de unos 10 minutos sobre un contenido y, generalmente, otra con ejercicios para su aplicación. Cada contenido se completa con actividades a realizar por el alumno, en forma de preguntas objetivas de opción múltiple. El material también se presenta en soporte documental para descargar. En el diseño del curso es primordial delimitar y secuenciar los contenidos de manera que cada video implica el desarrollo completo de un concepto que prepara para los siguientes.

Cada unidad didáctica concluye con una actividad de evaluación. Si la prueba se supera el estudiante puede pasar a la siguiente unidad y, en caso contrario, debe trabajarla más y volver a intentarlo. Se dispone de un foro en el que los alumnos plantean las dudas que les surgen, que pueden ser resueltas tanto por los profesores como por los alumnos de la comunidad de aprendizaje. La realización de actividades después de cada video permite al alumno autoevaluarse y obtener retroalimentación inmediata, y el foro crea un entorno de aprendizaje colaborativo que permite plantear y resolver dudas, así como compartir reflexiones con el resto de estudiantes y profesores. Una vez superadas las pruebas correspondientes a cada unidad el alumno realiza un examen final que le permite obtener una credencial digital, sin validez académica.

\subsection{La experiencia de MiriadaX}

En el curso ofertado en MiriadaX "El enlace y la nomenclatura de los compuestos químicos" los contenidos se agruparon en dos unidades didácticas, que se centraban en el estudio del enlace químico y en la nomenclatura de compuestos orgánicos e inorgánicos. La duración del curso fue de 6 semanas y se realizó entre febrero y abril de 2013.

Con esta apuesta nos iniciamos no sólo en el diseño del curso, sino también en el uso de una plataforma en desarrollo. La tarea fue ardua en lo que se refiere a la elaboración y grabación de los materiales y, especialmente, en la utilización de la plataforma, que presentaba ciertas carencias y problemas técnicos entre los que cabe destacan el no tener previsto el uso de fórmulas químicas y matemáticas. Esta experiencia, desconocida hasta entonces para los profesores que participamos, permitió la mejora técnica de la plataforma MiriadaX, así como de la propia plataforma de la Universitat Politècnica de València $\mathrm{UPV}[\mathrm{X}]$, con el fin de adaptarla a las necesidades de los cursos de las asignaturas de Química, Física y Matemáticas.

\section{(c)) EY-NC-ND 2014, Universitat Politècnica de València}

I Jornadas IN-RED (2014) 
El número de estudiantes inscritos fueron 1825, finalizaron el 70\% y superaron el examen el $15 \%$. Se recogieron datos, mediante encuestas, sobre: país de origen, sexo, nivel de estudios, conocimientos previos, cómo habían conocido el curso, horas dedicadas a la semana, expectativas cubiertas. También se les preguntó sobre la propia plataforma: velocidad, problemas, uso, etc.

Del análisis de estos datos disponibles se puede extraer la siguiente información:

- Siendo una plataforma orientada a la formación en habla hispana y portuguesa, el 56\% de los alumnos inscritos en el curso eran españoles y el resto pertenecía a diversos países de Sudamérica.

- Casi el 50\% tenían estudios universitarios, seguido de Bachillerato o nivel equivalente (28\%).

- El porcentaje de alumnos fue similar en ambos sexos.

- $\quad$ El $50 \%$ tenía formación previa en la materia.

- La mayoría (43\%) conoció el curso a través de la plataforma MiriadaX, el $27 \%$ se inscribió recomendado por algún conocido.

- La dedicación semanal al curso estaba entre menos de 3 horas (32\%), y 3-5 horas $(49 \%)$.

- Más del 90\% declaró que había conseguido cubrir sus expectativas.

- Respecto a la plataforma destacar que el 78\% respondió que velocidad era adecuada, el $84 \%$ respondió que el uso había sido correcto, y el 23\% indicó problemas con el uso que se fueron resolviendo.

- Los alumnos tenían edades entre 14 y 62 años, siendo el más numeroso el grupo comprendido entre 18 y 26 años.

\subsection{La experiencia de UPV[X]}

La plataforma UPV $[X]$ (www.upvx.es) consiste en un conjunto de aplicaciones desarrolladas por el Área de Sistemas de la Información y las Comunicaciones (ASIC) de la UPV. Las características particulares se pueden resumir en que:

- Se soporta en los servidores de la UPV y los videos están en YouTube.

- Es flexible, con poco requerimiento para su mantenimiento, de fácil manejo para el estudiante y para el profesor.

- Los cursos se generan utilizando una hoja de cálculo.

- Las evaluaciones han de ser pruebas objetivas de respuesta múltiple.

- Entre ediciones no se retira el material pero no están activas las pruebas de evaluación, los estudiantes registrados pueden revisar lo que vieron y preparase para la siguiente edición.

(cc) EY-NC-ND 2014, Universitat Politècnica de València

I Jornadas IN-RED (2014) 
- Se considera que para superar el curso es necesario resolver el 70\% de las cuestiones que se plantean, de manera que en esas condiciones se obtiene una credencial digital, sin validez académica, al acabar el curso.

En UPV $[X]$ se ofertan una serie de cursos de modo abierto, que se presentan mediante una grabación Polimedia donde se explican los objetivos, el contenido, los requisitos previos de los alumnos y el profesorado que los imparten. En la Fig. 1 se muestra el curso de "Introducción a la Química".

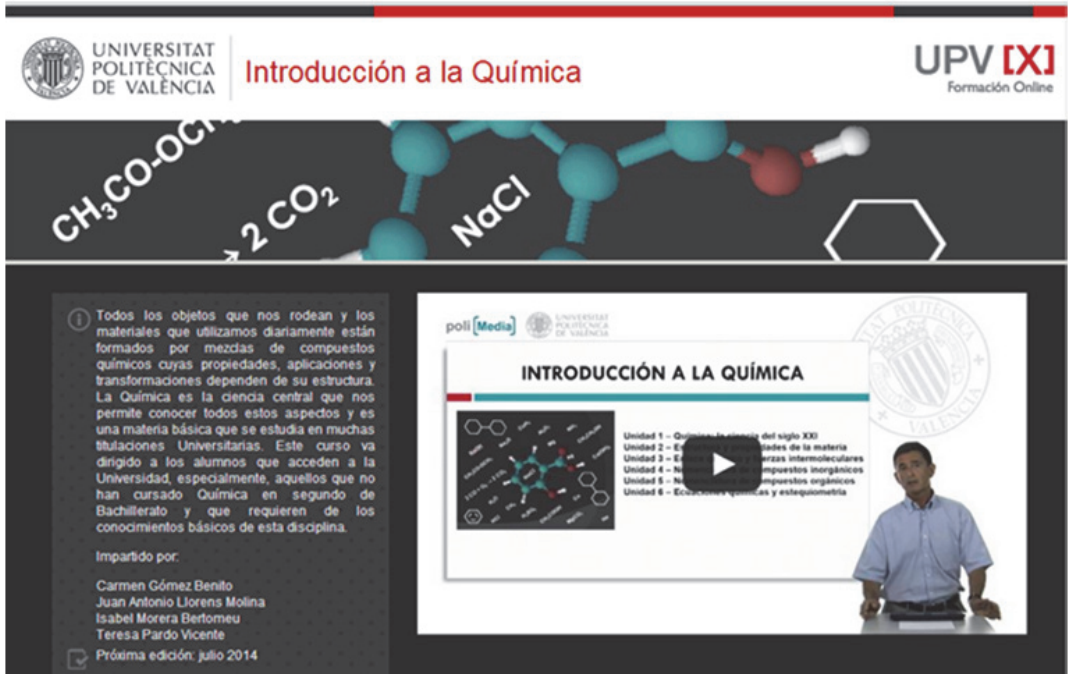

Fig. 1 Curso de Introducción a la Químia en UPV[X]

En este curso los contenidos se agrupan en seis unidades didácticas, la primera tiene un papel básicamente motivador y las restantes giran en torno a tres aspectos básicos de la Química: estructura de la materia, formulación y nomenclatura y aspectos cuantitativos de la reacción química, y se distribuyen del siguiente modo:

- Química: la ciencia del siglo XXI

- Estructura y propiedades de la materia

- Enlace químico y fuerzas intermoleculares

- Nomenclatura de compuestos inorgánicos

- Nomenclatura de compuestos orgánicos

- Ecuaciones químicas y estequiometría

\section{(cc) EY-NC-ND 2014, Universitat Politècnica de València}


La primera edición en UPV [X], dirigida a los alumnos de nuevo ingreso, se realizó entre julio y octubre de 2013 con una duración de 6 semanas. El curso se dio a conocer a través del Vicerrectorado de Alumnado y se incluyó como información en el sobre virtual de matrícula. Iniciado el curso académico 2013-14 se volvió a lanzar otra edición que se inició en octubre de 2013 y posteriormente, se abrió la última edición, con una duración de 12 semanas, a finales de febrero.

Se han recogido datos sobre el perfil de los registrados en las tres ediciones (para acceder a la información del curso se precisa del registro), que se muestran en la Tabla 1:

Tabla 1. Datos del perfil de los registrados

\begin{tabular}{|l|l|l|l|l|}
\hline \multicolumn{2}{|l|}{ Edición } & $1^{\mathrm{a}}$ & $2^{\mathrm{a}}$ & $3^{\mathrm{a}}$ \\
\hline Inscritos & 621 & 1038 & 471 \\
\hline España & $75 \%$ & $38 \%$ & $40 \%$ \\
\hline Hombres & $15-25$ & $65 \%$ & $55 \%$ & $60 \%$ \\
\hline \multirow{3}{*}{ Edades } & $25-60$ & $50 \%$ & $40 \%$ & $40 \%$ \\
\hline \multirow{3}{*}{$\begin{array}{l}\text { Nivel de } \\
\text { estudios }\end{array}$} & Bachillerato & $50 \%$ & $60 \%$ & $60 \%$ \\
\hline \multirow{4}{*}{$\begin{array}{l}\text { Fuente de } \\
\text { información }\end{array}$} & Grado & $25 \%$ & $35 \%$ & $35 \%$ \\
\cline { 2 - 5 } & Master & $6 \%$ & $10 \%$ & $10 \%$ \\
\cline { 2 - 5 } & Geb upv & $50 \%$ & $7 \%$ & $15 \%$ \\
\cline { 2 - 5 } & Amigos & $10 \%$ & $20 \%$ & $15 \%$ \\
\cline { 2 - 5 } & Internet & $6 \%$ & $12 \%$ & $10 \%$ \\
\cline { 2 - 5 } & Otros & $27 \%$ & $25 \%$ & $55 \%$ \\
\hline
\end{tabular}

Como se observa, el número de registrados en la primera edición es 621, en su mayoría españoles, de edades comprendidas entre 15 y 25 años, que conocieron el curso en la web de la UPV y procedían de Bachillerato. En la segunda y tercera edición se observa un cambio de perfil: aumenta la proporción de registrados de procedencia iberoamericana, lo que va asociado a una mayor diversidad en la vía de información por la que se conoce el curso y aumenta el nivel de formación de los usuarios. Estos resultados son coherentes con las fechas en que se abren las ediciones. En la primera, se entrevé el carácter propedéutico del curso orientado a los alumnos de nuevo ingreso en la Universidad. En las dos siguientes el cambio de perfil observado podría interpretarse en base al momento del curso académico en el que se pone en marcha. 
El ASIC realizó una encuesta a los que finalizaron el curso el con el fin de obtener información sobre diferentes aspectos. De los datos recogidos se puede afirmar que el principal motivo del estudiante para realizar el curso es su interés por aprender, seguido de completar los estudios, la utilidad para su trabajo, el prestigio de la Universidad y mejorar su curriculum, tal como se observa en la Fig. 2.

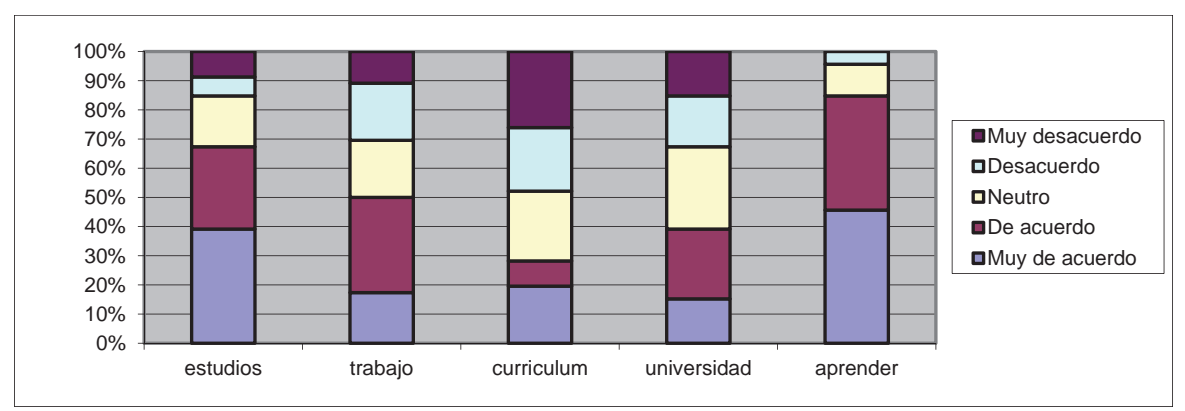

Fig.2 Porcentajes de respuesta al motivo de inscripción

La información obtenida de otros aspectos encuestados fueron:

- El nivel del curso es el adecuado (en relación a sus conocimientos previos) para el $78 \%$.

- $\quad$ El 68\% indica que ha aprendido entre bastante y mucho.

- La mayoría (83\%) manifiesta que sus expectativas han quedado sobradamente cubiertas.

- Respecto al contenido de los videos el $65 \%$ lo considera excelente y para el $27 \%$ es bueno. La duración de los videos es adecuada para el $90 \%$.

- La tutorización ha sido adecuada según la opinión del 76\%, siendo adecuada pero lenta para el $17 \%$.

- Aproximadamente el $80 \%$ considera que el nivel de los exámenes es adecuado a los conocimientos adquiridos y el $20 \%$ cree que son fáciles.

- El sistema de aprendizaje lo consideran excelente (casi perfecto) en un 39\%, seguido de bueno (57\%).

- El navegador más utilizado es el Chrome (46\%), seguido de Firefox (26\%) y Explorer (17\%).

- La ergonomía de la plataforma está muy bien valorada, el $87 \%$ la considera cómoda, su velocidad es adecuada para el $71 \%$ y muy satisfactoria para el $13 \%$. En cuanto al funcionamiento el $86 \%$ indica que ha funcionado 
perfectamente y el $11 \%$ destaca que ha habido alguna incidencia que se resolvió rápidamente.

De los datos diponibles se puede decir que por término medio, entre las tres ediciones, el $20 \%$ de los registrados consigue llegar a la última unidad didáctica. De los que finalizan el curso, el 25\% superan el examen, lo que les permite obtener la credencial. Cabe destacar que para obtener información general del curso se precisa el registro; el estudiante puede elegir entre seguir el curso o no hacerlo, de ahí la diferencia entre los registrados, los que lo siguen y los que finalmente realizan el examen.

Respecto al uso del foro, podemos afirmar que la participación ha sido notable, y es una buena herramienta para la tutorización, generando un clima apropiado para la comunicación, intercambio de ideas y conocimientos de los participantes.

En lo que se refiere al diseño y desarrollo del curso se puede destacar la satisfacción del grupo de los profesores por la tarea realizada, en todos los aspectos: el intercambio de ideas, la planificación del trabajo en equipo y el apoyo mutuo, requisitos imprescindibles para organizar este tipo de cursos. Por lo que respecta al diseño, consideramos que se ha realizado una selección y presentación de los contenidos que permite el seguimiento y la motivación del estudiante. La limitación que impone el no tener la posibilidad de interaccionar con el estudiante requiere tener ciertas cautelas para asegurar al máximo el seguimiento, como utilizar grabaciones cortas y amenas así como actividades de refuerzo que complementen la información de manera efectiva.

Partiendo de los datos de las dos primeras ediciones, consideramos conveniente ampliar el periodo de 6 semanas a 12. Actualmente se está analizando la información recogida en la última edición para poder comparar los datos, extraer conclusiones y realizar las adaptaciones necesarias para mejorar la propuesta.

\section{Conclusiones}

En este tipo de cursos es fundamental la selección, organización y presentación de los contenidos, aspectos clave para su éxito.

Los objetivos deben estar delimitados y ser acordes a las expectativas del estudiante, bien sea orientados al acceso a la Universidad o a otras metas académicas o formativas.

El momento en que se oferta el curso es trascendental, ya que orienta el perfil, condiciona el seguimiento del curso y puede influir decisivamente en la finalización del mismo. 
En cuanto a la plataforma, consideramos la conveniencia de incorporar nuevos instrumentos y métodos de evaluación, lo que incrementaría su calidad y daría más fiabilidad a la acreditación obtenida.

A los alumnos les motiva la credencial, por tanto sería conveniente que se le pudiera dar una cierta validez académica.

El trabajo en grupo de los profesores ha sido una experiencia muy satisfactoria, aunque el tiempo invertido ha sido mucho, los logros que se han conseguido compensan con creces el esfuerzo realizado.

\section{Referencias}

AMBRIZ, M. L. S. (2014). "Diseño de un MOOC utilizando el método de Jigsaw", en Revista de Educación Abierta y a Distancia en México, 1(2), p. 25-39.

BARBOZA, E. C., ARRUFAT, M. J. G. (2014). "Creación de MOOC universitarios con herramientas tecnológicas apropiadas"

http://gtea.uma.es/congresos/wp-content/uploads/2014/02/2.1.Comu_completa.pdf [consulta: 9 de junio de 2014].

DESPUJOL, I. (2013). "Experiencias y resultados de la iniciativa MOOC de la Universitat politecnica de Valencia", en Jornadas Técnicas de RedIRIS 2013, ETSII (UPM). Madrid. http://tv3.teltek.es/es/jt2013/matterhorn/189.html\#, [consulta : 9 de junio de 2014].

DOWNES, S. (2008). "Places to go: Connectivism \& connective knowledge", en Innovate: Journal of Online Education, 5(1).

http://scholar.google.es/scholar?q=Downes $\% 2 \mathrm{C}+2008 \% 2 \mathrm{C}+$ places + to + go\&btnG=\&hl=es\&as sdt=0 \%2C5, [consulta : 9 de junio de 2014].

DURALL, E., GROS, B., MAINA, M., JOHNSON, L., ADAMS, S. (2012). "Perspectivas tecnológicas: educación superior en Iberoamérica 2012-2017".

http://scholar.google.es/scholar?q=DURALL $\% 2 \mathrm{C}+\mathrm{E} . \% 2 \mathrm{C}+\mathrm{GROS} \% 2 \mathrm{C}+\mathrm{B} . \% 2 \mathrm{C}+\mathrm{MAINA} \% 2 \mathrm{C}+\mathrm{M} \& \mathrm{~b}$ tnG $=\& h l=e s \& a s \_s d t=0 \% 2 C 5$ [consulta : 9 de junio de 2014].

GEA, M., MONTES, R., ROJAS, B., MARIN, A., CAÑAS, A., BLANCO, I., GUTIERREZ, C. (2013). "Formación abierta sobre modelos de enseñanza masivos: nuevas tendencias hacia el aprendizaje social", en IV Congreso Internacional sobre Calidad y Accesibilidad de la Formación Virtual , Lisboa (Portugal), p. 17-19.

http://scholar.google.es/scholar?q=Gea\%2C+aprendizaje+social\%2C+2013\&btnG=\&hl=es\&as_sdt=0 \%2C5 [consulta : 9 de junio de 2014].

MÉNDEZ, C. M. (2013). "Diseño e implementación de cursos abiertos masivos en línea (MOOC): expectativas y consideraciones prácticas”. En Revista de la Educación a Distancia, 39.

http://www.um.es/ead/red/39

\section{(cc)) EY-NC-ND 2014, Universitat Politècnica de València}

I Jornadas IN-RED (2014) 
POY, R., GONZALES-AGUILAR, A. (2014). "Factores de éxito de los MOOC: algunas consideraciones críticas", en RISTI-Revista Ibérica de Sistemas e Tecnologias de Informação, (SPE1), p. $105-118$.

TARAGHI, B., EBNER, M., TILl, G., MÜHLbURGER, H. (2010). «Personal Learning Environment-a Conceptual Study », en International Journal of Emerging Technologies in Learning (iJET), 5(2010).

VAZQUEZ, E., MENDEZ, J. M., ROMAN, P., Y LOPEZ-MENESES, E. (2013). "Diseño у desarrollo del modelo pedagógico de la plataforma educativa Quantum University " http://scholar.google.es/scholar?q=VAZQUEZ\%2C+E.\%2C+MENDEZ\%2C+J.+M.\%2C+ROMAN\% 2C+P. $\% 2 \mathrm{C}+\mathrm{Y}+\mathrm{LOPEZ}-\mathrm{MENESES} \% 2 \mathrm{C}+\mathrm{E} .+\% 282013 \& \mathrm{btnG}=\& \mathrm{hl}=\mathrm{es} \&$ as_sdt=0\%2C5 , [consulta : 9 de junio de 2014].

VIGOTSKY, L. S. (1991). Obras Escogidas. Tomo I. Madrid, Visor. 


\title{
Les xarxes socials com a eines per a l'aprenentatge en l'àmbit universitari: una experiència de l'ús de Facebook® ${ }^{\circledR}$ per a la comunicació del professorat-alumnat
}

\section{Jaume Monfort i Signes ${ }^{\mathrm{a}}$, Begoña Fuentes Giner ${ }^{\mathrm{b}}$ i Inmaculada Oliver Faubel ${ }^{\mathrm{c}}$}

${ }^{a}$ Departament de Construccions Arquitectòniques. Universitat Politècnica de València. jaumemonfort@csa.upv.es ${ }^{\mathrm{b}}$ Departament de Construccions Arquitectòniques. Universitat Politècnica de València. bfuentes@csa.upv.es i ${ }^{c}$ Departament de Construccions Arquitectòniques. Universitat Politècnica de València.inolfau@csa.upv.es

\begin{abstract}
We can now affirm that social networks are a basic tool for a group of people to promote communication in everyday tasks collaboratively and ensuring that all group members are perceived as part of the community.

This communication is also now easy and permanent because of equipment available to the students and universal availability of wifi offered by Polytechnic University of València (UPV).

A priori these qualities of social networks suggest that their application would be appropriate in university areas to promote student learning and would create lasting exchange information networks.

This contribution describes the impact of using Facebook® as a communication tool in "Equipos de Obra", a subject of Arquitectura Técnica Degree in UPV.

Although Facebook® is a tool that students use often, in this case its use is an initiative of the teacher.

Questions such as if the use of Facebook® is a proper channel of communication in the university, or if students interact better, or if the tool modifies the teacher-student roles, will be answered. And finally, do social networks facilitate the university students learning process?
\end{abstract}

Keywords: learning, collaboration, communication, social networking

(cc) EY-NC-ND 2014, Universitat Politècnica de València

I Jornadas In-Red (2014) 
Les xarxes socials com a eines per a l'aprenentatge en l'àmbit universitari: una experiència de l'ús de Facebook® per a la comunicació del professorat-alumnat

\begin{abstract}
Resum
Podem afermar que en l'actualitat les xarxes socials representen una eina elemental per a promoure la comunicació d'un grup de persones en tasques quotidianes, d'una forma col-laborativa i aconseguint que tots els membres del grup es perceben com a part d'una mateixa comunitat.
\end{abstract}

A més aquesta comunicació actualment és fàcil i permanent tant pel que fa als dispositius dels què disposen els alumnes, com a la disponibilitat d'accés universal wifi que ofereix la Universitat Politècnica de València (UPV).

A priori aquestes qualitats de les xarxes socials fan pensar que la seua aplicació en àmbits universitaris seria adequada per afavorir l'aprenentatge de l'alumnat i crearia xarxes d'intercanvi d'informació perdurables en el temps.

Aquesta contribució descriu l'impacte de la utilització de Facebook® com a eina de comunicació en l'assignatura Equips d'Obra (Grau d'Arquitectura Tècnica. UPV). Tot i que Facebook® és una eina que els alumnes utilitzen normalment, ací la utilització ha estat una iniciativa del professor.

Es donen respostes a preguntes com: l'ús de Facebook® conforma un canal adequat de comunicació en l'àmbit universitari? interactua millor l'alumnat? es modifiquen els rols professorat-alumnat? Finalment, les xarxes socials afavoreixen el procés d'aprenentatge de l'alumnat universitari?

Paraules clau: aprenentatge, col-laboració, comunicació, xarxes socials

\title{
Introducció
}

En l'escenari acadèmic que es deriva de l'aplicació de Bolonya als ensenyaments universitaris, cobra especial importància la part de treball no presencial que l'alumne ha de desenvolupar per a l'adquisició de competències. Aquest mateix treball no presencial de l'alumne és una competència a adquirir en la majoria dels casos. I ho és per a l'alumne treballant en solitari però també treballant en col-laboració amb altres companys.

Més enllà de les eines docents que s'utilitzen per a possibilitar, afavorir i ajudar a l'estudiant en aquest temps en què treballa sense la tutela directa del seu professor i de les activitats 
didàctiques que aquest dissenye i facilite a l'alumne, el factor determinant perquè tot açò funcione és la comunicació entre els diferents agents que participen en aquest treball. La comunicació alumne-professor, professor-alumne i/o alumne-alumne no pot reduir-se a la què es pot donar de forma presencial. Açò aniria en contra de l'essència de la pròpia activitat $i$, per tant, de la competència que es pretén adquirir.

És per tant responsabilitat del docent posar a la disposició de l'alumnat un sistema eficaç de comunicació interna. Pot dissenyar-ho expressament, utilitzar els que la universitat posa al seu abast, o pot aprofitar-se de la familiaritat amb la qual els alumnes actuals es mouen en un tipus concret de sistemes comunicatius: les xarxes socials.

\section{El context: l'assignatura Equips d'Obra}

En l'aprenentatge basat en projectes (ABP) els alumnes, que realitzen un esforç en un temps determinat, han d'aconseguir l'objectiu específic de crear un servei o producte únic mitjançant la realització d'una sèrie de tasques i l'ús efectiu de recursos.

En el cas de l'assignatura Equips d'Obra del Grau d'Arquitectura Tècnica de la UPV, els alumnes, prenent el rol de cap d'obra d'una empresa constructora, han de obtindre com a producte final l'organització de les infraestructures necessàries (instal-lacions, eines, màquines i mitjans auxiliars) per tal de poder executar una obra de construcció; des de les fases inicials, en les que es treballa en el moviment de terres per tal de construir els fonaments de la construcció, fins que es realitzen els treballs d'acabats.

Es per això que l'ABP es va considerar la metodologia docent més adequada per l'aprenentatge del conjunt de l'assignatura Equips d'Obra. L'ABP s'estructura en el desenvolupament d'un treball en equip (3 alumnes) al llarg del curs. Aquest treball es divideix en 6 tasques a entregar, aproximadament cada quinze dies. El fil conductor d'aquest treball és el procés constructiu d'un edifici d'habitatges. Als alumnes se'ls facilita el projecte d'execució d'una obra real.

La docència de l'assignatura s'estructura en 3 sessions setmanals de 1,50 hores cadascuna. La primera sessió setmanal es una classe de teoria d'aula. Les altres dues són classes de pràctiques d'aula. En una d'aquestes dues sessions setmanals de pràctiques el grup de 40 alumnes aproximadament, es divideix en dos subgrups de 20. D'aquesta manera en les dues setmanes que hi ha entre dos lliuraments l'equip de treball disposa de 4 sessions de treball d'una hora i trenta minuts per a cadascuna de les tasques.

A banda del temps que dediquen a les tasques en horari de classe, els grups han de treballar també de forma autònoma fora de l'aula. L'assignatura té una càrrega de 6 ECTS que suposen un total de 165 hores de dedicació de l'alumnat (considerant 27,5 hores per ECTS).

\section{(c)) EY-NC-ND 2014, Universitat Politècnica de València}

I Jornadas IN-RED (2014) 
Les xarxes socials com a eines per a l'aprenentatge en l'àmbit universitari: una experiència de l'ús de Facebook® per a la comunicació del professorat-alumnat

D'aquestes 160 hores, 65 es corresponen a hores en l'aula (14 setmanes de 3 sessions de 1,5 hores), restant 100 hores de treball fora de l'aula. Considerant que l'avaluació del ABP suposa el $70 \%$ de la nota de l'alumne, caldria entendre que la dedicació que cada alumne ha de fer de forma autònoma per aquest treball és de 70 hores.

El fet que els alumnes s'enfronten al treball del projecte fora de les hores d'aula comporta necessàriament facilitar la comunicació constant entre professor i alumne. L'objectiu d'aquesta comunicació ha de ser guiar, orientar i resoldre dubtes a l'alumne i així assegurar l'èxit del seu procés d'aprenentatge. Si bé l'alumne té al seu abast les tutories presencials, aquestes en determinades ocasions no resulten les més adequades: preguntes puntuals que no precisen d'una explicació presencial, dificultat de concretar un horari, necessitat de desplaçament de l'alumne, prolongació en el temps a l'hora d'obtenir la resposta, etc.

Taula 1. Rensum context assignatura

\begin{tabular}{ll}
\hline Titulació & Grau en Enginyeria d'Edificació \\
\hline \multirow{2}{*}{ Assignatura } & $\begin{array}{l}\text { Equips d'Obra } \\
\text { 6é semestre } \\
\text { Docència assignada: 6 grups / 12 subgrups } \\
40 \text { alumnes per grup / 20 alumnes per subgrup }\end{array}$ \\
\hline $\begin{array}{l}\text { Metodologia } \\
\text { Aprenentatge }\end{array}$ & Aprenentatge Basat en Projectes (ABP) \\
\hline Treball de & Treball en grup \\
l'alumne & 3 alumnes per grup \\
\hline & Tasques lliurades \\
Avaluació & Exposició oral d'una de les tasques \\
& Prova objectiva \\
\hline
\end{tabular}

La Universitat, com a mesura alternativa a les tutories presencials, té habilitats uns canals de comunicació que poden fer servir els alumnes per connectar amb els seus professors. Aquets, podem anomenar oficials, són l'adreça de correu electrònic i la plataforma educativa Poliforma-T. Ambdues presenten una sèrie de deficiències que el seu ús en els darrers cursos s'han pogut comprovar. Respecte del correu electrònic podem destacar la saturació de correus que pot arribar a tindre el professor, per exemple quan la major part de la classe té el mateix dubte i tots fan servir el mail per consultar-li'n. Mentre pel que fa al Poliforma-T, el rebuig que, per diferents motius i de forma majoritària, causa a l'alumnat. 
En aquest context i a partir de la participació en un taller realitzat per l' Institut de Ciències de l'Educació (ICE) de la UPV, sobre l'ús de les xarxes socials com a eina docent i donat l' interès personal del professorat de l'assignatura en les possibilitats que aquestes xarxes poden aportar al procés d'aprenentatge de l'alumnat, es va decidir crear en el curs 2011-12 un grup de Facebook ${ }^{\circledR}$ per al seguiment de l'assignatura Equips d'Obra. Es pretenia un doble objectiu: d'una banda millorar la comunicació amb l'alumnat i per una altra donar major agilitat a la resolució dels dubtes que van sorgint a mesura que avança el curs. Donat l'èxit del grup, l'experiència es repeteix en els cursos 2012-13 i 2013-14.

\section{L'eina de comunicació: el grup de Facebook®}

El motiu pel qual es va seleccionar la xarxa social Facebook® ${ }^{\circledR}$ com a eina de comunicació per a l'assignatura, va ser un estudi de la UPV realitzat l'any 2011 on s'establia que els estudiants d'últims anys de carrera utilitzen majoritàriament aquesta xarxa per a la seua vida quotidiana (CABRERA, 2011). Una vegada definida la xarxa social, el segon pas va ser establir el tipus d'accés a utilitzar. Bàsicament existeixen en Facebook ${ }^{\circledR}$ tres tipus: perfil, pàgina o grup. A la Taula 2 s'arrepleguen les característiques de cadascun dels tipus.

Taula 2. Comparativa entre perfil, pàgina i grup de Facebook $®$

\begin{tabular}{ll}
\hline & Representa a una sola persona i porta el seu nom \\
Conté informació personal i privada \\
Perfil & Els contactes són anomenats amics i tenen accés al perfil de la persona \\
& Cal afegir als amics per a que accedisquen al perfil \\
Lés adequada per compartir informació personal en amistats & Representa a una organització, associació... \\
Conté informació pública de l'organització \\
Els membres són anomenats seguidors \\
Els membres són tots aquells que ho vulguen (pública) \\
Ideal com a eina publicitària \\
Representa a un conjunt de persones amb un interès comú \\
Conté la informació que aporten tots els seus membres \\
Els membres no tenen cap relació entre ells, tan sols comparteixen el grup \\
Es pot restringir les persones que accedisquen com a membres al grup \\
Perfecta per a conjunts reduïts de persones que comparteixen un interès \\
comú però no hi ha relació d'amistat i es vol garantir la privacitat dels \\
\hline
\end{tabular}

\section{(c)) EY-NC-ND 2014, Universitat Politècnica de València}

I Jornadas IN-RED (2014) 
Les xarxes socials com a eines per a l'aprenentatge en l'àmbit universitari: una experiència de l'ús de Facebook® per a la comunicació del professorat-alumnat

Analitzats els avantatges i desavantatges de tots ells, es va decidir optar per un grup per dos motius, d'una banda es garanteix la privacitat dels membres (tant del professor com dels alumnes) i d'altra es restringeix l'accés exclusivament als alumnes de l'assignatura.

El grup es va mostrar des del principi com una eina útil per a la comunicació, convertint-se ràpidament en el "tauler d'anuncis" de l'assignatura. Com ja s'ha dit, actualment l'alumnat de forma majoritària disposa de dispositius mòbils (telèfons i tabletes) amb connexió permanent a Internet. Aquests dispositius reben en temps real i sense necessitat d'accedir a cap aplicació (correu o Poliforma-T) els avisos que es “pengen” en el mur del Facebook®, fent vàlida aquella dita popular de "si la muntanya no va a Mahoma, Mahoma anirà a la muntanya".

El grup també resulta útil per a realitzar aclariments a dubtes que sorgeixen després d'una classe (Figura 1). En finalitzar una sessió i després de corregir una tasca plantejada en aquesta, s'observa que de forma majoritària l'alumnat comet el mateix error. Mitjançant una publicació en el mur es realitza l'aclariment pertinent. L'aplicació també permet a l'alumnat aportar els comentaris que estimen necessaris, contribuint així a un aprenentatge col·laboratiu.

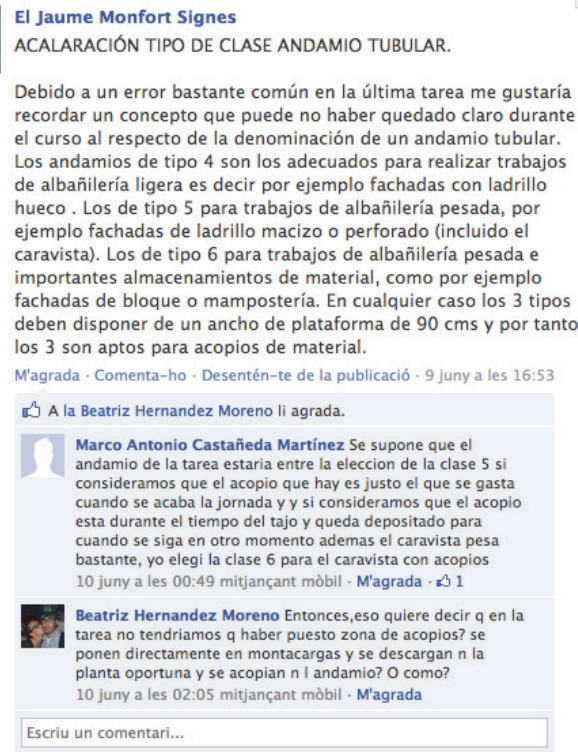

Fig. 1 Aclariment d'un dubte sorgit després d'una classe utilitzant el mur del Facebook® 
L'alumnat també pot utilitzar el grup per a plantejar aquells dubtes que van sorgint a mesura que avança en l'estudi de la matèria (Figura 2). La resposta és molt més ràpida que si ha d'esperar a una classe o sol-licitar una tutoria. Com els dubtes solen ser repetitius, un sol aclariment li facilita l'avanç en l'estudi a la resta de companys agilitant aquesta tasca al professorat.

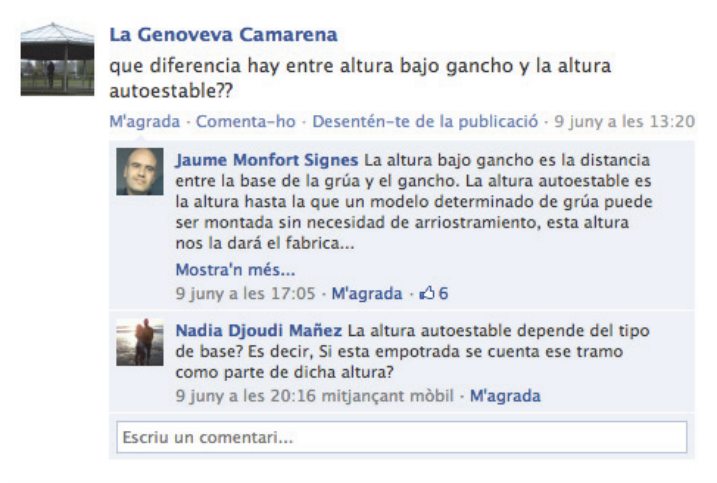

Fig. 2 Aclariment d'un dubte sorgit a unes alumnes mentre treballaven en casa utilitzant el mur del Facebook ${ }^{\circledR}$

\section{La mesura dels resultats: l'enquesta}

Segons el semblar dels professors, com ja s'avançava a l'apartat anterior, el grup es va mostrar des del seu inici en el curs 2011-12 un èxit. També ajudava a pensar-ho els comentaris que feien els alumnes en acabar el curs. A mode d'exemple durant el curs 201112 és realitza una pregunta "informal" als usuaris del grup sobre el funcionament del mateix. El 100\% dels alumnes consideren que aquest ha estat útil per al seguiment de l'assignatura (Figura 3) i també de forma majoritària opinen que altres assignatures deurien fer servir Facebook® (Figura 4).

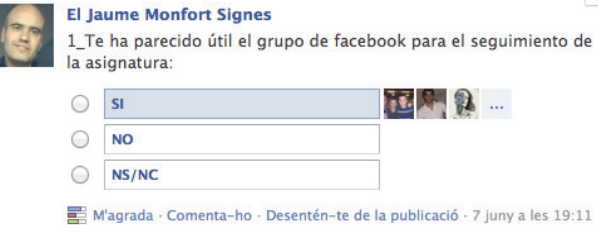

Fig. 3 Pregunta sobre l' utilitat del Facebook® per al seguiment de l'assignatura realitzada al final del curs 2011-12 (utilitzant el mur del Facebook®)

\section{(cc) EY-Nc-ND 2014, Universitat Politècnica de València}

I Jornadas IN-RED (2014) 
Les xarxes socials com a eines per a l'aprenentatge en l'àmbit universitari: una experiència de l'ús de Facebook® per a la comunicació del professorat-alumnat

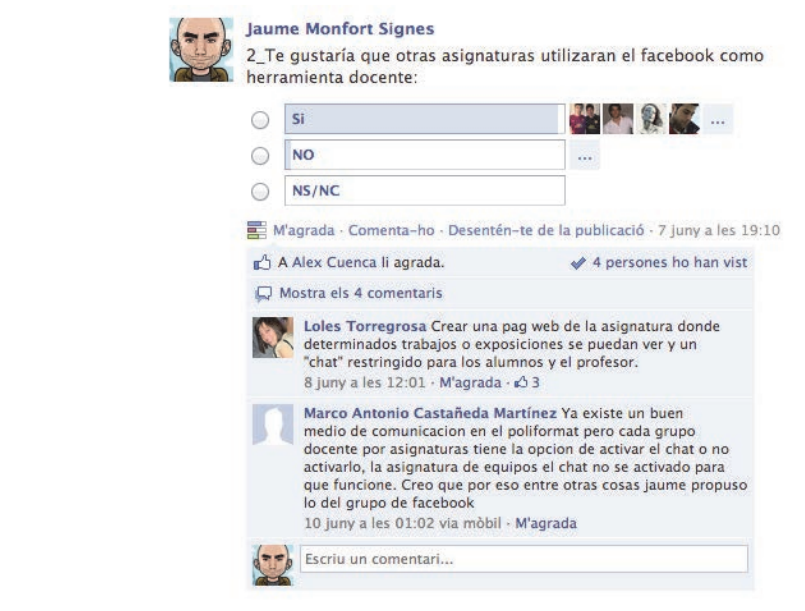

Fig. 4 Pregunta sobre l'ús del Facebook® en altres assignatures com a eina docent realitzada al final del curs 2011-12 (utilitzant el mur del Facebook®)

No obstant això, la constatació d'haver aconseguit el objectius passa per la realització d'una enquesta a l'alumnat més enllà de preguntes puntuals i apreciacions personals. Donat que a principi de l'actual curs ja s'està pensant en avaluar els resultats de l' utilització de les xarxes socials en l'aula, es va decidir implantar aquesta innovació només a la meitat dels grups. Així en acabar el semestre disposarem de l'opinió dels alumnes que utilitzaven Facebook® per a la comunicació fora de l'aula, front als que utilitzaven exclusivament les eines oficials (correu electrònic i Poliforma-T).

Així, per tal de conèixer l'opinió dels alumnes, l'última setmana de l'actual curs, es realitza una enquesta sobre l'ús del Facebook ${ }^{\circledR}$ com a eina docent. Les preguntes queden arreplegades a la Taula 3. Per tal de poder contrastar les respostes és passa una enquesta similar (Taula 4) als alumnes que no han utilitzat Facebook ${ }^{\circledR}$ respecte de l'ús que han fet del correu electrònic i Poliforma-T.

D'altra banda, paral-lelament a les enquestes i per comprovar la continuïtat dels grups de Facebook ${ }^{\circledR}$ creats en cursos passats, és realitzen al llarg de l'actual curs acadèmic una sèrie de publicacions en els grups dels cursos 2011-12 i 2012-13 amb l'objectiu de comprovar el grau de seguiment entre els alumnes que ja han aprovat l'assignatura i per tant ja estan completament desvinculats de la mateixa.

En el següent apartat trobem els resultats de les enquestes així com el grau de seguiment de les publicacions realitzades en els grups creats en els cursos anteriors. 
Taula 3. Enquesta alumnes que utilitzen Facebook $₫$

\begin{tabular}{ll}
\hline Pregunta 1 & $\begin{array}{l}\text { El sistema de comunicació alumnat-professor, per mitjà de la xarxa } \\
\text { social Facebook®, facilita la comunicació fora de l'aula }\end{array}$ \\
\hline Pregunta 2 & $\begin{array}{l}\text { El sistema de comunicació alumnat-professor, per mitjà de la xarxa } \\
\text { social Facebook®, fa més ràpida la comunicació fora de l'aula }\end{array}$ \\
\hline Pregunta 3 & $\begin{array}{l}\text { Preferisc utilitzar el sistema de comunicació actual (Facebook®) a les } \\
\text { tutories presencials }\end{array}$ \\
\hline Pregunta 4 & $\begin{array}{l}\text { La utilització de les xarxes socials en la docència facilita la comunicació } \\
\text { alumnat-professorat fora de l'aula }\end{array}$ \\
\hline Pregunta 5 & $\begin{array}{l}\text { La utilització de les xarxes socials per a la comunicació fora de l'aula fa } \\
\text { més proper al professor }\end{array}$ \\
\hline Pregunta 6 & $\begin{array}{l}\text { Indica la primera paraula que et ve a la ment quan penses en Facebook® } \\
\text { com a eina per a la comunicació fora de l'aula }\end{array}$ \\
\hline
\end{tabular}

Taula 4. Enquesta alumnes que no utilitzen Facebook $₫$

\begin{tabular}{ll}
\hline Pregunta 1 & $\begin{array}{l}\text { El sistema de comunicació alumnat-professor, per mitjà de la plataforma } \\
\text { Poliforma-T i/o correu electrònic, facilita la comunicació fora de l'aula }\end{array}$ \\
\hline Pregunta 2 & $\begin{array}{l}\text { El sistema de comunicació alumnat-professor, per mitjà de la plataforma } \\
\text { Poliforma-T i/o correu electrònic, fa més ràpida la comunicació fora de } \\
\text { l'aula }\end{array}$ \\
\hline Pregunta 3 & $\begin{array}{l}\text { Preferisc utilitzar el sistema de comunicació actual (Poliforma-T i/o } \\
\text { correu electrònic) a les tutories presencials }\end{array}$ \\
\hline Pregunta 4 & $\begin{array}{l}\text { La utilització de les xarxes socials en la docència, com alternativa a } \\
\text { Poliforma-T, facilitaria la comunicació alumnat-professorat fora de l'aula }\end{array}$ \\
\hline Pregunta 5 & $\begin{array}{l}\text { La utilització de les xarxes socials per a la comunicació fora de l'aula, } \\
\text { com alternativa al Poliforma-T, fa més proper al professor }\end{array}$ \\
\hline Pregunta 6 & $\begin{array}{l}\text { Indica la primera paraula que et ve a la ment quan penses en Poliforma-T } \\
\text { com a eina per a la comunicació fora de l'aula }\end{array}$ \\
\hline
\end{tabular}

\section{(c)) EY-NC-ND 2014, Universitat Politècnica de València}

I Jornadas IN-RED (2014) 
Les xarxes socials com a eines per a l'aprenentatge en l'àmbit universitari: una experiència de l'ús de Facebook® per a la comunicació del professorat-alumnat

\section{Les evidències: resultats i discussió de l'enquesta}

Respecte dels resultats de les enquestes cal destacar les següents diferències significatives entre els alumnes que han fet servir Facebook ${ }^{\circledR}$ dels que han continuat en les eines ofertes institucionalment per la UPV:

- A la pregunta si l'eina utilitzada ha facilitat la comunicació, el 100\% dels alumnes que fan servir la xarxa social es mostren partidaris (64\% completament d'acord i $36 \%$ més aviat d'acord). Per contra la majoria dels que utilitzen Poliforma-T i/o el correu electrònic exclusivament, és mostren indiferents $(50 \%)$, més aviat en desacord un $10 \%$, un $20 \%$ és mostra més aviat d'acord i un altre $20 \%$ totalment d'acord. (Figura 5)

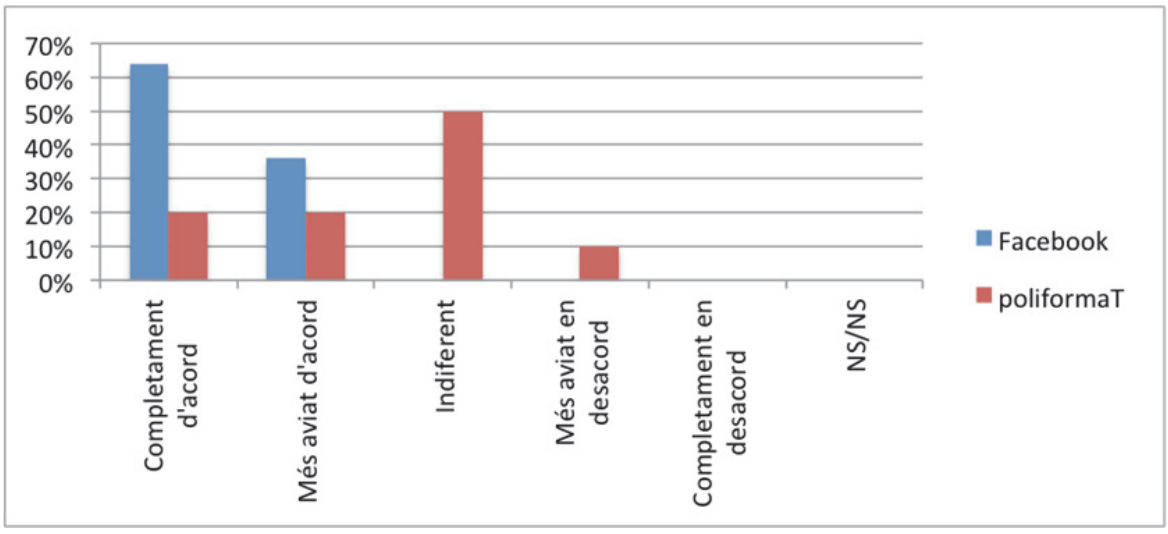

Fig. 5 Respostes a la pregunta 1: l'eina utilitzada ha facilitat la comunicació fora de l'aula

- A la segona pregunta (Figura 6), si l'eina fa més ràpida la comunicació, Els usuaris de la xarxa social estan completament d'acord (64\%) o més aviat d'acord (36\%), per contra només un 50\% dels que no l'han utilitzada pensen que les eines tradicionals li donen rapidesa a la comunicació (20\% completament d'acord i $30 \%$ més aviat d'acord). El 50\% restant es distribueix entre els indiferents (40\%) i els que manifesten trobar-se més aviat en desacord.

- A la pregunta si prefereixen fer servir la comunicació on-line front a les tutories presencials per resoldre dubtes (Figura 7), la majoria dels que utilitzen el Facebook® (64\%) es manifesten indiferents, tan sols un $7 \%$ es mostra partidari. Mentre els que utilitzen correu electrònic i/o Poliforma-T majoritàriament (50\%) estan més aviat en desacord front a un $30 \%$ que es mostra indiferent. 


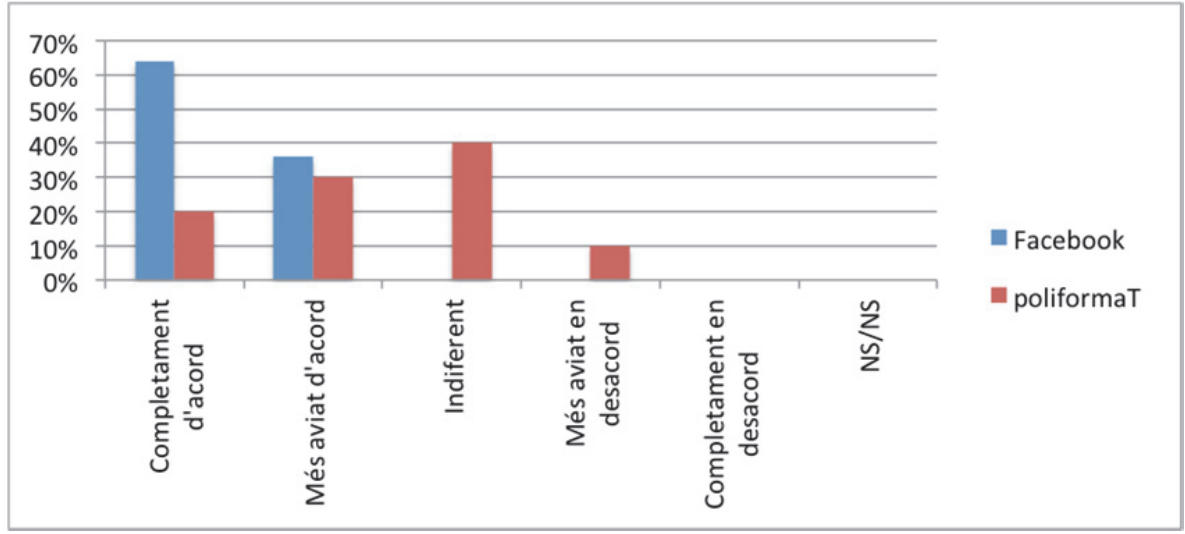

Fig. 6 Respostes a la pregunta 2: l'eina utilitzada fa més ràpida la comunicació fora de l'aula

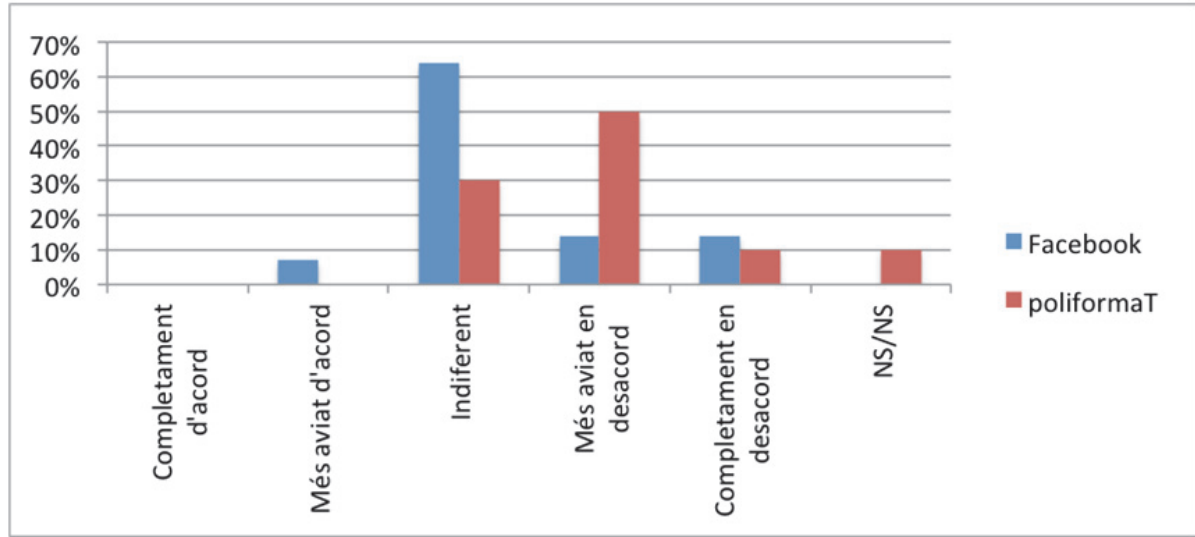

Fig. 7 Respostes a la pregunta 3: preferència de l'eina utilitzada front a les tutories presencials

- A la quarta pregunta (Figura 8), respecte a si les xarxes socials faciliten la comunicació fora de l'aula, torna a evidenciar-se la diferent opinió dels alumnes. Un 64\% dels que utilitzen aquestes xarxes socials per a l'assignatura estan completament d'acord i un 29\% més aviat d'acord. Els usuaris de Poliforma-T es troben més distribuïts (20\% completament d'acord, $30 \%$ més aviat d'acord, $10 \%$ indiferent, $20 \%$ més aviat en desacord, $10 \%$ completament en d'acord i un $10 \%$ no sap o no vol contestar).

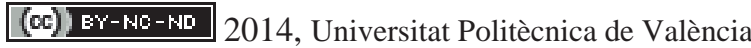

I Jornadas IN-RED (2014) 
Les xarxes socials com a eines per a l'aprenentatge en l'àmbit universitari: una experiència de l'ús de Facebook® per a la comunicació del professorat-alumnat

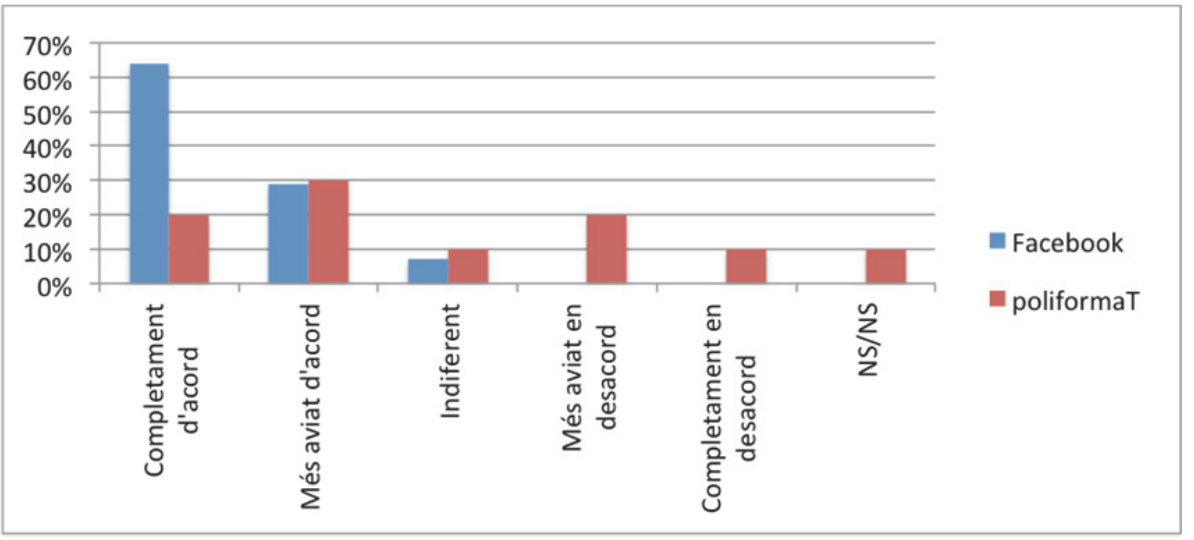

Fig. 8 Respostes a la pregunta 4: les xarxes socials faciliten la comunicació fora de l’aula

- A la cinquena pregunta (Figura 9), en el cas dels usuaris de Facebook®, un 57\% opina que l' utilització de les xarxes socials fan més proper al professor, front a un $22 \%$ que pensen el contrari. Els percentatges es mantenen en el cas dels que no usen Facebook®, un $60 \%$ consideren que el professor seria més proper front al $30 \%$ que opinen el contrari.

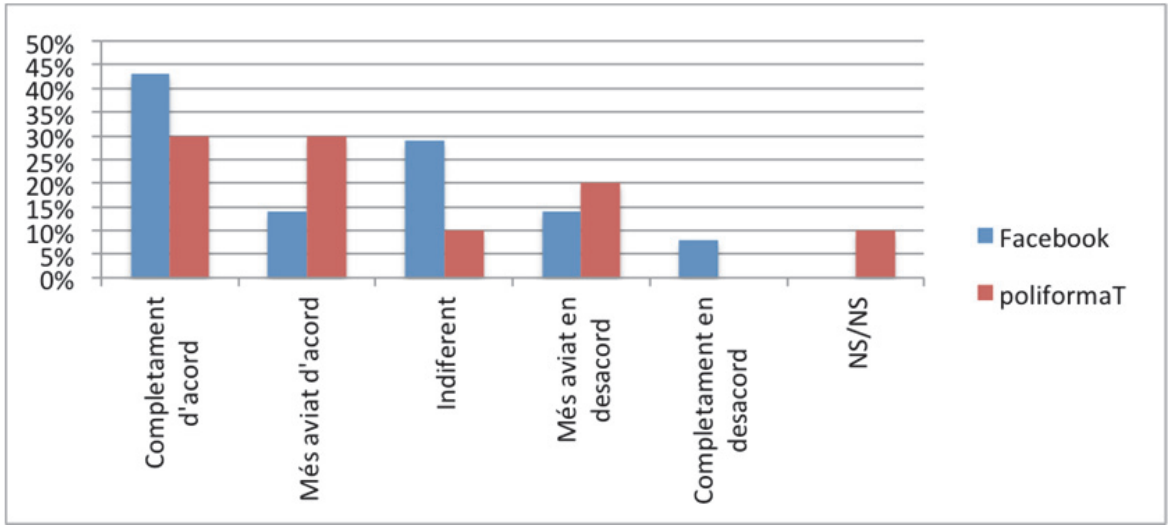

Fig. 9 Respostes a la pregunta 5: les xarxes socials fan més proper al professor

- Per últim respecte a les paraules que els venen a la ment al pensar en Facebook® com a eina docent, les més repetides són rapidesa i contacte. Pel que fa als que usen Poliforma-T no hi ha cap paraula què destaque sobre la resta però si cal remarcar l'aparició de mots com: nefasta o millorable.

(cc)) EY-NC-ND 2014, Universitat Politècnica de València I Jornadas IN-RED (2014) 
Per últim i respecte als usuaris dels grups de Facebook® dels cursos passats cal remarcar com aquests continuen seguint els comentaris que es deixen en el mur del grup. Així 43 alumnes del curs 2011-12 van veure una publicació del passat mes d'abril (Figura 10) fins i tot alguns van participar de la mateixa. Açò evidència que tot $i$ haver aprovat l'assignatura els alumnes continuen connectats entre ells i també amb el professorat.

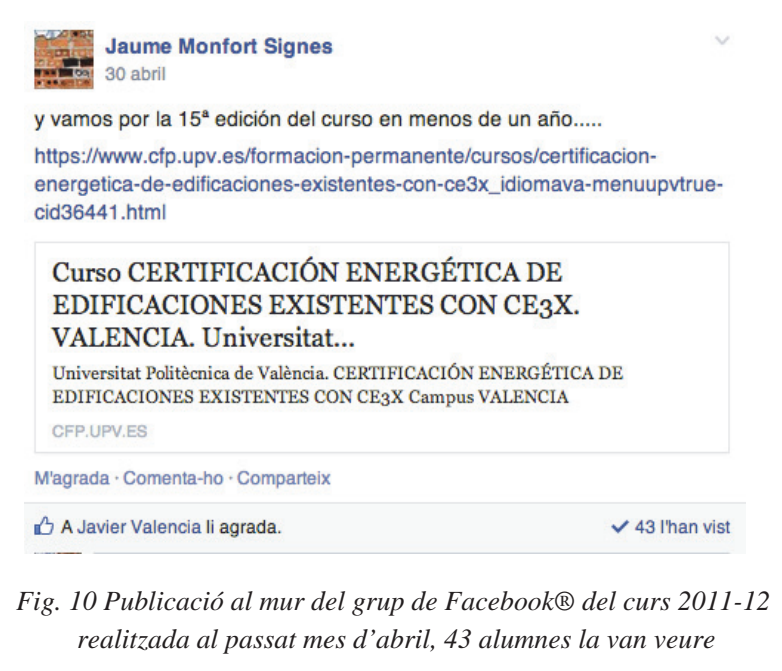

\section{Conclusions}

Desprès de l'anàlisi de les enquestes, que ens han donat dades directes de l'opinió dels alumnes de la utilització que fan de Facebook® i de les reunions de coordinació de la Unitat Docent, que ens han permès compartir impressions als professors, les conclusions es poden concretar en que:

- Les eines actuals de les que disposa la UPV de forma institucional per a la comunicació entre alumat i professorat fora de l'aula, Poliforma-T i correu electrònic, s'han quedat estancades i cal complementar-les amb les possibilitats que aporten les xarxes socials.

- La utilització de les xarxes socials, en el nostre cas Facebook®, facilita la comunicació fora de l'aula respecte a les eines institucionals, alhora que fan que aquesta comunicació siga més ràpida i fluida

- Els alumnes que han utilitzat les xarxes socials per a comunicar-se fora de l'aula, mostren una oposició menor a substituir les tutories presencials per la comunicació on-line utilitzant aquestes xarxes socials.

\section{(c)) EY-NC-ND 2014, Universitat Politècnica de València}


Les xarxes socials com a eines per a l'aprenentatge en l'àmbit universitari: una experiència de l'ús de Facebook® per a la comunicació del professorat-alumnat

- Les comunitats on-line que es creen en les xarxes socials són perdurables en el temps més enllà del semestre en el que s'imparteix l'assignatura.

- En últim lloc, la major part de l'alumnat considera que la utilització de les xarxes socials fan més proper al professor. És significatiu que aquesta opinió la mantenen tant els alumnes que han utilitzat Facebook® en l'assignatura com els que no.

\section{Agraïments}

Els autors d'aquest article agraïm la inestimable col-laboració dels alumnes d'Equips d'Obra del Grau d'Arquitectura Tècnica de la UPV.

\section{Referències}

BARA, J. (2003). Aprendizaje Basado en Problemas/Proyectos: ¿Qué, por qué, cómo?. Institut de Ciències de l'Educació. Barcelona.

BLANK, W. (1997). Authentic instruction. In W.E. Blank \& S. Harwell (Eds.), Promising practices for connecting high school to the real world, pp. 15-21. Tampa, University of South Florida.

CABRERA, M., CUENCA, L.L., BONET, A. i SIGALAT, E. (2011). "Uso de redes sociales y herramientas 2.0 en el campus de Gandia. Universitat Politència de València". Comunica 2.0. Congreso Universitario sondre Redes Sociales. Gandia (València).

DOMINGO, J. (2005). "L'aprenentatge cooperatiu: una eina al servei d'una altra manera de fer docència”. Jornada de presentació d'experiències. Girona.

KOLB, D.A. (1984). Experiential Learning: experience as the source of learning and development. Ed. New Jersey: Prentice-Hall.

SMITH, K.A. (1995). "Cooperative learning: effective teamwork for engineering classrooms". Proceedings Frontiers in Education Conference, paper 2b5, pp. 13-18, Atlanta.

TASCÓN, M. i CABERA, M. (2012). Escribir en internet: guía para los nuevos medios y las redes sociales. Galaxia Gutenberg. Barcelona.

TRUJILLO J., HINOJO, F.J. (2010). Apropiacion de recursos y estrategias 2.0 para la innovacion educativa en la docencia universitaria. Anuario interuniversitario de didactica.

TRUÑEZ, M. i SISTO, J. (2012). Las redes sociales como entorno docente: análisis del uso de Facebook en la docencia universitaria. Revista de medios y educación, cap 41, pp 77-92 


\title{
Diseño de objetos de aprendizaje en formato Polimedia para el desarrollo de actividades pre-laboratorio en química general
}

Llorens-Molina, Juan A. ${ }^{a}$, Atarés Huerta, Lorena ${ }^{a}$, Lacuesta Gilaberte, Raquel ${ }^{b}$,

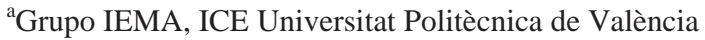

${ }^{\mathrm{b}}$ Universidad San Jorge, Zaragoza

\begin{abstract}
Pre-laboratory activities (prelabs) are a broadly extended educational practice in Higher Education. Their main objectives are the following: (a) To contribute to students' reflection about their experimental activities aims. (b) To introduce methodological prior knowledge as well as laboratory safety rules. (c) To put the laboratory work in the students' social, cultural and professional context.

The design, application and evaluation of prelab activities consisting of videotape records (Polimedia) and multiple choice tests by means of assessment tools in PoliformaT platform are proposed in this communication. They are applied to study of chemical equilibria in the subject: Chemical Foundations for Food Technology, in the 1st course of Food Science and Technology, at the Universitat Politècnica de València. The forum has been also used to solve doubts and provide complementary information.

A survey has been applied to analyze students' perceptions concerning the usefulness of this sort of activities, whose results show a mostly positive valuation. Nevertheless, some critical contributions are observed from a qualitative point of view. They are related mainly with the coherence among the diferent educational resources involved in laboratory activities.

Keywords: Prelab activities, laboratory, chemistry, audiovisual, assessment, Polimedia
\end{abstract}


Diseño de objetos de aprendizaje en formato Polimedia para el desarrollo de actividades prelaboratorio en química general

\begin{abstract}
Resumen
Las actividades prelaboratorio son una práctica educativa ampliamente extendida en la Educación Superior. Sus principales objetivos son: (a) Contribuir a que el alumnado reflexione sobre los objetivos de su actividad experimental en el contexto de la asignatura. (b) Introducir conocimientos previos de carácter metodológico o relacionados con la seguridad y (c) Contextualizar el trabajo experimental en el marco social, cultural y profesional de los estudiantes.

En esta comunicación se presenta el diseño, aplicación y evaluación de actividades pre-laboratorio consistentes en grabaciones Polimedia asociadas a una prueba de opción múltiple mediante la herramienta "exámenes" de PoliformaT. Han sido aplicadas al estudio de los equilibrios químicos, en la asignatura Fundamentos Químicos para la Ciencia y Tecnología de Alimentos, del primer curso de Ciencia y Tecnología de Alimentos (Universitat Politècnica de València). Se ha utilizado también el foro de la asignatura para resolver dudas y aportar información complementaria. Para analizar la percepción de los estudiantes sobre la utilidad de estas actividades se ha aplicado una encuesta, cuyos resultados muestran una valoración mayoritariamente positiva. No obstante, desde el punto de vista cualitativo se observan aportaciones críticas de interés, relacionadas principalmente con la coherencia entre los diferentes recursos educativos relacionados con el trabajo de laboratorio.
\end{abstract}

Palabras clave: Polimedia, actividad prelaboratorio, práctica de laboratorio, evaluación, química.

\title{
1. Introducción
}

\subsection{Papel actual de los medios audiovisuales en la enseñanza semipresencial}

Una de las consecuencias más importantes de la incorporación al Espacio Europeo de Educación Superior y la introducción de los créditos ECTS es el carácter semipresencial del proceso de aprendizaje. Hasta ahora, la enseñanza universitaria se ha basado en la transmisión de información en la clase, y los alumnos trataban de asimilar fuera del horario docente dicha información. Así, el trabajo del estudiante quedaba excluido del diseño educativo, sugiriéndose, a lo sumo, la realización de ejercicios, problemas, etc. como medio para preparar con éxito los exámenes. Tal vez, el cambio más profundo en el que estamos inmersos consista precisamente en la necesidad de incorporar en el diseño de los procesos de aprendizaje ese trabajo no presencial, integrándolo en una secuencia coherente que dé sentido global al conjunto de actividades realizadas por los alumnos. Tal como sugiere Bartolomé (2012) en un interesante y profundo análisis crítico sobre la incorporación de las 
nuevas tecnologías, el objetivo es la creación de entornos de aprendizaje donde la relación entorno-sujeto sea un aspecto prioritario frente a la enseñanza a distancia tradicional, centrada en el eje material-tutor. Un análisis más extenso de este análisis queda fuera del alcance de esta comunicación, pero implica una consecuencia decisiva en el contexto de nuestro trabajo y es la siguiente: la innovación no puede centrarse simplemente en lograr una mayor eficacia de cara los mismos objetivos de siempre, considerando el trabajo de laboratorio como una actividad complementaria de la teoría o meramente como el modo de adquirir destrezas manipulativas. Por el contrario, el reto consiste en lograr que la actividad experimental pueda integrarse como un elemento más del entorno de aprendizaje del alumno.

Las herramientas tecnológicas de las que actualmente disponemos nos brindan una excelente oportunidad para lograr esa integración. Dichas herramientas cumplen muy diversas funciones tales como interactividad, promoviendo la participación y facilitando la creación de entornos colaborativos (foros, chats, wikis, etc.). En cuanto a las ventajas que ofrecen los recursos multimedia, cabe destacar la facilidad para crear videos digitales y compartirlos en la web, así como la disponibilidad gratuita de materiales audiovisuales apropiados. Por otra parte, cabe destacar la disponibilidad también de software como CamStudio o Camtasia que ponen al alcance del profesorado la posibilidad de crear materiales audiovisuales de calidad para fines específicos y adaptados a las necesidades reales de un entorno de aprendizaje concreto. Por último hay que añadir la posibilidad de utilizar recursos como las pizarras digitales interactivas o incluso útiles de uso cotidiano como el teléfono móvil o las tabletas.

Con respecto al trabajo experimental, la potencialidad de los recursos audiovisuales es destacada también por Bartolomé (2012), que enumera el conjunto de posibilidades que ofrecen este tipo de medios. Concretamente, se refiere a la posibilidad de mostrar un proceso experimental antes de ser realizado (con todo lo que ello supone de cara a aspectos metodológicos y de seguridad), relacionarlo con la vida real, proporcionando una visión preliminar e intuitiva de un problema, mostrar comparativamente buenas y malas prácticas, etc. Además, el que sea una persona concreta la que pueda aparecer en la grabación, con todo el componente de comunicación no verbal que ello representa, tiene un impacto positivo en el estudiante.

Sin pretender hacer una discusión detallada de los criterios de calidad del material audiovisual que pueden consultarse en la bibliografía (Graells, 2005; Méndez, 2010), nos centramos en el recurso utilizado en la innovación que presentamos (Polimedia).

\section{(cc)) EY-NC-ND 2014, Universitat Politècnica de València}

I Jornadas IN-RED (2014) 
Diseño de objetos de aprendizaje en formato Polimedia para el desarrollo de actividades prelaboratorio en química general

\subsection{Utilización de Polimedia}

Polimedia es un sistema introducido en la Universidad Politécnica de Valencia para la creación de contenidos multimedia como apoyo a la docencia presencial, que abarca desde la preparación del material docente hasta la distribución a través de distintos medios (TV, Internet, $\mathrm{CD}$, etc.) a los destinatarios. El formato utilizado en este trabajo es posiblemente el más extendido y consiste en la grabación en video de una exposición de un profesor, el cual aparece en pantalla, en torno a una presentación mediante diapositivas, que puede incluir también diversos recursos multimedia como pequeños videos, animaciones, etc. Las principales finalidades desde el punto de vista educativo, de los Polimedia utilizados en este trabajo son los siguientes (Llorens-Molina, 2009):

- a) Introducción de conceptos específicos como refuerzo y revisión de su introducción en el aula

- b) Revisión de un conjunto de conceptos y ejemplos de carácter práctico con objeto de servir como material de repaso y síntesis.

- c) Introducción de conocimientos previos como prerrequisitos.

- d) Aspectos contextuales, con aspectos de interés social, económico o histórico, con finalidad fundamentalmente motivadora (y que con frecuencia amplían el contenido tratado en las clases presenciales)

- e) Profundización en determinados aspectos teóricos o experimentales del contenido

La experimentación realizada hasta el momento acerca de este modelo de actividad prelaboratorio es descrita en trabajos anteriores (Llorens-Molina, 2009, 2011, 2014). Los resultados muestran que el uso de este modelo permite ahorro de tiempo al poder sustituir casi totalmente la explicación de la práctica en la propia sesión de laboratorio; también mejora el conocimiento inicial de los estudiantes, contribuyendo a crear un entorno de aprendizaje mucho más vinculado a las características específicas de la titulación. Existe además un amplio consenso acerca de Polimedia y en general todas las tecnologías de la información en cuanto a que contribuyen a incrementar la efectividad y la posibilidad de actividades prelaboratorio aportándoles accesibilidad, versatilidad e interactividad (Nicholl, 1999).

\section{Objetivos}

El objetivo de esta comunicación es, en primer lugar, describir el diseño y aplicación de actividades pre-laboratorio encaminadas a mejorar el desarrollo y comprensión del trabajo experimental, así como su mejor integración en el contexto de la asignatura.

En segundo lugar, se pretende también evaluar la percepción que el alumnado ha tenido acerca de la utilidad de esta actividad, promoviendo un análisis crítico de la misma que nos permita mejorarla de cara a los próximos cursos. 


\section{Desarrollo de la innovación}

\subsection{Contexto}

La innovación presentada en esta comunicación consiste en el diseño y aplicación de tres actividades prelaboratorio consistentes en videos en formato Polimedia asociados a las correspondientes pruebas online de opción múltiple. Estas grabaciones tratan sobre las siguientes prácticas de laboratorio: (a) Estudio experimental de la leyes de velocidad de reacción, (b) Equilibrios ácido-base. Hidrólisis. Determinación de la acidez en productos naturales y (c) Equilibrios redox. Pilas y electrolisis, todas ellas impartidas dentro de la asignatura Fundamentos Químicos para la Ciencia y Tecnología de Alimentos.

Esta asignatura anual se imparte en el primer curso del Grado en Ciencia y Tecnología de Alimentos de la Escuela Técnica Superior de Ingeniería Agronómica y del Medio Natural de la Universitat Politècnica de València. Los resultados que se mostrarán se obtuvieron a lo largo del segundo cuatrimestre del curso 2013-2014, durante el cual el número de alumnos matriculados era 110, distribuidos en dos grupos.

Durante el primer cuatrimestre, en la misma asignatura, se utilizaron screencast como actividad prelaboratorio. Tratándose de los mismos alumnos, en este trabajo se comparó este recurso con los Polimedia.

\subsection{Elaboración de los Polimedia}

Se elaboraron tres videos didácticos en formato Polimedia, con diferentes contenidos en función de la práctica de laboratorio a la cual servirían como material de apoyo. En todos los casos se planteó una misma estructura, consistente en los siguientes apartados: contexto, objetivos, fundamento teórico y proceso. En el contexto se perseguía captar la atención del alumno con ejemplos de la vida cotidiana relacionados con el tema del vídeo (figuras 1 y 2). Tras la descripción de los objetivos (figura 3), se pasó a explicar el fundamento teórico imprescindible para la comprensión del experimento (figura 4) y finalmente el proceso a seguir para la realización del mismo (figura 5).

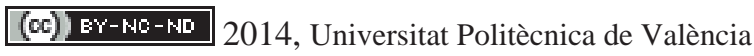

I Jornadas IN-RED (2014) 
Diseño de objetos de aprendizaje en formato Polimedia para el desarrollo de actividades prelaboratorio en química general

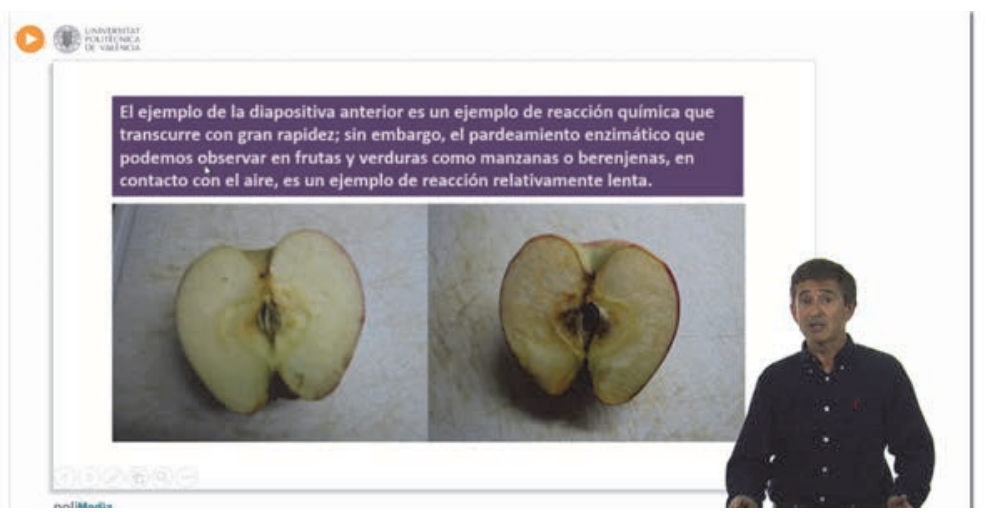

Fig. 1 Captura de pantalla del video "Estudio experimental de la leyes de velocidad de reacción"

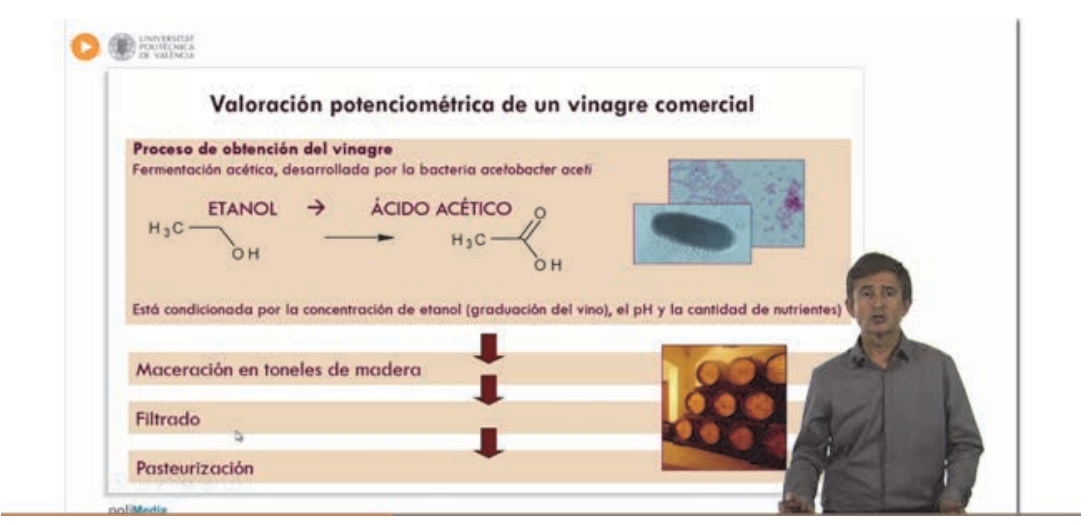

Fig. 2. Captura de pantalla del Polimedia: "Equilibrios ácido-base. Hidrólisis. Determinación de la acidez en productos naturales". El fotograma seleccionado forma parte de la introducción al contexto profesional de la práctica

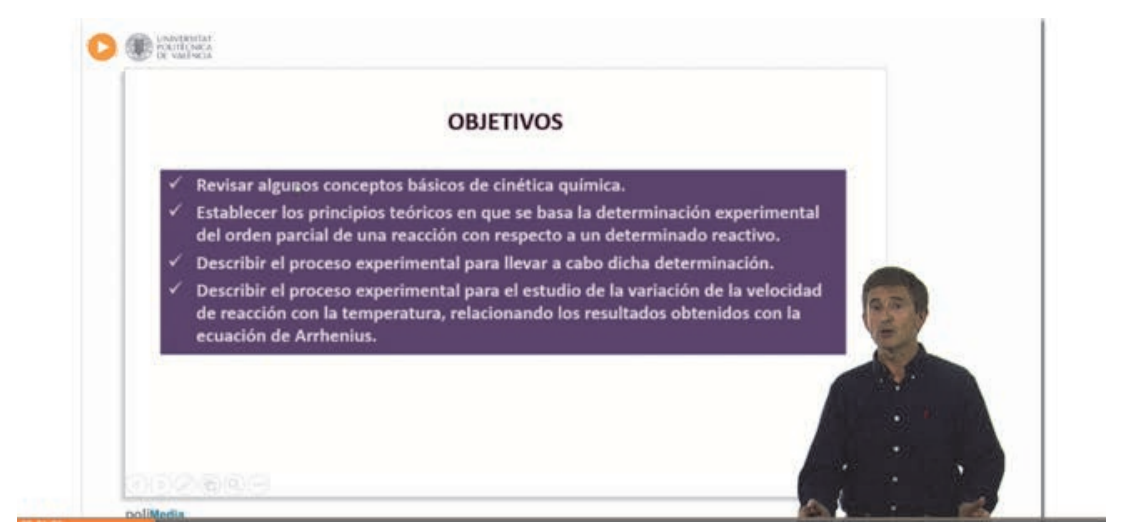

Fig. 3. Captura de pantalla del video "Estudio experimental de la leyes de velocidad de reacción"

(cc) EY-Nc-ND 2014, Universitat Politècnica de València

I Jornadas IN-RED (2014) 


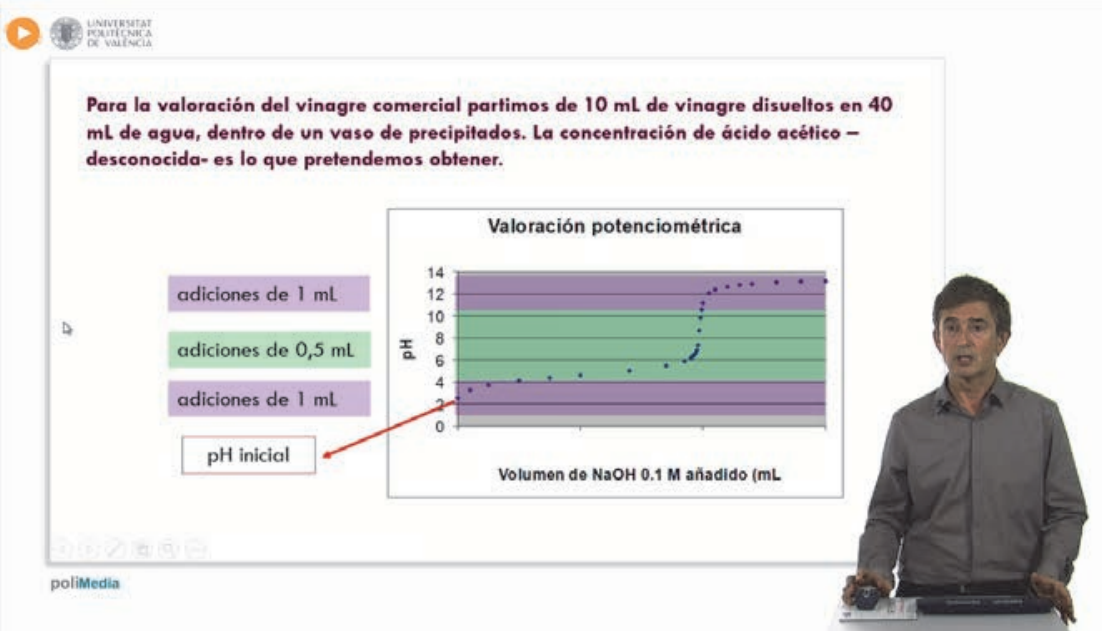

Fig. 4. Captura de pantalla del video "Equilibrios ácido-base. Hidrólisis. Determinación de la acidez en productos naturales"

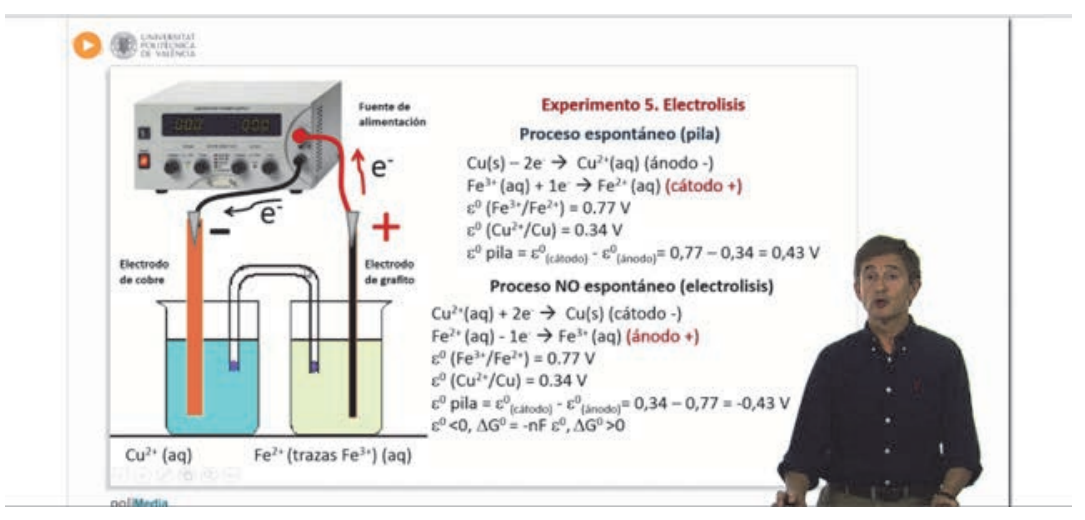

Fig. 5 Captura de pantalla del video "Equilibrios redox. Pilas y electrolisis"

\subsection{Diseño, utilización y evaluación de los tests prelaboratorio}

Cada uno de los tres tests prelaboratorio constó de 5 preguntas de opción multiple. Estos se diseñaron con el objetivo de garantizar la visualización del video antes de la realización de las prácticas. Se buscó además una desvinculación progresiva de las preguntas planteadas con el contenido del video. Así, para la primera de las tres prácticas las 5 preguntas podían contestarse fácilmente tras la visualización, mientras que para la última práctica sólo era el caso de una de ellas, siendo necesario cierto nivel de asimilación del contenido para

\section{(cc) EY-NC-ND 2014, Universitat Politècnica de València}

I Jornadas IN-RED (2014) 
Diseño de objetos de aprendizaje en formato Polimedia para el desarrollo de actividades prelaboratorio en química general

responder correctamente a las demás. Los alumnos completaron los tests de manera individual, a través de la herramienta "Exámenes" de la plataforma Poliformat. Los resultados obtenidos se guardaron automáticamente en la herramienta "Calificaciones", y tuvieron un peso del $10 \%$ de la calificación de prácticas.

\subsection{Encuestas de opinión sobre las actividades prelaboratorio}

Se pasaron encuestas en papel a dos de los subgrupos de prácticas, como muestra representativa del alumnado. Se obtuvo así la opinión de 30 alumnos. La figura 5 muestra el texto de la encuesta.

Por favor, a continuación responde a estas preguntas de cara a mejorar la docencia de la asignatura:

1. ¿Te han resultado útiles los vídeos + test en PoliformaT para realizar mejor las prácticas de laboratorio? (Justifica tu respuesta)

2. En general ¿Cuántas veces has visto los vídeos?

3. ¿Qué cambiarías en estas actividades prelaboratorio para que fueran más eficaces?

4. En las prácticas de la unidad 1 (Orgánica) se utilizaron "screencasts" (capturas de pantalla). En estas tres se han utilizado "Polimedias". ¿Cuál de las dos opciones prefieres? ¿Por qué?

iißMuchas gracias por tu ayuda!!!

Fig. 5 Texto de la encuesta de opinión

\section{Resultados}

Las respuestas a las cuestiones 1 y 2 de las encuestas de opinión vienen clasificadas en el diagrama de la figura 6. Se distinguen diferentes grupos de respuestas: las que consideran globalmente los dos elementos de la actividad (Polimedia y test) y aquéllas en las que se introduce algún tipo de valoración independiente para cada uno de estos recursos. En cada caso, las respuestas son clasificadas según consistan en una valoración positiva o negativa.

Las respuestas con un significado similar son agrupadas, indicándose su frecuencia, y cada una de las categorías establecidas es relacionada con la respuesta a la cuestión 2, relativa al número de visualizaciones del Polimedia efectuadas.

De los resultados obtenidos de estas dos primeras cuestiones se desprende que la valoración de la actividad es positiva y que ello se debe, principalmente, a la posibilidad que la actividad prelaboratorio ofrece de mostrar previamente el contenido de la clase de laboratorio. Tal vez sea la consecución de un objetivo muy limitado, pero es la función de presentación previa, de anticipación de la clase, el aspecto más valorado, junto a facilitar la 
comprensión de la práctica, que también es valorado por un número significativo de estudiantes. Esto, evidentemente, muestra que queda mucho camino por recorrer, ya que esa visión de la actividad prelaboratorio es todavía coherente con una visión muy limitada del trabajo de laboratorio, como mera visualización de fenómenos o comprobación de conocimientos supuestamente preadquiridos.

Generalmente, los videos son visualizados 2 o más veces, como ya observamos en estudios anteriores (Llorens-Molina, 2014). Al mismo tiempo, también puede observarse que la valoración negativa de algunos alumnos coincide con el hecho de que no han visto los videos.

El hecho de que el Polimedia y los test estén accesibles simultáneamente, puede, por supuesto, influir en el hecho de que se produzcan varias visualizaciones, lo cual interpretamos positivamente ya que puede favorecer un análisis más profundo de su contenido. Por otra parte, es habitual también que los alumnos pidan mantener abierta la actividad prelaboratorio durante todo el periodo que va desde su realización a la entrega del informe como ayuda para su elaboración.

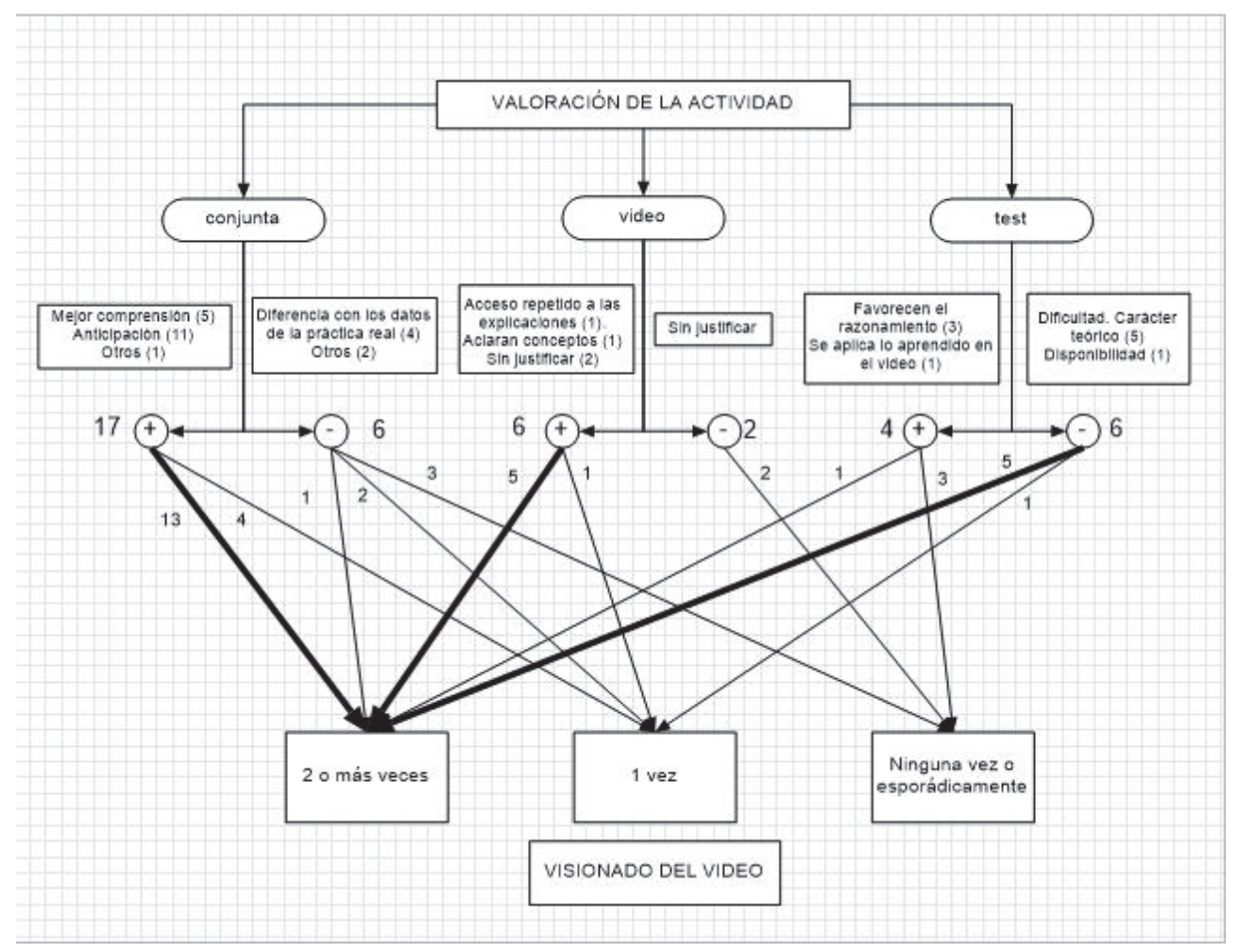

Fig. 6. Información obtenida de las cuestiones 1 y 2 de la encuesta.

\section{(c)) EY-NC-ND 2014, Universitat Politècnica de València}

I Jornadas IN-RED (2014) 
Diseño de objetos de aprendizaje en formato Polimedia para el desarrollo de actividades prelaboratorio en química general

En las valoraciones negativas aparecen dos aspectos críticos que merecen ser tenidos en cuenta. En primer lugar, la posible discordancia entre la información transmitida en el Polimedia, la contenida en los guiones de prácticas y la que va implícita en el material utilizado en el laboratorio: etiquetado de productos, pequeños cambios en el material proporcionado, etc. En efecto, esta discordancia suele estar siempre relacionada con pequeños cambios que introducen en las prácticas, bien relacionados con el material proporcionado, con la eliminación o sustitición de alguna etapa experimental, etc. Desde el punto de vista del profesorado, estas pequeñas incoherencias pueden parecer irrelevantes y suele suponerse que con aclaraciones previas al trabajo de laboratorio pueden considerarse resueltas. La experiencia nos indica lo contrario. La convergencia entre los diferentes recursos utilizados en el trabajo de laboratorio muestra ser un factor decisivo en el éxito de una sesión y su insuficiencia, por nimia que parezca, produce un efecto negativo. Este aspecto ha sido estudiado en profundidad en trabajos anteriores (Byrne, 1990, LlorensMolina, 2011).

El otro aspecto que es valorado negativamente por un cierto número de estudiantes es la dificultad de los tests. Tal como se indicaba anteriormente, sobre todo en el último, se incorporaron ítems cuya respuesta requería algo más que la mera visualización atenta del video, exigiendo el recurso una cierta comprensión de los contenidos del curso. Consideramos que el papel del test asociado al video es una cuestión abierta que convendrá definir en cursos posteriores.

A continuación se muestran, por orden de frecuencia, las respuestas de los estudiantes a la tercera pregunta de la encuesta de opinión.

\section{¿Qué cambiarías en estas actividades prelaboratorio para que fueran más eficaces?}

- Detallar más las etapas del proceso experimental (5)

- Mayor relación entre el contenido del video y las preguntas del test (4)

- Nada (4)

- Preguntas más sencillas e intuitivas en los test (4)

- Explicar la práctica en la clase anterior (2)

- Otras:

- Mayor valoración en la nota

- Insistir más en su realización

- Mayor claridad en el objetivo final

- Test más relacionado con el temario de clase

- Cambiar los guiones para que sean más claros y concisos

- Mayor facilidad para ser encontradas en PoliformaT 
Para interpretar estas respuestas es también necesario considerar lo indicado anteriormente sobre las cuestiones de los tests. Realmente fue el último (tal como además pudo constatarse hablando en clase con los alumnos) el que dio lugar a estas opiniones.

El hecho de que algunos estudiantes soliciten una mayor contribución de las actividades prelaboratorio en detallar el proceso experimental plantea una serie de interrogantes sobre la estructura del guión: ¿Habría que delimitar mejor su función? ¿Debería ser una ficha con instrucciones básicas y la base teórica pasar a la actividad prelaboratorio? ¿Debería formar parte todo de un documento único en formato electrónico que abarcara fundamentos teóricos, contextualización, guía experimental y actividades post-laboratorio: informes y cuestiones de profundización? Por otra parte, algunas de las sugerencias formuladas van también en la linea de lo apuntado al discutir las respuestas a las cuestiones 1 y 2 , sobre la coherencia de los diferentes recursos.

En cuanto a las respuestas proporcionadas a la pregunta 4 del cuestionario, 20 de los alumnos prefirieron los Polimedia mientras que sólo 4 se decantaron por los screencast. Los 6 restantes no respondieron a esa pregunta o no tenían preferencias. La Tabla 1 muestra las ventajas e inconvenientes de ambas opciones, según la visión de los alumnos.

Tabla 1. Ventajas e inconvenientes de Polimedias y screencast

\begin{tabular}{|l|l|l|}
\hline & Polimedia & Screencast \\
\hline Ventajas & $\begin{array}{l}\text { La presencia del profesor. } \\
\text { Mayor cercanía y }\end{array}$ & $\begin{array}{l}\text { El texto permite tomar más } \\
\text { fácilmente los datos (2)* } \\
\text { accesibilidad (4) } \\
\text { Mayor facilidad y } \\
\text { comodidad (2) }\end{array}$ \\
& Más sencillos \\
& Más claros \\
& $\begin{array}{l}\text { Se observa todo el } \\
\text { procedimiento } \\
\text { Es más detallado }\end{array}$ & \\
\hline Inconvenientes & $\begin{array}{l}\text { Es más fácil perderse. } \\
\text { Necesidad de verlo }\end{array}$ & \\
& repetidas veces.(2) & \\
\hline
\end{tabular}

*Es importante indicar que los PDFs con las presentaciones de los Polimedias también estaban en "recursos" de PoliformaT.

La tabla 2 recoge los índices de éxito (en términos porcentuales) en las pruebas de opción múltiple asociadas a las actividades prelaboratorio. Como puede observarse, la relación directa entre la respuesta de la pregunta y el contenido del video es un factor determinante para obtener índices de éxito elevados.

\section{(c) EY-NC-ND 2014, Universitat Politècnica de València}

I Jornadas IN-RED (2014) 
Diseño de objetos de aprendizaje en formato Polimedia para el desarrollo de actividades prelaboratorio en química general

Tabla 2. Puntuaciones (\% respuestas correctas) obtenidas en las pruebas de opción múltiple asociadas a cada actividad prelaboratorio (sobre fondo gris aquellos items cuya respuesta no se desprende directamente del contenido del video)

\begin{tabular}{|l|c|c|c|}
\hline Item & $\begin{array}{c}\text { Práctica 1 } \\
\text { Cinética química }\end{array}$ & $\begin{array}{c}\text { Práctica 2 } \\
\text { Equilibrios ácido-base }\end{array}$ & $\begin{array}{c}\text { Práctica 3 } \\
\text { Equilibrios redox }\end{array}$ \\
\hline 1 & 75 & 89 & 91 \\
\hline 2 & 89 & 92 & $\mathbf{2 0}$ \\
\hline 3 & 90 & 98 & $\mathbf{7 5}$ \\
\hline 4 & 83 & $\mathbf{5 4}$ & $\mathbf{4 7}$ \\
\hline 5 & 95 & 89 & $\mathbf{4 4}$ \\
\hline
\end{tabular}

Es interesante observar la notoria diferencia entre los grados de dificultad de las preguntas directamente relacionadas con el contenido de los videos con aquellas que exigían la extensión de estos conocimientos a otros ejemplos y situaciones. Este hecho puede relacionarse con los comentarios críticos acerca de la dificultad de las pruebas de opción múltiple que fueron registrados en la pregunta 1 de la encuesta (Fig. 1)

El uso del foro tuvo una incidencia muy escasa. Solamente se registraron unas pocas intervenciones tras la primera práctica. Una posible explicación de la no participación en el foro puede ser el modo de evaluar los informes, que son incluidos por los alumnos en "espacio compartido" de PoliformaT a medida que los van realizando. Tras una primera evaluación por el profesor en la que se indican los principales errores y sugerencias para su mejora, son devueltos a espacio compartido para su presentación y calificación. Es posible que los alumnos hayan percibido como más eficaz este modo de plantear sus dudas, sin embargo, no es posible así establecer una dinámica de trabajo colaborativo en la que los alumnos puedan realizar entre ellos sugerencias y correcciones. Dinamizar convenientemente el foro será pues uno de los principales retos a la hora de rediseñar la actividad experimental el curso próximo.

\section{Conclusiones}

Las actividades prelaboratorio son una práctica educativa ampliamente extendida en la Educación Superior, como se desprende de la amplia bibliografía referida a ellas. Por nuestra parte, tras su uso a lo largo de siete cursos consecutivos y a partir de la percepción de los alumnos las consideramos una práctica educativa suficientemente contrastada. Además, la plataforma PoliformaT nos ofrece la posibilidad de realizar una prueba objetiva asociada a los Polimedias, configurando así un modelo de actividad que los estudiantes, de modo mayoritario, consideran, año tras año, de utilidad. Ahora bien, de las opiniones del 
alumnado y de los resultados pueden deducirse algunas conclusiones que, pese al alcance necesariamente limitado de este tipo de experiencias, consideramos de indudable utilidad:

- Debe lograrse una completa integración entre todos los documentos de apoyo que se proprocionan al alumno para la realización de sus prácticas (guiones, etc.) y el contenido de la actividad prelaboratorio, tanto en relación al Polimedia como al test asociado. Dicha coherencia ha de extenderse además a todos y cada uno de los detalles que configuran el entorno de aprendizaje en el laboratorio: desde instrucciones metodológicas concretas, a la presentación del material y al etiquetado de los productos, etc.

- El papel del test debe ser, tal vez, revisado. Una opción es considerarlo simplemente como un recurso para el control de su visionado, algo así como los controles de lectura de un libro. Otra sería profundizar en la relación entre los contenidos teóricos y el trabajo experimental, aunque también este tipo preguntas podría tener un lugar más adecuado como cuestiones post-laboratorio.

- Parece importante que el contenido del Polimedia se proporcione también en PDF, ya que hace mucho más accesible la información que aporta y que muchas veces es esencial para el buen desarrollo de las sesiones de laboratorio.

- Se observa también la necesidad de consolidar de algún modo lo aprendido en el video, puesto que muchas de las cuestiones que los estudiantes formulan durante las sesiones evidencian una falta de comprensión global del objetivo de la práctica y de su sentido dentro de la asignatura (Llorens-Molina, 2012). Una posible mejora consistiría en ampliar el número de envíos para que un segundo visionado del video pueda servir de feed-back.

\section{Referencias}

BARTOLOMÉ PINA, A. (2012). "Entornos de aprendizaje mixto en educación superior”. RIED. Revista iberoamericana de educación a distancia, 11(1).

<http://scholar.google.es/scholar?q=bARTOLOM\%C3\%89+Pina\%2C+entornos+de+aprendizaje+en +educaci\%C3\%B3n+superior\&btnG=\&hl=es\&as_sdt=0\%2C5> [consulta : 9 de junio de 2014] BYRNE, M.S. (1990). “More effective practical work” en Education in chemistry, 1990, p. 12-13. GRAELLS, P.M. (2005). "Entornos formativos multimedia: elementos, plantillas de evaluación/criterios de calidad". Departamento de Pedagogía Aplicada, Facultad de Educación, Universidad Autónoma de Barcelona,

<http://scholar.google.es/scholar?hl=es\&as_sdt=0,5\&q=Graells+entornos+multimedia>, [consulta : 9 de junio de 2014]

LLORENS-MOLINA, J.A. (2009). "Design and assessment of an online prelab model in general chemistry: a case study" en Journal of the Research Center for Educational Technology, 4(2), p. 1531 .

\section{(cc) EY-NC-ND 2014, Universitat Politècnica de València}

I Jornadas IN-RED (2014) 
Diseño de objetos de aprendizaje en formato Polimedia para el desarrollo de actividades prelaboratorio en química general

LLORENS-MOLINA, J.A; SANZ, I. (2011). "Implementation of online prelab activities in introductory organic chemistry" en Promotion and Innovation with New Technologies in Engineering Education (FINTDI), 2011, p. 1-7.

LLORENS-MOLINA, J.A., LLORENS DE JAIME, J. ; SANZ, I. (2012). "La caracterización del ambiente de aprendizaje en un laboratorio de química general. mediante métodos de investigación social”. Enseñanza de las ciencias: revista de investigación y experiencias didácticas, 30(1), p. 5-22. LLORENS-MOLINA, J.A., VERDEGUER, M. (2014). "Audiovisual learning objects as support of an introductory organic chemistry course". 8th International Technology, Education and Development Conference (INTED 2014), p.6976-6984.

MÉNDEZ GARRIDO, J.M. (2010). "Pautas y criterios para el análisis y evaluación de materiales curriculares", 〈http://scholar.google.es/scholar?cluster=9639148194045177324\&hl=es\&as_sdt=0,5> [consulta: 9 de junio de 2014]

NICHOLLS, B. S. (1999). "Pre-laboratory support using dedicated software". University Chemistry Education, 3(1), p. 22-27.

$<$ http://scholar.google.es/scholar?q=Nicholl\%2C+prelaboratory\&btnG=\&hl=es\&as_sdt=0\%2C5> [consulta : 9 de junio de 2014] 
La aplicación de las TICs a través de la utilización de bases de datos y recursos online en la docencia

Francisca Ramón Fernández ${ }^{a}$, María Emilia Casar Furió ${ }^{b}$ y Vicent Giménez Chornet ${ }^{\mathrm{c}}$ ${ }^{a}$ Universitat Politècnica de València (ETSIAMN), frarafer@urb.upv.es, ${ }^{\mathrm{b}}$ Universitat Politècnica de València (ETSIE), macafu@urb.upv.es y ${ }^{c}$ Universitat Politècnica de València(ETSINF), vigicho@har.upv.es.

\begin{abstract}
The equipment EICE technological Resources for the juridical learning, the documentation and audio-visual communication (RETAJUDOCA) takes the technological resources as a principal line of performance for the learning. In this offer we present the experience of the base utilization of information in the teaching. The utilization of juridical bases of information, since he can be Westlaw, makes possible that they acquire a series of skills in the search of legislation and jurisprudence.

Likewise the SIMPLE connection infomática (UTILIZATION OF THE NET AND OF THE INSTITUTIONAL WEBS) with the public organisms in the own classroom allows the direct contact of the pupil with the existing reality, so much in source of information, files, since in his case, easy access to the documentation and necessary material in certain subjects for the correct and complete follow-up of the matter that is given (instruments of planning that apply and they are analyzed, etc ...); observing great motivation

In the Máster of Cultural Management the pupils take part using some technologies that it offers Google related to the management, as the Calendar, the Bookmarks, or the documentation in the cloud as Drive. Of special interest it is a work colaborativo, for groups, of project planning by means of the utilization of the software open source Gantt Project.
\end{abstract}

Keywords: TICs, Bases of information, Resources online

(cc) EY-NC-ND 2014, Universitat Politècnica de València

I Jornadas In-Red (2014) 
La aplicación de las TICs a través de la utilización de bases de datos y recursos online en la docencia

\section{Resumen}

El equipo EICE Recursos tecnológicos para el aprendizaje jurídico, la documentación y comunicación audiovisual (RETAJUDOCA) tiene como principal línea de actuación los recursos tecnológicos para el aprendizaje. En esta propuesta presentamos la experiencia de la utilización de bases de datos en la docencia. La utilización de bases de datos jurídicas, como puede ser Westlaw, posibilita que adquieran una serie de destrezas en la búsqueda de legislación y jurisprudencia.

Asimismo la SIMPLE conexión infomática (UTILIZACIÓN DE LA RED Y DE LAS WEBS INSTITUCIONALES) con los organismos públicos en la propia aula permite el contacto directo del alumno con la realidad existente, tanto en fuente de información, archivos, como en su caso, fácil acceso a la documentación y material necesario en determinadas asignaturas para el seguimiento correcto y completo de la materia que se imparte (instrumentos de planeamiento que rigen y se analizan, etc...); observando gran motivación.

En el Máster de Gestión Cultural los alumnos participan utilizando algunas tecnologías que ofrece Google relacionadas con la gestión, como el Calendario, los Bookmarks, o la documentación en la nube como Drive. De especial interés es un trabajo colaborativo, por grupos, de planificación de proyectos mediante la utilización del software open source Gantt Project.

Palabras clave: TICs, Bases de datos, Recursos online 


\section{Introducción}

Las TICs han propiciado un cambio en la metodología docente al introducirse recursos en los que se fomenta la interactividad y la superación de los tradicionales roles docentes y discentes (Canós, Ramón y Albadejo, 2008), en los que el alumno es el principal protagonista, con un aprendizaje autónomo (Canós y Ramón, 2005). Ello supone además un reto para el profesorado, ya que no puede ir dicha tecnología en detrimento de la calidad de la docencia; al contrario, supone una herramienta de la docencia tanto presencial como no presencial (Canós y Ramón, 2009). A ello se suma el aprendizaje que se desarrolla en disciplinas no técnicas, principalmente en las jurídicas y humanísticas, en las que la aplicación de las TICs supone una innovación en la tradicional pedagogía (Canós y Ramón, 2007a).

Junto a ello, la convergencia europea ha supuesto un incremento considerable de estas nuevas tecnologías, estableciéndose la información como competencia específica (Ramón y Saz, 2004) en muchas de las asignaturas que actualmente se imparten (Canós y Ramón, 2007b).

La potenciación de las TICs, nuevas tecnologías de la información y la comunicación, en el ámbito de la docencia que imparten los miembros del equipo EICE Recursos tecnológicos para el aprendizaje jurídico, la documentación y comunicación audiovisual (RETAJUDOCA) tiene como finalidad lograr los objetivos de máxima participación del alumnado y la utilización por parte del docente de una serie de recursos para innovar en el ámbito educativo, máxime cuando nos hallamos en un campus como es el de la UPV donde la experiencia práctica es una constante en consonancia con las enseñanzas técnicas de las titulaciones que aquí se imparten.

Los miembros que integran el equipo tienen un perfil multidisciplinar, tanto de Derecho, como de Documentación y Comunicación Audiovisual, lo que hace que se puedan generar sinergías óptimas para un intercambio de experiencias a favor de la mejora docente.

Los principales objetivos del grupo han sido los siguientes:

1. Dar a conocer y compartir la investigación y mejora en la docencia que realizamos los profesores que impartimos asignaturas jurídicas y del ámbito de las ciencias sociales, entre ellas, la documentación y la comunicación audiovisual, en las ingenierías y en las titulaciones no jurídicas de la UPV, tanto en el ámbito de la docencia reglada como en Máster y Posgrado.

2. Puesta en común, asesoramiento, difusión, divulgación y colaboración sobre el derecho, la documentación y la comunicación audiovisual, necesarios para disipar dudas y resolución de conflictos derivados de estas cuestiones.

\section{(c)) EY-NC-ND 2014, Universitat Politècnica de València}

I Jornadas IN-RED (2014) 
La aplicación de las TICs a través de la utilización de bases de datos y recursos online en la docencia

3. Difusión de las actividades a la Comunidad científica respecto a las innovaciones desarrolladas en la docencia impartida y la mayor participación del alumno, de acuerdo con las nuevas tecnologías de la comunicación y de la información (TICs).

4. Colaboración con otros profesores que comparten intereses comunes, así como, la colaboración con diversos equipos de innovación y calidad educativa que presten atención a las TICs.

5. Plasmación en los principales foros de divulgación de los resultados obtenidos en el equipo formado, con la finalidad de potenciar el conocimiento alcanzado y la mejora de tales resultados.

En las siguientes líneas se pondrá de manifiesto, bajo el marco del mismo EICE y partiendo de la misma innovación docente, diversas experiencias en diferentes áreas de conocimiento siendo en su mayoría necesario el trabajo colaborativo como metodología docente.

\section{Objetivos}

Los objetivos perseguidos son los siguientes:

- Planificación de la docencia (El profesor define los objetivos, la tarea, el proceso y la evaluación, sin embargo, no es él la fuente de información).

- Experiéncia práctica -aprender haciendo...- (Schank, 2013).

- Fomento del trabajo colaborativo mediante el trabajo en grupo (Ainscow \&West, 2006).

- Contacto con la realidad existente.

- "Tender un puente" al futuro profesional acorde con la titulación, mediante el conocimiento práctico.

\section{Desarrollo de la innovación}

Teniendo en cuenta el desarrollo de la sociedad de la información y la adquisición de competencias profesionales, se parte de las siguiente evolución que se inicia con la web 1.0 para pasar a la denominada web 2.0. Se basa en la creación de páginas web en las que se comparten y producen por los propios usuarios del portal, y que también puede ser compartida por varios portales (Ramón, Lloret, Tolosa, Giménez, Cabedo, Casar, Oltra y Fernández-Llebrez, 2010).

De igual modo, el incremento de la comunicación e interactividad se propicia con la web 2.0, ya que se produce una creciente conexión entre personas a nivel mundial fomentada por las tecnologías de la información y la comunicación, las TICs. (Ramón, Lloret, Tolosa, Giménez, Cabedo, Casar, Oltra, Fernández-Llebrez, Insausti y Vigil, 2012). 
La accesibilidad web nos permite que los servicios digitales sean utilizados por todas las personas, independientemente de sus capacidades, edad, cultura, posibilidades tecnológicas...

Hay gran cantidad de información para generar productos o servicios para diferentes con necesidades especiales: subtitulación, audiodescripción... sintetizadores de voz hardware y software, soportes de apoyo ...programas de ampliación de caracteres, lectores de pantalla... (Ramón, Giménez, Cabedo, Casar y Oltra, 2012).

Se ha utilizado la base de datos Westlaw, accesible de forma gratuita por parte del alumnado de la Universitat Politècnica de València, a través de los ordenadores conectados a la red UPV.

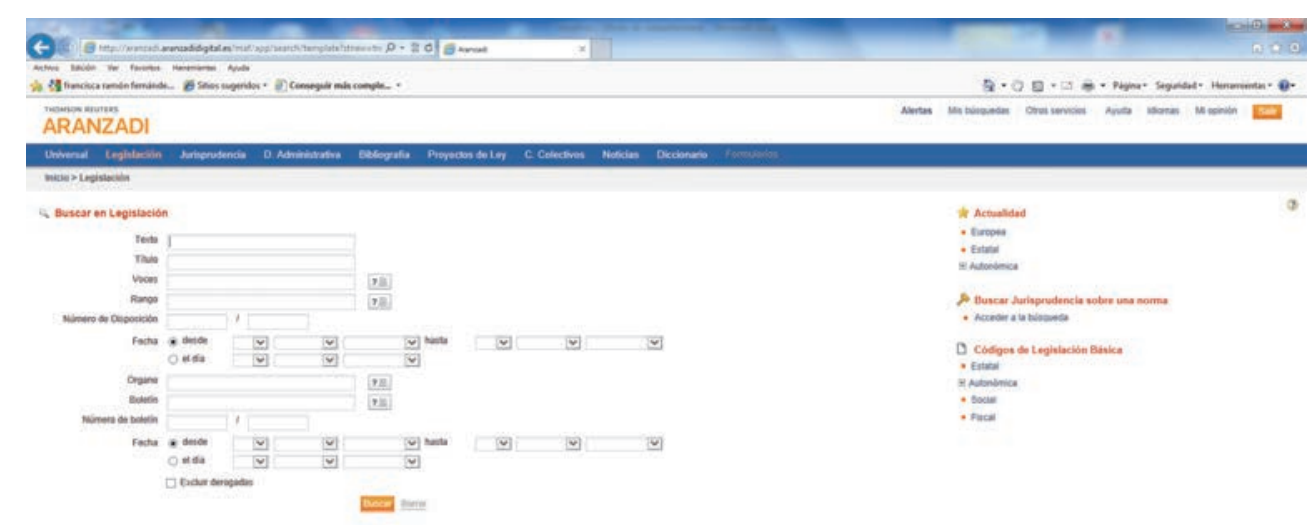

Fig. 1 Base de datos Westlaw. Fuente: www.westlaw.es

iGoogle es una herramienta web 2.0 que permite disponer de un mashup o página web personalizada, donde se pueden integrar mediante APIs diferentes contenidos digitales.

\section{Resultados}

En general, los resultados nos muestran una dinamización de las asignaturas en las que se utilizan las bases de datos referidas y los recursos online indicados, así como el fomento del autoaprendizaje por parte del alumnado, de perfil no jurídico, en la búsqueda de normativa y de jurisprudencia, así como de información y documentación aplicada a las tareas de las asignaturas.

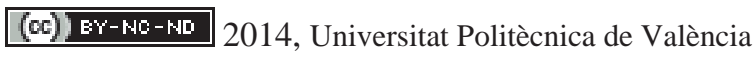

I Jornadas IN-RED (2014) 
La aplicación de las TICs a través de la utilización de bases de datos y recursos online en la docencia

Los alumnos han utilizado los gadgets más importantes para poder realizar un trabajo colaborativo: google docs, google calendar y bookmarks. Han puesto en práctica compartir documentos, establecer un calendario y recibir avisos mediante SMS, o importar sus marcadores o favoritos al iGoogle.

Particularmente, simplemente mediante la UTILIZACIÓN DE LA RED Y DE LAS WEBS INSTITUCIONALES (De Benito Crosetti, 2000) en la asignatura de gestión urbanística de la ETSIE de la UPV se ha podido observar el extraordinario resultado que ha supuesto, desde el punto de vista de la motivación y consecuente participación, como todos y cada uno de los alumnos que efectúan un normal seguimiento de dicha asignatura han funcionado perfectamente dentro de su grupo. Han podido acceder a la realidad existente facilmente y conocer de modo directo la documentación de los planes tanto aprobados como los que se hallan en trámite. Han aprendido de cara al futuro profesional que puede y debe consultarse la documentación que en su momento se les ha facilitado para la práctica de clase como marco legal existente en la práctica habitual en las competencias que les afecten.

Dicha participación y motivación optimizada con los resultados que a continuación se suceden:

Se trataba de parte de la evaluación final de la asignatura donde la práctica grupal contribuye en el seguimiento de curso como parte de la nota de seguimiento de prácticas, además de las prácticas individuales, en la primera parte de evaluación de la asignatura. Máxima obtención un punto sobre seis puntos, con participación del $85 \%$ de los alumnos de la clase en coherencia con el seguimiento normalizado además de otras pruebas prácticas:
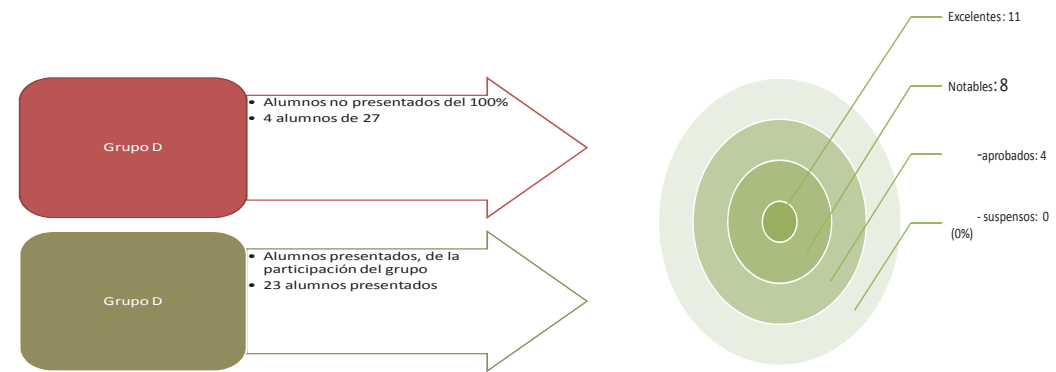

Fig. 2 Resultados evaluación parcial asignatura. Fuente: Elaboración propia

En el caso de la asignatura de "Legislación Patrimonial" la utilización de las TICs es bastante notoria, ya que en la siguiente figura se observa la utilización del apartado de recursos de la asignatura, que contiene numerosos enlaces a páginas webs y objetos de aprendizaje complementarios para el estudio de la asignatura. 

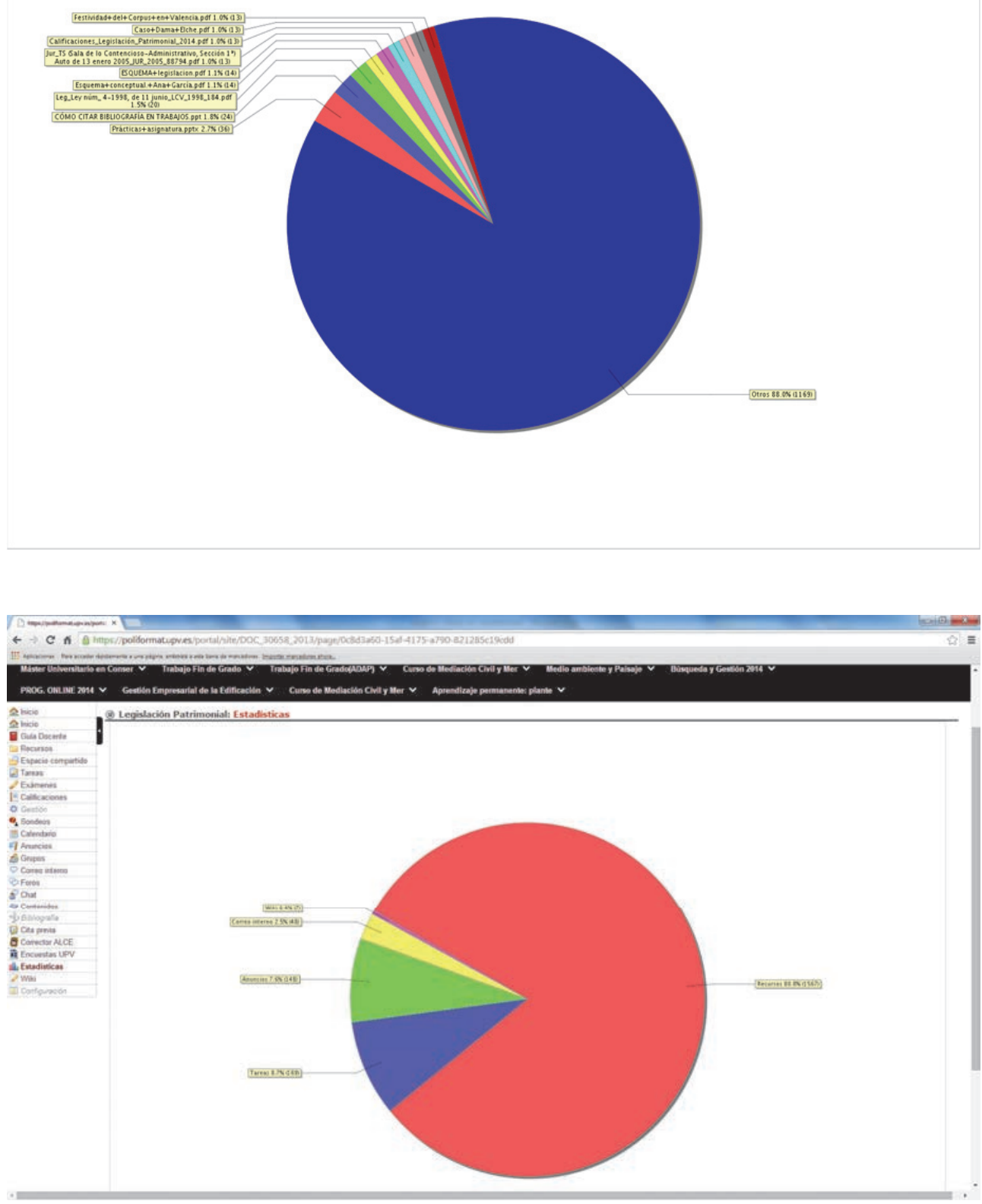

Fig. 3 y 4 Resultados consulta recursos asignatura "Legislación Patrimonial" en poliformat. Fuente: Poliformat

(c)) EY-NC-ND 2014, Universitat Politècnica de València

I Jornadas IN-RED (2014) 
La aplicación de las TICs a través de la utilización de bases de datos y recursos online en la docencia

En el Master en Gestión Cultural, en la asignatura "Gestión del conocimiento y recursos informáticos" los alumnos han aprendido aplicaciones informáticas en el laboratorio, algunas de ellas en línea y otras instaladas en local. El aprendizaque de aplicaciones informáticas no es una innovación docente en si, sino que la innovación ha sido mediante un aprendizaje colaborativo que permitiese a los alumnos comunicarse en grupo para elaborar un proyecto de caso practico sobre gestión cultural.

Los alumnos aprendieron a comunicarse con las aplicaciones que ofrece Google, especialmente mediante el calendario para proyectar actividades comunes, y en Google Docs para compartir documentos que trabajarían conjuntamente. Sin embargo la aplicación open source que más han trabajado ha sido la de Gantt Project (http://www.ganttproject.biz/), instalada en local.

Mediante el siguiente planteamiento de trabajo los alumnos han percivido el interés por un trabajo colaborativo:

- Los alumnos han recibido previamente una explicación del funcionamiento del software Gantt Project.

- Los alumnos ha realizado un grupo de trabajo para diseñar un projecto de gestión cultural, en papel, que han elaborado conjuntamente mediante reuniones de trabajo.

- Los alumnos han podido trasladar a la aplición informática el diseño del proyecto, reflejando las tareas, funciones y responsables de cada actividad. Han visto la posibilidad de publicar el proyecto en internet, aunque no lo hay llevado a la práctica para no difundir lo que es un ejercicio de clase

Tras el diseño del proyecto colaborativo los alumnos lo han defendido en clase, como si el resto de los alumnos fuesen clientes, demostrando la habilidad en la utilización de una herramienta informática.

\section{Conclusiones}

Especificamente, en la asignatura de gestión urbanística, se evalúa el trabajo y la metodología, dejando al margen la competitividad. Todos los miembros del grupo son mutuamente responsables del aprendizaje de cada uno de los demás. Los alumnos se han organizado el trabajo individual a partir de los materiales e indicaciones que el profesor les ha proporcionado y mediante la "realidad virtual" han podido fácilmente contactar con el entorno, han podido ver todos y cada unos de los instrumentos del planeamiento cuya teoría se les ha mostrado, lo cual ha hecho destacar especialmente la motivación de todo el equipo obteniendo unos resultados muy óptimos cuyas evidencias aquí se han mostrado.

En la asignatura "Gestión del conocimiento y recursos informáticos" del Master en Gestió cultural los alumnos han trabajado en grupo en diferentes herramientas de Google, 
especialmente en el Calendario y en Google Docs, y han elaborado un proyecto de gestión cultural con el software Gantt Projecte. El aliciente ha sido la generación de un archivo en HTML del projecto que los alumnos han defendido en clase.

\section{Referencias}

AINSCOW, M. \& WEST, M. (2006). Improving urban schools. Leadership and collaboration. Maidenhead: Open University Press.

CANÓS DARÓS, L. y RAMÓN FERNÁNDEZ, F. (2005). "Aplicación de las nuevas tecnologías para el trabajo autónomo del alumno". En Actas del XX Simposium Nacional de la Unión Científica Internacional de Radio. URSI 2005. Gandía: Editorial Universitat Politècnica de València. Páginas 1-4.

-(2007a) "La aplicación de las TICs en el aprendizaje de disciplinas jurídicas aplicadas en carreras técnicas en el marco de la convergencia europea". En Conocimiento Abierto, Sociedad Libre, Actas digitales del III Congreso ONLINE del Observatorio para la CiberSociedad. Barcelona: Editorial Meddia, cultura i comunicació. Páginas 1 a 7.

-(2007b) "La información como competencia específica en el contexto de convergencia europea". En Conocimiento Abierto, Sociedad Libre, Actas digitales del III Congreso ONLINE del Observatorio para la CiberSociedad. Barcelona: Editorial Meddia, cultura i comunicació. Páginas 1 a 11.

-(2009) "La calidad de la docencia respecto a las nuevas tecnologías y recursos didácticos" en Autogestión, cooperación y participación en las Ciencias Sociales, Valencia. Páginas 341-352.

CANÓS DARÓS, L., RAMÓN FERNÁNDEZ, F. y ALBALADEJO FERNÁNDEZSILGADO, M. (2008). "Los roles docentes y discentes ante las nuevas tecnologías y el proceso de convergencia europea". En CD Resúmenes comunicaciones $V$ Congreso Iberoamericano de Docencia Universitaria, Valencia: Edita AIDU. Asociación Iberoamericana de Didáctica Universitaria, Universidad Politécnica de Valencia e Instituto Ciencias de la Educación. Páginas 388 a 390.

DE BENITO CROSETTI, B. (2000). "Herramientas para la creación, distribución y gestión de cursos a través de Internet”. Edutec. Revista Electrónica de Tecnología Educativa. Núm. 12-Junio.

DURÁN, D. y MIQUEL, E. (2003). "Cooperar para enseñar y aprender". Cuadernos de pedagogía. $\mathrm{N}^{\circ}$ 331. Páginas 73-76.

MORIÑA, A. y PARRILLA, A. (2005). Criterios para la formación permanente del profesorado en el marco de la educación inclusiva. Revista de Educación, 339, 517-539.

PICO, M ${ }^{\text {a }}$ L. (2011). "Trabajos colaborativos: serie estrategias en el aula en el modelo 1 a 1/María Laura Pico y Cecilia Rodríguez”. Editorial: Educar: Buenos Aires. Páginas 1-58.

\section{(c)) EY-NC-ND 2014, Universitat Politècnica de València}

I Jornadas IN-RED (2014) 
La aplicación de las TICs a través de la utilización de bases de datos y recursos online en la docencia

RAMÓN FERNÁNDEZ, F. y SAZ GIL, Ma . I. (2004). "Las nuevas tecnologías como elemento facilitador de los métodos activos en la transmisión de competencias", En Hacia una docencia de calidad: políticas y experiencias. Actas del I Congreso de la Red Estatal de Docencia Universitaria y III Jornada de Mejora Educativa de la Universitat Jaume I. Castellón: Editorial Universitat Jaume I de Castellò. Páginas 330-341.

RAMÓN FERNÁNDEZ, F., GIMÉNEZ CHORNET, V., CABEDO MALLOL, V., CASAR FURIÓ, M. E. y OLTRA GUTIÉRREZ, J. V. (2012). "La comunicación 2.0”. En $V$ Jornada de Innovación Docente en la Escuela Técnica Superior de Ingeniería Informática, JIDINF 2012, Valencia: Editorial Universitat Politècnica de València. Páginas 1.

RAMÓN FERNÁNDEZ, F., LLORET ROMERO, N., TOLOSA ROBLEDO, L., GIMÉNEZ CHORNET, V., CABEDO MALLOL, V., CASAR FURIÓ, M. E., OLTRA GUTIÉRREZ, J. V. y FERNÁNDEZ-LLEBREZ MUÑOZ, J. (2010). "Recursos tecnológicos para el aprendizaje jurídico, la documentación y comunicación audiovisual". En III Jornada de Innovación Docente (JIDINF'10), Universidad Politécnica de Valencia, Valencia: Editorial Universitat Politècnica de València. Páginas 1.

RAMÓN FERNÁNDEZ, F., LLORET ROMERO, N., TOLOSA ROBLEDO, L., GIMÉNEZ CHORNET, V., CABEDO MALLOL, V., CASAR FURIÓ, M. E., OLTRA GUTIÉRREZ， J. V., FERNÁNDEZ-LLEBREZ MUÑOZ, J., INSAUSTI MACHINANDIARENA, P. DE y VIGIL DE INSAUSTI, A. (2012). "La utilización de materiales docentes en red". En IV Jornada de Innovación Docente (JINDINF'11), ETS Ingeniería Informática, Universitat Politècnica de València, Valencia: Editoras María José Castro Bleda, Esther Sanabria Codesal y Silvia Terrasa Barrena, Editorial Universitat Politècnica de València, Página 46.

SCHANK, R. (2013). "Enseñando a pensar". Erasmus ediciones. Barcelona. 
El uso de Internet como plataforma docente

\title{
Josep Prósper Ribes ${ }^{\mathrm{a}}$, Blas Payri ${ }^{\mathrm{b}}$, Francisca Ramón Fernández
}

${ }^{a}$ Universitat Politènica de València, jprosper@har.upv.es, ${ }^{b}$ Universitat Politècnica de València, bpayri@har.upv.es, 'Cuniversitat Politècnica de València, frarafer@urb.upv.es.

\begin{abstract}
Internet is an ideal medium for teaching and data exchange. Through Internet fundamental information can be spread (in private or open) on the course so that students always have a place to access data. For example for several academic courses, in the subject "Audiovisual Narrative" (4th degree in Communication Studies) a group of students elaborated a blog where they uploaded the technical specifications and basic information about the films they were required to view. Through the blog, students (although they may miss a class) obtained all the basic information and fundamental aspects on the mandatory films. Here we have a double function. First, the group of students, under the supervision of the teacher, must prepare a scholarly work, and be able to use new technologies for dissemination and updating. Second, via Internet, relevant data is provided to the other students. Internet enabled also the communication between teacher and student and exchanging all types of files. But there is also a very important third aspect: the public display of student work.
\end{abstract}

Keywords: Internet, teaching platform, film studies, information diffusion, information exchange. 


\begin{abstract}
Resumen
Internet es un medio ideal para la actividad docente y el intercambio de datos. A través de Internet se puede difundir (en privado o en abierto) información fundamental sobre la asignatura de forma que el alumno tenga siempre un lugar donde poder obtener datos. Por ejemplo, en la asignatura Narrativa Audiovisual (4 ${ }^{\circ}$ licenciatura en Comunicación Audiovisual), durante varios cursos, un grupo de alumnos elaboraban un blog donde colocaban las fichas técnicas e información básica de las películas de visión obligatoria en la asignatura. A través del blog, los alumnos (aunque pudieran faltar a alguna clase) obtenían toda la información básica sobre qué películas tenían que ver y sus aspectos fundamentales. Aquí nos encontramos con una doble función. En primer lugar, el grupo de alumnos, bajo la supervisión del profesor, debe preparar un trabajo académico y ser capaz de utilizar las nuevas tecnologías para su difusión y puesta al día. En segundo lugar, a través de Internet se suministran datos relevantes para el resto de alumnos.
\end{abstract}

A través de Internet también se pude establecer comunicación entre profesor y alumno e intercambiar todo tipo de archivos. Pero hay también un tercer aspecto muy importante: la exhibición pública del trabajo del alumno.

Palabras clave: Internet, plataforma docente, audiovisual, difusión, intercambio informativo.

\title{
- Introducción
}

El desarrollo de las Tecnologías de la información y la Comunicación (TIC) está permitiendo desarrollar unas formas de comunicarse y, por lo tanto, de obtener información completamente novedosas y que afectan a los procedimientos de trabajo y enseñanza. Es muy interesante el siguiente comentario de Micó: "Els TIC mostren el camí cap a un nou mon. En aquest entorn, no mana qui acumula més possessions, sinó qui té més conexions" (2012, p.. 109) Internet se ha convertido en un elemento clave del desarrollo social y, por lo tanto, de la vida laboral. El uso de Internet como elemento docente está muy asentado en la actualidad (Gewerc, Montero y Lama, 2014 o Hernández, González y Muñoz, 2014). Sin que suponga eliminar las relaciones interpersonales, que a nuestro juicio son fundamentales y deben seguir siendo el principal soporte de la actividad docente, se puede utilizar Internet para facilitar tanto el intercambio informativo entre profesor y alumnos o entre los propios 
alumnos y que se convierta en un instrumento básico para difundir, ya sea en abierto o cerrado, información sobre una asignatura concreta o un trabajo audiovisual determinado. $\mathrm{Al}$ margen de las horas de clase, en cualquier momento un alumno (o grupo de alumnos) puede difundir en Internet (privadamente o públicamente) un trabajo audiovisual que el profesor tranquilamente en su despacho puede revisar y corregir. Por ejemplo, a través de Vimeo (o de otras plataformas como YouTube) se puede adjuntar un reportaje audiovisual ya sea a través de un enlace privado (con la correspondiente contraseña) o de un enlace público. Es aconsejable un enlace privado cuando todavía está el audiovisual en fase de elaboración. Esta posibilidad ayuda mucho al profesor. Es más, en algunos casos una grabación puede llegar de forma instantánea a ser visionada por el profesor aunque se encuentre en otro espacio. Esto también es muy útil en caso de que alumno o profesor se encuentren en distintas ciudades. Por ejemplo, un alumno de doctorado en Tokio puede mostrar una grabación al profesor que se encuentre en su despacho de la UPV y realizar una primera valoración de urgencia.

Entre todas estas posibilidades que ofrecen los cibermedios, nosotros en nuestra tarea docente hemos explorado algunos aspectos: página web, difusión, intercambio informativo. En nuestra propuesta docente se valora la interactividad, la integración audio-escrito-visual de los medios hasta constituir un lenguaje multimedia y la instantaneidad. No es necesario disponer de una red propia, es decir, de una intranet, sino que a través de Internet se pueden desarrollar muchas actividades docentes.

Nuestra propuesta tiene cuatro aspectos que conviene diferenciar:

A) Trabajo del alumno que crea una página web.

B) Permitir al conjunto de los alumnos de una asignatura estar informado sobre el desarrollo docente de la misma.

C) Mantener comunicación constante entre el profesor y alumnos independientemente del lugar donde se encuentran.

D) Divulgación de una obra. A través de Internet se puede difundir una obra audiovisual y recibir los comentarios de los usuarios. Lógicamente, las opiniones serán de todo tipo, pero es un cauce importante para que los alumnos conozcan los efectos de su trabajo en una audiencia muy heterogénea.

\section{- Objetivos}

1.- Mantener una comunicación constante entre profesor y alumno independientemente del espacio.

\section{(c) EY-NC-ND 2014, Universitat Politècnica de València}

I Jornadas IN-RED (2014) 
2.- Permitir al profesor intervenir en cualquier momento sobre la actividad del alumno, ya sea aconsejando cualquier tipo de cambio o de actividad para mejorar el trabajo o simplemente realizando un seguimiento a los trabajos de los alumnos.

3.- Permitir al alumno desarrollar una actividad autónoma que tenga repercusión sobre la asignatura.

4.- Mantener informado al conjunto de alumnos sobre temas concretos de la asignatura.

5.- Divulgación, si procede, de los trabajos.

\section{- Desarrollo de la innovación}

\section{Creación de una página web}

De todas las propuesta planteadas (y realizadas), sin duda alguna la creación de una página web con información sobre películas fue la actividad más destacada e importante. El proyecto consistía en los siguientes aspectos y actividades:

1.- El trabajo se integró en la asignatura Narrativa Audiovisual, $4^{\circ}$ curso de la licenciatura en Comunicación Audiovisual.

2.- Los alumnos debían realizar toda la actividad, desde la creación de la página web hasta los contenidos informativos.

3.- El contenido de la página web consistía en una relación de las películas de visionado obligatorio en la asignatura. A través del blog, los alumnos (aunque pudieran faltar a alguna clase) obtenían toda la información básica sobre qué películas tenían que ver y sus aspectos fundamentales. Estos datos eran útiles para el examen y, por supuesto, para su formación.

4.- Sobre cada película se debía elaborar una ficha que incluyera datos técnicos, artísticos, sinopsis argumental, críticas y comentarios, así como una adecuada contextualización y aspectos particulares más destacados de la película.

El profesor indicaba a los alumnos qué películas eran de visionado obligatorio al tiempo que guiaba y supervisaba el trabajo del grupo de alumnos encargados de la elaboración de las fichas y su inclusión en la página web. Un ejemplo lo tenemos en la siguiente figura: 


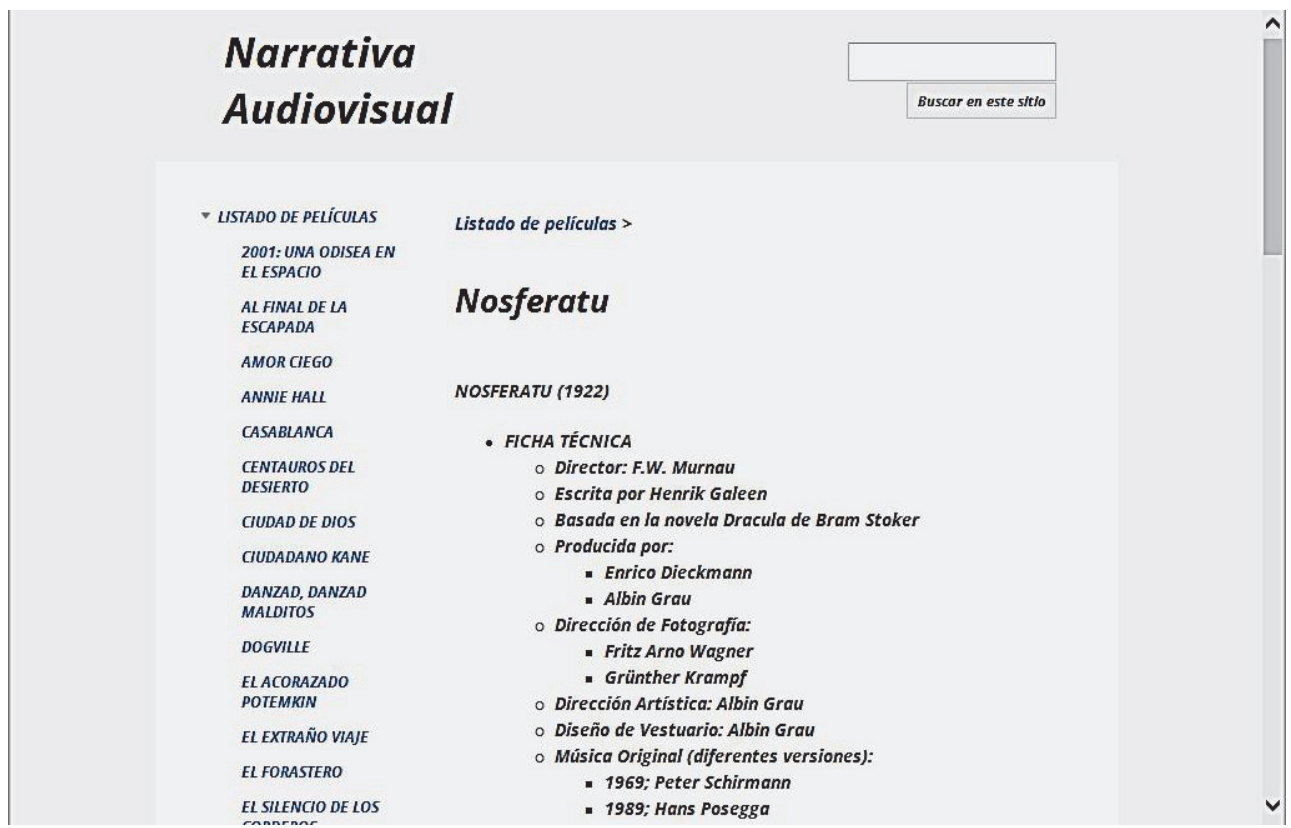

Fig. 1 Listado completo de las películas de visionado obligatorio. Ficha de "Nosferatu"

En este fragmento de la página web podemos observar el listado completo de las películas de visionado obligatorio a la izquierda. El alumno podía "pinchar" sobre el listado y aparecían los datos sobre la película. En el ejemplo se puede ver el inicio de la ficha técnica de la película Nosferatu.

Cada usuario utilizaba la página web según le convenia. Es interesante la siguiente apreciación de Mariano Cebrían:

"Además de esta capacidad de interrelacionar unos contenidos y tratamientos con otros, el usuario toma las rutas que desee; actúa con diversas opciones de navegación y explora otros recorridos según sus necesidades e intereses. No hay un seguimiento único sino que varía de unos usuarios a otros e incluso el mismo usuario ensaya caminos diferentes en cada uno de sus recorridos. Es una narración abierta y en gran parte compartida por los usuarios." (Cebrián, 2009, p. 20).

Los objetivos que se cumplieron con este trabajo fueron:

1.- Participación de los alumnos en el desarrollo de contenidos de la asignatura.

2.- El grupo de alumnos encargado de su elaboración tenía que realizar una importante labor de documentación. Por cierto, en este aspecto Internet supuso un buen aliado para conseguir información.

\section{(cc)) BY-NC-ND 2014, Universitat Politècnica de València}

I Jornadas IN-RED (2014) 


\section{El uso de Internet como plataforma docente}

3.- Todos los alumnos de la clase podían acceder a la información. De esta manera, durante las lecciones el profesor podía exponer los contenidos considerando que los alumnos ya tenían la información necesaria sobre las películas. Por ejemplo, si se hablaba en clase de la continuidad audiovisual, ya se había subido la ficha de las películas que debían ver los alumnos con los datos básicos. Así, el profesor podía centrar el tema con los ejemplos adecuados de esas películas que el alumno ya tenía como referencia.

Esta actividad se completaba con el visionado de dichas películas en el aula, fuera de las horas estrictamente lectivas. La proyección estaba organizada por los propios alumnos. Esta última actividad fue secundaria. Dependiendo de los cursos, la asistencia fue de más a menos, ya que los alumnos también podían ver fácilmente las películas por su cuenta a través, principalmente, de Internet.

\section{Intercambio y difusión}

La elaboración de ejercicios audiovisuales, ya sea para una asignatura de licenciatura o grado concreta o un trabajo de investigación doctoral, implica un proceso complejo donde no es habitual que el profesor pueda orientar al alumno en todas las fases, especialmente en el rodaje ya que habitualmente, profesor y alumno en están en espacios diferentes. Precisamente, la grabación de imágenes es uno de los momentos más delicados e importantes, ya que condiciona decisivamente el resto de las fases de producción audiovisual. No solamente por la consabida norma de que el único plano que no puede montarse es el plano no grabado, sino porque un procedimiento incorrecto puede significar que se tenga que proceder a grabar de nuevo o a montar con un material inadecuado. En este sentido, a través de Internet se puede intercambiar información entre alumnos y profesor para poder corregir errores o indicar posibilidades de grabación. Basta con tener un ordenador y un acceso a Internet para a través de una plataforma como YouTube o Vimeo para "subir" las imágenes que se están grabando y que el profesor pueda comentar. Obviamente, no se trata de "subir" todas las imágenes que se graban, sino solamente aquellas que puedan resultar dudosas, complejas o simplemente para solucionar una duda. Por ejemplo, mostrando el espacio donde se va a grabar a través de planos generales con distintos puntos de vista para buscar junto con el profesor el emplazamiento más adecuado para la cámara y la distancia focal óptima. Este procedimiento puede resultar más adecuado cuando en una clase, en horario docente, el profesor permanece en el aula con el ordenador conectado y diversos grupos de alumnos se encuentran grabando imágenes. El profesor recibe un correo donde se le notifica que un grupo de alumnos acaba de "subir" unas imágenes y el profesor las visiona y las comenta de forma inmediata. También esta cualidad de Internet se puede aprovechar para analizar otras fases de la realización de una producción audiovisual. Este procedimiento es especialmente esencial cuando un alumno se encuentre en otra ciudad o país realizando, por ejemplo, una investigación para una tesis 
doctoral. A través de Internet se pueden mandar las imágenes al profesor del trabajo que está realizando de forma que se puedan analizar y comentar en el momento oportuno. Como conclusión a este apartado, podemos indicar que a través del uso de Internet como plataforma docente, se consiguen los siguientes objetivos:

1.- Comunicación inmediata entre el alumno y el profesor independientemente del lugar en que se encuentren.

2.- Posibilidad de intercambiar archivos de video.

3.- El profesor puede revisar el trabajo audiovisual y responder de forma inmediata.

Un ejemplo de lo que estamos comentando lo tenemos en la siguiente imagen:

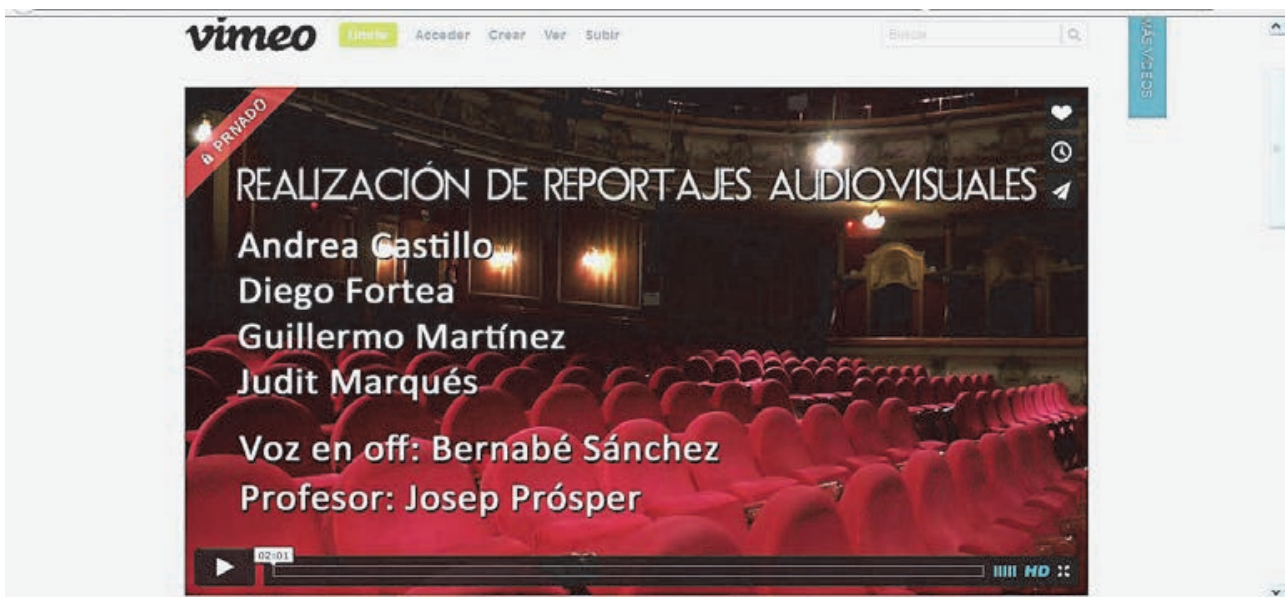

Fig. 2 Imagen de Vimeo: ilustración de las posibilidades para remitir archivos de video al profesor en privado. Caso de "Realización de reportajes audiovisuales"

En este caso, el grupo de alumnos "subió" el archivo de vídeo en privado para que el profesor lo pudiera revisar antes de la clase y realizar las indicaciones oportunas. El siguiente ejemplo, muestra las posibilidades que tiene el sistema para poder mandar desde cualquier lugar un archivo de video al profesor para que realice los comentarios pertinentes. En este caso, la lejanía en que se encuentra el doctorando no impide que la información pueda fluir adecuadamente en ambas direcciones. 


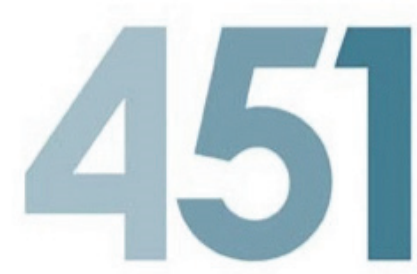

WEB

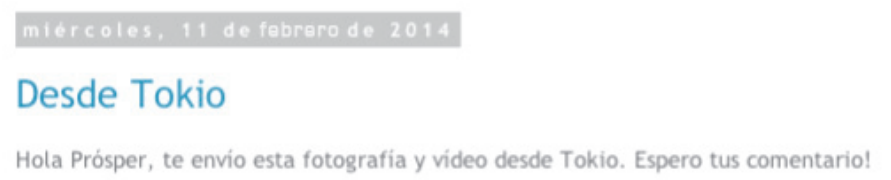

GODZILLA \& HIROSHIMA

Trailer Oficial

Trailer del documental

EL LIBRO DE UN LOCO

- El libro de un loco

REEL 451

- Reel 2008 - 2011

Video danza

- Video clip

- Pensamiento

- Instinto

- Sentimiento

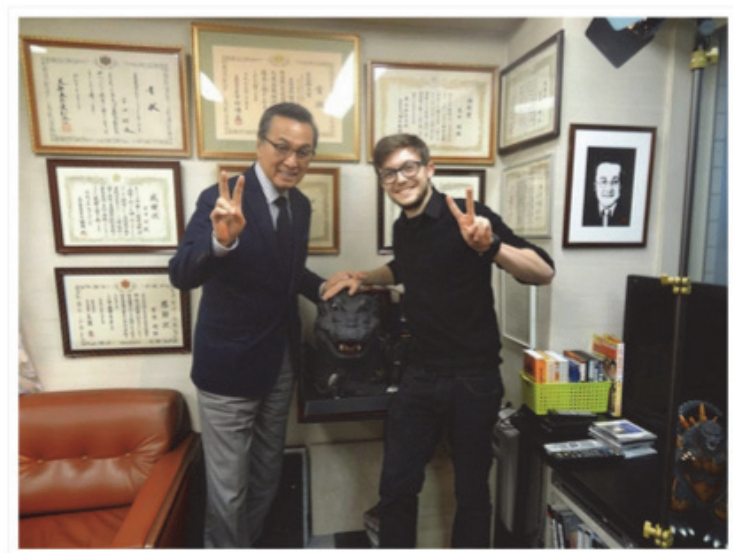

Documental rené magritte

- Drôle de bonhomme

- Homenaje a los Magritte

- Galería de imágenes

Video arte

- Sima

Festivales \& patrocinadores

Las Naves

Fundación VEO

Valencia Crea 2011

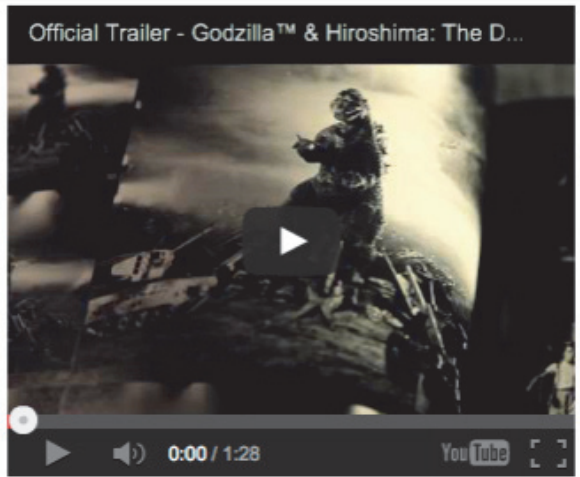

Fig. 4 Captura de pantalla de la web Producciones 451. Utilización de internet para eliminación de fronteras físicas en la relación con alumno. Imagen de alumno en Tokio 
Por otra parte, la difusión de los trabajos audiovisuales permite un doble objetivo:

1.- Divulgar el trabajo de los alumnos

2.- Recibir los comentarios de los usuarios que en ocasiones pueden servir tanto para introducir modificaciones en el trabajo expuesto como para futuras producciones.

Un ejemplo lo tenemos en el reportaje "No es país para comics" tal y como se muestra en la siguiente imagen:

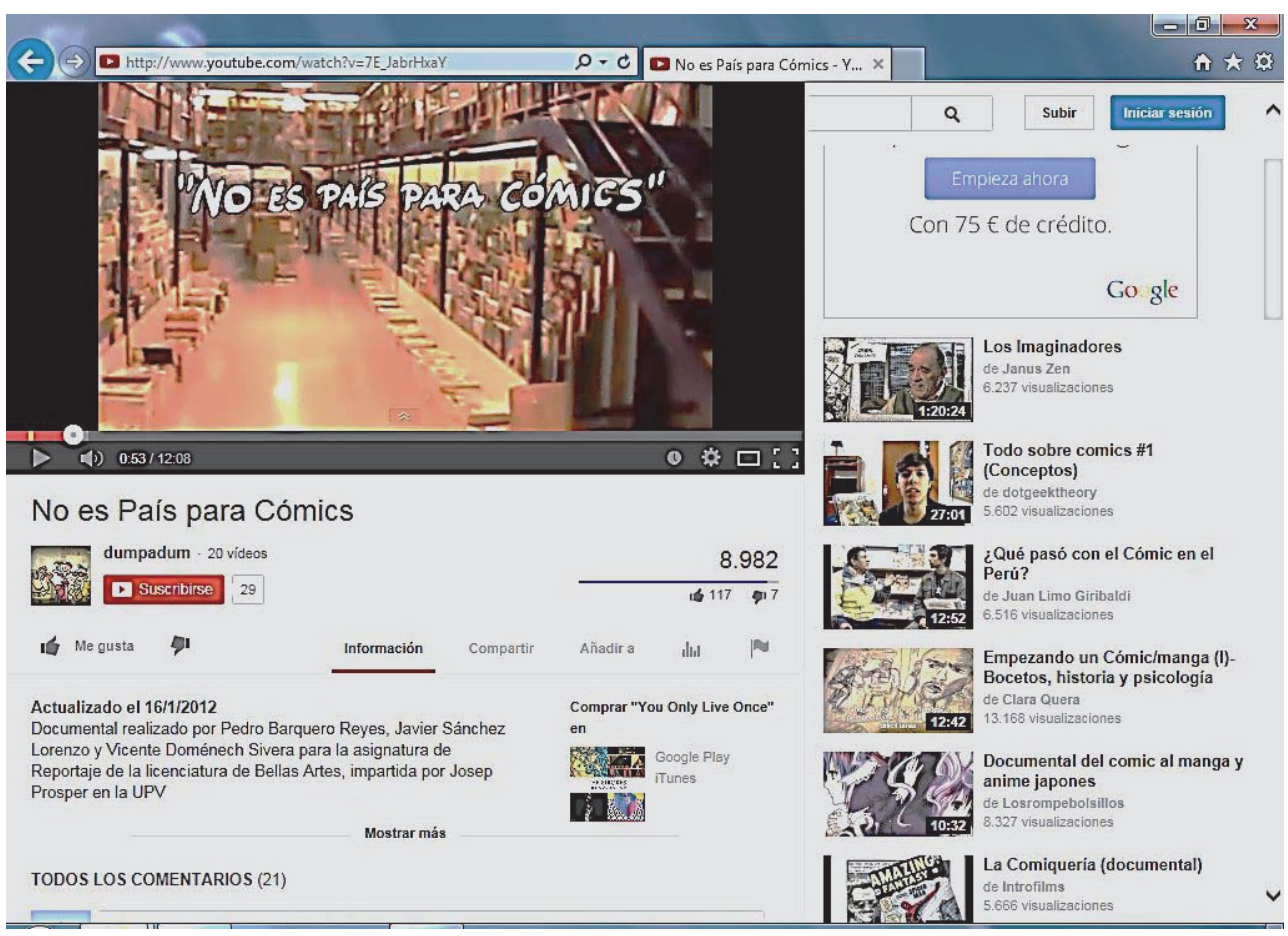

Fig. 5 Captura de pantalla de Youtube referente al reportaje "No es país para cómics"

Esta es una captura del 9 de junio del 2014. Todavía se podía ver el reportaje y realizar los comentarios oportunos.

\section{- $\quad$ Resultados}

La elaboración de una página web con información sobre películas de visionado obligatorio en la asignatura Narrativa Audiovisual resultó durante los diversos cursos que tuvo lugar, un éxito rotundo ya que proporcionó a todos los alumnos la posibilidad de obtener

\section{(cc)) BY-NC-ND 2014, Universitat Politècnica de València}

I Jornadas IN-RED (2014) 


\section{El uso de Internet como plataforma docente}

información sobre una de las bases fundamentales del curso: el acceso a información sobre relatos audiovisuales. La realización de sesiones de "vídeo-club" ya no fue tan exitosa, dado que los alumnos podían ver las películas a través de Internet, ya de forma individual o en pequeños grupos. De todas formas, nos encontramos con un uso muy importante de Internet en la asignatura: la posibilidad de ver producciones audiovisuales, algunas de ellas fuera de catálogo.

Por otra parte, involucrar a los alumnos en la elaboración de material docente (bajo la guía y supervisión del profesor) con repercusión en sus compañeros, tuvo muchos aspecto positivos, especialmente una mayor motivación en la elaboración de los trabajos.

Por lo que respecta a la utilización de Internet para intercambiar información sobre elaboración de producción audiovisual, principalmente, entre profesor y alumnos resulto básico cuando el alumno se encuentra en otra ciudad o país. En el resto de situaciones, permitir un intercambio fluido de información y comentarios del profesor que pueden modificar el trabajo del alumno resulta básico para guiar al alumno en un caso concreto con independencia del lugar donde se encuentre y de manera instantánea. Por supuesto, hay que contar con los medios adecuados. Esto es especialmente interesante, si en horas de clase el alumno debe realizar algún ejercicio o grabación que implique que tenga que desplazarse a un lugar alejado del aula, como es el caso de la asignatura Realización de reportajes audiovisuales. El profesor puede acceder al trabajo de forma instantánea y remitirle los comentarios oportunos. En esta utilización de Internet todavía faltan más experiencias para poder generalizar un procedimiento de trabajo concreto.

Sobre la difusión de trabajos tenemos pocos ejemplos, pero los audiovisuales difundidos han tenido una buena aceptación y los comentarios recibidos pueden ayudar a los autores a introducir modificaciones o a mejorar aspectos concretos de las producciones audiovisuales.

\section{- $\quad$ Conclusiones}

Internet permite tanto una inmediatez en el intercambio informativo como la posibilidad de almacenar información que un usuario pueda recuperar en cualquier momento y centrarse en los aspectos que le interesen. Estas cualidades permiten realizar una serie de actividades docentes que nos absolutamente impensables sin el recurso a Internet. Estas actividades permiten que los alumnos colaboren en la producción de material docente de una asignatura (siempre con la supervisión y guía del profesor) y que otros alumnos puedan acceder en cualquier momento y desde cualquier espacio a dicha información. Igualmente, permite mantener una relación informativa entre profesor y alumnos de forma que un trabajo se pueda valorar de forma inmediata y admite que el alumno pueda recibir las primeras 
orientaciones a lo ejecutado de forma instantánea. Además, permite divulgar cualquier producción audiovisual y conocer las valoraciones de los usuarios.

\section{Referencias}

CEBRIAN HERREROS, M. (2009). "Comunicación interactiva en los cibermedios" en Comunicar, Revista Científica de Educomunicación, vol. XVII, 33, p. 15-24.

GEWERC, A., MONTERO, L . y LAMA, M. (2014). “Colaboración y redes sociales en la enseñanza universitaria” en Comunicar, Revista Científica de Educomunicación, vol. XXI, 42, p. 55-63.

HERNANDEZ, N., GONZALEZ, M., y MUÑOZ, P. (2014). “La planificación del aprendizaje colaborativo en entornos" en Comunicar, Revista Científica de Educomunicación, vol. XXI, 42, p. 25-33.

MICÓ, J. (2012). Ciberètica. TIC i canvi de valors. Barcelona: Editorial Barcino. 


\title{
Gestión de Infraestructuras Virtuales Docentes en Asignaturas con Requisitos Computacionales*
}

\author{
Germán Moltó $^{1}$, Damián Segrelles ${ }^{1}$, Miguel Caballer ${ }^{1}$ y Ignacio Blanquer $^{2}$ \\ ${ }^{1}$ Instituto de Instrumentación para Imagen Molecular (I3M). Centro mixto CSIC - \\ Universitat Politècnica de València - CIEMAT, camino de Vera s/n, 46022 Valencia, \\ España
}

\begin{abstract}
This paper summarizes the experiences carried out in different subjects of the Master's Degree in Parallel and Distributed Computing of the Universitat Politècnica de València related to the management of virtualized computational infrastructures in the Cloud to perform lab activities. The diversity of computing infrastructures required to train the students in the different technologies, demanded the usage of automated infrastructure deployment tools using Cloud Computing platforms and techniques. These enabled to create clusters of PCs, Grid infrastructure testbeds and remote labs in a virtualized fashion on on-premise Cloud platforms and Amazon Web Services (AWS). For that, the Infrastructure Manager (IM) tool was employed, developed by the authors and released to the academic community. The results indicate a greater ease of usage for professors, a wide variety of platforms for students and a better usage of computational resources for the educational institution.
\end{abstract}

Keywords: Cloud Computing, Virtual Infrastructures, Remote Labs, Technology Enhanced Learning

\section{Resumen}

Este artículo resume las experiencias llevadas a cabo en asignaturas del Máster Universitario en Computación Paralela y Distribuida (MUCPD)

\footnotetext{
*Este artículo es una versión extendida y revisada del artículo "Gestión de Recursos Computacionales en el Cloud para Actividades Educativas" aceptado en las XX Jornadas sobre la Enseñanza Universitaria de la Informática (JENUI 2014), destinada a difundir la experiencia en la UPV. Los autores desean agradecer al Vicerrectorado de Estudios, Calidad y Acreditación la financiación recibida en el marco del proyecto PIME/2013/A/016/A.
} 
Gestión de Infraestructuras Virtuales Docentes en Asignaturas con Requisitos Computacionales

de la Universitat Politècnica de València (UPV) relativas a la gestión de infraestructuras computacionales virtuales en la nube para la realización de actividades prácticas. La diversidad de infraestructuras de cómputo necesarias para formar a los alumnos en las diferentes tecnologías precisó de usar herramientas de despliegue automatizado de dichas infraestructuras usando técnicas y plataformas de Cloud Computing. Esto permitió la creación de clusters de PCs, infraestructuras Grid de prueba y laboratorios de prácticas remotos de forma virtualizada, sobre plataformas Cloud propias y sobre Amazon Web Services (AWS). Para ello se utilizó la herramienta Infrastructure Manager (IM), desarrollada por los autores y puesta a disposición de la comunidad académica. Los resultados indican una mayor facilidad de uso para los profesores, diversidad de plataformas para los alumnos y un mejor aprovechamiento de los recursos de cómputo para la institución educativa.

Keywords: Cloud Computing, Infraestructuras Virtuales, Laboratorios Remotos, Aprendizaje Mejorado por la Tecnología.

\section{Introducción}

Existen numerosas asignaturas que requieren infraestructuras computacionales complejas de soporte a la docencia, como es el caso de las del Máster Universitario en Computación Paralela y Distribuida (MUCPD) de la Universitat Politècnica de València (UPV). En ellas, los alumnos deben interactuar con múltiples sistemas de cómputo como clusters de PCs, infraestructuras Grid, despliegues Cloud, clusters Hadoop, etc., con configuraciones específicas, complejas y costosas para soportar las diferentes actividades de aprendizaje. Los alumnos se conectan remotamente a dichas infraestructuras por medio de herramientas de línea de comandos usando SSH, escritorio remoto y también mediante navegadores web.

La gestión de dichas infraestructuras, cuando se implementan directamente con recursos físicos, no es trivial puesto que requiere recursos hardware dedicados junto con un mantenimiento y actualización para cada asignatura, lo cual es un reto técnico complejo además de dificultar el uso de dichos recursos de cómputo para otras actividades una vez finalizadas las asignaturas correspondientes.

En los últimos años, la virtualización se está utilizando en los laboratorios de prácticas para facilitar la compartición de recursos, aislando las diferentes instalaciones y evitando así las posibles incompatibilidades de requisitos software de las diferentes asignaturas. La virtualización facilita el despliegue de máquinas virtuales a partir de imágenes de máquinas virtuales (IMV) pre-configuradas con el software y la configuración necesaria para una o varias asignaturas. Sin embargo, el uso de IMVs requiere una actualización periódica para incluir parches de seguridad, actualizaciones de software, etc. Además, la virtualización por sí misma no gestiona las dependencias entre los recursos de cómputo para crear una infraestructura virtual compleja (por ejemplo, el despliegue de una infraestructura Grid requiere desplegar varias máquinas virtuales con configuraciones diferentes). 
Desde el curso 2013/2014, un grupo de profesores del MUCPD ${ }^{1}$ está utilizando infraestructuras virtuales computacionales aplicadas al ámbito educativo en diferentes asignaturas, usando la herramienta Infrastructure Manager (IM) ${ }^{2}$, desarrollada por el Grupo de Grid y Computación de Altas Prestaciones (GRyCAP) de la UPV. Esta herramienta permite el despliegue y configuración automatizada de infraestructuras virtuales complejas sobre plataformas Cloud tanto on-premise, es decir, en los recursos de cómputo propios dentro de la UPV o sobre un proveedor de recursos Cloud externo, como es el caso de Amazon Web Services (AWS).

Para los alumnos, este cambio es totalmente transparente, puesto que ellos acceden a las infraestructuras virtuales de forma remota y no tienen constancia de si son físicas o virtuales. Como ventaja adicional, se les puede ofrecer acceso a una gran variedad de infraestructuras de cómputo que, en caso de haber necesitado dedicar recursos físicos, no hubiera sido posible. La experiencia ha sido muy satisfactoria y puede exportarse a otras asignaturas de la UPV que requieran infraestructuras de cómputo como recursos fundamentales de aprendizaje para sus alumnos. El uso de esta herramienta introduce una flexibilidad y aprovechamiento de recursos de cómputo sin precedentes a través de la gestión de infraestructuras virtuales para actividades educativas.

El resto del artículo está estructurado como sigue. En primer lugar, la sección 2 presenta los objetivos de la innovación docente. A continuación, la sección 3 describe la plataforma desarrollada y su aplicación a diferentes asignaturas del MUCPD. Luego, la sección 4 aborda los principales resultados de la innovación, tanto desde el punto de vista del alumno como para el profesorado involucrado. Finalmente, la sección 5 resume los principales logros de la innovación y propone trabajos futuros.

\section{Objetivos}

El principal objetivo de la innovación docente consiste en evaluar las ventajas de usar herramientas automatizadas para el despliegue de infraestructuras virtualizadas de cómputo para la realización de actividades prácticas educativas. Concretamente, se pretende:

- Describir la plataforma desarrollada para el despliegue de las infraestructuras virtuales.

- Detallar diferentes casos de uso de la plataforma en asignaturas del Máster en Computación Paralela y Distribuida de la UPV.

- Evaluar las ventajas para profesores, alumnos y la propia institución educativa derivadas del uso de estas nuevas tecnologías.

\footnotetext{
${ }^{1}$ http://www.upv.es/titulaciones/MUCPD

${ }^{2}$ Infrastructure Manager (IM). http://www.grycap.upv.es/im
} 
Gestión de Infraestructuras Virtuales Docentes en Asignaturas con Requisitos Computacionales

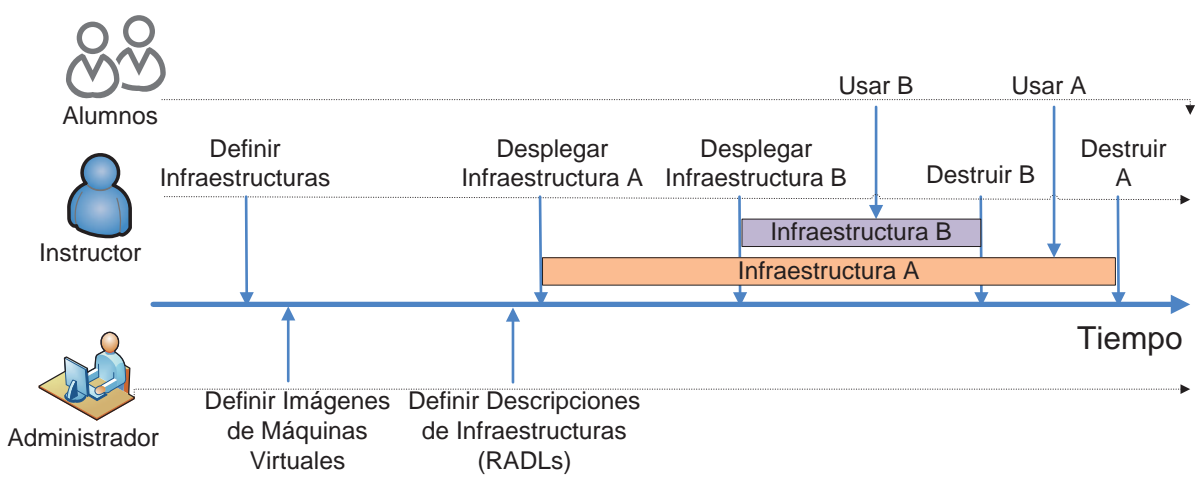

Fig. 1: Linea temporal de uso de ODISEA.

\section{Desarrollo de la innovación}

En esta sección se procede a describir la plataforma ODISEA (del inglés On-demand Deployment of Infrastructures to Support Educational Activities). A continuación se describen las experiencias de uso en diferentes asignaturas.

\subsection{La Plataforma ODISEA}

ODISEA permite la definición y gestión del ciclo de vida de infraestructuras virtuales configurables desplegadas sobre un despliegue Cloud de tipo IaaS (Infrastructure as a Service) con el objetivo de satisfacer los requisitos hardware, software y de configuración de una determinada actividad de laboratorio. El centro educativo puede disponer de dicho despliegue Cloud IaaS mediante el uso de alguna herramienta de creación de Clouds on-premise (como OpenNebula u OpenStack) o bien utilizar una infraestructura de Cloud público (como AWS). Estas plataformas Cloud permiten aprovisionar recursos de cómputo, en la forma de máquinas virtuales, de forma dinámica.

La Figura 1 resume el uso de la plataforma desde el punto de vista de los actores involucrados en la misma. En primer lugar, el instructor es el encargado de definir las necesidades de la actividad de laboratorio, en términos de hardware, software y configuración. Por ejemplo, para realizar una práctica de programación paralela puede ser necesario un cluster de 10 nodos configurados con GNU/Linux Ubuntu 12.04 LTS, compilador GCC, la librería de paso de mensajes OpenMPI y el sistema de colas Torque, además de 20 cuentas de usuario con unas determinadas contraseñas.

El administrador de la plataforma (perfil que puede recaer en el propio instructor, si dispone de conocimientos informáticos) se encarga de definir y preparar las imágenes de máquinas virtuales, únicamente en el caso de involucrar software que no pueda ser instalado de forma dinámica, o bien de elegir imágenes base sobre las que se instalará el software dinámicamente, así como su descripción declarativa en el lenguaje 


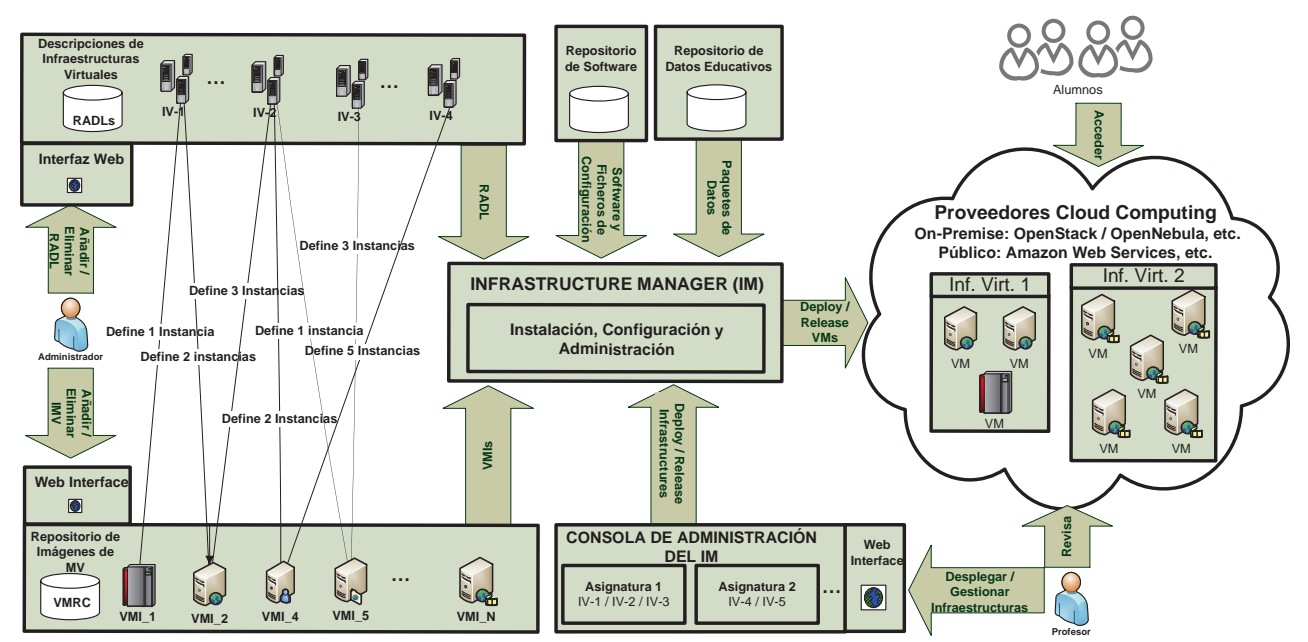

Fig. 2: Arquitectura general de ODISEA para el despliegue de infraestructuras virtuales educativas.

de alto nivel RADL (Resource and Application Description Language) (Caballer y col. 2014a). A continuación, el instructor realiza el despliegue de las infraestructuras necesarias para soportar las actividades prácticas, por medio de una interfaz gráfica o una interfaz de línea de comandos. Los alumnos se conectarán a la infraestructura típicamente mediante SSH o FreeNX (en el caso de Linux) o escritorio remoto para Windows. Una vez finalizada la actividad, las infraestructuras serán terminadas para evitar un consumo innecesario de recursos de cómputo.

La Figura 2 muestra la arquitectura de la plataforma, compuesta por: i) un catálogo y repositorio de IMVs, que permite indexarlas para poder buscar aquellas que cumplen unas determinadas características, implementado mediante el sistema VMRC (Virtual Machine image Repository and Catalog) (Carrión y col. 2010); ii) un conjunto de descripciones de infraestructuras virtuales, descritas en lenguaje RADL; iii) un repositorio de software y otro de material educativo que contienen los paquetes necesarios para la instalación en las infraestructuras; iv) un gestor de infraestructura, implementado mediante el sistema IM (Infrastructure Manager) (Caballer y col. 2014b) que coordina los componentes anteriores para realizar el despliegue de las infraestructuras sobre diferentes plataformas Cloud. El sistema actualmente permite usar OpenNebula, OpenStack y Amazon Web Services. 
Gestión de Infraestructuras Virtuales Docentes en Asignaturas con Requisitos Computacionales

\subsection{Experiencias de Uso}

En este apartado se detalla cómo se ha utilizado y aplicado la plataforma ODISEA en asignaturas del MUCPD de la UPV durante el curso 2013/2014. Este Máster tiene como objetivo formar investigadores y profesionales con experiencia en Computación Paralela, Sistemas Distribuidos y Sistemas Altamente Disponibles, Ciencias Computacionales y Tecnologías Grid y Cloud.

Concretamente, la plataforma ODISEA se ha utilizado para la gestión de los recursos computaciones que se requieren para las actividades prácticas de las asignaturas Infraestructuras Avanzadas Grid (IAG), Modelos Programación en Grid (MPG), Infraestructuras Avanzadas Cloud (IAC) y Modelos Programación en Cloud (MPC). Estas asignaturas se enmarcan dentro del campo de Tecnologías Grid y Cloud. En los siguientes apartados, se detallan por un lado aquellos recursos computacionales que se requieren para la impartición de las asignaturas, así como aquellas actividades realizadas para su puesta en marcha en ODISEA.

\subsubsection{Uso en las Asignaturas IAG y $M P G$}

La asignatura IAG introduce a los alumnos en la programación de aplicaciones y servicios que requieran del uso de infraestructuras Grid Avanzadas, tanto de tipo batch soportadas por el middleware EMI, como infraestructuras orientadas a servicios (OGSA) a través de Globus Toolkit 4. La asignatura MPG profundiza en modelos de programación mas específicos en el Grid, como los servicios de directorios OpenLDAP sobre los que se basan los sistemas de información Grid, la programación de trabajos Grid usando OpenMPI o la programación de trabajos interactivos para el Grid.

Para la consecución de los objetivos formativos planteados en ambas asignaturas, es de vital importancia dar un enfoque práctico, en la que se necesitan diversos recursos computaciones. El uso de estos recursos se van alternando en las prácticas, con lo que incluso en una misma sesión práctica son necesarios diferentes recursos.

Como primer paso para la utilización de ODISEA en IAG y MPG, el instructor de las asignaturas identificó los siguientes recursos computacionales requeridos para la realización de las prácticas:

- Recurso Servidor-VOMS. Este recurso solo se emplea durante una única sesión de IAG, en la que se tratan aspectos relacionados con la seguridad en el Grid y su programación mediante APIs. Todos los alumnos realizan la práctica interactuando con una única máquina de este tipo.

- Recurso Servidor-GT4. Este recurso se requiere en aquellas sesiones de prácticas correspondientes a la implementación de servicios Grid basados en OGSA. Este recurso se utiliza únicamente en la asignatura de MPG y durante varias sesiones prácticas. Se necesita un recurso de este tipo por cada alumno.

- Recurso EMI-UI. Este recurso se requiere en aquellas sesiones practicas en las que se necesite acceder a la infraestructura Grid nacional (ES-NGI) Spanish 


\begin{tabular}{cclcc} 
Recurso & Sistema Operativo & Software & Hardware \\
\hline Servidor-VOMS & Scientific Linux 5.1064 & VOMS Server & 512 MB RAM \\
\hline Servidor-GT4 & Scientific Linux 5.10 64 & Globus 4.2 Toolkit, & 1GB RAM \\
& & JDK 1.6, Ant 1.8, & \\
& & NetBeans & \\
\hline EMI-UI & Scientific Linux 5.10 64 & EMI-UI, OpenMPI & 512 MB RAM \\
\hline OpenLDAP & Scientific Linux 5.10 64 & OpenLDAP Server & 1 GB RAM
\end{tabular}

Tabla 1: Requisitos Hardware y Software de los recursos de IAG y MPG.

National Grid Initiative para el lanzamiento de trabajos. Este recurso se emplea tanto en las practicas de MPG como de IAG durante varias sesiones. Se necesita un único recurso de este tipo, configurado con una cuenta de usuario por alumno.

- Recurso OpenLDAP. Este recurso se utiliza durante varias sesiones de practicas, en las que se trabajan sobre los servicios de directorio LDAP. Este recurso solo se utiliza en la asignatura MPG y se requiere una instancia por alumno. Además se necesitan 4 recursos adicionales para la realización de las practicas y trabajos en grupo.

Como segundo paso, una vez identificados los recursos computacionales, el propio instructor detalla los requisitos hardware, software y de configuración, indicando la version del sistema operativo, paquetes software, RAM mínima necesaria, etc. (ver Tabla 1). Además, para cada recurso, debe detallar el proceso de instalación de los paquetes software así como aquellos aspectos de configuración que considere determinantes para la realización de las prácticas.

Como tercer paso, se traslada toda esta información al administrador de ODISEA, el cual se encarga de preparar las IMVs que se necesitan para la creación de los recursos. Para el caso específico de IAG y MPG se crearon dos IMVs, ambas con el sistema operativo Scientific Linux 5.10 version 64 bits, dado que todos los recursos son soportados por este sistema operativo. En una de las dos IMVs se preinstaló Globus Toolkit 4.2 y todo el software dependiente de este, debido a que el proceso de instalación y configuración automatizada de este paquete tarda horas y hace inviable su instalación en el momento del despliegue. El resto de software identificado en los recursos, se instalan en el mismo momento del despliegue, con lo que el propio administrador debe incluir estas instalaciones en el documento RADL, basándose en la información que le ha enviado el instructor respecto al hardware, software y configuración de los recursos.

Como último paso en el uso de ODISEA, el instructor realiza el despliegue de los recursos virtuales para dar soporte a las actividades prácticas programadas. Los alumnos se conectarán a las mismas típicamente mediante SSH o escritorio remoto. Una vez finalizada la actividad, los recursos se liberan para evitar un consumo innecesario de recursos de cómputo. 
Gestión de Infraestructuras Virtuales Docentes en Asignaturas con Requisitos Computacionales

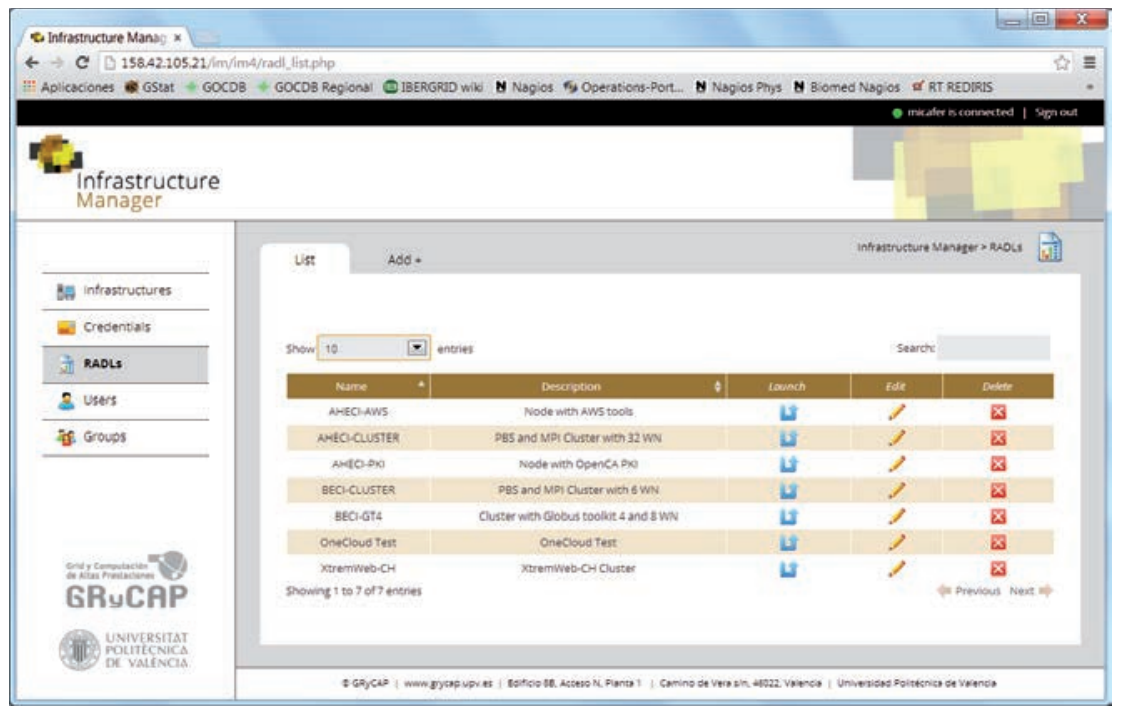

Fig. 3: Aspecto de la interfaz Web.

La Figura 3 muestra un aspecto de la interfaz web utilizada para interactuar con el componente IM de ODISEA. A través de la interfaz web es posible definir los diferentes documentos RADL de descripción de infraestructuras, así como monitorizar el estado de las infraestructuras virtuales desplegadas.

\subsubsection{Uso en las Asignaturas IAC y MPC}

La asignatura IAC (Infraestructuras Avanzadas en Cloud) aborda plataformas de aprovisionamiento de infraestructura como servicio (IaaS), ejemplificando sobre OpenNebula y Amazon Web Services. Se cubren herramientas de automatización de configuración como Ansible y el almacenamiento Cloud basado en ficheros y en sistemas de bases de datos tanto relacionales como de tipo NoSQL. En la asignatura MPC (Modelos de Programación en Cloud) se aborda el modelo MapReduce implementado mediante Apache Hadoop, el despliegue de clusters virtuales en la nube (mediante StarCluster) y el diseño de arquitecturas de aplicación para la nube. Todo ello, mediante un enfoque eminentemente práctico que requiere el uso de múltiples infraestructuras para soportar las actividades prácticas. A continuación se describen los recursos computacionales involucrados.

- Recurso ONE-UI. Se necesita un único recurso, compartido por todos los alumnos a través de múltiples cuentas de usuario, con la instalación un cliente de OpenNebula para poder aprovisionar máquinas virtuales sobre un despliegue en producción de OpenNebula disponible en nuestro centro de investigación.

- Recurso AWS-UI. Se necesita un único recurso, compartido por toda los alumnos mediante múltiples cuentas de usuario, con las herramientas necesarias para 


\begin{tabular}{cclc} 
Recurso & Sistema Operativo & Software & Hardware \\
\hline ONE-UI & Ubuntu 12.04 & Cliente OpenNebula & 512 MB RAM \\
\hline AWS-UI & Ubuntu 12.04 & AWS CLI & 1GB RAM \\
\hline AWS-DevOps & Ubuntu 12.04 & Ansible, Python & 512 MB RAM \\
\hline Cluster-Hadoop & Ubuntu 12.04 & $\begin{array}{l}\text { Hadoop, } \\
\text { HDFS }\end{array}$
\end{tabular}

Tabla 2: Requisitos Hardware y Software de los recursos de IAC y MPC.

interactuar mediante línea de comandos o de forma programática con los múltiples servicios de AWS tratados en las asignaturas (Amazon EC2, S3, RDS, Auto Scaling, CloudWatch y SNS). Este recurso consta de un componente que monitoriza periódicamente los recursos aprovisionados por los alumnos en AWS (que se facturan por horas) para poder avisar por correo electrónico al instructor con aquellos recursos que llevan más horas de ejecución de lo razonable.

- Recurso AWS-DevOps. Se necesitan dos recursos de este tipo por cada alumno, para que puedan realizar labores de configuración automatizada y simultánea de múltiples recursos de cómputo usando Ansible. Se combina con el recurso anterior (AWS-UI) al que los alumnos se conectan para luego configurar estos recursos.

- Recurso Cluster-Hadoop. Se necesita un único recurso de este tipo, que es un cluster virtual de entre 4-8 nodos (en función del número de alumnos) con soporte para Apache Hadoop en el que los alumnos practican con el modelo de programación MapReduce.

Todos los recursos mencionados anteriormente se despliegan justo antes de iniciarse la actividad educativa y se destruyen tras la finalización de las mismas. Esto evita que los ficheros creados por cualquier alumno (incluido posibles modificaciones no autorizadas del entorno) no sobrevivan para futuras ediciones.

La Tabla 2 resume los requisitos (o preferencias) hardware y software de los recursos necesarios para las asignaturas IAC y MPC. La descripción de los recursos se realizó en lenguaje RADL para disponer de descripciones de alto nivel que permitieran la capacidad de repetición determinista de los despliegues. Por ejemplo, el recurso Cluster-Hadoop puede ser desplegado con exactamente el mismo documento RADL tanto sobre el despliegue Cloud on-premise de OpenNebula de nuestro grupo de investigación como sobre Amazon Web Services. Esto permite que ante situaciones de sobrecarga en los recursos de cómputo locales, el instructor puede decidir desplegar su infraestructura virtual de prácticas en un proveedor de Cloud público sin necesidad de esfuerzo adicional. Esta característica introduce una importante flexibilidad para el instructor.

Para las asignaturas IAC y MPC, toda la instalación y configuración de la infraestructura se realizó justo en el momento del despliegue de las infraestructuras. Por lo

(oc) EY-No-No 2014, Universitat Politècnica de València

I Jornadas IN-RED (2014) 
Gestión de Infraestructuras Virtuales Docentes en Asignaturas con Requisitos Computacionales

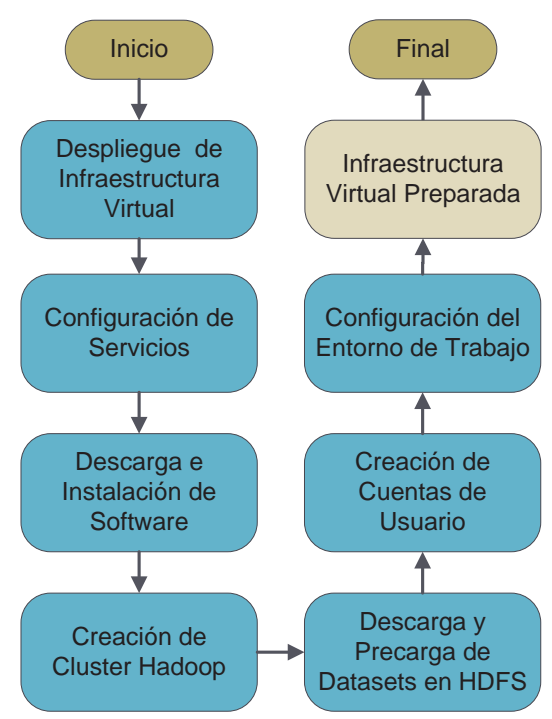

Fig. 4: Pasos realizados por ODISEA para desplegar un cluster Hadoop.

tanto, tan solo fue necesario usar una imagen de máquina virtual base de Ubuntu 12.04 LTS. Para tener una mejor idea de las capacidades de automatización de la plataforma, la Figura 4 muestra la secuencias de pasos que realiza automáticamente la plataforma ODISEA para desplegar el recurso Cluster-Hadoop, descrito anteriormente. En primer lugar se procede al aprovisionamiento (despliegue) de los recursos de cómputo. Por ejemplo, un total de 8 máquinas virtuales de Amazon EC2 (el servicio de IaaS de AWS). A continuación, es necesario proceder a la configuración de servicios. Esto implica, por ejemplo, modificar la configuración del servidor SSH para permitir el acceso de los alumnos via SSH.

A continuación se procede a la descarga e instalación del software mediante la conexión tanto al Repositorio de Software, implementado mediante un bucket de Amazon S3 (el servicio de almacenamiento de ficheros de AWS), como a repositorios de software externo para descargar e instalar software, como por ejemplo Apache Hadoop. La instalación y configuración provoca la creación de un cluster Hadoop, y el sistema de archivos distribuido HDFS. A continuación es necesario acceder al Repositorio de Material Educativo para descargar los conjuntos de datos (datasets) usados para las prácticas. Dicho repositorio está implementado sobre un servidor web del grupo de investigación, con un mirror en otro bucket de S3. Los conjuntos de datos se transfieren a HDFS para evitar que los alumnos realicen esa tarea de forma individualizada y, dado que son de solo lectura, para que haya una única copia y así reducir el espacio de almacenamiento requerido.

Posteriormente se procede a crear las cuentas de usuario con un conjunto de credenciales predeterminadas que serán distribuidas por correo electrónico a los alumnos. 


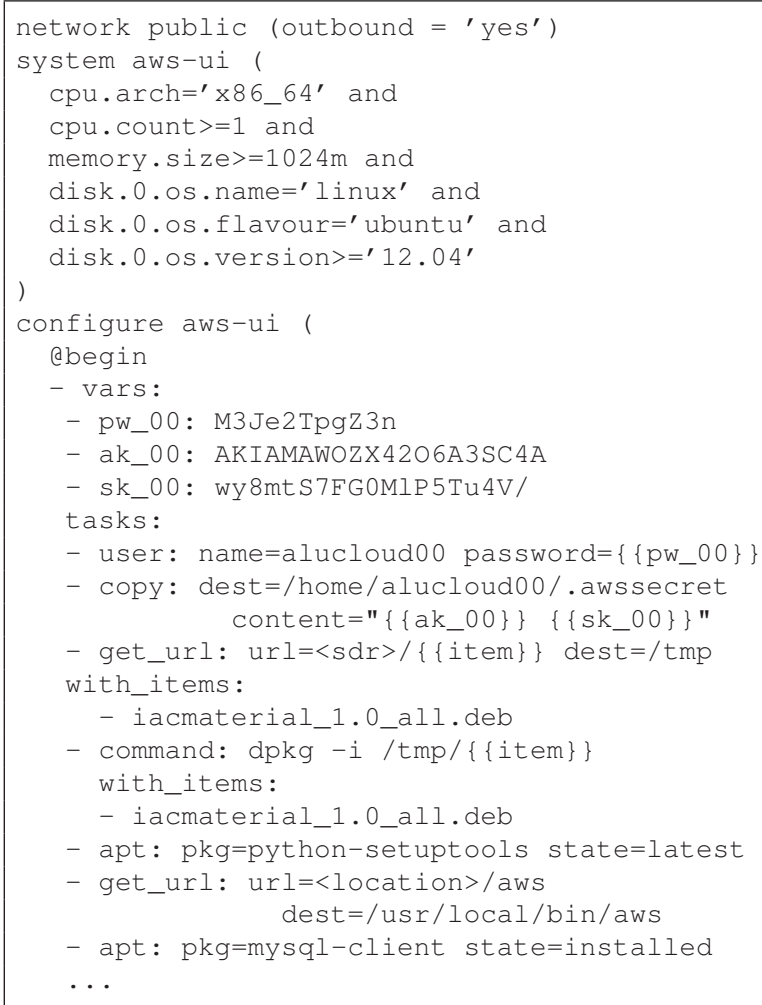

Fig. 5: Extracto de RADL para el recurso AWS-UI usado en la asignatura IAC.

Finalmente, se realiza la configuración del entorno de trabajo, creando los alias y scripts de soporte para las prácticas. Todo este procedimiento, completamente automatizado por la plataforma ODISEA a partir de la descripción en lenguaje RADL, da lugar a la infraestructura virtual preparada para ser accedido por los usuarios via SSH.

La Figura 5 muestra un extracto de documento RADL con tareas de configuración como crear una cuenta de usuario, descargar unos paquetes del repositorio educativo, instalar unos paquetes software, etc. 
Gestión de Infraestructuras Virtuales Docentes en Asignaturas con Requisitos Computacionales

\section{Resultados y Discusión}

El uso de ODISEA introduce una serie de ventajas sin precedentes en la gestión de recursos computacionales para actividades educativas. En primer lugar, el uso de un lenguaje de alto nivel declarativo para especificar los requisitos (hardware, software y de configuración) de una infraestructura virtual permite la creación de recetas (en lenguaje RADL) que garantizan un despliegue determinista de una infraestructura virtual. La misma receta puede ser desplegada sobre diferentes proveedores Cloud, dando lugar a exactamente la misma configuración de infraestructura virtual. Esto permite realizar las prácticas de laboratorio sobre los recursos de la entidad educativa (mediante el uso de un Cloud on-premise) y en situaciones de falta de disponibilidad de recursos, desplegar la infraestructura virtual sobre un proveedor de Cloud público (incurriendo eso sí en gastos). Los alumnos no perciben ninguna diferencia ya que el acceso a las infraestructuras es remoto, por lo que no importa la ubicación de la infraestructura virtual.

En segundo lugar, los documentos RADL permiten el despliegue automático de las infraestructuras virtuales de forma rápida (en el orden de minutos) lo que permite replicar un entorno de trabajo en caso de fallo de la infraestructura virtual. Esto ha sido especialmente útil en la asignatura IAC, donde el uso de cuentas de acceso a AWS unificadas a través del servicio IAM (Identity and Access Management) no permite evitar que un alumno elimine accidentalmente los recursos asignados para otro alumno. La existencia de estos documentos posibilitan desplegar nuevamente dichos recursos perfectamente configurados, evitando así interrupciones o demoras innecesarias en la realización de las prácticas.

En tercer lugar, los documentos RADL pueden reutilizarse de manera que es posible construir nuevas descripciones de recursos como composición de otros documentos existentes, dando lugar a infraestructuras más complejas. Esto permite que los profesores del MUCPD compartan descripciones de infraestructuras (por ejemplo, la descripción de un cluster de PCs virtual), mejorando así la cooperación entre los profesores.

En cuarto lugar, la flexibilidad introducida por el uso de infraestructuras de cómputo frente a infraestructuras físicas permite una mejor racionalización de los recursos de cómputo, usando una aproximación como la mostrada en la Figura 6. En ella, el profesor despliega la infraestructura al comienzo de la asignatura. Asumiendo una asignatura con periodicidad semanal, cuyas clases prácticas se realizan a unas horas determinadas, la infraestructura puede detenerse y volver a ser iniciada (por ejemplo al siguiente día de clase), de manera que cuando la asignatura finalice se proceda a terminar (destruir) la infraestructura. Esto permite que los recursos de cómputo físicos necesarios para ejecutar la infraestructura virtual únicamente se utilicen mientras la actividad educativa se esté realizando. Al mismo tiempo, posibilita emplear dichos recursos físicos sean empleados por las infraestructuras virtuales de otras asignaturas, redundando así en un mejor aprovechamiento de la capacidad de cómputo de una institución. 


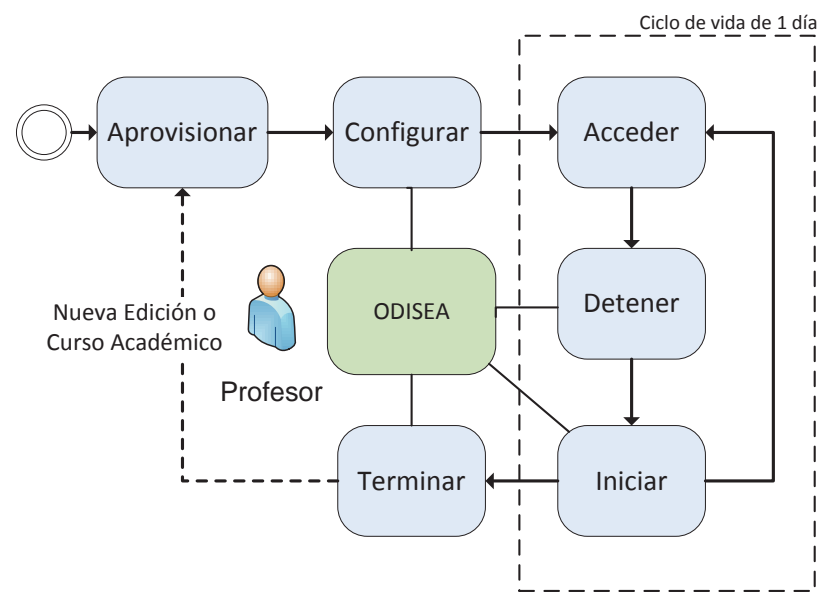

Fig. 6: Ciclo de vida de las infraestructuras virtuales.

En quinto lugar, la capacidad de aprovisionar recursos de un proveedor de Cloud público permite al instructor superar las limitaciones que la propia entidad educativa imponga con respecto al número de recursos utilizados. Un laboratorio físico de 20 equipos impone una limitación de 40 alumnos (2 personas por equipo). Sin embargo, un laboratorio con recursos virtualizados aprovisionados de un proveedor de Cloud público puede crecer de forma elástica en función del número de alumnos. El uso de recursos de un Cloud público cuando los recursos locales se encuentran saturados se denomina comúnmente Cloud bursting y permite disponer de un esquema como el que se muestra en la Figura 7.

Esto es especialmente útil para los cursos online, donde aumentos repentinos de la matrícula deben ir acompañados de incrementos en el número de recursos del laboratorio virtualizado. Con el auge de los MOOC, este tipo de técnicas cobra todavía mayor relevancia pudiendo ofrecer entornos remotos de realización de prácticas de capacidad elástica, cuyo tamaño dependa del número de alumnos en cada momento. Ofrecer un entorno pre-configurado, listo para usar por parte de los alumnos, facilita el acceso al alumno frente a otras alternativas que involucran la descarga e instalación de software, por ejemplo, para usar una máquina virtual pre-configurada que se ejecute en el equipo del alumno. 


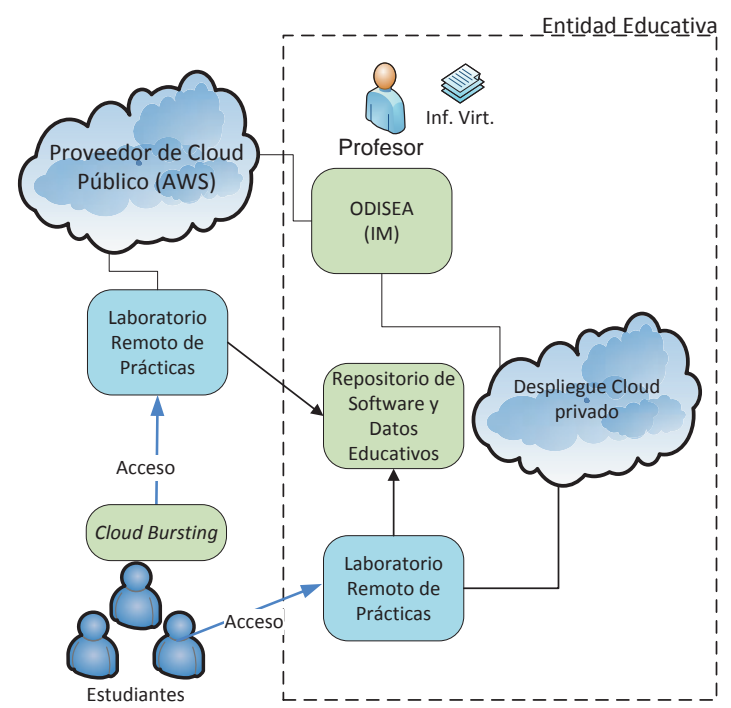

Fig. 7: Despliegue de laboratorios remotos de prácticas en diferentes plataformas Cloud.

\section{Conclusiones}

En este artículo se ha presentado el uso de la plataforma ODISEA para la gestión de recursos computacionales destinados a soportar actividades educativas. Se ha ejemplificado su uso en cuatro asignaturas del Máster Universitario de Computación Paralela y Distribuida de la Universitat Politècnica de València. El uso de esta plataforma ha facilitado el despliegue automático de las infraestructuras de laboratorio remoto, ha permitido el incremento dinámico de recursos en función del número de alumnos y ha posibilitado la creación de infraestructuras en diferentes proveedores Cloud. Esto ha permitido una flexibilidad sin precedentes para el instructor y el acceso a una gran variedad de infraestructuras por parte del alumno. Todo ello gracias a la utilización de técnicas de Cloud Computing soportadas por proveedores de Cloud Computing on-premise como OpenNebula y proveedores de Cloud público como Amazon Web Services. Parte de los desarrollos de ODISEA, como el Infrastructure Manager se han liberado a la comunidad académica ${ }^{3}$. Además, la plataforma puede ser utilizada directamente desde un navegador web para el despliegue de infraestructuras virtuales adaptadas a los requisitos del docente.

Existen varias líneas de trabajo futuro. En primer lugar se pretende mejorar la interfaz gráfica de la plataforma para facilitar a los instructores fuera del ámbito de la informática el uso de la misma. Por otro lado se explorará la viabilidad de integrar la plataforma desarrollada con las herramientas corporativas de la UPV. Esto permitiría

\footnotetext{
${ }^{3}$ http://www.grycap.upv.es/im
} 
el uso de la herramienta dentro del LMS utilizado para la gestión de las asignaturas ya que, en realidad, las infraestructuras virtuales deberían ser consideradas parte del material de la asignatura.

\section{Referencias bibliograficas}

Caballer, Miguel y col. (feb. de 2014a). "CodeCloud: A platform to enable execution of programming models on the Clouds". En: Journal of Systems and Software. ISSN: 01641212. DOI: $10.1016 / j \cdot j$.s. 2014.02 .005$.

Caballer, Miguel y col. (2014b). "Dynamic management of virtual infrastructures". En: Journal of Grid Computing. DOI: 10.1007/s10723-014-9296-5.

Carrión, Jose V. y col. (2010). "A Generic Catalog and Repository Service for Virtual Machine Images". En: 2nd International ICST Conference on Cloud Computing (CloudComp 2010).

NGI-ES. Spanish National Grid Initiative. 


\title{
Gestión Eficiente de Cursos Online: La Experiencia de @CursoCloudAWS en la UPV*
}

\section{Germán Moltó}

Instituto de Instrumentación para Imagen Molecular (I3M). Centro mixto CSIC Universitat Politècnica de València - CIEMAT, camino de Vera s/n, 46022 Valencia, España

\begin{abstract}
El creciente interés por la formación online es incuestionable hoy en día, con MOOCs siendo cursados por miles de alumnos. Sin embargo, para que la formación online se popularice es necesario que los profesores perciban que el esfuerzo necesario para preparar y gestionar un curso online es asumible. Este artículo propone una arquitectura basada en herramientas y servicios en la nube para simplificar la gestión de un curso online, desde el uso de laboratorios remotos automáticamente configurados hasta automatizar la comunicación con los estudiantes y recopilar retroalimentación sobre el curso. Esta aproximación ha sido aplicada en la producción, distribución y gestión del Curso Online de Cloud Computing con Amazon Web Services (@CursoCloudAWS $S^{1}$ ).El artículo describe la metodología, herramientas y resultados de la experiencia para destacar que es posible crear cursos online ofreciendo laboratorios remotos, con una minima carga de gestión para el instructor, al tiempo que se proporciona una experiencia de aprendizaje de alta calidad a una audiencia a escala mundial.
\end{abstract}

Keywords: Cloud Computing, MOOC, Technology-enhanced Learning, Remote Laboratories, Online Learning

\section{Resumen}

\footnotetext{
*Este artículo es una versión traducida, revisada y ampliada del artículo "On Using the Cloud to Support Online Courses" enviado al congreso internacional 2014 Frontiers in Education Conference (FIE 2014), destinada a difundir la experiencia en la UPV.

${ }^{1}$ La abreviatura @CursoCloudAWS se refiere a la cuenta de Twitter del curso, disponible en http://www.twitter.com/CursoCloudAWS
} 
The increasing interest of online learning is unquestionable nowadays, with MOOCs being taken by thousands of students. However, for online learning to go mainstream it is necessary that professors perceive that the effort required to prepare and manage an online course is manageable. For that, this paper proposes an architecture based on tools and Cloud services that simplifies the process of managing an online course, from delivering on-demand fully customized remote laboratories to communication automation for student engagement and feedback gathering. This approach has been applied to produce, distribute and manage an Online Course on Cloud Computing with AmazonWeb Services (@CursoCloudAWS). The paper describes the methodology, tools and results of this experience to point out that it is possible to deliver online courses with automatically provisioned remote labs, with minimal management overhead, while still providing a high quality learning experience to a worldwide audience.

Keywords: Cloud Computing, MOOC, Aprendizaje Mejorado por la Tecnología, Laboratorios Remotos, Formación Online.

\section{Introducción}

La formación online (Moore y Kearsley 2011) ha florecido en los últimos años con los avances en las redes de comunicación y el acceso ubicuo a Internet. Con el surgimiento de plataformas educativas como Coursera, edX o Udacity, profesores pioneros comenzaron a crear los llamados MOOCs (Massive Online Open Courses) que son cursados por miles de estudiantes de todo el mundo a través de Internet. De hecho, hoy en día existe numerosas herramientas y servicios para facilitar la creación de material educativo de acceso online. Por ello, es más fácil que nunca producir y gestionar cursos online de éxito que puedan ser cursados por estudiantes de cualquier parte del mundo (Sun y col. 2008).

Típicamente, los cursos online incluyen vídeo-lecciones, documentación, tests de opción múltiple y plataformas de comunicación y colaboración para conseguir una experiencia de aprendizaje remoto de calidad para el alumno. Los cursos relacionados con ingenierías suele requerir además la realización de prácticas de laboratorios donde los alumnos desarrollen las destrezas apropiadas mediante las herramientas usadas en sus correspondientes áreas de trabajo. Esto ha sido abordado en el pasado mediante diferentes aproximaciones que van desde el uso de i) simuladores, como por ejemplo los trabajos (Güney, Ekşi y Çakıroğlu 2011) y (Fang, Nielson y Kawamura 2013); ii) laboratorios virtuales (ver por ejemplo (Kolota 2011),(Alexiadis y Mitianoudis 2013)); iii) paquetes software para ser instalados, como es el caso de (Bezerra, Fraga y Dias 2013) y, iv) máquinas virtuales para ser descargadas por el alumno, como por ejemplo en (Gaspar y col. 2008) y (Romero-Zaldivar y col. 2012).

Cloud Computing y, especialmente, los servicios en la nube pueden ayudar en gran medida a soportar las actividades que surgen en la gestión de un curso online. Uno de los modelos de servicio del Cloud (ver (NIST) para más información) es SaaS (Software as a Service) donde se acceden a aplicaciones en línea a través de un navegador 
web, como es el caso de Google Apps. Otro modelo de servicio es IaaS (Infrastructure as a Service), en el que recursos de cómputo y almacenamiento se pueden aprovisionar de un proveedor de Cloud público mediante un modelo de pago por uso. Este artículo aboga por usar ambos modelos para gestionar eficientemente cursos online.

Concretamente, el artículo describe la experiencia del autor en producir y gestionar el Curso Online de Cloud Computing con Amazon Web Services, un curso de formación permanente ofertado desde el Instituto de Instrumentación para Imagen Molecular (I3M) de la Universitat Politècnica de València (UPV). Este curso se ofertó por primera vez en Julio de 2013 y en menos de un año se han realizado 7 ediciones del mismo (una edición cada 1-2 meses aproximadamente), con más de 150 alumnos formados (20-30 alumnos por edición) de más de siete países diferentes (principalmente de España y Latinoamérica), obteniendo una satisfacción promedio de 9.2 sobre 10. Además, el curso ofrece prácticas sobre laboratorios remotos, gestionados por el instructor, al que los alumnos se conectan en remoto para realizar actividades prácticas. Estos recursos se aprovisionan y configuran automáticamente sobre un proveedor Cloud usando herramientas desarrolladas en la UPV y puestas a disposición de la comunidad académica. Esto ha supuesto un reto técnico para automatizar al máximo la gestión del curso con el objetivo de reducir la carga del instructor sin menoscabo de la experiencia de aprendizaje del alumno. Por ello, este artículo resume la aproximación, herramientas, metodología y lecciones aprendidas en la gestión de un curso online de estas características.

El resto del artículo está estructurado como sigue. En primer lugar, la sección 2 presenta los objetivos de este artículo. A continuación, la sección 3 describe la innovación docente llevada a cabo mediante la descripción del curso así como las herramientas y metodología seguida para la gestión del mismo. Luego, la sección 4 describe los principales resultados obtenidos, tanto desde el punto de vista del alumno como del profesor. Finalmente, la sección 5 resume las principales conclusiones de este artículo dando pie a lineas futuras de trabajo.

\section{Objetivos}

El objetivo de este artículo y de la innovación docente llevada a cabo es analizar las ventajas de usar herramientas y servicios Cloud para la gestión eficiente de cursos online, especialmente aquellos que involucren la realización de actividades prácticas sobre un laboratorio que requiera recursos de cómputo. Se aborda en base a la experiencia de incorporación de estas técnicas de forma aplicada en el Curso Online de Cloud Computing con Amazon Web Services durante el curso 2013/2014.

Por lo tanto, son objetivos de este artículo:

- Introducir una arquitectura de servicios y componentes basada en servicios de la UPV, complementada con servicios externos para aquella funcionalidad necesaria no cubierta por dichos servicios, con el propósito de gestionar eficientemente un curso online. 


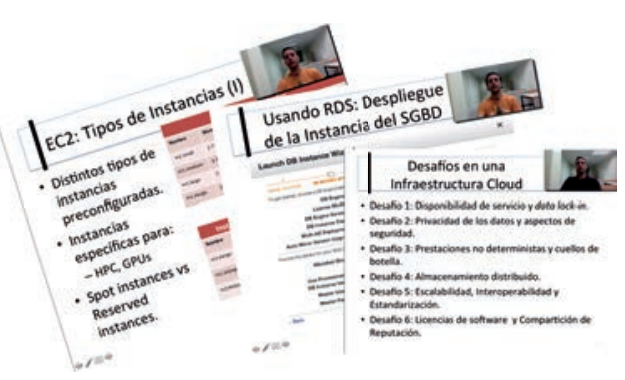

(a) Vídeo-lecciones

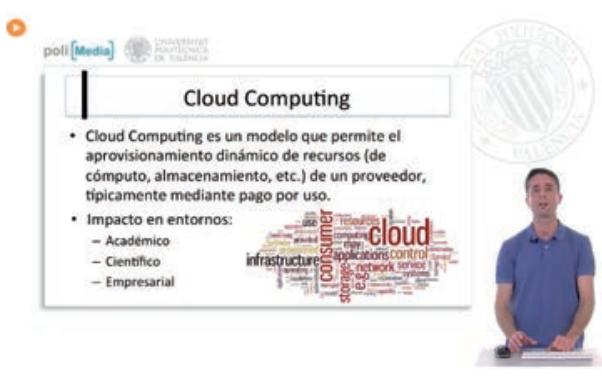

(b) Polimedia

Fig. 1: Aspecto de las vídeo-lecciones y del vídeo Polimedia de presentacion.

- Presentar las herramientas y servicios Cloud útiles para gestionar un curso online.

- Describir estrategias y técnicas para la gestión eficiente de un curso online.

Las experiencias descritas en el artículo son perfectamente aplicables a otros cursos y/o actividades educativas similares.

\section{Desarrollo de la innovación}

A continuación se describe brevemente el curso, se detalla la arquitectura de servicios Cloud utilizados, en la que se enmarca la principal innovación docente y, finalmente, se presentan estrategias para la gestión eficiente de este tipo de cursos.

\subsection{El Curso Online de Cloud Computing con Amazon Web Services}

Se trata de un curso online de 30 horas que dura cinco semanas, asumiendo una carga de trabajo de 1,2 horas por día lectivo, y que trata sobre Cloud Computing con un foco especial en Amazon Web Services (AWS), el proveedor Cloud pionero y actual líder. Se trata de un curso muy práctico, con laboratorios remotos de prácticas, que ayuda a los alumnos a conseguir las destrezas necesarias para dominar los servicios de AWS necesarios para crear arquitecturas de aplicaciones escalables para la nube. Es posible información adicional sobre el curso en su página web² .

El curso está estructurado en tres módulos que, a su vez, se dividen en una o más unidades. Cada unidad incluye una guía de aprendizaje del alumno que vertebra todos los recursos disponibles en el curso, resumidos a continuación:

\footnotetext{
${ }^{2}$ http://www.grycap.upv.es/cursocloudaws
} 


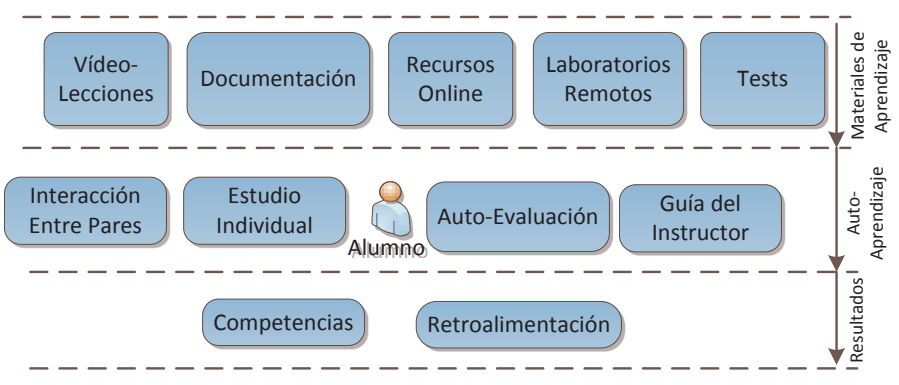

Fig. 2: Vista esquemática de un estudiante del curso online.

- Vídeo-lecciones. Vídeos de unos 10 minutos en los que aparece el instructor describiendo las ideas principales sobre un determinado tema, con la ayuda de un conjunto de transparencias, tal y como se muestra en la Figura 1.a.

- Documentación. Incluye guías (o boletines) para los laboratorios remotos, artículos académicos, actividades propuestas, documentos de referencia, estándares, etc.

- Recursos online. Incluyen el análisis de whitepapers, consultar información en las páginas web de los proveedores, evaluar herramientas software, etc.

- Laboratorios remotos. Los estudiantes se conectan a las máquinas remotas que están configuradas con las credenciales de acceso y las aplicaciones necesarias para realizar las prácticas sobre los servicios de AWS.

- Tests de auto-evaluación. Disponibles tras cada módulo para que el alumno tenga un indicador sobre su nivel de conocimientos.

- Plataforma de colaboración. Los estudiantes interactuan con otros alumnos y con el profesor por medio de herramientas síncronas (chat, vídeo-conferencia) y asíncronas (foro, mensajes).

Esta información se resume en la Figura 2 que proporciona una visión general de un estudiante en el contexto del curso online. El estudiante recibe acceso a todos los materiales de aprendizaje desde el inicio del curso. Trabaja de forma autónoma e interactúa con otros alumnos y con el instructor para conseguir los resultados de aprendizaje esperados del curso. También cumplimenta de forma opcional cuestionarios online para obtener retroalimentación sobre los principales aspectos del curso (vídeo-lecciones, guías prácticas, etc.). Esto permite mejorar progresivamente el material con todas las sugerencias de los alumnos para incrementar iterativamente la calidad del curso en base a los intereses de los propios alumnos. 


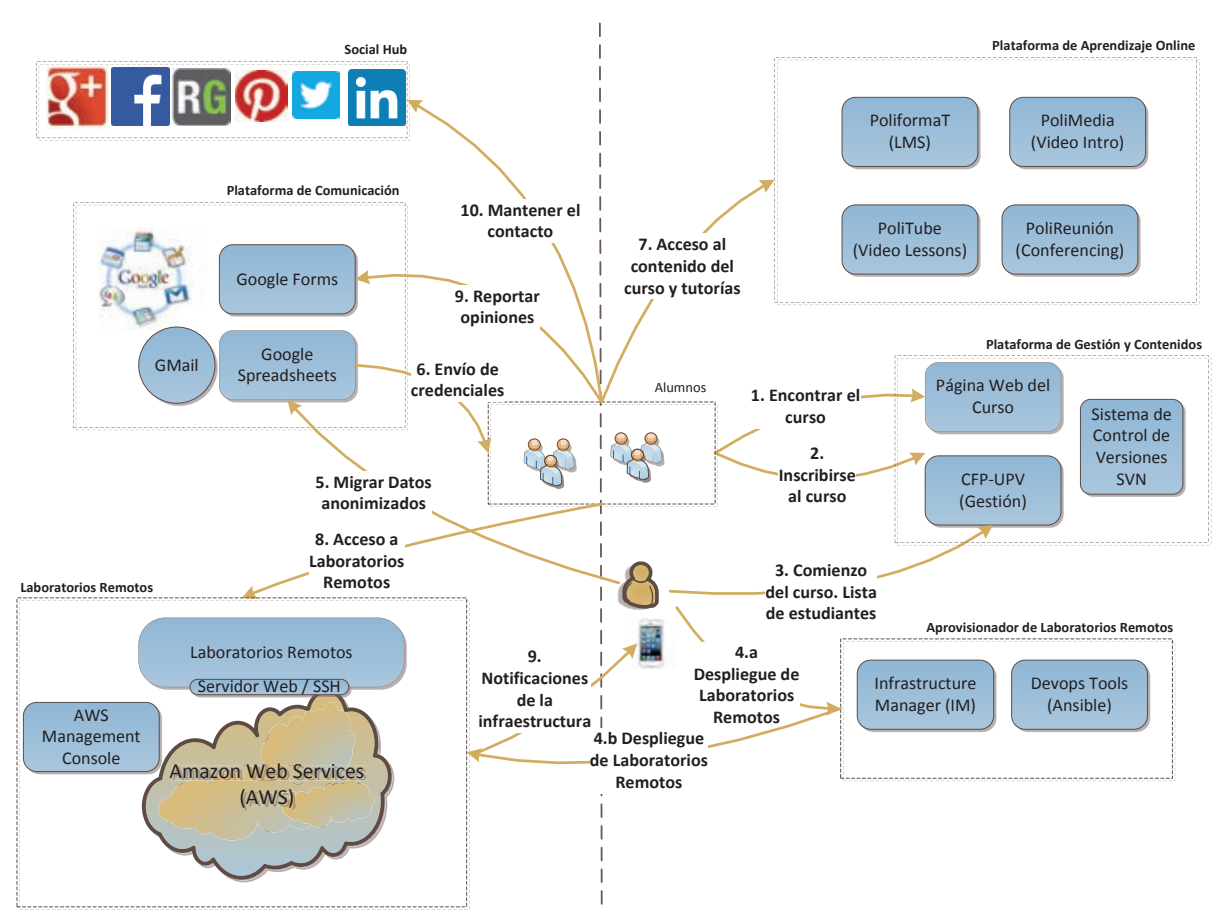

Fig. 3: Servicios involucrados en la gestión del curso online.

\subsection{Diagrama de Servicios Involucrados}

La Figura 3 describe los principales servicios, actores y componentes involucrados en el curso online. Los servicios proporcionados y/o disponibles desde la UPV están situados a la derecha de la figura mientras que los servicios de terceros se muestran en la parte izquierda de la figura.

Este es el flujo de trabajo que sigue un alumno típicamente. En primer lugar, los estudiantes acceden a la página web del curso para recopilar la información sobre el mismo (paso 1). Aquellos que desean inscribirse (paso 2) lo hacen a través del Centro de Formación Permanente (CFP) de la UPV. Una vez finalizado el periodo de inscripción y conocido el listado tentativo de alumnos (paso 3), el instructor despliega una o varias instancias de Laboratorios Remotos, que son máquinas virtuales desplegadas sobre AWS y configuradas dinámicamente para incluir todas las aplicaciones y configuración necesaria para realizar las actividades prácticas (paso 4). Las notificaciones sobre el estado de los Laboratorios Remotos se envían a lo largo del curso al teléfono móvil del instructor para asegurar alta disponibilidad para los estudiantes.

A continuación se migran datos parcialmente anonimizados de los estudiantes a una hoja de cálculo privada de Google Spreadsheets programada por el instructor para permitir el envío de mensajes personalizados e individualizados de forma masiva a los 
alumnos, funcionalidad que no soporta actualmente PoliformaT (paso 5). Esto permite mandar con un solo click mensajes periódicos personalizados para animar a los alumnos a realizar las actividades propuestas en el curso. Por ejemplo, las credenciales de acceso a los laboratorios remotos se envían por medio de estos mensajes personalizados (paso 6). Los estudiantes pueden acceder a la Plataforma de Aprendizaje Online y los Laboratorios Remotos para progresar a través del material educativo del curso (pasos 7 y 8). Después de cada módulo, se anima a los alumnos a valorar la calidad del mismo (paso 9), en función del nivel técnico, la calidad de las vídeo-lecciones y el grado de utilidad del módulo para el alumno. Para ello se utilizan cuestiones online de Google Forms con preguntas basadas en una escala. Los estudiantes pueden subscribirse a diferentes servicios online para recibir avisos sobre futuras convocatorias de cursos y estar actualizados con noticias y avisos relacionados a través del Social Hub (paso 10).

Las siguientes subsecciones describen brevemente cada componente para detallar las tecnologías empleadas, de manera que otros instructores puedan replicar las metodologías descritas en sus propios cursos online, si lo consideran apropiado.

\subsubsection{Plataforma de Gestión y Contenidos}

Esta involucra la creación de la página web del curso, desarrollada con Bootstrap, un framework para desarrollo web que permite adaptar automáticamente el contenido de la página para que se muestre correctamente tanto en ordenadores como en dispositivos móviles. Este es un aspecto importante considerando el incremento del acceso a la web a través de dispositivos móviles (Ally 2009). La web incluye una capa social proporcionada por AddThis, una plataforma de compartición de información social. Esto permite a los visitantes publicitar el curso en diferentes redes sociales de forma cómoda. Además, es conveniente utilizar técnicas básicas de posicionamiento en buscadores (SEO - Search Engine Optimization) (Lieberam-Schmidt 2010) para aparecer en posiciones relevantes de resultados de búsqueda de Google (y otros).

También se incluye un Sistema de Control de Versiones implementado con un repositorio Subversion (SVN) en el que el profesor almacena los documentos del curso, el código fuente de la página y las recetas de aprovisionamiento automático de los laboratorios remotos. Este repositorio se usa para desplegar fácilmente el contenido del curso no solo en PoliformaT sino también dentro de los laboratorios remotos de forma automatizada y ofrecida a través de un servidor web Apache. Esto permite ofrecer un acceso rápido al material para los alumnos que se matriculan una vez comenzado el curso (entre un 15-20\% de los alumnos de cada edición), para que no tengan que esperar a que el CFP les mande las credenciales. 


\subsubsection{Video-lecciones}

Las vídeo-lecciones se grabaron usando ScreenFlow con un portátil Macbook Pro usando la cámara integrada FaceTime y el micrófono interno en una sala silenciosa. Esto permite al instructor tener un control absoluto sobre el proceso de producción de los vídeos. Se usan plantillas de PowerPoint (tal y como se ve en la Figura 1.a) para homogeneizar el aspecto de las vídeo-lecciones e incorporar transparencias de título y resultados de aprendizaje, así como conclusiones antes y después de cada vídeolección, respectivamente. Un software alternativo para plataformas Windows podría ser Camtasia.

\subsubsection{Plataforma de Aprendizaje Online}

La plataforma de aprendizaje online usa los siguientes servicios:

- PoliformaT. Es el LMS (Learning Management System) corporativo de la UPV, basado en Sakai. Se utiliza la siguiente funcionalidad: i) Foros y Chat, donde los estudiantes plantean preguntas a ser contestadas por el profesor y por otros alumnos. Se puede gamificar (Deterding y col. 2011) si se considera necesario para aumentar la participación ofreciendo como recompensa el acceso a contenido adicional del curso; ii) Tests de auto-evaluación, que se generan con preguntas extraídas aleatoriamente de baterías de preguntas y que el alumno realiza tras cada modulo, siendo corregidas automáticamente; iii) Recursos, que contiene una página web que indexa todos los contenidos alojados en esta sección. Para solventar la escasa usabilidad del editor melete actualmente disponible en PoliformaT, el contenido del curso se estructura en un documento HTML (página web) que indexa todos los recursos almacenados en diferentes carpetas (guías, boletines, etc.). Este material se sube a la sección de Recursos a través de una conexión con el protocolo WebDAV usando la herramienta CyberDuck (para OS $\mathrm{X}$ ). Esto permite subir fácilmente el contenido del curso a PoliformaT de una sola vez, así como desacoplarlo de dicho LMS y desplegarlo en otra plataforma. Otros ejemplos de plataformas para desplegar cursos online son Udemy y Open edX.

- Polimedia. Es un servicio proporcionado por la UPV que permite la creación de vídeos con acabado profesional grabados en un estudio especializado donde aparece el instructor presentando unas transparencias. Sin embargo, la principal desventaja de esta alternativa es que el profesor no puede realizar ningún postproceso ni modificar el vídeo. El vídeo debe ser grabado de una sola vez o repetir la grabación en caso de fallo. Es útil para crear un vídeo de bienvenida de presentación del curso en una página web (tal y como se muestra en la Figura 1.b.

- Politube. Se trata de una plataforma de difusión de vídeos online proporcionada por la UPV donde las vídeo-lecciones se envían por streaming a los alumnos. Permite recopilar estadísticas de acceso a los vídeos. 
- Polireunión. Basada en Adobe Connect, esta es una plataforma de vídeo-conferencia web que permite a los profesores y estudiantes compartir conversaciones de video y de audio, documentos, pizarras, preguntas de opción múltiple, etc. Esta herramienta se utiliza especialmente para aquellas consultas que no puedan resolverse por e-mail. Únicamente es necesario un navegador web con soporte para Adobe Flash. También existen clientes para plataformas iOS (iPad y iPhone) aunque la funcionalidad es más reducida.

\subsubsection{Laboratorios Remotos y su Despliegue}

Los Laboratorios Remotos consisten en una o más máquinas virtuales que proporcionan un entorno pre-configurado para que los estudiantes puedan utilizar los servicios de AWS. Esto contrasta con la tendencia actual en cursos online y MOOCs de proporcionar un máquina virtual descargable para que los estudiantes la ejecuten en sus portátiles, teniendo que lidiar con la instalación y potenciales incompatibilidades de las mismas. Por el contrario, no es necesaria ninguna configuración especial para acceder a los laboratorios remotos del curso, más allá de un cliente SSH y un navegador web.

Para ello, cada Laboratorio Remoto se despliega y configura automáticamente para proporcionar: i) un conjunto de cuentas de usuario para acceder mediante SSH ; ii) la herramienta AWS CLI necesaria para interactuar con AWS y iii) una copia del material del curso accesible mediante un servidor web como mecanismo de respaldo para tener acceso al material en caso de fallo en PoliformaT o cuando el CFP todavía no ha mandado las credenciales de acceso al alumno. Esto permite que los alumnos tenga acceso rápido al material en cuanto formalizan la matrícula, sin tener que esperar unas cuentas horas hasta que el CFP entrega las credenciales al alumno y autoriza su acceso al sitio PoliformaT.

El Aprovisionador de Laboratorios Remotos (Moltó y Caballer 2013) es un sistema que permite desplegar infraestructuras virtuales complejas sobre proveedores Cloud, como es el caso de Amazon Web Services. El instructor proporciona la descripción de los laboratorios remotos indicando: i) los requisitos hardware necesarios (memoria RAM, arquitectura de CPU, etc.); ii) el sistema operativo, por ejemplo GNU/Linux Ubuntu 12.04 y iii) la configuración, que incluye cuentas de usuario, paquetes software y ficheros de configuración necesarios para que los alumnos se encuentren el entorno de trabajo listo para ser usado.

El despliegue de los Laboratorios Remotos se realiza usando la herramienta Infrastructure Manager (IM) ${ }^{3}$ una herramienta de código abierto, accesible también como servicio Cloud y puesta a disposición de la comunidad académica, que permite el despliegue de infraestructuras en múltiples infraestructuras Cloud. Esta herramienta puede ser reutilizada por otros docentes con requisitos similares. Es posible encontrar más información sobre esta herramienta en (Caballer y col. 2014).

\footnotetext{
${ }^{3}$ Infrastructure Manager - http://www.grycap.upv.es/im
} 


\subsubsection{Plataforma de Comunicación}

La Plataforma de Comunicación permite difundir mensajes personalizados a los estudiantes así como recopilar las opiniones de los alumnos sobre cada módulo del curso. Está basada en las herramientas gratuitas de Google Apps y consiste en una hoja de cálculo de Google Spreadsheets que recopila la asignación de credenciales y dirección IP del laboratorio remoto para cada alumno. Incluye una serie de scripts, programados por el autor, para el envío de e-mails en base a dicha información. Por ejemplo, al inicio del curso se envía un correo de bienvenida personalizado a cada alumno para incluir sus credenciales de acceso. Esto se realiza con un mínimo esfuerzo por parte del instructor, que únicamente debe importar el nombre y correo de los alumnos a dicha hoja privada y los mensajes se mandan con un solo click. También existe un calendario público creado con Google Calendar e integrado en la página web con una planificación de las futuras ediciones del mismo.

Tras cada módulo se anima al alumno a que valore la calidad del mismo en base a las vídeo-lecciones, la calidad técnica y su percepción del grado de utilidad de dicho módulo para el alumno. Esta información se manda por medio de formularios en línea creados con Google Forms para describir de forma cuantitativa la cálida de curso. También hay campos de respuesta abierta con sugerencias de mejora que puede realizar el alumno.

En los cursos online, cada duda surgida al alumno que no puede ser resuelta desde el material educativo puede convertirse en una pregunta al instructor, necesitando así su tiempo y atención. Para audiencias relativamente grandes esto puede ser una fuente de stress. Una aproximación efectiva es la actualización del material ante cualquier duda del alumno, con el objetivos de que ningún alumno se enfrente al mismo problema. Combinado con una sección de Preguntas Más Frecuentes, esto permite refinar de forma iterativa el material del curso de manera que converja iterativamente a un número despreciable de dudas. El objetivo es que el alumno se deslice por el material educativo con el mínimo número de escollos posible para ir adquiriendo las competencias definidas por el curso. Para ello, el material educativo, especialmente el de las prácticas, debe ser capaz de anticiparse a los problemas de los alumnos e incluir soluciones a casuística diversa para que el alumno pueda resolver de forma autónoma los problemas a los que se enfrente. De esta manera, el alumno no ralentiza su aprendizaje por unas dudas y el instructor no dedica tiempo a la resolución de las mismas. Una situación ideal para alumnos e instructores.

En cualquier caso, para un curso con carácter técnico y práctico es importante responder rápidamente a las cuestiones, dado que el alumno puede estar atascado en una parte práctica que involucra el uso de recursos computacionales reales (con un coste asociado para el curso). Cuanto más rápido y preciso se responda al alumno más alta será la tasa de satisfacción del alumno, como se demostrará más adelante en la sección de discusión. Para cursos donde los estudiantes se encuentran en diferentes zonas horarias esto supone un reto. La mayor de países de habla hispana están entre 4 y 7 husos horarios de diferencia respecto a España, por lo que es necesario utilizar 
un sistema notificación apropiada para alertar al instructor sobre las dudas de los alumnos.

Aunque existen sistemas de mensajería populares como WhatsApp, esto requiere dar el número de teléfono móvil del instructor a los alumnos, lo que puede derivar rápidamente en un abuso, además de requerir que los alumnos se instalen una aplicación no gratuita en sus dispositivos. Por el contrario, en nuestro curso hemos usado los filtros en el servidor de GMail de manera que aquellos mensajes que incluyan una determinada etiqueta en el asunto del mensaje ([CursoCloudAWS] en nuestro caso) se reenvíen automáticamente a una cuenta de correo de Boxcar $2^{4}$, para convertirlo en una notificación push entregada inmediatamente al móvil del instructor. Esto permite recibir una alerta en el móvil en cuestión 1-2 segundos tras el mensaje del alumno.

\subsubsection{Social Hub}

El Centro Social (o Social Hub) permite mantener el vínculo con antiguos alumnos así como servir de gancho para futuros estudiantes. Esto incluye desde servicios sociales, como Facebook, Twitter, LinkedIn o Google Plus a servicios académicos como Mendeley y ResearchGate, en el que se comparten anuncios, noticias, trabajos y artículos relacionados con el contenido del curso. Se han creado páginas específicas para el curso tanto en Facebook como en Google Plus para que los alumnos puedan indicar que les gusta el curso y darlo a conocer a sus contactos.

\subsubsection{Monitorización y Seguimiento}

La monitorización del estado de los laboratorios remotos es esencial para ofrecer alta disponibilidad a los alumnos. Para ello se utiliza un esquema de monitorización basado en Amazon SNS que permite definir una reglas que alertan mediante un mensaje de correo redirigido al teléfono del instructor. Esto permite alertar cuando el entorno deja de ser accesible o bien si el consumo de CPU supera el $70 \%$ durante al menos dos periodos de 5 minutos. Esto último podría ser un indicador de que hay muchos usuarios trabajando de forma concurrente, lo que puede solucionarse desplegando un nuevo laboratorio remoto.

Con respecto al seguimiento de los alumnos, éste se realiza de varias maneras. Por un lado, mediante las calificaciones obtenidas en los tests de auto-evaluación disponible en PoliformaT. Esto permite conocer el grado de progreso de un alumno, si bien la realización de los mismos es completamente opcional. Por otro lado, es posible conocer el grado de progreso de los alumnos en las prácticas. Para ello, se ha diseñado una herramienta que se ejecuta periódicamente varias veces a lo largo del día (desde los laboratorios remotos) para analizar el consumo de recursos de AWS que está realizando cada alumno. Esto permite, por un lado, recopilar de manera automática evidencias de la realización de las prácticas por parte de los alumnos. Por otro lado, permite

\footnotetext{
${ }^{4}$ Boxcar 2. https://boxcar.io/client
} 


\begin{tabular}{lc} 
Pregunta & Resultado Promedio \\
\hline El material del curso es suficientemente manejable & 9.10 \\
\hline Los métodos de enseñanza son adecuados a la materia & 9.03 \\
\hline Los Laboratorios Remotos han sido de utilidad & 8.93 \\
\hline $\begin{array}{l}\text { Los medios de comunicación han eliminado obstáculos } \\
\text { espacio-temporales }\end{array}$ & 9.18 \\
\hline El tutor domina los contenidos del curso & 9.58 \\
\hline El curso se ha adaptado a mi ritmo de aprendizaje & 8.45 \\
\hline El tutor ha atendido con rapidez mis consultas & 9.60 \\
\hline $\begin{array}{l}\text { Los medios usados para la formación (Internet }+ \text { Re- } \\
\text { mote Labs) tienen más ventajas que inconvenientes }\end{array}$ & 9.10 \\
\hline Estoy satisfecho con el resultado del curso & 9.20 \\
\hline
\end{tabular}

Tabla 1: Resultados promedios a lo largo de cinco ediciones (población de 73 estudiantes).

detectar consumos excesivos de recursos, por ejemplo cuando un alumno se olvida de detener una máquina virtual en AWS.

El instructor puede usar la aplicación para móvil AWS Management Console App para monitorizar y terminar ciertos recursos de AWS desde cualquier dispositivo basado en $\mathrm{iOS}$.

\section{Resultados y Discusión}

El Curso Online de Cloud Computing con Amazon Web Services (AWS) tuvo su primera edición en Julio de 2013 y se han realizado hasta el momento siete ediciones (una edición aproximadamente cada 1-2 meses), con más de 150 alumnos de siete países diferentes, principalmente de países de habla hispana como España, México, Colombia, Ecuador y Peru.

La evaluación del curso se ha realizado en base a los cuestionarios oficiales que manda el CFP para ser cumplimentados online por el estudiante, sin ninguna intervención por el profesor. Los resultados de dichas encuestas se publican tal cual tras cada edición en la página web del curso. El cuestionario incluye, entre otros, las preguntas mostradas en la tabla 1. 73 alumnos (de un total de 147, ya que únicamente están disponibles los resultados hasta la quinta edición) contestaron las preguntas, ya que su cumplimentación es opcional.

La evaluación tanto del curso como del tutor por parte de los estudiantes fueron consistentemente altas. Por ejemplo, los estudiantes calificaron con un 9.20 la satisfacción promedio con el curso a lo largo de diferentes ediciones. El material del curso y la metodología educativa fueron consideradas muy apropiadas. Además, los métodos de comunicación ofrecidos por el curso resolvieron las posibles barreras, facilitando a los alumnos conseguir los resultados del curso. Los comentarios escritos por los alumnos fueron extremadamente positivos. 
\# de Correos frente a \# de Estudiantes

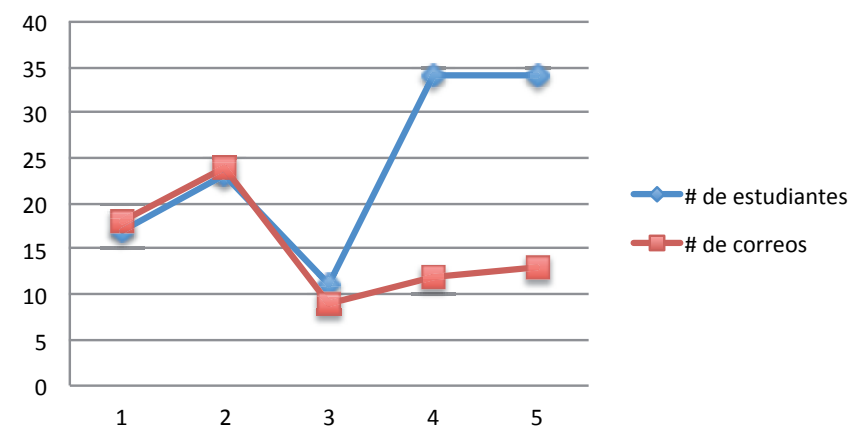

Fig. 4: Evolución del número de peticiones de ayuda de los estudiantes con respecto al número de alumnos matriculados en cada edición.

Los resultados también indican que los estudiantes perciben que el curso se adapta a su ritmo de aprendizaje. Esto es debido a la disponibilidad de todo el material educativo y los laboratorios remotos desde el inicio de cada edición. De hecho, una de las ventajas de los cursos online es evitar la sincronización de los estudiantes al ritmo indicado por el profesor, especialmente para alumnos con diferentes conocimientos previos. De hecho, los estudiantes aprenden a su ritmo sin ser obstaculizados por un instructor presencial que marque un ritmo. El instructor nunca debería ser un limitante para un estudiante avanzado que quiere aprender a un ritmo más rápido.

La Figura 4 muestra la evolución del número de correos electrónicos de alumnos, que precisaron la intervención del instructor. Se observa que la estrategia de mejora iterativa del material educativo ha permitido reducir el volumen de correos recibidos a aproximadamente 13 mensajes por edición (con un promedio de 26 alumnos por edición). Este número también incluye los mensajes publicados en el foro del curso (3-4 mensajes por edición) que principalmente reciben la contestación del tutor. Esta carga de trabajo es perfectamente asumible por un único tutor.

Para el instructor, la experiencia adquirida en la producción y gestión del curso online ha sido tremendamente gratificante. Producir materiales educativos que sean autocontenidos en la medida de la posible dirigidos a una audiencia amplia con diferentes conocimientos previos es un reto para un educador. Esto requiere crear materiales educativos muy detallados y con diversas medios (texto, vídeo, práctica, etc.) que permite sostener el interés de los alumnos para conseguir alcanzar las competencias del curso.

El despliegue automatizado de Laboratorios Remotos ha permitido desplegar entornos de prácticas consistentes, es decir, con exactamente la misma configuración, de una edición a otra. La gestión dinámica de infraestructuras virtuales introduce una flexibilidad sin precedentes.

(oc) EY-No-No 2014, Universitat Politècnica de València

I Jornadas IN-RED (2014) 


\section{Conclusiones}

Este artículo ha descrito una arquitectura que simplifica la gestión de un curso online mediante la combinación de herramientas gratuitas (o de bajo coste) y servicios en la nube, para ofrecerlo a alumnos de cualquier parte del mundo. El uso de servicios en la nube para facilitar la comunicación y aprovisionar Laboratorios Remotos introduce una gran flexibilidad en la gestión de cursos online. Con la ayuda de un portátil y una conexión a internet, un instructor puede hoy en día producir cursos online de gran calidad con un mínima carga de gestión.

Los trabajos futuros se encaminan a reformular el curso para soportar la característica de matrícula continua ofrecida por el CFP desde mediados de 2014. Esto permite eliminar el concepto de edición y permitir que el alumno se matricule en cualquier momento y pueda disponibles de acceso al material educativo y un determinado número de días para completar las actividades propuestas y obtener su certificado de aprovechamiento. Esto supone un paso fundamental en la corriente EaaS (Education as a Service) donde el alumno tiene acceso bajo demanda a la formación que necesita en cada momento.

El autor está profundamente convencido que la educación online debe adaptarse a las características de los estudiantes, especialmente para los cursos técnicos, donde la educación debe proporcionarse bajo de manda, adaptándose al horario del estudiante y no al del instructor. Para ello, las técnicas descritas en este artículo pueden ayudar a conseguir esa visión de EaaS y pueden ser extrapoladas a otras actividades y cursos.

\section{Referencias bibliográficas}

Alexiadis, Dimitrios S. y Nikolaos Mitianoudis (mayo de 2013). "MASTERS: A Virtual Lab on Multimedia Systems for Telecommunications, Medical, and Remote Sensing Applications". En: IEEE Transactions on Education 56.2, págs. 227-234. ISSN: 0018-9359. DOI: 10.1109/TE.2012.2210224.

Ally, Mohamed (Ed.) (2009). Mobile Learning: Transforming the Delivery of Education and Training. Au Press. ISBN: 1897425430.

Bezerra, Rui M F, Irene Fraga y Albino A Dias (ene. de 2013). "Utilization of integrated Michaelis-Menten equations for enzyme inhibition diagnosis and determination of kinetic constants using Solver supplement of Microsoft Office Excel." En: Computer methods and programs in biomedicine 109.1, págs. 26-31. ISSN: 1872-7565. DOI: $10.1016 / \mathrm{j}$.cmpb.2012.08.017.

Caballer, Miguel y col. (2014). "Dynamic management of virtual infrastructures". En: Journal of Grid Computing. DOI: 10.1007/s10723-014-9296-5. 
Deterding, Sebastian y col. (mayo de 2011). "Gamification. using game-design elements in non-gaming contexts". En: Proceedings of the 2011 annual conference extended abstracts on Human factors in computing systems - CHI EA '11. New York, New York, USA: ACM Press, pág. 2425. ISBN: 9781450302685. DOI: 10.1145/1979742.1979575.

Fang, Ning, Karen Nielson y Stephanie Kawamura (2013). Using Computer Simulations with a Real-World Engineering Example to Improve Student Learning of High School Physics: A Case Study of K-12 Engineering Education. eng.

Gaspar, Alessio y col. (mayo de 2008). "March of the (virtual) machines: past, present, and future milestones in the adoption of virtualization in computing education". En: Journal of Computing Sciences in Colleges 23.5, págs. 123-132. ISSN: 19374771 .

Güney, E, Z Ekşi y M Çakıroğlu (2011). "WebECG: A novel ECG simulator based on MATLAB Web Figure". En: Advances in Engineering Software.

Kolota, Jakub (2011). A Remote Laboratory for Learning with Automatic Control Systems and Process Visualization. eng.

Lieberam-Schmidt, Sönke (2010). "Search Engine Optimization". En: Analyzing and Influencing Search Engine Results. Wiesbaden: Gabler, págs. 163-203. ISBN: 9783-8349-2453-7. DOI: 10.1007/978-3-8349-8915-4.

Moltó, Germán y Miguel Caballer (2013). "Scalable Software Practice Environments Featuring Automatic Provision and Configuration in the Cloud". En: The 2013 International Conference on Parallel and Distributed Processing Techniques and Applications (PDPTA'13).

Moore, MG y G Kearsley (2011). Distance education: A systems view of online learning. Wadsworth Publishing. ISBN: 978-0534506889.

Romero-Zaldivar, Vicente-Arturo y col. (mayo de 2012). "Monitoring student progress using virtual appliances: A case study". En: Computers \& Education 58.4, págs. 1058-1067. ISSN: 03601315. DOI: 10.1016/j . compedu.2011.12.003.

Sun, Pei-Chen y col. (2008). "What drives a successful e-Learning? An empirical investigation of the critical factors influencing learner satisfaction". En: Computers and Education 50.4, págs. 1183-1202. 


\title{
Artículos docentes de estudios audiovisuales ilustrados con material audiovisual: HTML versus PDF con vídeo embarcado
}

\author{
Blas Payria $^{a}$, Rut Sanz Garijo ${ }^{\text {, Francisca Ramón Fernández }}{ }^{c}$ y Josep Prósper Ribes ${ }^{d}$ \\ a,b,c Universitat Politècnica de València, ${ }^{a}$ bpayri@har.upv.es, brusanga@alumni.upv.es, \\ `frarafer@urb.upv.es, ${ }^{\mathrm{c}}$ jprosper@har.upv.es.
}

\begin{abstract}
This article focuses on "teaching articles" in the field of media and music studies, where it is often necessary to use audio-visual examples to illustrate the concepts under study. The video (or audio) file is not used to teach a class (as in the usual educational videos), but is the proper object of study. We propose different ways to insert audio/video materials: linked or referenced (link to external http server), framed (delivered from external server but with the appearance of being embedded in the document text Video), and embarked (Video physically contained within the same document); as well as different languages or tools for insertion: text processors, HTML and PDF. Given that teaching articles are often required to be in PDF format, we analyze the possible workflow to create and maintain documents embedding video (interactive PDF with Adobe Acrobat Pro or InDesign), or simple links to videos stored streaming servers as politube. The difficulty of creation, maintenance and dissemination of these PDF documents with video, high weight and reading difficulty for the user, make it advisable to include HTML as a format for teaching articles.
\end{abstract}

Keywords: Teaching object, teaching article, media studies, interactive PDF, video.

\section{Resumen}

Se estudian los artículos docentes relativos al campo de estudios audiovisuales, donde suele ser imprescindible utilizar ejemplos audiovisuales para ilustrar los conceptos. El vídeo (o audio) no se utiliza para impartir una

(cc) EY-NC-ND 2014, Universitat Politècnica de València

I Jornadas In-Red (2014) 
Artículos docentes de estudios audiovisuales ilustrados con material audiovisual: HTML versus PDF con vídeo embarcado

clase (como en los vídeos docentes al uso), sino que es el propio objeto de estudio. Planteamos los diferentes modos de insertar materiales audiovisuales: enlazados o referenciados (enlace http a servidor externo), enmarcados (vídeo distribuido desde servidor externo pero con la apariencia de estar embebido en el documento de texto) y embarcados (vídeo contenido físicamente dentro del mismo documento); así como los diferentes lenguajes o herramientas para la inserción: pages y procesadores de documentos, HTML y PDF. Teniendo en cuenta que se suele requerir que los artículos docentes estén en formato PDF, se analiza el flujo de trabajo posible para crear y mantener artículos docentes que contengan vídeos embarcados (PDF interactivo con Adobe Acrobat Pro o InDesign), o simples enlaces a vídeos almacenados en servidores de streaming como el politube. La dificultad de creación, mantenimiento y difusión de estos PDF con vídeo y el peso y dificultad de lectura para el usuario hacen recomendable la utilización del formato HTML en la creación de artículos docentes útiles para el estudiante, y que son fácilmente gestionables con las herramientas recientes de Wordpress.

Palabras clave: Objeto de aprendizaje, audiovisual, estudios audiovisuales, PDF interactivo, video.

\section{Introducción}

En este artículo abordamos la necesidad de la ilustración con ejemplos audiovisuales de los llamados "artículos docentes", centrándonos en las asignaturas o campos que analizan la música y el audiovisual, es decir un campo en que los materiales audiovisuales son el objeto mismo de estudio y son intrínsecamente necesarios para el desarrollo del curso, ya que sirven para "reforzar la comprensión de conceptos complejos que por su naturaleza dinámica no pueden ser representados mediante textos o diagramas" (Bengochea, Budia y Medina, 2012). Descartamos pues el amplio corpus de investigación que indica de manera consistente que los vídeos docentes (entendidos como una clase con la voz del profesor) aportan una mejora significativa en el aprendizaje online para cualquier asignatura (Griffin, Mitchell, \& Thompson, 2009; Vázquez Cano, 2013), pero nos acercamos a las necesidades expresadas en varios campos respecto a la integración de contenidos multimedia o interactivos en los artículos académicos, como Ruthensteiner y Heß (2008) que explican el interés de utilizar herramientas como Adobe 3D toolkit para generar gráficos en artículos.

Este artículo aborda pues la utilización de material audiovisual insertado en texto escrito para ilustrar conceptos audiovisuales, en lo que sería un "artículo docente" ilustrado y útil en estudios audiovisuales, teniendo en cuenta que dichos artículos docentes suelen estar por defecto en PDF.

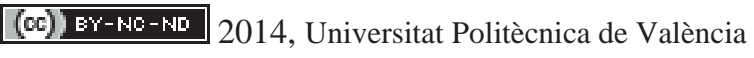

I Jornadas IN-RED (2014) 
Proponemos el análisis de webs docentes con textos docentes que embarcan vídeos para analizar las soluciones técnicas y de formato para el usuario, utilizando las webs docentes https://poliformat.upv.es/access/content/group/DOC_32094_2013/recursosSonoros/ y sobre todo http://sonido.blogs.upv.es, así como la web dedicada a la entrega de contenidos académicos por parte de los alumnos en http://sonidoextradiegetico1314.blogs.upv.es/.

\section{Ejemplos de páginas HTML sobre análisis audiovisual con contenidos audiovisuales}

Uno de las primeras necesidades que surgen en la docencia de análisis audiovisual, sobre todo cuando se analizan elementos dinámicos como el sonido o los movimientos de cámara, es la puesta a disposición de los diferentes ejemplos audiovisuales que se utilizan durante la clase presencial, de modo que los alumnos puedan revisar y asimilar los conceptos tratados. Esta es una necesidad aún más acuciante cuando se trata de docencia no presencial. Para ello, nos hemos decantado por la utilización del HTML para generar webs "tradicionales" en las que se insertan ejemplos de vídeo enmarcado, que se difunde a partir de un servidor de vídeo dedicado, en este caso Politube (http://politube.upv.es/), el servidor de streaming institucional de la Universitat Politècnica de València.

\subsection{Web creada con editor HTML albergado en el Poliformat}

La primera web se creó utilizando el editor HTML avanzado Dreamweaver de Realmac (http://realmacsoftware.com/rapidweaver/), equivalente a otro tipo de editores web como el más sencillo iWeb de Apple (http://es.wikipedia.org/wiki/IWeb), o el más avanzado y complejo Dreamweaver de Adobe (http://www.adobe.com/es/products/dreamweaver.html).

Se ha utilizado la plataforma Poliformat para albergar el contenido bajo esta dirección: https://poliformat.upv.es/access/content/group/DOC 32094_2013/recursosSonoros/ (Payri 2012), de la que se puede ver una captura de pantalla en la figura 1.

\section{(c) EY-NC-ND 2014, Universitat Politècnica de València}

I Jornadas IN-RED (2014) 
Artículos docentes de estudios audiovisuales ilustrados con material audiovisual: HTML versus PDF con vídeo embarcado

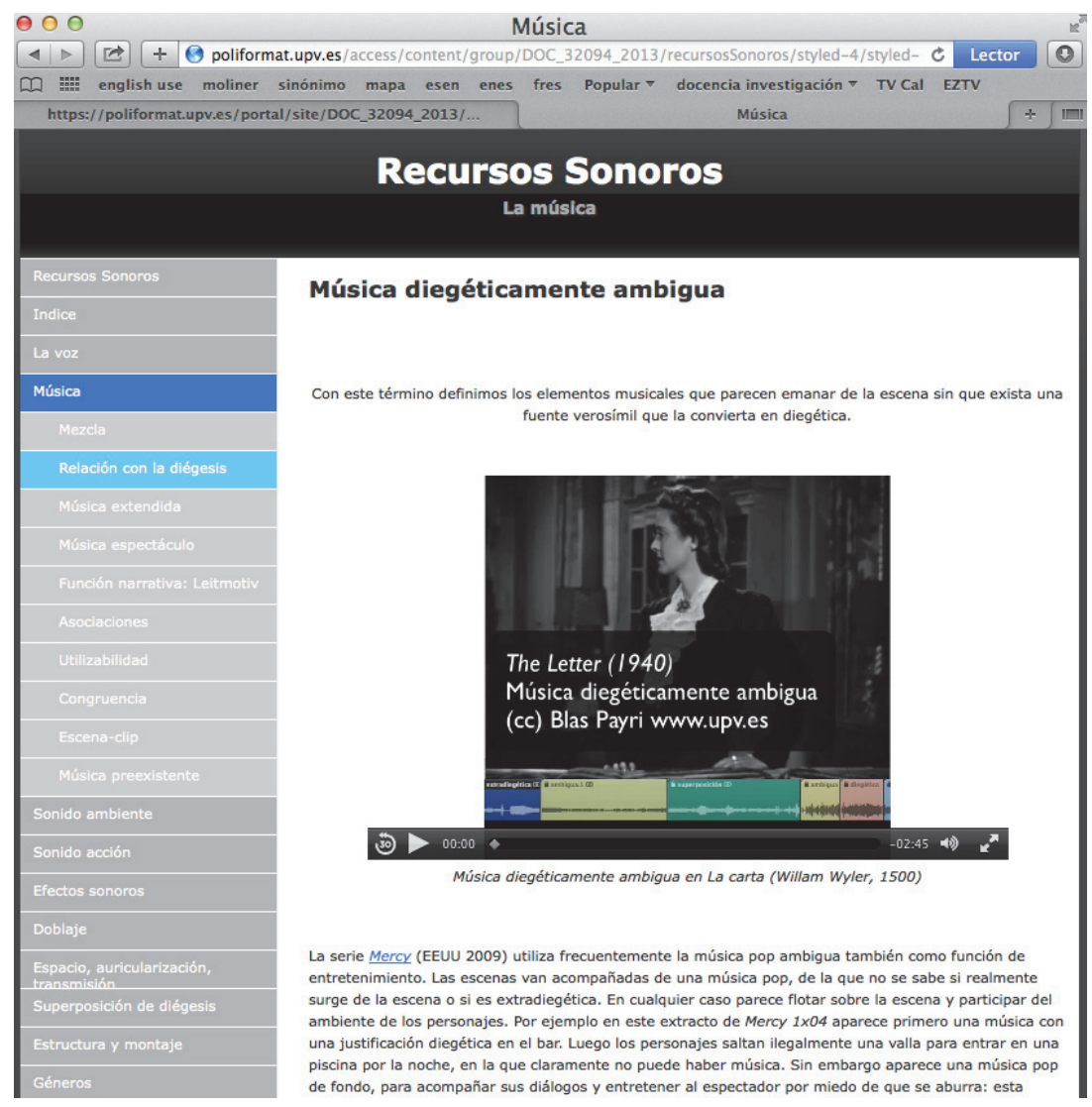

Fig. 1 Captura de pantalla de una web desarrollada con el editor de HTML Rapidweaver alojada en la sección Recursos del Poliformat. Disponible en:

https://poliformat.upv.es/access/content/group/DOC 32094 2013/recursosSonoros/styled-4/styled-79/index.html

En este caso, se va escribiendo el código (en un formato intermedio que puede contener entidades HTML) como se ve en la figura 2, y se puede visualizar de manera previa en la propia herramienta lo que resultará en un navegador HTML una vez publicado como se ilustra en la figura 3. Una vez escritas las diferentes páginas en Rapidweaver, se exporta como sitio web entero, con toda la estructura de páginas HTML, documentos gráficos y audiovisuales y las carpetas y subcarpetas correspondientes.

(c)) EY-NC-ND 2014, Universitat Politècnica de València

I Jornadas IN-RED (2014) 
Blas Payri, Rut Sanz Garijo, Francisca Ramón Fernández y Josep Prósper Ribes

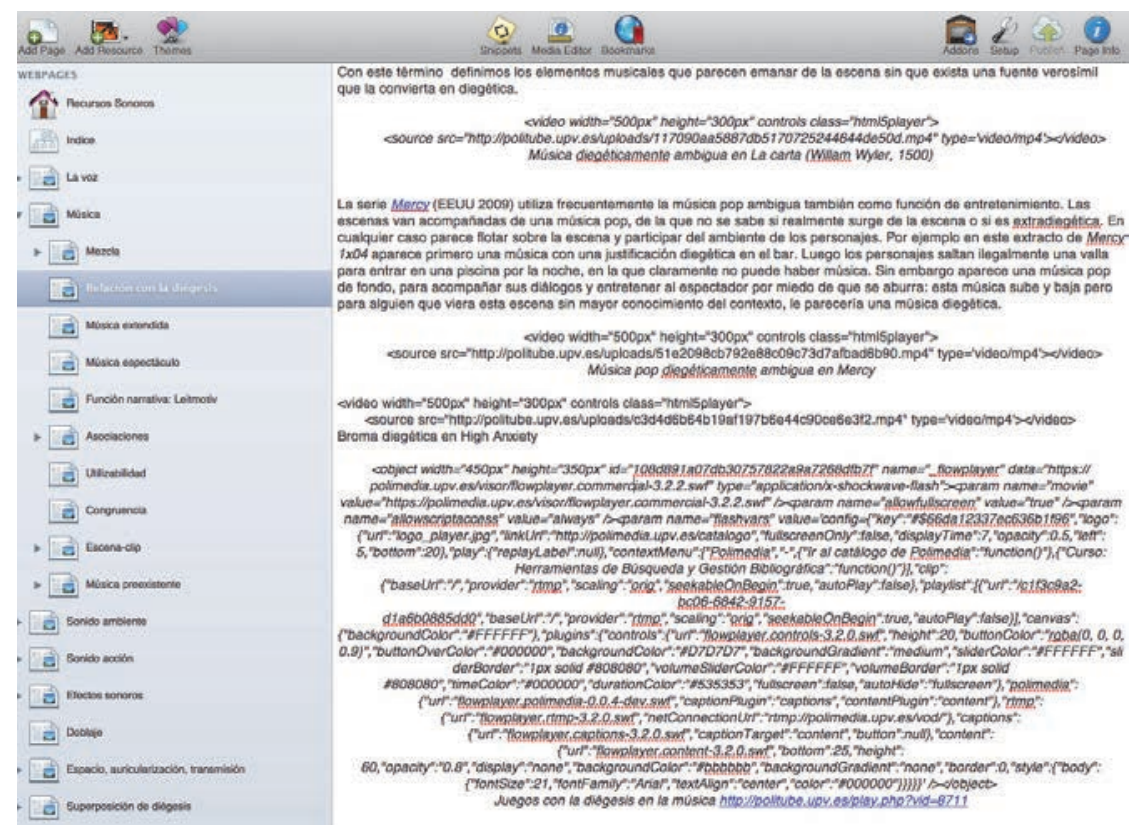

Fig. 2 Captura de pantalla del código que se va generando en la herramienta Rapidweaver

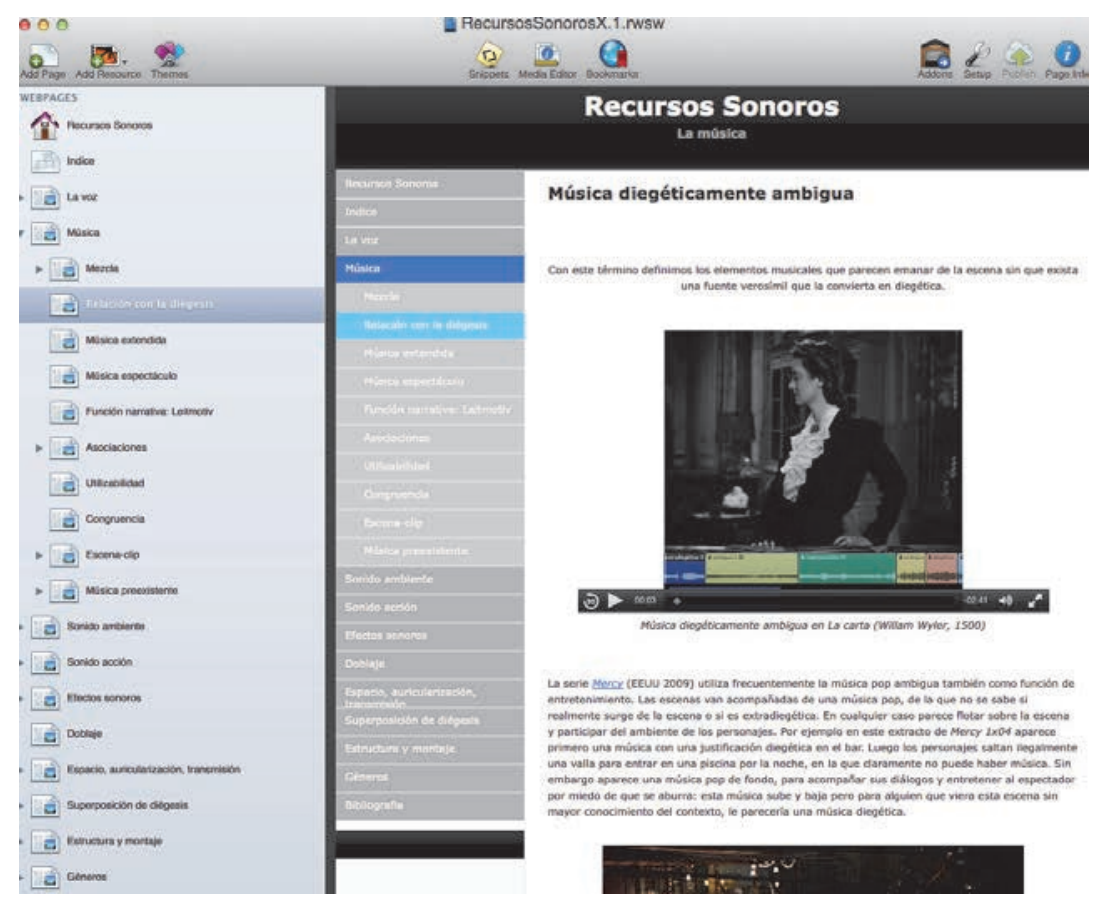

Fig. 3 Captura de pantalla de la visualización preliminar que va generando la herramienta Rapidweaver.

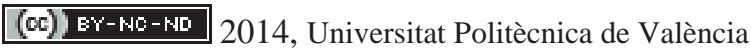

I Jornadas IN-RED (2014) 
Artículos docentes de estudios audiovisuales ilustrados con material audiovisual: HTML versus PDF con vídeo embarcado

\subsection{Web creada con Wordpress albergada en los blogs de la UPV}

La web más reciente para la docencia de conceptos audiovisuales ligados al sonido, que incluye gran número de ejemplos audiovisuales desarrollados ex professo se puede encontrar en http://sonido.blogs.upv.es.

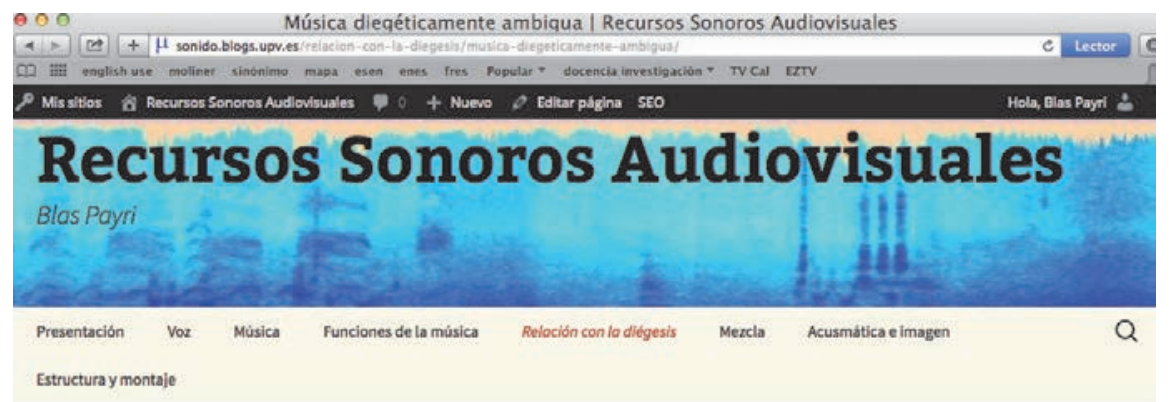

\section{Música diegéticamente ambigua}

Con este término definimos los elementos musicales que parecen emanar de la escena sin

que exista una fuente verosímil que la convierta en diegética.

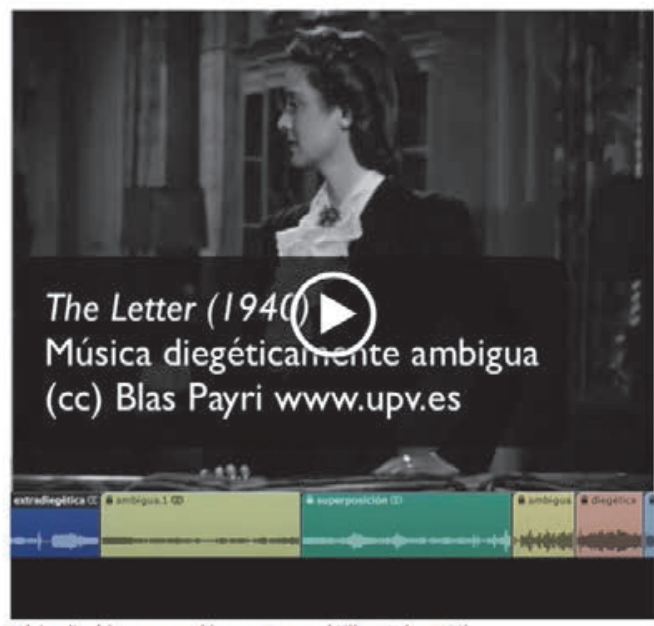

Música diegúticamente ambigua en La corta (Willam Wyler, 1500)

La serie Mercy (EEUU 2009) utiliza frecuentemente la música pop ambigua también como

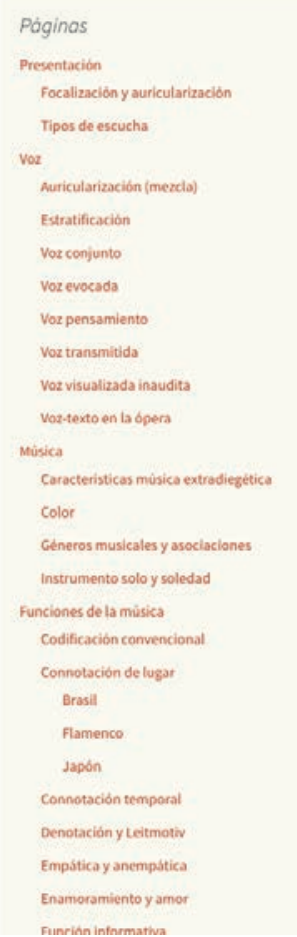

Fig. 4 Captura de pantalla de la página desarrollada con Wordpress en el servicio de blogs de la UPV, mostrando la página http://sonido.blogs.upv.es/relacion-con-la-diegesis/musica-diegeticamente-ambigua/

Se puede ver en la figura 4 una captura de pantalla de dicha web con el contenido similar al que podemos ver en las figuras anteriores. En la figura 5 se puede ver el texto que introduce el desarrollador, utilizando la interfaz en línea de los blogs desarrollados con Wordpress.

(c)) EY-NC-ND 2014, Universitat Politècnica de València I Jornadas IN-RED (2014) 
Como indica la propia página http://wordpress.org, "WordPress es un software web puedes utilizar para crear un hermoso sitio web o blog. Nos gusta decir que WordPress es libre y no tiene precio, al mismo tiempo. El software básico es construido por cientos de voluntarios de la comunidad, y cuando estés listo para más, hay miles de plugins y temas disponibles para transformar su sitio en casi cualquier cosa que puedas imaginar."

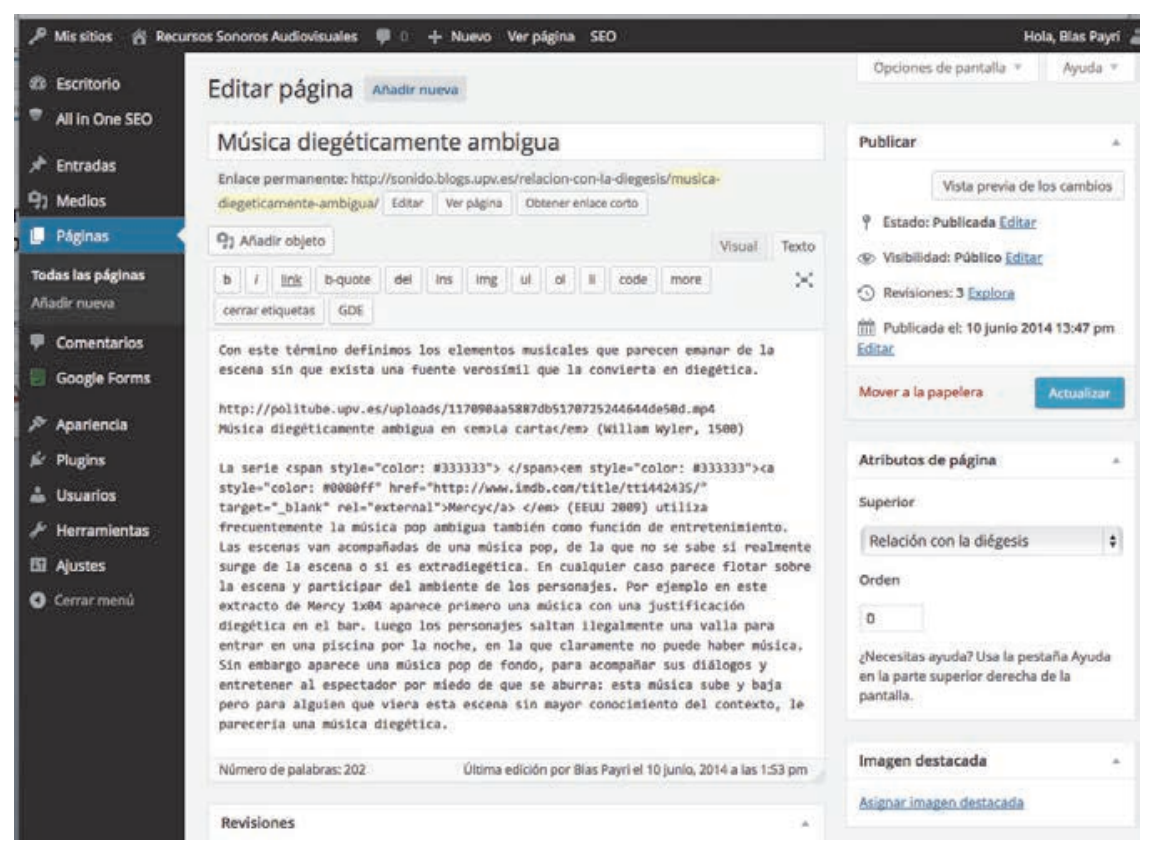

Fig. 5 Captura de pantalla de la página de desarrollo en línea de Wordpress en el servicio de blogs de la UPV.

Las ventajas de wordpress, albergado directamente en el servicio Poliblogs de la UPV (http://blogs.upv.es) y que puede ser utilizado por cualquier profesor o alumno de la Universidad, son las siguientes en cuanto al desarrollo de una web docente para contenidos audiovisuales:

- el desarrollo de contenidos es de fácil manejo.

- los contenidos se pueden añadir y editar desde cualquier lugar, utilizando un navegador y una conexión a internet.

- la inserción de material audiovisual es muy fácil tanto para vídeos albergados en politube (sitio institucional de la UPV http://politube.upv.es) como para servidores de vídeo convencionales como Youtube o Vimeo. Además, genera diferentes opciones de visualización de vídeos utilizando html5 o sistemas más antiguos en función del navegador, aunque siempre puede haber problemas de visualización en ciertos navegadores.

\section{(c)) EY-NC-ND 2014, Universitat Politècnica de València}

I Jornadas IN-RED (2014) 
Artículos docentes de estudios audiovisuales ilustrados con material audiovisual: HTML versus PDF con vídeo embarcado

- $\quad$ el resultado visual es atractivo y modulable, y se puede visualizar en ordenadores o en dispositivos móviles, teniendo una adaptación automática del formato y el tamaño

\section{Conceptos generales para la inserción de materiales audiovisuals}

Existen diferentes modos de integrar material musical o audiovisual dentro de un texto con finalidad docente, que podemos catalogar con los siguientes parámetros:

Referenciado o enlazado: un enlace http dirige hacia un sitio web externo donde se podrá reproducir el material (enlace externo, ver figura 8).

Enmarcado: el material audiovisual se visualiza/reproduce aparentemente dentro de la misma página de texto pero en realidad se reproduce desde un servidor de vídeo externo (ver figura 7)

Embarcado: el material audiovisual está directamente incluido en el fichero de texto, desde el que se visualiza/reproduce (ver figura 6)

Podemos considerar como material audiovisual integrado tanto el material enmarcado como embarcado. El audiovisual integrado en la página permite referenciar los ejemplos y reproducirlos en el texto mismo, lo que proporciona mayor fluidez y facilidad de uso y comprensión, y genera unas presentaciones más integradas y profesionales.

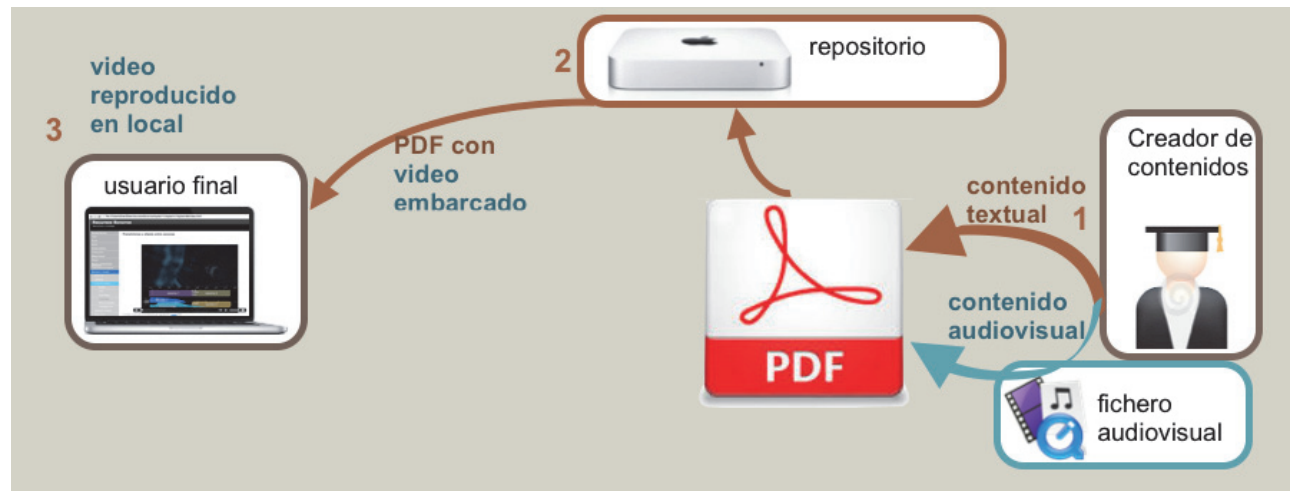

Fig. 6 La cadena de creación y visionado de contenidos textaules con material audiovisual utilizando PDF con video embarcado.

El HTML, el PDF interactivo y los procesadores de texto avanzados (Pages https://www.apple.com/es/mac/pages/, y en menor medida Microsoft Word) permiten embarcar ficheros de vídeo y audio (Payri, Prósper Ribes \& Ramón Fernández, 2013). La ventaja es que el estudiante puede ver el material fuera de línea y que el editor controla todo el material, pero los inconvenientes son que el documento final es mucho más pesado al cargar con todos los videos, que las modificaciones son muchos más pesadas, que se depende de los codecs y otros requerimientos técnicos que el usuario puede no tener, como se ilustra en la figura 6. 


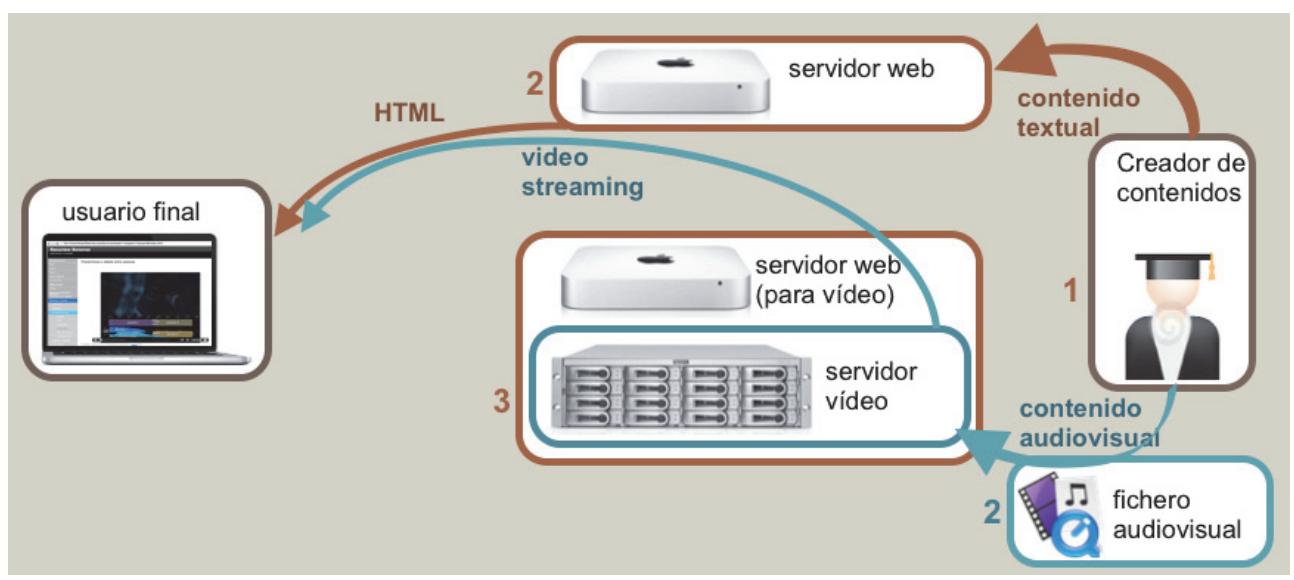

Fig. 7 La cadena de creación y visionado de contenidos textaules con material audiovisual utilizando una web HTML con videos enmarcados.

La integración de los contenidos de servidores de streaming en el texto sólo se puede conseguir con el HTML como se ilustra en la figura 7, y las ventajas incluyen el rápido y fácil acceso a todo el contenido por el usuario, la reutilizabilidad de los contenidos subidos al servidor por parte del profesor y la fácil actualización de los contenidos.

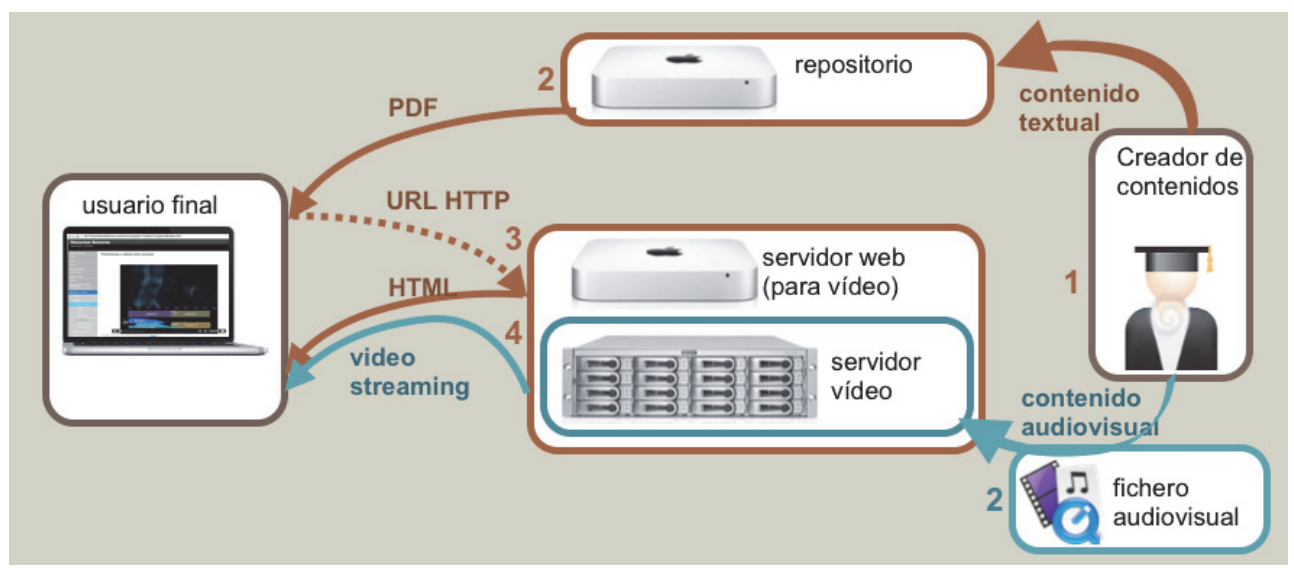

Fig. 8 La cadena de creación y visionado de contenidos textaules con material audiovisual utilizando PDF con enlaces a URLs.

La fácil accesibilidad de los contenidos es directamente un criterio de calidad contemplado en el estándar UNE 66181 (Hilera González, 2008), y además la ergonomía y calidad estética de disponer de los videos dentro del texto es un factor a tener en cuenta ya que "la facilidad para navegar, proporcionalidad adecuada de los elementos (desde un punto de vista funcional), disposición adecuada de los elementos (desde un punto de vista funcional) y la consistencia en el acomodo de los elementos, que se encuentran considerados en los

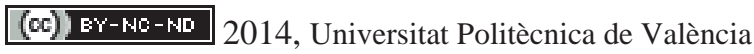

I Jornadas IN-RED (2014) 
Artículos docentes de estudios audiovisuales ilustrados con material audiovisual: HTML versus PDF con vídeo embarcado

elementos estéticos y ergonómicos se relacionan a la usabilidad" de los objetos de aprendizaje (Velázquez Amador, 2011). Por todas estas consideraciones, se recomienda el formato web, utilizando las normas de HTML5 para abstraerse de las idiosincrasias de navegadores y servidores, utilizando servidores de streaming institucionales como Politube (http://politube.upv.es/), el servidor de streaming propio de la UPV.

La opción del contenido referenciado o de enlaces externos es fácilmente implementable en cualquier documento html (web), pdf con enlaces, o incluso documentos de procesadores de texto habituales (pages, word), pero hace más compleja la navegabilidad, y, en cierto modo, interrumpe la continuidad del documento, como se puede ver en la figura 8 . Sin embargo es de muy fácil creación, ya que en general basta con copiar la url en un editor de texto para que el enlace se active, por ejemplo El leitmotiv en música audiovisual: Moon river http://politube.upv.es/play.php?vid=46239 (Payri 2010).

\section{Material audiovisual y PDF: Adobe Acrobat Pro e InDesign}

Como indicábamos anteriormente, si un artículo docente está en formato PDF. nos restringe o al contenido referenciado (con todos sus inconvenientes de usabilidad y navegabilidad) o al contenido embarcado en el PDF.

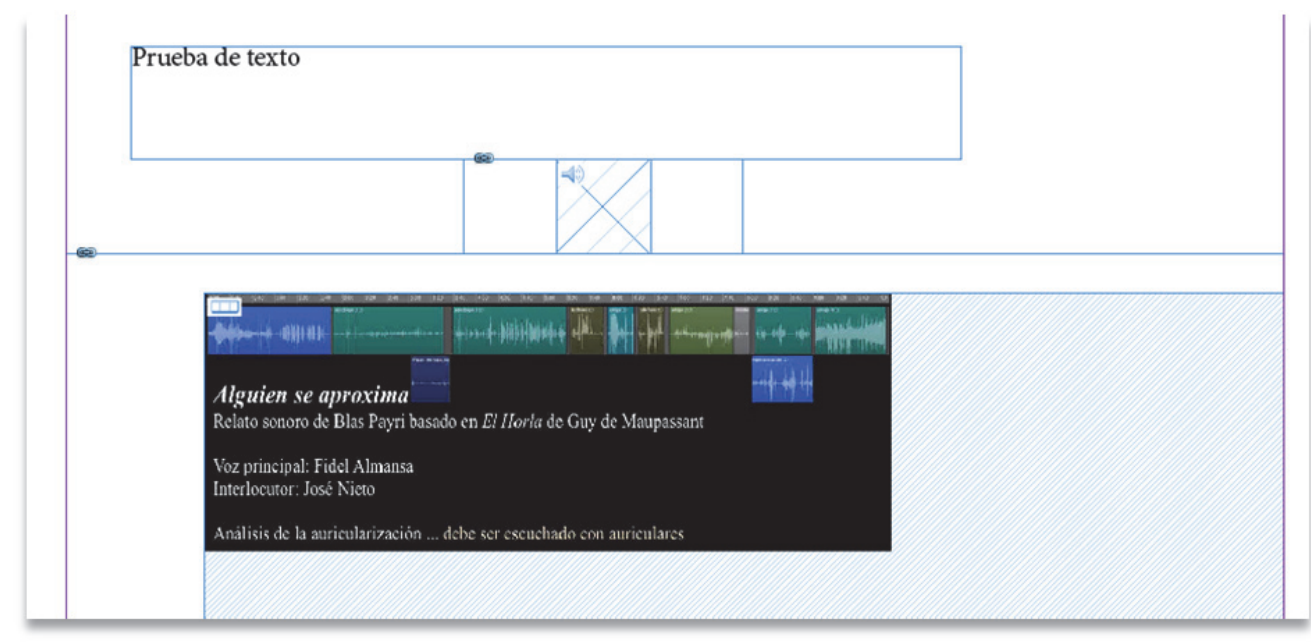

Fig. 9 Documento de InDesign donde se insertan objetos de texto y objetos audiovisuales para exportación a PDF

Para embarcar el contenido audiovisual en el documento PDF, existen solamente dos herramientas, desarrolladas por Adobe y que son de pago: Acrobat Pro e InDesign. En la figura 9, se puede ver un ejemplo de desarrollo en InDesign, y para más referencias se puede consultar el artículo presentado por Payri, Prósper Ribes, y Ramón Fernández (2012). En el caso de InDesign, "los clips de película y sonido añadidos a un documento se 
pueden reproducir una vez exportado el documento a Adobe PDF o SWF, y también si se exporta a XML y se reorganizan las etiquetas.

Puede importar archivos de vídeo con formato Flash Video (.FLV y .F4V), archivos con codificación H.264 (por ejemplo, MP4) y archivos SWF. Puede importar archivos de audio con formato MP3. Los archivos multimedia como QuickTime (.MOV), AVI y MPEG se admiten en los archivos PDF interactivos exportados, pero no en los archivos SWF ni FLA exportados. Recomendamos formatos como FLV, F4V, SWF, MP4 y MP3 para beneficiarse de la extensa compatibilidad para contenido multimedia enriquecido ofrecida por Acrobat 9, Acrobat Reader 9 y Adobe Flash Player 10 o posterior." (http://help.adobe.com/es_ES/indesign/cs/using/WS188C0BC9-4FED-4b4a-BC8C-

7E7C6E2BA7E1.html ). Es muy importante destacar que los PDF con vídeos embarcados no se pueden reproducir por otros lectores PDF generales como Vista Previa, y solamente se pueden leer por las versiones recientes de los productors de Adobe, y por ejemplo no se pueden reproducir en línea.

Indesign permite generar un PDF con vídeo embarcado a la vez que una versión HTML donde se vuelcan los vídeos en subcarpetas correspondientes, con lo que se podría publicar como documente HTML (webarchive) donde los contenidos audiovisuales están embarcados o servidos desde el mismo servidor web (y no por streaming o desde un servidor de vídeo).

Surge la cuestión de si se debe crear un material audiovisual específico para el PDF, con menos definición y tamaño menor de manera que no pese tanto el documento final, lo que supondría un trabajo añadido.

\section{Una experiencia concreta: del material audiovisual embarcado a enmarcado}

En las asignaturas de análisis o diseño de sonido audiovisual, esencialmente en el Máster de Postproducción Digital de la UPV, se ha optado por la entrega de los trabajos utilizando Pages para insertar vídeos en un documento de estilo académico (Payri 2009a, 2009b), es decir, con el material audiovisual embarcado (Payri 2013). Esto permite entregar el contenido audiovisual junto con los comentarios, en una suerte de artículo académico que respete las diferentes normas y que podría corresponder a los artículos docentes que tratamos aquí.

Para el curso 2013-14 se ha optado para la asignatura de Sonido Extradiegético crear en los blogs de la UPV una web específica que utiliza Wordpress, a la que los alumnos pueden acceder y crear nuevas páginas HTML que incluyan los vídeos enmarcados que se sirven desde Politube, y que se ilustra en la figura 10.

\section{(c) EY-NC-ND 2014, Universitat Politècnica de València}

I Jornadas IN-RED (2014) 
Artículos docentes de estudios audiovisuales ilustrados con material audiovisual: HTML versus PDF con vídeo embarcado

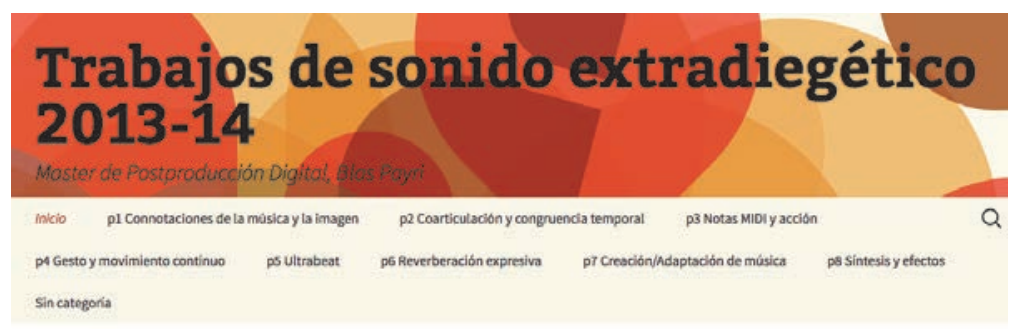

\section{Práctica 6 Reverberación expresiva (Jaime Bernabeu)}
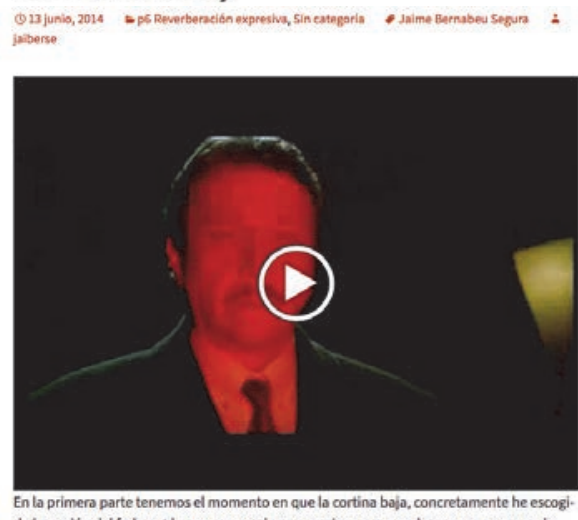

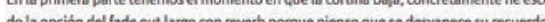

Fig. 10 Captura de pantalla de la página http://sonidoextradiegetico1314.blogs.upv.es en la que los alumnos van entregando las prácticas en forma de entradas html de un blog Wordpress.

Este procedimiento ha agilizado tanto la entrega y realización de los contenidos de las prácticas como su visualización y evaluación por el profesor. Permite además ofrecer ejemplos fácilmente navegables por cualquier usuario con los navegadores habituales, a la diferencia de un documento Pages que solamente es visible una vez descargado y visualizado con el programa mismo (aunque se puede generar ciertos contenidos multiplataforma con iCloud y Pages https://www.apple.com/es/icloud/ )

En la práctica, el contenido embarcado es engorroso, muy pesado y no tan fiable como el HTML que es un estándar abierto y largamente comprobado, por eso se va a descartar en futuras convocatorias la utilización de contenidos embarcados utilizando únicamente el formato HTML + vídeo enmarcado servido por un servidor tipo Politube.

\section{Conclusiones}

La experiencia descrita en los puntos anteriores indica que la mejor manera de crear artículos docentes que incluyan ejemplos audiovisuales es la utilización del HTML. De 
hecho, una revisión de las webs de revistas con artículos sobre música y audiovisual que contienen ejemplos audiovisuales siempre están en formato HTML con vídeos enmarcados (e.g. http://www.musimediane.com/).

Los artículos docentes restringidos a documentos PDF imponen dos opciones:

Un PDF que tiene enlaces a vídeos que estén en diferentes servidores de vídeo, lo que interrumpe la navegación y dificulta la experiencia del alumno

Un PDF interactivo que tenga los vídeos embarcados, lo que representa una dificultad alta de realización, de mantenimiento y difusión, y una usabilidad media para el usuario, y no se pone de hecho nunca en práctica en las revistas o páginas web docentes encontradas.

Partiendo de esta constatación, conviene pues adaptarse a las necesidades reales de los artículos docentes en el ámbito audiovisual y musical, evitando un proceso complicado y póco útil. Para ello, la solución ofertada por los blogs y webs basadas en la plataforma HTML, como los Poliblogs de la UPV, puede ser idónea en varios aspectos:

- $\quad$ Facilidad de uso por parte del profesor-usuario que crea el artículo docente

- $\quad$ Poliblogs permite la gestión de usuarios con diferentes niveles de acceso, creando el creador de contenidos, el validador y otras figuras que pueden corresponder directamente a las etapas de redacción, recepción, corrección y validación de unos artículos docentes revisados.

- $\quad$ Una vez validado el contenido del artículo docente, puede permanecer en el blog creado para la ocasión, y en ese blog se pueden crear categorías y subcategorías para clasificar los artículos, los usuarios finales pueden hacer búsquedas por autores o contenidos, y puede ser fácilmente indexado y navegado por buscadores como Google, generando una mayor visibilidad y utilizabilidad. Los artículos permanece con una fecha de publicación que puede ser luego referenciada.

Por estas razones, la inclusión del HTML como modo de presentación de los artículos docentes sería una ventaja para docentes y alumnos, y podría aprovechar las maneras más actuales y duraderas de creación de contenido a través de los blogs UPV que incluyen la gestión y actualización de Wordpress con todas las ventajas que ello implica.

\section{Referencias}

AENOR (2008). Gestión de la calidad. Calidad de la Formación Virtual. UNE 66181:2008. Madrid: AENOR.

ABDOUS, M. y YOSHIMURA, M. (2010). "Learner outcomes and satisfaction: A comparison of live video-streamed instruction, satellite broadcast instruction, and face-to-face instruction". Computers \& Education, 55 (2), pp. 733-741.

\section{(c)) EY-NC-ND 2014, Universitat Politècnica de València}

I Jornadas IN-RED (2014) 
Artículos docentes de estudios audiovisuales ilustrados con material audiovisual: HTML versus PDF con vídeo embarcado

BENGOCHEA, L., BUDIA, F. y MEDINA, J.A. (2012). "Videotutoriales subtitulados, un material didáctico accesible" en III Congreso Iberoamericano sobre Calidad y Accesibilidad de la Formación
Virtual
(CAFVIR).
Alcalá
de
Henares.
Disponible
en

http://www.esvial.org/cafvir2013/documentos/LibroActasCAFVIR2012.pdf

CETINA PRESUEL, R. y CORREDOIRA Y ALFONSO, L. (2011). "Vídeo on Demand para la Educación e Investigación: Excepciones al derecho de autor". ZER, vol. 16, 30, pp. 153-169. http://www.ehu.es/zer/hemeroteca/pdfs/zer30-08-cetina.pdf

GRIFFIN, D. K., MITCHELL, D., \& THOMPSON, S. J. (2009). Podcasting by synchronising PowerPoint and voice: What are the pedagogical benefits? Computers \& Education, 53, 532-539.

HILERA-GONZÁLEZ, J.R. (2008). "UNE 66181:2008, el primer estándar sobre calidad de la formación virtual". RED, Revista de Educación a Distancia, VII. http://www.um.es/ead/red/M7/hilera.pdf

PAYRI, B. (2009a). Insertar videos en Pages. http://politube.upv.es/play.php?vid=4202

-(2009b). Configurar vídeos en un documento académico. http://politube.upv.es/play.php?vid=4201

-(2012). Los recursos sonoros audiovisuales. <https://poliformat.upv.es/access/content/group/DOC_32094_2013/recursosSonoros/index.html> [Consulta: 16 de junio de 2014]

- (2013) Plantilla para el proyecto de análisis comparativo de recursos sonoros en series de ficción. Asignatura de Análisis avanzado de recursos narrativos sonoros, 2013-14. https://poliformat.upv.es/access/content/group/DOC_32094_2013/Plantilla\%2BRecursos\%2Bsonoros2 013-14.pages

PAYRI, B., PRÓSPER RIBES, J. y RAMÓN FERNÁNDEZ, F. (2012). "Comparativa de sistemas para introducir material audiovisual en documentos escritos" en Jornadas de Innovación Educativa. ICE: Universitat Politècnica de València. 262-266.

RUTHENSTEINER, B. y HESS, M. (2008). "Embedding 3D models of biological specimens in PDF publications". Microsc Res Tech, 71 (11), pp. 778-786. doi: 10.1002/jemt.20618

VÁZQUEZ CANO, E. (2013). El videoartículo: nuevo formato de divulgación en revistas científicas y su integración en MOOCs. Comunicar , 41, 83-91.

VELÁZQUEZ AMADOR, C.E. et alii (2011). "Una Experiencia en el Desarrollo Masivo de Objetos de Aprendizaje Empleando Parámetros de Calidad y un Proceso de Gestión Bien Definido". IEEERITA Revista Iberoamericana de Tecnologías del Aprendizaje, Vol. 6, 4, pp.155-163. http://rita.det.uvigo.es/201111/uploads/IEEE-RITA.2011.V6.N4.pdf 


\title{
Laboratorio Virtual Interactivo y Portable para el Estudio de Calidad de Servicio en Redes de Comunicaciones de Siguiente Generación (NGN)
}

Angel Gomez-Sacristan ${ }^{\mathrm{a}}$, Víctor M. Sempere Paya ${ }^{\mathrm{b}}$, Miguel A. Rodriguez-Hernandez aDCOM, Universitat Politécnica de Valéncia, Valencia, Spain. agomez@dcom.upv.es bITI, Universitat Politécnica de Valéncia, Valencia, Spain. vsempere@dcom.upv.es 'ITACA, Universitat Politécnica de Valéncia, Valencia, Spain. marodrig@ upvnet.upv.es

\begin{abstract}
Virtual Labs based on advanced simulation tools play an important role during student learning. The experimentation capacity and flexibility in the simulation hypotheses contribute to a better understanding of complex technologies using a graphical environment. Arbitrary systems can be designed, and with relative ease, measure their performances with changes as equipment and links capacity, traffic type, congestion control mechanisms, etc. This work describes a virtual lab developed for learning telecommunication Next Generation Networks (NGN) based on MetroEthernet Access Technologies.
\end{abstract}

Keywords: Virtual laboratory, communication engineering education, NGN, QoS, MetroEthernet

\footnotetext{
Resumen

Los Laboratorios Virtuales basados en herramientas avanzadas de simulación desempeñan un importante papel como facilitadoras del aprendizaje del alumno. La capacidad de experimentación que aportan y la flexibilidad en las hipótesis de simulación contribuyen a la mejor comprensión de tecnologías complejas bajo un entorno gráfico. Pueden diseñarse sistemas arbitrarios, y con relativa facilidad, evaluar su comportamiento ante cambios como capacidad de enlaces y equipos, naturaleza del tráfico, mecanismos de control de congestión, etc. Este trabajo describe un laboratorio virtual desarrollado para el aprendizaje de
}

(c) EY-NC-ND 2014, Universitat Politècnica de València

I Jornadas In-Red (2014) 


\author{
Redes de Telecomunicaciones de Siguiente Generación basadas en \\ tecnologías de acceso Metro-Ethernet.
}

Palabras clave: Laboratorio virtual, ingeniería de telecomunicaciones, redes de nueva generación, calidad de servicio, MetroEthernet

\title{
1. Introducción
}

La enseñanza en las Escuelas de Ingeniería, especialmente en aquellas relacionadas con las Tecnologías de la Información y de las Comunicaciones, donde el dinamismo y la innovación son continuos, se enfrenta a retos importantes. La evolución del modelo de aprendizaje, mayor peso de la actividad de laboratorio, requiere inversiones en equipamiento específico, en muchos casos inasumibles y en poco tiempo obsoletas. Por otra parte las nuevas tendencias docentes implican una participación más activa y autónoma del alumno durante el proceso de aprendizaje. Para conseguir los anteriores objetivos se presenta en este trabajo un laboratorio virtual dentro del ámbito de las telecomunicaciones que permite simular sistemas novedosos con una participación activa del alumno.

En los laboratorios virtuales de simulación, los sistemas y dispositivos reales son sustituidos por ordenadores que ejecutan los simuladores adecuados. Las redes de telecomunicación son sistemas en los que el número de elementos puede ser muy elevado y con grandes distancias entre ellos. Por ello, en muchos casos, la capacidad de experimentación sobre elementos reales por parte del alumno es imposible teniendo que recurrir a soluciones alternativas. En los laboratorios virtuales la capacidad de experimentación es alta debido a la flexibilidad en las hipótesis simulación, además los estudiantes suelen valorar positivamente los resultados obtenidos. Por lo tanto, simulación y laboratorios virtuales son una buena solución para la enseñanza en Ingeniería.

Para la implementación de los laboratorios virtuales se pueden tener en cuenta dos posibilidades. La primera consiste en plantear la realización de una plataforma de simulación con acceso vía internet donde el estudiante pueda trabajar de forma totalmente independiente y con acceso desde cualquier punto con conexión a internet, este es el modelo propuesto en (Marqués 2006). Un segundo planteamiento consiste en implementar el entorno de simulación dentro de una sala con ordenadores dentro de las dependencias de la universidad, como plantea (Dobrilovic, 2012). El laboratorio con acceso universal desde cualquier punto con conexión a internet es muy flexible e independiza los horarios de estudio de los alumnos, sin embargo, el alumno pierde la ayuda personalizada e inmediata 
del profesor para la resolución de problemas y dudas. Cuando el objeto de aprendizaje tiene un cierto grado de complejidad, es conveniente la presencia de un profesor que guíe de forma local al estudiante. En el laboratorio local se tiene al profesor pero sin embargo el alumno pierde la posibilidad de experimentar fuera de un horario predeterminado.

Con el fin de compatibilizar autonomía del estudiante y ayuda por parte del profesor, el presente trabajo plantea una práctica que se divide en varias etapas. La etapa inicial se realiza en un aula de ordenadores con presencia simultánea de estudiantes y profesor, donde los alumnos cuentan con ayuda para resolver sus dudas. La segunda etapa se realiza de forma autónoma por los alumnos y desde cualquier ordenador. Para hacer posibles estas dos etapas ha sido necesario realizar el laboratorio virtual sobre una sala con ordenadores en el recinto universitario, pero sobre un simulador de libre distribución que permite al estudiante la posibilidad de instalación en su ordenador personal. El software elegido para el desarrollo del laboratorio virtual ha sido el simulador de redes Omnet++. (OMNET)

Las redes de nueva generación (Next Generation Network, NGN) (ITU-T Y.2001), evolución de las redes existentes de voz, datos y multimedia, son objeto de estudio en la formación de los futuros ingenieros. A diferencia de las redes de telecomunicaciones clásicas, en NGN, servicios y aplicaciones de muy diferente naturaleza comparten recursos de una infraestructura común. Por ello es necesario introducir en la red mecanismos de gestión de tráfico que garanticen para cada uno de los servicios subyacentes el mantenimiento de los objetivos de calidad recogidos en las recomendaciones internacionales (ITU-T Y.2111, Y.2112).

El ecosistema Ethernet se está convirtiendo en un estándar de facto en entornos empresariales e industriales por sus características de sistema abierto, ubicuidad, mayor flexibilidad y menores costes. Servicios tradicionales incluidos voz, datos y multimedia, además de otros dispositivos de control y monitorización, como sensores y redes industriales, convergen hacia esta arquitectura

Con el cambio de paradigma que representa NGN, y la presencia ubicua de Ethernet, las redes de acceso basadas en esta tecnología, como Metro Ethernet (Metro Ethernet Forum) constituyen hoy el método preferido por muchas empresas para soportar todos los servicios de telecomunicación que requieren para sus procesos de negocio.

En un escenario real, múltiples fuentes y tráfico heterogéneo (isócrono para tráfico de voz, de tasa variable para servicios de vídeo, asíncrono para tráfico de alarmas, best-effort, etc.) con diferentes necesidades de latencia, pérdida de paquetes y jitter, compiten por un ancho de banda.

Los estándares MetroEthernet permiten la definición de diferentes mecanismos para priorizar unos tráficos sobre otros (Metro Ethernet Forum), pero describir analíticamente el

\section{(c)) EY-NC-ND 2014, Universitat Politècnica de València}




\section{Laboratorio virtual interactivo}

comportamiento de un interfaz de estas características es una tarea compleja. Sin embargo, simular escenarios MetroEthernet con fuentes de tráfico configurables y evaluar su respuesta ante diferentes variaciones de parámetros relevantes, puede contribuir a una mejor comprensión por parte del alumno de estos mecanismos y facilitar su aprendizaje.

El objetivo de este trabajo es describir una herramienta de simulación desarrollada para facilitar a los alumnos una mejor comprensión de los mecanismos relacionados con la Calidad de Servicio en redes MetroEthernet, así como los resultados obtenidos con ella, tanto desde el punto de vista de simulación de sistemas de comunicaciones como de los resultados de aprendizaje obtenidos al aplicarlos para la enseñanza.

El Laboratorio Virtual se ha desarrollado sobre el simulador de libre acceso OMNET++. La elección de un entorno abierto y portable para el diseño del Laboratorio Virtual ha permitido construir una metodología de aprendizaje basada en tres ejes: el trabajo autónomo del alumno para comprender aspectos teóricos del problema y el manejo de la herramienta de simulación, la iteración presencial alumno-profesor como referencia y supervisión en la realización de los diferentes experimentos y por último, el trabajo en equipo para compartir experiencias y afianzar los conocimientos adquiridos

La estructura de este paper es la siguiente: En el apartado 2 se describirán los objetivos y la metodología de aprendizaje. En el apartado 3 se explican de forma breve las características del entorno de simulación, Omnet++. En el apartado 4 se describe el laboratorio virtual. El apartado 5 trata sobre las simulaciones que realizan los alumnos con las herramientas previamente descritas. El apartado 6 presenta la evaluación del laboratorio virtual realizada por los alumnos mediante una encuesta de satisfacción tras haber concluido la práctica. Finalmente el apartado 7 contiene las conclusiones del artículo.

\section{Objetivos y Metodología de Aprendizaje}

La utilización de la herramienta de simulación propuesta requiere que el alumno posea conocimientos suficientes sobre arquitectura y protocolos utilizados en las redes de conmutación de paquetes. La simulación por tanto cubre el aprendizaje práctico de contenidos teóricos que han sido previamente desarrollados en el aula. Este laboratorio virtual forma parte de la asignatura de Redes de Acceso que se imparte en $3^{\circ}$ curso de Ingeniería de Telecomunicación en la Escuela de Ingenieros de Telecomunicación de la Universidad Politécnica de Valencia.

El primer objetivo que se persigue con este laboratorio virtual es conseguir que el alumno identifique los mecanismos relacionados con la calidad de servicio en redes MetroEthernet, comprenda su funcionamiento y extraiga conclusiones sobre cada una de los diferentes escenarios disponibles en el entorno de simulación. Un segundo objetivo pero no menos 
importante, es fomentar el trabajo en equipo, la colaboración e intercambio de ideas entre alumnos-profesor y por último responsabilidad y autonomía.

Para ello, esta práctica de 10 horas de duración, se ha dividido en tres fases diferenciadas. La primera fase consiste en una actividad autónoma del alumno, de unas dos horas de duración, soportado por un documento guía donde se repasa la base teórica con información suficiente para la realización de cada uno de los experimentos, tareas a realizar, hojas de resultados obtenidos etc. La segunda fase, de 4 horas en dos sesiones de laboratorio y grupos de trabajo de dos alumnos, consiste en la realización de un conjunto de tareasexperimentos de dificultad creciente con el soporte in-situ del profesor. La tercera fase, de 4 horas de duración en la que el alumno trabaja de forma autónoma con su propio ordenador y en horario libre, consiste en la realización de experimentos similares sobre un escenario de mayor complejidad. En este caso, el alumno cuenta con la tutoría on-line del profesor.

La verificación de que el alumno ha alcanzado los objetivos del aprendizaje se realiza mediante el análisis de la respuesta del alumno a diferentes cuestiones que se plantean en el manual del laboratorio, hojas de resultados y la evaluación continua del profesor.

Por la complejidad del entorno de simulación y de los propios experimentos, es conveniente la realización de parte de la práctica en el aula de ordenadores de la Universidad con la presencia in situ del profesor que imparte la asignatura para ofrecer soporte y facilitar el aprendizaje de los alumnos. Una vez conseguido que al alumno maneje adecuadamente el entorno, la última parte de la práctica podrá realizarla de manera autónoma. Para ello y entre otras razones, la práctica se ha desarrollado sobre un entorno de simulación abierto (opensource) y portable como es Omnet++.

\section{Descripción del Entorno de Simulación}

Para la implementación del Laboratorio Virtual se ha utilizado la herramienta OpenSource Omnet++ (Omnet) y elementos de la biblioteca inet convenientemente modificados. Se ha seleccionado OMNeT++ por su carácter abierto y gratuito, modularidad, facilidad de integración y experiencia previa de uso en otras tareas de investigación.

OMNeT++ es una herramienta de simulación de eventos discretos ampliamente utilizada en el diseño y evaluación de redes de telecomunicaciones, sistemas complejos de IT, redes de colas y arquitecturas hardware.

Un modelo de simulación en OMNeT++ consiste en módulos jerárquicamente anidados que se comunican mediante paso de mensajes. Los módulos activos se denominan módulos simples y su comportamiento se define mediante ficheros escritos en lenguaje C++. Los

\section{(cc)) EY-NC-ND 2014, Universitat Politècnica de València}




\section{Laboratorio virtual interactivo}

módulos simples pueden agruparse dentro de otros módulos, llamados módulos compuestos.

En la simulación de redes, los módulos simples pueden representar fuentes de tráfico, entidades de protocolo, dispositivos de red, estructuras de datos como tablas de encaminamiento, etc. Los nodos de red como hosts y routers son ejemplos de módulos compuestos, formados por módulos simples.

Para facilitar el desarrollo rápido de modelos de simulación, existen diferentes bibliotecas con módulos que simulan elementos de red y protocolos. Concretamente, la biblioteca llamada INET (Inet) contiene implementaciones de ciertos equipos y protocolos genéricos. Para el desarrollo del caso de estudio descrito en el presente artículo ha sido necesaria la creación de nuevos elementos funcionales para soportar tramas Ethernet etiquetadas con IEEE 802.1Q (IEEE), así como la modificación y ampliación del código de algunos elementos de la propia biblioteca INET. Un ejemplo del entorno de simulación puede observarse en la figura 1.

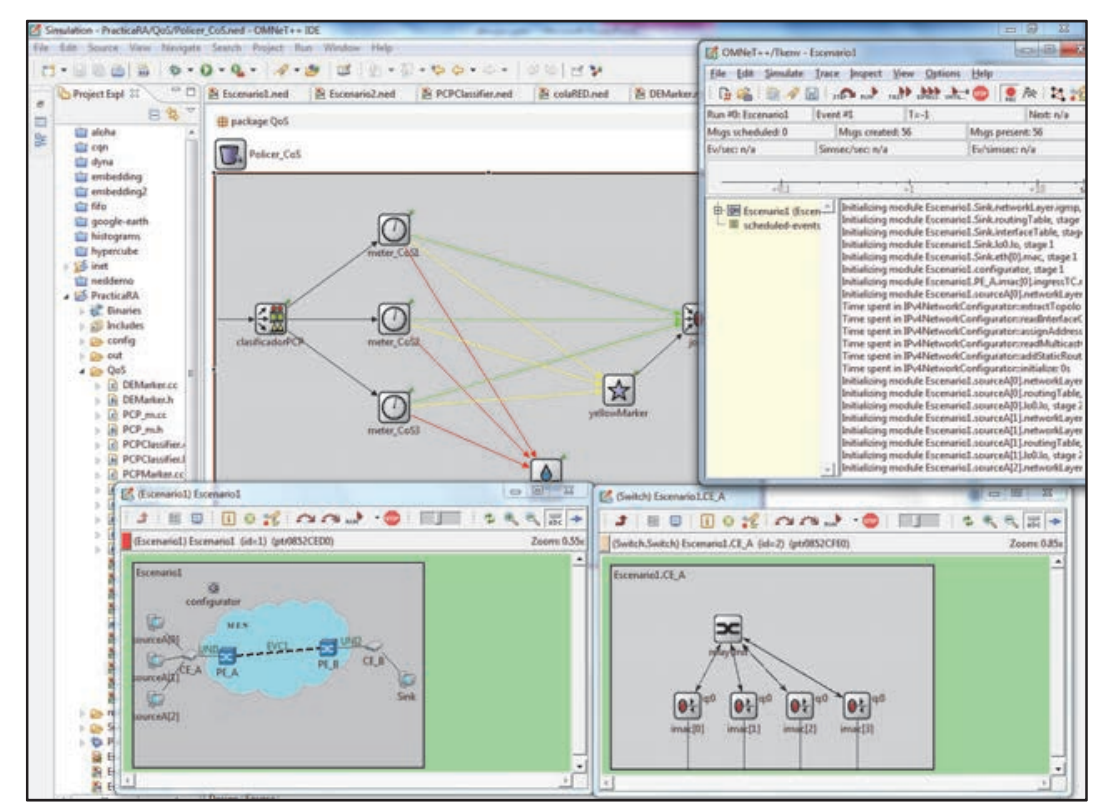

Fig 1. Entorno de Simulación 


\section{Descripción del Laboratorio Virtual}

El escenario desarrollado simula un entorno real de conectividad de una empresa a una red NGN con acceso MetroEthernet. Normalmente existirá un número arbitrario de fuentes de tráfico Ethernet conectadas a un Switch a través de una red local cableada o inalámbrica. Este switch, conocido como "Customer Equipment" (CE), realiza las funciones de marcado de tramas en función de la prioridad de cada fuente asignada por el usuario y realizará las funciones de interfaz con la red Metro Ethernet del Operador.

El nodo del Operador, conocido como "Provider Equipment" (PE) implementa entre otras, funciones policía, control del uso de recursos, y gestión de colas de salida para garantizar el cumplimiento del contrato de tráfico definido en el EVC (Ethernet Virtual Connection) cuyos parámetros principales son el caudal garantizado (CIR) y el caudal en exceso (EIR). En la figura 2 se observa la topología objeto de estudio.

En el escenario de trabajo propuesto se evalúa el comportamiento de un interfaz UNI (User Network Interface) MetroEthernet. Para ello se ha definido un servicio E-Line (Ethernet Private Line) con una conexión EVC punto a punto entre dos UNIs. Ambas UNIs son de $100 \mathrm{Mbps}$. Por simplicidad para el alumno se han definido tres tipos de fuentes con sus clases de servicio asociadas: voz, vídeo y best effort.

Cada una de estas fuentes, el interfaz UNI, los Ethernet Virtual Connection (EVC), el interfaz de salida, los mecanismos de control de tráfico, así como el tiempo de simulación son totalmente configurables mediante un fichero editable de inicialización

Los experimentos se han organizado para que el alumno pueda analizar el impacto en términos de Calidad de Servicio (pérdida de paquetes, retardo, jitter, efecto de unas fuentes sobre otras y otros aspectos de interés) por modificaciones en el ancho de banda disponible, caudal contratado, y activación de los mecanismos de control de tráfico. Los resultados de los diferentes experimentos se presentan tanto en formato gráfico como tabular para su posterior procesado.

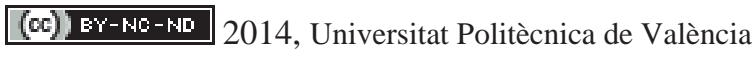

I Jornadas IN-RED (2014) 


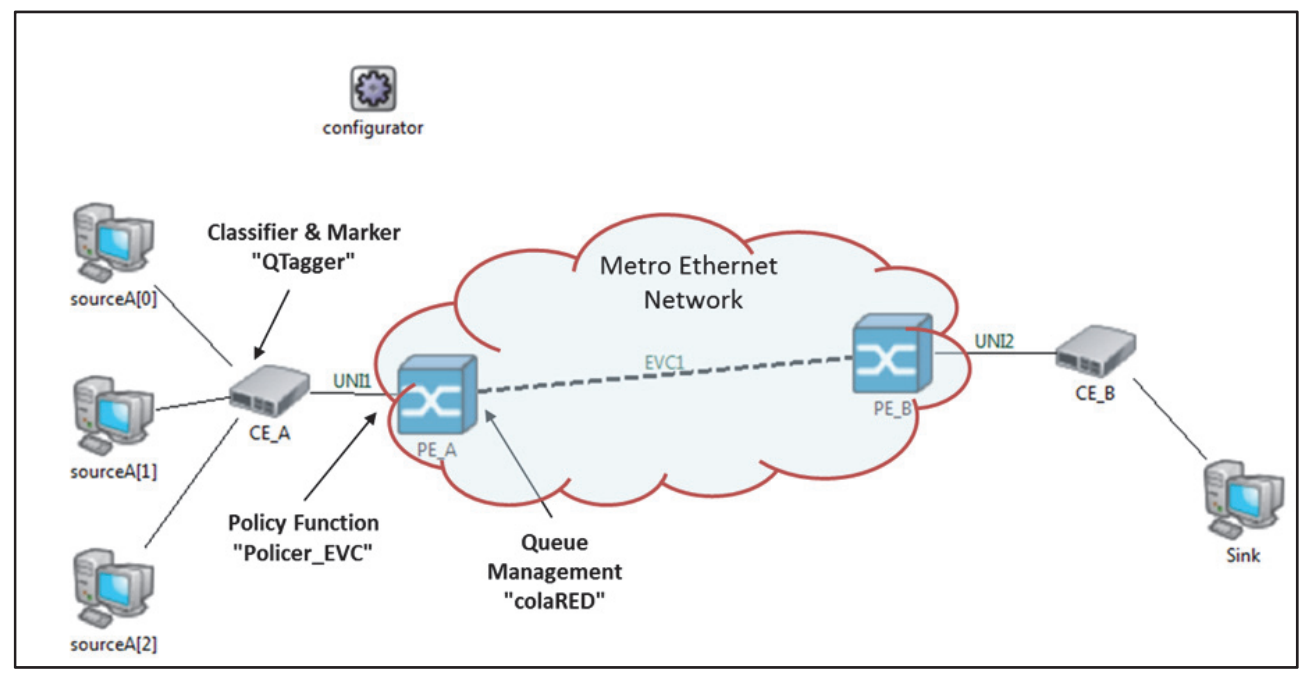

Fig 2. Escenario de Simulación de una Red

Durante la simulación se puede interactuar sobre cuatro bloques funcionales: Fuentes de tráfico, Marcado de tramas, Función policía y Gestión de colas. Las fuentes de tráfico son modeladas a partir del módulo "StandardHost" perteneciente a la biblioteca INET. Se trata de un módulo compuesto que a su vez contiene varios módulos simples, entre los cuales destacan los orientados a la generación de paquetes encapsulados en TCP o UDP. Dichos módulos simples ofrecen la posibilidad de generar flujos de paquetes cuyas características son totalmente configurables gracias a parámetros como el tamaño de los paquetes, el intervalo entre paquetes, duración de ráfagas o periodos de silencio. Se han configurado tres tipos de módulos que simulan tráfico de voz, video y best effort.

Una vez generado el tráfico es necesario identificarlo adecuadamente para que los nodos de la red (PE) sean capaces de diferenciarlos y aplicar las políticas de calidad de servicio apropiadas. Para ello los paquetes generados por cada una de las fuentes se marcan con un determinado valor de prioridad en el campo PCP (Priority Code Point) de la etiqueta IEEE 802.1Q.

La función policía es la encargada de comprobar y limitar el ancho de banda que consume cada clase de servicio. Se ha definido una función de policía asociada a cada una de las clases de servicio contratadas. El módulo diseñado para modelar esta función en el escenario de simulación es el módulo "Policer_CoS". Se trata de un módulo compuesto situado en la interfaz de entrada del nodo PE, el cual da acceso a la red del operador. Su funcionamiento está basado en el uso del algoritmo "trTCM" (two rate Three Color Meter) en su versión modificada descrita en la RFC 4115 (Aboul-Magd, 2005). 
El último paso para la implementación de QoS es la configuración de las colas de salida para ofrecer un tratamiento diferenciado a cada clase de servicio. Esta tarea es realizada por el módulo "colasCoS" situado en la interfaz de salida del nodo PE_A. En él se clasifica el tráfico entrante en tres clases de servicio con una cola asociada a cada una de dichas clases.

\section{Simulación y Resultados}

\subsection{Simulación de la Red sin Calidad de Servicio}

En este bloque se realizan 10 experimentos de creciente dificultad con el objetivo de que el alumno comprenda los efectos sobre el sistema producidos por variaciones de las características de las fuentes de tráfico, la longitud de las colas, el caudal contratado, etc.

El alumno debe configurar el escenario de simulación para cada experimento editando el fichero de inicialización del entorno de simulación con ciertos valores indicados en el documento guía, ejecutar el escenario e interpretar los resultados respondiendo a diversas cuestiones.

En este primer Bloque todos los tráficos tienen la misma prioridad y no se implementan mecanismos de QoS. Las tramas llegan al nodo "PE_A" sin distinción por Clases de Servicio (CoS) por lo que éste no puede activar los mecanismos de calidad de servicio disponibles. En este escenario la congestión de un nodo afecta al retardo de cualquier tipo de tráfico.

El perfil de ancho de banda contratado es por EVC (Ingress Bandwith Profile per EVC) y su cumplimiento se comprueba con el módulo "Policía"" (ver figura 3). En este caso, al no existir diferenciación por clases de servicio, se opta por marcar, en la función policía, las tramas conformes (tramas verdes) y la no conformes (tramas amarillas) con distintos valores de prioridad PCP simplemente para asegurar el caudal contratado en caso de congestión.

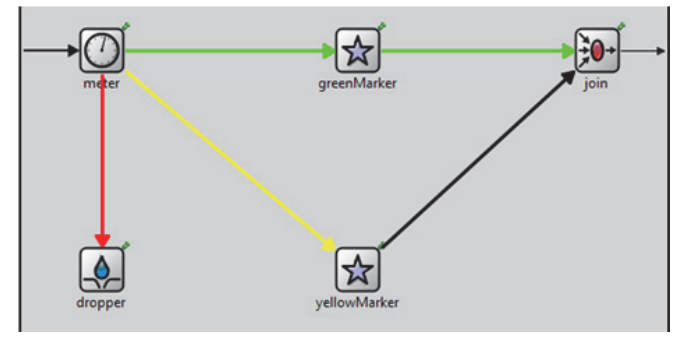

Fig 3 Módulo Policia 


\section{Laboratorio virtual interactivo}

En la interfaz de salida del nodo "PE_A" se lleva a cabo la gestión de colas. Para ello se hace uso del módulo "colaRED" (ver figura 4). Este módulo sólo implementa una cola de salida ya que en este ejercicio todo el tráfico recibe el mismo servicio. Su finalidad es simplemente la de dar servicio a las tramas verdes y descartar las amarillas cuando se experimente congestión en el nodo y así cumplir con el Caudal contratado. Esta tarea la realiza la función de descarte RED priorizando el descarte de tramas amarillas frente al descarte de tramas verdes cuando exista congestión.

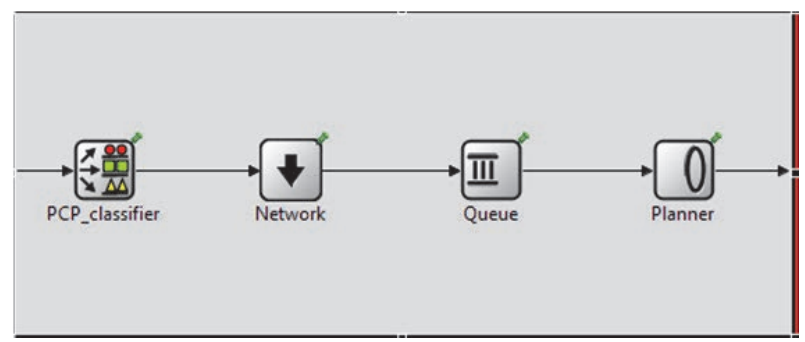

Fig 4 Módulo de Gestión de Colas

\subsection{Simulación de la Red con Calidad de Servicio}

En este segundo bloque que utiliza la misma metodología que en el Bloque anterior, se realizan 11 experimentos en los que el alumno podrá comprobar el efecto de la implementación de mecanismos de calidad de servicio (QoS) sobre el sistema de comunicaciones simulado. Para ello se diferencian los tipos de tráfico asignando tres tipos de prioridades, voz, vídeo y best effort. El escenario y el tráfico inicial es el mismo que en el ejercicio anterior, pero ahora el nodo "CE_A" va a marcar las tramas con los valores de prioridad PCP adecuados para diferenciar los tipos de tráfico.

Para marcar las tramas por clase de servicio se utiliza un clasificador que separa cada flujo de tráfico según su puerto destino, y tres marcadores (uno para cada CoS) que se encargan de escribir en el campo PCP de cada trama el valor adecuado para cada clase de servicio. En el escenario estos elementos se encuentran en un módulo llamado "QTagger" ubicado en el nodo "CE_A".

El perfil de ancho de banda contratado es por CoS (Ingress Bandwith Profile per CoS) se controla mediante el módulo "Policer_CoS". En este caso las tramas llegan a la función policía con el valor de prioridad PCP ya establecido, por lo que se ha decidido marcar las tramas no conformes con el valor de PCP correspondiente a "best effort" (baja prioridad) independientemente de la clase de servicio a la que pertenezcan, es decir, todo el tráfico que 
no cumpla el perfil, sea de la clase de servicio que sea, se envía a la cola menos prioritaria. Las tramas que sí que cumple el perfil de cada clase de servicio se transmiten con el valor PCP con el que llegaron y se envían a su cola correspondiente.

\subsection{Simulación de Red Basada en el Servicio E-line}

Una vez finalizada la actividad anterior, se propone al alumno un escenario de mayor complejidad basado en el servicio E-Line (Ethernet Virtual Private Line) con tráfico generado por tres sedes. En este caso, el tráfico de cada sede se clasifica y transporta en una Conexión Virtual Ethernet (EVC) que luego se multiplexa sobre un interfaz UNI en la salida de la red.

Este escenario persigue el alumno se familiarice con la gestión de recursos e ingeniería de tráfico utilizados por los Operadores de Red para garantizar la calidad de servicio contratada por cada usuario. Las funciones policía y de gestión de las clases de servicio son esencialmente las mismas que se implementan en el interfaz UNI pero la naturaleza del tráfico a gestionar será el agregado estadístico del tráfico generado por cada una de las fuentes en cada EVC.

El alumno trabaja con escenarios similares a los bloques I y II, con y sin calidad de servicio, extrapolado a un mayor número de fuentes y conexiones EVC e identificando el impacto de la gestión agregada de tráficos sobre un mismo EVC dentro de la red. Cada fuente de tráfico, interfaz UNI, PE y la gestión de colas puede ser configurados individualmente.

\section{Satisfacción de los Estudiantes con el Laboratorio Virtual}

Con el fin de evaluar el grado de satisfacción del alumno se realizó una encuesta a los alumnos que han realizado la práctica durante el curso 2013/2014. En concreto se pasó la encuesta a los alumnos de Redes de Acceso que se imparte en $3^{\circ}$ curso de Ingeniería de Telecomunicación en la Escuela de Ingenieros de Telecomunicación de la Universidad Politécnica de Valencia (Spain).

El formato de la encuesta contenía 10 preguntas que se evaluaban numéricamente entre 1 y 10. El formulario utilizado para la encuesta se muestra en la figura 5.

\section{(cc) EY-NC-ND 2014, Universitat Politècnica de València}


Laboratorio virtual interactivo

\begin{tabular}{||l|l||}
\hline \multicolumn{1}{|c||}{ CUESTIONES } & PUNTOS \\
\hline Me ha ayudado a comprender mejor los mecanismos de QoS. & \\
\hline La práctica es útil para mi aprendizaje. & \\
\hline Los ejemplos propuestos en la práctica son adecuados a la materia. & \\
\hline La organización de la práctica es clara y correcta. & \\
\hline El tiempo dedicado a la práctica ha sido suficiente. & \\
\hline El manejo del entorno de simulación ha resultado intuitivo. & \\
\hline El entorno de simulación gráfico ha facilitado el aprendizaje. & \\
\hline La tutorización local de la práctica por parte del profesor ha sido útil. & \\
\hline Valoro positivamente la posibilidad de continuar el trabajo en casa. & \\
\hline Mi valoración general de la práctica es positiva. & \\
\hline \hline
\end{tabular}

Fig 5 Formulario de la encuesta de satisfacción de alumnado

Los resultados de la evaluación de los alumnos fueron muy satisfactorios. La media de los resultados obtenidos para cada una de las preguntas se puede observar en la figura 6 .

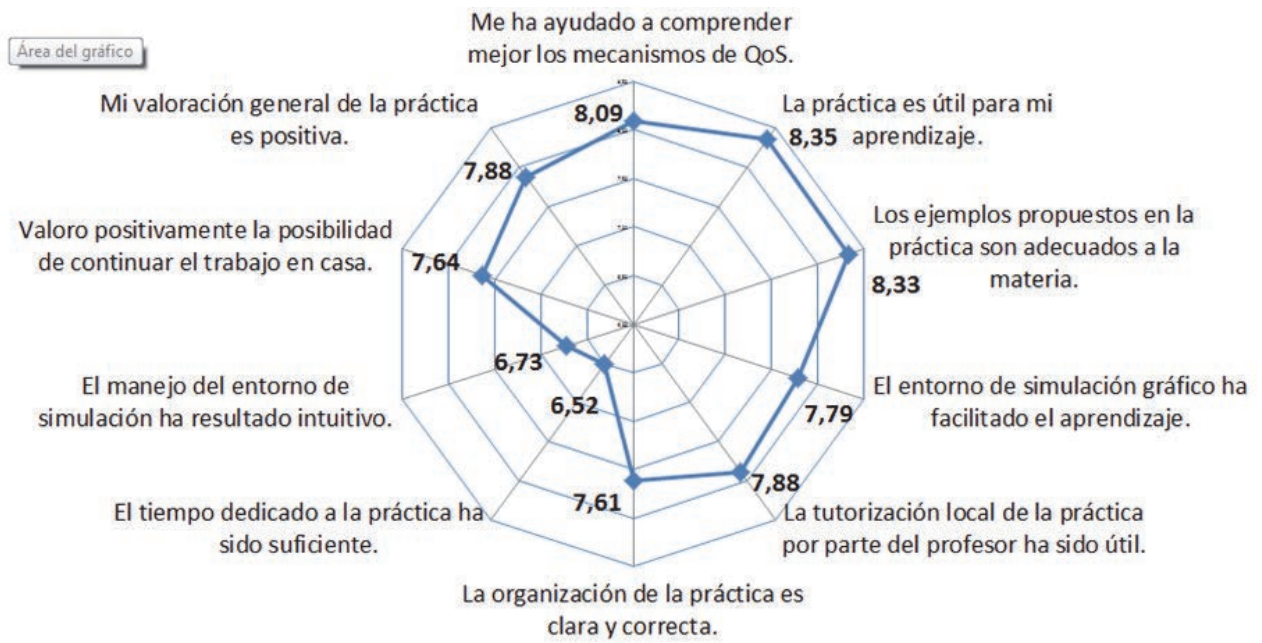

Fig 6 Resultados de la encuesta de satisfacción de alumnado

(c)) EY-NC-ND 2014, Universitat Politècnica de València

I Jornadas IN-RED (2014) 


\section{Conclusiones}

La utilización de entornos gráficos de simulación como Omnett++ aporta ventajas significativas en la enseñanza de ingenierías, especialmente en áreas relacionadas con las telecomunicaciones, donde el número, dispersión de los elementos y coste del equipamiento es elevado.

En el presente artículo se ha descrito un laboratorio virtual sobre Redes de Siguiente Generación basadas en tecnologías de acceso Metro-Ethernet para su utilización en tareas docentes y de investigación. La capacidad de experimentación que aporta el entorno descrito en el artículo y la flexibilidad en las hipótesis de simulación, contribuyen al mejor entendimiento de los mecanismos subyacentes de esta tecnología.

La elección de un entorno abierto y portable para el diseño del Laboratorio Virtual, ha permitido construir una metodología de aprendizaje basada en tres ejes: el trabajo autónomo del alumno para comprender aspectos teóricos del problema y el manejo de la herramienta de simulación, la iteración presencial alumno-profesor como referencia y supervisión en la realización de los diferentes experimentos y por último, el trabajo en equipo para compartir experiencias y afianzar los conocimientos adquiridos.

Complementariamente se ha realizado una encuesta de satisfacción al colectivo de alumnos para obtener información relevante sobre tres aspectos de interés: grado de consecución de los objetivos de aprendizaje, iteración profesor-alumno, y aspectos relacionados con la organización: facilidad de uso, calidad de la documentación, bibliografía, etc.

En cuanto al logro de los objetivos de aprendizaje, la interacción profesor-alumno, y la posibilidad de continuar el trabajo autónomo, los resultados han sido claramente satisfactorios. Los factores con mayor recorrido de mejora están relacionados con el manejo del entorno de simulación, ciertamente complejo y con el tiempo destinado a la realización de los experimentos. Aunque los alumnos finalizaron en su práctica totalidad las actividades programadas en el tiempo establecido, el aprendizaje del entorno de simulación consumió un tiempo significativo. Se está estudiando una posible acción de mejora consistente en impartir una formación básica del entorno Omnet++ antes de la práctica.

(cc)) EY-NC-ND 2014, Universitat Politècnica de València

I Jornadas IN-RED (2014) 


\section{Referencias}

ABOUL-MAGD O., RABIE S. (2005) A Differentiated Service Two-Rate, Three-Color Marker with Efficient Handling of in-Profile Traffic, RFC 4115.

DOBRILOVIC D., BRTKA V., BERKOVIC I., y ODADZIC B. (2012), Evaluation of the virtual network laboratory exercises using a method based on the rough set theory, Comput Appl Eng Educ vol. 20, pp. 29-37, DOI: 10.1002/cae.20370.

IEEE Std. 802.1Q-2011, Media Access Control (MAC) Bridges and Virtual Bridged Local Area Networks ISBN 978-0-7381-6708-4.

INET Project,"http://inet.omnetpp.org/

ITU-T Recommendations Y. 2001- Next generation Networks General Overview.

ITU-T Recommendations Y.2111: Next Generation Networks, Quality of Service and performance. Resource and admission control functions in next generation networks

ITU-T Recommendations Y.2112: Next Generation Networks, Quality of Service and performance. A QoS control architecture for Ethernet-based IP access networks

MARQUES J. M., LAZARO D., JUAN A. A., VILAJOSANA X., DOMINGO M., JORBA J. (2006), PlanetLab@UOC: A Real Lab Over the Internet to Experiment With Distributed Systems, Comput Appl Eng Educ vol. 21, pp. 265-275, DOI:10.1002/cae.20468.

METRO ETHERNET FORUM, www.metroethernetforum.org

OMNET Project, http://omnetpp.org/ 


\title{
Una herramienta informática eficaz y eficiente para la evaluación continua. Aplicación práctica a varias asignaturas de Teoría de
} Estructuras

\author{
José Casanova Colón ${ }^{a}$, Carlos R. Sánchez Carrataláb ${ }^{b}$ Carlos M. Lázaro Fernández ${ }^{\mathrm{c}}$ y \\ Salvador Monleón Cremades ${ }^{\mathrm{d}}$ \\ Departamento de Mecánica de los Medios Continuos y Teoría de Estructuras, Universitat Politècnica \\ de València. \\ jicasanova@mes.upv.es, ${ }^{\mathrm{b}}$ csanchez@mes.upv.es,${ }^{\mathrm{c}}$ carlafer@mes.upv.es, ${ }^{\mathrm{d}}$ smonleon@mes.upv.es
}

\begin{abstract}
This paper describes the main features and characteristics of a software tool that, when used in conjunction with the PoliformaT educational platform, allows to accurately correct a large number of exercises and provides appropriate feedback to students, all this with a manageable amount of work for the professor. Additionally, the way in which this tool has been used in three subjects in the field of the Theory of Structures corresponding to the first and second years of the Degree of Civil Engineering taught in the ETSICCP of the UPV is exposed, and the reasons for its adoption are argued. Finally, the relationship between scores on electronic submissions and on examinations are discussed, concluding that well managed submissions have contributed to student learning and enabled them to improve their score.
\end{abstract}

Keywords: continuous evaluation, automated correction, PoliformaT educational platform, teaching and learning methodologies, educative feedback, sustainable didactic approach.

\footnotetext{
Resumen

En esta ponencia se describe las principales funcionalidades y características de una herramienta informática que, usada conjuntamente con la plataforma educativa PoliformaT, permite corregir con precisión un número elevado de ejercicios y proporcionar la adecuada retroalimentación a los estudiantes, todo ello con una cantidad de trabajo asumible para el profesor. Asimismo, se expone la forma en que se ha utilizado esta herramienta en tres asignaturas de la rama de Teoría de Estructuras
}

(c)) EY-NC-ND 2014, Universitat Politècnica de València

I Jornadas In-Red (2014) 
Una herramienta informática eficaz y eficiente para la evaluación continua. Aplicación práctica a varias asignaturas de Teoría de Estructuras

correspondientes a primer y segundo curso del Grado de Ingeniería Civil que se imparte en la ETSICCP de la UPV, y se argumenta los motivos que han llevado a adoptarla. Finalmente, se presentan y analizan la relaciones entre las calificaciones obtenidas en las entregas electrónicas y en los exámenes, concluyendo que las entregas así gestionadas han contribuido al aprendizaje de los estudiantes y les han permitido mejorar su calificación.

Palabras clave: evaluación continua, corrección automatizada, plataforma educativa PoliformaT, metodologías de enseñanza y aprendizaje, retroalimentación educativa, planteamiento didáctico sostenible.

\section{Introducción}

La adaptación de las estructuras universitarias al Espacio Europeo de Educación Superior ha conllevado la definición de un nuevo marco académico cuya aplicación efectiva ha supuesto, entre otros cambios, la introducción sistemática de la evaluación continua, la cual ha traído consigo nuevas y variadas necesidades y desafíos docentes, no siempre abordados con éxito al intentar trasladar, sin más, las antiguas metodologías de evaluación "discreta". Desafortunadamente, en bastantes casos la supuesta adaptación se ha limitado a multiplicar el número de exámenes parciales y convertir el curso en una sucesión de pruebas objetivas, entregas de ejercicios, exposiciones de trabajos, etc. que pretenden hacer la evaluación lo más continua y detallada posible, pero cuya utilidad real para el aprendizaje es, en ocasiones, dudosa. Como consecuencia, el trabajo diario de nuestros estudiantes queda condicionado habitualmente por una apretada agenda sobre la que los profesores han anotado actividades de evaluación sin aparente solución de continuidad. En la mayoría de los casos, lo único que se ha conseguido con esto es que el alumno centre su atención en cumplir formalmente las actividades programadas.

En su lugar procedería establecer una secuencia lógica y ponderada de actividades de aprendizaje guiadas, supervisadas y, en general, evaluadas mediante los instrumentos de control adecuados que, además de valorar los resultados de forma precisa, deberían proporcionar una retroalimentación casi inmediata al estudiante. Así, la percepción de que se evalúan sus logros en las tareas de aprendizaje — en vez de sentirse bombardeados por un sinfín de pruebas exclusivamente de calificación — incentivaría la dedicación a ellas y favorecería el propio aprendizaje.

Por otra parte, en numerosas asignaturas del ámbito de la ingeniería la principal tarea de aprendizaje es la resolución de ejercicios con el fin de familiarizar al aprendiz con el modo de aplicación de las leyes básicas de la materia de que se trate y, a la vez, automatizar 
determinados procesos hasta convertirlos en mecánicos. El elevado número de alumnos por grupo, en especial en los primeros cursos, dificulta mucho el control de tales ejercicios.

La necesidad de verificar de forma adecuada un número suficiente de ejercicios de cada alumno ha sido objeto de atención por parte del primero de los autores desde hace mucho tiempo, lo que le llevó a desarrollar, hace casi diez años, un procedimiento informático de recogida de los resultados de tales ejercicios, corrección de los mismos y comunicación de la retroalimentación necesaria. La herramienta informática que más adelante se describe no es más que la evolución de aquel primer intento a lo largo de sucesivos cursos académicos. La problemática que aconsejó desarrollar el primer procedimiento de corrección y las ideas iniciales de éste se pueden encontrar en Casanova (2006). La primera utilización sistemática de la herramienta se describe en Casanova (2008).

Para finalizar esta introducción queremos citar unas palabras del insigne ingeniero de caminos D. Leonardo Torres Quevedo quien, en una conferencia pronunciada en 1913, daba algunos consejos sobre cómo deberían enfocarse, en su opinión, las enseñanzas técnicas. Uno de ellos (Torres-Quevedo, 2009) era:

"Insistir en los principios fundamentales. No basta que los alumnos los recuerden, no basta que los entiendan; es necesario que los manejen hasta que lleguen a aplicarlos intuitivamente, lo mismo que un buen obrero maneja la herramienta, sin pensar en las reglas que le enseñaron durante su aprendizaje."

En nuestra opinión, para conseguir que los alumnos manejen los principios fundamentales de su técnica hasta que lleguen a aplicarlos intuitivamente es necesario que los utilicen para resolver un número suficiente de ejercicios de complejidad creciente, sin caer en el error de aburrirlos reiterando el mismo ejercicio con diferentes datos, como nos previene el ilustre matemático George Pólya en el prólogo de su libro sobre resolución de problemas, cuando dice (Pólya, 1965):

“...un profesor de matemáticas tiene una gran oportunidad. Si dedica su tiempo a ejercitar a los alumnos en operaciones rutinarias, matará en ellos el interés, impedirá su desarrollo intelectual y acabará desaprovechando su oportunidad. Por el contrario, si pone a prueba la curiosidad de sus alumnos planteándoles problemas adecuados a sus conocimientos [...] podrá despertarles el gusto por el pensamiento independiente y proporcionarles ciertos recursos para ello."

\section{Objetivos}

En esta ponencia nos planteamos dos objetivos: en primer lugar, describir los programas informáticos que, usados conjuntamente con la plataforma educativa PoliformaT, permiten

\section{(c) EY-NC-ND 2014, Universitat Politècnica de València}

I Jornadas IN-RED (2014) 
Una herramienta informática eficaz y eficiente para la evaluación continua. Aplicación práctica a varias asignaturas de Teoría de Estructuras

recopilar los resultados obtenidos por los alumnos, corregirlos, calificarlos y devolver una retroalimentación suficiente, detallando simultáneamente la forma de utilizarlos desde el punto de vista del usuario informático; y, en segundo lugar, presentar los modos en que la herramienta informática se ha incorporado a la docencia de diferentes asignaturas y en distintos cursos, analizándolos y señalando fortalezas y debilidades.

\section{La herramienta informática: descripción y uso}

El uso de esta herramienta está ligado a la existencia de una o varias entregas de ejercicios en la asignatura. El intercambio de datos (distribución de enunciados, datos y plantillas, recogida de resultados y distribución de la retroalimentación) se realiza a través de la aplicación Tareas incluida en PoliformaT. La propia corrección y la generación de los informes de retroalimentación (que llamaremos hojas de resultados corregidas) se realiza mediante la aplicación ad hoc objeto de esta ponencia. A continuación se describe los documentos y programas utilizados en este proceso, agrupados en tres epígrafes: preparación de la tarea, generación del corrector, y corrección y retroalimentación.

\subsection{Preparación de la tarea}

Enunciados. Se facilitan en un archivo PDF. Se plantea los mismos ejercicios a todos los alumnos, pero, con el fin de conseguir que haya una parte de trabajo personal, a cada uno se le proporcionan con unos datos diferentes. Esto obliga al más desinteresado - que ha conseguido la solución de un compañero- a revisar someramente el problema y rehacer todos los cálculos. Por ello, los enunciados deben redactarse representando mediante letras los datos numéricos para luego facilitar a cada alumno los valores que adoptan en su caso.

Como ya se ha dicho, los ejercicios deben insistir en los principios fundamentales y suponer un reto que despierte el interés y la curiosidad de los alumnos. No tiene utilidad para el aprendizaje que sean una mera repetición de alguno ya conocido con otros datos.

Hoja de resultados vacía. Es una plantilla elaborada mediante una hoja Excel, en la que el alumno deberá escribir sus resultados en las casillas reservadas al efecto; tales casillas incluyen una validación - una limitación en cuanto al tipo de datos que admiten- que trata de impedir el uso de formatos que no se podrían corregir, y, a la vez, permite identificar esas casillas a las macroinstrucciones (o macros) que generan el corrector. En la plantilla se indica las unidades en las que se espera los resultados y toda la información necesaria para definirlos unívocamente, ya que el corrector precisa un resultado concreto escrito de una manera concreta. En ella conviene pedir algunos resultados intermedios, para no confiar todo el peso de la calificación a un solo valor. En la Fig. 1 se presenta un 
ejemplo de hoja de resultados vacía en la que se aprecia esto; el enunciado sólo pedía los resultados finales del primer y segundo apartado, respectivamente.

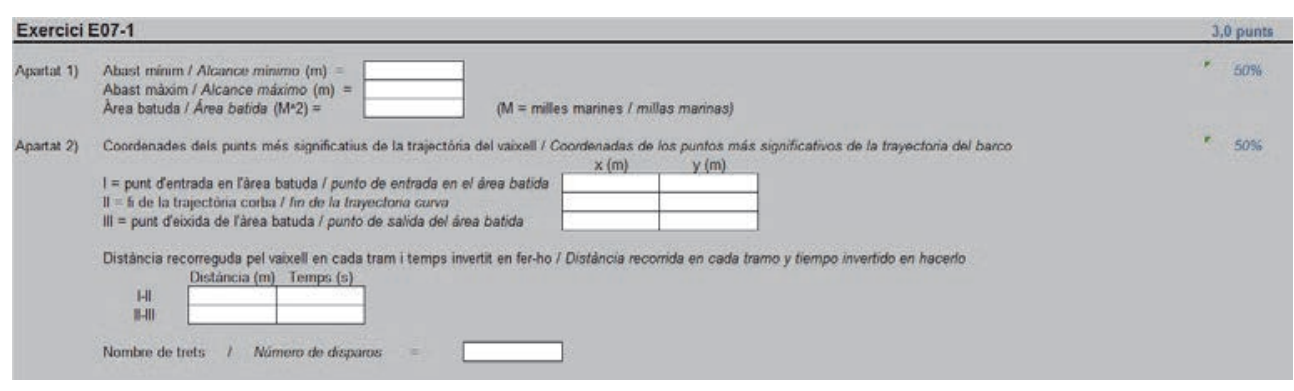

Fig. 1. Ejemplo de hoja de resultados vacía

Creación de la tarea en PoliformaT. Una vez preparados los enunciados y la hoja de datos, procede crear la tarea de PoliformaT que se usará para distribuir la información. En ella, además de las fechas de apertura y cierre, y la información que quiera suministrar el profesor, se debe incluir como adjuntos los archivos comentados hasta ahora, e indicar que la respuesta debe ser mediante un archivo adjunto, que la calificación es de tipo marca y que se permite un reenvío. El archivo adjunto será la hoja de resultados que luego se corregirá automáticamente; las otras dos características se aclararán más adelante.

La tarea se debe publicar en este momento, sin haber incluido todavía los datos particulares de cada alumno, que se proporcionarán luego simulando una corrección, ya que PoliformaT no permite facilitarlos directamente. La fecha de apertura de la tarea debe programarse previendo el tiempo necesario para estas operaciones, de modo que los estudiantes no puedan verla hasta que haya concluido el proceso.

Esta forma de proceder justifica la necesidad de permitir un reenvío; la plataforma considera así cualquier envío posterior de una corrección.

Hoja de datos. Los datos de los problemas se deben definir en función de varios parámetros que adopten un valor diferente para cada alumno. Nosotros utilizamos cinco, que son, respectivamente, el resto de dividir el número de orden del alumno en la lista de la asignatura por 2, 3, 4, 5 y 7. Esto genera un número de combinaciones diferentes igual al producto de los divisores, es decir, 840, más que suficiente en nuestro caso y casi en cualquier otro.

Los datos particulares de cada alumno se generan mediante un libro Excel de dos hojas llamado CREAR_DADES. En una de las hojas se calculan los valores de los datos a partir de los parámetros descritos y se presentan de forma que sean fáciles de interpretar; obviamente, debe de programarse para cada entrega de ejercicios. En la otra hoja figura la lista de alumnos con los parámetros correspondientes y se anotan variables auxiliares

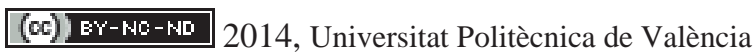

I Jornadas IN-RED (2014) 
Una herramienta informática eficaz y eficiente para la evaluación continua. Aplicación práctica a varias asignaturas de Teoría de Estructuras

cuando se preparan los datos para su distribución. La hoja de datos que recibirá cada alumno es una copia de la primera de éstas; la Fig. 2 muestra un ejemplo de hoja de datos.

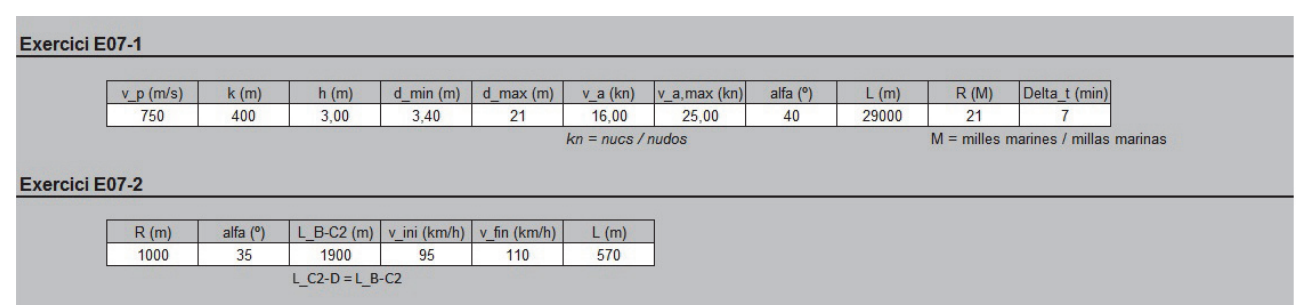

Fig. 2. Ejemplo de hoja de datos

Creación y distribución de la hoja de datos. Para crear y distribuir la hoja de datos de cada alumno se procede del modo siguiente:

1) Se descargan todos los envíos de la tarea, entrando en ella como si fuéramos a calificarla y pulsando en la opción Descargar todo del área 1 indicada en la Fig. 3. Con ello se obtiene un archivo (comprimido) que contiene una carpeta con la estructura descrita en la Fig. 4. Las subcarpetas "Envíos usuario" y "Envíos profesor" contendrán, respectivamente, los archivos que adjunte el usuario como resultado de su trabajo y los que adjunte el profesor como retroalimentación después de la corrección. En este momento ambas carpetas están vacías.

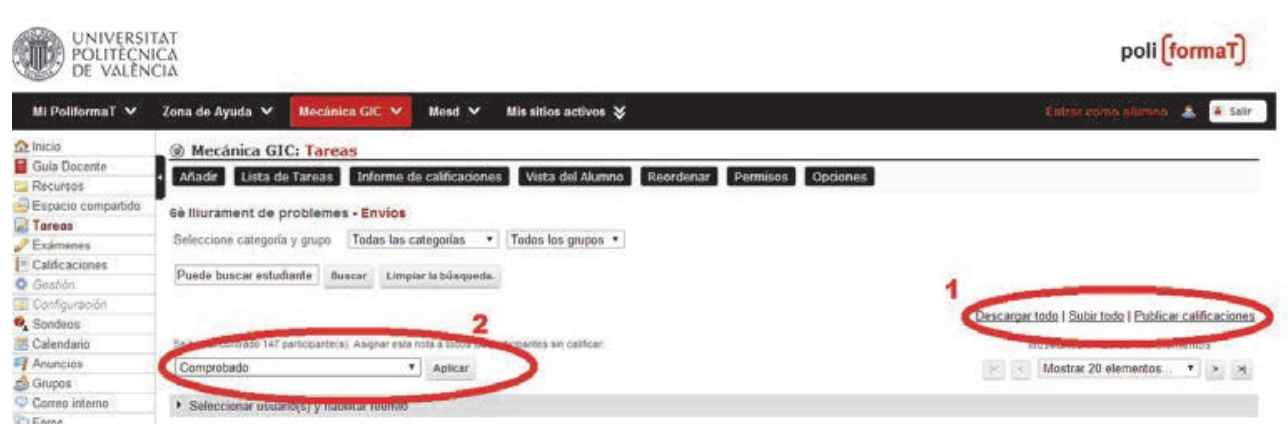

Fig. 3. Instrucciones de PoliformaT (en Tareas / Nombre de la tarea / Calificación) que se utilizan para la distribución de las hojas de datos y las hojas de resultados corregidas

2) Se descomprime el archivo, se copia en el directorio raíz el programa CREAR_DADES y se ejecuta la macro correspondiente, que lee el directorio de la carpeta y para cada entrada identifica al usuario, crea la hoja de datos correspondiente y la graba en la subcarpeta "Envíos profesor". 


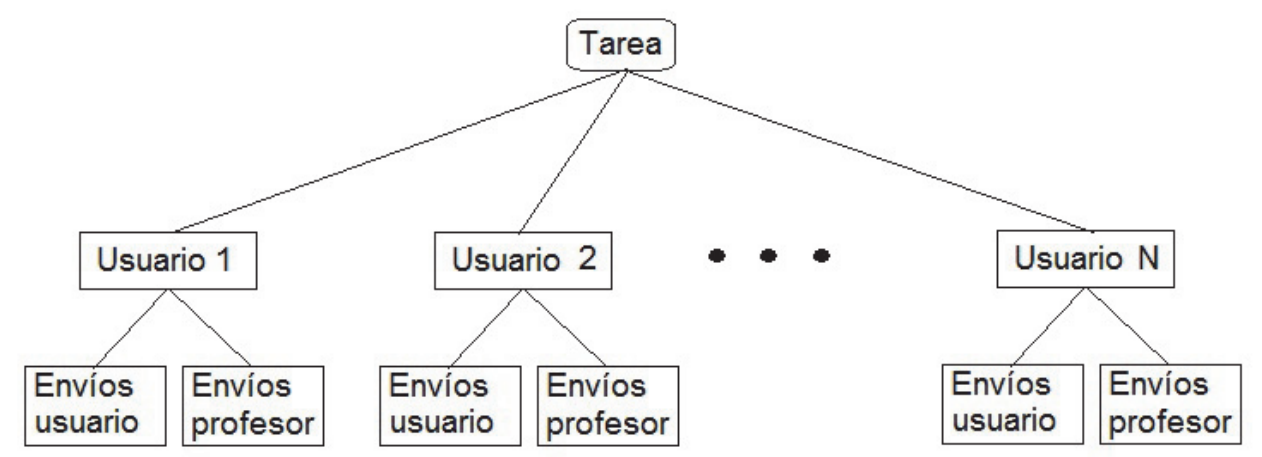

Fig. 4. Estructura de la carpeta de envíos de cada tarea

3) Finalizado el proceso anterior, se borra el programa CREAR_DADES de la carpeta, se comprime ésta y se sube el archivo a la tarea de PoliformaT, pulsando en la opción Subir todo del área 1 de la citada Fig. 3. Con ello cada alumno tiene en su carpeta de la tarea en PoliformaT su hoja de datos, aunque aún no puede verla.

4) Para indicar a la plataforma que muestre el resultado de la corrección, ya que así considera las hojas de datos, hay que poner nota a todos los alumnos pulsando el botón Aplicar que aparece en el área 2 de la Fig. 3, para luego comunicársela pulsando en la opción Publicar calificaciones en el área 1 de la misma Fig. 3. La necesidad de asignar una nota a cada alumno para concluir el proceso explica el porqué se ha escogido la opción de calificación marca, que utiliza la palabra "Comprobado" sin ninguna escala.

Finalizado este proceso, en cuanto se abra la tarea en la fecha programada, los alumnos podrán ver en ella la información general (enunciados, instrucciones y hoja de resultados vacía) y su hoja de datos particular.

\subsection{Preparación del corrector}

El corrector se elabora mediante una macro a partir de otra plantilla, que es un libro Excel bastante complejo. Sin entrar en los detalles de funcionamiento, cabe indicar que utiliza una copia de la Hoja de resultados vacía para saber en qué casillas debe buscar los datos y una copia de la lista de alumnos, los parámetros variables asociados a cada uno y las fórmulas usadas en el programa CREAR_DADES para crear los datos particulares de cada alumno. La parte más laboriosa de la elaboración del corrector es programar las soluciones de los ejercicios propuestos. Luego basta ejecutar la macro que lo genera y revisar la asignación de calificaciones, como se comentará más adelante.

\section{(c)) EY-NC-ND 2014, Universitat Politècnica de València}

I Jornadas IN-RED (2014) 
Una herramienta informática eficaz y eficiente para la evaluación continua. Aplicación práctica a varias asignaturas de Teoría de Estructuras

El corrector está concebido de manera que importe la hoja de resultados de cada alumno, compare los resultados contenidos en ella con los programados como correctos y calcule el error relativo $\varepsilon$. A partir de él, asigna a cada celda la calificación indicada en la Tabla 1.

Tabla 1. Criterios de calificación

\begin{tabular}{ccc}
\hline Intervalo & Calificación & Nota \\
\hline$\varepsilon \leq \varepsilon_{1}$ & Correcto o Bien & $N_{1}$ \\
$\varepsilon_{1}<\varepsilon \leq \varepsilon_{2}$ & Admisible & $N_{2}$ \\
$\varepsilon>\varepsilon_{2} \wedge\left|\log _{10}(\varepsilon+1)\right| \leq \varepsilon_{3}$ & Erróneo o Mal & 0 \\
$\left|\log _{10}(\varepsilon+1)\right|>\varepsilon_{3}$ & Fuera de orden de magnitud & $N_{3}$ \\
\hline
\end{tabular}

NOTA. La condición de fuera de orden de magnitud otorga esta calificación cuando el cociente entre el resultado del alumno y el correcto es mayor que $\varepsilon_{3}$ o menor que $1 / \varepsilon_{3}$.

Por defecto, $\varepsilon_{1}, \varepsilon_{2}$ y $\varepsilon_{3}$ son, respectivamente, $0,02,0,10$ y 1 , mientras que $N_{1}, N_{2}$ y $N_{3}$ son, respectivamente, 2, $1 \mathrm{y}-1$. El profesor puede cambiar cualquiera de estos seis valores, independientemente, para cada uno de los resultados pedidos, esto es, para cada casilla de la hoja de resultados; además, el corrector está programado para que, si sólo se cambia $N_{1}$, los valores de $N_{2}$ y $N_{3}$ pasen a ser $N_{1} / 2$ y $-N_{1} / 2$, respectivamente.

Para dar a cada casilla el peso que deba tener en la calificación del ejercicio se debe revisar la asignación automática de los valores de $N_{1}$, definiendo este parámetro en cada una como el porcentaje de la calificación del ejercicio que tal casilla debe determinar.

Existe la posibilidad de programar que un resultado fuera de orden de magnitud, o de signo contrario al esperado, en una casilla determinada se considere un error crítico y suponga una calificación de cero en el ejercicio o en la entrega completa.

\subsection{Entrega, corrección y retroalimentación}

Resuelto el ejercicio, el alumno escribe los resultados correspondientes en la hoja de resultados vacía, que así se convierte en su hoja de resultados, y la sube a la tarea de PoliformaT. No importa el nombre con el que se haya guardado.

Para el profesor que utiliza esta aplicación, el proceso de corrección y retroalimentación es idéntico al de creación de datos descrito en el epígrafe 3.1, aunque es evidente que las operaciones que exige son diferentes y más complejas, por lo que resulta algo más lento. Ahora el corrector genera para cada alumno una hoja de resultados corregida, que se distribuye como retroalimentación del mismo modo que antes se proporcionaron los datos.

Hoja de resultados corregida. Es una hoja Excel, copia de la hoja de resultados vacía, en la cual se ha escrito en cada una de las casillas reservadas a los resultados un código formado por una o dos letras y el cociente entre el resultado del alumno y el correcto. 
Además, para mostrar gráficamente el resultado de la corrección, se modifican los colores de fondo de las casillas en función de su calificación. La Tabla 2 describe el significado de dicho código y la Fig. 5 muestra un ejemplo de hoja de resultados corregida.

Tabla 2. Códigos de calificación

\begin{tabular}{ccc}
\hline Calificación & Inicial del código & Color del fondo \\
\hline Correcto o Bien & $\mathrm{B}$ & Blanco \\
\hline Admisible & $\mathrm{A}$ & Amarillo \\
Erróneo o Mal & $\mathrm{M}$ & Rosa \\
Fuera de orden de magnitud & $\mathrm{F}$ & Rojo \\
\hline Error crítico & $\mathrm{EC}$ & Negro \\
\hline
\end{tabular}

Retroalimentación. La hoja de resultados corregida constituye la retroalimentación del ejercicio. Para aprovecharla, se indica a los alumnos que conserven la resolución de los diferentes ejercicios y, cuando reciban esta información, la analicen tratando de identificar qué originó cada uno de los errores detectados, verificando si se trata de un error de transcripción, aritmético o de planteamiento, en este mismo orden. Explicado un resultado erróneo deben pasar al siguiente, comprobando primero que no es, simplemente, consecuencia de arrastrar uno anterior, y procediendo luego como en el primer caso, y así sucesivamente hasta justificar todas las casillas coloreadas.

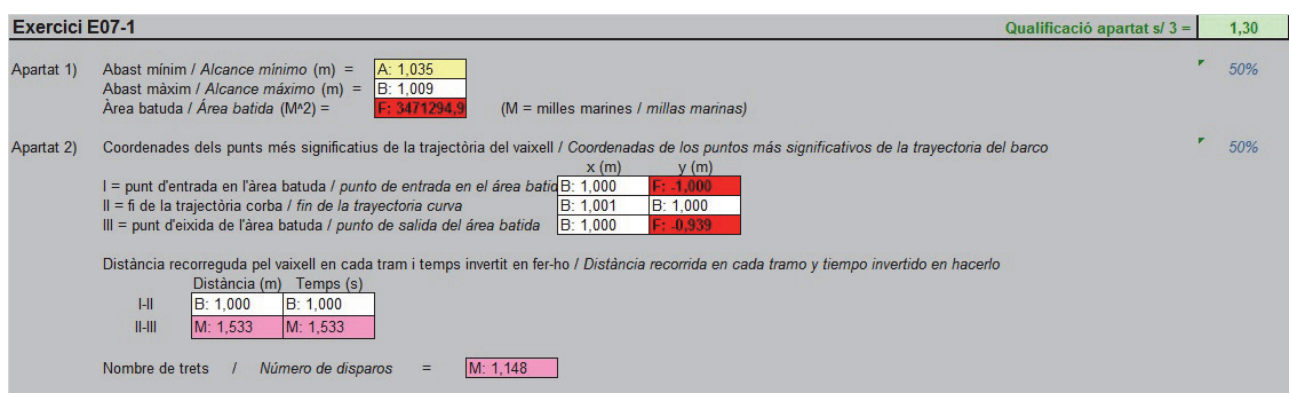

Fig. 5. Ejemplo de hoja de resultados corregida

En cualquier caso, los autores nunca han utilizado éste como el único procedimiento de retroalimentación. Siempre se ha dedicado una sesión anterior o posterior a la entrega para trabajar en el aula sobre los ejercicios y asegurar que todos los alumnos conocen el procedimiento correcto de resolución.

\section{Planteamientos didácticos apoyados en la aplicación}

La progresiva implantación del uso de la herramienta informática en distintas asignaturas se ha basado en la experiencia previa de los autores, una vez asumida la conveniencia de incorporar a lo largo del curso un número suficiente de ejercicios controlados, como

\section{(c)) EY-NC-ND 2014, Universitat Politècnica de València}

I Jornadas IN-RED (2014) 
Una herramienta informática eficaz y eficiente para la evaluación continua. Aplicación práctica a varias asignaturas de Teoría de Estructuras

procedimiento para asegurar un aprendizaje significativo de los principios básicos de la materia. Dicha implantación incluye la constatación de la necesidad de una herramienta como la descrita y la previsión de cómo podría materializarse (Casanova, 2006), el desarrollo de los elementos fundamentales de la misma y del planteamiento de las clases relacionadas con tales ejercicios (Casanova. 2008a, 2008b), así como la evolución de este planteamiento (Casanova, 2010). También se ha abordado su adaptación a las asignaturas de los nuevos planes de estudio de grado (Pallarés et al., 2013), en el contexto de la coordinación horizontal y vertical de las materias relacionadas con la Teoría de Estructuras dentro de las titulaciones de ingeniería civil (Sánchez-Carratalá et al., 2013).

A continuación se describe la experiencia en la aplicación de la herramienta objeto de esta ponencia a varias asignaturas impartidas en la Escuela Técnica Superior de Ingenieros de Caminos, Canales y Puertos (ETSICCP) de la Universidad Politécnica de Valencia (UPV). Una de ellas es Cálculo de Estructuras III ( $3^{\text {er }}$ curso, anual, 9 créditos; en adelante, CST3, plan 97 de ICCP). Las otras tres son Mecánica ( $1^{\text {er }}$ curso, $2^{\circ}$ cuatrimestre, 7,5 ECTS; en adelante, MECA), Mecánica del Sólido Deformable ( $2^{\circ}$ curso, $1^{\text {er }}$ cuatrimestre, 4,5 ECTS; en adelante, MESD) y Análisis de Estructuras ( $2^{\circ}$ curso, $2^{\circ}$ cuatrimestre, 4,5 ECTS; en adelante, AEST), todas ellas del Plan 2010 del Grado de Ingeniería Civil (GIC).

La primera asignatura en la que se aplicó esta herramienta fue CST3, que se ocupaba, en parte, de diversos métodos computacionales de cálculo de estructuras. Los ejercicios de dicha disciplina se caracterizan por ser largos, y exigir la manipulación de muchos datos y la realización de gran cantidad de cálculos. La aplicación de la herramienta en esa asignatura está bien documentada en Casanova (2006, 2008a, 2008b, 2010); los cambios que la herramienta ha experimentado desde entonces han servido para automatizar el proceso informático, pero no han afectado al modo de plantear las clases.

En los dos primeros cursos de vigencia del Plan 2010 no se recurrió a esta herramienta. Hubo ejercicios del tipo de los aquí tratados, que se resolvían en equipo en las clases prácticas, totalmente en el aula o tras una preparación individual previa. El curso 2010-11 (primer año de vigencia del nuevo plan), en MECA las entregas grupales no tenían peso en la calificación y sólo se corrigieron a final de curso en los casos dudosos. El curso 2011-12, en MECA y en MESD se controló la existencia de las entregas, que ya se presentaron a través de una tarea de PoliformaT, y se corrigió una muestra de las de cada alumno (Pallarés et al., 2013). La experiencia de todo ello aconsejó realizar una corrección más minuciosa de todas las entregas.

El curso 2012-2013, en MESD las clases prácticas se diseñaron como una reja o puzle de Aronson (Ledlow, 1996; López, 2005; Lane, 2008) en equipos de cuatro personas formados por los profesores sobre la base de los principios de máxima diversidad y, en la medida de lo posible, no preponderancia de sexo (Felder et al., 2001; Oakley et al., 2004). Se 
planteaban antes de la clase práctica cuatro ejercicios diferentes; cada alumno debía resolver uno de ellos y elaborar un esquema de resolución —una especie de diagrama de flujo del proceso - válido para cualquier ejercicio similar. En el aula, reunidos los alumnos que habían resuelto el mismo tipo de ejercicio, se debía afinar el esquema con la ayuda del profesor, para luego exponerlo a los compañeros del propio equipo, facilitándoles una copia del mismo. Finalmente, se planteaba como ejercicio de evaluación un problema similar a alguno de los estudiados para resolverlo individualmente, pudiendo usar los esquemas de resolución disponibles. En la práctica, hubo demasiados estudiantes que no traían su parte del trabajo preparada, con lo que faltaba información en muchos equipos y la clase resultaba poco productiva. La técnica tuvo que ser abandonada después de tres sesiones. Algunos alumnos se quejaron alegando que su equipo había funcionado bien, que con un esfuerzo moderado habían aprendido bastante y que los esquemas de resolución habían resultado útiles, aunque reconocieron que en el conjunto de la clase no ocurrió así.

Todo ello nos llevó a volver, en ese mismo curso, a un planteamiento individual en el que los poco aplicados, al menos, no perjudicaran a los alumnos interesados. Se plantearon trabajos individuales con los mismos problemas pero datos diferentes para cada alumno, corregidos con la aplicación objeto de esta ponencia. Los enunciados y datos se publicaban aproximadamente una semana antes de la sesión práctica prevista para trabajar sobre ellos. En éstas, se dedicaba una media hora a resolver dudas sobre los ejercicios y el resto (hora y media) a que cada alumno resolviera individualmente su caso, pudiendo usar libros y apuntes, así como preguntar dudas a los profesores. Se comprobó que así los estudiantes aprenden más porque se enfrentan a sí mismos durante la clase y, para evitar verse inactivos mientras sus compañeros avanzan, preparan —al menos un poco— la materia.

Este procedimiento, que mostró resultados satisfactorios al principio, se extendió en el $2^{\circ}$ cuatrimestre del curso 2012-2013 a MECA, y se ha mantenido durante el curso 2013-14, en el que se ha aplicado en MESD (una sesión semanal de tres horas, dedicando la última hora de cada sesión a las clases prácticas), en MECA (tres sesiones semanales de dos horas, dedicando quince sesiones completas a las clases prácticas) y en AEST (una sesión semanal de tres horas, dedicando las últimas dos horas en seis sesiones a las clases prácticas). Esta organización ha funcionado mejor en las asignaturas de $2^{\circ}$ curso que en la de $1^{\circ}$, y entre las de $2^{\circ}$ curso, mejor en la de $2^{\circ}$ cuatrimestre. Incluso en $1^{\text {er }}$ curso, los alumnos repetidores se han adaptado mejor que los nuevos. Lo interpretamos como que los alumnos necesitan un cierto rodaje hasta acostumbrarse a un método poco flexible en el aspecto formal, debido a las exigencias en cuanto a plazo y formato de un sistema controlado por el ordenador.

El planteamiento descrito ha mostrado un punto débil, para el que por ahora no tenemos solución. Antes de exponerlo, conviene señalar dos hechos que, probablemente, sean los

\section{(c)) EY-NC-ND 2014, Universitat Politècnica de València}

I Jornadas IN-RED (2014) 
Una herramienta informática eficaz y eficiente para la evaluación continua. Aplicación práctica a varias asignaturas de Teoría de Estructuras

causantes de esta disfunción: el extraño calendario académico y de exámenes ${ }^{1}$ y la anómala normativa reguladora de las entregas ${ }^{2}$ adoptados en la ETSICCP, que al limitar el número de entregas por asignatura a seis obliga a agrupar la presentación del trabajo de varias clases prácticas en una sola entrega (Casanova et al., 2013; Sánchez-Carratalá, 2014).

El citado punto débil es que, mediado el cuatrimestre, bastantes alumnos dejan de asistir a las clases prácticas o las abandonan en cuanto se ha pasado lista, mientras que otros se dedican en ellas a preparar el examen del viernes. De este modo desaprovechan el tiempo previsto para preparar los ejercicios y van dejándolos, confiando en que lo recuperarán antes de la entrega. La consecuencia es que aparecen muchas entregas incompletas o con ejercicios mal hechos. La necesidad de agrupar los ejercicios de varias clases prácticas en una sola entrega, y quizás la decisión de dejar un par de días entre la clase práctica y la entrega — por si era necesario concluir algún cálculo— han agravado el problema.

Por otra parte, cuando los ejercicios son mecánicos o plantean pocas dificultades (eso ocurre en AEST, en la que, fundamentalmente, es necesario automatizar unos procedimientos que los buenos alumnos captan enseguida), el grupo de los alumnos buenos y el de los repetidores suelen ir a las clases prácticas con los ejercicios resueltos, esperarse sólo hasta confirmar que su planteamiento es correcto y abandonar el aula. Es menos grave, pero tampoco es deseable. Ese tiempo se debería aprovechar mejor.

También es posible que en ese grupo de alumnos que abandonan el aula haya algunos a los que les han resuelto los ejercicios en una academia. Creemos que ello no es ningún problema, ya que luego deberán sacar una nota mínima en el examen para poder aprobar, cosa que no ocurrirá si se han limitado a copiar problemas durante todo el curso.

En resumen, creemos que la resolución individual con los ejercicios planteados unos días antes de la clase práctica, asegurándose que éstos no son triviales, y la entrega electrónica el mismo día de la mencionada clase es la manera idónea de utilizar esta herramienta cuando los grupos de aula son numerosos, como ocurre en los primeros cursos de grado de la ETSICCP (unos 80 alumnos por grupo). Con grupos menores, entre 30 y 40 alumnos, posiblemente el planteamiento de trabajo en equipo abandonado en MESD daría mejores resultados.

\footnotetext{
1 Acumula las clases en el primer mes del cuatrimestre (septiembre o febrero) para que durante el resto del período no haya docencia en viernes y éstos se dediquen sólo a exámenes (la mañana libre y el examen por la tarde).

2 Cuantifica el trabajo del alumno por asignatura en lugar de hacerlo por ECTS y establece un máximo de seis entregas por asignatura en fechas que deben negociarse con el coordinador de curso para evitar acumulaciones en el mismo período.
} 


\section{Resultados}

En la Fig. 6 se presenta la relación entre las notas obtenidas por un mismo estudiante en las entregas de ejercicios y en los exámenes realizados. En todos los casos las notas de las entregas son los valores finales en el curso 2013-2014, mientras que la nota de examen es la disponible en la fecha de redacción de la ponencia, que corresponde a la media de los parciales después de la recuperación en MESD, a la nota del primer parcial en MECA, y a la media de los parciales antes de la recuperación en AEST.

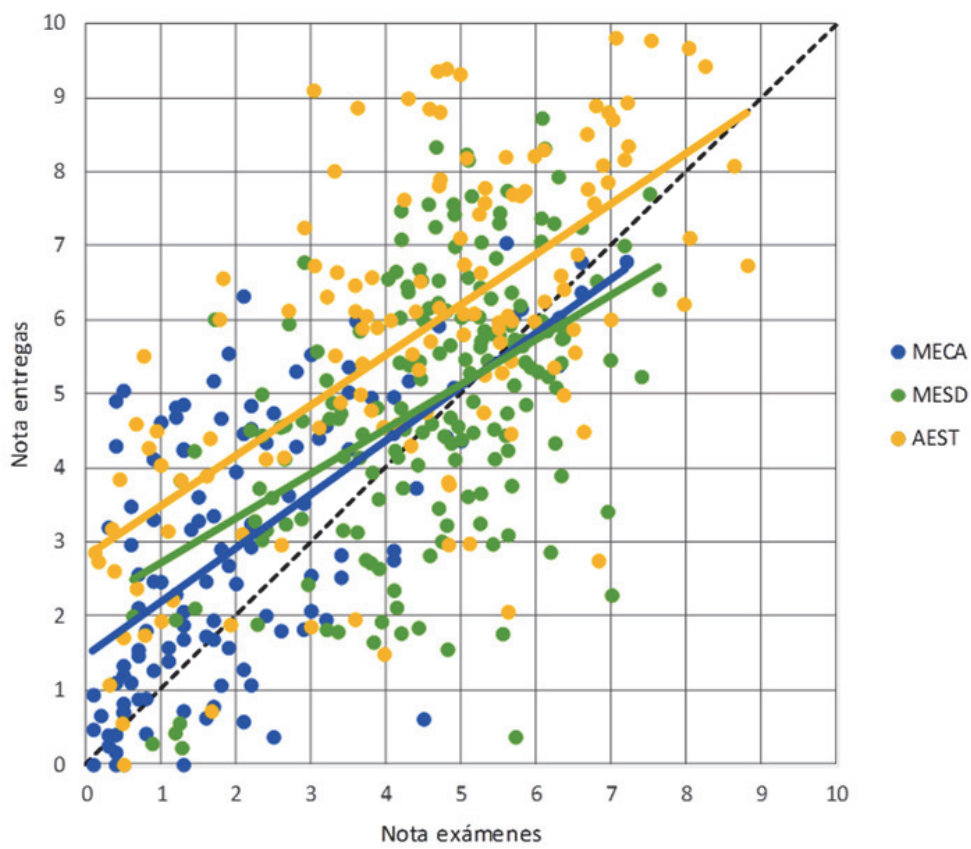

Fig. 6 Relación entre las notas obtenidas en las entregas y en los exámenes

Se ha ajustado sendas rectas de regresión a los diferentes valores que, aún presentando una correlación baja, indican, como era de esperar, que los resultados en las entregas y el examen son distintos pero pese a ello guardan cierta coherencia. Las entregas permiten mejorar la nota del examen en el rango bajo y medio de de ésta y afectan poco en el alto.

El análisis de la propia gráfica nos permite establecer conclusiones interesantes, relacionadas con los tipos de alumno que podemos encontrarnos. En primer lugar, los alumnos que obtienen una nota más alta en los exámenes consiguen una bastante parecida en las entregas. En segundo lugar, hay alumnos cuya nota en los exámenes es aceptable, pero la de las entregas es mucho mayor: creemos que se trata de aquéllos que, por motivos de tiempo o de nervios, se defienden mal en los exámenes. En tercer lugar, aparecen los que han rendido menos en las entregas que en los exámenes; incluyen buenos alumnos que,

\section{(c)) EY-NC-ND 2014, Universitat Politècnica de València}

I Jornadas IN-RED (2014) 
Una herramienta informática eficaz y eficiente para la evaluación continua. Aplicación práctica a varias asignaturas de Teoría de Estructuras

sabiendo que iban a responder bien en el examen, no se han tomado en serio las entregas y, sobre todo, aquéllos que se han dedicado cada semana al examen inmediato y luego les ha faltado tiempo, como ya se ha comentado con anterioridad. Por último, está el grupo de los que tienen calificaciones aceptables en las entregas y muy bajas en los exámenes; claramente, son los que se las copiaron o las trajeron de una academia. No debe preocuparnos: la exigencia de una nota mínima en el examen hará que ello no les sirva.

Asimismo, en la gráfica se constata que las notas de las entregas son mejores en AEST $\left(2^{\circ}\right.$ curso, $2^{\circ}$ cuatrimestre) que en MESD ( $2^{\circ}$ curso, $1^{\text {er }}$ cuatrimestre), y en ésta mejores a su vez que en MECA ( $1^{\mathrm{er}}$ curso, $2^{\circ}$ cuatrimestre). Creemos que indica que los alumnos se van acostumbrando a la herramienta y van aprendiendo a preparar sus trabajos para ese tipo de corrección. También indica mejor aprovechamiento a mayor madurez académica.

Otro resultado interesante es la influencia de las entregas en la calificación. En MESD, única asignatura en la que se dispone de todos los datos en el momento de redactar esta ponencia, 167 de los 212 alumnos mejoraron la calificación gracias al trabajo realizado a lo largo del curso, cuyo principal componente eran las entregas de ejercicios; de ellos, 31 alumnos aprobaron la asignatura gracias a las entregas, con una nota media de los exámenes inferior a 5,0 pero con calificaciones en cada parcial superiores o iguales a 4,0.

\section{Conclusiones}

Se ha descrito una herramienta informática que, en entregas de problemas gestionadas a través de PoliformaT, permite controlar con precisión los resultados de cada alumno, y proporcionarle una retroalimentación adecuada con un volumen de trabajo acotado del profesor. Asimismo, se ha expuesto de qué modo se está utilizando en la actualidad en grupos numerosos de primeros cursos y se ha justificado dicha organización.

Aunque sólo se haya contrastado indirectamente a través de la relación entre la nota de las entregas y la de los exámenes, los resultados expuestos nos permiten concluir que unas entregas de ejercicios bien seleccionados, con un nivel de dificultad adecuado, controladas con rigor y proporcionando retroalimentación suficiente, facilitan el aprendizaje y la comprensión de los principios fundamentales de la materia de que se trate. La herramienta informática presentada permite que todo ello resulte sostenible para el profesorado.

\section{Referencias}

Casanova, J. (2006). "Una experiència d'implantació de mètodes d'aprenentatge cooperatiu i d'avaluació formativa en grups nombrosos", en Actas $4^{\circ}$ Congreso Internacional de Docencia Universitaria e Innovación. Barcelona: UPC. [CD-ROM]

(c) EY-NC-ND 2014, Universitat Politècnica de València

I Jornadas IN-RED (2014) 
CASAnova, J. (2008a). "Una metodologia de resolució cooperativa de problemes en grups nombrosos", en Actas $5^{\circ}$ Congreso Internacional de Docencia Universitaria e Innovación. Girona: Servei de publicacions, Universitat de Girona. [CD-ROM]

Casanova, J. (2008b). "Una experiencia de aprendizaje cooperativo mixto, en grupos numerosos, apoyada en el uso de una plataforma de formación”. Fargueta, F., Fernández, A. y Maiques, J.M. (ed.) en Actas $5^{\circ}$ Congreso Iberoamericano de Docencia Universitaria. Valencia: UPV. [CD-ROM]

CASANOVA, J. (2010). "Una estratègia per reforçar els aprenentatges teòrics d'una matèria tècnica en grups nombrosos", en Actas $6^{\circ}$ Congreso Internacional de Docencia Universitaria e Innovación. Girona: Servei de publicacions, Universitat de Girona. [CD-ROM]

Casanova, J., SÁnchez-Carratalá, C.R. y Pallarés, F.J. (2013). "Propuestas de mejora en la aplicación práctica del marco normativo de Bolonia para facilitar el aprendizaje", en Actas III Jornadas Internacionales de Enseñanza de la Ingeniería Estructural. Madrid: ACHE. [CD-ROM]

FELDER, R.M. Y BRENT, R. (2001). "Effective strategies for cooperative learning", en Journal of Cooperation and Collaboration in College Teaching, Vol. 10, No. 2, pp. 69-75.

LANE, J.L. (2008). Jigsaw Strategy, Morrow, GA: Center for Instructional Development, Clayton State University. <http://www.clayton.edu/Portals/538/docs/jigsaw.pdf> [Consulta: 31/05/2014]

LEDLow, S. (1996). Using Jigsaw in the college classroom, Phoenix, AZ: Center for Learning and Teaching Excellence, Arizona State University.

〈http://www.hydroville.org/system/files/team_jigsaw.pdf> [Consulta: 31/05/2014]

LÓPEZ, F. (2005). Metodología participativa en la Enseñanza Universitaria. Madrid: Narcea.

OAKLEY, B. ET AL. (2004). "Turning students groups into effective teams", en Journal of Student Centered Learning, Vol. 2, No. 1, pp. 9-34.

Pallarés, F.J., Casanova, J. y Sánchez-Carratalá, C.R. (2013). "Implantación de asignaturas básicas de Ingeniería Estructural dentro de un nuevo plan de estudios de ingeniería civil: Un caso práctico", en Actas III Jornadas Internacionales de Enseñanza de la Ingeniería Estructural. Madrid: ACHE. [CD-ROM]

Pólya, G. (1965). Cómo plantear y resolver problemas. México: Trillas.

Sánchez-Carratalá, C.R., Pallarés, F.J. y Casanova, J. (2013). "Coordinación docente de las asignaturas de ingeniería estructural en los planes de estudios de ingeniería civil adaptados al EEES", en Actas III Jornadas Internacionales de Enseñanza de la Ingeniería Estructural. Madrid: ACHE. [CD-ROM]

SÁNCHEZ-CARRATALÁ, C.R. y CASANOvA, J. (2014). "Hacia un calendario académico diseñado para promover y facilitar el aprendizaje del alumno", en Actas Jornadas de Innovación Educativa y Docencia en Red, IN-RED 2014. Valencia: UPV. [en prensa]

Torres-Quevedo, L. (2009). "La enseñanza de la ingeniería en España”, en Ingeniería y Territorio, No. 87, pp. 85-95.

\section{(c)) EY-NC-ND 2014, Universitat Politècnica de València}

I Jornadas IN-RED (2014) 


\title{
Evaluación online versus evaluación presencial, ¿se pueden considerar equivalentes?
}

\author{
Ana Vidaurrea, Jaime Rierab, Miquel Ardid ${ }^{\mathrm{c}}$, José M Meseguer-Dueñas ${ }^{\mathrm{d}}$, José A \\ Gómez-Tejedor ${ }^{\mathrm{e}}$ \\ Departamento de Física Aplicada. Escuela Técnica Superior de Ingeniería del Disseño, Universitat \\ Politècnica de València, Camí de Vera, s/n,46022 València,

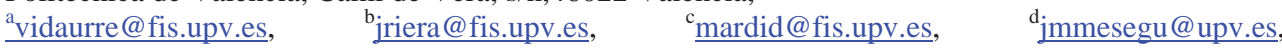 \\ jogomez@fis.upv.es
}

\begin{abstract}
In this paper we present the results of the application of a blended assessment (online and offprint) in 3 different degrees. The marks obtained by the students in both evaluation systems have been compared using the Passing Bablok regression method. The results show that there is a linear relationship between both variables. A bias analysis has been performed by means of a Bland-Altman plot. In the Aerospace degree case the online exam is part of the homework, students have two trials, and several days to fulfil the task. Its results present a higher bias (2 points over 10) and the regression line is the most different one from the equality line $Y=X$. In Design and Electronic degrees the online exam is performed in an unproctored environment, students only have one trial and a few hours to fulfill it. Their results show a bias in favor of online exam of 1 point over 10 and the regression line is quite similar to the equality line $Y=X$.
\end{abstract}

(cc) EY-NC-ND 2014, Universitat Politècnica de València

I Jornadas In-Red (2014) 
Evaluación online versus evaluación presencial, ¿se pueden considerar equivalentes?

Keywords: online exams, blended assessment, Passing-Bablock test, BlandAltman analysis

\begin{abstract}
Resumen
En este trabajo se presentan los resultados obtenidos en la aplicación de un sistema mixto de evaluación (online y examen escrito) en 3 titulaciones diferentes. Se han comparado las calificaciones obtenidas por los estudiantes en ambos sistemas de evaluación por el método de ajuste de la recta de regresión de Passing Bablok. Los resultados obtenidos muestran que se satisface una relación lineal entre ambas variables. La presencia de sesgos se ha analizado mediante los diagramas de Bland Altman. En el caso de la titulación de Aeroespacial la evaluación online se plantea como trabajo a realizar en casa, tienen varios días para resolverlo y dos intentos para cada examen. Este caso es el que presenta mayor sesgo (2 puntos sobre 10) y la recta del ajuste se diferencia más de la recta igualdad $Y=X$. En las titulaciones de Diseño y Electrónica el examen online se realiza sin la presencia del profesor, tienen un solo intento y la ventana para realizar el examen es de unas pocas horas. Los resultados muestran un sesgo en favor del examen online del orden de 1 punto y la recta de regresión se diferencia poco de la recta igualdad $Y=X$.
\end{abstract}

Palabras clave: exámenes online, sistema de evaluación mixta, test PassingBablock, análisis Bland-Altman

\title{
1. Introducción
}

La evaluación se puede definir como la medida de los logros y el progreso del alumno en un proceso de aprendizaje (Gikandi, 2011). La evaluación juega un papel fundamental para guiar a los estudiantes en su trabajo diario y contribuye en su proceso de aprendizaje efectivo (Bransford, 2000; Santos Guerra, 2003; Palmer, 2010). Por este motivo, el proceso de evaluación debe adaptarse a los objetivos propuestos en la materia. De esta forma, dependiendo de los objetivos específicos, es aconsejable utilizar diferentes métodos de evaluación durante todo el curso (Nowell et al., 2010). Habitualmente los temas de física se evalúan a partir de la resolución de cuestiones y problemas. Mediante este procedimiento se 
evalúa la capacidad de razonar y aplicar las leyes de la física a situaciones prácticas; la habilidad para manejar las magnitudes físicas y sus correspondientes unidades y la capacidad de analizar y proporcionar soluciones a problemas específicos. Esta evaluación suele consistir en un pequeño número de exámenes en los que los estudiantes resuelven cuestiones y problemas de forma individual ante la vigilancia del profesor. Además, los estudiantes realizan prácticas de laboratorio, en las que suelen trabajar en equipo y que son evaluadas a través de una memoria de laboratorio realizada en grupo.

La evaluación suele clasificarse en evaluación formativa y aditiva. La evaluación aditiva mide lo que los estudiantes han aprendido al final de una unidad o de un curso (Hargreaves, 2008). La evaluación formativa se refiere a la evaluación que se realiza durante el transcurso del curso, a fin de mejorar el aprendizaje (Vonderwell, 2007). Sin embargo, la distinción entre evaluación formativa y aditiva no es siempre clara (Smith, 2007). En la educación superior, estas dos formas de evaluación son importantes: la evaluación aditiva mide los logros alcanzados por los estudiantes para la obtención de un grado, y la evaluación formativa promueve la retroalimentación entre los estudiantes y los docentes con el objetivo de mejorar la enseñanza y el aprendizaje (Oosterhof, 2008). La evaluación formativa necesita retroalimentación inmediata y la posibilidad de que los estudiantes repitan y/o revisen la tarea insatisfactoria (Wolsey, 2008).

Uno de los desafíos a los que se enfrenta el docente es conseguir que los estudiantes comiencen a trabajar de forma continuada desde el inicio del curso. La evaluación continua nos puede ayudar a conseguir este objetivo. El método de evaluación continua se utiliza ampliamente en muchos sistemas educativos, a través de pruebas objetivas o de opción múltiple. Desde finales del siglo XX, las tecnologías de la información y la comunicación (TIC) han permitido el desarrollo de nuevas posibilidades para la evaluación, lo cual incluye la posibilidad de personalizar las evaluaciones (Yeh, 2010) y la capacidad de medir una gama más amplia de habilidades incluyendo no solo el mero conocimiento, sino también la aplicación de dicho conocimiento (Clarke, 2010). Estos nuevos sistemas de evaluación basados en las TIC deben centrarse en la búsqueda de formas de evaluar, que al mismo tiempo fomenten el desarrollo de capacidades y habilidades complejas (Webb, 2013). Además, las TIC permiten el desarrollo de herramientas de evaluación aplicables a un gran número de estudiantes, gracias a la corrección automática y a la puntuación inmediata permitiendo una evaluación continua sin sobrecargas para el docente (Gibbs, 1999; Bain, 2004; Vidaurre, 2011; Kuo, 2013). Para ir más allá de la evaluación continua, y conseguir una evaluación formativa (Hargreaves, 2008), el punto fundamental consiste en desarrollar buenas preguntas. El diseño de estas preguntas debe de estar basado en la comprensión de los objetivos de la evaluación. Una prueba es fehaciente cuando realmente mide lo que el evaluador quiere evaluar (Gikandi, 2011, Hewson, 2012). En el caso de la física, y otras materias afines, el conocimiento de la estructura de un problema es una

\section{(c)) EY-NC-ND 2014, Universitat Politècnica de València}

I Jornadas IN-RED (2014) 
herramienta muy útil que permite establecer un sistema de puntuaciones parciales a medida que el alumno consigue avanzar en la realización del problema (Singley, 2002).

En este contexto, para la preparación de este trabajo hemos utilizado la herramienta de exámenes en línea de PoliformaT, perteneciente al proyecto Sakai (https://sakaiproject.org), que se utiliza ampliamente en nuestra Universidad (Universitat Politècnica de València, España). Comenzamos a trabajar en baterías de preguntas, que consiste en conjuntos de preguntas numéricas de la asignatura de Física, agrupadas por unidades o sub-unidades, adecuadas para el primer curso de varios grados de la Escuela Técnica Superior de Ingeniería del Diseño (Valencia, España). Los exámenes se generan aleatoriamente a partir de estas baterías de preguntas.

Evaluar la resolución de problemas con ayuda de la tecnología es un reto considerable, porque hay poco conocimiento sobre cómo hacerlo con eficacia y eficiencia (Bennett, 2010). Aunque la evaluación a través de Internet se utiliza con frecuencia, hay pocos estudios que comparen la evaluación en línea con la evaluación tradicional escrita [Perrett, 2013]. Una pregunta a responder es si la puntuación obtenida por un estudiante sería similar en un examen escrito que en uno en línea. Esta pregunta puede ser respondida siguiendo los métodos para evaluar la concordancia en medidas cuantitativas. La comparación de dos métodos diferentes para medir la misma cantidad se puede realizar a través de un gráfico de dispersión en combinación con el análisis de regresión lineal y correlación (coeficiente de correlación de Pearson) (Galton, 1888; Pearson, 1895). Para profundizar todavía más la comparación entre las dos técnicas, se puede utilizar el método de regresión de Passing-Bablok que evalúa la significación de una coincidencia (Passing, 1983). Passing-Bablock es un método para estimar la ordenada en el origen y la pendiente y sus intervalos de confianza del 95\%, de una serie de datos experimentales. Mediante un gráfico de Bland-Altman (Altman, 1983; de Bland, 1986; de Bland, 1987) se puede realizar un análisis de sesgo. Bland y Altman propone un procedimiento gráfico, basado en el estudio de la diferencia entre los resultados de las dos técnicas comparada con la media de ambos. Ambos métodos de comparación se utilizan con frecuencia en la medicina y otros campos experimentales, así como en la educación (Pandey, 2008;. Van Nuland, 2007.).

En este trabajo se presentan los resultados de aplicación de una evaluación mixta en las asignaturas de Física correspondientes a tres grados diferentes en la ETS de Ingeniería del diseño, en el año académico 2011-12. La evaluación en estas asignaturas tiene diferentes componentes, entre ellos la evaluación online (cuestiones de respuesta numérica y resolución de problemas) y exámenes escritos (exámenes en el que el alumno debe resolver una serie de cuestiones y problemas). En este trabajo analizamos el rendimiento de los estudiantes en diferentes condiciones de aplicación de esta evaluación mixta. En particular, tratamos de verificar si el rendimiento de los estudiantes es diferente en los exámenes online y los exámenes escritos

(c)) EY-NC-ND 2014, Universitat Politècnica de València

I Jornadas IN-RED (2014) 
Con el fin de verificar o rechazar la hipótesis nula (ambos métodos son equivalentes) se han utilizado diferentes herramientas estadísticas. El trabajo se organiza de la siguiente manera. Tras explicar la metodología seguida en la configuración y la utilización de los exámenes online se describen los grupos de la muestra. En la siguiente sección se presentan los resultados obtenidos en los exámenes online y escritos en los diferentes grupos; Se describe la comparación de las notas medias y la significación de las diferencias. En la siguiente sección, mediante el método de regresión de Passing-Bablock se compara el rendimiento de los alumnos en los exámenes online y escritos. Luego se utiliza el diagrama de BlandAltman para destacar la presencia de sesgos al comparar los resultados de los estudiantes en ambos tipos de exámenes. La última sección incluye las conclusiones de los resultados obtenidos mediante las diferentes herramientas estadísticas y de la forma en la que estos se interpretan.

\section{Metodología}

El presente trabajo pretende analizar la evaluación online frente a los sistemas de evaluación tradicionales en la materia de Física (exámenes escritos, habitualmente de resolución de problemas). Dichos exámenes online no pretendes sustituir a los exámenes tradicionales sino más bien complementarlos. Es por ello que hemos planteado un sistema de evaluación en el que se combinan distintos sistemas contribuyendo con diferentes pesos a la evaluación de la asignatura. En todos los casos la evaluación comprende: varios exámenes escritos, realizados en el aula en presencia del profesor, varios exámenes online realizados fuera del aula, sin control del profesor, trabajos en equipo en los que los alumnos resuelven y presentan problemas en clase y trabajo de laboratorio que incluye la realización del experimento y la presentación de la memoria. El mayor porcentaje de la nota se asigna a los exámenes presenciales (entre el 40 y el 60\%); los exámenes online contribuyen con un 10-20\%, dependiendo de la titulación.

Los exámenes online se realizan a través de la plataforma PoliformaT que es la utilizada por la Universitat Politècnica de València (UPV), desarrollada a través del proyecto Sakai. Se trata de una aplicación informática con multitud de funcionalidades muy útiles para el desarrollo de las tareas docentes del profesor, de aprendizaje para los alumnos y de comunicación tanto alumno-profesor como alumno-alumno. La aplicación de exámenes online permite muchas posibilidades, empezando por los tipos de preguntas: tipo test, cuestiones numéricas (donde se aceptan intervalos para abarcar diferencias por redondeo), de texto específico, de texto abierto, etc. Las preguntas se almacenan en baterías. Al confeccionar un examen se extraen preguntas, de una o varias baterías, de forma aleatoria, consiguiendo que cada alumno tenga un examen diferente. El examen puede tener, o no, un

\section{(c)) EY-NC-ND 2014, Universitat Politècnica de València}

I Jornadas IN-RED (2014) 
tiempo fijo para resolverlo, se pueden permitir uno o varios intentos, se pueden añadir comentarios a las preguntas para mostrar al alumno tras la realización, etc.

De entre los distintos tipos de preguntas, las cuestiones de tipo numérico son las que más nos interesan para las asignaturas de Física, y por tanto las más utilizadas. Esto no implica necesariamente que se plantee una cuestión o problema y simplemente se pida el resultado final, sino al contrario, se puede preguntar al alumno sobre el valor de diferentes magnitudes que intervienen en el problema para que planteen y completen las diferentes ecuaciones que intervienen en la resolución del problema. De esta forma se está evaluando también el procedimiento para la resolución del problema, y al preguntar diversos aspectos se puede evaluar mejor la comprensión y capacidad del alumno, a la vez que se disminuyen y ponderan los posibles errores realizados en los cálculos. La Fig 1 muestra un ejemplo de pregunta de examen en la que los alumnos deben rellenar una serie de espacios en blanco que se corresponden con las ecuaciones del planteamiento del problema. Como puede verse, los textos se escriben en las tres lenguas en las que se imparte docencia en el Centro. Además, los datos están separados del texto. Esto tiene una doble finalidad: evita que se repitan en cada lengua con la posibilidad de discrepancias y facilita que se puedan generar de forma automática con ayuda de una hoja de cálculo. Así, es habitual que, para cada modelo de pregunta, se construyan otras equivalentes variando los datos.

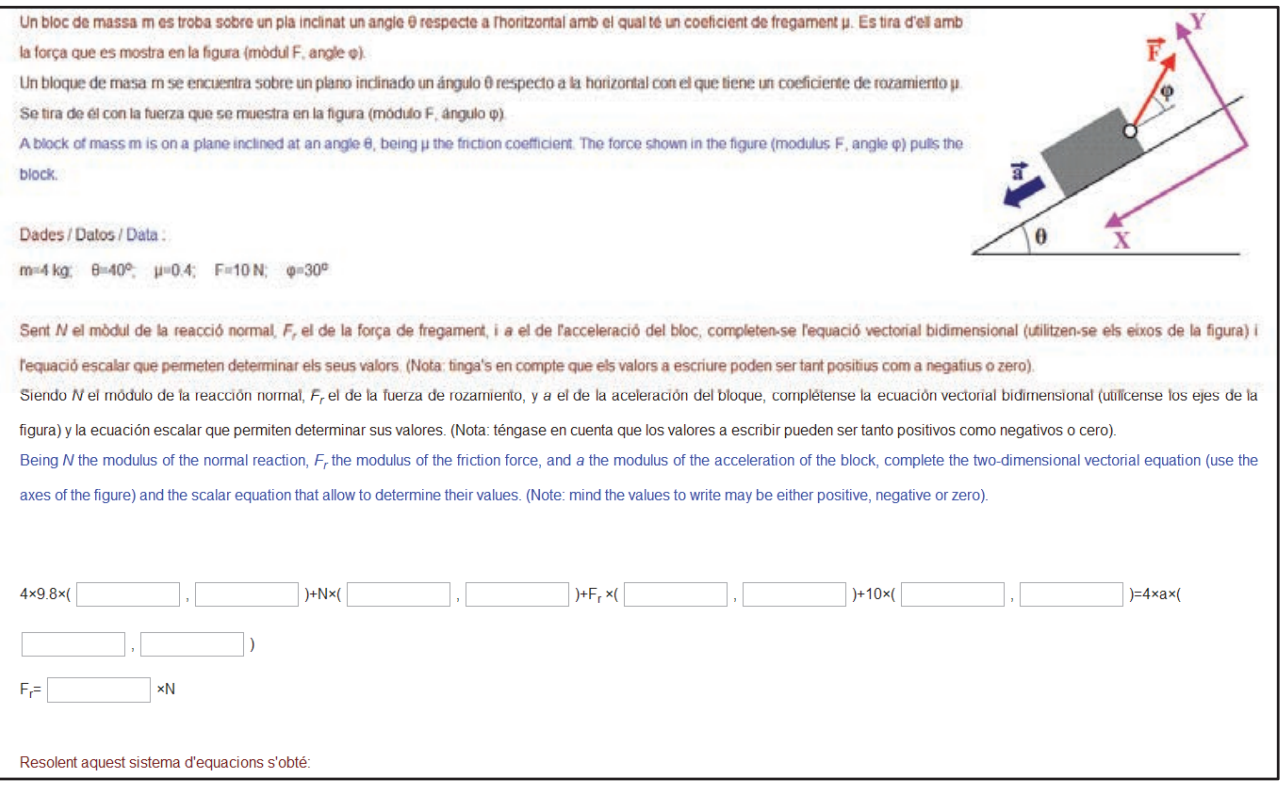

Fig. 1 Ejemplo de pregunta de los exámenes online de Física mediante PoliformaT. 
Nuestro planteamiento a la hora de elaborar los exámenes es que éstos sean objetivos, es decir, que sean calificados automáticamente por la aplicación. Esto permite una utilización de la herramienta optimizando su carácter formativo, ya que el estudiante conoce su puntuación inmediatamente después de la realización. Además, se preparan exámenes que no contribuyen a la calificación, que se pueden repetir tantas veces como se quiera, que incluyen comentarios sobre las respuestas, de forma que se puede repasar el tema y verificar de nuevo si se ha comprendido. Por otra parte, la rapidez en la corrección anima al profesor a utilizarlo como método de evaluación continua. Pero en este caso, es preciso diseñar adecuadamente la batería de preguntas y el examen para garantizar que cumple su misión.

\subsection{Descripción de los grupos}

Durante el curso académico 2011-2012, se llevó a cabo el modelo de evaluación mixta que se ha descrito en el apartado anterior en tres titulaciones de Grado de la Escuela Técnica Superior de Ingeniería del Diseño (ETSID): Ingeniería Aeroespacial (Aeroespacial), Ingeniería Industrial de Diseño y Desarrollo del Producto (Diseño), e Ingeniería Electrónica Industrial y Automática (Electrónica). En el caso de Ingeniería Aeroespacial, los exámenes online están enfocados a promover el trabajo continuo del alumno más que con fines de evaluación, aunque contribuyen a la nota con un peso del 10\%. Todos los estudiantes tienen el mismo modelo de problema, variando los datos de unos a otros; pueden realizar dos intentos y tienen varios días para realizar el examen. En las titulaciones de Diseño y Electrónica los exámenes online se realizan en una ventana de unas pocas horas, sólo tienen un intento y contribuyen a la nota con un peso del $20 \%$ en Diseño y del $15 \%$ en Electrónica. La tabla 1 presenta un resumen de la aplicación de los exámenes online y escritos en las 3 titulaciones.

Tabla 1. Condiciones de aplicación de los exámenes online y escrito en las 3 titulaciones.

\begin{tabular}{|c|c|c|c|c|c|}
\hline Titulación & $\begin{array}{c}\text { Número de } \\
\text { estudiantes }\end{array}$ & $\begin{array}{c}\text { Número de } \\
\text { exámenes } \\
\text { online }\end{array}$ & $\begin{array}{c}\text { Número de } \\
\text { exámenes }\end{array}$ & $\begin{array}{c}\text { Peso de los } \\
\text { exámenes }\end{array}$ & $\begin{array}{c}\text { Peso de los } \\
\text { exámenes } \\
\text { online }\end{array}$ \\
\hline Aerospacial & 84 & 10 & 6 & $10 \%$ & $60 \%$ \\
\hline
\end{tabular}

\section{(c)) EY-NC-ND 2014, Universitat Politècnica de València}

I Jornadas IN-RED (2014) 
Evaluación online versus evaluación presencial, ¿se pueden considerar equivalentes?

\begin{tabular}{|c|c|c|c|c|c|}
\hline Diseño & 135 & 5 & 5 & $20 \%$ & $60 \%$ \\
\hline Electrónica & 158 & 6 & 6 & $15 \%$ & $50 \%$ \\
\hline
\end{tabular}

\subsection{Análisis Estadístico}

Se ha utilizado el software SPSS para Windows version 16 (IBM, Somer, NY, USA) para realizar el análisis estadístico. Los test que se han llevado a cabo, han sido:

- Test ANOVA para analizar las posibles diferencias de la media de la nota de Poliformat de los tres grupos.

- Test Passing-Bablock para comparar la media de la poliformat para cada grupo con la respectiva media del examen.

- Análisis Bland-Altman con objeto de determinar el sesgo entre la nota Poliformat y examen de cada grupo.

Se tomó un nivel de significancia $\alpha$ de 0’05 para todos los test.

\section{Resultados y Discusión}

La Tabla 2 presenta un resumen de los resultados obtenidos, tanto en los exámenes online como escritos. Se presenta el valor medio \pm la desviación típica. La mayor diferencia entre las calificaciones obtenidas en los exámenes online y escritos tiene lugar en la titulación de Aeroespacial. Esto se explica fácilmente teniendo en cuenta las condiciones en las que se realizan los exámenes online: dos intentos, varios días para realizarlos, tal como se ha explicado previamente. Las diferencias obtenidas entre las calificaciones de los exámenes online y escritos en las titulaciones de Diseño y Electrónica son parecidas. Llama la atención la diferencia en las calificaciones entre las distintas titulaciones. Las calificaciones más altas las obtienen los estudiantes de la Titulación Aeroespacial, seguidos por los de Diseño, siendo las más bajas las de Electrónica. Puesto que son alumnos de primer curso, esto podría estar relacionado con la nota de corte de entrada, , o con otros factores que están fuera del control de esta experiencia. 
Tabla 2. Media y desviación típica de las calificaciones obtenidas en los exámenes online y escritos por los estudiantes de las 3 titulaciones.

\begin{tabular}{|c|c|c|}
\hline Grupo & Exámenes online & Exámenes escritos \\
\hline Aeroespacial & $8^{\prime} 02 \pm 1^{\prime} 5$ & $6^{\prime} 2 \pm 1^{\prime} 6$ \\
\hline Diseño & $7^{\prime} 0 \pm 2$ '0 & $5^{\prime} 8 \pm 1^{\prime} 4$ \\
\hline Electrónica & $6^{\prime} 0 \pm 2$ '1 & $5^{\prime} 1 \pm 22^{\prime} 2$ \\
\hline
\end{tabular}

Se ha realizado un análisis de Varianzas (ANOVA) para analizar las posibles diferencias de la media de la nota de exámenes online de los tres grupos. El test de Levene muestra diferencias significativas entre las varianzas de los diferentes grupos, por lo que se ha utilizado un método no paramétrico (Welch-ANOVA) para llevarlo a cabo. Sin embargo los resultados fueron muy similares a los obtenidos por el método paramétrico. El test ANOVA mostró diferencias significativas entre las medias de los tres grupos, por lo que se procedió a realizar un análisis de contrastes. El resultado obtenido fue consistente con nuestras espectativas. El análisis ANOVA obtuvo diferencias estadísticamente significativas para un contraste definido "a priori" para el grupo Aeroespacial con respecto a los otros dos $\left(\mathrm{p}<0^{\prime} 01\right)$, y para el grupo Electrónico frente al de Diseño ( $\left.<<0 ’ 01\right)$.

\subsection{Método de Passing Bablock.}

Si queremos verificar si los sistemas de evaluación online y escrito son equivalentes, deberíamos comprobar si los resultados de cada estudiante son los mismos en los dos tipos de examen. Para ello, hemos representado gráficamente (Fig 2) la calificación media de cada estudiante en los exámenes online frente a la media de los exámenes escritos. Si ambos sistemas de evaluación fueran completamente equivalentes, la relación entre X e Y vendría dada por la ecuación $\mathrm{Y}=\mathrm{X}$. Cuando no son idénticas, se pueden modelizar, entre otras, por la ecuación $Y=a X+b$. Esta aproximación lineal está basada en la suposición de que ambas variables están linealmente relacionadas. En nuestro caso, ambas variables son intercambiables y tienen la misma causa, lo que implica relación colateral (De la Macorra, 2002). Puesto que ni X ni Y están libres de error, la regresión lineal por mínimos cuadrados no es aconsejable. El método de regresión de Passing y Bablok (Passing, 1983) es un

\section{(cc)) EY-NC-ND 2014, Universitat Politècnica de València}

I Jornadas IN-RED (2014) 
método para calcular la ordenada en el origen $b$, y la pendiente $a$, así como sus intervalos de confianza del $95 \%$. Estos intervalos de confianza permiten establecer si hay diferencias significativas entre $b$ y 0 , y entre $a$ y 1 .
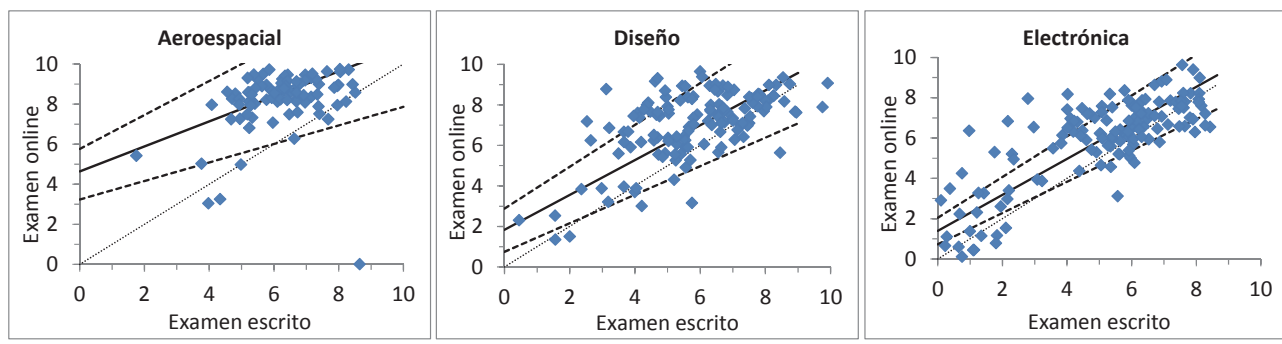

Fig 2. Aplicación del método de Passing-Bablock a la comparación entre los exámenes online y escritos. La línea sólida representa la recta de regression. La línea de puntos representa el ajuste perfecto, $Y=X$. Las líneas de trazos de cada lado marcan el $95 \%$ de interval de confianza.

La Fig. 2 representa la aplicación del método de Passing-Bablock a la comparación de los exámenes escritos y online de las tres titulaciones. La línea sólida en cada gráfica representa la línea de regresión mientras que la línea de puntos central representa la equivalencia perfecta $Y=X$. Las dos líneas de trazos a cada lado de la recta de regresión representan las rectas que marcan el intervalo de confianza del $95 \%$. Aunque se observa cierta dispersión, hay una clara correlación entre las calificaciones obtenidas en los exámenes online y las correspondientes a los exámenes escritos. Para el grupo de Aeroespacial la recta de regresión obtenida ha sido $Y=0^{\prime} 62 X+4{ }^{\prime} 64$, mientras que para diseño ha sido $Y=0$ '86 X+1'83, y para Electrónica $Y=0$ '89 X+1'4. El test CUSUM de linealidad mostró que no había desviación significativa de la linealidad (en todos los casos se encontró p>0’05).

\subsection{Análisis de Bland-Altman}

Con el fin de completar el análisis y determinar la presencia de sesgos en los resultados, se realizó un análisis de Bland-Altman. En este método se representa la diferencia entre los resultados obtenidos por los dos sistemas de evaluación con la media de ambos. La Tabla 3 resume los resultados obtenidos en las 3 titulaciones: la media de las diferencias y el intervalo de confianza del $95 \%$ (determinado por la media más/menos el doble de la desviación típica). De nuevo, encontramos un sesgo mayor en la Titulación de Aeroespacial, siendo el menor el de la titulación de Electrónica. Las diferencias encontradas entre la titulación de Aeroespacial se explican, una vez más, por el hecho de que los estudiantes pueden realizar dos intentos del examen, a lo largo de varios días. En el 
caso de Diseño, siendo el modelo de aplicación equivalente al de Electrónica, se puede explicar el sesgo hacia notas mayores por la mayor contribución a la calificación global; los estudiantes perciben como más importante aquello que más contribuye a su calificación, y le dedican mayor atención. Esto apoya el hecho de que la evaluación influye en la forma en que los estudiantes abordan una material, como ha sido comentado por otros autores (Nowell, 2010).

Table 3. Parámetros obtenidos de los diagramas de Bland-Altman para las 3 titulaciones.

\begin{tabular}{|c|c|c|}
\hline Grupo & Media de las diferencias & Límite de acuerdo \\
\hline Aeroespacial & 2.07 & $-0^{\prime} 39 / 4{ }^{\prime} 53$ \\
\hline Diseño & 1'19 & $-2{ }^{\prime} 33 / 4{ }^{\prime} 73$ \\
\hline Electrónica & 0'94 & $-3^{\prime} 43 / 5^{\prime} 31$ \\
\hline
\end{tabular}

En el grupo de Electrónica se presenta la mayor dispersión de datos. Hay casos en los que la media de los exámenes online es hasta 6 puntos superior que la de los exámenes escritos, lo que claramente representa una situación anómala, digna de seguir con atención. También hay estudiantes que obtienen peores resultados en los exámenes online que en los escritos, probablemente porque cometen pequeños errores que invalidan los resultados obtenidos en una prueba objetiva. Intentando paliar este hecho, los exámenes online cuentan con varios apartados, procurando que no sean interdependientes, pero esto no siempre es posible. También podría ocurrir que algunos estudiantes no estuvieran suficientemente motivados por el poco peso con el que estos ejercicios contribuyen a la nota final de la asignatura.
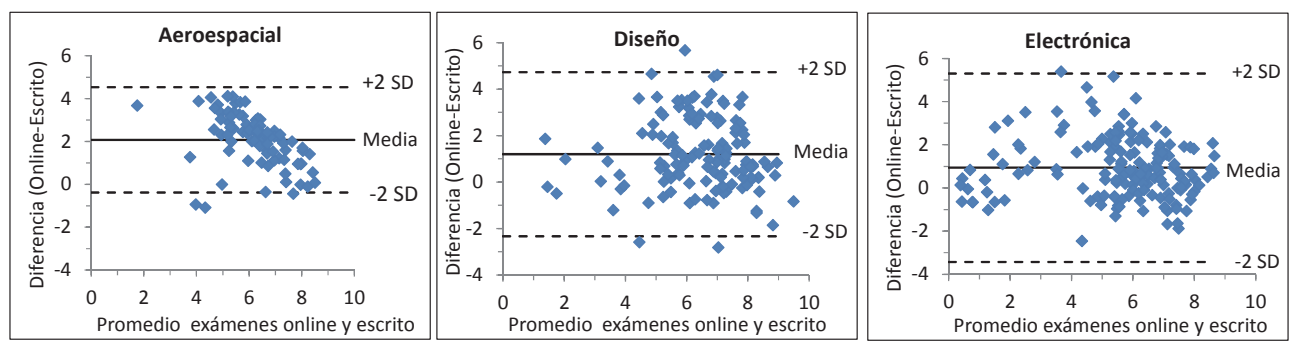

Fig 3. Diagramas Bland-Altman. Se representa la diferencia entre las calificaciones obtenidas en los exámenes online y los escritos respecto a la medias de ambos para los 3 grupos.

\section{(cc)) EY-NC-ND 2014, Universitat Politècnica de València}

I Jornadas IN-RED (2014) 
A través de una encuesta realizada a los estudiantes (Vidaurre, 2013) hemos podido constatar que, en general sí que le dan importancia a los exámenes online, los valoran especialmente como una herramienta de diagnóstico y guía en el aprendizaje. Consideran que les ayuda a estudiar, pero el aspecto en el que manifiestan algunas dudas es en el de su uso como herramienta de evaluación.

\section{Conclusiones}

En el presente trabajo se ha analizado la aplicación de un método de evaluación mixto en el que, entre otros, se utiliza un sistema de evaluación online, y un sistema tradicional de exámenes escritos. Se ha estudiado la aplicación a 3 titulaciones distintas con algunas diferencias en el planteamiento. En todos los casos la evaluación online está orientada a servir como complemento al estudio, aunque también contribuye a la calificación final. Cumple la finalidad de enfrentar al estudiante a una prueba relacionada con la materia que está estudiando, aunque, en general, se tiene menos presión que en un examen tradicional. Se encuentra en un ambiente más relajado, puede consultar fuentes e, incluso, a otras personas (en muchos casos compañeros).

A pesar de ello, los resultados demuestran que las calificaciones obtenidas en los exámenes online presentan cierta concordancia con los obtenidos en los exámenes escritos, que su utilización dentro de un contexto de evaluación mixta es recomendable porque aporta información relevante al estudiante sin sobrecargar al profesor. Tienen la ventaja de la inmediatez y contribuyen eficazmente a la evaluación formativa.

\section{Referencias}

AltMan D.G., y BLAND J.M. (1983). "Measurement in medicine: the analysis of method comparison studies" en The Statistician, vol. 32, p. 307-317.

BAIN, K. (2004), What the best college teachers do. Cambridge, MA, USA: Harvard University Press.

BenNETT, R.E. et al. (2010). "Measuring Problem Solving with Technology: A Demonstration Study for NAEP" en Journal of Technology, Learning, and Assessment, vol. 8 , issue 8 .

Bland, J.M., y Altman, D.G. (1986). "Statistical Methods for Assessing Agreement between Two Methods of Clinical Measurement" en Lancet, vol. 327, issue 8476, p. 307310 .

BLAND J.M., y ALTMAN DG. (1987). "Statistical methods for assessing agreement between measurement" en Biochimica Clinica, vol. 
11, p. 399-404.

Boston, C. (2002). "The concept of formative assessment" en Practical Assessment, Research \& Evaluation, vol. 8, issue 9.

BRANSFORD, J. D., Brown, A. L., y Cocking, R. R. (2000). How people learn: brain, mind, experience, and school (expanded ed.). Washington, DC: National Academy Press.

Clarke, J., y Dede, C. (2010). "Assessment, technology, and change" en Journal of Research in Teacher Education, vol 42, p. 309-328.

DE LA MACORRA, J.C., y ESCRIBANO, N.I. (2002). "Comparison of two methods to measure permeability of dentin" en Journal of Biomedical Materials Research, vol. 63, issue 5, p. 531-534.

Galton, F. (1888). "Co-relations and their measurement, chiefly from anthropometric data" en Proceedings of the Royal Society of London, vol. 45, p. 135-145

GIBBS, G. (1999). Assessment matters in higher education: choosing and using diverse approaches, Chapter 4: Using assessment strategically to change the way students learn. Buckingham, BUX, UK: Society for Research into Higher Education \& Open University Press,

GiKANDI, J. W., MorRow, D., DAvis, N.E. (2011). "Online formative assessment in higher education: A review of the literature" en Computers \& Education, vol. 57, issue 4, p. 2333 2351.

HARGREAVES E. (2008). The Routledge international encyclopedia of education. Abingdon, OX, UK: Routledge, Taylor \& Francis Group. Edited by McCulloch, G., \& Crook D., Pages 37-38.

Hewson, C. (2012). "Can online course-based assessment methods be fair and equitable? Relationships between students' preferences and performance within online and offline assessments" en Journal of Computer Assisted Learning, vol. 28, issue 5, p. 488-498.

HOLLISTER, K. K., y BERENSON, M. L. (2009). "Proctored versus unproctored online exams: Studying the impact of exam environment on student performance" en Decision Sciences Journal of Innovative Education, vol. 7, issue 1, p. 271-294.

KuO, C. Y., y Wu, H. K. (2013). "Toward an integrated model for designing assessment systems: An analysis of the current status of computer-based assessment in science" en Computers \& Education, vol. 68, p. 388-403.

Nowell, C., Gale, L. R., y HANDley, B. (2010). "Assessing faculty performance using student evaluations of teaching in an uncontrolled setting" en Assessment \& Evaluation in Higher Education, vol. 35, issue 4, p. 463-475.

Oosterhof, A., ConRad, R. M., y Ely, D. P. (2008). Assessing learners online. New Jersey: Pearson.

\section{(c)) EY-NC-ND 2014, Universitat Politècnica de València}


PALMER, S., y HolT, D. (2010). "Students' perceptions of the value of the elements of an online learning environment: looking back in moving forward" en Interactive Learning Environments, vol. 18, issue 2, p. 135-151.

PANDEY, V.A. et al. (2008). "Self-assessment of technical skill in surgery: the need for expert feedback" en Annals of the Royal College of Surgeons of England, vol. 90, issue 4, p. 286-290.

PAssing, H., y BABLOK, W. (1983). “A New Biometrical Procedure for Testing the Equality of Measurements from 2 Different Analytical Methods - Application of Linear-Regression Procedures for Method Comparison Studies in Clinical-Chemistry, Part I" en Journal of Clinical Chemistry and Clinical Biochemistry, vol. 21, issue 11, p. 709-720.

PEARSON, K. (1895). "Notes on regression and inheritance in the case of two parents" en Proceedings of the Royal Society of London, vol. 58, p. 240-242.

JAMIS J. PERRETT (2013): "Exploring graduate and undergraduate course evaluations administered on paper and online: a case study" en Assessment \& Evaluation in Higher Education, vol. 38, issue 1, p. 85-93.

SAntos Guerra, M. A. (2003). Una flecha en la diana. La evaluación como aprendizaje. Madrid, SP: Narcea.

Singley, M. K., y BenNetT, R. E. (2002). Item generation for test development, Chapter 14Item generation and beyond: Applications of schema theory to mathematics assessment. New York, NY, USA: Lawrence Erlbaum Associates.

SMITH, G. (2007). "How does student performance on formative assessments relate to learning assessed by exams?" en Journal of College Science Teaching, vol. 36, issue 7, p. $28-34$.

TAYLOR, J.A. (2008). “Assessment in first year university: A model to manage transition" en Journal of University Teaching and Learning Practice, vol. 5, issue 1, p. 19-33.

VAN NulAND, M. et al. (2007). "Comparison of two instruments for assessing communication skills in a general practice objective structured clinical examination" en Medical Education, vol. 41, issue 7, p. 676-683.

VIDAURRE, A. et al. (2011). "Utilización de baterías de preguntas para la confección de exámenes on-line. Su validación como herramienta de evaluación" en III Jornada Nacional sobre Estudios Universitarios: el presente de los nuevos títulos. Castellón: Universitat Jaume I.

Vidaurre A., Riera J., Meseguer-DueÑas J.M., GómeZ.TeJEdor J.A., Ardid M. (2013) "Análisis factorial de la encuesta de satisfacción de la herramienta examen de PoliformaT, en un contexto de mejora de la innovación” XXI Cóngreso de Innovación Educativa en las Enseñanzas Técnicas. Valencia, p. 1033-1043.

M. WeBb, D. GiBSON \& A. Forkosh-BARUCH (2013). "Challenges for information technology supporting educational assessment" en Journal of Computer Assisted Learning, vol. 29, issue 5, p. 451-462. 
WOLSEY, T. (2008). "Efficacy of instructor feedback on written work in an online program" en International Journal on ELearning, vol. 7, issue 2, p. 311-329.

Vonderwell, S., Liang, X., y Alderman, K. (2007). "Asynchronous discussions and assessment in online learning" en Journal of Research on Technology in Education, vol. 39, issue 3, p. 309-328.

YEH, S. S. (2010). "Understanding and addressing the achievement gap through individualized instruction and formative assessment" en Assessment in Education: Principles, Policy \& Practice, vol 17, p. 169-182. 


\title{
Integración de la Plataforma Educativa PoliformaT como Herramienta Facilitadora del Aprendizaje Autónomo en Primer Curso
}

\author{
Isabel MORERA, Julia ATIENZA, Ma José CLIMENT y Sara IBORRA
}

imorera@upvnet.upv.es, matien@qim.upv.es, mjcliol@qim.upv.es, siborra@itq.upv.es

GRUPO DE INNOVACIÓN E INVESTIGACIÓN EN METODOLOGÍAS ACTIVAS (GIIMA)

Departamento de Química. Universitat Politècnica de València.

Camino de Vera s/n. 46071-València

\begin{abstract}
In this paper the experience of integrating educational platform PoliformaT of the Universitat Politècnica de València, as technological resource to support self-learning and assessment, in the first year, is described. It has been implemented in the chemistry subject of several degrees taught in the Escuela Técnica Superior de Ingeniería Industrial and in the Escuela Técnica Superior de Ingeniería Agronómica y del Medio Natural. Tthe platform is used to generate tests, which students can access anytime, anywhere as self-assessment, while they acquire knowledge gradually. Our aproach constitutes a formative and summative assessment, because the activity is completed with exams which provide a computable score in the final mark. After detailed analysis of the result, it can be stated that the use of PoliformaT platform as a tool for self-learning in the first year, promotes student involvement, allowing them to build knowledge gradually. Moreover, self-assessment provides feedback to students to manage their learning, while allow us to evaluate the achieved learning.
\end{abstract}

Keywords: self-learning, first course, chemistry, technology resources, elearning platform 
Integración de la Plataforma Educativa PoliformaT como Herramienta Facilitadora del Aprendizaje Autónomo en Primer Curso

\begin{abstract}
Resumen
En esta comunicación se describe la experiencia de la integración de la plataforma educativa PoliformaT de la Universitat Politècnica de València, como recurso tecnológico de apoyo para el autoaprendizaje y la evaluación en primer curso. Se ha implementado en la asignatura de Química de varios títulos de Grado que se imparten en la Escuela Técnica Superior de Ingeniería Industrial y en la Escuela Técnica Superior de Ingeniería Agronómica y del Medio Natural. Consiste en la utilización de la plataforma para generar pruebas, a las que los alumnos pueden acceder en cualquier momento y desde cualquier lugar para autoeluarse, a la vez que van adquiriendo conocimientos progresivamente. Se trata de una evaluación formativa y sumativa ya que la actividad se completa con una prueba que proporciona una puntuación computable en la nota final. Del análisis de la experiencia realizada y de los resultados obtenidos se puede afirmar que el uso de la plataforma PoliformaT como herramienta para el aprendizaje autónomo en primer curso, promueve la implicación del estudiante y le permite construir conocimiento gradualmente y a su ritmo. Además la autoevaluación le proporciona retroalimentación para que pueda gestionar su aprendizaje al tiempo que nos permite evaluar el aprendizaje adquirido.
\end{abstract}

Palabras clave: aprendizaje autónomo, primer curso, química, recursos tecnológicos, plataforma e-learning

\title{
1.Introducción
}

La docencia universitaria en primer curso es una tarea compleja, especialmente en lo que se refiere a la heterogeneidad en el nivel de conocimientos que muestran los alumnos de nuevo ingreso. En el caso de la asignatura de Química en las titulaciones de Ingeniería, lo es más si cabe, por la coexistencia de alumnado con una buena formación previa, al haberla cursado en las diferentes modalidades de Bachillerato, con otro completamente profano en la materia. Con la introducción de los nuevos títulos de Grado en las enseñanzas de Ingeniería, el profesorado se ha enfrentado a una labor todavía más retadora: conseguir que los estudiantes, que en general consideran que no necesitan saber Química para ser ingenieros, la aprendan en un tiempo record, en un único cuatrimestre. Esto supone un inconveniente respecto a otras materias básicas de primer curso, como la Física y las Matemáticas, que disponen de más créditos y se imparten a lo largo de todo el curso académico.

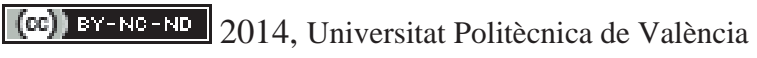

I Jornadas IN-RED (2014) 
Los primeros cursos son decisivos para la integración del alumno en la universidad, especialmente el primero es crítico, ya que todo el entorno es nuevo: la organización, los profesores, los métodos, los compañeros, etc. Los métodos de enseñanza y evaluación que utilizan los profesores influyen enormemente en el modo de aprender de sus alumnos y en su rendimiento académico (Gargallo, 2008 y 2010). Este aspecto es muy importante teniendo en cuenta la necesidad de que en la universidad se consiga una elevada tasa de éxito en el primer curso, se reduzca el fracaso escolar, y se motive a los alumnos recién ingresados, muchos de los cuales llegan a los grados sin haberlos elegido como primera opción, para desarrollar una carrera universitaria comprometida y eficaz.

En el entorno del EEES se concede una gran importancia a las actividades presenciales y no presenciales que un alumno debe desarrollar para conseguir su formación integral. Es necesario por tanto, no sólo proporcionar espacios de aprendizaje en al aula, sino también oportunidades para que el estudiante programe su acción formativa de manera progresiva, en función de sus conocimientos y en base a sus necesidades. Para ello se requiere proporcionar a los alumnos materiales atractivos que fomenten y sean el soporte de su formación no presencial. Esta tarea es especialmente importante en el caso de la enseñanzaaprendizaje en primer curso de educación superior, momento clave para reorientar los hábitos de los estudiantes con el fin de introducirlos en la dinámica del trabajo diario y del aprendizaje autónomo, que constituyen el primer paso para el éxito académico. En este contexto el uso de herramientas tecnológicas puede ser una estrategia para motivar al alumnado e introducirlo, desde el primer curso, en la dinámica del aprendizaje autónomo.

No cabe duda de que en la actualidad las tecnologías de la información y la comunicación (TIC) son herramientas de indiscutible valor y efectividad en la docencia y es difícil concebir el proceso de enseñanza-aprendizaje en la Universidad sin considerar el uso de las mismas. Un hecho que confirma esta idea es el empleo, cada vez más frecuente, de las plataformas educativas tecnológicas (plataformas e-learning). Actuamente casi todas las Universidades disponen de estas herramientas que permiten, entre otras acciones, crear y gestionar los contenidos educativos y de apoyo a la enseñanza-aprendizaje, así como generar instrumentos de evaluación y autoevaluación (Hernández, 2003 y Michavila, 2004).

El uso de las plataformas educativas require un cambio profundo en las concepciones sobre las metodologías docentes basadas en la clase magistral impartida por el profesor y los hábitos de aprendizaje memorísticos a los que se tiene acostumbrados a los estudiantes a lo largo de su vida académica, orientada a aprobar los exámenes. Aprender en un entorno mixto en el que se integre el uso del e-learning requiere que tanto profesores como estudiantes conozcan el uso de la herramienta (Canós, 2009), y estén dipuestos a hacer uso de ella. Esto puede suponer un inconveniente a la hora de la implementación de la tecnología en la docencia en los primeros cursos, con un elevado número de alumnos, a los que además de ayudarles a adquirir los conocimientos, habilidades y destrezas de las

\section{(c)) EY-NC-ND 2014, Universitat Politècnica de València}

I Jornadas IN-RED (2014) 
Integración de la Plataforma Educativa PoliformaT como Herramienta Facilitadora del Aprendizaje Autónomo en Primer Curso

materias básicas se les ha de adiestrar en el manejo de las herramientas tecnológicas; a ello hay que unir el esfuerzo y el tiempo que supone para el profesorado el diseño y preparación de materiales. La tecnología es una parte importante en el uso de las plataformas educativas para la enseñanza pero, no cabe duda que, una vez dominados los aspectos fundamentales en lo que se refiere a funcionamiento, constituye una oportunidad para transformar la docencia universitaria y optimizar la calidad de los aprendizajes de los alumnos (Roffe, 2002). De entre los aspectos positivos (Canós, 2009) del uso de las plataformas educativas, centrándonos en el aspecto a que en esta comunicación se refiere, se puede destacan que:

- Los recursos educativos son fácilmente accesible para los estudiantes.

- El estudiante puede mantener un ritmo de aprendizaje ajustado a sus necesidades.

- Proporciona flexibilidad en los tiempos y espacios dedicados al aprendizaje.

- Se obtiene información de resultados de manera rápida.

Del enorme abanico de plataformas educativas, la Universitat Politècnica de Valencia (UPV) incorpora en el curso 2006-2007 la plataforma de teleformación PoliformaT (www.poliformat.upv.es), basada en el sistema Sakai, con el fin de proporcionar una herramienta de apoyo para los profesores en la gestión de sus asignaturas. En esta plataforma se ofrece la información relativa a las mismas, entre las que cabe destacar el repositorio de contenidos, y permite gestionar la realización de tareas, exámenes, calificaciones, etc.

Aunque en la actualidad el uso de PoliformaT es general en el ámbito de la UPV, se pueden citar pocas referencias que focalicen su uso para propiciar el aprendizaje autónomo y la autoevaluación de los estudiantes en asignaturas de primer curso. En este sentido Sanabria (2008) describe algunas iniciativas de la utilización de la misma en la asignatura de Análisis Matemático, de primer curso de la titulación de Ingeniero en Informática, centrada en la realización de una serie de pruebas de evaluación diagnóstica, progresiva y continuada, mediante test de preguntas cortas al finalizar el estudio de cada bloque temático.

En este contexto y ante la disponibilidad de una plataforma como PoliformaT, nos planteamos la idea de explotar las posibilidades de su uso como estrategia para la evaluación de algunas actividades no presenciales de los alumnos de primer curso, al tiempo que estos pudiesen autoevaluarse y obtener retroalimentación sobre su nivel de conocimientos. Se trata de aprovechar los recursos tecnológicos disponibles y ponerlos al servicio del aprendizaje para conseguir que los estudiantes se impliquen en el proceso de enseñanza y se inicien en la práctica del aprendizaje autónomo, tan pronto como sea posible. 


\section{Objetivos}

- Incorporar los recursos tecnológicos disponibles como herramienta educativa y evaluativa.

- Iniciar a los estudiantes de primer curso en la práctica del aprendizaje autónomo.

- Generar motivación en el alumnado al aprender a su ritmo, de manera secuencial y progresiva para mejorar el rendimiento académico.

- Divulgar la experiencia adquirida para dinamizar su uso en otras asignaturas en el entorno universitario.

\section{Desarrollo de la innovación}

La experiencia se ha llevado a cabo en las asignaturas de Química de varios títulos de Grado que se imparten en la Universitat Politècnica de València. Las titulaciones implicadas son: Grado en Ingeniería de Organización Industrial (GIOI), Grado en Ingeniería en Tecnologías Industriales (GITI) y Grado en Ingeniería de la Energía (GIE), que se imparten en la Escuela Técnica Superior de Ingeniería Industrial (ETSII) y el Grado en Ingeniería Agroalimentaria y del Medio Rural (GIAMR) en la Escuela Técnica Superior de Ingeniería Agronómica y del Medio Natural (ETSIAMN). En la ETSII la denominación de la asignatura es "Química" mientras que la ETSIAMN, es "Química General". Todas tienen asignados 6 créditos ECTS, se incluyen como formación básica en primer curso y poseen un elevado número de alumnos. Respecto a la ubicación la asignatura "Química" del GIOI y "Química general" del GIAMR se imparten en el primer cuatrimestre y la asignatura "Química" de GIE y GITI se imparte en el segundo cuatrimestre.

En el caso de las asignaturas de "Química" que se imparten en la ETSII, la innovación se inició en el curso 2012-13 en el GIE y GITI y en el 2013-14 en el GIOI. Ha consistido en el uso de la opción de exámenes de la plataforma PoliformaT, para el diseño de baterías de preguntas de respuesta múltiple, que incluyen contenidos relativos a todos los temas que se imparten en el curso y que se agrupan en dos bloques, uno por cada evaluación parcial. En las preguntas se incluyen tanto aspectos teóricos que el estudiante debe dominar, como ejercicios de aplicación sencillos, que han de resolver mediante cálculos, para poder responder.

A partir de estas baterías se generan una serie de pruebas con preguntas elegidas aleatoriamente. Los alumnos tienen la posibilidad de acceder a la plataforma en cualquier momento y desde cualquier lugar para realizar las pruebas (autoevaluación libre) varias veces, de manera que van adquiriendo conocimientos progresivamente. En cada prueba se les informa de la nota obtenida, es una evaluación formativa que les sirve para diagnosticar

\section{(cc) EY-NC-ND 2014, Universitat Politècnica de València}

I Jornadas IN-RED (2014) 
Integración de la Plataforma Educativa PoliformaT como Herramienta Facilitadora del Aprendizaje Autónomo en Primer Curso

el grado de conocimiento de la materia. Posteriormente, se realiza un examen a partir de preguntas, también elegidas aleatoriamente, que los alumnos realizan en la misma plataforma. Para minimizar el plagio entre alumnos, además de aparecer las preguntas de manera aleatoria, se muestran en páginas Web diferente y el alumno no puede volver atrás. Una vez lanzada la pregunta se ha de contestar y seguir adelante con la siguiente. El sistema automáticamente evalúa y envía los resultados a la opción de calificaciones, por lo que es una herramienta muy cómoda para obtener las notas. El examen se realiza en fecha y horas determinadas, antes de cada uno de los dos exámenes parciales escritos, y cuya puntuación es computable en la nota final. Los dos exámenes en PoliformaT se puntuan con un $10 \%$ de la nota total final.

A modo de ejemplo en la Figura 1 se muestran dos imágenes que ilustran el tipo de preguntas que el alumno ha de responder en la plataforma.

Por lo que respecta a la asignatura de "Química General" de la ETSIAMN, la innovación se inicio en el curso 2010-11 y se ha centrado en las prácticas de laboratorio. En este caso, también la herramienta de exámenes de PoliformaT se usa como medio de evaluación de las actividades pre-laboratorio (Noguera, 2011). Para el diseño del cuestionario se sigue el mismo procedimiento descrito anteriormente. A partir de las baterías de preguntas de respuesta múltiple, se confecciona el cuestionario seleccionándolas de manera aleatoria y mostrándolas en páginas Web diferentes. Para el diseño de la actividad se realizó una adapación del manual de prácticas de laboratorio con el fin de que el alumno dispusiese de la información para contestar los cuestionarios mencionados y una serie de advertencias para evitar errores habituales en la realización de las prácticas. Para cada práctica se elaboró la correspondiente batería de preguntas que incluye conceptos teóricos y prácticos básicos de cada una de las sesiones de prácticas ordenadas en bloques (reconocimiento del material usado en la práctica, normas de seguridad, tratamiento de los residuos generados y otras dedicadas a los cálculos habituales en la práctica).

El alumno ha de contestar, antes de realizar cada sesión de laboratorio, al cuestionario correspondiente en el tiempo asignado (10 minutos), previa lectura del guión de la práctica que le permite conocer el fundamento teórico, los cálculos a realizar y el material a emplear. Los alumnos tienen acceso al cuestionario durante una semana, y lo pueden realizar dos veces, con el fin de que el alumno tenga la posibilidad de mejorar la nota de la primera respuesta, si así lo desea. El sistema automáticamente evalúa y envía el resultado de la nota más alta a la opción de calificaciones que es computable en la nota final. Los cuestionarios puntuan un $4 \%$ de la nota total final. Después de la sesión de prácticas los alumnos realizan un examen de prácticas. 


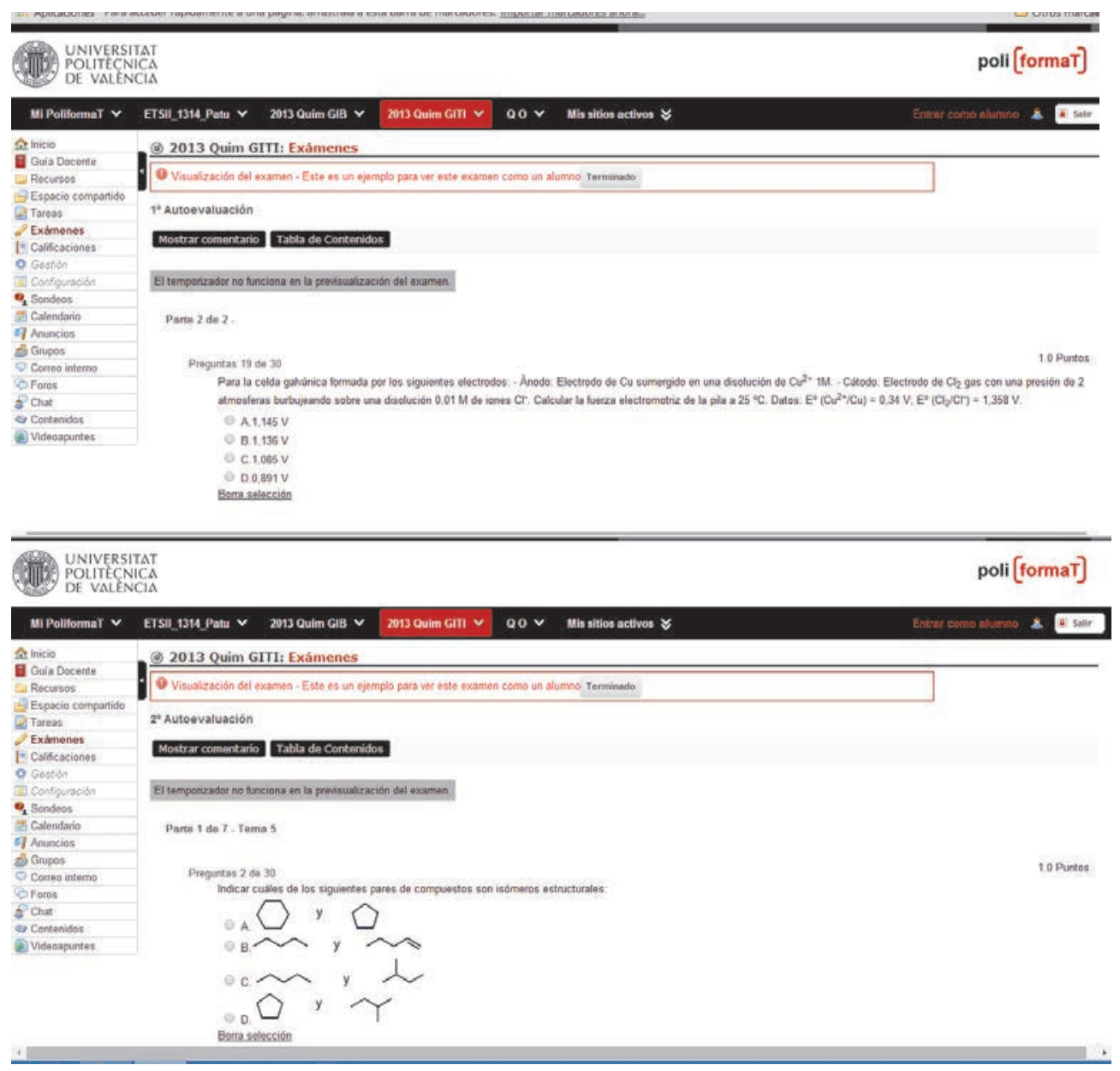

Figura 1. Imagen de la herramienta exámenes en poliformaT. Algunos ejemplos de las preguntas que el alumno ha de responder.

Mediante la plataforma PoliformaT se gestionan de manera sencilla los resultados puesto que además de obtener de forma automática la calificación, proporciona el número de intentos realizados y el tiempo que ha dedicado cada alumno a realizar la prueba. Además se pueden descargar los resultados individualizados por alumno o por pregunta, lo que permite detectar errores comunes y abordarlos al inicio de la sesión, consiguiendo así una retroalimentación verdaderamente efectiva.

Con el fin de valorar la eficacia de la integración de PoliformaT como herramienta facilitadora del aprendizaje autónomo en primer curso se han recogido y analizado datos del sobre el número de alumnos que se implican en la realización de las pruebas de

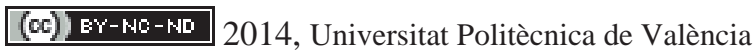

I Jornadas IN-RED (2014) 
Integración de la Plataforma Educativa PoliformaT como Herramienta Facilitadora del Aprendizaje Autónomo en Primer Curso

autoevaluación y los exámenes en caso de los títulos de la ETSII y los cuestionarios prelaboratorio en la ETSIAMN. También se han analizado el número de alumnos que aprueban los exámenes y los cuestionarios pre-laboratorio. A excepción del GIE, en las demás titulaciones existe más de un grupo de docencia. La toma de datos y el análisis de los mismos se ha llevado a cabo en los grupos en los que los autores, pertenecientes al Grupo de Innovación e Investigación en Metodologías Activas (GIIMA), imparten docencia. En el caso de la ETSII la muestra es de 370 alumnos entre los cursos 2012-13 y 2013-14, mientras que en la ETSIAM es de unos 200 entre los cursos 2011-12 y 2013-14.

\section{Resultados}

\subsection{Asignatura “Química” de GIOI, GITI y GIE.}

La experiencia se inició en el curso 2012-13 en el GIE y GITI, en los que la Química se imparte en el segundo cuatrimestre, como experiencia piloto con los alumnos que ya tenían cierta práctica en el uso de la plataforma para evitar el impacto de la falta experiencia en el resultado de la innovación, y se hizo extensivo en el segundo parcial del curso 2013-14 al título de GIOI, que tiene la docencia de esta asignatura en el primer cuatrimestre.

En la Figura 2 se muestra el porcentaje de presentados a las pruebas de autoevaluación libre, correspondientes a los dos parciales en ambos cursos académicos.

a)

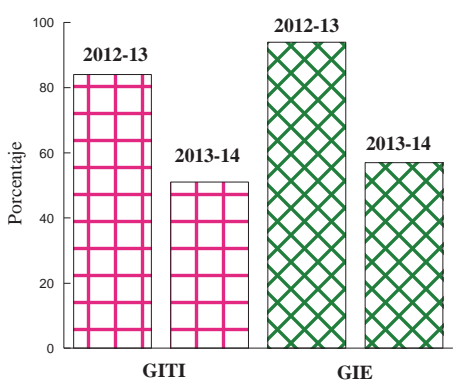

b)

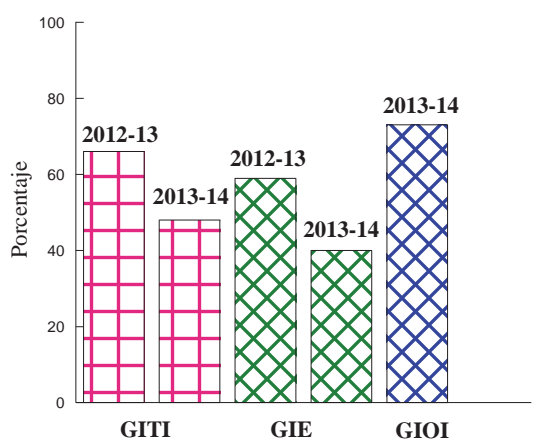

Figura 2. Presentados en la prueba de autoevaluación libre correspondiente al:

a) primer parcial y b) segundo parcial

Como se observa, el porcentaje de alumnos que realiza las pruebas está alrededor del $50 \%$ llegando a superar el 80\% en el curso 2012-13 en los títulos de GITI y GIE, lo que indica 
que una parte importante del alumnado se ha iniciado en el uso de la plataforma y se implica en la tarea de autoaprendizaje implementada. También se puede observar que los alumnos del GIOI (primer cuatrimestre) se implican llegando casi al $80 \%$ en el segundo parcial, lo que confirma que en general el alumnado está interesado en este tipo de tareas en las que la tecnología está presente.

Con respecto a los exámenes, los resultados se muestran en la Figura 3, en la que se ilustran los porcentajes de presentados y aprobados en los cursos 2012-13 y 2013-14 para el primer parcial en los títulos de GITI y GIE. Se observa que, en ambos títulos el porcentaje de presentados supera al 95\% y de aprobados supera el $90 \%$ y se mantiene en los dos cursos académicos. Las calificaciones obtenidas son mayores o iguales a 8.

a)

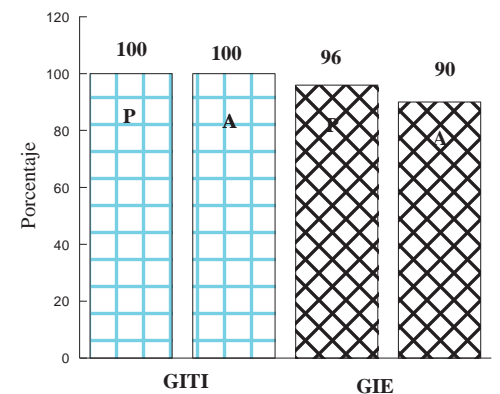

b)

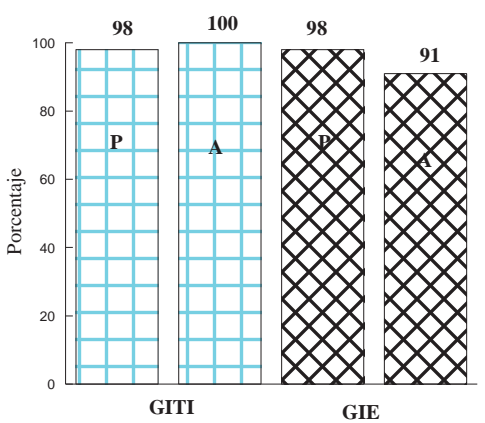

Figura 3. Presentados $(P)$ y aprobados $(A)$ en el examen en la plataforma correspondiente al primer parcial de los cursos: a) 2012-13 y b) 2013-14.

En la Figura 4 se muestran los equivalentes a la Figura 3, referidos al segundo parcial. Se observa que el porcentaje de presentados se mantiene en valores por encima del $80 \%$ y el de aprobados supera también este valor, y además las calificaciones se mantienen por encima de 8. Un dato significativo se tiene para el título de GIOI (primer cuatrimestre) en el que se destaca un elevado grado de participación (90\%) aunque el porcentaje de aprobados está alrededor del $66 \%$. Este resultado podría relacionarse con el desconcierto que provoca el uso de la herramienta por primera vez y cierta influencia de la fecha del examen que se realizó al día siguiente del periodo no lectivo vacacional de Navidad.

(c)) EY-NC-ND 2014, Universitat Politècnica de València

I Jornadas IN-RED (2014) 
Integración de la Plataforma Educativa PoliformaT como Herramienta Facilitadora del Aprendizaje Autónomo en Primer Curso

a)

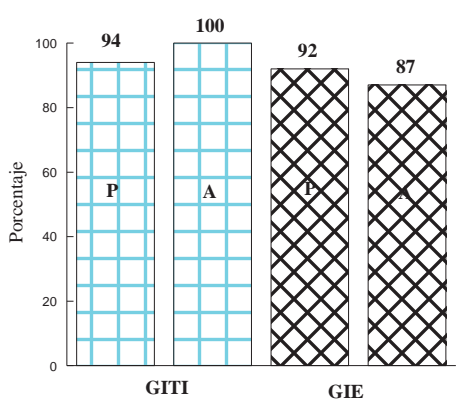

b)

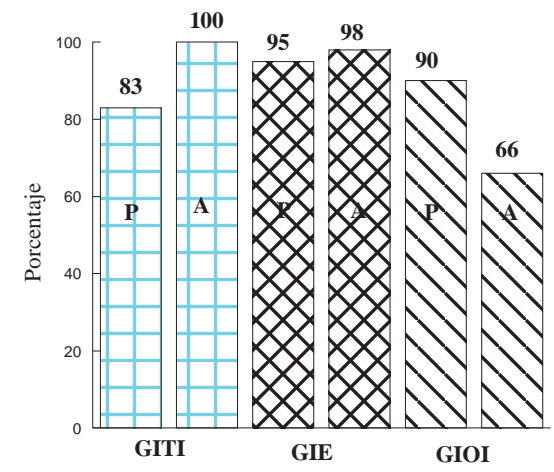

Figura 4. Presentados $(P)$ y aprobados $(A)$ en el examen en la plataforma correspondiente al segundo parcial de los cursos: a) 2012-13 y b) 2013-14.

\subsection{Asignatura "Química General” de GIAMR.}

Esta experiencia se ha realizado durante los cursos 2011-12, 2012-13 y 2013-14, y se dispone de información de un total de 204 alumnos. En la Tabla 1 se muestran los datos de participación y aprobados en los cuestionarios pre-laboratorio.

Tabla 1. Número de alumnos participantes en los distintos cursos del GIAMR

\begin{tabular}{lcccc}
\hline Curso & $\mathbf{2 0 1 1 - 1 2}$ & $\mathbf{2 0 1 2 - 1 3}$ & $\mathbf{2 0 1 3 - 1 4}$ & Total \\
Matriculados & 77 & 62 & 65 & 204 \\
Realizan pre- laboratorio & $58(75 \%)$ & $51(82 \%)$ & $60(92 \%)$ & 169 \\
Aprobados pre-laboratorio & $43(55 \%)$ & $33(53 \%)$ & $39(60 \%)$ & 115 \\
Realizan examen prácticas & $52(67 \%)$ & $47(76 \%)$ & $50(77 \%)$ & 149 \\
Aprobados examen prácticas & $29(38 \%)$ & $33(53 \%)$ & $13(20 \%)$ & 82 \\
\hline
\end{tabular}

Como puede verse, del total de alumnos matriculados en la asignatura en los tres cursos académcios, han participado en esta actividad 169 , lo que supone el $82 \%$. Respecto a los aprobados en los cuestionarios el porcentaje está alrededor del 55\% y las calificaciones obtenidas alrededor de 7 , lo que indica que los alumnos adquieren un aprendizaje, previo a la práctica, que es apropiado para poder llevarla a cabo con garantía y seguridad. Además, se ha aumentado el porcentaje de alumnos que, al finalizar las sesiones de prácticas,

(c)) EY-NC-ND 2014, Universitat Politècnica de València 
realizan el examen (aproximadamente el 70\%). Si bien el porcentaje de aprobados en el examen de prácticas no es satisfactorio, se ha podido constatar que, la introducción de esta innovación ha mejorado la actitud del estudiante en general, y se observa un mayor aprovechamiento en las sesiones de prácticas y una disminución de los los errores procedimentales. También se aprecia que los alumnos que han realizado los cuestionarios pre-laboratorio trabajan de manera más segura y menos mecánica, tienen mayor interés y son capaces de plantearse preguntas que hasta el momento ni se planteaban. Estas evidencias concuerdan con lo observado por Nicholls (1999).

\section{Conclusiones}

Del análisis de los datos obtenidos se puede afirmar que:

- La utilización de la plataforma PoliformaT promueve la implicación del estudiante, ya que la participación en las pruebas de autoevaluación y en los cuestionarios pre-laboratorio es muy elevada.

- En las pruebas de autoevaluación se observa un aumento progresivo de la nota que van obteniendo los alumnos, lo que confirma que van aquiriendo conocimiento gradualmente y a su ritmo.

- La información de la nota de la autoevaluación les proporciona retroalimentación sobre el grado de conocimiento adquirido.

- Los resultados obtenidos en los exámenes son muy satisfactorios y confirman que se consiguen los objetivos de aprendizaje propuestos.

- El porcentaje de alumnos que supera el examen pre-laboratorio así como las calificaciones obtenidas son adecuados.

- Con la introducción del cuestionario pre-laboratorio se ha observado que los alumnos aprovechan mejor las sesiones de prácticas, tienen una actitud más favorable al aprendizaje y ha aumentado el número de alumnos que supera el examen al finalizar las mismas.

\section{Referencias}

CANÓS, L. y CANÓS, M. (2009). "El uso de las nuevas tecnologías aplicadas a la educación superior”. En XVII Jornadas ASEPUMA-V Encuentro Internacional, Rect@ Vol Actas_17 Issue 1: 612 www.uv.es/asepuma/XVII/611.pdf [Consulta: 1 de junio de 2014]

GARGALLO, B. (2008). "Estilos de docencia y evaluación de los profesores universitarios y su influencia sobre los modos de aprender de sus estudiantes", en Revista Española de Pedagogía, 241, p. 425-445,

(c)) EY-NC-ND 2014, Universitat Politècnica de València

I Jornadas IN-RED (2014) 
Integración de la Plataforma Educativa PoliformaT como Herramienta Facilitadora del Aprendizaje Autónomo en Primer Curso

GARGAllo, B., GARFElla, P. R., PÉREZ, C. y FERnÁNDEZ, A. (2010). "Modelos de enseñanza y aprendizaje en la universidad. Ponencia presentada en el XIX Seminario Interuniversitario de Teoría de la Educación. Formación y participación de los estudiantes en la universidad. Madrid. Universidad Complutense.

http://www.ucm.es/info/site/docu/29site/ponencia3.pdf [Consulta: 1 de junio de 2014]

HERNÁNDEZ, C.M., ACOSTA, M.C., RODRÍGUEZ, E., GONZÁLEZ, E., y BORGES, M. (2003). "Uso de las TICs y Percepción de la Teleformación en alumnado universitario: una perspectiva diferencial en función del género y del ciclo de la carrera", en Interactive Educational Multimedia, No. 7, pp. 13-28.

MICHAVILA, F. (2004). "Estudio sobre innovaciones educativas basadas en las tecnologías de la información en la formación universitaria presencial y a distancia". MEC. EA2004/0041. http://www.centrorecursos.com/mec/ayudas/index.htm. [Consulta: 25 de mayo de 2014]

NICHOLLS, B. S. (1999). Pre-Laboratory support using dedicated software, University Chemistry Education, vol. 3, pp. 22-27.

NOGUERA P., TORTAJADA L. A., ATIENZA J., y HERRERO M. A. (2011). "Auto-evaluación previa a las prácticas de laboratorio químico: introducción al auto-aprendizaje”, en Arbor, 187, (Extra_3), p. 267-272.

Plataforma educativa de la UPV Poliforma. http://poliformat.upv.es [Consulta: 1 de junio de 2014]

ROFFE, I. (2002): "E-learning: engagement, enhancement and execution”, en Quality Assurance in Education, vol. 10, p.40-50.

SANABRIA, E. (2008). "Evaluación continua a través del PoliformaT", en Jornades d'Investigació en Docencia Universitaria [Recurso electrónico]: la construcció col-legiada del model docent universitari del segle XXI= Jornadas de Investigación en Docencia Universitaria: la construcción colegiada del modelo docente universitario del siglo XXI. (p. 156). Universitat d'Alacant. 


\title{
USO DEL SCREENCAST Y LA e-EVALUACIÓN EN LAS PRÁCTICAS DE LA ASIGNATURA "TECNOLOGÍA POSTCOSECHA" EN LA UNIVERSITAT POLITÈCNICA DE VALÈNCIA
}

Castelló, M.L. ${ }^{\text {a }}$, Cháfer, M. ${ }^{\text {, }}$, Conesa, C. , Ortolá, M.D. $^{\text {d }}$

a,b,c y d Departamento de Tecnología de Alimentos. Universitat Politècnica de València email ${ }^{\mathrm{a}}$ mcasgo@upvnet.upv.es, email ${ }^{\mathrm{b}}$ : $\quad$ mtchafer@tal.upv.es, email ${ }^{\mathrm{c}}$ : clcodo@upvnet.upv.es, email ${ }^{\mathrm{d}}$ : $\underline{\text { mdortola@tal.upv.es }}$

\begin{abstract}
Nowadays, thanks to the new technologies, there are more tools available to ease the lecturer's job as a guide for students in their process of learning. In this context, the fullfilment of different assignments is considerable improved when it is possible to access several times to the explatination to perform them. Likewise, it is widely proved that knowledge is reafirmed from the correction of mistakes. For that, it is important to know the reasons why the answer is wrong in each case.

Thus, the aim of this article is to show the teaching innovations applied in the subject of Postharvest Technology taught at university. Concretely, presentations with audio (screencast) have been incorporated to support the lectures carried out to perfom the practical tasks. Besides that, online exams have been used in PoliformaT educational Platform by programming the remarks for uncorrect answers.

Students appreciate these innovations in the teaching methodology and they have shown a remarkable perfomance. Furthermore, the participative assessment between lecturers and students has been incorporated, reaching previously and agreement in the assessment criteria.
\end{abstract}

Keywords: academic training, teaching methodology, participative assessment, screencast, online tests, feed-back

(cc) EY-NC-ND 2014, Universitat Politècnica de València

I Jornadas In-Red (2014) 
Uso del screencast y la e-evaluación en las prácticas de la asignatura "Tecnología Postcosecha" en la UPV

\begin{abstract}
Resumen
Gracias a las nuevas tecnologías, cada vez hay disponibles más herramientas que facilitan la labor del profesor como guía en el proceso de aprendizaje de los estudiantes. En este contexto, tener la oportunidad de poder acceder a la explicación realizada sobre una determinada tarea varias veces mejora sustancialmente su ejecución. Asimismo, de las correcciones de los errores cometidos en las pruebas de evaluación, se afianzan muchos conocimientos. Por ello, es importante conocer las razones por las que se ha fallado en cada caso.

Así, el objetivo de este artículo es presentar dos innovaciones docentes aplicadas en la asignatura de Tecnología Postcosecha en el ámbito universitario. Concretamente, se han incorporado presentaciones con audio (screencast) para apoyar las explicaciones llevadas a cabo para la realización de las prácticas y por otro lado se ha utilizado la herramienta de exámenes online de la plataforma PoliformaT programándola para mostrar comentarios en las preguntas incorrectas.
\end{abstract}

Los estudiantes han agradecido estas iniciativas en la metodología docente y el rendimiento en su trabajo ha sido notable. Además, se ha incorporado la evaluación participativa de las prácticas se ha llevado a cabo tanto por parte del profesorado como de los estudiantes, consensuando los criterios de valoración previamente.

Palabras clave: formación académica, metodología docente, evaluación participativa, screencast, exámenes online, feed-back

\title{
1. Introducción
}

No hay duda de que la formación universitaria requiere de una formación en competencias específicas de la profesión a la que van dirigidos dichos estudios, pero también en otras competencias transversales que les pueden ser de mucha utilidad a los futuros egresados para desarrollar con éxito su actividad laboral. Este trabajo se centra en el área de la postcosecha de frutas y hortalizas y la necesidad de dar una visión muy aplicada de los conceptos desarrollados en esta asignatura. De esta manera, las sesiones de prácticas de esta materia van dirigidas a evaluar el efecto de distintos recubrimientos céreos comerciales sobre la apariencia y la fisiología de naranjas y manzanas. Para ello, los alumnos trabajan en grupos, encerando con distintas formulaciones las frutas y analizando la pérdida de masa y el porcentaje de alteraciones presentado en las mismas, así como la evolución del brillo y de la tasa respiratoria a lo largo del almacenamiento en refrigeración y tras un periodo de

(c)) EY-NC-ND 2014, Universitat Politècnica de València

I Jornadas IN-RED (2014) 
simulación de distribución comercial. Con los datos recogidos en el laboratorio, entre todos los grupos, los estudiantes deben presentar un informe técnico que describa las diferencias encontradas entre las frutas tratadas con los distintos recubrimientos, indicando cuál sería el recomendable para cada caso. Para poder emitir dicho informe es necesario trabajar con promedios y desviaciones típicas de las determinaciones realizadas y también presentar gráficamente los resultados obtenidos incorporando las barras de error a las medias obtenidas. Además, tienen que hacer uso de varias fuentes bibliográficas para apoyar la justificación de los comentarios aportados en la memoria técnica. Así, se pretende que los estudiantes trabajen las competencias transversales del tratamiento de datos extrapolables a cualquier ámbito de su futuro laboral.

La asignatura "Tecnología Postcosecha" se imparte en $5^{\circ}$ curso del segundo ciclo de la Titulación de Ingeniero Agrónomo. No obstante, los alumnos todavía no son capaces de procesar los datos recogidos en un laboratorio con demasiada habilidad y presentan ciertas limitaciones en el manejo de la hoja de cálculo Excel. Dada la inminente finalización de sus estudios universitarios, consideramos importante desarrollar al máximo esta habilidad para contribuir a que sean más operativos. En experiencias previas, se ha visto que el nivel de conocimientos del alumnado en estas tecnologías, es bastante heterogéneo y esto unido a la limitación en el tiempo presencial del que se dispone en aula de informática, con frecuencia complica que todos los alumnos puedan seguir los pasos en el tratamiento de datos. Por ello, la posibilidad de ofrecerles a los estudiantes tutoriales de presentaciones con audio de los procedimientos para manejar los cálculos requeridos, les permite escucharlos tantas veces como sean necesarias para afianzar el conocimiento.

La memoria realizada será evaluada tanto por parte del profesorado como por parte de los alumnos mediante una rúbrica consensuada. Por otra parte, nos interesa también que los conceptos teóricos queden afianzados y para ello, los alumnos realizarán un examen online sobre las prácticas, con comentarios para las respuestas erróneas.

\section{Objetivos}

Con este trabajo se pretende poner de manifiesto los resultados de dos innovaciones docentes. Por un lado, la incorporaración de presentaciones con audio (screencast) para apoyar las explicaciones de las sesiones prácticas de la asignatura de Tecnología Postcosecha en el ámbito universitario, y por otro lado mostrar el uso de herramientas para la e-evaluación (exámenes online con comentarios) para mejorar el proceso de aprendizaje de esta asignatura a los futuros egresados. Además, se realiza una evaluación participativa del informe de prácticas, tanto por parte de los alumnos como de los profesores, a través de unos criterios de baremación previsamente establecidos de forma consensuada.

\section{(c)) EY-NC-ND 2014, Universitat Politècnica de València}

I Jornadas IN-RED (2014) 


\section{Desarrollo de la innovación}

Es importante destacar que en el curso 2013-2014 en la asignatura Postcosecha ha habido un número matriculado de alumnos reducido, por ser el ultimo año de impartición (finalizan los ciclos) y por ser una optativa. Por ello, los alumnos se han distribuido en dos grupos, de manera que una ha trabajado con naranjas y otro con manzanas.

\subsection{Uso de Screencast}

Como se ha comentado en la introducción, los screencasts son presentaciones con audio que los alumnos pueden ver repetidas veces en cualquier dispositivo electrónico con las prestaciones necesarias para hacerlo. Dicho de otro modo, una grabación de lo que ocurre en la pantalla de un ordenador (Gómez, 2012), por lo que en esta práctica se han utilizado para enseñar cómo manejar algunas de las herramientas del Excel para hacer los cálculos relativos al procesado de datos del efecto de los recubrimientos y condiciones de almacenamiento en las frutas estudiadas. Trabajos previos (Pappas, 2013 y Castelló et al., 2014) ponen en evidencia las ventajas del uso de los videos en el e-learning, ya que la capacidad de comunicación que suponen fomenta el pensamiento crítico y el análisis del tema de una manera más profunda.

En las Fig. 1 y 2 se presentan dos capturas de pantalla de dos videos utilizados en el desarrollo de estas sesiones prácticas, donde se explican con detalle los pasos que los alumnos deben seguir para realizar las determinaciones analíticas en el laboratorio correctamente, así como para procesar los datos recogidos.

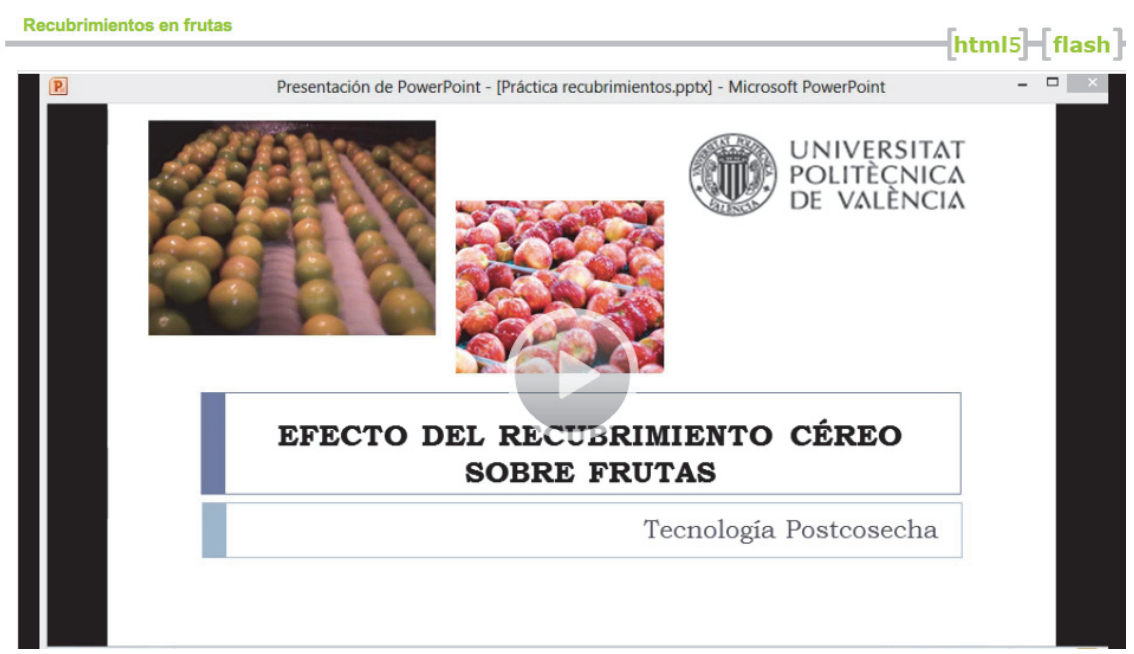

Fig. 1 Captura de pantalla de la explicación relativa a la fase de laboratorio de la práctica para evaluar el efecto de los recubrimientos céreos en las frutas (Fuente: http://politube.upv.es/play.php?vid=6048) 
En el caso del cálculo de la tasa respiratoria de frutas (Fig. 2), el uso de este Screencast ha sido de especial relevancia, por la limitación en el tiempo disponible de forma presencial para el tratamiento de datos. Así, los alumnos han podido visualizar la explicación de este cálculo tantas veces como lo han necesitado.

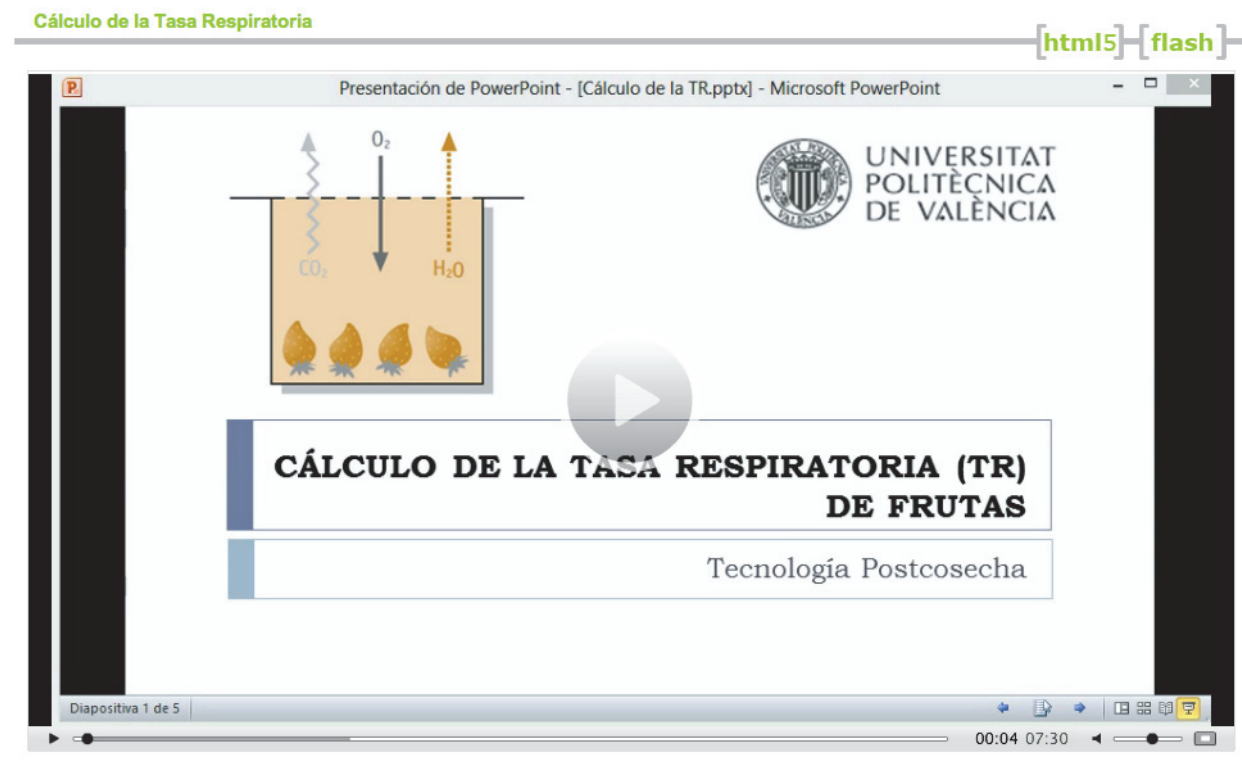

Fig. 2 Captura de pantalla de la explicación relativa al tratamiento de datos para el cálculo de la tasa respiratoria de frutas (Fuente: http://politube.upv.es/play.php?vid=60661)

\subsection{Exámenes online en la plataforma PoliformaT}

Respecto a los exámenes utilizados en cualquier plataforma educativa como herramienta de estímulo para favorecer al aprendizaje se ha trabajado considerablemente en los últimos años (Seguí et al., 2012; Castelló et al., 2014). Es evidente que de los errores se aprende y mucho. Por ello, facilitarles a los alumnos una batería de preguntas con comentarios vinculados a las preguntas erróneas, supone un refuerzo en el proceso de aprendizaje en un interfaz amigable, como son las plataformas educativas. En este sentido, en la Fig. 3 se presenta un ejemplo de los comentarios que les aparecen a los estudiantes cuando se equivocan en una pregunta relacionada, en este caso con los recubrimientos utilizados en frutas y hortalizas. Después del entrenamiento realizado, los alumnos deben hacer el test para ser evaluado de forma presencial. Este test consta de 10 preguntas verdadero o falso, de manera que cada pregunta supone un punto de la nota final del test y cada respuesta incorrecta descuentan media punto.

\section{(c)) EY-NC-ND 2014, Universitat Politècnica de València}

I Jornadas IN-RED (2014) 


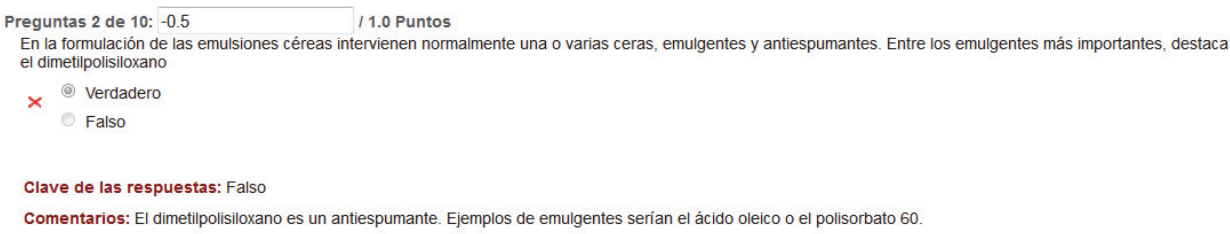

Fig. 3 Captura de pantalla del detalle de uno de los comentarios incluidos en una respuesta incorrecta

\subsection{Evaluación participativa}

Respecto a la forma de evaluar las sesiones de prácticas de la asignatura Tecnología Postcosecha del curso 2013-2014, es importante tener presente que se han combinado varios parámetros en la calificación final con el fin de implicar a los estudiantes en la evaluación, siguiendo las recomendaciones descritas por Rodríguez e Ibarra (2011). Así, un $30 \%$ de la nota corresponde al test realizado en la plataforma PoliformaT. El 70\% restante se obtiene de la evaluación del informe de prácticas llevado a cabo en Excel siguiendo las indicaciones comentadas anterioremente. Además, la evaluación del informe de prácticas se realiza tanto por parte del profesorado como por parte de los estudiantes, promediando ambas. La parte de los estudiantes es tanto una autoevaluación como una evaluación entre iguales, teniendo el mismo peso las mismas.

En la tabla 1 se detallan los criterios de evaluación consensuados entre los estudiantes y el profesorado, así como su porcentaje en la calificación final.

Tabla 1. Criterios de evaluación para la calificación del informe de prácticas de Postcosecha y porcentaje de cada ítem en la calificación

\begin{tabular}{lc}
\hline \multicolumn{1}{c}{ Criterio } & Porcentaje \\
\hline Introducir adecuadamente los datos en la plantilla de la hoja de cálculo & 5 \\
Calcular el promedio y la desviación típica de los parámetros en los que haya & 15 \\
repeticiones & 20 \\
Calcular correctamente la tasa respiratoria de la frutas & 20 \\
En una nueva hoja de cálculo que se nombrará como resumen, copiar mediante \\
pegado especial "vínculos" los valores del promedio y la desviación típica \\
$\begin{array}{l}\text { Trabajar sólo con las cifras significativas } \\
\text { Graficar los resultados obtenidos, indicando en el eje de abscisas las condiciones } \\
\text { de almacenamiento y en el ordenadas el valor del parámetro estudiado en función } \\
\text { del tipo de cera utilizado }\end{array}$ \\
$\begin{array}{l}\text { Comentar los resultados obtenidos en un informe de Excel, con cuadros de texto } \\
\text { y utilizando citas bibliográficas }\end{array}$ \\
\hline
\end{tabular}




\section{Resultados de la innovación}

En general, los estudiantes agradecen la dedicación del profesorado en ponerles al alcance los recursos tecnológicos disponibles para fomentar su interés por el aprendizaje de la asignatura. Además, hay evidencias del compromiso adquirido por los estudiantes para involucrarse en la evaluación de sus avances. Prueba de ello, son los comentarios recogidos en la Fig. 4 en la que se registran los porcentajes asociados a la consecución de los parámetros evaluados en el informe de la práctica, tanto para cada grupo, como en la evaluación entre iguales, así como la evaluación realizada por el profesorado. Como puede observarse en rojo aparecen reducidos las puntaciones máximas que podrían haber obtenido en cada item (Tabla 1) si lo hubieran realizado de forma completa.

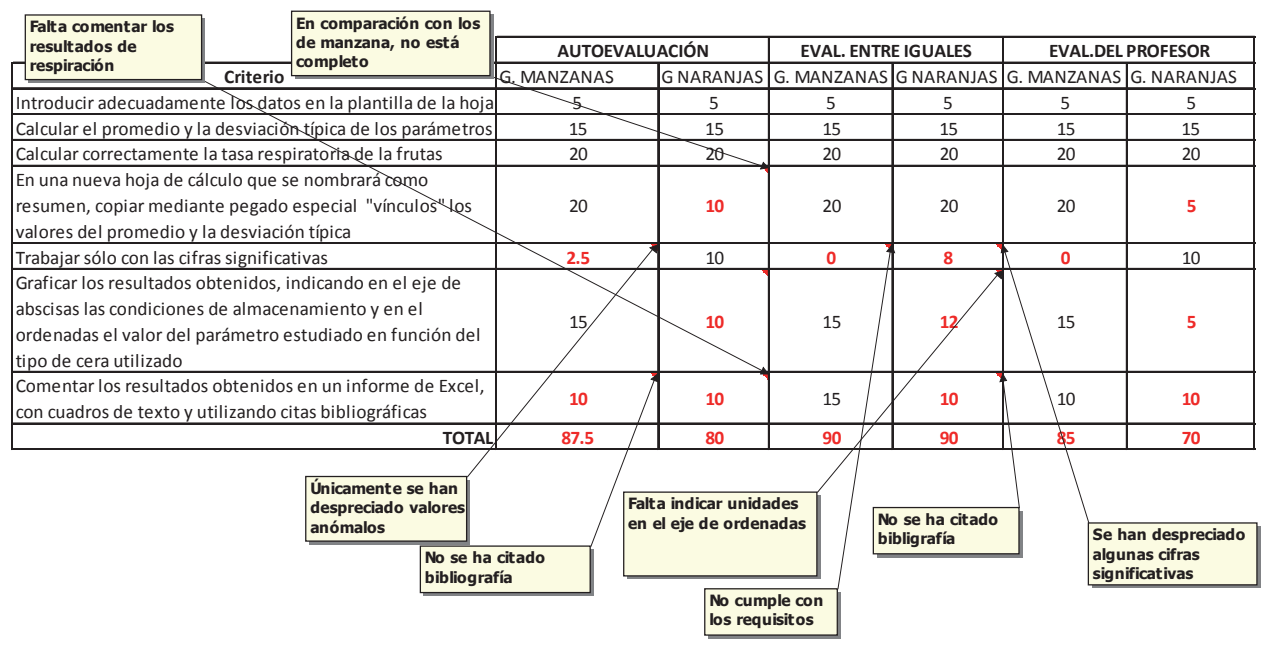

Fig. 4 Distribución de los porcentajes obtenidos en la evaluación participativa de cada uno de los criterios considerados en la calificación del informe de prácticas y comentarios de los alumnos

Por último, en la Fig. 5 se presenta el desglose de las notas obtenidas en cada acto de evaluación de la práctica de recubrimientos en frutas, destacando los buenos resultados obtenidos en las calificaciones finales.

(c) EY-NC-ND 2014, Universitat Politècnica de València

I Jornadas IN-RED (2014) 


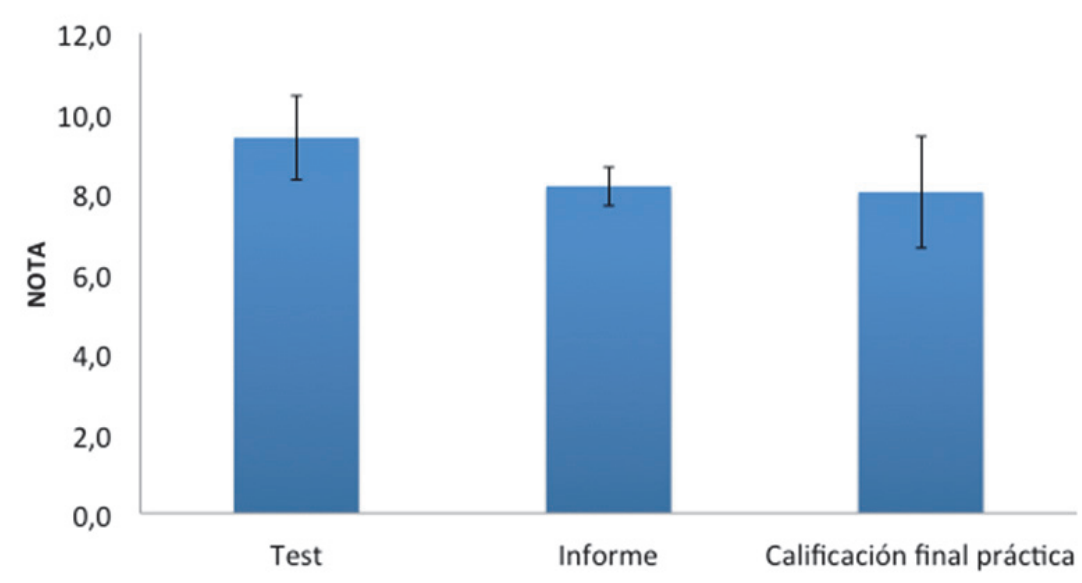

Fig. 5 Promedio de las notas obtenidas en el test de conceptos teóricos, el informe de prácticas y la calificación final de la práctica

\section{Conclusiones}

El uso de los screencast y la e-evaluación en la asignatura de Tecnología Postcosecha ha supuesto un elevado rendimiento en el trabajo de los estudiantes como se manifiesta en las buenas calificaciones obtenidas. Por otro lado, se considera que las herramientas empleadas en el desarrollo de esta asignatura suponen un avance considerable en las competencias transversales de procesado de datos, redacción de documentos, pensamiento crítico y de manejo de las tecnologías de la información.

\section{Referencias}

CASTELlÓ M.L., FITO, P.J. y TARRAZÓ, J. (2014a). Using videos to support learning in food engineering practical tasks. INTED 2014. $8^{\text {th }}$ International Technology, Educational and Develepment Conference Proceedings.

CASTELLÓ M.L., FITO, P.J. y TARRAZÓ, J. (2014b). Assessment of the starting point and the knowledge acquired after food engineering practical tasks using online tests taken twice on the poliformat platform. INTED 2014. $8^{\text {th }}$ International Technology, Educational and Develepment Conference Proceedings.

GÓMEZ, S. (2012). Screencast o Matic. Observatorio Tecnológico. Ministerio de Educación, Cultura y Deporte. <http : http://recursostic.educacion.es/observatorio/web/es/software/softwaregeneral/1055-screencast-o-matic> [Consulta: 9 de junio de 2014]

PAPPAS, C. (2013). 10 Tips To Effectively Use Videos in eLearning. Published online in Concepts. $<$ http://elearningindustry.com/10-tips-to-effectively-use-videos-in-elearning>[Consulta: 13 de marzo de 2014] 
RODRÍGUEZ, G. y IBARRA, S. (2011). e-Evaluación orientada al e-Aprendizaje estratégico en Educación Superior. Madrid: NARCEA, S.A. Ediciones

SEGUÍ, L., HEREDIA, A., BARRERA, C. y CASTELLÓ, M.L., (2012). Refuerzo de los contenidos relacionados con las clases prácticas mediante una estrategia de aprendizaje híbrido. IX Jornadas Internacionales de Innovación Universitaria (JIIU). Retos y oportunidades del desarrollo de los nuevos títulos en educación superior. Universidad Europea de Madrid.

VIDEO RECUBRIMIENTOS EN FRUTAS. Politube < http://politube.upv.es/play.php?vid=6048>.

VIDEO CÁlCULO DE LA TASA RESPIRATORIA. Politube

〈http://politube.upv.es/play.php?vid=60661>. 


\title{
¿Son eficaces los cuestionarios pre-laboratorio realizados on-line?
}

\author{
Patricia Noguera $^{\mathrm{a}}$, Sergi Morais ${ }^{\mathrm{b}}, \mathbf{M}^{\mathrm{a}}$ Asunción Herrero $^{\mathrm{c}}$, Julia Atienza ${ }^{\mathrm{d}}$, Luis A. \\ Tortajada $^{\mathrm{e}}$ \\ Departamento de Química, Universidad Politécnica de Valencia, España \\ apnoguera@qim.upv.es, ${ }^{\mathrm{b}}$ smorais@qim.upv.es, ${ }^{\mathrm{c}}$ maherrero@qim.upv.es, ${ }^{\mathrm{d}}$ matien@qim.upv.es y \\ eluitorge@qim.upv.es.
}

\begin{abstract}
The main purpose of on line pre-laboratory questionnaires is to increase the student's knowledge about the laboratory practice he is going to perform. If this objective is achieved, a better development of the laboratory session and a greater participation in their own learning process will also be accomplished, hence increasing the benefits of the practical sessions. This paper presents a critical review of the application of pre-lab questionnaires (supported in the e-learning platform PoliformaT) during a three academic year period (11/12-13/14) in three first-year chemistry subjects taught in different bachelor's degrees carried out at the Escuela Técnica Superior de Ingeniería Agroalimentaria y del Medio Natural.

The analysis of the pre-laboratory questionnaires generated by almost 1000 students allowed assessing the achievement of the objectives. A comparison of the scores achieved by the student on pre-laboratory questionnaire with the laboratory written exam is also carried out. In addition, the limitations of the implementation of this activity from the perspective of teacher and student are accounted for. Finally, and in order to increase the benefits in the laboratory sessions, a set improvements are proposed.
\end{abstract}

Keywords: e-learning, pre-lab questionnaires, evaluation, chemical laboratory practices, laboratory sessions

\section{(c)) BY-NC-ND 2014, Universitat Politècnica de València}




\begin{abstract}
Resumen
Los cuestionarios pre-laboratorio realizados on-line tienen la finalidad de incrementar los conocimientos del alumno sobre la práctica a realizar. De este modo se pretende favorecer un mejor desarrollo de la sesión presencial, una mayor implicación en su aprendizaje y, por tanto, un mayor aprovechamiento de las prácticas.

En este trabajo se presenta una revisión crítica de la aplicación de esta metodología (soportada en la plataforma e-learning PoliformaT) durante tres cursos académicos (11/12-13/14) en tres asignaturas de Química de primer curso de diferentes titulaciones impartidas en la Escuela Técnica Superior de Ingeniería Agroalimentaria y del Medio Natural. El análisis de los cuestionarios generados por casi 1000 alumnos ha permitido evaluar la consecución de los objetivos previstos. Se han comparado las calificaciones obtenidas en el cuestionario previo con la nota del examen escrito de prácticas. Además, se han establecido las limitaciones de la aplicación de esta actividad desde la perspectiva del profesor y del alumno, Finalmente, se proponen una serie de mejoras en la realización de esta actividad con el fin de conseguir un mayor aprovechamiento de las sesiones de laboratorio por parte de los alumnos.
\end{abstract}

Palabras clave: e-learning, cuestionarios previos, evaluación, prácticas de laboratorio químico 


\section{Introducción}

Las clases prácticas de laboratorio son una parte muy importante de la docencia, especialmente en carreras técnicas, ya que en ellas los alumnos adquieren destrezas procedimentales y actitudinales y afianzan conceptos teóricos. Sin embargo, los alumnos no llegan a valorar la importancia de las sesiones de prácticas en su formación, tanto académica como profesional y, en un gran número de casos, asisten con una actitud pasiva durante el desarrollo de éstas. Una de las razones principales de esta disposición es el gran volumen de información que el alumno recibe durante una sesión que, además, debe comprender, procesar y aplicar experimentalmente. De hecho, los conocimientos que adquiere no sólo son de tipo práctico (manipular equipos y productos químicos, aprender procedimientos de seguridad, medir de forma precisa, observar con cuidado) o científico (aprender a observar, deducir e interpretar) sino que, además, deben adquirir competencias generales (trabajo en equipo, realización de informes y presentaciones, participación en discusiones, manejo del tiempo, aprender a resolver problemas) (Figura 1).

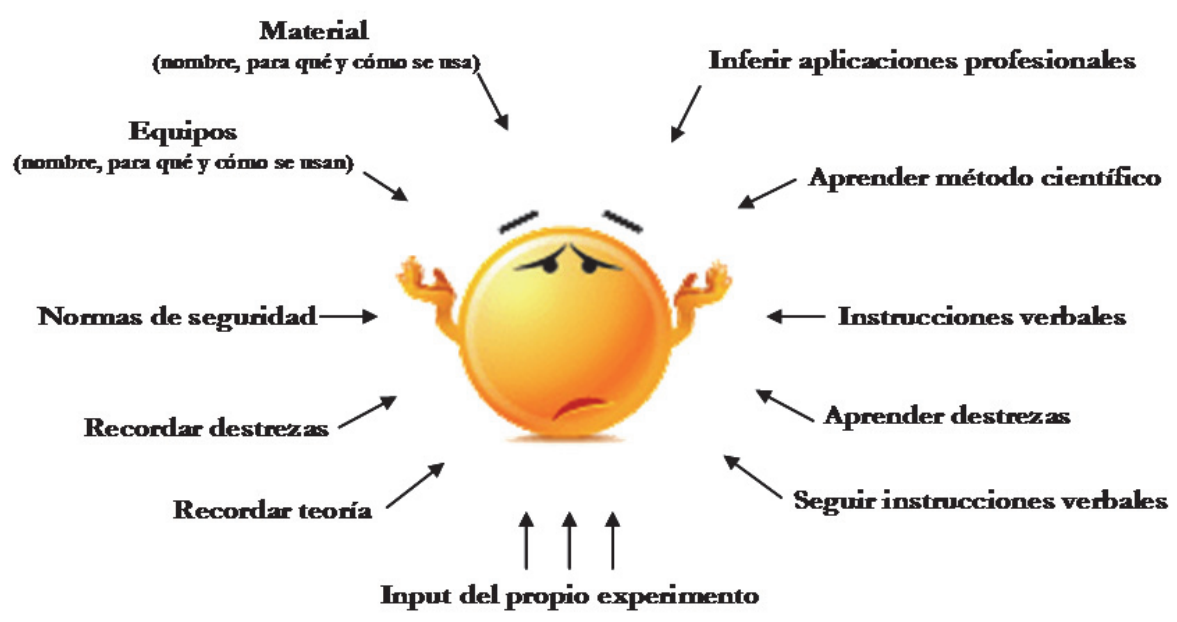

Fig. 1 Fuentes de información de un alumno en un laboratorio de química (Noguera et al., 2011)

En la bibliografía se describen múltiples estrategias para fomentar la actitud positiva del alumno y garantizar el correcto desarrollo de la actividad. Algunas de ellas son la incorporación de materiales multimedia que detallan técnicas específicas empleadas durante la sesión (Burewicz y Miranowicz, 2006), la elaboración de presentaciones en Internet (McKlelvy, 2008) o el uso de laboratorios virtuales (Dalgarno et al., 2009, Limniou et al, 2009 y Sierra et al, 2009). Otra tarea previa que también ha proporcionado excelentes resultados es la elaboración de cuestionarios previos que deben completarse antes de

\section{(c) ) EY-NC-ND 2014, Universitat Politècnica de València}

I Jornadas IN-RED (2014) 
realizar la sesión de prácticas. Para ello, se han propuesto diferentes programas informáticos específicos capaces de evaluar a los alumnos (Nicholls, 1999, Masson, 2001). En este sentido, las plataformas empleadas en la educación a distancia o e-learning pueden ser de gran utilidad (Yang y Tsai, 2010; Roffe, 2002). Estas disponen de herramientas que permiten gran flexibilidad en la forma en que se presentan las preguntas, pudiendo incluir animaciones o gráficos junto al texto, y controlar el tiempo para contestar o el número de repeticiones permitidas. Hay que resaltar que aunque los alumnos prefieren preguntas online animadas y/o interactivas frente a preguntas estáticas, la efectividad del aprendizaje no depende drásticamente del formato de pregunta (Yeung et al, 2009).

Los cuestionarios pre-laboratorio con estas plataformas presentan a priori una serie de ventajas: el alumno controla su proceso de aprendizaje -ya que pueden completarlos en el momento y lugar que deseen-, y se facilitan las tareas de corrección y de retroalimentación (Jenkins, 2004; Fike te al, 2010). Además, el alumno no está pasivo, interactúa con el ordenador.

Aunque los cuestionarios previos pueden conseguir que se adquieran una parte de los objetivos de aprendizaje, su aplicación a las sesiones de prácticas no es directa. Estos deben estar totalmente integrados en el conjunto de acciones relacionadas con las prácticas de laboratorio (Figura 2). Su diseño debe tener en cuenta aspectos relacionados con los objetivos de aprendizaje y el conocimiento previo de los alumnos. Además, se debe adaptar el manual de laboratorio, y las preguntas post-laboratorio (Tortajada-Genaro et al, 2013). Pese a ello, para aplicar esta metodología, no es necesario cambiar drásticamente los experimentos que se realizan, basta variar la forma en la que se desarrollan para conseguir grandes mejoras en el aprendizaje.

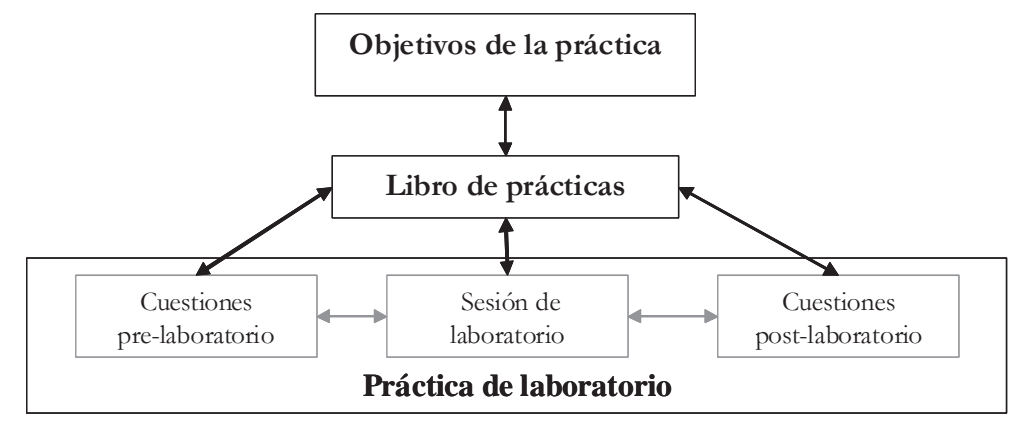

Figura 2. Actividades realizadas en las sesiones de laboratorio para alcanzar los objetivos de aprendizaje

En esta comunicación, se presenta una revisión crítica de la aplicación de los cuestionarios previos durante tres cursos académicos $(11 / 12,12 / 13$ y 13/14) en tres asignaturas de Química de primer curso de diferentes titulaciones impartidas en la Escuela Técnica 
Superior de Ingeniería Agroalimentaria y del Medio Natural. El objetivo es establecer la eficacia de la incorporación de cuestionarios pre-laboratorio en el proceso de aprendizaje de cada asignatura. Se evalúan los resultados académicos alcanzados por los alumnos en las prácticas. Asimismo se han establecido ventajas e inconvenientes de dicha actividad desde el punto de vista tanto del docente como del discente. Las conclusiones obtenidas del estudio permitirán la realización de adaptaciones para conseguir maximizar los resultados y obtener una serie de recomendaciones para que otros docentes universitarios puedan incluirlas en su metodología de enseñanza.

\section{Objetivos}

El objetivo general de este trabajo ha sido evaluar la efectividad de las actividades prelaboratorio de carácter no presencial para incrementar los conocimientos previos de los alumnos en las prácticas de laboratorio. Como objetivos parciales se ha propuesto que el alumno se implique más en su aprendizaje y, por tanto, el aprovechamiento de las sesiones de prácticas sea mayor. El alcance de estos objetivos se ha medido, comparando las calificaciones obtenidas tanto en el cuestionario previo como en el examen de prácticas. Además se han establecido las ventajas e inconvenientes de la aplicación de esta actividad tanto desde el punto de vista del docente como del alumno.

\section{Desarrollo de la innovación}

La acción propuesta se aplicó durante los cursos 2011-12, 2012-13 y 2013-14 en tres asignaturas de Química de primer curso de diferentes titulaciones de grado impartidas en la Escuela Técnica Superior de Ingeniería Agroalimentaria y del Medio Natural y participaron unos 1000 alumnos (Tabla 1). La plataforma PoliformaT (herramienta Exámenes) se utilizó como medio de evaluación de estas actividades pre-laboratorio.

Tabla 1. Número de alumnos participantes en los distintos grados

\begin{tabular}{ccccc}
\hline & $\mathbf{2 0 1 1 - 1 2}$ & $\mathbf{2 0 1 2 - 1 3}$ & $\mathbf{2 0 1 3 - 1 4}$ & Total \\
\hline $\begin{array}{c}\text { Grado en Ingeniería Forestal y del } \\
\begin{array}{c}\text { Medio Natural (GIF) } \\
\text { Grado en Ingeniería Agroalimentaria y } \\
\text { del Medio Rural (GIA) }\end{array}\end{array}$ & 53 & 41 & 37 & 131 \\
$\begin{array}{c}\text { Grado en Biotecnología (GB) } \\
\text { (G1 }\end{array}$ & 82 & 176 & 164 & 521 \\
& & & TOTAL & $\mathbf{9 5 5}$
\end{tabular}

La incorporación de esta actividad a la docencia implicó realizar una etapa de planificación previa durante el curso 2010-11 (Tortajada et al., 2011), elaborándose un listado de conceptos teórico-prácticos considerados como prerrequisitos, se modificó el sistema de evaluación, se diseñaron los cuestionarios y se realizó un nuevo manual de laboratorio.

\section{(cc) EY-NC-ND 2014, Universitat Politècnica de València}

I Jornadas IN-RED (2014) 
Aunque el desarrollo y aplicación de estas actividades se detallan en un trabajo previo (Noguera et al., 2011), se va a proceder a indicar, brevemente, el planteamiento de los cuestionarios previos.

La premisa a la hora de plantear los cuestionarios previos fue que un alumno debía contestar las preguntas con la información dada únicamente en el manual de prácticas (de ahí la necesidad de revisarlo y reeditarlo). El cuestionario de cada una de las prácticas estaba formado por diferentes bloques de preguntas. Uno estaba dedicado a la base teórica, otro al material de laboratorio específico o novedoso a utilizar en la misma (primera vez que el alumno lo empleaba), otro en el que se abordaban aspectos de seguridad y tratamiento de los residuos generados en la práctica, y, por último, un bloque dedicado a la realización de cálculos similares a los requeridos en la práctica. En la plataforma de elearning (PoliformaT), cada batería de preguntas estaba formada por, al menos, 10 preguntas de entre las que se seleccionaba de forma aleatoria una o dos (en función de la práctica). Con el fin de garantizar que los alumnos repasaran el material de preparación antes de rellenar el cuestionario, y evitar así una lectura superficial del mismo se limitaba el tiempo para completar el cuestionario, dependiendo del número total de preguntas. Para fomentar el interés por conseguir una mayor nota y reducir la presión por la evaluación, el alumno tenía una semana para completar el cuestionario, pudiéndolo realizar dos veces, y contabilizando la nota más alta. En la Figura 3, se muestran ejemplos de una página web tal y como la visualiza el alumno así como algunas cuestiones planteadas. Se observa que, además de aparecer el enunciado de la pregunta, el bloque al que pertenece la pregunta, y, en su caso, una figura asociada, se indica la puntuación de la pregunta y el tiempo restante para completar el cuestionario. 
Patricia Noguera, Sergi B. Morais, $M^{a}$ Asunción Herrero, Julia Atienza, Luis A. Tortajada

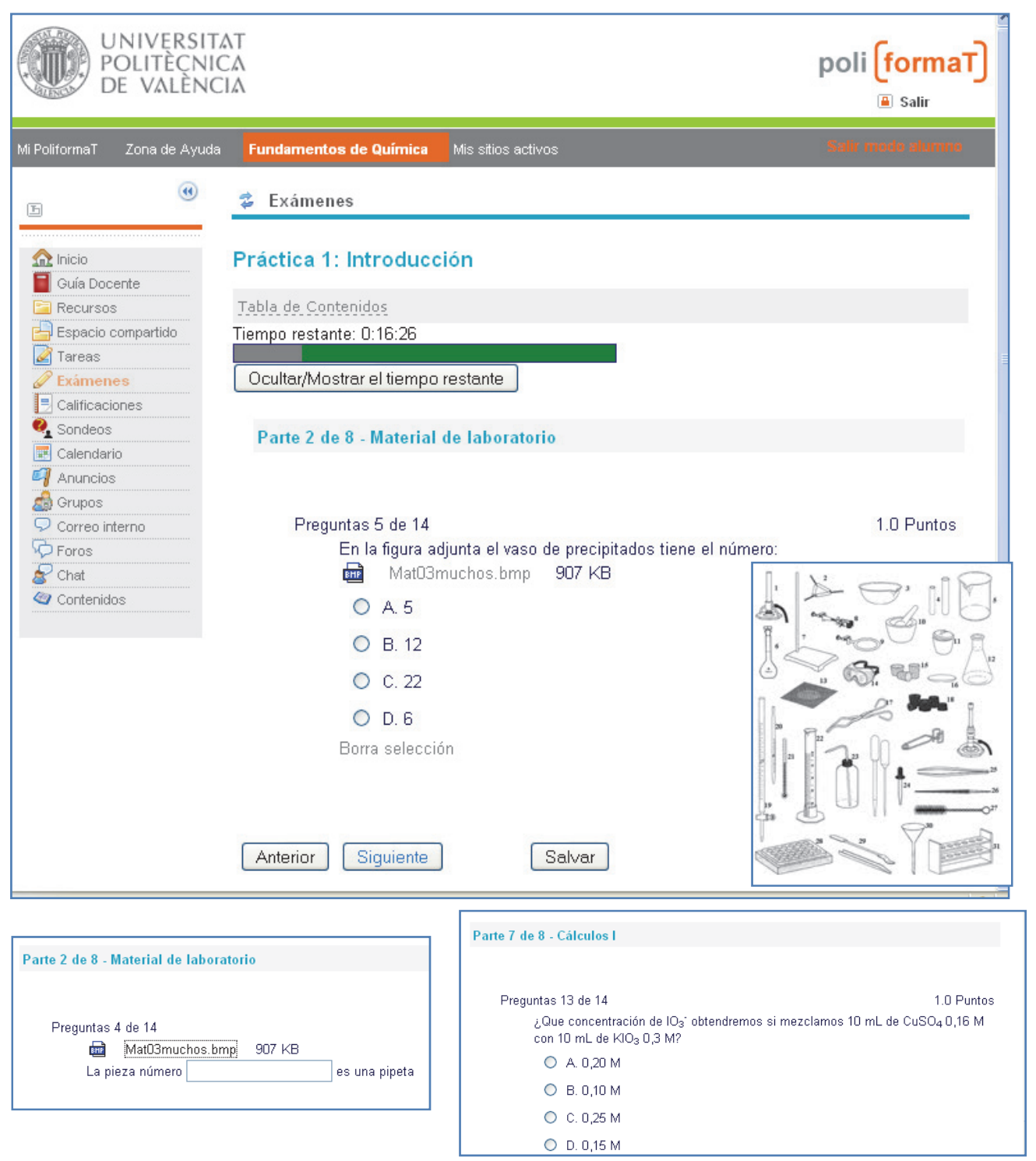

Fig. 3. Página web visualizada por el alumno (arriba) y alguna de las cuestiones planteadas (abajo)

Los resultados obtenidos por los alumnos en los cuestionarios previos para los tres cursos académicos se muestran en la Figura 4. Se trata de un gráfico de cajas donde se representa los valores límite para cada uno de los cuartiles ( $25 \%$ de la población estudiada). Así, el valor de la mediana (valor central) obtenido por los alumnos del Grado en Biotecnología (GB) en los tres cursos académicos osciló entre 9.3 y 9.8 , siendo mucho mayor que para el Grado en Ingeniería Forestal y del Medio Natural (GIF) y para el Grado en Ingeniería

\section{(c) EY-NG-ND 2014, Universitat Politècnica de València}

I Jornadas IN-RED (2014) 
Agroalimentaria y del Medio Rural (GIA), con valores 6.1-7.3 y 6.3-6.6, respectivamente. Por otro lado, es destacable que hay una gran dispersión de los resultados en los Grados de Ingeniería (tamaño cajas). Así, se observa que la población central de estudiantes, obtuvo una nota media en los cuestionarios pre-laboratorio en el rango 5.0-8.0 para los Grados de Ingeniería, mientras que para Grado en Biotecnología oscilaba en el rango 8.6-9.8

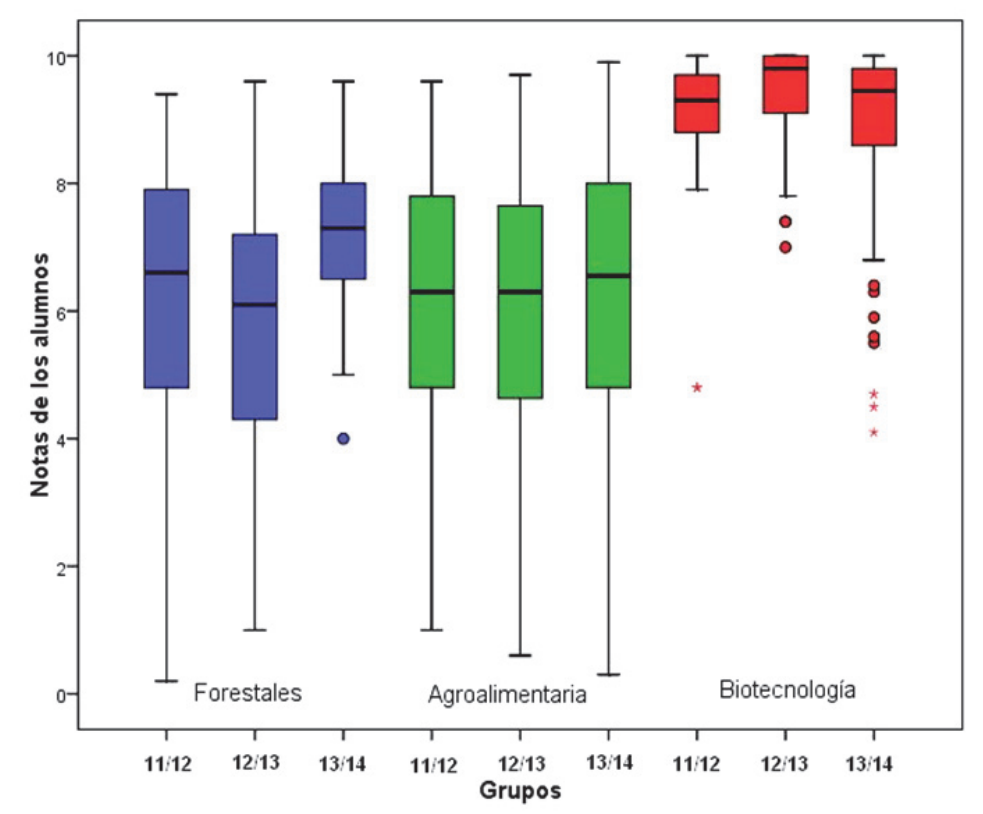

Fig. 4. Distribución de las notas promedio obtenidas por los alumnos en las actividades prelaboratorio para cada uno de los grados y curso académico

La plataforma PoliformaT facilita la gestión de los resultados, ya que almacena información relevante como el número de intentos realizados, la nota obtenida y el tiempo dedicado por cada alumno. Además se pueden descargar los resultados individualizados por alumno o por pregunta, lo que permite detectar fallos comunes y abordarlos al inicio de la sesión, consiguiendo así una retroalimentación verdaderamente efectiva. Esto permitió comparar, para cada uno de los alumnos, las notas obtenidas en el cuestionario de prácticas y en el examen de prácticas. A modo de resumen, en la Figura 5 se muestran los resultados promedio obtenidos en los cuestionarios pre laboratorio y la nota media de los exámenes de prácticas. Se observa que la nota del examen de prácticas es ligeramente inferior a la obtenida vía on-line. Además, es fácil ver que hay dos grupos muy diferenciados: los alumnos del GB tienen notas superiores a los que cursan el GIF o el GIA. Esta diferencia se puede atribuir a una serie de factores. El primero es la nota de entrada en la titulación (nota 
de la Pruebas de Acceso a la Universidad, PAU), superior para los alumnos del GB. El segundo es la formación previa, la mayoría de los alumnos que cursan los Grados en Ingeniería (GIF o GIA) no han cursado la asignatura de Química en segundo de Bachiller. Otro aspecto a considerar es la percepción que tiene el alumno por la asignatura; un alumno de GIF o GIA piensa que la química tiene muy poco interés tanto para su currículo académico como profesional, mientras que un alumno de GB percibe la química como una materia esencial para su formación.

El interés por la asignatura se refleja también en el porcentaje de participación de los alumnos, es decir, en el número de alumnos que realizan todos los cuestionarios previos. En el Grado en Biotecnología, la participación es próxima al $100 \%$ mientras que en los otros grados es menor (60-65\%).

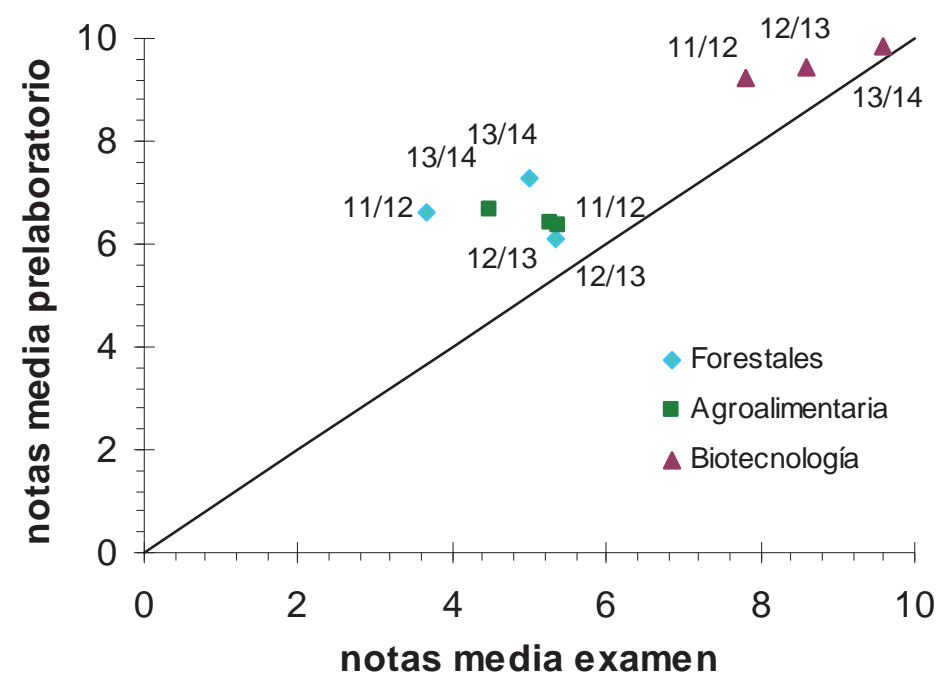

Fig. 5. Correlación entre las notas promedio obtenidas en las actividades prelaboratorio y las notas obtenidas en el examen de laboratorio para cada uno de los grupos estudiados

$\mathrm{Al}$ evaluar la eficacia de este tipo de cuestionarios es muy importante no centrarse solo en comparar datos, también se debe incluir una revisión crítica desde el punto de vista del profesor y del alumno. Una puesta en común por parte del profesorado permite destacar el cambio notable en la actitud de algunos alumnos, ya que estos no realizan la práctica de forma mecánica, tienen un mayor interés, e incluso profundizan en aspectos que de otra forma no lo harían. El mayor inconveniente detectado es la propia gestión de los cuestionarios y los problemas con la migración de archivos en la plataforma utilizada.

\section{(c) EY-NC-ND 2014, Universitat Politècnica de València}

I Jornadas IN-RED (2014) 
Respecto a los alumnos, hay que resaltar que, aunque detectan algún problema técnico de la plataforma, consideran que el nivel de las preguntas planteadas era fácil o muy fácil, que el tiempo para realizar los cuestionarios era suficiente y que les facilita la comprensión de la misma. Sin embargo, hay desacuerdo en la valoración de la eficacia de los mismos. Una parte del alumnado es favorable a realizar los cuestionarios, ya que los consideran una herramienta de ayuda a la hora de entrar en el laboratorio. Sin embargo, otros perciben esta actividad como una obligación, dejando de realizarla a lo largo del curso. Dicha heterogeneidad se ha interpretado como consecuencia de la diferente motivación del alumno por cursar la asignatura estando, en muchos casos, asociada a la preparación previa y a la nota de entrada en la Universidad.

\section{Propuestas de mejora}

Vistos los resultados, se propusieron diferentes acciones para conseguir que los cuestionarios pre-laboratorio sean una herramienta eficaz y alcanzar así un mayor aprovechamiento de las sesiones de laboratorio. La primera de ellas sería realizar los cuestionarios en el propio laboratorio, de este modo se conseguiría una mayor participación. Sin embargo, su aplicación provocaría una reducción del tiempo destinado a la realización de la práctica. Además, y debido a la falta de material informático (ordenadores) obligaría a realizarse en formato papel. Esto último genera una gran complejidad en la gestión de los resultados. Por otro lado, este tipo de actuación desperdiciaría la mayor ventaja del uso de cuestionarios on line: la retroalimentación ya que el poder descargar los resultados individualizados por alumno o por pregunta permite detectar fallos comunes y abordarlos al inicio de la sesión. Por todo esto se descartó realizar los cuestionarios en el laboratorio.

Otra acción es obligar a la realización de esta actividad exigiendo una nota mínima para acceder a la sesión práctica de laboratorio, y para aquellos alumnos que no realicen la actividad o no alcancen la nota mínima, la calificación del guión de prácticas que entregan con posterioridad a la realización presencial de la misma, se reducirá en un porcentaje por determinar. La combinación de estos dos requisitos presenta dos ventajas: se consigue una mayor participación y se obliga a que el alumno le dedique un tiempo y no la conteste al azar, de hecho es la que se va a aplicar en el próximo curso académico 2014/15.

\section{Conclusiones}

El aspecto más importante a la hora de aprovechar una sesión de prácticas de laboratorio es la motivación del alumnado. Este aspecto es muy difícil de conseguir ya que está asociada a 
la preparación previa, a la nota de entrada en la Universidad y a la percepción que el alumno tiene sobre la importancia de la asignatura en su profesión

Por ello, es primordial implicar a los alumnos en las sesiones de laboratorio, incluso antes de iniciar la sesión, y facilitar así su aprendizaje.

\section{Referencias}

BUREWICZ, A. y MIRANOWICZ, N. (2006) "Effectiveness of multimedia laboratory instruction" en Chemistry Education: Research and Practice, vol. 7, p. 1-12.

DALGARNO, B., BISHOP, A. G. , ADLONG, W. y BEDGOOD, D. R. (2009) "Effectiveness of a virtual laboratory as a preparatory resource for distance education chemistry students" en Computers \& Education, vol. 53, p. 853-865.

FIKE, D.S., DOYLE, D. y AND CONNELLY, R.J. (2010) "On-line vs paper evaluations of faculty: When less is just as good" en The Journal of Effective Teaching, vol. 2, p. 42-54.

JENKINS, M. (2004) "Unfulfilled promise: Formative assessment using computer-aided assessment" en Learning and Teaching in Higher Education, vol. 1, p. 67-80.

LIMNIOU, M, PAPADOPOULOS, N y WHITEHEAD, C (2009) "Integration of simulation into prelaboratory chemical course: Computer cluster versus WebCT" en Computers \& Education, vol. 52, p. $45-52$.

MASSON, M. R. (2001) "Experience with a random questionnaire generator in the chemistry laboratory and for other continuous assessment" en University Chemistry Education, vol. 5, p. 9-15.

MCKELVY, G.M. (2008) "Preparing for the chemistry laboratory: An internet presentation and assessment tool" en University Chemistry Education, vol. 2, p. 46-49.

NICHOLLS, B. S. (1999) "Pre-Laboratory support using dedicated software" en University Chemistry Education, vol. 3, p. 22-27.

NOGUERA MURRAY, P., TORTAJADA-GENARO, L.A., ATIENZA BORONAT, J., y HERRERO VILLÉN, A. (2011) "Auto-evaluación previa a las prácticas de laboratorio químico: introducción al auto-aprendizaje” en Arbor, vol. 187, p. 267-272.

ROFFE, I. (2002) "E-learning: engagement, enhancement and execution" en Quality Assurance in Education, vol. 10, p. 40-50.

SIERRA, J.; BOSQUE, J.; GARCIA, A.; BLANC, R.; DEL, M.; GAMIZ, L. y ALES, F. (2009) "Aprendizaje de procesos analíticos mediante clases prácticas con laboratorios virtuales" en Enseñanza de las Ciencias, Número Extra VIII Congreso Internacional sobre Investigación en Didáctica de las Ciencias, Barcelona, p. 2466-2470.

TORTAJAdA-GENARO, L.A., NOGUERA, P., ATIENZA, J., HERRERO, M.A., GARCíARUPÉREZ, J., SANCHIS, P., VIDAL, B., FENOLLOSA, M.L., RIBAL, F.J.,BES, M.A., BLASCO,

\section{(cc) BY-NC-ND 2014, Universitat Politècnica de València}

I Jornadas IN-RED (2014) 
E. y MUÑOZ, M.J. (2011) "Pre-laboratory self-assessment by e-learning platform Poliformat a multidisciplinar experience" en Promotion and Innovation with New Technologies in Engineering Education (FINTDI), IEEE Conferences, p. 1-4.

TORTAJADA-GENARO, L.A. y NOGUERA, P. (2013) "Diseño y aplicación de las rúbricas en la evaluación in situ del aprendizaje en el laboratorio" en Hekademos, vol. 13, p. 35-42.

YANG, Y.F. y TSAI, C.C. (2010). "Conceptions and approaches to learning through online peer assessment" en Learning and Instruction, vol. 20, p. 72-83.

YEUNG, A.; SCHMID, S. A.; GEORGE, A. V. y KING, M. (2009) 'Increasing students' interest and motivation through effective design on online learning environments" en Proceedings of the Motivating Science Undergraduates, A. Hugman (Ed.), Sydney, p. 132-138. 


\title{
Evaluación del proceso de revisión de transcripciones automáticas para vídeos poliMedia.*
}

\author{
Juan Daniel Valor Miró ${ }^{1}$, Rachel Nadine Spencer ${ }^{1}$, Alejandro Pérez \\ González de Martos $^{1}$, Gonçal Garcés Díaz-Munío ${ }^{1}$, Carlos Turró ${ }^{1}$, Jorge \\ Civera $^{1}$ y Alfons Juan ${ }^{1}$ \\ ${ }^{1}$ Universitat Politècnica de València
}

\begin{abstract}
Video lectures are a tool of proven value and wide acceptance in universities that are leading to platforms like poliMedia. transLectures is a European project that generates automatic high-quality transcriptions and translations for the poliMedia platform, and improve them by using massive adaptation and intelligent interaction techniques. In this paper we present the evaluation with lecturers carried out under the Docència en Xarxa 2012-2013 call, with the aim to study the process of supervise transcriptions, compared with to transcribe from scratch.
\end{abstract}

Keywords: ASR, transcriptions, evaluations, online teaching, poliMedia.

\section{Resumen}

Los vídeos docentes son una herramienta de demostrada utilidad y gran aceptación en el mundo universitario que están dando lugar a plataformas como poliMedia. transLectures es un proyecto europeo que genera transcripciones y traducciones automáticas de alta calidad para la plataforma poliMedia, mediante técnicas de adaptación masiva e interacción inteligente. En este artículo presentamos la evaluación con profesores que se realizó en el marco de Docència en Xarxa 2012-2013, con el objetivo de estudiar el proceso de supervisión de transcripciones, comparándolo con la obtención de la transcripción sin disponer de una transcripción automática previa.

Keywords: ASR, transcripciones, evaluaciones, docencia en red, poliMedia.

\footnotetext{
* The research leading to these results has received funding from the European Union Seventh Framework Programme (FP7/2007-2013) under grant agreement no. 287755.
} 
Evaluación del proceso de revisión de transcripciones automáticas para vídeos poliMedia.

\section{Introducción}

Los vídeos docentes son una herramienta de demostrada utilidad y gran aceptación en el mundo universitario que están dando lugar a plataformas como poliMedia (poliMedia 2007), plataforma de la Universitat Politècnica de València (UPV) que que permite la creación, publicación y difusión de este tipo de contenidos. En 2011 la UPV inició el proyecto europeo transLectures (Silvestre y col. 2012), con el objetivo de generar transcripciones y traducciones de forma automatizada en español, catalán e inglés para todo el repositorio de poliMedia, mediante el uso de técnicas estadísticas de aprendizaje automático (Valor Miró y col. 2012).

Sin embargo, a pesar de que la calidad de la transcripción automática se encuentra en un $80 \%$ de acierto en promedio, estas transcripciones automáticas poseen errores inherentes al proceso de obtención utilizado, por lo que es necesaria una revisión manual posterior para garantizar una calidad adecuada para el alumnado. El objetivo de este trabajo es evaluar este proceso de revisión manual a partir de transcripciones automáticas, para poder compararlo en términos de coste temporal con un proceso de obtención de transcripciones totalmente manual. Con este objetivo en mente, y en el marco de las ayudas de la UPV de Docencia en Red 2012-2013, pusimos en marcha un proceso de revisión de transcripciones automáticas por parte de los autores de los correspondientes vídeos poliMedia. Dichas evaluaciones se organizaron en 3 fases, con el objetivo de evaluar diversas versiones de nuestro sistema que fue refinado tras cada fase.

\section{2 transLectures}

transLectures es el acrónimo del proyecto europeo titulado "Transcription and Translation of Video Lectures" (FP7-ICT-2011-7), en el cual se aplican técnicas de reconocimiento automático del habla y de traducción automática con el objetivo de proveer transcripciones y traducciones de forma automatizada a grandes repositorios de vídeos docentes como poliMedia (Silvestre y col. 2012) o VideoLectures.NET. En este proyecto coordinado por la UPV colaboran dos socios académicos como son el Jozef Stefan Institute en Eslovenia y el Rheinisch-Westfaelische Technische Hochschule en Alemania, y tres socios industriales Deluxe Media Europe de Grecia, European Media Laboratory GmbH en Alemania y XEROX S.A.S. en Francia.

El objetivo científico principal de este proyecto es generar transcripciones y traducciones automáticas de alta calidad mediante técnicas de adaptación masiva e interacción inteligente. La adaptación masiva consiste en adaptar los modelos empleados en transcripción y traducción a las variables específicas de los vídeos docentes, como pueden ser el locutor y el tema. Por otro lado, la interacción inteligente consiste en intentar detectar los errores producidos en las transcripciones y traducciones, con el objetivo de presentárselos al usuario para su corrección. 


\section{3 poliMedia}

poliMedia es un sistema diseñado por la UPV para la creación de contenidos multimedia como apoyo a la docencia presencial, que abarca desde la preparación del material docente hasta la distribución a través de distintos medios a los destinatarios de los mismos (poliMedia 2007). El autor es el propietario intelectual de la obra, y es la UPV la que ofrece instrumentos, materiales y técnicos para la grabación de los vídeos docentes por parte del profesorado.

Los vídeos docentes que existen en la plataforma poliMedia, siguen un formato estándar en todos los vídeos, característico de la plataforma. Se trata de una vista conjunta de profesor y pantalla (diapositivas, programas, etc) en un mismo plano de cámara que no se mueve en todo el vídeo, como se puede observar en la Figura 1.

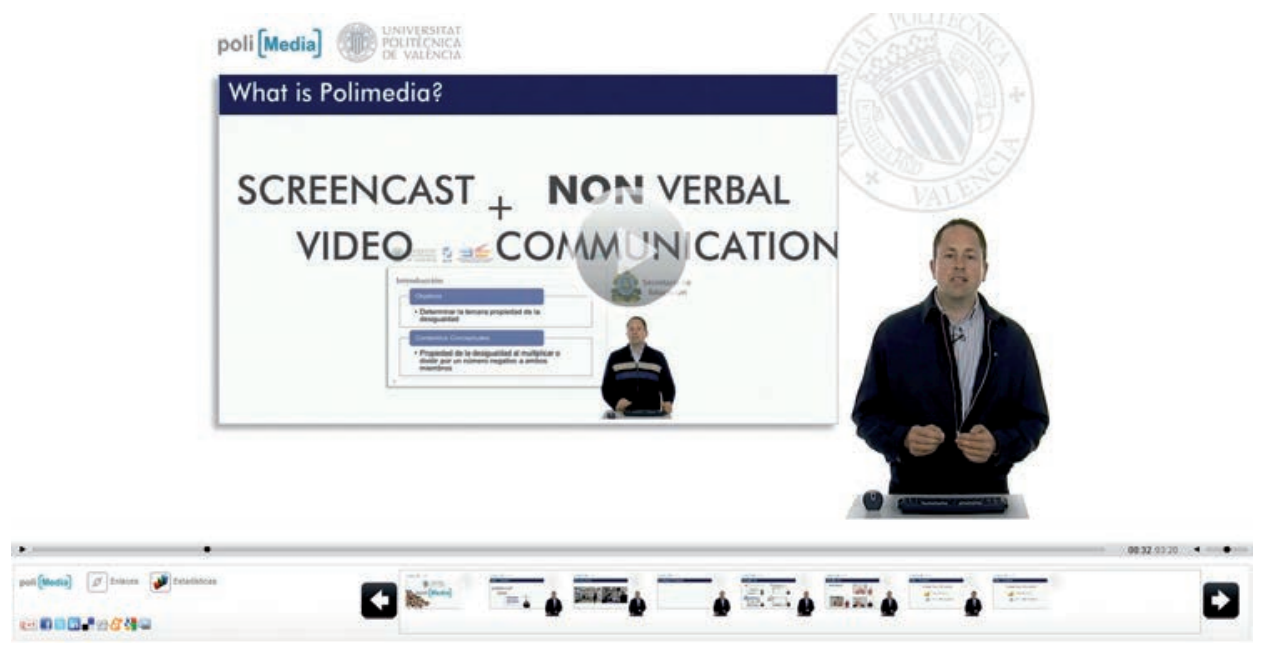

Fig. 1: Resultado final de un vídeo docente de poliMedia.

El proceso de publicación de vídeos docentes es muy simple: se graba en un estudio al profesor sobre un fondo blanco, y simultáneamente la pantalla del ordenador, que previamente habrá cargado algún tipo de recurso multimedia. Después se extrae la grabación del profesor y se mezcla con la de la pantalla según se observa en la Figura 1. Finalmente, este vídeo ya editado se distribuye a través del portal oficial de poliMedia.

Destacar que en las evaluaciones que se presentan en este artículo han participado profesores que previamente habían grabado material para el portal de poliMedia, y que se han llevado a cabo en el marco del programa Docència en Xarxa, que pretende incentivar entre el profesorado el uso de esta plataforma. 
Evaluación del proceso de revisión de transcripciones automáticas para vídeos poliMedia.

\section{Evaluaciones}

Como comentábamos, las evaluaciones se han llevado a cabo en el marco del programa Docència en Xarxa 2012-2013, en el que se ha invitado a los profesores a revisar las transcripciones de algunos de sus propios vídeos docentes de poliMedia. En total 27 profesores participaron en este estudio con un total de 86 vídeos docentes revisados, que fueron transcritos automáticamente utilizando el toolkit TLK (The TransLectures-UPV team 2013) desarrollado en el proyecto transLectures. Además, con el objetivo de organizar las evaluaciones, y probar nuevos modelos de interacción con el usuario, las evaluaciones fueron divididas en tres fases.

La primera fase consistió en una revisión de transcripciones generadas automáticamente basada en una interfaz web diseñada específicamente para este fin. Esta interfaz mostraba de forma sincronizada el vídeo y la transcripción para facilitar al usuario la detección de errores de transcripción. El usuario simplemente necesitaba hacer clic o presionar la tecla Intro sobre el segmento de transcripción errónea para poder modificarlo. Dicha interfaz puede verse en la Figura 2.

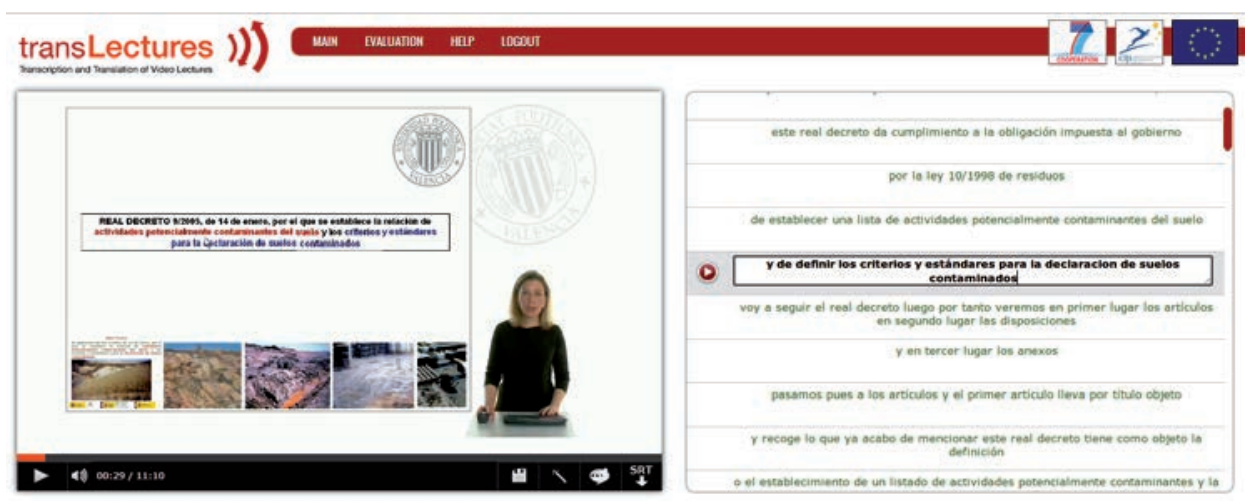

Fig. 2: Reproductor web de transLectures en modo edición manual.

En la segunda fase introdujimos un sistema basado en interacción inteligente (Serrano y col. 2013), que basándose en medidas de confianza (Sanchis, Juan y Vidal 2012) a nivel de palabra detectaba automáticamente aquellas palabras de la transcripción que probablemente fueran erróneas. De esta forma pretendíamos centrar la atención del usuario en dicha palabras que probablemente habrían sido incorrectamente reconocidas por el sistema de transcripción automática. En este caso, el sistema únicamente reproduce el segmento de audio correspondiente a estas palabras con el fin de ahorrar tiempo y esfuerzo al usuario. Sin embargo, esta detección de palabras erróneas no es perfecta, por lo que aunque la calidad de transcripción en general mejora mediante la revisión del usuario, la transcripción final sigue conteniendo errores de transcripción.

La tercera y última fase fue una combinación de las dos anteriores, diseñada para obtener transcripciones perfectas, pero aprovechando la detección eficiente de errores basada en medidas de confianza. Esta fase fue dividida en dos etapas. En la prime- 


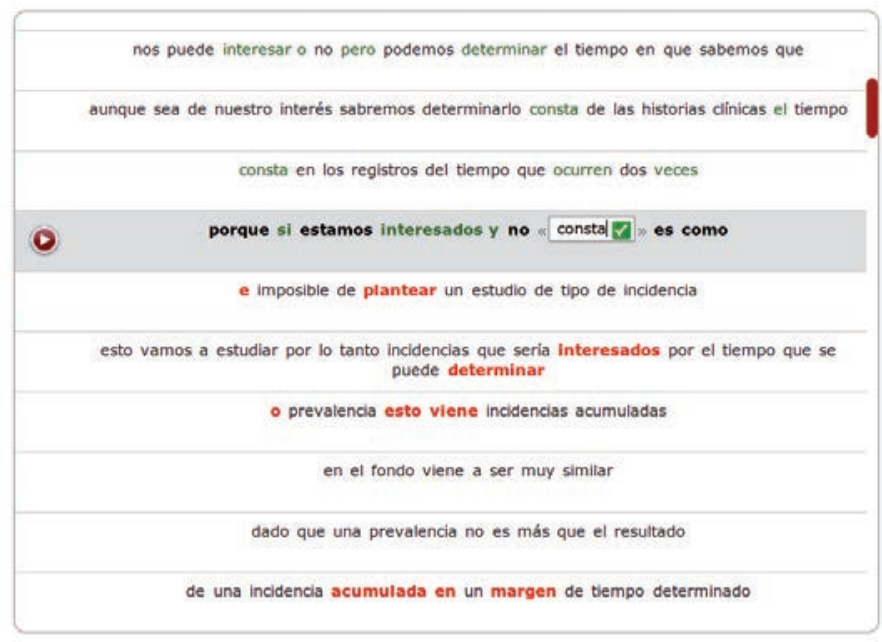

Fig. 3: Reproductor web de transLectures en modo interacción inteligente. Las palabras con baja confianza (probablemente erróneas) aparecen en rojo, y las revisadas en verde. La caja de edición puede ser expandida a izquierda y derecha pulsando en $<<$ ó $>>$, respectivamente.

ra etapa se mejoró la transcripción inicial mediante una revisión de transcripciones automáticas utilizando un protocolo similar al de la segunda fase. Tras esta primera revisión, el sistema de transcripción automática se volvió a entrenar incorporando las revisiones del usuario (Sanchez-Cortina y col. 2012), actualizándose seguidamente las transcripciones automáticas respetando las revisiones ya realizadas por el usuario. Finalmente se realizó una segunda etapa de revisión manual idéntica a la realizada en la primera fase. La idea es que la calidad de esta segunda transcripción sea lo suficientemente alta como para que la revisión requiera un menor tiempo, y que el tiempo total empleado en ambas etapas sea menor que el de la primera fase.

\section{Resultados}

Los resultados de las diferentes fases fueron recopilados en términos de Real Time Factor (RTF), Word Error Rate (WER), y una encuesta de satisfacción en escala de 0 a 10 que contempla diferentes aspectos de usabilidad y preferencias del usuario. El RTF se define como el ratio entre el tiempo empleado en la revisión y la duración del vídeo, mientras que el WER mide el ratio entre el número de palabras incorrectamente reconocidas automáticamente y el número total de palabras en la transcripción correcta proporcionada por el usuario.

Destacar que comparamos nuestros resultados con el tiempo necesario para obtener una transcripción totalmente manual (sin disponer de transcripción automática inicial), que se estima estar alrededor de 10 RTF para usuarios no expertos (Munteanu, Penn y Zhu 2009). Más concretamente, este tiempo necesario para generar 
Evaluación del proceso de revisión de transcripciones automáticas para vídeos poliMedia.

transcripciones totalmente manuales se ha corroborado experimentalmente sobre poliMedia (Valor Miró y col. 2012).

La Tabla 1 muestra por columnas de izquierda a derecha, el protocolo de revisión utilizado, los resultados de WER inicial obtenidos por la transcripción automática, los resultados de WER final tras la revisión del usuario, el tiempo empleado por el usuario en el proceso de revisión en términos de RTF y la valoración subjetiva del sistema recopilada por una encuesta tras finalizar el proceso de revisión. Por filas podemos observar los resultados de los diferentes protocolos de revisión, desde la revisión que se realiza sobre la transcripción generada automáticamente, pasando por el protocolo de interacción inteligente basado en medidas de confianza, y finalmente la revisión en dos etapas.

Tabla 1: Comparativa de protocolos de revisión de transcripciones automáticas.

\begin{tabular}{lcccc}
\multicolumn{1}{c}{ Protocolo de revisión } & WER inicial & WER final & RTF & Encuesta \\
\hline 1 - Revisión manual & 16.9 & 0.0 & 5.6 & 9.1 \\
2 - Interacción inteligente & 14.5 & 8.0 & 2.2 & 7.2 \\
3 - Revisión en dos etapas & 28.4 & 0.0 & 5.3 & 7.8
\end{tabular}

Los resultados obtenidos en las tres fases de la evaluación apuntan a que la interacción manual más sencilla utilizada en la primera fase es la preferida por nuestros usuarios, que consiguen reducir a la mitad el tiempo de obtención de una transcripción en comparación a realizarla totalmente manual. La revisión basada en medidas de confianza de la segunda fase requiere una menor dedicación por parte del usuario, pero el resultado es una transcripción con algunos errores que no son aceptable por nuestros usuarios dado el propósito docente de los vídeos. Finalmente, la tercera fase ofrece resultados de tiempo ligeramente mejores que la primera, pero debido a que el proceso en dos etapas es más complejo, los usuarios se decantaron por el protocolo de la primera fase.

\section{Conclusiones}

En este artículo hemos presentado una evaluación con profesores que se realizó en el marco de Docència en Xarxa 2012-2013, con el objetivo de obtener un sistema eficiente para realizar supervisiones de transcripciones de vídeos docentes de la plataforma poliMedia. También hemos presentado el proyecto transLectures que actualmente está ofreciendo transcripciones y traducciones automáticas para todos los vídeos docentes de la plataforma poliMedia de la UPV.

En las evaluaciones hemos comparado tres protocolos de revisión con el usuario, obteniendo en todos los casos tiempos de transcripción menores que si realizáramos la transcripción totalmente manual. Sin embargo, la técnica de interacción inteligente que limita el tiempo dedicado por el usuario a la revisión, a costa de proporcionar unas transcripciones imperfectas, no fue aceptada por los profesores. Por otro lado, 
la ligera mejora de tiempo obtenida en la tercera fase no justifica para los profesores la complejidad extra que añade una revisión en dos etapas.

Así pues, como conclusión principal destacamos que la revisión de las transcripciones generadas automáticamente es el protocolo de revisión mejor aceptado por los profesores. Este modelo obtiene una reducción de aproximadamente el $50 \%$ del tiempo necesario para generar una transcripción perfecta, al compararlo con el tiempo necesario para transcribir de forma totalmente manual.

\section{Referencias bibliográficas}

Munteanu, Cosmin, Gerald Penn y Xiaodan Zhu (2009). "Improving automatic speech recognition for lectures through transformation-based rules learned from minimal data". En: Proc. of ACL-AFNLP, págs. 764-772.

poliMedia (2007). The poliMedia tool. http://polimedia.blogs.upv.es/?lang=en.

Sanchez-Cortina, Isaias y col. (2012). "A prototype for interactive speech transcription balancing error and supervision effort". En: Proc. of ACM IUI, págs. 325-326.

Sanchis, Alberto, Alfons Juan y Enrique Vidal (2012). "A Word-Based Naïve Bayes Classifier for Confidence Estimation in Speech Recognition". En: IEEE Transactions on Audio, Speech, and Language Processing 20.2, págs. 565-574.

Serrano, Nicolás y col. (2013). "Interactive handwriting recognition with limited user effort". En: International Journal on Document Analysis and Recognition, págs. 1-13.

Silvestre, Joan Albert y col. (2012). "transLectures". En: Proceedings of IberSPEECH 2012.

The TransLectures-UPV team (2013). The TransLectures UPV toolkit (TLK). http: //www.translectures.eu/tlk.

Valor Miró, Juan Daniel y col. (2012). "Integrating a State-of-the-Art ASR System into the Opencast Matterhorn Platform". En: Advances in Speech and Language Technologies for Iberian Languages. Vol. 328. CCIS. Springer, págs. 237-246. ISBN: 978-3-642-35291-1. 


\title{
Plataforma digital para el Diseño y Espacio Público de la ciudad
}

\section{Mónica Val Fiel ${ }^{\mathrm{a}}$}

${ }^{a}$ Departamento de Expresión Gráfica Arquitectónica, Escuela Técnica Superior de Ingeniería del Diseño, Universitat Politècnica de València, movalfie@ega.upv.es

\begin{abstract}
The implementation of technology resources to support learning is a tool for the improvement of the quality of university education classroom. Therefore, it is showed the pilot experience in the creation and use of a web 2.0 platform as a teaching resource that enables a collaborative environment within the subject 'Design and Public Space' is presented in the Master in Design Engineering Degree.

The course addresses the design as a discipline for intervention in the public space of the city and every year proposes for this area of work development of a technical project. Thus, at an early stage, it arises the search and summary of reference works that are studied in the subsequent realization of the project throughout the term.

This implementation of a web environment has allowed the creation of an active and collaborative space between all students, structured, easy access and quick reference anytime. It has also collected the variety of interests, reflecting the diversity of degrees by students who enroll in the course, and also stands as the perfect combination for interdisciplinary work that is desirable in the intervention of public space in the city.
\end{abstract}

Keywords: digital platform, collaborative environment, e-learning, network learning, web usability, design, public space

\section{Resumen}

La implementación de recursos tecnológicos de apoyo al aprendizaje es una herramienta de interés para la mejora de la calidad de la enseñanza universitaria presencial. Por ello, se presenta la experiencia piloto en la creación y uso de una plataforma web 2.0 como recurso docente que hace 
posible un entorno colaborativo en el seno de la asignatura 'Diseño y espacio público', dentro del Máster Universitario en Ingeniería del Diseño.

La asignatura dirige el diseño como disciplina de intervención en el espacio público de la ciudad y cada año propone para este ámbito de trabajo el desarrollo de un proyecto técnico. De esta manera, en una fase inicial, se plantea la búsqueda y recopilación de trabajos que sean referencia de estudio para la realización posterior del proyecto a lo largo del cuatrimestre.

Esa implementación de un entorno web, ha permitido la creación de un espacio activo y colaborativo entre el conjunto de estudiantes, estructurado, de fácil acceso y de consulta rápida y en cualquier momento. Asimismo, ha recogido la pluralidad de intereses, reflejo de la diversidad de titulaciones de los alumnos que se matriculan en la asignatura, y además se erige como perfecta combinación para el trabajo interdisciplinar que es deseable en la intervención del espacio público de la ciudad.

Palabras clave: plataforma digital, entorno colaborativo, e-learning, aprendizaje en red, usabilidad web, diseño, espacio público

\section{Introducción}

La asignatura de Diseño y Espacio Público se imparte dentro del bloque de Productos de Uso Colectivo en el contexto del Máster Universitario en Ingeniería del Diseño de la Universitat Politècnica de València. Dicha asignatura está orientada al ámbito de la colectividad y, a través de una visión pluridisciplinar, presenta el diseño como herramienta y estrategia de intervención en el espacio público de la ciudad. Para ello, plantea el diseño y la elaboración de un proyecto técnico que se desarrolla a lo largo del segundo semestre del máster.

En ese proyecto, la metodología responde al proceso de diseño general, atendiendo a sus primeras fases, diseño conceptual y de detalle, con una definición del producto que se va a desarrollar desde el punto de vista de las necesidades que va a cubrir y dando respuesta al emplazamiento al que está destinado. El proyecto, en relación al objeto propuesto para cada año, inicia su desarrollo con una fase de estudio de distintos productos existentes en el mercado y con una investigación previa consistente en la búsqueda de documentación gráfica que sirva de referencia en relación a cuestiones de formalización, materialidad, montaje y construcción, etc. 
De acuerdo con los datos solicitados de manera anónima al grupo de alumnos matriculados en la asignatura, en dicha fase de información previa en la que se plantea la búsqueda de referentes en relación con la propuesta planteada, dos terceras partes de los alumnos confirmaron que desarrollaron la investigación exclusivamente vía web, mientras que el tercio restante compatibilizó las fuentes en un 80\%, también vía digital, y el 20\% restante a través de documentación en papel, lo que motivó la implementación de una nueva herramienta que facilitara esta tarea de recopilación.

En el presente curso se ha introducido un cambio significativo y en lugar del anexo de documentación gráfica comentada, que cada alumno incorporaba a su proyecto, se ha habilitado una plataforma web 2.0 (Downes, 2005) como herramienta interactiva donde el alumno, tras registrarse, accede a una área de subida de proyectos de referencia, consulta y valoración.

\section{Objetivos}

Con ello se pretende:

- Integrar un aprendizaje activo y colaborativo, y hacerlo accesible. Construir un repositorio común al que todo el grupo tiene acceso en cualquier momento.

- Estructurar la búsqueda de información. La usabilidad web permite de forma sencilla la incorporación de la documentación y la valoración del conjunto de proyectos.

- Evidenciar la pluralidad de planteamientos, una realidad muy a tener en cuenta de acuerdo con la diversidad de la formación previa del alumnado que se matricula en el bloque "Productos de uso colectivo" y que proviene de diversas titulaciones.

\section{Desarrollo de la innovación}

La incorporación de aportaciones individuales sistematizadas que vayan dirigiendo y definiendo un conjunto de referencias agrupadas en distintas temáticas y con un interés explícito, construye el conjunto de una investigación colectiva. Sin embargo, la plataforma no busca solamente el intercambio y la construcción de unas fuentes de referencias comunes junto con su análisis y crítica, sino evidenciar también los intereses e incentivar la posible agrupación en equipos de trabajo para el desarrollo de las siguientes fases del trabajo a realizar.

(cc) EY-NC-ND 2014, Universitat Politècnica de València

I Jornadas IN-RED (2014) 

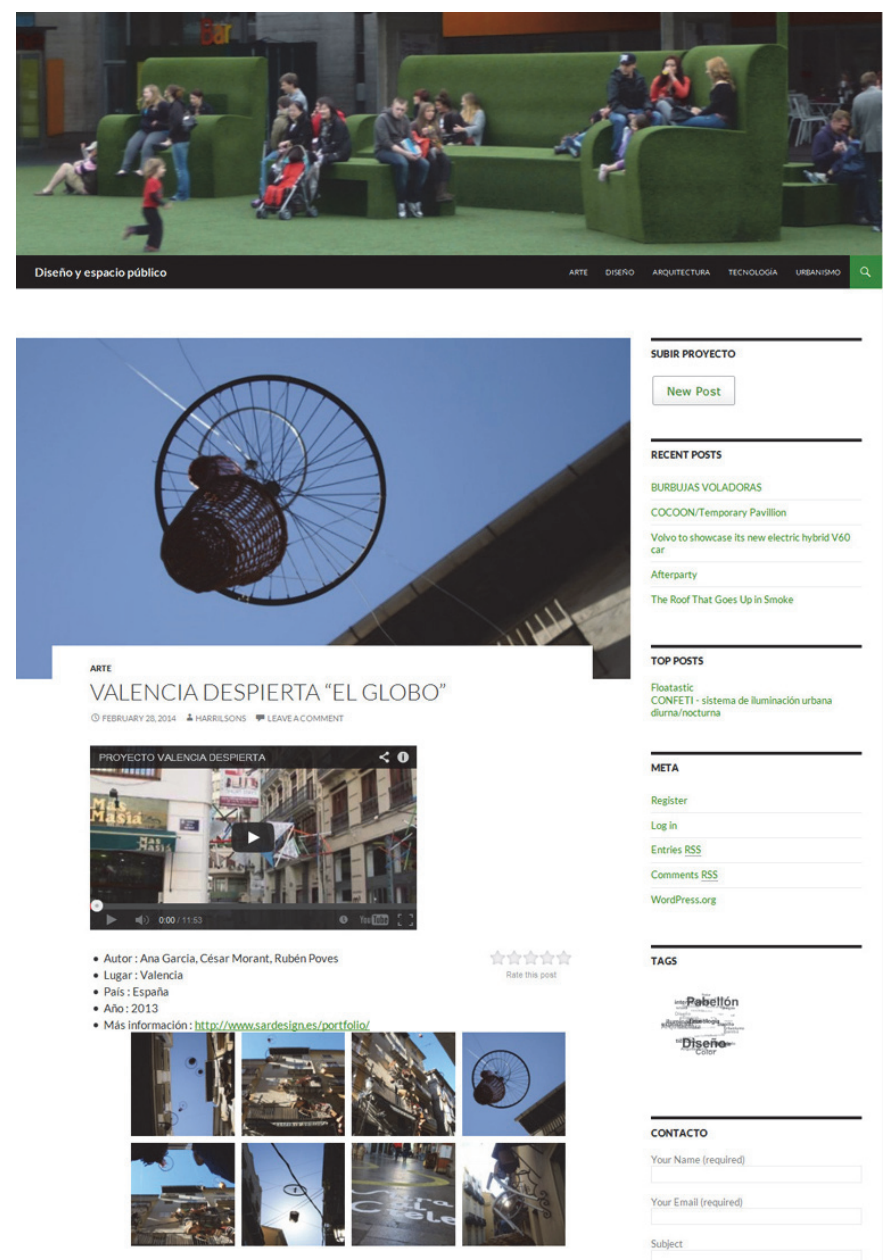

TACS

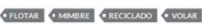

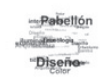

CONTACTO

CONTACTO

Your Email (reacuired)

subiect

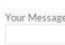

$\operatorname{sen} 0$

Fig. 1 Captura de pantalla del blog http://despaciopublico.blogs.upv.es/

\subsection{Aprendizaje activo, colaborativo y accesible}

Uno de los principales objetivos que se persiguen es promover un rol activo dentro del grupo de usuarios, donde el interactuar les permita desarrollar un repertorio compartido de recursos (Suarez, 2012). Además, el hacer accesible la información a todo el grupo en tiempo real, con la premisa de evitar la duplicidad de referencias, ha obligado a una investigación en mayor profundidad, que ha repercutido en el interés y la diversidad de los proyectos. 
Tras la evaluación de los trabajos recogidos durante el presente curso, los alumnos han destacado positivamente dos aspectos en el uso de la web: la motivación en la búsqueda, que ha sido valorada por el $85 \%$ del alumnado, y la diversidad de referencias, que ha sido avalada por el $100 \%$ de la clase.

Las gráficas que se adjuntan evidencian la actividad de la plataforma durante el periodo de un mes, que era el tiempo permitido para que los alumnos subieran sus proyectos de referencia. En ellas se muestra cómo ha sido utilizada la web, tanto para la presentación de proyectos como para la consulta de documentación a lo largo de ese mes.

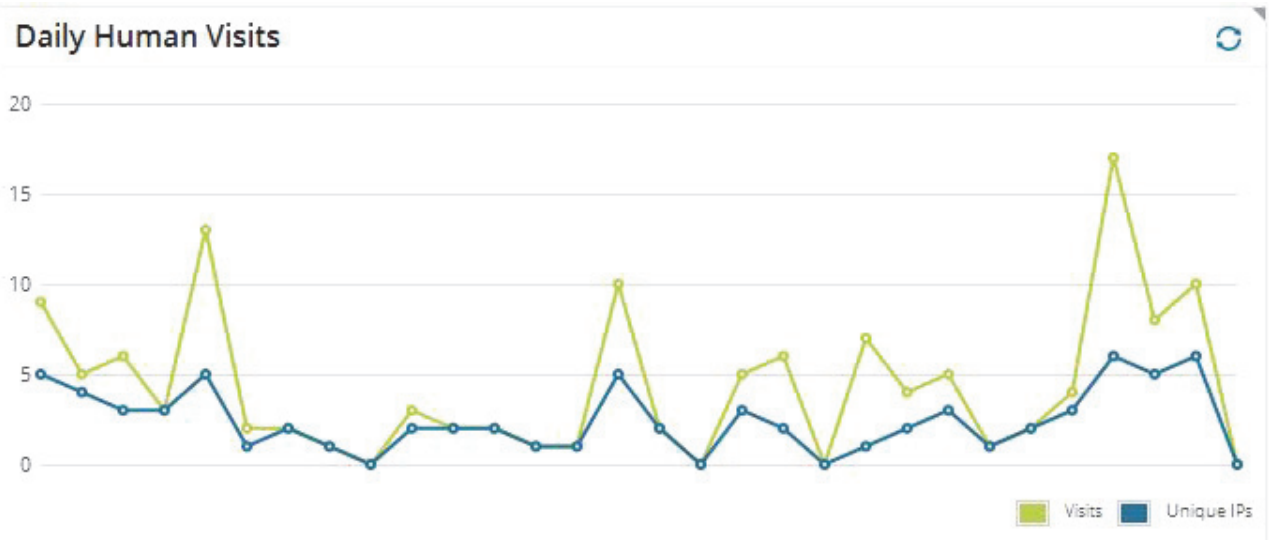

Fig. 2 Gráfica que recoge los accesos dirarios a la web durante el tiempo permitido para la incorporación de documentación (30 días).

Daily Pageviews

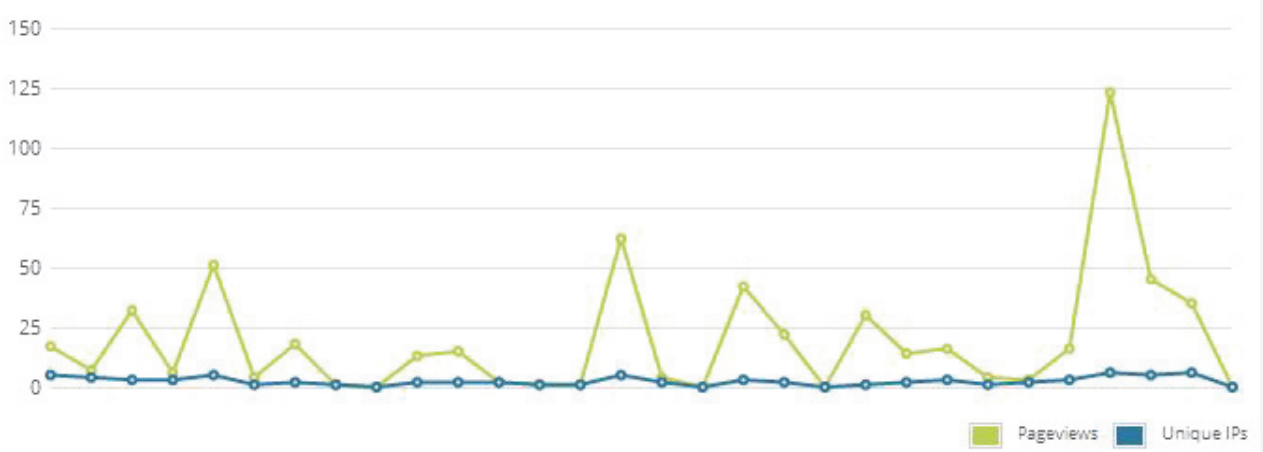

Fig. 3 Gráfica que recoge el número de páginas visitadas durante el tiempo permitido para la incorporación de documentación (30 días).

\section{(cc) BY-NC-ND 2014, Universitat Politècnica de València}

I Jornadas IN-RED (2014) 


\subsection{Documentación estructurada y de fácil incorporación}

Uno de los propósitos que se ha perseguido con más interés es que la herramienta fuese intuitiva y fácil de usar.

La definición de una plantilla común, con unos campos específicos a completar por los alumnos, permitió unificar los criterios en la implementación de la plataforma y alcanzar la síntesis de la información. Todo gracias a un interfaz intuitivo que incorporaba toda la documentación en una única subida (el conjunto de imágenes, url, vídeos, descripción, datos de identidad del proyecto, localización, etc.), dejando para una segunda fase la valoración y crítica de los proyectos publicados.

En una encuesta que se les pasó a los alumnos para recoger sus opiniones, el 100\% de los encuestados estuvo de acuerdo en que el contenido de la documentación era adecuado, permitiéndoles en cada caso y en función de sus intereses particulares investigar en mayor profundidad si así lo deseaban.
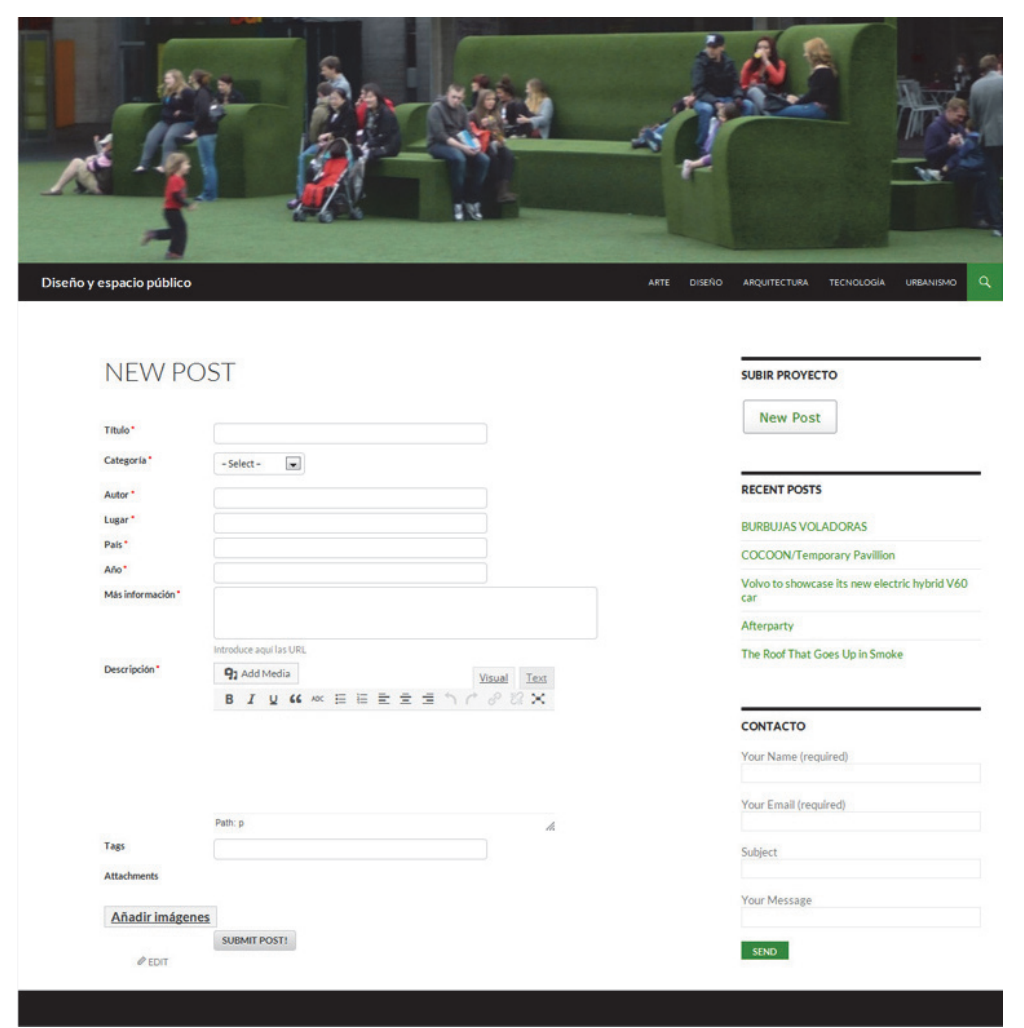

Fig. 4 Plantilla definida para la incorporación de proyectos solo accesible tras el registro del alumno y validación por parte del profesor responsable http://despaciopublico.blogs.upv.es/ 
Dentro de los aspectos más destacados, la facilidad de uso en la incorporación de documentación y la existencia de enlaces a otras webs que permiten ampliar la información sobre la documentación incorporada y que certifica la fuente primaria de la información, fueron las dos cuestiones más valoradas. Un $67 \%$ de los alumnos las destacó del conjunto (8 alumnos de los 12 que han participado en la actividad propuesta).

En un segundo nivel de valoración positiva, se incluyeron dos aspectos. El primero, el etiquetado semático, donde un $50 \%$ de los alumnos destacó que era interesante que los proyectos incorporados se les pudiese asignar determinadas etiquetas o palabras clave que los clasificara en subcategorías y que facilitara su búsqueda y consulta. En ese mismo nivel de interés, los alumnos destacaban la posibilidad de incluir vídeos que mostrasen aspectos más dinámicos de la instalación en estudio, como por ejemplo el proceso creativo o incluso el montaje de la instalación, siendo este uno de los aspectos de estudio en el desarrollo del proyecto posterior.

No obstante, en oposición a los puntos más positivos, hay que mencionar que los aspectos menos utilizados por los alumnos han sido los relacionados con los campos de valoración y de comentarios de las referencias en estudio.

\subsection{Pluralidad de planteamientos}

En el contexto del Diseño, y en este caso en relación al Espacio Público, es importante considerar que la investigación no se reduzca a su ámbito de intervención sino que se amplie a disciplinas afines según el campo de actuación (como por ejemplo la arquitectura, el arte, etc.)

Además, en esa dirección hay que destacar la formación interdisciplinar previa de los alumnos que se matriculan en el Máster de Diseño, ya que, por citar las más usuales, proceden de titulaciones como: Arquitectura, Diseño y Bellas Artes.

En este sentido, las categorías más desarrolladas en el presente curso, han sido las correspondientes al perfil del alumno matriculado. Así, de los 57 proyectos incorporados a la plataforma, el $44 \%$ corresponden a diseño y el $37 \%$ a arquitectura.

\section{Resultados}

Los resultados de la aplicación del recurso han puesto de manifiesto que:

- La investigación de cada alumno se expande y se hace accesible, permitiendo una participación activa y visible de todos los alumnos, y esto se justifica por las

(cc) BY-NC-ND 2014, Universitat Politècnica de València

I Jornadas IN-RED (2014) 
entradas a las páginas registradas. Además facilita la consulta y la referencia a determinados proyectos en posteriores fases de desarrollo del trabajo.

- El interfaz es un instrumento de uso sencillo y suficientemente conocido por los estudiantes. Es accesible desde cualquier navegador o incluso desde dispositivos móviles, tal y como lo han registrado también las estadísticas activadas en la web. Solo un 25\% del grupo constato haber participado activamente previamente en un blog, y sin embargo la usabilidad de la web fue una de las cuestiones más valoradas.

- Pese a que las categorías más trabajadas han sido aquellas que se corresponden con las titulaciones previas de los alumnos, la clasificación de la página web ha permitido cuestionar dichas categorías (que de otro modo estarían más limitadas) y hacer patente la riqueza en la diversidad de planteamientos. Además, haciendo evidentes las afinidades de los alumnos para el posterior desarrollo del proyecto, se ha posibilitado que estos puedan agruparse en base a intereses compartidos, lo que ha sido especialmente enriquecedor.

\section{Conclusiones}

Resulta evidente que la implementación de recursos tecnológicos de apoyo al aprendizaje mejora la calidad de la enseñanza universitaria (Núñez, 2012; Del Moral, 2012; GarcíaRuiz, 2014). En este caso, la implementación de una plataforma de documentación que recoja la búsqueda colectiva de referencias de interés (y que ha pervivido con el desarrollo del proyecto posterior), ha evidenciado ser un repositorio de gran interés. Asimismo, ha permitido recurrir a sus datos en cualquier momento y utilizarse como argumento visual para explicar determinadas cuestiones, tanto por parte del alumnado como del profesor.

En el conjunto del uso de la plataforma, cabría destacar, como más valorados, los siguientes aspectos: la definición de un formulario con los datos a rellenar (que ha facilitado la implementación de los datos del proyecto), las opciones de clasificación y definición de elementos dinámicos (como nubes de etiquetas y enlaces a otras webs) y la parte gráfica de la documentación incorporada (imágenes y vídeos). Y en lo que respecta a las cuestiones internas de la web, ha sido de gran utilidad el control total sobre los contenidos de fácil edición, junto con las herramientas estadísticas que han permitido evaluar su uso.

Por último, hay que señalar que el éxito de la implementación de la experiencia piloto queda avalado por los siguientes porcentajes: el $84 \%$ del alumnado encuestado considera que la herramienta es adecuada para la actividad propuesta, frente a un $16 \%$ que no se posiciona al respecto. 


\section{Referencias}

DEL MORAL, E.; VILLALUSTRE, L. (2012). "University teaching in the 2.0 era: virtual campus teaching competencies". Revista de Universidad y Sociedad del Conocimiento (RUSC). vol. 9, no 1. pp. 231-244 UOC. <http://dx.doi.org/10.7238/rusc.v9i1.1127 > [Consulta: 13 junio 2014]

DOWNES S. (2005). E-Learning 2.0, en "eLearn Magazine" October 16, 2005. <http://www.downes.ca/me/articles.htm > [Consulta: 13 junio 2014]

LARA, T (2005) "Blogs para educar. Uso de los blogs en una pedagogía constructivista". Revista Telos, $n^{\circ} 65$, Oct-Dic. pp. 86-93. Disponible en < http://tiscar.com/blogs-para-educar/> [Consulta: 13 junio 2014]

GARCÍA-RUIZ, R., GONZÁLEZ, N. \& CONTRERAS, P. (2014). "Competency training in universities via projects and Web 2.0 tools. Analysis of an experience". Revista de Universidad y Sociedad del Conocimiento (RUSC). Vol. 11, No 1. pp. 61-75. [Consulta: 13 junio 2014] $\langle$ http://dx.doi.org/10.7238/rusc.v11i1.1713>

NUÑEZ E., VACA JP. (2012). Creación y uso de una plataforma web como apoyo a las clases de aula. VII Jornada de Innovación Pedagógica "Experiencias de evaluación en e-learning". Madrid <http://moodle.upm.es/adamadrid/file.php/1/web_VII_jornadas_ADA/comunicaciones/31_Nunez_Va ca.pdf> [Consulta: 13 junio 2014]

SUÁREZ C., GROS B. (2012). Aprender en red de la interacción a la colaboración. Barcelona: UOC.

VAL, M. y BETETA, M. (2014). Diseño y Espacio Público < http://despaciopublico.blogs.upv.es/> [Consulta: 13 de junio de 2014] 


\title{
Sobre la elaboración de un curso masivo online abierto de Matemáticas orientado a los primeros cursos de grado de ingeniería.
}

\author{
Antonio-José Guirao a , Alicia Herrero ${ }^{\text {b }}$, Santiago-E. Moll ${ }^{c}$, José-A. Moraño ${ }^{\text {d }}$ \\ åDepto de Matemática Aplicada, Universitat Politècnica de València, Spain, anguisa2@mat.upv.es, \\ ${ }^{b}$ Depto de Matemática Aplicada, Universitat Politècnica de València, Spain, aherrero@mat.upv.es, \\ ${ }^{c}$ Depto de Matemática Aplicada, Universitat Politècnica de València, Spain, sanmollp@mat.upv.es, \\ ${ }^{\mathrm{d}}$ Depto de Matemática Aplicada, Universitat Politècnica de València, Spain, jomofer@ mat.upv.es.
}

\begin{abstract}
In recent years, there has been a huge developing in Massive Open Online Courses (MOOC), in order to soften the learning and as a complement to the knowledge needed by the students. MOOCs have become an important tool in the universities to supply any deficiencies in students of first courses. In this context we present several MOOCs whose aim is to match the level of the first year students in mathematics, mostly in engineering bachelors. We have developed two MOOCs, one introductory to mathematical language, the different number sets and their properties and another devoted to integral calculus. We are also developing two MOOCs more, covering topics of differential calculus and algebra. The themes are developed in a didactic way with short videos that would help students to reinforce or strengthen their knowledge and skills needed for optimal performance in engineering degrees. This methodology is intended to enhance the motivation and improve the perception of the subjects of mathematics by the students, helping them to understand the main concepts of the subjects and avoiding dropout of unmotivated students.
\end{abstract}

Keywords: MOOC, on-line knowledge, mathematics.

\author{
Resumen \\ En los últimos años, se vienen desarrollando Cursos Masivos Online \\ Abiertos (MOOC, de sus siglas en inglés), con el objetivo de facilitar el \\ aprendizaje y complementar los conocimientos que necesitan los estudiantes.
}


Sobre la elaboración de un curso masivo online abierto de Matemáticas orientado a los primeros cursos de grado de ingeniería

Los MOOC's pueden convertirse en una herramienta importante en el ámbito universitario para suplir las posibles carencias de los estudiantes de primeros cursos. En este marco presentamos varios MOOC's cuyo objetivo es equiparar el nivel en matemáticas de los estudiantes de primer año de los diferentes grados en ingeniería. Hemos elaborado dos MOOC's, uno de ellos introductorio al lenguaje matemático y a los diferentes conjuntos numéricos y sus propiedades y otro dedicado al cálculo integral. Se están elaborando además, dos MOOC's que abarcarán los temas de cálculo diferencial y álgebra. Los temas se han elaborado de forma didáctica y con videos breves que ayudarán al estudiante a afianzar o reforzar los conocimientos y competencias básicas que se necesitan para tener un rendimiento óptimo en los grados de ingeniería. Con esta metodología se persigue que la motivación y percepción de las asignaturas de matemáticas por parte de los estudiantes mejore, ayudándoles a comprender los principales conceptos de las asignaturas impartidas y evitar el abandono de los estudiantes no motivados.

Palabras clave: $M O O C$, clases on-line, matemáticas.

\section{Introducción}

En los últimos años, en la Universitat Politècnica de València, se vienen desarrollando Cursos Masivos Online Abiertos (MOOC), con el objetivo de facilitar el aprendizaje y complementar los conocimientos que necesitan los estudiantes. Los MOOC's pueden convertirse en una herramienta importante en el ámbito universitario para suplir las posibles carencias de los estudiantes de primeros cursos o bien desarrollar complementos paralelos a las enseñanzas impartidas. Grandes universidades como el Instituto Tecnológico de Massachusets (MIT) fueron pioneras en este tipo de enseñanzas, que han probado ser útiles y de mucho éxito.

MOOC es el acrónimo en inglés de massive open online course que traducido al español queda como cursos en línea masivos y abiertos, y es una modalidad de educación abierta, que se imparten en cursos de pre-grado ofrecidos gratuitamente a través de plataformas educativas, normalmente vinculadas con las universidades. El objetivo consiste en distribuir el conocimiento de forma que sea atractivo y esté al alcance de todos.

El término MOOC fue acuñado en el año 2008 por Dave Cormier cuando el número de inscritos a su curso Connectivism and Connective Knowledge (CCK08) aumentó a casi dos mil trescientos (2300) estudiantes. 
Para que la enseñanza a distancia pueda ser considerada MOOC debe cumplir los siguientes requisitos:

- Su estructura debe estar orientada al aprendizaje, con una serie de pruebas o de evaluaciones que puedan acreditar el conocimiento adquirido.

- El número de matriculados debe ser, en principio, ilimitado, o bien, al menos muy superior al número que podría haber en un curso presencial.

- El curso se imparte a distancia, siendo la red el medio de distribución y no requiere de asistencia presencial.

- Los materiales deben ser accesibles de forma gratuita.

Existen diferentes tipos de MOOC, en función de los objetivos, metodologías y resultados que se esperan.

En este marco, y gracias a la colaboración del DMA, presentamos varios MOOC's cuyo objetivo es equiparar el nivel de los estudiantes de primer año de los diferentes grados en ingeniería en matemáticas. Hemos elaborado dos MOOC's, uno de ellos introductorio al lenguaje matemático y a los diferentes conjuntos numéricos y sus propiedades y otro dedicado al cálculo integral. Se están elaborando además dos MOOC's más, que abarcarán los temas de cálculo diferencial y álgebra.

Con esta metodología se persigue en primer lugar que la motivación y percepción de las asignaturas de matemáticas por parte de los estudiantes mejore, ayudándoles a comprender los principales conceptos de la asignatura y evitar el abandono de la asignatura por parte de los estudiantes no motivados. El resultado final al que se aspira es lograr una más rápida y natural adquisición de las competencias específicas que les proporcionan las correspondientes asignaturas.

El curso de Matemáticas Básicas lleva poco tiempo en activo y ha tenido bastante éxito en cuanto al número de matriculados. El resto están previstos para el mes de julio de 2014. Por esta razón no se disponen de los datos necesarios oficiales con los que hacer un estudio pormenorizado de las fortalezas y carencias de los cursos, considerándolos como cursos MOOC. Los autores, como sondeo y estudio previo, han ido introduciendo las unidades que conforman los cursos como parte de un método de refuerzo en las asignaturas impartidas en los grados de Ingeniería Biomédica, Ingeniería de Tecnología Industrial, Ingeniería Aeroespacial e Ingeniería Electrónica. En todos los casos se ponía a disposición de los estudiantes los enlaces de los polimedias, que son las unidades atomizadas de los cursos, con un doble fin: que los estudiantes dispongan de una método para reforzar competencias y conocimientos y, por otra parte, evalúen de forma crítica los objetos de aprendizaje para

\section{(c) EY-NC-ND 2014, Universitat Politècnica de València}

I Jornadas IN-RED (2014) 
Sobre la elaboración de un curso masivo online abierto de Matemáticas orientado a los primeros cursos de grado de ingeniería

su mejora. Con el fin de recabar datos se les entregó una encuesta relativa a estos objetos de aprendizaje, y los resultados de estas encuestas se presentan en este artículo.

\section{Objetivo}

Uno de los principales problemas a los que se enfrentan los docentes en los primeros años de los grados que se imparten en la UPV, en particular, y en las universidades del territorio español en general, es la heterogeneidad de los conocimientos de los estudiantes de nuevo ingreso. Además, en algunas asignaturas, tras la adaptación al grado, se ha producido una reducción en el número de créditos, por lo que se ha reducido el tiempo que el docente dispone para ayudar a homogeneizar los conocimientos de todos los estudiantes.

Es por lo tanto un objetivo deseable intentar homogenizar los conocimientos de los estudiantes de nuevo ingreso (King, 2014 y Aiken, 2013). Si se lograra establecer unos conocimientos mínimos necesarios, asimilados por los estudiantes, el docente podría centrarse en desarrollar la materia de una forma más fluida y a un tempo mucho más adecuado a las competencias exigidas en los primeros años de universidad. Y este objetivo tiene un aliado óptimo en forma de cursos MOOC, que pueden complementar la docencia impartida por el docente durante el desarrollo de las clases. Para intentar paliar la diversidad de niveles y diferencia de conocimiento de los estudiantes, antes de entrar en la universidad, sería recomendable realizar estos cursos de nivelación antes de comenzar el año lectivo.

Por esta razón se ha programado que los cursos de matemáticas básicas comiencen una vez ha finalizado el proceso de selección de estudios. Los cursos programados son Bases Matemáticas, Bases Matemáticas: Derivadas (correspondiente a Cálculo diferencial), Bases Matemáticas: Integrales (correspondiente a Cálculo Integral) y Bases Matemáticas: Álgebra. Con estos cuatro cursos se cubren las necesidades matemáticas básicas de los estudiantes de nuevo ingreso.

Para el desarrollo de estos cursos se ha utilizado la plataforma UPV[X] Formación Online, que hasta ahora ha dado buenos resultados (UPV[X], 2014).

\section{Desarrollo de la innovación: Metodología Empleada}

El desarrollo de los cursos comienza con la planificación por parte de los integrantes del proyecto docente de la estructura del curso y con la selección de los conocimientos indispensables para que cualquier estudiante tenga garantías de éxito en el curso que acometerá en el grado elegido. La dificultad de la elección del temario adecuado radica en la heterogeneidad de los conocimientos antes mencionada y en la diversidad de grados y 
requisitos que se les exigen. A este respecto se decidió elegir una serie de puntos clasificados como conocimientos indispensables y basar los cursos sobre estos conceptos.

Una vez elegidos los conocimientos que deben adquirir los estudiantes se procede a planificar la evaluación y la disposición de los mismos. Esto determina la estructura del curso y su presentación al estudiante de nuevo ingreso. Los temas se disponen de forma que su utilidad e importancia sea el criterio de ordenación, siguiendo un orden lógico. El curso se divide en unidades, que el estudiante deberá ir completando. Para el desarrollo de una unidad los docentes deben preparar el temario en forma de videos docentes de duración reducida, para hacerlo más atractivos y de fácil asimilación. La atomización de la materia ha probado ser muy útil, pues el estudiante puede organizar la adquisición de conocimientos de una manera personalizada.

La evaluación, que se realiza por medio de tests al finalizar cada unidad, y mediante un test al finalizar el MOOC, debe tener unos objetivos muy claros (Kellogg, 2014). Es decir, la forma de evaluación:

- Debe ser clara y estar adaptada al nivel exigido

- Debe suponer un reto asumible para el estudiante

- Debe motivar el aprendizaje

- Debe proporcionar feedback al estudiante una vez realizada

Para que una evaluación cumpla todos estos requisitos, empleando únicamente tests de opción múltiple, los integrantes del proyecto deben preparar las preguntas de forma muy cuidadosa y meditada.

Cuando el curso ha sido preparado, es decir, el material está preparado, organizado y adecuado a los objetivos, se entrega para su publicación on-line.

El proceso básico que se sigue una vez el curso ha sido activado es la siguiente:

- Asimilación de contenidos: El estudiante visualiza los vídeos propuestos para cada unidad. El tiempo empleado en cada unidad ha sido optimizado, de forma que cada vídeo no excede de 10 minutos de duración. Esto hace que el proceso de asimilación de conocimientos sea paulatino, y el hecho de que sea el estudiante el que decide cuándo visualizar el siguiente es fundamental, pues es él mismo el que impone el ritmo de aprendizaje durante cada unidad. Cabe notar aquí que a pesar de esto el tiempo para completar cada unidad es limitado, lo que pensamos es necesario para lograr un compromiso más fuerte con la finalización del curso.

- Evaluación de la unidad: Una vez el estudiante ha finalizado el proceso de asimilación, comienza la fase de evaluación. Las herramientas de que se dispone son limitadas, restringiéndose a un test de opción múltiple. A medida que se mejore esta limitación en la

\section{(c)) EY-NC-ND 2014, Universitat Politècnica de València}

I Jornadas IN-RED (2014) 
Sobre la elaboración de un curso masivo online abierto de Matemáticas orientado a los primeros cursos de grado de ingeniería

plataforma, las posibilidades irán en aumento. Los test propuestos, como se ha explicado con anterioridad han sido adaptados a las necesidades del curso, y evalúan las competencias básicas expuestas en los vídeos. Para la realización de estos test, sólo es necesario haber asimilado todos los conceptos expuestos.

- Feedback: Cada vez que el estudiante responde a una pregunta de evaluación de contenidos, recibe respuesta inmediata en forma de felicitación, si la respuesta es correcta, o bien un mensaje de error con una orientación acerca de la respuesta correcta. En caso de tener dudas, puede acudir al foro o chat, donde, tras plantear la pregunta, esta puede ser respondida por los profesores o por los compañeros del MOOC. El sistema de respuestas ha funcionado adecuadamente hasta el momento.

- Evaluación final: Al finalizar las unidades, el estudiante debe ser evaluado de los conocimientos adquiridos en el curso. Esto se realiza con otro test que estará adaptado a los conocimientos básicos globales con la dificultad adecuada.

\section{Resultados}

Como se ha explicado en apartados anteriores, durante el curso académico 2013/14, los profesores involucrados en el proyecto de creación de los MOOC, han llevado a cabo sondeos sobre los vídeos realizados. Los estudiantes de Ingeniería Biomédica, Ingeniería en Tecnología Industrial, Ingeniería Aeroespacial e Ingeniería Electrónica han tenido a su disposición los enlaces a los vídeos durante el curso, pudiendo utilizarlos como refuerzo de la asignatura, y para su evaluación crítica. Se les ha presentado los cursos MOOC y su objetivo. Las preguntas y las respuestas se exponen a continuación.

Tabla 1: Percepción de los estudiantes en general

\begin{tabular}{|l|c|}
\hline $\begin{array}{l}\text { ¿Te han sido útiles los objetos de } \\
\text { aprendizaje durante el curso? }\end{array}$ & Respuestas \\
\hline Muy Poco & $0 \%$ \\
\hline Poco & $12,9 \%$ \\
\hline Indiferente & $12,9 \%$ \\
\hline Bastante & $54,83 \%$ \\
\hline Mucho & $19,35 \%$ \\
\hline N/D & $0 \%$ \\
\hline
\end{tabular}


Tabla 2: Profundidad de contenidos

\begin{tabular}{|l|c|}
\hline $\begin{array}{l}\text { ¿Crees que se debería profundizar más } \\
\text { en los contenidos? }\end{array}$ & Respuestas \\
\hline Muy Poco & $0 \%$ \\
\hline Poco & $25,81 \%$ \\
\hline Indiferente & $29,03 \%$ \\
\hline Bastante & $32,25 \%$ \\
\hline Mucho & $6,45 \%$ \\
\hline N/D & $6,5 \%$ \\
\hline
\end{tabular}

Tabla 3: Aplicación de conocimientos

\begin{tabular}{|l|c|}
\hline $\begin{array}{c}\text { ¿Has aplicado los conocimientos } \\
\text { adquiridos en los polimedias durante } \\
\text { el curso académico? }\end{array}$ & Respuestas \\
\hline Muy Poco & $0 \%$ \\
\hline Poco & $6,45 \%$ \\
\hline Indiferente & $19,35 \%$ \\
\hline Bastante & $41,93 \%$ \\
\hline Mucho & $32,25 \%$ \\
\hline N/D & $0 \%$ \\
\hline
\end{tabular}

Tabla 4: Apoyo clases Teoría/Problemas

\section{(c)) EY-NC-ND 2014, Universitat Politècnica de València}

I Jornadas IN-RED (2014) 
Sobre la elaboración de un curso masivo online abierto de Matemáticas orientado a los primeros cursos de grado de ingeniería

\begin{tabular}{|l|c|}
\hline $\begin{array}{c}\text { ¿Crees que se deberian utilizar } \\
\text { más los polimedias como } \\
\text { complemento de aprendizaje? }\end{array}$ & Respuestas \\
\hline Muy Poco & $0 \%$ \\
\hline Poco & $0 \%$ \\
\hline Indiferente & $6,45 \%$ \\
\hline Bastante & $48,38 \%$ \\
\hline Mucho & $45,16 \%$ \\
\hline N/D & $0 \%$ \\
\hline
\end{tabular}

Tabla 5: Cursos MOOC de refuerzo

\begin{tabular}{|l|c|}
\hline $\begin{array}{c}\text { ¿Estarias de acuerdo en implementar } \\
\text { cursos de refuerzo de forma paralela a } \\
\text { las clases tradicionales? }\end{array}$ & Respuestas \\
\hline Muy Poco & $0 \%$ \\
\hline Poco & $9,68 \%$ \\
\hline Indiferente & $22,58 \%$ \\
\hline Bastante & $45,16 \%$ \\
\hline Mucho & $19,35 \%$ \\
\hline N/D & $0 \%$ \\
\hline
\end{tabular}

Tabla 6: Valoración de los polimedias

(c)) BY-NC-ND 2014, Universitat Politècnica de València

I Jornadas IN-RED (2014) 


\begin{tabular}{|l|c|}
\hline \multicolumn{1}{|c|}{ ¿Cómo valoras los polimedias? } & Respuestas \\
\hline Muy Mal & $0 \%$ \\
\hline Mal & $9,68 \%$ \\
\hline Indiferente & $3,23 \%$ \\
\hline Bien & $35,48 \%$ \\
\hline Muy Bien & $48,39 \%$ \\
\hline N/D & $3,23 \%$ \\
\hline
\end{tabular}

Tabla 7: Interés en MOOCs en general

\begin{tabular}{|l|c|}
\hline $\begin{array}{l}\text { Si se realizan otros cursos MOOC sobre } \\
\text { otros temas científicos, ite } \\
\text { interesarían? }\end{array}$ & Respuestas \\
\hline Nada & $0 \%$ \\
\hline Algo & $3,23 \%$ \\
\hline Indiferente & $25,81 \%$ \\
\hline Bastante & $41,16 \%$ \\
\hline Mucho & $25,81 \%$ \\
\hline N/D & $0 \%$ \\
\hline
\end{tabular}

\section{Conclusiones}

De la encuesta realizada, se puede observar que a un 54,83\% de los estudiantes le pareció útiles los polimedias y muy útiles a un $19,35 \%$, es decir a casi un $75 \%$ de la clase le parecen útiles este tipo de objetos de aprendizaje.

En lo referente a los contenidos de los polimedias, un $40 \%$ aproximadamente piensan que los polimedias deberían profundizar más en los contenidos. Esto nos puede servir de índice para valorar la dificultad que tendrán los estudiantes para comprender los conceptos expuestos en los objetos de aprendizaje y también para plantear la posibilidad de extender los cursos de forma que abarquen más conocimientos de mayor nivel.

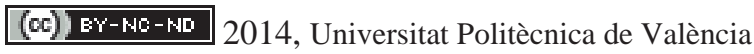

I Jornadas IN-RED (2014) 
Sobre la elaboración de un curso masivo online abierto de Matemáticas orientado a los primeros cursos de grado de ingeniería

Sobre la utilidad de los polimedias durante el curso lectivo, se puede apreciar que casi un $75 \%$ de los estudiantes hicieron uso de los polimedias para reforzar los conocimientos impartidos en las clases de Teoría/Prácticas. En el porcentaje hemos incluido a los que usaron esta herramienta bastante y mucho. Esto parece indicar que si se ofrece a los estudiantes la posibilidad de disponer de este tipo de objeto de aprendizaje, harán buen uso de él y lo valorarán positivamente.

Del resto de preguntas y respuestas, nos gustaría destacar el interés que muestran los estudiantes en el desarrollo de este tipo de cursos, y la posibilidad de ampliar la oferta educativa con los cursos MOOC.

Como conclusión general, podemos afirmar que la aceptación para este tipo de cursos parece ser muy alta y que la estrategia de presentar a los estudiantes cursos de homogeneización de conocimientos como los planteados en este artículo proporcionará a los estudiantes las herramientas necesarias para asentar los conocimientos y facilitar la transición de Bachiller a los primeros cursos de grado.

Durante el curso académico entrante se monitorizará los progresos de los alumnos de nuevo ingreso que completen los cursos propuestos con el fin de seguir mejorando los cursos y adaptarlos a las necesidades de los estudiantes.

\section{Agradecimientos}

Está investigación ha estado parcialmente financiada con la Ayuda a Proyectos de Innovación Docente, PID-DMA-2013.

\section{Bibliografía}

\section{Referencias electrónicas}

CRUE. Conferencia de Rectores de las Universidades Españolas, $<$ http://www.crue.org/Legislacion/Paginas/Legislacion-Ensenanaza.aspx?Mobile=0> [Consulta: 27 Febrero 2014]

UPV $[X]$ <http://www.upvx.es> [Consulta: 10 Junio 2014]

\section{Artículos}

AIKEN, J.M., et al. (2013). "The Initial State of Students Taking an Introductory PhysicsMOOC" en PERC Proceedings 2013., Cornwell University. pp. 295-309. 
KELLOGG, S. (2013). "Online learning: how to make a MOOC" en Nature, Vol.499(7458), pp.369-71 [Revista Peer Reviewed]

KING, C., ROBINSON, A., VICKERS, J. (2014). "Online education: Targeted MOOC captivates students" en Nature. Vol. 505(7481).

(c)) EY-NC-ND 2014, Universitat Politècnica de València

I Jornadas IN-RED (2014) 


\title{
Utilización de laboratorios virtuales para la realización de prácticas de física
}

\author{
José Antonio Gómez-Tejedor ${ }^{1}$ \\ ${ }^{1}$ Universitat Politècnica de València
}

\begin{abstract}
This paper describes a virtual physics laboratory based in Easy Java Simulations, accessible through the Internet, through which the student can perform the labs sesions in the subject of Physics. Besides various simulations in the same environment, for displaying different physical phenomena are presented. In this virtual laboratory and simulations, it should be mention that the students have to perform different measurament on the computer screen, and have to obtain results in the same way they would do in the physics laboratory of the subject.
\end{abstract}

Keywords: ${ }^{A} T_{E} X$, Distance education, Physics, virtual lab, mechanics, Easy Java Simulations.

\section{Resumen}

Este trabajo describe un laboratorio virtual de física basado en Easy Java Simulations, accesible a través de Internet, mediante el cual el alumno puede realizar las prácticas de laboratorio de la asignatura de Física. Además se presentan diversas simulaciones realizadas en el mismo entorno, para la visualización de diferentes fenómenos físicos. Destacan en este laboratorio virtual y simulaciones, la posibilidad de que el alumno realice diversas medidas sobre la pantalla del ordenador, y pueda obtener resultados de la misma forma que lo haría en el laboratorio de física de la asignatura.

Keywords: LATEX, Enseñanza a distancia, física, laboratorio virtual, mecánica, simulaciones Easy Java. 


\section{Introducción}

Los estudiantes que cursan el laboratorio de la asignatura Fundamentos Físicos de la Ingeniería o similares, deben familiarizarse con una serie de aparatos, equipamiento y técnicas de trabajo totalmente nuevas para la mayoría de ellos. En este aprendizaje, el alumno se encuentra con la falta de herramientas para su trabajo individual, puesto que no tiene la posibilidad de realizar las prácticas fuera del laboratorio.

Este trabajo describe un laboratorio virtual de física basado en Easy Java (Esquembre 2014), accesible a través de Internet, de modo que el alumno disponga de una herramienta útil y versátil para facilitar su estudio individual. De esta forma, el trabajo se engloba en la tendencia actual de la aplicación de las nuevas tecnologías a metodologías activas de aprendizaje, para potenciar así el autoaprendizaje y el aprendizaje integral de los estudiantes (Gómez-Tejedor, Martínez y Vidaurre 2008; Gómez-Tejedor y G. 2009).

La idea de laboratorios virtuales basados en web no es nueva, ya en los años noventa aparecieron los primeros trabajos pioneros en esta línea, entre los que se puede citar los trabajos de Hoffman y col. 1994; Potter y col. 1996; Preis y col. 1997 entre otros. Aun así, este tema ha recibido mucha más atención en el últimos años debido a la implementación de nuevas tecnologías de enseñanza en el aula, y la rápida expansión de Internet. Actualmente, se pueden encontrar un gran número de laboratorios virtuales on-line. Estos laboratorios virtuales cubren temáticas muy diferentes: medida de dureza en metales (Hashemi, Chandrashekar y Anderson 2006), microbiología (Sancho y col. 2006), ingeniería de terremotos (Gao y col. 2005), aplicaciones medioambientales (Ascione y col. 2006), motores (Dias, Violato y Martins 2012), comunicación digital (Zhan, Porter y Morgan 2014), electrónica (I. A. Garcia, Pacheco y J. N. Garcia 2014) y simulación de circuitos electrónicos (Gómez-Tejedor, Martínez y Vidaurre 2008; Gómez-Tejedor y G. 2009; Bingol y Pacaci 2010; Zacharia y Jong 2014), por nombrar unos pocos de los muchos existentes, algunos de ellos pioneros en esta línea. Todos estos laboratorios virtuales están basados en simulaciones mediante ordenador, y han sido desarrollados en diferentes lenguajes de programación como Java, Matlab, LabView o Macromedia Flash.

Desde hace unos años, han ido apareciendo nuevas herramientas de desarrollo que no necesitan grandes conocimientos de programación, lo cual facilita en gran medida la creación de estos laboratorios virtuales, y abre nuevas posibilidades para todos aquellos profesores que no son expertos en programación. Por ejemplo, MatLab y Mathematica incorporan herramientas que permiten crear fácilmente aplicaciones web, pudiendo realizar diferentes simulaciones de procesos, en los que el usuario puede interactuar con la aplicación web. En esta línea podemos citar los trabajos de Savas y Erdal 2010; Andres Ramos-Paja, Ramirez Scarpetta y Martinez-Salamero 2010; Duque Grajales y col. 2009 entre muchos otros.

En este trabajo, se ha utilizado la herramienta Easy Java Simulations, desarrollada por Francisco Esquembre (Esquembre 2014), quien lo distribuye bajo Licencia Pública 
General de GNU (GPL de GNU), y que forma parte del proyecto Open Source Physics (Open Source Physics 2014).

El laboratorio remoto presentado en este trabajo permite realizar diferentes prácticas de física, con lo cual se puede elaborar un programa completo de prácticas de laboratorio de la asignatura de Fundamentos Físicos de la Ingeniería, presente en primer curso de Ingeniería. Los applets descritos en este trabajo se encuentran disponibles para su uso en el repositorio institucional de la Universitat Politècnica de València RiuNet como objetos de aprendizaje. En este trabajo se han seleccionado unos pocos de estos objetos de aprendizaje. Para una relación completa de dichos objetos, se puede consultar la base de datos del repositorio institucional de la Universitat Politècnica de València RiuNet, mediante la búsqueda por autor (Gómez-Tejedor 2014).

\section{Objetivos}

El uso de un entorno virtual no es idéntico a la utilización de dispositivos reales en un laboratorio de física. Sin embargo, esta propuesta no pretende sustituir las prácticas de laboratorio sino que pretende combinar la realización de prácticas virtuales con la realización de prácticas presenciales en el laboratorio. En este sentido, cabe destacar tres objetivos que se pretenden alcanzar mediante esta propuesta:

1. El alumno puede utilizar las simulaciones para la preparación de las prácticas del laboratorio real. El alumno puede realizar las prácticas virtuales antes que las reales, de modo que llegue al laboratorio con un conocimiento más amplio de la experiencia que la mera lectura del guión de prácticas.

2. El profesor puede utilizar estos applets para ampliar los objetivos de una sesión de laboratorio. Una vez realizada la práctica real, puede pedir al alumno trabajo adicional mediante las simulaciones.

3. En algunos casos, mediante el laboratorio virtual se pueden abordar prácticas de laboratorio que por razones de tiempo o de presupuesto no se puedan realizar en el laboratorio real. Como ejemplo, en el laboratorio de física de la ETSID, debido a su coste y su tamaño, disponemos únicamente de un carril cinemático, mientras que gracias al laboratorio virtual podemos disponer de una simulación del carril cinemático para cada alumno.

\section{Desarrollo de la innovación}

Easy Java Simulations, EJS, es una herramienta de software diseñada para la creación de simulaciones mediante ordenador de forma rápida y sencilla. Más concretamente, es lo que se denomina un "generador de código", en concreto de código java. En cierta forma, se puede considerar también como una "herramienta de autor". La virtud más destacada de EJS es que permite la creación de programas con un entorno gráfico más

(oc) EY-No-No 2014, Universitat Politècnica de València

I Jornadas IN-RED (2014) 
o menos sofisticado mediante una aplicación gráfica relativamente sencilla de utilizar, y que no requiere grandes conocimientos de programación.

Una característica fundamental de EJS es que su diseño se centra en el contenido de la simulación, y no en los detalles técnicos de programación. De esta forma, EJS dispone de un conjunto bastante amplio de herramientas sencillas, que combinadas adecuadamente permiten realizar gran cantidad de acciones. El resultado final es que con muy pocos conocimientos de programación, se pueden obtener simulaciones que fácilmente pueden ser confundidas con creaciones de un programador profesional.

Por otro lado, hay que destacar que EJS trabaja en el lenguaje de programación Java, creando applets que pueden visualizarse en cualquier navegador web, independientemente del sistema operativo utilizado. Esto permite que las simulaciones creadas puedan ser distribuidas por Internet, y le confiere un carácter universal. En la última versión de EJS se incluye también la posibilidad de ejecutar las simulaciones en tablets y smartphones.

A continuación se presentan una serie de simulaciones realizadas mediante la aplicación EJS. Mediante estas simulaciones se puede desarrollar un programa de laboratorio de mecánica de la asignatura de Fundamentos Físicos de Ingeniería de primer curso de ingeniería.

En las simulaciones realizadas, y que se presentan en este trabajo hay que destacar dos aspectos fundamentales:

- En primer lugar la sencillez. Se ha buscado ante todo, que las simulaciones creadas sean fáciles de utilizar por parte de un alumno, de forma que no tenga que emplear demasiado tiempo en intentar aprender su funcionamiento, y pueda centrar su atención en los fenómenos físicos que se están simulando.

- En segundo lugar la "aleatoriedad"del sistema. Esto abarca dos aspectos fundamentales. Por un lado, cada vez que el alumno abre la aplicación, los parámetros característicos que definen la simulación se escogen de forma aleatoria entre un rango adecuado de valores. Por ejemplo, en el caso de tiro parabólico se escoge el valor de la velocidad inicial, para el rozamiento estático se toma un valor del coeficiente de rozamiento, etc. De esta forma, se consigue que alumnos diferentes tengan conjuntos de datos diferentes. Por otro lado, todos sabemos que cuando se repite una medida, el resultado obtenido puede variar (errores accidentales debidos a pequeñas causas aleatorias). Las simulaciones incorporan un pequeño factor adicional de aleatoriedad, que hace que diferentes medidas de la misma magnitud pueda dar resultados ligeramente diferentes. De esta forma, se introduce la necesidad del tratamiento de errores en las medidas realizadas, aspecto fundamental a considerar en cualquier curso de Fundamentos Físicos de la Ingeniería.

Mediante las simulaciones que se presentan en este trabajo, se pueden hacer las prácticas de laboratorio que se detallan en las secciones siguientes. 


\subsection{Cinemática del sólido rígido}

Este applet simula el movimiento combinado de rotación y traslación de un sólido rígido (un disco en este caso): se lanza un disco con una determinada velocidad inicial $v_{0}$, formando un determinado ángulo con la horizontal $\alpha$. Dicho disco, al mismo tiempo tiene un movimiento de rotación a velocidad angular constante $\omega$. Para facilitar la visualización del movimiento, sobre el borde del disco hay marcado un punto rojo. Durante el movimiento se observa en la pantalla en un trazo azul la trayectoria seguida por el centro de masas, y en color rojo, la trayectoria del punto externo al disco (ver Figura 1).

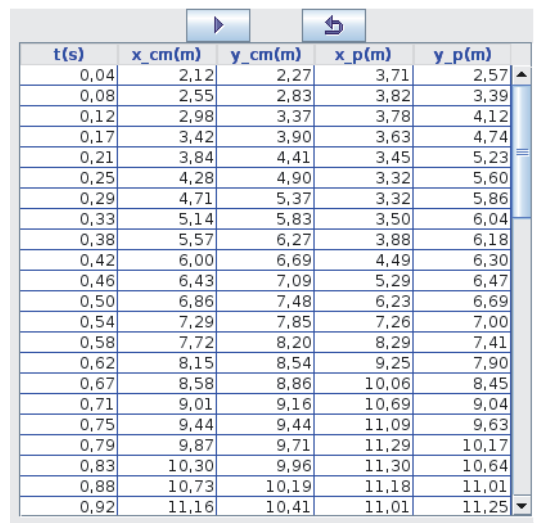

Fig. 1: Ejemplo del movimiento realizado por el disco en su movimiento, y los datos experimentales correspondientes.

Al mismo tiempo, se va registrando en una tabla el tiempo, la posición del centro de masas y la posición del punto marcado en rojo del disco. Esos datos pueden ser copiados para luego analizarlos mediante una hoja de cálculo. A partir de los datos obtenidos por el alumno, se puede calcular los parámetros del movimiento.

\subsection{Interferencia de dos ondas}

El applet simula la emisión de dos ondas sonoras, que interfieren en un punto. Se observan los máximos y mínimos de la interferencia, lo cual permite calcular la velocidad del sonido (Figura 2).

Mediante la regla podemos determinar la posición del primer mínimo en $r_{1}=3 \mathrm{~cm}$ (ver Figura 2), y la posición del segundo mínimo en $r_{1}=10 \mathrm{~cm}$ (Figura no mostrada), de modo que la diferencia entre ambos mínimos es de $7 \mathrm{~cm}$, con lo cual la longitud de onda de la señal es de $7 \mathrm{~cm}$. Como la frecuencia de los altavoces se ha fijado en $5 \mathrm{kHz}$, obtenemos que la velocidad del sonido en el aire es igual a $v=5 \cdot 10^{3} \times 7 \cdot 10^{-2}=350$ $\mathrm{m} / \mathrm{s}$. 


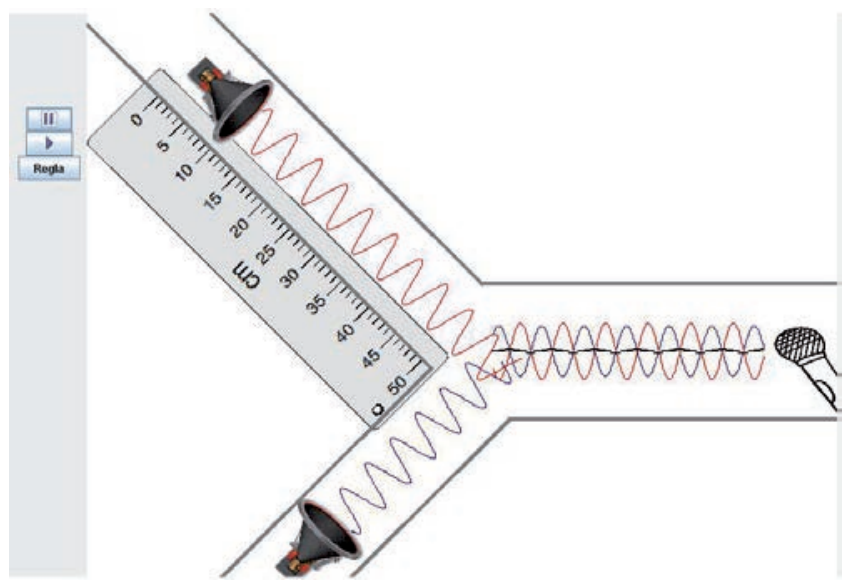

Fig. 2: Interferencia destructiva de dos ondas sonoras.

\subsection{Plano inclinado. Determinación del coeficiente de rozamiento estático}

En este applet disponemos de un plano inclinado, en el que se puede variar el ángulo que forma con la horizontal (Figura 3). Sobre dicho plano se encuentra un bloque en reposo. $\mathrm{Al}$ ir aumentando el ángulo que forma con la horizontal, en el momento que la componente del peso paralela al plano supera la fuerza de rozamiento estático, el bloque comienza a deslizar por el plano inclinado. A partir de dicho ángulo, podemos determinar el valor del coeficiente de rozamiento estático.

El applet dispone también de un cronómetro para medir el tiempo de caída, y una escala para medir la distancia. Con ello se puede calcular también la aceleración de caída, y el coeficiente de rozamiento dinámico del bloque.

\subsection{Tiro parabólico}

En este applet disponemos de un cañón que lanza un proyectil, que sigue la trayectoria de un tiro parabólico. Mediante una escala situada en la parte inferior se puede medir el alcance del proyectil, y mediante un cronómetro el tiempo que tarda en llegar el proyectil. Se puede variar el ángulo que forma el cañón con la horizontal, para estudiar como varía la trayectoria en función de dicho ángulo. A partir de los datos obtenidos del alcance y el tiempo, el alumno puede calcular también la velocidad inicial del proyectil. 


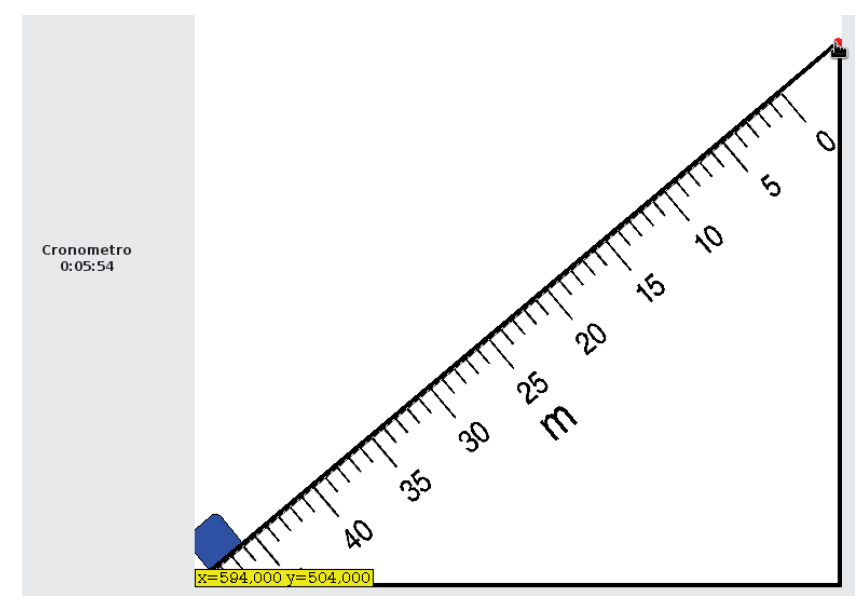

Fig. 3: Plano inclinado

\section{Resultados}

Las primeras experiencias llevadas a cabo con alumnos muestran un grado de satisfacción bastante grande con las simulaciones, y los alumnos manifiestan que ha sido una herramienta útil en su proceso de aprendizaje. La mayoría de los alumnos piensan que la realización de las prácticas virtuales les ha ayudado a la preparación y mejor comprensión de las prácticas reales. Las instrucciones de la web, combinado con la sencillez de las simulaciones, les han permitido entender y realizar la práctica virtual sin dificultades.

En varios casos, se han utilizado estas prácticas virtuales para alumnos con problemas para acudir al laboratorio. En estos casos, los alumnos han realizado la práctica de forma satisfactoria, y la mayor dificultad ha sido el análisis de los datos experimentales obtenidos, al no disponer de la ayuda del profesor, junto con la escasa experiencia en el manejo de la hoja de cálculo. Por ello, en estas situaciones, propongo complementar la realización de las prácticas virtuales, con un sistema de tutorías on-line. Así mismo, creo que es importante explicar a los alumnos el manejo de la hoja de cálculo en una sesión presencial en un aula informática. 


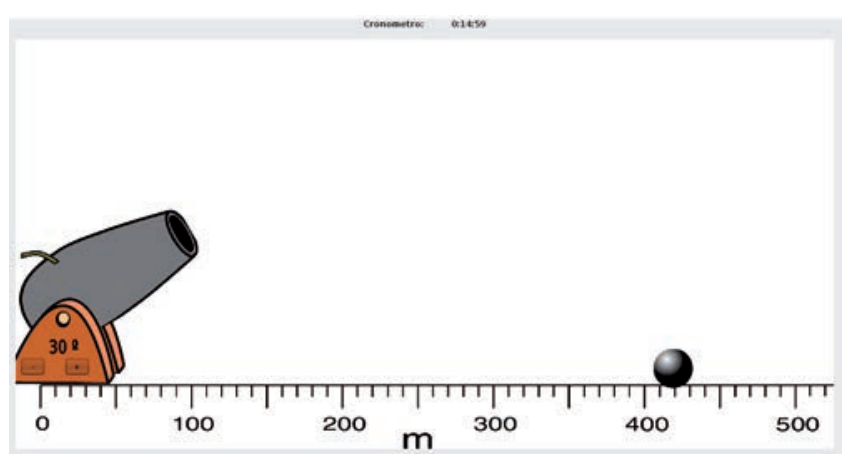

Fig. 4: Tiro parabólico

\section{Conclusiones}

Como conclusión final, se pude decir que este trabajo introduce una importante innovación en la metodología de enseñanza utilizada en el laboratorio, ya que permite a los estudiantes realizar las prácticas de laboratorio mediante cualquier ordenador conectado a Internet. La práctica se puede llevar a cabo de forma individual o en pequeños grupos, y sin un horario prefijado. Esto permite a los estudiantes regular su proceso de aprendizaje, invirtiendo el tiempo que sea necesario en cada práctica de laboratorio.

Se podría argumentar que el uso de un entorno virtual no es idéntico a la utilización de dispositivos reales, en un laboratorio de física. Sin embargo, esta propuesta pretende combinar la realización de prácticas virtuales con la realización de prácticas presenciales en el laboratorio, y en ningún caso sustituir las prácticas reales por prácticas virtuales, ya que la experiencia adquirida por el alumno en estas prácticas reales no puede ser en ningún caso reemplazada por la realización virtual del experimento.

\section{Agradecimientos}

El autor de este trabajo agradece el apoyo del Instituto de Ciencias de la Educación de la UPV, programa de Equipos de Innovación y Calidad Educativa, por el apoyo al Equipo de Innovación en Metodologías Activas para el Aprendizaje de la Física (e-MACAFI), del cual formo parte. 


\section{Referencias bibliográficas}

Andres Ramos-Paja, C., J. M. Ramirez Scarpetta y L. Martinez-Salamero (2010). "Integrated Learning Platform for Internet-Based Control-Engineering Education". English. En: IEEE TRANSACTIONS ON INDUSTRIAL ELECTRONICS 57.10, 3284-3296. ISSN: 0278-0046. DOI: \{10.1109/TIE. 2010.2043033\}.

Ascione, I. y col. (2006). "A Grid Computing Based Virtual Laboratory for Environmental Simulations". En: Euro-Par 2006 Parallel Processing. Ed. por WolfgangE. Nagel, WolfgangV. Walter y Wolfgang Lehner. Vol. 4128. Lecture Notes in Computer Science. Springer Berlin Heidelberg, págs. 1085-1094. ISBN: 978-3-54037783-2. DOI: 10.1007/11823285_114.

Bingol, O. y S. Pacaci (2010). "A virtual laboratory for fuzzy logic controlled DC motors". English. En: INTERNATIONAL JOURNAL OF THE PHYSICAL SCIENCES 5.16, 2493-2502. ISSN: 1992-1950.

Dias, J. N., G. O. Violato y C. A. Martins (2012). "Dynamic model of a twostroke glow engine from experimental data". English. En: PROCEEDINGS OF THE INSTITUTION OF MECHANICAL ENGINEERS PART G-JOURNAL OF AEROSPACE ENGINEERING 226.G12, 1502-1512. ISSN: 0954-4100. DOI: $\{10.1177 / 0954410011426371\}$.

Duque Grajales, J. E. y col. (2009). "System for Processing and Simulation of Brain Signals". English. En: 2009 IEEE LATIN-AMERICAN CONFERENCE ON COMMUNICATIONS (LATINCOM 2009). Ed. por Velasquez, CE. IEEE Latin-American Conference on Communications, Medellin, COLOMBIA, SEP 10-11, 2009. IEEE Commun Soc. 345 E 47TH ST, NEW YORK, NY 10017 USA: IEEE, 195-200. ISBN: $978-1-4244-4387-1$.

Esquembre, F. (2014). EasyJava Simulations. URL: http://www.um.es/fem/Ejs/.

Gao, Y. y col. (2005). "Java-powered virtual laboratories for earthquake engineering education". En: Computer Applications in Engineering Education 13.3, págs. 200-212. ISSN: 1099-0542. DOI: 10.1002/cae.20050.

Garcia, I. A., C. L. Pacheco y J. N. Garcia (2014). "Enhancing education in electronic sciences using virtual laboratories developed with effective practices". English. En: COMPUTER APPLICATIONS IN ENGINEERING EDUCATION 22.2, 283-296. ISSN: 1061-3773. DOI: $\{10.1002 /$ cae.20554\}.

Gómez-Tejedor, J.A. (2014). Plan Docencia en Red. Laboratorios virtuales. URL: http: //riunet . upv . es / handle/10251/11259/browse? authority=171609\&type= author. 
Gómez-Tejedor, J.A. y Moltó. G. (2009). Technologies Shaping Instruction and Distance Education: New Studies and Utilizations. Chapter 7: Online Learning of Electrical Circuits through a Virtual Laboratory. Ed. por Dr. Mahbubur Rahman Syed. IGI Global.

Gómez-Tejedor, J.A., G.M. Martínez y C.B. Vidaurre (2008). "An Online Virtual Laboratory of Electricity". En: International Journal of Distance Education Technologies 6.2, págs. 21-34. DOI: 10.4018/jdet.2008040102.

Hashemi, J., N. Chandrashekar y E. E. Anderson (2006). "Design and Development of an Interactive Web-based Environment for Measurement of Hardness in Metals: a Distance Learning Tool". En: International Journal of Engineering Education 22.5, págs. 993-1002.

Hoffman, C. M. y col. (1994). "SoftLab?A virtual laboratory for computational science". En: Mathematics and Computers in Simulation (MATCOM) 36.4, págs. 479-491.

Open Source Physics (2014). URL: http://www.opensourcephysics.org/.

Potter, C. y col. (1996). "EVAC: a virtual environment for control of remote imaging instrumentation". En: Computer Graphics and Applications, IEEE 16.4, págs. 62-66. ISSN: 0272-1716. DOI: 10.1109/38.511856.

Preis, K. y col. (1997). "A virtual electromagnetic laboratory for the classroom and the WWW". En: IEEE Transactions on Magnetics 33, págs. 1990-1993. DOI: 10.1109/20.582690.

Sancho, P. y col. (2006). "A Blended Learning Experience for Teaching Microbiology". En: American Journal of Pharmaceutical Education 70.5, pág. 120.

Savas, K. y H. Erdal (2010). "Automatic control simulation environment system (ACSES) designed as a virtual tool for control education". English. En: INNOVATION AND CREATIVITY IN EDUCATION. Ed. por Uzunboylu, H. Vol. 2. Procedia Social and Behavioral Sciences 2. 2nd World Conference on Educational Sciences (WCES-2010), Bahceschir Univ, Istanbul, TURKEY, FEB 04-08, 2010. SARA BURGERHARTSTRAAT 25, PO BOX 211, 1000 AE AMSTERDAM, NETHERLANDS: ELSEVIER SCIENCE BV, 5233-5237. DOI: $\{10.1016 /$ j.sbspro.2010.03.851\}.

Zacharia, Z. C. y T. de Jong (2014). "The Effects on Students' Conceptual Understanding of Electric Circuits of Introducing Virtual Manipulatives Within a Physical Manipulatives-Oriented Curriculum". English. En: COGNITION AND INSTRUCTION 32.2, 101-158. ISSN: 0737-0008. DOI: \{10.1080/07370008. 2014. 887083\}. 
Zhan, W., J. R. Porter y J. A. Morgan (2014). "Experiential Learning of Digital Communication Using LabVIEW". English. En: IEEE TRANSACTIONS ON EDUCATION 57.1, 34-41. ISSN: 0018-9359. DOI: \{10.1109/TE.2013.2264059\}. 


\title{
Flipped Classroom: Reflexiones y opiniones de los implicados
}

\section{Cristina Jordán Lluch ${ }^{a}$, María José Pérez-Peñalver ${ }^{a}$ y Esther Sanabria-Codesal ${ }^{a}$}

${ }^{a}$ Departamento de Matemática Aplicada, Universitat Politècnica de València, Camí Vera s/n, 46022, Valencia, e-mail: cJordán@mat.upv.es,mjperez@mat.upv.es y esanabri@mat.upv.es

\begin{abstract}
The flipped classroom or reverse class, takes advantage of the rise of new technologies to improve student learning through the exchange of teacherstudent roles: the student begins the study of matter outside the classroom and deepens in it with the teacher support and discussion with peers into the classroom session. This experience tells us that it has advantages in terms of a deeper learning, to the acquisition of generic skills and student motivation in the classroom but it also has aspects that may hinder its implementation as it requires a lot of preparatory work and planning by teacher and it is not always well accepted by students.
\end{abstract}

Keywords: Flipped classroom, Inverted class, TIC, mathematics.

\begin{abstract}
Resumen
La denominada flipped classroom o clase invertida, permite aprovechar el auge de las nuevas tecnologías para mejorar el aprendizaje de los alumnos mediante el intercambio de roles profesor-alumno: el alumno inicia el estudio de la materia fuera del aula y lo profundiza en una sesión presencial con el apoyo del profesor y la discusión con el resto de compañeros. Tras exponer brevemente en que consiste esta metodología y sus antecedentes, comentamos una experiencia llevada a cabo en nuestros grupos, así como los resultados obtenidos y las opiniones de los alumnos al respecto de la metodología aplicada. La experiencia realizada nos indica que la flipped classroom presenta ventajas como un aprendizaje más profundo, la adquisición de competencias transversales y la motivación del alumno en el aula, aunque también presenta aspectos que pueden dificultar su implementación, como el trabajo previo y planificación necesaria por parte del profesor y no ser siempre bien aceptada por los estudiantes.
\end{abstract}

Palabras clave: Flipped classroom, Clase invertida, TIC, matemáticas. 
Flipped Classroom: Reflexiones y opiniones de los implicados

\section{Introducción}

En el momento que vivimos, donde las nuevas tecnologías de la información (TIC) están al alcance de todos, es interesante replantearnos nuestra labor como docentes y analizar en qué medida es conveniente introducir las TIC en nuestras aulas, para mejorar la comunicación con nuestros alumnos y favorecer así un aprendizaje más significativo.

Sin rechazar métodos más tradicionales como la clase magistral, nos podemos plantear si no sería más provechoso dedicar el tiempo de la clase presencial a actividades que involucren activamente al alumno, con el fin de que nuestra aportación no se reduzca a una mera transmisión de conocimientos. Gracias a los recursos tecnológicos de los que disponemos actualmente, ésta puede hacerse utilizando vídeos, foros de discusión u otros materiales interactivos. Así, podríamos trabajar en el aula con los alumnos tareas que requieran mayor debate y discusión, con lo que favorecemos la interacción con el profesor y el resto de compañeros.

De esta manera nace la denominada clase invertida o flipped classroom, donde vídeos y lecciones interactivas, a los que los alumnos tienen acceso antes de la clase, permiten convertir el aula en un lugar donde resolver problemas y ampliar conceptos, a través de un aprendizaje colaborativo (Lage et al., 2000; Bergmann y Sams, 2012; Tucker, 2012). Estas propuestas se enmarcan dentro de los métodos docentes conocidos como peer instruction (Crouch y Mazur, 2001) y just-in-time teaching (Novak et al. 1999).

Durante los últimos años hemos dedicado parte de nuestro tiempo a crear distintos materiales digitales dentro del plan Docencia en Red de la UPV. Nuestro trabajo ha obtenido reconocimiento en los últimos años, siendo finalista de la III Edición de los premios ME-Universia a la iniciativa OpenCourseWare en 2010, así como recibiendo dos premios: Premio del Open Course Ware Consortium a las mejores asignaturas multimedia del año 2011 a la OCW Estructuras Matemáticas para la Informática II y una Mención Especial al MOOC Aplicaciones de la teoría de grafos a la vida real de la I Edición del Premios MECD-Telefónica Learning Services-Universia 2013.

La experiencia adquirida a lo largo de estos años en la generación y utilización de los mencionados materiales nos ha permitido, a partir de ellos, adoptar la metodología de la clase invertida en algunos de nuestros grupos, en concreto en las asignaturas Matemática Discreta (MAD) y Grafos, Modelos y Aplicaciones (GMA), ambas del Grado en Ingeniería Informática de la Universitat Politècnica de València. 


\section{Objetivos}

Nuestro objetivo en este trabajo consiste en analizar los resultados obtenidos utilizando clase invertida tanto en alumnos de primer curso, en la asignatura MAD, como en alumnos más maduros que cursan la optativa de cuarto curso GMA, recogiendo el feedback que los alumnos nos han transmitido sobre esta experiencia a través de una encuesta.

Además, añadimos algunas reflexiones sobre los factores a tener en cuenta para llevar a cabo con éxito la educación inversa, entre otros, cómo deben prepararse los materiales y cómo planificar el trabajo presencial y no presencial del alumno.

\section{Desarrollo de la innovación}

Durante el curso 2013-2014 hemos implementado la metodología de la clase invertida en las asignaturas MAD y GMA, ambas del Grado en Ingeniería Informática de la Universitat Politècnica de València. El contenido y enfoque de las matemáticas ha evolucionado mucho a lo largo de los años. Por un lado, cada nuevo plan de estudios ha supuesto un importante recorte en el número de créditos asignado a ésta y por otro el desarrollo de las nuevas tecnologías ha conducido y permitido cambiar el planteamiento y los métodos de aprendizaje.

Debemos tener en cuenta que las matemáticas son siempre vistas como mínimo con recelo por la mayoría de nuestros estudiantes y que el enfoque de la titulación que se imparte en nuestra escuela es más práctico que teórico, lo que no favorece la percepción de su utilidad por parte de los alumnos. Por ello, cuando en el año 2007 la UPV puso en marcha un proyecto: Docencia en red para fomentar la docencia con apoyo de, entre otros materiales digitales, vídeos llamados Polimedias (Turró et al., 2010), nos pareció un método prometedor y atractivo para facilitar el aprendizaje de nuestros alumnos, siendo utilizados en un primer momento como refuerzo de las clases presenciales (Jordán, 2009).

Empezamos la aproximación a la flip education en el curso académico 2011-12, en el que de forma esporádica indicábamos a los alumnos que visualizaran algunos de los Polimedias antes de asistir a clase.

El proceso de la educación inversa consiste en términos generales en que la adquisición de conocimientos la realiza el alumno de forma autónoma, a partir de material elaborado por el profesor previamente a la sesión presencial, mientras que la labor del profesor se centra en fomentar el aprendizaje activo y cooperativo de los alumnos.

En nuestra opinión, es interesante la utilización de vídeos Polimedia a la hora de aplicar la educación inversa (Figura 1) aunque se podría llevar a cabo con otro tipo de materiales, como por ejemplo con OCW (Jordán y Torregrosa, 2010; Jordán, 2010; Jordán, 2014). Aunque consideramos que el fomentar la correcta lectura-escritura del lenguaje científico es necesario, dada la idiosincrasia del alumno medio actual, los vídeos le son más cercanos que cualquier texto escrito, por claro e iluminador que éste sea. Aconsejamos por tanto, en el caso de utilizar material escrito, acompañarlo con vídeos que faciliten el acercamiento del estudiante a la materia, dado que, si encuentra complicada la lectura de los textos

\section{(c)) EY-NC-ND 2014, Universitat Politècnica de València}

I Jornadas IN-RED (2014) 
propuestos, algunos alumnos no realizarán el trabajo previo, y esto conllevaría de forma natural el fracaso de la metodología.

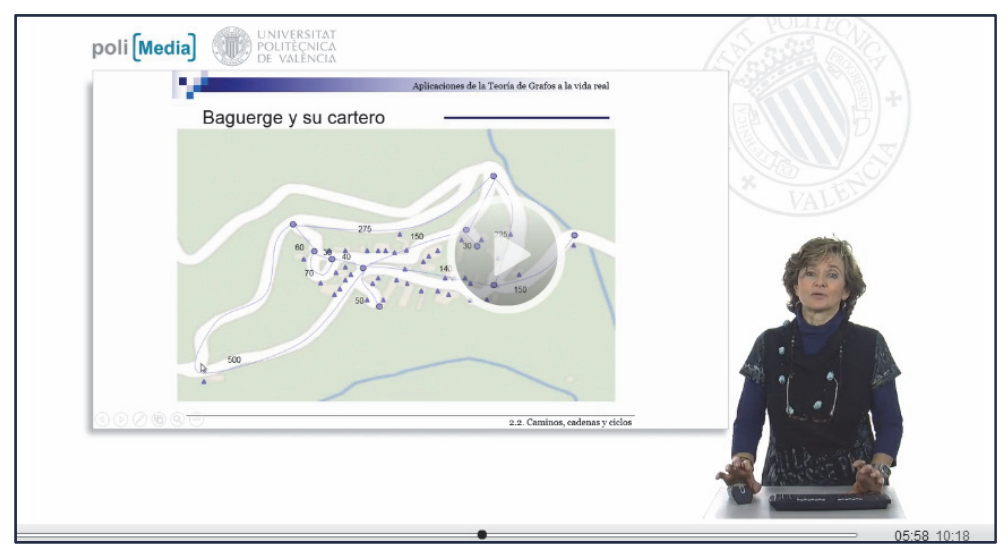

Fig. 1: Imagen de un vídeo Polimedia

Nuestra experiencia en este sentido nos ha llevado a adoptar, durante el curso académico 2013-2014, la metodología de la clase invertida en la asignatura de primero, con 6 créditos asignados, Matemática Discreta (MAD), y la de cuarto, Grafos, Modelos y Aplicaciones (GMA), asignatura de 4,5 créditos, ambas del Grado en Ingeniería Informática de la Universitat Politècnica de València en las que utilizamos tanto metodologías activas como evaluación continua.

En estas asignaturas la teoría de grafos es parte fundamental del temario, estudiándose los conceptos más básicos en el laboratorio de la asignatura de primero y profundizando en temas específicos, relacionados con la ingeniería informática, en la asignatura optativa de cuarto. Esta teoría necesita la introducción de mucha terminología sencilla de comprender, que expuesta en clase puede resultar tediosa, por lo que la educación inversa nos ha parecido adecuada para su aprendizaje.

Puesto que los alumnos deben realizar un trabajo previo a la sesión de aula, la implementación de esta nueva metodología pasa por, en primer lugar, disponer con suficiente antelación de un listado del trabajo a preparar, explicado de forma clara y detallada. Por ello, introducimos la guía didáctica, documento en el que se refleja la tarea del alumno para la próxima sesión, así como cualquier otro comentario que el profesor considere oportuno incluir (ver Figura 2).

En nuestro caso, las tareas principales previas a una sesión presencial consisten en visualizar algunos Polimedias. Esto les permitirá resolver en clase preguntas básicas referentes a los conceptos estudiados, para comprobar su correcta asimilación. A estas preguntas las llamamos coloquialmente "preguntas flip" e incluyen tanto cuestiones sencillas, relacionadas directamente con definiciones o enunciados, como preguntas que ponen de manifiesto algunos aspectos que, por nuestra experiencia, sabemos que pasan desapercibidos en una primera lectura, o se prestan a confusión, malas interpretaciones, etc. 


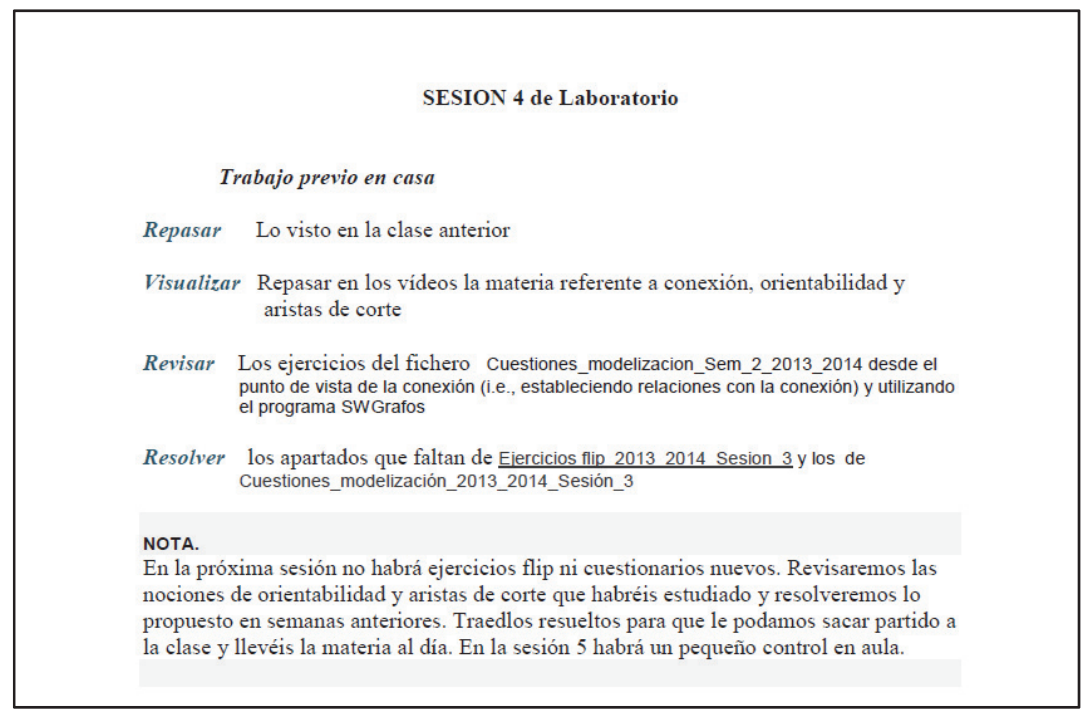

Fig. 2: Ejemplo de guía didáctica

A continuación, resolvemos ejemplos básicos de modelización en los que se aplican los conceptos estudiados.

Se completa la clase con ampliación de la teoría y resolución de problemas más avanzados, en los que se cuenta con la participación activa del alumnado.

Con esta metodología conseguimos profundizar en la teoría de grafos de una manera más aplicada que con la clase tradicional.

El éxito de la educación inversa depende en nuestra opinión de muchos factores. Destacamos a continuación algunos aspectos de esta metodología que afectan tanto al profesor como al alumno (Jordán et al., 2014).

\section{Aspectos relacionados con el profesor}

En este apartado recogemos algunos puntos que consideramos importante considerar a la hora de implantar la educación inversa.

\subsection{Trabajo previo por parte del profesor}

La implantación de esta metodología supone una gran inversion inicial de tiempo ya que debemos generar un material docente adecuado, así como las guías didácticas necesarias para llevar a cabo su implementación.

\section{(c)) EY-NC-ND 2014, Universitat Politècnica de València}

I Jornadas IN-RED (2014) 
Nuestra metodología se apoya principalmente en vídeos cuya creación debe ser particularmente cuidadosa en los siguientes aspectos:

- Claridad en la exposición

- Transparencias bien estructuradas y con numerosos ejemplos

- Grabaciones entre 5 y 10 minutos

- Presentación atractiva

\subsection{Planificación de la estructura de las clases}

Respecto a la planificación, debemos tener en cuenta que a pesar de que las sesiones de aula estén separadas en el tiempo, no es conveniente saturar a los alumnos con la visualización de muchos vídeos para la siguiente sesión, aunque éstos sean cortos. La experiencia nos muestra que los visualizan más rápido y con menos detalle. En consecuencia debemos tener en cuenta que:

- Es preferible la visualización de sólo 2 o 3 vídeos entre cada par de sesiones

- Aplicar la metodología principalmente en la introducción de puntos nuevos dentro de cada tema

- Combinar la educación inversa con otras metodologías activas

\subsection{Atención a los alumnos}

El profesor debe estar muy alerta a la participación de cada alumno, por lo que:

- El tamaño de grupo grande dificulta mucho la implementación de esta metodología

- El profesor debe hacer preguntas a todos y cada uno de los alumnos, para conseguir que ninguno pueda esconderse en el mutismo, buscando de esta manera que la participación en el aula sea un acicate para que el alumno estudie antes de cada sesión

\section{Aspectos relacionados con el alumno}

Al utilizar la educación inversa como metodología, estamos exigiendo una colaboración activa y continua al alumno que, aunque redunde en resultados de aprendizaje más significativos, no siempre es fácil de conseguir. A continuación enumeramos los principales aspectos a tener en cuenta en este sentido.

\subsection{Factores externos}

Los factores más habituales según nuestra experiencia son:

- La carga de trabajo del resto de asignaturas o la presión de tener un examen próximo

- Actividades extracurriculares del alumno que le dificulten la primera toma de contacto con los conceptos que van a ser analizados en el aula, lo cual atenta contra los principios de esta metodología 


\subsection{Rechazo a la innovación}

Generalmente, las innovaciones en el proceso de enseñanza-aprendizaje van a tener al principio de su aplicación un cierto rechazo por parte de los alumnos, quizás motivado por un estilo de aprendizaje diferente al predominante desde su infancia.

\subsection{Mejora de los resultados de aprendizaje}

Evidentemente un trabajo continuado constituye los cimientos de un aprendizaje más significativo, por tanto es importante explicar a los alumnos en qué consiste esta nueva metodología y hacer hincapié en que si participan el resultado será más satisfactorio, ya que:

- Mejora la interacción profesor-alumno y entre alumnos

- Proporciona más tiempo para resolver cuestiones en el aula, lo que consigue afianzar de manera más significativa las competencias de la materia

\section{Resultados}

Cada vez que introducimos una innovación docente en nuestras aulas es conveniente evaluar los resultados obtenidos como consecuencia de su aplicación y no dejarnos llevar sólo por nuestra percepción del éxito obtenido.

En el caso de la educación inversa, a fin de analizar la opinión de los alumnos que durante el presente curso académico 2013-2014 han cursado la asignatura Matemática Discreta (MAD) en el grupo D, así como los alumnos de la asignatura optativa Grafos, modelos y aplicaciones (GMA), donde hemos aplicado la metodología anteriormente descrita, hemos planteado dos cuestionarios on-line mediante Google Docs, uno para cada asignatura.

Para las preguntas orientadas a conocer la opinión que los alumnos tienen de la flip education, hemos utilizado la técnica de Escala de Likert, ya que según J. C Nunnally este tipo de escalas sumativas constituyen el mejor método para el escalamiento de actitudes verbalizadas (Nunnally, 1987).

\section{Análisis de los resultados}

Analizamos a continuación el feedback que los alumnos matriculados en las asignaturas: Matemática Discreta (MAD) y Grafos, modelos y aplicaciones (GMA), durante el presente curso académico 2013-2014, nos han transmitido sobre su experiencia con la eduación inversa, a través de los cuestionarios on-line que les hemos planteado para recabar sus opiniones al respecto.

\section{(c)) EY-NC-ND 2014, Universitat Politècnica de València}

I Jornadas IN-RED (2014) 


\subsection{Encuesta realizada a los alumnos de la asignatura MAD.}

La asignatura básica MAD que corresponde a la materia de Matemáticas se imparte en el primer curso del Grado en Ingeniería Informática de la Universitat Politècnica de València. A continuación presentamos los resultados de la encuesta realizada voluntariamente por 20 de los 50 alumnos matriculados en el curso 2013-2014, una vez terminado el curso.

Los alumnos que contestaron la encuesta se decantan, en su mayoría, por la metodología tradicional $(60 \%)$ frente a la flip education. Señalamos que el $86 \%$ de este porcentaje de alumnos ha accedido a la universidad desde ciclos formativos (Jordán et al., 2014).

Atendiendo a la nota de entrada a la universidad de estos alumnos (Figura 3), observamos que aquellos con nota de entrada menor que siete prefieren la educación inversa $(67 \%)$, mientras que los alumnos con notas superiores prefieren la tradicional (28\%).

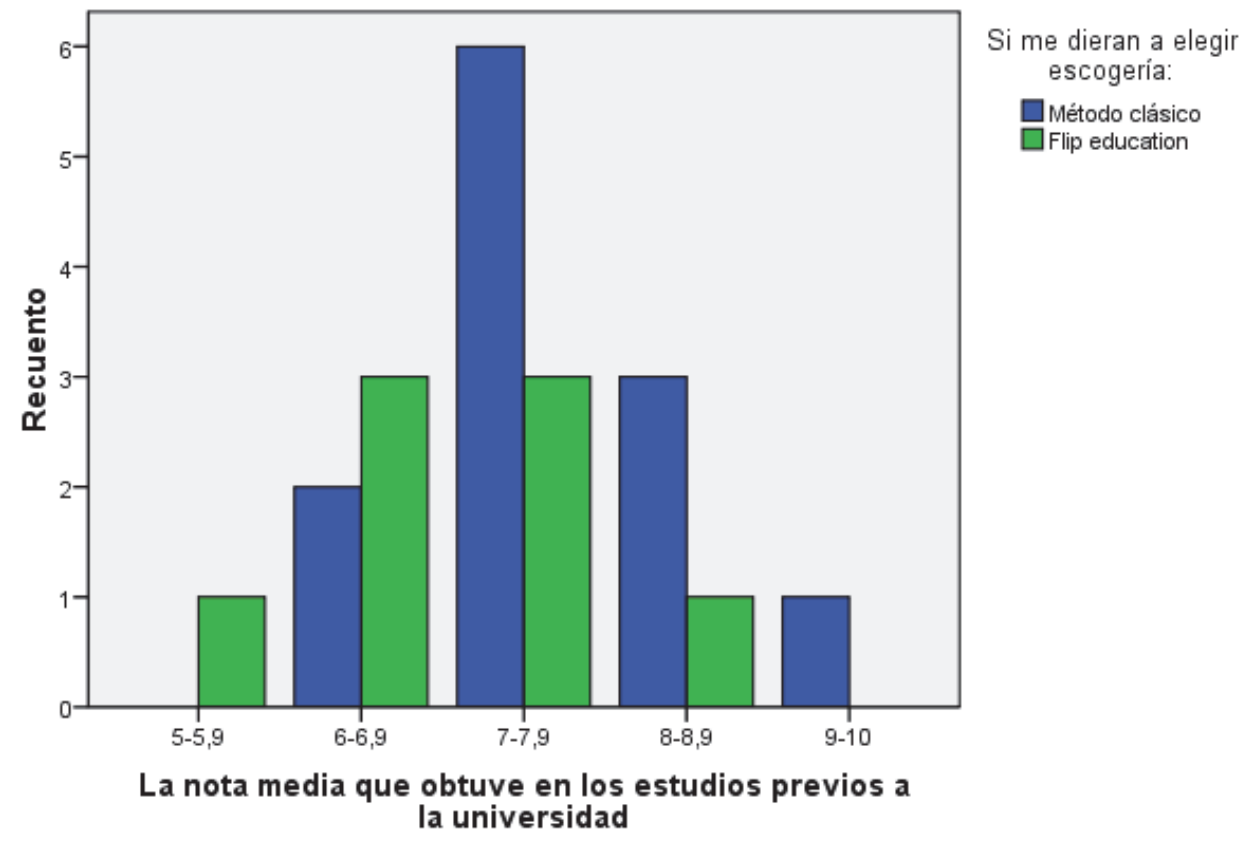

Fig.3: La nota de los estudios previos a la universidad frente a la preferencia por la metodología clásica o la inversa.

Sin embargo, atendiendo a la nota final que los alumnos han obtenido en la asignatura, aproximadamente la mitad de aquellos cuya nota se encuentra en la franja 6 - 8.9 prefieren la educación inversa, frente a la otra mitad que se decanta por el método clásico (54\%$45 \%$ ). Los alumnos cuyas notas están fuera de la franja anterior optan mayoritariamente por el método tradicional (22\%-78\%) (Jordán et al., 2014).

El análisis de estos resultados parece indicar una cierta resistencia a la innovación por parte de los estudiantes. El perfil de alumno más preparado o capacitado prefiere una metodología 
tradicional, en nuestra opinión esto se debe a que en la metodología tradicional se encuentra más cómodo y es más independiente para organizarse como quiera, mientras que el alumno en la franja de perfiles medios o bajos es el que más ventajas encuentra a la flip education. Son precisamente estos alumnos los que motivan la puesta en marcha de nuestras innovaciones ya que constituyen el conjunto más sensible a los beneficios de nuestras experiencias en el aula.

Contrastan estos resultados con el hecho de que al $90 \%$ les gusta bastante o mucho la metodogía utilizada y de que al $95 \%$ el ambiente de la clase les ha resultado bastante o muy agradable (Jordán et al., 2014).

En la Figura 4 se muestran otros resultados de la encuesta, relacionados con opiniones, de los que se deduce que la mayoría de los alumnos están de acuerdo con los materiales y las propuestas que les plantea la asignatura y, sobre todo, que el esfuerzo realizado merece la pena.

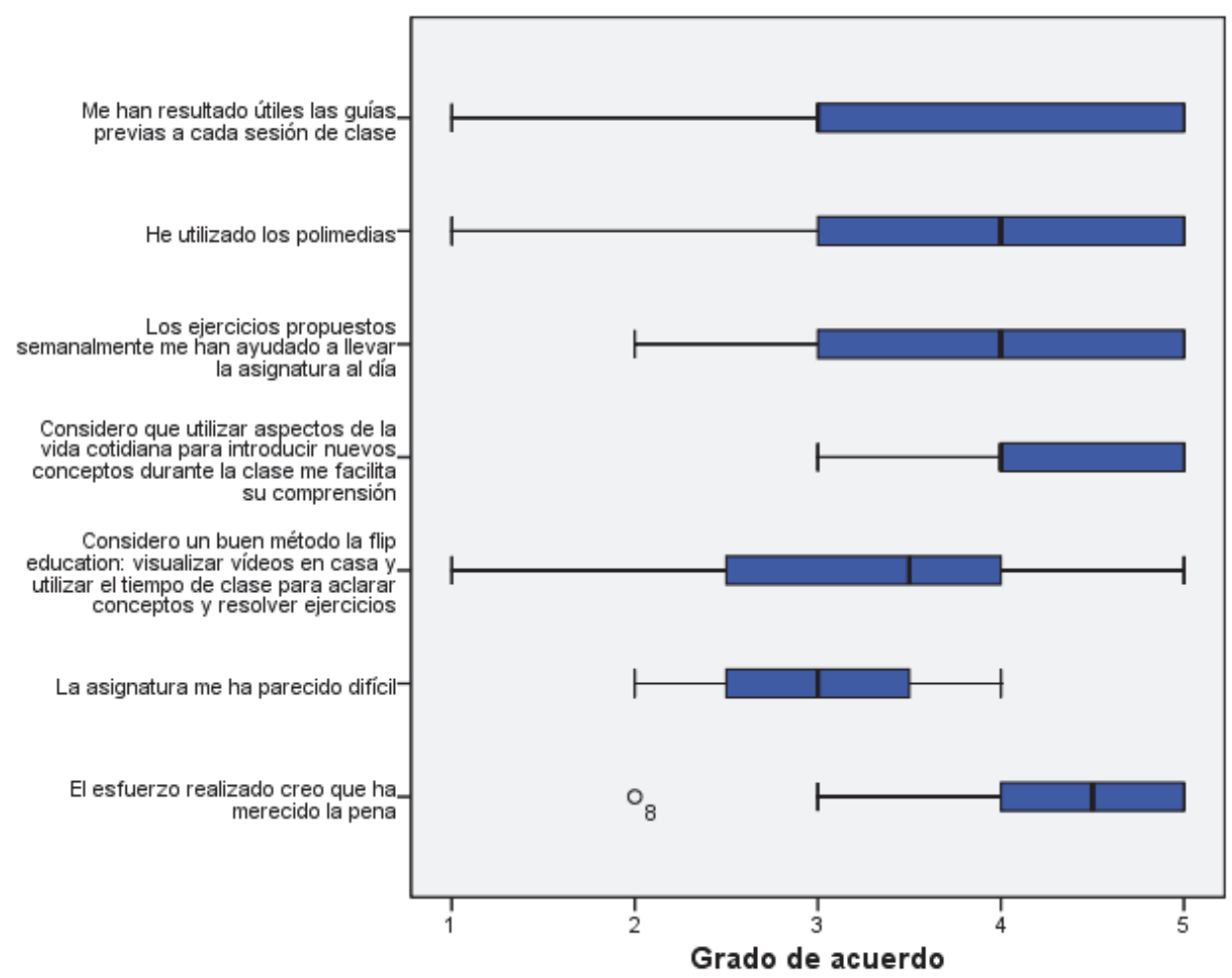

Fig.4: Grado de acuerdo con las afirmaciones que se presentan.

\subsection{Encuesta realizada a los alumnos de la asignatura GMA.}

La asignatura GMA es una optativa de cuarto curso del Grado en Ingeniería Informática de la Universitat Politècnica de València, en la que se matricularon en el curso 2013-2014 ocho alumnos, uno de los cuales dejó de asistir y participar en ella pocas sesiones después

\section{(cc) EY-NC-ND 2014, Universitat Politècnica de València}

I Jornadas IN-RED (2014) 
de su comienzo. La encuesta que contestaron el resto de alumnos consta de diferentes preguntas relativas a la asignatura y su metodología, algunas de ellas abiertas, a fin de que los alumnos pudiesen expresar sus opiniones e inquietudes.

Como observamos en la tablas 1 y 2 los alumnos se muestran satisfechos con la organización, metodología y evaluación de la asignatura. En relación al tiempo de dedicación, aunque piensan que globalmente es adecuado, opinan que la nueva metodología les lleva a trabajar durante todo el curso, teniendo también un pico de trabajo, al igual que el resto de materias, al finalizarlo, por lo que tienen la sensación de haber trabajado más que en otras asignaturas.

Tabla 1. Respuestas de la encuesta GMA

\begin{tabular}{|l|c|c|}
\hline $\begin{array}{l}\text { Desde el principio de curso tenía claro en que iba a } \\
\text { consistir la metodología utilizada en las clases (Flip } \\
\text { education) }\end{array}$ & Frecuencia & Porcentaje \\
\hline Sí & 3 & 42,9 \\
No & 3 & 42,9 \\
No del todo porque & 1 & 14,3 \\
\hline Consideras que la metodología aplicada se ha ajustado & Frecuencia & Porcentaje \\
a lo previsto inicialmente & 7 & 100,0 \\
\hline Sí & Frecuencia & Porcentaje \\
\hline Los videos Polimedia son adecuados & 2 & 28,6 \\
\hline Medio & 4 & 57,1 \\
Bastante de acuerdo & 1 & 14,3 \\
Totalmente de acuerdo & Frecuencia & Porcentaje \\
\hline Las guías didácticas son adecuadas & 1 & 14,3 \\
\hline Bastante en desacuerdo & 3 & 42,9 \\
Bastante de acuerdo & 3 & 42,9 \\
\hline Totalmente de acuerdo & Frecuencia & Porcentaje \\
\hline Los ejercicios flip son adecuados & 2 & 28,6 \\
\hline Bastante de acuerdo & 5 & 71,4 \\
\hline Totalmente de acuerdo & Frecuencia & Porcentaje \\
\hline Las cuestiones de modelización son adecuadas & 1 & 14,3 \\
\hline Medio & 6 & 85,7 \\
\hline Totalmente de acuerdo & Frecuencia & Porcentaje \\
\hline Los ejercicios entregables son adecuados & 1 & 14,3 \\
\hline Medio & 28,6 \\
Bastante de acuerdo & & 57,1 \\
\hline Totalmente de acuerdo & & \\
\hline
\end{tabular}


Tabla 2. Respuestas de la encuesta GMA

\begin{tabular}{|c|c|c|}
\hline $\begin{array}{l}\text { En tu opinión, llevar al día GMA con la metodología aplicada es } \\
\text { compatible con el trabajo no presencial de otras asignaturas }\end{array}$ & Frecuencia & Porcentaje \\
\hline En general sí & 7 & 100,0 \\
\hline $\begin{array}{l}\text { En general sí } \\
\text { No, porque }\end{array}$ & $\begin{array}{l}2 \\
5\end{array}$ & $\begin{array}{l}28,6 \\
71,4\end{array}$ \\
\hline $\begin{array}{l}\text { Te resulta interesante conocer a priori los contenidos que se van a } \\
\text { trabajar en clase }\end{array}$ & Frecuencia & Porcentaje \\
\hline $\begin{array}{l}\text { Sí, porque en clase puedo aclarar las dudas y profundizar en los } \\
\text { conceptos } \\
\text { Sí, aunque pienso que no compensa el esfuerzo realizado }\end{array}$ & 6 & $\begin{array}{l}85,7 \\
14,3\end{array}$ \\
\hline ¿Qué te ha parecido el ritmo de la clase en términos generales? & Frecuencia & Porcentaje \\
\hline $\begin{array}{l}\text { Rápido } \\
\text { Adecuado }\end{array}$ & $\begin{array}{l}1 \\
6 \\
\end{array}$ & $\begin{array}{l}14,3 \\
85,7\end{array}$ \\
\hline ¿Crees que la asignatura está bien planificada? & Frecuencia & Porcentaje \\
\hline Sí & 7 & 100,0 \\
\hline ¿Crees que la carga semanal de trabajo es adecuada? & Frecuencia & Porcentaje \\
\hline $\begin{array}{l}\text { Sí } \\
\text { No, porque }\end{array}$ & $\begin{array}{l}3 \\
4 \\
\end{array}$ & $\begin{array}{l}42,9 \\
57,1 \\
\end{array}$ \\
\hline ¿Crees que la carga global de la asignatura es adecuada? & Frecuencia & Porcentaje \\
\hline Sí & 7 & 100,0 \\
\hline ¿Crees que la carga global de la asignatura es adecuada? & Frecuencia & Porcentaje \\
\hline Sí & 7 & 100,0 \\
\hline ¿Te ha resultado interesante la asignatura? & Frecuencia & Porcentaje \\
\hline $\begin{array}{l}\text { Bastante } \\
\text { Mucho }\end{array}$ & $\begin{array}{l}2 \\
5 \\
\end{array}$ & $\begin{array}{l}28,6 \\
71,4\end{array}$ \\
\hline $\begin{array}{l}\text { Piensas que la evaluación se ha correspondido con la metodología y } \\
\text { contenidos del curso }\end{array}$ & Frecuencia & Porcentaje \\
\hline Sí & 7 & 100,0 \\
\hline
\end{tabular}

A continuación citamos los aspectos favorables de la educación inversa que han reflejado los alumnos en la pregunta de respuesta abierta:

- Facilidad de aprendizaje

- $\quad$ Tienes un fuerte refuerzo de contenidos que puedes consultar en cualquier momento y se aprende más en las clases presenciales

- No te dejas la materia para el final

(c)) EY-NC-ND 2014, Universitat Politècnica de València

I Jornadas IN-RED (2014) 
- Las clases son más amenas, con más ejercicios y menos teoría

- Cantidad de trabajo mejor distribuida y clases más dinámicas en las que se trabajan los conceptos en lugar de tantas horas de teoría

- Ofrece más tiempo para que el profesor y los alumnos discutan los conocimientos aprendidos, y se resuelvan dudas y ejercicios durante las clases

Los aspectos mejorables que los alumnos han señalado en la correspondiente pregunta abierta son:

- Distribuir mejor la carga de los ejercicios, ya que si la teoría es no presencial si ademas añadimos muchos ejercicios... demasiadas horas dedicadas a la asignatura.

- Si un alumno no revisa en casa los contenidos que se van a trabajar posteriormente en clase, desaprovecha mucho la clase con respecto a sus compañeros, y si hace esto a menudo, puede descolgarse y desanimarse.

- Proporcionar distintas metas a distintos perfiles de alumnos, para que no se creen lagunas en el grupo de la asignatura.

\section{Conclusiones}

El análisis de las encuestas realizadas a los alumnos nos muestra que pesar de que aunque los alumnos de primero no han manifestado abiertamente su preferencia por la metodología de la clase invertida, a la gran mayoría de los estudiantes les resulta atractiva la experiencia en general, valoran positivamente los materiales utilizados, y encuentran que el esfuerzo ha merecido la pena. Observamos que nuestros resultados coinciden en términos generales con los estudios realizados por otros autores (Bishop y Verleger, 2013), concretamente dentro del área de mátematicas, donde además aparece que tienen una mejor percepción hacia la utilidad de las matemáticas en sus disciplinas (Talbert, 2012; McGivney-Burelle y Fei Xue 2013, Love et al. 2013). Quizás los mayores comentarios adversos se refieren a la organización y cantidad del tiempo de estudio no presencial, por lo que sería conveniente ajustar las actividades propuestas durante la parte final de la asignatura, cuando la carga de trabajo del estudiante es mayor.

El éxito de la educación inversa depende de muchos factores, tanto relacionados con el profesor como con los alumnos.

Uno de los más significativos en lo que al alumnado se refiere es el hecho de que con la flip education exigimos del alumno una colaboración directa y continua, que no siempre es fácil de conseguir. Por ello, es importante motivarlos explicándoles claramente las ventajas que esta metodología ofrece, poniendo de manifiesto que si participan el resultado será más satisfactorio y el trabajo realizado durante el curso resultará más productivo; los profesores deben por tanto recabar suficientes datos para realizar una buena evaluación formativa (Talbert, 2012; Tucker, 2012; Miller, 2012).

Por otro lado, si nos decidimos a aplicar esta metodología, debemos tener en cuenta el esfuerzo que supondrá generar el material docente adecuado, las guías didácticas necesarias para llevar a cabo su implementación, así como la planificación exhaustiva de las clases 
presenciales y no presenciales y el seguimiento adecuado de la evolución de los alumnos lo que incrementará notablemente el trabajo del profesor, especialmente en las primeras experiencias.

\section{Agradecimientos}

M. J. Pérez Peñalver y Esther Sanabria Codesal agradecen el apoyo de la Universidad Politécnica de Valencia a través de los grupos EICE a los que pertenenecen: IEMA (Innovación en la Evaluación para la Mejora del Aprendizaje Activo) y EITACURTE (Equipo de Innovación sobre Técnicas Activas, Colaborativas y Utilización de Recursos Tecnológicos), respectivamente.

\section{Referencias}

BERGMANN, J. AND SAMS, A. (2012). Flip Your Classroom: Talk to Every Student in Every Class Every Day. International Society for Technology in Education.

BISHOP, J. L. AND VERLEGER, M. A. (2013). "The flipped classroom: A survey of the research “. In ASEE National Conference Proceedings, Atlanta, GA

CROUCH, C. H., \& MAZUR, E. (2001). "Peer instruction: Ten years of experience and results". American Journal of Physics, 69 (9), pp. 970-977.

JORDÁN, C. (2009). "Utilización correcta e incorrecta de los ficheros Polimedia“. Actas de la JIDINF'09. Valencia.

JORDÁN, C. (2014). Materiales docentes de la asignatura Estructuras Matemáticas para la

Informática II.

<http://www.upv.es/pls/oalu/sic_asi.Sak_Recursos_ocw?P_OCW=E\&P_ASI=6024\&P_CACA=2010

$\&$ P_IDIOMA=c\&P_VISTA=MSE > [Consulta: Junio 2014]

JORDÁN LLUCH, C. Y SANABRIA-CODESAL, E. (2013). "Grafos hamiltonianos en el diseño de viajes". Modelling in Science Education and Learning, 6, pp. 133-143.

JORDÁN LLUCH, C., SANABRIA-CODESAL, E., PEREZ-PEÑALVER, M.J. (2012). "Estrategias matemáticas en la ONU”. Pensamiento Matemático, 2 (2), pp. 55-66.

JORDÁN LLUCH, C., SANABRIA-CODESAL, E., PEREZ-PEÑALVER, M.J. (2014). “ Investigación del impacto en un aula de matemáticas al utilizar flip education”. Pensamiento Matemático, 4 (2), to appear.

JORDÁN, C., TORREGROSA, J.R. (2008). "Docencia en red: un paso adelante en el uso de nuevas tecnologías“, Proc. de las VI Jornadas de redes de investigación en docencia universitaria, p.726, Alicante.

\section{(c)) EY-NC-ND 2014, Universitat Politècnica de València}

I Jornadas IN-RED (2014) 
Flipped Classroom: Reflexiones y opiniones de los implicados

JORDÁN, C., TORREGROSA, J.R. (2008). "Los objetos de aprendizaje y el nuevo contexto educativo“, Actas del V Congreso Iberoamericano de Docencia Universitaria, Valencia.

JORDÁN, C., TORREGROSA, J.R. (2010). “ Las OCW en el nuevo contexto educativo“. Actas de las VIII Jornadas de Redes de Investigación en Docencia Universitaria, Alicante.

LAGE, M. J., PLATT, G. J., AND TREGLIA, M. (2000). "Inverting the classroom: A gateway to creating an inclusive learning environment“. The Journal of Economic Education, 31(1), pp. 30-43.

LOVE, B., HODGE, A., Grandgenett. N. and Swift, A. (2014). W. Student learning and perceptions in a flipped linear algebra course, International Journal of Mathematical Education in Science and Technology, 45(3), pp. 317-324.

<http://dx.doi.org/10.1080/0020739X.2013.822582> [Consulta: Junio 2014]

MCGIVNEY-BURELLE, J. AND XUE, F. (2013). "Flipping Calculus“. PRIMUS, 23(5), pp. 477486.

< http://dx.doi.org/10.1080/10511970.2012.757571 >[Consulta: Junio 2014]

MILLER, A. (2012). Five best practices for the flipped classroom. Retrieved April, 16. <http://ticharter33.org/library/TIarticle36.pdf> [Consulta: Junio 2014]

NOVAK, G. M., GAVRIN, A. Y WOLFGANG, C. (1999). Just-in-time teaching: Blending active learning with web technology. Prentice Hall PTR.

NUNNALLY, J. C. (1987), Teoría psicométrica. México: Trillas.

TALBERT, R. (2012). Inverted classroom. Colleagues, 9 (1), pp. 7.

TALBERT, R. (2012). "Learning MATLAB in the inverted classroom". In American Society for Engineering Education.

< http://www.asee.org/public/conferences/8/papers/3680/view> [Consulta: Junio 2014]

TUCKER, B. (2012). “The flipped classroom“. Education Next, 12(1), pp. 82-83., 2012.

TURRO, C., CAÑERO, A., BUSQUETS, J., "Video Learning Objects Creation with Polimedia“. IEEE International Symposium on Multimedia, pp. 371-376, 2010. 


\title{
Experiencias de aplicación de la simulación empleando software libre y gratuito en la enseñanza de las ingenierías de la rama industrial
}

\author{
Asunción Santafé Moros ${ }^{a}$, José M. Gozálvez Zafrilla ${ }^{a}$, Javier Navarro Laboulais \\ Salvador Cardona Navarrete ${ }^{a}$, Rafael Miró Herrero ${ }^{a}$, Juan Carlos García Díaz \\ a Departamento de Ingeniería Química y Nuclear, Universitat Politècnica de Valencia, \\ assanmo@iqn.upv.es \\ ${ }^{\mathrm{b}}$ Departamento de Estadística e Investigación Operativa, Universitat Politècnica de Valencia.
}

\begin{abstract}
Resumen
En este trabajo se presentan las experiencias de utilización de software libre y gratuito llevadas a cabo por el Equipo de Innovación y Calidad Educativa ASEI (Aplicación de la Simulación en la Enseñanza de la Ingeniería) en asignaturas de las áreas de Ingeniería Química, Nuclear y Estadística que requieren la utilización de software de cálculo y herramientas de simulación. El software libre puede ser utilizado como una herramienta en metodologías docentes basadas en el uso de la simulación en el aula de teoría o bien como una forma de disminuir los costes en la enseñanza y aportar nuevos valores. Adecuadamente empleadas, las metodologías basadas en el uso de programas de simulación pueden estimular la capacidad de autoaprendizaje del alumno. En esta comunicación se muestran ejemplos del amplio abanico de aplicaciones de software que se pueden utilizar sin representar coste para la Universidad y posteriormente para la empresa.
\end{abstract}

Palabras clave: competencias, formación, metodologías activas, simulación, software libre. 
Experiencias de aplicación de la simulación empleando software libre y gratuito en la enseñanza de las ingenierías de la rama industrial

\section{Introducción}

En este trabajo se presentan distintas experiencias de utilización de software libre y gratuito llevadas a cabo por el Equipo de Innovación y Calidad Educativa ASEI (Aplicación de la Simulación en la Enseñanza de la Ingeniería) (ASEI, 2012). Estas experiencias se desarrollaron en asignaturas de las áreas de Ingeniería Química, Ingeniería Nuclear y Estadística industrial que requieren la utilización de software de cálculo y herramientas de simulación. La mayor parte de las experiencias comenzaron a desarrollarse dentro del Proyecto de Innovación y Mejora Educativa SIMULIB "Utilización de herramientas de simulación en software libre como metodología de bajo coste para aumentar el rendimiento de la enseñanza" (PIME A20/11 de la UPV) con el objetivo de investigar, experimentar y evaluar diferentes herramientas de simulación de software libre.

El equipo ASEI es un foro de intercambio de experiencias y un instrumento para trabajar de forma coordinada en el desarrollo de metodologías basadas en la aplicación de la simulación en el aula que buscan mejorar la docencia y facilitar el autoaprendizaje mediante la utilización de herramientas de simulación.

Existen en la actualidad plataformas de cálculo y simulación ofrecidas por casas comerciales que destacan por su potencia, fiabilidad, facilidad de manejo y potencia de representación gráfica. No obstante, presentan los siguientes inconvenientes:

- En la mayoría de los casos, el alumno no puede realizar las tareas no presenciales en su domicilio, a no ser que emplee una copia no legal o que incremente su permanencia en el Centro.

- Finalizada la vida universitaria puede no disponer de ellas en su trabajo, perdiéndose el esfuerzo realizado y las capacidades adquiridas.

- Representan un elevado coste económico para las instituciones de enseñanza.

- Son muchas veces cajas negras cerradas siendo la base de su funcionamiento no siempre conocida, repercutiendo negativamente en la calidad de la simulación.

Por otra parte existen otras herramientas encuadradas en las categorías free/libre/opensource software que son agrupadas bajo las siglas FLOSS, y que, denominaremos simplemente como "software libre" en el contexto de esta comunicación. La utilización de estas herramientas en la enseñanza puede hacer frente a los inconvenientes mencionados. No obstante, precisa de la implantación de nuevas metodologías de enseñanza para solucionar una dificultad de manejo derivada de trabajar con entornos de trabajo a los que los alumnos están menos habituados.

Las plataformas de simulación basadas en software libre son fácilmente accesibles y habitualmente están disponibles para diversos sistemas operativos, no representando su uso coste económico alguno. Sin embargo, suelen presentar algunos inconvenientes, como son:

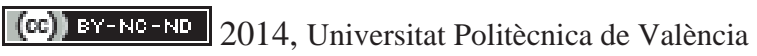

I Jornadas IN-RED (2014) 
Asunción Santafé Moros, José M. Gozálvez Zafrilla, Javier Navarro Laboulais, Salvador Cardona Navarrete, Rafael Miró Herrero, Juan Carlos García Díaz

- Suelen ser buenas para aplicaciones concretas pero pueden presentar prestaciones inferiores en ciertos rangos de aplicación.

- En la mayoría de casos el interfaz es menos amigable o desarrollado.

- Excesiva complejidad de uso en algunos casos.

- Existen numerosas plataformas de simulación con niveles de complejidad, elaboración y pretensiones que hacen difícil su comparación y compatibilidad.

Estos inconvenientes pueden paliarse mediante un mayor conocimiento de las distintas posibilidades de software libre y una mayor formación en las técnicas de uso.

Una formación basada en la filosofía del software libre no sólo permitirá al alumno adquirir competencias específicas de su titulación, sino también rentabilizar profesionalmente las herramientas aprendidas, ahorrando a su vez recursos económicos a las instituciones de enseñanza.

\section{Objetivos}

Los objetivos principales que nos propusimos con el proyecto se derivaron de una reflexión sobre la utilización que estábamos realizando de la simulación en la enseñanza y fueron los siguientes:

- Establecer metodologías docentes para usar la simulación en el aula de teoría para explicar conceptos y para su uso en el autoaprendizaje.

- Desarrollar metodologías activas basadas en el aprendizaje mediante proyectos de simulación propuestos al alumno empleando software libre o gratuito.

- Abrir la posibilidad de utilizar un amplio abanico de aplicaciones de software que no representan coste para la Universidad y posteriormente para la empresa.

- Mejorar la capacidad de autoaprendizaje del alumno estimulando el uso de programas de simulación.

Adicionalmente y como consecuencia del alcance de estos objetivos se espera el objetivo ético de inculcar a través de la utilización de software libre una transición hacia un modo de vida más economicista que no busque siempre soluciones caras pero de poco esfuerzo.

\section{Desarrollo de la innovación}

Se realizó un análisis del software comercial que se estaba utilizando en tareas de simulación y se identificó el software libre que podría utilizarse para sustituir en parte el software comercial o para complementarlo. De esta manera se consideraron tres grandes grupos de software:

(c)) EY-NC-ND 2014, Universitat Politècnica de València

I Jornadas IN-RED (2014) 
Experiencias de aplicación de la simulación empleando software libre y gratuito en la enseñanza de las ingenierías de la rama industrial

I. Software matemático o de programación con carácter generalista útil para realizar cálculos o implementar modelos.

II. Aplicaciones generales de simulación (simuladores de procesos y de sistemas, programas de multifísica y de Dinámica de Fluidos Computacional).

III. Programas para cálculos y simulaciones específicas de ingeniería.

Por motivos prácticos, el análisis no podía realizarse sobre toda la ingeniería en general. Por ello, se centró en áreas concretas de la Ingeniería Química, Ingeniería Nuclear y Estadística industrial para poder aplicarlo sobre asignaturas concretas donde los profesores del equipo ASEI impartían docencia. De esta forma se identificaron tres áreas diferentes donde se hacía ya un uso importante de las técnicas de simulación y que, por tanto, resultaban áreas potenciales para una posible introducción del software libre y gratuito. Las áreas y proyectos relacionados fueron los siguientes:

- $\quad$ Simulación de Procesos químicos

P1) Evaluación de software libre para Modelado y simulación de Procesos

P2) Planteamiento de casos para resolver empleando software libre

- $\quad$ Cinética química y Reactores

P3) Utilización en dispositivos móviles de software libre para la resolución matemática de mecanismos cinéticos complejos.

P4) Simulación dinámica intuitiva de reactores mediante el software libre SCILAB-XCOS

- $\quad$ Análisis de sensibilidad e incertidumbre

P5) Introducción de R y DAKOTA como softwares libres en análisis de códigos computacionales complejos aplicables en la industria nuclear o en campos de la ingeniería donde se emplea la Estadística industrial

P6) Desarrollo de scripts para métodos de Montecarlo.

\subsection{Introducción de software libre en el Área de Simulación de Procesos}

\subsubsection{Antecedentes}

En este caso se involucraron las asignaturas "Simulación y Optimización de Procesos Químicos" de $5^{\circ}$ de Ingeniero Químico, "Modelización, Simulación y Optimización de Procesos de Membrana y Medioambientales" del Máster de Seguridad Industrial y Medioambiente y "Análisis y Simulación de Procesos" de $3^{\circ}$ del Grado en Ingeniería Química de la ETSII y de la EPS-Alcoy. 
Asunción Santafé Moros, José M. Gozálvez Zafrilla, Javier Navarro Laboulais, Salvador Cardona Navarrete, Rafael Miró Herrero, Juan Carlos García Díaz

En estas asignaturas se requiere que el alumno se forme en dos aspectos:

- La implementación y resolución de modelos.

- La utilización de programas de simulación de procesos.

Para el primer aspecto resulta fundamental que el alumno adquiera cierta maestría con un software matemático o un lenguaje de programación para la aplicación de métodos numéricos y programación. En nuestro caso hemos utilizado los programas MATHCAD® y MATLAB®, con los cuales hemos desarrollado abundantes ejemplos para los alumnos (Gozálvez et al. 2011, Santafé el al. 2013) y que son utilizados por los alumnos en la resolución de problemas prácticos en el laboratorio informático. La elección de MATHCAD vino determinada por su facilidad de uso y por presentar una visualización cercana a la notación matemática convencional. MATLAB es utilizado en nivel de máster por su mayor potencia y por ser más adecuado para los cálculos de ingeniería que los lenguajes de programación de uso general. Además se han creado también objetos de aprendizaje en forma de laboratorios virtuales de simulación o vídeos que ilustran al alumno con ejemplos de aplicación y con los que puede explorar el efecto de los parámetros (Gozálvez , 2009 y Santafé, 2009).

Los Simuladores de Procesos son utilizados en situaciones en las que la resolución del problema mediante cálculo y programación es prácticamente inviable. En nuestro caso el software comercial de simulación utilizado $\mathrm{CHEMCAD}^{\circledR}$ ofrece licencias a un coste no excesivamente oneroso, pero no facilita el acceso libre a los alumnos, con lo cual éstos no pueden practicar en casa.

\subsubsection{Evaluación de software libre para modelado y Simulación de Procesos}

Uno de los temores de los profesores de las asignaturas es que las instituciones universitarias no puedan continuar afrontando el pago de licencias. Por ello, realizamos una búsqueda de alternativas de software libre dentro de las categorías de cálculo y de Simulación de Procesos.

En una primera fase se realizó un análisis exploratorio de posibles candidatos a sustituir el software comercial que estamos utilizando. Nos fue de gran ayuda los siguientes listados (Wikipedia 2012 y 2013). De esta manera en lo que concierne al software matemático, se determinarón SMATH (Smath developers) como alternativa a MATHCAD, OCTAVE (Octave Project) y SCILAB (SCILAB Enterprises) como alternativas a MATLAB, y CALC (Apache OpenOffice) como alternativa a EXCEL de Office.

En lo que concierne a Simuladores de Procesos libres se analizaron inicialmente dos alternativas DWSIM (DWSIM-Wiki) y COCO (Amsterchem-COCO) que en este caso

\section{(cc) EY-NC-ND 2014, Universitat Politècnica de València}

I Jornadas IN-RED (2014) 
Experiencias de aplicación de la simulación empleando software libre y gratuito en la enseñanza de las ingenierías de la rama industrial

fueron evaluadas por grupos de alumnos ya formados en el uso del simulador comercial CHEMCAD que usamos actualmente. Como trabajo de curso se le pidió que instalaran el simulador de procesos libre y que trataran de realizar un caso similar a los efectuados en prácticas.

El análisis de los resultados de este trabajo llevó a centrarnos exclusivamente en la opción de COCO (CAPE Open to CAPE open) por parecer más completo. Además, existe un programa de conexión con MATLAB (Amsterchem-connector) que permite la elaboración de módelos de nuevas unidades con MATLAB o SCILAB (Gozálvez et al., 2014). COCO ha sido investigado en más profundidad, pidiéndole a alumnos de buen rendimiento que intentaran resolver un proceso complejo proporcionándoles subrutinas realizadas en MATLAB de determinadas unidades y animándoles a realizar otra (Fig. 1). Además se pidió a los alumnos una evaluación completa de las dificultades que representa frente al programa comercial.

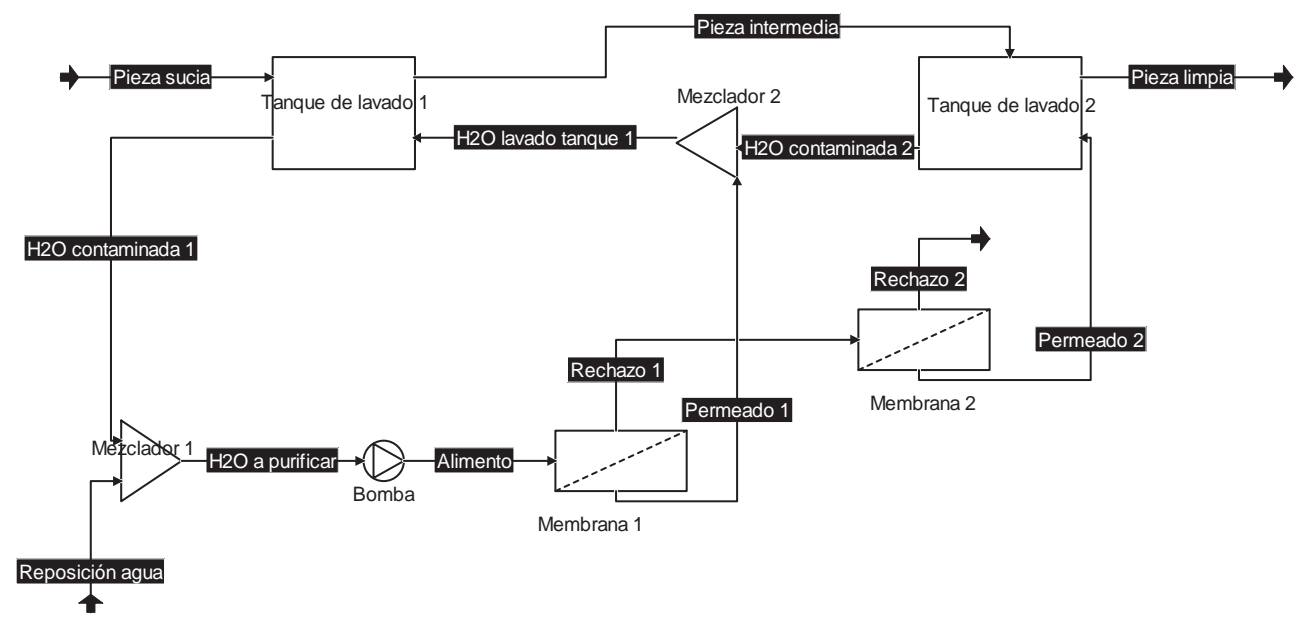

Fig. 1 Proceso realizado en COCO en colaboración con alumnos

\subsubsection{Planteamiento de casos para resolver empleando software libre}

La acción en este caso ha consistido en plantear un problema a los alumnos a través de estas dos variantes:

1) Problema sencillo relacionado con ingeniería química sin definir el software a utilizar.

2) Problema de nivel profesional que se debe resolver empleando un software libre o gratuito determinado combinado con herramientas comerciales conocidas por el alumno. 
Asunción Santafé Moros, José M. Gozálvez Zafrilla, Javier Navarro Laboulais, Salvador Cardona Navarrete, Rafael Miró Herrero, Juan Carlos García Díaz

La primera opción se ha utilizado como propuesta de trabajo de curso para grupos de alumnos. El grupo debe buscar en Internet software que puede ser utilizado para resolver el problema, quedando expresamente prohibido el uso de software comercial craqueado. Posteriormente el grupo recibe asesoramiento del profesor en tres ocasiones, planteamiento, resolución y propuestas de presentación. Finalmente el trabajo es presentado en clase, incluyendo los siguientes puntos: descripción del problema, explicación del software, posibles modelos que utiliza en relación a lo aprendido en teoría y análisis crítico de resultados. Hay que indicar que el profesor conocía al menos una opción de software libre que se podía utilizar, para el caso de que el alumno no fuera capaz de encontrarlo. No obstante, los alumnos eran capaces de localizarlo en la mayor parte de las ocasiones, incluso localizando otro distinto del conocido por el profesor.

En la segunda opción se planteaba un problema común de cierta complejidad a toda la clase y todos los alumnos deben emplear el mismo software. Se daba libertad para utilizar software no necesariamente libre en el análisis de los resultados obtenidos. Este trabajo se realiza de forma práctica a lo largo de varios días y con mínima asistencia del profesor en el uso del software libre el cual deben aprender los alumnos utilizando la ayuda o explorando sus opciones.

Para este tipo de trabajos resultan muy interesantes los programas de organizaciones gubernamentales como la Environmental Protection Agency (EPA) de los EE.UU. y el software de diseño de instalaciones que ofrecen las casas comerciales. Mostramos a continuación dos ejemplos de trabajos propuestos:

- Trabajo ejemplo 1. Usar el software TANKS de la EPA (EPA-USA) para estimar las emisiones de tanques de almacenamiento de hidrocarburo. El hidrocarburo o mezcla de hidrocarburos, así como la localización de la instalación son propuestos por el profesor y diferentes para cada alumno. Emplear información climatológica disponible en la web. Realizar cálculos de dispersión de contaminantes basados en la norma empleando modelos de dispersión gaussiana.

La Fig. 2 corresponde a la pantalla de entrada de datos metereológicos en el programa Tanks. Estos datos pueden ser obtenidos a través de la web. El alumno añade información química sobre la mezcla, tipo de tanque y régimen de llenado y vaciado y con ello obtiene una estimación de la emisión. La Fig. 3 corresponde al cálculo de la dispersión de contaminante en la dirección del viento predominante empleando los algoritmos de dispersión gaussiana especificados en las normas NTP 327 y 329 que debieron encontrar. Otros alumnos se decidieron por realizar el cálculo en MATHCAD o en MATLAB.

(c)) EY-NC-ND 2014, Universitat Politècnica de València

I Jornadas IN-RED (2014) 
Experiencias de aplicación de la simulación empleando software libre y gratuito en la enseñanza de las ingenierías de la rama industrial

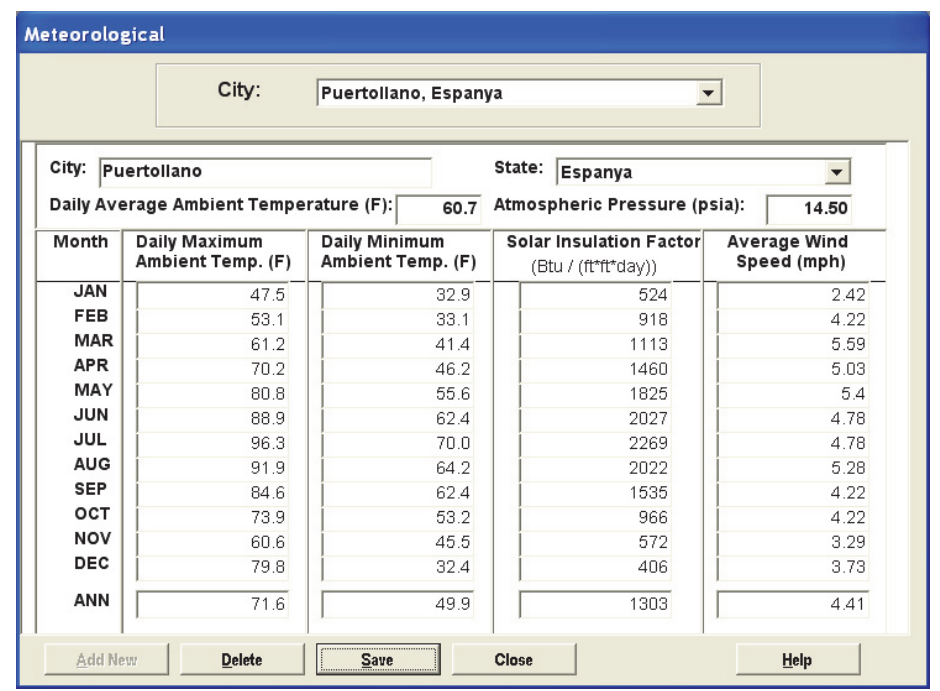

Fig. 2 Entrada de datos meterológicos en el software Tanksde la EPA

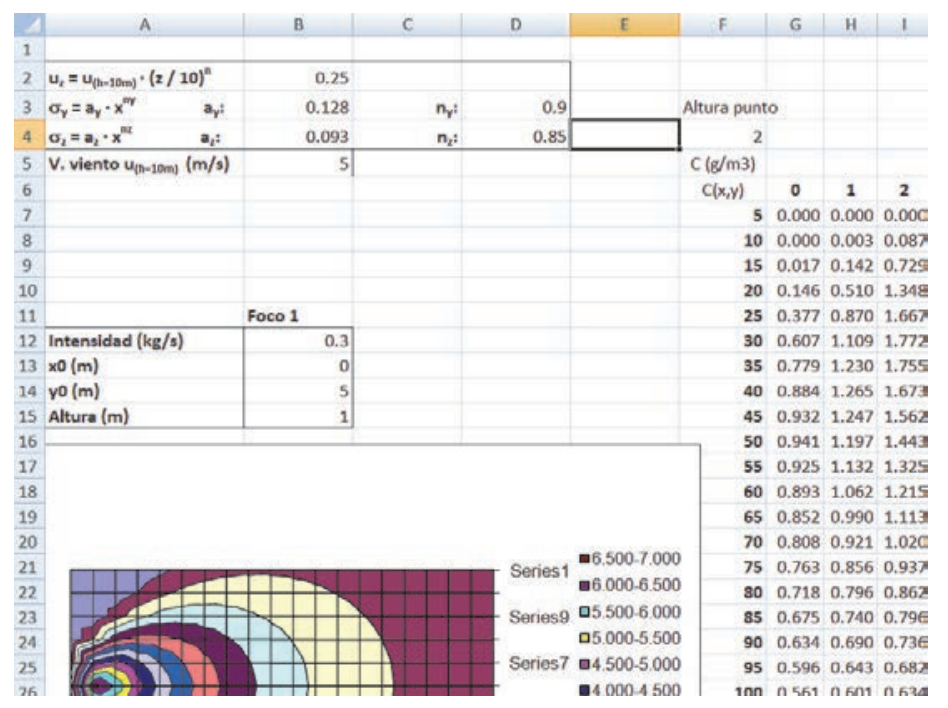

Fig. 3 Cálculo de dispersión gaussiana correspondiente a los datos de emisión calculados con Tanks

- Trabajo ejemplo 2: Diseñar un proceso de membranas empleando software gratuito de casas comerciales, p.e. ROSA ${ }^{\circledR}$ (Dow), IMSDesign ${ }^{\circledR}$ (Hydranautics) o ROPRO®. Se le indica al alumno las características del agua a tratar y la conversión de producto.

(cc) EY-NC-ND 2014, Universitat Politècnica de València

I Jornadas IN-RED (2014) 
Asunción Santafé Moros, José M. Gozálvez Zafrilla, Javier Navarro Laboulais, Salvador Cardona Navarrete, Rafael Miró Herrero, Juan Carlos García Díaz

La Fig. 4 representa la pantalla para el cuarto nivel donde se define la configuración del proceso. Los resultados obtenidos (Fig. 5) serán normalmente tratados en EXCEL.

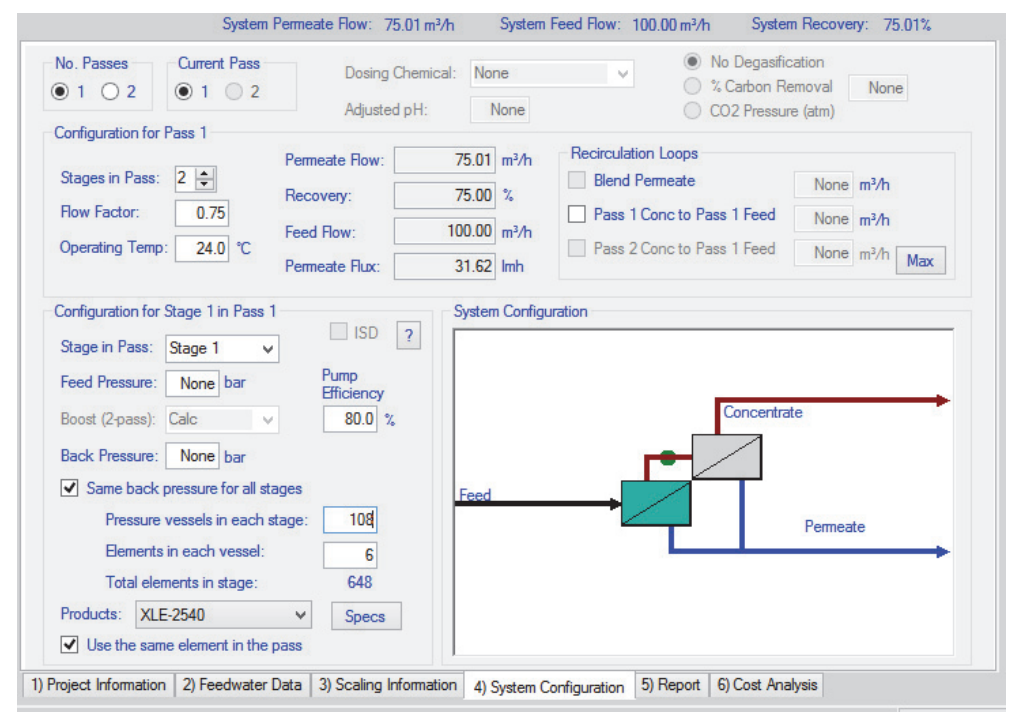

Fig. 4 Pantalla de definición del proceso en el programa de diseño de membranas ROSA

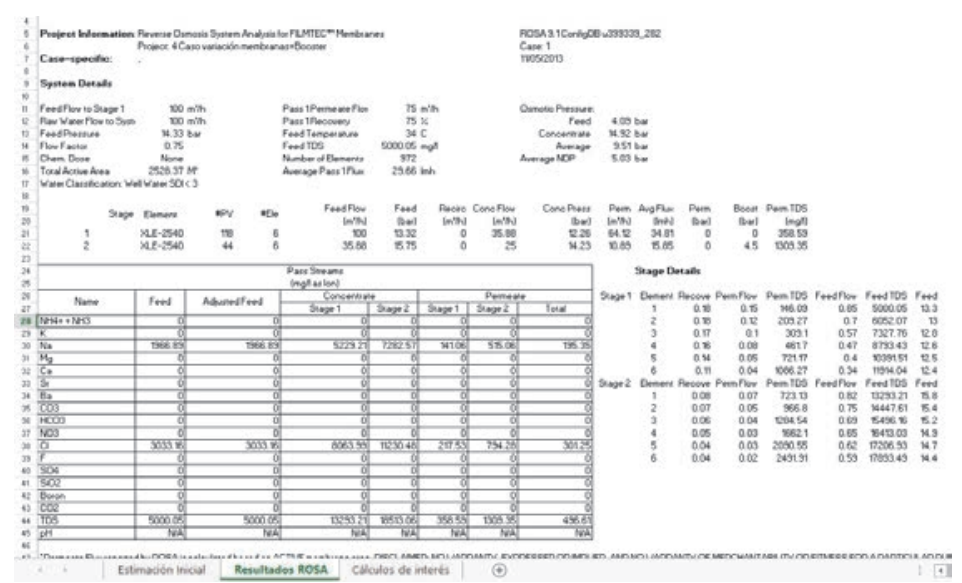

Fig. 5 Pantalla de resultados del programa de diseño de membranas ROSA

\section{(c)) EY-NC-ND 2014, Universitat Politècnica de València}

I Jornadas IN-RED (2014) 
Experiencias de aplicación de la simulación empleando software libre y gratuito en la enseñanza de las ingenierías de la rama industrial

\subsection{Introducción de herramientas de software libre en Cinética Química y Reactores}

\subsubsection{Antecedentes}

La incontenible expansión de dispositivos móviles, vista como una amenaza para el normal desarrollo de las clases, debe ser considerada como una herramienta alternativa docente que posibilite una mayor interacción e investigación por parte del alumno para las actividades concretas a desarrollar en sus asignaturas. Trasladar o desarrollar aplicaciones docentes para estos dispositivos requiere facilitar al usuario (al estudiante) el acceso, la ejecución y entrega de los resultados a través de una plataforma estándar y de libre distribución.

El desarrollo de asignaturas del ámbito de la Ingeniería de Reactores está normalmente limitado por la complejidad de los problemas que pueden ser tratados en el aula. Un ejemplo es la simulación dinámica de reactores químicos, que viene explicada por sistemas de ecuaciones diferenciales ordinarias. SIMULINK es una herramienta de simulación dinámica de MATLAB que ofrece la ventaja, frente a la programación directa, de un entorno gráfico intuitivo en el que se combinan series de bloques que llevan asociados diferentes funciones, desde el cálculo integral o diferencial, a la generación y almacenamiento de datos o la representación gráfica. Una vez modelado el proceso a simular, la construcción del diagrama de bloques es una tarea que los alumnos suelen realizar con relativa facilidad y rapidez, permitiéndoles generar diferentes simulaciones en poco tiempo y analizar el efecto de diversos parámetros sobre la simulación.

3.2.2. Herramientas de manipulación en dispositivos móviles con software de libre distribución

Con este módulo se genera de forma automática los sistemas de ecuaciones algebraicodiferenciales correspondientes a mecanismos complejos de reacción tales como el mostrado en la Fig. 6 que corresponde a reacciones que se dan en un proceso de desinfección de aguas. Con ello los alumnos son capaces de formular en estos términos la dinámica de las reacciones químicas con pequeñas aplicaciones y pueden comprobar sus resultados inmediatamente.

$$
\begin{aligned}
& \mathrm{A}+\mathrm{B} \rightleftarrows \mathrm{I} \\
& \mathrm{I} \longrightarrow \mathrm{P}+\mathrm{Q} \\
& \mathrm{P}+\mathrm{B} \longrightarrow \mathrm{R} \\
& \mathrm{R}+\mathrm{B} \rightleftarrows \mathrm{S}
\end{aligned}
$$

Fig. 6. Mecanismo de reacción 
Asunción Santafé Moros, José M. Gozálvez Zafrilla, Javier Navarro Laboulais, Salvador Cardona Navarrete, Rafael Miró Herrero, Juan Carlos García Díaz

$$
v=\left(\begin{array}{ccccccc}
-1 & -1 & 1 & 0 & 0 & 0 & 0 \\
1 & 1 & -1 & 0 & 0 & 0 & 0 \\
0 & 0 & -1 & 1 & 1 & 0 & 0 \\
0 & -1 & 0 & -1 & 0 & 1 & 0 \\
0 & -1 & 0 & 0 & 0 & -1 & 1 \\
0 & 1 & 0 & 0 & 0 & 1 & -1
\end{array}\right)
$$

Toda la información relevante del mecanismo de reacción indicado en la Fig. 6 está contenida en la matriz estequiométrica del sistema (1) (Rawlings, 2002). Se ha desarrollado una herramienta con la plataforma MATHEMATICA que resuelve numéricamente el mecanismo indicado con los objetivos de posibilitar al alumno ejercitarse en la manipulación de mecanismos complejos a partir de sus matrices estequiométricas y de que sea capaz de analizar los resultados obtenidos. Dado que el acceso al programa MATHEMATICA está limitado a la intranet de la Universidad, se está pensado en alojar la aplicación en servidores internos en un Formato de Documento Computable (CDF) (Wolfram) para que los alumnos puedan acceder a la aplicación desde sus dispositivos móviles desde cualquier punto con acceso a internet. Si bien Mathematica es un software comercial, el lector de documentos $\mathrm{CDF}$ es de libre distribución e integra toda la capacidad computacional que precisa el documento.

\subsubsection{Simulación dinámica intuitiva de reactores químicos. Alternativas de software libre}

La desventaja de utilizar SIMULINK para la simulación del comportamiento de reactores químicos radica en que forma parte de un software comercial cuyo uso fuera del ámbito de la universidad queda restringido. No obstante, el software libre SCILAB, equivalente a MATLAB, lleva incorporado un simulador dinámico muy similar a SIMULINK, XCOS, cuyo entorno gráfico es muy parecido al de SIMULINK. Aunque en un principio las asignaturas están diseñadas para que los trabajos se realicen en SIMULINK, se ha potenciado que los alumnos también hagan uso de XCOS para simular procesos dinámicos. Para ello tienen que realizar los trabajos utilizando las dos herramientas (SIMULINK y XCOS), contrastando que los resultados obtenidos con ambos programas son idénticos. Uno de los apartados del trabajo consiste en un análisis comparativo entre ambas herramientas, en cuanto a las ventajas e inconvenientes que han encontrado. Es de mucha utilidad el análisis de la valoración que hacen los alumnos al comparar SIMULINK y XCOS. En función de estos resultados se tomará la decisión futura de utilizar sólo XCOS en las clases o seguir con ambas herramientas.

(c) EY-NC-ND 2014, Universitat Politècnica de València

I Jornadas IN-RED (2014) 
Experiencias de aplicación de la simulación empleando software libre y gratuito en la enseñanza de las ingenierías de la rama industrial

\subsection{Introducción de herramientas para Análisis de Sensibilidad e Incertidumbre}

\subsubsection{Antecedentes}

Hoy día no se concibe la enseñanza de técnicas estadísticas a ingenieros sin la utilización de software estadístico que permita de forma rápida y fiable la realización de complejos cálculos necesarios para la validación de datos experimentales y toma de decisiones cada vez más frecuentes en la industrial moderna. El software estadístico comercial es caro y suele estar accesible sólo a grandes organizaciones como universidades y empresas. Por ello se hace indispensable que el alumno pueda conocer software libre que pueda utilizar en su posterior carrera profesional de forma totalmente accesible y sin coste económico.

En el caso de la Ingeniería Nuclear, muchos de los cursos existentes tienen el objetivo de enseñar Seguridad Nuclear a usuarios avanzados de los programas informáticos o como una herramienta para la investigación (en tesis doctorales, por ejemplo), por tanto el estudiante objetivo es un posgraduado. Pero el número de cursos dedicados a mejorar el currículo técnico en base al uso de códigos computacionales aplicados a la Ingeniería Nuclear es muy limitado (principalmente termohidráulica y neutrónica).

En este trabajo pretendemos proponer al alumno una serie de herramientas estadísticas implementadas en software libre que le permitan llevar a cabo estudios de Análisis de Sensibilidad e Incertidumbre en códigos computacionales complejos.

\subsubsection{Enseñanza de $R$ y DAKOTA}

Las acciones llevadas a cabo han sido la introducción de los lenguajes de programación R y DAKOTA como software libre en Análisis de Sensibilidad e Incertidumbre en códigos computacionales complejos aplicables, no sólo en la industria nuclear, sino también en otros campos de la ingeniería. $\mathrm{R}$ es un lenguaje y entorno de programación para análisis estadístico y gráfico con posibilidad de cargar diferentes bibliotecas o paquetes con finalidades específicas de cálculo o gráfico. Se trata de un proyecto de software libre, que es actualmente muy utilizado en investigación por la comunidad estadística. Una de las características más sobresalientes de $\mathrm{R}$ es su enorme flexibilidad lo que lo hace muy adecuado para el uso del estudiante. DAKOTA es un software que sirve para aplicaciones específicas en el Análisis de Sensibilidad e Incertidumbre. La enseñanza de estas aplicaciones de software constituye un valor en sí mismo pues son de aplicación directa en la vida profesional del alumno. 
Asunción Santafé Moros, José M. Gozálvez Zafrilla, Javier Navarro Laboulais, Salvador Cardona Navarrete, Rafael Miró Herrero, Juan Carlos García Díaz

\subsubsection{Desarrollo de scripts mediante métodos Montecarlo}

Se han desarrollado scripts que generan mediante métodos Montecarlo simulaciones que son capaces de propagar la incertidumbre de variables y parámetros de entrada de un modelo computacional complejo y estudiar finalmente la sensibilidad de los resultados del modelo a las variables de entrada e identificar de este modo qué variables tienen un mayor impacto en los resultados finales. Para ello se han utilizado dos paquetes específicos para el Análisis de Sensibilidad e Incertidumbre: Package "Tolerance" que provee de funciones para estimar límites de tolerancia para todo tipo de distribuciones, y el Package "Sensitivity" que provee funciones para realizar el análisis de sensibilidad global de las salidas del modelo. Estos scripts son utilizados por los alumnos y se les enseña la capacidad de ampliarlos y modificarlos.

\section{Resultados}

A continuación se exponen los resultados más relevantes obtenidos en las distintas experiencias.

\subsection{Resultados de la introducción de software libre en el Área de Simulación de Procesos}

\subsubsection{Evaluación de software libre para modelado y Simulación de Procesos}

De la exploración de software libre alternativo, inicialmente muy amplia, se pasó a seleccionar las mejores alternativas de software libre (Tabla 1). En esa misma tabla se incluyen los puntos fuertes y puntos débiles más destacados, pudiéndose concluir lo siguiente:

- EXCEL podría llegar a ser sustituido por la aplicación CALC de OpenOffice, pero aún no resulta necesario.

- En cuanto a MATHCAD, que es nuestra herramienta principal, la única alternativa existente con notación matemática SMATH (Smath) no resulta viable por no disponer de los métodos numéricos que necesitamos. La única solución posible sería evolucionar hacia MATLAB o software libre equivalente, lo cual no es muy deseable pues se pierde la representación simbólica de MATHCAD.

- De las dos opciones para sustituir a MATLAB, OCTAVE podría ser la mejor opción por cuanto su sintaxis es muy similar a la de MATLAB lo que permitiría emplear con pequeñas modificaciones todo el abundante material realizado en ese entorno. No

(cc) EY-NC-ND 2014, Universitat Politècnica de València

I Jornadas IN-RED (2014) 
Experiencias de aplicación de la simulación empleando software libre y gratuito en la enseñanza de las ingenierías de la rama industrial

obstante, SCILAB puede ser adecuado. Respecto de MATLAB ambas opciones pierden sobretodo la facilidad de depuración de errores y asistencia a la programación de la que disponen las últimas versiones.

- En cuanto a los Simuladores de Procesos parece que hay un abismo importante entre las versiones libres y las comerciales, mucho mayor que el existente con el software matemático. Las versiones libres resultaron más dificultosas para los alumnos, lentas y de difícil convergencia. Por otra parte, en el software libre muchas unidades no están implementadas y hay un déficit grande de datos termodinámicos. No obstante, en el caso de COCO la posibilidad de programar unidades en MATLAB se revela una gran ventaja pues permite proponer trabajos en los que el proceso esté ya definido por el ordenador y donde el alumno realiza la programación de una unidad específica. Eso sí, al ser la dificultad mucho mayor, recomendamos emplearlo en asignaturas de Máster.

- En cuanto a los programas de Multifísica y de Dinámica de Fluidos Computacional, existe una opción de software libre OPENFOAM viable a nivel de uso, pero que requiere la preparación de ejemplos elaborados previamente por el profesor para que sean factibles para una sesión de clase.

Tabla 1. Equivalencias de software para Simulación de Procesos

\begin{tabular}{|c|c|c|c|}
\hline $\begin{array}{l}\text { Software } \\
\text { comercial }\end{array}$ & Software libre & Puntos fuertes & Puntos débiles \\
\hline EXCEL & $\begin{array}{l}\text { CALC (Open } \\
\text { Office) }\end{array}$ & Muy similar a Excel & $\begin{array}{l}\text { Inferior en algunas } \\
\text { características }\end{array}$ \\
\hline MATHCAD & SMATH STUDIO & $\begin{array}{l}\text { Visualización en formato } \\
\text { matemático }\end{array}$ & $\begin{array}{l}\text { Faltan métodos } \\
\text { matemáticos empleados } \\
\text { en las asignaturas }\end{array}$ \\
\hline MATLAB & OCTAVE & $\begin{array}{l}\text { Sintáxis prácticamente } \\
\text { similar a MATLAB }\end{array}$ & $\begin{array}{l}\text { No tiene un equivalente } \\
\text { de SIMULINK }\end{array}$ \\
\hline MATLAB & SCILAB & $\begin{array}{l}\text { Posee XCOS (una } \\
\text { toolbox análoga a } \\
\text { SIMULINK) }\end{array}$ & $\begin{array}{l}\text { Menos parecido a } \\
\text { MATLAB }\end{array}$ \\
\hline \multirow[t]{2}{*}{ CHEMCAD } & DWSIM & $\begin{array}{l}\text { Interfaz gráfica } \\
\text { aceptable }\end{array}$ & $\begin{array}{l}\text { Menos potente que } \\
\text { Chemcad }\end{array}$ \\
\hline & $\mathrm{COCO}$ & $\begin{array}{l}\text { Posibilidad de } \\
\text { implementar nuevas } \\
\text { unidades }\end{array}$ & $\begin{array}{l}\text { Menos potente que } \\
\text { Chemcad }\end{array}$ \\
\hline COMSOL & OPENFOAM & Potente y versátil & Dificil de utilizar \\
\hline
\end{tabular}


En resumen, en lo que respecta al software de análisis matemático y simulación de procesos, al menos podemos decir que, en el caso de indisponibilidad del software comercial, se podrían cubrir unos mínimos docentes. No obstante, se necesita realizar un esfuerzo importante en la preparación de guías y ejemplos para lograr una sustitución completa.

\subsubsection{Planteamiento de casos para resolver empleando software libre}

La realización de proyectos utilizando software libre, ha obtenido muy buenos resultados.

En el caso de la asignatura "Simulación y Optimización de Procesos Químicos" de Ingeniero Químico se aplicó la modalidad de trabajo en grupo en el curso 2012. Los alumnos podían decidir realizar el trabajo o evitarlo dando el porcentaje que representaba al examen (12\%). Más del $90 \%$ de los alumnos escogió realizar el trabajo, además los alumnos mostraron satisfacción general el día de las presentaciones sobre los trabajos que habían sido capaces de realizar. La gran motivación alcanzada en la mayoría de grupos se explica por la sensación de logro obtenida al poder alcanzar dominio sobre un software antes desconocido y ser capaces de resolver un problema concreto prácticamente por sí mismos. Además, se contribuyó sin duda a la mejora de la interacción grupal y de habilidades de exposición de resultados.

En el caso de la asignatura "Modelización y Optimización de Procesos de Membrana y Medioambiente" donde se experimentó con la modalidad de proyecto más del $90 \%$ de los alumnos encuestados consideraron conveniente su introducción. La motivación fue muy alta, asistiéndose de manera generalizada a todas las clases de apoyo a la realización del trabajo. Además, valoraron de forma positiva disponer del software. Solo un porcentaje mínimo de los alumnos no presentó el trabajo (5\%).

Podemos considerar que las perspectivas de esta metodología son satisfactorias. Los proyectos con software libre ya van a quedar establecidos como parte fundamental de la asignatura "Modelización y Optimización de Procesos de Membrana y Medioambiente" y en la nueva asignatura del Máster de Ingeniero Químico "Modelización y Optimización de Procesos Químicos" que sustituye a "Simulación y Optimización de Procesos Químicos”.

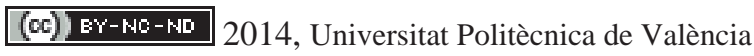

I Jornadas IN-RED (2014) 
Experiencias de aplicación de la simulación empleando software libre y gratuito en la enseñanza de las ingenierías de la rama industrial

4.2. Resultados de la introducción de herramientas de software libre en Cinética Química y Reactores

\subsubsection{Resultados y perspectivas}

Considerar una alternativa como el formato CDF es atractivo por cuanto permite desarrollar aplicaciones potentes trasladables inmediatamente a diferentes entornos y sistemas operativos (MSWindows, Mac o Linux).

Los resultados derivados de la utilización de SIMULINK y XCOS han sido muy satisfactorios por cuanto que el alumno interioriza con facilidad la modelización de la dinámica de reactores. Esto es especialmente interesante en alumnos sin destrezas de programación plenamente desarrolladas. Adicionalmente, estas herramientas permiten explorar el comportamiento de sistemas no lineales y su correspondiente equivalente linealizado, lo cual es también de interés para el desarrollo de las materias relacionadas con el Control de Procesos.

\subsection{Resultados de la introducción de herramientas para Análisis de Sensibilidad e Incertidumbre}

\subsubsection{Resultados}

Se ha constatado que el alumno de nivel de máster y doctorado posee capacidad suficiente para la utilización de estas aplicaciones de software avanzadas.

El hecho de proporcionar al alumno herramientas que va a poder utilizar directamente en su vida profesional ha constituido un elemento de motivación muy importante.

\subsubsection{Perspectivas}

La utilización de software estadístico libre está cada vez más extendida en la comunidad científica internacional proporcionando herramientas estadística avanzadas en tiempo casi real a los potenciales usuarios mucho antes que cualquier software comercial que además supone grandes inversiones. Por todo ello el futuro ingeniero va a poder contar con herramientas estadística ilimitadas totalmente accesibles, mantenidas y mejoradas por una comunidad científica sin ánimo de lucro. 
Asunción Santafé Moros, José M. Gozálvez Zafrilla, Javier Navarro Laboulais, Salvador Cardona Navarrete, Rafael Miró Herrero, Juan Carlos García Díaz

\section{Conclusiones}

Hemos presentado tres áreas de la ingeniería diferentes donde se ha aplicado software libre en la enseñanza, habiéndose observándose diferencias en función del nivel del alumnado y del tipo de aplicación.

Una de las limitaciones para implantar el software libre es que muchas veces las interfaces de las versiones libres en desarrollo no son tan atractivas como la del software comercial, lo cual requiere un esfuerzo adicional por parte del profesorado para clarificar el uso del entorno.

En un futuro cercano se tendrá que propiciar los métodos de aprendizaje a partir de dispositivos móviles, ampliamente utilizados por los alumnos.

En general, podemos decir que el software libre es cada vez más potente y que un futuro cercano podría llegar a cubrir por sí solo la mayor parte de las necesidades docentes, quedando el software comercial para cubrir necesidades específicas en la vida laboral.

\section{Agradecimientos}

Los miembros del grupo ASEI agradecen a Vicerrectorado de Estudios y Convergencia Europea y al Instituto de Ciencias de Educación de la Universitat Politècnica de València la concesión del PIME A20-11 "Utilización de herramientas de simulación en software libre como metodología de bajo coste para aumentar el rendimiento de la enseñanza (SIMULIB)"

\section{Referencias}

AMSTERCHEM-COCO "Página de descarga del simulador COCO" <http://www.cocosimulator.org/> [Consulta : 11 de junio de 2014]

AmsterChEM-CONNECTOR "Página de descarga de MATLAB-CAPE Open y SCILAB-CAPE Open" $<$ http://www.amsterchem.com/downloads.html> [Consulta : 11 de junio de 2014] [institucional]

APACHe OpenOfFice "Página oficial de Open Office" <http://www.openoffice.org/> [Consulta : 11 de junio de 2014]

ASEI (2012) “Constitución del blog ASEI" > http://asei.blogs.upv.es/ > en ASEI (EICE de la UPV) [Consulta : 11 de junio de 2014]

(c) $\mathbf{\text { EY-NC-ND }}$ 2014, Universitat Politècnica de València

I Jornadas IN-RED (2014) 
Experiencias de aplicación de la simulación empleando software libre y gratuito en la enseñanza de las ingenierías de la rama industrial

Dow "Página de descarga del software ROSA (Reverse Osmosis System Analysis) de Dow-Filmtec" <http://www.dowwaterandprocess.com/en/resources/rosa_system_design_software> [Consulta : 11 de junio de 2014]

DWSIM-WIKI "Página de descarga del software de Simulación de Procesos DWSIM" <http://dwsim.inforside.com.br/wiki/index.php?title=Main_Page > [Consulta : 11 de junio de 2014]

EPA-USA "Página de descarga de 1 software Tanks 4.09 y recomendaciones para Windows 7 o sistema superior" <http://www.epa.gov/ttnchie1/software/tanks/> [Consulta : 11 de junio de 2014]

Gozalvez Zafrilla, J.M., Santafe Moros, A. (2008) "Enseñanza de la simulación de procesos de membrana mediante objetos de aprendizaje y herramientas de cálculo". V Congreso Iberoamericano de Docencia Universitaria - Enseñar y aprender en la enseñanza del siglo XXI. Valencia

Gozalvez Zafrilla, J.M. (2009) "Objetos de aprendizaje (localizables en buscador)" <http://riunet.upv.es/discover> [Consulta : 11 de junio de 2014]

Gozalvez Zafrilla, J.M. y Santafe Moros, A. (2011). Análisis y simulación con MATHCAD y MATLAB de procesos de parámetros globalizados. Valencia: Editorial Universitat Politècnica de València

Gozalvez Zafrilla, J.M., SANTAFe Moros, A., SANCHIS, M., GOMIS, J. (2014) "Implementation of membrane models on a CAPE-open tool to simulate a process including reverse osmosis stages" Iberoamerican Conference on Membrane Science and Technology (CITEM 2014). Santander : Universidad de Cantabria. 168-169

HYDRANAUTICS "Página de descarga de IMSDESIGN"

<http://www.hydranautics.com/index.php?pagename=imsdesign> [Consulta : 11 de junio de 2014]

OCTAVE ProJECT "Página oficial del proyecto GNU Octave" <http://www.gnu.org/software/octave/> [Consulta : 11 de junio de 2014]

RAwlings, J.B., EKERDT, J.G (2002). "Chemical reactor analysis and design fundamentals". Madison (EEUU): Nob Hill Pub

SAntAFE Moros, A. (2009) "Objetos de aprendizaje (localizables en buscador)" <http://riunet.upv.es/discover> [Consulta : 11 de junio de 2014]

Santafe Moros, A., Gozalvez Zafrilla, J.M. y J. Lora (2013). Cálculo de operaciones de separación con MATHCAD. Valencia : Editorial Universitat Politècnica de València (versiones en papel y en e-book)

SCILAB ENTERPRISES "Página oficial del proyecto SCILAB" <http://www.SCILAB.org/> [Consulta : 11 de junio de 2014]

SMATH DEVELOPERS "Página oficial Smath Studio" <http://smathstudio.com/> [Consulta : 11 de junio de 2014]

(cc)) EY-NC-ND 2014, Universitat Politècnica de València

I Jornadas IN-RED (2014) 
Asunción Santafé Moros, José M. Gozálvez Zafrilla, Javier Navarro Laboulais, Salvador Cardona Navarrete, Rafael Miró Herrero, Juan Carlos García Díaz

WIKIPEDIA (2012) "Listado de simuladores de procesos químicos"

<http://en.wikipedia.org/wiki/List_of_chemical_process_simulators> [Consulta : 11 de junio de 2014]

WiKIPEDIA (2013) "Listado de software de análisis numérico"

<http://en.wikipedia.org/wiki/List_of_numerical_analysis_software> [Consulta : 11 de junio de 2014]

WOLFRAM "Página oficial de Wolfram-Mathematica" <http://www.wolfram.com/cdf-player/> [Consulta : 11 de junio de 2014]

(cc) EY-NC-ND 2014, Universitat Politècnica de València

I Jornadas IN-RED (2014) 


\title{
Retos de la Agricultura y la Alimentación en el siglo XXI, una experiencia de aprendizaje colaborativo ${ }^{1}$
}

\author{
Víctor Martínez Gómez ${ }^{\mathrm{a}}$, Olga M. Moreno Pérez ${ }^{\mathrm{b}}$, Raúl Compés López ${ }^{\mathrm{c}}$, Lorena \\ Tudela Marco ${ }^{\mathrm{d}}$ José $\mathrm{M}^{\mathrm{a}}$ García Álvarez-Coque ${ }^{\mathrm{e}}$ \\ avicmargo@esp.upv.es, bomoreno@esp.upv.es, rrcompes@esp.upv.es, \\ ${ }^{\mathrm{d}}$ lotumar@etsia.upv.es, ${ }^{\mathrm{j}} \mathrm{jmgarcia} @$ upvnet.upv.es \\ Grupo de Economía Internacional y Desarrollo. Universitat Politècnica de València \\ ETSIAMN, Edif.3B Cami de Vera, s/n 46022 Valencia, Spain
}

\begin{abstract}
The main objective of this contribution is to share the collaborative learning experience of the Massive Open Online Course (MOOC) "Challenges for agriculture and food in the 21st century".

The course promotes and strengthens a space for debate and joint reflection on the far-reaching subject of agriculture and food question "How do we feed a growing population in a sustainable way? and how do we address the growing problems of limited natural resources worldwide? We take a connective MOOC as an opportunity to encourage self-learning and to express different views, practices and realities over the agriculture. Statistics on monitoring and participation were successful, with over 1160 participants who finished the activities of the first edition (a third of members registered). This brought us to carry on with the second edition in the UPVx platform, where we obtain similar satisfactory rates of completion.
\end{abstract}

This emergent vision of education is being well received and could be a useful tool to solve the increasing demand of plural knowledge. Our

\footnotetext{
${ }^{1}$ Los autores agradecen el apoyo del proyecto 'Organizational forms of innovation in agri-food sector and its effects on economic outcomes and innovation performance' (AGL2012-39793-C03-02) financiado por el Ministerio de Economía y Competitividad. Asimismo agradecen la asistencia técnica del Área de Sistemas de Información y Comunicación de la UPV, y la colaboración de Sara Hernández y Rosmery Ramos en las labores de dinamización de los foros.
}

(c)) BY-NC-ND 2014, Universitat Politècnica de València I Jornadas In-Red (2014) 
Retos de la Agricultura y la Alimentación en el siglo XXI, una experiencia de aprendizaje colaborativo

goal is to share the lessons learned in order to work on further improvements, enhance exchange knowlegde and encourage spillovers over the education system.

Keywords: MOOC, coperative learning, plural knowlegde, food and agriculture.

\section{Resumen}

El principal objetivo de esta contribución es compartir una experiencia de aprendizaje colaborativo basada en el curso online masivo y abierto (MOOC) "Retos de la agricultura y la alimentación en el siglo XXI".

El curso genera un espacio de debate y reflexión en torno a la agricultura y la alimentación a partir de una cuestión de gran alcance “¿Cómo asumir el reto de alimentar una población creciente en un planeta donde los recursos son limitados?". Entendemos el MOOC como una oportunidad para fomentar el autoaprendizaje, y expresar diferentes visiones y realidades de la agricultura. Las estadísticas de participación y seguimiento del curso fueron exitosas, con 1.160 participantes que finalizaron las actividades en la primera edicion, lo que supuso aproximadamente un tercio de los inscritos. Ello nos animó a lanzar la segunda edición del curso en la plataforma UPVx, con tasas de finalización igualmente satisfactorias.

Esta emergente modalidad de aprendizaje está siendo bien recibida y se va consolidando como una herramienta útil, capaz de dar respuesta a una demanda creciente de conocimiento plural. Sin duda, también plantean retos y dudas a resolver. Nuestra intención es compartir lo aprendido para ser capaces de incorporar mejoras, aplicarlas en beneficio del conocimiento con la intención de aumentar las posibilidades de intercambio y aprovechar spill-overs sobre el resto del sistema educativo.

Palabras clave: MOOC, aprendizaje colaborativo, conocimiento plural, agricultura y alimentacion. 


\section{Introducción}

Los MOOC (acrónimo en inglés de Massive Open Online Course) son conocidos como cursos online masivos y abiertos ofrecidos gratuitamente a través de una plataforma educativa en Internet. Se caracterizan por priorizar la liberación del conocimiento con la intención de que llegue al máximo público posible. En España los primeros cursos comenzaron en el año 2012 y desde entonces no ha dejado de aumentar su oferta y el número de participantes. Esta iniciativa recibió una buena acogida por parte de la Universitat Politècnica de València (UPV), que no dudo en asumir el reto y compartir la propuesta con su equipo de profesores.

Toda actividad formativa debe responder a unas necesidades reales, y en nuestro caso nos planteamos el problema de alimentar al planeta ante una poblacion creciente, con instituciones y expertos que sugieren que la producción agraria del planeta tendrá que aumentar un $60 \%$ para poder alimentar esa población. Lógicamente, este problema despierta muchas preguntas y alguna que otra respuesta. Ante esta situacion, entendimos que cualquier aproximación requiere un espíritu crítico (Tomlinson, 2011).

¿Seremos capaces de aumentar la producción sin agotar los recursos del planeta? ¿Es realmente imprescindible incrementar la producción? ¿No tendríamos que cambiar nuestro estilo de vida y los hábitos de la alimentación? ¿Cómo mejorar los medios de subsistencia de la población rural sin debilitar su capital social? ¿Pueden administrarse los recursos para un futuro sostenible y justo? ¿Cómo mitigar y adaptar las sociedades al cambio climático? ¿Qué es el derecho a la alimentación? Son cuestiones básicas y debatibles, por ahora sin respuesta evidentes.

La respuesta del MOOC Retos fue la de abrir un espacio de reflexión en torno a la agricultura y la alimentación, sin repuestas preconcebidas. El MOOC es una gran oportunidad para fomentar el autoaprendizaje, y expresar diferentes visiones y realidades. Dos han sido las ediciones del curso "Retos de la Agricultura y la Alimentación en el siglo XXI". En la primera edición (2013), se elaboraron un total de 32 videos breves (una media de 7 minutos) con una síntesis de contenidos básicos, fuentes de información adicionales y propuestas de debate, divididos en 8 unidades,

(c)) EY-NC-ND 2014, Universitat Politècnica de València 
que se fueron activando de forma progresiva a lo largo de 8 semanas. En la segunda edición (2014), se propusieron videos cortos adicionales, unos de producción de la Cátedra Tierra Ciudadana y otros de la UPV-TV, con testimonios de actores como desencadenantes de los debates que se activaron en los foros del curso.

En las próximas páginas compartirmos las principales lecciones aprendidas de la experiencia de aprendizaje colaborativo basada el curso "Retos", con la intencion de colaborar en la construccion y mejora de esta herramienta de intercambio de conocimiento.

\section{Los cursos MOOC ¿una experiencia especial?}

Un MOOC es, por encima de todo, un curso, por lo tanto tiene unas lecciones, unos materiales, unas herramientas de comunicación. Pero un MOOC es, sobre todo, una experiencia compartida, una fecha de inicio y finalización para todos los participantes y algún tipo de acreditación.

Ahora bien, ¿qué hace un curso MOOC sea una experiencia especial?. Es la idea del conocimiento abierto. Porque el conocimiento no está encerrado en las Universidades sino que se almacena sobre el terreno y en cada experiencia. Esta es la idea que guió la elaboración del International Assessment of Agricultural Knowledge Science and Technology for Development (IASSTD) iniciado en 2002, que refuerza la propuesta de repensar nuestro sistema alimentario global para que pueda alimentar personas, crear comunidades y economías saludables de forma sostenible. Lo que implica contemplar todas la visiones, tácita y explícita, del conocimiento. E impulsar un desarrollo tecnológico, pero también las mejores practicas de un conocimiento tradicional transmitidas entre generaciones de agricultores.

"Retos" planteó un espacio para compartir conocimiento. Es muy gratificante cuando se comparte de una manera global, entre cientos o miles de personas, en forma de foros de debate, donde participan consumidores, agricultores, doctores en economía y estudiantes de agronomía, por citar alunos ejemplos. Sin duda, una de las características innovadoras de los MOOCs es la dinamización de conocimientos que se comparten entre todos los que intervienen en los foros a través de un debate respetuoso e inclusivo.

(cc) BY-NC-ND 2014, Universitat Politècnica de València

I Jornadas IN-RED (2014) 


\subsection{Una experiencia online}

Los cursos online se multiplicaron hace ya más de quince años, y ya no son nada nuevo en el mundo educativo. Miembros del Grupo de Economía Internacional y Desarrollo de la UPV participaron en el Proyecto FODEPAL de formación en economía y política agraria para América Latina, auspiciado por la AECID y la FAO entre 1999 y 2008. Durante esa experiencia, aprendimos que en los cursos online la instrucción clave es la sencillez, la posibilidad de transmitir rapidamente y sin malentendidos. pero la sencillez no es fácil de alcanzar. Si abres un foro tienes que dejar que los participantes del curso abran hilos de discusión como en la primera edición Retos, con 248 hilos de discusión con más de 3.500 mensajes (en la segunda edición se abrieron más de 500 hilos con más de 2000 mensajes). Los tutores intentamos vamos abriendo temas y orientando mediante un blog, aunque solo para decirles que hay tiempo para realizar actividades, y darles un poco de ánimo para que no vayan abandonando.

No es fácil organizar un MOOC, y la sencillez debe ser una guía. Pero también la flexibilidad. No vaya ser que al ordenar tanto, la gente se sienta encorsetada y luego no participe. Es importante dejar un margen de flexibilidad y permitir que se equivoquen porque la manera de aprender es fallando también. El teórico de la comunicación Clay Shirky apunta en una deliciosa charla cómo las instituiones cerradas (¿es la universidad una de ellas?) van cerrando paso a redes flexibles donde las contribuciones pequeñas y la cooperación fluida reemplazan la comunicación jerárquica y excesivamente planificada. " 2 "Retos" puede considerarse un MOOC (con "c" de conectividad) como comunidad discursiva que crea un conocimiento conjunto (Siemens, 2005).

\subsection{Una experiencia abierta}

Un elemento revolucionario de los MOOCs es su carácter abierto. Para ello tiene que ser muy fácil registrarse y ser gratuito. Las lecciones se graban previamente, en formato Polimedia o en objetos de aprendizaje y se registran en Youtube ${ }^{3}$. De hecho, los videos siempre están accesibles en youtube. Pero sólo se convierte en un curso cuando se incorporan fechas de

\footnotetext{
${ }^{2}$ Ver TED Global (2005). Institutions vs. collaboration by Clay Shirky: http://www.ted.com/talks/clay_shirky_on_institutions_versus_collaboration.

${ }^{3}$ Ver Lista "Retos de la Agricultura y la Alimentación en el siglo XXI"
} 
inicio y de finalización y unas protocolos de funcionamiento para una experiencia compartida. Esos protocolos de colaboración son los que convierten a "Retos" en una experiencia. Estando los contenidos disponibles en abierto, se ofrecen a lo largo del curso distantas actividades, cuestionarios y foros. De ahí salen los debates, y se van respondiendo los alumnos entre sí.

Que un MOOC sea abierto no significa que el MOOC sea libre de costes. De hecho, ha habido un gran esfuerzo de voluntariado en la realización de la primera generación de MOOCs de la UPV, cuyos costes se controlan por la experiencia acumulada en la universidad en cursos online.

Pero la inversión en horas de trabajo puede ser sustancial. Algunas escuelas privadas gastan muchos miles de euros en un curso (millones en algún caso), que no es el caso de los MOOCs de la Politécnica. La UPV optimiza sus recursos, pero es claro que un MOOC tiene un coste. Cuando el curso llega a miles de personas, el coste por persona se reduce, y el coste por participante puede situarse entre uno a cinco euros. Así, puede tratarse de una inversión eficiente para una universidad pública. Puede hablarse también de un modelo de negocio, como forma de recuperación de algunos costes, pero el planteamiento debe tener una visión a largo plazo, para poder legitimar el modelo ante la sociedad. Lógicamente, Retos ha sido una oportunidad para dar a conocer las formaciones en Economía Agroalimentaria y otras ciencias sociales de la UPV. Hay muchas otras ventajas como los materiales producidos que usamos en nuestra docencia reglada, y la misma promoción de la UPV como polo, más bien como dinamizador, de conocimiento. Hay muchos participantes que no mandan mensajes en el foro, pero estaban ahí, conocen tu trabajo y tu universidad, y que es grato conocer en reuniones y congresos cuando le dicen a una docente de Retos "Hola, doctora, gracias por su clase".

\section{3 ¿Qué significa "masivo”?}

El término "masivo" comporta algunos problemas. El número de participantes depende de cuál es el público objetivo y de cómo lo vas a enfocar. Ni de lejos podíamos llegar a los 160 mil del curso de Inteligencia Artificial promovido en 2011 por Thrun y Norvig, máxime con un curso en lengua española. En el caso de Retos, un curso de agricultura, es facil que no se encuentre un publico masivo, no porque el número de afectados por la

(cc) BY-NC-ND 2014, Universitat Politècnica de València

I Jornadas IN-RED (2014) 
temática agraria no sea multitudinario (de hecho, hay cientos de millones de agricultores y miles de millones de consumidores de alimentos), sino porque el número de personas dedicada a pensar en soluciones para los problemas globales de la agricultura es limitado. Hablamos de una tematica mas bien especializada. Y de un método que incorpora una comunidad virtual, que es uno de los atractivos de Retos, pero que va restringiendo la masividad del curso. En nuestro caso, la primera edición de Retos arrancó con 3.530 inscritos de 40 nacionalidades diferentes. En miles de mensajes los participantes se esfuerzan en reflejar sus opiniones, dudas, ejemplos y propuestas.

\section{Figura 1. Seguimiento del MOOC Retos $1^{\circ}$ y $2^{\circ}$ Edicion. Porcentaje de participantes que finalizan Módulos}

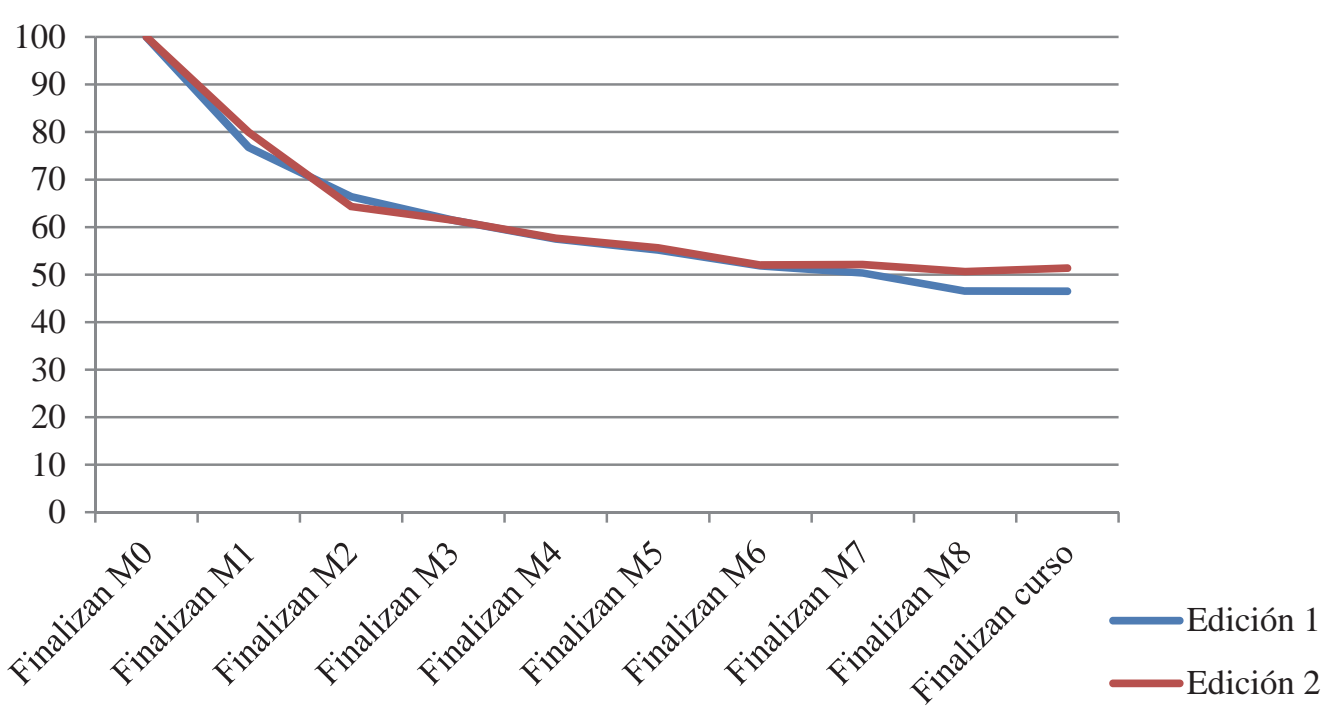

Fuente: Calculado por los autores.

Un problema de la masividad es el abandono y esto es lo que se muestra en la curva de seguimiento de la Figura 1. Se observa la tendencia enforma de L con una tasa de abandono cercana al $40 \%$ de los iniciados a la altura de la segunda semana, pero una estabilidad notable a partir de la sexta semana. De hecho, que finalicen el curso un 50\% de los iniciados (es decir, los que realizan el Módulo 0 introductorio), puede ser considerado un resultado satisfactorio. De hecho, según un estudio reciente de la Escuela Europea de Dirección de Empresas, la tasa de abandono de MOOCs en España es 
cercana al $90 \%{ }^{4}$. En ambas ediciones de Retos, la tasa de seguimiento primero cae drásticamente pero luego ya enlaza a una meseta, donde se reducen en numero de abandonos, siendo la tasa de finalización superior en Retos 2 que en Retos 1.

Es destacable que la tasa de finalización no cambió significativamente con el cambio de plataforma de este curso, que realizó la primera edición con Miriada X y la segunda edición con UPVx.

\subsection{Perfil de los participantes}

El cambio a la plataforma soportada por UPVx ha permitido mantener la esencia del conocimiento abierto del curso, aunque el número de participantes descendió a la mitad, frente a la edición anterior soportada por MiríadaX. Finalizaron "Retos 2", 616 participantes, frente a los 1160 de "Retos 1". Nuestra valoración de este descenso no es negativa, dado que el ámbito de difusión de una plataforma universitaria específica como UPVx tiene que ser necesariamente más restringido que el de toda la red Universia, que da difusión a Miriada X.

Al inicio del curso los participantes reciben una encuesta voluntaria que permite orientar sobre el perfil de los participantes. Esto ha sido de mucha utilidad en el diseño de la segunda edición, que ha estado algo más focalizada en su temática y nivel. A la altura de la redacción de este trabajo, nos encontramos procesando los datos de la segunda edición de Retos, por lo que sólo presentamos resultados de la primera edición. A continuacion destacamos algunos de los datos de interes:

El país de origen de los alumnos mayoritariamente fue España, pero hubo una presencia significativa de participantes de países de América Latina como Colombia y México (ver Figura 2). Estamos hablando, por ejemplo, de unos cuatrocientos inscritos de Colombia.

Figura 2. Distribución del seguimiento por paises de la $1^{\circ}$ Edicion de Retos

\footnotetext{
${ }^{4}$ Ver Carrizosa, S. (2014) "La deserción puede con los cursos online", El País 12 de Enero de 2014, http://economia.elpais.com/economia/2014/01/10/actualidad/1389360489_728192.html
}

(cc)) BY-NC-ND 2014, Universitat Politècnica de València

I Jornadas IN-RED (2014) 


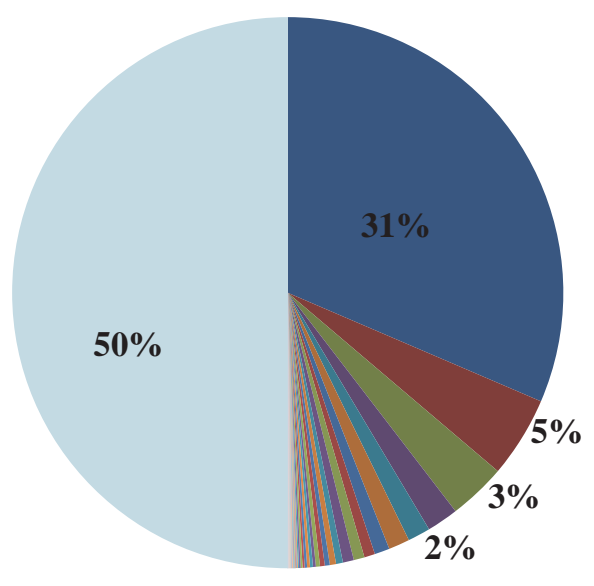

Fuente: Equipo ASIC-UPV

España
- Colombia
México
q Perú
- Argentina
Venezuela
Brasil
Italia
Chile
Bolivia
Ecuador
- Uruguay
Francia
El Salvador
- Portugal
- Costa Rica
Sin especificar
Alemania

Alemania

Es interesante destacar la participacion de las mujeres, en porcentajes cercanos al $60 \%$ de los participantes. En cuanto a la edad, la franja mayoritaria era entre 24 y 33 años. ¿Puede indicar que existe un mayor interés por los problemas de los campesinos y el medio rural en este grupo?

En relación al nivel de estudios de los participantes, no se pedia ningún requisito previo. Sin embargo, los resultados reflejan que del total de los participantes, el 56\% había completado un grado universitario, el $23 \%$ una maestría y el 5\% un doctorado universitario. Es un nivel de estudios relativamente elevado para un curso introductorio, lo que sugiere que quizás estos temas se perciban como una especialización: de hecho, comprender los procesos alimentarios no supone adquirir conocimiento de una técnica básica. Y explica que aunque el número de egresados haya sido cercano a 2000 en dos ediciones, no hablamos de un curso de masividad elevada, comparada con otros.

Por ultimo, en la encuesta se les pregutaba a los participantes como conocieron la iniciativa de retos. Sin duda, el papel de la Plataforma MiríadaX, impulsada por toda la red Universia, favoreció que un $28 \%$ de los 
participantes conocieran Retos. Sin embargo, un 33\% lo conocieron porque se lo había recomendado un amigo y a continuación los medios de comunicación como Facebook y las redes sociales tuvieron un papel fundamental.

\section{Conclusiones}

En ambas ediciones de "Retos" las estadísticas de participación y seguimiento fueron satisfactorias: un tercio de los inscritos y la mitad de los que iniciaron el test inicial del Módulo 0 finalizaron el curso. Sin embargo, consideramos que la valoración del curso debe ir más allá que algunos indicadores numéricos. Porque el conocimiento no está encerrado en las Universidades sino que se extiende sobre el terreno y en experiencias cuya aplicación requiere participación social. Y la realidad es que estas incipientes modalidades de docencia están siendo bien recibidas y se van consolidando como una herramienta útil, capaz de dar respuesta a una demanda creciente de conocimiento. Sin duda, también plantean desafíos y dudas a resolver: ¿Cuál es su coste? ¿Cómo certificar y verificar su seguimiento? ¿Existe algún filtro previo de calidad? ¿Cuáles son sus ventajas para la universidad?.

Todas estas preguntas indican que estas iniciativas de coordinación flexible del conocimiento seguirán evolucionando desde este estado incipiente. Por lo tanto, estamos aprendiendo y a tiempo de incorporar mejoras, aplicarlas en beneficio del conocimiento y aumentar las posibilidades de intercambio y aprovechar spill-overs sobre el resto del sistema educativo.

\section{Referencias}

Siemens, G. (2005) Conectivismo: Una teoría de la enseñanza para la era digital, International Journal of Instructional Technology and Distance Learning 2 (10).

Tomlinson, I. (2011) Doubling food production to feed 9 billion: a critical perspective on a key discourse on food security in the UK, Journal of Rural Studies XXX: 1-10. 


\title{
Estrategias y herramientas para fomentar la participación y el feedback rápido en clase: Smartphones como Clickers
}

Juan Carlos Ruiz García , David de Andres Martínez ${ }^{\mathrm{b}}$, Eva Antonino Daviu ${ }^{\mathrm{b}}$, José Vicente Ballester Server ${ }^{\mathrm{d}}$, Carmina Gisbert Doménech ${ }^{\mathrm{e}}$, Alberto Palomares Chust ${ }^{\mathrm{f}}$, Antonio Peña Cerdán ${ }^{\mathrm{g}}$ y Carlos Villavieja Llorente ${ }^{\mathrm{h}}$

a DISCA-UPV, jcruizg@disca.upv.es, b DISCA-UPV, ddandres@disca.upv.es, c DCOM-UPV, evanda@upvnet.upv.es, Universitat de València (UV), jvballester@pros.upv.es, ${ }^{\mathrm{e}}$ BTC-UPV, cgisbert@btc.upv.es, ${ }^{\mathrm{f}}$ DSIC-UPV, apalomares@dsic.upv.es, ${ }^{\mathrm{g}}$ PRA-UPV, anpecer2@pra.upv.es, y ${ }^{\text {h } H A R, ~ c a v i l l a v @ h a r . u p v . e s . ~}$

\begin{abstract}
Audience Response Systems (ARS) enable interactions promiting students's participation in classes and providing fast feedback of class status to teachers. In these systems, the use of an answer wireless device, named clicker, is necessary. Most of the times, clickers are specific and expensive devices, whick limits their practical use in classes. The proliferation of tablets and smartphones among students offers the possibility of exploiting the use of such devices in class as clickers. This paper explains the research carried out by the EICE TASCA (Tools and Strategies for Competences Assessment) group in this particular domain. On one hand, the document reviews i) the different strategies and activities supported by clickers, ii) the various types of questions that can be formulated to students using this devices and iii) the diversity of tools and technologies enabling the use of smartphones and tablets as clickers. On the other hand, the contribution reports on the experiences carried out by TASCA members and analyses the advantages and disadvantages of using mobile devices as clickers in classes.
\end{abstract}

Keywords: fast feedback, Classroom/Student/Audience Response Systems (ARS), Mobile devices, Smartphone, Tablet, Student participation in class

\begin{abstract}
Resumen
Los sistemas de respuesta de la audiencia facilitan la interacción profesor-alumno, fomentando la participación del discente mientras se realimenta al docente con información sobre lo trabajado en clase. Para ello, es necesario el uso de un tipo de dispositivo inalámbrico de respuesta que se conoce comúnmente con el nombre de clicker. En muchas soluciones, estos clickers son específicos y caros, lo que limita en la práctica su uso en las aulas. El uso generalizado de tabletas y smartphones entre los alumnos abre una puerta a la explotación de dichos dispositivos móviles como clickers. A partir del trabajo realizado por el EICE Tools and Strategies for Competences Assessment (TASCA) en el marco de los Proyectos de Innovación y Mejora Educativa promovidos por la Universitat Politècnica de València, este artículo revisa las diferentes estrategias y actividades soportadas por los clickers, los
\end{abstract}


diferentes tipos de pregunta que permiten plantear a los alumnos y las herramientas existentes que permiten el uso de smartphones y tabletas como clickers. Además se reportan las experiencias realizadas por los miembros del grupo TASCA en este ámbito haciendo hincapié en las ventajas, inconvenientes y utilidad del uso de los dispositivos móviles como clickers en clase.

Palabras clave: Sistemas de respuesta de la audiencialalumnado, participación del alumno en clase, realimentación rápida en el aula, dispositivos móviles, smartphones, tabletas, clickers

\section{Introducción}

Los sistemas de respuesta de la audiencia, del inglés Classroom/Student/Audience Response Systems (ARS) [1][2] permiten realizer preguntas colectiveas a una audiencia y recoger las respuestas individuales emitidas por la misma mediante unos dispositivos inalámbricos, comúnmente conocidos como clikers. Estos sistemas pueden ser utilizados en el aula para realizar encuestas, preguntas para fomentar el debate, efectuar un seguimiento de la clase o realizar actividades de evaluación continua a los alumnos.

Los beneficios que, desde una perspectiva docente, ofrecen los ARS son múltiples [3] e incluyen los siguientes aspectos: i) mejoran la atención de los alumnos [4], que decae al cabo de 10-18 minutos de escucha pasiva [5]; ii) mejoran la participación activa del alumno [6], ya que todos deben contestar a las preguntas, lo que puede redundar en la asimilación de los contenidos abordados en la clase; iii) permiten la participación anónima de los alumnos [7], evitando conflictos con alumnos tímidos o preguntas delicadas relativas a temas éticos y morales; iv) permiten comprobar el nivel de comprensión de los alumnos y adaptar la clase para clarificar los aspectos principales tratados (feedback inmediato [8]); v) permiten obtener información global e individualizada para, entre otras cosas, obtener la relación de asistentes, realizar el seguimiento individualizado de los alumnos y obtener datos que puedan ser posteriormente analizados para investigaciones relativas a experiencias educativas; y vi) crean un entorno de aprendizaje interactivo y ameno [9].

A pesar de las grandes posibilidades docentes ofrecidas por los ARS su uso práctico en las aulas está bastante limitado actualmente. Por un lado, muchas de las soluciones existentes, como EduClik (http://educlick.es), eInstruction (http://www.einstruction.com/) o SMART Technologies (http://smarttech.com/us), son propietarias y requiren del uso de programas y dispositivos emisores y receptores específicos que tienen un coste no despreciable y que, en general, se integran poco o mal con el resto de tecnologías existentes ya en los centros educativos para uso docente. Por otro lado, el uso de estos sistemas de respuesta en clase no es evidente y necesita que, tanto de profesores como de alumnos, aprendan a servirse del sistema, lo que require de un tiempo del que en muchas ocasiones se carece, y además, estén capacitados técnicamente para desplegarlo y manipularlo, algo que no siempre sucede.

Sin embargo, la democratización que han experimentado los dispositivos móviles en los últimos años abre la puerta al uso de los teléfonos inteligentes y las tabletas como clickers de propósito general en las aulas. En efecto, prácticamente la totalidad del alumnado universitario dispone actualmente de un dispositivo móvil propio con conectividad inalámbrica [10]. Este hecho, unido a que la mayor parte de los centros educativos ofrezcan 
hoy en día conectividad inalámbrica a sus alumnos, portales y herramientas de e-learning, así como modernas aulas equipadas con ordenadores y proyectores, nos permite afirmar que todo lo necesario para explotar los beneficios de los ARS en las aulas está a nuestra disposición si deseamos utilizarlo. Además, la familiaridad con la que nos relacionamos con los dispositivos y utilizamos sus capacidades de procesamiento, almacenamiento y comunicación, hace pensar que la complejidad técnica y la inversión temporal necesarias para utilizar dichos sistemas serán en la práctica muy reducidos.

A pesar de todo, la gran barrera para la adopción de los ARS en las aulas es el desconocimiento de este tipo de sistemas, de sus beneficios para la docencia y de su facilidad de uso si se emplean dispositivos móviles como clickers.

En este artículo vamos a abordar:

- Las diferentes estrategias/actividades soportadas por los clickers, tales como la evaluación sumativa, la evaluación formativa, la enseñanza de contingencia, la enseñanza entre pares, el control de asistencia, etc.

- Los diferentes tipos de pregunta soportados para facilitar dichas estrategias, tales como de memorización, entendimiento conceptual, aplicación, pensamiento crítico, perspectiva del estudiante, nivel de confianza, monitorización, experimentación, etc.

- Las diversas herramientas gratuitas existentes que permiten la utilización de los propios dispositivos móviles de los alumnos para responder a las preguntas planteadas.

- Las experiencias realizadas por los miembros del grupo TASCA en las diferentes asignaturas que imparten para aportar su experiencia, haciendo hincapié en las ventajas, inconvenientes y utilidad del uso de las diversas estrategias y herramientas presentadas.

\section{Estrategias y Actividades soportadas por los clickers en clase}

Un ARS está típicamente formado por un hardware (clicker y dispositivo receptor) y un software (programa) que posibilitan el despliegue de distintas actividades en el aula. Su funcionamiento básico es el que sigue:

- El profesor propone una pregunta a sus estudiantes que muestra a través del proyector del aula conectado a su ordenador.

- Cada estudiante remite su respuesta a la pregunta planteada a través de un transmisor (clicker) que se comunica inalámbricamente con el receptor de información que el professor tiene también conectado al su ordenador.

- Para el procesamiento de la información recibida el profesor utiliza un software que procesa, bien local bien remotamente, las respuestas suministradas.

Una vez procesadas las respuestas, el professor obtiene una realimentación que puede utilizar con distintos propósitos en base al tipo de actividad que haya deseado plantear. Típicamente lo que se suele buscar es involucrar más a los alumnos en la clase dándoles la 
oportunidad de participar activamente en la misma. Las distintas estratégias y actividades que es posible desplegar con ayuda de los clickers se han resumido en la Tabla 1.

Tabla 1. Estrategias y actividades soportadas por los clickers en clase

\begin{tabular}{|c|c|}
\hline Actividad / Estrategia & Explicación \\
\hline Control de asistencia & $\begin{array}{l}\text { Los clickers pueden servir para controlar la asistencia a clase directamente o para determinar, de manera } \\
\text { indirecta, qué estudiantes utilizan sus clickers en clase, y por tanto participan activamente en la misma. }\end{array}$ \\
\hline Evaluación sumativa & $\begin{array}{l}\text { Los clickers pueden usarse para evaluar ciertos aspectos de una asignatura por medio de test o cuestiones de } \\
\text { selección múltiple. Las pruebas pueden plantearse de manera grupal, en la que todos los alumnos avanzan } \\
\text { al mismo ritmo, o de manera individual, en la que cada estudiante contesta a las preguntas a su ritmo }\end{array}$ \\
\hline Evaluación formativa & $\begin{array}{l}\text { Los clickers pueden utilizarse para plantear cuestiones a los alumnos y recoger sus respuesta con el } \\
\text { propósito de realimentar en tiempo real a profesores y alumnos sobre cómo está discurriendo la clase y en } \\
\text { qué grado se están asimilando los conceptos trabajados. Los estudiantes pueden servirse de este feedback } \\
\text { para monitorizar su proceso de aprendizaje, y los profesores pueden reorientar sus clases "en marcha" en } \\
\text { base a las necesidades y carencias detectadas en lo alumnos. Algunas soluciones permiten que, además de } \\
\text { contestar, los estudiantes indiquen el nivel de confianza (alto, medio y bajo) que tienen en su respuesta. Así } \\
\text { la realimentación proporcionada al profesor es de grano más fino. Los profesores podrían i) asignar una } \\
\text { nota a los alumnos que realicen estas evaluaciones formativas para motivarles a participar, ii) bonificar sólo } \\
\text { a aquellos alumnos que proporcionen respuestas correctas con el objetivo de que se tomen más en serio la } \\
\text { actividad, o iiii) plantear una mezcla de las dos anteriores proponiendo una pequeña bonificación a aquellos } \\
\text { que por lo menos lo intenten, aunque sus respuestas sean erróneas. }\end{array}$ \\
\hline Propuesta personalizada & $\begin{array}{l}\text { Los clickers pueden servir para registrar las respuestas de los alumnos y proponer en base a sus respuestas } \\
\text { erróneas tareas a entregar en la siguiente clase. }\end{array}$ \\
\hline Recolección de tareas & $\begin{array}{l}\text { Los clickers permiten que los estudiantes guarden las respuestas que suministrar a las preguntas de } \\
\text { respuesta múltiple o respuesta libre. Si estas preguntas se plantean al término de una clase a todos los } \\
\text { alumnos, dándoles el tiempo de trabajar las respuesta entre una clase y la siguiente clase, es posible recoger } \\
\text { evidencias del estudio realizado por los alumnos al comienzo de la siguiente clase. Dichas evidencias } \\
\text { pueden utilizarse para forzar un repaso general en caso de necesidad y/o para evaluar a los alumnos. }\end{array}$ \\
\hline Motivación de temáticas & $\begin{array}{l}\text { Plantear una cuestión, proporciona a los estudiantes el tiempo necesario para pensar, analizar las distintas } \\
\text { respuestas posibles, permitiéndole posicionarse y notificar su respuesta utilizando los clikers que haya en } \\
\text { clase. Si a continuación, el docente muestra las distintas respuestas suministradas, la actividad puede ser de } \\
\text { gran utilidad para lanzar una discusión en clase. En cualquier caso, siempre será una actividad mucho más } \\
\text { efectiva, que dirigir la pregunta al primero de los estudiantes que levante la mano. }\end{array}$ \\
\hline Enseñanza condicionada & $\begin{array}{l}\text { Plantear una pregunta a los alumnos con el objeto de averiguar el concepto bajo estudio ha sido o no } \\
\text { comprendido es otro tipo de actividad a la que los clickers pueden ayudar. Así el profesor puede decidir, } \\
\text { con conocimiento de causa, si debe pasar a trabajar otro concepto o si por el contrario necesitar reforzar con } \\
\text { explicaciones y material adicional lo que se está trabajando actualmente [11]. }\end{array}$ \\
\hline Formación por pares & $\begin{array}{l}\text { El profesor plantea una pregunta a sus estudiantes, que tras reflexionarla la contestan utilizando sus } \\
\text { clickers. El profesor estudia el histograma de respuestas proporcionadas por los alumnos. Si un número } \\
\text { significativo de los mismos se equivoca, el profesor solicita a los estudiantes que discutan la pregunta con } \\
\text { "su vecino" en el aula durante unos minutos. A continuación, cada estudiante vuelve a responder } \\
\text { individualmente. En muchos casos, aunque no siempre, esta técnica sule llevar a que el porcentaje de } \\
\text { estudiantes que proporciona una respuesta correcta aumente. El mérito de esta técnica es el de ofrecer un } \\
\text { método muy simple para lanzar discusiones en clase sobre el material del curso que involucren a la } \\
\text { totalidad de estudiantes en el aula. }\end{array}$ \\
\hline Repetición de preguntas & $\begin{array}{l}\text { En la instrucción por pares anteriormente mencionada, los estudiantes respondían a la pregunta dos veces - } \\
\text { una primera vez tras una reflexión propia y otra tras una reflexión con su vecino en el aula. Algunos } \\
\text { profesores proponen plantear la misma pregunta varias veces, en distintos turnos de respuesta, planteando } \\
\text { distintas actividades en cada turno, para ayudarles a comprender mejor la respuesta a la pregunta. Por } \\
\text { ejemplo, el instructor podría hacer que los estudiantes respondieran individualmente primero. A } \\
\text { continuación, podrían trabajar la respuesta con su vecino y participar en una puesta en común realizada con } \\
\text { todos los alumnos de clase. Luego, el profesor podría complementar dichas actividades con una pequeña } \\
\text { clase sobre la cuestión objeto de estudio, para finalmente volver a solicitar a los estudiantes que } \\
\text { respondieran a la misma pregunta. Esta técnica muestra su efectividad con preguntan particularmente } \\
\text { complejas pues permite a los estudiantes descubrir y explorar el material docente suministrado para trabajar } \\
\text { el tema bajo estudio. }\end{array}$ \\
\hline $\begin{array}{l}\text { Formación dirigida por } \\
\quad \text { preguntas }\end{array}$ & $\begin{array}{l}\text { Esta técnica combina la enseñanza condicionada con la instrucción por pares. Las clases se plantean } \\
\text { integramente en base a preguntas a responder con los clickers. Lo que se pregunta depende completamente } \\
\text { de lo que los alumnos responden. Por tanto, el profesor necesita una buena pila de preguntas para cada } \\
\text { aspecto a trabajar. A medida que los estudiantes contestan, y en base a las contestaciones dadas, el profesor } \\
\text { plantea nuevas preguntas sobre nuevos temas, o reincide en el mismo tema con nuevas preguntas [11]. }\end{array}$ \\
\hline $\begin{array}{l}\text { Clases estilo "elige tu } \\
\text { propia aventura" }\end{array}$ & $\begin{array}{l}\text { Con esta estrategia, el profesor plantea un problema junto con distintas alternativas de resolución del } \\
\text { mismo. Los alumnos votan una de las alternativas que es la que primero se estudia. A continuación se elige } \\
\text { la siguiente alternativa [13]. }\end{array}$ \\
\hline
\end{tabular}

(cc) EY-NC-ND 2014, UniversitatPolitècnica de València

I Jornadas IN-RED (2014) 


\section{Tipos de pregunta típicamente propuestos}

Muchos profesores ven a los clickers como un medio limitado para evaluar la capacidad de los estudiantes a recordar y repetir conceptos y hechos. Opinan que las preguntas de respuesta verdadero/falso, selección simple o multiple, son muy básicas. Sin embargo éstas pueden servir a muchos propósitos distintos en clase, incluyendo la evaluación de las capacidades más elevadas de conocimiento y análisis. Puesto que la utilidad de los clickers no se limita sólo a evaluar a los alumnos sino también a involucrarlos en la clase algunas de las preguntas que pueden llegar a plantearse pueden ser mucho más sofisticadas que las que finalmente suelen incluirse en los exámenes. La Tabla 2 lista algunos de esto tipos de preguntas.

Tabla 2. Tipos de preguntas a las que podemos reponder con un clicker

\begin{tabular}{|c|c|}
\hline Tipo de pregunta & Explicación \\
\hline de repetición & $\begin{array}{l}\text { Estas preguntas se utilizan para interrogar a los estudiantes sobre hechos, conceptos o técnicas estudiadas } \\
\text { en clase. A menudo se utilizan para ver si los estudiantes han revisado el material de clase y se han } \\
\text { quedado con los conceptos más importantes explicados. Esta preguntas rara vez generan debate y no } \\
\text { requieren acceder a habilidades de pensamiento muy elevadas. }\end{array}$ \\
\hline de comprensión conceptual & $\begin{array}{l}\text { Estas preguntas evalúan la capacidad del estudiante a comprender conceptos importantes. Las opciones } \\
\text { de respuesta se basan a menudo en errores comunes de los estudiantes y permiten a los profesores } \\
\text { identificar y solventar errores de concepto en los estudiantes. Las preguntas en las que se solicita la } \\
\text { clasificación de ejemplos, la asociación de características con coneptos o la selección de la mejor } \\
\text { definición para un concepto son algunos ejemplos de este tipo de preguntas. }\end{array}$ \\
\hline de aplicación & $\begin{array}{l}\text { Estas preguntas requieren del uso del concocimiento estudiado para comprender situaciones y contextos } \\
\text { de uso. En éstas a menudo se solicita a los estudiantes que tomen una decisión, o que realicen una } \\
\text { elección, por ejemplo, conectando el contenido del curso con situaciones reales, implementando } \\
\text { procedimientos o técnicas, o prediciendo el resultado de un experimento. }\end{array}$ \\
\hline de razonamiento crítico & $\begin{array}{l}\text { Estas preguntas trabajan a los niveles más elevados de pensamiento que define la taxonomía de Bloom. } \\
\text { Requieren que los estudiantes analicen relaciones entre múltiples conceptos o evalúen situaciones } \\
\text { partiendo de criterios concretos. A menudo estas preguntas incluye múltiples respuestas correctas, y se } \\
\text { solicita al alumno que escoja la más correcta de todas. Aunque estas preguntas no son las más apropiadas } \\
\text { para un examen, permiten lanzar a debate un tema en clase. }\end{array}$ \\
\hline de percepción del alumno & $\begin{array}{l}\text { En estas preguntas se solicita a los alumnos que compartan sus opiniones o experiencias con la clase. No } \\
\text { hay respuestas correctas ni incorrectas, pero permiten presentar al resto de la clase las distintas } \\
\text { perspectivas con la que un problema puede plantarse y abordarse. A menudo, generan un buen debate, } \\
\text { sobre todo cuando lo que se analizan son temas de índole ético, legal o moral. Permiten a los estudiantes } \\
\text { conectar sus experiencias personales con el contenido del curso más abstracto. El anonimato que } \\
\text { proporcionan los clickers es un ingrediente esencial para que estas preguntas realmente aporten algo en } \\
\text { clase. }\end{array}$ \\
\hline de grado de confianza & $\begin{array}{l}\text { Se pregunta a los estudiantes sobre el grado de confianza que tienen en la respuesta que acaban de } \\
\text { proporcionar. Ese grado de confianza puede ser alto, medio o bajo y permite al alumno matizar la } \\
\text { respuesta que proporcionan, dándose al mismo tiempo cuenta de las limitaciones existentes en su proceso } \\
\text { de aprendizaje. También es posible plantear esta preguntas en formato "predictivo", es decir, } \\
\text { interrogando a los alumnos sobre el grado de confianza que tienen en contestar correctamente la } \\
\text { siguiente pregunta que se les va a proponer, a persar de no conocerla. }\end{array}$ \\
\hline de monitorización & $\begin{array}{l}\text { Estas preguntas permiten al profesor conocer cómo están siguiendo los estudiantes el proceso de } \\
\text { aprendizaje que éste ha fijado en un curso. Por ejemplo, una semana antes de realizar una prueba de } \\
\text { evaluación, los profesores pueden preguntar a los estudiantes por su estado de progreso en la preparación } \\
\text { de dicha prueba. También es posible preguntarles sobre el tiempo que han empleado en realizar una de } \\
\text { las pruebas modelo disponibles. Los clickers pueden servir además para averiguar si los alumnos } \\
\text { recuerdan las reglas de evaluación establecidas al principio del curso. }\end{array}$ \\
\hline
\end{tabular}

\section{Selección de un sistema de respuesta adecuado}

La gran penetración de las TIC en la enseñanza moderna en los últimos años ha hecho que esto sea así. De hecho, hoy en día es difícil concebir una docencia de calidad sin un ordenador. Más aún, es rara la Universidad que no cuenta ya con una plataforma de elearning propia, como PoliformaT en la Universitat Politècnica de València, que no equipa

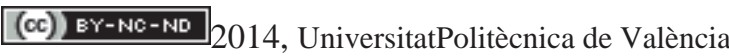

I Jornadas IN-RED (2014) 
sus aulas con un proyector y con el software necesario para gestionar dicha proyección, y que no provee a los alumnos con conectividad inalámbrica WIFI para que puedan acceder a los contenidos en todo momento y lugar de la universidad.

En definitiva, estamos rodeados de todo lo necesario para poder utilizar los clickers en clase. Por una parte el proyector del aula servirá para proporcionar la realimentación necesaria a profesor y alumnos. Por otra, el ordenador del profesor, conectado a la red de la universidad, podrá actuar como receptor de respuesta. Lo único que falta es el dispositivo clicker físico y el SW de gestión de respuesta que es necesario poseer. Lo primero, el clicker, lo proporcionan los propios estudiantes, puest prácticamente todos poseen acualmente un Tablet o un teléfono inteligente. En esta sección nos centramos en estudiar qué alternativas tenemos a nivel de SW, sobre todo abordando el estudio de aquellas alternativas que son gratuitas. De esta forma podremos construir un ARS a coste casi nulo.

Planteamos tres requisitos para escoger una solución SW para nuestro ARS. Primero, la solución debe ser portátil, es decir debe poder funcionar en todos los ordenadores (la parte de recepción y gestión de las respuestas) y dispositivos móviles (la parte de emisión de las respuestas) con indepencia del sistema operativo o plataforma que éste requiera. Segundo, no debe requerir ningún tipo de instalación ni en el ordenador del profesor ni en el dispositivo móvil del alumno. Y Tercero, la solución debe ser funcional (ofreciendo buenas prestaciones, emisión de informes y alta usabilidad) a un coste aceptable, a poder ser nulo.

Partiendo de estos requisitos resulta obvio que nos decantaremos por sistemas de respuesta basados en web como los repertoriados en http://www.polleverywhere.com/vs y que, de entre los existentes, nos declinaremos por una solución de propósito general y gratuita que pueda ser utilizada también desde dispositivos móviles. La Tabla 3 sintetiza las características más importantes que hemos considerado en las plataformas bajo estudio.

Tabla 3. Comparativa de sistemas de respuesta basados en web

\begin{tabular}{|c|c|c|c|c|c|c|c|}
\hline Producto & Polleverywhere & Socrative & Top Hat Monocle & SMSPoll.net & ClickerSchool & Text The Mob & Shakespeak \\
\hline Web & polleverywhere.com & socrative.com & tophatmonocle.com & $\underline{\text { smspoll.net }}$ & clickerschool.com & $\underline{\underline{\text { textthemob.com }}}$ & shakespeak.com \\
\hline Fiabilidad & $99.98 \%$ & $99.74 \%$ & -- & $99.52 \%$ & -- & -- & $99.99 \%$ \\
\hline Coste & $15 \$$ a $1400 \$$ año & Gratuito & $4000 \$$ de por vida & $15 \$$ a $850 \$$ año & $88 \$$ a $25000 \$$ año & Gratis a $15 \$$ mes & $45,31 \$ /$ mes/profesor \\
\hline $\begin{array}{c}\text { Sistemas } \\
\text { respuesta }\end{array}$ & $\begin{array}{c}\text { Text, Smartphone, } \\
\text { web, iPad, Twitter, } \\
\text { widget }\end{array}$ & $\begin{array}{c}\text { iPhone app, } \\
\text { Android app, } \\
\text { web }\end{array}$ & Text, web & $\begin{array}{c}\text { Text, } \\
\text { Smartphene, } \\
\text { widget }\end{array}$ & Clicker, web & $\begin{array}{c}\text { Text, web } \\
\text { Text, smartphone, } \\
\text { web, Twitter }\end{array}$ \\
\hline Informes & Pagando & Gratuito & Pagando & Gratuito & Pagando & Gratuito & Gratuito \\
\hline
\end{tabular}

Como puede observarse la mayor parte de los sistemas bajo estudio ofrecen niveles de fiabilidad altos, con lo que pueden resultar útiles a nuestros propósitos. De entre los 4 sistemas para los que los parámetros de fiabilidad son conocidos, los 4 ofrecen soporte a dispositivos móviles. Estudiando el detalle de dicho soporte, la mayor parte de los sistemas exige del uso de apps (aplicaciones móviles) específicas, lo que limita el uso del sistema sólo a aquellos dispositivos para los que exista una app compatible. Sin embargo, Socrative y Polleverywhere se singularizan por ofrecer webs "responsive", es decir, webs que adaptan su apariencia al tipo de dispositivo desde el que se consumen sus contenidos. Así, ambos sistemas ofrecen webs HTML5 accesibles directamente a través de un simple navegador web. Por tanto, no es necesaria la instalación de ninguna aplicación ni en los dispositivos 
móviles de los alumnos, que jugarán el papel de clickers, ni en el ordenador del profesor, que servirá para moderar cada cuestionario, recopilar y analizar las respuestas proporcionadas y finalmente proporcionar un informe que ilustre los resultados obtenidos con la actividad propuesta. A este nivel cabe subrayar que, salvo Socrative, todos los sistemas ofrecen planes de pago. Esto hace que los servicios gratuitos ofrecidos estén muy limitados, bien a pocas encuestas y pocas respuestas por encuesta, con lo que resultan inútiles en contextos de uso en los que se tienen muchos estudiante, bien a no ofrecer informes al final sobre el análisis de respuestas realizado, con lo que no se obtendría realimentación alguna en ese caso. Por ello la herramienta escogida para nuestros experimentos es Socrative ya que no limita ni el número de encuestas que pueden realizarse, ni el número de respuestas que pueden recibirse por encuestas. Además la obtención de informes es completamente gratuita.

En su segunda versión, en estado beta de momento, Socrative (http://beta.socrative.com) ofrece una interfaz web de tipo "responsive" basada en HTML5. Por ello el sistema de respuestas que ofrece es completamente funcional sin necesidad de instalar ningún SW ni en el ordenador del profesor ni en ningún dispositivo móvil.

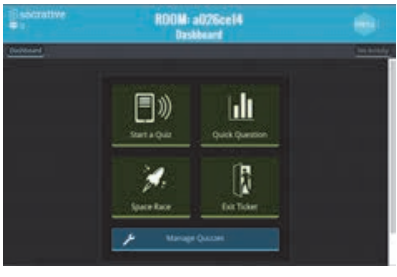

b. Panel de control principal

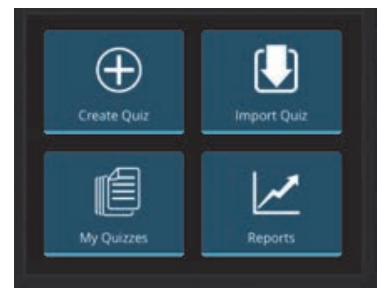

c. Gestión de cuestionarios e informes

Figura 1. Capturas de la interfaz web ofrecida por Socrative

\subsection{El trabajo del profesor con Socrative}

Tras autenticarse en el sistema (ver Figura 1.a), el profesor accede al panel de control principal (Figura 1.b) desde el que puede publicar un cuestionario a sus alumnos, una cuestión rápida, plantear una competición o salir del sistema. Cabe señalar que en este panel de control se encuentra un identificador de sala o clase virtual, a026ce14 en nuestro caso. Este identificador debe ser suministrado a los alumnos para que se conecten al sistema y puedan participar de las actividades que proponga el profesor. Desde el panel de control principal también es posible acceder al panel de gestión de cuestionarios e informes a través del cuál se introducen las cuestiones o pruebas de test en el sistema (Figura 1.c). 
Los cuestionarios se construyen a través de 3 tipos básicos de preguntas (Figura 2.a). Las preguntas de selección múltiple engloban a la de selección simple y se formulan indicando el conjunto de respuestas correctas a cada pregunta (Figura 2.b). Además se permite proporcionar un comentario final para explicar la pregunta y sus respuestas. Lo mismo sucede con las preguntas de tipo verdadero/falso (Figura 2.c). Finalmente, si lo que se busca es que el alumno aporte su punto de vista, también es posible formular preguntas con respuesta abierta (y corta, ver Figura 2.d). Destacar que todos los tipos de preguntas permiten asociar a la pregunta formulada una imagen, algo muy útil cuando, por ejemplo, se necesita mostrar código o un esquema.

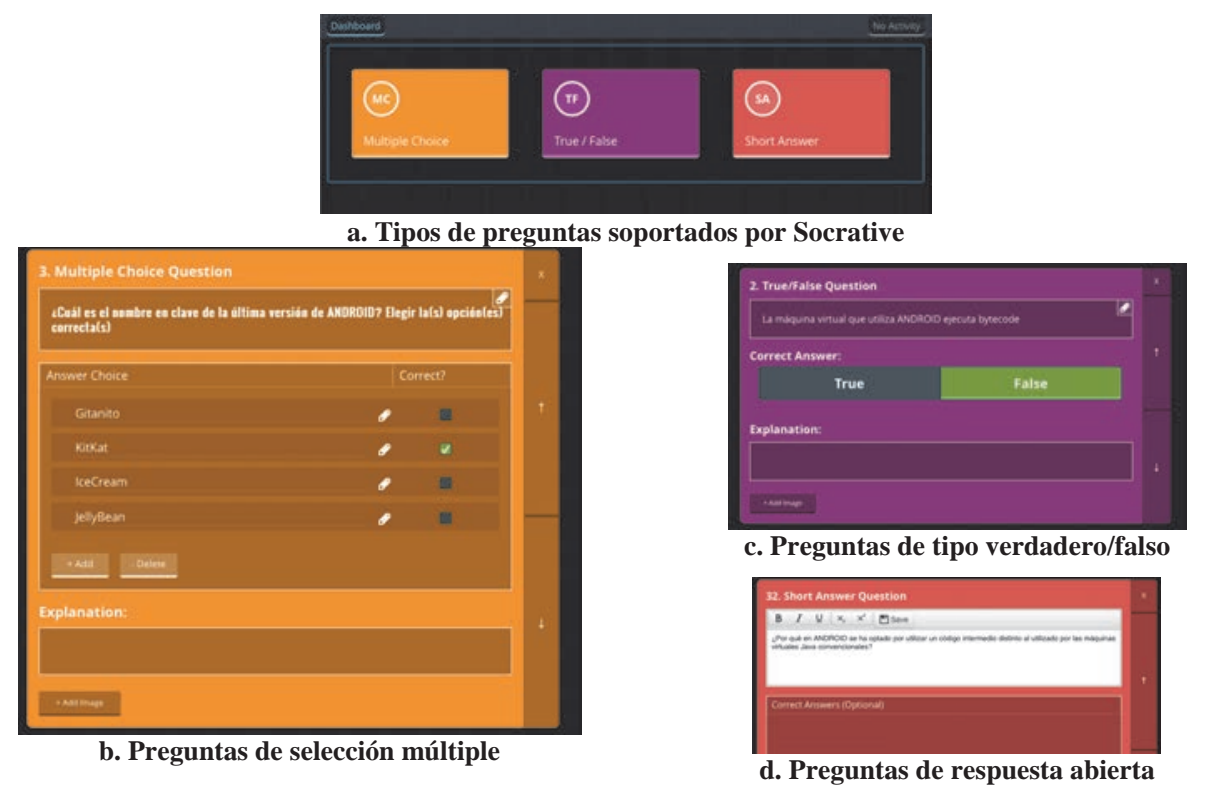

Figura 2. Preguntas en Socrative

Si el profesor opta por plantear una pregunta rápida ésta puede formularse y lanzarse directamente en clase, mostrándose el informe de respuestas al final. En todo momento el profesor tiene el control de la pregunta, pudiendo cerrarla cuando lo desee.

Si en lugar de una pregunta rápida opta por plantear una actividad consistente en responder a un cuestionario, éste debe seleccionarse de entre todos los que el profesor haya preparado. Contrariamente a la pregunta rápida, el cuestionario debe prepararse previamente. La Figura 3 muestra el tipo de listado desde el que el profesor seleccionará el cuestionario que desea proponer a sus alumnos.

Si por el contrario, el profesor desea que realizar el cuestionario sea más divertido para los alumnos, y que éstos trabajen en grupos, entonces puede plantear una competición. Para ello se selecciona uno de los cuestionarios preparados, el número de equipos que participarán y el método de selección a utilizar para definir los equipos. La actividad 
consiste en responder el cuestionario proporcionando el mayor número posible de respuestas correctas en el menor tiempo. La Figura 4 muestra este tipo de actividad.

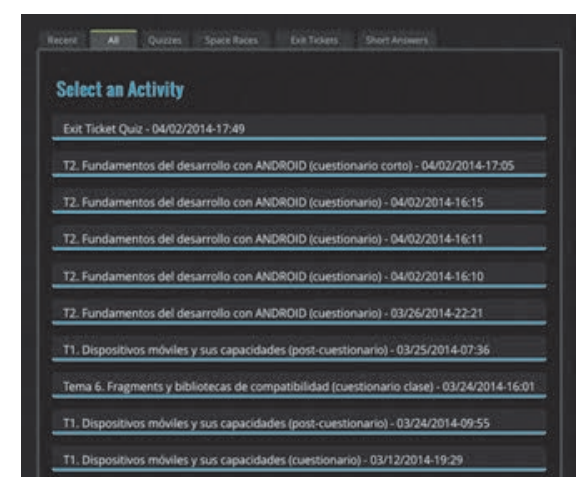

Figura 3. Selección de un cuestionario para una prueba en clase
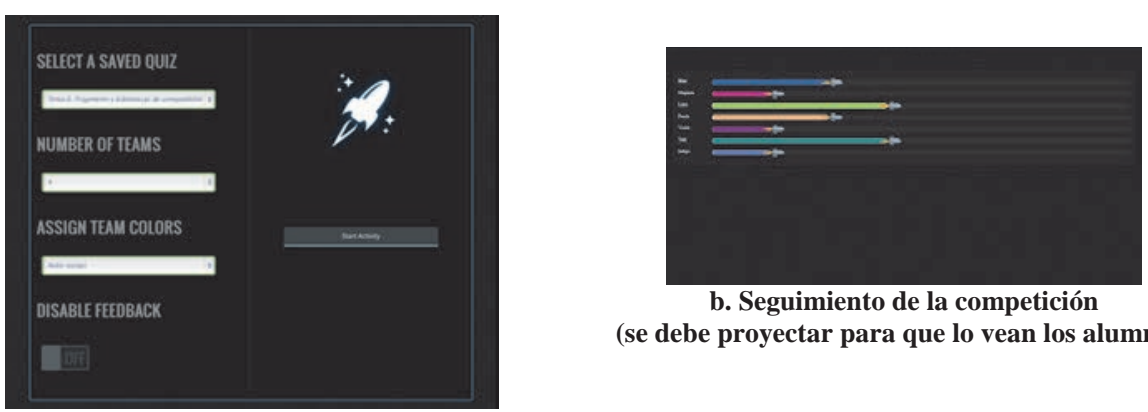

(se debe proyectar para que lo vean los alumnos)

a. Lanzamiento de la competición

Figura 4. Actividad de competición

\subsection{Uso del dispositivo móvil como Clicker}

Cuando el profesor suministra a los alumnos el identificador del aula virtual en la que publica las actividades, éstos pueden conectarse a la misma utilizando el cliente web de su portátil, tableta o teléfono inteligente (Figura 5.a). Con lo que en la práctica, serán estos dispositivos los que actuarán de clickers en la clase.

Independientemente del dispositivo utilizado, el alumno tendrá que esperar a que el profesor publique la actividad a realizar, y una vez publicada contestar a la pregunta, o serie de preguntas, que se le formule (Figura 5.b). En la se muestra un ejemplo de una pregunta rápida de tipo verdadero/falso lanzada en clase. Como puede apreciarse la pregunta no tiene enunciado porque el profesor la habrá planteado previamente en el aula.

\section{Experiencias en aula}

Con el objetivo de mostrar la viabilidad y el interés de introducir los clickers en clase se planteó el uso de Socrative en el marco de las siguientes asignaturas UPV:

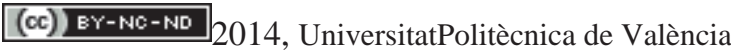

I Jornadas IN-RED (2014) 
- Soluciones informáticas para dispositivos móviles (SDM), ofertada como asignatura de formación complementaria en $4^{\circ}$ del Grado de Ingeniería Informática.

- Diseño de sistemas digitales (DSD), ofertada como asignatura obligatoria en $3^{\circ}$ de la rama de Ingeniería de computadores del Grado de Ingeniería Informática.

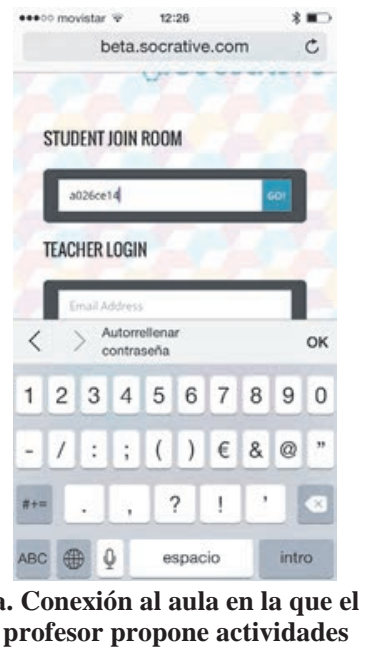

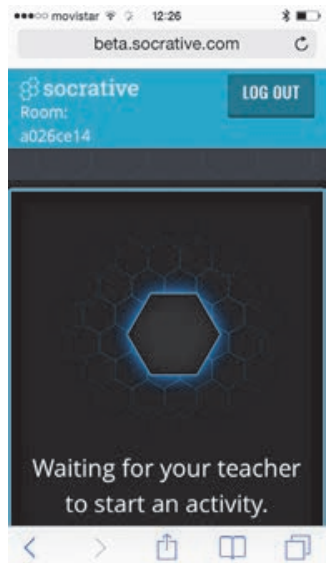

b. Esperando la publicación de una actividad

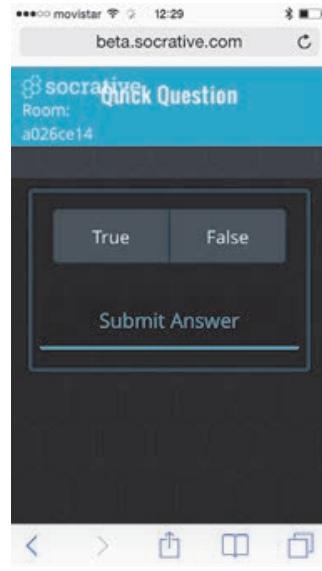

c. Contestando a la pregunta formulada

Figura 5. Uso de un dispositivo móvil como Clicker

Tal y como se esperaba por la temática de la asignatura, el 100\% de los estudiantes de SDM tenían un teléfono inteligente, una tableta o un portáitl y pudieron participar en la experiencia. Aunque menos esperado, lo mismo sucedión con la asignatura DSD. En SDM, se planteó una competición entre equipos de alumnos para valorar el grado de preparación de los alumnos de cara al examen de la asignatura, con lo que se planteron preguntas de todos los temas. El objetivo era el de detectar las carencias existentes y ofrecer una clase de repaso orientada a subsanarlas. En el caso de DSD, lo que se propuso fue un questionario para valorar el grado de asimilación de los conceptos trabajados en el tema de VHDL de la asignatura. Los informes relativos a las experiencias llevadas a cabo se muestran en la Figura 6 y Figura 7. Aquellas cuestiones que obtuvieron un porcentaje de respuesta inferior al $65 \%$, fueron reforzadas en clase, bien mediante repaso, bien mediante actividades complementarias que se propusieron.

\section{Conclusiones}

Este trabajo muestra que los clikers son un medio actualemente barato para obtener feedback rápido del trabajo realizado en clase. Además de involucrar activamente al alumno en las actividades del aula, la información que suministran es de gran interés para profundizar en los contenidos que necesitan ser revisados. 
Aunque a primera vista pueda parecer que la principal barrera a la adopción de este tipo de soluciones es tecnológica, se ha demostrado en este trabajo la facilidad con la que estos sistemas pueden utilizarse, y su bajo coste de uso. Pensamos que el desconocimiento del tipo de preguntas y actividades que los clickers permiten trabajar y desplegar en clase, hace que los profesores duden de su utilidad.

En este artículo se han repasado todos estos puntos para clarificarlos y mostrar lo fácil que puede ser pasar de la teoría a la práctica. El hecho de que la mayor parte de los alumnos, por no decir el $100 \%$ de los mismos, dispongan de una tableta, un teléfono inteligente y/o un portátil demuestra que ya no existe ninguna barrera para explotar las bondades de los clickers en el aula universitaria.

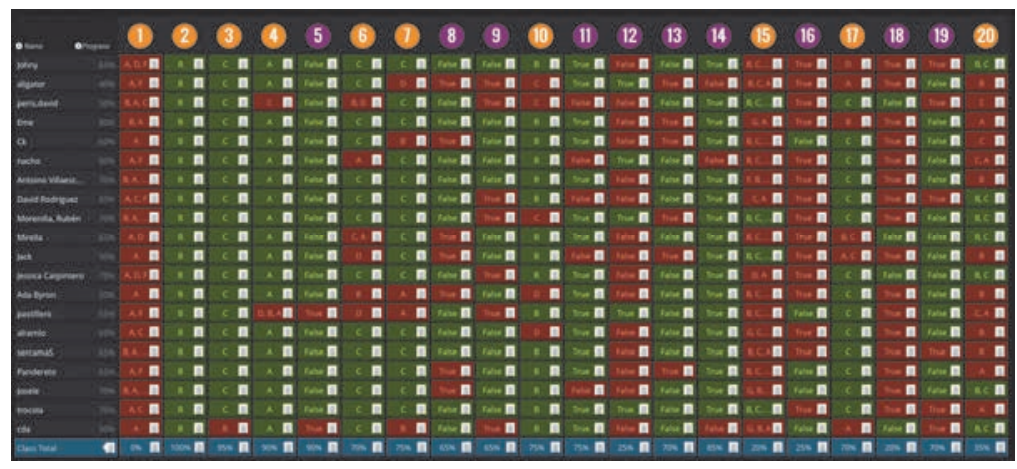

Figura 6. Informe web de asignatura SDM

(Información relevante para la preparación de la clase de repaso de la asignatura)

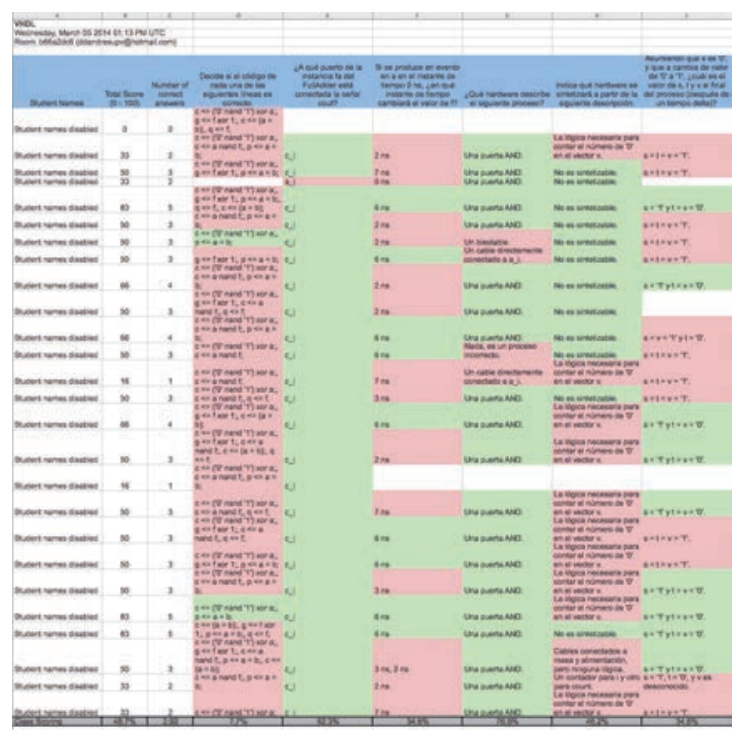

Figura 7. Informe excel de asignatura DSD

(Grado de asimilación de los conceptos básicos ligados al trabajo con VHDL)

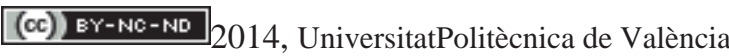

I Jornadas IN-RED (2014) 


\section{Referencias}

[1] Kaleta, Robert, and Joosten, Tanya. Student Response Systems: A University of Wisconsin System Study of Clickers, Educause Center for Applied Research Research Bulletin. Vol. 2007, Issue 10, May 8, 2007, pp. 46.

[2] Miller, Redonda G., Ashar, Bimal H. and Getz, Kelly J. "Evaluation of an audience response system for the continuing education of health professionals" Journal of Continuing Education in the Health Professions. Vol. 23, No. 2, 2003. pp.109-115.

[3] D. Bruff, Teaching with Classroom Response Systems: Creating Active Learning Environments, Jossey-Bass ed., 2009, pp. 240.

[4] R.G. Miller, B. H. Ashar and K. J. Getz, Evaluation of an audience response system for the continuing education of health professionals, Journal of Continuing Education in the Health Professions, vol. 23, no. 2, 2003, pp. 109-115.

[5] J. Middendorf and A. Kalish, The "Change-Up" in Lectures, The National Teaching and Learning Forum, vol. 5, no. 2, 1996, pp. 1-5.

[6] M. Martyn, Clickers in the Classroom: An Active Learning Approach, EDUCAUSE Quarterly, no. 2, 2007, pp. 71-74.

[7] S. W. Draper and M. I. Brown, Increasing interactivity in lectures using an electronic voting system, Journal of Computer Assisted Learning, vol. 20, no. 2, 2004, pp. 81-94.

[8] M. Patry, Clickers in Large Classes: From Student Perceptions Towards an Understanding of Best Practices, International Journal for the Scholarship of Teaching and Learning, vol. 3, no. 2, 2009, pp. 1-11.

[9] I. Beatty, Transforming Student Learning with Classroom Communication Systems, Research Bulletin from Educause Center for Applied Research, no. 3, 2004, pp. 1-13.

[10] C. Cantillo Valero, M. Roura Redondo y A. Sánchez Palacín, Tendencias actuales en el uso de dispositivos móviles en educación, La Educación revista digital - Tema: Aprendizaje móvil, nº 147, ISSN: 2218-2756, 21 pp. Junio 2012.

[11] Beatty, I., Gerace, W., Leonard, W., \& Dufresne, R., Designing effective questions for classroom response system teaching. American Journal of Physics, 74(1), 31-39, 2006.

[12] Mazur, E. (1997). Peer instruction: A user's manual. Upper Saddle River, NJ: Prentice Hall.

[13] Hinde, K., \& Hunt, A. Using the personal response system to enhance student learning: Some evidence from teaching economics. In Banks, D. A. (Ed.), Audience Response Systems in Higher Education: Applications and Cases. Hershey, PA: Information Science Publishing, 2006. 
Evaluación in-situ de las prácticas de laboratorio: una herramienta asequible para la mejora de la motivación y del aprovechamiento del alumno en el laboratorio. La experiencia en máquinas y tecnología eléctrica de la ETSII

Javier Martínez Román, Ruben Puche Panadero, Juan Pérez Cruz, Manuel Pineda Sánchez, Martín Riera Guasp y José Roger Folch

${ }^{a}$ Universitat Politècnica de València, Departamento de Ingeniería Eléctrica, jmroman@die.upv.es, rupucpa@die.upv.es, juperez@die.upv.es, jroger@die.upv.es

\begin{abstract}
It is not unusual that the student attitude during the laboratory sessions and the evaluation method used give rise to difficulties and controversy. This paper explains the solution chosen in the frame of the Electrical Machines and Electric Technology laboratories. The method chosen is based in short exams made up by multiple choice or simple numeric questions implemented in Poliformat. This exams are to be taken at the end of the laboratory session using Android Tablet-PCs. This evaluation method was first introduced in the Electrical Machines and Electric Technology laboratories in October 2012 and, since then, the students have sit about 5000 exams in this fashion. The students have accepted this new evaluation method quite positively. The instructors appreciate specially the positive influence the new system has had on the students' attitude and also in their learning.
\end{abstract}

Keywords: evaluation, closed questions, numerical questions, PoliformaT, laboratory, Tablet-PC.

\title{
Resumen
}

La actitud de los alumnos durante las prácticas de laboratorio y la forma de evaluación de las mismas pueden a menudo plantear dificultades. Esta contribución muestra la opción adoptada en los laboratorios de máquinas y tecnología eléctrica de la ETSII basada en la realización de pruebas objetivas de corta duración realizadas al finalizar cada sesión de laboratorio, implementadas en PoliformaT y que los alumnos cumplimentan

(cc)) EY-NC-ND 2014, Universitat Politècnica de València

I Jornadas In-Red (2014) 
Evaluación in-situ de las prácticas de laboratorio: una herramienta asequible para la mejora de la motivación y del aprovechamiento del alumno en el laboratorio. La experiencia en máquinas y tecnología eléctrica de la ETSII

en tabletas Android. Este tipo de evaluación se puso en práctica en octubre de 2012 y desde entonces se han realizado cerca de 5000 exámenes. La aceptación por parte de los alumnos ha sido muy positiva y, por parte del profesorado, se destaca sobre todo la positiva influencia en la actitud de los alumnos y la mejora en su aprendizaje.

Palabras clave: evaluación, prueba objetiva, PoliformaT, prácticas de laboratorio, Tablet-PC.

\section{Introducción}

A pesar del esfuerzo combinado humano y material en preparar e implantar prácticas de laboratorio que contribuyan al aprendizaje de los alumnos, lo cierto es que es habitual que los docentes perciban un estado de falta de interés de los alumnos por las prácticas de laboratorio. Esta falta de interés está motivada por varios factores, entre los que los más importantes son:

- El peso, a menudo relativamente bajo, que la evaluación de las prácticas de laboratorio tiene en la calificación final de la asignatura. Las prácticas de laboratorio representan típicamente un $20 \%$ del total de actividades presenciales de las asignaturas en los grados de Ingeniero en Tecnologías Industriales y en Energía de la Escuela Técnica Superior de Ingenieros Industriales de Valencia, Universitat Politècnica de València. Su peso en la calificación final debería suponer un porcentaje similar.

- El momento de la evaluación relativamente distante en el tiempo del momento de realización de las prácticas. Si se tienen en cuenta los dos métodos de evaluación más habituales, memorias de prácticas y preguntas en los exámenes reglados, en ambos casos, aunque por distintos motivos, se introduce un retraso significativo entre el momento en que se realiza la práctica de laboratorio y el momento en que el alumno es evaluado o, en cualquier caso, produce los materiales que van a ser objeto de la evaluación. En el caso de las memorias, la carga continua de trabajo durante el curso requerida por el conjunto de las asignaturas y la existencia de una fecha límite hacen que la redacción de las mismas se separe con mucha frecuencia del momento de realización de la práctica y se acerque mucho a la fecha límite indicada. En el caso de los exámenes reglados, su realización en periodos separados de los dedicados a la docencia presencial también los separa habitualmente varias semanas de los momentos de realización de las prácticas.

- La carga de trabajo continuada del alumno durante el periodo de docencia presencial es también motivo de que las prácticas de laboratorio se puedan percibir como un distractor de tareas que requieren la dedicación inmediata del alumno.

(cc) EY-NC-ND 2014, Universitat Politècnica de València

I Jornadas IN-RED (2014) 
Como se ha comentado, los sistemas tradicionales de evaluación de las prácticas de laboratorio son la realización de memorias y/o preguntas dedicadas en los exámenes reglados. Ambos sistemas tienen inconvenientes además de los ya citados en relación a la motivación de los alumnos. En cuanto a las memorias de prácticas, algunos de los inconvenientes más importantes son:

- La dificultad para interpretar los valores y resultados tomados durante la sesión de prácticas si la memoria no se realiza de forma inmediata.

- El aumento de la carga de trabajo del alumno durante el periodo de docencia presencial, que detrae recursos del esfuerzo necesario para seguir al día todas las asignaturas.

- La elevada dedicación requerida del profesorado para evaluar las memorias de prácticas.

En cuanto a la evaluación de las prácticas de laboratorio mediante preguntas que forman parte de los exámenes reglados, también tiene inconvenientes como:

- La dificultad para evaluar habilidades procedimentales.

- La dificultad para contrastar los resultados obtenidos en el laboratorio con los obtenidos en las clases de aula, dificultad asociada a la separación temporal entre las prácticas y los exámenes.

- La dedicación requerida por el profesorado para evaluar la parte de prácticas de los exámenes de la asignatura.

Para intentar evitar estas dificultades se ha diseñado y puesto en marcha un sistema de evaluación nuevo basado en la realización de pruebas objetivas de corta duración realizadas al finalizar cada sesión de laboratorio, implementadas en PoliformaT y que los alumnos cumplimentan en tabletas Android. Este tipo de evaluación se lleva realizando en las asignaturas de Máquinas Eléctricas (Serrano, 2013 y Martínez, 2014) y de Tecnología Eléctrica (Roger, 2000 y Roger 2011), tanto de la titulación Ingeniero Industrial - preBolonia - como de los grados de Ingeniero en Tecnologías Industriales y en Energía de la ETSII de Valencia, desde octubre de 2012, con cerca de 5000 exámenes realizados y evaluados por alrededor de 1400 alumnos diferentes en sesiones supervisadas por una decena de profesores. Aunque no ha sido razonable investigar la opinión de los alumnos sobre el sistema de evaluación de forma generalizada dado que no tienen la posibilidad de comparar con el sistema anterior, lo cierto es que la opinión mayoritaria cuando se ha solicitado de manera informal coincide esencialmente con la percepción del profesorado involucrado: una mejora significativa de la actitud, motivación y aprovechamiento del alumno. También se presentan comparativas entre los resultados de la evaluación previos y posteriores a la utilización de este sistema.

\section{(c) EY-NC-ND 2014, Universitat Politècnica de València}


Evaluación in-situ de las prácticas de laboratorio: una herramienta asequible para la mejora de la motivación y del aprovechamiento del alumno en el laboratorio. La experiencia en máquinas y tecnología eléctrica de la ETSII

\section{Objetivos}

Los objetivos del sistema de evaluación diseñado y puesto en marcha eran, básicamente, evitar los inconvenientes descritos de los sistemas de evaluación tradicionales. Entre ellos y como más destacados:

- Mejorar la motivación de los alumnos en las sesiones de prácticas.

- Acercar en sentido temporal la evaluación de las prácticas a su realización.

- Reducir en lo posible la carga de trabajo de los alumnos asociada a la preparación de los exámenes o memorias de prácticas.

- Favorecer la interpretación correcta de los resultados obtenidos durante la realización de las prácticas.

- Facilitar el establecimiento de relaciones entre los resultados de las prácticas de laboratorio y los de las clases de aula.

- Mejorar los resultados de la evaluación de conocimientos procedimentales asociados a la realización de ensayos.

Además de éstos, también se consideró importante que el sistema de evaluación cumpliera las siguientes características:

- Soporte de tamaño reducido que no interfiriera con los otros usos de los espacios en los que se desarrollan las prácticas de laboratorio.

- Coste asequible que permita su puesta en marcha ante las limitaciones presupuestarias actuales.

- Reutilización de sus componentes para otros usos dentro del propio laboratorio.

\section{Evaluación in-situ de las prácticas de laboratorio}

Teniendo en cuenta los objetivos citados se diseñó un nuevo sistema de evaluación para los laboratorios de máquinas y tecnología eléctrica de la ETSII basada en la realización de pruebas objetivas de corta duración realizadas al finalizar cada sesión de laboratorio, implementadas en PoliformaT y que los alumnos cumplimentan en tabletas Android. A continuación se describen las principales características de este nuevo sistema de evaluación.

Las pruebas deben ser objetivas compuestas por preguntas de respuesta múltiple y numéricas. Las pruebas objetivas aportan la posibilidad de cubrir múltiples objetivos de aprendizaje con duraciones relativamente cortas. Las preguntas de opción múltiple son especialmente adecuadas para evaluar conocimientos procedimentales y para comprobar si el alumno ha asimilado los principales objetivos de aprendizaje de la práctica. Por eso se centran usualmente en la correcta secuencia de operaciones durante los ensayos, en la adecuada conexión de los aparatos de medida y de los equipos a ensayar, en las limitaciones a tener en cuenta durante la realización de los ensayos y en las conclusiones 
más importantes a obtener como consecuencia de los resultados observados. Las preguntas numéricas son adecuadas para evaluar la habilidad para relacionar mediante cálculo los resultados directos de los ensayos con otras magnitudes que permiten una interpretación más rica de los ensayos. Asimismo, también permiten evaluar la correcta realización de los ensayos. Para ello fue necesario analizar, en todos los casos factibles, previamente todos los equipos a ensayar y los límites razonables de las condiciones de ensayo para poder fijar los límites admisibles de los valores medidos durante los ensayos. A título de ejemplo se ensayaron todos los transformadores a utilizar en las prácticas de circuitos magnéticos en todas las configuraciones posibles y dentro de los márgenes establecidos para las condiciones de los ensayos. Los resultados de estos ensayos proporcionaron un intervalo de variación para ciertos de sus parámetros, intervalos que, junto con las condiciones límite inferior y superior de alimentación en cada ensayo permiten obtener un rango de resultados admisibles relativamente estrecho y diferenciado para los resultados de cada ensayo. Al preguntar al alumno el resultado concreto en un ensayo y compararlo con el rango admisible se comprueba si, globalmente, el ensayo por él realizado ha sido correcto.

Una característica fundamental de las pruebas es que deben realizarse al finalizar el trabajo práctico de los alumnos como elemento final de la sesión de prácticas y dentro del tiempo asignado a la sesión. Esto favorece el aprendizaje continuado en la asignatura, estimula la actitud y atención de los alumnos durante la sesión, mejora la retención de los alumnos al evaluar de forma inmediata y activa estrategias de evaluación formativa.

Las pruebas deben ser de corta duración para no detraer excesivo tiempo del disponible para la realización de los ensayos. Las prácticas de las dos asignaturas citadas tienen una duración de 180 minutos y por eso se decidió que las pruebas debían estar formadas por un total de 10 preguntas y un tiempo máximo de resolución de 20 minutos, es decir, un poco más del 10\% de la duración de la sesión de prácticas.

Las pruebas deben estar implementadas con el apartado de exámenes en PoliformaT, que cuenta con muchas ventajas para la evaluación en la universidad, por ejemplo la integración cómoda con las bases de datos de alumnos y de calificaciones. De las diferentes opciones de configuración de exámenes se ha elegido la de prueba lineal sin posibilidad de navegación dentro de la prueba (adelante y atrás) con cada pregunta en una página web separada. El motivo de esta elección es el espacio reducido para la realización de los exámenes en el que no se puede dejar espacio de separación entre los alumnos. Por ello es importante que, además de que el examen se construya a partir de baterías de muchas preguntas, el alumno deba contestar cada pregunta en el momento que se le plantea y no esperar a más tarde para poder comparar con los compañeros que tiene cerca. En cuanto a las baterías de preguntas se han confeccionado con la estructura de árbol provista por la aplicación con ramificaciones a nivel de asignatura, práctica y objetivo formativo. La Tabla 1 recoge el número total de preguntas y su subdivisión en sub-baterías asociadas a objetivos formativos concretos para las 3 y 4 prácticas respectivamente de las asignaturas de Máquinas Eléctricas y Tecnología Eléctrica.

\section{(c)) EY-NC-ND 2014, Universitat Politècnica de València}

I Jornadas IN-RED (2014) 
Evaluación in-situ de las prácticas de laboratorio: una herramienta asequible para la mejora de la motivación y del aprovechamiento del alumno en el laboratorio. La experiencia en máquinas y tecnología eléctrica de la ETSII

Las pruebas están constituidas en todos los casos por 10 preguntas. En los casos en que el número de objetivos (sub-baterías) es inferior a 10, se priorizan estos objetivos y se incluye un mayor número de preguntas en el examen de cada alumno procedentes de las subbaterías asociadas a objetivos de mayor peso relativo.

Tabla 1 Estructura de las baterías de preguntas.

\begin{tabular}{|l|r|r|r|}
\hline Asignatura & \multicolumn{1}{|c|}{ Práctica } & \multicolumn{1}{r|}{ Objetivos } & $\mathbf{N}^{\circ}$ de preguntas \\
\hline \multirow{3}{*}{ Máquinas eléctricas } & 1 & 7 & 33 \\
\cline { 2 - 4 } & 2 & 10 & 77 \\
\cline { 2 - 4 } & 3 & 9 & 42 \\
\hline \multirow{2}{*}{ Tecnología Eléctrica } & 1 & 10 & 76 \\
\cline { 2 - 4 } & 2 & 10 & 40 \\
\cline { 2 - 4 } & 3 & 10 & 65 \\
\cline { 2 - 4 } & 4 & 10 & 40 \\
\hline
\end{tabular}

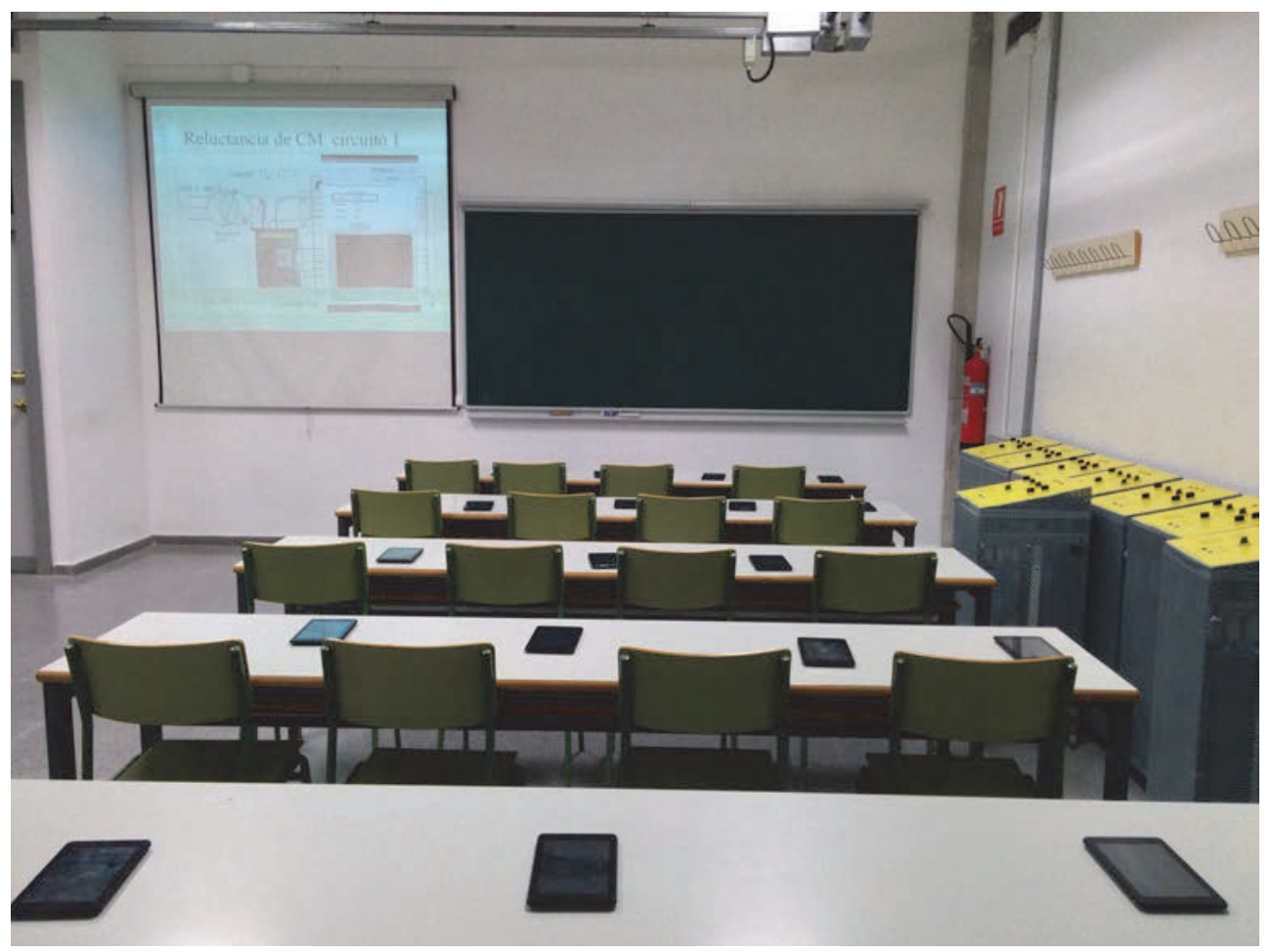

Fig. 1 Fotografía del aula del laboratorio de máquinas y tecnología eléctrica del Departamento de Ingeniería Eléctrica.

(c)) EY-NC-ND 2014, Universitat Politècnica de València

I Jornadas IN-RED (2014) 
El soporte físico elegido para la realización de las pruebas son tabletas Android. Este soporte presenta muchas ventajas respecto de equipos más voluminosos como PCs de sobremesa, entre otras las que se describen a continuación. El tamaño es muy reducido lo que permite disponer al menos de tantos puestos de evaluación como de asientos en el aula sin molestar en la mesa (Fig. 1) y de su almacenaje sencillo durante periodos de no utilización. Esto ha permitido utilizar la misma parte del laboratorio que se dedica a la explicación previa al trabajo de los alumnos para la evaluación, simplificando mucho el desarrollo de las prácticas. Este espacio hubiera sido claramente insuficiente si se hubieran utilizado otras plataformas del tipo ordenador compatible tipo PC. Además, el coste es bastante asequible, y ha podido ser sufragado con el presupuesto general de la unidad docente. Esto también supone una diferencia importante con los equipos tipo compatible PC. Por último, las tabletas adquiridas se están reutilizando como elemento constituyente de instrumentos virtuales en las propias prácticas de laboratorio para la representación de los resultados de los ensayos mediante su conexión inalámbrica a tarjetas de adquisición de datos y para la visualización y estructuración de dichos datos de forma que sean mucho más significativos de cara al aprendizaje del alumno.

La Fig. 2 muestra a título de ejemplo una captura de pantalla tomada sobre una de las tabletas utilizadas para la realización de los exámenes. Las tabletas están conectadas por WiFi a UPVNET y el control de acceso a las mismas se realiza por la propia plataforma PoliformaT. El acceso al examen está restringido a los alumnos de las asignaturas en cuestión durante las fechas y horas de realización de las prácticas. El acceso está restringido también a las IP de las tabletas del laboratorio, lo que aumenta considerablemente la seguridad en cuanto a la autoría del examen, ya que sólo se puede cumplimentar en el laboratorio en presencia y bajo control del profesor responsable de la sesión de prácticas. 


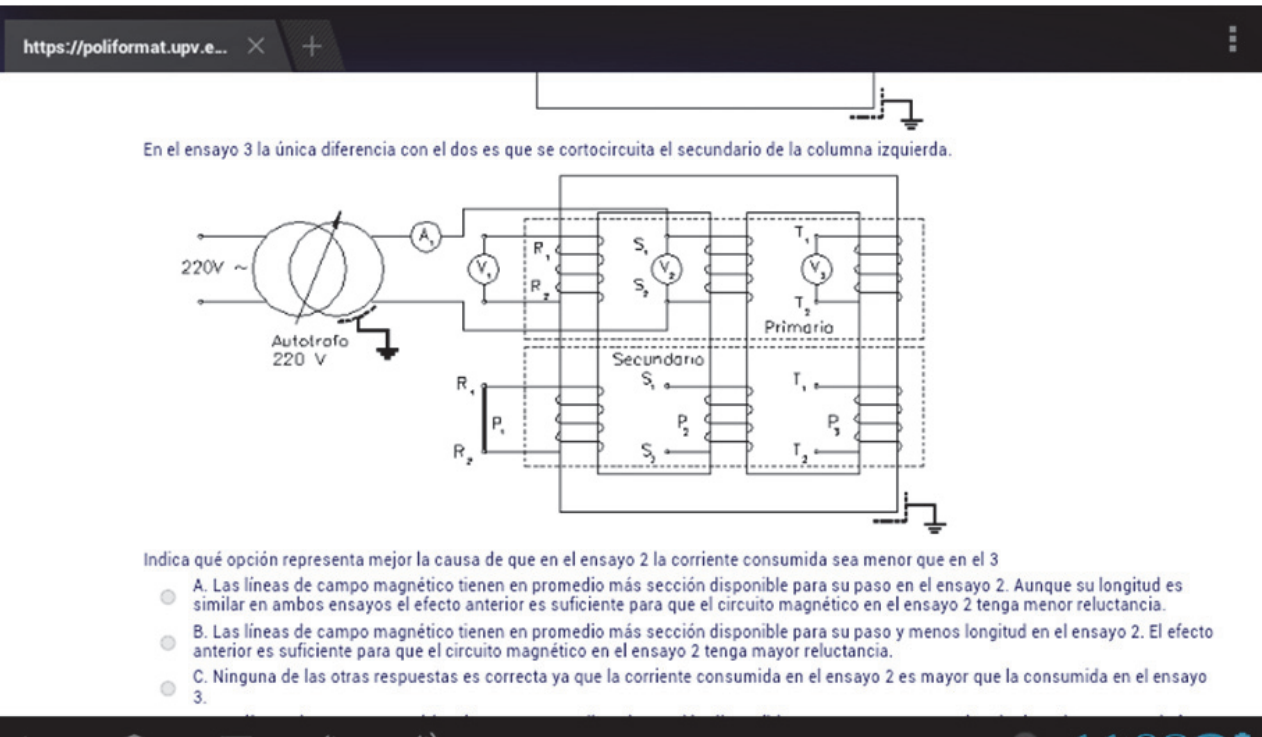

\section{$\hookleftarrow \triangleleft \square$ ఈ)}

Fig. 2 Captura de pantalla durante la realización de un examen en una tableta tipo Android. Asignatura: Máquinas Eléctricas, Práctica: 1.- Circuitos Magnéticos

\section{Resultados}

El nuevo sistema de evaluación se viene utilizando desde el segundo cuatrimestre del curso 2012-2013 para la asignatura de Máquinas Eléctricas (dos convocatorias) y desde el primer cuatrimestre del curso 2013-2014 para la asignatura de Tecnología Eléctrica (una convocatoria). Los resultados comparados de este sistema de evaluación con el anterior, que estaba basado en dos preguntas de respuesta abierta en el examen final de la asignatura se pueden observar, para la asignatura Máquinas Eléctricas, en cuanto a la calificación media final de la parte de prácticas, en la Fig. 3 y para la asignatura Tecnología Eléctrica en la Fig. 4 (datos de alumnos por convocatoria respectivamente en Tabla 2 y Tabla 3 ). 


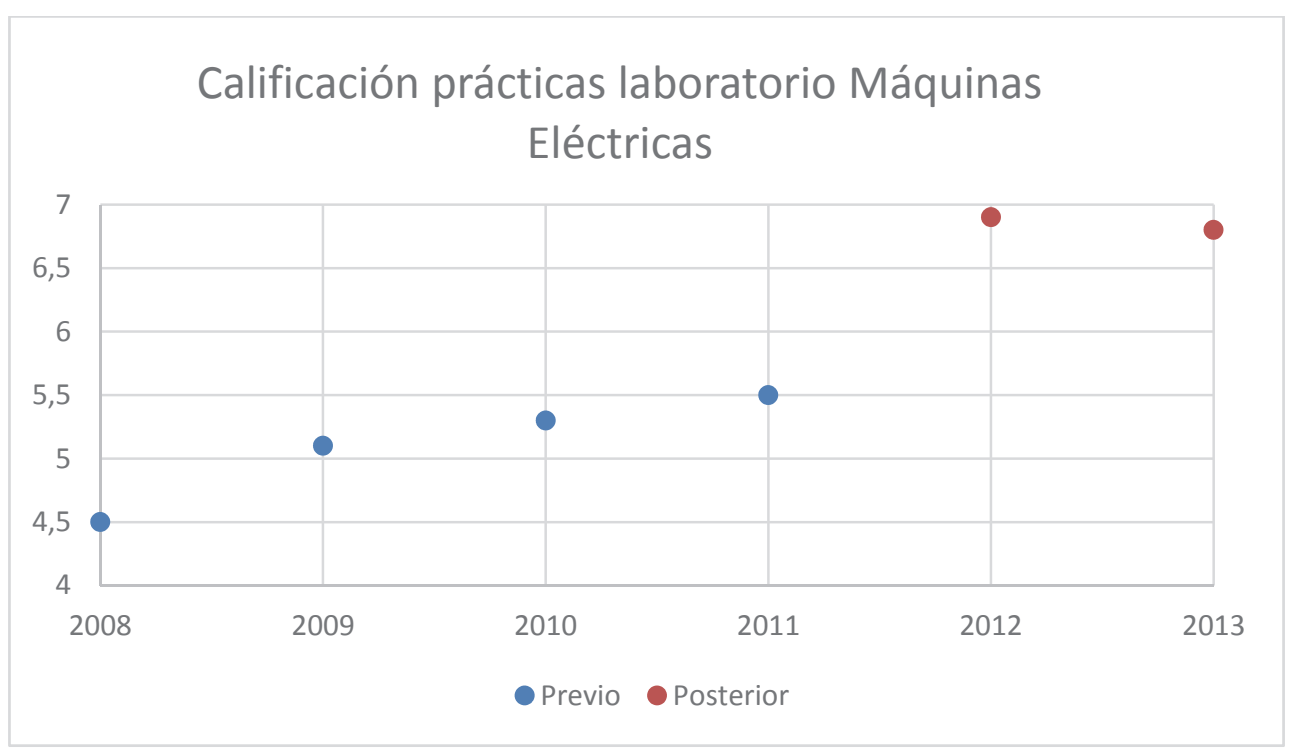

Fig. 3 Calificación de las prácticas de laboratorio de Máquinas Eléctricas: nota media de laboratorio en los últimos 6 años. Hasta 2011 previo a la implantación del nuevo sistema de evaluación y a partir de 2012 tras su implantación.

Tabla 2 Alumnos por convocatoria para los datos de la 3

\begin{tabular}{|l|l|l|l|l|l|l|}
\hline \multicolumn{3}{|c|}{ Previo } & \multicolumn{3}{c|}{ Posterior } \\
\hline Año & 2008 & 2009 & 2010 & 2011 & 2012 & 2013 \\
\hline Alumnos & 378 & 370 & 383 & 401 & 204 & 382 \\
\hline
\end{tabular}

Las Fig. 3 y 4 muestran una mejora en las calificaciones de algo más de un punto en valor medio antes y después de introducir el nuevo sistema de evaluación en esta asignatura. Es importante tener en cuenta que sólo se dispone de datos fiables con el nuevo sistema de evaluación para las dos últimas convocatorias de Máquinas Eléctricas y para la última de Tecnología Eléctrica y que, por lo tanto, es pronto para garantizar que dicha mejora se mantenga en el tiempo. Además, no se debe considerar que esa mejora se pueda achacar completamente al cambio en el sistema de evaluación ya que otros factores (especialmente la dificultad promedio de las preguntas del sistema previo y del nuevo, que es difícil de evaluar de forma independiente) pueden haber influido en dicho cambio. 
Evaluación in-situ de las prácticas de laboratorio: una herramienta asequible para la mejora de la motivación y del aprovechamiento del alumno en el laboratorio. La experiencia en máquinas y tecnología eléctrica de la ETSII

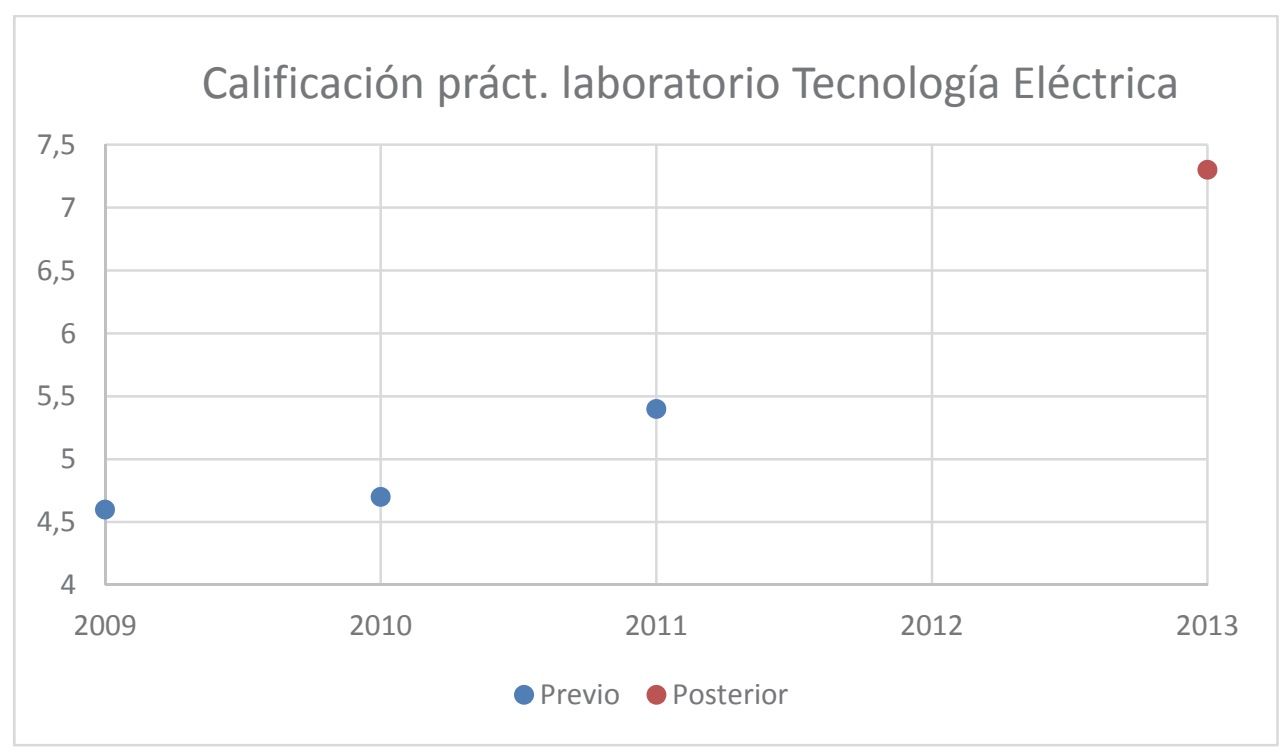

Fig. 4 Calificación de las prácticas de laboratorio de Tecnología Eléctrica: nota media de laboratorio en los últimos 5 años. Hasta 2011 previo a la implantación del nuevo sistema de evaluación y a partir de 2013 tras su implantación. La asignatura no se impartió el curso 2012-2013 por el cambio de plan de estudios.

Tabla 3 Alumnos por convocatoria para los datos de la Fig. 4

\begin{tabular}{|c|c|c|c|c|}
\hline \multicolumn{4}{|c|}{ Previo } & Posterior \\
\hline Año & 2009 & 2010 & 2011 & 2013 \\
\hline Alumnos & 482 & 522 & 677 & 235 \\
\hline
\end{tabular}

Adicionalmente a las diferencias indicadas en la nota media promedio, es también muy importante dejar constancia de los cambios percibidos por el profesorado a consecuencia del nuevo sistema de evaluación. Aunque esta percepción del profesorado no se ha cuantificado mediante, por ejemplo, una encuesta, lo cierto es que la opinión generalizada del profesorado que imparte las prácticas de laboratorio se puede resumir en los siguientes puntos:

- Una mejora significativa de la actitud de los alumnos ante las prácticas de laboratorio ya que están más atentos durante la explicación, más comprometidos durante la realización de los ensayos y más perceptivos en cuanto a los resultados de los ensayos y su relación con los obtenidos en las clases de aula. Se ha constatado además que es mejor la preparación de alumnos previa a la práctica, habiendo leído muchos de ellos el manual de prácticas con antelación a la sesión. 
Javier Martínez Román, Ruben Puche Panadero, Juan Pérez Cruz, Manuel Pineda

Sánchez, Martín Riera Guasp y José Roger Folch

- Una mejor valoración por parte de los alumnos del sistema de evaluación, ya que la inmediatez les facilita la correlación entre las observaciones durante la realización de la práctica y las cuestiones planteadas en la evaluación. Esta mejora de la valoración se debe también a verse liberados de la necesidad de confeccionar memorias de prácticas o de preparar la parte de prácticas de cara a los exámenes reglados de la asignatura.

\section{Conclusiones}

Esta contribución ha presentado un nuevo sistema de evaluación tal como se ha puesto en práctica para las asignaturas de Máquinas Eléctricas y Tecnología Eléctrica de los Grados de Ingeniero en Tecnologías Industriales y en Energía de la ETSII de Valencia. El sistema de evaluación se ha diseñado para evitar los principales inconvenientes de la evaluación tradicional de las prácticas de laboratorio y se basa en los siguientes aspectos fundamentales:

- Pruebas objetivas con preguntas de respuesta múltiple (procedimientos y métodos de la sesión) y numéricas (pequeños cálculos sobre objetivos y/o lecturas de ensayos).

- Corta duración (20 min) para no detraer excesivo tiempo del disponible para el trabajo práctico de los alumnos.

- Al finalizar la sesión fundamentalmente para: favorecer el aprendizaje continuado en la asignatura, estimular la actitud y atención de los alumnos durante la sesión, mejorar la retención de los alumnos al evaluar de forma inmediata y activar estrategias de evaluación formativa.

- Implementadas con el apartado de exámenes en PoliformaT, que cuenta con muchas ventajas para la evaluación en la universidad, por ejemplo la integración cómoda con las bases de datos de alumnos y de calificaciones.

- Soporte físico elegido para la realización de las pruebas: tabletas Android. Presenta muchas ventajas respecto de equipos más voluminosos como PCs de sobremesa, entre otras:

- Tamaño muy reducido que permite disponer al menos de tantos puestos de evaluación como de asientos en el aula sin molestar en la mesa y de su almacenaje sencillo durante periodos de no utilización.

- Coste asequible, que ha podido ser sufragado con el presupuesto general de la unidad docente.

- Reutilización como elemento constituyente de instrumentos virtuales en las propias prácticas de laboratorio.

El nuevo sistema de evaluación se ha puesto en marcha en los dos últimos cursos y se ha podido observar una mejora en las calificaciones medias de prácticas y, especialmente, una mejora significativa de la motivación de los alumnos durante las mismas, alumnos que

\section{(cc) EY-NC-ND 2014, Universitat Politècnica de València}

I Jornadas IN-RED (2014) 
Evaluación in-situ de las prácticas de laboratorio: una herramienta asequible para la mejora de la motivación y del aprovechamiento del alumno en el laboratorio. La experiencia en máquinas y tecnología eléctrica de la ETSII

están más atentos durante la explicación, más comprometidos durante la realización de los ensayos y más perceptivos en cuanto a los resultados de los ensayos y su relación con los obtenidos en las clases de aula. Si bien los datos en cuanto a calificaciones pueden ser todavía insuficientes para garantizar la efectividad del nuevo sistema en la mejora del rendimiento de los alumnos, lo cierto es que sólo la mejora de la actitud percibida por los profesores es una clara ventaja respecto de los sistemas de evaluación tradicionales, mejora que estamos convencidos que ha influido en los resultados obtenidos por los alumnos.

\section{Referencias}

MARTINEZ , J (2014). Ensayos de Máquinas Eléctricas. Valencia: Editorial UPV. [Martínez Román, J. Pérez Cruz, J. y Pineda Sánchez, M.]

ROGER, J (2000). Tecnología Eléctrica. Valencia: Editorial UPV. [Roger Folch, J. Riera Guasp, M, Roldán Porta, C.]

ROGER, J (2011). Prácticas de Tecnología Eléctrica. Valencia: Editorial UPV. [Roger Folch, J. et al.]

SERRANO (2013). Máquinas Eléctricas. Valencia: Editorial UPV. [Serrano Iribarnegaray, L. y Martínez Román, J.] 


\title{
La herramienta MOOC como curso de nivelación en Física para estudiantes universitarios de Ciencias
}

Pilar Candelas Valiente ${ }^{a}$, Marcos H. Gimenez Valentin ${ }^{a}, M^{a}$ Angeles HernándezFenollosa $^{a^{*}, \text { Constanza Rubio Michavila }}{ }^{a}$, Joaquin Cerdá Boluda ${ }^{b}$, Jaime L. Busquets Mataix

${ }^{a}$ Departamento de Física Aplicada, Universitat Politècnica de València, 46022 Camino de Vera s/n, Valencia, España,

${ }^{b}$ D. Ing. Electrónica, Universitat Politècnica de València 46022 Camino de Vera s/n, Valencia, España

`Área de Sistemas de Información y Comunicaciones, Universitat Politècnica de València, Camino de Vera s/n, Valencia, España

*E-mail: $\underline{\text { mhernan@fis.upv.es }}$

\begin{abstract}
We show in this paper a powerful tool that will establish the basis of knowledge that comprises the prerequisites of the physical skills necessary to face successfully scientific careers. Looking for maximum dissemination and its effective implementation and teaching by professors involved, we have chosen to publish this tool as a course MOOC (Massive Online Course and Open). That is, learning is organized in coordination using various technological tools: content generation in video format, alternating issues to control learning, testing, support forums, etc.

The course covers the content through PowerPoint presentations developed by the professors of the Department of Applied Physics, in the Polytechnic University of Valencia (UPV). Includes original graphics and simulations, allowing an analysis and understanding of all the concepts and phenomena studied in a very enjoyable and educational way for students. The image of the teacher, explaining everything that is analyzed in different slides exposed, accompanies all presentations. This format, known as Polimedia, has been designed by the UPV for easily creating multimedia educational content with high resolution and economically.
\end{abstract}

(c) EY-NC-ND 2014, Universitat Politècnica de València

I Jornadas In-Red (2014) 
Keywords: MOOC, MOOC Pedagogy, Learning in MOOC, Physical Prerequisites, Education Technology

\footnotetext{
Resumen

Mostramos en este trabajo una potente herramienta que va a sentar las bases de los conocimientos que conforman los prerrequisitos de los conocimientos físicos necesarios para afrontar con éxito las carreras de ciencias. Buscando la máxima difusión, así como su realización e impartición efectiva por parte de profesores participantes, se ha optado por publicar esta herramienta, en forma de curso MOOC (Curso On-line Masivo y Abierto). Es decir, el aprendizaje se ha organizado utilizando de manera coordinada distintas herramientas tecnológicas: generación de contenidos en formato vídeo, alternando cuestiones para controlar el aprendizaje, exámenes, soporte en foros de discusión, etc.

El curso abarca los contenidos mediante presentaciones PowerPoint desarrolladas por los profesores del departamento de Física Aplicada de la Universitat Politècnica de Valencia (UPV). Se incluyen gráficos y simulaciones originales, permitiendo un análisis y comprensión de todos los conceptos y fenómenos estudiados de una forma muy amena y didáctica para los estudiantes. La imagen del profesor que explica todo lo que se va analizando en las distintas diapositivas expuestas acompaña todas las presentaciones. Este formato, conocido como Polimedia, ha sido diseñado por la UPV para la creación de contenidos educativos multimedia de alta resolución de forma fácil y económica.
}

Palabras clave: MOOC, Pedagogía de los MOOC, Aprendizaje en los MOOC, prerrequisitos de física, Tecnología Educativa

\section{Introducción}

Como punto de partida en cualquier tipo de estudios superiores de ciencias, los estudiantes deben tener una buena base en matemáticas, física y química, y tener interés en otros temas relacionados con otras disciplinas de acuerdo con las distintas especialidades científicas.

(c)) EY-NC-ND 2014, Universitat Politècnica de València 
Como ejemplo, si el estudiante quiere conseguir su título en ingeniería biomédica tiene que mostrar interés para la biología y la medicina. También es recomendable la curiosidad científica y el sentido práctico. Además, es importante tener la capacidad de esfuerzo y perseverancia, ser capaz de organizar el tiempo y para trabajar en equipo. Todos estos hechos asegurarán el progreso en los estudios, pero en el marco actual de los estudios preuniversitarios encontramos que no siempre nuestros estudiantes tienen la base sólida que sería deseable tener. Un problema común proviene de la gran diversidad de formas que hacen posible llegar a los estudios universitarios. Con el fin de enfocar la situación que se plantea, vamos a exponer brevemente el panorama real que encontramos en la plataforma española para llegar a la universidad con el objetivo de desarrollar un alto grado de educación en estudios de ciencias (ya sean en ingenierías como en Físicas, Biología, etc...). Tomaremos como ejemplo representativo, la universidad donde los autores hemos desarrollado la mayor parte de nuestra labor docente profesional, la Universitat Politècnica de València (UPV) con 27 grados de licenciatura en diferentes ramas de la ingeniería. Contamos con 36.187 estudiantes en total y cada año unos 4.300 estudiantes inician su licenciatura en nuestro Campus Universitario.

Los estudiantes que llegan a la universidad pueden proceder de estudios de la escuela secundaria de pregrado, de un ciclo, más de 25 años, de 40 años, más de 45 años, otra universidad, una escuela extranjera y títulos universitarios de la UPV. Las notas de corte son las calificaciones de los alumnos que han sido admitidos en último lugar en cada carrera universitaria. Estos resultados no están relacionados con la dificultad de cada carrera. El hecho de que el acceso tenga en cuenta una nota más o menos elevada sólo indica una carrera más o menos atractiva o demandada para la mayoría de los estudiantes. La nota de corte general se calcula sobre un total de 14 puntos. Esta tabla es indicativa y sólo sirve a los estudiantes interesados en conocer que estudios son los más demandados.

En este amplio panorama de las diferentes procedencias de los estudiantes también encontramos alumnos que no habrán adquirido los necesarios conocimientos en matemáticas y física necesarios para su buena formación académica debido a que estas asignaturas no fueron las opciones elegidas en su escuela secundaria durante los últimos cursos. Una gran parte de estos estudiantes están pensando en obtener una mejor puntuación en su plan de estudios, con el fin de llegar a las notas de corte necesarias para una licenciatura específica, y se olvidan de adquirir una sólida base necesaria para lo que desean estudiar.

Conscientes de estas dificultades los profesores del departamento de Física aplicada de la Universitat Politècnica de València (UPV) hemos invertido un gran esfuerzo en ofrecer, a los futuros estudiantes universitarios de cualquier carrera científica, una herramienta muy potente que les va a ofrecer todo lo que necesitan para comenzar sus estudios universitarios, sin carencias en los conocimientos de las magnitudes y principios físicos. Se trata de un

(cc) BY-NC-ND 2014, Universitat Politècnica de València

I Jornadas IN-RED (2014) 
curso que los estudiantes pueden seguir desde sus casas, con ejemplos familiares para ellos basados en el deporte, y a través de dos nuevos amigos, Jota y Amanda, que compartirán con ellos sus dos grandes pasiones.....ilos deportes y la aventura del saber!. Con el fin de buscar la máxima difusión entre los posibles interesados, así como su realización e impartición efectiva por parte de profesores participantes, se ha optado por publicar el curso en formato MOOC, es decir, como Curso On-line Masivo y Abierto. Esta es una tendencia surgida recientemente entre las universidades más potentes del mundo, basada en la organización del aprendizaje utilizando de manera coordinada una serie de herramientas tecnológicas disponibles como son: generación de contenidos en formato de vídeo, alternando cuestiones para el control del aprendizaje, exámenes, soporte en foros de discusión, etc.

\subsection{Antecedentes de los MOOC'S}

Al ser MOOC el acrónimo en inglés de Massive Online Open Courses, en castellano podemos referirnos a ellos como cursos COMA, Cursos Online Masivos y Abiertos. Los cursos masivos no han sido otra cosa que la evolución de la educación abierta en internet. Desde una concepción conectivista, donde la creación del conocimiento se basa en el establecimiento de conexiones, está claro que cuanto mayor sea el número de nodos, más posibilidades de aprendizaje hay en un curso determinado. Por lo tanto, el cambio desde las plataformas educativas cerradas a entornos de aprendizaje abiertos ha supuesto la posibilidad de que miles de personas de todo el mundo sigan diferentes iniciativas educativas. Es ahí donde reside su gran fuerza, y es por lo que nacieron, de una forma más o menos intencionada, los cursos masivos en el año 2008 (Yuan, 2013). George Siemens y Stephen Downes crearon el que podría ser primer Mooc: "Connectivism and Connective Knowledge (CCK08)" (Fini, 2009). A partir de ahí, y con la colaboración de Dave Cormier y Bryan Alexander, este grupo ha ido ofreciendo multitud de cursos abiertos: CCK09, CCK11, CCK12, Future of Education, PLENK, LAK11, LAK12, Change11, Critical Literacies, entre otros.

Dado el auge que han experimentado este tipo de cursos, aparecieron iniciativas privadas, que con la colaboración de grandes expertos de cada materia, profesores de las más prestigiosas universidades de Estados Unidos, se convirtieron en grandes éxitos como son los casos de Udacity y Coursera (UNESCO ). El caso de Sebastian Thrun fue uno de los más mediáticos y eso contribuyó a una mayor expansión del número de iniciativas y seguidores de los mooc. Edx, la segunda gran plataforma para Mooc del Instituto Tecnológico de Massachussets (MIT) vino a confirmar la importancia de la tendencia de los cursos masivos y a reforzar la sensación de que es un movimiento que está llamado a cambiar la educación, puesto que las mejores universidades del mundo se han unido a él.

(c)) BY-NC-ND 2014, Universitat Politècnica de València 
Como comentaba, la publicación de una entrevista de Sebastian Thrun en New York Times, que se hacía eco de la afirmación en un discurso en Alemania de Enero de 2012, en el que aseguraba que una vez impartido el MOOC ya no iba a poder volver a la Universidad de Stanford, creó una suerte de expectación en conocer acerca de este tipo de cursos. Acceso al artículo.

En España, Crypt4you fue la primera iniciativa de un mooc en español. Dirigido por los Doctores Jorge Ramió y Alfonso Muñoz. Se trata de un curso de criptografía para programadores y está respaldado por la Universidad Politécnica de Madrid. A esto se ha unido la gran incorporación de la plataforma en español de MIRIADAX, impulsada por Telefónica y Universia (quien integra a 1.232 universidades de 23 países de Iberoamérica). Recientemente tanto Coursera como Edx han ampliado el número de universidades que ofrecen cursos a través de sus plataformas, incluyendo en esta oleada universidades de paises hispanohablantes.

Todo este movimiento, además, ha creado una discusión acerca del futuro de la educación superior, del papel de las universidades y del aprendizaje a lo largo de la vida y su impacto en la empleabilidad.

Las características de un Mooc son:

-No tener limitación en las matriculaciones.

-Poder ser seguido online.

-De carácter abierto y gratuito. Con materiales accesibles de forma gratuita

-Se trata de un curso que tiene una estructura de contenido y pruebas de evaluación y está orientado al aprendizaje.

\section{Objetivos}

El principal objetivo de los profesores del Departamento de Física Aplicada de diferentes escuelas de la UPV es el de homogeneizar los conocimientos que presentan los alumnos dentro de los distintos bloques temáticos que conforman el temario de la física clásica. Así mismo prepara a los estudiantes consiguiendo las habilidades y la comprensión académica requerida para adquirir el conocimiento y las actitudes necesarias en estudios universitarios de grado.

Para conseguir este objetivo global y con el fin de buscar la máxima difusión entre los posibles interesados, así como su realización e impartición efectiva por parte de profesores participantes, se ha optado por publicar el curso en formato MOOC. Durante el curso se van abarcando todos los contenidos a través de presentaciones, desarrolladas por los profesores del departamento de Física Aplicada de la UPV, en PowerPoint. Se incluyen gráficos y simulaciones, desarrolladas también originalmente por el profesor Cerdá, que permiten un

(c) EY-NC-ND 2014, Universitat Politècnica de València

I Jornadas IN-RED (2014) 
análisis y comprensión de todos los conceptos y fenómenos estudiados de una forma muy amena y didáctica para los estudiantes. Estas presentaciones vienen acompañadas de la imagen del profesor que se encarga de explicar todo lo que se va analizando en las distintas diapositivas expuestas. Este formato, bautizado con el nombre de Polimedia, ha sido diseñado por la Universitat Politècnica de València, para la creación de contenidos educativos multimedia de alta resolución de forma fácil y económica. Durante el curso se integran evaluaciones formativas que proporcionan una retroalimentación a los estudiantes durante el aprendizaje; recursos de video enfocados a reforzar las explicaciones formativas; y un proceso de aprendizaje diseñado sobre los conceptos esenciales para adquirir un conocimiento global de los distintas partes de la física.

Los MOOC'S que estamos desarrollando son adecuados para estudiantes con poco o ningún conocimiento de la física. En estos cursos se examinan los Principios básicos sobre los que la disciplina de la física se funda y se orientan hacia el desarrollo de habilidades para entender y resolver distintos tipos de problemas. En resumen, deseamos preparar a los estudiantes para la universidad, los oficios y los programas de distintas disciplinas de ciencias que requieren Física como prerrequisito.

\section{Desarrollo de la innovación}

La primera experiencia que los autores de este trabajo hemos tenido ha sido con el diseño e impartición de un MOOC titulado "Fundamentos de Mecánica para el estudio de la ingeniería", siendo su primera aparición en la plataforma Miriada X. Ha sido diseñado para servir como curso introductorio en las ingenierías de pregrado y en estudios de ciencias en general.

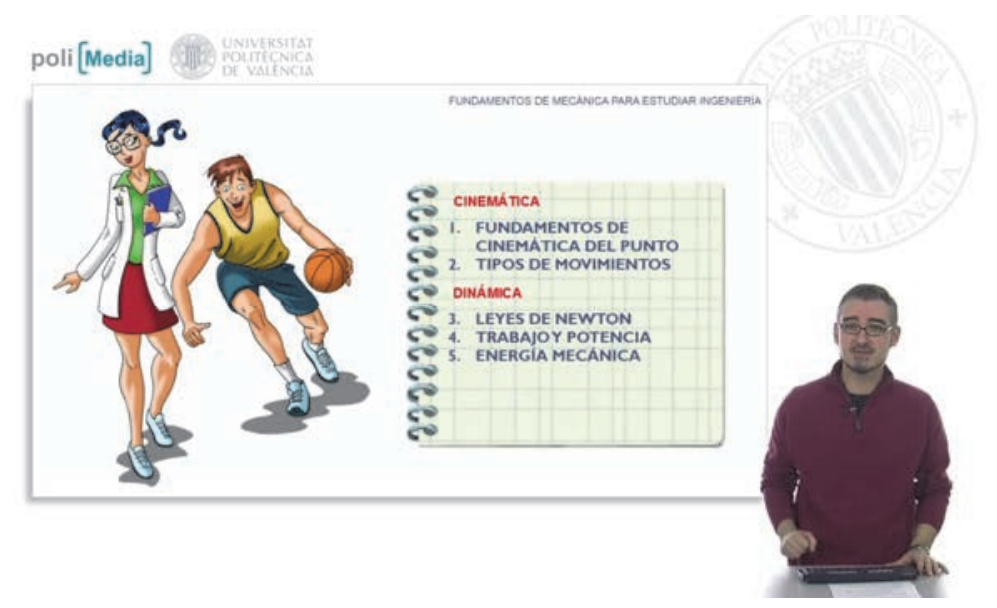

Fig. 1. Imagen del curso en la que se muestra la diapositiva con Jota y Amanda, que ayudan a clarificar los conceptos que se abordan en el curso "Fundamentos de mecánica para estudiar ingeniería”.

(c) BY-NC-ND 2014, Universitat Politècnica de València

I Jornadas IN-RED (2014) 
El curso está estructurado en cinco módulos como se muestra en la Fig. 1., y se espera que sea seguido por cinco semanas y cada formato de módulo permite a los participantes ver una serie de videos cortos (con un formato Polimedia) preparado por el profesor que detalla un tema tópico en particular para cada una de las semanas especificadas del curso. El formato utiliza un aprendizaje asincrónico, para que los participantes puedan ver el video en los momentos que mejor se adapten a ellos a causa de sus zonas horarias. En cada tema, hay pruebas en línea que permiten que los participantes respondan y comprueben su comprensión del concepto o la información presentada, así como material complementario. Para completar cada curso existe otra prueba de opción múltiple sobre los conceptos explicados en el módulo correspondiente. A través de los foros, los estudiantes tienen la oportunidad de preguntar acerca de lo que no entienden o preguntas que puedan surgir tanto a los alumnos del curso o el maestro; profesores y alumnos del curso pueden contestar o hacer sugerencias.

Para aprobar cada una de las pruebas de módulos, se requiere una puntuación del 100\%. Para lograr esto se puede intentar la prueba tantas veces como sea necesario, aprendiendo así cada vez de los errores cometidos. El modelo de aprendizaje de MiríadaX MOOC es el auto-aprendizaje, social y de colaboración más que un modelo evaluativo. Sin embargo, sí que existe un modelo de certificaciones o distintivos:

Certificación de Participación: promulgadas por MiríadaX a cualquier estudiante que ha participado en más de $80 \%$ del curso.

Los estudiantes que habían aprobado un examen final, en el que deben obtener una nota de $60 \%$ como mínimo, después de un máximo de dos intentos, consiguen un "Certificado de superación del curso", firmado por el profesor y emitido por la UPV. En esta primera edición, este certificado es libre.

Por otra parte, también pretende acreditar el reconocimiento de las universidades y el reconocimiento de la certificación por cualquiera de las empresas que puedan estar interesadas en las calificaciones de los estudiantes.

Este curso aparece en la actualidad, de forma continua, en el portal de la Universitat Politècnica de València (UPV) que comenzó su andadura en enero de 2013 (UPV [X]). Se trata de un nuevo portal para los profesores de la UPV que imparten sus propios MOOCs. UPV $[X]$ es parte de su propio proyecto Aula Abierta y añade una amplia gama de herramientas educativas basadas en las nuevas tecnologías que la UPV ofrece a sus estudiantes y profesores. Entre otras cosas, Polimedia (un sistema para desarrollar videos educativos de calidad rápidamente y a un bajo costo de producción), Policonecta (plataforma de aula virtual), Polireunión (tutoriales de herramientas y consultas on-line) y

(c) EY-NC-ND 2014, Universitat Politècnica de València

I Jornadas IN-RED (2014) 
Vídeoapuntes (un servicio que permite grabar clases magistrales récord en forma sin ayuda) pueden ser mencionadas. Con UPV [X], la Universitat Politècnica de València tiene el compromiso de facilitar el acceso a una educación de calidad en todo el mundo, lo que contribuye a la extensión de este nuevo formato de la enseñanza en español.

En la actualidad el mismo equipo de profesores contamos con un nuevo MOOC pero centrado en esta ocasión en la parte de la Física del electromagnetismo. En este nuevo curso hemos introducido más experiencias de aula, ya que el actual sistema de grabación de Polimedias nos permite mostrar con gran facilidad, esto consigue una importante repercusión didáctica. En la Fig. 2 se muestra una de estas experiencias utilizando el generador de Van der Graaf.

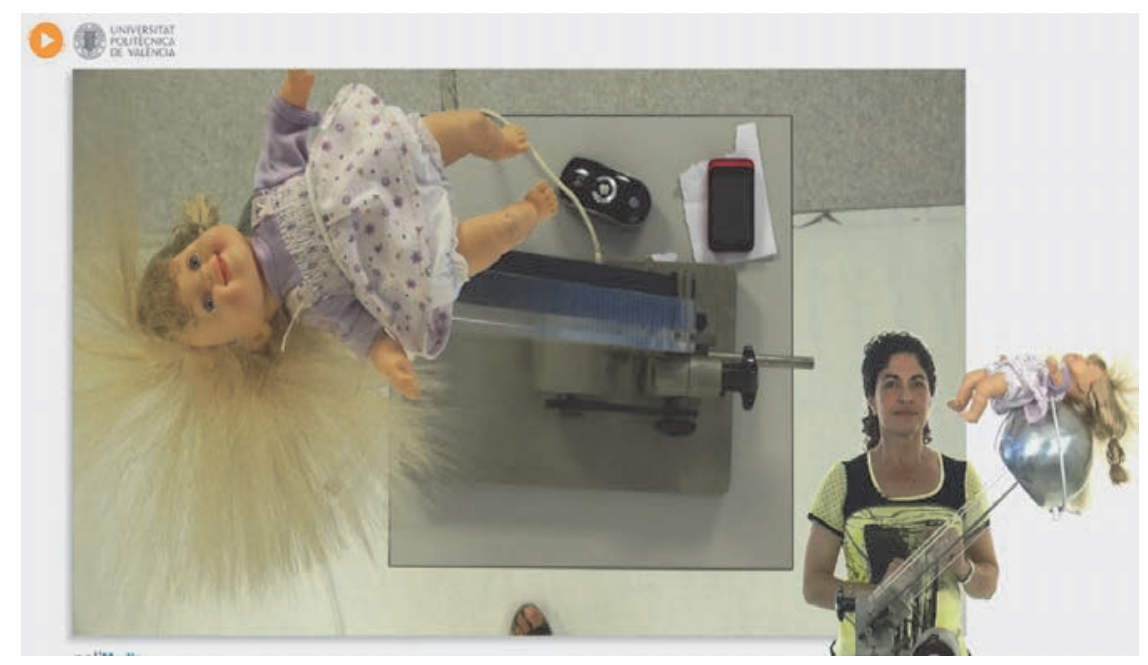

Fig. 2. Imagen de de una de las experiencias de aula haciendo uso del generador de Van der Graaf y mostrando todos sus efectos gracias a la cámara cenital disponible en los recursos Polimedia de $U P V[X]$

\section{Resultados}

Con el fin de conocer las características y las experiencias de aprendizaje, así como las expectativas de los participantes en el curso el equipo de investigación decidimos utilizar métodos mixtos (cualitativos y cuantitativos) (Fournier, 2011). Cuando los estudiantes decidieron inscribirse en el curso, debían rellenar un cuestionario. 66\% de los participantes eran de diferentes partes de América Latina y el 44\% de España (véase Fig. 3). Para dar una idea de los antecedentes de los participantes, la Fig. 4 muestra los niveles de estudios donde el $38 \%$ tienen estudios universitarios o estudios universitarios similares y el 39\% están empezando estudios universitarios.

(c)) EY-NC-ND 2014, Universitat Politècnica de València 


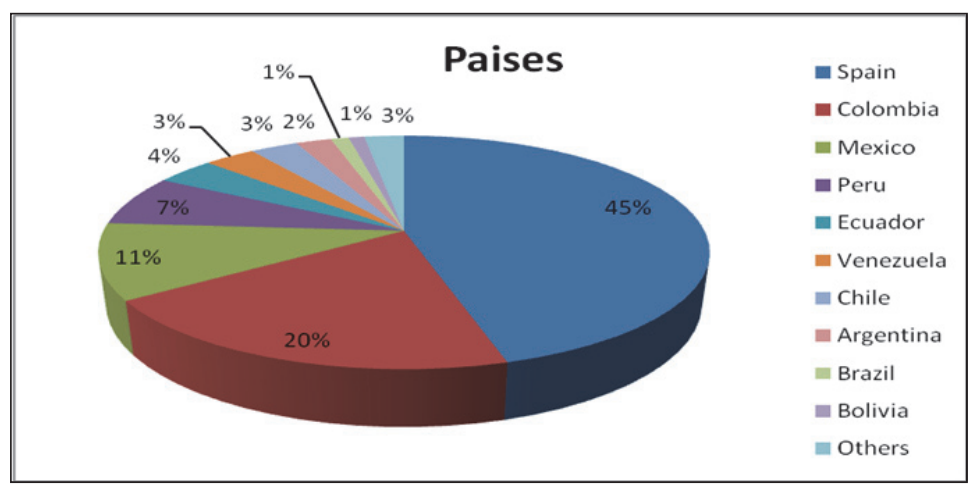

Fig. 3. Países participantes

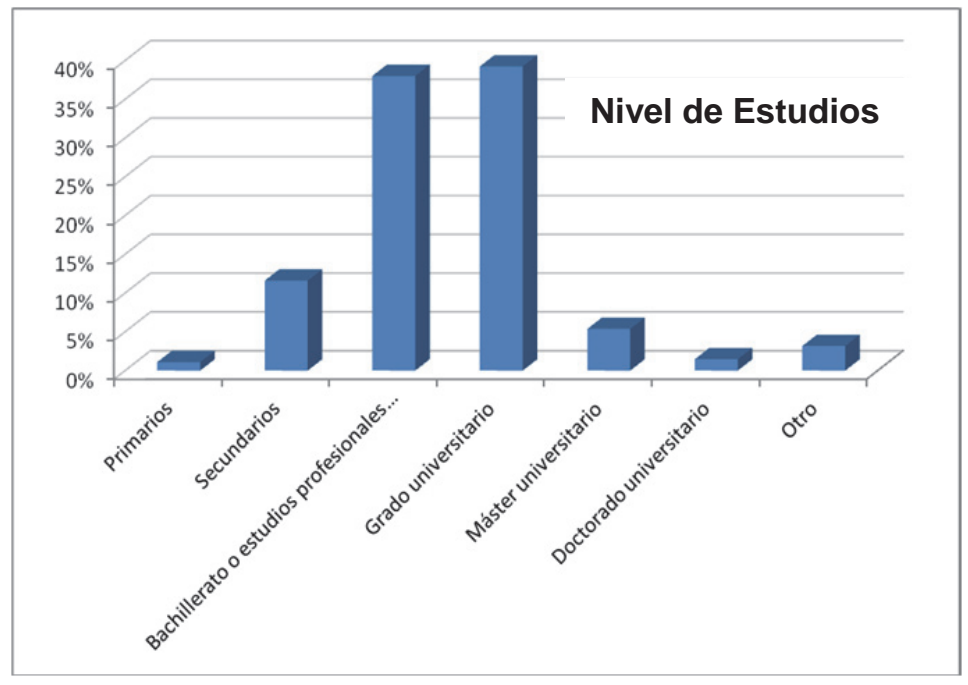

Fig. 4. Nivel de estudios de los estudiantes participantes

Con el fin de conocer su nivel de conocimientos previos en Física se les preguntó al respecto y los resultados aparecen en la Fig. 5. Cuando comenzó el curso, 1.115 se habían registrado, que aumentó a 1.638 al final del curso. De estas inscripciones, el 12\% completó el curso y, finalmente, el $85 \%$ de ellos obtuvo el logro insignia. Algunos de los estudiantes estaban interesados en aprender tanto como sea posible en lugar de obtener el certificado de superación, por lo que la diferencia se debe a que algunos de ellos no hicieron el examen final para obtener este tipo de certificación.

\section{(c) BY-NC-ND 2014, Universitat Politècnica de València}

I Jornadas IN-RED (2014) 
Los participantes indicaron que los recursos del curso, tales como videos, cuestionarios y ejercicios propuestos fueron suficientes para hacerles entender lo que tratamos de ayudarles a asimilar (54\% de ellos estuvo muy de acuerdo). Algunos de los participantes que no completaron el curso dijeron que estaban interesados en él, pero, en ese momento no tenían tiempo para hacerlo. Ellos estaban interesados en saber cuándo íbamos a abrirlo de nuevo para que puedan completarlo.

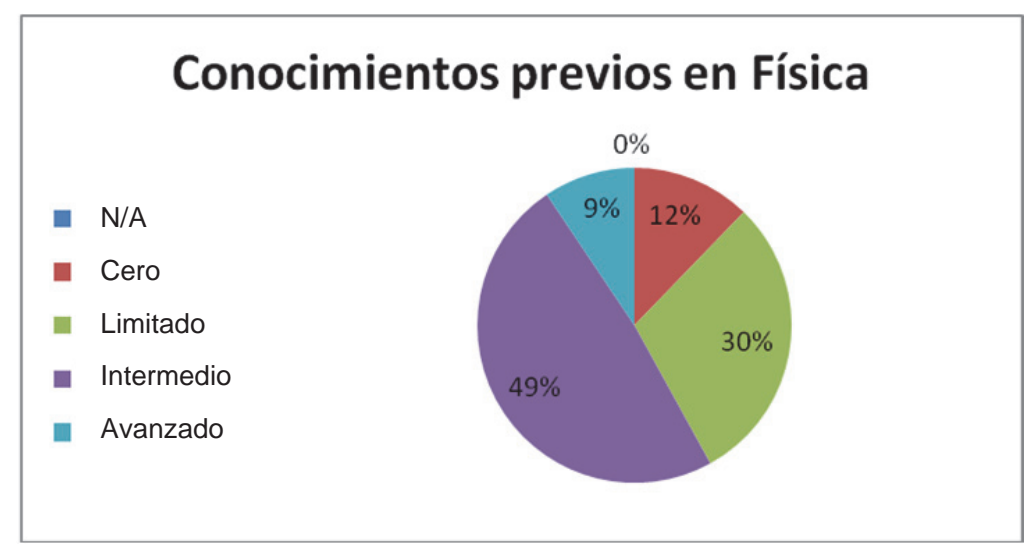

Fig. 5. Conocimientos previos en Física. N/A indica no aplicable, Limitado indica que poseen algo de conocimiento pero les gustaría ampliarlo y Avanzado indica que ellos piensan que poseen un alto nivel en esta materia.

Actualmente los profesores, del Departamento de Física Aplicada de la UPV, que hemos realizamos el primer MOOC de introducción a los principios de mecánica y que estamos desarrollando nuevos cursos en la plataforma de UPV $[\mathrm{X}]$ y relacionados con prerrequisitos de Física, estamos muy satisfechos con los logros conseguidos. Son muchos de nuestros propios alumnos los que nos van dando ideas nuevas que vamos incorporando y, además de agradecernos el poder contar con esta nueva herramienta, nos demuestran con su evolución académica lo acertado de la idea que hemos empezado a desarrollar y perfeccionar.

\section{Conclusiones}

En esta comunicación hemos presentado los grandes desafíos que hemos abordado con el trabajo desarrollado:

- Utilizar la tecnología para mejorar la pedagogía, la gestión y los resultados educativos. La mayoría de las clases universitarias en nuestro país contienen una dispersión dramática de los niveles de aprendizaje. Los programas que buscan adaptar la enseñanza a nivel de aprendizaje de los estudiantes han demostrado su eficacia, y la tecnología educativa que adapta la instrucción a los niveles de conocimiento de los estudiantes pueden desempeñar un papel importante. Además, las tecnologías de monitoreo ayudan a mejorar los resultados e incentivan los

(cc) EY-NC-ND 2014, Universitat Politècnica de València 
Pilar Candelas Valiente, Marcos H. Giménez Valentin, Mángeles Hernández-Fenollosa, Constanza Rubio Michavila, Joaquin Cerdá Boluda, Jaime L. Busquets Mataix

sistemas educativos donde existen carencias en determinados conocimientos previos.

- Mejorar el acceso universitario con una calidad en los conocimientos requeridos en distintas disciplinas científicas. Existe evidencia sustancial sobre la forma de aumentar la cantidad y calidad de una formación sólida en distintos campos científicos. Podemos conseguir una buena formación curricular para que nuestros estudiantes no se sientan desmotivados a causa de las lagunas que puedan sentir en su formación previa.

- Con el objetivo de dar soporte a la necesidad de aprendizaje permanente, se ha creado una nueva herramienta que facilita todo lo comentado en los puntos anteriores: el MOOC (Massive Open Course Online). Y con esta idea la UPV ha creado el portal de la UPV-X y esto permite que sus profesores calificados puedan ofrecer cursos gratuitos en línea en todo el mundo. En concreto, varios profesores del Departamento de Física Aplicada han diseñado un primer MOOC centrados en los prerrequisitos de Física en la parte de Mecánica y actualmente ya se cuenta con uno centrado en Electromagnetismo con el mismo formato. Estos cursos están disponibles en la UPV-X (http://www.upvx.es).

\section{Referencias}

Fini, A. (2009). "The technological dimension of a massive open online course: The case of the CCK08. Course tools" en The International Review Of Research In Open And Distance Learning, vol. 10, issue 5, p. 1-26.

Fournier, H. Kop, R, Sitlia, H. (2011). "The value of learning analytics to networked learning on a personal learning environment". 1st International Conference Learning Analytics and Knowledge, Banff, Alberta, February 27-March 1.

MIT - MASSACHUSETTS INSTITUTE OF TECHNOLOGY, 6.002x (Circuits and Electronics) <http://6002x.mitx.mit.edu/> [Consulta: 12 de enero de 2014].

MIRIADA X, <http://www.miriadax.net/ > [Consulta: 28 de junio de 2013]

UNIVERSITAT POLITÈCNICA DE VALENCIA. UPV[X] formación Online < http:// www.upvx.es/>.

UNESCO (2005), Open Content for Higher Education . $<$ http://www.unesco.org/iiep/virtualuniversity/media/forum/oer_forum_session_2 note.pdf $>$ [Consulta:13 de abril de 2014].

Yuan, L. y Powell, S. (2013). MOOCs and Open Education: Implications for Higher Education. White Paper. Reino Unido: University of Bolton: CETIS.

(c) BY-NC-ND 2014, Universitat Politècnica de València

I Jornadas IN-RED (2014) 


\title{
Uso didáctico de dispositivos móviles en primer curso del Grado en Biotecnología
}

\author{
Maria Desamparados Vargas Colás
}

Equipo de Innovación y Calidad Educativa "RIAD”, Dept. Tecnología de Alimentos, Escuela Técnica Superior de Ingeniería Agronómica y del Medio Natural, Universitat Politècnica de València

\begin{abstract}
This work describes and evaluates an experience with the tool SOCRATIVE. This free web application, which is based on a classroom response system, can be used from mobile devices. In the Academic Year 2013-2014, the tool was used weekly in the lectures of Thermodynamics, which is a first-year subject of the Degree in Biotechnology. At the end of the course, the students' point of view was evaluated through an opinion poll. Almost all the students that answered the questions of the survey considered the tool as being innovative and useful. A high percentage of students stated that the use of the tool encourages their participation in the classroom, promotes active learning and makes the lectures be more dynamic.
\end{abstract}

Keywords: classroom response system, active methodologies, mobile device, active learning

\section{Resumen}

En este trabajo se describe y evalúa una experiencia sobre la utilización de la aplicación SOCRATIVE (gratuita y accesible desde su página web), basada en un sistema de respuesta inteligente a través de dispositivos móviles. En el curso 2013-2014, la aplicación fue utilizada con una periodicidad semanal en las clases de teoría de aula de "Termodinámica", asignatura de primer curso del Grado en Biotecnología de la Universitat Politècnica de València. Al final del curso, se planteó una encuesta a través de PoliformaT para conocer la opinión del alumnado y valorar la experiencia en el contexto del proceso de enseñanza-aprendizaje de la asignatura. Casi la totalidad de los alumno/as que participaron en la encuesta manifestó que se trataba de una herramienta novedosa y útil. Un 
Uso didáctico de dispositivos móviles en primer curso del Grado en Biotecnología

gran porcentaje afirmaron que el uso de la herramienta fomenta la participación en el aula, el aprendizaje activo y hace las sesiones de teoría más dinámicas.

Palabras clave: sistema de respuesta en el aula, metodologías activas, dispositivos móviles, lección magistral participativa

\section{Introducción}

En asignaturas fundamentales, con gran carga teórica y grupos números de alumnos, características de los primeros cursos universitarios, la metodología docente más utilizada en el aula sigue siendo la lección magistral. Las clases tienen una duración media de 90 minutos, por lo que resulta necesario dinamizar las sesiones con actividades que fomenten la participación del alumnado. El uso de sistemas de respuesta en el aula, ofrece la posibilidad de aumentar la interactividad en las clases al mismo tiempo que permite obtener información sobre el nivel de comprensión y adquisición de conocimientos del alumnado. El sistema de mandos interactivos resulta difícil de implementar en aulas con gran número de alumnos, ya que exige una fuerte inversión institucional (Murray et al., 2012). Estos sistemas están generalmente limitados en cuanto a grado de interacción y retroalimentación alumno-profesor (Beuckman et al., 2007), y además requieren el aprendizaje de un software por parte del profesorado, que tiene además que distribuir y custodiar los mandos.

Por otra parte, cada vez son más los alumnos que acuden a las aulas con dispositivos móviles (teléfonos, ordenadores portátiles y tabletas) que tienen conectividad a la red inalámbrica gratuita de la Universidad. Estos elementos, que a priori podrían ser motivo de distracción, impulsan y favorecen el desarrollo de competencias transversales básicas si se integran de manera adecuada en el proceso de enseñanza-aprendizaje en el aula (Cantillo et al., 2012). Así, los dispositivos móviles, ofrecen un gran número de posibilidades en relación al uso de recursos educativos disponibles on-line y entre ellos los sistemas de respuesta en el aula. En concreto, en este trabajo se ha utilizado el sistema de respuesta inteligente SOCRATIVE, un recurso que se puede utilizar on-line (compatible con cualquier navegador) y con apps gratuitas para iOS, Android y Windows Mobile. Esta aplicación, desarrollada por educadores e ingenieros, posibilita plantear preguntas con un amplio rango de opciones y obtener respuestas en tiempo real de una manera flexible e intuitiva (Liu y Taylor, 2013). Además, el software permite guardar baterías de preguntas y agruparlas por temas, sesiones, dificultad, etc. También ofrece la posibilidad de que el alumno vaya obteniendo resultados y estadísticas a medida que va respondiendo cada pregunta y obtener una retroalimentación continua del grado de asimilación de su aprendizaje. 


\section{Objetivos}

El objetivo de la innovación que se describe en este trabajo fue evaluar la utilización de un sistema de respuesta en el aula a través de dispositivos móviles como herramienta de apoyo al proceso de enseñanza-aprendizaje en primer curso de Grado.

\section{Desarrollo de la innovación}

En el curso 2013-2014, el sistema de respuesta en el aula SOCRATIVE fue utilizado desde dispositivos móviles en las clases de "Termodinámica", asignatura de primer curso del Grado en Biotecnología de la Universitat Politècnica de València. La asignatura es cuatrimestral (116 alumnos/as), tiene dos grupos de teoría (grupo de docencia en Castellano y grupo de Alto Rendimiento Académico o ARA), y fue impartida en dos sesiones semanales de trabajo presencial en el aula. La teoría de la asignatura se distribuyó en 7 temas. La herramienta de respuesta inteligente se utilizó al final de cada sesión de teoría y una vez a la semana, de manera que al menos se planteó una actividad para cada uno de los temas. .

Para poder utilizar la aplicación en el aula, previamente la profesora creó una cuenta en la web de SOCRATIVE (Figura 1), introduciendo su dirección de correo electrónico y una clave.

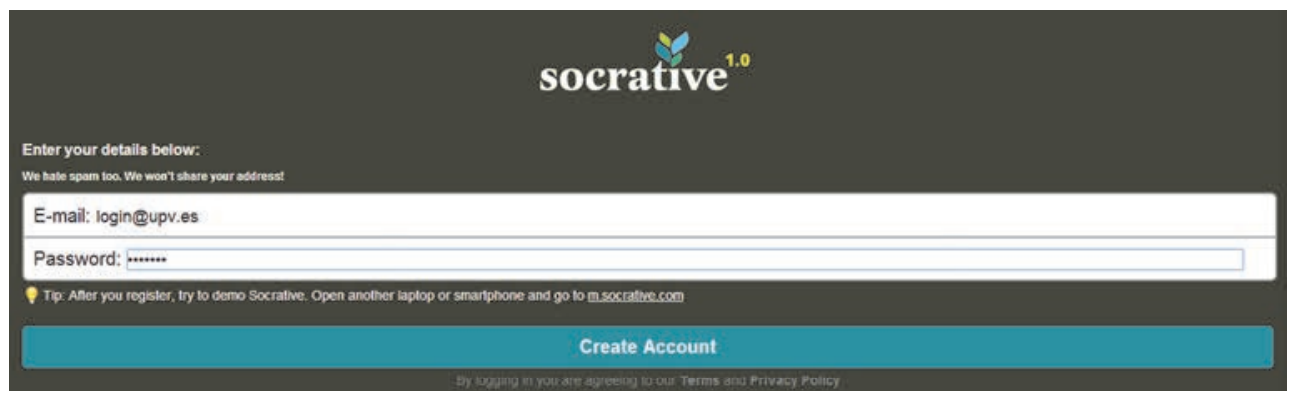

Fig. 1. Captura de la pantalla de registro de SOCRATIVE.

A continuación, se accedió a la pantalla principal (Figura 2a) desde donde se visualizan las diferentes opciones de creación, edición y gestión de baterías de preguntas ("Manage Quizzes”. La interfaz de la aplicación es muy intuitiva y sencilla y se requiere muy poco tiempo para familiarizarse con la aplicación. Además, en la web de SOCRATIVE se incluye un video tutorial con explicaciones sencillas. Desde la ventana "Manage Quizzes" se crearon y almacenaron los diferentes test de verdadero o falso (uno por cada uno de los temas de la asignatura). En la Figura 2b se muestra a modo de ejemplo una pregunta del test "Segunda Ley de la Termodinámica". Hay que marcar la respuesta correcta y, si se

\section{(c) EY-NC-ND 2014, Universitat Politècnica de València}

I Jornadas IN-RED (2014) 
considera pertinente, añadir una explicación que podrá ver el alumno una vez haya contestado la pregunta.

\begin{tabular}{|c|c|}
\hline $\begin{array}{l}\text { My Room Number } \\
\text { Students In Room }\end{array}$ & (a) PANTALLA PRINCIPAL \\
\hline \multicolumn{2}{|l|}{ Single Quention Activitios } \\
\hline \multicolumn{2}{|l|}{ 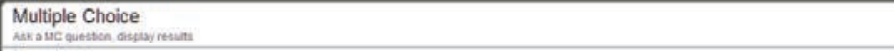 } \\
\hline \multicolumn{2}{|l|}{ 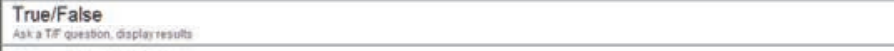 } \\
\hline \multicolumn{2}{|l|}{$\begin{array}{l}\text { Short Answer } \\
\text { Open-mbesc quaston auplay tesponses }\end{array}$} \\
\hline \multicolumn{2}{|l|}{ Quiz-Baned Activites } \\
\hline \multicolumn{2}{|l|}{$\begin{array}{l}\text { Start Quiz } \\
\text { Runasee-mose que: }\end{array}$} \\
\hline \multicolumn{2}{|l|}{$\begin{array}{l}\text { Exit Ticket } \\
\text { det an ansed-das putechece }\end{array}$} \\
\hline \multicolumn{2}{|c|}{$\begin{array}{l}\text { Space Race } \\
\text { fun avicu gume }\end{array}$} \\
\hline \multicolumn{2}{|c|}{ Create. Edit and Import Quizzes } \\
\hline \multicolumn{2}{|c|}{ 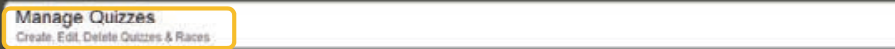 } \\
\hline \multicolumn{2}{|l|}{ My Account } \\
\hline \multicolumn{2}{|l|}{ 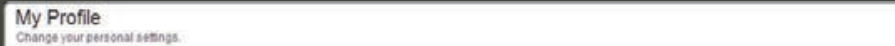 } \\
\hline \multicolumn{2}{|l|}{$\begin{array}{l}\text { Clear Room } \\
\text { hernowe al uners tion toom }\end{array}$} \\
\hline $\begin{array}{l}\text { Log Out } \\
\text { cog out or Pocasinit }\end{array}$ & \\
\hline
\end{tabular}

Quiz name: Segunda Ley de la TD

(b) VENTANA “Manage Quizzes”

Sharing

Enable sharing to get a SOC number. Other teachers can import this quiz in the 'Import Quiz' area by entering this SOC number.

$\square$ Enable Sharing Not Shared

\section{Question 1 (Multiple Choice):}

Select the square checks to mark correct answers (optional)

Question: En un proceso reversible la entropía del universo aumenta

Add Image

$\square$ Answer 1: Verdadero

Answer 2: Falso

Answer 3: Optional

Answer 4: Optional

Answer 5: Optional

Explanation: En un proceso reversible la entropía del universo es constante

Choose the type of question to add:

Multiple Choice

Short Answer

Fig. 2. (a) Imagen de la pantalla principal de SOCRATIVE y (b) de la ventana disponible para la edición de baterías de preguntas ("Manage Quizzes").

(cc) EY-NC-ND 2014, Universitat Politècnica de València

I Jornadas IN-RED (2014) 
Antes de iniciar cada uno de los cuestionarios almacenados, la profesora accedió desde un dispositivo móvil o desde el ordenador del Aula la aplicación SOCRATIVE (Figura 3).

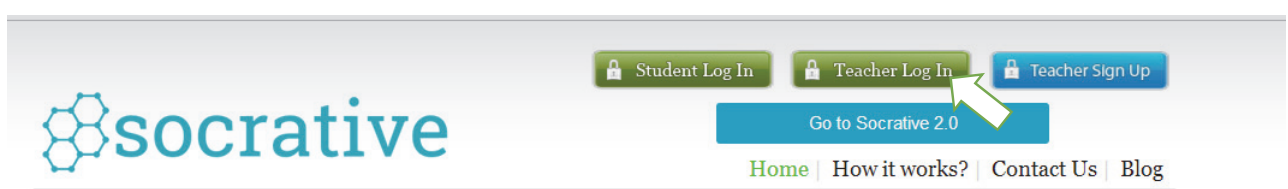

Fig. 3. Captura de la pantalla de inicio de SOCRATIVE.

Una vez introducidos mail y contraseña, desde la pantalla principal (Figura 2a) se accedió a la ventana "Start Quiz" (Figura 4), desde donde se seleccionó el test a realizar ("Primer día de clase" en el ejemplo que se muestra).

My Room Number

Students In Room

Primer día de clase

Student Paced Quiz

Students answer questions at their own pace.

Teacher Paced Quiz

Run a pre-made quiz where you set the pace.

Advanced Quiz Options

Click the checkbox to activate/deactivate options

Randomize Answer Choices

aultiple choice answers will be displayed in a random order

Disable Immediate Right/Wrong Feedback

Students will not receive feedback about whether they got a question right or wrong

Hide Question Explanations

Explanations will not be shown for answered questions

Fig. 4. Captura de pantalla de la ventana disponible para iniciar las baterías de preguntas

En cuanto a las opciones disponibles para la realización de los cuestionarios, en esta experiencia se permitió que el alumno fuera contestando las preguntas a su ritmo ("Student Paced Quiz").

A continuación, cada alumno accedió a SOCRATIVE desde su dispositivos móvil introduciendo el código ("My room number") proporcionado por la profesora (Figura 5). Como primera pregunta y por defecto, siembre se pide la identificación del alumno. Se

\section{(c)) EY-NC-ND 2014, Universitat Politècnica de València}

I Jornadas IN-RED (2014) 
indicó que el alumno que quisiera que su nombre no se viera reflejado cuando se analizaran las respuestas podía introducir un pseudónimo o un código.

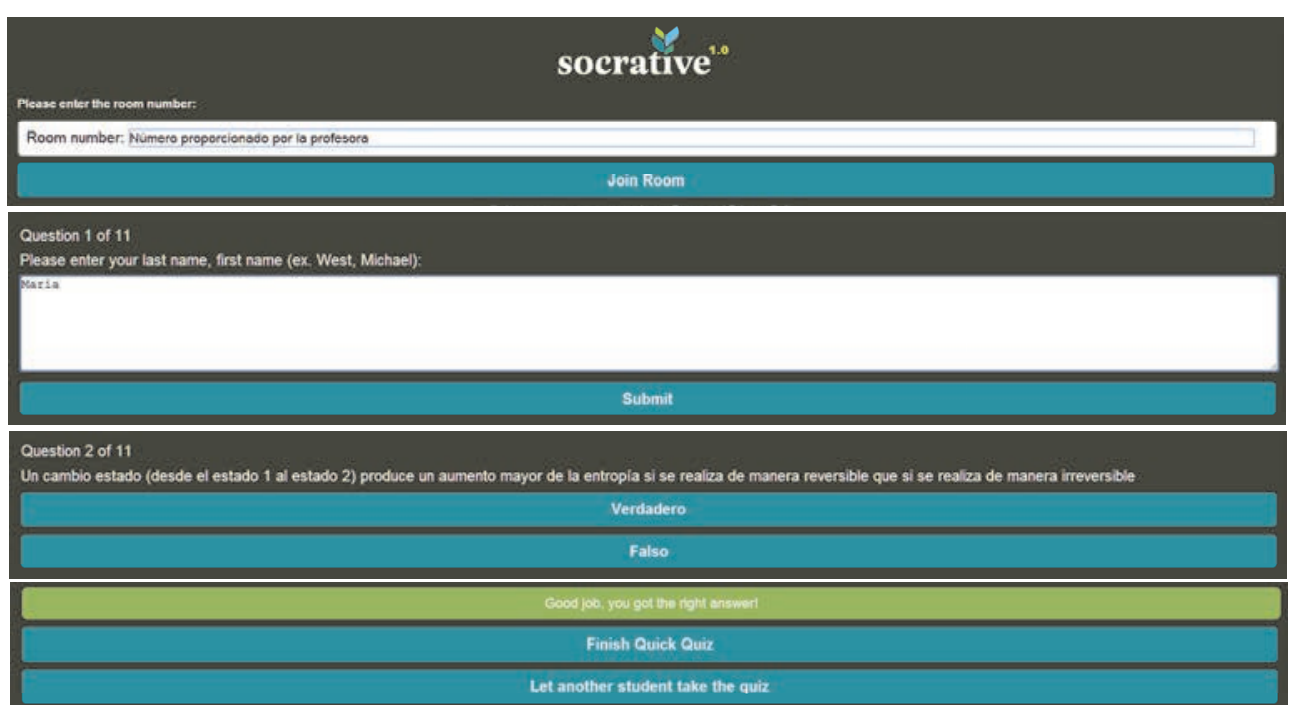

Fig. 5. Capturas de pantalla de la aplicación SOCRATIVE en "Student Login"

En la Figura 5 se muestra un ejemplo con una pregunta de uno de los cuestionarios. Después de contestar, el sistema indicó si la respuesta es correcta (verde) o incorrecta (rojo). Una vez finalizado el test, el alumno pudo simplemente finalizar o bien pasarle su dispositivo móvil a un compañero para que hiciera el test. Esto es especialmente interesante ya que permite que el alumno que se queda sin batería o que ha olvidado o no ha podido traer su dispositivo pueda participar en la experiencia.

Después de cuestionario, y una vez finalizaron todos los alumnos, el software permitió descargar una hoja de cálculo con los resultados y estadísticas. Dichos resultados fueron proyectados en el aula para revisar las respuestas y aclarar las dudas.

Para obtener el punto de vista del alumnado, y evaluar la experiencia se planteó una encuesta de opinión a través de PoliformaT. Las preguntas y afirmaciones presentadas a los alumnos se recogen en la Tabla 1. Las cuatro primeras preguntas, pretendían recoger información sobre la disponibilidad de dispositivos móviles y las experiencias previas del alumnado con herramientas de respuesta interactiva. La encuesta también contenía nueve preguntas en las que el alumnado debía expresar su opinión (de acuerdo o en desacuerdo) con una serie de afirmaciones sobre la utilidad de SOCRATIVE y su experiencia en el aula. Por último, se mostraron dos preguntas de respuesta abierta donde el alumnado podía expresar libremente su opinión sobre la frecuencia de uso del sistema en el aula, ventajas, inconvenientes, etc. 
Tabla 1. Características de la encuesta de evaluación de la herramienta Socrative

\begin{tabular}{|c|c|c|}
\hline Pregunta/ & Contenido & Clave de respuesta \\
\hline \multicolumn{3}{|l|}{ Afirmación } \\
\hline 1 & $\begin{array}{l}\text { Antes del curso de termodinámica, ¿has utilizado la } \\
\text { herramienta Socrative de respuesta inteligente? }\end{array}$ & Sí/No \\
\hline 2 & $\begin{array}{l}\text { ¿Has utilizado otro sistema de respuesta interactiva } \\
\text { en el Aula en otras asignaturas? }\end{array}$ & Sí/No \\
\hline 3 & $\begin{array}{l}\text { En caso de respuesta afirmativa, ¿qué sistema } \\
\text { utilizaste? }\end{array}$ & Texto \\
\hline 4 & $\begin{array}{l}\text { ¿Tienes un dispositivo portátil (teléfono, tableta, } \\
\text { ordenador) con acceso a internet? }\end{array}$ & Sí/No \\
\hline 5 & $\begin{array}{l}\text { La utilización de la herramienta Socrative fomenta la } \\
\text { participación en las clases y el aprendizaje activo }\end{array}$ & En desacuerdo/De acuerdo \\
\hline 6 & $\begin{array}{l}\text { La herramienta Socrative de respuesta inteligente } \\
\text { aumenta mi motivación e interés por asistir a las } \\
\text { clases }\end{array}$ & En desacuerdo/De acuerdo \\
\hline 7 & La herramienta Socrative me parece útil & En desacuerdo/De acuerdo \\
\hline 8 & $\begin{array}{l}\text { La herramienta Socrative me ayuda a retener y } \\
\text { comprender mejor los conceptos tratados en el Aula }\end{array}$ & En desacuerdo/De acuerdo \\
\hline 9 & $\begin{array}{l}\text { El uso de la herramienta Socrative mejora mi nivel } \\
\text { de atención }\end{array}$ & En desacuerdo/De acuerdo \\
\hline 10 & $\begin{array}{l}\text { Me gustaría que el sistema Socrative se utilizara en } \\
\text { otras asignaturas }\end{array}$ & En desacuerdo/De acuerdo \\
\hline 11 & $\begin{array}{l}\text { El sistema Socrative me parece adecuado para la } \\
\text { Evaluación continua de la asignatura }\end{array}$ & En desacuerdo/De acuerdo \\
\hline 12 & $\begin{array}{l}\text { El sistema Socrative me parece adecuado para el } \\
\text { control de asistencia en el Aula }\end{array}$ & En desacuerdo/De acuerdo \\
\hline 13 & $\begin{array}{l}\text { La herramienta Socrative hace las clases más } \\
\text { dinámicas }\end{array}$ & En desacuerdo/De acuerdo \\
\hline 14 & $\begin{array}{l}\text { ¿Con que frecuencia se debería utilizar la } \\
\text { herramienta? ¿En todas las clases? ¿Una vez por } \\
\text { semana? }\end{array}$ & Texto \\
\hline 15 & $\begin{array}{l}\text { ¿Tienes algún comentario adicional sobre la } \\
\text { herramienta Socrative? Observaciones, ventajas, } \\
\text { inconvenientes, etc. Tu respuesta es muy valiosa, por } \\
\text { favor contesta. }\end{array}$ & Texto \\
\hline
\end{tabular}

\section{(cc) BY-NC-ND 2014, Universitat Politècnica de València}

I Jornadas IN-RED (2014) 
Uso didáctico de dispositivos móviles en primer curso del Grado en Biotecnología

\section{Resultados}

En la Tabla 2 se muestran los resultados en relación al acceso a dispositivos móviles y el conocimiento previo del alumnado sobre la herramienta.

Tabla 2. Resultados de la encuesta de evaluación I.

\begin{tabular}{lcc}
\hline \multicolumn{1}{c}{ Ítem } & $\begin{array}{c}\text { Grupo } \\
\text { Castellano }\end{array}$ & $\begin{array}{c}\text { Grupo } \\
\text { ARA }\end{array}$ \\
\hline Participación en la encuesta $^{1}$ & $61.5 \%$ & $49 \%$ \\
\hline $\begin{array}{l}\text { Ha utilizado la herramienta SOCRATIVE de } \\
\text { respuesta inteligente en otro contexto }\end{array}$ & $0 \%$ & $0 \%$ \\
\hline $\begin{array}{l}\text { Ha utilizado otro sistema de respuesta } \\
\text { interactiva en el Aula en otras asignaturas }\end{array}$ & $10 \%$ & $16 \%$ \\
\hline \multicolumn{2}{l}{$\begin{array}{l}\text { Dispone de un dispositivo portátil }{ }^{2} \\
{ }^{1} \text { Porcentaje sobre el total de alumnos matriculados }(\mathrm{n}=65, \text { grupo en castellano; } \mathrm{n}=51, \text { grupo ARA). }\end{array}$} & \\
${ }^{2}$ Porcentaje sobre el total de alumnos que realizaron la encuesta $(\mathrm{n}=40$, grupo en castellano; $\mathrm{n}=25$, grupo ARA)
\end{tabular}

Hay que señalar que el nivel de participación en la encuesta fue menor en el grupo ARA que en el grupo castellano. No obstante, los resultados fueron bastante similares. El 100\% de los alumnos manifestaron que nunca habían utilizado la herramienta y casi la totalidad de los alumnos dispone de un dispositivo portátil. En cuanto a la utilización de otros sistemas, el porcentaje fue bajo. Además, los alumnos que manifestaron haber utilizado otros sistemas no supieron identificarlo.

La Figura 4 muestra el porcentaje de alumnos que manifestaron estar de acuerdo con cada una de las afirmaciones sobre SOCRATIVE (Tabla 1).

\section{La herramienta utilizada desde dispositivos móviles...}

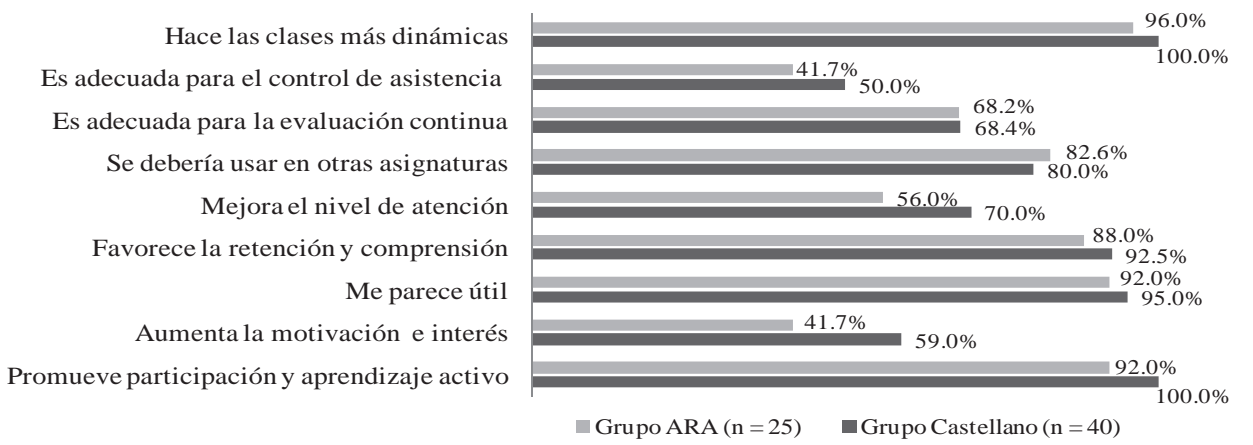

Fig.4. Resultados de la encuesta de evaluación II: Porcentaje de alumnos que manifestaron estar de acuerdo para cada una de las afirmaciones sobre la herramienta SOCRATIVE. 
Una vez más, no parece haber diferencias importantes entre los dos grupos, aunque en general el grupo ARA muestra unos porcentajes menores para todos los aspectos valorados. Un porcentaje superior al $90 \%$ del alumnado consideró que la herramienta utilizada es útil, promueve la participación y el aprendizaje activo y hace las clases más dinámicas. Los porcentajes fueron menores cuando se trataron aspectos relacionados con la evaluación de la asignatura y el control de asistencia, como era esperable. Los menores porcentajes se obtuvieron para la afirmación relacionada con la motivación e interés, con diferencias importantes en el grado de acuerdo, entre los dos grupos poniendo de relieve la gran carga subjetiva relacionada con la motivación de la diversidad de alumnos.

Finalmente, en la Tabla 3 se resumen los comentarios para cada uno de los grupos en relación a las preguntas 14 y 15 de la encuesta (Tabla 1).

Tabla 3. Observaciones recogidas en la encuesta de evaluación sobre SOCRATIVE.

\begin{tabular}{|c|c|}
\hline Grupo Castellano & Grupo ARA \\
\hline $\begin{array}{l}\text { "Me parece un método adecuado para fomentar } \\
\text { la participación." } \\
\text { "Hay veces que la pregunta no está clara, } \\
\text { porque está demasiado rebuscada" }\end{array}$ & $\begin{array}{l}\text { "Me parece una muy buena herramienta pues } \\
\text { nos obliga a atender durante toda la clase y } \\
\text { además la hace mucho más amena." } \\
\text { "Te hace reflexionar sobre la asignatura." }\end{array}$ \\
\hline $\begin{array}{l}\text { "Se debe usar en todas las clases para } \\
\text { comprobar si se ha entendido la lección que se } \\
\text { ha impartido" }\end{array}$ & $\begin{array}{l}\text { "Es útil para afianzar conceptos y entender } \\
\text { mejor aquellos que solo con la teoría no han } \\
\text { quedado claros." }\end{array}$ \\
\hline $\begin{array}{l}\text { "Me parece un buen apoyo para comprender } \\
\text { aspectos teóricos de la asignatura". } \\
\text { "Hace la clase más interesante y ya no es } \\
\text { siempre el tener que escribir en un papel, hace } \\
\text { la clase más dinámica." } \\
\text { "Es una buena manera de repasar lo que hemos } \\
\text { dado en la clase y de aclarar las dudas que } \\
\text { podamos tener". } \\
\text { "Me parece muy útil y dinámica para aclarar y } \\
\text { fijar conocimientos y prepararnos de cara al } \\
\text { examen. Además nos demuestra a nosotros } \\
\text { mismos nuestro nivel y las cosas que debemos } \\
\text { mejorar." } \\
\text { “... se debería haber utilizado más y con un } \\
\text { poco más de tiempo a la hora de comentar las } \\
\text { preguntas...” } \\
\text { " ... posant-nos a prova en comú, podem debatir } \\
\text { entre nosaltres les respostes de les preguntes i } \\
\text { d'aquest mode els conceptes es queden molt } \\
\text { millor." }\end{array}$ & $\begin{array}{l}\text { "Me parece una buena herramienta con la que se } \\
\text { aprende y ayuda a ver qué es lo importante en el } \\
\text { temario." } \\
\text { "Me parece una forma de retener mejor la } \\
\text { información cuando acaba la clase, y si quedan } \\
\text { dudas, al hacer el test Socrative se resuelven." } \\
\text { "Es más conveniente utilizarlo al final de la } \\
\text { clase y nunca entre medias de ninguna } \\
\text { explicación, o entre medias de explicaciones de } \\
\text { diferentes." } \\
\text { "Permite retener mejor lo que se ha explicado } \\
\text { en clase" } \\
\text { "Se debería utilizar en cada clase, o cada dos } \\
\text { clases." } \\
\text { "Se debería utilizar al acabar cada tema si es } \\
\text { para repasar los conceptos clave." "... si el tema } \\
\text { es muy largo, por ejemplo, con dos bloques, } \\
\text { después de cada bloque." "...en todas las clases } \\
\text { resultaría algo abrumador." }\end{array}$ \\
\hline
\end{tabular}

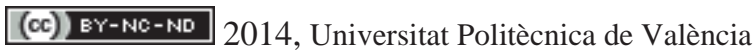

I Jornadas IN-RED (2014) 
Los comentarios son en general positivos y en la línea de lo mostrado en la Figura 4. En cuanto a la frecuencia recomendada de uso de SOCRATIVE en el aula, parece que es difícil encontrar la receta al gusto de todos los alumnos. No obstante, parece que la periodicidad semanal fue adecuada para un gran número de alumnos.

\section{Conclusiones}

El sistema de respuesta en el aula utilizado desde dispositivos móviles se mostró como una herramienta novedosa y útil para el alumnado de primer curso de Grado. Así, fomentó la participación en el aula, el aprendizaje activo e hizo las sesiones de teoría más dinámicas. En experiencias futuras, se explorarán otras posibilidades y opciones que ofrece la herramienta utilizada para tratar de que contribuya en mayor medida en el aumento de la motivación del alumnado.

\section{Referencias}

BEUCKMAN, J., SANJAY REBELLO, ZOLLMAN, D. (2007). "The impact of a Classroom Interaction System on Student Learning". Physics Education Research Conference 2006, Syracuse, New York, July 26-27, 2006, pp. 129-132 <http://www.compadre.org/Repository/document/ServeFile.cfm?ID=5270\&DocID=209 4> [Consulta: 12 de junio de 2014]

CANTILlO, C., ROURA, M., SÁNCHEZ, A. (2012). "Tendencias actuales en el uso de dispositivos móviles en educación". Revista OEA La Educación Digital Magazine, junio 2012, $147, \quad$ pp. 1-21. <http://cede.lboro.ac.uk/ee2012/papers/ee2012_submission_122_gp.pdf> [Consulta: 12 de junio de 2014]

Liu, D. Y. T., Taylor, C.E. (2013). "Engaging students in large lectures of introductory biology and molecular biology service courses using student response systems". Proceedings of the Australian Conference on Science and Mathematics Education, Australian National University, Sept 19th to Sept 21st, 2013, ACSME Proceedings| Students in transition - The learners' journey, pp. 154-162,

MURRAY, P. B., ROSSITER, J. A., PANOUTSOS, G. (2012). "Promoting the use of clickers across a whole engineering faculty: how, why and is it worth it?". Engineering Education 2012 Conference, Coventry, UK, September 2012, pp. 18-20. 〈http://educoas.org/portal/la_educacion_digital/147/pdf/ART_UNNED_EN.pdf〉 [Consulta: 12 de junio de 2014]

SOCRATIVE.< www.socrative.com> [Consulta: 12 de junio de 2014] 


\title{
Valor añadido de la utilización de las TIC por parte de Usuarios con Discapacidad Psíquica. Experiencia de una Emisora de Radio en un Centro Ocupacional de Empleo
}

\section{Carlos Hernández Franco ${ }^{a}$, Luisa Tolosa Robledo y José Ramón Díaz Sáenz ${ }^{\mathrm{a}}$}

${ }^{a}$ Escuela Técnica Superior de Ingenieros de Telecomunicación, bepartamento de Comunicación Audiovisual, Documentación e Historia del Arte.

\begin{abstract}
The article proposes to study the possibilities of sound component of technologies to facilitate the inclusion of mentally disabled people. The acquisition of skills on the use of technologies for audiovisual composition can be obtained at the Universitat Politècnica de València through formal education as given in Audiovisual Communication and Audiovisual specialties in Telecommunications. It is possible to study these specialties in vocational training centers or in specific courses in previous levels (Primary and / or Secondary shools) however, we have found no record of experiences that have been directed towards the mentally handicapped people. We have used the planning applied in audiovisual projects of university students in communication studies, adjusting to the motivations of this particular group, generating various scripts that facilitate the mentally handicapped people to approach and understanding of the resources that current technology allows. We have prepared a few sessions with a group of users froma a Occupational Center of Valencia, accompanied by their monitors, psychologist and principal of the Center, which enabled us to assess the outcome of the workshop made. In this proposal the students have been active and we have obtained very positive results.
\end{abstract}

Keywords: Audiovisual workshop, mental disability, digital resources, Valencia, Inclusion, Radio, Internet

(c) EY-NC-ND 2014, Universitat Politècnica de València

I Jornadas In-Red (2014) 
Valor añadido de la utilización de las TIC por parte de Usuarios con Discapacidad Psíquica. Experiencia de una Emisora de Radio en un Centro Ocupacional de Empleo

\begin{abstract}
Resumen
Se propone estudiar las posibilidades de la componente sonora de las tecnologías para facilitar la inclusión de personas discapacitadas psíquicamente. La adquisición de competencias sobre el uso de las tecnologías para la composición audiovisual se puede realizar en la Universitat Politècnica de València a través de la formación reglada impartida en titulaciones como la de Comunicación Audiovisual o especialidades de Imagen y Sonido en Telecomunicación. También se puede recurrir a especialidades en la Formación Profesional o cursos específicos en niveles anteriores (Enseñanza Primaria y/o Secundaria) sin embargo, no hemos encontrado antecedentes sobre experiencias que se hayan dirigido hacia los discapacitados psíquicos. Hemos utilizado la planificación aplicada en los proyectos audiovisuales de los alumnos universitarios de Comunicación Audiovisual, ajustándola a las motivaciones de este colectivo concreto, generando diversos guiones que faciliten a los discapacitados psíquicos el acercamiento y comprensión de los recursos que permite la tecnología actual. Hemos preparado unas sesiones con un grupo de usuarios de un Centro Ocupacional de Valencia, acompañados de monitores, psicóloga y directora del Centro, que nos han permitido evaluar el resultado del taller realizado. En esta propuesta los alumnos han participado activamente y los resultados obtenidos han sido muy positivos.
\end{abstract}

Palabras clave: Taller audiovisual, discapacidad psíquica, recursos digitales, Comunidad Valenciana, Inclusión, Emisora de radio, Internet

\title{
1. Introducción
}

\subsection{La radio como elemento dinamizador del potencial humano.}

El desarrollo de la electrónica analógica y la aparición de los primeros receptores radiofónicos o "transistores" durante la década de los años 50, posibilitó la popularización de la radio como un medio de comunicación de masas.

Si bien los primeros trabajos de Marconi a finales del siglo XIX y principios del siglo XX habían posibilitado la aparición de las primeras emisoras de radiodifusión, no fue hasta el desarrollo de los primeros dispositivos electrónicos de estado sólido, con la consiguiente reducción de las dimensiones y los costos de los equipos receptores, que se puede hablar de una radio "individualizada".

(c)) EY-NC-ND 2014, Universitat Politècnica de València

I Jornadas IN-RED (2014) 
Además, es a partir de ese momento, y junto a la utilización y explotación de la frecuencia modulada, cuando se multiplica el número de emisoras de radiodifusión públicas y privadas para cubrir la demanda informativa. Aunque el desarrollo constante de la electrónica de estado sólido y el incremento de la escala de integración de los dispositivos ha favorecido cambios novedosos en los medios técnicos utilizados en la radiodifusión sonora, la aparición de la electrónica digital, el desarrollo de nuevos sistemas de telecomunicación y la difusión del uso de Internet obligan a un replanteamiento en cuanto a la forma de hacer radio y los servicios que la misma presta a sus oyentes (Martí, 2000; Lloret, 2005).

La radiodifusión, tal y como la entendemos ahora, deberá ajustarse a las necesidades de un ciudadano que vive, estudia y/o trabaja en una Sociedad de la Información y el Conocimiento que potencia el intercambio informativo "en tiempo real", el uso de las tecnologías multimedia, la cultura de la conectividad, la movilidad, la producción de contenidos propios, etc. Y este ajuste o adaptación de la radiodifusión abarca tanto a los niveles nacionales, autonómicos y municipales como comunitarios (Hernández, 2004).

Para conseguir que una emisora de radio cumpla su cometido informativo, deberá contar con la infraestructura técnica necesaria para poder emitir sus programas (vía espacio radioeléctrico o vía Internet). Debemos destacar que este tipo de infraestructura ha cambiado de forma vertiginosa en un espacio muy breve de tiempo. Donde antes eran esenciales platinas de cassette, $\mathrm{CD}$, o magnetófonos en los que se requería gran habilidad y destreza, ahora sólo hará falta un ordenador personal y hacer un "click" de ratón. La utilización de este último en la "emisora", como símbolo o icono fundamental de la Sociedad de la Información y el Conocimiento, facilitará enormemente las tareas a realizar por el personal aunque este no sea un especialista altamente cualificado.

El ordenador ha relegado al olvido a un sinfín de "aparatos" reproductores. Utilizando toda una "suite" de aplicaciones informáticas orientadas al sonido, y diseñadas algunas para su uso en la radiodifusión podremos lograr una emisión óptima. El ordenador "podrá realizar las funciones del locutor" habiendo especificado este, previamente, todas las órdenes necesarias para que se emitan los contenidos sin que, en un momento dado, sea necesaria la presencia humana para presionar el botón de "play" (Ramírez, 2004).

Para una emisora de radio actual las Tecnologías de la Información y las Comunicaciones (TIC) resultarán un valioso y a la vez asequible recurso, cuyo usabilidad permitirá realizar una emisión continuada con una calidad aceptable, evitando la necesidad de contar con una plantilla de recursos humanos elevada. No obstante, se debe intentar crear un colectivo que se encargue de dotar de contenidos a la emisión radiofónica. En este sentido, el papel del "colaborador" (en nuestro caso los usuarios con discapacidad psíquica del Centro Ocupacional La Torre) será fundamental.

\section{(c)) EY-NC-ND 2014, Universitat Politècnica de València}

I Jornadas IN-RED (2014) 
Valor añadido de la utilización de las TIC por parte de Usuarios con Discapacidad Psíquica.

Experiencia de una Emisora de Radio en un Centro Ocupacional de Empleo

El colaborador, al que habrá que formar en el uso de las TIC, será el encargado de aportar sus conocimientos en un campo específico canalizándolos por medio de un programa radiofónico. Así pues, en la "parrilla" de programación de la radio se pueden plantear una serie de programas "especializados" que una radio comercial desestimaría con total seguridad, abordando temas como la salud, recetas de cocina, actividades diarias, proyectos formativos, etc. Cada colaborador puede ser experto en una o varias materias y a su vez la persona encargada de conjugar los esfuerzos y aptitudes. Las TIC dinamizan de este modo todo el potencial humano del centro.

\subsection{La radio como elemento dinamizador en la enseñanza.}

Uno de los pioneros en introducir cambios en la enseñanza en el siglo XX fue el pedagogo Célestin Freinet ( 1896-1966), maestro de escuela que propugnó la experiencia como base del aprendizaje. Para ello introdujo diversas técnicas que facilitaban que los alumnos pudieran formular y expresar sus experiencias en el aula. La más famosa fue la utilización de la imprenta para la creación de un periódico escolar, como instrumento para fomentar la creatividad de los alumnos, plasmar sus vivencias y sus relaciones con el entorno, con lo que éstos cubrían sus necesidades de comunicación, desarrollando, a su vez, las capacidades para ello.

Con ello fomentaba la funcionalidad del trabajo, ya que se crean objetivos que implican que el trabajo realizado tenga sentido, utilidad y el principio de cooperación, a través de la creación de un ambiente en el aula en el que existen elementos mediadores en la relación maestro-alumno. Esto conlleva la cooperación entre alumnos, alumnos-maestros y entre maestros; esta última con la finalidad de compartir experiencias y dialogar, poniendo en común los problemas y las posibles soluciones.

Por otra parte, McLuhan (1911-1980) considerado unos de los fundadores de los estudios de los medios de comunicación postuló la expresión "el aula sin muros" en estos términos:

"Hoy en nuestras ciudades, la mayor parte de la enseñanza tiene lugar fuera de la escuela. La cantidad de información comunicada por la prensa, las revistas, las películas, la televisión y la radio, exceden en gran medida a la cantidad de información comunicada por la instrucción y los textos en la escuela. Este desafio ha destruido el monopolio del libro como ayuda a la enseñanza y ha derribado los propios muros de las aulas de modo tan repentino que estamos confundidos, desconcertados" (McLuhan, 1968: 235-236). 
El uso adecuado de las TIC en la enseñanza, desde edades bien tempranas como puede ser la educación infantil a partir de los 3 años, puede favorecer el desarrollo de capacidades y habilidades, tanto individuales como colectivas, relacionadas con la forma de entender el mundo que nos rodea, expresar nuestras ideas, sentimientos, emociones, estimular la curiosidad, etc. Una pizarra digital, una animación, un vídeo, un texto interactivo, etc., pueden facilitar el entendimiento a todos los alumnos de una clase, sin duda alguna heterogénea como la mayoría de las clases.

Algunas comunidades de aprendizaje (esto es, en el proceso de enseñanza participan alumnos, profesores y familiares) han comenzado a utilizar la radio como un elemento facilitador y dinamizador de las actividades de esta "estructura" organizativa en la educación. Por ejemplo, crear una "emisora" de radio en el colegio cuyos contenidos radiofónicos o "programas" sean el reflejo del día a día del centro. En la clase de "lengua" se pueden redactar las noticias... En la clase de conocimiento del medio se puede preparar el parte meteorológico diario para la zona así como programas relacionados con la vida del lugar, el medio ambiente, los usos y costumbre, etc. Lo mismo en la clase de historia, matemáticas, ciencias, etc...

Y toda la comunidad de aprendizaje puede participar de esta iniciativa, convirtiéndose en "colaboradores" de la "emisora escolar"... Aprender los aspectos técnicos y de usabilidad que hacen posible una emisión de contenidos que se preparan en el aula, se graban en el aula o espacio destinado para los equipos de la emisora y luego se emiten vía espacio radioeléctrico (esto es, la radio tradicional) o vía internet. Asimismo, los contenidos se pueden "colgar en la nube" (Dropbox, Soundcloud, Spreaker, etc.) para ser distribuidos o descargados por los posibles "oyentes".

Un magnífico ejemplo de todo lo anterior, es la radio escolar "Sierra de Arcos" del Colegio Rural Agrupado de Ariño Alloza, en la provincia de Teruel, Aragón. A través de su blog http://arininos2.blogspot.com.es/ se puede comprobar cómo el uso de las TIC posibilita el aprendizaje de los alumnos de estas dos pequeñas localidades, alejadas físicamente de las grandes ciudades pero en el centro de la "modernidad" gracias al buen uso de ellas. Una comunidad que durante el invierno se queda muchas veces aislada y que continúa aprendiendo... O una comunidad de aprendizaje que hace frente a gastos y problemas económicos debido a la crisis de forma imaginativa y solidaria.

Hemos visitado en diversas ocasiones dicha comunidad de aprendizaje, siempre dispuesta a recibir a cualquier persona interesada en esta experiencia formativa. De un año a otro realizan innovaciones educativas que mantienen activa la idea de enseñar en cada momento de acuerdo con el avance de la sociedad, los conocimientos y las propias TIC. Pero siempre respetando la forma natural en que un niño o niña aprende y la necesidad de un vínculo estrecho entre la escuela y la familia.

\section{(c)) EY-NC-ND 2014, Universitat Politècnica de València}

I Jornadas IN-RED (2014) 
Valor añadido de la utilización de las TIC por parte de Usuarios con Discapacidad Psíquica.

Experiencia de una Emisora de Radio en un Centro Ocupacional de Empleo

Convencidos de las ventajas de toda esta experiencia del Colegio Rural Agrupado de Ariño Alloza, y específicamente de las relacionadas con la radio escolar, es que hemos comenzado a trabajar en la creación de una similar en un Centro Ocupacional para discapacitados psíquicos de Valencia.

La adquisición de competencias sobre el uso de las TIC para la composición audiovisual se puede realizar en la Universitat Politècnica de València (UPV) a través de la formación reglada impartida en titulaciones como la de Comunicación Audiovisual o especialidades de Imagen y Sonido en Telecomunicación. También se puede recurrir a especialidades en la Formación Profesional o cursos específicos en niveles anteriores (Enseñanza Primaria y/o Secundaria). Sin embargo, no hemos encontrado antecedentes sobre experiencias que se hayan dirigido hacia los discapacitados psíquicos.

\section{Objetivos}

\subsection{Objetivo general}

Nos proponemos estudiar las posibilidades de la componente sonora de las TIC para facilitar la inclusión (que no integración) de personas discapacitadas psíquicamente, a través de la creación de una "emisora" o productos radiofónicos por parte de los usuarios del Centro Ocupacional La Torre, de Valencia, que les permita crear contenidos que abre líneas de comunicación entre estas personas y su familia y entorno en primer lugar, y con el resto de la sociedad en general.

\subsection{Objetivos específicos}

Generar una discusión abierta sobre las experiencias sentidas al elaborar un producto radiofónico y que los alumnos:

- Desarrollen actitudes de organización tanto para su trabajo individual como para el trabajo en equipo.

- Adquieran valores asertivos con el equipo.

- Comprendan los conceptos básicos de la grabación radiofónica.

- Adquieran confianza en la destreza y habilidad en el manejo de las herramientas necesarias para producir el relato radiofónico.

- Desarrollen un juicio crítico y unos esquemas de pensamiento que permitan enjuiciar y resolver las nuevas piezas radiofónicas que creen. 


\section{Metodología}

Hemos utilizado la planificación aplicada en los proyectos audiovisuales de los alumnos universitarios de Comunicación Audiovisual, ajustándola a las motivaciones de este colectivo concreto, generando diversos guiones que faciliten a los discapacitados psíquicos el acercamiento y comprensión de los recursos que permite la tecnología actual. Hemos preparado unas sesiones con un grupo de usuarios del Centro Ocupacional "La Torre" de Valencia, acompañados de monitores, psicóloga y directora del Centro, que nos han permitido evaluar el resultado del taller realizado. La metodología empleada para realizar el Taller Radiofónico se desarrolló con las etapas descritas en los siguientes puntos:

\subsection{Definición del proyecto.}

Realización de podcasts de carácter informativo, lúdico, documental con guión libre, con diálogo, música y sonido diegético o no, generado por los grupos de usuarios del C.O. La Torre de Valencia, acompañados por sus monitores, psicólogas y directora del Centro, que se alojarán en la nube y podrán descargarse para su audición.

\subsection{Características del proyecto.}

Elaboración de cuñas de una duración aproximada entre 10 y 20 minutos realizados por los alumnos del centro con el apoyo de sus monitores para su difusión a través de Internet y que sus familias puedan conocer las actividades que llevan a cabo.

\subsection{Materiales.}

El hardware mínimamente imprescindible está integrado por: mesa de mezcla, micrófonos, auriculares, tarjeta digitalizadora (Podcastudio Behringer) y PC de soporte.

Las herramientas informáticas de software necesarias para la creación de contenidos radiofónicos y su difusión son:

- un reproductor de audio, hemos elegido el WinAmp,

- un programa dedicado a la edición y procesado de sonido que nos permita grabar los programas y las cuñas publicitarias, realizar labores de postproducción, etc., elegimos el Soundforge,

- un conversor de formatos que haga posible digitalizar los $\mathrm{CD}$ de música de los que disponemos, usamos el dBpowerAMP,

- una aplicación que nos permita "automatizar" la emisión, utilizamos ZaraRadio,

- para la transmisión en directo usamos la aplicación Spreaker.

\section{(cc) EY-NC-ND 2014, Universitat Politècnica de València}

I Jornadas IN-RED (2014) 
Valor añadido de la utilización de las TIC por parte de Usuarios con Discapacidad Psíquica.

Experiencia de una Emisora de Radio en un Centro Ocupacional de Empleo

Es posible descargar de las páginas oficiales correspondientes, versiones gratuitas de estas aplicaciones con vista a reducir el costo de implementabilidad y operatividad (Hernández, Viñals, Lloret, 2004).

Además hay que disponer de espacio de almacenamiento en la nube, para lo que hemos utilizado la plataforma Dropbox.

Asimismo es necesario el acceso a Internet, y conocer distintos repositorios de recursos sonoros gratuitos que puedan ser utilizados por los usuarios para la creación de sus podcasts.

\subsection{Formación previa.}

Para poner en marcha el proyecto hay una serie de decisiones que tuvieron que tomarse para asegurar el buen fin del mismo, además de la búsqueda de sugerencias sobre la creación de una emisora por internet por parte de personas y/u organizaciones con experiencia previa. En primer lugar, la planificación sobre los materiales necesarios:

El conjunto de Podcastudio de Behringer, disponer de una relación de bases de datos de sonidos, revisión de modelos sencillos de guiones radiofónicos, alojamiento en internet, definición de cuñas de presentación, editor de sonido y tutoriales, Zara radio...

Se realizaron varias sesiones con la directora y las psicólogas del Centro para nominar a las personas idóneas para responsabilizarse de la actividad, tanto usuarios como monitores, y darles información básica sobre las diferencias entre el mundo analógico y el digital, aclarándoles conceptos tales como frecuencia de muestreo, profundidad de bits y número de canales para ayudarles a entender mejor el software de edición de sonido.

Se impartieron unas clases teórico-prácticas sobre las funcionalidades mínimas necesarias con SoundForge (grabación, eliminación de defectos, silencios, mezclas de archivos, volumen, ecos, etc.) tras descargar una versión abierta por no ser actual, pero suficiente.

También se realizaron prácticas de acceso a bases de datos de todo tipo de sonidos (animales, naturaleza, urbanos, concentraciones...), tutoriales disponibles de SoundForge, página web de Spreaker (para transmisión en directo) y SoundCloud y Dropbox (para hosting).

Posteriormente, probamos y pusimos en marcha el Podcastudio. Para facilitar la autosuficiencia e incrementar la confianza de los monitores, dada la cierta complejidad de conexiones para personas profanas en el uso de mesas de mezclas, grabamos un corto archivo de sonido contando las conexiones y posiciones de los interruptores y mandos, fotografiándolos para poderlo replicar sin problemas.

Finalmente, se utilizaron SoundForge, las páginas de archivos de sonidos del Ministerio de Educación y Find Sounds, y se comenzó a grabar en directo mezclando archivos. Subiendo a Dropbox las primeras prueba de emisión. 


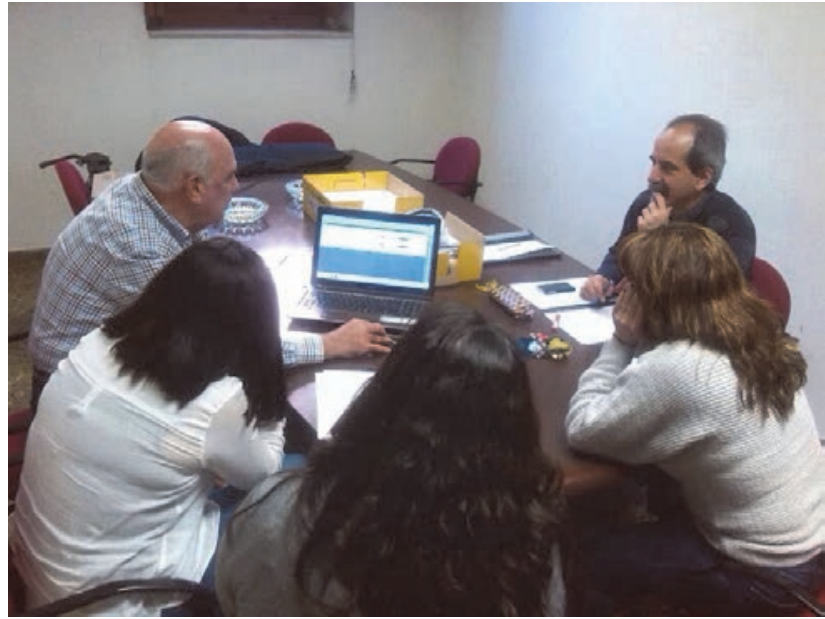

Fig. 1. Formación de monitores del Centro "La Torre".

\subsection{Fases de ejecución del proyecto radiofónico.}

1. Idea.

2. Alternativas de Guión.

3. Diseño de Grabación (localización de archivos sonoros libres de derechos de autor para su utilización).

4. Guión Técnico: micrófonos necesarios, niveles de volumen, duración, intervenciones, secuencias, etc.

5. Plan de grabación (preparación según localizaciones, recursos necesarios y sesiones de grabación).

6. Grabación.

7. Edición, montaje y sonorización.

\section{(cc) EY-NC-ND 2014, Universitat Politècnica de València}

I Jornadas IN-RED (2014) 
Valor añadido de la utilización de las TIC por parte de Usuarios con Discapacidad Psíquica. Experiencia de una Emisora de Radio en un Centro Ocupacional de Empleo

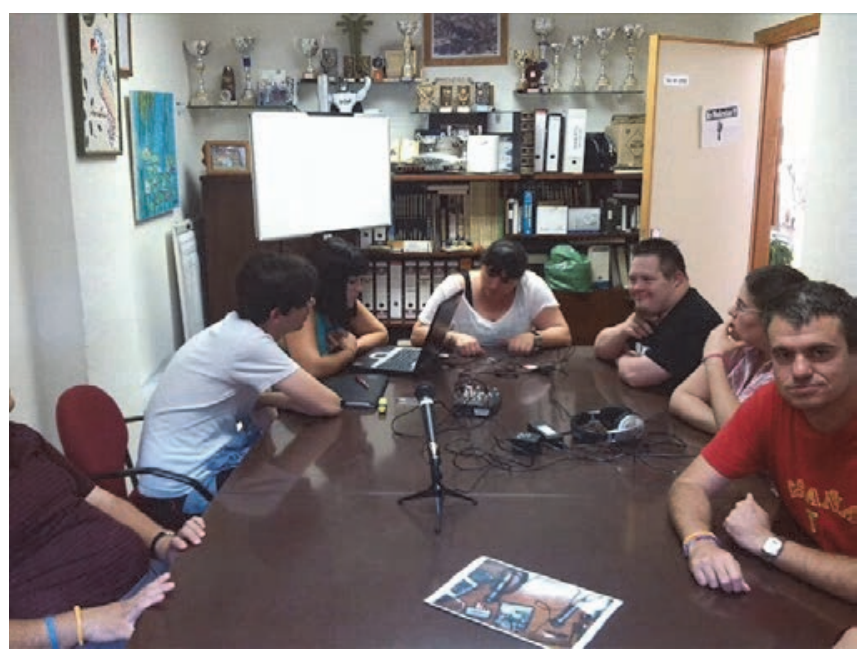

Fig. 2. Preparación del guión.

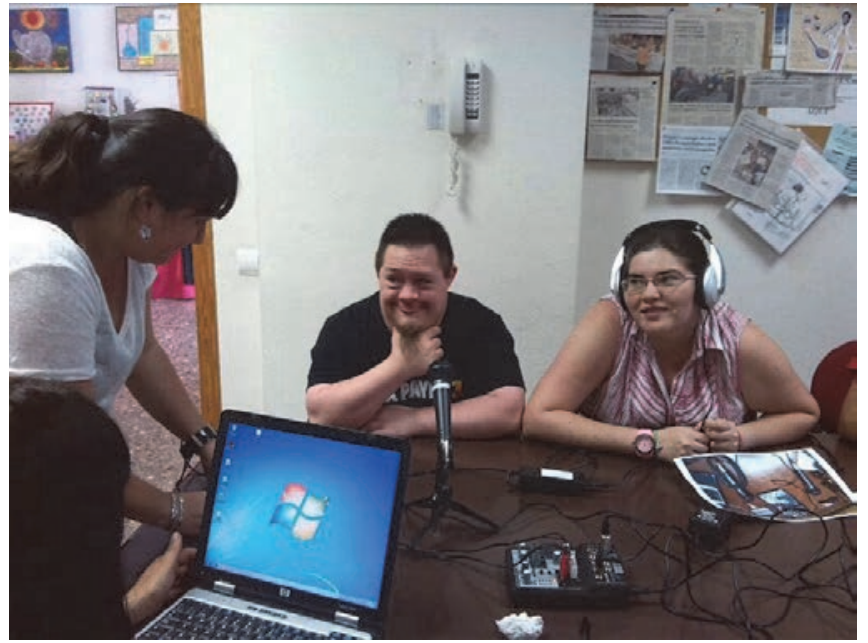

Fig. 3. Preparación de la grabación.

\subsection{Roles en la ejecución del proyecto radiofónico}

1. Idea: la general / todos los alumnos. La específica / profesores-monitores

2. Guión: todos los alumnos, profesionales del C.O. y profesores.

3. Diseño Montaje: Monitores.

4. Guión Técnico: Monitores.

5. Plan de grabación: Monitores.

6. Grabación: Alumnos / Monitores.

7. Edición, Montaje y sonorización: Profesores /Monitores.

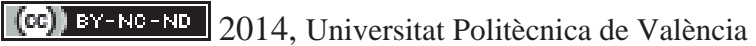




\subsection{Experiencia de grabación.}

Desde principio de junio se han grabado varios podcasts de prueba sobre diversos tipos de contenidos y, aún habiendo sido subidos a Dropbox, estamos estudiando la mejor forma para denominarlos para que usuarios, familiares, amigos...puedan acceder a los contenidos que deseen de forma sencilla y rápida. Concretamente, estamos analizando los diversos conceptos que puede ser necesario utilizar en la denominación de cada archivo, o las etiquetas o metadatos aconsejables para ser fácilmente utilizable en la localización por fecha, entrevistados / entrevistadores, temática, etc. De forma que la aplicación de hosting permita y facilite su uso.

\subsection{Guión de la grabación.}

El Guión de la grabación deberá incluir estos contenidos:

1. Sintonía

2. Bienvenida.

3. Sintonía

4. Presentación.

5. Contenido

6. Despedida

7. Anuncio de la próxima grabación.

8. Sintonía.

9. Cierre.

Por último, es necesario recoger unas recomendaciones imprescindibles para el buen desarrollo de la grabación que conviene transmitir y tener en cuenta cuando se desarrolle una actividad de este tipo:

- Las conexiones eléctricas se realizarán siempre a enchufes con toma de tierra.

- Queda terminantemente prohibido el uso de regletas o cajas de conexión, que pueden sobrecargar excesivamente la toma de corriente.

- Como información adicional, la responsabilidad sobre el cuidado y custodia del material abarca por el día total de la grabación; siendo del monitor correspondiente.

- Mantener silencio: no mover papeles, llaveros, pulseras, etc., desconectar teléfonos móviles, mantener la distancia idónea del micrófono ..

(cc)) EY-NC-ND 2014, Universitat Politècnica de València

I Jornadas IN-RED (2014) 
Valor añadido de la utilización de las TIC por parte de Usuarios con Discapacidad Psíquica.

Experiencia de una Emisora de Radio en un Centro Ocupacional de Empleo

\section{Resultados}

Los alumnos han participado activamente, siendo los resultados obtenidos muy positivos y estimulantes. Se han realizado sesiones sobre la forma de generar un guión radiofónico, localización de bases de datos de sonidos, almacenamiento de ficheros utilizando las técnicas de cloud computing, transmisión en directo a través de internet, mostrando las funciones básicas de un editor de sonido, enseñando el funcionamiento de los elementos básicos de hardware (micrófonos, mesa de mezcla, funciones de las tarjeta digitalizadora, etc.), en las que los usuarios han planteado sus propias iniciativas.

En esta primera fase, las grabaciones se están realizando en el propio Centro Ocupacional a través de unas sesiones de preparación del guión-redacción de contenidos y de la locución propiamente dicha. Tanto durante las grabaciones como en la posterior emisión, hemos podido observar cómo reaccionan, aceptan, colaboran y se integran en su confección para, de esa forma, analizar y estudiar el alcance de su motivación y su aprendizaje, así como, para este colectivo en particular, mejorar su inclusión social.

Se prevé realizar sesiones de grabación también fuera del Centro, aprovechando acontecimientos del barrio, salidas, excursiones, etc.

\section{Conclusiones}

Los resultados nos están permitiendo corregir los contenidos y planificación de la actividad de forma que sean extrapolables (y esto es muy importante) a otros centros educativos y ocupacionales de este tipo de usuarios de la Comunidad Valenciana, que puedan permitir preparar cursos específicos para que, desde organizaciones como el propio Centro de Formación Permanente (CFP) de la UPV, puedan proponerse a organizaciones de soporte de estos colectivos.

Este tipo de actividad potencia la inclusión en la sociedad a personas con mayores dificultades pues las TIC permiten, de forma muy sencilla, adquirir los conocimientos suficientes para formar parte de un equipo en el que tan sólo se necesitan un smartphone con grabadora, conocimientos básicos de edición, navegación por Internet, imaginación y conciencia solidaria

El informe que nos presentó la psicóloga del Centro, tras observar las reacciones de los alumnos durante el día de la sesión, y los siguientes, se pueden resumir en los siguientes beneficios: 
- Conocer y aprender a manejar las nuevas tecnologías necesarias para poner en marcha un programa de radio.

- Realizar un programa de radio en el que los protagonistas sean las personas con discapacidad intelectual.

- Que la radio sea un medio comunicativo entre la comunidad y las personas con discapacidad intelectual.

- Dar a conocer las actividades que se realizan en el Centro Ocupacional La Torre a las familias y a la población en general.

- Que se convierta en un medio de expresión de sus necesidades, preferencias, gustos, aficiones....

- Poner énfasis en las posibilidades de cada persona y no en el déficit.

- Fomentar sus capacidades a través de la motivación, orgullo, autoestima, etc., como puede ser su propia demanda de apoyo de competencias linguísticas (incremento de sesiones de logopedia).

- Fomentar la cooperación a través de actividades colaborativas.

\section{Referencias}

HERNÁNDEZ FRANCO, C., VIÑALS BLASCO, M. J. y LLORET MAURI, J. (2004) "Formación en Inteligencia Artificial y Sistemas Digitales Aplicadas al Control de una Organización de la Comunidad Valenciana". 3ra Conferencia Iberoamericana en Sistemas, Cibernética e Informática (CISCI), Orlando, Florida, USA, 1-8

LLORET MAURI, J. (2005) "Radio en Internet: Audio Streaming y Aplicaciones". Workshop R@DIO’05 "Desde Marconi hasta la Sociedad de la Información”. Universitat Politécnica de València, 1-5

McLUHAN, M. (1968). Comprender los medios de comunicación. Barcelona : Ed. Paidós.

MARTI, J. M. (2000) De la Idea a l'Antena, Técniques de Programació Radiofónica, Pòrtic.

RAMÍREZ QUERALT, A. (2004) "La Radio Municipal de la Comunidad Valenciana en Internet: Relación o Flirteo". IV Congreso de Comunicación Local, Universidad Jaume I, Castellón 1-10

RUBIO PERIS, J. (2004) Estudio de Propagación de la Emisora Llosa FM 107.2 de la Llosa de Ranes. Proyecto Fin de Carrera. Universitat Politècnica de València. 


\title{
Conversem en línia
}

\section{Débora Escrivà $^{\mathrm{a}}$ i Neus Vicens ${ }^{\mathrm{b}}$}

${ }^{a}$ Tècnica mitjana lingüística, professora i responsable de l'organització dels grups de conversa de valencià, Servei de Promoció i Normalització Lingüística, Universitat Politècnica de València deesfus@upv.es; beditora, traductora de l'editorial Voramar/Santillana i professora dels grups de conversa de valencià, Servei de Promoció i Normalització Lingüística, a la Universitat Politècnica de València, neusvimo@gmail.com.

\begin{abstract}
The aim of this presentation is to share our experience concerning the use of Poli[ReunióN] an e-learning virtual synchronous tool developed by the Universitat Politècnica de València (UPV) to practise oral expression of Valencian language in the Groups of Conversation organized by the Servei de Promoció i Normalització Lingüistica (SPNL). We show that a lot of advantages of physical attendant classes are accomplished during these virtual teaching taking advantage too of the positive aspects of virtual learning. Furthermore we explain technical issues concerning this tool. The results of our experience encourage teachers at the UPV to integrate Poli[ReunióN] during learning processes implementing oral expression among others.
\end{abstract}

\section{Keywords:}

e-learning, synchronous virtual learning, Poli[ReunióN], oral expression, valencian language.

\section{Resum}

L'objectiu d'aquesta presentació és compartir l'experiència de l'ús de Poli[Reunión], l'eina virtual síncrona d'aprenentatge en línia desenvolupada per la Universitat Politècnica de València (UPV), per practicar l'habilitat de l'expressió oral en valencià en els Grups de Conversa de valencià que organitza el Servei de Promoció i Normalització Lingüística (SPNL). Veurem que molts avantatges de les classes presencials es poden 
aprofitar en l'ensenyament en línia $i$, també, s'hi afigen els trets positius que caracteritzen aquest tipus d'aprenentatge en línia. A més a més, aprofundirem en els aspectes tècnics relacionats amb l'eina. Amb la nostra experiència animem el professorat de la UPV a integrar l'eina Poli[ReunióN] per a l'aprenentatge de les habilitats d'expressió oral entre d'altres.

Paraules clau: aprenentatge en línia, aprenentatge virtual sincrònic, Poli[ReunióN], expressió oral, valencià.

\section{Introducció}

Des de l'any 2003, i a través del Centre d'Autoaprenentatge de Valencià, el Servei de Promoció i Normalització Lingüística (SPNL) de la Universitat Politècnica de València (UPV) organitza els grups de conversa de valencià en la modalitat presencial per a tots els membres de la comunitat universitària, amb l'objectiu de: $a$ ) millorar la fluïdesa oral en valencià, $b$ ) fomentar l'intercanvi conversacional, $c$ ) fomentar l'autoavaluació tant a nivell de lectura com d'expressió oral, $d$ ) orientar els assistents per tal de preparar les proves orals dels exàmens de la UPV. Aquesta activitat també contribueix a dur a terme l'objectiu de potenciar els valors i la formació integral de les persones de l'Eix III Compromís social i valors, del Pla Estratègic de la UPV (2007-2014).

Després de deu anys d'experiència en entorns presencials, el personal responsable dels grups de conversa es va plantejar la possibilitat d'impartir aquests grups en la modalitat no presencial. L'objectiu dels grups de conversa en línia era contribuir al compromís que té la UPV d'estimular les possibilitats d'usar les tecnologies de la informació i les comunicacions (TIC), a l'hora d'oferir ensenyaments teòrics i pràctics de qualitat. Amb l'aplicació de les TIC als grups de conversa de valencià, es completava la formació que ofereix l'SPNL a través dels cursos de valencià de llengua no sols en la modalitat semipresencial, sinó també en la modalitat de cursos en línia, però, sobretot, es donava un servei que permetia practicar la conversa en línia, des de qualsevol lloc i per a tots els membres de la comunitat universitària.

Abans de posar en pràctica el projecte, ens vam informar sobre les eines que ens podia oferir la UPV. Vam tenir diferents reunions amb el personal tècnic de l'Àrea de Sistemes de la Informació i les Comunicacions (ASIC) i, finalment, ens decidírem per desenvolupar el nostre plantejament amb l'ajuda de l'eina d'Aprenentatge Virtual Síncrona (AVIS) Poli[ReunióN] basada en el sistema d'AdobeConnect. Aquesta eina es desenvolupa a partir de 2010 a la UPV amb l'objectiu de "crear entorns AVIS on el professorat i l'alumnat poden col-laborar en temps real a través d'un entorn virtual accessible a través d'Internet"

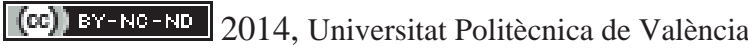

I Jornadas IN-RED (2014) 
(Moltó, 2011). Paral·lelament a les reunions que es feren amb els encarregats de l'eina, es tingueren en compte els treballs publicats anteriorment (del 2010 al 2013) en què "Poli[ReunióN] va demostrar ser útil" després d'haver-se aplicat en diferents assignatures i en diferents activitats educatives com ara tutories virtuals (grupals o individuals), lliçons magistrals a distància i activitats col-laboratives, en diferents àrees de la UPV (Monserrat, 2012). Poli[ReunióN] permet mantenir conferències a través de l'àudio i del vídeo i compartir documents o arxius en diferents formats (imatge i so).

Aquest treball mostra l'experiència d'aquesta iniciativa a l'hora d'oferir grups de conversa de valencià en línia i usar l'eina Poli[ReunióN], per tal d'impartir-ne les sessions durant el curs acadèmic de 2013-2014.

\section{Materials i mètodes}

Les eines AVIS proporcionen experiències similars a les que es donen en entorns presencials. L'eina Poli[ReunióN] permet mantenir "la interacció pròpia de les classes presencials, en usar un ordinador com a interfície de comunicacions entre l'alumnat i el professorat", (Monserrat $i$ altres, 2011). Així doncs, sempre que els grups no superen un màxim de 10 persones, les condicions de treball amb l'eina Poli[ReunióN] són les mateixes que trobem als grups presencials als quals assisteixen un màxim de 12 persones. L'eina ens acosta a les classes presencials perquè permet compartir arxius, veure l'alumnat, parlar-hi $\mathrm{i}$ fer grups de treball en la mateixa sala virtual.

Tenint en compte aquesta característica, les sessions dels grups de conversa conserven l'estructura plantejada per a les classes que s'imparteixen a les instal-lacions del Centre d'Autoaprenentatge de Valencià (CAV) de la UPV. Ho evidencia el fet que el material que es prepara per a les classes presencials dels grups de conversa és el mateix que el de les classes en línia d'aquests grups. A les classes presencials la unitat didàctica es reparteix mitjançant fotocòpies i, a les classes en línia, l'amfitrió (professor) compareix la unitat didàctica en la part esquerra de la pantalla, com es veu en la imatge següent.

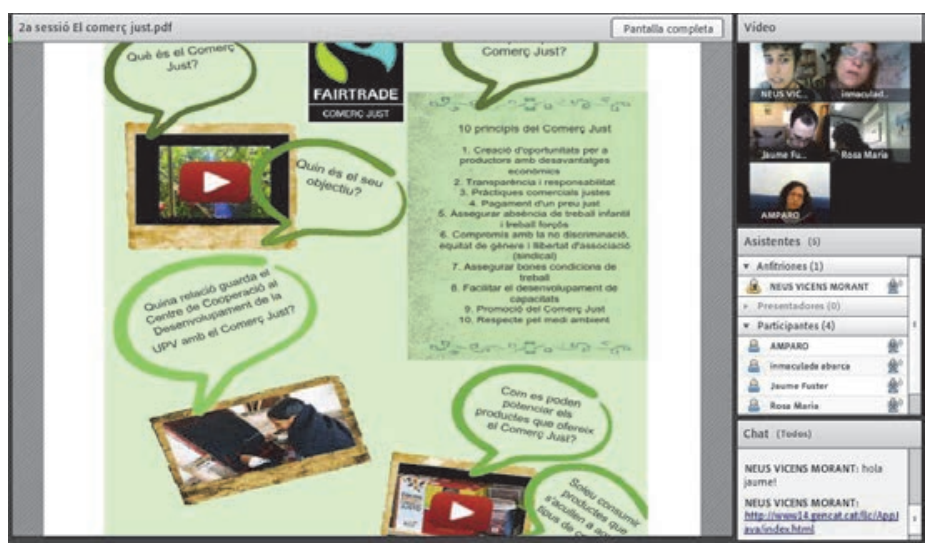

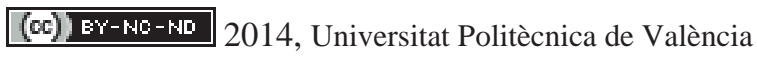

I Jornadas IN-RED (2014) 
Fig. 1 Aula virtual de la classe de conversa visualització dels alumnes amb la unitat didàctica en format PDF de la sessió

Per poder comprendre millor com s'usa l'eina a les classes en línia, tot seguit expliquem el desenvolupament d'una sessió dels grups de conversa virtuals.

- Introducció del tema i vocabulari. S'inicia la classe fent una pluja d'idees al voltant d'un tema proposat que varia en cada sessió. Aquesta pluja d'idees es realitza mitjançant les aportacions que fan els alumnes. El professorat, com en una classe presencial, anima els alumnes perquè facen les seues aportacions.

Com que aquesta eina afavoreix la col-laboració entre les persones assistents, el professorat aprofita que pot canviar els rols de l'alumnat perquè la sessió siga més participativa. Quan l'alumnat passa de ser "participant" a ser "presentador", pot escriure les seues idees directament en l'arxiu o pod destinat a les notes i participar en la pluja d'idees, sense que el professorat controle aquesta acció.

- Informació sobre el tema. Una vegada l'alumnat ha acabat de fer les seues aportacions inicials, es dóna més informació del tema tractat. El professorat posa vídeos, imatges, pàgines web en la part de la pantalla que comparteix amb l'alumnat. Però sempre és el professorat qui controla aquest arxiu.

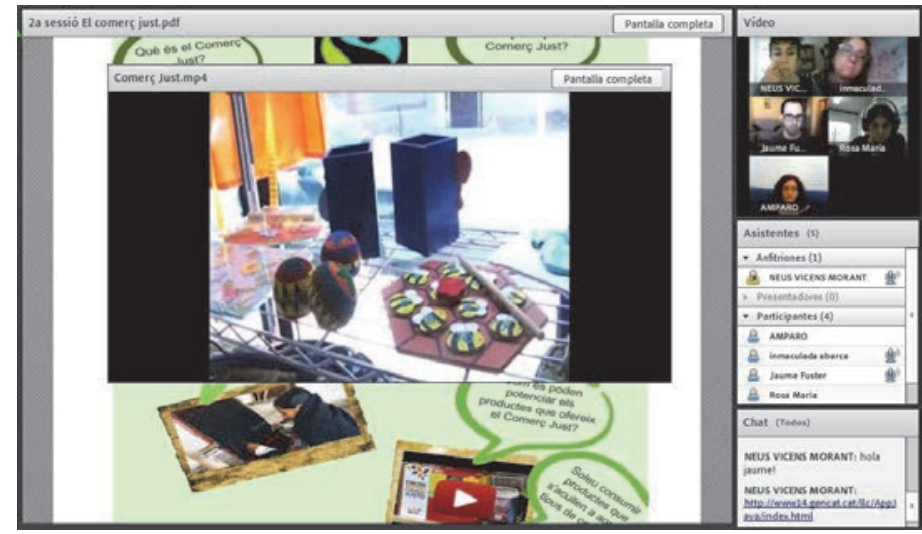

Fig. 2 Aula virtual de la classe de conversa visualització dels alumnes compartint un vídeo 


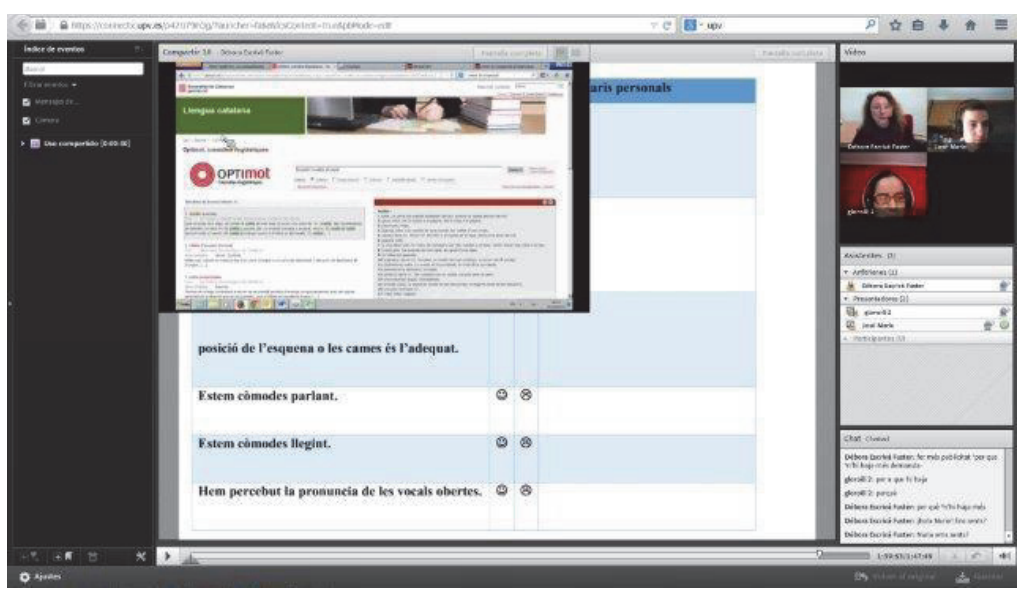

Fig. 3 Aula virtual de la classe de conversa visualització de la pantalla compartida per a mostrar pàgines d'Internet

- Fonètica. Després de fer les aportacions sobre el tema, se centra l'atenció de l'alumnat sobre els aspectes fonètics que treballaran juntament amb el tema de la sessió. Aquest apartat sempre es troba en el PDF principal que es comparteix amb l'alumnat durant tota la sessió. El professorat exemplifica els sons i fa practicar-los a l'alumnat.

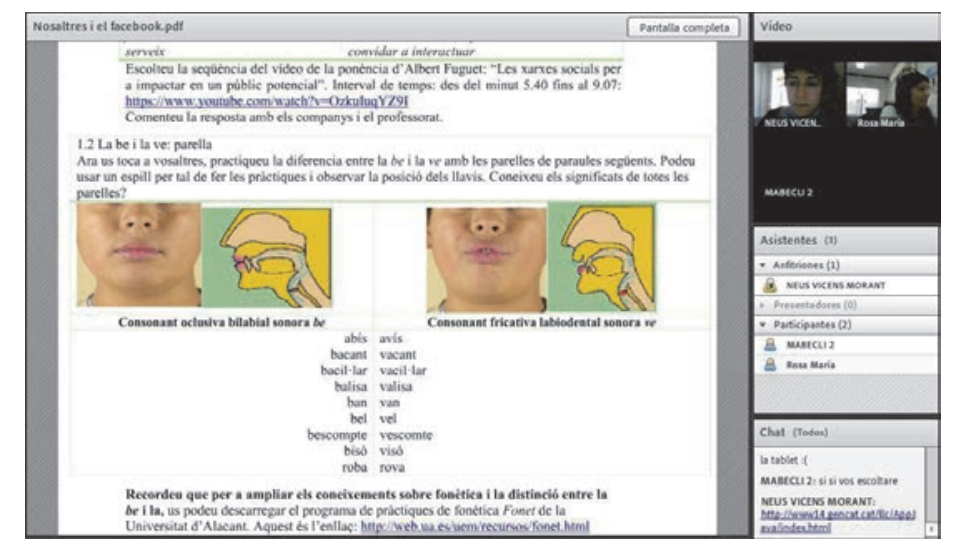

Fig. 4 Aula virtual de la classe de conversa visualització dels alumnes de l'apartat de fonètica del PDF

- Lectura. L'alumnat treballa en silenci la lectura del text que es troba en el PDF. De vegades, escolten l'àudio del text que el professorat comparteix. L'alumnat, d'acord amb la dinàmica d'intervencions que suggerisca el professorat, llegeix en veu alta el text $\mathrm{i}$ el professorat fa després les correccions que considera convenients.

- Conversa-debat. Es planteja un debat. De vegades, amb l'eina es fan grups de dos perquè treballen per parelles. Així interactuen entre ells sense molestar la resta de companys. Una vegada han treballat sobre què diran en les seues intervencions, tornen tots a la sala

\section{(c)) EY-NC-ND 2014, Universitat Politècnica de València}

I Jornadas IN-RED (2014) 
comuna, si s'han activat els grups, i es fa el debat seguint el torn de paraula que dóna el professorat.

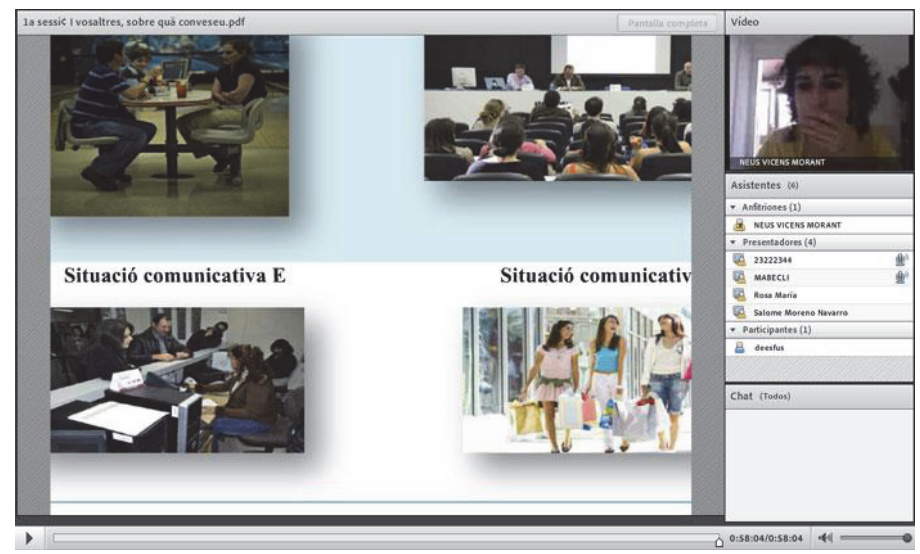

Fig. 5 Aula virtual de la classe de conversa amb els grups creats

- Autoavaluació i correccions. L'alumnat fa la seua autoavaluació i, tot seguit, el professorat mostra i comenta les notes que ha pres durant les intervencions. Les notes han estat ocultes en l'àrea de l'amfitrió, per tal de no molestar l'alumnat mentre exposa les seues idees.

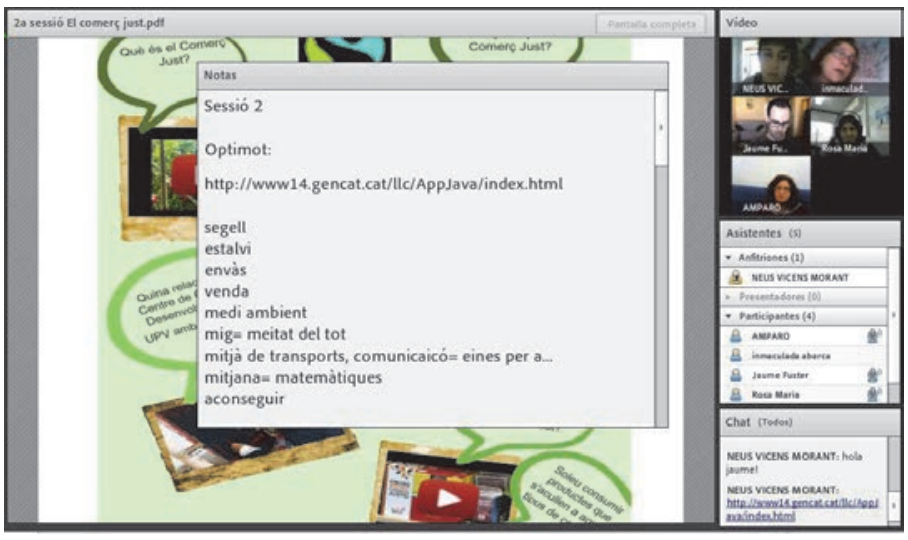

Fig. 6 Aula virtual de la classe de conversa visualització dels alumnes amb les notes de correcció

- Repàs de vocabulari. Abans d'acabar la sessió es fa un repàs del vocabulari que es troba en la part final del PDF de cada sessió, tal com es fa a les classes presencials.

Totes les sessions s'enregistren perquè les puga veure l'alumnat a posteriori, fet que contribueix a fomentar l'autoavaluació.

(c)) EY-NC-ND 2014, Universitat Politècnica de València 
La visualització del professorat, amb rol d'amfitrió, varia una mica en la visió de l'alumnat, amb rol de participant. El més rellevant és que a la dreta de la pantalla, el professorat gaudeix d'un espai ocult per a l'alumnat. En aquest indret es poden prendre notes per comentar després amb l'alumnat i reservar tots els arxius que no volem que estiguen visibles durant tota la sessió.

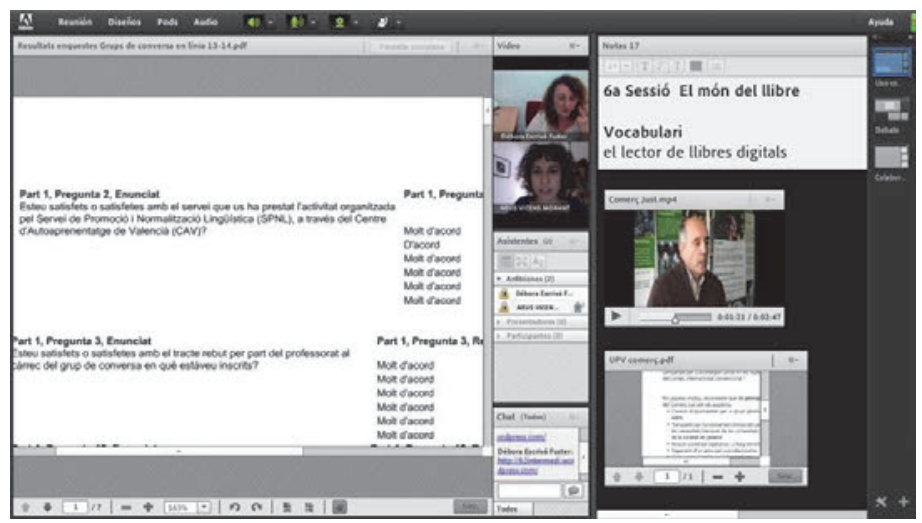

Fig. 7 Aula virtual de la classe de conversa visualització de les professores

\section{Discussió}

Des del punt de vista del professorat, l'experiència dels grups de conversa en línia ha estat molt satisfactòria. Cal ser conscients que l'èxit aconseguit a l'hora d'integrar l'eina ha sigut possible gràcies a la formació tècnica i didàctica del professorat. S'hi van dedicar al voltant de 10 a 15 hores a conéixer les prestacions de l'eina, per tal d'usar-la amb comoditat. D'altra banda, el professorat va organitzar una sessió presencial per a l'alumnat i va establir-hi diferents connexions, abans de l'inici dels grups de conversa. Els objectius d'aquestes sessions eren els següents: comprovar la qualitat de les connexions dels dispositius que havia d'usar l'alumnat per a les sessions, mostrar-los la interfície i orientarlos en les accions que havien de fer per tal de connectar-se a la sala, a més d'explicar-los el funcionament de les sessions. Compartim, doncs, el que expressen els treballs anteriors quan es refereixen a "la necessitat d'emprar una o dues sessions presencials per a ensenyar l'alumnat a utilitzar l'eina i la necessitat, al mateix temps, que el professorat hi estiga avesat", (Monserrat, 2012). Amb aquest objectiu, el professorat va elaborar una guia específica per als grups de conversa en línia que incloïa informació relacionada amb els aspectes tècnics de l'eina $\mathrm{i}$ amb la metodologia didàctica que s'havia d'aplicar a les sessions.

Pel que fa a l'estudiantat, aquest també va trobar molt satisfactori l'ús de l'eina Poli[ReunióN] per a practicar la conversa en línia. Així ho demostren les enquestes de

\section{(c)) EY-NC-ND 2014, Universitat Politècnica de València}

I Jornadas IN-RED (2014) 
satisfacció en línia que va respondre l'alumnat, a través del PoliformaT. Durant el curs acadèmic 2013-2014, es van inscriure 16 persones en els grups de conversa en línia i van respondre l'enquesta 10 . Hi hagué un $80 \%$ que estava molt d'acord que l'eina era útil, un $10 \%$ que estava d'acord que era útil i un $10 \%$ que estava indecís si aquesta era útil.

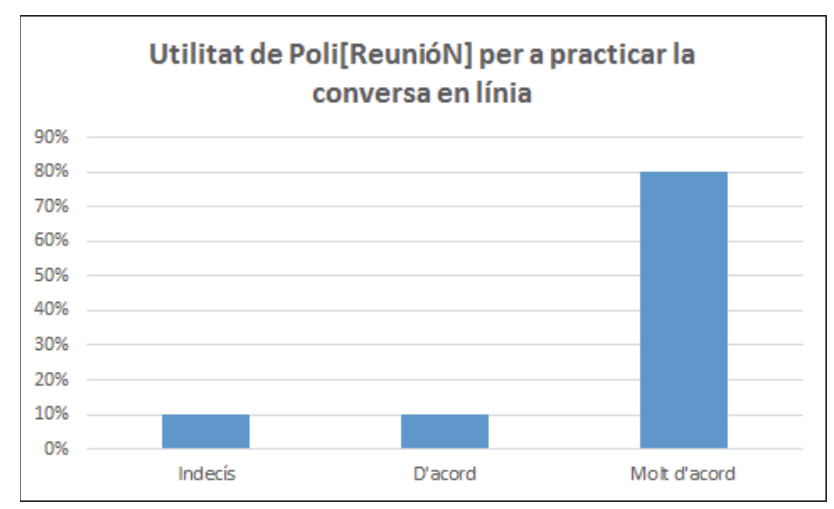

Fig. 8 Resultats de les enquestes de satisfacció de l'alumnat a l'hora d'usar l'eina Poli[ReunióN] en els grups de conversa en línia (2013-2014)

Els resultats de l'experiència són satisfactoris tant per al professorat com per a l'estudiantat, però no hem d'oblidar que "l'èxit de Poli[ReunióN], i en general de qualsevol eina virtual de comunicació síncrona, depén de la qualitat de les connexions", (Monserrat, 2012). D'aquesta, en depenen la qualitat del so i la qualitat de la imatge que afecten directament el nivell de satisfacció que mostren les persones a l'hora de considerar que Poli[ReunióN] és idònia per a practicar la conversa en línia. Lligat a l'èxit de l'eina també trobem que cal continuar treballant en les millores i els avanços de Poli[ReunióN], per tal de poder donar una oferta més amena i adaptada a la persona usuària. Amb tot això, dividim les nostres aportacions i les de l'alumnat en els apartats següents:

\subsection{La connectivitat}

Tot i que s'ha usat la versió actualitzada d'aquesta eina, s'han tingut diferents problemes relacionats amb la connexió. En algunes ocasions es produïen desconnexions breus que aturaven la marxa normal de la classe.

\subsection{La qualitat del so}

En general l'alumnat ha valorat que la qualitat del so era bona. Però, de vegades, si la connexió a Internet dels participants no era bona, escoltaven el so amb retard, amb eco o entretallat. Això dificultava l'agilitat de les converses. Posat cas que s'usaren tauletes, hi havia moments en què la veu i la imatge no estaven sincronitzades. L'alumnat ho expressa en els comentaris de les enquestes: 
"Hi ha hagut alguns problemes de connexió amb Poli[ReunióN] i problemes de retardament de la veu que dificultaven la conversa algunes vegades."

"Els problemes que havia sofert eren per l'ús d'una tauleta digital al grup de conversa. També crec que això feia que no poguera veure més de dues persones en moviment i que, a vegades, se solaparen les converses. Tots aquests problemes em sembla que tenien el mateix punt en comú i era el sistema de la tauleta digital."

\subsection{La càmera web}

En d'altres casos, la connexió ha afectat la càmera web de l'alumnat i no s'hi ha pogut connectar. Aquest fet ha impossibilitat que gran part de les sessions es feren sense que poguérem veure aquest assistent. Per poder esmenar aquest error, es va usar la càmera web del telèfon mòbil.

\subsection{El format dels documents}

$\mathrm{Cal}$ recordar que sols es poden compartir arxius en format PDF. Moltes vegades ens seria útil poder compartir PowerPoints i Words perquè augmentarien les possibilitats de treballar de manera col-laborativa en el document. Per exemple, seria útil per poder escriure la pluja d'idees o realitzar els exercicis de fonètica o de vocabulari que es proposen en la unitat didàctica d'una manera conjunta en el document compartit. Aquesta activitat sols es pot fer amb l'arxiu o pod destinat a les notes i promovent els participants a presentadors. Una alumna comenta: "trobe a faltar una eina per poder subratllar en el document que compartim".

\subsection{La navegació per Internet}

Seria recomanable poder navegar en pàgines web des de la mateixa eina de Poli[ReunióN] sense haver de compartir la pantalla de l'amfitrió com es fa actualment.

\subsection{L'accés a la sala virtual}

L'eina encara no està integrada en la plataforma de formació en línia PoliformaT, però sí que permet que s'enllace com a URL externa. De manera que facilita tenir accés a la sala i, a més, navegar per la resta d'eines de què disposa PoliformaT: repositori de materials (unitats didàctiques per als grups de conversa en format PDF, àudios que s'usen de suport per als textos que s'hi han de treballar, els enllaços a diccionaris...), correu intern, fòrum, etc.

Com a proposta de millora, ens agradaria que l'alumnat inscrit en els grups de conversa en línia poguera entrar a la sala directament sense la necessitat que l'amfitrió (professorat) els haja de donar permís per accedir-hi. També seria adequat que tingueren permís per poder activar-se el micròfon i la càmera sense que el professorat hi intervinguera.

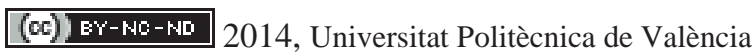




\subsection{El programari: Linux}

Poli[ReunióN] no té una versió per al sistema operatiu Linux, fet que tanca portes a usuaris d'aquest sistema lliure. Una alumna feia el comentari següent: "tenia al meu ordinador el sistema Linux/Ubuntu i a la tauleta, l'Android, em va resultar una mica difícil connectar-me al grup de conversa en línia".

\section{8 La interacció virtual}

Encara que la interacció entre el professorat i l'alumnat ha sigut fluïda i molt similar a la que es manté en una classe presencial, s'ha de prestar una atenció especial a l'intercanvi dels torns de paraula. El professorat i l'alumnat mateix han d'usar els noms en cada interacció perquè s'hi mantinga un bon intercanvi durant la classe. L'absència de contacte ocular directe minva la resposta verbal immediata. És per això que un aspecte tan fonamental en les converses com són els codis no verbals no es perceben amb tanta claredat com en una classe presencial on podem veure el cos sencer dels participants.

\section{Conclusions}

Després d'aquesta experiència ens agradaria acabar aquest escrit animant els docents a començar projectes com el nostre, on les TIC siguen una eina que done suport al procés d'ensenyament i aprenentatge tant de llengües com d'altres matèries de les àrees tècniques que s'imparteixen a la UPV.

D'una banda, segons els comentaris que ha deixat l'alumnat d'aquests grups podem dir que és molt positiu poder fer les classes des de qualsevol lloc amb un dispositiu (ordinador, tauleta digital o telèfons intel-ligents) i connexió a Internet. Aquesta opció de classes en línia ajuda a compaginar l'agenda tan atapeïda que tenen els treballadors de la UPV o l'estudiantat. Com s'afirma en les enquestes dels alumnes: "ha sigut molt útil, per l'horari, pel contingut del curs, i per l'eina en línia. ja que no podria anar al Politècnic amb l'horari de treball que tinc."

D'altra banda, l'alumnat agraeix molt el fet que es puguen sentir com a classe, que aprenguen dels companys i que hagen d'expressar-se oralment en públic. La sensació de tenir un públic s'aconsegueix amb aquesta eina on tots es miren, s'escolten, es valoren, s'avaluen i s'autoavaluen. Citem els comentaris de dues alumnes:

"L'eina em pareix molt adequada per a l'exercici de l'activitat. Es poden realitzar les funcions bàsiques i necessàries per a l'aprenentatge: permet compartir documents, treballar en línia amb el bloc de notes i parlar tots al mateix temps o per grups. Es pot treballar amb documents compartits i formar xicotets grups de treball. El nombre d'alumnes en aquesta classe era l'adequat per a poder gaudir d'un bon aprenentatge i que la classe fóra amena." 
"Com que som diferents alumnes pots també conèixer més gent i aprendre també de la resta de companyes i veure les seues errades i comparar si tu també les fas."

Cal recordar el compromís que adquireix la UPV a l'hora de desenvolupar aquest tipus d'eines i hem de procurar integrar-les en les assignatures o cursos que puguem impartir en qualsevol modalitat d'ensenyament i aprenentatge, bé siga de manera presencial, semipresencial o en línia. Sols així podrem contribuir en la millora d'aquestes eines i arribar al nivell de competència digital necessari per a una societat tan canviant com la nostra. Les TIC cada vegada més ens obrin més portes i l'ensenyament en línia contribueix al que es desitja actualment: aprendre al llarg de la vida sense límit de temps ni d'espai.

\section{Agraïments}

Les autores volem agrair al personal tècnic de l'Àrea de Sistemes de la Informació i les Comunicacions i al Servei de Promoció i Normalització Lingüística per donar-nos suport a l'hora de dur a terme el projecte dels grups de conversa de valencià en línia.

\section{Referències}

Adobe Connect. www.adobe.com/products/adobeconnect.html

A. FITA, J.F. MONSERRAT, G. MOLTÓ, E.M. MESTRE, A. RODRÍGUEZ-BURRUEZO, (2011). "Multidisciplinary Experiences at University Degrees in the Use of Synchronous E-learning", en International Conference The Future of Education., Florència, pàg. 121-127.

CARNICER-ANDRÉS, M. P.; GOMIS-PÉREZ, A. M.; LAJARA-CAMILLERI, N.; OREA-VEGA, G., (2013). "Evaluación de Herramientas de Teledocencia: Experiencia en Cursos de Postgrado ", en XI Jornadas de Redes de Investigación en Docencia Universitaria. Alacant. (En premsa)

MOLTÓ, G.; FITA, A. M.; MONSERRAT, J. F.; MESTRE, E. M.; RODRÍGUEZ-BURRUEZO, A.; RUIZ, J. C. (2011). "La tutoría virtual para la autogestión del aprendizaje en las enseñanzas técnicas" en III Congreso Internacional UNIVEST.

MONSERRAT, J. F.; FITA, A. M.; MOLTÓ, G.; RODRÍGUEZ-BURRUEZO, A.; (2011). "Experiencias de Uso de la Herramienta de Aprendizaje Virtual Síncrono Poli[ReunióN] " en Jornada de Innovación Docente ICE-UPV. València.

MONSERRAT, J. F, (2012). "Integración de las Herramientas Poli[ReunióN] y Politube en la Práctica Docente en la UPV”, en Jornadas de Innovación Educativa. València.

Reserva de Salas Virtuales. Poli[ReunióN]. <https://polireunion.upv.es/> [Consulta: juny 2014]

\section{(cc) BY-NC-ND 2014, Universitat Politècnica de València}

I Jornadas IN-RED (2014) 


\title{
Diseño de materiales didácticos online para fomentar el aprendizaje autónomo del alumno.
}

Eva García Martínez ${ }^{\text {a }}$, Isabel Fernández Segovia ${ }^{\text {b y Ana Fuentes López }}{ }^{\text {c }}$

aDpto.Tecnología de Alimentos, ETSIAMN, evgarmar@tal.upv.es, ${ }^{b}$ Dpto. Tecnología de Alimentos, ETSIAMN, isferse1@tal.upv.es, ${ }^{c}$ Dpto Tecnología de Alimentos, ETSIAMN, anfuelo@upvnet.upv.es.

\begin{abstract}
Adaptation of subjects to the European Space for Higher Education has brought a reduction in the hours of class attendance and has increased the student independent work. This involves restructuring of teaching and the using of active teaching and learning methodologies. The PoliformaT platform, as well as the use of information and communication technologies (ICT), constitute tools that can help the teacher to encourage independent study and self regulation of the student. In this sense, the objective of this work is to design interactive learning materials and then determine the degree of satisfaction of students, regarding their experience and the use they have made of these tools and their usefulness to support the self-directed learning. The effect of using these resources in improving student efficiency is also analyzed.
\end{abstract}

Keywords: Independent learning, interactive learning materials, information and communication technologies (ICT), PoliformaT, learning objects. 


\begin{abstract}
Resumen
La reconversión de las asignaturas al sistema de créditos del Espacio Europeo de Educación Superior ha traído consigo una reducción de las horas de clase presenciales y un incremento de la carga de trabajo autónomo del estudiante, lo cual conlleva la reestructuración de las mismas mediante el uso de metodologías activas de enseñanza-aprendizaje. La plataforma PoliformaT, así como la utilización de las tecnologías de la información y la comunicación (TIC), se constituyen como herramientas que puede ayudar al profesor a fomentar el trabajo autónomo del alumno. En este sentido, el objetivo de este trabajo es diseñar materiales didácticos interactivos y posteriormente conocer el grado de satisfacción de los alumnos, respecto a su experiencia y al uso que ellos han hecho de estas herramientas y de su utilidad como apoyo al auto aprendizaje dirigido. También se analizará el efecto del uso de estos recursos en la mejora del rendimiento de los alumnos.
\end{abstract}

Palabras clave: trabajo autónomo, material didáctico interactivo, tecnologías de la información y la comunicación (TIC), poliformaT, objetos de aprendizaje.

\title{
Introducción
}

La reconversión de las asignaturas al sistema de créditos del Espacio Europeo de Educación Superior ha traído consigo una reducción de las horas de clase presenciales y un incremento de la carga de trabajo autónomo del estudiante, lo cual conlleva la reestructuración de las mismas mediante el uso de metodologías activas de enseñanza-aprendizaje.

El estudio y trabajo autónomo es una modalidad de aprendizaje en la que el estudiante se responsabiliza de la organización de su trabajo y de la adquisición de las diferentes competencias según su propio ritmo. Implica por parte de quien aprende asumir la responsabilidad y el control del proceso personal de aprendizaje, así como las decisiones sobre la planificación, realización y evaluación de la experiencia de aprendizaje. Según Merrian y Caffarella (1991) se trata de una forma de estudio en la cual los alumnos tienen la responsabilidad de planear, llevar a cabo y evaluar sus actividades de aprendizaje.

El estudiante autónomo, como sujeto activo de su propio aprendizaje, se formula metas, organiza el conocimiento, construye significados, utiliza estrategias adecuadas y elige los 
momentos que considera pertinentes para adquirir, desarrollar y generalizar lo aprendido (Pozo y Monereo, 1999).

El aprendizaje autónomo, en estudiantes de Educación Superior, parece estar constituido (Vermunt, 2005) por tres importantes aspectos:

a) Estrategias cognitivas o procedimientos intencionales que permiten al estudiante tomar las decisiones oportunas de cara a mejorar su estudio y rendimiento;

b) Estrategias metacognitivas o de reflexión sobre el propio proceso de aprendizaje y

c) Estrategias de apoyo referidas al autocontrol del esfuerzo y de la persistencia, y a promover condiciones que faciliten afectivamente el estudio.

La autonomía personal en el aprendizaje se refiere a la propia capacidad de aprender a aprender (Monereo y Pozo, 2002). Así pues, el aprendizaje autónomo es un proceso que permite al estudiante ser autor de su propio desarrollo. La estimulación de este aprendizaje persigue, esencialmente, junto a la generación de espacios de libertad curricular, lograr en el estudiante, y en consecuencia en el futuro profesional, un grado de autonomía que lo habilite para su propio gobierno, el aprendizaje continuo, la toma de decisiones y la gestión independiente o vinculada a otros profesionales. Por ello en el empleo de metodologías de enseñanza-aprendizaje para favorecer el aprendizaje autónomo de los alumnos, es esencial que se tenga en cuenta: la contextualización de los aprendizajes, la reflexión personal, la construcción de conocimientos, la aplicación práctica de los mismos y la evaluación del proceso realizado (Brockett y Hiemstra, 1991).

En este ámbito, el estudiante además, precisa un mecanismo de feed-back auto-orientado durante el aprendizaje, en el que él mismo controla la efectividad de sus estrategias y técnicas y responde a ese feedback de maneras diferentes (Beltrán, 2003).

En el aprendizaje autónomo del estudiante el profesor es fundamentalmente mediador del aprendizaje entre los contenidos y la actividad constructivista del estudiante. El profesor en el proceso enseñanza-aprendizaje de su materia trata de formar aprendices estratégicos, es decir, potenciar la actuación estratégica de los estudiantes de forma que cada cual elabore su modelo personal de funcionamiento y de acción y sea capaz de regularlo y mejorarlo de manera progresivamente más autónoma (Lobato, 2006).

Por otro lado, el desarrollo y la práctica del aprendizaje autónomo actualmente se abre a nuevos escenarios y espacios organizativos, gracias especialmente a las nuevas posibilidades que ofrecen las nuevas Tecnologías de la Información y Comunicación (TICs) y los desarrollos en telecomunicaciones. Las tecnologías de la información y de la comunicación no sólo aparecen como un entorno y como herramientas del proceso instructivo, sino también como posibilitadoras de unos nuevos espacios de promoción y desarrollo de la autonomía del estudiante. La emergencia de los sistemas semipresenciales

\section{(c)) EY-NC-ND 2014, Universitat Politècnica de València}

I Jornadas IN-RED (2014) 
con su formato de tutoría, el correo electrónico, los foros, los nuevos formatos de interacción, la inclusión de contenidos multimedia, etc., suponen un nuevo escenario en el que cobra un relieve singular el estudio y el trabajo autónomo del estudiante universitario. En los últimos años, en la Universidad Politécnica de Valencia se han desarrollado múltiples acciones, entre las que se puede destacar la implantación de la plataforma docente PoliformaT. Esta permite la puesta en marcha de nuevos entornos de colaboración y aprendizaje, y abre un campo interesante de acciones enfocadas al proceso de enseñanzaaprendizaje, tanto para el profesor, como para el alumno. Así, la plataforma telemática PoliformaT y el empleo de Objetos de Aprendizaje como recurso de apoyo a la docencia presencial, son algunas de las líneas posibles de actuación, constituyéndose como herramientas que pueden ayudar al profesor a fomentar el trabajo autónomo del alumno.

\section{Objetivos}

El objetivo general de este trabajo es diseñar materiales didácticos interactivos empleando como herramienta la plataforma interactiva PoliformaT para fomentar el trabajo autónomo del alumno. Una vez puesta a punto la metodología a emplear durante el curso académico, al final del mismo se pretende conocer el grado de satisfacción de los alumnos. Para ello se diseñará una encuesta en la que se abordarán cuestiones referentes a la experiencia del estudiante y al uso que se ha hecho de estas herramientas y de su utilidad como apoyo al auto aprendizaje dirigido. También se pretende analizar el efecto del uso de estos recursos en la mejora del rendimiento de los alumnos.

Los objetivos específicos de este trabajo son:

- Fomentar el interés y la motivación en el proceso de aprendizaje de los alumnos

- Incentivar el trabajo autónomo de los alumnos

- Reforzar el uso de las Nuevas Tecnologías de la Información y Comunicación (TICs)

\section{Desarrollo de la innovación}

La presente innovación se realizará durante el curso 2014-2015 en una asignatura de tercer curso del Grado en Ciencia y Tecnología de Alimentos (Análisis y Control de Calidad de Alimentos I), que se imparte en la Escuela Técnica Superior de Ingeniería Agronómica y el Medio Natural de la Universidad Politécnica de Valencia. Esta asignatura de 6 créditos, se distribuye en 2,5 horas semanales de teoría y 3 horas de prácticas de laboratorio. El objetivo general de la asignatura es que el alumno conozca las diferentes metodologías químicas e 
instrumentales de análisis de los constituyentes mayoritarios y minoritarios de los alimentos para el control de calidad de los alimentos.

En los dos años que lleva impartiéndose esta asignatura, el número de alumnus matriculado ha aumentado, así, durante el curso 2012/2013 se matricularon 38 alumnos, y en el curso 2013/2014 se matricularon 65 alumnos. Del número de matriculados, en general un 80\% asisten habitualmente a clase de teoría. Los contenidos teóricos de la asignatura se relacionan directamente con los análisis realizados y los resultados obtenidos durante las sesiones prácticas de laboratorio, las cuales son de asistencia obligatoria.

En la actualidad, para el desarrollo del programa presencial de teoría se emplea la lección magistral y se intercala la resolución de casos como actividad de trabajo en grupo, facilitándose para ello, información bibliográfica. De esta manera, se formenta la capacidad de análisis y de síntesis, se reflexiona sobre los contenidos y los aplican a casos reales. El final de la actividad corresponde a un debate posterior donde toda la clase participa. En cuanto a las sesiones de prácticas de laboratorio, los alumnos realizan análisis de control de calidad específicos de distintos grupos de alimentos e industrias agroalimentarias, organizados en 9 sesiones de prácticas a lo largo del segundo cuatrimestre. En relación al sistema de evaluación, actualmente consta de dos examenes escritos de preguntas de respuesta abierta y tipo test que suponen el $80 \%$ de la nota final, un trabajo académico de las memorias de practicas de laboratorio que tienen que exponer oralmente al final de curso (que supone un 10\%) y la resolución de un caso donde los alumnos aplican los conceptos teóricos y prácticos de la asignatura a la resolución de una problemática surgida en la industria agroalimentaria (10\% de la nota final).

La nueva planificación de la asignatura se realizará a partir del curso próximo 2014/2015. Para fomenter el interés y la motivación en el proceso de aprendizaje de los alumnos, así como incentivar el trabajo autónomo, se pretende diseñar y desarrollar los objetivos, contenidos, materiales y evaluación de las distintas Unidades didácticas en el entorno en línea de la plataforma PoliformaT como apoyo a la docencia presencial.

En general se seguirá una misma configuración en la estructura del contenido de las Unidades que el alumno deberá trabajar desde casa: Introducción y Objetivos del tema dentro del contexto de la asignatura. En este punto se establecerá un enlace a la herramienta de "Sondeos" de PoliformaT donde el alumno debe contestar un breve cuestionario de conocimientos previos. Después se planteará la lectura de un texto y/o un visionado de un objeto de aprendizaje o un video screencast de apoyo. Los contenidos abordados de esta manera estarán relacionados tanto con aspectos teóricos como prácticos de la asignatura. Tras la realización de estas actividades se propondrá contestar a una serie de preguntas tipo test de refuerzo o bien se establecerá un enlace a una tarea o a un ejercicio práctico sobre los mismos (Figura 1). La resolución de estas tareas se podrá producir, bien inmediatamente

\section{(cc) EY-NC-ND 2014, Universitat Politècnica de València}

I Jornadas IN-RED (2014) 
tras la realización de la actividad (Figura 2), o bien en la siguiente clase presencial. En este tipo de metodología, es importante que cada apartado descrito conste de instrucciones detalladas para despertar la atención y la motivación del alumno, así como también debe figurar el tiempo aproximado de duración de la actividad para que el estudiante se sienta guiado en todo momento. Se emplearán mapas conceptuales y diagramas para relacionar la información.

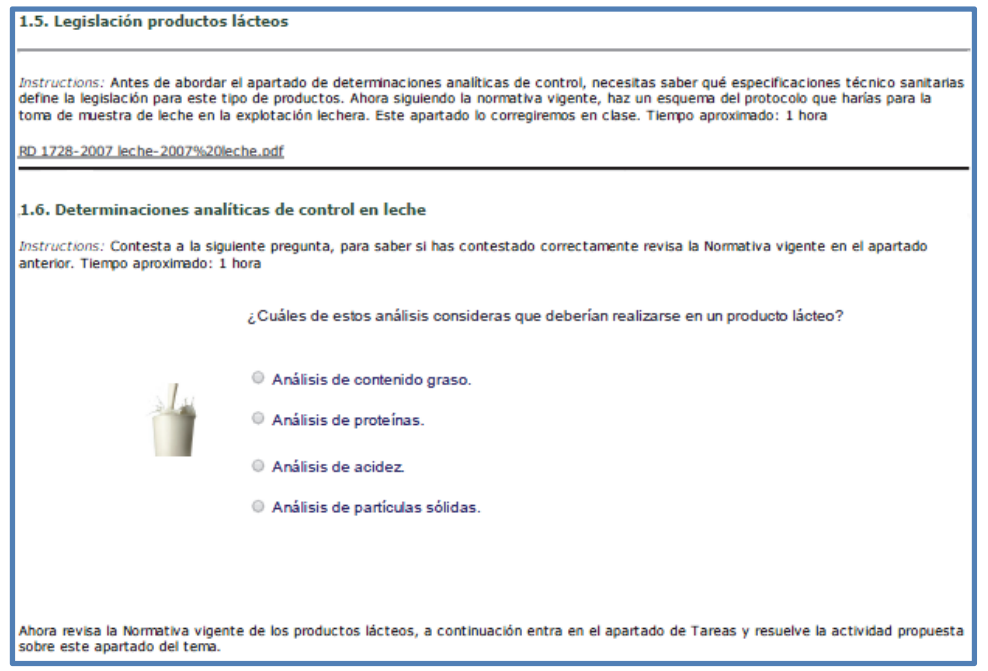

Fig. 1 Ejemplo de ejercicio práctico a realizar tras la lectura de contenidos teóricos y preguntas tipo test de refuerzo.

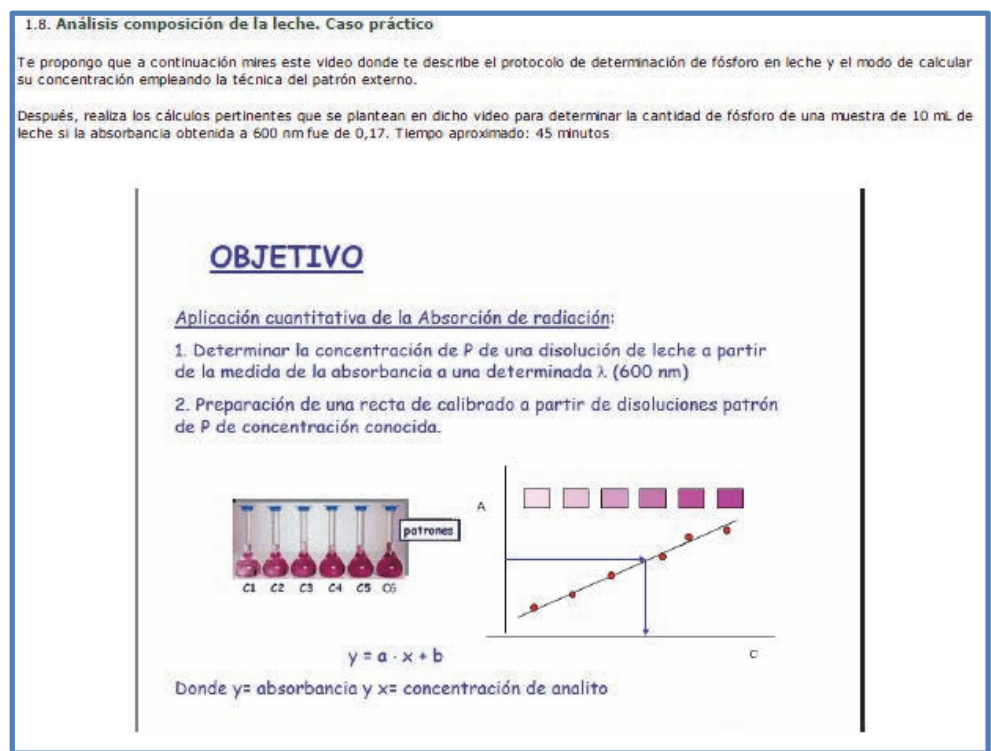

(c)) EY-NC-ND 2014, Universitat Politècnica de València

I Jornadas IN-RED (2014) 
Fig. 2 Ejemplo de ejercicio práctico resuelto a través del visionado de un objeto de aprendizaje..

Por último, para comprobar si se han cumplido con los objetivos de aprendizaje propuestos en cada módulo, se animará a los estudiantes a contestar un examen tipo test ubicado en el apartado de "Evaluación" de la misma plataforma PoliformaT. Este examen estará diseñado de tal manera que al finalizar el mismo, el alumno sabrá su puntuación, así como recibirá feed back sobre los errores cometidos. De esta manera, el alumno obtiene retroalimentación, siendo capaz de autoevaluarse y comprobar su grado de aprendizaje y la propia asimilación de conceptos. En general, las dudas, errores, etc. producidos a lo largo de la ejecución de las tareas propuestas serán comentados para su subsanación y comprensión en la siguiente sesión de aula. Esta actividad se realizará en grupos, para que sea más enriquecedor y todos los alumnos puedan aprender resolviendo no solo sus dudas o errores, etc. sino también las posibles dudas, fallos y errores de sus compañeros. En este punto el alumno aplicará de modo práctico los conceptos asimilados de forma autónoma. El professor, como guía del aprendizaje, atenderá estas cuestiones planteadas por los alumnos en el aula como una actividad tutorizada en grupo a modo de aplicación práctica de los contenidos abordados. De esta manera también se pretende mejorar la relación alumnoprofesor, así como obtener un mejor conocimiento de las carencias de los alumnos en cada instante del curso, con la finalidad de propiciar un mejor ambiente de aprendizaje.

\section{Resultados}

Los resultados de satisfacción de los alumnos debido a la innovación introducida en la metodología de enseñanza-aprendizaje empleada en la asignatura de Análisis y Control de Calidad de Alimentos I durante el curso 2014/2015, se recopilarán mediante el pase de encuestas a los alumnos. Esta encuesta estará dividida en cuatro bloques. Por un lado se realizarán preguntas referidas al manejo y utilidad de la plataforma PoliformaT. Así, se pretende obtener información en torno a la facilidad/dificultad de uso de esta herramienta. También se preguntará sobre el número de objetos de aprendizaje o screencast propuestos visionados, el número de veces que han sido consultados y el tiempo dedicado a los mismos.

Otro bloque, al que el alumno deberá responder según una escala de valoración del 1 (totalmente de acuerdo) al 6 (no dispongo de elementos de juicio), se centrará en cuestiones como la duración de los objetos de aprendizaje y de resolución de las tareas, ejercicios y exámenes propuestos, sobre la estructura seguida en los contenidos teóricos y prácticos, etc.

\section{(cc) EY-NC-ND 2014, Universitat Politècnica de València}

I Jornadas IN-RED (2014) 
En un tercer bloque de la encuesta, más centrado en el grado de satisfacción del proceso de enseñanza-aprendizaje, se ahondará en cuestiones tales como el rol del profesor, la comprensión o asimilación de los contenidos teóricos y prácticos, la utilizad de la resolución de dudas-tutorización grupal en el aula, la dificultad de la evaluación, etc.

Por último, el cuarto bloque abordará el grado de satisfacción general de la utilización plataforma PoliformaT como herramienta de enseñanza-aprendizaje para el fomento del trabajo autónomo, incidiendo también en los hábitos/motivaciones de realización de las actividades propuestas y del visionado de los objetos de aprendizaje y screencast (dónde los veo, cuándo, por qué), así como en la utilidad de los mismos (repaso o refuerzo de otros conceptos, etc.). También se incluirán en este apartado preguntas acerca de las preferencias de los alumnos en cuanto a la modalidad de enseñanza empleada (presencial, semipresencial, en línea). En cada uno de los bloques los alumnos contestarán a las preguntas pertinentes referidas, concretamente, a las actividades realizadas y objetos de aprendizaje o screencast visionados, etc., aunque no necesariamente se correspondan con todos los propuestos por el profesor.

Además, el grado de asimilación de los contenidos debido a la implantación de la nueva metodología de autoregulación del aprendizaje se observará comparando las notas medias actuales recogidas en cursos anteriores, con las notas finales obtenidas tras las correspondientes evaluaciones sumativas del nuevo curso.

Por otro lado, la implicación y la motivación de los alumnos en el proceso de aprendizaje se verá reflejado en el grado de participación de los alumnos en cada una de las actividades planteadas fuera y dentro del aula.

Los resultados obtenidos en esta innovación se tomarán como referencia para mejorar el empleo de la plataforma PoliformaT, optimizando su uso como herramienta de apoyo a la docencia presencial e incentivando el trabajo autónomo del alumno.

\section{Conclusiones}

Con esta innovación se pretende diseñar materiales didácticos interactivos empleando como herramienta la plataforma interactiva PoliformaT para fomentar el trabajo autónomo del alumno. De esta manera, se fomentará el interés y la motivación de los estudiantes en el propio proceso de aprendizaje. Los resultados se recopilarán por medio de cuestionarios y encuestas de satisfación. Las conclusiones deberán ser corroboradas en próximos cursos académicos para poder afirmar que el uso de esta herramienta redunda en una mejora del aprendizaje del estudiante, animando a los profesores a seguir esforzándose y elaborando más recursos digitales e interactivos como herramientas de apoyo y complemento para el major aprovechamiento de las clases presenciales. 


\section{Referencias}

BELTRÁN, J. (2003). "Estrategias de aprendizaje” en Revista de Educación, 332, 55-73. Madrid.

BENITO, A.y CRUZ, A. (2005). Nuevas claves para la docencia universitaria en el Espacio Europeo de Educación Superior. Madrid: Narcea S.A

BROCKETT, R. y HIEMSTRA, R. (1991). Self-direction in adult learning: perspectives on theory, research, and practice. New York, USA: Routledge.

LOBATO, C. (2006). "Estudio y trabajo autónomo del estudiante" en DE MIGUEL, M. Metodologías de enseñanza y aprendizaje para el desarrollo de competencias. Madrid: Alianza Universidad. 191-223.

MERRIAM, S. B. y CAFFARELLA, R. S. (2002). Learning in adulthood: A comprehensive guide. San Francisco.

POZO, J.I. y MONEREO, C. (1999). El aprendizaje estratégico: enseñar a aprender desde el currículo. Madrid: Santillana/Aula XXI.

VERMUNT, J. (2005). "Relations between student learning patterns and personal and contextual factors and academic performance" en Higher Education, 49, 205-234.

(cc) EY-NC-ND 2014, Universitat Politècnica de València

I Jornadas IN-RED (2014) 


\title{
Automatización del seguimiento de alumnos en formación no presencial como apoyo a otras actividades docentes
}

\author{
Soriano J. ${ }^{\text {a }}$, Cabrera Jr. E. ${ }^{\text {, }}$, Cobacho R. ${ }^{\text {c }}$ y Arregui F.J. ${ }^{d}$ \\ ${ }^{a}$ ITA. Dep. Ingeniería Hidráulica y Medio Ambiente, Universitat Politècnica de València. \\ Jasool@ita.upv.es, ${ }^{\text {b}}$ ITA. Dep. Ingeniería Hidráulica y Medio Ambiente, Universitat Politècnica \\ de València. qcabrera@ita.upv.es, ' $I T A$. Dep. Ingeniería Hidráulica y Medio Ambiente, \\ Universitat Politècnica de València. rcobacho@ita.upv.es y ${ }^{\mathrm{d}}$ ITA. Dep. Ingeniería Hidráulica y \\ Medio Ambiente, Universitat Politècnica de València. farregui@ita.upv.es).
}

\begin{abstract}
Both online and mix learning (more commonly known as semi-attendance or blended learning) have experienced significant growth over the last decades, given the advantages they possess when compared with purely presential learning. For these modalities to be more efficient, a constant follow-up of the student's evolution must be performed, which is not a simple task when dealing with training activities which involve a large number of students that can be located in different continents. Under these circumstances, the automatization of the aforesaid follow-up can be an efficient solution which can also be implemented as a back-up tool for other tasks. The current paper describes the developed platform to automatize the student's follow-up in non-presential training. The design of adequate control laws bears a significant weight in this automatization. The document also portrays the reception by the students, educational implications and activity suggestions targeted to both to college students and active professionals.
\end{abstract}

Keywords: student monitoring, student assessment, e-learning 


\section{Resumen}

Tanto la formación online como la mixta (más conocida como semipresencial o blended learning), han mostrado un gran crecimiento en las últimas décadas, dadas las ventajas que presentan frente a la formación puramente presencial. Para que estas modalidades sean más eficientes es necesario mantener un seguimiento de la evolución del alumno, tarea nada insignificante en actividades formativas con un elevado número de alumnos, o emplazados en diferentes continentes. En estas circunstancias, la automatización del seguimiento es una alternativa eficiente que puede ser utilizada como apoyo de otras actividades. En el presente trabajo se describe la plataforma desarrollada para automatizar el seguimiento de los alumnos en formación no presencial. El diseño de unas adecuadas reglas de control tiene un peso significativo en esta automatización. Se presenta además la acogida por parte de los alumnos, las implicaciones docentes, y las recomendaciones en actividades dirigidas tanto de estudiantes universitarios como de profesionales en activo.

Palabras clave: Seguimiento alumnos, automatización, formación online 


\section{Introducción}

El uso de internet en tareas de formación y evaluación ha experimentado un rápido crecimiento en las últimas décadas, y la oferta de cursos y titulaciones en este formato no ha hecho más que aumentar. Así se evidencia al examinar la oferta formativa online de grandes instituciones de capacitación. Del mismo modo, la previsión de nuevos actividades formativas para los próximos años es más que evidente. Esto se debe a las considerables ventajas que presenta la formación online frente a la formación convencional o de aula. Algunos autores incluso han demostrado que estas actividades pueden llegar a ser tan eficientes como las actividades presenciales convencionales (Allen and Seaman, 2004; Oslon and Wisher, 2002).

Sin embargo, también son notables los inconvenientes que presenta esta modalidad elearning. Entre ellos, los más destacados son la pérdida del trato personal alumno-docente, o los retos a los que éste último se enfrenta con las nuevas condiciones de contorno. Algunos autores citan retos más significativos de esta modalidad formativa; como la necesidad de ofrecer contenidos de calidad, conocer la tecnología a emplear, estudiar los requerimientos particulares de los diferentes estudiantes, o incluso contar con un conocimiento mínimo de las técnicas pedagógicas recomendadas para esta formación (Harasim, 1990; Bonk, 2001, 2009).

Para facilitar el éxito de acciones formativas en formato no presencial, una tarea imprescindible es el correcto seguimiento de los alumnos. Esto ha resultado ser crítico por ejemplo para la formación de trabajadores en activo, quienes compaginan su trabajo con actividades de formación online (Cabrera et al., 2012). Sin embargo, el correcto desarrollo de estas tareas implica una significante carga de trabajo para el docente, no sólo en lo que respecta a la atención del alumno a la hora de atender a sus dudas, disponer de una visión conjunta de su progreso a lo largo de todo el curso no es inmediato.

En tareas de seguimiento de alumnos, especialmente en un entorno no presencial, una herramienta automática en la que se apoye el docente resulta ser muy recomendable. Esta herramienta debe ser entendida como un complemento dentro de las estrategias pedagógicas convencionales, tal como algunos autores han vinculado al concepto de active learning (Chickering and Gamson, 1987).

\section{Objetivos}

Generalmente el seguimiento de alumnos en formación no presencial se basa en una asistencia puntual, bien durante o después de un acto de evaluación, o atendiendo a las consultas que puntualmente realizan los alumnos. En el presente trabajo se muestra un

\section{(c) EY-NC-ND 2014, Universitat Politècnica de València}

I Jornadas IN-RED (2014): 
complemento a dicho seguimiento, especialmente en actividades de formación con carácter no presencial, a partir del desarrollo de una herramienta automática (capa lógica). Los objetivos planteados con el trabajo son:

- Presentar la herramienta de seguimiento automático.

- Mostrar las ventajas que aporta esta herramienta.

- Identificar los retos y dificultades en su implementación.

- Trasmitir las experiencias y resultados obtenidos.

\section{La herramienta automática de seguimiento. Capa lógica}

Como complemento a las tareas usuales de seguimiento de alumnos, se ha diseñado una aplicación que permite interaccionar con el alumno de forma automática, a partir del chequeo de condiciones previamente definidas, y las correspondientes respuestas en forma de mensajes personalizados.

La herramienta automática de seguimiento está formada por un editor de condiciones lógicas, que permite definir las diferentes reglas de control, y asociarlas a los diferentes cursos o grupos de alumnos. Todas estas reglas de control son almacenadas convenientemente en una base de datos.

Por otro lado, la capa lógica cuenta con un entorno de usuario, que permite la visualización de los mensajes que el alumno recibe de forma particularizada en tiempo real. A su vez, la herramienta está presente en el interfaz del usuario, de esta forma el alumno puede consultar su histórico de mensajes.

Finalmente, la herramienta cuenta con un gestor de la aplicación al que tienen acceso los tutores. Desde aquí se centralizan todos los mensajes que reciben los alumnos, y al mismo tiempo aporta una visión inmediata sobre el seguimiento de cada alumno.

\subsection{Las condiciones lógicas}

Las reglas de control o condiciones lógicas están formadas por un conjunto de cláusulas de condición y cláusulas de acción. Las clausulas de condición se activan o desactivan en función del progreso del alumno. Asimismo, estas cláusulas pueden anidarse con operadores lógicos para su combinación. La herramienta de seguimiento permite la definición de condiciones lógicas tal como muestra la Fig. 1.

Las cláusulas de condición se han agrupado en los siguientes grupos:

- Resultados de evaluación (por ejemplo notas en puntos de control o en test de las diferentes unidades). 
- Tiempos de dedicación (detecta reducidos tiempo en unidades del curso o por el contrario excesivos tiempos de permanencia).

- Tiempos de acceso (detecta lapsos de tiempo sin acceso al material).

- Posición relativa (posibilita la detección de dónde se encuentra el alumno, por ejemplo para la activación de contenidos o el envío de información al tutor).

- Acceso a caminos alternativos (detecta si el alumno accede a los diferentes materiales de aclaración distribuidos por el curso).

- Acceso a descargas (detecta si el alumno descarga material complementario).

- Otros cursos (permite conocer el progreso del alumno en otros cursos en los que ha estado matriculado).

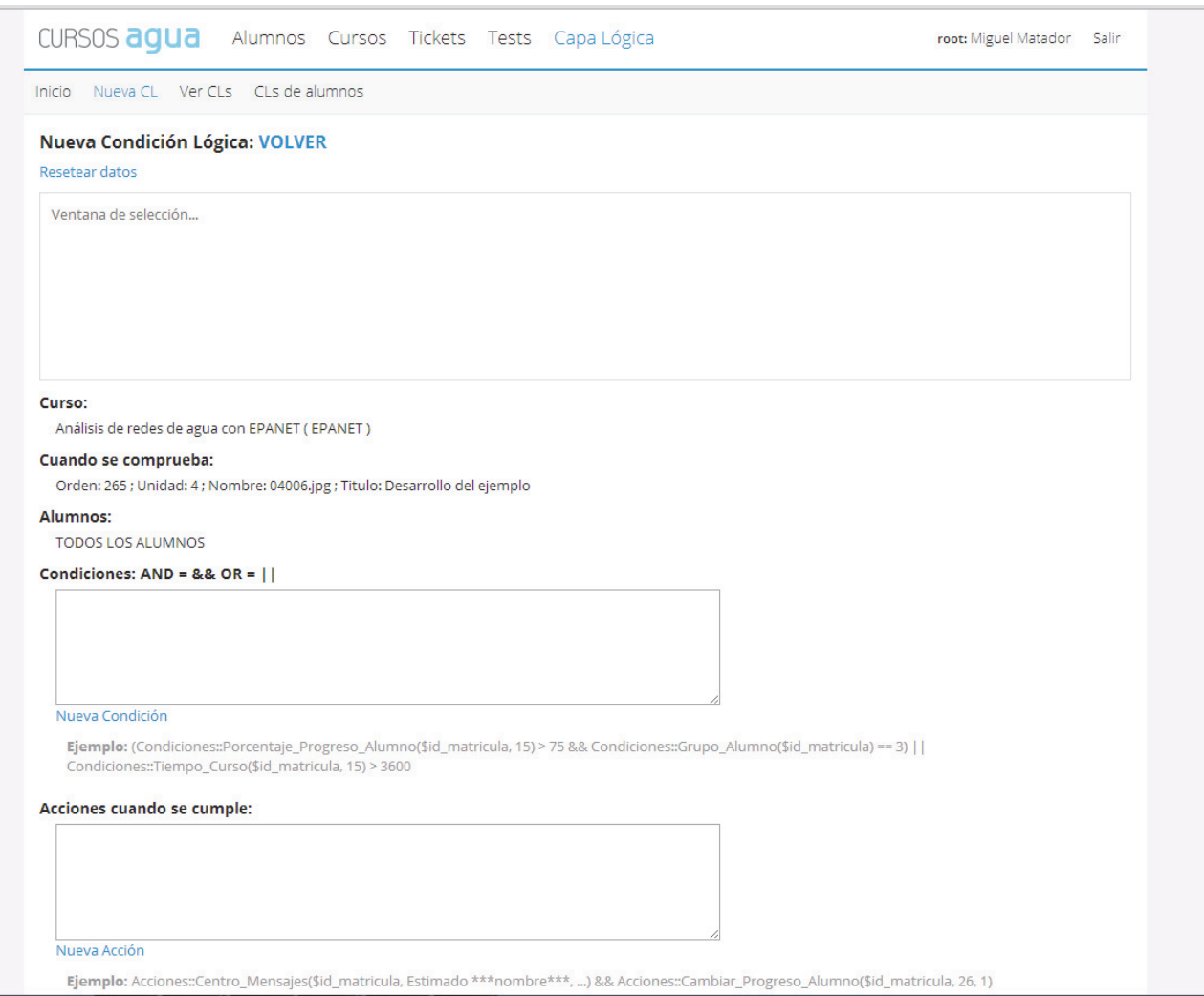

Fig. 1 Menú para la definición de capas lógicas.

Por otro lado, las reglas de control se completan con las correspondientes cláusulas de acción, las cuales se activan a través de las condiciones anteriormente comentadas. Actualmente, dichas cláusulas se han centrado en el envío de mensajes bien al tutor o al alumno, con recomendaciones o instrucciones concretas, con el propósito de influir en su progreso.

\section{(cc) EY-NC-ND 2014, Universitat Politècnica de València}

I Jornadas IN-RED (2014): 
Las condiciones lógicas deben estar diseñadas para cada curso o para cada plan formativo, ya que las condiciones generalmente son propias de cada acción formativa. Del mismo modo, también es conveniente poder considerar grupos de alumnos que compartan características comunes, por ejemplo la definición de un grupo de alumnos de una misma empresa puede permitir comparar su progreso o avisar de tareas programadas específicas.

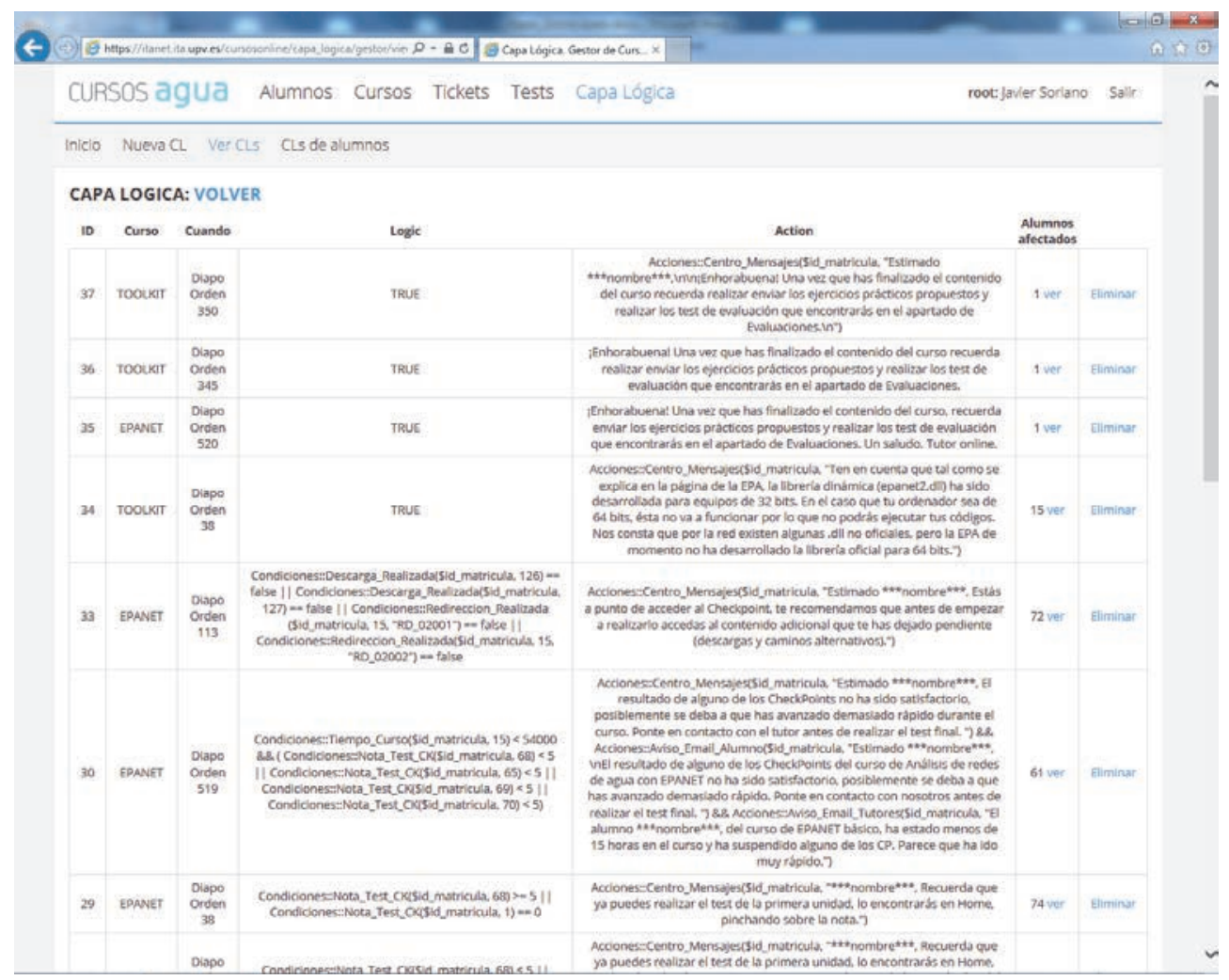

Fig. 2 Base de datos de la capa lógica.

\subsection{Entorno del usuario}

El alumno recibe mensajes instantáneos durante su progreso en el curso. Estos mensajes aparecen directamente superpuestos en las imágenes del curso (Fig. 3-a), y están relacionados con su evolución o resultados obtenidos en las pruebas de evaluación y control. Otros mensajes generales, por ejemplo los relacionados con fechas o avisos del tutor, le aparecen al alumno en el momento de iniciar el curso, o bien instantáneamente si se encuentra realizando el mismo.

(c)) EY-NC-ND 2014, Universitat Politècnica de València 
Por otro lado, la plataforma cuenta con un visor donde se centralizan todos los mensajes que ha recibido el alumno (Fig. 3-b). De esta forma el alumno puede en cualquier momento consultar mensajes antiguos o aquéllos que todavía tiene pendientes. Esta misma información la puede encontrar en la propia interfaz de la plataforma, a través de un indicador numérico situado sobre el propio icono del usuario (Fig. 3-c).

a)

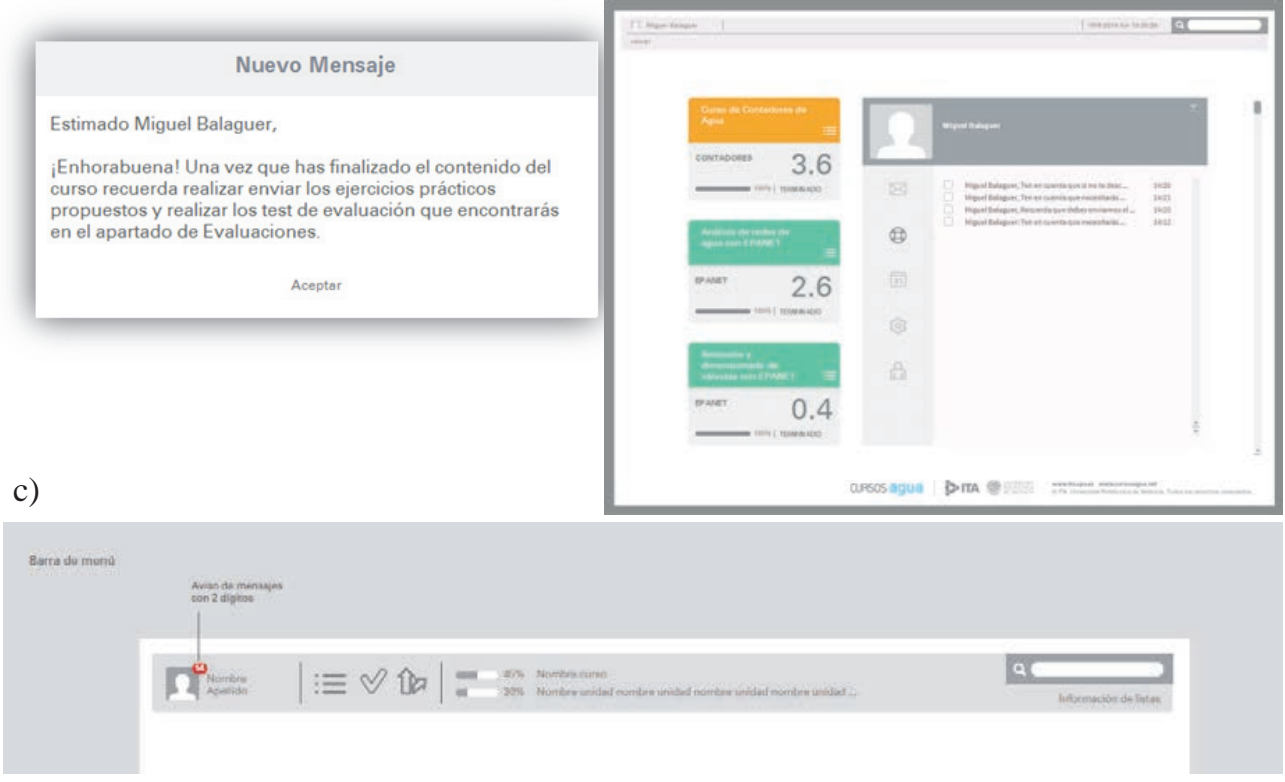

b)

Fig. 3 a) Ejemplo de mensaje enviado a un alumno. b) Visor de mensajes dentro del menú principal de la plataforma de cursos. c) Aviso de mensajes pendiente en la interfaz de la plataforma.

\subsection{Gestor de la aplicación}

El tutor en todo momento debe conocer los mensajes que ha recibido un alumno, ya que en caso contrario se pierde la eficiencia en su seguimiento. Las consultas puntuales que el alumno hace, muchas veces están aclaradas en el propio material del curso (bien en el material principal o en material de apoyo). En estos casos, una revisión previa de los mensajes por parte del tutor puede facilitar la redirección del alumno a un punto concreto del curso, o bien detectar la necesidad de modificar contenidos.

Para estos propósitos, la herramienta de seguimiento cuenta con un gestor de consultas asociadas a cada alumno (Fig. 4). Desde este gestor se pueden consultar los detalles de cada unas de las condiciones de control que le afectan al alumno, y al mismo tiempo posibilita analizar cómo le afecta al alumno en su progreso.

\section{(cc) EY-NC-ND 2014, Universitat Politècnica de València}

I Jornadas IN-RED (2014): 


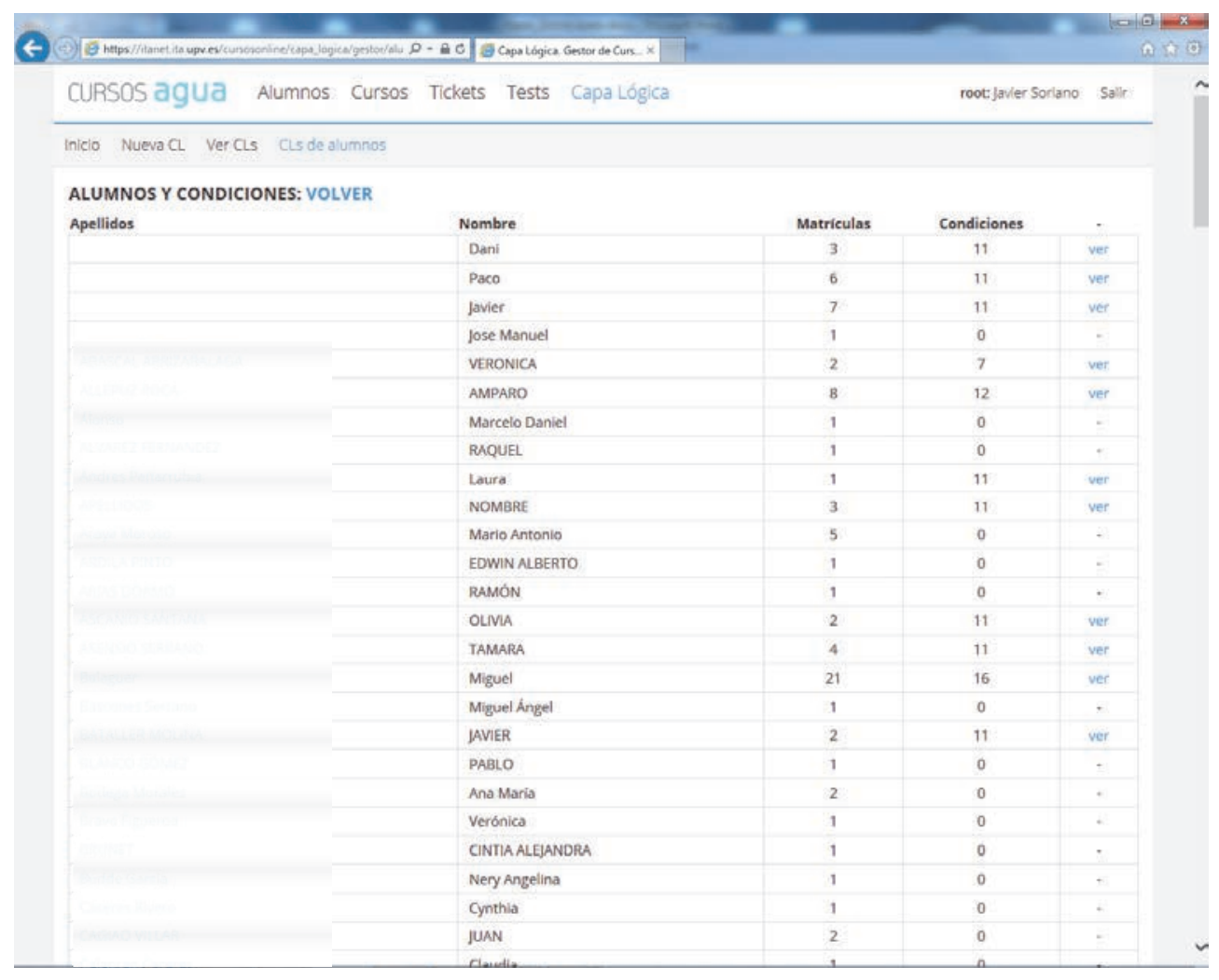

Fig. 4 Captura del gestor de mensajes por alumno.

\section{Experiencia en el curso online de EPANET}

La implementación de la herramienta automática de seguimiento se ha realizado sobre uno de los cursos online que oferta el grupo con mayor número de alumnos, "Análisis y diseño de redes de agua con EPANET". El principal objetivo de dicho curso es dotar al alumno de una destreza en el manejo del software de simulación hidráulica, para ello el alumno cuenta con descripciones teóricas junto con ejercicios guiados. El curso se imparte completamente online a través de una plataforma propietaria diseñada específicamente para estos cursos (Soriano et al. 2010; www.cursosagua.net). La dedicación media por alumno está en torno a las $60 \mathrm{~h}$.

En la edición en la que se realizó la prueba piloto, el curso contaba con aproximadamente 40 alumnos matriculados. El perfil de estos alumnos es mayoritariamente el de técnicos de empresas de agua en activo, que desarrollan dicha actividad formativa fuera de su horario normal de trabajo. Para el conjunto de alumnos se definieron unas reglas de control genéricas, particularizando algunas concretas para los alumnos de empresa. 


\subsection{Ventajas aportadas desde el punto de vista de la tutorización}

La capa lógica ha reducido de forma significativa el tiempo dedicado por los docentes en tareas básicas de tutorización, por ejemplo en la aclaración de conceptos ya explicados en el material del curso. Por ejemplo, el fallo en una pregunta de evaluación y la posterior sugerencia automática de contenidos relacionados, ha reducido el número de consultas. Con el seguimiento convencional, muchas veces los alumnos no resolvían sus dudas, o sólo consultaban al principio del curso, o se interesaban por dudas muy concretas.

La reducción de consultas básicas ha derivado en una asistencia de mayor nivel, pudiendo contar con una visión global de cada alumno. Al respecto, ha sido más sencillo detectar comportamientos irregulares durante la realización del curso.

El alumno no experimenta tanto contraste de horarios de tutorización. Esto destaca especialmente si alumno y tutor se encuentran en diferentes usos. El seguimiento exclusivo por email o telefónicamente, y los retrasos en la aclaración de consultas, muchas veces desencadenan en la interrupción del desarrollo de curso.

\subsection{Dificultades experimentadas}

La definición de todas las reglas de control no es inmediata, y precisa de una importante dedicación por parte del docente. Del mismo modo, se precisa un conocimiento detallado de los contenidos del curso, y en especial de aquellas zonas didácticamente más conflictivas (por la dificultad en su seguimiento o por la necesidad de unos conocimientos mínimos del alumno). Un historial de consultas de alumnos en ediciones anteriores facilita el conocimiento de estos puntos. Además, el esfuerzo inicial en la definición de las regla de control se diluye a medida que se realizan nuevas ediciones del curso, ya que gran parte de las reglas de control pueden ser heredadas.

También se ha detectado la pérdida de efectividad cuando el alumno experimenta un envío masivo de mensajes. Los primeros mensajes son valorados positivamente por el alumno, quien atiende a la sugerencia, pero cesa dicho interés si la carga es excesiva. Por tanto, un curso debe contar con un equilibrio entre las necesidades de tutorización automática y la propia asistencia del tutor.

Por otro lado, es difícil prestar atención de forma personalizada a un alumno, es decir la programación de reglas de control genéricas para un alumno tipo, difícilmente son extrapolables a la totalidad de alumnos. Por ello, es posible que las recomendaciones enviadas no apliquen (por ejemplo la recomendación de pasar por unos contenidos no siempre es necesaria, o un tiempo de dedicación reducido en una determinada zona no implica que el alumno no domine dichos contenidos). Las reglas de control por tanto deben ser cuidadosamente diseñadas, y en la medida de lo posible definidas para grupos que mantengan características comunes.

\section{(c) EY-NC-ND 2014, Universitat Politècnica de València}

I Jornadas IN-RED (2014): 


\subsection{Experiencia del alumno}

Los alumnos tutorizados han aceptado positivamente el uso de este tipo de seguimiento frente al seguimiento convencional, y como complemento a éste. Principalmente perciben una mayor cercanía y acompañamiento durante la realización del curso, como contrapartida al carácter impersonal inherente a la formación no presencial.

Los alumnos con tutorización han mostrado un mayor seguimiento del curso, con una dedicación más concentrada y con menos interrupciones. Aunque el tamaño de la muestra no era importante para obtener conclusiones al respecto, es posible que estas interrupciones temporales estén asociadas al tiempo de asistencia del tutor.

Por otro lado, la definición de reglas de control posibilita que el alumno detecte con mayor rapidez aquellos aspectos más importantes del curso, y con ello, que le preste más atención. También facilita la detección de sus debilidades.

Como se ha comentado, es importante llegar a un equilibrio entre el apoyo al alumno y la sobrecarga de mensajes. Una sobreasignación de reglas de control reduce la eficiencia del seguimiento, y puede conducir a que el alumno muestre quejas al respecto.

\section{Conclusiones}

La utilización de herramientas automáticas para el seguimiento de alumnos en formación no presencial presenta numerosas ventajas desde el punto de vista docente. En estos casos el alumno percibe un mayor acompañamiento durante el curso. Asimismo, el alumno detecta sus debilidades prácticamente en tiempo real, lo que le permite centrarse en resolver sus conflictos o dudas, sin necesidad muchas veces de consultar a los tutores. Esto se consigue redirigiendo al alumno automáticamente a una zona concreta del curso o sugiriéndole material complementario.

A su vez, la aclaración de consultas de forma autónoma por parte del alumno reduce el tiempo de asistencia del docente, por ejemplo en consultas correctamente aclaradas en el contenido del curso. Esto permite al docente atender dudas de mayor entidad, y dedicar más tiempo a analizar el progreso global del alumno consultando directamente su ficha personal.

Finalmente, se destaca que el diseño de las reglas de control no es inmediato, y deben definirse de forma particularizada para cada curso y grupo de alumnos. Esto requiere un tiempo de dedicación por parte del docente nada despreciable, pero que se reduce significativamente con el número de ediciones del curso. La experiencia de alumnos también puede ser muy útil a la hora de mejorar los contenidos o la asistencia en posteriores ediciones. 


\section{Referencias}

ALLEN E.I. y SEAMAN J. (2004). "Entering the Mainstream: The Quality and Extent of Online Education in the United States, 2003 and 2004". Needham, Mass.: The Sloan Consortium.

BONK C.J. (2001). "Online teaching in an online world. Bloomington", in: CourseShare.com. Retrieved January 1, 2002.

BONK, C.J. (2009). "The World is Open: How Web Technology is Revolutionizing Education". San Francisco, CA: Jossey-Bass, a Wiley imprint.

CABRERA JR. E., SORIANO J., COBACHO R. Y ARREGUI F.J. (2012). “Aspectos clave para un e-learning efectivo en la formación de profesionales. Jornadas de Innovación Educativa”, Universitat Politècnica de València. 12-13 julio 2012, Valencia. ISBN : 978-84-8363-926-9.

CHICKERING, A.W., AND GAMSON, Z.F. (1987). "Seven principles for good practice in undergraduate education”. AAHE Bulletin, Vol. 39, No 7, pp.: 3-7.

CURSOS AGUA - ITA UPV (2014). <http://www.cursosagua.net> [Consulta: 17 de junio de 2014]

HARASIM L. (ed.) (1990). “Online Education. Perspectives on a New Environment”. Praeger, New York.

OLSON T.M AND. WISHER R.A. (2002). "The Effectiveness of Web-Based Instruction: An Initial Inquiry”. International Review of Research in Openand Distance Learning, Vol. 3, No 2, pp.: 1-17.

SORIANO J., ARREGUI F.J., COBACHO R., CABRERA JR. E. (2010). "Plataforma online para la formación de profesionales". XVIII Jornadas Internacionales Universitarias de Tecnología Educativa, JUTE 2010. 9-10 septiembre 2010, Gandía (Valencia).

(cc) EY-NC-ND 2014, Universitat Politècnica de València

I Jornadas IN-RED (2014): 


\title{
Uso de la e-Rúbrica para la evaluación de competencias en el aprendizaje de Estadística
}

Elena Vázquez ${ }^{\mathrm{a}}$, Andrea Conchado y Rosa María Alcover $^{\mathrm{c}}$

${ }^{a}$ Dto. de Estadística e Investigación Operativa Aplicadas y Calidad (DEIOAC), Universitat Politècnica de València (UPV), evazquez@eio.upv.es ${ }^{\mathrm{b}}$ Dto. de Estadística e Investigación Operativa Aplicadas y Calidad, UPV, anconpei@eio.upv.es y ${ }^{\mathrm{c} D}$ to. De Estadística e Investigación Operativa Aplicadas y Calidad, UPV, ralcover@eio.upv.es.

\begin{abstract}
The aim of this paper is to design and validate a rubric for formative assessment of «Approach and solving statistical problems» competence in the subject «Statistics» imparted during the first year of the Degree in Computer Engineering. The methodology used for the research is based on the review of the this competence construct, and from such review the proposal of an initial 13-item grid, arranged in three dimensions: approach, implementation and results. Achievement levels for each item were measured using a sixpoint Likert scale. The rubric was implemented using the collaborative tool 'e-Rúbrica', which allowed to conduc a pilot test. The application of factor analysis techniques on the data obtained showed that the students' scores for the different items can be grouped together as it has been defined in the section, explaining up to $78.7 \%$ of the common variance.
\end{abstract}

Keywords: competences, formative assessment, validation, e-rubric, statistics

\footnotetext{
Resumen

El objetivo de este trabajo es diseñar y validar una rúbrica para la evaluación formativa de la competencia «Planteamiento y resolución de problemas estadísticos» en la asignatura «Estadística», impartida durante el primer curso del Grado en Ingeniería Informática. La metodología de trabajo se basó en la revisión del constructo de esta competencia y, a partir de dicha revisión, la propuesta de una parrilla inicial de 13 items, estructurada en tres dimensiones: planteamiento, ejecución y resultados. Los niveles de desempeño en cada ítem se midieron mediante una escala Likert
}

(c)) EY-NC-ND 2014, Universitat Politècnica de València

I Jornadas In-Red (2014) 
de seis puntos. La implementación de la rúbrica se realizó a través de la herramienta colaborativa «e-rúbrica», que permitió la realización de una prueba piloto. La aplicación de técnicas de análisis factorial a los datos obtenidos mostró que las puntuaciones de los alumnos a los distintos ítems pueden agruparse tal y como se ha definido en la rúbrica, explicando el $78.7 \%$ de la varianza común. Sin embargo, dos ítems relacionados con el rigor matemático y el orden en la presentación de resultados, mostraron menores comunalidades respecto a la escala de medición de la rúbrica, indicando menores contribuciones a la estructura factorial identificada y por tanto, menor capacidad discriminante respecto al resto de los ítems.

Palabras clave: competencias, evaluación formativa, validación, e-rúbrica, estadística

\section{Introducción}

La creciente demanda de formación sobre habilidades y actitudes en el ámbito laboral junto con los recientes desarrollos de los sistemas de gestión de la calidad en la Educación Superior que emerge del preoceso de convergencia al Espacio Europeo de Educación Superior (EEES) han convertido el estudio por competencias en la piedra angular del diseño curricular de las materias que constituyen las nuevas titulaciones de Grado y Máster y de los sistemas de evaluación interna de la propia universidad (Conchado, 2011; Conchado et al. 2012). Esta recientemente incorporada formación por competencias supone la introducción de un nuevo modelo formativo que se sustenta, en primer lugar, en las teorías cognoscitivas, pues se ocupa de la manera en la que el aprendiz adquiere y aplica los conocimientos y las habilidades, y en segundo lugar en las teorías constructivistas del aprendizaje, al enfatizar la enseñanza centrada en el estudiante, y la relación de nuevos conocimientos con los ya adquiridos (Lasnier, 2000).

Partiendo de este escenario formativo, Fernández (2010) propone que el triángulo básico sobre el que se debería asentar el proceso de evaluación de las competencias debe basarse en la realización de tareas complejas o situaciones problemas, donde el estudiante movilice y combine ciertos recursos adecuadamente para poder responder con autonomía. Estas tareas deben presentarse con un nivel de complejidad escalonada y utilizando instrumentos de evaluación adecuados. Estas situaciones problema se definen análogamente a la metodología de aprendizaje basado en problemas (en adelante ABP) donde se parte de una situación problema, que el profesor presenta a los alumnos, a partir de la cual identifican sus necesidades de aprendizaje y recogen información para complementar sus conocimientos y habilidades previos, para finalmente ser resuelta por los estudiantes y presentada y discutida ante el profesor y el resto de estudiantes (De Miguel, 2005). 
Por otro lado, la enseñanza de la estadística supone un reto adicional para los profesores en esta materia, debido no sólo a la complejidad inherente de los principios de esta materia, sino porque debe adaptarse a las necesidades y contextos de cada área de conocimiento donde se aplica. Aunque tradicionalmente, la enseñanza de la estadística se ha basado en la transmisión de conceptos y conocimientos abstractos, frecuentemente poco alejados de la realidad, ya en 1987 Schoenfeld indica que la instrucción matemática debe incorporar estrategias para que el estudiante aprenda a leer, a conceptualizar y a escribir argumentos matemáticos, y plantea el uso del ABP preentándola como una metodología docente apropiada y adecuada a las necesidades formativas de los alumnos en esta materia. Específicamente, Schoenfeld enfatiza en que el estudiante debe reflexionar constantemente acerca de los aspectos relacionados con el problema en cada fase de la resolución: análisis, exploración y verificación de la solución. Dicha concepción de la competencia de resolución de problemas estadísticos propuesta por Schoenfeld se ha tomado como referencia en la delimitación conceptual del constructo a evaluar en este trabajo.

De hecho, se considera que uno de los principales objetivos de la formación en estadística es la adquisición de competencias de resolución de problemas y habilidades de análisis de datos (Moore, 1990). Para ello, es necesario que los profesores de estadística sepan crear entornos de aprendizaje donde los estudiantes se sientan cómodos para explorar distintas estrategias de solución, así como para seleccionar y descartar aquellas que no sean adecuadas. En los casos en que los estudiantes se sienten especialmente motivados a profundizar en determinadas cuestiones, esto es, que no tienen simplemente una solución correcta o incorrecta, y que además les motiva a aplicar y experimentar con distintas técnicas estadísticas, el enfoque de estas clases podrá considerarse constructivista, donde el profesor actúa simplemente como facilitador del aprendizaje del alumno (Mvududu, 2005). Posteriormente, otras investigaciones apuntaron a la necesidad de desarrollar estrategias de aprendizaje alternativas con el fin de mejorar el impacto de la enseñanza de la estadística en los estudiantes (Chance, 1997; Cobb, 1993; Garfield, 1994; Hubbard, 1997). Si bien no parece haber ningún elemento en común a dichas metodologías, lo cierto es que todas ellas incluyen cierto enfoque constructivista, aunque no se haya indicado explícitamente (Mvududu, 2005), como el desarrollo de comunidades de aprendizaje para aprendizaje colaborativo, un mayor enfoque del aprendizaje hacia el estudiante y el empleo combinado de distintos instrumentos de evaluación para cada resultado del aprendizaje. En cualquier caso, muchos profesores que imparten clases en estadística hoy en día, se plantean utilizar métodos de enseñanza - aprendizaje alternativos con el fin de crear estos entornos de aprendizaje constructivistas, que resultan muy distintos a los que se empleaban cuando ellos estudiaban (Garfield y Ben-Zvi, 2007).

Sin embargo, como expone Savin - Baden (2004) la evaluación de la eficacia del ABP es uno de los aspectos más controvertidos de esta metodología, debido a la combinación de resultados de aprendizaje que habitualmente los alumnos adquieren mediante esta herramienta docente. Nendaz y Tekian (1999) ya señalaron anteriormente la imposibilidad

\section{(c)) EY-NC-ND 2014, Universitat Politècnica de València}


de utilizar los sistemas de evaluación tradicionales para medir los resultados obtenidos mediante esta metodología por falta de alineación curricular entre metodologías docentes e instrumentos evaluativos. Swanson et al. (1998) aportaron una clasificación de los instrumentos de evaluación disponibles entonces para medir el grado de adquisición de competencias de resolución de problemas: desde exámenes tipo test, exámenes de respuesta abierta con mayor o menor grado de estructuración, exámenes orales, estudio de casos y por supuesto resolución de problemas de análisis. No obstante, unos años más tarde Gijbels et al. (2005) señalaron que la elección de uno u otro método podían condicionar el efecto aparente del ABP sobre el aprendizaje de los alumnos, en función del enfoque de evaluación de cada instrumento. Así, se confirmaba el patrón observado en estudios anteriores, según el cual los alumnos que estudiaron con metodologías tradicionales tendían a obtener mejores puntuaciones cuando el instrumento se centraba en la comprensión y relación de conocimientos y conceptos. Por el contrario, los alumnos que estudiaron a través de $\mathrm{ABP}$ obtuvieron mejores puntuaciones con aquellos instrumentos orientados a la aplicación de conocimientos en la práctica y razonamiento abstracto.

Desde entonces, se han propuesto muy diversos instrumentos utilizados en la denominada evaluación del desempeño, adecuados para evaluar resultados de aprendizaje complejos. Sin embargo, la rúbrica es el instrumento que mayor versatilidad y su potencialidad didáctica ha mostrado, como un instrumento capaz de contribuir significativamente a la mejora de los proceso de enseñanza - aprendizaje en su conjunto. En este sentido, la rúbrica se define como puntuaciones usadas en la evaluación del desempeño de los estudiantes que describen las características específicas de un producto, proyecto o tarea en varios niveles de rendimiento, con el fin de clarificar lo que se espera del trabajo del alumno, de valorar su ejecución y de facilitar la proporción de feedback (Andrade, 2005; Blanco, 2008). Concretamente, para la metodología del ABP, Villa y Poblete (2011) proponen, a partir de las aportaciones de Poblete (2008) y Mac-Donald, Boud, Francis y Gonczi (2000) la utilización de instrumentos de evaluación basados en informes con la solución de la situación problemática. En este contexto las rúbricas constituyen una ayuda tanto al profesor como al estudiante, favoreciendo hablar un lenguaje común, al traducir un concepto abstracto como es el número a matices de desempeño y comportamiento (Villa y Poblete, 2011).

\section{Objetivos}

El objetivo de este trabajo es diseñar y validar una e-rúbrica para la evaluación de la competencia «Planteamiento y resolución de problemas estadísticos». Esta rúbrica se propone como un instrumento para la evaluación formativa de competencias en la asignatura «Estadística», impartida durante el primer curso del Grado en Ingeniería Informática (GII) de la Universitat Politècnica de València (UPV). Para ello se utilizará la 
herramienta colaborativa para la generación de rúbricas «e-Rúbrica», federada por el grupo de investigación GTEA de la Universidad de Málaga. Asimismo, se analizará cuantitativamente el impacto de su utilización, así como su alcance y limitaciones desde un punto de vista pedagógico. De este modo, se pretende aportar un nuevo instrumento para la evaluación formativa en el ámbito específico de la estadística, que hasta el momento no ha sido desarrollado en investigaciones anteriores.

\section{Desarrollo de la innovación}

Siguiendo el consejo de Marín-García (2012), el proceso de elaboración y validación de la e-rúbrica se estructura en cuatro fases siguiendo la metodología Instrument Development and Construct Validation (IDCV) (Onwuegbuzie et al., 2010) que se estructura en las siguientes fases: justificación del estudio, delimitación conceptual del constructo a evaluar, construcción y evaluación cualitativa de ítems, análisis estadístico de los ítems, estudio de la dimensionalidad del instrumento. Asimismo, se han considerado las directrices propuestas por Mertler (2005) para el diseño y desarrollo de rúbricas, que guardan un alto nivel de paralelismo con la anterior metodología, pues recomienda en primer lugar que se considere el contexto y la concepción general del trabajo o tarea, para describir a continuación los atributos del desempeño óptimo y agruparlos en torno a dimensiones o componentes del trabajo o tarea. Seguidamente es necesario diseñar la escala para valorar el nivel de desempeño en cada categoría-dimensión y completar los descriptores de cada nivel. Por último, se sugiere seleccionar muestras de trabajo que ilustren cada uno de los niveles de desempeño con el fin de someter el instrumento a revisión por parte de alumnos y colegas. Finalmente, se han considerado en la medida de lo posible, las normas para el desarrollo de estudios instrumentales propuestas por Carretero-Dios (2005). Estas fases de la metodología Instrument Development and Construct Validation (IDCV) (Fig. 1) se detallan a lo largo de los siguientes epígrafes del trabajo.

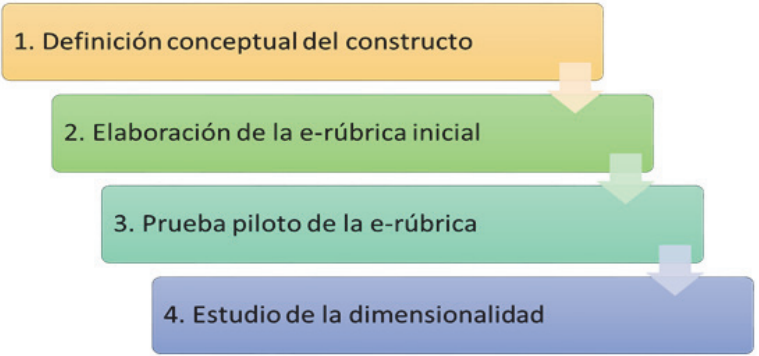

Fig. 1 Fases elaboración y validación de la e-rúbrica

\subsection{Definición conceptual del constructo}

Las competencias son características no observables directamente, por lo que deben cuantificarse a partir de evidencias recogidas empíricamente, por tanto, partiremos de la

\section{(c)) EY-NC-ND 2014, Universitat Politècnica de València}

I Jornadas IN-RED (2014) 
hipótesis de que la competencia a evaluar «Planteamiento y resolución de problemas estadísticos» (en adelante PRPE) puede considerarse un constructo.

El objeto de esta fase consiste en llevar a cabo la delimitación conceptual de dicho constructo. Con esa finalidad nos hemos basado en las fases propuestas por Schoenfeld (1987) «Análisis, Exploración y Verificación de la Solución» y por Mario de Miguel (2005), de acuerdo con el método de enseñanza «Aprendizaje Basado en Problemas» (ABP).

La definición conceptual de la competencia «Planteamiento y resolución de problemas estadísticos» que se propone en este trabajo contempla un constructo con una estructura factorial subyacente de tres dimensiones: Planteamiento (PLANT), Ejecución (EJEC) y Resultados (RESUL). El modelo conceptual que hipotetiza el constructo «Planteamiento y resolución de problemas estadísticos» se muestra en la Fig. 2.

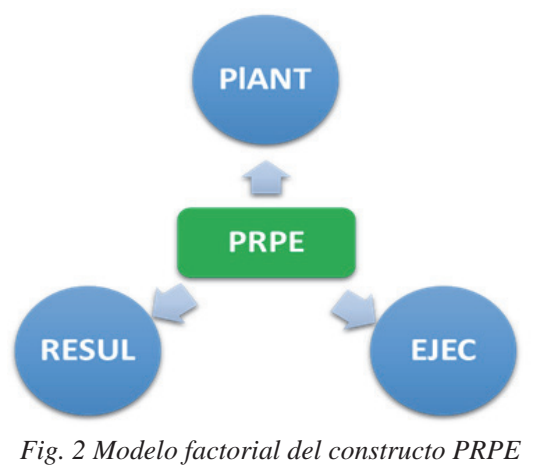

\subsection{Elaboración de la rúbrica inicial}

Una vez delimitada la definición conceptual del constructo, en este apartado se aborda la construcción y evaluación cualitativa de los ítems que formarán parte del instrumento que permitirá recoger las evidencias del proceso de evaluación formativa. Estos ítems se agruparon de acuerdo a las tres dimensiones definidas para el constructo PRPE y constituyen la parrilla inical de la rúbrica. En primer lugar se ha efectuado una revisión de los niveles competenciales y resultados del aprendizaje definidos en la guía docente de la asignatura, de acuerdo a la Taxonomía de Bloom (1956). Esta revisión se ha centrado en las competencias básicas del título de GII: «Capacidad para la resolución de problemas matemáticos» $\mathrm{y}$ «Aptitud para aplicar los conocimientos», específicamente los relativos al área de la estadística y más concretamente en la competencia relacionada con la resolución de problemas de distribuciones de probabilidad, tanto continuas como discretas.

Los ítems de la parrilla inicial, así como la escala y criterios de valoración de éstos se definieron partiendo de entrevistas en profundidad con seis profesores del área de la 
Estadística, aportaciones recibidas a través de la plataforma web «e-Rúbrica» (GTEA, 2014), y el documento de definición de las trece dimensiones competenciales de la UPV (Vicerrectorado de Estudios y Convergencia Europea 2012). Esta lista detallada fue revisada y depurada por tres profesores de Estadística de forma cualitativa. En base a los comentarios de los profesores, se redujo de 20 a 14 ítems agrupados en las tres dimensiones competenciales propuestas. Asimismo, se propusieron los siguientes criterios de evaluación, medidos en base a una escala Likert de seis puntos, que se muestran en la Tabla 1:

Tabla 1. Criterios de evaluación de la rúbrica

\begin{tabular}{lr}
\hline Criterio & Valoración \\
\hline $1=$ No Competente & $0 \%$ \\
$2=$ Insuficiente & $20 \%$ \\
$3=$ Mejorable & $40 \%$ \\
$4=$ Competente & $60 \%$ \\
$5=$ Altamente competente & $80 \%$ \\
$6=$ Excelente & $100 \%$ \\
\hline
\end{tabular}

En la Tabla 2 se muestra la parrilla inicial propuesta para la rúbrica obtenida a partir de los resultados del apartado anterior detallando los ítems, su contribución en la calificación de la dimensión asociada (peso en \%), la dimensión asociada correspondiente y la contribución de ésta al constructo PRPR (peso en \%).

Tabla 2. Parrilla inicial de items de la rúbrica

\begin{tabular}{|c|c|c|c|c|}
\hline Item & Descripción & $\begin{array}{c}\text { Peso } \\
\%\end{array}$ & Dimensión & $\begin{array}{c}\text { Peso } \\
\%\end{array}$ \\
\hline 1 & $\begin{array}{l}\text { Identificar las variables aleatorias que aparecen implícita } \\
\text { o explícitamente }\end{array}$ & $20 \%$ & \multirow{5}{*}{ PLANT } & \multirow{5}{*}{$33,3 \%$} \\
\hline 2 & $\begin{array}{l}\text { Generalizar el comportamiento de cada variable aleatoria } \\
\text { mediante distribuciones de probabilidad }\end{array}$ & $20 \%$ & & \\
\hline 3 & $\begin{array}{l}\text { Identificar los parámetros poblacionales de la distribución } \\
\text { de probabilidad }\end{array}$ & $20 \%$ & & \\
\hline 4 & Razonar abstractamente & $20 \%$ & & \\
\hline 5 & $\begin{array}{l}\text { Formular la combinación lineal de distintas distribuciones } \\
\text { de probabilidad }\end{array}$ & $20 \%$ & & \\
\hline 6 & Aplicar la terminología estadística & $20 \%$ & \multirow{5}{*}{ EJEC } & \multirow{5}{*}{$33,3 \%$} \\
\hline 7 & Calcular los parámetros poblacionales de combinaciones & $20 \%$ & & \\
\hline 8 & $\begin{array}{l}\text { lineales de distribuciones de probabilidad } \\
\text { Demostrar rigor matemático }\end{array}$ & $20 \%$ & & \\
\hline 9 & Razonar abstractamente & $20 \%$ & & \\
\hline 10 & Seleccionar estrategias efectivas & $20 \%$ & & \\
\hline 11 & Presentar resultados de forma ordenada y organizada & $25 \%$ & RESUL & $33,3 \%$ \\
\hline
\end{tabular}

(cc) EY-NC-ND 2014, Universitat Politècnica de València

I Jornadas IN-RED (2014) 
Uso de la e-Rúbrica para la evaluación de competencias en el aprendizaje de Estadística

12 Redactar conclusiones extraídas utilizando terminología $\quad 25 \%$ estadística

13 Interpretar resultados $25 \%$

14 Evaluar críticamente resultados $25 \%$

Como se desprende de Tabla 2 cada criterio de evaluación tiene el mismo peso para cada dimensión del constructo PRPE y cada dimensión se valora por igual también.

\subsection{Prueba de la e-rúbrica y análisis estadístico de los items}

\subsubsection{Prueba piloto de la parrilla}

Con el fin de validar y revisar la parrilla inicial se diseñó y llevó a cabo la prueba piloto que se describe seguidamente. En primer lugar se diseñaron dos actividades de enseñanza aprendizaje, basadas en la resolución de un problema sobre distribuciones de probabilidad para variables aleatorias continuas y discretas, respectivamente.

La parrilla inicial se implementó utilizando la plataforma colaborativa «e-Rúbrica», a la que se puede acceder para ver la implementación específica de la rúbrica mediante el enlace https://gteavirtual.org/rubric/?mod=rubric\&scr=register\&irb=3663 (Fig. 2).

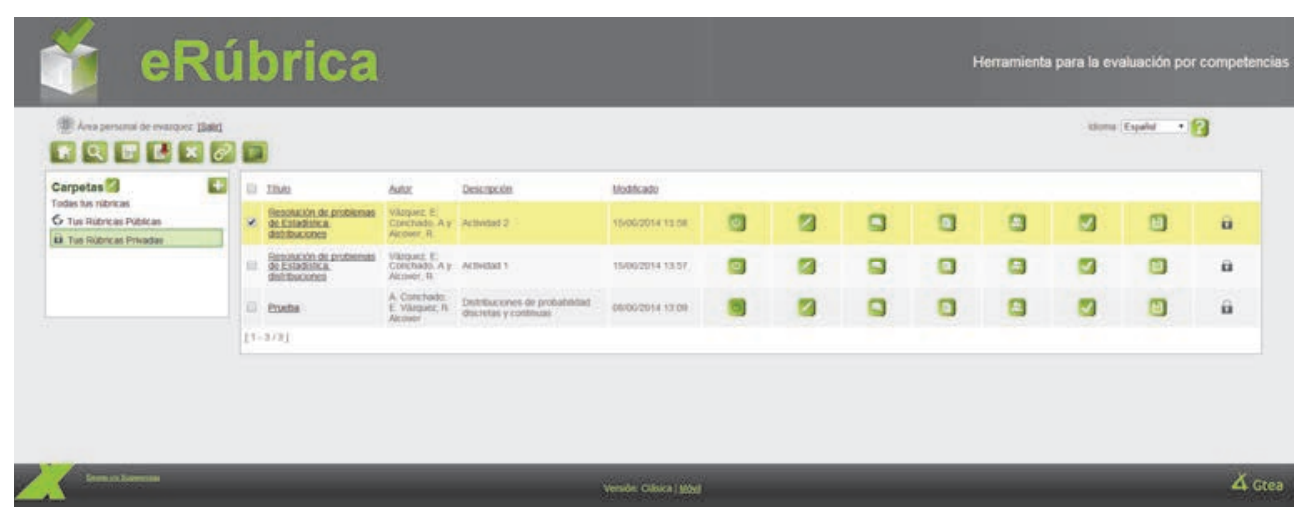

Fig. 2 Acceso a la e-rúbrica

Esta plataforma constituye una herramienta de gran utilidad, pues permite la interoperatividad con distintos entornos y sistemas tecnológicos de las universidades españolas mediante el sistema SIR de RedIris. Para facilitar el acceso y uso de la plataforma a los evaluadores y alumnos evaluados a través de la e-rúbrica se elaboró adicionalmente un pequeño manual de usuario sobre el modo de registrase, acceder y utilizar dicha plataforma para la evalución formativa. 
Después de dar a conocer con detalle las instrucciones necesarias, se obtuvo una muestra aleatoria compuesta por nueve alumnos, de entre los diferentes grupos de 1er curso del GII en la asignatura de Estadística, incluyendo alumnos matriculados en distintos idiomas y turnos de asistencia. La actividad que debían realizar estos alumnos era el planteamiento, ejecución y redacción de resultados en las dos actividades de enseñanza - aprendizaje propuestas por los profesores. No obstante, el experimento se diseño completamente al azar tratando de evitar la posible influencia de factores no controlables, tales como las diferencias en el profesorado o el nivel de los alumnos, que pueden introducir sesgos en los resultados. Finalmente, cada uno de los nueve alumnos fueron evaluados on-line de forma anónima por dos profesores diferentes utilizando la parrilla inicial mediante la herramienta «e-Rúbrica» generando de esta forma 36 evaluaciones. En la Fig. 3 se muestra una vista parcial de los resultados tal y como los ven los evaluadores.

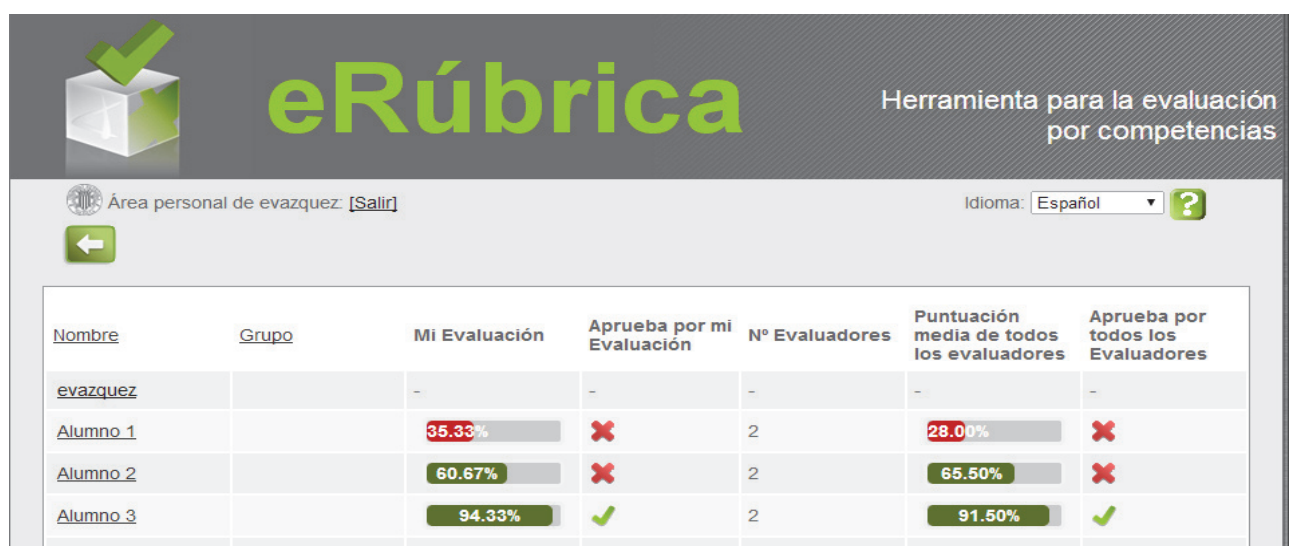

Fig. 3 Vista parcial de los resultados de la evaluación. Rol evaluador

\subsubsection{Análisis estadístico de los items}

En esta fase, al objeto de validar el instrumento de medición para el constructo PRPE y confirmar si la estructura interna de los ítems analizados se puede asimilar al modelo teórico propuesto, se efectúa el estudio de la dimensionalidad de los ítems. Para ello, se analizaron las calificaciones obtenidas en la prueba piloto mediante técnicas de reducción de la dimensión para identificar posibles solapamientos y redundancias entre ítems, así como agrupaciones consistentes con la literatura previa.

En este sentido, el recurso a técnicas estadísticas de análisis multivariante como Análisis Factorial (AF) se hace indispensable debido al tipo de resultados de aprendizaje complejos que habitualmente se pretenden evaluar mediante rúbricas. Es importante señalar que, aunque el AF no descubre constructos sino que revela su presencia o ausencia, si el fundamento teórico y la elección de las variables que intervienen en el análisis son

\section{(c)) EY-NC-ND 2014, Universitat Politècnica de València}

I Jornadas IN-RED (2014) 
adecuados, puede usarse con fines de validación, aunque no tenga la misma potencia probatoria que tiene los modelos causales como las ecuaciones estructurales (Tourón, 1989).

Con el fin de detectar datos anómalos y/o el incumplimiento de alguna de las hipótesis que deben asumir los datos analizados para que los resultados del AF sean válidos, se realizó de forma previa un estudio exploratorio de los datos. Este análisis preliminar confirmó el cumplimiento de las hipótesis estadísticas básicas para la aplicación de técnicas multivariantes. En consecuencia, se aplicaron dichas técnicas de AF utilizando la técnica de Análisis de Componentes Principales (ACP) como método de extracción de los factores o dimensiones subyacentes. La pertinencia de la aplicación de esta técnica a los datos analizados se comprobó mediante el Índice K-M-O de adecuación muestral (KMO=0,733) y el test de esfericidad de Bartlett. El Índice K-M-O resultó ser superior a 0,7 y la Prueba de esfericidad de Bartlett fue no significativa $\left(\chi^{2}=440,2 ; p\right.$-valor $\left.<0,001\right)$ lo que indica una buena adecuación muestral para que el AF pueda conducir a resultados válidos. Por último, con el fin de mejorar la interpretabilidad de los factores extraídos se aplicó el método de rotación Oblimin Directo. Dado que un alumno que es competente en la dimensión de ejecución de un problema es probable que también lo sea en la dimensión del planteamiento, pero no viceversa, conideramos que entre los factores puede haber cierto grado de relación y que, por tanto, no son ortogonales. Es por ello que se ha elgido una técnica de rotación oblícua. Todos los análisis estadísticos se ejecutaron mediante el paquete SPSS (versión 16).

\section{Resultados}

Los resultados del AF revelaron una estructura factorial subyacente de tres factores o dimensiones, de acuerdo al criterio de Kaiser (autovalores > 1), tal y como se había hipotetizado en el modelo conceptual del constructo PRPE. Estos tres factores son capaces, por sí mismos, de explicar un $78,7 \%$ de la varianza común observada en los datos sin pérdida significativa de información. Por tanto, el modelo teórico del constructo PRPE basado en tres dimensiones competenciales se reproduce con bastante claridad (Tabla 3).

Tabla 3. Resultados del análisis factorial

\begin{tabular}{ccc}
\hline $\begin{array}{c}\text { Dimensiones del } \\
\text { constructo }\end{array}$ & Nombre & Items de la parrilla \\
\hline 1 & Planteamiento & $1,2,3,4$ y 5 \\
2 & Ejecución & $6,7,9$ y 10 \\
3 & Resultados & $11,12,13$ y 14 \\
\hline
\end{tabular}

Con la excepción de los ítems 8 y 11, todos los demás ítems cargan en la dimensión propuesta por el modelo en mayor grado que en cualquier otra obtenidas (Tabla 4). La 
mayor parte de los pesos factoriales son mayores de 0,87 , no habiendo ninguno menor de 0,30 . Asimismo, para la inmensa mayoría de los ítems, las cargas factoriales de éstos asociados a los factores que no les corresponden según el modelo hipotetizado son todas menores de 0,2. En cuanto a los ítems con menor contribución a la estructura factorial, el ítem 8 ("Demostrar rigor matemático") presenta cargas factoriales inferiores al umbral recomendado de 0,3 por Hair, Anderson, Tatham y Black (2007) así como un valor de comunalidad $(0,161)$ inferior a 0,3 . Del mismo modo, el ítem 11 ("Presentar resultados de forma ordenada y organizada") no supera los límites inferiores recomendados en cuanto a comunalidad $(0,571)$ al tiempo que las cargas factoriales alcanzan magnitudes similares en los factores 1 y 2 (Planteamiento y Ejecución). En el resto de los ítems, la contribución de cada uno a su factor asociado, resultó muy alta, con comunalidades cuyos valores están comprendidos entre 0,8 y 0,9 en todos los casos, lo cual permite realcionar claramente cada ítem con una única dimensión o factor asociado.

Tabla 4. Matriz de cargas de los factores rotados

\begin{tabular}{|c|c|c|c|c|}
\hline \multirow[t]{2}{*}{ Iten } & \multirow{2}{*}{ Descripción } & \multicolumn{3}{|c|}{ Factor } \\
\hline & & 1 & 2 & 3 \\
\hline 1 & $\begin{array}{l}\text { Identificar las variables aleatorias que aparecen implícita o } \\
\text { explícitamente }\end{array}$ & 0,97 & & \\
\hline 2 & $\begin{array}{l}\text { Generalizar el comportamiento de cada variable aleatoria } \\
\text { mediante distribuciones de probabilidad }\end{array}$ & 0,91 & & \\
\hline 3 & $\begin{array}{l}\text { Identificar los parámetros poblacionales de la distribución de } \\
\text { probabilidad }\end{array}$ & 0,83 & & \\
\hline 4 & Razonar abstractamente & 0,69 & & \\
\hline 5 & $\begin{array}{l}\text { Formular la combinación lineal de distintas distribuciones de } \\
\text { probabilidad }\end{array}$ & 0,88 & & \\
\hline 6 & Aplicar la terminología estadística & & $-0,89$ & \\
\hline 7 & $\begin{array}{l}\text { Calcular los parámetros poblacionales de combinaciones } \\
\text { lineales de distribuciones de probabilidad }\end{array}$ & & $-0,90$ & \\
\hline 8 & Demostrar rigor matemático & & & \\
\hline 9 & Razonar abstractamente & & $-0,90$ & \\
\hline 10 & Seleccionar estrategias efectivas & & $-0,93$ & \\
\hline 11 & Presentar resultados de forma ordenada y organizada & & 0,46 & 0,62 \\
\hline 12 & $\begin{array}{l}\text { Redactar conclusiones extraídas utilizando terminología } \\
\text { estadística }\end{array}$ & & & 0,93 \\
\hline 13 & Interpretar resultados & & & 0,88 \\
\hline 14 & Evaluar críticamente resultados & & & 0,88 \\
\hline
\end{tabular}

\section{Conclusiones}

La principal innovación docente del presente trabajo es la aportación de un instrumento de evaluación basado en el esquema de la rúbrica, diseñado específicamente para la evaluación formativa de un modelo conceptual de la competencia «Planteamiento y resolución de problemas estadísticos» para la materia de Estadística en el Grado de Ingeniería Informática

\section{(cc) EY-NC-ND 2014, Universitat Politècnica de València}

I Jornadas IN-RED (2014) 
de la Universitat Politècnica de València a partir de tres dimensiones competenciales (Planteamiento, Ejecución y Resultados)

Se ha construido un instrumento inicial para dicha competencia mediante el diseño de una rúbrica elaborada a partir de las aportaciones de expertos en la materia y de investigaciones anteriores y usando una herramienta virtual colaborativa federada (e-Rúbrica). Dicha rúbrica inicial se ha evaluado y validado mediante la realización de una prueba piloto y el análisis estadístico de los resultados obtenidos.

Los resultados del análisis estadístico ponen de manifiesto, con bastante claridad, la consistencia de las dimensiones hipotetizadas y, por tanto, la concordancia con las dimensiones iniciales propuestas del modelo conceptual planteado. Cabe destacar el caso concreto de los ítems relativos al rigor matemático y el orden en la presentación de resultados que, como cabía esperar, han mostrado menor capacidad discriminante entre las dimensiones propuestas. Retomando la concepción de la competencia de resolución de problemas estadísticos propuesta por Schoenfeld (1987), basada fundamentalmente en la incorporación de estrategias para que el estudiante aprenda a leer, a conceptualizar y a escribir argumentos matemáticos, se evidencia que ambas habilidades no parecen ser determinantes para la adquisición de la competencia PRPE. En el desarrollo de la parrilla definitiva de ítems, cabría plantearse si el comportamiento de un alumno competente en resolución de problemas estadísticos debe demostrar necesariamente rigor matemático, considerándolo como un ítem más, o por el contrario, éste aparece ya incluido en el resto de ítems. En cuanto al ítem referente al orden en la presentación de resultados, también habría que planterase si se mantiene en la pariilla o si su contribución queda parcialmente enmascarada con el resto de los ítems de la dimensión Resultados.

Como principal limitación del estudio, es necesario señalar que el tamaño de la muestra, así como la población concreta de la que ha sido extraída, no permite la extrapolación de las conclusiones de este estudio a otros ámbitos académicos. En cualquier caso, las conclusiones extraídas de estos análisis, permitieron obtener una parrilla depurada y revisada de ítems, que será susceptible de mejora en futuras investigaciones, en base a estudios cualitativos y estimaciones de validez y fiabilidad.

\section{Referencias}

ANDRADE, H. (2011). “Teaching with rubrics” en College Teaching, 53 (1) 27-30.

BLANCO, A. (2008). "Las rúbricas un instrumento útil en la evaluación de competencias" en Prieto, L. (Coord.), Blanco, A., Morales, P. y Torre, J.C. La enseñanza universitaria centrada en el aprendizaje: estrategias útiles para el profesorado. Barcelona: Octaedro-ICE de la Universidad de Barcelona. 
Vázquez, E., Conchado, A. y Alcover, $R$.

BLOOM, B.S. (1956). Taxonomy of Educational Objectives: The Classification of Educational Goals. Handbook I: Cognitive Domain. New York: McKay.

CARRETERO-DIOS, H Y PEREZ, C. (2005). "Normas para el desarrollo y revisión de estudios instrumentales" en International Journal of Clinical and Health Psychology 2005, Vol. 5, $\mathrm{N}^{\circ}$ 3, pp. 521-551.

CHANCE, B. I. (1997). "Experiences with authentic assessment techniques in an introductory statistics course" en Journal of Statistics Education, 5(3).

COBB, G. W. (1993). "Reconsidering statistics education: a National Science Foundation conference" en Journal of Statistics Education,1(1).

CONCHADO PEIRÓ, A. (2011). Modelización multivariante de los Procesos de Enseñanza Aprendizaje basados en Competencias en Educación Superior. Tesis Doctoral. Valencia: Universitat Politècnica de València, <http://riunet.upv.es/handle/10251/12099> [Consulta: 16 de junio 2014]

CONCHADO, A., VÁZQUEZ, E. y ALCOVER, R. (2012). "Estudio sobre competencias en la materia de Estadística del Grado en Ingeniería Informática" en JIDINF'12 V Jornada de Innovación Docente. Valencia. Disponible en < http://jidinf12.webs.upv.es/posters> [Consulta: 2 de mayo de 2014]

DE Miguel, M., AlfARO, I., APODACA, P., ARIAS, J. M., GARCiA, E., LOBATO, C. Y PÉREZ, A. (2005). Modalidades de enseñanza centradas en el desarrollo de competencias. Orientaciones para promover el cambio metodológico en el Espacio Europeo de Educación Superior. Madrid: Programa de Estudios y Análisis. Dirección General de Universidades. Ministerio de Educación y Ciencia.

DE LA SERNA, M. C., FIGUEIRA, M. E. M., ARRUFAT, M. J. G., \& RIVAS, M. R. (2011) "La erúbrica para la evaluación: una experiencia de colaboración interuniversitaria en materia tic " Universidad de Málaga en Uso y buenas prácticas con TIC. $2^{\circ}$ Congreso Internacional. Málaga: Universidad de Málaga.

FERNÁNDEZ, A. (2010). "La evaluación orientada al aprendizaje en un modelo de formación por competencias en la educación universitaria" en Revista de Docencia Universitaria, 8(1): 11-34.

GARFIELD, J.B. (1994). "Beyond testing and grading: using assessment to improve student learning” en Journal of Statistics Education, 2(1).

GARFIELD, J. AND BEN-ZVI, D. (2007). "How students learn statistics revisited: A currentreview of research on teaching and learning statistics"en International Statistical Review, 75(3), 372-396.

GIJBELS, D., DOCHY, F., VAN DEN BOSSCHE, P., AND SEGERS, M. (2005). "Effects of problem-based learning: a meta-analysis from the angle of assessment" en Rev. Educ. Res., 75(1), 27 61.

GTEA. eRúbrica. Herramienta para la evaluación por competencias. <https://gteavirtual.org/rubric/ $>$ [Consulta: 9 de junio de 2014]

HAIR, J. F., TATHAM, R. L., ANDERSON, R. E., \& BLACK, W. (2006). Multivariate data analysis (Vol. 6). Upper Saddle River, NJ: Pearson Prentice Hall.

\section{(c) EY-NC-ND 2014, Universitat Politècnica de València}

I Jornadas IN-RED (2014) 
Uso de la e-Rúbrica para la evaluación de competencias en el aprendizaje de Estadística

HUBBARD, R. (1997). "Assessment and the process of learning statistics" en Journal of Statistics Education, 5(1).

LASNIER, F. (2000). Réussir la formation par compétences. Montréal : Guérin.

MARÍN-GARCÍA, J. A., WATTS, F. FERNÁNDEZ MARCH, A., AZNAR-MAS, L. E., PÉREZ PEÑALVER, M. J., MONTERO-FLETA, B., GARCÍA-CARBONELL, A., GONZÁLEZ-LADRÓNDE-GUEVARA, F., ANDREU-ANDRÉS, M. A., SANZ-BERZOSA, I. y OROZCO-MESANA, J. (2012) "Validación de una rúbrica para la evaluación de la competencia de innovación en alumnos universitarios" Instituto de Ciencias de la Educación (ICE) en Jornadasde Innovación Educativa en la UPV. Valencia: Universitat Politècnica de València. ISBN 978-84-8363-926-9.

VICERRECTORADO DE ESTUDIOS Y CONVERGENCIA EUROPEA. (2012). Dimensiones Competenciales. Diseño de Titulaciones. Documento Marco UPV. Valencia: < www.upv.es/entidades/VECE/infoweb/vece/info/> [Consulta: 1 de mayo de 2014].

MCDONALD, R.; BOUD, D.; FRANCIS, J. y GONZCI, A. (2000). "Nuevas perspectivas sobre la evaluación" en Boletin Cinterfor, 149, mayo-agosto, 41-72.

MVUDUDU, N. (2005). "Constructivism in the Statistics Classroom: From Theory to Practice" en Teaching Statistics, 27: 49-54

NENDAZ, M. R. AND TEKIAN, A. (1999). “Assessment in problembased learning medical schools: a literature review”en Teaching Learn. Med., 11(4), 232-243.

ONWUEGBUZIE, A. J., BUSTAMANTE, R. M., \& NELSON, J. A. (2010). "Mixed research as a tool for developing quantitative instruments" en Journal of Mixed Methods Research, Vol. 4, No 1, pp 56-78.

POBLETE, M. (2008). "El aprendizaje basado en competencias: claves docentes" en IV Congreso internacional: La renovación de metodologías docentes centradas en el nuevo proceso de aprendizaje del alumno. Valladolid. Universidad Europea Miguel de Cervantes.

Portal oficial de la Comunidad de prácticas para la evaluación con eRúbricas "CoRubric". <http://erubrica.uma.es/INDEX.PHP/> [Consulta: 16 de junio de 2014]

SAVIN-BADEN, M. (2004). "Understanding the impact of assessment on students in problem-based learning” en Innov. Educ. Teaching Int., 41(2), 223-233.

SCHOENFELD, A. H. (1987). "What's all the fuss about metacognition?" en Cognitive science and mathematics education. Ed. A. H. Schoenfeld. Hillsdale, NJ: Lawrence Erlbaum Associates. (pp. 189215).

SWANSON, D. B., CASE, S. M., AND VAN DER VLEUTEN, C. P. M. (1998). Strategies for student assessment. In The Challenge of Problem-Based Learning, 2nd ed., edited by D. Boud and G. Feletti, pp. 269-282. London: Kogan Page.

VILLA, A. Y POBLETE, M. (2011). "Evaluación de competencias genéricas: principios, oportunidades y limitaciones" en Revista de Pedagogía, 63(1):147-170.

(c)) EY-NC-ND 2014, Universitat Politècnica de València

I Jornadas IN-RED (2014) 
Vázquez, E., Conchado, A. y Alcover, $R$.

TOURÓN, J. (1989). "La validación de constructo: su aplicación al CEED (Cuestionario para la evaluación de la eficacia docente)” en Bordón, Vol. 4, № 41, pp 735-756.

\section{(cc) EY-NC-ND 2014, Universitat Politècnica de València}

I Jornadas IN-RED (2014) 


\title{
La enseñanza y aprendizaje de gestión de proyectos a través de distintas metodologías docentes
}

\author{
Andrea Conchado ${ }^{\mathrm{a}}$, Elena Vázquez ${ }^{\mathrm{b}}$ y Concepción Maroto ${ }^{\mathrm{c}}$ \\ ${ }^{a}$ Departamento de Estadística e Investigación Operativa Aplicadas y Calidad \\ anconpei@eio.upv.es \\ ${ }^{\mathrm{b}}$ Departamento de Estadística e Investigación Operativa Aplicadas y Calidad \\ evazquez@eio.upv.es \\ ${ }^{\mathrm{c}}$ Departamento de Estadística e Investigación Operativa Aplicadas y Calidad \\ cmaroto@eio.upv.es
}

\begin{abstract}
The aim of this work is to compare the perception of students enrolled in two subjects about project management, based on different modes of teaching and learning: Master Lectures versus Project Oriented Learning. The comparison of results allowed us to identify different students' assessment as regards to approaches to learning, perceived level of autonomous learning as well as applicability of the contents and acquisition of competencies. With this aim, a Spanish version of the Revised two factor Study Process Questionnaire (R-SPQ-2F) (Cuestionario de Procesos en el Estudio, CPE) was used and specific questions about previous issues were asked to students. Results showed a clear relation between the use of the Project Oriented Learning methodology and higher levels of deep approaches to learning, as well as a higher perceived level of autonomous learning and applicability of contents to the professional environment. On the contrary, Master Lectures were mainly linked to surface approaches to learnings. As regards to the acquisition of competencies, some similarities and differences were identified, depending on the methodology. Due to the limitations of the study, this work aims to be an initial and exploratory study, and conclusions should be taken into consideration just in the context of this research.
\end{abstract}

Keywords: project management, approaches to learning, competencies, modes of teaching and learning, study processes 


\begin{abstract}
Resumen
El objetivo del trabajo es comparar la percepción de los estudiantes matriculados en dos asignaturas sobre gestión de proyectos, basadas en distintas metodologías docentes: Lección Magistral, frente a Aprendizaje Orientado a Proyectos. La comparación de los resultados obtenidos mediante ambas modalidades de enseñanza - aprendizaje ha permitido identificar distintas valoraciones de los alumnos en cuanto a los enfoques de aprendizaje, la percepción del grado de aprendizaje autónomo así como la aplicabilidad de los contenidos y las competencias adquiridas. Para ello se aplicó el Cuestionario de Procesos en el Estudio (CPE) y se plantearon cuestiones específicas sobre los aspectos anteriores. Los resultados mostraron una clara asociación entre el uso del aprendizaje orientado a proyectos y mayores niveles de aprendizaje mediante enfoque profundo, así como una mayor percepción de autonomía en el aprendizaje y aplicabilidad de los contenidos al contexto profesional. Por el contrario, el uso de lección magistral mostró una clara relación con un enfoque de aprendizaje superficial. En cuanto a las competencias adquiridas mediante ambas metodologías, se identificaron ciertas similitudes y discrepancias. Debido a las limitaciones del estudio, este trabajo se plantea como un análisis descriptivo cuyas conclusiones deben ser interpretadas en el contexto de la investigación.
\end{abstract}

Palabras clave: gestión de proyectos, enfoques de aprendizaje, competencias, metodología docente, procesos de estudio

\title{
1. Introducción
}

Durante muchos años la lección magistral o método expositivo ha sido el principal método de enseñanza - aprendizaje, sobre todo en el ámbito universitario. Esta metodología tiene como objetivo presentar un tema estructurado lógicamente y se centra fundamentalmente en la exposición verbal por parte del profesor de los contenidos sobre la materia objeto de estudio (De Miguel, 2005). Tiene ventajas indiscutibles frente a otras metodologías, como la posibilidad de transmitir un gran volumen de información en poco tiempo y a un número elevado de estudiantes, y en determinadas áreas de conocimiento, puede resultar la modalidad más adecuada para una primera aproximación a los contenidos de una materia.

No obstante, en este contexto de aprendizaje se corre el riesgo de que los estudiantes adquieran conocimientos sin ningún significado para ellos, con la consiguiente probabilidad de ser olvidado rápidamente después de la evaluación (Gerritsen, 1999). Asimismo este 
contexto de aprendizaje apenas fomenta la implicación de los estudiantes, lo cual se manifiesta habitualmente en una motivación muy baja en el aprendizaje de la materia. Por último, se ha señalado que la subdivisión de la materia de estudio en diversas asignaturas y temas resulta un tanto artificial y alejada de la realidad, generalmente organizada en torno a problemas, cuya resolución habitualmente requiere la aplicación de conocimientos procedentes de diversas materias. En otras palabras, se considera que la estructuración de contenidos realizada en la lección magistral no refleja la interdisciplinariedad de las situaciones que posteriormente deberán afrontar los titulados universitarios.

Estos inconvenientes inherentes al uso exclusivo de la lección magistral como metodología docente, conllevan el empleo, complementario o alternativo, de otras herramientas que aporten un nuevo enfoque a los procesos de enseñanza - aprendizaje, fomentando una mayor participación activa por parte del estudiante. Entre estas metodologías de aprendizaje activo, el aprendizaje orientado a proyectos surge un método en el que los estudiantes llevan a cabo la realización de un proyecto en un tiempo determinado para resolver un problema o abordar una tarea mediante la planificación, diseño y realización de una serie de actividades, y todo ello a partir del desarrollo y aplicación de aprendizajes adquiridos y del uso efectivo de recursos (De Miguel, 2005). Dichos proyectos deben plantearse en base a preguntas o problemas que supongan un reto e impliquen a los alumnos en el diseño, resolución de problemas, toma de decisiones y actividades de investigación y les permitan trabajar de forma relativamente autónoma a lo largo de períodos prolongados de tiempo (Jones, Rasmussen y Moffitt, 1997; Thomas, Mergendoller, y Michaelson, 1999). Fundamentalmente existen varios criterios que caracterizan, y distinguen, a los proyectos utilizados en esta metología de otras actividades de enseñanza - aprendizaje. En primer lugar, deben plantearse en base a los contenidos fundamentales de la asignatura y orientan a los estudiantes hacia su estudio. Estos proyectos deben formular cuestiones que fomenten en los alumnos el desarrollo de investigaciones constructivistas, dirigidas por ellos en la medida de lo posible, y lo más cercanas posible al entorno profesional real al que deberán enfrentarse una vez finalicen sus estudios (Diehl et al., 1999).

Los proyectos planteados a los estudiantes de acuerdo con estos criterios suelen resultar muy motivadores para aquellos alumnos que abordan sus estudios con un enfoque de aprendizaje profundo, frente a aquellos que lo hacen con un enfoque superficial (Ames, 1992). El término enfoque del aprendizaje se define como los procesos de aprendizaje que emergen de la percepción que el estudiante tiene de la tarea académica influida por sus propias características personales (Marton y Säljö, 1976a, 1976b). Estos enfoques del aprendizaje están influidos tanto por las características personales del estudiante y el contexto de enseñanza, como por la interacción entre ambos elementos. En ningún caso se trata de características psicológicas estables, sino que dependen de la naturaleza de la tarea, el sistema de evaluación, del método de enseñanza, de la percepción que el estudiante

\section{(c) EY-NC-ND 2014, Universitat Politècnica de València}

I Jornadas IN-RED (2014) 
desarrolle, de la relevancia del curso, del interés del estudiante o su estilo de aprendizaje (Hernández et al. 2002a; Laurillard 1979).

Atendiendo a las motivaciones y estrategias de los estudiantes, es posible identificar hasta tres enfoques diferentes de aprendizaje, siendo formas transculturales o universales de aproximarse al aprendizaje, independientemente del sistema educativo nacional (Abalde et al., 2001). En primer lugar el enfoque superficial se basa en una motivación extrínseca. En este caso el aprendizaje en el contexto académico se considera un medio para lograr un objetivo concreto, como conseguir trabajo o aprobar un examen y las estrategias para lograrlo se basan en minimizar el esfuerzo y reproducir lo aprendido a través de un aprendizaje memorístico. Este enfoque superficial es adoptado como consecuencia de la percepción insatisfactoria que el estudiante tiene del ambiente de aprendizaje, de forma que considera que las tareas y procesos de aprendizaje son algo impuesto externamente. Por ello, el estudiante se limita a completar los requisitos mínimos exigido en cada tarea y memorizar para los exámenes sin relacionar los contenidos estudiados ni reflexionar sobre su transferencia. Según Valle (2000), en este caso el esfuerzo de los estudiantes no está guiado por ninguna de las metas relacionadas con la motivación (aprendizaje y rendimiento), sino por la meta de evitación del trabajo. A continuación el enfoque profundo se basa en una motivación propia del estudiante por las materias de forma que el estudiante se interesa por el trabajo académico y tiene la intención de comprender e interaccionar con los contenidos previos. Las estrategias surgen de esa motivación y se utilizan para maximizar la comprensión, de forma que la curiosidad del individuo sea satisfecha. Por último el enfoque de alto rendimiento se basa en la valoración que el individuo hace de sí mismo a través de la obtención de un alto rendimiento académico. Esta motivación constituye una forma particular de motivación extrínseca características de estudiantes competitivos, auto-disciplinados, esmerados y sistemáticos y cumplen todos los requisitos que demanda la educación superior. En estas circunstancias las estrategias se relacionan con la organización del tiempo, la organización del espacio y el dominio de las materias de la forma más eficiente posible (Ruiz et al., 2008).

Por otro lado, el aprendizaje orientado a proyectos no solo se asocia a mayores niveles de aprendizaje con enfoque profundo, sino que fortalece la autoconfianza de los estudiantes, al fomentar que tomen sus propias decisiones y actuaciones de forma independiente. De hecho, ambos elementos parecen estar interrelacionados, pues la experiencia y evaluación del desempeño de los estudiantes en situaciones cercanas a su entorno profesional real es lo que orienta el aprendizaje de los alumnos hacia un enfoque profundo basado en el dominio de la materia y herramientas metacognitivas (Blumenfeld et al., 1991). Esta aplicación de los conocimientos, habilidades y actitudes adquiridas a situaciones concretas, hace que el aprendizaje sea más motivador, pero sobre todo en aquellos casos en que los proyectos guarden semejanzas con las situaciones profesionales reales que tratan de representar. En 
caso de que los proyectos simulen ser un ejercicio docente más, alejado de la realidad laboral de los estudios, se corre el riesgo de que el efecto sea exactamente el opuesto al deseado, una mayor desmotivación y aburrimiento por parte de los alumnos (Brown, Collins \& Duguid, 1989).

En cualquier caso, ninguna de estas asociaciones con aspectos psicológicos del aprendizaje tiene sentido si no se identifica un instrumento de medida adecuado para cuantificar la eficacia del aprendizaje orientado a proyectos. Así, los sistemas de evaluación por cuestionarios y autoevaluaciones por parte de los estudiantes surgen como una opción muy fácil de implementar a nivel institucional y se fundamenta en preguntar a los alumnos sobre el nivel percibido de beneficios e impacto de la metodología docente en su aprendizaje. No obstante, es necesario señalar que dichas autoevaluaciones no son medidas de qué ha pasado realmente, sino de lo que los estudiantes dicen que ha pasado. Por tanto, resulta fundamental ser consciente del error de medida que se produce en las valoraciones de los encuestados, siempre que se trabaje con datos obtenidos a partir de sus autoevaluaciones.

La autoevaluación por parte de los estudiantes ya ha sido utilizada anteriormente en investigaciones relacionadas con los efectos del aprendizaje orientado a proyectos. Tretten y Zachariou (1995) desarrollaron una investigación en cuatro escuelas de educación primaria que recientemente había iniciado un programa de formación en base a esta metodología. En este estudio 64 profesores fueron encuestados y una parte considerable de ellos afirmó que dicha metodología tiene diversos beneficios para los estudiantes, como actitudes más positivas hacia el aprendizaje, hábitos de trabajo, habilidades de resolución de problemas y autoestima. Unos años más tarde Peck, Peck, Sentz y Zasa (1998) encuestaron a estudiantes de educación secundaria, matriculados en un curso de humanidades que igualmente reportaron un incremento en su nivel de aprendizaje gracias al uso de esta metodología. Igualmente Bartscher, Gould y Nutter (1999) enfocaron sus estudios hacia los alumnos con bajos niveles de motivación y concluyeron que, después de la participación en proyectos, la mayoría de estos estudiantes afirmaron que les había ayudado a aumentar su motivación e incrementar su interés en la asignatura. Sin embargo, todos estos estudios mencionaron en algún punto de las investigaciones la dificultad de medir de forma objetiva la eficacia de cualquier metodología docente en base a autoevaluaciones mediante cuestionarios. Concretamente apuntaron hacia la existencia de cierta predisposición entre los estudiantes a puntuar o evaluar mejor determinadas experiencias de aprendizaje, sobre todo en los casos en que habían resultado novedosas, provocadoras e incluso divertidas respecto a las actividades habituales desarrolladas en el aula. 


\section{Objetivos}

Considerando las investigaciones precedentes, que enfatizan en la utilidad del aprendizaje orientado a proyectos como una metodología adecuada para la mejora del aprendizaje en determinados contextos, y la carencia de estudios cuantitativos y comparativos que corroboren dicha hipótesis en el ámbito de los estudios universitarios, el presente trabajo plantea comparar la percepción de los estudiantes matriculados en distintas asignaturas sobre Gestión de Proyectos, basadas en lección magistral y aprendizaje orientado a proyectos respectivamente. Dicho objetivo se plantea con el fin de identificar los puntos fuertes y débiles de cada una de estas metodologías, a partir de las valoraciones de los alumnos en cuanto a sus enfoques de aprendizaje, su grado de satisfacción con la asignatura y su nivel de motivación al estudiar.

\section{Desarrollo de la innovación}

\section{Datos}

La metodología de trabajo utilizada en este estudio se basa en la valoración del impacto de cada metodología se centrará en el análisis de las percepciones de los alumnos sobre la docencia impartida en ambas modalidades. Para ello, se enviaron invitaciones a cumplimentar el cuestionario a dos grupos de alumnos matriculados en asignaturas relacionadas con la gestión de proyectos. El primer grupo lo formaban 168 alumnos matriculados en la asignatura «Gestión de Proyectos» de $3^{\circ}$ del Grado en Ingeniería Informática que cursaban la asignatura de forma obligatoria. En estas circunstancias, la impartición de los contenidos teóricos comunes se basa en una metodología tradicional de lección magistral y resolución de ejercicios y problemas, que se evalúa mediante la entrega de problemas resueltos y exámenes de respuesta cerrada. Cabe destacar que, aunque el número de alumnos matriculados en esta asignatura es muy superior (373 alumnos) únicamente se incluyó en la población de estudio a los alumnos matriculados con los profesores que impartían clases en ambos grupos, para evitar el posible sesgo introducidos por el cambio de profesor.

Por el contrario, el segundo grupo tenía un tamaño más reducido, formado por 33 alumnos, matriculados en «Gestión de Proyectos en el Sector Público» de la Facultad de Administración y Dirección de Empresas, diseñada en base a metodologías más innovadoras, basadas en aprendizaje orientado en proyectos. Esta metodología es apropiada en este contexto pues en principio favorece un aprendizaje integrador y autónomo de las competencias, al tiempo que permite aplicar lo aprendido a situaciones concretas, relacionadas con el ámbito profesional u otra área de interés del alumno. Además, puesto que los alumnos son de último curso, la aplicación de esta metodología docente resulta adecuada, puesto que los alumnos habían alcanzado la madurez suficiente para trabajar de esta forma. Así, a lo largo del curso los alumnos debían elaborar un proyecto en un área de 
interés para ellos, aplicando los conocimientos y habilidades adquiridos en las clases teóricas y prácticas. Este proyecto tuvo un peso de un $70 \%$ en la calificación final de la asignatura.

Las invitaciones al cuestionario se enviaron tras la finalización de las clases y de forma previa a la publicación de calificaciones correspondientes al último acto de evaluación, para evitar posibles sesgos por la obtención de buenos (o malos) resultados académicos. Se obtuvieron 78 respuestas en el grupo impartido mediante lección magistral y 22 respuestas en el grupo impartido mediante aprendizaje orientado a proyectos. Considerando población finita y un error $\mathrm{p}=\mathrm{q}=0.5$, la muestra de alumnos que estudiaban con lección magistral alcanzó un error muestral del $8.1 \%$, mientras que los resultados obtenidos con la muestra de alumnos que trabajaron con aprendizaje orientado a proyectos obtuvo un error muestral del 12.3\%. Son errores relativamente altos, si se pretendiera extrapolar los resultados del estudio a una población más amplia, pero puesto que se trata de un estudio descriptivo, se consideran aceptables.

Para limitar la longitud del cuestionario no se incluyeron en la encuesta cuestiones de tipo sociodemográfico. Sin embargo, las características generales de la población de alumnos que asistían a clase mediante lección magistral eran en su mayoría alumnos hombres, frente a una mayoría de alumnas mujeres en el grupo de alumnos que trabajaron la asignatura mediante aprendizaje orientado a proyectos.

\section{Instrumentos}

Existen diversos instrumentos de medida en forma de cuestionarios, diseñados con el fin de medir los enfoques del aprendizaje entre los estudiantes universitarios. El primer instrumento definido en esta línea fue el cuestionario Inventario de Enfoques de Estudio (ASI: Approaches to Studying Inventory) propuesto por Entwistle y Ramsden (Entwistle et al. 1979; Entwistle \& Ramsden 1983). Este cuestionario fue revisado posteriormente por Entwistle y Tait (1990) y se renombró como Revised Approaches to Studying Inventory (RASI). A pesar de que éste fue el primer instrumento propuesto, su uso no se encuentra tan generalizado y aplicable al ámbito universitario como el elaborado por Biggs (1987). El cuestionario recibe el nombre de Cuestionario de Procesos de Estudio (CPE) (SPQ: Study Process Questionnaire) y está compuesto por cuarenta y dos ítems con tres escalas, correspondientes a los tres enfoques de aprendizaje (profundo, superficial y logro) y seis subescalas que contienen ítems referentes a los componentes motivacionales y estratégicos. Este cuestionario fue revisado posteriormente y se renombró como Revised two factor Study Process Questionnaire (R-SPQ-2F) por Biggs (2001). Esta revisión se realizó con el fin de adaptarlo a las características propias de los estudiantes universitarios actuales. Esta nueva versión del cuestionario está compuesta por veinte ítems y presenta dos escalas,

\section{(cc) BY-NC-ND 2014, Universitat Politècnica de València}

I Jornadas IN-RED (2014) 
correspondientes a los enfoques profundo y superficial, y cuatro subescalas en función de la componente, motivacional o estratégica. El cuestionario de procesos de aprendizaje ha sido adaptado y aplicado a dos muestras españolas con resultados muy similares a los obtenidos por otros estudios, tanto en su fiabilidad como en su validez de constructo (Hernández et al. 2002b; Hernández et al. 2005). Esta versión del instrumento fue la seleccionada para su aplicación en este trabajo, por su simplicidad respecto a otros instrumentos de medida así como por haberse validado previamente en el contexto e idioma español.

Otros cuestionarios equivalentes desarrollados como instrumentos para la medición de los enfoques del aprendizaje son el cuestionario Approaches and Study Skills Inventory for Students desarrollado por Tait et al. (1998) y que pone de manifiesto el grado de correspondencia existente entre el ASI y el SPQ. Igualmente el cuestionario Inventory of Learning Styles (ILS) propuesto por Vermunt ( 1996).

Respecto a las cuestiones sobre aplicabilidad de los contenidos de la asignatura y desarrollo de habilidades de aprendizaje autónomo, fueron redactadas ad-hoc para los objetivos de esta investigación. La escala de respuesta también fue una escala Likert de 1 a 5, pero en este caso representaba el nivel de acuerdo de los alumnos con cada afirmación, de modo que $1=$ Muy en desacuerdo y $5=$ Muy de acuerdo.

Asimismo, para valorar las percepciones de los alumnos sobre la adquisición de competencias, se les preguntó en qué medida habían adquirido las competencias que se incluyen en la guía docente de cada asignatura (formuladas de forma simplificada). La escala de respuesta se mantuvo en una escala Likert de 5 puntos, pero en este caso varía el significado asociado a las categorías de respuesta, de modo que $1=$ Nada, $5=$ Mucho.

\section{Resultados}

En primer lugar se han obtenido los estadísticos descriptivos correspondientes a la batería de 20 ítems del Cuestionario de Procesos de Estudio, con el fin de identificar posibles relaciones entre las respuestas de los alumnos, y la metodología docente empleada en cada grupo. A pesar de que los resultados no han permitido discriminar entre las distintas estrategias y motivaciones que caracterizan el aprendizaje de los alumnos, sí es posible observar ciertas asociaciones entre la metodología empleada y el enfoque de aprendizaje.

Así, la Tabla 1 muestra las puntuaciones promedio a cada ítem en función de la metodología empleada, así como las diferencias entre grupos y el nivel de significación correspondiente que indica aquellas diferencias estadísticamente significativas. Como se observa en la tabla, los alumnos que trabajaron la asignatura mediante aprendizaje orientado a proyectos (A.O.P.) valoraron con mayores puntuaciones promedio todos los ítems relativos al enfoque profundo, mientras que los alumnos que asistían a clases impartidas mediante lección magistral (L.M.) alcanzaron las mayores puntuaciones en los 
ítems sobre enfoque superficial. Todas las diferencias observadas se evaluaron como estadísticamente significativas $(\alpha=0.01)$, a través de análisis de la varianza y el estadístico $F$ de Snedecor asociado.

Los ítems más discriminantes, ubicados en los extremos superior e inferior de la tabla, ordenada de mayor a menor en función de la diferencia en valores promedio, fueron «He dedicado tiempo a ampliar los temas buscando información adicional» más valorada por los alumnos que asistieron a clases impartidas mediante aprendizaje orientado a proyectos (A.O.P.) y "En esta asignatura he estudiado solo lo que me han señalado los profesores, nada extra» más valorada por los alumnos matriculos en grupos que se impartían mediante lección magistral (L.M.).

Tabla 1. Puntuaciones promedio al Cuestionario de Procesos de Estudio y diferencias entre grupos, por metodología docente

\begin{tabular}{|c|c|c|c|c|c|}
\hline Asignatura & L.M. & A.O.P. & Dif. & $\mathbf{F}$ & Sig. \\
\hline He dedicado tiempo a ampliar los temas buscando información adicional & $\times 2.00$ & $\checkmark 3.19$ & 1.19 & 21.21 & .000 \\
\hline $\begin{array}{l}\text { He querido preparar esta asignatura bien, porque me ha parecido } \\
\text { interesante }\end{array}$ & $\times 2.92$ & $\checkmark 3.90$ & 0.98 & 16.57 & .000 \\
\hline $\begin{array}{l}\text { Cuando voy a clase de esta asignatura, llevo algunas cuestiones para } \\
\text { preguntar }\end{array}$ & $\times 2.13$ & 3.05 & 0.92 & 13.03 & .000 \\
\hline He profundizado en determinados temas que me parecían interesantes & × 2.51 & 3.10 & 0.58 & 4.98 & .028 \\
\hline $\begin{array}{l}\text { A la hora de estudiarla, la he trabajado bastante para formarme una } \\
\text { opinión personal al respecto y así quedar satisfecho }\end{array}$ & $\times 3.23$ & 3.81 & 0.58 & 5.54 & .021 \\
\hline $\begin{array}{l}\text { Los temas me han resultado interesantes una vez que he profundizado en } \\
\text { ellos }\end{array}$ & $\times 3.29$ & 3.81 & 0.52 & 4.68 & .033 \\
\hline $\begin{array}{l}\text { Para mí, estudiar esta asignatura ha sido como leer una buena novela o ver } \\
\text { una buena película }\end{array}$ & $\times 2.29$ & 22.81 & 0.51 & 4.27 & .041 \\
\hline $\begin{array}{l}\text { Estudiar esta asignatura me ha producido un sentimiento de satisfacción } \\
\text { personal }\end{array}$ & $\times 3.05$ & $\checkmark 3.52$ & 0.47 & 4.02 & .048 \\
\hline No veo ninguna ventaja en estudiar los temas en profundidad & 22.54 & × 2.10 & -0.44 & 2.44 & .122 \\
\hline $\begin{array}{l}\text { Creo que tengo más posibilidades de aprobar si memorizo lo más } \\
\text { importante, más que si me pongo a comprenderlo }\end{array}$ & 2.19 & $\times 1.60$ & -0.59 & 4.57 & .035 \\
\hline Procuro estudiar la may or parte del temario sugerido por el profesor/a & 4.14 & × 3.37 & -0.77 & 10.33 & .002 \\
\hline $\begin{array}{l}\text { Como no me parece una asignatura muy interesante, he procurado } \\
\text { trabajar lo mínimo }\end{array}$ & 2.41 & $\times 1.62$ & -0.79 & 9.15 & .003 \\
\hline $\begin{array}{l}\text { Lo mejor para aprobar este examen es tratar de recordar las respuestas } \\
\text { que preveo que van a salir en el examen }\end{array}$ & 3.01 & × 2.19 & -0.82 & 7.53 & .007 \\
\hline Mi objetivo es aprobarla haciendo el menor trabajo posible & 2.96 & $\times 1.95$ & -1.01 & 11.36 & .001 \\
\hline $\begin{array}{l}\text { Realmente solo he estudiado los apuntes y test de clase, entiendo que } \\
\text { buscar información complementaria por mi parte es una pérdida de }\end{array}$ & $\checkmark 3.17$ & × 1.90 & -1.27 & 21.77 & .000 \\
\hline Empleo poco tiempo en estudiar lo que sé que no va para examen & $\checkmark 3.99$ & × 2.67 & -1.32 & 26.00 & .000 \\
\hline $\begin{array}{l}\text { Creo que no tiene sentido esperar que los alumnos dediquemos tiempo a } \\
\text { los temas que no van para examen }\end{array}$ & 3.24 & $\times 1.90$ & -1.34 & 19.68 & .000 \\
\hline $\begin{array}{l}\text { Algunas partes las he estudiado mecánicamente hasta aprenderlas de } \\
\text { memoria }\end{array}$ & 3.03 & × 1.67 & -1.36 & 18.45 & .000 \\
\hline $\begin{array}{l}\text { En esta asignatura, he estudiado solo lo que me han señalado los } \\
\text { profesores, nada extra }\end{array}$ & 3.74 & $\times 2.33$ & -1.41 & 27.63 & .000 \\
\hline
\end{tabular}

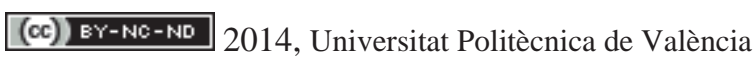

I Jornadas IN-RED (2014) 
En lo que respecta a las cuestiones sobre aplicabilidad de los contenidos de la asignatura y desarrollo de habilidades de aprendizaje autónomo también obtuvieron puntuaciones promedio siempre significativamente superiores los alumnos matriculados en el grupo impartido mediante aprendizaje orientado a proyectos (A.O.P.), a las obtenidas por los alumnos matriculados en los grupos impartidos mediante lección magistral (L.M.), como se muestra en la Tabla 2.

Tabla 2. Puntuaciones promedio a cuestiones específicas sobre aprendizaje autónomo y aplicabilidad de la asignatura y diferencias entre grupos, por metodología docente

\begin{tabular}{|l|c|c|c|c|c|}
\hline Asignatura & L.M. & A.O.P. & Dif. & F & Sig. \\
\hline $\begin{array}{l}\text { Estudiar esta asignatura me ha ayudado a desarrollar mis } \\
\text { habilidades de aprendizaje autónomo }\end{array}$ & $\times 2.91$ & 4.00 & 1.09 & 16.10 & .000 \\
\hline $\begin{array}{l}\text { Los contenidos y herramientas, y en definitiva las } \\
\text { competencias, que he adquirido en esta asignatura pueden ser } \\
\text { útiles en mi carrera profesional }\end{array}$ & $\times 3.67$ & 4.05 & 0.38 & 2.23 & .138 \\
\hline $\begin{array}{l}\text { Creo que aplicaré lo que he aprendido en esta asignatura en mi } \\
\text { carrera profesional }\end{array}$ & $\times 3.61$ & 3.95 & 0.34 & 1.43 & .234 \\
\hline
\end{tabular}

No obstante, resulta especialmente interesante comparar las valoraciones de los alumnos matriculados en ambos grupos en lo concerniente a la adquisición de competencias. Como se observa en los siguientes gráficos, la competencia que más dicen haber adquirido todos los alumnos es «Planificación y dirección de proyectos», independientemente de la metodología docente empleada. «Trabajo en equipo» también se encuentra en las primeras posiciones en ambos casos, mientras las competencias más específicas se ubican en los últimos puestos del ranking («Elaboración de pliegos de condiciones técnicas» y «Diseño y evaluación de sistemas informáticos»). Otras competencias, como «Negociación y Razonamiento abstracto» también se sitúan entre las competencias menos valoradas por los alumnos. Por el contrario, algunas competencias varían en su posición en función de la asignatura, como «Comunicación» (en tercer puesto para el grupo impartido mediante lección magistral y décimo puesto para el grupo impartido mediante aprendizaje orientado a proyectos), «Liderazgo» (en cuarto puesto para el grupo impartido mediante lección magistral y octavo puesto para el grupo impartido mediante aprendizaje orientado a proyectos). Especialmente interesante resulta el caso de la competencia «Aprendizaje autónomo», que también varía su posición en función de la asignatura considerada (en sexto puesto para el grupo impartido mediante lección magistral y tercer puesto para el grupo impartido mediante aprendizaje orientado a proyectos). 
Conchado, A., Vázquez, E. y Maroto, C.

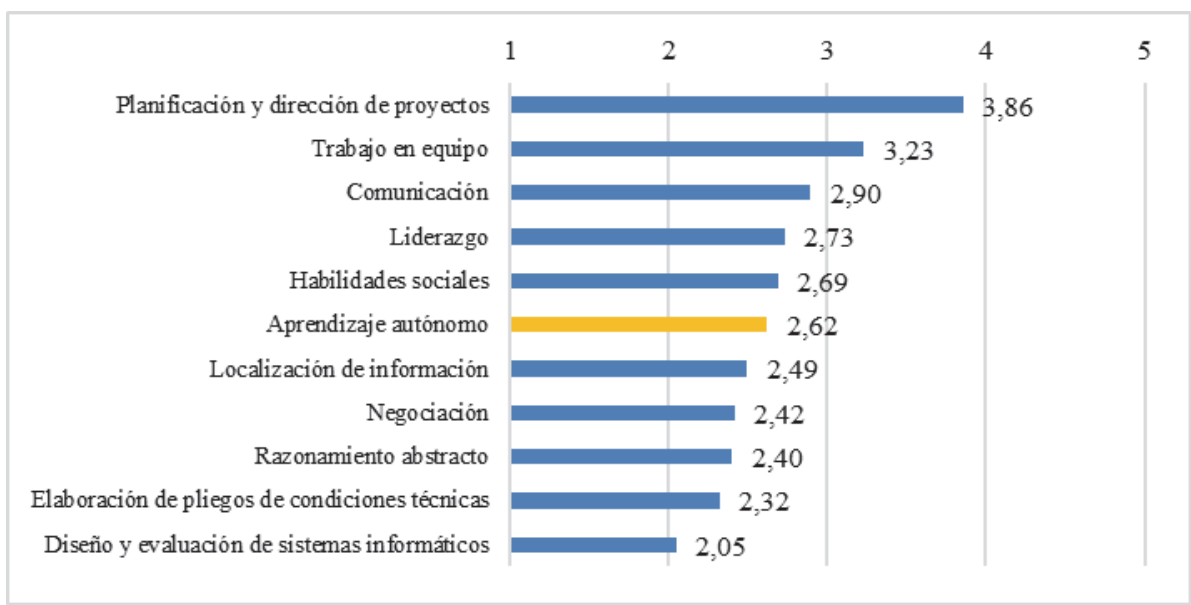

Fig. 1. Puntuaciones promedio en las valoraciones a las competencias adquiridas en el grupo impartido mediante lección magistral

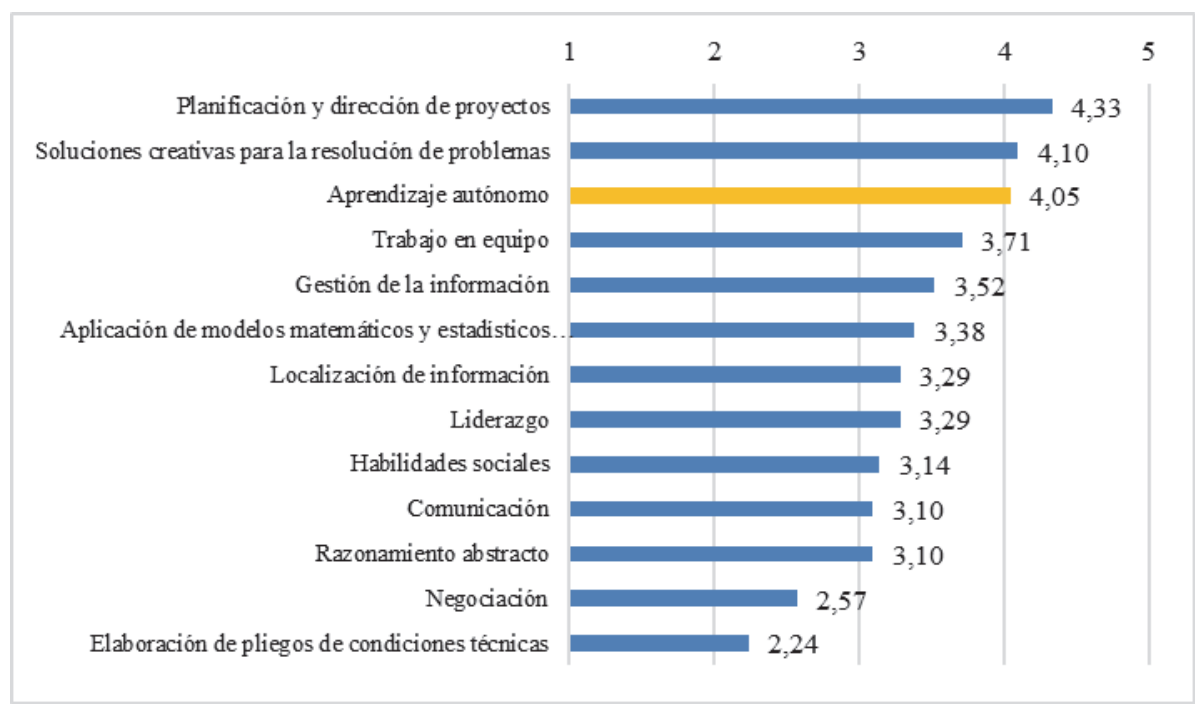

Fig. 2. Puntuaciones promedio en las valoraciones a las competencias adquiridas en el grupo impartido mediante aprendizaje orientado a proyectos

Para profundizar en estos resultados descriptivos, que indican la presencia de dos perfiles de alumnos con distintos enfoques del aprendizaje, asociados al empleo de cada metodología docente, se aplicaron técnicas de análisis factorial que permitieron identificar dimensiones comunes en las respuestas al Cuestionario de Procesos de Aprendizaje. La

\section{(cc) EY-NC-ND 2014, Universitat Politècnica de València}

I Jornadas IN-RED (2014) 
aplicación de estas técnicas multivariantes se consideró adecuada al disponer de muestra suficiente $(\mathrm{N}=100)$ y una medida de adecuación muestral cercana a la unidad $(\mathrm{KMO}=1)$. Asimismo la prueba de esfericidad de Barlett resultó significativa para el conjunto de la muestra $\left(\chi^{2}=1098.3, \mathrm{p}=0.000\right)$.

El método de extracción de factores fue máxima verosimilitud y aunque el número de factores recomendado por el criterio de Kaiser (autovalores > 1) fue seis, se decidió retener únicamente dos factores, que explicaban el $47 \%$ de la variabilidad de los datos. Las razones para tomar esta decisión fueron la coherencia con la estructura del cuestionario, y el elevado porcentaje de varianza explicado por estos dos primeros factores, tal y como se observa en la Tabla 3:

Tabla 3. Autovalores y porcentaje de varianza explicado, en función del número de factores extraídos

\begin{tabular}{|c|c|c|}
\hline Autovalores & $\begin{array}{c}\text { \% de la } \\
\text { varianza }\end{array}$ & \% acumulado \\
\hline 7.940 & 36.090 & 36.090 \\
2.419 & 10.993 & 47.084 \\
1.474 & 6.698 & 53.782 \\
1.264 & 5.743 & 59.525 \\
1.240 & 5.638 & 65.164 \\
1.140 & 5.182 & 70.346 \\
\hline
\end{tabular}

Para mejorar la interpretabilidad de los resultados se aplicó una rotación ortogonal de tipo Varimax a la solución obtenida, tras la cual se obtuvo la matriz de cargas factoriales rotadas que se muestra en la Tabla 4. En esta tabla se observa que el primer factor se caracteriza por tener altas cargas factoriales (superiores a 0.3 en valor absoluto) en todos los ítems relativos al enfoque superficial. Igualmente ocurre en el segundo factor respecto al enfoque profundo. Es necesario destacar que algunos ítems se redactaron en dirección negativa, y por tanto, aunque muestran altas cargas factoriales, tienen signo negativo.

Tabla 4. Matriz de cargas factoriales rotadas con rotación Varimax

\begin{tabular}{|l|c|c|}
\hline & \multicolumn{2}{|c|}{ Factor } \\
\cline { 2 - 3 } & \multicolumn{1}{|c|}{1} & \multicolumn{1}{|c|}{2} \\
\hline En esta asignatura, he estudiado solo lo que me han señalado los profesores, nada extra & .806 & .052 \\
He dedicado tiempo a ampliar los temas buscando información adicional & -.769 & .138 \\
Empleo poco tiempo en estudiar lo que sé que no va para examen & .692 & -.252 \\
Mi objetivo es aprobarla haciendo el menor trabajo posible & .632 & -.331 \\
Realmente solo he estudiado los apuntes y test de clase, entiendo que buscar información & .611 & -.195 \\
complementaria por mi parte es una pérdida de tiempo & & \\
Cuando voy a clase de esta asignatura, llevo algunas cuestiones para preguntar & -.589 & .132 \\
Creo que no tiene sentido esperar que los alumnos dediquemos tiempo a los temas que no & .535 & -.101 \\
van para examen & &
\end{tabular}




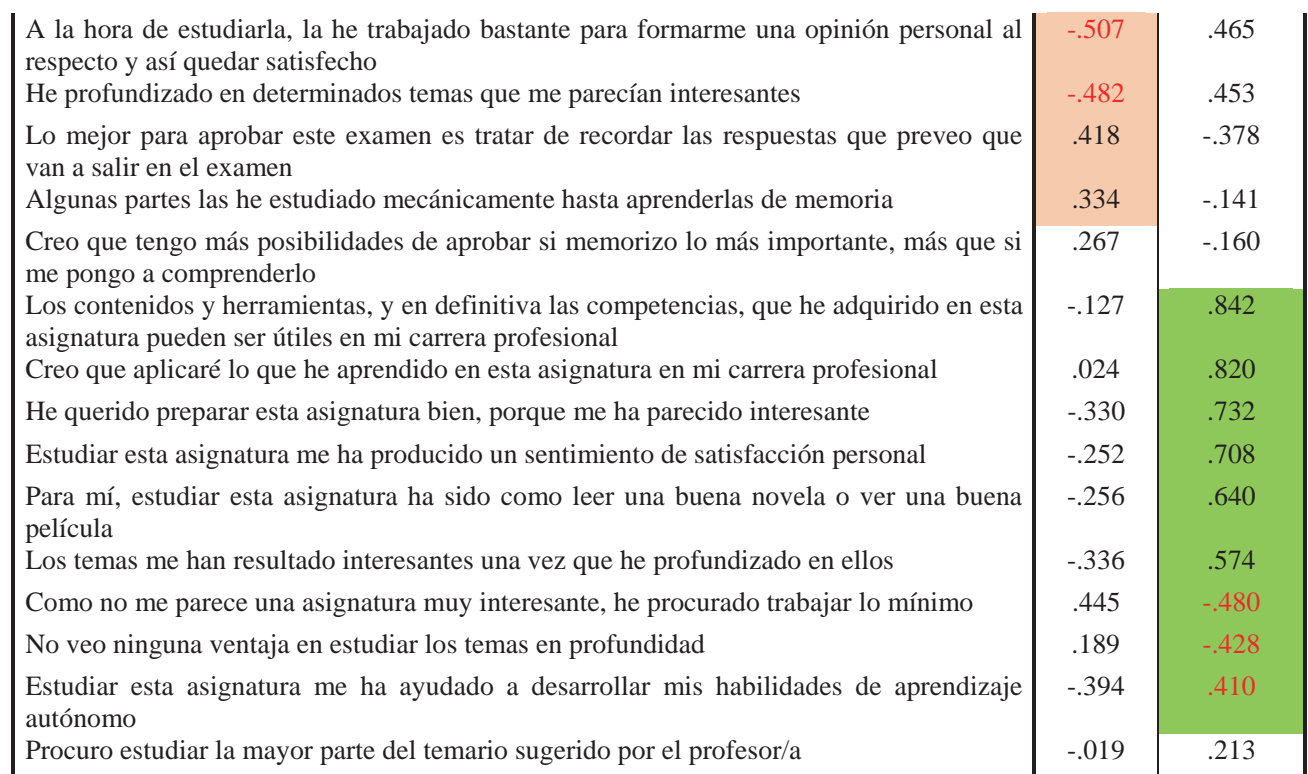

En la Tabla 4 también se observa la presencia de dos ítems que no cargan significativamente en ninguno de los factores. Ambos ítems resultaron ser poco discriminantes pues no diferencian claramente entre ambos factores, por lo que podrían ser excluídos del estudio sin pérdida de información relevante. Este resultado queda reflejado en las bajas comunalidades de ambos ítems ( «Creo que tengo más posibilidades de aprobar si memorizo lo más importante, más que si me pongo a comprenderlo» con comunalidad = 0.097; «Procuro estudiar la mayor parte del temario sugerido por el profesor/a» con comunalidad $=0.213$ ), inferiores en ambos casos al umbral de 0.3 , recomendado por Hair, Anderson, Tatham y Black (2007).

\section{Conclusiones}

En conclusión, la metodología docente del aprendizaje basado en proyectos para la impartición de la asignaturas sobre la temática de Gestión de proyectos parece relacionarse con un mayor enfoque profundo hacia la asignatura por parte de los estudiantes. Por el contrario, el empleo de metodologías basadas en lección magistral parece fomentar un enfoque superficial, encaminado hacia la superación de los requisitos mínimos para aprobarla y conseguir las metas estipuladas por el programa de estudios sobre la asignatura. Respecto a la aplicabilidad de los contenidos y autonomía en el aprendizaje también parece estar favorecido por el empleo de aprendizaje orientado a proyectos, frente al uso de la lección magistral.

\section{(c)) BY-NC-ND 2014, Universitat Politècnica de València}

I Jornadas IN-RED (2014) 
Por otro lado, las competencias que los alumnos perciben que adquieren gracias a ambas metodologías guardan ciertas similitudes y discrepancias. Mientras que todos coinciden en que la asignatura les ayuda a adquirir competencias relacionadas con la planificación y gestión de proyectos y trabajo en equipo, también parecen estar de acuerdo en que contribuye poco al aprendizaje de competencias específicas de su área de estudio así como a negociar. Por otra parte, la contribución a determinadas competencias, como aprendizaje autónomo, liderazgo y comunicación parece estar condicionado por el empleo de la metodología docente.

En cualquier caso, aunque parece evidente la existencia de dos perfiles de alumnos en función del enfoque con que abordan la asignatura así como la vinculación de dicho enfoque con el empleo de ambas metodologías docentes, es necesario señalar las limitaciones del estudio en cuanto a la comparación de percepciones por parte de alumnos en distintos contextos académicos. Mientras que la asignatura es optativa y está relacionada con el área de conocimiento principal de los alumnos que asisten a clases planteadas mediante aprendizaje orientado a proyectos, ocurre lo contrario para los alumnos que asisten a clases impartidas mediante lección magistral. En este último caso la asignatura es obligatoria y se encuentra poco relacionada con su área de conocimiento y especialidad. Sería pertinente en futuras investigaciones, replicar los análisis realizados en asignaturas de la misma temática pero impartidas en distintos entornos de aprendizaje, aumentando así el tamaño de muestra disponible y la posibilidad de extrapolación de las conclusiones del estudio.

\section{Referencias}

Abalde, E., Muñoz, M., Buendía, L., Olmedo, E. M., Berrocal, E. y Cajide, J. (2001). Los enfoques de aprendizaje en estudiantes universitarios españoles. Revista de Investigación Educativa, 19, 465-489.

Ames, C. (1992). Classrooms: goals, structures, and student motivation. Journal of Educational Psychology, 84, 261-271.

Bartscher, K., Gould, B., \& Nutter, S. (1995). Increasing student motivation through projectbased learning. Master's Research Project, Saint Xavier and IRI Skylight. (ED 392 549).

Biggs, J., Kember, D. y Leung.D. (2001). The revised two-factor Study Process Questionnaire: R-SPQ-2F. British Journal of Educational Psychology, 4, 21-39.

Blumenfeld, P., Soloway, E., Marx, R., Krajcik, J., Guzdial, M., \& Palincsar, A. (1991). Motivating project-based learning: Sustaining the doing, supporting the learning. Educational Psychologist, 26 (3\&4), 369-398. 
Brown, J. S. , Collins, A. \& Duguid, P. (1989) Situated cognition of learning. Educational Researcher, 18, 32-42.

De Miguel, M., Alfaro, I., Apodaca, P., Arias, J. M., Garcia, E., Lobato, C. y Pérez, A. (2005). Modalidades de enseñanza centradas en el desarrollo de competencias. Orientaciones para promover el cambio metodológico en el Espacio Europeo de Educación Superior. Madrid: Programa de Estudios y Análisis. Dirección General de Universidades. Ministerio de Educación y Ciencia.

Diehl, W., Grobe, T., Lopez, H., \& Cabral, C. (1999). Project-based learning: A strategy for teaching and learning. Boston, MA: Center for Youth Development and Education, Corporation for Business, Work, and Learning.

Entwistle, N., Hanley, M. y Hounsell, D. (1979). Identifying distinctive approaches to studying. Higher Education, 8, 365-380.

Entwistle, N. y Ramsden, P. (1983). Understanding student learning. London: Croom Helm.

Entwistle, N. y Tait, H. (1990). Approaches to evaluation, evaluation of teaching y preferent for contrating academia environment. Higher Education, 19, 169-194.

Gerritsen, R. (1999). Do students study more throughly within a problem-based learning environments course. En J. Hommes (Ed) Educational innovation in Economics y Business IV: Learning in a changing environment (pp. 127-141). Dordrecth / Boston / London: Kluwer Academic Publishers.

Hair, J. F., Anderson, R., Tatham, R. y Black, W. (2007). Análisis Multivariante. Madrid: Prentice Hall.

Hernández, F., Fernández, C., Martínez, P., Hervás, R. M. y Maquillón, J. (2002a). Consistencia entre motivos y estrategias de aprendizaje en estudiantes universitarios. Revista de Investigación Educativa, 20, 487-510.

Hernández, F., García, P. y Maquillón, J. (2005). Análisis del cuestionario de procesos de estudio - 2 factores de Biggs en estudiantes universitarios españoles. Revista Fuentes, 6.

Jones, B. F., Rasmussen, C. M., \& Moffitt, M. C. (1997). Real-life problem solving.: A collaborative approach to interdisciplinary learning. Washington, DC: American Psychological Association.

Laurillard, D. (1979). The processes of student learning. Higher Education, 8, 395-409.

Marton, F. y Säljo, R. (1976a). On qualitative differences in learning: I Outcome and process. British Journal of Educational Psychology, 46, 3-11.

(cc) BY-NC-ND 2014, Universitat Politècnica de València

I Jornadas IN-RED (2014) 
Marton, F. y Säljo, R. (1976b). On qualitative differences in learning: II Outcome as a function of the learner's conception of the task. British Journal of Educational Psychology, 46, 115-127.

Peck, J. K., Peck, W., Sentz, J., y Zasa, R. (1998). Students' perceptions of literacy learning in a project based curriculum. In E. G. Stutevant, \& J. Dugan (Eds.). Literacy and community: The twentieth yearbook: A peer reviewed publication of the College Reading Association, (pp. 94-100). Carrollton, GA: Beacon.

Ruiz, E., Hernández, F. y Ureña, F. (2008). Evaluación y calidad del aprendizaje en Educación Superior. Murcia: Diego Marín Librero Editor.

Tait, H., Entwistle, N. y McCune, V. (1998). ASSIST: A reconceptualization of the approaches to Studying Inventory. En C. Rust (Ed) Improving Student Learning: Improving students as learners Oxford: Oxford Brookes University. The Oxford Centre for Staff y Learning Development.

Thomas, J. W., Mergendoller, J. R., and Michaelson, A. (1999). Project-based learning: A handbook for middle and high school teachers. Novato, CA: The Buck Institute for Education.

Tippelt, R. y Lindemann, H. (2001). El método de proyectos. Descargado de: http://cmapspublic.ihmc.us/rid=1KFJWWJ3B-11D27DY-1P5D/metodo\%20proyectos.pdf [06/06/2014]

Tretten, R. \& Zachariou, P. (1995). Learning about project-based learning: Self-assessment preliminary report of results. San Rafael, CA: The Autodesk Foundation.

Valle, A., González, R., Núñez, J. C., Suárez, J. M., Piñeiro, I. y Rodríguez, I. (2000). Enfoques de aprendizaje en estudiantes universitarios. Psicothema, 12, 368-375.

Vermunt, J. D. (1996). Metacognitive, cognitive y affective aspects of learning styles y strategies: A phenomenographic analysis. Higher Education, 31, 25-50. 


\title{
DYAGATS-demo una herramienta para entender visualmente los comportamientos transitorios
}

\section{Joaquín Izquierdo ${ }^{a}$ y Francisco J. Izquierdo ${ }^{a}$}

${ }^{a}$ FluIng-Instituto de Matemática Multidisciplinar - Universitat Politècnica de València.

\begin{abstract}
Transients are among the most difficult physical concepts for students to understand. In general, transient phenomena are described by systems of partial differential equations, frequently nonlinear, whose analytical solution is complex or simply impossible. In addition, the boundary conditions are described by constitutive equations that can also be expressed by complex systems of algebraic and differential equations. The third point, which makes it difficult the understanding of transient behaviors, lies in the need to jointly solve all these equations so that the solution is interpretable and usable. In this paper we present an interactive tool that allows the user to vary the basic parameters that describe certain transients, and experiment with various boundary conditions. We describe its basic operation and present examples that allow a quick insight into the specific behavior of certain transients. The use of this tool will provide the user with essential competences for understanding and interpreting transients, a starting point for managerial competencies on systems where transient phenomena are of importance. The tool can be freely downloaded from a website maintained by the authors.
\end{abstract}

Keywords: Transient phenomena, boundary conditions, constitutive equations, visualization

\footnotetext{
Resumen

Los fenómenos transitorios son algunos de los conceptos físicos de más difícil comprensión por parte de los estudiantes. En general, son descritos por sistemas de ecuaciones en derivadas parciales, con frecuencia no lineales, cuya resolución por métodos analíticos es compleja o, simplemente, imposible. Además, las condiciones de contorno del problema son descritas por ecuaciones constitutivas que también pueden expresarse mediante
} 
complejos sistemas de ecuaciones algebraico-diferenciales. El tercer punto, que hace difícil el entendimiento del fenómeno, radica en la necesidad de resolver conjuntamente las ecuaciones diferenciales y las ecuaciones constitutivas de forma tal que la solución sea interpretable y utilizable. En este artículo presentamos una herramienta interactiva que permite al usuario variar los parámetros fundamentales que describen ciertos fenómenos transitorios así como experimentar con condiciones de contorno diversas. Describimos su funcionamiento básico y presentamos ejemplos que permiten una rápida introspección en el comportamiento específico de ciertos transitorios. El uso de esta herramienta proporcionará al usuario competencias imprescindibles para la compresión e interpretación de los fenómenos transitorios, punto de partida para una capacidad competencial en la gestión de sistemas donde los transitorios son fenómenos de importancia. La herramienta puede ser libremente bajada de una página de internet mantenida por los autores.

Palabras clave: Fenómenos transitorios, condiciones de contorno, ecuaciones constitutivas, visualización

\section{Introducción}

Los estados transitorios se crean en cualquier entorno sometido a evolución temporal, por ejemplo en las instalaciones eléctricas e hidráulicas, en el tráfico rodado, etc., por perturbaciones que sobrevienen de manera programada o imprevista en uno o varios de sus puntos, y que pueden llevar al sistema a puntos alejados de su punto de diseño. Especialmente los transitorios rápidos, pueden dar lugar a efectos indeseables que conviene prever para evitar sus efectos, a veces de proporciones desastrosas.

Los elementos que integran tales sistemas tienen comportamientos específicos, no necesariamente autónomos y, además, interactúan entre sí, en parte de manera predefinida, de acuerdo a sus parámetros específicos de diseño. Sin embargo, la aparición en el entorno de estados fuera del punto de diseño hace que el comportamiento de tales elementos quede condicionado por sucesiones de eventos ante los que se debe reaccionar o responder adecuadamente.

Los gestores de tales entornos son responsables de la integridad de los sistemas que gestionan, ya que su fallo puede provocar irregularidades en el entorno que, con frecuencia, son inaceptables o incluso irreversibles. Como consecuencia, necesitan competencias adecuadas que les habiliten para entenderlos y saber cómo controlarlos. 
La importancia de una comprensión adecuada de los comportamientos transitorios, especialmente los denominados transitorios rápidos, es esencial en el diseño de tales entornos de modo que proporcionen de manera eficiente y sin fallos inadmisibles la funcionalidad para la que están previstos.

Dada su complejidad, los conceptos transitorios han presentado tradicionalmente dificultades de comprensión importantes para los estudiantes. Las razones son diversas y se describen en el apartado 3, tras presentar los objetivos en el apartado 2. La sección 4 presenta ejemplos y resultados, y el artículo se cierra con la sección 5 dedicada a las conclusiones.

\section{Objetivos}

Dado el objetivo introductorio de esta contribución, nos centramos en el caso de una onda que se propaga en un espacio unidimensional. La onda se propaga a cierta velocidad característica del medio en el que viaja. La expresión clásica $\xi=f(x-a t)$ representa una tal onda que se propaga en el sentido positivo del eje de abscisas a velocidad $a$. Si $f(x)$ es una expresión que representa cierta perturbación, la misma expresión $f$, pero sustituyendo $x$ por $x-b$, representa una perturbación de idéntica forma pero desplazada sobre el eje positivo de abscisas una distancia $b$ (ver Figura 1). Análogamente, $f(x+b)$ representa la misma perturbación desplazada en sentido negativo sobre el eje horizontal una distancia $b$. Es decir, la forma de la perturbación original se transmite haciendo fluir la información en cualquier dirección, en general; ver, por ejemplo el capítulo 3 de (Abreu et al. 1995).

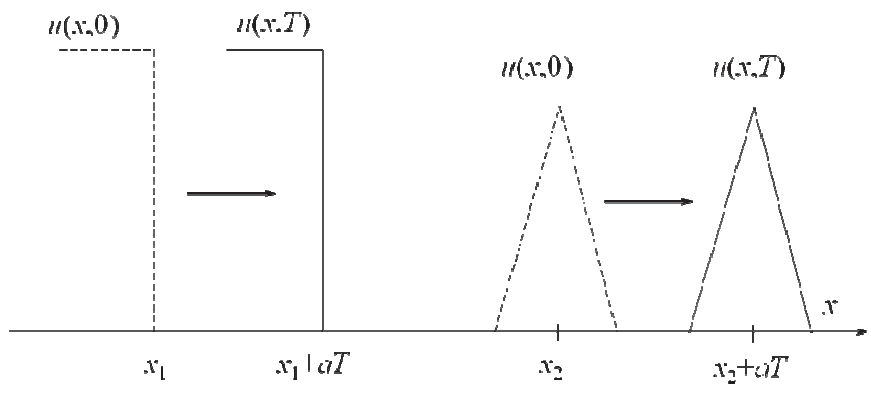

Fig. 1 Transmisión de información mediante ondas unidimensionales

Desde que von Riemann (von Riemann, 1869) obtuvo la solución de la ecuación de ondas,

$$
u_{t t}-a^{2} u_{x x}=\left(u_{t}+a u_{x}\right)\left(u_{t}-a u_{x}\right)=0,
$$

\section{(cc) EY-NC-ND 2014, Universitat Politècnica de València}

I Jornadas IN-RED (2014) 
donde los subíndices expresan derivadas parciales respecto a tiempo y espacio, sobreponiendo las soluciones portadas por dos ondas viajeras,

$$
u(x, t)=F(x+a t)+f(x-a t)
$$

es perfectamente conocido en el estudio de los transitorios, que la transmisión de perturbaciones es un fenómeno de transmisión de información, es decir, un fenómeno de comunicación. Dada la información correspondiente a un estado inestable de partida del sistema, posiblemente creado por una perturbación acaecida, - una condición inicial -, es posible construir su evolución futura a través de las llamadas líneas características (hipersuperficies características, en general) simplemente transmitiendo información.

El objetivo general de esta contribución es

- proporcionar al alumno una herramienta con la que visualizar tal transmisión de información, de manera que mejore su comprensión de los fenómenos y comportamientos transitorios.

Como objetivos específicos podemos citar:

- Reconocer los parámetros básicos que gobiernan la transmisión de información en los fenómenos transitorios.

- Utilizar tales parámetros para visualizar distintos tipos de transmisión de información.

- Utilizar tales parámetros para reproducir situaciones de cambios de distinta entidad en un sistema.

- Observar el comportamiento de los dispositivos presentes en el sistema respecto de las perturbaciones: generadores, transmisores, amortiguadores, etc.

\section{Desarrollo de la innovación}

En primer lugar presentamos algunas ideas que proporcionan una idea de la magnitud de la dificultad en la simulación de transitorios. Para ello, repasamos los elementos que permiten tal simulación. Concretamente, en la sección 3.1 presentamos de manera somera un ejemplo del tipo de ecuaciones que aparecen en las aplicaciones. En el apartado 3.2 proporcionamos un ejemplo significativo de la dificultad en la modelación de algunos dispositivos presentes en las instalaciones. Por concretar ideas, nos centramos en el caso específico de los transitorios hidráulicos en sistemas a presión. Finalmente, presentamos la herramienta y la solución visual que aporta. 


\subsection{La modelación del fenómeno transitorio}

Los efectos transitorios puros, es decir, la transmisión de perturbaciones en entornos abiertos (una línea sin extremos, por ejemplo), se describen, en general, mediante sistemas de ecuaciones en derivadas parciales, con frecuencia no lineales, cuya solución analítica es muy compleja o simplemente inviable, por lo que se necesitan métodos computacionales potentes (Abreu et al., 1999).

Por ejemplo, los transitorios hidráulicos en sistemas a presión vienen descritos por las ecuaciones de continuidad y de movimiento. Por simplicidad, nos restringimos aquí al caso de flujo unidimensional, como hemos comentado, dentro de una línea constituida por un tubo cilíndrico. El fenómeno en la línea se describe en términos de dos variables dependientes, la altura piezométrica, $H(t, x)$, y la velocidad del fluido, $V(t, x)$, (Abreu et al., 1995; Chaudhry, 1986; Wylie and Streeter, 1993). Las ecuaciones de continuidad y de movimiento constituyen un sistema de ecuaciones en derivadas parciales de primer orden que, utilizando notación matricial (Izquierdo et al., 2004) se puede escribir

$$
\left(\begin{array}{l}
H \\
V
\end{array}\right)_{t}+A(V)\left(\begin{array}{l}
H \\
V
\end{array}\right)_{x}=B(V)
$$

Donde, de nuevo, los subíndices $t$ y $x$ representan derivadas parciales respecto a tiempo y espacio, respectivamente, $\mathrm{y}$

$$
A(V)=\left(\begin{array}{cc}
V & a^{2} / g \\
g & V
\end{array}\right), B(V)=\left(\begin{array}{c}
-V \sin \theta \\
-f V|V| /(2 D)
\end{array}\right) .
$$

La celeridad o velocidad de propagación de las ondas en el medio, $a$, la fricción, $f$, el diámetro, $D$, y la pendiente, $\theta$, son parámetros del tubo, constantes en el tiempo. Estos parámetros, sin embargo, pueden ser distintos para cada tubo. Finalmente, $g$ es la constante de la gravedad.

La expresión (1) es un sistema de EDPs no lineal e hiperbólico, ya que la matriz $A(V)$ tiene valores propios reales simples para cada $V$. En efecto, la ecuación característica de $A(V)$ es $(V-\lambda)^{2}-a^{2}=0$, con raíces $\lambda=V \pm a$ reales distintas, teniendo en cuenta que $a$ es al menos un orden de magnitud superior a $V$ en los sistemas hidráulicos a presión.

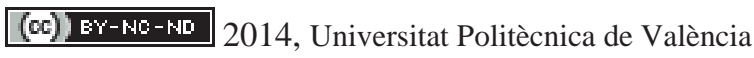

I Jornadas IN-RED (2014) 
El sistema (1) no es más que una representación, para los sistemas hidráulicos a presión, de la denominada ecuación de ondas (con pérdidas) que gobierna, en general, el comportamiento de las perturbaciones a través del sistema correspondiente. Sin embargo, otros elementos del sistema situados en los nodos, que sirven de unión o conexión a las distintas líneas, son también partes constitutivas de gran importancia en el sistema. Damos unas breves consideraciones en el siguiente apartado.

\subsection{La modelación de los elementos del sistema}

Las ecuaciones (de onda) gobiernan la transmisión de las perturbaciones. Sin embargo, otros elementos situados en el sistema (por ejemplo, en los extremos de las líneas) exhiben comportamientos variados (generan, transmiten, absorben, etc. las perturbaciones) descritos, a su vez, por sistemas de ecuaciones que varían desde simples relaciones algebraicas hasta complicados sistemas de ecuaciones algebraico-diferenciales cuya solución puede ser también muy compleja.

Por ejemplo (también dentro del campo de los sistemas hidráulicos a presión), el comportamiento de un grupo de bombeo puede ser modelado por el siguiente sistema de ecuaciones (Izquierdo e Iglesias, 2002).

- La ecuación de la energía requiere que la diferencia entre la altura piezométrica de descarga, $H_{d}$, y la de aspiración o succión, $H_{s}$, coincida con la diferencia entre la altura que proporciona la bomba, $\Delta H_{p}$, y la pérdida de altura, $\Delta H_{e}$, en los elementos resistivos del elemento: $H_{d}-H_{s}=\Delta H_{p}-\Delta H_{e}$.

- La pérdida viene caracterizada por $\Delta H_{e}=K_{e} Q|Q|$, donde $K_{e}=$ coeficiente total de pérdidas de los elementos resistivos.

- La altura dinámica de la bomba puede representarse (Chaudhry, 1987; Wylie and Streeter, 1993) por $\Delta H_{p}=H_{r} h=H_{r}\left(\alpha^{2}+q^{2}\right) f(\theta)$, donde $H_{\mathrm{r}}=$ altura de referencia, $\alpha=$ velocidad de rotación relativa de la bomba, definida por $\alpha=\omega / \omega_{r}$, siendo $\omega=$ velocidad de rotación de la bomba y $\omega_{r}=$ velocidad de rotación nominal de la bomba, $q=$ ratio entre $Q$ y $Q_{\mathrm{r}}=$ caudal de referencia, $\theta=\operatorname{atan} 2(\alpha / q)$, y $f(\theta)$ la curva adimensional de la altura de Suter (Marchal et al., 1965).

- La ecuación del par, $M=-I(\mathrm{~d} \omega / \mathrm{d} t)$, tras ser integrada utilizando una aproximación trapezoidal de segundo orden, y utilizando la curva adimensional del par de Suter, $\varphi(\theta)$, se puede escribir como $\lambda \alpha+\left(\alpha^{2}+q^{2}\right) \varphi(\theta)+V=0$, donde $\lambda=\left(2 I \omega_{\mathrm{r}}\right) /\left(M_{\mathrm{r}} \Delta t\right)$, siendo $I=$ inercia conjunta del propulsor, el fluido en el rodete y el propio rodete de la bomba, $M_{\mathrm{r}}=$ par de referencia, $\Delta t=$ intervalo temporal utilizado en el método numérico, y $V=$ una constante que aparece al integrar y que depende de $\lambda, \alpha$ y $M_{\mathrm{r}}$.

(c) EY-NC-ND 2014, Universitat Politècnica de València

I Jornadas IN-RED (2014) 
Este sistema de ecuaciones es claramente no lineal. Su solución, utilizando, por ejemplo, el método de Newton-Raphson, precisa de una representación diferenciable de las curvas de Suter. Ya que estas curvas vienen dadas en la literatura por puntos, es preciso utilizar una técnica, como los splines cúbicos, por ejemplo, para obtener expresiones diferenciables para las curvas. Este no es más que un ejemplo del conjunto de dificultades a superar en la simulación de transitorios.

Finalmente, la solución conjunta se debe realizar mediante simulación utilizando métodos computacionales que deben armonizar y sincronizar el comportamiento de perturbaciones y acciones de los elementos del sistema; ver (Abreu et al. 1995).

\subsection{DYAGATS-demo, la herramienta}

DYAGATS es el acrónimo de 'Diseño Y Análisis del Golpe de Ariete en Tubería Simple'. La versión profesional de este programa permite modelar fenómenos transitorios en tuberías a presión. Además, incluye, por tanto, la simulación de los elementos adecuados de protección, su ubicación y su comportamiento. Cuidadosamente diseñados, tales elementos consiguen mantener segura en todo momento la instalación. La simulación mediante ordenador de tales dispositivos y sus comportamientos, aunque sin pretender sustituir a la capacidad de diseño y de solución de problemas del ingeniero, es una herramienta insustituible para la elaboración del esquema de protección antiariete más adecuado.

Las características principales de la herramienta son:

- Edición gráfica en pantalla

- Combinación de diferentes elementos y dispositivos de protección

- Estudio de tuberías de topología y características no uniformes

- Cálculo del régimen permanente y de la evolución del transitorio

- Asistentes de cálculo para variables hidráulicas

- Bases de datos de elementos comerciales

Además Dyagats 2.0 es extremadamente versátil en el tratamiento de los resultados y permite

- Animación gráfica de la evolución del transitorio y presentación numérica del mismo

- Creación de informes y gráficos profesionales

- Compatibilidad de formatos con MS Excel® que permite la personalización de gráficas e informes numéricos

DYAGATS-demo hereda la mayoría de estas características, aunque restringe algunas de sus capacidades. Dado su objetivo, las dimensiones del sistema a estudiar están limitadas a

\section{(c)) EY-NC-ND 2014, Universitat Politècnica de València}

I Jornadas IN-RED (2014) 
dos tramos de tubería con sus respectivos tres elementos situados en sus extremos. Por otra parte, la creación de informes y la compatibilidad con MS Excel están también inhibidas.

Describimos de manera breve, a continuación la herramienta, que puede descargarse desde el sitio: http://fluing.upv.es/formulario.php. Al rellenar el formulario hay que seleccionar Dyagats marcando el radio button correspondiente.

\subsubsection{Entrada de datos}

Se realiza a través de un interfaz gráfico de edición y tratamiento de datos. Basta pinchar el botón correspondiente en la barra de herramientas de dispositivos y soltar el dispositivo elegido en la ubicación deseada sobre la pantalla gráfica a escala. Se utilizan métodos de trabajo estándar de Windows que hacen simple el manejo de la herramienta.

\subsubsection{Asistentes de cálculo}

Para utilizar la herramienta no se requiere el conocimiento de complicadas fórmulas hidráulicas. Todos aquellos datos que requieren de ayuda en su obtención disponen de algún asistente de cálculo.

\subsection{3. $\quad$ Bases de Datos}

Con la herramienta se puede introducir datos reales ya que dispone de bases de datos facilitados por fabricantes con productos disponibles en el mercado español.

\subsubsection{Cálculo}

DYAGATS utiliza el Método de las Características (MC) para el tratamiento de las complejas ecuaciones que describen los transitorios. El MC ha probado ser superior a todos los demás métodos de cálculo: es sencillo de programar, computacionalmente eficiente y permite capturar frentes de onda abruptos mejor que los demás métodos, ilustrando perfectamente la propagación de las ondas. El comportamiento de los dispositivos ha sido modelado utilizando técnicas numéricas potentes. Así es posible integrar un amplio número de dispositivos y combinaciones de ellos que hacen la simulación más real.

\subsubsection{Presentación de resultados}


En el desarrollo de la herramienta ha sido clave la idea de que los resultados se entienden mejor de manera gráfica. Se puede ver la animación de un transitorio mientras se realiza el cálculo, que se puede detener en cualquier momento. Se pueden modificar parámetros, y volver de nuevo al cálculo en las nuevas condiciones. Esta es la característica clave a la que este artículo se refiere.

\subsubsection{Otros (editores de tablas y de gráficos)}

Es posible importar o exportar hojas de MS Excel® que contengan las características de los dispositivos, el perfil detallado de la instalación o los últimos datos reales obtenidos. La salida gráfica de DYAGATS presenta múltiples posibilidades, pudiendo elegirse el aspecto que mejor se adapte al objetivo actual.

\section{Ejemplos y Resultados}

En este apartado presentamos una propuesta en forma de tutorial de tareas a realizar por el usuario de la herramienta mediante un conjunto de ejemplos específicos que le oriente en el camino hacia una rápida adquisición de las competencias y objetivos anunciados.

\subsection{Creación de un entorno básico para ondas viajeras}

Este primer ejemplo se desarrolla con todo detalle para introducir al usuario en el manejo general de la herramienta.

- Abra la aplicación, elegir un archivo nuevo y aceptar los valores propuestos para la escala (en ejemplos más avanzados el usuario podrá modificarla a discreción).

- Ubique un depósito (pinchar sobre el botón indicado en la Figura 2 y soltarlo) en la posición $(0,0)$, y ubique una válvula (pinchando y soltando) sobre la posición $(1000,0)$. Automáticamente se crea una línea entre ambos dispositivos.

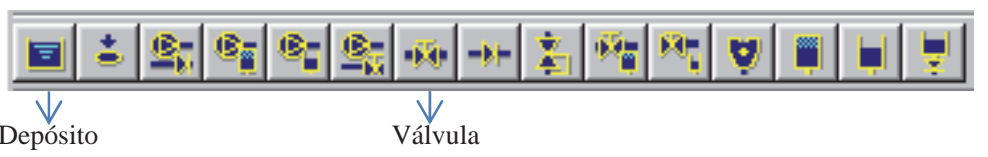

Fig. 2 Barra de herramienta de dispositivos

- Dobleclique sobre la línea y elegir sus propiedades: Longitud $=1000 \mathrm{~m}$ (ya asignada); diámetro $=0,25 \mathrm{~m}$ y celeridad $=500 \mathrm{~m} / \mathrm{seg}$.

- Dobleclique en el depósito, elija las propiedades de depósito y válvula, y acepte:

○ depósito (Nudo 1): Nivel $=21 \mathrm{~m}$

\section{(cc) EY-NC-ND 2014, Universitat Politècnica de València}

I Jornadas IN-RED (2014) 
- válvula (Nudo 2), como en la Figura 3. Una válvula teórica del diámetro de la tubería, con un coeficiente Kvo (característica de la válvula) realiza una operación dada por los tiempos y los grados de apertura definidos.

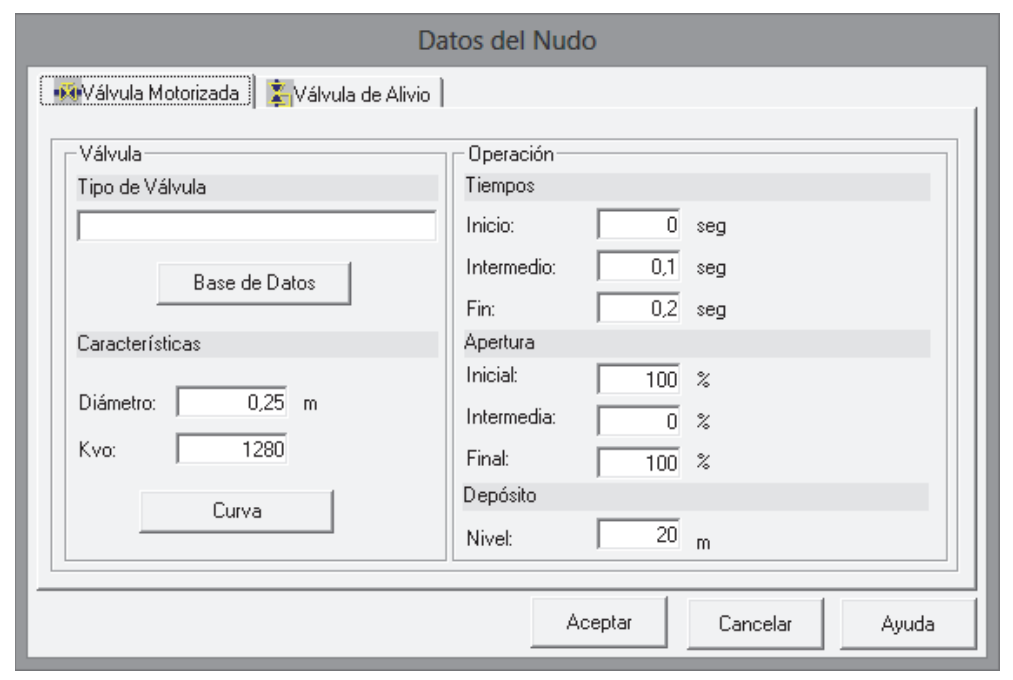

Fig. 3 Datos de la válvula que provoca la perturbación

- Calcule el régimen permanente, que es la condición inicial para este transitorio,

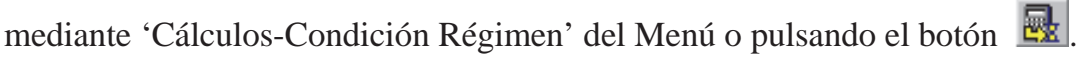

- Vea ahora la perturbación mediante 'Cálculos-Transitorio-Cálculo de Transitorio' o pulsando el botón 撕. Aparece una pantalla de menor tamaño donde se visualiza el transitorio. Clique en 'Inicio' y pulse el botón '-' repetidamente hasta conseguir que el intervalo temporal sea de $0,2 \mathrm{~s}$ y el número de puntos de cálculo de 101.

- Pulse 'Aceptar' y observe la onda, generada por la operación de la válvula, propagarse hacia el depósito para reflejarse en él y volver de nuevo hacia la válvula, de manera indefinida ${ }^{1}$.

- Utilizando el mismo ejemplo base, realice los siguientes experimentos:

- Cambie los tiempos de operación de la válvula y los grados de apertura. Por ejemplo, ponga el tiempo 'Fin:' a $0.5 \mathrm{seg}$ y observe cómo ahora la onda no es simétrica.

\footnotetext{
${ }^{1}$ La amplitud de la onda disminuye en este caso debido al fenómeno de la turbulencia y de la rugosidad del tubo (si se ha introducido algún valor no nulo).
} 
- Programe ahora un cierre de válvula (pasando el grado de apertura de 100 a algún valor intermedio y finalmente a 0 ). Consiga que la línea de máximos no supere los $40 \mathrm{~m}$ en ningún punto de la tubería.

- Cambie la celeridad de la tubería y observe los efectos sobre la velocidad de propagación de la onda y sobre el tamaño de la perturbación para una misma operación.

\subsection{Incrementando la complejidad}

Partiendo del ejemplo básico anterior realice las siguientes tareas. En este caso, comprobará cómo la transmisión de la información se produce de maneras distintas cuando las propiedades del medio cambian.

- Introduzca un nodo intermedio (clicando en \pm y soltándolo) en la posición $(500,0)$. Ahora tiene dos tramos de tubería que han heredado las propiedades de la anterior ${ }^{2}$. Continúe con los dos subapartados siguientes.

4.2.1. Variando las propiedades de las líneas

- Dobleclique sobre la tubería y modifique alguno de sus datos. Por ejemplo, simplemente cambie la celeridad de cualquiera de ellas (de manera que ambos tramos tengan valores distintos, obviamente). También puede modificar el diámetro. Nota: sea razonable en los valores que introduce.

- En cualquiera de los casos calcule el Régimen 聂 primero y el Transitorio 瞖 después, como se ha detallado en el ejemplo base. Observe todo lo que ocurra y trate de entender los distintos comportamientos observados.

4.2.2. Variando el tipo de dispositivo intermedio

- Dobleclique en el nudo intermedio y elija, en 'Tipo de Nudo', 'Rotura', por ejemplo. Clique el botón 'Datos del Nudo' y dé un valor de 10000, por ejemplo, a la ' $\mathrm{K}$ de pérdidas'. Para ver el efecto aislado de la rotura de una tubería, haga que la válvula del Nudo 3 no opere durante la simulación; para ello, basta, por ejemplo, hacer que todo el tiempo su grado de apertura sea del 100\%. Visualice ahora el transitorio. Recuerde: primero Régimen y luego Transitorio. Pruebe con otros valores de la $\mathrm{K}$.

\footnotetext{
2 Observe que esta demo no permite introducir ya más nodos ni otros dispositivos intermedios. La versión profesional del programa sí tiene esta opción habilitada.
}

(c)) EY-NC-ND 2014, Universitat Politècnica de València

I Jornadas IN-RED (2014) 
- Sustituya 'Rotura' por 'Chimenea'. En 'Datos del Nudo' elija un valor para la 'Sección' de la chimenea. Visualice de nuevo. Observe cómo este dispositivo se convierte en un amortiguador de las perturbaciones. Es uno de los dispositivos de protección utilizados en algunas instalaciones hidráulicas.

- Si tiene familiaridad con otras clases de dispositivos, juegue con ellos y sus propiedades.

\subsection{Problemas reales sobre transitorios hidráulicos}

En el sitio http://fluing.upv.es/dyagats.php, encontrará también un enlace denominado 'ejemplos documentados', donde se pueden descargar un conjunto de problemas de interés en el campo de la Hidráulica a presión. Específicamente, los problemas que se plantean son los siguientes.

- Cierre de Válvula. Se trata de un ejemplo muy desarrollado que no solo constituye una introducción rápida a las posibilidades del programa, sino que también presenta ciertos hechos de importancia relacionados con uno de los transitorios más habituales en una instalación hidráulica. Siga este ejemplo antes de trabajar con los demás, ya que en los demás hay referencias continuas a acciones, opciones y elementos de trabajo que solo aparecen en este primer ejemplo.

- Parada de grupo de bombeo. Es un ejemplo del otro tipo de transitorio más habitual en las instalaciones hidráulicas: la parada del grupo de bombeo por caída de la corriente eléctrica. Para el proyecto de una instalación específica se discuten un conjunto de posibilidades encaminadas a la determinación de la estrategia de protección antiariete más adecuada.

- El papel de la inercia en un grupo de bombeo. Se valora cómo la inercia del grupo de bombeo es un parámetro esencial en la parada del grupo y cómo distintas impulsiones necesitan de tratamientos distintos.

- Protección de una impulsión. Este caso, planteado por un usuario del programa hace unos años, describe un procedimiento de optimización de la estrategia de protección de una impulsión mediante la utilización sinérgica de dos dispositivos de protección.

\section{Conclusiones}

El estudio de los transitorios presenta una dificultad adicional respecto de los fenómenos estacionarios, al añadirse el tiempo como variable independiente. Como consecuencia, los fenómenos transitorios presentan dificultades añadidas para los estudiantes y también para los gestores de instalaciones y entornos donde tales efectos son relevantes. Entender el 
concepto de transitorio es, sin embargo, sencillo si se realiza de manera adecuada. En este artículo hemos presentado una herramienta visual que, restringida básicamente al campo de la Hidráulica a presión, permite al usuario visualizar y, por tanto, entender de manera más firme las bases de los transitorios.

Utilizando esta herramienta, que abre al usuario un amplísimo abanico de posibilidades de uso y experimentación, se sientan las bases para la adquisición de una serie de competencias que pueden considerarse el punto de partida para la meta de una carrera que consiste en la capacidad de toma de decisiones respecto a los comportamientos transitorios en entornos e instalaciones profesionales.

Hasta la fecha, son muchos los usuarios de la herramienta profesional denominada DYAGATS (más de 400 licencias de uso distribuidas por España y Latinoamérica, básicamente). Se trata de profesionales de la Hidráulica urbana en Consultorías y Asesorías técnicas, en Departamentos técnicos de gobiernos de distinto nivel, etc., que la utilizan a diario como sistema de apoyo a la decisión. Este artículo pretende poner de manifiesto su utilidad también en campo educacional, mientras no renuncia a presentar la potencia de dicha herramienta.

\section{Referencias}

Abreu, J.M., Guarga, R. e Izquierdo, J. (Eds.) (1995). Transitorios y oscilaciones en sistemas hidráulicos a presión. Universidad de Coímbra, Universidad Politécnica de Valencia y Universidad de la República Oriental del Uruguay.

Abreu, J, Cabrera, E., Izquierdo, J y García-Serra, J. (1999). "Flow modeling in pressurized systems revisited" en Journal of Hydraulic Engineering 125(11), 1154-1169.

Chaudhry, M.H. (1986). Applied Hydraulic Transients. New York: Van Nostram Reinhold.

IzQuierdo, J. e Iglesias, P.L. (2002). "Mathematical Modeling of Hydraulic Transients in Simple Systems" en Mathematical and Computer Modeling 35(7), 801-812.

IzQUiERDo, J. e IGLESIAS, P.L. (2004). "Mathematical Modeling of Hydraulic Transients in Complex Systems" en Mathematical and Computer Modeling 39(4-5), 529-540.

MARChAL, M., Flesh, G. y Suter, P. (1965). "The calculation of Waterhammer problems by means of digital computer" en Proceedings International Symposium on Water hammer in pumped storage projects, ASME, 168-188.

von Riemann, B. (1869). Partielle Differentailgleichungen. Ed. Braunwnschweig.

WyLie, E.B. y Streeter, V.L. (1993). Fluid Transients in Systems. Englewood Cliffs, N.J., Prentice Hall.

\section{(c) EY-NC-ND 2014, Universitat Politècnica de València}

I Jornadas IN-RED (2014) 


\title{
Implementación y evaluación del uso de metodologías no tradicionales en el aprendizaje de Ciencia de Materiales
}

\author{
Sahuquillo, O. ${ }^{\text {a }}$, Sonseca, A. ${ }^{\text {b }}$, Giménez, E. \\ Departamento de Ingeniería Mecánica y de Materiales \\ Universitat Politècnica de Valencia, Camino de Vera s/n, 46022, Valencia \\ Email: aossana@upvnet.upv.es, ${ }^{b}$ agsonol@posgrado.upv.es, ${ }^{c}$ enrique.gimenez@mcm.upv.es
}

\begin{abstract}
This paper focused on the implementation of methodologies based on information and communication technologies (ICT) and active methodologies, for the results evaluation obtained in the $2^{\text {nd }}$ year Materials Science course of the Chemical Engineering Degree. The methodology has focused on development of active student learning outside the classroom through the implementation of online tasks resolution as part of formative assessment and also the use in the classroom of active group activities, using Aronson's puzzle.

The developed innovation has resulted to an increased level of participation of the student in the individual proposed tasks outside the classroom, reaching values of $91 \%$. These activities have resulted a higher percentage of students passed compared to the previous year. Likewise, the group dynamic carried out in the laboratory classes has been well received by students, improving the student's performance.
\end{abstract}

Keywords: motivation, continous evaluation, ICT, Aronson's puzzle

\footnotetext{
Resumen

El presente trabajo se centra en la implementación de metodologías basadas en tecnologías de la información y telecomunicación (TIC) y de metodologías activas, para la evaluación de los resultados obtenidos en la asignatura de segundo curso Ciencia de Materiales del Grado en Ingeniería Química. La
}

\section{(c) EY-NC-ND 2014, Universitat Politècnica de València}

I Jornadas In-Red (2014) 
Implementación y evaluación del uso de metodologías no tradicionales en el aprendizaje de Ciencia de Materiales

metodología empleada se ha focalizado en potenciar el aprendizaje activo de los alumnos fuera del aula, a través de la implementación de tareas de resolución online como parte de la evaluación formativa y la utilización de dinámicas de grupo activas en el aula, utilizando la técnica del puzle de Aronson.

La innovación desarrollada se ha traducido en un incremento del nivel de participación por parte del alumno en las tareas propuestas fuera del aula como trabajo autónomo, alcanzando valores de participación del 91\%. Estas actividades han dado lugar a un mayor porcentaje de aprobados respecto al curso anterior. Asimismo, la dinámica de grupo realizada en las prácticas de laboratorio ha tenido una buena aceptación por el alumnado, mejorando el rendimiento de los alumnos.

Palabras clave: motivación, evaluación continua, TIC, puzle de Aronson

\section{Introducción}

El Espacio Europeo en Educación Superior es una iniciativa de la Unión Europea para el desarrollo del proceso de convergencia educativa (Zabalza, 2008), y surge como compromiso ante la necesidad de cambio en el sistema de educación superior. Propiciando un cambio en la filosofía del proceso de enseñanza del sistema educativo empleado hasta ahora. Con el consecuente cambio de mentalidad en el sistema educativo de educación superior, situando al estudiante en el centro del proceso de enseñanza-aprendizaje (Bain, 2007). Esto ha supuesto, por tanto, un proceso de adaptación progresivo tanto en la sistemática metodológica utilizada, donde el uso de las tecnologías de la información y telecomunicación (TIC) han ido ganando relevancia, así como en la actividad a desarrollar por los protagonistas del proceso enseñanza-aprendizaje. Redefiniendo los roles de profesores y alumnos, y siempre sin perder de vista al alumno como principal protagonista y organizador de su propio proceso de aprendizaje. En un proceso donde el alumno debe de aprender a aprender, guidado por la figura del profesor que debe retroalimentarle a lo largo del proceso (Díaz-Barriga, 2002; Vanhoof 2005).

Desde el inicio de la implantación progresiva de los nuevos grados dentro del marco de la convergencia europea, el presente curso se ha completado el establecimiento total del nuevo plan de estudios de las titulaciones de grado. La revisión y análisis de la metodología y resultados de las asignaturas lleva a detectar aspectos susceptibles de mejora y con ello la posibilidad de plantear innovaciones. En este sentido por ejemplo, la falta de motivación por parte del alumnado en la materia, puede llevar a plantear nuevas formas metodológicas para abordarla, por ejemplo, el uso de las TIC, como herramienta útil de apoyo en 
el aprendizaje (Ferrero, 2009), o la utilización de metodologías activas de trabajo grupal como la técnica del Puzle de Aronson (Martínez, 2010;Traver, 2004). En ese sentido, el trabajo plantea la adaptación de parte del trabajo a realizar por el alumno de forma autónoma, aprovechando la oportunidad que brindan las tecnologías de comunicación y las dinámicas activas, con el objeto de mantener la asignatura, tras varios años activa en el grado, en una dinámica de revisión y readadptación. Reajustándola de acuerdo a las necesidades y lo que es más importante a mantener al alumnado motivado por la misma y contribuir a su aprendizaje autónomo. De ahí que se plantee el evaluar la bondad de las TIC, con la readaptación de lo planteado hasta la fecha como trabajo no presencial a la manera tradicional, determinando el grado de aceptación por los alumnos y los resultados obtenidos. Asumiendo metodologías o herramientas que aunque disponibles, no se habían explorado dentro de este proceso de readaptación del material a la nuevas tecnologías de comunicación, buscando mejorar el rendimiento de los alumnos y valorar el potencial de la metodología para el aprendizaje.

\section{Objetivos}

La presente innovación docente en la asignatura Ciencia de Materiales plantea como objetivo general: mejorar el nivel de aprendizaje y de rendimiento en la asignatura Ciencia de Materiales por parte de los estudiantes, para que las metodologías empleadas les sirvan de ayuda en la preparación, el estudio y el aprendizaje continuo de la asignatura.

En base al objetivo general planteado, se definen una serie de objetivos parciales, que pasan por implementar actividades online para fomentar el aprendizaje continuo y profundo de los alumnos, a partir de la resolución de problemas como parte del trabajo autónomo del alumno. Experimentar el uso de una técnica de trabajo colaborativo, para la realización de la introducción a la sesión de prácticas, haciéndoles participes y protagonistas de la misma, mediante el uso de la técnica del puzle de Aronson. Buscando con todo ello trabajar la motivación de los estudiantes en los trabajos y tareas no presenciales asociados a la asignatura.

\section{Desarrollo de la innovación}

La asignatura de Ciencia de Materiales en el Grado de Ingeniería Química es una asignatura de carácter obligatorio de $2^{\circ}$ curso, teniendo asignados 4.5 créditos. Desde la implantación del nuevo título de Grado de Ingeniería Química en la Escuela Técnica Superior de Ingenieros Industriales (E.T.S.I.I.) de la Universitat Politècnica de València (UPV) han transcurrido cuatro años, habiéndose impartido hasta la actualidad durante tres cursos.

\section{(cc) EY-NC-ND 2014, Universitat Politècnica de València}


Implementación y evaluación del uso de metodologías no tradicionales en el aprendizaje de Ciencia de Materiales

La Ciencia de Materiales se considera una asignatura de fundamentos y por tanto tiene carácter descriptivo. Se centra fundamentalmente en las distintas familias de materiales y en su relación con las propiedades macroscópicas y microestructurales que presentan. Esto plantea al alumnado, de forma generalizada, dificultades en la comprensión de la materia, por esto se hace necesaria una revisión de algunos aspectos de la metodología docente empleada hasta el momento, de modo que pueda suponer una mejora del aprovechamiento del aprendizaje por parte de los estudiantes. Cabe destacar el papel fundamental que juega la evaluación continua en todo el proceso de aprendizaje, persiguiendo que el alumno consiga un aprendizaje de mayor profundidad en la materia.

En general, la medotodología empleada en la asignatura consiste en una parte expositiva y descriptiva de la materia, complementándose con las sesiones de prácticas y la resolución de problemas, parte de ellos en forma de entregables. Proponiendo problemas en clase para que los alumnos los entreguen individualmente de forma periódica durante el semestre, resolviéndolos en horas no presenciales y como parte del trabajo autónomo, siendo este trabajo voluntario y con una valoración del $5 \%$ sobre la nota final. En este contexto, y en base a la experiencia previa de cursos anteriores, se observó que los entregables de problemas sobre la materia, no resultaban una tarea atractiva para los estudiantes, a pesar de la importancia de la misma como entrenamiento y preparación para la resolución de problemas similares a los del examen de la asignatura y que tienen como objeto afianzar los conceptos de las asignatura.

Adicionalmente, la asignatura busca que los alumnos tengan cierto grado de autonomía a la hora de trabajar y asimilar la materia, aprender a aprender. En el curso actual, y a diferencia de los cursos previos, a modo de experiencia piloto se introdujo como principal cambio metodológico que los alumnos no presentarían memorias con los resultados de prácticas, aunque se les requería una preparación de las prácticas, que consistía en la lectura previa del guión de prácticas para conocer el trabajo a desarrollar en laboratorio, los resultados relevantes y las conclusiones a obtener. Previa a la realización de la práctica los alumnos tenían a su disposición online, a través de PoliformaT los guiones de prácticas a trabajar durante las sesiones, donde se recogen los objetivos, la metodología procedimental y un apartado de resultados y discusión de los mismos. Con respecto a esta tarea se observó que los estudiantes no mostraban interés por la preparación previa ni por el trabajo posterior derivado de las prácticas de laboratorio, a pesar de que el contenido de las prácticas se evaluaba posteriormente en dos exámenes presenciales que supone un $5 \%$ en la nota final.

Los dos aspectos detectados nos hicieron plantear innovaciones con dos concepciones diferentes: La primera de ellas de carácter preventivo, buscando comparado con cursos anteriores incrementar el nivel de participación en la tarea de los entregables de problemas, y con ello mejorar el aprendizaje de los alumnos y facilitar la preparación de la asignatura.

(c)) EY-NC-ND 2014, Universitat Politècnica de València

I Jornadas IN-RED (2014) 
La segunda con carácter correctivo en virtud dinámica observada en el presente curso, centrándose en la actitud de los alumnos y el bajo esfuerzo dedicado a la preparación de las prácticas de laboratorio. En este sentido se plantearon innovaciones para mejorar el rendimiento de los alumnos incluyendo en ambos casos, 1) resolución de problemas y 2) preparación previa de las prácticas, la incorporación de las TIC como metodologías activas en la docencia en la asignatura de Ciencia de Materiales. En el primer caso planteándolo como la herramienta online con la que realizar la tarea y en el caso de la preparación de las prácticas para obtener feedback por parte de los alumnos de la metodología activa y colaborativa usada en la introducción de la práctica.

1) En el caso de los entregables de problemas y aprovechando el potencial de las TIC sobre el aprendizaje, se replanteó la metodología de una actividad que ya se realizaba en curso anteriores. Consistente en la realización de un trabajo no presencial de entregables de problemas de la asignatura realizados a lo largo del cuatrimestre, esta vez planteado como pruebas online temporizadas de resolución voluntaria e individual, formando parte del trabajo no presencial de alumno y de su evaluación continua, y respecto a cursos anteriores sin variar su ponderación en la nota final. La resolución de problemas se planteará asociada a la finalización del tema de teoría relacionado. En total se plantearon cuatro ejercicios distribuidos a lo largo del cuatrimestre y implementados en la plataforma PoliformaT de la UPV, para posteriormente, evaluar y comparar los resultados del curso con cursos previos.

2) Ante la falta de interés y compromiso mostrada en la preparación de las primeras sesiones de prácticas, donde no leían los guiones de prácticas antes de las sesiones en el laboratorio y con el objetivo de que conocieran el contenido teórico y práctico del material suministrado, se diseña una parte introductoria a la sesión de laboratorio basada en trabajo colaborativo y con carácter activo, cediendo gran parte de la responsabilidad de la continuidad de la sesión a los alumnos; la técnica utilizada fue el puzle de Aronson. Con el objeto de que se responsabilizaran en una parcela concreta y elaboraran la introducción a la sesión de laboratorio, en lugar del profesor que lo realiza habitualmente. Teniendo en cuenta el número de experiencias de la sesión de prácticas, esta definiría el número de grupos de expertos y el número de miembros de cada grupo. De este modo, cada grupo base constaba de cuatro miembros, y cada uno de ellos intervendría en un grupo de expertos. $\mathrm{Al}$ ser la primera vez que se utilizaba, se planteó como una experiencia piloto. Analizando los resultados de las evaluaciones realizadas por los alumnos así como la retroalimentación suministrada por la respuesta voluntaria de los alumnos a un cuestionario online sobre la sesión a través de nueve preguntas, realizada a través de la herramienta Sondeos en PoliformaT.

\section{(c)) EY-NC-ND 2014, Universitat Politècnica de València}


Implementación y evaluación del uso de metodologías no tradicionales en el aprendizaje de Ciencia de Materiales

\section{Resultados}

En este apartado se presentan los resultados y la discusión de las evidencias de la innovación llevada a cabo en la asignatura. En concreto, las evidencias incluirán las calificaciones obtenidas por los alumnos, el nivel de participación de los alumnos en las tareas y la opinión de los alumnos recogida en la encuesta.

Comenzando con los entregables de problemas planteados para la resolución online, en primer lugar se analizará los datos obtenidos de participación del alumnado. En este sentido, la participación promedio de alumnos que han realizado los 4 ejercicios planteados ha sido 96 de un total de 106 alumnos, lo que supone un porcentaje de participación cercano al 91\%. En la Fig. 1, se recogen los datos de participación desde el inicio de la titualción de grado (GIQ), así como el del último curso de la antigua titulación de Ingeniería Química (IQ: 2010-11), por ser la predecesora de la asignatura del grado.

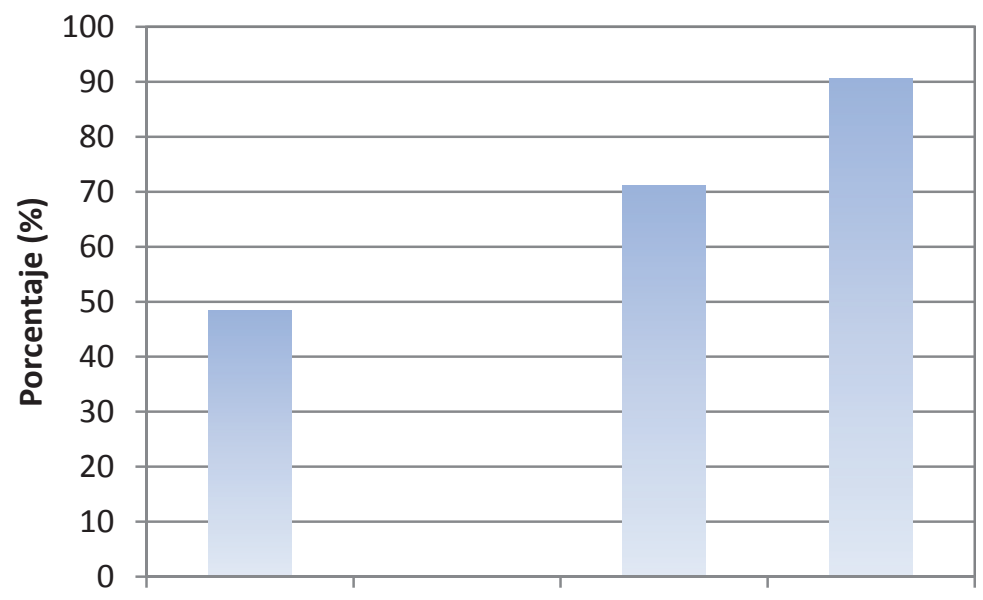

IQ: 2011-12 GIQ: 2011-12 GIQ: 2012-13 GIQ: 2013-14

Fig. 1 Participación de los alumnos en los entregables por curso

Como se puede comprobar la participación más alta se ha producido justamente en la titulación de grado del presente curso GIQ 2013-2014, cercano a un 20\% superior con respecto al curso anterior, teniendo en cuenta como se ha mencionado, que su participación es voluntaria y el bajo peso en la nota final, del 5\%. Y respecto al último curso de la titución de Ingeniería Química (IQ: 2011-12), el incremento es superior al 40\%. Indicar que el primer curso del grado no hay participación debido a que no se planteó la tarea de entregables de problemas. 
Los resultados de alumnos aprobados por curso (\%) mediante evaluación contínua, se recogen en la Fig. 2.

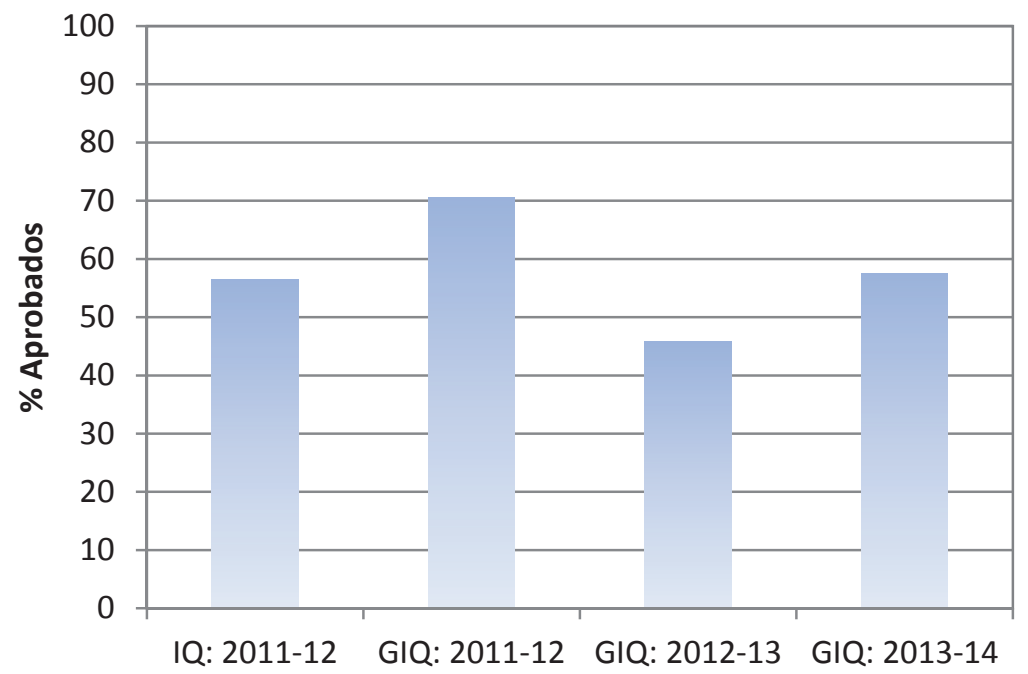

Fig. 2 Alumnos aprobados por evaluación contínua en cada curso

En cuanto a la el porcentajes de aprobados, en el curso GIQ: 2013-14 sin ser los resultados más altos, destacar respecto al curso anterior la tendencia al alza, con un incremento superior al $12 \%$, en ambos cursos trabajando los entregables de problemas aunque con diferente metodología, siendo en 2013-14 donde se trabajaron mediante herramientas online. A pesar que el primer curso impartido en el grado GIQ: 2011-12 es donde se obtuvieron mayor número de aprobados, el hecho de no trabajar con los entregables de problemas, se considera que derivará en un aprendizaje menos profundo.

La Fig. 3, muestra la nota media de los alumnos aprobados en cada curso. Destacando que la nota media del GIQ: 2013-14 que es similar a la del curso GIQ: 2011-12, aunque en este caso con un esfuerzo extra por parte de los alumnos como resultado de trabajar los entregables de problemas.

Las calificaciones obtenidas por los alumnos aprobados en evaluación continua, ver Fig. 4, nos muestra mejores calificaciones en los alumnos de la antigua titulación (IQ: 2011-12), posiblemente debido a otros factores como el mayor grado de madurez de los alumnos debido a que la asignatura se encuentra en cuarto curso y en el Grado en segundo. Si centrámos el análisis en los dos últimos cursos por ser similares en cuanto a metodologías y edad de los alumnos, se observa que las calificaciones obtenidas por los alumnos son superiores en el curso GIQ: 2013-14, coincidiendo a su vez con el mayor nivel de

\section{(cc) EY-NC-ND 2014, Universitat Politècnica de València}

I Jornadas IN-RED (2014) 
Implementación y evaluación del uso de metodologías no tradicionales en el aprendizaje de Ciencia de Materiales

participación en la tarea de los entregables de problemas y con calificaciones similares al curso GIQ:2011-12 donde no se requirieron los entregables.

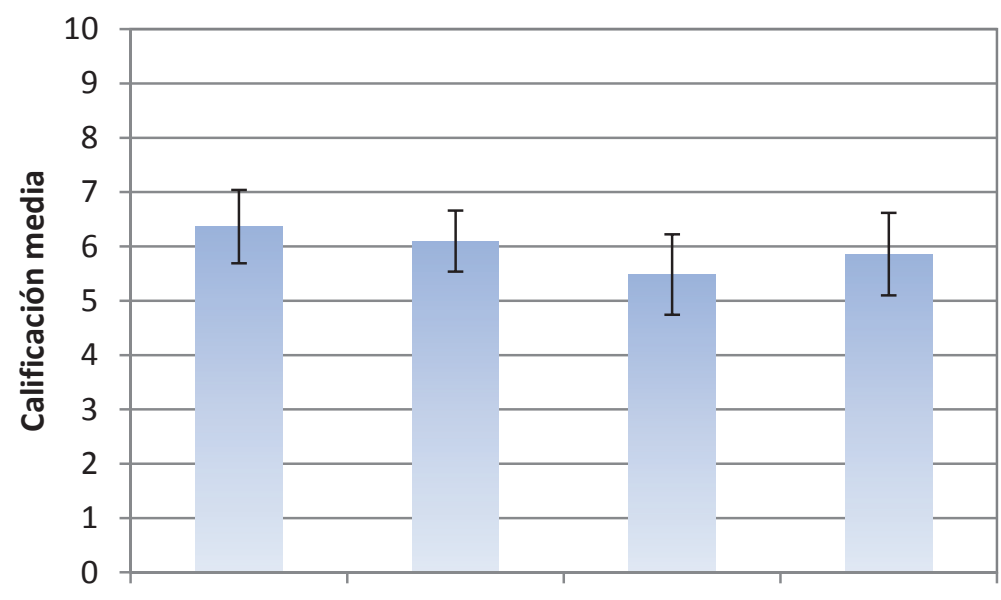

IQ: 2011-12 GIQ: 2011-12 GIQ: 2012-13 GIQ: 2013-14

Fig. 3 Calificaciones promedio de alumnos aprobados por evaluación contínua

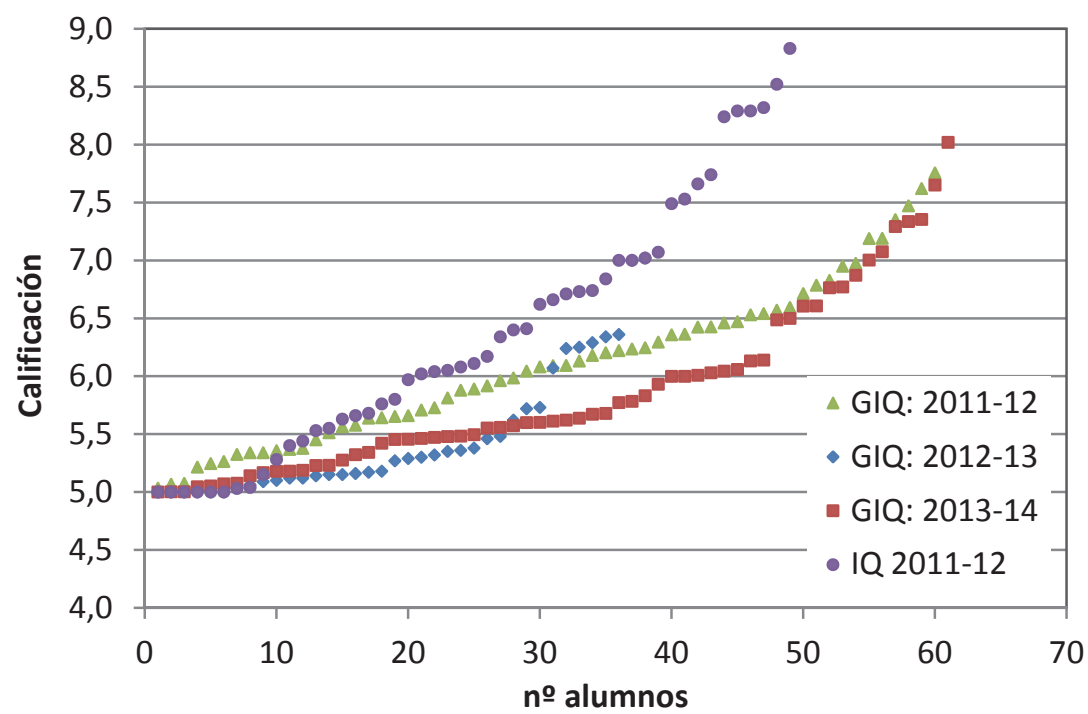

Fig. 4 Calificaciones de alumnos aprobados por evaluación contínua

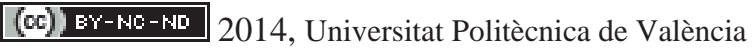
I Jornadas IN-RED (2014) 
Viendo la comparativa de los porcentajes de calificaciones de la evaluación continua de los dos últimos curso, Fig. 5, al ser los más similares en cuanto a tareas realizadas, se deduce que en el último curso GIQ:2013-14, de un lado la tasa de aprobados es mayor y además también lo es la proporción de alumnos con calificaciones superiores.

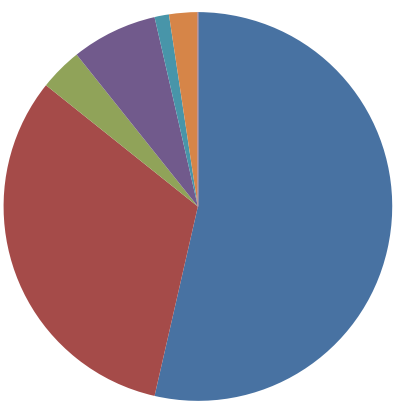

(a)

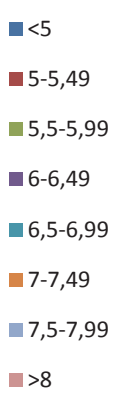

$>8$

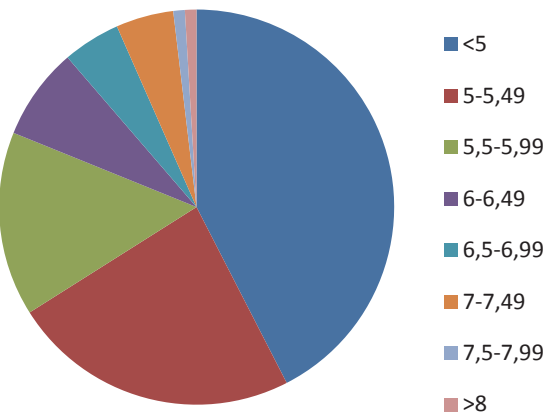

(b)

Fig. 5 Calificaciones del curso por nota: (a) GIQ:2012-13 y (b) GIQ:2013-14

Indicar finalmente que en el curso GIQ:2013-14 de los alumnos aprobados por evaluación continua, el $83.6 \%$ hicieron y aprobaron los entregables a través de la plataforma online. Y que del total de alumnos sólo el 9\% superó la asignatura sin superar los entregables. De ahí que se considere fundamental la realización de los entregables de problemas, como tarea formativa y de aprendizaje de la asignatura, objetivo con el que se plantea dicha tarea. El elevado nivel de participación en la tarea de los entregables pone de manifiesto la bondad del uso de las TIC, observando de los resultados que les resulta atractivo y les motiva para ponerse a trabajar, pudiendo aprovercharlo para su aprendizaje.

Continuando con la técnica de trabajo colaborativo de la introducción a la sesión de prácticas (puzle de Aronson), y teniendo en cuenta el principal objetivo cambiar la dinámica pasiva de los alumnos, además de darles a conocer la información a su disposición en los guiones de prácticas y que aspectos a trabajar para sacar mayor rendimiento de las prácticas y que fueran consciente que ese trabajo era la base para ayudarles a preparar los test de evaluación de prácticas. En la Fig. 6 se muestan los resultados de los alumnos de GIQ:2013-14 en el primer y segundo test de evaluación de las prácticas, correspondientes a la primera y segunda parte de la asignatura. Observándose una mejora en cuanto al número de alumnos que superan el segundo test respecto del primero, con un aumento cercano al $10 \%$, además de incrementarse considerablemente las notas obtenidas por los alumnos, alcanzando valores superiores a 9, respecto a los próximos a 7 del primer test realizado.

\section{(cc) EY-NC-ND 2014, Universitat Politècnica de València}


Implementación y evaluación del uso de metodologías no tradicionales en el aprendizaje de Ciencia de Materiales

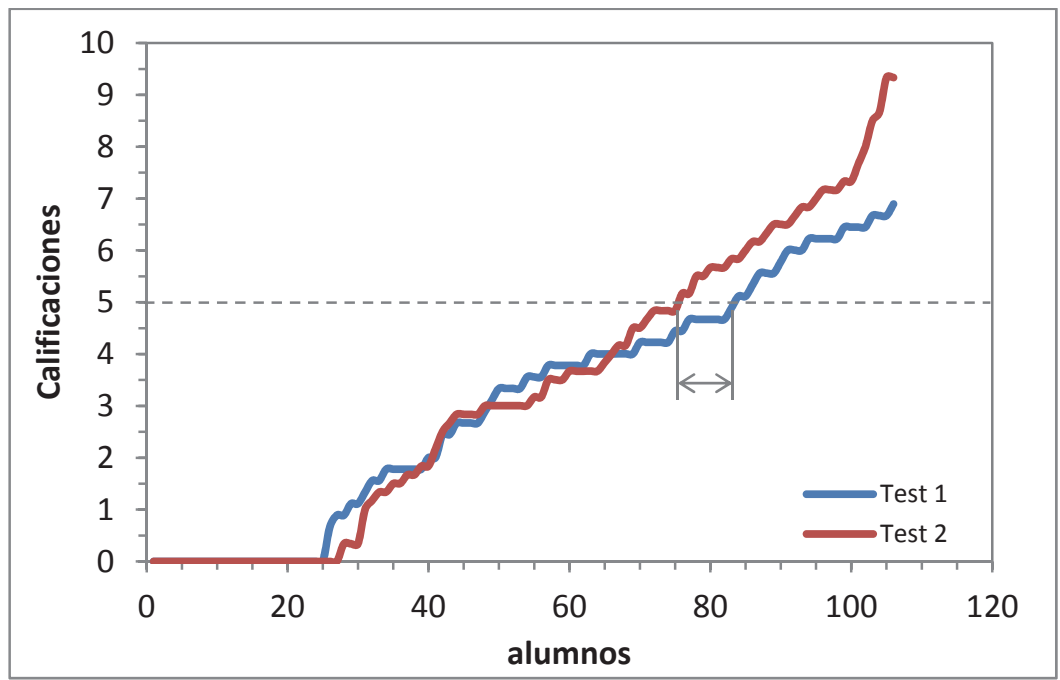

Fig. 6 Calificaciones de alumnos en los test de prácticas de laboratorio

Como resultado de esta experiencia piloto se consideró fundamental el obtener información de la opinión de los alumnos a través de la encuesta de opinión, realizado con la herramienta Sondeos de PoliformaT. Siendo esta participación anónima y totalmente voluntaria. La participación en esta actividad, colateral en la asignatura, se situó en el entorno del 55\%, considerando altamente satisfactorio el nivel de participación. De la experiencia empleando el puzle de Aronson para realizar una introducción con participación activa de los alumnos, destacar los resultados obtenidos en dos de las nueve preguntas planteadas: "Indicar el porcentaje de conocimiento que tenían sobre los aspectos a trabajar (de la información que figuraba en el guión de prácticas disponible en PoliformaT) antes y después de la dinámica de grupo empleada en la sesión de prácticas (experiencias a realizar, metodología a seguir en los ensayos y resultados que debías obtener).

Tabla 1. Resultados de la encuesta sobre el nivel de conocimiento de aspectos a trabajar

\begin{tabular}{ccc}
\hline \% Conocimiento & \% Antes de iniciar la práctica & \% Después de Puzle de Aronson \\
\hline $0-10$ & 23 & 0 \\
$10-25$ & 25 & 10 \\
$25-50$ & 27 & 7 \\
$50-75$ & 18 & 57 \\
$75-100$ & 7 & 26 \\
\hline
\end{tabular}

(cc)) EY-NC-ND 2014, Universitat Politècnica de València

I Jornadas IN-RED (2014) 
En los resultados se observa que antes de la dinámica activa grupal un $75 \%$, tenía un conocimiento sobre el trabajo a realizar, inferior al 50\%, y tras el desarrollo de la misma el el $75 \%$ se sitúa entre el 50-100\%. Además, el 62\% considera que el utilizar metodologías diferentes a las trabajadas hata el momento, se ha traducido en un nivel de motivación alto o muy alto. Y aproximadamente el $70 \%$, muestra buena o muy buena predisposición a utilizar esta metodología en otras sesiones, considerando esta información interesante al ser la primera vez que se empleaba esta metodología.

Del análisis de los datos reportados se deduce el éxito de la experiencia ya que cumple con el objetivo que se planteó que era aumentar el conocimiento sobre lo que se iba a trabajar en la sesión mediante el uso de metodologías activas y motivar al alumnado no sólo en esta sesión sino para las futuras sesiones, mejorando los resultados obtenidos considerablemente en la evaluación de la segunda parte de las prácticas de laboratorio.

\section{Conclusiones}

La búsqueda de aumentar la motivación, en términos de participación en las tareas de trabajo no presencial, se ha alcanzado con el cambio metodológico de la tarea de los entregables de problemas, comprobando de este modo la bondad de las TIC como un recurso atractivo para el estudiante y que hay que aprovechar para su aprendizaje. Además de aumentar la motivación del alumnado a la hora de participar en las tareas asociadas a la asignatura, como en la encuesta volutaria de retroalimentación del uso de la técnica puzle de Aronson.

La tarea de trabajar los entregables como parte del entrenamiento y aprendizaje de la asignatura, es valida como metodología formativa y se ve reflejado en los resultados obtenidos en la evaluación continua.

La inclusión de la metodología activa y colaborativa en la introducción de la sesión de prácticas, ha tenido una buena aceptación por el alumnado, motivándoles para la sesión, además de incrementar sustancialemente el conocimiento sobre la práctica respecto a antes de empezarla, además de mejorar los resultados obtenidos en la última evaluación realizada.

\section{Referencias}

BAIN, K. (2007). Lo que hacen los mejores profesores universitarios. Valencia: Publicacions de la Universitat de València.

DÍAZ-BARRIGA, F. (2002). "Estrategias docentes para un aprendizaje significativo". Mexico: McGraw-Hill.

\section{(c) EY-NC-ND 2014, Universitat Politècnica de València}


Implementación y evaluación del uso de metodologías no tradicionales en el aprendizaje de Ciencia de Materiales

FERRERO, C.; MARTÍNEZ, A:I.; OTERO, M ${ }^{\mathrm{a} C}$. (2009). Ventajas del uso de las TICs en el proceso de enseñanaza-aprendizaje desde la óptica de los docentes universitarios españoles. EDITEC, Revista Electrónica de Tecnología Educativa. Núm. 29. <http://webcache.googleusercontent.com/search?q=cache:http://edutec.rediris.es/Revelec2/revelec29/ articulos_n29_pdf/5Edutec-E_Ferro-Martinez-Otero_n29.pdf> [Consulta: 30 de mayo de 2014]

MARTÍNEZ, J.P.; GÓMEZ, F. (2010). La técnica del puzle de Aronson: descripción y desarrollo. En Arnaiz, P.; Hurtado, Ma.D., Soto, F.J. (Coords.) 25 Años de Integración Escolar en España: Tecnología e Inclusión en el ámbito educativo, laboral y comunitario. Murcia: Consejería de Educación Formación y Empleo.

TRAVER, J.A., GARCÍA, R. (2004), La enseñanaza-aprendizaje de la actitud de solidaridad en el aula: una propuesta de trabajo centrada en la aplicación de la técnica puzle de Aronson, en Revista Española de Pedagogía, 229, p.419-437.

VANHOOF, J.; VAN PETEGEM, P. (2005). Feedback of performance indicators as a strategic instrument for school improvement. REICE - Revista Electrónica Iberoamericana sobre Calidad, Eficacia y Cambio en Educación, Vol.3, No. 1. 〈http://www.redalyc.org/pdf/551/55130119.pdf> [Consulta: 28 de mayo de 2014]

ZABALZA, M.A. (2008). El Espacio Europeo de Educación Superior: innovación en la enseñanza univeristaria, en Innovación Educativa, nº18, p. 69-95. 


\title{
Tabletas y tinta digital. Casos de uso en distintos ámbitos educativos
}

José-V. Benlloch-Dualde ${ }^{\mathrm{a}}$, Angel Perles ${ }^{\mathrm{a}}$, Lenin Lemus ${ }^{\mathrm{a}}$, Pedro Gil ${ }^{\mathrm{a}}$, Daniela Gil ${ }^{\mathrm{b}}$, Félix Buendía $^{a}$, Juan-Carlos Cano ${ }^{a}$, Sara Blanc ${ }^{a}$, Juan V. Capella ${ }^{a}$

${ }^{a}$ Departamento de Informática de Sistemas y Computadores, \{jbenlloc, aperles, lemus, pgil, fbuendia, jucano, sablacla, jcapella@disca.upv.es $\},{ }^{b}$ Departamento de Lingǘstica Aplicada, dagil@ idm.upv.es.

\begin{abstract}
Starting from the work of the iNNOVATiNK team during the recent years, this paper describes several case studies about the use of digital ink technologies in various educational contexts. Although most cases have been applied to subjects in the field of Computer Engineering, it is of particular interest an application example in an adult course offered by the Senior University at the UPV, as well as the first experiments carried out in sixth grade of elementary school (K-12). For each of the selected cases, their strengths and weaknesses are presented, with particular attention to its impact on learning. To sum up, the future working plan of our team is outlined, that given the current difficulties in renewing the equipment available, is addressed both to incorporate new low cost devices as well as student devices, according to the BYOD (Bring your Own Device) philosophy.
\end{abstract}

Keywords: digital ink, tablets, mobile devices, mobile learning, adult education

\section{Resumen}

A partir de la labor realizada por el Equipo de Innovación y Calidad Educativa iNNOVATiNK durante estos últimos años, el presente trabajo describe varios casos de uso de las tecnologías de tinta digital en distintos contextos educativos. Aunque la mayoría de los casos se han aplicado a asignaturas en el ámbito de la Ingeniería Informática, resulta de especial interés un ejemplo de aplicación en un curso perteneciente a la oferta formativa de la Universitat Senior de la UPV, así como las primeras experiencias realizadas en sexto curso de enseñanza primaria. Para los 
distintos ejemplos seleccionados, se presentan sus fortalezas y debilidades, con especial atención a su impacto en el aprendizaje. Para concluir el trabajo se apuntan las líneas futuras de nuestro equipo que, dadas las dificultades actuales para renovar los equipos disponibles, van encaminadas a incorporar los dispositivos de los propios alumnos, siguiendo la filosofía conocida como BYOD (Bring your Own Device).

Palabras clave: tinta digital, tabletas, dispositivos móviles, aprendizaje móvil, educación para adultos

\section{Introducción}

El aprendizaje móvil (mobile learning) puede verse como cualquier forma de aprendizaje que sucede gracias a la mediación de tecnologías móviles (Winters, 2006). Este término se refiere a una combinación de hardware, sistemas operativos, interconexión y software, incluyendo el contenido, las plataformas de aprendizaje, y las aplicaciones (UNESCO, 2011). Ejemplos de este tipo de dispositivos son las Personal Digital Assistants (PDAs), los Classroom Response Systems (CRS), los e-readers, las videoconsolas portátiles (tipo PSP), los smartphones y, por supuesto, los dispositivos sobre los que se centra buena parte de este trabajo, las tabletas, en sus diferentes tipos.

Informes recientes como el prestigioso informe Horizon (Johnson, Adams y Cummins, 2012), dirigido conjuntamente por el New Media Consortium (NMC) y EDUCAUSE Learning Initiative (ELI), cuyo objetivo es analizar las tecnologías emergentes que tendrán una mayor repercusión en la docencia, el aprendizaje y la investigación creativa, en su edición del 2012 para la enseñanza universitaria, incluye a las tabletas como tecnologías de horizonte a corto plazo que se han vuelto omnipresentes en la vida diaria. En dicho informe se afirma: "por lo menos en el mundo desarrollado, los estudiantes universitarios tienen cada vez mayores posibilidades de aprender con la ayuda de estos dispositivos cuando quieran y desde donde quieran".

Las numerosas posibilidades de las tabletas en el ámbito formativo se pueden incrementar de forma sustancial cuando incorporamos, como elemento de la interfaz de usuario, una especie de bolígrafo que produce tinta digital, dando nombre a las llamadas "Tecnologías de Tinta Digital" (Pen-based Technology). Estos dispositivos permiten realizar todo tipo de trazos a mano alzada para escribir, dibujar, realizar esquemas y diagramas, producir bocetos, expresar ideas de forma visual, todo ello de forma semejante a como se haría con un bolígrafo y un papel, pero con las ventajas añadidas de las representaciones en formato digital.

A partir de la labor realizada por el Equipo de Innovación y Calidad Educativa iNNOVATiNK durante estos últimos años, el presente trabajo resume varios casos de uso de 
estas tecnologías en contextos educativos bien diferentes. Aunque la mayoría de los casos se han aplicado a asignaturas en el ámbito de la Ingeniería Informática, resulta de especial interés un ejemplo de aplicación en un curso perteneciente a la oferta formativa de la Universitat Senior de la UPV, así como las primeras experiencias realizadas en sexto curso de enseñanza primaria.

El resto del trabajo se estructura de la siguiente manera: la sección 2 presenta los objetivos del estudio; la sección 3 describe los diferentes casos de uso de las tecnologías; la sección 4 aborda el análisis de los resultados obtenidos y su discusión; por último, la sección 5 ofrece las principales conclusiones.

\section{Objetivos}

Este trabajo se enmarca en los objetivos generales del equipo iNNOVATiNK que, desde su constitución en el año 2010, se propuso:

- Presentar, en primer término, a nuestra comunidad universitaria, las posibilidades instructivas de las tecnologías de tinta digital.

- Formar profesores en el uso de estas tecnologías.

- Fomentar en nuestra comunidad la adopción de estas tecnologías.

- Evaluar el uso de estas tecnologías en distintos ámbitos.

- Compartir la experiencia en el desarrollo de actividades de aprendizaje a realizar en entornos que incorporen dispositivos con tinta digital.

Las primeros casos de estudio hicieron uso de la infraestructura de Tabletas PC (TPC) disponible en la ETSINF, incorporando metodologías activas basadas en la utilización de la tinta digital como elemento central de motivación e interacción profesor-estudiante. Las primeras asignaturas implicadas fueron las siguientes: Redes de Área Local y Ampliación de Tecnología de Computadores (ITIS), impartidas por el Dpto. de Informática de Sistemas y Computadores (DISCA); Estructura de Datos y Algoritmos y Sistemas Operativos (ITIG e ITIS), ambas impartidas por el DSIC; y Guión Multimedia (ITIG e ITIS), impartida por el Dpto. de Comunicación Audiovisual, Documentación e Historia del Arte. Con la puesta en marcha del Grado en Ingeniería Informática, surgieron nuevos casos de estudio aplicados a asignaturas como Fundamentos Físicos de la Informática, impartida por el Dpto. de Física Aplicada; Fundamentos de Computadores y Tecnología de Computadores, impartidas por el DISCA; y Alemán elemental para intercambio académico y profesional, impartida por el Dpto. de Lingüística Aplicada.

Todos los casos anteriores son ejemplos de aplicación de las tecnologías de tinta digital en el ámbito de la educación superior. En este trabajo nos planteamos como objetivo particular investigar también las posibilidades formativas de estas tecnologías en ámbitos distintos.

\section{(cc)) EY-NC-ND 2014, Universitat Politècnica de València}

I Jornadas IN-RED (2014) 
Por una parte, se han introducido en un curso destinado a formación de adultos y, por otra, en un curso de sexto de enseñanza primaria.

\section{Casos de estudio}

En esta sección se describen varios casos de incorporación de las Tecnologías de Tinta Digital (TTD) en distintos contextos educativos. Como se verá, tanto el diseño experimental como los objetivos que se plantean en cada uno de ellos, son bien diferentes.

\subsection{Grado en Ingeniería Informática}

Comenzamos la descripción de los casos de estudio con las experiencias desarrolladas en dos asignaturas obligatorias de primer curso del Grado en Ingeniería Informática (GII), Fundamentos de Computadores (FCO) y Tecnología de Computadores (TCO), ambas impartidas por el DISCA. A diferencia de algunas experiencias previas, en ambos casos se aplican sobre grupos convencionales de matrícula, en lugar de hacerse sobre grupos pilotos de 20 alumnos, el número de TPC disponibles. En función de la disponibilidad horaria de los profesores participantes en las mismas, se escogen unos determinados grupos como experimentales (o grupos Tablet). Dado que el tamaño de los grupos convencionales creció bastante respecto al de los grupos pilotos anteriores, hubo que escoger un aula que aceptara esa nueva capacidad, tal y como muestra la Fig. 1. Desafortunadamente, el número de TPC disponibles para las experiencias no se pudo aumentar por lo que, en numerosas ocasiones, se tenían que compartir entre pares de estudiantes, o incluso complementarlas con portátiles convencionales, o netbooks, conectados vía USB a tabletas gráficas.

La Tabla 1 sintetiza los datos principales de las experiencias en aula llevadas a cabo en las asignaturas FCO y TCO durante los dos últimos cursos. Como se puede observar, uno de los grupos experimentales en las dos asignaturas, y durante los dos cursos, es un grupo con docencia en inglés (referido en la Tabla 1 como ENG). Dado que el número de alumnos previsto para este grupo era algo inferior al resto, parecía un buen candidato para nuestras actuaciones, habida cuenta del número de TPC. En el caso de la asignatura TCO, adicionalmente se escogió cada año uno de los grupos convencionales, de acuerdo con la disponibilidad horaria del profesor participante. Todos los grupos experimentales eran de turno de mañana. 


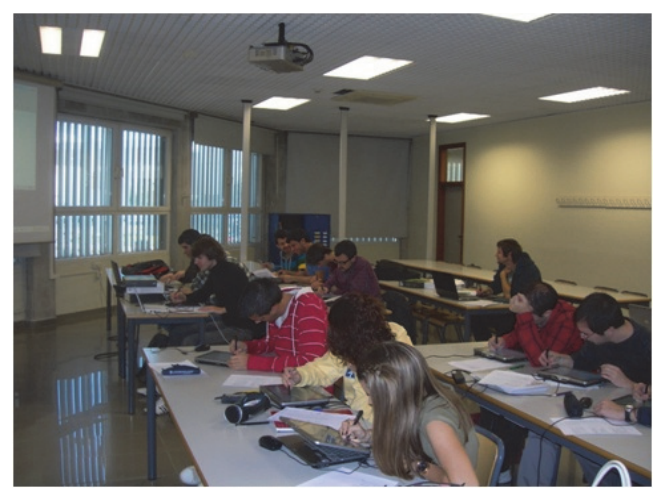

Fig. 1 Aula utilizada con los grupos Tablet en las experiencias de GII

Tabla 1: Resumen de las experiencias en aula en los cursos 2011-12 y 2012-13

\begin{tabular}{|c|c|c|c|c|c|}
\hline \multirow{2}{*}{ Asignatura } & \multirow{2}{*}{ Titulación } & Año & $\begin{array}{c}\text { Curso } \\
\text { Cuatrimestre }\end{array}$ & Grupo & \#Alumnos \\
\hline \multirow{2}{*}{ FCO } & \multirow{2}{*}{ GII } & $2011-12$ & $1 \mathrm{~A}$ & ENG & 32 \\
\cline { 3 - 6 } & & $2012-13$ & $1 \mathrm{~A}$ & ENG & 38 \\
\hline \multirow{2}{*}{ TCO } & \multirow{2}{*}{ GII } & $2011-12$ & $1 \mathrm{~B}$ & ENG & 34 \\
\cline { 3 - 6 } & & $2012-13$ & $1 \mathrm{~B}$ & Convencional & 49 \\
\cline { 5 - 6 } & & & & Cong & 33 \\
\hline
\end{tabular}

La incorporación de las TTD en estos grupos se plantea los siguientes objetivos:

- Favorecer la interacción profesor-alumno en las sesiones de aula.

- Fomentar la actividad del alumno, al tiempo que se facilita su evaluación formativa.

- Mejorar la realimentación que se proporciona al alumno sobre sus logros de aprendizaje.

- Incrementar el rendimiento académico.

Respecto a los materiales, se ha intentado adaptar los recursos existentes en la asignatura para así poder explotar las posibilidades formativas de las tecnologías y, en particular, de la tinta digital, al tiempo que se generan recursos adicionales, como las presentaciones con las anotaciones del profesor, o soluciones modelo a las actividades planteadas.

Para evaluar el impacto de la incorporación de las TTD en el aprendizaje de los alumnos de los grupos experimentales, se han introducido unas variables observables numéricas que,

(c) EY-NC-ND 2014, Universitat Politècnica de València

I Jornadas IN-RED (2014) 
además de contribuir en el análisis del rendimiento académico de los estudiantes, buscan captar su grado de actividad en el seguimiento de las asignaturas. Con este propósito, los indicadores escogidos son: la nota de lo que se denomina "actividad del estudiante" (Act_Est) que, en función de las asignaturas y grupos, se puede definir de forma ligeramente distinta, aunque siempre cumpliendo con unos criterios generales consensuados por el equipo docente de las asignaturas; la calificación media en los exámenes parciales (Parciales), pruebas escritas que son comunes a todos los grupos de la asignatura y, por tanto, representan el indicador de rendimiento más objetivo e independiente de profesores y grupos; por último, la nota final (Final), que recoge todas las dimensiones evaluadas en la asignatura, con sus correspondientes pesos, representando así el logro global del alumno en la asignatura.

Para cada una de las variables, se realiza un estudio descriptivo calculando valores estadísticos de posición, como la media y la mediana, y de dispersión, como la desviación típica, la varianza, el rango, o el intervalo intercuartil, entre otros.

Los valores obtenidos en los grupos experimentales que utilizan TTD (referidos como grupos Tablet) se comparan con los calculados para los que denominaremos grupos Control, o de contraste, esto es, aquéllos que han continuado con un enfoque tradicional, pero que tienen características comparables a los primeros. Se ha de intentar que los resultados de la innovación sean, en la medida de lo posible, independientes de las singularidades de los grupos que participan en la misma. Para ello, y dada su relevancia en el rendimiento académico a nivel universitario constatada en la literatura (Fornés et al., 2008), se ha considerado la nota de acceso como variable fundamental a la hora de seleccionar los grupos Control.

Con el fin de contar también con datos cualitativos, al final de los cursos se pasó un cuestionario de 20 ítems que incluía una escala Likert de 5 puntos, desde "Totalmente en Desacuerdo" a "Totalmente de Acuerdo". Las cuestiones recogían información sobre distintos aspectos relacionados con las TTD como su usabilidad, eficacia, productividad o satisfacción con las mismas, seguidas de unas cuestiones centradas en las metodologías empleadas y el aprendizaje del estudiante y, finalmente, un último bloque relacionado con las expectativas y la satisfacción global de los estudiantes con las experiencias.

\subsection{Formación de adultos}

El segundo caso de estudio se encuadra en la oferta formativa de la Universitat Senior de la Universitat Politècnica de València (UPV). En concreto, se trata del curso "Comprendiendo a la juventud: aprende a sacar partido a los móviles y tablets" que, desde el año 2013, se oferta a mayores de 55 años. Esto es, el público potencial lo componen personas de muy 
distintos perfiles, más aun si tenemos en cuanto que no se requiere un conocimiento previo en cuestiones tecnológicas.

A la hora de diseñar este tipo de cursos (Dillard, 2012), hay que tener en cuenta que los objetivos de aprendizaje de este colectivo no suelen coincidir con los propios de la formación reglada. Por ello, tanto los recursos como las actividades de aprendizaje se han de dirigir a la consecución de unas habilidades prácticas, que enlacen con la experiencia previa de las personas adultas. Además, debemos considerar que en este tipo de colectivos es más habitual encontrar algún tipo de discapacidad, o simplemente que han llegado a un umbral de edad que dificulta el aprendizaje.

Por todo lo anteriormente expuesto, en el curso se han primado los objetivos de tipo práctico (procedural) sobre los conceptuales. De esta forma, el curso se propone la adquisición de habilidades en el manejo de dispositivos móviles y sus aplicaciones. También se ha insistido en fomentar una serie de actitudes encaminadas a un uso responsable de las tecnologías, así como a reforzar la capacidad de un aprendizaje autónomo.

El curso se organiza en sesiones que incluyen actividades con una planificación temporal muy definida y, en la medida de lo posible, independientes entre sí. Esta independencia es muy matizada, pues se parte de habilidades adquiridas en sesiones anteriores que, en muchas ocasiones, precisan de técnicas de repetición para este tipo de público. Los materiales de apoyo desarrollados se basan en guiones y tutoriales disponibles en la Web del curso (Fig. 2), que contienen las instrucciones básicas de las unidades que componen cada módulo, y que se complementan con una serie de actividades propuestas para un trabajo guiado de los alumnos.

La implantación del curso se ha llevado a cabo en dos grupos con unos 24 alumnos por grupo, que asisten a un aula convencional dotada con proyector multimedia. A cada par de alumnos se le asigna un dispositivo móvil, bien una tableta de bajo coste (con pantallas de distintos tamaños: 7", 9", 9,7" ó 10'1") o un smartphone, con sistema operativo Android. La docencia se imparte de forma presencial por dos profesores que alternan sus roles. Mientras uno de ellos explica los conceptos teóricos y las actividades a realizar durante la sesión, el otro profesor asiste a los alumnos en sus dudas sobre el manejo de los dispositivos.

A diferencia del caso anterior de formación reglada, los cursos para adultos no utilizan indicadores formales de rendimiento académico, y ni siquiera se puede contar con los registros de actividad de la correspondiente plataforma e-learning, habituales en los contextos de cursos online. En este caso, se trataría más bien de evaluar las habilidades alcanzadas de forma cualitativa, analizando por ejemplo si son capaces de realizar una tarea que se considere fundamental.

\section{(c) EY-NC-ND 2014, Universitat Politècnica de València}




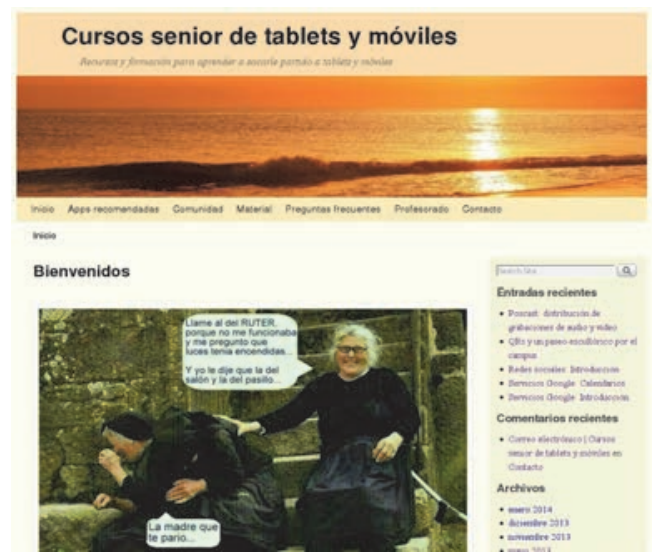

Fig. 2 Portal del curso de formación de adultos

Con el fin de contar con datos cualitativos para la evaluación, a mitad del curso se pasó un cuestionario con 8 ítems que utilizaba una escala Likert de 5 puntos. El instrumento utilizado pretendía recabar las opiniones de los alumnos en cuestiones relacionadas, entre otras cosas, con si se estaban cumpliendo sus expectativas, una primera valoración de la utilidad de las tecnologías móviles, o hasta qué punto los conceptos explicados les resultaban fáciles de entender.

\subsection{Enseñanza primaria}

En este último caso se planteó realizar una experiencia de uso de las TPC en Enseñanza Primaria. En concreto, durante el curso 2011-12, se desarrolló una sesión de 90 minutos en la clase de sexto curso del CEIP Santa Teresa, de Valencia. El grupo contaba con unos 25 alumnos, de los que tres de ellos presentaban casos de dificultades en el aprendizaje.

La sesión se planteó como una sesión completamente práctica, donde cada par de alumnos compartían una TPC interconectada en red a la tableta del profesor que, a su vez, tenía conectado su equipo a un proyector multimedia.

De acuerdo con la profesora, se diseñaron actividades adaptadas a las posibilidades de las TTD. En primer lugar se realizó una actividad de presentación para familiarizarse con la tecnología para, a continuación, pasar a actividades de matemáticas y conocimiento del medio, de distinto nivel de dificultad. La Fig. 3 muestra un par de ejemplos de respuestas elaboradas durante la sesión (izda. actividad de presentación y dcha., actividad de conocimiento del medio). 
Dado que se trataba de una experiencia puntual, no se realizó ninguna recogida formal de datos para evaluar la experiencia, sino que se entrevistó a la profesora para que valorara la sesión.
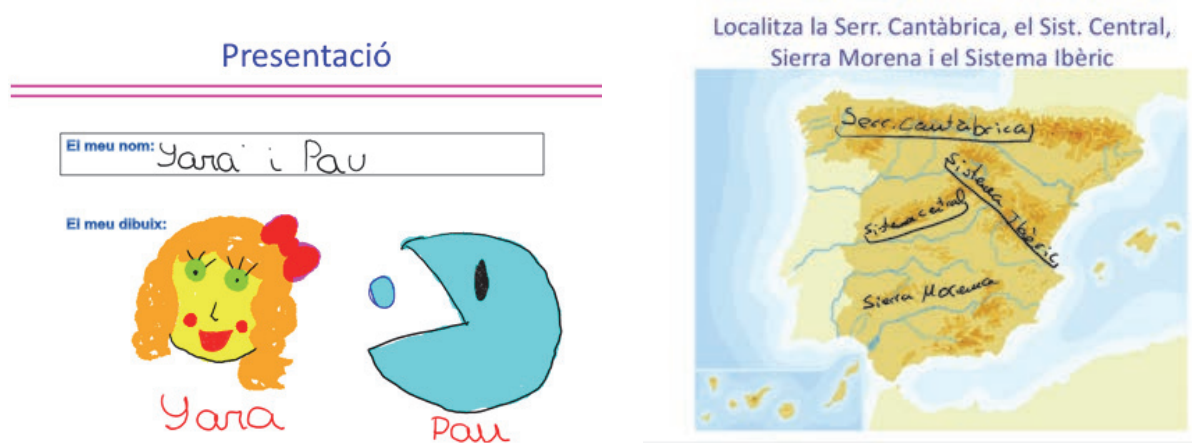

Fig. 3 Ejemplos de actividades con tinta digital

\section{Resultados}

En esta sección se resumen los principales resultados obtenidos en los casos de estudio que, como se describió anteriormente, utilizan enfoques bastante distintos. Para las asignaturas de GII se dispone tanto de resultados cuantitativos como cualitativos, mientras que en los otros dos casos, se dispone únicamente de datos cualitativos.

\subsection{Grado en Ingeniería Informática}

Para cada uno de los dos últimos cursos académicos, y para las dos asignaturas objeto de las experiencias en aula (FCO y TCO), se han generado las tablas con los principales valores de rendimiento académico. En el conjunto de datos se distinguen tres colectivos de alumnos: el grupo Tablet (o experimental), el grupo Control, y lo que hemos llamado grupo Todos, que incluye a todos los grupos de la asignatura a excepción de los experimentales.

Con el propósito de obtener una idea más visual de la información relevante, para los tres indicadores descritos anteriormente (Act_Est, Parciales y Final), y para los mismos tres colectivos (Tablet, Control, Todos), se han generado los llamados diagramas de "caja y bigotes" (box-and-whisker plot o boxplot) (Williamson, 2010), dado que permiten visualizar una gran cantidad de información estadística de una forma compacta.

En la Tabla 2 se observa que tanto las tasas de presentados, como las tasas de rendimiento y de éxito son, en general, bastante altas para todos los colectivos y cursos analizados, lo que sin duda guarda relación con unos buenos resultados generales de rendimiento en la asignatura FCO. No obstante, para los dos cursos analizados, el grupo Tablet obtiene mejores resultados que el grupo Control, tanto en tasa de rendimiento como en tasa de

\section{(c)) EY-NC-ND 2014, Universitat Politècnica de València}

I Jornadas IN-RED (2014) 
éxito. Lo mismo sucede respecto al grupo Todos, lo que en este caso podría estar relacionado con diferencias notables en las notas de acceso.

Los diagramas de caja y bigotes correspondientes al curso 2011-12 (Fig. 4) y 2012-13 (Fig. 5) muestran resultados en la misma línea. Para los tres indicadores, tanto el cuartil inferior (Q1) como la mediana correspondientes al grupo Tablet, son siempre mejores que los valores correspondientes en los otros dos colectivos (Control y Todos). En el curso 201213, eso mismo se puede decir respecto del cuartil superior (Q3), de modo que las "cajas" del grupo Tablet, para los tres indicadores, se observan como desplazadas hacia arriba respecto de las de los otros dos grupos, estando el grupo Control también por arriba del grupo Todos, cosa que curiosamente no sucede en el curso 2011-12, pese a unas diferencias en las notas de acceso del mismo orden. En ambos cursos, sin embargo, la dispersión de los datos en el grupo Tablet es menor que en los colectivos Control y Todos.

Tabla 2: Resumen de datos de rendimiento en FCO

\begin{tabular}{|c|c|c|c|c|c|c|c|c|}
\hline Grupo & $\begin{array}{c}\text { Nota } \\
\text { Acceso }\end{array}$ & \#Matric & \#Present & \#Aptos & $\begin{array}{c}\text { Tasa } \\
\text { presentados }\end{array}$ & $\begin{array}{c}\text { Tasa } \\
\text { rendimiento }\end{array}$ & $\begin{array}{c}\text { Tasa } \\
\text { éxito }\end{array}$ \\
\hline \multicolumn{7}{|c|}{ Curso 2011-12 } \\
\hline Tablet E & 9,11 & 32 & 32 & 25 & $100,00 \%$ & $78,13 \%$ & $78,13 \%$ \\
\hline Control C & 9,09 & 49 & 49 & 34 & $100,00 \%$ & $69,39 \%$ & $69,39 \%$ \\
\hline Todos (- E) & 7,59 & 405 & 396 & 295 & $97,78 \%$ & $72,84 \%$ & $74,49 \%$ \\
\hline & & 38 & 36 & 35 & $94,74 \%$ & $92,11 \%$ & $97,22 \%$ \\
\hline Tablet E & 9,69 & 38 & 50 & 43 & $98,04 \%$ & $84,31 \%$ & $86,00 \%$ \\
\hline Control C & 9,20 & 51 & 50 & 329 & 243 & $94,54 \%$ & $69,83 \%$ & $73,86 \%$ \\
\hline Todos (- E) & 7,92 & 348 & & & & \\
\hline
\end{tabular}

En lo que respecta a la asignatura TCO, en la Tabla 3 se observa nuevamente que la media de las notas de acceso en los grupos Tablet y Control es bastante similar para los dos cursos, si bien en este caso la diferencia respecto al grupo Todos es bastante menor. Este hecho se justifica por la inclusión en los grupos experimentales (y también en los de control) de otro grupo adicional al de docencia en inglés. En general, para el caso de la asignatura TCO los distintos datos de rendimiento son peores que los de FCO, si bien este hecho es habitual en los registros históricos de ambas asignaturas. 


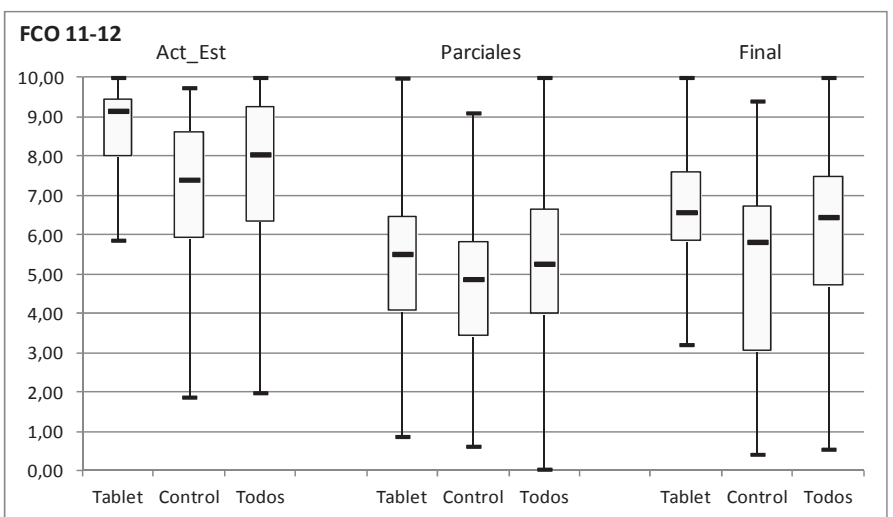

Fig. 4 Diagramas de caja y bigotes para FCO, curso 2011-12

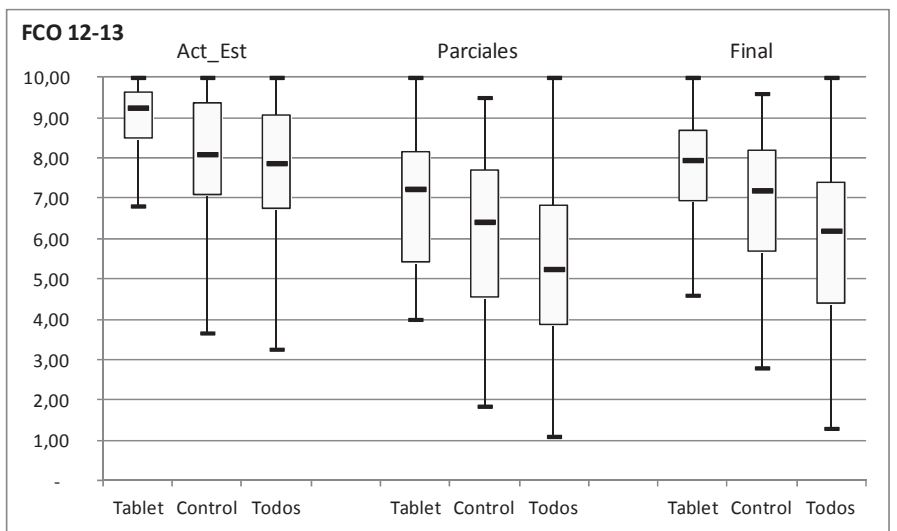

Fig. 5 Diagramas de caja y bigotes para FCO, curso 2012-13

La tasa de presentados en el grupo Tablet es algo mejor que en los otros dos colectivos, para los dos cursos. Sin embargo, respecto de los otros dos indicadores, mientras que en el curso 2012-13 las tasas de rendimiento y éxito son algo mejores en el grupo Tablet que en el grupo Control, sucede lo contrario en el curso 2011-12, donde es el grupo Control el que obtiene mejores resultados. Para los dos cursos analizados, el grupo Tablet presenta mejores tasas de rendimiento y éxito que el grupo Todos, si bien en este caso las diferencias son bastante menores que para la asignatura FCO.

En lo que respecta al curso 2011-12, en la Fig. 6 se observa que para el indicador Parciales la mediana en los grupos Tablet es algo mayor que las medianas en los grupos Control y Todos, aunque las diferencias son muy pequeñas. Sin embargo, para el indicador Act_Est sucede lo contrario, mientras que los valores centrales en el indicador Final resultan muy similares, si bien algo mayor en el grupo Control. De nuevo, no se aprecia una tendencia

\section{(c) EY-NC-ND 2014, Universitat Politècnica de València}

I Jornadas IN-RED (2014) 
clara en las distintas distribuciones, con rangos de dispersión y posición de los cuartiles que varían según los indicadores y grupos.

Tabla 3: Resumen de datos de rendimiento en TCO

\begin{tabular}{|c|c|c|c|c|c|c|c|c|}
\hline Grupos & $\begin{array}{c}\text { Nota } \\
\text { Acceso }\end{array}$ & \#Matric & \#Present & \#Aptos & $\begin{array}{c}\text { Tasa } \\
\text { presentados }\end{array}$ & $\begin{array}{c}\text { Tasa } \\
\text { rendimiento }\end{array}$ & $\begin{array}{c}\text { Tasa } \\
\text { éxito }\end{array}$ \\
\hline \multicolumn{7}{|c|}{ Curso $2011-12$} \\
\hline Tablet (E y F) & 8,71 & 83 & 75 & 47 & $90,36 \%$ & $56,63 \%$ & $62,67 \%$ \\
\hline Control (C y D) & 8,67 & 120 & 106 & 74 & $88,33 \%$ & $61,67 \%$ & $69,81 \%$ \\
\hline Todos - (E y F) & 7,52 & 470 & 416 & 260 & $88,51 \%$ & $55,32 \%$ & $62,50 \%$ \\
\hline \multicolumn{7}{|c|}{ Curso $2012-13$} & \\
\hline Tablet (E y H) & 8,57 & 74 & 64 & 48 & $88,89 \%$ & $64,86 \%$ & $75,00 \%$ \\
\hline Control (B y C) & 8,53 & 98 & 86 & 63 & $87,76 \%$ & $64,29 \%$ & $73,26 \%$ \\
\hline Todos - (E y H) & 8,05 & 439 & 354 & 264 & $80,64 \%$ & $60,14 \%$ & $74,58 \%$ \\
\hline
\end{tabular}

En relación al curso 2012-13 (Fig. 7), los valores centrales para el indicador Act_Est son bastante parecidos, aunque algo mejor en el grupo Control que en el grupo Tablet. Sin embargo, en el caso de los indicadores Parciales y Final, tanto el cuartil inferior (Q1) como la mediana correspondientes al grupo Tablet son claramente mejores a los valores correspondientes en los otros dos colectivos (Control y Todos). Esto mismo sucede para el cuartil superior (Q3), aunque en el caso de la variable Final, cuando se comparan los grupos Tablet con los grupos Control apenas hay diferencia. Con esta pequeña excepción, y para esos mismos indicadores (Parciales y Final), se observa también un desplazamiento hacia arriba de las "cajas" del grupo Tablet frente a los otros dos, indicando unos resultados mejores en esa mitad de la población, que se corresponde con la zona central de la distribución (desde $Q 1$ a $Q 3)$.

A modo de resumen conviene señalar que, para los dos cursos analizados, el indicador Parciales, que representa la nota más homogénea entre los distintos grupos, y en los dos cursos analizados, muestra un valor central para el grupo Tablet que es superior a los valores centrales de los grupos Control y Todos. Para el mismo indicador, se observa que el cuartil superior $(Q 3)$ en el grupo Tablet también es superior al de los otros dos. Sin embargo, para el cuartil inferior (Q1), se cumple en el curso 2012-13, pero no en el 201112, donde el grupo Control presenta un valor algo mayor al de los otros dos colectivos.

Respecto a los resultados de los cuestionarios, y centrándonos en las preguntas relacionadas con el enfoque metodológico y su relación con el aprendizaje, un $73 \%$ declaró que el 
enfoque utilizado aumentó su motivación por la asignatura; un 68\% respondió que el enfoque les ayudó a implicarse y trabajar más en el aula, mientras que el porcentaje bajó al $60 \%$ cuando se pregunta si ha contribuido a aumentar la interacción con el profesor, o a facilitar el trabajo colaborativo. Respecto al aprendizaje, un $82 \%$ considera que mejoró su experiencia de aprendizaje y un $73 \%$ afirma que aprendió más y mejor. Un 15\%, sin embargo, considera que las TTD han contribuido a la distracción y un $24 \%$ se declaran neutros en esta cuestión, lo que manifiesta que es un aspecto a vigilar, al menos entre nuestros alumnos de primer curso.

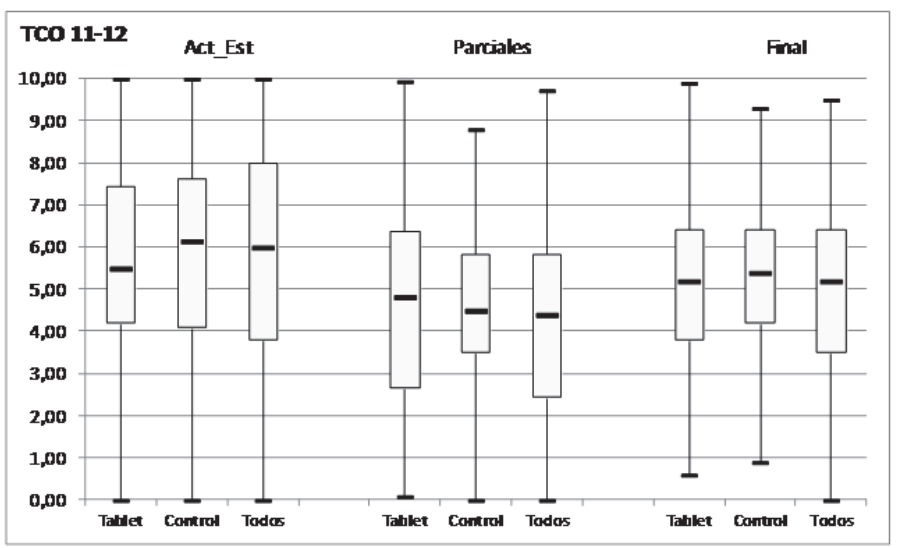

Fig. 6 Diagramas de caja y bigotes para TCO, curso 2011-12

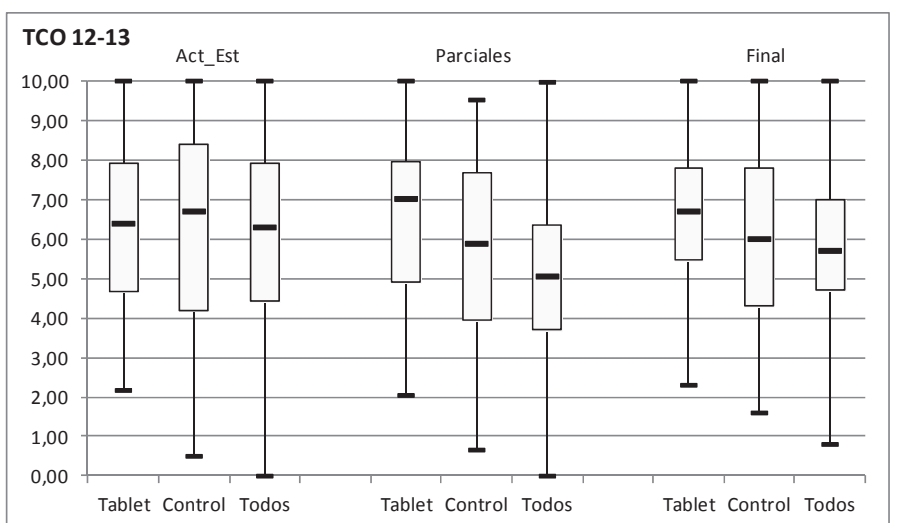

Fig. 7 Diagramas de caja y bigotes para TCO, curso 2012-13

\subsection{Formación de adultos}

En la Fig. 8 se muestra un histograma que recoge los porcentajes de usuarios con una percepción positiva sobre las cuestiones planteadas. Destacan porcentajes superiores al $80 \%$ en cuanto a la facilidad de uso de los dispositivos o la visualización de los contenidos en los

\section{(c)) EY-NC-ND 2014, Universitat Politècnica de València}

I Jornadas IN-RED (2014) 
dispositivos utilizados. Sin embargo, el cumplimiento de expectativas o la valoración de los recursos de aprendizaje ofrecidos rondaban un $50 \%$.

Por último, señalar que para complementar la información cualitativa obtenida con los cuestionarios, se han utilizado también los datos procedentes del registro o log de actividades del propio dispositivo móvil. Ello hace posible el análisis del grado de cumplimiento de las tareas propuestas a los alumnos y, a su vez, facilita una interpretación más ajustada de las percepciones manifestadas por los alumnos.

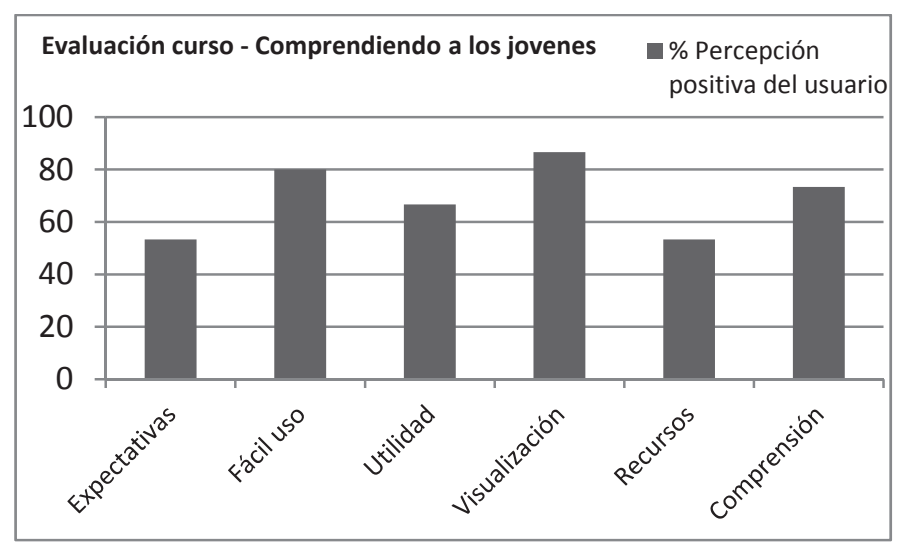

Fig. 8 Respuestas al cuestionario de valoración

En resumen creemos que los dispositivos móviles pueden suponer una ayuda inestimable que permite integrar a las personas adultas en un proceso de apoyo y aprendizaje individualizado a través de unas interfaces que, en principio, se han mostrado intuitivas y fáciles de usar. Sin embargo, no es menos cierto que el uso de tales dispositivos puede suponer una dificultad añadida dada la proliferación de contenidos, recursos y servicios asociados a estas tecnologías, circunstancia que puede conducir a la confusión, dispersión o pérdida de concentración en los alumnos.

\subsection{Enseñanza primaria}

Aunque como se describió anteriormente, se trata de una experiencia puntual, la profesora destacó muy positivamente la implicación de los alumnos en la sesión y, en particular, la de aquéllos con problemas de aprendizaje. Los alumnos se sienten motivados cuando ven sus contribuciones publicadas en el proyector y se sienten cómodos usando el bolígrafo sobre la tableta PC, pues les permite expresarse libremente. No obstante, hay que tener en cuenta el efecto "novedad" que supuso la incorporación de las tecnologías en el aula, lo que ha podido suponer una motivación extra en el comportamiento de los estudiantes. 


\section{Conclusiones}

Este trabajo ha presentado varios casos de uso de las TTD en contextos educativos muy diferentes, desde la enseñanza reglada universitaria, pasando por la formación de adultos o la enseñanza primaria. Si bien las experiencias han tenido planteamientos y alcances bien distintos, todas ellas han demostrado el potencial de las tecnologías y el impacto positivo, aunque moderado, en el aprendizaje. No obstante, conviene señalar que su impacto depende, en gran medida, de un adecuado diseño instructivo que posibilite una incorporación eficaz de las tecnologías, acorde con el contexto y los objetivos planteados.

Las líneas futuras de nuestro equipo vienen condicionadas por las dificultades actuales para renovar las tabletas disponibles, por lo que se plantea la incorporación de nuevos dispositivos móviles de bajo coste (tabletas y smartphones), así como los dispositivos de los propios alumnos, siguiendo la filosofía conocida como BYOD (Bring your Own Device). Para ello resulta necesario trabajar en lo adopción o desarrollo de nuevas herramientas que faciliten el uso de la tinta digital en estos dispositivos. Este enfoque nos permitiría abordar nuevos casos de estudio y ampliar los ámbitos. Resulta de particular interés el uso de estas tecnologías en la enseñanza secundaria, para lo que nuestro equipo ha contactado con una serie de centros con el fin de colaborar en su implantación.

\section{Referencias}

DILLARD, A.. (2012) Mobile Instructional Design Principles for Adult Learner. Capstone Report. University of Oregon, 2012.

https://scholarsbank.uoregon.edu/xmlui/bitstream/handle/1794/12253/Dillard2012.pdf?sequ ence $=1$. [Consulta: 9 de mayo de 2014].

FORNES, A., CONEJERO, J.A., MOLINA, A., PEREZ, A., VENDRELL, E., TERRASA, A. and SANCHIS, E. (2008). "Predicting success in the computer science degree using ROC analysis". En WORLDCOMP'2008, Int. Conf. Frontiers Educ.: Computer Sci. and Computer Eng. Las Vegas, NV: CSREA Press.

JOHNSON, L., ADAMS, S. y CUMMINS, M. (2012). Informe Horizon del NMC: Edición para la enseñanza universitaria. Austin, Tejas: The New Media Consortium.

UNESCO (2011). Mobile Learning Week Report

http://www.unesco.org/new/fileadmin/MULTIMEDIA/HQ/ED/ICT/pdf/UNESCO\%20MLW\%20repo rt\%20final\%2019jan.pdf. [Consulta: 9 de mayo de 2014].

WILLIAMSON, D. (2010). Box and Whisker Charts

http://www.duncanwil.co.uk/pdfs/boxplot_07.pdf. [Consulta: 17 de marzo de 2014]

WINTERS, N. (2006) "What is mobile learning?", in Big issues in mobile learning. Report of a workshop by the Kaleidoscope Network of Excellence Mobile Learning Initiative. Univ. of Nottingham, UK. 5-9. http://matchsz.inf.elte.hu/tt/docs/Sharples-20062.pdf. [Consulta: 17 de marzo de 2014].

\section{(cc) EY-NC-ND 2014, Universitat Politècnica de València}

I Jornadas IN-RED (2014) 


\title{
Presentaciones Interactivas Multimedia para el Autoaprendizaje
}

\section{Alfredo García García y Francisco Javier Camacho Torregrosa ${ }^{\text {b }}$}

${ }^{a}$ Catedrático, Departamento de Ingeniería e Infraestructuras de los Transportes, UPV, agarciag@tra.upv.es

${ }^{\text {b} P r o f e s o r ~ a y u d a n t e, ~ D e p a r t a m e n t o ~ d e ~ I n g e n i e r i ́ a ~ e ~ I n f r a e s t r u c t u r a s ~ d e ~ l o s ~ T r a n s p o r t e s, ~ U P V, ~}$ fracator@tra.upv.es

\begin{abstract}
This paper presents the development and teaching possibilities of a new learning tool. It combines combines both the synthetic approach offered by traditional presentations and the possibility of completing them with additional content. This new tool is called IMPS (Interactive, Multimedia Presentation for Self-Learning).

Initially, it may appear as a classic presentation, but it presents some interactive controls that show additional information.

This new tool may be used in different ways. For teachers, this tool allows them to variate the rythm of the lecture, by showing more or less information. On the other hand, students can use this tool before or after the lecture. The additional content controls makes it posible to show more or less information depending on students' preferences. This makes IMPS suitable for being used at massive online courses and for helping students to develop self-learning skills.
\end{abstract}

This tool can also be used for auto-assessment. Depending on the answer provided by the student, the IMPS can indicate whether it is true or false, also providing feedback.

Keywords: Electronic Learning, Multimedia, Presentation, Self-Learning

\section{Resumen}

En este trabajo se presenta el desarrollo y posibilidades didácticas de un nuevo objeto de aprendizaje, que pretende unir en un único recurso la sencillez de una presentación tradicional junto con el detalle que 
poroporciona el material adicional. Dicho objeto recibe el nombre de PIMA (Presentación Interactiva Multimedia para el Autoaprendizaje).

El desarrollo de este elemento parte de la base de una presentación tradicional, a la que se le añade interactividad e información adicional.

Este objeto puede ser utilizado de formas diferentes según el enfoque del profesor o del alumno. Para el profesor facilita el desarrollo de las clases, ya que puede desplegar el contenido adicional a voluntad. Desde el punto de vista del alumno, puede utilizarlo antes o después de la lección magistral, para aprender de forma autónoma la misma o para reforzar los aspectos que hayan quedado dudosos.

Este recurso puede utilizarse igualmente para la autoevaluación, en forma de preguntas tipo test. En función de la respuesta proporcionada por el alumno, el objeto puede indicar si es correcto o incorrecto, así como la retroalimentación necesaria para corregir las lagunas advertidas.

Palabras clave: Aprendizaje online, Multimedia, Presentación, Autoaprendizaje

\section{Introducción}

La convergencia y homologación de estudios dentro del Espacio Europeo de Educación Superior (EEES) ha cambiado en gran medida el concepto de enseñanza-aprendizaje existente anteriormente en el ámbito universitario y, especialmente, dentro de las ingenierías. Si bien antes se prestaba una mayor atención a la enseñanza por parte del profesor, el actual modelo se centra más en el proceso de aprendizaje del alumno, actuando el docente como un guía. De hecho, la capacidad de aprendizaje autónomo es una competencia que el alumno debe adquirir a lo largo de su proceso de formación (forma parte de las competencias centradas en la dimensión cognitiva-actitudinal del conocimiento, las cuales se diferencian de las competencias centradas en el desempeño, según Christensen (2008)).

Otra de las causas que está produciendo grandes cambios en el actual sistema de enseñanzaaprendizaje lo constituye la globalización y las Tecnologías de la Información y las Comunicaciones (TIC). Estas nuevas capacidades han supuesto unas importantes ventajas, tanto a la hora de concebir y diseñar nuevos recursos para el proceso, como de posibilitar la educación incluso a miles de kilómetros de distancia y de forma masiva (Fernández et al., 2009). 
Debido a estos cambios en el paradigma de la relación profesor-alumno, se deben reconsiderar los planteamientos docentes clásicos, básicamente hacia dos objetivos:

- Convertir al alumno en el protagonista activo de su propio aprendizaje, lo que le permitirá desarrollar la competencia específica correspondiente.

- Modelar unos métodos de enseñanza que sean adaptables en función de las capacidades, aptitudes y limitaciones de un estudiante mucho más heterogéneo.

Este planteamiento no sólo es adecuado desde el punto de vista del alumno, sino que también lo es desde el propio profesor. Al ser un público potencialmente mucho más numeroso, aumenta también su heterogeneidad. Esto supone que, si bien en un enfoque tradicional la lección magistral podía ser adecuada dada la relativa homogeneidad del alumnado, en la actualidad cada vez presenta más limitaciones. Así pues, la propia lección magistral ha cambiado paulatinamente, quedando reducida a la exposición del tronco principal de la lección, siendo los alumnos los encargados de completar el resto del esquema.

Por otra parte, es conocido también que las personas recopilan, procesan y organizan la información de muy diversos modos. A este proceso se le denomina "estilo de aprendizaje", y existen diferentes modelos, destacando el de Felder-Sylvermann (FSLSM) (Carmona, Castillo y Millán, 2009), que ha sido aplicado en un gran número de sistemas de e-learning. Según dicho modelo, las personas pueden ser clasificadas atendiendo a cuatro dimensiones:

- Procesamiento. Diferenciando entre personas activas (capaces de entender la información únicamente si han hablado de ella) de las reflexivas (prefieren pensar sobre el tema antes que pronunciarse al respecto).

- Percepción. Dentro de este campo existen las personas sensitivas (aprenden a partir de la observación) y las intuitivas (prefieren innovar a la hora de encontrar soluciones).

- Entrada. Personas visuales, que no encuentran dificultades en interpretar imágenes, diagramas, etc., frente a las personas verbales, que prefieren explicaciones orales o escritas.

- Comprensión. Las personas secuenciales estructuran el proceso de aprendizaje mediante la lógica y la sucesión de pasos, mientras que las personas globales prefieren analizar el problema en su conjunto.

En una lección magistral tradicional, el profesor debía encontrar la forma de comunicarse con todos los alumnos, atendiendo a las capacidades que él observase predominantes y, en caso de falta de comprensión, adaptar la explicación según otro enfoque. Esta posibilidad de adaptación debería quedar igualmente reflejada en los objetos de aprendizaje utilizados. Sin embargo, incluso entre los alumnos de una misma ingeniería existen amplias

\section{(c)) EY-NC-ND 2014, Universitat Politècnica de València}

I Jornadas IN-RED (2014) 
heterogeneidades (Solís y Arcudia, 2010), por lo que los recursos suelen ser más efectivos para unos individuos que para otros.

Se pueden clasificar las herramientas didácticas actualmente existentes en dos tipos: las que sirven para la introducción y desarrollo de un tema de forma presencial y las que son empleadas para ampliar la información. Un ejemplo de las primeras serían las presentaciones asistidas por medio de un programa informático, utilizadas habitualmente en el desarrollo de la clase magistral; mientras que un ejemplo de las segundas podría ser el material de consulta, como libros, apuntes, etc. Ambas herramientas tienen puntos de conexión, aunque su planteamiento y concepción son mayormente diferentes.

Las presentaciones que se desarrollan para la clase magistral suelen ser un compendio de los materiales que el profesor considera más importantes. A lo largo de la exposición, el profesor utilizará estas presentaciones como guía, profundizando en aquellos aspectos que considere convenientes. Esta presentación debe contener únicamente los puntos más importantes y constituir una guía para el seguimiento de la lección. No se trata, por tanto, de una recopilación de la totalidad del material.

Una limitación importante de estas presentaciones es que deben ser concebidas para ser expuestas en el tiempo que dura una lección magistral (o múltiplos de ella), por lo que los contenidos deben estar cuidadosamente seleccionados. Otra limitación existente es su diseño. La presentación será visualizada en público, a un auditorio que puede llegar incluso a más de un centenar de personas. Esto provoca que factores como las condiciones de iluminación de la sala, los colores y el tamaño de la letra tienen una importante repercusión en la transmisión de los conocimientos. A tal efecto hay diversas recomendaciones y reglas de buenas prácticas. Obviamente, también debe limitarse la cantidad de contenidos por diapositiva, debiendo el profesor discernir muy claramente entre lo esencial y lo accesorio.

Los materiales de consulta pueden ser considerados como la fuente, que contienen en su mayor parte la materia que es necesario asimilar. Estos materiales, generalmente recomendados por el profesor, son utilizados por parte del alumno con el fin de ampliar y asimilar el conocimiento. Es decir, su objetivo es la profundización. El alumno es quien decide qué material utilizar, y es él también quien escoge el ritmo de trabajo y en qué partes centrarse. Permite, por tanto, una mayor personalización del proceso de aprendizaje. Sin embargo, tiene como inconveniente que no se trata de una herramienta generalmente creada ad hoc para una asignatura.

Las nuevas tecnologías, incluyendo especialmente las nuevas capacidades de comunicación masiva y a distancia, además de las proporcionadas a través de las redes sociales, han permitido el desarrollo y la mejora de las herramientas anteriores. Un ejemplo de ello es el screencast, que aúna en un vídeo la presentación oral de un tema junto con las diapositivas correspondientes. Otro ejemplo son los vídeos didácticos o el empleo de blogs para la 
enseñanza. Este tipo de objetos permite, por una parte llegar a un número de personas mucho mayor. Por otra parte, permiten al alumno aprender de forma autónoma, puesto que suelen desarrollar ampliamente los conceptos expuestos.

Los dos materiales de aprendizaje anteriores (presentación en clase y material de consulta) pretenden ser complementarios. Así pues, los primeros sirven para iniciar al alumno en la materia, mientras que los segundos tienen como objetivo la ampliación, perfeccionamiento y consolidación de conocimientos. Sin embargo, la concepción de los mismos es, por lo general, completamente diferente $\mathrm{y}$, en algunas ocasiones, puede ser incluso contraproducente. En los casos en los que el profesor es el autor del material de consulta y/o que las presentaciones que utilice en el curso sigan un esquema similar, ambos materiales se complementarán de forma adecuada y el proceso de aprendizaje será más natural. Sin embargo, en caso de que no sea así, por lo general el orden expositivo para introducir una temática puede ser muy diferente al utilizado en el material de consulta, siendo en ocasiones el salto entre ambos tipos de material excesivo para el alumno. Frente a esta doble visión del tipo de material para el aprendizaje, cabe destacar también que ninguno de ellos está enfocado al aprendizaje autónomo desde un primer momento, ya que las diapositivas necesitan complementarse de la explicación del profesor, y el material de consulta en muchas ocasiones requiere un cierto conocimiento inicial.

Se dispone, por tanto, de un gran número de herramientas complementarias que abarcan muchos medios de difusión, diferentes enfoques del aprendizaje y diverso tipo de contenido, pero no existe un objeto intermedio que permita llegar a un gran número de personas, autónomo y adaptable a diversos estilos de enseñanza y de aprendizaje.

\section{Objetivos}

En este trabajo se presenta el desarrollo y posibilidades didácticas de un nuevo objeto de aprendizaje que pretende unir en un único recurso la sencillez de una presentación junto con la profundidad del material adicional, con la ventaja añadida de que pueda ser utilizado tanto en el aula como de forma autónoma por parte del alumno. Para conseguir tan diversos objetivos, en este recurso deberá jugar un papel fundamental la interactividad con el alumno. De este modo el propio alumno adaptará el uso del recurso a sus necesidades.

Por otra parte, este objeto pretende unir las dos herramientas planteadas anteriormente: la presentación como guía y el material de consulta. Esto permite una doble utilización, ya que podrá ser utilizado tanto durante la lección magistral como por parte del alumno en su aprendizaje autónomo. Debido a todas estas ventajas y a sus posibilidades, se ha decidido llamar al recurso como Presentación Interactiva Multimedia para el Autoaprendizaje (PIMA).

\section{(c)) BY-NC-ND 2014, Universitat Politècnica de València}

I Jornadas IN-RED (2014) 
A continuación se resumen los objetivos específicos que se pretenden conseguir con este objeto:

- Replantear el objeto de aprendizaje que se suele utilizar en la enseñanza universitaria, persiguiendo más si cabe el aprendizaje autónomo por parte del alumno.

- Incorporar en un único objeto una mayor cantidad de información multimedia, para así reducir la cantidad de recursos necesarios dispersos.

- Facilitar que sea el propio alumno el que marque el ritmo de aprendizaje, por medio de la interactividad con el objeto.

- Permitir un desarrollo sencillo de esta herramienta, sin necesidad de recurrir a otro tipo de herramientas de diseño de presentaciones que las habituales, ni a programación específica.

Aumentar la motivación de los alumnos por el aprendizaje autónomo y lograr de este modo que la fase presencial se emplee para desarrollar y consolidar los conceptos más importantes y las posibles aplicaciones prácticas.

\section{Desarrollo de la innovación}

El desarrollo de este elemento parte de una presentación, como las utilizadas tradicionalmente para el apoyo en la lección magistral. Un ejemplo aparece en la Figura 1, correspondiente a un objeto de aprendizaje sobre las redes viarias y sus elementos. Para ello pueden emplearse multitud de herramientas, como por ejemplo Microsoft Office PowerPoint, Adobe Flash, Prezi, etc. Nótese en dicha figura que no existe aparente diferencia respecto de una presentación tradicional.

Sin embargo, este objeto presenta dos importantes mejoras respecto de la presentación tradicional, como son:

- La interactividad.

- La inclusión de información adicional dentro de la misma.

La interactividad se logra por medio de la colocación de hipervínculos y de botones de navegación en las diapositivas. Los hipervínculos aparecen resaltados en color verde en la Figura 1, y sirven para acceder a una diapositiva u otra, según quiera avanzarse en el estudio del tema. Las lecciones están estructuradas por bloques, cada uno de ellos con su índice temático particular, a los cuales se accede desde un índice general. Así pues, el recorrido de las diapositivas no se realiza de forma secuencial, sino que puede adaptarse según requiera el usuario. Al final de cada bloque se regresa al índice temático correspondiente y, desde allí, será posible acceder al índice general. Debido a todas las 
posibilidades de navegación, es también importante que el color de los hipervínculos cambie una vez ya ha sido visitado. La Figura 2 muestra un ejemplo. Se recomienda que esta diferencia de colores sea suficiente pero no excesiva, para no fomentar la confusión.

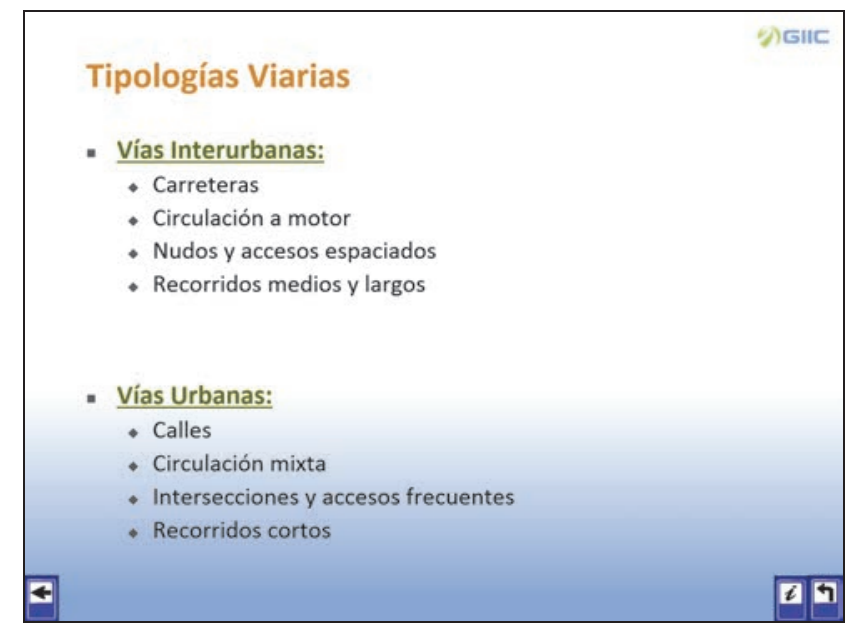

Fig. 1. Ejemplo de una diapositiva del objeto de aprendizaje.

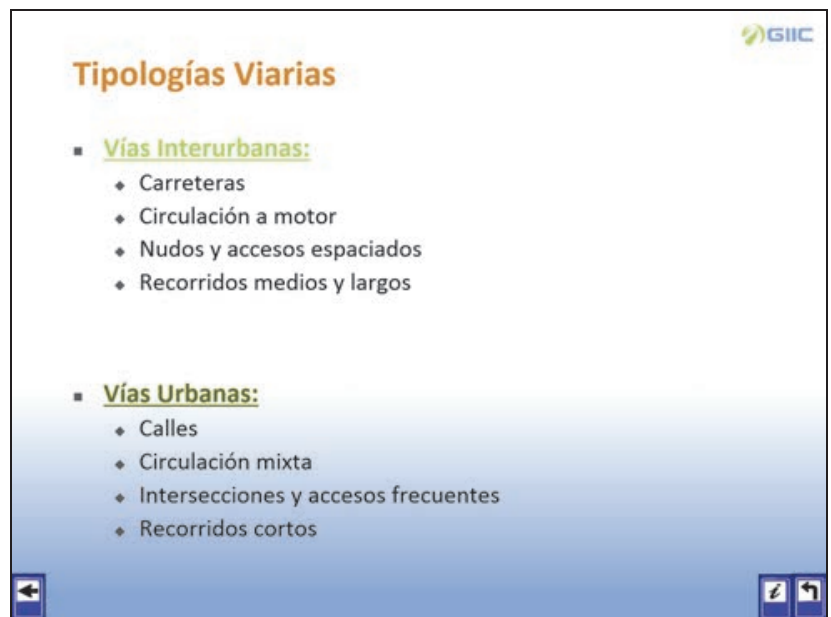

Fig. 2. Ejemplo de la presentación con un hipervínculo visitado.

Los botones de navegación son igualmente hipervínculos, pero se encuentran en todas las diapositivas y su función es homogénea. Cabe destacar que el alumno tenderá de forma natural a recorrer la presentación de forma secuencial, por lo que se debe desactivar la opción de avanzar por la presentación mediante clic del ratón. De este modo se fuerza al usuario a que utilice los botones de navegación. En la Figura 3 se muestran los botones de navegación básicos:

\section{(cc) BY-NC-ND 2014, Universitat Politècnica de València}

I Jornadas IN-RED (2014) 
- Atrás. Permite retroceder a la última diapositiva vista.

- Adelante. Posibilita avanzar a la diapositiva siguiente. Únicamente se encuentra en aquellas diapositivas que presentan una continuidad temática.

- Volver al menú. En aquellas diapositivas que finalizan un bloque temático, este botón permite retroceder al índice anterior correspondiente.

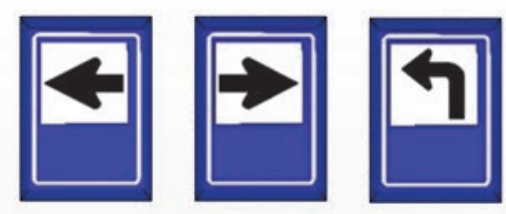

Fig. 3. Botones de navegación.

Esta forma de navegar por la presentación permite al usuario recorrer la misma de forma jerárquica, sin perder la referencia del índice general y los índices intermedios en torno a los cuales se estructura el tema. Se trata de un planteamiento, por lo que también serían aceptables esquemas alternativos.

La inclusión de información adicional es el aspecto más novedoso de este objeto, y el que realmente permite aunar en un recurso único las ventajas de la presentación y de los materiales complementarios. Tal y como se aprecia en la Figura 1, además de los botones de navegación aparece otro en la esquina inferior derecha, con el símbolo " $i$ " (haciendo referencia de forma intuitiva a "información"). Este control muestra (u oculta) otros iconos, situados junto al concepto al que estén referidos. La Figura 4 muestra la diapositiva de la Figura 1 tras hacer clic en el icono de información.

Estos nuevos iconos aparecen a la izquierda o a la derecha del elemento completado, y su tamaño es menor que el comando inicial. Haciendo clic sobre cada uno de ellos permite mostrar información adicional asociada al elemento correspondiente. Un ejemplo es la Figura 5, donde se ha hecho clic para ampliar la información de "Vías Interurbanas" y en el icono de la imagen. Como puede verse, el nuevo cartel de información adicional completa el contenido esquemático anterior y permite dar una visión global. Es importante que dicho contenido no oculte el contenido inicial correspondiente (en este caso "Vías Interurbanas" y las viñetas asociadas). También hay que cuidar el orden de todos los elementos en cuanto a su profundidad. Al oprimir de nuevo sobre el botón de información, el contenido se oculta. 


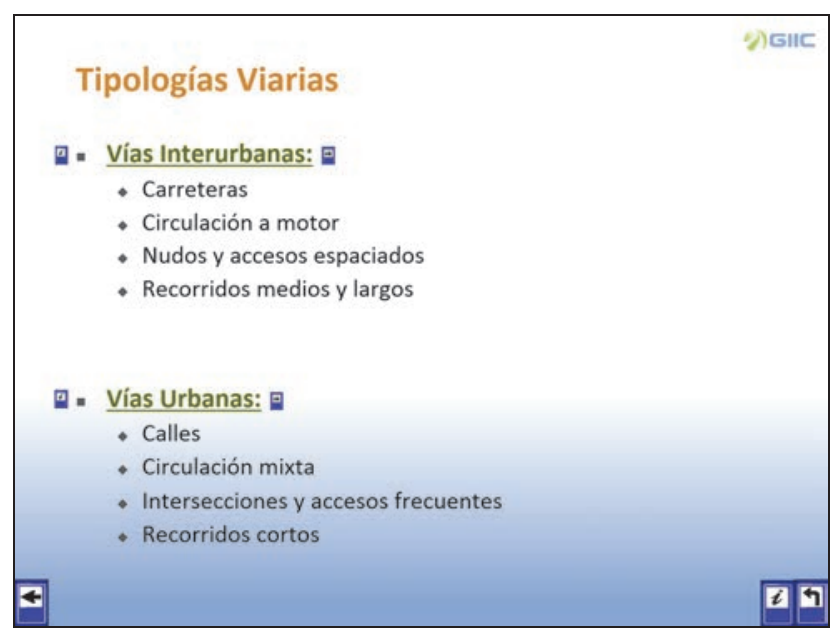

Fig. 4. Ejemplo de la diapositiva de la Figura 1 tras hacer clic en el botón de información.

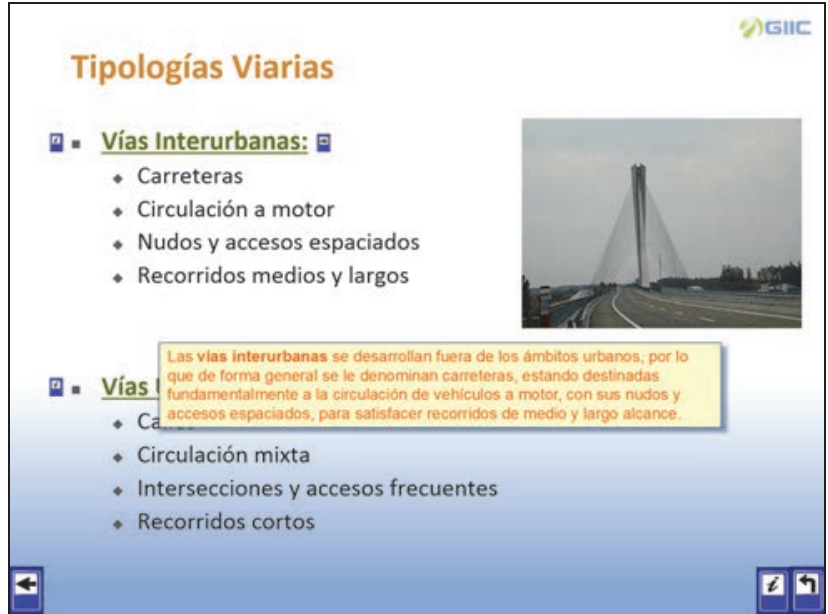

Fig. 5. Diapositiva tras hacer clic sobre el icono de información complementaria de "Vías interurbanas" y el de la imagen correspondiente.

Además de textos e imágenes, también pueden utilizarse otros elementos como vídeos, tablas, o cualquier otro objeto susceptible de ser incrustado (y animado) en el programa de edición.

Los iconos de información adicional deben indicar de forma intuitiva el tipo de información complementaria. La Figura 6 muestra las dos figuras utilizadas en este ejemplo. La de la izquierda indica "información adicional", y se utiliza tanto para desplegar los iconos de información secundarios como para mostrar el contenido de tipo texto. El icono de la derecha se corresponde con una cámara fotográfica, haciendo referencia a que el contenido

\section{(c)) EY-NC-ND 2014, Universitat Politècnica de València}

I Jornadas IN-RED (2014) 
complementario será una imagen. En este caso se optó por utilizar estos iconos porque se corresponden con señales de información de carreteras, lo cual está completamente relacionado con la materia del ejemplo utilizado.

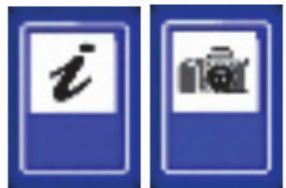

Fig. 6. Iconos de información complementaria.

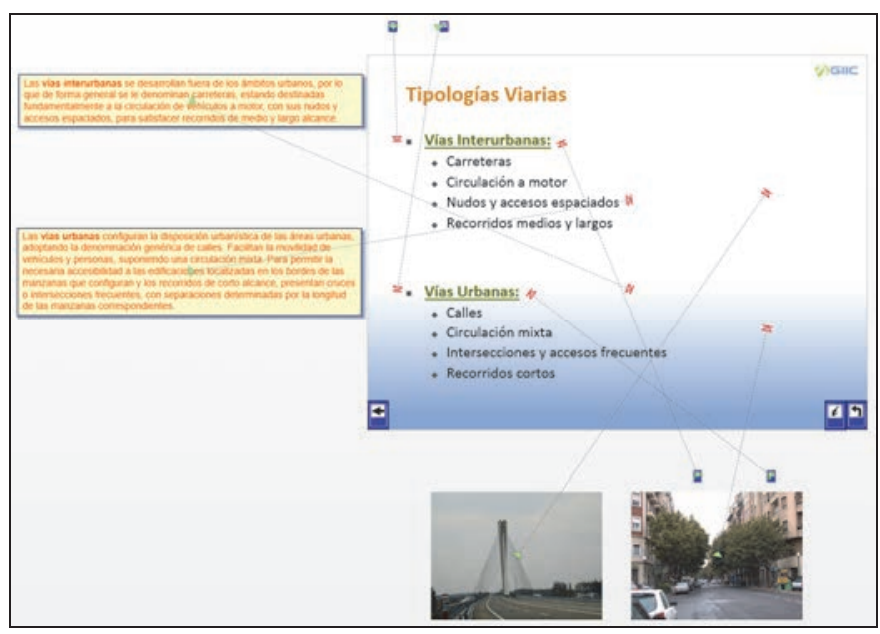

Fig. 7. Diseño de la diapositiva anterior

Al igual que en el caso de los botones de navegación, estos elementos también se han incrustado haciendo uso de las posibilidades que nos ofrecen los programas de diseño de presentaciones. Así pues, la información adicional debe introducirse como cuadros de texto, imágenes, vídeos, etc. Estos elementos deben situarse (en modo de edición) fuera del espacio de la diapositiva. Existe un motivo para ello: por lo general es recomendable que el alumno lleve las diapositivas impresas al aula, para seguir de una forma cómoda la lección y así tomar las notas necesarias. En caso de situar los elementos en la situación donde aparecerán, ocultarán el contenido primario. La Figura 7 muestra la diapositiva interactiva de ejemplo en modo de edición. La Figura 8 muestra un ejemplo de página de notas impresa por los alumnos para llevar al aula (como puede observarse, no aparece el contenido adicional, apareciendo las diapositivas de forma limpia). 


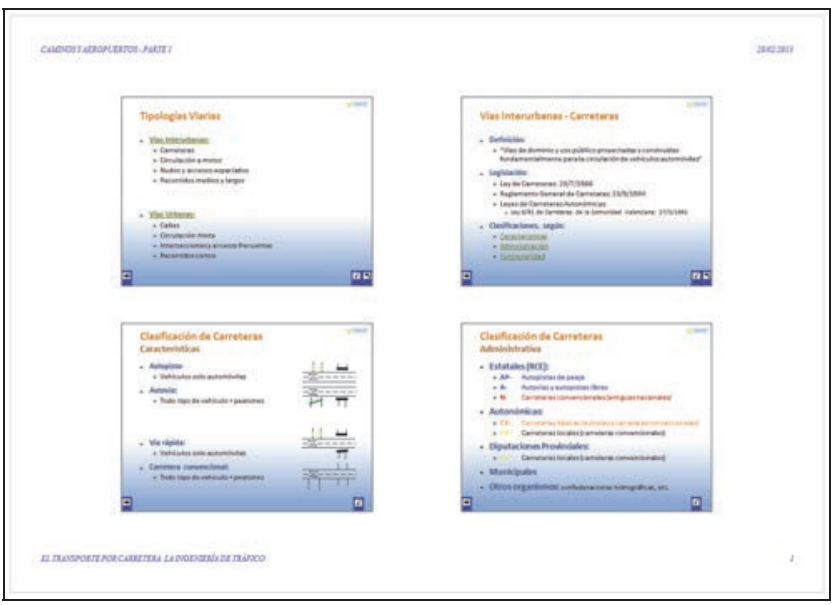

Fig. 8. Ejemplo de página con las diapositivas impresas por el alumno, para llevar al aula.

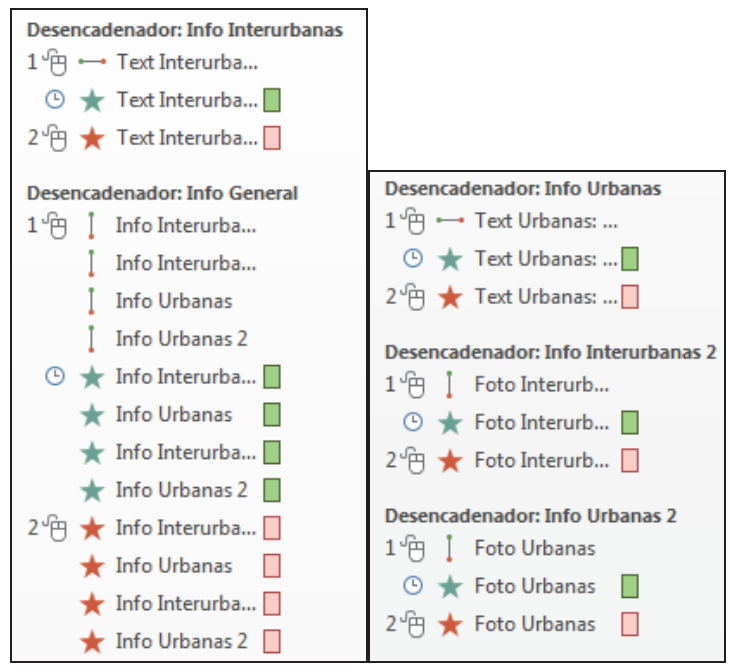

Fig. 9. Animaciones empleadas en la diapositiva (Microsoft PowerPoint).

Para que posteriormente el contenido aparezca al hacer clic sobre el botón correspondiente, es necesario "traer" el elemento a la zona de visualización. Esto es posible hacerlo empleando trayectorias de animación, tal y como muestra la Figura 7. Es preferible, por motivos estéticos, que el contenido aparezca directamente en la presentación y no lo haga desde un lateral. Para ello bastará con hacer que la aparición de dicha información se haga en dos fases, ambas asociadas al mismo desencadenador: el botón de información asociado. Así pues, al hacer clic en dicho botón se activará la animación de trayectoria de movimiento, que trasladará el cuadro de texto o la imagen a la zona donde se desea que aparezca. Posteriormente, y de forma automática, se le asocia una animación de aparición

\section{(c)) BY-NC-ND 2014, Universitat Politècnica de València}

I Jornadas IN-RED (2014) 
(en este caso se han asociado animaciones de desvanecimiento). El efecto final para el usuario es que el elemento aparece directamente sobre la presentación. La Figura 9 muestra un ejemplo de la programación de los desencadenadores para el caso de aparición de dos elementos.

\section{Resultados}

En el apartado anterior se ha descrito la funcionalidad y la creación de este nuevo objeto de aprendizaje, la PIMA. En este apartado se muestran algunos ejemplos de utilidades finales.

\subsection{Utilización para el Autoaprendizaje}

La PIMA fue diseñada desde un primer momento con el objetivo de que sea especialmente indicada para el aprendizaje autónomo. Las ventajas más importantes en este campo son:

1. En un mismo recurso está la información básica y la de ampliación. Al compartir estructura, la información resulta más intuitiva. El alumno distingue más fácilmente entre lo esencial y lo complementario.

2. El proceso de guiado facilita enormemente el autoaprendizaje. El entorno de navegación facilita que el alumno adquiera en un orden determinado los conocimientos. Puede ir hacia atrás o saltarse partes que ya tiene superadas, por lo que adapta el ritmo de aprendizaje a sus necesidades y capacidades.

3. Permite contrastar conceptos. La información complementaria de aspectos similares (o contrapuestos) puede situarse de forma que pueda visionarse a la vez. De esta forma es más sencillo realizar la asociación de conceptos (Figura 10).

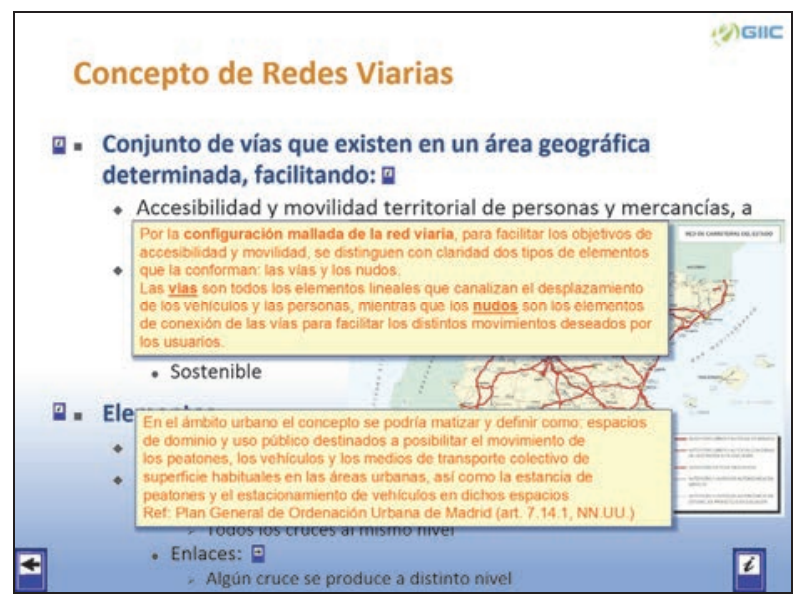

Fig. 10. Ejemplo de contraste de información complementaria. 


\subsection{Utilización en el Aula}

La PIMA, empleada en la lección magistral, cuenta con un gran número de ventajas respecto de la presentación tradicional. Estas ventajas se exponen a continuación:

1. Se trata de una presentación tradicional que contiene información complementaria. Por ello, en función de como se desarrolle la lección magistral, el docente puede recurrir a su utilización o no. Un ejemplo muy común es para evitar desajustes en el tiempo de desarrollo de la misma. Si el saldo es favorable, el docente puede mostrar más información de la que inicialmente tenía previsto. En caso contrario, puede decidir no mostrarla, sabiendo que los alumnos sí dispondrán de ella. Otra opción sería crear recursos diferentes dentro de una misma presentación en función de diversos estilos de aprendizaje. Recursos diferentes pueden contener un mismo concepto desde diferentes enfoques.

2. La información adicional existe y los alumnos son conscientes de ello. Ello reduce la necesidad de tomar notas en el aula, por lo que la atención se centra mayormente en la labor del docente. Se consigue así una mejor transmisión del conocimiento.

3. Ahorro de tiempo durante la lección magistral. El profesor puede plantear la lección diciéndoles a los alumnos (en la clase de antes) que estudien por adelantado la lección. El hecho de que los alumnos acudan al aula con los conocimientos básicos asentados presenta dos ventajas. Por una parte se optimiza el tiempo en el aula, obviando la explicación de los conceptos más básicos. Por otra parte, el docente reafirma unos conocimientos que de este modo no son nuevos para el alumnado, logrando una mayor efectividad. Además, se puede dedicar más tiempo a actividades prácticas que permitan consolidar esos conocimientos.

4. Guía impresa de la clase. Los alumnos pueden llevar a clase las diapositivas impresas, para realizar un mejor seguimiento.

\subsection{Utilización para la Autoevaluación del Alumno}

Otra posible opción de utilización es la autoevaluación del alumno de ciertos conceptos. Un ejemplo sería situar, en cada diapositiva, una pregunta con respuesta tipo test (de dos o más opciones). El alumno podría hacer clic en la que considere correcta y, acto seguido, aparece la corrección, indicando si es verdadero o falso.

La ventaja es que en caso de fallo puede configurarse la diapositiva para que muestre el texto, hipervínculos o contenidos adicionales que justifiquen el error, y guiar al alumno hacia su rectificación. Como es ampliamente sabido, ciertas partes de los temarios son más propensas a ser malinterpretadas por parte de los alumnos. Generalmente estas malas interpretaciones suelen poder agruparse en diferentes categorías. Podría, por ejemplo,

(cc) BY-NC-ND 2014, Universitat Politècnica de València

I Jornadas IN-RED (2014) 
configurarse las respuestas en función de estos grupos y así tratar de forma particular cada uno de ellos.

\subsection{Creación}

Nótese que el número de animaciones necesarias es elevado, incluso para una diapositiva sencilla. Por ello, a la hora de crear este tipo de recurso, se recomiendan dos cosas:

- No incrustar demasiados elementos adicionales en una diapositiva.

- Resulta muy conveniente crear una plantilla con un número elevado de elementos de información (10 por ejemplo), con todas las animaciones y desencadenadores. Partiendo de esta plantilla es fácil borrar los elementos no usados.

Hay que cuidar mucho el material adicional que se inserta. Pese a que se inserta más contenido que en una presentación tradicional, ello no implica que el alumno no deba consultar otros recursos. Todo ello quedará a criterio del docente.

La inclusión de material adicional también da pie a que se amplíe la presentación con ejemplos, casos prácticos, y anécdotas, que si bien sirven para comprender o reforzar los conceptos desde otro punto de vista, no son material adicional que el alumno deba estudiar. Por ello, debería tenerse también en cuenta que el alumno debe distinguir claramente lo que es importante y lo que es accesorio. Ello puede hacerse utilizando, por ejemplo, algún indicador o color distinto en cada caso.

En el proceso de diseño hay que cuidar igualmente la posición de todos los objetos, procurando que puedan ser visualizados al mismo tiempo los conceptos opuestos o complementarios, y que no tapen el contenido del cual dependen. Ello condiciona, aunque no pudiera parecer tan evidente desde un primer momento, la propia configuración de la presentación inicial.

El diseño de los botones de navegación debe ser intuitivo y fácil de entender. En las figuras anteriores ello se consigue mediante un formato similar de dichos botones, que contraste claramente con el fondo, y una colocación homogénea.

El contenido adicional, una vez mostrado, debe destacar lo suficiente respecto del fondo. Por ello, a cada cuadro o imagen complementaria se le ha dotado de un marco y sombreado.

\section{Conclusiones}

En este trabajo se ha presentado un objeto de aprendizaje innovador que permite aunar las ventajas de la sencillez de edición y uso de una presentación tradicional junto con la profundidad y variedad del material de consulta adicional. La concepción de dicho objeto 
es tal que permite ser utilizado tanto en la lección magistral como por el alumno en su aprendizaje de forma autónoma, tanto previa como posteriormente a dicha lección.

El objeto básicamente se compone de una presentación tradicional, configurada para ser recorrida mediante botones de navegación, y que dispone también de botones adicionales informativos a los que se les puede oprimir y ofrecen información adicional y complementaria. Es por ello que se le da el nombre de Presentación Interactiva Multimedia para el Autoaprendizaje (PIMA).

Se trata, pues, de un objeto de aprendizaje muy interactivo, adaptable para cada alumno según sus necesidades en una zona u otra del tema (puesto que es él quien lo recorre y quien decide en qué partes centrarse más o dónde necesita más atención). Permite, por tanto, separar de una forma más clara el trabajo del profesor en clase y el individual a realizar por los alumnos.

\section{Referencias}

CHRISTENSEN, H. (2008). "De las competencias a los objetivos educacionales". Ciencia e Ingeniería en la formación de ingenieros para el siglo XXI. Bogotá: ACOFI, pp. $42-58$

FERNÁNDEZ SÁNCHEZ, P. et al. (2009). "El aprendizaje activo mediante la autoevaluación utilizando un laboratorio virtual" en IEEE-RITA, vol. 4, núm 1, pp. 53-62.

CARMONA MÁRQUEZ, C.; CASTILLO JORDÁN, G. y MILLÁN VALLDEPERAS, E. (2009). "Modelo Bayesiano del Alumno basado en el Estilo de Aprendizaje y las Preferencias", en IEEE-RITA, vol. 4, no. 2, pp. 139-146.

SOLÍS CARCAÑO, R. y ARCUDIA ABAD, C. (2010). "Estilos de aprendizaje de los estudiantes en ingeniería civil", en Revista Educación en Ingeniería, número 10, pp. 24-36.

(c)) EY-NC-ND 2014, Universitat Politècnica de València

I Jornadas IN-RED (2014) 


\title{
Uso de herramientas on-line de evaluación y autoevaluación para la mejora del aprendizaje activo. Una experiencia en Contaminación y Tratamiento de Aguas.
}

\section{Jesús Mengual Cuquerella y Juan Andrés González Romero}

Departamento de Ingeniería Hidráulica y Medio Ambiente - Escuela Politécnica Superior de Gandia (jemencu@hma.upv.es, juagonr1@hma.upv.es)

\begin{abstract}
The adaptation of the educational model to the European Higher Education Area requires, among other things, tools that allow a continuous evaluation. In this sense, the use of on-line self-evaluation tests allows both the student and teacher carry out continuous monitoring of developments in their learning. In the subject Pollution and Treatment of Water taught in the Degree in Environmental Sciences of the UPV the "Exámenes" tool, included in the PoliformaT platform, for testing on-line evaluation is used in order to promote continuous evaluation and facilitate active learning by students. The experience involves programming formative self-evaluation tests after completion of each topic or didactic unit. The realization of tests allows students to achieve a progressive consolidation of partial contents that improves the understanding of more advanced contents as the use of practical activities scheduled. The use of new technologies allows have remote tools that facilitate the task of monitoring that, otherwise, would be infeasible for large groups. Furthermore, the results are incorporated into evaluation system, complementing the continuous evaluation of the course.
\end{abstract}

Keywords: On-line technological resources, remote evaluation, selfevaluation, active learning

\footnotetext{
Resumen

La adaptación del modelo educativo al Espacio Europeo de Educación Superior requiere, entre otros aspectos, de herramientas que permitan una evaluación continua. En este sentido, la disponibilidad de pruebas de
} 
Uso de herramientas on-line de evaluación y autoevaluación para la mejora del aprendizaje activo. Una experiencia en Contaminación y Tratamiento de Aguas.

autoevaluación on-line permite tanto al alumno como profesor realizar un seguimiento continuado acerca de la evolución de su aprendizaje. En la asignatura Contaminación y Tratamiento de Aguas impartida en el Grado en Ciencias Ambientales de la UPV se utiliza la herramienta "Exámenes" incluida en la plataforma PoliformaT para la realización de pruebas de evaluación on-line con el objetivo de favorecer la evaluación continua y facilitar un aprendizaje activo por parte del alumno. La experiencia consiste en la programación de cuestionarios y pruebas de autoevaluación formativa tras la finalización de cada tema o unidad didáctica. La realización de las pruebas permite al alumno lograr una consolidación progresiva de contenidos parciales que mejora tanto la comprensión de contenidos más avanzados como el aprovechamiento de las actividades prácticas programadas. El uso de las nuevas tecnologías permite disponer de herramientas a distancia que facilitan la tarea de seguimiento que, de otro modo, resultaría inviable para grupos numerosos. Además, los resultados obtenidos se incorporan al sistema de evaluación, complementando la evaluación continua de la asignatura.

Palabras clave: Recursos tecnológicos on-line, evaluación a distancia, autoevaluación, aprendizaje activo

\section{Introducción}

El Espacio Europeo de Educación Superior representa un nuevo paradigma pedagógico basado en técnicas que permitan involucrar a los estudiantes en el proceso de aprendizaje. Estas metodologías implican un papel activo por parte del estudiante el cual le permitará alcanzar mayor efectividad en su formación (McKeachie, 1986). La función del profesor debería dirigirse, por lo tanto, a facilitar dicho proceso al alumno, es decir, ser un guía, un apoyo durante la etapa formativa (Claux, 2001). Para alcanzar esta nueva función es necesaria la introducción de nuevas metodologías pedagógicas (De Miguel, 2006). El empleo de tecnologías de la información y comunicación (TIC) es adecuado dentro de este contexto, dado que mejoran el proceso de aprendizaje y contribuyen a la inmersión del estudiante en la sociedad de la información (Zhu, 2006).

En este contexto de desarrollo continuo, la disponibilidad de herramientas que permitan la evaluación autónoma de dicho proceso de enseñanza-aprendizaje por parte del alumno es esencial como una referencia de que se van alcanzando los difentes objetivos perseguidos. A su vez, dichas herramientas también son una excelente fuente de información para el 
docente, dado que le permiten analizar cual es la evolución de sus estudiantes, la asimilación de conceptos y reenfocar la docencia en función de los resultados obtenidos, reforzando aquellas áreas que tengan una peor asimilación.

\section{Objetivos}

El objetivo de este estudio es analizar el uso de Tecnologías de la Información y Comunicación (TIC) en la asignatura de Contaminación y Tratamiento de Aguas del Grado en Ciencias Ambientales de la Universidad Politécnica de Valencia (UPV). En concreto se trata de fomentar el empleo de pruebas on-line de autoevaluación de los conceptos teóricos desarrollados en las sesiones de teoría de aula. Dichas pruebas tienen varios objetivos secundarios implícitos: fomentar el estudio de los conceptos teóricos vistos en clase de forma secuencial y continua así como permitir, tanto al estudiante como al profesor, seguir y controlar el proceso de enseñanza-aprendizaje.

\section{Desarrollo de la innovación}

\subsection{Contexto}

Contaminación y Tratamiento de Aguas es una asignatura que se imparte en el tercer curso del Grado en Ciencias Ambientales de la UPV, en el Campus de Gandía. Dicha asignatura es una adaptación de la asigntarua que se impartía en la antigua Licenciatura en Ciencias Ambientales del mismo campus. La nueva asignatura tiene asignados 6 créditos y se encuentran repartidos de la siguiente manera:

- $\quad 2,8$ teoría de aula

- $\quad 0,8$ prácticas de aula

- $\quad 0,6$ seminarios

- $\quad 1,4$ prácticas de laboratorio

- $\quad 0,4$ práctica de campo

La asignatura se subdivide en dos unidades didácticas básicas. La primera de Calidad y Contaminación del Agua y la segunda de Corrección de la Calidad del Agua. A su vez, cada unidad didáctica está formada por distintos temas, cuatro temas la primera unidad y cuatro la segunda. Esta asignatura tiene como peculiaridad que gran parte de sus contenidos están muy interrelacionados; se requiere un conocimiento previo para poder avanzar en la temática. Este aspecto conlleva que la segunda unidad didáctica sea más compleja que la primera, requiriendo dominar los conceptos vistos previamente.

(cc) EY-NC-ND 2014, Universitat Politècnica de València

I Jornadas IN-RED (2014) 
Uso de herramientas on-line de evaluación y autoevaluación para la mejora del aprendizaje activo. Una experiencia en Contaminación y Tratamiento de Aguas.

El método de evaluación se basa en la realización de dos pruebas individuales escritas relacionadas con la parte de teoría de aula (50\%), realizadas tras la finalización del desarrollo teórico de cada unidad, presentación de diferentes trabajos individuales o en pareja a lo largo del curso, relacionados con las prácticas de aula y seminarios (25\%) así como la asintencia al laboratorio y presentación de informes de resultados grupales (25\%). Se pretende, con dicho sistema de evaluación, fomentar el trabajo diario y continuo del alumno a lo largo del curso, para así mejorar su proceso de aprendizaje.

\subsection{Descripción de la nueva metodología}

En la asignatura equivalente del antiguo plan de estudios, en la que se realizaba un único exámen para evaluar los conceptos teóricos, se observaba que los conceptos teóricos no quedaban bien asimilados y que los estudiantes no seguían fácilmente el hilo de las explicaciones durante el curso. Este hecho se reflejaba en tasas de abandono mayores y menores tasas de aprobados. En base a esta experiencia previa se planteó, para la nueva asignatura del Grado, un sistema de evaluación en el que se realizara una prueba escrita tras terminar cada una de las unidades didácticas, con lo que se pretendía fomentar una formación más secuencial y continua. Además, dada la mayor complejidad de la segunda unidad, se planteó la alternativa de realizar pruebas de tipo test on-line tras finalizar cada uno de los temas de esta segunda unidad. Este tipo de pruebas fomentaría en el alumno un estudio de cada tema en el momento de su finalización así como una autoevaluación de los conocimientos adquiridos sobre el mismo. A su vez, este estudio más continuo por parte del alumno permitiría seguir mejor los temas posteriores.

Para la realización de este tipo de pruebas se utilizó la herramiento "Exámenes" presente en la plataforma PoliformaT. Dicha herramienta permite hacer exámenes de tipo on-line con distintos tipos de preguntas, controlando aquellos estudiantes que los realizan, tiempo invertido en su realización, envío de comentarios para reforzar las cuestiones respondidas y, "lo más importante", la posibilidad de corrección automática con la generación del fichero correspondiente, lo que es de gran ayuda cuando se incrementa el número de actos de evaluación y la cantidad de alumnos es elevada.

En este caso concreto, las pruebas eran activadas el día en que se terminaba de impartir el tema en cuestión y se les daba un plazo de una semana a los estudiantes durante el cual podrían realizarla. Además, tenían la posibilidad de realizar la prueba a distancia. La prueba estaba temporizada, dando un tiempo de un minuto por pregunta a responder. Una vez iniciada la prueba debían terminarla. Los estudiantes tenían que contestar de forma secuencial a las preguntas y solo se permitía un envío. Tras la realización de la prueba el sistema les indicaba la puntuación obtenida, pero sin el envío de ningún tipo de comentarios 
ni posibilidad de revisar los errores y aciertos. A todas estas pruebas en conjunto se les dio un peso simbólico en la evaluación global de la asignatura de un 5\% del total.

\section{Resultados}

En el siguiente capítulo se pretende mostrar los resultados más destacables de la aplicación de la metodología de evaluación propuesta.

En función de los datos mostrados en la Tabla 1 se puede deducir que la aceptación de este tipo de metodología por parte de los alumnos es alta, sin que, a priori, tenga un gran efecto motivador el 5\% que estas pruebas tienen sobre la nota final. Se puede apreciar como, restándole los porcentajes de alumnos que desde el principio no participaron en la asignatura (valores entre paréntesis), los porcentajes son relativamente bajos, alta participación.

Tabla 1. Porcentaje de No-Presentados a las pruebas de autoevaluación ${ }^{a}$

\begin{tabular}{cccccc}
\hline Curso & Prueba 1 & Prueba 2 & Prueba 3 & Prueba 4 & NP $^{b}$ \\
\hline $\mathbf{2 0 1 1}$ & $14,3(4,8)$ & $9,5(0,0)$ & $19,0(9,5)$ & $15,0(5,5)$ & 9,5 \\
\hline $\mathbf{2 0 1 2}$ & $23,1(3,7)$ & $30,8(11,4)$ & $25,6(6,2)$ & - & 19,4 \\
\hline $\mathbf{2 0 1 3}$ & $28,6(25,0)$ & $19,6(16,0)$ & $12,5(8,9)$ & $12,5(8,9)$ & 3,6 \\
\hline
\end{tabular}

${ }^{a}$ Valores mostrados en tanto por cien (\%)

${ }^{b}$ Porcentaje (\%) de alumnos que desde el principio no participó en la asignatura

Los valores promedio de participación son de un 95,1\% el año 2011, un 92,3\% el 2012 y un $85,3 \%$ el 2013. Los valores son relativamente altos, aunque el del último año presenta un resultado anormalmente bajo. Este hecho puede estar relacionado, entre otros factores, a un grupo bastante desmotivado. Las causas de dicha desmotivación no son objeto del presente estudio. Para reafirmar dicha afirmación, se han determinado los porcentajes de asistencia a una estación depuradora de aguas residuales real, práctica de campo voluntaria, sin valoración en la nota final. Estos valores, sin tener en cuenta aquellos alumnos que desde el principio se dejaron la asignatura, son de un 94,7\% para el año 2011, un 93,8\% para el 2012 y, sin embargo, un 75,9\% para el año 2013. Como se verá posteriormente, esta menor participación en las actividades programadas tendrá consecuencias negativas.

También se descarta la posible dificultad de las pruebas realizadas, que conlleve una desmotivación por parte del alumnado. La nota promedio de todas las pruebas realizdas durante estos tres años se situó en un 7,0. En la Figura 1 se muestra un histograma en el que

\section{(cc) EY-NC-ND 2014, Universitat Politècnica de València}

I Jornadas IN-RED (2014) 
Uso de herramientas on-line de evaluación y autoevaluación para la mejora del aprendizaje activo. Una experiencia en Contaminación y Tratamiento de Aguas.

se pueden observar las frecuencias de las diferentes calificaciones obtenidas para todas las pruebas realizadas. Se puede ver como el nivel de dificultad de las pruebas no es muy exigente con el grupo de estudio, permitiendo obtener altas calificaciones.

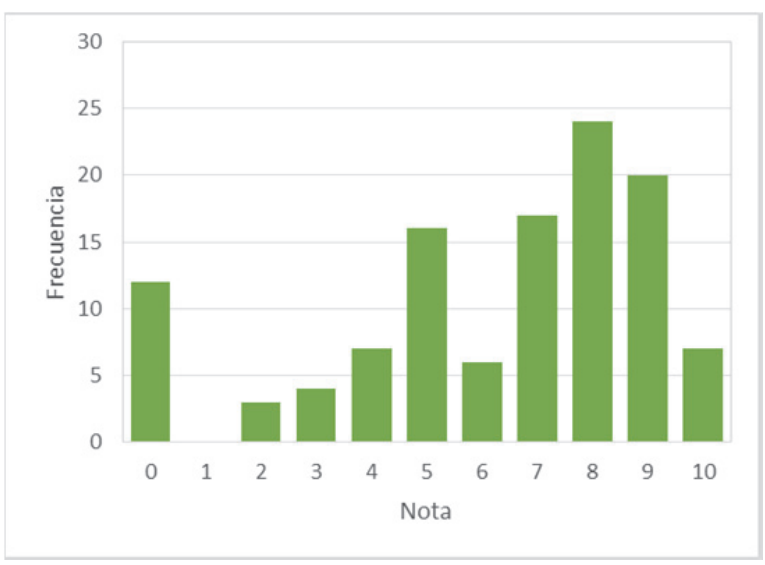

Figura 1. Histograma de notas del total de pruebas realizadas

En la Figura 2 se puede apreciar la posible relación existente entre la nota promedio obtenida en las pruebas de autoevaluación y la nota final y nota de teoría para todos los alumnos de los tres cursos considerados. Inicialmente se puede apreciar que existe una relación ascendente entre dichas variables. Conforme se obtiene mayor puntuación en las autoevaluaciones mayores notas finales se obtienen. Sin embargo, es destacable que dicha
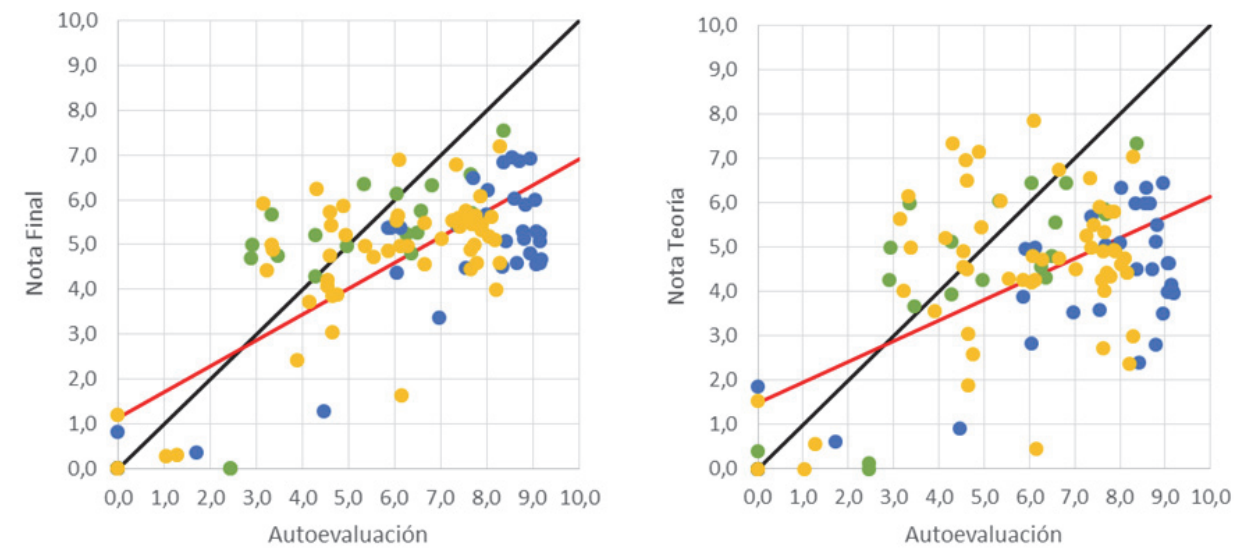

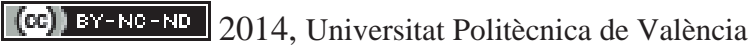

I Jornadas IN-RED (2014) 
Figura 2. Relación entre la nota final y la de la parte de Teoría con la autoevaluación.

Curso: $2011(\bullet), 2012(\bullet), 2013(\bullet) / /$ Regresión lineal (-)

relación, al contrario de lo que cabría esperar, tiene una mayor dispersión cuando se compara la nota de teoría con la de la autoevaluación. Estando dichas pruebas relacionadas con los conceptos teóricos, cabría esperar una menor dispersión. Existen distintas causas posibles para explicar dicho efecto. Quizá una de las más importantes se deba a que existe una gran diferencia entre el tipo de preguntas realizadas en las autoevaluaciones con las realizas en las pruebas escritas. En este sentido habría que mejorar la asimilación de los conceptos vistos en las autoevaluaciones. De todas formas, si que se puede apreciar que en la nota final de la asignatura existe una relación positiva y que se aproxima más hacia la asíntota, implicando que aquellos que mejores notas obtienen, por lo general, mejores valores de autoevaluación presentan, lo que puede estar relacionado con un mejor seguimiento y asimilación de las clases teóricas.

Un hecho curioso a destacar es la relación que presenta la autoevaluación con el resto de actos de evaluación presentes en la asignatura, esto es, prácticas de aula y de laboratorio.
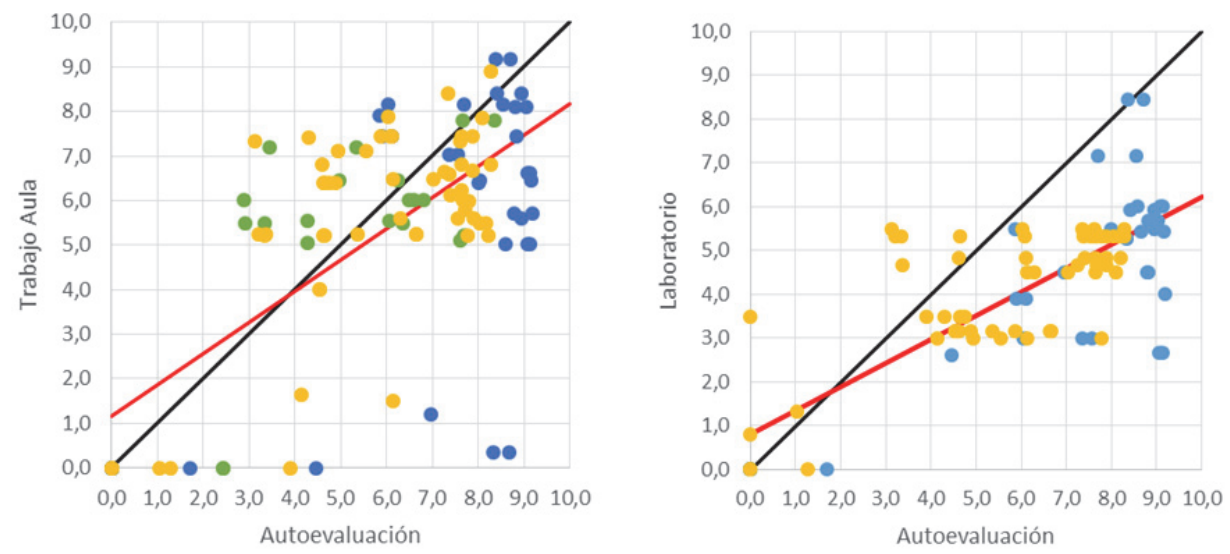

Figura 3. Relación entre el trabajo de aula y de laboratorio con la autoevaluación.

Curso: $2011(\bullet), 2012(\bullet), 2013(\bullet) / /$ Regresión lineal (-)

Como puede apreciarse en la Figura 3, la relación entre estas variables también es creciente, pero la existente entre el trabajo de aula y la autoevaluación está más próxima a la asíntota, presentando una mayor dependencia con respecto a la autoevaluación que las prácticas de

\section{(cc) EY-NC-ND 2014, Universitat Politècnica de València}

I Jornadas IN-RED (2014) 
Uso de herramientas on-line de evaluación y autoevaluación para la mejora del aprendizaje activo. Una experiencia en Contaminación y Tratamiento de Aguas.

laboratorio. La posible causa de este hecho está en que, a diferencia de lo que sucede con las prácticas de laboratorio, los trabajos de aula se realizan de forma individual o en parejas, por lo que una mayor nota implica una mayor implicación y dedicación, al igual que con la autoevaluación. Por el contrario, en las prácticas de laboratorio se trabaja en grupos de 5-6 personas, por lo que los resultados pueden estar parcialmente enmascarados por miembros del grupo que se impliquen más frente a otros que lo hagan en menor proporción. En este sentido, este estudio ha permitido observar que, para una evaluación más justa, una labor pendiente es la de mejorar la evaluación individualizada del trabajo de laboratorio.

Por útlimo, sería importante poder ver cual es el resultado en el rendimiento de los estudiantes de los cambios metodológicos introducidos en la asignatura. En la Tabla 2 se muestran los porcentajes de presentados y de aprobados de aquellos presentados para diferentes cursos, tanto de los del Grado como de los últimos de la antigua Licenciatura.

Tabla 2. Comparativa del rendimiento académico

\begin{tabular}{ccc}
\hline Curso & Presentados (\%) & Aprobados (\%) \\
\hline $\mathbf{2 0 0 9}$ (Lic.) & 80,0 & 85,0 \\
\hline $\mathbf{2 0 1 0}$ (Lic.) & 75,0 & 88,5 \\
\hline $\mathbf{2 0 1 1}$ (Grado) & 90,5 & 94,7 \\
\hline $\mathbf{2 0 1 2}$ (Grado) & $80,6^{a}$ & 93,1 \\
\hline $\mathbf{2 0 1 3}$ (Grado) & 96,4 & 77,8 \\
\hline $\begin{array}{l}\text { Valor anormalmento bajo debido a que muchos estudiantes estaban } \\
\text { matriculados pero participando en el programa Erasmus. }\end{array}$
\end{tabular}

Como se puede apreciar, la nueva metodología empleada ha permitido aumentar el numero de alumnos que se presentan a los diferentes actos de evaluación, con lo que se disminuye la tasa de abandonos. Además, el porcentaje de aprobados de aquellos que siguen la asignatura ha aumentado de forma significativa. Cabe destacar que el último curso registrado, 2013, presenta el valor más bajo de toda la serie estudiada. Este hecho se relaciona con la menor motivación mostrada por este grupo, tal y como se ha indicado anteriormente. La falta de motivación en el grupo no solo ha llevado a una menor tasa de aprobados, sino que la nota media del grupo ha descendido de un valor en torno al 6,0 para los cursos anteriores a un 5,2 para el curso 2013. 
Jesús Mengual Cuquerella Juan Andrés González Romero

\section{Conclusiones}

A partir de los resultados mostrados en este estudio se pueden obtener las siguientes conclusiones y acciones de mejora futuras:

- El sistema de autoevaluación tiene una buena aceptación por parte del alumnado. Para mejorar dicha apreciación se plantea la posibilidad de llevar a cabo encuestas de opinión a los estudiantes sobre la metodología empleada.

- Para que esta metodología de los mejores resultados es necesario trabajar con un grupo motivado, que participe activamente en el proceso de aprendizaje. Mejorar dicho aspecto así como replantear el peso sobre la nota final de las actividades individuales.

- Existe una relación positiva entre el resultado final de evaluación y las autoevaluaciones. Sin embargo, no está tan clara la relación entre la asimilación de conceptos teóricos y la autoevaluación. Se plantea la posibilidad de reforzar la retroalimentación en las pruebas de evaluación, emplenado para ello las herramientas que aporta la plataforma (comentarios a las preguntas mal contestadas, revisión de las contestaciones, etc.)

- Mejorar la evaluación individualizada de las prácticas de laboratorio. Para ello se plantea un mayor seguimiento de los alumnos durante la realización de las mismas, intentar trabajar con grupos más reducidos y llevar a cabo, a parte de los informes grupales a presentar, pruebas de evaluación individualizadas.

\section{Referencias}

CLAUX, M., KANASHIRO, Y., y YOUNG, A. (2001). Modelos Psicológicos de la Instrucción. Lima: Ministerio de Educación.

DE MIGUEL, M. (2006). Metodología de Enseñanza y Aprendizaje para el Desarrollo de Competencias. Madrid: Alianza.

McKEACHIE, W. (1986). Teaching Tips: A Guidebook For The Beginning College Teacher (8th Edition). Lexington, Mass., D.C. Heath and Co.

ZHU, E. y KAPLAN, M. (2006). Technology and Teaching. Teaching tips: Strategies, research and theory for college and university teachers (12th ed.) In W. J. McKeachie (Ed.). Boston, MA: Houghton Mifflin.

(c)) EY-NC-ND 2014, Universitat Politècnica de València

I Jornadas IN-RED (2014) 
Jornadas In-Red 2014

Universitat Politècnica de València

\title{
Desarrollo de laboratorios virtuales con Mathematica y su aplicación a la docencia en red en el ámbito de la Ingeniería Ambiental
}

Enrique Asensi ${ }^{\mathrm{a}}$ y Elena Alemany ${ }^{\mathrm{b}}$

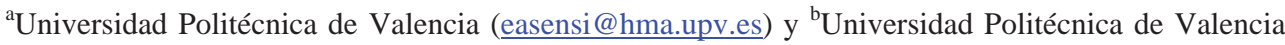
(ealemany@mat.upv.es).

\begin{abstract}
Problems to be solved in the context of environmental engineering require the use of complicated mathematical models, as well as empirical formula and design criteria that happen to be often complex and little intuitive for the student. In this paper the advantages of using the Mathematica program to create virtual laboratories are pointed out. Examples of application of virtual laboratories developed with Mathematica are also shown to facilitate the learning process in the classroom, and also during the self-teaching period, of a student in the field of Environmental Engineering. In particular it aims to highlight the difficulties that can be overcome when learning mathematical models of contaminant transport in the environment and in the design of facilities for wastewater treatment.
\end{abstract}

Keywords: Virtual labs, Mathematica, Environmental engineering

\footnotetext{
Resumen

Los problemas que plantea resolver la Ingeniería Ambiental precisan del uso de complejos modelos matemáticos, así como de fórmulas empíricas y de criterios de diseño que resultan ser en muchos casos complicados y poco intuitivos para el alumno. En este trabajo se indican las ventajas de utilizar el programa Mathematica para crear laboratorios virtuales. También se muestran ejemplos de aplicación de laboratorios virtuales desarrollados con Mathematica para facilitar el proceso de aprendizaje tanto en el aula, como en la fase de aprendizaje autónomo del alumno, en el ámbito de la Ingeniería Ambienta. En particular se pretende destacar las dificultades que se pueden superar en el aprendizaje de modelos matemáticos de transporte de
}

(c)) EY-NC-ND 2014, Universitat Politècnica de València

I Jornadas In-Red (2014) 
Desarrollo de laboratorios virtuales con Mathematica y su aplicación a la docencia en red en el ámbito de la Ingeniería Ambiental

contaminantes en el medio natural y en el diseño de instalaciones de tratamiento de aguas residuales.

Palabras clave: Laboratorios virtuales, Mathematica, Ingeniería ambiental

\section{Introducción}

El proceso de Convergencia Europea en las enseñanzas universitarias está suponiendo el desarrollo e introducción de nuevas metodologías docentes como complemento a la enseñanza presencial, así como, la necesidad de utilizar las nuevas tecnologías de la información en el proceso de enseñanza-aprendizaje.

Durante los últimos años la Universidad Politécnica de Valencia (UPV) ha desarrollado el plan de acción de Docencia en Red (UPV, 2013) con el fin de intensificar el uso de las nuevas tecnologías de la información y las comunicaciones en la docencia. Entre otros objetivos, este plan pretende incentivar la producción de materiales educativos destinados a enriquecer el repositorio de objetos virtuales de aprendizaje RIUNET.

La UPV define un objeto de aprendizaje como "la unidad mínima de aprendizaje, en formato digital, que puede ser reusada y secuenciada". Los criterios que establece la UPV para que un objeto virtual pueda ser considerado un objeto de aprendizaje son los siguientes (UPV, 2007):

- Con formato digital, accesible y utilizable desde internet

- Con propósito pedagógico para facilitar el aprendizaje del alumno

- De contenido interactivo para incentivar la participación activa del alumno

- Indivisible e independiente de otros objetos de aprendizaje

- Reutilizable en distintos contextos educativos

- Junto con otros objetos de aprendizaje permite alcanzar objetivos de aprendizaje más amplios formando parte de módulos de aprendizaje

Los laboratorios virtuales son objetos de aprendizaje cuyo objetivo principal es el apoyo a la docencia presencial mediante el uso de simulaciones numéricas interactivas. La UPV permite desarrollar los laboratorios virtuales para ser depositados en su repositorio RIUNET mediante Flash, Applets de Java, Matlab Builder o Mathematica.

En esta contribución se pretende destacar las ventajas de desarrollar los laboratorios virtuales con el programa Mathematica y mostrar la aplicación práctica de los laboratorios virtuales en la docencia de asignaturas del área de Ingeniería Ambiental.

\section{Objetivos}

El presente trabajo se plantea los siguientes objetivos: 
- Describir las ventajas de utilizar el programa Mathematica para el desarrollo de laboratorios virtuales.

- Mostrar la aplicación de los laboratorios virtuales como una herramienta útil que permite mejorar el aprendizaje del alumno en el ámbito de la Ingeniería Ambiental.

\section{Desarrollo de la innovación}

\section{Desarrollo de laboratorios virtuales con Mathematica}

Mathematica es un programa de cálculo simbólico y numérico que fue originalmente desarrollado por Stephen Wolfram. Mathematica es ampliamente utilizado en las áreas científicas y tecnológicas, tanto para la realización de cálculos complejos en proyectos de investigación como para la docencia universitaria.

Nuestra experiencia nos ha mostrado que el uso de las metodologías docentes tradicionales no son suficientes para que el alumno adquiera el grado de conocimientos, habilidades y competencias deseado. Con el objetivo de facilitar el aprendizaje del alumno en el aula, los autores han desarrollado en los últimos años más de veinte laboratorios virtuales con Mathematica. Estos laboratorios se han utilizado como una herramienta complementaria en la docencia presencial de modelos de calidad de aguas superficiales y de métodos de tratamiento de las aguas residuales.

Las ventajas de utilizar el programa Mathematica para desarrolllar laboratorios virtuales son las siguientes:

- Se puede crear una intefaz gráfica de fácil manejo y atractiva para el alumno, permitiendo contextualizar el problema estudiado mediante una representación visual del mismo. Para ello Mathematica dispone de un tipo de documento especial denominado CDF (Formato de Documento Computable) que permite fácilmente convertir cualquier cálculo realizado con Mathematica en una aplicación interactiva.

- El programa permite realizar simulaciones dinámicas e interactivas para mejorar la comprensión por parte del alumno de problemas complejos. El alumno puede explorar el problema estudiado modificando los datos de partida, puede interarcionar en tiempo real con los resultados obtenidos, así como manipular y cambiar el modo de visualizar los resultados gráficos.

- Existe un amplísimo repositorio de laboratorios virtuales denominado Proyecto de Demostraciones Wolfram (Wolfram, 2014) de código abierto que pueden ser adaptodos y modificados por el profesor para ser utilizados en el aula en una gran

(cc) EY-NC-ND 2014, Universitat Politècnica de València

I Jornadas IN-RED (2014) 
Desarrollo de laboratorios virtuales con Mathematica y su aplicación a la docencia en red en el ámbito de la Ingeniería Ambiental

variedad de áreas de conocimiento: matemáticas, ciencias, economía, ingeniería, bellas artes, etc.

- Desde el punto de vista del profesor, una vez adquiridos los conocimientos básicos necesarios el esfuerzo necesario para crear laboratorios virtuales es reducido. Esto es debido a que los objetos de aprendizaje creados con Mathematica son fácilmente reutilizables, por lo que pueden ser modificados para crear nuevos laboratorios virtuales.

- Mathematica permite resolver a través de la red y en tiempo real problemas con cálculos recursivos y numéricos complejos sin necesidad de que el alumno precise instalar el programa Mathematica.

- Mathematica dispone de una extensa librería de funciones que pueden ser utilizadas para desarrollar los objetos de aprendizaje en cualquier área de conocimiento: matemáticas, estadística, análisis de datos, procesamiento y análisis de imágenes, sistemas de control, procesamiento de señales, etc.

Un aspecto importante a la hora de crear un laboratorio virtual es reducir el tiempo de aprendizaje en el uso del laboratorio. Para ello es aconsejable diseñar los laboratorios con una interfaz sencilla y gráfica. A ser posible sería conveniente utilizar siempre el mismo tipo de interfaz e incluir en el propio laboratorio unas breves instrucciones para su uso, sus objetivos para orientar al alumno en su interacción con el objeto de aprendizaje e incluir una breve descripción para contextualizar el laboratorio con los contenidos y conceptos que se pretenden trabajar en el mismo. Mathematica permite fácilmente incluir todos estos elementos utilizando una interfaz con pestañas. A modo de ejemplo se describe a continuación la interfaz utilizada en los laboratorios virtuales desarrollados por los autores.

Los laboratorios constan de un título situado en la parte superior y de una ventana con cuatro pestañas (figura 1). La pestaña principal "Simulación" permite interactuar dinámicamente a través de los controles situados en unas cajas de color azul, mientras que en una caja blanca se muestran los resultados de la simulación realizada en forma de gráficos y tablas. Los alumnos pueden utilizar los laboratorios virtuales a través del repositorio institucional de la Universidad Politécnica de Valencia (Riunet), por lo que para facilitar su uso fuera del aula se han añadido otras pestañas con información adicional. En la pestaña "instrucciones" se describe cómo introducir los datos necesarios y cómo usar dinámicamente el laboratorio mediante las barras de desplazamiento, menús desplegables, etc. También se describen brevemente los contenidos teóricos necesarios relacionados con la simulación realizada por el laboratorio (pestaña "Descripción") y los objetivos del laboratorio (pestaña "Objetivos"). 


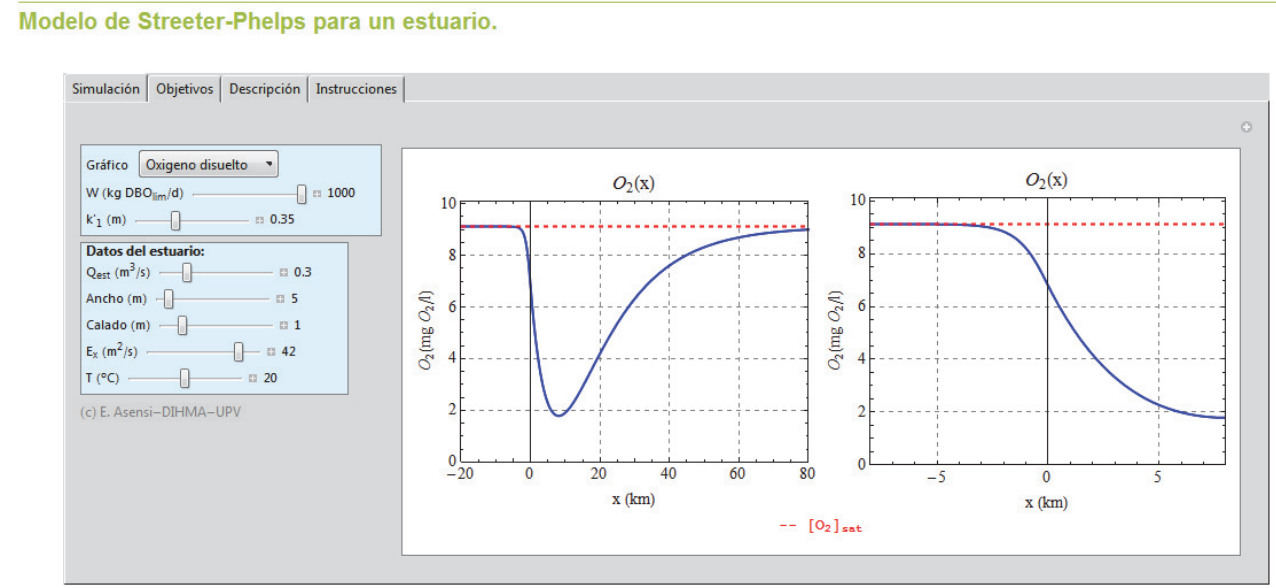

Fig. 1 Ejemplo de la interfaz de un laboratorio virtual desarrollado con Mathematica

\section{Resultados}

Los problemas que plantea resolver la Ingeniería Ambiental precisan del uso de modelos matemáticos complejos, así como de fórmulas empíricas y de criterios de diseño que resultan ser en muchos casos complejos y poco intuitivos para el alumno. En este apartado se describe la aplicación de los laboratorios virtuales desarrollados con Mathematica para facilitar el aprendizaje en el aula del proceso de modelización matemática en el contexto de la calidad de las aguas superficiales y en el diseño de instalaciones de tratamiento de aguas residuales

\subsection{Aplicación de los laboratorios virtuales en la modelización de la calidad de las aguas superficiales}

En varias titulaciones de la Universidad Politécnica de Valencia se imparten asignaturas donde se estudian modelos de calidad de aguas superficiales: Licenciatura en Ciencias Ambientales, Máster en Ingeniería Hidráulica y Medio Ambiente y Máster en Ingeniería Ambiental.

El objetivo principal de estas asignaturas es que el alumno aprenda a plantear y utilizar modelos matemáticos de calidad de aguas superficiales (Barat, 2003). El alumno debe ser capaz de plantear modelos predictivos sencillos que describan la evolución de los contaminantes más habituales en ríos, lagos y estuarios. Por otra parte el alumno debe saber aplicar los modelos matemáticos desarrollados a la gestión de los recursos hídricos desde el punto de vista de la calidad de las aguas.

\section{(cc) EY-NC-ND 2014, Universitat Politècnica de València}

I Jornadas IN-RED (2014) 
Desarrollo de laboratorios virtuales con Mathematica y su aplicación a la docencia en red en el ámbito de la Ingeniería Ambiental

Los modelos de calidad de aguas se basan en el planteamiento de las ecuaciones de balance de materia que describen los procesos de transporte y transformación (físicos, químicos y biológicos) que sufren los contaminantes en las aguas superficiales. Desde el punto de vista matemático, las ecuaciones de balance son ecuaciones en derivadas parciales de $2^{\circ}$ orden con tres dimensiones espaciales y una $4^{\mathrm{a}}$ dimensión temporal, cuya solución proporciona la concentración de las sustancias estudiadas en cualquier momento y posición. La ecuación diferencial que representa la variación de la concentración de un contaminante en función del tiempo, en un elemento diferencial de volumen es (Martín, 1999):

$\frac{\partial C}{\partial t}=-\frac{\partial}{\partial x}\left(u_{x} C\right)-\frac{\partial}{\partial y}\left(u_{y} C\right)-\frac{\partial}{\partial z}\left(u_{x} C\right)+\frac{\partial}{\partial x}\left(E_{x} \frac{\partial C}{\partial x}\right)+\frac{\partial}{\partial y}\left(E_{y} \frac{\partial C}{\partial y}\right)+\frac{\partial}{\partial z}\left(E_{z} \frac{\partial C}{\partial z}\right)+S_{K}$ donde:

- C: concentración del contaminante (mg/l)

- $\quad \mathrm{u}_{\mathrm{x}}, \mathrm{u}_{\mathrm{y}}, \mathrm{u}_{\mathrm{z}}$ : componentes del vector velocidad del agua $(\mathrm{m} / \mathrm{s})$.

- $\quad E_{x}, E_{y}, E_{z}$ : coeficientes de dispersión longitudinal, transversal y vertical $\left(\mathrm{m}^{2} / \mathrm{s}\right)$.

- $\quad \mathrm{S}_{\mathrm{K}}$ : términos fuente o sumidero del contaminante $(\mathrm{mg} / \mathrm{l} \mathrm{s})$.

La complejidad que conlleva la construcción, estudio y aplicación de estos modelos hace necesario el uso de laboratorios virtuales. Los laboratorios virtuales permiten estudiar y analizar las soluciones obtenidas en función de los valores de los parámetros del modelo y de las condiciones de contorno. En muchos casos las ecuaciones de balance planteadas no tienen solución analítica o bien su solución no permite entender fácilmente el modelo estudiado.

A modo de ejemplo se muestra un laboratorio virtual en el que se estudia la evolución del oxígeno disuelto en un río sometido a un vertido de aguas residuales (Asensi, 2012a).

\section{Laboratorio virtual. Materia orgánica y oxígeno disuelto en un río. Estudio del estado transitorio y del estado estacionario.}

Se supone un río con mezcla transversal completa (río de dimensión 1), velocidad del agua constante y sin transporte dispersivo $(\mathrm{E}=0)$. Además se considera que se produce un vertido puntual y constante de materia orgánica en el punto $\mathrm{x}_{0}$ (figura 2). 


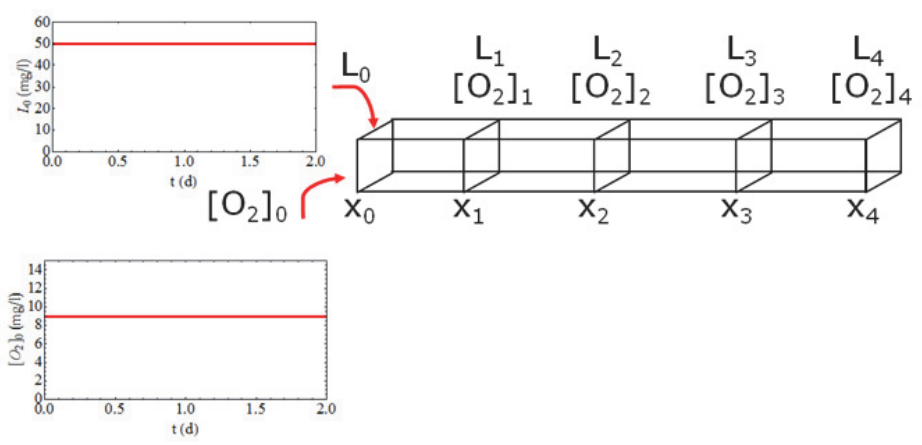

Figura 2 Vertido puntual y constante de materia orgánica en un río

Las ecuaciones de balance necesarias para modelizar la concentración de materia orgánica (L) y de oxígeno disuelto $\left(\mathrm{O}_{2}\right)$ en el río son:

$$
\begin{aligned}
& \frac{\partial L}{\partial t}=-u \frac{\partial L}{\partial x}-k_{1}{ }^{\prime} L \frac{O_{2}}{K_{s}+O_{2}} \\
& \frac{\partial O_{2}}{\partial t}=-u \frac{\partial O_{2}}{\partial x}-k_{1}{ }^{\prime} L \frac{O_{2}}{K_{s}+O_{2}}+k_{2}{ }^{\prime}\left(O_{2 s a t}-O_{2}\right)
\end{aligned}
$$

Una vez se ha planteado el modelo en el aula, la principal dificultad consiste en entender el modelo. El modelo no tiene solución analítica y es poco intuitivo, por lo que resulta de gran utilidad el uso de un laboratorio virtual para visualizar lo que ocurre en el río después del vertido y para interactuar con el modelo. Además, el laboratorio virtual permite introducir y/o reforzar conceptos importantes que son poco intuitivos para el alumno.

El laboratorio virtual resuelve numéricamente las ecuaciones de balance y muestra gráficamente la concentración de materia orgánica y oxígeno disuelto en el río, en función del tiempo (figura 3). El laboratorio permite introducir al alumno los conceptos de estado transitorio y de estado estacionario, para ello se puede mostrar cómo evoluciona la materia orgánica y el oxígeno disuelto en el río desde que se inicia el vertido hasta que su concentración no varía en el río con el tiempo.

Para entender mejor el modelo, el laboratorio permite estudiar la evolución de la concentración de la materia orgánica y del oxígeno disuelto en el río en función de los parámetros que definen los procesos (degradabilidad de la materia orgánica, temperatura del agua, velocidad del río) y de las condiciones de contorno debidas al vertido (materia orgánica y oxígeno disuelto en el punto de vertido).

Otro concepto importante con el que se puede trabajar con este laboratorio es el de anoxia. Simulando un vertido de materia orgánica rápidamente biodegradable o un vertido con un

\section{(c)) EY-NC-ND 2014, Universitat Politècnica de València}

I Jornadas IN-RED (2014) 
Desarrollo de laboratorios virtuales con Mathematica y su aplicación a la docencia en red en el ámbito de la Ingeniería Ambiental

elevado contenido en materia orgánica, se puede mostrar que en determinados puntos del río la concentración de oxígeno es próxima a cero o incluso cero y destacar los problemas ambientales asociados a esta situación (figura 4). En este punto se puede justificar al alumno la utilidad de los modelos de calidad de aguas para gestionar el vertido realizado con el fin de fijar el grado de depuración que se debe realizar para evitar esta situación y conseguir unos niveles de oxígeno disuelto mínimos.

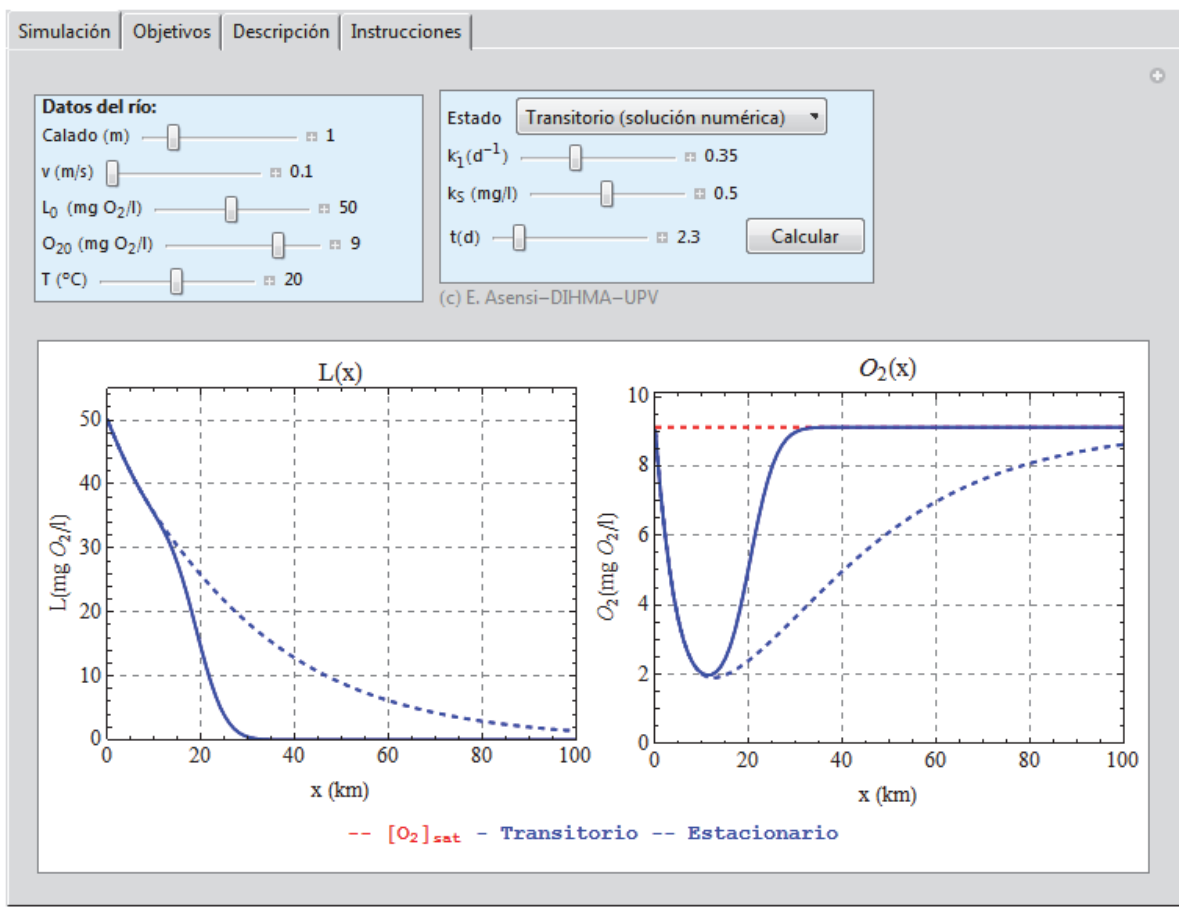

Figura 3. Laboratorio virtual. Materia orgánica y oxígeno disuelto en un río.
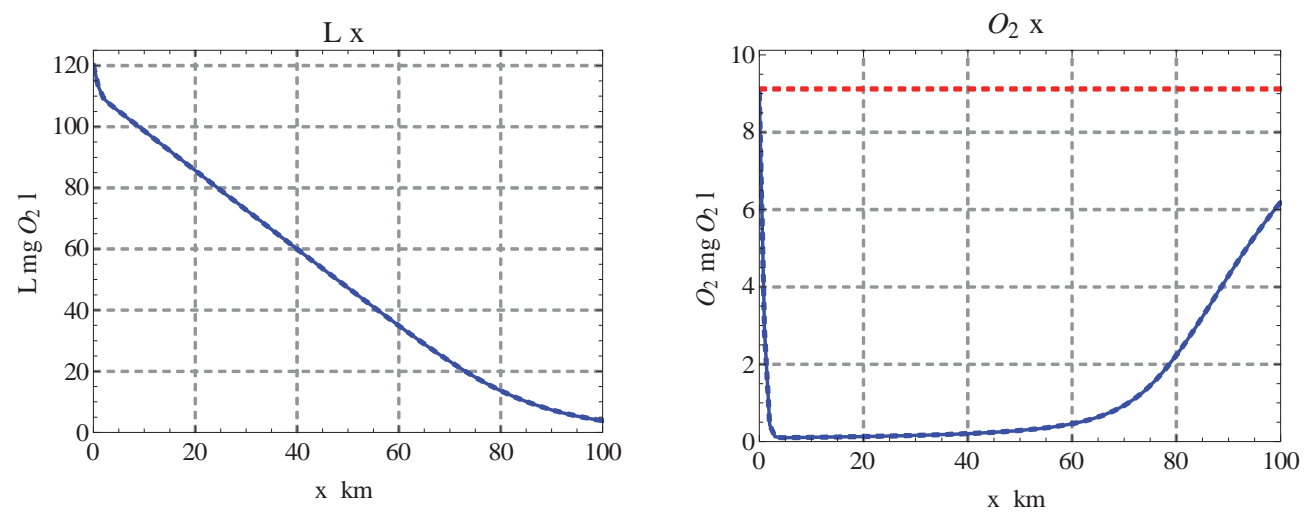

Figura 4. Materia orgánica y oxígeno disuelto en un río. Anoxia.

(c)) EY-NC-ND 2014, Universitat Politècnica de València

I Jornadas IN-RED (2014) 


\subsection{Aplicación de los laboratorios virtuales al diseño de instalaciones de tratamiento de aguas residuales}

Al igual que ocurre con los modelos de calidad de aguas superficiales, en muchas titulaciones de la UPV se estudia el diseño de instalaciones de tratamiento de aguas residuales. El diseño de los elementos de tratamiento de una depuradora de aguas residuales se realiza utilizando criterios de diseño basados en la experiencia y apoyándose en modelos matemáticos que describen los procesos físicos, químicos y biológicos que tienen lugar en el elemento que se pretende diseñar.

Tradicionalmente el dimensionamiento de los elementos de tratamiento se aborda presentando al alumno los criterios de diseño, las ecuaciones de diseño y la secuencia de pasos necesaria para realizar el diseño. Normalmente se resuelve un caso práctico en la pizarra. Si el problema resuelto es complejo, el alumno no asimila en muchos casos los conceptos que fundamentan el diseño.

A continuación se describen varios laboratorios virtuales que pueden ser utilizados para facilitar el aprendizaje por parte del alumno de los métodos de diseño de tratamientos biológicos mediante fangos activados.

Laboratorios virtuales. Calidad del efluente, consumo de oxígeno y producción de fangos en un tratamiento biológico de aguas residuales mediante fangos activados.

Para diseñar un tratamiento biológico mediante fangos activados es necesario conocer la calidad del agua residual que se quiere tratar, de modo que el alumno debe fijar a priori el valor de los criterios de diseño de tiempo de retención celular $\left(\theta_{\mathrm{c}}\right)$ y de concentración de sólidos suspendidos en el reactor de fangos activados $\left(X_{S S T}\right)$. Posteriormente se deben aplicar las siguientes ecuaciones para obtener el volumen del reactor, la calidad del agua a la salida del tratamiento, la producción de fangos y las necesidades de oxígeno del tratamiento (Ferrer, 2013).

$$
\begin{gathered}
S_{S}=\frac{k_{S}\left(\theta_{c}^{-1}+b_{H}\right)}{\mu_{m H}-\left(\theta_{c}^{-1}+b_{H}\right)} \\
S_{N H}=\frac{k_{N H}\left(\theta_{c}^{-1}+b_{A}\right)}{\mu_{m A}-\left(\theta_{c}^{-1}+b_{A}\right)} \\
V X_{H}=\frac{Q Y_{H}\left(S_{T 0}-S_{S}\right)}{\theta_{c}^{-1}+b_{H}}
\end{gathered}
$$

(c)) EY-NC-ND 2014, Universitat Politècnica de València

I Jornadas IN-RED (2014) 
Desarrollo de laboratorios virtuales con Mathematica y su aplicación a la docencia en red en el ámbito de la Ingeniería Ambiental

$$
\begin{aligned}
& Q \Delta X_{H}=\frac{V X_{H}}{\theta_{c}} \\
& Q \Delta X_{H I}=f_{D H} b_{H} V X_{H} \\
& V X_{A}=\frac{Y_{A}\left(Q \theta_{C}\left(N H_{T 0}-S_{N H}\right)-0.087\left(1+\theta_{C} f_{D H} b_{H}\right) V X_{H}\right)}{1+0.087 Y_{A}\left(1+\theta_{C} f_{D A} b_{A}\right)+\theta_{C} b_{A}} \\
& Q \Delta X_{A}=\frac{V X_{A}}{\theta_{c}} \\
& Q \Delta X_{A I}=f_{D A} b_{A} V X_{A} \\
& Q \Delta X=Q \Delta X_{H}+Q \Delta X_{H I}+Q \Delta X_{A}+Q \Delta X_{A I} \\
& Q \Delta X_{T}=Q X_{I 0}+Q \Delta X \\
& Q \Delta X_{S S T}=Q X_{S S N V 0}+Q X_{S S V N B 0}+i_{S S T X I}\left(Q \Delta X_{A I}+Q \Delta X_{H I}\right)+i_{\text {SSTBM }}\left(Q \Delta X_{A}+Q \Delta X_{H}\right) \\
& Q \Delta X_{S S V}=Q \Delta X_{S S T}-Q X_{S S N V 0} \\
& \% S S V=\frac{Q \Delta X_{S S V}}{Q \Delta X_{S S T}} 100 \\
& V=\frac{Q \Delta X_{S S T} \theta_{c}}{X_{S S T}} \\
& C_{m T}=\frac{Q S_{T o} f}{V X_{S S T}} \\
& r=\left(1-\frac{\theta}{\theta_{c}}\right) \frac{X_{S S T}}{X_{T r}-X_{S S T}} \\
& S_{T}=S_{S}+S_{I 0}+S S_{e f l} \frac{Q \Delta X_{T}}{Q \Delta X_{S S T}} \\
& S_{T D B O 5}=S_{S} f+S S_{e f l} \frac{\left(Q \Delta X_{H}+Q \Delta X_{A}\right) f}{Q \Delta X_{S S T}} \\
& N H_{T}=S_{N H}+S S_{e f l} \frac{\left(Q \Delta X_{H}+Q \Delta X_{A}\right)}{Q \Delta X_{S S T}} 0.087 \\
& S_{N O}=S_{N O o}+\frac{\mu_{m N} S_{N H} X_{A}}{Y_{A}\left(k_{N H}+S_{N H}\right)} \theta
\end{aligned}
$$




$$
\begin{aligned}
& S_{P}=P T_{0}-\frac{Q \Delta X}{Q} 0.017 \\
& P_{T}=S_{P}+S S_{e f l} \frac{Q \Delta X}{Q \Delta X_{S S T}} 0.017 \\
& M O_{A}=4.57 Q\left(N H_{T o}-S_{N H}-0.087 \frac{Q \Delta X}{Q}\right)-\left(Q \Delta X_{A}+Q \Delta X_{A I}\right) \\
& M O_{H}=Q\left(S_{T o}-S_{S}\right)-\left(Q \Delta X_{H}+Q \Delta X_{H I}\right) \\
& M O_{T}=M O_{H}+M O_{A}
\end{aligned}
$$

El proceso de diseño es largo, de modo que si la elección de los valores de los criterios de diseño no es adecuada el proceso de cálculo debe repetirse hasta que se cumplan los criterios de vertido exigidos.

A continuación se presentan los laboratorios virtuales que resuelven estas ecuaciones y permiten calcular el consumo de oxígeno (figura 5), la calidad del efluente (figura 6) y la producción de fangos (figura 7) en función del caudal y la calidad del agua que se desea tratar y de los criterios de diseño.

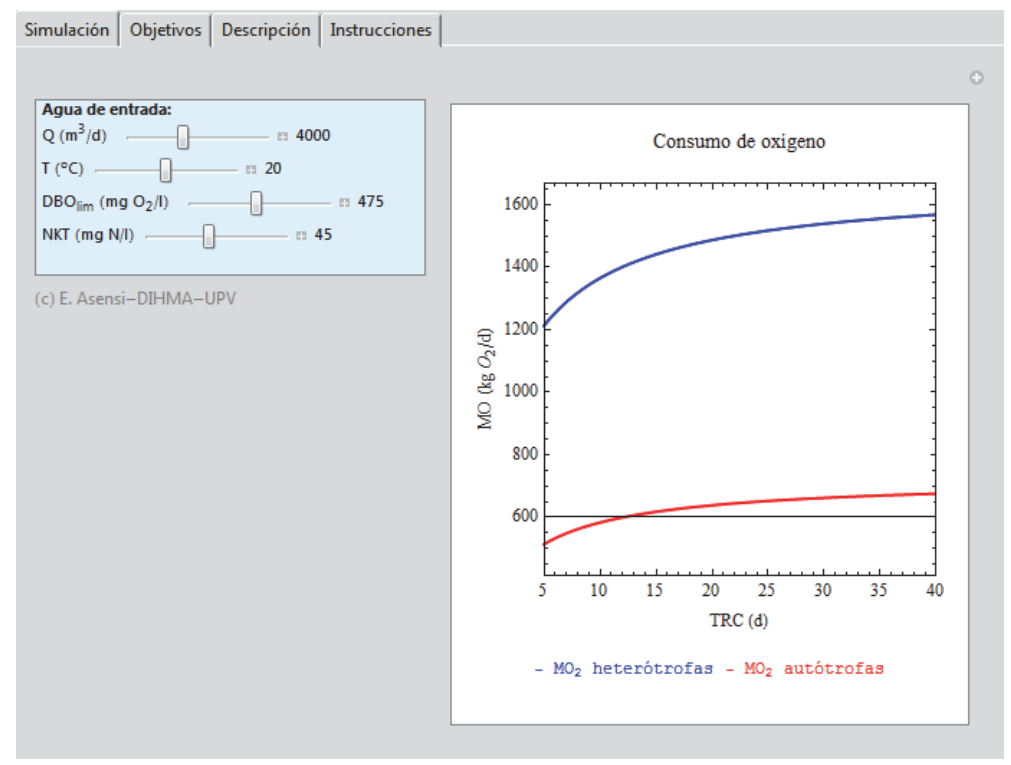

Figura 5. Laboratorio virtual. Consumo de oxígeno en un tratamiento biológico de aguas residuales mediante fangos activados (Asensi, 2012b).

\section{(c)) EY-NC-ND 2014, Universitat Politècnica de València}

I Jornadas IN-RED (2014) 
Desarrollo de laboratorios virtuales con Mathematica y su aplicación a la docencia en red en el ámbito de la Ingeniería Ambiental

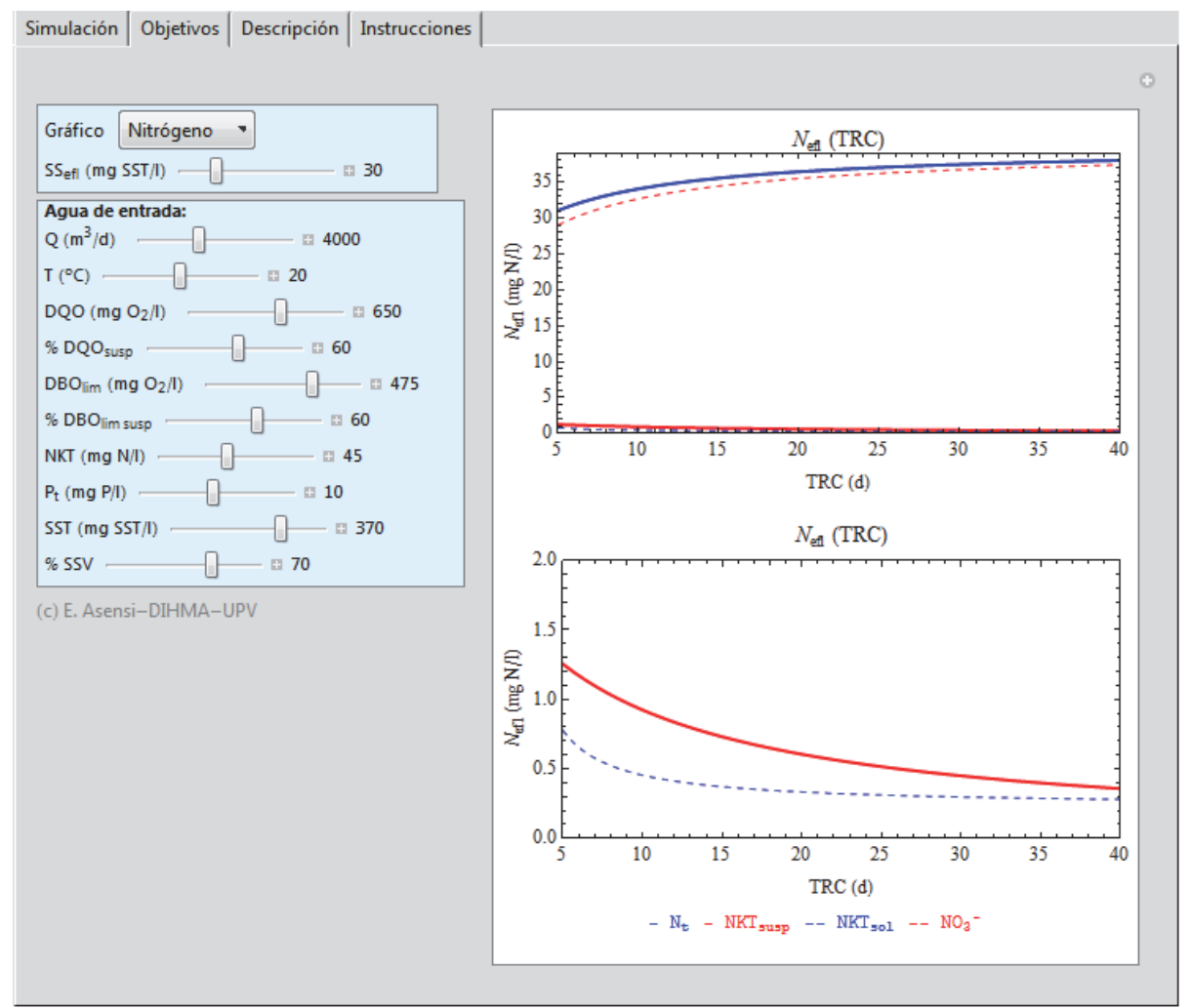

Figura 6. Laboratorio virtual. Calidad del efluente en un tratamiento biológico de aguas residuales mediante fangos activados (Asensi, 2012c).

Una vez se han planteado y estudiado con detalle los pasos necesarios para realizar el diseño en la pizarra, se pueden utilizar los laboratorios virtuales para plantear a los alumnos distintas situaciones que pueden ser resueltas en el aula. Así por ejemplo, se puede cambiar el tipo de agua residual a tratar con el objetivo de buscar rápidamente el diseño óptimo que cumple los límites de vertido sin la necesidad de volver a realizar todos los cálculos.

El tiempo de retención celular es un concepto fundamental en el diseño de un tratamiento biológico. Debido a la complejidad de las ecuaciones que se deben utilizar, el proceso de diseño es poco intuitivo para el alumno. Los laboratorios virtuales ayudan a entender el modelo utilizado en el diseño y permiten al alumno visualizar el efecto que tiene el tiempo de retención celular en la calidad del efluente, la producción de fangos y el consumo de oxígeno.

A partir de estos laboratorios se pueden introducir nuevos conceptos al alumno, como son: estabilización del fango, proceso de oxidación total, convencional y de alta carga, generación de debris, etc. 


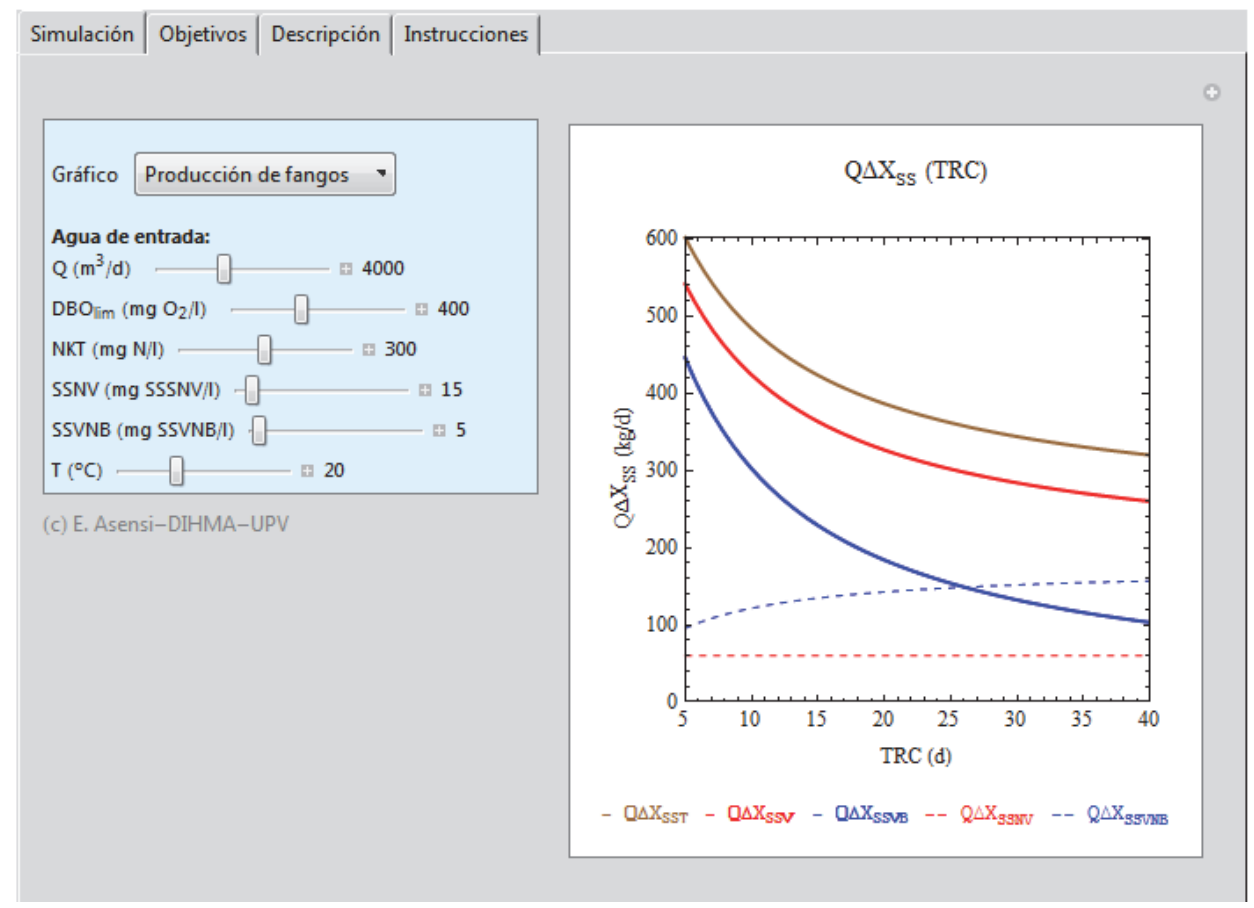

Figura 7. Laboratorio virtual. Producción de fangos en un tratamiento biológico de aguas residuales mediante fangos activados (Asensi, 2012d).

\section{Conclusiones}

Los problemas que plantea resolver la Ingeniería Ambiental precisan del uso de modelos matemáticos complejos y de criterios de diseño que resultan ser en muchos casos poco intuitivos para el alumno. En este trabajo se ha mostrado la aplicación de varios ejemplos de laboratorios virtuales desarrollados con Mathematica para facilitar el aprendizaje tanto en el aula, como en la fase de aprendizaje autónomo del alumno, en el ámbito de la Ingeniería Ambiental. En particular se han descrito algunas de las dificultades que se pueden superar en el proceso de aprendizaje de los modelos matemáticos de transporte de contaminantes en el medio natural y en el diseño de instalaciones de tratamiento de aguas residuales.

La experiencia en el uso de los laboratorios virtuales ha demostrado que son una herramienta eficaz que permite realizar simulaciones que ayudan a una mejor compresión de los modelos y de los métodos de diseño por parte del alumno. Los laboratorios permiten

\section{(c) EY-NC-ND 2014, Universitat Politècnica de València}

I Jornadas IN-RED (2014) 
Desarrollo de laboratorios virtuales con Mathematica y su aplicación a la docencia en red en el ámbito de la Ingeniería Ambiental

al alumno interactuar y experimentar activamente con los modelos matemáticos y relacionar la formulación matemática utilizada con el problema estudiado.

También se puede destacar que los laboratorios son útiles para introducir y hacer comprender al alumno conceptos básicos, que en muchos casos son difíciles de explicar y poco intuitivos, por medio de la experiencia e interacción dinámica con los laboratorios virtuales.

Por otro lado podemos recordar las principales ventajas de utilizar el programa Mathematica como herramienta para desarrollar laboratorios virtuales:

- El programa permite realizar simulaciones dinámicas e interactivas de problemas complejos permitiendo representar visualmente el problema estudiado.

- Se pueden crear laboratorios con una interfaz gráfica que sea atractiva para el alumno.

- Existe un amplio repositorio de código abierto de laboratorios virtuales que pueden ser fácilmente modificados y adaptados a las necesidades de cada asignatura.

- El uso de una misma interfaz gráfica en los laboartorios virtuales permite reducir el tiempo de aprendizaje del alumno en el manejo de los laboratorios.

Varios indicadores docentes ponen de manifiesto que el uso de los laboratorios virtuales supone una mejora en el aprendizaje del alumno (Alemany, 2013). Así, por ejemplo, la asistencia y participación activa de los alumnos en el aula se ha incrementado. Como dato objetivo se ha observado que la valoración de los alumnos hacia el uso de estas metodologías docentes, que se recoge de sus respuestas a las encuestas de docencia, ha sido muy positiva, así como la valoración general de la docencia realizada por el profesor en el aula.

\section{Referencias}

ALEMANY E. y ASENSI E. (2013) "Los objetos de aprendizaje como herramienta complementaria en la docencia de modelos de calidad de aguas superficiales" en Modelling in Science Education and Learning, vol. 6(2), issue 5, p.53-65.

ASENSI E. (2012a). Materia orgánica y oxígeno disuelto en un río. Estudio del estado transitorio y del estado estacionario. Objeto de aprendizaje. Riunet. UPV. <http://riunet.upv.es/> [Consulta: 15 de junio de 2014]

ASENSI E. (2012b). Consumo de oxígeno en un tratamiento biológico de aguas residuales mediante fangos activados.. Objeto de aprendizaje. Riunet. UPV. <http://riunet.upv.es/> [Consulta: 15 de junio de 2014]

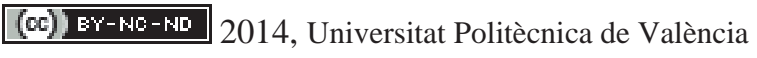

I Jornadas IN-RED (2014) 
ASENSI E. (2012c). Calidad del efluente en un tratamiento biológico de aguas residuales mediante fangos activados. Objeto de aprendizaje. Riunet. UPV. <http://riunet.upv.es/> [Consulta: 15 de junio de 2014]

ASENSI E. (2012d). Producción de fangos en un tratamiento biológico de aguas residuales mediante fangos activados. Objeto de aprendizaje. Riunet. UPV. <http://riunet.upv.es/> [Consulta: 15 de junio de 2014]

BARAT R., MARTIN M. y ASENSI E. (2003) "La docencia de la asignatura de calidad de aguas / Teaching in water quality course". En: I Encuentro Internacional de Enseñanza de la Ingeniería Civil. Ciudad Real

FERRER J. y SECO A. (2013). Tratamiento biológico de aguas residuales. Valencia: Editorial $U P V$.

MARTÍN M. y MARZAL P. (1999). Modelación de la Calidad del Agua. Valencia : Editorial UPV.

UPV (2013). Plan de acción "Docencia en Red”. Curso académico 2013/2014. < http://www.upv.es> [Consulta: 15 de junio de 2014]

UPV (2007). Plan de acciones para la convergencia europea (PACE). <http://www.upv.es/vece/central_pace.htm> [Consulta: 15 de junio de 2014]

WOLFRAM MATHEMATICA. Wolfram Demostrations Project. <http://demonstrations. wolfram.com/index.html> [Consulta: 15 de junio de 2014] 


\title{
Desarrollo de una guía para el uso de los social media en la mejora de la comunicación profesor-alumno. Aplicación al aprendizaje inverso
}

\begin{abstract}
Angeles Calducha ${ }^{a}$ Lola Teruel ${ }^{b}$, Jose-Luis Poza-Lujan ${ }^{a}$, Marga Cabrera ${ }^{b}$, Ana Albors, Miguel Rebollo ${ }^{c}$ y Rebeca Díez-Somavillab

a'Escuela Técnica Superior de Ingeniería Informática (mcalduch@eio.upv.es, jopolu@disca.upv.es), bEscuela Politécnica Superior de Gandia (dteruel@upvnet.upv.es, mcabrera@upvnet.upv.es, rdiez@har.upv.es), ${ }^{c}$ Facultad de Administración y Dirección de Empresas (mrebollo@upv.es), y ${ }^{\mathrm{d}}$ Escuela Técnica Superior de Ingeniería Agronómica y del Medio Natural (aalbors@tal.upv.es).
\end{abstract}

\begin{abstract}
Universities have experienced a significative advance in the use of social networks as a support of high education processes. Through the experience of QTALNET, a research group about the use of social networks in learning (EICE-UPV program), we have observed the advantages of the use of social networks and the benefit provided to students and other teachers.

Currently, there is a trend in the application of a learning methodology known as flip teaching, flipped classroom or reverse teaching. In this methodology, is the student who must first prepare the session, usually through the individual study of theoretical concepts. The face to face session becomes an collaborative, application session (usually groupal practical exercises) to resolve doubts and consolidate the concepts.

In this paper, the basis for the use of social networks in teaching methodology based on a flipped learning classroom is presented. Social networks are perfect to be applied in this type of methodology, allowing sharing resources, comment and establish fluid communication between all participants
\end{abstract}

Keywords: social networks, flip teaching, communication 
Desarrollo de una guía para el uso de los social media en la mejora de la comunicación profesor-alumno. Aplicación al aprendizaje inverso

\begin{abstract}
Resumen
La utilización de las redes sociales como apoyo a la docencia universitaria es un avance que está experimentado la universidad. A lo largo de la experiencia del grupo QTALNET, como grupo de investigación basado en la docencia apoyada en redes sociales dentro del programa de grupos EICE de la UPV, hemos observado las ventajas que tiene el uso de las redes sociales y hemos experimentado el beneficio que ofrecen a los alumnos y a otros docentes. Actualmente existe una tendencia en la aplicación de la metodología docente conocida como flip teaching, flipped classroom o aprendizaje inverso. Dicha metodología consiste en que el alumno debe preparar previamente la sesión docente (generalmente los conceptos teóricos) y consultar al profesor, o a los compañeros, aquellas dudas que surjan en esta fase. La sesión presencial se convierte en una sesión de aplicación (generalmente ejercicios prácticos) y colaboración para la resolución de las dudas y el afianzamiento de los conceptos.

En este artículo, se sientan las bases para el empleo de las redes sociales en la docencia basada en a metodología flipped classroom. Las redes sociales son perfectas para ser aplicadas en este tipo de metodologías, ya que permiten compartir material, comentarlo y establecer una comunicación fluida entre todos los participantes.
\end{abstract}

Palabras clave: redes sociales, fip teaching, comunicación

\title{
1. Introducción
}

La utilización de las redes sociales como apoyo a la docencia universitaria es un avance que está experimentado la universidad. No todos los docentes están dispuestos a dar este paso, en muchos casos por desconocimiento o por la pereza de afrontar nuevas herramientas que desconocen. A lo largo de la experiencia del grupo QTALNET, como grupo de investigación basado en la docencia apoyada en redes sociales dentro del programa de grupos EICE de la UPV, hemos observado las ventajas que tiene el uso de las redes sociales y hemos experimentado el beneficio que ofrecen a los alumnos y a otros docentes.

En este artículo se presenta el desarrollo, por parte del grupo QTALNET, de una guía de carácter docente que afiance los puntos clave para la comunicación con el alumnado universitario a partir de la experiencia de varios profesores en diferentes cursos y estudios.

(c)) EY-NC-ND 2014, Universitat Politècnica de València

I Jornadas IN-RED (2014) 
Se pretende enfatizar en cuáles son los pasos que han de dar los docentes para crear este sistema de comunicación a través de redes sociales, con los cuales están familiarizados los estudiantes, así como unas reglas básicas que mejoren la comunicación profesor-alumno, el rendimiento académico y la colaboración y trabajo en equipo entre los interesados.

El objetivo principal del artículo es presentar una guía sencilla que facilite la labor del docente y englobe las normas básicas de convivencia y aplicación en el día a día de la comunicación de una asignatura a través de un grupo privado de Facebook. Esta guía se está desarrollando bajo el proyecto PIME de la UPV A12/13.

Como parte del uso de las redes sociales, cabe destacar las enormes ventajas que tienen para ser empleadas en el aprendizaje inverso, como plataforma online donde preparar las sesiones. Podríamos decir que la enseñanza presencial apoyada en plataformas online, como son los grupos privados de Facebook o los mensajes entre seguidores de Twitter, pueden promover cambios significativos en la comunicación con el alumnado, siendo al mismo tiempo un recurso bien valorado por los estudiantes y válido para ser empleado en la metodología basada en el aprendizaje inverso.

\section{Entorno de trabajo y objetivos}

\subsection{Clase inversa o 'flipped classroom'}

Una de las definiciones más simples de aprendizaje inverso (se emplea este término a partir de ahora en lugar de los anglicismos "flip teaching" o "flipped classroom") es la proporcionada por Lage y Piatt (2000): "Invertir la clase significa que los eventos que tradicionalmente tienen lugar en el aula se realizan ahora fuera de ella y viceversa". Pero aunque esta definición captura lo fundamental, no recoge adecuadamente lo que realmente implica, que va un poco más allá de una simple reordenación de las tareas y los tiempos.

Para que una iniciativa se pueda considerar como aprendizaje inverso, las actividades a realizar en clase deben consistir en tareas interactivas de aprendizaje en grupo, siguiendo las teorías de los aprendizajes centrados en el estudiante. De la misma forma, debe haber una reinterpretación de las tareas a realizar en casa, que deben ir más allá de la simple visualización de clases grabadas en vídeo. Según Bishop y Verleger (2013), el aprendizaje inverso "es una técnica educativa que consiste en dos partes: actividades de aprendizaje en grupo interactivas dentro del aula e instrucción individualizada basada en el ordenador fuera de ella."

Otra definición más completa que hace hincapié sobre cómo deben ser estas actividades es la proporcionada por la Flipped Learning Network (2014), según la cual el aprendizaje inverso "es una aproximación pedagógica en la que la instrucción directa se desplaza del

\section{(c)) EY-NC-ND 2014, Universitat Politècnica de València}

I Jornadas IN-RED (2014) 
Desarrollo de una guía para el uso de los social media en la mejora de la comunicación profesor-alumno. Aplicación al aprendizaje inverso

espacio de aprendizaje grupal a un espacio individual; y el espacio grupal resultante se transforma en un entorno de aprendizaje dinámico e interactivo en el que el educador guía a los estudiantes para que apliquen los conceptos aprendidos y fomenta la creatividad en el área de estudio" (figura 1).

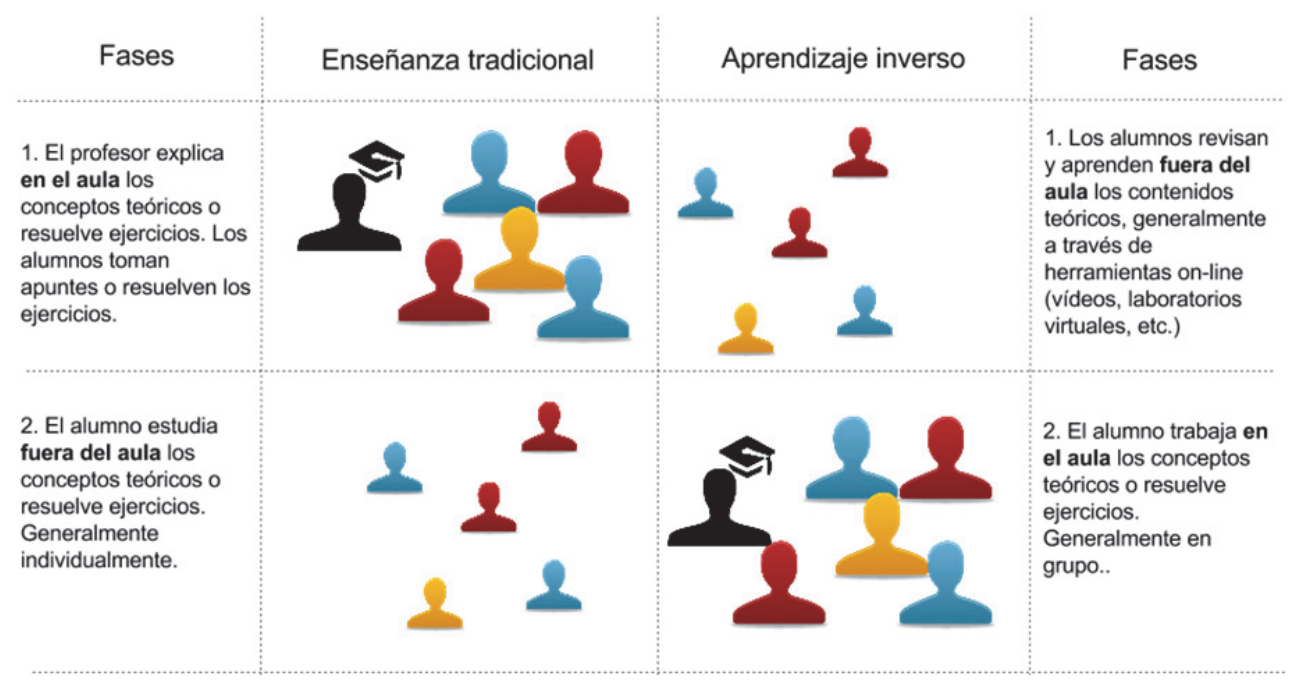

Fig. 1 Comparación de las fases entre la enseñanza tradicional y el aprendizaje inverso

De esta manera, hay una diferencia clara entre la clase inversa y el aprendizaje inverso y los términos no son intercambiables. Así pues, muchos profesores pueden invertir sus clases, haciendo que los alumnos lean, visualicen vídeos o resuelvan problemas fuera del aula. Pero para que realmente sea aprendizaje inverso debe apoyarse en 4 pilares:

1. Entorno flexible: deben en crearse espacios en los que los propios alumnos puedan decidir cuándo y dónde aprender. Por su parte, los educadores deben ser flexibles en sus expectativas acerca de los momentos de estudio y de evaluación.

2. Cultura de aprendizaje: en lugar de un enfoque centrado en el profesor, el aprendizaje inverso requiere modelos centrados en el alumno, dónde éste se involucre de forma activa en la construcción y la evaluación de sus aprendizajes mientras participa en las amplias oportunidades de aprendizaje creadas para el aula.

3. Contenido intencional: los profesores deben reflexionar sobre el propio modelo de aprendizaje inverso para conseguir maximizar la eficacia de los métodos y estrategias activas utilizados en el aula.

4. Educador profesional: el aprendizaje inverso requiere en el aula de un profesional de la educación que observe a los estudiantes, proporcione reglamentación relevante y a tiempo y evalúe el trabajo realizado. Debe ser reflexivo, conectar con

(c)) EY-NC-ND 2014, Universitat Politècnica de València

I Jornadas IN-RED (2014) 
los alumnos, aceptar las críticas constructivas y ser tolerante a un cierto caos controlado. El profesor es el catalizador que hace que ocurra el aprendizaje.

El aprendizaje inverso tiene aspectos positivos y negativos que deben tenerse en cuenta a la hora de su implantación en una asignatura, en una materia o incluso en un plan de estudios completo.

Como aspectos favorables cabe destacar los siguientes:

- El alumno es el responsable de tomar la iniciativa en el aprendizaje, por lo que aumenta su sentido de la responsabilidad.

- El alumno dispone de diversos medios para aprender los mismos conceptos teóricos (diversos vídeos, apuntes, etc.), por lo que se adapta el contenido al estilo de aprendizaje específico de cada alumno.

- El alumno puede profundizar en un concepto tanto como el material suministrado lo permita, o incluso buscar más información en Internet.

- El alumno puede ser consciente de su nivel de adquisición de los conceptos básicos antes de adentrarse a practicarlos, además puede dejar aquellos conocimientos que no comprende para entenderlos en la sesión de trabajo en el aula.

Como aspectos desfavorables, se pueden destacar los siguientes:

- Obliga al estudiante a disponer de conexión de internet y ordenador o dispositivo móvil en el que reproducir el material preparatorio de la sesión.

- El alumno no puede preguntar a un vídeo las dudas surgidas en la preparación, es decir que el alumno tiene dificultad en comprender aquellos conceptos que no le quedan claros.

- Generalmente, el alumno debe ser evaluado previamente para conocer si ha adquirido el nivel de conocimientos previos necesarios a la sesión de trabajo en el aula. Esto puede generar cierto desgaste en el alumno al estar siendo examinado continuamente.

- Obliga al profesor a un trabajo minucioso de preparación de material previo y a un seguimiento más exhaustivo del estudiante.

Los aspectos positivos, expuestos anteriormente, pueden reforzarse mediante el empleo de las redes sociales; mientras que los aspectos negativos pueden paliarse también mediante el uso de las redes sociales. Más adelante, se mostrará cómo las redes sociales mejoran estos dos aspectos.

(c) EY-NC-ND 2014, Universitat Politècnica de València

I Jornadas IN-RED (2014) 
Desarrollo de una guía para el uso de los social media en la mejora de la comunicación profesor-alumno. Aplicación al aprendizaje inverso

\subsection{Social media en la enseñanza}

En la actualidad, los Social Media, que incluyen las redes sociales, son las nuevas herramientas pedagógicas del proceso de enseñanza-aprendizaje universitario. Son el entorno de referencia para los alumnos de una generación que se mueve con facilidad en las mismas (Del Fresno, 2011). Los docentes pueden aprovechar las herramientas de los social media para estimular la atención e interés de sus estudiantes, reforzar la relación estudianteprofesor y alumno-alumno, así como promover aprendizajes significativos y optimizar el esfuerzo de todos los participantes en el proceso.

Entre las redes sociales, Facebook supone un nuevo entorno de comunicación, una nueva opción de proximidad en las relaciones docentes trasladando el aula a los entornos virtuales (Túñez y Sixto, 2011). El profesor puede emplear estas vías de comunicación desde el punto pedagógico, convertirse en "guía" empleando estrategias de aprendizaje implementadas sobre la red social: trabajo colaborativo e interactivo, estudio de casos nuevos, incluso procesos de simulación y resolución de problemas en grupo a tiempo real. Las redes sociales permiten al alumno hacerse partícipe en el proceso, adoptando nuevas estrategias, aportando soluciones diferentes y actualizadas, esto es, tomando control sobre su aprendizaje, la propia práctica y también del entorno creado (red, docente, alumno). De este modo, se establecen en el alumno herramientas que le permitan hacer frente a nuevas situaciones y alcanzar así un aprendizaje significativo (Camacho, 2010).

Ante la pregunta ¿cómo se pueden emplear las redes sociales en el proceso de enseñanzaaprendizaje?, los expertos no están de acuerdo en los beneficios o los perjuicios del uso de éstas y de la tecnología en general (Carr, 2011; Shirky, 2010). Sin embargo, considerando la amplia utilización de las redes sociales, especialmente entre los estudiantes universitarios, es más que conveniente su uso en el proceso de enseñanza-aprendizaje, siempre partiendo de que deben contribuir principalmente a mejorar la comunicación con el objetivo de aumentar la implicación de los alumnos en su propio proceso de aprendizaje.

\subsection{Objetivos e hipótesis de trabajo}

A partir de la experiencia que el grupo QTALNET ha obtenido en estos últimos cursos y dado que la enseñanza basada en el aprendizaje inverso es una apuesta de la UPV, parece conveniente combinar la experiencia con las oportunidades que la metodología de aprendizaje inverso brinda. Para ello, uno de los objetivos del grupo consiste en estudiar cómo las redes sociales pueden dar soporte a este tipo de enseñanza, de la misma forma que dan soporte a la enseñanza universitaria independientemente de la metodología empleada. 
Este objetivo genera diversas hipótesis que deberán ser estudiadas a lo largo de los próximos cursos. Las hipótesis de trabajo son las siguientes.

- Las redes sociales y los Learning Management Systems (LMS) corporativos permiten proporcionar al alumno diversos medios de aprender los mismos conceptos teóricos.

- Las redes sociales y los LMS corporativos permiten realizar un seguimiento de la actividad preparatoria que el estudiante lleva a cabo en la primera fase de el aprendizaje inverso.

- Las redes sociales facilitan el trabajo colaborativo de los estudiantes en la preparación y resolución de dudas que se plantea en la primera fase de el aprendizaje inverso.

- Las redes sociales facilitan el trabajo colaborativo de los estudiantes, lo que permite descargar al profesor de la tarea de preparación de material.

Estas hipótesis plantean reforzar diversos aspectos positivos y resolver aspectos negativos de los que se han expuesto anteriormente. Las hipótesis se irán estudiando a medida que se realicen los experimentos correspondientes. Se espera que los resultados puedan ser publicados a partir del curso 2014-15.

\section{Desarrollo de la innovación}

\subsection{Herramientas de los social media}

Twiter es la herramienta de social media más inmediata, su inmediatez la sitúa entre las aplicaciones de "corto plazo", es decir aquellas en las que un mensaje de un usuario llega de inmediato a los seguidores. Este tipo de herramientas permite analizar las tendencias (trending topic, en lenguaje Twittero) y las conexiones dinámicas en las redes (liderazgo y seguimiento de usuarios).

Las herramientas de social media denominadas de medio plazo serían aquellas que permiten el establecimiento de una conversación en el tiempo para la resolución o refuerzo de temas concretos planteados a petición del estudiante o propuestos por el profesor. Se destacan en este apartado las distintas herramientas susceptibles de ser empleadas en las redes sociales y aquellas dedicadas a la consulta donde se sitúan las encuestas que propone la red social Facebook, las cuales vienen a servir como medio de refuerzo del conocimiento transmitido, situando al alumno en una posición activa y participativa frente a un tema propuesto.

\section{(cc)) EY-NC-ND 2014, Universitat Politècnica de València}


Desarrollo de una guía para el uso de los social media en la mejora de la comunicación profesor-alumno. Aplicación al aprendizaje inverso

Igualmente, en relación a esta misma red social, se debe comentar la importancia del intercambio de información a través de las aportaciones realizadas por los participantes en el muro y sus potencialidades. Entre ellas, la posibilidad de etiquetar a un alumno amplifica el poder de la función apelativa del lenguaje, siendo el alumno el que recibe la acción y despierta el interés por el tema planteado.

Estas herramientas "de medio plazo" permiten alcanzar y reforzar la consecución de competencias, tales como la comunicación efectiva, a la vez que sirven de repositorio en el tiempo para su consulta posterior. Asimismo, cabe destacar el refuerzo de otras dimensiones competenciales como la aplicación y pensamiento crítico a través de la invitación a la preparación del trabajo previo a la clase o la resolución de dudas tanto entre alumno-profesor como entre pares.

Finalmente, las universidades disponen de espacios específicos similares a las redes sociales, pero con una orientación a largo plazo y basadas en los LMS. En el caso de la UPV se emplea la herramienta PoliformaT, en la que el profesor y los alumnos disponen de una gran cantidad de herramientas que facilitan la docencia no presencial, tan necesaria en el aprendizaje inverso.

\subsection{Guía del uso de las redes sociales en la enseñanza}

El grupo de trabajo QTALNET ha desarrollado una guía de cómo aplicar las redes sociales en la docencia universitaria con el caso concreto de Facebook. La guía organiza las acciones que se deben tomar en las redes sociales en diferentes fases (figura 2).

\begin{tabular}{|c|c|c|c|c|}
\hline \multirow{2}{*}{ Fase I: previa } & \multicolumn{3}{|c|}{ Fase II: docente } & \multirow{2}{*}{ Fase III: posterior } \\
\hline & II.1: inicio & II.2: desarrollo & II.3: final & \\
\hline $\begin{array}{l}\text { Planificación del modelo } \\
\text { de grupo Facebook en la } \\
\text { asignatura. } \\
\text { Determinación de las } \\
\text { normas de uso del } \\
\text { grupo. } \\
\text { Determinación de la } \\
\text { evaluación. }\end{array}$ & $\begin{array}{l}\text { Ensayos del } \\
\text { funcionamien } \\
\text { to del grupo. } \\
\text { Localización } \\
\text { de } \\
\text { estudiantes }\end{array}$ & $\begin{array}{l}\text { Publicación del material de cada } \\
\text { una de las sesiones de la } \\
\text { enseñanza inversa. } \\
\text { Seguimiento del aprendizaje } \\
\text { Resolución de dudas por } \\
\text { compañeros. } \\
\text { Terapia de grupo. }\end{array}$ & $\begin{array}{l}\text { Cierre de las } \\
\text { actividades. } \\
\text { Evaluación de } \\
\text { las actividades } \\
\text { realizadas } \\
\text { durante el } \\
\text { desarrollo. }\end{array}$ & $\begin{array}{l}\text { Cierre del grupo o } \\
\text { posterior uso para } \\
\text { mantener los contactos } \\
\text { del curso. }\end{array}$ \\
\hline
\end{tabular}

Fig. 2 Fases y principales acciones cuando se emplean las redes sociales en la docencia

En el siguiente apartado se describe cómo se debe actuar en los casos concretos de la fase de desarrollo; donde, además de emplear la red social como soporte a la docencia, se desea que proporcione soporte al aprendizaje inverso. 


\section{Caso de estudio: redes sociales en el aprendizaje inverso}

\subsection{Preparación de la sesión: adquisición de los conocimientos teóricos}

En el aprendizaje inverso, el alumno debe preparar la sesión presencial previamente de forma autónoma. Generalmente, se emplea la lectura de información bibliográfica, la visualización de transparencias o la reproducción de vídeos. Las plataformas corporativas basadas en LMS permiten la difusión y el uso de este tipo de material, pero no permiten el añadir metainformación, como son las visualizaciones que ha tenido y especialmente los comentarios. este aspecto sí que lo permiten las redes sociales (figura 3).

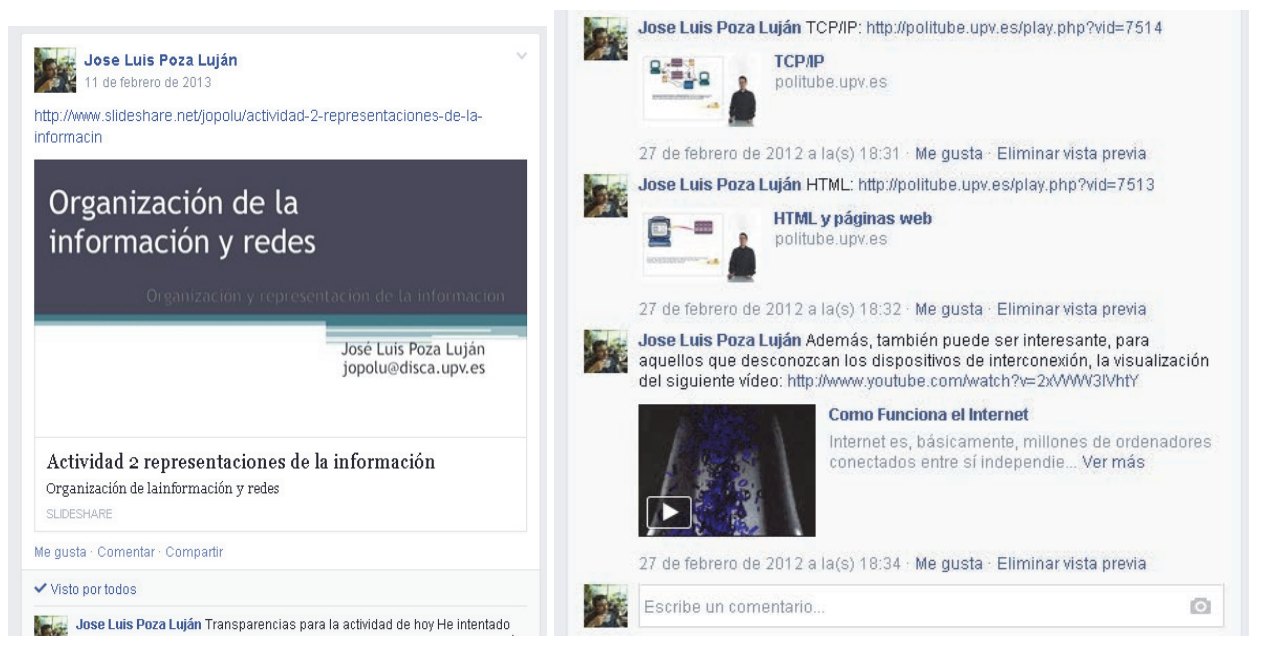

Fig. 3 Ejemplo de publicación de transparencias (izquierda) y de vídeos (derecha) a través de los cuales se desarrolla el aprendizaje de los conceptos teóricos por parte del alumno.

Cabe destacar que el uso de las redes sociales no sustituye a los LMS en este aspecto, ya que los vídeos y transparencias deben ser almacenados y, sobre todo, organizados de una forma coherente y única. Esto último se logra teniendo un único repositorio de material, que en el caso de la Universitat Politècnica de València es el PoliformaT para material clásico y Politube para material audiovisual multimedia.

\subsection{Preparación de la sesión: resolución de dudas}

Aunque la primera fase en el aprendizaje inverso consiste en la preparación, generalmente de forma individual, de la sesión por parte del alumno, no siempre los contenidos pueden ser asimilados por completo o fácilmente. Para mejorar esta fase del aprendizaje inverso, las redes sociales permiten comentar, mediante los foros o hilos de conversación, aquellos aspectos que no han quedado aclarados (figura 4).

\section{(c)) EY-NC-ND 2014, Universitat Politècnica de València}

I Jornadas IN-RED (2014) 
Desarrollo de una guía para el uso de los social media en la mejora de la comunicación profesor-alumno. Aplicación al aprendizaje inverso

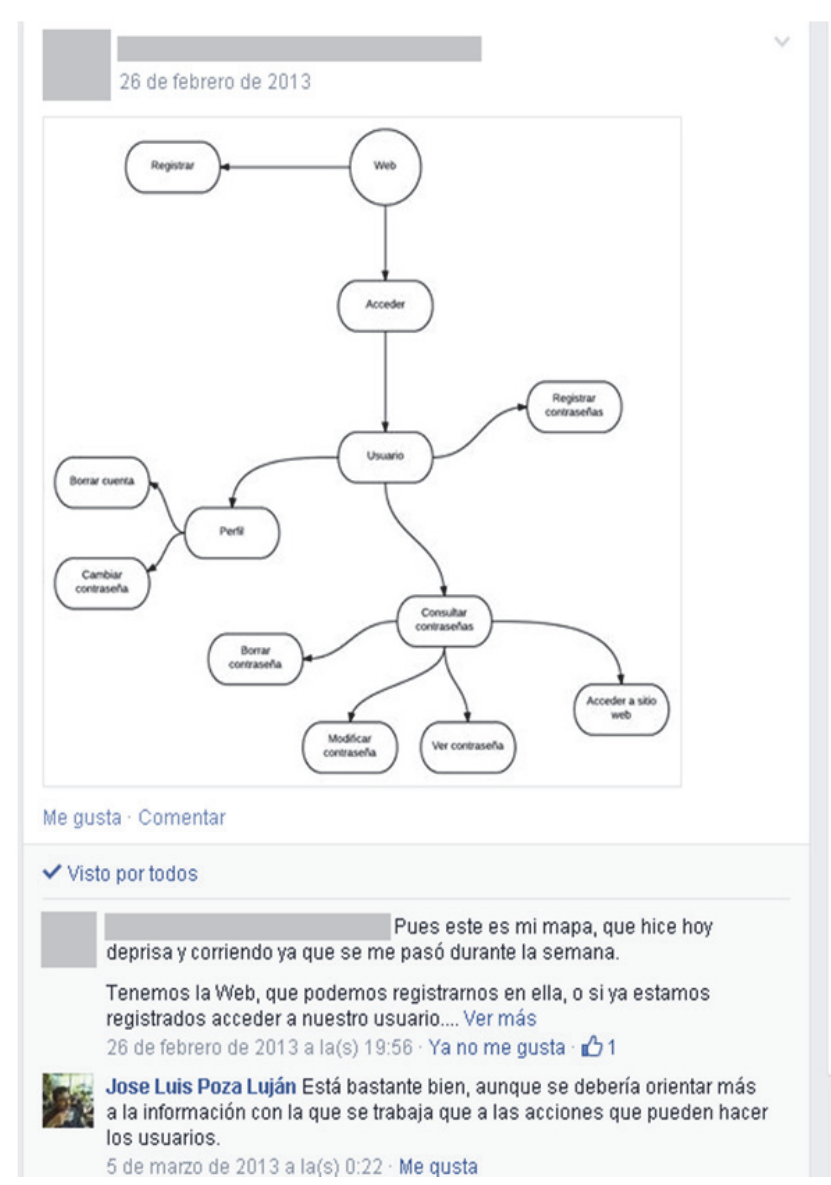

Fig. 4. Ejemplo de revisión del trabajo previo de un alumno antes de la sesión de trabajo en aula

El uso de las redes sociales, en esta fase, es de especial interés, ya que una duda expresada por un alumno, puede ser resuelta por el profesor, pero también por otros compañeros. Además, el uso de las redes sociales tiene un valor añadido: el profesor puede conocer las dudas surgidas durante el aprendizaje autónomo del alumno y saber con qué nivel afrontan la sesión presencial, por lo que puede adaptar la sesión presencial al nivel del grupo.

\section{Caso de estudio: redes sociales en el aprendizaje inverso}

En los dos apartados anteriores se han mostrado ejemplos de cómo se usan parte de las herramientas de las redes sociales para la preparación de las sesiones presenciales. No son las únicas herramientas, los social media permiten muchos más usos (figura 5).

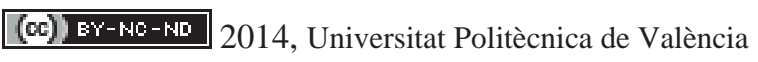




\section{Social Media en el aprendizaje inverso}

\begin{tabular}{|c|c|c|c|}
\hline & Estudiante & Twitter & Facebook Google+ \\
\hline \multirow{2}{*}{$\begin{array}{r}\text { Fase } 1 \\
\text { Preparación } \\
\text { de la sesión }\end{array}$} & $\begin{array}{l}\text { Prepara los conceptos } \\
\text { teóricos de la sesión } \\
\text { presencial. }\end{array}$ & $\begin{array}{l}\text { Permite conocer (por } \\
\text { medio del hashtag } \\
\text { relacionado con el } \\
\text { tema) el seguimiento } \\
\text { del mismo por parte de } \\
\text { los alumno }\end{array}$ & $\begin{array}{l}\text { Facilita el compartir el } \\
\text { material multimedia, así } \\
\text { como conocer la opinión de } \\
\text { los estudiantes acerca del } \\
\text { contenido. }\end{array}$ \\
\hline & $\begin{array}{l}\text { Plantea dudas acerca } \\
\text { de los conocimientos } \\
\text { adquiridos en la } \\
\text { preparación. }\end{array}$ & $\begin{array}{l}\text { Avisa y conecta a los } \\
\text { estudiantes acerca de } \\
\text { las dudas que van } \\
\text { surgiendo y cuáles son } \\
\text { las que más } \\
\text { seguimiento tienen } \\
\text { (trending topic) }\end{array}$ & $\begin{array}{l}\text { Proporciona un espacio } \\
\text { común (muro) donde los } \\
\text { estudiantes y el profesor } \\
\text { pueden resolver las dudas } \\
\text { planteadas. }\end{array}$ \\
\hline $\begin{array}{r}\text { Fase } 2 \\
\text { Sesión } \\
\text { presencial }\end{array}$ & $\begin{array}{l}\text { Trabaja junto a los } \\
\text { compañeros y el } \\
\text { profesor los } \\
\text { conceptos preparados } \\
\text { (aplicaciiones } \\
\text { prácticas, casos y } \\
\text { proyectos) }\end{array}$ & & \\
\hline
\end{tabular}

Fig. 5. El papel de los social media en el aprendizaje inverso.

Tal como se ha presentado en el artículo, las redes sociales son una herramienta muy potente para ser empleadas en la docencia, y especialmente en el ámbito universitario. El hecho de que haya una personalización de las publicaciones y una gestión de los avisos, las hace ideales para la docencia basada en el aprendizaje inverso.

Dado que se está trabajando en estos temas, no se dispone de resultados acerca de la opinión de los estudiantes al respecto del uso de las redes ni de mediciones acerca del impacto en la mejoría de las evaluaciones de los alumnos usando estas metodologías. Sin embargo, en la experiencia de los profesores a lo largo de estos cursos, sí que se aprecia una gran aceptación en el uso de las redes sociales por parte de los alumnos y de los profesores. Esta aceptación se debe especialmente a la orientación social y colaborativa que el adquiere el proceso de enseñanza-aprendizaje.

\section{Agradecimientos}

El presente trabajo se ha realizado gracias al proyecto PIME A12/13: Elaboración de la guía de uso eficaz de las redes sociales en la docencia universitaria, de la Universitat Politècnica de València

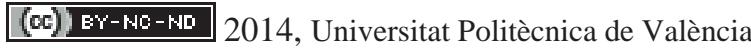

I Jornadas IN-RED (2014) 
Desarrollo de una guía para el uso de los social media en la mejora de la comunicación profesor-alumno. Aplicación al aprendizaje inverso

\section{Referencias}

J.L. Bishop and M.A. Verleger (2013) The Flipped Classroom: A Survey of the Research. En Proc. of 120th ASEE Annual Conference and Exposition.

M. Camacho (2010). Las redes sociales para enseñar y aprender. Reflexiones pedagógicas básicas. Aprendizaje con redes sociales. Tejidos educativos para los nuevos entornos. Sevilla: Ed. L. Castañeda.

N.G. Carr (2011). Superficiales ¿Qué está haciendo internet con nuestras mentes? Madrid: Ed. Taurus.

M. Del Fresno (2011). Infosociabilidad: monitorización e investigación en la web 2.0 para la toma de decisiones. En El profesional de la información, 20(5), 548-554.

Flipped Learning Network (2014). What is Flipped Learning [en línea] Disponible en <http://flippedlearning.org/domain/46> [consulta: 17 junio 2014]

M.J. Lage, and G. Platt. (2000) The internet and the inverted classroom. En The Journal of Economic Education, 31(1): 11 .

José Luis Poza-Lujan, Ángeles Calduch Losa, Ana Albors, Marga Cabrera, Rebeca Díez-Somavilla, María Dolores Teruel Serrano, Miguel Rebollo Pedruelo (2013) Medición de la actividad de grupos en redes sociales para el apoyo a la docencia universitaria. En Proc. de II Congreso Internacional sobre Aprendizaje, Innovación y Competitividad, pp. 274-279.

C. Shirky (2010). Excedente Cognitivo. Creatividad y generosidad en la era conectada. Bilbao: Ed. Deusto.

M. Túñez y , J. Sixto (2011). Las redes sociales como entorno docente: Análisis del uso de Facebook en la docencia universitaria. En Píxel-Bit. Revista de Medios y Educación. 41, 77-92. 


\title{
Redes de Distribución de Contenidos para la Mejora de la Práctica Docente en estudios de Máster de Ingeniería
}

\author{
Roberto Llorente $^{\mathrm{a}}$, Maria Morant ${ }^{\mathrm{b}}$, Benjamin Sarria ${ }^{\mathrm{c}}$, M. Salomé Moreno ${ }^{\mathrm{d}}$
}

${ }^{a}$ Departamento de Comunicaciones, Universitat Politècnica de València, rllorent@dcom.upv.es

b I.U. de Tecnología Nanofotónica, Universitat Politècnica de València, mmorant@ntc.upv.es

${ }^{c}$ Facultad de Medicina, Universitat de València Estudi General, benjamin.sarria@uv.es

${ }^{\mathrm{d}}$ Departamento de Urbanismo, Universitat Politècnica de València, smoreno@upvnet.upv.es

\begin{abstract}
This paper includes content distribution networks in teaching activities in Higher Education. New information and communications technologies are used for presenting content to the students in the classroom. Data gathering is achieved with a novel tool that enables providing ad-hoc practical exercises to the students to be answered in the classroom. This new content can be accessed directly from the students' mobile devices and is compatible with Android, iOS and Windows Phone operative systems. It also enables capturing handwritten data which reduces the time spent in solving the exercises and enables finishing the tasks during the class.

The results gathered in the Master Engineering subject called "Energy efficiency and new generation optical networks" at UPV point out that the students are more motivated during the class when using new technologies. The students' interest and participation increased in comparison with the previous year and the students performed both individual and collaborative work to solve the proposed tasks.
\end{abstract}

Keywords: New methodologies, new technologies, learning in the classroom, content distribution networks, collaborative work

\section{Resumen}

Este artículo propone el uso de redes de distribución de contenidos para la mejora de la práctica docente. En esta innovación se ha integrado el uso de nuevas herramientas TIC para la presentación de contenidos en el aula. La herramienta de captura de datos permite proporcionar ejercicios cortos personalizados a los alumnos para su realización en el aula. La herramienta 
Redes de Distribución de Contenidos para la Mejora de la Práctica Docente en estudios de Máster de Ingeniería

propuesta permite el acceso a los contenidos desde los propios dispositivos móviles de los alumnos, ya sean Android, iOS, o Windows Phone. Además se incluye la posibilidad de capturar la respuesta mediante escritura natural directamente desde el dispositivo móvil, lo que reduce el tiempo de respuesta de los alumnos y les permite terminar la tarea en clase.

En este artículo se recogen los resultados de la experiencia docente realizada en la asignatura de Máster "Eficiencia Energética y Redes Ópticas de Nueva Generación” de la UPV. Los resultados obtenidos indican una gran motivación de los alumnos por el seguimiento de la clase. El hecho de realizar correctamente el ejercicio y que el resultado se tenga en cuenta en sus calificaciones hace que los alumnos se esfuercen y recurran al trabajo tanto individual como colaborativo de un modo natural.

Palabras clave: Nuevas metodologías, aprendizaje en el aula, trabajo colaborativo.

\section{Introducción}

El Espacio Europeo de Educación Superior (EEES) implica la adquisición por parte de los alumnos de una serie de competencias que el sistema educativo debe impulsar como objetivos del aprendizaje. Los principios del EEES se plantearon en el Convenio de Bolonia de 1999 y fue aprobado por el Parlamento Europeo en 2001. El eje didáctico del EEES se basa en un proceso de enseñanza-aprendizaje donde el alumno pasa a ser protagonista de su propio aprendizaje y el profesor asume la responsabilidad de diseñar y proponer los contenidos y métodos didácticos sobre la materia. Las actividades diseñadas por el profesor deben dinamizar la actividad de estudio, guiar al alumnado durante el proceso de enseñanza-aprendizaje, así como evaluar y facilitar la retroalimentación (feedback) del aprendizaje. Este último punto, el de la evaluación y feedback es muy importante en el modelo de aprendizaje actual de las universidades españolas con el fin de poder orientar la actividad formativa más conveniente hacia los intereses intelectuales y profesionales de los estudiantes.

En el proceso de convergencia hacia el EEES de los últimos años, los procesos de evaluación han adquirido una nueva dimensión para valorar si el estudiante ha adquirido las competencias planteadas en los títulos académicos. Tradicionalmente, la evaluación se había centrado en la última etapa del aprendizaje mediante una prueba o examen final donde, en general, los alumnos se preocupaban más en aprobar el examen que en aprender (Delgado, et al. 2006). En el nuevo EEES ya no se evalúan "materias" sino que se evalúan competencias, por lo que la evaluación se vincula a la ejecución de labores específicas que 
demuestren el dominio del alumno en dichas funciones. La evaluación debe ser un proceso continuo integrado al proceso de formación, que tiene por objeto determinar qué aspectos se han adquirido correctamente y cuáles no, con la intención de garantizar la calidad global de proceso de formación (Delgado, et al. 2006). Para ello, la evaluación no puede consistir en una única prueba final, sino que el progreso del estudiante debe evaluarse a lo largo de todo el proceso de enseñanza-aprendizaje mediante una evaluación formativa (Cabrera, 2003) que proporcione la correcta orientación y retro-alimentación (feedback) a los alumnos sobre la consecución de los objetivos de aprendizaje.

No obstante, las limitaciones que nos podemos encontrar cuando intentamos realizar un gran número de ejercicios de evaluación, son tanto de capacidad como temporales. Por un lado, es prácticamente imposible para el profesor revisar uno por uno los ejercicios hechos por los alumnos en tiempo real, para poder darles el feedback adecuado sobre los resultados del ejercicio, y por otro lado, las limitaciones temporales en el aula impiden que el alumno tenga tiempo suficiente para completar la tarea, lo que puede acabar frustrando y perjudicando al alumno si se sobrecarga de trabajo a realizar en casa (Huertas y Agudo, 2003).

Gracias a las nuevas metodologías de evaluación continua y de trabajo en el aula, la eficacia de estudios tanto a nivel de Grado como de Máster puede verse muy beneficiada si conseguimos que el alumno realice la mayor parte del proceso de construcción del aprendizaje en el aula, durante la práctica docente. Para ello, en este artículo se propone el uso de redes de distribución de contenidos en el aula para recoger resultados en tiempo real y así mejorar la práctica docente.

Las tecnologías de la información y la comunicación (TIC) ofrecen nuevas posibilidades en la producción y en la transmisión de conocimientos (Delgado y Oliver, 2006). Las TIC aplicadas al proceso de enseñanza-aprendizaje facilitan el trabajo del docente (Domingo y Marqués, 2011). En nuestro campo de aplicación, el uso de las TIC en el aula permite: (1) el acceso a todo tipo de información actualizada, (2) comunicarse rápidamente para difundir o intercambiar información y (3) almacenar datos de forma inmediata.

Un ejemplo de integración de las TIC en el entorno educativo es la plataforma de formación llamada PoliformaT, desarrollada por la Universitat Politècnica de València (UPV) en el curso 2006/2007 para apoyar tanto a profesores como a alumnos en la gestión de las diferentes asignaturas de un programa de estudios. Esta plataforma dispone de diferentes herramientas como repositorio de documentos, prácticas online, exámenes, foros, etc. PoliformaT facilita un aprendizaje progresivo ya que proporciona un acceso continuado a las actividades propuestas periódicamente para realizar un seguimiento más realista de la adquisición de competencias de los alumnos (Sanabria, 2008).

\section{(cc) EY-NC-ND 2014, Universitat Politècnica de València}

I Jornadas IN-RED (2014) 
Redes de Distribución de Contenidos para la Mejora de la Práctica Docente en estudios de Máster de Ingeniería

En este trabajo se va un paso más allá mediante la integración en el aula de una herramienta docente que permite la presentación de varios ejercicios en el proyector del aula y la captura de la respuesta de los alumnos mediante escritura natural sobre los propios dispositivos móviles de los alumnos.

Asímismo se recogen los resultados de la experiencia docente realizada en la asignatura "Eficiencia Energética y Redes Ópticas de Nueva Generación" (código UPV 31970) del Máster Universitario en Tecnologías, Sistemas y Redes de Comunicación de la Universitat Politècnica de València.

\section{Objetivos}

El objetivo principal de esta innovación docente es incorporar el uso de las redes de distribución de contenidos (CDN del inglés Content Distribution Networks) combinadas con herramientas de captura de datos (Data Gathering Tools) en la práctica docente dentro del aula. El uso de estas nuevas herramientas en actividades individuales y de grupo realizadas en el aula permite a los alumnos efectuar la tarea más rápidamente y finalizarla en el tiempo disponible de clase. De esta manera se consolidan los conceptos teóricos presentados en clase mediante la realización inmediata de ejercicios prácticos cortos, evaluables y directamente relacionados con el tema que acaban de estudiar.

Los objetivos concretos de esta experiencia se definen como:

Objetivo \#1: Utilizar nuevas herramientas TIC para la presentación de contenidos en el aula

- Evaluar diferentes opciones de nuevas herramientas que permitan el acceso desde los dispositivos móviles propios de los alumnos, ya utilicen sistema operativo Android, iOS o Windows Phone

Objetivo \#2: Uso de redes CDN para captura de datos en el aula

- Incorporar una herramienta de captura de datos que permita a los alumnos proporcionar los resultados de ejercicios prácticos cortos realizados en el aula

- Incluir la posibilidad capturar la respuesta de los alumnos mediante escritura natural directamente desde el dispositivo móvil

- Obtener los resultados de los ejercicios propuestos

Objetivo \#3: Observar y monitorizar las reacciones de los alumnos ante esta innovación

Objetivo \#4: Obtener feedback de los alumnos respecto a los resultados obtenidos en la asignatura tras la implantación de esta experiencia piloto. 


\section{Desarrollo de la innovación}

\subsection{Integración de las TIC para la presentación de contenidos en el aula}

Como novedad en el Curso 2013/2014, se ha combinado la presentación de contenidos mediante el uso de un proyector en el laboratorio del Centro de Tecnología Nanofotónica y de una pantalla digital, tal como se muestra en la Fig. 1 y en la Fig. 2.

(a)

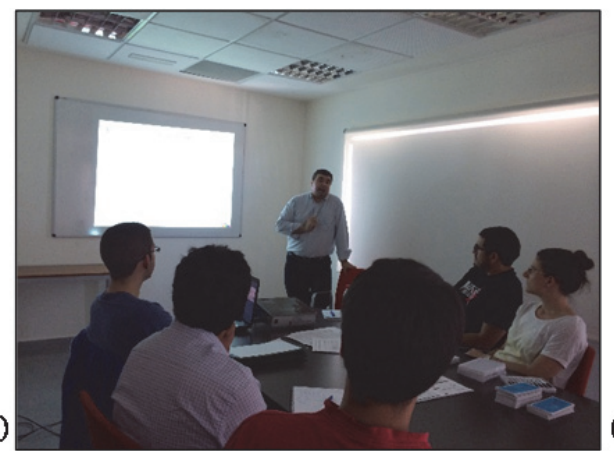

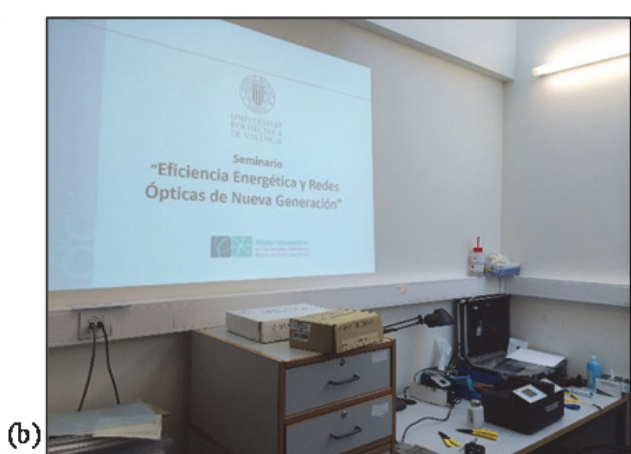

Fig. 1. Ejemplo de proyección de contenidos durante el seminario en el curso 2013/2014 durante: (a) la explicación teórica, (b) la sesión práctica de laboratorio
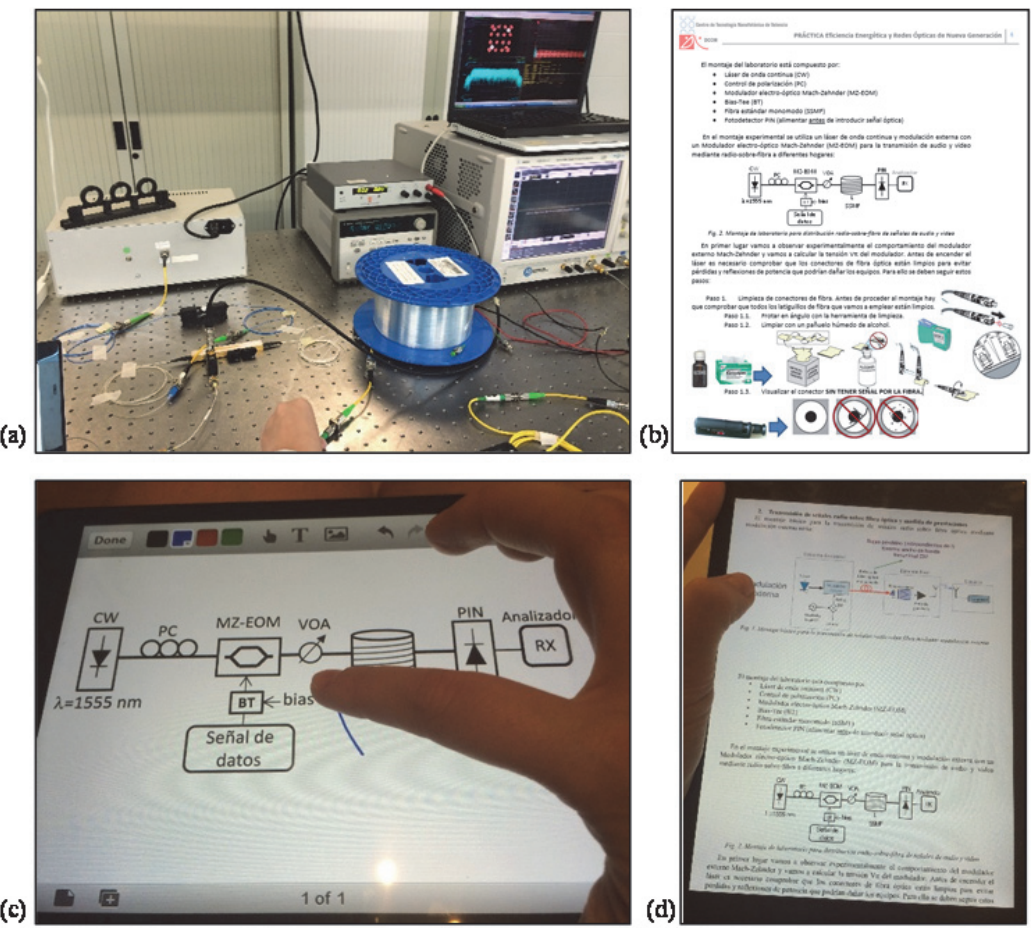

Fig. 2. Sesión de práctica en el laboratorio del curso 2013/2014 con integración del uso de las TIC: (a) foto del montaje experimental, (b) memoria de prácticas, (c) uso de pantalla digital para la explicación del montaje, (d) consulta de contenidos mediante dispositivo móvil en el aula

\section{(cc) EY-NC-ND 2014, Universitat Politècnica de València}

I Jornadas IN-RED (2014) 
Redes de Distribución de Contenidos para la Mejora de la Práctica Docente en estudios de Máster de Ingeniería

La Fig. 2(a) muestra una foto hecha en el laboratorio del montaje experimental preparado en el laboratorio según los contenidos que resultan más interesantes para los alumnos matriculados en el curso (Morant y Llorente, 2012). En este caso, para el curso 2013/2014 se diseñó una práctica que consistía en la preparación de una maqueta de red óptica mediante el fusionado de fibra y su integración en un montaje experimental para la evaluación de la eficiencia energética. La Fig. 2(b) muestra una captura de la memoria de prácticas de la asignatura, mientras que las Fig. 2(c) y (d) muestran la innovación docente introducida en este curso. En esta innovación se utilizó una pantalla digital para analizar el montaje de laboratorio junto al montaje real.

Como se puede ver en la Fig. 2(c) los alumnos tenían que identificar los componentes utilizados en el montaje y explicar brevemente en el aula la función principal de cada uno de ellos. Durante la realización de la práctica, los profesores plantearon una serie de ejercicios cortos sobre el funcionamiento concreto de alguno de los dispositivos que componían el montaje de laboratorio. Además los alumnos podían consultar contenidos de la asignatura con sus dispositivos móviles, tal como se muestra en la Fig. 2(d).

\subsection{Herramienta para captura de datos en dispositivos móviles}

Para alcanzar los objetivos propuestos, durante el curso 2013/14 se ha desarrollado una herramienta docente que permite la presentación de varios ejercicios en el proyector del aula y la captura de la respuesta de los alumnos mediante escritura natural sobre los propios dispositivos móviles de los alumnos, sea éste un dispositivo Android, iOS o Windows Phone.

La herramienta desarrollada presenta al alumno una aplicación que recoge el concepto básico que ha sido expuesto recientemente por el profesor, tal y como se puede ver en el ejemplo de la Fig. 3(a), y le plantea un ejercicio corto y directo sobre ese concepto. El ejemplo de visualización del ejercicio en una tableta se muestra en la Fig. 3(b).

Asimismo, la herramienta permite variar los datos del ejercicio de modo particular para cada alumno. De esta manera el estudiante puede trabajar en grupo para conocer el procedimiento de solución, pero debe aplicarlo individualmente. Así se evita el caso de alumnos pasivos que simplemente copian el resultado, y les obliga a aprender el procedimiento y a participar en la tarea.

La aplicación captura el resultado en escritura natural sobre el dispositivo móvil tal como se puede ver en el ejemplo de la Fig. 3(c) -en este caso funcionando en un teléfono móvil-, y es enviada "push" mediante una red de distribución de contenidos, activada por el profesor justo después de presentar el ejercicio en el proyector. 
La Fig. 3(d) muestra un ejemplo del ejercicio propuesto donde los alumnos debían describir el funcionamiento de un modulador óptico externo Mach-Zehnder y marcar las zonas de modulación lineal y de máxima y mínima transmisión.
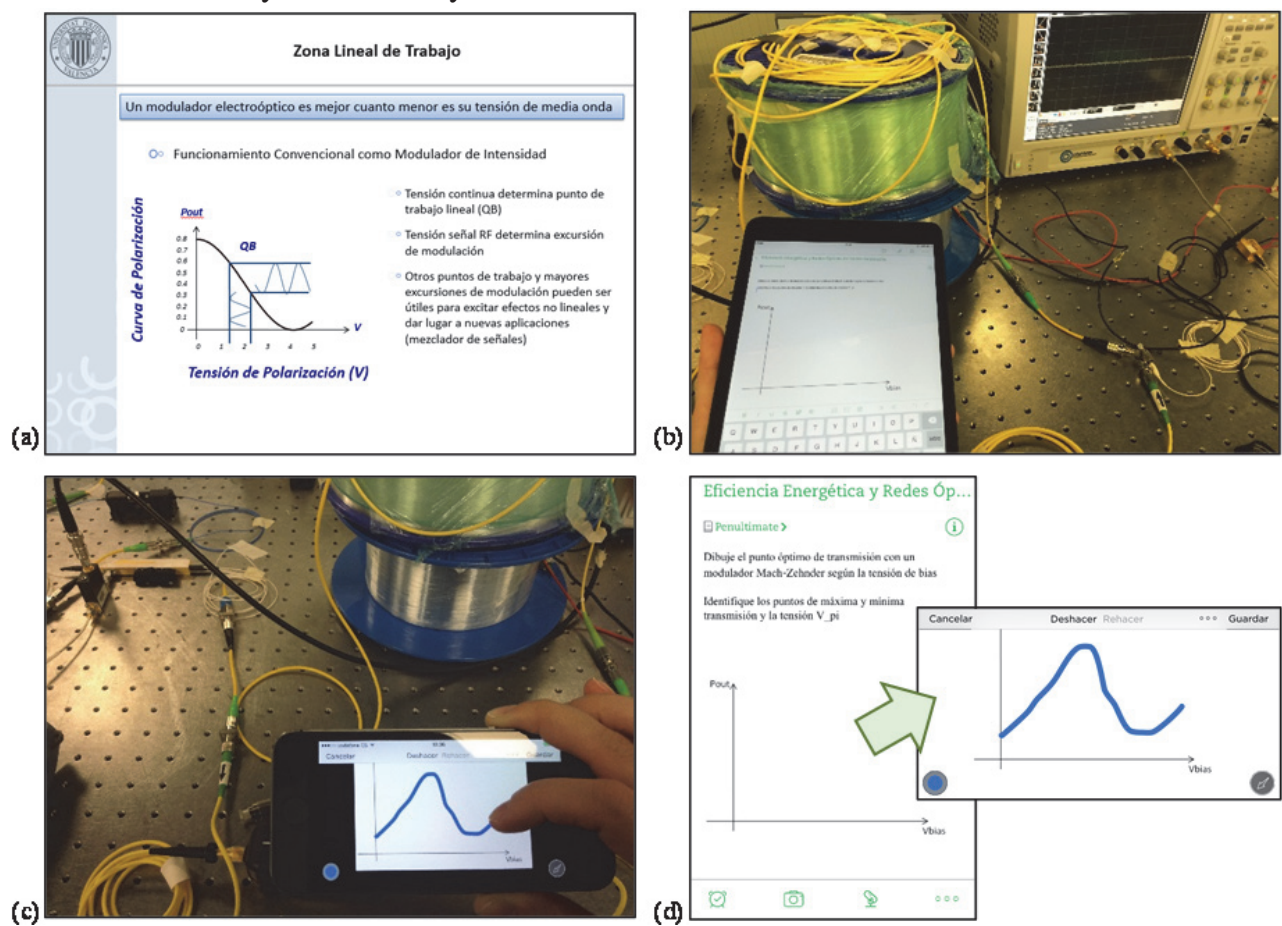

Fig. 3. (a) Resumen de los conceptos teóricos explicados en clase, (b) ejemplo del uso del herramienta CDN para plantear ejercicios cortos en el aula en dispositivos móviles, (c)-(d) captura de datos en escritura natural

\subsection{Uso de nuevas tecnologías TIC para monitorizar a los alumnos}

Para la monitorización de las actuaciones de los alumnos, junto con profesorado de la UPV y de la Universitat de València Estudi General (UVeg), se ha realizado un estudio en paralelo sobre técnicas de retroalimentación o feedback aplicado a diferentes tareas. Además, dado que en la sesión práctica se van a utilizar dispositivos móviles para la captura de datos de los alumnos, como novedad en este curso el profesor ha incluido una aplicación para obtener más datos sobre el comportamiento de los alumnos durante la realización de los ejercicios y así poder proporcionar un mejor feedback a los alumnos sobre sus avances en clase.

Aunque existen varias aplicaciones disponibles en la actualidad para poder capturar la evolución de los alumnos en clase, en este caso hemos seleccionado la aplicación ClassDOJO para monitorizar al grupo de alumnos. El control de esta aplicación es sencillo y ahorra tiempo al profesor en recoger datos sobre los avances personalizados de cada alumno mientras están realizando las tareas.

\section{(c)) EY-NC-ND 2014, Universitat Politècnica de València}

I Jornadas IN-RED (2014) 
Redes de Distribución de Contenidos para la Mejora de la Práctica Docente en estudios de Máster de Ingeniería

La aplicación también permite almacenar datos sobre la asistencia de los alumnos y guardar feedback de refuerzo positivo por alumno o por grupo, tal y como se muestra en la Fig. 4(a), así como aspectos a mejorar -Fig. 4(b)-.

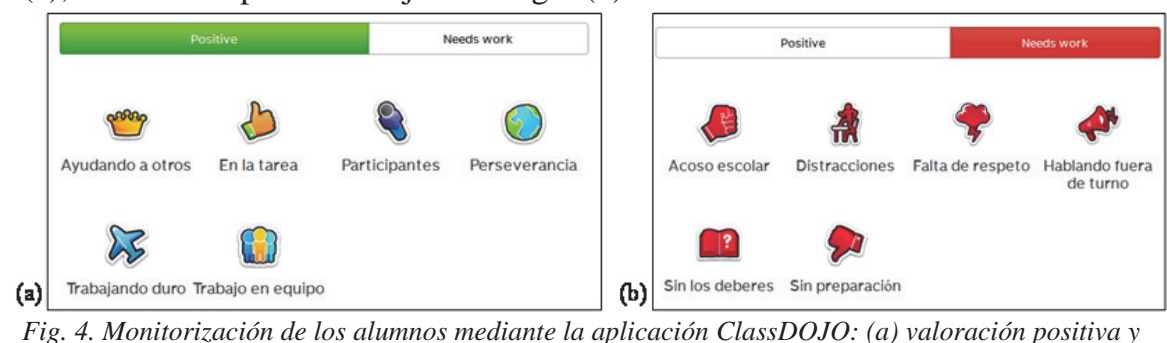

(b) aspectos a mejorar

\subsection{Análisis del feedback obtenido de los alumnos}

Como último paso en esta experiencia piloto, se han recogido en este curso las opiniones de los alumnos sobre la innovación docente. Además se ha realizado un análisis de la evolución de la nota media obtenida por los alumnos en la asignatura en los últimos cursos.

\section{Resultados}

Los resultados de esta experiencia docente se han analizado en la asignatura "Eficiencia Energética y Redes Ópticas de Nueva Generación" (código 31970) del Máster Universitario en Tecnologías, Sistemas y Redes de Comunicación de la UPV.

La Fig. 5 muestra un ejemplo de la captura de datos con la aplicación ClassDOJO utilizando nombres alterados de los alumnos por cuestiones de privacidad. La aplicación permite recopilar datos guardando la asistencia de los alumnos cada día de clase (o los días que consideremos necesarios) tal como se puede observar en el ejemplo de la Fig. 5(a), así como obtener informes y estadísticas globales sobre las actividades de los alumnos según su comportamiento en el aula -Fig. 5(b)-.
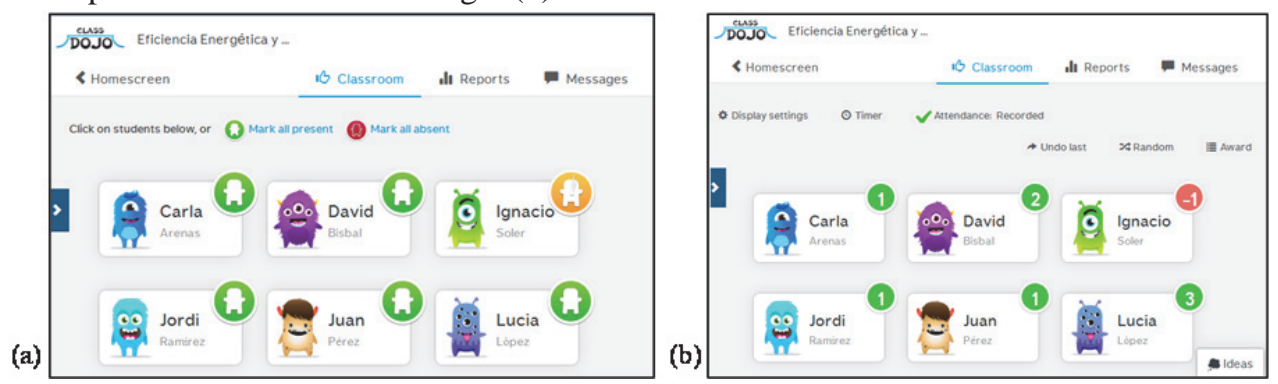

Fig. 5. Ejemplo de captura de datos de los avances de los alumnos mediante la aplicación ClassDOJO (nombres alterados por privacidad): (a) Control de asistencia y (b) monitorización de esfuerzo general 
La Fig. 6 muestra un ejemplo de los datos recopilados por el grupo durante la sesión práctica en el laboratorio en el curso 2013/2014, donde un $84 \%$ de las valoraciones fueron positivas incluyendo trabajo en equipo, ayudando a otros y realizando la tarea propuesta en el aula. Sólo un alumno se presentó a clase sin tener el trabajo previo concluido.

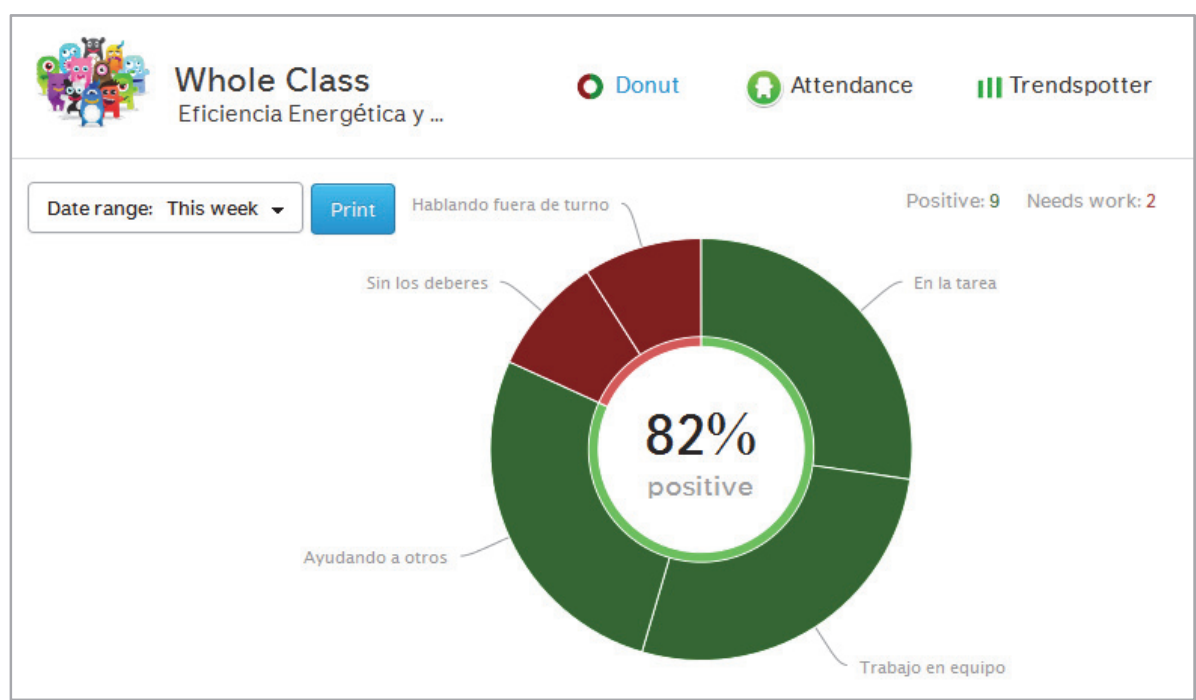

Fig. 6. Ejemplo de los resultados capturados durante la sesión de laboratorio en el curso 2013/2014

En este estudio consideramos un grupo reducido de seis alumnos, por lo que la relación profesor-alumno es más estrecha que en clases numerosas. No obstante en grupos más grandes, el uso de este tipo de aplicaciones facilitaría al profesorado recordar los nombres y poder monitorizar los avances de cada alumno o grupo de alumnos en diferentes momentos de la práctica docente.

En cuanto a la percepción sobre el uso de esta nueva herramienta docente para la distribución de contenidos y de captura de datos, cabe señalar que la innovación tuvo una buena aceptación por parte de los alumnos. Los estudiantes valoraron muy positivamente el desarrollo de la práctica, sobretodo la parte de descripción y análisis del montaje experimental. Del mismo modo, consideraron importante que la herramienta pudiera utilizarse desde diferentes dispositivos móviles de manera que todos los alumnos pudieran tener acceso a los contenidos.

Finalmente, se ha procedido a realizar un análisis de la evolución de la nota media de los alumnos a lo largo de los últimos años. Esta evolución se muestra en la Fig. 7. En esta asignatura de máster se han ido realizando diferentes innovaciones docentes a lo largo de los últimos años. En concreto, en el curso 2010/2011 se llevó a cabo una colaboración entre alumnos de Grado y Máster de Telecomunicaciones durante la sesión práctica de laboratorio para potenciar el proceso de enseñanza-aprendizaje mediante la enseñanza a

\section{(cc) EY-NC-ND 2014, Universitat Politècnica de València}

I Jornadas IN-RED (2014) 
Redes de Distribución de Contenidos para la Mejora de la Práctica Docente en estudios de Máster de Ingeniería

través de la práctica "learning by doing" y enseñando a otros (Llorente, Morant y Balbastre, 2011). Como se puede observar en la Fig. 7, el resultado de los alumnos en ese curso mejoró mucho, dado que estuvieron más participativos y los alumnos de Máster tuvieron la ocasión de interaccionar con los alumnos de Grado y explicarles conceptos que ya conocían. En cambio, los peores resultados se obtuvieron el curso pasado, en el que se produjo un aumento del número de alumnos proveniente de otras universidades y con perfiles diversos (un 75\%) que encontraron dificultades con algunos de los conceptos que se tratan en la asignatura. No obstante, aunque en el presente curso también ha habido una cantidad considerable de alumnos de otras universidades (casi el 60\%), la innovación introducida para la distribución de contenidos y explicación de los conceptos ha mejorado los resultados en 2.3 puntos de media respecto al curso anterior.

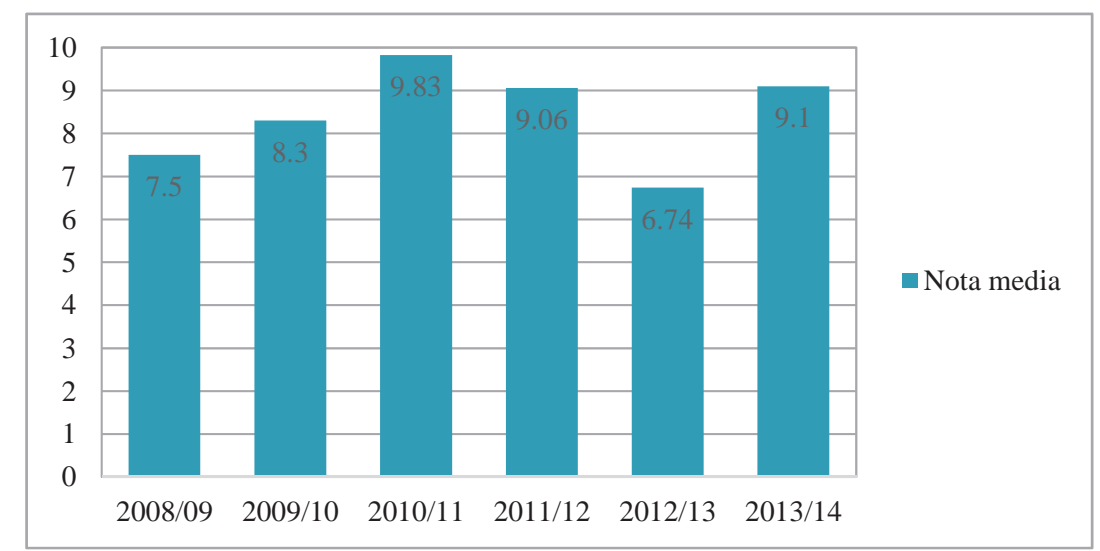

Fig. 7. Evolución de la nota media de los alumnos desde el curso 2008/2009 hasta la actualidad

\section{Conclusiones}

En este artículo se propone el uso de redes de distribución de contenidos para la mejora de la práctica docente en estudios universitarios tanto de Grado como de Máster. Los resultados de la prueba piloto se han realizado en una asignatura de Máster de Ingeniería de Telecomunicaciones de la UPV. En la innovación propuesta en el curso 2013/2014 se ha integrado el uso de nuevas herramientas TIC para la presentación de contenidos en el aula. La herramienta utilizada permite el acceso a los contenidos desde los propios dispositivos móviles de los alumnos, ya sean iOS, Android o Windows Phone. La herramienta de captura de datos permite proporcionar ejercicios cortos personalizados a los alumnos para su realización en el aula. Además se incluye la posibilidad de capturar la respuesta de los alumnos tanto por teclado como por escritura natural directamente desde el dispositivo móvil, lo que reduce el tiempo de respuesta de los alumnos y les permite terminar la tarea en clase. La posibilidad de realizar ejercicios prácticos cortos en el aula permite consolidar los conceptos teóricos presentados en clase. 
En esta innovación, el profesorado ha monitorizado el comportamiento de los alumnos en el aula. El 84\% de las valoraciones fueron positivas incluyendo trabajo en equipo, ayudando a otros y realizando la tarea propuesta en clase. El feedback obtenido respecto a la innovación tuvo buena aceptación por parte de los alumnos. Los alumnos valoraron muy positivamente el desarrollo de la práctica, sobretodo la parte de descripción y análisis del montaje experimental utilizando TIC mediante proyección y pantalla digital. Respecto a la captura de datos, la respuesta mediante escritura natural fue bien acogida por la comodidad y rapidez de respuesta. Los alumnos consideraron importante que la herramienta pudiera utilizarse desde diferentes dispositivos móviles.

Después de esta experiencia piloto con un grupo reducido de alumnos, el profesorado se plantea utilizar esta nueva herramienta docente en el próximo curso 2014/2015 con grupos más numerosos y observar la mejora en diferentes asignaturas de Grado y Máster de ingeniería y medicina.

\section{Referencias}

CABrera, A. (2003). Evaluación de la formación. Ed. Síntesis Cabrera, pág. 17-36.

Delgado, A.M, y Oliver, R. (2006). "La evaluación continua en un nuevo escenario docente", Revista de Universidad y Sociedad del Conocimiento, Vol. 3, No. 1.

Delgado, A.M., Borge, R., García, J., Oliver, R., y Salomón, L. (2006). Evaluación de las competencias en el Espacio Europeo de Educación Superior. Una experiencia desde el Derecho y la Ciencia Política. J.M Bosch (ed.), Estud. pedagóg. Vol. 32, No. 2, Valdivia.

Domingo, M. y MARQués, P. (2011). "Aulas 2.0 y uso de las TIC en la práctica docente" Comunicar, Vol. 37, no. XIX, pp. 169-175.

Huertas, J.A., Agudo, R. (2003). "Concepciones de los estudiantes sobre la motivación". En C. Monereo y J.I. Pozo (Eds.) La universidad antela nueva cultura educativa. Enseñar y aprender para la autonomía. Ed. Síntesis / Universitat Autònoma de Barcelona.

Llorente, R., Morant, M., y Balbastre, J.V. (2011). "Fast knowledge building by cross-disciplinar cooperative learning", Proceedings of International Conference on Education, Research and Innovation ICERI2011, Ed. IATED.

Morant, M. y Llorente, R. (2012). "Técnica de motivación docente mediante el auto diseño de actividades prácticas en laboratorio", Jornadas de Innovación Educativa de la UPV 2012, Ed. Instituto de Ciencias de la Educación (ICE).

SANABria, E. (2008). "Una experiencia de evaluación continua a través de PoliformaT", V Congreso Iberoamericano de Docencia Universitaria, Valencia.

(cc) EY-NC-ND 2014, Universitat Politècnica de València

I Jornadas IN-RED (2014) 


\title{
Evolución de una Experiencia de Formación Semipresencial para una Empresa Nacional
}

Sandra Sendra ${ }^{a}$, Jose M. Jiménez ${ }^{a}$, Jaime Lloret ${ }^{a}$ y María-Cinta Vincent-Vela ${ }^{b}$

${ }^{a}$ Departamento de Comunicaciones. Universitat Politècnica de València. C/ Camino de Vera s/n. 46022-Valencia.Valencia.sansenco@posgrado.upv.es, jojiher@dcom.upv.es, jlloret@dcom.upv.es y ${ }^{b}$ Departamento de Ingeniería Química y Nuclear. Universitat Politècnica de València. C/ Camino de Vera s/n. 46022- Valencia. Valencia. mavinve@iqn.upv.es

\begin{abstract}
This paper presents a training plan in the form of blended learning carried out with professionals of the national company ADIF. Throughout this study, we will present the course content and the pursued objectives. This paper also analyzes the profile of the students included in this course and reviews, in terms of age and gender, how they impact to the class results. Most of the course is conducted through two learning platforms. But during the attendance days, students perform collaborative practice on real devices. We explain each activity incorporated to the course, virtual practices simulators, real and remote practices, exams performed and their weight over the final grade, etc..) Finally, we will show the alumni opinions and their qualifications during the years which we have followed this training plan. As we will see in the results, the best or worst acceptance of this type of teaching innovations are affected by the age of the participants and their knowledge of these new technologies.
\end{abstract}

Keywords: Plan training, practical skills, online platform, software for education.

\footnotetext{
Resumen

Este artículo expone un plan formativo en régimen semi-presencial llevado a cabo con profesionales de la empresa nacional ADIF. A lo largo de este estudio, se presenta en contenido del curso y los objetivos que persigue. Así mismo, analizaremos el perfil de los alumnos a los que dirigimos este curso y veremos qué alumnos recibimos, en lo referente a edades y género. La mayor
}

(c) EY-NC-ND 2014, Universitat Politècnica de València

I Jornadas In-Red (2014) 
parte del curso se realiza a través de 2 plataformas de aprendizaje, pero se incluyen jornadas presenciales para la realización de prácticas colaborativas sobre dispositivos reales. Se explicará cada una de las actividades incorporadas en el curso, como prácticas virtuales con simuladores, prácticas remotas reales, prácticas presenciales, exámenes a realizar y su peso sobre la nota final, etc.) Finalmente, se presentan las opiniones de los alumnos de los 3 años durante los cuales se ha seguido este plan formativo y las calificaciones obtenidas. Como veremos en los resultados, la mejor o peor aceptación de este tipo de innovaciones docentes, se ven afectadas por la edad de los participantes y su conocimiento de estas nuevas tecnologías.

Palabras clave: Plan formativo, habilidades prácticas, plataforma online, software para educación.

\section{Introducción}

Uno de los mayores problemas que se encuentran a la hora de formar a los trabajadores de una empresa de carácter nacional, con múltiples emplazamientos y trabajadores repartidos por toda la geografía del país, es realizar una correcta planificación tanto teórica como práctica. Tanto la plataforma docente online (Bri, 2008) (Bri, 2009), como las herramientas software que permitan realizar actividades prácticas en casa(Garcia, 2008), y las prácticas remotas (Lloret, 2008), deben elegirse cuidadosamente, para evitar problemas de incompatibilidades con los equipos de los estudiantes, asi como para conseguir un mayor transferencia de conocimiento a los alumnos.

En este artículo se expone un plan formativo semipresencial que se ha llevado a cabo con la empresa nacional ADIF (Lloret, 2004). Se analizarán los módulos en los que se ha estructurado el curso con el objetivo de conseguir mayor rendimiento del alumno. Se explicará cada una de las actividades incorporadas en el curso (prácticas virtuales con simuladores, prácticas remotas reales, prácticas presenciales, etc.) y los efectos que se deseaban conseguir con ellas. Además, se detallará la planificación de evaluaciones, tanto parciales como globales, llevadas a cabo durante el curso. Finalmente, se presentarán y analizarán tanto la opinión de los alumnos como los resultados de las evaluaciones realizadas durante 3 años consecutivos. El curso incluido en el plan formativo incluye 2 certificaciones, la certificación universitaria, y la certificación de empresa (Lloret, 2013).

El resto del artículo se estructura como sigue. La sección 1 muestra algunas propuestas de innovación docente desarrolladas y aplicadas en distintos ámbitos. La sección 2 explone el contenido del curso y los objetivos que persigue. La innovación docente que proponemos, así como el modo de evaluación seguida, es explicada en la sección 3. La sección 4 muestra 
los resultados ontenidos de este plan formativo. Finalmente, la sección 5 hace una discusión sobre las conclusiones extraidas a partir de los resultados obtenidos y futuros trabajos.

\section{Trabajos relacionados}

En los últimos 10 años, nuestra sociedad a sufrido grandes cambios en el modo de manera de relacionarnos, de comunicarnos, de trabajar, de comprar, de informarnos, de aprender, etc. Estos cambios han venido generados por la proliferación de las nuevas tecnologías, nuevos sistemas, sistemas inteligentes como teléfonos y tablets, etc. (Marcelo, 2013). Hoy en día utilizamos estos avances tecnológicos para mejorar nuestras rutinas diarias. Teniendo en cuenta estos aspectos, debemos empezar a cambiar el modo de transmitir conocimiento a nuestros alumnos, haciendo uso de estas nuevas tecnologías

A.L. Marinez propuso en (Martínez, 2014) un estudio para dar a conocer las actividades formativas para integrar las TIC en las aulas. La autora incorporó diversas herramientas propuestas en diversos proyectos de investigación docente, para la elaboración de material docente de diversas asignaturas. Los resultados mostraron que los estudiantes han ampliado notablemente su bagaje de conocimientos teóricos y prácticos. Esots cambios en los estudiantes ha llevados a los profesores de estas asignaturas a tener que actualizar al tener que actualizar, ampliar y mejorar la terminología informática, aprender a manejar plataformas de aprendizaje y participar en la creación de redes de aprendizaje.

M. Medrano y otros (Medrano, 2012) analizn cómo mejorar el proceso de enseñanzaaprendizaje de los alumnos del Centro de Estudios Superiores de la Aviación de la Universidad Rovira i Virgili con el uso de herramientas TIC en cabina durante la instrucción de vuelo. Los autores han utilizado Tablet para la recogida y posterior procesado de los datos de posición del avión yla cantidad de documentos necesarios para la instrucción. El estudio muestra los beneficios e inconvenientes que proporcionan estos dispositivos electrónicos en el proceso formativo y propone la creación de una metodología específica para casos estos casos de docencia.

E. L. Meneses y otros describen una experiencia universitaria con mapas conceptuales interactivos sobre los principales ámbitos de intervención socioeducativa del educador social/ trabajador social (Meneses, 2012) La experiencia es desarrollada con 115 estudiantes. Los resultados muestran que el uso de estos mapas conceptuales fomentan la actividad y autonomía de los estudiantes en el proceso de construcción del conocimiento.

Finalmente, M. A. Moreira y otros (Moreira, 2010) presentan el diseño y resultados de un estudio realizado en la Universidad de La Laguna destinado a identificar buenas prácticas de aulas virtuales en la docencia universitaria desarrolladas bajo la modalidad de enseñanza semipresencial. Los resultados mostrados por este estudio depuestran que esta metodología

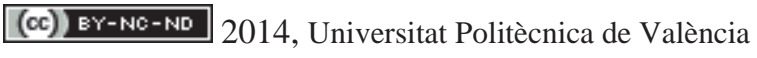

I Jornadas IN-RED (2014) 
genera gran interés en desarrollar nuevas actividades, por parte de los estudiantes. También muestra mejoras en los procesos comunicativos entre profesorado y alumnado.

Como podemos ver, existen infinidad de propuestas de innovaciones docentes pero la mayoría de ellas implantadas en entornos universitarios. Por ello, nosotros hemos querido probar este tipo de planes formativos novedosos en cursos dirigidos a profesionales que presentan varios niveles de conocimiento sobre las nuevas tecnologías.

\section{Contenido y objetivos del curso}

El curso "Ordenadores, sistemas operativos de red y seguridad informática" está enfocado a la formación de profesionales para la reparación y mantenimiento de ordenadores e instalación de redes informáticas. Estos conocimientos permiten detectar y corregir las averías típicas de un ordenador de tipo pc, además de adquirir los conocimientos necesarios para la instalación y configuración de redes locales de ordenadores, a nivel de hardware y sistemas operativos. Finalmente los alumnos aprenden destrezas a nivel de seguridad informática en sistemas operativos. Este curso se engloba dentro del título "Especialista universitario en redes y comunicaciones de ordenadores". El contenido de este curso se muestra en la Tabla 1.

\subsection{Objetivos del curso}

Los objetivos específicos que se persiguen en este curso son los siguientes:

- Dar al alumno/a una adecuada formación técnica en reparación y mantenimiento de ordenadores e instalación de redes informáticas, capacitándolo/a para detectar y corregir las averías típicas de un ordenador de tipo PC y para la configuración de redes locales de ordenadores, a nivel de hardware y sistemas operativos.

- Se tratarán temas de seguridad informática en sistemas operativos.

- Diseñar, instalar configurar y administrar redes de ordenadores para pequeñas y medianas empresas.

- Conocer las tecnologías Ethernet en profundidad para poder encontrar fallos en las redes de ordenadores.

\subsection{Perfil de los alumnos}

Los alumnos que realizan este curso son trabajadores de la propia empresa. Suelen llegar tanto hombres como mujeres, aunque estas últimas con un menor número. Tambien observamos grandes diferencias en las edades de los alumnos. De hecho, los grupos están 
bastante diferenciados. Por una parte recibimos gente bastante joven, con amplios conocimientos de la las nuevas tecnologías y manejo de ordenadores, el segundo es gente con edades incluso superiores a los 50 años que no presentan gran fluidez en el manejo de ordenadores. La Tabla 2 muestra un resumen de los perfiles de los alumnos que hemos recibido durante los 3 cursos.

Tabla 1. Contenido del curso, dividido por capítulos

\begin{tabular}{|c|c|c|}
\hline Capítulo & Nombre & Descripción \\
\hline Capítulo 1 & $\begin{array}{l}\text { Introducción a los ordenadores } \\
\text { personales }\end{array}$ & Describe los ordenadores personales \\
\hline Capítulo 2 & $\begin{array}{l}\text { Normas y procesos llevados a } \\
\text { cabo en el laboratorio }\end{array}$ & $\begin{array}{l}\text { Describe los procedimientos seguros a seguir en el } \\
\text { laboratorio y el uso adecuado de herramientas }\end{array}$ \\
\hline Capítulo 3 & Ensamblaje de un ordenador & $\begin{array}{l}\text { Ensamblaje de un PC a partir de componentes } \\
\text { compatibles y actualizar un sistema informático } \\
\text { para cumplir con los requisitos }\end{array}$ \\
\hline Capítulo 4 & $\begin{array}{l}\text { Mantenimiento preventivo y } \\
\text { resolución de problemas }\end{array}$ & $\begin{array}{l}\text { Explica las reglas básicas de mantenimiento } \\
\text { preventivo y el proceso de resolución de problemas }\end{array}$ \\
\hline Capítulo 5 & Sistema operativos & $\begin{array}{l}\text { Define como instalar, actualizar, navegar y } \\
\text { solucionar problemas de varios sistemas operativos }\end{array}$ \\
\hline Capítulo 6 & Redes & Describe como crear y mantener una red \\
\hline Capítulo 7 & Laptops & $\begin{array}{l}\text { Describe cómo están compuestas los ordenadores } \\
\text { portátiles, configuración básica, mantenimiento y } \\
\text { resolución de problemas }\end{array}$ \\
\hline Capítulo 8 & Dispositivos moviles & $\begin{array}{l}\text { Describe los sistemas operativos, configuración } \\
\text { básica, el mantenimiento, la seguridad, y la } \\
\text { reparación de los dispositivos móviles. }\end{array}$ \\
\hline Capítulo 9 & Impresoras & $\begin{array}{l}\text { Procedimientos y configuraciones requeridos para } \\
\text { las impresoras }\end{array}$ \\
\hline Capítulo 10 & Seguridad & $\begin{array}{l}\text { Explicar la importancia de la seguridad, describir } \\
\text { los procedimientos y medidas de seguridad }\end{array}$ \\
\hline Capítulo 11 & $\begin{array}{l}\text { Habilidades de comunicación } \\
\text { de Professional de las TIC }\end{array}$ & $\begin{array}{l}\text { Describir las habilidades de comunicación que } \\
\text { necesitan los profesionales de TI }\end{array}$ \\
\hline Capítulo 12 & Resolución de problemas & $\begin{array}{l}\text { Realizar procedimientos de solución de problemas } \\
\text { avanzados de ordenadores, sistemas operativos, } \\
\text { ordenadores portátiles, impresoras y redes }\end{array}$ \\
\hline
\end{tabular}

Tabla 2. Perfil de los alumnos de los tres cursos

\begin{tabular}{ccccccc}
\hline & \multicolumn{2}{c}{ Curso 2012 } & \multicolumn{2}{c}{ Curso 2013 } & \multicolumn{2}{c}{ Curso 2014 } \\
& Hombres & Mujeres & Hombres & Mujeres & Hombres & Mujeres \\
\hline $\begin{array}{c}\text { Total de Alumnos } \\
\text { \% alumnos menores de }\end{array}$ & 12 & 3 & 8 & 1 & 11 & 0 \\
$\mathbf{4 0}$ años & \multicolumn{2}{c}{$50 \%$} & & $37.5 \%$ & $2 \%$ \\
\hline
\end{tabular}

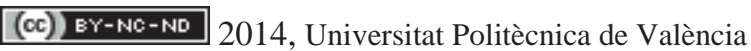

I Jornadas IN-RED (2014) 


\section{Desarrollo de la innovación}

El curso tiene una duración de 5 semanas durante las cuales los alumnos deben estudiar y preparar los diferentes temas contenidos en el curso. Cada tema tiene asociadas una serie de prácticas que los alumnos deberán entregar periódicamente, acorde con unas fechas preestablecidas. Finalmente el contenido es evaluado mediante exámenes parciales y finales controlados remotamente. Dicha metodología incluye un seguimiento personalizado de cada alumno a través de tutorías online. En esa sección vamos a explicar toda la metodología llevada a cabo dentro de este curso. También se mostrarán las 2 plataformas de aprendizaje utilizadas para proporcionar al alumno el contenido del curso y la atención a través de tuturias y correo electrónico que precisen.

\subsection{Actividades contenidas en el curso}

El curso de "Ordenadores, sistemas operativos de red y seguridad informática" siguiendo un régimen semipresencial fue iniciada en el año 2012. La utilización de ambas plataformas, a pesar de ser utilizadas con anterioridad de forma separada, se han mejorardo y juntado para conseguir los objetivos de este curso. Las plataformas online posibilitan la mejora en la dinámica del progreso del curso aunque exige igualmente el desarrollo de materiales didácticos específicos y pensados para este nuevo entorno de aprendizaje. Lo cierto es que el uso de internet y las redes nos ha permitido desarrollar un modelo de enseñanza mucho más flexible donde prevalece la actividad y participación de los alumnos junto a la adquisición del conocimiento, que en sí, la propia evaluación o valoración numérica de los conocimientos adquiridos.

Sin embargo, debido a las características y perfil de nuestros alumnos, nos podemos encontrar con la desventaja de tener que aumentar y estimular el hábito de estudio continuo y esfuerzo por su parte. Por ello, este curso necesita de una supervisión casi personalizada por parte de los profesores a través de tutorías online y correo electrónico.

La metodología de este curso se centra principalemnte en la participación del estudiante en su propio proceso de aprendizaje, de forma que los alumnos no sean sólo receptores de conocimientos. Este curso pretende dar y mostrar a los alumnos las herramientas necesarias para que puedan contruir ellos mismos, sus conocimientos en cooperación con el profesor y con el resto de sus compañeros. Esta estrategia es conocida como modelo de exposición y reconstrucción del conocimiento y pretende generar aprendices estratégicos.

Para tal fin, es importante marcar una serie de tareas y objetivos específicos para fomentar las estrategias cognitivas de exploración y descubrimiento. Con ello, ayudamos al alumno a que aprenda a planificarse sus actividades. Organiza y elabora la información del curso contribuye a la mejor comprensión de su contenido. 
Con el fin de fomentar dicho trabajo, se proponen una serie de actividades para cada módulo contenido en el curso, que implicará el esfuerzo continuado y pautado a medida que avanza el curso. La actividad educativa se estructurará en las siguientes actividades:

\subsubsection{Actividad no presencial: Trabajo autónomo del alumno}

El estudio autónomo es una estrategia metodológica basada en el autodidactismo y en la capacidad de los estudiantes para aprender desde la propia iniciativa y con motivación. Por lo general, el trabajo autónomo del alumno, se entienede como una actividad individual, sin embargo, en nuestras asignaturas apostamos por el trabajo colaborativo. Por ello incluimos el foro, donde los alumnus y profesores pueden compartir comentarios y dudas para res respondidos por cualquier integrante del foro.

Adicionalmente a las tareas de estudio, se incluyen un conjunto de 5-6 prácticas, por módulo, que los alumnos deben realizar. Los resultados de estas prácticas son enviados a los tutores, para posteriormente ser evaluadas. Existe otra práctica realizada en tiempo real, pero de forma remota, donde los donde los alumnos, realizan una serie de actividades sobre un servidor ubicado en Centro de formación de ADIF en Valencia. Todas estas prácticas están oriendadas al trabajo y configuración con distintos sistemas operativos, que pueden ser instalados sobre maquinas virtuales o nativos. Finalmente, la actividad no presencial incluye exámenes parciales que los alumnos realizarán a través de la plataforma de aprendizaje de Cisco.

\subsubsection{Actividad presencial: Trabajo colaborativo de los alumnos.}

Tras completar la fase no presencial, se establecen 2 jornadas presenciales donde se realizan prácticas sobre equipos reales y losexámenes finales. Estas prácticas son totalmente colaborativas. De hecho, si el equipo de trabajo no es capaz de trabajar conjuntamente, la realización de estas prácticas puede resultar muy larga. Con estas prácticas fomentamos la participación de todos los miembros y la organización. También se ponen de manifiesto las dotes de liderazgo de algunos miembros.

\subsection{Plataformas de aprendizaje online: Centro de Formación Virtual de ADIF y NetSpace de Cisco Networking Academy.}

El proceso del curso es llevado a cabo con la ayuda de 2 plataformas de aprendizaje online. Por una parte la empresa ADIF dispone de una plataforma llamada Centro de Formación Virtual (CFV). Dicha plataforma es utilizada por alumnos y tutores para intercambiar todo tipo de información, como dudas y preguntas, tutorías, materiar docente, software para la

\section{(cc) BY-NC-ND 2014, Universitat Politècnica de València}


elaboración de las prácticas, etc. Como partes importantes y distintivas de esta plataforma contiene:

- Apartado de Aula, que permite al profesor un listado de los alumnos que tutoriza

- Índice del curso, que permite a los alumnos acceder al contenido del curso. También al calendario y planificación del curso, documentos de ayuda para aprender a utilizar ambas plataformas y una descripción sobre la metodilogía que seguirá el curso.

- Sección de Tutorias, donde los alumnos pueden plantear todas las dudas y preguntas a sus tutor, de forma personalizada. Las tutorías, también son usadas para la entrega de las prácticas.

- Foro del curso, donde los alumnos y profesores pueden enviar mensaje a todos los integrantes del grupo. El foro es usado para plantear dudas generalizadas, que van siendo respondidas por los tutores. Los alumnos suelen aportar sus contribuciones sobre los temas planteados.

En el índice del curso, dentro del contenido del curso, los alumnos tienen disponibles todas practicas divididas en módulos (ver Figura 1). Desde esta interfaz web los alumnos se descargan tanto el enunciado como las hojas de respuestas que, tras ser rellenadas, son enviadas a los profesores.

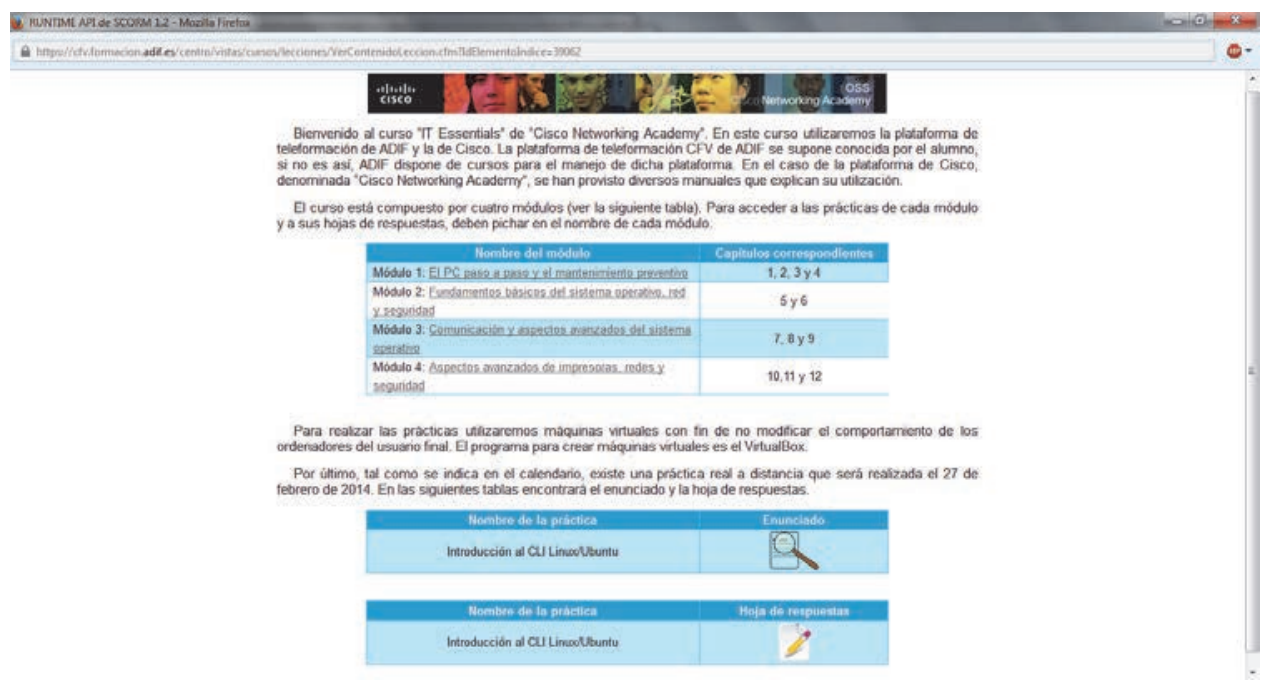

Fig. 1 Plataforma para descargar los enunciados de practicas y las horjas de respuesta

El contenido teórico del curso es proporcionado a través de la plataforma NetSpace de Cisco Networking Academy. Al inicio del curso, cada alumno es registrado como miembro de la academia local que gestiona el curso. Se le adjudica un usuario y contraseña que 
utilizarán para acceder tanto a los contenidos del curso como a otros recursos que Cisco ofrece a sus estudiantes. La Figura 2 muestra la ventana principal de la plataforma NetSpace de Cisco.

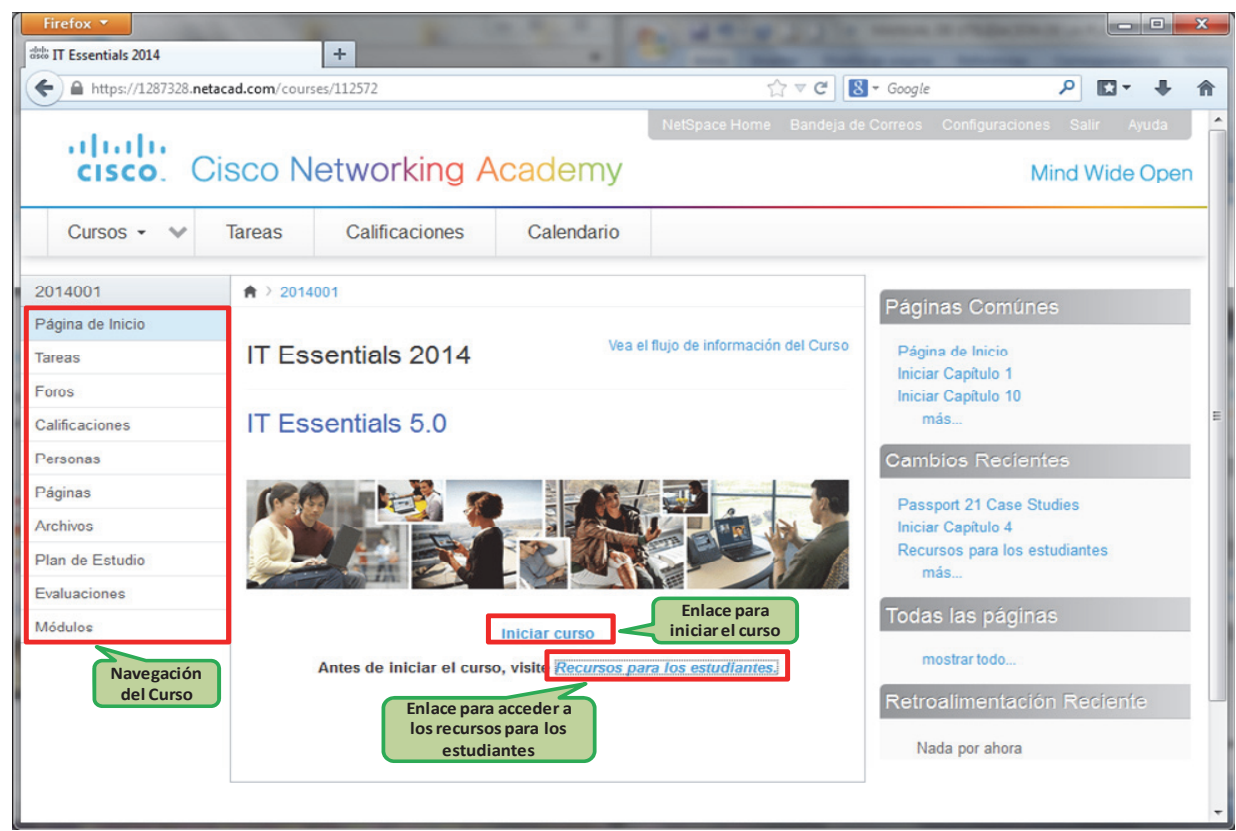

Fig. 2 Ventana principal de NetSpace de Cisco

Esta página contiene los enlaces directos a los diferentes módulos del curos, así como a los exámenes puntuables del capítulo y cuestionario preparatorio de cada capítulo. Pulsando en el enlace "Iniciar Curso", accedemos a la ventana de contenido (ver Figura 3).

Si pulsamos en Iniciar Capítulo nos dirige al contenido del capítulo. La Figura 4 muestra la ventana principal de la curricula, donde los alumnos pueden leer y estudiar todo el contenido de los capítulos. Además, todo el texto está acompañado de ilustraciones y videos demostrativos, que ayudan a la comprensión del contenido teórico.

Al final de cada capítulo, los alumnos tienen disponibles un cuestionario no evaluable que los ayuda a comprobar su nivel de comprensión del contenido y profundizar en aquellos aspectos que fallen.

(cc)) BY-NC-ND 2014, Universitat Politècnica de València

I Jornadas IN-RED (2014) 


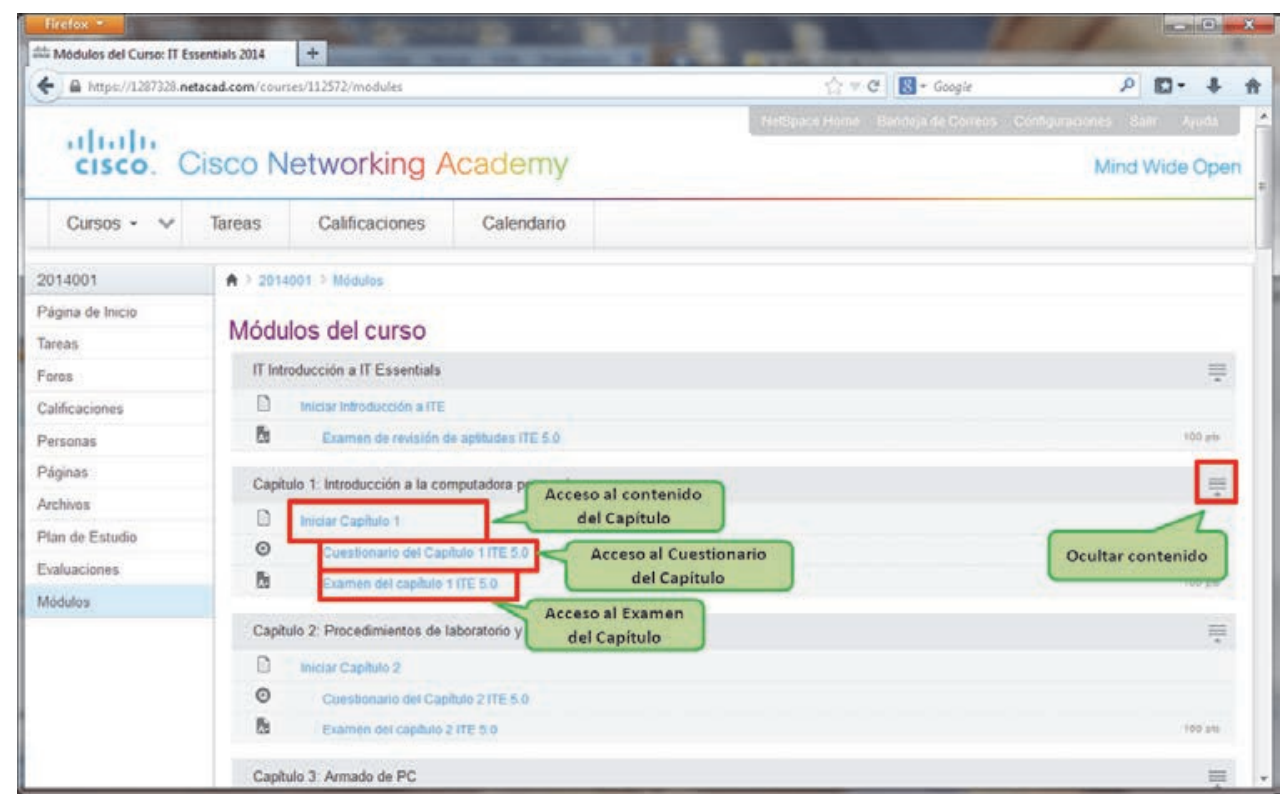

Fig. 3 Contenido del curso

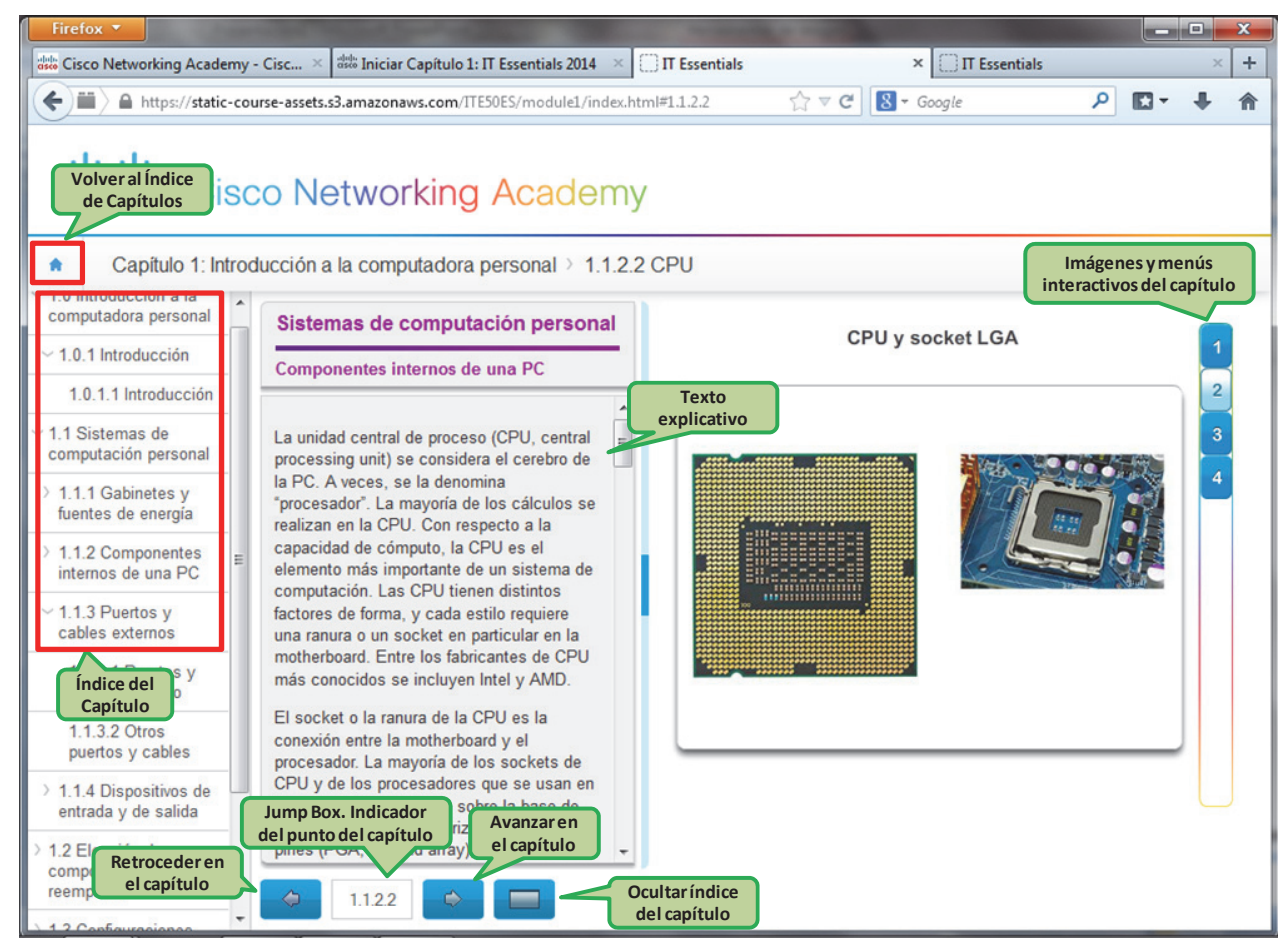

Fig. 4 Curricula cel curso con el contenido de cada tema

(cc) EY-NC-ND 2014, Universitat Politècnica de València

I Jornadas IN-RED (2014) 


\subsection{Evaluación de las actividades}

Dentro de las actividades presenciales, se incluye la evaluación final del curso Por una parte se realizan examenes individuals, donde se evaluan los conocimientos adquiridos a nivel teórico y práctico. El examen de destrezas prácticas se realiza en grupos, tal y como se realizan las prácticas de la jornada anterior. La calificación del examen práctico consta de dos partes. Por una parte, se evaluan last areas realizadas de forma individual por cada alumno. La segunda parte de la nota es global para todos los integrantes del grupo y se evalua si se han cumplido los objetivos globales del examen. Estos objetivos están relacionados con la correcta interconexión de todos los dipositivos, que sus configuraciones sean correctos y que las autenticaciones de los clientes, sobre los servidores se realicen sin problemas. Los exámenes teóricos se realizan a través de la plataforma NetSpace de Cisco. La Figura 5 muestra la ventana de acceso a las pruebas de evaluación.

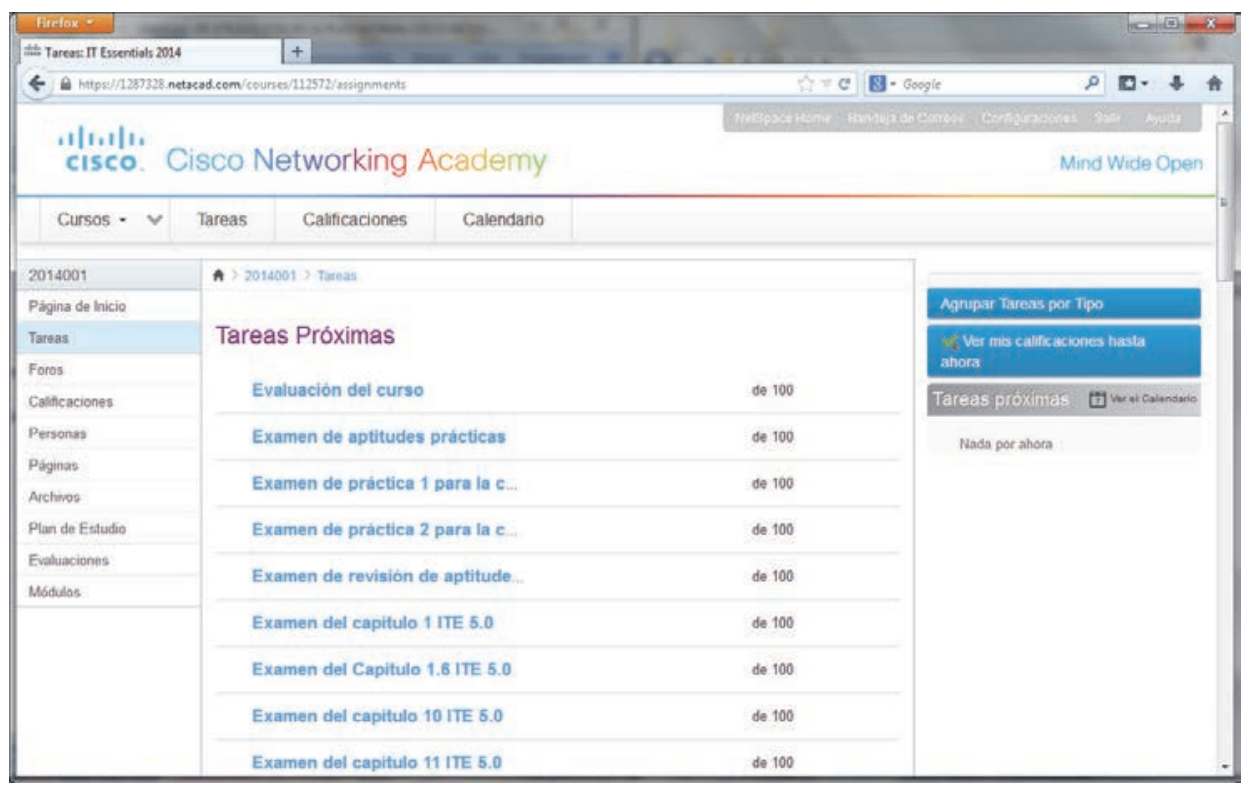

Fig. 5 Ventana de acceso a los exámenes

Tras finalizar el examen, los alumnos pueden consultar sus calificaciones de manera inmediata. La Figura 6 las calificaciones del alumno, así como el peso de cada uno de los examines, sobre la nota final. La plataforma NetSpace establece que la nota minima para aprobar sus exámenes es un $60 \%$ (equivalente a un 6 sobre 10). Si algún alumno, no está convencido de la nota obtenida se le da la posibilidad de repetir el examen, con la salvedad que la nota del aprobado se incrementará al 70\%. Esto es así, debibo a que Cisco asegura que todos sus alumnos cumplen los requisitos y objetivos del curso, antes de recibir su certificación.

\section{(cc) EY-NC-ND 2014, Universitat Politècnica de València}

I Jornadas IN-RED (2014) 


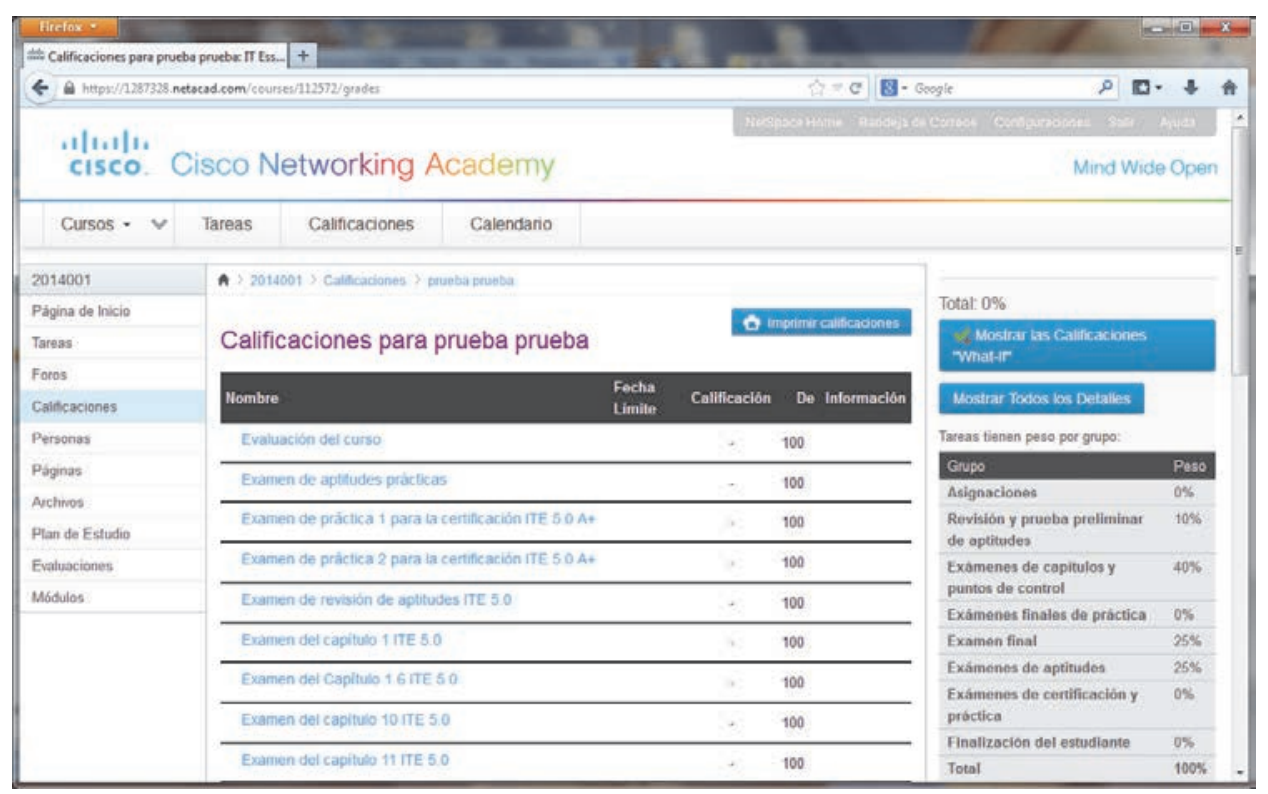

Fig. 6 Ventana de calificaciones

Para la evaluación de este curso se tienen en cuenta todas las tareas realizadas por los alumnos. Recordemos que la primera parte del curso se desarrollaba totalmente online, con entregas periódicas de ejercicios. Durante este periodo, se realizan los exámenes parciales de cada tema. Además, los alumnos debían realizar una práctica remota sobre una máquina ubicada en Valencia, desde sus oficinas. Finalmente en las sesiones presenciales, se realizanu na serie de prácticas grupales donde los alumnos aplicaban todos los conocimientos aprendidos durante el curso. El curso finalizaba con la elaboración de los exámenes finales, tanto teóricos como prácticos. La Tabla 3 resume los exámenes realizados y su peso sobre la nota final

Tabla 3. Descripción de los exámenes

\begin{tabular}{|c|c|c|}
\hline $\begin{array}{l}\text { Denominación } \\
\text { del examen }\end{array}$ & Descripción & Peso \\
\hline $\begin{array}{l}\text { Examen de } \\
\text { Revisión de } \\
\text { Aptitudes }\end{array}$ & $\begin{array}{l}\text { Realizado al inicio del curso de forma inividual. Realizado a } \\
\text { través de la plataforma NetSpace }\end{array}$ & $10 \%$ \\
\hline $\begin{array}{l}\text { Exámenes de } \\
\text { aptitudes Prácticas }\end{array}$ & $\begin{array}{c}\text { Realizada por grupos, en el laboratorio y engloba todos los } \\
\text { conocimientos adquiridos durante las prácticas entregadas y las } \\
\text { prácticas realizadas en las jornadas presenciales. }\end{array}$ & $20 \%$ \\
\hline $\begin{array}{l}12 \text { exámenes } \\
\text { parciales y } \\
\text { Exámen punto de }\end{array}$ & $\begin{array}{l}\text { Exámenes parciales realizados a lo largo del curso realizado de } \\
\text { forma inividual. El examen de punto de control engloba los } \\
\text { contenidos teóricos de los capítulos de } 1 \text { al } 6 \text {, realizado de forma }\end{array}$ & $40 \%$ \\
\hline
\end{tabular}


control inividual. Realizados a través de la plataforma NetSpace

Exámen teórico Examen que engloba los contenidos teóricos de todos los final capítulos, realizado de forma inividual. Realizado a través de la plataforma NetSpace

Las notas finales del curso se calculan como la media aritmética de los trabajos entregados a través de las tutorias y los exámenes realizados en las jornadas presenciales, es decir (Ecuacion 1):

Nota Final $=\frac{\text { Nota pricticas entregadas (On line) }+ \text { Nota exinenes (preandiales }}{n}$

\section{Resultados}

Tras finalizar cada uno de los cursos se realizaron sus correspondiente encuestas donde se preguntaba a los alumnos su opinión, en cuanto a contenido, recursos, medios didácticos utilizados, profesorado, metodología y organización del curso, etc. La Figura 7 muestra los resultados de las encuestas para el curso 2012. Como podemos observar los resultados fueron bastante satisfactorios. Prácticamente todas las calificaciones obtenidad se situan por encima del 7 sobre 10. La Figura 8 muestra los resultados de las encuestas para el curso 2013. Durante este curso los resultados de las valoraciones se situaron todas por encima del aprobado, aunque los resultado fueron ligeramente inferiores a los resultados obtenidos en el curso 2012. La Figura 9 muestra los resultados de las encuestas para el curso celebrado en el año 2014. En comparación con los resultados obtenidos en el curso 2013, podemos observar que aspectos como los contenidos y metodología, medios didácticos y diración del curso, obtiene mejores resultados. Finalmente la Figura 10 muestra las notas medias obtenidas por los alumnos. podemos observar las notas medias se situan en los tres casos por encima del 8 sobre 10 .

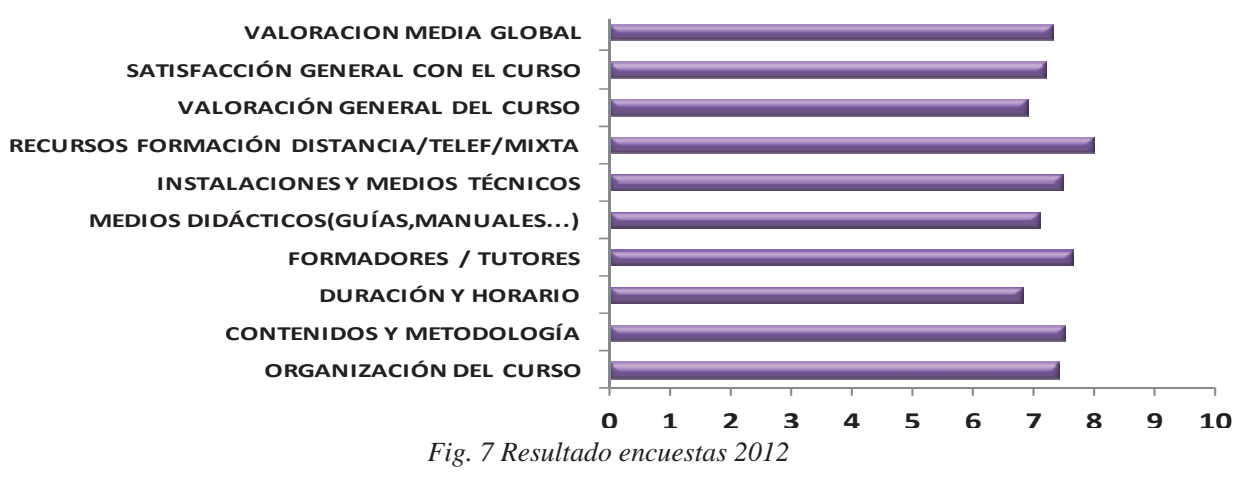

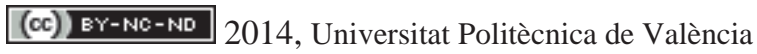

I Jornadas IN-RED (2014) 


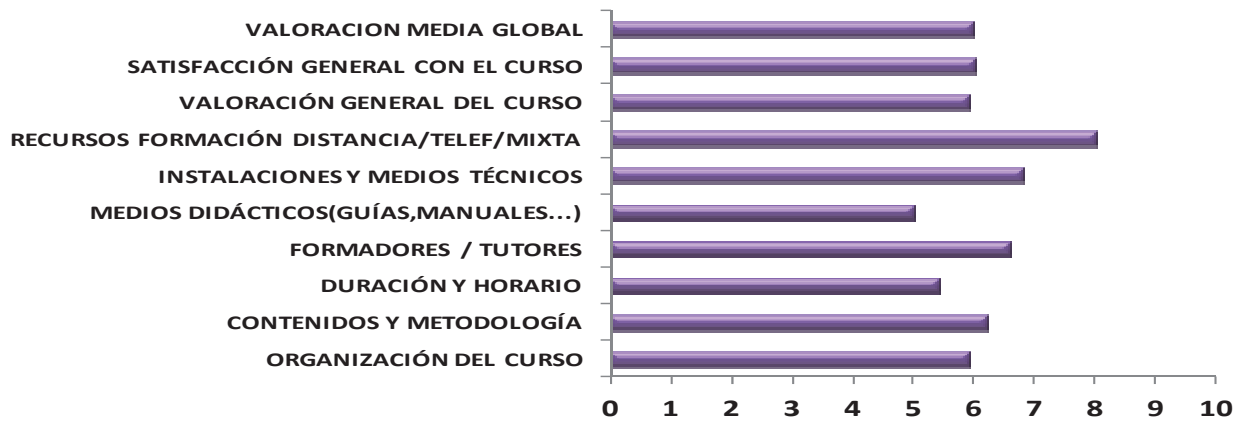

Fig. 8 Resultado encuestas 2013

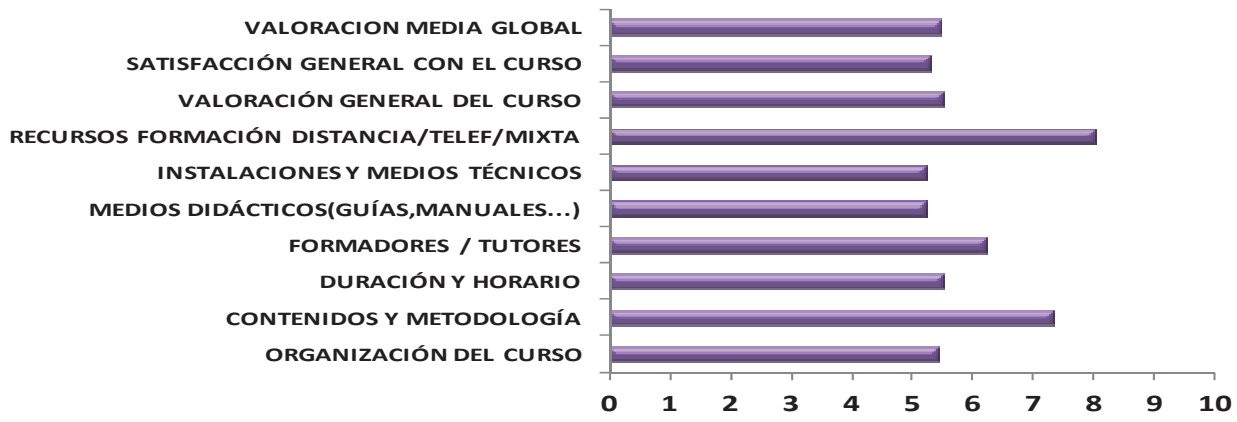

Fig. 9 Resultado encuestas 2014

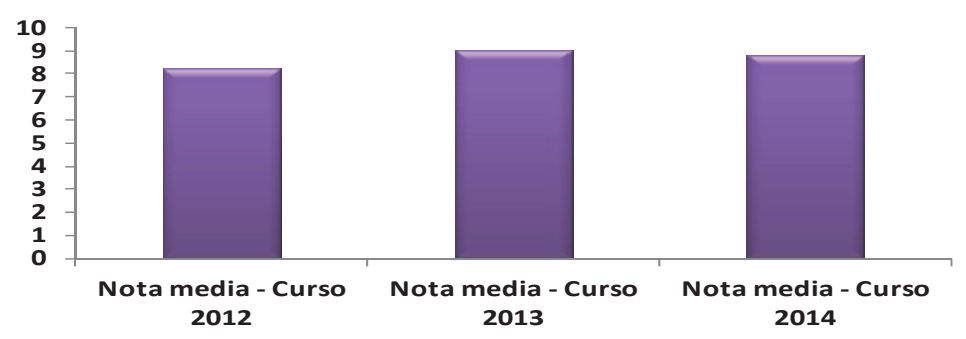

Fig. 10 Notas medias obtenidas por los alumnos en los 3 cursos

\section{Conclusiones}

En este artículo hemos presentado un plan formativo en régimen semipresencial impartido en la empresa nacional ADIF, durante los años 2012, 2013 y 2014. A partir de los resultados analizados y teniendo en cuenta el perfil de los alumnos que hemos tenido en cada uno de los cursos, extraemos varias conclusiones. La primera de ellas, es que en vista de las notas medias obtenidas por los alumnos, esta metodología es muy efectiva, pues consigue que los alumnos aprendan los conocimientos que establece el curso y consiguen cumplir tanto los objetivos de los profesores como los requisitos mínimos que Cisco establece a sus alumnos. Por otra parte, los resultados de las encuestas, empeoran 
ligeramente para los dos últimos cursos. Considerando este factor, analizamos el perfil de los alumnos, y nos dimos cuenta que uno de los parámetros a tener en cuenta a la hora de implantar nuevas metodologías docentes, es la edad de los alumnos. Como podemos ver en la Tabla 1, los dos últimos cursos, gran parte de los alumnos tenían edades superiores a los 40 años. Este hecho implica un mayor desconocimiento y menor fluidez en el uso de las nuevas tecnologías. Tras finalizar el curso todos los alumnos que han superado el curso reciben dos certificados. Como trabajo futuro, nos gustaría extender esta metodología a algunas asignaturas de titulaciones universitarias, donde los alumnos son más jóvenes y por tanto su conocimiento sobre nuevas tecnologías mucho más amplico. Estamos seguros, que este plan formativo dará buenos resultados, tanto a nivel de calificaciones, como de satisfacción.

\section{Referencias}

BRI, D., COLL, H., GARCÍA, M., LLORET, J. (2008). Analysis and Comparative of Virtual Learning Environments, The 5th WSEAS / IASME International Conference on engineering education (EE'08), Heraklion, Creta (Grecia), 22 al 24 de Julio de 2008

BRI, D., GARCIA, M., COLL, H., LLORET, J. (2009). A study of virtual learning environments. WSEAS Transactions on Advances in Engineering Education, 6(1), 33-43.

GARCIA, M., COLL, H., BRI, D., LLORET, J. (2008)., Software Tools and Simulators in the Education of Engineering of Telecommunications, The 5th WSEAS / IASME International Conference on engineering education (EE'08), Heraklion, Creta (Grecia), 22 al 24 de Julio de 2008

LLORET J, DIAZ J.R., JIMÉNEZ J.M., (2004) Creation and Development of an E-Learning Formative Plan, Sefi Annual Conference 2004, Valencia (España), 8-10 de Septiembre de 2004

LLORET, J., JIMENEZ, J. M., DIAZ, J. R., LLORET, G. (2008) A Remote Network Laboratory to Improve University Classes, The 5th WSEAS / IASME International Conference on engineering education (EE'08), Heraklion, Creta (Grecia), 22 al 24 de Julio de 2008

LLORET, J., VINCENT VELA, M. C., POZA PLAZA, E. D. L., DOMÈNECH DE SORIA, J., \& PEÑA-ORTIZ, R. (2013). Industry Certificate Courses Enhance University Experts and Masters, IV International UNIVEST Conference (Univest 2013), Gerona (España), 4-5 de Julio 2013

MARCELO, C. (2013). Las tecnologías para la innovación y la práctica docente. Revista Brasileira de Educação, 18(52), 25-47.

MARTíNEZ, A. L., GALLEGO, M. R. (2014). Proyectos de innovación para integrar las tic en la formación inicial docente. Pixel-Bit: Revista de medios y educación, (44), 157-168.

MEDRANO, M., BASORA, E., MARTORELL, I., HERNÁNDEZ, M., TRAVERIA, M., BRET, D., GAVALDÀ, J. (2012). Mejora del proceso de enseñanza-aprendizaje en entornos tecnológicos extremadamente cambiantes mediante la implantación de tic. El caso cesda. CIDUI-Llibre d'actes, 1(1).

MENESES, E. L., SANCHIZ, D. C., GARCÍA, E. P. (2012). Innovación docente con tecnologías de la información y la comunicación 2.0 en Ciencias Sociales: Una propuesta de trabajo con mapas conceptuales interactivos. REDEX-Revista de Educación de Extremadura, 2(3), 105-133.

MOREIRA, M. A., SANTOS, M. B. S. N., VARGAS, E. F. (2010). Buenas prácticas de aulas virtuales en la docencia universitaria semipresencial. Teoría de la Educación. Educación y Cultura en la Sociedad de la Información, 11(1), 7-31.

\section{(c)) EY-NC-ND 2014, Universitat Politècnica de València}

I Jornadas IN-RED (2014) 


\title{
Reflexión sobre la creación de objetos de aprendizaje para la iniciación en procesos escultóricos en el ámbito de la enseñanza en Bellas Artes. Breve comentario sobre otros tutoriales en la Red.
}

\author{
María Zárraga Llorens \\ Profesora contratada Doctor. \\ Departamento de Escultura. Facultad de Bellas Artes. Universitat Politécnica de València. \\ jozarllo@esc.upv.es
}

\begin{abstract}
This work is a reflection on the learning objects, called Polimedia that we have done as a teaching material to support the learning of the subject of sculpture and in general within the artistic teaching, because they are freely available on the platform Politube of the Polytechnic University of Valencia. It was necessary to gather the experience, making report on the use of learning objects created to date, evaluate and share the results.
\end{abstract}

Keywords: sculpture, Polimedias, Learning objects, tools, procedures, teaching material, video

\begin{abstract}
Resumen
Este trabajo es una reflexión sobre los Objetos de aprendizaje, llamados Polimedia que hemos realizado como material didáctico de apoyo al aprendizaje de la asignatura de Escultura y en general dentro de las enseñanzas artísticas, porque son de libre acceso para su consulta en la plataforma Politube de la Universidad Politécnica de Valencia. Era necesario recopilar la experiencia, hacer memoria sobre el uso de los Objetos de aprendizaje creados hasta la fecha y valorar y poner en común los resultados obtenidos.
\end{abstract}

Palabras clave: escultura, Polimedias, Objetos de aprendizaje, herramientas, procedimientos, material docente, vídeo. 
Reflexión sobre la creación de objetos de aprendizaje para la iniciación en procesos escultóricos en el ámbito de la enseñanza en Bellas Artes. Breve comentario sobre otros tutoriales en la Red.

\section{Introducción}

\section{Objetivos}

-Intercambiar la experiencia educativa a partir de la creación de un Objeto de aprendizaje.

-Continuar creando Polimedias dentro del ámbito de la escultura y en relación con la materia impartida.

-Construir recursos tecnológicos con un contenido muy visual pero analizando la estructura narrativa en relación a su funcionalidad y contexto docente.

-Crear únicamente material didáctico que se basa en los contenidos del curso.

- Valorar la eficacia de los Polimedias a partir de la experiencia con los alumnos de la asignatura Escultura II en Bellas Artes.

-Evaluar el contenido, idoneidad, duración de los Polimedias realizados hasta la fecha.

-Comparar la estructura de los objetos de aprendizaje que hemos construido con herramientas similares existentes en otras plataformas de uso público como Internet y a los que accede el alumnado.

-Caracterizar a los objetos de aprendizaje con un sello de especificidad y rigurosidad académica, sin por ello dejar de ser atractivos pero diferenciarlos de otros productos y tutoriales de acceso público.

\section{Metodología}

El método de trabajo para crear los Objetos de aprendizaje y luego convertirlos en Polimedia ha consistido en sistematizar todo el proceso de forma ordenada. Para ello, se pensó en la adaptación del contenido a la fórmula de Objeto de aprendizaje.

En primer lugar, se intentó crear un tipo de Objeto que recogiera ciertas herramientas y máquinas para realizar determinados trabajos de construcción con los materiales adecuados, siendo este Objeto el básico de procedimientos escultóricos que corresponden a segundo curso de Escultura.

Una segunda opción fue crear un Objeto dedicado a la soldadura con arco eléctrico, dado que es un tipo de procedimiento complejo y que requiere mayor número de explicaciones en el aula. Y por último se estudió crear otro Objeto dedicado a la soldadura con estaño para trabajar esculturas con alambre ya que también era un procedimiento que despertaba el interés de los alumnos y que en apariencia es un proceso más sencillo. 
Se planificaron las actividades de grabación de las imágenes de acuerdo a cada uno de los procedimientos que se querían reflejar y la coordinación con los alumnos que podían participar y que en ese momento estaban realizando una actividad en relación con esas técnicas.

Se fueron recogiendo datos específicos para cada Objeto y se recopilaron imágenes fotográficas y vídeos de las diferentes etapas de procesos de trabajo y como aplicar las herramientas propias de cada disciplina.

En las figuras que mostramos a continuación se pueden ver ejemplos de fotos tomadas para enseñar un proceso paso a paso.
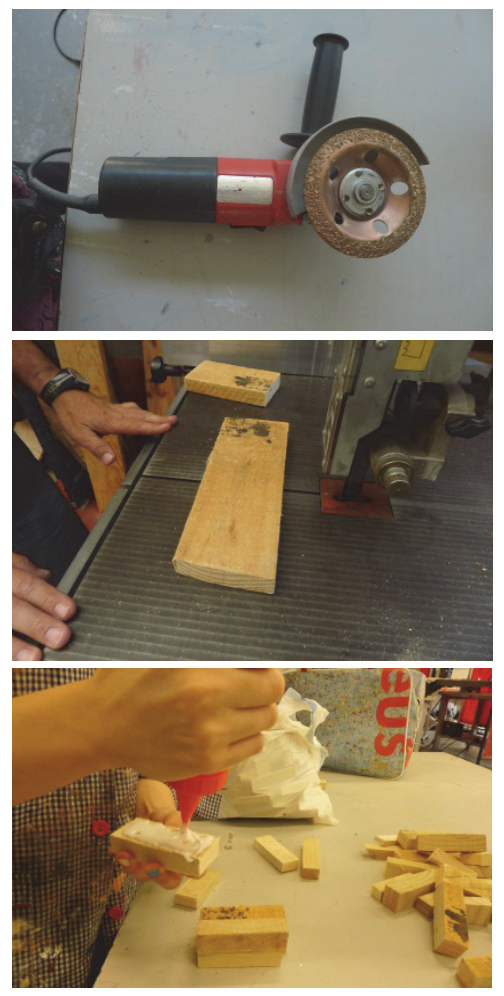

Figura 1, 2 y 3.

Fotos de herramientas, máquinas y encolado de madera

Se pensó en la búsqueda de información a partir de fuentes bibliográficas sobre las formas de trabajo y aplicaciones de las herramientas al trabajo. Al mismo tiempo se consultaron otras fuentes, en este caso se habló con los técnicos de los laboratorios, sobre usos concretos de las herramientas.

\section{(c)) EY-NC-ND 2014, Universitat Politècnica de València}

I Jornadas IN-RED (2014) 
Reflexión sobre la creación de objetos de aprendizaje para la iniciación en procesos escultóricos en el ámbito de la enseñanza en Bellas Artes. Breve comentario sobre otros tutoriales en la Red.

Una vez conseguido el material gráfico, se buscó la manera de ordenar de forma adecuada el conjunto de imágenes y crear un texto, un relato paralelo. Para ello, se hizo un sencillo guión o storyboard para tener claro un montaje consecutivo de las imágenes e intentar reflejar el orden que sigue cada etapa de un proceso.

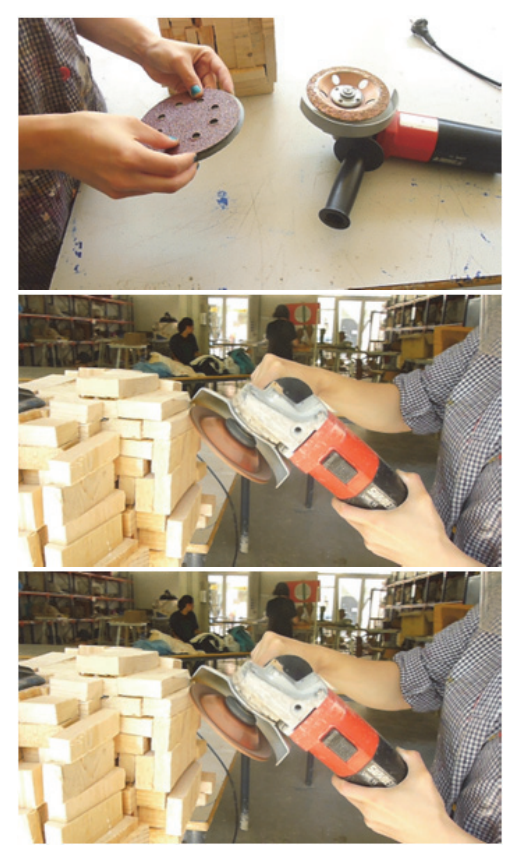

Figuras 4, 5, 6.

Fotos de proceso de talla de madera

Para crear los Polimedias es necesario contactar con la Unidad de recursos audiovisuales que depende del ICE. Con la ayuda del personal técnico del ICE se editaron e incorporaron las secuencias de vídeo al archivo definitivo para la posterior grabación de las imágenes del profesor.

Posteriormente a la edición de estos Polimedias se fueron descubriendo en Internet, toda la amplia oferta de productos en relación con la divulgación de forma amateur o más o menos profesional, de procesos de trabajo en relación con la escultura. Era necesario comparar este tipo de productos realizados de forma autodidacta por aficionados, estudiantes o profesionales, con los Objetos que pretendíamos crear, y al mismo tiempo reflexionar sobre su capacidad real, sobre la forma como están ejecutados y como proporcionan la información, si esta es suficiente y cumple las expectativas. Si en definitiva, enseñan a partir de la manera como están realizados.

(c)) EY-NC-ND 2014, Universitat Politècnica de València 


\section{El método de trabajo en el aula}

Para controlar la eficacia de este material en el alumnado y obtener respuesta, es necesario comenzar cada año, enseñando a los alumnos los Objetos de aprendizaje al inicio de un bloque temático para que se familiaricen con las herramientas de que disponemos en el aula y que conozcan los materiales apropiados. Este material se visiona en el formato previo o el archivo donde no se incluye la figura del profesor. La visión en el conjunto de la clase de este material de trabajo ayuda al profesor en el siguiente paso que es el contacto directo con las herramientas y la enseñanza individualizada. La pauta de trabajo cada curso en el aula es la siguiente, ver los Polimedias con los alumnos paso a paso, leerlos y recomendar su revisión en horas no lectivas. Al mismo tiempo, se hace necesario recordar paulatinamente la consulta de Politube para descubrir la oferta de otros Polimedias interesantes para ampliar su aprendizaje. Después se comprueba con el trabajo individual si han consultado el material como se les ha aconsejado.

\section{Desarrollo}

En esta presentación como ya se ha indicado, se recoge de forma resumida la experiencia iniciada en 2010 con la creación de Objetos de aprendizaje destinados a la iniciación y enseñanza de diferentes procesos escultóricos en relación con las prácticas y contenidos que los alumnos de Escultura de segundo curso realizan y aprenden en la titulación de Bellas Artes. El propósito de esta iniciativa y siguiendo las orientaciones que se formulan desde el Instituto de Ciencias de la Educación para la fabricación de este tipo de material didáctico, fue la de construir un objeto fundamentalmente práctico. En primer lugar, debía de ser útil para la revisión y consulta del alumno en horas de trabajo fuera del aula. Y en segundo lugar, debía significar una herramienta de apoyo para el profesor.

Después de años de docencia, se tomó la iniciativa de participar en la convocatoria de Docencia en Red. La decisión fue crear unos objetos que resumieran algunos de los contenidos que se trabajan en el aula, reuniendo las explicaciones que verbalmente se dan en clase y recrear las acciones que se llevan a cabo para llevar a término un ejercicio. Comenzamos a documentar con fotografías y vídeos aquellos momentos que ilustran los pasos necesarios para la consecución de un trabajo, a partir del uso de una determinada herramienta.

Por tanto, consideramos que el Powerpoint que debíamos construir debía recoger la información de forma nítida y siguiendo un orden de explicaciones como si el profesor las diera en clase. Crear una serie de diapositivas de texto, además de diapositivas con texto que incorporaran fotos fijas y secuencias de vídeo de corta duración. Todo esto como trabajo previo a la grabación del Polimedia en el plató de televisión.

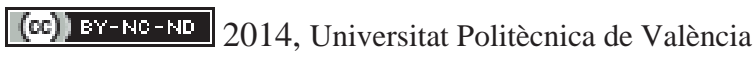

I Jornadas IN-RED (2014) 
Reflexión sobre la creación de objetos de aprendizaje para la iniciación en procesos escultóricos en el ámbito de la enseñanza en Bellas Artes. Breve comentario sobre otros tutoriales en la Red.

Posteriormente a la edición de estos Polimedias fuimos descubriendo en Internet, toda la amplia oferta de productos en relación con la divulgación y enseñanza de forma amateur de variados procesos de trabajo en relación con la materia de nuestros objetos de aprendizaje.

La prospección de algunos tutoriales relacionados con los procedimientos escultóricos a los que tienen acceso fácilmente los alumnos en Internet y que inician en una práctica determinada nos hizo reflexionar sobre la manera en que están ejecutados. Es decir, con una escasa planificación, describiendo el hecho desde el principio hasta el final de la actividad y con escaso montaje de imágenes. Esto significa, mal sonido, explicaciones improvisadas y comentarios coloquiales. Sin embargo, habría que reflexionar sí, esta "familiaridad" en la concepción del producto les beneficia para el público en general. En la práctica del aula, se comprueba que los alumnos prefieren acceder a estos tutoriales desde Youtube pero por desconocimiento de otras posibilidades.

Hasta la actualidad se observa que los alumnos desconocen las herramientas de aprendizaje digital que les proporciona el ámbito académico y como señalan las investigadoras de la Universidad de Córdoba, Marín, V. y Maldonado, G. A (2010), con respecto a las herramientas de apoyo al proceso de aprendizaje, los estudiantes las emplean de forma escasa así como las herramientas del curso y las de diseño del plan de estudio destacando que las posibilidades didácticas que les ofrece la plataforma son escasamente empleadas por ellos. Constatamos que están acostumbrados a la búsqueda inmediata de tutoriales en Internet y desconocen la plataforma Politube.

De acuerdo con los comentarios anteriores, observamos desde el principio que era y es necesario presentar cada año a los alumnos los Objetos de aprendizaje y acompañarles en su manejo. Es cierto que el Polimedia no suple el contacto directo, pero en el caso de la no presencia del profesor el objeto cumple su cometido, siendo una herramienta facilitadora. (Hernandez Franco, C. A., 2011).

Creemos que es importante recordar a los estudiantes que esta herramienta está construida por sus profesores y por tanto contiene información sobre la materia que va a evaluación, como si se tratara de apuntes de clase y en esto reside su eficacia.

Concluimos esta reflexión y análisis considerando que los Objetos realizados hasta la fecha son adecuados en su contenido y apropiados por su lenguaje y duración a quien van dirigidos. Y sin perder el rigor que debe caracterizarlos deben ser dinámicos y atractivos por su abundancia de fotos descriptivas y secuencias de vídeo. 


\section{Resultados}

Los resultados de este trabajo se pueden ver en Politube:

1-"Iniciación a la soldadura con estaño para la construcción de esculturas con alambre" http://politube.upv.es/play.php?vid=3079

2-"Iniciación a la soldadura por arco eléctrico con electrodos"

http://politube.upv.es/play.php?vid=3082

3-"Procedimientos escultóricos"

http://politube.upv.es/play.php?vid=3152

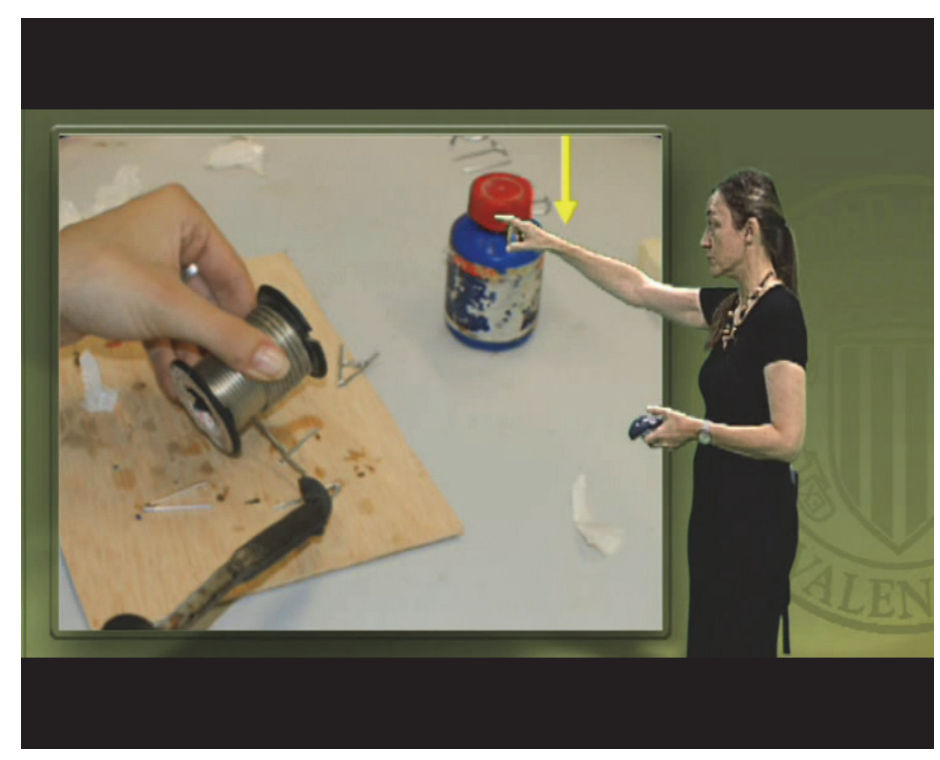

Fig. 7. Diapositiva del Polimedia $n^{\circ} 1$

\section{(cc) EY-NC-ND 2014, Universitat Politècnica de València}

I Jornadas IN-RED (2014) 
Reflexión sobre la creación de objetos de aprendizaje para la iniciación en procesos escultóricos en el ámbito de la enseñanza en Bellas Artes. Breve comentario sobre otros tutoriales en la Red.

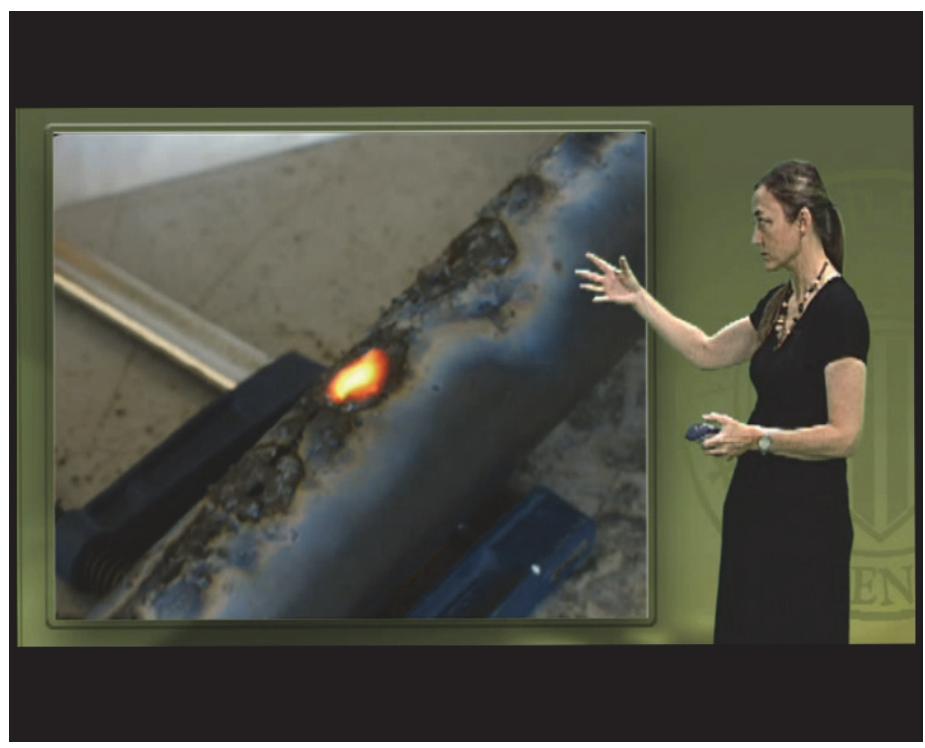

Fig. 8. Diapositiva del Polimedia $n^{o} 2$

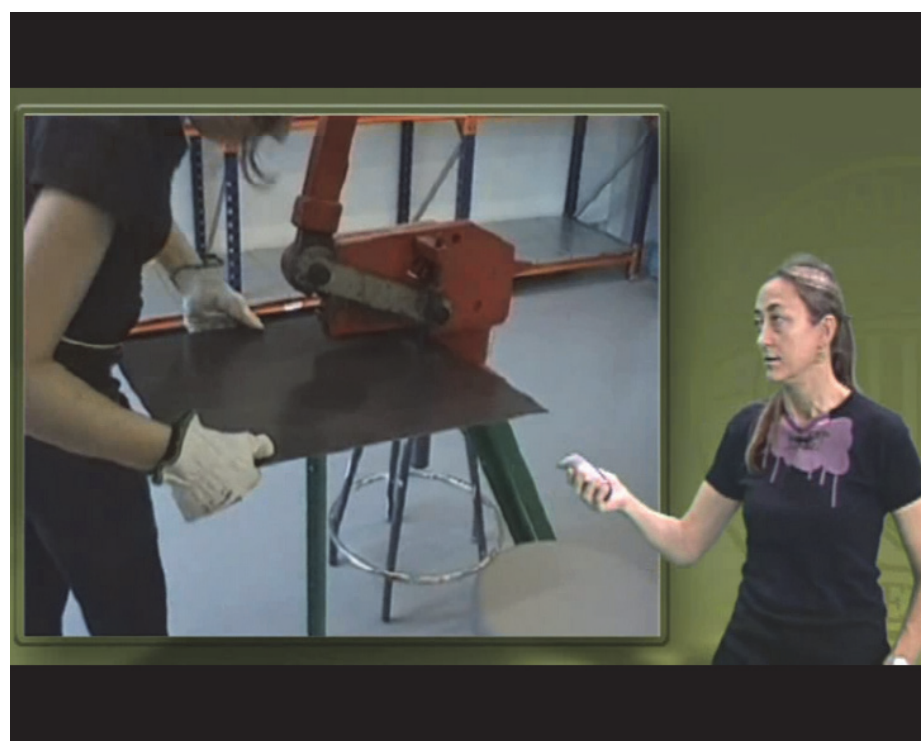

Fig. 9. Diapositiva del Polimedia $n^{\circ} 3$

(c)) EY-NC-ND 2014, Universitat Politècnica de València

I Jornadas IN-RED (2014) 


\section{Conclusiones}

A partir de nuestra experiencia podemos confirmar que el objeto de aprendizaje facilita desde el primer momento la labor del profesor ya que resume el contenido de forma visual y concentra la atención de los alumnos, que fijan todos a la vez su atención en la pantalla. Hay que tener en cuenta la presencia masiva de alumnos en estas aulas y la dificultad para enseñar ciertas actividades a un grupo grande.

En la práctica se constata que si el profesor recuerda la existencia y la consulta del Objeto de Aprendizaje, incluyendo la URL en el programa de la asignatura y especificando la pertinencia de su consulta, en este caso si se obtienen buenos resultados.

En estos momentos, con la facilidad de acceso a Internet que tienen los estudiantes o un público interesado en la materia, el Objeto de aprendizaje es un elemento más que compite ante la sobreabundancia de información. Por tanto, es lógico que el estudiante se pierda ante la oferta de recursos y consulte muchos y de diferente procedencia. De ahí, que se constata el necesario consejo por parte del profesor en la conveniencia de visionar estos Objetos de aprendizaje creados como material docente para llevar a cabo sus prácticas.

En general en este tipo de tutoriales al que acuden con tanta facilidad los alumnos para consultar como se realizan o se utilizan herramientas y materiales, carecen de una estructura o planificación, ya que normalmente se trata de un plano secuencia que recoge todo el proceso desde el principio hasta el final de aquello que se quiere mostrar. Cuando el relato se alarga se hace un corte, algún fundido. En todos los casos hay una edición de la imagen sencilla y al relato con imágenes le acompaña la voz en off de un narrador o el propio actor que ejecuta el trabajo, narra en primera persona la acción.

Todo esto nos lleva a señalar que aunque con los tutoriales de Internet se pueda aprender, consideramos que frente a los Polimedias editados por la UPV, hay visibles diferencias de planteamiento. $\mathrm{Y}$ en definitiva, de comprensión del producto.

Cuando hemos preguntado a los alumnos se confirma que saben apreciar y diferenciar entre los tutoriales de Internet y los que en este caso, les hemos ofrecido. Una de las consideraciones más importantes consiste en saber que el material del Polimedia, es la forma de ejecución que se les va a demandar y esto significa un mayor interés por su consulta.

Con respecto al uso y opinión del alumnado, se observa que aquellos alumnos que comienzan de forma autónoma un ejercicio y no necesitan dirección previa, han revisado los Polimedias, ya que preguntan sobre lo que han visto. Más tarde confirmamos en las memorias que demandamos al finalizar un ejercicio que entre las fuentes consultadas aparecen con frecuencia las URL de los Objetos mencionados y esto nos lleva a pensar que

\section{(cc) BY-NC-ND 2014, Universitat Politècnica de València}

I Jornadas IN-RED (2014) 
Reflexión sobre la creación de objetos de aprendizaje para la iniciación en procesos escultóricos en el ámbito de la enseñanza en Bellas Artes. Breve comentario sobre otros tutoriales en la Red.

un cincuenta por cien de los alumnos, al menos se interesan por estas herramientas educativas.

Podemos concluir finalmente que pasado un tiempo observamos con respecto a los Polimedias que hemos descrito y de los que mostramos fotogramas que, todavía tienen vigencia pero que la propia dinámica del aula, reclama reciclar contenidos y ampliar con otros Objetos que establezcan una continuidad.

\section{Referencias}

\section{Revista electrónica}

MARÍN, V. y MALDONADO, G. A (2010). Pixel-Bit. Revista de Medios y Educación.

ISSS: 1133-8482 - No 38 Julio- Diciembre 2010, p. 125

http://dialnet.unirioja.es/servlet/articulo?codigo=3361595 (Consulta:12 de junio de 2014)

\section{Polimedias}

HERNANDEZ FRANCO, C. A. (2011) Recursos educativos en la red. Educación 2.0 y tecnologías sociales

https://polimedia.upv.es/visor/?id=b0b45461-5fb5-c441-a887-03645737ed2b

HERNANDEZ FRANCO, C. A. (2011) Cultura y Telecomunicaciones

https://polimedia.upv.es/visor/?id=da0d7f6c-bd6a-3745-aa2e-6398c9e14677

Web

AAVV. Concepto de objeto de aprendizaje.

http://www.upv.es/contenidos/DOCENRED/infoweb/docenred/info/714512normalc.html 


\title{
Una herramienta docente para el estudio de los sistemas dinámicos lineales
}

\section{Fernando Giménez ${ }^{a}$ y Juan A. Monsoriu ${ }^{b}$}

aDepartamento de Matemática Aplicada, Universitat Politècnica de València, Spain, fgimenez@mat.upv.es, ${ }^{\mathrm{b}}$ Departamento de Física Aplicada, Universitat Politècnica de València, Spain, jmonsori@fis.upv.es.

\begin{abstract}
A great variety of complex real-life problems are modelized using ordinary differential equations and partial derivatives. This happens for example with dynamic systems, physical systems whose state evolves over time. In this work we present a virtual laboratory for teaching purposes that allows to study continuous linear dynamic systems of two and three dimensions from an analytical and graphical point of view.
\end{abstract}

Keywords: dynamic system, orbit, trajectory, attractor, repulsor, flow, chaos, stability, Matlab, virtual laboratory

\begin{abstract}
Resumen
Una gran variedad de problemas complejos de la vida real se modelizan a partir de ecuaciones diferenciales ordinarias y en derivadas parciales. Esto ocurre por ejemplo con los sistemas dinámicos, sistemas físicos cuyo estado evoluciona con el tiempo. En este trabajo presentamos un laboratorio virtual de carácter docente que permite estudiar desde el punto de vista analítico y gráfico los sistemas dinámicos lineales continuos de dimensiones 2 y 3 .
\end{abstract}

Palabras clave: sistema dinámico, orbita, trayectoria, atractor, repulsor, flujo, caos, estabilidad, Matlab, laboratorio virtual

\section{Introducción}

El uso de metodologías activas puede permitir que los alumnos adquieran más fácilmente competencias y capacidades (Benito, 2006). Una de las metodologías más interesantes está basada en el uso de laboratorios virtuales en la docencia, los cuales proporcionan ventajas

(cc) EY-NC-ND 2014, Universitat Politècnica de València

I Jornadas In-Red (2014) 
significativas, como por ejemplo la interactividad y la respuesta dinámica. Como señalan Jimoyiannis y Komis (Jimoyiannis, 2001), estos laboratorios dan a los estudiantes medios para desarrollar su propia comprensión de la teoría o fenómeno a estudiar. Para esta tarea el laboratorio permite a los usuarios un control de las variables del proceso en orden a analizar y asimilar los distintos conceptos y relaciones y, además, pueden mostrar todo tipo de información gráfica.

En lo que sigue vamos a mostrar una aplicación docente desarrollada como una interfaz gráfica de usuario de Matlab (GUI), con el objetivo de estudiar desde el punto de vista analítico y gráfico los sistemas dinámicos lineales continuos, de manera que los alumnos además de conocer explícitamente cuales son las soluciones, conozcan determinadas propiedades de carácter cualitativo tales como la periodicidad, si sus valores se encuentran dentro de un conjunto acotado al variar el tiempo, si para algunas soluciones existe el límite cuando el tiempo tiende a infinito, para tratar de averiguar el comportamiento del sistema físico a largo plazo, que existen algunos sistemas que no tienen el comportamiento regular esperado, sino que este puede manifestarse caótico. El uso de ordenador con sus enormes capacidades gráficas y de cálculo se muestra crucial a la hora de explicar desde un punto de vista intuitivo lo que son y las características de este tipo de sistemas dinámicos. Los alumnos podrán manejar y entender los conceptos de flujo, diagrama de fases, espacios de estado, trayectorias, puntos de equilibrio, soluciones periódicas, atractores, estabilidad, etc. En la herramienta nos centramos en sistemas de dimensiones 2 y 3, que son fácilmente visualizables. Puede consultarse (Depcik, 2005) sobre las GUI's en general y (Barragan, 2014) sobre las GUI'S de Matlab.

\section{Objetivos}

Algunos de los objetivos que se prestenden alcanzar con la herramienta docente presentada en este trabajo son los siguientes:

- Afianzar los conocimientos teóricos adquiridos por los alumnos sobre teoría de sistemas dinámicos lineales continuos

- Conocer las soluciones analíticas en los casos de dimensiones 2 y 3.

- Estudiat las orbitas y trayectorias de las soluciones de los problemas de valores inciales correspondientes y la relación que tienen con los valores propios de la matriz que define el sistema dinámico

- Conocer con detalle la interpretación geométrica del flujo, diagrama de fases, espacios de estado, etc.

- Reconocer puntos de equilibrio estables e inestables a partir del flujo o de las trayectorias de puntos próximos 
- Visualizar la estabilidad o inestabilidad de un sistema

- Reconocer los atractores y repulsores y la relación que tienen estos puntos con los valores propios de la matriz que define el sistema dinámico

\section{Propuesta de la innovación y desarrollo}

En este apartado haremos una pequeña introducción teórica sobre sistemas dinámicos lineales continuos, describimos con detalle el laboratorio virtual con ejemplos y proponemos una metodología de investigación para comprobar si el laboratorio virtual presentado mejora o no la adquisición de resultados de aprendizaje por parte de los alumnos.

\subsection{Sistemas autónomos lineales continuos}

Según (Aracil, 2007) un sistema dinámico (SD) de manera intuitiva puede definirse como un conjunto de componentes conectados entre ellos de modo que presenten un comportamiento coordinado y realicen una tarea determinada. Aquellos que vienen descritos por ecuaciones diferenciales reciben el nombre de sistemas dinámicos continuos.

El sistema incluye el conjunto X, llamado espacio de estados, de los posibles estados que puede alcanzar y una regla o ley que regula la evolución de los estados en el tiempo. La componente principal de un sistema dinámico consiste en la regla que asigna a un estado incial $x_{0}$ el estado $x_{t}$ correspondiente al instante $t$. Sea $\varphi_{t}: X \rightarrow X$ la aplicaciñon dada por $\varphi_{t}\left(x_{0}\right)=x_{t}$. Al conjunto de funciones $\left\{\varphi_{t}\right\}_{t \in[0,+\infty[}$ se le denomina flujo.

En el caso de que el sistema dinámico venga dado por una ecuación de la forma

$$
u^{\prime}=f(t, u)
$$

donde $u: I \subset R \rightarrow R^{n}$ el espacio de estados es $X=R^{n}$ y el correspondiente flujo viene dado por

$$
\varphi: R \times R^{n} \rightarrow R^{n}
$$

donde $\varphi\left(t, u_{0}\right)=u(t)$ con $u(t)$ la solución de (1) satisfaciendo $u(0)=u_{0}$. Si la función $f$ no depende del tiempo diremos que se trata de un sistema autónomo.

Dado un punto $u_{0} \in R^{n}$ al conjunto $\{u(t): \mathrm{t} \in \mathrm{I}\} \subset R^{n}$ se le denomia orbita o trayectoria. Un punto de equilibrio es la trayectoria de una solución constante. El diagrama de fases es el conjunto de las trayectorias de sus soluciones. Si todas las trayectorias de una determinada región del espacio de fases convergen a un único punto se dice que dicho punto es un atractor o pozo. Si a un punto dado no le llega ninguna trayectoria de puntos cercanos excepto la trayectoria constante se dice que dicho punto es un repulsor o fuente.

\section{(cc) EY-NC-ND 2014, Universitat Politècnica de València}

I Jornadas IN-RED (2014) 
En el estudio de los sistemas dinámicos continuos también son de interés los conceptos de estabilidad, inestabilidad, estabilidad asintótica, trayectorias periódicas, etc.

En este trabajo consideraremos el caso especial de sistemas dinámicos continuos lineales dados por

$$
u^{\prime}=A u
$$

donde $A$ es una matriz de dimensión dos o tres. Es bien conocido que el comportamiento cualitativo de este tipo de SD depende de los valores propios de la matriz.

Para profundizar sobre el tema se pueden consultar las refencias (Lacomba, 2000), (Rivero, 2007) y (Nagle, 2005).

\subsection{El laboratorio virtual}

Se ha diseñado el laboratorio virtual sdlineal para su uso tanto en las aulas informáticas como en ordenadores particulares, aunque no se disponga del paquete Matlab. En cualquier caso se facilitará al alumno una guía detallada del laboratorio virtual.

El laboratorio puede verse en la figura 1. La interfaz consta de dos partes principales. En la parte lateral izquierda se encuentran los campos donde el usuario introduce los parámetros de entrada. En la parte lateral derecha se encuentra una ventana gráfica en donde se genera los resultados gráficos correspondientes.

Los parámetros de entrada de la aplicación son:

- A: Matriz que define el sistema dinámico

- $\mathrm{u} 0$ : Coordenadas del punto inicial de la trayectoria

- t0: Valor inicial del tiempo

- tn: Valor final del tiempo

- Lx: Longitud inicial para el eje X

- Ly: Longitud inicial para el eje Y

- Lz: Longitud inicial para el eje Z (sólo se usa si es un SD 2-dimensional)

- $\quad$ Tipo de gráfico: a elegir entre Orbita 2D, Orbita 3D y Flujo.

Sólo en el caso 2-dimensional y si se desea visualizar el flujo su deben de usar los siguientes parámetros:

- $\quad \mathrm{n}$ : Número de subdivisiones para el eje $\mathrm{X}$

- $\quad$ m: Número de subdivisiones para el eje Y

(cc)) EY-NC-ND 2014, Universitat Politècnica de València

I Jornadas IN-RED (2014) 
- Número de flechas: Número de flechas en posiciones aleatorias que se dibujan para cada una de las trayectorias

El botón Dibujar permite obtener la gráfica correspondiente a la trayectoria (orbita) de la solución del SD que pasa por el punto dado por u0, si se ha elegido Orbita 2D u Orbita3D y el diagrama del flujo si se ha elegido esa opción en el tipo de gráfico. En el caso de díbujo de orbitas se genera una gráfica animada, con un pequeño círculo rojo que describe la orbita correspondiente desde el punto inicial. La región en donde se díbuja la orbita 2D o el flujo es el rectángulo[ $-\mathrm{Lx}, \mathrm{Lx}] \times[-\mathrm{Ly}, \mathrm{Ly}]$. Si se trata de una orbita 3D la región es el prisma $[-\mathrm{Lx}, \mathrm{Lx}] \times[-\mathrm{Ly}, \mathrm{Ly}] \times[-\mathrm{Lz}, \mathrm{Lz}]$.

La salida gráfica se muestra en la ventana derecha de la GUI.

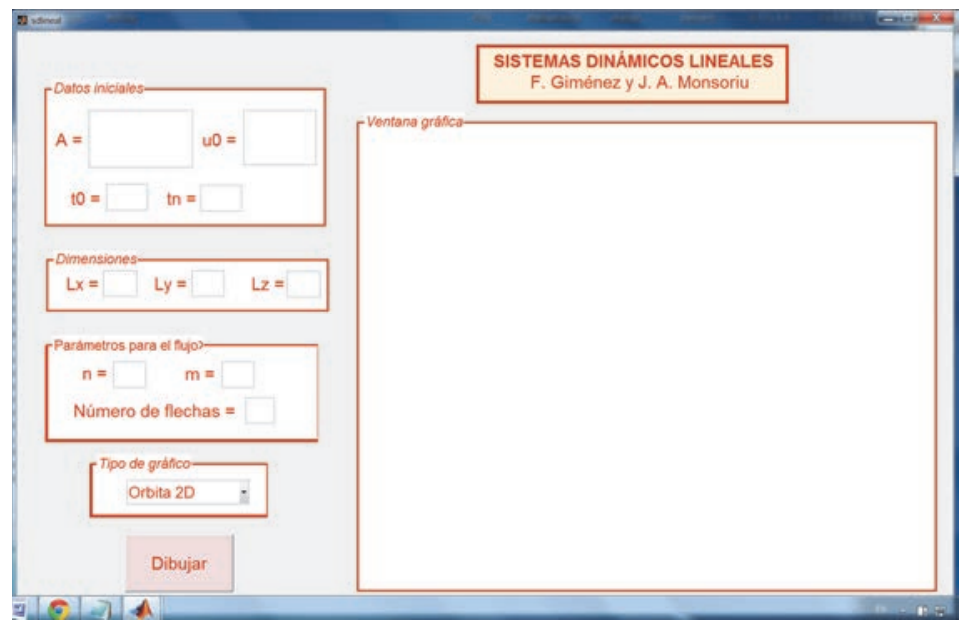

Fig. 1 Interfaz del laboratorio virtual

\subsubsection{Ejemplo}

Dado el SD lineal

$$
\left[\begin{array}{l}
u_{1}^{\prime} \\
u_{2}^{\prime}
\end{array}\right]=\left[\begin{array}{ll}
0 & -2 \\
1 & -1
\end{array}\right]\left[\begin{array}{l}
u_{1} \\
u_{2}
\end{array}\right]
$$

la figura 2 muestra la trayectoria correpondiente al punto $u_{0}=(1,1)$ para el intervalo de tiempo $[0,10]$. Podemos observar que la orbita converge al origen. La figura 3 representa el flujo correspondiente a SD anterior en el rectángulo $[-1,1] \times[-1,1]$. Se deduce que $(0,0)$ es un atractor. Observese que todas las trayectorias son de tipo espiral. Sabemos entonces, por la teoría, que los valores propios de la matriz de la ecuación diferencial que define el SD tienen parte real negativa. En efecto éstos son $-0.5000+1.3229 i$ y $-0.5000-1.3229 i$.

\section{(cc) EY-NC-ND 2014, Universitat Politècnica de València}

I Jornadas IN-RED (2014) 
Una herramienta docente para el estudio de los sistemas dinámicos lineales

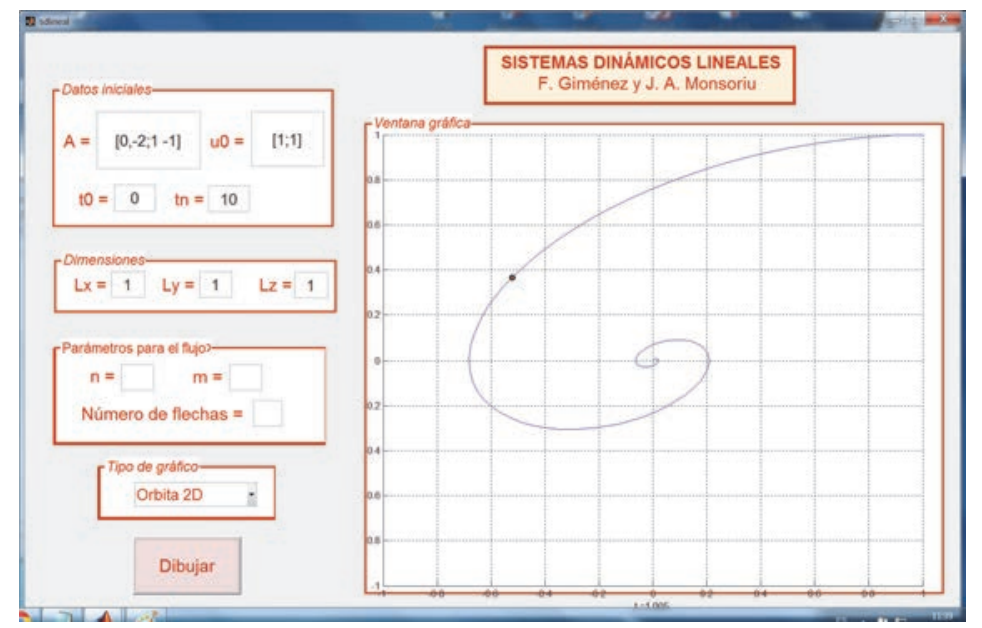

Fig. 2. Trayectoria del punto correspondiente al ejemplo 3.3.1

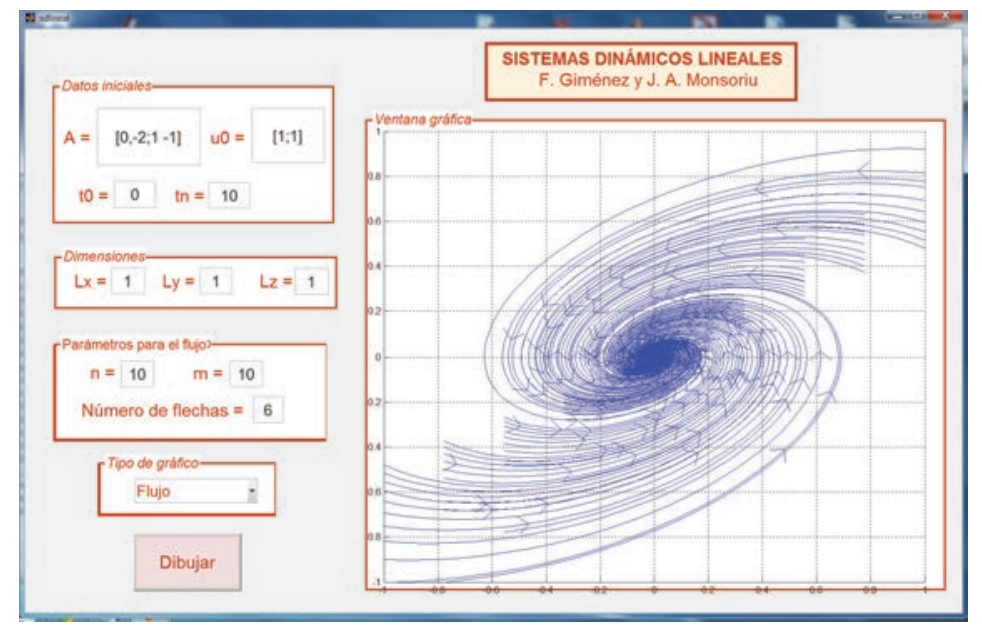

Fig. 3. Diagrama del flujo correspondiente al ejemplo 3.3.1

\subsubsection{Ejemplo}

Dado el SD lineal

$$
\left[\begin{array}{l}
u_{1}{ }^{\prime} \\
u_{2}{ }^{\prime} \\
u_{3}{ }^{\prime}
\end{array}\right]=\left[\begin{array}{ccc}
0 & -2 & 0 \\
1 & -1 & 0 \\
0 & 0 & -2
\end{array}\right]\left[\begin{array}{l}
u_{1} \\
u_{2} \\
u_{3}
\end{array}\right]
$$

la figura 2 muestra la trayectoria correpondiente al punto $u_{0}=(1,1,1)$ para el intervalo de tiempo $[0,10]$. Observese que todas las trayectorias son de tipo espiral. En este caso el punto $(0,0,0)$ es un atractor, lo que concuerda con el hecho de que los valores propios de la

(cc)) EY-NC-ND 2014, Universitat Politècnica de València 
matriz del sistema tengan su parte real negativa (en concreto son $-2,-0.5000+1.3229 i$ y $0.5000-1.3229 \mathrm{i})$.

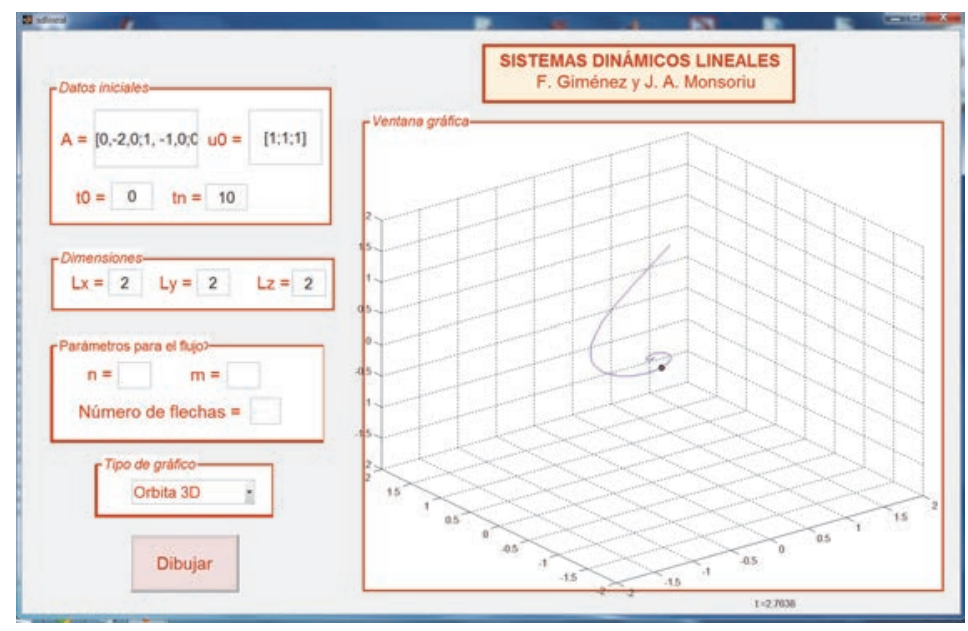

Fig. 4. Trayectoria del punto correspondiente al ejemplo 3.3 .2

\subsection{Propuesta metodológica.}

Con está herramienta creemos que el alumno podrá asimilar más fácilmente los conceptos relacionados con la teoría cualitativa de sistemas dinámicos lineales continuos, de manera que la información de tipo gráfico que aporta el laboratorio virtual ayude a la compresión de la parte análitica.

Se propone la siguiente metodología a seguir en las asignaturas de ecuaciones diferenciales de las ingenierías y, en general, en aquellas disciplinas de carácter científico en donde se necesita conocer y manejar los sistemas dinámicos continuos:

1) Introducción en las clases habituales de aula de los conceptos teóricos necesarios relacionados con los SD lineales continuos de dimensiones 2 y 3 .

2) En las clases de laboratorio de ordenador se explicará con detalle como se usa la herramienta docente sdlineal para obtener información relativa a las trayectorias y flujos correspondientes de los SD.

3) Se propondrán una serie de ejercicios ilustrativos en donde los alumnos tengan que deducir a partir de la información gráfica proporcionada por la aplicación informática aspectos relacionados con el tipo de trayectoria, la existencia de

\section{(cc) EY-NC-ND 2014, Universitat Politècnica de València}

I Jornadas IN-RED (2014) 
Una herramienta docente para el estudio de los sistemas dinámicos lineales

puntos de equilibrios, atractores y repulsores, la existencia de trayetorias periódicas, etc. A continuación se trataría de que los estudiantes resuelvan los problemas planteados de forma analítica.

Para valorar la incidencia de esta metodología se propone la realización de una pequeña encuesta al final de la sesión práctica.

Los pasos 2) y 3) propuestos también son susceptibles de realizarse de manera autónoma y autodidacta por parte del alumno en su propio ordenador.

\section{Resultados}

En el curso 2014-2015 se va a proceder a realizar esta experiencia que proponemos en las asignaturas de Matemáticas III de las titulaciones de Grado en Ingeniería en Tecnologías Industriales. A la finalización de ésta se procederá a realizar una valoración de la posible mejora en la adquisición de resultados de aprendizaje por parte de nuestros alumnos por medio de una encuesta. También se valorará la incidencia que tiene en los resultados académicos por medio de varias preguntas del examen de la asignatura.

\section{Conclusiones}

Creemos que el laboratorio virtual que presentamos junto con la propuesta metodológica para su utilización puede ser útil en aquellas asignaturas en donde se estudien en profundidad los sistemas dinámicos debido a las múltiples aplicaciones en muy diversos campos. Podemos valorar muy positivamente la sencillez de manejo, rapidez, opciones gráficas e interactividad. En posteriores trabajos, los autores pretendemos desarrollar una interfaz gráfica de usuario de Matlab que permita el estudio de sistemas dinámicos continuos no lineales de dimensiones 2 y 3 .

\section{Agradecimientos}

Los autores agradecen al Instituto de Ciencias de la Educación de la Universitat Politècnica de València por su ayuda al Equipo de Innovación y Calidad Educativa MOMA.

\section{Referencias}

ARACIL, J., GORDILlO, F. y SALAS F. (2007). Notas del curso "Análisis de Sistemas no Lineales", Universidad de Sevilla 
BARRAGAN, D. (2014). La web de MATLAB, SIMULINK, VHDL, microcontroladores... http://www.matpic.com

BENITO, A., PORTELA, A. y Rodríguez, R. M. (2006). “Análisis de la enseñanza de la Física en Europa: el fomento de competencias generales en estudiantes universitarios”. Revista Iberoamericana de Educación, número 38/7.

DEPCIK, C. y ASSANIS, D.N. (2005). "Graphical user interfaces in an engineer in educational environment”. Comput. Appl. Eng. Educ. Vol. 13.

LACOMBA, E. A. (2000). “Los sistemas dinámicos, ¿qué son y para que sirven?”. Miscelánea Matemática, 32, 39-50.

JIMOYAINNI, A. y KOMIS, V. (2001). "Computer simulations in physics teaching and learning". Computers \& Education 36, 183-204

NAGLE, K. R., SAFF, E. F. y SNIDER, A. D. (2005) Ecuaciones diferenciales y problemas con valores en la frontera. Pearson, Addison Wesley

RIVERO, L. F. (2007). Atractores globales: teoría y resultados para sistemas autónomos y no autónomos. Trabajo final del Master en Investigación Matemática. Facultad de Matemáticas. Universidad Complutense de Madrid.

(c) $\mathbf{\text { EY-NC-ND }}$ 2014, Universitat Politècnica de València

I Jornadas IN-RED (2014) 


\title{
Los MOOCs aplicados a la Geomática: tasa de éxito, redes sociales e impacto social.
}

Ph.D. Israel Quintanilla ${ }^{\mathrm{a}}$, Aurea Gallego

${ }^{a}$ Dpto. de Ing. Cartográfica-UPV. iquinta@cgf.upv.es ${ }^{b}$ Dpto. de Ing. Cartográfica-UPV. augalsal@cgf.upv.es

\begin{abstract}
The execution of the MOOC "Dispositivos Móviles-aplicaciones a la ingeniería y la gestión del territorio" in the platform MiriadaX in its first edition at a Latin-American level has marked a before and an after on the way to interact with the students.

We have to question to analyse the reasons for the high level of students enrolled (more than 6000) and the success of the online course.

We have analysed the variables related to the process: choice of subject (geomatics), diffusion in social networks, characteristics of the students, content of the courses, interaction with the students during the course, grade of difficulty of the course, dates of the course.

We have also executed two more editions on the platform UPVX with lower number of students but with the same degree of success. This will allow us to corroborate the analysed variables.
\end{abstract}

Key words: $M O O C$, geomatics, social networks 


\title{
Keywords:
}

\begin{abstract}
Resumen
La realización del MOOC "Dispositivos Móviles-aplicaciones a la ingeniería y la gestión del territorio" en la plataforma MiriadaX en su primera edición a nivel iberoamericano, marcó un antes y un después en la forma de interactuar con el alumno a través de la formación online. El elevado número de alumnos matriculados (más de 6000) y la tasa de éxito (más de 2000) tan alta hizo que nos preguntáramos cual eran los motivos de estos resultados. Se analizan las diferentes variables que participaron en el proceso: temática elegida (Geomática), difusión en redes sociales, tipología del alumnado, contenidos impartidos, interacción con el alumno en el curso, dificultad del curso, duración del curso, fechas realizadas. Asimismo, se han realizado otras dos ediciones en la plataforma UPVX con resultados inferiores en cuanto a número de alumnos, pero similares en tasa de éxito que permitirán corroborar las variables analizadas.
\end{abstract}

Palabras clave: $M O O C$, Geomática, tasa de éxito, redes sociales

\section{Introducción}

La formación online se ha transformado desde el nacimiento de los MOOC (Massive Open Online Course) como consecuencia de la evolución tecnológica que permite interactuar a multiples usuarios en servidores en tiempo real y acceder a los contenidos que ofrecen dichas plataformas. El primer hito en la historia de MOOC viene ligado en el otoño de 2011 cuando más de 160000 personas se matricularon en un curso de Inteligencia artificial ofrecido por Sebastian Thrun y Peter Norvig en la Universidad de Stanford, aunque según las bibliografías sobre el tema el primer MOOC se inició en la Universidad Estatal de Utah en agosto de 2007.

El éxito de este tipo de formación creció de forma exponencial debido a las características del mismo:

- Formación e-learning: estructura orientada al aprendizaje, que suele conllevar una serie de pruebas o de evaluaciones para acreditar el conocimiento adquirido.

- Masivo: El número de posibles matriculados es, en principio, ilimitado, o bien en una cantidad muy superior a la que podría contarse en un curso presencial. El alcance es global. 
- En línea: El curso es a distancia, e Internet es el principal medio de comunicación. No requiere la asistencia a un aula.

- Abierto: Los materiales son accesibles de forma gratuita en Internet. Ello no implica que puedan ser reutilizados en otros cursos.

De esta forma, profesores de las más prestigiosas universidades de Estados Unidos, se convirtieron en grandes éxitos como son los casos de Udacity y Coursera. El caso de Sebastian Thrun fue uno de los más mediáticos y eso contribuyó a una mayor expansión del número de iniciativas y seguidores de los MOOC. Edx, la segunda gran plataforma para Mooc del Instituto Tecnológico de Massachussets (MIT) vino a confirmar la importancia de la tendencia de los cursos masivos y a reforzar la sensación de que es un movimiento que está llamado a cambiar la educación, puesto que las mejores universidades del mundo se han unido a él.

En España, Crypt4you fue la primera iniciativa de un mooc en español. Dirigido por los Doctores Jorge Ramió y Alfonso Muñoz. Se trata de un curso de criptografía para programadores y está respaldado por la Universidad Politécnica de Madrid.

A esto se ha unido la gran incorporación de la plataforma en español de MiriadaX, impulsada por Telefónica y Universia (quien integra a 1.232 universidades de 23 países de Iberoamérica). Y es en esta plataforma, y en su primera edición, el 4 de marzo del 2013, donde se lanzó el curso "Dispositivos Móviles-aplicaciones a la ingeniería y la gestión del territorio" por primera vez con una afluencia de mas de 6.000 alumnos inscritos.

\section{Objetivos}

En este paper se pretende analizar cuáles son las condiciones del éxito de un MOOC de temática tan específica como es la Geomática en las diversas plataformas en que se ha ofertado: MiriadaX y UPVX, a partir del análisis de las variables que intervienen en la impartición de esta formación online obtenidas a partir de las encuestas realizadas antes y después de la formación.

\section{El MOOC de Geomática en la Plataforma MiriadaX}

En febrero de 2013, la primera plataforma de MOOC iberoamericana, MiriadaX, lanzó su primera edición, en la que participaron 19 universidades con una oferta de 58 cursos, de los cuales 14 eran cursos ofertados por la Universidad Politécnica de Valencia (UPV). Fue en esta plataforma donde se oferto por primera vez el MOOC: "Dispositivos Móvilesaplicaciones a la ingeniería y la gestión del territorio" en el que se inscribieron 6626 alumnos, pudiendo ser considerado este número de matriculados como un éxito debido a la cierta especificidad de sus contenidos que van orientados a la aplicación de la Geomática a la gestión del territorio y la Ingeniería (ver figura 1). Este curso se encontraba en cuarta posición de los 14 cursos ofertados por la UPV en esta plataforma, detrás de cursos de

\section{(cc) BY-NC-ND 2014, Universitat Politècnica de València}

I Jornadas IN-RED (2014) 
temática más generalistas o actuales como: Android (29543 alumnos, el más numeroso de todos), Excel 2010 (10360) y Buscar en Internet (8447). Este hecho, nos obligó a preguntarnos el porqué del éxito, y a través del responsable de la gestión y aspectos técnicos de los cursos ofertados por la UPV, Ignacio Despujol Zabala, se procedió a establecer encuestas donde se pudieran estudiar las variables que intervienen en este tipo de formación.

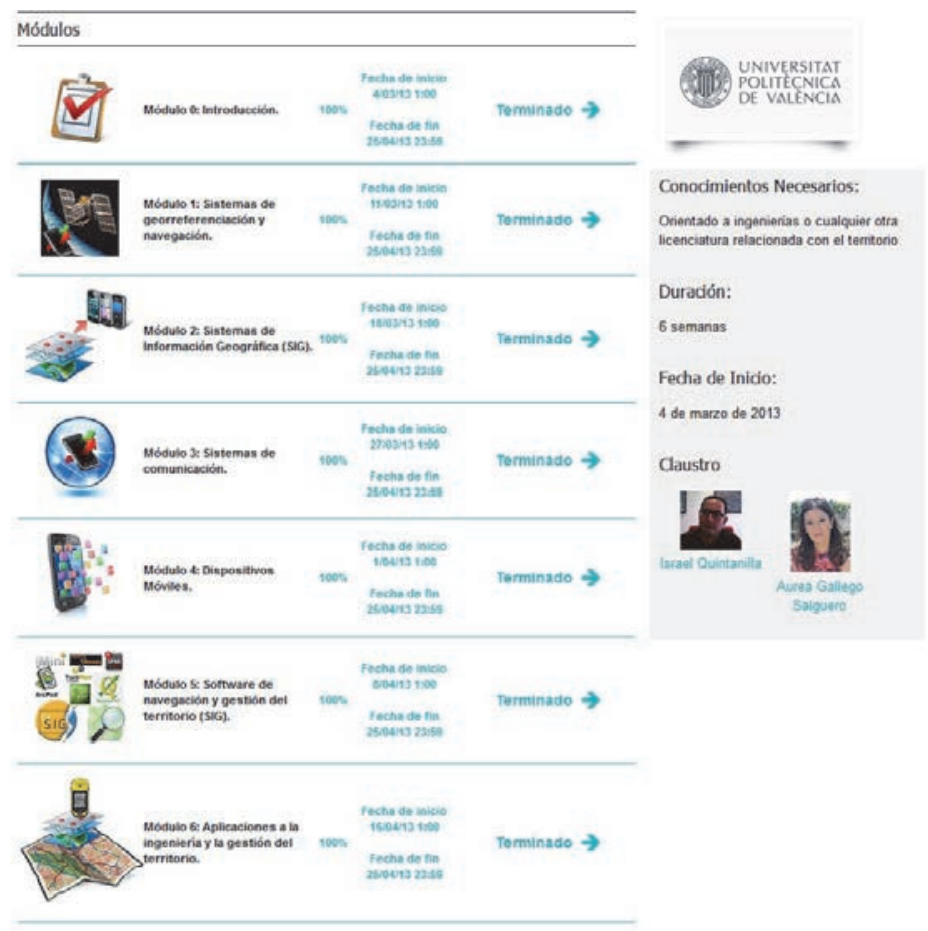

Fig. 1 Estructura y profesorado del MOOC

\subsection{Resultados: análisis de los datos obtenidos.}

En un primer momento, el seguimiento que se hizo de la inscripción de los alumnos fue hecho de forma objetiva y consultando el número de inscritos en la plataforma, y aunque no disponemos de datos de la evolución temporal, sí que constatamos que cuando nosotros hicimos difusión en grupos específicos de Geomática en las redes sociales (Facebook, twitter, linkedin, listas de distribución...) el aumento de alumnos inscritos fue mucho mayor y crecía paulatinamente a medida que pasaban los días. De este hecho se deduce 
algo obvio en estos días, que es el usos de las redes y canales sociales específicos para hacer difusión de temáticas de contenidos no generalistas. (ver figura 2)

\subsubsection{Datos al inicio del curso}

Mostramos a continuación un extracto de datos significativos a partir de una encuesta elaborada por nosotros, al inicio del curso, donde intentábamos obtener información de las características de los alumnos que iban a realizar la formación. No está respondido por todos los alumnos pues era opcional, pero la muestra es más que representativa: 1437 alumnos.

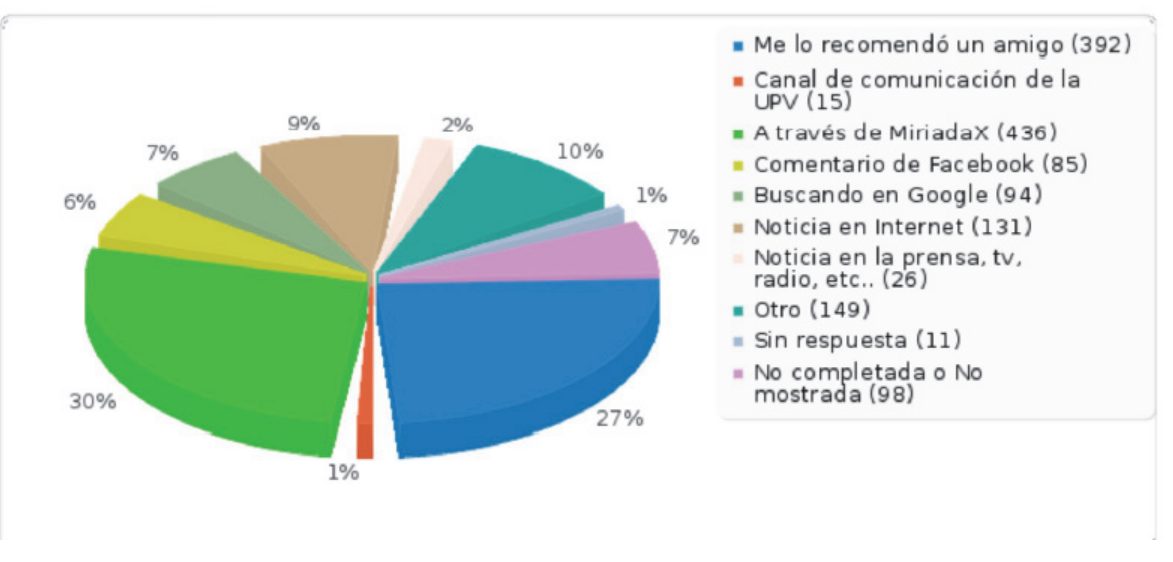

Fig. 2 Como conoció el curso

Esta gráfica muestra que las redes sociales son actualmente el mayor canal de difusión (MiriadaX hacia difusión a través de las mismas) 
Resumen de campo para titulacion

\begin{tabular}{|c|c|c|}
\hline Opción & Cuenta & Porcentaje \\
\hline Ingeniería en Geomática y Topografía (A1) & 133 & $9.26 \%$ \\
\hline Ingeniería en Geodesia y Cartografía (A2) & 49 & $3.41 \%$ \\
\hline Ingeniería Agronómica/Agricola (A3) & 86 & $5.98 \%$ \\
\hline Ingenieria de Montes/Forestal (A4) & 68 & $4.73 \%$ \\
\hline Ingeniería Civil/Caminos (A5) & 56 & $3.90 \%$ \\
\hline Ingeniería Informática (A6) & 143 & $9.95 \%$ \\
\hline Ingeniería de Telecomunicación (A7) & 86 & $5.98 \%$ \\
\hline Geografía (A8) & 148 & $10.30 \%$ \\
\hline Geología (A9) & 22 & $1.53 \%$ \\
\hline Biología (10) & 49 & $3.41 \%$ \\
\hline Ciencias Ambientales (11) & 74 & $5.15 \%$ \\
\hline Otro Revisar & 230 & $16.01 \%$ \\
\hline Sin respuesta & 30 & $2.09 \%$ \\
\hline No completada o No mostrada & 263 & $18.30 \%$ \\
\hline
\end{tabular}

Fig. 3 Estudios de los alumnos

$\begin{array}{rcc} & \text { Resumen de campo para Ocupacionprofesional } \\ \text { ¿En qué situación laboral te encuentras? } & \text { Cuenta } & \text { Porcentaje } \\ \text { Opción } & 255 & 17.75 \% \\ \text { Estudiando (A1) } & 399 & 27.77 \% \\ \text { Desempleado (A2) } & 321 & 22.34 \% \\ \text { Empleado en la administración pública (A4) } & 194 & 13.50 \% \\ \text { Empleado por cuenta propia (A5) } & 124 & 8.63 \% \\ \text { Jubilado (A6) } & 1 & 0.07 \% \\ \text { Otro Revisar } & 34 & 2.37 \% \\ \text { Sin respuesta } & 11 & 0.77 \% \\ \text { No completada o No mostrada } & 98 & 6.82 \%\end{array}$

Fig. 4 Ocupación profesional

A la vista de la figura 3 podemos observar que solo el 12,67 \% (la suma de las dos primeras titulaciones) son específicas de la Geomática, y que el resto son otras disciplinas e ingenierías que de alguna manera guardan relación con esta temática y su uso para la gestión del territorio con dispositivos móviles. En la figura 4, vemos que la tendencia mayoritaria es gente en desempleo y estudiantes, llegando al 45,52\% de los alumnos, lo que nos indica la tipología de alumnos que demanda este tipo de formación.

También se realizaron preguntas sobre el nivel de conocimiento que los alumnos tenían sobre los módulos y temáticas a tratar en el curso, con el objetivo de orientarlo en función de esta variable, y la mayoría disponían de conocimientos medios. Si buscamos la correlación entre los módulos del curso, que abarcaban contenidos de diferentes temáticas

(cc) BY-NC-ND 2014, Universitat Politècnica de València 
(ver figura 1) y los estudios que tenían los alumnos, que como hemos visto, existe una gran variedad de titulaciones, vemos que esta correlación es alta, y se puede extraer, que una de las claves del éxito, es el ofertar contenidos multidisciplinares con un objetivo único y de alto contenido tecnológico, en este caso la gestión del territorio y la ingeniería con Dispositivos Móviles.

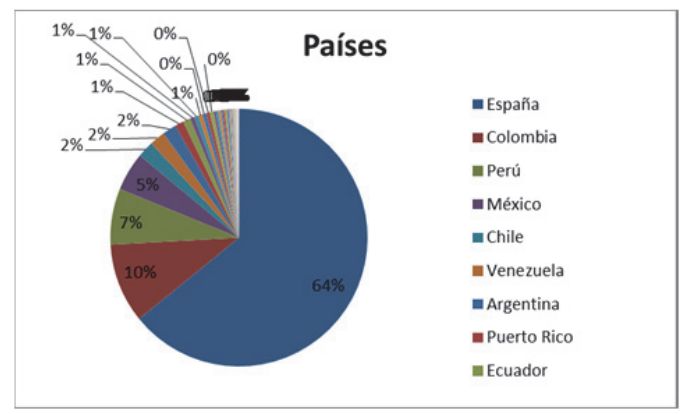

Fig. 5 Procedencia de los alumnos

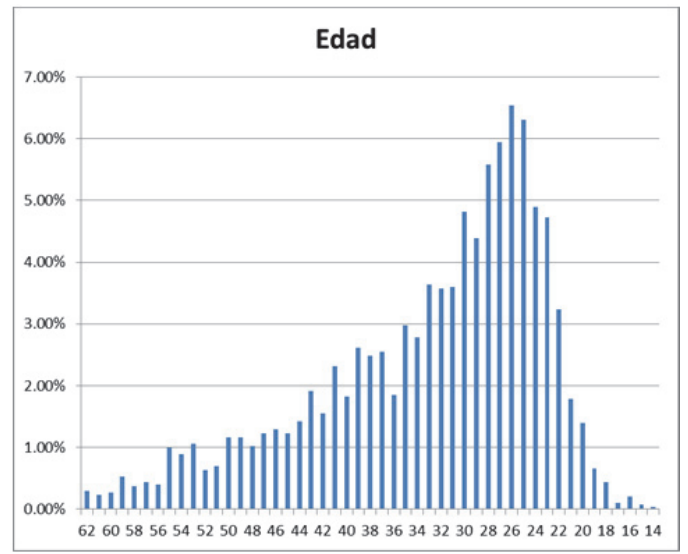

Fig. 6 Edades de los alumnos

Datos a tener en cuenta son que el $64 \%$ es de procedencia española, lo que indica que en el fondo, a pesar de ser una plataforma iberoamericana, no cumplió este objetivo como tal, y que, aunque la mayoría de alumnos se encuentran entre 22 y 32 años, vemos que existen alumnos de todas las edades, lo que indica también la heterogeneidad en este sentido.

\subsubsection{Datos al finalizar el curso}

Al finalizar el curso, se realizó una encuesta que realizaron 3043 alumnos, al ver este número que dobla a los que la realizaron al inicio, quizá ya tengamos una respuesta clara de que el interés del alumno creció a medida que avanzó en los contenidos del curso.

\section{(c)) EY-NC-ND 2014, Universitat Politècnica de València}

I Jornadas IN-RED (2014) 
Al número de matriculados que finalizaron el curso fue de 2054 alumnos, de los 6626 que comenzaron, una tasa de éxito del $31 \%$, algo inusual en este tipo de formación, donde la media de la tasa de éxito es del 10-15\%.

Como expondremos en las conclusiones, esto es debido a varios factores: contenidos multidisciplinares, sesiones cortas de videos, practicas complementarias en todos los módulos, participación muy activa del foro, evaluación continua...

Mostramos a continuación datos extraídos de las encuestas, donde se aprecia el grado de satisfacción de los alumnos que lo cursaron:

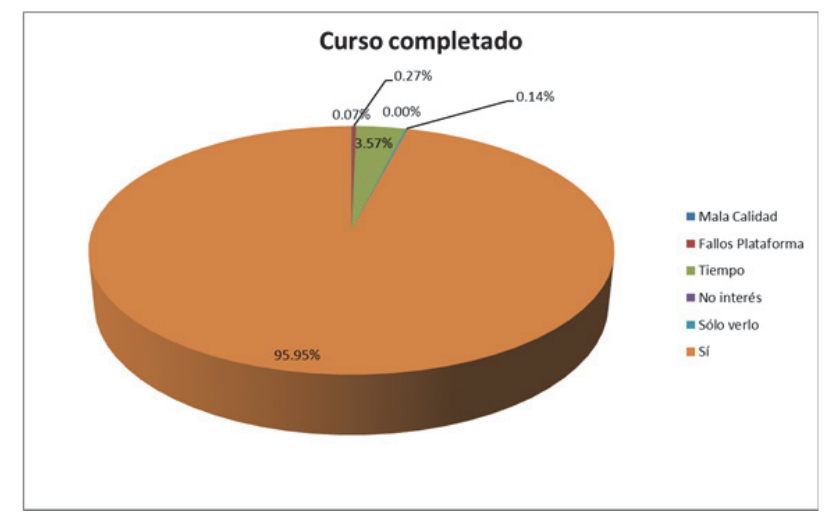

Fig. 7 ¿Has completado el curso?

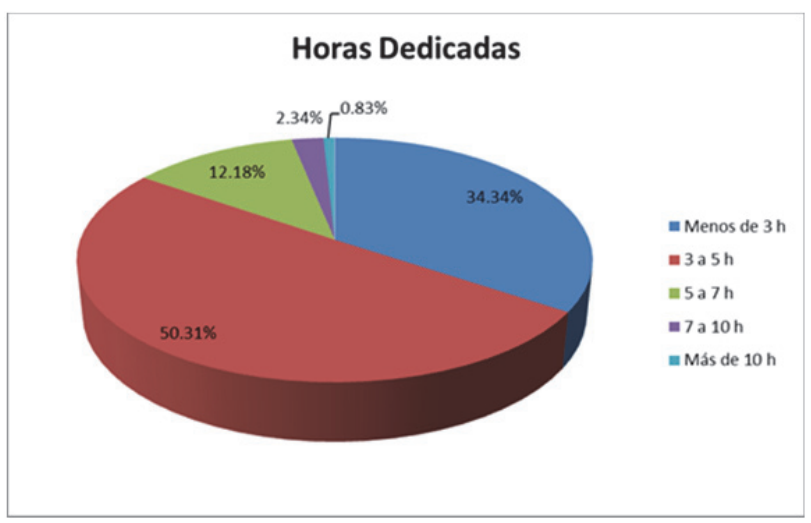

Fig. 8 A la semana le he dedicado al curso:

Vemos que la causa principal de abandono, es la falta de tiempo, lo que indica que una de las claves del éxito en este tipo de formación es hacer contenidos que no necesiten una gran dedicación de tiempo, pues, en líneas generales, siempre se compaginan con actividades, o bien de otro tipo de estudios, o bien profesionales. Como vemos en la figura 8 , la media es de 3 a 5 horas a la semana que es lo que se recomienda en este tipo de formación.

(c)) EY-NC-ND 2014, Universitat Politècnica de València 


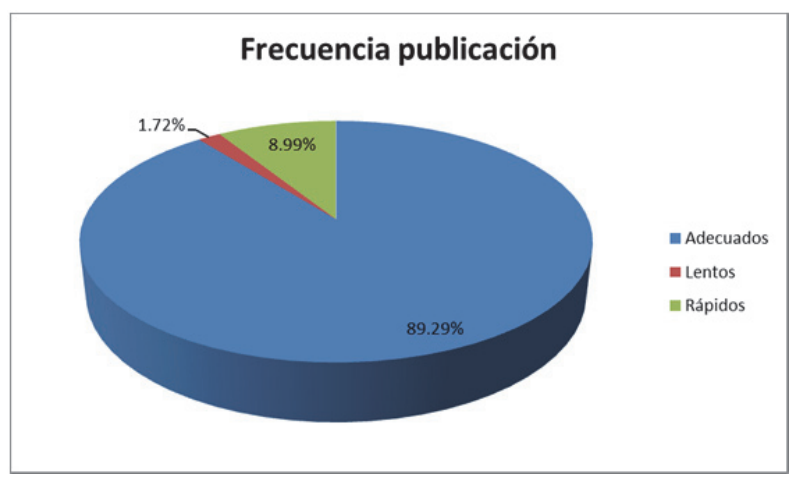

Fig. 9 La frecuencia de publicación y el ritmo de aprendizaje del curso me han resultado:

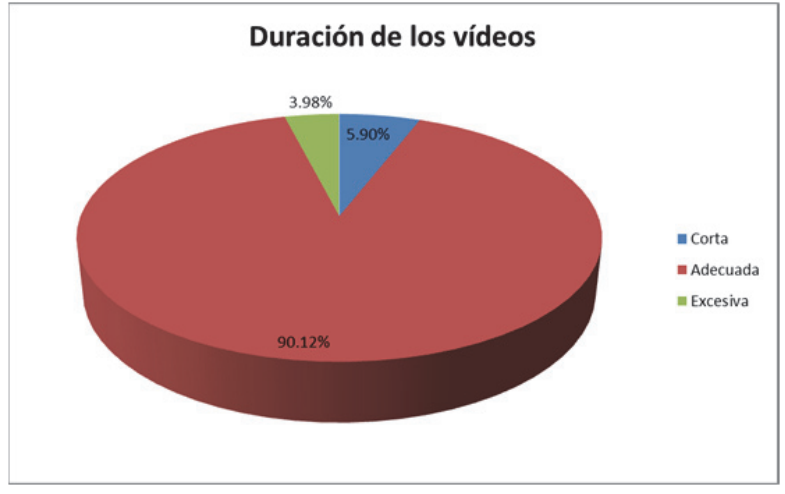

Fig. 10 La duración de los vídeos me ha parecido:

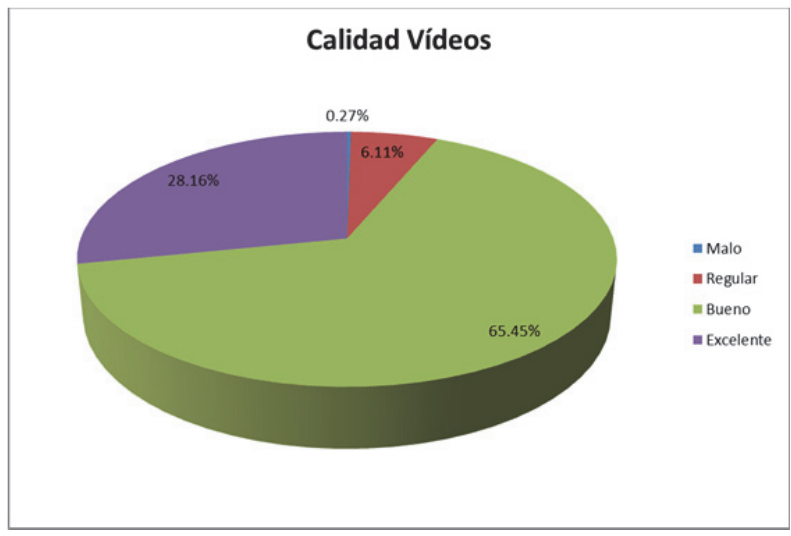

Fig. 11 El contenido de los vídeos me ha parecido:

Otras variables fundamentales para que el alumno siga con continuidad el curso y no lo abandone, es que el ritmo de aprendizaje sea el adecuado, eso se consigue con una duración adecuada y una calidad de los contenidos que se muestran en el curso (figuras 9, 10 y 11)

\section{(c)) EY-NC-ND 2014, Universitat Politècnica de València}

I Jornadas IN-RED (2014) 


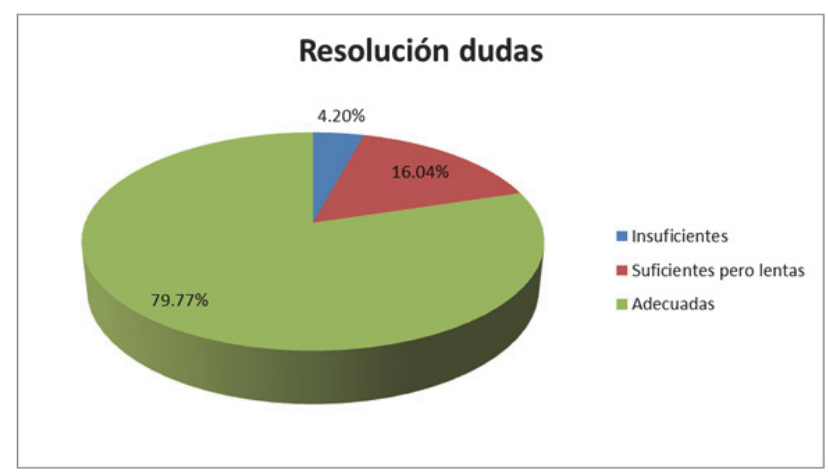

Fig. 12 Las opciones de resolución de dudas me han parecido:

Desde nuestro punto de vista, y observando la figura 12, es fundamental mantener una interaccion con el alumno a través de los medios que proporcionan estas plataformas (foros, chats...) para resolver las dudas y motivar la participación de los alumnos a través de cuestiones planteadas en los foros sobre las temáticas vistas en la parte teórica y práctica.

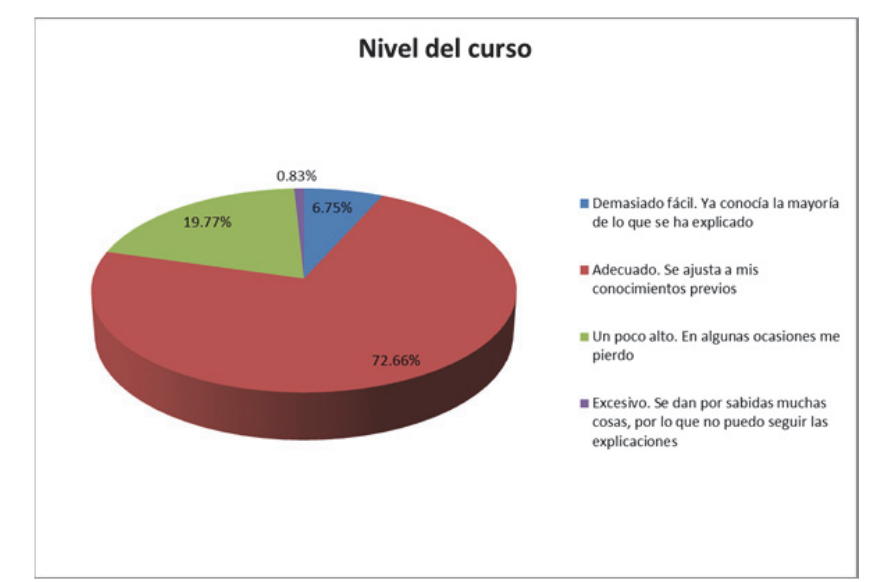

Fig. 13 ¿Cómo ves el nivel del curso en relación a tus conocimientos previos? 


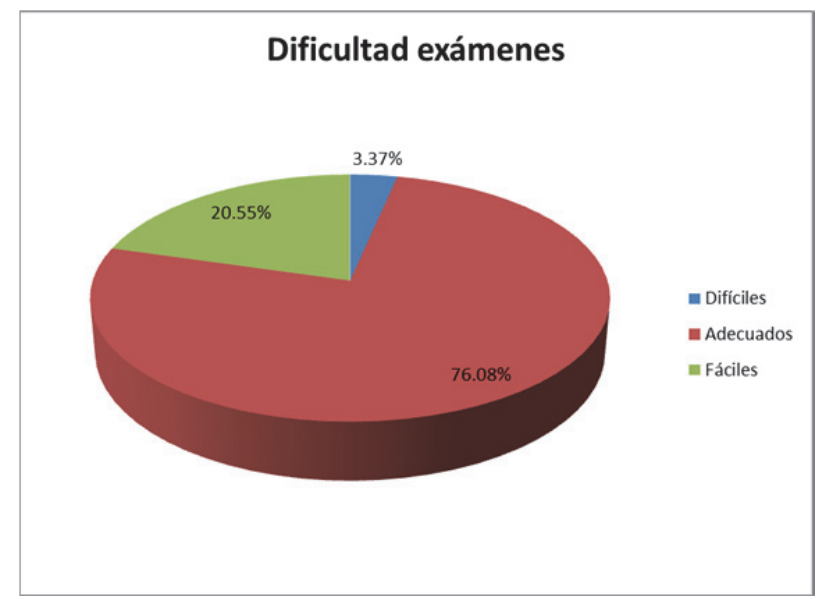

Fig. 14 Los exámenes y actividades me han parecido:

La capacidad de mantener el nivel de dificultad del curso acorde a las expectativas y el potencial de los alumnos, es otra de las variables fundamentales para que el alumno mantenga su atención e intente aprender los contenidos nuevos. Para ello es fundamental establecer una encuesta al inicio de conocimientos previos, como hicimos en este curso, con el objetivo de poder adaptar los contenidos a los alumnos, en nuestro caso, alumnos muy multidisciplinares. De igual forma, es necesario combinar esto con la resolución de dudas en los foros, tal y como acabamos de ver.

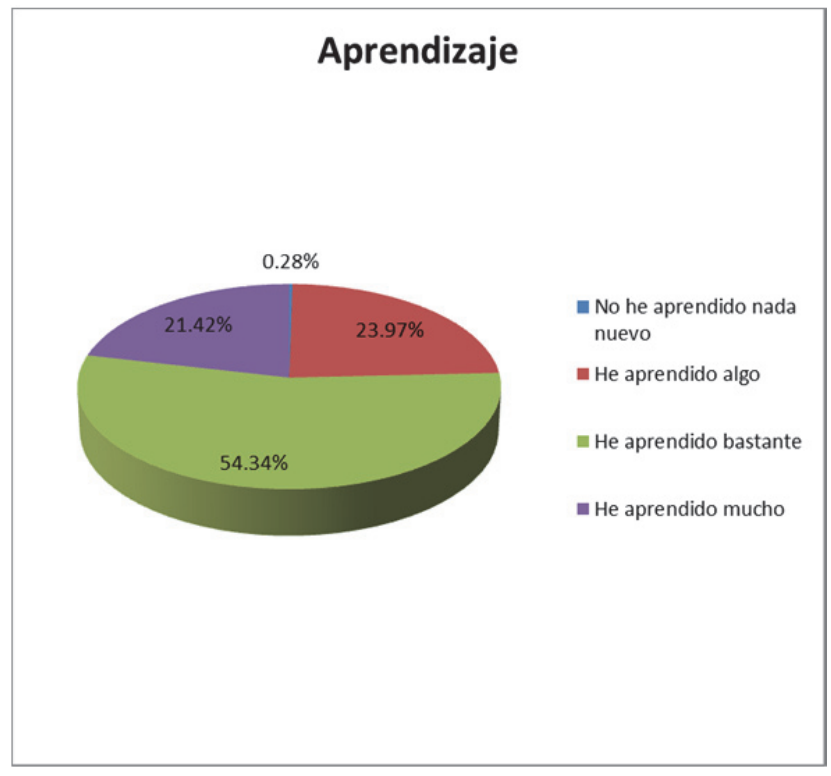

Fig. 14 En general con el curso:

\section{(c)) EY-NC-ND 2014, Universitat Politècnica de València}

I Jornadas IN-RED (2014) 


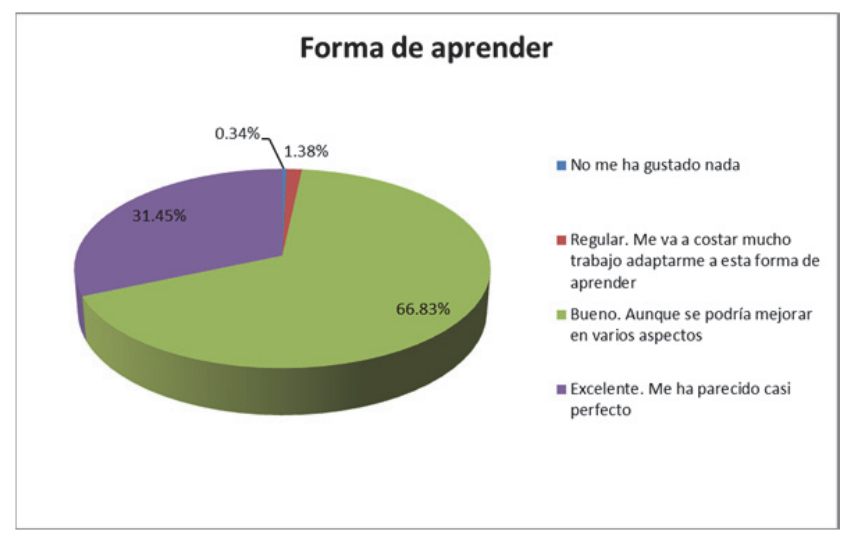

Fig. 15 ¿Cómo valoras el sistema de aprendizaje utilizado?

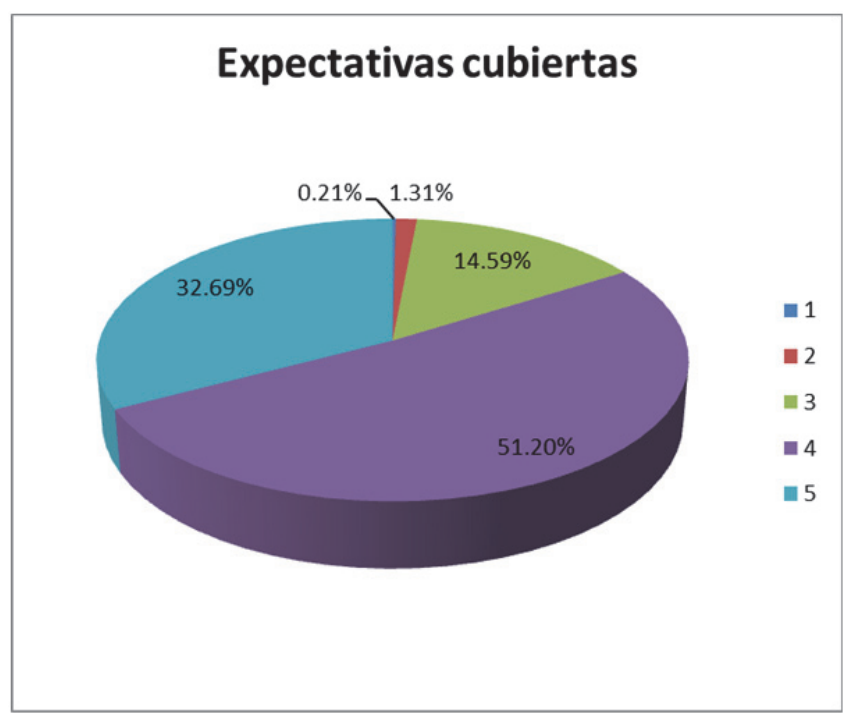

Fig. 16 Mis expectativas con el curso han quedado satisfechas (5 totalmente, 1 nada)

Las figuras 14, 15 y 16 muestran como, el haber realizado las acciones vistas anteriormente, es decir, buscar contenidos multidisciplinares y de novedad tecnológica, dotar al curso de un tiempo de dedicación adecuado, mantener la calidad y duración de los contenidos, interactuar con el alumno en los foros planteando y resolviendo dudas sobre las temáticas vistas, establecer un nivel de dificultad adecuado tanto en la formación como en la evaluación y que vaya evolucionando a medida que lo hace el curso, el control de estas variables hace que el alumno cumpla con sus expectativas y haya aprendido lo que necesitaba o andaba buscando. 


\section{Conclusiones}

Después de la realización de este MOOC sobre Geomática aplicada a la gestión del territorio en la plataforma MiriadaX, se realizaron dos nuevas ediciones en la plataforma UPVX, en las cuales disminuyeron el número de alumnos, debido en gran parte a un menor alcance mediático de la misma. No obstante, las cifras obtenidas también fueron satisfactorias. En la primera edición en esta plataforma se consiguieron 651 alumnos pues las acciones de difusión no fueron al mismo nivel que en MiriadaX, y en una segunda, en la que la plataforma UPVX era ya más conocida, se alcanzaron 2060 alumnos. No obstante, cabe destacar un hecho muy importante, y es que la tasa de éxito, aunque fue menor que en MiriadaX (14\% y $16 \%$ respectivamente) los alumnos que acabaron una vez comenzada la primera actividad evaluatoria, fueron un 62 y $73 \%$ respectivamente, un valor superior, al que se alcanzó, en Miriada X que fue de un 55\%. Eso significa que los alumnos que comienzan el curso se mantienen en un porcentaje mayor en el curso (menor tasa de abandono) a medida que el profesorado tiene una mayor experiencia en este tipo de formación, y es capaz de sacar conclusiones como las que hemos mostrado aquí, para que las expectativas del curso se cumplan y el MOOC se pueda considerar un éxito.

Por último, cabe destacar, lo que llevamos remarcando a lo largo del artículo, que la clave del éxito no es solo una única variable, sino la conjunción de todas ellas, y en este caso en el que la temática era de cierta especificidad, como es la Geomática, se consiguió un éxito gracias a mantener no solo contenidos multidisciplinares y de alto contenido tecnológico, sino también a tener en cuenta las variables estudiadas en este paper y que ya hemos analizado a través de los datos aportados por las encuestas.

\section{Referencias}

MOOC.ES. Plataforma sobre MOOC. < http://www.mooc.es/que-es-un-mooc/> [Consulta: 2 de junio de 2014]

Despujol, I. Turro, C. Busquets, J. Botti, V. (2014). "Evaluation and field trials of MOOC Platforms in the Spanish-speaking community". En EMOOCs-European MOOCs Stakehollders Summit. Ecole Polytechniq Federale de Lausan: Editorial PAU education. 293 paginas.

\section{(c) EY-NC-ND 2014, Universitat Politècnica de València}

I Jornadas IN-RED (2014) 


\section{Sesión 2}

Metodologías activas para el aprendizaje 


\title{
Experiencias en el uso de la herramienta Lego Serious Play® en la Facultad de ADE
}

\section{José Albors-Garrigós ${ }^{\mathrm{a}}$, María De-Miguel-Molina ${ }^{\mathrm{b}}$, Blanca De-Miguel-Molina ${ }^{\mathrm{c}}$ y María-Del-Val Segarra-Oña ${ }^{d}$}

${ }^{a}$ Departamento de Organización de Empresas, Universitat Politécnica de València, jalbors@omp.upv.es, b Departamento de Organización de Empresas, Universitat Politécnica de València, mademi@omp.upv.es, ${ }^{c}$ Departamento de Organización de Empresas, Universitat Politécnica de València, bdemigu@omp.upv.es y ${ }^{\mathrm{d}}$ Departamento de Organización de Empresas, Universitat Politécnica de València, maseo@omp.upv.es

\begin{abstract}
LEGO® SERIOUS PLAY® (LSP) is an innovative educational tool that can contribute to bringing innovation and improve the performance of work groups and thus, companies and organizations. Over two years, and after receiving proper training from a qualified expert in business game, a group of teachers of the Faculty of Business Administration have been conducting practice for Masters or Advanced courses using the LSP method. After the experiences with around 150 students we appreciate the advantages and disadvantages of the tool and the results we have obtained. Our experience has concluded that, indeed, greater efficiency is achieved in the learning and communicational objectives and in the group innovation, while we could assess other skills in students, such as the ability to be creative and communicative.
\end{abstract}

Keywords: business game, Lego Serious Play, creativity, learning process, communication.

\section{Resumen}

LEGO ${ }^{\circledR}$ SERIOUS PLAY® (LSP) es un método innovador que puede contribuir a introducir la innovación y mejorar el rendimiento de los grupos de trabajo y, por ende, de las empresas y las organizaciones. A lo largo de dos cursos, y tras recibir la formación apropiada por parte de un experto cualificado, un grupo de profesores de ADE hemos estado realizando 
algunas prácticas en asignaturas de Máster o de cursos avanzados utilizando la metodología LSP. Tras las experiencias vividas con unos 150 alumnos valoramos las ventajas e inconvenientes de la herramienta y los resultados que hemos obtenido. La experiencia ha concluido que, efectivamente, se logra una mayor eficiencia en los objetivos de aprendizaje y en la gestión de la comunicación e innovación grupal, a la vez que se pueden valorar otro tipo de competencias en el alumno, como la capacidad de ser creativo y de comunicar.

Palabras clave: juegos de empresa, Lego Serious Play, creatividad, proceso de aprendizaje, comunicación.

\section{Introducción}

LEGO ${ }^{\circledR}$ SERIOUS PLAY ${ }^{\circledR}$ (LSP) es un método experimental diseñado para mejorar la dinámica de innovación y el rendimiento de las organizaciones. Basado en investigaciones experimentales que demuestran que este tipo de juegos utilizados en el aprendizaje ayudan a lograr una comprensión más profunda y más significativa del mundo, el entorno y sus posibilidades, LSP profundiza el proceso de reflexión y apoya un diálogo efectivo entre los miembros de la organización. La experiencia demuestra que LSP es un método innovador que puede contribuir a introducir la innovación y mejorar el rendimiento de los grupos de trabajo y, por ende, de las empresas y las organizaciones.

En el LSP los participantes desarrollan las tareas del grupo mediante la construcción de modelos simbólicos y metafóricos con las piezas LEGO y los presentan y comentan con los demás participantes en el grupo.

LSP se desarrolló a finales de los 90 por la propia empresa LEGO, que en plena crisis necesitaba desarrollar una nueva estrategia. Los impulsores fueron Johann Roos, Bart Victor y Robert Rasmussen. A partir de 2002 se comercializó fuera de LEGO.

En 2010 se comenzaron a difundir los principios básicos y la filosofía de LSP y se crearon nuevas aplicaciones, como URL - Requisitos de usuarios con LEGO.

LSP se basa en un conjunto de valores básicos, que se podrían resumir del siguiente modo:

(a) La respuesta está en el sistema, (b) todo el mundo debe expresar su / sus reflexiones y

(c) no hay una sola respuesta correcta a un problema o planteamiento (Järvinen, 1998).

El proceso LSP Core se basa en cuatro pasos esenciales:

a) El facilitador plantea un desafío.

b) Los participantes construyen sus respuestas usando las piezas LEGO.

c) Los participantes comparten sus respuestas con los demás participantes.

(c)) EY-NC-ND 2014, Universitat Politècnica de València

I Jornadas IN-RED (2014) 
d) Los participantes reflexionan sobre lo que han visto y oído.

El concepto LSP se basa en algunas teorías fundamentales: la importancia del juego como una forma de aprender a través de la exploración y la narración; el construccionismo; la conexión mano-mente como un nuevo camino para el pensamiento creativo y expresivo; y el papel de los diferentes tipos de imaginación.

\section{Objetivo}

El objetivo principal del trabajo ha sido valorar la experiencia en el uso de la herramienta para saber si ha ayudado a los alumnos en el aprendizaje y en la adquisición de competencias específicas como el trabajo en equipo, la creatividad y la comunicación. Tras las experiencias vividas con unos 150 alumnos podemos evaluar las ventajas e inconvenientes de la herramienta y los resultados que hemos obtenido.

\section{Desarrollo}

A lo largo de dos cursos, y tras recibir la formación apropiada por parte de un experto cualificado, formador acreditado por Lego ${ }^{\circledR}$ en el uso de la herramienta, un grupo de profesores de ADE hemos estado realizando algunas prácticas en asignaturas de Máster o de cursos avanzados utilizando la metodología LSP.

Sin embargo, este estudio lo basamos en los datos empíricos de los que disponemos de una muestra de 99 alumnos de $3^{\circ}$ curso del Grado en Gestión y Administración Pública, dentro de la asignatura Dirección Estratégica de Organizaciones Públicas.

A los alumnos les solicitamos que realizasen un informe libre sobre su experiencia en el uso de la herramienta, de no más de una cara de folio. Con dichos informes, hemos realizado un análisis de contenido (Berg y Lune, 2012; Bernard, 2000; Weber, 1990), buscando las palabras o expresiones que LSP entiende que se adquieren tras su uso. Estas fueron:

- Intercambiar ideas.

- Ser entretenido/diferente.

- Enriquecedor.

- Conciliar/consensuar.

- Interactuar/participar.

- Aprender conocimientos/aplicar.

- Creatividad. 


\section{Resultados}

Tras codificar las diferentes palabras/expresiones, pasamos a contabilizar su uso en los informes realizados por los alumnos y contabilizamos su frecuencia, tal como puede observarse en la Tabla 1.

\section{Tabla 1. Porcentaje de palabra/expresión entre 99 informes}

\begin{tabular}{cc}
\hline Palabras/expresiones & \% frecuencia \\
\hline intercambiar ideas & $60,61 \%$ \\
entretenido/diferente & $60,61 \%$ \\
enriquecedor & $31,31 \%$ \\
conciliar/consensuar & $31,31 \%$ \\
interactuar/participar & $53,54 \%$ \\
aprender conocimientos/aplicar & $24,24 \%$ \\
& $30,30 \%$ \\
\hline
\end{tabular}

Como podemos observar en la Figura 1, los aspectos más valorados por los alumnos fueron: intercambiar ideas, ser una herramienta diferente y entretenida y dar mayor posibilidad a los integrantes del grupo de interactuar y participar.

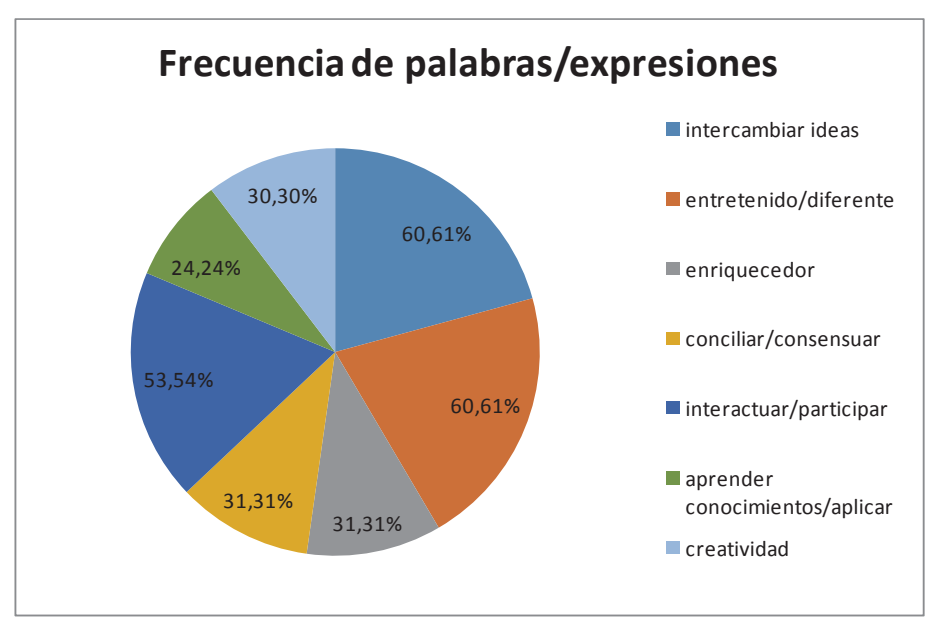

Fig. 1 Frecuencia de palabras/expresiones, elaboración propia 
Sin embargo, también podemos observar que los alumnos no acaban de apreciar la aplicación de la teoría en el juego o la creatividad que proporciona, si bien sí que se valoran sólo lo hacen algunos integrantes de la muestra.

Desde el punto de vista de valoración de otro tipo de competencias por parte de los profesores, se pudo observar cómo de los 99 alumnos un 71,72\% obtuvieron mejores resultados en esta práctica que en el examen, mientras que sólo un 28,28\% obtuvieron en el examen mejor nota que en la práctica. Con ello corraboramos lo que pudimos observar durante la práctica, que algunos alumnos manifestaron una creatividad y participación muy superior a la que suelen mostrar en otro tipo de prácticas (Figura 2).

A la hora de expresar con las piezas lo que representaba para ellos un servicio público y cómo lo mejorarían, intercambiando sus diferentes ideas, fueron capaces de crear modelos más elaborados y enriquecidos, aportando visiones más innovadoras.

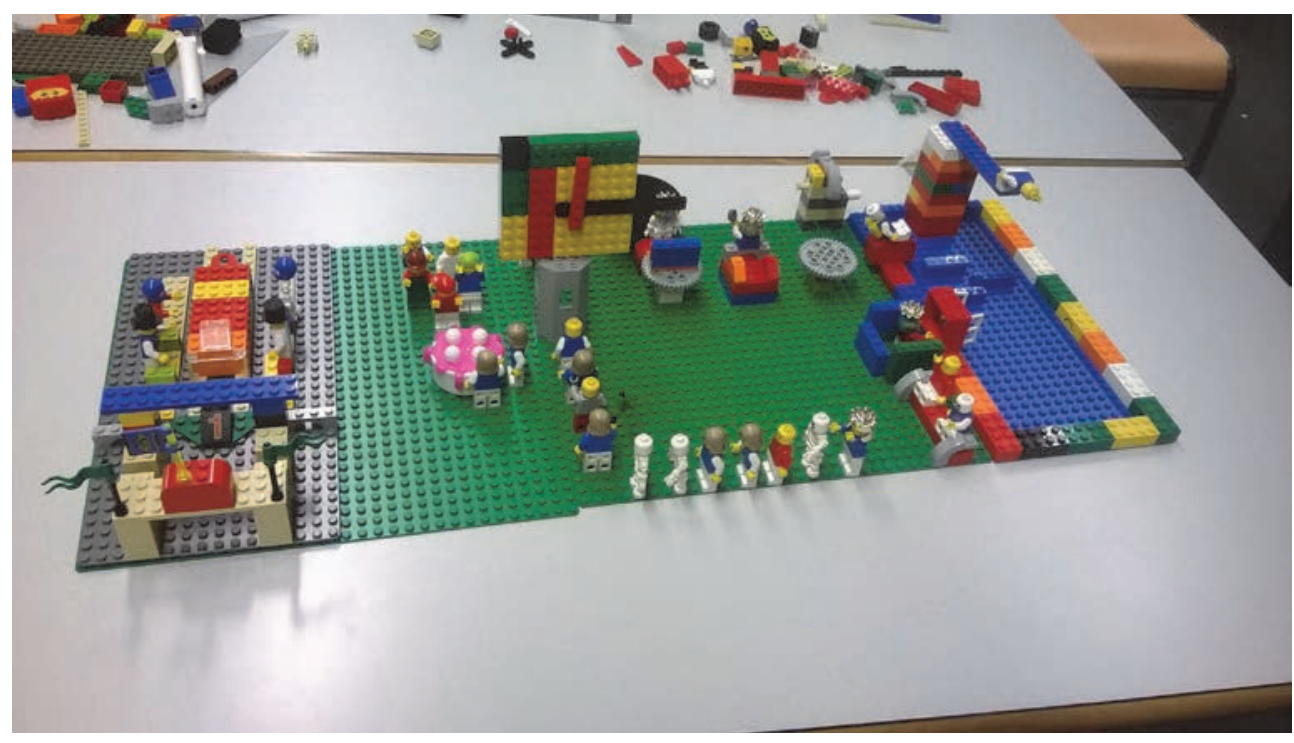

Fig. 2 Lanscape realizado por los alumnos con LSP, elaboración propia

\section{Conclusiones}

La herramienta es muy potente para fomentar la creatividad de los alumnos pero, al mismo tiempo requiere de un enfoque apropiado. Hay que tener muy claros los objetivos a perseguir para que no se convierta en un simple tiempo de esparcimiento, sino en la obtención de un resultado enriquecido por las aportaciones de todos los miembros del

(c)) EY-NC-ND 2014, Universitat Politècnica de València

I Jornadas IN-RED (2014) 
equipo. Tampoco es conveniente abusar de la herramienta para no desvirtuar su impacto por lo que es preferible combinarla con otro tipo de herramientas que fomenten el trabajo en equipo, como el canvas o juegos de equipo.

La herramienta logra que los alumnos participen al $100 \%$, incluso aquellos que, por timidez, son reacios a ello. Fomenta además la dinámica y la creatividad del grupo

La experiencia ha concluido que, efectivamente, se logra una mayor eficiencia en los objetivos de aprendizaje y en la gestión de la comunicación e innovación grupal, a la vez que se pueden valorar otro tipo de competencias en el alumno, como la capacidad de ser creativo y de comunicar.

Finalmente, la labor del consultor a la hora de dar la formación necesaria es vital para ir mejorando y afinando el uso de la herramienta.

\section{Referencias}

Berg, B.L. \& Lune, H. (2012). Qualitative Research Methods for the Social Sciences. Pearson, New Jersey.

Bernard, H. (2000). Social research methods: Qualitative and quantitative approaches. London: Sage.

Järvinen, E. M. (1998). The Lego/Logo Learning Environment in Technology Education: An

Experiment in a Finnish Context. Journal of Technology Education, 9(2), 25-37.

Weber, R.P. (1990). Basic Content Analysis, 2nd edition, Series: Quantitative Applications in the

Social Sciences, number 49. Sage University Paper: Newbury Park, California. 


\title{
Utilización del LEGO® Serious Play® en Clases de Marketing en Empresas de Servicios
}

\author{
Sofia Estelles-Miguel ${ }^{\mathrm{a}}$, Teresa Barbera Ribera ${ }^{\mathrm{b}}$, Jose Miguel Albarracin Guillem ${ }^{\mathrm{c}}$, \\ Marta Palmer Gato ${ }^{\mathrm{d}}$ \\ Departamento de Organización de Empresas, Universitat Politècnica de València. \\ asoesmi@omp.upv.es; ${ }^{\text {b }}$ mabarri@upvnet.upv.es; ${ }^{\text {cjmalbarr@omp.upv.es; }{ }^{\mathrm{d}} \text { marpalga@ @omp.upv.es }}$
}

\begin{abstract}
This paper focuses on exposing the educational innovation process that has been launched in the 2013-2014 academic year in Services Business Marketing belonging to the $5^{\text {th }}$ degree course in the Faculty of Business Administration of the Universitat Politècnica de València. On that subject, and during classroom practices we have used the "LEGO® Serious Play®" tool known as "gamification tools" for developing a SWOT (an acronym for Weaknesses, Threats, Strengths and Opportunities), this tool helps in the development of students'creativity and serves as a link in the development of the activity as you can see in this paper.
\end{abstract}

Keywords: Gammification, Creativity, Educational Innovation, Lego Serious Play, SWOT, Metodología.

\begin{abstract}
Resumen
El presente artículo se centra en exponer el proceso de innovación docente que se ha puesto en marcha durante el curso académico 2013-2014 en la asignatura de Marketing en Empresas de Servicios, perteneciente al $5^{\circ}$ curso de Licenciatura en la Facultad de Administración de Empresas de la Universitat Politècnica de València. En dicha asignatura y durante unas prácticas de aula se ha utilizado el "LEGO® Serious Play®" una herramienta de las conocidas como "herramientas de gamificación" para el desarrollo de un DAFO (acrónimo de Debilidades, Amenazas, Fortalezas y Oportunidades), esta herramienta ayuda en el desarrollo de la creatividad de los alumnos y sirve como nexo de unión en el desarrollo de la actividad como se puede ver en el presente trabajo.
\end{abstract}

(cc) EY-NC-ND 2014, Universitat Politècnica de València

I Jornadas In-Red (2014) 
Palabras clave: Gamificación, Creatividad, Innovación Educativa, Lego Serious Play, DAFO, Metodología.

\section{Introducción}

El presente artículo explica la utilización del "LEGO® Serious Play®" una herramienta de las que hoy en día se nombran como "gamificación", en las clases de Marketing en Empresas de Servicios en la Facultad de Administración de Empresas de la Universitat Politècnica de Valencia.

Para lo cual se describirá el diseño de la experiencia (en la que se tienen en cuenta lo que se busca con dicha experiencia, problemas que pueden aparecer en la realización de la experiencia, y como solucionarlos conforme vayan apareciendo, así como otras particularidades a tener en cuenta), se definen los objetivos a conseguir por la utilización de esta herramienta. Se recoge la información recopilada por los profesores durante la realización de la experiencia (problemas que aparecieron, algunos con los que se contaba y otros con los que no, como fueron solucionados los mismos, etc).

Finalmente se recogen los resultados obtenidos en la realización de la experiencia, que fueron muy interesantes al utilizarse como herramienta para definir parte del DAFO, lo que serían Debilidades, Amenazas, Fortalezas y Debilidades de la Facultad en la que se realizo la experiencia,con lo que aparecen resultados muy interesantes.

Hay que decir que la presente experiencia se realizó en dos grupos distintos, el de mañana (castellano) y el de tarde (valenciano) y con un número muy dispar de alumnos en el de la mañana fueron 50 alumnos, mientras que en el de tarde tan solo participaron 12 alumnos. También se explican los problemas obtenidos con unos y con otros debidos al tamaño de grupo.

La estructura del presente artículo es la siguiente una introducción, un apartado en el que se definen los objetivos de la presente experiencia (punto 1), un apartado en el que se define y se desarrolla la experiencia (punto 2), un apartado en el que se presentan los resultados de la experiencia (punto 3) y finamente un apartado de conclusiones (punto 4).

\section{Objetivos de la Experiencia}

La presente experiencia se realizo con los siguientes objetivos:

- Plantear una experiencia de trabajo en grupo diferente.

- Identificar las Debilidades y Fortalezas de la Facultad de Administración de Empresas de la Universidad Politécnica de Valencia.

- Fomentar la creatividad del alumnado a la hora de elaborar un DAFO.

- Aumentar la participación de los alumnos en los trabajos en grupo. 
- Que los alumnos se sintieran integrados en el trabajo y que sus ideas se tienen en cuenta.

- Identificar como el equipo puede mejorar el rendimiento individual.

\section{Aprender Jugando ó Gaminificación}

El término Gamificación no apareció hasta 2008 y su uso no empezó a generalizarse hasta 2010 (Paharia, 2010). La Gamificación es un concepto emergente en el campo de las disciplinas académicas. Este termino es entendido como "la integración de dinámicas de juego en entornos no lúdicos" (Deterding et al., 2011).

Uno de los objetivos de la gamificación es convertir los entornos no lúdicos en más divertidos y atrayentes (Huotari and Hamari, 2012). Lo que se pretende con ello explotar la esencia de los juegos: diversión, participación y pasión (Deloite, 2012). También se define la gamificación como una actitud, una estrategia de aprendizaje y un movimiento (Kapp, 2012).

La gamificación está despertando un interés creciente en distintos ámbitos de la sociedad. De hecho, existen distintos estudios que apuntan a que gracias a la expansión de la tecnología móvil, la gamificación se convertirá en una tendencia significativa en los próximos años (BBVA, 2012 y Deloitte, 2012), estimándose que en 2015 más del 50\% de las organizaciones que gestionan procesos de innovación los van a gamificar (Gartner, 2011).

Todos los juegos tienen cuatro rasgos comunes: una meta, reglas, un sistema de retroalimentación o feedback y la participación voluntaria (Mc.Gonigal, 2011). Las mecánicas del juego son las distintas acciones, comportamientos, técnicas y mecanismos de control que se utilizan para convertir en juego una actividad (Kapp, 2012). Con ellas se consigue crear una experiencia atractiva y de fácil adhesión para el jugador. Incluye: puntos, niveles, premios, bienes virtuales, clasificaciones, desafíos, misiones o retos y regalos.

Las dinámicas del juego son el efecto, motivación y deseos que persiguen los usuarios y que se basan a su vez en las necesidades fundamentales del ser humano (Maslow, 1943 y Reiss, 2004).

Durante el juego las personas se dejan fluir, que es un estado de placer espontáneo en el cual la persona está involucrada plenamente en una tarea gracias a una profunda motivación (CsikSzentmihalyi, 1996). Un estado donde el individuo se encuentra en el nivel perfecto de sus habilidades: ni sin suficientes desafíos (aburrido) ni con demasiados (ansiedad y frustación). Ligado a este concepto, se encuentran las motivaciones extrínsecas e intrínssecas. La primera viene determinada por el entorno y tiene por objetivo conseguir una meta externa (reconocimiento o recompensa) mientras que la segunda es la que lleva al

\section{(c) EY-NC-ND 2014, Universitat Politècnica de València}

I Jornadas IN-RED (2014) 
individuo a realizar una actividad por su propio gusto, porque le resulta por sí misma interesante y satisfactoria (Amabille, 1999). En las actividades de gamificación la más importante es la motivación intrínseca porque es la que consigue enganchar al participante.

Ese enganche o compromiso hace referencia a la implicación, es decir, el vínculo que crea el participante. Pueden aparecer tres tipos de compromiso: cognitivo, emocional y físico (May et al., 2004).

A nivel de marketing, se considera que la gamificación ayuda a las empresas a aumentar la participación del usuario, la fidelización y el reconocimiento de la marca, y a formar a los empleados (Meloni, 2012). Existen títulos dedicados a la gamificación en marketing (Hamari and Lehdonvirta, 2010; Huotari and Hamari, 2012 y Oliver Pérez, 2012).

\subsection{LEGO® Serious Play ${ }^{\circledR}$}

Hace 10 años, el fabricante de juguetes danés LEGO®, famoso en todo el mundo por sus coloridas y versátiles piezas, se planteó el siguiente reto de gestión interna: cómo hacer que los procesos de planificación de estrategias corporativas fuesen un ejercicio de equipo más eficaz, en el que todos los trabajadores se comprometiesen a implementar el resultado. Kjeld Kirk Kristiansen concibió la idea de lo que hoy se conoce como LEGO® Serious Play ${ }^{\circledR}$ (Juego Serio de LEGO ${ }^{\circledR}$ ), un método de resolución de problemas y una herramienta de comunicación basada en el uso del mayor éxito de ventas de los juegos de construcción: el LEGO®.

Todas las personas participantes, de forma individual o colectiva, una vez escenifican su modelo pueden simular cambios que permiten visionar futuros cambios y sus posibles consecuencias dentro de la organización.

El juego reúne algunas de las características más importantes para aprender: lo primero es que apela a la motivación de las personas; lo segundo es que aprendes haciendo, nadie puede jugar por ti sino que es una experiencia personal e intrasferible, y lo tercero es que el error es parte consustancial del juego, y saber convivir y aprender de él resulta crítico. Por si fuese poco, el juego es innovador, es lúdico, promueve la creatividad, facilita la comunicación espontánea, es una dinámica positiva, es eminentemente colaborativo, genera compromiso, todos participan, entrega espacios de libertad, es democrático (nadie tiene privilegios sobre los demás) y jugando podemos simular y anticipar la realidad antes de que ocurra.

Se marca un objetivo, y el alumno tiene que lanzarse a la acción, para resolver el desafío planteado.

Entre las ventajas que aporta a las organizaciones el LEGO® Serious Play® se encuentran: 
- Permite a los participantes involucrarse personalmente, construyendo de forma permanente y positiva, evitando la catarsis y la crítica descalificadora en el marco de un verdadero trabajo en equipo.

- Promueve el propio descubrimiento generando compromiso y confianza con el equipo, el problema, el proyecto o la compañía.

- Facilita el tratamiento de situaciones reales en escenarios concretos, aprendiendo a priorizar, tomas decisiones y descubrir los principios básicos que nos guían en el momento de la decisión.

- Esta metodología permite integrar de manera simple y rápida factores muy diversos y complejos de un entorno que es dinámico y complejo, lo que con otras metodologías requiere transacciones muchos más largas para tener una visión completa.

\subsection{Desarrollo de la Actividad de Innovación}

Al principio de la presente experiencia, se les indicaron a los alumnos los objetivos de la actividad y como la debían realizar.

Objetivos:

- Localizar las Debilidades y Fortalezas de la Facultad en la que estudian.

Forma de Trabajo:

1. Se dividió a los alumnos en dos grupos y se les puso en una mesa grande de trabajo ( $3 \times 3$ metros) y se les entregaron gran cantidad de piezas de LEGO ${ }^{\circ}$ en el centro de la misma.

2. Cada alumno debía realizar un modelo con las piezas de LEGO® que represente la idea que quiere transmitir, en función de la mesa en que se encuentre planteará Debilidades o Fortalezas. Cada uno puede utilizar los colores, tamaños y formas que considere necesarios para explicar su modelo.

3. Una vez los alumnos han terminado sus modelos, se los deben explicar al resto de su grupo, nadie puede criticar las ideas expuestas.

4. Cuando todos los alumnos han terminado de explicar sus modelos, entre todo el grupo deben decidir como integran los distintos modelos en uno sólo, poniendo las ideas más importantes o decisivas en el centro y añadiendo todas las ideas en círculos concéntricos, en función de su relación o importancia.

5. Una vez se ha terminado el modelo, cada grupo explicará su modelo al otro grupo, aquí tampoco se puede criticar.

6. Una vez finalizado los alumnos pueden decidir pasar una parte de su modelo al otro modelo si consideran que es lo adecuado, es decir, que representa mejor algo que está en el otro modelo.

(c) EY-NC-ND 2014, Universitat Politècnica de València

I Jornadas IN-RED (2014) 
Para la actividad arriba explicada los alumnos dispusieron de 2 horas de clase. La profesora no podía asesorar, ni explicar, ni ayudar, sólo da las normas y posteriormente observa y anota, finalmente es la que realiza las listas de las Fortalezas y Debilidades que indican los alumnos y realiza las fotos de los modelos terminados.

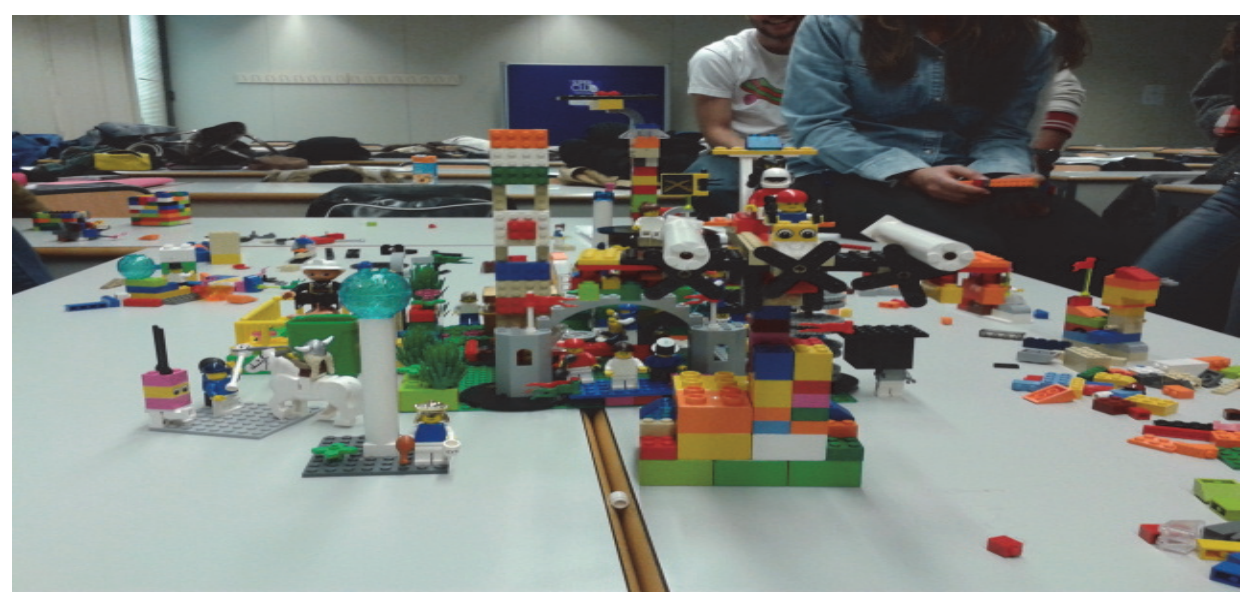

Fig. 1 Fotografía del modelo visto de frente

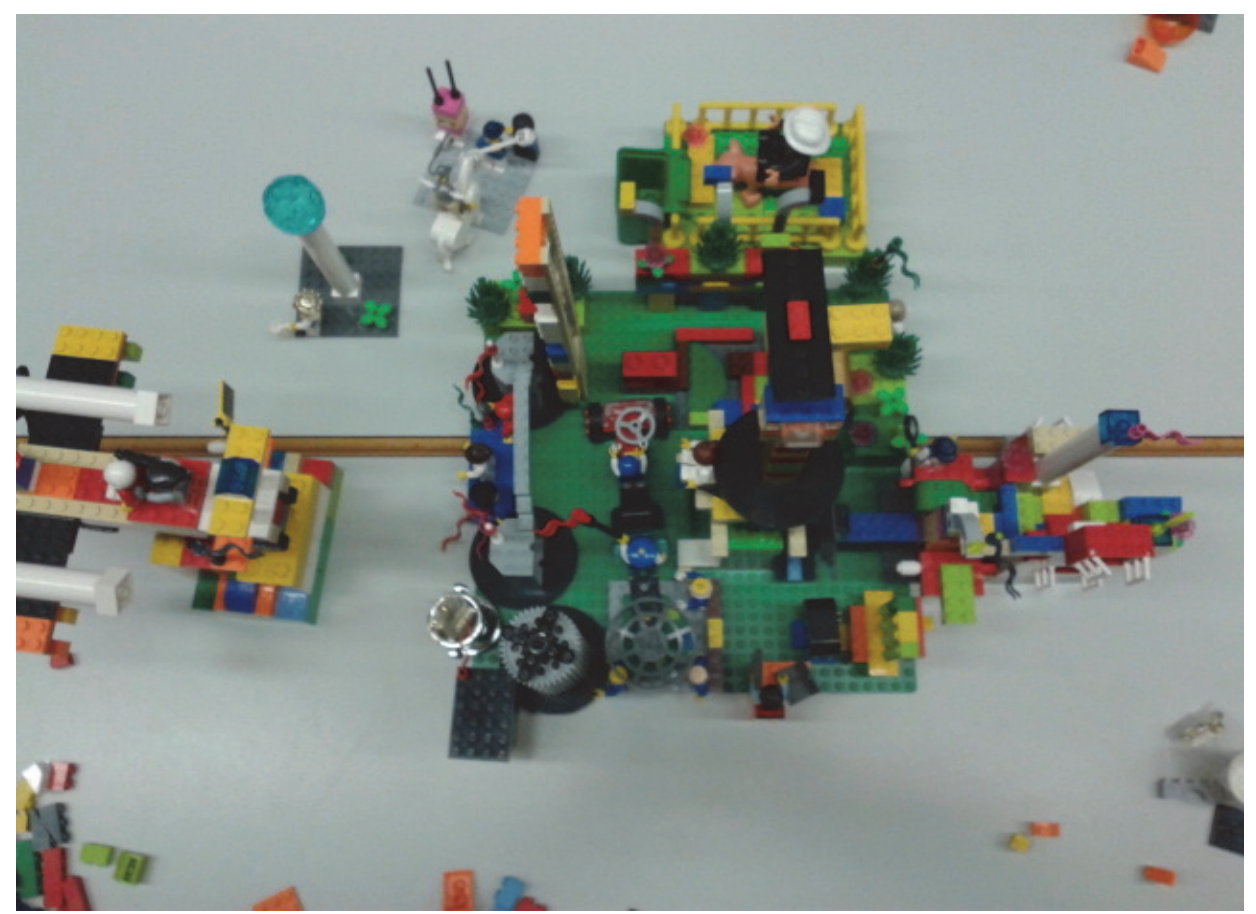

Fig. 2 Fotografía del modelo visto desde arriba

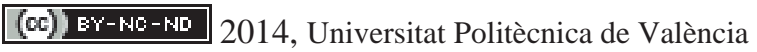

I Jornadas IN-RED (2014) 


\section{Resultados}

Durante las sesiones realizadas con la metodología explicada se obtuvieron una gran cantidad de aportaciones por parte de los alumnos, con ellas se han realizado listas de Fortalezas y Debilidades.

Tabla 1. Fortalezas

\begin{tabular}{|c|c|}
\hline Ratio profesor-alumno & Prácticas remuneradas \\
\hline Prestigio de los profesores & Relevancia a la hora de encontrar trabajo. \\
\hline La arquitectura de los edificios & Relación con las empresas \\
\hline $\begin{array}{l}\text { Buenas instalaciones (Biblioteca general, } \\
\text { biblioteca en cada escuela, salones de actos, } \\
\text { zonas verdes, deportivas, cafeterías...) }\end{array}$ & $\begin{array}{l}\text { Movilidad internacional } \text { (acuerdos } \\
\text { importantes con otras universidades, } \\
\text { programas de intercambio) }\end{array}$ \\
\hline Bases para el futuro laboral & Universidad Pública \\
\hline Aplicación práctica y mejor preparación & Ligas internas de deporte \\
\hline $\begin{array}{l}\text { Integración de personas (razas y culturas } \\
\text { distintas). }\end{array}$ & $\begin{array}{l}\text { FADE se aprovecha de las tecnologías de la } \\
\text { UPV }\end{array}$ \\
\hline Aparcamiento & Fomentan la creatividad \\
\hline Prestigio & Red (riunet, poliformaT, politube) \\
\hline Buena conexión WIFI & Innovación \\
\hline Centralización de los Servicios & Títulos propios \\
\hline Las personas (PDI, PAS, alumnos) & Las herramientas que te da. \\
\hline Capacidad para observar el mercado laboral & Inversión en $\mathrm{I}+\mathrm{D}+\mathrm{i}$ \\
\hline $\begin{array}{l}\text { Mix de conocimiento que ayuda a abrir } \\
\text { puertas en el mercado laboral }\end{array}$ & $\begin{array}{l}\text { Importancia del Medio Ambiente y del } \\
\text { reciclaje }\end{array}$ \\
\hline Limpieza & Prácticas en Empresas fuera de España \\
\hline
\end{tabular}

Como se puede observar muchas de ellas no se nos habrían ocurrido a la gente que estamos tiempo trabajando en esta Universidad, sin embargo los alumnos y mediante esta técnica que ayuda en la creación de ideas obtuvieron todas las arriba mencionadas.

\section{(c) EY-NC-ND 2014, Universitat Politècnica de València}

I Jornadas IN-RED (2014) 
Tabla 2. Debilidades

\begin{tabular}{|c|c|}
\hline $\begin{array}{l}\text { Sensación de frío cuando no funciona el } \\
\text { aire acondicionado en invierno (sobre todo } \\
\text { lunes por la mañana y en baños). }\end{array}$ & $\begin{array}{l}\text { Falta de organización de la Facultad en } \\
\text { cuanto a los alumnos Erasmus y la } \\
\text { organización de sus clases. }\end{array}$ \\
\hline $\begin{array}{l}\text { Poca atención individualizada a los } \\
\text { alumnos, con respecto a sus necesidades de } \\
\text { aprendizaje. }\end{array}$ & $\begin{array}{l}\text { La obligación de asistencia a todas las } \\
\text { clases, en muchos casos no tiene sentido. }\end{array}$ \\
\hline Ordenadores lentos. & Aulas con poca luz natural. \\
\hline $\begin{array}{l}\text { Máquinas de VENDING altos precios de } \\
\text { sus productos y casi siempre vacías o con } \\
\text { falta de reposición. }\end{array}$ & $\begin{array}{l}\text { Los profesores les dan poca flexibilidad a } \\
\text { los alumnos (cuando por ejemplo trabajan y } \\
\text { tienen que compatibilizarlo) }\end{array}$ \\
\hline $\begin{array}{l}\text { Cola eterna en la cantina más cercana a la } \\
\text { hora de comer y almorzar y mala comida. }\end{array}$ & $\begin{array}{l}\text { Gran tiempo que pasa entre el examen y los } \\
\text { resultados de los mismos, }\end{array}$ \\
\hline $\begin{array}{l}\text { Parking de FADE pocas plazas sobre todo } \\
\text { para alumnos }\end{array}$ & $\begin{array}{l}\text { Soledad, es la única Facultad no técnica, } \\
\text { rodeada por Escuelas Técnicas. }\end{array}$ \\
\hline No hay servicio de reprografía. & El mal olor que proviene de las granjas \\
\hline $\begin{array}{l}\text { Poca previsión en las obras (ejemplo las del } \\
\text { parking) }\end{array}$ & $\begin{array}{l}\text { Poca implicación de algunos profesores (no } \\
\text { se preparan las clases, clases no } \\
\text { estandarizadas entre mañanas y tarde, etc). }\end{array}$ \\
\hline Altos precios de las tasas con las subidas & Tener que pagar el servicio de deportes. \\
\hline $\begin{array}{l}\text { El decanato esta muy separado de la } \\
\text { realidad. }\end{array}$ & $\begin{array}{l}\text { No rentabilizan el tiempo, por la mala } \\
\text { organización de las clases. }\end{array}$ \\
\hline Mala organización. & Mala distribución de las instalaciones. \\
\hline Plan de estudios es un sin sentido. & No les enseñan a interpretar la Bolsa. \\
\hline Opinan que delegación es una mafia & Muy saturados \\
\hline $\begin{array}{l}\text { Gran burocratización (problemas para } \\
\text { cambiarse de prácticas o clase) }\end{array}$ & $\begin{array}{l}\text { En ocasiones no les enseñan nada en las } \\
\text { clases prácticas. }\end{array}$ \\
\hline $\begin{array}{l}\text { Cuartos de baño (a veces no hay papel } \\
\text { higiénico, no funciona el dispensador, etc.) }\end{array}$ & $\begin{array}{l}\text { Bedelería falta de atención al personal (no } \\
\text { avisan si falta un profesor y lo de objetos } \\
\text { perdidos esta fuera y desaparecen las cosas) }\end{array}$ \\
\hline
\end{tabular}




\section{Conclusiones}

Después de haber realizado toda la experiencia, las conclusiones que se pueden obtener de la misma es que todas las nuevas actividades son interesantes, y despiertan el interés de los alumnos, siempre y cuando estén bien planificadas y realizadas.

Se han cumplido todos los objetivos planteados, al diseñar esta actividad, es decir:

- Se ha realizado una experiencia de trabajo en grupo de forma diferente.

- Se han identificado las Debilidades y Fortalezas de la Facultad de Administración de Empresas de la Universidad Politécnica de Valencia, por parte de los alumnos de la asignatura.

- Se ha fomentado la creatividad del alumnado a la hora de elaborar un DAFO, como se puede comprobar al ver la larga lista de ideas propuestas, en otras ocasiones cuando se ha hecho de forma distinta, las ideas han sido más escasas.

- Se ha aumentado la participación de los alumnos en los trabajos en grupo, los alumnos con estas dinámicas se involucran más.

- Los alumnos se sienten como parte de un todo.

- Los alumnos se han dado cuenta de que con las ideas de los demás podían mejorar las suyas y ellos podían mejorar las de los demás.

Todos los alumnos han valorado muy positivamente la actividad, nunca habían realizado esta actividad con anterioridad y les ha gustado mucho. Para los profesores, aunque supone un gran esfuerzo el tener que diseñar nuevas actividades y llevarlas a cabo, ha resultado muy agradable, por ver, que realmente es más participativo, se entienden mejor las ideas, y se desarrolla mejor el trabajo.

Seguiremos trabajando en estas líneas y en las siguientes experiencias se pasará un formulario al concluirlas para recoger de forma más directa y ordenada las impresiones de los alumnos.

\section{Agradecimientos}

Grupo de Investigación e Innovación educativa en metodologías activas para el desarrollo y evaluación de competencias genéricas interpersonales (MACGI). PIME 2013-2014.

\section{Referencias}

AMABILE, T. (1996). Creativity in Context: Update to the Social Psychology of Creativity. Boulder, CO, US. Westview Press.

BBVA (2012). Gamificación. El Negocio de la Diversión. Innovation Edge.

CSIKSZENTMIHALTY, I.S. (1992). Optimal Experience: Psychological Studies of Flow in Consciousness. Cambridge University Press.

(c)) EY-NC-ND 2014, Universitat Politècnica de València

I Jornadas IN-RED (2014) 
DETERDING, S., DIXON, D., KHALED, R. \& NACKE, L. (2011, September). From Game Design Elements to Gamefulness: Defining Gamification. En Proceding of the 15th International Academic MindTrek Conference. Envisioning Future Media Environments. ACM. pp. 9-15.

DELOITTE (2012). Tech Trends 2012. Elevate IT for Digital Business. Technology Trends.

GARTNER (2011). Gartner Gamification Report 2011

<http://www.gamification.org/wiki/Gartner_Gamification_Report_2011> [Consulta: 16 de abril de 2014].

HAMARI, J. \& LEHDONVIRTA, V. (2010). «Game Desing as Marketing: How Game Mechanics Create Demand for Virtual Goods» en Journal of Business Science \& Applied Management (2010, Vol. 5, nº1, pp.14-29).

HUOTARI, K. \& HAMARI, J. (2012, October). Defining Gamification: A Service marketing Perspective. En Proceding of the 16th International Academic MindTrek Conference. Tampere, Finlandia. pp. 17-22.

KAPP, K.M. (2012). The Gamification of Learning and Instruction: Game-Based Methods and Strategies for Training and Education. San Franscisco: Pfeiffer.

MASLOW, A.H. (1943). «A Theory of Human Motivation» en Psychological Review (1943, Vol. 50, n4, pp. 370-396).

MAY, D.R.; GILSON, R.L. \& HARTER, L.M. (2004). «The Psycological Conditions of Meaningfulness, Safety and Availability and the Engagement of the Human Spirit at Work» en Journal of Occupational and Organizational Psychology (2004, Vol. 77, nº1, pp. 11-37).

MC.GONIGAL, J. (2011). Reality is Broken. Why Games Make us Better and How the Can Change the World. London. Penguin Press, H.C.

MELONI, W. \& HIRMRT. W.M.R. (2012). Gamification in 2012. Market Update. Consumer and Enterprise Market Trends. http://goo.gl/75Ph5. [Consulta: 29 de abril de 2014].

PÉREZ, O. (2012). «El Valor del Juego. Ludificación en la Narrativa Audiovisual Contemporánea» en TELOS Revista de Pensamiento sobre Comunicación, Tecnología y Sociedad (2012, Diciembre, n93, pp. 23-33).

REISS, S. (2004). «Multifaceted Nature of Intrinsic Motivation: The Theory of 16 Basic Desires» en Review of General Psychology (2004, Vol. 8, n³, pp. 179-193). 


\title{
Bolonya, millora els resultats? Comparació de la metodologia docent dins d'una mateixa assignatura
}

Maria Teresa Montañés, Rita Sánchez-Tovar

Departament d'Enginyeria Química i Nuclear. Universitat Politècnica de València. Camí de Vera, s/n. 46022 València, Espanya. Telèfon: 963879637. Fax: 963877639. tmontane@iqn.es.

\begin{abstract}
After four years of implementation of the Bologna Process in Industrial Technology Degree, the aim of this study is to evaluate the success of the plan and teaching methodology used in the course Environmental Technology (existing as well in old plan Industrial Engineering). Some of the innovations are a direct result of adaptation to the Bologna Process, such as restructuring the content and the new way of assessing students. However, to give effect to the principles of the Bologna Process, it was necessary to introduce other innovations. Since the objectives of the course remains the same, and as the number of contact hours is lower now, we had to introduce some mechanism to motivate students to work at home additionally. Thus, the main innovation introduced in this course is to raise an exercise at the beginning of each teaching units that can solve them by introducing the concepts that they go to class. According to the analyzed results, we can conclude that the new teaching method has enabled more students pass the course. In addition, you get the course approved by the student having a more complete knowledge of all this and not just some specific issues.
\end{abstract}

Keywords: methodology, evaluation, Bologna.

\footnotetext{
Resum

Després de quatre anys d'implementació del Pla Bolonya al Grau en Enginyeria en Tecnologies Industrials, l'objectiu d'aquest estudi és avaluar l'èxit del pla $i$ la metodologia docent utilitzada dins de l'assignatura Tecnologia del Medi Ambient (també existent al pla antic Enginyeria Industrial). Algunes de les innovacions introduïdes són conseqüència directa de l'adaptació al Pla Bolonya, com ara la reestructuració dels continguts i la
}

(c) EY-NC-ND 2014, Universitat Politècnica de València

I Jornadas In-Red (2014) 
Bolonya, millora els resultats? Comparació de la metodologia docent dins d'una mateixa assignatura.

nova forma d'avaluar l'alumne. Tanmateix, per fer efectius els principis del Pla Bolonya, calia introduir-hi altres innovacions. Atès que els objectius de l'assignatura continuen sent els mateixos, i com que ara el nombre d'hores presencials és inferior, s'hi havia d'introduir algun mecanisme per motivar els alumnes a treballar a casa de forma addicional. Així, la principal innovació introduïda a l'assignatura és plantejar un exercici a l'inici de cadascuna de les unitats didàctiques perquè ells el puguen resoldre segons es vagen introduint els conceptes a l'aula. D'acord amb els resultats analitzats, es pot concloure que la nova metodologia docent ha permès que més alumnes aproven l'assignatura. A més, s'aconsegueix que l'alumne aprove l'assignatura tenint un coneixement més complet del conjunt d'aquesta $i$ no només d'alguns temes determinats.

Paraules clau: metodologia, avaluació, Bolonya.

\section{Introducció}

Després de la Declaració de la Sorbona en 1998, signada pels ministres d'Educació de França, Alemanya, Itàlia i el Regne Unit, vint-i-cinc països europeus més van ratificar la declaració de Bolonya l'any 1999. El Procés de Bolonya constitueix una reforma dels sistemes d'educació superior en vint-i-nou països de la Unió Europea.

\subsection{Objectius del Pla de Bolonya}

El principal objectiu del Procés de Bolonya és dur a terme una profunda reforma del sistema universitari a Europa, per mitjà de la construcció del denominat Espai Europeu d'Educació Superior (EEES), dissenyat a partir del model anglosaxó i organitzat, segons el mateix tractat, tenint en compte principis de qualitat, mobilitat, diversitat i competitivitat. En aquest sentit, el Pla pretén aconseguir, entre altres coses, la total mobilitat estudiantil dins del continent i l'homogeneïtzació dels estudis superiors a Europa, per a posar fi a l'actual laberint de convalidacions. Es pretén així mateix aconseguir un sistema d'educació superior competitiu, atractiu per a la resta del món, i que atraga estudiants i investigadors d'altres països, com també adequar els ensenyaments a les necessitats del mercat laboral. En general, es busca el concepte d'educació al llarg de tota la vida (lifelong learning, en anglès), en un procés permanent d'interacció entre formació i treball, i un canvi en els mètodes d'ensenyament, amb una atenció més individualitzada a l'alumne (més tutories i

(cc) EY-NC-ND 2014, Universitat Politècnica de València

I Jornadas IN-RED (2014) 
treball personal, menys classes tradicionals). El fi últim és incrementar l'ocupació a la Unió Europea (Fernández Liria i Serrano García, 2009).

\subsection{Principis del Pla de Bolonya}

En el Pla de Bolonya, el crèdit es constitueix en la unitat de mesura acadèmica en els ensenyaments universitaris oficials, juntament amb l'anomenat suplement al títol (o suplement de diploma, SD), un document adjunt al títol que facilita el reconeixement acadèmic i professional de les qualificacions obtingudes. En general, totes les carreres tindran una formació inicial de 240 crèdits, equivalents a Espanya a quatre anys (més temps en el cas d'algunes carreres, com ara Arquitectura o Medicina). Amb aquest primer nivell d'estudis s'obtindrà el títol de llicenciat, enginyer o arquitecte (Montoro Curiel, 2010).

Es destaca que en el Pla de Bolonya compten no sols les hores de classes teòriques (les impartides pel professor i les hores d'examen), sinó també el treball que ha de dur a terme l'alumne (elaboració de treballs, seminaris, hores d'estudi). En termes generals, els estudiants han de fer més pràctiques i tenir un paper més actiu. Cada crèdit ECTS (sistema europeu de transferència de crèdits, per les sigles en anglès) correspon a un nombre d'hores setmanals entre 25 i 30 , de les quals tan sols 10 seran lectives. Els crèdits s'annexen al títol, on a més es descriuen els estudis cursats per fer possible l'homologació a Europa. Amb això, i amb l'experiència prèvia del Programa Erasmus, es pretén afavorir la mobilitat estudiantil i laboral.

El sistema de titulacions està estructurat en dos cicles: grau, d'educació més generalista, i postgrau, d'educació especialitzada. L'accés al segon cicle requereix haver completat amb èxit el primer cicle en un període mínim de tres anys (a Espanya, llevat d'excepcions, quatre). Amb el segon cicle s'obté el grau de mestria (màster) i/o doctor (doctorat).

\subsection{Avantatges i inconvenients del Pla de Bolonya}

Els detractors del Pla Bolonya destaquen que, en la pràctica, el sistema de crèdits introduït equipara l'horari estudiantil a un horari laboral, a causa de l'augment d'hores obligatòries, i impedeix compaginar els estudis amb una feina. Respecte a les noves titulacions, els que s'oposen al Pla denuncien que l'increment de les despeses econòmiques necessàries per a obtenir les de segon cicle es traduirà en una elitització de la universitat, ja que no tots els estudiants s'ho podran permetre. En aquest sentit, assenyalen que deixaran d'existir les beques actuals, que seran substituïdes per les anomenades beques préstecs (préstecs bancaris que cal tornar amb interessos). També critiquen que el títol de grau serà comparable a l'actual FP i que suposarà una formació bàsica i poc especialitzada encaminada a l'obtenció de treballadors precaris. Es critica també que les carreres que

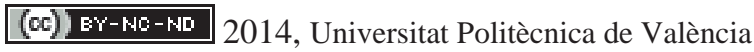

I Jornadas IN-RED (2014) 
Bolonya, millora els resultats? Comparació de la metodologia docent dins d'una mateixa assignatura.

s'impartisquen en les universitats estaran a partir d'ara basades en criteris de pura rendibilitat, que establirà l'Agència d'Avaluació Nacional de Qualitat i Acreditació (ANECA), fet que comportarà la marginació de les carreres menys tècniques o pràctiques. Alguns crítics han assenyalat també el fet que, més enllà de gaudir d'una beca Erasmus d'un any, a Espanya el nombre d'alumnes que vol estudiar, o treballar després, en altres països no és prou gran per a justificar una reforma d'aquestes dimensions. També s'ha denunciat que el Pla es va aprovar sense el necessari debat públic previ (Arriazu Muñoz, 2013).

Els defensors del Pla Bolonya sostenen que aquest millorarà les eixides laborals dels universitaris, ja que els títols estaran reconeguts en tots els països signants, i els nous plans d'estudis estaran més orientats a la formació de professionals que demana la societat, amb una major especialització. Respecte al sistema de crèdits, consideren que organitza d'una manera més real el temps dels estudiants, establint límits d'hores i creant la possibilitat d'estudiar a temps parcial per a poder treballar, matriculant-se en menys crèdits. També defenen que es valore més el treball global de l'alumne i la seua iniciativa que simplement el fet d'assistir a classes magistrals. Així mateix, argumenten que el sistema de grau i postgrau és el que funciona actualment en la majoria dels països del món. Bàsicament, els defensors del Pla entenen que es tracta d'una aposta estratègica a mitjà i llarg termini per a millorar la societat europea en conjunt a través de la creació d'ocupació, i per mitjà d'un sistema universitari més racional i universal. La nova societat europea, entenen, necessita universitaris formats més d'acord amb les necessitats laborals actuals, més adaptables i més disposats a canviar de lloc de treball i de residència (Arriazu Muñoz, 2013; Fernández Liria i Serrano García, 2009; Montoro Curiel, 2010).

\section{Objectius}

El Pla de Bolonya s'instaurà per reformar el sistema universitari a Europa mitjançant l'espai europeu d'educació superior. Després de quatre anys d'implementació del Pla Bolonya al Grau en Enginyeria en Tecnologies Industrials, l'objectiu d'aquest estudi és avaluar l'èxit del pla i la metodologia docent utilitzada dins de l'assignatura Tecnologia del Medi Ambient (denominada al pla antic Enginyeria Industrial, Ciència i Tecnologia del Medi Ambient). Cal destacar que per a efectuar la comparativa s'ha escollit una assignatura el contingut conceptual i el professorat de la qual és el mateix abans i després de la implementació del Pla Bolonya, i les variacions introduïdes només fan referència a la metodologia docent aplicada. 


\section{Desenvolupament de la innovació}

\subsection{Descripció de l’assignatura abans del Pla Bolonya}

L'assignatura Ciència i Tecnologia del Medi Ambient s'impartia dins de la titulació Enginyeria Industrial, constituïda per un total de 5 cursos acadèmics. Aquesta era una assignatura troncal de quart curs corresponent al primer quadrimestre, la qual s'ha impartit durant quasi 15 anys, des del curs 1995-1996 fins al curs 2012-2013. Aquesta assignatura suposava un total de 6 crèdits, dels quals 4,8 corresponien a teoria més pràctica d'aula, i els 1,2 crèdits restants corresponien a pràctiques. Això implicava una cadència de 4 hores setmanals distribuïdes en 2 sessions per setmana de 2 hores amb un descans d'uns 10 minuts de durada, al llarg de 12 setmanes lectives. A banda, l'alumne havia d'efectuar un total de 3 sessions pràctiques de 4 hores de durada cadascuna, les quals, a diferència de les sessions d'aula, no tenien un horari preestablert, amb la dificultat d'organització que això comportava. Les sessions pràctiques consistien en una pràctica de laboratori, una pràctica a l'aula informàtica i una pràctica de camp, en què s'efectuava una visita a una instal·lació relacionada amb l'assignatura.

L'avaluació de l'assignatura s'efectuava mitjançant una prova escrita, que englobava tots els continguts de l'assignatura, i els informes que elaboraven els alumnes de les pràctiques. La prova escrita consistia en 12 qüestions de resposta oberta que abastaven tot el temari (distribuïdes proporcionalment segons l'extensió dels temes) i un total de 3 problemes de càlcul. L'alumne podia efectuar aquesta prova escrita en acabar el primer quadrimestre, i si no s'hi presentava o no la superava, tenia l'opció d'efectuar-la en acabar el segon quadrimestre, és a dir, uns 6 mesos després.

La nota final de l'assignatura es calculava de la manera següent: el $15 \%$ corresponia a la nota dels informes de les pràctiques i el $85 \%$ restant corresponia a la nota de la prova escrita (en què el 65\% de la nota corresponia a les qüestions i el 35\% als problemes).

\subsection{Descripció de l'assignatura després del Pla Bolonya}

Amb l'adaptació al Pla Bolonya, l'anterior titulació Enginyeria Industrial s'ha transformat en el Grau en Enginyeria en Tecnologies Industrials (constituït per un total de 4 cursos acadèmics) més un Màster Universitari en Enginyeria Industrial (constituït per 2 cursos acadèmics). A més, l'antiga assignatura Ciència i Tecnologia del Medi Ambient ha passat a anomenar-se Tecnologia del Medi Ambient i ha experimentat alguns canvis.

(cc) EY-NC-ND 2014, Universitat Politècnica de València

I Jornadas IN-RED (2014) 
Bolonya, millora els resultats? Comparació de la metodologia docent dins d'una mateixa assignatura.

L'assignatura Tecnologia del Medi Ambient del Grau en Enginyeria en Tecnologies Industrials és una assignatura obligatòria de tercer curs corresponent al primer semestre. Això implica que els alumnes que la cursen, en general, tenen un any menys; tanmateix, no s'han observat diferències significatives al respecte. Actualment, aquesta assignatura ja s'ha impartit durant 2 anys, des del curs 2012-2013 fins al curs actual. Aquesta assignatura suposa un total de 4,5 crèdits ECTS, dels quals 3,6 corresponen a teoria més pràctica d'aula, i els 0,9 restants corresponen a pràctiques. Això implica una cadència de 3 hores setmanals distribuïdes en 2 sessions per setmana d'1 hora i mitja de durada, en les quals s'ha suprimit el descans que s'efectuava, i tot això al llarg de 12 setmanes lectives. Així, en reduir les hores presencials, l'alumne posseeix un temps addicional per repassar i preparar l'assignatura fora de l'aula d'acord amb els principis del Pla Bolonya.

A més, l'alumne ha d'efectuar un total de 4 sessions pràctiques de 2 hores i 15 minuts de durada cadascuna, les quals ara sí que tenen un horari preestablert (d'aquesta manera el problema de l'organització queda solucionat). Es tracta de dues sessions de laboratori i dues sessions a l'aula informàtica. Així, com es pot veure, s'ha duplicat el nombre de pràctiques, tant informàtiques com de laboratori, per poder avaluar de forma més precisa, a més dels coneixements adquirits pels alumnes, les seues habilitats i destreses. Això ha suposat una adaptació de les pràctiques antigues, en haver de suprimir alguns assajos de llarga durada i introduir-ne de nous adaptats al temps disponible. Per una altra banda, com a resposta a l'interès de l'alumnat, s'ha mantingut la sessió durant la qual es realitzava una visita a una empresa del sector mediambiental, però, actualment, es tracta d'una visita de caràcter opcional fora de l'horari preestablert. En aquest sentit, l'experiència ha estat positiva, ja que gran part de l'alumnat ha efectuat la visita proposada.

Taula 2. Comparació dels crèdits de l'assignatura abans i després del Pla Bolonya

\begin{tabular}{ccc}
\hline $\begin{array}{c}\text { Distribució de } \\
\text { crèdits }\end{array}$ & $\begin{array}{c}\text { Abans del } \\
\text { Pla Bolonya }\end{array}$ & $\begin{array}{c}\text { Després del } \\
\text { Pla Bolonya }\end{array}$ \\
\hline Aula & 4,8 & 3,6 \\
Pràctiques & 1,2 & 0,9 \\
\hline TOTAL & 6,0 & 4,5 ECTS \\
\hline
\end{tabular}

La forma d'avaluació s'ha adaptat al Pla Bolonya, de manera que es té una retroalimentació contínua amb l'alumne i el professor coneix els punts forts i febles de la classe, de tal manera que s'hi poden introduir a temps les millores o els conceptes que es consideren més 
oportuns. Així, l'alumne efectua dues proves escrites i ha d'elaborar un informe de cadascuna de les pràctiques. Les proves escrites consisteixen en 6 qüestions de resposta oberta i 1 o 2 problemes de càlcul, depenent de la prova. L'alumne efectua la primera prova després de les 6 primeres setmanes lectives i la segona prova després de les altres 6 setmanes. Si l'alumne no s'hi presenta o no supera alguna de les dues proves escrites, té l'opció d'efectuar-les en acabar el primer semestre i abans de començar el segon (unes dues setmanes després de la segona prova).

Aquest nou sistema d'avaluació ha implicat haver de fer una reestructuració de l'assignatura, per poder dividir els continguts en dues parts diferenciades i coherents. Així, els temes s'han agrupat en 4 unitats didàctiques: contaminació d'aigües, contaminació atmosfèrica, residus, i prevenció i control integrats de la contaminació, per tal que els alumnes es preparen 2 unitats per cadascun dels parcials.

La nova temporalització de les proves escrites comporta una sèrie d'avantatges, però també alguns inconvenients. L'estructura actual obliga l'alumne a dur al dia l'assignatura, la qual cosa és coherent amb els principis del Pla Bolonya. A més, això els ajuda a seguir les explicacions de l'aula amb major fluïdesa i això es reflecteix en una major interacció alumne-professor dins de l'aula. Ara bé, atès el nombre d'alumnes (uns 350), la situació resulta un poc més estressant per al professor, de cara a la correcció de les proves escrites, a causa del poc de temps que hi ha entre la segona prova i l'examen final.

La nota final de l'assignatura es calcula de així: un 20\% correspon a la nota dels informes de les pràctiques, un $40 \%$ a la nota de la primera prova escrita i el $40 \%$ restant correspon a la segona prova escrita. A la primera prova escrita, un $75 \%$ de la nota correspon a les qüestions i el $25 \%$ restant al problema de càlcul; a la segona prova escrita, un $65 \%$ de la nota correspon a les qüestions i el $35 \%$ restant als dos problemes de càlcul.

Taula 3. Comparació del sistema d'avaluació de l'assignatura abans i després del Pla Bolonya

\begin{tabular}{ccccc}
\hline \multirow{2}{*}{$\begin{array}{c}\text { Actes } \\
\text { d'avaluació }\end{array}$} & \multicolumn{2}{c}{ Abans del Pla Bolonya } & \multicolumn{2}{c}{ Després del Pla Bolonya } \\
\cline { 2 - 5 } & Nombre & $\%$ nota final & Nombre & $\%$ nota final \\
\hline $\begin{array}{c}\text { Prova escrita de } \\
\text { resposta oberta }\end{array}$ & 1 & 85 & 2 & 80 \\
$\begin{array}{c}\text { Informes de les } \\
\text { pràctiques }\end{array}$ & 2 & 15 & 4 & 20 \\
\hline
\end{tabular}

(cc)) EY-NC-ND 2014, Universitat Politècnica de València

I Jornadas IN-RED (2014) 
Bolonya, millora els resultats? Comparació de la metodologia docent dins d'una mateixa assignatura.

\subsection{Innovacions introduïdes}

Algunes de les innovacions introduïdes són conseqüència directa de l'adaptació al Pla Bolonya i ja han sigut descrites abans, com és el cas de la reestructuració dels continguts i de les pràctiques, i la nova forma d'avaluar l'alumne. Tanmateix, perquè aquesta adaptació no fóra només això, per fer efectius els principis del Pla Bolonya, calia introduir altres innovacions a l'assignatura.

Atès que els objectius de l'assignatura són els mateixos, abans i després del Pla Bolonya, i com que el nombre d'hores presencials és inferior, calia introduir-hi algun mecanisme per motivar els alumnes a treballar a casa de forma addicional. Així, la principal innovació que s'ha introduït a l'assignatura és plantejar un exercici a l'inici de cadascuna de les unitats didàctiques perquè ells el puguen resoldre segons es vagen introduint els conceptes a l'aula.

A la figura 1 es mostra un exemple d'un dels exercicis plantejats, concretament el corresponent a la primera unitat didàctica. A l'enunciat de l'exercici s'utilitza vocabulari i conceptes que l'alumne encara no coneix. D'aquesta manera es pretén motivar l'alumne perquè comence a investigar pel seu compte el significat del vocabulari específic de l'assignatura i, a més, estiga pendent de les explicacions que es faran més endavant a l'aula. Amb l'exercici plantejat també es vol presentar l'alumne quins són els coneixements que es pretén que adquirisca en finalitzar la unitat temàtica. Per una altra banda, es vol que l'alumne treballe i consulte informació actualitzada, en aquest cas, de les estacions depuradores d'aigües residuals (EDAR) de la Comunitat Valenciana. 


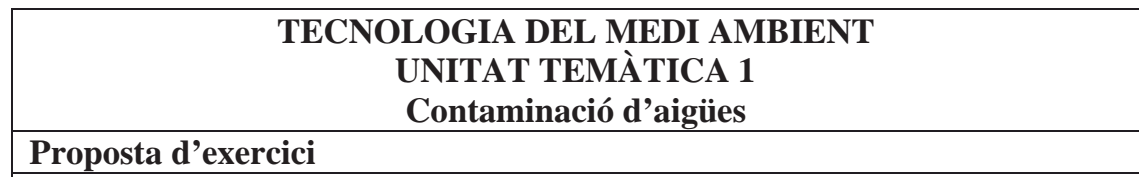

Entra a la pàgina web de l'Entitat de Sanejament d'Aigües (EPSAR; http://www.epsar.gva.es) i respon les qüestions següents:

1. Fes una ullada a les diverses EDAR que apareixen i indica quin és el sistema de tractament secundari més utilitzat a la línia d'aigües.

2. Fes una ullada a les diverses EDAR que apareixen i indica quin és el sistema de tractament de fangs més utilitzat.

3. Consulta l'EDAR de Gandia - la Safor:

a) Enumera els diferents elements/equips de l'EDAR.

b) Intenta identificar els diferents elements/equips a la fotografia que apareix de la vista aèria de l'EDAR.

c) Dibuixa l'esquema de la línia d'aigües mitjançant un diagrama de blocs. Assenyala a l'esquema totes les entrades i les eixides.

d) Dibuixa l'esquema de la línia de fangs mitjançant un diagrama de blocs. Assenyala a l'esquema totes les entrades i eixides.

e) Identifica tots els consums d'energia que es produeixen als elements/equips de l'EDAR.

f) Indica quins són els recursos que té l'EDAR per poder suplir part dels consums energètics que has identificat abans.

4. Busca una EDAR amb un tractament secundari diferent al de l'EDAR de Gandia - la Safor. Dibuixa l'esquema de la línia d'aigües mitjançant un diagrama de blocs. Assenyala les diferències respecte a l'altra EDAR.

5. Busca una EDAR amb un tractament de fangs diferent al de l'EDAR de Gandia - la Safor. Dibuixa l'esquema de la línia de fangs mitjançant un diagrama de blocs. Assenyala les diferències respecte a l'altra EDAR.

6. Busca una EDAR que dispose de tractament terciari a la línia d'aigües. Per què creus que necessitarà aplicar aquest tractament terciari?

7. Proposa un esquema per a una EDAR que ha de tractar una aigua residual amb les característiques següents: 100.000 he, 500 ppm de SS (dels quals el $10 \%$ són sedimentables), 2.000 ppm de $\mathrm{DBO}_{5}, 10.000 \mathrm{ppm}$ de DQO i un valor de $\mathrm{pH}$ igual a 4 . 
Bolonya, millora els resultats? Comparació de la metodologia docent dins d'una mateixa assignatura.

Fig. 1 Exemple d'exercici proposat a l'inici d'una unitat didàctica

\section{Resultats}

En aquest estudi s'han comparat les notes dels alumnes obtingudes durant els últims quatre anys de l'assignatura dins del pla antic amb les obtingudes als dos últims anys de la implementació del Pla Bolonya. La taula 3 mostra la distribució en \% de les notes finals dels alumnes (al pla antic s'han tingut en compte les dues convocatòries de manera conjunta). El nombre d'alumnes es troba estabilitzat al voltant de 350, independentment de si l'assignatura s'impartia abans o després del Pla Bolonya. L'excepció observada al curs 2012-2013 del pla antic, amb uns 500 alumnes, es deu al fet que aquest va ser l'últim any de l'assignatura amb docència; això va influir notablement en els resultats.

Taula 3. Notes finals dels alumnes en l'assignatura abans i després del Pla Bolonya

\begin{tabular}{ccccccc}
\hline \multirow{2}{*}{$\begin{array}{c}\text { Distribució de } \\
\text { notes (\%) }\end{array}$} & \multicolumn{5}{c}{$\begin{array}{c}\text { Abans del } \\
\text { Pla Bolonya }\end{array}$} & \multicolumn{2}{c}{$\begin{array}{c}\text { Després del } \\
\text { Pla Bolonya }\end{array}$} \\
\cline { 2 - 7 } & $2009 / 10$ & $2010 / 11$ & $2011 / 12$ & $2012 / 13$ & $2012 / 13$ & $2013 / 14$ \\
\hline Excel·lent & 3,44 & 3,48 & 2,93 & 2,77 & 5,2 & 4,61 \\
Notable & 21,56 & 25,22 & 29,64 & 29,5 & 50,15 & 37,75 \\
Aprovat & 51,88 & 49,86 & 49,51 & 36,04 & 33,03 & 39,77 \\
Suspès & 21,56 & 21,16 & 13,36 & 30,1 & 6,73 & 8,65 \\
No presentat & 1,56 & 0,29 & 4,56 & 1,58 & 4,89 & 9,22 \\
\hline $\begin{array}{c}\text { Nombre } \\
\text { d'alumnes }\end{array}$ & 323 & 351 & 339 & 506 & 353 & 338 \\
\hline
\end{tabular}

Amb els resultats de la taula 3 s'ha calculat la mitjana de 3 cursos abans del Pla Bolonya (no s'han tingut en compte les dades anormals del curs 2012-2013) i dels 2 cursos després del Pla Bolonya. Així, abans del Pla Bolonya, els resultats mostren un 3,28\% d'excel-lents, un $25,47 \%$ de notables, un $50,42 \%$ d'aprovats, un $18,69 \%$ de suspesos i un $2,14 \%$ de no presentats. En canvi, després del Pla Bolonya, els resultats han passat a ser un 4,91\% 
d'excel-lents, un $43,95 \%$ de notables, un $36,40 \%$ d'aprovats, un $7,69 \%$ de suspesos i un $7,06 \%$ de no presentats.

D'acord amb els resultats, sembla que amb el Pla Bolonya el nombre de suspesos ha disminuït aproximadament un $10 \%$, i a més s'hi ha produït un desplaçament d'un $10 \%$ de les notes dels alumnes d'aprovat a notable. Per això, es pot concloure que la metodologia docent utilitzada ha permès que més alumnes aproven l'assignatura i els coneixements d'aquesta siguin superiors.

Un paràmetre que pot donar una idea del seguiment de l'assignatura per part de l'alumne és el nombre d'alumnes que no es presenten als exàmens. Amb el pla antic, quan l'alumne s'havia d'examinar de tota l'assignatura en una única prova escrita amb dues oportunitats, el percentatge d'alumnes no presentats a la convocatòria ordinària era d'una mitjana del $45 \%$, un valor prou elevat. Això és un indicador del fet que gran part de l'alumnat no portava l'assignatura al dia. Després, a la convocatòria extraordinària, el percentatge de no presentats baixava al 30\% (valor calculat respecte als presentables en aquesta segona convocatòria), però fins i tot així és un valor relativament elevat. En canvi, amb el pla nou els percentatges de no presentats es redueixen substancialment. Tant al primer com al segon parcial, els alumnes no presentats només suposen un 11\%, la qual cosa pot indicar que el seguiment diari de l'assignatura per part dels alumnes és major.

Per acabar, es pot afirmar que els coneixements adquirits pels alumnes amb el pla nou és major. L'anàlisi de les notes així ho ha demostrat, però no només per això. Cal indicar que amb el pla vell, en examinar-se de tot el temari amb una única prova escrita, hi havia molts alumnes que es preparaven només alguns temes i se'n deixaven altres sense estudiar. La prova està en el fet que molts es deixaven en blanc les preguntes corresponents als últims temes i, fins i tot així, podien aprovar. En canvi, amb el pla nou, això no és possible. Com que hi ha dues proves escrites diferenciades, cal estudiar tot el temari per poder aprovar l'assignatura. Per tant, es pot concloure que l'alumne adquireix un coneixement més complet de l'assignatura.

\section{Conclusions}

D'acord amb els resultats analitzats, es pot concloure que la metodologia docent utilitzada en l'assignatura Tecnologia del Medi Ambient després d'adaptar-la al Pla de Bolonya ha permès que més alumnes aproven l'assignatura i que els coneixements adquirits d'aquesta siguen superiors. A més, amb aquesta nova metodologia s'aconsegueix que l'alumne aprove l'assignatura tenint un coneixement més complet del conjunt d'aquesta i no només d'alguns temes determinats, que en un examen global de l'assignatura podrien arribar a sumar un $50 \%$.

\section{(cc) EY-NC-ND 2014, Universitat Politècnica de València}


Bolonya, millora els resultats? Comparació de la metodologia docent dins d'una mateixa assignatura.

Agraïments: els autors volem expressar el nostre agraïment al Servei de Promoció i Normalització Lingüística de la Universitat Politècnica de València per la revisió efectuada d'aquest treball.

\section{Referències}

ARRIAZU MUÑOZ, R. (2013). La adaptación del Plan Bolonia en las aulas. Una perspectiva histórica y crítica para entender las claves y estrategias de las universidades españolas. Barcelona: Editorial Octaedro SL.

FERNÁNDEZ LIRIA, C. i SERRANO GARCÍA, C. (2009), El plan Bolonia. Madrid: Los libros de la Catarata.

MONTERO CURIEL, M. (2010). "El Proceso de Bolonia y las nuevas competencias" en Tejuelo, vol. 9, p. 19-37. 


\title{
La educación entre iguales a través de proyectos colaborativos 2.0
}

Wenceslao García Puchades ${ }^{\mathrm{a}}$

${ }^{a}$ Profesor asociado del Departamento de Comunicación Audiovisual, Documentación e Historia del Arte de la Universidad Politécnica de Valencia. E-mail: wengarpu@upv.es

\begin{abstract}
Through this propousal of educational innovation we have attempted to achieve that our students, with the excuse of carring out a collaborative research project about participative art through Web 2.0, experience the challenges of participating in a peer-to-peer community interaction. By offering an online environment as a common base and taking some premises from the pedagogy of peer tutoring, we have tried to make them explore diverse tools, skills and attitudes that allow them to be communicated and organized by themselves regardless of their individual and collective identity.
\end{abstract}

Keywords: inoperative community, peer tutoring, Jean-Luc Nancy, ignorant schoolmaster, E-learning

\begin{abstract}
Resumen
A través de la presente propuesta de innovación docente hemos tratado de conseguir que nuestro alumnado, con el pretexto de llevar a cabo un proyecto de investigación colaborativa sobre el arte participativo en la Web 2.0, vivenciara los retos que implica participar en una comunidad de interacción entre iguales. Ofreciéndoles como base el entorno online y haciendo uso de premisas pedagógicas derivadas de la tutorización entre pares, hemos intentado que explorasen diversas herramientas, habilidades y actitudes que les permitieran comunicarse y organizarse por sí mismos con independencia de su identidad individual o colectiva.
\end{abstract}

Palabras clave: comunidad desobrada, tutorización entre pares, Jean-Luc Nancy, maestro ignorante, Jacques Rancière, E-learning 


\section{Introducción}

La siguiente propuesta de innovación docente se enmarca dentro de la asignatura "Arte participativo: Creación compartida en la era de la Web 2.0", impartida en el Master de Producción Artística de la Facultad de Bellas Artes de San Carlos de la Universidad Politécnica de Valencia, y dentro del proyecto de investigación "El arte de la participación. El uso de las tecnologías de la información como herramienta de creación colectiva en el arte contemporáneo hispanoamericano" con número de referencia HAR2012-33154. Dicho proyecto de investigación aborda desde una perspectiva política algunos proyectos artísticos interesados en la construcción de nuevas formas de comunidades más igualitarias. Desde esta perspectiva estético-política hemos desarrollado la asignatura "Arte participativo". Dicha asignatura está constituida por un bloque práctico y téorico: En el primero los alumnos aprenden diferentes estrategias para construir su propia plataforma online y buscar así diversos tipos de colaboraciones -crowdfunding y crowdsourcinghaciendo buen uso de las redes sociales; en el segundo, los alumnos analizan desde el plano de la filosofía política las nuevas formas de comunidad que se están generando en el ámbito del arte participativo 2.0. Desde nuestro punto de vista, dichas formas de colaboración online ponen en práctica aquello que el filósofo francés Jean-Luc Nancy denominó con el término de "comunidad desobrada" (Nancy, 2001). La "comunidad desobrada" nombra la igual capacidad de los individuos para interactuar con otros individuos cualesquiera a la hora de llevar a cabo un proyecto común. Nuestra innovación docente pretende experimentar esta hipótesis. Ubicados en el ámbito de la enseñanza de la filosofía política, nuestra intención es transmitir el concepto de "comunidad desobrada", no desde una perspectiva teórica, sino práctica. Así, con la excusa de un proyecto de investigación colaborativa sobre el arte participativo en la Web 2.0, nuestros alumnos vivenciarán los retos que implica participar en una comunidad de interacción entre iguales.

Ahora bien, ¿cuál es la metodología docente más coherente para llevar a cabo esta tarea? Con otras palabras, ¿cómo conseguir que la enseñanza del maestro no contradiga la comunidad igualitaria que los alumnos pretenden experimentar? Mediante la educación entre iguales. En ella el maestro debe delegar la responsabilidad de llevar a cabo su proyecto en los propios alumnos, de manera que cada uno de ellos se convierte en tutor de cada uno de sus compañeros. Esto implica que cualquiera de los alumnos pueda evaluar el trabajo realizado por sus compañeros. Sin embargo, para garantizar las premisas igualitarias de la situación educativa, es necesario que todas las evaluaciones estén referenciadas a una información compartida, de manera que todos tengan acceso a ella. Por esta razón consideramos que el aprendizaje colaborativo asistido por ordenador (Computer Supported Collaborative Learning) es la metodología docente que más podría favorecer la educación entre iguales. Gracias a los recursos informáticos los alumnos tendrían acceso a un espacio 
compartido que hace posible que cualquiera evalúe el trabajo de un compañero refiriéndolo a una información accesible.

En el siguiente documento describiremos cómo se ha desarrollado esta experiencia en la asignatura de "Arte y participación" del curso 2013-14. Antes de realizar dicha descripción argumentaremos los principios igualitarios sobre los que se sostiene la "comunidad desobrada" teorizada por el filósofo Jean-Luc Nancy. Posteriormente trataremos de justificar por qué un entorno colaborativo asistido por ordenador es el más adecuado para experimentar dicha comunidad. Finalmente describiremos cómo se ha llevado a cabo nuestra experiencia y los resultados obtenidos.

\section{Marco conceptual}

El concepto de "comunidad" está nuevamente de moda. Los avances en las tecnologías aplicadas a la comunicación han favorecido la aparición de nuevas formas de experimentar nuestro "ser-juntos" que nos hacen replantear las discusiones acerca del concepto de "comunidad". Hasta el momento muchas de estas experiencias del "en-común" se fundamentaban en una serie de "lazos comunes" -étnicos, nacionales, ideológicos, sindicales, etc.- que diferenciaban a las diferentes comunidades entre sí (Wilson, 2006; Anderson, 1991). Sin embargo, hoy en día, las formas inteligibles que antes parecían garantizarnos un contorno común, estable y duradero han entrado en colapso. La causa de esta crisis reside, en parte, en el carácter dinámico (líquido, diría Baumann) de nuestra sociedad global. En una sociedad como la actual, en la que las tecnologías hace que nada deje de moverse, tales formas se muestran como lo que son, "puro espectro" (Pelbart, 2009; Bauman, 2001).

A pesar de la crisis de las categorías transcendentales que antes daban forma a nuestras experiencias en común, algunos filósofos contemporáneos no han renunciado a cuestionarse cual es el significado de "comunidad" y han abordado dicho concepto desde el plano de la inmanencia (Lawlor, 2006; Blanchot, 2002; Agamben, 1996; Virno, 2003; Hardt y Negri, 2004). Pero quizás, haya sido el filósofo francés Jean-Luc Nancy uno de los teóricos que más ha pensado el carácter co-originario de la existencia humana (Nancy, 2006). En muchos de sus trabajos, Nancy denomina esta situación "en-común" o comunidad de la existencia como "comunidad desobrada" (Nancy, 2001). Esta comunidad de interacción existencial tiene tres características: 1) es independiente de los rasgos particulares (físicos, intelectuales, habilidades, etc.) de cada uno de sus individuos, ya que cualquiera es capaz de interactuar con cualquier otro con independencia de dichos rasgos; 2) es independiente de los rasgos del colectivo, ya que esta interacción se da con independencia de las propiedades comunes de sus componentes (etnia, ideología, hábitos sociales, etc.); y 3) es independiente de las características del sitio donde esta ubicada (nacionalidad, ciudadanía,

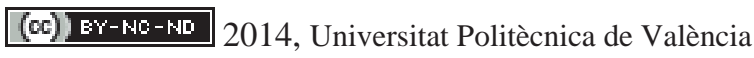

I Jornadas IN-RED (2014) 
etc.). Por tanto, podemos definir la comunidad desobrada como la condición de la existencia humana que posibilita que cualquier individuo pueda comunicarse con cualquier otro individuo sin estar determinado de manera previa por una identidad individual, colectiva o situacional.

Sin embargo, en nuestra opinión, lo realmente interesante del concepto de "comunidad desobrada" es que nos permite establecer las condiciones para pensar en la existencia de una comunidad de interacción entre iguales. La clave de esta igualdad se fundamentaría en el hecho de que, en ausencia de propiedades que los identifiquen como pertenecientes a un individuo, un colectivo o un lugar, sus miembros aparecerían como simples singularidades cualesquiera agrupadas en torno a un proyecto en común. Partiendo de este principio podemos deducir tres rasgos característicos de esta comunidad de comunicación entre iguales. El primero sería el carácter anónimo de sus individuos, en la medida en que éstos carecen de propiedades particulares que los identifiquen. El segundo sería su carácter abierto, en la medida en que carecería de una característica común que nos permita identificarla como un colectivo cerrado y, por tanto, excluyente. Y el tercero sería su carácter ubicuo, en la medida en que el colectivo se desarrollaría con independencia de su situación. Por tanto, por "comunidad desobrada" podemos entender una categoría existencial con la que Nancy pretende señalar la igual capacidad del ser humano para poder realizar proyectos en colaboración con otros de una manera anónima, abierta y ubicua.

\section{Objetivos}

Con nuestra propuesta didáctica pretendemos que nuestro alumnado experimente esta comunidad de interacción entre iguales. Para ello llevarán a cabo un proyecto de investigación colaborativo, relacionado con el arte participativo en la Web 2.0. Se trata, por tanto de conseguir que nuestros alumnos desarrollen la siguiente competencia:

- Aprender por sí mismos a experimentar habilidades y actitudes comunicativas que les permitan llevar a cabo un proyecto de investigación colaborativo a partir de premisas igualitarias basadas en el anonimato, la apertura y la ubicuidad.

Los objetivos generales que subyacen a dicha competencia podríamos enumerarlos como siguen:

- Aplicar herramientas colaborativas adecuadas para el desarrollo de la tarea

- Desarrollar habilidades organizativas que permitan realizar un proyecto colectivo entre iguales

- Adquirir valores individuales y colectivos que favorezca el trabajo colaborativo entre iguales: empatía, solidaridad, respecto, responsabilidad o iniciativa personal 


\section{Justificación metodológica}

En nuestra innovación docente la metodología empleada no debe contemplarse como un medio o instrumento para alcanzar los objetivos planteados, sino como un fin en sí mismo. Dado que la finalidad de nuestro propuesta es conseguir que los alumnos se experimenten a sí mismos como individuos capaces de relacionarse con cualquier otro individuo para llevar a cabo un proyecto colaborativo con independencia de sus identidades, el proceso de aprendizaje se convierte en elemento esencial de dicha experiencia.

El profesor, por tanto, debe posibilitar dicho proceso vivencial desde el comienzo. Para ello debe construir una situación de aprendizaje fundamentada en los principios igualitarios que lo caracterizan. Algunos pedagogos han denominado dicha situación con el término "tutorización entre iguales" (Peer tutoring). La tutorización entre iguales prove "a particular kind of community: that of status equals, or peers" (Bruffee, 1984, 92). Se trata, por tanto, de un tipo de aprendizaje colaborativo que permite que los estudiantes, organizándose por sí mismos, sean capaces de enseñarse entre ellos. El profesor no pretende enseñar nada a los alumnos, sino generar un contexto social en el que aprendan a aprender. La tutorización entre iguales ubica el proceso de enseñanza-aprendizaje en una calle de dos direcciones, en la medida en que un alumno-tutor enseña-aprende de otros alumnos-tutores atendiendo a las necesidades del grupo (Kunsch, Jitendra, \& Sood, 2007; Burnish, Fuchs \& Fuchs, 2005; Topping, 2008).

Para conseguir construir dicho contexto aprendizaje el profesor debería adoptar el rol de un "maestro ignorante" (Rancière, 2003). La figura del maestro ignorante tiene dos componentes: por un lado es maestro porque es el responsable de construir esta situación de enseñanza entre iguales; y por otro lado es ignorante, porque contesta con más preguntas las preguntas que les realizan sus alumnos (Freire y Faundez, 2013). Ahora bien en su obra, Rancière detalla cuales son las condiciones para construir esta situación didáctica. Para el filósofo francés, una situación de enseñanza entre iguales sólo es posible si existe un objeto compartido al que cualquiera de los participantes pueda acudir para corroborar las opiniones del resto de los participantes (Rancière, 2003). Desde nuestro punto de vista, el filósofo francés focaliza la cuestión de la enseñanza entre iguales en el objeto compartido. Todo proceso de enseñanza entre iguales requiere un objeto al que cualquiera pueda acceder de manera que nadie pueda enseñar nada a nadie sin una referencia compartida que haga objetiva su evaluación.

Pues bien, si aplicamos los postulados de Nancy acerca la "comunidad de interacción entre iguales" y de Rancière acerca el "maestro ignorante" a la tutorización entre iguales, podríamos sustraer unos principios sobre la construcción de situaciones de aprendizaje colaborativo basados en principios igualitarios. Así podríamos concluir que dicha situación

\section{(cc) EY-NC-ND 2014, Universitat Politècnica de València}

I Jornadas IN-RED (2014) 
de aprendizaje se fundamentaría en un objeto compartido por todos los alumnos con independencia de sus características individuales y colectivas y del lugar donde se encuentren. Una vez el maestro a construido dicha situación, los alumnos llevarían a cabo sus propios proyectos de investigación adoptando igualmente el rol de alumno o tutor de acuerdo a les necesidades que le vayan surgiendo. Eso sí, siempre con la condición de que todo lo que se diga pueda ser evaluado por cualquier de los participantes acudiendo al objeto compartido.

Desde nuestro punto de vista, las situaciones de aprendizaje colaborativo asistido por ordenador (Computer Supported Collaborative Learning - CSCL) se muestran como el marco educativo más adecuado para llevar a cabo este proceso de tutorización entre pares (Ehlers, 2007; Koschmann, 1996; Stahl, 2001). A través de este marco, el profesor puede construir un entorno que favorezca el aprendizaje colaborativo basado en los principios igualitarios nombrados anteriormente. Dicho entorno ofrece a todos los alumnos un objeto, a saber, la Web 2.0, que puede ser accesible a cualquiera con independencia de sus características individuales, colectivas y situacionales. A través de la Web 2.0, el profesor puede construir una situación de aprendizaje entre iguales que les permita llevar un proyecto de investigación colaborativo, bajo la condición de que todo lo que acontezca en dicho proyecto, sea accesible a todos los alumnos. Nuestra hipótesis es que gracias a esta situación los alumnos experimentarán qué es una comunidad desobrada, o lo que es lo mismo, la igual capacidad de los seres humanos para participar en un proyecto común más allá de identidades predeterminadas.

De esta manera, la evaluación de este proyecto consistirá en la observación del cumplimiento de dicha hipótesis. Para ello se observará si los alumnos han sido capaces de buscar de manera colectiva herramientas online que les permitan llevar a cabo su tarea, desarrollar habilidades comunicativas y organizativas que les permitan mantener un diálogo constante entre ellos y adquirir unas actitudes que favorezca dicho proceso colaborativo.

\section{Descripción de la experiencia docente}

Dicha experiencia de innovación docente en la Web 2.0 se ha llevado a cabo, tal y como hemos mencionado, en la asignatura "Arte participativo: Creación compartida en la era de la Web 2.0", impartida en el Master de Producción Artística de la Facultad de Bellas Artes de San Carlos de la Universidad Politécnica de Valencia. La experiencia se ha realizado en 5 sesiones de 3 horas cada una y en ella han participado 12 alumnos, cuyos perfiles académicos venían principalmente del ámbito de la creación artística y plástica.

El objetivo que nos planteamos consistía en que los alumnos fueran capaces de llevar a un proceso de investigación colaborativa en el que analizaran diferentes aspectos conceptuales 
relacionados con el arte participativo a través de la Web 2.0. El resultado final de dicha investigación debería quedar reflejado en un documento común. Ahora bien, dado que la metodología elegida es la tutorización entre pares asistida por ordenadores, tanto el proceso de investigación como su resultado final debería estar accesible a todos ellos en Internet. En ella, nuestros alumnos, deberían buscar no sólo la información que le permitera escribir el texto final, sino las herramientas organizativas adecuadas para llevarlo a cabo su tarea de manera colaborativa.

Nuestra tarea como maestros ignorantes sería doble: En tanto maestros instauramos las condiciones o premisas que delimitaban la situación de aprendizaje entre pares. Así les planteamos el objetivo del trabajo y compartimos con ellos las direcciones de correo de todos los alumnos que formaban parte del grupo. La situación de aprendizaje quedaba así definida por un espacio compartido asistido por ordenadores y unas identidades cualquiera. Por otro lado, en tanto que ignorantes, nuestra tarea consistía en facilitar su aprendizaje entre pares a través de la Web 2.0. Para ello simplemente nos limitamos a utilizar preguntas. Tal y como teorizan Freire y Faundez (2013), a través del uso continuo de preguntas pretendemos delegar la autoridad del proceso de enseñanza en los propios alumnos, quienes, en última instancia, serán quienes deben crear su propio camino de aprendizaje.

Para esta tarea realizamos un sencillo plan de previsión de preguntas de acuerdo a las fases básicas de las que consta un proceso de investigación, a saber: la elección del ámbito de estudio, la identificación de palabras claves, la formulación de la pregunta de la investigación, la recopilación y análisis de datos, la escritura del texto. Basándonos en dichas fases, formulamos diferentes preguntas con el objetivo de facilitar la realización estructurada de su proyecto. Las preguntas fueron las siguientes: ¿Seríais capaces de escribir un texto colaborativo sobre el "Arte participativo en la Web 2.0" haciendo uso de Internet y partiendo de esta lista de direcciones de email de vuestros compañeros de clase? ¿Qué instrumentos necesitaréis para comunicaros? ¿Qué palabras claves están relacionadas con dicho ámbito? ¿Qué herramienta necesitaríais para llevar a cabo esta tarea de brainstorming colectivo? ¿Podrías elaborar una pregunta que hiciera uso de al menos dos de estas palabras claves y que oriente vuestra investigación? ¿Qué herramienta online es útil para argumentar y tomar decisiones? ¿Qué herramienta es la más adecuada para recopilar información sobre un tema de manera colaborativa? ¿Qué herramienta es la más adecuada para escribir un texto de manera colaborativa?

\section{Resultados}

Tal y como hemos mencionado en los apartados anteriores la finalidad de esta propuesta docente era la transmisión del concepto político de "comunidad desobrada" o "comunidad

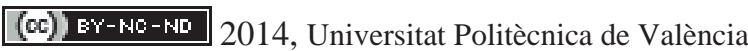

I Jornadas IN-RED (2014) 
de interacción entre iguales" a través de un proyecto de investigación colaborativa en la Web 2.0. Con ella pretendíamos que nuestro alumnado desarrollara ciertas competencias sociales que les permitieran organizarse de la manera más efectiva posible para llevar a cabo dicho proyecto. De igual manera hemos visto que el desarrollo de dichas competencias iban asociadas al aprendizaje de ciertas herramientas informáticas, la aplicación de habilidades comunicativas y organizativas, y el desarrollo de actitudes adecuadas.

El aprendizaje de dichas herramientas y la puesta en práctica de habilidades y actitudes colaborativas han sido facilitadas por diferentes preguntas que marcaron las diferentes fases de un proyecto de investigación. En lo referente al aprendizaje de herramientas colaborativas, cabe decir que a través de las dos primeras preguntas pretendíamos que los alumnos establecieran las bases de su entorno comunicativo online. Para ello buscaron plataformas que les permitieran conversar. Sus resultados los enviaron por email y la plataforma elegida fue "stinto.net" (fig. 1).

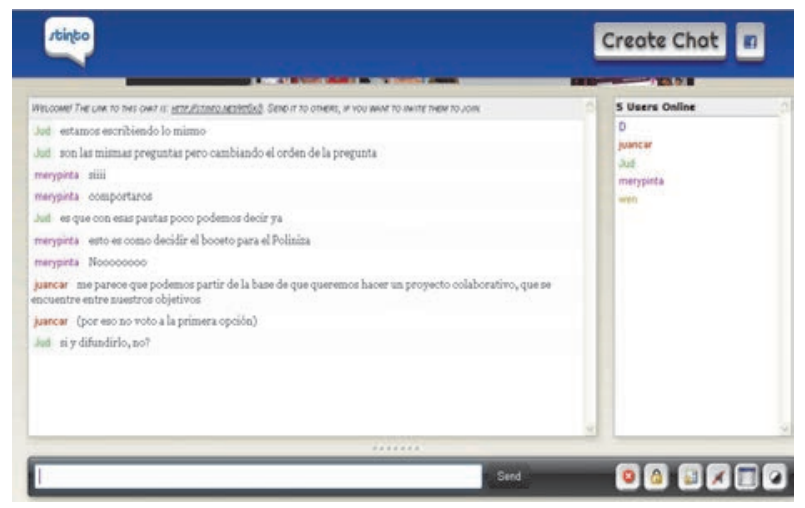

Fig. 1 Conversación en "stinto.net"

Una vez establecido dicho espacio les planteamos que buscaran palabras claves sobre el tema a estudiar. Para realizar dicha este brainstorming les pedimos que buscaran alguna herramienta colaborativa útil. Los alumnos decidieron utilizar "answergarden.ch" (fig. 2). 


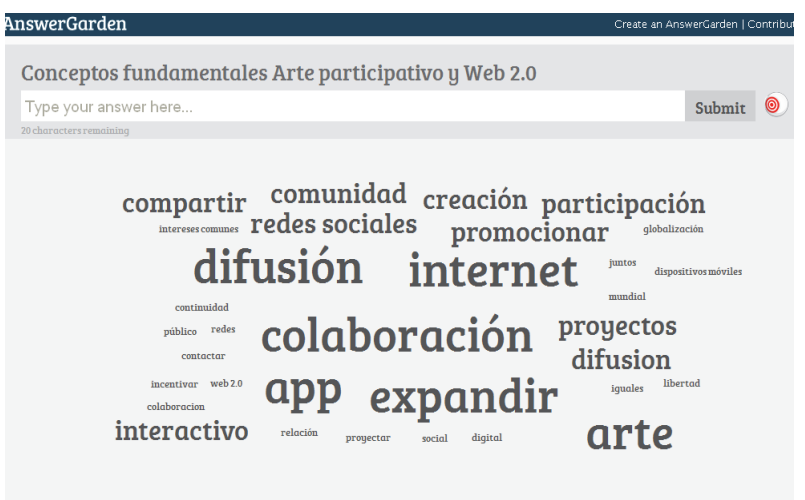

Fig. 2 Brainstorming en "answergarden.ch"

A continuación les propusimos que elaboraran la pregunta que iba a guiar su investigación. Dicha pregunta tenía que incluir dos de las palabras claves presentadas. Cada alumnos planteó su propia pregunta. Para poder decidir qué pregunta era la más adecuada les pedimos que buscaran una herramienta online que les permitiera tomar dicha decisión de manera argumentada. Tras un largo debate en el chat, la plataforma elegida fue "trider.com" (fig. 3).

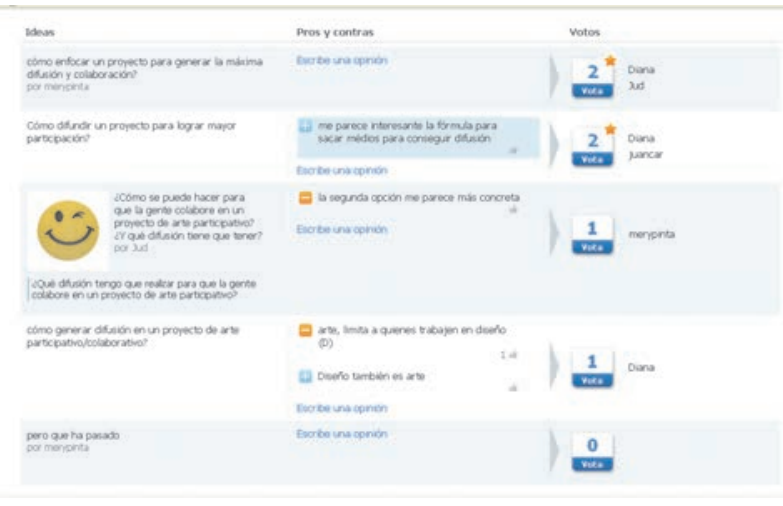

Fig. 3 Toma de decisiones en "tricider.com"

A través de dicha plataforma los alumnos decidieron la siguiente pregunta de la investigación: "¿Cómo enfocar un proyecto para generar la máxima difusión y colaboración?" Una vez descrita la pregunta se les preguntó si podrían encontrar algún espacio online que les permitieran compartir la información que iban encontrando en Internet sobre el tema. De entre varias plataformas existentes para esta tarea los alumnos eligieron "Mural.ly" (fig. 4), una pizarra colaborativa que permite ordenar de una manera visualmente atractiva diferentes documentos acerca un tema.

\section{(c) EY-NC-ND 2014, Universitat Politècnica de València}

I Jornadas IN-RED (2014) 


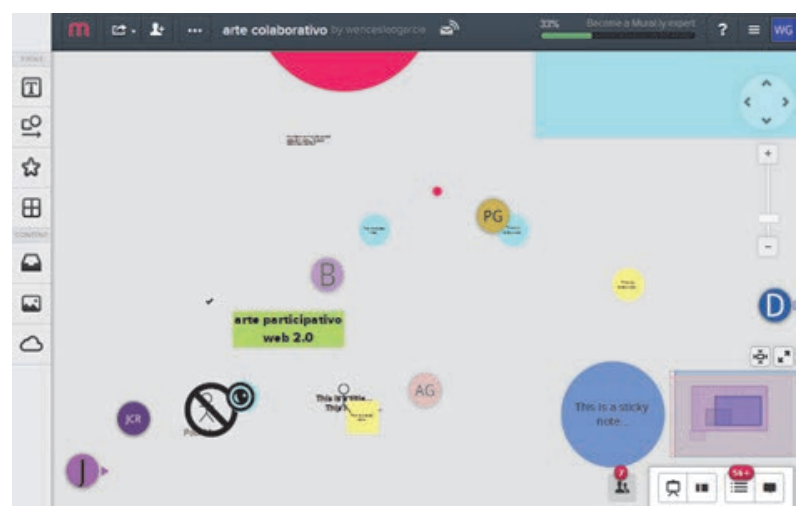

Fig. 4 Recopilar información en "mural.ly"

Finalmente se les pidió que escribieran un texto que respondiera a la pregunta que se habían planteado utilizando el material que habían compartido en el mural. Para ello se les pidió que buscaran una herramienta de escritura colaborativa online. Los alumnos eligieron "docs.google.com" (fig. 5).

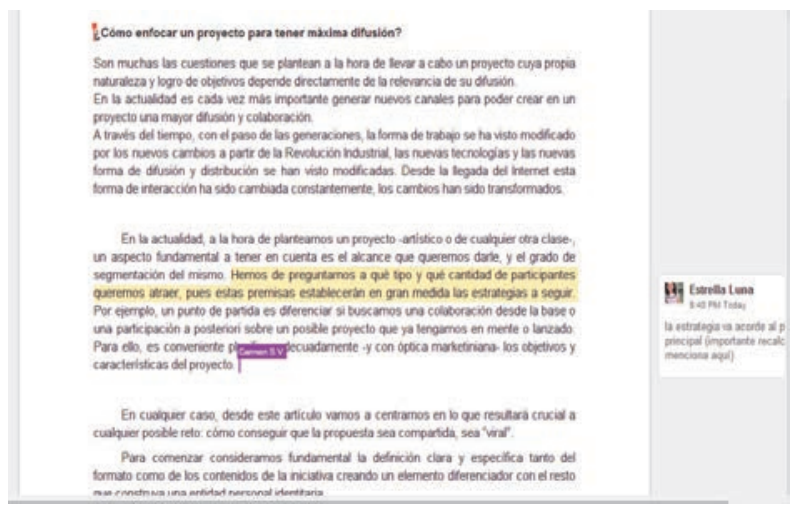

Fig. 5 Escritura colaborativa en "docs.google.com"

Más allá de la calidad del texto final, la experiencia fue interesante porque, a lo largo de todo el proyecto, los alumnos se vieron en la necesidad de desarrollar diferentes habilidades comunicativas y organizativas con independencia de las características individuales o colectivas del grupo. Cabe destacar las dificultades que tuvieron al comienzo de la experiencia antes de tener un espacio compartido para dialogar. La comunicación a través del correo electrónico ralentizó el comienzo del proyecto propiamente. Otro aspecto que realentizó el proceso fue el hecho de que los alumnos se pusieran de acuerdo sobre qué decisiones debían pasarse por la plataforma online de toma de decisión o qué decisiones se podían tomar en el propio chat. Por otro lado, en la tarea de construcción de un mural 
colaborativo, se identificaron diferentes ritmos y estrategias de trabajo diferente. Este hecho dio lugar a un mural fragmentado. En nuestra opinión, esta fragmentación se vio reflejada también en el texto escrito. Sin embargo su segmentación no fue únicamente debida al modo en que los alumnos elaboraron el mural, sino al modo en que se organizaron a la hora de escribir el texto. Al elegir repartirse el texto por apartados temáticas, perdieron de vista la coherencia global del argumento. Y todo ello a pesar de que había un encargado de su maquetación y de corrección ortográfica.

Finalmente, al acabar la experiencia colaborativa se le preguntó qué actitudes pensaban que resultaban necesarias para llevar a cabo con eficiencia dicho proyecto. Los alumnos destacaron que las actitudes más importantes para el desarrollo de dicha tarea son la empatía, la motivación individual y colectiva y la responsabilidad.

\section{Conclusiones}

Nos planteábamos al comenzar esta propuesta docente el reto de transmitir a nuestro alumnado la experiencia de participar en una "comunidad desobrada" o "comunidad de interacción entre iguales". Tras el estudio de algunos textos de filosofía política y pedagogía llegamos a la conclusión que dicha experiencia podría llevarse a cabo mediada por la realización de un proyecto colaborativo a través de la Web 2.0. Dicho proyecto posibilitaría que nuestro alumnado interactuara entre sí con independencia de la identidad individual o colectiva de sus participantes. Para ello se verían en la obligación de experimentar herramientas colaborativas online, poner en práctica habilidades comunicativas y organizativas, y desarrollar determinadas actitudes individuales y colectivas.

En primer lugar, cabe destacar que los alumnos han explorado la Red en busca de diferentes herramientas colaborativas que les permitieran llevar a cabo su proyecto. Sin embargo es importante destacar que muchos de ellos han tenido problemas a la hora de dominar la aplicación lo suficiente como para poder actuar con el resto en igual de condiciones. Esto condiciona ligeramente la situación igualitaria que pretendíamos instaurar desde el comienzo, ya que aquellos que tenían más solvencia en el uso de herramientas online adquieren rápidamente un rol dominante en el proyecto.

En segundo lugar, resulta interesante observar cómo los alumnos, inmersos en un contexto en el que de manera predeterminada no tienen referencia acerca de la identidad de sus colaboradores, se han visto obligados a atender al devenir del proyecto para organizarse. A lo largo de dicho proyecto fueron estudiando las características de los miembros de la comunidad: sus habilidades online, su iniciativa, su carácter mediador, etc. Podríamos decir que la identidad colectiva estaba determinaba por el desarrollo del proyecto. Dicha

\section{(c) EY-NC-ND 2014, Universitat Politècnica de València}

I Jornadas IN-RED (2014) 
identidad era una identidad abierta y flexible, ya que en la medida en que no se conocía el resultado final, dependía de cada una de las decisiones que iban tomando sus participantes. Por otro lado, existían las identidades individuales de los miembros de la comunidad. Estas identidades se fueron creando mediados por su actuación dentro de la propia comunidad. Se trataría de una identidad $a d-h o c$ en la medida en que sólo tenía sentido como participante dentro del proyecto compartido.

En tercer lugar, destacar el componente afectivo y actitudinal de dicha experiencia docente. De acuerdo a lo dicho por los propios alumnos, la empatía, la motivación y la responsabilidad, se muestran como actitudes fundamentales para llevar a cabo este proyecto. La empatía, o capacidad de ponerse en el lugar del otro, es requerida para afrontar los conflictos que surgen de la exigencia igualitaria de la interacción; la motivación, individual y colectiva, señalaría el interés o voluntad de cada uno de los participantes por colaborar en el proyecto; y finalmente, la responsabilidad, nombraría el compromiso voluntario de cada uno de los participantes con el proyecto colectivo.

Para acabar nos gustaría señalar una línea de trabajo futura que se deriva de esta experiencia docente. Nuestra intención es ampliar dicha experiencia al desarrollo de un proyecto cultural colaborativo a través de la Web 2.0. Para ello añadiríamos a la metodología del curso la técnica del puzle de Aronson. Así, en la primera parte del curso llevaríamos a cabo un proyecto colaborativo similar al que hemos realizado por el que se identificarían "expertos" de cada una de las fases de la elaboración de un proyecto de innovación. Estos "expertos" desarrollarían sus capacidades en la parte intermedia del curso. Así, en la parte final del curso regresarían a su grupo y llevarían a cabo el proyecto final con más conocimientos y habilidades de las que comenzaron.

\section{Bibliografía}

Agamben, G. (1996). La comunidad que viene, traducción por J. L. Villacañas y C. La Rocca, Valencia: Pretextos.

ANDERSON, B. (1991). Comunidades imaginadas. Reflexiones sobre el origen y la difusión del nacionalismo, traducido por E. L. Suárez. México: Fondo de Cultura Económica.

BADIOU, A. (2009). L’hypothèse communiste. París: Nouvelles Éditions Lignes.

Bauman, Z. (2001). Community. Seeking safety in an insecure World. Cambridge: Polity Press.

BLANCHOT, M. (2002). La comunidad inconfesable, traducción por I. Herrera. Madrid: Arena Libros. 
BURNISH, FUCHS \& FUCHS (2005). "Peer-assisted learning strategies: An evidence-based practice to promote reading achievement" en Learning Disabilities Research \& Practice, vol. 15 , núm. 2, pp. 85-91.

EHLERS, U. (2007). "A new pathway for e-learning: From distribution to collaboration and competence in e-learning" en AACE Journal, vol. 16, núm. 2, pp. 187-202

Freire, P., y Faundez A. (2013). Por una pedagogía de la preguntan. Crítica a una educación basada en respuestas a preguntas inexistentes. $5^{\circ}$ ed., Argentina: Siglo Veintiuno.

HARDt, M. y NegRI, A. (2004). Multitud. Guía y democracia en la era del Imperio, traducción por J. A. Bravo, Buenos Aires: Debate.

Kunsch, C., JitendRA, A., \& SoOd, S. (2007). "The effects of peer-mediated instruction in mathematics for students with learning problems: A research synthesis" en Learning Disabilities Research \& Practice, vol. 22, núm. 1, pp. 1-12.

Koschmann, T. (1996). "Paradigm shifts and instructional technology: An introduction" en Koschmann, T. (Ed.), CSCL: Theory and practice of an emerging paradigm. Mahwah, NJ: Lawrence Erlbaum.

LAWLOR, L. (2006). The Implications of Immanence. Toward a New Concept of Life, New York: Fordham University Press.

NANCY, J.-L. (2001). La comunidad desobrada, trad. Pablo Perera, Madrid: Arena Libros.

NANCY, J.-L. (2006). Ser singular plural, traducción por Antonio Tudela. Madrid: Arena Libros.

Pelbart, P. (2009). Filosofía de la deserción: nihilismo, locura y comunidad. Buenos Aires: Tinta Limón.

RANCIÈRE, J. (2003). El maestro ignorante. Cinco lecciones sobre la emancipación intelectual, trad. Núria Estrach. Barcelona: Laertes

STAHL, G. (Ed.) (2001). Computer support for collaborative learning: Foundations for a CSCL community. Hillsdale, NJ: Lawrence Erlbaum

TopPING, K. (2008). Peer-assisted learning: A practical guide for teachers. Newton, Mass.: Brookline Books.

VIRNO, P. (2003). Gramática de la multitud, traducción por A. Gómez, J. D. Estop, Miguel Santucho, Madrid: Traficante de sueños.

WILSON, M. A. (2006). Technically together: rethinking community within techno-society, Nueva York: Peter Lang Publishing.

\section{(cc)) EY-NC-ND 2014, Universitat Politècnica de València}

I Jornadas IN-RED (2014) 


\title{
Workshop Docente de Construcción con Superficies Singulares
}

\author{
Igor Fernández Plazaola ${ }^{1}$, Francisco Sanchis Sampedro² , Jaime Llinares Millán ${ }^{3}$, Jose \\ Miguel Molines Cano ${ }^{4}$ \\ ${ }^{1}$ Universitat Politècnica de València, Dpto. de organización de empresas, iplazaola@ doe.upv.es \\ ${ }^{2}$ Universitat Politècnica de València, Dpto. de expresión gráfica, fsanchis@ega.upv.es \\ ${ }^{3}$ Universitat Politècnica de València, Dpto. de construcciones arquitectónicas jllinares@csa.upv.es \\ ${ }^{4}$ Universitat Politècnica de València, Dpto. de construcciones arquitectónicas, jomoca1@upv.es
}

\begin{abstract}
Integrated into ACTIE (Transverse Activities in Engineering Building) EICE activities and because of the EXCO XXVIII Technology Construction Exhibition organized by ETSIE every year at Feria Valencia, a free workshop was opened and ran to all students. It consisted on building an artifact of $3 x$ 3 meters, designed from the simplification of an existing building, the ES The Rebollet Oliva (Valencia) consisting of singular surfaces, hyperbolic paraboloid.

In this context, the workshop "Singular Surface Construction"was born, whose aim was to analyze a complex geometric element and prototype it using the model as a teaching object with recycled material.

The first pre-workshop work consisted in realizing the project, extracting technical data and finding suitable recycled material with the technical requirements of rigidity and inertia to build a prototype. With all 10 students group distributed workrd with project based learning techniques.

Students had an absolute involvement and great initiative and creativity in the performance of practical development of theoretical content needed in their training.
\end{abstract}

Keywords: PBL, workshop, teaching model 
Workshop Docente de Construcción con Superficies Singulares

\begin{abstract}
Resumen
Integrado dentro de las actividades del EICE ACTIE (Actividades Transversales en Ingeniería de Edificación) y con motivo de la EXCO XXVIII Salón Tecnológico de la Construcción que todos los años organiza la ETSIE en Feria Valencia, se planteó un workshop gratuito y abierto a todos los alumnos de la escuela consiste en la construcción de un artefacto de 3 × 3 metros, diseñado a partir de la simplificación de un edificio existente, la E.S. El Rebollet de Oliva (Valencia) compuesto por superficies singulares, paraboloides hiperbólicos.
\end{abstract}

En este contexto nació el taller de Construcción de Superficies Singulares, cuyo objetivo era analizar un elemento geométrico complejo y prototiparlo mediante el uso de la maqueta como objeto docente con material reciclado.

Los primeros trabajos pre-taller consistieron en realizar el proyecto, extracción de datos técnicos, búsqueda de materiales reciclados adecuados con los requerimientos técnicos de rigidez e inercia, ejecución de un prototipo. Con todo ello los 10 alumnos integrantes distribuidos por grupos desarrollaron con técnicas de actividades basadas en proyectos el reto propuesto.

Los alumnos tuvieron una implicación absoluta y gran iniciativa y creatividad en el desempeño del desarrollo práctico de contenidos teóricos necesarios en su formación profesional.

Palabras clave: $A B P$, workshop, taller, maqueta docente

\title{
Introducción
}

La geometría desde siempre ha sido el instrumento que ha permitido a los arquitectos, de muy diversas formas, unir la creatividad del proceso de diseño, con las necesidades estructurales y constructivas. Es por tanto una herramienta fundamental de diseño y análisis de la Arquitectura y su uso en fases tempranas de proyecto es imprescindible debido a que soluciona problemas posteriores durante la construcción y el comportamiento estructural del edificio.

Dejando de lado criterios estructurales y constructivos, y centrándonos en aspectos únicamente formales, la geometría se ha convertido en la herramienta de la que dispone el arquitecto para luchar contra el minimalismo impuesto durante las primeras décadas del siglo XX.

"Liberada la arquitectura del recurso del ornamento, la geometría se convierte de esta manera en la responsable de la expresión arquitectónica" (Crespo 2005)

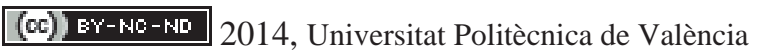

I Jornadas IN-RED (2014) 
El uso de las superficies geométricas regulares y totalmente definidas ha ayudado a resolver de manera natural e intuitiva problemas constructivos y estructurales a lo largo de la historia de la arquitectura. No es el objeto de la presente comunicación, pero por realizar un acercamiento a este aspecto de la historia de la arquitectura, hay que destacar el hábil uso de la geometría en las bóvedas y cúpulas de la antigüedad que permitió en su día la cubrición de grandes espacios y construir edificios que no haber sido "geometrizados" no se podrían haber materializado. Ya a finales del s XIX y comienzos del s XX y debido al desarrollo de nuevos materiales como el acero aplicado en edificación o el hormigón armado con su moldeablidad, el repertorio formal de la arquitectura se enriqueció. Por destacar un material, el resultado del uso expresivo del hormigón (Such 2005) dio como resultado un novedoso repertorio formal. Además de repetir formas clásicas como las bóvedas cilíndricas o las cúpulas esféricas, aparecieron nuevas superficies como las superficies regladas de doble curvatura: Paraboloide hiperbólico, hiperboloide hiperbólico, conoide... posteriormente veremos que también se han utilizado superficies irregulares gracias a la moldeabilidad del material.

Con la aparición de las curvas y superficies de Bezier a finales de los años 60 provenientes de la industria automovilística, aplicadas posteriormente a los programas de dibujo asistido por ordenador, el diseño de una nueva arquitectura que ya no solo se basa en formas regladas sino en todo tipo de formas orgánicas e irregulares se hizo posible. Las consecuencias del uso de estos programas y "superficies informatizadas" han llevado a una gran heterodoxia arquitectónica, llena de formas caprichosas a modo de esculturas gigantescas con una amplia libertad de concepción pero con una total indiferencia a las leyes de la física.

"Extraño manierismo adolescente con el imperdonable pecado de la aconstructividad"

(Araujo 2005)

Se hace por tanto necesaria una formación de nuestros estudiantes en los principios básicos de la geometría aplicada a la arquitectura, y en concreto, en el conocimiento de las superficies geométricas de mayor uso en la edificación y que gracias a sus singulares características resuelven los problemas constructivos y estructurales de una manera óptima y eficaz.

\section{Uso de las maquetas como herramienta en arquitectura}

La maqueta como herramienta de diseño y experimentación en arquitectura se ha utilizado desde muy antiguo. Los ensayos sobre modelo físico reducido ya los utilizó Leonardo Da Vinci en el renacimiento y más recientemente Antoni Gaudí, siempre en búsqueda de la geometría más eficiente para construir formas novedosas eficientes. Arquitectos como Félix Candela, Frei Otto, Pier Luigi Nervi... e ingenieros como Eduardo Torroja 1960, Heinz Isler, Heinz Hossdorf... comenzaron a realizar ensayos "científicos" sobre modelos físicos

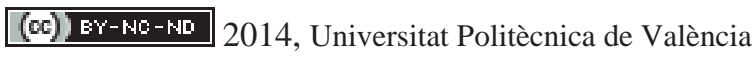

I Jornadas IN-RED (2014) 
reducidos, que aunque con un carácter diferente, buscaban cuantificar el uso de las maquetas en búsqueda de la geometría más eficaz desde el punto de vista estructural(Cassinello 2006).

Podríamos decir que las maquetas han ayudado en la historia de la arquitectura a buscar geometrías y formas novedosas y comprender su funcionamiento estructural, así como las propiedades intrínsecas de los materiales utilizados para construirlas. Esto es lo que ha llevado a desarrollar metodologías basadas en el ensayo experimental sobre modelos físicos reducidos (Andrade 1999).

Desde el punto de vista pedagógico, el modelo físico construido por el alumno ayuda a una mejor comprensión de los principios de una forma, sus características geométricas, sus leyes de generación... aspectos que resultan mucho más difíciles de transmitir con los medios gráficos y los sistemas de representación tradicionales (Sanchis 2013).

\section{El contexto - EXCO, salón internacional de la construcción}

Como ya viene siendo tradicional, desde la ETS de Ingeniería de Edificación se ha organizado en Feria Valencia la $28^{\mathrm{a}}$ edición de EXCO, Salón Internacional de la Construcción, con motivo de CEVISAMA 2014, que tuvo lugar los días 11 al 14 de febrero.

Durante esos días, y en horario de mañana y tarde, se organizaron una serie de conferencias sobre temas relacionados con la edificación, en las que participaron profesores de diversas universidades y técnicos con amplia experiencia profesional. También se realizó una exposición de "Tecnología e Investigación Científica en Edificación” en la que participaron profesores de la ETS de Ingeniería de Edificación.

De forma paralela a estas actividades y como novedad, en esta edición se organizaron una serie de "workshops" sobre temas relacionados con la construcción, que tienen como objetivo la participación de los alumnos y pretenden ser un complemento a su formación técnica. En este contexto y con metodologías de aprendizaje basado en projectos (ABP) por su dinamismo, teoría y sus diferencias con metodologías tradicionales Kubiatki (2011) llevamos a la práctica el tallere de trabajo que se refleja en esta comunicación y que a continuación se describirá con detalle.

\section{Objetivos}

Los objetivos perseguidos por este workshop; dirigido a alumnos pertenecientes a diferentes niveles, eran fundamentalmente tres:

- Comprender el diseño de un elemento constructivo compuesto por superficies singulares y que los alumnos fueran capaces de comprender la simplificación geométrica propuesta. 
Fernandez-Plazaola, Igor, Sanchis-Sampedro, Francisco, Llinares-Millán, Jaime, Molines-Cano, Jose Miguel

- Realizar un caso práctico de construcción, preparando los elementos básicos para la construcción y resolviendo los encuentros entre elementos y las diversas partes del artefacto.

- Utilizar materiales no convencionales y reciclados que se alejan de los habituales que suelen estudiar en las asignaturas del grado y que por tanto el alumno no tiene prejuzgados, lo que le obliga a dar una respuesta a un nuevo problema constructivo.

\section{Desarrollo de la innovación}

Como ya se ha comentado en la introducción, en el ámbito de la Feria de la Tecnología de la Construcción EXCO 2014, y como viene ocurriendo desde hace años y es tradición en la Escuela Técnica Superior de Ingeniería de Edificación, toda la docencia se traslada durante su duración a las aulas de Feria. En esta edición desde la dirección de EXCO surgió como una nueva iniciativa, en el ámbito de apostar por nuevas metodologías docentes activas y enfocadas al espíritu del nuevo Espacio Europeo de Educación Superior, la posibilidad de ofertar talleres formativos para los alumnos.

La ETSIE puso a disposición de los docentes el entorno y, hasta donde fuera posible, el material para que aquellos docentes que así lo desearan pudiesen organizar cualquier tipo de taller que se saliese de la docencia reglada y estuviese enfocado a las competencias profesionales de la titulación. La normativa marcada por parte de la organización de EXCO consistía en la realización de los talleres los días 12 y 13 de febrero en horario de 12 a $14 \mathrm{~h}$ justo después de las conferencias programadas. Esto nos daba una duración de 4h para la realización total del taller. El resultado del mismo se podría exponer el día 15 en el Centro de Eventos de Feria Valencia. Para todo ello la dirección nos proporcionó áreas de trabajo acordes a las necesidades del taller, suministro eléctrico, limpieza y una subvención para los materiales empleados en el mismo. En este contexto se presentaron por parte del cuerpo docente de la escuela un total de 8 talleres, algunos de construcción, otros de habilidades orales, internacionalización y búsqueda de empleo o lingüísticas.

En este entorno los autores plantearon la posibilidad de ofrecer un taller en el que los alumnos pudieran desarrollar diversas competencias de manera práctica y rápida. En base a nuestras experiencias docentes e investigadoras decidimos aunar conocimientos de todos los autores, por un lado el ámbito de la geometría y su desarrollo, por otro el empleo de metodologías activas como el aprendizaje basado en proyectos (ABP), también fundamentos de construcción y diseño de estructuras. En este contexto nació el taller de Construcción con Superficies Singulares, cuyo objetivo como ya hemos planteado era analizar un elemento geométrico complejo y construirlo en base a una maqueta con material reciclado.

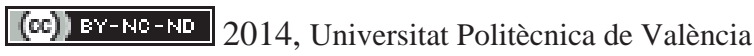

I Jornadas IN-RED (2014) 
Con los objetivos establecidos y la aceptación por parte de la dirección de EXCO, los primeros trabajos consistieron en dar a conocer el taller entre los alumnos de la escuela. Para ello se publicitó a dos niveles, por un lado desde la propia web de la Escuela como una opción formativa de EXCO a la que los alumnos podían apuntarse libremente y sin coste alguno, y por otro lado por parte de los profesores involucrados a sus propios alumnos. El perfil al que se dirigía el taller fundamentalmente eran los alumnos de primer curso de Geometría Descriptiva, los cuales en esos momentos estaban cursando el bloque temático correspondiente a superficies geométricas, y los alumnos de Trabajo Final de Grado, que habían de diseñar una cubierta ligera basada en superficies singulares. Con esto lo que se pretendía era crear un grupo heterogéneo con alumnos de diferentes niveles y fomentar la verticalidad del workshop. El número de participantes estaba limitado a 10 alumnos, esta limitación venía impuesta por la cantidad de tareas que había que desempeñar, los grupos que se podían asignar y el número de integrantes de estos grupos. Las solicitudes fueron muy superiores a la oferta del taller llegando casi a la veintena. En este punto se tenían 2 opciones, o duplicábamos el taller o manteníamos la limitación. Se tomó la decisión de mantener la limitación y no admitir más alumnos por varios motivos. En primer lugar era una experiencia novedosa para los docentes organizadores del mismo y queríamos mantener un control sobre el desarrollo de la actividad, y en segundo lugar habían otras ofertas formativas que no habían cubierto su cupo mínimo y desde la organización de EXCO se sugirió que los alumnos se repartieran entre todos los talleres.

Una vez que el desarrollo del taller estaba garantizado los autores comenzaron con la organización y el diseño en detalle del mismo. Se seleccionó como figura geométrica a analizar y aplicar constructivamente por los alumnos el paraboloide hiperbólico. Las razones para ello fueron varias. Por un lado el hecho de que los alumnos de TFG tuvieran que realizar un diseño de una cubierta con una geometría singular, siendo ésta una de las formas no convencionales más utilizadas en edificación. Por otro lado, que en las clases posteriores a la celebración de EXCO, los alumnos de Geometría Descriptiva tuvieran planificada la docencia sobre superficies regladas. Y por último, se eligió realizar el modelo basado en la geometrización de la cubierta de la estación de servicio del Rebollet en Oliva ya que en la exposición que también se realizaba esos días sobre investigación científica en edificación había unos paneles sobre este edificio (ver figura 1), que analizaban su geometría y hacían una simplificación geométrica de su cubierta (ver figura 2) y que por tanto servían para contextualizarla y relacionar todas las actividades de EXCO. 


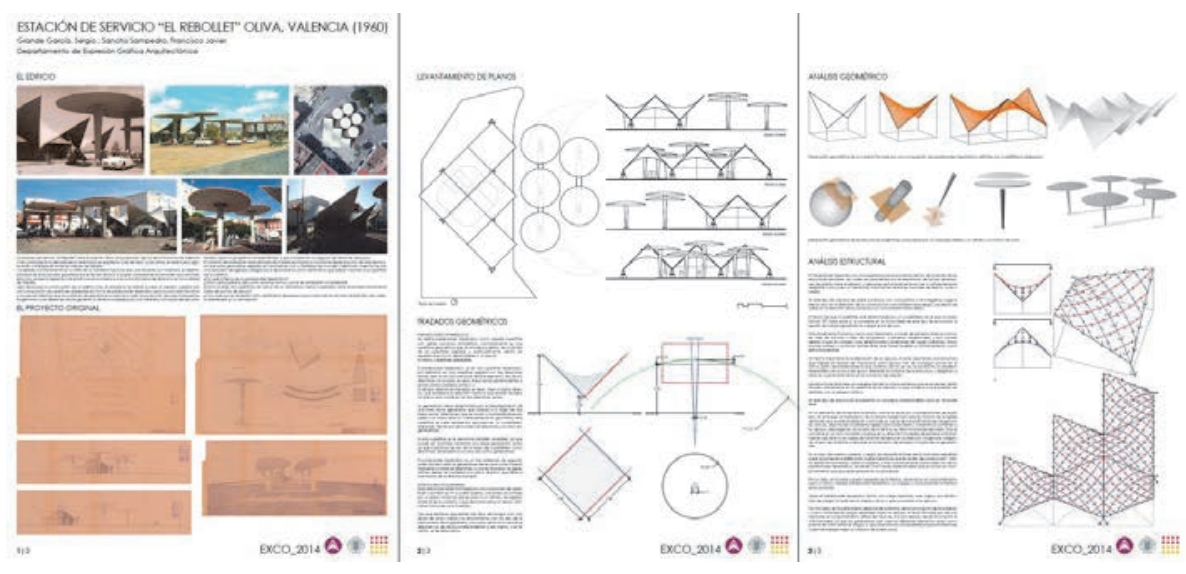

Figura 1 · Paneles de la exposición sobre la ES el Rebollet de Oliva

Para llevar a cabo el taller hizo falta realizar un anteproyecto de la maqueta que queríamos desarrollar. Se realizó una representación virtual en AutoCAD de la ES de Oliva objeto de estudio. Trazamos su planimetría simplificando sus elementos característicos como son sus directrices y generatrices, dándoles las dimensiones de los materiales que íbamos a emplear con la finalidad de conocer las dimensiones y ángulos exactos que se producían en el modelo, y de esta manera poder reproducirlos a menor escala (ver figura 3). Del mismo modo había que estudiar los apoyos y dar una solución que hiciera la maqueta estable.

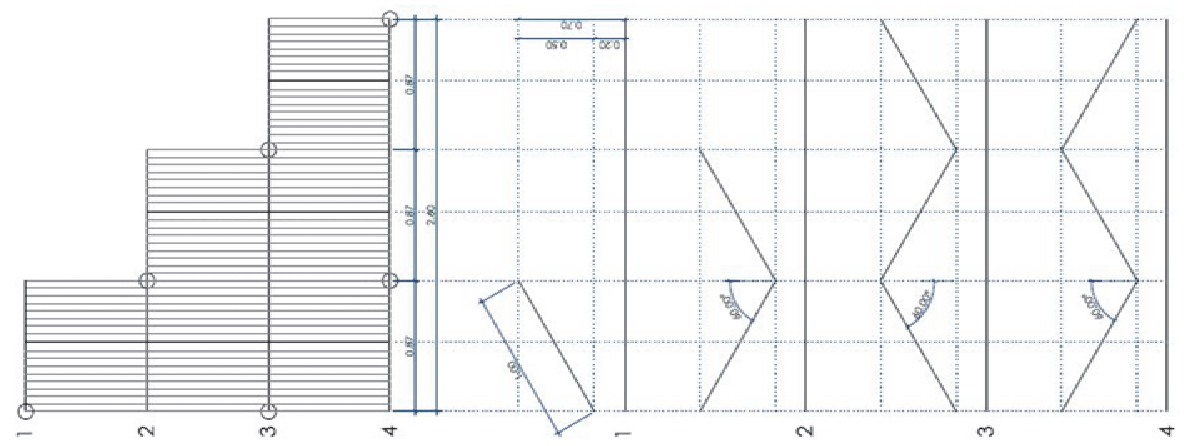

Figura $2 \cdot$ Esquema de la simplificación de la cubierta con el análisis dimensional del modelo

Una vez analizado dimensional y constructivamente el modelo, un aspecto importante de desarrollo del taller era el reciclaje de elementos para conformar la maqueta. Habíamos recogido de distintos puntos de la ciudad tubos de cartón de distintas dimensiones y diámetros, cuerdas y varillas. El concepto de reciclaje de materiales y de "coste cero" era uno de los mensajes que se quería transmitir a los alumnos.

\section{(c) EY-NC-ND 2014, Universitat Politècnica de València}

I Jornadas IN-RED (2014) 
En base al modelo analizado y el material con el que contábamos se tomó la decisión de las dimensiones finales de la maqueta a realizar por los alumnos que se quedó fijada en $3 \times 3$ metros. Consistiría entonces en una composición de 6 paraboloide hiperbólicos, considerados como módulo de composición, estando cada uno de estos incluido dentro de un cuadrilátero alabeado de 1 metro de lado. La maqueta contaría por tanto con 6 apoyos.

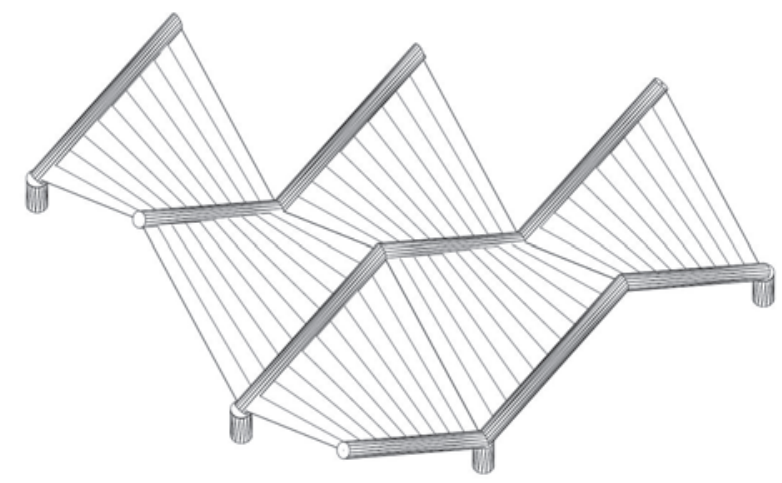

Figura 3. Imagen tridimensional del modelo con grosores

El siguiente paso dentro del anteproyecto del taller consistió en realizar una maqueta de una de las uniones (ver figura 4) con el material encontrado con tal de asegurarnos que su materialización era factible y reunía las características necesarias sobre todo de rigidez. Los profesores organizadores hicimos un modelo de unión que consideramos viable, el cual utilizamos posteriormente para mostrar a los alumnos el trabajo que debían realizar.

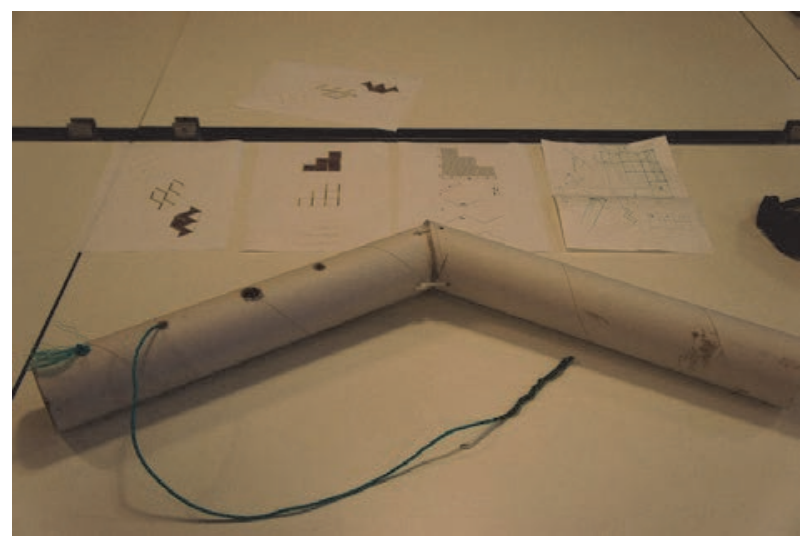

Figura 4 Prototipo de unión entre tubos, esquemas y bocetos del modelo

Con todos los preparativos se realizó el taller con la participación de 10 alumnos. El primer paso fue la explicación del taller y los antecedentes del mismo. Aprovechando la exposición de paneles sobre la ES el Rebollet de Oliva que ya hemos comentado 
anteriormente, se les explicó a los alumnos los fundamentos de las formas a analizar, su aplicabilidad idiosincrasia y complejidad (ver figura 5).
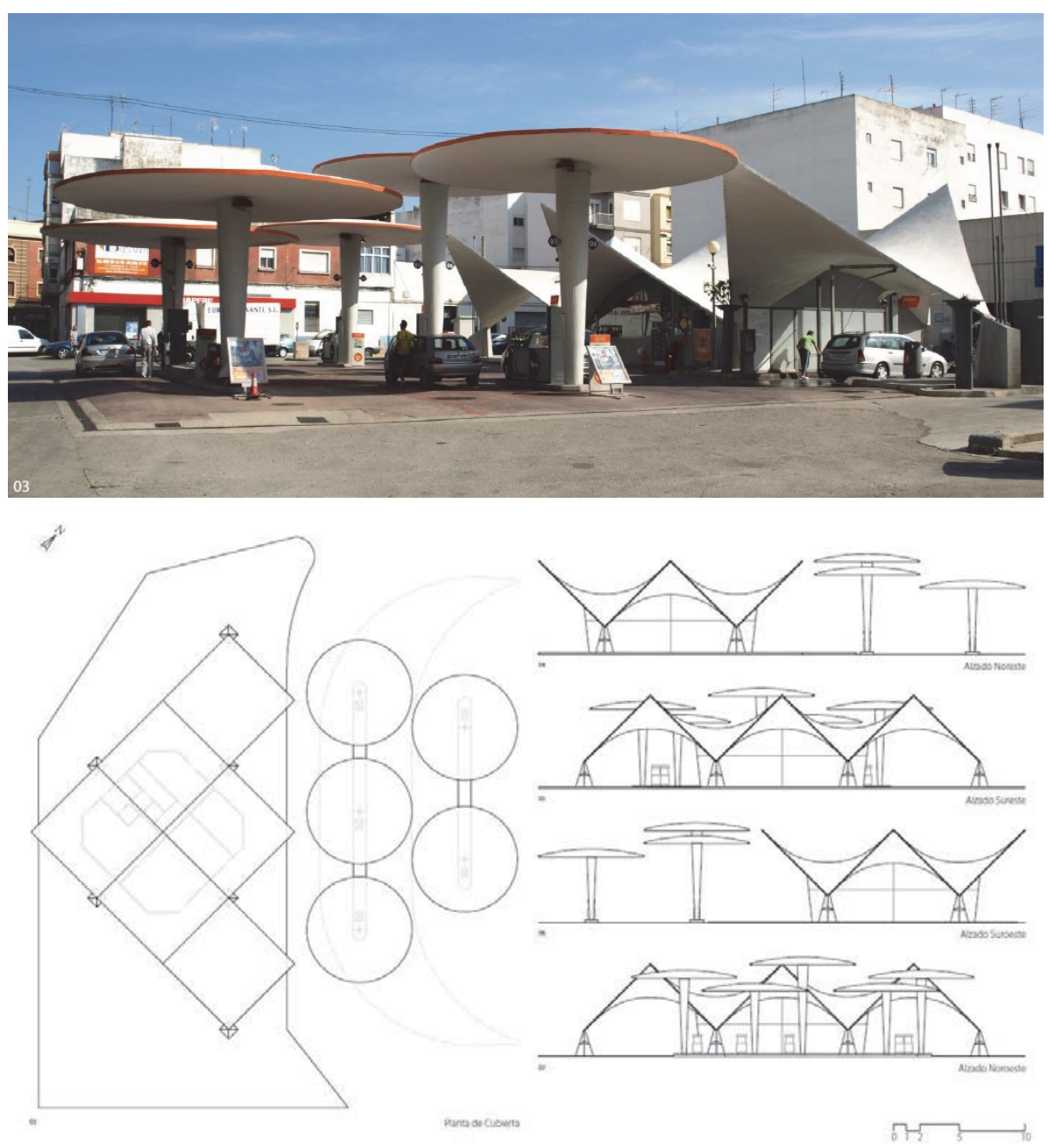

Figura $5 \cdot$ La ES el Rebollet de Oliva (Valencia) que sirvió como modelo de análisis

Una vez conocido el estado final al que queríamos llegar con el taller, se analizó con los alumnos el anteproyecto que habíamos realizado, planos, materiales y herramientas. Con el nudo prototipado en la mano y las herramientas disponibles (ver figura 6) los alumnos empezaron a entender la dimensión y las tareas a realizar en el taller. Una vez presentado el reto, los tiempos, los materiales y las herramientas les explicamos a los alumnos que tenían libertad total para el desarrollo del taller y que nuestra tarea consistiría en aconsejarles y explicarles aquellos aspectos conceptuales o de ejecución que pudiesen necesitar.

(c) EY-NC-ND 2014, Universitat Politècnica de València

I Jornadas IN-RED (2014) 


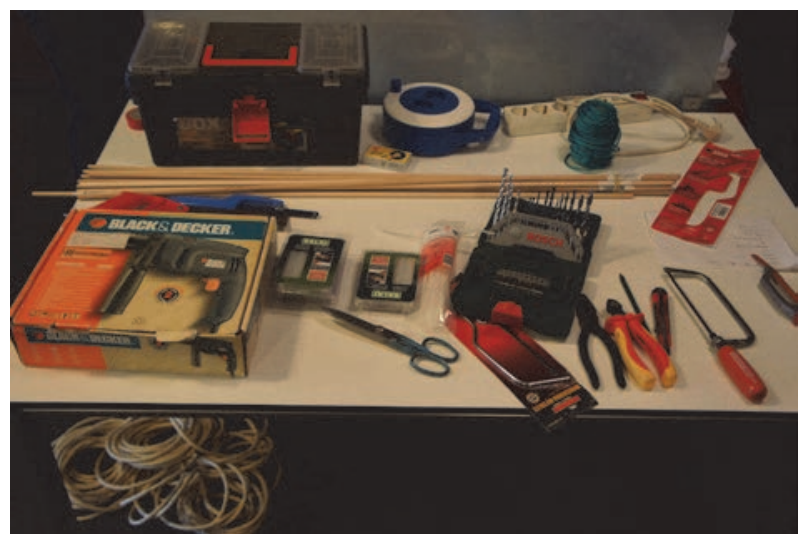

Figura $6 \cdot$ Herramientas utilizadas para la ejecución del modelo

Los alumnos del taller no habían trabajado juntos anteriormente, excepto algún caso puntual, y lo primero que hicieron fue repartirse tareas por equipos. Analizaron las tareas necesarias para conseguir el objetivo y fueron adjudicándose las mismas en función de preferencias e incluso habilidades personales que decían poseer.

- Corte de los tubos en longitud.

- Corte de los tubos en ángulo.

- Perforación de los tubos para pasar el material de cubrición y las varillas rigidizadoras.

- Unión de los nudos de encuentro

La primera sesión, la del día 12, se realizaron todas las tareas de corte y preparación (ver figura 7). Las mayores dificultades estribaron en el uso de algunas herramientas para conseguir por ejemplo el ángulo necesario en el nudo de los tubos que tenia que ser exacto y limpio.
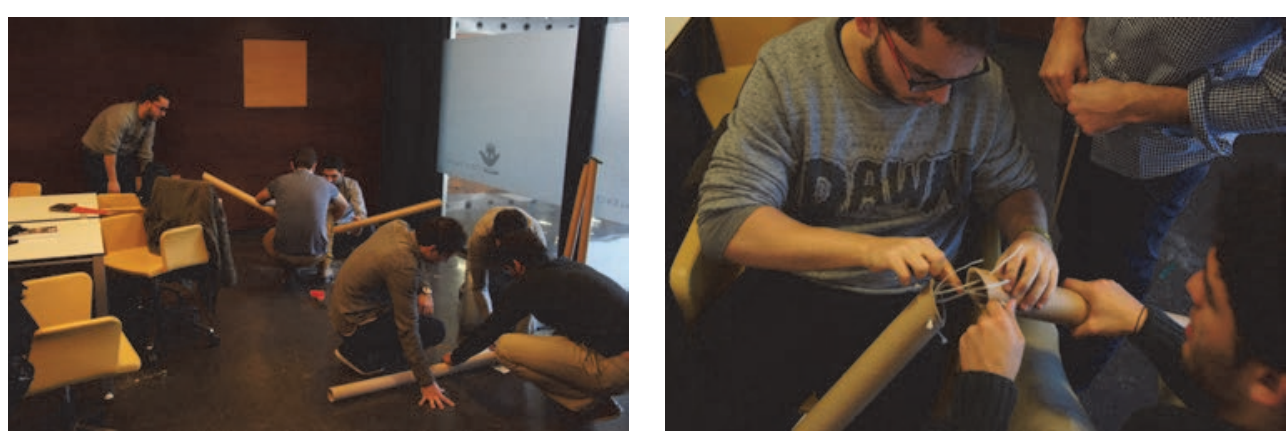

Figura $7 \cdot$ Alumnos durante el proceso de corte y ensamblaje de piezas 
Fernandez-Plazaola, Igor, Sanchis-Sampedro, Francisco, Llinares-Millán, Jaime, Molines-Cano, Jose Miguel

La segunda sesión el trabajo se dividió en dos momentos. Una primera fase consistió en el ensamblaje de cada una de las partes del día anterior y el traslado de la maqueta a la zona de la exposición (ver figura 8). Para estos trabajos se mantuvieron los grupos organizados el día anterior. Una vez en la zona de exposición los alumnos se reorganizaron para comenzar el montaje de la estructura, consistente en un primer ensamblaje con varillas y el posterior atado con cuerdas. Esta fue una fase delicada y que necesitó de la colaboración de todo el equipo ya que la estructura no se estabilizó hasta el final. Por último y con la colaboración de todos a un mismo tiempo, la maqueta se izó hasta colocarse sobre los apoyos definitivos que la separaban unos $50 \mathrm{~cm}$ del suelo, lo cual reforzaba su carácter singular.
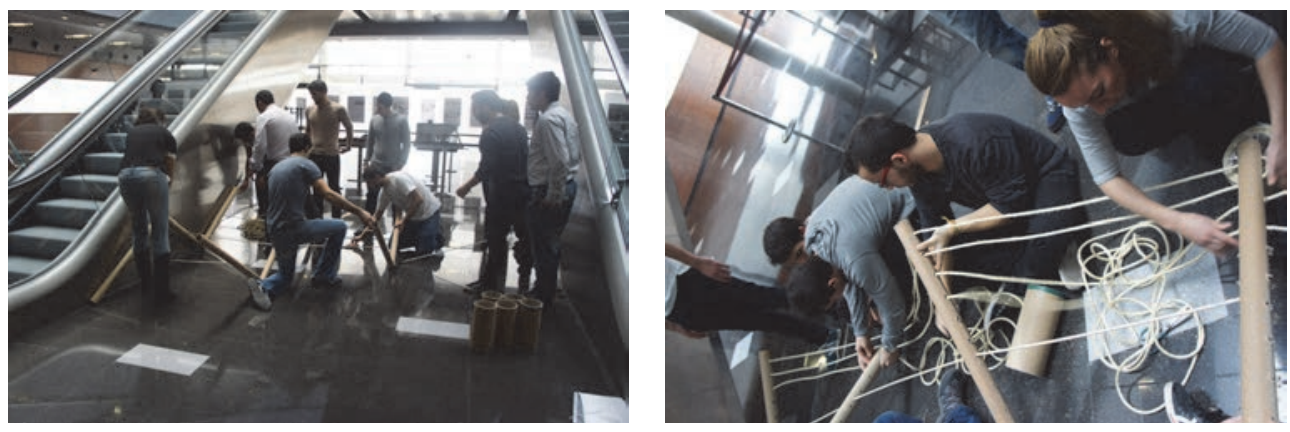

Figura 8. Alumnos durante el proceso de montaje

Ese mismo día del montaje y exposición, y justo al finalizar el taller se realizó una evaluación del taller, tanto en su desarrollo como en la consecución de los objetivos iniciales. Los alumnos evaluaron la presentación y explicaciones, el desarrollo, los materiales y técnicas empleados aportando posibilidades de mejora (ver figura 9).

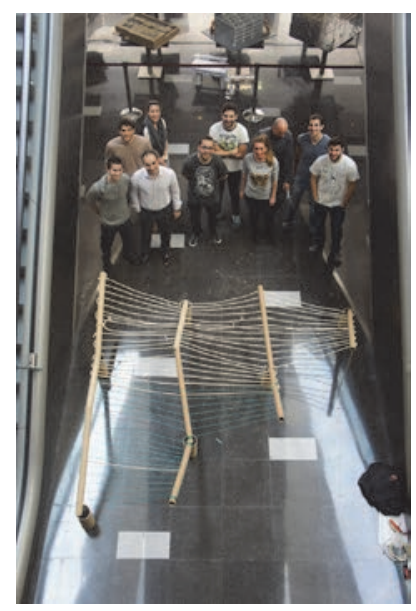

Figura $9 \cdot$ El equipo posando junto al modelo

(c)) EY-NC-ND 2014, Universitat Politècnica de València

I Jornadas IN-RED (2014) 

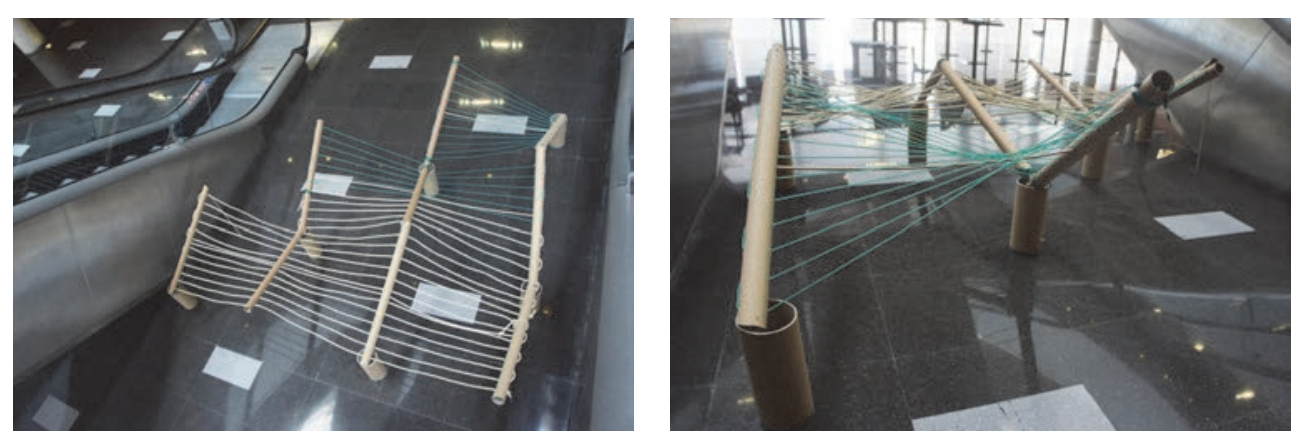

Figura 10 · El modelo finalizado y expuesto el último día de EXCO_2014

\section{Resultados}

Los resultados del taller se pueden analizar desde diversos puntos de vista,

- La aplicación de metodologías activas de enseñanza-aprendizaje mediante el empleo del ABP.

- La materialización de elementos constructivos a escala.

- Verticalidad de los alumnos integrantes del taller.

- Aplicabilidad y extrapolación de conocimientos adquiridos.

- Discusión resumen de la actividad.

Desde el punto de vista de la aplicación de metodologías ABP el resultado ha sido tremendamente satisfactorio. El reto fue asumido como tal por los alumnos y su nivel de implicación fue absoluto desde el inicio. Los alumnos establecieron sin nuestra ayuda sus grupos de trabajo en base a sus propias competencias. Cabe resaltar por ejemplo que una de las alumnas era la que se encargaba de realizar los taladros en los tubos para materializar las generatrices, citándola textualmente "Si queréis me encargo del taladro dado que estoy muy acostumbrada a ayudar a mi padre en su taller". Del mismo modo desde el inicio planificaron las distintas tareas a desarrollar para lo cual nos solicitaron cierta información sobre dudas que se les planteaban. El taller se desarrolló en un entorno de autoaprendizaje, ya que este se basaba en sus necesidades reales para resolver un problema competencial intrínseco a su futura titulación. El trabajo colaborativo fue constante durante todo el proceso y cada miembro aportaba sus conocimientos y habilidades para superar el reto. La metodología ABP funcionó a la perfección, los docentes íbamos guiando y explicando a medida que los alumnos avanzaban con su reto y eran conscientes de sus propias carencias y necesidades. El proceso de enseñanza-aprendizaje se estaba basando en una motivación intrínseca proveniente de su deseo de ser capaces de materializar un elemento que entendían como complejo. 
Fernandez-Plazaola, Igor, Sanchis-Sampedro, Francisco, Llinares-Millán, Jaime, Molines-Cano, Jose Miguel

Desde el punto de vista de la materialización de un elemento constructivo a escala por los propios alumnos (ver figura 10) aporta importantes beneficios para su formación. Los alumnos se han organizado, han estudiado y analizado un proyecto, han tomado decisiones, han dado y acatado sugerencias y han ejecutado tareas sencillas para un fin complejo. La maqueta como elemento docente les ha ayudado a entender conceptos geométricos y estructurales. De hecho para el montaje final de la maqueta en el lugar de exposición era necesario que todos participaran para sujetarla hasta estar completamente montada y ubicada. Por su idiosincrasia estas estructuras no son estables por si mismas hasta estar completas. Los alumnos no creían que con los apoyos planteados fuera estable y no se atrevían a soltarla. Los 2 profesores tuvieron que decir en varias ocasiones "Ya está acabada, soltadla, no va a caerse" los alumnos no querían soltarla porque consideraban que se caería y su sorpresa fue mayúscula cuando a la tercera conseguimos que la soltaran y la estructura se mantuvo por si misma. Este ejercicio del paso del proyecto y cálculo a la materialización, ayuda al alumno a concatenar y fijar distintos conocimientos y formación previa adquiridos temporal y físicamente en momentos dispares a lo largo del grado.

Un resultado inesperado del taller fue la verticalidad del mismo en cuanto a que los integrantes fueron alumnos de todos los cursos del grado. Trabajaron mano a mano alumnos de primero junto con alumnos que estaban realizando su proyecto final de grado. En este sentido no solo los mayores aportaban, si no que los de primero por el hecho de tener los conocimientos de geometría más recientes eran capaces de explicar a los de últimos cursos ciertos aspectos geométricos que los de últimos cursos ya tenían olvidados. Un resultado interesante de esta experiencia es que los alumnos de primero participantes han obtenido buenas calificaciones en la asignatura reglada de geometría, siendo unos de los pocos en aprobar la asignatura por curso. Como resultado docente del taller cabria decir que de los 5 proyectos finales de grado que se están desarrollando en la Escuela sobre superficies geométricas singulares 2 son realizados por integrantes del taller y ambos versan sobre paraboloides hiperbólicos. Los alumnos gracias al taller han adquirido una sensibilidad y conocimiento hacia esta figura geométrica que les confiere la seguridad necesaria como para escogerla como elemento principal de su proyecto final de grado.

Como resultado del taller el último ejercicio realizado fue una discusión entre todos los integrantes, docentes incluidos, sobre el desarrollo del mismo, tanto en aspectos formales como de contenido y resultados. En esta discusión se debatieron, procesos, métodos, herramientas, materiales y aspectos que mejorarían el elemento construido. Prácticamente todos los alumnos aportaron algo a la discusión, todos ellos consideraban la actividad como muy enriquecedora y repetirían la experiencia sin dudarlo aplicándolo a otros elementos constructivos. Fue significativo que casi todos ellos tenían aportaciones a las herramientas y materiales empleados dado que esta es una competencia profesional básica del grado.

(c)) EY-NC-ND 2014, Universitat Politècnica de València

I Jornadas IN-RED (2014) 
Workshop Docente de Construcción con Superficies Singulares

\section{Conclusiones}

Las conclusiones se pueden hacer atendiendo por un lado a la actividad en si misma y por otro al artefacto-maqueta obtenido.

Con todo lo expuesto anteriormente podemos concluir que las metodologías activas de enseñanza-aprendizaje como el ABP son tremendamente ricas para el alumnado. Este extremo no es ni mucho menos novedoso, sin embargo siguen sin ser usadas extensivamente en la docencia reglada. Actividades tan concretas y acotadas en el tiempo como un taller de 4 horas consiguen un nivel de implicación en el alumnado que conlleva un aprendizaje profundo del tema tratado, lo que debería ser un objetivo en si mismo de todas las asignaturas de cualquier grado. Las aportaciones, ideas, y creatividad demostradas por los alumnos sorprendieron sobremanera a los docentes que en su día a día en la Escuela no consiguen ese nivel de implicación con otras actividades. La verticalidad del taller le dotó de una riqueza inesperada, en la que no solo los alumnos de últimos cursos tenían aportaciones, si no que los de primero también ponian su granito de arena y salieron reforzados en cuanto a su seguridad y gusto por la titulación. La metodología ABP ha conseguido en un plazo de tiempo muy corto un nivel de enseñanza-aprendizaje que dudamos que hubiera sido posible con otras metodologías. Del mismo modo los alumnos en base a resultados conseguidos en ulteriores pruebas evaluables de la asignatura de geometría consiguieron un aprendizaje profundo y anclado a sus conocimientos previos. En cuanto a la organización, 10 alumnos y 2 docentes es un número óptimo para la realización del mismo. El espacio utilizado aunque adecuado estaba apartado del resto de actividades de la feria y creemos que mayor visibilidad favorecerían el desarrollo de este tipo de actividades y el nivel de implicación de los distintos actores en el proceso de enseñanzaaprendizaje activo podría ser mayor.

En cuanto a la materialización del proyecto en la maqueta los alumnos y nosotros extrajimos distintas conclusiones. En cuanto a las cuerdas empleadas para visibilizar las generatrices, se emplearon 2, resultando más efectiva la más ligera y plastificada. Su menor peso propio le confería un mejor aspecto general, al no generarse catenaria, y su acabado plástico facilitaba su inserción a lo largo de todas las perforaciones. La maqueta adolece de estabilidad intrínseca durante su fase de montaje y precisa de ciertos rigidizadores. Las varillas de madera empleadas de $0,5 \mathrm{~cm}$ no resultaron suficientes y sería necesario emplear un mayor diámetro. Así mismo sería necesario estudiar algún elemento extra que dotara de cierta estabilidad a la maqueta para evitar que 8 personas sean necesarias durante su montaje. Los alumnos aportaron la necesidad de que los tubos de cartón que conformaban las directrices fuesen todos iguales en cuanto a diámetro y espesor, ya que esto facilitaría y homogeneizaria los nudos mejorando el resultado estructural. 
Fernandez-Plazaola, Igor, Sanchis-Sampedro, Francisco, Llinares-Millán, Jaime, Molines-Cano, Jose Miguel

En todo caso el total de alumnos participantes demostraron su interés en repetir experiencias semejantes y nos planteaban preguntas en torno a porqué la docencia reglada no incluia experiencias semejantes. Los autores están también contentos con los resultados obtenidos en el taller y les gustaría desarrollar más experiencias semejantes.

\section{Referencias}

ANDRADE, C. et al. (1999) Centenario de Eduardo Torroja (Ciencia, Tecnología y Empresa). Informes de la Construcción, vol. 51, nº 462, p. 5-8.

ARAUJO ARMERO, R. (2005) Geometría, técnica y arquitectura. Madrid . Revista Tectónica ${ }^{\circ} 17$

CASSINEllO, P. (2206) En Memoria de Heinz Hossdorf. Informes de la Construcción, vol. $58, \mathrm{n}^{\circ} 502$.

CRESPO CABILLO, I. (2005) Control gráfico de formas y superficies de transición. Barcelona : Tesis doctoral - Universitat Politècnica de Catalunya.

JORDÁ SUCH, C. (2005) El hormigón armado y el desarrollo de la tipología laminar: la transformación del canon en la arquitectura moderna" IV Congreso Nacional de Historia de la Construcción. Cádiz.

SANCHIS SAMPEDRO, F J. (2013) Las maquetas como herramienta docente en la enseñanza de la Geometría Descriptiva. $35^{\circ}$ Convegno internazionale dei docenti della rappresentazione. Matera, Italia.

TORROJA, E. (1960) Razón y ser de los tipos estructurales. CSIC. Madrid.

KUBIATKO, M. y VACULOVÁ, I. (2011) Project-based learning: characteristic and the experiences with application in the science subjects. Energy Education Scienc e and Technology Part B: Social and Educational Studies Vol. 3, Issue 1,pp. 65-74

(cc) EY-NC-ND 2014, Universitat Politècnica de València

I Jornadas IN-RED (2014) 


\title{
Sobre el laboratorio de Matemáticas en primer curso del Grado en Ingeniería Aeroespacial
}

\author{
Santiago-E. Moll ${ }^{a}$, José-A. Moraño ${ }^{b}$, María-D. Rosellóc ${ }^{c}$ Luis M. Sánchez Ruiz ${ }^{d}$
}

åDepto de Matemática Aplicada, Universitat Politècnica de València, Spain, sanmollp@mat.upv.es, bepto de Matemática Aplicada, Universitat Politècnica de València, Spain, jomofer@mat.upv.es, ${ }^{c}$ Depto de Matemática Aplicada, Universitat Politècnica de València, Spain, drosello@mat.upv.es, ${ }^{\mathrm{d}}$ Depto de Matemática Aplicada, Universitat Politècnica de València, Spain, $\underline{\text { mssr@mat.upv.es. }}$

\begin{abstract}
With the implementation of the Bologna process and the new studies in Aerospace Engineering, taught at ETSID, practices had to be redesigned because of the reduction in the teaching load and yet all its contents covering specific skills needed to be acquired. Therefore, the methodology used was substantially modified in lab sessions and we generalized the use of the educational platform PoliformaT to all lab sessions, using the software MATHEMATICA. In this paper we introduce the methodology implemented in laboratory classes, using PoliformaT platform for students in a guided but autonomous way to prepare properly each lab session and reinforce the knowledge taught in Theory-Practices sessions. This methodology aims firstly to improve the motivation and perception of students toward the subject, helping them to understand the main concepts and avoiding abandonment, and secondly to achieve a more rapid and natural acquisition of specific skills. We have developed a survey and analyzed the opinions and results of students.
\end{abstract}

Keywords: Laboratory sessions, educational platform, mathematics, engineering.

\footnotetext{
Resumen

Con la implementación del proceso de Bolonia y del nuevo Grado en Ingeniería Aeroespacial, que se imparte en la ETSID, las prácticas tuvieron que ser rediseñadas debido a la reducción de la carga lectiva de las mismas y sin embargo todos sus contenidos cubrían competencias específicas que
}

(cc) EY-NC-ND 2014, Universitat Politècnica de València

I Jornadas In-Red (2014) 
debían seguir adquiriéndose. Por ello se modificó sustancialmente la metodología empleada en prácticas de laboratorio y se generalizó el uso de la plataforma educativa PoliformaT a todas las clases de laboratorio de matemáticas de la titulación, mediante el software MATHEMATICA. En este trabajo se presenta la metodología implementada en las clases de laboratorio, en la que aprovechamos la plataforma Poliformat para que los alumnos de una forma guiada, pero autónoma, puedan prepararse de forma adecuada cada sesión de laboratorio, y reforzar los conocimientos vistos previamente. Con esta metodología se persigue en primer lugar que la motivación y percepción de la asignatura por parte de los estudiantes mejore, ayudándoles a comprender los principales conceptos de la asignatura y evitar el abandono de la asignatura, y en segundo lugar lograr una más rápida y natural adquisición de las competencias específicas. Se ha elaborado un sondeo y se analizan las opiniones y resultados de los estudiantes.

Palabras clave: Clases de laboratorio de Matemáticas, plataforma educativa, matemáticas en ingeniería.

\section{Introducción}

La Universitat Politècnica de València (UPV) se ha visto inmersa en un proceso de cambio con el objetivo de adaptar sus grados al proceso de Bolonia (CRUE, 2014 y Bologna Process, 2014). En particular, el Grado de Ingeniería Aeroespacial impartida en la Escuela Técnica Superior de Ingeniería del Diseño (ETSID) ha pasado de ser un grado de 5 años a uno de 4. Esto ha significado una profunda transformación en algunas materias.

Una de estas materias es Matemáticas, que ha pasado de tener 15 créditos (10.5 cr. Teoría/Problemas y 4.5 cr. de Prácticas de Laboratorio) a 12 créditos $(9$ cr. Teoría/Problemas y $3 \mathrm{cr}$. de Prácticas de Laboratorio). Por lo tanto, las clases de laboratorio de Matemáticas, que se llevan a cabo utilizando el software MATHEMATICA han sufrido una reducción de un tercio en el número de créditos asignados.

El hecho de usar la plataforma educativa conocida como PoliformaT, y desarrollada por la UPV a partir de la plataforma educativa Sakai (Sakai Porject, 2014), ha suavizado nuestra transición, aprovechando al máximo las TIC para mejorar y modernizar las posibilidades de aprendizaje de nuestros estudiantes. 
En la Sección 2 de este artículo mostraremos algunos de los cambios que hemos realizado en la materia y algunas de las herramientas que hemos usado para adaptarnos al nuevo entorno. La sección 3 recoge los resultados obtenidos por los estudiantes.

Incluimos la opinión de los estudiantes sobre el desarrollo de la metodología usada y algunas facetas del curso en la Sección 4, y finalmente, en la Sección 5 se exponen las conclusiones obtenidas.

\section{Objetivo: Adaptando las clases de laboratorio de Matemáticas a los nuevos cambios}

La reducción de 1/3 en las clases de laboratorio de Matemáticas sufrida en la Ingeniería Aeroespacial - pasando de 90 minutos cada semana a 60 minutos a partir del año académico 2010/11- no debía implicar una reducción en los contenidos abarcados ya que Matemáticas es una asignatura básica, y todos los temas tratados son necesarios en el curriculum del estudiante.

Por lo tanto, se estableció que la adaptación no debería ser sólo accidental, sino integral, y que se debían tomar las acciones necesarias para que en el proceso se siguieran las siguientes directrices:

- El estudiante debe trabajar más fuera de clase, y menos dentro de la clase.

- El docente debe programar las actividades que los estudiantes realizarán de forma autónoma e independiente.

- El docente debe organizar la evaluación de dichas actividades.

\section{Desarrollo de la innovación: Metodología Empleada}

Los autores han adaptado los contenidos y la secuenciación de las sesiones de laboratorio con el objetivo de hacer el proceso de adaptación eficiente. Las clases de laboratorio se estructuran de la siguiente forma: se solicita a los estudiantes que preparen cada sesión de forma autónoma, utilizando los conceptos matemáticos que se han visto previamente en las clases de teoría/práctica.

Usando la herramienta Recursos (ver Figura 1) de PoliformaT, y de forma semanal, los profesores proporcionan el material con la información necesaria para que los estudiantes aprendan a resolver el tipo de ejercicios que se trabajarán y evaluarán en la siguiente sesión.

(c)) EY-NC-ND 2014, Universitat Politècnica de València

I Jornadas IN-RED (2014) 


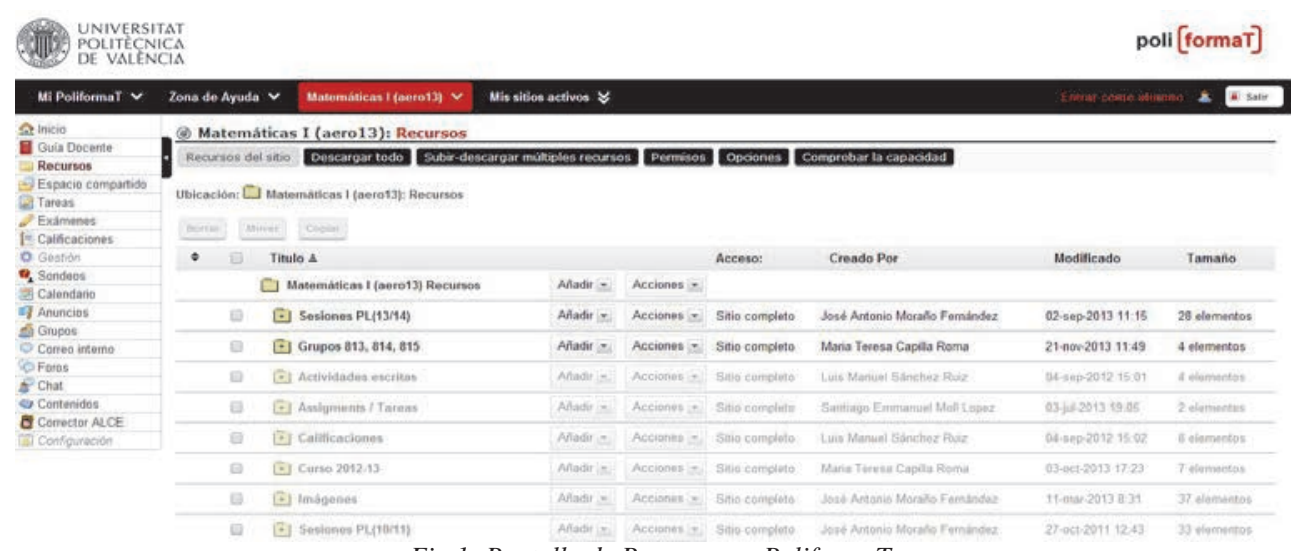

Fig 1: Pantalla de Recursos en PoliformaT

A continuación cada estudiante emplea los conocimientos adquiridos en la clase de Teoría/Problemas y el software MATHEMATICA para realizar las tareas asignadas, utilizando las instrucciones antes mencionadas, ya sea en casa o en las aulas de laboratorio de libre acceso disponibles en la ETSID. Además de las instrucciones, se proporciona a los estudiantes una lista de ejercicios y textos educativos (Moraño, 2008,2012) que les permite practicar y comprobar que han comprendido los temas que son objeto de estudio.

La primera parte de cada sesión de laboratorio (20 min approx.) se dedica a resolver cualquier duda que puedan tener los estudiantes y a proporcionar las soluciones de los ejercicios propuestos. Durante el resto de la sesión (40 min approx.) los estudiantes deben resolver ejercicios propuestos a través de otra herramienta de PoliformaT: Exámenes (ver Figura 2). Estos ejercicios se realizan de forma individual por cada estudiante en la sesión de laboratorio, mientras el profesor ayuda a los estudiantes que lo necesiten.

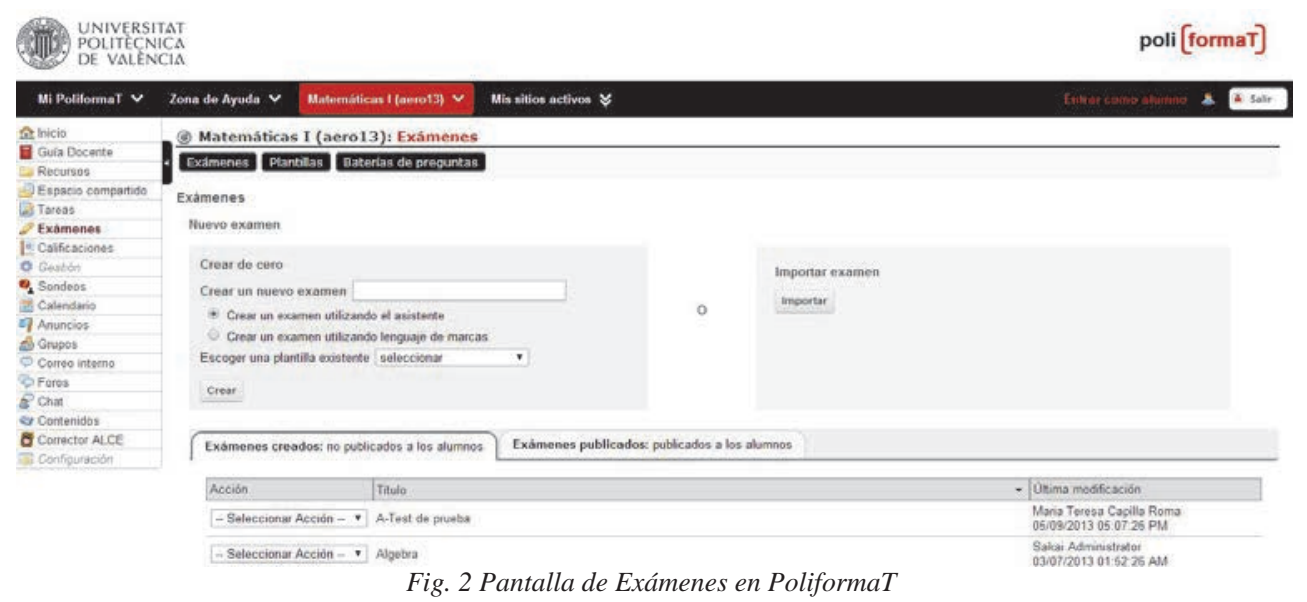

(c)) EY-NC-ND 2014, Universitat Politècnica de València

I Jornadas IN-RED (2014) 
Los docentes pueden controlar el ordenador desde el que el estudiante está haciendo su tarea, cambiando la Configuración en cada sesión. Es posible configurar el nombre de usuario, la contraseña, las restricciones de las IP y el tiempo seleccionado para cada ejercicio.

Todas las notas obtenidas pueden ser cargadas automáticamente en la herramienta Calificaciones de PoliformaT (ver Figura 3). Seleccionando cada sesión en la herramienta Calificaciones somos capaces de ver, filtrar y reordenar las notas obtenidas por los estudiantes.

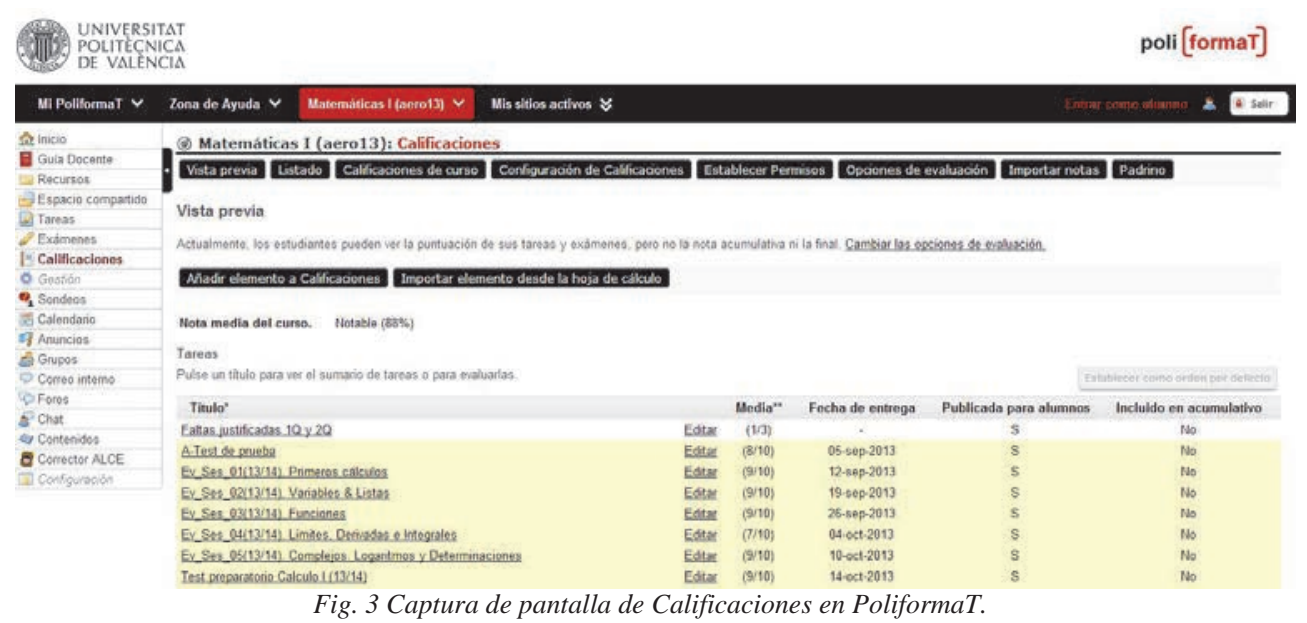

\section{Resultados}

Los resultados de los estudiantes han mejorado en términos generales como consecuencia de su participación en las sesiones de laboratorio semanales relacionadas con los contenidos teóricos previamente trabajados. Y los abandonos se han reducido muy significativamente.

La metodología llevada a cabo fue presentada dentro de la UPV y tras un proceso de revisión por pares fue aprobado como Proyecto de Innovación, hecho debidamente reconocido al final del artículo. Dentro de este marco, el rendimiento de los estudiantes está siendo constantemente examinado por los profesores de la asignatura durante el año académico 2013/14.

La Tabla I recoge las notas de las prácticas de laboratorio obtenidas por los estudiantes desde 2009/10 hasta el 2012/13. En ella, $N$ representa el número de estudiantes matriculados, y para $i=1,2, M_{i}$ representa la media obtenida por los estudiantes en las

\section{(c)) EY-NC-ND 2014, Universitat Politècnica de València}

I Jornadas IN-RED (2014) 
sesiones semanales durante el semestre I de cada año, mientras que $E_{i}$ representa la media de las notas obtenidas por los estudiantes en el examen individual durante el semestre $i$.

Las sesiones semanales tienen un peso del $40 \%$ en las notas de Laboratorio, el $60 \%$ restante se calcula a partir de los exámenes de laboratorio individuales. Por su parte, la nota de la parte de Laboratorio representa un $25 \%$ de la nota final de la asignatura.

Tabla 1: Comparación de las notas de prácticas de laboratorio

\begin{tabular}{lccccc}
\hline & $\mathbf{N}$ & $\mathbf{M}_{\mathbf{1}}$ & $\mathbf{E}_{\mathbf{1}}$ & $\mathbf{M}_{\mathbf{2}}$ & $\mathbf{E}_{\mathbf{2}}$ \\
\hline $2009 / 10$ & 100 & 6.4 & 4.6 & 6.6 & 5.7 \\
$2010 / 11$ & 102 & 8.8 & 5.2 & 7.6 & 6.5 \\
$2011 / 12$ & 119 & 7.7 & 5.8 & 7.8 & 7.3 \\
$2012 / 13$ & 122 & 8.7 & 5.6 & 8.8 & 8.1 \\
\hline
\end{tabular}

Podemos notar que la media de las sesiones semanales, así como las notas obtenidas en los exámenes han aumentado desde 2010/11, a partir de cuando los estudiantes debían prepararse las sesiones de laboratorio de forma previa. En todos los casos, la desviación típica de los resultados fue pequeña, sin que se diera el caso de un estudiante que suspendiera la parte de laboratorio y aprobara la parte de Teoría/Problemas de la asignatura. El rendimiento general mejoró y los abandonos fueron casi inexistentes.

\subsection{Percepción de los estudiantes}

Durante el año académico 2009/10 se consultó la opinión de los estudiantes sobre diferentes cuestiones, de forma totalmente anónima, mediante la herramienta Encuestas (Sakai Project, 2014). Los autores han usado esta herramienta y el mismo cuestionario desde 2010/11. En las siguientes tablas podemos comparar las opiniones de los estudiantes.

Las primeras dos cuestiones se centran en la organización de las propias sesiones de laboratorio. El cuestionario y las opiniones recogidas se muestran en la Tabla 2.

Tabla 2: Percepción de los estudiantes en las prácticas de laboratorio en general

\begin{tabular}{ccccc}
\hline $\begin{array}{c}\text { ¿Piensas que el número de prácticas realizadas es } \\
\text { adecuado para aprender el contenido de la asignatura? }\end{array}$ & $\mathbf{0 9 / 1 0}$ & $\mathbf{1 0 / 1 1}$ & $\mathbf{1 1 / 1 2}$ & $\mathbf{1 2 / 1 3}$ \\
\hline $\mathrm{Si}$ & $92 \%$ & $73 \%$ & $78 \%$ & $85 \%$ \\
Debería haber más & $4 \%$ & $14 \%$ & $2 \%$ & $7 \%$ \\
Debería haber menos & $4 \%$ & $14 \%$ & $20 \%$ & $7 \%$ \\
\hline
\end{tabular}




\begin{tabular}{cccccc}
\hline $\begin{array}{c}\text { ¿Piensas que la tarea de la práctica de laboratorio de cada } \\
\text { sesión se ajusta a los contenidos desarrollados en clase? }\end{array}$ & $\mathbf{0 9 / 1 0}$ & $\mathbf{1 0 / 1 1}$ & $\mathbf{1 1 / 1 2}$ & $\mathbf{1 2 / 1 3}$ \\
\hline Mucho & $34 \%$ & $8 \%$ & $19 \%$ & $29 \%$ \\
Suficiente & $51 \%$ & $67 \%$ & $68 \%$ & $58 \%$ \\
Poco & $15 \%$ & $26 \%$ & $13 \%$ & $13 \%$ \\
\hline
\end{tabular}

Queda claro que la gran mayoría de estudiantes piensa que las prácticas realizadas eran consistentes con el curso. Aunque haremos algunos comentarios más tarde, es conveniente comentar que durante el curso 2009/10 tuvimos sesiones de laboratorio de 90 minutos y que los estudiantes no tuvieron que preparar las sesiones por adelantado y que fueron capaces de aprender en clase. La opinión de los autores es que, en 2010/11 y en los años posteriores, los estudiantes han comprendido la pregunta de la siguiente forma: si cada práctica se ajusta a los contenidos desarrollados durante la primera parte de la sesión, cuando los profesores se referían en realidad al contenido estudiado previamente en clases teóricas y de problemas.

El segundo bloque de preguntas tiene como objetivo averiguar la opinión de los estudiantes sobre los beneficios del uso de la plataforma en las sesiones de prácticas de laboratorio (Tabla 3).

Tabla 3: Sobre el uso del PoliformaT en las sesiones de prácticas de laboratorio

\begin{tabular}{ccccc}
\hline $\begin{array}{c}\text { Usar PoliformaT en las sesiones de prácticas de } \\
\text { laboratorio: }\end{array}$ & $\mathbf{0 9 / 1 0}$ & $\mathbf{1 0 / 1 1}$ & $\mathbf{1 1 / 1 2}$ & $\mathbf{1 2 / 1 3}$ \\
\hline Hace más fácil aprender los contenidos de la asignatura & $48 \%$ & $48 \%$ & $68 \%$ & $84 \%$ \\
Hace más difícil aprender los contenidos de la asignatura & $4 \%$ & $5 \%$ & $7 \%$ & $2 \%$ \\
$\begin{array}{c}\text { No hay ninguna diferencia al aprender los contenidos de la } \\
\text { asignatura }\end{array}$ & $48 \%$ & $47 \%$ & $25 \%$ & $14 \%$ \\
\hline
\end{tabular}

\begin{tabular}{cccccc}
\hline $\begin{array}{c}\text { Creo que ser evaluado en prácticas de laboratorio a través } \\
\text { de PoliformaT al final de cada sesión de laboratorio es } \\
\text { bueno para mi aprendizaje: }\end{array}$ & $\mathbf{0 9 / 1 0}$ & $\mathbf{1 0 / 1 1}$ & $\mathbf{1 1 / 1 2}$ & $\mathbf{1 2 / 1 3}$ \\
\hline Si, es bueno & $73 \%$ & $59 \%$ & $71 \%$ & $76 \%$ \\
No, no es bueno & $8 \%$ & $11 \%$ & $11 \%$ & $5 \%$ \\
No lo sé & $19 \%$ & $30 \%$ & $18 \%$ & $18 \%$ \\
\hline
\end{tabular}

(cc) EY-NC-ND 2014, Universitat Politècnica de València

I Jornadas IN-RED (2014) 
De acuerdo con los resultados, vemos que los estudiantes no tiene una perspectiva negativa hacia el uso de la plataforma (2-7\% piensan que puede ser más difícil usando la plataforma, y sólo al 5-11\% de los estudiantes no les gusta ser evaluados al final de cada sesión).

Las siguientes dos preguntas tratan de buscar la percepción de los estudiantes sobre el software MATHEMATICA usado y la posibilidad de transferir esta forma de evaluación a la parte de Teoría-problemas (Tabla 4).

Tabla 4: Opinión de los estudiantes sobre el MATHEMATICA y la transferencia a T/P

\begin{tabular}{|c|c|c|c|c|}
\hline Creo que el software MATHEMATICA: & $09 / 10$ & $10 / 11$ & $11 / 12$ & $12 / 13$ \\
\hline $\begin{array}{l}\text { Permite entender mejor la parte teórica de la asignatura y me } \\
\text { permitirá sacarle provecho en el futuro }\end{array}$ & $79 \%$ & $61 \%$ & $67 \%$ & $79 \%$ \\
\hline Es una herramienta que usaré sólo para cálculos & $17 \%$ & $36 \%$ & $24 \%$ & $15 \%$ \\
\hline $\begin{array}{l}\text { Su aprendizaje no compensa, existen otros software más } \\
\text { sencillos de usar }\end{array}$ & $4 \%$ & $3 \%$ & $9 \%$ & $5 \%$ \\
\hline $\begin{array}{l}\text { ¿Crees que sería una Buena opción que las sesiones de } \\
\text { Teoría-Problemas se llevaran a cabo con un test de } \\
\text { PoliformaT durante algún día cada semana? }\end{array}$ & $09 / 10$ & $10 / 11$ & $11 / 12$ & $12 / 13$ \\
\hline Si, sería bueno & $57 \%$ & $48 \%$ & $55 \%$ & $54 \%$ \\
\hline No, no sería una Buena idea & $24 \%$ & $25 \%$ & $20 \%$ & $24 \%$ \\
\hline No lo sé & $18 \%$ & $27 \%$ & $25 \%$ & $22 \%$ \\
\hline
\end{tabular}

\section{Conclusiones}

Durante el curso académico 2009/10 los estudiantes fueron capaces de preparar y aprender el tema que había que trabajar durante cada sesión en la primera parte de la clase, mientras que a partir de 2010/11 se ha pedido a los estudiantes que trabajen cada sesión previamente ellos mismos. De las encuestas y de los resultados obtenidos se deduce que la opinión de las clases de laboratorio ha empeorado, sin embargo encontramos la paradoja de que los resultados y el rendimiento han mejorado.

Quizás su impresión viene motivada por la sensación de que sería mejor aprender y trabajar la práctica completa en la clase y resolver cualquier duda de forma inmediata. Sin embargo este trabajo extra ha sido recompensado en el rendimiento general. 
En la Tabla 2 los estudiantes expresaron que las prácticas eran apropiadas al contenido del curso y a la asignatura. En la Tabla 3 podemos ver que muchos estudiantes piensan que las sesiones de prácticas de laboratorio hicieron más fáciles (o que no había ninguna diferencia) el aprendizaje de los contenidos de la asignatura usando PoliformaT, y piensan que ser evaluados al final de cada sesión práctica a través de PoliformaT es bueno para su aprendizaje.

Finalmente, la Tabla 4 muestra que los estudiantes están contentos con el software matemático usado y consideran una buena idea usar la plataforma para mejorar el aprendizaje de las sesiones de Teoría/Problemas.

\section{Agradecimientos}

Los autores agradecen el apoyo de la Ayuda a Proyectos de Innovación Docente, PIDDMA-2013, del Departamento de Matemática Aplicada de la Universitat Politècnica de València; del Proyecto de Innovación y Mejora Educativa PIME B-11 del Vicerrectorado de Estudios y Convergencia Europea (VECE), UPV 2012; y PIME/2013/A/025/B del Vicerrectorado de Estudios, Calidad y Acreditación (VECA), UPV $2013 .$.

\section{Referencias}

Bologna Process Website, <http://www.ond.vlaanderen.be/hogeronderwijs/bologna> [Consulta: 27 Febrero 2014]

CRUE. Conferencia de Rectores de las Universidades Españolas, <http://www.crue.org/Legislacion/Paginas/Legislacion-Ensenanaza.aspx?Mobile=0> [Consulta: 27 Febrero 2014]

MORAÑO, J. A. y SÁNCHEZ RUIZ, L. M. (2008). Cálculo y Álgebra con Mathematica 6. Valencia: Editorial Universitat Politècnica de València.

MORAÑO, J. A. y SÁNCHEZ RUIZ, L. M. (2010). "Mathematics for Engineering from a platform based in the project Sakai" en Proceedings of 2010 International Conference on Engineering Education, ICEE-2010. Gliwice, Polonia. Páginas 1084_1241, Session T11E.

MORAÑO, J. A. y SÁNCHEZ RUIZ, L. M. (2012). Cálculo y Álgebra con Mathematica 8. Valencia: Editorial Universitat Politècnica de València.

SAKAI PROJECT. <http://sakaiproject.org/> [Consulta: 27 Febrero 2014]

(c)) EY-NC-ND 2014, Universitat Politècnica de València

I Jornadas IN-RED (2014) 


\title{
El poder de la colaboración
}

\author{
Anna Vidal Meló ${ }^{a}$, Bernardino Roig Sala ${ }^{b}$, Vicente D. Estruch Fuster ${ }^{c}$, Francisco J. \\ Boigues Planes ${ }^{d}$, Romina del Rey Tormose, Jesús Alba ${ }^{\mathrm{f}}$, Almanzor Sapena Piera ${ }^{\mathrm{g}}$ \\ aavidal@mat.upv.es,_bbroig@mat.upv.es,_ ${ }^{c}$ vdestruc@mat.upv.es, $\quad{ }^{d}$ fraboipl@mat.upv.es, \\ roderey@doctor.upv.es, ${ }^{\mathrm{f}}$ jesalba@ fis.upv.es, ${ }^{\mathrm{g}}$ alsapie@ mat.upv.es \\ Grup d'Innovació Educativa i Recerca en Màteries Cientifiques (GIERMAC) \\ Campus de Gandia de la Universidad Politécnica de Valencia, C. Paranimf, n ${ }^{\circ}$ 1. 46730-Grau de \\ Gandia (Valencia). Teléfono: 962849333. Fax: 962849309.
}

\begin{abstract}
The implementation of the EHEA has meant that students must acquire another set of cross-generic competences, as is the teamwork, in addition to the specific competences corresponding to each subject or course of the grade studies. When addressing and achieving the objective of the teamwork competence, there are several methodologies. In some of them, after forming the work teams, work is posed so that each group solves a problem. In contrast to the previous approach, the methodology presented is in line to work with independent and collaborative groups, promoting collaborative and cooperative interaction between different groups to achieve common goals, or goals closely related for the different groups.

This article presents 4 of the works proposed in the subject Mathematics 2 GISTSI first course, developed based on working in autonomous and collaborative groups. Some of the works have been designed from multidisciplinary approaches, with the previous collaboration of teachers from different disciplines. Products obtained by students through the added power provided by collaboration, are also shown.
\end{abstract}

Keywords: group work, collaborative work, graphic representation, mathematics. 
El poder de la colaboración

\begin{abstract}
Resumen
La implantación del EEES ha dado lugar a que, además de las competencias específicas de cada materia o asignatura de los estudios de Grado, el alumnado adquiera otra serie de competencias de carácter transversal o genérico, como es la del trabajo en equipo. A la hora de abordar y de concretar el objetivo de la competencia del trabajo en grupo, existen diversas metodologías. En algunas de ellas, tras formarse los grupos, se plantean trabajos de forma que cada grupo resuelve un problema. En contraposición a este planteamiento, la propuesta metodológica que presentamos va en la línea de trabajar con grupos autónomos y colaborativos, potenciando la interacción colaborativa y cooperativa entre grupos distintos para la consecución de unas metas que serán comunes o estarán íntimamente relacionadas para los distintos grupos.
\end{abstract}

En este artículo se exponen 4 de los trabajos planteados en las prácticas de la asignatura de Matemáticas 2 del primer curso del Grado de Ingeniería de Sistemas de Telecomunicación, Sonido e Imagen (GISTSI), desarrollados en base al trabajo en grupos autónomos y colaborativos. Algunos de los trabajos se han diseñado desde planteamientos multidisciplinares con la colaboración previa de profesores de distintas disciplinas. Se muestran también los productos obtenidos por el alumnado gracias al poder añadido que proporciona la colaboración.

Palabras clave: trabajo en grupo, trabajo colaborativo, representación gráfica, matemáticas.

\title{
1. Introducción
}

La implantación del EEES ha dado lugar a que, además de las competencias específicas de cada materia o asignatura de los estudios de Grado, el alumnado adquiera otra serie de competencias de carácter transversal o genérico. Éstas forman parte del perfil del egresado, y le capacitan como profesional y ciudadano y deben desarrollarse en sus estudios universitarios (Blanco, 2009). En el caso de la Universitat Politècnica de València, se han enumerado según los siguientes apartados: Conocimiento, compresión e integración; aplicación pensamiento práctico; análisis y resolución de problemas; investigación, innovación y creatividad; diseño y proyecto; trabajo en equipo y liderazgo; responsabilidad ética y profesional; comunicación efectiva; pensamiento crítico; conocimiento de 
Anna Vidal Meló, Bernardino Roig Sala, Vicente D. Estruch Fuster, Francisco J. Boigues Planes, Romina del Rey Tormos, Jesús Alba, Almanzor Sapena Piera

problemas contemporáneos; aprendizaje permanente; planificación y gestión del tiempo e instrumental especifico.

La competencia de trabajo en equipo, por oposición a la individualización, se evidencia como necesaria dado el cambio habido en la estructuración y funcionamiento de la sociedad actual. Las tareas, en general, son cada vez más complejas y, por lo tanto, más difíciles de abordar individualmente. Por esta razón, hoy en día, cualquier organización, empresa o entidad, sea pública o privada, exige con interés creciente la competencia transversal de trabajo en equipo.

La exigencia social de la competencia del trabajo en equipo obviamente, como otras, se ha tenido que trasladar al mundo académico, y para ello se han aprovechado los cambios estructurales que conlleva la puesta en marcha del EEES. En este contexto de cambio y consolidación académica, la realización de trabajos en grupo es cada vez más frecuente en el desarrollo docente de gran diversidad de materias, en la mayoría de estudios a nivel universitario. No obstante, a la hora de abordar y de concretar el objetivo de la competencia del trabajo en grupo, existen diversas metodologías que se integran a su vez en una gran variedad de diseños de la actividad docente, a desarrollar tanto en el aula como fuera de ella. En las experiencias aplicadas para desarrollar la competencia del trabajo en grupo, lo más común es encontrarnos con metodologías de trabajo en base a la formación de grupos autónomos y autosuficientes. Según estas metodologías, tras formarse los grupos, se plantean trabajos de forma que cada grupo resuelve un problema, que en ocasiones podría ser idéntico para todos los grupos, de forma autónoma y autosuficiente, es decir un grupo no necesita del resto de grupos para desarrollar su trabajo y cumplir unos objetivos finalistas que son independientes de los del resto de los grupos. Según esta metodología no existe, por ser innecesario, compromiso alguno entre los grupos de trabajo, ni en el desarrollo del trabajo ni en los objetivos. Inevitablemente, nos encontramos con grupos que fracasan en los objetivos a cumplir por el abandono de parte o de la totalidad de sus miembros. La autonomía y autosuficiencia de un grupo frente al resto, aporta ciertamente un medio de autodefensa frente al abandono de una parte ya que el resultado de un grupo no se verá influido por los resultados, o por la ausencia de éstos, del resto de grupos.

En contraposición al planteamiento clásico descrito anteriormente, la propuesta metodológica que presentamos va en la línea de trabajar con grupos autónomos y colaborativos, es decir potenciar la interacción colaborativa y cooperativa entre grupos distintos en la consecución de unas metas que serán comunes o estarán íntimamente relacionadas para los distintos grupos. Este planteamiento, que de entrada exige una interrelación positiva entre grupos para la consecución de los objetivos globales, permite conseguir una mayor productividad efectiva, que también es percibida por el alumno, lo cual constituye un elemento de motivación añadido.

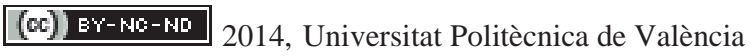

I Jornadas IN-RED (2014) 
En la siguiente sección de este trabajo mostramos los objetivos que nos hicieron aplicar esta metodología y en la tercera sección describimos cuatro de los trabajos colaborativos, o proyectos, realizados por el alumnado del GISTSI impartido en el Campus de Gandia de la UPV. Estos trabajos, voluntarios, se realizan en las prácticas de la asignatura de primer curso Matemáticas 2, representando entre un 20\% o 25\% de la nota final de la asignatura. Como resultados mostramos la consecución de nuestros objetivos en cuanto a la participación del alumnado y su valoración de cada uno de los proyectos.

\section{Objetivos}

En cursos anteriores al 2009-2010 la evaluación de las prácticas (informáticas) de la asignatura de Matemáticas 2 pasó de hacerse a través de una o varias pruebas parciales, a la realización de varios trabajos en grupo. Pero esta última metodología fallaba debido a que a mitad de curso el desmembramiento de los grupos se hacía notable por el abandono de parte o de la totalidad de sus miembros.

Desde el curso 2009-2010, con la intención de fomentar que el alumnado participara de forma activa y constante durante el curso en las prácticas, se han ido incorporando una serie de trabajos colaborativos o proyectos, cuyo éxito exige de la colaboración del mayor número de grupos y donde se trata de alcanzar un objetivo final, que se concreta en la obtención de un producto. En uno de los proyectos, descrito en la sección 3.1, la participación de todos los grupos es imprescindible para la obtención del producto. Los productos de otros años sirven de motivación en los siguientes cursos.

Otro de los objetivos que nos planteamos es el conseguir una valoración positiva del alumnado respecto a las prácticas y los proyectos. Para ello después de cada uno, y desde PoliformaT, se le pide su valoración, entre otras cosas en cuanto al grado de interés así como también la aportación de sugerencias u observaciones.

\section{Desarrollo de la innovación}

A continuación se describen 4 de los proyectos planteados y desarrollados en base al trabajo en grupos autónomos y colaborativos. En todos ellos el papel del profesor es fundamental en cuanto a que, después de la corrección y filtrado de los resultados correctos, es el encargado de juntar todas las piezas del puzzle (cada uno de los trabajos de los equipos) para generar el producto final. Éste se deja en PoliformaT para que puedan verlo los alumnos de la asignatura.

Algunos de los trabajos se han diseñado desde planteamientos multidisciplinares con la colaboración previa de profesores de distintas disciplinas. 
Anna Vidal Meló, Bernardino Roig Sala, Vicente D. Estruch Fuster, Francisco J. Boigues Planes, Romina del Rey Tormos, Jesús Alba, Almanzor Sapena Piera

\subsection{Crear una colección de curvas en forma paramétrica o polar}

Cada equipo, siguiendo una especie de yincana matemática (Vidal, 2103), representa varias curvas (en forma paramétrica o polar). En la yincana se pide localizar, tanto en textos bibliográficos de la Biblioteca de nuestro Campus como en documentos de internet, las ecuaciones de varias curvas. También se pide que, voluntariamente, localicen alguna curva más en internet. De esta forma se amplían las posibilidades de cara a yincanas de próximos años. Cada grupo presenta 4 o 5 transparencias, a partir de una plantilla común en Power Point. Uno de los productos finales ha sido la publicación una Issuu (Vidal, 2014).

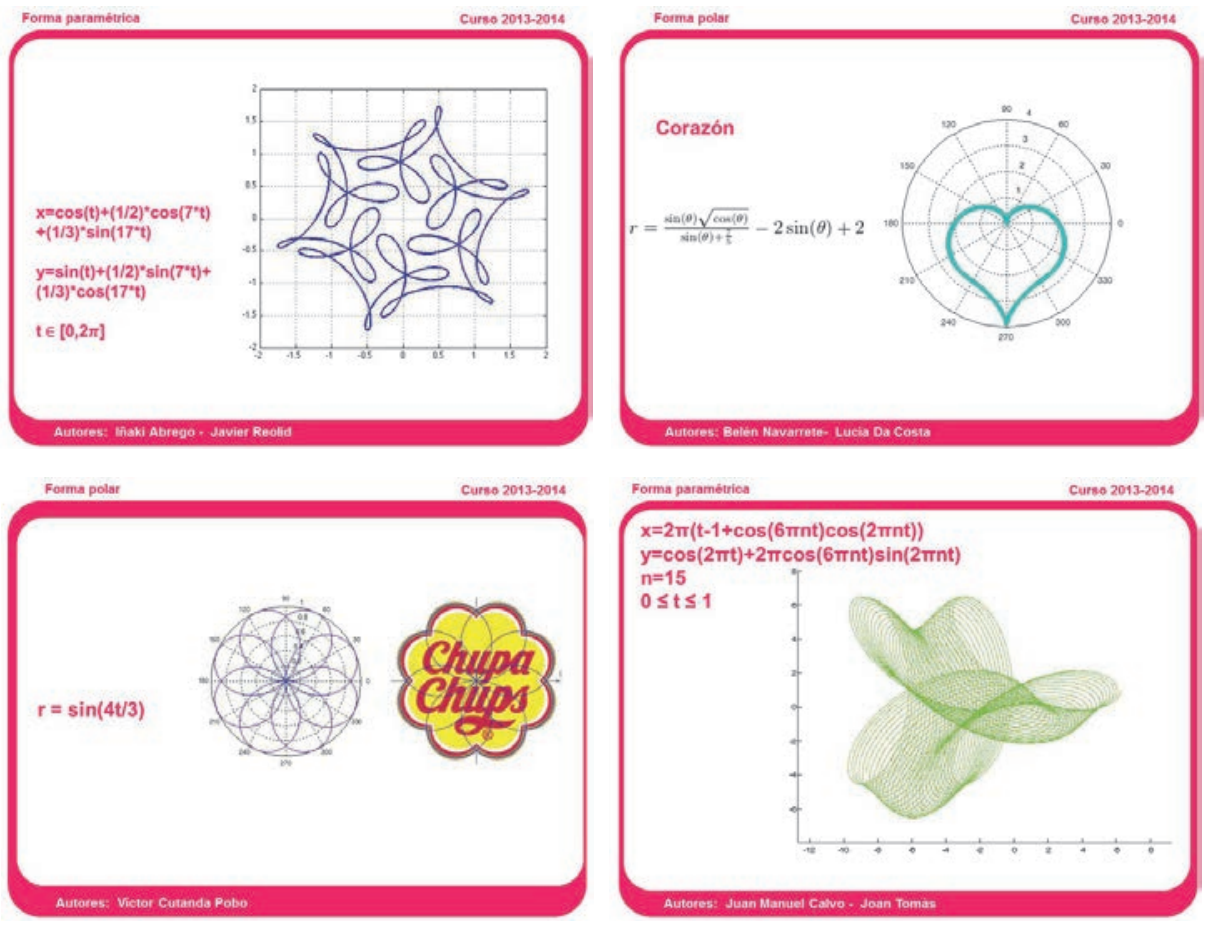

Fig.1 Algunas de las curvas de la colección generada en el curso 2013-2014

En la Fig. 1 aparecen varias de las transparencias que forman parte de la colección del curso 2013-2014, cuya colección total contiene 53 dibujos, igual que en el curso 2012-2103.

\subsection{Crear una colección de gráficas de superficies tridimensionales en forma paramétrica}

Partiendo de las ecuaciones que se pueden encontrar en programas como el de libre utilización k3dsurf creado por Abderrahman Taha, o bien en webs como la del Departamento de Xeometría e Topoloxía de la USC (Universidade de Santiago de

\section{(cc)) BY-NC-ND 2014, Universitat Politècnica de València}

I Jornadas IN-RED (2014) 
Compostela), se ha conseguido realizar varias de estas colecciones. Cada uno de los grupos, y de forma similar al trabajo realizado con las curvas en paramétricas o en polares, debe presentar una colección de varias transparencias Power Point correspondientes a las gráficas de superficies en forma paramétrica.

En el curso 2011-2012 la colección fue de 56 superficies cuyas ecuaciones fueron entresacadas fundamentalmente de k3dsurf. Durante los cursos 2012-2013 y 2013-2014 se ha trabajado con superficies de la citada web de la USC. En el curso 2012-2013 se generaron 57; en el actual 81, algunas de las cuales podemos observar en la Fig. 2.
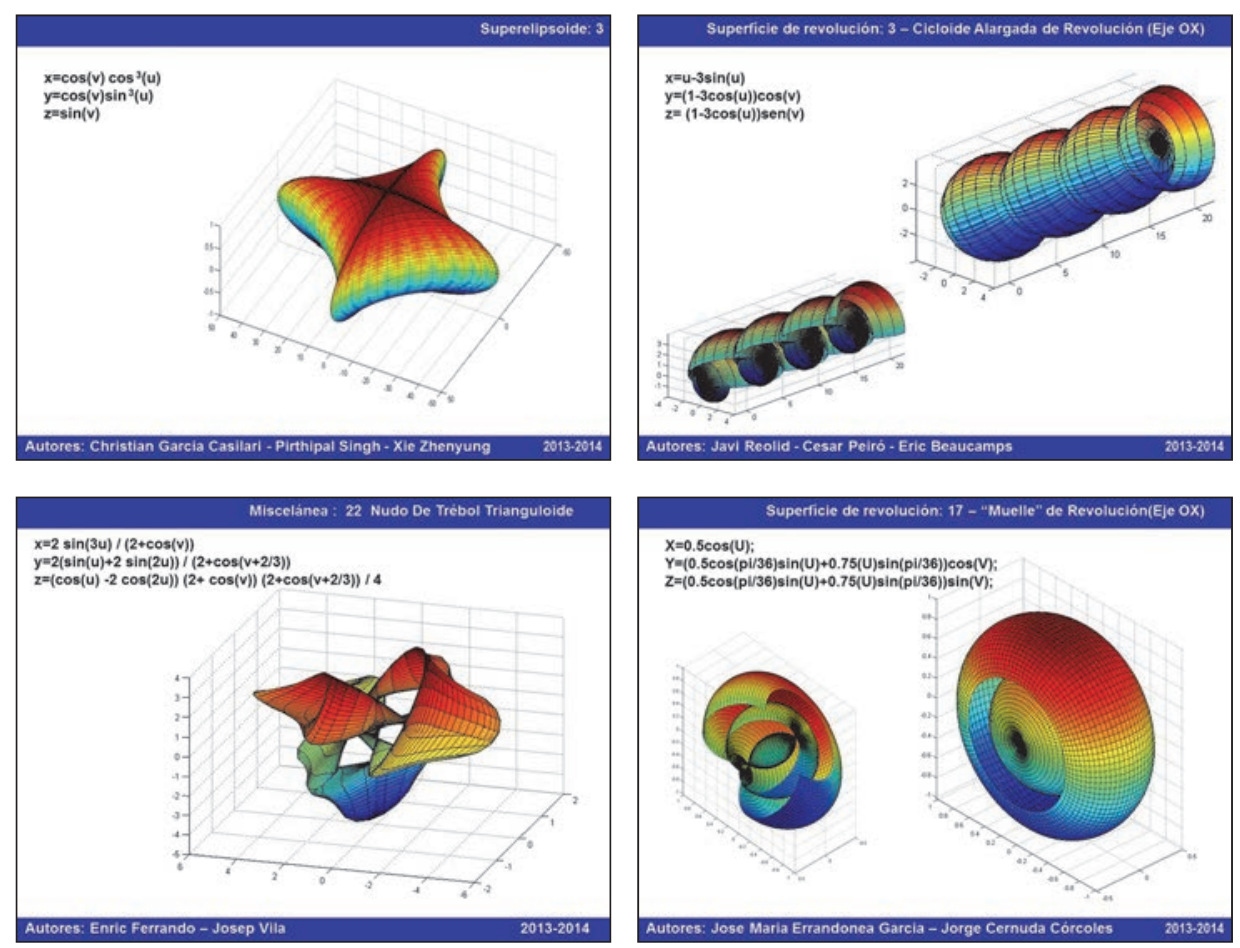

Fig. 2 Algunas de las superficies de la colección generada en el curso 2013-2014

\subsection{Representación en tres dimensiones de mapas topográficos}

Los inicios de la experiencia se sitúan antes del 2009, en los que cada grupo debía, a partir de un pequeño mapa topográfico obtenido desde el Google Maps, hacer una representación 3D. Los mapas no tenían relación unos con otros, siendo el trabajo de cada grupo independiente del resto. Pero en el curso 2009-2010, se planteó la representación de un mapa topográfico más amplio. Dividiendo el mapa en secciones, cada equipo se encarga de la representación de su sección, pero interactuando con los equipos que representan las secciones contiguas, lo cual es fundamental para asegurar la continuidad del dibujo (Vidal, 
Anna Vidal Meló, Bernardino Roig Sala, Vicente D. Estruch Fuster, Francisco J. Boigues Planes, Romina del Rey Tormos, Jesús Alba, Almanzor Sapena Piera

2014). Las representaciones obtenidas durante estos cursos han sido Ordesa y Monte Perdido (2009-2010), en los cursos 2010-2011 y 2012-2013 un mapa desde Gandia hasta La Valldigna, y finalmente, en el curso 2013-2014 una parte de los Picos de Europa, como se ve en las Figuras 3, 4 y 5 .

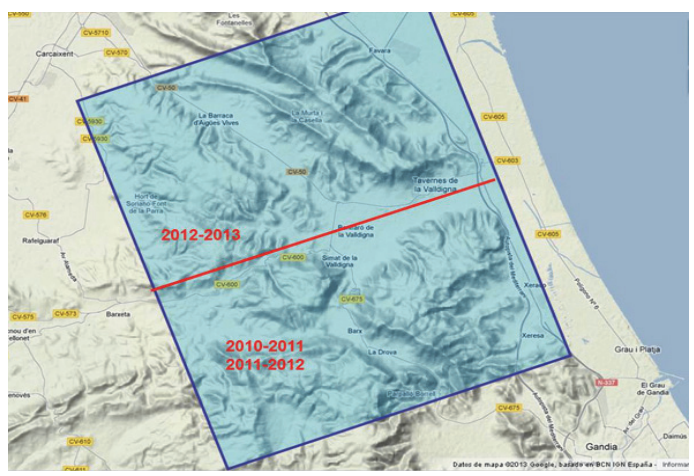

Fig. 3 Proyectos realizados durante tres cursos consecutivos: entre Gandia y La Valldigna

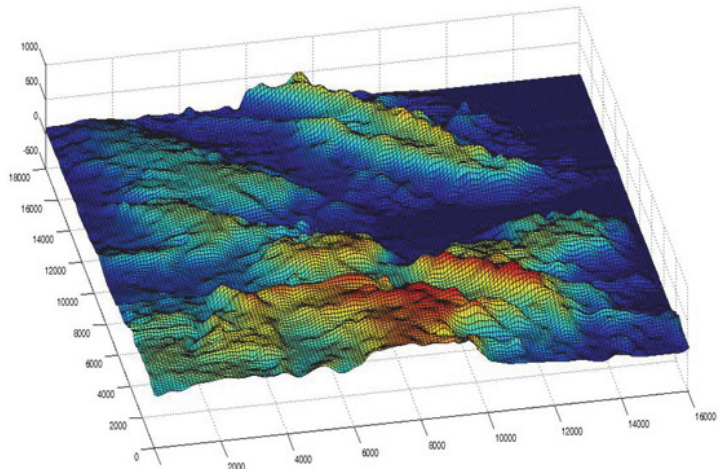

Fig. 4 Producto global resultado desde los cursos 2010-2011 hasta el 2012-2013

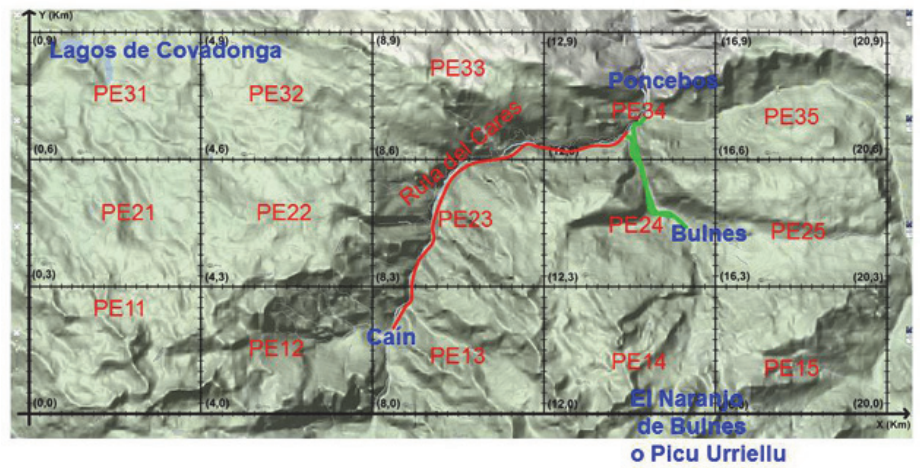

Fig.5 Mapa topográfico y división en secciones, del curso 2013-2014

\section{(cc) EY-NC-ND 2014, Universitat Politècnica de València}

I Jornadas IN-RED (2014) 


\subsection{Estudio de la contaminación acústica en una zona}

Este estudio se realiza en dos prácticas, una en el primer semestre y otra en el segundo. El material de partida son varios mapas acústicos, similares a los de las figuras 6 y 7 , de una misma zona pero con condiciones diferentes (por ejemplo en un caso se cambia el asfalto de las vías, en otro se cambian direcciones de tránsito o se coloca una barrera acústica en determinado lugar, ...). Las zonas estudiadas han sido: un sector con un hospital (curso 2011-2012), otro con una carretera que separa una zona escolar de una residencia (20122013) y durante el curso 2013-2014, una zona muy conocida por el alumnado, la zona cercana a la Biblioteca (CRAI), que incluye rotondas y con ruido ocasionado por el tráfico.

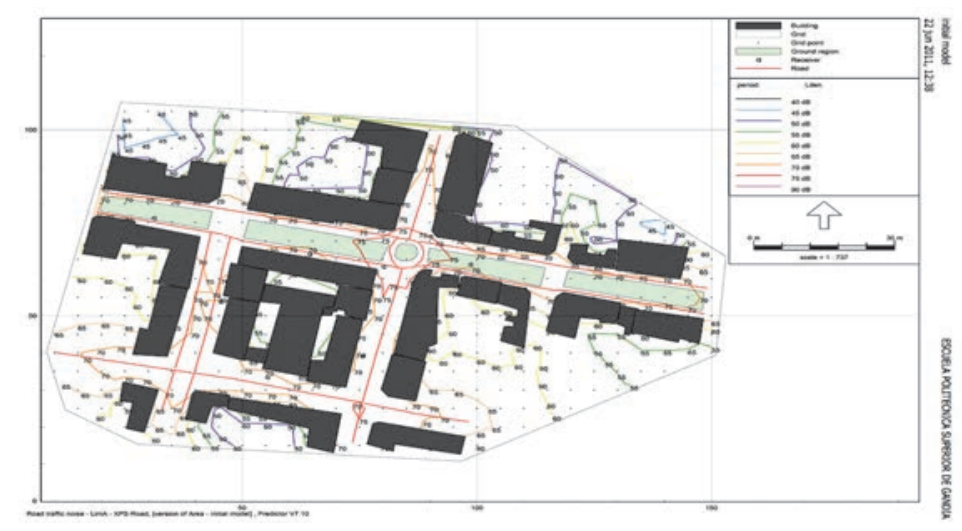

Fig.6 Mapa acústico del curso 2011-2012.

En la primera práctica cada grupo y siguiendo una misma dirección sobre cada uno de los mapas, estudia el efecto de las medidas consideradas. El profesor se encarga de juntar todas las direcciones y conseguir un barrido global de la zona.

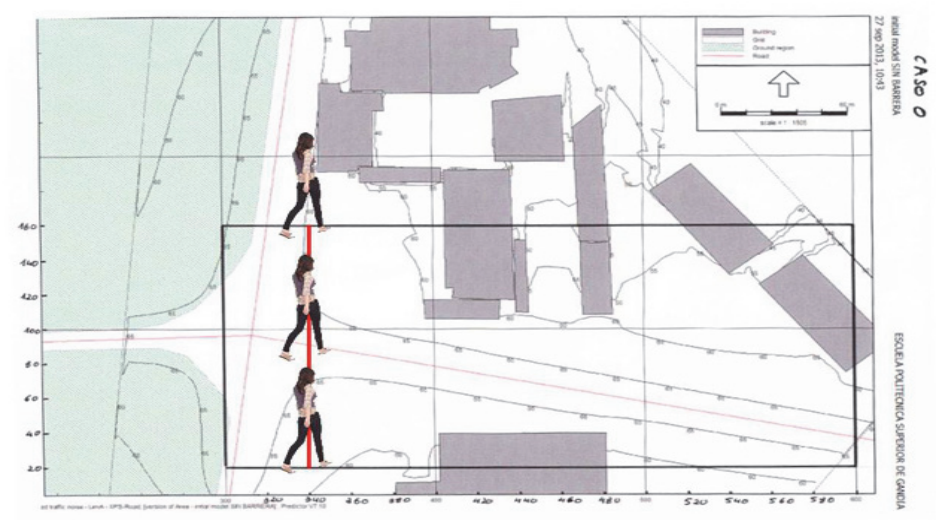

Fig. 7 Zona a estudiar en la dirección vertical 340, curso 2013-2014. 
Anna Vidal Meló, Bernardino Roig Sala, Vicente D. Estruch Fuster, Francisco J. Boigues Planes, Romina del Rey Tormos, Jesús Alba, Almanzor Sapena Piera

En la práctica del segundo semestre, cada equipo estudia globalmente sólo uno de los casos, obteniendo un mapa de color correspondiente a los niveles de $\mathrm{dB}$, y que deben compartir con el resto de grupos, para que todos ellos puedan obtener conclusiones acerca de cómo influye cada una de las medidas correctoras. Por ejemplo, durante el curso 2013-2014 se ha considerado un caso inicial, Caso 0 de partida, en el que se refleja la existencia de una rotonda cercana a la Biblioteca y una vía de doble circulación; en el Caso 1 se considera la instalación de una gran pantalla acústica que bordea frontalmente el edificio, y en el Caso 2 la eliminación del tráfico por la vía y la creación de un boulevard peatonal. En la Fig. 8 se aprecian los mapas de color obtenidos en cada caso.
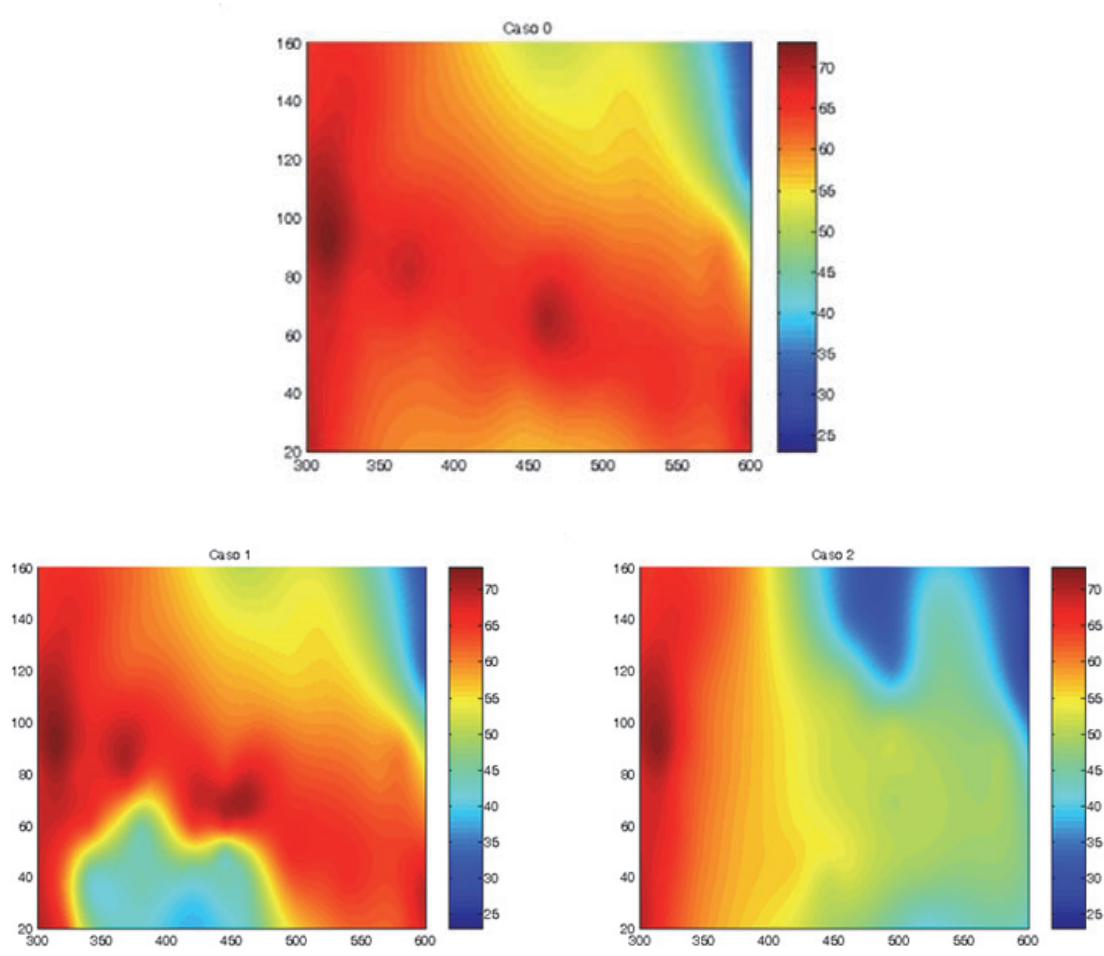

Fig. 8 Mapas de color del curso 2013-2014

Cabe señalar que tanto para este proyecto como para el anteriormente descrito, en la sesión de prácticas hacemos uso del puzzle de Aronson (Aronson, 1978, 1997) como método de enseñanza-aprendizaje.

Esta experiencia educativa se ha realizado gracias a dos Proyectos de Innovación y Mejora Educativa en los que se plantea la colaboración entre las asignaturas de Matemáticas 2 y Acústica para la aplicación de metodologías activas en primer curso del GISTSI.

\section{(c) EY-NC-ND 2014, Universitat Politècnica de València}

I Jornadas IN-RED (2014) 


\section{Resultados}

Como ya se ha indicado, uno de los principales objetivos, descritos anteriormente, que nos planteamos con los Proyectos de Innovación y Mejora Educativa, era el aumentar la participación del alumnado en la realización de los proyectos. Por otra parte también es de nuestro interés proponer proyectos que sean de interés para nuestros alumnos y que ellos puedan aportar sus opiniones. Es lo que pasamos a exponer a continuación.

\subsection{Sobre la participación del alumnado}

La Tabla 1. muestra que nuestro objetivo principal se está cumpliendo.

Tabla 1. Alumnado participante en las prácticas

\begin{tabular}{|c|c|}
\hline Curso & Porcentaje de alumnado participante en los Proyectos \\
\hline $\mathbf{1 0 - 1 1}$ & $67.5 \%$ \\
\hline $\mathbf{1 1 - 1 2}$ & $67 \%$ \\
\hline $\mathbf{1 2 - 1 3}$ & $78.2 \%$ \\
\hline $\mathbf{1 3 - 1 4}$ & $85.5 \%$ \\
\hline
\end{tabular}

Además un 25\% del alumnado aprueba la asignatura por la realización de estos proyectos.

\subsection{Sobre el grado de interés de los proyectos}

Después de la realización de cada proyecto, el alumnado puede opinar acerca de su interés (ninguno, poco, indiferente, interesante o muy interesante). En las Tablas 2, 3 y 4 recogemos los datos, sobre el total de alumnos que han realizado la valoración, del alumnado a los que les ha resultado interesante o muy interesante el proyecto en cuestión.

Tabla 2. Valoración sobre el proyecto de curvas

\begin{tabular}{|c|c|c|c|}
\cline { 2 - 4 } \multicolumn{1}{c|}{} & $\begin{array}{c}\mathbf{N}^{\mathbf{0}} \text { encuestas } \\
\text { realizadas }\end{array}$ & $\begin{array}{c}\mathbf{N}^{\mathbf{0}} \\
\text { interesados }\end{array}$ & $\%$ \\
\hline $\mathbf{2 0 1 2 - 2 0 1 3}$ & 38 & 31 & $81.6 \%$ \\
\hline $\mathbf{2 0 1 3 - 2 0 1 4}$ & 39 & 36 & $92.3 \%$ \\
\hline
\end{tabular}


Anna Vidal Meló, Bernardino Roig Sala, Vicente D. Estruch Fuster, Francisco J. Boigues Planes, Romina del Rey Tormos, Jesús Alba, Almanzor Sapena Piera

Tabla 3. Valoración sobre el proyecto de las superficies

\begin{tabular}{|c|c|c|c|}
\cline { 2 - 4 } \multicolumn{1}{c|}{} & $\mathbf{N}^{\mathbf{0}}$ Encuestas realizadas & $\mathbf{N}^{\mathbf{0}}$ Interesados & \% Interesados \\
\hline $\mathbf{2 0 1 2 - 2 0 1 3}$ & 33 & 24 & $72.7 \%$ \\
\hline $\mathbf{2 0 1 3 - 2 0 1 4}$ & 24 & 19 & $79.2 \%$ \\
\hline
\end{tabular}

Tabla 4. Valoración sobre el proyecto del mapa topográfico y del acústico

\begin{tabular}{|c|c|c|c|c|c|}
\cline { 2 - 6 } \multicolumn{1}{c|}{} & $\begin{array}{c}\mathbf{N}^{\mathbf{0}} \\
\text { encuestas } \\
\text { realizadas }\end{array}$ & $\begin{array}{c}\mathbf{N}^{\mathbf{0}} \text { interesados } \\
\text { en mapas } \\
\text { topográficos }\end{array}$ & $\begin{array}{c}\text { \% mapas } \\
\text { topográficos }\end{array}$ & $\begin{array}{c}\mathbf{N}^{\circ} \text { interesados } \\
\text { en mapas } \\
\text { acústicos }\end{array}$ & $\begin{array}{c}\text { \% mapas } \\
\text { acústicos }\end{array}$ \\
\hline $\mathbf{2 0 1 2 - 2 0 1 3}$ & 43 & 37 & $86 \%$ & 35 & $81.4 \%$ \\
\hline $\mathbf{2 0 1 3 - 2 0 1 4}$ & 29 & 26 & $89.7 \%$ & 24 & $82.8 \%$ \\
\hline
\end{tabular}

\section{Conclusiones}

Del apartado anterior deducimos que tanto la participación del alumnado como el interés por los proyectos, va creciendo año a año. A continuación exponemos algunas de las opiniones recogidas durante estos dos últimos cursos obtenidas de las valoraciones que aporta el alumnado en cada una de las prácticas y proyectos relacionados:

- Sobre el proyecto de curvas

La mayoría lo define como divertido:

- Ha sido una práctica que para mi es divertida y no muy complicada.

- La práctica ha estado muy chula.

- Voy a definir esta práctica con la palabra "diversión".

- Ha sido interesante estudiarla tanto por la curiosidad de las formas geométricas que hacen las ecuaciones, las formas y demás como lo que vimos en clase de la rampa que frecuenta para patinar, que es en la que más velocidad se alcanza.

- He encontrado la práctica interesante, al principio un poco complicada por ser la primera vez que utilizo Matlab para representar curvas. Pero vale la pena porque algunas curvas tienen formas interesantes y bonitas.

- La práctica me ha parecido sencilla, y me ha parecido de muy buena idea implementar la búsqueda de Internet y libros, en estas actividades.

- Me ha parecido muy interesante la práctica y muy entretenida. 
- Me ha parecido interesante las curvas que salían cambiando valores en la misma ecuación y la cantidad de ellas que había.

○ Que bien!!!! me encanto!!!!!! es fácil!!!!! i can play!!!!

- Me ha gustado esta práctica ya que hemos visto curvas muy vistas en sonido como la cardioide o la de flor.

- Al buscar una curva opcional adecuada por internet e encontrado una gran variedad de sitios interesantes sobre el tema que probablemente no hubiera visitado si no fuera por la práctica. Además el poder crear mis propias curvas con Matlab utilizando como modelos las que encontrado en libros y paginas me resulta muy entretenido.'

Respecto a la metodología exigida de la yincana de buscar en la Biblioteca:

- Me ha gustado mucho el modo de buscar cada uno sus propias ecuaciones en los libros de la biblioteca, por una parte porque muchos habrán entrado a esta gracias a la práctica ...

- Esta práctica está muy bien, ya que no solo aprendemos cosas nuevas, sino que también nos ayuda a conocer la biblioteca del campus, y cómo encontrar el material que necesitamos.

- Lo de la yincana me ha parecido muy curioso, hablé con la bibliotecaria que esto lo llevas haciendo bastantes años para que aprendiésemos a buscar cualquier cosa de la biblioteca y más de uno habrá aprendido.

- Me ha parecido interesante, por que gracias a esta práctica he estado en la biblioteca de la universidad y aprendido a buscar libros en ella.

Propuestas aportadas que sugieren nuevas ideas:

- Sería interesante plantear hacer una construcción de alguna montaña rusa, un puente caprichoso utilizando este tipo de curvas.

- Ha resultado muy interesante ya que he logrado observar y a la vez aprender que mediante formulas matemáticas podemos obtener diseños y gráficas bastante interesantes. Aun que yo quería adjuntarle opcionalmente el icono de Batman, pero me resulto bastante complicado pasarlo a matlab :(

- Me ha parecido bastante interesante dado que algunas de las curvas paramétricas que hemos visto se utilizan en física o en otras asignaturas como las curvas de Lissajous que se estudia para movimientos armónicos simples en física. Las cardiodes también son bastante interesantes dado que muestran el comportamiento de un unidireccional de tipo sm57.

(cc) EY-NC-ND 2014, Universitat Politècnica de València

I Jornadas IN-RED (2014) 
Anna Vidal Meló, Bernardino Roig Sala, Vicente D. Estruch Fuster, Francisco J. Boigues Planes, Romina del Rey Tormos, Jesús Alba, Almanzor Sapena Piera

Una última opinión relacionada con otro de los objetivos de cualquier proceso de enseñanza, el despertar el interés:

- Debo admitir que a parte de las ecuaciones mandadas, me ha gustado probar otras de otros compañeros para ver como quedan.

- $\quad$ Sobre el proyecto de superficies

Las opiniones son similares al de curvas:

- Me ha parecido interesante y una de las mejores junto con la de curvas.

- Ha sido interesante ver como se pueden representar figuras tan extrañas.

- Es interesante. Se obtienen figuras curiosas.

- Esta practica y la de los mapas han sido las que mas me han gustado ya que esta muy bien ver representado el trabajo en graficas $3 D$.

Respecto a la metodología seguida en prácticas:

- Esta práctica está muy bien explicada. Además lo de llevar los "juguetes” estuvo muy simpático.

Detectando errores en la página web de la USC:

- La práctica me ha parecido sencilla e interesante, ... Hemos tenido algún problema con las ecuaciones de la página web que tenían algún error.

- Me gustaría resaltar que algunas ecuaciones estaban mal, pero gracias a internet pudimos completarlas. En general la práctica me ha gustado y el grupo ha trabajado con éxito.

Propuestas aportadas que sugieren nuevas ideas:

- Me ha resultado interesante por sus múltiples aplicaciones. Una de ellas con la que estoy familiarizado es en los mapas de los videojuegos en los que se pueden observar cantidad de estas figuras.

- Sobre el proyecto de mapas topográficos y acústicos

- Me ha parecido una práctica bastante interesante y amena. He podido ver y aprender gracias a las figuras, fotos y mapas.

- Muy buena práctica, espero poder ver el resultado final.

- Creo que la parte del mapa topográfico es la práctica más interesante que hemos hecho hasta el momento. 
- Es una práctica muy interesante, visualmente entretenida, sobretodo la parte topográfica. Personalmente es la práctica que más me ha gustado.

- Esta practica me ha resultado interesante ya que puedes aprender la representación real en $3 D$ de un lugar.

- Esta práctica me ha gustado porque la llevábamos bien preparada y nos ha sido más fácil que las anteriores. también me ha gustado el resultado del trabajo del mapa topográfico.

- Me ha gustado bastante el proyecto del mapa acústico. Me ha resultado interesante poder volver a visualizar los resultados de la práctica 1 pero esta vez mejor hecha, con resultados globales.

Respecto a la metodología utilizada en la práctica:

- Es la práctica mas completa que hemos hecho, ya que hemos trabajado en equipo y la práctica ha sido divertida.

- Me ha gustado mucho esta práctica, no solo por que parte del trabajo pudo hacerse en clase con atención de la profesora, si no por la metodología del puzzle de Aronson y la predisposición de mi equipo a trabajar y prepararse a pesar de tener exámenes esta semana.

- El puzzle de Aronson me parece una metodología muy muy interesante porque ha sido mucho más fácil realizar la práctica y entenderla.

- El método utilizado para realizar esta práctica es muy productivo y facilita mucho el trabajo. La práctica me ha parecido muy interesante, cuando tenga tiempo intentare representar una montaña de mi zona.

Propuestas aportadas que sugieren nuevas ideas:

- La práctica es bastante entretenida, pero mejor si fuera más grande. (Idea loca: una ciudad, con las medidas de los edificios las calles y parques ... O algo así.).

- Los mapas topográficos no tenían demasiada definición para algunas cosas, aunque hemos entrado en google maps para ver si podíamos obtener una mejor visualización y tampoco. Como sugerencia, se podría visualizar la zona a representar con el programa google Earth que ofrece modelos en $3 D$ de todo el planeta y se ven muy bien todas las montañas y otros lugares. Nosotros hemos podido observar en dicho programa un pico que no sabíamos si subía o bajaba.

(cc) EY-NC-ND 2014, Universitat Politècnica de València

I Jornadas IN-RED (2014) 
Anna Vidal Meló, Bernardino Roig Sala, Vicente D. Estruch Fuster, Francisco J. Boigues Planes, Romina del Rey Tormos, Jesús Alba, Almanzor Sapena Piera

\section{Referencias}

ARONSON,E., BLANEY, N., STEPHIN, C., SIKES, J. \& SNAPP, M. (1978). "The Jigsaw Classroom". Beverly Hills, California. Sage Publications.

ARONSON, E., PATNOE, S. (1997). “ The Jigsaw Classroom, Building Cooperation in the Classroom”. United States. Longman (second edition).

BLANCO FERNÁNDEZ, A. (2009). "Desarrollo y evaluación de competencias en educación superior”. ,Narcea SA de ediciones.

DEPARTAMENTO DE XEOMETRÍA E TOPOLOXÍA. 〈http://xtsunxet.usc.es/galeria.htm>. [Consulta: 13 de junio de 2014].

TAHA, A. K3DSurf. <http://k3dsurf.sourceforge.net/>. [Consulta: 13 de junio de 2014].

VIDAL MELÓ, A., ROIG SALA, B., ESTRUCH FUSTER, V.D., BOIGUES PLANES, F.J., DEL REY, R., y ALBA, J. (2012). "Rompiendo con la rutina: dos experiencias matemáticas con el puzle de aronson” en XX CUIEET. Las Palmas de Gran Canaria. 12 páginas.

VIDAL MELÓ, A., ROIG SALA, B., ESTRUCH FUSTER, V.D., BOIGUES PLANES, y F.J. (2013). "Una yincana para descubrir y generar curvas en un trabajo cooperativo", en Actas del XXI CUIEET. Valencia. 950-961.

VIDAL MELÓ, A., ROIG SALA, B., ESTRUCH FUSTER, V.D., BOIGUES PLANES, F.J., DEL REY, R., y ALBA, J. (2014) “ Modelos de mapas topográficos y acústicos: del papel al ordenador” en Modelling in Science Education and Learning. Volume 7, No. 1, 2014. 67-81.

VIDAL MELÓ, A. Curves of Mathematical gymkhana. <http://issuu.com/anna_vidal/docs/curves_of_mathematical_gymkhana>. [Consulta: 13 de junio de 2014]. 


\title{
Fabricación de una lámpara para el estudio de la resistencia eléctrica
}

\section{Romina del Rey Tormos ${ }^{\mathrm{a}}$, Jesús Alba Fernández ${ }^{\mathrm{a}}$ y Laura Bertó Carbó ${ }^{\mathrm{a}}$}

${ }^{a}$ Universitat Politècnica de Valéncia, Escuela Politécnica Superior de Gandia, Centro de Tecnologías Físicas: Acústica, Materiales y Astrofísica, C/Paraninfo $\mathrm{n}^{\circ} 1$ - 46715 Grao de Gandia. roderey@doctor.upv.es, jesalba@ fis.upv.es, y lauberca@upvnet.upv.es.

\begin{abstract}
This report shows what has been the methodology followed in the annual matter of physics, given in the Bachelor's Degree in Telecommunications engineering, Sound and Image, of the Polytechnic University of Valencia, to explain to the students the Ohm's Law, within the unit called "Current and Circuits of Direct Current".

With the aim to strengthen the inquisitiveness of the first year students and motivate to the future engineer on the projects approach to solving problems, a homemade lamp was used, trying to replicate the experience of Thomas Alva Edison. In order to do this, we used a mine of a propelling pencil taken at its ends with two cables, a roll of duct tape, a glass jar, a roll of toilet paper and a plate. The assembly is subjected to a potential difference that can be achieved with batteries

Students must answer a number of questions after performing or witnessing this curious and easy experiment. Within the planning of the course 13 control problems are made. The problem posed on the basis of this experiment is the problem where the students have obtained higher scores.
\end{abstract}

Keywords: Motivation, methodology, teaching based on project, active methodology

\section{Resumen}

En este trabajo se presenta la metodología seguida en la asignatura anual de Física del Grado en Ingeniería de Telecomunicación, Sonido e Imagen de la Universitat Politècnica de Valencia para acercar y explicar al alumnado la 
Fabricación de una lámpara para el estudio de la resistencia eléctrica

Ley de Ohm, dentro de la unidad "Corriente y Circuitos de Corriente Continua”.

Con el objetivo de potenciar la inquietud del alumnado de primer curso del citado grado en las ciencias básicas de la física, y motivar así al futuro ingeniero en el planteamiento de proyectos para la resolución de problemas, se construye en clase una lámpara casera, intentando replicar la experiencia de Thomas Alva Edison. Para ello se utiliza una mina de lápiz que se sujeta en sus extremos con dos cables, un rollo de cinta aislante, un bote de cristal, un rollo de papel higiénico y un plato. El conjunto se somete a una diferencia de potencial que puede conseguirse con pilas.

Los alumnos después de realizar o presenciar este curioso y fácil experimento, deberán responder una serie de preguntas. Dentro de la planificación de la asignatura se realizan 13 problemas de control. El problema planteado en base a esta experiencia es en el que los alumnos han obtenido las mayores puntuaciones.

Palabras clave: motivación, metodología, enseñanza basada en proyecto, metodología activa.

\section{Introducción}

En este trabajo se presenta la metodología seguida en la asignatura de física del Grado en Ingeniería de Telecomunicación, Sonido e Imagen de la Universitat Politècnica de Valencia para acercar y explicar al alumnado la Ley de Ohm. Física es una de las materias de formación básica de carácter anual. Una de las unidades temáticas dentro de su planificación es "Corriente y Circuitos de Corriente Continua", donde la Ley de Ohm y la resistencia eléctrica, analizada desde un punto de vista formal, tienen un papel fundamental (Tipler, 2013).

Con el objetivo de potenciar la inquietud del alumnado de primer curso del citado grado en las ciencias básicas de la física, y motivar así al futuro ingeniero en el planteamiento de proyectos para la resolución de problemas, se construye en clase una lámpara casera, como una experiencia que intenta aproximar al grupo a la experiencia de Thomas Alva Edison. Para ello se utiliza una mina de lápiz que se sujeta en sus extremos con dos cables. Con un rollo de cinta aislante, un bote de cristal, un rollo de papel higiénico y un plato se acaba el diseño. El conjunto se somete a una diferencia de potencial equivalente al de una batería de coche (que puede conseguirse con ocho pilas) y la mina se enciende. En ese momento se determina la corriente eléctrica. El experimento, pues, se lleva a cabo con materiales cotidianos y de fácil acceso. Previamente a esto, se tiene que realizar una búsqueda de

(c)) EY-NC-ND 2014, Universitat Politècnica de València

I Jornadas IN-RED (2014) 
experiencias similares para valorar que tipo de bombilla construir, puesto que hay muchas versiones al respecto (Experimentos caseros, 2014)(Experimentos de física, 2014)(Los experimentos caseros, 2014).

Los alumnos después de realizar o presenciar este curioso y fácil experimento, deberán responder una serie de preguntas referentes a la resistencia y resistividad eléctrica de la mina utilizada. También deben comparar estos valores con valores que presentan las minas de sus compañeros, minas de mayor o menor longitud o minas con distintos diámetros. Por último, los alumnos deberán comparar el valor del resultado de sus experimentos con los valores "teóricos" de las minas, y comentar las posibles discrepancias.

Dado que el experimento llama la atención los resultados son muy positivos, puesto que existe una preocupación por saber construir y conocer cuáles son los fundamentos en lo que se basa, permitiendo introducir así los conocimientos de la unidad didáctica.

\section{Objetivos}

En este trabajo se plantea una experiencia de desarrollo de un pequeño proyecto que sirva para que el alumno se motive a la hora de abordar la materia de "Corriente y Circuitos de Corriente Continua": una bombilla casera. La construcción de esta bombilla permite que el alumno entre de manera natural en el detalle del comportamiento microscópico de la corriente eléctrica, el comportamiento con la temperatura, y otros interesantes, que de otra forma se abordan sólo en base a fórmulas y ejemplo muy clásicos y poco amables.

El objetivo, por tanto es, en base a un proyecto, motivar al alumno para que pueda aprender de forma aplicada la materia descrita. Como objetivo corolario de éste, el aumento del rendimiento en esta unidad didáctica en concreto, que en años anteriores ha tenido peores resultados en comparación a otras de las que se imparten en física.

\section{Desarrollo de la innovación}

Una bombilla casera puede construirse de varias formas. Sólo hay que realizar una búsqueda en la web y pueden verse diferentes montajes experimentales (Experimentos caseros, 2014)(Experimentos de física, 2014)(Los experimentos caseros, 2014). Para el filamento de las bombillas suele proponerse un trozo de cable de hilo único al que se le saca el hilo de cobre interior, de sección de $2 \mathrm{~mm}$ o similar y se le da forma de espiral como el filamento de la bombilla. En otras versiones el filamento es una mina de lápiz, de un portaminas o similar. En este caso a veces lo denominan "bombilla de Efecto Joule".

\section{(c) EY-NC-ND 2014, Universitat Politècnica de València}

I Jornadas IN-RED (2014) 
El filamento elegido se conecta a dos cables y se sumerge en un bote de vidrio transparente que le da la apariencia de bombilla. En algunas versiones los cables atraviesan una tapa metálica. En otras se apoya en un plato, un recipiente metálico, un molde de aluminio, etc. El sistema construido se alimenta de diferente forma en función de las versiones: con una pila de petaca de $4,5 \mathrm{~V}$, con 6 pilas de $1,5 \mathrm{~V}$ en serie, con una pequeña batería de $12 \mathrm{~V}$, con una fuente de alimentación, etc. Al poner en marcha el circuito, el filamento se enciende.

En nuestro caso se ha decidido utilizar como filamento mina de lápiz HB comercial $6 \mathrm{~cm}$ de longitud y 0,5 mm de diámetro. El material de la mina estará compuesto por un porcentaje elevado de grafito. Este filamento se conecta a dos cables cocodrilo-banana apoyados sobre un soporte de cartón (rollo de papel higiénico o similar) e introducido en un bote de vidrio reciclado. Las pinzas cocodrilo hay que colocarlas con precaución para no romper la mina, lo más al borde posible. El sistema se apoya sobre un plato y se alimenta con una fuente de alimentación a 5 V. En la figura 1 se muestra el montaje antes de ponerlo en marcha. En la figura 2 se muestra la bombilla casera encendida.

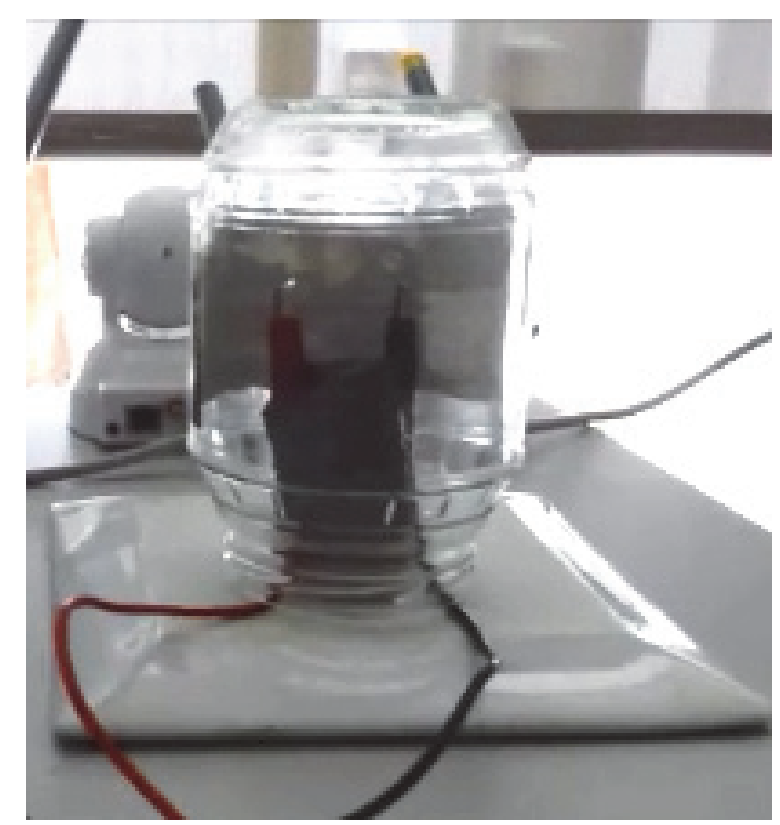

Fig. 1 Detalle de montaje inicial 


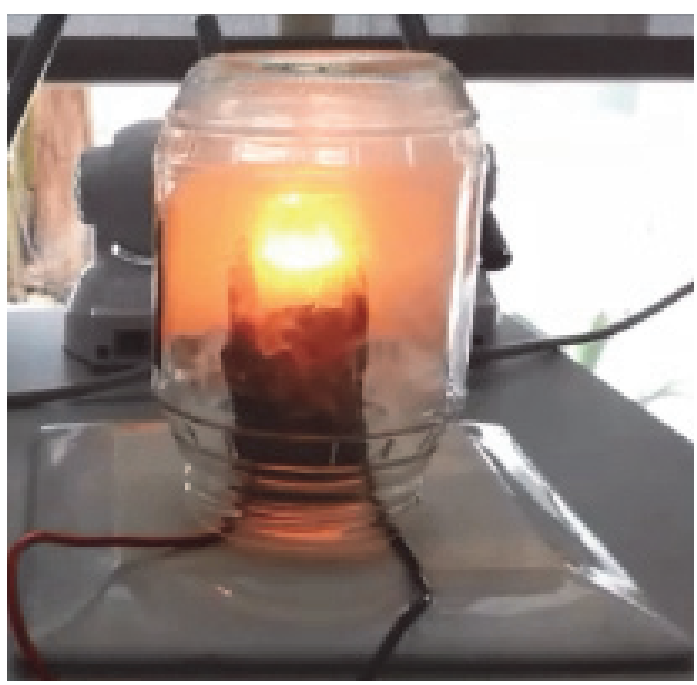

Fig. 2 Detalle del montaje encendido

Para realizar la experiencia, en primer lugar se mide con un multímetro la resistencia eléctrica "en frío" del filamento junto con los cables. En nuestro caso, 3,7 Ohmios.

A continuación se coloca el multímetro en modo amperímetro para poder determinar la corriente que atraviesa el circuito cuando los alimentemos con $5 \mathrm{~V}$. Al conectar el sistema se graba un video con un móvil, donde se ve la bombilla casera y el multímetro. Mediante este video puede anotarse la intensidad de corriente que registra el multímetro en función del tiempo. Al realizar el cociente entre la diferencia de potencial (de $5 \mathrm{~V}$ ) y la intensidad de corriente en función del tiempo se puede estimar el valor de la resistencia eléctrica en función del tiempo.

En la figura 3 se muestran algunos resultados de este procedimiento en cinco casos diferentes (R1, R2, R3H, R4H, R5), obtenidos de los vídeos grabados. Puede verse la misma tendencia en todos los casos. En primer lugar la resistencia eléctrica disminuye rápidamente y se estabiliza. Esto ocurre inicialmente, desde que se pone en marcha el circuito hasta que la bombilla se enciende. Posteriormente se mantiene estabilizada unos segundos. En ese tiempo la luz se muestra más o menos estable. Llega un momento que la resistencia empieza a aumentar de valor de forma progresiva. Al mismo tiempo puede verse cómo aumenta la luminosidad de la bombilla hasta que al final la mina se rompe. Puede verse consumida por el centro de la mina totalmente, con forma cónica desde el centro más o menos a los bordes. En la figura 4 se muestra el estado final. En todo este proceso, aparece humo dentro del bote, debido a la combustión del grafito.

Puede verse así el comportamiento teórico. Al calentarse la resistencia de la mina disminuye. En el momento que la superficie de la mina combustiona con el oxígeno,

\section{(c)) EY-NC-ND 2014, Universitat Politècnica de València}

I Jornadas IN-RED (2014) 
empieza a reducirse el diámetro de la mina, lo que debe producir un aumento de la resistencia, hasta que se produce la rotura.

El comportamiento descrito es similar para las cinco muestras que se grafican en la figura 3. Analizando con detalle, las curvas son casi iguales para R1, R2 y R5. Las pequeñas diferencias se deben a que el tiempo en el que se inicia el video no es siempre igual en los tres casos y eso produce un pequeño desfase. Sin embargo, puede observarse cómo para R3H y R4H las curvas están más "estiradas" en el tiempo. Esto es debido a que, después de R2 no se ha vaciado el humo que había dentro del tarro. Por tanto hay menos oxígeno dentro del bote. Esto también sucede con R4H. Al tener menos oxígeno, tarda más tiempo en combustionar, manteniendo más tiempo la resistencia eléctrica. Una vez observado esto, se asegura que se vacia de humo el bote y se mide R5. Puede verse de nuevo cómo vuelve a tener la misma curva.

En la figura 5 se añade un detalle de comparación de R1, R2 y R5. En este caso puede verse cómo las curvas son muy parecidas. En esta grafica aun se puede observar que la curva de R2 se alarga por algo de humo de la medida de R1. En la figura 6, un detalle de comparación de R1 con R3H y R4H. Aquí se observa cómo la curva se estira temporalmente a causa del humo interior, por descenso del oxígeno.

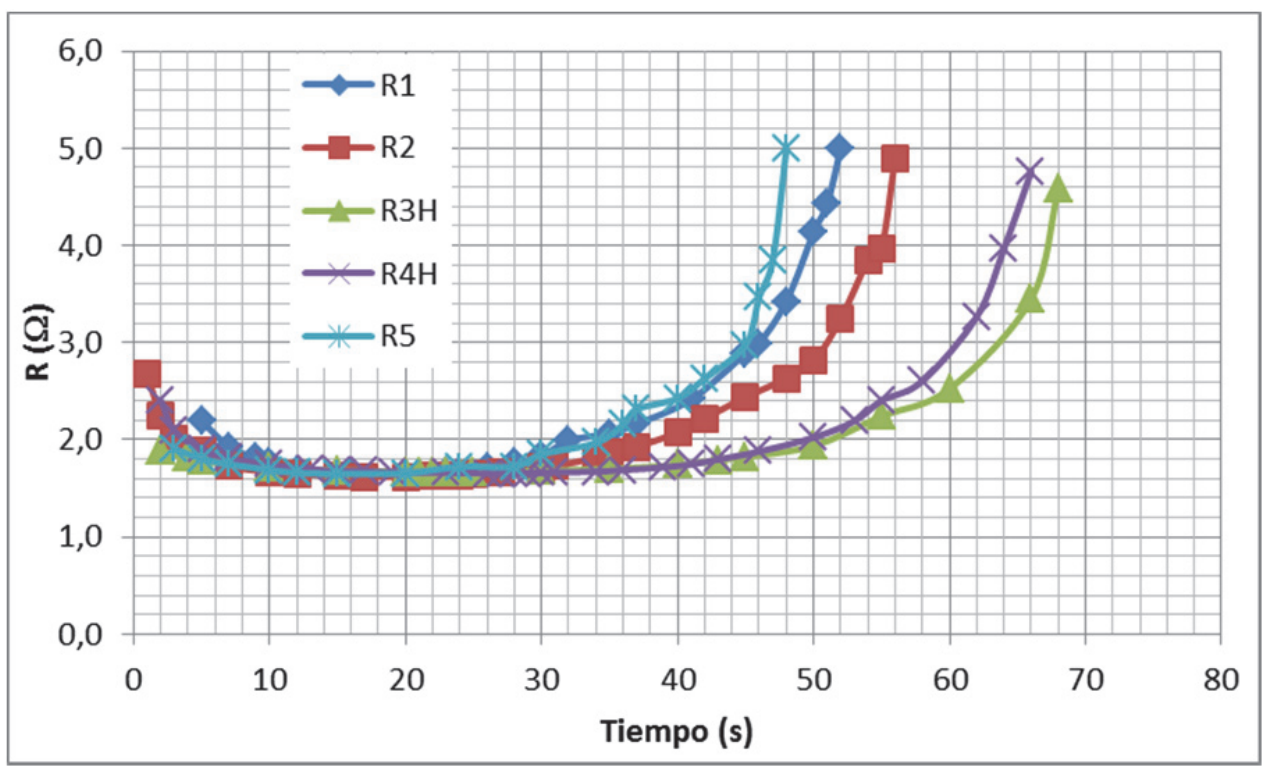

Fig. 3 Resultados de 5 medidas diferentes en base a los videos grabados 
Romina del Rey Tormos, Jesús Alba Fernández y Laura Bertó Carbó

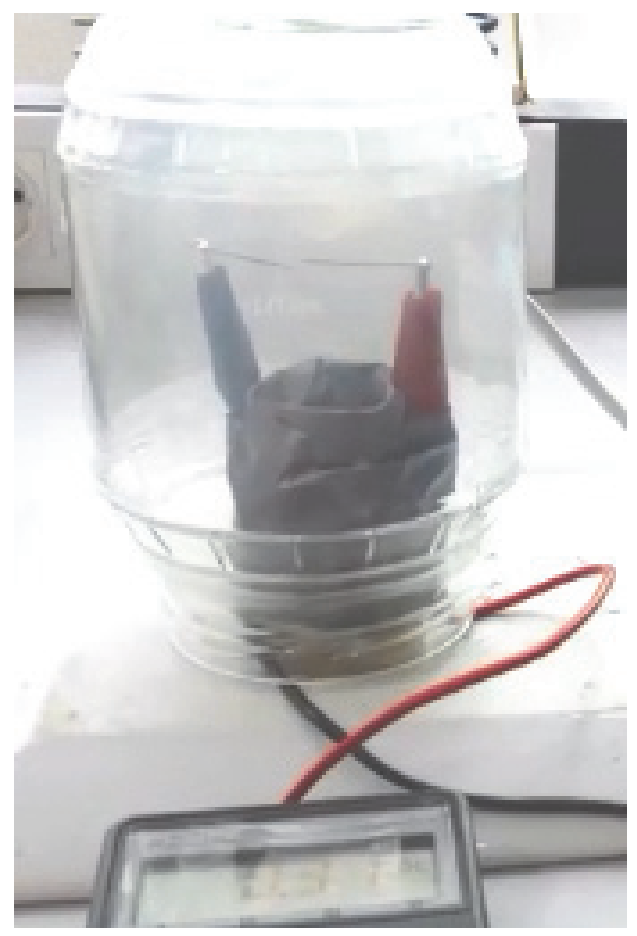

Fig. 4 Detalle de la mina fundida al final del proceso

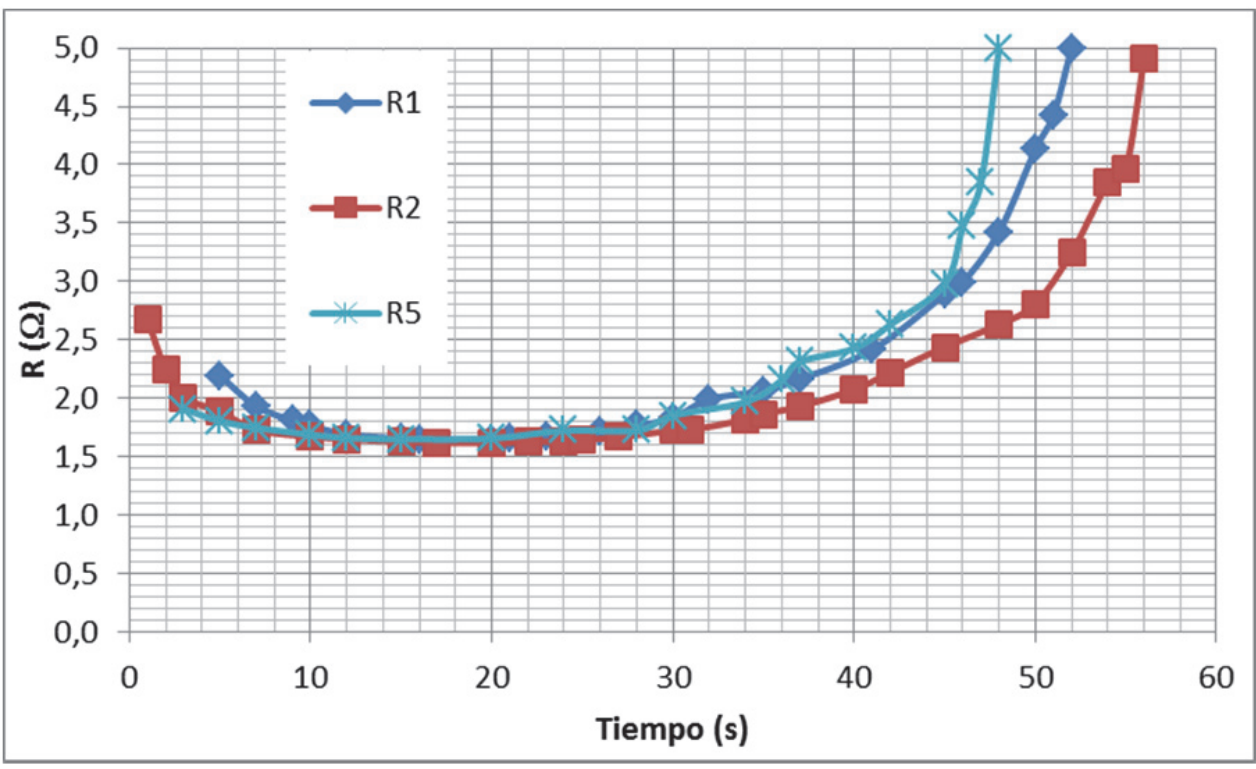

Fig. 5 Resultados de R1, R2 y R5 (resistencias similares)

(c)) EY-NC-ND 2014, Universitat Politècnica de València

I Jornadas IN-RED (2014) 
En la figura 7 se añade una nueva experiencia. Se parte una mina y se deja sólo un trozo. Uno de los trozos se utiliza de nuevo como filamento. Aparece en la gráfica la curva R7T con el resultado del corte. Se observa claramente el comportamiento teórico. Al reducir la longitud, la resistencia eléctrica también disminuye. Al poner en marcha el circuito se produce una disminución de la resistencia eléctrica que se estabiliza en un valor más bajo que en el caso sin cortar. Este periodo de estabilización es más corto, debido al corte de la longitud y la resistencia aumenta rápidamente hasta romperse.

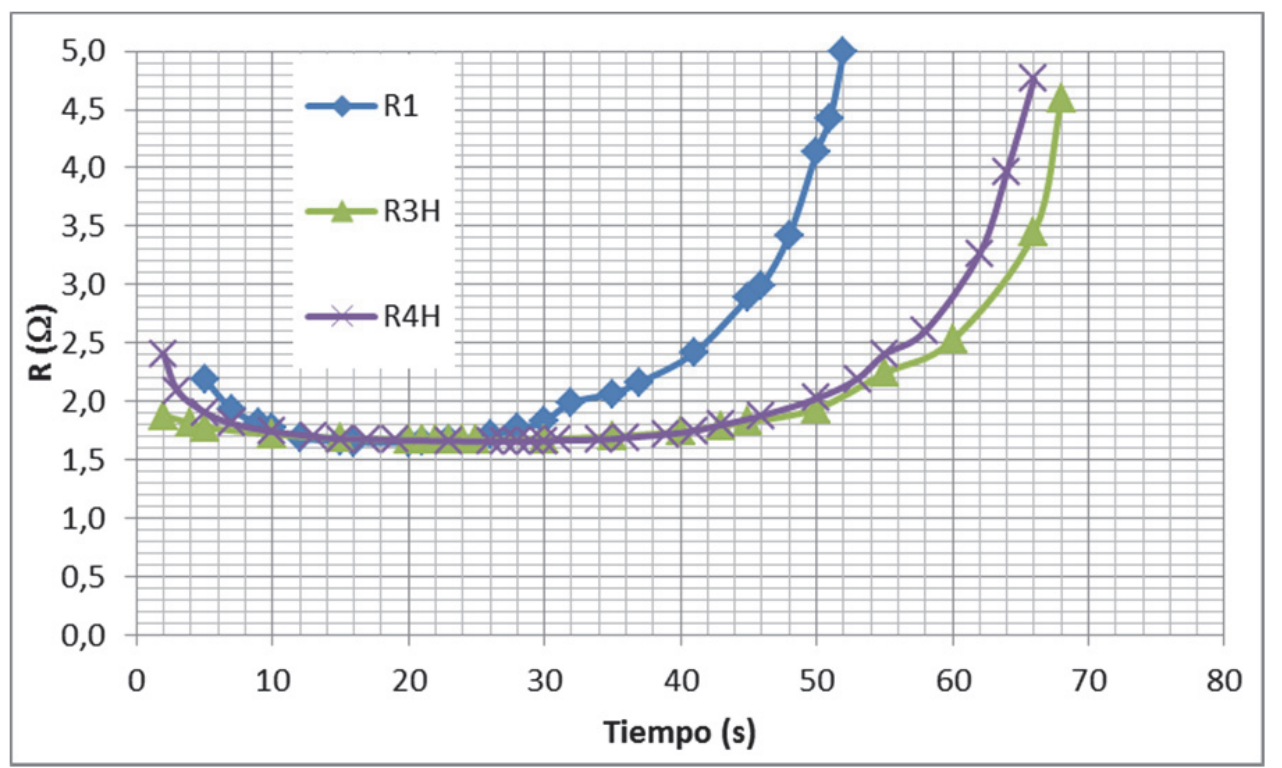

Fig. 6 Resultados de R1, R3H y R4H (efecto del humo) 


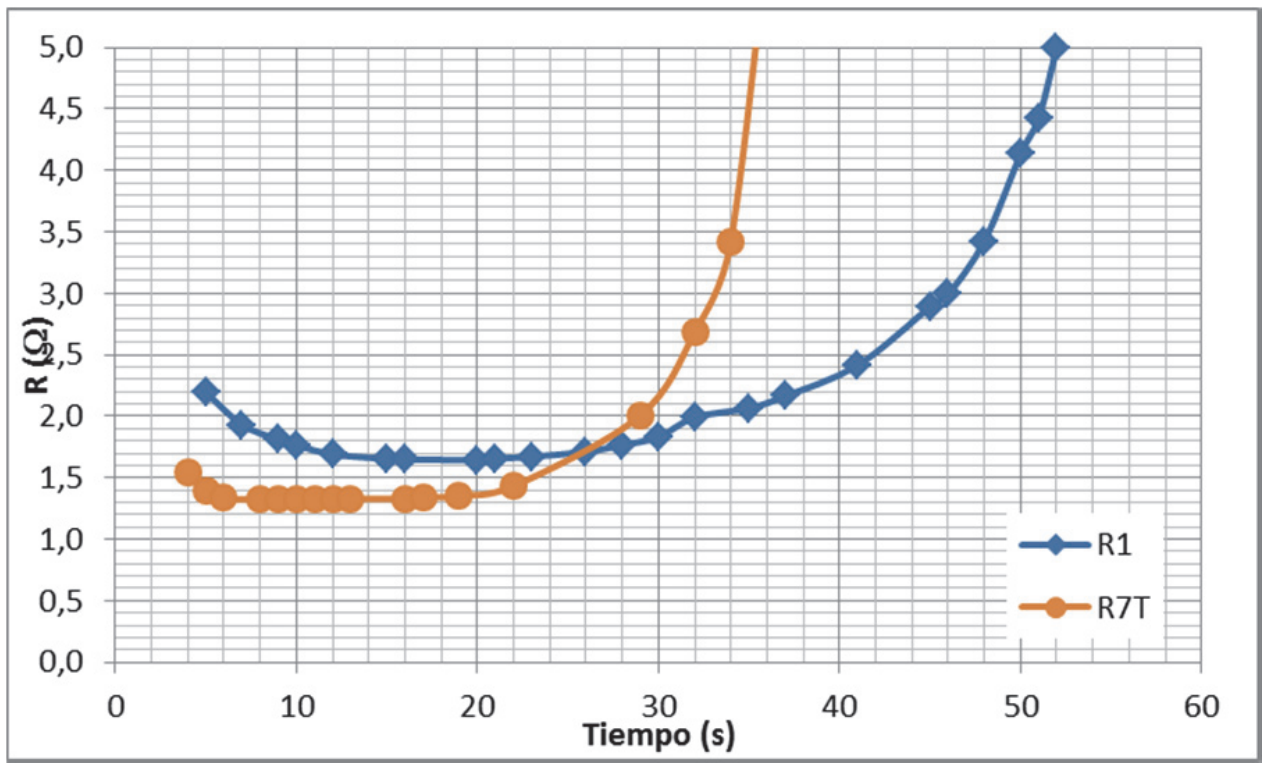

Fig. 7 Comparativa de medidas entre una resistencia cortada $(R 7 T)$ y original $(R 1)$

\section{Conclusiones}

De este trabajo pueden extraerse varias conclusiones que deberán revisarse en próximos cursos. Respecto a la unidad didáctica trabajada, se ha conseguido montar un pequeño proyecto aplicado que refleja los contenidos de la unidad. El alumno puede montar de forma sencilla el experimento, hacerlo en su casa, ver efectos de diferentes marcas de minas, de diferentes durezas (HB, 2B, etc.) de aumentos y disminuciones de longitudes, de voltaje, etc. Por tanto, abre la puerta a la experimentación propia y a la obtención de conclusiones también propias en base a un procedimiento de método científico.

Hay que destacar también que esta unidad didáctica "compite" en el tiempo con otras de asignaturas de electrónica, donde manejan de forma práctica y amena, las resistencias, potenciómetros, y otros elementos similares a un nivel más macroscópico y aplicado, que es más atractivo para los alumnos. En este sentido también se consigue trabajar de forma atractiva.

También es necesario conocer la forma de evaluar en Física. La evaluación de la asignatura de física se realiza en base a 13 problemas de control anuales, 7 exámenes tipo test, 7 memorias de prácticas y dos exámenes parciales que en conjunto cuentan sólo el 25\% de la nota final. Los alumnos tienen una carga anual de evaluación que puede llegar a cansarlos, teniendo en cuenta, si se cuenta una media de 32 semanas anuales, la distribución de estos

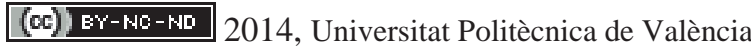

I Jornadas IN-RED (2014) 
problemas cada dos semanas. Este cansancio en la evaluación se refleja después en la respuesta de los alumnos.

En el caso de la experiencia que se presenta, uno de los problemas (este curso en número 9) hace referencia explícita a la experiencia de la bombilla. De los 13 problemas planteados, este problema ha sido uno de máxima nota. Las otras notas altas se deben a problemas donde se ha trabajado con la misma filosofía: una peonza de inversión, la semiesfera elástica, los globos que se cargan electrostáticamente, etc. También forma parte del examen final, siendo la pregunta con mayor puntuación. Queda ver la respuesta en próximos cursos.

\section{Referencias}

EXPERIMENTOS CASEROS. <http://www.experimentoscaseros.info/2012/11/como-hacer-unabombilla-casera.html > [Consulta: 17 de junio de 2014]

EXPERIMENTOS CASEROS. <http://www.experimentoscaseros.org/2010/10/bombilla-de-

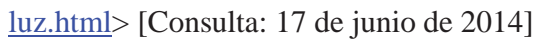

EXPERIMENTOS DE FISICA. <http://www.experimentosdefisica.net/lampara-casera-efecto-joule/> [Consulta: 17 de junio de 2014]

LOS EXPERIMENTOS CASEROS $\quad$ (BLOG).
experimentoscaseros.blogspot.com.es/2010/05/bombilla-de-luz-casero.html> [Consulta: $17 \mathrm{de}$ junio de 2014]

TIPLER P. y MOSCA G. (2013). FÍSICA para la ciencia y la tecnología. $6^{\mathrm{a}}$ edición. EDITORIAL REVERTÉ. 


\title{
Estrategias para el fomento del debate en el aula mediante la corrección en grupo: aplicación de una nueva propuesta en el área de la Edificación.
}

\section{Ignacio Payá Zaforteza}

${ }^{a}$ Universitat Politècnica de València, ETSI Caminos, Canales y Puertos, Departamento de Ingeniería de la Construcción y Proyectos de Ingeniería Civil, email: igpaza@cst.upv.es

\begin{abstract}
The implementation of the new curricula adapted to the Bologna process requires a change in the educational model. The new model is centered on the student and requires new teaching methodologies. This paper presents an innovation implemented in two courses related to building structural analysis taught at the Escuela de Ingenieros de Caminos (School of Civil Engineering) of the Universitat Politècnica de València. Some teaching units of these courses are developed in an unconventional way as the students have to solve a practical exercise related to the teaching unit before the complete theoretical background is provided.

These practical exercises enable to give a preliminary explanation of the theoretical contents of the teaching units as well as to develop an instructive debate. The exercises are based on forensic engineering case studies or in the analysis of major works of structural engineering and are solved in group. The professor selects some of the students' answers and scans them. These selection is shown to the students using the slide projector when the exercise is corrected and is used as a basis to outline a debate. The application of the methodology shows that it engages the students because it uses case studies related to their future professional life and it uses their own answers as a basic element.
\end{abstract}

Keywords: active learning, forensic engineering, case study method. 
Estrategias para el fomento del debate en el aula mediante la corrección en grupo: aplicación de una nueva propuesta en el área de la Edificación

\begin{abstract}
Resumen
La implantación de los nuevos planes de estudio adaptados al EEES implica un modelo educativo centrado en el alumno y nuevas metodologías docentes. Esta ponencia presenta una innovación desarrollada en dos asignaturas del ámbito de la edificación impartidas en la Escuela de Ingenieros de Caminos de la Universitat Politècnica de València. En ellas se plantean algunos temas de forma inversa a la tradicional: con un ejercicio práctico al comienzo del tema seguido del desarrollo detallado posterior de los conceptos teóricos. El ejercicio inicial es una excusa para dar una primera explicación de los contenidos teóricos y permite plantear un instructivo debate. Los ejercicios están basados en casos de patología estructural o en obras significativas de ingeniería estructural y se resuelven en grupo. El profesor recoge las respuestas, las corrige y escanea una selección de ellas. Esta selección se muestra de forma anónima a los alumnos en una segunda sesión y se emplea como una excusa para un debate en el que cada respuesta sucesiva es una aproximación más cercana a la solución del ejercicio. De esta manera se consigue un debate activo y fructífero, pues los alumnos se motivan al trabajar con casos reales y al tomar como base sus propias respuestas. En la ponencia explicará la metodología al detalle junto con un ejemplo concretos de aplicación.
\end{abstract}

Palabras clave: aprendizaje activo, patología estructural, método del caso.

\title{
1. Introducción
}

La implantación del Espacio Europeo de Educación Superior ha supuesto pasar de una "universidad del enseñar" centrada en el profesor y dominada por la lección magistral a una "universidad del aprender" que busca el aprendizaje autónomo, significativo y cooperativo del alumno. Este cambio, no es posible sin nuevos métodos de enseñanzaaprendizaje que impliquen activamente al alumno.

Bonwell y Eison (1991) definieron las metodologías activas como aquellas actividades en las que los alumnos participan haciendo cosas y reflexionando sobre lo que están realizando. Estas metodologías generan aprendizajes más profundos, significativos y duraderos a la vez que facilitan la transferencia a contextos más heterogéneos (de la CruzTomé, 2003). Los ejemplos de su empleo en el ámbito de la ingeniería estructural son numerosos. Por ejemplo, Giménez et al. (2013) han diseñado y ensayado maquetas de edificaciones para que futuros arquitectos aprendan el comportamiento de las estructuras de edificación, Valverde et al. (2013) han promovido cine fórums relacionados con diferentes aspectos de la ingeniería estructural y Payá-Zaforteza et al. (2013) han 
empleado metodologías activas en viajes de estudios centrados en la enseñanza del arte estructural y de la historia de la construcción.

En este contexto general, este artículo muestra una actividad desarrollada en dos asignaturas, "Edificación" del Grado en Ingeniería de Obras Públicas y "Proyecto y construcción de estructuras de edificación" del título de Ingeniero de Caminos del plan de estudios de 1997, impartidas en la Escuela de Ingenieros de Caminos de la Universitat Politècnica de València. La actividad se desarrolla en el ámbito de la ingeniería estructural, pero su contenido es fácilmente adaptable y generalizable a otras áreas de conocimiento.

\section{Objetivos de la actividad innovadora.}

La actividad consiste en el análisis por los alumnos de ejercicios relacionados con casos de patología estructural o con obras singulares de ingeniería estructural. El ejercicio se plantea al principio de cada tema y antes de la explicación detallada en clase de los conceptos teóricos necesarios para su resolución, por lo que los alumnos deben "bucear" en su poso estructural y preguntar al profesor las dudas que les surjan durante la resolución del ejercicio. La actividad se plantea siguiendo la metodología que se describe en el apartado 3 y persigue los objetivos siguientes:

1) Promover la discusión grupal, el trabajo en equipo y el aprendizaje cooperativo.

2) Incrementar la motivación del alumno al plantearle la resolución de problemas relacionados con el desarrollo de la profesión y que precisan de la aplicación de los conocimientos adquiridos durante el curso.

3) Fomentar la toma de conciencia sobre la responsabilidad del ingeniero estructural al estar la mayoría de los ejercicios planteados basados en casos de patología estructural.

4) Facilitar el aprendizaje de los contenidos de las unidades teóricas al provocar que los alumnos a reflexionen sobre los aspectos fundamentales de cada tema antes de desarrollar sus correspondientes conceptos teóricos.

\section{Desarrollo de la innovación}

\subsection{Descripción}

La aplicación de la innovación sigue los pasos siguientes:

- Se explica a la clase la actividad a realizar mostrando imágenes de la estructura a analizar o de la patología estructural a resolver.

- Se resuelve la actividad por grupos de alumnos. Mientras los alumnos resuelven la actividad, tienen la oportunidad de preguntar al profesor las dudas que les vayan surgiendo. Este diálogo permite al profesor evaluar la comprensión que los alumnos tienen de los conceptos con los que se trabaja en la actividad.

(cc)) EY-NC-ND 2014, Universitat Politècnica de València

I Jornadas IN-RED (2014) 
Estrategias para el fomento del debate en el aula mediante la corrección en grupo: aplicación de una nueva propuesta en el área de la Edificación

- El profesor recoge las respuestas de los alumnos y las evalúa. Tras ello, selecciona algunas de las respuestas de los alumnos y las escanea.

- El profesor monta una presentación con las respuestas seleccionadas. En esa presentación las respuestas de los alumnos se muestran de forma secuencial en grado creciente de proximidad a la respuesta a la pregunta(s) formulada(s). Además, cada transparencia de la presentación lleva asociada una o varias preguntas que se plantean a los alumnos con la finalidad de crear un debate.

\subsection{Ejemplo de aplicación}

Se muestra a continuación un ejemplo de aplicación. El ejemplo sirve de introducción a la unidad didáctica en la que se explican los principales sistemas estructurales empleados en edificación y se basa en el análisis de las estructuras del Mercado Colón de Valencia. Más concretamente, se muestran a los alumnos varias imágenes del edificio (Fig. 1) y se les pide que:

- Indiquen de forma cualitativa los cargas que actúan sobre la estructura.

- Identifiquen y dibujen los sistemas estructurales empleados para resistirlas.

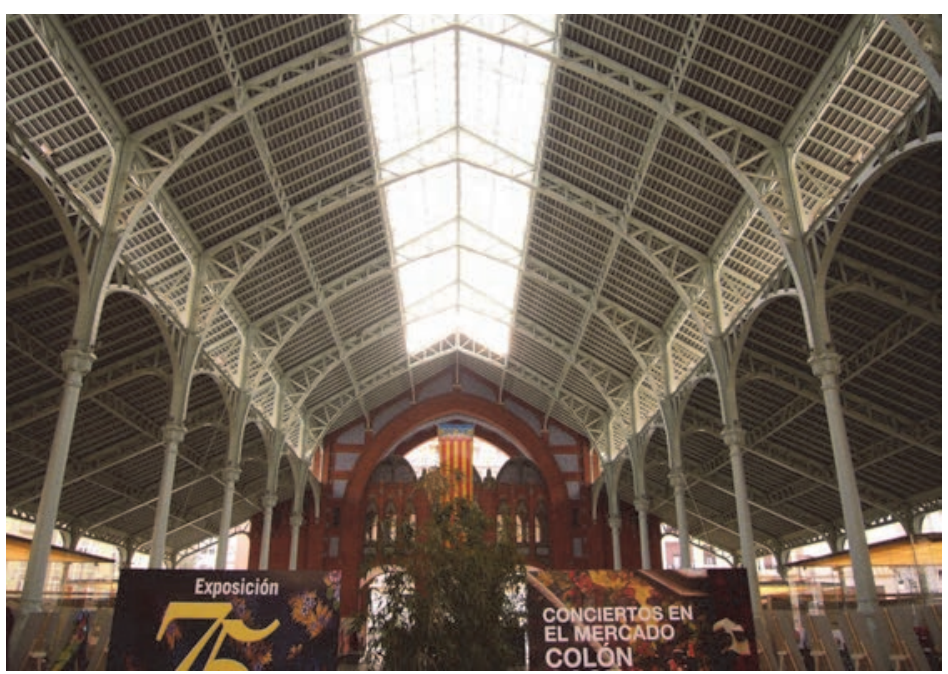

Fig. 1 Actividad sobre el Mercado Colón de Valencia: ejemplo de una de las imágenes empleadas para ilustrar el problema planteado a los alumnos

La Fig. 2 muestra una selección de la secuencia de imágenes y preguntas planteadas a partir de las propias respuestas de los alumnos. En este caso particular, los aspectos sobre los que se debate son:

- Fig. 2a. Acciones que actúan sobre la estructura, forma de representar las acciones. 
- Fig. 2b. Idealización de la estructura mediante un modelo estructural. Representación adecuada de los diferentes componentes de la estructura.

- $\quad$ Fig. 2c. Necesidad de dotar a la estructura de una estabilidad espacial al existir las estructuras reales en un espacio tridimensional.

- $\quad$ Fig. 2d. Mecanismos empleados para resistir la acción del viento.

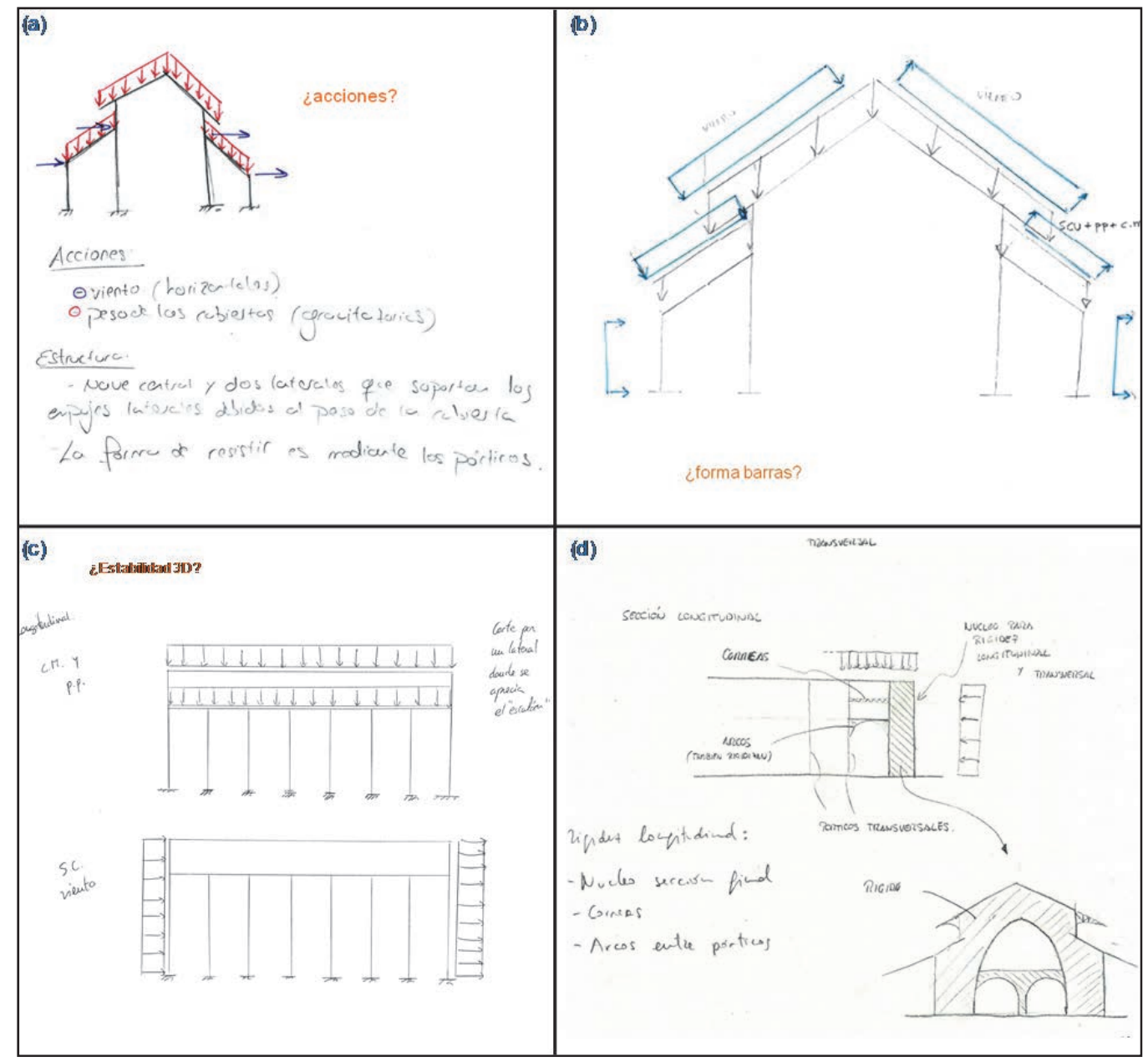

Fig. 2 Actividad sobre el Mercado Colón de Valencia: selección de algunas de las respuestas de los alumnos escaneadas y proyectadas en clase que muestran un acercamiento progresivo a la solución del problema. En naranja se muestran algunas de las preguntas planteadas por el profesor mientras se proyectan las imágenes

(c)) EY-NC-ND 2014, Universitat Politècnica de València

I Jornadas IN-RED (2014) 
Estrategias para el fomento del debate en el aula mediante la corrección en grupo: aplicación de una nueva propuesta en el área de la Edificación

\section{Resultados}

La Tabla 1 muestra los resultados de una encuesta pasada a los alumnos para conocer su opinión sobre la actividad realizada. La encuesta muestra claramente que la mayoría de los alumnos prefiere una metodología docente como la empleada a la metodología clásica de la lección magistral y que la actividad incrementa el interés y comprensión del alumnado. Desde el punto de vista del profesor es necesario destacar que el describir la solución del problema a partir de las respuestas dadas por los alumnos proyectadas anónimamente sobre una pantalla consigue captar totalmente su atención y contribuye a crear un ambiente en el aula que favorece el debate.

Tabla 2. Resultados de una encuesta sobre la metodología empleada (Payá Zaforteza et al., 2009)

\begin{tabular}{|c|c|c|c|c|c|}
\hline Pregunta & $\begin{array}{c}\text { Tot. de } \\
\text { acuerdo }\end{array}$ & $\begin{array}{c}\text { Más } \\
\text { bien de } \\
\text { acuerdo }\end{array}$ & $\begin{array}{c}\text { Indife- } \\
\text { rente }\end{array}$ & $\begin{array}{l}\text { Más bien } \\
\text { en } \\
\text { desacuer- } \\
\text { do }\end{array}$ & $\begin{array}{l}\text { Total- } \\
\text { mente en } \\
\text { desacuer- } \\
\text { do }\end{array}$ \\
\hline $\begin{array}{l}\text { Las cuestiones previas que se } \\
\text { plantean al principio de cada tema } \\
\text { incrementan mi interés por el } \\
\text { mismo }\end{array}$ & $13.3 \%$ & $68.3 \%$ & $18.4 \%$ & $0 \%$ & $0 \%$ \\
\hline $\begin{array}{l}\text { Las cuestiones previas me } \\
\text { permiten comprender el temario } \\
\text { que posteriormente se explica con } \\
\text { mayor facilidad }\end{array}$ & $16.7 \%$ & $48.3 \%$ & $33.3 \%$ & $1.7 \%$ & $0 \%$ \\
\hline $\begin{array}{l}\text { Prefiero la metodología docente } \\
\text { en la que una o varias cuestiones } \\
\text { previas preceden a la explicación } \\
\text { de un tema a la metodología } \\
\text { clásica de la clase magistral }\end{array}$ & $41.7 \%$ & $38.3 \%$ & $15.0 \%$ & $5.0 \%$ & $0 \%$ \\
\hline
\end{tabular}

\section{Conclusiones}

Este artículo presenta una experiencia de metodología activa desarrollada en asignaturas del ámbito de la edificación. La experiencia ha tenido un gran éxito y puede ser fácilmente extrapolada a otras áreas de conocimiento. Los siguientes elementos son muy importantes 
para el éxito de la actividad: (1) la actividad tiene que conseguir que el alumno reflexione y bucee en su poso estructural, (2) es imprescindible corregir la actividad y emplear algunas de respuestas seleccionadas de los alumnos como base para un debate en el aula.

\section{Referencias}

BONWELL C., EISON J. (1991). Active learning: Creating Excitement in the Classroom. Washington: ERIC Clearinghouse on Higher Education, Washington University.

DE LA CRUZ TOMÉ M.A. (2003). "El proceso de convergencia europea: ocasión de modernizar la universidad española si se produce un cambio de mentalidad en gestores, profesores y estudiantes". Aula Abierta, 82: 191-216.

GIMÉNEZ SANCHO A., CAÑAVATE GRIMAL A., BLECUA UDIA C. (2013). "Experiencia en la enseñanza del comportamiento estructural a través de maquetas para alumnos de arquitectura" En Comunicaciones de las III Jornadas Internacionales de Enseñanza de la Ingeniería Estructural. Madrid: Asociación Científico Técnica del Hormigón Estructural.

PAYÁ ZAFORTEZA I., GARZÓN-ROCA J., PELLICER ARMIÑANA T., ADAM MARTÍNEZ J.M., CALDERÓN GARCÍA P.A. (2013). "Arte Estructural en Oporto o cómo aprender estructuras disfrutando" En Comunicaciones de las III Jornadas Internacionales de Enseñanza de la Ingeniería Estructural. Madrid: Asociación Científico Técnica del Hormigón Estructural.

PAYÁ ZAFORTEZA I., ADAM-MARTÍNEZ J.M., PELLICER ARMIÑANA T., CALDERÓN P.A. (2009). "Use of ConcepTest in a Course on Building Structural Analysis for Teaching Construction History" En Proceedings of the Third International Congress on Construction History. Cottbus: Brandenburg University of Technology.

PAYÁ ZAFORTEZA I., GARZÓN-ROCA J., PELLICER ARMIÑANA T., ADAM MARTÍNEZ J.M., CALDERÓN GARCÍA P.A. (2013). "Arte Estructural en Oporto o cómo aprender estructuras disfrutando" En Comunicaciones de las III Jornadas Internacionales de Enseñanza de la Ingeniería Estructural. Madrid: Asociación Científico Técnica del Hormigón Estructural.

VALVERDE ARAGÓN L., BLASCO MIGUEL J., ALDABO FERNÁNDEZ F. (2013) "Cine fórum estructural". En Comunicaciones de las III Jornadas Internacionales de Enseñanza de la Ingeniería Estructural. Madrid: Asociación Científico Técnica del Hormigón Estructural. 


\title{
Una aplicación del técnica del puzle de Aronson para desarrollar la comprensión de la importancia social de la ingeniería estructural y adquirir competencias lingüísticas en idiomas extranjeros
}

Ignacio Payá Zaforteza ${ }^{\text {a }}$

${ }^{a}$ Universitat Politècnica de València, ETSI Caminos, Canales y Puertos, Departamento de Ingeniería de la Construcción y Proyectos de Ingeniería Civil, email: igpaza@cst.upv.es

\begin{abstract}
Engineering education in general and structural engineering education in particular has traditionally paid a lot of attention to the development of technical competences and has left behind aspects such as the relations between engineering and society or aesthetics. However, this should not be the case because the engineer develops his/her profession within a specific environmental and social context. At the same time, and given the current and future conditions of the labor market in Spain, it is very important for future professionals to master foreign languages, and above all, English. University language courses are designed to meet this goal, but to reach a greater effectiveness, these courses be supported by other activities.

Within this general context, this paper presents an application of the Aronson Puzzle in the course "Philosophy of Structures" (Tipología Estructural) of the Bachelor in Civil Engineering taught at Universitat Politècnica de València. In this technique, the students work in groups in the analysis of a scientific-technical paper written in English that links bridge design to ethics, aesthetics and society. The paper presents the context and content of the innovation as well as the basics of the Aronson Puzzle technique and a qualitative assessment of the innovation success.
\end{abstract}

Keywords: engineering, society, aesthetics, puzzle of Aronson, linguistic competences. 
Una aplicación del puzle de Aronson para desarrollar la comprensión de la importancia social de la ingeniería estructural y adquirir competencias lingüísticas en idiomas extranjeros

\begin{abstract}
Resumen
La educación en el ámbito de la ingeniería estructural (y en muchas otras ramas) se ha centrado generalmente en los aspectos técnicos de la profesión y ha dejado de lado aspectos como la estética o la relación de la ingeniería con la sociedad. Sin embargo, esto no debería ser así porque el ingeniero desarrolla su acción en un cierto contexto medioambiental y social. Al mismo tiempo, y dadas las condiciones actuales y previsibles en un futuro del mercado de trabajo, existe un consenso sobre la importancia de que los universitarios dominen idiomas extranjeros y sobre todo el inglés. Estas competencias lingüísticas se adquieren en asignaturas de idiomas, pero es conveniente apoyarlas y reforzarlas de forma transversal.

En este contexto general, este artículo presenta una aplicación de la técnica del puzle de Aronson en la asignatura de Tipología Estructural del Grado en Ingeniería Civil que se imparte en la Escuela de Ingenieros de Caminos de la Universitat Politècnica de València. En esta técnica, los alumnos trabajan en grupos en el análisis de un artículo científico-técnico escrito en inglés que relaciona el proyecto de puentes con la ética, la estética y la sociedad. La ponencia presentará el contexto y el contenido de la innovación junto con los fundamentos de la técnica del puzle de Aronson y una evaluación cualitativa de su éxito.
\end{abstract}

Palabras clave: ingeniería, sociedad, estética, puzle de Aronson, competencias lingüísticas.

\title{
1. Introducción
}

La enseñanza de la ingeniería civil en general y de la ingeniería estructural en particular ha centrado su atención en los aspectos técnicos de la profesión y ha dejado en un lugar secundario aspectos como la ética, la estética o las relaciones de la ingeniería con la sociedad. Sin embargo, la ingeniería no es un fin en sí misma, sino que debe estar al servicio de la sociedad y, por tanto, es importante que los alumnos conozcan las dimensiones sociales de su trabajo. Investigaciones recientes como el documental de J. Évole "Cuando éramos ricos" (2011) muestra algunas consecuencias de no haber tenido presente la dimensión social de la obra de ingeniería en el pasado reciente.

Por otro lado, las circunstancias actuales de la economía española con una tasa de paro entre la población joven (menor de 25 años) del 55.48\% (Europa Press, 2014), con las empresas buscando internacionalizarse y con muchos jóvenes emigrando para encontrar trabajo (Naciones Unidas, 2014), hacen ahora más necesario que nunca el dominar idiomas extranjeros y, muy especialmente, el inglés. 
En este contexto general resulta de gran importancia que los alumnos tomen conciencia de las repercusiones sociales de la ingeniería y que las competencias lingüísticas en idiomas extranjeros se trabajen no solo desde las asignaturas de idiomas, sino también en otras asignaturas de forma transversal. Esta ponencia presenta una actividad desarrollada con esa doble finalidad en la asignatura de Tipología Estructural del Grado de Ingeniería Civil (GIC) que se imparte en la ETSI de Caminos, Canales y Puertos de la Universitat Politècnica de València. Es una asignatura optativa que contó en el curso 2013-14 (primer curso de impartición) con 30 alumnos y cuyos objetivos básicos son:

1) Analizar el funcionamiento de los principales sistemas estructurales (vigas, cables, arcos y sistemas combinados) a través de ejemplos concretos de estructuras reales proyectadas por los grandes maestros de la ingeniería estructural.

2) Valorar críticamente la obra de ingeniería estructural teniendo en cuenta sus componentes científica, social, y simbólica (estética).

Una descripción detallada de la asignatura y de las metodologías docentes empleadas puede verse en Payá-Zaforteza y Lázaro-Fernández (2014).

\section{Objetivos de la actividad innovadora.}

La actividad consiste en el análisis detallado y puesta en común del artículo "A Bridge is More than a Bridge: Aesthetics, Cost and Ethics in Bridge Design" (Sobrino, 2013) en base a unas preguntas planteadas por el profesor. La actividad se plantea siguiendo la metodología del puzle de Aronson tal y como se describe en el apartado 3 y tiene los objetivos siguientes:

1) Promover la discusión grupal, el trabajo en equipo, el aprendizaje cooperativo y la adquisición de competencias lingüísticas en inglés técnico.

2) Desarrollar el espíritu crítico aplicado a la ingeniería estructural y a la arquitectura.

Estos objetivos se incluyen explícitamente en el enunciado de la actividad que se proporciona a los alumnos. La actividad se realiza para introducir la asignatura en una de sus primeras clases.

\section{Desarrollo de la innovación}

\subsection{Descripción de la técnica del puzle de Aronson}

El puzle de Aronson es una técnica desarrollada por Elliot Aronson junto con sus alumnos de la Universidad de Texas en Austin en 1971. La técnica se desarrolló en el ámbito de la enseñanza con niños para integrar a los alumnos con menos capacidades de forma que un sistema competitivo de aprendizaje se transformara en un sistema cooperativo (Aronson, 2011, 2014). La técnica se emplea para trabajar un material académico que se ha dividido en una serie de partes. Su aplicación sigue los pasos siguientes:

\section{(c)) EY-NC-ND 2014, Universitat Politècnica de València}

I Jornadas IN-RED (2014) 
Una aplicación del puzle de Aronson para desarrollar la comprensión de la importancia social de la ingeniería estructural y adquirir competencias lingüísticas en idiomas extranjeros

- Se explica a la clase la actividad a realizar.

- Se crean grupos (grupos puzle) para trabajar el material. El número de miembros de cada grupo es igual al número de partes en que se ha dividido el material.

- Se reparten las partes entre los miembros del grupo base y cada miembro del grupo debe comprender, analizar y trabajar la parte del material que le ha tocado.

- Se crean grupos nuevos (grupos de expertos) cuyos componentes son los miembros de cada uno de los grupos base que han trabajado la misma parte del material. Los miembros de los grupos de expertos debaten la parte del material que habían trabajado previamente de forma individual.

- Los alumnos vuelven al grupo puzle y enseñan lo aprendido al resto de los miembros del grupo.

La técnica se ha aplicado con éxito en muchos campos - consúltese Vidal et al. (2011) y Thibaut (2008) para ver algunos ejemplos- y, con ella se pueden conseguir, entre otros, los objetivos siguientes (véase Martínez y Gómez, 2010):

- Promover el auto aprendizaje y el aprendizaje cooperativo,

- Facilitar el aprendizaje significativo y autónomo,

- Aumentar el rendimiento académico.

\subsection{Desarrollo}

Para aplicar el puzle de Aronson al análisis del artículo de J. Sobrino, se crean grupos puzle de tres alumnos y se plantean una serie de cuestiones a los alumnos que deben responder. Algunas de estas preguntas son:

(1) ¿Es para J. Sobrino un puente simplemente un medio para ir de un sitio a otro? ¿Por qué?

(2) ¿Crees que el autor considera que los puentes pueden ser obras de arte? ¿Por qué?

(3) ¿Cuál crees que es la diferencia entre "coste” y "valor”? ¿Cuáles son los peligros de confundir ambos conceptos?

(4) ¿Qué es un "puente simbólico"?

(5) Según el autor ¿Cree el gran público que los buenos puentes son creados por los ingenieros?

(6) ¿Conduce para el autor la "honestidad estructural" de forma automática al "buen proyecto"? ¿Por qué?

(7) ¿Qué incremento de coste respecto a la opción más económica es aceptable?

(8) ¿Cómo interpretas la frase siguiente "A sensible and lightweight bridge may cost more than its bulky standard counterpart, but this difference in cost must result from less material consumption and correspondingly more labor, which makes it ecologically and socially more valuable as well as more beautiful."? 
Tras el debate del texto dentro de los grupos de expertos y su explicación al resto de miembros en los grupos puzle, se procede a un debate con el conjunto de la clase planteado en base a las preguntas propuestas.

\section{Resultados}

La lectura de las respuestas de los alumnos a las preguntas planteadas proporciona una evidencia clara de que la actividad potencia el desarrollo del espíritu crítico y hace conscientes a los alumnos de la dimensión social de la estructura. Algunas de estas respuestas son:

“(...) un puente no es solo una pasarela; es un legado cultural que refleja la sociedad que lo produce. No sirven solo para salvar obstáculos; un puente tiene capacidad para emocionar a quien lo contempla"

“ (...) la estética y la contextualización [del puente] en el entorno deben ser también criterios a considerar [en el proyecto de puentes] (...)"

"lo realmente importante es conseguir la excelencia en conceptos de eficiencia, economía y elegancia"

"El coste trata solamente del precio de la obra mientras que el valor habla de la repercusión que tiene sobre la sociedad y lo que transmite y aporta a la misma. Si se confunden ambos conceptos [valor y coste] se puede tener la errónea idea de que la solución con menos coste es la de más valor"

"[la honestidad estructural] no conduce automáticamente al buen proyecto. Establece una definición correcta como base, pero se tiene que completar con otras ideas (...) se debe complementar con el diseño ético y estético"

"los aumentos de coste en lo estético deben de ser racionalmente basados en la ética de la administración de los recursos económicos"

Por otro lado, y desde el punto de vista del docente, hay que destacar que la actividad se desarrolló en un ambiente de gran dinamismo, participación y aprendizaje cooperativo, lo que hizo que la actividad fuera amena y entretenida a pesar de lo abstracto de alguno de los conceptos trabajados. También hay que destacar que de la lectura de las respuestas de los alumnos a las preguntas planteadas se puede deducir que éstos comprendieron las ideas principales del texto y que, por tanto, su lectura atenta fue un instrumento válido para reforzar sus conocimientos de inglés. En este aspecto hay que indicar que el profesor pudo comprobar cómo el aprendizaje cooperativo empezaba desde el primer momento, a la hora de entender los términos en inglés existentes en el texto. Por todo ello, la valoración personal de la experiencia es muy positiva.

\section{(c) EY-NC-ND 2014, Universitat Politècnica de València}


Una aplicación del puzle de Aronson para desarrollar la comprensión de la importancia social de la ingeniería estructural y adquirir competencias lingüísticas en idiomas extranjeros

\section{Conclusiones}

Este artículo presenta una experiencia de aprendizaje cooperativo mediante la técnica del puzle de Aronson desarrollado en la asignatura de "Tipología Estructural" que se imparte en cuarto curso del Grado en Ingeniería Civil de la UPV. La actividad contribuye a desarrollar la capacidad de crítica de los alumnos a la vez que afianza sus conocimientos de inglés. Los resultados de la misma han sido muy positivos, tanto por el grado de cumplimiento de los objetivos planteados como por la actitud del alumnado y la atmósfera en la que se desarrolló la actividad.

\section{Referencias}

ARONSON, E., PATNOE, S. (2011). Cooperation in the classroom: The jigsaw method (3rd ed.). London: Pinter \& Martin, Ltd.

ARONSON, E. (2014). Jigsaw Classroom < http://www.jigsaw.org> [Consulta: 22 de mayo de 2014].

ARONSON E. Entrevista publicada en:

<http://www.dailymotion.com/video/xfk9hg_colaboracion-el-efecto-de-clase-puzzle-eliotaronson_school> [Consulta: 22 de mayo de 2014].

ÉVOLE J. (2011). Cuando éramos ricos. Programa “Salvados” emitido el 9 de octubre de 2011.

EUROPA PRESS (2014). La tasa de paro juvenil escala seis décimas y se sitúa en el 55,48\% por la caída de la actividad. Publicado en la edición digital de El Mundo el día 30/4/2014. y [Consulta: 22 de mayo de 2015].

MARTÍNEZ, J. Y GÓMEZ, F. (2010). "La técnica puzzle de Aronson: descripción y desarrollo". En Arnaiz, P.; Hurtado, Ma.D. y Soto, F.J. (Coord.) 25 Años de Integración Escolar en España: Tecnología e Inclusión en el ámbito educativo, laboral y comunitario. Murcia: Consejería de Educación, Formación y Empleo.

NACIONES UNIDAS, CENTRO REGIONAL DE INFORMACIÓN PARA EUROPA OCCIDENTAL. Los españoles vuelven a ser emigrantes. < http://www.unric.org/es/desempleojuvenil/279-los-espanoles-vuelven-a-ser-emigrantes >

PAYÁ ZAFORTEZA I., LÁZARO-FERNÁNDEZ C. (2014). "Structural Engineering is Much More than Formulas: Introducing a New Course on Philosophy of Structures". En Proc. of the 37th IABSE Symposium Madrid 2014 Engineering for Progress, Nature and People. Zurich: International Association for Bridge and Structural Engineering.

SOBRINO J. (2013). "A Bridge is More Than a Bridge: Aesthetics, Cost and Ethics in Bridge Design”. Structural Engineering International 23(3): 340-345.

VIDAL MELÓ A. et al. (2011) "Una experiencia con el puzzle de Aronson en una asignatura de Matemáticas”. En Jornadas de Innovación Educativa. Valencia: Universidad Politécnica de Valencia. Disponible en: http://www.dcomg.upv.es/ chernan/jj_ii_ice_2011/ [Consulta: 22 de mayo de 2015] 
THIBAUT TADEO E. (2008). "Topología para $2^{\circ}$ de ESO con la técnica del puzzle de Aronson" en Suma 58:41-48.

(cc) EY-NC-ND 2014, Universitat Politècnica de València

I Jornadas IN-RED (2014) 
Jornadas In-Red 2014

Universitat Politècnica de València

\title{
Metodologías docentes activas de incidencia social aplicadas en las enseñanzas artísticas universitarias \\ Paula Santiago Martín de Madrid
}

Doctora en Bellas Artes. Profesora de la Facultad de Bellas Artes de la Universitat Politècnia de València. Investigadora en el Centro de Investigación Arte y Entorno CIAE-UPV (masanma6@pin.upv.es)

\begin{abstract}
This paper addresses the idea of a university education where along with the development of competencies and skills, we can help our students develop attitudes that contribute to reflection on our social environment. Therefore, a teaching-learning process is proposed where the contents of the subject revolve around a series of cross-cutting issues. the students work in real contexts that lead them to reflect on various problematic social. In this respect and for or to illustrate our approach, it has been taken as an example one of the activities developed in course "presentation and disclosure of artwork" that is imparted by the Department of Painting of the Faculty of Fine Arts in Valencia.
\end{abstract}

Keywords: training, skills, methodology, social engagement, teaching, learning, fine arts

\section{Resumen}

El presente texto parte de la idea de una formación universitaria que, junto con el desarrollo de competencias y capacidades profesionales, ayude a desarrollar actitudes en nuestro alumnado que contribuyan a la reflexión sobre nuestro entorno social. Por tanto, se propone un proceso de enseñanza-aprendizaje en la que los contenidos de la materia giren en torno a una serie de temas transversales, proponiendo al alumnado prácticas activas para realizar en contextos reales que les lleven a la reflexión sobre diversas problemáticas sociales. En este sentido y para ilustrar nuestra propuesta, se ha tomado como ejemplo una de las actividades desarrollada en el marco de la asignatura "Presentación y divulgación de la obra de arte" impartida actualmente en Grado por el Departamento de Pintura de la Facultad de Bellas Artes de Valencia.

Palabras clave: formación, competencias, metodología, compromiso social, enseñanzas artísticas, bellas artes

(c)) EY-NC-ND 2014, Universitat Politècnica de València

I Jornadas In-Red (2014) 
Metodologías docentes activas de incidencia social aplicadas en las enseñanzas artísticas universitarias

\section{Introducción}

En diversas plataformas y foros se ha venido reiterando el hecho de que una de las funciones fundamentales de la institución universitaria es la de formar ciudadanos. Por otro lado, numerosos autores hacen alusión a la importancia de formar a nuestros estudiantes de manera activa, fomentando la creatividad y el juicio crítico en una sociedad global que cambia con gran rapidez (Bauman, 2013).

En este sentido, cabe decir que el sistema universitario español ha experimentado en los últimos años una significativa transformación que se ha desarrollado de manera paralela a la evolución social en la que el mismo se encuentra inserto. Actualmente, las enseñanzas universitarias en Bellas Artes, además de formar artistas plásticos en su acepción más amplia, proporcionan una formación teórica, práctica y metodológica en las distintas especificaciones formales que puede adoptar la práctica artística y sus aplicaciones. Estas enseñanzas promueven, al mismo tiempo, una actitud crítica y creadora a partir del conocimiento de las corrientes del pensamiento estético.

Asimismo las universidades se encuentran integradas dentro de un modelo social en perpetuo cambio. En el mismo, el progreso y el bienestar colectivos se vinculan a la competitividad existente entre países y al tejido económico que estos crean, cuestiones todas ellas que dependen crecientemente de la capacidad para generar y transmitir conocimiento. Ello hace que sea fundamental disponer de un sistema de educación superior de calidad que simultáneamente tenga la capacidad de ser integrador y flexible (Cortina, 1997) y que, a su vez, permita establecer relaciones fluidas entre el sistema universitario y el conjunto de la sociedad.

Desde esta perspectiva, entendemos que la docencia universitaria ofrece una gran oportunidad para desarrollar, junto a una formación en competencias y capacidades profesionales, actitudes en el alumnado que contribuyan a la reflexión sobre nuestro entorno y la mejora social. Se trata, por tanto, de una formación en la que los contenidos de la materia giran en torno a una serie de temas transversales, proponiendo al alumnado prácticas activas que les lleven a la reflexión sobre diversas problemáticas sociales.

En el marco de la asignatura Presentación y divulgación de la obra de arte impartida por el Departamento de Pintura de la Facultad de Bellas Artes de Valencia se han diseñado una serie de actividades destinadas a contextos reales cuyo objetivo es el de potenciar el desarrollo de las capacidades propias de la materia, favoreciendo al mismo tiempo el interés en temas que reclaman un compromiso social. Para el desarrollo de las actividades planteadas, el alumnado trabaja con diversas metodologías llevando a cabo actividades que integran procesos de investigación, trabajos de campo, debates, etc. con la finalidad de dar 
forma a proyectos que, si bien ponen de manifiesto el desarrollo de capacidades profesionales, contemplan al mismo tiempo aspectos de contenido social.

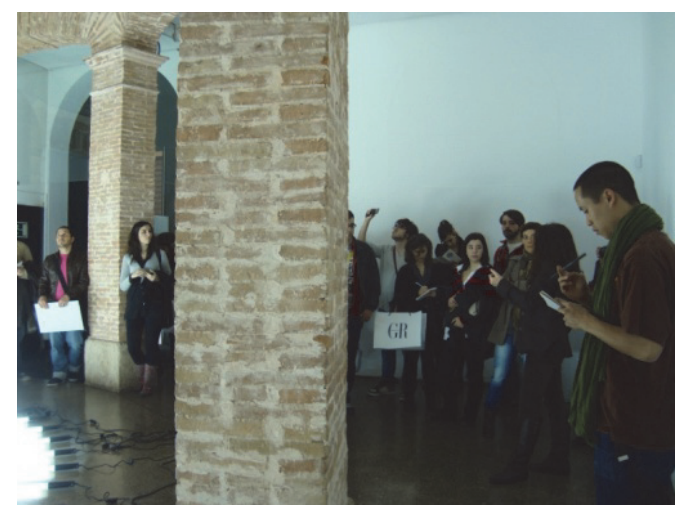

Fig. 1 Trabajo de campo para estudio de espacio expositivo alumnado asignatura Presentación y divulgación de la obra de arte

\section{Un nuevo espacio para las enseñanzas artísticas}

Si bien en las enseñanzas artísticas el proceso de enseñanza-aprendizaje (Domènech, 1999) se ha basado tradicionalmente en una retroalimentación constante en talleres y/o laboratorios concebidos como núcleos de trabajo, investigación y experimentación bajo la tutela del profesorado, con la adaptación de los estudios universitarios de Bellas Artes al Espacio Europeo de Educación Superior y la aplicación de los ECTS, este modelo se ha visto favorecido notablemente. La apuesta por la creación de espacios de confluencia e interrelación de lenguajes hace que en los mismos sea imprescindible la acción tutorial por parte del profesorado, ya que el actual sistema de enseñanza se encuentra mucho más orientado hacia el aprender que hacia el enseñar. Asimismo, los talleres tienen como objetivo primordial estimular los procesos experimentales y favorecer la valoración crítica, hecho que se complementa con la potenciación de competencias y habilidades en el discente.

Por otro lado, los estudios realizados durante el proceso de adaptación al Espacio Europeo nos indican algunas coincidencias en la tipología del alumnado. Coincidencias que no sólo afectan a su perfil, sino también a las nuevas necesidades que tienen los estudiantes y que vienen determinadas por la evolución social y del conocimiento. La demanda de los estudiantes se centra, cada vez más, en la adquisición de conceptos innovadores, en el mestizaje y/o cruce de lenguajes y en el uso generalizado de nuevas tecnologías. A nivel creativo este hecho pone de relieve hasta qué punto no desean comprometerse con una única vía artística que marque de forma unidireccional y restrictiva el modo de trabajar.

\section{(c) EY-NC-ND 2014, Universitat Politècnica de València}

I Jornadas IN-RED (2014) 
Metodologías docentes activas de incidencia social aplicadas en las enseñanzas artísticas universitarias

Asimismo, cabe señalar que la ya citada inmersión en una sociedad global y en crecimiento ha posibilitado un importante desarrollo de la industria cultural con las consiguientes oportunidades laborales para los egresados de las facultades de Bellas Artes. Nuevos museos, centros culturales públicos o privados, programas e industria cultural y de la imagen, empresas de diseño, industria de la moda, etc., han favorecido la necesidad de potenciar determinadas capacidades en el alumnado que den respuesta a las nuevas necesidades.

En cuanto a la inserción laboral, nuestros titulados están abiertos a las nuevas profesiones en las que la creatividad actúa como motor básico, constatándose un aumento del autoempleo y la generación de microempresas. El listado de salidas laborales disponibles es amplio con aplicaciones múltiples y variadas:

- Gestión cultural, montaje y diseño expositivo, comisariado, asesoría y asistencia en eventos culturales.

- Nuevas tecnologías, multimedia de audiovisuales, imagen digital y creación de entornos virtuales.

- Docencia, profesores/as de dibujo y artes plásticas tanto en la enseñanza pública como en la privada.

- Imagen digital e informática gráfica.

- Diseño gráfico, industrial, de mobiliario y efímero.

- Artes gráficas, cartelismo, animación e ilustración.

- Diseño y montaje de exposiciones, escenografías, instalaciones efímeras y simulaciones tridimensionales.

- Media-art, impresión gráfica y arte electrónico.

- Restauración y conservación del patrimonio cultural y museístico.

\section{Contextos reales y metodologías activas en el marco de la asignatura Presentación y divulgación de la obra de arte}

En este nuevo contexto se ha impulsando un cambio metodológico que posibilita situar en el centro del proceso educativo el aprendizaje del estudiante desde una perspectiva de aprendizaje a lo largo de la vida, ya que en la actualidad los conocimientos adquiridos se han de conformar como base y punto de partida de unas destrezas que puedan adecuarse a contextos laborales, económicos y sociales que, con gran rapidez, están sometidos a transformaciones y reajustes.

En este sentido, en el marco de la asignatura Presentación y divulgación de la obra de arte se ha adaptado el formato y la temática de la oferta de conocimientos a las nuevas necesidades. La demanda ocasionada por nuevas profesiones relacionadas con la gestión

(c)) EY-NC-ND 2014, Universitat Politècnica de València

I Jornadas IN-RED (2014) 
cultural ha generado la necesidad de ofertar conocimientos vinculados con la postproducción de la obra de arte, con su divulgación y con las metodologías de exposición. Este hecho ha motivado algunas de las actuaciones concretas llevadas a cabo, tanto en lo que respecta a la planificación, como al desarrollo de la materia, ya que partimos de la necesidad de diseñar una serie de actividades que den respuesta a los objetivos preestablecidos para el desarrollo de las capacidades a adquirir. Asimismo, las actividades responden a un sistema basado en metodologías activas, vinculadas entre ellas y que responden a un proceso de aprendizaje dinámico y transversal. Actividades que, por otro lado, pueden definirse por su operatividad y/o funcionalidad real. Para ello, desarrollamos los aspectos contemplados en el programa de la asignatura tomando como punto de partida un conjunto de trabajos de carácter práctico y en numerosas ocasiones para su aplicación en contextos reales.

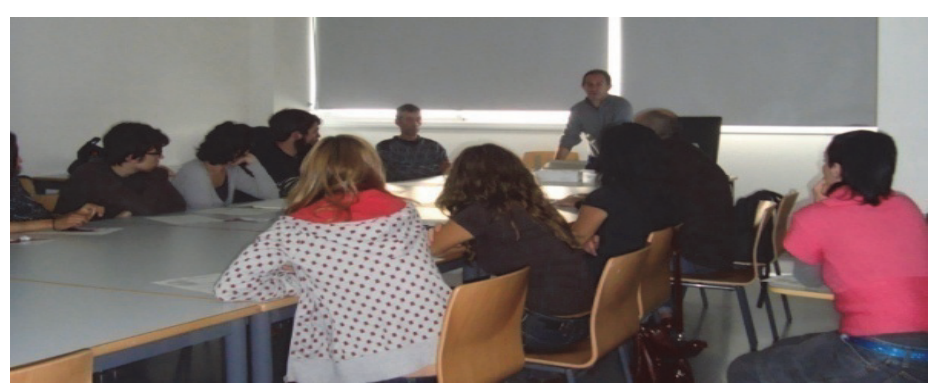

Fig.2 Exposición de grupo en el aula

alumnado asignatura Presentación y divulgación de la obra de arte

Por otro lado, a la hora de llevar a cabo la planificación de la asignatura no sólo hemos seleccionado, organizado y elaborado contenidos, sino que hemos centrado nuestra atención en generar y diseñar procesos de aprendizaje que permitan al alumnado desarrollar estrategias analíticas, críticas, reflexivas y creativas en relación al ámbito social en el que se encuentran inmersos. Esta posición conlleva generar un sistema en el que el alumnado, contando con nuestra ayuda, busca información y establece nexos significativos con experiencias y habilidades previas a la vez que se implica con una temática concreta de carácter social.

\section{Objetivos de la asignatura}

El alumnado de Bellas Artes, cuando desarrolla un proyecto, lleva a cabo una praxis integral en la cual se enfrenta a un proceso que comprende todos los pasos que se extienden desde la ideación hasta su materialización. De este modo, aplica de manera global los

\section{(c) EY-NC-ND 2014, Universitat Politècnica de València}

I Jornadas IN-RED (2014) 
Metodologías docentes activas de incidencia social aplicadas en las enseñanzas artísticas universitarias

conocimientos adquiridos, hecho que le lleva a utilizar sistemas proyectivos, conocimientos técnicos y materiales, aspectos de composición y contextualización, etc.

Esta suma de etapas y situaciones tan diversas que abarca cuestiones proyectuales, procesuales y resolutivas y que contiene diferentes planos de realidad, confluye en la concreción de un discurso individualizado. Desde esta perspectiva, el concepto de transversalidad (Morin, 2010) favorece particularmente el aprendizaje del proceso artístico, ya que el alumnado puede experimentar, investigar y aplicar métodos, procedimientos y procesos instrumentales dirigidos a realizar un acto creativo.

Teniendo en consideración estos aspectos, el objetivo general es el de favorecer la realización de proyectos expositivos coherentes con el marco social contemporáneo y con el profesional. Proyectos concebidos como un sistema en el que intervienen cuestiones relacionadas con la conceptualización, el diseño, la organización y la comunicación.

Nos planteamos, asimismo potenciar el desarrollo de capacidades específicas y transversales relacionadas con la materia:

Capacidades específicas

- Conocimiento de las características de los espacios y medios de exposición.

- Conocimiento de los diferentes agentes artísticos y su funcionamiento.

- Capacidad para generar y gestionar la producción artística.

- Habilidad para realizar proyectos artísticos con repercusión social.

- Habilidad para una presentación adecuada de los proyectos artísticos.

- Habilidad para la integración de la obra en relación con su entorno y exhibición.

- Habilidad para comunicar y difundir proyectos artísticos.

- Desarrollo de estrategias relativas a la adecuación de la obra a un entorno concreto.

- Habilidad para establecer relaciones con entidades públicas y privadas.

- Habilidad para la divulgación de muestras expositivas.

- Conocimiento de instituciones y organismos culturales.

Capacidades transversales

- Conocimiento básico de la metodología de investigación.

- Capacidad para generar proyectos socio-culturales.

- Capacidad para exponer oralmente y por escrito con claridad proyectos artísticos.

- Capacidad de (auto)reflexión analítica y (auto)crítica en el trabajo artístico.

- Capacidad de trabajar en equipo.

- Capacidad de organizar, desarrollar y resolver el trabajo mediante la aplicación de estrategias de interacción.

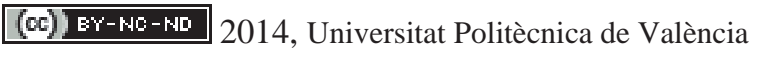

I Jornadas IN-RED (2014) 
Junto a esta formación en competencias y capacidades profesionales, nuestro objetivo se centra en potenciar actitudes en el alumnado que contribuyan a la reflexión sobre nuestro entorno social. Se trata, por tanto, de proponer una serie de temas transversales para la realización de prácticas activas destinadas a contextos reales cuyo objetivo es el de favorecer el desarrollo de las capacidades propias de la materia, favoreciendo al mismo tiempo el interés en temas que reclaman un compromiso social. Para ello se incorporan diferentes metodologías que integran procesos de investigación, trabajos de campo, debates, etc.

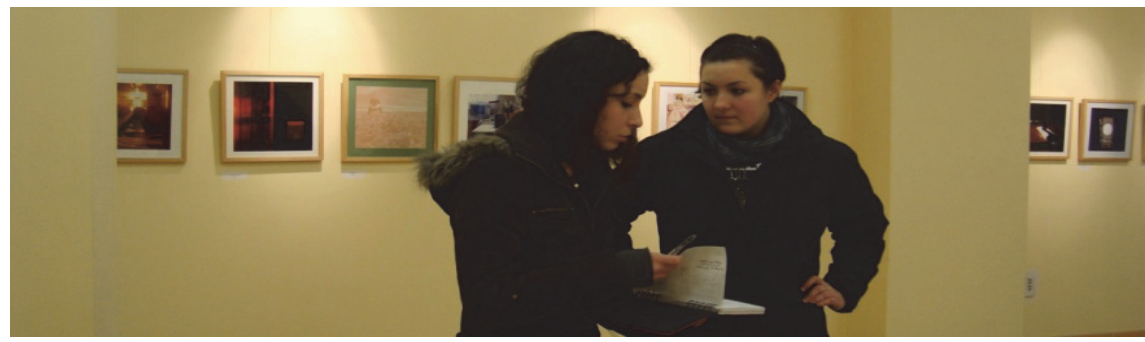

Fig. 3 Trabajo de campo para montaje expositivo alumnado asignatura Presentación y divulgación de la obra de arte

\section{Desarrollo de la innovación: Propuesta expositiva colectiva de implicación social}

Adoptando la metodología del estudio de caso (Merrian, 1998) y partiendo, por ello, del caso concreto de una de las asignaturas de las que somos responsables docentes, deseamos utilizar la misma con el objetivo de analizar la aplicación de determinadas metodologías didácticas para así valorar su repercusión en la motivación de nuestro alumnado.

De cara a contextualizar la actividad que sirve como ejemplo de nuestra práctica (Propuesta expositiva colectiva de implicación social) cabe decir que la unidad didáctica en la que se enmarca aborda aspectos relativos a la gestión expositiva. La asignatura, en su conjunto, responde a un formato de taller y para el estudio de la materia partimos de una serie específica de actividades que generan, de forma implícita, unos determinados aprendizajes. El programa de la asignatura, estructurado en cuatro unidades didácticas, agrupa diez temas articulados en torno a una serie de actividades diseñadas para la consecución de los objetivos propuestos y que responden a las capacidades señaladas en el epígrafe anterior.

A su vez, las actividades — caracterizadas por sus diferentes niveles de complejidad, así como por la aplicación y desarrollo de diversas metodologías — han sido diseñadas con el objeto de dar respuesta a las diferentes inquietudes y/o intereses detectados en el conjunto

\section{(c) EY-NC-ND 2014, Universitat Politècnica de València}

I Jornadas IN-RED (2014) 
Metodologías docentes activas de incidencia social aplicadas en las enseñanzas artísticas universitarias

del alumnado, unos intereses que se hallan configurados en función de las líneas de intensificación que los estudiantes han venido desarrollando durante la carrera. En este contexto, la participación activa del alumnado es un elemento prioritario en el marco de actuación de la asignatura, por lo que la realización de trabajos grupales, la puesta en común de los mismos y la defensa y exposición oral de los resultados poseen un sentido fundamental.

A su vez, las unidades didácticas se estructuran en dos partes. En la primera nos centramos en cuestiones asociadas a la presentación y divulgación del trabajo creativo del alumnado, por lo que las actividades propuestas poseen un carácter individualizado, si bien los resultados están sometidos a la puesta en común en el contexto del aula. En la segunda parte, el interés quedará focalizado en el ámbito en el que se exhibe la obra —-social, institucional, de mercado, etc.- - por lo que las metodologías aplicadas para la realización de las actividades incorporan numerosos trabajos grupales. Por otro lado, las actividades se han diseñado de forma progresiva, es decir, los planteamientos fijados en cada una de ellas gozan de continuidad con respecto a los fijados en la anterior.

La actividad Propuesta expositiva colectiva de implicación social se encuentra inserta en una unidad didáctica en la que partimos del hecho de que la exposición contiene una dimensión amplia en la que no sólo se hacen visibles determinados objetos artísticos. Por el contrario, se trata de un acto de comunicación en el que el público, encargado de su interpretación, tiene protagonismo, ya que si bien la exposición se puede concebir como una escenificación, el objeto y/o resultado presentados (obras) desempeñan un importante rol comunicativo con capacidad para suscitar el debate social.

La presente actividad se inicia con un ejercicio de reflexión en el que el alumnado, organizado en grupos, lleva a cabo la lectura y exposición oral de un libro mediante una metodología de puzzle. El texto aborda el análisis de diferentes obras realizadas por artistas de prestigio internacional en un entorno concreto de problemática social en la ciudad de Nueva York durante la década de 1970 (Candela, 2007). Obras, que por otro lado, tuvieron una gran repercusión en su contexto y en las respectivas trayectorias de sus artífices. Cada equipo narra al resto de compañeros y compañeras los contenidos más relevantes de los diferentes capítulos que integran el ensayo propuesto, haciendo especial alusión a la problemática social en la que las obras estudiadas fueron realizadas.

A continuación, y con la pretensión de alcanzar los objetivos asociados a las capacidades específicas señaladas en el epígrafe precedente, se plantea la realización de una exposición colectiva para ser realizada en un espacio real. El hecho de llevar a cabo un trabajo con unas expectativas reales constituye un aliciente fundamental en el desarrollo de la materia, razón por la que para la presente actividad se ha contado con la colaboración de espacios expositivos del Ayuntamiento de Valencia. 
En este sentido, la actividad conlleva para el alumnado la ejecución de una serie de actuaciones en contextos externos al ámbito universitario. Las mismas se concretan en la elaboración de una propuesta expositiva que supone la realización de las siguientes tareas:

- Investigación en relación a una temática social de actualidad (lecturas grupales, debates, investigación en la web, etc.)

- Configuración de un proyecto expositivo.

- Materialización de una obra/proyecto que sintetice el tema abordado.

- Gestión asociada a la solicitud de espacios expositivos.

- Creación y mantenimiento de relaciones con la entidad expositiva.

- Gestión de esponsorización.

- Estudio técnico del espacio expositivo.

- Elaboración de simulaciones digitales.

- Diseño y elaboración de material divulgativo.

- Diseño, instalación y montaje técnico de las obras.

- Elaboración de nota de prensa para los medios de comunicación.
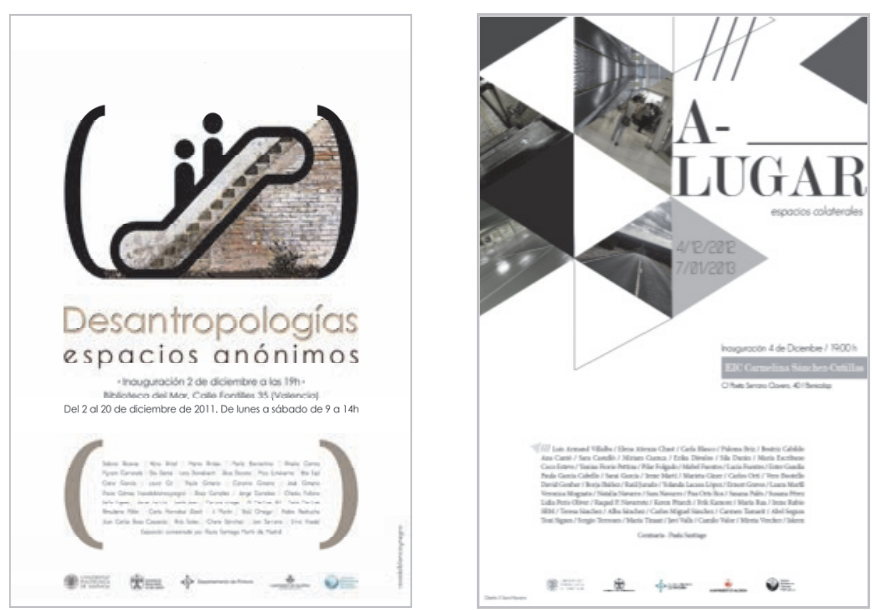

Fig. 4 Material divulgativo (cartelería) para exposiciones colectivas de temática social celebradas en espacios expositivos del Ayuntamiento de Valencia 2011-2012 alumnado asignatura Presentación y divulgación de la obra de arte

Cabe señalar que en cada una de las fases en las que hemos dividido el esquema anterior se celebran diversas puestas en común con los resultados parciales obtenidos. Todas las decisiones son tomadas en el contexto del aula con el consenso colectivo y el alumnado

\section{(cc)) EY-NC-ND 2014, Universitat Politècnica de València}

I Jornadas IN-RED (2014) 
Metodologías docentes activas de incidencia social aplicadas en las enseñanzas artísticas universitarias

adopta, en función de su perfil, diferentes roles en el proceso de desarrollo de la actividad: coordinación expositiva, diseño de material divulgativo, comunicación con otros agentes, etc.
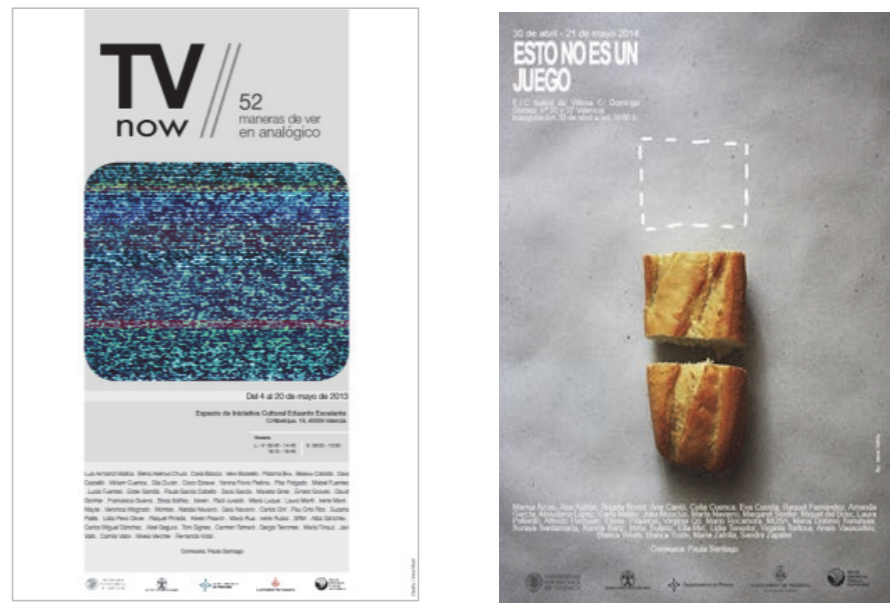

Fig. 5 Material divulgativo (cartelería) para exposiciones colectivas de temática social celebradas en espacios expositivos del Ayuntamiento de Valencia 2013-2014 alumnado asignatura Presentación y divulgación de la obra de arte

Para la materialización del proyecto, más allá de la motivación e implicación que supone la temática abordada, el alumnado incorpora capacidades profesionales relacionadas con su formación. Este se ve en la necesidad de llevar a cabo estructuras proyectuales con la incorporación de elementos básicos. Asimismo ha de mantener relaciones con agentes externos al ámbito universitario ya que realiza una solicitud formal de un espacio expositivo con necesidades concretas en relación al volumen de obra, el contexto y marco conceptual, el periodo de tiempo, artistas participantes, etc. Paralelamente, se sitúa en el supuesto de solicitar una esponsorización y/o patrocinio a una entidad privada. Finalmente, teniendo en cuenta las características específicas de la muestra expositiva colectiva propuesta, el alumnado se encarga de asignar un título a la misma y diseñar un material divulgativo que tendrá difusión real.

Como decíamos anteriormente, las diferentes propuestas se analizan en el aula de forma colectiva, para lo que en numerosas ocasiones se entregan diferentes modelos de ficha al alumnado que le sirven como guía. Estas tienen como objeto la valoración de las propuestas efectuadas, ya que a partir de los resultados obtenidos se selecciona el trabajo definitivo. Por ejemplo, a la hora de llevar a cabo el diseño de material divulgativo se toman en consideración aspectos relacionados con la claridad y capacidad comunicativa, calidad, 
composición, adecuación del diseño a los contenidos de la muestra, idea y resolución técnica, etc.
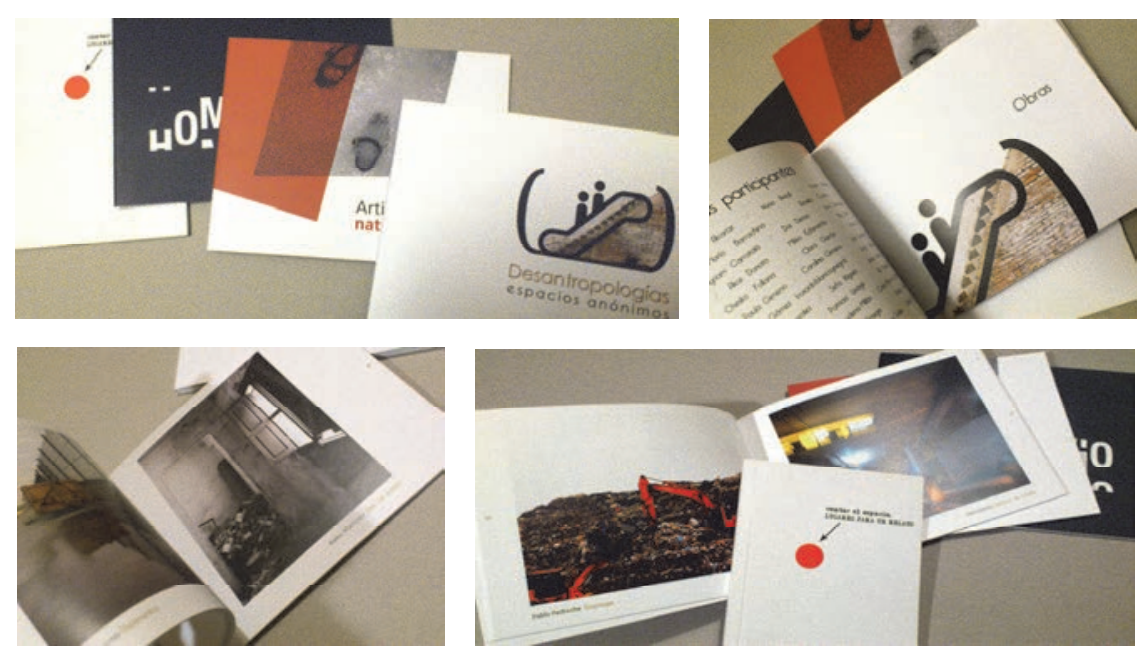

Fig. 6 Material divulgativo (catálogos) para exposiciones colectivas de temática social celebradas en espacios expositivos del Ayuntamiento de Valencia alumnado asignatura Presentación y divulgación de la obra de arte

\section{Resultados}

Para cubrir los objetivos planteados en la asignatura, hemos tomado como punto de partida un conjunto de trabajos de carácter plenamente aplicado ajustados a contextos reales. A su vez, nos hemos valido de estrategias y metodologías en las que se ha solicitado la participación y el compromiso del alumnado más allá del marco universitario. Cabe decir que los resultados obtenidos han sido muy positivos destacando notablemente el incremento de la motivación por parte de los estudiantes. No obstante, los resultados derivados de las experiencias realizadas indican que la incorporación transversal de una temática social eleva el nivel de compromiso de las personas implicadas.

Siguiendo la metodología señalada, los diferentes colectivos de alumnado que han pasado por la asignatura han desarrollado y celebrado numerosas exposiciones en espacios reales. Durante los últimos años, y centrándonos en aquellas exposiciones que han abordado temas de carácter social, podemos destacar propuestas y proyectos artísticos colectivos relacionados con:

- La distribución de los alimentos en un mundo global.

- El desarrollo de los entornos urbanos y su sostenibilidad.

\section{(cc) EY-NC-ND 2014, Universitat Politècnica de València}

I Jornadas IN-RED (2014) 
Metodologías docentes activas de incidencia social aplicadas en las enseñanzas artísticas universitarias

- El papel de la información en las sociedades contemporáneas.

- La incidencia de los movimientos sociales.

- Las repercusiones sociales derivadas de conflictos bélicos.

- La desaparición de entornos naturales.

- El uso de la vía pública.

- Los movimientos migratorios.

Asimismo, y con el objetivo de favorecer la motivación de nuestros estudiantes, cabe destacar que diversos proyectos, elaborados según la metodología indicada, han sido enviados a convocatorias públicas organizadas por instituciones públicas y/o privadas obteniendo buenos resultados. En la misma dirección se ha colaborado en las convocatorias anuales de CALSICOVA.

Para finalizar, nos gustaría añadir un aspecto relativo a los resultados obtenidos con respecto a la metodología de trabajo en grupo. Si bien a la hora de realizar la propuesta, el alumnado se muestra escéptico con respecto a las posibilidades de aprendizaje que ofrece la realización de la actividad mediante el trabajo grupal, una vez llevada a término, la percepción del estudiante varía notablemente. Este resultado ha sido constatado en encuestas específicas realizadas al finalizar el curso. En las mismas esta modalidad de trabajo es considerada como prioritaria en lo que se refiere a la adquisición de conocimientos profesionales.

Asimismo, pensamos que la actividad en su conjunto es susceptible de mejoras encaminadas a favorecer la participación y motivación del alumnado. Por esta razón y de cara a futuros cursos se ha previsto generar un blog que recoja las impresiones, comentarios, resultados de investigación, materialización de obras, etc. sobre el tema abordado. Al mismo tiempo, este servirá como plataforma de divulgación de los resultados.

\section{Conclusiones}

En función de lo señalado, consideramos que los resultados obtenidos no se derivan sólo de las cualidades intrínsecas de la materia impartida, sino que están igualmente vinculados a su presentación didáctica y a los contenidos transversales de sensibilización social planteados. Durante el proceso de planificación de la asignatura nos planteamos estructurar un material, así como centrar nuestra atención en el diseño formativo-integral de procesos de aprendizaje que permitan al alumnado desarrollar estrategias a través de las cuales este pueda aprender a resolver problemas concretos, fomentando, a su vez, su participación activa (Imbernon Muñoz y Medina Moya, 2008) y su implicación en temas contemporáneos de carácter social. 
En todo momento, las actividades propuestas han intentado resolver adecuadamente cuestiones relativas a:

- La utilidad que para nuestros estudiantes puede tener lo enseñado-aprendido.

- Las capacidades a desarrollar, tanto específicas como transversales.

- La puesta en marcha de una dinámica de clase activa y motivadora.

Si consideramos los resultados obtenidos en los años de docencia impartida en la citada asignatura, podemos concluir que el alumnado desarrolla de manera más óptima su aprendizaje $-\mathrm{y}$, por tanto, su motivación se ve notablemente incrementada- si son incorporados los siguientes elementos en las prácticas a desarrollar:

- El uso de temas de interés social.

- La inserción de los resultados en contextos reales.

- La implicación directa en los contenidos de la materia y desarrollo de los mismos.

\section{Referencias}

BAuman, Z. (2013). Sobre la educación en un mundo líquido. Barcelona: Paidós.

CANDEla, I. (2007). Sombras de ciudad. Arte y transformación urbana en Nueva York, 1970-1990. Madrid: Alianza Editorial.

Cortina, A. (1997). Ciudadanos del mundo. Hacia una teoría de la ciudadanía. Madrid: Alianza Editorial.

DOMÉNECH, F. (1999). Proceso de enseñanza - aprendizaje universitario. Castellón: Universitat Jaume I.

IMBERNON MUÑOZ, F. Y MEDINA MOYA, J. L. (2008). Metodología participativa en el aula universitaria. La participación del alumnado. Barcelona: Octaedro/ICE Universitat de Barcelona.

Merriam, S. B. (1998). Qualitative Research and Case Study Applications in Education. San Francisco: Jossey-Bass.

MoRALES, P. y LANDA, V. (2004). “Aprendizaje basado en problemas” en Theoría, vol. 13, 145-157.

MoRIN, E. (2010). Pensar la complejidad. Crisis y metamorfosis. Valencia: PUV.

(cc) EY-NC-ND 2014, Universitat Politècnica de València

I Jornadas IN-RED (2014) 


\title{
Reforzar la enseñanza de las matemáticas desde el primer curso de grado con proyectos
}

Francisco J. Boigues a, Vicente D. Estruch a , Anna Vidal a y Bernardino Roig a

anstituto de Investigación para la Gestión Integrada de Zonas Costeras, fraboipl@mat.upv.es , vdestruc@mat.upv.es, avidal@mat.upv.es, broig@mat.upv.es

\begin{abstract}
The way to build mathematical knowledge of a scientist / engineer differs from that corresponding to the student who accesses a degree in mathematics or other sciences. Learning based on the process of establishing, analyze and validate mathematical models allows the effective acquisition of math skills. In addition, activities based on mathematical modeling can be motivating elements in the teaching / learning process, arousing student interest to cognitive basis on which fundamental mathematical concepts are developed in the mathematical training of future scientist or engineer.
\end{abstract}

Keywords: Mathematical modeling, TSR, computer tool, projects, motivation.

\footnotetext{
Resumen

La manera de construir el conocimiento matemático de un científico/ingeniero difiere de la que corresponde al estudiante que accede a un grado en matemáticas o en otras ciencias. El aprendizaje en base al proceso de establecer, analizar y validar modelos matemáticos permite la adquisición efectiva de competencias matemáticas. Pero además, las actividades basadas en la modelización matemática pueden constituir elementos motivadores en el proceso de enseñanza/aprendizaje, despertando el interés del alumno hacia bases cognitivas sobre las cuáles se desarrollan conceptos matemáticos fundamentales en la formación matemática del futuro científico o ingeniero.
}

Palabras clave: Modelización matemática, REI, herramienta informática, proyectos, motivación.

(cc) EY-NC-ND 2014, Universitat Politècnica de València

I Jornadas In-Red (2014) 


\section{Introducción}

Está fuera de toda duda que la formación del científico y la del ingeniero queda incompleta sin una formación de calidad en matemáticas. En ambos casos el elemento común es que, en general, la formación requerida ha de ir orientada hacia la práctica, hacia las aplicaciones, o lo que es lo mismo hacia los modelos. En general, un modelo científico no es más que una herramienta del pensamiento que establece una abstracción de la realidad. Se trata de representar elementos reales en el plano abstracto, a partir de los cuales el científico pretende aproximarse a la realidad para, sobre la base de la información que proporciona el modelo, dar solución a necesidades generales de conocimiento o más concretamente resolver problemas, es decir, satisfacer necesidades de carácter práctico. La manera de construir el conocimiento matemático en ciencia empírica o en ingeniería difiere de la que corresponde a las matemática, o a la física teórica. A grandes rasgos, por ejemplo, para el ingeniero la vertiente de resolver problemas técnicos es mucho más importante que la de-del conocimiento básico por sí mismo.

Además el futuro científico o ingeniero espera de las matemáticas, ya desde primer curso, incluso a nivel emocional, una "utilidad" que le permita comprender mejor los diferentes problemas que se le plantean y poder encontrar soluciones adecuadas. Téngase en cuenta que, en muchas ocasiones, el rechazo cultural a las matemáticas, y por lo tanto a la racionalidad del pensamiento crítico, viene motivado por la poca eficiencia de los docentes a la hora de resaltar también el valor instrumental de las matemáticas. Se han realizado diversos estudios sobre la influencia de los factores emocionales en el rendimiento matemático de los estudiantes (Bhownik y Banerjee, 2013). Se podría destacar que la actitud esta relacionada significativamente con el rendimiento, resaltando en concreto la influencia que tiene el factor "utilidad de las matemáticas" en lograr una actitud más positiva hacia el quehacer matemático de los estudiantes (Zan y Di Martino, 2007).

Por lo tanto, es fundamental que en un diseño metodológico concreto del proceso de enseñanza/aprendizaje de las matemáticas en el contexto de estudios de grado de ciencias empíricas e ingeniería, se tenga en cuenta la necesidad de transmitir al alumno la potencia de la matemática como medio para representar eficazmente la realidad estática o cambiante.

Como concreción de las ideas expuestas anteriormente, presentamos una serie de trabajos prácticos que abordan problemas contextualizados, que llamamos proyectos, los cuales se han desarrollado, durante varios cursos, en la asignatura Matemáticas de primer curso del grado en Ciencias Ambientales, en la Escuela Politécnica Superior de Gandia de la Universidad Politécnica de Valencia. 


\section{Objetivos}

Los objetivos fundamentales de los proyectos desarrollados es:

a) Afianzar determinadas nociones teóricas desarrolladas en clase.

b) Introducir conceptos matemáticos nuevos, no vistos en las clases teóricas.

c) Modificar la actitud del alumno ante el aprendizaje de las matemáticas, acentuando la utilidad del conocimiento matemático para modelar y resolver problemas.

Más adelante mostraremos algunos proyectos concretos desarrollados en la asignatura de Matemáticas: El papel de las matrices en modelos de transmisión de plagas, la integral en modelos para la gestión del territorio y la derivada en modelos para la planificación de recursos pesqueros sostenibles (Boigues et al 2011, 2011a, 2013). Estos proyectos se desarrollan en laboratorio informático, en sesiones prácticas de dos horas, siguiendo en algunos casos estrategias de trabajo colaborativo, aunque en todos los casos en la evaluación se otorga un peso significativo al trabajo individual.

\section{Desarrollo de la innovación}

\subsection{Marco teórico}

Las propuestas docentes descritas asumen, en línea con Artigue et al. (2007), Drijvers et al. (2010) y Camacho et al. (2008), que la construcción del conocimiento matemático, en un entorno práctico, debe apoyarse en una enseñanza contextualizada, en la modelizaciónsimulación como recurso para la comprensión de conceptos, en la resolución de problemas y en el uso de Sistemas de Cálculo Simbólico (CAS).

La Teoría Antropológica de lo Didáctico (TAD) constituye un marco teórico que contextualiza la actividad matemática en el conjunto de las actividades humanas y de las instituciones sociales. La TAD introduce en los sistemas de enseñanza procesos de estudio funcionales, que permiten superar la monumentalización de la matemática (la matemática como un todo totalmente terminado), tanto a nivel cognitivo como procedimental, mediante procesos que permiten analizar y resolver situaciones problemáticas cercanas a la realidad. Los Recorridos de Estudio y de Investigación (REI) son mecanismos didácticos, propuestos por la TAD, que se diseñan a partir de la búsqueda de respuestas a cuestiones que, para ser resueltas, requieren de la construcción de una secuencia más o menos compleja de praxeologías completas y articuladas (Serrano et al., 2007).

La idea final es que los REI funcionen localmente como mecanismos didácticos capaces de superar la tradicional desarticulación o atomización de las matemáticas a nivel universitario. Estos mecanismos tendrían una función articuladora que se deriva en gran

\section{(c)) EY-NC-ND 2014, Universitat Politècnica de València}

I Jornadas IN-RED (2014) 
medida de su capacidad para permitir que la modelización matemática asuma un papel más importante en los procesos de enseñanza/aprendizaje (Boigues et al., 2011), estableciendo el principio básico por el cual hacer matemáticas consiste esencialmente en un trabajo activo y continuo de modelización matemática.

Un REI se inicia con una cuestión generadora, que llamaremos $C_{0}$, la cual, tras establecer las correspondientes hipótesis de trabajo, actuará como germen para otras cuestiones derivadas. De esta forma, las matemáticas dejan de ser el motivo y el origen de los problemas planteados para convertirse fundamentalmente en el medio para poder resolverlos. Las diversas respuestas a las cuestiones derivadas constituyen la respuesta global a la cuestión generadora (figura 1).

Un REI puede abordar el estudio de un tema completo o partes de un tema, a partir de considerar cuestiones generadoras adecuadas en cada caso.

En el desarrollo de un REI, un elemento importante sería lo que que denominaremos el “nivel de acompañamiento del profesor" en el REI o lo que es lo mismo, el grado de intervención del profesor junto a los alumnos en el recorrido. Distinguiríamos entre el recorrido con total acompañamiento, en el que el profesor guía y sigue de cerca el trabajo de los alumnos, corrigiendo las posibles desviaciones de la senda más o menos marcada y el recorrido sin acompañamiento, donde el trabajo de los alumnos sería totalmente autónomo. Entre ambos extremos se pueden plantear múltiples estados intermedios.

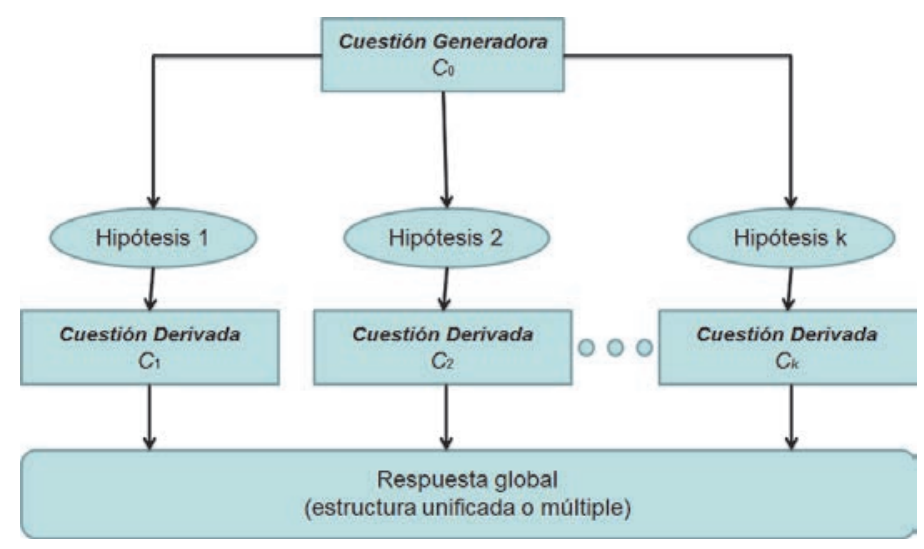

Figura 1.- Esquema genérico de un REI

En este trabajo se exponen tres proyectos desarrollados, desde la estructura REI, en la asignatura Fundamentos Matemáticos para el Estudio del Medio Ambiente, en la Escuela Politécnica Superior de Gandia.

(cc) BY-NC-ND 2014, Universitat Politècnica de València 


\subsection{Proyectos REI}

3.2.1 Un modelo de expansión de plagas (Boigues et al, 2011)

Duración: 3 sesiones de 2 horas.

\section{El problema real $\left(C_{0}\right)$}

Supongamos cierta población de árboles de un bosque, formada por $N$ individuos, valor que suponemos no varía en el periodo de tiempo considerado (sistema cerrado). Se detecta una plaga o enfermedad que, en principio, no produce mortalidad y que inmuniza contra la misma al árbol que la ha sufrido. Diariamente, un $m \%$ de los árboles sanos contraen la enfermedad quedando infectados, y un $c \%$ de los infectados sanan volviéndose inmunes a la enfermedad.

Se desea averiguar la evolución de la enfermedad a lo largo de los 21 días de un determinado mes, sabiendo que inicialmente el número de árboles es de 9000, de los cuales 1000 estaban infectados y ninguno es inmune todavía. Conocemos el índice de propagación de la plaga que es del $1 \%$ diario. Además, también diariamente, un $2 \%$ de los infectados sanan.

\section{Cuestiones derivadas a resolver:}

$H_{1}$ : El sistema real se puede modelar considerando diversas variables que evolucionan con el tiempo

$C_{1}$ ¿Cuáles son las variables involucradas en el sistema?

$\mathrm{H}_{2}$ : La evolución temporal de las variables admite una representación gráfica para representar su evolución con el paso de una etapa a otra

$C_{2}$ ¿Cómo podemos representar gráficamente la transición de estados (evolución de las variables del modelo) al pasar de un mes a otro?

$H_{3}$ : La evolución del sistema real se puede modelar mediante un sistema de ecuaciones en diferencias.

$C_{3}$ ¿Cuáles son las ecuaciones que describen la evolución del sistema?

$H_{4}$ : El sistema de ecuaciones en diferencias que representa el sistema real admite una representación matricial.

$C_{4}$ ¿La evolución del sistema (las ecuaciones que lo describen), admite una representación matricial?

$H_{5}$ : El modelo matemático puede ser resuelto numéricamente.

$C_{5}$ ¿Cómo podemos resolver numéricamente el sistema?

$H_{6}:$ La evolución temporal de las variables del sistema puede ser representada gráficamente.

\section{(c) EY-NC-ND 2014, Universitat Politècnica de València}

I Jornadas IN-RED (2014) 
Reforzar la enseñanza de las matemáticas desde el primer curso de grado con proyectos

$C_{6}$ ¿Cómo podemos representar gráficamente la evolución del sistema?

Se plantea asumir mortalidad en el modelo. Consideremos una nueva variable, que representaría a los árboles infectados que mueren en el instante $t$, y $\mu \times 100 \%$ es el porcentaje de la población enferma que muere en el transcurso de un día a otro.

$H_{7}$ : Para considerar la mortalidad, hay que añadir una nueva variable al modelo. Reformulando las ecuaciones que lo describen podemos obtener un nueva representación matricial del sistema.

$C_{7}$ ¿Cómo podemos reformular el modelo para asumir la mortalidad?

La respuesta global al proyecto incluye los siguientes aspectos:

- Reconocer, como modelo que describe el proceso, una cadena de Markov explorando las características de la matriz de transición de estados.

- La descripción del comportamiento del sistema conociendo las características de la matriz de transición.

- Descubrimiento de la posibilidad de modelar situaciones más complejas incluyendo más variables en el modelo y, por lo tanto, incrementando el tamaño de la matriz de transición.

- La simulación numérica y gráfica permitirán visualizar la evolución de los estados del sistema en cierto interalo temporal discreto preestablecido.

Los conceptos matemáticos básicos sobre los que se trabajará a lo largo del proyecto son: Representación matricial de un sistema lineal discreto de primer orden y su resolución numérica y analítica. Operaciones con matrices. Cálculo de valores y vectores propios.

Para desarrollar el proyecto, se utiliza la técnica del trabajo en grupo. Para la evaluación del mismo se han ensayado dos experiencias. En la primera experiencia de evaluación, cada grupo tiene que que elaborar una memoria de la actividad y realizar una presentación en público de los principales resultados, en la que ha de participar todo el grupo. En la presentación los profesores realizaban diversas preguntas a los alumnos para obtener una idea del nivel de comprensión. Se otorga una nota a partir de la valoración de la memoria presentada (trabajo académico) y de la presentación realizada (observación).

Otra experiencia de evaluación ha sido la de valorar también la memoria de la actividad que se exige realizar, y e lugar de la presentación pública, se realiza una prueba objetiva de respuesta abierta donde se plantean al alumno cuestiones sobre pequeñas variaciones del modelo inicial.

3.2.2 Un modelo en la gestión del territorio (Boigues et al., 2011a)

Duración: 1 sesión de 2 horas.

(c)) EY-NC-ND 2014, Universitat Politècnica de València

I Jornadas IN-RED (2014) 


\section{El problema real $\left(C_{0}\right)$}

Un problema de interés en gestión del territorio es la cuantificación de la superficie de un espacio geográfico así como la valoración de la evolución del mismo por el efecto de determinadas actividades humanas. Se plantea a los alumnos el problema de determinar la superficie que ocupa la zona inundada de un humedal. En base a imágenes aéreas o de satélite (figura 2), habrá que delimitar el contorno del lago que ha de ser estudiado (lago de Anna). Se ha de determinar la superficie del humedal y la longitud de un camino de acceso, que se observa en la imagen, el que va de A a B.

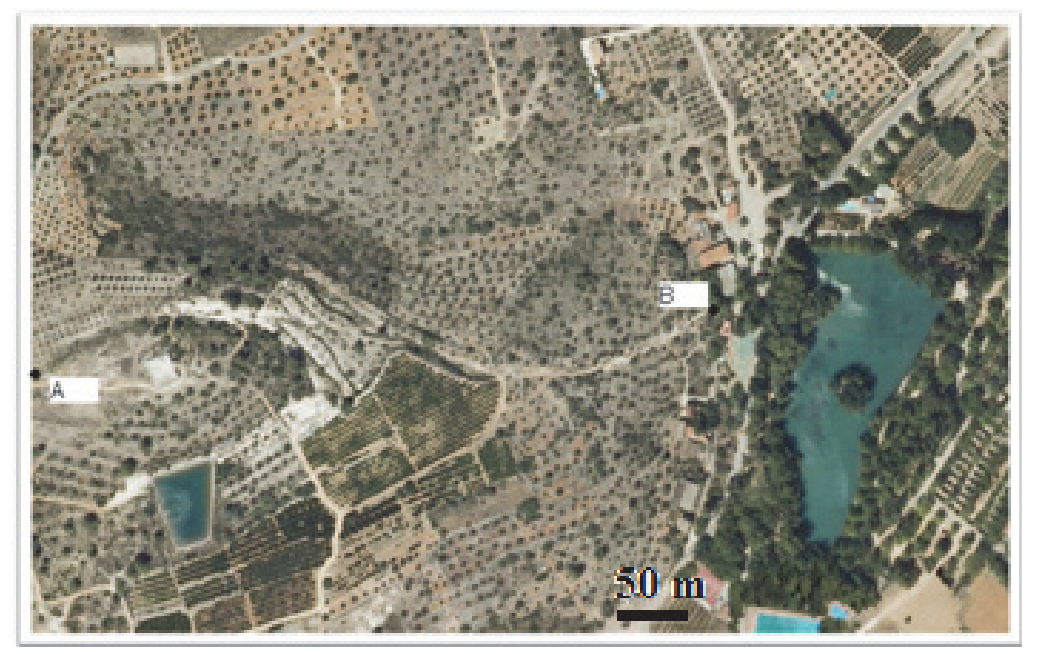

Figura 2.- Vista aérea del lago y del camino de acceso

\section{Cuestiones derivadas a resolver:}

$H_{1}$ : Podemos aproximar el contorno del lago mediante puntos y segmentos, formando poligonales.

$C_{1}$ ¿Cómo podemos aproximarnos al contorno real del lago a partir de un conjunto discreto de puntos de su contorno?

$\mathrm{H}_{2}$ : Podemos aproximar el contorno del lago estableciendo puntos de referencia, y ajustando los mismos mediante polinomios.

$C_{2}$ ¿Cómo podemos aproximarnos al contorno real del lago a partir de dos funciones polinómicas que se ajusten a puntos de su contorno?

$\mathrm{H}_{3}$ : Podemos aproximarnos al camino de acceso mediante puntos y segmentos, formando poligonales.

\section{(cc) EY-NC-ND 2014, Universitat Politècnica de València}

I Jornadas IN-RED (2014) 
$C_{3}$ ¿Cómo podemos aproximarnos mediante poligonales al camino de acceso, desde el punto $\mathrm{A}$ al punto $\mathrm{B}$ ?

$H_{4}$ : Podemos aproximarnos al camino de acceso estableciendo puntos de referencia, y ajustando los mismos mediante polinomios.

$\mathrm{C}_{4}$ ¿Cómo podemos aproximarnos mediante una función polinómica al camino de acceso, desde el punto $\mathrm{A}$ al punto $\mathrm{B}$ ?

$H_{5}$ : Podemos aproximarnos al área del lago mediante el calculo del área limitada, superior e inferoromente, por gráficas de funciones polinomiales.

$C_{5}$ ¿Cómo obtener una aproximación al área del lago?

$H_{6}$ : Podemos aproximar la longitud del camino de acceso mediante el calculo de la longitud de una parte de la gráfica de una función polinomial.

$C_{6}$ ¿Cómo obtener una aproximación a la longitud del camino desde el punto A al punto B?

La respuesta global del proyecto consiste en la descripción de alguna características morfométricas del lago (forma, superficie) mediante elementos de simulación (poligonales, gráficas de funciones polinómicas) así como la caracterización morfométrica de un camino de acceso (forma del trazado, área del lago y longitud del camino de acceso).

Los conceptos matemáticos básicos sobre los que se trabajará a lo largo del proyecto son el ajuste polinomial por mínimos cuadrados, y la aplicación de la integral definida al cálculo de superficies de figuras planas y al cálculo de longitudes de curvas planas.

La evaluación de este proyecto se realiza sobre la memoria que, individualmente, cada alumno presenta al finalizar el mismo (trabajo académico). La memoria se basa en un guión diseñado al efecto, donde se plantean las cuestiones que hay que resolver y que que cada alumno, de forma individual, cumplimentará al final de la sesión.

\subsubsection{Un modelo de gestión sostenible de la pesca (Boigues et al., 2013)}

Duración: 3 sesiones de 2 horas.

\section{El problema real $\left(C_{0}\right)$}

Una región basa su economía fundamentalmente en la pesca de bajura. Existiendo un peligro real de sobreexplotación para los recursos pesqueros de la región, se ha decidido una parada biológica para la pesca. El estudio de la evolución de la población durante la parada puede ayudar a tomar algunas decisiones, como por ejemplo calcular la duración aproximada necesaria de la parada biológica y estudiar la posibilidad de establecer una cuota sostenible de pesca en un futuro. La especie que se pesca es endémica de las aguas de la región, por lo que no hay que considerar movimientos migratorios. Se puede afrontar el 
estudio utilizando modelos en tiempo discreto con etapas mensuales. Para ello, mediante diversos métodos, se ha estimado la población de dichos peces en meses sucesivos. Se proporciona una tabla que muestra el número de peces estimados cada més durante nueve meses de parada biológica. Se quiere estudiar el comportamiento de la evolución del número de individuos con el tiempo para establecer tendencias y para, a continuación, estudiar qué ocurre al considerar la actividad pesquera y, en el caso de que sea posible, asegurar que la pesca constituye una actividad sostenible, es decir compatible con el crecimiento natural de la población de peces, asegurando una población estable.

\section{Cuestiones derivadas a resolver:}

$H_{1}$ : Podemos representar el crecimiento mediante modelos sencillos basados en ecuaciones en diferencias

$C_{1}$. ¿Existen modelos discretos sencillos que se ajusten a los datos?

$\mathrm{H}_{2}$ : El modelo matemático permite hacer predicciones sobre la evolución a corto plazo de la población de peces.

$C_{2}$ ¿En su caso, cuanto tiempo se estima que puede pasar hasta llegar a cierto número de individuos (3.400.000)? (El valor indicado es fruto de un pacto y se supone que es una cantidad razonable para plantear la vuelta a la actividad pesquera)

$H_{3}$ : El modelo matemático permite hacer predicciones sobre la evolución a largo plazo de la población de peces.

$C_{3}$ ¿Los modelo considerados indican lo que sucederá a largo plazo a largo plazo?

Los modelos considerados explican la evolución de la población en la situación de parada biológica (sin pesca).

$H_{4}$ : Podemos introducir la actividad pesquera modificando levemente el modelo matemático inicial.

$C_{4}$ ¿Cómo podemos introducir la actividad pesquera en los modelos?

$H_{5}$ : El modelo matemático permite hacer predicciones sobre la evolución de la población de peces cuando hay actividad pesquera.

$C_{5}$ ¿ Cómo se comportan los modelos al considerar la pesca?

La respuesta global incluirá:

- La modelación de la evolución de la población de peces mediante distintos modelos no lineales en tiempo discreto.

- La valoración de la bondad del ajuste de los modelos a los valores de la población del periodo sin pesca.

- El estudio de los nuevos modelos obtenidos al considerar la actividad pesquera.

\section{(c) EY-NC-ND 2014, Universitat Politècnica de València}


- La decisión final sobre una estrategia de pesca sostenible según un criterio biológico preestablecido.

Este proyecto se desarrolla en grupo y se evalua a partir de la valoración de la memoria del proyecto (trabajo académico) y de una prueba objetiva de respuesta abierta, que se desarrolla en la última, sesión, en la cual se plantean cuestiones en base a pequeñas variaciones sobre el modelo inicial obtenido.

\section{Resultados}

Destacamos algunos resultados obtenidos a lo largo de tres años de experiencia en los que se han desarrollado los proyectos, los cuales han contado con el respaldo de diversos programas institucionales de innovación docente de la U.P.V. En primer lugar destacamos que, con la puesta en práctica de los proyectos, se produce una mayor implicación de los estudiantes en su aprendizaje, lo cual se concreta en una mayor asistencia a las clases prácticas respecto de las clases teóricas (cerca del $80 \%$ sobre matriculados) y también en una mayor presencia en los controles de evaluación. Por otra parte, es destacable la valoración positiva que los propios estudiantes dan a aprender matemáticas en base a proyectos. No se pueden obviar determinadas dificultades, subsanables casi todas, que tienen su origen en la difícil sincronización de las prácticas con las clases teóricas y en la complicada distribución temporal de la asignatura a lo largo del curso. La técnica del trabajo en grupo también conlleva problemas a la hora de poder asegurar que todos los miembros del grupo han trabajado. El presentar una memoria del proyecto no resuelve este problema, pero la presentación pública, con la obligación de que todos los miembros del grupo participen en la misma, junto con las preguntas que se realizan al final de la presentación, permite valorar la implicación de cada miembro del grupo en el trabajo y el nivel de conocimiento al que ha llegado cada alumno. No obstante, es constatable que los alumnos de primer curso tienen muchas dificultades a la hora de preparar una correcta presentación pública de resultados. Es por esto que se ensayó la alternativa de evaluación mediante una prueba escrita de respuesta abierta en base a cuestiones planteadas sobre pequeñas variaciones sobre el modelo inicial. La experiencia indica que, para preparar la prueba escrita de respuesta abierta, los alumnos se esfuerzan en conocer bién todos los aspectos del proyecto desarrollado y se obtienen mejores resultados desde el punto de vista del nivel de conocimiento alcanzado. Por otra parte, no podemos afirmar que la metodología expuesta aporte una mejora significativa del número de aprobados sobre matriculados.

Es necesario remarcar que, debido a las limitaciones que impone el Plan de Ordenación Docente, se dispone de poco tiempo para facilitar que los alumnos lleguen a conocer suficientemente el CAS manejado, en nuestro caso MatLab ${ }^{\odot}$. Esto dificulta la utilización fluída del programa para resolver los problemas planteados en los proyectos, teniendo que 
dedicarse demasiado tiempo a resolver problemas técnicos relacionados con la sintaxis propia, y necesariamente estricta, del lenguaje de programación y con el manejo del programa.

\section{Conclusiones}

Las experiencias expuestas se pueden resumir como prácticas de introducción o refuerzo de conceptos matemáticos mediante el desarrollo de proyectos de modelización matemática, estructurados como REI, utilizando un asistente matemático $\left(\mathrm{MatLab}^{\odot}\right)$ para la génesis instrumental de los modelos.

Una valoración reflexiva, desde un punto de vista cualitativo, de las experiencias expuestas, en su globalidad, nos lleva a constatar el hecho de que la introducción de la modelización en la enseñanza de la Matemática Aplicada acerca al alumno a la matemática, reforzando que los estudiantes puedan llegar a percibir que las matemáticas son importantes fuera de su ámbito propio, apreciando e interiorizando que las matemáticas son muy útiles para afrontar problemas ligados a diversas disciplinas.

\section{Referencias}

ARTIGUE, M., BATANERO C. \& KENT, P. (2007), Mathematics thinking and learning at post secondary level. In Fr. Lester (ed.), Second Handbook of research on Mathematiccs Teaching and learning. NCTM-IAP; Charlotte, NC, 1011-1045.

BARQUERO, B., BOSCH, M. \& GASCÓN, J. (2006). "Una nova organització del currículum de matemàtiques de primer curs universitari de ciències: els Recorreguts d'Estudi i Investigació". Actes del Congrés Internacional de Docència Universitària i Innovació, Barcelona. juliol 2006.

BHOWMIK, M.; BANERJEE, B. (2013). "Fuzzy measure of secondary students' attitude towards Mathematics." International Journal of Research Studies in Educatión, Vol. 2, n ${ }^{\circ}$ 2, pp 21-30.

BOIGUES, F.J, ESTRUCH, V.D., ROIG, B., VIDAL, A. (2011). "Un modelo de transmisión de plagas para la enseñanza del álgebra lineal en el contexto de estudios en ciencias ambientales". Modelling in Science Education and Learning, 4, $\mathrm{N}^{\circ}$ 8, pp. 105-117.

BOIGUES, F.J, ESTRUCH, V.D., PASTOR, J. (2011a) "Prácticas y proyectos con Matlab. Matemáticas para el estudio del medio ambiente”, Valencia. Editorial UPV.

BOIGUES, F.J, ESTRUCH, V.D., ROIG, B., ROPIG, B., VIDAL, A. (2013). "Una propuesta de Recorrido de Estudio e Investigación (REI): Diseño, simulación y decisión de una estrategia de pesca sostenible". Modelling in Science Education and Learning, 6, $\mathrm{N}^{\mathrm{o}} 2$, pp. 5-19.

\section{(c)) EY-NC-ND 2014, Universitat Politècnica de València}

I Jornadas IN-RED (2014) 
CAMACHO, M., DEPOOL, R. Y GARBIN, S. (2008). "Integral definida en diversos contextos. Un estudio de casos”. Educación Matemática,. 20(3), pp. 33-57.

DRIJVERS, P., KIERAN C. Y MARIOTTI, M. (2010): "Integrating Technology into Mathematics Education: Theoretical Perspectives.” In C. Hoyles y L.B. Lagrange (eds.), Mathematics Education, pp.89-132. New York: Springer.

SERRANO, L.; BOSCH, M.; GASCÓN, J. (2007). "Cómo hacer una previsión de ventas": propuesta de recorrido de estudio e investigación en un primer curso universitario de administración y dirección de empresas." II Congreso Internacional sobre la Teoría Antropológica de lo Didáctico. Francia. Noviembre 2007. Disponible en: http://www4.ujaen.es/ aestepa/TAD_II/Comunicaciones_TAD_II/25\%20-

$\%$ 20Serrano_Bosch_Gascon_congres_TAD_2.pdf.

ZAN, R.; DI MARTINO P. (2007). "Attitude toward mathematics: overcoming the positive/negative dichotomy." The Montana Council of Teachers of Mathematics, Monograph 3, pp. 157-168. 


\title{
Metodología para la definición de casos de estudio
}

\author{
Faustino Alarcón ${ }^{\mathrm{a}}$, MME Alemany ${ }^{\mathrm{b}}$, Andrés Boza $^{\mathrm{c}}$, Llanos Cuenca ${ }^{\mathrm{d}}$, Marta \\ Fernández-Diego ${ }^{\mathrm{e}}$, Leonor Ruiz ${ }^{\mathrm{f}}$
}

${ }^{a, b}$ Escuela Técnica Superior de Ingeniería Industrial. Departamento de Organización de Empresas.

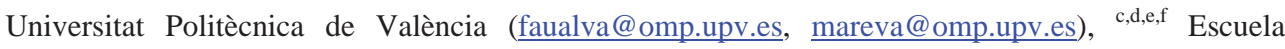
Técnica Superior de Ingeniería Informática. Departamento de Organización de Empresas. Universitat Politècnica de València (aboza@omp.upv.es, llcuenca@omp.upv.es, marferdi@omp.upv.es, 1ruiz@omp.upv.es)

\begin{abstract}
This paper presents a methodology for the definition of case studies as a technique for collaborative learning in the context of university teaching, which is focused on the acquisition of skills required by companies. Starting from a literature review and their analysis, the methodology proposed is detailed distinguishing the main phases of planning and design of the case study. The process of methodology application is presented distinguishing whether it is a new case or it is an application to an existing case. Innovation centers to define what are the elements that should be taken into account in the definition of a case study, not only in how it should be applied in the classroom.
\end{abstract}

Keywords: collaborative learning, active learning, learning techniques, case stuies, case study methodology 


\begin{abstract}
Resumen
Este artículo presenta una metodología para la definición de casos de estudio como técnica de aprendizaje colaborativo en el contexto de la docencia universitaria, orientada a la adquisición de competencias profesionales demandadas por las empresas, en la que partiendo de una revisión de la literatura así como el análisis de la misma, a continuación se detalla la metodología propuesta distinguiendo las fases principales de planificación y redacción del caso, y se presenta el proceso de aplicación de la metodología distinguiendo si se trata de un caso nuevo o de su aplicación a un caso ya existente. La innovacion se centra de definir cuales son los elementos que se deben tener en cuenta en la definición de un caso de estudio, no tanto en cómo debe ser su aplicación en el aula.
\end{abstract}

Palabras clave: aprendizaje colaborativo, aprendizaje activo, técnicas de aprendizaje, casos de estudio, metodología del caso de estudio.

\title{
1. Introducción
}

El aprendizaje colaborativo es una forma de enseñanza que involucra a los estudiantes que trabajan juntos para lograr un objetivo común (Felder y Brent, 1994). Incorpora la colaboración como una filosofía de interacción, donde los estudiantes son responsables de sus acciones de aprendizaje, y respetan las capacidades y aportaciones de sus compañeros. La colaboración es un proceso exigente en la que los participantes comparten información, recursos y responsabilidades.

La colaboración consiste en el compromiso mutuo de los participantes para resolver un problema juntos, lo que implica la confianza mutua y por lo tanto requiere tiempo, esfuerzo y dedicación. Las contribuciones individuales a la creación de valor son mucho más difíciles de determinar en el aprendizaje colaborativo.

Estas características están relacionadas con algunas de las competencias profesionales demandadas por las empresas para los estudiantes (Alemany et al., 2003)

- Habilidad en la resolución de problemas.

- Responsabilidad en la resolución de problemas.

- Dominio de las técnicas de expresión oral y escrita.

- La integración rápida en la empresa.

(cc) EY-NC-ND 2014, UniversitatPolitècnica de València

I Jornadas IN-RED (2014) 
- Adaptación a las limitaciones del mundo real.

- Trabajo en equipo.

- Capacidad para trabajar por los niveles demandados en tiempo y costo adecuado.

- Capacidad para trabajar en varios problemas al mismo tiempo.

Las necesidades de formación deben adaptarse cada vez más a la demanda de la sociedad en general y de las empresas. Dentro de las técnicas de aprendizaje colaborativo, los métodos basados en la experiencia o métodos experienciales tienen el potencial de superar muchas de las limitaciones del paradigma tradicional. Los métodos pedagógicos más directamente relacionados con el aprendizaje experiencial son el método del caso y los modelos de simulación. Ambos se caracterizan porque permiten que el alumno viva una realidad empresarial y aprenda a través de la experiencia derivada de la misma.

Incorporar el aprendizaje basado en la experiencia y en concreto el método del caso (MdC) en la docencia universitaria es una metodología activa que mejora las habilidades en la materia, ya que permite a los alumnos trabajar desde un enfoque profesional los problemas de un dominio determinado.

Si los alumnos participan activamente en su aprendizaje se mejorará su motivación sobre el tema. A través del estudio de casos se mejora la participación activa, cooperación y el diálogo democrático de los estudiantes sobre una situación real. Se centra en el razonamiento de los estudiantes y en su capacidad de estructurar el problema y el trabajo para lograr una solución (Boehrer, y Linsky, 1990). Asopa y Beve (2001) definen el MdC como un método de aprendizaje basado en la participación activa, cooperativa y en el diálogo democrático de los estudiantes sobre una situación real.

\section{Objetivo}

Las nuevas tendencias en el proceso de enseñanza-aprendizaje conceden un papel más activo para el estudiante. El aprendizaje es más eficaz cuando los estudiantes participan activamente en el proceso de aprendizaje. El enfoque de casos de estudio en la enseñanza es una forma en que se pueden implementar las estrategias de aprendizaje activo.

Este artículo presenta una metodología para la definición de casos de estudio distinguiendo las fases principales de planificación y redacción del caso. La investigaciones tradicionalmente han ido dirigidas hacia la apliación del caso en el aula y no tanto a la definición del caso en si mismo. Aquí radica la innovación de la propuesta.

\section{Desarrollo de la innovación}

La metodología de investigación seguida, se basa en el proceso de revisión de la literatura que permita identificar los elementos necesarios para el diseño de casos de estudio. Fink (1998) define la revisión de la literatura como un diseño sistemático, explícito y

\section{(c)) EY-NC-ND 2014, UniversitatPolitècnica de València}

I Jornadas IN-RED (2014) 
reproducible para identificar, la evaluación y la interpretación de las normas existentes de los documentos registrados. La revisión de la literatura, por lo general, apunta a dos objetivos: en primer lugar, un resumen de las investigaciones existentes mediante la identificación de patrones, temas y cuestiones y en segundo lugar, ayudar a identificar el contenido de la materia analizada y contribuir al desarrollo de la misma (Seurign and Müller, 2008).

Los pasos seguidos en la revisión bibliográfica (basados en Mayring, 2002) son recopilación de material, análisis descriptivo, selección y evaluación:

Recopilación del material: La búsqueda se ha realizado sobre Google Académico (scholar.google.es) y Scopus.

La búsqueda se ha llevado a cabo sobre la combinación de los siguientes términos.

Término 1: collaborative learning, active learning, learning techniques

Término 2: case study, case study methodology, case study guidelines,

Análisis descriptivo: En el análisis descriptivo se obtienen los aspectos formales del material a analizar, como son el número de resultados encontrados, número de resultados por año, etc. lo que proporciona la base para el consecuente análisis teórico.

Selección: En esta fase, los artículos que dieron como resultado al aplicar el filtro anterior fueron analizados, en primer lugar, a través de su abstract, lo que permitió descartar la mayor parte de ellos al alejarse del objeto de estudio.

La selección final dio como resultado un total de 18 artículos.

Evaluación: Estos artículos se analizaron de acuerdo a lasdimensiones propuestas por los autores de este artículo, lo que ha permitido la revisión y análisis con más detalle. Las dimensiones se resumen en la Tabla 1:

Tabla 1. Dimensiones definidas para el análisis de la literatura

\begin{tabular}{|c|c|}
\hline Definiciones & $\begin{array}{l}\text { Recopilación de las definiciones que se incluyan en el artículo. Pueden ser: } \\
\text { "método", "caso", "método del caso", "caso de estudio", "metodología", } \\
\text { etc. }\end{array}$ \\
\hline Roles & $\begin{array}{l}\text { Descripción de roles identificados en el artículo. Principalmente serán } \\
\text { "profesor" y "alumno", puede ser también, "grupo" o "equipo", } \\
\text { "diferentes roles dentro del equipo", etc. }\end{array}$ \\
\hline Clasificación & $\begin{array}{l}\text { Clasificaciones propuestas o utilizadas en el artículo. Puede ser } \\
\text { clasificación de alumnos, de temas a tratar, de tipos de casos, etc. }\end{array}$ \\
\hline $\begin{array}{l}\text { Metodología de } \\
\text { definición }\end{array}$ & Metodología seguida o propuesta para la construcción del caso. \\
\hline $\begin{array}{l}\text { Metodología de } \\
\text { implantación }\end{array}$ & Metodología seguida o propuesta para el desarrollo de los casos en el aula. \\
\hline Metodología de & Metodología seguida o propuesta para la evaluación (y/o calificación) a \\
\hline
\end{tabular}

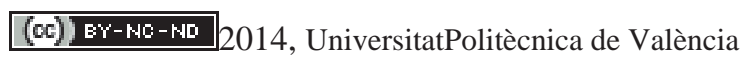

I Jornadas IN-RED (2014) 
Faustino Alarcón, MME Alemany, Andrés Boza , Llanos Cuenca, Marta Fernández, Leonor Ruiz

\begin{tabular}{|cl|}
\hline evaluación & los alumnos. \\
Recursos & $\begin{array}{l}\text { Identificación de los recursos (humanos o materiales) utilizados o } \\
\text { propuestos, para la definición, desarrollo y/o evaluación del caso en el } \\
\text { aula. }\end{array}$ \\
\hline Resultados & Resumen de los resultados descritos en el artículo. \\
Conclusiones & Resumen de las conclusiones principales del artículo. \\
Líneas futuras o & Líneas de trabajo futuro o aspectos a mejorar identificados en el artículo. \\
propuestas de mejora & \\
\hline
\end{tabular}

La revisión de la literatura ha permitido identificar tres tipos de uso de los casos de estudio: 1) los artículos analizados utilizan los casos de estudio como base para una investigación, 2) en este tipo, los casos de uso son tomados como aplicación y/o validación de una investigación, y 3) los artículos se basan en el proceso de definición, aplicación y/o evaluación de casos de estudio. Los dos primeros quedan fuera del alcance de este artículo. El número final de artículos se redujo a 8.

Las dimensiones propuestas para el análisis de los artículos nos permiten concluir que, la metodología de casos de estudio debe tener en cuenta, 1) el proceso de "definición" del caso a utilizar, 2) el proceso de aplicación del caso de estudio en el aula, "desarrollo" y 3 ) el proceso de evaluación y/o calificación a aplicar, "evaluación”. Estos tres elementos estarán influenciados por 4) los participantes en las diferentes etapas, "roles" y 5) los medios disponibles, "recursos". La Figura 1 refleja la relación entre estos elementos.

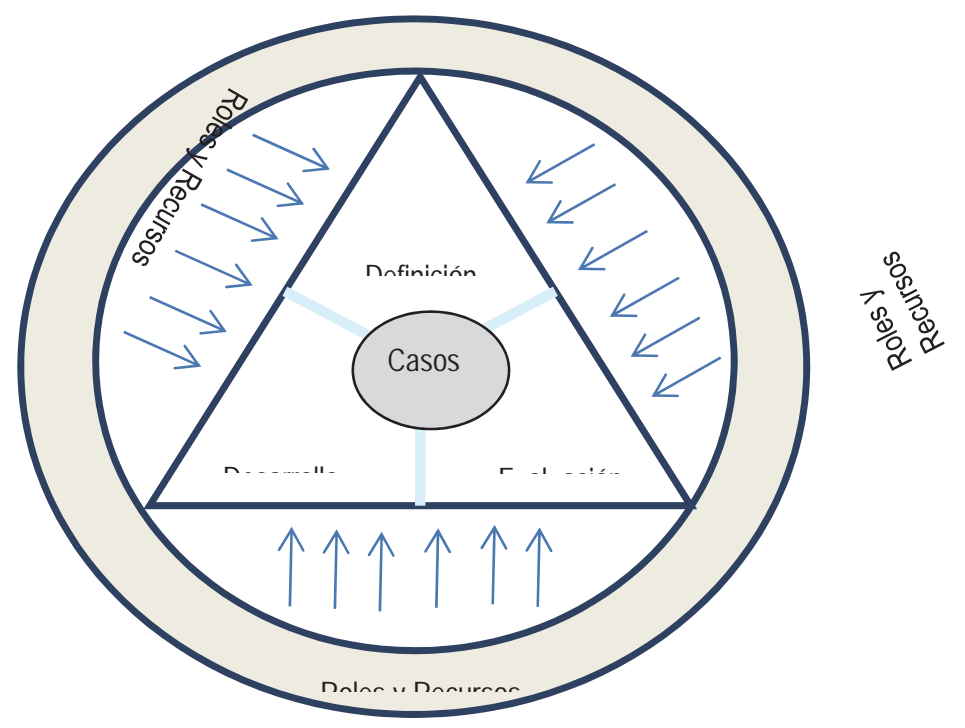

Fig. 1 Elementos a considerar en la metodología de casos de estudio

\section{(c)) EY-NC-ND 2014, UniversitatPolitècnica de València}

I Jornadas IN-RED (2014) 
El objetivo de este trabajo se centra en la definición de casos de estudio, lo que corresponde con el proceso de definición del caso, no tanto en su desarrollo y evaluación.

En este sentido, la revisión de la literatura ha permitido identificar una serie de aspectos que deben ser tenidos en cuenta durante la definición del caso. Estos aspectos los hemos clasificados en dos grupos, aquellos que son referidos a la preparación previa (definición del objetivo, preparación del material, etc.) y aquellos que hacen referencia a la redacción del caso, que incluyen el texto del caso, las preguntas a contestar y el cuaderno del profesor o "teaching note" asociado al caso (Tabla 2).

Tabla 2. Dimensiones definidas para el análisis de la literatura

\begin{tabular}{|c|c|c|c|c|c|c|}
\hline \multirow[t]{3}{*}{ Autor } & \multicolumn{6}{|c|}{ Definición de casos de estudio } \\
\hline & \multicolumn{2}{|c|}{ Preparación previa } & \multicolumn{4}{|c|}{ Redacción } \\
\hline & Objetivo & $\begin{array}{c}\text { Recopilación de } \\
\text { material }\end{array}$ & $\begin{array}{c}\text { Texto } \\
\text { del caso }\end{array}$ & $\begin{array}{c}\text { Preguntas a } \\
\text { responder }\end{array}$ & Validación & $\begin{array}{c}\text { Teaching } \\
\text { notes }\end{array}$ \\
\hline Gini, 1985 & $\bullet$ & & $\bullet$ & & & \\
\hline $\begin{array}{c}\text { Morra, y } \\
\text { Friedlander,1990 }\end{array}$ & $\bullet$ & $\bullet$ & $\bullet$ & $\bullet$ & & $\bullet$ \\
\hline Cappel, 2002 & - & & - & & - & - \\
\hline Farhoomand, 2004 & $\bullet$ & & $\bullet$ & & & $\bullet$ \\
\hline Generalitat, 2006 & $\bullet$ & $\bullet$ & $\bullet$ & $\bullet$ & & \\
\hline UPM, 2008 & $\bullet$ & $\bullet$ & $\bullet$ & & & \\
\hline Herrera, 2009 & $\bullet$ & & - & $\bullet$ & & \\
\hline $\begin{array}{c}\text { Reddy and } \\
\text { Agrawal, } 2012\end{array}$ & $\bullet$ & $\bullet$ & $\bullet$ & & & $\bullet$ \\
\hline
\end{tabular}

La revisión llevada a cabo será el punto de partida para propuesta de metodología de definición de casos de estudio.

\section{Resultados}

A partir de la revisión anterior se realiza la siguiente propuesta.

La definición del caso de estudio debe tener dos fases claramente diferenciadas:planteamiento y redacción del caso.

\subsection{Planteamiento}

En primer lugar, en la fase de planteamiento se debe identificar el objetivo perseguido donde se debe indicar: área, tema y entorno donde se centra el caso, audiencia a la que va dirigido, finalidad o propósito, indicando además ¿cuál es el problema? o ¿qué está en juego?, ¿qué problema está siendo ilustrado?, ¿cuáles son los temas subyacente?, ¿quién es la audiencia objetivo?, ¿cuáles son los objetivos específicos para estas audiencias?, ¿qué teorías o conceptos se van a enseñar a través del caso?. 
Una vez obtenida la respuesta a las preguntas anteriores, se estará en disposición de recopilar y preparar el material necesario. Esta fase debe incluir investigar y recopilar información suficiente, recolección de datos secundarios que puedan ayudar a la selección y clasificación de los datos principales, analizar y tratar esos datos para dar forma a la situación o problema, así como a la información necesaria para el caso.

\subsection{Redacción}

La primera parte de la redacción es el texto del caso para ello se debe escribir una primera versión, en la que se debe tener en cuenta el material que se entregará al alumno pudiendo ser más o menos extenso y adoptar diversas formas según las finalidades perseguidas y la modalidad adoptada: puede incluir el relato de una situación y documentación diversa (gráficos, actas, legislación u otras). La situación presentada tiene que ser real, o bien posible, lógica y admisible. De acuerdo a Reddy and Agraval, 2012; Generalitat, 2006; Gini, 1985; Farhoomand, 2004, la estructura del caso debe ser:1) un párrafo de apertura donde se indique la introducción al caso, pistas para casos secundarios, se pueden hacer antes del tema principal, durante el desarrollo de la acción o después de que se complete la acción.El párrafo de apertura puede introducir antecedentes, tiempo, localización, personas, organización, cuestiones importantes y materia, la extensión dependerá de la extensión total del caso se estudio. Debe responder a las preguntas qué, quien, por qué, cuándo y dónde (Farhoomand, 2004); 2) El cuerpo del caso donde se reflejan los datos relevantes del mismo, naturaleza y actuales tendencias en la industria y ámbito geográfico (local y global) que sean clave para el caso; 3) Conclusiones, explicar resumidamente el caso, por ejemplo incluir lo que sería, si no, por el contrario, en la próxima oportunidad, etc. por último,4) El "teaching notes" o cuaderno del profesor, debe incluir visión general del caso, objetivos de aprendizaje, discusión y tareas a asignar a los alumnos. Elaborar las preguntas es un aspecto clave, ¿qué está pasando?, ¿cuál es el problema?, ¿por qué se plantea? ¿intereses de protagonistas? ¿acciones a emprender?. Es decir, preparar preguntas que, por su formulación, obligan a los alumnos a una reflexión inteligente sobre los problemas que plantea el caso. Debe pensarse sobre la manera en que los estudiantes participarán en la discusión, debe incluir también Análisis del caso y Feedback. Otra información complementaria que incluiría el teaching notes es: los usos potenciales del caso, audiencia potencia, aproximación / plan de enseñanza sugerido, lecturas o referencias adicionales sugeridos, análisis, informática y soporte multi-media, en su caso.

Otra parte importante es la validación del caso. En ella, debe tenerse en cuenta 1) correspondencia entre los hechos planteados en el caso y los objetivos de aprendizaje promovidos, ¿qué teorías o conceptos se van a enseñar a través del caso?, 2) validación gramatical, revisión por pares, etc., 3) Es el caso lo suficientemente rico en términos de matices contextuales, 4) ¿Cómo reaccionan los estudiantes con el caso? ¿es lo suficientemente difícil? ¿interesante? 5) ¿Hay suficiente tensión dinámica en el caso de

\section{(cc) EY-NC-ND 2014, UniversitatPolitècnica de València}

I Jornadas IN-RED (2014) 
producir puntos de vista conflictivos y competencia?6) ¿Es el caso de estudio interesante y útil para la enseñanza? Esta validación debe llevarse a cabo tanto a lo largo del proceso de redacción como después de su aplicación en el aula y analizando los resultados obtenidos.

\section{Conclusiones}

La metodología de casos de estudio favorece la participación activa de los estudiantes en su aprendizaje y mejora su motivación sobre el tema. En ocasiones es difícil encontrar casos de estudio que se adapten a los objetivos de aprendizaje perseguidos y a los estudiantes con los que se desea aplicar esta metodología. En ese caso, es necesario un proceso de elaboración y o adaptación de los casos de estudio. La presente comunicación propone una metodología de definición de casos de estudio, indicando detalladamente qué se debe incluir en cada fase. La revisión de la literatura ha permitido identificar los principales aspectos a incluir y la definición de una metodología completa.

\section{Referencias}

Alemany MME., Cuenca L., Boza A., Ortiz A. 2003 “Education for learning”. International Conference on Engineering Education, Valencia.

Asopa, B. Y BEYE, G. (2001). Appendix 2: The case method. [Disponible en http://www.fao.org/docrep/W7500E/w7500e0b.htm] [Consulta fecha: Marzo 2013]

Boehrer, J. Y M. LINSKY (1990). “Teachingwith Cases: LearningtoQuestion”, en Svinicki, M.D. (ed.), TheChangingFace of CollegeTeaching. New DirectionsforTeaching and Learning, no. 42. San Francisco: Jossey-Bass.

Cappel J. Writing IS Teaching Cases: Guidelines for JISE Journal of Information Systems Education, Vol. 13(4)

Generalitat, 2006 Ficha metodológica coordinada por la Universidad Politécnica de Valencia. Mayo 2006. Versión 1

Gini A.R. The Case Method: A Perspective Journal of Business Ethics 4 (1985) 351-352.

Farhoomand A. Writing teaching cases: A quick reference guide. Communications of AIS, Volume 13 Article 9

Herrera M., 2009. Método del caso en b-learning. Tesis Doctoral. Universidad Politécnica de Cataluña

Morra L. Friedlander A. Evaluaciones mediante Estudios de Caso [www.worldbank.org/html/oed] [Consulta fecha: Marzo 2013] 
UPM, 2008 El Método del Caso. Servicio de Innovación Educativa de la Universidad Politécnica de Madrid. [Disponible en http://innovacioneducativa.upm.es/guias/MdCguia.pdf ] [Consulta fecha: Mayo 2013]

Felder, R.M., and Brent, R. (1994). CooperativeLearning in TechnicalCourses: Procedures Mayring P. Einfü hrung in die qualitative Sozialforschung - eine Anleitung zum qualitativen Denken. [Introduction to qualitative social research]. Weinheim, Germany: Beltz Verlag; 2002.

Pitfalls, and Payoffs. ERIC DocumentReproductionService, ED377038. http://www.ncsu.edu/felder-public/Papers/Coopreport.html

Reddy K. and Agrawal R. Designing Case Studies from Secondary Sources - A Conceptual Framework International Management Review Vol. 8 No. 2201263

Seuring S., Müller M. From a literature review to a conceptual framework for sustainable supply chain management Journal of Cleaner Production 16 (2008) 1699-1710 


\title{
Metodologías activas en la asignatura "Ejercicio Libre de la Profesión de Ingeniero de Telecomunicación"
}

\section{M.C. Part-Escriva}

Departamento de Comunicaciones - Universitat Politècnica de València - xpart@dcom.upv.es

\begin{abstract}
The main purpose of this educational experience is the introduction of active methodologies to acquire transversal or generic competences in the framework of the subject "Professional Practice of Telecommunications Engineering", a subject of Bachelor's Degree in Telecommunications Systems, Sound and Image Engineering. In this way, the classic model for students' training in the area of telecommunication engineering projects will be enhanced with:
\end{abstract}

- Ability to express themselves properly in public

- Ability to communicate in writing skills

- Ability to establish interpersonal communication skills and to participate in working groups

- Ability to review projects and to evaluate them

- Ability to plan a project

- Motivation to engage professional projects: entrepreneurship

The subject "Professional Practice of Telecommunications Engineering" $4^{\text {th }}$ year), focuses on basis of professional projects of Telecommunications Engineering.

You can opt for a classic education with a passive student and a teacher who explains the main types of technical projects to be developed, and classic evaluation to get students marks, or for active methodologies to achieve generic competences in future engineers and peer and self-assessment methods for evaluation. This is the experience that we will describe.

Keywords: 
Metodologías activas en la asignatura "Ejercicio Libre de la Profesión de Ingeniero de Telecomunicación

Active methodologies, peer-assessment, self-assessment, generic or transversal competences, motivation, projects.

\section{Resumen}

El objetivo principal de esta experiencia docente es la introducción de metodologías activas para la adquisición de una serie de competencias transversales o genéricas en el marco de la asignatura "Ejercicio libre de la profesión de Ingeniero de Telecomunicación” del Grado en Ingeniería de Sistemas de Telecomunicación, Sonido e Imagen, enriqueciendo la clásica formación técnica del alumno en el área de los proyectos de ingeniería de telecomunicación con:

- Capacidad de expresarse correctamente en público

- Capacidad de comunicar los conocimientos por escrito

- Capacidad de establecer una buena comunicación interpersonal y de trabajar en grupo

- Capacidad crítica en la evaluación de proyectos

- Capacidad de planificar un proyecto

- Motivación para dedicarse al libre ejercicio de la profesión: emprendedurismo

La asignatura, de $4^{\circ}$ curso del Grado en Ingeniería de Sistemas de Telecomunicación, Sonido e Imagen, se enfoca a que el alumno adquiera los conocimientos básicos para el Ejercicio Libre de la Profesión de Ingeniero de Telecomunicación.

Se puede optar por una enseñanza clásica en la que el profesor explique cómo se elaboran los principales tipos de proyectos técnicos, y finalmente se evalúe al alumno, o aplicar metodologías activas para desarrollar, además, competencias transversales en el futuro ingeniero. Esta es la experiencia que vamos a describir.

\section{Palabras clave:}

Metodologías activas, evaluación entre pares, autoevaluación, competencias genéricas o transversales, motivación, proyectos. 


\section{Introducción}

En los últimos años, en el ámbito universitario, a partir del proceso de Bolonia que supone la adaptación al Espacio Europeo de Educación Superior, hemos asistido a la transición desde un modelo educativo centrado en la enseñanza hacia un nuevo modelo centrado en el aprendizaje.

Este enfoque supone una renovación metodológica, el nuevo modelo debe enseñar al alumno a aprender (concepto anglosajón "competences for lifelong learning"). La utilización de las metodologías activas implica el cambio de un aprendizaje receptivo, con un alumno pasivo que fundamentalmente asiste a clases magistrales, memoriza contenidos y estudia para aprobar, a un aprendizaje constructivo (la psicología constructivista se basa en que para que se produzca aprendizaje, el conocimiento debe ser construido o reconstruido por el propio sujeto que aprende a través de la acción) en el que el profesor tutoriza al estudiante que asume de forma activa su aprendizaje.

$\mathrm{Si}$ atendemos a estudios que demuestran el escaso porcentaje de retención mediante el uso de métodos de enseñanza tradicional, como se aprecia en la figura 1, el profesor universitario no debe concentrar sus esfuerzos únicamente en impartir clases magistrales sino en asignar al alumno un papel activo, que, por otra parte, le formará en capacidades para que él pueda desempeñar de forma autónoma lo que se proponga en su futuro profesional.

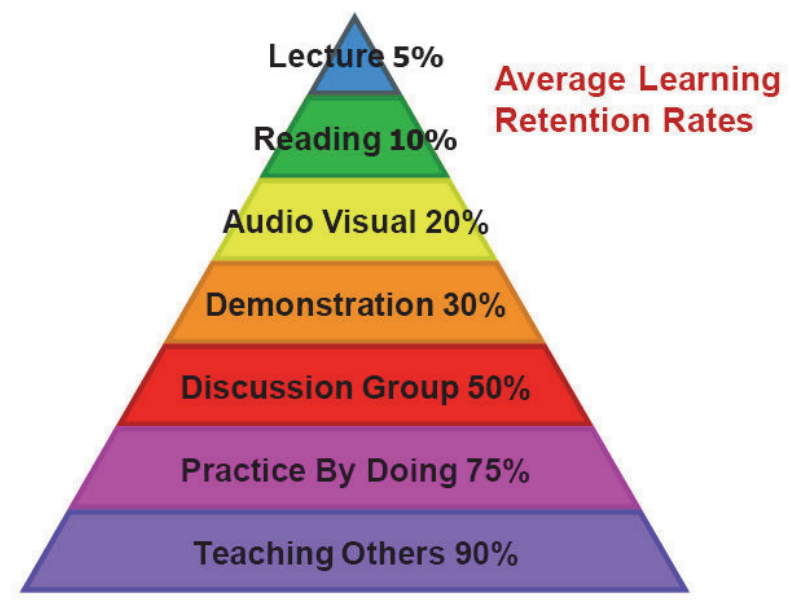

Source: National Training Laboratories, Bethel, Maine

Fig. 1 Porcentajes de retención para distintos modelos de enseñanza 
Metodologías activas en la asignatura "Ejercicio Libre de la Profesión de Ingeniero de Telecomunicación

En este contexto, abordé la asignatura de $4^{\circ}$ curso del Grado en Ingeniería de Sistemas de Telecomunicación, Sonido e Imagen, que se ha impartido por primera vez en el presente curso 2013-14, "Ejercicio Libre de la Profesión de Ingeniero de Telecomunicación".

La asignatura reúne una serie de características que animan a experimentar nuevas metodologías docentes: es una asignatura de $4^{\circ}$ curso, de contenido muy aplicado, en un contexto en continuo cambio, puesto que cada tipo de proyecto técnico se ciñe a una legislación, normativa y desarrollo que cambia con nueva reglamentación y con la aparición de nuevas tecnologías.

\section{Objetivos}

El objetivo principal de esta experiencia docente es la introducción de metodologías activas para la adquisición de una serie de competencias transversales o genéricas en el marco de la asignatura "Ejercicio libre de la profesión de Ingeniero de Telecomunicación" del Grado en Ingeniería de Sistemas de Telecomunicación, Sonido e Imagen, enriqueciendo la clásica formación técnica del alumno en el área de los proyectos de ingeniería de telecomunicación con:

- Capacidad de expresarse correctamente en público

- Capacidad de comunicar los conocimientos por escrito

- Capacidad de establecer una buena comunicación interpersonal y de trabajar en grupo

- Capacidad crítica en la evaluación de proyectos

- Capacidad de planificar un proyecto

- Motivación para dedicarse al libre ejercicio de la profesión: emprendedurismo

Para cumplir el objetivo deseado, en primer lugar, debemos plantearnos cómo asumirá el estudiante el papel activo que le permitirá alcanzar con éxito la meta, que no es únicamente aprobar la asignatura, sino que, en el transcurso de la misma, ha debido adquirir las competencias transversales citadas.

Es importante, desde el primer momento, explicar al alumno qué se espera de él y ser coherente en la evaluación elegida: no sirve de nada afirmar la importancia de que el alumno sea capaz de trabajar en grupo, documentarse, evaluar y corregir los trabajos, y finalmente presentar un proyecto técnico del área de telecomunicaciones, si, al terminar el semestre, el trabajo le puntúa, por ejemplo, un $10 \%$ de la nota global. Si queremos que dedique toda su energía a una actividad porque la consideramos muy relevante y enriquecedora, la evaluación ha de ser coherente.

De igual manera, el profesor debe preparar estrategias para los distintos tipos de alumnos, cada persona trabaja de forma distinta, existen alumnos brillantes y participativos, brillantes pero individualistas, otros quizá no tan brillantes pero activos, motivados, líderes, etc. 


\section{Desarrollo de la innovación}

De modo sintético, se trata de dar el paso de un modelo centrado en la clase magistral a un modelo en el que se empleen metodologías activas de forma que se asegure una mayor retención de conocimientos en el alumno que "aprende haciendo". No es un salto al vacío, a lo largo de los años, el profesor universitario ya ha experimentado metodologías novedosas de seminarios, trabajo de laboratorio, experiencias de campo, trabajo cooperativo, estudio de casos, etc.

No existe una metodología buena o mala, no es necesario renunciar a la clase magistral ni desdeñar el rol del profesor como fuente de información.

Las metodologías activas que se introduzcan deben aplicarse atendiendo a los objetivos que se persiguen. En este caso, según se ha expuesto anteriormente, el objetivo principal de esta experiencia la adquisición de una serie de competencias transversales o genéricas en el marco de la asignatura "Ejercicio libre de la profesión de Ingeniero de Telecomunicación".

La correcta planificación de las actividades sustentará el éxito de la experiencia. En el caso que se expone, la planificación establecida fue:

Durante la primera clase, el profesor expone el enfoque de la asignatura. Queda claro desde el primer minuto que los alumnos van a trabajar en grupo y de forma bastante autónoma (el grado de autonomía dependerá básicamente de su implicación y de lo que observe el profesor) y que su nota dependerá del proyecto técnico que presenten, pero que serán evaluados de forma continua y no sólo por el contenido técnico de su trabajo.

Puesto que la asignatura es de $4^{\circ}$ curso, semestre $\mathrm{B}$, los estudiantes se conocen y ya tienen sus preferencias a la hora de formar grupo. Se les puede permitir formar grupo según decidan los propios estudiantes o intervenir para corregir si se detecta algún problema. La primera entrega que realizan el primer día de clase es una hoja con los nombres de los alumnos que forman el grupo y sus datos (correo, móvil, etc.) y una parrilla horaria con las horas semanales en que van a trabajar en grupo y dónde se van a reunir. Todos los miembros del grupo deben firmar este documento que les supone un contrato con la asignatura y con los compañeros.

A continuación, se dedica la segunda clase a explicar qué es el Ejercicio Libre de la profesión, agentes del sector y su papel, se describen los distintos tipos de proyectos técnicos enmarcados en el ejercicio libre y se da una visión general de este tipo de trabajos profesionales. Al finalizar esta clase, los alumnos ya deben abordar su primera tarea de forma autónoma: a partir del abanico de trabajos profesionales que se les ha expuesto, han de elegir el proyecto técnico que quieren realizar. Para que este paso resulte lo más provechoso posible, la estrategia que impuse, pero que puede revisarse en distintos contextos, es: cada grupo contempla un mínimo de tres tipos de proyectos y se documenta

\section{(cc) EY-NC-ND 2014, Universitat Politècnica de València}

I Jornadas IN-RED (2014) 
Metodologías activas en la asignatura "Ejercicio Libre de la Profesión de Ingeniero de Telecomunicación

sobre ellos. En la siguiente clase, deben exponer en 10' los pros y contras de cada proyecto, qué les ha gustado y les ha conducido a una elección razonada del proyecto.

Un peldaño más en la carrera hacia el éxito del aprendizaje se introduce aquí con una reunión virtual: es obligatorio que, antes de presentar el trabajo, el grupo mantenga una tutoría virtual a través de la herramienta Polireunión basada en Adobe Connect. En realidad, la tutoría puede no ser necesaria en este momento, pero es la herramienta que se les muestra para que hagan uso de ella a lo largo del semestre.

En mi opinión, esta tarea inicial ya despierta su sentido crítico y de síntesis, en Internet pueden encontrar cientos de páginas con información sobre proyectos técnicos de telecomunicación, pero deben resaltar lo más relevante y seleccionar las fuentes fiables. Por otra parte, es una primera decisión estratégica del grupo: no siempre todos los componentes se inclinan por el mismo proyecto. De cualquier manera, aún sería posible reasignar los grupos. Por último, el que sean conscientes de que han firmado un contrato con unas horas de dedicación al proyecto, horas en las que todos los componentes del grupo han de asistir y trabajar y, en su caso, reunirse de forma física o virtual con el profesor, asegura la implicación del estudiante.

Llegados a este punto, tenemos los grupos formados, unas horas de trabajo semanales acordadas, un lugar de reunión establecido y un proyecto elegido.

El profesor debe revisar la documentación sobre la que empezará el grupo a trabajar y dar las indicaciones oportunas. Es muy importante la retroalimentación a lo largo del proceso, se establecen puntos de control y se requiere la evaluación de los alumnos sobre su propio trabajo y el de los compañeros, con herramientas sencillas como la tabla de la figura 2.

Las clases que se suceden a lo largo del semestre enfocan el proceso de aprendizajeenseñanza como trabajo cooperativo entre alumnos del grupo y entre el profesor y los alumnos. Los métodos adecuados, en esta asignatura en particular, abarcan la lección magistral participativa, el trabajo cooperativo y el aprendizaje orientado a proyectos.

El trabajo cooperativo se define como "Estrategias de enseñanza en las que los estudiantes trabajan divididos en pequeños grupos en actividades de aprendizaje y son evaluados según la productividad del grupo".

El aprendizaje orientado a proyectos se define como "Estrategia en la que el producto del proceso de aprendizaje es un proyecto o programa de intervención profesional, en torno al cual se articulan todas las actividades formativas".

Según lo anterior, y aunque no podría asegurar que aplique los métodos anteriores en su definición más estricta o purista, los alumnos trabajan en grupos y van abordando, guiados por el profesor, todos los conocimientos necesarios para realizar un proyecto técnico de 
telecomunicaciones. Por ejemplo, si eligen un proyecto en el ámbito de la radiodifusión y van a realizar un proyecto técnico de "emisora en ondas métricas con modulación de frecuencia”, las actividades de aprendizaje que realizarán y que se les irán evaluando serían, por ejemplo, estudio del terreno y ubicación de la emisora, cálculo de cobertura, estudio de emisiones radioeléctricas, etc. Todas estas actividades son necesarias y se incluyen en el proyecto real.

El aprendizaje basado en proyectos recogería que el grupo, siguiendo con el ejemplo anterior, fijadas todas las actividades pertinentes, acometería su proyecto con la libertad de escoger, por ejemplo, catálogos de fabricantes, validación de los trámites administrativos, etc. de forma, que, finalmente, lo que obtienen es un proyecto real de "emisora en ondas métricas con modulación de frecuencia".

Rellena una columna para cada componente del grupo con la siguiente escala:

0: nunca, 1: a veces, 2: casi siempre, 3 : siempre

\begin{tabular}{|l|l|l|l|}
\hline & Nombre1 & Nombre & Nombre3 \\
\hline Acude puntualmente a las reuniones & & & \\
\hline Muestra respeto por los demás & & & \\
\hline Participa en el trabajo del grupo & & & \\
\hline $\begin{array}{l}\text { Escucha a los demás y comenta de forma } \\
\text { constructiva }\end{array}$ & & & \\
\hline $\begin{array}{l}\text { Es correcto en la expresión escrita de sus } \\
\text { trabajos }\end{array}$ & & & \\
\hline Aporta información relevante & & & \\
\hline Ayuda al correcto desempeño de las tareas & & & \\
\hline Evita actitudes dominantes & & & \\
\hline Se compromete con sus tareas & & & \\
\hline Ayuda en la resolución de conflictos & & & \\
\hline
\end{tabular}

Fig.2 Ejemplo de rúbrica para evaluación de los compañeros de grupo 
Metodologías activas en la asignatura "Ejercicio Libre de la Profesión de Ingeniero de Telecomunicación

\section{Resultados}

En cada paso expuesto, además de trabajar e interactuar de forma responsable en el grupo, los estudiantes han sido capaces de autoevaluarse y evaluar a sus compañeros de grupo, pues así se establece en los puntos de control, y en casos particulares, como proyectos que compartan alguna actividad (por ejemplo, cálculo de coberturas en proyectos distintos de radiodifusión) evalúan al resto de compañeros. Han planificado su tiempo y han llegado al proyecto final que se les exige desarrollando su capacidad de expresión escrita (lógicamente, puesto que es un proyecto escrito el resultado) y de expresión oral (porque realizan 3 exposiciones a lo largo del semestre). Con ello, en mi opinión, han adquirido las competencias transversales que planteé al inicio, y, desde el punto de vista de la adquisición de conocimiento, el aprendizaje "haciendo" el proyecto se muestra más eficiente, de forma que, a lo largo de los años, los ingenieros que hemos graduado recordarán este tipo de proyectos y podrán abordarlos con éxito. Como guinda, probablemente algunos alumnos sientan el gusanillo del emprendedurismo y se animen a desarrollar el ejercicio libre de la profesión en su carrera laboral.

\section{Conclusiones}

Quizá resulte aventurado extraer conclusiones de una experiencia docente que está en sus albores y se antoja necesario realizar un seguimiento más extenso. En este primer año, el $100 \%$ de los alumnos han asistido a clase, a las reuniones y han aprobado con buena nota, por lo que el resultado no podría ser más alentador.

Compartiendo la experiencia con otros compañeros docentes, ciertos estudiantes se muestran reacios a este tipo de metodologías, quizá porque les supone una mayor carga de trabajo, o, al menos, una obligación de asistencia a reuniones y a clases. En el caso particular de la asignatura que comento, los estudiantes se han mostrado muy participativos, se trata de un grupo de $4^{\circ}$ con pocos alumnos y los contenidos de la asignatura son muy prácticos, lo que da mucha facilidad para la adopción de la metodología descrita.

Es muy importante la labor del profesor, debe preparar un material básico de calidad y ha de tutorizar constantemente el trabajo de cada grupo, al menos hasta que el proyecto se encuentre bien encaminado. Quizá los docentes de carreras técnicas necesitamos, por otra parte, cierta formación en resolución de conflictos que puedan surgir en el grupo y herramientas para reconducir situaciones no deseadas.

De cualquier manera y como conclusión final, es una experiencia que vale la pena en todos los aspectos: los estudiantes aprenden los conocimientos específicos de la asignatura de forma más eficiente y duradera, adquieren competencias transversales imprescindibles en su carrera profesional y la labor del profesor, aceptando una mayor carga de trabajo, resulta más satisfactoria. 


\section{Referencias}

FERNÁNDEZ MARCH, A. (2006). "Metodologías activas para la formación de competencias" en Educatio Siglo XXI, vol. 24, pp.35-56.

UNIVERSIDAD DE DEUSTO. Tuning Educational Structures in Europe (2003).

< http://www.deusto-publicaciones.es/deusto/index.php/es/tuning-es/tuning-educational-es>

AREVALILLO-HERRÁEZ, M. (2010). “Utilización de una herramienta online para la realización de tutorías remotas: una experiencia práctica” en @ TIC, Revista de Innovación Educativa 5: 65-70.

GARCÍA-ALMIÑANA, D. y AMANTE GARCÍA, B. (2006). Algunas experiencias de aplicación del aprendizaje cooperativo y del aprendizaje basado en proyectos. UPCommons.upc.edu <http://upcommons.upc.edu/e-prints/bitstream/2117/9489/1/06UPC\%20complert\%20zamora\%20AC-

PBL\%20REV060531.pdf > 


\title{
Diseño y evaluación de una actividad de aprendizaje basado en proyectos en el contexto de la Higiene analítica
}

\section{Pilar Aragón Revuelta ${ }^{a}$}

Universitat Politècnica de Valencia. Departamento de Química. Cno.de Vera s/n, 46022- Valencia. paragon@qim.upv.es.

\begin{abstract}
Posgraduate studies require one or more team projects that achieve, in addition to the acquisition of specific skills that some general skills (currently skill dimensions). In this work, we evaluated the acquisition of certain skills described in the qualification. To achieve this goal, we have designed and evaluated a teamwork activity, supported in PoliformaT, applied to the subject of Analytical Hygiene of Master's Degree in Occupational Risk Prevention. The platform allows to follow up the different stages of activity at individual and group levels in order to evaluate later. Teamwork has enabled most students the acquisition of the skill dimensions worked, especially teamwork and leadership and critical thinking and specific competencies of the subject. A rubric allows a better evaluating of new dimensions of competence and, it can be concluded that $90 \%$ of students perceive it, as very suitable platform for assessing the activity, and they also promote autonomous work, aid learning and it is also interactive.
\end{abstract}

Keywords: competencial dimensions, teamwork, evaluation, rubric, PoliformaT platform.

\section{Resumen}

Las titulaciones de posgrado demandan uno o varios proyectos en equipo que logren trabajar, además de la adquisición de competencias específicas, algunas competencias generales (actualmente dimensiones competenciales). En este trabajo, se ha evaluado la adquisición de algunas competencias descritas en la titulación. Para alcanzar este objetivo, se ha diseñado y evaluado una actividad de trabajo en equipo, soportada en PoliformaT, aplicada a la asignatura de Higiene Analítica del máster de Prevención de Riesgos Laborales. La plataforma permite seguir la ejecución, en tiempo y forma, de las distintas etapas de la actividad a nivel individual y de grupo

(cc) EY-NC-ND 2014, Universitat Politècnica de València

I Jornadas In-Red (2014) 
Diseño y evaluación de una actividad de aprendizaje basado en proyectos en el contexto de la Higiene analítica

con el fin de evaluarla posteriormente. El trabajo ha permitido a la mayoría de los alumnos adquirir las dimensiones competenciales trabajadas, sobre todo "trabajo en equipo y liderazgo" y "pensamiento crítico" así como las competencias específicas propias de la asignatura. La rúbrica diseñada permite evaluar mejor las nuevas dimensiones competenciales y, en general, se puede concluir que un $\mathbf{9 0 \%}$ de alumnos perciben la Plataforma como "muy adecuada" o "bastante adecuada" para realizar la actividad, valorando que fomenta el trabajo autónomo, ayuda a aprender y es interactiva.

Palabras clave: dimensiones competenciales, trabajo en equipo, evaluación, rúbrica, plataforma PoliformaT.

\section{Introducción}

Las titulaciones de posgrado suelen demandar uno o varios proyectos en equipo que exijan la aplicación de conocimientos multidisciplinares. Con ello se persigue la adquisición de competencias generales además de las específicas. Sin embargo, frecuentemente tanto alumno como profesor se centran en la tarea técnica que se demanda (el primero en la ejecución y el segundo en su evaluación) y relegan la adquisición de competencias generales. A este problema se suma que, actualmente, en la mayoría de las titulaciones nos encontramos con extensos listados de competencias definidas, con enfoques diferentes según la fuente de procedencia (UPV, 2014). Además, no se han sistematizado mecanismos de evaluación que garanticen su adquisición y, en ocasiones, el alumno no conoce con detalle cómo va a ser evaluado ni el profesor evalua todos los aspectos más allá de la ejecución del producto final. Esto se traduce en una desmotivación hacia los trabajos y proyectos, que se perciben como un lastre a su formación más que como una oportunidad para contextualizar los conocimientos adquiridos, enfrentándose a problemas reales similares a los que se encontrarán en la práctica profesional. En concreto, para los técnicos prevencionistas es muy importante aunar el conocimiento adquirido en las distintas materias a la hora de elaborar un informe de prevención de riesgos laborales.

Para adquirir las competencias generales, además de las específicas, es necesario plantear el acceso a referentes que faciliten evaluación a los equipos de profesores (Viles et al, 2013). Dichos referente han sido definidos en 13 dimensiones competenciales, recogidas en el Documento de Dimensiones Competenciales de la Universitat Politècnica de Valencia (UPV, 2014) que pretenden sintetizar el perfil competencial que adquieren todos sus alumnos, garantizando además el marco de referencia de algunas titulaciones con regulaciones o recomendaciones específicas. 


\section{Objetivos}

En este trabajo, se ha querido evaluar la adquisición de algunas competencias descritas en la titulación así como otras que aparecen en la nueva relación de dimensiones competenciales (DC) propuestas por la UPV y que no figuraban en esta titulación, como es el caso de la DC 6: (trabajo en equipo y liderazgo). Para alcanzar este objetivo, se ha diseñado y evaluado una actividad de trabajo en equipo, soportada en PoliformaT (PFT), aplicada a la asignatura de Higiene Analítica del máster de Prevención de Riesgos Laborales. La plataforma permite seguir la ejecución, en tiempo y forma, de las distintas etapas de la actividad a nivel individual y de grupo con el fin de evaluarla posteriormente.

\section{Desarrollo de la innovación}

La actividad se ha planteado como trabajo en equipo formado libremente con un número de miembros entre 3 y 5 y con un jefe de equipo, designado por lo miembros, que servirá como interlocutor, facilitando que el ambiente sea más agradable (Craig, 2008). Para evitar que se acumule la tarea a final de curso, se ha definido un calendario de entrega de documentos que los alumnos pueden consultar en el apartado de Recursos del PFT. Abarca desde el día 1 de la presentación de la actividad, hasta la fecha final del documento escrito 11 semanas después (día 78), con entregas a nivel individual y colectivo. En él se definen las distintas etapas y fases del proyecto así como las puestas en común llevadas a cabo como actividad presencial en el aula, consiguiendo que los alumnos estén implicados en el supuesto a lo largo de todo el cuatrimestre. Esta entrega deberá realizarse a través del espacio compartido de PFT. El seguimiento de la actividad mostrará si todos los miembros del equipo han colaborado y se han responsabilizado de las tareas que ellos mismos se habían asignado. El trabajo consta de tres etapas con dos fases cada una. En una primera fase, soportada en red, el profesor entrega unos documentos iniciales con el planteamiento del problema y en una segunda fase la plataforma se utiliza para el envío de documentos elaborados por los alumnos, así como para obtener feed-back entre iguales y con el profesor.

Se ha considerado que es importante transmitir la utilidad de la actividad para conseguir una mayor implicación y entusiasmo. Para ello, como punto de partida se ha estudiado la percepción, por parte de los alumnos, sobre la adquisición de las dimensiones competenciales trabajadas y de las competencias específicas, utilizando el cuestionario que se muestra en la figura 1. Se ha utilizado el modelo de respuesta graduada de la escala Likert utilizado en la Universitat Politècnica de Valencia para las encuestas de opinión del alumnado (UPV, 2007). El tamaño de la muestra es de 21 alumnos encuestados y la población total de alumnos implicados en la actividad es de 25 . En la misma figura se recoge el cuestionario con los ítems 11-14 relativos al sistema de evaluación que se discutirán más adelante.

\section{(c)) EY-NC-ND 2014, Universitat Politècnica de València}

I Jornadas IN-RED (2014) 
Diseño y evaluación de una actividad de aprendizaje basado en proyectos en el contexto de la Higiene analítica

\begin{tabular}{|c|c|c|c|c|c|c|c|c|}
\hline \multicolumn{9}{|c|}{$\begin{array}{l}\text { PERCEPCION DEL GRADO DE ADQUISICIÓN DE LAS COMPETENCIAS } \\
\text { Realiza una marca en forma de aspa en la casilla que elijas según la siguiente escala de } \\
\text { valoración: }\end{array}$} \\
\hline $\begin{array}{c}1 \\
\text { Totalmente en } \\
\text { desacuerdo }\end{array}$ & $\begin{array}{c}2 \\
\text { Más bien en } \\
\text { desacuerdo }\end{array}$ & $\begin{array}{l}\text { 3. Término } \\
\text { medio }\end{array}$ & $\begin{array}{c}4 \\
\text { Más bien de } \\
\text { acuerdo }\end{array}$ & \multicolumn{5}{|c|}{$\begin{array}{c}5 \\
\begin{array}{c}\text { Totalmente de } \\
\text { acuerdo }\end{array} \\
\end{array}$} \\
\hline \multicolumn{4}{|c|}{$\begin{array}{l}\text { 1. La actividad me ha permitido aplicar los conocimientos adquiridos en } \\
\text { la asignatura }\end{array}$} & \begin{tabular}{|l|}
1 \\
\end{tabular} & 2 & \begin{tabular}{|l|}
3 \\
\end{tabular} & 4 & 5 \\
\hline \multicolumn{4}{|c|}{$\begin{array}{l}\text { 2. La actividad ha fomentado mi capacidad de resolución de problemas } \\
\text { en entornos nuevos o multidisciplinares relacionados con la prevención } \\
\text { de riesgos laborales }\end{array}$} & \begin{tabular}{|l|}
1 \\
\end{tabular} & \begin{tabular}{|l}
2 \\
\end{tabular} & \begin{tabular}{|l|}
3 \\
\end{tabular} & 4 & 5 \\
\hline \multicolumn{4}{|c|}{$\begin{array}{l}\text { 3. La ejecución de este proyecto me ha permitido integrar } \\
\text { conocimientos adquiridos en otras asignaturas }\end{array}$} & \begin{tabular}{|l|}
1 \\
\end{tabular} & 2 & \begin{tabular}{|l|}
3 \\
\end{tabular} & \begin{tabular}{|l|}
4 \\
\end{tabular} & 5 \\
\hline \multicolumn{4}{|c|}{$\begin{array}{l}\text { 4. La información reunida me ha ayudado a formular juicios en relación } \\
\text { a la evaluación de la exposición a agentes químicos en el entorno } \\
\text { laboral }\end{array}$} & \begin{tabular}{|l|}
1 \\
\end{tabular} & 2 & \begin{tabular}{|l|}
3 \\
\end{tabular} & \begin{tabular}{|l|}
4 \\
\end{tabular} & 5 \\
\hline \multicolumn{4}{|c|}{$\begin{array}{l}\text { 5. El desarrollo de esta actividad me ha ayudado a reflexionar sobre } \\
\text { las responsabilidades sociales y éticas que se derivan de la aplicación } \\
\text { de estos juicios emitidos. }\end{array}$} & \begin{tabular}{|l|}
1 \\
\end{tabular} & 2 & \begin{tabular}{|l|}
3 \\
\end{tabular} & & 5 \\
\hline \multicolumn{4}{|c|}{$\begin{array}{l}\text { 6. La actividad me ha permitido mejorar mi habilidad para comunicar } \\
\text { las conclusiones obtenidas a públicos especializados y no } \\
\text { especializados de un modo claro y sin ambigüedades. }\end{array}$} & \begin{tabular}{|l|}
1 \\
\end{tabular} & 2 & \begin{tabular}{|l|}
3 \\
\end{tabular} & 4 & 5 \\
\hline \multicolumn{4}{|c|}{$\begin{array}{l}\text { 7. El desarrollo de la actividad me ha motivado a utilizar la legislación y } \\
\text { normativa específica en materia de higiene industrial. }\end{array}$} & \begin{tabular}{|l|}
1 \\
\end{tabular} & \begin{tabular}{|l|}
2 \\
\end{tabular} & \begin{tabular}{|l|}
3 \\
\end{tabular} & 4 & 5 \\
\hline \multicolumn{4}{|c|}{$\begin{array}{l}\text { 8. Esta actividad me ha ayudado a identificar las caracteristicas y los } \\
\text { efectos de los agentes químicos }\end{array}$} & \begin{tabular}{|l|}
1 \\
\end{tabular} & \begin{tabular}{|l|}
2 \\
\end{tabular} & \begin{tabular}{|l|}
3 \\
\end{tabular} & 4 & 5 \\
\hline \multicolumn{4}{|c|}{$\begin{array}{l}\text { 9. La ejecución de este trabajo me ha permitido adquierir los } \\
\text { conocimientos técnicos suficientes para realizar evaluaciones de } \\
\text { riesgos y plantear medidas correctoras ante riesgos de naturaleza } \\
\text { química. }\end{array}$} & \begin{tabular}{|l|}
1 \\
\end{tabular} & 2 & \begin{tabular}{|l|}
3 \\
\end{tabular} & 4 & 5 \\
\hline \multicolumn{4}{|c|}{$\begin{array}{l}\text { 10. La actividad me ha permitido aplicar los fundamentos y el manejo } \\
\text { de las principales técnicas de análisis químico en el campo de la } \\
\text { higiene. }\end{array}$} & \begin{tabular}{|l|}
1 \\
\end{tabular} & \begin{tabular}{|l|} 
\\
\end{tabular} & \begin{tabular}{|l|}
3 \\
\end{tabular} & 4 & 5 \\
\hline \multicolumn{9}{|c|}{ SATISFACCIÓN DEL SISTEMA DE EVALUACIÓN DE LA ACTIVIDAD } \\
\hline \multicolumn{4}{|c|}{$\begin{array}{l}\text { 11. Las categorias y subcategorias recogidas en la tabla valoran } \\
\text { adecuadamente las competencias generales que se deseaba adquirir }\end{array}$} & \begin{tabular}{|l|}
1 \\
\end{tabular} & 2 & \begin{tabular}{|l|}
3 \\
\end{tabular} & 4 & 5 \\
\hline \multicolumn{4}{|c|}{$\begin{array}{l}\text { 12. Las categorias reflejadas valoran adecuadamente las categorias } \\
\text { especificas que se deseaba adquirir }\end{array}$} & \begin{tabular}{|l|}
1 \\
\end{tabular} & \begin{tabular}{|l|}
2 \\
\end{tabular} & \begin{tabular}{|l|}
3 \\
\end{tabular} & 4 & 5 \\
\hline \multicolumn{4}{|c|}{$\begin{array}{l}\text { 13. Los porcentajes asignados a cada categoría y subcategoría me } \\
\text { parecen adecuados }\end{array}$} & & \begin{tabular}{|l|}
2 \\
\end{tabular} & \begin{tabular}{|l|}
3 \\
\end{tabular} & & 5 \\
\hline \multicolumn{4}{|c|}{$\begin{array}{l}\text { 14. Las puntuaciones asignadas a cada nivel (excelente, buen trabajo, } \\
\text { etc...) me parecen adecuados }\end{array}$} & & \begin{tabular}{|l|}
2 \\
\end{tabular} & \begin{tabular}{|l|}
3 \\
\end{tabular} & 4 & 5 \\
\hline
\end{tabular}

Fig. 1 Cuestionario utilizado para estudiar la percepción por parte de los alumnos sobre la adquisición de las competencias generales y específicas y el sistema de evaluación.

Debido a que la equivalencia entre la anterior definición de competencias y la nueva, de dimensiones competenciales, no es unívoca, se ha recogido la equivalencia entre ambas en 
la tabla 1. Las dimensiones competenciales DC6 y DC9 no figuran en las competencias actuales de la titulación. La DC6 figura en la mayoría de las titulaciones por lo que se ha incluido en este estudio.

Tabla 1. Dimensiones competenciales y Competencias específicas seleccionadas

\begin{tabular}{lccc}
\hline Dimensiones competenciales/Competencias específicas & Código & $\begin{array}{c}\text { Titulacion } \\
\text { actual. }\end{array}$ \\
\hline $\begin{array}{l}\text { Aplicación pensamiento práctico: Aplicar los conocimientos a la práctica, } \\
\text { atendiendo a la información disponible, y estableciendo el proceso a seguir }\end{array}$ & & $\mathrm{G} 2$ \\
para alcanzar los objetivos con eficacia y eficiencia & & \\
$\begin{array}{l}\text { Análisis y resolución de problemas: Analizar y resolver problemas de } \\
\text { forma efectiva, identificando y definiendo los elementos significativos que } \\
\text { lo constituyen. }\end{array}$ & DC3 & G2 \\
$\begin{array}{l}\text { Trabajo en equipo y liderazgo: Trabajar y liderar equipos de forma } \\
\text { efectiva para la consecución de objetivos comunes, contribuyendo al } \\
\text { desarrollo personal y profesional de los mismos. }\end{array}$ & \\
$\begin{array}{l}\text { Responsabilidad ética y profesional: Actuar con responsabilidad ética y } \\
\text { profesional ante uno mismo y los demás. }\end{array}$ & DC7 & G3 \\
$\begin{array}{l}\text { Comunicación efectiva: Comunicarse de manera efectiva, tanto de forma } \\
\text { oral como escrita, utilizando adecuadamente los recursos necesarios y } \\
\text { adaptándose a las características de la situación y la audiencia. }\end{array}$ & DC8 & G4 \\
$\begin{array}{l}\text { Pensamiento crítico: Desarrollar un pensamiento crítico interesándose por } \\
\text { los fundamentos en los que se asientan las ideas, acciones y juicios, tanto } \\
\text { propios como ajenos. }\end{array}$ & DC9 & \\
\hline $\begin{array}{l}\text { Utilizar la legislación y normativa específica en materia de higiene } \\
\text { industrial. Identificar las características y los efectos de los agentes } \\
\text { químicos, físicos y biológicos. Adquirir los conocimientos técnicos } \\
\text { suficientes para realizar evaluaciones de riesgos y plantear medidas } \\
\text { correctoras ante riesgos de naturaleza química, física o biológica. }\end{array}$ & & \\
$\begin{array}{l}\text { Aplicar los fundamentos y el manejo de las principales técnicas de análisis } \\
\text { químico en el campo de la higiene. }\end{array}$ & & E18 & \\
\hline
\end{tabular}

Una vez definidas las competencias, se deben implementar los procesos sistemáticos para la evaluación de la medida en que se alcanzan dichas competencias. Es decir deben evaluarse los resultados de aprendizaje que previamente se han definido en las competencias.

Para estudiar la relación entre las competencias seleccionadas y su evaluación, se ha diseñado una rúbrica que contempla tanto la adquisición de competencias generales como específicas basada en las categorías y puntuaciones recogidas en la bibliografía (Rubistar, 2011) pero adaptada al entorno. En la figura 2 se muestra dicha rúbrica junto con los porcentajes de calificación de cada ítem y la puntuación asignada a cada uno en función del

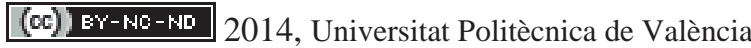

I Jornadas IN-RED (2014) 
Diseño y evaluación de una actividad de aprendizaje basado en proyectos en el contexto de la Higiene analítica

grado de consecución de dicha competencia. En ella se presentan los distintos aspectos a valorar en la ejecución y entrega del supuesto de "Evaluación de la exposición ambiental a agentes químicos en el lugar de trabajo" para la asignatura de Higiene analítica. Cada aspecto está englobado en una categoría en función de su utilidad para medir la adquisición de competencias generales o específicas de acuerdo al Plan de Estudios de la Titulación de "Master en Prevención de Riesgos Laborales".

\begin{tabular}{|c|c|c|c|c|c|}
\hline CATEGORIA & SUBCATEGORIAA & $\begin{array}{c}\text { EXCELENTE } \\
(9-10)\end{array}$ & $\begin{array}{l}\text { BUEN TRABAJO } \\
(7-9)\end{array}$ & $\begin{array}{l}\text { PODRIA ESTAR MEJOR } \\
\text { (5.7) }\end{array}$ & $\begin{array}{l}\text { NECESITA MEJORAR } \\
(0.5)\end{array}$ \\
\hline \multirow{4}{*}{$\begin{array}{l}\text { COMPETENCIAS } \\
\text { GENERALES } \\
40 \%\end{array}$} & $\begin{array}{l}\text { Actitud y } \\
\text { compromiso (10\%) }\end{array}$ & $\begin{array}{l}\text { Participó en la puesta en } \\
\text { común y realizó sus tareas } \\
\text { a tiempo }\end{array}$ & $\begin{array}{l}\text { Realizó sus tareas a tempo } \\
\text { pero no participó en la } \\
\text { puesta en común }\end{array}$ & $\begin{array}{l}\text { No realizó sus tareas a } \\
\text { tiempo pero participó en la } \\
\text { puesta en común }\end{array}$ & $\begin{array}{l}\text { No realizó sus tareas a } \\
\text { tiempo ni participó en la } \\
\text { puesta en común }\end{array}$ \\
\hline & $\begin{array}{l}\text { Solución de } \\
\text { problemas (10\%) }\end{array}$ & $\begin{array}{l}\text { Aportó soluciones a más } \\
\text { de dos tercios de los } \\
\text { problemas presentados }\end{array}$ & $\begin{array}{l}\text { Aportó soluciones a más de } \\
\text { un tercio de los problemas } \\
\text { presentados }\end{array}$ & $\begin{array}{l}\text { Aportó soluciones a menos } \\
\text { de un tercio de los } \\
\text { problemas presentados }\end{array}$ & $\begin{array}{l}\text { No aportó ninguna } \\
\text { solución }\end{array}$ \\
\hline & $\begin{array}{l}\text { Aspectos formales } \\
\text { del trabajo }(10 \%)\end{array}$ & $\begin{array}{l}\text { El trabajo comunica de } \\
\text { forma clara los resultados } \\
\text { obtenidos y la } \\
\text { presentación es correcta }\end{array}$ & $\begin{array}{l}\text { El trabajo comunica de } \\
\text { forma clara los resultados } \\
\text { obtenidos pero la } \\
\text { presentación no es correcta }\end{array}$ & $\begin{array}{l}\text { El trabajo no comunica de } \\
\text { forma clara los resultados } \\
\text { obtenidos aunque las } \\
\text { presentación es correcta }\end{array}$ & 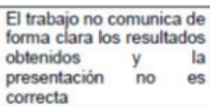 \\
\hline & $\begin{array}{l}\text { Calidad del trabajo } \\
\text { colaborativo (10\%) }\end{array}$ & $\begin{array}{l}\text { El trabajo colectivo ha } \\
\text { mejorado respecto a las } \\
\text { aportaciones individuales } \\
\text { en las tres fases }\end{array}$ & $\begin{array}{l}\text { El trabajo colectivo ha } \\
\text { mejorado respecto a las } \\
\text { aportaciones individuales al } \\
\text { menos en dos de las tres } \\
\text { fases }\end{array}$ & $\begin{array}{l}\text { El trabajo colectivo ha } \\
\text { mejorado respecto a las } \\
\text { aportaciones individuales en } \\
\text { alguna de las tres fases }\end{array}$ & $\begin{array}{l}\text { El trabajo colectivo no ha } \\
\text { mejorado respecto a las } \\
\text { aportaciones individuales. }\end{array}$ \\
\hline \multirow{6}{*}{$\begin{array}{l}\text { COMPETENCIAS } \\
\text { ESPECIFICAS } \\
(60 \%)\end{array}$} & $\begin{array}{l}\text { Aplicación correcta } \\
\text { de la legislación y } \\
\text { normativa } \\
\text { especifica (10\%) }\end{array}$ & 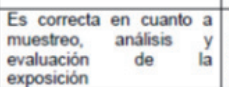 & $\begin{array}{l}\text { No es correcta en cuanto a } \\
\text { análisis y muestreo pero si } \\
\text { en cuanto a evaluación de la } \\
\text { exposición }\end{array}$ & $\begin{array}{l}\text { Es correcta en cuanto a } \\
\text { muestreo, analisis pero no } \\
\text { en cuanto a evaluación de } \\
\text { la exposición }\end{array}$ & $\begin{array}{l}\text { No es correcta en ningún } \\
\text { caso }\end{array}$ \\
\hline & $\begin{array}{l}\text { Los agentes } \\
\text { quimicos fueron } \\
\text { identificados } \\
\text { correctamente } \\
(\mathbf{1 0 \% )}\end{array}$ & Todos & Bastantes & \begin{tabular}{|l|l|} 
Pocos \\
\end{tabular} & Ninguno \\
\hline & $\begin{array}{l}\text { Los cálculos de } \\
\text { Evaluación de la } \\
\text { exposición han } \\
\text { sido rigurosos } \\
(10 \%)\end{array}$ & $\begin{array}{l}\text { Han sido muy rigurosos y } \\
\text { exhaustivos }\end{array}$ & $\begin{array}{l}\text { Han sido rigurosos pero } \\
\text { poco exhaustivos }\end{array}$ & Han sido poco rigurosos & Son incorrectos \\
\hline & $\begin{array}{l}\text { Método de } \\
\text { muestreo } \\
\text { propuesto (10\%) }\end{array}$ & $\begin{array}{l}\text { Es el más adecuado de } \\
\text { acuerdo con el supuesto }\end{array}$ & $\begin{array}{l}\text { Es adecuado pero podria } \\
\text { haberse mejorado }\end{array}$ & $\begin{array}{l}\text { Cumple los requerimientos } \\
\text { minimos exigidos }\end{array}$ & $\begin{array}{l}\text { Es insuficiente } \\
\text { inadecuado }\end{array}$ \\
\hline & $\begin{array}{l}\text { Método de análisis } \\
(10 \%)\end{array}$ & $\begin{array}{l}\text { Los cálculos han sido } \\
\text { correctos }\end{array}$ & $\begin{array}{l}\text { El planteamiento es correcto } \\
\text { pero hay algún fallo en la } \\
\text { ejecución }\end{array}$ & $\begin{array}{l}\text { El planteamiento es correcto } \\
\text { pero hay varios fallos en la } \\
\text { ejecución }\end{array}$ & Deben repetirse \\
\hline & $\begin{array}{l}\text { Las medidas } \\
\text { correctoras } \\
\text { propuestas }(10 \%)\end{array}$ & $\begin{array}{l}\text { Son las más adecuadas a } \\
\text { la Evaluación realizada }\end{array}$ & $\begin{array}{l}\text { Son adecuadas, pero } \\
\text { podrian mejorarse }\end{array}$ & Son las minimas aceptables & $\begin{array}{l}\text { Son insuficientes para } \\
\text { solucionar el problema }\end{array}$ \\
\hline
\end{tabular}

Fig. 2 Rubrica diseñada para medir la adquisición de las competencias seleccionadas..

El grado de aceptación de este sistema de evaluación por parte del alumnado ha sido medido mediante 4 aspectos (ítems 11-14 del cuestinario presentado en la figura 1). Se ha mantenido la misma escala que en los ítems 1-10.

Finalmente, se ha querido estudiar el uso de la Plataforma como facilitador de la tarea y valor añadido a la actividad tal y como ha sido diseñada. Para ello se han tabulado los usos de las distintas herramientas para cada alumno en relación con el trabajo propuesto. Además, se ha querido estudiar la percepción de los alumnos sobre dichas herramientas a través de 6 items de respuesta múltiple, que pretenden comparar el uso real de las distintas herramientas disponibles en la Plataforma con las preferencias respecto a algunas herramientas poco potenciadas en esta actividad. En la figura 3 se recoge el cuestionario utilizado. Las preguntas y respuestas han sido seleccionadas con mínimas adaptaciones al contexto del cuestionario propuesto por Olmo et al (2012). 


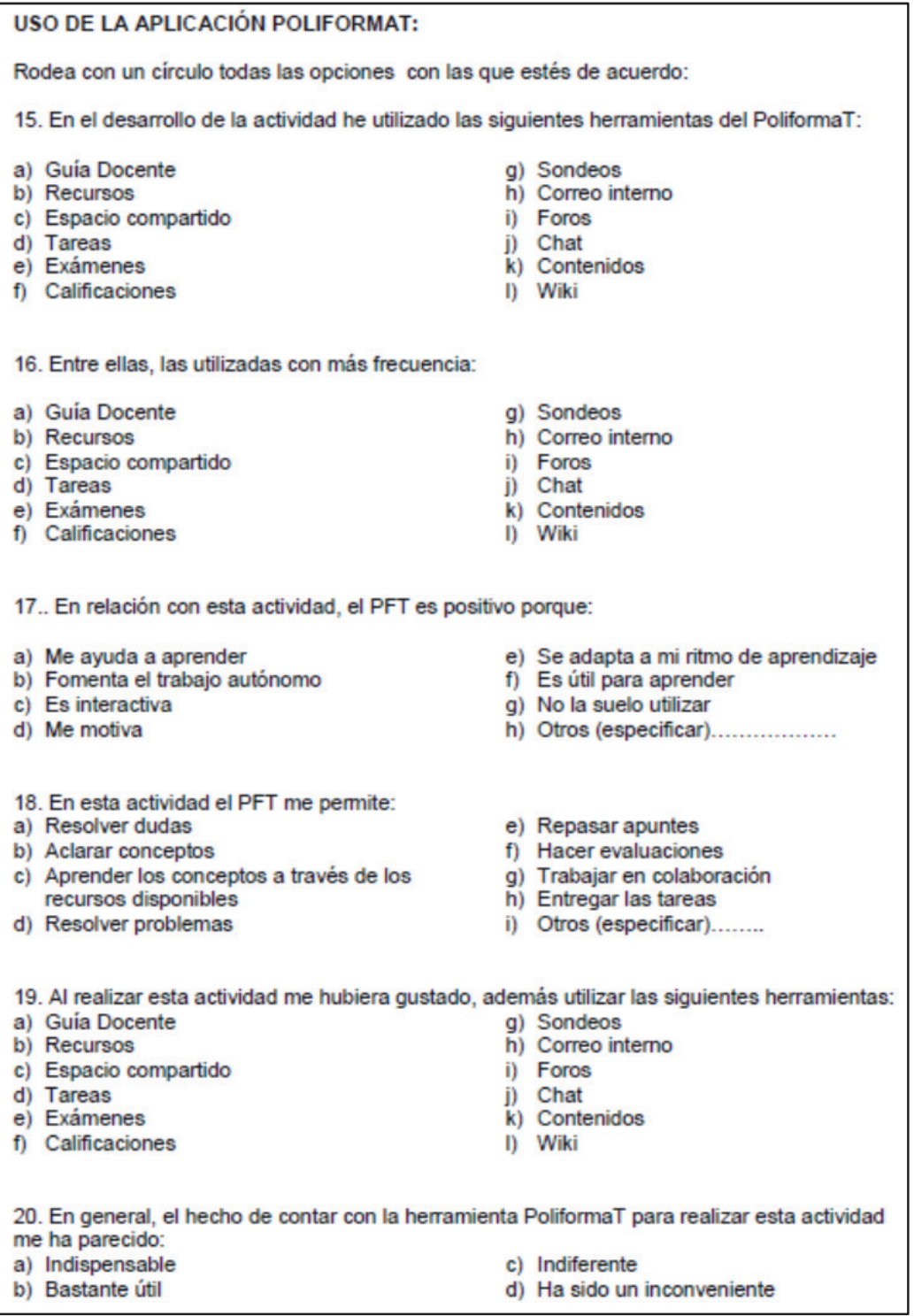

Fig. 3. Modelo de cuestionario para medir el uso y preferencias de las herramientas de la Plataforma PFT.

Algunas de las tareas y aspectos evaluados permiten medir distintas competencias, generales y específicas. Por ejemplo, ser capaz de realizar una correcta evaluación de la exposición permitirá aplicar la legislación específica, pero también permitirá formular juicios de valor sobre la responsabilidad social y ética de la empresa. En la tabla 2 se resume la relación entre las competencias trabajadas, los ítems del cuestionario de percepción de la adquisición de esas competencias por parte del alumnado y las categorías

\section{(c)) EY-NC-ND 2014, Universitat Politècnica de València}

I Jornadas IN-RED (2014) 
Diseño y evaluación de una actividad de aprendizaje basado en proyectos en el contexto de la Higiene analítica

de la rúbrica que evalúan las distintas competencias. Las competencias específicas son medidas desde distintos aspectos por lo que corresponden a varias categorías de la rúbrica.

Tabla 2. Correspondencia entre la competencia estudiada, los ítems de la encuesta y la rúbrica diseñada.

\begin{tabular}{lll}
\hline Código & Item Encuesta & Item Rúbrica \\
\hline DC2 & P1, P3 y P10. & R5-R10 \\
DC3 & P2. & R2 \\
DC6 & $\begin{array}{l}\text { No incluida como tal en las } \\
\text { competencias actuales }\end{array}$ & R1 y R4 \\
& P5 & \\
DC7 & P6 & R10. \\
DC8 & P4. & R3 \\
DC9 & P7, P8 y P9. & R7 \\
E7 & P10. & R6, R5, R7 y R10. \\
E18 & & R8, R9 y R10. \\
\hline
\end{tabular}

Nótese que algunas de las tareas y aspectos evaluados permiten medir distintas competencias, generales y específicas. Por ejemplo ser capaz de realizar una correcta evaluación de la exposición permitirá aplicar correctamente, la legislación específica pero también permitirá formular juicios de valor sobre la responsabilidad social y ética de la empresa.

Una vez realizadas las encuestas se procederá a analizar los resultados mediante estadística descriptiva clásica, utilizando como herramienta el software STATGRAPHICS.

\section{Resultados}

Al finalizar el curso, se utilizó la ríbrica diseñada para evaluar el trabajo realizado por los alumnos, tanto a nivel individual como colectivo. El histograma de calificaciones obtenidas en cada subcategoría se muestra junto a su valor medio y la correspondencia con las competencias que se valoraban (figura 4). Los resultados de las calificaciones reflejan que la mayoría de los alumnos han adquirido, en buena medida, las dimensiones competenciales y las competencias específicas seleccionadas. Además, un $20 \%$ de los alumnos han hecho un trabajo excelente. 


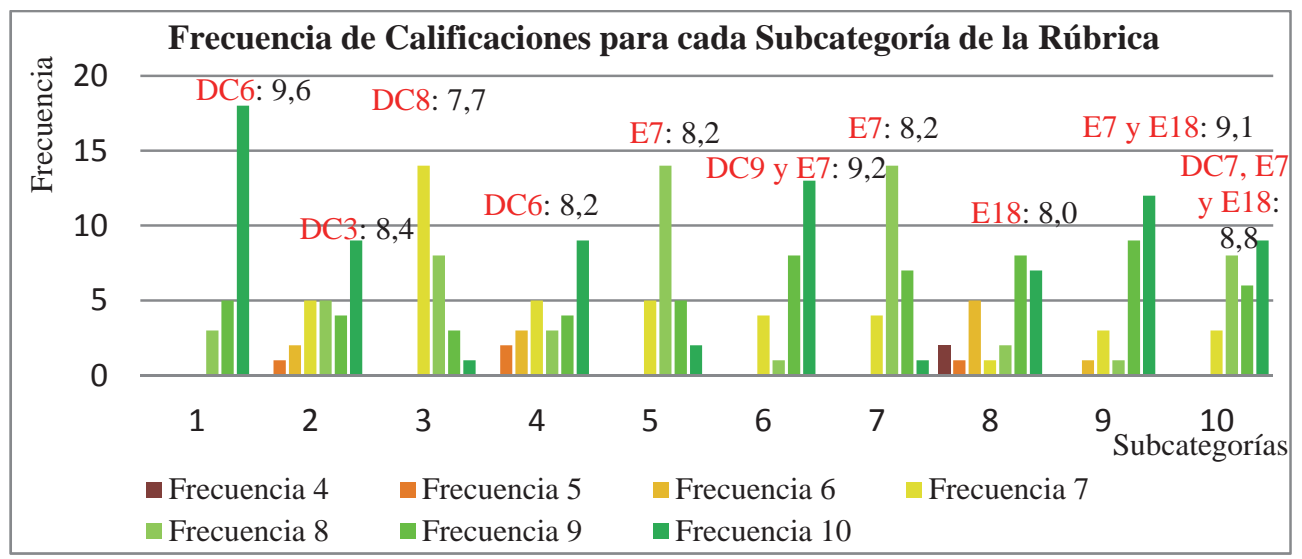

Fig. 4 Frecuencia de calificaciones obtenidas para los 25 alumnos evaluados. Subcategorías: 1- Actitud y compromiso; 2- Solución de problemas; 3-Aspectos formales del trabajo; 4-Calidad del trabajo colaborativo; 5Aplicación correcta de la Legislación y normativa específica; 6-Identificación correcta de agentes químicos; 7 Cálculos de Evaluación de la exposición; 8-Método de muestreo adecuados; 9-Métodos de análisis adecuados; 10-Medidas correctoras adecuadas Los valores encima de cada subcategoría representan la media aritmética obtenida por los alumnos en cada una de ellas. Los códigos en rojo corresponden a la competencia evaluada.

Mediante el cuestionario que se mostró en la figura 1 se ha estudiado la percepción del alumnado sobre la adquisición de estas competencias. En la tabla 3 se resumen los parámetros clásicos de la estadística descriptiva para las preguntas 1-10 y en la figura 5 se recoge el histograma con la frecuencia de respuestas a las preguntas 1-10.

Tabla 3. Resultados de los parámetros estadísticos correspondientes a las preguntas 1-10.

\begin{tabular}{ccccccccccc}
\hline & P1 & P2 & P3 & P4 & P5 & P6 & P7 & P8 & P9 & P10 \\
\hline Frecuencia & 21 & 21 & 21 & 20 & 21 & 21 & 21 & 21 & 21 & 21 \\
Mediana & & & & & & & & & & \\
muestral & 4 & 3 & 3 & 4 & 3 & 3 & 3 & 4 & 3 & 3 \\
Media & & & & & & & & & & \\
muestral & 3,7 & 3,3 & 2,9 & 3,6 & 3,4 & 3,19 & 3,24 & 3,71 & 3,4 & 3,3 \\
$\begin{array}{c}\text { Desviación } \\
\text { típica }\end{array}$ & 0,6 & 0,9 & 0,7 & 0,7 & 0,8 & 0,7 & 0,8 & 0,6 & 0,8 & 0,9 \\
$\begin{array}{c}\text { Int. Conf. } \\
\text { (95\%) }\end{array}$ & {$[3,4-$} & {$[2,9-$} & {$[2,6-$} & {$[3,2-$} & {$[3,1-$} & {$[2,9-$} & {$[2,9-$} & {$[3,5-$} & {$[3,0-$} & {$[2,0-$} \\
& $3,7]$ & $3,2]$ & $3,9]$ & $3,8]$ & $3,5]$ & $3,6]$ & $4,0]$ & $3,7]$ & $3,7]$ \\
\hline
\end{tabular}

(cc) EY-NC-ND 2014, Universitat Politècnica de València

I Jornadas IN-RED (2014) 
Diseño y evaluación de una actividad de aprendizaje basado en proyectos en el contexto de la Higiene analítica

Los resultados muestran que los ítems mejor valorados son el 1 (la actividad me ha permitido aplicar los conocimientos adquiridos en la asignatura), el 4 (la información reunida me ha ayudado a formular juicios en relación a la evaluación de la exposición a agentes químicos en el entorno laboral y el 8 (esta actividad me ha ayudado a identificar las características y los efectos de los agentes químicos) por lo que se puede deducir que las competencias más percibidas por los alumnos han sido DC2 (Aplicación pensamiento práctico); DC9 (Pensamiento crítico) y el segundo aspecto de la E7 (Identificar las características y los efectos de los agentes químicos, físicos y biológicos).

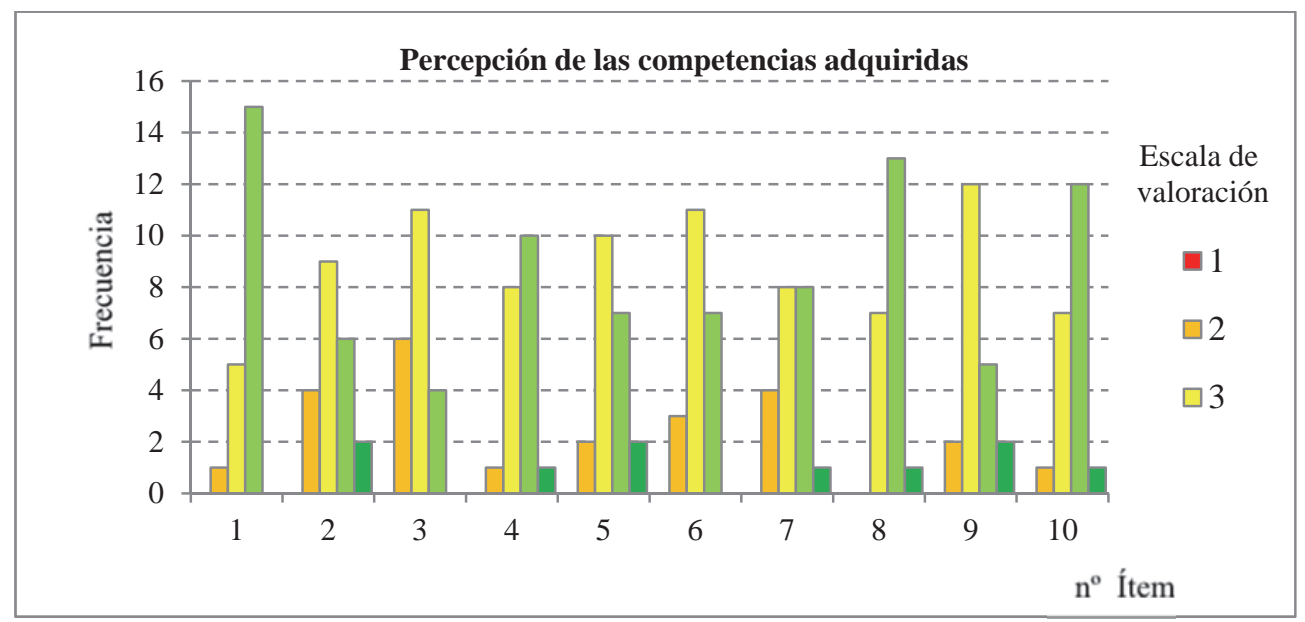

Fig. 5 Resultados del cuestionario sobre la percepción de los alumnos acerca de las competencias adquiridas. $N^{o}$ ítem: 1-Aplicar los conocimientos adquiridos; 2-Resolución de problemas multidisciplinares; 3-Integrar conocimientos adquiridos en otras asignaturas; 4-Formular juicios en relación a la evaluación de la exposición; 5-Responsabilidades sociales y éticas que se derivan de la aplicación de estos juicios emitidos; 6-Habilidad para comunicar las conclusiones a públicos especializados y no especializados; 7-Utilizar la legislación específica de higiene industrial; 8-Identificar agentes químicos; 9-Realizar evaluaciones de riesgos y plantear medidas correctoras; 10-Fundamento de técnicas de análisis químico.

El ítem menos valorado fue el 3 (la ejecución de este proyecto me ha permitido integrar conocimientos adquiridos en otras asignaturas.) que también mide otro aspecto de la dimensión competencial DC2. A la vista de estos resultados podemos concluir que, si bien los alumnos reconocen un sentido práctico al trabajo ejecutado, lo relacionan muy directamente con la asignatura que lo propone, pero no tanto con otras de la titulación.

Respecto a la percepción de competencias generales o específicas, no se encontró una tendencia diferente, ya que el ANOVA realizado no mostró diferencias significativas al $95 \%$. 
Al relacionar estos resultados de la percepción de la adquisición de competencias, con las calificaciones obtenidas a través de la rúbrica diseñada, se observa que las mejores puntuaciones en la evaluación corresponden a las subcategorías 1 y 9 que se relacionan respectivamente con las competencias DC6 (Trabajo en equipo y liderazgo) y las dos específicas (E7 y E18). A continuación se muestran los resultados respecto a la percepción de la rúbrica utilizada (figura 6 y tabla 4).

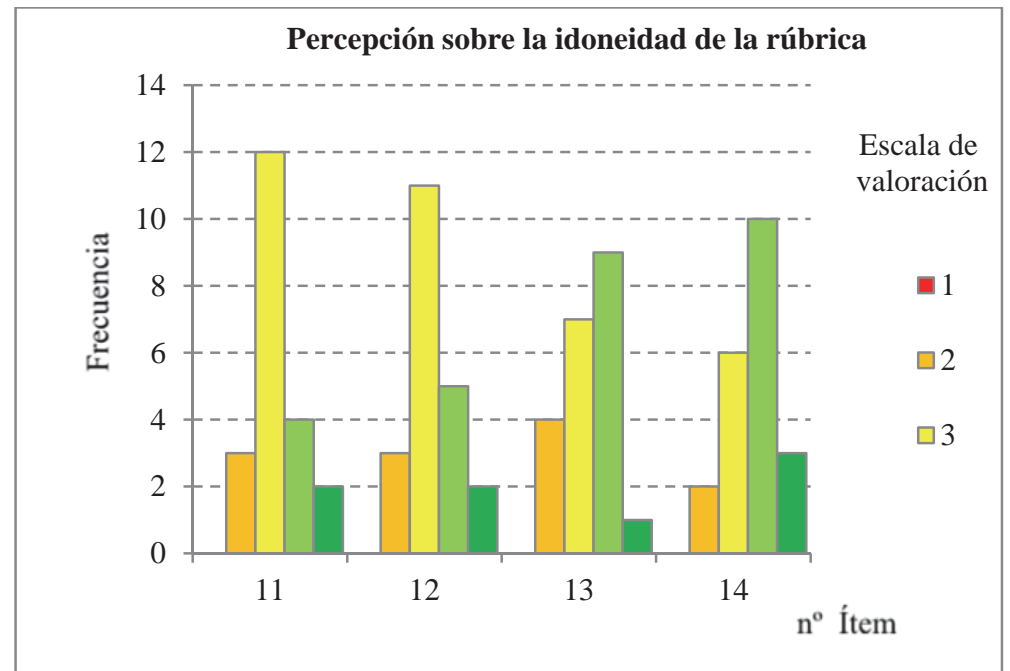

Fig. 6 Resultados del cuestionario sobre la percepción de los alumnos acerca de la idoneidad de la rúbrica. 11. $n^{o}$ de ítem: 11-Las categorías y subcategorías recogidas en la tabla valoran adecuadamente las competencias generales que se deseaba adquirir; 12-Las categorías reflejadas valoran adecuadamente las categorías específicas que se deseaba adquirir; 13-Los porcentajes asignados a cada categoría y subcategoría me parecen adecuados; 14- Las puntuaciones asignadas a cada nivel (excelente, buen trabajo, etc...) me parecen adecuados.

La rúbrica diseñada permite evaluar mejor las competencias generales. No obstante, los alumnos no perciben este sistema de evaluación como muy positivo y parecen poco familiarizados con la evaluación basada en competencias, incluso la propia terminología les resulta ajena. Perciben como positivo que la terminología de la escala utilizada para evaluar sea la de excelente a necesita mejorar.

En cuanto a la utilización de la PFT, mediante diagramas radiales, se muestra el uso por parte de los alumnos de las distintas herramientas en relación con el trabajo propuesto, así como las preferencias sobre ellas (figura 6).

Se observa que las herramientas más utilizadas han sido Recursos y Espacio compartido pues son cita obligada para poder seguir la actividad. Otras de uso voluntario, como el correo interno, tuvieron un seguimiento moderado. Los motivos principales por los que valoraron la plataforma en relación con la actividad, fueron que fomenta el trabajo autónomo, les ayuda a aprender (un $48 \%$ ) y es interactiva (43\%).

\section{(cc) EY-NC-ND 2014, Universitat Politècnica de València}

I Jornadas IN-RED (2014) 
Diseño y evaluación de una actividad de aprendizaje basado en proyectos en el contexto de la Higiene analítica

Tabla 4. Resultados de los parámetros estadísticos correspondientes a las preguntas 11-14

\begin{tabular}{ccccc}
\hline & P11 & P12 & P13 & P14 \\
\hline Frecuencia & 21 & 21 & 21 & 20 \\
Mediana muestral & 3 & 3 & 3 & 4 \\
Media muestral & 3,2 & 3,3 & 3,3 & 3,7 \\
Desviación típica & 0,8 & 0,8 & 0,9 & 0,9 \\
Int. Conf.(95\%) & $2,9-3,6$ & $2,9-3,7$ & $2,9-3,7$ & $3,3-4,1$ \\
\hline
\end{tabular}

Un 71\% reconoció su utilidad para entregar las tareas y repasar apuntes, así como fomentar la colaboración (33\%). La baja puntuación respecto a resolver dudas y aclarar conceptos es debida en gran parte al uso del correo corporativo del profesor que, en general, resulta más inmediato, ya que los alumnos no tienen que esperar a que el profesor entre en la Plataforma. Además, la configuración de este correo en los teléfonos móviles no es óptima y los alumnos prefieren el uso de su propio correo.

Es interesante destacar que un 33\% de alumnos echó en falta la habilitación de un foro, que será incorporado en próximas ediciones. Respecto al Chat, aunque el $24 \%$ demandó su uso, la mayoría de los alumnos han relegado esta herramienta debido a la rápida extensión del uso de teléfonos inteligentes con aplicaciones de mensajería multiplataforma. En la mayoría de asignaturas, los alumnos crean grupos cerrados que les permiten intercambiar información en tiempo real, con imágenes de problemas, apuntes, etc., sin necesidad de conectarse a la plataforma que, por razones obvias de seguridad, es un proceso mucho más complejo y lento. Por ello, si se pretende para próximas ediciones fomentar el Chat, habrá que valorar los resultados obtenidos en el futuro.Vista la Plataforma en su conjunto, como herramienta útil, un $90 \%$ de alumnos la perciben como muy adecuada o bastante adecuada para realizar la actividad, sin embargo llama la atención que un $10 \%$ la percibe como un inconveniente, tal vez por falta de familiarización. 


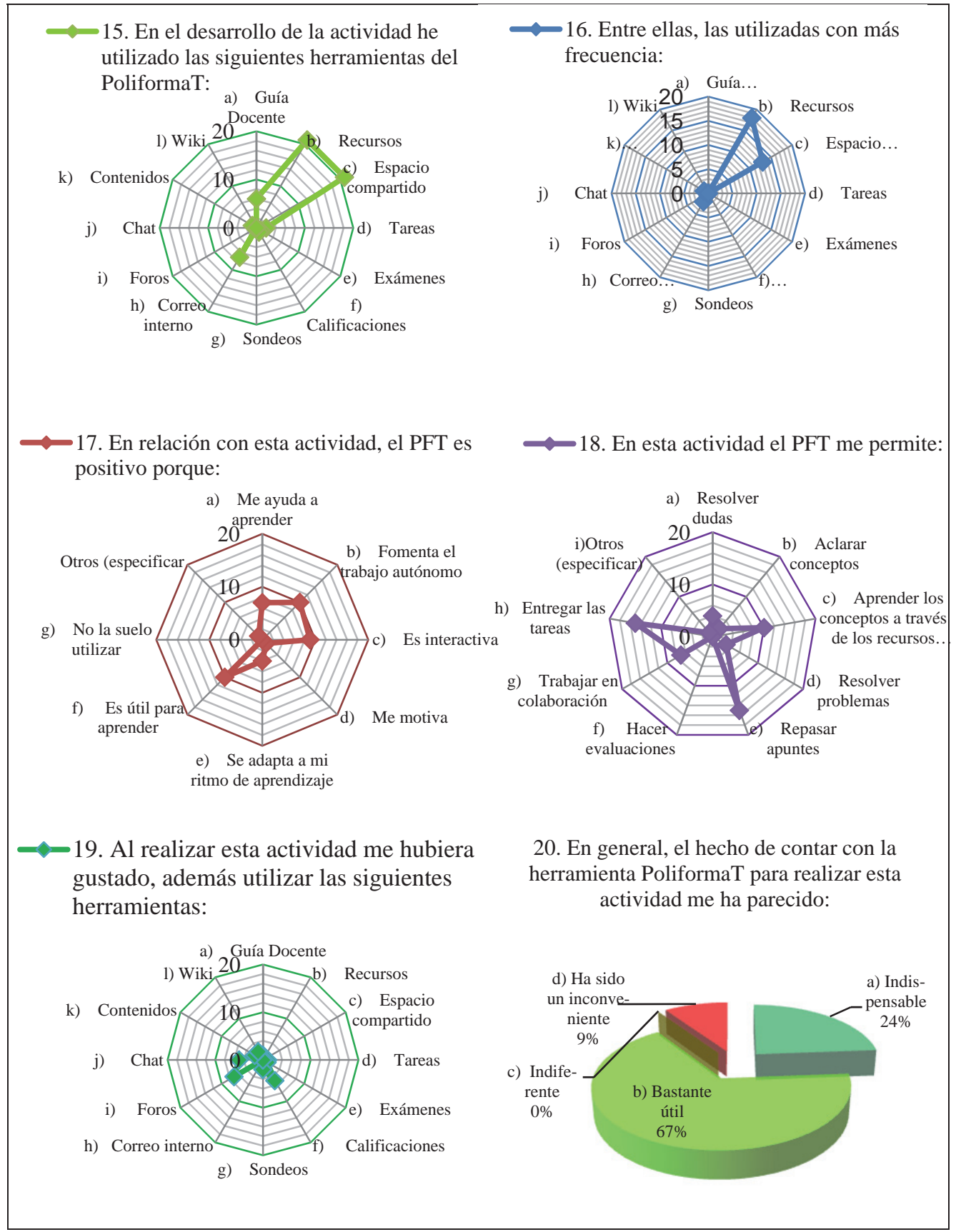

Figura 6. uso y preferencias por parte del alumnado de las distintas herramientas de PoliformaT.

\section{(cc) EY-NC-ND 2014, Universitat Politècnica de València}

I Jornadas IN-RED (2014) 
Diseño y evaluación de una actividad de aprendizaje basado en proyectos en el contexto de la Higiene analítica

\section{Conclusiones}

Los resultados de las calificaciones sobre el trabajo en equipo reflejan que la mayoría de los alumnos han adquirido en buena medida las dimensiones competenciales que se han trabajado (sobre todo DC6 y DC9 )y las competencias específicas. Además, un 20\% de los alumnos han hecho un trabajo excelente.

Las dos dimensiones competenciales más percibidas por los alumnos han sido DC2: (Aplicación pensamiento práctico) que se corresponde con el ítem 1 (La actividad me ha permitido aplicar los conocimientos adquiridos en la asignatura) y DC9 (Pensamiento crítico) que se corresponde con el ítem 4 (La información reunida me ha ayudado a formular juicios en relación a la evaluación de la exposición a agentes químicos en el entorno laboral). En cuanto a competencias específicas la mejor percibida ha sido E7, en el aspecto correspondiente al ítem 8 (Esta actividad me ha ayudado a identificar las características y los efectos de los agentes químicos).

Comparados con los datos de años anteriores cuya evaluación seguía criterios más tradicionales centrados en la tarea, podemos concluir que la rúbrica diseñada permite evaluar mejor las competencias generales. Aunque los alumnos consideran positivo que la terminología utilizada para evaluar utilice una escala de medida desde "excelente" hasta "necesita mejorar", no parecen familiarizados con la evaluación basada en dimensiones competenciales y competencias específicas, incluso la propia terminología les resulta ajena.

Las herramientas de la plataforma PoliformaT más utilizadas han sido Recursos y Espacio compartido (necesarias para seguir la actividad) mientras que el correo interno tuvo un seguimiento moderado porque necesita mejorar la adecuación a los teléfonos inteligentes. Una amplia mayoría de los alumnos reconoció la utilidad de PoliformaT para entregar tareas y repasar apuntes, así como fomentar la colaboración. Además, se ha previsto incorporar en próximas ediciones un foro y un chat ya que un grupo significativo de alumnos lo valoraron positivamente.

En general, se puede concluir que un $90 \%$ de alumnos perciben la Plataforma como muy adecuada o bastante adecuada para realizar la actividad. Los motivos principales por los que valoraron la plataforma en relación con la actividad, fueron que fomenta el trabajo autónomo, les ayuda a aprender y es interactiva.

\section{Referencias}

BRUNNING R.H., SCHRAW G.J. y RONNING R.R. (1995), Cognitive Psychology and Instruction 2nd ed., Englewoods Cliffs (ed.) New Jersey: Prentice Hall.

CRAIG, K.B. (2008). Investigating Teamwork Competencies in the Value Chain of a Selected Wool Brokerage Logistics Department. Dissertation for the Degree Masters Bussiness Administration. 
Nelson Mandela Metropolitan University, Business School. <http://www.nmmu.ac.za/ documents/theses/Teamwork\%20Competencies.pdf (.pdf)> [Consulta:12 de mayo de 2014].

OLMO, F., GÓMEZ, B. y LABRADOR, M.-J. (2012). Plataforma educativa y aprendizaje activo. La universidad: una institución de la sociedad. 1-27. Universidad Pompeu Fabra. Barcelona. <http://www.cidui.org/revista-cidui12/index.php/cidui12/issue/archive > [Consulta: 6 mayo de 2014].

RUBISTAR. (2011). Evaluación de los aprendizajes:trabajo colaborativoRubric ID:2065062 Collaborative Work Skills:. Teachers.org (C) 2000-2008, ALTEC at the University of Kansas <http://rubistar.4teachers.org/index.php?screen=ShowRubric\& rubric_id=2065062\&> [Consulta: 3 de marzo de 2014].

STATGRAPHICS® Plus. v 5.1 (2001). Statistical Graphics Corporation. Statgraphics.net. Madrid.

UNIVERSITAT POLITÈCNICA DE VALENCIA. (2007). Anexo IV del Manual de Evaluación de la Actividad Docente del Profesorado de la Universitat Politècnica de València. <https://www.upv.es/entidades/ICE/info/Muy_importante.pdf>[Consulta: 10 de marzo de 2014].

UNIVERSITAT POLITÈCNICA DE VALENCIA. (2014). Extraído del borrador del Marco UPV de definición y evaluación de adquisición de competencias. <www.upv.es/contenidos/ ICEP/info/DimensionesCompetenciales.pdf > [Consulta: 9 de junio de 2014.]

VILES, E.; ZÁRRAGA, M.; JACA, C. (2014). Herramienta para evaluar el funcionamiento de los equipos de trabajo en entornos docentes. Intangible Capital; 201, 3- 9(1): 281-304- Universidad Politécnica de Cataluña Omnia Science Online ISSN: 1697-9818 - Print ISSN: 2014-3214 [http://dx.doi.org/10.3926/ ic. 399> [Consulta: 29 de abril de 2014]

(c) $\mathbf{\text { EY-NC-ND }}$ 2014, Universitat Politècnica de València

I Jornadas IN-RED (2014) 


\title{
Trabajo en equipo: una oportunidad para adquirir dimensiones competenciales
}

M. Ardid Ramírez ${ }^{\mathrm{a}}$, V. Paula Cuenca Gotor ${ }^{\mathrm{b}}$, J.M. Meseguer-Dueñas ${ }^{\mathrm{c}}$, J. Molina Mateo $^{\mathrm{d}}$, J. Riera Guasp ${ }^{\mathrm{e}}$, I. Salinas Marín ${ }^{\mathrm{f}}$, A. Vidaurre Garayo ${ }^{\mathrm{g}}$

Escola Tècnica Superior d'Enginyeria del Disseny, Universitat Politècnica de València, Camí de Vera, s/n,46022València, ${ }^{a}$ mardid@fis.upv.es, ${ }^{b}$ vacuego@fis.upv.es, ${ }^{2}$ jmmesegu@upv.es, dimmateo@fis.upv.es, ${ }^{j}$ jriera@fis.upv.es, ${ }^{\text {is }}$ islinas@fis.upv.es, ${ }^{g}$ vidaurre@fis.upv.es

\begin{abstract}
We used teamwork to effectively introduce transversal competences in the objectives of the Physics subject. The results of teamwork with the individual one have been compared, and we have evaluated the evolution of the competence "Communicating effectively with written documents" along the course using a dedicated rubric. Finally, students have been surveyed about their opinion regarding the methodology of teamwork, pros and cons of it, on the outcome of teamwork, as well as on the role of the teacher. Results show that there is an improvement in transversal competences using teamwork, and that the rubric is a good tool to evaluate them. Students generally have good opinion of teamwork, though they manifest imbalances in the work of the various components of the group.
\end{abstract}

Keywords: generic skills, cooperative work, evaluation, rubric, poll.

\begin{abstract}
Resumen
Se ha utilizado el trabajo en equipo para introducir de manera efectiva competencias transversales entre los objetivos de asignaturas de la materia Física. Se ha comparado el resultado del trabajo en equipo con el individual, y se ha valorado la evolución de la competencia "Comunicarse de manera efectiva de forma escrita" a lo largo de un curso trabajando en equipo mediante la utilización de una rúbrica. Por último, se ha encuestado a los alumnos sobre su opinión respecto del método de trabajo, pros y contras del trabajo en equipo, sobre el resultado del trabajo en equipo y sobre el papel del profesor. Los resultados muestran que el trabajo en equipo supone una mejora en otras competencias transversales, y que la rúbrica es una buena herramienta para evaluarlas. Los alumnos en general tienen buena opinión
\end{abstract}

(c)) EY-NC-ND 2014, Universitat Politècnica de València

I Jornadas In-Red (2014) 
Trabajo en equipo: una oportunidad para adquirir dimensiones competenciales

del trabajo en equipo, aunque manifiestan desequilibrios en el trabajo realizado por los diferentes componentes del mismo.

Palabras clave: competencias transversales, trabajo en equipo, evaluación, rúbrica, encuesta.

\section{Introducción}

En la última convocatoria de Proyectos de Innovación Docente de la Universitat Politècnica de València se hacía especial mención a la necesidad de buscar instrumentos para definir, poner en práctica y evaluar las competencias transversales en los títulos de grado. El documento "MARCO UPV DE DEFINICIÓN Y EVALUACIÓN DE ADQUISICIÓN DE COMPETENCIAS" [UPV, 2014] hace referencia a la imperiosa necesidad de revisar las competencias de las titulaciones, y una vez establecidas, garantizarlas y habilitar mecanismos para poder evaluarlas.

El sistema de asignación de competencias a materias y asignaturas en los actuales títulos de grado no deja clara la forma de incorporar las denominadas dimensiones competenciales de carácter transversal al trabajo de los alumnos. Si, por ejemplo, analizamos el Grado en Ingeniería Eléctrica de la Escola Tècnica Superior d'Enginyeria del Disseny (ETSID) de la Universitat Politècnica de València (UPV), en la definición de competencias encontramos 10 generales y 32 específicas. En las generales encontramos tres que podrían considerarse como dimensiones competenciales transversales:

- Capacidad de resolver problemas con iniciativa, toma de decisiones, creatividad, razonamiento crítico y de comunicar y transmitir conocimientos, habilidades y destrezas en el campo de la Ingeniería Industrial.

- Capacidad de trabajar en un entorno multilingüe y multidisciplinar.

- Poseer una cultura histórico-social y sensibilidad estética.

La primera es de un contenido tan amplio que abarcaría buena parte de las dimensiones competenciales descritas en el documento marco citado [UPV, 2014], mientras que la tercera no parece concretar claramente a qué se refiere. En las competencias específicas no encontramos ninguna que pueda considerarse como transversal.

De este modo, aunque buena parte de los profesores intentemos incorporar estas competencias en la programación real de nuestras asignaturas, cualquier acción que iniciamos en este sentido queda oculta, no aparece hasta el momento en las guías docentes, y además a los alumnos no se les hace patente la importancia que tienen para su formación como futuros graduados. Esto contrasta con la importancia que se les da tanto desde estamentos académicos como desde el de los empresarios y agentes empleadores [LIAO, 2013]. 
En el documento marco de la UPV [UPV, 2014] se ha hecho un importante trabajo definiendo un total de 13 dimensiones competenciales (DC). Algunas de ellas han estado contempladas, de una forma u otra, en el trabajo cotidiano del profesorado desde hace tiempo, pero otras suponen un reto tanto en el qué hacer para garantizar que los alumnos las adquieran, como en el método de evaluarlas. Podemos decir que la experiencia de mucho tiempo nos da confianza de poder evaluar competencias relacionadas con los conocimientos de las materias de una manera razonable y contrastada, y que la inexperiencia nos hace inseguros para, una vez planteada una competencia transversal, poder evaluar en qué medida los alumnos la han adquirido. Por otro lado, fijar unos objetivos competenciales que sean alcanzables de manera razonable y mesurables es todo un reto.

Los autores del trabajo hemos intentado incorporar buena parte de las DC transversales al trabajo de los alumnos durante los últimos cursos. Pertenecemos al Departamento de Física Aplicada (DFA) de la UPV, e impartimos docencia en la ETSID. La materia que trabajamos en diferentes grados (ingenierías Aeroespacial IAE, Diseño Industrial IDI, Eléctrica IEL y Electrónica y Automática Industrial IEA) es Fundamentos de Física, que en general se desglosa en una asignatura de Física general y otra de Física de especialidad (por ejemplo, en los grados IEL y IEA la Física de especialidad es Electricidad). Una característica común de la metodología docente que utilizamos en los distintos grupos es el uso de herramientas de e-learning con nuestros alumnos. Los alumnos realizan exámenes on-line, entregan tareas mediante la plataforma de formación, tienen tutorías electrónicas, etc.

En nuestra materia hay dimensiones competenciales genéricas que de forma habitual entran a formar parte de las competencias de las guías docentes: DC2 Aplicación pensamiento práctico y DC3 Análisis y resolución de problemas. Pero hay otras dimensiones que están incorporadas en la programación, que forman parte de nuestros objetivos, pero que, hasta el momento, no se han explicitado en la guía docente (el modelo y normas de las guías docentes no nos permiten hacer referencia a más de tres competencias). En la tabla 1 se detallan estas competencias transversales.

Tabla 1: dimensiones competenciales transversales en Fundamentos de Física

\begin{tabular}{l|l}
\hline Dimensión & Descripción \\
\hline $\begin{array}{l}\text { DC2 Aplicación pen- } \\
\text { samiento práctico }\end{array}$ & $\begin{array}{l}\text { Aplicar los conocimientos a la práctica, atendiendo a la informa- } \\
\text { ción disponible, y estableciendo el proceso a seguir para lograr } \\
\text { los objetivos con eficacia y eficiencia. }\end{array}$ \\
$\begin{array}{l}\text { DC3 Análisis y resolu- } \\
\text { ción de problemas } \\
\text { definiendo y resolver problemas de forma efectiva, identificando y }\end{array}$ \\
$\begin{array}{l}\text { DC6 Trabajo en equipo } \\
\text { y liderazgajar y liderativos que los constituyen. } \\
\text { de objetivos comunes, y contribuir al desarrollo personal y pro- } \\
\text { fesional de estos. }\end{array}$
\end{tabular}

(cc)) EY-NC-ND 2014, Universitat Politècnica de València

I Jornadas IN-RED (2014) 
DC7 Responsabilidad ética y profesional

DC8 Comunicación efectiva

DC9 Pensamiento crítico

DC12 Planificación y gestión del tiempo
Actuar con responsabilidad ética y profesional ante uno mismo y los demás.

Comunicarse de manera efectiva, tanto de forma oral como escrita, utilizando adecuadamente los recursos necesarios y adaptándose a las características de la situación y la audiencia.

Desarrollar un pensamiento crítico interesándose por los fundamentos en los cuales se asientan ideas, acciones y juicios, tanto propios como ajenos.

Planificar adecuadamente el tiempo disponible y programar las actividades necesarias para lograr los objetivos, tanto académicos y profesionales cómo personales.

Sobre estas últimas dimensiones centramos el análisis del trabajo. Queremos evaluar, mejorar y dar visibilidad, de la manera más eficiente, al trabajo que realizamos sobre ellas.

Buena parte del trabajo en nuestras asignaturas lo hacemos girar alrededor de la competencia DC6 Trabajo en equipo y liderazgo, entendiendo el trabajo en equipo en su sentido de trabajo cooperativo [JOHNSON, 1999; NOONAN, 2013], que

“...debe entenderse como el que implica un grupo de personas trabajando de manera coordinada en la ejecución de un proyecto."

La consecuencia de esta forma de trabajar es que la responsabilidad del resultado final es del equipo y no cada uno de sus miembros de forma independiente. Cada miembro puede estar especializado en un área determinada, o ser responsable de un cometido, pero sólo si todos ellos cumplen su función el proyecto finalizará con éxito.

\section{Objetivos}

Basados en todo lo anterior, nuestra hipótesis de partida es la siguiente:

La competencia DC6 Trabajo en equipo y liderazgo, es un buen instrumento para poder adquirir el resto de dimensiones competenciales.

Para poder evaluar la validez de la hipótesis, hemos hecho un seguimiento de la competencia DC8 Comunicación efectiva, en lo referido a Comunicarse de manera efectiva de forma escrita. Para objetivar al máximo la evaluación de los resultados, hemos hecho el seguimiento del trabajo durante un curso mediante rúbrica.

La opinión de los alumnos es relevante en cuanto a sujetos de la adquisición de competencias. Es nuestro objetivo que los alumnos sean conscientes de que las competencias transversales forman parte importante de su formación, y pretendemos que a través de la meto- 
dología empleada lleguen a comprenderlo. Para evaluar si lo hemos conseguido hemos realizado una encuesta con alumnos de diferentes grados.

\section{Metodología del trabajo}

La metodología empleada se basa en el trabajo conjunto y continuado de alumnos y profesores, en el uso de la plataforma de e-learning de la Universidad (Poli[formaT] [SAKAI, 2014]), y en las condiciones de organización docente del centro: grupos numerosos y desdobles de alumnos para prácticas de aula y de laboratorio que se realizan en un único espacio compartiendo aula varios profesores. Este último factor, que a priori podría considerarse como un problema, se ha reconvertido en oportunidad para aplicar metodologías novedosas, y experimentar en la incorporación de nuevas competencias en la formación de los alumnos. La metodología es común a la misma materia de cuatro grados diferentes, aunque en el presente trabajo nos centraremos en los resultados obtenidos en tres de ellos: Ingeniería Aeroespacial, Ingeniería del Diseño Industrial e Ingeniería Electrónica y Automática Industrial.

\subsection{Trabajo en equipo}

$\mathrm{Al}$ inicio del curso los alumnos de cada grupo (de entre 70 y 80 alumnos) se organizan en equipos de cinco o seis alumnos. Estos equipos son los mismos para las dos asignaturas de la materia, y son fijos para todo el curso. Para cada asignatura deben realizar en equipo diferentes actividades evaluables, que se resumen en la tabla 2.

Tabla 2: actividades realizadas en equipo

\begin{tabular}{l|l}
\hline Actividad & N \\
\hline $\begin{array}{l}\text { Redactar documento con la resolución de un problema propuesto de } \\
\text { cada tema. }\end{array}$ & 6 documentos \\
$\begin{array}{l}\text { Realizar la presentación de la resolución de los problemas en el aula } \\
\text { ante sus compañeros y profesores. }\end{array}$ & 6 presentaciones \\
$\begin{array}{l}\text { Realización de la parte experimental de las prácticas al laboratorio y } \\
\text { Elaboración de las memorias de las prácticas. }\end{array}$ & 6 prácticas \\
& 6 documentos
\end{tabular}

Estas actividades realizadas en equipo suponen el $20 \%$ en el grado de Ingeniería del Diseño Industrial y 35\% de la calificación de la asignatura en el grado en Ingeniería Electrónica y Automática Industrial.

De las dimensiones competenciales que trabajamos, indicamos en la tabla 3 las que se trabajan con cada actividad.

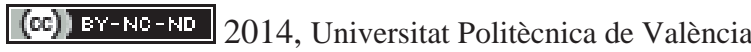

I Jornadas IN-RED (2014) 
Trabajo en equipo: una oportunidad para adquirir dimensiones competenciales

Tabla 3: dimensiones y actividades en equipo

\begin{tabular}{|c|c|c|c|}
\hline Dimensión & Documentos & Presentació pública & Laboratorio \\
\hline $\begin{array}{l}\text { DC6 Trabajo en } \\
\text { equipo y liderazgo }\end{array}$ & Fundamental & Fundamental & Fundamental \\
\hline $\begin{array}{l}\text { DC7 Responsabili- } \\
\text { dad ética y profesio- } \\
\text { nal }\end{array}$ & Corresponsabilidad & Corresponsabilidad & Corresponsabilidad \\
\hline $\begin{array}{l}\text { DC8 Comunicación } \\
\text { efectiva }\end{array}$ & $\begin{array}{l}\text { Redacción de do- } \\
\text { cumento académico }\end{array}$ & $\begin{array}{l}\text { Presentación y ex- } \\
\text { presión oral }\end{array}$ & \\
\hline $\begin{array}{l}\text { DC9 Pensamiento } \\
\text { crítico }\end{array}$ & & $\begin{array}{l}\text { Evaluación de otros } \\
\text { equipos }\end{array}$ & \\
\hline $\begin{array}{l}\text { DC12 Planificación y } \\
\text { gestión del tiempo }\end{array}$ & $\begin{array}{l}\text { Organización } \\
\text { trabajo }\end{array}$ & $\begin{array}{l}\text { Preparación y tiempo } \\
\text { de presentación }\end{array}$ & $\begin{array}{l}\text { Organización } \\
\text { trabajo }\end{array}$ \\
\hline
\end{tabular}

El resto de la calificación la obtienen mediante trabajo individual. El trabajo en equipo de los alumnos se basa, por tanto, en dos pilares principales: por una parte en la resolución de problemas en equipo y, por otra parte, el trabajo en el laboratorio. Para controlar este proceso, el trabajo de los alumnos se desarrolla en las prácticas de aula con dos profesores que intervienen simultáneamente en clase y en las prácticas de laboratorio se incorpora un tercer profesor, dado que se realiza en un aula laboratorio con capacidad para todo el grupo. De esta forma se asegura una atención personalizada para cada equipo y alumno.

\section{Resultados del trabajo en equipo}

Aportamos tres valoraciones hechas con metodoloía diferente del trabajo en equipo: comparamos los resultados del trabajo en equipo con el trabajo individual (exámenes escritos y exámenes on-line, en los que el grupo ha estado trabajando en los últimos años [VIDAURRE, 2011, 2011, 2012; ARDID, 2012]), valoramos mediante rúbrica la evolución a lo largo del curso de una de las competencias y analizamos los resultados de una encuesta de opinión de los alumnos sobre el trabajo en equipo.

\subsection{Resultados del trabajo en equipo $v s$ trabajo individual}

En un primer paso se procedió a evaluar los resultados globales de los trabajos realizados en equipo comparándolos con las calificaciones obtenidas por los mismos alumnos en las tareas individuales. En la tabla 4 se puede apreciar que la media del trabajo individual es muy similar en las dos titulaciones (sobre 6.6), igual que la media del trabajo en equipo (alrededor de 8 puntos). El trabajo individual presenta mayor variabilidad que el trabajo en equipo. En ambos casos existe una tendencia al alza de la puntuación de los trabajos en 
equipo respecto a los individuales (sobre 1.5 puntos). Por tanto, en las dos titulaciones se puede apreciar un efecto similar de la metodología, lo cual parece indicar que el resultado de la metodología de trabajo en equipo parece ser independiente del profesorado concreto que la lleve a cabo y de la titulación.

Tabla 4: Media (M) y Desviación típica (D) del trabajo individual, del trabajo por equipos para el número de alumnos $(\mathrm{N})$ de diversas titulaciones para el curso 2012-2013.

\begin{tabular}{l|c|c|c|c|c}
\hline $\begin{array}{c}\text { 2012-2013 } \\
\text { grados }\end{array}$ & $\mathbf{N}$ & $\begin{array}{c}\text { M trabajo } \\
\text { individual }\end{array}$ & $\begin{array}{c}\text { D trabajo } \\
\text { individual }\end{array}$ & M equipo & D equipo \\
\hline Diseño & 135 & 6.56 & 1.54 & 8.15 & 1.28 \\
Electrónicos & 159 & 6.61 & 1.52 & 7.95 & 1.38
\end{tabular}

Al comparar los resultados individuales, figura 1, podemos observar como la calificación del trabajo en equipo tiene un mayor sesgo hacia valores superiores cuanto menor es la calificación del trabajo individual. Esta afirmación se puede deducir y cuantificar fácilmente a partir de las líneas verde y roja de la figura 1, correspondiente a la mejor recta de regresión y a la recta $\mathrm{y}=\mathrm{x}$ respectivamente.
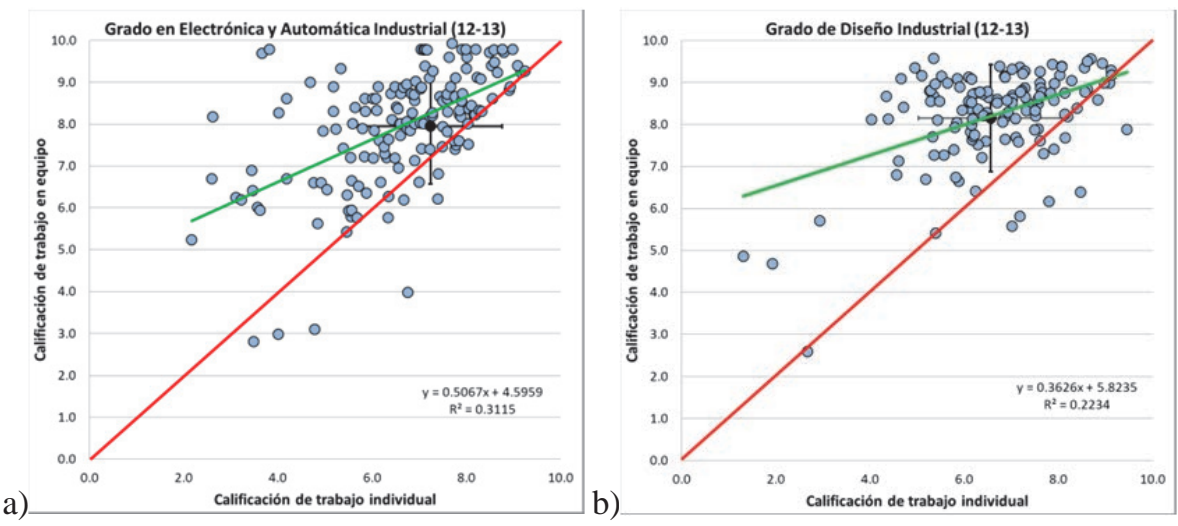

Fig. 1: a) Calificación en equipo frente calificación individual para los estudiantes del grado en Ingeniería Electrónica y Automática Industrial, y b) para los estudiantes del grado en Ingeniería del Diseño. En negro el valor promedio con las barras de la desviación típica. Línea roja $y=x$. Línea verde la recta de regresión.

Se puede concluir que, en líneas generales, existe una correlación entre las calificaciones individuales y las de equipo, en especial entre los alumnos de calificaciones medias-altas. Esta correlación indica que el trabajo en equipo también valora el aprendizaje individual de cada uno de los miembros del grupo, en especial de los que obtienen calificaciones de

\section{(c) EY-NC-ND 2014, Universitat Politècnica de València}

I Jornadas IN-RED (2014) 
aprobado o superior. En los alumnos con peores resultados individuales, el trabajo en equipo mejora sus resultados y beneficia su calificación final.

\subsection{Medida de los resultados en dimensiones competenciales: La comunicación efecti- va de forma escrita.}

Para observar de forma objetiva la evolución de La comunicación efectiva de forma escrita a lo largo del curso, y ver el efecto sobre ellas del trabajo en equipo, se decidió el uso de la rúbrica [ARDID, 2014] . Este método de evaluación está ampliamente contrastado para esta finalidad [HUI-JUNG, 2013; SHANDLE, 2012]. A partir de diferentes ejemplos [FORMANDO ESCRITORES...,2014] se elaboró una rúbrica con las siguientes categorías y pesos:

Tabla 5: Rúbrica para evaluación de ejercicios de Prácticas de Aula.

\begin{tabular}{l|c}
\hline \multicolumn{1}{c|}{ CATEGORÍA } & PESO \% \\
\hline PRESENTACIÓN Y ORGANIZACIÓN & 10 \\
REDACCIÓN GRAMATICAL & 10 \\
DESARROLLO MATEMÁTICO (expresión matemática), DIAGRAMAS Y & 40 \\
DIBUJOS & 40 \\
DOMINIO Y COMPRENSIÓN DEL TEMA & 4
\end{tabular}

Cada categoría se dividía en cinco niveles con valor 10, 8, 5, 2 y 0 puntos.

Para el ensayo se escogieron los seis trabajos (documentos en los que se desarrolla un ejercicio propuesto) realizados por cuatro equipos escogidos: uno con alumnos académicos de la zona baja, dos de la zona intermedia y otro de calificaciones altas. Para contrastar la evaluación de nuestra rúbrica, dos evaluadores, que analizaron conjuntamente cómo aplicar la rúbrica, revisaron los trabajos valorando cada categoría, con lo que se obtuvo una calificación promedio de los trabajos de cada equipo.

En la figura 2 se comparan las valoraciones realizadas por los dos evaluadores, la calificación final (Fig 2a) y la de una de las categorías, la A (Fig 2b). En todas las categorías y en todos los ejercicios evaluados, las diferencias de valoración entre los dos evaluadores eran como máximo de un nivel. Los resultados están de acuerdo con el objetivo de la rúbrica: clarificar los aspectos evaluables y objetivar al máximo las evaluaciones. 

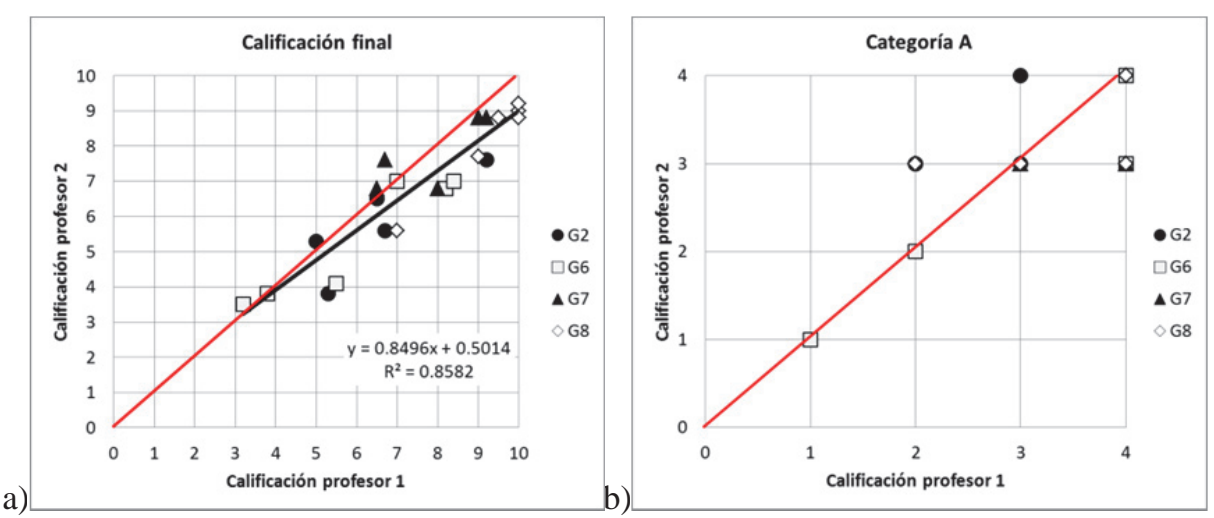

Fig. 2: a) Comparación de la calificación de los 6 documento de los equipos (G2, G6, G7 y G8) realizada por los dos evaluadores, linea en rojo $x=y$, linea de regresión en negro. $b$ ) Comparación de la valoración de la categoría A de los 6 documento de los equipos realizada por los dos evaluadores.

En la figura 3 podemos observar la evolución, desde el primer documento al sexto, de la calificación promedio de todos los equipos.

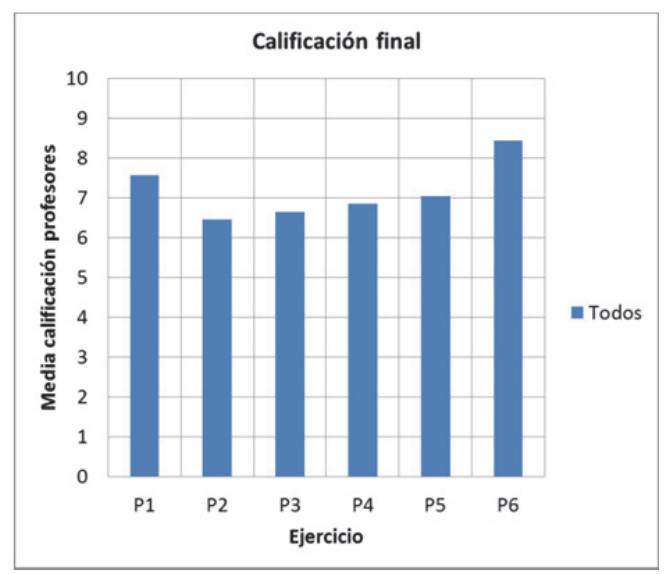

Fig. 3: Calificación promedio de los 6 documento de los equipos .

Excepto en el caso del equipo con calificaciones más altas (con una valoración excelente en todos los trabajos que sube la media del primer documento, en todos los casos analizados la tendencia es hacia la mejora con el transcurso del tiempo, tanto en la calificación final como en todas las categorías de nuestra rúbrica. El trabajo en equipo parece mejorar la competencia Comunicación efectiva de forma escrita.

\section{(c)) EY-NC-ND 2014, Universitat Politècnica de València}

I Jornadas IN-RED (2014) 
Trabajo en equipo: una oportunidad para adquirir dimensiones competenciales

Teniendo en cuenta estos resultados, pensamos que la metodología que hemos empleado, trabajo en equipo y evaluación de competencias mediante rúbrica, puede ser también útil para la evaluación del resto de competencias transversales.

\section{3. ¿Qué opinan los alumnos? Resultados de la encuesta sobre el trabajo en equipo.}

Se realizó una encuesta anónima a los alumnos que habían trabajado en equipos en los grados de Diseño Industrial (IDI), Ingeniería Aeroespacial ( IAE) e Ingeniería Electrónica y Automática(IEA). La encuesta fue contestada por 59, 44 y 43 alumnos respectivamente. Las preguntas se estructuraron en cuatro bloques, detallados en la tabla 6.

Tabla 6: bloques de preguntas de la encuesta

\begin{tabular}{ll}
\hline & Bloque \\
\hline A & Sobre el método de trabajo \\
B & Pros y contras del trabajo en equipo \\
C & Opinión sobre el resultado del trabajo en equipo \\
D & Valoración sobre el papel del profesor
\end{tabular}

Las preguntas están recogidas en la tabla 7. A estas preguntas hay que añadir una pregunta abierta que también se incluyó en la encuesta para que los alumnos dieran su opinión sobre el funcionamiento del trabajo en equipo.

Tabla 7: Preguntas de la encuesta de opinión sobre el trabajo en equipo.

\begin{tabular}{l|l}
\hline & Pregunta \\
\hline PA1 & En promedio, ¿Con qué frecuencia os habéis reunido? \\
PA2 & Todos los miembros del grupo suelen acudir a las reuniones. \\
PA3 & Las reuniones han estado bien organizadas. \\
PA4 & Se ha empleado comunicación telemática. \\
PB5 & Los conflictos surgidos en el grupo se han resuelto satisfactoriamente. \\
PB6 & Me he sentido a gusto en el grupo. \\
PB7 & Me he sentido apoyado por mis compañeros. \\
PB8 & Con el trabajo en grupo he obtenido mejores resultados que trabajando en solitario. \\
PC9 & El trabajo en grupo ha contribuido a mejorar mi formación. \\
PC10 & Considero que, aproximadamente, todos los componentes del grupo han contribui- \\
& do por igual. \\
PC11 & La puesta en común y discusión de las aportaciones individuales ha mejorado el \\
& resultado final del trabajo.
\end{tabular}


PC12 Considero que el trabajo en grupo ha sido eficaz.

PD13 Las instrucciones relativas al trabajo en grupo dadas por el profesor han sido claras y precisas.

PD14 Nos hemos sentido suficientemente guiados por el profesorado.

PD15 Considero que el trabajo en grupo ha sido adecuadamente valorado.

La primera pregunta trata sobre la frecuencia con la que se realizaban las reuniones de trabajo. En la figura 4a observamos que el promedio está sobre una reunión cada 10-11 días (dando un peso de 30 a mensualmente, 15 quincenalmente, 7 semanalmente y 3.5 a varias veces por semana). La mayoría se reúnen cada semana o quincenalmente, excepto en el grado de IEL, en los que un $35 \%$ se reúnen varias veces por semana (Fig 4b). Este resultado nos indica que en este grado un buen número de alumnos ha utilizado el trabajo en equipo de manera destacada, y presumiblemente para hacer un trabajo completo de las asignaturas contempladas.
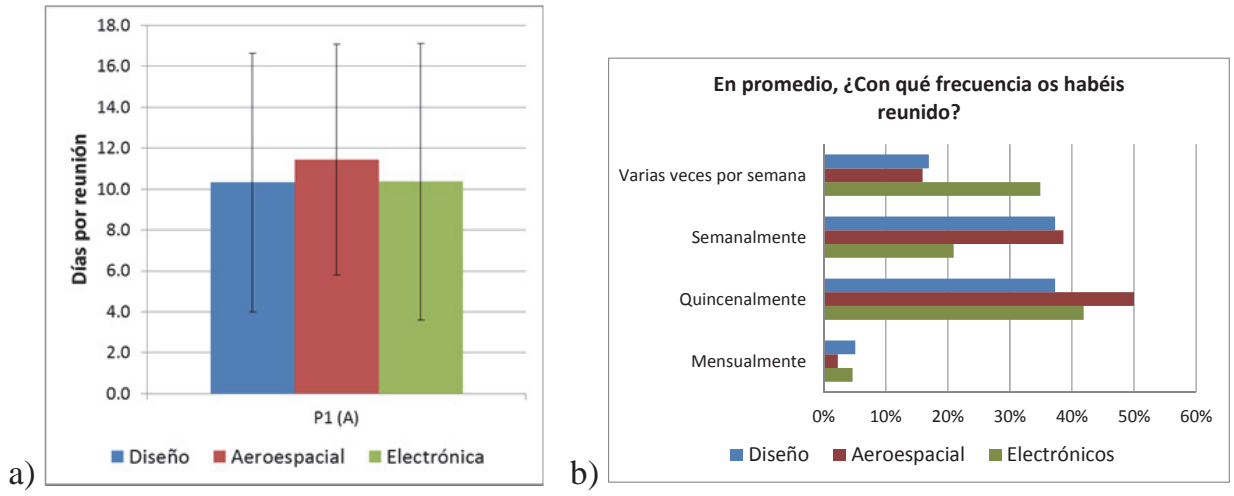

Figura 4: frecuencia de las reuniones de los equipos a) distribución de las reuniones y b) promedio de frecuencia de reuniones y su desviación típica.

Para una primera valoración de los resultados de la encuesta, hemos calculado el valor de las respuestas dándole a cada opción un peso (10 a Totalmente de Acuerdo, 7.5 De Acuerdo, 5 a Valoración Intermedia, 2.5 a Desacuerdo, y 0 a Totalmente en desacuerdo). Los resultados, con la desviación típica, son los de la figura 5. Podemos observar una cierta dispersión en las valoraciones de las respuestas de cada titulación excepto en la pregunta PA4 y en las tres últimas preguntas (PD13, PD14 y PD15). Las respuestas de IAE e IDI tienen una buena valoración, entre 7.5 y 8.5, en los bloques A y B (metodología de trabajo y pros y contras), mientras que las respuestas de IEA son muy críticas con valoraciones alrededor de 5 puntos. En la afirmación PB8, Con el trabajo en grupo he obtenido mejores

(c) EY-NC-ND 2014, Universitat Politècnica de València

I Jornadas IN-RED (2014) 
Trabajo en equipo: una oportunidad para adquirir dimensiones competenciales

resultados que trabajando en solitario, coinciden en la valoración baja IDI y IEA, mientras que IAE tiene una valoración positiva de 8 puntos.

Las preguntas PD13, PD14 y PD15 son las relacionadas con el papel del profesor, y en ellas los alumnos de las tres titulaciones están totalmente de acuerdo: valoran por igual que los profesores han dado instrucciones claras, han guiado el trabajo y lo han valorado adecuadamente con una media por encima de 6 puntos y una desviación típica sobre 2 puntos.

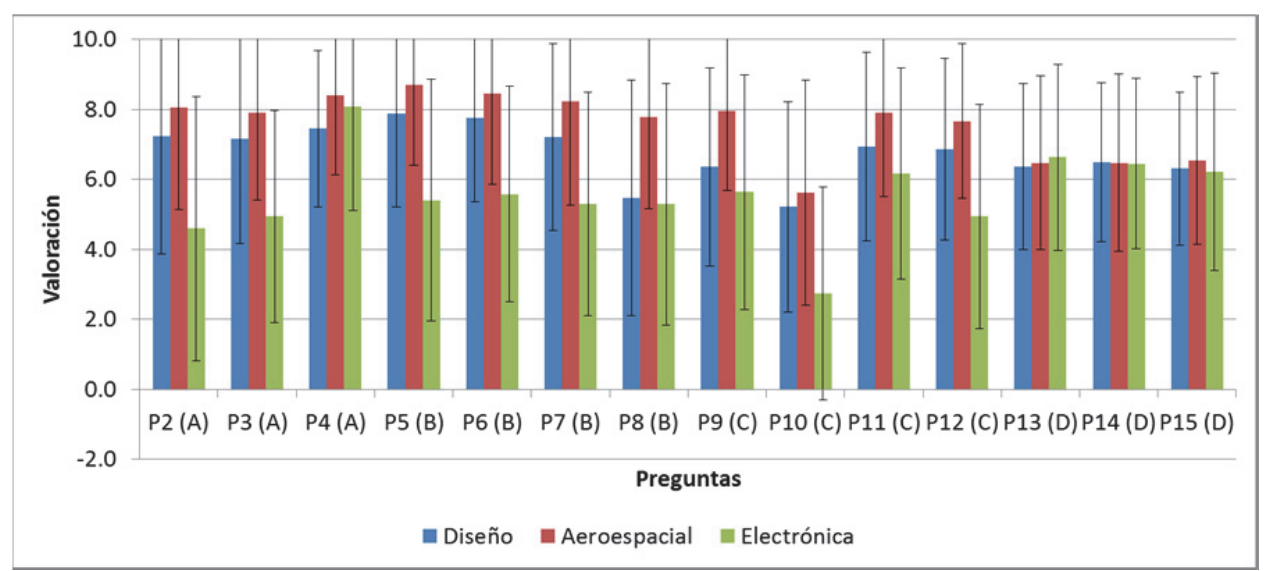

Fig 5.Promedio de las respuestas de cada titulación a las preguntas de la encuesta

Para ver con más detalle este dato, en la figura 6 se muestra el resultado a la pregunta 15: Considero que el trabajo en grupo ha sido adecuadamente valorado. Podemos observar como entre el $52 \%$ y el $65 \%$ estan de acuerdo o totalment de acuerdo con la afirmación, y precisamente el grupo más crítico con el trabajo en equipo, Electrónicos, es el que da un mayor porcentaje de acuerdo en este item (aunque la valoración promedio es ligeramente superior en IAE como vemos en Fig 5).

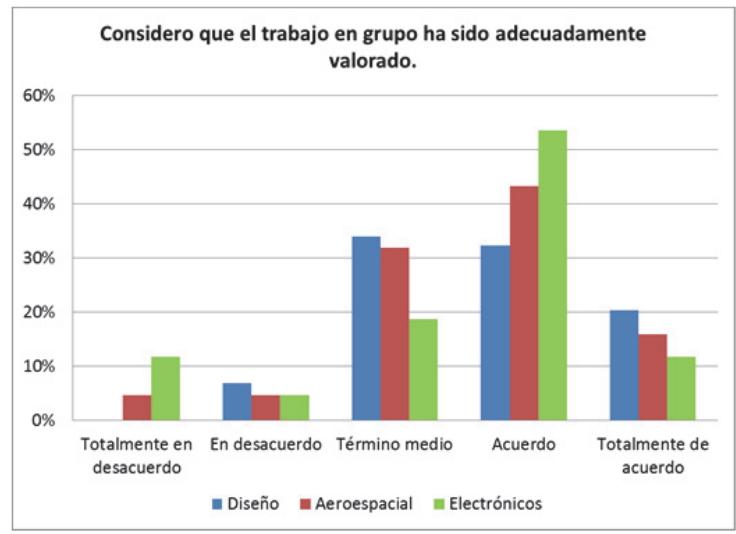

Fig 6. Respuestas a la afirmación sobre la valoración del trabajo en equipo.

(c)) EY-NC-ND 2014, Universitat Politècnica de València

I Jornadas IN-RED (2014) 
La pregunta PA4, en la que también hay coincidencia en las tres titulaciones, trata sobre el uso de la comunicación telemática. En la figura 7 podemos observar como en las tres titulaciones más del $75 \%$ están de acuerdo o totalmente de acuerdo con la afirmaciónEste resultado está en consonancia con la información obtenida directamente de los alumnos al formarse los equipos sobre el tipo de sistema de comunicación que utilizarían: WhatsApp, Dropbox y Drive eran, en todos los casos, los medios para comunicarse e intercambiar documentos (sorprendentemente el correo electrónico no se mencionó). Tambien reafirma el resultado un muestreo hecho en clase con 70 alumnos: el 100\% tenían Smartphone y lo podía conectar sin problemas a la Wi-Fi del aula y entraba en la plataforma Poli[formaT] de la universidad.

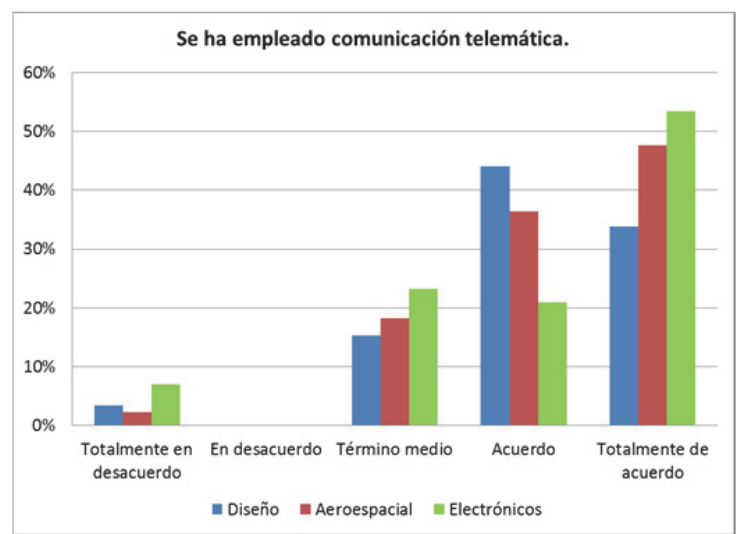

Fig 7. Respuestas a la afirmación sobre el uso de comunicación telemática.

En la Fig. 5 destaca por su baja valoración la afirmación P10, sobre si el trabajo ha sido equilibrado entre los componentes del equipo. En la figura 8 vemos con más detalle las respuestas: en particular para el caso IEA, en donde las reuniones han sido más frecuentes, casi el 50\% está totalmente en desacuerdo con la afirmación. Éste es un punto crítico en el que se debe trabajar para poder mejorar el método, y parece necesaria una mayor motivación de la importancia del trabajo de equipo en la formación de los alumnos, así como una mayor supervisión del profesor para que se equilibre el trabajo de todos. 


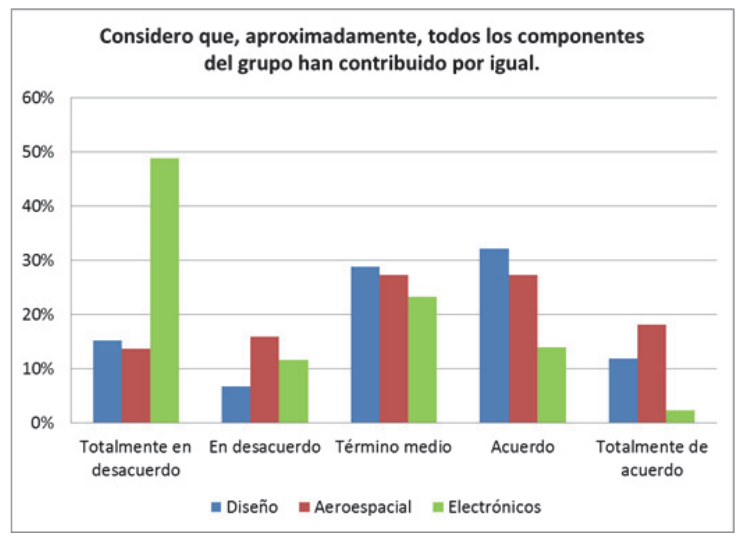

Fig 8. Respuestas a la afirmación sobre que todos los componentes del grupo han contribuido por igual.

Las respuestas a la pregunta abierta, Añade cualquier comentario que consideres relevante y no haya sido tratado en las preguntas anteriores, necesita un trabajo posterior de análisis, que se complementará con la preparación y realización de entrevistas individuales y en grupo. Esta parte del trabajo está pendiente de realización.

\section{Conclusiones}

De los resultados obtenidos en el trabajo, se pueden obtener distintas conclusiones.

Respecto a la relación entre trabajo individual/equipo, en líneas generales, existe una correlación entre las calificaciones individuales y las de equipo, en especial entre los alumnos de calificaciones medias-altas.

La utilización del trabajo en equipo y evaluación de competencias mediante rúbrica ha sido una metodología útil de la evaluación de la competencia "comunicación efectiva de la forma escrita ", y puede resultar una metodología adecuada para evaluar el resto de competencias transversales.

Por último, la valoración de los alumnos del trabajo en grupo ha sido positiva. Destaca, sin embargo, sus dudas sobre el reparto equitativo del trabajo entre los componentes del grupo.

Este resultado marca una necesaria línea de actuación del profesorado, via orientación y "profesionalización" del concepto de "trabajo en equipo", y en último caso, si lo anterior no fuera suficiente, exigiría un seguimiento para la corrección de comportamientos insolidarios. 
Los resultados de la encuesta de opinión sobre el trabajo en equipo merecen ser matizados. Los resultados de la pregunta abierta, que no han sido mostrados, y posteriores entrevistas con los alumnos, serán objeto de un trabajo posterior.

\section{Agradecimientos}

Este trabajo se ha realizado con la financiación de la convocatoria de 2013 de Proyectos de Innovación y Mejora Educativa (PIME) de la Universitat Politècnica de València (referencia B10-13).

\section{Referencias bibliográficas}

ARDID RAMÍREZ, M.; VIDAURRE, A.; SALINAS, I.; RIERA, J.; MONSORIU, J.A.; MESEGUER, J.M.; GÓMEZ-TEJEDOR, J.A.; GIMÉNEZ, M.H. International Conference on Education and New Learning Technologies, Barcelona (2012) 2927.

ARDID RAMÍREZ, M.; PAULA CUENCA GOTOR, V.; GÓMEZ-TEJEDOR, J.A.; MESEGUERDUEÑAS, J.M.; MOLINA MATEO, J. ; RIERA GUASP, J.; SALINAS MARÍN, I.; VIDAURRE GARAYO, A. CUIEET 2014. XXII Congreso Universitario de Innovación Educativa en las Enseñanzas Técnicas. Almaden, 2014

FORMANDO ESCRITORES EN LA UNIVERSIDAD. PROYECTO DE INNOVACIÓN: La evaluación formativa de la competencia en comunicación oral y escrita en el primer curso del grado de logopedia de la UCLM. <http://g6logopediauclm.blogspot.com.es/p/rubricas.html> (Consulta 20-052014)

HUI-JUNG, C.; JUI-LIN, S.; CHIN-CHENG, C.; YEUN-MIN, T.; MEI-HUNG, C. Journal of Chemical Education 90 (2013) 1296

LIAO, C.H.; YANGT, M.H.; YANG, B.C. Journal of Computer Assisted Learning 29 (2013) 530

JOHNSON, D.; JOHNSON, J.; HOLUBEC, Y.E. "El aprendizaje cooperativo en el aula" Paidós (1999)

NOONAN, M. Nurse Education Today 33 (2013) 1422

SAKAI. <http://www.sakaiproject.org/> (Consulta 20-05-2014)

SHANDLE, S.E.; BROWN, E.C.; TOWNS, M.H.; WARNER, D.L. Journal of Chemical Education 89 (2012)319-325

VIDAURRE , A.; ARDID, M.; GIMÉNEZ, M.H. ; GÓMEZ, J.A.; MANJÓN, F.J. ; MESEGUER, J.M.; MONSORIU, J.A.; RIERA, J. 5th International Conference of Education, Research and Innovation, Madrid (2012) 784.

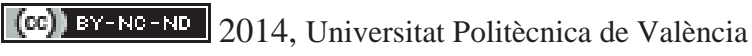

I Jornadas IN-RED (2014) 
Trabajo en equipo: una oportunidad para adquirir dimensiones competenciales

VIDAURRE, A.; SALINAS, I.; RIERA, J.; MONSORIU, J.A.; MESEGUER, J.M.; GÓMEZ, J.A.; GIMENEZ, M.; ARDID, M. I Congreso Internacional sobre Aprendizaje, Innovación y Competitividad, Madrid (2011)

VIDAURRE, A.; RIERA, J.; MONSORIU, JA.; MESEGUER, J.M.; GIMÉNEZ, M.H.; ARDID, M. III Jornada Nacional sobre Estudios Universitarios, Castellón (2011).

UPV. Dimensiones Competenciales. <http://www.upv.es/contenidos/ICEP/info/ DimensionesCompetenciales.pdf $>$ (Consulta 20-05-2014)

(c)) EY-NC-ND 2014, Universitat Politècnica de València I Jornadas IN-RED (2014) 
Jornadas In-Red 2014

Universitat Politècnica de València

\title{
El Aprendizaje Activo en Primer Curso de Ingeniería desde la Perspectiva de los Estudiantes
}

\author{
Inmaculada BAUTISTA ${ }^{\mathrm{a}}$, Julia ATIENZA ${ }^{\mathrm{a}}$; M $^{\mathrm{a}}$ José CLIMENT $^{\mathrm{a}}$, Sara IBORRA ${ }^{\mathrm{a}}$, \\ Isabel MORERA ${ }^{\mathrm{a}}$ y Amparo RIBES $^{\mathrm{b}}$
}

ảDepartamento de Química: ibautista@qim.upv.es, matien@qim.upv.es, mjcliol@qim.upv.es, siborra@itq.upv.es, $\underline{\text { imorera@ upvnet.upv.es, }}{ }^{\mathrm{b}}$ Departamento de Máquinas y Motores Térmicos: aribes@ter.upv.es

GRUPO DE INNOVACIÓN E INVESTIGACIÓN EN METODOLOGÍAS ACTIVAS (GIIMA)

Universitat Politècnica de València. Camino de Vera s/n. 46071-València

\begin{abstract}
The present work analyses the assessment carried out by students on the first course of the different Degrees taught at the Universitat Politècnica de València on the use of the different techniques of active and cooperative learning as tools for skills training. A questionnaire was performed to find out their opinion regarding the degree of satisfaction and the usefulness for learning of the teaching-learning activities carried out as well as a questionnaire of critical incidents regarding the Professor's teaching performance and the student involvement. From the data assessment it can be highlighted that the students appreciate the teacher's work on the design and implementation of learning-based methodologies. Also they are particularly pleased to be actively involved and that it is a tool very useful for learning. Regarding the cooperative learning in teams, opinions differ depending on the degree of autonomy of the student and the difficulty of the tasks to be performed: the students positively value problems solving and are more reluctant when they have to develop and present their work orally. This experience has allowed us to identify the strengths and weakness points and to obtain the necessary feedback to redirect and adapt the approaches used.
\end{abstract}

Keywords: Active and Cooperative Learning, engineering first courses, classroom research.

(c) EY-NC-ND 2014, Universitat Politècnica de València

I Jornadas In-Red (2014) 


\begin{abstract}
Resumen
En este trabajo se analiza la valoración que realizan estudiantes de primer curso de diferentes títulos de Grado, que se imparten en la Universitat Politècnica de València, sobre el uso de diferentes técnicas de aprendizaje activo y cooperativo, como herramientas para su formación en competencias. Se ha realizado un cuestionario para conocer su opinión respecto al grado de satisfacción y la utilidad para el aprendizaje sobre las actividades de enseñanza-aprendizaje realizadas, así como un cuestionario de incidencias críticas, sobre la actuación docente del profesor y la implicación del estudiante. Del análisis de datos se puede destacar que los alumnos aprecian la labor del profesor en el diseño y aplicación de metodologías basadas en el aprendizaje, que se muestran especialmente satisfechos de participar activamente y que les es de mucha utilidad para aprender. Respecto al aprendizaje cooperativo en equipos existen opiniones diversas, en función del grado de autonomía del estudiante y de la dificultad de las tareas a realizar: valoran positivamente la resolución de problemas y se muestran más reacios cuando han de elaborar trabajos y exponerlos oralmente. Esta experiencia nos ha permitido detectar puntos fuertes y débiles y obtener la retroalimentación necesaria para reorientar y adaptar las estrategias metodológicas utilizadas.
\end{abstract}

Palabras clave: Investigación en el aula, primer curso, aprendizaje activo, estudiantes de ingeniería

\title{
1.Introducción
}

La Universidad está inmersa en un proceso de cambio en el que se encuentran implicados los estudiantes, que deben asumir el papel de protagonistas de su propio aprendizaje, los profesores, que tenemos el reto de reorientar la formación de acuerdo con la realidad social y las demandas del mercado laboral, y las instituciones, que han de proporcionar las condiciones para que se pueda llevar a cabo un proceso de enseñanza-aprendizaje de calidad. Todo ello implica cambios significativos que hemos de diseñar, aplicar, gestionar, analizar y evaluar. Si tenemos en cuenta que uno de los principales objetivos de ese cambio, según el Proyecto Tuning, es el desarrollo y consolidación de competencias instrumentales, interpersonales y sistémicas que permitan a los individuos en formación el acceso al mundo laboral con una mejor capacitación, desde las instituciones se debería fomentar y sistematizar la aplicación de determinadas acciones que posibiliten la adquisición de dichas 
competencias en el ámbito del proceso de enseñanza-aprendizaje centrado en la participación activa de los estudiantes (Rust, 2002).

Numerosas investigaciones muestran que los alumnos tienen distintas formas de orientar su aprendizaje: el aprendizaje superficial, en el que el estudiante memoriza conocimientos desconectados que debe reproducir posteriormente, y el aprendizaje profundo donde el estudiante conecta ideas y conceptos, piensa e integra contenidos y tareas, y encuentra el sentido de lo que esta aprendiendo (Gibbs, 1992). Para que exista un aprendizaje profundo se requiere de motivación e implicación del alumno, que se consigue mediante la implementación de una metodología de enseñanza centrada en el estudiante y sistema de evaluación acorde con la misma. La enseñanza centrada en el estudiante es, en esencia, cualquier método de enseñanza orientado a conseguir el compromiso de los alumnos en su proceso de aprendizaje. La actividad del estudiante y su compromiso en el proceso de aprendizaje dentro y fuera del aula es, por tanto, la base del aprendizaje activo. En este contexto se requiere de un cambio en los hábitos de enseñanza del profesorado, que deben orientarse hacia un análisis del modo en que los estudiantes aprenden para diseñar métodos adaptados a los diferentes perfiles de estos y buscar herramientas que le permitan establecer un diagnóstico del grado de consecución de los objetivos de aprendizaje.

La tarea de enseñar en primer curso en la Universidad es compleja, tanto por la heterogeneidad en el nivel de conocimientos de los alumnos de nuevo ingreso como por la discrepancia entre sus expectativas y la realidad con que se encuentran. Para el profesorado implicado en la docencia es importante tener información del impacto de la metodología empleada sobre el aprendizaje del alumno y, en primer curso, todavía más. Analizar el impacto de esta acción y reflexionar sobre las mejoras metodológicas ensayadas es una acción necesaria y en este sentido el Grupo de Innovación e Investigación en Metodologías Activas (GIIMA) estamos recopilando esta información a partir de varios proyectos de investigación orientados a implementar el aprendizaje activo en asignaturas de primer curso. Uno de los objetivos de la investigación se centra en obtener de los estudiantes la retroalimentación necesaria para reorientar y adaptar las estrategias metodológicas utilizadas, para ello, es importante conocer la visión que tienen los estudiantes acerca de la realidad educativa en la que están inmersos.

Las encuestas de satisfacción del alumnado (Lawall, 1998) son una importantísima fuente de información y de mejora continua y permiten analizar la percepción de los usuarios directos de la enseñanza y replantear la metodología docente, las actividades propuestas y los recursos utilizados (Prince, 2004). Así, en esta comunicación se presenta información acerca de la reflexión y opinión que, sobre la innovación metodológica basada en la práctica del aprendizaje activo, hacen más de 350 estudiantes de diversas asignaturas de primer curso de Grado, que se imparten en varios títulos en la Universitat Politècnica de València

\section{(c)) EY-NC-ND 2014, Universitat Politècnica de València}

I Jornadas IN-RED (2014) 


\section{Objetivos}

Los objetivos de la comunicación son:

- Analizar la valoración que hacen los estudiantes de primer curso de Grado sobre el uso de diferentes técnicas de aprendizaje activo y cooperativo.

- Reflexionar sobre el impacto de la introducción de estrategias metodológicas activas en la motivación y el aprendizaje de los estudiantes.

- Divulgar la experiencia realizada para dinamizar su uso en otras asignaturas en entornos similares.

\section{Desarrollo de la innovación}

La innovación se ha llevado a cabo en diferentes asignaturas de primer curso de varios títulos de Grado que se imparten en la Universitat Politècnica de València, como puede verse en la Figura 1.

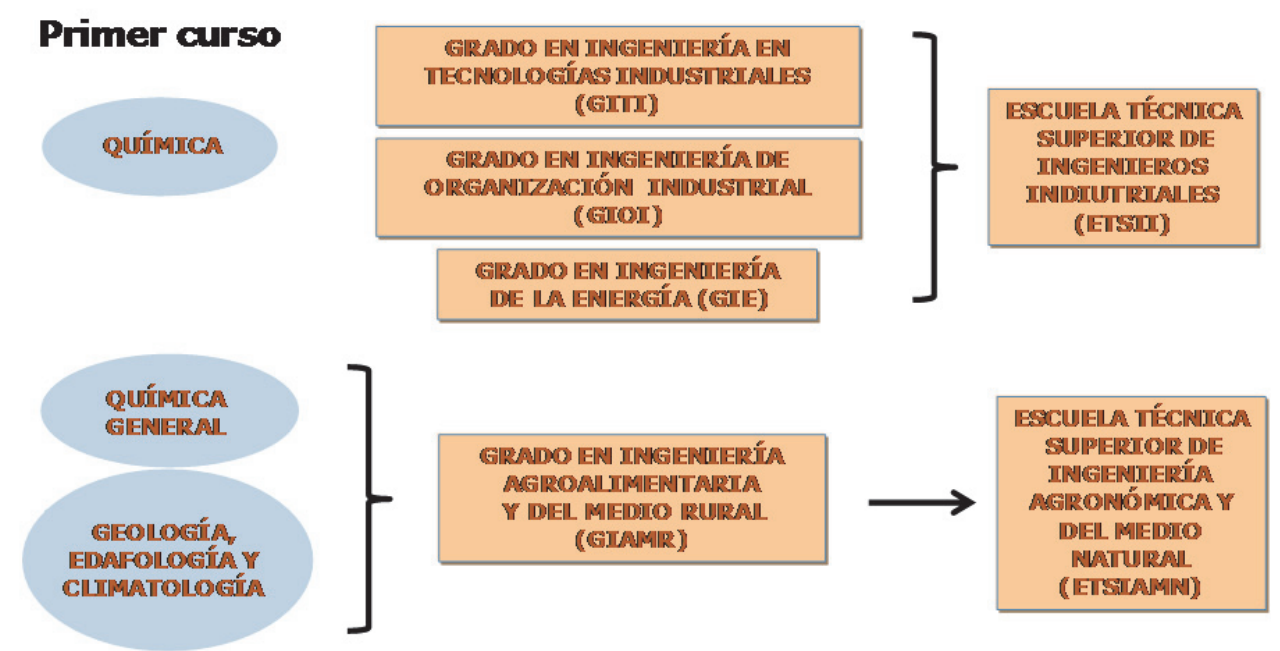

Fig 1. Contexto de las asignaturas y títulos en los que se ha realizado el estudio

Las asignaturas "Química" y "Química general" tiene asignados 6 créditos ECTS y la "Geología, Edafología y Climatología" 9 créditos y se incluyen como formación básica en primer curso. Una caracterísica importante y común en todas ellas es el elevado número de alumnos. Respecto a la ubicación es de destacar que la asignatura "Química" del GIOI y

(c)) BY-NC-ND 2014, Universitat Politècnica de València 
"Química general" del GIAMR se imparten en el primer cuatrimestre. La asignatura "Química” de GIE y GITI se imparte en el segundo cuatrimestre y "Geología, Edafología y Climatología” es anual. En algunas titulaciones existe más de un grupo, y en ese caso, se ha valorado la opinión de los alumnos del grupo impartido por el profesor perteneciente al GIIMA.

La elección de estas asignaturas como objetivo de innovación e investigación educativa se basa en la propia práctica docente de varios de los profesores del equipo GIIMA, y en la experiencia conjunta adquirida por todo el equipo en la formación y aplicación de diferentes métodos y técnicas activas de enseñanza-aprendizaje, en diferentes ámbitos.

La experiencia de los autores en la docencia de primer curso nos ha permitido constatar que en las titulaciones técnicas, ingresan estudiantes procedentes de diferentes opciones de Bachillerato, con niveles de formación en las asignaturas básicas muy heterogéneos y además, algunos llegan a los Grados sin haberlos elegido como primera opción. La situación llega a tal extremo que los alumnos pueden no haber cursado asignaturas en Bachiller, que en los actuales títulos de Grado Universitario de la Politécnica son de formación básica y se incluyen en el Plan de Estudios en primer curso; este es el caso por ejemplo de la asignatura de Química. Por todo ello, bastantes estudiantes se encuentran en una situación a la que les resulta difícil adaptarse, bien porque no es acorde a sus expectativas o porque les falta, en ocasiones, el nivel formativo básico requerido para llevar adelante los estudios en que se encuentran matriculados. Esto les lleva, en algunos casos, a entrar en un círculo que empieza con la pérdida de interés por el aprendizaje de las materias del título, sigue con la desmotivación y la falta de asistencia a clase y termina con el abandono de los estudios.

Los métodos de enseñanza y evaluación que utilizan los profesores influyen enormemente en el modo de aprender de sus alumnos y en su rendimiento académico (Gargallo, 2008 y 2010). Este aspecto es muy importante teniendo en cuenta la necesidad de que en la Universidad se consiga una elevada tasa de éxito en primer curso y se motive a los alumnos recién ingresados para desarrollar una carrera universitaria comprometida y eficaz.

En este sentido el GIIMA ha trabajado en diferentes Proyectos de Innovación y Mejora Educativa (PIME) poniendo el énfasis en introducir mejoras metodológicas, en asignaturas de primer curso, basadas en el aprendizaje activo. (PIME A008/10, PIME A24/11 y PIME A18/12). Como objetivo principal nos propusimos diseñar e implementar técnicas activas, atendiendo a la diversidad de niveles de formación previa de los alumnos de cada título (Morera, 2012). Se pusieron en marcha diversas innovaciones contextualizadas en función de las características de los grupos y de los docentes, destinadas a fomentar la participación activa del estudiante en el aula.

En los Grados de la ETSII, donde los contenidos de las asignaturas eran iguales el

\section{(c)) EY-NC-ND 2014, Universitat Politècnica de València}

I Jornadas IN-RED (2014) 
proceso se abordo de forma conjunta. Frente a la diversidad de formación de los alumnos en el aula se propuso la implementación de la clase magistral participativa, que propicia la interacción profesor-alumno. Se optó por un modelo del aprendizaje cooperativo, que permite la interacción alumno-alumno, para lo cual se planificaron una serie de tareas que se desarrollan en equipos de trabajo. Las tareas a realizar son de dos tipos: la resolución de problemas en grupo, que el profesor corrige y les devuelve; y la elaboración y exposición de un trabajo monográfico sobre las aplicaciones industriales de los compuestos orgánicos. Por otro lado, se diseñaron dos actividades a realizar mediante la herramienta de gestión docente PoliformaT. Una de ellas tiene como finalidad la autoevaluación de los estudiantes, justo antes de cada uno de los dos exámenes parciales escritos. La otra consiste en una prueba post-laboratorio que se realiza después de cada una de las sesiones prácticas. Además, en el caso del grupo de GITI (docencia en valenciano), la clase magistral participativa se ha dinamizado con la utilización de la pregunta como recurso pedagógico y se han incorporado la tarea personal corregida por el profesor y las tutorías programadas con el fin de atender a la diversidad en cuanto a la formación previa, por tratarse de alumnos que proceden de poblaciones con un número limitado de centros donde se imparte el Bachillerato y tienen dificultad para elegir las opciones más acordes al título que desean estudiar. De esta forma el profesor tiene una retroalimentación sobre el grado de captación de conceptos que tiene el alumno durante la clase magistral y sobre el grado de consecución de los objetivos y puede realizar un seguimiento pormenorizado del trabajo diario del alumno.

En el GIAMR la innovación se ha centrado en la necesidad de actuar sobre una situación particular que es el nivel bajo de los alumnos ya que la nota de acceso es más baja que en los otros títulos (Morera, 2012) y los alumnos en general, están poco motivados. La metodología se ha basado en la utilización de la clase magistral participativa y la realización de seminarios, con pequeños grupos de alumnos, orientados a la resolución de problemas en grupos. Además, se ha completado con actividades a través de la plataforma PoliformaT. En el caso de la asignatura Química general, en base a la experiencia previa del profesor, se constata que los alumnos se muestran apáticos y con poco interés por el aprendizaje y muy especialmente a la hora de realizar las prácticas de laboratorio. Con el fin de mejorar esta situación se han diseñado unos cuestionarios que se responden a través de la plataforma, antes de cada sesión de prácticas, test pre-laboratorio, con el fin de que el alumno acuda a cada sesión con una visión conjunta de la práctica a realizar, se sienta más preparado para realizarla, aumente la confianza en sí mismo y se consiga un mayor aprovechamiento de las experiencias realizadas.

En la asignatura Geología, edafología y climatología, para la clase magistral participativa se ha usado también la pregunta como recurso pedagógico, con el fin de conseguir la retroalimentación necesaria para corregir errores de concepto que se puedan 
presentan de forma generalizada.

En los seminarios se utilizan problemas personalizados: los alumnos tienen un enunciado de problema común, con la secuencia de resolución desglosada, y cada alumno tiene una combinación de varios datos aleatorios que conducen a resultados diferentes. Los alumnos se agrupan como quieren para resolver los ejercicios y tienen libertad para consultar con sus compañeros o con el profesor. Al final entregan la solución personalizada al profesor que la devuelve corregida en la siguiente sesión indicando los fallos que han tenido. También se han diseñado unos ficheros de autocorrección de las prácticas de laboratorio y de campo a través de una hoja de cálculo (Bautista, 2011), mediante los cuales el alumno puede comprobar si ha realizado de forma correcta y ha utilizado bien las unidades en los cálculos que ha hecho en las prácticas de laboratorio.

Teniendo en cuenta toda esta variedad de contextos, es importante tener una retroalimentación sobre el impacto de la introducción de estrategias metodológicas activas en la motivación y el aprendizaje de los estudiantes, así como conocer la visión de los estudiantes sobre el uso de diferentes técnicas de aprendizaje activo y cooperativo. Esta acción constituía uno de los objetivos de los proyectos PIME anteriormente citados y para ello se diseñó un cuestionario (escala tipo Likert de 5 puntos) para conocer la utilidad y el grado de satisfacción de los estudiantes sobre las diferentes actividades de enseñanzaaprendizaje realizadas. Estos cuestionarios se han formulado según las diferentes técnicas utilizadas como herramientas de aprendizaje en cada asignatura. Además, se ha elaborado un cuestionario de incidencias críticas (CUIC), en el que los alumnos opinan sobre los aspectos positivos y a mejorar de la actuación docente del profesor y de la implicación del estudiante.

El pase de todos los cuestionarios se ha llevado a cabo al finalizar las actividades presenciales y garantizando el anonimato de los participantes. En el caso de las asignaturas que se imparten en el primer cuatrimestre (Química de GIOI y Química General de GIAMR), se ha pasado sólo el CUIC, mientras que para las que se imparten o finalizan en el segundo cuatrimestre (Química de GITI y GIE y Geología, edafología y climatología de GIAMR) se dispone también de los datos del cuestionario de escala Likert.

\section{Resultados}

Se han analizado las respuestas obtenidas en los cuestionarios tipo Likert para conocer la utilidad y el grado de satisfacción de los estudiantes sobre las diferentes actividades de enseñanza-aprendizaje realizadas. Los resultados para cada una de las asignaturas se muestran en las Figuras 2, 3 y 4.

\section{(c) EY-NC-ND 2014, Universitat Politècnica de València}

I Jornadas IN-RED (2014) 


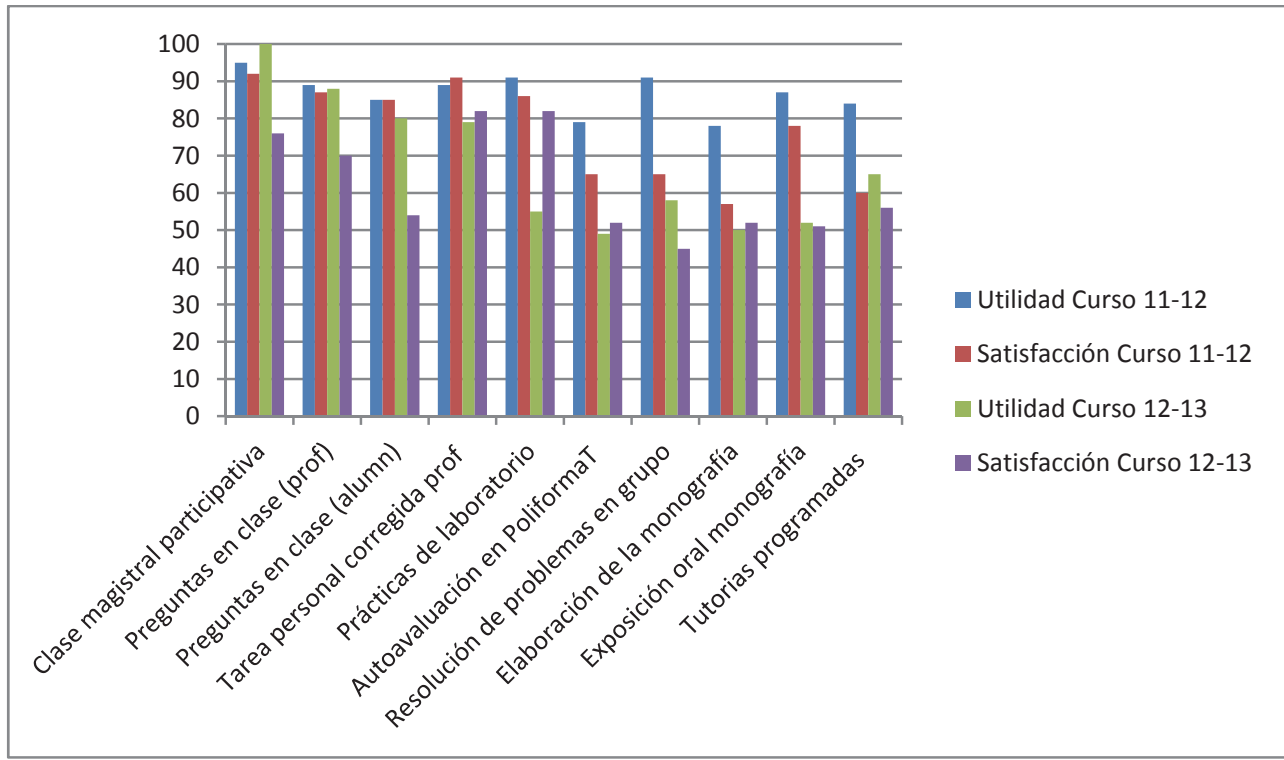

Fig 2. Porcentaje de alumnos que responden entre 4 y 5 en la escala Likert al grado de utilidad y satisfacción en la asignatura Química del GITI.

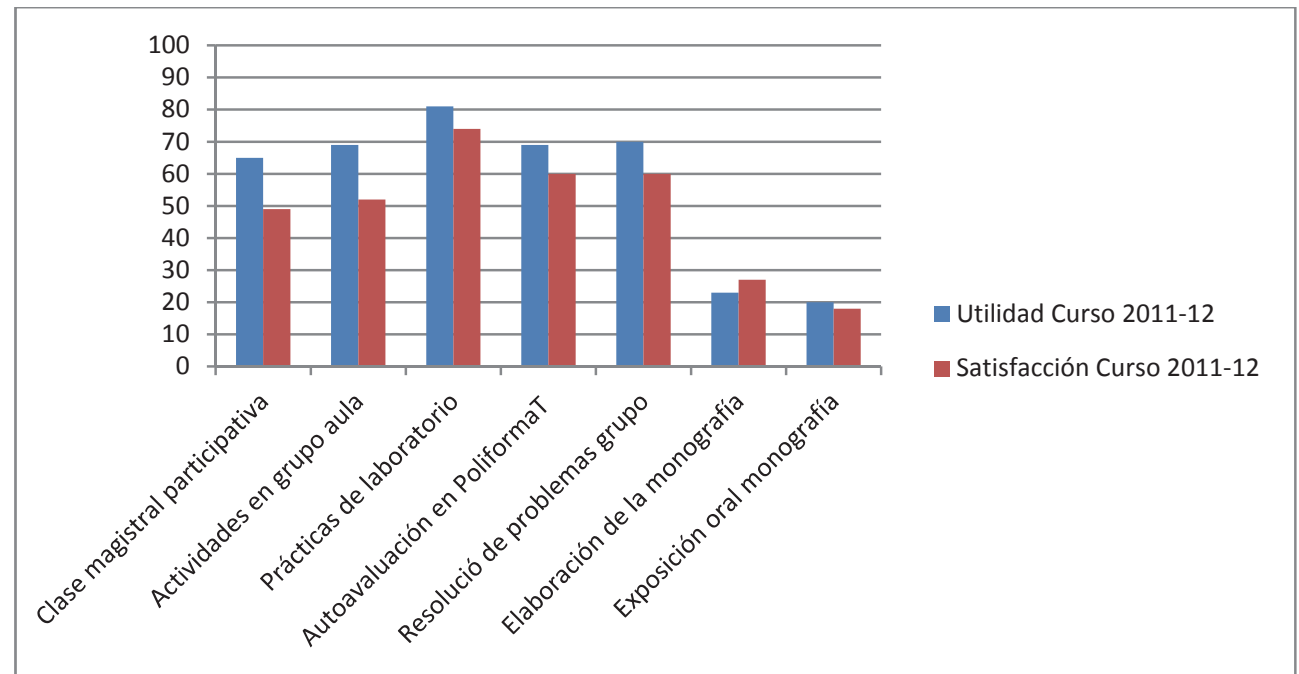

Fig 3. Porcentaje de alumnos que responden entre 4 y 5 en la escala Likert al grado de utilidad y satisfacción en la asignatura Química del GIE.

(cc)) EY-NC-ND 2014, Universitat Politècnica de València I Jornadas IN-RED (2014) 


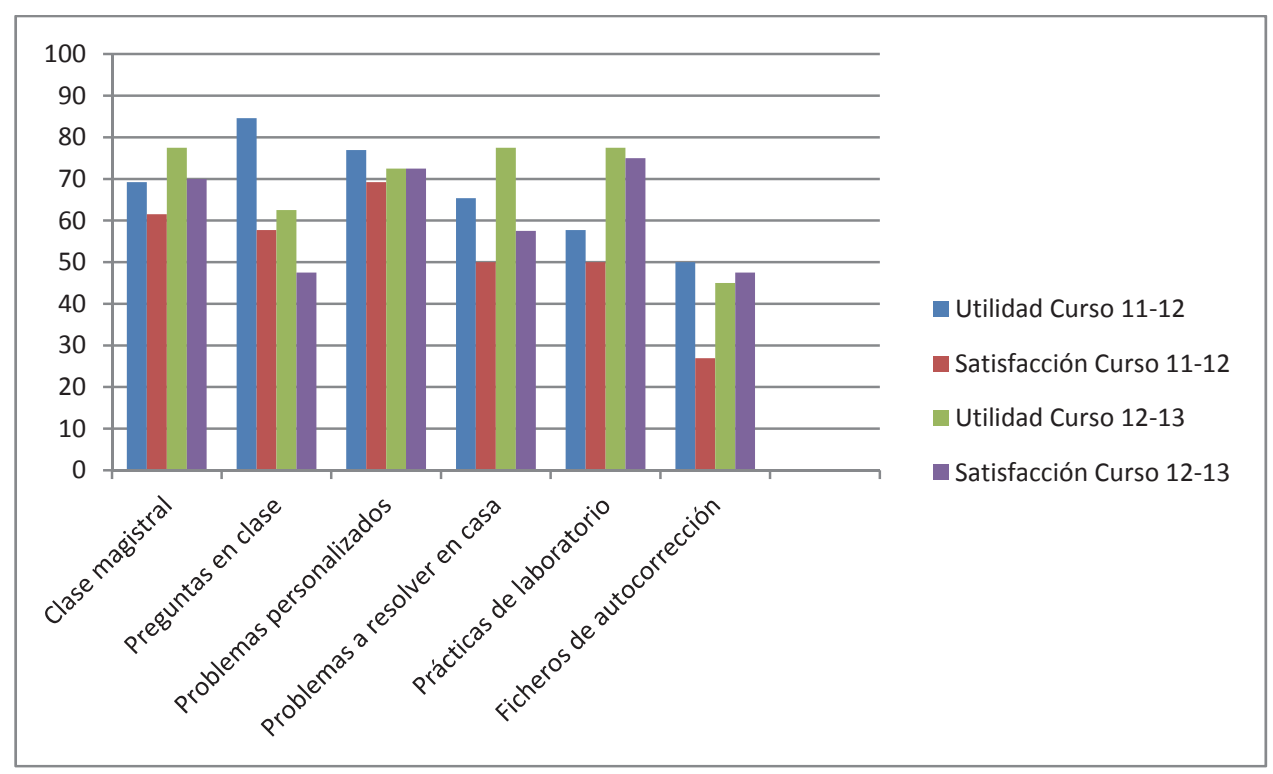

Fig 4. Porcentaje de alumnos que responden entre 4 y 5 en la escala Likert al grado de utilidad y satisfacción en la asignatura Geología, edafología y climatología del GIAMR

Como se puede observar en las figuras anteriores, en general los alumnos tienen una opinión favorable sobre las metodologías que implican de una forma activa al alumno en su propio aprendizaje. Cabe destacar que el grado de utilidad tiene un nivel ligeramente superior al de satisfacción en la mayoría de los ítems. Entre las actividades más valoradas, tanto en su utilidad para aprender como en el grado de satisfacción, están los problemas personalizados (GIAMR) y la tarea personal corregida por el profesor (GITI), lo que demuestra que los alumnos se encuentran satisfechos de obtener de forma rápida información sobre sus conocimientos y consolidar su nivel de progreso. El porcentaje de alumnos que valoran entre alto y muy alto grado de utilidad la clase magistral participativa está entre el 65 y el $100 \%$.

Respecto al uso de la pregunta como recurso pedagógico (GIAMR y GITI), las respuestas indican que es una estrategia que los alumnos encuentran bastante útil, aunque manifiestan no estar tan satisfechos en realizarla. La razón podría estar en que se requiere de una gran atención en la clase y de un seguimiento continuo de la explicación, que no siempre pueden mantener.

En el caso de la titulación de GIAMR, entre las actividades menos valoradas están los ficheros de autocorrección, probablemente porque necesitan utilizar como herramienta la hoja de cálculo Excel, para lo cual no están demasiado formados, y además no todos los

\section{(c) EY-NC-ND 2014, Universitat Politècnica de València}

I Jornadas IN-RED (2014) 
alumnos la tienen disponible en sus ordenadores personales. Para la asignatura Química de GITI y GIE las actividades menos valoradas son las que se corresponden con el aprendizaje cooperativo: la elaboración en grupo de un trabajo monográfico y la exposición oral del mismo por el grupo. De estos resultados se desprende que, cuando se les pregunta, los alumnos se manifiestan reacios al trabajo en grupo y especialmente cuando se trata de realizar una tarea de cierta complejidad, que además deben presentar al resto de compañeros mediante exposición oral.

También se han recopilado y analizado todas las respuestas abiertas obtenidas en el CUIC sobre la actuación docente del profesor en el proceso de enseñanza-aprendizaje activo así como la implicación del estudiante, en los cursos 2011-2012 y 2012-2013. Los alumnos tienen la posibilidad de expresar su opinión de manera libre y las respuestas son diversas. En la tabla 1 y 2 se han recogido sólo las opiniones coincidentes de los alumnos pertenecientes a todas las asignaturas, independientemente de la idiosincrasia del profesor y de las características del grupo. Cada una de las opiniones se acompaña, entre paréntesis, de la frecuencia con la que ha sido expresada.

Del análisis de las respuestas de este cuestionario, se puede decir que el uso de metodologías activas contribuye a generar espacios en los que se propicia el aprendizaje: preocupación por el seguimiento de los alumnos, motivación del alumnado, buen clima en el aula, etc. y los alumnos lo valoran muy positivamente. Además, también se observa que el uso de estrategias que fomentan la participación del alumno, no va en detrimento de la formación del mismo, ya que valoran muy positivamente que el profesor domine la materia, planifique las clases y las actividades, explique bien e insista en los conceptos fundamentales.

Como aspectos a mejorar, los alumnos inciden en la idea de que el profesor debe moderar, en la justa medida, la actuación del alumno tanto por exceso (demasiado control) como por defecto (demasiada permisividad).

Este cuestionario nos ha permitido constatar que el alumno, también en primer curso, puede ser reflexivo y crítico tanto con el profesor como consigo mismo. De hecho, los alumnos destacan positivamente el esfuerzo que realizan para llevar las tareas al día y asistir y atender en clase y al mismo tiempo reconocen que podrían trabajar más, prestar más atención y hablar menos en clase. 
Inmaculada Bautista, Julia Atienza, Ma José Climent, Sara Iborra, Isabel Morera y Amparo Ribes

Tabla 1. Opiniones de los alumnos respecto a la actuación docente del profesor

\begin{tabular}{|c|c|c|}
\hline & ASPECTOS POSITIVOS & A MEJORAR \\
\hline 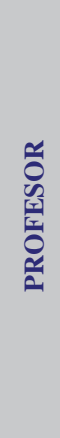 & 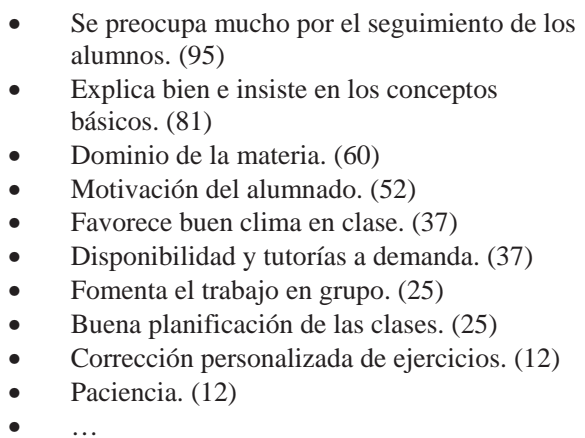 & $\begin{array}{l}\text { - No hay nada para mejorar, está bien. (23) } \\
\text { - Demasiada permisividad. (20) } \\
\text { - Forma de explicar, habla demasiado } \\
\text { rápido. (19) } \\
\text { - Hacer más problemas. (15) } \\
\text { - Repasar conceptos básicos que el alumno } \\
\quad \text { debería saber.(16) } \\
\text { - Mejorar la distribución del tiempo. (10) } \\
\text { - Demasiado control al alumno. (8) } \\
\text {-... }\end{array}$ \\
\hline
\end{tabular}

Tabla 2. Opiniones de los alumnos respecto a su implicación en el aprendizaje

\begin{tabular}{|c|c|c|}
\hline & ASPECTOS POSITIVOS & A MEJORAR \\
\hline$\sum_{\substack{z \\
\mathbf{z}}}^{0}$ & $\begin{array}{l}\text { - Llevar la faena y la asignatura al día. (68) } \\
\text { - Asistencia y atención en clase. (28) } \\
\text { - Gran interés por la asignatura. (23) } \\
\text { - Trabaja bien en grupo. (22) } \\
\text { - Gran motivación. (17) } \\
\text { - Trabajador. (16) } \\
\text { - Buen ambiente de trabajo en clase. (12) } \\
\text {-... }\end{array}$ & $\begin{array}{l}\text { - Más estudio diario. (105) } \\
\text { - Hablar menos. (34) } \\
\text { - Asistir más a clase. (2) } \\
\text { - Más atención en clase. (10) } \\
\text { - Mayor implicación en clase. (12) } \\
\text { - Trabajar mejor en grupo. (3) } \\
\text { - ... }\end{array}$ \\
\hline
\end{tabular}

\section{Conclusiones}

Del análisis de los datos y de las opiniones recogidas en el estudio se puede concluir que:

- Los alumnos de primer curso aprecian la labor llevada a cabo por el profesor en el diseño y aplicación de metodologías basadas en el aprendizaje.

- Se muestran especialmente satisfechos de participar activamente y les es de mucha utilidad para aprender.

- Están satisfechos y les resulta muy útil que se les proporcione una retroalimentación rápida del aprendizaje conseguido.

- El aprendizaje cooperativo en equipos les resulta útil para aprender cuando realizan actividades de resolución de problemas.

\section{(c) EY-NC-ND 2014, Universitat Politècnica de València}

I Jornadas IN-RED (2014) 
- Los alumnos manifiestan que el trabajo en equipo, cuando se trata de realizar una tarea de cierta complejidad como elaborar una monografía y presentarla al resto de compañeros, les resulta poco satisfactorio. Sin embargo, los profesores percibimos que la tarea la realizan relativamente bien, y en la exposición oral se cumplen ciertamente los objetivos que se pretenden alcanzar al realizar esta actividad en el primer curso de la titulación.

- La reflexión sobre las experiencias en el aprendizaje de los alumnos y las opiniones y percepciones de los mismos, así como la detección de puntos fuertes y débiles en diferentes aspectos del proceso seguido nos ha permitido obtener la retroalimentación necesaria para reorientar y adaptar las estrategias metodológicas en acciones futuras.

\section{Referencias}

BAUTISTA I., LIDÓN, A.; LULL-NOGUERA, C. SERRANO, A. (2011) Impacto de la Evaluación Formativa en el aprendizaje del alumno. IV Jornada de Innovación Docente JIDINF'11

GARGALlO, B. (2008). "Estilos de docencia y evaluación de los profesores universitarios y su influencia sobre los modos de aprender de sus estudiantes", en Revista Española de Pedagogía, 241, p. $425-445$.

GARGallo, B., GARFElla, P. R., PÉreZ, C. y FERnÁndeZ, A. (2010). "Modelos de enseñanza y aprendizaje en la universidad. Ponencia presentada en el XIX Seminario Interuniversitario de Teoría de la Educación. Formación y participación de los estudiantes en la universidad. Madrid. Universidad Complutense.

http://www.ucm.es/info/site/docu/29site/ponencia3.pdf [Consulta: 1 de junio de 2014]

GIBBS G. (1992). Improving the quality of student learning through course design. R. Barnett (Ed.), Learning to effect, SRHE \& Open University Press, Milton Keynes UK (1992), pp. 149-165.

LAWALL, M.L. (1998). Students rating teaching. How student feedback can inform your teaching. University teaching services, The University of Manitoba. http://wwwice.upc.edu/pro_accio/seeq/millora.pdf. [Consulta: 30 de enero de 2013]

MORERA, I., ATIENZA, J.; BAUTISTA, I.; CLIMENT, M.J.; IBORRA, S.; RIBES, A. (2012) Innovación Metodológica: Experiencias en la Asignatura de Química en Escuelas de Ingeniería. I Jornades d'innovació educativa UPV 2012

PIME A008/10. (Curso 2010-11). "Motivación en el aula y disminución del abandono de asignaturas en primer curso mediante la implementación de metodologías activas" Vicerrectorado de Estudios y Convergencia Europea (VECE). UPV.

PIME A24/11. (Curso 2011-12). "La reflexión en la acción. Un estudio de análisis y de mejora metodológica en las aulas de primer curso de ingeniería". Vicerrectorado de Estudios y Convergencia Europea (VECE). UPV. 
PIME A18/12. Curso (2012 -2013). "Práctica reflexiva e implicación metodológica. Un estudio en las aulas de primer curso de ingeniería."

PRINCE, M. (2004). "Does Active Learning Work? A Review of the Research" en Journal of engineering education 93 (3):223-231

Proyecto Tuning Educational Structures in Europe: final report. Disponible en http://www.unideusto.org/tuningeu [Consulta: 1 de junio de 2014]

RUST, C. (2002)."The impact of assessment on student learning How can the research literature practically help to inform the development of departmental assessment strategies and learner-centred assessment practices?" en Active learning in higher education Vol 3(2). p.145-158 
Los retornables: evaluación continúa y entre pares

\begin{abstract}
Antonio Martí-Campoy ${ }^{a}$, Salvador Petit Martía, María Teresa Gassó Matoses ${ }^{b}$, Vicente Atienza Vanacloig ${ }^{a}$ y Franciso Rodríguez-Ballester ${ }^{a}$

${ }^{a}$ Departamento de Informática de Sistemas y Computadores. Escola Técnica Superior d'Enginyeria Informàtica. Universitat Politècnica de València. \{amarti, spetit, vatienza, prodrig\}@disca.upv.es, ${ }^{\mathrm{b}}$ Departamento de Matemática Aplicada. Escola Técnica Superior d'Enginyeria Informàtica. Universitat Politècnica de València. mgasso@mat.upv.es.
\end{abstract}

\begin{abstract}
In this paper, we present the returnable, a tool to assist teachers and students in the learning process.

A returnable, which at first glance seems a simple set of test exercises, becomes in practice a powerful tool to assist learning. The returnable is used to motivate the student, especially during the first stages of the course, and to help the teacher to assess student's work in a continuous way.

Keywords: continuous assessment, peer assessment, computer engineering degree

Resumen

En este trabajo presentamos una herramienta de enseñanza llamada retornable. Un retornable es más que un conjunto de ejercicios de clase tipo examen, su interés radica en la forma en que se utiliza. El retornable se ha convertido en una herramienta de motivación, útil para fomentar el trabajo de los estudiantes sobre todo en las primeras etapas del curso y para ayudar al profesor a la evaluación continua de los estudiantes.
\end{abstract}

Palabras clave: evaluación continua, evaluación por pares, grado en informática.

(c)) EY-NC-ND 2014, Universitat Politècnica de València

I Jornadas In-Red (2014) 


\section{Introducción}

La adaptación de los estudios universitarios en España con el nuevo modelo de Bolonia ha traído no sólo una reorganización de las materias, asignaturas y cursos, sino también cambios en cómo se debe evaluar a los estudiantes. Estos cambios son especialmente importantes, ya que afectan a como se deben evaluar diferentes aspectos de aprendizaje. En lugar de organizar la evaluación exclusivamente en torno a los contenidos de un curso o materia, la nueva evaluación se ocupa también de las habilidades y competencias que los estudiantes deben alcanzar. A fin de evaluar estas competencias, el estudiante debe ser instruido en ellas durante su proceso de aprendizaje.

En este contexto se plantea un nuevo reto: integrar las habilidades del aprendizaje y la evaluación de los contenidos, así como los comportamientos que pueden ser específicos de la asignatura o más generales, es decir, en relación con todo el grado, a lo largo del horario del curso, haciendo uso de los mismos recursos, o incluso de menos, que en el plan de estudios anterior. Observaremos que las horas de enseñanza en el aula y tutorías son más escasas, ya que la introducción de las nuevas titulaciones ha supuesto, en muchos casos, una reducción significativa en el número de horas asignadas a estas actividades.

Para alcanzar este objetivo no hay una sola respuesta. El problema debe abordarse con el uso de múltiples herramientas y estrategias que, adecuadamente combinadas facilitarán los resultados de aprendizaje tanto específicos de una asignatura como generales al grado.

En este trabajo, presentamos una herramienta simple pero eficaz, llamada retornables, dedicada a la enseñanza y el aprendizaje de temas específicos que intentar también instruir a los alumnos y evaluar en competencias generales del grado en Ingeniería Informática y del grado en Ingeniería de Tecnologías y Servicios de Telecomunicación. Esta herramienta ha sido utilizada en las asignaturas Fundamentos de Computadores, Cano (2010), impartida en primer semestre de ambos grados, y en la asignatura de Álgebra que se imparte en el segundo semestre del grado en Ingeniería Informática.

Un retornable consiste en un conjunto de ejercicios perteneciente a un tema. A pesar de su simplicidad, el valor principal de la herramienta se debe a la forma en que se usa, que se organiza en torno a la evaluación por pares. Hay una gran cantidad de trabajos previos relacionados con enfoques de evaluación por pares. Una parte importante de estos estudios se centra en los beneficios de la revisión por pares en clase. Autores cómo Krathwohl (1964) y Davies (1998) afirman que debido a que la evaluación y la crítica son habilidades de alto nivel en la Taxonomía de Bloom (1994), los estudiantes que participan en los procesos de revisión por pares no sólo mejoran el aprendizaje de los conceptos básicos de la materia, sino también logran una mejora de resultados de aprendizaje de nivel superior.

(c)) BY-NC-ND 2014, Universitat Politècnica de València

I Jornadas IN-RED (2014) 
Hamer (2005) y Wolfe (2004) hacen hincapié en la creciente cantidad de oportunidades de retroalimentación para el aprendizaje, mientras que Davies (1998) detecta que al evaluar el trabajo de sus compañeros, los estudiantes mejoran su habilidad de auto-evaluación.

Debido a estos beneficios, hace ya 40 años que Ford (1973) aplicó esquemas de revisión por pares en cursos de redacción literaria. Muchas han sido las disciplinas en las que se ha utilizado la revisión por pares, cómo MacAlpine (1999) y Rafiq (1996) en ingeniería, Earl (1986) en matemáticas, López (1999) en educación y Persons (1998) en economía. Recientemente se han publicado trabajos en el área de la arquitectura de computadores, Gehringer (2003), y los sistemas operativos, Riesco (2007).

El resto de este trabajo se organiza de la siguiente manera. La sección 1 describe la herramienta, su uso, así como sus principales características. La sección 2 presenta las experiencias llevadas a cabo con los retornables, y la sección 3 discute resultados académicos y de satisfacción de los alumnos. Por último, las conclusiones se presentan en la Sección 4.

\section{Descripción, uso y propiedades de los retornables}

Los principales objetivos que se persiguen con el uso de los retornables son tres: primero, motivar a los estudiantes para que trabajen todos los contenidos de la asignatura, tanto de teoría como de prácticas, desde el inicio del curso y de forma continua; segundo, ayudar a los estudiantes a desarrollar competencias transversales y de alto nivel; y en tercer lugar, ayudar al profesor a evaluar de forma continua a los alumnos. La consecución de estos tres objetivos debe hacerse evitando sobrecargar a los estudiantes y al profesor.

Un retornable no se puede definir simplemente como un conjunto de entregables con ejercicios, ya que su valor principal proviene de la forma en que se utiliza, lo que da un conjunto de características que son útiles para alcanzar los objetivos mencionados. En las secciones siguientes se describen qué es un retornable, su uso, y las características que ofrece.

\subsection{Componentes de los retornables}

Para facilitar la evaluación continua, se plantea un retornable por cada tema del curso. Un retornable se compone de dos elementos:

Un par de boletines con ejercicios. Cada boletín incluye un ejercicio diferente que trabaja una parte de los contenidos y competencias relativos al tema correspondiente. Los dos boletines juntos cubren todos los objetivos del tema. Por otra parte, se busca que estos ejercicios sean similares a aquellos que se propondrán en pruebas de evaluación posteriores.

(cc)) EY-NC-ND 2014, Universitat Politècnica de València

I Jornadas IN-RED (2014) 
Criterios de evaluación. Los boletines también incluyen criterios de evaluación cuyo principal objetivo es ayudar a los estudiantes a llevar a cabo la evaluación por pares. Sin embargo, mediante la incorporación de los criterios de evaluación también se consiguen dos objetivos adicionales. Primero, se promueven puntuaciones consistentes, ya que todos los pares usan los mismos criterios. Segundo, se conciencia al alumno acerca del impacto en la evaluación de las diversas partes y aspectos de los ejercicios. Este conocimiento es útil para la preparación y el estudio en pruebas posteriores.

\subsection{Uso de los retornables}

Utilizados de la forma adecuada, los retornables se convierten en una potente herramienta para ayudar tanto a estudiantes como profesores durante el proceso de aprendizaje. La Fig. 1 presenta la utilización de los retornables como un flujo de trabajo compuesto por varias etapas. El trabajo en las etapas resaltadas en verde corresponde al profesor, mientras que el trabajo de las etapas destacadas en color naranja es llevado a cabo por los estudiantes. El trabajo correspondiente a la última etapa inicialmente está asignado al profesor. Sin embargo, esta última etapa también representa el principio del trabajo del estudiante de cara a evaluaciones futuras, por lo que se destaca en ambos colores. Cada una de las etapas de la figura se describe a continuación.

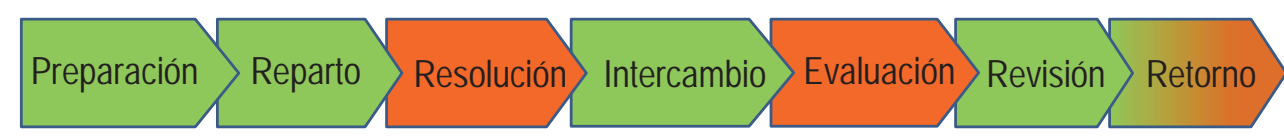

Fig. 1. Flujo de uso de los retornables.

Preparación. Una vez que un tema determinado del curso ha sido tratado en clase, el profesor prepara la documentación descrita en la sección 1.1.

Reparto. Cada estudiante recibe uno y sólo uno de los boletines que componen el retornable correspondiente al tema tratado. Es importante que la distribución de los dos boletines sea uniforme (es decir, mitad y mitad), ya que es fundamental para el correcto funcionamiento de las etapas siguientes. Una manera sencilla de conseguir la mencionada distribución es confiar al profesor la responsabilidad de realizar el reparto. Sin embargo, este método no suele ser motivador para el alumno. Alternativamente, hay varias maneras sencillas de captar la atención de los alumnos, evitando a la vez repartos muy desiguales. Por ejemplo, el profesor puede pedir al alumno lanzar una moneda al aire y elegir el boletín en función del resultado, o también en función de sus datos personales (por ejemplo, si el día de nacimiento o el número de letras en el nombre del alumno es par o impar, elegir el color preferido entre dos opciones, etc.), y utilizar esta información para repartir los boletines. De esta manera, el alumno se motiva al sentirse participe en el proceso. 
Resolución. Cada alumno debe resolver los ejercicios de su boletín. No hay ninguna restricción sobre cómo realizar esta tarea, es decir, un estudiante puede resolverlo por sí solo o con la ayuda y colaboración de otros compañeros de clase. La fecha límite para devolver el boletín resuelto es de aproximadamente de una semana. Este relativamente corto plazo evita que los estudiantes retrasen el trabajo en el proceso de aprendizaje. Sin embargo, es aconsejable consultar a los estudiantes sobre su agenda con respecto a otras materias académicas. De nuevo, consultar a los estudiantes evita que se sientan ajenos al proceso. Además, la imposición de plazos estrictos puede resultar en que algunos alumnos intenten obtener la respuesta a los ejercicios con ayuda externa pero sin haberlos trabajado ellos mismos suficientemente.

Intercambio. Transcurrido el plazo establecido o acordado con los estudiantes, estos devuelven los boletines resueltos al profesor, el cual los redistribuye lo más pronto posible, asegurándose de que cada alumno recibe un modelo de boletín diferente del que resolvió en la etapa anterior. Esta última condición también es crítica, puesto que ambos modelos se complementan para cubrir el tema correspondiente. Por lo tanto, en aras de un aprendizaje más completo es recomendable que todos los estudiantes tengan acceso a ambos.

Evaluación. En esta etapa, los criterios de evaluación mencionados en la sección 1.1 son utilizados por los estudiantes para evaluar el trabajo realizado por sus compañeros de clase. A los alumnos se les indica que no sólo den una nota, sino que hagan todos los comentarios $\mathrm{y}$ anotaciones que crean adecuadas. Un aspecto clave a considerar es que el profesor no ofrece las soluciones, por lo que los evaluadores tienen que resolver los ejercicios por sí mismos. Como en la etapa de resolución, un evaluador puede desarrollar una solución completa o basarse en la solución de otro(s) compañero(s). Diferentes soluciones también pueden ser comparadas y analizadas. Nótese que, de acuerdo con la taxonomía de Bloom, el análisis y la evaluación de las soluciones propuestas por compañeros es una tarea de más alto nivel que simplemente resolver el ejercicio [2,3]. Finalmente, el periodo para llevar a cabo la evaluación es similar al periodo utilizado para resolver el ejercicio.

Revisión. Los estudiantes devuelven los boletines con sus evaluaciones al profesor, que puede revisar un subconjunto de ellas, desde todas a ninguna. La revisión tiene múltiples objetivos: i) reducir el estrés que sufren algunos estudiantes al evaluar a sus compañeros de clase, ii) detectar errores importantes en la aplicación de los criterios de evaluación, y iii) encontrar los errores más comunes en la resolución y en la evaluación, lo que permite al profesor distinguir los puntos débiles que deben ser reforzados en el proceso de aprendizaje. Se pueden utilizar diferentes estrategias para elegir qué boletines deben ser revisados. Por ejemplo, una revisión completa de todas las evaluaciones, una revisión al azar, centrarse en las puntuaciones extremas, llevar un histórico de evaluaciones anteriores,

(c)) EY-NC-ND 2014, Universitat Politècnica de València

I Jornadas IN-RED (2014) 
etc. Nótese que la discusión sobre las ventajas e inconvenientes de las diferentes estrategias se encuentra fuera del alcance de este artículo.

Retorno. Por último, el retornable regresa al autor que lo resolvió inicialmente en la etapa de resolución. Vuelve con las puntuaciones y comentarios producidos en las etapas de evaluación y revisión. Por tanto, a través de las múltiples etapas comentadas, un conjunto inicialmente sencillo de ejercicios se convierte en una potente herramienta para el aprendizaje y el estudio.

\subsection{Propiedades de los retornables}

La Fig. 2 representa las principales características de los retornables. Un subconjunto de estas características, resaltado en rojo, está parcialmente opuesto al otro subconjunto, resaltado en azul. Sin embargo, el diseño y el uso de los retornables debe realizarse para equilibrar adecuadamente ambos subconjuntos. Una descripción detallada de estas características se presenta a continuación, centrándose en las características opuestas a considerar.

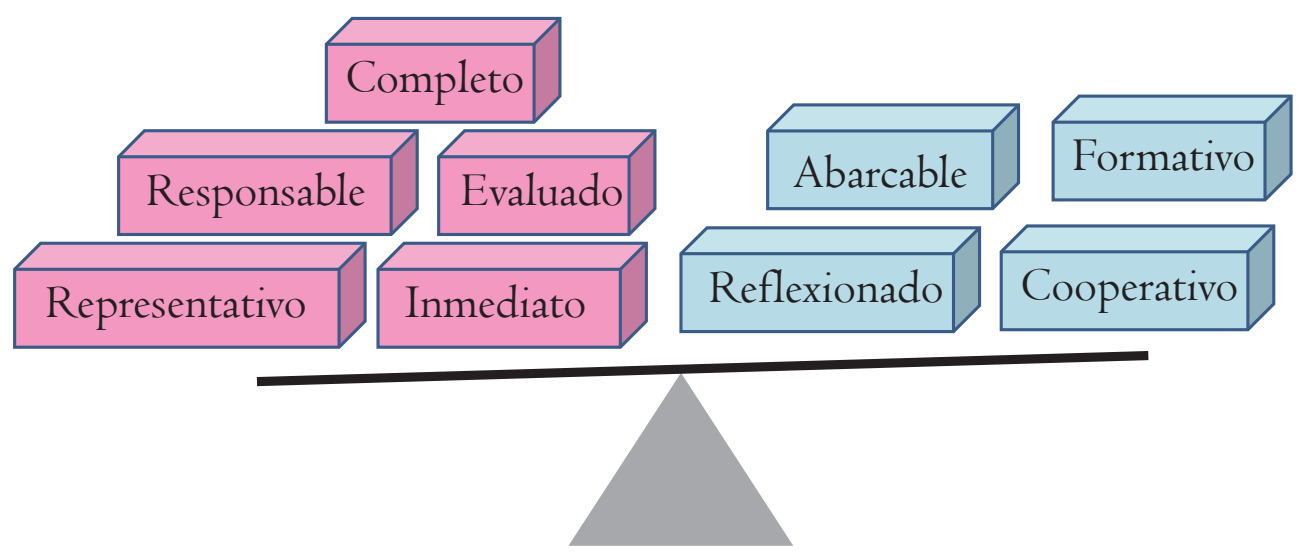

Fig. 2. Características y propiedades de los retornables.

Completo y representativo frente a abarcable. El retornable ayuda al estudiante a aprender todos los contenidos, en el sentido más amplio, de la asignatura, ya que incluye tanto la teoría (ideas y conceptos principales) como las prácticas (métodos, procedimientos y habilidades) de todos los temas de la asignatura. Además, los retornables son representativos de cómo se evalúa a los alumnos en las futuras pruebas principales de evaluación del curso.

Por otro lado, el retornable es abarcable. El esfuerzo y el tiempo necesario para resolver un retornable están acotados. El diseño de un retornable tiene en cuenta que los estudiantes están asistiendo a otros cursos, con el fin de evitar que los estudiantes terminen saturados por el exceso de tareas.

(c)) EY-NC-ND 2014, Universitat Politècnica de València

I Jornadas IN-RED (2014) 
Evaluado frente a formativo. El retornable evalúa el progreso de los estudiantes para ayudar al profesor a verificar que el proceso de aprendizaje se desarrolla satisfactoriamente. Pero, al mismo tiempo, el retornable es formativo, es decir, los estudiantes aprenden mientras resuelve los ejercicios y sobre todo mientras evalúa a sus compañeros. El objetivo es mostrar a los alumnos si están en el camino para alcanzar los objetivos de aprendizaje.

Inmediato frente a reflexionado. Una de las principales razones por las que los retornables son formativos es por su inmediatez. Los estudiantes empiezan a trabajar con el retornable tan pronto como se les enseña lo suficiente como para utilizarlo. Esto promueve el estudio temprano y permite a los estudiantes aplicar los resultados para mejorar su proceso de aprendizaje.

Sin embargo, es importante que los estudiantes piensen sobre cómo están haciendo su trabajo. Dado que esta tarea requiere tiempo, el profesor y los alumnos deben llegar a un acuerdo sobre el tiempo necesario para realizar las diferentes tareas y elegir los plazos adecuados.

Cooperativo frente a responsabilidad individual. Por último, esta herramienta docente fomenta dos actitudes: cooperación y responsabilidad. La cooperación es una habilidad de gran alcance, ya que cuando un compañero ayuda a otro a resolver un ejercicio, los dos mejoran sus conocimientos y habilidades. Sin embargo, antes de recurrir a la ayuda externa, el estudiante debe ser responsable de propio aprendizaje tratando seriamente de resolver la tarea.

\section{Experiencias}

Los retornables se utilizaron por primera vez durante el año académico 2010/11 en un único grupo de la asignatura Fundamentos de Computadores perteneciente al grado en Ingeniería Informática (GII) de la Escola Tècnica Superior d'Enginyeria Informàtica. La experiencia se repitió al año siguiente, esta vez con la participación de tres profesores y tres grupos de la misma asignatura. Todos los profesores manifestaron su satisfacción con la experiencia.

En el año académico 2012/13 se mantuvo el uso de retornables en los citados tres grupos de Fundamentos de Computadores del GII, pero además se utilizaron en otra asignatura, de igual nombre, pero perteneciente al Grado en Ingeniería de Tecnologías y Servicios de Telecomunicación (GITST) de la Escuela Técnica Superior de Ingenieros de Telecomunicación. Tres grupos de alumnos de este último grado participan en la experiencia, y un nuevo profesor se une a los tres que ya habían utilizado los retornables en el curso anterior. Nuevamente, todos los profesores se sienten satisfechos y manifiestan su intención de seguir utilizando los retornables.

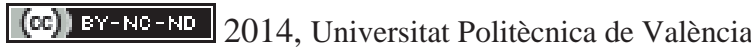

I Jornadas IN-RED (2014) 
En el curso 2013/2014, dos nuevos grupos de Fundamentos de Computadores del GII se unen a la experiencia, siendo cinco de los diez grupos de la asignatura los que usan los retornables. En el GITST se mantienen los tres grupos.

Pero lo más importante es que los retornables saltan de área de conocimiento y se utilizan en un grupo de la asignatura Álgebra del GII.

En el curso actual siete profesores distintos han utilizado los retornables, y en los cuatro años académicos en que se han usado los retornables, nueve profesores diferentes han participado en la experiencia, y todos ellos han mostrado su satisfacción.

La Tabla 1 muestra los datos de alumnos, grupos y profesores que han utilizado los retornables.

Tabla 1. Número de grupos, alumnos y profesores que han utilizado los retornables.

\begin{tabular}{|c|c|c|c|c|c|}
\hline & Curso & 2010/11 & 2011/12 & $2012 / 13$ & $2012 / 13$ \\
\hline \multirow{3}{*}{$\begin{array}{c}\text { Fund. de } \\
\text { computadores } \\
\text { GII }\end{array}$} & Grupos & 1 & 3 & 3 & 5 \\
\hline & Alumnos & 40 & 110 & 110 & 165 \\
\hline & Profesores & 1 & 3 & 3 & 5 \\
\hline \multirow{3}{*}{$\begin{array}{c}\text { Álgebra } \\
\text { GII }\end{array}$} & Grupos & - & - & - & 1 \\
\hline & Alumnos & - & - & - & 40 \\
\hline & Profesores & - & - & - & 1 \\
\hline \multirow{3}{*}{$\begin{array}{c}\text { Fund. de } \\
\text { computadores } \\
\text { GITST }\end{array}$} & Grupos & - & - & 3 & 3 \\
\hline & Alumnos & - & - & 120 & 120 \\
\hline & Profesores & - & - & 3 & 3 \\
\hline \multirow{3}{*}{ Total } & Grupos & 1 & 3 & 6 & 9 \\
\hline & Alumnos & 40 & 110 & 230 & 325 \\
\hline & Profesores & 1 & 3 & 4 & 7 \\
\hline
\end{tabular}

\section{Resultados}

Los resultados de esta experiencia se han analizado desde cuatro puntos de vista. La satisfacción de los alumnos, validez de la corrección de los alumnos, la tasa de abandono, y por último, el rendimiento académico en los exámenes individuales y presenciales.

\subsection{Satisfacción de los alumnos}

Para conocer la satisfacción de los alumnos se les pidió a los alumnos que rellenaran una llenar una breve encuesta con 15 preguntas y un comentario de espacio libre respecto a distintos aspectos del uso de los retornables. El número de estudiantes que respondió la encuesta en Fundamentos de Computadores del GII fue de 114, en Álgebra del GII fue de 19, y en Fundamentos de Computadores de GITST fue de 61. 
A continuación se presenta la lista de las preguntas utilizadas en la encuesta y el análisis de los resultados obtenidos. Para cada pregunta el estudiante puede seleccionar una entre cinco respuestas: Totalmente en desacuerdo; En desacuerdo; Neutral; De acuerdo; Totalmente de acuerdo. Los valores numéricos asignados a cada respuesta son de 0, 2.5, 5, 7.5 y 10 , respectivamente.

Para realizar el análisis, las preguntas se han agrupado en cuatro conjuntos, relacionados con diferentes aspectos del uso de los retornables.

Listado de preguntas:

Grupo 1: Sobre la resolución del retornable:

a) El tiempo de entrega ha sido el adecuado

b) El esfuerzo requerido ha sido el adecuado

c) El retornable abarca todo lo que se pregunta en el examen

d) Las cuestiones de los retornables me han ayudado a preparar el examen

Grupo 2: Sobre la corrección del retornable de un compañero:

e) El tiempo de entrega ha sido el adecuado

f) El esfuerzo requerido ha sido el adecuado

g) Ha requerido un esfuerzo mayor que el dedicado a realizar mi propio retornable

h) Prefiero que los ejercicios hubiesen sido los mismos que en mi propio retornable.

i) Los criterios de corrección (denominados rúbricas) son suficientemente claros.

j) Teniendo en cuenta mis limitaciones, creo que mi forma de evaluar a mis compañeros ha sido la correcta.

k) Teniendo en cuenta las limitaciones de mis compañeros, creo que su forma de evaluarme ha sido la correcta.

Grupo 3: Cuestiones generales

1) Los retornables me ayudan a llevar al día la asignatura.

m) Creo que esta actividad no debería afectar a la nota final de la asignatura.

n) Considero que los retornables son una buena herramienta de estudio.

Grupo 4: Satisfacción global con los retornables

(cc)) EY-NC-ND 2014, Universitat Politècnica de València

I Jornadas IN-RED (2014) 
o) Considero que el resultado global ha sido positivo.

La Fig. 3 muestra el valor medio de las respuestas de los alumnos para cada una de las preguntas de la encuesta, separadas por asignaturas. En la figura se puede observar que los estudiantes de las tres asignaturas tienen opiniones similares. Para la mayoría de las preguntas la media se sitúa alrededor del 7, lo que indica que los alumnos están de acuerdo con la afirmación presentada en la pregunta y que implica satisfacción con el uso de los retornables.

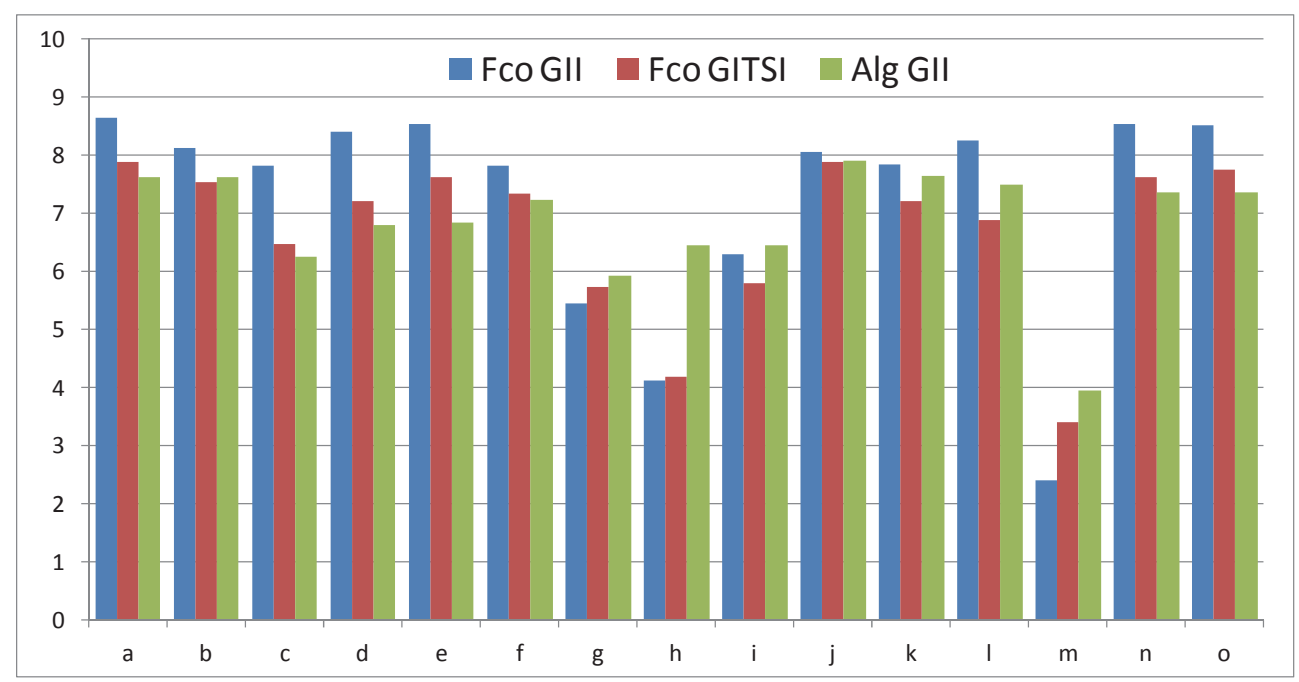

Fig. 3. Resultados numéricos de las encuestas a los alumnos para las tres asignaturas.

Hay algunos casos que deben ser analizados con detalle.

En la pregunta g la media es inferior a 6 para las tres asignaturas, lo que indica que evaluar el retornable de los compañeros les ha representado un esfuerzo mayor que resolver su propio retornable, pero este esfuerzo no ha sido excesivo.

En la pregunta h la media se sitúa en 4 para las asignaturas Fco de los dos grados y sube hasta más de 6 para Alg. Mientras que los alumnos de Fco prefieren que los ejercicios que resuelven sean distintos de los que evalúan, los alumnos de Alg prefieren lo contrario. Los autores desconocen en este momento la razón de esta discrepancia.

En la pregunta i, con una media alrededor de 6, los alumnos manifiestan que los criterios de corrección no son todo lo útiles que desearían. Algunos alumnos han explicitado este aspecto en la respuesta libre. 
En la pregunta $\mathrm{m}$, con la media más baja de todas, entre 2 y 4 según la asignatura, los alumnos dejan claro que quieren que su trabajo sea considerado para la nota de la asignatura. Sin embargo, los alumnos de Alg lo creen menos conveniente que los otros alumnos.

Por último, la pregunta n, "Considero que los retornables son una buena herramienta de estudio." y la pregunta o, "Considero que el resultado global ha sido positivo." son un resumen claro de lo manifestado por los alumnos en el resto de las preguntas: los alumnos de Fco del GII están muy satisfechos con los retornables, los alumnos de Fco del GITST lo están algo menos, y por último y aunque también muy satisfechos, los alumnos de Alg son los de menor grado de satisfacción, posiblemente porque es el primer año que se utilizan en esta asignatura. Experiencias futuras permitirán descubrir si esta tendencia se mantiene y en ese caso cuáles son las causas.

Las Fig. 4 a Fig. 7 muestran el grado de satisfacción de los alumnos de las tres asignaturas conjuntamente, agrupando las preguntas en cuatro dimensiones.

Tal como muestra la Fig. 4, más del $80 \%$ de los estudiantes de las tres asignaturas considera suficiente el tiempo y el esfuerzo necesario para resolver el retornable.

La Fig. 5 muestra que a los estudiantes también les parece adecuado el tiempo y el esfuerzo necesario para corregir los retornables de sus compañeros. En esta gráfica se incluyen también las preguntas sobre la calidad de la evaluación realizada por ellos mismos y por sus compañeros. Sin embargo, en este caso esta mayoría se queda en el 75\%, y comparando con la Fig. 4, puede verse un trasvase de alumnos de más de un 10\% desde el sector "Muy adecuado" a los sectores inferiores. Esto indica claramente que evaluar el trabajo de los pares es una tarea más compleja y un desafío para los estudiantes, posiblemente porque no han sido entrenados tan intensamente como en la resolución de problemas.

La Fig. 6 incluye las cuestiones c, d y 1, que evalúan si los alumnos consideran que los retornables les ayudan a estudiar los exámenes y a mantener el estudio diario. El $76 \%$ de los alumnos considera que esto es cierto, destacando que el $43 \%$ de los estudiantes los considera muy útiles para preparar la asignatura.

Finalmente la Fig. 7 agrupa las dos últimas preguntas, que preguntan directamente si los retornables son una buena herramienta de estudio y si su uso ha representado ha proporcionado una experiencia satisfactoria. La mayoría de los alumnos, el 51\% se muestra muy satisfecho con los retornables, y se alcanza el $83 \%$ si se suman aquellos que se sienten satisfechos.

\section{(cc) EY-NC-ND 2014, Universitat Politècnica de València}

I Jornadas IN-RED (2014) 
La conclusión es clara. Los alumnos se sienten muy satisfechos con el uso de los retornables, y aunque la tarea de corrección y evaluación de sus compañeros les resulta más complicada que la resolución de ejercicios, sigue resultándoles provechosa y satisfactoria.

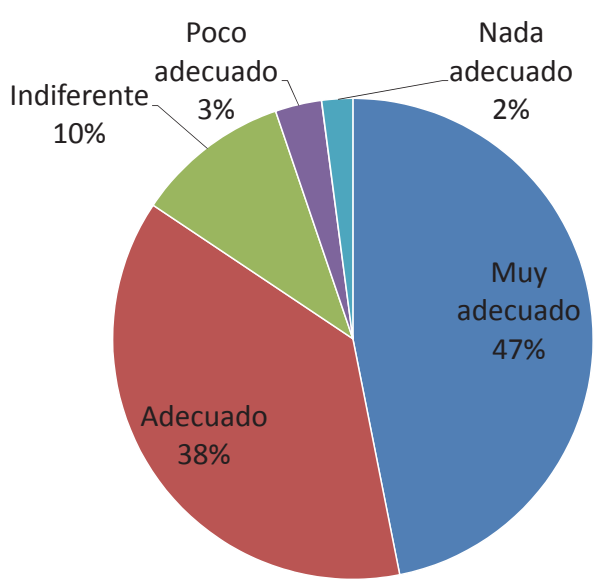

Fig. 4. Dificultad y tiempo al responder el retornable.

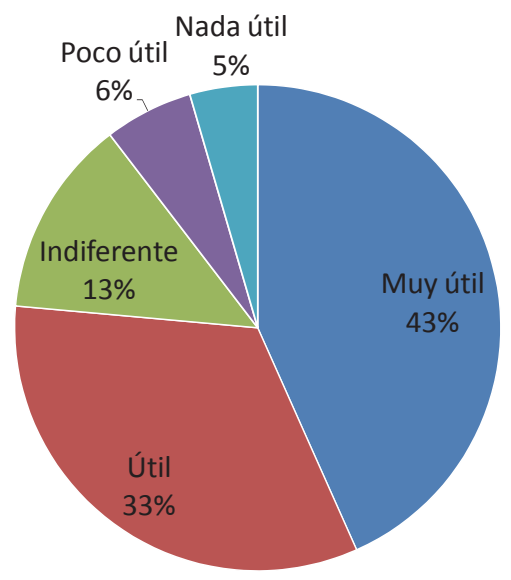

Fig. 6. Utilidad del retornable para estudiar.

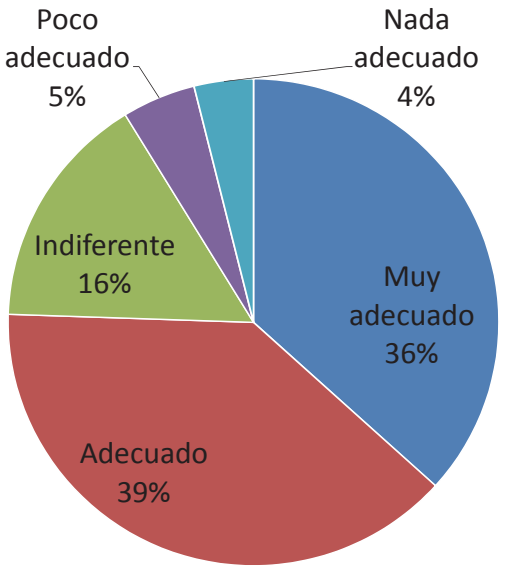

Fig. 5. Dificultad y tiempo al corregir el retornable.

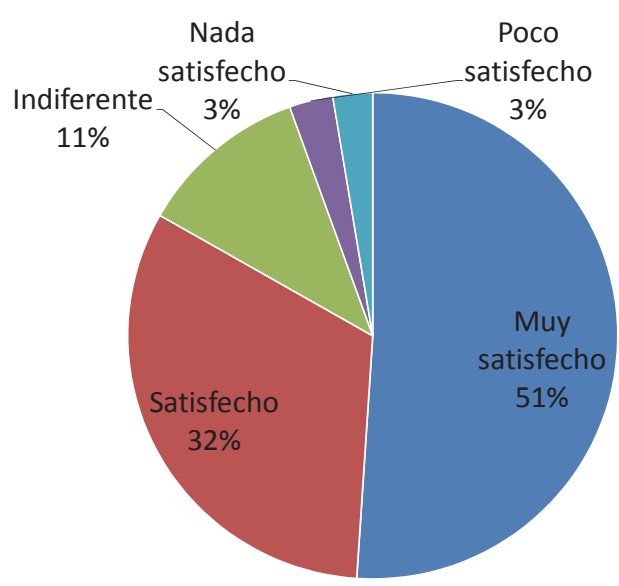

Fig. 7. Satisfacción general con el retornable.

\subsection{Validez de la corrección de los alumnos}

Una de las inquietudes más frecuentes en los profesores que participan en la experiencia, y en aquellos compañeros a los que se les explica el uso de los retornables, es si los alumnos corrigen adecuadamente, y en bastantes casos se preguntas si los alumnos no hacen trampas, dando a sus compañeros notas más altas de lo que corresponden. Cuando, además,

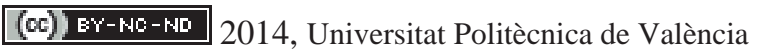


se indica que los profesores pueden revisar o no estas correcciones, la inquietud se acrecenta.

Todos los profesores que han utilizado los retornables tienen su opinión, coincidente, en que los alumnos corrigen muy bien, que la nota que ponen sería la misma que el profesor, e incluso, que a veces son demasiado estrictos, dando notas inferiores que las que daría el profesor. También es cierto que en algunos casos los alumnos puntúan al alza, dando como buenos ejercicios mal resueltos. Estos casos, en opinión de los profesores participantes en la experiencia, son mínimos, y corresponden con alumnos que tienen un conocimiento nulo del tema y son incapaces de realizar una evaluación detallada.

Durante el presente curso, uno de los profesores realizó una revisión completa de las correcciones realizadas por sus alumnos. El número de alumnos era de 49 y se revisaron aproximadamente 129 retornables. Los resultados fueron que en el $90 \%$ de los casos no había diferencia significativa en la nota indicada por el alumno y la nota indicada por el profesor. Es importante remarcar que la nota de todos los retornables representa entre un $10 \%$ y $20 \%$ de la nota final, según la asignatura, y que por tanto cada retornable puede representarle al alumno entre un $2 \%$ y $4 \%$ de la nota final, por lo que pequeñas diferencias entre la nota del alumno y la del profesor tiene poco efecto en la nota final del alumno.

En el resto de casos, la nota indicada por el alumno era menor que la que proponía el profesor, excepto en un caso, en la que el alumno corrector daba por buenos ejercicios que estaban mal. En ningún caso se ha encontrado una corrección maliciosa.

Otro de los resultados que se quiere estudiar es si hay correlación entre la nota que los alumnos obtienen en los retornables y la nota que obtienen en los exámenes. Las condiciones en que se realizan estos ejercicios, el retornable y los exámenes, son muy diferentes. El primero es en casa, sin límite de tiempo, con cualquier tipo de recurso disponible. El segundo es con tiempo límite, sin ningún tipo de ayuda y con una repercusión mucho mayor sobre la nota final.

Dado que la asignatura Álgebra se imparte en el segundo semestre, todavía no se disponen de datos consolidados de los resultados de los exámenes, por lo que no se incluye dicha asignatura en este análisis.

Para Fundamentos de Computadores del GII, el coeficiente de correlación de Pearson entre la nota de los retornables y la nota media de los exámenes presenciales es de 0,36. La Fig. 8 muestra el gráfico de dispersión de la nota de los retornables frente a la nota media del examen. Se han descartado los alumnos que no tenían nota en alguna de las pruebas o han participado en el retornable. La imagen muestra que para la mayoría de los alumnos que

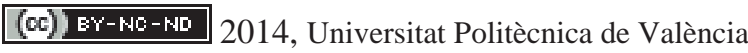

I Jornadas IN-RED (2014) 
tienen buena nota en el retornable han sacado también buena nota en el examen, ya que el número de alumnos en el cuadrante superior derecho es mayor que en los otros tres cuadrantes. El total de alumnos mostrados en la gráfica es de 159.

Para Fundamentos de Computadores de GITST el coeficiente de correlación es 0.57, y la Fig. 9 muestra claramente que hacer unos buenos retornables es un buen comienzo para obtener buena nota en los exámenes. El número total de alumnos presentados en la gráfica es de 87. Se han descartado los alumnos que no se han presentado a todos los exámenes o no han participado en los retornables.

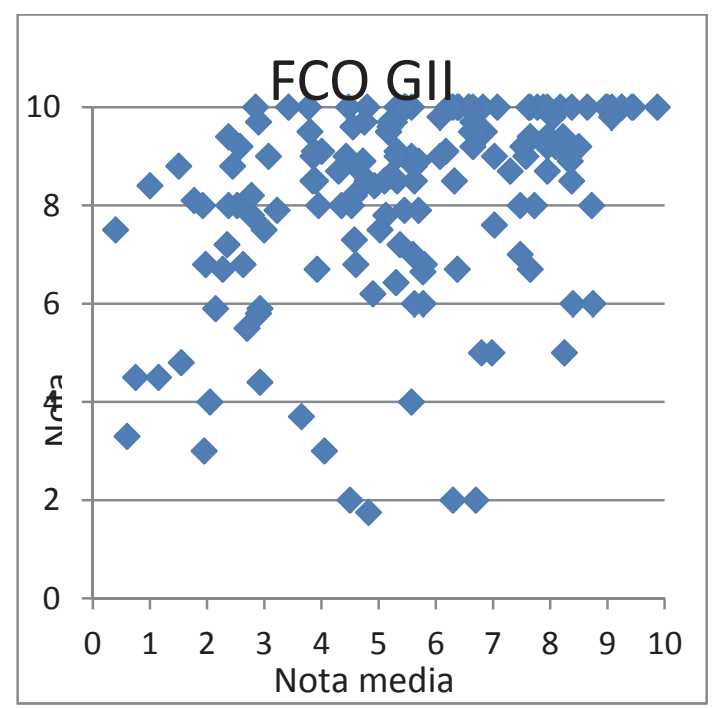

Fig. 8. Gráfico de dispersión entre la nota de los retornables y la nota media de los exámenes para FCO del GII 


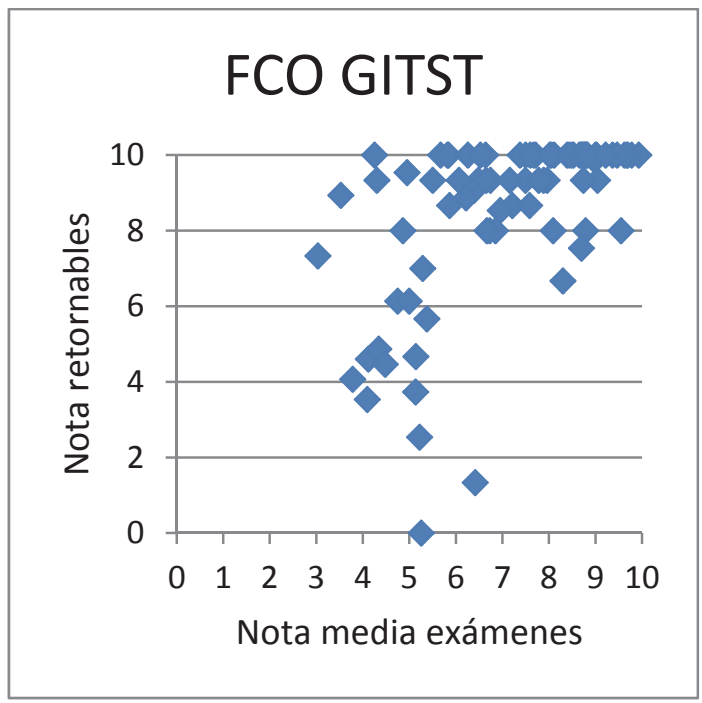

Fig. 9. Gráfico de dispersión entre la nota de los retornables y la nota media de los exámenes para FCO del GITST

La correlación mostrada entre las notas de los retornables y las notas en los exámenes puede indicar dos cosas. Por un lado que los alumnos corrigen adecuadamente los retornables, y por el otro que los alumnos que hacen correctamente los retornables aprenden lo que se espera de ellos en el examen. Sin embargo una buena nota en los retornables no es garantía de una buena nota en los exámenes.

\subsection{Tasa de abandono}

Uno de los objetivos de la evaluación continua es mantener al alumno al día y evitar que abandone la asignatura. Este es también un objetivo de los retornables, y la Tabla 2 muestra, para FCO del GII, el número de no presentados (NP) y el porcentaje que representa sobre el número de alumnos de cada grupo, así como los totales. Los grupos de clase se muestran en la columna de la izquierda para aquellos que han utilizado retornables, y en la columna de la izquierda los que no han utilizado retornables.

No se muestran datos para FCO del GITST ya que todos los grupos han utilizado los retornables, por lo que no es posible realizar comparaciones.

Tabla 2. Número y porcentaje de alumnos no presentados por grupos para FCO GII.

\begin{tabular}{llllllll}
\hline & \multicolumn{3}{c}{ Con retornable } & & \multicolumn{3}{c}{ Sin retornable } \\
Grupo & NP & $\%$ & Total alumnos & Grupo & NP & $\%$ & Total alumnos \\
\hline
\end{tabular}

\section{(cc) EY-NC-ND 2014, Universitat Politècnica de València}

I Jornadas IN-RED (2014) 


\begin{tabular}{crrrcrrc}
\hline $\mathrm{A}(\mathrm{Val})$ & 1 & 2,70 & 37 & $\mathrm{~B}($ Val $)$ & 1 & 2,86 & 35 \\
$\mathrm{C}$ & 4 & 8,16 & 49 & $\mathrm{D}$ & 4 & 8,51 & 47 \\
$\mathrm{~F}$ & 6 & 13,64 & 44 & $\mathrm{E}(\mathrm{ARA})$ & 0 & 0 & 31 \\
$\mathrm{G}$ & 5 & 10,87 & 46 & $\mathrm{H}$ & 3 & 6,67 & 45 \\
$\mathrm{I}$ & 3 & 7,32 & 41 & $\mathrm{~J}$ & 9 & 25 & 36 \\
Total & 19 & 9 & 217 & Total & 17 & 9 & 194 \\
\hline
\end{tabular}

El primer dato que destaca es el grupo ARA, en el que todos los alumnos se han presentado. El segundo dato destacado es el grupo J, con un porcentaje de no presentados del $25 \%$, muy superior a la media de la asignatura, que se sitúa en el $9 \%$. Se trata de un curso con horario de tarde, donde se combinan alumnos que trabajan con alumnos con notas de acceso muy bajas y/o que la titulación no era su primera opción. Los autores creen que el uso o no de los retornables no afecta al índice de presentados en este grupo.

$\mathrm{Si}$ se observa grupo por grupo, hay una gran variabilidad en el porcentaje de no presentados, aunque parece que los grupos con retornables arrojan peores resultados, es decir, mayor tasa de abandono. Sin embargo, si se mira el total, la diferencia es de sólo dos alumnos, y no hay diferencia en el porcentaje, por lo que es complicado decidir si el uso de los retornables mejora o empeora el número de presentados. En este punto es importante recordar que los grupos que no usan retornables también utilizan algún tipo de evaluación continua, como pequeños controles o el uso de entregables corregidos por el profesor, con la misma planificación temporal que los retornables, por lo que una posible conclusión es que los retornables no son mejores ni peores, en cuanto a tasa de abandono que otras técnicas de evaluación continua.

\subsection{Rendimiento académico}

Es complicado comparar el rendimiento de un grupo en años diferentes ya que existen muchos factores que modifican su nota: el nivel académico de los alumnos cuando acceden a la universidad ya que se trata de asignaturas de primer año, el profesor que imparte cada grupo, la asignación de alumnos que el centro hace a cada grupo, el horario asignado, factores que en mayor o menor medida varían cada año y pueden producir pequeñas variaciones en la nota media de los grupos.

La comparación del rendimiento entre grupos en el mismo curso es también complicada, ya que la asignación de alumnos a grupos que realiza el centro se basa en la nota de acceso a la universidad, asignando por orden de nota de mayor a menor empezando por el primer grupo y cambiando de grupo cuando se cubren las plazas disponibles. Esto propicia que el rendimiento y los resultados académicos suelan seguir una tendencia descendente con el orden de grupo. Además, los alumnos pueden indicar su preferencia de idioma (valenciano 
o castellano) por lo que la asignación no es completamente ordenada por nota. También entra en juego el grupo ARA, alumnos con nota de entrada excepcional pero que se escoge de forma voluntaria. Por último, alumnos con notas bajas y que son admitidos de forma tardía pueden ser asignados a cualquier grupo, terminando muchas veces en el grupo B de valenciano. Todo esto hace que una pequeña actividad como son los retornables pueda difícilmente mostrar un gran efecto en la nota que obtienen los estudiantes.

La Tabla 3 muestra la nota media de cada grupo en los exámenes presenciales separando los grupos entre los que han utilizado retornables y los que no. El valor numérico entre paréntesis $(4,60)$ de la última fila corresponde con la media en la nota de exámenes de los grupos que no usaron retornable sin considerar el grupo ARA.

Los resultados no muestran grandes diferencias. Si se incluye en los resultados el grupo ARA, un grupo especial, la media de los grupos que no utilizaron retornables es mayor, 4,92 frente al 4,79. Pero si retiramos el grupo ARA del análisis, la media es menor para los grupos que no usaron retornables, 4,60 frente al 4,79. En ambos casos la diferencia entre las medias es muy pequeña ( 0.13 a favor de los que no han usado los retornables incluyendo el grupo ARA y 0.19 a favor de los que sí han usado los retornables sin incluir el grupo ARA) y los autores creen que no es significativa, y que por tanto no se puede atribuir al uso de los retornables una mejora de los resultados académicos.

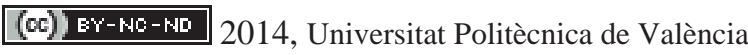

I Jornadas IN-RED (2014) 
Los retornables: evaluación continúa y entre pares

Tabla 3. Nota media de los examines por grupos para FCO GII

\begin{tabular}{cccccc}
\hline & \multicolumn{3}{c}{ Con retornable } & \multicolumn{3}{c}{ Sin retornable } \\
Grupo & Nota media & Total alumnos & Grupo & Nota media & Total alumnos \\
\hline A (Val) & 5,07 & 37 & B (Val) & 4,11 & 35 \\
C & 5,75 & 49 & D & 5,08 & 47 \\
F & 4,86 & 44 & E (ARA) & 6,18 & 31 \\
G & 4,37 & 46 & H & 4,72 & 45 \\
I & 3,91 & 41 & J & 4,51 & 36 \\
Total & 4,79 & 217 & Total & $4,92(4,60)$ & 194 \\
\hline
\end{tabular}

\section{Conclusiones}

El cambio metodológico causado por la implantación de los nuevos títulos de grado en la Universitat Politècnica de València ofrece una clara oportunidad para mejorar las prácticas educativas.

Aprovechando esta oportunidad se han utilizado los retornables, una herramienta docente que tiene por objeto incrementar el trabajo del alumno fuera del aula, motivar a los estudiantes, entrenarlos en competencias de alto nivel y aumentar su conciencia sobre la importancia y el impacto de su trabajo. Y al mismo tiempo, evitar una sobrecarga de trabajo tanto a los alumnos como a los profesores.

Mediante el uso de los retornables se consigue reforzar el proceso de aprendizaje de los alumnos de una manera flexible y entretenida. Además, en comparación con los modelos más tradicionales de aprendizaje, se fomenta la participación de los estudiantes en las diferentes etapas en que se divide el uso de los retornables.

La evaluación por pares, que es parte intrínseca del uso de los retornables, permite que los alumnos adquieran habilidades y competencias de alto nivel y transversales al grado. Los resultados presentados muestran que emitir un juicio sobre el trabajo de un compañero es una tarea en la que los alumnos no se sienten tan cómodos como en la resolución de problemas y exámenes. Y esto es probablemente debido a qué han practicado esta actividad en pocas o ninguna ocasión.

Sin embargo, las notas que los alumnos asignan a sus compañeros corresponden en la mayoría de los casos no sólo con las notas que les pondría el profesor, sino con las notas que los alumnos obtienen en los exámenes. Aunque los criterios de corrección incluidos en los retornables les parecen insuficientes, son capaces de hacer un gran trabajo.

(cc) EY-NC-ND 2014, Universitat Politècnica de València

I Jornadas IN-RED (2014) 
La mayor aportación de los retornables es la inclusión en el proceso de aprendizaje de los alumnos de unas competencias transversales y de alto nivel como es la evaluación y emisión de un juicio sobre el trabajo de un compañero.

Más aún, este aprendizaje en otras competencias no específicas de la asignatura se consigue, tal como muestran los resultados, sin reducir el rendimiento académico en las competencias específicas de la asignatura, ni tampoco otros indicadores académicos como la tasa de abandono.

Por último, pero no menos importante, la gran aceptación que esta herramienta ha tenido por la gran mayoría de los alumnos, tal como muestran los resultados numéricos de las encuestas, pero realmente se aprecia en los comentarios libres que los alumnos se han tomado la molestia de escribir.

\section{Agradecimientos}

Este trabajo ha sido financiado en parte por la Escola Tècnica Superior d'Enginyeria Informàtica de la Universitat Politècnica de València y por el programa Proyectos de Innovación y Mejora Educativa PIME/2013/A/026/B de la Universitat Politècnica de València.

\section{Referencias}

BLOOM, B. S. (1994). "Reflections on the development and use of the taxonomy". In Rehage, Kenneth J.; Anderson, Lorin W.; Sosniak, Lauren A. Bloom's taxonomy: A fortyyear retrospective. Chicago. National Society for the Study of Education. 93 (2). Yearbook of the National Society for the Study of Education.

Cano, J.C.; Poza, J.L.; Petit, S.; Alonso, M.; Yuste, P.; Acebrón, F.; Martí, A.; Posadas, J.L.; Atienza, V.; Lemus, L.; RodrígueZ, F. (2010) "Fundamentos de Computadores. Grado en Ingeniería Informática". En III Jornada de Innovación Docente. ETSInf. UPV.

DAVIES, R. and BERROW, T. (1998) "An evaluation of the use of computer supported peer review for developing higher-level skills" Journal Computers \& Education. Volume 30 Issue 1-2, Jan./Feb. 1998. Pages 111-115.

FORD, B.W. (1973). "The Effects of Peer Editing/Grading on the Grammar-Usage and Theme-Composition Ability of College Freshmen". Ed. Dissertation Abstracts International. The University of Oklahoma, USA.

\section{(cc) EY-NC-ND 2014, Universitat Politècnica de València}

I Jornadas IN-RED (2014) 
KENNETH, J.H., MA, T. K., and KWONG, H. F. (2005) "A method of automatic grade calibration in peer assessment," In Proceedings of the 7th Australasian conference on Computing education (ACE '05)

Krathwohl, D. R.; Bloom, B. S.; MasiA, B. (1964). Taxonomy of Educational Objectives: The Classification of Educational Goals - Handbook 2: Affective Domai., Longman, London, UK.

MACALPINE, J. M. K. (1999) "Improving and Encouraging Peer Assessment of Student Presentations," In Assessment \& Evaluation in Higher Education, Vol. 24, Iss. 1, 1999.

RAFIQ, Y., FULLERTON, H. (1996). "Peer Assessment of Group Projects in Civil Engineering," in Assessment \& Evaluation in Higher Education, Vol. 21, Iss. 1, 1996.

WOLFE, W. J. (2004). "Online student peer reviews," In Proceedings of the 5th conference on Information technology education (CITC5 '04)

EARL, S. E. (1986). "Staff And Peer Assessment Measuring An Individual's Contribution To Group Performance" In Assessment \& Evaluation in Higher Education, Vol. 11, Iss. 1.

LOPEZ-REAL, F., RITA-CHAN, Y. P. (1999). "Peer Assessment of a Group Project in a Primary Mathematics Education Course," In Assessment \& Evaluation in Higher Education, Vol. 24, Iss. 1.

PERSONS, O. S. (1998), "Factors Influencing Students' Peer Evaluation in Cooperative Learning," In Journal of Education for Business, Vol. 73, Iss. 4.

GEHRINGER, E. F. (2003). "Electronic peer review builds resources for teaching computer architecture," In 2003 American Society for Engineering Education Annual Conference, Electrical \& Computer Engineering Division.

RIESCO-ALBIZU, M., DÍAZ-FONDÓN, M. (2007). "La revisión entre iguales como herramienta de aprendizaje y evaluación en la asignatura de sistemas operativos" En actas de las XIII Jornadas de Enseñanza Universitaria de la Informática (Jenui 2007), 


\title{
Seguimiento y evaluación del Proceso de enseñanza-aprendizaje en asignaturas de Ingeniería Química.
}

Iborra-Clar, M.I., García-Castelló, E.M, Alcaina-Miranda, M.I., Sancho-Fernández M.P., Iborra-Clar A., Lora-García, J.

Departamento de Ingeniería Química y Nuclear. Universitat Politècnica de Valencia

Camino de Vera s/n. C. Postal 46022 - Valencia

\begin{abstract}
The use of computer tools and all the possibilities that can offer, represent an important part of new teaching methodologies that include criteria for monitoring and evaluation of the student learning role. This aspect become more important in the development of the work of teachers. In the new studies in the European Higher Education, the individual work of the students, the self-learning and self-assessment, begins to be significant in the balance with which the student will be evaluated. When the number of students per class is large (80-100 students), each student will develop an individual level that is proportional to their capacities and work invested in studying the subject. Due to the intrinsic characteristics of Chemical Engineering, eminently practical and with a high level of experimentation, much of the study is based largely on the implementation and monitoring of case studies and problem solving. It is thus essential to use specifics of spreadsheet and software of process design (Mathcad, Matlab, CHEMCAD, etc).
\end{abstract}

Keywords:

Monitoring, self-assessment, self-learning, teacher-student interaction, teachers platforms.

\section{Resumen}

El empleo de herramientas informáticas y todas las posibilidades que ofrecen, juegan un papel muy importante para la incorporación de nuevas 
Seguimiento y Evaluación del Proceso de Enseñanza-Aprendizaje en Asignaturas de Ingeniería Química

metodologías docentes que contemplen criterios de seguimiento y evaluación del aprendizaje del alumno, ya que este aspecto adquiera mayor importancia en el desarrollo de la labor del profesor.

En los nuevos planes de estudio deltro de Espacio Europeo de Enseñanaza Superior, el trabajo individual del alumno, la labor de autoaprendizaje y su seguimiento, toman relevancia en la ponderación de la nota con la que el alumno será evaluado. Cuando además el número de alumnos por curso es numeroso (80-100 alumnos), cada alumno desarrollará un nivel individual que será proporcional a sus capacidades y al trabajo invertido en estudio de la materia.

Debido a las características intrínsecas de la Ingeniería Química, ya que es una titulación con elevado grado de experimentalidad y eminentemente práctica, gran parte del estudio de la misma se basa en la realización y seguimiento de casos prácticos y la resolución de problemas, por lo resulta imprescindible además, el empleo de programas informáticos de cálculo y diseño de procesos (Mathcad, Mathlab, Chemcad, etc.)

\section{Palabras clave:}

Seguimiento, autoevaluación, autoaprendizaje, interacción profesor-alumno, plataformas docentes.

\section{Introducción}

Las herramientas informáticas juegan un papel primordial en la instauración de los nuevos planes de estudio en todas las ramas de ingeniería. Debido a que son unas disciplinas eminentemente experimentales, la incorporación de nuevas metodologías docentes que potencien criterios de seguimiento y evaluación del aprendizaje del alumno, es fundamental en el desarrollo de la labor del profesor. En estos nuevos planes, el trabajo individual del alumno y su seguimiento, toman relevancia en la ponderación de la nota final con la que el alumno será evaluado. Por lo tanto, habrá que reorientar la metodología docente hacia metodologías que permitan evaluar la labor de autoaprendizaje del alumno (siempre guiado por el profesor) cuando además el número de alumnos es numeroso (80-100 alumnos). De esta manera, cada alumno desarrollará un nivel individual que será proporcional al trabajo invertido en la práctica y estudio de la materia.

Actualmente la mayoría de las Universidades Españolas cuentan con plataformas de seguimiento docente que permite mantener al alumnoy al profesor conectado on-line con la asignatura desde cualquier terminal de ordenador, tablet, móvil, etc. El rápido avance de la

(c)) EY-NC-ND 2014, Universitat Politècnica de València

I Jornadas IN-RED (2014) 
Iborra-Clar, M.I., García-Castelló, E.M, Alcaina-Miranda, M.I., Sancho-Fernández,M.P., Iborra-Clar A., Lora-García, J.

tecnología informática permite favorecer el proceso interactivo profesor-alumno y facilita el aprendizaje de la materia mediante la disponibilidad in-situ de todo tipo de material docente previamente publicado en red.

En este sentido, la CODDIQ (Conferencia de Directores y Decanos de Ingeniería Química), motivada por esta iniciativa, está elaborando una plataforma para el intercambio interuniversitario de material docente a nivel nacional, para la rama de Ingeneiría Química. Desde el año 2012 se realiza anualmente un Congreso de Innovación Docente en Ingeniería Química (CIDIQ) donde se hace patente la inquietud en este ámbito por la incorporación de nuevas metodologías.

La Universitat Politécnica de Valencia dispone desde hace más de una década de una plataforma docente, Poliforma-T, que ofrece numerosas posibilidades para el desarrollo de actividades on-line, siendo fundamental para el buen aprovechamiento y manejo, su constante renovación y adaptación a las nuevas titulaciones.

De forma complementaria, en la UPV se dispone de la plataforma Riu-Net, cuyo objetivo es ofrecer acceso en Internet a la producción científica, académica y corporativa de la comunidad universitaria con la finalidad de aumentar su visibilidad y hacerla accesible y preservable. Esta plataforma está formada por diferentes tipos de documentos, como objetos de aprendizaje (Polimedia, Laboratorios virtuales y artículos docentes), tesis doctorales, artículos de revistas, mapas, trabajos académicos, trabajos creativos, fondo patrimonial, material docente, multimedia, producción institucional, revistas electrónicas y actas de congresos.

Dentro del estudio de la Ingeniería, y concretamente la Ingeniería Química, debido a las características intrínsecas de estas titulaciones, gran parte del aprendizaje se basa en la realización y seguimiento de casos prácticos y resolución de problemas, por lo que resulta interesante contar con la posibilidad de introducir de manera gradual al alumno en el planteamiento y resolución de los mismos, a través de la utilización de programas informáticos de cálculo y diseño de procesos (Mathcad, Mathlab, Chemcad, etc.) (Rafael et al, 2007).

\section{Objetivos}

Dentros de los objetivos desarrollados, se encuentra la creación de una base de datos con diversos materiales de apoyo para su inclusión en cualquiera de las plataformas (Colección de problemas auto-guiados a diferentes niveles, colección de problemas resueltos, unidades temáticas complementarias, objetos de aprendizaje, artículos científicos, bases de datos experimentales, etc.)

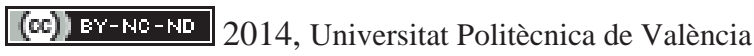

I Jornadas IN-RED (2014) 
Asimísmo, la elaboración de un portafolio interactivo on-line que posibilita el aprendizaje y evaluación del alumno haciendo uso del material docente publicado en red, y que permite al profesor evaluar sus capacidades de una determinada disciplina de estudio.

\section{Desarrollo de la innovación}

La innovación que se ha venido incorporando de manera gradual al grueso de asignaturas troncales del Grado en Ingeniería Química de la UPV, hace referencia a la metodología de trabajo del material disponible para la impartición de cada una de las asignaturas.

Dentro de este grupo de asignaturas, se encuentran: Bases de la Ingeniería Química ( $2^{\circ}$ Curso Cuatrimestre A), Transferencia de Materia ( $2^{\circ}$ Curso Cuatrimestre B), Operaciones de Separación (3er Curso cuatrimestre A), Análisis y Simulación de Procesos (3er Curso Cuatrimestre B), y las diferentes asignaturas de Experimentación en Ingeniería Química que apoyan mediante la realización de prácticas de laboratorio, los contenidos teóricos impartidos en las asignaturas anteriores.

\subsection{Recursos en PoliformaT}

En el grueso de las asignaturas troncales, los contenidos teóricos son suministrados mediante la plataforma PoliformaT en la web de cada asignatura, si bien para cada asignatura el profesor responsable decide según su criterio que documentación se le proporciona al alumno y a que nivel, en función de los objetivos del curso. En el apartado "Recursos" de la plataforma se le proporciona al alumno toda aquella documentación que se requiere para el seguimiento de las clases teóricas (los temas elaborados y /o las presentaciones de los temas), así como documentación complementaria, tal como artículos de publicaciones científicas, bibliografía específica para cada tema que se encuentra enlazada con la Biblioteca de la UPV, objetos de aprendizaje, etc.

Además se introducen una serie de apartados donde se encuentran los enunciados de problemas a realizar en aula de informática, y la resolución de los mismos, con el fín de que el alumno proceda a su auto-evaluación. Colecciones de problemas complementarias, propuestos y resueltos, exámenes de la asignatura de cursos anteriores, etc.

Tal y como se muestra en la Figura 1, en el apartado "Recursos" de Poliforma, se encuentran estructuradas unas carpetas en las cuales se incluye el temario de la asignatura y las presentaciones realizadas en clase, el enunciado de los problemas correspondientes y posteriormente el problema resuelto (en formato pdf) para su autoevaluación, así como otras carpetas con colecciones de problemas autoguiados en mayor o menor medida, la carpeta de "Tareas", donde el alumno encuentra enunciadas tareas de la semana que debe 
Iborra-Clar, M.I., García-Castelló, E.M, Alcaina-Miranda, M.I., Sancho-Fernández M.P., Iborra-Clar A., Lora-García, J.

realizar, documentación adicional (en este caso dos ficheros con el tutorial del programa de cálculo empleado para la resolución de problemas, Mathcad), así como exámenes de otros años, artículos si fuera necesario, documentación de apoyo, etc.

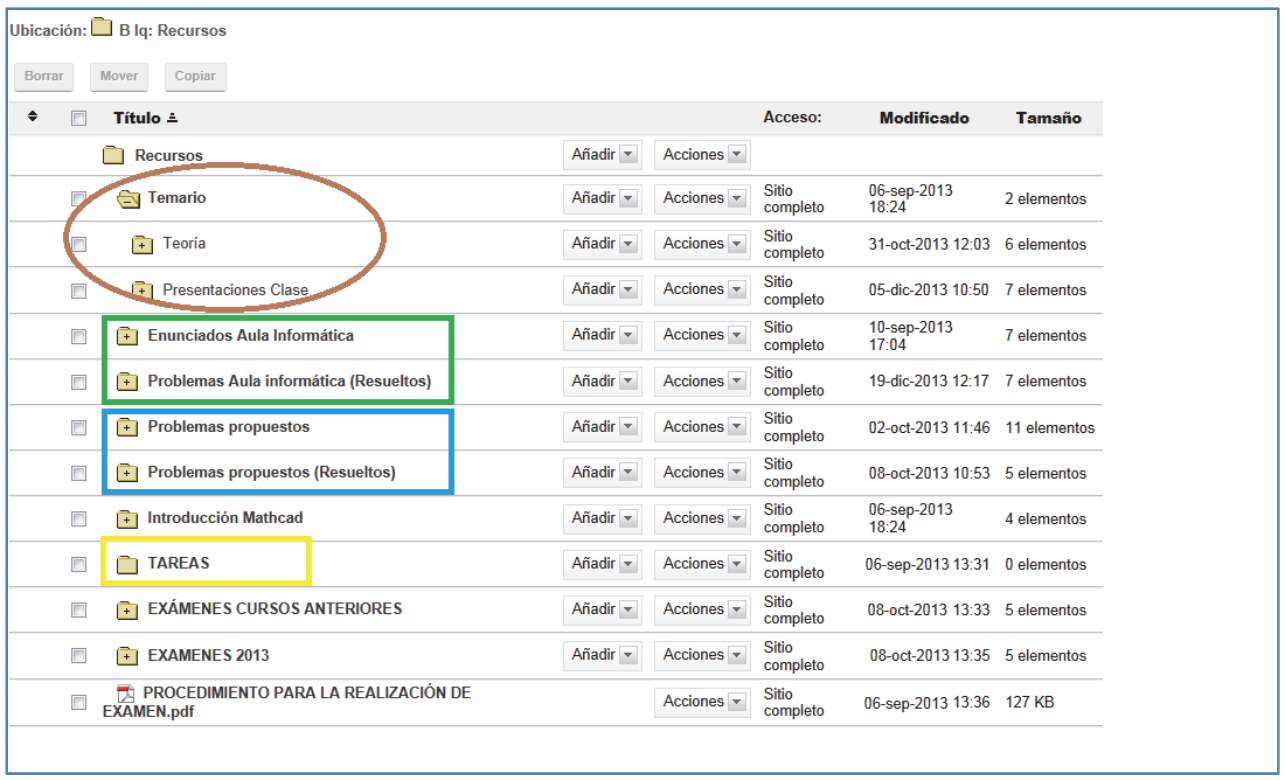

Figura 1. Apartado "Recursos" de una asignatura troncal tipo de Ingeniería Química.

Por otro lado, cada alumno posee una carpeta en el apartado "Espacio compartido" que solo es visible por los profesores de la asignatura y el propio alumno. Mediante esta carpeta se produce el intercambio de documentación profesor/alumno, muy importante para el seguimiento y evaluación continuada del mismo. Así, el alumno sube periódicamente su trabajo y el profesor corrige y adjunta las modificaciones del mismo, y a su vez le permite observar la evolución del alumno.

\subsection{Test de seguimiento}

Como parte del seguimiento semanal, se realizan unos test breves (entre 7 y 10 preguntas para responder entre unos 10/15 minutos), la mayoria de preguntas de opción múltiple muy básicas, con el fin de que el alumno que no haya asistido a la clase de teoría, se vea en la obligación de repasar los apuntes impartidos ese día, además de reforzar los conocimientos teóricos que se van a utilizar en la clase de problemas.

\section{(cc) EY-NC-ND 2014, Universitat Politècnica de València}

I Jornadas IN-RED (2014) 
Seguimiento y Evaluación del Proceso de Enseñanza-Aprendizaje en Asignaturas de Ingeniería Química

El test se activa al comienzo de la clase, y automáticamente lo recoge en el tiempo predeterminado. La puntuación obtenida por cada alumno se reserva en el apartado de calificaciones, obteniendo así el alumno una nota de seguimiento que pondera entre el $10 \mathrm{y}$ el $20 \%$ de la nota del curso.

En la Figura 2 se observa la nota de seguimiento promedio de la clase a lo largo del curso

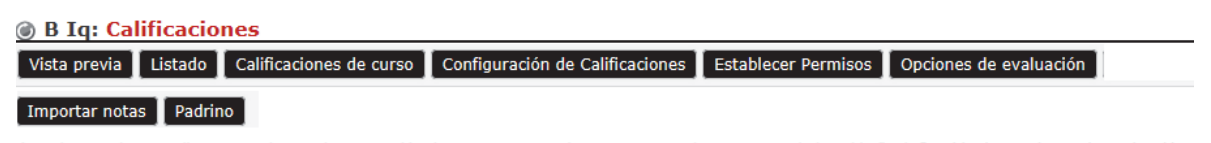

Actualmente, los estudiantes pueden ver la puntuación de sus tareas y exámenes, pero no la nota acumulativa ni la final. Cambiar las opciones de evaluación.

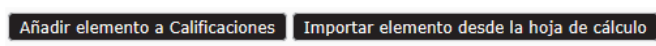

\begin{tabular}{|c|c|c|c|c|c|c|c|c|}
\hline Nota media del curso. & probado & $69 \%)$ & & & & & & \\
\hline Tareas & & & & & & & & \\
\hline Pulse un título para ver el sume & ario de ta & reas o para & evaluarlas. & Establecer como orden por defecto & & & & \\
\hline Titulo* & & Media** & Fecha de entrega & a Publicada para alumnos & Incluido en acumulativo & Orden & anc & do $\equiv$ \\
\hline Test1Viernes-2013-14 & Editar & $(52 \%)$ & 20-sep-2013 & s & Si & 1 & & 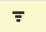 \\
\hline Test1Lunes-BIQ-2013 & Editar & $(35 \%)$ & 23-sep-2013 & s & Si & 2 & 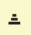 & $\mp$ \\
\hline Test-viernes-2-BIQ2 & Editar & $61 \%$ & 26-sep-2013 & s & Si & 3 & $\doteq$ & $\bar{F}+\mathrm{r}-\mathrm{x}$ \\
\hline Test2L-BIQ-2013/14 & Editar & $73 \%$ & 30-sep-2013 & $\mathrm{s}$ & Si & 4 & 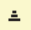 & 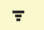 \\
\hline Test2L-BIQ2º $-13 / 14$ & Editar & $70 \%$ & 30-sep-2013 & $\mathrm{s}$ & Sí & 5 & $\doteq$ & $\bar{F}+\mathrm{r}-\mathrm{x}$ \\
\hline$\underline{\text { Test3-BIQViernes }}$ & $\underline{\text { Editar }}$ & $35 \%$ & 04-oct-2013 & s & Sí & 6 & $\underline{\underline{\underline{1}}}$ & $\bar{F}$ \\
\hline Test3-BIQLunes & Editar & $52 \%$ & 07-oct-2013 & s & Si & 7 & $\underline{\underline{1}}$ & $\bar{F}$ \\
\hline$\underline{\text { Test-BMNE-viernes11 }}$ & Editar & $94 \%$ & $11-$ oct-2013 & $\mathrm{s}$ & Si & 8 & $\underline{\underline{\prime}}$ & $\mp$ \\
\hline Test-No-estacionario-LUNES & Editar & $36 \%$ & 14-oct-2013 & $\mathrm{s}$ & Sí & 9 & 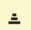 & $\bar{F}+\mathrm{r}+\mathrm{r}-\mathrm{s}$ \\
\hline$\underline{\text { Test ETAPAS-VIERNES }}$ & Editar & $71 \%$ & 08-nov-2013 & s & Si & 10 & $\underline{\underline{\underline{ }}}$ & $\bar{\nabla}$ \\
\hline Etapas-Lunes 2013 & Editar & $42 \%$ & 11-nov-2013 & $\mathrm{s}$ & Sí & 11 & $\underline{\underline{ }}$ & $\overline{7}$ \\
\hline$\underline{\text { Test-5V-BIQ }}$ & Editar & $77 \%$ & 29-nov-2013 & $\mathrm{s}$ & Si & 12 & $\underline{\underline{\prime}}$ & $\overline{7}$ \\
\hline Test-5L-BIQ & Editar & $91 \%$ & 02-dic-2013 & $\mathrm{s}$ & Si & 13 & $\underline{\underline{\underline{1}}}$ & $\bar{F}$ \\
\hline Test-AD-Lunes & Editar & $72 \%$ & 09-dic-2013 & s & Sí & 14 & $\underline{\underline{z}}$ & $\overline{7}$ \\
\hline Viernes13-AD & Editar & $86 \%$ & 13-dic-2013 & $\mathrm{s}$ & Si & 15 & $\underline{\underline{\prime}}$ & $\bar{F}+\mathrm{r}-\mathrm{r}$ \\
\hline
\end{tabular}

Figura 2. Apartado "Calificaciones" de los exámenes del tipo test.

Además con el tiempo de impartición de la asignatura, se ha ido disponiendo de una baterías de preguntas, clasificadas por su contenido, donde se almacenan múltiples cuestiones para conformar los test. Así como una serie de exámenes ya conformados, que se pueden editar, modificar y/o adjuntar nuevas preguntas.

Los exámenes pueden ser además de tipo test temporizado o no, de relacionar preguntas y respuestas, respuesta breve, verdadero/falso, encuesta, etc. Por lo que en función de la materia a examinar será mas adecuado un tipo u otro de examen.

(c)) EY-NC-ND 2014, Universitat Politècnica de València

I Jornadas IN-RED (2014) 
Iborra-Clar, M.I., García-Castelló, E.M, Alcaina-Miranda, M.I., Sancho-Fernández,M.P. Iborra-Clar A., Lora-García, J.

En la figura 3 se observa la batería de preguntas disponibles para una asignatura y como se observa por la fecha de modificación de los ficheros, se ha ido implementando durante varios cursos.

\begin{tabular}{|c|c|c|c|c|}
\hline \multicolumn{2}{|c|}{ Nombre de bateria $=$} & \multirow{2}{*}{$\frac{\text { Creador }}{\text { María Isabel Iborra Clar }}$} & \multirow{2}{*}{$\frac{\text { Última modificación }}{15 / 06 / 2012}$} & \multirow{2}{*}{$\frac{\text { Prequntas }}{13}$} \\
\hline 9 & $\begin{array}{l}\text { Agitación de fluidos } \\
\underline{\text { Añadir I Copiar I Mover I Compartir }}\end{array}$ & & & \\
\hline 9 & $\begin{array}{l}\text { Analisis Dimensional } \\
\underline{\text { Añadir I Copiar I Mover I Compartir }}\end{array}$ & María Isabel Iborra Clar & $30 / 11 / 2011$ & 17 \\
\hline 9 & $\begin{array}{l}\text { Balance de energía } \\
\text { Añadir I Copiar I Mover I Compartir }\end{array}$ & María Isabel Iborra Clar & 07/01/2010 & 18 \\
\hline 9 & $\begin{array}{l}\text { BE-Esperanza } \\
\text { Añadir I Copiar I Mover I Compartir }\end{array}$ & María Isabel Iborra Clar & $20 / 06 / 2012$ & 13 \\
\hline 9 & $\begin{array}{l}\text { BE-Exp } \\
\text { Añadir I Copiar I Mover I Compartir }\end{array}$ & María Isabel Iborra Clar & $15 / 06 / 2012$ & 21 \\
\hline 9 & $\begin{array}{l}\text { BM-Reacción química } \\
\text { Añadir I Copiar I Mover I Compartir }\end{array}$ & María Isabel Iborra Clar & 05/10/2012 & 10 \\
\hline 9 & $\begin{array}{l}\text { Desalación } \\
\underline{\text { Añadir I Copiar | Mover I Compartir }}\end{array}$ & María Isabel Iborra Clar & $01 / 12 / 2010$ & 26 \\
\hline 9 & $\begin{array}{l}\text { Difusividad } \\
\underline{\text { Añadir I Copiar | Mover I Compartir }}\end{array}$ & María Isabel Iborra Clar & $16 / 12 / 2008$ & 26 \\
\hline 9 & $\begin{array}{l}\text { Etapas de equilibrio } \\
\text { Añadir I Copiar I Mover I Compartir }\end{array}$ & María Isabel Iborra Clar & $09 / 11 / 2011$ & 10 \\
\hline 9 & $\begin{array}{l}\text { examen 5A } \\
\text { Añadir I Copiar I Mover I Compartir }\end{array}$ & María Isabel Iborra Clar & $24 / 02 / 2009$ & 9 \\
\hline$\Delta$ & $\begin{array}{l}\text { Examen POB-2009-1 } \\
\text { Añadir I Copiar I Mover I Compartir }\end{array}$ & María Isabel Iborra Clar & 03/09/2009 & 25 \\
\hline 9 & $\begin{array}{l}\text { Filtración } \\
\text { Añadir | Copiar | Mover I Dejar de Compartir }\end{array}$ & Alicia Iborra Clar & $12 / 12 / 2008$ & 10 \\
\hline 9 & $\begin{array}{l}\text { Partículas } \\
\text { Añadir I Copiar I Mover I Dejar de Compartir }\end{array}$ & $\mathrm{M}^{\mathrm{a}}$ Amparo Bes Piá & $22 / 12 / 2008$ & 8 \\
\hline 9 & $\begin{array}{l}\text { Riesgos Laboratorios } \\
\underline{\text { Añadir I Copiar I Mover I Compartir }}\end{array}$ & María Isabel Iborra Clar & 04/09/2012 & 21 \\
\hline 9 & $\begin{array}{l}\text { Saponificación } \\
\text { Añadir I Copiar I Mover I Dejar de Compartir }\end{array}$ & Beatriz Elena Cuartas Uribe & $15 / 12 / 2008$ & 8 \\
\hline 9 & $\begin{array}{l}\text { Sedimentación } \\
\text { Añadir I Copiar I Mover I Dejar de Compartir }\end{array}$ & Beatriz Elena Cuartas Uribe & $15 / 12 / 2008$ & 12 \\
\hline 9 & $\begin{array}{l}\text { Seguridad en el laboratorio } \\
\underline{\text { Añadir I Copiar I Mover I Compartir }}\end{array}$ & María Isabel Iborra Clar & $25 / 01 / 2013$ & 12 \\
\hline 9 & $\begin{array}{l}\text { Simulación hidraúlica } \\
\text { Añadir I Copiar I Mover | Dejar de Compartir }\end{array}$ & Alicia Iborra Clar & $12 / 12 / 2008$ & 9 \\
\hline 9 & $\begin{array}{l}\text { Solido-Liquido } \\
\underline{\text { Añadir I Copiar I Mover I Compartir }}\end{array}$ & María Isabel Iborra Clar & $15 / 06 / 2012$ & 4 \\
\hline
\end{tabular}

Figura 3. Bateria de preguntas de la asignatura.

En la siguiente figura se muestra un ejemplo de parte de un examen tipo test tal y como lo visualiza el alumno.

(c) EY-NC-ND 2014, Universitat Politècnica de València

I Jornadas IN-RED (2014) 
Seguimiento y Evaluación del Proceso de Enseñanza-Aprendizaje en Asignaturas de Ingeniería Química

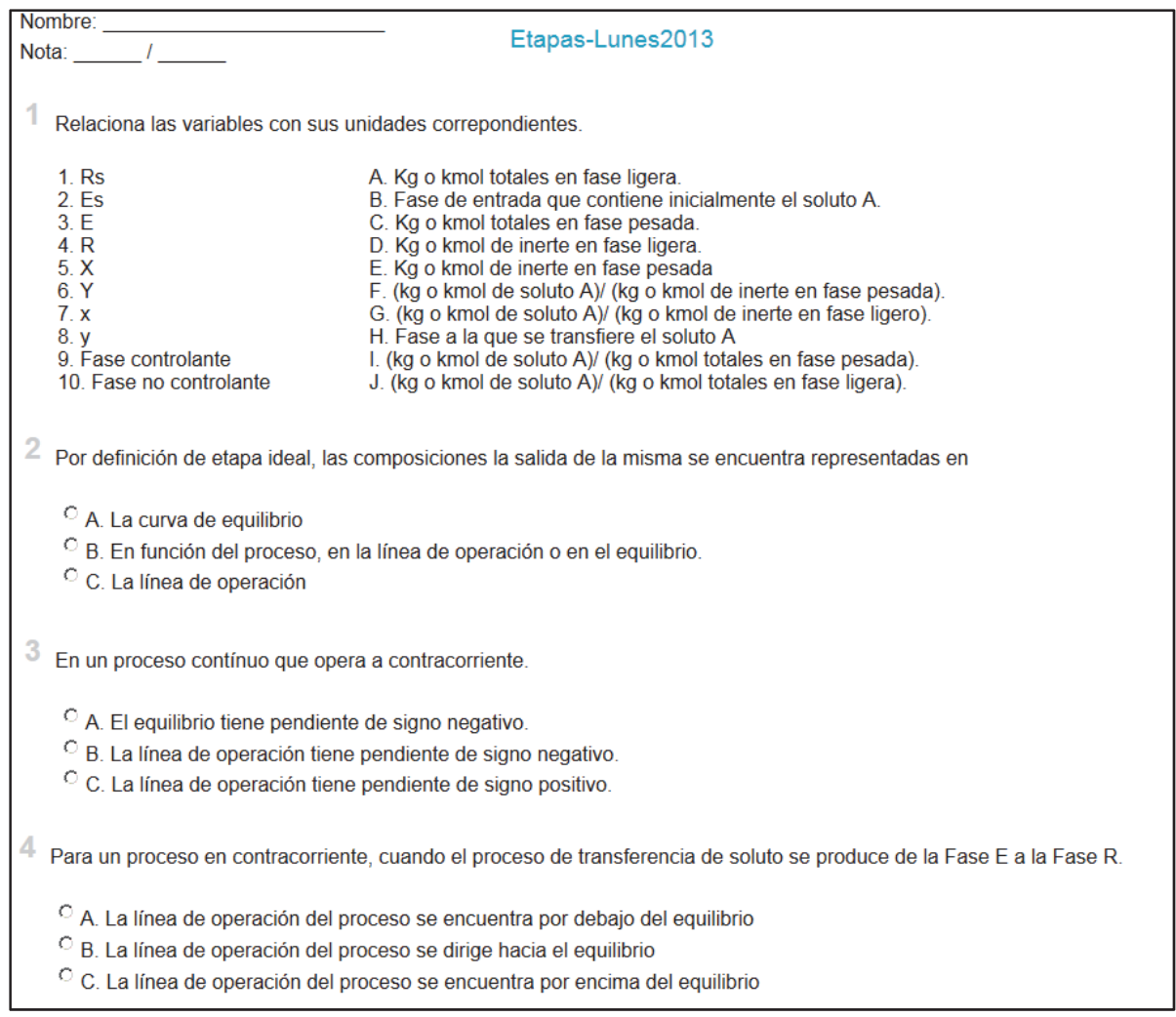

Figura 4. Ejemplo de un examen tipo test.

\subsection{Actividades complementarias}

Como actividades para reforzar los conocimientos adquiridos en cada asignatura, se proponen la realización de diversas actividades complementarias, tales como la realización de seminarios grupales, trabajos académicos individuales, exposición oral de trabajos, análisis de resultados y toma de decisiones (Murugesan et al, 2005).

Para ellos se le suministar los documentos elaborados por el profesor con la información correspondiente o las bases de datos y bibliografía específica para que el alumno seleccione según su criterio la información más adecuada (Shallcross, 2013). Esta parte es muy importante para que el alumno se familiarice con artículos científicos, manuales ingenieriles, obtención de propiedades físico-químicas, y resultados experimentales referenciados, etc. 
Iborra-Clar, M.I., García-Castelló, E.M, Alcaina-Miranda, M.I., Sancho-Fernández,M.P., Iborra-Clar A., Lora-García, J.

De igual manera, mediante la incorporación de objetos de aprendizaje elaborados por los mismos profesores, se conforma una base de datos publicada en Riu-net, donde el alumno puede acceder y complementar su formación.

\subsection{Mejoras a introducir}

Debido a que la incorporación de nuevas metodologías docentes debe ser algo dinámico, se está poniendo en marcha la incorporación de un portafolio virtual donde cada alumno tenga constancia de todos sus actos de evaluación, trabajos, seminarios, exposiciones, etc. Dentro de cada asignatura.

Por un lado, una de los conceptos que más se ha debatido a lo largo del periodo de puesta en marcha del Espacio Europeo de Educación Superior (EEES) es el de acquisición de «competencias».

Mediante la adquisición de las competencias y destrezas de naturaleza no académica y disciplinar, se aspira a que la educación superior cumpla su papel en la economía y la sociedad, no basta la acumulación de conocimientos académicos sino que es indispensables que los egresados puedan insertarse eficazmente en la vida laboral, económica y social (Salubaru el al, 2011).

En las nuevas titulaciones, para mantener estos criterios y directrices asi como para garantizar la calidad de la misma, se crearon las Agencias de Calidad externas a las Universidades (ANECA), que en nuestro caso audita en diferentes niveles del sistema educativo. Así pues los Grados son auditados a los 6 años y los Masters son auditados a los 4 años de su implantación. Como parte de estas auditorias, se encuentra la evaluación de las competencias transversales que el alumno ha adquirido.

Mediante la elaboración del portafolio, como documento que constate la evaluación y seguimiento del alumno durante el curso, se puede acreditar que se cumplen con los criterios de calidad establecidos en el EEES.

\section{Resultados y conclusiones}

Los resultados de la aplicación delas nuevas metodologías se han evaluado a partir de las estadísticas obtenidas para las diversas asignaturas, analizando el porcentaje de alumnos aprobados suspensos y no presentados por convocatoria.

Como conclusión se podría decir que tanto a partir de las diversas actividades propuestas como de la documentación que se vá incorporando gradualmente a lo largo del curso, se puede conformar una especie de portafolio, que permite evaluar la actividad del alumno así

\section{(cc) EY-NC-ND 2014, Universitat Politècnica de València}

I Jornadas IN-RED (2014) 
Seguimiento y Evaluación del Proceso de Enseñanza-Aprendizaje en Asignaturas de Ingeniería Química

como su aprendizaje. De esta manera, el procentaje de la nota obtenida en la asignatura, no se limita a calificación obtenida en un solo acto de evaluación como sería el examen tradicional.

Esta labor contínua realizada tanto por el alumno como por el profesor a lo largo del curso, permite mejorar el rendicimento académico del alumno, su motivación por la asignatura, y reduce el grado de abandono, tal y como se visualiza a modo de ejemplo en la figura 5 mediante las estadísticas obtenidas durante los últimos años para una determinada asignatura.

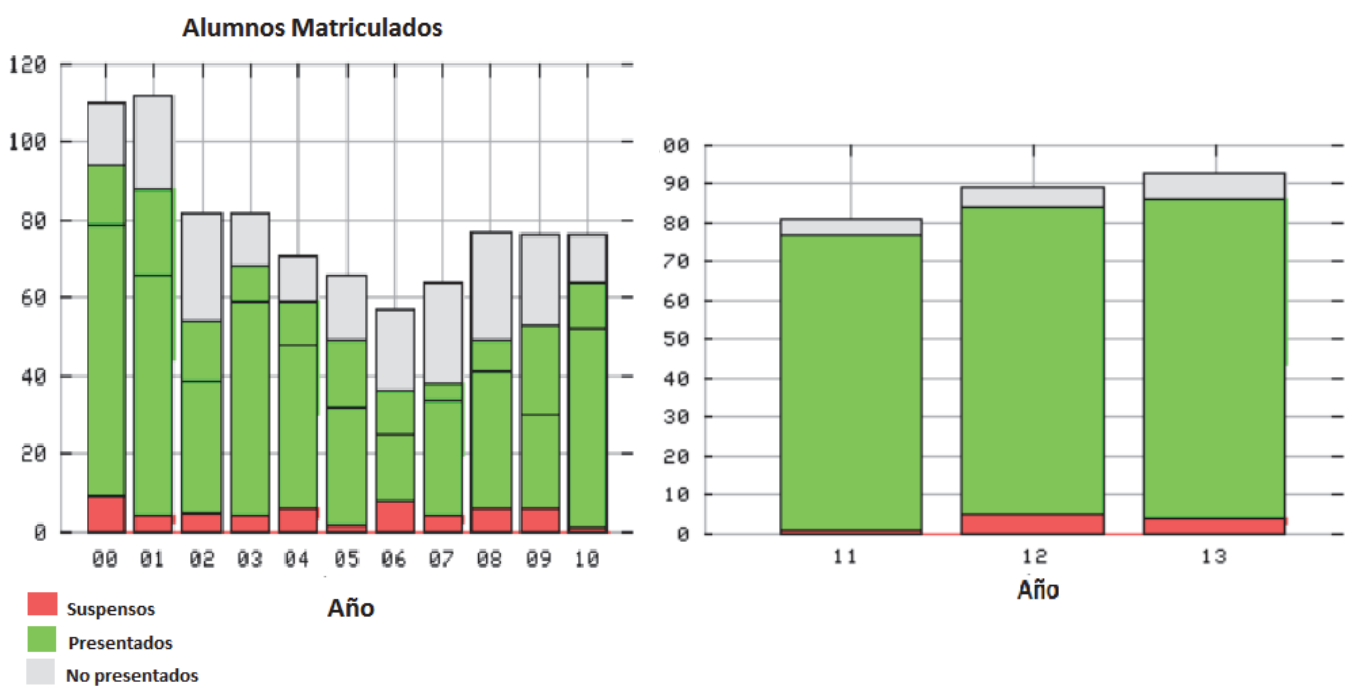

Figura 5. Resultados estadísticos de una asignatura

\section{Bibliografía}

I Congreso de Innovacion Docente en Ingeniería Química. Universidad de Granada, 2012. www.ciddiq.es

II Congreso de Innovacion Docente en Ingeniería Química. Univeridad de Valencia, 2014. www.ciddiq.es

Murugesan, S., Ginige, A.”Web Engineering: Introduction and Perspectives”. Woojong Suh. (C) 2005, Idea Group Inc.

Rafael, A., Bernardo, F., Ferreira, L., Rasteiro, M. and Teixeira, J. "Virtual applications using a web platform to teach chemical engineering. The Distillation Case" IChemE, Part D, Education for Chemical Engineers, 2007, 2: 20-28 
Iborra-Clar, M.I., García-Castelló, E.M, Alcaina-Miranda, M.I., Sancho-Fernández M.P., Iborra-Clar A., Lora-García, J.

Salaburu, P, Haug,G., Mora,J.G. "España y el proceso de Bolonia. Un encuentro imprescindible" Ed. Academia Europea de Ciencias y Artes España. 2011. ISBN 978-84614-7183-6

Shallcross. D.'Safety education through case study presentations". Education for Chemical Engineers 8 (2013) e-12 e-30

Web de conferencia de Directores y Decanos de Ingeniería Química. www.coddiq.es. 


\title{
Melodías con Arduino en Teoría de Circuitos
}

\section{Carlos Hernández Franco}

Escuela Técnica Superior de Ingenieros de Telecomunicación, chernan@dcom.upv.es

\begin{abstract}
"Melodies with Arduino" has a main objective to promote in students who begins studying Telecommunications studies the curiosity, creativity and passion for the "invention". This is, to put into practice in form of "small" technical projects all the knowledge they acquire in the sessions of theory. And this knowledge not only correspond with those of "Circuit Theory", syllabus belonging to the first semester of the first year of the Degree in Engineering Technology and Telecommunication Services where this proposal develops educational innovation, but also those other knowledge acquired during their formation, such as, for example, mathematics, physics and programming. With this proposal, it aims to promote, in simple way, the passion for entrepreneurship in the classroom. Certainly, they are freshmen, but we consider it necessary to develop these capabilities from the first day they come to our school and leave it for later courses can be undoubtedly a waste of all the creative potential of students in our classrooms. From our point of view, this proposal ensures an effective transversality of learning and teaching activities.
\end{abstract}

Keywords: Creativity, Transversality, Arduino, Circuit Theory.

\begin{abstract}
Resumen
"Melodías con Arduino" tiene como objetivo principal fomentar en el alumnado que comienza sus estudios de Telecomunicaciones la curiosidad, la creatividad y la pasión por la "invención”. Esto es, llevar a la práctica en forma de "pequeños" proyectos técnicos, todos los conocimientos que va adquiriendo en las distintas sesiones de teoría. Y estos conocimientos no sólo se corresponden con los de "Teoría de Circuitos", asignatura del primer cuatrimestre del primer curso del Grado en Ingeniería de Tecnologías y Servicios de Telecomunicación donde se desarrolla esta propuesta de
\end{abstract}

(c) $)$ EY-NC-ND 2014, Universitat Politècnica de València

I Jornadas In-Red (2014) 
innovación educativa, sino también aquellos conocimientos que adquiere en otras asignaturas de su itinerario formativo, como pueden ser, por ejemplo, las Matemáticas, la Física y la Programación. Con esto se persigue fomentar, aunque sea de forma incipiente, la pasión por emprender en el aula. Cierto que son alumnos de primer curso, pero consideramos que es necesario desarrollar estas capacidades desde el primer día que llegan a nuestra Escuela y que dejarlo para cursos posteriores puede resultar, sin duda, un desaprovechamiento de todo el potencial creativo del alumnado de nuestras aulas. En nuestra opinión, esta propuesta garantiza una transversalidad efectiva del aprendizaje y de la propia labor docente del profesorado de la titulación.

Palabras clave: Creatividad, Transversalidad, Arduino, Teoría de Circuitos.

\section{Introducción}

"Melodías con Arduino" tiene como objetivo principal fomentar en el alumnado que comienza sus estudios de Telecomunicaciones la curiosidad, la creatividad y la pasión por la "invención". Esto es, llevar a la práctica en forma de "pequeños" proyectos técnicos, todos los conocimientos que va adquiriendo en las distintas sesiones de teoría. Y estos conocimientos no sólo se corresponden con los de "Teoría de Circuitos", asignatura del primer cuatrimestre del primer curso del Grado en Ingeniería de Tecnologías y Servicios de Telecomunicación donde se desarrolla esta propuesta de innovación educativa, sino también aquellos conocimientos que adquiere en otras asignaturas de su itinerario formativo, como pueden ser, por ejemplo, las Matemáticas, la Física y la Programación.

A nuestro modo de entender, esta propuesta garantiza una transversalidad efectiva del aprendizaje y de la propia labor docente del profesorado de la titulación. Haciendo uso de Arduino, una plataforma "open hardware" diseñada para el "prototipado" fácil e intuitivo, al alumnado se le propone el diseño, la implementación y la puesta a punto de un "sistema" para la generación de melodías musicales (se fomenta y organiza, desde el primer momento, el trabajo colaborativo en grupos de 3 a 5 compañeros).

Para ello deberá el alumnado hacer uso de todo el conocimiento que vaya adquiriendo en clases a la vez que debe proceder a la búsqueda de otros conocimientos necesarios en portales de fabricantes de equipos y componentes (españoles e internacionales), fórums de programadores (sean estos profesionales o no), en revistas y newsletters especializadas, etc. 
Se le advierte que en todo momento deberán ser críticos y muy reflexivos con la información de la cual disponen. Con esto se persigue el desarrollar en el alumnado la capacidad (o competencia) de saber qué información resulta útil y cuál no y la forma o manera en que ésta se "convierte" en conocimiento. Claro está, la propuesta tecnológica deberá funcionar y la misma será presentada y "defendida" en una sesión de clases frente al resto del alumnado.

Hemos comprobado durante el desempeño de nuestra labor docente, la inmensa dificultad que constituye para nuestros estudiantes exponer y defender en público un determinado trabajo. El desarrollar esta habilidad comunicativa (otra competencia más...) resultará vital en su carrera profesional. "Melodías con Arduino" no es más que una primera propuesta de proyecto técnico. Llegado a este punto, se "invita" al alumnado a que propongan sus ideas en forma de proyecto y las desarrollen.

Con esto se persigue fomentar, aunque sea de forma incipiente, la pasión por emprender en el aula. Cierto que son alumnos de primer curso, pero consideramos que es necesario desarrollar estas capacidades desde el primer día que llegan a nuestra Escuela y que dejarlo para cursos posteriores puede resultar, sin duda, un desaprovechamiento de todo el potencial creativo del alumnado de nuestras aulas.

\section{1. ¿Cómo fomentar la creatividad y la transversalidad en el aprendizaje?}

Una vez expuestos los principios básicos de la "Teoría de Circuitos", durante las dos primeras sesiones de clases del curso aproximadamente, el alumnado comienza el estudio de diversos componentes pasivos que le permitirán diseñar circuitos eléctricos de relativa sencillez, pero que serán la base, en otras asignaturas, para el diseño de otros más complejos.

Los elementos pasivos son el resistor, el condensador y el inductor o bobina. Es muy importante definir en clases por qué se estudian y que función práctica, o aplicación, tienen los mismos. Por ejemplo, el resistor permite limitar la corriente eléctrica que circula por las distintas ramas del circuito, el condensador sirve para el almacenamiento de energía y el inductor para evitar "picos de corriente", entre otras muchas funciones. Asimismo, es muy importante explicar (y comprobar que lo entienden) todo el "andamiaje" matemático y físico que caracteriza y describe el comportamiento de estos elementos pasivos.

Es preciso que el profesorado mantenga en todo momento el interés de la clase por lo que se explica, apoyándose para ello en conceptos teóricos, videos, simulaciones, fotografías, esquemas y gráficos, etc. Una herramienta de gran utilidad para comprobar conceptos, resolver ecuaciones, buscar información, etc., es la conocida como WolframAlpha (gratuita en entorno web) de fácil uso (WolframAlpha, 2014).

\section{(cc) EY-NC-ND 2014, Universitat Politècnica de València}

I Jornadas IN-RED (2014) 
Y en este sentido, esto es, el uso de un programa, enlazaría de forma directa (la transversalidad en el aprendizaje) con otra de las asignaturas del cuatrimestre: "Programación". En nuestra opinión, es esta una de las asignaturas que más llaman la atención y la curiosidad de los alumnos de nuevo ingreso. También, una de las que presenta ante ellos un "lenguaje nuevo" (software) que les posibilita ampliar, especificar y modificar el comportamiento de la parte física de un circuito (hardware).

Al principio, esta posibilidad resulta "extraña" y bastante "abstracta" para muchos de ellos, dado que, normalmente, en los niveles anteriores de enseñanza no se suelen estudiar conceptos de programación. Llegados a este punto, tenemos un aula donde con imaginación y creatividad se pueden "mezclar" las Matemáticas, con la Física, la Programación y la "Teoría de Circuitos".

\section{Plataforma Arduino y el "prototipado" de proyectos técnicos}

Arduino es una plataforma electrónica abierta para la creación de prototipos basada en software y hardware flexibles y fáciles de usar. Se creó para ser utilizada por artistas, diseñadores, aficionados a la electrónica y la programación y cualquier persona interesada en crear entornos u objetos interactivos (Arduino, 2014; Banzi, 2011; Culkin 2011).

Arduino puede adquirir información de su "entorno" a través de sus pines o terminales de entrada mediante el uso de sensores (luz, temperatura, humedad, presión, proximidad, etc.) pudiendo interaccionar con dicho entorno mediante el uso de controladores, actuadores, luces, motores, válvulas, altavoces, diodos leds, etc. (Plataforma Arduino, 2014), Fig. 1.

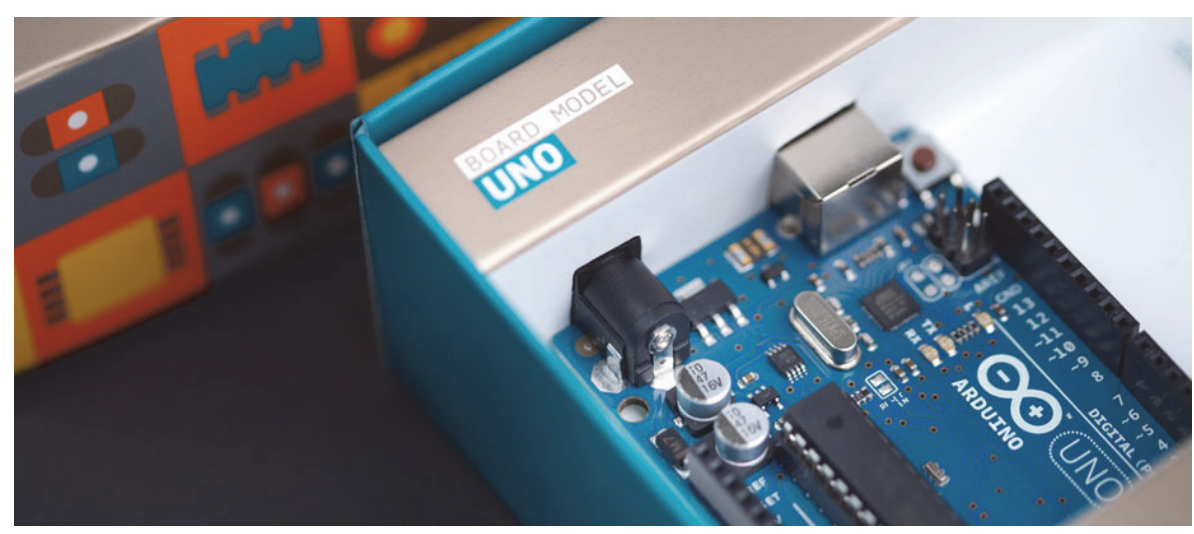

Fig. 1 Plataforma Arduino UNO, muy popular en el "prototipado" de proyectos 
"Melodías con Arduino" no es más que una primera propuesta de "proyecto técnico" al alumnado. Si logramos motivarlos con la misma, este podría proponer otros proyectos a realizar durante las sesiones de clases, e incluso, una vez finalizado el cuatrimestre. Debemos señalar que el estudio de esta plataforma y su entorno de programación (basado en un lenguaje muy parecido al C o al Java) no forma parte de la guía docente de la asignatura "Teoría de Circuitos" y por tanto de sus contenidos.

Lo que le proponemos al alumnado es aprender nuevos conceptos y adquirir nuevas habilidades que sin duda alguna les resultarán de gran utilidad para entender los contenidos de otras asignaturas, del mismo cuatrimestre o de otros cursos. Recomendaciones bibliográficas y apoyos durante las horas de tutorías facilitan esta propuesta de innovación docente y transversalidad en el aprendizaje, Fig. 2.

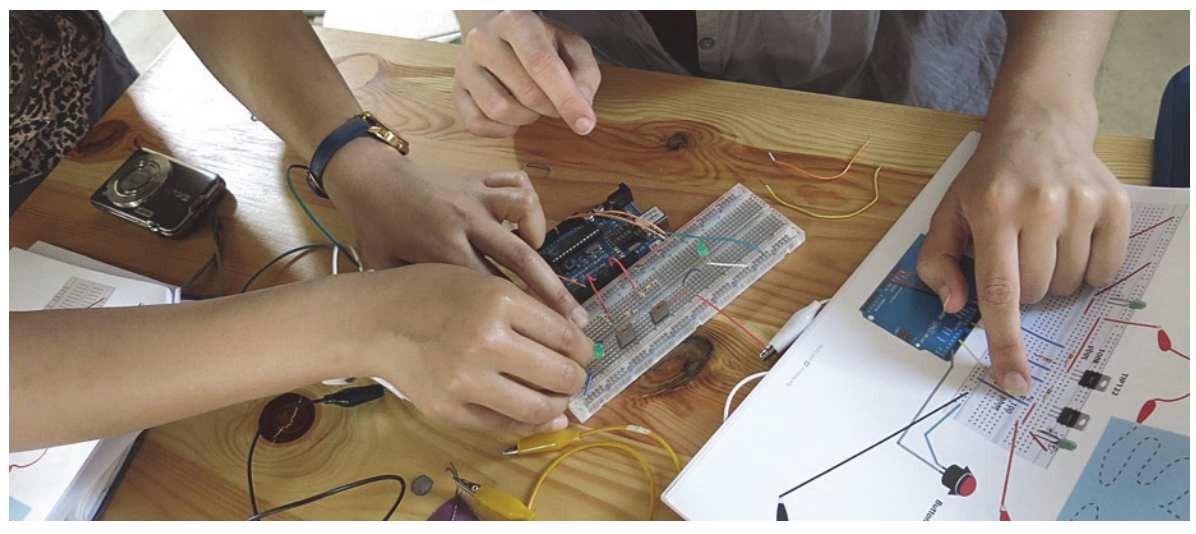

Fig. 2 Combinando conocimientos teóricos con habilidades prácticas

\section{Metodología del proyecto "Melodías con Arduino" y sus resultados}

Propuesta de "plan de trabajo" para el desarrollo de la innovación docente:

1. Explicar en clases qué es "Melodías con Arduino" (propuesta/ejemplo), Fig. 3

2. Selección de los alumnos interesados en participar (formación de grupos)

3. Calendario de Tutorías específicas para el estudio de los contenidos, Fig. 4

4. Experimentación en el laboratorio con la plataforma Arduino

5. Preparación de la presentación (Power Point, vídeos, etc.), Fig. 5

6. Presentación en sesión de clases (alumnos y otros profesores), Figs. 6 y 7

7. Mejoras y sugerencias para próximos proyectos técnicos... 

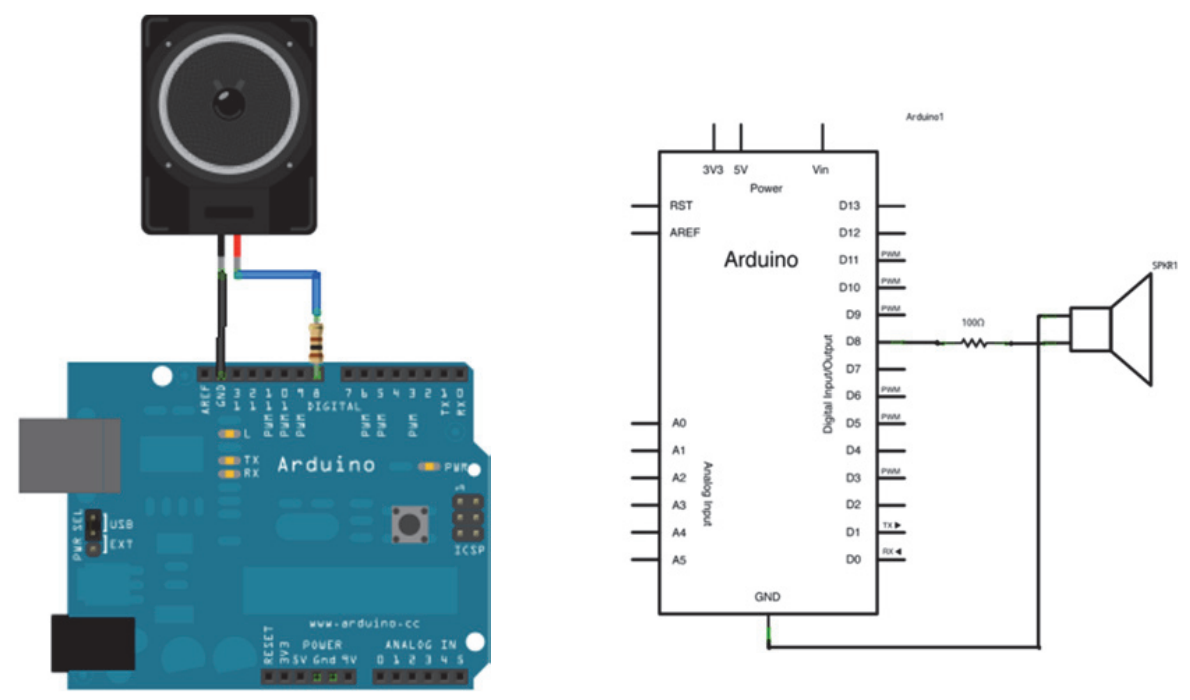

Fig. 3 Proyecto técnico "Melodías con Arduino"

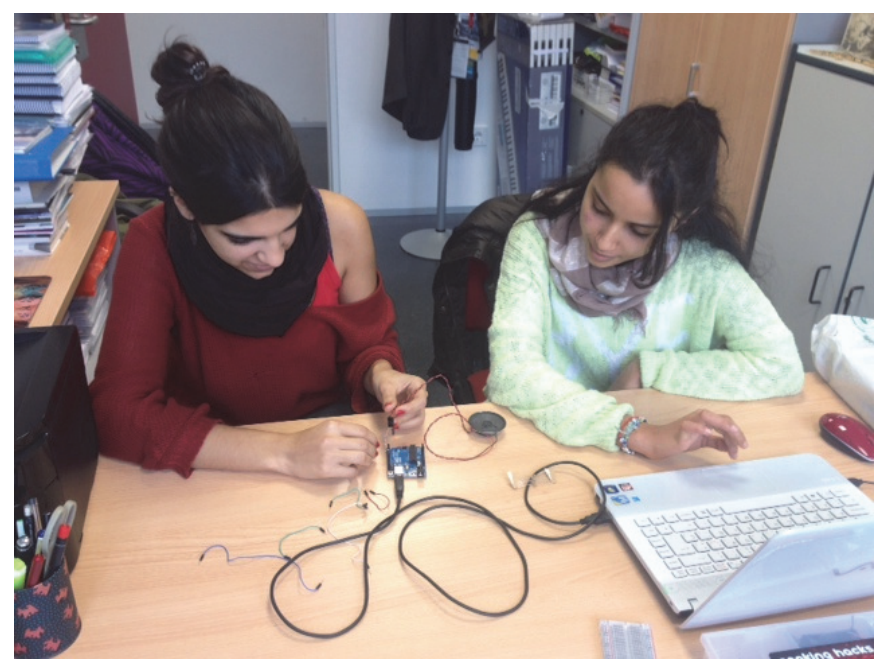

Fig. 4 Tutorías para analizar e implementar el circuito "generador de melodías"

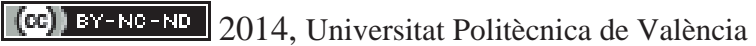
I Jornadas IN-RED (2014) 

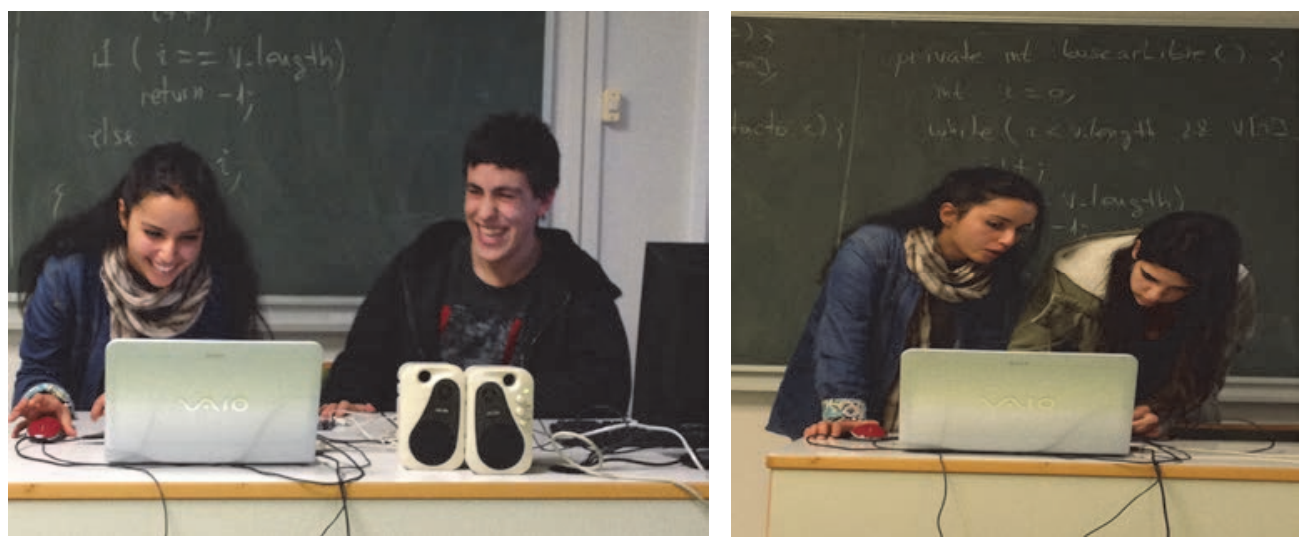

Fig. 5 Preparación de la "demo" en la sesión de clases

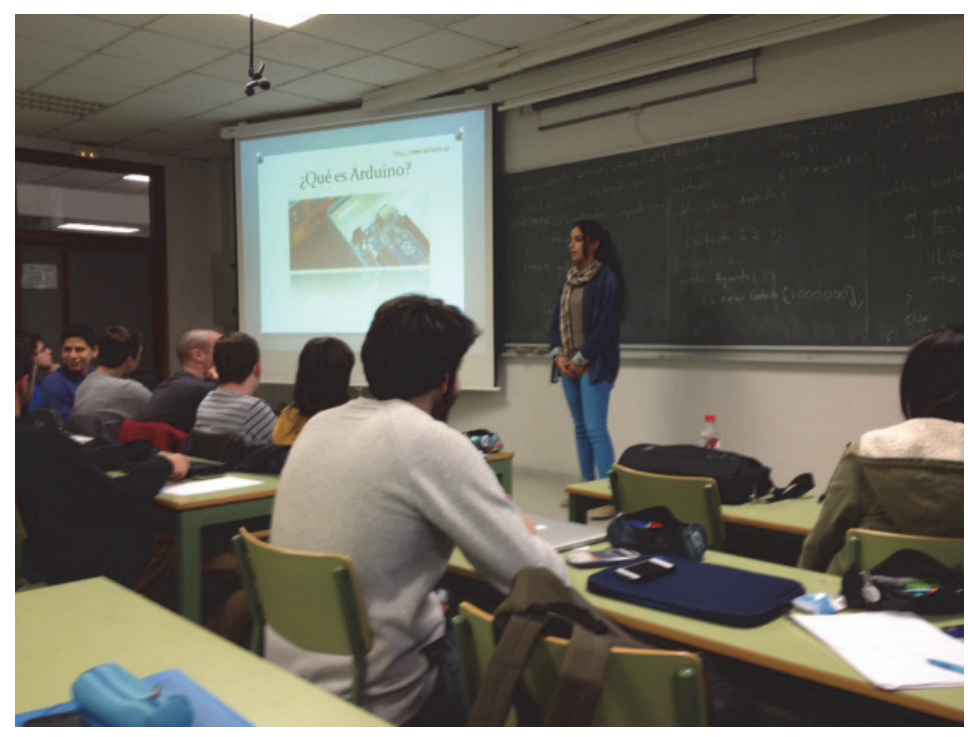

Fig. 6 Presentación de la "demo" en la sesión de clases

En todo momento, el alumnado debe percibir que el plan de trabajo propuesto, que debe ser flexible y ajustarse al calendario de actividades del mismo, puede ayudarle a ampliar sus conocimientos desarrollando nuevas habilidades prácticas y "comunicativas" que serán de gran utilidad en su desempeño profesional. Asimismo, es muy recomendable contar con el apoyo, comentarios y sugerencias de los profesores del grado. En nuestro caso, el profesor de Programación estuvo informado sobre el desarrollo de esta iniciativa, el trabajo realizado por el alumnado y participando en la demostración realizada en la sesión de clase.

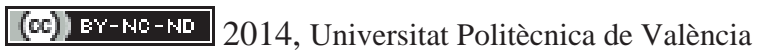

I Jornadas IN-RED (2014) 


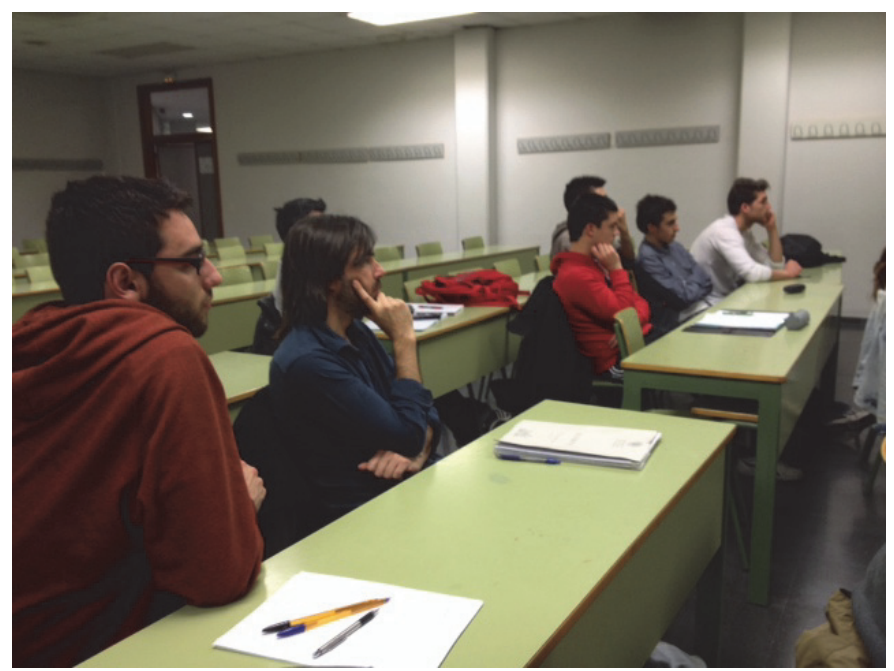

Fig. 7 El Profesor de la asignatura "Programación" asiste a la "demo" en la sesión de clases

Descripción del programa de control del "generador de melodías"...

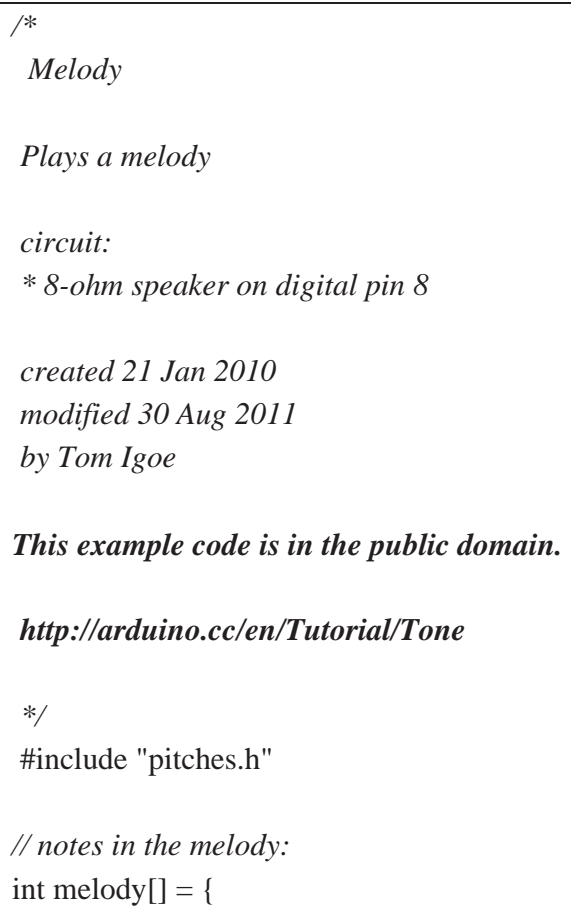

(c)) EY-NC-ND 2014, Universitat Politècnica de València 


\section{NOTE_C4, NOTE_G3,NOTE_G3, NOTE_A3, NOTE_G3,0, NOTE_B3, NOTE_C4\};}

// note durations: $4=$ quarter note, $8=$ eighth note, etc.:

int noteDurations[] $=\{$

$4,8,8,4,4,4,4,4\}$;

void $\operatorname{setup}()\{$

// iterate over the notes of the melody:

for (int thisNote $=0$; thisNote $<8$; thisNote++) \{

// to calculate the note duration, take one second

// divided by the note type.

//e.g. quarter note $=1000 / 4$, eighth note $=1000 / 8$, etc.

int noteDuration $=1000 /$ noteDurations [thisNote];

tone( 8 , melody[thisNote],noteDuration);

// to distinguish the notes, set a minimum time between them.

// the note's duration $+30 \%$ seems to work well:

int pauseBetweenNotes $=$ noteDuration $* 1.30$;

delay(pauseBetweenNotes);

// stop the tone playing:

noTone(8);

\}

\}

void loop() \{

// no need to repeat the melody.

\}

$/ * * * * * * * * * * * * * * * * * * * * * * * * * * * * * * * * * * * * * * * * * * * * * * * * *$

* Public Constants

*******************************************************

\#define NOTE_BO 31

\#define NOTE_C1 33

\#define NOTE_CS1 35

\#define NOTE_D1 37

\#define NOTE_DS1 39

\#define NOTE_E1 41

\#define NOTE_F1 44

\#define NOTE_FS1 46

\#define NOTE_G1 49

(c)) EY-NC-ND 2014, Universitat Politècnica de València

I Jornadas IN-RED (2014) 


\section{Conclusiones}

Consideramos que "Melodías con Arduino" consiguió el objetivo principal que se planteó y que es fomentar en el alumnado que comienza sus estudios de Telecomunicaciones la curiosidad, la creatividad y la pasión por la "invención”. Esto es, llevar a la práctica en forma de "pequeños" proyectos técnicos, todos los conocimientos que va adquiriendo en las distintas sesiones de teoría. Y estos conocimientos no sólo se corresponden con los de la asignatura "Teoría de Circuitos".

A nuestro modo de entender, esta propuesta garantiza una transversalidad efectiva del aprendizaje y de la propia labor docente del profesorado de la titulación. Con un costo reducido al hacer uso de hardware y software abiertos, se fomenta el trabajo colaborativo entre los alumnos a la vez que se desarrolla en ellos la idea de aplicar permanentemente todo lo que aprende, exponerlo ante los demás (competencia fundamental), etc. La evaluación de estos conocimientos y habilidades se realiza entonces de una forma que va más allá del examen "tradicional" escrito en el aula.

Por otro lado, y no menos importante, con esta propuesta se persigue fomentar, aunque sea de forma incipiente, la pasión por emprender en el aula. Cierto que son alumnos de primer curso, pero consideramos que es necesario desarrollar estas capacidades desde el primer día que llegan a nuestra Escuela y que dejarlo para cursos posteriores puede resultar, sin duda, un desaprovechamiento de todo el potencial creativo del alumnado de nuestras aulas.

Los autores quieren expresar su agradecimiento a todo el alumnado que de una forma u otra ha colaborado en el desarrollo de esta propuesta de innovación docente, muy especialmente a los alumnos Laura Calabuig Benítez, Aicha Dreif Aourass y Cristian Antón Rodríguez. Asimismo, al profesor de la asignatura "Programación" Rafael Llobet Azpitarte por sus recomendaciones y apoyo constante.

\section{Referencias}

ARDUINO. Portal Oficial. < www.arduino.cc > [Consulta: 13 de junio de 2014]

BANZI M. (2011)."Getting Started with Arduino”, O'Reilly Media

CULKIN, J. (2011). "Introducción a Arduino". < http://www.jodyculkin.com/comics2/introduction-to-arduino > [Consulta: 13 de junio de 2014]

PLATAFORMA ARDUINO. Plataforma Arduino. < http://es.wikipedia.org/wiki/Arduino > [Consulta: 13 de junio de 2014]

WOLFRAMALPHA. Portal Oficial. < www.wolframalpha.com > [Consulta: 13 de junio de 2014] 
Jornadas In-Red 2014

Universitat Politècnica de València

\title{
La co-evaluación como sistema de evaluación del trabajo colaborativo
}

E. De la Poza ${ }^{a^{*}, J}$ Josep Domènech ${ }^{\mathrm{a}}$, N.Guadalajara ${ }^{\mathrm{a}}$, F. Más ${ }^{\mathrm{a}}$, V. Martínez ${ }^{\mathrm{a}}$, I.Barrachina ${ }^{\mathrm{a}}$, M.L. Martía ${ }^{\mathrm{a}}$ D.Vivas ${ }^{\mathrm{a}}$.

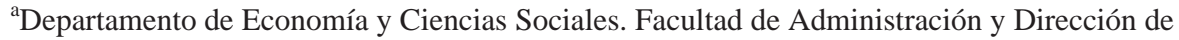
Empresas. Universitat Politècnica de València. Camino de Vera s/n. 46022. Valencia *email: elpopla@esp.upv.es-

\section{Abstract}

The university system in Spain in their adaptation to the context of European approval requires the efforts of university teachers who in the course of their work, they use new tools for assessing the skills of university students. In this paper is presented an application of co-assessment and evaluation system of the collaborative work subject to a first degree course given at the Universitat Politècnica de València.

Keywords: collaborative work, co-evaluation, teaching, competencies.

\begin{abstract}
Resumen
El sistema universitario en España en su proceso de adaptación al marco de homologación Europeo requiere del esfuerzo de los docentes universitarios quienes en el desarrollo de su labor, se sirven de nuevos instrumentos para la evaluar las competencias de los alumnos universitarios. En este trabajo se presenta una aplicación de la co-evaluación como sistema de evaluación del trabajo colaborativo a una asignatura de Grado de primer curso impartida en la Universitat Politècnica de València
\end{abstract}


Palabras clave: trabajo colaborativo, co-evaluación, docente
competencias

\section{Introducción}

Como consecuencia de la implantación del Sistema de Educación Superior Europeo, en las Universidades españolas se está viviendo un proceso de cambio que afecta a todos los agentes del proceso educativo: los alumnos, profesores, gestores del sistema educativo, las familias de los alumnos, las empresas, todos de una u otra forma se ven afectados por la reforma del Sistema de Educación Superior Europeo (Iranzo et al., 2012).

Los contenidos de los títulos también han sido reformulados, así como el concepto de crédito. En la actualidad, los créditos ECTS definen no sólo el número de horas que el alumno dedica en el aula, sino también el número de horas que el alumno debe dedicar a la asignatura (horas de estudio, ejercicios, trabajos en grupo, lecturas, etc....).

En este contexto de cambio, las Universidades Públicas Españolas se encuentran con un problema adicional, y es la masificación en las aulas, que dificulta la implantación de los Acuerdos de Bolonia ( los grupos de clase no deben superar los 50 alumnos). Es decir, se quiere garantizar una educación de calidad, y en la que el docente sea capaz de evaluar el aprendizaje de los estudiantes de forma continua, por tanto, a través de diversas pruebas evaluatorias [1,2,3], en las que se mida el grado de adquisición de competencias, entendiendo éstas como la suma de conocimientos, habilidades, actitudes y valores que permitirán al alumno enfrentarse a distintos tipos de problemas, tanto en contextos académicos como profesionales (Ariño, 2010; Jornet, 2010).

Sin embargo, ¿Cuáles son las herramientas que el docente puede hacer uso en el contexto actual?. Lógicamente, cuando el tamaño de los grupos son reducidos, las dinámicas a aplicar en clase son muy diversas, sin embargo, en la medida que el número de alumnos aumenta, la dificultad de la adecuada evaluación continua que Bolonia implica, resulta más difícil, (Trotter, 2006).

En consecuencia, se han desarrollado en los últimos años distintas propuestas para el desarrollo del proceso de aprendizaje y su evaluación en las aulas. De hecho, surge el aprendizaje colaborativo definido por Dillenbourg (1996) como la situación en la cual una o más personas aprenden e intentan aprender algo en forma conjunta. (...). En este sentido, el docente es quién debería definir el conjunto de personas así como la tarea, trabajo, proyecto que desarrollan juntos.

Cabrero (2003) unifica la definición de trabajo colaborativo y cooperativo en una única y establece que el aprendizaje colaborativo es "una metodología de enseñanza basada en la creencia de que el aprendizaje se incrementa cuando los 
estudiantes desarrollan destrezas cooperativas para aprender de los problemas y acciones educativas en las cuales se ven inmersos". Por tanto, el trabajo cooperativo, requiere la división de tareas entre los componentes del grupo. Por ejemplo, el docente propone un problema e indica al grupo que tareas deben desarrollar, si bien es el grupo como equipo quien distribuye las tareas entre los miembros, responsabilizándose cada uno por la solución de una parte del problema. Esto implica que cada estudiante se hace cargo de un aspecto y luego se ponen en común los resultados.

El grupo de trabajo debe ser pequeño, y en él, cada miembro se responsabiliza tanto de su aprendizaje, como de que el resto de miembros del grupo realiza sus tareas correctamente. Los estudiantes al trabajar conjuntamente, aprenden a compartir ideas y recursos, y deben trabajan colaborativamente/cooperativamente en la consecución de los objetivos propuestos por el profesor.

Los profesores no dictan instrucciones específicas, más bien permiten a los estudiantes elegir y variar sobre lo esencial de la clase y las metas a lograr, de este modo facilitan la participación de los estudiantes en su propio proceso de aprendizaje. (De la Poza y Doménech, 2011).

Para el docente evaluar los resultados del grupo puede constituir un desafío, en cuanto que debe aplicarse un sistema justo para los individuos pero que reconozca el esfuerzo, el progreso realizado en grupo (Puigvert Planagumà, 2009)

La promoción grupal (tanto la obtención de logros, como el grupo mismo, se encarga de dar realimentación al progreso de cada individuo) (Nicol, 2006). En consecuencia el grupo debe construirse, y reforzarse, y el docente debe dar libertad pero guiar este proceso con el fin de reducir cualquier problema que desvíe el grupo de sus objetivos, ( Schermerhorn, 2011).

En este contexto de trabajo colaborativo, el docente establece las técnicas de evaluación de aprendizaje, entre las que se enmarca la presentación pública de los resultados del trabajo colaborativo, así como del proceso que ha dado lugar a dichos resultados, y las metodologías empleadas por el grupo. La presentación pública ante el resto de alumnos de cada grupo es una de las técnicas de evaluación usualmente empleadas por el docente, a través de las cuales, los componentes del grupo exponen al resto de sus compañeros siguiendo un guión previamente diseñado por el docente, los principales aspectos y resultados de su trabajo.

El docente debe valorar el proceso de aprendizaje grupal a través de la exposición pública del trabajo colaborativo, y en consecuencia el profesor centra su atención en el grupo que expone en cada momento.

En esta situación se plantea como principal problema, la falta de atención/motivación por parte del resto de compañeros ante la exposición pública de otro grupo, bien porque el contenido que sus compañeros presentan no es

\section{(c) EY-NC-ND 2014, Universitat Politècnica de València}

I Jornadas IN-RED (2014) 
evaluado a través de pruebas objetivas, bien porque no forma parte del contenido del programa de la asignatura al tratarse de una aplicación, o caso de investigación...es decir, no existen elementos extrínsecos al alumno que ejerzan un efecto de motivación en éste, lo que puede derivar a un ambiente en el aula de falta de atención generalizada. Así, se desarrolla un sistema de coevaluación integrado en el sistema de evaluación del trabajo colaborativo para fomentar el nivel de motivación y aprendizaje del alumno. En este trabajo se presenta una aplicación del sistema de co-evaluación como sistema de evaluación del trabajo grupal en una asignatura de Grado, como es Empresa, perteneciente al área de Economía Aplicada e impartida en el primer curso y primer semester.

\section{La asignatura de Empresa}

La asignatura de Negocios es un curso obligatorio para los alumnos de primer curso de las titulaciones de Grado en Ingenierías impartidas en la UPV. La asignatura está constituida para que el alumno alcance las competencias establecidas en el programa, y sea capaz de transferir sus conocimientos al ámbito laboral. El curso presenta una introducción al sector aeronáutico y no se requiere conocimientos previos de economía. El contenido del curso está dividido en cinco módulos que abarcan 15 capítulos. El primer módulo es una introducción a los mercados, y agentes que actúan en ellos, el segundo está relacionado con el sistema de producción, el tercero son bases módulo sobre marketing, la cuarta parte del temario se centra en el proceso de toma de decisiones financieras e inversión, y el último módulo está relacionado con el análisis de la información económico financiera. Cada módulo consta de 4 unidades, excepto el último módulo que queda constituido por tres. La duración del curso es de 150 horas, distribuidas a lo largo de un semestre (15 semanas lectivas). La metodología del curso se compone de clases teóricas (1.5 horas/semana), sesiones de laboratorio (1 hora/semana), y clases aplicadas (1,5 horas/semana).

La Tabla 1 muestra la metodología aplicada para el curso y su relación con el número de horas que el alumno dedica a cada actividad.

Tabla 1. Metodología del curso y distribución temporal de las actividades.

\begin{tabular}{|c|c|c|c|c|c|}
\hline & \multicolumn{5}{|c|}{ ACTIVIDADES (numero de horas) } \\
\hline & \multicolumn{3}{|c|}{$\begin{array}{l}\text { Asistencia a } \\
\text { clase }\end{array}$} & \multirow{2}{*}{$\begin{array}{l}\text { Trabajo } \\
\text { en casa }\end{array}$} & \multirow[b]{2}{*}{ Total } \\
\hline Metodología & ST & SL & SP & & \\
\hline Explicación de conceptos & 30 & & & 30 & 60 \\
\hline
\end{tabular}




\begin{tabular}{|c|c|c|c|c|c|}
\hline Solución de ejercicios & & 15 & 2 & 10 & 27 \\
\hline Trabajo en grupos & & & 3 & & 3 \\
\hline Estudios del caso & & & 2 & & 2 \\
\hline Aprendizaje basado en problemas & & & 3 & 13 & 16 \\
\hline Aprendizaje basado en proyecto & & & 3 & 20 & 23 \\
\hline Presentación de proyectos & & & 2 & 13 & 15 \\
\hline Evaluaciones & & 4 & & & 4 \\
\hline Total & 30 & 15 & 15 & 86 & 150 \\
\hline ST=Sesión Teórica; SL=Sesión de Laboratorio; SP=Sesión de Prácticas \\
\hline
\end{tabular}

Acerca de los requisitos del curso, es importante mencionar que los estudiantes deben asistir por lo menos al $80 \%$ de las clases teóricas, las clases prácticas y de laboratorio, así como obtener una calificación final igual o superior a 5 para aprobar la asignatura.

Una parte importante del sistema de aprendizaje continuo es la constante evaluación del aprendizaje adquirido por el alumno y la demostración sobre los conceptos y las ideas aprehendidas. La evaluación continua se presenta como la herramienta que el profesor utiliza para comprobar si el alumno avanza en el proceso de aprendizaje.

El proceso de aprendizaje se clasifica a través de 4 sistemas de evaluación expresadas de la siguiente manera:

- Exámenes de opción múltiple: Examen escrito con varias preguntas en las que el estudiante tiene que elegir la respuesta correcta. La evaluación a través de múltiples opciones con un peso del $40 \%$ en la nota final. El estudiante tiene que realizar 4 pruebas de opción múltiple temporizadas durante las sesiones de clase, lo largo del semestre a través de la plataforma PoliformaT de la UPV. Cada prueba evaluatoria tiene un peso del $10 \%$ de la nota final, cada una consta de 20 preguntas con 4 alternativas posibles donde sólo una respuesta es correcta. Una respuesta incorrecta penaliza.

- Proyecto: una estrategia didáctica en la que el alumno desarrolla de forma grupal, un tema relacionado con el sector aeroespacial. Al comienzo del curso, se organizan los equipos, cada equipo se compone de 4 alumnos. Cada equipo elige un capítulo del curso para desarrollar un proyecto. El proyecto será presentado al resto de sus compañeros de clase en una fecha específica. Este sistema de aprendizaje se evalua a través de dos elementos: El informe del proyecto (peso del $15 \%$ de la nota final), presentación pública del proyecto representa el 15\% restante. Las presentaciones se llevan a cabo al final de cada unidad.

\section{(cc)) BY-NC-ND 2014, Universitat Politècnica de València}

I Jornadas IN-RED (2014) 
Por lo tanto, este sistema de evaluación no solo intenta desarrollar el trabajo en equipo, sino también el aprendizaje de la planificación de las tareas, la gestión de recursos como el tiempo y los recursos humanos, así como el logro de los resultados esperados.

- Observación: La estrategia basada en la recopilación de datos relacionados con el tema y aprender a través del desarrollo de tareas y ejercicios. Durante las sesiones de laboratorio los estudiantes desarrollan los ejercicios y tareas relacionadas con los conceptos y las ideas explicadas en las sesiones teóricas. El peso de este sistema de evaluación será el $15 \%$ de la nota final.

- Co-evaluación: La actividad en la cual los estudiantes evalúan a sus compañeros de clase. Cada equipo prepara un ejercicio sobre el proyecto presentado para evaluar sus compañeros de clase. De esta manera, cada estudiante realiza (n-1) ejercicios propuestos por sus compañeros de clase. El peso de este sistema de evaluación es $15 \%$.

Los sistemas de co-evaluación y proyecto se encuentran directamente relacionados, de forma que el equipo que realiza la presentación debe desarrollar un ejercicio en el que evalúe el nivel de comprensión que sus compañeros han hecho de los contenidos presentados. Así, el equipo que presenta su trabajo obtiene información sobre el nivel de conocimiento de la clase y la atención prestada. Cabe destacar que cada uno de los ejercicios propuestos por los equipos fueron supervisados con anterioridad por el profesor.

De manera paralela, cada miembro del grupo debe evaluar el nivel de logro y desarrollo del grupo, entendiendo éste como una unidad, cuyos resultados son asumidos por todos los miembros del grupo como propios. Para ello, se desarrolla una rúbrica que tiene por objeto cuantificar los distintos ámbitos de trabajo, y desarrollo del grupo, (Tabla 2). 
Tabla 2. Rúbrica para medir el grado de desarrollo grupal.

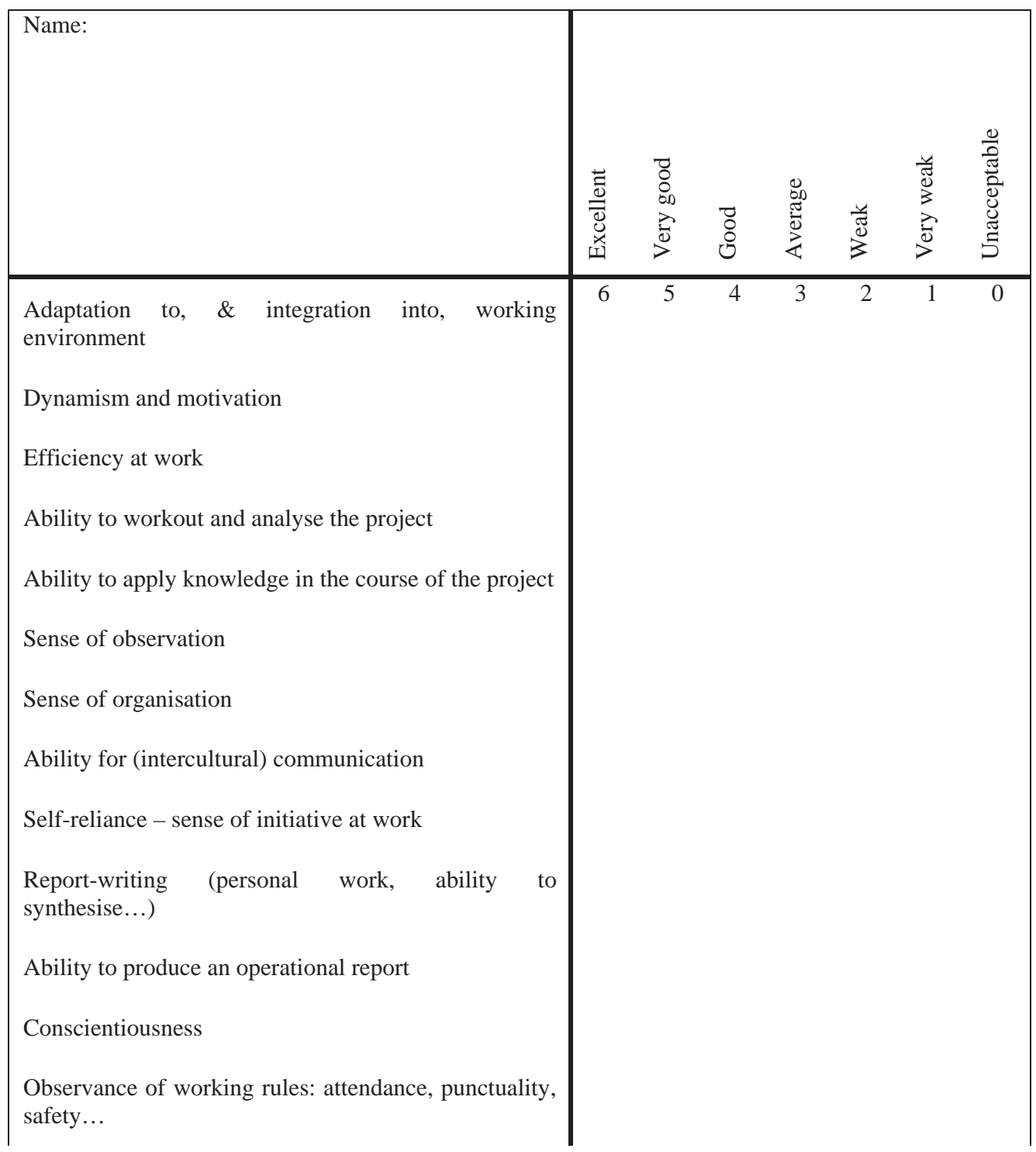

En este sentido es muy importante la labor del docente quien comunica al grupo la importancia del efecto multiplicativo del grupo, frente a la suma de trabajos individuales, es decir, la generación de sinergias intragrupales.

(c)) EY-NC-ND 2014, Universitat Politècnica de València

I Jornadas IN-RED (2014) 


\section{Resultados}

La valoración de la aplicación de la co-evaluación como sistema de evaluación conectado con la evaluación pública del proyecto grupal ha sido analizada desde varios ejes:

Desde el punto de vista numérico, la influencia que la co-evaluación (15\% nota final) genera en la nota final del alumnos es positiva, se ha observado como los (n-1) ejercicios realizados a lo largo del curso por cada uno de los alumnos ha producido una mejora en la nota final resultante, ya que el $60 \%$ de los alumnos obtuvieron la maxima calificación, y el $40 \%$ restante obtuvieron una calificación superior al $70 \%$.

Si bien los resultados numéricos son considerables, el valor de la co-evaluación es más que por su medida numérica, relevante por el componente intangible derivado del mismo. Por una parte el grupo que presenta su proyecto recibe la atención completa del público, reforzando el contenido de su mensaje y su actitud ante el grupo fomentando las competencias comunicativas. Por otra parte, los compañeros que escuchan la presentación adoptan una actitud de escucha, aprenden de un compañero igual a ellos, lo que fomenta el respeto y la retroalimentación del conjunto de la clase.

En tercer lugar, la co-evaluación intragrupal a través de la rúbrica propuesta permite que cada individuo del grupo adquiera conciencia de la situación grupal, y se valore la percepción del grupo desde la esfera individual. Los resultados medios obtenidos permiten iniciar la conversación en el grupo sobre los aspectos a mejorar, y los objetivos alcanzados.

Asimismo se preguntó a los alumnos sobre el nivel de satisfacción con el sistema de evaluación llevado a cabo, y todos confirmaron su satisfacción fundamentalmente con el sistema de evaluación por co-evaluación, seguida de la evaluación por proyectos.

\section{Conclusiones}

El trabajo grupal constituye en si mismo una herramienta de aprendizaje sobre planificación, organización, liderazgo y control de la acción hacia la consecución de objetivos que deben ser comunes y compartidos por el grupo.

En este trabajo se ha presentado la co-evaluación como sistema de evaluación del trabajo grupal desde dos ámbitos. En primer lugar se ha presentado la coevaluación realizada desde un equipo (grupo de alumnos que desarrollan un proyecto) al conjunto de la clase, en donde la co-evaluación mide en este caso la capacidad de transferencia del aprendizaje del alumno. 
En segundo lugar se ha utilizado la co-evaluación a través de la aplicación de rúbricas para evaluar el nivel de logro, actitudes y comportamientos intragruaples. Así, cada miembro del grupo adquiere conciencia de su pertenencia como individuo a un equipo.

La relevancia de la co-evaluación radica en reflexionar sobre la capacidad de logro de objetivos, así como de comunicar y aprender de otros compañeros. Se debe entender la co-evaluación como el motor propulsor del aprendizaje, y por tanto, se debe potenciar su utilización combinada con otras técnicas de evaluación del aprendizaje.

\section{Referencias}

ARIÑO, A (2010). La gestión del conocimiento y la cultura en el Espacio Europeo de Educación Superior (en prensa).

CABRERO, J. (2003). Principios pedagógicos, psicológicos y sociológicos del trabajo colaborativo: su proyección en la tele-enseñanza.

DILlENBOURG, P., BAKER, M., BLAYE, A. \& O'MALLEY, C.(1996) The evolution of research on collaborative learning. In E. Spada \& P. Reiman (Eds) Learning in Humans and Machine: Towards an interdisciplinary learning science. (Pp. 189-211). Oxford: Elsevier.

DE LA POZA, E., DOMÉNECH, J. (2011), Proyecto "Creación de una empresa": El trabajo en grupo como forma de evaluación en una asignatura de primer curso de grado. III Jornada nacional sobre estudios universitarios: El presente de los nuevos títulos (JNEU 2011).

KLING, N., D. MCCORKLE, C. MILLER, AND J. REARDON (2005). The impact of testing frequency on student performance in a marketing course. Journal of Education for Business 81, 67-72.

KUO, T. and SIMON, A. (2009). How many tests do we really need? College Teaching 57, $156-160$.

IRANZO, E., GIMENO, E., SÁNCHEZ DELGADO, P. Estrategias de evaluación de competencias de los alumnos universitarios a través del trabajo grupal. Revista Iberoamericana de Evaluación Educativa, 2012, Vol 5, N 1.

JORNET, J.M. (2010). La evaluación de los aprendizajes universitarios, III Jornada de intercambio de grupos de formación del profesorado, (en prensa, Publicaciones de la Universidad de Cádiz) 
MARRIOTT, P. (2009). Students' evaluation of the use of online summative assessment on an undergraduate financial accounting module. British Journal of Educational Technology 40, 237- 254.

NICOL, D. J. and MACFARLANE-DICK, D. (2006). Formative assessment and self-regulated learning: A model and seven principles of good feedback practice. Studies in Higher Education 31, 199-218.

PUIGVERT PLANAGUMÀ, G.(Coor.) (2009). Guia per a l'avaluació de competències en l'àrea d'Humanitats. Colección Guies d'avaluació de competències Ed. AQU Catalunya.

SCHERMERHORN, J. (2011). Learn to succeed, $12^{\text {th }}$ Edition, Estados Unidos.

TROTTER, E. (2006). Student perceptions of continuous summative assessment. Assessment \& Evaluation in Higher Education 31, 505-521.

TRUJILLO, J.(1998). Trabajo en equipo, una propuesta para los procesos de enseñanza, IV Congresso RIBIE, Brasilia 1998. 


\title{
EPS, un proyecto multidisciplinar internacional
}

\section{Isabel Gasch $^{\mathrm{a}}$, Pedro Fuentes ${ }^{\mathrm{b}}$ y Marina Puyuelo}

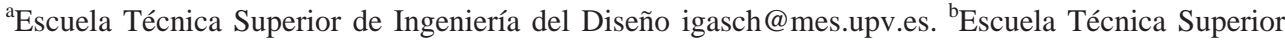

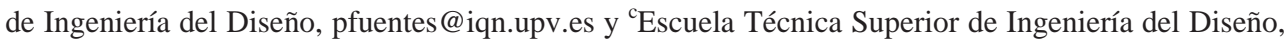
mapuca@ega.upv.es.

\begin{abstract}
In the area of engineering is very common to solve a complex problem through multidisciplinary teams. In the framework of the European Higher Education Area, multidisciplinary projects have become increasingly important since they allow, among other goals, to acquire or improve different generic/transversal competences.

In the Universitat Politècnica de València, the School of Design Engineering introduced in 2005 the European Project Semester (EPS), a program whose methodology is based on Project Based Learning, and where these projects are multidisciplinary and international, being English the language of instruction.

This paper shows the methodology to carry out this program in which students gain experience as part of a multidisciplinary and multicultural team to solve a complex problem of design and engineering. Furthermore, a specific example of a project is exposed.
\end{abstract}

Keywords: Project-based learning, multicultural, multidisciplinary, structural design, urban planning.

\footnotetext{
Resumen

En el área de la ingeniería es muy común que la forma de abordar un problema complejo sea a través de equipos multidisciplinares. En el marco del Espacio Europeo de Educación Superior, los proyectos multidisciplinares han ido adquiriendo cada vez mayor importancia ya que permiten, entre otros objetivos, adquirir o mejorar diversas competencias transversales.

En la Universitat Politècnica de València, la Escuela Técnica Superior de Ingeniería del Diseño implantó en 2005 el European Project Semester(EPS),
}

(cc) EY-NC-ND 2014, Universitat Politècnica de València

I Jornadas In-Red (2014) 
un programa cuya metodología está basada en el Aprendizaje Basado en Proyectos, y donde estos proyectos son multidisciplinares e internacionales, siendo el inglés la lengua vehicular.

En el presente trabajo se expone la metodología seguida para poder llevar a cabo este programa en el que los estudiantes adquieren experiencia como parte de un equipo multidisciplinar y multicultural de trabajo para resolver un problema complejo de ingeniería y diseño, aprendiendo de manera activa, manteniéndose motivados y comprometidos. Además se expone un ejemplo concreto de un proyecto.

Palabras clave: Aprendizaje basado en proyectos, multicultural, multidisciplinar, diseño estructural, planificación urbanística.

\section{Introducción}

En el área de la ingeniería es muy común que la forma de abordar un problema complejo sea a través de equipos multidisciplinares. En el marco del Espacio Europeo de Educación Superior (EEES) (Official European Higher Education Area website), los proyectos multidisciplinares han ido adquiriendo cada vez mayor importancia ya que permiten, entre otros objetivos, adquirir o mejorar diversas competencias transversales. Sin embargo, el desarrollo de este tipo de proyectos, dentro de la educación, no es una tarea sencilla. Ni en lo referente al proyecto en sí, para poder ajustarlo a un caso real, ni en la composición de los equipos multidisciplinares.

La Escuela Técnica Superior de Ingeniería del Diseño (Universitat Politècnica de València) implantó en 2005 el European Project Semester (EPS), un programa cuya metodología está basada en el Aprendizaje Basado en Proyectos (Harwell, 1997; García-Almiñana, 2006; de los Ríos, 2010; Yadav, 2011), donde estos proyectos son multidisciplinares e internacionales (Andersen, 2003), y cuya lengua vehicular es el inglés. Los equipos que se forman están integrados por personas con diferentes perfiles, áreas disciplinares, idiomas y culturas que trabajan juntos para realizar proyectos basados en problemas reales. Estas diferencias ofrecen grandes oportunidades para el aprendizaje y enriquecen a los estudiantes para trabajar en ambientes diversos y globales.

El EPS es un programa que nació en Dinamarca en 1995 (Hansen, 2010). Actualmente, además de en la Universitat Politècnica de València (España) se ofrece en St. Poelten (Austria), Antwerp (Bélgica), Bucharest (Rumanía), Vasa (Finlandia), Tarbes (Francia), Kiel (Alemania), 's-Hertogenbosch (Holanda), Delft (Holanda), Oslo (Noruega), Lodz (Polonia), Porto (Portugal) y en Vilanova i la Geltrú (España). 
El programa incluye tanto cursos como el desarrollo de un proyecto.

Los cursos (10 ECTS) incluyen, entre otros:

$\checkmark$ Habilidades de comunicación

$\checkmark$ Aprendizaje basado en proyectos

$\checkmark$ Planificación y gestión de proyectos

$\checkmark$ Innovación sistemática

$\checkmark$ Ingeniería de diseño de producto

$\checkmark$ Teambuilding

$\checkmark \quad$ Lengua y cultura españolas

El proyecto (20 ECTS) es llevado a cabo por un equipo de estudiantes de distintas nacionalidades y especialidades. Se busca que el proyecto sea lo más real posible, intentando que, en la medida de lo posible, haya alguna empresa involucrada en el proyecto.

En el presente trabajo se expone la metodología seguida para poder llevar a cabo este programa en el que los estudiantes adquieren experiencia como parte de un equipo multidisciplinar y multicultural de trabajo para resolver un problema complejo de ingeniería y diseño, aprendiendo de manera activa, manteniéndose motivados y comprometidos.

Además se expone un ejemplo concreto de un proyecto supervisado por un profesor del Departamento de Mecánica de los Medios Continuos y Teoría de Estructuras donde se describen las actuaciones llevadas a cabo durante el proyecto, la supervisión y las soluciones finales propuestas.

\section{Objetivos}

Como se ha dicho anteriormente, en el EPS un equipo multicultural y multidisciplinar de alumnos lleva a cabo un proyecto basado en un problema real. El desarrollo de este proyecto implica que el estudiante no sólo adquiere conocimientos sino que también desarrolla competencias transversales y actitudes, tales como trabajo en equipo y liderazgo, comunicación efectiva o comprensión e integración.

El uso de esta metodología tiene como objetivo fomentar el aprendizaje activo y facilitar el logro de dichas competencias. Así mismo, favorece el intercambio cultural entre los distintos estudiantes.

(cc) EY-NC-ND 2014, Universitat Politècnica de València

I Jornadas IN-RED (2014) 


\section{Desarrollo de la innovación}

En el desarrollo del EPS se pueden identificar las siguientes fases:

\subsection{Definición del proyecto}

Esta tarea es llevada a cabo por los supervisores. Basándose en antecedentes y experiencia previa, éstos identifican un problema en la vida real el cual los estudiantes puedan resolver. Se recomienda que el problema esté estrechamente relacionado con la industria o con un servicio concreto y tenga un punto de partida claramente definido, lo cual crea una mayor motivación a los estudiantes. Al final, se llega a crear un amplio espectro de propuestas donde los estudiantes pueden desarrollar un proyecto y ofrecer soluciones a problemas complejos.

Los proyectos integran actividades prácticas, con un enfoque interdisciplinar y de trabajo en equipo. El objetivo es que los estudiantes aprendan lo que realmente significa trabajar en un contexto integrado.

\subsection{Definición del curso}

En esta fase se define el esquema general del curso, incluyendo la planificación de las evaluaciones iniciales, intermedias y finales y las distintas entregas de los informes. Se acaba también de definir el grupo de supervisores, que pertenecen a distintas áreas de especialización, así como el comité de evaluación.

\subsection{Definición de los equipos}

Antes de venir a Valencia, los alumnos realizan una preselección de los proyectos en los que les gustaría participar, por orden de prioridad. Una vez aquí, cada supervisor realiza una presentación de su proyecto y resuelve las dudas que puedan surgirles a los estudiantes sobre el mismo.

A partir de esto, se anima a los estudiantes a que elijan un proyecto basándose en sus intereses y motivaciones, orientándoles en por qué deberían o no elegir un proyecto determinado. Se forman grupos de 4 a 8 estudiantes, intentando que el grupo abarque el mayor número de nacionalidades posibles.

Los alumnos reciben cursos de teambuilding y realizan el BELBIN@ TEAM ROLE para que cada uno conozca su rol dentro del equipo. En un equipo se necesitan diferentes roles, por lo que es importante que los alumnos conozcan cuáles son las cualidades personales relacionadas con el trabajo en equipo. Esto les permite ver la importancia de las diferencias 
y que todas las personalidades tienen aspectos positivos y negativos. Deben apreciar la diversidad, aunque a veces esta puede hacer más difícil la cooperación.

\subsection{Lluvia de ideas y planificación}

Una vez los alumnos han elegido el proyecto y formado los equipos, se reúnen por primera vez con su supervisor. El objetivo principal del proyecto está definido, pero es en esta primera reunión donde se buscan definir unos objetivos más concretos mediante una lluvia de ideas donde participan todos los miembros del equipo. De esta forma pasan a tomar una mayor conciencia del proyecto y empiezan a integrarse y formar parte de él. Además, se busca realizar una primera planificación del proyecto.

\subsection{Definición de tareas}

Cada proyecto es un conjunto de diferentes tareas, que además pueden estar relacionadas con diferentes áreas. Los supervisores, deben ayudar a los estudiantes a realizar un diagrama de Gantt con el desglose de las distintas actividades (WBS), así como una matriz de responsabilidades.

\subsection{Desarrollo y evaluación del "mid-term project"}

Desde el inicio hasta aproximadamente la mitad del semestre, los alumnos desarrollan el mid-term project. Se realizan reuniones semanales entre el supervisor del proyecto y los alumnos en las cuales, no sólo se tratan aspectos técnicos del proyecto sino también los posibles conflictos que pueden surgir dentro del grupo. En estas reuniones los alumnos aprenden a preparar el orden del día y a redactar el acta de una reunión, adoptando el rol de presidente y secretario de ésta de forma alterna. Además de estas reuniones, los alumnos tienen reuniones en las que no se ve involucrado el supervisor y que son necesarias para el avance del proyecto.

A mitad semestre, además de la entrega del mid-term report, dos de los alumnos del equipo realizan la presentación de éste. Para la realización de ésta los alumnos cuentan con un experto en habilidades de comunicación que les orienta en cómo realizar una buena presentación. La presentación se lleva a cabo en presencia de un comité evaluador y del resto de alumnos del EPS, que también emiten una evaluación. Este acto ofrece la oportunidad al alumno de revisar o darle un nuevo enfoque a ciertos aspectos del proyecto de acuerdo con el feedback recibido por parte de los evaluadores (Irons, 2008). Es también una oportunidad para mejorar habilidades de presentación oral, defensa de ideas...

\section{(c) EY-NC-ND 2014, Universitat Politècnica de València}

I Jornadas IN-RED (2014) 
Por otra parte, en esta fase, el alumno realiza una autoevaluación y una evaluación de los miembros de su equipo (evaluación por pares), que permite desarrollar capacidades de reflexión, toma de decisiones, autocrítica y aceptación de las ideas de los demás, negociación y compromiso para cumplir lo acordado, etc. (Bretones-Román, 2008; Somervell, 1993).

\subsection{Desarrollo y evaluación del proyecto.}

Una vez superada la mitad del semestre, el equipo continúa con la realización de las tareas programadas para la consecución del proyecto. Las reuniones semanales con el supervisor del proyecto se siguen manteniendo, así como las reuniones entre los miembros del equipo.

Los estudiantes son una parte activa de su proceso de aprendizaje, contribuyendo activamente en el trabajo en equipo, desarrollando una actitud enfocada hacia el "nosotros" y no hacia el "yo" en busca del buen funcionamiento del grupo.

El proceso de aprendizaje es iterativo, el trabajo debe estar bien estructurado y tener cierta disciplina si se quiere entregar a tiempo el proyecto.

El trabajo de los estudiantes finaliza con la entrega final el proyecto y la posterior presentación oral, por parte de otros dos o tres miembros del equipo. Al igual que la que se realiza a mitad semestre, ésta se lleva a cabo en presencia de un comité evaluador y del resto de alumnos del EPS, que vuelven a emitir su evaluación. La evaluación final tiene en cuenta las autoevaluaciones, las evaluaciones por pares, las evaluaciones del comité evaluador y la evaluación realizada por el supervisor.

\section{Resultados}

En el curso 2013-2014 el proyecto propuesto por Isabel Gasch, llamado MESTALLA XXI, consistía en realizar el plan urbanístico de los terrenos de Mestalla, los cuales quedarán libres cuando el Valencia C.F. se traslade al nuevo estadio que se está construyendo en la Avenida de las Cortes Valencianas.

El equipo que realizó el proyecto estaba integrado seis alumnos de cuatro nacionalidades distintas (finlandesa, francesa, holandesa y sueca) y con titulaciones distintas.

El principal objetivo del proyecto, definido por los alumnos, era "Crear un lugar que respetara el medio ambiente donde todo el mundo pueda encontrarse, interactuar y disfrutar de su tiempo libre". 
La metodología de trabajo consistió en la utilización de una serie de herramientas y métodos a partir de los cuales definieron parte de las especificaciones del proyecto. Estos métodos son:

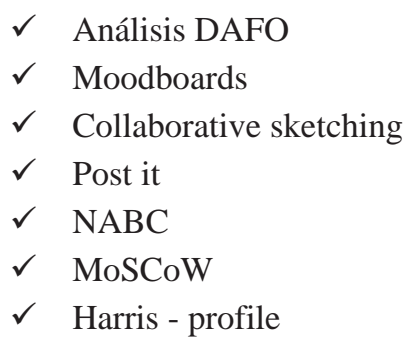

$\checkmark$ Moodboards

$\checkmark$ Collaborative sketching

$\checkmark$ Post it

$\checkmark$ NABC

$\checkmark \mathrm{MoSCoW}$

$\checkmark$ Harris - profile

Además, para acabar de definir el proyecto se realizó un estudio general sobre la cultura española, el clima, las fuentes de energía, los materiales, las distintas normativas aplicables, así como un estudio más pormenorizado del área de Mestalla (población, conexiones...), el arte en la ciudad de Valencia y los parques competidores. Asimismo, se realizó una encuesta para conocer la opinión de la gente de los alrededores del estadio sobre su futuro uso.

Para completar todo este estudio previo, y crear una mayor cohesión de los miembros del grupo, se realizó una visita con la tutora al estadio de Mestalla. Por su parte, los alumnos, también acudieron a uno de los partidos del Valencia C.F. para vivir un partido en Mestalla y conocer así mejor lo que significa el club y el estadio para sus aficionados.

Con los resultados de todo lo descrito anteriormente, crearon distintos conceptos del área de Mestalla. Para su evaluación y posterior toma de decisiones sobre el concepto final, contaron con la ayuda de un arquitecto valenciano que se reunió con ellos y les dio su opinión, ideas así como algunos consejos prácticos.

A partir de esta reunión y tras diversas reuniones del grupo, se eligió el concepto final del área, el cual se muestra en la Figura 1.

(cc) EY-NC-ND 2014, Universitat Politècnica de València

I Jornadas IN-RED (2014) 


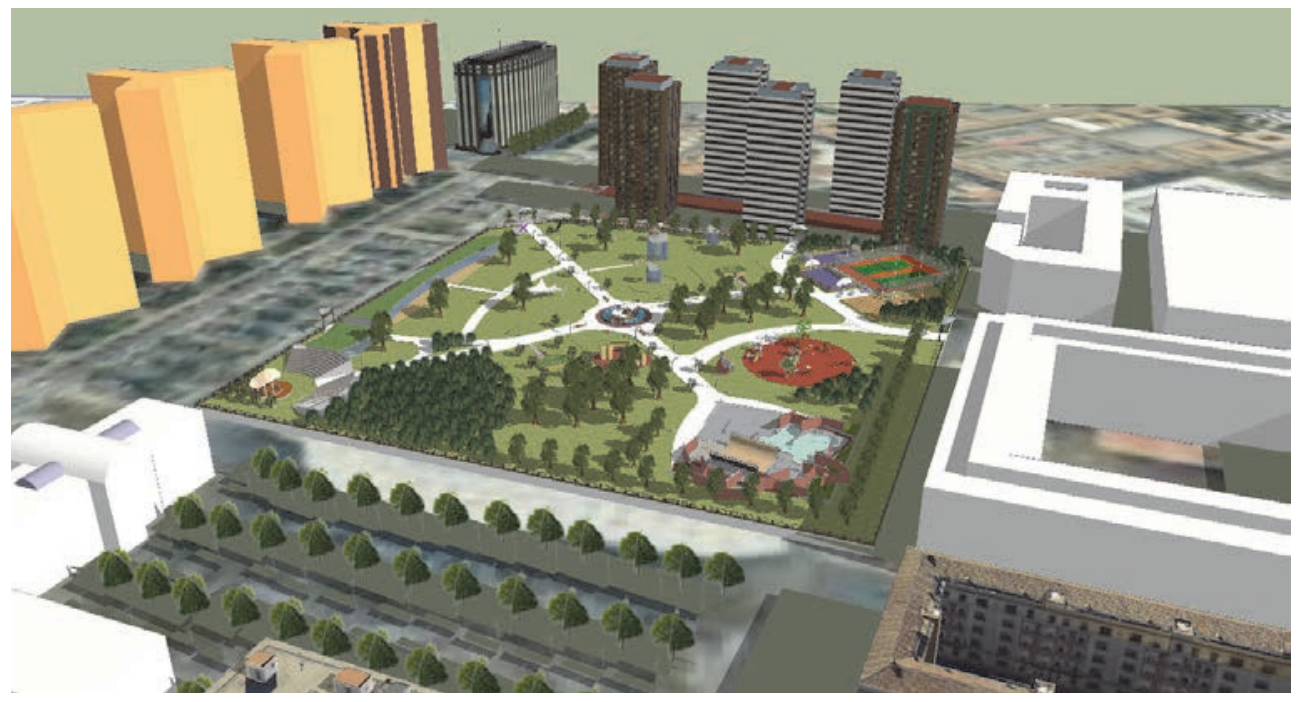

Fig. 1 Concepto final (Creco - Parque Mestalla (EPS 2013))

El parque diseñado cuenta con los siguientes elementos principales:

$\checkmark$ Escenario, pantalla y anfiteatro

$\checkmark$ Pista de skate

$\checkmark$ Paredes para graffiti

$\checkmark$ Rocódromo

$\checkmark$ Fuente central

$\checkmark$ Parque de juegos infantiles

$\checkmark$ Salas de talleres/estudio

$\checkmark$ Bosque

$\checkmark$ Área de exposición

$\checkmark$ Zona de picnic

$\checkmark$ Escuela de arte y música

$\checkmark$ Bar y restaurante.

De estos, y a grandes rasgos, se diseñaron la fuente central (Figura 2), la escuela de arte y música y el edificio del restaurante (Figura 3). 


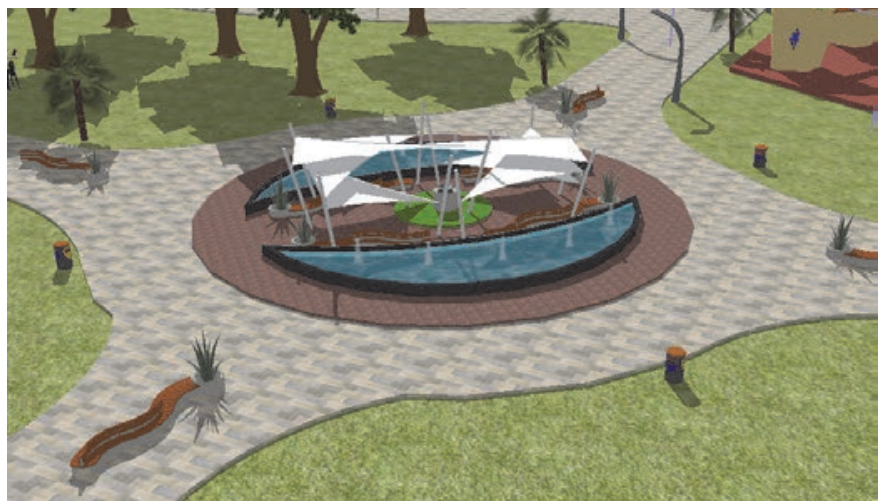

Fig. 2 Fuente central

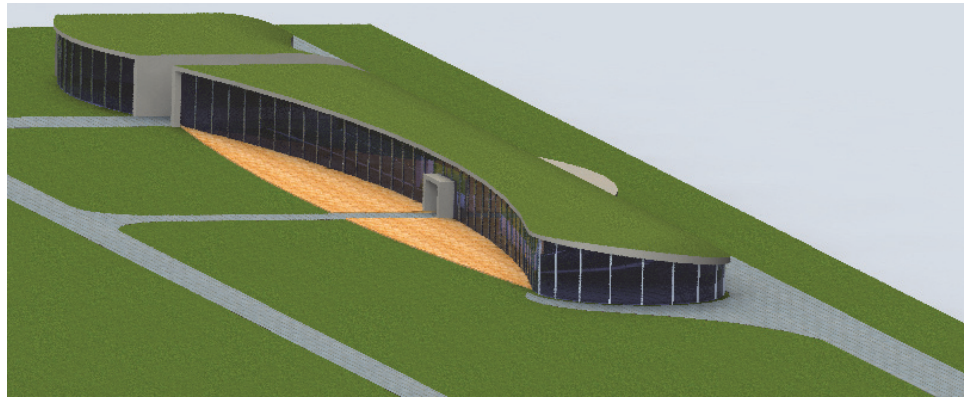

Fig. 3 Edificio de la Escuela de artes y música y Restaurante

Una vez realizado el diseño general del área, trabajaron de forma individual o por parejas en temas más afines a sus estudios, abordando cuatro grandes áreas:

$\checkmark$ Estructuras/Construcción. Por un lado los alumnos abordaron el diseño y cálculo de la estructura de los baños a instalar en el parque (Figura 4, Figura 5), teniendo en cuenta también la accesibilidad. Por otro, hicieron el dimensionamiento de las tuberías del agua de la fuente central.

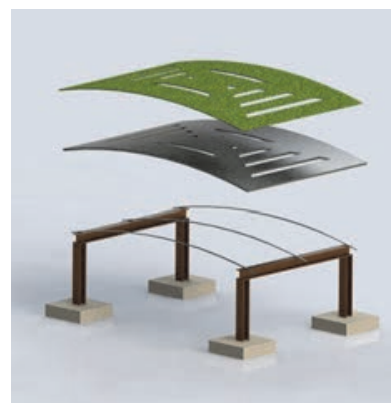

Fig. 4 Diseño del edificio de los baños

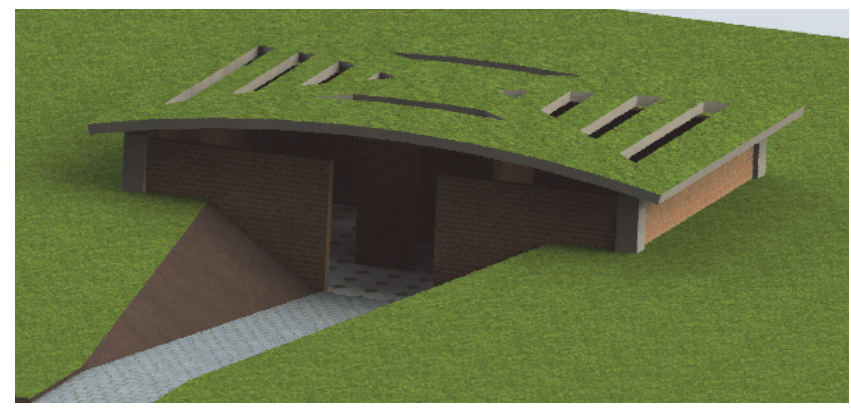

Fig. 5 Elementos de la estructura de los baños

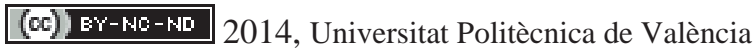

I Jornadas IN-RED (2014) 
$\checkmark$ Energía. Los alumnos estudiaron la viabilidad de la utilización de diferentes fuentes de energía renovable. Así, propusieron el uso de energía solar mediante la instalación de paneles solares en los baños, el anfiteatro y las salas de estudio, y la colocación de una fachada fotovoltaica ventilada en los edificios de la escuela de artes y música y en el restaurante, así como en las salas de estudio.

$\checkmark \quad$ Marketing. Los alumnos realizaron un plan de marketing completo.

$\checkmark$ Diseño y Desarrollo de Producto. Los alumnos que trabajaron en esta área se centraron en el diseño completo de parte del mobiliario urbano del parque, concretamente en los bancos (Figura 6), las farolas y las papeleras (Figuras 7 y 8), y de las salas de estudio (destinadas a la práctica de la música y la pintura) y su mobiliario adaptable a distintos usos (Figuras 9 y 10).

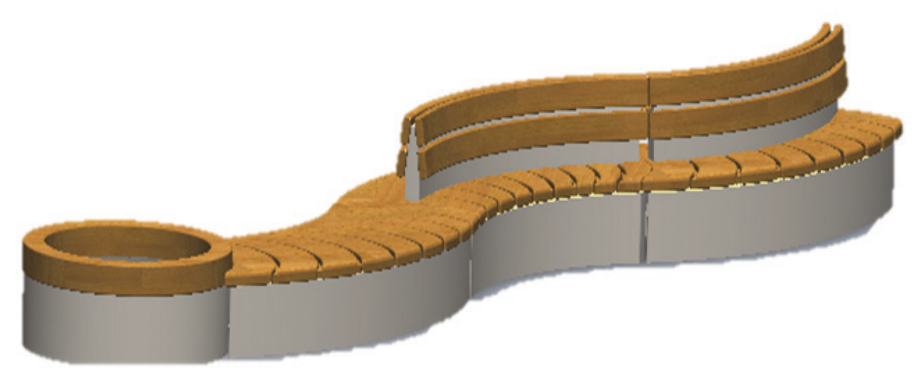

Fig. 6 Diseño de los bancos

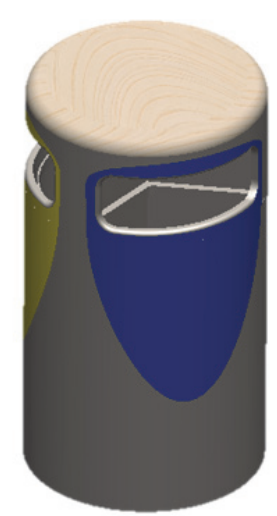

Fig. 7 Diseño de las papeleras

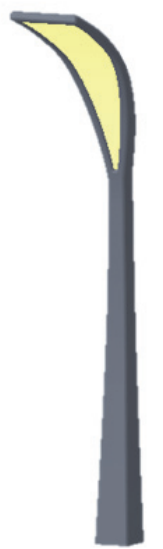

Fig. 8 Diseño de las farolas 

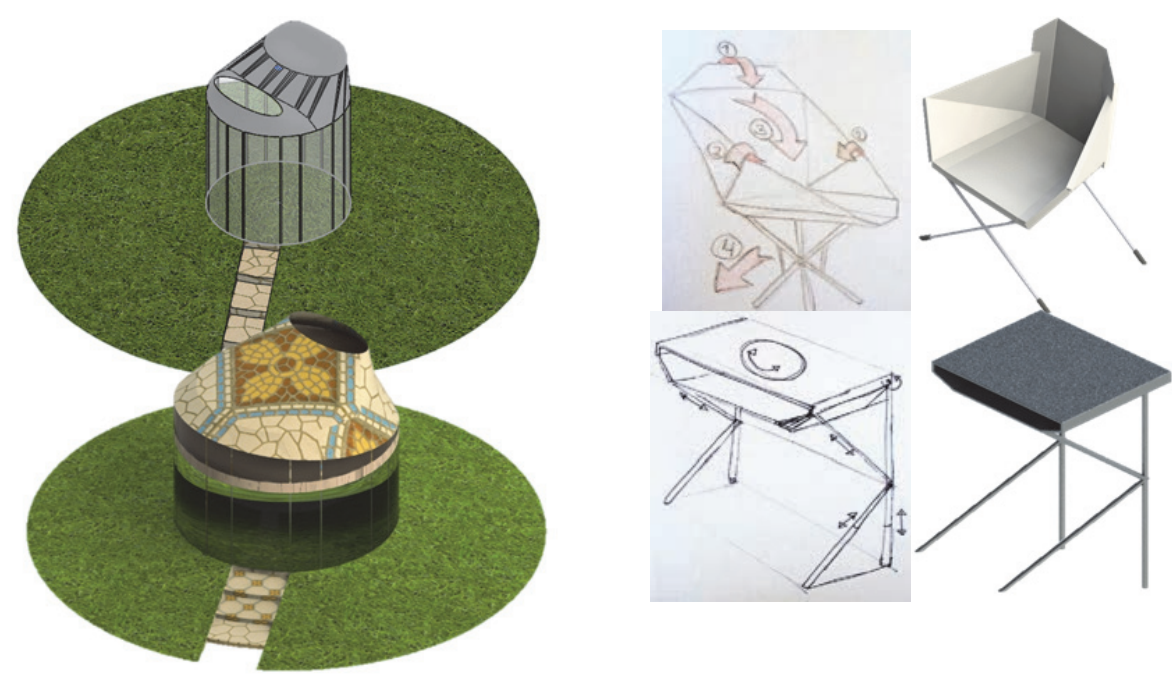

\section{Conclusiones}

No todo el aprendizaje debe estar basado en proyectos. Cada asignatura es diferente, así como sus alumnos y profesores. Por tanto hay que adaptar el método de aprendizaje a las circunstancias existentes en cada caso e ir combinando distintos métodos.

No obstante, un semestre como el EPS, donde se realiza un proyecto multidisciplinar y multicultural, es beneficioso para los alumnos puesto que permite a éstos:

$\checkmark$ Adquirir experiencia como parte de un equipo multidisciplinar y multicultural de trabajo para resolver un problema complejo de ingeniería y diseño.

$\checkmark$ Aprender de manera activa, manteniéndolos motivados y comprometidos.

$\checkmark$ Potenciar su creatividad.

$\checkmark$ Aprender a apreciar la diversidad.

$\checkmark$ Fomentar el trabajo en equipo en su totalidad: más "nosotros", menos "tú y yo".

$\checkmark$ Obtener una experiencia personal positiva. Durante la realización del semestre se crea una red internacional y ésta permanece a lo largo de los años, manteniéndose en contacto.

$\checkmark$ Crecer como personas.

$\checkmark$ Facilitar la incorporación del alumno a la práctica profesional.

\section{(cc) EY-NC-ND 2014, Universitat Politècnica de València}

I Jornadas IN-RED (2014) 


\section{Referencias}

ANDERSEN, A. (2003). "Diversity in cultures and teamwork". En Annual Conference ProceedingsAmerican Society For Engineering Education, Tennessee, USA.

CBELBIN ASSOCIATES Belbin $\odot$ Team Roles. <http://www.belbin.com> [Consulta: 7 de octubre de 2013].

BRETONES ROMAN, A. (2008). "Participación del alumnado de educación superior en su evaluación”. Revista de Educación, vol. 347, pp. 181-202.

Creco - Parque Mestalla (EPS 2013) <https://www.youtube.com/watch?v=NFuw3-hsTck>

DE LOS RIOS, I. et al. (2010), "Project-based learning in engineering higher education: two decades of teaching competences in real environments", Procedia - Social and Behavioral Sciences, vol. 2, issue 2, pp. 1368-1378.

CEUROPEAN HIGHER EDUCATION AREA Bologna Process - European Higher Education Area <http:// www.ehea.info> [Consulta: 2 de octubre de 2014].

GARCIA-ALMIÑANA, D., AMANTE, B. (2006). "Algunas experiencias de aplicación del aprendizaje cooperativo y del aprendizaje basado en proyectos". En I Jornadas de Innovación Educativa, Zamora, España.

HANSEN, J. (2010). "European Project Semester - how engineering students can achieve important competences". En Proceedings of ICEE, Gliwice, Poland.

HARWELL, S. (1997). "Project-based learning" en Promising practices for connecting high school to the real world. W.E. Blank \& S. Harwell (Eds.), Tampa, FL: University of South Florida. 1997, pp. 23-28.

IRONS, A. (2008). Enhancing learning through formative assessment and feedback. London and New York. Routledge.

SOMERVELL, H. (1993). "Issues in assessment, enterprise and Higher education: the case for selfpeer and collaborative assessment". Assessment \& Evaluation in Higher Education, vol. 18, issue 3, pp. 221-233.

YADAV, A. (2011). "Problem-based learning: influence on students' learning in an Electrical Engineering course", Journal of Engineering Education, Vol. 100, issue 2, pp. 253-280. 


\title{
Experiencia de un proyecto de aprendizaje basado en proyectos prácticos: Análisis de la eficiencia energética de una vivienda
}

\author{
Jorge Payáa, Rafael Royo ${ }^{\mathrm{a}}$

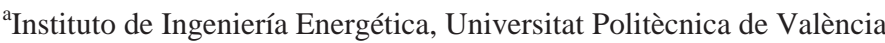 \\ Camino de Vera s/n Edificio 8E cubo F planta 5, Valencia 46022, Spain \\ E-mail: jorpaher@iie.upv.es (Jorge Payá)
}

\begin{abstract}
This study presents the experience in an educational project in the field of engineering. A conventional evaluation system has been replaced by a more active and self-learning system based on a practical project. In particular, the students have to carry out in teams an energy audit of their house. This is consequently a small-scale project of an energy audit in the industry. By means of this project, the motivation and the development of transversal competences such as team work are enhanced.

The experience both from the point of view of the teachers and the students has been addressed by means of specific surveys filled by the students. The results are globally promising, although they highlight that significant improvements are still required. The students are practically in unanimous agreement that their motivation and their assimilation of concepts has increased. Nevertheless, the results have also shown the necessity to provide all of the material for the project since the beginning of the course, and to readapt the theoretical courses in order to make them more consistent with the practical project.
\end{abstract}

Keywords: project-based learning, transversal competences, evaluation

(c) EY-NC-ND 2014, Universitat Politècnica de València

I Jornadas In-Red (2014) 
Experiencia de un proyecto de aprendizaje basado en proyectos prácticos: Análisis de la eficiencia energética de una vivienda

\section{Introducción}

Actualmente, la tendencia en la educación es a promover el aprendizaje activo por parte del alumno y al establecimiento de un sistema de enseñanza-aprendizaje basado en competencias (Tardif, 2006). El cambio desde planes de estudio basados en el contenido hacia planes basados en competencias supone unas ciertas complicaciones iniciales por todos los cambios necesarios en la adaptación del material docente, la planificación de las clases y contenidos, así como el sistema de evaluación (Tardif, 2006; Biggs, 2005; Lasnier, 2000; Fernández March, 2010).

En el presente trabajo se exponen los resultados de un trabajo de innovación docente que se está realizando desde 2013. Se trata de un sistema de enseñanza a través de proyectos, donde los alumnos deben, en grupos de dos o tres, realizar una auditoría energética de su propia vivienda y proponer medidas de ahorro energético. A continuación se describen los objetivos, el desarrollo del trabajo y los resultados más relevantes.

\section{Objetivos}

El trabajo realizado se enmarca dentro del Master de Tecnología Energética para el Desarrollo Sostenible impartido en la Universitat Politècnica de València. En concreto, en la asignatura de "Análisis y Optimización Energética de Instalaciones" se propone como trabajo práctico el análisis de una instalación real, la vivienda de cada alumno, un caso de gran interés pues a priori puede tener distintos tipos de consumo, como electricidad, agua o gas natural. Así pues, la metodología seguida en esta auditoría energética es perfectamente extropolable a casos reales en la industria. Además, se persigue un objetivo colateral que es la mayor concienciación de los usuarios sobre los beneficios medioambientales que se pueden alcanzar mediante una mejor gestión energética de las viviendas. Para la realización de los trabajos, los alumnos tienen a su disposición diversos recursos tecnológicos tales como contadores de energía y foros de seguimiento on-line.

\section{Desarrollo de la innovación}

Este nuevo sistema de enseñanza-aprendizaje se planteó por primera vez en 2013 y en la presente comunicación se analizan los resultados obtenidos en este último curso 2013-2014. Para llevar a cabo este cambio en el sistema, se planificaron inicialmente las clases de manera que los objetivos de los trabajos se presentaran de manera clara desde el primer día de clase. Todas las clases posteriores hasta la defensa de los trabajos consisten en prácticas o clases de teoría relacionadas con la auditoría energética, o clases de seguimiento donde de manera conjunta se comenta el progreso de todos los grupos. 
Una vez finalizado el trabajo, cada grupo debe exponer sus resultados ante los demás compañeros y el profesor. Se insiste a lo largo del curso en la importancia de realizar un trabajo contínuo, y en preparar suficientemente la presentación para que se realice con soltura y de manera estructurada.

Tras la evaluación de los trabajos de los alumnos, se percibió una opinión bastante diversa sobre el interés de estos proyectos dentro de su formación. Por ello, se solicitó a los alumnos que rellenaran una encuesta anónima que consistía en 15 preguntas y una vez analizados los resultados, se comentaron también con ellos para comprender la amplitud de todas las opiniones recogidas. Los resultados más relevantes se analizan a continuación, y se comentan junto con la experiencia vivida desde el punto de vista del profesor.

\section{Resultados}

Los resultados del presente proyecto se han desglosado a continuación en tres ejes fundamentales que son la calidad del método de enseñanza-aprendizaje planteado, la organización de las clases y las competencias transversales.

\subsection{Calidad del método de enseñanza-aprendizaje mediante trabajos}

En primer lugar cabe destacar que los alumnos no están todavía familiarizados con este tipo de metodologías de enseñanza-aprendizaje basados en proyectos. Esto aumenta la incertidumbre de los alumnos, que sólo puede paliarse si se explican los objetivos de manera suficientemente clara desde el principio del curso y si además se realiza un seguimiento contínuo de su progreso.

Mediante la realización de trabajos o proyectos prácticos, cabía esperar inicialmente que los alumnos trabajarían la asignatura de manera más contínua que en otras asignaturas. Sin embargo, tal y como refleja la Fig. 1, la opinión entre los alumnos es muy diversa. El motivo es que los trabajos requieren una primera toma de datos a partir de la cual se puede realizar la auditoría energética. Sin embargo, sólo se disponía de 2 contadores de energía por lo que cada grupo sólo dispuso de un contador durante una semana a lo largo del cuatrimestre. Esta limitación en cuanto a material ha provocado que los alumnos que recibieron el contador más tarde no pudieron realizar un trabajo tan contínuo como los demás. Por ello, una de las mejoras contempladas de cara a años posteriores es la adquisición de dos contadores adicionales, con el objetivo de que todos los grupos puedan realizar la toma de medidas a lo largo del primer mes del curso. Cabe destacar también que la habilitación de un foro en internet fue de gran utilidad para profesores y alumnos ya que

\section{(cc) EY-NC-ND 2014, Universitat Politècnica de València}

I Jornadas IN-RED (2014) 
Experiencia de un proyecto de aprendizaje basado en proyectos prácticos: Análisis de la eficiencia energética de una vivienda

permitió saber en todo momento qué grupo tenía cada uno de los contadores y facilitar su intercambio entre los distintos equipos.

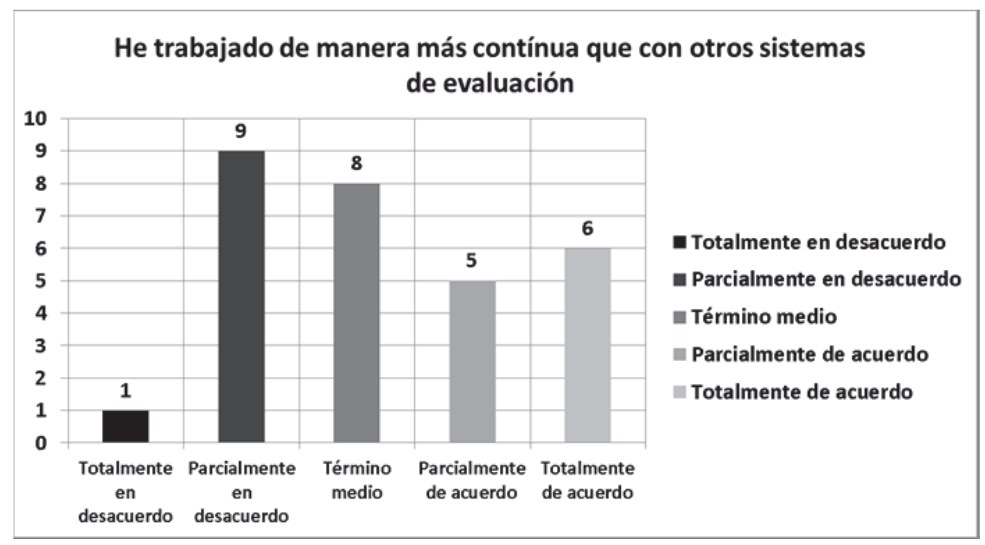

Fig. 1 Continuidad del trabajo de los alumnos a lo largo del curso

Otra idea preconcebida durante la preparación del curso es que la realización de un trabajo práctico permitiría a los alumnos recordar en mayor medida lo aprendido. En este sentido, tal y como muestra la Fig. 2, la opinión del alumnado es prácticamente unánime y piensan que, desde el punto de vista de la asimilación de conceptos, este tipo de metodología ha resultado muy beneficioso. Esto se puede explicar porque el trabajo fomenta la asimilación activa de conceptos, la implicación práctica de los alumnos y también por la componente social de trabajar en equipo y compartir opiniones o críticas.

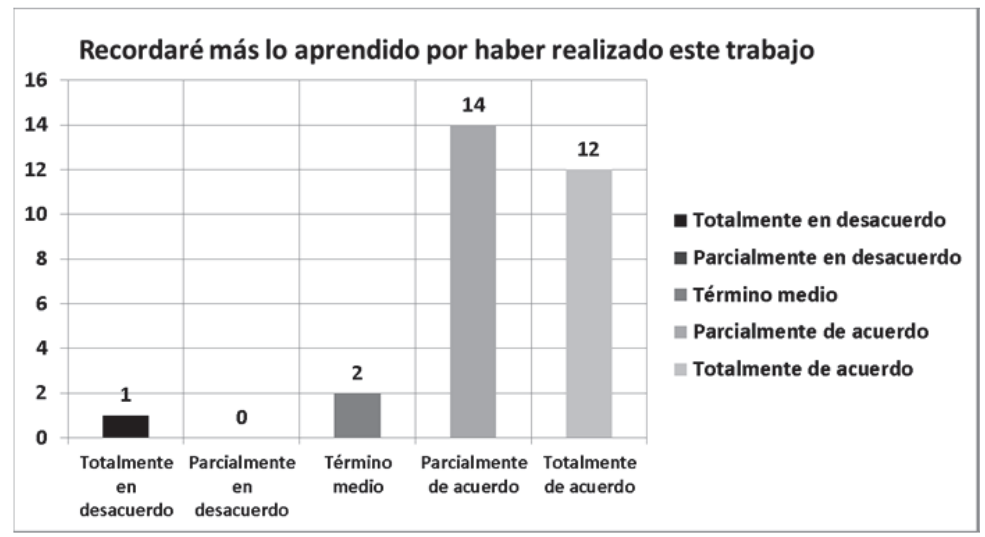

Fig. 2 Grado de asimilación de conceptos

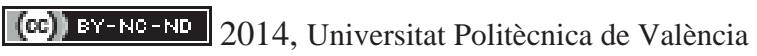
I Jornadas IN-RED (2014) 


\subsection{Organización de las clases o del material disponible}

Un aspecto fundamental para el profesor es conocer qué percepción ha tenido el alumno respecto a la organización de las clases y del material disponible. Dado que muchos de estos resultados son muy específicos, importantes para el profesor, pero no tanto para el público general, se ha limitado este apartado a las preguntas de índole más general.

En la Fig. 3 se muestra la opinión de los alumnos ante la pregunta de si el sistema de evaluación era claro desde el primer día del curso. Pese a haber insistido en la primera clase sobre el sistema de evaluación, la opinión es bastante variada. Si bien es cierto que la mayoría de las opiniones son positivas, 10 alumnos de 29 no están de acuerdo con este punto. El motivo parece ser que, pese a la explicación de la metodología, y apoyándose en una presentación, los alumnos habrían preferido disponer de información más concreta sobre los trabajos (detalle sobre la evaluación, medios disponibles, etc...). Esta información se añadió dos semanas antes de la defensa de los trabajos, lo cual se considera como poca antelación según estos 10 alumnos. Por ello, otra mejora prevista para años posteriores es que todo el material relacionado con el trabajo esté disponible desde el principio, lo que por supuesto es prácticamente imposible en los primeros cursos ya que los profesores deben adaptarse a medida que avanza el curso y que detectan las necesidades de los alumnos.

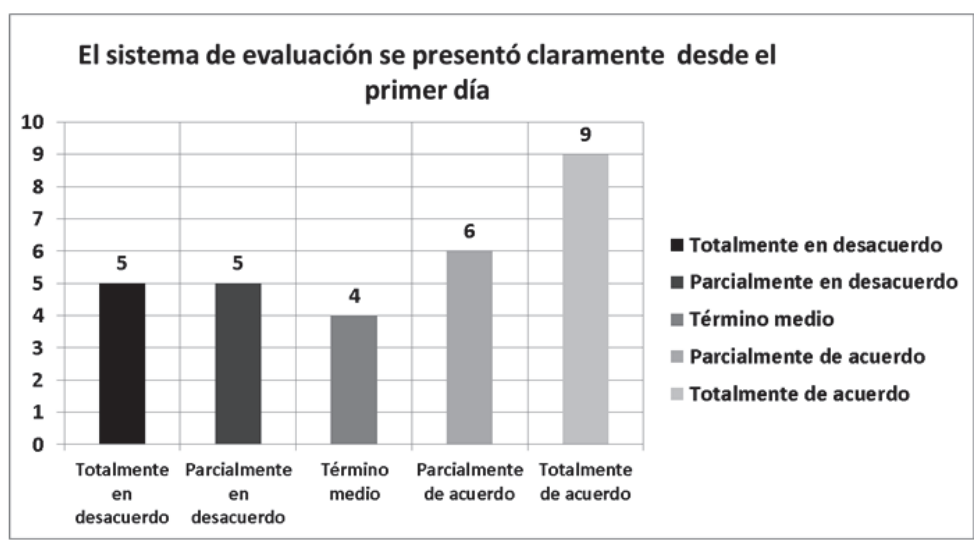

Fig. 3 Claridad del sistema de evaluación

En la Fig. 4 se muestra la opinión de los alumnos sobre la aplicación de conceptos vistos en teoría en aula a la hora de desarrollar los trabajos. La opinión está claramente dividida, por lo que se trata de uno de los puntos en los que se debería incidir más en años posteriores. Este resultado refleja claramente la necesidad de readaptar las clases de teoría en aula. Si bien tenían buenos resultados con un método de enseñanza más clásico, al incorporar este

\section{(cc) EY-NC-ND 2014, Universitat Politècnica de València}

I Jornadas IN-RED (2014) 
Experiencia de un proyecto de aprendizaje basado en proyectos prácticos: Análisis de la eficiencia energética de una vivienda

trabajo práctico los alumnos perciben poca relación entre los conceptos vistos en teoría de aula con esta parte más práctica.

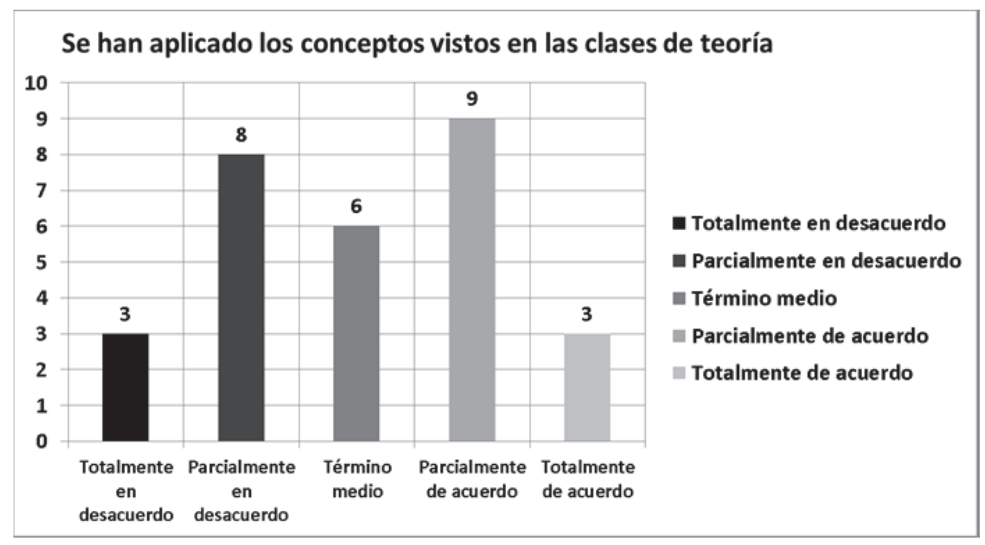

Fig. 4 Relación entre las clases de teoría y el trabajo

\subsection{Competencias transversales}

Tal y como se ha explicado anteriormente, los trabajos se realizan por lo general en grupos de 2 y excepcionalmente en grupos de 3 para cuadrar grupos. Uno de los objetivos perseguidos es favorecer el desarrollo de competencias transversales como el trabajo en equipo o la capacidad de comunicación oral a la hora de defender los resultados en una presentación.

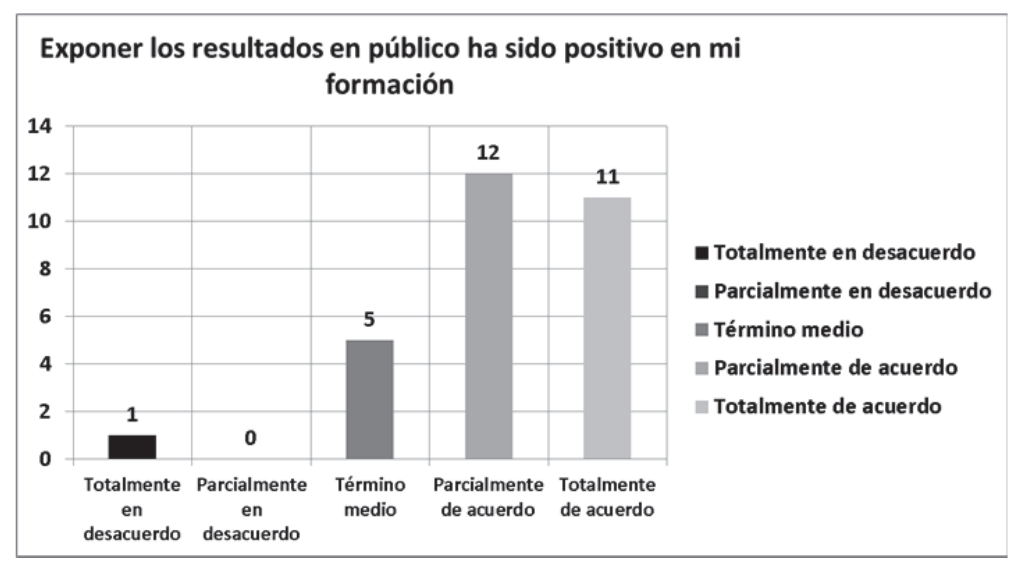

Fig. 5 Percepción de la competencia transversal de comunicación oral de resultados

(c)) EY-NC-ND 2014, Universitat Politècnica de València 
En la Fig. 5 se muestra que los alumnos han valorado muy positivamente la exposición y defensa pública de los trabajos. Pese a que cada trabajo tiene unas condiciones de contorno distintas, las propuestas de ahorro energético son finalmente parecidas y resulta por tanto muy enriquecedor para los alumnos, no sólo por practicar sus habilidades en el discurso y exposición de resultados, sino también por el aprendizaje adicional que supone escuchar los resultados de los demás trabajos.

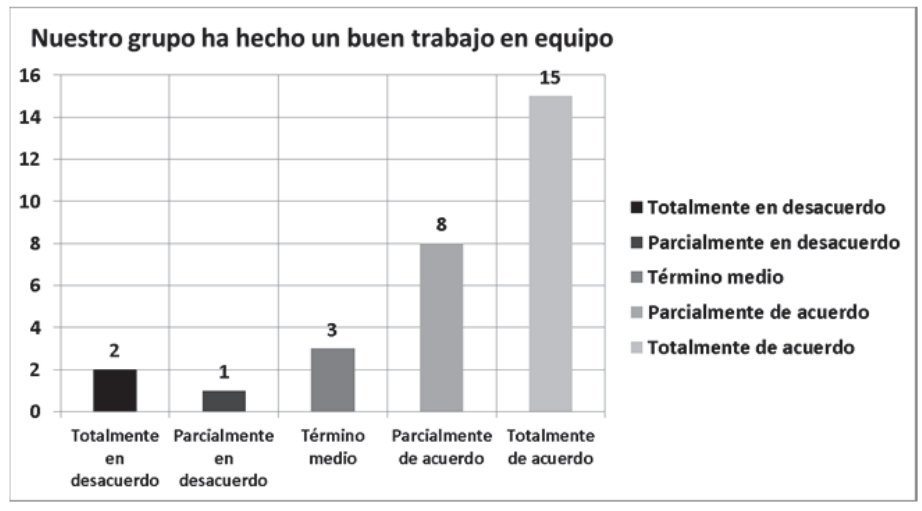

Fig. 6 Percepción de la competencia transversal de trabajo en equipo

En cuanto a la percepción de los alumnos respecto al trabajo en equipo (Fig. 6), pese a que prácticamente todos consideran que han realizado un buen trabajo en equipo, sí cabe destacar que una proporción minoritaria (3 de 29 alumnos) no están de acuerdo en que hayan realizado un buen equipo. A menudo, en cualquier trabajo compartido, el trabajo y esfuerzo de cada componente del grupo no están bien compensados. Si se ve esta cifra respecto al número de grupos, esto implicaría que alrededor de 6 grupos de cerca de 14 encuestados no repartieron equitativamente el trabajo. Por tanto, para años posteriores sería interesante que los alumnos destaquen claramente durante su presentación cómo han dividido su trabajo para poder evaluar en qué medida el trabajo en equipo ha sido eficaz, y que realicen una auto-evaluación. 
Experiencia de un proyecto de aprendizaje basado en proyectos prácticos: Análisis de la eficiencia energética de una vivienda

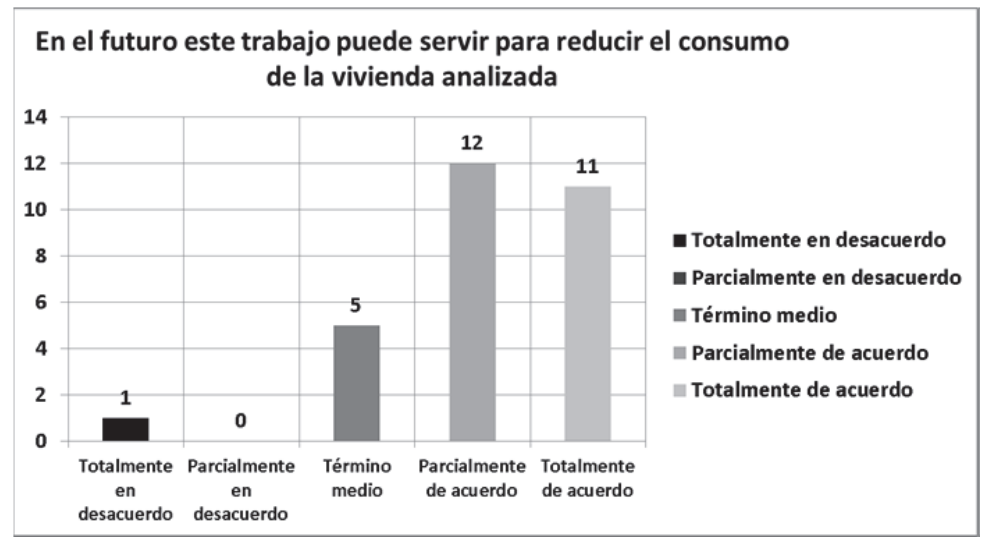

Fig. 7 Beneficios energéticos y medioambientales del proyecto

Finalmente, en la Fig. 7 se muestra uno de los objetivos "colaterales" esperados mediante la realización de este trabajo. Al realizar una auditoría energética de la vivienda de los alumnos, se esperaba que a posteriori comentaran los resultados con el resto de familia o compañeros de la vivienda. Esto es efectivamente lo que ha ocurrido, y en la mayoría de los casos (23 de 29) los alumnos están parcial o totalmente de acuerdo con que el trabajo ha elevado el grado de concienciación de los habitantes de su vivienda y también su conocimiento sobre medidas sencillas que pueden tomar para reducir su consumo y consecuentemente su gasto energético.

\section{Conclusiones}

La puesta en marcha del sistema de enseñanza-aprendizaje por proyectos planteado en este trabajo ha supuesto un gran reto. Los resultados son globalmente positivos, pero al igual que ocurre con otros métodos similares se han detectado mejoras importantes a realizar en los próximos cursos.

Ha sido fundamental la realización de encuestas específicas para analizar y comprender la opinión del alumnado. Sólo de esta manera se puede comprender qué mejoras resultan más necesarias de cara a años posteriores. Se ha detectado que es fundamental entregar desde el principio del curso toda la información y material relacionado con los trabajos. Esto permitiría a todos los alumnos empezar su trabajo desde el primer día de clase y que su esfuerzo y dedicación sean realmente contínuos.

Desde el punto de vista de las competencias transversales, la opinión del alumnado es muy positiva respecto al desarrollo de habilidades de comunicación o de trabajo en equipo. Una

(c)) EY-NC-ND 2014, Universitat Politècnica de València

I Jornadas IN-RED (2014) 
posible mejora, aunque menos prioritaria, sería intentar favorecer que el trabajo en equipo sea más efectivo, y poder incluír también la percepción de los alumnos sobre este punto dentro de la evaluación.

Finalmente, resulta muy alentador ver que el beneficio de la puesta en marcha de este método no sólo repercute sobre el desarrollo de estas competencias transversales, sino que también está permitiendo una mayor concienciación sobre el consumo energético en las viviendas y sobre cómo reducirlo en los próximos años.

\section{Referencias}

BIGGS, J.B. (2005). Calidad del aprendizaje universitario. Madrid: Nancea.

FERNANDEZ MARCH, A. (2010). "La evaluación orientada al aprendizaje en un modelo de formación por competencias en la educación universitaria” en Revista de Docencia Universitaria, 8, 1, 11-34.

LASNIER, F. (2000). Réussir la formation par compétences. Montréal: Guérin Éditeur.

TARDIF, J. (2006). L'évaluation des compétences. Documenter le parcours de développement. Montréal: Chenelière Éducation.

(cc) EY-NC-ND 2014, Universitat Politècnica de València

I Jornadas IN-RED (2014) 


\title{
Mejora del sistema de evaluación de las prácticas con ordenador en la asignatura de Matemáticas I para el Grado de Ingeniería en Diseño Industrial y Desarrollo de Productos
}

\author{
Jose Antonio Moraño Fernández ${ }^{a}$, Jose Antonio Verdoy González ${ }^{b}$, María Belén \\ García Mora $^{c}$ y Esther Sanabria Codesal ${ }^{\mathrm{d}}$ \\ a'Dpto. de Matemática Aplicada, Universitat Politècnica de València, Spain, jomofer@mat.upv.es, \\ ${ }^{\text {b}}$ Dpto. de Matemática Aplicada, Universitat Politècnica de València, Spain, javerdoy@mat.upv.es, \\ ${ }^{c}$ Depto de Matemática Aplicada, Universitat Politècnica de València, Spain, magarmo5@mat.upv.es \\ y ${ }^{\mathrm{d}}$ Dpto. de Matemática Aplicada, Universitat Politècnica de València, Spain, esanabri@ mat.upv.es.
}

\begin{abstract}
During the year 2012-2013 the authors of this study, teachers of the subject Mathematics I for the degree in Industrial Design Engineering and Product Development, taught in the School of Design Engineering have performed changes in the methodology of the Practice with Computer of this subject, especially in the field of assessment. This part of the subject has been adapted from a working system almost exclusively in the classroom to a working system base on a type of "reverse class" where the student must prepare the content before attending the classroom session. Throughout the year 2013-2014 we have settled the changes and the work has continued in the same line.

This paper presents the improvements achieved with these changes, the process followed in the transformation, some examples of the material used in each phase and how achievements in attendance and ratings are managed by the teacher and students. Finally, the results of a survey students about this new way of working are also shown.
\end{abstract}

Keywords: Flipped classroom, Comprehensive evaluation, Laboratory sessions, Mathematics.

(cc) EY-NC-ND 2014, Universitat Politècnica de València

I Jornadas In-Red (2014) 
Mejora del sistema de evaluación de las prácticas con ordenador en la asignatura de Matemáticas I para el Grado de Ingeniería en Diseño Industrial y Desarrollo de Productos

\begin{abstract}
Resumen
Durante el curso 2012-2013 los autores de este trabajo, profesores de la asignatura de Matemáticas I para la titulación de Grado de Ingeniería en Diseño Industrial y Desarrollo de Productos que se imparte en la Escuela Técnica Superior de Ingeniería del Diseño, han realizado modificaciones en la metodología de las Prácticas con Ordenador de la asignatura, sobretodo en el ámbito de su evaluación. Esta parte de la asignatura ha sido adaptada pasando de trabajarse casi exclusivamente en la clase presencial a un sistema de trabajo de tipo "clase inversa" donde el alumno debe preparar los contenidos antes de asistir a la sesión presencial. A lo largo del curso 2013-2014 se han asentado los cambios y se ha continuado trabajando en la misma línea.
\end{abstract}

Este artículo presenta las mejoras conseguidas con estos cambios, el proceso seguido en la transformación, algunos ejemplos del material empleado en cada fase y como se gestionan por parte del profesor y del alumno los resultados obtenidos tanto en asistencia como en calificaciones. Finalmente, también se muestran los resultados de un sondeo realizado a los alumnos sobre esta nueva forma de trabajar.

Palabras clave: Clase inversa, Evaluación exhaustiva, Clases de Matemáticas con ordenador, Matemáticas.

\title{
Introducción
}

El Vicerrectorado de Estudios, Calidad y Acreditación de la Universidat Politècnica de València (UPV) a través del Instituto de Ciencias de la Educación realiza cada año una convocatoria de ayudas para la realización de Proyectos de Innovación y Mejora Educativa (PIME). Durante el curso 2012-2013 los autores de este trabajo, profesores de la asignatura de Matemáticas I para la titulación de Grado de Ingeniería en Diseño Industrial y Desarrollo de Productos que se imparte en la Escuela Técnica Superior de Ingeniería del Diseño (ETSID), han realizado dentro del proyecto PIME B-11, modificaciones en la metodología de las Prácticas con Ordenador (PL) de la asignatura, sobretodo en el ámbito de su evaluación.

La asignatura objeto de cambios es una asignatura anual, de primer curso y con 9 ECTS de los que 3 son de PL. En los cursos 2012/2013 y 2013/2014 la asignatura tuvo una media de 150 alumnos en dos turnos donde para las sesiones de PL se desdoblaban en 4 grupos de unos 25 por las mañanas y 3 grupos de unos 20 por la tarde. 
Los principales objetivos de este proyecto han sido mejorar el aprovechamiento del tiempo que el alumno está de forma presencial en el aula (Soesanto, 2012) y tener más información de si el alumno va comprendiendo y va siendo competente para resolver los problemas de cada tema del curso.

Durante los cursos 2012/13 y 2013/2014 se han realizado modificaciones en el sistema de trabajo del alumno principalmente en las sesiones de PL, donde se ha pasado de un sistema casi exclusivamente de trabajo en el aula a un sistema de tipo 'clase inversa'. Esta adaptación ha requerido por parte del profesorado una división del trabajo de cada sesión en diversas fases (Sánchez, 2012) y la elaboración del material necesario para cada una de estas fases.

En este artículo se explica el proceso seguido en esta transformación, se muestran ejemplos del material empleado en cada fase, como se gestiona por parte del profesor y del alumno y los resultados obtenidos tanto en asistencia como en calificaciones. También se muestran algunas dificultades encontradas en el proceso con sus propuestas de superación: alumnos que no preparan la sesión, otros que durante la sesión copian resultados sin aprender el procedimiento, etc.

Finalmente, también se muestran los resultados de un sondeo realizado a los alumnos sobre esta nueva forma de trabajar.

\section{Objetivos}

Tal y como semencionaba en la Introducción uno de los objetivos es la mejora del aprovechamiento del tiempo que el alumno está de forma presencial en el aula. Hasta el comienzo de este proyecto los alumnos asistían a las sesiones de PL sin preparación previa por lo que gran parte del tiempo de clase se dedicaba a leer, comprender y resolver las dudas que se presentaban. A continuación ya se podían hacer ejemplos un poco más avanzsdos y algunos ejercicios, pero el tiempo que quedaba para éstos ya era escaso. Para hacer una evaluación de las sesiones las actividades debían ser breves haciendo que no se pudiese realmente saber si el alumno había adquirido esa competencia durante la sesión. Si bien es verdad que esas competencias pueden ser evaluadas en un examen posterior, éste puede ser muy tarde para que la evaluación sea realmente formativa quedándose únicamente en sumativa.

Nuestro objetivo es por tanto que el alumno se prepare cada sesión con antelación para conseguir que la fase de lectura, comprensión y realización de ejemplos no se realice durante la clase. De esta manera el tiempo presencial se aprovecha más y mejor resolviendo situaciones más complicadas en los ejemplos, dudas más significativas y destacando más detalladamente los conceptos que se consideran importantes.

\section{(c)) EY-NC-ND 2014, Universitat Politècnica de València}

I Jornadas IN-RED (2014) 
Mejora del sistema de evaluación de las prácticas con ordenador en la asignatura de Matemáticas I para el Grado de Ingeniería en Diseño Industrial y Desarrollo de Productos

Por otra parte, no todos los alumnos tienen la misma capacidad para leer y comprender al mismo ritmo los contenidos que se tratan, pero este sistema permite que cada alumno dedique el tiempo necesario para que su acceso a la sesión presencial sea en similiares condiciones, siendo por tanto este último, otro objetivo de la nueva metodología.

También queremos destacar como objetivo del cambio metodológico la necesidad de disponer de más y más frecuente información de como el alumno lleva su aprendizaje, es decir, si el alumno va comprendiendo y va adquiriendo las competencias necesarias para resolver los problemas de cada tema del curso.

\section{Desarrollo de la innovación}

La tarea de las prácticas de Matemáticas con ordenador durante el curso es desarrollada por el alumno en 27 sesiones. Para cada una de ellas hemos proyectado tres fases principales: la primera es una preparación previa del tema que va a trabajarse en la sesión, la segunda (ya presencial) se realiza en lo primeros 30' de la clase donde se resuelven dudas, ejemplos y algunos ejercicios que se han propuesto y una tercera fase de evaluación/aprendizaje donde el alumno realiza unos ejercicios de los que es evaluado a través de la plataforma PoliformaT (García-Mora, 2013), que la UPV tiene al servicio de profesores y alumnos. Esta evaluación se realiza con la asistencia por parte del profesor, lo que nos ha hecho pensar en la necesidad de mantener dos exámenes al curso con evaluación sin asesoramiento del profesor durante la prueba.

En cada una de las fases el profesorado ha tenido que elaborar el material necesario:

\section{Instrucciones}

Para cada sesión, el profesorado ha redactado unas instrucciones que guían al alumno sobre el trabajo que debe ir realizando para acceder apropiadamente a la sesión. 


\section{Mi PoliformaT $\vee$ Matemáticas I (DIS13) $\vee$ Matemáticas I (aero13) $\vee$}

\begin{tabular}{|c|c|c|c|}
\hline Configuración & 3) Mat & mátic & S I (DIS13): Recursos \\
\hline 的 Inicio & & & \\
\hline [ Guia Docente & Ubicac & $\square \mathrm{m}$ & emáticas I (DIS13): Recursos / PL(511+51: \\
\hline 9 Anuncios & & & \\
\hline 国 Calendario & Borrar & Mover & Copiar \\
\hline \&. Grupos & & & \\
\hline Recursos & 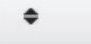 & $\square$ & Titulo 三 \\
\hline$\bullet$ Contenidos & & & PL(511+512+513+514) \\
\hline Exámenes & & & PL(0T1+012+013+014) \\
\hline I Calificaciones & & $\square$ & Fes seopl.pdf \\
\hline$\exists$ Espacio compartido & & & \\
\hline (2) Tareas & & $\square$ & 플 instrucciones sesión 01pl.pdf \\
\hline \% Gestión & & & \\
\hline (5) Correo interno & & $\square$ & instrucciones sesión 02pl.pdf \\
\hline$Q_{2}$ Sondeos & & 口 & 걱 instrucciones sesión 03pl.pdf \\
\hline Foros & & ש & \\
\hline$\&$ Chat & & $\square$ & 퍽 instrucciones sesión 04pl.pdf \\
\hline & & $\square$ & 를 instrucciones sesión 05pl.pdf \\
\hline
\end{tabular}

Fig. 1. Fragmento de instrucciones dispuestas en Recursos de la plataforma

En las instrucciones se indican, en primer lugar, los contenidos teóricos que van a ser utilizados y que han sido estudiados con antelación en las sesiones de teoría/problemas. A continuación se indica que sección del libro de prácticas (Moraño, 2012) esta asociada a las competencias que se van a trabajar en la sesión. En el libro aparecen ejemplos ya resueltos con explicaciones que el alumno debe ir realizando y comprendiendo. Finalmente, se propone al alumno la resolución de una serie de ejercicios que no están desarrollados en el libro para que él mismo sepa si sabe resolverlos.

\section{Preparación de la sesión (dudas posibles y contenidos importantes).}

Para la primera parte de la sesión presencial también es necesaria la elaboración de material que favorezca la eficiencia temporal de esa parte. Básicamente deben prepararse las posibles dudas que vayan a ser planteadas en la segunda fase y las explicaciones de los contenidos considerados importantes de la sesión por si estos aspectos relevantes no apareciesen entre las dudas.

\section{Elaboración y redacción de las cuestiones para la evaluación de la sesión}

Se han creado varias preguntas para cada sesión. Estas preguntas se proponen a través de la plataforma PoliformaT y son ejercicios que el alumno debe realizar con el ordenador durante la última fase. En su elaboración se ha tenido en cuenta que concuerde tanto con las instrucciones como con los ejemplos y los ejercicios que se han propuesto. Por lo general las respuestas son celdas que deben ser rellenadas con valores numéricos, ver Fig. 2.

\section{(c)) EY-NC-ND 2014, Universitat Politècnica de València}

I Jornadas IN-RED (2014) 
Mejora del sistema de evaluación de las prácticas con ordenador en la asignatura de Matemáticas I para el Grado de Ingeniería en Diseño Industrial y Desarrollo de Productos

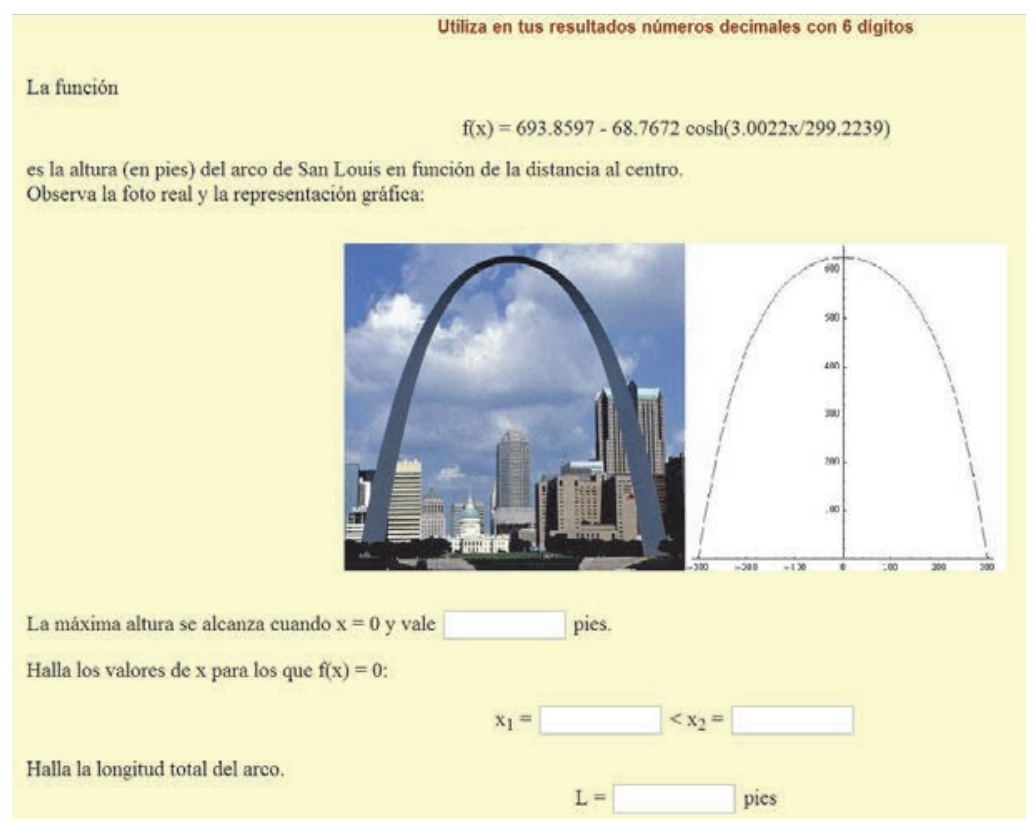

Fig. 2. Ejemplo de pregunta de tipo valor numérico

El uso de la plataforma en la última fase de la sesión permite tener las correcciones de los ejercicios nada más terminar la prueba lo que hace que el alumno tenga un feedback más pronto. Otra virtud de las pruebas a través de la plataforma, es la posibilidad de dejar durante todo el curso, acceso a la visualización de la prueba.

También facilita la gestión de las notas mediante la Herramienta de la plataforma 'Calificaciones'. Esta gestión mejora para el profesor que puede filtrar por grupos, o ver todas las calificaciones de un alumno, etc., y también mejora para el alumno porque puede ver en cualquier momento que sesiones (con sus competencias correspondientes) son las que necesitan un repaso. 


\begin{tabular}{|c|c|c|c|}
\hline Titulo* & Fecha de entrega $三$ & Log & Nota $^{* *}$ \\
\hline Actividades en clase & 01-sep-2013 & 踾 ( & 1) \\
\hline Ev ses 01 (13/14). Primeros cálculos con Mathematica & 11-sep-2013 & & 6 \\
\hline Ev Ses $02(13 / 14)$. Variables y Funciones & 18-sep-2013 & & 10 \\
\hline Ev Ses 03 (13/14). F. Hiperbólicas y Gráficas Cartesianas & 25-sep-2013 & & 3,7 \\
\hline Ev Ses 04 (13/14). Resolución de ecuaciones. & 02-oct-2013 & & 8,1 \\
\hline Ev Ses 05 (13/14). Limites y Derivadas. & 08-oct-2013 & & 7,7 \\
\hline Test 1(13/14) - Unidad 1 & 14-oct-2013 & & 5,39 \\
\hline Ev Ses 06 (13/14). Gráficas 3D y Derivadas Parciales. & 16-oct-2013 & & 9,5 \\
\hline Ev Ses 07 (13/14). Gradiente y Derivadas direccionales. & 23-oct-2013 & & 8,5 \\
\hline Ev Ses 08 (13/14). Hessiano y Extremos libres & 30-oct-2013 & & 7,15 \\
\hline Ev Ses 09 (13/14). Gráficas l: Agrupar, func. especiales y animaciones. & 06-nov-2013 & & 10 \\
\hline Ev Ses 10 (13/14). Extremos Condicionados & 13-nov-2013 & & 5,5 \\
\hline
\end{tabular}

Fig. 3. Utilizando 'Calificaciones' el alumno detecta que competencias están peor adquiridas

\section{Resultados}

Los resultados pueden analizarse desde el punto de vista de las calificaciones, ver Tabla 1.

Tabla 1. Calificaciones en PL

\begin{tabular}{lcc}
\hline & $\mathbf{1 2 / 1 3}$ & $\mathbf{1 3 / 1 4}$ \\
\hline Sesiones PL (27) & 8,17 & 8,24 \\
Exámenes PL (3) & 6,86 & 6,85
\end{tabular}

Desde nuestro punto de vista estas calificaciones son bastante aceptables y muestran cierta discrepancia entre las sesiones y los exámenes porque en estos últimos el profesor no está asistiendo al alumno.

También pueden considerarse los resultados por porcentajes o tasas de rendimiento pero en este caso considerando la asignatura globalmente y no sólo la parte de PL, ver Tabla 2.

Tabla 2. Tasas de rendimiento y de abandono

\section{(c)) EY-NC-ND 2014, Universitat Politècnica de València}

I Jornadas IN-RED (2014) 
Mejora del sistema de evaluación de las prácticas con ordenador en la asignatura de Matemáticas I para el Grado de Ingeniería en Diseño Industrial y Desarrollo de Productos

\begin{tabular}{ccc}
\hline NP & $2 \%$ & $2 \%$ \\
Suspensos & $10 \%$ & $9 \%$ \\
Aprobados & $88 \%$ & $89 \%$ \\
\hline *Datos no oficiales en el momento de la redacción del artículo
\end{tabular}

Aunque estos resultados son más globales que la parte de la asignatura que hemos modificado creemos que mantener al alumno activo para preparar las sesiones de PL cada semana le fuerza a repasar las sesiones de teoría/problemas teniendo por tanto influencia en la tasa de abandono y en la de rendimiento.

Finalmente también debemos tener en cuenta la visión del alumno, para lo que hemos realizado estos dos cursos un sondeo con diversas preguntas que pueden verse en la Tabla 3.

Tabla 3. Opiniones de los alumnos (\%)

\begin{tabular}{|l|c|c|}
\hline & $\begin{array}{c}\text { Sí } \\
(\mathbf{1 2 - 1 3 / 1 3 - 1 4})\end{array}$ & $\begin{array}{c}\text { No o No sabe } \\
(\mathbf{1 2 - 1 3 / 1 3 - 1 4})\end{array}$ \\
\hline $\begin{array}{l}\text { ¿El número de prácticas ha sido el adecuado para } \\
\text { aprender los contenidos de la asignatura? }\end{array}$ & $92 / 94$ & 8 / 6 \\
\hline $\begin{array}{l}\text { ¿Usar PoliformaT en las sesiones de PL hace que los } \\
\text { contenidos se aprendan mejor? }\end{array}$ & 84 / 88 & $16 / 12$ \\
\hline $\begin{array}{l}\text { ¿La evaluación realizada en cada sesión de PL se } \\
\text { ajusta a lo aprendido en las clases? }\end{array}$ & $96 / 93$ & $4 / 7$ \\
\hline $\begin{array}{l}\text { ¿La evaluación con PoliformaT al final de cada } \\
\text { sesión de PL favorece el proceso de aprendizaje? }\end{array}$ & $94 / 94$ & $6 / 6$ \\
\hline $\begin{array}{l}\text { ¿Crees que sería bueno para el proceso de } \\
\text { aprendizaje acabar las sesiones de TP con un test } \\
\text { mediante PoliformaT sobre lo tratado? }\end{array}$ & $36 / 62$ & $17+47 / 16+22$ \\
\hline
\end{tabular}

En general, el uso de la plataforma para evaluar las sesiones de PL es aceptado en todos los aspectos consultados: número de prácticas, ajuste a los contenidos y a lo explicado en las clases y mejora del proceso de aprendizaje. La última de las cuestiones de la Tabla 3 se refiere a la extensión del método a las clases de teoría/problemas. Sobre esta cuestión ha habido cierta transición de un año a otro sobre todo en el número de indecisos que ha pasado de un $47 \%$ a solo un $22 \%$. En nuestra opinión este cambio puede ser debido a que 
este curso ya se han realizado algunas actividades de este tipo en las sesiones de teoría/problemas por lo que los alumnos sí tienen una referencia de como pueden ser este tipo de preguntas.

Este año se ha añadido una pregunta al sondeo para consultar cuántas horas dedica cada uno a la preparación previa de cada sesión. La pregunta ha sido: “¿Cuántas horas dedicas como media a la semana para preparar cada práctica?" y la distribución de respuestas ha sido 58\% menos de 1 hora, $29 \%$ entre 1 y dos horas y un $13 \%$ más de dos horas. Este resultado viene a validar la consecución del objetivo de que cada alumno pueda preparar su sesión según sus posibilidades.

\section{Conclusiones}

La tasa de abandono es notablemente baja $2 \%$ y la tasa de rendimiento es bastante aceptable cerca de un $88 \%$ los últimos dos años.

La opinión de los alumnos muestra con claridad que el nuevo sistema de trabajo y evaluación en las sesiones de PL es aceptado y aunque expresan más dudas en cuanto a si este sistema sería trasladable a las sesiones de teoría/problemas su opinión se vuelve más favorable cuando conocen el tipo de preguntas que se harían. Todo esto lleva a los autores a la conclusión de que la nueva forma de trabajo en la asignatura de Matemáticas está teniendo éxito y goza de buena aceptación.

Para intentar seguir mejorando este proceso de aprendizaje, los autores tienen previsto incorporar más preguntas a través de PoliformaT al final de cada sesión de teoría/problemas. Este nuevo plan de trabajo pretende que el alumno asista a todas las sesiones y que haga un esfuerzo por atender y entender las clases incluso con su preparación previa. Esta tarea, que proporciona al estudiante un mayor aprendizaje de los conceptos necesarios para la sesión, presenta ciertas dificultades de infraestructura que están siendo estudiadas con la ETSID y el Departamento de Matemática Aplicada (DMA) de la UPV.

\section{Agradecimientos}

Los autores agradecen al Departamento de Matemática Aplicada de la UPV por el establecimiento de ayudas a proyectos educativos innovadores, a la ETSID por su apoyo continuo en los proyectos de innovación docente y al Vicerrectorado de Estudios y Convergencia Europea de la UPV por su colaboración con el proyecto de innovación y mejora educativa (PIME) B-11.

\section{(cc) EY-NC-ND 2014, Universitat Politècnica de València}


Mejora del sistema de evaluación de las prácticas con ordenador en la asignatura de Matemáticas I para el Grado de Ingeniería en Diseño Industrial y Desarrollo de Productos

\section{Referencias}

\section{Libro}

MORAÑO FERNÁNDEZ, JA., SÁNCHEZ RUIZ, LM. (2012). Cálculo y Álgebra con Mathematica 8. València: Universitat Politècnica de València.

\section{Ponencias de congresos}

GARCÍA-MORA, B., (2013). “ Adaptación a una metodología más activa e implementación de evaluación continua en Matemáticas del Grado en Diseño Industrial”. XXI Congreso Universitario de Innovación Educativa en las Enseñanzas Técnicas 2013. Valencia.

SÁNCHEZ RUIZ LM., MORAÑO FERNANDEZ, JA., ROSELLÓ FERRAGUT,MD., (2012). "Fitting Mathematics to EHEA in Aerospace Engineering at the School of Design Engineering ETSID in Valencia (Spain)". International Conference on Engineering Education, ICEE-2012. Turku, Finland. Paper: W2A-5-W2A-7.

SOESANTO K., (2012). “ Motivational education for science course ”. International Conference on Teaching, Assessment, and Learning for Engineering IEEE-TALE 2012. Hong Kong. Paper 221. 


\title{
Experiencias de innovación docente y uso de nuevas tecnologías en la enseñanza del tratamiento de la imagen digital en Geomática
}

María Joaquina Porres de la Haza, Alfonso Fernández-Sarría, Jorge Abel Recio Recio Dpto. Ing. Cartográfica, Geodesia y Fotogrametría, Universitat Politècnica de València. Camino de Vera s/n, 46022, Valencia (España). Tel: 963877000-ext 75574, Fax: 963877559, e-mail: mporres@cgf.upv.es, afernan@cgf.upv.es, jrecio@cgf.upv.es.

\begin{abstract}
Resumen
La asignatura de Tratamiento de la imagen digital se encuentra en segundo de Grado en Ingeniería en Geomática y Topografía. Sus seis créditos se reparten en tres de teoría de aula y tres de prácticas de laboratorio.

En este trabajo se muestra cómo se ha organizado la docencia y las metodologías empleadas en la asignatura buscando el aprendizaje autónomo y significativo del alumno, intentando aumentar su motivación e implicación. Se pretende cambiar la tendencia pasiva del alumno hacia un aprendizaje activo dentro y fuera del aula que le permita llegar a las clases con el material trabajado y dispuesto a resolver las cuestiones que se planteen y a obtener e interpretar resultados.

Se diseñaron clases prácticas basadas en los contenidos teóricos, con videos de 10 minutos (Polimedias) sobre cómo ejecutar las prácticas y con un test que permite evaluar los resultados y recoger los comentarios que se derivan del desarrollo de las prácticas.
\end{abstract}

Sin embargo, es necesario avanzar en el diseño de actividades encaminadas hacia la docencia inversa (flip teaching), es decir hacia clases en las que el alumno debata y resuelva las dudas y cuestiones que se le planteen y que le permitan abandonar la posición de alumno pasivo.

Palabras clave: Geomática, aprendizaje activo, organización del aprendizaje, docencia inversa, flip teaching.

(cc) EY-NC-ND 2014, Universitat Politècnica de València

I Jornadas In-Red (2014) 
Experiencias de innovación docente y uso de nuevas tecnologías en la enseñanza del tratamiento de la imagen digital en Geomática

\section{Introducción}

La asignatura Tratamiento de la imagen digital se encuentra inserta en el segundo curso de los estudios de Grado en Ingeniería en Geomática y Topografía. Los seis créditos que cursa el alumno se reparten en tres de teoría de aula y tres de prácticas de laboratorio. Los conceptos desarrollados en la asignatura sirven de vehículo, de instrumento, para análisis y aplicaciones desarrolladas en asignaturas de cursos posteriores.

Durante los últimos tres años, el desarrollo de las tecnologías docentes ha favorecido la producción de material que permite un aprendizaje efectivo y un mejor aprovechamiento del tiempo por parte del alumnado. En el caso de esta asignatura, esta efervescencia de material no se acompañó de un cambio en las metodologías docentes, lo que provocó que el alumno adoptara posturas pasivas, poco motivadas y con escaso grado de implicación ya que los recursos elaborados por el profesorado recogían de forma organizada todo lo que era necesario aprender en la asignatura. Se observó que con todo el temario desarrollado en el material que tenían a su disposición, los alumnos acudían, en el mejor de los casos, a las clases magistrales únicamente a escuchar y se implicaban poco en el aprendizaje. Esta actitud produjo que el alumno redujera la capacidad de poner en práctica ciertos conceptos y buscara su aplicabilidad, además de que le resultaba difícil desarrollar algo que no figurara explícitamente en el material.

En este trabajo se pretende mostrar cómo se ha organizado la docencia y las metodologías empleadas en la asignatura con el fin de facilitar el aprendizaje autónomo y significativo del alumno, intentando aumentar su motivación e implicación. Se pretende dar un giro importante a la asignatura y tender al flip teaching o modelo de docencia inversa.

La docencia flip teaching trata de orientar la planificación de las clases de una asignatura, o parte de ella, desde una perspectiva contraria a la habitual. Consiste en hacer una clase al revés, el alumno asiste a una clase particular en casa sin el profesor y trabaja los deberes en clase con el profesor (Fidalgo, 2013). Para poder llevarla a cabo se han de elaborar materiales docentes diferentes a los clásicos manuales de apuntes y con un enfoque más interactivo. Clases grabadas en vídeo, apuntes online con enlaces a blogs, páginas web de organismos públicos, repositorio de datos,... por los que el alumno se pueda mover con total libertad y sin los condicionantes de una clase presencial.

Respecto a la parte presencial, los alumnos deben trabajar sobre los contenidos expuestos en los vídeos, por ejemplo, bien para aplicarlos, criticarlos o desarrollarlos. Esta fase de trabajo puede ser de tipo colaborativo en grupos en los que además, se definan roles dentro de cada uno para aportar una perspectiva más constructiva a ese trabajo y se genere aprendizaje. 
Este modelo, al combinar la enseñanza presencial y virtual en el entorno de las nuevas tecnologías de la comunicación, permite aprovechar el interés de los estudiantes por estas nuevas herramientas tecnológicas (Tobar, 2012) lo que puede redundar positivamente en la motivación e interés que muestren hacia los contenidos y actividades planteadas.

Bishop y Verleger, 2013, citan los resultados de múltiples trabajos con una línea común a todos ellos: Los resultados de esta estrategia docente son muy positivos, aunque hay estudiantes que pueden mostrarse reacios. Los alumnos que tienen clases en vídeos a su disposición asisten a las clases mucho mejor preparados que aquellos que disponen de libros de texto y el rendimiento académico mejora.

\section{Objetivos}

La experiencia tiene como objetivo invertir la tendencia pasiva del alumno hacia un aprendizaje activo dentro y fuera del aula que le permita llegar a las clases prácticas con el material trabajado y dispuesto a resolver las cuestiones que se planteen y con los conocimientos necesarios para ejecutarlas.

El segundo objetivo pretende que el alumno adquiera el hábito de organizar y planificar el tiempo de trabajo. Conociendo la programación y los contenidos así como los recursos que tiene a su disposición, debe realizar una organización y planificación temporal optimizada desde el primer momento de la asignatura reduciendo en lo posible los picos de trabajo.

Todas las acciones de mejora previstas en la asignatura conllevan dedicar más tiempo a casos de estudio y aplicaciones. Las actividades se centran en la fase analítica más que en el uso sucesivo de una serie de comandos de un determinado software. El objetivo de ello es que aumente la motivación del alumno hacia la materia al comprender mejor su utilidad.

\section{Desarrollo de la innovación}

El proyecto comienza por la planificación temporal de la asignatura. La distribución de las clases prácticas a lo largo del cuatrimestre se realiza cuidando que los conceptos teóricos necesarios para desarrollar las aplicaciones se desarrollen, siempre que sea posible, una semana antes de su puesta en práctica.

En las clases teóricas se explican los conceptos y el manejo de las herramientas que deberán tratar durante la parte práctica, aludiendo repetidamente, tanto en la clase magistral como en los recursos, a las posibles aplicaciones de dichas herramientas. Los recursos teóricos consisten en apuntes docentes de cada una de las unidades. Algunos de ellos están

\section{(c)) EY-NC-ND 2014, Universitat Politècnica de València}

I Jornadas IN-RED (2014) 
Experiencias de innovación docente y uso de nuevas tecnologías en la enseñanza del tratamiento de la imagen digital en Geomática

publicados en Riunet como artículos docentes (http://hdl.handle.net/10251/30214), los cuales abarcan partes importantes del temario.

La innovación docente se pone en marcha principalmente en la parte práctica de la asignatura. Para ello se diseñaron clases prácticas basadas en los contenidos comentados en teoría, con videos introductorios de 10 minutos que les muestran cómo ejecutar las prácticas y con un test que permite evaluar los resultados y recoger los comentarios que se derivan de la ejecución de las prácticas.

Cada práctica, asociada a una unidad, se realiza en dos o tres sesiones. El material de cada práctica lleva consigo una serie de recursos, disponibles para el alumno desde comienzos de curso, que le permitirán preparar la ejecución de las mismas:

- El guión de cada una de las sesiones, con las instrucciones y herramientas necesarias para el desarrollo de las aplicaciones (figura 1). A lo largo del guión se intercalan las preguntas del cuestionario que se deben ir rellenando conforme se avanza en el desarrollo de la práctica.

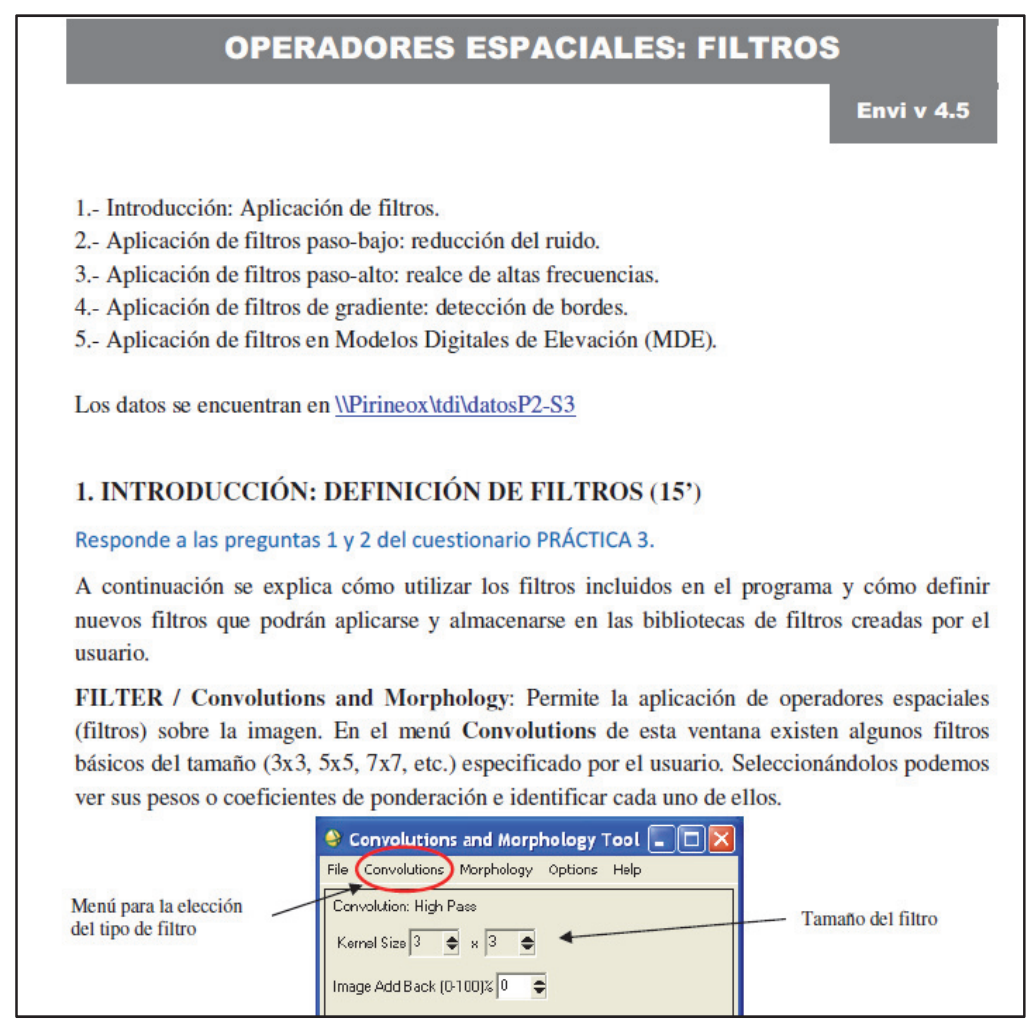

Fig. 1. Guión de una práctica.

(c)) EY-NC-ND 2014, Universitat Politècnica de València

I Jornadas IN-RED (2014) 
- Un Polimedia explicando cómo usar las herramientas descritas previamente en teoría (figura 2).

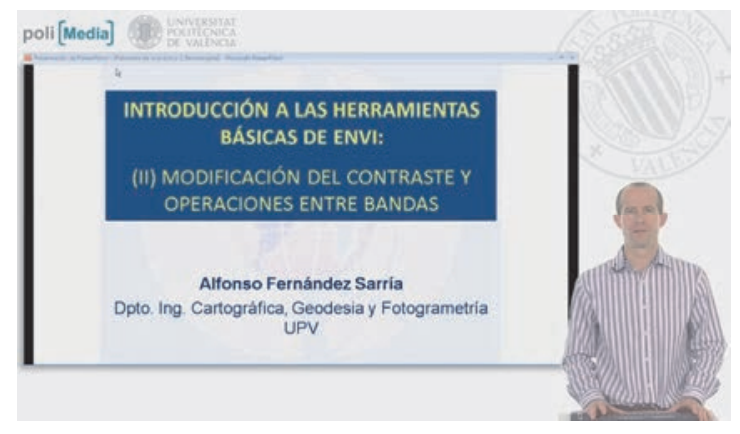

Fig. 2. Ejemplo de una grabación Polimedia.

- Un cuestionario de evaluación en PoliformaT en el que se combinan preguntas objetivas y cortas e incluso se adjuntan algunos de los archivos resultantes de la práctica (figura 3). Este cuestionario está formado, mayoritariamente, por preguntas acerca de la metodología seguida en el desarrollo de la práctica, de los resultados, de su análisis e interpretación.

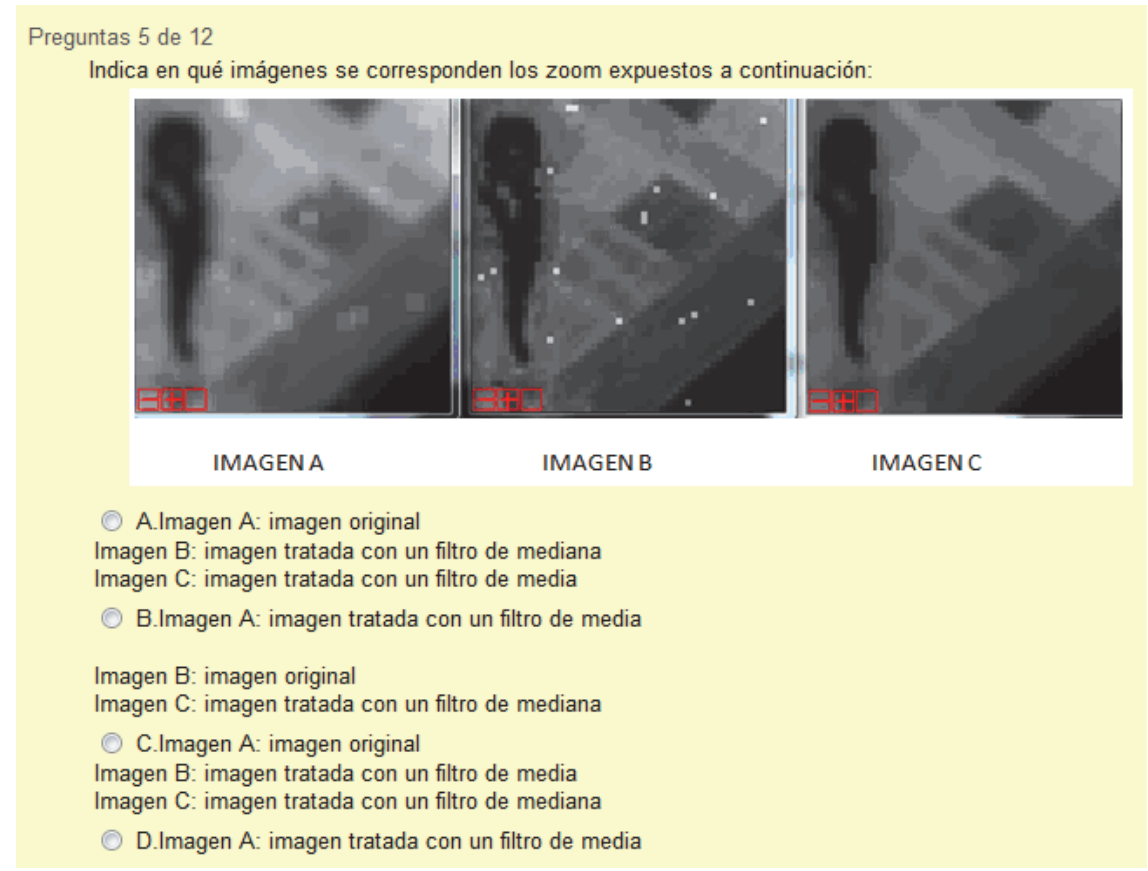

Fig. 3. Ejemplo de una pregunta del cuestionario de evaluación.

\section{(cc) EY-Nc-ND 2014, Universitat Politècnica de València}

I Jornadas IN-RED (2014) 
Experiencias de innovación docente y uso de nuevas tecnologías en la enseñanza del tratamiento de la imagen digital en Geomática

En alguna ocasión se introduce inicialmente alguna pregunta teórica que permite al alumno comprobar si comprende el uso de la metodología correctamente (figura 4).

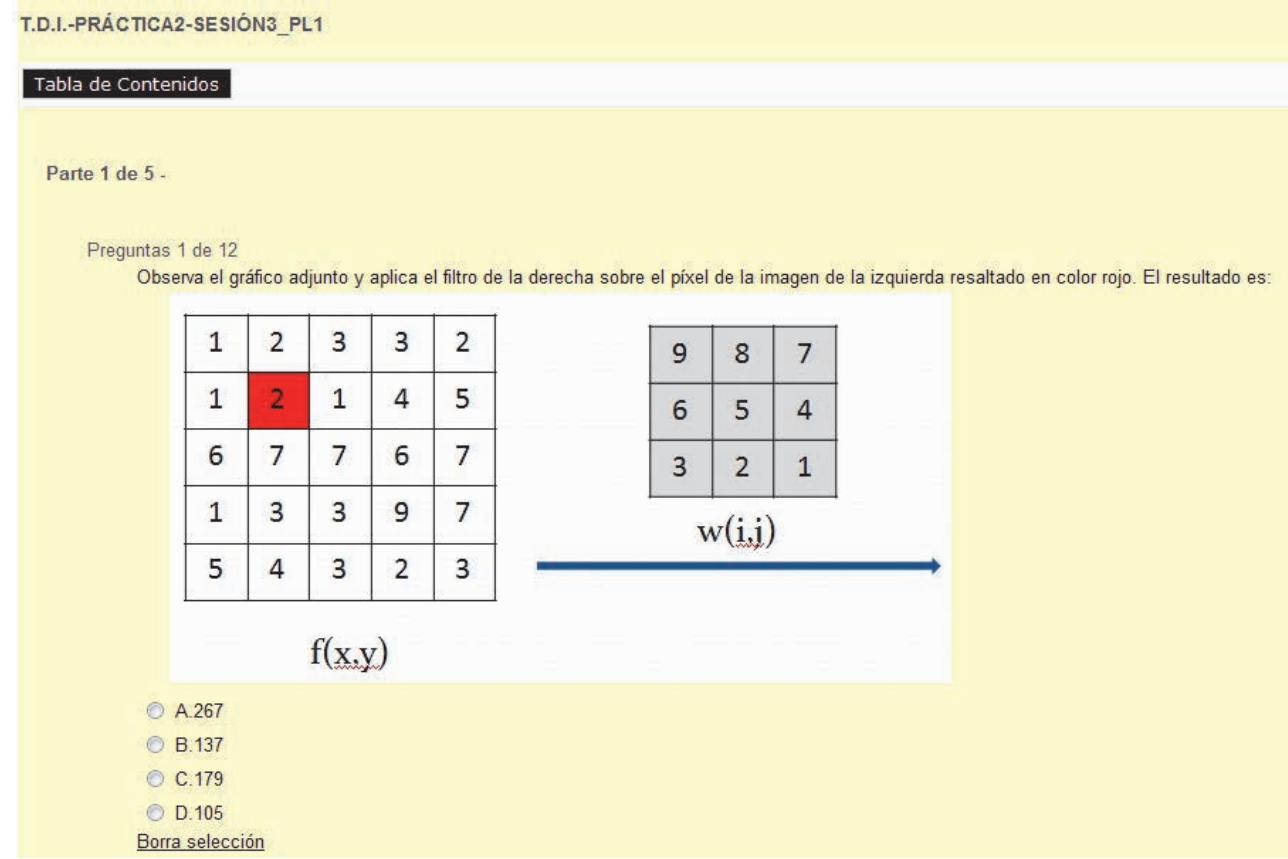

Fig. 4 Ejemplo de una pregunta del cuestionario de evaluación.

El cuestionario se habilita a través de PoliformaT/Exámenes, durante el periodo que dura la sesión de prácticas. El profesor, durante la sesión, ayuda al alumno con las cuestiones que le resulten más complicadas. Sin embargo, para poder completar con éxito toda la práctica, será necesario que el alumno haya preparado y leído los contenidos teóricos para poder resolver en la sesión las cuestiones requeridas. En el caso contrario, es posible que no llegue a completar el cuestionario.

La evaluación de las prácticas es continua y en ocasiones inmediata. Cada cuestionario se califica y su nota promedia con el resto. A los alumnos con ausencias justificadas se le permite la posibilidad de realizar la práctica habilitándoles, por un tiempo igual al de sus compañeros, el cuestionario.

La elaboración del material, la organización de las prácticas y su evaluación permiten a los alumnos organizar su aprendizaje, aumentar su motivación y llegar a las clases prácticas dispuestos a poner en práctica lo aprendido y a obtener e interpretar resultados. 


\section{Resultados y conclusiones}

Si bien hay que trabajar en obtener evidencias objetivas que permitan medir el grado de mejora en el aprendizaje, sí que existen apreciaciones que indican el cambio a la hora de enfrentarse a las prácticas. La postura pasiva del alumnado, una vez entendida la dinámica de la asignatura, se vuelve inquietud incluso en las clases teóricas, donde intentan, mediante sus preguntas, aclarar lo que seguro después van a emplear en las prácticas.

El resultado es un alumno que, a lo largo del cuatrimestre, aprende a organizar y optimizar el aprendizaje y se concentra en aplicarlo. El alumnado acepta la nueva metodología, ya que entre otras ventajas, le resulta más motivador poner en práctica lo asimilado previamente, sin quedarse a la espera de que se lo cuenten y le permite optimizar su tiempo sin tener que redactar y editar memorias o trabajos a posteriori en horario extraescolar. Se ha dado el caso de ser el alumno el que exige al profesor el material de una práctica para poder preparársela antes de la clase correspondiente, en el caso de no estar disponible este material en los plazos acordados.

Con las prácticas guiadas y el cuestionario, el alumno se concentra más en el análisis de los resultados metodológicos y no tanto en el empleo de una serie de herramientas sin valorar sus resultados. Además, y gracias a la inmediatez de las calificaciones, el alumno puede medir sus esfuerzos, rectificar su trayectoria y mejorar sus resultados dedicando más tiempo a las prácticas posteriores. La tasa de rendimiento obtenida en el total de la asignatura llega al $81 \%$, lo que corrobora que los esfuerzos realizados van en la dirección correcta.

Es necesario destacar algunas consideraciones a tener en cuenta en cursos sucesivos:

a. El alumnado debe ser consciente desde el primer día del tipo de metodología a emplear. Para ello, sería conveniente organizar algún tipo de actividad que permita asegurarse que el alumno conoce cómo se va a proceder. Se podría presentar la metodología mediante la lectura de un artículo sobre docencia inversa y la participación en foros habilitados para ello.

b. Los cuestionarios deben ser sencillos en las primeras prácticas e ir aumentando en contenidos específicos a medida que avanza el cuatrimestre. De esta manera, el alumno se va adaptando progresivamente a la metodología.

c. Este tipo de metodologías permite trabajar competencias transversales como la gestión efectiva del tiempo, la aplicación del pensamiento práctico y el análisis y resolución de problemas, por lo que es necesario buscar un equilibrio eficiente que permita al alumno trabajarlas sin detrimento de las competencias específicas.

d. El alumno se enfrenta a los cuestionarios como si de un examen se tratara. Esto causa cierto estrés que debe tratarse mediante la explicación del sistema de evaluación y el correcto escalado de los contenidos asociados a cada una de las prácticas.

\section{(c) EY-NC-ND 2014, Universitat Politècnica de València}

I Jornadas IN-RED (2014) 
Experiencias de innovación docente y uso de nuevas tecnologías en la enseñanza del tratamiento de la imagen digital en Geomática

e. La necesidad de preparar eficientemente las clases prácticas induce al alumno a participar de forma activa en las clases teóricas. Sin embargo es necesario avanzar en el diseño de actividades que encaminen mejor las clases magistrales hacia la docencia inversa (flip teaching), es decir, hacia clases en las que el alumno debata y resuelva las dudas y cuestiones que se le planteen y que le permitan abandonar la posición de alumno pasivo.

\section{Referencias}

BISHOP, J. L. y VERLEGER, M. A. (2013). “The Flipped Classroom: A survey of the research”. En 120th ASEE Annual Conference \& Exposition. Atlanta. Disponible en <http://www.asee.org/file_server/papers/attachment/file/0003/3259/6219.pdf> [Consulta: 11 de junio de 2014].

FIDALGO, A. (2013) 'Qué es Flip Teaching, Flipped Classroom o Clase Inversa' en Innovación Educativa, Blog de Angel Fidalgo para reflexionar sobre innovación educativa, 14 de febrero. $<$ http://innovacioneducativa.wordpress.com/2013/02/14/que-es-flip-teaching-flipped-classroom-oclase-inversa/> [Consulta: 10 de junio 2014]

TOBAR, E. (2012) 'Flip Teaching: un modelo distinto de enseñanza' en Maestros del web, 11 de diciembre. $\quad<$ http://www.maestrosdelweb.com/editorial/flip-teaching-un-modelo-distinto-deensenanza/> [Consulta: 11 de junio 2014].

UNIVERSITAT POLITÈCNICA DE VALÈNCIA. Guía para la creación de objetos de aprendizaje. 〈http://www.upv.es/contenidos/DOCENRED/infoweb/docenred/info/guia.pdf〉 [Consulta: $14 \mathrm{de}$ junio de 2014].

UNIVERSITAT POLITÈCNICA DE VALÈNCIA. Portal Polimedia. <http://polimedia.blogs.upv.es/> [Consulta: 2 de junio de 2014]. 


\title{
Combinación de aprendizaje tradicional y colaborativo para mejorar la motivación en el estudio de las redes de computadores
}

\section{Elvira Baydal ${ }^{\mathrm{a}}$}

${ }^{a}$ Departamento de Ingeniería de Computadores (DISCA), Universitat Politècnica de València, Camino de Vera 14, València 46022, e-mail: elvira@ disca.upv.es.

\begin{abstract}
This paper presents the educational strategy carried out in the "Computer Network" course of the Computer Egineering degree at the Politechnical University of Valencia (UPV) during the first semester of 2013. The main goal of this experiment was to improve student's motivation towards the subject, and promote autonomous and steady working. To achieve this goal, we combined lectures and problem sessions in the classroom, with autonomous but guided texbook readings through a list of questions prepared by the instructor. Afterward, those questions were publicly discussed in the classroom. This active learning-based pedagogy made easier to detect and correct misconceptions. The instructor was in charge of moderating the discussion and helping to reach conclusions. Right answers or interesting questions were rewarded with marks for the global grade.
\end{abstract}

This working approach improved in a significant way the classroom attitude of many students. In a questionnaire carried out to reflect student's satisfaction at the end of the term, it was shown that $76 \%$ of the students were more motivated to study the subject.

Keywords: Engineering education, metodology, motivation, collaborative learning, autonomous learnig, self-learning, transversal skills, peer instruction.

\section{Resumen}

Este trabajo presenta la experiencia llevada a cabo en uno de los grupos de la asignatura de "Redes de Computadores" del grado en Ingeniería en Informática de la Universidad Politécnica de Valencia, durante el curso académico 2012-13. El objetivo de la misma fue mejorar la motivación de los alumnos por la asignatura, así como fomentar el trabajo continuo y 
Combinación de aprendizaje tradicional y colaborativo para mejorar la motivación en el estudio de las redes de computadores

autónomo. Para conseguirlo, se combinaron las sesiones de clase magistral y resolución de problemas, con el estudio autónomo por parte del alumno, previo a las sesiones de aula pero dirigido a través de una serie de cuestiones planteadas por el profesor. Dichas cuestiones se discutian de forma pública posteriormente en el aula. Esta metodología activa facilitaba la detección y corrección de los errores de concepto por parte del alumno. El profesor se encargaba de moderar la discusión y de ayudar a extraer las conclusiones. Las intervenciones correctas permitían al alumno mejorar su nota de la asignatura.

Esta dinámica de trabajo mejoró claramente la actitud en el aula de muchos de los estudiantes. En un cuestionario sobre satisfacción realizado al final del cuatrimestre a los alumnos del grupo objeto del estudio, el 76\% manifestó que le había motivado a estudiar la asignatura.

Palabras clave: metodología, motivación, aprendizaje colaborativo, aprendizaje autónomo, lectura dirigida, competencias transversales, enseñanza por compañeros.

\section{Introducción}

La falta de motivación del alumnado es un problema frecuente en muchas universidades y que genera preocupación en el ámbito academico, como demuestran las numerosas publicaciones en torno al mismo (Astin, 1993; Rengel, 2012; Jong, 2013). Esta falta de motivación puede deberse a diversos factores, algunos de ellos específicamente relacionados con los nuevos currículos de la Universidad Española y otros relacionados con los estudios universitarios de la Ingeniería Informática en general.

Entre los factores que pueden influir en la falta de motivación del alumnado en Ingeniería Informática podemos citar:

- Por una parte, el hecho de que la disciplina Informática representa todavía una mejor vía de acceso al empleo que muchas otras. Esto ha provocado la aparición de un gran número de escuelas universitarias o facultades donde se imparte la titulación. En el caso concreto de la comunidad valenciana, se imparte en 4 centros (U. Politècnica de Valencia (sedes de Valencia y Alcoi), Universitat de València y Universitat de Castellón). La elevada oferta de plazas permite el acceso al grado a alumnos que han solicitado acceder a otras titulaciones sin éxito, pero que no están realmente interesados en estudiar informática. Por otra parte, la mayor posibilidad de acceso laboral conduce, en algunos casos, a alumnos que acceden a los estudios 
por recomendación familiar pero no por convencimiento propio. Situaciones similares se han detectado en otros países (Baxter y Hatt, 2000).

- Alumnos que han entrado en contacto con la disciplina en asignaturas de ESO a nivel de usuario y que llegan a la titulación con una idea equivocada.

Por otra parte, la asignatura objeto de la experiencia cuenta con su propia problemática específica al ser una asignatura anual que convive principalmente con asignaturas cuatrimestrales. La implantación de los nuevos planes de estudio siguiendo las directrices del EEES ha generado una mayor carga de trabajo autónomo por parte del alumno. Además, en muchos casos, el alumno de los primeros cursos no está todavía acostumbrado a planificar su trabajo a medio plazo. Esto puede provocar que en los períodos de mayor carga, el alumno medio pueda verse sobrepasado y opte por seleccionar y preparar sólo los trabajos o pruebas más rentables en cuanto a puntuación. La asignatura de Redes de Computadores del grado en Ingeniería Informática de la Universitat Politècnica de Valencia (UPV) es una asignatura anual, frente al resto de las asignaturas del $2^{\circ}$ curso excepto Estructura de Computadores, que son todas cuatrimestrales (ESCUELA TÉCNICA SUPERIOR DE INGENIERÍA INFORMÁTICA, 2013 ; BOE, 2011). En este grado en Informática, la evaluación suele realizarse siguiendo las recomendaciones institucionales de la ETSINF: 60\% examen, 20\% laboratorio, 20\% trabajo de clase. Al intentar llevar a cabo una evaluación continua, cada uno de estos apartados se evalúa a su vez mediante distintas pruebas o trabajos, que contribuyen con distinto peso a la nota final. Esto resulta perjudicial para las asignaturas anuales a la hora de conseguir dedicación por parte de los alumnos, ya que al competir por los puntos, habitualmente sus pruebas o trabajos "valdrán" la mitad que el trabajo equivalente de una asignatura cuatrimestral.

Además, aunque la asistencia a las sesiones de aula está fuertemente recomendada en el grado, y se controla mediante partes de firma para evitar el absentismo, si el alumno asiste pero posteriormente no dedica tiempo de estudio a la asignatura, al cabo de unas pocas sesiones ya no podrá seguir los conceptos adecuadamente ni participar de forma activa en el trabajo del aula, por lo que la mera asistencia resultará poco útil.

\section{Objetivos}

Se buscó como objetivos principales incrementar la atención y participación del alumno en el aula, mejorar su motivación por la asignatura y el tiempo de dedicación a la misma fuera de las sesiones de aula. Todos ellos factores clave para lograr mejorar el aprendizaje (Astin, 1993, Hake, 1998) e incrementar la tasa de rendimiento. Para conseguirlo, se buscó un tipo de aprendizaje más activo y autónomo. Se combinaron las sesiones de clase magistral y resolución de problemas, con el estudio autónomo por parte del alumno, previo a las sesiones de aula pero dirigido a través de una serie de cuestiones planteadas por el profesor.

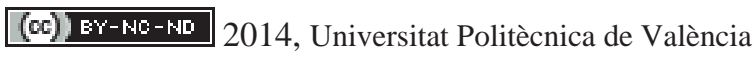

I Jornadas IN-RED (2014) 
Combinación de aprendizaje tradicional y colaborativo para mejorar la motivación en el estudio de las redes de computadores

Dichas cuestiones se discutían de forma pública posteriormente en el aula. De esta forma se potenciaba la competencia transversal de expresión oral. También el espíritu crítico, ya que el alumno podía mejorar o poner en duda la respuesta dada previamente por un compañero. Todas las intervenciones adecuadas recibían "positivos" que contribuían al 20\% de la nota de aula. Se buscó el trabajo cooperativo entre los alumnos para ayudar a clarificar los conceptos (Johnson, 1998, Prince, 2004).

Además, la discusión pública también permitía detectar los fallos en la comprensión de los conceptos más complejos o más abstractos que frecuentemente concurren en diferentes alumnos, potenciando el aprendizaje y al mismo tiempo proporcionando mayor satisfacción al estudiante. El valor de este tipo de discusión a nivel de aula y dirigido por el profesor se ha estudiado ya en otras experiencias, mostrando sus ventajas para todos los grupos de estudiantes (de nivel bajo, medio y alto) y resultando de ayuda especialmente para los alumnos menos diestros en la disciplina (Zingaro y Porter, 2013).

Por otra parte, el estudio autónomo pero dirigido mediante los cuestionarios cubría también el objetivo de familiarizar al alumno con el uso de bibliografía para obtener la información deseada de una fuente de forma directa, y no preprocesada a través del discurso de un profesor. Aunque típicamente al alumno se le proporciona una bibliografía recomendada y se le anima a utilizarla, la mayor parte de los estudiantes de nuestra asignatura no suelen hacerlo. Una buena forma de iniciarles puede ser proporcionales apoyo específico para analizar, facilitar y extraer el máximo rendimiento a la lectura indicada (Esper, 2012). De hecho la asignatura de "Redes de Computadores" procura utilizar durante todo el curso el mismo texto de apoyo básico (Kurose, 2010) y proporciona al alumno un índice detallado de cada tema, indicando la correspondencia de cada punto del temario en el libro de referencia. Pese a ello, la mayor parte de estudiantes tiende a apoyarse en las transparencias de la asignatura y los boletines de problemas, como principal y prácticamente único material para el estudio de la misma. Hay que señalar que se advierte a los alumnos durante la sesión de presentación del curso que las transparencias son el material de apoyo del profesor para impartir sus clases pero que no deben utilizarse como manual de estudio

\section{Desarrollo de la innovación}

La experiencia tuvo lugar durante el segundo cuatrimestre del curso académico 2012-13, en la asignatura de Redes de Computadores del grado en Ingeniería Informática de la UPV. Se aplicó sólo a uno de los grupos (formado por 44 alumnos) de los que constituían el total del curso. Inicialmente, en septiembre el grupo experimental contaba con 61 alumnos pero tras finalizar el primer cuatrimestre, su número se redujo a 46 , de los que dos tenían dispensa para no acudir a las sesiones de aula. 
De las 15 sesiones de 2 horas disponibles en el cuatrimestre para trabajo en el aula, en 7 de ellas se sustituyó la clase magistral por discusión pública de cuestiones sobre los contenidos correspondientes. Los estudiantes disponían de un boletín que incluía la lista de cuestiones con una semana de antelación y debían preparar las respuestas previamente a la sesión de aula, de forma individual o en grupo. De hecho, la misma distribución de grupos, de 4 o 5 estudiantes, se utilizaba también para el trabajo en las sesiones de aula. La preparación de las cuestiones estaba enfocada para utilizar el libro de referencia de la asignatura, indicándose antes de cada bloque de cuestiones relacionadas el punto del tema que había que estudiar. Adicionalmente, se podía también utilizar como material complementario las transparencias del profesor. El boletín contenía tanto cuestiones básicas, cuya respuesta podia obtenerse directamente del libro de texto, como preguntas sobre conceptos más abstractos o no inmediatos y que invitaban más a la reflexión.

La sesión de aula comenzaba con la discusión de las cuestiones planteadas para ese día. Cada pregunta se planteaba de forma pública a uno de los grupos y cualquiera de sus miembros podía responder o completar la respuesta dada por su compañero. Seguidamente, los grupos restantes también podían intervenir para rebatir la respuesta, completarla o plantear sus dudas. Las intervenciones correctas se premiaban con "positivos" que contribuían al 20\% que representa el porcentaje de la nota de aula para cada cuatrimestre. Durante el proceso, el profesor regulaba las intervenciones y ayudaba a extraer conclusiones, en caso necesario.

Los exámenes de la asignatura incluyeron cuestiones del estilo de las propuestas en los boletines, además de la resolución de problemas.

\section{Resultados}

Las intervenciones fueron más numerosas al comienzo del cuatrimestre, decayeron cuando llegó el período de los exámenes parciales, y volvieron a repuntar posteriormente ligeramente, aunque sin alcanzar las cotas iniciales. Nótese que en nuestra escuela durante los exámenes parciales de mitad del cuatrimestre no se interrumpen las clases, sino que los exámenes tienen lugar los lunes durante varias semanas. De los 42 alumnos del grupo, 15 no intervinieron públicamente en ninguna sesión mientras que 10 de ellos lo hicieron en 3 ó más del total de 7, una o varias veces durante la misma sesión. Los porcentajes asociados a estos valores de participación por número de sesiones se muestran en la Figura 1. En ella se ha interpretado que el alumno participó activamente si expuso su contribución a nivel de aula. Hay que hacer notar que también los alumnos que no intervinieron públicamente pueden haver participado a nivel más restringido en su grupo y además se beneficiaron de los comentarios y dudas de sus compañeros.

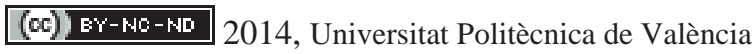

I Jornadas IN-RED (2014) 
Combinación de aprendizaje tradicional y colaborativo para mejorar la motivación en el estudio de las redes de computadores

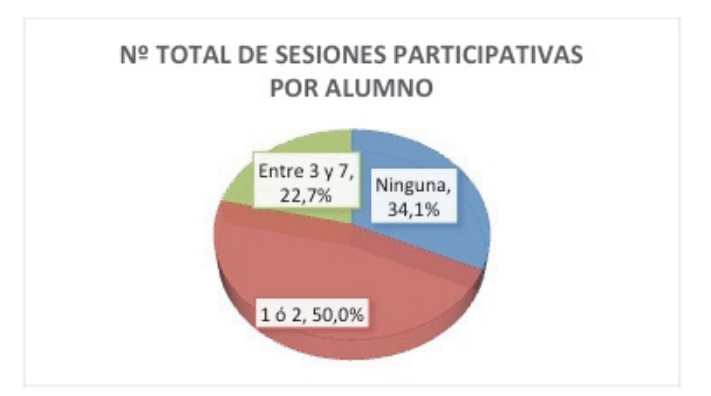

Fig. 1. Total de sesiones en las cada alumno participó activamente.

La forma de trabajo mejoró claramente el interés y la participación en el aula de muchos de los componentes del grupo, y se tradujo en un incremento superior a 2 puntos en la nota media de los parciales de ese grupo correspondientes al cuatrimestre B. En la asignatura objeto de estudio, la nota del cuatrimestre B suele ser ligeramente superior a la del cuatrimestre A, pero en este caso el incremento fue el más alto de todos los grupos del curso, y del orden del doble o mayor al que se produjo en tres de los otros grupos. Hay que señalar que el profesor fue el mismo durante los dos cuatrimestres y que todos los grupos realizaron los mismos exámenes parciales.

Tabla 1. Nota media de los exámenes parciales por cuatrimestre en los grupos de la asignatura. Curso 2012-13.

\begin{tabular}{cccc}
\hline Grupo & Nota media 1P & Nota Media 2P & $\begin{array}{c}\text { Incremento entre } \\
\text { cuatrimestre A y B }\end{array}$ \\
\hline 1 & 4,80 & 5,56 & 0,76 \\
2 & 4,79 & 5,86 & 1,07 \\
3 & 4,66 & 6,65 & 1,99 \\
4 & 4,17 & 6,53 & 0,81 \\
5 & 5,59 & 6,11 & 0,52 \\
Experiencia & 4,17 & 6,20 & 2,03 \\
\hline
\end{tabular}

Además de la mejora en la nota media, hay que señalar el incremento del porcentaje de aprobados en los exámenes pasó de ser el 33,9\% en el primer cuatrimestre, al $80 \%$ en el segundo. Lo que indica una mejora general de la mayoría de los alumnos y no sólo los de mayor nivel académico. También la nota de aula se vio beneficiada, aunque no se ha comparado con la de los otros grupos por haberse evaluado de forma distinta.

(c)) EY-NC-ND 2014, Universitat Politècnica de València

I Jornadas IN-RED (2014) 
En un cuestionario anónimo sobre satisfacción, realizado al final del cuatrimestre a los alumnos del grupo objeto del estudio, el 73,8\% se mostraron satisfechos con la experiencia y un $76 \%$ manifestó que le había motivado a estudiar la asignatura. La tabla 2 muestra los resultados a una de las preguntas del cuestionario relacionada con la motivación. La última pregunta era de respuesta abierta y permitía a los alumnos hacer sugerencias y/críticas. Entre las sugerencias planteadas cabe citar reducir el número de cuestiones para discutir en clase las más específicas y de mayor nivel, dejando las más básicas sólo para el estudio fuera del aula, ya que un período muy largo de discusión también llegaba a resultarles pesado.

Tabla 2. Respuesta a la pregunta "La metodología de las cuestiones, ¿te ha motivado a estudiar?" de la encuesta sobre la metodología aplicada.

\begin{tabular}{lc}
\hline Frecuencia & Respuestas (\%) \\
\hline Todas las semanas & 7,14 \\
En general, sí & 33,33 \\
En las semanas con menor carga de & 35,71 \\
otras asignaturas & \\
Sólo al principio & 16,67 \\
Nunca & 7,14 \\
\hline
\end{tabular}

\section{Conclusiones y trabajo futuro}

Consideramos que la experiencia de reducir el tiempo de lección magistral, sustituyéndolo por la discusion de cuestiones previamente preparadas fuera del aula fue positiva, en general. Mejoró el clima del aula, favoreció la participación de los estudiantes y su interés por la asignatura. Lo que trajo consigo un mejor resultado en los exámenes de la mayoría de los alumnos.

Al tratarse de una primera experiencia, quedan aspectos por mejorar. En próximas ediciones la discusión en el aula debería limitarse a las cuestiones más interesantes, los contenidos más simples podrían evaluarse simplemente con un test de 5' al inicio de la sesión. Esto aligeraría la sesión y, además, liberaría tiempo que podría dedicarse a la resolución de más ejercicios en el aula

\section{(cc) EY-NC-ND 2014, Universitat Politècnica de València}

I Jornadas IN-RED (2014) 
Combinación de aprendizaje tradicional y colaborativo para mejorar la motivación en el estudio de las redes de computadores

\section{Referencias}

ASTIN, A (1993). What matters in College ?; Four Critical Years Revisited. San Francisco, CA : Josey-Bass.

BAXTER, A. y HATT, S. (2000). "Everything must go!”, en Journal of Further and Higher Education, vol. 24, issue 1, p. 5-14.

ESCUELA TÉCNICA SUPERIOR DE INGENIERÍA INFORMÁTICA - UPV (2013). Grado en Ingeniería Informática. http://gradoinf.webs.upv.es/?page_id=331> [Consulta: 10 de junio de 2014]

España. Plan de estudios de graduado en ingeniería informática, BOE, 16 de abril de 2011, núm. 91, pp. 39974-39975.

ESPER, S., SIMON, B. y QUINTIN, C. (2012). "Exploratory Homeworks : An Active Learning Tool for Textbook Reading" en International Computing Education Research 2012 (ICER 2012). ACM New York, NY, USA. 105-110.

HAKE, R. (1998). "Interactive Engagement versus Traditional Methods: A six-Thousand-Student Survey of Mechanics Test data for Introductory Physics Courses", en American Journal of Physics, Vol. 66, No. 1, p. 64-74.

JOHNSON, D. W., JOHNSON, R. T. y SMITH, K. A. (1998). "Cooperative Learning Returns To College: What Evidence Is There That It Works?" Change: The Magazine of Higher Learning. Vol. 30 , issue 4 , p. 27-35.

http://www.tandfonline.com/doi/abs/10.1080/.U5sm3ZQwBqI [Consulta : 10 de junio de 2014]

JONG, B., LAI C., y otros (2013). "Using Game-Based Cooperative Learning to Improve Learning Motivation: A study of Online Game Use in an Operating System Course”. Vol. 56, issue 2, p. 183190.

KUROSE, R. (2010). Redes de Computadores. Un enfoque descendente. Madrid: Addison-Wesley.

PRINCE, M. (2004). "Does active learning work? A Review of the Research". Journal of Engineering Education. Vol. 93, issue 3, p. 223-231.

RENGEL, R. MARTíN, M.J. Y VASALLO, B.G. (2012). "Supervised Coursework as a Way of Improving Motivation in the Learning of Digital Electronics". IEEE Trans. on Education. Vol. 55, issue 4, p. 525-528.

ZINGARO, D. y PORTER, L. (2013). "Peer Instruction in Computing: The value of instructor intervention". Computers \& Education. Vol 71, p. 87-97.

<http://dx.doi.org/10.1016/j.compedu.2013.09.015> 


\title{
La Mirada Cautiva: un escenario de enseñanza-aprendizaje en Comunicación Audiovisual.
}

Marina Segarra García

Universidad Politécnica de Valencia - email: msegarra@har.upv.es

\begin{abstract}
La Mirada Cautiva" is a scenario designed to encourage and empower final year students with their learning and expand their autonomy over their training in Communication Studies. Students are asked to produce an audiovisual non-fiction piece and engage in active and collaborative learning. The scenario brings them into direct contact with their professional field, in terms of course content and having to find renowned experts in their industry and interview leading professionals. The work enhances their criticaljudgement and showcases their professional skills and attitudes to people outside the classroom. As a result, their level of autonomy and responsibility is raised because the results will be seen outside academia, through the promotion and dissemination of the audiovisual pieces they produce in an audiovisual online magazine created expressly for that purpose. The set of learning objectives and strategies, sequentialisation and tasks that comprise this scenario help to clarify their skills and shortcomings, which can then be promoted or corrected.
\end{abstract}

Keywords: Educational Scenario, Active and collaborative learning, Selfassessment, social networks, audiovisual online magazine, nonfiction genres, interviews, skills and professional attitudes, autonomy, commitment, responsibility, quality..

\section{Resumen}

El escenario de "La Mirada Cautiva" ha sido ideado para estimular y responsabilizar al alumno, en el último año de carrera, con su aprendizaje y ampliar su autonomía de cara a su capacitación profesional en Comunicación Audiovisual. Todo ello debe suceder durante el proceso de elaboración de una pieza audiovisual de no-ficción y a través de una experiencia de aprendizaje activo y colaborativo. Así, el diseño de este

(cc) EY-NC-ND 2014, Universitat Politècnica de València

I Jornadas In-Red (2014) 
escenario permite al alumno entrar en contacto directo con su ámbito profesional, tanto a través de los contenidos tratados, como por tener que buscar expertos de reconocido prestigio de su sector y realizar entrevistas a destacados profesionales, lo que potencia su juicio crítico, al poner en evidencia sus aptitudes y actitudes profesionales frente a miradas ajenas al aula. Como consecuencia, se eleva su nivel de autonomía y responsabilidad, pues además, sus resultados serán vistos fuera del ámbito académico, gracias a la promoción y difusión de las piezas audiovisuales obtenidas a través de una revista audiovisual on-line ${ }^{l}$ creada exprofeso para ello. El conjunto de objetivos y estrategias de aprendizaje, su secuencialización y las tareas que constituyen este escenario, ayuda a clarificar sus habilidades y carencias, pudiendo incidir sobre ellas para potenciarlas o subsanarlas.

Palabras clave: Escenario Docente, Aprendizaje Activo y Colaborativo, Autoevaluación, Redes Sociales, Revista Audiovisual on line, Internet, Géneros de no-ficción, Entrevistas, Aptitudes y Actitudes profesionales, Autonomía, Compromiso, Responsabilidad, Calidad.

\section{Introducción}

"Los 'buenos' profesores no son simplemente presentadores carismáticos, persuasivos y expertos; más bien son capaces de ofrecer poderosas tareas cognitivas y sociales a sus alumnos para que éstos puedan hacer un uso productivo de las mismas" (Hopkins, 2000, 144).

Las palabras de Hopkins, deberían ser un faro y un importante estímulo para revisar nuestra labor como docentes, de cara a poder mejorarla. Podríamos decir que un proceso de reflexión sobre una premisa así, fue una de las motivaciones para abordar el enfoque docente de "Realización de Productos de No-Ficción" - una asignatura optativa de especialización, del último semestre del plan de estudios de la Licenciatura en Comunicación Audiovisual de la UPV. Si además estamos de acuerdo con que enseñar, entre otras cosas, es "saber crear buenos y poderosos contextos/ oportunidades lexcusas de aprendizaje, integrando contenidos, proceso y clima de interacción social en torno a las experiencias de aprendizaje... y estableciendo profesional y comprometidamente una integración dialéctica entre currículum, enseñanza y aprendizaje -o que- (...) una buena enseñanza se articula en torno a poderosas experiencias de aprendizaje" (Domingo, 2003:6) la necesidad de plantear y desarrollar el diseño de un escenario de aprendizaje que permitiera poderosas experiencias profesionales para esta asignatura, fue la otra importante motivación, en la medida que "El escenario determina la actuación de los sujetos, por ello,

${ }^{1}$ Vid: http://lamiradacautiva.webs.upv.es/LaMiradaCautiva/LaMiradaCautiva.html 
facilita la enseñanza, genera el aprendizaje y el desarrollo de los sujetos en su condición individual y colectiva"(López Quintero, 2005:105). Esta ponencia presenta una descripción de dicho diseño y de los logros obtenidos tras los seis años de duración ${ }^{2}$ de esta experiencia docente.

\subsection{Objetivos curriculares de la asignatura}

El objetivo curricular global de esta asignatura, concebida como un taller de realización, era que el alumno se enfrentase a trabajar a nivel práctico con los géneros audiovisuales más destacados de la No-Ficción ${ }^{3}$ y con las técnicas de producción y realización propias de dichas obras. Mediante procesos característicos de un 'taller" ${ }^{4}$ pero con estrategias de trabajo colaborativo en equipo, de cara a conseguir que los productos que se generasen en el aula poseyeran un enfoque y una visión madura y reflexiva sobre los temas abordados, dando una interpretación creativa y, sobre todo, profesional. Sin duda un enorme reto.

Para emprender el diseño ${ }^{5}$ de este escenario de aprendizaje $^{6}$ fue necesario renovar y entramar diversas metodologías y estrategias docentes con el propio proceso de enseñanzaaprendizaje de los contenidos curriculares fundamentales de esta disciplina. En la medida que la creación de productos de 'no-ficción' -y la elaboración de reportajes, entrevistas, documentales, etc.- requiere hibridar tanto conocimientos de manejo de medios técnicos, de procesos de producción o de lenguajes propiamente audiovisuales, como requiere generar

\footnotetext{
2 Debemos excluir el curso 2005-2006, el primer año que fue impartida esta materia, durante el cual no fuimos responsables de esta asignatura. La experiencia se inicia pues, en el curso 2006-2007 y finaliza en el 2012- 2013 ya que el curso 2013-14 no tiene docencia presencial, puesto que la Licenciatura está en proceso de extinción.

3 Siguiendo a Cebrián Herreros (1992), los Géneros Audiovisuales de No-ficción, como "modalidades de aproximación, configuración e interpretación de la realidad"(Cebrian,1992:35) se clasifican en tres grandes tipologías, a saber: Géneros Expresivos y Testimoniales -entre los que encontraríamos la Editorial, el Comentario, la Crítica o la Crónica. En una segunda tipología estarían los Géneros Referenciales y Expositivos como la Noticia, el Documental, el Reportaje o el Reportaje de Investigación. Por último, dentro de una tercera tipología, el autor propone los Géneros Dialógicos y Apelativos como la Encuesta o la Entrevista.

4 Realizando una necesaria acotación "El taller implica como su nombre lo indica, un lugar donde se trabaja y se elabora. Es una forma de enseñar y aprender mediante la realización de algo. Se aprende desde lo vivencial y no desde la transmisión. Predomina el aprendizaje sobre la enseñanza. Se trata entonces de un aprender haciendo, donde los conocimientos se adquieren a través de una práctica concreta, realizando algo relacionado con la formación que se pretende proporcionar a los participantes. Es una metodología participativa en la que se enseña y se aprende a través de una tarea conjunta"(Careaga et Alt., 2006:5)

5 "Diseñar significa estructurar con antelación cada uno de los aspectos que permiten desarrollar con eficiencia y calidad el proceso educativo, es un proceso de anticipación pormenorizado tanto de la enseñanza como del aprendizaje”(López, 2005: 214)

${ }^{6}$ El significado de escenario de aprendizaje supone, de cara a su diseño, poder definir un caso que sea capaz de simular situaciones reales de una manera controlada (Cfr. Romiszowski, 1984) con el objeto de familiarizar al estudiante con conceptos, contenidos o procesos dentro de un contexto significativo y relacionado con su utilización profesional posterior (Dahlgren, 2001:263-282). En última instancia, este diseño debía abordar necesariamente la definición de roles, actividades, recursos y herramientas (Pernin, 2005).
}

(c)) BY-NC-ND 2014, Universitat Politècnica de València

I Jornadas IN-RED (2014) 
asimismo un aprendizaje basado en la indagación (Inquiry-based learning) para la creación de contenidos, por todo ello los objetivos formativos curriculares debían ser:

- Capacitar al alumno en los procesos y técnicas de guión, producción y realización audiovisual específicos para productos de No Ficción:

- Establecer las pautas de género, para poder reconocer las tipologías más relevantes de los productos de no-ficción y sus modalidades particulares de realización.

- Trabajar con los particulares procesos de ideación y creación para, a través de ello, darle a conocer al alumno las principales claves para la elaboración de un discurso audiovisual.

- Reflexionar sobre el concepto de 'argumentación' en la obra audiovisual de no-ficción (abordándolo a través de un proceso propio de elaboración de su guión, realización y montaje).

Y tal vez el mas importante:

- Capacitar al alumno para que pudiera enfrentarse ante situaciones futuras similares dada su inminente integración al ejercicio profesional. Ello planteaba la cuestión de mayor reto ¿cómo lograr el último y mas estratégico de los objetivos?:

- Conseguir en los productos que se generaran dentro del aula, un enfoque y calidad de realización totalmente profesionales, incorporando en su ejecución todas las destrezas y conocimientos adquiridos previamente por el aprendiz (sus saberes, a menudo, están fragmentados y en compartimentos estanco y el alumno no es consciente de ello).

A partir de estos objetivos formativos y para concebir dicho escenario fue necesario:

- Reflexionar sobre cuales debían ser los roles de los 'actores' (profesor, alumnos).

- Diseñar, seleccionar y secuencializar las distintas actividades a realizar?

- Generar recursos ${ }^{8}$ y herramientas conceptuales adecuados.

\footnotetext{
${ }^{7}$ Para trazar pautas del proceso de investigación sobre los temas a desarrollar en las piezas audiovisuales, y en la medida que existen ciertos paralelismos entre un 'proceso de indagación' y el de creación de un guión de no-ficción, decidimos aplicar los tres momentos de la "Técnica Inquiry" (Hudspith, 2001) (Vid. Fig.1 -flujo Inquiry-) e integrarlos con los propios de creación de un guión. En la imagen $n^{\circ} 1$ podemos ver las correspondencias entre el flujo de trabajo que establece esta técnica y el que requiere la indagación sobre el tema que será objeto y contenido de la pieza audiovisual elaborar en equipo.

${ }^{8}$ Entre ellos, la creación de la propia página web, la identidad visual del escenario así como todo el grafismo que empaquetaría las piezas y que por exceder los lindes de la materia, fue asumido íntegramente por el profesor.
} 


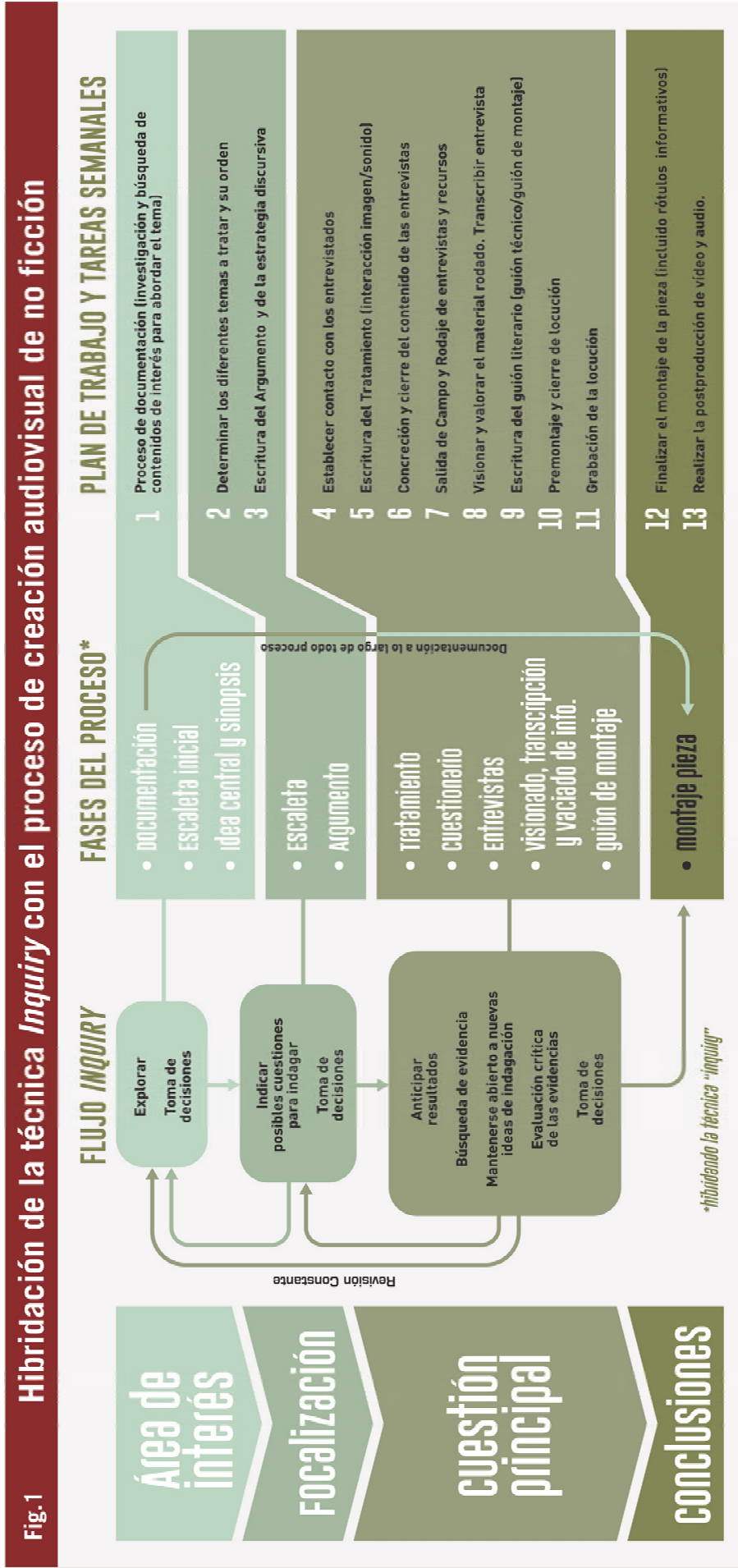

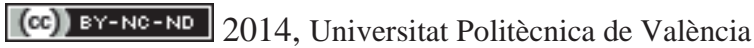

I Jornadas IN-RED (2014) 
- Incluir todo ello bajo estrategias de Aprendizaje Basado en Problemas (ABP), para conseguir que los estudiantes asumieran un rol similar al de los profesionales en la vida real ${ }^{9}$.

- Definir el propio 'producto' sobre el que deberían efectuar su actividad audiovisual.

- Definir un escenario que les procurara una inmersión real en una situación que necesitase de una resolución 'fuera de las aulas' para que, gracias al ABP, los estudiantes pusieran en juego hábitos, capacidades y destrezas imprescindibles para su profesión.

En sí, la estrategia formativa a diseñar, debía situar a los estudiantes en roles de la vida real y en un lugar simbólico que requiriese la adopción por su parte de una perspectiva diferente a la acostumbrada, de cara a la resolución del problema de un modo profesional. Por tanto y a nivel de renovación de la metodología educativa, uno de los objetivos mas importantes a fomentar era el de potenciar las competencias profesionales en Comunicación Audiovisual del alumno ${ }^{10}$ a través de técnicas o estratégicas metodológicas que asegurasen un óptimo proceso de enseñanza-aprendizaje, puesto que estaban a punto de salir al mercado laboral. Por ello era tan necesario diseñar todo un escenario particular de la asignatura que permitiera a los alumnos poner estas competencias en juego y, sobre todo, poder coevaluarlas, para así establecer mejoras a lo largo del proceso ${ }^{11}$. Por lo tanto, había que crear una 'experiencia de aprendizaje' autónomo y grupal que actuara en ese sentido durante todo el proceso de realización de sus productos de No-Ficción y ello sería, a nuestro modo de ver, lo que les permitiría evaluar el estado de su capacitación profesional.

\section{Objetivos de este escenario de aprendizaje:}

Hoy en día nadie pone en duda que para poder abordar nuevos modelos educativos es vital provocar cambios profundos en la propia metodología educativa, y por ello, un claro objetivo a conseguir gracias a este escenario era el de generar un marco totalmente

\footnotetext{
${ }^{9}$ Las indicaciones de Prieto (2007: 66) quien cita a su vez a Johnson y Johnson (2004), fueron de gran ayuda al referir las cuatro fases y las competencias que son necesarias para que el docente ponga en práctica (desde la preparación hasta la evaluación) una actividad de aprendizaje cooperativo.

${ }^{10}$ Hablamos de competencias especificas, mas vinculadas al ámbito de las destrezas que se espera tenga el egresado en una determinada área de actuación concreta como profesional, si bien y como indica Rue (2007) "cada carrera tiene un campo de profesionalidad muy diversificado", y dado que "Una competencia es la facultad de movilizar un conjunto de recursos cognoscitivos (conocimientos, capacidades, información, etc.) para enfrentar con pertinencia y eficacia a una familia de situaciones." (Gentile, 2000: 19-31) debíamos priorizar los procedimentales -aquellos que permiten consolidar sus destrezas en técnicas audiovisuales, pero también los de comprensión, análisis, y síntesis para enfrentarse al trabajo de investigación, sin olvidar las competencias propias para trabajar en equipo de manera colaborativa (cfr. con nuestro apartado 1.1. sobre la evaluación)

${ }^{11}$ Un proceso que incluía también la convocatoria extraordinaria de septiembre, en el caso de aquellos alumnos que hubieran asistido con regularidad, siguiendo asimismo con tutorización de su trabajo hasta darlo por concluido. Puesto que ellos mismos decidían no presentarse para corregir, subsanar y enriquecer, la calidad de su pieza audiovisual.
} 
diferente de relaciones en el aula pero también, en el propio proceso educativo y revisar el 'objeto' de la educación, estimulando en los alumnos su capacidad analítica y crítica durante los procesos de 'consumo' de la información - el docente hasta ahora era el poseedor de la información, suministrándosela unidireccionalmente a los alumnos-. Por último, al realizar un cambio de método, de proceso y de objeto es evidente que el propio contenido de la educación también se verá afectado.

Lo primero que percibimos es que este proceso docente necesitaba provocar un cambio de actitud en el alumno. Había que hacerles reflexionar sobre el hecho de que dentro de muy poco ya no iban a tener delante una pizarra y un profesor que, ante cualquier problema durante su ejercicio profesional, les diera la solución. Ello, no sólo debía estar presente a lo largo de todo el proceso, sino que debía pasar a un primer plano en el día a día del aula: Conseguir que los alumnos fueran conscientes de que cada nueva situación profesional iba a requerir de ellos una solución diferente y por ello, su motivación dentro de la asignatura debía ser la de 'aprender a hacer' y 'aprender a aprender' y no simplemente 'aprobar'. En sí, crear un entorno que le generase cada día esa reflexión. Para ello, y como estrategia, se planteo el enfrentar al alumno ante profesionales, ideando en paralelo un 'conjunto de fases sucesivas de aprendizaje' que le evidenciaran sus capacidades, aptitudes y actitudes ante el trabajo profesional, para poder co-evaluarlas y así perfeccionarlas.

Así, un importante objetivo que debía fomentar el cambio metodológico era que el alumno adquiriera un rol activo, convirtiéndose en el 'protagonista de su formación', lo que implicaba:

- Darle mayor responsabilidad: De modo que lo que se tuviera que hacer no fuera para 'satisfacer al profesor y aprobar', sino para conseguir, con calidad, los objetivos marcados por el problema planteado, junto a las expectativas de tener que situarse bajo la atenta mirada de profesionales, en el mundo profesional real, y no bajo esa mirada acostumbrada y, en ocasiones, cargada de prejuicios hacia su profesor. Pero también,

- Una mayor autonomía: Para ello, el alumno debía ser quién, trabajando con su grupo ${ }^{12}$ :

- Se fijara objetivos a conseguir, dentro de un proceso pautado con antelación ${ }^{13}$.

- Planificara las tareas necesarias ${ }^{14}$

- y que se planteara cuál quería que fuera su listón de calidad ${ }^{15}$.

\footnotetext{
12 Anualmente, los alumnos estaban divididos en 2 grupos de prácticas de laboratorio de aprox. 25 alumnos cada uno y dentro de estos grupos se formaban equipos de entre 4 y 6 alumnos como máximo.

${ }^{13}$ Plan de trabajo genérico (ver cronograma en Fig.2)

${ }^{14}$ Tareas debían desarrollarse semanalmente, por etapas, con unos objetivos parciales a cubrir cada semana (ver Fig.1)

${ }^{15}$ A través de una reflexión autocrítica 'provocada' por el profesor.
}

(c)) BY-NC-ND 2014, Universitat Politècnica de València

I Jornadas IN-RED (2014) 
- Que fuera capaz de determinar, por sí mismo, los métodos y estrategias para conseguir los objetivos marcados ${ }^{16}$.

- Así como, que fuera capaz de co-evaluar, sus logros, carencias y errores paso a paso ${ }^{17}$.

Si bien, el profesor estaría ahí para evidenciárselos. Convenciéndoles de que éste era el modo como se construye poco a poco el conocimiento.

Para conseguir estos objetivos, el papel del profesor también debía transformarse y pasar de ser un mero 'emisor de contenidos y de información', a orientar su labor, a tutorizar, facilitar, guiar, motivar, ayudar, informar, etc. y, por tanto, acompañarle durante todo el proceso, orientarte, evaluar sus logros y evidenciar sus errores, apoyándole como aprendiz que aún era, en sí, enseñarle "a aprender a aprender".

Así todas las acciones de aprendizaje concretas, inducidas por este 'escenario', buscaban conseguir en el alumno como objetivos de aprendizaje:

- El Compromiso con lo que hace, cómo lo hace y con los resultados que logra y, a partir de ello, que fuera capaz de proponerse mejoras ${ }^{18}$.

- Las Actitudes colaborativas fomentando el trabajo con sus compañeros de grupo, aprendiendo a compartir información y a redistribuir acciones para facilitar la colaboración en equipo, responsabilizándose de sus tareas, intercambiando experiencias y opiniones con sus compañeros, etc.

- Las Destrezas profesionales para lo que es clave la interactuación social con un entorno totalmente profesional, poniendo al alumno frente a profesionales y ante los que tiene que 'demostrar' y 'demostrarse' su profesionalidad.

- Y la Autonomía desarrollando un pensamiento crítico gracias a potenciar su capacidad de auto-evaluación.

En resumen, que a través de ello el alumno fuera capaz de responsabilizarse con su aprendizaje.

En cuanto al propio Proceso de Aprendizaje el escenario debía permitir al alumno poder aplicar sus conocimientos previos ante situaciones y problemas nuevos ${ }^{19}$, en la medida que

\footnotetext{
${ }^{16} \mathrm{Al}$ inicio de cada fase se establecían de antemano, y en sesiones bajo la tipología de clase magistral, las directrices, algunos modelos y ejemplos junto a las pautas a seguir.

${ }^{17} \mathrm{~A}$ capacidades adquiridas y que el alumno rellanaría fase a fase tras cada experiencia.

18 Aunque, ese terrible ‘chip del aprobado' que tienen implantado, con frecuencia les pone a la defensiva, excusando y justificando cualquier error frente al profesor-juez, algo que cuesta mucho trabajar.
} 
-tal y como postularon Ausubel et Alt. (1976)- el aprendizaje debe ser significativo, no memorístico, y para ello los nuevos conocimientos deben relacionarse con los saberes previos que posea el aprendiz. Con ello podemos lograr que el alumno pueda ser capaz de observar su 'talento y aptitudes' para emplear dichos conocimientos previos a un problema diferente y, a través de una vivencia directa de aplicación de sus habilidades y destrezas, es el modo como podemos desarrollar su confianza y su autonomía, pero también, llegan a ser conscientes de sus limitaciones. $\mathrm{Y}$ así, enfrentándose a sus limitaciones, es como pueden aprender a adaptarse ante situaciones nuevas, al observar su capacidad de aprender nuevos aspectos (cognoscitivos, procedimentales y/o actitudinales) haciendo pasar a un plano consciente cuales son realmente sus aptitudes y actitudes ante la resolución de problemas puntuales y concretos, a la vez que como aprendiz es también consciente de su nivel de responsabilización, implicación y preocupación por la calidad de su trabajo.

Por ello, era necesario que todo ese proceso permitiera también la auto-evaluación de sus 'aptitudes' y 'actitudes' y así, conocer (por si mismo), su grado de competencia profesional ante la resolución de un proceso también profesional, en este caso concreto, la realización de una pieza audiovisual de No-ficción.

\subsection{La evaluación a lo largo del proceso:}

La evaluación de todo este proceso incluye aspectos que ponen de relieve esas 'actitudes' y 'aptitudes' y sus 'competencias' ante la simulación de un proceso profesional de "realización de productos de No-ficción" trabajados en equipo ${ }^{20}$. Se trata pues de una evaluación continua, que permite la corrección de errores durante todo el proceso junto a la cumplimentación de una encuesta-formulario evaluativo que rellena cada alumno y en el que tiene en cuenta:

Sus habilidades para trabajar de forma autónoma

- Responsabilización de tareas.

- La observación de sus capacidades para organizar y planificar el proceso

\footnotetext{
${ }^{19}$ La autora de esta ponencia posee un profundo conocimiento de esta titulación, no solo por el hecho de haber sido ponente de su plan de estudios y mas tarde responsable de su implantación en la EPSG-Campus de Gandía de la UPV, sino por haber sido su directora académica a lo largo de los cinco años que llegó a término su implantación. Se trataba de una titulación joven, que fue sustituida tras pocos años de andadura, al entrar en vigor los Grados, al ser una carrera de 5 años. Sin embargo las metodologías activas o el trabajo en equipo basado en proyectos, fueron contemplados desde sus primeros pasos, por cuanto éste debate ya estaba en marcha en el momento de su implantación (curso 2001-2002).

${ }^{20}$ Morales (2007: 135) señala que "lo que podemos cuestionar es que por el mero hecho de trabajar en equipo se aprende a trabajar en Aprendizaje Cooperativo equipo (...) saber trabajar en equipo es una competencia profesional que no se va a aprender si no se ejercita y evalúa durante el proceso de enseñanza-aprendizaje”, es evidente que el aprendizaje y el trabajo en equipo solo pueden ser eficaces si el profesor incluye en el aula la reflexión sobre ellos y se co-evalúan.
}

\section{(c)) EY-NC-ND 2014, Universitat Politècnica de València}

I Jornadas IN-RED (2014) 
Su rendimiento, aptitud y actitud en un proceso colaborativo (de trabajo en equipo):

- Aprendiendo en colaboración (de las propuestas, habilidades y soluciones de sus compañeros)

- Fomentando el debate y la crítica

- El compromiso

- Sus habilidades sociales y grupales, sus riquezas, potenciales y debilidades.

Su habilidad de gestión de la información:

- Su capacidad de análisis y síntesis

- Su capacidad de aplicar sus conocimientos a problemas/situaciones nuevas.

Su compromiso con la 'calidad profesional' de los resultados.

Y todo ello de cada una de las fases del proceso. Esta valoración se imbrica junto a la Evaluación continua del profesor -que se basa en la observación de todos estos aspectos a lo largo del proceso de aprendizaje-, pero también, de resultados globales obtenidos por el grupo. Esta evaluación no se centra única y exclusivamente en los resultados alcanzados por el alumno y su equipo (el producto final), como suele ser habitual en muchas asignaturas.

\section{Desarrollo de la innovación}

Las Metodologías docentes de Aprendizaje Activo, como sabemos, son aquellas en las que una experiencia concreta o situación cotidiana, activa el conocimiento que el alumno ya posee, siendo capaces de generalizar esos conocimientos y extrapolarlos -transferirlos- a la situación nueva, madurando los conocimientos y habilidades que el alumno ya posee y su aprendizaje se contrasta al probar que puede ser útil en nuevas situaciones o experiencias. Por otra parte el Aprendizaje cooperativo, es una continuidad del aprendizaje activo, en donde el grupo es un aspecto importante del proceso y el profesor es un facilitador o supervisor de las tareas y por lo tanto el promotor de las habilidades o hábitos de cooperación. De modo que los estudiantes se convierten en constructores, descubridores y transformadores de sus propios conocimientos desde la perspectiva de la colaboración, así como desde las relaciones interpersonales afectivas.

El objetivo de la aplicación de las metodologías de aprendizaje activo y cooperativo como paisaje de fondo del escenario era claramente plantear el aprendizaje de manera diferente, a lo que ellos estaban acostumbrados, es decir actuar sobre:

- En el modo de recepción de la información, no dando clases teóricas como tales sino como guías para su indagación y experiencia práctica. 
- Partiendo de la experiencia directa, para llegar después al conocimiento, extrayéndolo de los resultados, sin duda tanto de los aciertos, pero fundamentalmente de los errores.

- y sobre todo, cómo el alumno procesaría la información recibida desde el punto de vista práctico (taller) al conceptual (reflexión y conclusiones)

Y todo ello con la clara intención de conseguir que el alumno se comprometa con lo que hace, con cómo lo hace y con los resultados que logre. Y lo mas importante: que sea capaz de proponer mejoras. Algo ante lo que los alumnos son muy reticentes (pues piensan que si evidencian sus errores o los reconocen, darán pié a una penalización por parte del profesor, intentando, por el contrario, excusarlos y justificarlos a toda costa).

\subsection{El escenario:}

Proceso de creación de piezas audiovisuales de calidad, tratando aspectos de interés sobre la Comunicación Audiovisual y utilizando diferentes géneros de NO-FICCIÓN en función del enfoque y del formato que necesite cada contenido y cada pieza, es vertebrado a través de la Revista audiovisual on-line "La mirada cautiva" cuya temática sirve para que el alumno amplíe sus conocimientos sobre su campo profesional futuro (indagando sobre nuevos conocimientos o profundizando sobre los que ya posee). Pero también, el propio proceso de producción y realización de contenidos para dicha revista, pone a prueba lo que se supone que el alumno ya sabe, al haber cursado diferentes materias en los cuatro años previos (sobre guión, producción, realización, montaje y edición, de estrategias discursivas audiovisuales para ficción, etc.) y sus habilidades (su capacidad de organización, de compromiso con sus resultados, su rendimiento en un trabajo en equipo, etc.) obligándole así a profundizar en su capacitación profesional de creación audiovisual (de productos de No ficción) y a perfeccionarla, corregirla y potenciarla, introduciendo al tiempo los nuevos contenidos específicos de esta materia.

\subsection{Funciones de este escenario}

Como ya se ha comentado, una importante función de las técnicas o estratégicas metodológicas utilizadas para asegurar el proceso de enseñanza-aprendizaje es que los alumnos entren en relación directa con su campo profesional (tanto por los contenidos abordados -ampliando su conocimiento enciclopédico-, como por tener que realizar un contacto real inmersivo en el mundo profesional: búsqueda de expertos y de profesionales , realización de contactos y de entrevistas) a través de ello también se consigue algo interesante: el alumno se da a conocer profesionalmente, en acción ${ }^{21}$. Pero sobre todo,

\footnotetext{
21 Los alumnos de este modo entran en contacto directo con los propios profesionales, a través de las entrevistas o el propio trabajo de campo. Esto puede (o no) permitir también, una cierta promoción en el caso de que hagan un buen trabajo algo de lo que el equipo es consciente, en ultima instancia y una vez realizada la pieza audiovisual, se les manda una carta, por deferencia y
}

(c)) EY-NC-ND 2014, Universitat Politècnica de València

I Jornadas IN-RED (2014) 
muestran su 'saber hacer' ante profesionales y no sólo ante el profesor. Los alumnos, desde el principio son conscientes de que en esta asignatura no se hacen simulacros académicos, sino acciones reales en las que ellos deberán poner en juego todo su nivel de conocimientos, teniendo que aplicar lo que saben ante la mirada crítica de aquellos profesionales con los que contactan, para obtener su opinión experta sobre el tema tratado-.

\subsubsection{Técnica aprendizaje cooperativo empleada.}

La técnica de aprendizaje cooperativo empleada está basada en la de Grupos de Investigación ("Group-Investigation"22) pese a ser una de las más complejas de todas las técnicas de aprendizaje cooperativo, es la que mejor responde a la filosofía de los grupos cooperativos (Cfr. García, R. Et Alt, 2001) y está pensada para proporcionar a los alumnos una mayor variedad de experiencias de aprendizaje que otros métodos. Sin duda la idónea para abordar el proceso de ideación y creación de un producto de no-ficción ya que una técnica de estas características implica:

A) Que los alumnos subdivididos en pequeños grupos, en función de los aspectos a estudiar, elijan los subtemas específicos dentro de un tema o problema general, que normalmente es delineado por el profesor. En nuestro caso, el tema o problema general es la comunicación audiovisual acotada gracias a los enfoques de los ocho apartados en los que se dividen los contenidos de "La Mirada Cautiva":

- Panorama: el objetivo comunicativo es dar una visión de conjunto sobre un tema de interés, un tema polémico o bien, sobre alguna cuestión compleja de la profesión o del propio ámbito de la comunicación audiovisual, de sus salidas profesionales. Objetivo el análisis de un fenómeno complejo o su estado de la cuestión.

- Perfiles: Reportaje con entrevista a un profesional consagrado del sector audiovisual o multimedia (en este espacio tienen cabida los grandes profesionales o bien excepcionalmente noveles que, por cualquier motivo, hayan despuntado en el panorama actual). El objetivo comunicativo es reconstruir una biografía que destaque los rasgos peculiares, personalidad y punto de vista de un profesional de cualquier medio de comunicación AV (Cine, Radio, Tv, Internet, Animación, Videojuegos, New Media, etc.)

- Un poco de Historia: Recoger un hito o hecho histórico de cualquier medio de Comunicación Audiovisual. La argumentación debe permitir el que se establezca una

\footnotetext{
agradecimiento por su colaboración, a los entrevistados, en la que se incluye el enlace a la página web, dando así a conocer los resultados obtenidos.

22 Este método o técnica fue diseñada por Shlomo Sharan y Yael Sharan (Sharan \& Sharan, 1992), de la Universidad de Tel-Aviv. (Cfr. JOHNSON, D et Alt.: 1999).
} 
relación/reflexión con algún hecho contemporáneo a través de breves microdocumentales que nos hablen de la historia del cine, la radio, la televisión, Internet, etc.

- Imágenes y sociedad: Reflexión sobre la comunicación audiovisual en la sociedad contemporánea: su impacto, horizonte, relación, conflicto, etc. A lo largo de las sucesivas ediciones cobra protagonismo Internet y las Redes Sociales.

- Jóvenes Promesas: Pieza dedicada a presentar a jóvenes que empiezan a despuntar en el campo profesional por ejercer profesionalmente bien mientras siguen sus estudios o bien recién licenciados (como ejemplo de ello es el haber realizado trabajo profesional con relevancia, haber sido premiados en certámenes de prestigio, etc.) esta temática ayuda a observar cómo son los primeros pasos de la profesión, de manera ejemplarizante.

- ¿Cómo se hace?: Se trata de un espacio en donde se plantean claves del lenguaje audiovisual, de ciertas técnicas, procesos o productos, abordándolos en diferentes medios.

- La parrilla a la plancha: Espacio de crítica, pero desde una mirada profesional, sobre los programas de televisión de las distintas cadenas (si bien también pueden aparecer alabanzas a formatos y contenidos televisivos interesantes o novedosos)

- Lo que deberías saber: Empezó siendo un espacio dedicado a la "Agenda de actos y convocatorias de interés" y de "Noticias del sector Audiovisual". (Siempre con noticias retrospectivas y/o convocatorias anuales, para evitar un desfase de su actualidad). Hace dos años le dimos un giro a esta sección hacia temas "peculiares, raros o curiosos".

B) Que los estudiantes y el profesor planeen cooperativamente las metas, las tareas y los procedimientos concretos que se proponen para abordar y resolver los temas seleccionados. C) El desarrollo del plan: los alumnos desarrollan el plan, mientras que el profesor sigue el progreso de cada grupo y presta la ayuda que le requiere.

\subsection{Dinámica y plan de trabajo:}

Los alumnos conforman grupos de trabajo y eligen el apartado la sección de La Mirada Cautiva sobre la que les interesa trabajar y proponen el tema ${ }^{23}$. El plan de trabajo detallado, a realizar por grupo, con fechas de cierre de cada fase y tarea se crea y presenta tras dar a conocer el proceso al detalle, en la segunda semana. La entrega de las tareas es semanal y se realiza a través de PoliformaT.

3.3.1. Planning de previsiones /plan de trabajo:

\footnotetext{
${ }^{23}$ Los equipos presentan al conjunto de la clase y defienden posibles temas, viéndose cual de ellos puede tener mayor interés y no ha sido ya tratado, esta sesión conjunta la denominamos "Consejo de Redacción".
}

\section{(cc) BY-NC-ND 2014, Universitat Politècnica de València}

I Jornadas IN-RED (2014) 


\section{La Mirada Cautiva: un escenario de enseñanza-aprendizaje en Comunicación Audiovisual}

A partir de un planning inicial ${ }^{24}$ aportado por el profesor (Fig.1) y de los objetivos $\operatorname{marcados}^{25}$, cada grupo crea y establece su propio planning previo. Este plan de trabajo deberá ser sometido a controles periódicos. El Planning se estructura en torno a 13 fases asociadas a tareas (Fig.1-2) y con objetivos semanales, imprescindibles para poder cumplir plazos previstos.

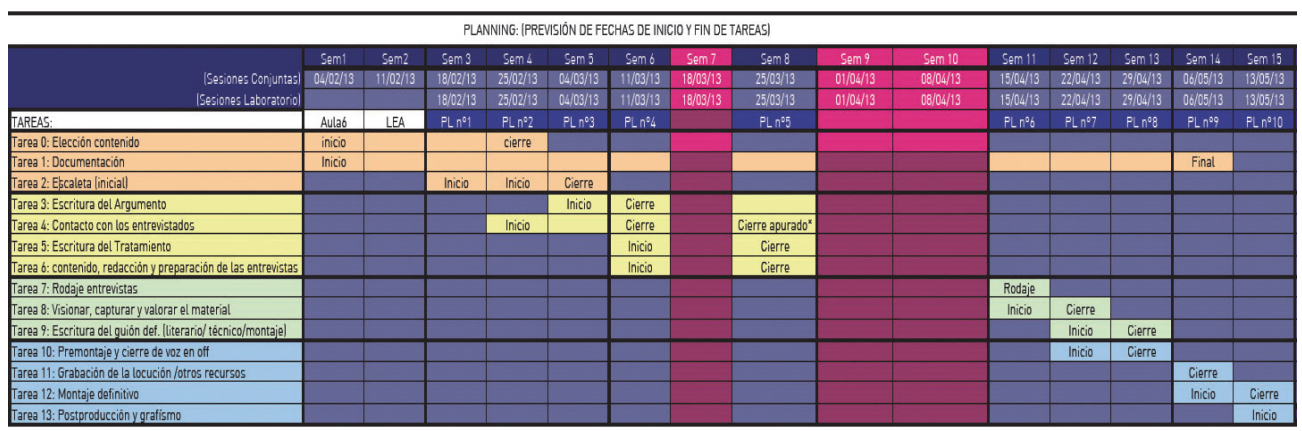

Fig. 1 Planning inicial

\subsubsection{Dinámica de trabajo: tareas y entregas semanales}

Durante las fases de Ideación y Preproducción (tareas 1 a 6), se trabajan los diferentes estadios del guión ${ }^{26}$. La mecánica organizativa y de trabajo es la siguiente: durante las sesiones conjuntas, se dan pautas y contenidos. En sesiones prácticas cada equipo aborda su tarea, tras las directrices establecidas en la sesión conjunta y la completa mediante un trabajo semanal autónomo. Tras el cierre de la tarea, remite el documento al profesor (vía PoliformaT) ${ }^{27}$. El profesor se documenta sobre el tema, estudia las ideas, sugiere correcciones, aporta nueva información y devuelve al grupo el/los documentos para la siguiente sesión de práctica. En ella el grupo trabaja con las matizaciones, aportaciones y sugerencias realizadas por el profesor y reelabora el documento para volverlo a remitir. A partir de la fase de contactos con expertos y profesionales, la preparación de la entrevista y el rodaje, es cuando se produce un gran cambio en ellos, siendo entonces conscientes de

\footnotetext{
24 Creado a partir del tiempo de duración de la asignatura (16 semanas) y el total de sesiones de prácticas de laboratorio (10 sesiones) y de sesiones conjuntas (16),

${ }^{25}$ Cfr. Con nuestro apartado 3.2.1 Técnica aprendizaje cooperativo empleada. En concreto las 8 tipologías de productos.

${ }^{26}$ Aún en fase de ideación e indagación del proyecto y de creación de los primeros pasos del guión de no-ficción (un proceso que se inicia con idea central o story-line, la sinopsis y la escaleta inicial y evoluciona mediante la escritura del Argumento, esta fase corresponden con la de Exploración del área de interés y la de Focalización del flujo Inquiry (Fig.1). una vez cerrada la estrategia discursiva se pasa a las fases de Tratamiento, el Guión literario, el Técnico y el de Montaje)

${ }^{27}$ Los grupos de alumnos cuya sesión práctica son los lunes efectúan las entregas hasta el siguiente miércoles mientras que los que tienen la sesión de práctica el jueves, las entregas son hasta el siguiente lunes.
} 
que su trabajo, ya no es un mero trabajo de clase.

\section{Resultados}

Creemos que deberían hablar por si mismas las nueve ediciones de 'La Mirada Cautiva' con un total de 73 piezas audiovisuales producidas, entre 2007 y 2013, y con una duración de entre $15^{\prime}, 30$ ' y 60 ' cada una de ellas.

\section{Conclusiones}

Lograr el compromiso del alumno con su aprendizaje es la clave fundamental para el éxito de este modelo docente, el compromiso de uno mismo con su capacitación profesional. En estos seis años estamos convencidos de que hemos conseguido una adecuada motivación gracias a este proyecto educativo y gracias, también, a haber transformado el papel del profesor -hasta ahora juez supremo-, hacia un nuevo modelo de relación con el alumno: el de cómplice, guía y facilitador..., haciendo que el papel crítico, en este caso, recaiga sobre los 'profesionales' a los que se les ha de entrevistar o, mejor dicho, en los propios alumnos quienes por estar frente a una situación real y ante la mirada de esos profesionales, han tenido que cambiar rápidamente su 'chip', pasando a ser ellos sus propios jueces. Y todo ello gracias a haber generado este nuevo escenario, integrando en él la plataforma de exhibición de sus logros (la web de la revista audiovisual) que permite un radical cambio de actitud. Sin embargo: hay alumnos que lo han entendido, un porcentaje bastante elevado, y hay quienes no. Hay alumnos conscientes y responsables con su aprendizaje ${ }^{28} \ldots$ y quienes siguen preguntando al profesor 'que es lo que tengo que hacer' (para aprobar la asignatura). O quienes no dejan que se les "enseñe a aprender", porque les parece que no hay nada que aprender (desgraciadamente a veces es difícil cambiar la motivación de esos alumnos).

\section{Referencias}

AUSUBEL, D., NOVAK, J., HANESIAN, H. (1976) Psicología cognitiva. Un punto de vista cognoscitivo. México: Trillas.

CAREAGA, A., SICA, R., CIRILLO, A., \& DA LUZ, S. (2006). Aportes para diseñar e implementar un taller. En 8vo. Seminario-Taller en Desarrollo Profesional Médico Continuo (DPMC), 2das
Jornadas
de
Experiencias
educativas
en
DPMC.

http://www.dem.fmed.edu.uy/Unidad\%20Psicopedagogica/Documentos/Fundamentacion_talleres.pdf [Consulta: 4 de junio de 2010].

CEBRIÁN HERREROS, Mariano (1992): Géneros informativos audiovisuales : radio, televisión, periodismo gráfico, cine, video. Madrid, Ed. Ciencia 3.

\footnotetext{
${ }^{28}$ De hecho, muchos de los alumnos no presentados a una convocatoria, fueron alumnos que habiendo seguido semana a semana el proceso, al final se dieron cuenta de que no habían alcanzado una calidad profesional en sus resultados audiovisuales y decidieron no presentarse para corregir y subsanar los errores, de cara a estar plenamente satisfechos con su pieza audiovisual.
}

(c)) BY-NC-ND 2014, Universitat Politècnica de València

I Jornadas IN-RED (2014) 
DE ZUBIRÍA SAMPER, Julián (2006): Los modelos pedagógicos. Hacía una pedagogía dialogante. Coop. Editorial Magisterio.

DAHLGREN, M.A., \& Öberg, G. (2001): Questioning to learn and learning to question: Structure and function of problem-based learning scenarios in environmental science education. Higher Education, 41.

DOMINGO SEGOVIA, J. (2003). Dimensiones y escenarios del buen aprendizaje para todos. Revista Electrónica Iberoamericana sobre Calidad, Eficacia y Cambio en Educación, 1(2) <http://www.ice.deusto.es/rinace/reice/vol1n2/Domingo.pdf>. Consultado el 6 de Mayo de 2014.

GARCÍA, R., TRAVER, J., Y CANDELA, I. (2001). Aprendizaje cooperativo. Fundamentos, características y técnicas. Madrid: CCS.

HUDSPITH R. C., \& JENKINS H. (2001), “Teaching the Art of Inquiry”. Halifax, Canadá: Society for Teaching and Learning in Higher Education.

HOPKINS, D. (2000). Powerful learning, powerful teaching and powerful schools; Journal of Educational Change.

JOHNSON, D., JOHNSON, R., Y HOLUBEC, E. (1999). El aprendizaje cooperativo en el aula. Buenos Aires: Paidós.

LÓPEZ QUINTERO, S.N. (2005). Teoría y Diseños Didácticos. Guía y Módulo. Colombia, Medellín. PRIETO, L. (2007). El aprendizaje cooperativo. Madrid: PPC.

PERNIN, J.L., LEJEUNE, A. (2005): Modèles pour la réutilisation des scénarios d'apprentissage: limites d'IMS LD, U. Project, Editor. Atelier sur IMS LD, organisé par l'AFNOR (CN36) et le projet européen UNFOLD, 31 mars et 1er avril 2005, Paris: Paris.

GENTILE, PAOLA, BENCINI, ROBERTA (2000): "Construindo competências. Entrevista com Philippe Perrenoud, Universidade de Genebra" In Nova Escola (Brasil), Setembro de 2000, pp. 1931. <http://www.unige.ch/fapse/SSE/teachers/perrenoud/php main/php 2000/2000 31.html> [Consulta: 10 de mayo de 2012].

ROMISZOWSKI, A.J. (1984): Producing Instructional Systems. London, Kogan Page.

RUE, J (2007): Enseñar en la Universidad: el EEES como reto para la educación superior. - Madrid Edit. Enarcea. 


\title{
Una experiencia interdisciplinar en Educación Superior con la música como elemento vehicular ¿Qué tienen en común estudiantes de Arquitectura y del Máster de Transportes, la escenografía, el paisaje y la ópera?
}

\author{
M. Salomé Moreno Navarro ${ }^{a}$, Jesús Navarro Morcillo ${ }^{b}$, Eloïna García Felix ${ }^{\mathrm{c}}$ y Víctor \\ Manuel Gil ${ }^{\mathrm{d}}$ \\ a'Departament d'Urbanisme, Universitat Politècnica de València, smoreno@upvnet.upv.es, \\ ${ }^{\mathrm{b}}$ Departamen de Projectes Arquitectònics, Universitat Politècnica de València, jenamor@pra.upv.es, \\ 'Institut de Ciències de 1'Educació, Universitat Politècnica de València, algarcia@ice.upv.es y \\ ${ }^{\mathrm{d}}$ Responsable de Projectes Educatius. Departament de Dramatúrgia, Publicacions i Educació \\ Palau de les Arts Reina Sofía, Fundació de la Comunitat Valenciana, vgil@lesarts.com
}

\begin{abstract}
The process in which our university studies have been adapted to European Higher Education Area has favored the design of new degrees with an enormous multidisciplinary character. Experience shown in this paper joins two groups of students belonging to the Master's Degree in Transport, Planning and Urban Development who have worked concepts such as stage design and landscape from the complementariness of their disciplines. Design disciplines related to humans, have a clear relationship with the landscape. Refer to it, serve inspiring element and, at the same time shape it and transform. Present work shows how the use of music as a universal language has shown itself as a solid vehicle as well as an efficient tool to accelerate interdisciplinary learning process, generating at the same time and by itself, an additional value to learning.
\end{abstract}

Keywords: Higher Education, Interdisciplinarity, Values, Opera

\footnotetext{
Resumen

El proceso de adaptación de nuestros títulos universitario al Espacio Europeo de Educación Superior ha propiciado la creación de las nuevas titulaciones con un marcado carácter interdisciplicar. La experiencia que aquí se presenta reúne a dos grupos de alumnos del Master de Ingeniería en
} 
Una experiencia interdisciplinar en Educación Superior con la música como elemento vehicular ¿Qué tienen en común estudiantes de Arquitectura y del Máster de Transportes, la escenografía, el paisaje y la ópera?

Transportes, Territorio y Urbanismo y de Arquitectura que han trabajado, desde la complementariedad de sus disciplinas, los conceptos de escenografía y paisaje. Las disciplinas del diseño relacionadas con el hombre, tienen una clara relación con el paisaje. Se refieren a él, sirven de elemento inspirador y al mismo tiempo lo conforman y lo transforman. El presente trabajo evidencia cómo el uso de la música, como lenguaje universal, se ha mostrado capaz de actuar como elemento vehicular sólido y como una eficaz herramienta aceleradora en el proceso de aprendizaje interdisciplinar que se presenta, generando a su vez, en sí misma, un valor añadido al propio aprendizaje.

Palabras clave: Educación Superior, Interdisciplinariedad, Valores, Ópera

\section{Introducción}

La formación en competencias conlleva integrar disciplinas, conocimientos, habilidades, prácticas y valores. La integración disciplinar es parte fundamental si queremos formar profesionales más universales y mejores para afrontar las transformaciones que el mundo laboral demanda.

Trabajar contenidos desde puntos de vista complementarios en una experiencia interdisciplinar, permite elaborar marcos conceptuales más generales en los cuales, las diferentes disciplinas en contacto, son a la vez modificadas y pasan así a depender unas de otras, tal y como ocurre en la vida real. Así, las propuestas interdisciplinares en la educación superior nos sirven como alternativa al problema de fragmentación del conocimiento que genera la superespecialización, favoreciendo espacios y modelos de aprendizaje que sirven para reconectar esta dispersión (Pozuelos et al, 2012).

Se trata pues de salirse de los estrechos márgenes de las asignaturas para considerar una nueva dimensión del objeto de estudio, o lo que se designa como un razonamiento a varias voces (Muñoz y jeris, 2005).

Para conseguir una red de contenidos y competencias que trascienda la lógica disciplinar no bastan los procedimientos clásicos ideados para la transmisión memorística y mecánica del conocimiento disciplinar, sino que, en estos momentos, para mejorar las prácticas docentes y el conocimiento en las aulas universitarias, precisamos de un marco, de unas estrategias y de unos instrumentos que ayuden tanto en esa tarea de integración de los contenidos como en su análisis y comprensión (pozuelos et al., 2012).

(c)) BY-NC-ND 2014, UniversitatPolitècnica de València

I Jornadas IN-RED (2014) 
Así, el enfoque interdisciplinar debe ser, por encima de todo, un intercambio de distintos conocimientos y experiencias, enmarcados en una estructura de trabajo común que es compartida por todas las disciplinas implicadas (Gibbons, 1997), integradas de tal modo, que el conjunto que definen resulta mucho más complejo que la suma de sus partes (Morin, 1998).

En referencia a lo anterior, diversos estudios que tratan sobre la mejora de la enseñanza universitaria advierten de la escasa transferencia que se observa en los conocimientos tratados en las asignaturas cuando estas se consideran de manera individual. En consecuencia, se alude al potencial que encierra desarrollar experiencias en las que los contenidos se conecten y se presenten como situaciones reales, ganando en comprensión y funcionalidad (UNESCO, 1998; Briscall, 2000; Wall y Shankar, 2008; Cuadrado et al., 2009; Gómez, 2009).

En este sentido, Durante el curso 2013-2014, dos profesores de la Universitat Politècnica de València, con la colaboración del responsable de proyectos educativos del Departament de Dramatúrgia, Publicacions i Educació del Palau de les Arts Reina Sofía de Valencia, hemos realizado una experiencia de innovación educativa interdisciplinar con alumnos de dos grupos de titulaciones diferentes de la universidad.

El hilo conductor del poyecto, el paralelismo que existe entre la escenografía y el paisaje, nos pareció un tema muy interesante ya que esta relación se remonta a los orígenes del teatro. Las experiencias arqueológicas y antropológicas confirman que en las culturas originarias, el paisaje ha tenido un valor simbólico profundamente unido a la ritualidad, siendo en todos los casos el primer receptor (y al mismo tiempo contenedor) de las manifestaciones religiosas del hombre. (Coccia, 2009)

Por otro lado, más allá de las evidentes connotaciones geográficas y escalares con las que definimos el paisaje, tenemos dos aspectos que lo convierten en algo singular: la mirada y la representación artística. Ya ampliamente estudiado, el tema de la presencia del hombre como condición fundamental de la existencia de un "paisaje", nos lleva a entender el mismo como una construcción cultural, y como tal, el paisaje también ha de ser entendido como elemento de diseño (Martignoni, 2009).

Aunque el espacio teatral ha merecido diversos nombres a lo largo de la historia, el escenógrafo es desde tiempos helénicos el encargado de crear y desarrollar el ambiente que buscara reflejar el mundo poético que se quiere contar. Ese "paisaje artificial" estará idealmente desarrollado en función del contexto dramático.

Teniendo en cuenta la historia del teatro en Occidente (y en consecuencia de la escenografía) podemos considerar que en los últimos cuatro siglos, la composición y dibujo de escena se ha desarrollado mayormente en espacios "neutrales" como el teatro Isabelino,

\section{(cc) EY-NC-ND 2014, UniversitatPolitècnica de València}

I Jornadas IN-RED (2014) 
Una experiencia interdisciplinar en Educación Superior con la música como elemento vehicular ¿Qué tienen en común estudiantes de Arquitectura y del Máster de Transportes, la escenografía, el paisaje y la ópera?

el teatro a la italiana y, en el ámbito contemporáneo, la cámara negra. Sin embargo, hoy parece surgir una nueva necesidad que propone volver al origen en búsqueda de nuevos códigos, nuevas formas y sobretodo de nuevos significados en el mundo de la representación. En este encuentro, el paisaje natural, elegido como fuente generadora de ideas, abre la puerta a nuevas formas de expresión y experimentación (Coccia, 2009).

Ahora bien, el paisaje es cambiante, y la escenografía, en este contexto, también puede entenderse como un paisaje efímero. Así, por un lado los paisajes-escenografías suceden durante un tiempo y modifican visual y conceptualmente el espacio natural, y por otro, hay escenografías teatrales, que utilizan el paisaje como espacios contenedores, y esto nos lleva apreguntarnos ¿cuál origina a cuál? Esta dualidad es la que nos ha hecho plantear la actividad centrada en estos dos aspectos y en las diferentes maneras que tenemos de entenderlos.

En este contexto, utilizando como elemento vehicular la ópera, diez alumnos del título de arquitecto de la Escuela Técnica Superior de Arquitectura (ETSA) y diez alumnos del Máster de Tranportes, Territorio y Urbanismo (MATTU) de la escuela Técnica Superior de Ingenieros de Caminos Canales y Puertos (ETSICCP), hemos trabajado los conceptos de escenografía y paisaje, bajo puntos de vista complementarios, en función de cada una de las disciplinas involucradas en el proyecto.

\section{Objetivos}

Los objetivos del proyecto son:

- Comprobar el grado de significatividad que tiene el aprendizaje interdisciplinar en el proceso de formación que conlleva el trabajar en equipo desde un proyecto compartido.

- Que los alumnos relacionen conceptos, aparentemente diferenciados, en ambientes colaborativos fuera del aula, en presencia de estímulos ajenos al ámbito académico.

- Que el alumno comprenda, reconozca y valore el paisaje desde la perspectiva de su diseño y de las posibilidades de intervención en el mismo.

- Demostrar que el uso de la música, como lenguaje universal, se muestra capaz de actuar como elemento vehicular sólido y como una eficaz herramienta aceleradora en el proceso de aprendizaje interdisciplinar, generando a su vez, en sí misma, un valor añadido al propio aprendizaje.

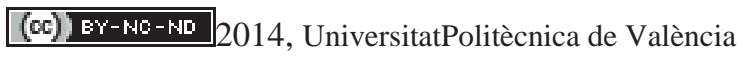

I Jornadas IN-RED (2014) 


\section{Desarrollo de la innovación}

La experiencia se ha venido desarrollando durante la anualidad 2013-2014 (los dos semestres del curso). Para ello, la planificación propuesta consistió en la realización de una serie de actividades, que se desarrollaron al final del primer semestre y principios del segundo. Dichas actividades consistieron en :

- Un acercamiento hacia el proceso de creación, diseño y materialización de un montaje escenográfico como elemento de creación de paisaje

- Análisis de materiales proporcionados por los profesores sobre los temas a trabajar durante el curso.

- Realización de varios talleres.

\subsection{Encuentros con Directores de Escena y Directores Musicales}

Se han mantenido encuentros en primera persona, interactuando con los directores musicales y de escena de dos producciones óperas, en los que se ha asistido a parte de los ensayos de trabajo y se ha visualizado y comprobado el proceso final en ensayos previos a un estreno.

El primer encuentro se realizó durante el mes de diciembre de 2013 y fue con el director musical Federico Maria Sardelli y el director de escena y movimiento coreográfico Davide Livermore (Fig. 1). En esta ocasión, ambos directores hablaron con el grupo sobre la relación entre la música y su representación, la importancia de la contextualización de la historia que se representa y de cómo los medios musicales y formales pueden servir para crear todo el imaginario necesario para comunicar aquello que se quiere.

Tras el encuentro, asistimos en la sal Martín y Soler al ensayo del primer acto de la ópera barroca "L’Incoronazione di Dario" de Antonio Vivaldi, lo que permitió observar en directo el proceso de trabajo que lleva a la realización de una producción de ópera.
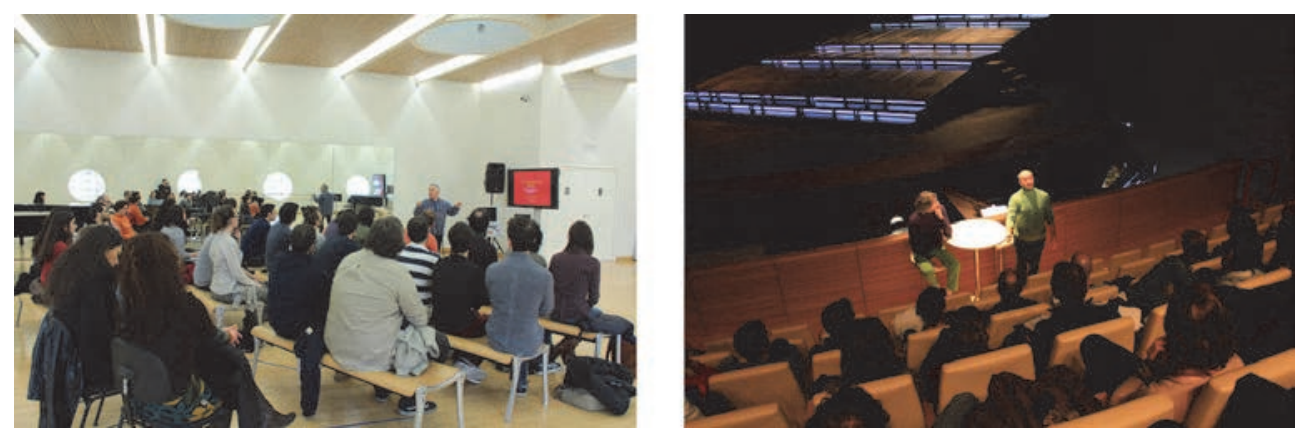

Fig. 1 Imágenes de los encuentros con Joan Font (izda) y con Federico Sardelli y Davide Livermore (dcha)

\section{(cc) EY-NC-ND 2014, UniversitatPolitècnica de València}

I Jornadas IN-RED (2014) 
Una experiencia interdisciplinar en Educación Superior con la música como elemento vehicular ¿Qué tienen en común estudiantes de Arquitectura y del Máster de Transportes, la escenografía, el paisaje y la ópera?

El segundo encuentro tuvo lugar en febrero de 2014 con el director de escena Joan Font (Fig. 1) que, del mismo modo y durante una hora, habló con el grupo sobre el proceso de creación de la escenografía y vestuario de la ópera "L Italiana in Algeri" de Rossini, contextualizando este proceso con el significado de la historia y con el particular modo de verla que cada director de escena tiene. Tras el encuentro, pudimos asimismo asistir al primer acto de uno de los ensayos previos que en esta ocasión tuvo lugar en el la Sala Principal del Palau de Les Arts.

\subsection{Visualización de tres producciones de la temporada 2013-2014}

Se ha asistido a tres funciones de la Programación general de la temporada 2013-2014 con el fin de visualizar el resultado final de las producciones, todo ello dentro del programa educativo "Siente la Ópera" que pone en marcha cada año la Fundación Les Arts.

Las funciones a las que se ha asistido son las siguientes (Fig. 2):

DIE WALKÜRE, de Richard Wagner en el mes de noviembre de 2013, con dirección musical de Zubin Mehta y dirección de escena de Carlus Padrissa (La Fura dels Baus), interpretada por Jennífer Wilson, Thornas Johannes Mayer, Nikolai Schukoff, Heidi Melton, Stephen Milling y Elisabeth Kulrnan.

L'INCORONAZIONE DI DARIO de Antonio Vivaldi en el mes de diciembre 2013 con dirección musical de Federico Maria Sardelli y dirección de escena y movimiento coreográfico Davide Livermore.

L'ITALIANA IN ALGERI de Gioacchino Rossini en el mes de marzo de 2014 con dirección musical de Ottavio Dantone y dirección de escena Joan Font, interpretada por Erwin Schrott y Silvia Tro.

En otro orden de cosas, durante el curso, se han realizado dos talleres con los alumnos en colaboración con el Instituto de Ciencias de la Educación (ICE) de la UPV (Fig. 3) en el que mediante técnicas diferenciadas, se ha trabajado sobre el lema "Paisajes vemos, de su creación no sabemos".

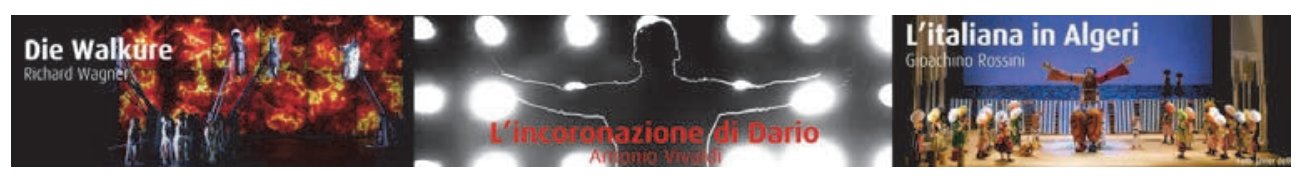

Fig. 2 Funciones a las que han asistido los alumnos: Die Walküre, L'Incoronazioe di dario y L'Italiana in Algeri 


\subsection{Talleres realizados}

Sobre la actividad y a lo largo del año, se han realizado los dos talleres que se detallan a continuación:

Taller I: Con este primer taller queríamos comprobar, tras la experiencia realizada, hasta qué punto había cambiado la percepción de los alumnos respecto del objeto del proyecto. Los objetivos de este primer taller fueron:

- Determinar la repercusión de la actividad llevada a cabo durante el curso.

- Revisar el concepto de "paisaje".

- Verificar la percepción del alumno sobre el papel de la música como elemento vehicular de aprendizaje.

Para ello utilizamos la técnica del Metaplan y lanzamos al grupo la siguiente pregunta:

OPERA-PAISAJE-ESPACIO-NOSOTROS-YO ¿Cómo relacionaríamos estos conceptos?
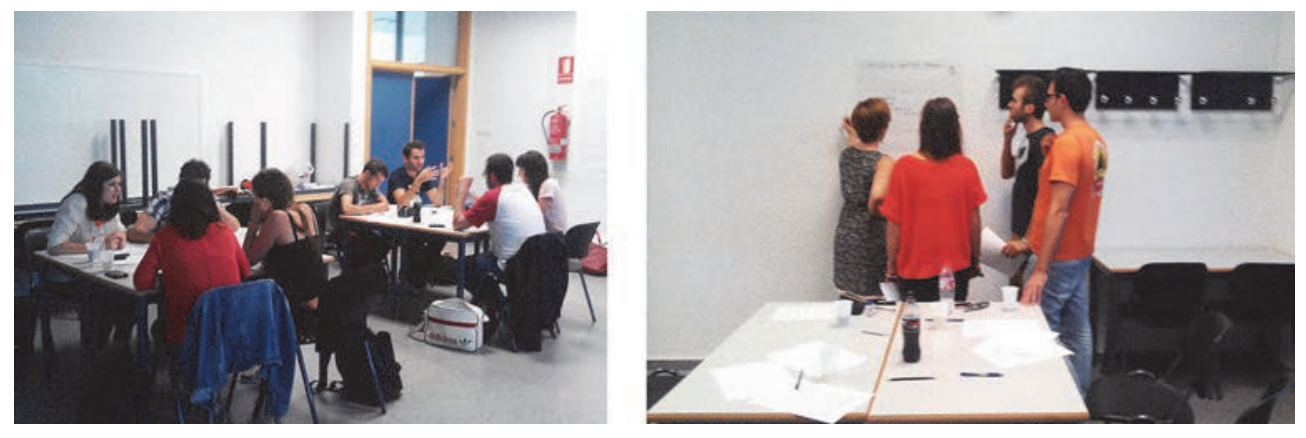

Fig.3 Imágenes de los talleres realizados

El procedimiento llevado a cabo y la estructura de la actividad se inició con la creación de grupos de cuatro personas, seguidamente se explicó cómo iba a ser el desarrollo de la misma al grupo, así como la planificación del taller, que se estruscturó según el siguiente esquema:

- 5': Reflexión individual

- 20': Brainstorming sobre la cuestión propuesta

- 5': Priorización en el subgrupo (6 votos por persona)

- 20': Exposición plenaria y detección de categorías

- 10’: Votación general (6 votos por persona)

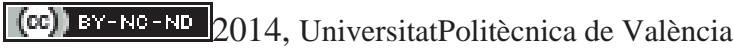

I Jornadas IN-RED (2014) 
Una experiencia interdisciplinar en Educación Superior con la música como elemento vehicular ¿Qué tienen en común estudiantes de Arquitectura y del Máster de Transportes, la escenografía, el paisaje y la ópera?

Taller II: El segundo taller, denominado "Mejorando entre todos", se les facilitó a los alumnos un cuestionario de preguntas abiertas y dispusieron de 10 minutos para contestarlas de manera individual. Transcurrido dicho tiempo, durante 20 minutos, en grupo se comentaron las respuestas a cada una de las cuestiones planteadas. Las 9 preguntas planteadas fueron las siguientes:

1. ¿Qué se te pasaba por la cabeza cuando te apuntaste a esta actividad? ¿Qué expectativas tenías?

2. ¿Qué es lo que más te ha interesado?

3. ¿Qué es lo que más te ha sorprendido?

4. ¿Qué incorporarías a la actividad para hacerla más interesante?

5. ¿Repetirías?

6. Esta experiencia te ha permitido aprender

7. ¿Qué cambios has percibido en tu relación con el grupo al compartir una experiencia fuera del ámbito universitario?

8. ¿Ha cambiado tu percepción de la música y de la ópera en concreto? ¿En qué sentido?

9. ¿Tienes alguna duda que preguntar a los que hemos organizado la actividad?

Y que se se corresponden con tres aspectos fundamentales que queríamos conocer sobre la experiencia:

- Nivel de motivación del alumno de cara a la actividad realizada

- Resultados de la experiencia respecto de los objetivos planteados

- Propuestas de mejora de la actividad

En último lugar, y con el objetivo de valorar la percepción del alumno sobre la actividad global realizada a lo largo del curso, se elaboró un sencillo cuestionario de valoración, con respuestas abiertas en cada uno de los ítems planteados, para que el alumno pudiese ampliar su opinión y el feedback al profesor fuese más explícito. El desarrollo de ese cuestionario se puede observar en la Fig. 4 


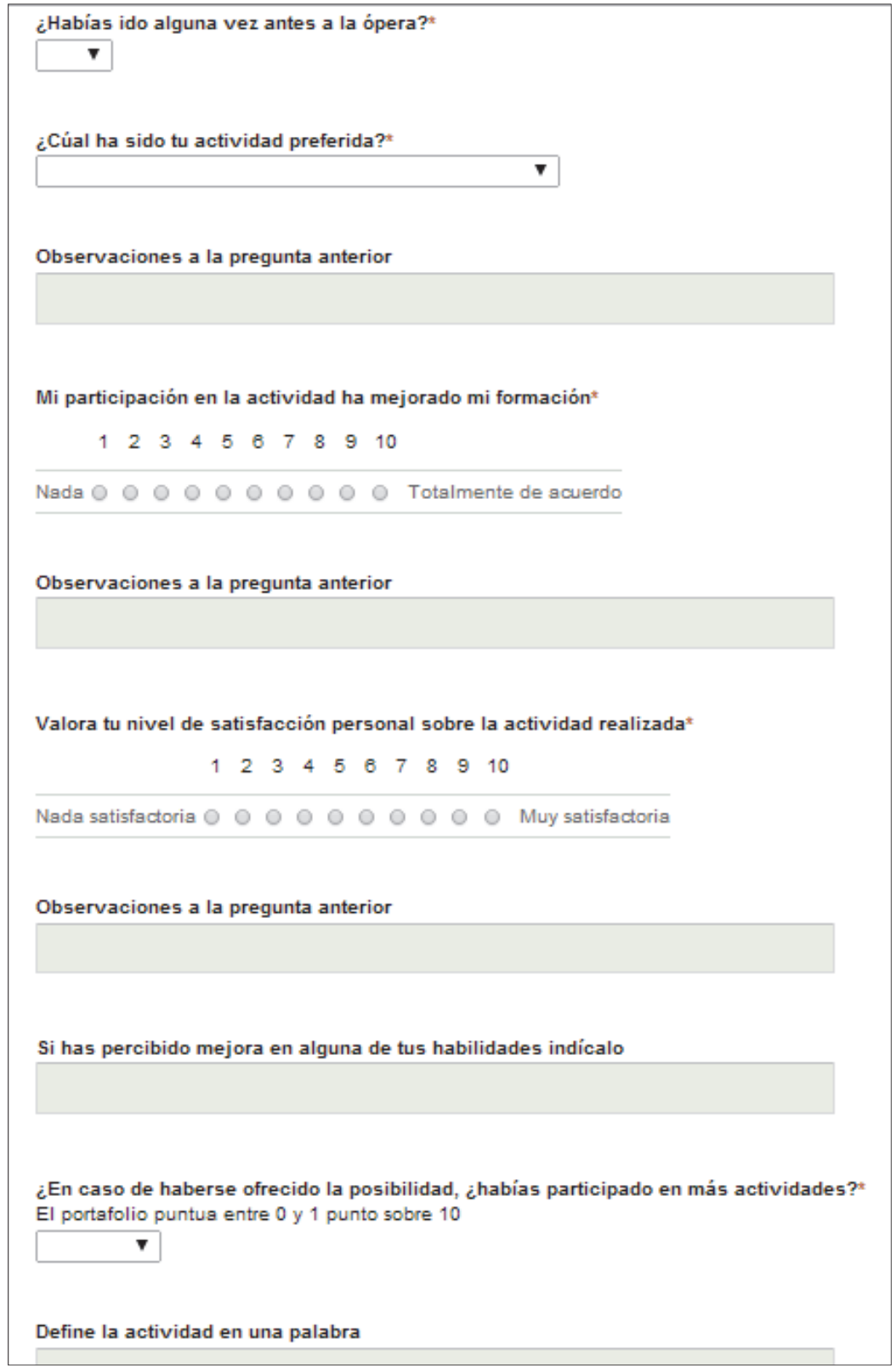

Fig. 4 Cuestionario final sobre la percepción del alumno.

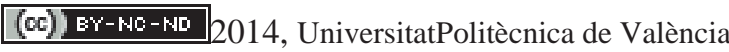

I Jornadas IN-RED (2014) 
Una experiencia interdisciplinar en Educación Superior con la música como elemento vehicular ¿Qué tienen en común estudiantes de Arquitectura y del Máster de Transportes, la escenografía, el paisaje y la ópera?

\section{Resultados}

Las conclusiones del primer taller, recogidas en los distintos paneles realizados por los alumnos (Fig. 5), han sido plasmadas en el informe elaborado utilizando la técnica del Metaplan.

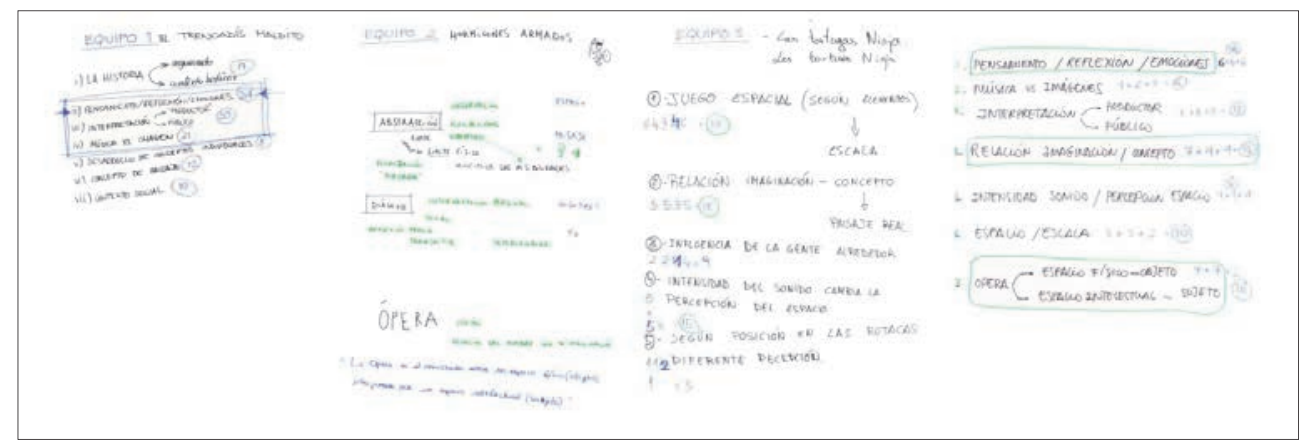

Fig.5 Imágenes de las distintas propuestasy conclusiones realizadas por los alumnos en el taller I

Así, los resultados obtenidos respecto de los objetivos que nos planteamos en inicio han sido lo siguientes:

O1.- Repercusión de la actividad: La actividad ha cambiado la percepción que los alumnos tenían del espacio de manera que, si en el inicio del curso los alumnos concebían el espacio desde una mera concepción de "espacio físico", tras la actividad, mediante un proceso de abstracción, se ha transformado en otro tipo de visión, que en el taller se denominó "espacio conceptual".

O2.-El concepto de paisaje: La significación de este concepto ha evolucionado para los alumnos adquiriendo unas connotonaciones en las que se entremezclan conceptos como el pensamiento, la reflexión, las emociones o la imaginación.

O3.-El papel de la música en la experiencia: La música ha sido el elmento clave conector que les ha permitido relacionar el espacio físico (objeto), con el espacio intelectual (sujeto).

En el caso del segundo taller, los resultados obtenidos respecto de los objetivos planteados han sido los siguientes (Fig. 6):

(c) EY-NC-ND 2014, UniversitatPolitècnica de València

I Jornadas IN-RED (2014) 


\begin{tabular}{|c|c|}
\hline OBJETIVO & RESULTADOS \\
\hline Motivación & $\begin{array}{l}\text { - El motivo inicial de participar era la curiosidad por } \\
\text { conocer la ópera y el edificio } \\
\text { - Tras haber participado, todos los alumnos repetirían la } \\
\text { actividad }\end{array}$ \\
\hline Resultados & $\begin{array}{l}\text { - Lo que más les había interesado y/o sorprendido fue la } \\
\text { forma en cómo transmitían su mensaje los profesionales } \\
\text { de la escena y la cantidad de trabajo en equipo que hay } \\
\text { detrás de un montaje de estas características. } \\
\text { - Aprender nuevas maneras de enfocar el trabajo, de } \\
\text { representar e incluso de pensar las cosas. } \\
\text { - Alta valoración de las nuevas relaciones de grupo que se } \\
\text { - habían creado. } \\
\text { - Reforzamiento de la relación alumno-profesor } \\
\text { lejano que acaban percibiéndolo como próximo y posible }\end{array}$ \\
\hline Propuestas & $\begin{array}{l}\text { - Hubo unanimidad en la propuesta de incorporar a la } \\
\text { actividad, después de cada ópera, sesiones de reflexión } \\
\text { para compartir, debatir y poner en común la experiencia } \\
\text { realizada. } \\
\text { - También, en cada una de las disciplinas, propusieron la } \\
\text { posibilidad de realizar algún taller de escenografía } \\
\text { aplicada. }\end{array}$ \\
\hline
\end{tabular}

Por último, los resultados de la encuesta realizada con la herramienta Google drive, arrojan los siguientes resultados:

Las actividades más valoradas (50\%) tenían que ver con los procesos de concepción (encuentros con los directores musicales y de escena) y elaboración (ensayos previos) de las producciones.

En una escala [0-10], el 83\% de los alumnos que la actividad ha mejorado su formación. Apuntan además que esa formación no ha sido sólo en competencias técnicas sino en el hecho de que les ha permitido crecer como personas.

En una escala [0-10], el $92 \%$ de los alumnos asignaron valores entre 9 y 10 al grado de satisfacción que les había producido realizar la actividad. Destaca, entre las opiniones

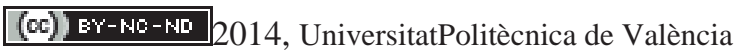

I Jornadas IN-RED (2014) 
Una experiencia interdisciplinar en Educación Superior con la música como elemento vehicular ¿Qué tienen en común estudiantes de Arquitectura y del Máster de Transportes, la escenografía, el paisaje y la ópera?

vertidas sobre esta cuestión, que la experiencia les había permitido relacionarse con sus compañeros de una forma diferente, fuera del espacio de la universidad, que reconocían como muy enriquecedora. En este sentido, también apuntaban que la experiencia les había llevado a cambiar la percepción que de sus profesores tenían hasta ese momento.

A la pregunta sobre si habían percibido alguna mejora en sus habilidades, los alumnos han contestado de forma mayoritaria que ésta se traduce en un mayor interés en abrirse a ofertas culturales nuevas y a su mejora en su capacidad de abstracción a la hora de abordar una nueva empresa.

Por último, cuando se les ha pedido que describan en una palabra la experiencia vivida, los adjetivos utilizados han sido: enriquecedora, satisfacción, descubrimiento conexión, reflexión y disfrute.

\section{Conclusiones}

La experiencia, desde un punto de vista global, se puede considerar como muy satisfactoria. Su desarrollo se ha producido dentro del marco de lo planificado y los resultados han sido excelentes. Como conclusiones de la misma se confirman las siguientes:

La experiencia nos ha permitido constatar un alto grado de significatividad en la experiencia interdiciplinar llevada a cabo. Los alumnos han sido capaces de relacionar conceptos complejos en un ambiente colaborativo que se ha desarrollado en un entorno fuera del espacio académico usual.

Se verifica una revisión del concepto de paisaje por parte de los alumnos contemplando sus posibilidades respecto a su diseño y concepción.

La utilización de un lenguaje universal como la música favorece el trabajo en grupos interdisciplinares al comportarse ésta como un excelente medio vehicular. La música ha favorecido claramente la conexión entre los diferentes grupos disciplinares, yendo más allá de un mero intercambio de conocimientos y experiencias, lo que ha permitido que los resultados obtenidos tengan un alto grado de complejidad.

La experiencia ha aportado un valor añadido a los propios objetivos planteados en un inicio. Así, los alumnos han reconocido que se han visto favorecidas la relaciones interpersonales entre los miembros del grupo y entre el grupo y los profesores. También se constata un cambio en la actitud de los alumnos hacia actividades culturales que hasta ese momento se percibían como algo ajeno a ellos, demostrando ahora su interés, no sólo por esta actividad, sino también por otras que en principio tenían idéntica consideración.

(c)) BY-NC-ND 2014, UniversitatPolitècnica de València

I Jornadas IN-RED (2014) 
Como propuestas de futuro se plantean dos acciones de inmediata implantación:

- Rediseño de la planificación de la experiencia a la vista de los resultados obtenidos, y que incorporaría las sugerencias planteadas por los alumnos en el taller realizado.

- La formalización de contratos de prácticas con el Palau de Les Arts Reina Sofía, para los alumnos participantes en la experiencia, que se llevarían a cabo en el departamento técnico responsable de la concepción y puesta en marcha de la escenografía de una producción.

\section{Referencias}

BRICALL, J. M. (2000). "Informe Universidad 2000”. Conferencia de Rectores de las Universidades Españolas (CRUE) n < http://www.oei.es/oeivirt/bricall.htm> [Consultado: 15 de febrero 2014]

CHÍAS, P. Y DE BLAS F. (2006). "Análisis crítico del montaje escenográfico de la ópera Oedipus Rex (Edipo Rey), de Igor Stravisnky”. Curso de Doctorado: Música y arquitectura, Espacios y Paisajes Sonoros. Madrid: ETSAM. <http://ocw.upm.es/expresion-graficaarquitectonica/musica-y-arquitectura-espacios-y-paisajes-

sonoros/contenidos/Practicas/Practica-2-Analisis-de-una-opera-contemporanea/analisis15.pdf> [Consulta: 9 de julio 2013]

COCCIA, C. (2009). "Escenografía. Teatro. Paisaje". Cuadernos del Centro de Estudios en Diseño y Comunicación [Ensayos]. Cuaderno 30, año 10, N³0, Noviembre 2009, pp. 21-33

CUADRADO, M., RUIZ MOLINA, M. ${ }^{a}$ E. Y COCA, M. (2009). "Participación y rendimiento del estudiante universitario en un proyecto docente interdisciplinar, bilingüe y virtual". Revista de Educación, 348, 505-518.

FELSENHARDT, C. (2009). "Arquitectura. Paisaje”. Cuadernos del Centro de Estudios en Diseño y Comunicación. [Ensayos]. Cuaderno 30, año 10, № 30, Noviembre 2009, pp. 35-48

GIBBONS, M. (1997). La nueva producción del conocimiento. La dinámica de la ciencia y la investigación en las sociedades contemporáneas. Barcelona: Ediciones Pomares-Corredor

GÓMEZ, M. ${ }^{a}$ V. (2009). "A transversalidade como abertura máxima para a didáctica e a formação contemporâneas". Revista Iberoamericana de Educación, 48/3.

MARTIGNONI, J. (2009). "El paisaje como referente de diseño". Cuadernos del Centro de Estudios en Diseño y Comunicación [Ensayos]. Cuaderno 30, año 10, № 30, Noviembre 2009, pp. 9-20

MORIN, E. (1998). Sobre la reforma de la Universidad. J. Porta y M. LLadonosa (coords.), La Universidad en el cambio de siglo. Madrid: Alianza Editorial.

MUÑOZ, K. Y JERIS, L. (2005). "Learning to Be Interdisciplinary". Health Education Journal, <http://hej.sagepub.com> [Consultado: 17 de septiembre 2013]

(c) ) EY-NC-ND 2014, UniversitatPolitècnica de València

I Jornadas IN-RED (2014) 
Una experiencia interdisciplinar en Educación Superior con la música como elemento vehicular ¿Qué tienen en común estudiantes de Arquitectura y del Máster de Transportes, la escenografía, el paisaje y la ópera?

NOVOA, G. (2009). "Historia. Marcas a través del tiempo. Paisaje". Cuadernos del Centro de Estudios en Diseño y comunicación [Ensayos]. Cuaderno 30, año 10, № 30, Noviembre 2009, pp. 49-61

PAZUELOS ESTRADA, F.J., RODRÍGUEZ MIRANDA, F.P. Y TRAVÉ GONZÁLEZ, G. (2012). "El enfoque interdisciplinar en la enseñanza universitaria y el aprendizaje basado en la investigación. Un estudio de caso en el marco de la formación”. Revista de Educación, 357. Enero abril 2012, pp. 561-585

SAltZMAN, A. (2009). “Cuerpo. Vestido. Paisaje”. Cuadernos del Centro de Estudios en Diseño y Comunicación [Ensayos]. Cuaderno 30, año 10, No 30, Noviembre 2009, pp. 63-75

UNESCO (1998). Declaración mundial sobre la educación superior en el siglo XXI: visión y acción. <http://unesdoc.unesco.org/images/0011/001138/113878so.pdf >, [Consultado: 26 de octubre 2013]

(c) ) EY-NC-ND 2014, UniversitatPolitècnica de València 


\title{
APRENDIZAJE BASADO EN PROBLEMAS A ESCALA. LA MAGIA DE LAS ESTRUCTURAS DE PAPEL
}

\author{
Jaime Llinares Millán ${ }^{1}$ Jose Miguel Molines Cano $^{2}$, Igor Fernández Plazaola ${ }^{3}$, \\ Francisco Sanchis Sampedro ${ }^{4}$ \\ ${ }^{1}$ Universitat Politècnica de València, Dpto. de construcciones arquitectónicas j1linares@csa.upv.es \\ ${ }^{2}$ Universitat Politècnica de València, Dpto. de construcciones arquitectónicas, jomoca1@upv.es \\ ${ }^{3}$ Universitat Politècnica de València, Dpto. de organización de empresas, iplazaola@doe.upv.es \\ ${ }^{4}$ Universitat Politècnica de València, Dpto. de expresión gráfica, fsanchis@ega.upv.es
}

\begin{abstract}
In the model proposed by the School of Engineering Building in his journeys from EXCO teaching framework, the workshop included "magic paper structures" associated with different core subjects of the degree. The shop consists of representing how the current structures operate by scale models role played by parts which can be easily obtained by a different folded base part (in this case, an A4 page).

In a second phase, students must pass a basic problem by building a structure using the pieces that have previously been made. In this case you must form a structure to save a free distance of 1 meter, with a minimum height of 0.6 meters and a minimum support weight of 4 kilos. After that, load tests are performed on the structure until it collapses.

The results obtained are compared in two different aspects. On the one hand it is found that the models made by students and modeled as real structures behave similarly. On the other hand knowledge acquired by the students through a written test at the end of the workshop are checked.
\end{abstract}

Keywords: structural design, scale models, paper architecture, case-based learning 
Aprendizaje basado en problemas a escala. La magia de las estructuras de papel

\begin{abstract}
Resumen
En el marco docente propuesto por la Escuela Técnica Superior de Ingeniería de Edificación dentro de sus jornadas de la EXCO, se ha incluido el taller "la magia de las estructuras de papel" relacionado con diferentes asignaturas troncales de la titulación.

El taller consiste en representar cómo funcionan las estructuras actuales mediante modelos a escala reproducidas mediante piezas de papel las cuales pueden obtenerse fácilmente mediante diferentes plegados de una pieza base (en este caso un folio A4).

En una segunda fase, los alumnos deberán superar un problema básico mediante la construcción de una estructura empleando a las piezas que previamente se han conformado. En este caso se debe conformar una estructura que salve una distancia libre de 1 metro, con una altura mínima de 0,6 metros y que soporte un peso mínimo de 4 kilos. Tras esto, se realizarán pruebas de carga en las estructura hasta que colapse.

Los resultados obtenidos se comparan en dos vertientes distintas. Por un lado se comprueba que los modelos realizados por los alumnos y los modelizados como estructuras reales se comportan de un modo similar. Por otro lado se comprueban conocimientos adquiridos por el alumnado mediante una prueba escrita al terminar el taller.
\end{abstract}

Palabras clave: cálculo estructural, modelos a escala, arquitectura de papel, aprendizaje basado en caso

\title{
Introducción
}

En los últimos años, una de las evoluciones de las metodologías docentes más importantes ha sido el aprendizaje basado en la práctica. Los nuevos planes de estudio apuestan por modelos de enseñanza donde el alumno, mediante la práctica, tienen una experiencia práctica aplicada de los conocimientos adquiridsos en el aula. Esta metodología permite a la vez reforzar y ampliar conocimientos (reforzar la teoría mediante la aplicación en casos prácticos, y ampliar añadiendo la experiencia del alumno sobre el tema trabajado). (HEYMAN 1999)

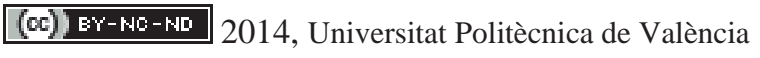

I Jornadas IN-RED (2014) 
Dentro del ámbito de la ingeniería de la edificación (que incluye titulaciones como arquitectura, ingeniería de edificación o incluso, ingeniería industrial mediante la especialidad de edificación) una de las áreas temáticas más compleja de visualizar para el alumno es el cálculo estructural. Es necesario tener conocimientos básicos de mecánica estructural, cálculo de esfuerzos y resistencia de materiales, todo ello aplicado en estructuras tridimensionales. Es por ello que las metodologías activas basadas en modelos a escala parecen ajustarse a la perfección a esta área de conocimiento.

En el marco docente propuesto por la Escuela Técnica Superior de Ingeniería de Edificación dentro de sus jornadas de la EXCO (Exposición de Construcción, exposición de la escuela presente dentro de la feria CEVISAMA-Cerámica, Vidrio, Saneamiento y Mármol), se ha incluido el taller "la magia de las estructuras de papel" relacionado con diferentes asignaturas troncales de la titulación.

Este artículo trata de explicar los objetivos, metodología y resultados obtenidos en dicho taller. Pese a ser una experiencia piloto (con tiempo y material limitado) los resultados han sido muy positivos, permitiendo al alumnado comprobar el funcionamiento de una estrutura mediante un modelo a escala realizado con papel.

\section{Ojetivos}

Esta actividad presenta dos niveles diferenciados de objetivos. En una capa o nivel más directo, los que llamaríamos objetivos principales, se cubren las necesidades propias de las asignaturas relacionadas con el cálculo de estructuras (competencias específicas y resultados de aprendizaje).

En otro nivel más genérico, los que llamaríamos objetivos secundarios, se explotan algunas de las capacidades básicas del alumno de una ingeniería (competencias genéricas de la titulación).

\subsection{Objetivos principales}

Los objetivos principales del taller son:

- Dotar a los alumnos de herramientas sencillas a escala para el cálculo de estructuras. Esto aporta al alumno dos herramientas que podrá aplicar en diferentes fases temporales de su formación. De forma instantánea, el alumno adquiere una metodología nueva de comprobación de lo aprendido en el aula (metodología conformada mediante elementos sencillos y de fácil acceso). A largo plazo, en un nivel profesional, se adquiere un conocimiento más amplio de la escala a emplear

\section{(c)) EY-NC-ND 2014, Universitat Politècnica de València}

I Jornadas IN-RED (2014) 
en la realidad, es decir, se adquiere una coherencia formal en el factor a escala a emplear.

- Centrar al alumno en el diseño de estructuras huyendo de las soluciones habituales. Este posiblemente es el objetivo más ambicioso de todos. La tecnología ha evolucionado mucho en los últimos años. Esta evolución, en contra de lo que pudiera parecer mas habitual, lo que ha hecho es estandarizar el diseo estrutural, de manera que el alumno ha perdido la capacidad de "crear" o diseñar estructuras novedosas. En esta actividad, al trabajar con elementos no estandarizados (papel plegado) el alumno puede ampliar sus miras y capacidad de diseño.

- Explicar y recordar algunos conceptos estructurales mediante la creación del modelo.

\subsection{Objetivos secundarios}

Los objetivos secundarios son:

- Desarrollo de las capacidades de trabajo en grupo (YUS 1996)

- Aplicación de las matemáticas en problemas tridimensionales (YUS 1996)

- Aplicación de softwares de cálculo

\section{Desarrollo de la innovación}

La innovación se divide en 4 fases, fase formativa, fase constructiva, fase de puesta en carga y fase de verificación.

\subsection{Fase formativa}

Se explican las bases de cálculo de la actividad. Se muestra la relación de resistencia a tracción y compresión del papel respecto a la de varios elementos habituales en el ámbito de la construcción (ladrillos, hormigón, etc...). El alumno debe tener una idea básica de la proporción entre papel (modelo a escala) y elementos de construcción (construcción real). (TORROJA 1960)

El siguiente paso es formar grupos de trabajo. En este caso, debido a las dimensiones del aula se conforman tres grupos de 6 personas cada grupo. Mientras se conforman los grupos se les orienta de como funciona un buen equipo multidisclipinar (un subequipo de diseño, otro de fabricación de elementos, otro de construcción, etc...). No se les obliga a formalizar estos subgrupos, pero si se les orienta para ver como reaccioan.

Finalmente, se les ayuda con la fabricación de los primeros módulos constructivos realizados en papel. En este caso dada la limitación temporal se redujo todo a cinco 
elementos básicos, un tubo, un perfil rectangular, un perfil triangular, escuadras resistentes y trozos de folios trabajando como cables (a tracción). La idea aplicada en un modelo con mayor caaga temporal sería el ir enseñando poco a poco más piezas, para que los alumnos pudiesen también crear sus propios elementos.

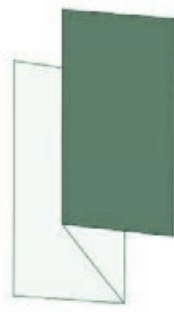

Plegado en acordeón

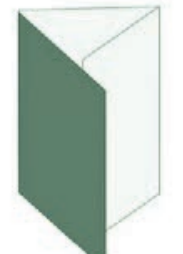

Plegado envolvente

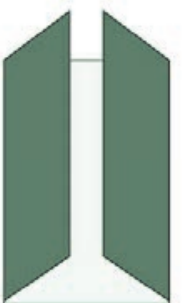

Plegado en ventana

Fig. 1 Diferntes eljemplos de plegado

\subsection{Fase constructiva}

En esta fase comienza el ensamblaje de las diferentes piezas. Se les asesora para formalizar un pequeño mono de cálculo previo antes de empezar a unir piezas, aunque tampoco es necesario. El objetivo principal de esta fase es que experimenten con diferentes configuraciones y materiales de anclaje (uniendo piezas, mediante celo, etc...)

Cuando ha pasado un tiempo prudencial y han experimentado con las diferentes uniones, se les explica el cometido de la actividad (objetivos estructurales a superar). En este caso se les propone que creen una esctrutura que:

- Supere un vano mínimo de $80 \mathrm{~cm}$

- Tenga una altura superior a $80 \mathrm{~cm}$

- Emplee el mínimo número de piezas (folios) posible

- Soporte la mayor carga posible

En caso de poder disponer de más tiempo, resultaría interesante poner como objetivo un baremo de cargas, por ejemplo, que la estructura soporte un ladrillo pero colapse con dos. Esto haría que ajustasen mucho más el cálculo de los diferentes elementos. De momento, en esta experiencia piloto nos limitamos a poder cargar la estructura lo máximo posible.

Llegados a este punto es recomendable el mostrar algunas fotografías o esquemas de estructuras espaciales reales (puentes, silos, gruas, etc...) para que tengan una refencia visual real.

(c) EY-NC-ND 2014, Universitat Politècnica de València

I Jornadas IN-RED (2014) 
Aprendizaje basado en problemas a escala. La magia de las estructuras de papel

\subsection{Fase de puesta en carga}

Pasada la fase de testeo de los materiales, y ya con los diseños construidos se pasa a la fase de puesta en carga. Esta fase básicamente tiene como objetivo el ir cargando la estructura para ver que estructura soporta más peso sin llegar a colapsar. En este caso, al tratarse de un taller de corta duración simplemente se tiene en cuenta que la estructura no colapse, sin embargo, para talleres de larga duración cada grupo de trabajo tendría un ficha con los siguientes apartados:

Tabla 1. Ejemplo de ficha de trabajo de grupo

\begin{tabular}{|l|l|}
\hline \multicolumn{2}{|l|}{ GRUPO DE TRABAJO: Los terremotos } \\
\hline Miembros: & Juan Pardo Gómez \\
\hline & Ana Esteban Soler \\
\hline $\mathrm{N}^{\text {o de folios }}$ & José Molines Plazaola \\
\hline Altura alcanzada & 143 \\
\hline Anchura salvada & 123 cm \\
\hline Carga aplicada & 98 cm \\
\hline $1 \mathrm{~kg}$ & No se altera \\
\hline $1,5 \mathrm{Kg}$ & No se altera \\
\hline $2 \mathrm{Kg}$ & Empiezan a doblarse los soportes \\
\hline $2,5 \mathrm{Kg}$ & Se tensan los cables \\
\hline $3 \mathrm{Kg}$ & Eolapsa la estrema de deforma mucho, casi \\
\hline $3,5 \mathrm{Kg}$ & tocalo \\
\hline
\end{tabular}

A partir de estos resultados, si fuese necesario se crearía una rúbrica de evaluación del trabajo para poder evaluar el trabajo del equipo. (MONTENEGRO 2003)

(c)) EY-NC-ND 2014, Universitat Politècnica de València

I Jornadas IN-RED (2014) 


\subsection{Fase de verificación}

Una vez pasado la puesta en carga, y observado con que carga la estructura se deforma, la fase final consiste en modelizar dicha estructura en algún software informático de cálculo de estructuras e intentar comprobar si existe alguna relación entre el papel y la realidad.

En este caso se emplea el software CYPE con base de modelización tridimensional emdiante el software AUTOCAD, obteniendo modelos muy completos. En el taller realizado, la verificación se realizó convirtiendo la estructura de papel en estructura de perfiles de acero (más fácil establecer una relación lineal), sin embargo, en talleres de mayor duración se plantea que trabajen con acero, ladrillo y hormigón. (ASADIA et al 2012)

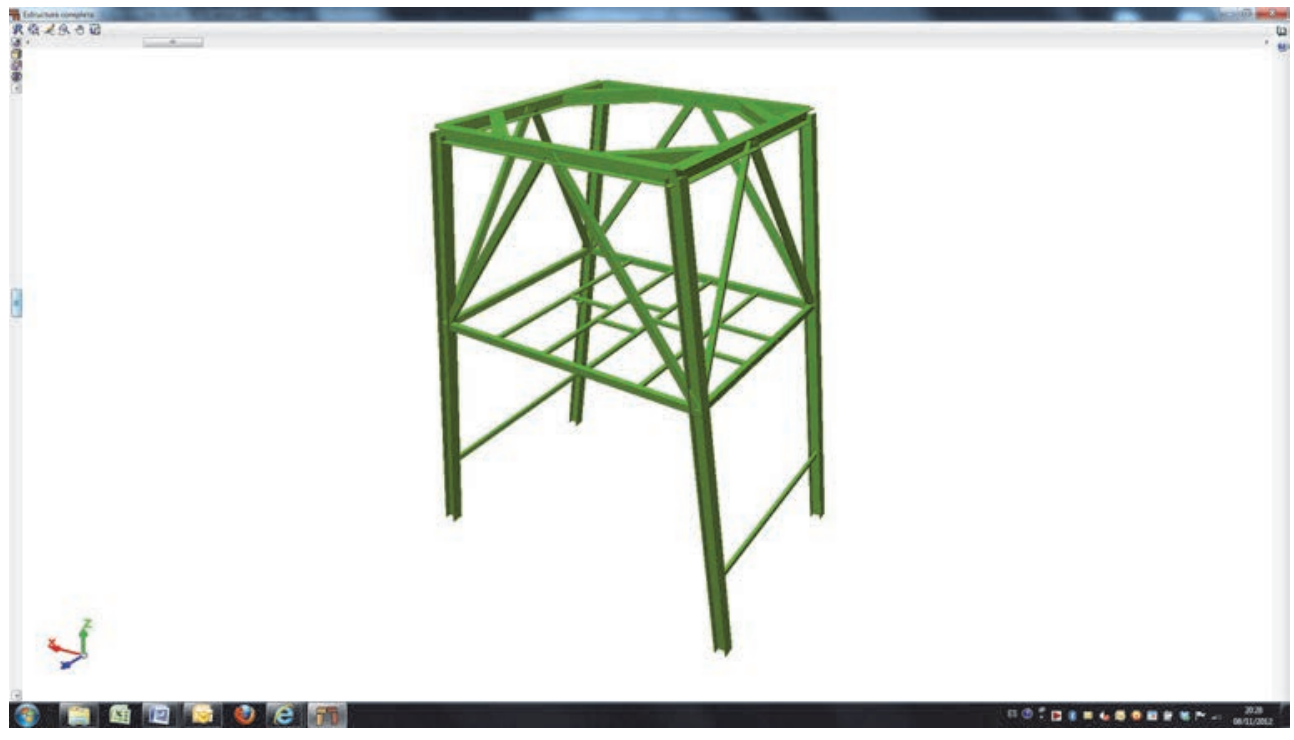

Fig. 2 Ejemplo de modelización en CYPE de una estructura del taller

\section{Resultados}

Los resultados obtenidos en el taller fueron bastante positivos, sobretodo teniendo en cuenta que se trataba de un taller de dos días y con asistencia optativa. El alumnado presente disfrutó mucho de la experiencia y se completarón tres estructuras capaces de soportar más de 20 kilos de peso cada una.

En el apartado organizativo, una de las sorpresas fue como se divieron rápidamente por aptitudes personales dentro de los grupos sin apenas necesidad de dirección. Un grupo que

(c)) EY-NC-ND 2014, Universitat Politècnica de València

I Jornadas IN-RED (2014) 
diseñaba, otro que construía, otro que ejercía de I+D probando nuevas combinaciones, etc...

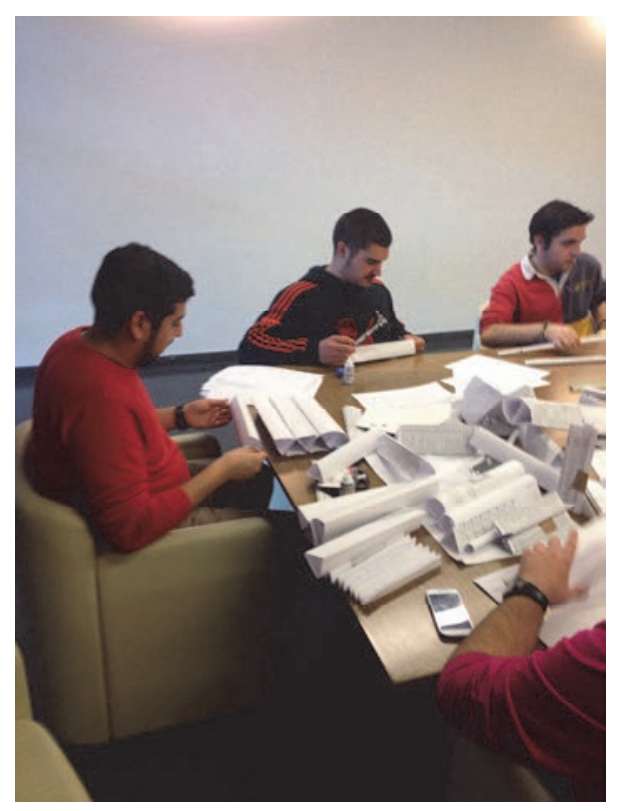

Fig. 3 Imagen de uno de los grupos de trabajo en pleno montaje

Al llegar a la fase de puesta en carga los alumnos convirtieron esta fase en un concurso, lo cual tuvo resultados muy positivos también, dado que el ambiente en el aula fue muy buen, permitiendo el taer más objetos para cargar las estructuras.

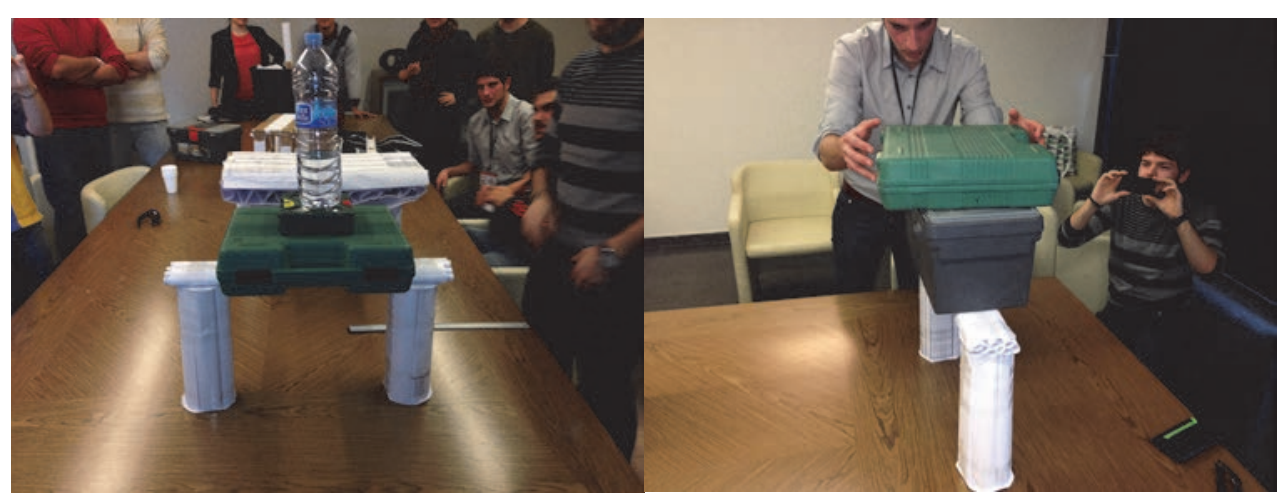

Fig. 4 Diferentes ejemplos de puesta en carga de una estructura

No obstante, el resultado más satisfactoria ha sido la fase de verificación realizada por parte de los alumnos. Mediante el empleo del software CYPE se han reproducido los modelos, y

(c)) EY-NC-ND 2014, Universitat Politècnica de València

I Jornadas IN-RED (2014) 
se han calibrado mediante la respuesta del papel y convertido esa misma respuesta al acero. Los resultados obtenidos han sido más cercanos todavía a la realidad de lo que se esperaba. El resumen de los resultados se incluye en la siguiente tabla (los resultados se muetran en la misma escala):

Tabla I1. Resultados obtenidos en la fase de verificación

\begin{tabular}{|c|c|}
\hline \multicolumn{2}{|l|}{ GRUPO DE TRABAJO I } \\
\hline Deformación vertical modelo en papel & Deformación vertical modelo en acero (virtual) \\
\hline $12,5 \mathrm{~cm}$ & $16 \mathrm{~cm}$ \\
\hline $\begin{array}{l}\text { Deformación horizontal modelo en } \\
\text { papel }\end{array}$ & $\begin{array}{l}\text { Deformación horizontal modelo en acero } \\
\text { (virtual) }\end{array}$ \\
\hline $3,4 \mathrm{~cm}$ & $4 \mathrm{~cm}$ \\
\hline \multicolumn{2}{|l|}{ GRUPO DE TRABAJO II } \\
\hline Deformación vertical modelo en papel & Deformación vertical modelo en acero (virtual) \\
\hline $21 \mathrm{~cm}$ & $24,5 \mathrm{~cm}$ \\
\hline $\begin{array}{l}\text { Deformación horizontal modelo en } \\
\text { papel }\end{array}$ & $\begin{array}{l}\text { Deformación horizontal modelo en acero } \\
\text { (virtual) }\end{array}$ \\
\hline $8,6 \mathrm{~cm}$ & $7,3 \mathrm{~cm}$ \\
\hline \multicolumn{2}{|l|}{ GRUPO DE TRABAJO III } \\
\hline Deformación vertical modelo en papel & Deformación vertical modelo en acero (virtual) \\
\hline $1,5 \mathrm{~cm}$ & $0,3 \mathrm{~cm}$ \\
\hline $\begin{array}{l}\text { Deformación horizontal modelo en } \\
\text { papel }\end{array}$ & $\begin{array}{l}\text { Deformación horizontal modelo en acero } \\
\text { (virtual) }\end{array}$ \\
\hline $0 \mathrm{~cm}$ & $0 \mathrm{~cm}$ \\
\hline
\end{tabular}

Los resultados obtenidos muestran una linealidad en las deformaciones más que aceptables. Teniendo en cuenta que el cálculo de estructuras siempre va ligado a un factor de mayoración o corrección de 1,6 en acero, los resultados obtenidos mediante el sistema de modelo a escala de papel serían más que válidos.

(c)) EY-NC-ND 2014, Universitat Politècnica de València

I Jornadas IN-RED (2014) 
Aprendizaje basado en problemas a escala. La magia de las estructuras de papel

\section{Conclusiones}

Las conclusiones obtenidas de esta primera experiencia las vamos a dividir en tres bloques a tenor del área a la que afectan.

\subsection{Aprendizaje del alumnado}

El alumnado ha conseguido experimentar los resultados de un cálculo de estructuras sin necesidad de efectuar cálculos matemáticos. Se ha comprobado que los alumnos que más dificultades han demostrado para superar las signaturas de cálculo de estructuras en su titulación no se han visto limitados a la hora de realizar este taller, es más, alumnos que no han superado todavía la totalidad de las asignaturas de cálculo de estructuras, han demostrado un mayor interés en este tipo de metodologías que les ayudan a pensar de una forma más práctica.

\subsection{Ejecución del taller}

Este taller ha sido una experiencia piloto, y como tal, ha tenido muchas limitaciones y problemas de inicio (falta de tiempo, de material, detección de fallos y corrección en tiempo real). Sin embargo ha demostrado ser una buena base de trabajo para poder realizar la siguiente fase evolutiva lógica. El objetivo que se tiene ahora en mente es poder trabajar en paralelo con las asignaturas de cálculo de estructucturas de la titulación, de manera que lo que se vaya explicando en el aula se vaya experimentado con modelos a escala.

\subsection{Realidad de los resultados obtenidos}

La mayor de las sorpresas ha sido la similitud de los resultados obtenidos. En un principio se estimaba una desviación del 20-30\% respecto del modelo a escala, sin embargo algunas de las simualaciones han conseguido desviaciones inferiores al $4 \%$ en los resultados de deformaciones y rotura de elementos. Se espera poder trabajar en esta línea con otro tipo de simulaciones, softwares, etc...

\section{Agradecimientos}

Este taller piloto no hubiese sido posible sin el soporte de la Escuela Técnica Superior de Ingeniería de Edificación. 


\section{Referencias}

ASADIA, E. GAMEIRO, M. HENGGELER, C. DIASC, L. (2012). « Multi-objective optimization for building retrofit strategies: A model and an application" en Energy and Buildings (2012, vol44, 81-87).

HEYMAN, J (1999). Teoría, historia y restauración de estructuras de fábrica: colección de ensayos. Barcelona. Editrial Reverté.

MONTENEGRO, A (2003). Evaluación del desempeño docente: fundamentos, modelos e instrumentos. Madrid. Coop. Editorial magisterio.

TORROJA, E. (1960) Razón y ser de los tipos estructurales. Madrid. CSIC

YUS, R. (1996). Temas transversales: hacia una nueva escuela. Barcelona. Editorial Grao. 


\title{
Un laboratorio virtual pare el estudio de vibraciones en membranas a partir de mallados hexagonales
}

\section{Fernando Giménez ${ }^{\mathrm{a}}$, José F. Giménez ${ }^{\mathrm{b}}$ y Juan A. Monsoriu ${ }^{\mathrm{c}}$}

àDepartamento de Matemática Aplicada, Universitat Politècnica de València, Spain, fgimenez@mat.upv.es, ${ }^{b}$ Escuela Técnica Superior de Ingeniería del Diseño, Universitat Politècnica de València, Spain, jgimluj@etsii.upv.es y ${ }^{\mathrm{c}}$ Departamento de Física Aplicada, Universitat Politècnica de València, Spain, jmonsori@fis.upv.es.

\begin{abstract}
The study of membranes and plates vibrations is of interest in many fields of Engineering, Architecture, and Physics. The vibrational motion of a flexible, thin, and homogeneous membrane, under certain conditions, is modelized by the two-dimensional wave equation. If the method of separation of variables is applied to part that is not time-dependent, it is reduced to the Helmholtz equation, whose solutions for given boundary conditions are called normal modes of vibration of the membrane (resonances). In this work we present a Matlab virtual laboratory based on the application of the finite differences method with hexagonal meshes to obtain and visualize different vibration modes for Dirichlet or Neuman boundary conditions in complex domains.
\end{abstract}

Keywords: membrane, vibration, virtual laboratory, frecuency, normal mode, Matlab

\section{Resumen}

El estudio de las vibraciones de membranas y placas tienen un gran interés en muchos campos de la ingeniería, arquitectura y física. El movimiento de vibración de una membrana flexible, delgada y homogénea, bajo ciertas condiciones, viene modelado por la ecuación de onda bidimensional. Si se aplica el método de separación de variables la parte que no es dependiente de tiempo se reduce a la ecuación Helmholtz, cuyas soluciones para condiciones de contorno dadas constituyen los llamados modos normales de vibración de la membrana (resonancias). En este trabajo presentamos un laboratorio virtual de Matlab, basado en la aplicación del método de las diferencias fintas con mallados de tipo hexagonal, que permite obtener $y$

(cc) EY-NC-ND 2014, Universitat Politècnica de València

I Jornadas In-Red (2014) 
Un laboratorio virtual pare el estudio de vibraciones en membranas a partir de mallados hexagonales

visualizar los distintos modos de vibración para condiciones de frontera de Dirichlet o Neuman en dominios complejos.

Palabras clave: membrana, vibración, laboratorio virtual, frecuancia,modo normal, Matlab

\section{Introducción}

En el estudio el proceso de enseñanza-aprendizaje de la física cobra cada vez más importancia el uso de aplicaciones informáticas de carácter docente con la idea de afianzar los conocimientos adquiridos por los alumnos. El objetivo es lograr la conformación, en el individuo, de una visión del mundo, de servir de puente para pasar de un conocimiento común a uno más elaborado, sistemático y científico, y de posibilitar de modo sencillo el desarrollo y adquisición de capacidades tales como el razonamiento (Mcdermott, 2000), la resolución de problemas (Watts, 1991) o las habilidades experimentales (Arion, 2000). El uso de metodologías activas puede permitir que los alumnos adquieran más fácilmente competencias y capacidades (Benito, 2006).

En este marco presentamos una Interfaz Gráfica de Usuario (GUI) de Matlab que puede utilizarse en las prácticas docentes de aquellas asignaturas universitarias que estudien el movimiento vibratorio. En particular mostramos como pueden obtenerse de manera aproximada los modos normales de vibración utilizando el método de las diferencias finitas generalizadas (MDFG) a partir de mallados hexagonales, los cuales, en muchos casos, se adaptan mejor que los rectangulares a dominios complicados. Las utilidades gráficas de MATLAB, junto con su accesibilidad y facilidad de uso, lo convierten en una herramienta muy adecuada para la simulación de procesos físicos en donde el alumno puede controlar las variables que intervienen, así como analizar su influencia en el resultado. El laboratorio virtual sirve visualizar los modos de vibración de una membrana para las condiciones iniciales de Dirichlet o Neuman. La aplicación permite determinar las líneas nodales de las resonancias (regiones en donde no aparecen desplazamientos transversales). Puede consultarse la referencia (Depcik, 2005) para profundizar sobre las GUI en general y la referencia (Barragán, 2014) sobre las GUI de Matlab

\section{Objetivos}

Con la herramienta que hemos desarrollado se plantean conseguir los siguientes objetivos:

- Afianzar los conocimientos teóricos adquiridos por los alumnos sobre teoría de vibraciones

- Interpretar gráficamente los modos de vibración de una membrana

- Conocer el método de las diferencias finitas usando mallados de tipo hexagonal

(c)) EY-NC-ND 2014, Universitat Politècnica de València

I Jornadas IN-RED (2014) 
- Comparar dicho método con el MDFG de mallados rectangulares y con el método de los elementos finitos

- Observar la influencia que tiene la forma de una membrana en las soluciones encontradas

- Analizar de que manera se elige el dominio del mallado hexagonal que aproxima a uno dado

- Establecer diferencias en la forma en que se trabaja cuando se trata de condiciones de contorno de Dirichlet o de Neuman

- Estudiar la influencia que tienela elección del tamaño de paso en el error que se comete

- Establecer una comparación entre los resultados analíticos conocidos para algunos tipos de membrana particulares con los obtenidos con este método

\section{Desarrollo de la innovación}

En lo que sigue haremos una pequeña introducción teórica sobre los modos normales de vibración de una membrana y de como se aplica el MDFG de mallados hexagonales al cálculo de dichos modos, presentaremos el laboratorio virtual y veremos um par de ejemplos. Se ha diseñado este laboratorio virtual para su uso tanto en las aulas informáticas como en ordenadores particulares, aunque no se disponga del paquete Matlab. En cualquier caso se facilitará al alumno una guía detallada del laboratorio virtual.

\subsection{Modos normales de vibración de una membrana}

El movimiento de una membrana $D$ delgada y uniforme con rigidez despreciable, que es perfectamente elástica, sin amortiguamiento y que vibra con desplazamientos $U(x, y, t)$ de amplitud pequeños, tiene por ecuación del movimiento a

$$
\nabla^{2} U=\frac{1}{c^{2}} \frac{\partial^{2} U}{\partial t^{2}}
$$

donde $\nabla^{2} U=\frac{\partial^{2}}{\partial x^{2}}+\frac{\partial^{2}}{\partial y^{2}}$ es el laplaciano de $U, c=\sqrt{T / \rho_{S}}$ siendo $T$ la tensión de la membrana y $\rho_{S}$ la densidad superficial (Kinsler, 1988). La ecuación diferencial (1) se llama ecuación de onda bidimensional (ver [1]). Si suponemos que la solución de (1) tiene la forma

$$
U(x, y, t)=u(x, y) e^{i \omega t}
$$

Es fácil deducir que $u$ cumple la ecuación de Helmhotz

\section{(c)) EY-NC-ND 2014, Universitat Politècnica de València}

I Jornadas IN-RED (2014) 
Un laboratorio virtual pare el estudio de vibraciones en membranas a partir de mallados hexagonales

$$
-\nabla^{2} u=\lambda u
$$

con $\lambda=\left(\frac{w}{c}\right)^{2}$. Las soluciones de (2) para una membrana de forma y condiciones de frontera dades son los llamados modos normales de vibración de dicha membrana.

Para placas la ecuación del movimiento es considerablemente más complicada [6], sin embargo bajo ciertas condiciones, los modos normales se pueden aproximar por una ecuación diferencial del tipo (2).

Solamente en unos pocos casos (rectángulo, círculo y algunos otros dominios en donde una adecuada elección del sistema de coordenades simplifique las ecuaciones) son conocidos explícitamente los modos normales de vibración.

\subsection{Aproximación por el método de las diferencias finitas}

Dado un dominio del plano $D \subset R^{2}$ con borde $\partial D$ el problema de valores propios de Dirichlet para el laplaciano consiste en encontrar aquellos valores $\lambda$ para los cuales la ecuación diferencial

$$
-\nabla^{2} u=\lambda u
$$

con $\left.u\right|_{\partial D}=0$ tiene solución no trivial.

El problema de valores propios de Neuman para el laplaciano consiste en encontrar aquellos valores $\lambda$ para los cuales la ecuación diferencial

$$
-\nabla^{2} u=\lambda u
$$

$\left.\operatorname{con}\left(\frac{\partial u}{\partial \vec{n}}\right)\right|_{\partial D}=0$ tiene solución no trivial, donde

$$
\frac{\partial u}{\partial \vec{n}}=\operatorname{grad}(u) \cdot \vec{n}
$$

indica la derivada direccional en la dirección dada por el vector normal $\vec{n}$ a $\partial D$.

Es conocido que en ambos casos existe una sucesión de valores $0<\lambda_{1} \leq \lambda_{2} \leq \lambda_{3} \leq$.. ( $0=\lambda_{1} \leq \lambda_{2} \leq \lambda_{3} \leq \ldots$ resp.), llamados valores propios, que son solución del problema de Dirichlet (Neuman resp.). A las funciones soluciones $u_{i}$ se les llama funciones propias asociadas al valor propio $\lambda_{i}$. Si pensamos en $D$ como el dominio definido por la membrana tenemos una sucesión de frecuencias características de los modos de vibración libres

$$
f_{i}:=\frac{w_{i}}{2 \pi}=\frac{c \sqrt{\lambda_{i}}}{2 \pi}, \quad i=1,2, \ldots
$$


El método de las diferencias finitas basado en mallados hexagonales puede usarse para obtenir aproximadamente las soluciones de (2) para el caso de dominios cualesquiera. Se puede utilizar el siguiente procedimiento:

1. Se inscribe el dominio en un cuadrado $[0, L] \times[0, L]$

2. Se considera un mallado de tipo hexagonal en dicho dominio con tamaño de paso (apotema) $h=\frac{L}{N}$ para un entero $N$ dado. Denotemos por $\left(x_{i}, y_{j}\right)$ los nodos correspondientes

3. Dado un nodo $\left(x_{i}, y_{j}\right) \epsilon D$ diremos que es interior si los 6 nodos del hexágono cuyo centro es $\left(x_{i}, y_{j}\right)$ pertenecen a $D$ y que es un nodo frontera en otro caso.

De esta forma aproximamos el dominio $D$ a un dominio $\widetilde{D}$ (formado por los nodos interiores y frontera) susceptible de aplicarle el método de las diferencias finitas. En la figura 1 puede verse el dominio $\widetilde{D}$ correspondiente al mallado utilizado para

$$
D=\left\{(x, y):(x-1)^{2}+(y-1)^{2} \leq 1\right\}
$$

trabajando con el cuadrado $[0,2] \times[0,2]$ y $N=10$.

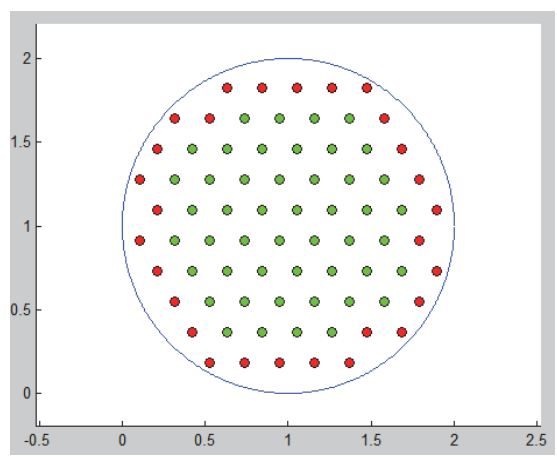

Fig. 1 Dominio $\widetilde{D}$

En la figura 2 se puede la notación que se ha elegido para los nodos.

$$
\begin{aligned}
& \left(x_{i}, y_{j+1}\right) \quad \mathrm{O}^{\left(x_{i+1}, y_{j+1}\right)} \\
& \left(x_{i-1}, y_{j}\right) \bigcirc \stackrel{\left(x_{i}, y_{j}\right)}{\bigcirc} \bigcirc\left(x_{i+1}, y_{j}\right) \\
& \underset{\left(x_{i}, y_{j-1}\right)}{\mathrm{O}_{\left(x_{i+1}, y_{j-1}\right)}}
\end{aligned}
$$

Fig. 2 Representación de los nodos

\section{(cc) EY-NC-ND 2014, Universitat Politècnica de València}

I Jornadas IN-RED (2014) 
Un laboratorio virtual pare el estudio de vibraciones en membranas a partir de mallados hexagonales

En cada uno de los nodos interiores de $\tilde{D}$ tenemos la ecuación en diferencias

$$
-\frac{\frac{2}{3} u_{i-1, j}+\frac{2}{3} u_{i+1, j+} \frac{2}{3} u_{i, j-1}+\frac{2}{3} u_{i+1, j}+\frac{2}{3} u_{i, j+1}+\frac{2}{3} u_{i+1, j}-4 u_{i, j}}{h^{2}}=\lambda u_{i, j}
$$

donde $u_{i, j} \approx u\left(x_{i}, y_{j}\right)$. Utilizando de manera adecuada las condiciones iniciales en los nodos fronteras se obtiene un sistema de ecuaciones lineales de la forma $(A-\lambda I) U=0$. Los valores propios de $A$ son aproximaciones de $\operatorname{los} \lambda_{i}$ y el correspondiente vector propio es una aproximación de la función propia en los puntos $\left(x_{i}, y_{j}\right)$.

Puede consultarse (Kinsler, 1988) para los aspectos teóricos relacionados con la teoría de vibraciones en membranas y (Casasús, 2011) para un estudio detallado de cómo se aplica el método de las diferencias finitas a problemas de vibraciones en membranas. En (Giménez, 2014) se presenta un laboratorio virtual que permite el estudio de las vibraciones usando mallados de tipo rectangular.

\subsection{El laboratorio virtual}

El laboratorio virtual vibrahex que presentamos puede verse en la figura 3. La interfaz consta de dos partes principales. En la parte lateral izquierda se encuentran los campos donde el usuario introduce los parámetros de entrada. En la parte lateral derecha se encuentra una ventana gráfica en donde se genera los resultados gráficos correspondientes.

Los parámetros de entrada de la aplicación vibrahex son:

- $\quad$ L: longitud del cuadrado que contiene al dominio

- $\quad \mathrm{N}$ : número de subintervalos en que se realiza la discretizacion

- Frecuencias: indica los órdenes de las frecuencias propias (valores propios) para la que se desea calcular las correspondientes soluciones. Puede ser un único valor o varios. En este segundo caso se escribe i:j para calcular todos los modos se vibración desde el i hasta el j.

- Definición del dominio: se establece por medio de una o varias desigualdades en las variables x e y. Si se deja en blanco se toma $D=[0, L] \times[0, L]$.

- Condiciones de frontera: Dirichlet o Neuman

- $\quad$ Tipo de gráfica: superficie, seudocolores o superficie en movimiento.

El botón Dibujar permite obtener en primer lugar un gráfico del mallado y el dominio y pasados unos segundos las gráficas de los modos normales de vibración. 


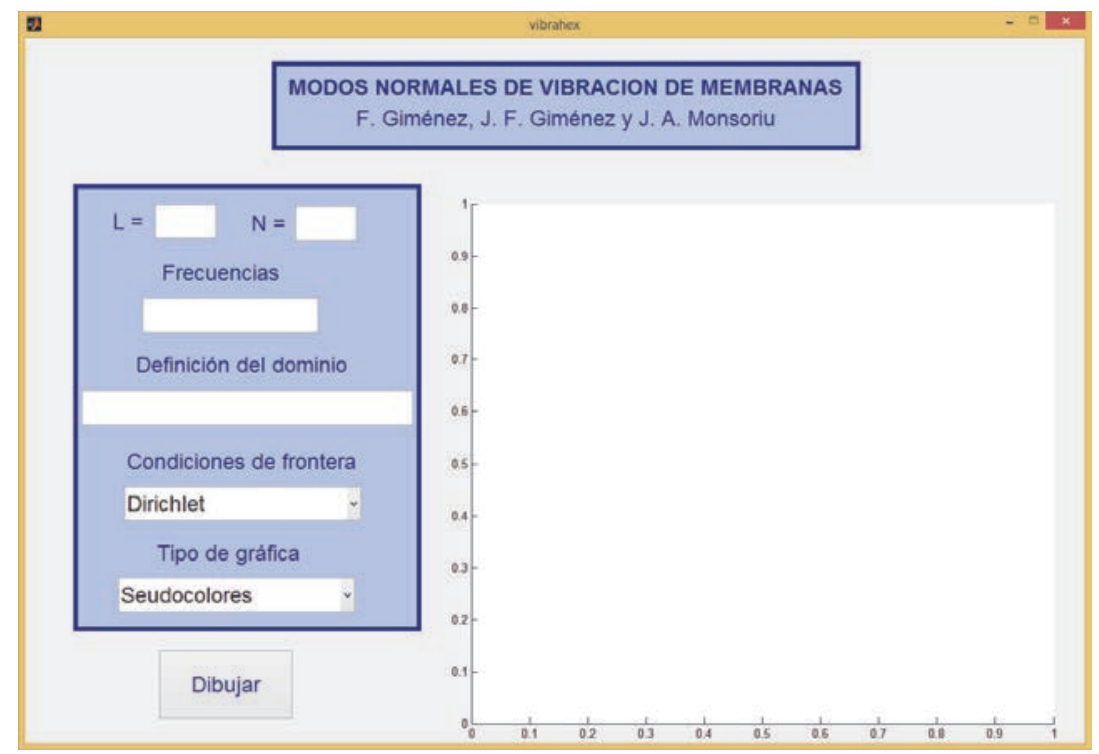

Fig. 3 Interfaz del laboratorio virtual

\subsubsection{Ejemplo}

En este ejemplo se muestra la gráfica (superficie) correspondiente al quinto modo de vibración de un círculo para el problema de Dirichlet. Aquí hemos tomado $D=$ $\left\{(x, y):(x-1)^{2}+(y-1)^{2} \leq 1\right\}$. Se ha tomado $L=2$ y $N=50$.

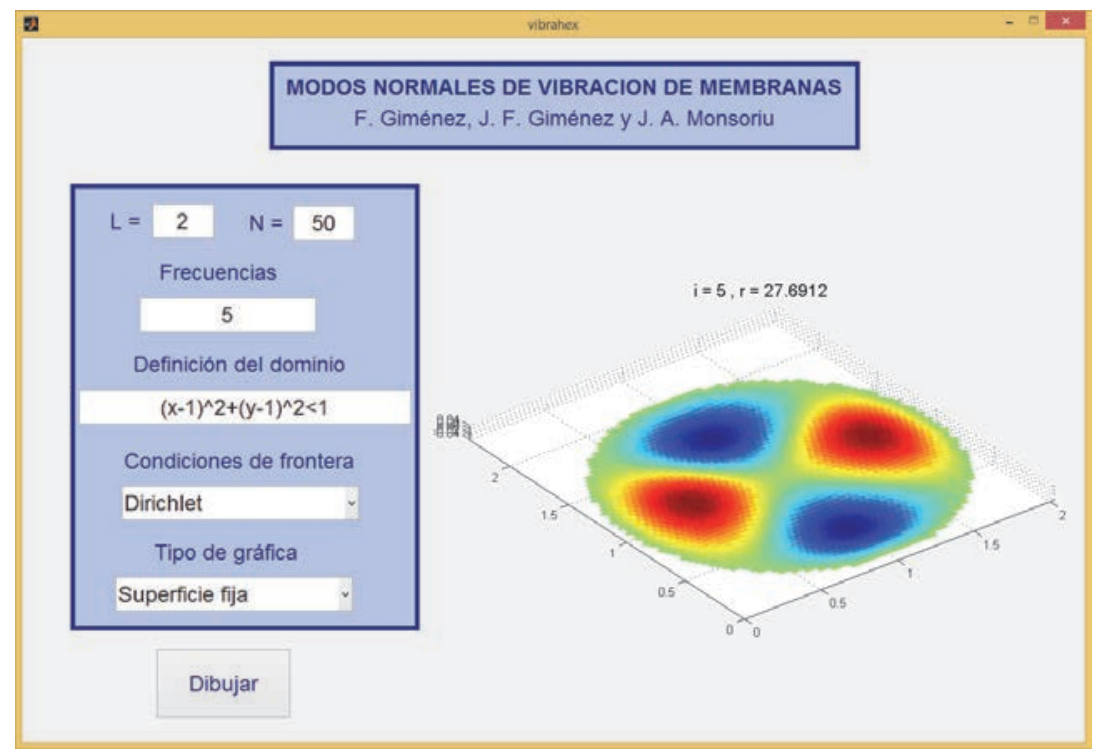

Fig. 4. Función propia correspondiente a $\lambda_{5}$ en un círculo (Dirichlet)

\section{(cc) EY-NC-ND 2014, Universitat Politècnica de València}

I Jornadas IN-RED (2014) 
Un laboratorio virtual pare el estudio de vibraciones en membranas a partir de mallados hexagonales

\subsubsection{Ejemplo}

En la siguiente figura se muestran los 6 primeros modos normales de vibración no constantes para el problema de Neuman correspondiente a una estrella de Koch de orden 2. Se ha tomado $L=1$ y $N=81$.
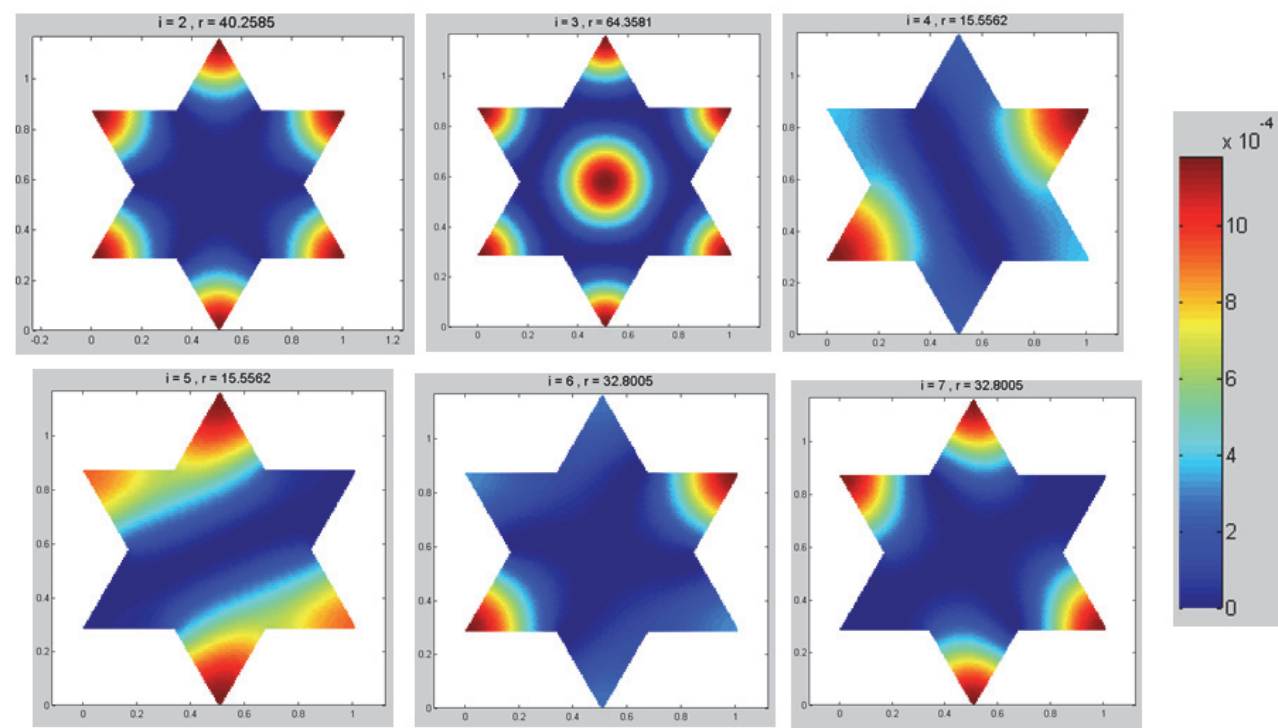

Fig. 5. Ocho primeros modos normales para una estrella de Koch de orden 2 (Neuman)

\section{Resultados}

Se prevee el uso de la apliación que presentamos por parte de los alumnos que estudian la teoría de vibraciones bidimensional, de manera que puedan estudiar con detalle la teoría subyacente, las propiedades más importantes y su aplicación a ejemplos reales. Por otra parte también es recomendable su uso en aquellas asignaturas de cálculo numérico de las ingenierías dedicadas a la resolución de problemas de valores iniciales por medio del método de las diferencias finitas.

Durante el curso 2013-2014 se realizó una practica de laboratorio de ordenador en la asignatura Métodos Matemáticos del grado en Ingeniería en Tecnologías Industriales en donde se estudió la aplicación del método de las diferencias finitas con mallados rectangulares para el estudio de la ecuación del calor, la ecuación de ondas y el problema de valores propios para el laplaciano. En este último caso se utilizó también la aplicación docente vibrahex por parte de los alumnos, lo que les permitió profundizar en el método de las diferencias finitas en mallados hexagonales, compararlo con el de mallados 
rectangulares y trabajar con una aplicación interesante de la ingeniería. La experiencia puede calificarse de muy fructífera.

\section{Conclusiones}

El laboratorio virtual que presentamos puede representar una excelente herramienta, desde el punto de vista docente, para el estudio de los modos normales de vibración de una membrana con borde fijo o libre, dada su facilidad de uso e inmediatez en la generación de los diagramas correspondientes. Puede usarse en asignaturas de Física y Resistencia de Materiales en las carreras de Ingeniería Técnica. También puede ser útil en asignaturas de Cálculo Numérico en donde se trabaje con el método de las diferencias finitas. En posteriores trabajos, los autores pretendemos aumentar el campo de aplicación de este laboratorio virtual para el caso de condiciones de frontera.

\section{Agradecimientos}

Los autores agradecen al Instituto de Ciencias de la Educación de la Universitat Politècnica de València por su ayuda al Equipo de Innovación y Calidad Educativa MOMA.

\section{Referencias}

ARION, D. N., CROSBY, K. M. y MURPHY, E.A. (2000). "Case Study Experiments in the Introductory Physics Curriculum". The Physics Teacher, 38 (6), pp. 373-376.

BARRAGAN, D. La web de MATLAB, SIMULINK, VHDL, microcontroladores... http://www.matpic.com (2014)

BENITO, A., PORTELA, A. y Rodríguez, R. M. (2006). "Análisis de la enseñanza de la Física en Europa: el fomento de competencias generales en estudiantes universitarios". Revista Iberoamericana de Educación, número 38/7.

CASASÚS, A. (2011) Aplicación del método de las diferencias finitas generalizadas a problemas de elasto-dinámica. Tesis Doctoral, ETS Ingenieros Industriales, UNED.

DEPCIK, C. y ASSANIS, D.N. (2005). "Graphical user interfaces in an engineer in educational environment”. Comput. Appl. Eng. Educ. Vol. 13.

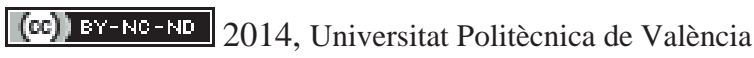

I Jornadas IN-RED (2014) 
Un laboratorio virtual pare el estudio de vibraciones en membranas a partir de mallados hexagonales

GIMÉNEZ, F., GÍMENEZ, J. F. y MONSORIU, J. M. (2014). "Digital simulation of plate resonances using Matlab", en Giménez, F., Giménez, J. F. y Monsoriu, J. A. Proceedings of INTED2014 Conference, Valencia.

KINSLER, L. E. (1988). Fundamentos de Acústica, Ed. Limusa.

MCDERMOTT, L. C., SHAFFER P. S. y CONSTANTINOU, C. P. (2000). "Preparing Teachers to Teach Physics and Physical Science by Inquiry". Physics Education, 35 (6), pp. 411-416.

WATTS , C. (1991). The Science of Problem Solving: A Practical Guide for Science Teachers, Cassell Educational, London. 


\title{
El diccionario visual como introducción al conocimiento de la construcción arquitectónica
}

\author{
Vicente López Mateu ${ }^{a}$, Santiago Tormo Esteve ${ }^{b}$ y Javier Benlloch Marco ${ }^{c}$ \\ ${ }^{a}$ Departamento de construcciones arquitectónicas Universitat Politécnica de Valencia \\ viloma@csa.upv.es, ${ }^{\mathrm{b}}$ Departamento de construcciones arquitectónicas Universitat Politécnica de \\ Valencia santores@gmail.com ${ }^{\mathrm{c}}$ Departamento de construcciones arquitectónicas Universitat \\ Politécnica de Valencia jbenllo@csa.upv.es
}

\begin{abstract}
La asignatura Introducción a la Construcción del grado de arquitectura es la primera que aborda el descubrimiento de la materialidad propia de la arquitectura. Está enfocada hacia el reconocimiento de los elementos que forman los edificios y sus fases de construcción básicas. En el proceso de aprendizaje los estudiantes entran en el mundo de la construcción a través de prácticas en las que aparecen numerosos conceptos y términos complejos que inicialmente desconocen. Por lo tanto, una de las primeras necesidades es el reconocimiento y uso adecuado de una terminología técnica propia de la arquitectura y particular de la construcción. Tras varios años de docencia, se ha desarrollado y mejorado una práctica específica para este fin que se denomina Diccionario Visual de Términos Arquitectónicos. Está basada en el trabajo autónomo de los alumnos durante todo el periodo de docencia con la tutorización y revisiones de los profesores. Consiste en la búsqueda, clasificación y reconocimiento de una serie de términos constructivos. Esta herramienta docente ha resultado básica para el rápido desarrollo de las habilidades y competencias de comprensión, descripción y expresión de los alumnos. Se aportan en esta comunicación el proceso de génesis, desarrollo y resultados de esta metodología activa de aprendizaje.
\end{abstract}

Keywords: enseñanza en construcción, aprendizaje autónomo, formación en construcción arquitectónica, reconocimiento constructivo visual.

(c) $)$ EY-NC-ND 2014, Universitat Politècnica de València

I Jornadas In-Red (2014) 
El diccionario visual como introducción al conocimiento de la construcción arquitectónica

\begin{abstract}
The subject "Introducción a la Construcción" of the architecture degree is the first that deals with the discovery of the materiality characteristic from architecture. It is focused on the recognition of the basic elements that make up the buildings and their construction stage. In the learning process, students are introduced in the world of construction through different practices in which there are many concepts and complex terms that initially are unknown for them. Therefore, one of the first needs for these students is recognition and proper use of technical terminology of the architecture and construction particularly. After several years of teaching, it has been developed and improved a specific practice for this purpose which is called "Diccionario visual de Términos Arquitectónicos". This practice is based on the independent work of students during the entire period of teaching, with the tutoring and review of teachers. The task consists of the search, classification and recognition of a building terminology list. This teaching tool has been essential to the rapid development of the skills and competences of understanding, description and expression of the students. This paper provides the genesis, development and results of this active learning methodology process.
\end{abstract}

Keywords: education in building technology, autonomous learning, training in architectural construction, constructive visual recognition.

\title{
Introducción
}

La asignatura de Introducción a la Construcción inició su docencia en el curso 2002-2003, siendo dirigida y coordinada por la arquitecta y catedrática del Departamento de Construcciones Arquitectónicas Da Liliana Palaia Pérez. Posteriormente en el año 20052006 se realizó la adaptación al EEES y recientemente en el curso 2009-2010 al actual plan de estudios de grado en fundamentos de la arquitectura. Como asignatura de nueva creación venía a cubrir un vacío fundamental en la formación inicial de los arquitectos, el aprendizaje preparatorio en aspectos constructivos. Se trataba fundamentalmente del reconocimiento de elementos, sistemas y procesos que forman parte de un edificio y llevan a un proyecto de edificación a convertirse en realidad. En este ámbito la combinación equilibrada de los aspectos creativos y técnicos en la formación de los futuros arquitectos es fundamental, y requiere de una base sólida con su propio lenguaje y vocabulario, en definitiva, entender desde el principio la importancia de la materialidad en la arquitectura.

(c)) EY-NC-ND 2014, Universitat Politècnica de València

I Jornadas IN-RED (2014) 


\section{Objetivos}

El objetivo principal de esta innovación docente que se viene realizando como práctica durante el periodo lectivo (un cuatrimestre) es desarrollar de forma rápida en los alumnos las capacidades de reconocimiento visual, comprensión y descripción de los términos arquitectónicos y constructivos.

Esto resulta clave para los estudiantes de nuevo ingreso ya que en poco tiempo deben reconocer y aprender mucha terminología de tipo técnico que resulta esencial para su formación en esta asignatura y para otras que desarrollan simultáneamente o se desarrollarán en el resto de sus estudios de arquitectura.

Al mismo tiempo, con esta actividad se busca una serie de objetivos genéricos o transversales que pueden resumirse en los siguientes:

- Buscar información de forma autónoma

- Interpretar y elaborar la información

- Reconocer e identificar elementos complejos.

- Clasificar y sintetizar la información

- Explicar y resumir cuestiones técnicas complejas

- Localizar, datar y citar adecuadamente las fuentes utilizadas.

Debe tenerse en cuenta que resulta primordial que los estudiantes puedan desarrollar estas competencias de manera autónoma, simultánea, activa y coordinada durante todo el trabajo, con el rigor universitario que resulta necesario. Este planteamiento a los estudiantes el control y los hace responsables de su aprendizaje,

El desafío y la cuestión fundamental de estos objetivos planteados es elaborar y desarrollar una tarea que fuera suficientemente completa, dinámica y atractiva para los alumnos, pudiéndola realizar en un espacio muy breve de tiempo. El planteamiento general desarrolla la independencia y autonomía del estudiante para la organización temporal.

\section{Desarrollo de la innovación}

\subsection{Organización y metodología general}

La actividad consiste fundamentalmente en elaborar un diccionario gráfico con fotografías en las que se interpretan y señalan los términos, indicándose junto a ellos su definición. Esta definición, o más bien explicación, debe ser propia de cada alumno, a partir de la documentación e información que se haya recabado previamente para reconocer el término o elemento constructivo concreto.

El trabajo es cooperativo, se realiza en grupos que han ido variando según los cursos de tres a cuatro alumnos, pudiéndose confeccionar en castellano o en valenciano. Alternativamente

\section{(c) EY-NC-ND 2014, Universitat Politècnica de València}

I Jornadas IN-RED (2014) 
se puede introducir los nombres de los términos en otros idiomas, siendo los más habituales el inglés, francés o el italiano, pero se han dado casos también de otros idiomas como rumano.

Este hecho ha resultado especialmente interesante y útil tanto para nuestros alumnos, que van introduciéndose en otros idiomas como para alumnos procedentes de otros países, principalmente ERASMUS, los que han manifestado que les resulta especialmente útil y provechoso.

La metodología propuesta consiste en la búsqueda de las definiciones a partir de una relación de términos predeterminada y cambiante cada curso académico. Los términos propuestos actualmente son doscientos, repartidos en todas las unidades temáticas que se estudian en el programa de la asignatura, que tendrán que clasificar y agrupar por temas a través de un índice.

\subsection{Formatos y medios utilizados}

En los primeros cursos en los que se planteó esta actividad se dieron unas indicaciones básicas: organización general y estructura del trabajo, tamaño de papel, etc. Los resultados fueron buenos pero se produjo una gran dispersión de formas de entrega, llegando incluso algunas a lo anecdótico.

Para evitar que esto sucediera y que los alumnos emplearan un tiempo muy valioso en el formato o programa concreto, se les facilitan actualmente varias plantillas realizadas con distintos programas informáticos, para que las pueden emplear como directamente o como guíra para realizar su propia maquetación del trabajo.

No obstante, se deja libertad para realizarlo de cualquier otra forma con unas normas mínimas de entrega, que se realice dentro de las dimensiones de un A4, ya sea vertical u horizontal, y que la presentación sea en formato digital u opcionalmente en papel.

El empleo de estas plantillas permite unificar los trabajos, facilita su organización, revisión y corrección. Cada vez es mayoritario el número de alumnos que entregan estas prácticas de en formato digital, lo cual supone un ahorro considerable de medios y recursos, así como la rápida transmisión y verificación de los trabajos.

El listado cada año es cambiante para evitar la copia de los trabajos de años anteriores y se requiere que se indique el emplazamiento y la fecha en que se han realizado la fotografías, no aceptándose fotografías de años anteriores, por lo que resulta relativamente sencillo verificar si las imágenes son originales con los medios actualmente disponibles. 

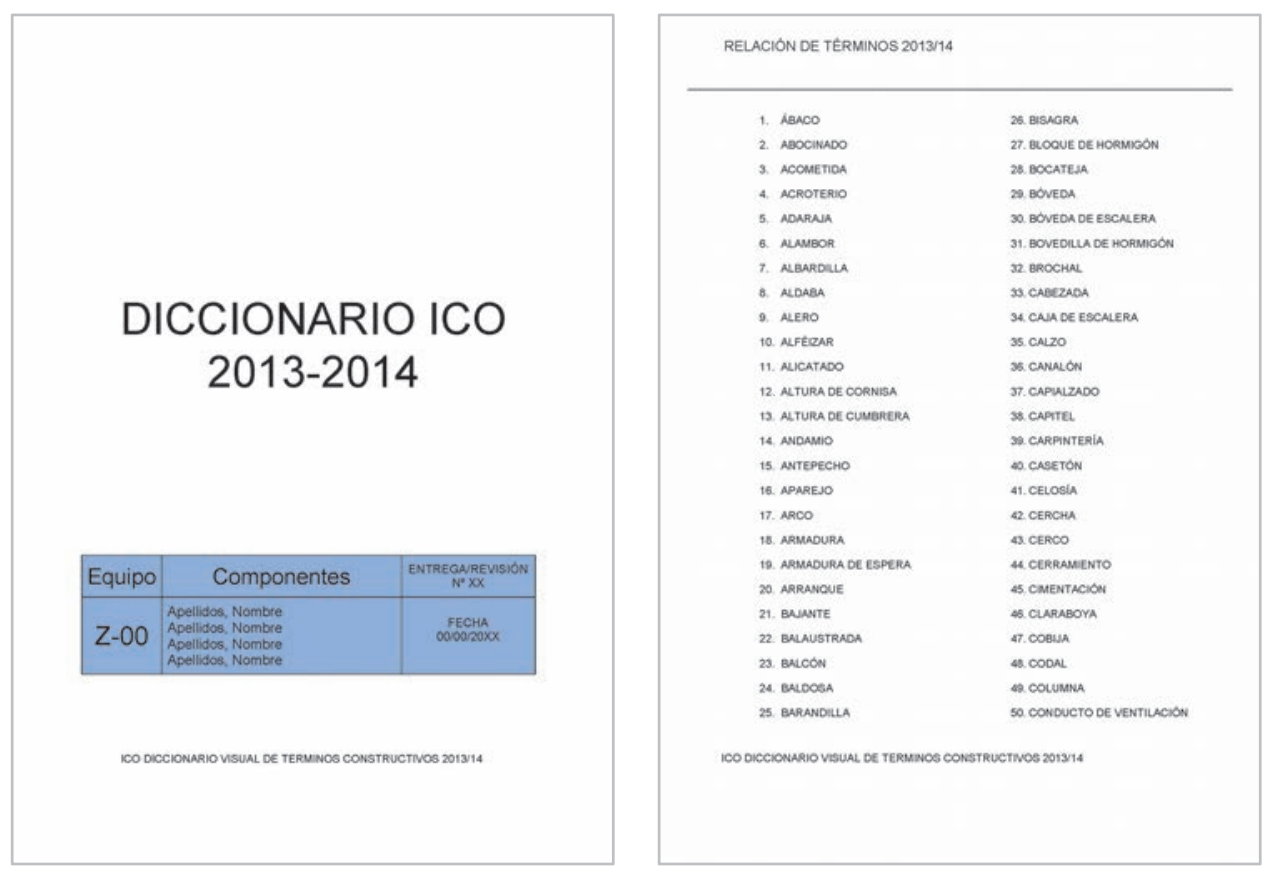

Fig. 1 y 2 Formato básico propuesto a los alumnos para la entrega y lista de términos que deben localizar ordenada inicialmente de manera alfabética

El formato de las entregas intermedias y final es de documentos PDF sin protección, con identificación en el archivo del grupo y los componentes, lo que permite su clasificación de forma sencilla. Esto permite su entrega, revisión y corrección sencilla a través de la plataforma PoliformaT, permitiendo comentarios, notas y en su caso reenvíos de la tarea. Este feedback es imprescindible para conseguir dos objetivos: el esfuerzo progresivo y el reconocimiento del propio proceso de aprendizaje.

Para distinguir los grupos y realizar la clasificación de los términos los alumnos utilizan abundantes recursos gráficos, como colores, flechas, símbolos, etc., (como puede apreciarse en las imágenes adjuntas) lo que permite que el conjunto del trabajo sea muy legible. A su vez resulta una herramienta de estudio muy adecuada, ya que esta información la pueden utilizar para su estudio y consulta en preparación de las pruebas objetivas.

El empleo de estos medios, nomenclaturas y forma de intercambio de archivos supone también un avance en su formación de los estudiantes enfocada hacia el trabajo profesional, ya que actualmente los proyectos profesionales se desarrollan utilizando medios y tecnologías similares para su presentación o transmisión y en su caso verificación.

\section{(c)) EY-NC-ND 2014, Universitat Politècnica de València}

I Jornadas IN-RED (2014) 

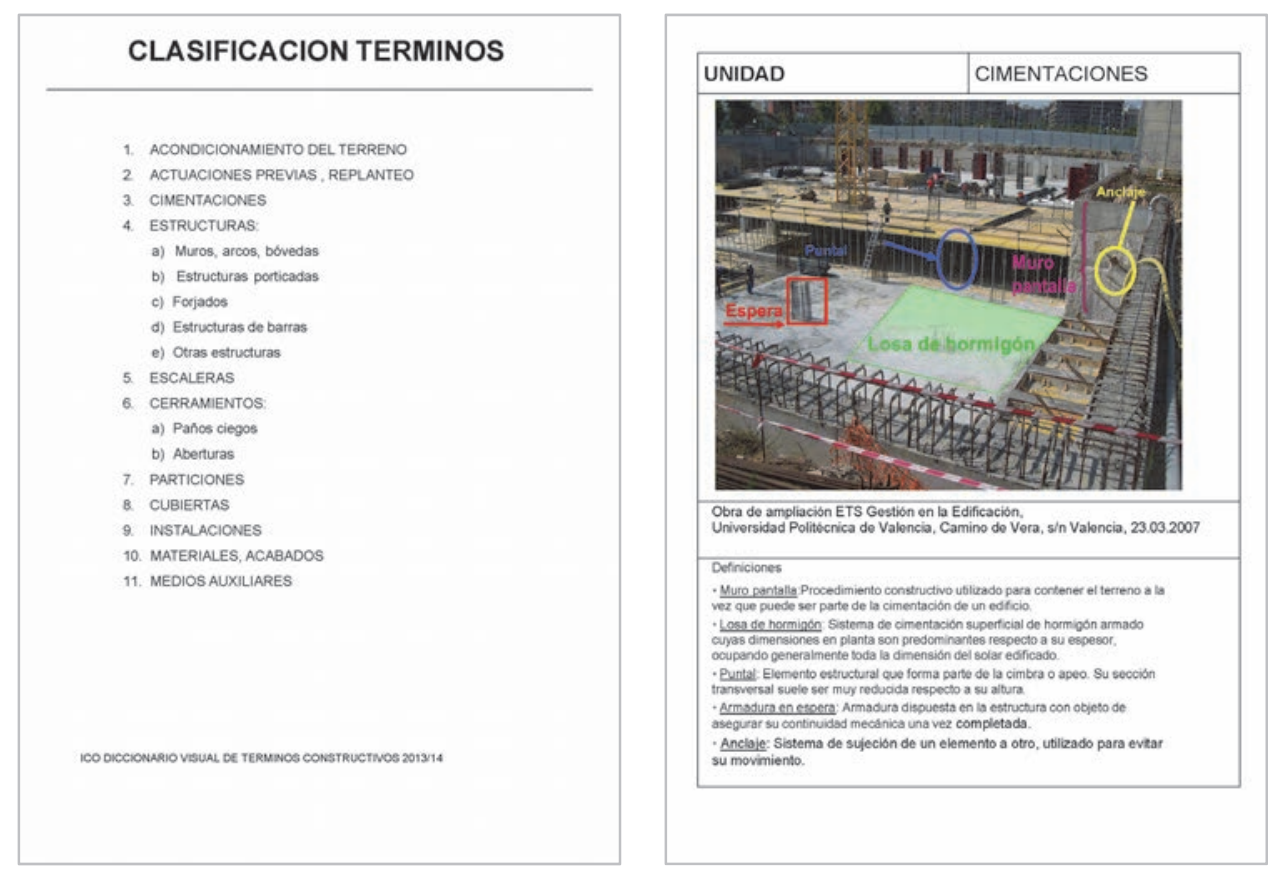

Fig.3 y 4 Grupos de clasificación propuestos y página que se propone como modelo de trabajo en la que se encuentra la fotografía de un edificio en construcción, la identificación de los términos y las definiciones

\subsection{Fuentes consultadas}

Los alumnos pueden localizar los términos a través de las fuentes que elijan, bien documentales, como los diccionarios propuestos en la bibliografía, recursos informáticos páginas web, catálogos, etc. Resulta fundamental que los recursos recomendados y seleccionados por los profesores combinen los componentes escritos y gráficos para que resulte más fácil y productiva la consulta.

Con esta primera búsqueda los alumnos tienen la referencia del término. En cualquier caso, resulta indispensable que se realice una elaboración propia de las definiciones evitando la copia poco reflexiva que a veces llega a una lectura muy breve en la que no se comprende realmente el contenido.

Posteriormente se propone un índice dentro del cual los términos se van agrupando por temas, familias o tipologías constructivas. La clasificación se realiza al principio y se va repasando y revisando a medida que se avanza en los contenidos de la asignatura. De esta manera los alumnos van adelantando conocimientos y explorándolos ellos mismos, a la vez que posteriormente los corrigen en función de su avance en la asignatura. 

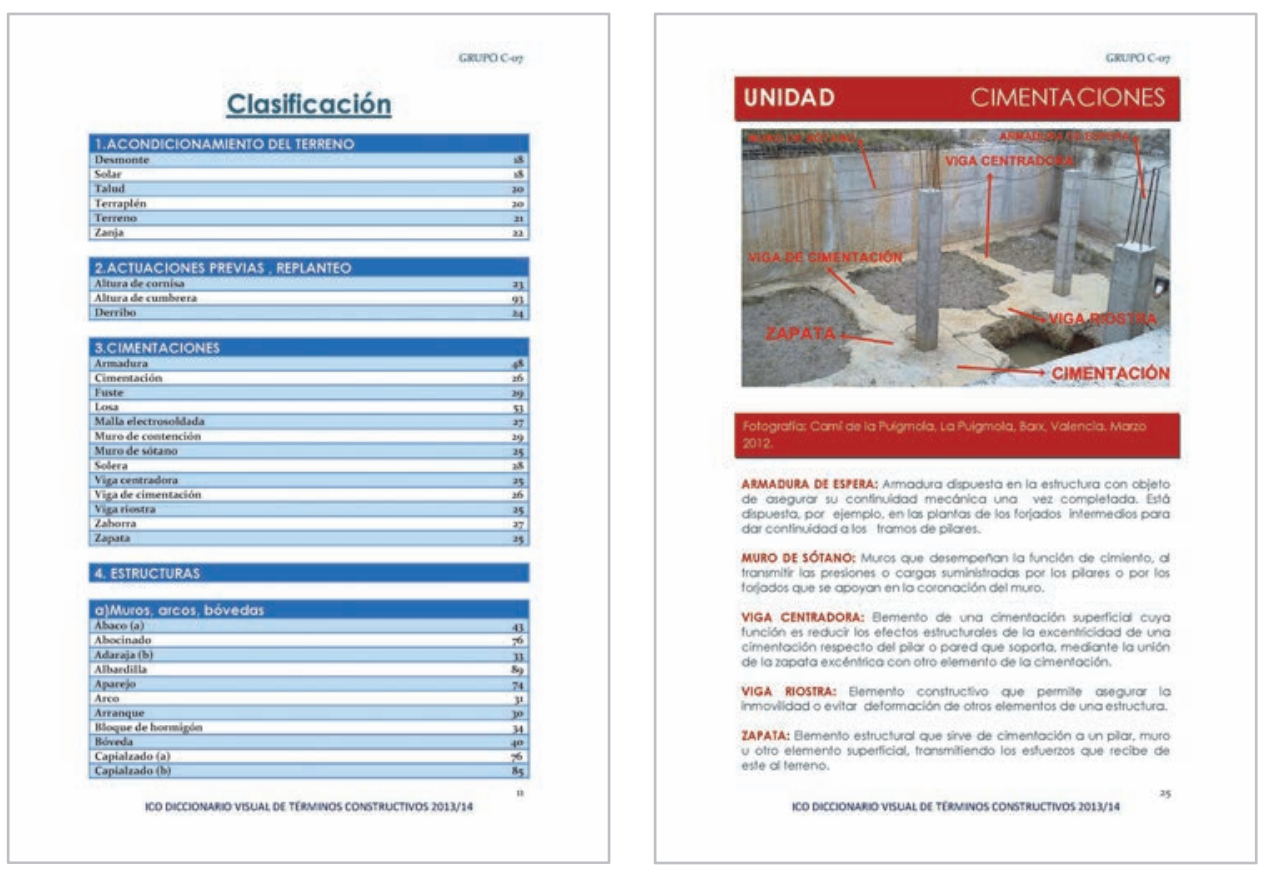

Fig.5 y 6 Imágenes dela clasificación y páginas intermedias de los trabajos realizados. (Fuente trabajo 2013_14, alumnos: Climent, A., De Blas M.,Maestro, L, Punter, S.).

Se produce también un aprendizaje cooperativo ya que al principio suelen realizar una división del trabajo por número de términos, pero pronto descubren que los términos están relacionados unos con otros y deben clasificarlos de manera colectiva, lo que obliga a varias reflexiones dentro del grupo. Asimismo, ante dificultades o falta de acuerdo en el grupo se produce el aprendizaje guiado y tutorizado, recurriendo a las tutorías y a las indicaciones de los profesores.

Cada término debe quedar identificado en una fotografía que el alumno haya realizado, con localización y fecha para una mejor contextualización e identificación del entorno, en el que se visualice claramente ese elemento. Con esto se consigue un mayor esfuerzo de reconocimiento ya que se aplica cada definición a la realidad, buscando en todas las manifestaciones arquitectónicas y constructivas los términos que están aprendiendo.

La escala también varía, desde los elementos o edificios en su conjunto: su estructura parte desde los cerramientos exteriores, cubierta, etc., a pequeños detalles interiores como pueden ser las escaleras o elementos de revestimiento o acabado. Todos ellos son importantes y de esta manera los estudiantes reconocen también la visión general y las distintas escalas.

\section{(cc) EY-NC-ND 2014, Universitat Politècnica de València}

I Jornadas IN-RED (2014) 

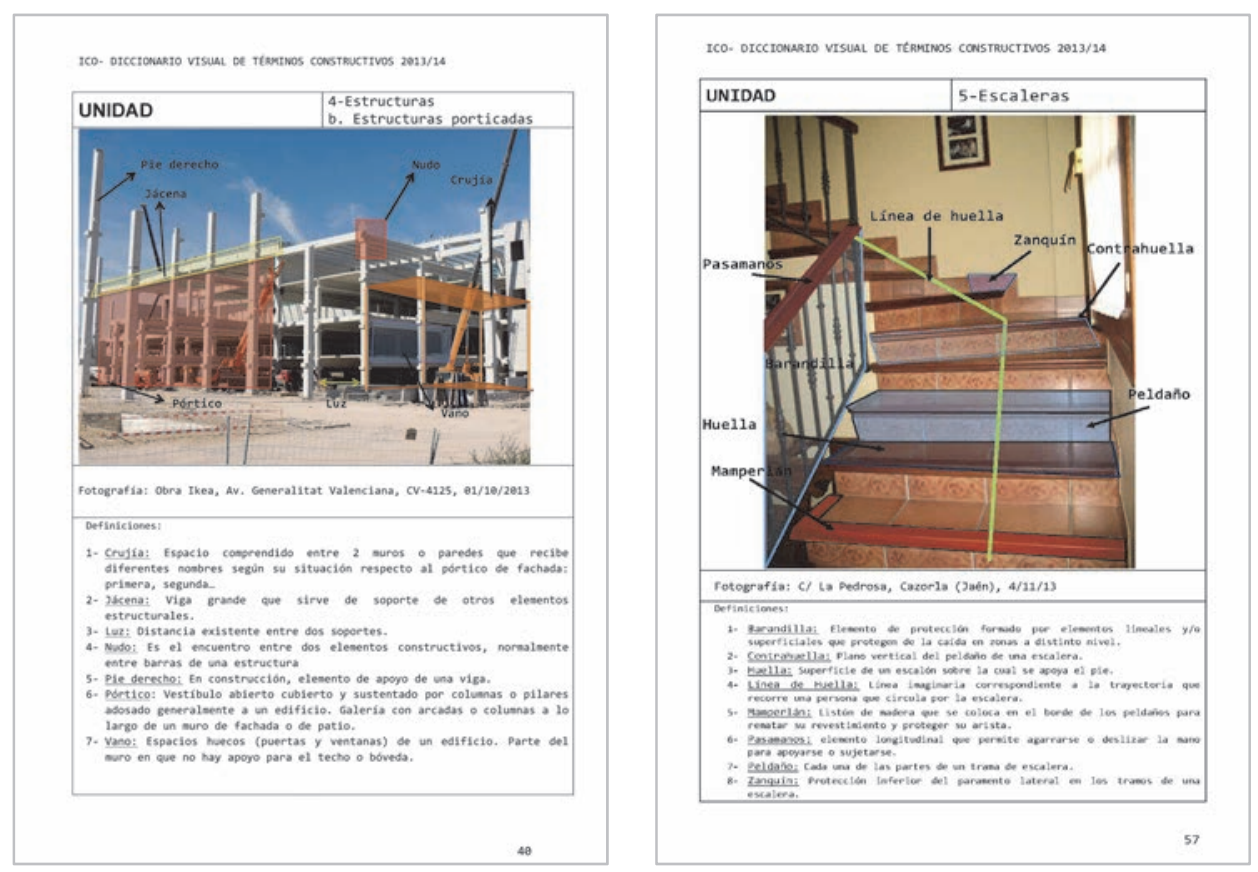

Fig.7 y 8 Imágenes de páginas intermedias de los trabajos realizados por los alumnos.

(Fuente trabajo 2013_14, alumnos: Burgos, M. , Peiro, J, Pérez, A., Pérez, F.M.).

Se procura que para reducir la extensión del trabajo y por la propia didáctica del mismo en una sola imagen aparezcan el mayor número de términos posibles y que dichos términos pertenezcan a la misma unidad o grupo de clasificación inicial. De esta manera las imágenes tienen que ser seguir esta pauta, evitando que sean tomadas o seleccionadas de forma aleatoria.

La revisión y seguimiento de este trabajo en tutorías consiste en la aclaración de dudas sobre las palabras más complejas, que presentan dificultades de comprensión o diferenciación. En algunos casos se presta atención puntual a la formalización propiamente del trabajo y ocasionalmente a su exposición o revisión en el aula ante los compañeros.

\subsection{Retos y dificultades}

Uno de los grandes retos para los alumnos es encontrar todas las palabras del listado, que como se ha indicado anteriormente es cambiante. Este listado debe ser estudiado detenidamente por los profesores para que los términos no resulten muy complejos de localizar, teniendo en cuenta sobre todo que hoy en día el número de obras y la actividad en la construcción ha descendido notablemente. 
Otra de las peculiaridades a las que se enfrentan, son las palabras sinónimas (con idéntico o similar significado) o las homónimas, aquellas que según el contexto pueden tener significados o matices diferentes. En estos casos es donde se produce el mayor esfuerzo de los alumnos, ya que casi siempre constituyen las preguntas más frecuentes durante las revisiones que se realizan a lo largo del curso. De esta manera se consigue un esfuerzo gradual, que les lleva a niveles más complejos de aprendizaje.

El reto que supone este trabajo y el interés que desarrolla en los alumnos les lleva a fijarse activamente en los edificios, preguntar en aquellos lugares que se encuentran en construcción a los encargados, jefes de obra, o dirección facultativa, aunque no puedan acceder siempre a las obras por motivos de seguridad.

Se consigue de esta forma que el trabajo trascienda el ámbito de las aulas y que los estudiantes busquen en el ámbito que les rodea y se involucren todavía más en el campo profesional que dentro de unos años desarrollarán. Esto enlaza directamente con el carácter de tipo práctico y aplicado de la asignatura.

\section{Resultados}

\subsection{Valoraciones y datos obtenidos}

Han sido numerosos los reconocimientos recibidos por la asignatura en general y para este trabajo en particular por parte de la Dirección de la ETSAV en los primeros años de docencia (curso 2002-2003) y de los profesores de otras asignaturas, pues se trata de unos elementos y un lenguaje técnico común a todas ellas.

Este trabajo tiene un peso en la nota final del $25 \%$ y las notas medias obtenidas en el mismo en los últimos cursos en todos los grupos superan la nota de 7,50 puntos, siendo también bastantes grupos, aproximadamente un 10\%, los que alcanzan una calificación de sobresaliente.

En las encuestas realizadas anualmente siempre se valora positivamente este trabajo en concreto por encima de un $70 \%$ de los alumnos consideran que el trabajo resulta útil o muy útil para el reconocimiento de los términos constructivos.

\subsection{Revisión y propuestas de mejora}

Sin embargo en los recientes resultados del curso 2013-14 empiezan a darse algunos casos aislados pero cada vez más frecuentes de reproducción parcial de trabajos de cursos anteriores. Esto nos lleva a que en estos momentos los profesores estemos planteando una revisión de esta actividad.

En este sentido caben plantearse revisiones intermedias, pequeños controles o seguimientos del trabajo realizado por los alumnos, aunque dado el volumen de trabajo que esto supone

\section{(cc) EY-NC-ND 2014, Universitat Politècnica de València}

I Jornadas IN-RED (2014) 
requiere el apoyo de plataformas que permitan realizar pruebas objetivas de tipo sencillo y rápido.

Hay que procurar establecer un número recomendado y máximo de medios de consulta, ya que los estudiantes tienden a la dispersión, al recurso más sencillo y a una verificación de las fuentes muy somera o inexistente.

Resulta necesario también establecer un mayor número de controles o revisiones ya que la organización del tiempo y su gestión por parte de los alumnos resulta compleja en las primeras etapas de formación universitaria.

\subsection{Aplicación en otros ámbitos de la docencia}

Aunque se desconocen experiencias similares en otros campos de la docencia, cabe entender que esta metodología es fácilmente trasladable a otras disciplinas en las cuales sea necesario introducir un vocabulario técnico específico de forma visual, buscando un aprendizaje lo más rápido posible.

En otros campos donde se trate de conceptos ideas o contenidos más generales o abstractos resultaría un poco compleja su traslación.

\section{Referencias}

CRISPÍN BERNARDO, M.L., coord.(2011), Aprendizaje autónomo : orientaciones para la docencia. Mexico Universidad Iberoamericana, AC

LÓPEZ MATEU, V., PALAIA PÉREZ, L., BENLLOCH MARCO, J., (2006). "Estrategias y experiencias en el aprendizaje inicial de Construcción Arquitectónica dentro del Espacio Europeo de Educación Superior" Universidad de Salamanca. En I Jornadas de Innovación Educativa de la Escuela Politécnica Superior de Zamora Páginas 1-9

LÓPEZ MATEU, V., TORMO ESTEVE, S., ALVAREZ GONZALEZ, M.A., BENLLOCH MARCO, J., (2013). "Estrategias y experiencias en el aprendizaje inicial de Construcción Arquitectónica dentro del Espacio Europeo de Educación Superior" Cabrera I., Ferrer, C. (ed.). En Arquitectura v2020. La enseñanza y la profesión del arquitecto en un mundo en cambio. Valencia: Editorial. Universidad Politécnica de Valencia Páginas 69-77.

MAS TOMAS, A., BLASCO GARCIA, V., GONZALEZ PEREZ, G., GIL BENSO, E (2007) “Tecnología arquitectónica, construcción” En V Jornades de Xarxes d'Investigació en Docència Universitària [Recurso electrónico]: V Jornadas de Redes de Investigación en Docencia Universitaria. Paginas 41-45 


\title{
Metodología activa en las clases de laboratorio de Matemáticas III en el segundo año del Grado en Ingeniería
}

\author{
Sergio Blanes ${ }^{a}$, Santiago-E. Moll ${ }^{b}$, José-V. Romero ${ }^{c}$, María-D. Roselló ${ }^{d}$ \\ åDepto de Matemática Aplicada, Universitat Politècnica de València, Spain, serblaza@mat.upv.es, \\ bepto de Matemática Aplicada, Universitat Politècnica de València, Spain, sanmollp@mat.upv.es, \\ ${ }^{c}$ Depto de Matemática Aplicada, Universitat Politècnica de València, Spain, jvromero@mat.upv.es, \\ ${ }^{\mathrm{d}}$ Depto de Matemática Aplicada, Universitat Politècnica de València, Spain, drosello@ mat.upv.es.
}

\begin{abstract}
Based in the new technologies and educational innovation promoted by the UPV, and in particular by the School of Design Engineering, we have adapted the methodology and assessment of students in Mathematics III, subject in the second year in Aerospace Engineering, trying to stimulate the learning and make it compatible with new technologies and the math skills needed in this course. For this reason lab sessions are structured in three stages. In the first stage, students, following guidelines established by the teachers, prepare the session independently. In the second phase, which takes place in the laboratory sessions, students have the opportunity to strengthen these concepts. The third stage begins when the student is provided with the feedback of the test. This methodology has achieved very good results in monitoring classes, and has reduced absenteeism, achieving very good partial results. We have made a survey with the corresponding PoliformaT tool to obtain information about the sessions and student assessment.
\end{abstract}

Keywords: Laboratory sessions, educational platform, mathematics, engineering.

\section{Resumen}

Siguiendo la línea de innovación educativa y nuevas tecnologías promovida por la UPV, y en concreto por la Escuela Técnica Superior de Ingeniería del Diseño, hemos adaptado la metodología y evaluación de los estudiantes de Matemáticas III, asignatura de segundo curso del grado en Ingeniería Aeroespacial, para tratar de dinamizar el aprendizaje y compatibilizarlo con

(cc) EY-NC-ND 2014, Universitat Politècnica de València

I Jornadas In-Red (2014) 
Metodología activa en las clases de laboratorio de Matemáticas III en el segundo año del Grado en Ingeniería

las nuevas tecnologías y competencias matemáticas necesarias en este curso de grado. Para ello se han estructurado las clases de laboratorio en tres fases. En la primera, los estudiantes, siguiendo unas pautas establecidas por los docentes, preparan la sesión de forma autónoma. En la segunda fase, que tiene lugar en la sesión de laboratorio, los estudiantes tienen la oportunidad de afianzar esos conceptos. La tercera fase comienza cuando se proporciona al estudiante feedback de forma inmediata. Esta metodología, hasta la fecha ha conseguido muy buenos resultados en el seguimiento de las clases, y se ha reducido el ausentismo, alcanzando muy buenos resultados parciales. Se ha elaborado un sondeo con la herramienta correspondiente del PoliformaT, para recabar información sobre las sesiones y la evaluación de los estudiantes. Se presenta un estudio con las opiniones.

Palabras clave: Clases de laboratorio de Matemáticas, plataforma educativa, matemáticas en ingeniería.

\section{Introducción}

El Grado en Ingeniería Aeroespacial, de 4 años de duración, se imparte en la Escuela Técnica Superior de Ingeniería del Diseño (ETSID) de la Universitat Politècnica de València (UPV). Las asignaturas de matemáticas se imparten en primer y segundo curso y, excepto estadística, se imparten en tres materias: Matemáticas I, Matemáticas II y Matemáticas III que han sido asignadas al Departamento de Matemática Aplicada de la UPV, en el cual se encuentran integrados los autores. La asignatura de Estadística se imparte en segundo curso, pero por el Departamento de Estadística Aplicada e Investigación Operativa y Calidad, que está a cargo de las asignaturas de Estadística en la ETSID.

Matemáticas I es una asignatura de primer curso, anual, de 12 créditos (9 créditos de teoría/problemas y 3 créditos de prácticas de laboratorio). Matemáticas II es una asignatura de segundo año de 6 créditos ( 4.5 créditos de teoría/problemas y 1.5 créditos de prácticas de laboratorio) que se imparte en el tercer semestre, y Matemáticas III es una asignatura que se imparte en el cuarto semestre de 6 créditos (4.5 créditos de teoría/problemas y 1.5 créditos de prácticas de laboratorio), [UPV].

Los conocimientos de matemáticas de los estudiantes de ingeniería son diferentes si comparamos a los estudiantes de nuevo ingreso y de segundo año. El background de los primeros es heterogéneo, en cambio el de los segundos es bastante más homogéneo. Esto se pone de manifiesto en la forma en que las sesiones de laboratorio se incorporan a la asignatura. En el primer año académico los estudiantes son alentados a trabajar de forma 
autónoma de forma que puedan homogeneizar las habilidades requeridas para sus estudios. Sin embargo, los estudiantes de segundo año son más homogéneos en cuanto a los conocimientos y habilidades matemáticas, y están ya más acostumbrados a la metodología educativa. Por lo tanto los profesores pueden concentrarse en desarrollar contenidos adecuados para maximizar el aprendizaje de los estudiantes.

Por otra parte, la UPV ha construido una plataforma educativa basada en la plataforma educativa SAKAI. Esta plataforma es conocida como PoliformaT e incluye diferentes herramientas como pueden ser Recursos, Dropbox, Chat, Mensajes, Tareas y evaluaciones online, entre otras. Este cambio tecnológico ha proporcionado la oportunidad para mejorar y modernizar las posibilidades de aprendizaje y la asimilación de competencias de nuestros estudiantes. Hemos empezado aplicando esta plataforma en las sesiones de laboratorio y en la presentación de tareas.

Los sistemas algebraicos computarizados estándar (CAS, de sus siglas en inglés) son usados comúnmente por los profesores de ingeniería, (Tonkes, 2005, Aslaken, 1995, Franco, 2000). Cómo incorporar estos sistemas a las sesiones de prácticas y a su correspondiente evaluación es un asunto clave. La UPV dispone de una licencia de campus de los programas MATHEMATICA y MATLAB. Estos CAS tienen diferentes capacidades que nuestros estudiantes pueden aprovechar de forma temporal en las diferentes asignaturas de matemáticas.

El principal objetivo de la metodología descrita en este artículo, para la asignatura de Matemáticas III del segundo año del Grado en Ingeniería Aeroespacial, es evitar el abandono estudiantil intentando incrementar el interés por la asignatura, así como la asimilación de las competencias necesarias.

El artículo se organiza como sigue: En la sección 1 se describen las principales características de la asignatura de matemáticas de segundo año, Matemáticas III. En la sección 2 presentamos la metodología y la evaluación de competencias usada en la asignatura Matemáticas III durante el año académico 2013/14. La nueva metodología combina clases tradicionales con nuevas tecnologías. Por último en la Sección 3 se presentan los resultados parciales obtenidos en Matemáticas III por los estudiantes, además de algunos comentarios y propuestas de mejora.

\section{Objetivo: Clases de Matemáticas durante el segundo curso}

La asignatura de matemáticas de segundo año, Matemáticas III, es obligatoria para los estudiantes de ingeniería de segundo año. Estos estudiantes han cursado Matemáticas I en el primer año de carrera.

En el año 2013/14 se matricularon 120 alumnos, razón por la que si dividió a los estudiantes en dos grupos de Teoría/Problemas (TP): Uno de los grupos de 50 estudiantes y

\section{(c) EY-NC-ND 2014, Universitat Politècnica de València}

I Jornadas IN-RED (2014) 
Metodología activa en las clases de laboratorio de Matemáticas III en el segundo año del Grado en Ingeniería

el otro de 70. Esta diferencia es debida al hecho de que el primer grupo es impartido en inglés, y el máximo de alumnos permitidos en este tipo de grupos es de 50. El resto de estudiantes que no optaron por este grupo o su matrícula fue rechazada por diferentes razones (nota de corte insuficiente o nivel de inglés bajo) son matriculados en el otro grupo.

Los contenidos que se cubren en los dos grupos son los mismos, la única diferencia es la docencia en inglés. Estos estudiantes, a su vez, son divididos en 5 grupos de 25 estudiantes aproximadamente para las sesiones de laboratorio ( 2 impartidos en inglés y 3 en castellano).

Los temas impartidos en la asignatura de Matemáticas III son:

- Variable compleja: Funciones de variable compleja, series complejas numéricas y funcionales, transformadas integrales (Fourier y Laplace) y aplicaciones, la transformada Zeta y aplicaciones.

- Métodos numéricos: Modelización matemática en problemas de ingeniería, métodos numéricos para resolver problemas de valor inicial, métodos numéricos para resolver problemas de valor frontera.

En lo que respecta a las clases de laboratorio usamos el potencial de las CAS y los estudiantes aprenden su manejo. Todos los procedimientos en Matemáticas III son analíticos, por esta razón es conveniente el uso de los programas matemáticos. Los estudiantes de segundo curso están familiarizados con los programas pues los han utilizado en el curso anterior, en concreto el MATHEMATICA se usa de forma semanal en la asignatura de Matemáticas I (Moraño, 2012).

Por otra parte, Matemáticas III se divide en dos bloques diferentes: Variable Compleja y métodos numéricos. Para la parte de Variable Compleja se ha decidió usar el programa MATHEMATICA pues es más apropiado para los cálculos que se necesitan. En cambio para la parte de métodos numéricos se ha optado por el programa MATLAB ya que se los estudiantes han adquirido las destrezas necesarias con este programa en la asignatura de Programación y porque se adapta mejor al enfoque de la asignatura. Obviamente la UPV dispone de la correspondiente licencia de campus.

Como es sabido, hay muchos aspectos que diferencian un estudiante de nuevo ingreso y un estudiante de segundo curso. Entre estos aspectos se encuentran los conocimientos matemáticos. Durante el primer año, los conocimientos previos en matemáticas son bastante heterogéneos, en cambio en segundo curso los conocimientos son bastante homogéneos y autónomos a la hora de trabajar y desarrollar sus capacidades. Como los estudiantes están más acostumbrados a la metodología empleada, a trabajar en grupo e individualmente, podemos centrar nuestros esfuerzos en desarrollar contenido de forma que los estudiantes adquieran las capacidades específicas de cada materia. 
En cuanto a los laboratorios de matemáticas se refiere, tenemos que a diferencia de las clases de laboratorio de primer curso, estos tienen una duración de hora y media. Los alumnos de segundo curso al dominar más los programas que se emplean y estar acostumbrados a la metodología, pueden emplear más tiempo en desarrollar los conocimientos adquiridos.

\section{Desarrollo de la innovación: Metodología Empleada}

En esta sección se describe la metodología empleada en el curso académico 2013/14 en Matemáticas III, así como la evaluación de las competencias.

\section{A. Desarrollo y evaluación}

Como se discutió en la sección anterior, la asignatura de matemáticas impartida el segundo año académico Matemáticas III es de carácter semestral. Tiene 6 créditos distribuidos en 4.5 créditos de teoría/problemas y 1.5 créditos de laboratorio de prácticas.

Tanto en la metodología como la evaluación se distinguen dos componentes, la correspondiente a teoría/problemas (TP) y los laboratorios de matemáticas (ML).

La nota final $(F G)$ de los estudiantes viene dada por la fórmula

$$
F G=83 \% T P+17 \% M L
$$

Donde $T P$ representa la nota de teoría/problemas y $M L$ es la nota correspondiente a la parte de laboratorio de matemáticas. El valor máximo para $F G$ es 10 y la forma de obtenerlo es descrita en la siguiente sección. El mínimo valor para aprobar la asignatura es un 5 de un máximo de 10.

Notar que las prácticas de laboratorio tienen un peso relativamente pequeño, a pesar de que la componente práctica tiene un peso importante en la adquisición de competencias.

\section{B. Teoría y problemas}

Los 4.5 créditos de teoría/problemas se imparten en dos sesiones semanales de 1.5 horas cada una y durante 15 semanas. Al final de cada parte, el profesor propone una colección de problemas que los alumnos deben resolver de forma fluida. Si el estudiante no es capaz de resolverlos se le recomienda acudir a una tutoría con el profesor.

A lo largo del semestre se realizan tres exámenes. En cada uno de ellos se repasan los conceptos ya vistos y se plantean problemas clave. Esto permite medir el grado de adquisición de las competencias por parte de los estudiantes.

También, antes de cada examen, el estudiante debe realizar al menos una tarea. Los profesores usan la herramienta de la plataforma PoliformaT para asignarlas. La tarea debe

\section{(c) EY-NC-ND 2014, Universitat Politècnica de València}

I Jornadas IN-RED (2014) 
Metodología activa en las clases de laboratorio de Matemáticas III en el segundo año del Grado en Ingeniería

entregarse en mano. Estas tareas permiten al estudiante comprobar el nivel de conocimiento o el grado de competencia adquirido.

En Matemáticas III se usa un método mixto en el cual el estudiante de segundo curso introduce las respuestas de la tarea a través de la herramienta Exámenes del PoliformaT. Esta herramienta proporciona al estudiante la posibilidad de conocer su evaluación de forma rápida y con feedback de forma que el estudiante pueda preguntar dudas o consultar con el profesor, y por tanto consolidar el conocimiento. La nota provisional se completará con la valoración de las tareas entregadas a mano.

Finalmente, la nota de la parte de TP se obtiene mediante la fórmula

$$
T P=90 \% E x+10 \% \text { Ass }
$$

En esta fórmula, Ex representa a las notas de las pruebas de evaluación del grado y Ass es la nota de las tareas. El máximo valor de Ass es de 10.

Observamos que en (2) la calificación de Ass tiene poco peso debido al hecho de que no se realiza en ningún entorno controlado, a pesar de que son una parte fundamental para adquirir las competencias adecuadas.

\section{Laboratorio de Matemáticas}

Las clases de laboratorio de matemáticas tienen una duración de 1.5 horas y se imparten durante 10 semanas. Esto permite al docente algo de libertad para ajustarlas de la forma más apropiada. Cada clase de laboratorio tiene alrededor de 25 alumnos.

Cada sesión es evaluada, utilizando el programa adecuado.

El proceso se puede dividir en 3 etapas.

Etapa previa: Usando la herramienta Recursos de PoliformaT, los profesores proporcionan una guía con la parte de la asignatura que deberán preparar antes de la sesión de laboratorio (Bishop, 2013 y Mason, 2013). Esto incluye la parte de teoría que debe ser revisada y aspectos de computación para cada sesión. El estudiante debe trabajar de forma autónoma. En caso de que él alumno tenga alguna duda, estas pueden ser resueltas antes de la sesión de laboratorio usando la herramienta Mensajes o Chat del PoliformaT. Si la pregunta no puede ser resuelta por estos medios, el estudiante es alentado a acudir a una tutoría con el profesor.

Etapa in situ: Los primeros 30 minutos se dedican a discutir los aspectos estudiados por los estudiantes. Durante los últimos 60 minutos, los estudiantes de segundo curso tienen que resolver, usando el programa apropiado, los ejercicios y preguntas propuestas a través de la herramienta Exámenes de PoliformaT. Estos ejercicios deben realizarse por cada 
estudiante durante la clase de laboratorio. El instructor está disponible para que los estudiantes resuelvan dudas puntuales. En la última pregunta del test, el estudiante debe adjuntar el fichero (o ficheros) en el que se encuentran las instrucciones necesarias para resolver los ejercicios. De esta forma el profesor dispone, no sólo de los resultados numéricos, sino también de todo el procedimiento completo.

Etapa posterior: Los estudiantes pueden ver las preguntas que han realizado en el test, sus respuestas y la puntuación de cada pregunta, junto con la respuesta correcta del ejercicio. En esta etapa, si el estudiante tiene errores en el test, debe saber cuáles son. Si algún estudiante no sabe todavía como hacer alguna tarea o no está de acuerdo con alguna parte del test, éste se reúne con el profesor para poder discutir las respuestas y la puntuación. En este proceso el profesor descarga el fichero del alumno y se revisa con el estudiante, de forma que la revisión de los conceptos pueda ser instructiva.

Con esta metodología se consigue que el estudiante trabaje de forma diaria. Las puntuaciones obtenidas en las sesiones de laboratorio influirán en la evaluación continua. Además los estudiantes necesitan comprender los conceptos trabajados en teoría/problemas para poder explotar al máximo el potencial de los programas de cálculo. Los estudiantes son capaces de conocer con esta metodología el grado de asimilación de los diversos conceptos clave de la asignatura antes de presentarse a los diferentes test. Además, de esta forma, evitamos el absentismo y por lo tanto posibles abandonos, pues los conceptos se introducen de forma gradual en la asignatura.

Las notas de $M L$ se obtienen como sigue

$$
M L=60 \% L E+40 \% A W L S
$$

Donde $L E$ representa a las notas de los exámenes de laboratorio y $A W L S$ las notas de las sesiones semanales de laboratorio. El valor máximo de $L E$ y $A W L S$ es de 10.

\section{Resultados}

En la Tabla I se presentan los resultados obtenidos por los estudiantes de Matemáticas III. La notación usada es la misma que hemos empleado a lo largo del artículo. En cada celda encontramos el número de estudiantes que han obtenido cada una de las notas correspondientes a las mostradas en la primera fila. La nota final se encuentra en la última columna.

\section{(c) EY-NC-ND 2014, Universitat Politècnica de València}

I Jornadas IN-RED (2014) 
Metodología activa en las clases de laboratorio de Matemáticas III en el segundo año del Grado en Ingeniería

Tabla 1: Notas de los estudiantes

\begin{tabular}{|lccc|}
\hline & $E x$ & Ass & A WSL \\
\hline Excelente & 20 & 84 & 35 \\
\hline Notable & 40 & 30 & 74 \\
\hline Bien & 29 & 1 & 8 \\
\hline Aprobado & 13 & 2 & 3 \\
\hline Suspendido & 18 & 3 & 0 \\
\hline No presentado & 0 & 0 & 0 \\
\hline
\end{tabular}

Con respecto a las notas obtenidas en prácticas de laboratorio de forma semanal tenemos los siguientes resultados

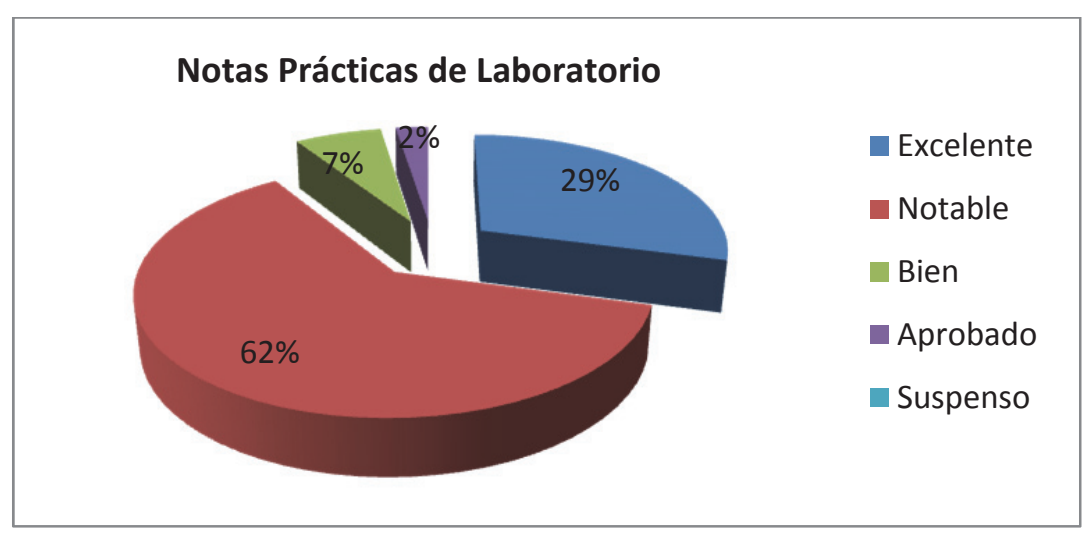

Los resultados obtenidos muestran que los estudiantes se interesan por las prácticas, acuden puntualmente y se preparan las sesiones de forma adecuada. Casi un $30 \%$ de la clase ha obtenido sobresaliente y un $62 \%$ notable.

En lo que respecta a las notas de las tareas obtenemos de nuevo buenos resultados, a saber, prácticamente el $80 \%$ de las notas son sobresalientes. Esto se debe a que los estudiantes tienen un plazo bastante amplio de entrega. 


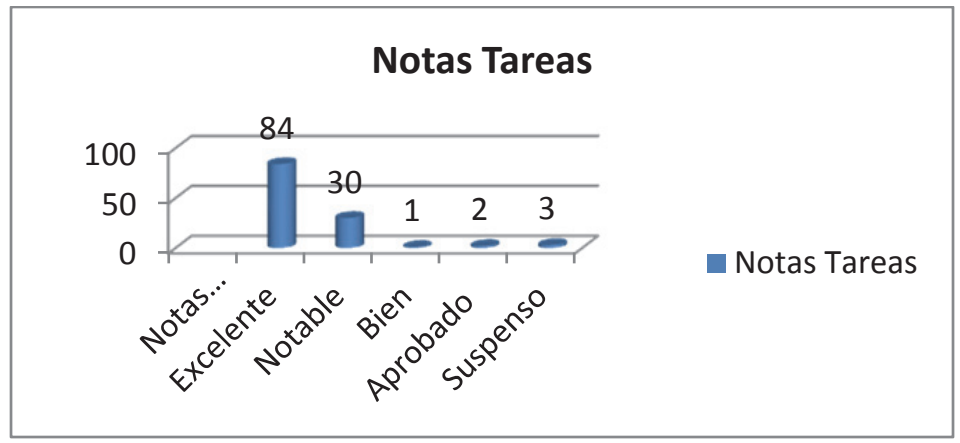

Si consideramos las notas de los exámenes de teoría/problemas, las notas han quedado como sigue

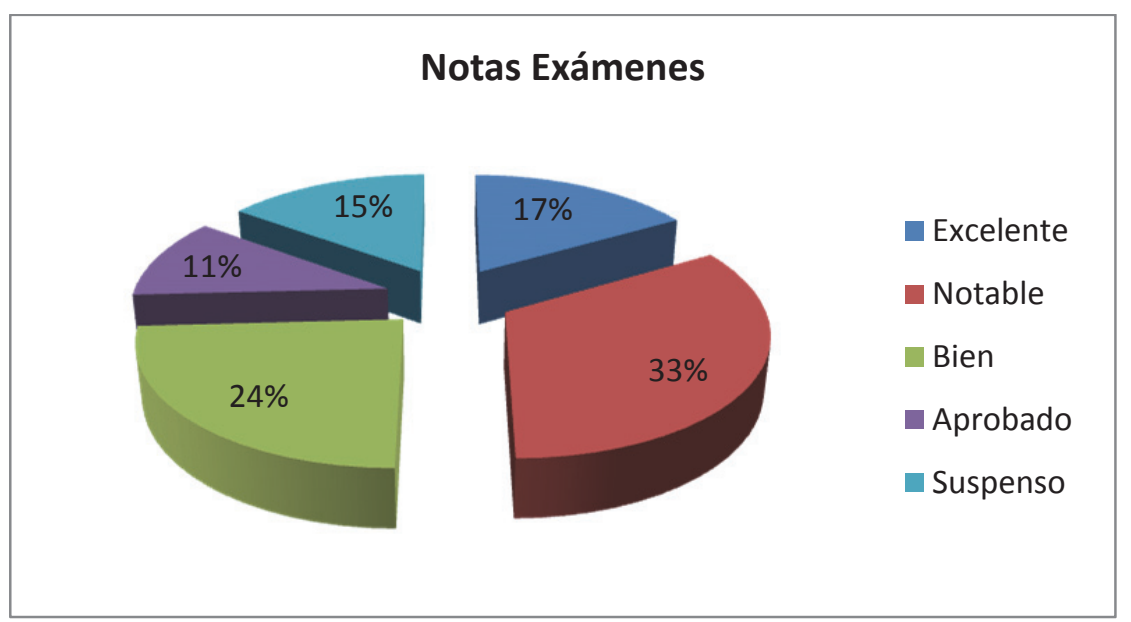

Se puede apreciar en este caso una mayor dispersión de valores. En este caso, la prueba es controlada por los docentes y con un tiempo limitado.

Para medir la dispersión entre las notas de PL y las Tareas con las notas obtenidas en el examen de TP, hemos calculado la media entre PL y Ass en primer lugar y, a continuación, la diferencia en valor absoluto con la nota de TP, obteniendo el siguiente gráfico

\section{(c)) EY-NC-ND 2014, Universitat Politècnica de València}


Metodología activa en las clases de laboratorio de Matemáticas III en el segundo año del Grado en Ingeniería

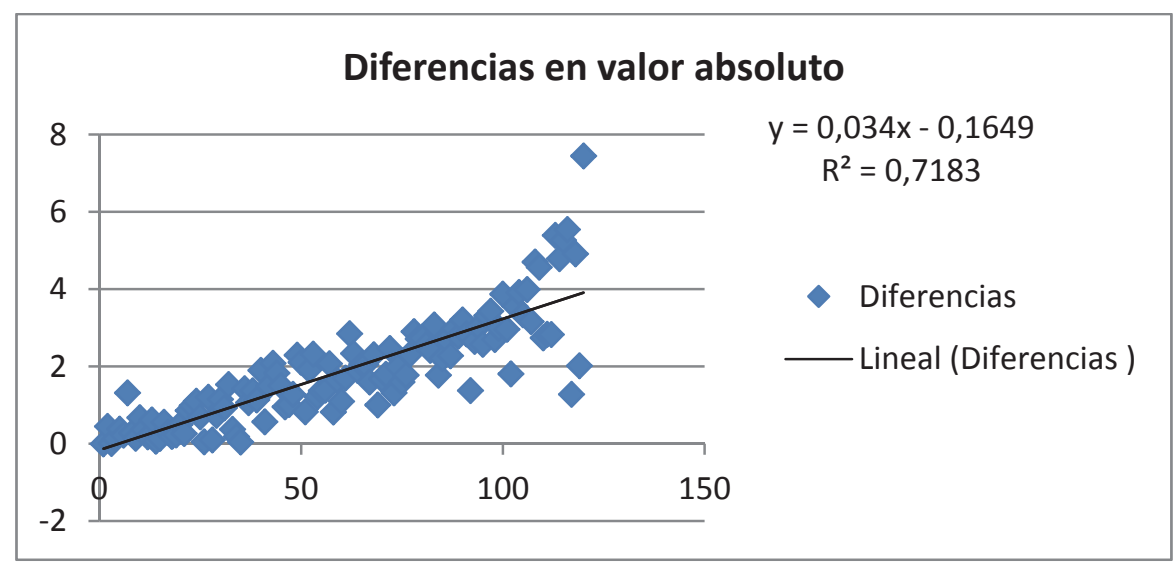

Como se puede apreciar en el gráfico, la dispersión entre los datos no es muy significativa entre los valores, excepto en algún caso puntual que se puede detectar.

El control de la dispersión nos permite estudiar los casos más llamativos, y localizar aquellos alumnos que a pesar de tener buenas notas en PL y Ass, no han obtenido una nota acorde con lo esperado en TP. Hemos obtenido que aproximadamente el $90 \%$ de los estudiantes muestran una dispersión de menos de 2 puntos con la nota esperada.

Los resultados obtenidos en Matemáticas III reflejan que los estudiantes se han involucrado en su aprendizaje (tareas, sesiones semanales, evaluaciones) y en consecuencia no ha habido abandonos. Hemos experimentado una tasa de éxito del $91 \%$.

Por otra parte consideramos conveniente realizar encuestas de opinión sobre varios aspectos relacionados con el año académico y sobre el desarrollo del curso. En particular nos gusta tener las opiniones sobre:

- Contenidos de las sesiones de laboratorio (partes de la asignatura que sientan que no se han cubierto de forma apropiada en clase)

- Estructura y número de las sesiones

- Número de tareas

- Tareas parcialmente evaluadas con PoliformaT

Para conseguir esto se realizan encuestas a los estudiantes a través de la herramienta Encuestas de PoliformaT. 


\section{Conclusiones}

La nueva metodología implementada está dando buenos resultados durante el curso académico 2013/14. Las notas obtenidas por los alumnos han mejorado respecto a las notas del año anterior. Al ser una asignatura de nueva implantación no disponemos de muchos datos para poder realizar una comparación exhaustiva. Si podemos afirmar que hemos conseguido una tasa de abandono del $0 \%$ y que los estudiantes han mostrado interés y motivación durante todo el curso. También hemos podido constatar que el trabajo y la evaluación continua han hecho que los estudiantes puedan prepararse con éxito los exámenes de TP. Se ha observado una buena correlación entre las notas obtenidas en PL+Ass y las notas TP.

Los buenos resultados nos llevan a pensar que la estructura docente que hemos implantado facilita el aprendizaje continuo y promueve el trabajo autónomo con éxito. Para ello, el diseño de las PL y Ass ha sido la clave en el aprendizaje: la dificultad y la utilidad de las tareas propuestas debe fomentar el aprendizaje y motivar al alumno. En base a los resultados obtenidos, podemos afirmar que los objetivos se han cumplido aunque se pueden introducir mejoras.

\section{Agradecimientos}

Los autores agradecen el apoyo de la Ayuda a Proyectos de Innovación Docente, PIDDMA-2013, del Departamento de Matemática Aplicada de la Universitat Politècnica de València; del Proyecto de Innovación y Mejora Educativa PIME B-11 del Vicerrectorado de Estudios y Convergencia Europea (VECE), UPV 2012; y PIME/2013/A/025/B del Vicerrectorado de Estudios, Calidad y Acreditación (VECA), UPV 2013.

\section{Bibliografía}

\section{Referencias electrónicas}

Bologna Process Website, <http://www.ond.vlaanderen.be/hogeronderwijs/bologna> [Consulta: 27 Febrero 2014]

CRUE. Conferencia de Rectores de las Universidades Españolas, <http://www.crue.org/Legislacion/Paginas/Legislacion-Ensenanaza.aspx?Mobile=0> [Consulta: 27 Febrero 2014]

SAKAI PROJECT. <http://sakaiproject.org/> [Consulta: 10 Junio 2014]

UPV, Página Web de la UPV, <www.upv.es> [Consulta: 10 Junio 2014]

\section{(c) EY-NC-ND 2014, Universitat Politècnica de València}

I Jornadas IN-RED (2014) 
Metodología activa en las clases de laboratorio de Matemáticas III en el segundo año del Grado en Ingeniería

\section{Artículos}

TONKES, E., LOCH, B., STACE, A. (2005). "An innovative learning model for computation in first year mathematics" en Int. J. Math. Educ. Sci. Tech. Vol. 36(7), pp. 751-759.

FRANCO, A. et al. (2000). "Learning calculus of several variables with new technologies" en Int. J. Comput. Alg. Math. Educ., vol. 7(4), pp. 295-309.

\section{Libros}

BLANES, S., GINESTAR, D., ROSELLÓ, M.D. (2014). Introducción a los métodos numéricos para ecuaciones diferenciales. Valencia: Editorial Universitat Politècnica de València.

MORAÑO, J. A. y SÁNCHEZ RUIZ, L. M. (2012). Cálculo y Álgebra con Mathematica 8. Valencia: Editorial Universitat Politècnica de València.

SANCHEZ RUIZ, L.M., LEGUA, M.P. (2010). Fundamentos de variable compleja y aplicaciones. Valencia: Editorial Universitat Politècnica de València.

\section{Capítulos de libro}

MORAÑO, J. A. y SÁNCHEZ RUIZ, L. M. (2010). Mathematics for Engineering from a platform based in the project Sakai. Gliwice, Polonia: Proceedings of 2010 International Conference on Engineering Education, ICEE-2010. Páginas 1084_1241, Session T11E.

ASLAKEN, H. (1995). Some thoughts about the use of computer algebra systems in university teaching. Singapur: Innovative Use of Technology for Teaching \& Research in Mathematics, Proceedings of the First Asian Technology Conference in Mathematics 1995 Singapore. Association of Mathematics Educators, pp. 81-84.

BISHOP, J., VERLEGER, M.A. (2013). The flipped classroom: A survey of the research, Atlanta: ASEE National Conference Proceedings.

MASON, G.S., SHUMAN, T.R., COOK, K.E. (2013). Comparing the Effectiveness of an Inverted Classroom to a Traditional Classroom in an Upper-Division Engineering Course. IEEE Transaction on Education, pp. 1-6. 


\title{
Estudio de las aberraciones en la formación de imágenes mediante un laboratorio virtual
}

\author{
V. Ferrando ${ }^{a}$, L. Remón ${ }^{b}$, A. Pons-Martíc, W. D. Furlan ${ }^{c}$ y J. A. Monsoriu ${ }^{a}$ \\ ${ }^{a}$ Centro de Tecnologías Físicas, Universitat Politècnica de València, 46022 Valencia, \\ viferma1@upvnet.upv.es, ${ }^{\mathrm{b}} \mathrm{AJL}$ Ophthalmic SA, 01510 Miñano (Álava) y ${ }^{\mathrm{c}}$ Departamento de Óptica, \\ Universitat de València, 46100 Burjassot (Valencia).
}

\begin{abstract}
In this work we present a virtual laboratory, SIMAG, developed in MATLAB GUI (Graphical User Interface) to be used in Physics or Optics and Opthometry courses as an informatic tool which allows to do different Fourier optical computations. With this program the appearence of any image can be computed only convolving the initial object by the Point Spread Function (PSF) of a determined optical system. The PSF is obtained from the aberration map which is provided by comercial machines as do the topographers and the aberrometers.

As an example, this virtual laboratory allows the students to know objectively how does a person whith a determined refractive error (myopia, hypermetropia and/or astigmatism) will see or the appearence of determined scene or optotype throught an ophthalmic lens. Moreover, this software allows to visualize what kind of aberrations affect more to the image quality.
\end{abstract}

Keywords: Zernike, aberrations, simulation, Imaging, optical quality.

\section{Resumen}

En este trabajo presentamos un laboratorio virtual, SIMAG, desarrollado en MATLAB GUI (Interfaz Gráfica de Usuario) para su uso en cursos de Física o Óptica y Optometría como una herramienta informática que permite realizar diferentes operaciones de procesado en el campo de la óptica de Fourier. Con el programa se puede determinar la apariencia de cualquier imagen sin más que convolucionar el objeto inicial por la respuesta 
impulsional (PSF, del inglés Point Spread Function) de un determinado sistema óptico. La PSF se obtiene computacionalmente a partir del mapa de aberraciones que proporcionan aparatos comerciales tales como topógrafos o aberrómetros.

A modo de ejemplo, este laboratorio permite a los estudiantes conocer de manera objetiva como verá un determinado sujeto con un error refractivo concreto (miopía, hipermetropía o/y astigmatismo) o la apariencia de una determinada escena u optotipo a través de una lente oftálmica. Además, el software permite visualizar que tipo de aberraciones afectan más a la calidad de imagen.

Palabras clave: Zernike, aberraciones, simulación, formación de imágenes, calidad óptica.

\section{Introducción}

La calidad de imagen en sistemas ópticos formadores de imagen (ej: lentes oftálmicas, microscopios...) cuyos medios son transparentes, está limitada por difracción y aberraciones (Hopkins, 1985). La difracción es inevitable y aparece porque hay un diafragma que limita el ancho del haz que atraviesa el sistema. Sin embargo, las aberraciones son defectos que hacen que las imágenes que produce un sistema óptico no sean perfectas (Comastri, 2011). Para el cómputo de las aberraciones en los últimos años se han desarrollado diferentes tecnologías tales como sensor Shack-Hartmann (Born, 1987), trazado de rayos láser y topógrafos que permiten determinar el mapa de aberraciones total y conocer la magnitud de cada una de las mismas en cualquier sistema óptico.

A partir del mapa de aberraciones medido y utilizando la teoría de Fourier se puede determinar la apariencia de cualquier imagen sin más que convolucionar el objeto inicial por la PSF del sistema (Goodman, 1996). En Óptica, se utiliza esta teoría para estudiar el modo en el cual un sistema transfiere a la imagen la información presente en el objeto.

De esta manera se puede obtener de manera objetiva una representación de como ve por ejemplo un paciente sometido a un determinado tratamiento o la imagen que proporciona un microscopio de una determinada muestra. En este trabajo se presenta un laboratorio virtual dirigido a estudiantes de Óptica y Optometría, en el cual se estudian de manera visual el efecto y la interacción de las diferentes aberraciones sobre la calidad de imagen haciendo uso de la teoría de Fourier. 


\section{Objetivos}

El objetivo de este trabajo es la creación de un laboratorio virtual como herramienta de aprendizaje de los efectos que tienen las diferentes aberraciones ópticas. En particular, nos centraremos en el efecto introducido por las diferentes aberraciones, descompuestas en la base de polinomios de Zernike, en los sistemas formadores de imágenes.

\section{Desarrollo de la innovación}

El software desarrollado nos permite analizar la calidad de imagen de una lente cuya distribución de fase se reconstruye a partir de los polinomios de Zernike. Mediante este software estudiaremos, desde un punto de vista didáctico, el efecto de las diferentes aberraciones en la formación de imágenes. Para ello debemos introducir manualmente el valor de los coeficientes de Zernike de la lente a simular o cargar un archivo con la lista de valores (ver Fig. 1). Además, podemos seleccionar la imagen a analizar de una lista de líneas de optotipos de diferentes tamaños o cargar una imagen almacenada en el ordenador. Tras estas selecciones veremos en la fila superior la fase reconstruida de la lente correspondiente y su PSF incoherente, y en la fila inferior tenemos la imagen original y la imagen simulada a través de la lente.

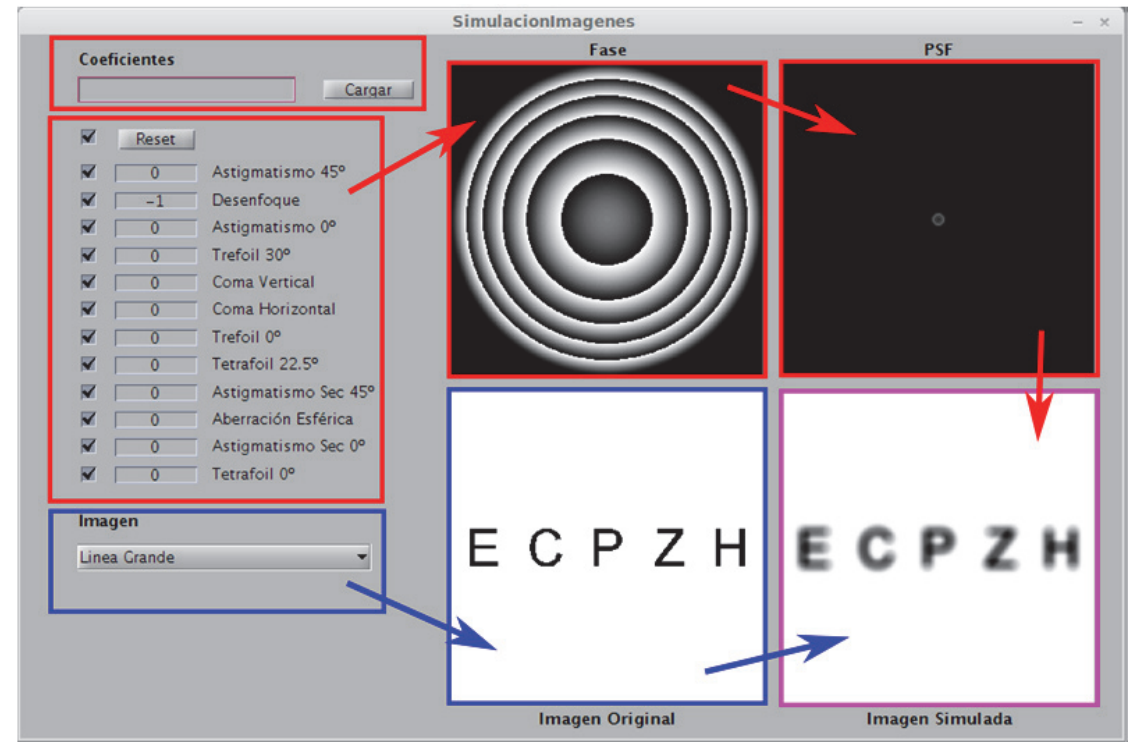

Fig. 1Interfaz grafica de la aplicación con el esquema de funcionamiento. En rojo se indican los controles de la lente a analizar y en azul los selectores de la imagen objeto. 


\subsection{Funcionamiento de la aplicación}

Cualquier función bidimensional puede escribirse como una combinación lineal de coeficientes de Zernike que escribimos como:

$$
W(x, y)=\sum_{i} a_{i} Z_{i}(x, y)
$$

siendo $a_{i}$ los coeficientes de Zernike y $Z_{i}(x, y)$ los polinomios de Zernike.

Así pues, en esta aplicación podemos seleccionar hasta el orden 15 que es suficiente para estudiar los efectos de desenfoque, astigmatismos, comma, trefoil, aberración esférica, tetrafoil y todas las combinaciones entre ellos. Los coeficientes de tilt y piston no se toman en cuenta ya que no introducen cambios en la calidad de imagen.

Para obtener la PSF incoherente del sistema calculamos el valor absoluto al cuadrado de la transformada de Fourier bidimensional de la distribución de fase. Dado que la distribución de fase esta muestreada aplicaremos la transformada de Fourier rápida (FFT) bidimensional, que nos queda como

$$
P S F_{\text {inc }}(x, y)=\left|\sum_{k=1}^{N} \sum_{l=1}^{N} W(k, l) e^{-2 \pi i(x-1)(k-1) / N} e^{-2 \pi i(y-1)(l-1) / N}\right|^{2},
$$

donde $\mathrm{N}$ es el tamaño en puntos de muestreo de la fase.

Una vez obtenida la PSF incoherente se puede calcular la imagen simulada (Imagen) como la convolución de la imagen original (objeto) por la PSF incoherente del sistema. Esta operación es lenta, por lo que decidimos modificarla y obtener la Imagen mediante la transformada de Fourier del producto de la transformada de Fourier del objeto por la OTF incoherente (transformada de Fourier de la PSF incoherente), es decir,

$$
\begin{aligned}
\text { Imagen }=\text { Objeto } & \otimes P F S_{\text {inc }}= \\
& =\mathcal{F}^{-1}\left(\mathcal{F}\left(\text { Objeto } \otimes P F S_{\text {inc }}\right)\right)=\mathcal{F}^{-1}\left(\mathcal{F}(\text { Objeto }) \cdot \mathcal{F}\left(P S F_{\text {inc }}\right)\right)= \\
& =\mathcal{F}^{-1}\left(\mathcal{F}(\text { Objeto }) \cdot \text { OTF }_{\text {inc }}\right)
\end{aligned}
$$

siendo $\mathcal{F}$ la transformada de Fourier y $\mathcal{F}^{-1}$ la transformada de Fourier inversa.

\section{Resultados}

Mediante el software que presentamos se han realizado diferentes estudios, con carácter docente, del efecto de las aberraciones en la calidad óptica de las imágenes formadas. En ellos se observa como se modifica la imagen original al cambiar los coeficientes de Zernike de la lente analizada. 
En la Fig. 2 vemos como afecta el parámetro del desenfoque a la formación de imágenes para la línea de optotipos. Se puede observar que los desenfoques positivos y negativos tienen el mismo efecto sobre la imagen.
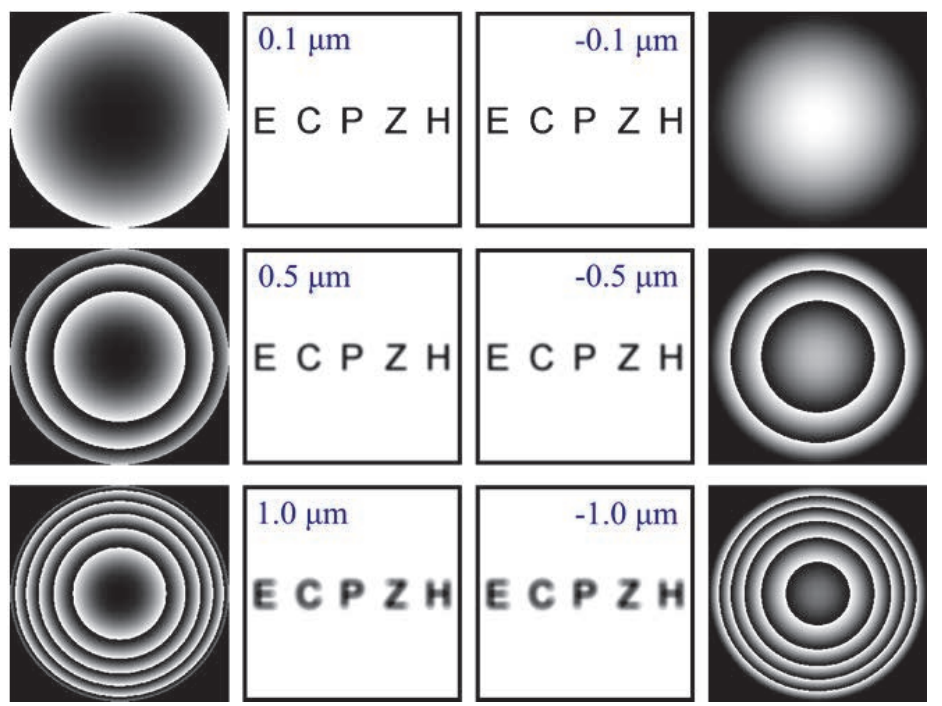

Fig. 2 Simulación de la formación de imagen a través de lentes con diferentes valores para el coeficiente de desenfoque.

En la Fig. 3 estudiamos el efecto de los astigmatismos a $0^{\circ}$ y $45^{\circ}$ para valores positivos y negativos del coeficiente correspondiente compensados con un desenfoque del mismo valor absoluto.

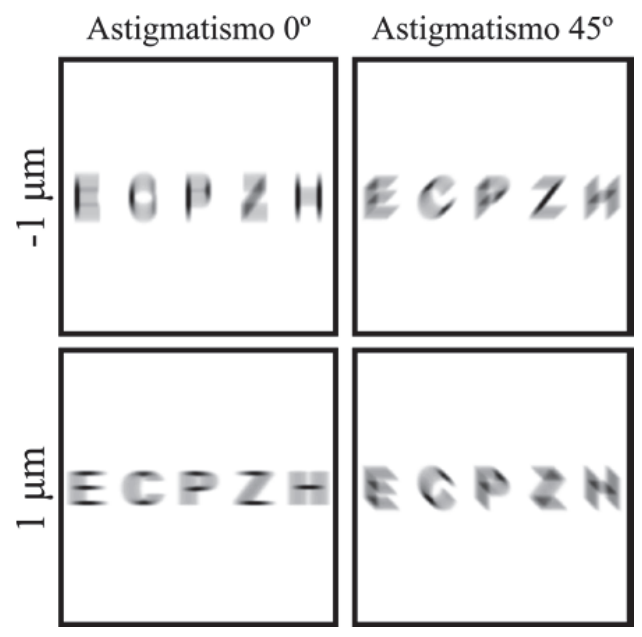

Fig. 3 Simulación de imagen a través de lentes astigmáticas con valores de diferente signo para los coeficientes de astigmatismo a $0^{\circ}$ y $45^{\circ}$ compensadas con un coeficiente de desenfoque de $1 \mu \mathrm{m}$.

\section{(c)) EY-NC-ND 2014, Universitat Politècnica de València}

I Jornadas IN-RED (2014) 
Para estudiar el fenómeno conocido como inversión de contraste utilizaremos como objeto la imagen de la estrella de Siemens. En la Fig. 4 se pueden comparar la imagen original y la simulación a través de una lente cuyo coeficiente de desenfoque es de $1 \mu \mathrm{m}$. Se observa como en ciertos intervalos radiales el valor de la imagen obtenida esta invertido respecto al del objeto.

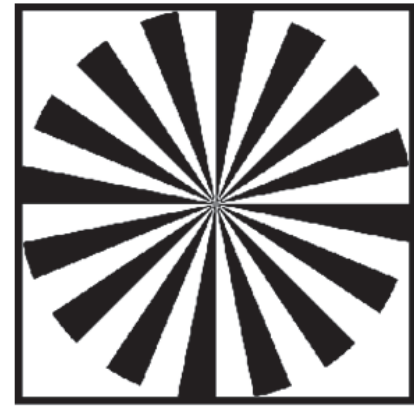

Objeto

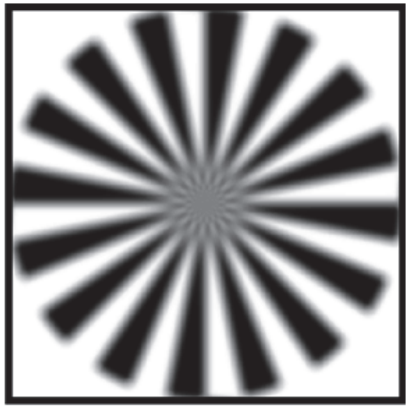

Imagen

Fig. 4 Imagen de la estrella de Siemens formada por una lente con un coeficiente de desenfoque de $1 \mu \mathrm{m}$.

Finalmente estudiamos el efecto de la compensación de aberración esférica en la formación de imágenes. Para ello suponemos una aberración esférica fija de $1 \mu \mathrm{m}$ y cambiaremos el desenfoque. En la Fig. 5 podemos comparar las imágenes obtenidas con diferentes intensidades del desenfoque. Vemos que con un desenfoque de alrededor de $2 \mu \mathrm{m}$ se puede compensar parcialmente la aberración esférica de $1 \mu \mathrm{m}$.

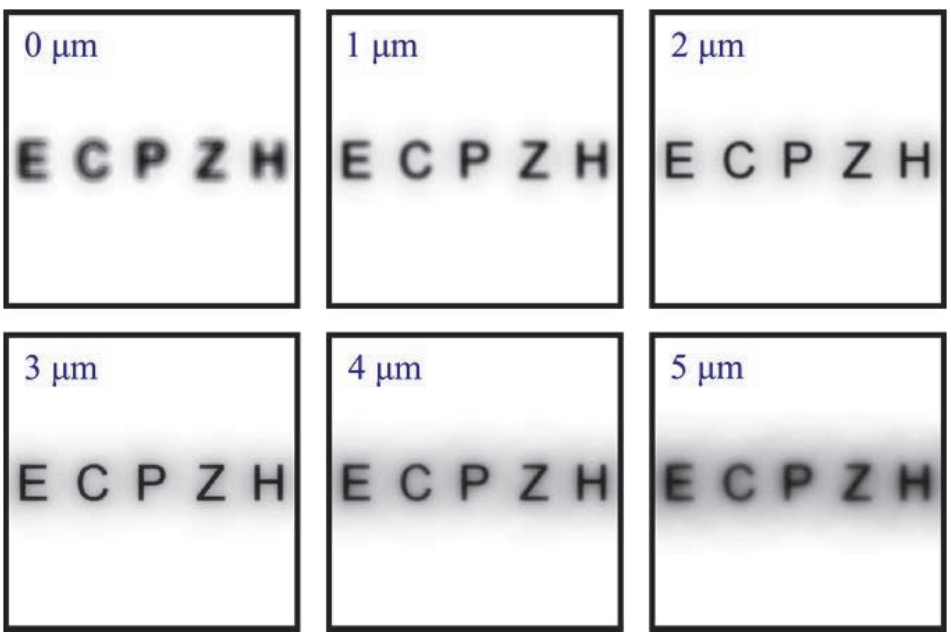

Fig. 5 Imágenes formadas por lentes con un coeficiente de aberración esférica de $1 \mu m$ compensado parcialmente con diferentes coeficientes de desenfoque. 


\section{Conclusiones}

El software propuesto permite estudiar el efecto de las aberraciones presentes en cualquier sistema óptico en la calidad de imagen que éste proporciona. Los ejemplos presentados muestran claramente como ciertos valores de aberraciones tales como desenfoque, astigmatismo o aberración esférica influyen en la apariencia de un determinado objeto y como la interacción entre aberraciones produce una mejoría de la apariencia del mismo. Desde el punto de vista didáctico, el programa permite estudiar ciertos aspectos de la teoría de Fourier y la teoría utilizada en Óptica Física y Geométrica para evaluar el comportamiento de sistemas formadores de imágenes, es decir, se explican conceptos referentes a la aberración de onda (W), la respuesta impusional (PSF) y se analiza el uso de los coeficientes de Zernike. El software propuesto va dirigido a estudiantes que proceden de carreras universitarias tales como Física y/o Óptica y Optometría. En el último caso, será de gran utilidad ya que se puede obtener de manera objetiva una representación de como ve el paciente sometido a un determinado tratamiento.

\section{Agradecimientos}

Los autores de los Grupos de Innovación Docente MoMa de la Universitat Politècnica de València e IndopTIC (GCID35/2009) de la Universitat de València, agradecen el apoyo institucional y económico recibido de sus respectivas universidades para el desarrollo de sus proyectos de innovación. Por último, los dos grupos agradecen al Vicerrectorado de Cultura e Igualdad de la Universitat de València, su apoyo para la constitución de la Red Valenciana de Innovación Educativa.

\section{Referencias}

HOPKINS, H.H. (1985) "Image formation by a general optical system. 1: General Theory" en Applied Optics, vol. 24, issue 16, p. 2491-2505.

COMASTRI, S.A., MARTÍN, G. y BIANCHETTI, A. (2011) "Variación de las aberraciones introducidas por una lente oftálmica monofocal al modificar la pupila" en Universidad de Belgrano, $\mathrm{n}^{\circ}$ 256, p. 1-14.

BORN, M. y WOLF, B. (1987). Principles of Optics. Oxford: Pergamon Press.

GOODMAN, J.W. (1996). Introduction to Fourier Optics. New York: Mc Graw-Hill.

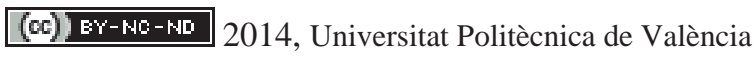

I Jornadas IN-RED (2014) 
Jornadas In-Red 2014

Universitat Politècnica de València

\title{
El uso de las metodologías activas. El feedback/feedforward como herramienta eficaz para mejorar los resultados de los estudiantes
}

\author{
M. Salomé Moreno Navarro ${ }^{\mathrm{a}}$, Maria Morant Pérez ${ }^{\mathrm{b}}$, Roberto Llorente $\mathrm{Sáez}^{\mathrm{c}}$ y \\ Benjamín Sarria Chust ${ }^{\mathrm{d}}$ \\ âDepartament d'Urbanisme, Universitat Politècnica de València, smoreno@upvnet.upv.es, ${ }^{\mathrm{b}}$ Instituto \\ Universitario de Tecnología Nanofotónica, Universitat Politècnica de València, mmorant@ntc.upv.es, \\ cDepartamento de Comunicaciones, Universitat Politècnica de València, rllorent@dcom.upv.es, y \\ ${ }^{\mathrm{d}}$ Facultat de Medicina, Universitat de València Estudi General, benjamin.sarria@uv.es
}

\begin{abstract}
The role of feedback and feedforward (prospective feedback) is to report the results of an activity along the students' learning progress and to provide useful information for their immediate and near future activities in both academical and professional fields. The feedback allows the students to know the extent to which the learning objectives have been achieved and to receive proper guidance for future tasks. However, the effectiveness of feedback and feedforward in Higher Education does not occur linearly and depends on several factors which, if they are taken into account, contribute to improve significantly the learning outcomes. This paper presents the experience carried out by a group of professors from the Universitat Politècnica de València and Universitat de Valencia on a pilot proposal about how to use the feedback and feedforward confirming that it is widely effective in complex learning situations.
\end{abstract}

Keywords: feedback, feedforward, assessment, competences, higher education.

\footnotetext{
Resumen

La función del feedback (retroalimentación) y del feedforward (retroalimentación prospectiva) es la de informar sobre los resultados de una actividad, del progreso en el aprendizaje de los alumnos y de aquella información útil para su futuro inmediato y cercano tanto en el ámbito académico como laboral. El feedback permite a los alumnos conocer hasta
}

(cc) EY-NC-ND 2014, Universitat Politècnica de València

I Jornadas In-Red (2014) 
El uso de las metodologías activas. El feedback-feedforward como herramienta eficaz para mejorar los resultados de los estudiantes

qué punto se han conseguido los objetivos de aprendizaje propuestos y sirven como orientación para futuras tareas. Sin embargo, la eficacia del feedback y del feedforward en la educación superior no se produce de forma lineal y depende de diversos factores que, si son tenidos en cuenta, contribuyen a mejorar sensiblemente los resultados de aprendizaje. Este artículo presenta los resultados de la experiencia llevada a cabo por un grupo de profesores de la Universitat Politècnica de València y de la Universitat de València de una propuesta piloto sobre cómo utilizar el feedback y el feedforward confirmando que el uso de estas técnicas contribuye eficazmente en situaciones de aprendizaje complejo.

Palabras clave: retroalimentación, feedback, feedforward, evaluación, competencias, educación superior.

\section{Introducción}

En el marco del Espacio Europeo de Educación Superior (EEES) la implementación del uso de metodologías activas de enseñanza se ha convertido en un reto para el profesorado universitario que busca, por una parte, favorecer el aprendizaje autónomo de los estudiantes y, por otro, implementar sistemas de formación y evaluación eficaces (Domingo y Marqués, 2011). En este sentido, la evaluación juega un papel esencial porque no sólo sirve para que el alumno reconozca sus errores e intente evitarlos en un futuro, sino que ha de servir para para que éste sea capaz de identificar las vías para superarlos.

En este sentido, "el feedback formativo representa la información comunicada al estudiante con la intención de modificar su manera de pensar o su comportamiento y con el deseo de mejorar su aprendizaje" (Shute, 2007). Esta posición permite a los estudiantes establecer una serie de expectativas sobre ellos mismo y sobre las decisiones que toman y que influyen sobre sus propias prácticas (Ion et al, 2013), (Shute, 2007), (Stiggins, 2008).

Según diversos autores (Ion et al, 2013), para obtener un máximo beneficio, esta técnica ha de ser ofrecida sobre un producto (trabajo), sobre el proceso (cómo se ha hecho) y sobre el progreso registrado del aprendizaje del alumno (la mejora a lo largo del tiempo) (Xie y Sharma, 2005), (Shute, 2007), (Stiggins, 2008). Así, se subraya la importancia del soporte que se ha de ofrecer a los estudiantes para que sean capaces de aumentar su responsabilidad sobre el propio aprendizaje y para hacer progresos hacia "la autonomía para actuar" (Kimbell \& Stables 2008, p. 224).

Partiendo de que una competencia es la selección y combinación pertinente de conocimientos, habilidades, destrezas, actitudes, valores y normas que permiten dar respuesta a una situación compleja en un contexto determinado (Perrenoud, 2004), el

(c)) BY-NC-ND 2014, Universitat Politècnica de València

I Jornadas IN-RED (2014) 
estudio de la efectividad del feedback es bastante reciente, y no digamos del feedforward entendido como retroalimentación prospectiva. Es decir, como aquella información útil para el futuro inmediato y mediato y tanto académico como laboral (Ion et al, 2013).

Padilla y Gil (2008, p.471) señalan que "mientras que el feedback engloba comentarios sobre la labor realizada, el feedforward incluye información que pretende ayudar al estudiante a que en el futuro haga mejor tareas similares". En vez de observar los errores para corregirlos, lo que intenta es anticiparse a ellos para que éstos no ocurran. En este sentido, la evaluación se convierte en la herramienta más importante para desarrollar competencias (Ion et al, 2013).

Así, las características deseables que debería tener un buen feedbacklfeedforward, según Re-Engineering Assessment Practices (REAP) de 2009 son (Ion et al 2013):

- Ayudar a aclarar lo que significa una buena ejecución según los objetivos, estableciendo los criterios y las normas.

- Animar a dedicar tiempo y el esfuerzo en tareas de aprendizaje que suponga un reto para el alumno.

- Proporcionar información de alta calidad que ayude a los estudiantes a la autoevaluación.

- Proporcionar oportunidades para minimizar cualquier diferencia entre el desarrollo del conocimiento actual y el deseado.

- Favorecer un impacto positivo sobre el aprendizaje final (evaluación sumativa).

- Estimular la interacción y el diálogo sobre el estudio (entre pares y entre el profesor y el estudiante).

- Facilitar el desarrollo de la autoevaluación y la reflexión sobre el estudio.

- Permitir una metodología de enseñanza flexible adaptando los criterios, el peso de las diversas evidencias y considerando el tiempo dedicado a la evaluación.

- Implicar a los estudiantes en la toma de decisiones sobre el diseño y las prácticas de evaluación.

- Apoyar el desarrollo de grupos de estudiantes y de comunidades de aprendizaje y estimular la autoestima y la motivación.

- Proporcionar información a los profesores que puede ser usada para mejorar la enseñanza.

Por otra parte, existen diversas variables de otra índole que inciden directamente sobre el aprendizaje complejo y sobre cómo conseguir un mayor grado de eficacia en el proceso de enseñanza-aprendizaje. Por ejemplo, los resultados más notables se obtienen cuando el feedback se utiliza en el aprendizaje y realización de tareas simples de tipo sensorial y motriz. Cuando el feedback se utiliza en situaciones complejas, en las que intervienen muchas variables, su eficacia no es tan patente, ni fácilmente comprobable (Marchago,

\section{(cc) EY-NC-ND 2014, Universitat Politècnica de València}

I Jornadas IN-RED (2014) 
El uso de las metodologías activas. El feedback-feedforward como herramienta eficaz para mejorar los resultados de los estudiantes

1992). Esto significa que, para muchos autores, el proceso del feedback no es eficaz en sí mismo y ésto va a depender de los siguientes factores (Marchago, 1989):

- Las características del emisor o persona que da el feedback

- La naturaleza del mensaje o información

- La persona que recibe el feedback

De este modo, el concepto (autoconcepto) que el alumno tiene de sí mismo es crucial a la hora de que el feedback que reciba sea efectivo (por ejemplo, los alumnos con autoconcepto positivo son más receptivos con respecto a la información que se les da). De la misma manera, el feedback positivo (aquel que refuerza lo que el alumno hace bien) resulta eficaz en la mayoría de los casos mientras que el feedback negativo resulta más efectivo en alumnos con autoconcepto positivo que se deriva en una mejora efectiva en el rendimiento académico (aunque a veces se traduce en una reducción de esfuerzo). Por otro lado, en situaciones experimentales, el feedback neutro no resulta eficaz ni para mejorar significativamente el rendimiento, ni para empeorarlo (Marchago, 1992).

Esto significa, tal y como señalan diversos autores (Ferrero y Martín, 2011), (ChabotChabot, 2009), que las emociones impactan sobre el rendimiento y por lo tanto es muy importante la labor del docente a la hora de realizar las devoluciones de las evaluaciones, que lo haga de manera tal, que sin dejar de puntualizar los puntos débiles del trabajo del alumno, se tengan en consideración los puntos fuertes manteniendo una actitud asertiva con el alumno.

Del mismo modo, se motiva más y mejor a quienes han vivido mayores y mejores experiencias en el aula. Está aceptado que, en situaciones complejas de enseñanzaaprendizaje, nos importan más los procesos que los resultados. Posiblemente sea porque los procesos permanecen siempre y sirven de refuerzo o motivación para posteriores aprendizajes. Realmente, debemos reconocer que una actividad es significativa, cuando significa algo para el alumno, bien porque se identifica con ella, porque vea alguna utilidad o porque le entretiene o divierte (Dale, 1969) (Díez et al, 2012).

A la vista de lo analizado, un grupo de profesores de la Universitat Politècnica de València (UPV) y de la Universitat de València Estudi General (UVeg) nos hemos planteado realizar una propuesta piloto sobre cómo utilizar el feedback y el feedforward para que éste se muestre eficaz de manera generalizada en situaciones de aprendizaje complejo. La innovación que aquí se presenta viene motivada por la necesidad de comprender como funciona el feedback/feedforward eficaz, intentar sistematizar el uso de esta herramienta para mejorar la capacidad de autorregulación de los alumnos, su autonomía y por ende obtener una mejora en sus resultados.

(cc) BY-NC-ND 2014, Universitat Politècnica de València

I Jornadas IN-RED (2014) 
Moreno Navarro, M.S.; Morant Pérez, M.; Llorente Sáez, R.; Sarria Chust, B.

\section{Objetivos}

Los objetivos de esta experiencia piloto pueden resumirse en:

- Reconocer diferentes estrategias de feedback efectivo en las relaciones alumnoprofesor, alumno-alumno a aplicar en el aula.

- Diseñar e implementar un protocolo planificado de pautas de actuación, que proporcione un feedbacklfeedforward, eficaz en situaciones de aprendizaje complejos tanto en la relación entre pares (alumno-alumno) como entre profesoralumno.

- Conocer la percepción del alumno sobre el feedback recibido.

\section{Desarrollo de la innovación}

La actuación de esta innovación docente se ha desarrollado en el curso académico 20132014. El conjunto de profesores que compone el grupo de trabajo, durante el primer semestre, ha estado trabajando sobre el concepto de feedbacklfeedforward y su aplicación en asignaturas de Grado y Máster de estudios de Ingeniería y Medicina. En esta prueba piloto se diseñaron y pusieron en práctica distintas experiencias innovadoras, del uso de esta herramienta en el aula, en la asignaturas de "Evaluación Ambiental de Planes y Programas y la Intervención en el Paisaje" del Máster de Transportes, Territorio y Urbanismo de la UPV, "Farmacología General de órganos y Sistemas" del Grado de Medicina de la UVeg y "Eficiencia Energética y Redes Ópticas de Nueva Generación" del Máster Universitario en Tecnologías, Sistemas y Redes de Comunicación de la UPV, y posteriormente se realizó un trabajo de análisis sobre la repercusión que dichos cambios provocaban en la respuesta, motivación y resultados de los alumnos. Posteriormente se trabajó en la posibilidad de extrapolar y unificar estrategias con el fin de elaborar unas pautas comunes que pudiesen formar parte de una planificación en una asignatura del segundo semestre.

Dichas experiencias consistieron básicamente en:

- Sesiones individuales y grupales, de diferente índole y concepción, diseñadas para orientar a los alumnos en la propuesta, seguimiento y evaluación de tareas con distinta dificultad.

- Implementación de diferentes sistemas de coevaluación en algunas tareas.

- Desarrollo y utilización de una aplicación docente, que permite el planteamiento de ejercicios particularizados durante la sesión en el aula.

- Utilización de la plataforma PoliformaT (UPV), Aula Virtual (UVeg) y del correo electrónico para dar feedback no presencial.

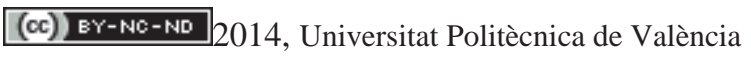

I Jornadas IN-RED (2014) 
El uso de las metodologías activas. El feedback-feedforward como herramienta eficaz para mejorar los resultados de los estudiantes

Como consecuencia de los resultados obtenidos durante el primer semestre, se seleccionaron una serie de actuaciones que permitían una aplicación planificada en el segundo semestre, y se decidió implantarla en la asignatura de "Impacto Ambiental de la Obra Civil", de $5^{\circ}$ curso de la Licenciatura en Ciencias Ambientales y del Máster de Transportes, Territorio y Urbanismo de la UPV. Esta asignatura del segundo semestre reúne las características idóneas para llevar a cabo la prueba sobre las conclusiones extraídas durante el primer semestre.

La planificación de la actuación en este segundo período se centró en lo siguiente:

1. Comunicar la planificación de las tareas a realizar a principio de curso, explicando a los alumnos que después de cada tarea recibirán, de manera individualizada o en grupo, el correspondiente feedback/feedforward, entendidos como la manera constructiva de recibir información para mejorar su producción y para provocar la reflexión sobre lo aprendido y su aplicación dentro y fuera del ámbito académico.

2. Generar desde el principio del curso un clima propicio de confianza para que la información pueda fluir con naturalidad, aún en el caso de que la información recibida no siempre sea lo esperado, propiciando opiniones fundamentadas que favorezcan su progreso profesional.

3. Proceder, en un plazo no superior a una semana después de la finalización de cada tarea, a realizar el correspondiente feedbacklfeedforward, preferiblemente en sesiones presenciales, ya sean individuales o grupales, o en última instancia por vía electrónica.

4. En los casos de autoevaluación y coevaluación, los propios alumnos proporcionan el correspondiente feedback a sus compañeros en sesiones grupales.

5. Asumir por parte del profesorado que, ante situaciones de riesgo negativas o muy negativas, su actitud ha de ser asertiva.

6. Utilizar terminología en positivo e intentar evitar los verbos negativos como "excluye, reprime, rechaza, censura, disimula, oculta".

7. A final de curso, realizar una sesión individual y/o grupal recapitulando la progresión de los alumnos a lo largo del semestre y su proyección de futuro.

Para ello, se planificaron para el curso un total de 5 tareas, de las cuales cuatro llevaban aparejadas una exposición/comunicación al resto de los compañeros del curso (dos de manera individual y dos en grupos de dos o tres personas): La competencia seleccionada como objetivo de coevaluación o autoevaluación fue la de comunicar eficazmente.

En la primera sesión con el grupo, tras dar a conocer la planificación del semestre, se explicó cuál iba a ser el sistema general a utilizar durante el curso, tanto para la elaboración y estructuración de las tareas planificadas como las claves para su realización y las rúbricas de evaluación a utilizar.

(cc)) EY-NC-ND 2014, Universitat Politècnica de València 
A partir de ese momento, se siguió el esquema de trabajo antes descrito para las tareas cuya evaluación se realizaba por el profesor, y para las de coevaluación se llevaron a cabo distintas acciones a fin de mejorar, a través del feedback, las habilidades comunicativas de los alumnos. Para ello se partió de la situación personal de cada alumno, en cuanto a las habilidades adquiridas hasta ese momento en esa competencia, y se trabajó individualmente su mejora con el profesor y con el feedback proveniente de la evaluación realizada por sus compañeros (Tareas 1 y 3). En la Tarea 4, se planteó un nuevo desafío al grupo ya que la exposición fue grupal.

Además de la evaluación mediante la rúbrica habitual, se grabaron algunas de las intervenciones (tal como se muestra en la Fig. 1) y se facilitó a los alumnos una guía de observación para que las valorasen. Cada alumno valoraba a dos de sus compañeros de clase. Esta guía permite al alumno reflexionar, no sólo sobre cómo actúa o interactúa su compañero, sino que también le hace reflexionar sobre otros aspectos de la comunicación como son el uso de técnicas argumentativas, el espacio, la iluminación, y el lenguaje no verbal, entre otros.
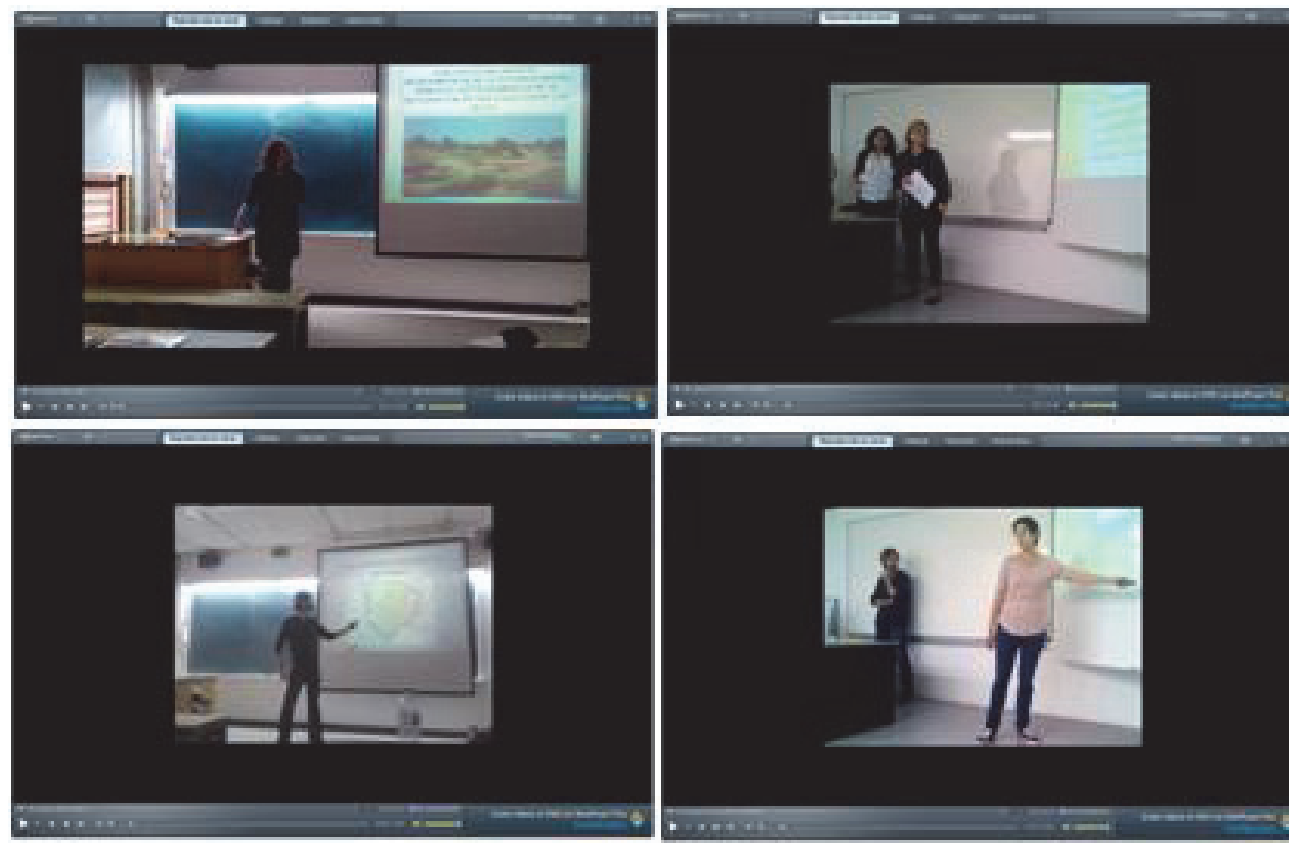

Fig. 1. Capturas de algunas de las intervenciones individuales y grupales realizadas por los alumnos en el aula

Por último, se han verificado los cambios operados en los resultados de los alumnos, de manera global y tarea a tarea, así como la realización y pase de un cuestionario general sobre la experiencia realizada.

\section{(cc) BY-NC-ND 2014, Universitat Politècnica de València}

I Jornadas IN-RED (2014) 
El uso de las metodologías activas. El feedback-feedforward como herramienta eficaz para mejorar los resultados de los estudiantes

Este cuestionario se divide en dos partes, en la primera se realizan dos preguntas generales, una es que valore una serie de cualidades (de nada a indispensable) en un profesor:

- Su credibilidad o prestigio

- Su habilidad para valorar la actividad de los demás

- Su habilidad para dar una información oportuna, interesante, o creativa

- Su habilidad para reorientar la clase

- Su autoridad

- Su proximidad

En la otra se pide al alumno que valore las características de un feedback eficaz:

- El contenido (el mensaje)

- El modo de darlo (cómo lo hace, el lenguaje utilizado, etc.)

- Su frecuencia y a tiempo (antes, durante y tras realizar cada tarea)

- $\quad$ El que sea constructivo

- Que refuerce aquello que hago bien

La segunda parte se centra en el proceso de aprendizaje a lo largo del curso:

- Las sesiones con el profesor me han ayudado a aclarar lo que significa una buena ejecución de las tareas (objetivos, criterios, normas)

- Las sesiones con el profesor me han proporcionado una información de alta calidad que me ha ayudado a autoevaluarme

- La actuación del profesor me ha animado a dedicar tiempo y esfuerzo en tareas de aprendizajes retadoras

- El feedback de mis compañeros me ha ayudado a mejorar la ejecución de las tareas

- El feedback recibido me ha proporcionado oportunidades para minimizar las diferencias entre lo que he hecho y lo que quería hacer

- El proceso seguido durante el curso ha estimulado la interacción y el diálogo sobre el objeto de las tareas tanto con el profesor como entre los alumnos

- El proceso seguido durante el curso ha facilitado el desarrollo de la autoevaluación y de la reflexión

- El curso ha propiciado el desarrollo de los grupos de estudiantes estimulando la autoestima y la motivación

- El proceso seguido durante el curso ha facilitado el desarrollo de la autoevaluación y de la reflexión

- Creo que la interacción más directa alumno-profesor proporciona al profesor una valiosa información que puede ser usada para mejorar la enseñanza

- Creo que mi implicación ha influido en la orientación y en el éxito del curso.

- Siento que en este curso he tenido una progresión positiva evidente en el aprendizaje a lo largo del mismo.

(cc) BY-NC-ND 2014, Universitat Politècnica de València

I Jornadas IN-RED (2014) 


\section{Resultados}

Respecto de los resultados globales del curso, podemos comprobar en los gráficos que se incluyen en las Fig. 2 y Fig. 3 como por un lado el resultado global obtenido ha sido significativamente mejor tras la experiencia realizada (tanto tarea a tarea, como en el resultado final) y, lo que quizá nos resulta más interesante, que la progresión en resultados a lo largo del curso 2013-2014, ha sido constante y ascendente.

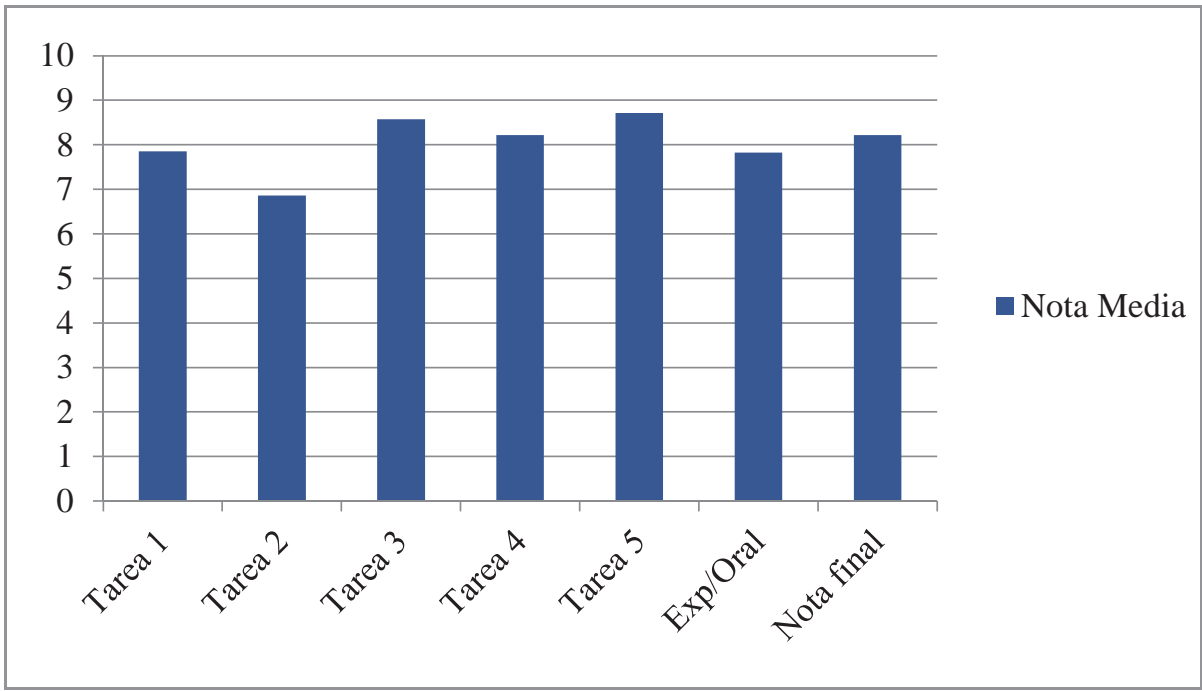

Fig. 2. Resultados académicos correspondientes al curso 2012-2013.

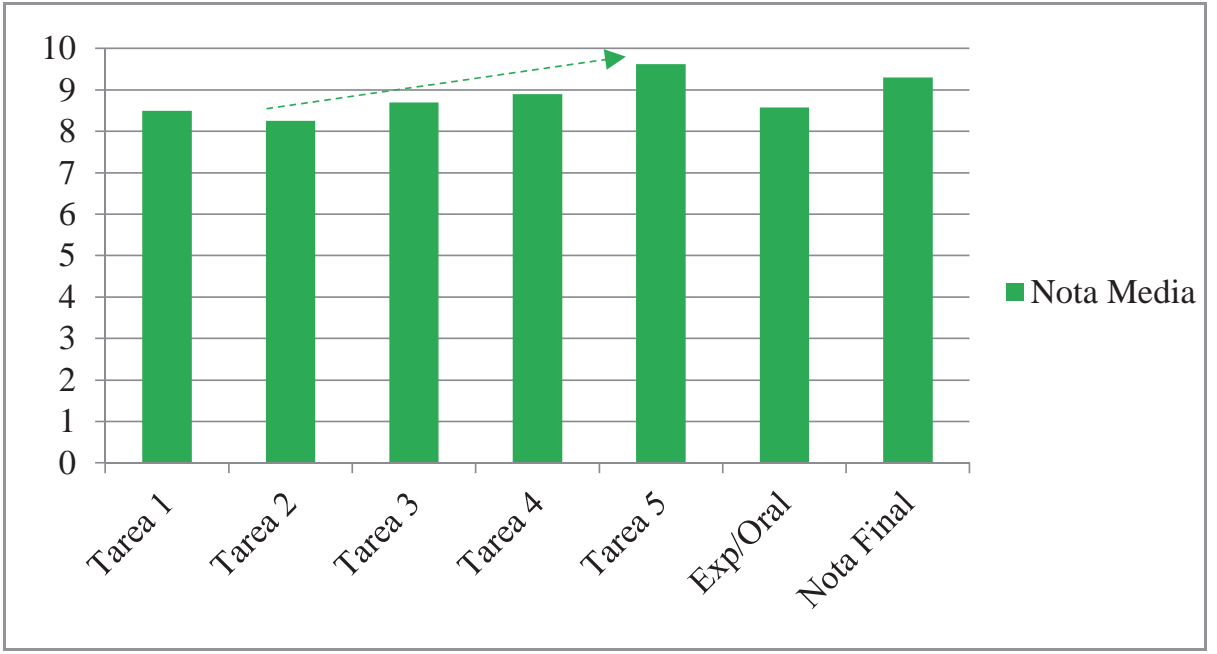

Fig. 3. Resultados académicos correspondientes al curso 2013-2014. 
El uso de las metodologías activas. El feedback-feedforward como herramienta eficaz para mejorar los resultados de los estudiantes

Respecto de los resultados en la competencia de comunicación efectiva (Fig. 4), la nota global media obtenida por los alumnos también ha sido mejor en esta segunda anualidad, observándose los siguientes resultados: hay una mejora de los resultados entre la T1 y la T3, ambas de tipo individual, produciéndose un descenso en la T4 (primera de carácter grupal) que tras la experiencia de las grabaciones y de la evaluación, con la guía de observación facilitada, no sólo produce una mejora respecto de la experiencia anterior, sino que lo hace también respecto de la correspondiente a las exposiciones de carácter individual.

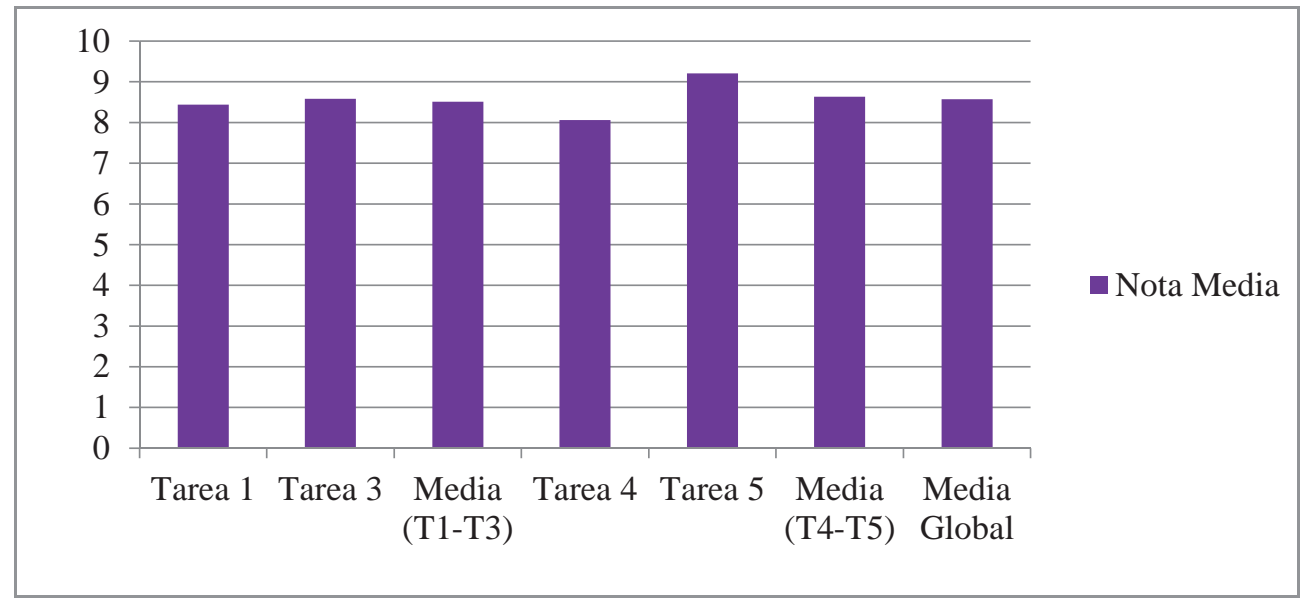

Fig. 4. Resultados correspondientes al trabajo de coevaluación realizado sobre la competencia comunicativa en el curso 2013-2014.

En cuanto a los resultados del cuestionario realizado, en los aspectos generales del profesor, lo menos valorado (aunque con una buena consideración) por los alumnos es su prestigio y su autoridad (dándole valores entre "ni mucho ni poco" y "mucho"), valorando sobretodo su habilidad para valorar la actividad de los demás, la habilidad para dar información oportuna, interesante o creativa y su habilidad para reorientar la clase (entre "mucho" e "indispensable"). El resto de cuestiones, también muy apreciadas por los alumnos, se valoran en el rango de "más bien mucha" y "mucha importancia".

En cuanto al tipo de feedback, los alumnos se decantan por la importancia en el modo de darlo, en su frecuencia y a tiempo, en que sea constructivo y que refuerce aquello que se hace bien (el 50\% piensa que es esencial y entorno al 33\% lo valora mucho), valorando algo menos el contenido del mensaje (para el $33 \%$ es esencial y otro $33 \%$ lo valora mucho).

En cuanto a la actuación del profesor durante el curso, los alumnos piensan que ésta ha sido facilitadora, estimulante y eficaz en su progresión de aprendizaje, fomentando la reflexión y la autoevaluación, con valoraciones entre el rango de 8 y 10 en más de un $80 \%$ de los casos. 
En cuanto a la valoración de su propio papel y el de sus compañeros en todo este proceso, el $80 \%$ de las respuestas se encuentra entre los valores de 7 a 10. Asimismo, es de destacar su opinión sobre el hecho de que un proceso de interacción más directa alumno-profesor puede redundar en una mejora de la enseñanza (el 100\% de los alumnos valora la importancia de este concepto entre 8 y 10).

\section{Conclusiones}

A la vista de los resultados obtenidos, se confirma que el uso del feedback/feedforward en aprendizajes complejos se muestra realmente efectivo cuando se realiza de manera planificada y se siguen una serie de pautas y recomendaciones que el alumno sabe reconocer y que convierten en significativo el aprendizaje que éste lleva a cabo durante el curso.

Los estudiantes han valorado positivamente la propuesta llevada a cabo durante el presente curso en esta experiencia piloto. Los alumnos confirman que se ha incrementado su motivación, si bien se deberá trabajar más en el refuerzo del mensaje (no sólo en el proceso) y en mejorar la calidad del feedback cuando éste se da en formato no presencial.

Es también muy importante señalar que pequeños cambios actitudinales en cómo el profesor debe dar el feedback/feedforward (incluyendo el uso del lenguaje positivo, asertividad, refuerzo positivo, mostrar cercanía, etc.) producen un efecto inesperado en cómo se percibe el mensaje y en cómo se implican los estudiantes en el trabajo diario, mejorando además el clima de la clase. Creemos que tanto la UPV como la UVeg deberían ofrecer formación al profesorado en este sentido.

En conclusión, estimamos que los resultados obtenidos son satisfactorios y como propuesta de mejora nos planteamos la planificación de esta herramienta para el siguiente curso 20142015, en las distintas asignaturas que impartimos, ya que el uso del feedback/feedforward con los criterios que marca este trabajo se ha mostrado muy efectiva.

\section{Referencias}

Domingo, M. y MARquès, P. (2011). "Aulas 2.0 y uso de las TIC en la práctica docente" en Comunicar, 37(XIX), 169-175.

Снавот, D. у Снавот М. (2009). Pedagogía emocional. Sentir para aprender. Integración de la inteligencia emocional en el aprendizaje. México: Alfaomega Grupo Editor.

Dale, E. (1969). Audiovisual methods in teaching. New York: The Dryden Press.

(cc) BY-NC-ND 2014, Universitat Politècnica de València

I Jornadas IN-RED (2014) 
El uso de las metodologías activas. El feedback-feedforward como herramienta eficaz para mejorar los resultados de los estudiantes

DíEZ, A. et al. (2012), "El feedback en la comunicación, un binomio a renovar en el Espacio Europeo de Educación Superior (EEES)" en Revista de Comunicación Vivat Academia. Febrero 2012. Núm. Especial Año XIV pp.612-628

FERRERO, M.I. y MARTín, M. (2010). "La importancia del feedback constructivo en la evaluación de las ejecuciones musicales grupales" en Actas de la IX reunión Sociedad Argentina para las ciencias cognitivas de la música (SACCoM). Buenos Aires. Disponible <http://www.saccom.org.ar/2010_reunion9/actas/47.Ferrero-Martin.pdf $>$ [Consulta: 10 octubre de 2013]

Ion, G., Silva, P. y Cano García, E. (2013), "El feedback y el feedforward en la evaluación de las competencias de estudiantes universitarios" en Profesorado. Revista de currículum y formación del profesorado. Vol.17, 2

Kimbell, R. y Stables, K. (2008). Researching Design Learning. London: Springer.

Marchago Salvador, J. (1992). "El autoconcepto como factor condicionante de la eficacia del feedback sobre el rendimiento" en Aprendizaje. Revista de Psicología Social. Vol. 7 (2) 195-211

PADILLA, M.T. y GIL, J. (2008). "La evaluación orientada al aprendizaje en la Educación Superior: condiciones y estrategias para su aplicación en la docencia universitaria" en Revista Española de Pedagogía, 241, 467-486

Perrenoud, P. (2004).Diez nuevas competencias para enseñar. Barcelona: Graó.

REAP (2009). Re-Engineering Assessment Practices www.reap.ac.uk [Consulta: 15 noviembre de 2013]

SHUTE, V. J. (2007). "Focus on formative feedback en Research Report. Princeton: Educational Testing Service.

Stiggins, R.J. (2008). Student-involved classroom assessment, Upper Saddle River, NJ: Merrill Prentice Hall.

XIE, Y. \& Sharma, P. (2005). Students lived experiences of using blogs in a class: An exploratory study. Consultada 4 mayo,

2012. 〈http://eric.ed.gov/ERICDocs/data/ericdocs2/content_storage_01/0000000b/80/2b/c6/bc.pdf >

[Consulta: 15 octubre de 2013] 


\title{
Simulaciones digitales en Física: un ejemplo para el estudio de la polarización lineal
}

\author{
Amparo Pons-Martía, Juan C. Barreiro a , Lluis Martínez-León \\ Fernándo Giménez ${ }^{\mathrm{c}}$ y Juan A. Monsoriu ${ }^{\mathrm{d}}$
}

${ }^{a}$ Departamento de Óptica, Universitat de València, 46100 Burjassot (Valencia), amparo.ponsmarti@uv.es, 'bepartament de Física/INIT, Universitat Jaume I, 12071 Castelló de la Plana, ${ }^{c}$ Departamento de Matemática Aplicada, Universitat Politècnica de València, 46022 Valencia y ${ }^{\mathrm{d} C}$ Centro de Tecnologías Físicas, Universitat Politècnica de València, 46022 Valencia,

\begin{abstract}
In this paper we presents a new Applet developed to study linear polarization of light by using linear polarizers. When a linearly polarized light beam passes through a linear polarizer, the transmitted intensity depends on the relative angle between the vibration plane of light and the transmission axis of the polarizer (Malus's Law). This virtual laboratory allows students to see the effect of the action of one or more polarizers on the intensity of a nonpolarized incident light beam.
\end{abstract}

Keywords: Virtual Laboratory, Polarization, Malus's Law

\begin{abstract}
Resumen
En este trabajo se presenta un nuevo Applet para el estudio de la polarización lineal de la luz mediante el uso de polarizadores lineales. Cuando un haz de luz linealmente polarizada incide sobre un polarizador lineal, la intensidad transmitida depende del ángulo relativo entre el plano de vibración de la luz y el eje de transmisión del polarizador (ley de Malus). Este laboratorio virtual permite a los estudiantes ver el efecto de la actuación de uno o más polarizadores sobre la intensidad de un haz incidente no polarizado.
\end{abstract}

Palabras clave: Laboratorio Virtual, Polarizacion, Ley de Malus 


\section{Introducción}

Con la incorporación de las Tecnologías de la Información y las Comunicaciones (TICs) a la educación, se abre un abanico de nuevas posibilidades para la modelización y simulación digital de todo tipo de fenómenos naturales. La interactividad que proporcionan está en sintonía con las actuales corrientes pedagógicas constructivistas, centradas en el estudiante, quien debe construir su cuerpo de conocimientos con la ayuda del profesor (Jimoyiannis, 2001).

Numerosas investigaciones llevadas a cabo en distintos niveles educativos han mostrado las ventajas de procesos del aprendizaje basados en simulaciones digitales (Esquembre, 2002). Sin embargo, conviene tener en cuenta que la eficacia didáctica de estos procesos no está ligada directamente al uso de las simulaciones, sino a su correcta integración en el plan global de aprendizaje (Steinberg, 2000).

El hecho de que las TICs se encuentren en pleno proceso de desarrollo, debe animar a investigar nuevas posibilidades de las mismas. Así, los laboratorios virtuales son una herramienta científica que ofrece gran potencial para la transmisión de conocimientos científicos, a través de modelos basados en la experiencia (Vidaurre, 2002). Con ellos podemos representar fenómenos físicos con la suficiente verosimilitud para que sean perfectamente identificables con situaciones reales. Por otro lado, podemos filtrarlos de ruidos (idealizarlos), de tal manera que el concepto científico que subyace en ellos surja con total nitidez. De esta forma se puede conseguir que la transición entre el concepto científico y el modelo cognoscitivo del mismo, sea sencilla. Una posterior integración de su modelo matemático posibilitará un mayor afianzamiento del conocimiento del concepto y servirá de enlace con el campo de las aplicaciones.

Entre los numerosos formatos que se han utilizado para el desarrollo de laboratorios virtuales (Depcik, 2005), destacan los Applet implementados con Java (Deitel, 2004). En este contexto, presentamos un nuevo Applet para el estudio de la polarización lineal de la luz mediante el uso de polarizadores lineales. Cuando un haz de luz linealmente polarizada incide sobre un polarizador lineal la intensidad transmitida, que depende del ángulo relativo entre el plano de vibración de la luz y el eje de transmisión del polarizador, se puede expresar mediante la ley de Malus (Hecht, 2001). Esta simulación permite ver el efecto de la actuación de uno o más polarizadores sobre la intensidad de un haz incidente de luz no polarizada. Se pueden seleccionar hasta tres polarizadores lineales, de los que es posible variar la orientación de su eje de transmisión, comprobando de este modo el cumplimiento de la ley de Malus. La simulación se ha programado en lenguaje estándar HTML5 + Java script para que pueda ser utilizado en los navegadores más habituales.

El Applet presentado forma parte de un proyecto más amplio desarrollado en el marco de la Red Valenciana de Innovación Educativa en Óptica que se constituyó el pasado curso académico 2012-13. La Red está formada por tres grupos de trabajo pertenecientes la 
Universitat de València, la Universitat Jaume I de Castelló y la Universitat Politècnica de València que han decidido aunar esfuerzos para llevar a cabo diversos proyectos en el ámbito de la innovación educativa (Pons-Martí, 2014).

\section{Objetivos}

La polarización de la luz es objeto de estudio en todos los cursos básicos de Física y la comprobación experimental de la ley de Malus suele ser una práctica de laboratorio habitual en muchos de ellos. Por ello, el Applet que se presenta puede ser muy útil para complementar los contenidos desarrollados en las clases teóricas y de laboratorio.

El objetivo concreto del Applet es proporcionar a los estudiantes una herramienta docente interactiva y de fácil manejo para el estudio de la polarización lineal de los haces luminosos. Como es bien conocido (Hecht, 2001), cuando un haz de luz no polarizada incide sobre un polarizador lineal, la luz transmitida por éste pasa a estar linealmente polarizada a lo largo de una dirección que recibe el nombre de eje de transmisión del polarizador. Además, si el polarizador es ideal (esto es, absorbe la luz que oscila perpendicularmente a su eje de transmisión y es perfectamente transparente a la luz que oscila paralelamente a este eje), la intensidad de la luz linealmente polarizada emergente es exactamente la mitad de la de la luz natural incidente. Si lo que incide sobre el polarizador lineal es luz linealmente polarizada, el polarizador proporciona de nuevo luz polarizada a lo largo de su eje de transmisión, pero el valor de la intensidad transmitida, I, viene ahora dado por la ley de Malus,

$$
I=I_{0} \cos ^{2} \alpha
$$

donde $I_{0}$ es la intensidad del haz de luz incidente y $\alpha$ es el ángulo formado por la dirección de vibración de la luz incidente con el eje de transmisión del polarizador. En el Applet se dispone de un conjunto de tres polarizadores lineales giratorios (que pueden activarse de uno en uno) sobre los que incide un haz de luz no polarizada. Variando la orientación del eje de transmisión de los polarizadores puede constatarse que la intensidad del haz transmitido por el conjunto va cambiando de acuerdo con la ley de Malus.

Como objetivos complementarios se pretende, por un lado, motivar a los estudiantes en el estudio de la Física presentando sus contenidos, en este caso la polarización de la luz, de modo y atractivo y, por otro, potenciar su trabajo autónomo proporcionándoles una herramienta docente versátil y accesible para su uso las $24 \mathrm{~h}$.

\section{(c) EY-NC-ND 2014, Universitat Politècnica de València}

I Jornadas IN-RED (2014) 


\section{Desarrollo de la innovación}

El aspecto de la página de inicio del Applet se muestra en la Fig1. Como puede comprobarse el diseño utilizado para la representación de los elementos representados es realista de modo que la identificación de los mismos por parte del usuario sea inmediata. En primer lugar se representa una fuente de luz monocromática no polarizada que junto a una lente convergente proporciona el haz plano, de Intensidad igual a 100 unidades arbitrarias, que incide sobre el conjunto de polarizadores (tres como máximo). Cada polarizador puede activarse individualmente y variar la orientación de su correspondiente eje de transmisión haciendo uso del cursor o introduciendo el valor numérico del ángulo (de $0^{\circ}$ a $360^{\circ}$, con una cifra decimal) en el cuadro de valores asociado. El elemento final del dispositivo representa un detector que registra la intensidad total transmitida por el conjunto de polarizadores, cuyo valor se muestra en el recuadro situado junto a él.

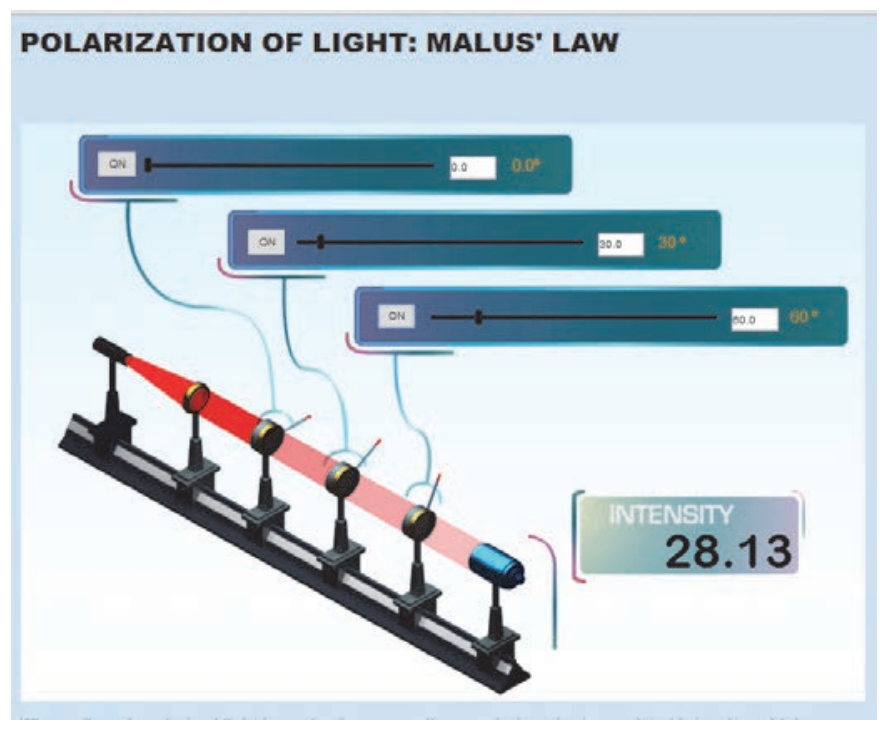

Fig1. Impresión de pantalla de la página de inicio del Applet

En las experiencias de laboratorio para la comprobación de la ley de Malus lo habitual es utilizar únicamente dos polarizadores. Con el primero de ellos se obtiene un haz de luz polarizada linealmente en una cierta dirección y al variar la orientación del eje de transmisión del segundo puede comprobarse que la intensidad final transmitida cumple la ley de Malus. En la simulación presentada pueden activarse hasta tres polarizadores lo cual supone una generalización y permite, como se mostrará en el apartado de Resultados, plantear algunas cuestiones interesantes como, por ejemplo ¿qué ocurre si entre dos polarizadores cruzados (con sus ejes a $90^{\circ}$ ) que en conjunto, de acuerdo con la ley de Malus, bloquean el paso de la luz, se intercala un tercer polarizador? 
En cuanto a los aspectos de carácter técnico, la simulación se ha programado en lenguaje estándar HTML5 + Java script para que pueda ser utilizado en los navegadores más habituales (Internet Explorer, Mozilla, Google Chrome, etc...).

\section{Resultados}

En las siguientes figuras se muestran algunos casos típicos que es posible analizar mediante el Applet desarrollado. En el primer caso (ver Fig.2 A y B), activando un solo polarizador, se puede comprobar que el valor de la intensidad final es independiente de la orientación del eje de transmisión. Esto se debe a que el haz incidente de luz no polarizada puede descomponerse siempre en dos componente iguales y perpendiculares entre sí, una vibrando paralelamente al eje de transmisión del polarizador y otra que lo hace en el plano perpendicular, de modo que en todos los casos se transmite la componente paralela al eje de transmisión y se bloque la perpendicular.

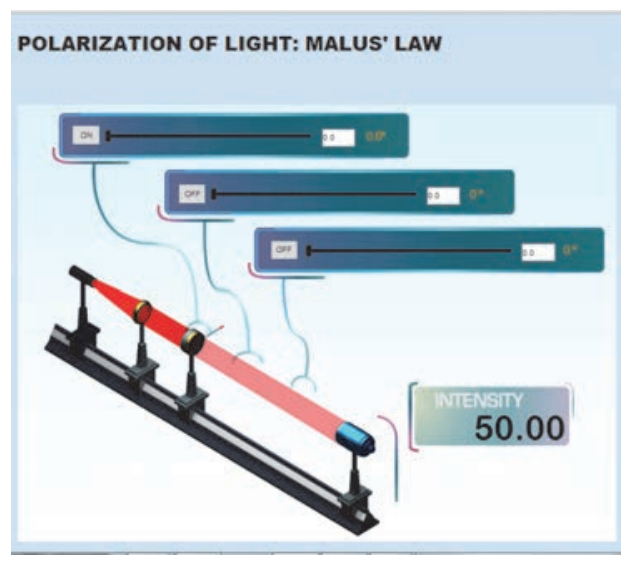

A)

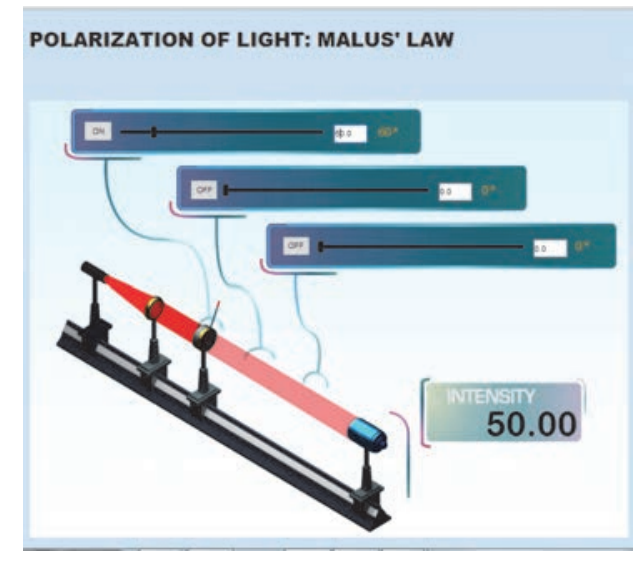

B)

Fig2. Con un solo polarizador lineal la intensidad final es independiente de la orientación del eje de transmisión

En el siguiente ejemplo se muestra la utilidad de disponer de tres polarizadores lineales. Cuando el haz de luz incide sobre el conjunto de dos polarizadores con sus ejes cruzados (formando un ángulo de $90^{\circ}$ entre ellos), la intensidad total transmitida es nula (ver Fig.3A). Sin embargo, al intercalar entre ellos un tercer polarizador lineal, la intensidad es función del ángulo relativo entre los ejes de los tres polarizadores (ver Fig.3B y Fig3.C). Puede comprobarse que, de acuerdo con la ley de Malus, salvo en los dos casos en los que el eje del nuevo polarizador sea paralelo al del primero o último, la intensidad total transmitida deja de ser nula (ver Fig3.D)

\section{(c) EY-NC-ND 2014, Universitat Politècnica de València}

I Jornadas IN-RED (2014) 


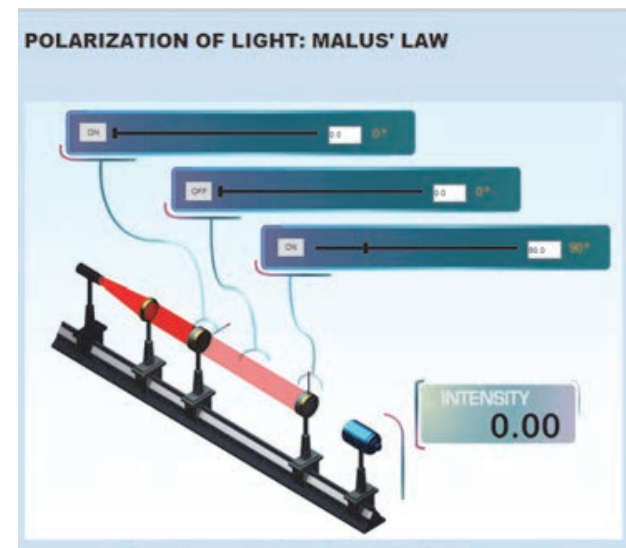

A)

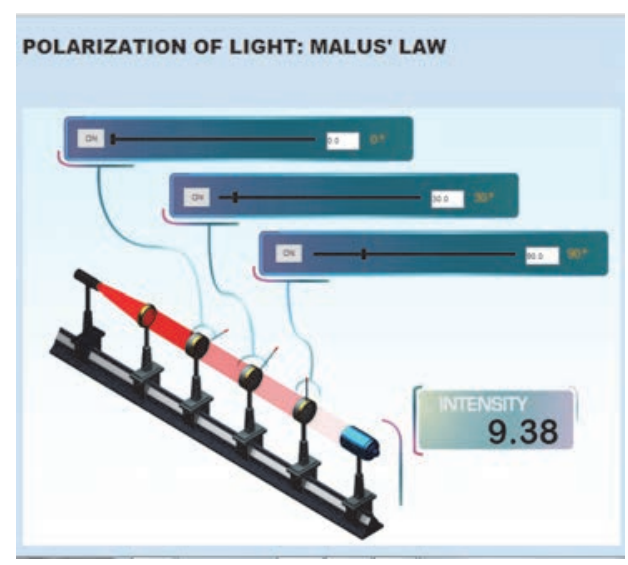

C)

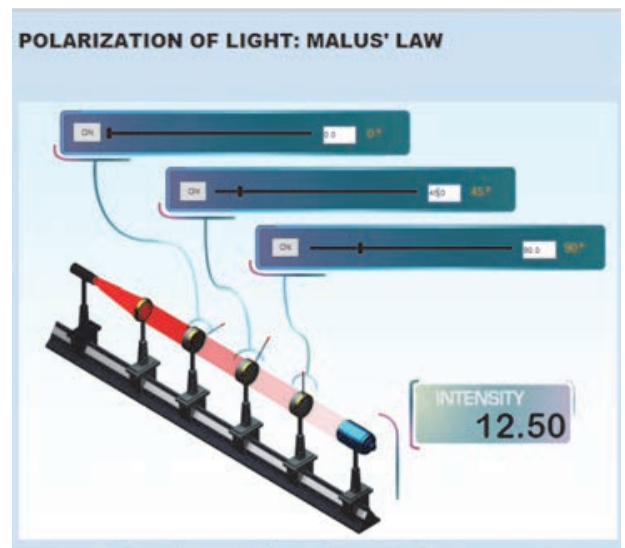

B)

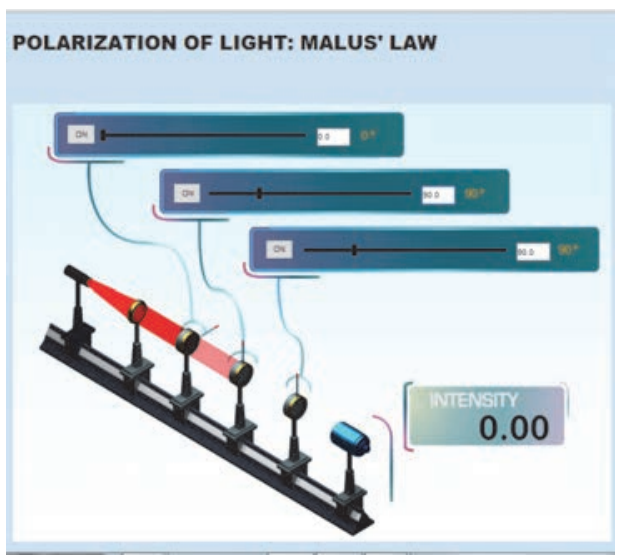

D)

Fig3. Un conjunto de dos polarizadores lineales con sus ejes cruzados bloquea el paso de la luz. Al intercalar entre ellos un tercer polarizador lineal, la intensidad total transmitida deja de ser nula

\section{Conclusiones}

El Applet que presentamos es una herramienta docente innovadora para el estudio de la polarización de la luz. A través de un diseño sencillo y realista se ofrece a los estudiantes la posibilidad de revisar y profundizar en los conocimientos de las propiedades de los polarizadores lineales. El uso de tres polarizadores lineales, en lugar de dos como es lo habitual en las experiencias de laboratorio, supone una generalización en el estudio de la ley de Malus y propicia el planteamiento de interesantes cuestiones sobre el comportamiento de la luz polarizada. Por otro lado, su carácter interactivo y su plena accesibilidad a través de los exploradores más habituales, convierten a este laboratorio 
virtual en una herramienta de estudio que puede ser muy útil y atractiva tanto para los docentes como para los estudiantes.

Por último queremos resaltar que el desarrollo del Applet ha contribuido a reforzar el trabajo de colaboración entre los tres grupos que integran la Red Valenciana de Innovación Educativa en Óptica.

\section{Agradecimientos}

Los autores de los Grupos de Innovación Docente, IndopTIC (GCID35/2009) de la Universitat de València, MoMa de la Universitat Politècnica de València y Equipo de enseñanza y divulgación de la Física de la Universitat Jaume I, agradecen el apoyo institucional y económico recibido de sus respectivas universidades para el desarrollo de sus proyectos de innovación. Por último, los tres grupos agradecen al Vicerrectorado de Cultura e Igualdad de la Universitat de València, su apoyo para la constitución de la Red Valenciana de Innovación Educativa en Óptica.

\section{Referencias}

DEITEL, H.M. Y DEITEL, P.J. (2004). Cómo programar en Java. Pearson Education.

DEPCIK, C. Y ASSANIS, D.N. (2005), "Graphical user interfaces in an engineering educational environment". Comput. Appl. Eng. Educ. 13, pp. 48-59.

ESQUEMBRE, F. (2002). "Computers in physics education". Comput. Phys. Commun. 147, pp. 1318.

HECHT, E. (2001). Optica. Addison-Wesley.

JIMOYIANNIS A., Y KOMIS V. (2001). "Computer simulations in physics teaching and learning". Computer \& Education, 36, pp. 183-204.

PONS-MARTÍ, A., BARREIRO, J.C., FERNÁNDEZ-ALONSO, M., MARTÍNEZ-LEÓN, LL., GIMÉNEZ, M.H., Y MONSORIU J.A. (2014). "Valencian Network of Educational Innovation in Optics". Mult. J. Edu. Soc \& Tec. Sci. 1, pp. 153-168.

STEINBERG, R.N. (2000). "Computers in teaching science: To simulate or not to simulate". Am. J. Phys 68, pp. S37-S41.

VIDAURRE, A, RIERA, J., JIMÉNEZ, M.H. Y MONSORIU, J.A. (2002). "Contribution of simulation in visualizing physics processes". Comput. Appl. Eng. Educ. 10, pp. 45-49.

(cc) EY-NC-ND 2014, Universitat Politècnica de València

I Jornadas IN-RED (2014) 
Jornadas In-Red 2014

Universitat Politècnica de València

\title{
Estrategias emocionales para promover la excelencia del alumnado
}

\footnotetext{
Alejandro Rodríguez ${ }^{\mathrm{a}}$, Alfonso Martínez ${ }^{\mathrm{b}}$, Ana Jiménez ${ }^{\mathrm{c}}$, Héctor Moreno ${ }^{\mathrm{d}}$, Ignacio Guillén $^{\mathrm{e}}$, Marta Cabedo ${ }^{\mathrm{b}}$, Salvador Calvet ${ }^{\mathrm{f}}$, Sara Ibáñez ${ }^{\mathrm{d}}$

Grupo Interdisciplinar Para el Aprendizaje Universitario (GRIPAU). Universitat Politècnica de València. ${ }^{\mathrm{a}}$ Departamento de Dibujo, ${ }^{\mathrm{b}}$ Departamento de Comunicaciones, ${ }^{\mathrm{c}}$ Departamento de Biotecnología, ${ }^{\mathrm{d}}$ Departamento de Producción Vegetal, ${ }^{\mathrm{e}}$ Departamento de Física Aplicada, fDepartamento de Ciencia Animal. Contacto: e-mail: marcafab@dcom.upv.es
}

\begin{abstract}
This paper describes the work developed during the last year by the Team in Education Innovation and Quality GRIPAU in the UPV. To this multidisciplinary team of professors, developing strategies to enhance student's motivation is one of the main goals. These strategies may allow students a significant learning, and thus the excellence in their learning. An excellent learning may be defined not only considering theoretical contents, but also the development of certain capabilities, sensitization with their environment or development of critical thinking. To this aim, a series of strategies potentially enhancing this learning have been defined. These strategies have been applied in eight subjects belonging to very different areas of knowledge and evaluated using a common methodology consisting in surveys to students at the beginning and at the end of the course. In general, the methodologies used in this study were positively rated by students and a tendency to improve the development of certain cross competences was detected. It can be concluded that enhancing student's reflection on his own learning is an effective strategy to motivate students and promote an excellent learning.
\end{abstract}

Keywords: generic skill, motivation, significant learning, excellence 


\begin{abstract}
Resumen
Esta comunicación describe el trabajo desarrollado en el último año por el Equipo de Innovación y Calidad Educativa (EICE) GRIPAU en la UPV. Este es un equipo multidisciplinar de profesores tiene como uno de sus principales objetivos desarrollar estrategias que favorezcan la motivación del alumnado como herramienta para que estos alcancen un aprendizaje significativo, y en última instancia, la excelencia en su aprendizaje. Esta excelencia se define no solo considerando el aprendizaje de contenidos teóricos, sino también mediante el desarrollo de competencias y habilidades, sensibilización con el entorno, y desarrollo del pensamiento crítico. En primer lugar, se han definido una serie de estrategias que potencialmente pueden permitir este aprendizaje significativo, estableciendo unas líneas comunes de actuación. Estas estrategias han sido aplicadas en ocho asignaturas de áreas de conocimiento muy dispares, y evaluadas mediante una metodología común que consiste en el seguimiento de resultados objetivos y el análisis encuestas pasadas a los alumnos al principio y al final de la asignatura. En general, las metodologías utilizadas han sido valoradas positivamente por parte de los alumnos y se ha observado una tendencia a mejorar el desarrollo de determinadas competencias transversales en función de las metodologías empleadas. Puede concluirse que favorecer la reflexión del alumno acerca de su propio aprendizaje es una estrategia de motivación que favorece un aprendizaje profundo
\end{abstract}

Palabras clave: competencia genérica, motivación, aprendizaje significativo, excelencia

(cc) EY-NC-ND 2014, Universitat Politècnica de València

I Jornadas IN-RED (2014) 


\section{Introducción}

Los autores de la presente comunicación forman parte de un Equipo de Innovación y Calidad Educativa (EICE) de la Universitat Politècnica de València denominado GRIPAU (Grupo Interdisciplinario Para el Aprendizaje Universitario), que está compuesto por profesores que llevan a cabo su docencia en diversas disciplinas como agronomía, tecnología de los alimentos, bellas artes, arquitectura, forestales-ambientales y telecomunicaciones. Este equipo se plantea a partir de la experiencia como grupo base dentro de la edición número 10 del Programa FIPPU (Formación Inicial del Profesorado Universitario) de la Universitat Politècnica de Valencia (UPV). En el seno de este grupo, se crea en 2009 el equipo de trabajo multidisciplinar GRIPAU, que aborda y comparte inquietudes docentes comunes para un entorno universitario abierto al cambio y a la mejora, que se materializan en la participación en congresos y la puesta en marcha de actividades de enseñanza-aprendizaje conjuntas.

El principal objetivo de GRIPAU es desarrollar nuevas metodología docentes que aumenten la motivación y favorezcan el aprendizaje significativo de los alumnos. Así, los resultados obtenidos por GRIPAU en los últimos años han sido fruto del intenso trabajo colaborativo realizado, que se ha visto propiciado por una profunda reflexión sobre la complejidad de los procesos de aprendizaje. La búsqueda de la excelencia es una meta ambiciosa que requiere la puesta en marcha de una gran cantidad de recursos humanos. Por tanto, la excelencia no debe considerarse como un objetivo, sino como una consecuencia de un largo y laborioso proceso de interacción continua, comparación y por supuesto, de reflexión (Rinaudo, 2006). No hay fórmulas, ni técnicas o metodologías mágicas. Una estrategia podría propiciar algunos cambios en la actitud del alumno. Sin embargo, la combinación de ésta con una metodología divergente, ponderará el valor de una actuación para determinados casos. Pero de ninguna manera, se puede asumir como una fórmula susceptible de poder repetirse en circunstancias similares.

Cómo ya hemos mencionado anteriormente, todo el grupo de innovación detectó como problemática común en sus respectivas asignaturas, una falta de motivación generalizada en el alumnado. En el caso de Bellas Artes, no era tanto una desmotivación como una diferenciada actitud de inicio condicionada por la expectativa en unos resultados muy definidos. Esta situación nos condujo en primer lugar a diferenciar entre dos grupos de alumnos. El primero, los que se habían matriculado a la asignatura porque esperaban obtener una utilidad muy concreta (motivación extrínseca) (Rinaudo, 2003). El segundo grupo, lo conforman aquellos estudiantes que se encontraban en clase por el puro placer de aprender, por la satisfacción del descubrimiento del conocimiento por sí mismo (motivación intrínseca). "Es el gozar, no el poseer, lo que nos hace felices" (Montaigne, 2005).

\section{(c) EY-NC-ND 2014, Universitat Politècnica de València}


Cuando hablamos de estrategias emotivas nos referimos principalmente a acciones que fomenten la seguridad en el alumno; asumiendo precisamente que mediante la duda, la incertidumbre y el error, podemos llegar a la verdad. Sin equivocación no hay aprendizaje.

En un principio puede parecer que estos objetivos son difusos o poco claros. No obstante, conforme el alumno va familiarizándose con la dinámica de la clase, empieza a asimilar en primer lugar que las expectativas iniciales se van diluyendo, para comprender que lo más importante no es el qué sino el cómo se hace. Para ello hay que aceptar que el proceso de trabajo es igual o incluso más importante que el resultado. En el proceso de aprendizaje hay que situar a la persona en una situación poco habitual. Es la única manera de ejercitar el sentido de adaptación para poder reaccionar antes cualquier circunstancia desconocida.

Una educación fascinada por los contenidos y la 'transmisión de conocimientos' tan valorada en las áreas técnicas, es antagonista a la educación integral, centrada más en proporcionar los elementos para una autorregulación de las condiciones del aprendizaje. Esta vertiente sería creativa por definición, mientras que la primera se asume como previsora y convergente.

Según Guilford (1978), los cuatro pilares de la creatividad son la fluidez, flexibilidad, elaboración y finalmente como consecuencia de todo lo anterior, la originalidad. La originalidad en cuanto a la capacidad de poder generar un gran número de ideas. Es necesario generar muchas alternativas. Con respecto a la flexibilidad, se fomenta mediante la capacidad de generar alternativas inusuales. Implica la actuación del pensamiento lateral para encontrar opciones sorprendentes. El tercer fundamento es el de la elaboración. Es decir, el proceso. Es el más importante porque nos ayuda a comprender que las ideas e innovaciones no nacen de la noche a la mañana. Requieren por lo tanto, de un trabajo arduo, constante y paciente. La pérdida del resultado como expectativa es un gran paso para asumir la importancia del proceso. La meta es el propio camino (Metacognición). Cabría entonces plantearse aquí la excelencia como un cambio de actitud hacia una orientación creativa del pensamiento. Tal y como lo plantea Martínez Criado (1991), una alternativa necesaria y natural en la formación integral de personas.

Finalmente la originalidad es la consecuencia del desarrollo de la fluidez, flexibilidad y la elaboración. No es posible ser original sin proceso. Las innovaciones surgen cuando no tenemos que batallar con el medio de nuestra expresión, sino cuando nos hacemos uno con él. En nuestro caso se fomenta en el alumno la capacidad de elección, para fomentar el sentido de responsabilidad ante los errores o fracasos y asumirlos entonces como parte imprescindible del aprendizaje significativo.

$\mathrm{Si}$ propiciamos un cambio de actitud en el alumno, es consecuente que valoremos el desarrollo del ser antes que el saber y fomentar desde luego el hacer para poder llegar ser. 
Por otro lado, para saber deberíamos antes que nada facilitar el manejo de los procesos cognitivos, tales como la observación, la discriminación, la recogida y organización de la información. Lo que permite reflexionar sobre el propio proceso de aprendizaje generando hipótesis y evaluando las posibles interferencias y lo más importante, encontrar las alternativas para saber cómo las hemos solventado.

El objetivo de la metodología que se propone a continuación, no es únicamente trabajar y evaluar las competencias genéricas definida por la UPV, sino desarrollar unas metacompetencias de autoreflexión y motivación. La verdadera innovación no se encuentra en las propias herramientas, sino en la mente del que las utiliza.

Un verdadero cambio de paradigma no es superficial. Lo significativo del ser humano no está su capacidad para poder ir a la esencia de los problemas mediante un profundo cuestionamiento de todo lo que nos rodea (Chomsky, 2001). Es necesario dudar de todo, ser crítico con las apariencias y las certezas, buscar siempre la estructura de la problemática por más elocuente parezca, en definitiva hay que buscar el argumento.

\section{Objetivos}

Este trabajo presenta los resultados del proyecto de investigación docente "Estrategias emocionales para promover la excelencia del alumnado" en el que durante el último año GRIPAU ha centrado su actuación. Este proyecto tiene como principal objetivo poner en marcha metodologías basadas en la motivación que permitan al alumno avanzar hacia la excelencia, entendida ésta desde el punto de vista del desarrollo integral del alumnado, es decir, no solo considerando el aprendizaje de contenidos teóricos, sino también el desarrollo de competencias y habilidades, sensibilización con el entorno, y desarrollo del pensamiento crítico, en consecuencia al desarrollo de su inteligencia emocional.

¿Cómo son nuestros estudiantes universitarios? ¿Son excelentes? ¿Los dirigimos hacia la excelencia? ¿Conseguimos motivarlos hacia dicho objetivo? ¿Aprenden con las asignaturas que les ofertamos? Todas estas preguntas son las que nos hemos planteado en el presente caso de estudio donde desde ópticas muy distintas de alumnado: estudiantes de bellas artes, tecnología de los alimentos, telecomunicaciones, agrónomos, arquitectos, etc., podemos testar cuál es el estado de las metodologías empleadas, el estado competencial de los alumnos y su repercusión en la excelencia docente.

\section{(c) EY-NC-ND 2014, Universitat Politècnica de València}

I Jornadas IN-RED (2014) 


\section{Desarrollo de la innovación}

\subsection{Asignaturas implicadas}

Este apartado es una aproximación a las diferentes estrategias y herramientas que se han trabajado en las distintas asignaturas que se detallan en el presente estudio. A pesar de las diferencias notables entre las distintas asignaturas que se muestran a continuación (Tabla 1), se ha encontrado un enfoque común en muchas de ellas, debido al trabajo conjunto que lleva realizando el grupo GRIPAU. Esto se debe al espacio de reflexión que se establece entre el grupo de profesores y que ha permitido conocer la experiencia satisfactoria en otras asignaturas y la posibilidad de implementarlo en las propias.

Tabla 1. Asignaturas en las que se ha realizado la innovación

\begin{tabular}{|c|c|c|c|c|}
\hline Código & Titulo & Titulación & Curso & $\mathrm{N}^{\circ}$ alumnos \\
\hline$\# 1$ & Salud pública & $\begin{array}{c}\text { Grado en Ciencia y Tecnología } \\
\text { de los Alimentos (GCTA) }\end{array}$ & $3^{\circ}$ & 57 \\
\hline$\# 2$ & $\begin{array}{l}\text { Producción de } \\
\text { monogástricos }\end{array}$ & Ingeniero Agrónomo (IA) & $5^{\circ}$ & 20 \\
\hline$\# 3$ & Clasificación de suelos & $\begin{array}{c}\text { Ingeniero Agrónomo (IA) } \\
\text { Ingeniero de Montes (IA) } \\
\text { M. Producción Vegetal (MPV) }\end{array}$ & $\begin{array}{c}4^{\circ} \\
/ \text { Master }\end{array}$ & 30 \\
\hline$\# 4$ & Comunicaciones ópticas & $\begin{array}{l}\text { Grado en Ingeniería de } \\
\text { Sistemas de Telecomunicación, } \\
\text { Sonido e Imagen. (GISTSI) }\end{array}$ & $3^{\circ}$ & 11 \\
\hline$\# 5$ & Sistemas de TV y video & $\begin{array}{l}\text { Grado en Ingeniería de } \\
\text { Sistemas de Telecomunicación, } \\
\text { Sonido e Imagen. (GISTSI) }\end{array}$ & $3^{\circ}$ & 40 \\
\hline \#6 & Eficiencia energética & $\begin{array}{l}\text { Máster Universitario en } \\
\text { Edificación. (MUE) }\end{array}$ & Master & 29 \\
\hline$\# 7$ & $\begin{array}{l}\text { Fundamentos de Grabado e } \\
\text { impresión }\end{array}$ & Grado en Bellas Artes. (GBA) & $3^{\circ}$ & 25 \\
\hline \#8 & Trabajo Final de Grado & $\begin{array}{l}\text { Grado en Arquitectura Técnica. } \\
\text { (GAT) }\end{array}$ & $4^{\circ}$ & 12 \\
\hline
\end{tabular}

\subsection{Estrategias y herramientas comunes para favorecer la motivación}

A lo largo de nuestra trayectoria como grupo hemos reflexionado sobre la importancia de las estrategias emocionales como aquellas que nuestros alumnos deben adquirir, pues son las más demandadas en el mundo real y es necesario que sean parte crucial dentro del 
ecosistema del aula. Ese proceso se materializa en la utilización de las siguientes estrategias, algunas de ellas íntimamente conectadas, no pudiendo en ocasiones separarlas para su utilización. Dichas estrategias se han aplicado en distintas asignaturas según se indica en la Tabla 1.

(1) Contextualizar: enmarcar la asignatura en la titulación, mediante la puesta en valor de las relaciones existentes con el resto de materias de la titulación, apoyándose en la propia experiencia personal de los alumnos de cara que auto reflexionen sobre la importancia de los contenidos a desarrollar y su proyección de futuro.

(2) Empatía: a partir de reflexiones sobre experiencias propias y vivencias que puedan ayudar a entender determinados conceptos expuestos en las asignaturas.

(3) Pensamiento Crítico: consecuencia de la reflexión propia sobre contenidos desarrollados en las distintas materias, elaborada en base a la experiencia personal.

(4) Conciencia Social: los alumnos no deben ser ajenos a la realidad social que les rodea y que determinará en ocasiones el desempeño futuro de sus competencias profesionales y laborales.

(5) Transferencia a la vida laboral: el empleo de esta estrategia se fundamenta en la búsqueda del apoyo de la futura vida laboral en la motivación extrínseca para el desarrollo de las tareas y contenidos asociados en la materia. Esto se consigue mediante herramientas diferentes, desde el desarrollo de proyectos sobre temáticas reales y a nivel profesional como con el trabajo en equipo o la presentación y defensa de un tema concreto en público

(6) Casos Reales: potenciar la proyección de las materias desarrolladas apoyándose en experiencias reales, tanto propias como ajenas. De este modo se interioriza la aplicabilidad de los contenidos desarrollados y su transferencia a la vida real.

(7) Debate de actualidad: mediante el empleo de noticias actuales relacionadas con los conceptos que se trabajan en el aula, para crear un espacio de reflexión y debate

(8) Actitudes Positivas: incentivar el humor, valorar el esfuerzo, programando tareas para que adquieran los contenidos requeridos de una forma que aumente la satisfacción al elaborar un material de calidad. Esto permite aumentar el rendimiento del alumno y la satisfacción. 
Estrategias emocionales para promover la excelencia del alumnado

Tabla 2. Estrategias utilizadas en cada asignatura

\begin{tabular}{|l|l|l|l|l|l|l|l|l|}
\hline \multirow{2}{*}{ Asignatura } & \multicolumn{7}{c|}{ Estrategias* } \\
\cline { 2 - 9 } & $(1)$ & $(2)$ & (3) & (4) & (5) & (6) & (7) & (8) \\
\hline \#1. Salud pública & & & & & & & & \\
\hline \#2. Producción de monogástricos & & & & & & & & \\
\hline \#3. Clasificación de suelos & & & & & & & & \\
\hline \#4. Comunicaciones ópticas & & & & & & & & \\
\hline \#5. Sistemas de TV y video & & & & & & & & \\
\hline \#6. Eficiencia energética & & & & & & & & \\
\hline \#7. Fundamentos de Grabado e impresión & & & & & & & & \\
\hline \#8. Trabajo Final de Grado & & & & & & & & \\
\hline
\end{tabular}

Con el fin de alcanzar la consecución de dichas competencias, se han utilizado distintas herramientas que se han trabajado para el desarrollo emocional del alumno a la vez que adquieren las competencias específicas propias de cada materia, en la Tabla 3 se muestran dichas herramientas y las distintas asignaturas que las han empleado.

Tabla 3. Estrategias utilizadas en cada asignatura

\begin{tabular}{|c|c|c|c|c|c|c|c|c|}
\hline \multirow[b]{2}{*}{ Asignatura } & \multicolumn{8}{|c|}{ Herramientas } \\
\hline & 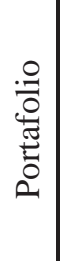 & 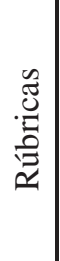 & 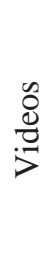 & 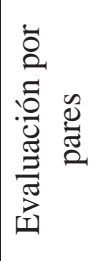 & 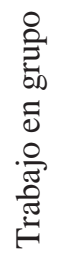 & 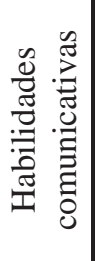 & $\begin{array}{l}0 \\
0 \\
0 \\
0 \\
0 \\
0 \\
0\end{array}$ & 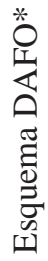 \\
\hline \#1. Salud pública & & & & & & & & \\
\hline \#2. Producción de monogástricos & & & & & & & & \\
\hline \#3. Clasificación de suelos & & & & & & & & \\
\hline \#4. Comunicaciones ópticas & & & & & & & & \\
\hline \#5. Sistemas de TV y video & & & & & & & & \\
\hline \#6. Eficiencia energética & & & & & & & & \\
\hline \#7. Fundamentos de grabado e impresión & & & & & & & & \\
\hline \#8. Trabajo Final de Grado & & & & & & & & \\
\hline
\end{tabular}

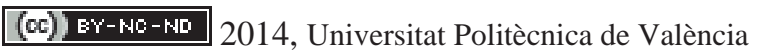

I Jornadas IN-RED (2014) 


\subsection{Evaluación de la innovación: encuestas inicial y final}

Se han empleado encuestas como herramientas dentro del proceso de evaluación de la innovación llevada a cabo en el presente trabajo. Con ellas se pretende cubrir dos objetivos: evaluación de la innovación y autorreflexión del alumnado. Estos dos puntos de análisis nos van a extraer las estrategias y herramientas comunes que permiten favorecer la motivación del alumno y su crecimiento en la destreza de las competencias y habilidades, que provocarán la excelencia en su proceso de aprendizaje.

Así pues, se han elaborado dos encuestas a realizar por el alumno el primer y último día de clase. Cabe destacar que éstas han sido confeccionadas para que puedan ser utilizadas en las asignaturas de este estudio pertenecientes a áreas de conocimiento muy dispares y de esta forma poder extraer unas conclusiones comunes ya sean asignaturas muy tecnológicas como artísticas.

Al inicio del cuatrimestre se ha pasado un cuestionario de opinión a los alumnos para conocer su grado de motivación. En este cuestionario se les pregunta qué referencias tienen de la asignatura, cuáles son sus expectativas respecto a la misma, qué esperan aprender, y cuál es su nivel de partida en competencias genéricas como trabajo en equipo, búsqueda de información, resolución de problemas y exposición oral. También se les pregunta qué nota final esperan obtener. Igualmente, se solicita a los alumnos que indiquen su DNI para poder correlacionar los resultados de este cuestionario de opinión inicial con el que se pasa a final de curso.

Al final del cuatrimestre, los alumnos han completado de forma voluntaria otro cuestionario, a partir del cual se pretende determinar si la asignatura ha cubierto sus expectativas, si la asignatura les ha parecido difícil, si les ha parecido útil para su futuro profesional, y si recomendarían la asignatura a otros compañeros. Además, se les pide que valoren su nivel de adquisición de competencias.

\section{Resultados}

El estudio desarrollado por el grupo interdisciplinar GRIPAU en un total de 8 asignaturas y 5 centros universitarios pertenecientes a la Universitat Politècnica de València ha contado con la participación total de 216 alumnos. Los resultados generados por la variabilidad de alumnos nos permitirán por tanto establecer un "dibujo" del estudiante universitario actual en la Politécnica de Valencia.

La motivación de los alumnos es básica en la búsqueda de la excelencia docente, puesto que promover en ellos la motivación por aprender es una clave fundamental para garantizar que puedan asumir con éxito un estilo de aprendizaje más autónomo y exigente (Romero y Pérez 2009). Los resultados revelan que el $77 \%$ de los alumnos encuestados elegirían la asignatura aunque no fuese obligatoria (Figura 1). Esto nos revela que algún aspecto de las

\section{(c)) EY-NC-ND 2014, Universitat Politècnica de València}

I Jornadas IN-RED (2014) 
asignaturas les motiva. Sin embargo, esto no se manifiesta tan marcadamente en la pregunta de si conocías la asignatura anteriormente, puesto que la mitad de los alumnos no sabía nada sobre ella. Este resultado nos revela que el "nombre" de la asignatura ejerce en un primer instante un efecto "motivador" sobre los alumnos. En la misma línea, la inicial motivación de los alumnos no se ve reflejada en cómo se informan sobre los contenidos de la asignatura. Debemos suponer que un alumno muy motivado inicialmente, debería indagar y conocer todos los aspectos de ésta. De este modo el $43 \%$ se informó a través de la plataforma PoliformaT durante el desarrollo del curso, seguido del 32\% que se informó el día de la presentación de la asignatura y el $22 \%$ por los comentarios de alumnos de otros cursos. De estos datos podemos establecer que los alumnos están parcialmente motivados al inicio del curso, pero ¿se motivaran con el desarrollo de éste? ¿Seremos capaces los docentes de ofrecer retos motivadores? Y definitivamente ¿conseguiremos la excelencia de nuestros alumnos?

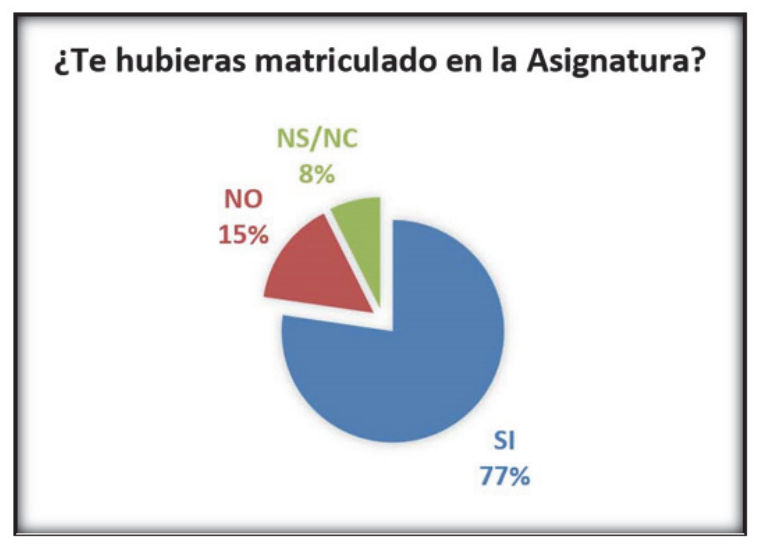

Fig. 1: Elección de la asignatura en la encuesta inicial.

Posiblemente la idea inicial de nuestros alumnos sobre las asignaturas este influenciada por la "lejanía" que muchas veces existe entre la docencia universitaria y la realidad social o entorno que nos rodea. En este sentido inicialmente el 53\% de los alumnos comentan que no han conocido o relacionado ninguna noticia en los medios de comunicación con la asignatura. Del $47 \%$ restante, el $45 \%$ ha visto noticias relacionadas en la televisión, el 33\% en la web y el $20 \%$ en prensa. Únicamente un estudiante de los 216 estudiados supo de la existencia de noticias sobre la asignatura en una revista de divulgación científica, que debería ser la fuente de información con mayor calidad científica. ¿No tienen una aplicación real nuestras asignaturas en la sociedad? ¿No sabemos transmitir ese valor de conocimiento sobre la realidad social que nos rodea?

El desarrollo de las diferentes estrategias y metodologías en las asignaturas dio lugar a los resultados que los alumnos contestaron al finalizar cada una de las asignaturas cursadas. 
Estos resultados muestran un dato esperanzador: Los alumnos han sido motivados a lo largo del curso por las estrategias aplicadas, en gran medida al comprobar que los conocimientos adquiridos tienen una aplicación práctica sobre nuestro entorno social.

El 91\% de los alumnos concluyen que la asignatura ha satisfecho sus expectativas iniciales, destacando el $72 \%$ que no ha sido difícil de abordar los conocimientos científicos en la asignatura. En este sentido el $88 \%$ ve positiva para su futuro profesional los conocimientos adquiridos y el $82 \%$ la recomendaría (Figura 2). Con todos estos datos podemos decir que los estudiantes muestreados son motivados por las metodologías docentes aplicadas ya que aumenta el porcentaje de gente que de manera voluntaria recomendaría/cogería de nuevo la asignatura: del $77 \%$ al $82 \%$.

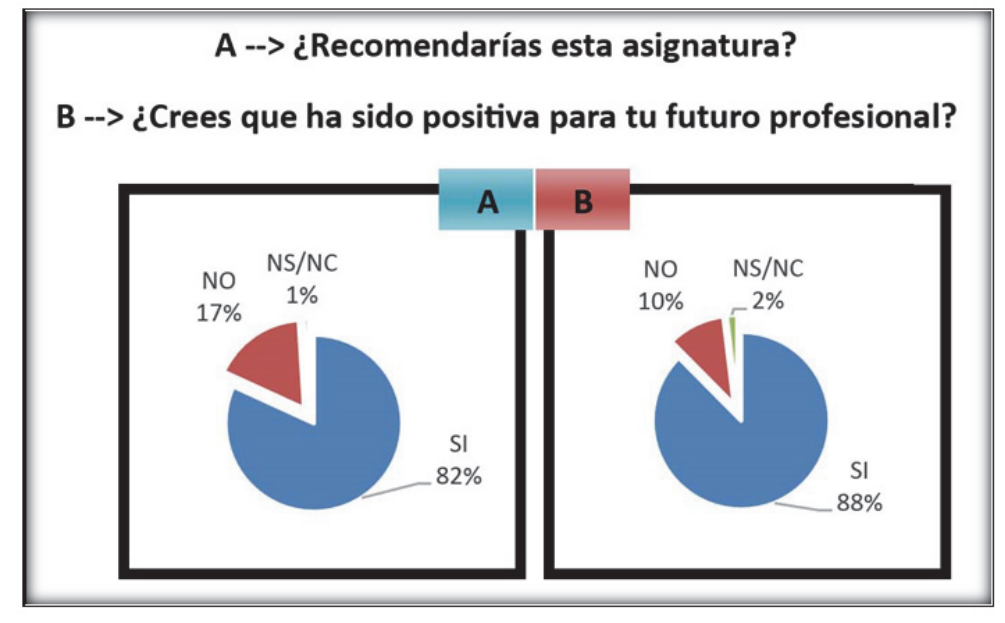

Fig. 2: Satisfacción final

Además, el alumno cambia su percepción social de los conocimientos adquiridos en su asignatura, puesto que el $72 \%$ corrobora que su percepción social sobre noticias e información en los medios ha variado desde el inicio del curso. La aplicación práctica de conocimientos en la vida real es una de las motivaciones más importantes en un estudiante universitario de últimos cursos de carrera como los encuestados aquí, puesto que observa como sus conocimientos pueden ser aplicados en su quehacer diario.

Por lo que respecta al nivel competencial de nuestros alumnos, el $62 \%$ se manifiesta al inicio del curso con una capacidad alta en el manejo de las redes sociales, siendo su descenso al final del curso poco relevante. Es de esperar que los alumnos sean capaces de manejar las nuevas tecnologías, puesto que la sociedad actual las absorbe de manera natural. Del mismo modo y al vivir en una sociedad de la información, el 73.4\% de los alumnos se considera bueno en la búsqueda de información, siendo al finalizar el curso un $82 \%$ de los alumnos los que se consideran en este nivel (figura 3). De este modo,

\section{(c)) EY-NC-ND 2014, Universitat Politècnica de València}

I Jornadas IN-RED (2014) 
estudiantes que al principio del curso se consideraban con un nivel bajo/medio han desarrollado esta competencia en las diferentes estrategias empleadas en las asignaturas. El mismo caso ocurre en el desarrollo de la redacción escrita. Los alumnos son capaces al final de curso y tras su autorreflexión sobre lo aprendido en la asignatura, de concluir que han mejorado su capacidad para la redacción escrita y más concretamente a un nivel científicoartístico-profesional (figura 3).

Por otra parte, el poliformaT, es una herramienta básica en la universidad puesto que es el principal canal de comunicación no física entre el alumno y el profesor. Todos se consideran buenos usuarios del poliformaT al principio del curso, pero al final hay una reducción del $0.6 \%$.

\section{NIVEL COMPENTENCIAL EN ALUMNOS DE LA UPV}
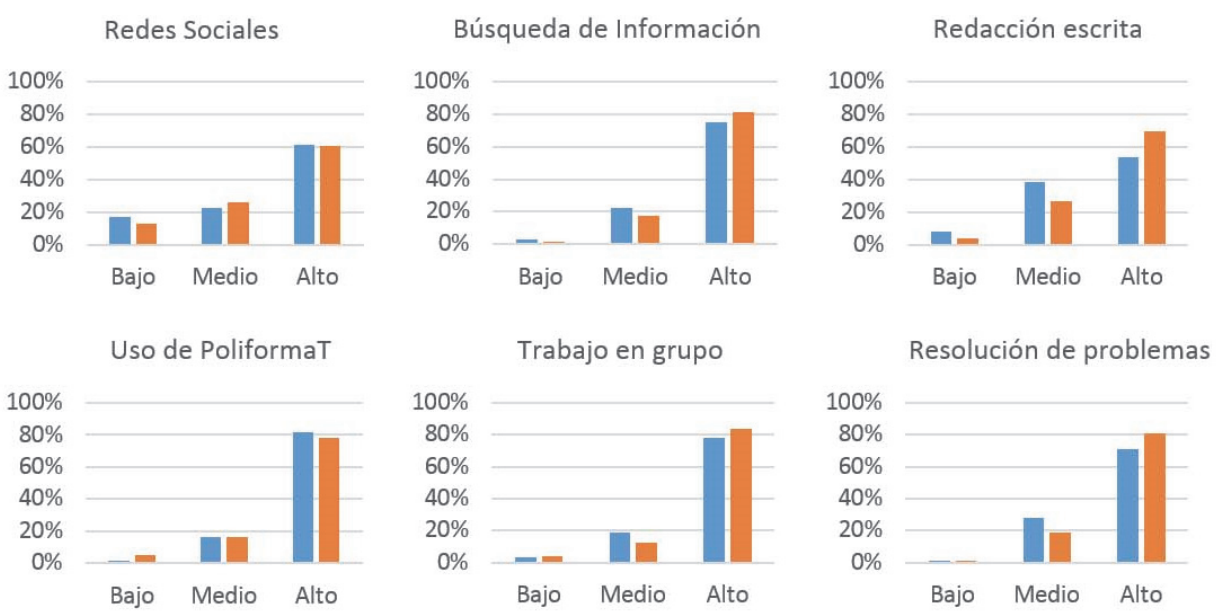

Hablar en Público
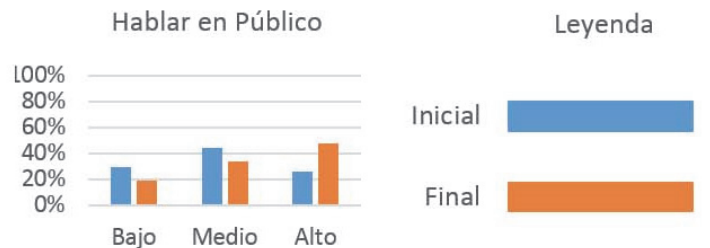

Fig.3: Grado de consecución de competencias transversales

La percepción del alumno respecto al trabajo en grupo aumenta y a la capacidad de resolución de problemas, también lo hace con el transcurso del curso. En este sentido los alumnos se enfrentan de manera autónoma o grupal a la realización de diferentes tareas o retos que les hacen mejorar esta habilidad. Por último y aunque mejora respecto al inicio del curso, los alumnos tienen un gran problema con la capacidad de hablar en público que 
les llega incluso a atemorizar. Mejorar dicha capacidad a nivel general es un reto que nos debemos de plantear como docentes, en base a su futuro profesional.

Desde la implantación del Plan Bolonia, en la universidad española se habla de cambios de paradigmas en la educación superior. El aprender cobra relevancia en contraposición al enseñar; la transmisión de conocimientos cede su papel por el de la adquisición de competencias. La innovación y el súbito reconocimiento del pensamiento creativo, la inteligencia emocional, social, los procesos emotivos del conocimiento, a veces quedan relegados por el conocimiento científico y la consecución de méritos. ¿Pero realmente es lo que nuestros alumnos buscan y la sociedad actual necesita?

\section{Conclusiones}

- Las metodologías empleadas en las diferentes asignaturas ponen de manifiesto a través de las encuestas que son unas buenas herramientas para motivar a los alumnos

- La percepción general de los alumnos frente a las habilidades encuestadas ha manifestado que aquellas de índole tecnológica son ampliamente valoradas como adquiridas, mientras que las de desarrollo personal presentan una evolución menor, pese a todo, las encuestas indican que una predisposición por parte del alumnado en mejorar sus competencias y habilidades.

- La competencia de hablar en público es un problema para nuestros alumnos. De los resultados derivados, podríamos indicar que como docentes debemos mejorarlo, pero al ver que es un resultado general, se debería de fomentar u ofertar cursos o actividades a nivel general de la universidad en la que el medio oral fuera clave. De esta forma mejoraríamos claramente esta competencia que es la que peor resultados recoge.

- La autorreflexión realizada por los alumnos ha facilitado el aprendizaje significativo y les ha hecho recapacitar sobre sus fortalezas y debilidades. Si buscamos la excelencia docente, que los alumnos se sitúen y descubran sus deficiencias, los enriquece en el proceso de aprendizaje, pues les plantea un nuevo reto al que se deben enfrentar lo más motivados posibles.

- Esta investigación demuestra que un grupo interdisciplinar de innovación educativa puede desarrollar estrategias comunes para favorecer la motivación y excelencia del alumno en áreas de conocimiento muy dispares.

\section{Referencias}

CHOMSKY, Noam. La (Des)educación. Ed. Crítica, S.L., Barcelona, 2001.

\section{(c) EY-NC-ND 2014, Universitat Politècnica de València}


GUILFORD, J. P. (1978). La Creatividad, presente, pasado y futuro. Guilford, JP y otros.Creatividad y educación.-Paidos.

MARTÍNEZ CRIADO, G. (1991). Modelo psiconalítico de estimulación creativa. MARÍN, R. y DE LA TORRE, S.: Manual de la creatividad. Vicens Vives, Barcelona, 110-115.

MONTAIGNE, Michel; PICAZO, María Dolores; MONTOJO, Almudena. Ensayos. Gredos, 2005.

ORDINE, Nuccio. La utilidad de lo inútil. Ed Acantilado, Barcelona, 2013

RINAUDO, María Cristina; CHIECHER, Analía; DONOLO, Danilo. Motivación y uso de estrategias en estudiantes universitarios: su evaluación a partir del Motivated Strategies Learning Questionnaire. 2003.

RINAUDO, María Cristina, María Laura DE LA BARRERA, and D. DONOLO. "Motivación para el aprendizaje en alumnos universitarios." Revista electrónica de motivación y emoción 9.22 (2006).

ROMERO, M.; PÉREZ, M. Cómo motivar a aprender en la universidad: una estrategia fundamental contra el fracaso académico en los nuevos modelos educativos. Revista Iberoamericana de Educación, 51: 87-105, 2009

UPV- UNIVERSIDAD POLITÉCNICA DE VALENCIA. Plan estratégico UPV 2007/2014. Valencia: Masmedios, 2007. 



\section{Sesión 3}

\section{Actividades de aprendizaje y evaluación}




\title{
Análisis de dos modelos de evaluación de competencias relacionadas con actividades de prácticas de primer curso de grado. Percepción por alumnos y profesores.
}

\author{
${ }^{a}$ Rosa Maria Belda, ${ }^{b}$ Fernando Fornes, ${ }^{c}$ Consuelo Monerri, ${ }^{\mathrm{d}}$ Sergio G Nebauer, \\ ${ }^{\mathrm{e}}$ Milagros del Saz, ${ }^{\mathrm{f}}$ Penny MacDonald, ${ }^{\mathrm{g}}$ Debra Westall \\ a, b, c, d, e, f, g Escuela Técnica Superior de Ingeniería Agronómica y del Medio Natural \\ Universitat Politècnica de València \\ armbelda@bvg.upv.es; $\quad$ bffornes@bvg.upv.es; $\quad$ c cmonerri@bvg.upv.es; $\quad$ s sergonne@ bvg.upv.es; \\ emasaru@idm.upv.es; ${ }^{\mathrm{f}}$ penny@idm.upv.es; ${ }^{\mathrm{g}}$ dwestall@upvnet.upv.es
}

\begin{abstract}
The teachers of EICE BeCool conducted an innovative educational project for students of Biotechnology: They designed the evaluation of laboratory activities for Biología Celular. Two types of evaluation were analyzed: 1) a questionnaire on the practicals and 2 ) the presentation of a scientific article. All students undertook the two activities in teams. Procedure: 1 ) design of the questionnaire and of the material needed for the scientific article ; 2) design of evaluation criteria; 3) implementation of activities ; 4) analysis of students' and teachers' perception of the two systems and 5) analysis of students' performance. Results were analyzed by qualitative analysis using the open question "Comment on the two evaluation systems for practicals of Biología Celular", which was aimed at students and teachers, and by descriptive statistics, using the marks obtained by the students. From the qualitative analysis unexpected issues emerged, which will be useful in the application of these systems in subsequent years. As for the results, students improved concentration and follow-up of the practicals in the evaluation by questionnaire. The evaluation by scientific article develops horizontal competences such as understanding and integration of knowledge, teamwork and leadership, effective communication and instrumentation specific to the subject.
\end{abstract}

(cc) EY-NC-ND 2014, Universitat Politècnica de València

I Jornadas In-Red (2014) 
Análisis de dos modelos de evaluación de competencias relacionadas con actividades de prácticas de primer curso de grado. Percepción por alumnos y profesores

\title{
Keywords:
}

evaluation, Ground Theory, innovative methodologies, lab activities, teaching-learning processes

\begin{abstract}
Resumen
Los profesores del EICE BeCool realizamos un proyecto de innovación educativa para alumnos de Biotecnología. Se diseñó la evaluación de actividades de laboratorio de Biología Celular analizándose dos tipos de evaluación: 1) cuestionarios de prácticas y 2) redacción de un artículo científico. Todos los alumnos realizaron las dos actividades por equipos. Procedimiento: 1) elaborar el cuestionario de prácticas y el material de apoyo para el artículo científico; 2) diseñar criterios de evaluación; 3) implementar actividades; 4) analizar la valoración de alumnos y profesores y 5) analizar el rendimiento de los alumnos. Se analizaron los resultados mediante técnicas de análisis cualitativo utilizando la cuestión abierta "Opina sobre los dos sistemas de evaluación de prácticas de Biología Celular y compáralos" dirigida a alumnos y profesores y mediante estadística descriptiva utilizando las notas obtenidas por los alumnos. Del análisis cualitativo emergieron temas inesperados que resultarán muy útiles en la aplicación de estos sistemas en cursos sucesivos. En cuanto a los resultados, los alumnos mejoran la atención y seguimiento de las prácticas en la evaluación por cuestionario. La evaluación mediante artículo científico supone que desarrollen algunas competencias como la de comprensión e integración, trabajo en equipo y liderazgo, comunicación efectiva $e$ instrumental específica.
\end{abstract}

\section{Palabras clave:}

actividades de laboratorio, evaluación, metodologías de enseñanzaaprendizaje, metodologías innovativas, Teoría Fundamentada

\section{Introducción}

La Universitat Politècnica de València (UPV) asignó grupos de Alto Rendimiento Académico (ARA) a aquellas titulaciones de grado a las que los alumnos accedían con notas de PAU superiores a 11 sobre 14. Es el caso del grado de Biotecnología que se imparte en la Escuela Técnica Superior de Ingeniería Agronómica y del Medio Natural.

(cc) EY-NC-ND 2014, Universitat Politècnica de València 
Entre los requisitos de los grupos ARA está el de que el 50\% de la docencia se imparte en inglés.

El cambio de paradigma educativo que supone la formación por competencias (Fernández, 2010) llevó a los profesores de Biología Celular e Inglés I de la titulación de Biotecnología a colaborar en la realización de actividades académicas conjuntas. Las actividades que se describen en este trabajo formaron parte de un Proyecto de Innovación y Mejora Educativa PIME 2013 financiado por la Universitat Politècnica de València.

Dentro del marco de las Dimensiones Competenciales UPV que se publicaron en 2013 diseñamos dos actividades relacionadas con las prácticas de laboratorio de Biología Celular: 1) cuestionario sobre cada práctica y 2) artículo científico sobre una práctica. Pretendíamos desarrollar y evaluar las competencias de "Trabajo en equipo y liderazgo" definida como "Trabajar y liderar equipos de forma efectiva para la consecución de objetivos comunes, contribuyendo al desarrollo personal y profesional de los mismos", "Comunicación efectiva" definida como "Comunicarse de manera efectiva, tanto de forma oral como escrita, utilizando adecuadamente los recursos necesarios y adaptándose a las características de la situación y la audiencia" y "Instrumental específica" definida como la "Capacidad para utilizar las técnicas, las habilidades y las herramientas actualizadas necesarias para la práctica de la profesión"

(http://www.upv.es/contenidos/ICEP/info/DimensionesCompetenciales.pdf).

\subsection{Hipótesis de trabajo}

Se partió de las siguientes hipótesis de trabajo:

1. La evaluación por cuestionarios después de cada práctica supondría que los alumnos trabajarían con interés la práctica. Para evitar que se limitaran a copiar explicaciones del profesor las preguntas del cuestionario habrían de suponer un cierto trabajo de búsqueda en la bibliografía y de reflexión del alumno.

2. La evaluación por artículo científico permitiría desarrollar competencias profesionales a nivel básico. Debería hacerse emulando a un grupo de científicos profesionales que presentan un artículo de una de sus investigaciones a una revista de impacto del ámbito de la biotecnología. Al tratarse de alumnos de primer curso la exigencia se centraría en la comprensión de la actividad realizada en el laboratorio y en la presentación formal del artículo.

\subsection{Objetivo}

(c) EY-NC-ND 2014, Universitat Politècnica de València

I Jornadas IN-RED (2014) 
Análisis de dos modelos de evaluación de competencias relacionadas con actividades de prácticas de primer curso de grado. Percepción por alumnos y profesores

Valoración de los dos sistemas de evaluación de prácticas de laboratorio de Biología Celular: a) cuestionarios de prácticas y b) artículo científico

1. Estudio cualitativo de la percepción de alumnos y profesores de ambos sistemas de evaluación.

2. Estudio cuantitativo del rendimiento de los alumnos.

3. Comparación de ambos.

\section{Metodología}

\subsection{Actividades realizadas}

Las actividades realizadas en el presente estudio se secuenciaron del siguiente modo:

- Preparación del material de apoyo para la realización del artículo científico por los profesores de inglés y de biología y preparación de los cuestionarios de prácticas por los profesores de biología.

- Publicación de ambos tipos de materiales en la plataforma de la asignatura.

- Presentación de las actividades a los alumnos el primer día de clase por el profesor responsable de la asignatura. Se les indica que deberán hacer equipos de 5 personas y que el equipo será el mismo para los dos tipos de actividades. Todos los grupos realizarán los dos tipos de actividades. La calificación será la mejor de las obtenidas por los dos métodos de evaluación.

- Presentación del material de apoyo para la realización del artículo científico y explicación de cómo adecuarlo formalmente en inglés por los profesores de inglés y de biología.

- El cuestionario de cada práctica constaba de 3-4 preguntas que estaban disponibles al finalizar la práctica y que debían entregarse a la semana siguiente

- Para el artículo científico contaban con seis semanas desde la realización de la práctica hasta la fecha de entrega.

- El último día de clase de prácticas, antes de saber su calificación en las mismas, los alumnos respondieron a la pregunta "Give your opinion on the two evaluation systems". Eran conocedores de la pregunta con una semana de antelación y se les dieron 15 minutos para responder. Respondieron 108 alumnos y se procesaron todas las respuestas.

- Tanto el cuestionario de cada práctica como el artículo científico fueron corregidos por profesores de Biología Celular y por profesores de Inglés I. 
- Tras la calificación todos los profesores respondieron a la pregunta "Give your opinion on the two evaluation systems".

\subsection{Metodología de análisis}

Para el estudio de los resultados se utilizaron dos métodos de análisis: el análisis cualitativo para interpretar la percepción de alumnos y profesores en las respuestas a la pregunta abierta y el análisis cuantitativo para estudiar el rendimiento de los alumnos.

\section{Resultados}

\subsection{Análisis de la valoración de alumnos y profesores de las actividades de evaluación}

El análisis de la valoración de las actividades de evaluación ha sido un análisis cualitativo basado en la Teoría Fundamentada (Scott and Howell, 2008). Se escogió este tipo de análisis de la valoración de alumnos y profesores porque permitía la interpretación de los discursos y de las estructuras latentes que podría ayudar a mejorar las actividades en cursos siguientes. Se consideraron dos tipos: "alumno" y "profesor" porque consideramos que representaban variables discursivas diferentes. Sin embargo, en algunos aspectos concretos se vio el interés de desdoblar "profesor" en "profesor de biología" y "profesor de inglés".

En primer lugar se utilizó la estrategia de codificación abierta para identificar los temas y categorías emergentes. Respecto a la organización de los temas se diferenciaron en aspectos centrales, aspectos secundarios y aspectos recurrentes. Se codificaron los relatos en base a dos conceptos nucleares y 10 categorías para alumnos y 7 para profesores. Se diseñó una matriz conceptual del relato que permitía una visión globalizadora y que se utilizó como modelo interpretativo. Finalmente se elaboró el informe como descripción narrativa.

Los dos conceptos nucleares fueron: percepción de la evaluación por cuestionario de cada práctica y percepción de la evaluación por artículo científico de una práctica, tanto para el tipo "alumno" como para el tipo "profesor". Hubo categorías coincidentes para los dos tipos: preferencia, implicación en las actividades, proyección de la actividad, percepción sobre calificaciones, recursos y opinión sobre el trabajo en grupo. En el tipo "alumno" además emergieron las siguientes: dedicación, coherencia con las actividades de laboratorio, falta de experiencia y percepción general y en el tipo "profesor" sugerencias.

Desde la perspectiva del "alumno" la proyección de la actividad emergió como categoría aglutinante de aspectos centrales del discurso. La realización del artículo científico les parecía útil, que enseñaba a redactar informes científicos, a citar adecuadamente y a hacer gráficas. Perciben que "prepara para el futuro" y les "hace sentirse parte del mundo científico". En relación con ello hablaban de falta de experiencia: es la primera vez que se

\section{(c) EY-NC-ND 2014, Universitat Politècnica de València}

I Jornadas IN-RED (2014) 
Análisis de dos modelos de evaluación de competencias relacionadas con actividades de prácticas de primer curso de grado. Percepción por alumnos y profesores

enfrentan a este tipo de trabajos, no se sienten preparados y les parece "difícil porque no tenemos experiencia". Paralelamente consideran que "cuesta elaborarlo", que "es largo", "requiere más tiempo" y "requiere mucha dedicación". No obstante, al comparar la dedicación con el sistema cuestionario consideraban que el artículo científico "permitía más flexibilidad temporal al tener más tiempo" y "no quitaba tanto tiempo" mientras que el cuestionario "requería reunirse (el equipo) cada semana" y "era difícil la puesta en común" al tener que buscar tiempo. Respecto al cuestionario de cada práctica emergió una categoría imprevista: la coherencia con las actividades del laboratorio. Los alumnos "no encuentran relación directa con las prácticas". Este aspecto resultó recurrente apareciendo en el 40\% de las respuestas. Para ellos, que hubiera que buscar información bibliográfica para resolver las cuestiones las hacía "difíciles" y consideraban que "no se correspondían con su nivel" por lo que a sus ojos la actividad no servía para evaluar las prácticas de laboratorio. Su percepción sobre el sistema cuestionario no era, sin embargo, negativa porque consideraban que las preguntas eran "interesantes", "entretenidas" y "variadas" y lo hubieran visto "bien si hubieran estado más relacionadas con las prácticas”. Además observaban que les implicaba en las prácticas porque "obligan a estar atento durante las sesiones" y "permiten afianzar conocimientos y profundizar" y pedían que "se clarificara la bibliografía". Por otro lado la realización del artículo científico permitía que "se profundizara", "se entendiera mejor la práctica", "se recopilara mucha información interesante" y que "todos los esfuerzos confluyeran en un trabajo a fondo". Valoraron positivamente el material de apoyo del que disponían en la plataforma y las explicaciones para la realización del artículo, indicando que "(los profesores) se esmeran en concretar todos los aspectos del artículo" y "encontramos útil el material (en la plataforma)". Con todo, solicitaban que se "explicara mejor como enfocar y presentar la 'Introducción", que era el apartado donde se sentían más inseguros ya que tenía más libertad de contenidos. Otro aspecto recurrente a resaltar fue la percepción sobre las calificaciones (no habían recibido ninguna nota cuando contestaron a la pregunta de opinión). Consideran que con el cuestionario "se incluyen todas las prácticas en la evaluación" y "no te juegas la nota a una práctica" mientras que con el artículo "te juegas la nota en un solo trabajo" y hay "menos oportunidades de sacar buena nota". Además solicitaban que las cuestiones "se corrigieran al día para poder mejorarlas". Un aspecto secundario pero que se manifestó en el 33\% de los casos fue la valoración del trabajo en grupo. Consideraron que ambas actividades "acostumbran a trabajar en equipo", que el trabajar "en equipo da seguridad", que "permite resolver problemas" y que "permite repartir el trabajo". No obstante, afirmaban que eran "demasiados en el grupo", que "había mucha diversidad de opiniones" y que "no quedan todos satisfechos". Aunque la preferencia por uno de los dos sistemas no figuraba en la pregunta, el $61 \%$ se manifestó al respecto: el $21 \%$ prefirieron el cuestionario y el $40 \%$ el artículo científico. 
Desde la perspectiva del "profesor" hay que tener presente que expresaron su opinión después de calificar. Respecto a la implicación de los alumnos en las actividades señalan que las cuestiones permiten el "análisis y maduración de contenidos" y que si sólo se realizara el artículo científico "concentrarían sus esfuerzos sólo en esa práctica”. Por otro lado, consideran que "no suelen entender bien la estructura/filosofía del artículo" aunque sí que "trabajan bien los resultados y la interpretación". Valoran que desarrollan "competencias y habilidades que no vienen dadas directamente por realizar las prácticas" y que es "recomendable como primera aproximación al tratamiento de datos". Los "profesores de inglés" señalaron que el artículo era "linguistically and cognitively the more interesting option" y que permitía que "they become familiarized with the structure of scientific/academic articles which is obviously beneficial to them, not only for their university work (projects, TFG, etc.), but thereafter", que además proporcionaba "more freedom to choose what aspects to write about" y que suponía "more research into other aspects of the task proposed" y que, en general, era "most challenging for the students". Respecto al cuestionario subrayaron que exigía de los estudiantes "more specific information and a 'finer' analysis of the task at hand". Con relación a los recursos "los profesores de biología" señalaron que los alumnos acudían con demasiada exclusividad a internet para responder al cuestionario y que "se debería ajustar la complejidad de las cuestiones" y "proponer cuestiones que requieran directamente libros recomendados". Los profesores también opinaron sobre el trabajo en equipos resaltando que estos no deberían ser de más de tres estudiantes además de reconocer que "el trabajo en grupo les obliga a negociar respuestas, la forma de presentación...". Como aspectos secundarios surgió la dedicación del profesor en tareas de evaluación que se consideraba superior en el sistema de preguntas y la pertinencia de ambos sistemas, que de seguir manteniéndose implicaría la reducción del cuestionario.

\subsection{Análisis del rendimiento de los alumnos}

El análisis del rendimiento de los alumnos ha sido cuantitativo y se ha utilizado estadística descriptiva (medias, desviaciones estándar) y análisis de frecuencias.

La media de las notas obtenidas mediante artículo científico fue de 7,02 con una desviación de 1,52 y la de notas obtenidas en cuestionario fue de 7,06 con una desviación de 1,28, lo que indicaría que apenas hay sesgo por un sistema u otro, especialmente por parte del profesor que corrige. Se calculó la diferencia entre los dos sistemas por equipos y se promedió obteniéndose el valor de 1,05, es decir podía obtenerse de media 1,05 puntos más dependiendo del sistema de evaluación. El histograma de frecuencias (Fig. 1) muestra que la mayoría de alumnos obtuvo mejor nota por el artículo científico que por el cuestionario y

\section{(c) EY-NC-ND 2014, Universitat Politècnica de València}

I Jornadas IN-RED (2014) 
Análisis de dos modelos de evaluación de competencias relacionadas con actividades de prácticas de primer curso de grado. Percepción por alumnos y profesores

que aquellos alumnos que habían obtenido más nota por el artículo científico habían presentado menor diferencia entre sistemas de evaluación.

\section{Conclusiones}

El estudio comparativo de dos actividades evaluables referidas a las prácticas de laboratorio ha permitido resaltar sus fuerzas y debilidades, no sólo desde la perspectiva del profesor sino también del alumno, pudiendo valorar aspectos que no se perciben teniendo en cuenta exclusivamente las calificaciones.

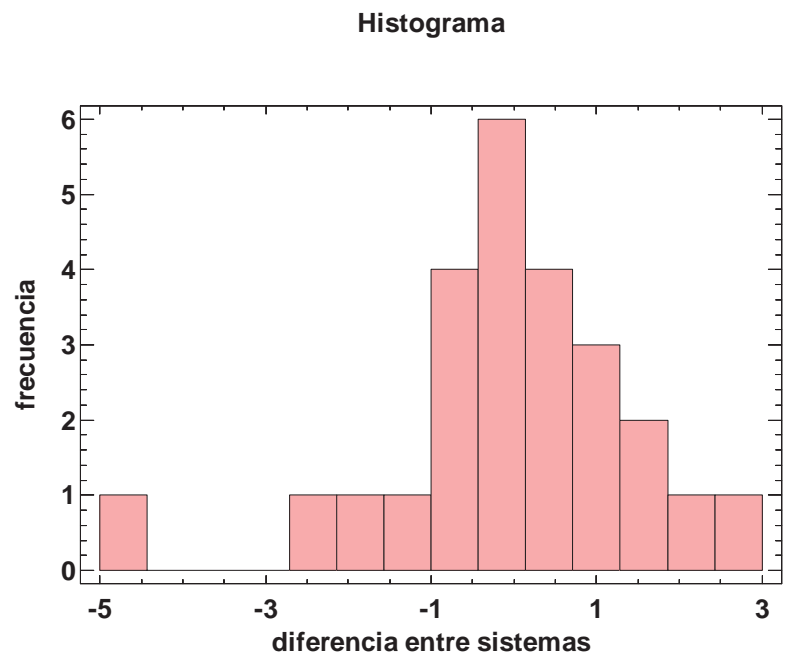

Fig. 1. Histograma de frecuencias de los valores de la diferencia en nota de los dos sistemas de evaluación. El valor positivo para los que obtuvieron mayor nota en el artículo y el negativo para los que la obtuvieron en el cuestionario.

\section{Agradecimientos}

Este proyecto ha sido financiado por la Universitat Politècnica de València. Los autores desean agradecer la inestimable colaboración de los alumnos de Biología Celular del curso 2013-2014. 
Rosa Maria Belda, Fernando Fornes, Consuelo Monerri, Sergio G Nebauer, Milagros del Saz, Penny MacDonald, Debra Westall

\section{Referencias}

FERNÁNDEZ MARCH, A. (2010). "La evaluación orientada al aprendizaje en un modelo de formación por competencias en la educación universitaria" en Revista de Docencia Universitaria, vol. 8, issue 1, p. 11-34.

SCOTT, K., HOWELL, D. (2008). "Clarifying Analysis and Interpretation in Grounded Theory: Using a Conditional Relationship Guide and Reflective Coding Matrix”. International Journal of Qualitative Methods, vol. 7, issue 2, p. 1-15.

VICERRECTORADO DE ESTUDIOS, CALIDAD Y ACREDITACIÓN DE LA UNIVERSITAT POLITÈCNICA DE VALÈNCIA. Área de Instituto de Ciencias de la Educación ICE-

Profesorado <http://www.upv.es/contenidos/ICEP/info/DimensionesCompetenciales.pdf $>$ [Consulta: 27 de febrero de. 2014]

(c)) EY-NC-ND 2014, Universitat Politècnica de València

I Jornadas IN-RED (2014) 


\title{
Valoración de las dimensiones competenciales UPV en los Trabajos Fin de Máster de las titulaciones en Ciencias Sociales
}

\author{
Roberto Cervelló-Royo ${ }^{\mathrm{a}}$, Juan Carlos Cortés-López ${ }^{\mathrm{b}}$, Blanca de-Miguel-Molina ${ }^{\mathrm{c}}$, \\ María de-Miguel-Molina ${ }^{\mathrm{d}}$, Gabriela Ribes-Giner ${ }^{\mathrm{e}}$, Rosario Perelló-Marín', José \\ Albors-Garrigós ${ }^{g}$, María-del-Val Segarra-Oña ${ }^{h}$, Fernando García-García ${ }^{i}$ Ángel \\ Peiró-Signes ${ }^{j}$, José-Luis Hervás-Oliver ${ }^{k}$
}

a Departamento de Economía y Ciencias Sociales. Universitat Politècnica de València, rocerro@esp.upv.es, ${ }^{\mathrm{b}}$ Departamento de Matemática Aplicada. Universitat Politècnica de València, jccortes@imm.upv.es, ${ }^{c}$ Departamento de Organización de Empresas. Universitat Politècnica de València, bdemigu@omp.upv.es, d Departamento de Organización de Empresas. Universitat Politècnica de València, mademi@omp.upv.es, e Departamento de Organización de Empresas. Universitat Politècnica de València, gabrigi@omp.upv.es, ${ }^{\mathrm{f}}$ Departamento de Organización de Empresas. Universitat Politècnica de València, rperell@upvnet.upv.es, g Departamento de Organización de Empresas. Universitat Politècnica de València, jalbors@ omp.upv.es, ${ }^{\mathrm{h}}$ Departamento de Organización de Empresas. Universitat Politècnica de València, maseo@omp.upv.es, Departamento de Economía y Ciencias Sociales. Universitat Politècnica de València, fergarga@esp.upv.es, j Departamento de Organización de Empresas. Universitat Politècnica de València, anpeisig@omp.upv.es, ${ }^{k}$ Departamento de Organización de Empresas. Universitat Politècnica de València, jose.hervas@omp.upv.es

\begin{abstract}
This paper analyzes the different point of views given by mentors and reviewers about competencies to be achieved by students in the Degree's Final Project and Master's Dissertation in the Faculty of Business Administration. The skills used are the Competence Dimensions (CD) defined by the UPV for Bachelor and Master programs. The data comes from a survey conducted by professors teaching in Bachelor Degrees and Master Degrees, and who have supervised final projects or have participated in the assessment. Regarding Degree's Final Project (DFP), 12 tutors and 16 reviewers responded the survey. As far as Master's Dissertation (MT) concerns, there were responses from 18 mentors and 12 reviewers for the investigator profile; and 18 mentors and 12 reviewers for the professional
\end{abstract}

(cc) EY-NC-ND 2014, Universitat Politècnica de València

I Jornadas In-Red (2014) 
Valoración de las dimensiones competenciales UPV en los Trabajos Fin de Máster de las titulaciones en Ciencias Sociales

profile. The methodology used for data analysis was social network analysis. The results show differences in rating of competences between reviewers and mentors, the former being less demanding in rating competencies. Furthermore, it was observed a higher valuation when considering Master's thesis and specially for professional profile.

Keywords: Skills, tutors, Reviewers, Master's Dissertation, Degree's final project.

\begin{abstract}
Resumen
Este trabajo analiza las diferencias encontradas en la valoración, por parte de los tutores y evaluadores, de las competencias a alcanzar por los alumnos en los Trabajos Fin de Grado y Fin de Máster en la Facultad de ADE. Las competencias que se han analizado son las Dimensiones Competenciales (DC) definidas por la UPV para los programas de Grado y Máster. Los datos proceden de una encuesta elaborada por profesores que imparten docencia en los Grados y Másteres oficiales de la Facultad, y que han tutorizado trabajos o han participado en tribunales para evaluarlos. En total contestaron 12 profesores tutores y 16 evaluadores de Trabajo final de grado (TFG). Referente a trabajos final de master (TFM), se obtuvieron respuestas de 18 tutores y 12 evaluadores de TFM de perfil investigador; y 18 tutores y 12 evaluadores de TFM con perfil profesional. Como metodología para el analisis de datos se ha utilizado el análisis de redes sociales. Los resultados muestran diferencias en la valoración de las competencias entre evaluadores y tutores, siendo los primeros menos exigentes en la valoración de las competencias. Se aprecia, además, una valoración más elevada cuando el trabajo es de Fin de Máster y tiene perfil profesional.
\end{abstract}

Palabras clave: Competencias, Tutores, Evaluadores, TFM (Trabajo Final de Máster), TFG (Trabajo Final de Grado).

\title{
1. Introducción
}

En el estudio de empleabilidad de Titulados de la Universitat Politècnica de València (UPV) de 2010 (UPV, 2010) se describen las competencias necesarias para el desempeño del puesto de trabajo. De la misma manera, el Vicerrectorado de Estudios, Calidad y Acreditación (VECA) en el Documento de MARCO UPV DE DEFINICIÓN Y

(c)) EY-NC-ND 2014, Universitat Politècnica de València

I Jornadas IN-RED (2014) 
Roberto Cervelló-Royo, Juan Carlos Cortés-López, Blanca de-Miguel-Molina, María de-Miguel-Molina, Gabriela Ribes-Giner, Rosario Perelló-Marín, José Albors-Garrigós, María-del-Val Segarra-Oña, Fernando García-García, Ángel Peiró-Signes, José-Luis Hervás-Oliver

EVALUACIÓN DE ADQUISICIÓN DE COMPETENCIAS (UPV, 2013) hace mención expresa a dichas dimensiones competenciales.

Las competencias utilizadas en este trabajo corresponden a las Dimensiones Competenciales definidas por la UPV para los programas de Grado y Máster. Dichas competencias son las siguientes:

DC1 Comprensión e integración en la elaboración del Trabajo: Demostrar la comprensión e integración del conocimiento tanto de la propia especialización como en otros contextos más amplios.

DC2 Aplicación pensamiento práctico en la elaboración del Trabajo: Aplicar los conocimientos a la práctica, atendiendo a la información disponible, y estableciendo el proceso a seguir para alcanzar los objetivos con eficacia y eficiencia.

DC3 Análisis y resolución de problemas en la elaboración del Trabajo: Analizar y resolver problemas de forma efectiva, identificando y definiendo los elementos significativos que lo constituyen.

DC4 Innovación, creatividad y emprendimiento en la elaboración del Trabajo: Innovar para responder satisfactoriamente y de forma original a las necesidades $y$ demandas personales, organizativas y sociales con actitud emprendedora.

DC5 Diseño y proyecto en la elaboración del Trabajo: Diseñar, dirigir y evaluar una idea de manera eficaz hasta concretarla en un proyecto.

DC6 Trabajo en equipo y liderazgo en la elaboración del Trabajo: Trabajar y liderar equipos de forma efectiva para la consecución de objetivos comunes, contribuyendo al desarrollo personal y profesional de los mismos.

DC7 Responsabilidad ética y profesional en la elaboración del Trabajo: Actuar con responsabilidad ética y profesional ante uno mismo y los demás.

DC8 Comunicación efectiva en la elaboración del Trabajo: Comunicarse de manera efectiva, tanto de forma oral como escrita, utilizando adecuadamente los recursos necesarios y adaptándose a las características de la situación y la audiencia.

DC9 Pensamiento crítico en la elaboración del Trabajo: Desarrollar un pensamiento crítico interesándose por los fundamentos en los que se asientan las ideas, acciones y juicios, tanto propios como ajenos.

DC10 Conocimiento de los problemas contemporáneos en la elaboración del Trabajo.

\section{(cc) EY-NC-ND 2014, Universitat Politècnica de València}

I Jornadas IN-RED (2014) 
Valoración de las dimensiones competenciales UPV en los Trabajos Fin de Máster de las titulaciones en Ciencias Sociales

DC11 Aprendizaje permanente en la elaboración del Trabajo: Utilizar el aprendizaje de manera estratégica, autónoma y flexible, a lo largo de toda la vida, en función del objetivo perseguido.

DC12 Planificación y gestión del tiempo en la elaboración del Trabajo: Planificar adecuadamente el tiempo disponible y programar las actividades necesarias para alcanzar los objetivos, tanto académico-profesionales como personales.

DC13 Instrumental específica en la elaboración del Trabajo: Capacidad para utilizar las técnicas, las habilidades y las herramientas actualizadas necesarias para la práctica de la profesión.

\section{Objetivos}

Teniendo en cuenta las dimensiones competenciales citadas en el apartado anterior, el presente trabajo tiene por objeto analizar las diferencias encontradas en la valoración, por parte de los tutores y evaluadores, de las competencias a alcanzar por los alumnos en los Trabajos Fin de Grado y Fin de Máster en la Facultad de ADE de la UPV.

\section{Desarrollo de la innovación}

A fin de poder analizar la relevancia que le otorgan tanto tutores como evaluadores a las diferentes competencias, y las diferencias que existen entre las percepciones de las distintas figuras en función de si se trata de evaluadores o tutores de un TFG o un TFM con carácter investigador o profesional, se ha diseñado el siguiente estudio cuantitativo.

Como primer paso, se ha elaborado una encuesta. Para ello, han participado profesores que imparten docencia en los grados y Másteres oficiales de la Facultad, y que han tutorizado trabajos o han participado en tribunales para evaluarlos.

Dicha encuesta fue enviada de manera electrónica a los profesores de la facultad de ADE de la universidad politécnica de valencia que, o bien actúan como tutores o como evaluadores de TFG y/o TFM.

En total, 12 profesores contestaron como tutores de TFG, 16 como evaluadores de TFG, 18 como tutores de TFM con perfil investigador, 12 como evaluadores de TFM de perfil investigador, 18 como tutores de TFM con perfil profesional y 12 como evaluadores de TFM con perfil profesional. En las respuestas se utilizó una escala Likert de 1 a 5, siendo 5 el valor máximo.

La metodología utilizada para analizar los datos ha sido el análisis de redes sociales, con redes de modo 2 , donde las filas eran los profesores que contestaron a cada encuesta y las columnas la importancia otorgada a cada una de las 13 competencias. 
Roberto Cervelló-Royo, Juan Carlos Cortés-López, Blanca de-Miguel-Molina, María de-Miguel-Molina, Gabriela Ribes-Giner, Rosario Perelló-Marín, José Albors-Garrigós, María-del-Val Segarra-Oña, Fernando García-García, Ángel Peiró-Signes, José-Luis Hervás-Oliver

\section{Resultados}

Los resultados muestran diferencias en la valoración de las competencias entre evaluadores y tutores, siendo los primeros menos exigentes en la valoración de las competencias. Se aprecia, además, una valoración más elevada cuando el trabajo es de Fin de Máster y tiene perfil profesional.

La valoración de las competencias varía entre tutores y evaluadores, así como entre los tipos de trabajos (todos los resultados del estudio pueden verse en el Apéndice a este estudio). Incluimos aquí una tabla comparativa (Tabla 1) que permite observar más claramente, especialmente en la tutorización y evaluación de TFM, que hay discrepancias en la valoración de las competencias.

Tabla 1. Diferencias en la valoración de competencias. Elaboración propia.

\begin{tabular}{|c|c|c|c|c|c|}
\hline & Densidad & $\begin{array}{c}\text { Centralidad de } \\
\text { grado }\end{array}$ & Eigenvector & Cercanía & Intermediación \\
\hline Tutor TFG & $70,5 \%$ & $8,1,2,3,13$ & $8,2,3,13$ & $8,1,2,3,13$ & 8,1 \\
\hline $\begin{array}{c}\text { Evaluador } \\
\text { TFG }\end{array}$ & $60,1 \%$ & $8,1,2$ & 8 & $8,1,2$ & 8 \\
\hline $\begin{array}{c}\text { Tutor TFM } \\
\text { investigación }\end{array}$ & $77,8 \%$ & $3,1,7,9,12$ & $3,1,7,9$ & $3,1,7,9,12$ & 3,12 \\
\hline $\begin{array}{c}\text { Evaluador } \\
\text { TFM } \\
\text { investigación }\end{array}$ & $69,2 \%$ & $1,8,9$ & 1 & $1,8,9$ & 1 \\
\hline $\begin{array}{l}\text { Tutor TFM } \\
\text { profesional }\end{array}$ & $82,1 \%$ & $1,2,12$ & $1,2,12$ & $1,2,12$ & $1,2,12$ \\
\hline $\begin{array}{l}\text { Evaluador } \\
\text { TFM } \\
\text { profesional }\end{array}$ & $73,1 \%$ & $1,4,8$ & 4,8 & $1,4,8$ & $1,4,8$ \\
\hline
\end{tabular}

Fuente: Elaboración propia a partir de los datos de la encuesta

Los resultados del estudio son importantes, al dar un paso más en la determinación de las competencias que deben adquirir los alumnos en los trabajos finales. Podemos observar que en todo caso la densidad de los grafos analizados en la Tabla 1 es elevada, lo cual indica el alto grado de conexión entre las competencias que se han evaluado y las valoraciones de los encuestados. El siguiente paso será analizar cuál es la causa de esas diferencias y plantear soluciones en el caso que sea necesario.

(c)) EY-NC-ND 2014, Universitat Politècnica de València

I Jornadas IN-RED (2014) 
Valoración de las dimensiones competenciales UPV en los Trabajos Fin de Máster de las titulaciones en Ciencias Sociales

A partir de la Tabla 1 y utilizando la interpretación de sus columnas, en particular de la "centralidad de eigenvector" cabe destacar que respecto del "Tutor de Trabajo Final de Grado (TFG)", son las siguientes competencias las que tienen una mayor influencia en los nodos de la red y, por tanto, las que los tutores de TFG consideran más importantes.

- $\quad$ DC8 Comunicación efectiva en la elaboración del Trabajo.

- $\quad$ DC2 Aplicación pensamiento práctico en la elaboración del Trabajo.

- DC3 Análisis y resolución de problemas en la elaboración del Trabajo.

- DC13 Instrumental específica en la elaboración del Trabajo.

Esta interpretación queda reforzada por la coincidencia de las competencias anteriores al analizar la "centralidad de grado" del grafo.

Del mismo modo y respecto del "Evaluador de Trabajo Final de Grado (TFG)", es la siguiente competencia la que se considera más importante.

- $\quad$ DC8 Comunicación efectiva en la elaboración del Trabajo.

Creemos que esto es debido a que la labor principal del evaluador se limita a la evaluación del acto de defensa del TFG. No obstante, el hecho de que el $\mathrm{n}^{\circ}$ de enlaces de los nodos que representan las competencias DC1 y DC2 sean, junto con la competencia DC8, las mayores (véase en la Tabla 1 la columna "centralidad de grado"); nos indica que al igual que para el “Tutor TFG” las competencias DC1 y DC2 son también importantes.

Para el caso de las Tesinas Fin de Master (TFMs) con un enfoque investigador y desde la perspectiva del "Tutor de Trabajo Final de Master (TFM) Investigación”, son las siguientes competencias las que tienen una mayor influencia:

- $\quad$ DC1 Comprensión e integración en la elaboración del Trabajo.

- DC3 Análisis y resolución de problemas en la elaboración del Trabajo.

- DC7 Responsabilidad ética y profesional en la elaboración del Trabajo.

- DC9 Pensamiento crítico en la elaboración del Trabajo.

De nuevo, como en el caso anterior de Tutor TFG, esta interpretación queda reforzada por la coincidencia de las competencias anteriores al analizar la "centralidad del grado" del grafo.

Al observar los resultados para el "Evaluador de Trabajo Final de Master (TFM) Investigación", es la siguiente competencia la que se considera más importante.

- DC1 Comprensión e integración en la elaboración del Trabajo.

A diferencia del caso anterior, no se valora tanto el acto de defensa del trabajo, como la consistencia del contenido del trabajo. No obstante, el elevado $\mathrm{n}^{\circ}$ de enlaces de los nodos

(c)) EY-NC-ND 2014, Universitat Politècnica de València

I Jornadas IN-RED (2014) 
Roberto Cervelló-Royo, Juan Carlos Cortés-López, Blanca de-Miguel-Molina, María de-Miguel-Molina, Gabriela Ribes-Giner, Rosario Perelló-Marín, José Albors-Garrigós, María-del-Val Segarra-Oña, Fernando García-García, Ángel Peiró-Signes, José-Luis Hervás-Oliver

que representa la competencia DC1, queda reforzado por el resultado obtenido al calcular la "centralidad de grado" del grafo.

Finalmente, Tesinas Fin de Master (TFMs) con un enfoque profesional y desde la perspectiva del "Tutor de Trabajo Final de Master (TFM) Profesional”, son las siguientes competencias las que tienen una mayor influencia:

- DC1 Comprensión e integración en la elaboración del Trabajo.

- DC2 Aplicación pensamiento práctico en la elaboración del Trabajo.

- DC12 Planificación y gestión del tiempo en la elaboración del Trabajo.

Las cuales quedan completamente reforzadas atendiendo a la "centralidad del grado" del grafo.

Al observar los resultados para el "Evaluador de Trabajo Final de Master (TFM) Profesional", son las siguientes competencias las más valoradas:

- DC4 Innovación, creatividad y emprendimiento en la elaboración del Trabajo.

- DC8 Comunicación efectiva en la elaboración del Trabajo.

Como podemos apreciar, en este caso las competencias que tienen mayor peso para el "Evaluador del TFM profesional" no coinciden con las del "Tutor del TFM profesional". Por un parte, los Tutores valoran más aspectos relacionados con la memoria y su elaboración mientras que los Evaluadores otorgan una mayor importancia a aspectos más prácticos de cara al mundo empresarial como son la innovación, la capacidad de comunicación de la idea, etc.

\section{Conclusiones}

De acuerdo a las dimensiones competenciales propuestas por el Documento de MARCO UPV DE DEFINICIÓN Y EVALUACIÓN DE ADQUISICIÓN DE COMPETENCIAS (UPV, 2013) y el estudio de empleabilidad llevado a cabo por la UPV en el que se describen las competencias necesarias para el desempeño del puesto de trabajo. Se llevó a cabo un estudio basado en redes sociales sobre los datos recogidos en encuestas realizadas por profesores tutores y evaluadores de TFGs y TFMs con orientación investigadora y/o profesional a partir de los cuales se obtuvieron como principales conclusiones:

1) Para conseguir una mayor coincidencia entre evaluador y tutor, sería conveniente que el evaluador tuviera un seguimiento mediante informes parciales de la evaluación del progreso del estudiante en la elaboración de su TFG y/o TFM.

2) Se ha observado que el evaluador considera un menor número de competencias que el tutor a la hora de valorar el trabajo realizado por el estudiante.

(cc)) EY-NC-ND 2014, Universitat Politècnica de València

I Jornadas IN-RED (2014) 
Valoración de las dimensiones competenciales UPV en los Trabajos Fin de Máster de las titulaciones en Ciencias Sociales

\section{Referencias}

UPV (2010): El estudio de empleabilidad de Titulados de la Universitat Politècnica de Valéncia $(U P V)$, Informe del Consejo Económico y Social de la Comunidad de Madrid. Minerva Ediciones.

UPV (2013): Marco UPV de definición y evaluación de adquisición de competencias: http://www.upv.es/contenidos/ICEP/info/DimensionesCompetenciales.pdf

\section{Apéndice}

Tabla 1. Valoración de cada competencia por los tutores de TFG. Elaboración propia.

\begin{tabular}{|c|c|c|c|c|c|c|c|c|c|c|c|c|c|}
\hline & $\begin{array}{l}I M P \\
T F G \\
D C 1\end{array}$ & $\begin{array}{l}I M P \\
T F G \\
D C 2\end{array}$ & $\begin{array}{l}I M P \\
T F G \\
D C 3\end{array}$ & $\begin{array}{l}I M P \\
T F G \\
D C 4\end{array}$ & $\begin{array}{l}I M P \\
T F G \\
D C 5\end{array}$ & $\begin{array}{l}I M P \\
T F G \\
D C 6\end{array}$ & $\begin{array}{l}I M P \\
T F G \\
D C 7\end{array}$ & $\begin{array}{l}I M P \\
T F G \\
D C 8\end{array}$ & $\begin{array}{l}I M P \\
T F G \\
D C 9\end{array}$ & $\begin{array}{l}I M P \\
T F G \\
D C 10\end{array}$ & $\begin{array}{l}I M P \\
T F G \\
D C 11\end{array}$ & $\begin{array}{l}I M P \\
T F G \\
D C 12\end{array}$ & $\begin{array}{l}I M P \\
T F G \\
D C 13\end{array}$ \\
\hline $\begin{array}{l}\text { TUT } \\
\text { TFG1 }\end{array}$ & 5 & 5 & 4 & 4 & 4 & 2 & 4 & 4 & 4 & 3 & 3 & 4 & 4 \\
\hline $\begin{array}{l}\text { TUT } \\
\text { TFG2 }\end{array}$ & 4 & 5 & 4 & 4 & 5 & 3 & 5 & 5 & 5 & 4 & 3 & 4 & 4 \\
\hline $\begin{array}{l}\text { TUT } \\
\text { TFG3 }\end{array}$ & 5 & 4 & 4 & 3 & 5 & 4 & 4 & 5 & 4 & 3 & 4 & 3 & 4 \\
\hline $\begin{array}{l}\text { TUT } \\
\text { TFG4 }\end{array}$ & 4 & 2 & 2 & 3 & 4 & 2 & 4 & 4 & 2 & 3 & 2 & 3 & 2 \\
\hline $\begin{array}{l}\text { TUT } \\
\text { TFG5 }\end{array}$ & 4 & 5 & 4 & 3 & 5 & 1 & 5 & 5 & 5 & 4 & 4 & 4 & 4 \\
\hline $\begin{array}{l}\text { TUT } \\
\text { TFG6 }\end{array}$ & 3 & 4 & 5 & 4 & 5 & 3 & 5 & 5 & 4 & 4 & 5 & 5 & 5 \\
\hline $\begin{array}{l}\text { TUT } \\
\text { TFG7 }\end{array}$ & 4 & 5 & 4 & 3 & 4 & 3 & 5 & 5 & 4 & 4 & 3 & 3 & 4 \\
\hline $\begin{array}{l}\text { TUT } \\
\text { TFG8 }\end{array}$ & 5 & 5 & 4 & 4 & 4 & 3 & 4 & 4 & 5 & 4 & 3 & 5 & 4 \\
\hline $\begin{array}{l}\text { TUT } \\
\text { TFG9 }\end{array}$ & 4 & 4 & 5 & 2 & 3 & 2 & 5 & 5 & 5 & 4 & 5 & 4 & 4 \\
\hline $\begin{array}{l}\text { TUT } \\
\text { TFG10 }\end{array}$ & 4 & 4 & 4 & 3 & 3 & 2 & 3 & 5 & 4 & 4 & 4 & 4 & 4 \\
\hline $\begin{array}{l}\text { TUT } \\
\text { TFG11 }\end{array}$ & 4 & 4 & 5 & 2 & 4 & 2 & 4 & 5 & 3 & 3 & 2 & 3 & 4 \\
\hline $\begin{array}{l}\text { TUT } \\
\text { TFG12 }\end{array}$ & 4 & 5 & 4 & 3 & 3 & 1 & 3 & 4 & 4 & 1 & 2 & 4 & 4 \\
\hline
\end{tabular}

(c)) EY-NC-ND 2014, Universitat Politècnica de València 
Roberto Cervelló-Royo, Juan Carlos Cortés-López, Blanca de-Miguel-Molina, María de-Miguel-Molina, Gabriela Ribes-Giner, Rosario Perelló-Marín, José Albors-Garrigós, María-del-Val Segarra-Oña, Fernando García-García, Ángel Peiró-Signes, José-Luis Hervás-Oliver

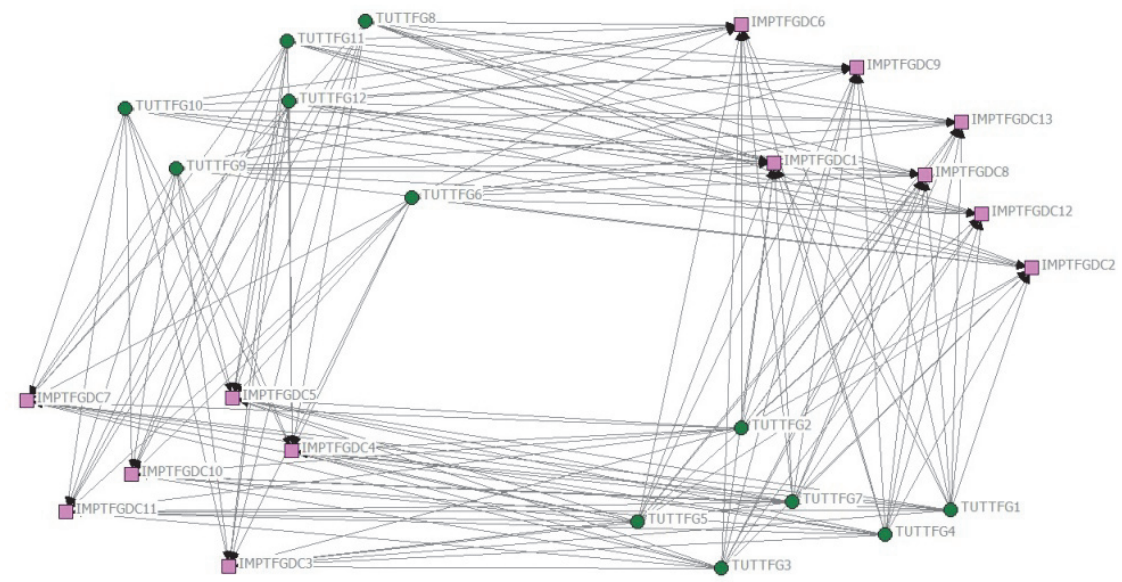

Figura 1. Red (sin dicotomizar) entre tutores de TFG e importancia que dan a cada competencia. Elaboración propia.

Tabla 2. Importancia otorgada a cada competencia por los evaluadores de TFG. Elaboración propia.

\begin{tabular}{|c|c|c|c|c|c|c|c|c|c|c|c|c|c|}
\hline & $\begin{array}{l}I M P \\
T F G \\
D C 1\end{array}$ & $\begin{array}{l}I M P \\
T F G \\
D C 2\end{array}$ & $\begin{array}{l}I M P \\
T F G \\
D C 3\end{array}$ & $\begin{array}{l}I M P \\
T F G \\
D C 4\end{array}$ & $\begin{array}{l}I M P \\
T F G \\
D C 5\end{array}$ & $\begin{array}{l}I M P \\
T F G \\
D C 6\end{array}$ & $\begin{array}{l}I M P \\
T F G \\
D C 7\end{array}$ & $\begin{array}{l}I M P \\
T F G \\
D C 8\end{array}$ & $\begin{array}{l}I M P \\
T F G \\
D C 9\end{array}$ & $\begin{array}{l}I M P \\
T F G \\
D C 10\end{array}$ & $\begin{array}{l}I M P \\
T F G \\
D C 11\end{array}$ & $\begin{array}{l}I M P \\
T F G \\
D C 12\end{array}$ & $\begin{array}{l}I M P \\
T F G \\
D C 13\end{array}$ \\
\hline $\begin{array}{l}\text { EVAL } \\
\text { TFG1 }\end{array}$ & 5 & 5 & 3 & 4 & 4 & 3 & 3 & 5 & 4 & 5 & $\overline{4}$ & 4 & $\overline{5}$ \\
\hline $\begin{array}{l}\text { EVAL } \\
\text { TFG2 }\end{array}$ & 4 & 4 & 5 & 4 & 5 & 2 & 2 & 5 & 2 & 3 & 2 & 2 & 4 \\
\hline $\begin{array}{l}\text { EVAL } \\
\text { TFG3 }\end{array}$ & 4 & 5 & 5 & 3 & 4 & 2 & 2 & 5 & 2 & 3 & 2 & 2 & 4 \\
\hline $\begin{array}{l}\text { EVAL } \\
\text { TFG4 }\end{array}$ & 5 & 5 & 4 & 3 & 4 & 1 & 2 & 4 & 2 & 2 & 2 & 2 & 4 \\
\hline $\begin{array}{l}\text { EVAL } \\
\text { TFG5 }\end{array}$ & 4 & 4 & 4 & 1 & 4 & 2 & 2 & 5 & 3 & 2 & 2 & 2 & 4 \\
\hline $\begin{array}{l}\text { EVAL } \\
\text { TFG6 }\end{array}$ & 4 & 4 & 5 & 4 & 5 & 2 & 5 & 5 & 4 & 4 & 3 & 2 & 4 \\
\hline $\begin{array}{l}\text { EVAL } \\
\text { TFG7 }\end{array}$ & 3 & 4 & 3 & 3 & 4 & 2 & 5 & 5 & 4 & 2 & 4 & 5 & 2 \\
\hline $\begin{array}{l}\text { EVALT } \\
\text { FG8 }\end{array}$ & 4 & 4 & 4 & 3 & 5 & 4 & 4 & 5 & 4 & 3 & 4 & 4 & 4 \\
\hline $\begin{array}{l}\text { EVALT } \\
\text { FG9 }\end{array}$ & 4 & 3 & 3 & 3 & 3 & 2 & 3 & 4 & 2 & 3 & 2 & 4 & 2 \\
\hline $\begin{array}{l}\text { EVALT } \\
\text { FG10 }\end{array}$ & 5 & 5 & 5 & 4 & 5 & 1 & 5 & 5 & 5 & 4 & 4 & 4 & 4 \\
\hline $\begin{array}{l}\text { EVALT } \\
\text { FG11 }\end{array}$ & 3 & 3 & 3 & 3 & 4 & 3 & 5 & 5 & 3 & 4 & 4 & 5 & 4 \\
\hline $\begin{array}{l}\text { EVALT } \\
\text { FG12 }\end{array}$ & 5 & 4 & 4 & 4 & 4 & 3 & 4 & 5 & 4 & 4 & 3 & 5 & 4 \\
\hline $\begin{array}{l}\text { EVALT } \\
\text { FG13 }\end{array}$ & 4 & 4 & 4 & 3 & 4 & 1 & 5 & 5 & 4 & 5 & 4 & 4 & 4 \\
\hline $\begin{array}{l}\text { EVALT } \\
\text { FG14 }\end{array}$ & 4 & 4 & 2 & 2 & 2 & 2 & 5 & 5 & 4 & 4 & 2 & 2 & 4 \\
\hline $\begin{array}{l}\text { EVALT } \\
\text { FG15 }\end{array}$ & 4 & 4 & 5 & 3 & 5 & 2 & 2 & 5 & 2 & 2 & 1 & 2 & 4 \\
\hline
\end{tabular}

\section{(cc) EY-NC-ND 2014, Universitat Politècnica de València}

I Jornadas IN-RED (2014) 
Valoración de las dimensiones competenciales UPV en los Trabajos Fin de Máster de las titulaciones en Ciencias Sociales

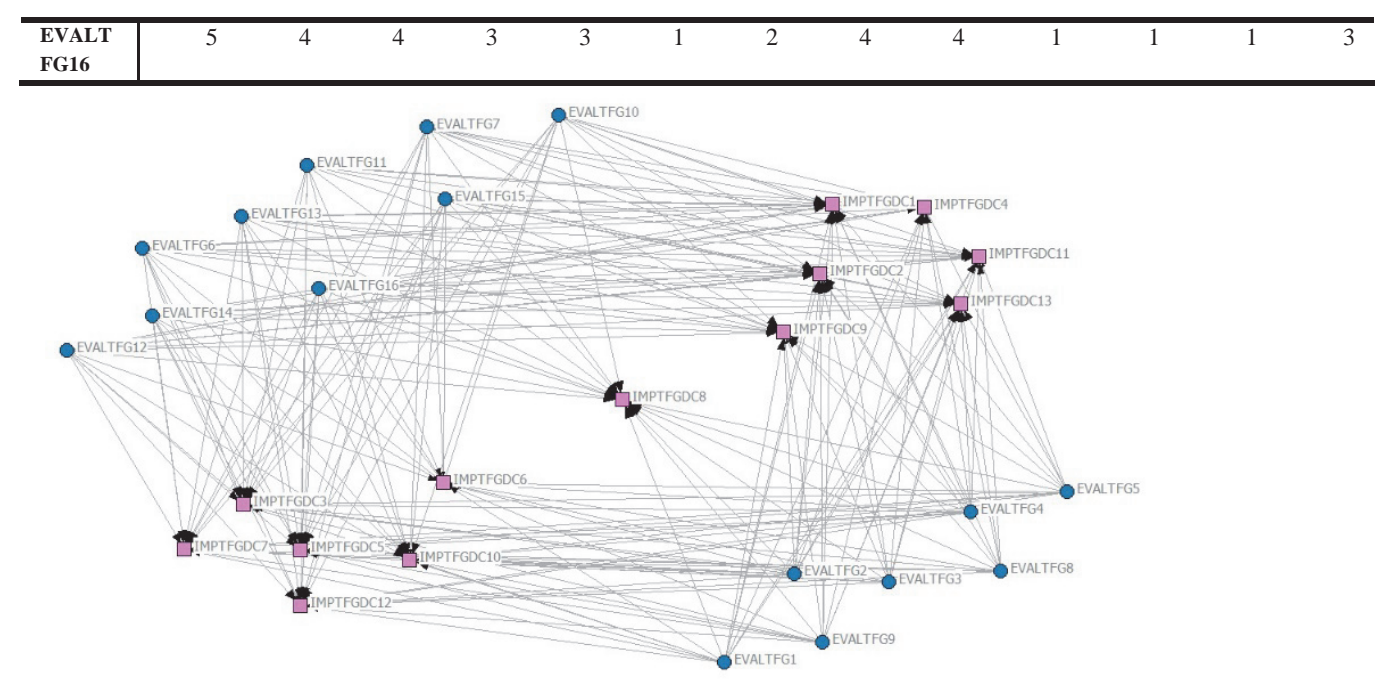

Figura 2. Red entre evaluadores de TFG e importancia que dan a cada competencia. Elaboración propia.

Tabla 3. Importancia otorgada a cada competencia por los tutores de TFM investigador. Elaboración propia.

\begin{tabular}{|c|c|c|c|c|c|c|c|c|c|c|c|c|c|}
\hline & $\begin{array}{l}I M P \\
T F M \\
I N V \\
D C 1\end{array}$ & $\begin{array}{l}I M P \\
T F M \\
I N V \\
D C 2\end{array}$ & $\begin{array}{l}I M P \\
T F M \\
I N V \\
D C 3\end{array}$ & $\begin{array}{l}I M P \\
T F M \\
I N V \\
D C 4\end{array}$ & $\begin{array}{l}I M P \\
T F M \\
I N V \\
D C 5\end{array}$ & $\begin{array}{l}I M P \\
T F M \\
I N V \\
D C 6\end{array}$ & $\begin{array}{l}I M P \\
T F M \\
I N V \\
D C 7\end{array}$ & $\begin{array}{l}I M P \\
T F M \\
I N V \\
D C 8\end{array}$ & $\begin{array}{l}I M P \\
T F M \\
I N V \\
D C 9\end{array}$ & $\begin{array}{l}I M P \\
T F M \\
I N V \\
D C 10\end{array}$ & $\begin{array}{l}I M P \\
T F M \\
I N V \\
D C 11\end{array}$ & $\begin{array}{l}I M P \\
T F M \\
I N V \\
D C 12\end{array}$ & $\begin{array}{l}I M P \\
T F M \\
I N V \\
D C 13\end{array}$ \\
\hline $\begin{array}{l}\text { TUT } \\
\text { TFM } \\
\text { INV1 }\end{array}$ & 5 & 4 & 4 & 5 & 5 & 3 & 4 & 5 & 4 & 3 & 4 & 4 & 3 \\
\hline $\begin{array}{l}\text { TUT } \\
\text { TFM } \\
\text { INV2 }\end{array}$ & 4 & 4 & 4 & 3 & 3 & 3 & 3 & 3 & 3 & 3 & 3 & 4 & 4 \\
\hline $\begin{array}{l}\text { TUT } \\
\text { TFM } \\
\text { INV3 }\end{array}$ & 4 & 2 & 4 & 2 & 4 & 2 & 5 & 5 & 4 & 4 & 5 & 5 & 5 \\
\hline $\begin{array}{l}\text { TUT } \\
\text { TFM } \\
\text { INV4 }\end{array}$ & 5 & 5 & 5 & 4 & 4 & 3 & 4 & 5 & 5 & 5 & 3 & 4 & 3 \\
\hline $\begin{array}{l}\text { TUT } \\
\text { TFM } \\
\text { INV5 }\end{array}$ & 3 & 5 & 5 & 4 & 4 & 1 & 5 & 3 & 5 & 5 & 3 & 5 & 3 \\
\hline $\begin{array}{l}\text { TUT } \\
\text { TFM } \\
\text { INV6 }\end{array}$ & 5 & 4 & 5 & 3 & 4 & 2 & 4 & 4 & 4 & 4 & 4 & 3 & 5 \\
\hline $\begin{array}{l}\text { TUT } \\
\text { TFM } \\
\text { INV7 }\end{array}$ & 4 & 4 & 4 & 4 & 4 & 3 & 4 & 4 & 5 & 5 & 4 & 5 & 4 \\
\hline $\begin{array}{l}\text { TUT } \\
\text { TFM } \\
\text { INV8 }\end{array}$ & 4 & 4 & 4 & 3 & 4 & 2 & 4 & 4 & 4 & 4 & 3 & 4 & 4 \\
\hline
\end{tabular}

(c)) EY-NC-ND 2014, Universitat Politècnica de València 
Roberto Cervelló-Royo, Juan Carlos Cortés-López, Blanca de-Miguel-Molina, María de-Miguel-Molina, Gabriela Ribes-Giner, Rosario Perelló-Marín, José Albors-Garrigós, María-del-Val Segarra-Oña Fernando García-García, Ángel Peiró-Signes, José-Luis Hervás-Oliver

\begin{tabular}{|c|c|c|c|c|c|c|c|c|c|c|c|c|c|}
\hline & $\begin{array}{l}I M P \\
T F M \\
I N V \\
D C 1\end{array}$ & $\begin{array}{l}I M P \\
T F M \\
I N V \\
D C 2\end{array}$ & $\begin{array}{l}I M P \\
T F M \\
I N V \\
D C 3\end{array}$ & $\begin{array}{l}I M P \\
T F M \\
I N V \\
D C 4\end{array}$ & $\begin{array}{l}I M P \\
T F M \\
I N V \\
D C 5\end{array}$ & $\begin{array}{l}I M P \\
T F M \\
I N V \\
D C 6\end{array}$ & $\begin{array}{l}I M P \\
T F M \\
I N V \\
D C 7\end{array}$ & $\begin{array}{l}I M P \\
T F M \\
I N V \\
D C 8\end{array}$ & $\begin{array}{l}I M P \\
T F M \\
I N V \\
D C 9\end{array}$ & $\begin{array}{l}I M P \\
T F M \\
I N V \\
D C 10\end{array}$ & $\begin{array}{l}I M P \\
T F M \\
I N V \\
D C 11\end{array}$ & $\begin{array}{l}I M P \\
T F M \\
I N V \\
D C 12\end{array}$ & $\begin{array}{l}I M P \\
T F M \\
I N V \\
D C 13\end{array}$ \\
\hline $\begin{array}{l}\text { TUT } \\
\text { TFM } \\
\text { INV9 }\end{array}$ & 5 & 5 & 4 & 4 & 4 & 3 & 5 & 5 & 5 & 3 & 4 & 4 & 3 \\
\hline $\begin{array}{l}\text { TUT } \\
\text { TFM } \\
\text { INV10 }\end{array}$ & 5 & 4 & 4 & 3 & 5 & 3 & 5 & 5 & 5 & 5 & 5 & 5 & 5 \\
\hline $\begin{array}{l}\text { TUT } \\
\text { TFM } \\
\text { INV11 }\end{array}$ & 4 & 4 & 4 & 4 & 4 & 4 & 4 & 4 & 4 & 4 & 4 & 4 & 4 \\
\hline $\begin{array}{l}\text { TUT } \\
\text { TFM } \\
\text { INV12 }\end{array}$ & 5 & 5 & 4 & 4 & 4 & 2 & 5 & 4 & 4 & 5 & 4 & 4 & 4 \\
\hline $\begin{array}{l}\text { TUT } \\
\text { TFM } \\
\text { INV13 }\end{array}$ & 4 & 4 & 4 & 4 & 5 & 3 & 5 & 4 & 5 & 3 & 4 & 4 & 4 \\
\hline $\begin{array}{l}\text { TUT } \\
\text { TFM } \\
\text { INV14 }\end{array}$ & 4 & 3 & 5 & 5 & 5 & 3 & 4 & 4 & 5 & 5 & 4 & 4 & 3 \\
\hline $\begin{array}{l}\text { TUT } \\
\text { TFM } \\
\text { INV15 }\end{array}$ & 5 & 5 & 5 & 4 & 4 & 2 & 5 & 5 & 5 & 4 & 3 & 4 & 4 \\
\hline $\begin{array}{l}\text { TUT } \\
\text { TFM } \\
\text { INV16 }\end{array}$ & 5 & 5 & 5 & 4 & 4 & 3 & 4 & 3 & 4 & 3 & 4 & 4 & 3 \\
\hline $\begin{array}{l}\text { TUT } \\
\text { TFM } \\
\text { INV17 }\end{array}$ & 4 & 5 & 5 & 2 & 3 & 3 & 4 & 5 & 4 & 4 & 5 & 5 & 5 \\
\hline $\begin{array}{l}\text { TUT } \\
\text { TFM } \\
\text { INV18 }\end{array}$ & 4 & 3 & 4 & 4 & 5 & 1 & 5 & 4 & 5 & 4 & 5 & 5 & 3 \\
\hline
\end{tabular}

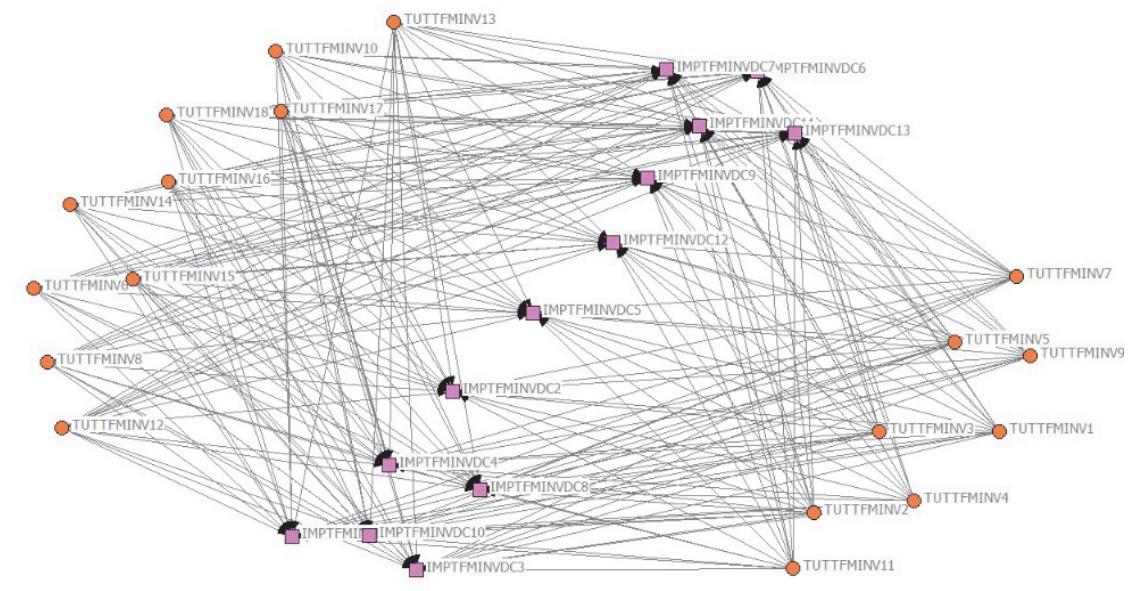

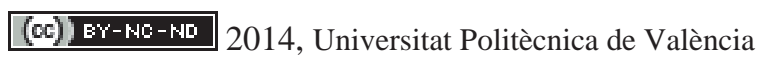

I Jornadas IN-RED (2014) 
Valoración de las dimensiones competenciales UPV en los Trabajos Fin de Máster de las titulaciones en Ciencias Sociales

Figura 3. Red entre tutores TFM investigación e importancia de las competencias. Elaboración propia.

Tabla 4. Importancia otorgada a cada competencia por los evaluadores de TFM investigación. Elaboración propia.

\begin{tabular}{|c|c|c|c|c|c|c|c|c|c|c|c|c|c|}
\hline & $\begin{array}{l}I M P \\
T F M \\
I N V \\
D C 1\end{array}$ & $\begin{array}{l}I M P \\
T F M \\
I N V \\
D C 2\end{array}$ & $\begin{array}{l}I M P \\
T F M \\
I N V \\
D C 3\end{array}$ & $\begin{array}{l}I M P \\
T F M \\
I N V \\
D C 4\end{array}$ & $\begin{array}{l}I M P \\
T F M \\
I N V \\
D C 5\end{array}$ & $\begin{array}{l}I M P \\
T F M \\
I N V \\
D C 6\end{array}$ & $\begin{array}{l}I M P \\
T F M \\
I N V \\
D C 7\end{array}$ & $\begin{array}{l}I M P \\
T F M \\
I N V \\
D C 8\end{array}$ & $\begin{array}{l}I M P \\
T F M \\
I N V \\
D C 9\end{array}$ & $\begin{array}{l}I M P \\
T F M \\
I N V \\
D C 10\end{array}$ & $\begin{array}{l}I M P \\
T F M \\
I N V \\
D C 11\end{array}$ & $\begin{array}{l}I M P \\
T F M \\
I N V \\
D C 12\end{array}$ & $\begin{array}{l}I M P \\
T F M \\
I N V \\
D C 13\end{array}$ \\
\hline $\begin{array}{l}\text { EVAL } \\
\text { TFM } \\
\text { INV1 }\end{array}$ & 5 & 4 & 5 & 4 & 4 & 3 & 4 & 5 & 4 & 3 & 3 & 2 & 4 \\
\hline $\begin{array}{l}\text { EVAL } \\
\text { TFM } \\
\text { INV2 }\end{array}$ & 4 & 3 & 2 & 5 & 2 & 2 & 3 & 5 & 5 & 2 & 3 & 5 & 4 \\
\hline $\begin{array}{l}\text { EVAL } \\
\text { TFM } \\
\text { INV3 }\end{array}$ & 4 & 4 & 5 & 3 & 5 & 3 & 4 & 5 & 5 & 4 & 4 & 4 & 4 \\
\hline $\begin{array}{l}\text { EVAL } \\
\text { TFM } \\
\text { INV4 }\end{array}$ & 5 & 3 & 4 & 5 & 3 & 2 & 5 & 3 & 4 & 5 & 4 & 5 & 2 \\
\hline $\begin{array}{l}\text { EVAL } \\
\text { TFM } \\
\text { INV5 }\end{array}$ & 5 & 3 & 4 & 2 & 4 & 2 & 4 & 5 & 4 & 5 & 3 & 5 & 3 \\
\hline $\begin{array}{l}\text { EVAL } \\
\text { TFM } \\
\text { INV6 }\end{array}$ & 5 & 4 & 5 & 4 & 4 & 4 & 4 & 4 & 5 & 5 & 4 & 5 & 4 \\
\hline $\begin{array}{l}\text { EVAL } \\
\text { TFM } \\
\text { INV7 }\end{array}$ & 5 & 4 & 5 & 4 & 5 & 3 & 5 & 5 & 5 & 4 & 4 & 5 & 5 \\
\hline $\begin{array}{l}\text { EVAL } \\
\text { TFM } \\
\text { INV8 }\end{array}$ & 5 & 3 & 4 & 5 & 5 & 2 & 4 & 5 & 4 & 4 & 3 & 3 & 4 \\
\hline $\begin{array}{l}\text { EVAL } \\
\text { TFM } \\
\text { INV9 }\end{array}$ & 5 & 4 & 4 & 5 & 4 & 3 & 5 & 5 & 5 & 5 & 4 & 4 & 4 \\
\hline $\begin{array}{l}\text { EVAL } \\
\text { TFM } \\
\text { INV10 }\end{array}$ & 5 & 5 & 3 & 3 & 3 & 3 & 4 & 5 & 5 & 5 & 5 & 5 & 3 \\
\hline $\begin{array}{l}\text { EVAL } \\
\text { TFM } \\
\text { INV11 }\end{array}$ & 4 & 4 & 5 & 4 & 5 & 2 & 2 & 5 & 3 & 3 & 2 & 2 & 3 \\
\hline $\begin{array}{l}\text { EVAL } \\
\text { TFM } \\
\text { INV12 }\end{array}$ & 4 & 4 & 4 & 3 & 4 & 1 & 3 & 5 & 4 & 1 & 1 & 2 & 2 \\
\hline
\end{tabular}

(c)) EY-NC-ND 2014, Universitat Politècnica de València I Jornadas IN-RED (2014) 
Roberto Cervelló-Royo, Juan Carlos Cortés-López, Blanca de-Miguel-Molina, María de-Miguel-Molina, Gabriela Ribes-Giner, Rosario Perelló-Marín, José Albors-Garrigós, María-del-Val Segarra-Oña, Fernando García-García, Ángel Peiró-Signes, José-Luis Hervás-Oliver

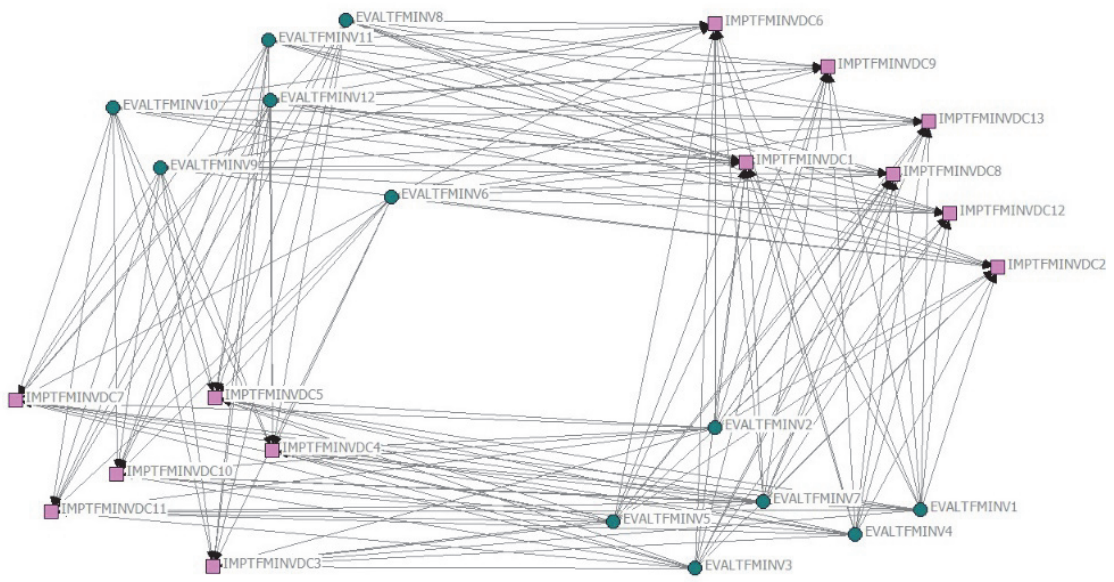

Figura 4. Red entre evaluadores TFM investigación y competencias. Elaboración propia.

(cc) EY-NC-ND 2014, Universitat Politècnica de València

I Jornadas IN-RED (2014) 
Jornadas In-Red 2014

Universitat Politècnica de València

\title{
Análisis de las Dimensiones Competenciales Incluidas en Diferentes Asignaturas en Ingenierías
}

\author{
Esther Sanabria-Codesal ${ }^{a}$, Ignacio Bosch ${ }^{b}$, María-Cinta Vincent-Vela ${ }^{c}$, Jaime Lloret ${ }^{b}$, \\ Silvia Álvarez-Blanco ${ }^{c,}$ Lucía Romero Pérez ${ }^{\mathrm{d}}$ \\ ${ }^{\mathrm{a}}$ Departament de Matemàtica Aplicada,Universitat Politècnica de València, Camí Vera s/n, 46022, \\ Valencia, e-mail: esanabri@ mat.upv.es, ${ }^{\text {b }}$ Departament de Comunicacions, Universitat Politècnica de \\ València, Calle Paranimf 1, 46730, Gandia, València, e-mail: igbosroi@ dcom.upv.es, \\ jlloret@dcom.upv.es y ${ }^{c}$ Departament d'Enginyeria Química i Nuclear,Universitat Politècnica de \\ València, Camí Vera s/n, 46022, Valencia,e-mail: mavinve@iqn.upv.es, sialvare@iqn.upv.es \\ ${ }^{\mathrm{d}}$ Departament d'Enginyeria Electrònica, Universitat Politècnica de València, Camí Vera s/n, 46022, \\ Valencia, e-mail: lurope@eln.upv.es
}

\begin{abstract}
Many diverse skills are associated to the grades in our universities because each individual subject incorporates multiple particular aspects, which sometimes are not sufficiently coordinated with the other subjects of the degree. Moreover, in some cases the acquisition of these skills by the students at the end of the course is not checked. The objective of this work is to assess the achievement of the competence dimensions proposed by the Polytechnic University of Valencia in the subjects by the students.

In this work, the competency dimensions included in the educational guides of three subjects of three grades are reviewed. Moreover, the results of a survey designed to ask the students about the achievement of the skills included in the guides of their subjects are analyzed. Our work reveals that student expectancies about competence acquisition are highly fulfilled. This observation does not depend on the marks on the subject either the academic origin of the student. However, the practice of the methods explained in the subjects should be more exhaustively considered, as it is the weakest point.
\end{abstract}

Keywords: Dimensions of Competence, skills and abilities, results analysis. 


\begin{abstract}
Resumen
Los títulos que existen en nuestras universidades tienen asociadas muchas y muy diversas competencias debido a que cada asignatura incorpora múltiples aspectos particulares, en ocasiones no suficientemente coordinados con el resto de materias de la titulación. Además, en algunos casos no se comprueba si los alumnos han adquirido estas competencias una vez cursadas las asignaturas. Por esta razón es necesario revisar si se están aplicando las dimensiones competenciales propuestas por la Universidad Politécnica de Valencia, en las asignaturas de sus grados y verificar si los alumnos están adquiriendo esas competencias.

En este artículo revisamos las dimensiones competenciales que se incluyen en las guías docentes de tres asignaturas de tres grados ofertados en nuestra universidad y analizamos los resultados de encuestas donde los alumnos analizan en qué medida consideran que han adquirido estas competencias. Este análisis revela que existe un elevado grado de satisfacción del alumnado con la adquisición de competencias de las asignaturas independientemente de la procedencia académica del alumno o de su nota final en la asignatura. Sin embargo, es necesario profundizar en la aplicación práctica de los métodos explicados en las asignaturas, ya que este aspecto es el peor valorado.
\end{abstract}

Palabras clave: Dimensiones Competenciales, destrezas y habilidades, análisis de resultados.

\title{
Introducción
}

El Espacio Europeo de Educación Superior (EEES) ha traído consigo un cambio en la orientación de la enseñanza, marcando un nuevo paradigma de aprendizaje en la educación superior pasando de centrarnos en el aprendizaje de contenidos, a una orientación completamente diferente basada en resultados de aprendizaje y desarrollo de competencias (Goñi, 2005, Lloret, 2006). Este cambio no debe afectar únicamente al diseño de las propuestas metodológicas (De Miguel, 2006), sino también a los procesos evaluativos (González, 2003, Cano, 2008).

Con el objetivo de avanzar en la dirección que marca el Proceso de Bolonia la Universitat Politècnica de València (UPV) se ha planteado el estudio y comparación de distintos referentes para simplificar la definición de las competencias en sus titulaciones e implantar los necesarios procesos de evaluación. Resultado de este análisis surgen las denominadas Dimensiones Competenciales (DC) que sintetizan el perfil competencial que adquieren los alumnos de la UPV. El documento que define las dimensiones competenciales de la UPV ("Dimensiones Competenciales UPV", 2014) contempla 13 conceptos que contemplan las Competencias genéricas y transversales (Hué, 2008) y se definen en términos de resultados de aprendizaje para los niveles de grado y máster. 
Esther Sanabria-Codesal, Ignacio Bosch, María-Cinta Vincent-Vela, Jaime Lloret, Silvia Álvarez-Blanco, Lucía Romero Pérez

La siguiente lista muestra las dimensiones competenciales UPV:

- DC1: Comprensión e integración.

Demostrar la comprensión e integración del conocimiento tanto de la propia especialización como en otros contextos más amplios

- DC2: Aplicación pensamiento práctico.

Aplicar los conocimientos a la práctica, atendiendo a la información disponible, y estableciendo el proceso a seguir para alcanzar los objetivos con eficacia y eficiencia.

- DC3: Análisis y resolución de problemas.

Analizar y resolver problemas de forma efectiva, identificando y definiendo los elementos significativos que lo constituyen.

- DC4: Innovación, creatividad y emprendimiento.

Innovar para responder satisfactoriamente y de forma original a las necesidades y demandas personales, organizativas y sociales con actitud emprendedora.

- DC5: Diseño y proyecto.

Diseñar, dirigir y evaluar una idea de manera eficaz hasta concretarla en un proyecto.

- DC6: Trabajo en equipo y liderazgo.

Trabajar y liderar equipos de forma efectiva para la consecución de objetivos comunes, contribuyendo al desarrollo personal y profesional de los mismos.

- DC7: Responsabilidad ética y profesional.

Actuar con responsabilidad ética y profesional ante uno mismo y los demás.

- DC8: Comunicación efectiva.

Comunicarse de manera efectiva, tanto de forma oral como escrita, utilizando adecuadamente los recursos necesarios y adaptándose a las características de la situación y la audiencia.

- DC9: Pensamiento crítico.

Desarrollar un pensamiento crítico interesándose por los fundamentos en los que se asientan las ideas, acciones y juicios, tanto propios como ajenos.

- DC10: Conocimiento de los problemas contemporáneos.

- DC11: Aprendizaje permanente.

Utilizar el aprendizaje de manera estratégica, autónoma y flexible, a lo largo de toda la vida, en función del objetivo perseguido.

- DC12: Planificación y gestión del tiempo.

Planificar adecuadamente el tiempo disponible y programar las actividades necesarias para alcanzar los objetivos, tanto académicos-profesionales como personales.

- DC13: Instrumental específica.

Capacidad para utilizar las técnicas, las habilidades y las herramientas actualizadas necesarias para la práctica de la profesión.

(c)) BY-NC-ND 2014, Universitat Politècnica de València

I Jornadas IN-RED (2014) 


\section{Objetivos}

En este trabajo revisaremos si las competencias que se incluyen en las guías docentes de las asignaturas analizadas están integradas en las dimensiones competenciales marcadas por la UPV. Estas asignaturas son:

- Reactores Químicos, del tercer curso del Grado en Ingeniería Química

- Matemáticas II, del segundo curso del Grado en Ingeniería Mecánica

- Señales y Sistemas, del segundo curso del Grado en Ingeniería de Tecnologías y Servicios de Telecomunicación

Por otro lado, estamos interesados en conocer en qué medida los alumnos que cursan dichas asignaturas consideran que han adquirido las competencias que se incluyen en las guías docentes de éstas, puesto que desde el punto de vista del profesorado que las imparte, los métodos de evaluación utilizados y la metodología docente aplicada lo garantizan suficientemente.

\section{Desarrollo de la innovación}

Hemos planteado el estudio a través de una encuesta de opinión a los alumnos que han cursado las asignaturas durante el presente curso académico 2013-2014. Las encuestas se han realizado a través de un formulario on-line elaborado con la herramienta Google Docs. La encuesta ha tenido el mismo número de preguntas y han sido del mismo tipo, pero adaptadas a las competencias de cada asignatura sobre la que se encuestaba.

Con estos resultados, analizamos la opinión que los alumnos tienen sobre el nivel que han adquirido en las competencias asociadas a estas asignaturas utilizando para mediarlas la técnica de Escala de Likert, ya que las escalas sumativas constituyen el mejor método para el escalamiento de actitudes verbalizadas (Nunnally, 1987).

Para elaborar el formulario hemos extraído de la guía docente las competencias genéricas y específicas propias de cada materia y hemos pedido a los alumnos que puntúen en qué medida piensan que el cursar las asignaturas ha contribuido a adquirir cada una de estas competencias según el baremo $1=$ Nada y $5=$ =Mucho (con tres escalas mas intermedias).

\section{Resultados}

\section{Competencias}

Las tablas 1, 2 y 3 muestran las competencias genéricas y específicas propias de las asignaturas Reactores Químicos, Matemáticas II y Señales y Sistemas, respectivamente. A cada una de ellas se le ha asignado un código, que utilizaremos posteriormente en las 
Esther Sanabria-Codesal, Ignacio Bosch, María-Cinta Vincent-Vela, Jaime Lloret, Silvia Álvarez-Blanco, Lucía Romero Pérez

siguientes gráficas, así como la dimensión competencial con la que está relacionada. Cabe destacar que en las asignaturas básicas de segundo curso se están trabajando dimensiones competenciales que a priori tienen un nivel de complejidad menor (DC1, DC2) que en la asignatura de tercer curso (DC4, DC5, DC9, DC11). En todas ellas se trabajan las dimensiones competenciales DC3: Análisis y resolución de problemas y DC13: Instrumental específica de cada materia, adaptándolas, eso sí, al nivel de complejidad requerido en cada curso.

En la asignatura de Reactores Químicos han contestado la encuesta un total de 22 alumnos de los 82 matriculados. En la asignatura de Matemáticas II han contestado la encuesta un total de 60 alumnos de los 172 matriculados. En la asignatura de Señales y Sistemas, del segundo curso del Grado en Ingeniería de Tecnologías y Servicios de Telecomunicación han contestado la encuesta un total de 47 alumnos de los 200 matriculados.

Realizaremos a continuación un análisis cuantitativo de los datos recopilados en las tres asignaturas, atendiendo a diferentes puntos de vista como son la procedencia del alumno o la nota final obtenida en la asignatura.

Tabla 1. Códigos asignados a las competencias de la asignatura Reactores Químicos

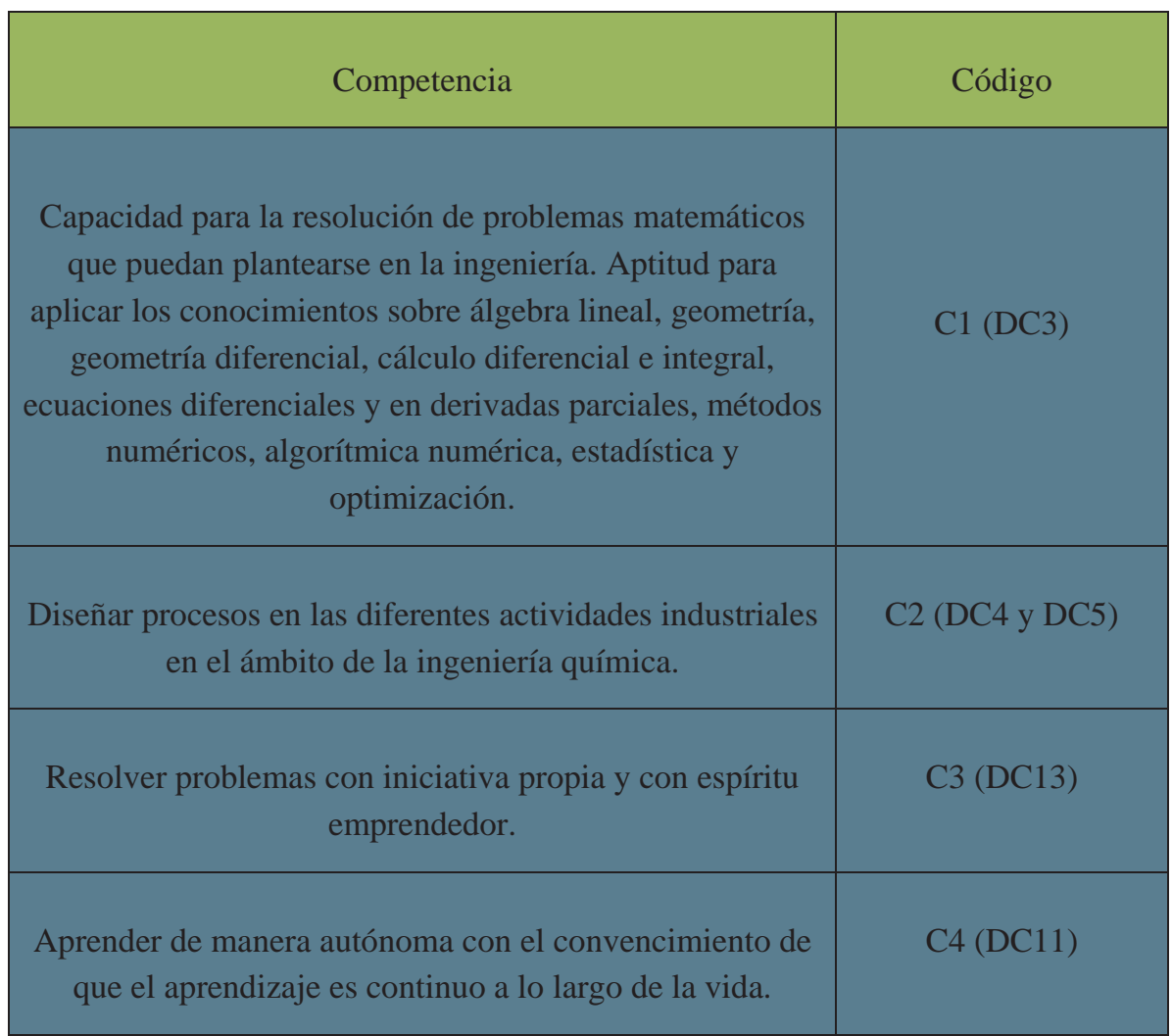

(cc)) BY-NC-ND

2014, Universitat Politècnica de València

I Jornadas IN-RED (2014) 
Análisis de las Dimensiones Competenciales incluidas en diferentes asignaturas en ingenierías

Tomar decisiones y razonar de forma crítica.

Tabla 2. Códigos asignados a las competencias de la asignatura Matemáticas II

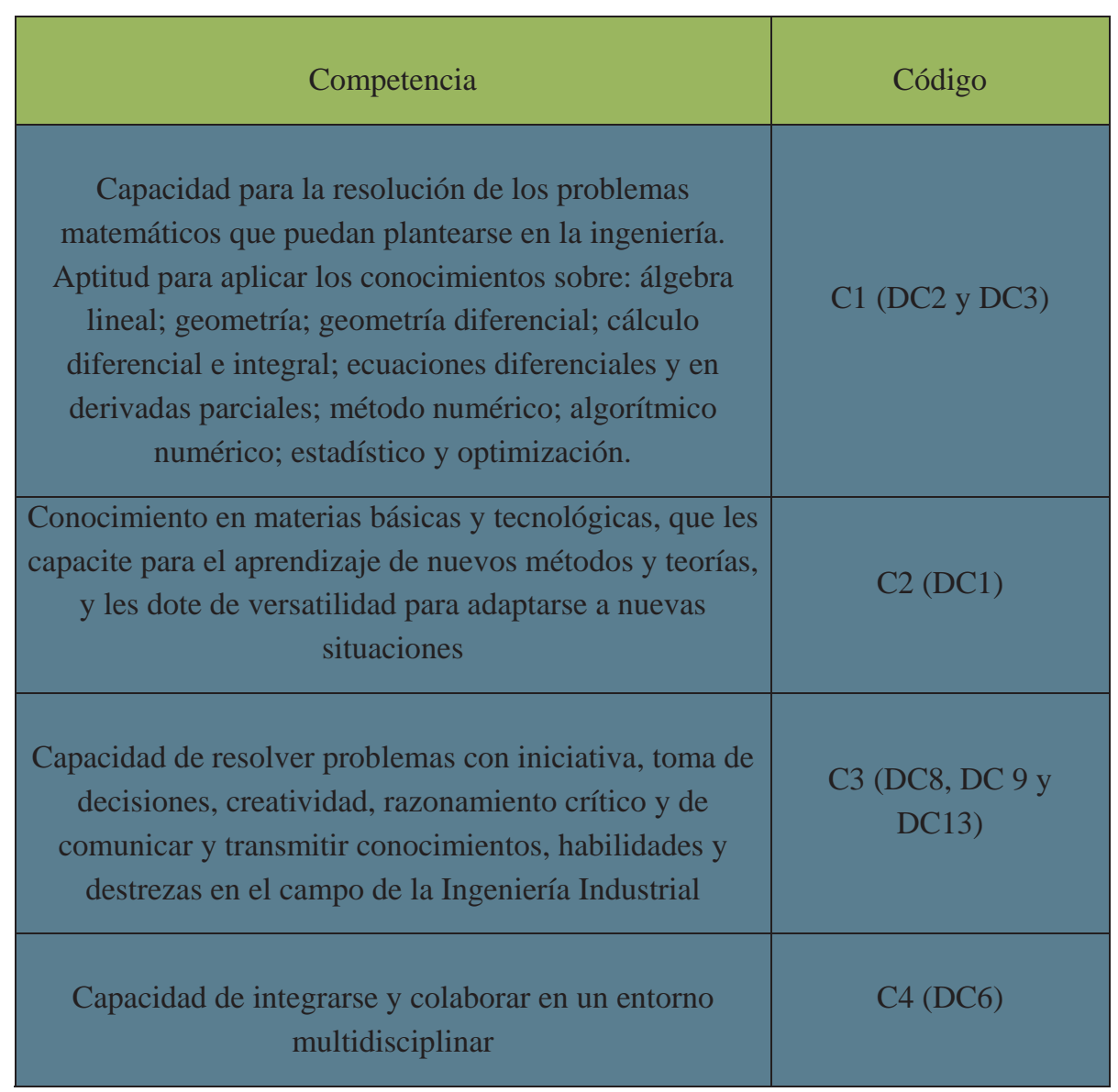

Tabla 3. Códigos asignados a las competencias de la asignatura Señales y Sistemas

\begin{tabular}{|c|c|}
\hline Competencia & Código \\
\hline $\begin{array}{c}\text { Comprensión y dominio de los conceptos básicos de } \\
\text { sistemas lineales y las funciones y transformadas }\end{array}$ & $\mathrm{C} 1$ (DC13) \\
\hline
\end{tabular}

(cc) EY-NC-ND

2014, Universitat Politècnica de València

I Jornadas IN-RED (2014) 
Esther Sanabria-Codesal, Ignacio Bosch, María-Cinta Vincent-Vela, Jaime Lloret, Silvia Álvarez-Blanco, Lucía Romero Pérez

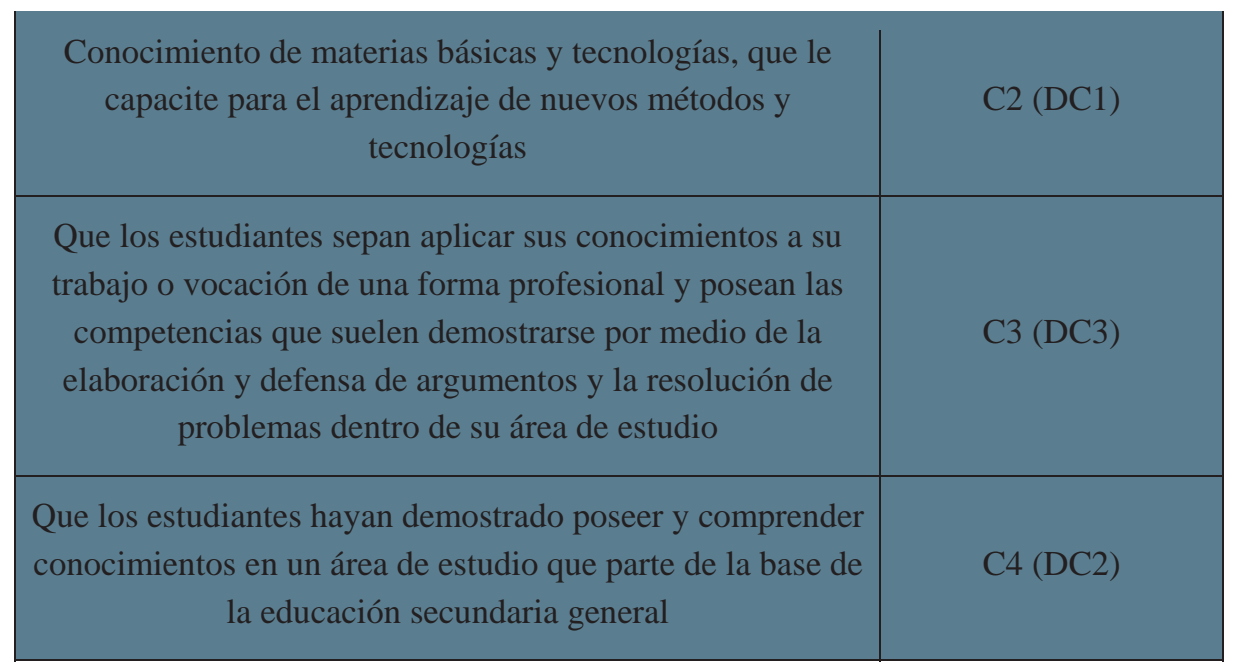

\subsection{Frecuencia de las competencias}

En primer lugar analizaremos las puntuaciones totales obtenidas en cada competencia de cada asignatura.

El número de veces que los alumnos puntúan de 1 a 5 cada una de las competencias de las asignaturas Reactores Químicos, Matemáticas II y Señales y Sistemas puede observarse en las tablas 4,5 y 6 y en las figuras 1,2 y 3 , respectivamente.

En general el alumnado está satisfecho con las competencias adquiridas en las tres asignaturas. En la asignatura Matemáticas II la mayor frecuencia de puntuaciones está en el 4 y el 5, mientras que en las asignaturas Reactores Químicos y Señales y Sistemas la mayor frecuencia de puntuaciones está en el 3 y el 4.

Tabla 4. Frecuencia de las competencias de la asignatura Reactores Químicos

\begin{tabular}{|l|c|c|c|c|c|}
\cline { 2 - 6 } \multicolumn{1}{c|}{} & 5 & 4 & 3 & 2 & 1 \\
\hline C1 & 1 & 8 & 9 & 4 & 0 \\
\hline C2 & 1 & 13 & 6 & 2 & 0 \\
\hline C3 & 2 & 5 & 8 & 7 & 0 \\
\hline C4 & 3 & 8 & 7 & 4 & 0 \\
\hline
\end{tabular}

(c)) EY-NC-ND 2014, Universitat Politècnica de València

I Jornadas IN-RED (2014) 
Análisis de las Dimensiones Competenciales incluidas en diferentes asignaturas en ingenierías

\begin{tabular}{|l|l|l|l|l|l|}
\hline C5 & 5 & 9 & 5 & 3 & 0 \\
\hline
\end{tabular}

Tabla 5. Frecuencia de las competencias de la asignatura Matemáticas II

\begin{tabular}{|l|c|c|c|c|c|}
\cline { 2 - 6 } \multicolumn{1}{c|}{} & 5 & 4 & 3 & 2 & 1 \\
\hline C1 & 10 & 34 & 12 & 3 & 1 \\
\hline C2 & 9 & 32 & 14 & 5 & 0 \\
\hline C3 & 7 & 23 & 23 & 7 & 0 \\
\hline C4 & 13 & 28 & 15 & 3 & 1 \\
\hline
\end{tabular}

Tabla 6. Frecuencia de las competencias de la asignatura Señales y Sistemas

\begin{tabular}{|l|c|c|c|c|c|}
\cline { 2 - 6 } \multicolumn{1}{c|}{} & 5 & 4 & 3 & 2 & 1 \\
\hline C1 & 9 & 21 & 11 & 5 & 1 \\
\hline C2 & 8 & 22 & 11 & 5 & 1 \\
\hline C3 & 6 & 18 & 12 & 8 & 3 \\
\hline C4 & 8 & 16 & 16 & 4 & 3 \\
\hline
\end{tabular}

En la Figura 1 puede observarse que las competencias mejor valoradas por los estudiantes de Reactores Químicos son la competencia 2: "Diseñar procesos en las diferentes actividades industriales en el ámbito de la ingeniería química", y la 5: "Tomar decisiones y razonar de forma crítica", y peor valorada la competencia 3: "Resolver problemas con iniciativa propia y con espíritu emprendedor". 
Esther Sanabria-Codesal, Ignacio Bosch, María-Cinta Vincent-Vela, Jaime Lloret, Silvia Álvarez-Blanco, Lucía Romero Pérez

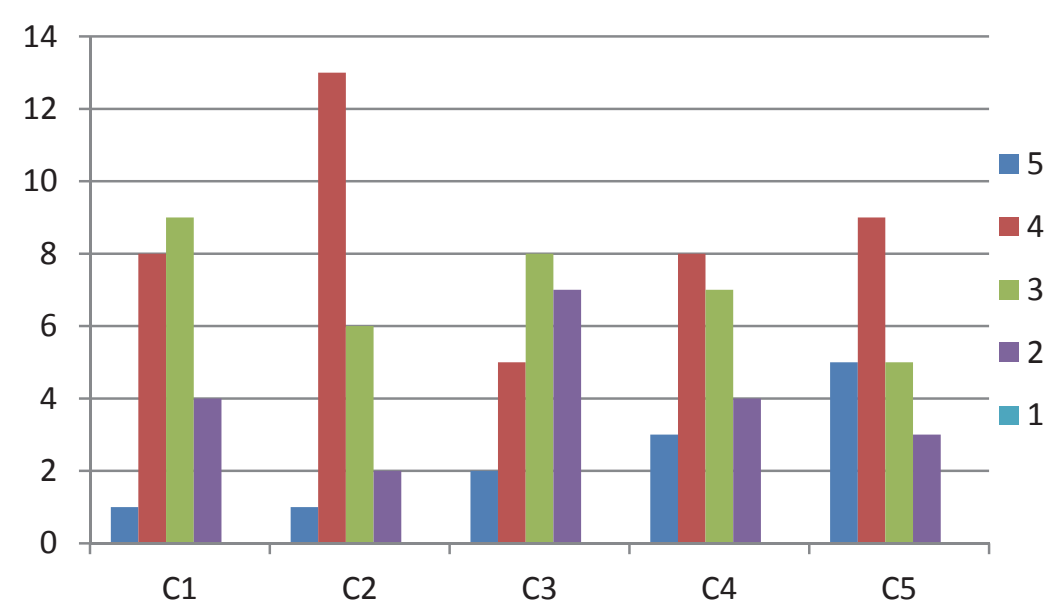

Figura 1. Frecuencia de las competencias de la asignatura Reactores Químicos

En la Figura 2 y 3 observamos que en caso de Matemáticas II y Señales y Sistemas la competencia peor valorada es la C3: "Capacidad de resolver problemas, razonamiento crítico y transmitir conocimientos, habilidades y destrezas en Ingeniería Industrial" en el caso de Matemáticas II y "Que los estudiantes sepan aplicar sus conocimientos a su trabajo o vocación de una forma profesional y posean las competencias que suelen demostrarse por medio de la elaboración y defensa de argumentos y la resolución de problemas dentro de su área de estudio" en el caso de Señales y Sistemas.

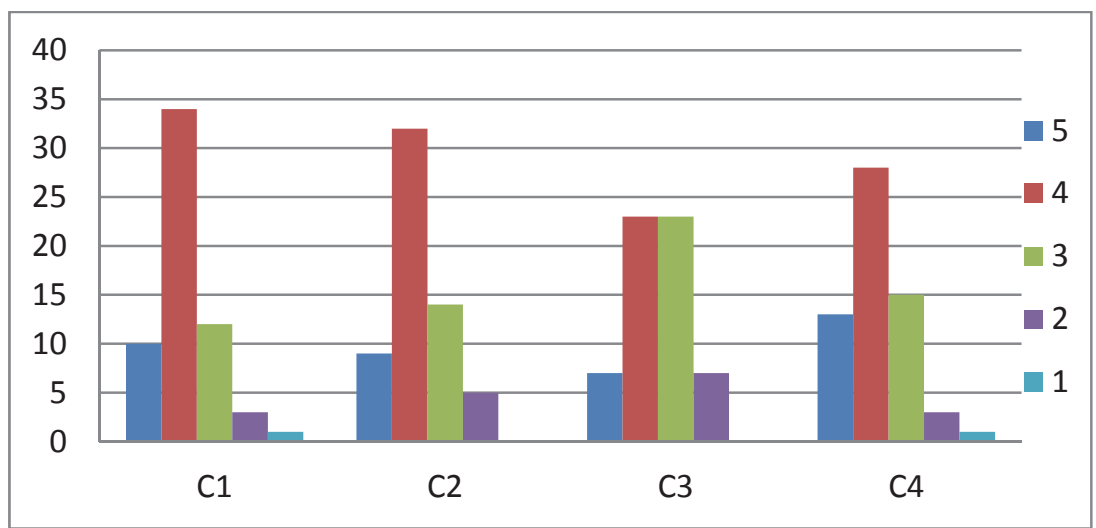

Figura 2. Frecuencia de las competencias Matemáticas II

(cc) EY-NC-ND 2014, Universitat Politècnica de València

I Jornadas IN-RED (2014) 


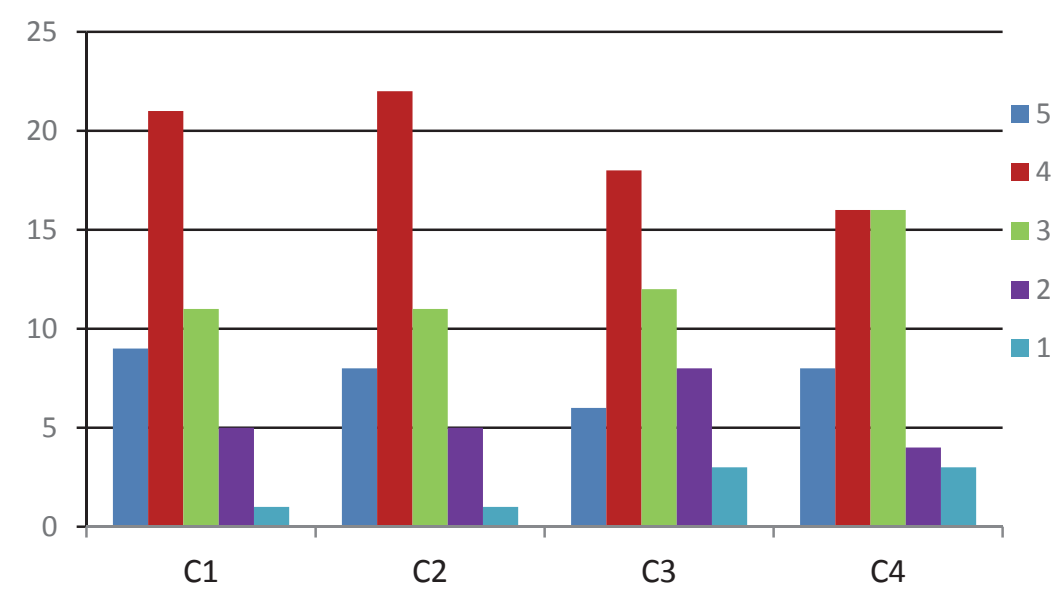

Figura 3. Frecuencia de las competencias de la asignatura Señales y Sistemas

\subsection{Puntuación de las competencias según procedencia del alumno}

En este apartado analizamos la puntuación que el alumno otorga al nivel alcanzado en las diferentes competencias atendiendo a como accedió al Grado, bien sea a través de Bachillerato y pruebas de acceso (B), Ciclos formativos de grado superior (F), o Acceso para mayores de 25 o 49 años (M). Es importante matizar que la mayor parte de los alumnos encuestados proceden de Bachillerato.

En el caso de la asignatura de Reactores Químicos todos los alumnos accedieron al Grado, a través de Bachillerato, por lo que no es posible realizar este tipo de análisis. Sin embargo en esta asignatura se preguntó a los alumnos por las competencias que creen que debería proporcionar la asignatura de Reactores Químicos, no siendo obligatorio contestar a esta pregunta. Las respuestas fueron las siguientes:

Alumno 1: "Creo que las citadas son las competencias que debería aportar la asignatura, sin embargo, en mi caso no ha sido así, ya que no superé el examen final."

Alumno 2: "Considero que es una de las asignaturas más imprescindibles de nuestra carrera ya que muchos de los trabajos que se ofrecen en el mercado laboral para graduados en Ingeniería Química, se trata de como optimizar los Reactores Químicos, como emplear más 
Esther Sanabria-Codesal, Ignacio Bosch, María-Cinta Vincent-Vela, Jaime Lloret, Silvia Álvarez-Blanco, Lucía Romero Pérez

o menos disolvente o simplemente ponerlos en funcionamiento y hacer controles de ellos. Considero que está muy bien enfocada la asignatura. Enhorabuena por el trabajo empleado en ella y sobre todo por el interés al finalizar dicha asignatura."

Alumno 3: "En mi opinión, el objetivo de la asignatura consistiría en conocer el funcionamiento y diseño de Reactores Químicos. Creo que supone una buena base teórica para posteriormente saber utilizar y optimizar este tipo de herramientas."

Alumno 4: "Interdisciplinariedad"

Alumno 5: "En mi opinión he alcanzado las competencias que pide la asignatura"

El alumno 1 suspendió la asignatura, mientras que los alumnos 2-5 obtuvieron un aprobado.

En las asignaturas de Matemáticas II y Señales y Sistemas, la mayoría de los alumnos se decanta por valores a partir de 3 en la valoración de todas las competencias encuestadas, independientemente del origen del alumno, cabe destacar sin embargo que los alumnos procedentes de ciclos o acceso para mayores valoran más positivamente las competencias adquiridas en la asignatura, como observamos en las Figuras 4 y 5 .

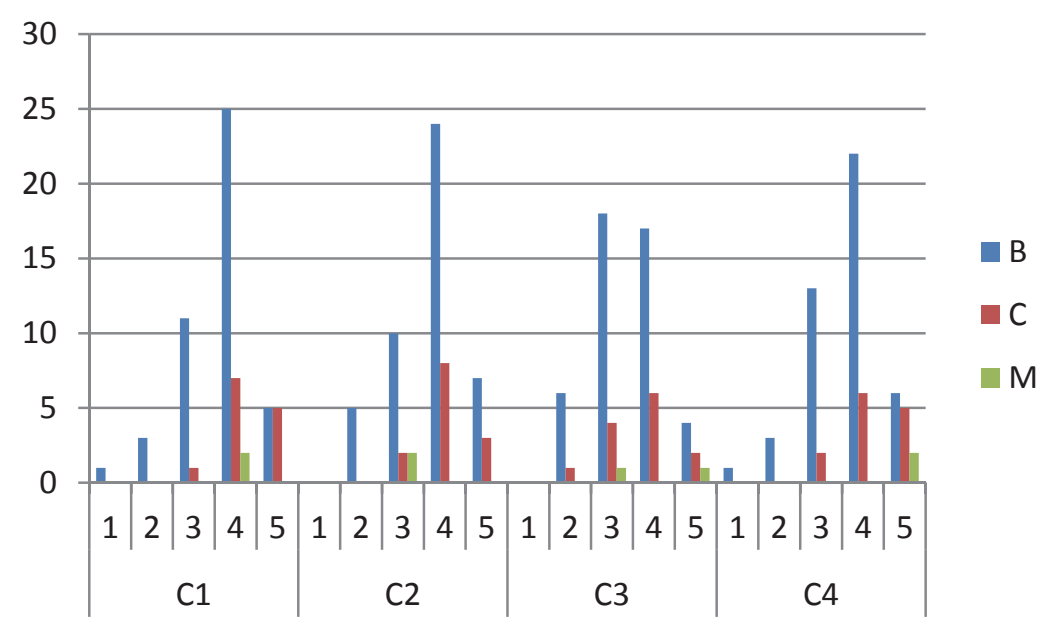

Figura 4. Puntuación de acuerdo con la procedencia del alumno en Matemáticas II

\section{(c)) EY-NC-ND 2014, Universitat Politècnica de València}

I Jornadas IN-RED (2014) 
Análisis de las Dimensiones Competenciales incluidas en diferentes asignaturas en ingenierías

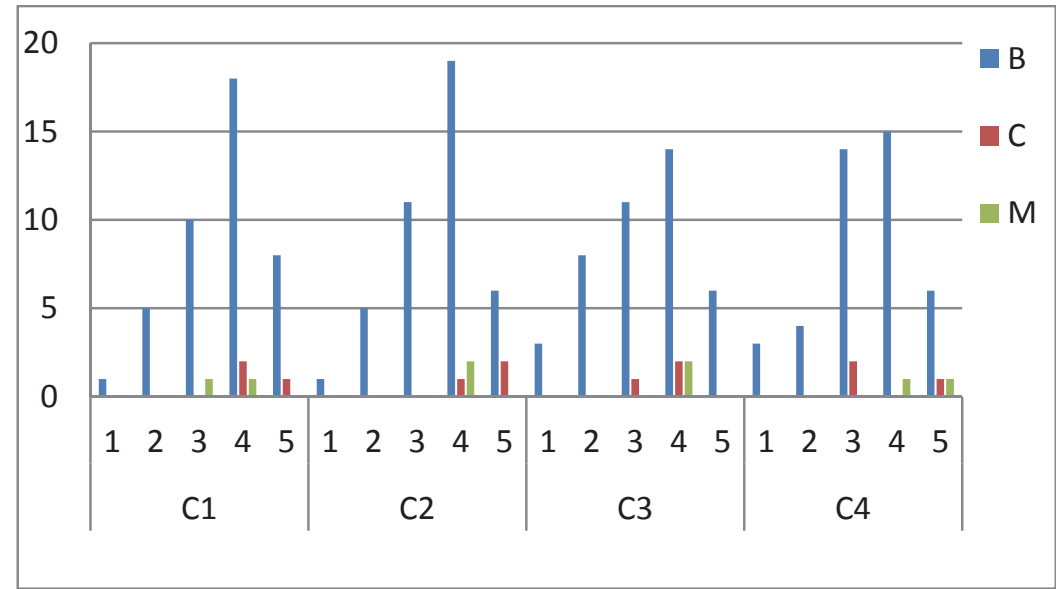

Figura 5. Puntuación de acuerdo con la procedencia del alumno en Señales y Sistemas

\subsection{Puntuación de las competencias según nota final obtenida.}

Por último analizamos la puntuación que los alumnos otorgan al nivel adquirido en las competencias según la nota final. En la asignatura Reactores Químicos de los 22 encuestados hay 5 notables, 12 aprobados y 5 suspendidos. En la Figura 6 no se observa correlación entre la nota obtenida por los alumnos en la asignatura y la valoración que hacen de las competencias.

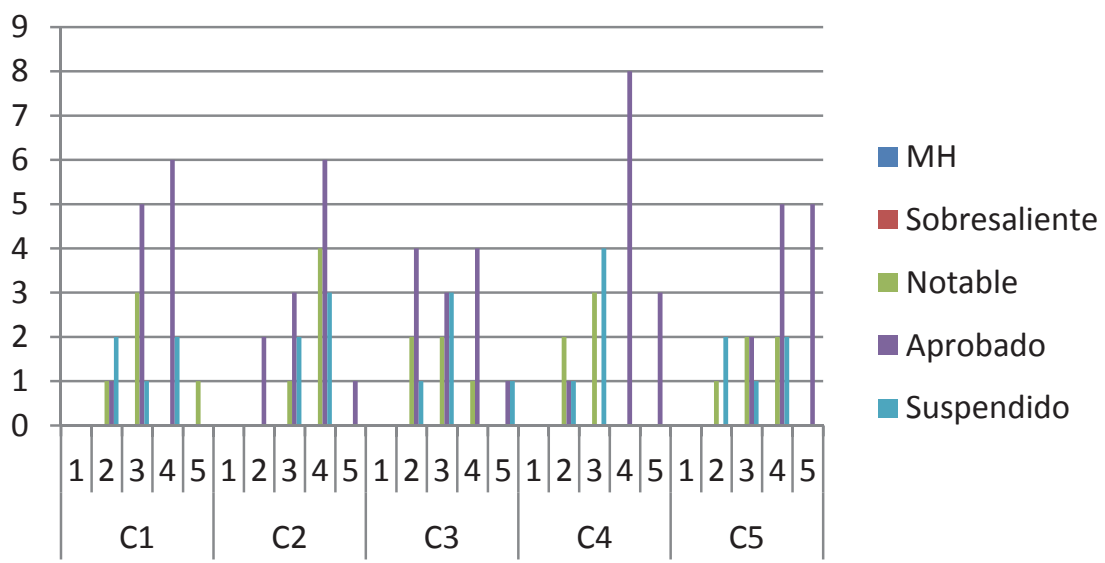

Figura 6. Puntuación de acuerdo con la nota del alumno en Reactores Químicos

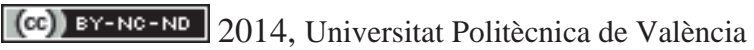
I Jornadas IN-RED (2014) 
Esther Sanabria-Codesal, Ignacio Bosch, María-Cinta Vincent-Vela, Jaime Lloret, Silvia Álvarez-Blanco, Lucía Romero Pérez

En la asignatura Matemáticas II se observa que en general la valoración es mejor cuanta mayor calificación se haya obtenido (Figura 7). Sin embargo, en la competencia 3: Capacidad de resolver problemas, razonamiento crítico y transmitir conocimientos, habilidades y destrezas en Ingeniería Industrial, vemos que incluso en el caso de personas con buena nota no hay una satisfacción plena.

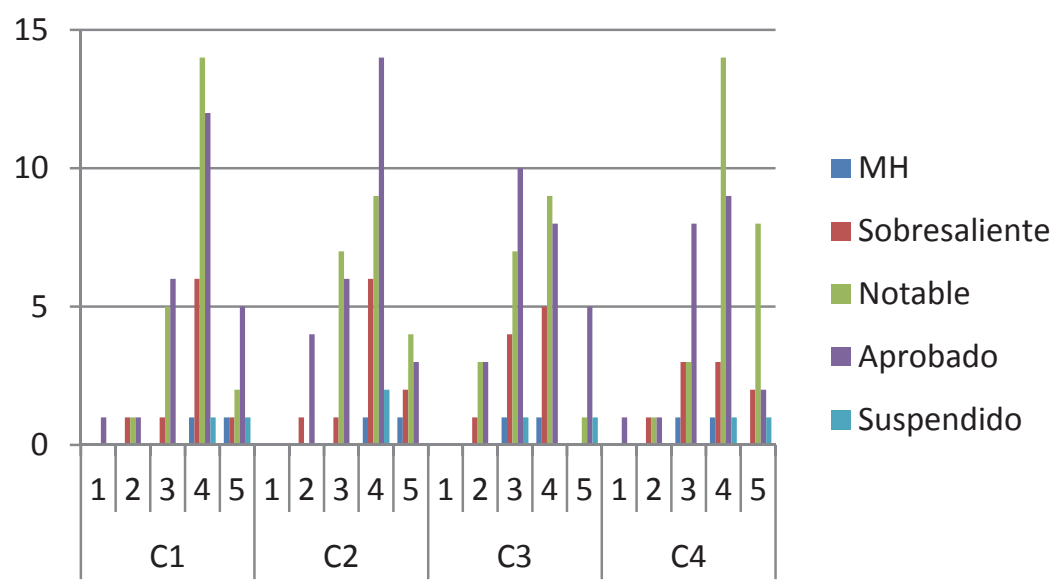

Figura 7. Puntuación de acuerdo con la nota del alumno en la Matemáticas II

En Señales y Sistemas también se observa que en general la valoración es mejor cuanta mayor calificación se haya obtenido, prácticamente para todas las competencias por igual (Figura 8). Cabe destacar que solo 5 de los 42 alumnos aprobados que han contestado la encuesta superaron la asignatura gracias a la posibilidad de realizar una recuperación final, aprobando la gran mayoría gracias a la evaluación continua con parciales y prácticas.

(c)) BY-NC-ND 2014, Universitat Politècnica de València

I Jornadas IN-RED (2014) 


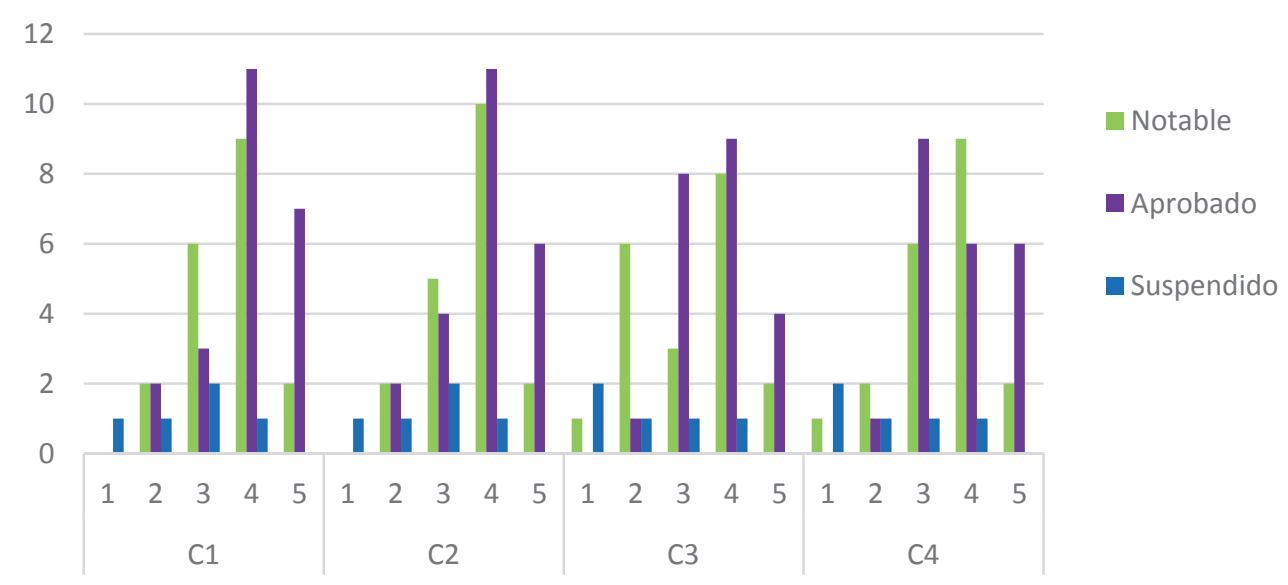

Figura 8. Puntuación de acuerdo con la nota del alumno en Señales y Sistemas

\section{Conclusiones}

Del análisis de nuestro estudio, podemos concluir que existe un elevado grado de satisfacción del alumnado con la adquisición de competencias de las asignaturas, independientemente de la procedencia del alumno o de su nota final en la asignatura. Se puede deducir que de alguna forma ya se están teniendo en cuenta éstas competencias transversales en la calificación de la asignatura, pero de una forma meramente intuitiva y nada formal. Esto nos podría llevar a plantear la necesidad de evaluar de forma autónoma cada competencia transversal como un elemento más a valorar en la calificación final de la asignatura.

A pesar de todo, queda patente que es necesario profundizar en la aplicación práctica de los métodos explicados, debido a la evidente necesidad de conexión de los graduados en ingeniería con las necesidades del mundo real.

Por tanto, para mejorar las carencias detectadas en este estudio, proponemos un cambio en las actividades programadas, priorizando en el trabajo realizado en ellas la modelización de problemas multidisciplinares, lo más realistas e integrados en el área profesional de los futuros graduados que nos sea posible, con el objetivo de resaltar la utilidad y aplicabilidad de los conocimientos impartidos. 
Esther Sanabria-Codesal, Ignacio Bosch, María-Cinta Vincent-Vela, Jaime Lloret, Silvia Álvarez-Blanco, Lucía Romero Pérez

\section{Referencias}

CANO GARCÍA, M.E. (2008). "La evaluación por competencias en la educación superior" en Revista de Currículum y Formación de Profesorado, vol. 12, núm. 3, p. 1-16.

DE MIGUEL DÍAZ, M. (2006). "Metodologías de enseñanza y aprendizaje para el desarrollo de competencias. Orientaciones para el profesorado universitario antes el espacio europeo de educación superior” Madrid: Alianza Editorial.

GONZÁLEZ, O. (2003). "Evaluación basada en competencias” en Revista de Investigación, núm. 5, PP-0002.26/E004-N. Venezuela: Editorial Universidad del Zulia, Maracaibo.

GOÑI ZABALA, J. M. (2005). "El espacio europeo de educación superior, un reto para la universidad: Competencias, tareas y evaluación, los ejes del currículum universitario" Barcelona: Editorial Octaedro, S.L.

HUÉ GARCÍA, C. (2008). "Competencias genéricas y transversales de los titulados universitarios" Editorial: ICE de la Universidad de Zaragoza. Documento disponible en web: www.unizar.es/ice/images/storiess/publicacionesICE/Col.\%20Documentos\%2008.pdf.

LLORET, J., JIMENEZ, J. M., BORONAT, F., TOMAS J. Y DIAZ, J. R. (2006). Utilización de diversas metodologías didácticas para desarrollar las habilidades de los estudiantes de Ingeniería Técnica de Telecomunicaciones, Congreso Internacional de Docencia Universitaria e Innovación (CIDUI 2006), Barcelona, 5-7 de Julio de 2006

NUNNALLY, J.C. (1987). Psychometric Theory. New York: Mac Graw-Hill.

VICERRECORADO DE ESTUDIOS, CALIDAD Y ACREDITACIÓN, MARCO UPV DE DEFINICIÓN Y EVALUACIÓN DE ADQUISICIÓN DE COMPETENCIAS, "Dimensiones Competenciales UPV". Disponible en:

http://www.upv.es/contenidos/ICEP/info/DimensionesCompetenciales.pdf [Consulta: 11 de junio de 2014]

(c)) BY-NC-ND 2014, Universitat Politècnica de València

I Jornadas IN-RED (2014) 


\title{
Evaluación mediante encuestas al alumnado de la adecuación del uso de simuladores de procesos para mejorar el aprendizaje en Ingeniería Química
}

\author{
María-José Corbatón-Báguena ${ }^{a}$, Silvia Álvarez-Blanco ${ }^{a}$, María-Cinta Vincent-Vela ${ }^{a}$ y \\ Jaime Lloret $^{\text {b }}$ \\ ${ }^{a}$ Departamento de Ingeniería Química y Nuclear. Universitat Politècnica de València. C/ Camino de \\ Vera s/n. 46022- Valencia. Valencia. E-mail: macorba@upvnet.upv.es, sialvare@iqn.upv.es, \\ mavinve@iqn.upv.es y ${ }^{\mathrm{b}}$ Instituto de Investigación para la Gestión Integrada de Zonas Costeras \\ (IGIC). Universitat Politècnica de València. Calle Paranimf 1. 46730 - Gandia. Valencia. E-mail: \\ jlloret@dcom.upv.es
}

\begin{abstract}
Utilization of commercial process simulators in Engineering courses has increased in the last years as a teaching tool for students. In this work, the influence of the commercial simulator CHEMCAD in the learning process of third-year students of Chemical Engineering is evaluated. By means of their responses in surveys, the general satisfaction of students concerning the methodology followed during the practical lessons is determined. The results demonstrates that most of the students agree the fact that CHEMCAD simulator is useful to calculate complex systems in a faster and easier way, to extrapolate results from lab scale to industrial scale and to understand more easily how several equipments from the chemical industries work. Regarding to the methodology, students opinions were divided although most of them consider it adequate.
\end{abstract}

Keywords: Practical habilities, Software for education, Simulators.

\section{Resumen}

El uso de simuladores comerciales de procesos en diversas asignaturas de Ingeniería ha aumentado considerablemente en los últimos años como refuerzo en la enseñanza de los alumnos. En este trabajo, se evalua la 
Evaluación mediante encuestas al alumnado de la adecuación del uso de simuladores de procesos para mejorar el aprendizaje en Ingeniería Química

influencia del simulador comercial CHEMCAD en el aprendizaje de los alumnos de tercer curso del Grado en Ingeniería Química. Mediante la respuesta de los alumnos a distintas preguntas formuladas en_-_encuestas se ha determinado la satisfacción general de los mismos respecto a la metodología seguida durante la realización de las clases prácticas. Los resultados indican que la mayoría de los alumnos destacan la utilidad del simulador CHEMCAD para realizar cálculos de sistemas complejos de una manera más rápida y sencilla, para extrapolar sistemas de escala laboratorio a escala industrial y para comprender más fácilmente el funcionamiento de distintos equipos propios de la industria química. En cuanto a la metodología, existe una mayor división de opiniones entre el alumnado, aunque la mayoría la considera adecuada.

Palabras clave: Habilidades prácticas, Software para Educación, Simuladores.

\section{Introducción}

El aumento considerable del uso de simuladores de procesos en distintos ámbitos industriales durante los últimos años ha promovido la implantación de estos sistemas en los planes de estudio de diversas titulaciones, entre ellas, la Ingeniería Química (Dahm, 2002). Entre las muchas ventajas de los simuladores comerciales de procesos se pueden destacar las siguientes: disponen de un amplio banco de datos de distintos componentes, permiten evaluar los distintos modos de funcionamiento de un proceso o equipo, realizando su dimensionamiento y es posible modificar las variables que intervienen en un proceso o equipo y proponer alternativas de operación del mismo (Toselli, 2009). Por este motivo, cada vez más asignaturas complementan las clases teóricas con prácticas en las que los alumnos utilizan los simuladores comerciales para desarrollar trabajos en grupo (García, 2008a). Además, actualmente están apareciendo multiples tipos de simuladores gratuitos, en su gran mayoría de código libre, que han facilitado su incorporación en multiples areas (García, 2008b).

La utilización de estos simuladores comerciales presenta numerosos beneficios en el aprendizaje de los alumnos (Díaz, 1992; Zumalacárregui, 2001; Wankat, 2002). Entre ellos cabe destacar la facilidad de comprensión de los conceptos teóricos y de la representación de los procesos químicos a estudiar. Díaz y Zumalacárregui (Díaz, 1992) calcularon balances de masa en sistemas complejos mediante simuladores como medio de enseñanza 
en alumnos de tercer año de la titulación de Ingeniería Química. Zumalacárregui de Cárdenas y Valverde Palomino (Zumalacárregui, 2001) plantearon un ejercicio práctico a alumnos de la asignatura de Simulación de Procesos de la titulación de Ingeniería Química basado en el diseño de una central térmica de gasificación integrada con ciclo combinado mediante el simulador HYSYS. Mediante este ejercicio, los alumnos reforzaron conceptos teóricos estudiados durante la titulación así como cualidades relacionadas con el trabajo en grupo (responsabilidad, ejercicio correcto de la crítica y habilidad de la comunicación oral). Wankat (Wankat, 2002) utilizó el simulador ASPEN PLUS en clases prácticas con alumnos de Ingeniería Química. Los resultados de las encuestas demostraron que el aprendizaje de los alumnos mejoró tras la utilización del simulador. Además, los alumnos valoraron positivamente su uso como medio para comprender mejor los conceptos teóricos.

La estructura del artículo es como sigue a continuación. En la sección 2 presentamos los objtetivos del trabajo. El desarrollo de innovación, incluyendo la metodología y la evaluación se incluye en la sección 3. La sección 4 muestra los resultados obtenidos en el presente trabajo. Finalmente, la sección 5 incluye las conclusiones.

\section{Objetivos}

El principal objetivo de este estudio consiste en evaluar la influencia de la utilización de un simulador comercial de procesos (CHEMCAD) (Chemcad, 2014) en el aprendizaje de alumnos de tercer curso del Grado en Ingeniería Química. Tras la realización de diversas clases prácticas con el simulador se ha determinado el grado de satisfacción de los alumnos con el uso del simulador y con la metodología seguida en las clases mediante una serie de encuestas realizadas al final del curso.

\section{Desarrollo de la Innovación}

\subsection{Metodología}

En el Departamento de Ingeniería Química y Nuclear de la Univeristat Politècnica de València se dispone del software CHEMCAD para impartir las clases prácticas de simulación de procesos correspondientes a asignaturas de tercer curso del Grado en Ingeniería Química. Su empleo se ha estructurado de un modo gradual, comenzando por la simulación de equipos sencillos de manera individual hasta llegar a plantear un ejercicio práctico en el que distintas operaciones intervienen de manera conjunta.

Se realizaron un total de cuatro clases prácticas con el simulador CHEMCAD en grupos reducidos de alumnos (aproximadamente 15 alumnos por grupo). Cada alumno disponía de un ordenador donde realizar los distintos ejercicios planteados y unos apuntes de referencia

\section{(c)) EY-NC-ND 2014, UniversitatPolitècnica de València}

I Jornadas IN-RED (2014) 
Evaluación mediante encuestas al alumnado de la adecuación del uso de simuladores de procesos para mejorar el aprendizaje en Ingeniería Química

sobre el funcionamiento del software en función del tipo de sistema o equipo a simular. Al comienzo de cada sesión práctica, se llevaba a cabo una breve introducción sobre los conceptos teóricos más importantes a aplicar en la realización de los ejercicios, así como los modos de operación de cada sistema o equipo.

En la última sesión, los alumnos tuvieron que simular un proceso de obtención de una corriente líquida concentrada en acetona a partir de una corriente gaseosa que contiene una cantidad conocida de acetona. El proceso no estaba completamente definido y no existía una única solución o un único diseño correcto por lo que se planteaba un problema de respuesta abierta. Los alumnos debían escoger las unidades de procesos adecuadas y combinarlas de forma óptima. Este proceso se realizaba siempre con el asesoramiento del profesor. Además, los alumnos debían plantear las recirculaciones necesarias para conseguir el máximo aprovechamiento energético y de materia prima. Para ello, se comenzaba escogiendo la alternativa más sencilla y se continuaba complicando el diagrama de flujo a medida que se detectan posibles problemas durante la simulación. A modo de ejemplo en la Figura 1 se muestra un diagrama de flujo de uno de los procesos simulados.

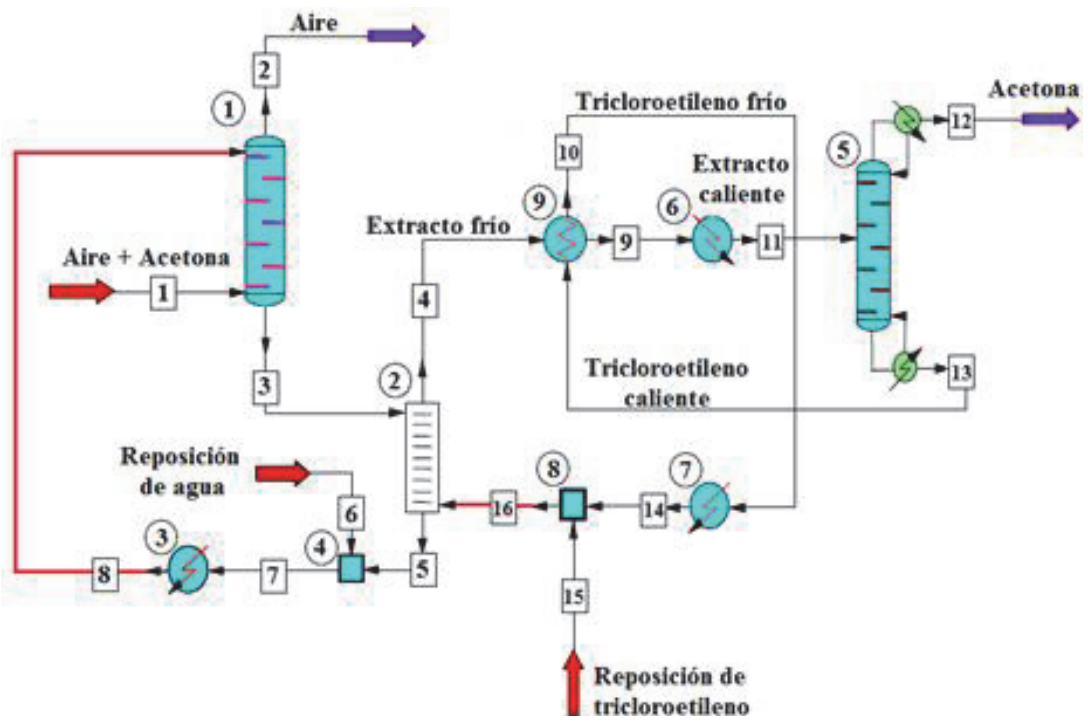

Fig. 1. Sistema de recuperación de acetona

\subsection{Evaluación de la satisfacción de los alumnos}

Al finalizar las clases prácticas, se evaluó el grado de satisfacción de los alumnos con el simulador CHEMCAD mediante encuestas. Las preguntas se dividieron en tres bloques 
(Percepción inicial de los alumnos, Valoración de las clases prácticas y Satisfacción general), tal y como se observa en la Tabla 1.

A cada una de dichas preguntas, los alumnos respondieron de acuerdo con el siguiente código numérico:

1. Muy en desacuerdo

2. En desacuerdo

\section{Normal}

4. De acuerdo

5. Muy de acuerdo

La evaluación de las preguntas de cada bloque se realizó promediando el número de preguntas con la puntuación obtenida en cada una de ellas según el código numérico anterior. La puntuación global de cada uno de los bloques se realizó promediando la puntuación de cada una de las preguntas de dicho bloque con el número de preguntas. Además, se calculó la desviación estándar para cada una de las preguntas planteadas. La puntuación y los valores de desviación estándar obtenidos en cada pregunta se muestran en la Tabla 1. 
Evaluación mediante encuestas al alumnado de la adecuación del uso de simuladores de procesos para mejorar el aprendizaje en Ingeniería Química

Tabla 1. Listado de preguntas: puntuación y desviación estándar

\begin{tabular}{|c|c|c|}
\hline Pregunta & Puntuación & $\begin{array}{l}\text { Desviación } \\
\text { estándar }\end{array}$ \\
\hline Bloque 1. Percepción inicial de los alumnos & 4 & \\
\hline $\begin{array}{l}\text { 1.1. Un simulador permite realizar cálculos de sistemas complejos } \\
\text { de una manera más rápida y sencilla. }\end{array}$ & 4 & 0.79 \\
\hline $\begin{array}{l}\text { 1.2. Es posible extrapolar sistemas de escala laboratorio a escala } \\
\text { industrial mediante el uso del simulador. }\end{array}$ & 4 & 0.71 \\
\hline $\begin{array}{l}\text { 1.3. La interfaz gráfica del simulador ayuda a comprender el } \\
\text { funcionamiento de distintos equipos utilizados en la Ingeniería } \\
\text { Química. }\end{array}$ & 4 & 0.80 \\
\hline Bloque 2. Valoración de las clases prácticas & 3 & \\
\hline $\begin{array}{l}\text { 2.1. Una breve explicación teórica sobre el funcionamiento del } \\
\text { simulador al comienzo de la clase resulta útil para la posterior } \\
\text { realización de los ejercicios. }\end{array}$ & 4 & 1.07 \\
\hline $\begin{array}{l}\text { 2.2. La división de las clases de acuerdo con el tipo de } \\
\text { sistema/equipo permite entender mejor la asignatura. }\end{array}$ & 3 & 1.17 \\
\hline $\begin{array}{l}\text { 2.3. El porcentaje asignado en la asignatura a las clases prácticas } \\
\text { con el simulador es adecuado. }\end{array}$ & 3 & 0.94 \\
\hline $\begin{array}{l}\text { 2.4. Debería haber un mayor número de clases prácticas con el } \\
\text { simulador. }\end{array}$ & 3 & 1.17 \\
\hline Bloque 3. Satisfacción general & 3 & \\
\hline $\begin{array}{l}\text { 3.1. El uso del simulador ayuda a comprender mejor los conceptos } \\
\text { teóricos. }\end{array}$ & 3 & 1.02 \\
\hline $\begin{array}{l}\text { 3.2. Considero que la metodología seguida en las clases prácticas es } \\
\text { adecuada. }\end{array}$ & 3 & 1.11 \\
\hline $\begin{array}{l}\text { 3.3. La división entre las clases teóricas y prácticas ayuda a los } \\
\text { alumnos a asimilar mejor los conceptos. }\end{array}$ & 3 & 0.95 \\
\hline $\begin{array}{l}\text { 3.4. El uso del simulador ayuda a entender mejor los procesos } \\
\text { propios de la Ingeniería Química. }\end{array}$ & 4 & 0.87 \\
\hline $\begin{array}{l}\text { 3.5. En general, considero positivo el uso del simulador } \\
\text { CHEMCAD. }\end{array}$ & 3 & 1.01 \\
\hline
\end{tabular}




\section{Resultados}

A partir de los datos mostrados en la Tabla 1 se puede concluir que la percepción inicial de los alumnos es muy favorable a la utilización del simulador CHEMCAD, puesto que la puntuación media del Bloque 1 es de 4. Además, en este bloque la mayoría de los alumnos coincidían en las ventajas que ofrece el simulador CHEMCAD para realizar cálculos de sistemas complejos de una manera más rápida y sencilla, para extrapolar sistemas de escala laboratorio a escala industrial y para comprender más fácilmente el funcionamiento de distintos equipos utilizados en las industrias del sector químico.

En el Bloque 2, los alumnos valoraron la metodología seguida durante las clases prácticas con el simulador. En este caso, existe una mayor diferencia de opiniones entre el alumnado, con valores de desviación estándar alrededor de 1. A pesar de ello, la mayoría de los alumnos se muestra de acuerdo con que se realice una breve explicación teórica al inicio de cada clase sobre cada uno de los equipos o procesos a simular. Por otra parte, los alumnos discrepan en cuanto a la división de las clases de acuerdo con el tipo de sistema/equipo y el número de clases prácticas con el simulador para comprender mejor la asignatura, aunque la mayoría consideran adecuados ambos aspectos. Para mejorar este aspecto, se podrían plantear distintas alternativas. Una de ellas consistiría en aumentar el número de clases prácticas simulando en las últimas procesos de mayor dificultad donde los alumnos deban escoger de manera justificada el tipo de equipo o sistema. De esta forma, se mantendría la división en función del sistema/equipo en las primeras clases a la vez que en las últimas los alumnos refuerzan los conocimientos adquiridos con más ejercicios adicionales donde intervienen distintos equipos. Otra de las alternativas implicaría proponer a los alumnos un ejercicio puntuable a entregar por grupos. Así, además de poner en común lo aprendido en las clases prácticas, se potencian en los alumnos otras habilidades, como el trabajo en equipo o la comunicación oral.

Finalmente, en el Bloque 3 sobre la satisfacción general de los alumnos, la diferencia de opiniones en cuanto a la metodología seguida durante las clases prácticas queda reflejada en la puntuación de las preguntas 3.2. y 3.3. y en la puntuación global del bloque (ver Tabla 1). En estos casos, la puntuación obtenida fue de 3. Por el contrario, la desviación estándar es menor en el caso de la pregunta 3.4. sobre si el uso del simulador permite comprender mejor los procesos propios de la Ingeniería Química. En este caso, la mayoría de los alumnos se mostraron de acuerdo con la pregunta planteada, obteniéndose una puntuación de 4 . 
Evaluación mediante encuestas al alumnado de la adecuación del uso de simuladores de procesos para mejorar el aprendizaje en Ingeniería Química

\section{Conclusiones}

En este trabajo se ha analizado la influencia del simulador comercial CHEMCAD en el aprendizaje de alumnos de tercer curso del Grado en Ingeniería Química. A partir de las respuestas obtenidas por los alumnos mediante una encuesta, se puede concluir lo siguiente:

- La mayoría de los alumnos consideran positivo la utilización de CHEMCAD para agilizar cálculos complejos, realizar un cambio de escala de un proceso o equipo y comprender el funcionamiento de los mismos.

- Existe división de opiniones en cuanto al número de clases prácticas y la división de las mismas de acuerdo con el tipo de equipo/proceso, discrepando sobre la metodología seguida en las clases.

- Distintas medidas podrían implementarse para tratar de mejorar la opinión de los alumnos en cuanto a la metodología seguida, aumentando el número de clases prácticas y realizando ejercicios de mayor dificultad o bien proponiendo un ejercicio entregable por grupos para fomentar el trabajo en equipo.

En futuros trabajos observaremos cómo influyen otros simuladores en el aprendizaje de los alumnos. Además, se aplicaran otras metodologías didácticas para poder observar si se puede alcanzar mas efectividad en la enseñanaza utilizando dicho CHEMCAD.

\section{Referencias}

CHEMCAD website (2014), Disponible en http://www.chemstations.com/

DAHM, K., HESKETH, R.P., SAVELSKI, M.J. (2002). "Is process simulation used effectively in ChE courses" en Chemical Engineering Education. 36 (3), 192-203.

DÍAZ J., ZUMALACÁRREGUI L. (1992). “Aplicación de las técnicas de computación en las asignaturas de la disciplina Principios de Ingeniería Química” en Educación Química. 3 (4), 280-283.

GARCÍA PINEDA M., BORONAT SEGUÍ F., LLORET MAURI J. (2008a). "Network simulators comparative from the educational point of view". En: International Technology, Education and Development Conference (3-5 Marzo 2008, Valencia).

GARCÍA, M., COLL, H., BRI, D., LLORET, J., (2008b). "Software Tools and Simulators in the Education of Engineering of Telecommunications", En: The 5th WSEAS / IASME International Conference on ENGINEERING EDUCATION (EE'08) (22 al 24 de Julio de 2008, Heraklion, Creta (Grecia)).

TOSELLI L.A. et al. (2009). "Aplicación del Simulador ChemCAD ${ }^{\mathrm{TM}}$ en la Enseñanza en Carreras de Ingeniería” en Formación Universitaria. 2 (3), 19-24.

(cc) EY-NC-ND 2014, UniversitatPolitècnica de València

I Jornadas IN-RED (2014) 
WANKAT P.C. (2002). "Integrating the Use of Commercial Simulators into Lecture Courses" en Journal of Engineering Education. 91 (1), 19-23.

ZUMALACÁRREGUI L., VALVERDE J.L. (2001). "Ejemplo para el uso de un simulador en los estudios de ingeniería química" en Educación Química. 12 (4), 203-208. 


\title{
Mejora de la evaluación de alumnos usando métodos de decisión multicriterio
}

Juan A. Marin-Garcia ${ }^{a}$, Pablo Aragonés Beltran ${ }^{\mathbf{b}}$ Monica Garcia Melón ${ }^{\mathrm{b}}$

${ }^{a}$ ROGLE. Dpto. de Organización de Empresas. Universidad Politécnica de Valencia. Camino de Vera S/N 46022 Valencia.jamarin@omp.upv.es.

${ }^{\mathrm{b}}$ Grupo de Valoración y decisión multicriterio. Departamento de Proyectos de Ingeniería, Universidad Politécnia de Valencia

\begin{abstract}
The aim of this paper is to test, in a subject with few students, if teachers put notes correctly ordered according to the degree of learning objectives of the course and if that order is similar when comparing various sources-student peer assessment and self assessment-. We want to develop a method that, in the future, we should see if it is feasible even with large groups. With the proposed methodology is possible to create an ordered list of students from more to less degree of competence, having a distance between them (in one dimension) that reflects the degree of learning of each (knowledge, skills and attitudes). We also show the consistency of the data used to calculate a student's grade.
\end{abstract}

Keywords: AHP,higher education,student assessment, peer assessment, self assessment,teacher assessment, multicriteria decision method.

\section{Resumen}

El objetivo de esta comunicación es comprobar, en una asignatura con pocos alumnos, si las notas que ponemos los profesores en el sistema de evaluación de la asignatura ordenan a los alumnos correctamente en función del grado de aprendizaje de los objetivos de la asignatura y ese orden es parecido al contrastar varias fuentes -observaciones del profesor, auto evaluación del alumno y evaluación de los compañeros- y desarrollar un método que, en el futuro, deberíamos comprobar si es viable incluso con grupos numerosos. Con la metodología propuesta es posible crear una lista 
ordenada de alumnos desde el que más domina una competencia al que menos domina, teniendo una distancia entre ellos (en una dimensión) que refleje el grado de aprendizaje de cada uno de ellos (conocimientos, habilidades y actitudes). También mostramos la consistencia de los datos usados para calcular la nota del alumno.

Palabras clave: AHP,Evaluación de estudiantes, educación universitaria, evaluación por compañeros, auto-evaluación, evaluación del profesor, método de decisión multicriterio.

\section{Introducción}

Desde hace un tiempo, existe un creciente interés por enfocar las titulaciones universitarias hacia el desarrollo de competencias profesionales (Lohmann et al., 2006). Para ello, es necesario no sólo identificar cuáles son las competencias prioritarias para el perfil profesional de la titulación, sino también, los resultados de aprendizaje; los niveles que discriminan entre un resultado pobre y uno sobresaliente; los instrumentos para evaluar la adquisición de la competencia y el modo en que vamos a proporcionar información a los alumnos para que puedan progresar en su aprendizaje (Marin-Garcia et al., 2009; Terry et al., 2002).

Una de las competencias más demandadas en las sociedades avanzadas es la competencia de innovación, que aparece reflejada en la mayoría de los planes de estudios de España bajo diferentes nombres (innovación, creatividad, emprendimiento, habilidad para tomar decisiones, capacidad para resolver problemas...) (Andreu Andrés y García-Casas, 2014; Ingols y Shapiro, 2014; Marin-Garcia et al., 2008; Mula et al., 2012).

La innovación es un proceso que permite la creación, adaptación, implantación o explotación de nuevos productos, servicios, métodos o procedimientos, suministros, mercados, modelo de negocio o modelos de gestión; que permiten la mejora del desempeño de una organización, equipo o persona. (Comisión Europea, 1995; Gee, 1981; Goffin y Mitchell, 2010; González Pernía y Peña-Legazkue, 2007; Goswami y Mathew, 2005; Klippel et al., 2008; Lawson y Samson, 2001; Lehto et al., 2011; Lyons et al., 2007; MarinGarcia et al., 2011; Mol y Birkinshaw, 2009; Schumpeter, 1934; Tonnessen, 2005; Vaccaro et al., 2012). Sin embargo, no está tan claro en qué consiste, como desarrollar o como medir la competencia que permite a una persona ser innovadora o contribuir a la innovación de una organización.

Una competencia se puede definir como el desempeño adecuado de tareas en contextos complejos que requieren la activación e integración de conocimientos, procedimientos de decisión, capacidades, habilidades, actitudes y valores con autonomía y responsabilidad 
(European Commission, 2008; Fernández March, 2010; Lasnier, 2000; Perrenoud, 2005; Villa Sánchez y Poblete, 2007).

Centrándonos en la competencia de innovación (figura 1), podemos considerar tres dimensiones en las que agrupar habilidades o comportamientos: individual, interpersonal y red (Lehto et al., 2011; Marin-Garcia et al., 2013; Penttilä y Kairisto-Mertanene, 2012; Watts et al., 2012; Watts et al., 2013). El desglose completo puede verse en el anexo 1.

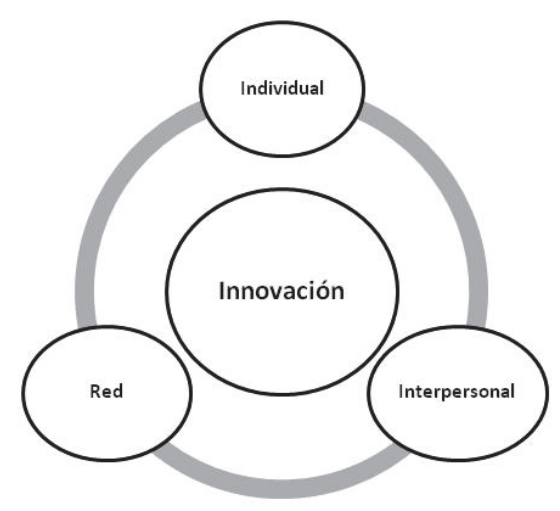

Figura 1. Modelo de competencias para la innovación. Fuente: (Marin-Garcia et al., 2013)

\section{Objetivos}

El objetivo de esta comunicación es comprobar, en una asignatura con pocos alumnos, si las notas que ponemos los profesores en el sistema de evaluación de la asignatura ordenan a los alumnos correctamente en función del grado de aprendizaje de los objetivos de la asignatura y ese orden es parecido al contrastar varias fuentes -observaciones del profesor, auto evaluación del alumno y evaluación de los compañeros-. Junto con eso, desarrollamos un método que, en el futuro, deberíamos comprobar si es viable incluso con grupos numerosos. De este modo, podremos extender las conclusiones de estudios actuales que consideran que las puntuaciones de alumnos y profesores no son significativamente diferentes(Andreu Andrés y García-Casas, 2014; Lind et al., 2002; Marin-Garcia, 2009) y aportaremos una nueva forma de captura de datos de evaluación que simplifica la tarea del evaluador, mantiene la precisión de las puntuaciones y exige un tiempo razonable y sostenible para ser completada tanto por alumnos como por profesores.

\section{(c) EY-NC-ND 2014, Universitat Politècnica de València}

I Jornadas IN-RED (2014) 


\begin{tabular}{ll}
\hline crit00 & $\begin{array}{l}\text { Ser una persona innovadora. Valora la competencia para fomentar la } \\
\text { innovación, considerando la innovación como un proceso que permite la } \\
\text { creación y puesta en práctica de algo (producto o servicio, métodos, } \\
\text { mercados, suministros, modelos de negocios, modelos de gestión o tareas en } \\
\text { general) que sea percibido como novedad por la organización/grupo y que } \\
\text { persiga una mejora del rendimiento o resultados de la organización/grupo }\end{array}$ \\
\hline crit01 & Propongo nuevas maneras de poner en marcha las ideas \\
\hline crit02 & Anticipo cómo se pueden desarrollar los acontecimientos \\
\hline crit03 & Colaboro activamente \\
\hline crit04 & Contribuyo al buen funcionamiento del grupo \\
\hline crit05 & Tengo en cuenta el impacto social de la tarea \\
\hline crit06 & Hago que los demás contribuyan en las tareas del grupo \\
\hline crit07 & Escucho a mis compañeros de grupo \\
\hline crit08 & Afronto los conflictos con flexibilidad con el fin de alcanzar acuerdos \\
\hline crit10 & Identifico las relaciones entre las diferentes partes o aspectos de la tarea \\
\hline crit11 & Propongo ideas relacionadas con la resolución de la tarea \\
\hline crit12 & Soy perseverante en la consecución de los objetivos \\
\hline crit13 & Oriento la tarea hacia el objetivo \\
\hline crit14 & Uso contactos externos al grupo para que nos ayuden a alcanzar nuestros \\
\hline crit15 & objetivos \\
\hline crit16 & Puedo trabajar en grupos multidisciplinares \\
\hline crit17 & Transmito ideas de manera efectiva \\
\hline crit18 & Evalúo las ventajas y desventajas de las acciones \\
\hline crit19 & Establezco un ambiente constructivo en el grupo a través del diálogo \\
\hline crit20 & Utilizo hábilmente los recursos disponibles \\
\hline crit21 & Puedo trabajar en grupos multiculturales \\
\hline crit22 & Abordo la tarea desde diferentes puntos de vista \\
\hline crit23 & Presento ideas creativas \\
\hline Tomo iniciativas \\
\hline
\end{tabular}

Tabla 1. Dimensiones de la competencia de innovación. Fuente: (Watts et al., 2013)

Los datos que analizaremos en este trabajo se corresponden a una asignatura de máster de 5 ECTS, con 10 alumnos organizados en dos grupos de 5 alumnos cada uno, con un sólo profesor impartiendo la asignatura. Analizaremos las notas correspondientes a la competencia de innovación de los estudiantes, articulada como 25 habilidades (crit01 a crit25) agrupadas en 3 categorías de capacidades de innovación (Marin-Garcia et al., 2013), más una pregunta unidimensional sobre la competencia de innovación en general (crit00). Los datos fueron tomados durante el curso 2013-14. Cada alumno recibe las evaluaciones 
de todos los miembros de su grupo, la puntuación derivada de la media geométrica de las puntuaciones de sus compañeros de grupo (juicio agregado) y la del profesor. En total se han construido 364 matrices (26 matrices por cada alumno, 26matrices de juicios agregados para cada grupo y 26 matrices con la puntuación del profesor para cada grupo)

En esta investigación se ha considerado que todos los criterios tenían el mismo peso (no hemos hecho la ponderación jerárquica de los criterios), de modo que la nota ponderada es el promedio de las notas de cada criterio.

\section{Desarrollo de la innovación}

En esta investigación asumimos que la evaluación es una decisión multicriterio, puesto que para evaluar a un alumno hay que considerar diferentes cualidades o aptitudes que están en conflicto. Esto significa que cuando se intenta encontrar una solución buena desde unos puntos de vista ocurre que es mala o peor que otra respecto a otros puntos de vista. De este modo hay que encontrar soluciones de compromiso, ya que generalmente será difícil encontrar una solución que sea la mejor desde todos los puntos de vista.

De los diferentes métodos de decisión multicriterio hemos seleccionad AHP por considerarlo el más adecuado al problema que nos hemos planteado. El proceso, propuesto por Saaty (1980), se basa en el hecho de que la complejidad inherente a un problema de múltiples criterios de toma de decisiones puede ser resuelto a través de la construcción de estructuras jerárquicas que constan de un objetivo, criterios y alternativas. El método tiene la ventaja de ser fácil de explicar a las personas que tienen que valorar los diferentes criterios o alternativas de una manera sencilla y sistemática.

Los pasos básicos de los que consta este método son:

1 . Definir el problema de evaluacion/priorización.

2 . Identificar los criterios y las alternativas pertinentes para resolver el problema.

3 Estructurar el problema en una jerarquía de diferentes niveles que constituyen: la meta , criterios, subcriterios y alternativas.

4. Hacer comparaciones por pares en cada nivel jerárquico con respecto a un elemento específico (sean criterios o alternativas a valorar).

En cada nivel jerárquico las comparaciones por pares se hacen con sentencias que utilizan valores numéricos tomados de la escala fundamental absoluta AHP de 1-9 (ver Tabla 2). En la Figura 2 mostramos un ejemplo de comparación pareada que formaría parte de un cuestionario AHP para la valoración de alternativas (estudiantes).

\section{(c)) EY-NC-ND 2014, Universitat Politècnica de València}

I Jornadas IN-RED (2014) 


\begin{tabular}{cll}
\hline $\begin{array}{c}\text { Escala } \\
\text { numérica } \\
1\end{array}$ & Iguales & \multicolumn{1}{c}{ Escala verbal } \\
3 & Moderadamente mejor & $\begin{array}{l}\text { Eos estudiantes tienen habilidades } \\
\text { semejantes } \\
\text { La experiencia y la habilidad están a } \\
\text { favor de una de las personas } \\
\text { Una persona es fuertemente más } \\
\text { competente que la otra en la habilidad } \\
\text { evaluada } \\
\text { Una persona es mucho más competente } \\
\text { que la otra } \\
\text { Una persona está totalmente en un nivel } \\
\text { superior a otra } \\
\text { Se usan como compromiso entre dos } \\
\text { juicios. }\end{array}$ \\
\hline Euertemente mejor & Extremadamente mejor &
\end{tabular}

Tabla 2.- Escala de comparación binaria adaptada de Saaty (1980) para comparación de rendimiento de estudiantes

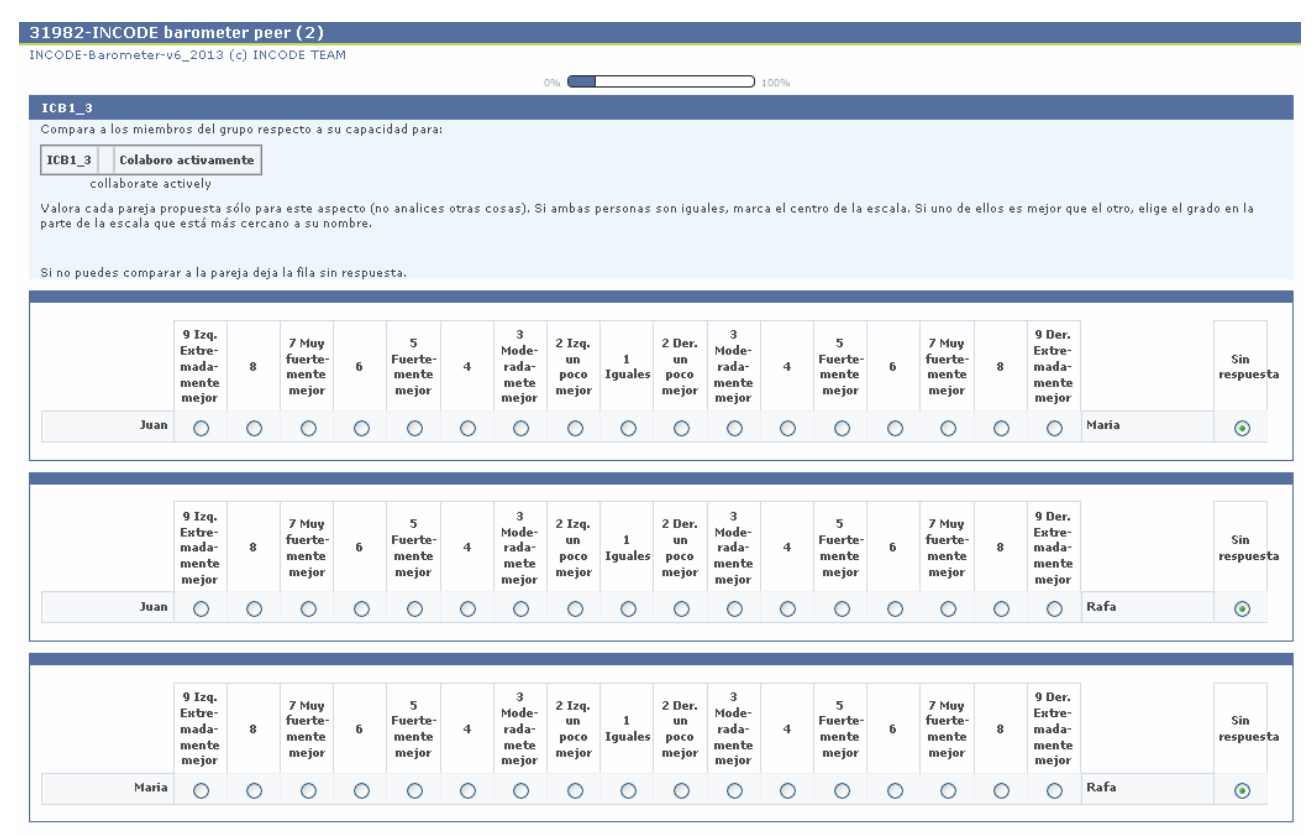

Figura 2.- Cuestionario para la comparación pareada

(c)) EY-NC-ND 2014, Universitat Politècnica de València

I Jornadas IN-RED (2014) 
La recolección de datos requiere $n$ (n-1)/2 comparaciones, donde $n$ es el número de elementos a comparar. En nuestro caso, estudiantes en un grupo. Debemos tener en cuenta que los elementos de la diagonal (comparación de un elemento consigo mismo) son iguales o '1 ' y, el resto de elementos de la matriz, serán simplemente los recíprocos de las comparaciones anteriores.

5. Construir matrices de dominación.

Las comparaciones del punto 4, llevan a matrices de dominación que son positivas y recíprocas (aij $=1 /$ aji). El AHP consigue así tener todos los datos en una sola escala unidimensional de prioridades.

6 . Obtención de las prioridades en cada nivel de la jerarquía.

Una vez se dispone de la matriz de juicios de comparaciones de los criterios o alternativas, las prioridades de estos elementos se pueden obtener mediante el cálculo del vector propio principal de la matriz $\mathrm{W}$ de juicios [A] .

$$
\mathrm{Aw}=\lambda_{\max } \mathrm{W}
$$

Siendo $\lambda_{\max }$ el autovalor mayor de la matriz A y W su correspondiente autovector.

Debido a que los juicios son subjetivos, éstos no siempre cumplen a la perfección la propiedad de la transitividad, y por ello se dice que no son consistentes. La consistencia de la matriz se puede calcular con el Ratio de Consistencia (CR por sus siglas en inglés)

$$
\mathrm{CR}=\frac{\mathrm{Cl}}{\mathrm{RI}} \quad \mathrm{Cl}=\frac{\lambda_{\max }-\mathrm{n}}{\mathrm{n}-1}
$$

Donde

CI es el Índice de Consistencia (Consistency Index)

n el número de elementos que se comparan entre sí en la matriz de juicios

RI el Índice Aleatorio (Random Index) que depende del tamaño de la matriz de comparaciones:

\begin{tabular}{|l|l|l|r|r|r|r|r|r|r|r|}
\hline $\mathbf{n}$ & 1 & 2 & 3 & 4 & 5 & 6 & 7 & 8 & 9 & 10 \\
\hline $\mathbf{R I}$ & 0 & 0 & 0,58 & 0,9 & 1,12 & 1,24 & 1,32 & 1,41 & 1,45 & 1,49 \\
\hline
\end{tabular}

$\mathrm{Si}$ el CR es mayor que el $10 \%$ se considera que los juicios introducidos en la matriz no son consistentes, pueden no ser fidedignos y por ello deben ser revisados 


\section{Resultados}

Los datos se recogieron mediante un cuestionario Web. En la primera pantalla se identificaba el nombre del grupo, el número de componentes y el nombre de los mismos (Figura 3). Era obligatorio que el orden en que se introducían los componentes del grupo fuese el mismo para todos los alumnos del grupo. Se verificó manualmente esta condición al descargar los datos (ningún incumplimiento). A continuación se presentaban varias pantallas, una por cada criterio evaluado, donde los alumnos comparaban las parejas del grupo, incluyéndose ellos mismo respecto a ese criterio ( Figura 2).

Para los análisis de fiabilidad intra-rater usaremos los Coeficientes de Correlación Intraclase (ICC $(\mathrm{k})$, ICC $(\mathrm{C}, \mathrm{k})$, ICC $(\mathrm{A}, \mathrm{k})$ ) (Morley, 2009; Viladrich Segués y Doval Dieguez, 2011). Cada uno de estos coeficientes se puede calcular para una evaluación o para el promedio de evaluaciones. Se diferencian en el uso de un factor con efectos aleatorios y medida de acuerdo (ICC(k)), dos factores de efectos aleatorios con medida de consistencia $(\mathrm{ICC}(\mathrm{C}, \mathrm{k}))$ o dos factores de efectos aleatorios y medida de acuerdo (ICC(A,k). En los tres casos, cada objeto/persona recibe el mismo número de evaluaciones.

Como simplificación vamos a considera que la importancia de todos los criterios es la misma (todos tienen el mismo peso para calcular la prioridad de las "alternativas")

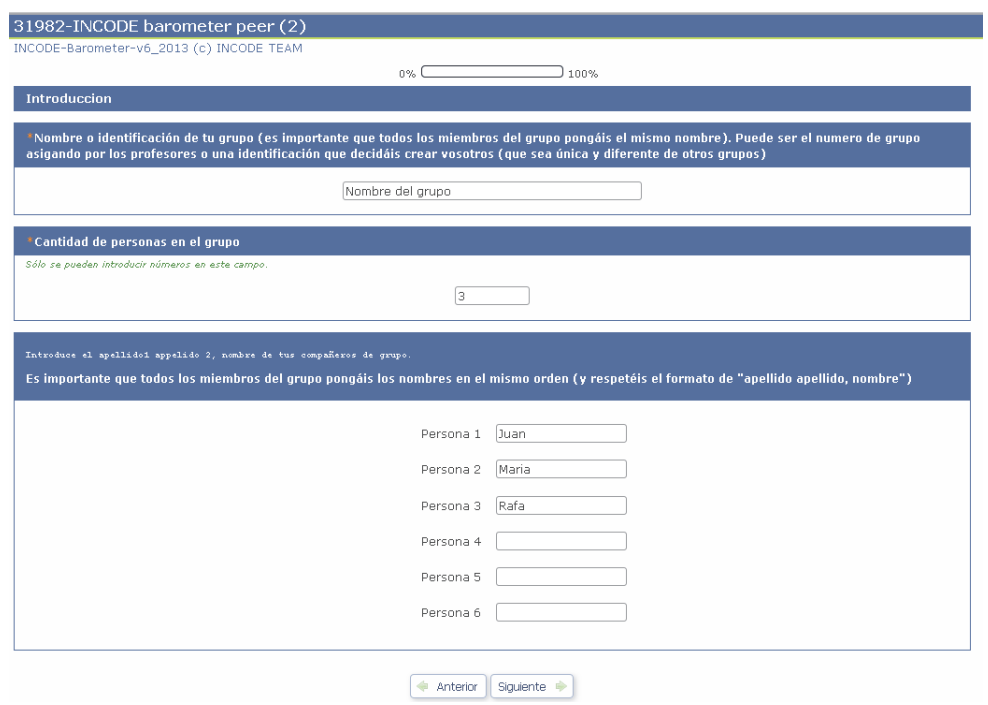

Figura 3.- pantalla inicial del cuestionario web.

\subsection{Consistencia intra-rater}

En la Tabla 3 presentamos el Ratio de Consistencia de las 364 matrices construidas. En rojo hemos marcado las celdas cuyos valores de inconsistencia son superiores al nivel 
recomendado (10\%). Una primera lectura nos permite comprobar que las valoraciones del profesor son más consistentes que las de los alumnos. Sin embargo, hay que resaltar que 5 de los 10 alumnos presentan una consistencia excelente en todas las matrices evaluadas (que no sea tan buena como la del profesor, no implica que no pueda ser perfecta para la evaluación de sus compañeros). Además, en determinados criterios, como el Crti04 (evaluar las ventajas y desventajas de las acciones), las valoraciones de los alumnos son mucho más consistentes que las del profesor. También se puede comprobar que, en el agregado de juicios de los alumnos de un grupo, la consistencia es mejor que en la valoración individual de uno solo de sus alumnos (cosa lógica) y que sus valores son muy próximos a los del profesor (y en cualquier caso excelentes). Esto es importante, porque a pesar de que hay alumnos muy inconsistentes y que en uno de los grupos, cuatro de los 5 componentes, han tenido problemas de consistencia en varias matrices, en el agregado de juicios se han resuelto las inconsistencias.

En algunas de las matrices del profesor, la inconsistencia es cero porque se trata de un criterio (una matriz) donde los alumnos no han discriminado. Por ejemplo "actitud ética" o "trabajar en grupos multidisciplinares" o cosas similares donde todos los alumnos han sido vistos iguales (en algunos casos porque parece que realmente son iguales $\mathrm{y}$, en otros, porque en las actividades de clase observadas no han dado juego para poner en marcha esa "capacidad" o todos la han puesto en juego de manera muy parecida, no apreciando el profesor diferencias entre ellos). Es normal que los profesores no vean diferencias en algunos criterios porque, en este caso, se observaba a los alumnos un conjunto de 15-20 horas en total a lo largo del curso (actividades de 20' hasta 150 minutos, realizadas durante las clases). Eso significa que a cada grupo se les observa entre 7-10 horas y en cada grupo había 5 alumnos (a los que se observaba a la vez). Sin embargo los alumnos han trabajado juntos, como mínimo, 30 horas durante la asignatura (evidentemente ellos se acaban conociendo mejor de lo que les conoce el profesor). Además, compartían otras 4 asignaturas más en el máster y, aunque en el formulario para evaluarse, se les remarcaba que valoraran lo que hacían en LA asignatura solamente, es posible que hayan valorado a la persona en conjunto de todas las asignaturas).

Por otra parte, se puede detectar que hay dos alumnos (Gr01A103 y Gr02Al10) con muchos problemas de inconsistencia. Estos problemas pueden ser debidos a que se ha tomado la actividad de evaluación con poco rigor, que no hayan comprendido los criterios, que no hayan estado atentos durante la activad de grupo y, por lo tanto, no sepan como valorar a sus compañeros, a que sean malos evaluadores en general o a algún otro motivo. En cualquier caso, este método nos permite detectar los alumnos con puntuaciones problemáticas y decidir qué hacer (eliminar esos registros del análisis, formar al alumno como evaluador o incluso poner una nota que discrimine la capacidad de evaluación si ese fuese un objetivo de aprendizaje de la asignatura).

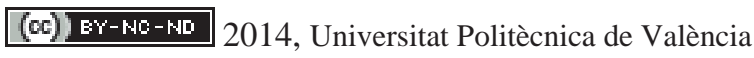

I Jornadas IN-RED (2014) 
Además, podemos comprobar que la mayoría de los criterios no han representado un problema para los diferentes evaluadores, aunque hay algunos criterios que han sido problemáticos para alumnos que, en general, no presentan problemas de consistencia. Por ejemplo crit01 (presenta ideas adecuadas a la tarea) y crit03 (presenta nuevas formas de implantar las ideas). En otras palabras, es posible analizar qué criterios pueden haber resultado más problemáticos en general y cuáles lo son para determinados evaluadores (alumnos o profesor), de modo que se puede incidir en la explicación o proceso de evaluación de esos criterios para mejorar la consistencia de las evaluaciones futuras de los evaluadores.

\begin{tabular}{|c|c|c|c|c|c|c|c|c|c|c|c|c|c|c|}
\hline $\begin{array}{l}\text { Evaluador-- } \\
>\end{array}$ & \begin{tabular}{|l|} 
Agregad \\
O Juicio \\
Gr1
\end{tabular} & \begin{tabular}{|l|} 
Agregad \\
O Juicio \\
Gr2 \\
\end{tabular} & \begin{tabular}{|l|} 
Gro1 \\
Al01
\end{tabular} & \begin{tabular}{|l} 
Gro1 \\
Al02
\end{tabular} & \begin{tabular}{|l} 
Gro1 \\
Al03
\end{tabular} & $\begin{array}{l}\text { Gro1 } \\
\text { Al04 }\end{array}$ & \begin{tabular}{|l|} 
Gro1 \\
Al05
\end{tabular} & \begin{tabular}{|l|} 
Gro2 \\
Al06
\end{tabular} & \begin{tabular}{|l} 
Gro2 \\
Al07
\end{tabular} & \begin{tabular}{|l} 
Gro2 \\
Al08
\end{tabular} & \begin{tabular}{|l} 
Gro2 \\
Al09
\end{tabular} & \begin{tabular}{|l|l} 
Gro2 \\
Al10
\end{tabular} & $\begin{array}{l}\text { Prof } \\
\text { Gr1 }\end{array}$ & $\begin{array}{l}\text { Prof } \\
\text { Gr2 }\end{array}$ \\
\hline CR_critoo & $1,3 \%$ & $2,3 \%$ & $1.4 \%$ & $2,0 \%$ & $4,5 \%$ & $3,3 \%$ & $3,6 \%$ & $8.6 \%$ & $2,0 \%$ & $7.7 \%$ & $6,7 \%$ & $21,7 \%$ & $0,4 \%$ & $2,2 \%$ \\
\hline CR_crit01 & $0,5 \%$ & $3,2 \%$ & $0,0 \%$ & $1,2 \%$ & $6,8 \%$ & $0,0 \%$ & $4,7 \%$ & $3,1 \%$ & $10,1 \%$ & $4.4 \%$ & $11,9 \%$ & $43,2 \%$ & $0,0 \%$ & $0,0 \%$ \\
\hline CR_crit02 & $1,6 \%$ & $4,9 \%$ & $2,7 \%$ & $1,9 \%$ & $32,3 \%$ & $0,0 \%$ & $5,8 \%$ & $0,0 \%$ & $5,7 \%$ & $10,3 \%$ & $1,5 \%$ & $110,5 \%$ & $0,0 \%$ & $0,0 \%$ \\
\hline CR_crit03 & $0,5 \%$ & $0,7 \%$ & $3,2 \%$ & $0,0 \%$ & $7,7 \%$ & $0,7 \%$ & $8,1 \%$ & $4,3 \%$ & $15,2 \%$ & $10,1 \%$ & $7,1 \%$ & $22,7 \%$ & $0,0 \%$ & $0,0 \%$ \\
\hline CR_crit04 & $1,6 \%$ & $1,1 \%$ & $2,7 \%$ & $0,0 \%$ & $19,8 \%$ & $1,1 \%$ & $0,2 \%$ & $2.5 \%$ & $11,1 \%$ & $2,8 \%$ & $4,5 \%$ & $19,6 \%$ & $8.2 \%$ & $4,8 \%$ \\
\hline CR_crit05 & $0,7 \%$ & $1,0 \%$ & $0,4 \%$ & $1,2 \%$ & $3,6 \%$ & $0,0 \%$ & $7,0 \%$ & $3,7 \%$ & $3,9 \%$ & $17,9 \%$ & $1,6 \%$ & $24,9 \%$ & $0,0 \%$ & $0,0 \%$ \\
\hline CR_crito6 & $1,6 \%$ & $1,3 \%$ & $4.8 \%$ & $0.0 \%$ & $32,7 \%$ & $0,4 \%$ & $5,5 \%$ & $0,3 \%$ & $8,7 \%$ & $1.2 \%$ & $6,0 \%$ & $9,7 \%$ & $0,0 \%$ & $0,4 \%$ \\
\hline CR_crit07 & $0,9 \%$ & $0,9 \%$ & $1,9 \%$ & $0,0 \%$ & $14,6 \%$ & $0,8 \%$ & $0,0 \%$ & $0,4 \%$ & $9,0 \%$ & $4,0 \%$ & $8,6 \%$ & $0,0 \%$ & $0,0 \%$ & $4,3 \%$ \\
\hline CR_crit08 & $0.2 \%$ & $1,6 \%$ & $1,8 \%$ & $0,0 \%$ & $2,6 \%$ & $0,0 \%$ & $0,0 \%$ & $0.5 \%$ & $1,4 \%$ & $0,0 \%$ & $5,2 \%$ & $32,0 \%$ & $0,0 \%$ & $0,0 \%$ \\
\hline CR_crit09 & $0,3 \%$ & $1,9 \%$ & $0,8 \%$ & $0,0 \%$ & $9,6 \%$ & $0,0 \%$ & $3.2 \%$ & $1,5 \%$ & $9,8 \%$ & $8,1 \%$ & $5,4 \%$ & $27.1 \%$ & $0,0 \%$ & $0,0 \%$ \\
\hline$C R_{\text {Crit10 }}$ & $0,5 \%$ & $2,9 \%$ & $0.2 \%$ & $0,0 \%$ & $4,0 \%$ & $0.0 \%$ & $8,9 \%$ & $1,2 \%$ & $4,6 \%$ & $3,1 \%$ & $10,2 \%$ & $34,7 \%$ & $0,5 \%$ & $0,0 \%$ \\
\hline CR_crit11 & $1,0 \%$ & $1,1 \%$ & $0,2 \%$ & $0,0 \%$ & $11,3 \%$ & $0,0 \%$ & $3,2 \%$ & $1,7 \%$ & $4,3 \%$ & $3,1 \%$ & $6,8 \%$ & $33,2 \%$ & $0,0 \%$ & $0,2 \%$ \\
\hline CR_crit12 & $0,5 \%$ & $3.5 \%$ & $3,3 \%$ & $0,0 \%$ & $2,2 \%$ & $0,0 \%$ & $3,7 \%$ & $0,3 \%$ & $5,5 \%$ & $7,4 \%$ & $8,6 \%$ & $24.6 \%$ & $0,0 \%$ & $0,0 \%$ \\
\hline$C R_{\text {CCrit13 }}$ & $0,3 \%$ & $0,7 \%$ & $0,0 \%$ & $0,0 \%$ & $1,8 \%$ & $1,4 \%$ & $0,0 \%$ & $1,4 \%$ & $0,0 \%$ & $6,3 \%$ & $2,9 \%$ & $0,0 \%$ & $0,0 \%$ & $0,0 \%$ \\
\hline CR_crit14 & $0,4 \%$ & $2,0 \%$ & $0,2 \%$ & $0,0 \%$ & $9,6 \%$ & $0,0 \%$ & $0.0 \%$ & $0.0 \%$ & $2.4 \%$ & $1,0 \%$ & $9,1 \%$ & $14,2 \%$ & $0,0 \%$ & $0,0 \%$ \\
\hline CR_crit15 & $1,1 \%$ & $0,7 \%$ & $0,0 \%$ & $0,0 \%$ & $6,6 \%$ & $2,6 \%$ & $6,0 \%$ & $0,8 \%$ & $9,8 \%$ & $3,1 \%$ & $6,6 \%$ & $29,9 \%$ & $0,0 \%$ & $0,0 \%$ \\
\hline$C R_{\text {Crit116 }}$ & $0.5 \%$ & $2,4 \%$ & $1,5 \%$ & $0,0 \%$ & $10,2 \%$ & $0,0 \%$ & $0.0 \%$ & $0,0 \%$ & $1,0 \%$ & $1,8 \%$ & $5,7 \%$ & $46,4 \%$ & $0,0 \%$ & $0,0 \%$ \\
\hline CR_crit17 & $0,5 \%$ & $1,9 \%$ & $0,2 \%$ & $0,0 \%$ & $11,2 \%$ & $0,0 \%$ & $0,0 \%$ & $5,1 \%$ & $1,9 \%$ & $1,0 \%$ & $10,0 \%$ & $43,7 \%$ & $1,2 \%$ & $0,3 \%$ \\
\hline$C R_{\text {Crit118 }}$ & $0,7 \%$ & $0,6 \%$ & $0,0 \%$ & $0,0 \%$ & $8,4 \%$ & $0,2 \%$ & $2,2 \%$ & $0,0 \%$ & $6,1 \%$ & $3,8 \%$ & $3,6 \%$ & $0,0 \%$ & $0,0 \%$ & $0,0 \%$ \\
\hline CR_crit19 & $0,4 \%$ & $1,3 \%$ & $2,4 \%$ & $0,0 \%$ & $4,2 \%$ & $0,0 \%$ & $0,0 \%$ & $0,0 \%$ & $1,2 \%$ & $2,4 \%$ & $1,9 \%$ & $20,6 \%$ & $0,0 \%$ & $0,0 \%$ \\
\hline CR_crit20 & $0,5 \%$ & $1,2 \%$ & $0,3 \%$ & $0,0 \%$ & $6,7 \%$ & $0,0 \%$ & $1,2 \%$ & $1,1 \%$ & $2,5 \%$ & $1,1 \%$ & $1,7 \%$ & $20.6 \%$ & $0,0 \%$ & $0,0 \%$ \\
\hline$C R_{\text {Crit21 }}$ & $0,3 \%$ & $0,4 \%$ & $0.2 \%$ & $3,9 \%$ & $3,6 \%$ & $0,0 \%$ & $0,2 \%$ & $2,4 \%$ & $7,9 \%$ & $5,7 \%$ & $4,8 \%$ & $0,0 \%$ & $0,0 \%$ & $1,2 \%$ \\
\hline CR_crit22 & $0,1 \%$ & $2,7 \%$ & $1,5 \%$ & $0,0 \%$ & $8,8 \%$ & $0,2 \%$ & $4,3 \%$ & $2,5 \%$ & $3.9 \%$ & $2,5 \%$ & $1,9 \%$ & $49,8 \%$ & $0,0 \%$ & $0,0 \%$ \\
\hline$C R_{\text {CCrit23 }}$ & $0,4 \%$ & $0,3 \%$ & $2,7 \%$ & $0,0 \%$ & $5,6 \%$ & $0,3 \%$ & $5,5 \%$ & $7,2 \%$ & $3,1 \%$ & $1,5 \%$ & $4,9 \%$ & $0,0 \%$ & $0,0 \%$ & $0,0 \%$ \\
\hline CR_crit24 & $0,3 \%$ & $0,7 \%$ & $1,5 \%$ & $0,0 \%$ & $7,9 \%$ & $0,0 \%$ & $0,0 \%$ & $3,0 \%$ & $3,9 \%$ & $0,0 \%$ & $1,1 \%$ & $0,0 \%$ & $0,0 \%$ & $0,0 \%$ \\
\hline CR crit25 & $0,1 \%$ & $0,5 \%$ & $0,0 \%$ & $0,0 \%$ & $3,1 \%$ & $0.0 \%$ & $0,0 \%$ & $0,5 \%$ & $0,9 \%$ & $0.0 \%$ & $6,1 \%$ & $0,0 \%$ & $0,0 \%$ & $0,0 \%$ \\
\hline
\end{tabular}

Tabla 3. Ratio de Consistencia de cada una de las matrices generadas a partir de los datos

\subsection{Consistencia inter-rater}

La consistencia entre evaluadores la hemos analizado mediante Coeficientes de Correlación Intraclase aplicados a las puntuaciones obtenidas por cada alumno. Hemos analizado los datos con dos enfoques. En el primero (Figura 4 y Tabla 4) cada fila de la tabla de datos contiene la puntuación obtenida por un alumno, tras aplicar AHP, para cada uno de los criterios de evaluación (columnas), para un evaluador concreto. El análisis se hace agrupando los datos de un alumno para todos los evaluadores y comprueba si los evaluadores perciben de manera similar al alumno, usando los 26 criterios. Esto nos permite ver si hay algún alumno difícil de evaluar. Es decir, si hay algún alumno donde los evaluadores dan puntuaciones diferentes usando los 26 criterios como base para la 
comparación. Los alumnos donde los evaluadores están más de acuerdo son Gr02A108 y Gr02A109, mientras que Gr01Al03 es un alumno que los evaluadores muestran escasísimo acuerdo y fiabilidad.

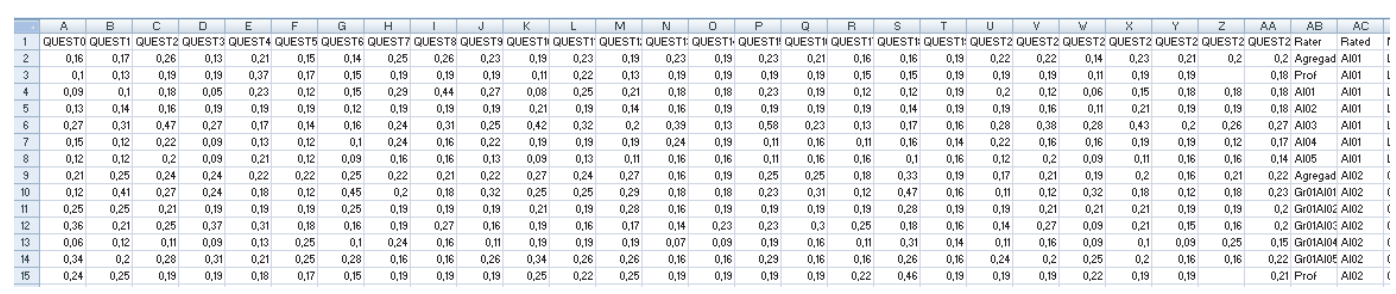

Figura 4. Tabla parcial de datos A para evaluar consistencia inter-rater según modelo de Morley(2009). Questxx es cada uno de los criterios de evaluación.

\begin{tabular}{lcccrrrr}
\hline Rated & ICC1 & \multicolumn{1}{c}{ ICC2 } & ICC3 & multICC1 & multICC2 & multICC3 & MSERROR \\
\hline A101 &, 1006 &, 2022 &, 1394 &, 4474 &, 6473 &, 5399 &, 0031 \\
A102 &, 1718 &, 2203 &, 1886 &, 6004 &, 6717 &, 6274 &, 0031 \\
A103 &,- 0261 &,- 0290 &,- 0298 &,- 2256 &,- 2565 &,- 2653 &, 0079 \\
A104 &, 0973 &, 1307 &, 1138 &, 4357 &, 5186 &, 4793 &, 0057 \\
A105 &, 1515 &, 2322 &, 1792 &, 5571 &, 6806 &, 6061 &, 0048 \\
A106 &, 0616 &, 1186 &, 0916 &, 3197 &, 4908 &, 4195 &, 0097 \\
A107 &, 1735 &, 2058 &, 1854 &, 5993 &, 6487 &, 6185 &, 0118 \\
A108 &, 2541 &, 3253 &, 2719 &, 7036 &, 7706 &, 7224 &, 0020 \\
A109 &, 3115 &, 3521 &, 3207 &, 7582 &, 7902 &, 7659 &, 0132 \\
A110 &, 1064 &, 2136 &, 1469 &, 4522 &, 6531 &, 5442 &, 0020 \\
\hline
\end{tabular}

Tabla 4 Resultados ICC basado en alumnos. Análisis según Morley (2009)

En el segundo (Figura 5) cada fila de la tabla de datos contiene la puntuación en uno de los criterios de evaluación, obtenida tras aplicar AHP con los datos de un evaluador, para todos los alumnos evaluados (columnas). El análisis se hace agrupando primero los datos por grupo de alumnos y después por criterio para todos los evaluadores y comprueba si los evaluadores valoran de manera similar el criterio, usando a los 5 alumnos del grupo como sujetos evaluados. Esto nos permite ver donde los evaluadores presentan más de acuerdo o

(c)) EY-NC-ND 2014, Universitat Politècnica de València

I Jornadas IN-RED (2014) 
Mejora de la evaluación de alumnos usando métodos de decisión multicriterio

fiabilidad y si hay algún criterio difícil de evaluar. Es decir, si hay algún criterio donde los evaluadores dan puntuaciones diferentes entre sí (Tabla 5).

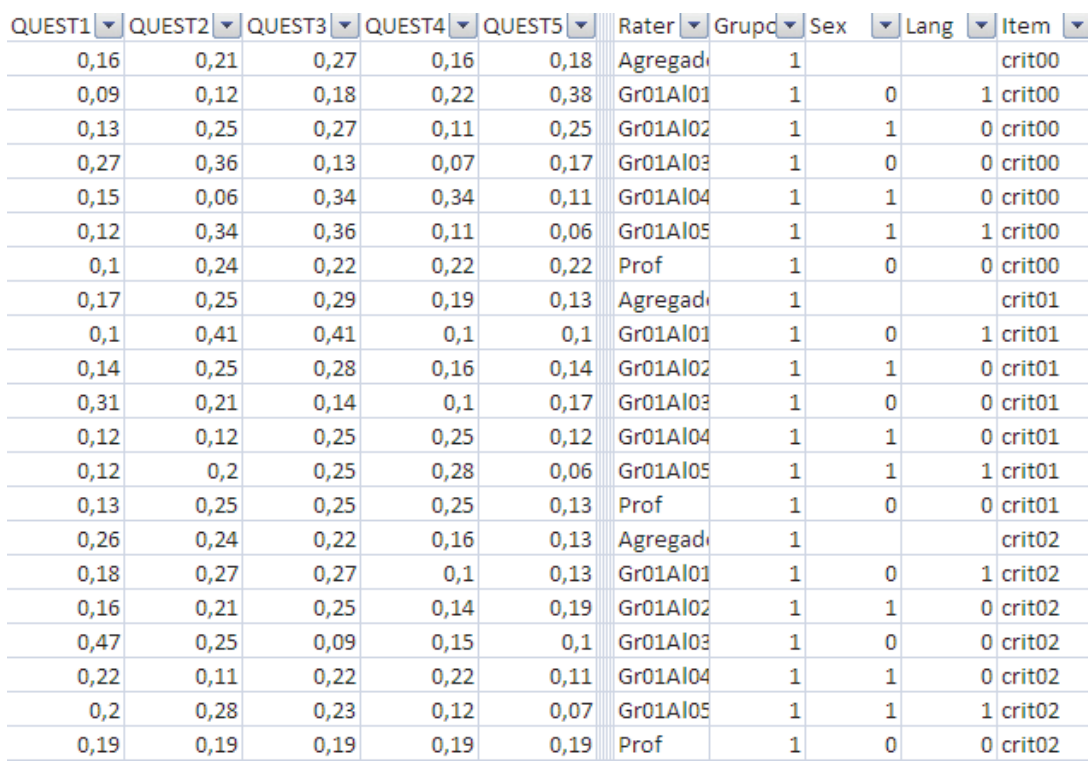

Figura 5. Tabla parcial de datos B para evaluar consistencia inter-rater según modelo de Morley(2009). Questxx es cada uno de los alumnos evaluados.

\begin{tabular}{llll}
\hline & Alta & Media & Nula \\
\hline Grupo 1 & Crit01-03 & Crit00 & Crit05 \\
& Crit06-09 & Crit04 & Crit10 \\
Crit11-14 & Crit15 & Crit21 \\
Crit16-19 & Crit20 & Crit22 \\
Crit23-24 & Ponderado & Crit25 \\
& Crit00 & Crit08 & Crit17 \\
& Crit01-07 & Crit20 & \\
& Crit10-16 & & \\
Crit18 & & \\
\hline
\end{tabular}

Tabla 5.- criterios clasificados en función del acuerdo o fiabilidad de los evaluadores basados en ICC. Análisis según Morley (2009).

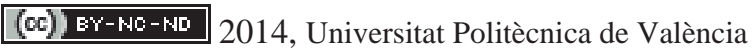




\section{Conclusiones}

Consideramos que las principales contribuciones de nuestro trabajo son:

- Para los investigadores en el área de AHP, nuestra investigación compara la fiabilidad de las comparaciones pareadas, así como su viabilidad en un contexto poco trabajado (la docencia universitaria).

- Para los investigadores en metodología de evaluación, proporcionamos evidencias de la fiabilidad y validez de un modelo evaluativo basado en decisiones multicriterio.

- Para los docentes universitarios, analizamos las ventajas e inconvenientes de la aplicación del método de decisiones multicriterio AHP para resolver los problemas enunciados en la introducción de este artículo.

Sin embargo el uso de comparación pareada plantea la dificultada adicional de integrar en un sólo orden los grupos "disjuntos" en los que dividimos las clases para evitar tener comparaciones pareadas de más de 6 elementos, que se ha demostrado que conducen a evaluaciones inconsistentes en parte por la saturación del evaluador. Si necesitamos tener grupos de más de 6 alumnos, nuestra propuesta es crear dos subgrupos con uno o dos alumnos redundantes (por ejemplo en grupos de 10, dos grupos de 6 donde un alumno repite en ambos, solo evalúa en uno pero es valuado en los dos grupos, no se le pide aumentar el trabajo). O también pueden ser 3 grupos de 4 con un alumno al azar para reescalar las medidas.

\section{Referencias}

ANDREU ANDRÉS, M. A.; GARCÍA-CASAS, M. (2014): La Evaluación De La Participación En Equipos De Trabajo Universitarios (Assessment of Participation in Higher Education Team Working Activities). WPOM-Working Papers on Operations Management, 5 (1).

COMISIÓN EUROPEA. (1995). Libro verde de la innovación.Comisión Europea (ES/13/95/55220800.P00).

EUROPEAN COMMISSION. (2008). The European Qualifications Framework for Lifelong Learning (EQF). Luxembourg: Office for Official Publications of the European Communities.

FERNÁNDEZ MARCH, A. (2010): La Evaluación Orientada Al Aprendizaje En Un Modelo De Formación Por Competencias En La Educación Universitaria. Revista De Docencia Universitaria, 8 (1): 11-34.

GEE, S. (1981). Technology transfer, innovation \& international cometitiveness. New York: Wiley \& Sons.

GOFFIN, K.; MITCHELL, R. (2010). Innovation management. New York: PalgraveMacMillan.

\section{(c)) EY-NC-ND 2014, Universitat Politècnica de València}

I Jornadas IN-RED (2014) 
GONZÁLEZ PERNÍA, J. L.; PEÑA-LEGAZKUE, I. (2007): Determinantes De La Capacidad De Innovación De Los Negocios Emprendedores En España. Economia Industrial (363): 129-147.

GOSWAMI, S.; MATHEW, M. (2005): Definition of Innovation Revisited: An Empirical Study on Indian Information Technology Industry. International Journal of Innovation Management, 09 (03): 371-383.

INGOLS, C.; SHAPIRO, M. (2014): Concrete Steps for Assessing the Soft Skills in an MBA Program. Journal of Management Education, 38 (3): 412-435.

KLIPPEL, A. F.; PETTER, C. O.; ANTUNES, J. (2008): Management Innovation, a Way for Mining Companies to Survive in a Globalized World. Utilities Policy, 16 (4): 332-333. LASNIER, F. (2000). Réussir la formation par compétences. Montréal : Guérin.

LAWSON, B.; SAMSON, D. (2001): Developing Innovation Capability in Organizations: A Dynamic Capabilities Approach. International Journal of Innovation Management, 05 (03): 377-400.

LEHTO, A.; KAIRISTO-MERTANENE, L.; PENTTILÄ, T. (2011). Towards innovation pedagogy. A new approach to teaching and learning for universities of applied sciences.

Turku: Turku University of Apllied Sciences.

LIND, D. S.; REKKAS, S.; BUI, V.; LAM, T.; BEIERLE, E.; COPELAND, I. I. I. (2002): Competency-Based Student Self-Assessment on a Surgery Rotation. Journal of Surgical Research, 105 (1): 31-34.

LOHMANN, J. R.; ROLLINS, H. A.; HOEY, J. J. (2006): Defining, Developing and Assessing Global Competence in Engineers. European Journal of Engineering Education, 31 (1): 119-131.

LYONS, R. K.; CHATMAN, J. A.; JOYCE, C. K. (2007): Innovation in Services:

Corporate Culture and Investment Banking. California Management Review, 50 (1): 174191.

MARIN-GARCIA, J. A. (2009): Los Alumnos y Los Profesores Como Evaluadores. Aplicación a La Calificación De Presentaciones Orales. Revista Española De Pedagogía, 67 (242): 79-97.

MARIN-GARCIA, J. A.; AZNAR-MAS, L. E.; GONZÁLEZ-LADRÓN-DE-GEVARA, F. (2011): Innovation Types and Talent Managment for Innovation. Working Papers on Operations Management, 2 (2): 25-31.

MARIN-GARCIA, J. A.; GARCIA-SABATER, J. P.; MIRALLES, C.; RODRÍGUEZ

VILLALOBOS, A. (2008): Profile and Competences of Spanish Industrial Engineers in the European Higher Education Area (EHEA). Journal of Industrial Engineering and Management, 1 (2): 269-284.

MARIN-GARCIA, J. A.; GARCIA-SABATER, J. P.; PERELLO-MARIN, M. R.;

CANOS-DAROS, L. (2009): Proposal of Skills for the Bachelor Degree of Industrial Engineering in the Context of the New Curriculum. Intangible Capital, 5 (4): 387-406. MARIN-GARCIA, J. A.; PEREZ-PEÑALVER, M. J.; WATTS, F. (2013): How to Assess Innovation Competence in Services: The Case of University Students. Dirección y Organización (50): 48-62.

MOL, M. J.; BIRKINSHAW, J. (2009): The Sources of Management Innovation: When Firms Introduce New Management Practices. Journal of Business Research, 62 (12): 12691280 . 
MORLEY, D. D. (2009): SPSS Macros for Assessing the Reliability and Agreement of Student Evaluations of Teaching. Assessment \& Evaluation in Higher Education, 34 (6): 659-671.

MULA, J.; DÍAS-MADROÑERO, M.; POLER, R. (2012): Configuración Del Grado En Ingeniería De Organización Industrial En Las Universidades Españolas. Dirección y Organización, 47: 5-20.

PENTTILÄ, T.; KAIRISTO-MERTANENE, L. (2012): "Innovation Competence

Barometer ICB - a Tool for Assessing Students' Innovation Competences As Learning

Outcomes in Higher Education". Valencia, Spain.:

PERRENOUD, P. (2005): "La Universitat Entre La Transmissió De Coneixements i El Desenvolupament De Competències. El Debat Sobre Les Competències a L'Ensenyament Universitari ". ICE UB. Documents de Docència Universitària, núm. 5.

SCHUMPETER, J. (1934). The Theory of Economic Development. Cambridge, MA:

Harvard University Press.

TERRY, R. E.; HARB, J. N.; HECKER, W. C.; WILDING, W. V. (2002): Definition of Student Competencies and Development of an Educational Plan to Assess Student Mastery Level. International Journal of Engineering Education, JAM-PDF (2): 225-235.

TONNESSEN, T. (2005): Continuous Innovation Through Company Wide Employee Participation. TQM Magazine, 17 (2): 195-207.

VACCARO, I. G.; JANSEN, J. J. P.; VAN DEN BOSCH, F. A. J.; VOLBERDA, H. W. (2012): Management Innovation and Leadership: The Moderating Role of Organizational Size. Journal of Management Studies, 49 (1): 28-51.

VILADRICH SEGUÉS, M. C.; DOVAL DIEGUEZ, E. (2011). Medición: fiabilidad y validez. Bellaterra: Laboratori d'Estadística Aplicada i de Modelització (UAB).

VILLA SÁNCHEZ, A.; POBLETE, M. (2007). Aprendizaje basado en competencias. Una propuesta para la evaluación de las competencias genéricas. Bilbao: Universidad de Deusto.

WATTS, F.; GARCIA-CARBONELL, A.; ANDREU ANDRÉS, M. A. (2013). Innovation competencies development: INCODE barometer and use guide. Turku: Turku University od Applied Sciences.

WATTS, F.; MARIN-GARCIA, J. A.; GARCIA-CARBONELL, A.; AZNAR-MAS, L. E. (2012): Validation of a Rubric to Assess Innovation Competence. Working Papers on Operations Management, 3 (1): 61-70. 


\title{
Desarrollo de competencias genéricas en las asignaturas de Física de la E.T.S.I.Telecomunicación
}

\author{
Álvaro Page ${ }^{a}$, Constanza Rubio ${ }^{a}$, Pilar Candelas ${ }^{\mathrm{a}}$, Francisco Belmar ${ }^{\mathrm{a}}$ \\ ${ }^{a}$ Dpto. Física Aplicada. Escuela Técnica Superior de Ingenieros de Telecomunicación. Universitat \\ Politècnica de València, València (SPAIN). alvaro.page@gmail.com, crubiom@fis.upv.es, \\ pcandelas@fis.upv.es, fbelmar@fis.upv.es.
}

\begin{abstract}
Traditionally, education in first year technical courses in Spain has had a highly theoretical approach, focused on the acquisition of specific competencies related to basic subjects such as physics or mathematics. This approach does not help to improve the learning curve of high school students that focuses more on acquiring knowledge than in learning how to use this to solve real problems. The aim of this paper is to present an experience developed in the E.T.S.I. Telecomunicación of València to assist the development of generic competencies in the field of Physics during the first year of the course. To do this, we have organized different projects that contribute to the improvement of knowledge and skills both in the field of mechanics and in the development of different generic competencies: implementation and practical thinking, analysis and problem solving, critical thinking, teamwork, leadership, effective communication, planning and time management. Although the results are encouraging, we have detected the advisability of incorporating these activities into more subjects, so that students perceive them as part of formal education and not as a singular experience.
\end{abstract}

Keywords: Generic Competencies, smartphone, home experiments, Physics Laboratory.

(c) EY-NC-ND 2014, Universitat Politècnica de València

I Jornadas In-Red (2014) 


\section{Resumen}

Tradicionalmente, la enseñanza en el primer curso de las carreras técnicas en España, ha tenido un enfoque muy teórico, centrado en la adquisición de competencias específicas relacionadas con las materias básicas como la física o las matemáticas. Este enfoque no ayuda a mejorar el esquema de aprendizaje de los estudiantes de Bachillerato, centrado más en la adquisición de conocimientos que en aprender a utilizarlos para resolver problemas reales. El objetivo de este trabajo es presentar una experiencia, desarrollada en la E.T.S.I de Telecomunicación de València, para que la materia de Física favorezca el desarrollo de las competencias genéricas durante el primer año de carrera. Para ello, se han organizado diferentes proyectos o trabajos, que contribuyen tanto a la mejora de los conocimientos $y$ habilidades en el campo de la Mecánica, como al desarrollo de competencias genéricas: aplicación y pensamiento práctico, análisis y resolución de problemas, pensamiento crítico, trabajo en equipo, liderazgo, comunicación efectiva, planificación y gestión del tiempo. Aunque los resultados son esperanzadores, hemos detectado la conveniencia de incorporar estas actividades en más materias, de manera que los alumnos las perciban como parte de la formación reglada y no como una experiencia singular.

Palabras clave: Competencias genéricas, teléfono móvil, experimentos caseros, Laboratorio de física.

(c)) EY-NC-ND 2014, Universitat Politècnica de València 


\section{Introducción}

Tradicionalmente, las enseñanzas de primer curso en las escuelas de ingeniería en España han tenido un enfoque demasiado teórico y poco práctico, centrado más en la adquisición de habilidades específicas relacionadas con temas fundamentales como la física o las matemáticas, que en las competencias genéricas. El desarrollo de estas competencias genéricas se ha designado normalmente a cursos de nivel superior. Este enfoque hace que sea más difícil mejorar la curva de aprendizaje de los estudiantes de secundaria centrado más en la obtención de los conocimientos, que en aprender cómo utilizar éstos para resolver problemas reales.

En las últimas décadas, se ha visto la necesidad que tienen los empleados de poseer estas competencias genéricas para tener éxito profesionalmente. Las nuevas tecnologías han proporcionado a las personas un medio para obtener y compartir información especializada de forma rápida y sencilla, reduciendo así la necesidad de tener habilidades de memorización de la información técnica. Por el contrario, la capacidad de procesar, gestionar, comunicar y aplicar el conocimiento en diferentes situaciones es ahora considerada como vital para el éxito en el trabajo. Actualmente, en el mercado laboral, los empresarios de todo el mundo buscan empleados que posean no sólo conocimientos técnicos de alto nivel, sino también un alto nivel de competencias genéricas.

Las Competencias Genéricas (CG) son habilidades y destrezas no técnicas, transferibles, necesarias para el empleo, es decir, se pueden aprender y desarrollar de diferentes maneras y en una amplia variedad de entornos de aprendizaje. Por otra parte, en los estudiantes de ingeniería, las competencias deben ser adaptadas a su formación como ingenieros. A estas competencias que los estudiantes de ingeniería deben alcanzar nos referiremos como Competencias Genéricas de Ingeniería (CGI). Estas competencias se definen como aquellas que son importantes en todas las áreas de la ingeniería, y que facilitan el éxito de los ingenieros en su vida profesional (Young, 2010).

Múltiples estudios han identificado una brecha entre las competencias genéricas adquiridas durante la formación del alumno de ingeniería y las necesarias para su desarrollo profesional.

Recientemente, en el estudio SPINE (Bodmer, 2002) se pusieron de manifiesto lagunas en las habilidades de comunicación, liderazgo y habilidades sociales. Otras encuestas y revisiones del sistema educativo en ingeniería muestran grandes carencias en temas similares (Bons, 2003; Connelly, 1996; Nair, 2009). La competencia peor adquirida, según Scott y Yates (Scott, 2002) es la inteligencia emocional.

Tras el proceso de evaluación por el "Accreditation Board for Engineering and Technology" (ABET), del grado de "Ingeniero de Telecomunicación" que se imparte en la

(cc) EY-NC-ND 2014, Universitat Politècnica de València

I Jornadas IN-RED (2014) 
Universitat Politècnica de València, se ha considerado necesario introducir actividades educativas que permitan la adquisición de CGI.

Teniendo esto en cuenta, se han diseñado algunas actividades en las que los alumnos realizarán trabajos en grupo, lo que permitirá el desarrollo de estas competencias que son complementarias a las habilidades específicas relacionadas con los contenidos propios del campo de la Física. Estas actividades ayudan a los estudiantes a entender sus fortalezas y debilidades personales en las CGI, así como controlar su propio desarrollo fijándose las metas adecuadas.

En concreto, las competencias que se deben alcanzar con este tipo de actividades son:

(a) Planificación / organización: la capacidad para planificar el trabajo y para completar los proyectos a tiempo.

(b) Capacidad de análisis / investigación: la capacidad de aplicar los conocimientos de matemáticas, ciencia e ingeniería.

(c) Competencia numérica: la capacidad para diseñar y realizar experimentos, así como analizar e interpretar los datos.

(d) Trabajo en equipo: la capacidad de funcionar en equipos multidisciplinares.

(e) Resolución de problemas: la capacidad para identificar, formular y resolver problemas de ingeniería.

(f) Habilidades de comunicación: la capacidad de comunicarse de manera efectiva.

(g) Habilidades en TIC: la capacidad de utilizar las técnicas, habilidades y herramientas modernas de ingeniería necesarias para la práctica de su profesión.

A continuación se presenta la metodología empleada, los trabajos propuestos y los resultados obtenidos en la E.T.S. Ingenieros de Telecomunicación de la Universitat Politècnica de València para desarrollar CG de Física en el primer curso del Grado en Ingeniería de Tecnologías y Servicios de Telecomunicación.

Hay que señalar que en todo el documento los términos "competencias" y "habilidades" se utilizan de manera indistinta.

\section{Objetivos}

El objetivo de este trabajo es presentar una experiencia, desarrollada en la Escuela Técnica Superior de Ingenieros de Telecomunicación de Valencia, para que la materia de Física favorezca el desarrollo de las competencias genéricas durante el primer año de carrera.

Para ello, se han organizado diferentes proyectos o trabajos, que contribuyen tanto a la mejora de los conocimientos y habilidades en el campo de la Mecánica, como al desarrollo

(c)) EY-NC-ND 2014, Universitat Politècnica de València 
de diferentes competencias genéricas: aplicación y pensamiento práctico, análisis y resolución de problemas, pensamiento crítico, trabajo en equipo, liderazgo, comunicación efectiva, planificación y gestión del tiempo.

Los trabajos consisten en una serie de experimentos caseros que los propios estudiantes deben llevar a cabo de forma que ilustren los diferentes principios y fenómenos de la mecánica (conservación de la energía, las leyes de Newton, oscilaciones lineales y no lineales, velocidad límite...). Como equipo de medida deben utilizar un smartphone, dispositivo que está al alcance de todos los estudiantes y con el que están familiarizados. De esta forma pueden llevar a cabo un estudio cuantitativo de los fenómenos analizados, lo que supone una diferencia considerable con las experiencias realizadas en Bachillerato, de carácter más cualitativo. Las técnicas de medición utilizadas son el video análisis y la acelerometría.

Los alumnos desarrollan el trabajo en equipo como si fuese un trabajo de investigación, debiendo aportar una organización del equipo de trabajo, un plan de trabajo, memoria de material y métodos utilizados, resultados y discusión. El proyecto culmina con sesiones públicas de presentación oral.

A pesar de los limitados conocimientos teóricos de los alumnos, se ha pretendido que el trabajo se desarrolle de una forma autónoma y colaborativa, de manera que se enfrenten a la resolución de problemas prácticos desde su entrada en la universidad

\section{Desarrollo de la innovación}

Con el fin de lograr las CGI enumeradas en el apartado anterior, hemos propuesto varios trabajos experimentales a través de los cuales los estudiantes desarrollarán estas competencias.

Los estudiantes se organizan en grupos de cuatro. Cada uno de estos grupos debe desarrollar un experimento casero que previamente le ha sido asignado, utilizando material común y al alcance de todos. La intención es que sean capaces de reproducir un fenómeno que ilustre un principio físico, de analizarlo e interpretar resultados. Como equipamiento fundamental de medición van a utilizar un dispositivo muy común hoy en día: un smartphone. Estos teléfonos están equipados con una cámara de vídeo y un acelerómetro. La cámara de video les va a permitir medir, con bastante precisión, movimientos lentos, mientras que el acelerómetro les permitirá registrar la aceleración de ciertos movimientos. El profesor les proporcionará los documentos de ayuda en el manejo y operación del acelerómetro y el análisis de video.

A cada grupo se les proporciona una guía general de desarrollo del trabajo que incluye:

- Breve descripción del experimento.

(cc) EY-NC-ND 2014, Universitat Politècnica de València

I Jornadas IN-RED (2014) 
- Lista de tareas mínimas a realizar.

- Algunos consejos prácticos para desarrollar el experimento.

- Contenido mínimo de la memoria.

- Problemas o cuestiones a responder.

Esta guía del experimento se preparó para ayudar al alumno en el desarrollo de los trabajos y especificar los objetivos mínimos que debían alcanzar. No obstante, una de las finalidades del trabajo era que los alumnos desarrollasen las capacidades para buscar y seleccionar información, para analizarla y aplicar modelos, interpretar resultados y sacar conclusiones. Por ello, el contenido de esta guía es meramente orientativo, siendo la creatividad, iniciativa y capacidad de trabajo en equipo de los alumnos lo que determina la calidad del trabajo final, además de su conocimiento sobre la materia.

Además se organizó un foro de discusión en PoliformaT (plataforma de e-learning que la UPV dispone) para intercambiar información y resolver dudas entre estudiantes. Si el profesor observase que existe un punto donde el alumnado tiene grandes dificultades podrá intervenir como orientador, siendo el propio alumnado el que debe ser capaz de llegar a una solución final. Estas actividades se complementaron con otras de tutoría presencial (dos por grupo, una al principio del trabajo y otra hacia la mitad), y con tutorías individuales a demanda a través de correo electrónico.

De forma paralela a la entrega de material, los profesores impartieron una charla informativa donde se explicó a los alumnos qué se esperaba con esta actividad, las competencias a adquirir y la programación de las actividades a desarrollar. A partir de la información proporcionada, los alumnos se organizaron agrupándose en grupos de cuatro y preparando un plan de trabajo. Este plan de trabajo fue revisado por los profesores para evaluarlo y para corregirlo en los casos necesarios.

Un mes después de comenzado el trabajo, cada grupo debía entregar una serie de problemas de control para llevar a cabo el experimento. Estos ejercicios se apartan bastante de los problemas de clase y se centraban en cálculos relacionados con la ejecución del experimento y las técnicas de medición. Se trataba de que los alumnos profundizaran en las bases teóricas del experimento y que obtuviesen información preliminar para diseñar adecuadamente el mismo. A partir de aquí, diseñaron y desarrollaron los experimentos, analizando los resultados y preparon la memoria correspondiente. Además, se prepararon presentaciones en equipo y un vídeo de demostración del trabajo realizado. Estos trabajos fueron expuestos de forma pública para su calificación final. La metodología llevada a cabo queda esquematizada en el diagrama de flujo de la Fig. 1

(c)) EY-NC-ND 2014, Universitat Politècnica de València 


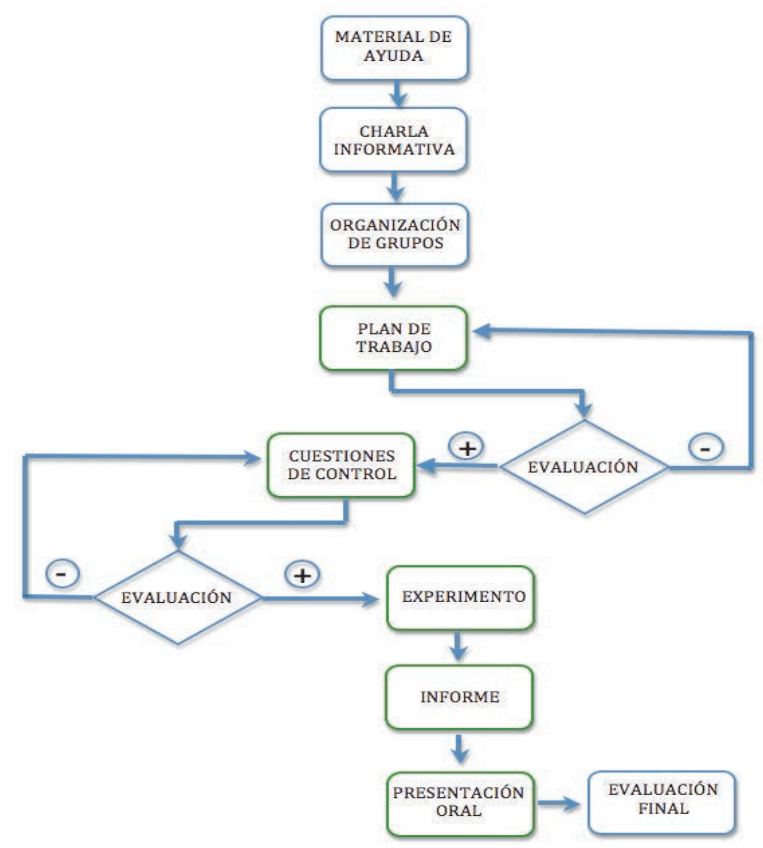

Fig. 1 Diagrama de flujo de la metodología seguida en los trabajos

\subsection{Lista de trabajos}

Los experimentos seleccionados corresponden a fenómenos mecánicos que pueden analizarse mediante video análisis o con un acelerómetro. En la tabla 1 se muestran la lista de trabajos propuestos, los objetivos y métodos de análisis empleados en cada uno de ellos.

\begin{tabular}{|c|c|c|}
\hline TRABAJO & $\begin{array}{c}\text { OBJETIVOS } \\
\text { HIPÓTESIS A CONTRASTAR }\end{array}$ & $\begin{array}{c}\text { TÉCNICA } \\
\text { EXPERIMENTAL }\end{array}$ \\
\hline $\begin{array}{l}\text { Oscilaciones } \\
\text { lineales de un } \\
\text { péndulo. Relación } \\
\text { entre la frecuencia y } \\
\text { la longitud. }\end{array}$ & $\begin{array}{l}\text { - Para pequeñas oscilaciones, el movimiento } \\
\text { del péndulo es un MAS. } \\
\text { - La frecuencia de las oscilaciones depende de } \\
\text { la longitud del péndulo. } \\
\text { - La frecuencia de las oscilaciones es } \\
\text { independiente de la amplitud, siempre que se } \\
\text { mantenga la condición de pequeñas } \\
\text { oscilaciones. }\end{array}$ & Vídeo análisis \\
\hline $\begin{array}{l}\text { Oscilaciones } \\
\text { lineales de un } \\
\text { péndulo. Relación } \\
\text { entre la frecuencia y } \\
\text { la longitud. }\end{array}$ & - $\quad$ Los mismos que el trabajo anterior. & Acelerómetro \\
\hline
\end{tabular}

(c)) EY-NC-ND 2014, Universitat Politècnica de València

I Jornadas IN-RED (2014) 


\begin{tabular}{|c|c|c|}
\hline $\begin{array}{l}\text { Oscilaciones de un } \\
\text { muelle. Relación } \\
\text { entre la frecuencia y } \\
\text { la masa }\end{array}$ & $\begin{array}{l}\text { - El movimiento del sistema masa-muelle es un } \\
\text { MAS. } \\
\text { - La frecuencia de las oscilaciones depende de } \\
\text { la masa del sistema. } \\
\text { - La frecuencia de las oscilaciones es } \\
\text { independiente de la amplitud. }\end{array}$ & Vídeo análisis \\
\hline $\begin{array}{l}\text { Oscilaciones de un } \\
\text { muelle. Relación } \\
\text { entre elongación y } \\
\text { aceleración. }\end{array}$ & $\begin{array}{l}\text { - La frecuencia de las oscilaciones es } \\
\text { independiente de la amplitud } \\
\text { - } \begin{array}{l}\text { Hay una relación lineal entre la amplitud del } \\
\text { movimiento y la amplitud de la aceleración. }\end{array} \\
\text { - La constante de proporcionalidad es el } \\
\text { cuadrado de la pulsación }\end{array}$ & Acelerómetro \\
\hline $\begin{array}{l}\text { Conservación de la } \\
\text { energía mecánica de } \\
\text { un péndulo. }\end{array}$ & $\begin{array}{l}\text { - Verificar la conservación de la energía } \\
\text { mecánica. }\end{array}$ & Vídeo análisis \\
\hline $\begin{array}{l}\text { Conservación de la } \\
\text { energía mecánica en } \\
\text { un muelle }\end{array}$ & $\begin{array}{l}\text { - Verificar la conservación de la energía } \\
\text { mecánica. }\end{array}$ & Vídeo análisis \\
\hline $\begin{array}{ll}\text { Conservación } & \text { de } \\
\text { energía en un } \\
\text { péndulo elástico. }\end{array}$ & $\begin{array}{l}\text { - Verificar la conservación de la energía } \\
\text { mecánica. }\end{array}$ & Vídeo análisis \\
\hline $\begin{array}{l}\text { Oscilaciones } \\
\text { transversales de un } \\
\text { péndulo elástico. }\end{array}$ & $\begin{array}{l}\text { - Eligiendo las condiciones iniciales adecuadas } \\
\text { la trayectoria es rectilínea y horizontal } \\
\text { - } \quad \text { El movimiento es armónico }\end{array}$ & Vídeo análisis \\
\hline $\begin{array}{l}\text { Medida de la } \\
\text { aceleración normal } \\
\text { con acelerómetro. }\end{array}$ & $\begin{array}{l}\text { - Comprobar que la aceleración normal en un } \\
\text { movimiento circular de w dada es } \\
\text { proporcional a R. } \\
\text { - Para un R dado, la aceleración es } \\
\text { proporcional al cuadrado de la velocidad } \\
\text { angular }\end{array}$ & Acelerómetro \\
\hline $\begin{array}{lr}\text { Determinación de la } \\
\text { velocidad límite } \\
\text { considerando } & \text { el } \\
\text { rozamiento con el } \\
\text { aire. }\end{array}$ & $\begin{array}{l}\text { - La caída con rozamiento depende de la } \\
\text { velocidad. } \\
\text { - Determinación de la velocidad límite. }\end{array}$ & Vídeo análisis \\
\hline
\end{tabular}

Tabla 1. Objetivos y técnica experimental empleada en cada trabajo 


\subsection{Evaluación}

Con el fin de evaluar si los alumnos han alcanzado estas competencias, se ha desarrollado una rúbrica de evaluación utilizando diferentes aspectos relacionados con los objetivos programados. A continuación se presenta la lista de competencias a evaluar, relacionadas con la habilidad que los alumnos deben alcanzar. En la tabla 2 se relaciona cada competencia con la actividad evaluada.

(a) Planificación/Organización: La capacidad de planificar y priorizar su carga de trabajo, así como ejecutar varias tareas a la vez.

(b) Capacidad de análisis/investigación: La persona debe tener las habilidades necesarias para aplicar los principios matemáticos básicos y deben ser capaces de razonar matemáticamente, comprender una demostración matemática y comunicarse en el lenguaje matemático.

(c) Competencia Numérica: Incluye la capacidad de utilizar y manipular herramientas y máquinas tecnológicas, así como datos científicos para lograr un objetivo o llegar a una decisión o conclusión basada en pruebas. Las personas deben ser capaces de reconocer los rasgos esenciales de la investigación científica y la capacidad de comunicar las conclusiones y el razonamiento que les condujo a ellas.

(d) Trabajo en equipo: Las habilidades englobadas en esta competencia se refieren a la habilidad para interactuar eficazmente en el ámbito público y para manifestar solidaridad e interés por resolver los problemas que afectan al equipo. Conlleva la reflexión crítica y creativa, y la participación constructiva en el grupo, así como la toma de decisiones.

(e) Resolución de Problemas: Es la capacidad de analizar situaciones problemáticas, en busca de los datos pertinentes, el diagnóstico de la información con el fin de resolver problemas; la generalización de las soluciones alternativas para encontrar la mejor solución.

(f) Habilidades de comunicación: Los elementos fundamentales de esta competencia incluyen la capacidad de comunicarse de manera constructiva en distintos entornos, mostrar tolerancia, expresar y comprender puntos de vista diferentes, negociar sabiendo inspirar confianza y sentir empatía. Las personas deben ser capaces de gestionar el estrés y la frustración, así como expresarlos de una manera constructiva, y también distinguir las relaciones profesionales de las personales.

(g) Habilidades en TIC: En este apartado se incluyen la capacidad de buscar, obtener y procesar la información y utilizarla de manera crítica y sistemática. Los estudiantes deben ser capaces de utilizar herramientas para producir, presentar y comprender información técnica. Así mismo deben de ser capaces de acceder, buscar y utilizar servicios accesibles por Internet. Por ultimo, debe contemplarse también la capacidad de aprender y adaptarse a las nuevas tecnologías.

(cc) EY-NC-ND 2014, Universitat Politècnica de València

I Jornadas IN-RED (2014) 


\begin{tabular}{|l|l|}
\hline COMPETENCIAS & ACTIVIDAD EVALUADA \\
\hline Planificación/Organización & Elaboración del plan de trabajo y cumplimiento del mismo. \\
\hline Capacidad de análisis/investigación & $\begin{array}{l}\text { Planteamiento del problema. Realización de cuestiones } \\
\text { para resolver problema propuesto. }\end{array}$ \\
\hline Resolución de Problemas & Apartado de discusión de la memoria. \\
\hline Competencia Numérica & $\begin{array}{l}\text { Diseño y realización del experimento, toma de datos, así } \\
\text { como el procesado y análisis posterior de los mismos. }\end{array}$ \\
\hline Trabajo en Equipo & $\begin{array}{l}\text { Coordinación entre los distintos miembros del equipo para } \\
\text { la elaboración y presentación de todo el proyecto. }\end{array}$ \\
\hline Habilidades de Comunicación & $\begin{array}{l}\text { Realización de la memoria técnica y presentación oral del } \\
\text { trabajo. }\end{array}$ \\
\hline Habilidades en TIC & $\begin{array}{l}\text { Análisis de datos, redacción de la memoria y elaboración } \\
\text { de las transparencias necesarias para la exposición oral. }\end{array}$ \\
\hline
\end{tabular}

Tabla 2. Competencias y actividades evaluadas correspondientes

Además de las calificaciones formales, también se recogieron opiniones de los alumnos mediante preguntas en la defensa pública de los trabajos. En particular, se les preguntó sobre las principales dificultades encontradas para desarrollar los trabajos, oportunidades de mejora para ocasiones futuras y nivel de satisfacción con la experiencia.

\section{Resultados}

En esta experiencia piloto participaron inicialmente 171 alumnos, lo que constituye el 96.6 $\%$ de los alumnos matriculados en la asignatura de Física I. A lo largo del desarrollo del trabajo se fueron desenganchando algunos grupos, que no siguieron los planes de trabajo trazados y no acabaron los trabajos, como se comenta más adelante.

La participación de los estudiantes fue bastante activa. Además de asistir a las tutorías en grupo, los profesores atendieron del orden de 75 e-mails solicitando aclaraciones y ayudas puntuales. Por el contario, la participación en el foro fue bastante reducida

Casi todos los grupos de trabajo entregaron un plan de trabajo razonablemente realista y detallado, con las fases necesarias para llevar el trabajo a cabo. La calificación de este apartado fue de $7.95 \pm 2.51$ (media \pm std, en una escala de 0 a 10 ).

Sin embargo el nivel de cumplimiento de los cronogramas fue bastante desigual. Aunque la mayoría de alumnos aportaron los entregables en el límite marcado, la mayoría (un 80\%) apuró los plazos máximos, incumpliendo sus propios planes de trabajo. Las principales causas fueron la descoordinación entre los miembros de los equipos, la falta de un liderazgo

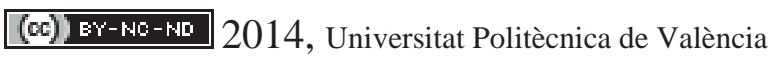


claro y considerar que el plan de trabajo es un mero documento formal que no es necesario seguir.

La resolución de las cuestiones relacionadas con los diseños experimentales resultó difícil para muchos grupos. La calificación media en este apartado fue de 6.27 puntos (std=2.53). Un $18 \%$ de alumnos abandonó la realización del trabajo en esta fase. Además un $27 \%$ de los que entregaron las cuestiones no alcanzaron el aprobado. La causa principal de estos discretos resultados fue que el tipo de cuestiones planteadas se alejaban de los problemas resueltos en teoría o de los que se plantean en las prácticas de laboratorio. Por otra parte, muchos alumnos no supieron buscar la información necesaria para resolver este tipo de cuestiones.

Todos los grupos aprendieron a manejar las técnicas de medición asociadas a su trabajo (videoanálisis o sensores de aceleración). La mayoría de los trabajos usaron elementos cotidianos para construir los montajes experimentales. Sin embargo, en unos pocos casos se realizaron auténticos proyectos de ingeniería, con la construcción

El experimento fue totalmente acabado y presentado por un $75 \%$ de los alumnos (128 alumnos). En términos generales, los experimentos se realizaron de manera correcta. De los alumnos que acabaron el trabajo la mayoría realizó una memoria bien planteada, escrita y presentada. No obstante, sólo una tercera parte de los grupos presentaron trabajos con un buen tratamiento de datos, una discusión bien fundamentada y la estructura propia de un trabajo técnico-científico. Aunque casi todos consiguieron contrastar las hipótesis planteadas, la mayoría se limitó a demostraciones semicuantitativas. Un porcentaje pequeño de trabajos (9\%) no supieron desarrollar el estudio experimental o bien obtuvieron resultados completamente incorrectos por errores de ejecución o de interpretación de las mediciones.

La calidad de las presentaciones orales fue bastante desigual. En algunos grupos (aproximadamente la tercera parte de los alumnos) las presentaciones fueron muy elaboradas, incluyendo animaciones, inserción de vídeos y con buenas intervenciones de los componentes de los equipos. Por el contrario, otra tercera parte tuvo problemas para exponer en público. Las razones principales en estos grupos fue, la precipitación en la preparación de los trabajos y la falta de costumbre para presentar un trabajo en público. Más del $60 \%$ de los alumnos reconocieron que era la primera vez que tenían que presentar un trabajo en público delante de un tribunal de profesores.

La práctica totalidad de los alumnos ha considerado que la experiencia ha merecido la pena, por ser la primera vez que se enfrentan a la necesidad de resolver un problema real de forma autónoma y usando sus medios y conocimientos. En general, la realización del trabajo les ha resultado más costosa de lo que esperaban. Las principales oportunidades de mejora señaladas han sido las siguientes:

(cc) EY-NC-ND 2014, Universitat Politècnica de València

I Jornadas IN-RED (2014) 
- Organizar mejor el tiempo y respetar el plan de trabajo establecido. Aunque los planes de trabajo presentados al principio eran formalmente correctos, la mayoría no los siguió, lo que condujo a apurar los plazos.

- Dificultades al abordar problemas reales con los modelos teóricos que manejan en clase. Dificultades para interpretar las desviaciones entre el modelo y la realidad y para controlar dichas desviaciones mediante mejoras en el diseño experimental.

- Necesidad de coordinación y liderazgo en los grupos. Muchos grupos no han tenido un líder o han presentado problemas de coordinación.

- Necesidad de mejorar las habilidades de comunicación. Muchos alumnos no tienen costumbre de hablar en público ni de defender el trabajo realizado en un debate con profesores o con compañeros.

\section{Discusión y conclusiones}

Como se ha comentado en la Introducción, la enseñanza en el primer curso de las Ingenierías en España tiene un carácter demasiado teórico y poco práctico. Siguiendo una tradición que tiene su origen en las antiguas Escuelas de Ingenieros, con frecuencia se desarrollan materias orientadas a dotar a los alumnos de conocimientos muy teóricos, con poco énfasis en la resolución de problemas prácticos.

Incluso en asignaturas de carácter experimental, como es la Física, la carga de laboratorio es muy reducida (menos del $20 \%$ de los créditos) y las prácticas de laboratorio se suelen diseñar básicamente como apoyo al aprendizaje de modelos teóricos. En efecto, en muchos casos las prácticas son experiencias diseñadas por los profesores para ilustrar un fenómeno que aparece en estado puro, casi sin margen para el error. Los alumnos se limitan e seguir un guión preestablecido sin posibilidad de plantear alternativas, proponer innovaciones ni casi para cometer errores.

Sin entrar a discutir si este enfoque es o no el adecuado para proporcionar una formación teórica básica para avanzar más rápidamente en cursos posteriores, la realidad es que no contribuye a mejorar las competencias transversales de los alumnos. Los cambios introducidos en el proceso de convergencia europea quizás han mitigado algo este enfoque cartesiano de la formación de los ingenieros, pero no ha supuesto la modificación de la enseñanza que todos esperábamos cuando se planteó.

De ahí el interés de plantear a los alumnos pequeños proyectos que favorezcan el desarrollo de competencias transversales desde su entrada en la Universidad. En esta línea la experiencia piloto desarrollada en la ETSI Telecomunicación nos ha servido para identificar algunos déficits formativos que nos ayudarán a mejorar el planteamiento de las asignaturas de Física

(cc) EY-NC-ND 2014, Universitat Politècnica de València 
Los proyectos planteados a los alumnos son en todos los casos de una complejidad teórica muy baja y en ellos se manejan modelos y conceptos que, en principio, suponíamos conocidos por los alumnos. Sin embargo muchos estudiantes sólo han resuelto problemas en el papel, donde se plantean situaciones ideales para aplicar modelos simples. También han aplicado esos conocimientos a las prácticas de laboratorio, donde las condiciones están tan controladas que los modelos se cumplen sin demasiados problemas. Sin embargo, cuando se han tenido que enfrentar a un problema real, no siempre están en condiciones de identificar las características básicas del problema y aplicar el modelo idóneo que representa su comportamiento. Del mismo modo, no siempre saben explicar o afrontar las desviaciones entre los resultados proporcionados por los modelos y los medidos en la realidad.

Por otra parte, pensamos que la enseñanza actual está muy tutelada por el profesor. Al dedicar demasiado tiempo a explicar conceptos teóricos, quizás se descuide la importancia de desarrollar el espíritu crítico, la creatividad. El trabajo de los alumnos se vuelve demasiado dependiente no se desarrolla la capacidad para trabajar y aprender con un amplio margen de autonomía.

Este exceso de control tiene consecuencias indeseables sobre la formación de nuestros alumnos. Cuando se les pide que ellos mismos organicen el desarrollo de un trabajo en equipo, tienen problemas muy importantes para planificar su tiempo, prever posibles problemas y cumplir los plazos que ellos mismo se han fijado.

Otro aspecto importante es la comunicación de resultados. Como hemos podido comprobar un porcentaje alto de alumnos nunca ha tenido ocasión de defender un trabajo propio de forma oral en público. Muchos tienen problemas para desarrollar una presentación oral. Esto contrasta con lo que se hace en otros entornos educativos desde niveles de enseñanza previos a la Universidad. Por tanto consideramos que este es uno de los aspectos a mejorar. Los propios alumnos reconocen que es un déficit que han descubierto gracias a esta experiencia y un aspecto de su formación que tienen que mejorar.

En cuanto al enfoque de los trabajos y el tipo de elementos usados, hay que destacar la excelente aceptación que ha tenido el uso de smartphones para realizar los experimentos caseros. Muchos alumnos no conocían las posibilidades de los sensores de un smartphone y han entendido perfectamente las ventajas que les ofrecen para desarrollar sus propias experiencias.

No hemos encontrado ningún problema en que los alumnos aprendan de forma completamente autónoma el manejo del software asociado para el análisis de vídeos o de los registros de aceleración, así como para el tratamiento de datos o elaboración de graficas o presentaciones. Cuando una herramienta es necesaria para resolver un problema real, se aprende mucho más rápido que cuando se plantea en un contexto meramente teórico. Así,

(cc) EY-NC-ND 2014, Universitat Politècnica de València

I Jornadas IN-RED (2014) 
muchos alumnos han aprendido en profundidad el uso de programas de videoanálisis, conversión de ficheros de video, edición de vídeos, etc.

En definitiva, se trata de una experiencia muy positiva para los alumnos y para los profesores de la asignatura. Los resultados de esta primera experiencia nos permitirán mejorar en años posteriores y quizás modificar el planteamiento de nuestras asignaturas en la medida en la que el rígido sistema educativo español y las importantes restricciones económicas que sufrimos lo permitan.

\section{Referencias}

BODMER, C., LEU, A., MIRA, L., and RUTTER, H. (2002). SPINE: Successful Practices in International Engineering Education: Engineers Shaped our Future IngCH.

BONS, W. and McLAY, A. (2003). "Re-engineering. Engineering Curricula for Tomorrow's Engineering". $14^{\text {th }}$ Annual Australian Association for Engineering Education Conference.

CONNELLY, J.D. and MIDDLENTON, J.C.R. (1996). "Personal and Professional Skills for Engineering: One Industry’s Perspective”. Eng. Sc. Educ. J. 5(3), pp. 139-144.

NAIR, C.S., PATIL, A. AND MERTOVA, P. (2009). "Re-engineering graduate skills- a case of study". Eur. J. Eng. Educ. 34(2), pp. 131-139.

OFFICIAL JOURNAL OF THE EUROPEAN UNION, (2006). "The Key competences for lifelong learning- A European framework".

(http://eur-lex.europa.eu/LexUriServ/site/en/oj/2006/1_394/1_39420061230en00100018.pdf).

[Consulta: 10 Noviembre 2013]

SCOTT, G. and YATES, K.W. (2002). "Using successful graduates to improve the quality of undergraduate engineering programmes". Eur. J. Eng. Educ. 27(4), pp.363-378.

YOUNG, J. and CHAPMAN, E. (2010). "Generic Competency Frameworks: A Brief Historical Overview". ERP. 37(1), pp. 1-24. 


\title{
Evaluación integral de las prácticas de laboratorio
}

Nuria Martínez-Navarrete ${ }^{a}$ y María del Mar Camacho Vidal ${ }^{b}$

${ }^{a}$ Departamento de Tecnología de Alimentos, Universitat Politècnica de València. nmartin@tal.upv.es, ${ }^{\text {b}}$ Departamento de Tecnología de Alimentos, Universitat Politècnica de València. mdmcamvi@tal.upv.es

\begin{abstract}
The labs complement the theoretical part of each subject and both teachings should not be handled separately. In addition, the practical credits offer to the student a training that involves hardly communicable aspects in a master class. Learned concepts and acquired skills are difficult to be assessed with conventional acts. It is for this reason that it has been very common to overburden the student with practical reports that end up being a very hard working in some cases and in others mere plagiarism. In this project, three stages are proposed to evaluate lab: pre, onsite and post-implementation. Previous and post stages will be evaluated by the corresponding questionnaires designed by the teacher, using the platform PoliformaT of the UPV or equivalent as the University. In the first case the aim will be to ensure the pre-reading and understanding by the student of the work to be performed in the laboratory. The post to practice questionnaire will focus on the results obtained, calculations performed, utility, etc.. As the most novel aspect arises the evaluation of the practice in situ, i.e. during its development, by a group of students called experts. To this end, all the students will be distributed in groups of expert so that each expert group will cover at least one practice. His role as experts will be completed with the preparation, guidance and assessment of the practice when performing peers. For evaluation, experts will develop and use a template, agreeded with the teacher, that meets the intended competencies that students must acquire in the lab.
\end{abstract}

Keywords: Laboratory practice, methodology, evaluation, questionnaire, rating scale.

\section{Resumen}

Si bien es cierto que las prácticas de laboratorio complementan la parte teórica de cada asignatura y ambas enseñanzas no deberían manejarse por separado, también es cierto que los créditos prácticos suponen una formación que implica aspectos difícilmente transmisibles en una clase

(cc) EY-NC-ND 2014, Universitat Politècnica de València

I Jornadas IN-RED (2014) 


\section{Evaluación integral de las prácticas de laboratorio}

magistral. No solo se aprenden conceptos sino que se adquieren destrezas de difícil evaluación con los actos convencionales. Es por esto por lo que ha sido muy frecuente la sobrecarga de trabajo al alumno con informes de prácticas que acaban siendo muy laboriosos en algunos casos y meros plagios en otros. En este proyecto se propone la evaluación de la práctica de laboratorio en tres etapas: previa, in situ y posterior a su realización. Las etapas previa y posterior serán evaluadas mediante los correspondientes cuestionarios diseñados por el profesor, utilizando la plataforma poliformaT de la UPV o su equivalente según la Universidad. En el primer caso el objetivo será asegurar la lectura y comprensión previa por parte del alumno del trabajo que va a realizar en el laboratorio. El cuestionario posterior a la práctica versará sobre los resultados obtenidos, cálculos a realizar, utilidad de los mismos, etc. Como aspecto más novedoso se plantea la evaluación de la práctica in situ, es decir, durante el desarrollo de la misma, por parte de un grupo de alumnos a los que denominaremos expertos. Para ello, todos los alumnos se distribuirán en grupos de expertos de manera que cada grupo lo será de al menos una práctica. Su formación como expertos requerirá primero de un adiestramiento por parte del profesor. Su papel como expertos se completará con la preparación, guía y evaluación de la práctica cuando la realicen sus compañeros. Para la evaluación los propios expertos elaborarán y utilizarán una plantilla que, consensuada con el profesor, responda a las competencias que se pretende que los alumnos adquieran con la práctica de laboratorio.

Palabras clave: prácticas de laboratorio, metodología, evaluación, cuestionario, escala de evaluación.

\section{Introducción}

Las prácticas de laboratorio, en muchas asignaturas, constituyen un elemento imprescindible en la formación del alumno, ya que complementan la parte teórica, implicando aspectos difícilmente transmisibles en una clase magistral. Las prácticas de laboratorio permiten a los estudiantes no solo aprender conceptos, sino desarrollar competencias en la aplicación de conocimientos, habilidades y actitudes en situaciones reales. De esta forma dan sentido a la teoría, al llevarla a la práctica, y aprenden a reconocer los aspectos más importantes y los problemas inherentes a ella. Una de las herramientas más utilizadas para la evaluación del aprendizaje en las prácticas de laboratorio es el informe, que acaba siendo muy laborioso en algunos casos y un mero plagio entre alumnos 
en otros. Además, con este método, en general se evalúa el resultado final y no el proceso que, por otra parte, es imprescindible para la evaluación del trabajo práctico. En este sentido, se han descrito numerosos trabajos en los que se utilizan instrumentos de observación directa de los estudiantes durante la realización de las actividades, como las escalas de evaluación también denominadas rúbricas, que, a través de unas guías de puntuación, permiten recoger información sobre la adquisición de procedimientos y actitudes, con el fin de clarificar lo que se espera del trabajo del alumno, valorar cómo lo ejecuta y facilitar la retroalimentación (Artigas, 2000; Blanco, 2008; Muñoz, 2012). Por otra parte, se hace imprescindible asegurar la lectura y comprensión previa por parte del alumno del trabajo que va a realizar en el laboratorio y el análisis de los resultados obtenidos, cálculos a realizar, utilidad de los mismos, etc. En la bibliografía se han descrito tareas que permiten este tipo de controles (Noguera, 2011) y que pueden ayudar al profesor a la evaluación global de las prácticas. Una de las técnicas que mejores resultados ha proporcionado y que es sencilla a la hora de aplicarla, es la realización de cuestionarios que deben completarse antes y/o después de realizar la sesión práctica. En este sentido, las plataformas docentes utilizadas en el caso de muchas universidades (poliformaT en la UPV) pueden ser de gran utilizad ya que facilitan el proceso tanto al profesor como al alumno.

\section{Objetivo}

El objetivo del presente trabajo es la propuesta de una metodología que ayude en la difícil tarea de la evaluación de las práctica de laboratorio. Se propone la puesta en marcha de tres etapas evaluadoras: previa, in situ y posterior a la realización del trabajo en el laboratorio.

\section{Desarrollo de la innovación}

Las asignaturas para las que se ha planteado la propuesta de mejora son asignaturas del Grado en Ciencia y Tecnología de Alimentos pertenecientes a las Unidades Docentes de Fisicoquímica y Calidad. Son asignaturas troncales con numerosos alumnos y con una carga práctica importante, por lo que la valoración de las prácticas de laboratorio tiene un gran peso en la nota final de la asignatura.

Todas las prácticas de estas asignaturas se diseñan teniendo en cuenta que los alimentos deben responder a unas normas de calidad que establece la legislación pero, además, han de satisfacer las expectativas del consumidor respecto a su calidad sensorial, nutritiva y funcional. En este sentido, es fundamental dar a conocer al alumno tanto los métodos que permiten el análisis de la composición de los alimentos como los de análisis de las propiedades físicas que más influyen en la aceptación del producto. Este sería, por lo tanto, el objetivo de la práctica propuesta para un alimento concreto. Durante el desarrollo de la

\section{(cc) EY-NC-ND 2014, Universitat Politècnica de València}

I Jornadas IN-RED (2014) 


\section{Evaluación integral de las prácticas de laboratorio}

práctica el alumno debe identificar los componentes mayoritarios (agua, grasa, proteínas, carbohidratos, fibra) del alimento en cuestión y también algunos minoritarios como vitaminas y minerales y aprender a analizarlos. También debe aprender a medir algunas propiedades físicas de interés como pueden ser la densidad, el color y la viscosidad, consistencia o textura. Para ello, el alumno dispone de una guía de la práctica en la que se detalla el alimento a analizar, la metodología a seguir y los equipos a utilizar. En la guía se indican las precauciones especiales que se deben tener con algunos de los reactivos y/o equipos a utilizar, así como el procedimiento de cálculo en su caso.

La evaluación de la práctica de laboratorio se realizará en tres etapas: previa, in situ y posterior a su realización. Para la evaluación de la etapa previa, cuyo objetivo es asegurar la lectura y comprensión previa por parte del alumno del trabajo que va a realizar en el laboratorio, se diseñará un cuestionario. El alumno accederá y rellenará dicho cuestionario, utilizando la plataforma poliformaT de la UPV, en un plazo no superior a 72 horas antes de la realización de la práctica. Esta plataforma de la UPV permite que el profesor limite el periodo de tiempo en el que los alumnos pueden acceder a determinados documentos, como el cuestionario que nos ocupa, y permite su envío por parte del alumno, una vez cumplimentado, dentro de ese mismo plazo. El cuestionario que se diseñará con este fin recogerá preguntas relacionadas con el alimento a analizar, los componentes y propiedades a analizar, la metodología a seguir, los equipos a utilizar, las precauciones a tomar y los resultados a obtener. El profesor comprobará, a través de la plataforma poliformaT, si el alumno ha contestado al cuestionario, ya que es obligatorio haberlo hecho antes del comienzo de la realización de la práctica en el laboratorio. En caso contrario, el alumno no podrá entrar a la sesión práctica y su nota será no presentado.

Como aspecto más novedoso en este proyecto se plantea la evaluación del alumno in situ, es decir, durante el desarrollo de la práctica en el laboratorio. Los protagonistas de esta etapa son los propios alumnos. Para cada práctica a realizar durante el curso se formará a un grupo de alumnos expertos en esa práctica, de manera que al finalizar el curso todos los alumnos han tenido este papel en alguna de las sesiones. Su formación como expertos supone que ellos mismos realizarán previamente la actividad práctica bajo las instrucciones del profesor. Su papel como expertos se completará con la explicación, guía y evaluación de la práctica mientras la realizan sus compañeros. Para la evaluación se diseñará una plantilla que, consensuada con el profesor, debe responder a las competencias que los alumnos tienen que adquirir con la práctica de laboratorio realizada. El grupo de alumnos "expertos" evaluarán a cada uno de sus compañeros utilizando como criterio de evaluación la escala: Insuficiente, Regular, Bien y Muy bien, que posteriormente será trasladada a anotaciones numéricas

Para la evaluación de la etapa posterior a la realización de la práctica de laboratorio, se elaborará un cuestionario que versará sobre los resultados obtenidos, cálculos a realizar, 
utilidad de los mismos, etc. Este cuestionario será contestado por los alumnos en un plazo determinado por el profesor inferior a $72 \mathrm{~h}$ y tendrá como finalidad evaluar el resultado final y la comprensión de todos los aspectos relacionados con la práctica.

\section{Resultados}

A continuación se muestran las herramientas diseñadas para la evaluación de una práctica tipo en las 3 etapas propuestas.

En la Figura 1 se muestra un ejemplo de un cuestionario de evaluación de la etapa previa con el aspecto que la plataforma PoliformaT ofrece al alumno mientras lo está rellenando.

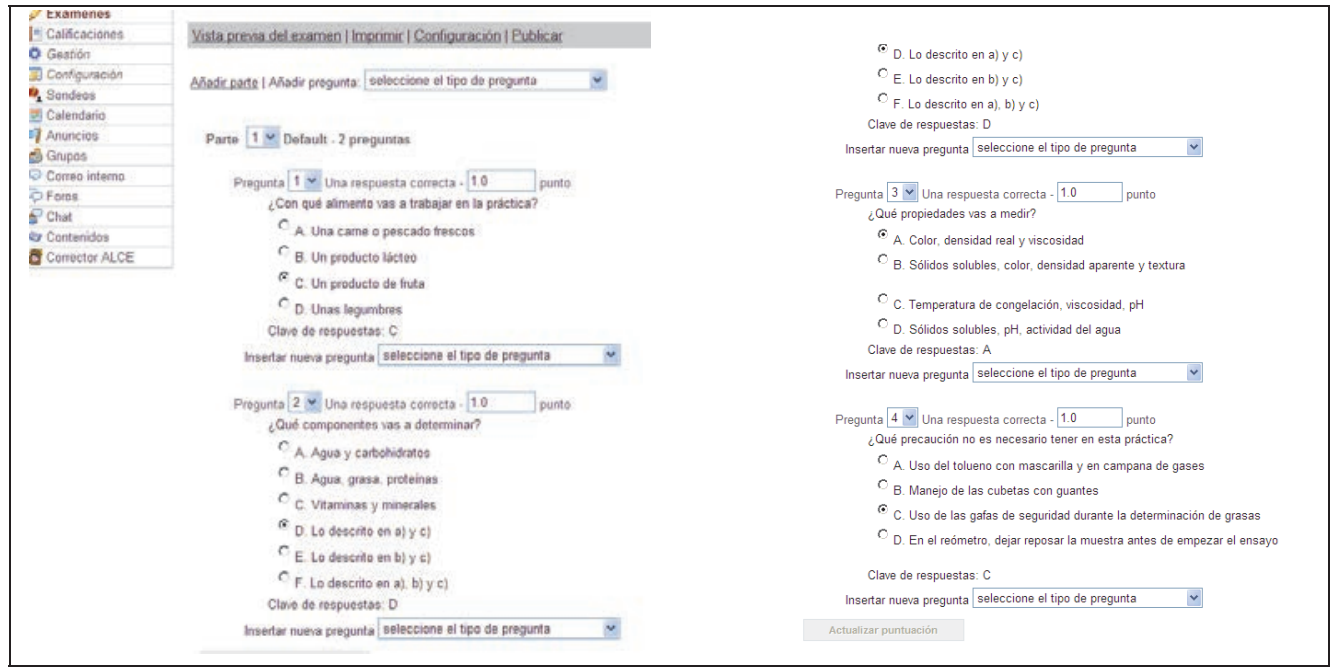

Figura 1. Ejemplo de cuestionario publicado para cumplimentar por el alumno en la plataforma poliformaT previamente a la realización de la práctica.

En la Tabla 1 se presenta un ejemplo de plantilla correspondiente a las competencias que los alumnos deben adquirir con la práctica de laboratorio y que los expertos utilizan para evaluar in situ. Como ya se ha comentado, esta plantilla ha sido diseñada por el grupo de alumnos expertos y supervisada por el profesor.

La plataforma PoliformaT, permite diseñar diferentes tipos de preguntas que ayudarán al profesor a elaborar los cuestionarios teniendo en cuenta los contenidos y los objetivos que en cada práctica se deben conseguir. Así, se puede optar por preguntas de tipo test con opción múltiple, encuestas, preguntas de respuesta corta, con espacios en blanco para

\section{(cc) EY-NC-ND 2014, Universitat Politècnica de València}

I Jornadas IN-RED (2014) 


\section{Evaluación integral de las prácticas de laboratorio}

completar, de respuesta numérica, preguntas de relacionar, del tipo verdadero/falso o preguntas en las que se pueden subir ficheros con imágenes, documentos...

(c) EY-NC-ND 2014, Universitat Politècnica de València I Jornadas IN-RED (2014) 

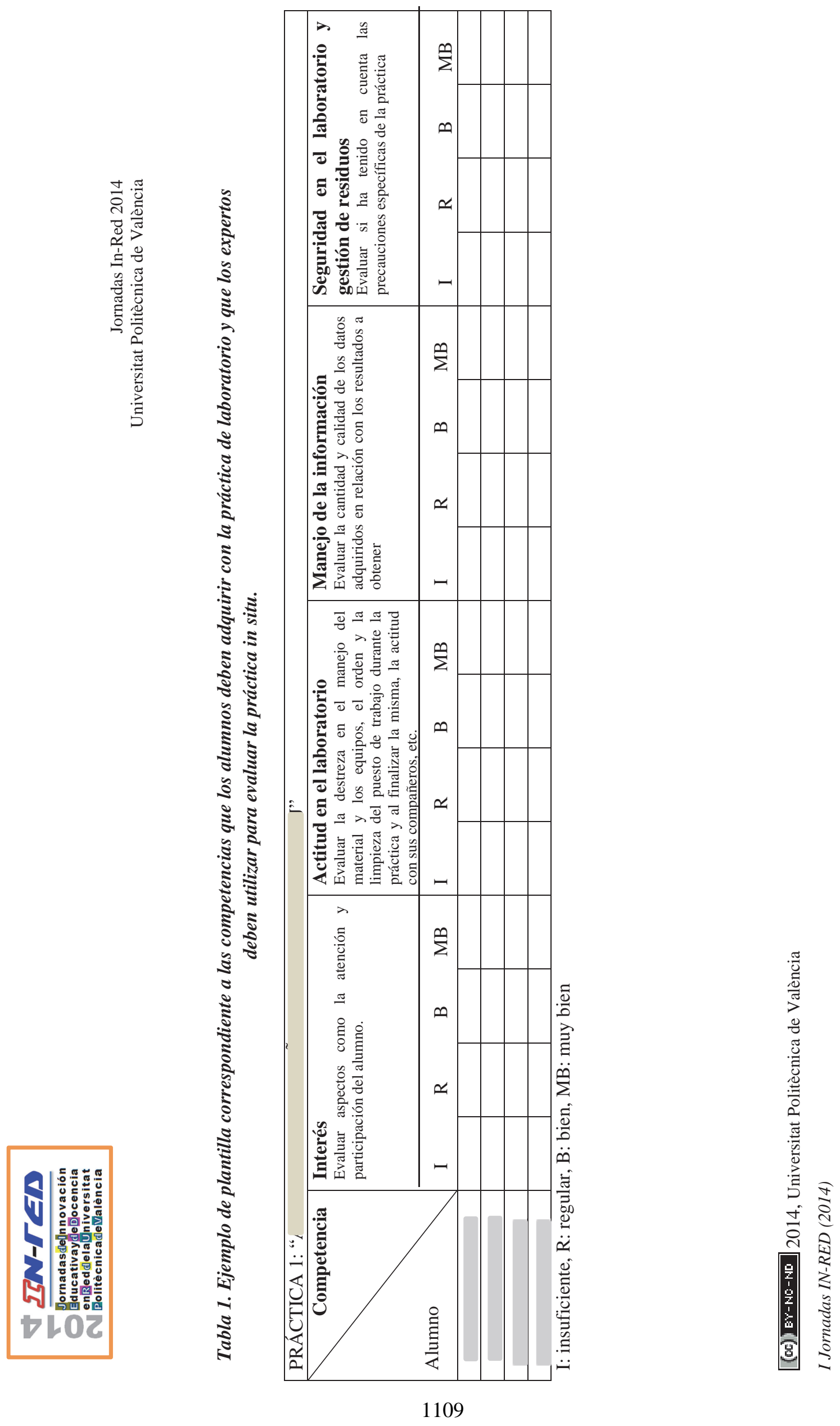
Las Figuras 2 y 3 muestran dos cuestiones diseñadas según el formato "subir ficheros" de la plataforma poliformaT. Estas cuestiones son un ejemplo del modo en que los alumnos deben presentar los resultados obtenidos para su evaluación en la etapa final. Este tipo de pregunta permite poner el texto de la pregunta y subir un fichero que el alumno podrá abrir para rellenarlo y enviarlo. Este fichero puede tener formato Excel, Word... Las figuras que se muestran presentan de forma combinada el texto de la pregunta, tal y como les aparece en la plataforma, y el fichero adjunto una vez lo han abierto.

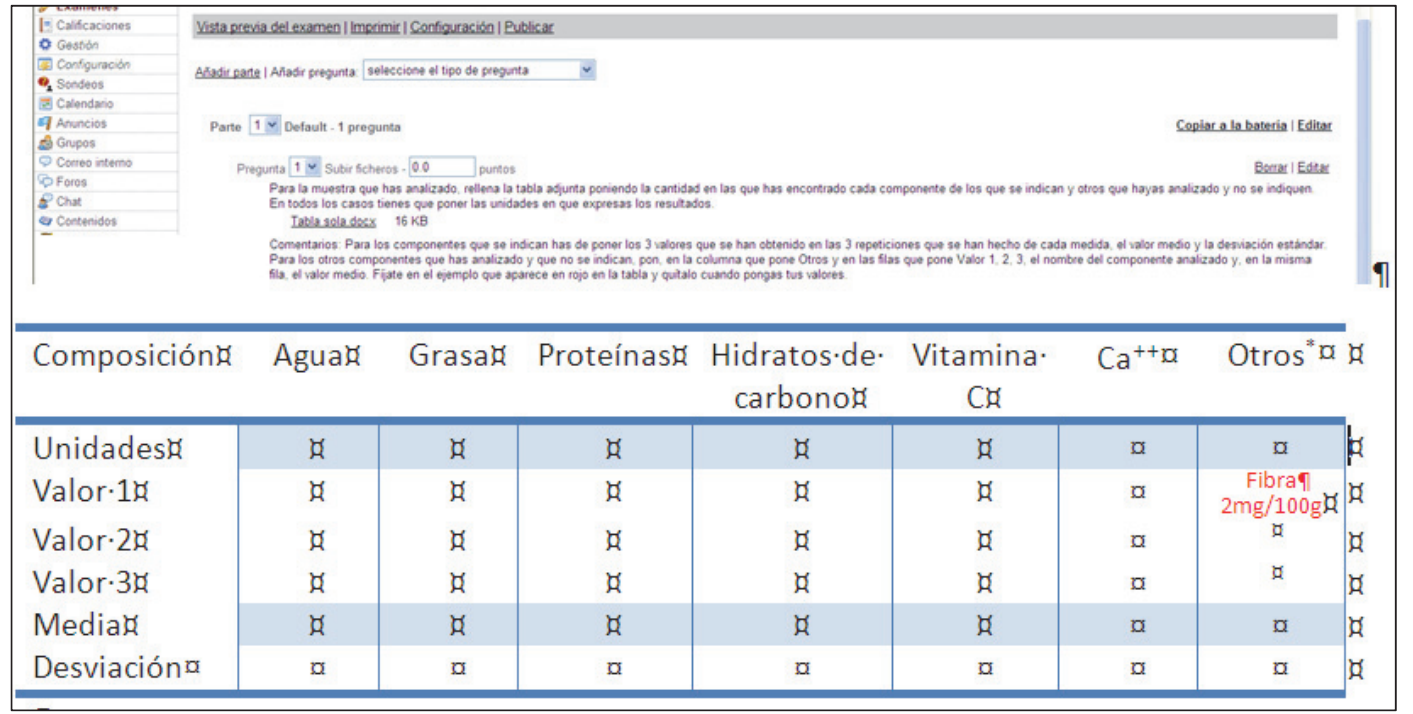

Figura 2. Ejemplo de cuestión diseñada para la evaluación de la práctica en su etapa final haciendo uso de la plataforma Poliformat según el tipo de pregunta "subir fichero". 


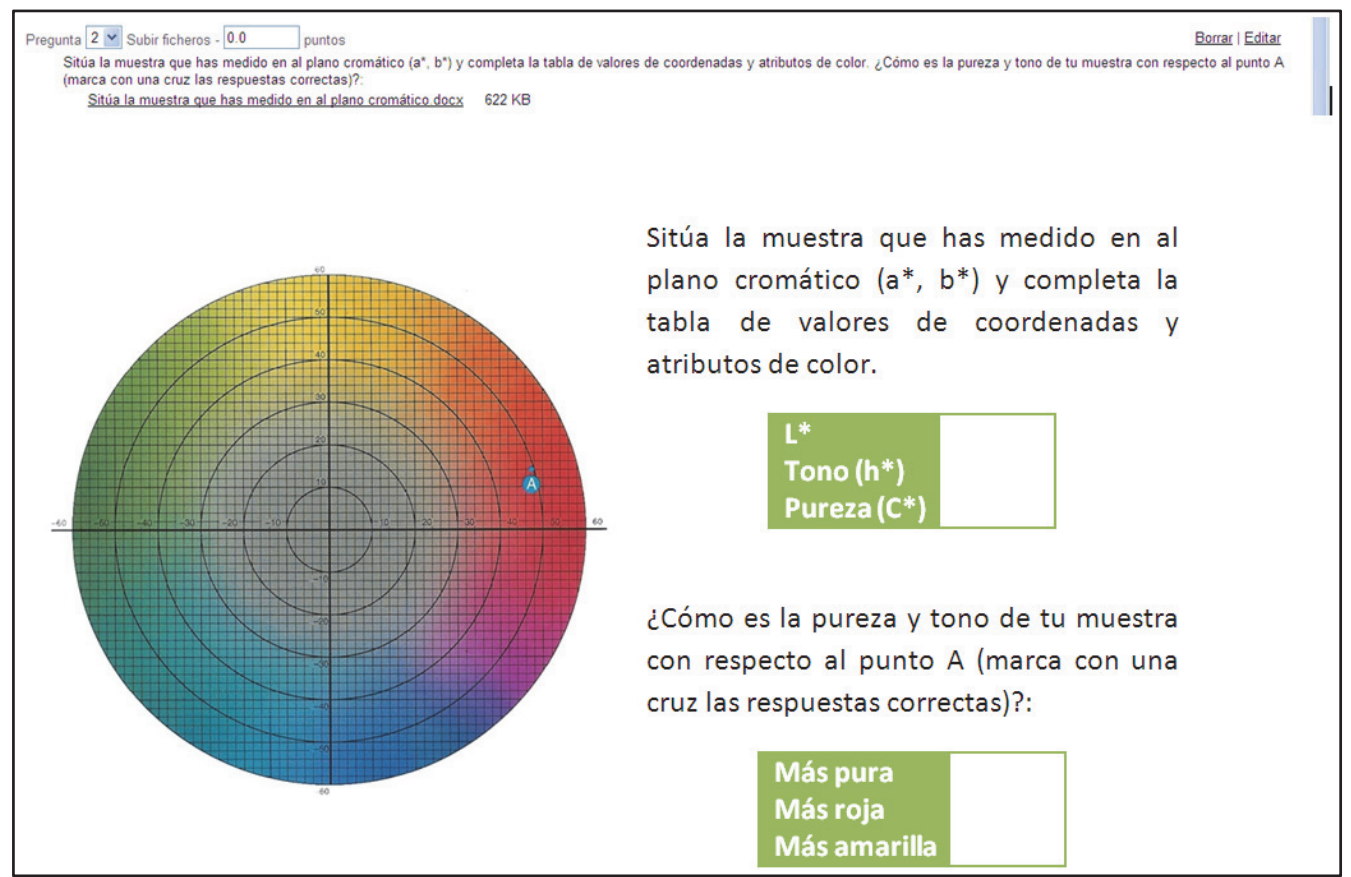

Figura 3. Ejemplo de cuestión diseñada para la evaluación de la práctica en su etapa final haciendo uso de la plataforma PoliformaT según el tipo de pregunta "subir fichero".

En las figuras 4 y 5 se muestran diferentes tipos de preguntas que permite diseñar la plataforma poliformaT entre las que se encuentran preguntas de respuesta numérica (Figura 4a), de respuesta corta (Figura 4b) y con espacio en blanco para completar y verdadero/falso (Figura 5).

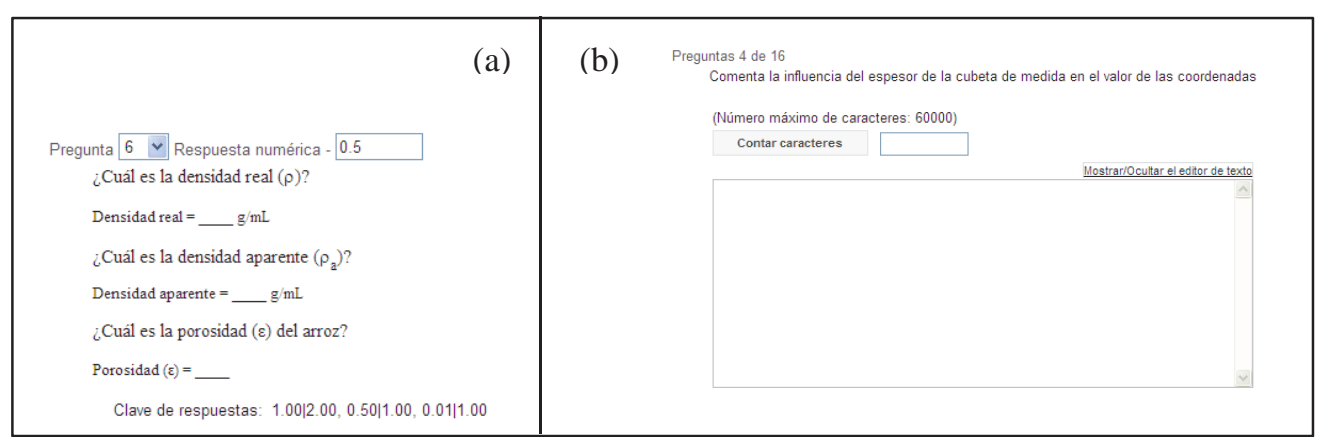

Figura 4. Ejemplo de cuestión diseñada para la evaluación de la práctica en su etapa final haciendo uso de la plataforma Poliformat según el tipo de pregunta "respuesta numérica" (a) y "respuesta corta" (b).

\section{(c)) EY-NC-ND 2014, Universitat Politècnica de València}

I Jornadas IN-RED (2014) 


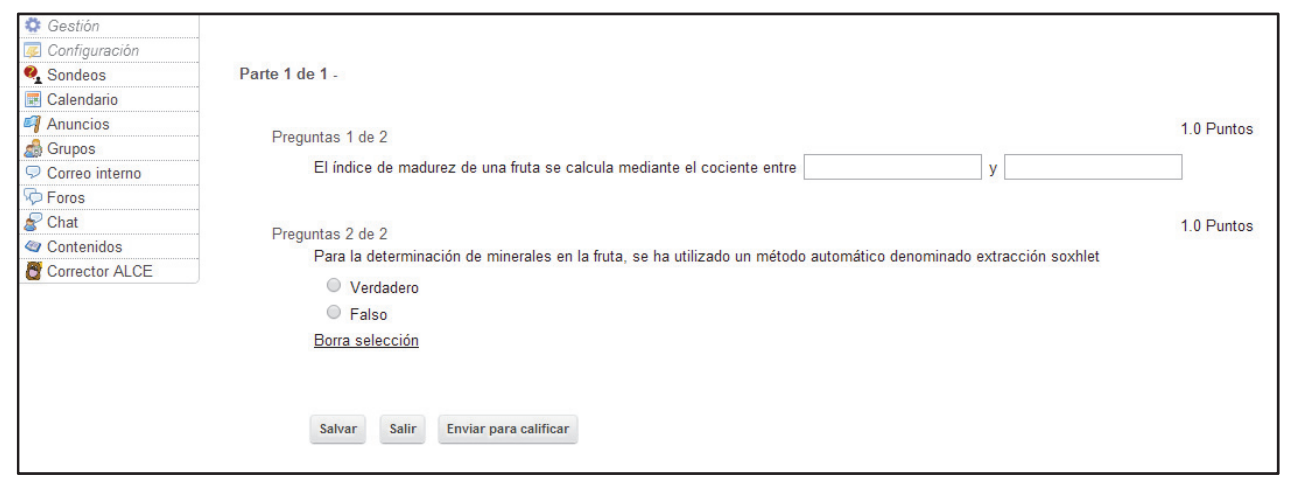

Figura 5. Ejemplo de cuestión diseñada para la evaluación de la práctica en su etapa final haciendo uso de la plataforma Poliformat según el tipo de pregunta "con espacio en blanco para completar" $y$ "verdadero/falso".

\section{Conclusiones}

En este trabajo se ha conseguido hacer uso de una herramienta institucional para resolver un problema importante para el profesor como es el de la evaluación de las prácticas de laboratorio. El diseño que se ha llevado a cabo de los instrumentos de evaluación permite la recolección de datos en el momento de la realización de la práctica y, como máximo en el plazo de 1 semana alrededor de ésta y, además, con la implicación de los propios alumnos. De esta forma se consigue conocer las deficiencias en los conocimientos adquiridos de manera casi inmediata, lo que permite poner soluciones en caso necesario.

\section{Referencias}

ARTIGAS, J.L Y FALCÓ, J. (2000). "Evaluación del aprendizaje de los alumnos de los grupos numerosos: una propuesta concreta". IV Congreso de Tecnologías aplicadas a la enseñanza electrónica. Barcelona: TAEE2000. 59-62.

BLANCO, A., MORALES, P., TORRE J.C. (2008). Las rúbricas un instrumento útil en la evaluación de competencias, en La enseñanza universitaria centrada en el aprendizaje: estrategias útiles para el profesorado. L. Prieto (Coord.), Barcelona: Octaedro-ICE Universidad de Barcelona.

MUÑOZ, M.J., BLASCO, E., BES, M.A., GARCÍA, J., SANCHIS, P., VIDAL, B., FENOLlOSA, M.L., RIBAL, F.J., TORTAJADA, L.A., NOGUERA, P. (2012). "Evaluación de las prácticas mediante rúbricas: experiencia multidisciplinar". Proceedings. Jornada de Innovación ICE-UPV. Valencia: Editorial UPV 
NOGUERA, P, TORTAJADA, L.A. ATIENZA, J, HERREERO, M.A. (2011). "Autoevaluación previa a las prácticas de laboratorio químico: introducción al autoaprendizaje" en ARBOR Ciencia, Pensamiento y Cultura .Vol. 187 - Extra 3 - diciembre (2011) 267272. 


\title{
¿SE PUEDE EVALUAR EL TRABAJO EN GRUPO DE FORMA INDIVIDUAL?. EXPERIENCIA PILOTO EN UNA ASIGNATURA EXPERIMENTAL.
}

\author{
Beatriz Cuartas-Uribe ${ }^{a}$, Amparo Bes-Piáb ${ }^{\text {, M.Isabel Iborra-Clar }}{ }^{c}$, Alicia Iborra-Clar ${ }^{\mathrm{d}}$ \\ and Esperanza García-Castello ${ }^{\mathrm{e}}$ \\ a Universidad Politécnica de Valencia, beacuau1@iqn.upv.es, ${ }^{\mathrm{b}}$ Universidad Politécnica de Valencia, \\ mbespia@iqn.upv.es, 'Cuniversidad Politécnica de Valencia, miborra@iqn.upv.es, Universidad \\ Politécnica de Valencia, aiborra@iqn.upv.es, Universidad Politécnica de Valencia, \\ egarcia1@iqn.upv.es.
}

\begin{abstract}
El presente trabajo se centra en la competencia transversal "trabajo en grupo", que es una de las competencias que debe adquirir el alumno para desarrollar adecuadamente su futuro profesional. En este sentido, se ha marcado el siguiente objetivo: favorecer la participación del alumno en la evaluación del funcionamiento de su grupo de trabajo tanto de forma individual como grupal. Se pretende evitar que la nota final de la asignatura se centre en el 'producto final' (trabajos académicos + examen), detectar a los alumnos que no participan activamente en las diferentes tareas grupales ("alumnos manta") y, en definitiva, obtener evaluaciones globales más justas de esta asignatura que es íntegramente experimental.

La metodología de evaluación del trabajo en grupo aplicada se denomina "Evaluación en tres tiempos" y de forma paralela los profesores participan también teniendo como guía una "rúbrica de evaluación" que abarca los campos conceptual, procedimental y actitudinal.

Los resultados han mostrado que, mayoritariamente, los alumnos se implican en el proceso de evaluación interna del trabajo en grupo y muestran la evolución de cada uno de los miembros en el tiempo. Así, se han observado diferentes tendencias en los comportamientos de los grupos clasificadas
\end{abstract}


como tendencia "NO CRÍTICA", "CRÍTICA con cambios" y "CRÍTICA sin cambios".

Keywords: Competencia transversal, trabajo en grupo, evaluación compartida, encuestas, experimentación.

\section{Introducción}

La necesidad de que el alumno adquiera las competencias tanto específicas como transversales al finalizar sus estudios nos ha motivado a evaluar la adquisición de la competencia transversal "trabajo en equipo" en una asignatura $100 \%$ experimental. Para llevar a cabo este objetivo se han contemplado diferentes metodologías de innovación, entre las que se han seleccionado dos técnicas fáciles de diagnóstico de grupo como son "Evaluación en tres tiempos" y "rúbricas de evaluación".

Ambas técnicas nos permiten indagar tanto en el proceso como el producto motivando al alumno a que sea partícipe de su propio aprendizaje a partir de sus reflexiones en el ámbito de la evaluación.

La idea de aplicar ambas metodologías surge como una necesidad de los profesores de evaluar de una manera más justa el trabajo grupal de los alumnos. Aprovechando la experiencia del grupo de investigación docente IEMA de la Unversitat Politècnica de València, dado a conocer a través de los cursos del Instituto de las Ciencia de la Educación de la misma universidad, esta publicación pretende ser un punto de arranque en este campo de la evaluación tan interesante.

\section{Objetivos}

El principal objetivo del trabajo es evaluar el funcionamiento de los grupos de trabajo a través de encuestas de evaluación en las que el alumno evalúa el funcionamiento de su grupo tanto de forma individual como grupal.

Como objetivos secundarios se plantean:

- Calificar tanto el proceso de aprendizaje como el 'producto final' (trabajos académicos + examen), 
Cuartas-Uribe B., Bes-Piá M., Iborra-Clarc M.I., Iborra-Clar A., García-Castello E.

- Identificar a los alumnos que no participan activamente en las diferentes tareas grupales ("alumnos manta").

- Evaluar en un futuro de forma más justa asignaturas experimentales contrastando las evaluaciones de los alumnos con las de los profesores.

\section{Desarrollo de la innovación}

La experiencia piloto se ha realizado en la asignatura "Experimentación en Ingeniería Química I", de la titulación de grado de Ingeniero Químico. Ésta se imparte por cinco profesoras íntegramente en el laboratorio y está relacionada con los conocimientos teóricos de las asignaturas Cinética Química y Catálisis y Transferencia de materia. El número total de alumnos matriculados en este curso académico ha sido de 87, los cuales se distribuyeron en grupos de 4 ó 5 componentes, que se conservan durante el cuatrimestre. Los datos experimentales recogidos en cada sesión de prácticas se utilizan para elaborar un trabajo académico que deben entregar a la semana siguiente. Por lo tanto, se debe trabajar en grupo tanto en el laboratorio como fuera del mismo para la realización de los trabajos académicos.

Para poder llevar a cabo los objetivos planteados se propone la siguiente metodología de trabajo que consta de dos partes: "Evaluación en tres tiempos" y "Rúbrica de evaluación".

a) "Evaluación en tres tiempos".

Cada alumno evalúa a través de una encuesta el funcionamiento del grupo, de cada uno de sus miembros (co-evaluación) y de él mismo (autoevaluación) en tres momentos diferentes del semestre: inicial, intermedia y final, y de forma anónima. La plantilla de encuesta se corresponde a la elaborada por García-Carbonell y Watts, 2013.

Esta metodología permite evaluar la actitud de los miembros del grupo y no los conocimientos, ni procedimientos asociados a los contenidos de la asignatura. En este caso la efectividad del trabajo en grupo se mide en términos de: organización, coordinación tareas y/o participación activa.

b) "Rúbrica de evaluación".

En las rúbricas de evaluación se recogen los ítems que evalúan los profesores en las sesiones de laboratorio y que hacen referencia a las tres dimensiones competenciales: conceptual, procedimental y actitudinal. 
¿Se puede evaluar el trabajo en grupo de forma individual?. Experiencia piloto en una asignatura experimental.

Esta rúbrica se entrega al inicio del semestre a los alumnos para que estén informados de los aspectos en los que van a ser evaluados en el laboratorio. En la Tabla 1, se recoge el modelo de rúbrica utilizado.

Los resultados que reflejan la aplicación de ambas metodologías se recogen en la evaluación final de la asignatura de siguiente manera:

NOTA FINAL: nota prácticas + nota examen.

- Nota prácticas (50\%): trabajos académicos $(70 \%)+$ nota informe previo $(10 \%)+$ cuaderno de laboratorio $(10 \%)+$ observación $(10 \%)$.

- $\quad$ Nota examen (50\%).

Tabla 1. Rubrica de evaluación.

\begin{tabular}{|l|l|l|l|}
\hline Calificación & $\mathrm{A}=2$ & $\mathrm{~B}=1$ & $\mathrm{C}=0$ \\
\hline Puntualidad & Llegan todos puntuales & $\begin{array}{l}\text { Algún componente llega hasta } \\
15 \mathrm{~min} \text { después de la hora de } \\
\text { inicio }\end{array}$ & $\begin{array}{l}\text { La mayor parte } \\
\text { del grupo llega } \\
\text { tarde * }\end{array}$ \\
\hline Informe Previo & Lo hacen correctamente & Lo hacen pero no está correcto & No lo hacen \\
\hline Organización & $\begin{array}{l}\text { Se reparten el trabajo } \\
\text { equitativamente }\end{array}$ & $\begin{array}{l}\text { Trabajan todos pero mal } \\
\text { organizados }\end{array}$ & $\begin{array}{l}\text { No trabajan todos } \\
\text { los componentes }\end{array}$ \\
\hline Resultados & $\begin{array}{l}\text { Consiguen terminar la } \\
\text { práctica con resultados } \\
\text { correctos }\end{array}$ & $\begin{array}{l}\text { Consiguen terminar la práctica } \\
\text { pero los resultados no son } \\
\text { correctos }\end{array}$ & $\begin{array}{l}\text { No consiguen } \\
\text { terminar } \\
\text { práctica }\end{array}$ \\
\hline Limpieza & $\begin{array}{l}\text { Dejan todo como al } \\
\text { principio }\end{array}$ & $\begin{array}{l}\text { Mejorable } \\
\text { No limpian }\end{array}$ \\
\hline
\end{tabular}

*El alumno que llegue 30 minutos tarde deberá recuperar la práctica otro día.

Nota máxima $=10$. Valor a utilizar para ponderar la nota de comportamiento en el laboratorio.

\section{Resultados}

Del total de los 20 grupos de prácticas se han seleccionado los resultados más representativos obtenidos en la "Evaluación en tres tiempos". En general, se han observado tres tendencias que se han clasificado como: tendencia "NO CRÍTICA", "CRÍTICA con cambios" y "CRÍTICA sin cambios" (Fig. 1, Fig. 2 y Fig. 3, respectivamente). 
En la Fig.1 se muestran los resultados de uno de los grupos con tendencia "NO CRÍTICA" en la cual los alumnos se valoran positivamente en los tres momentos evaluados. Por lo tanto, se observa una actitud "corporativa" entre sus miembros. Inicialmente, y como cabría esperar entre compañeros que trabajan juntos por primera vez, los resultados varían entre muy buenos y excelentes. En la evaluación intermedia aumenta la tendencia hacia la evaluación muy buena pero manteniendo también la excelente. Y, en la evaluación final, todos se puntuan excelente. Sin embargo, cabe comentar que este resultado no se corresponde con los resultados en los trabajos académicos. Como excepción, hubo un grupo donde no se podría hablar de corporativismo ni falta de actitud crítica ya que las notas de las memorias de prácticas son muy altas y se entiende que el grupo ha trabajado muy bien lo que justifica, en este caso, que todos los alumnos se puntuaran positivamente.

\begin{tabular}{|c|c|c|c|c|c|c|c|c|c|c|c|c|c|c|c|}
\hline \multirow[b]{2}{*}{ GRUPOM } & \multicolumn{5}{|c|}{ Evaluación inicial (17-21 Febrero) } & \multicolumn{5}{|c|}{ Evaluación intermedia (3-7 Marzo) } & \multicolumn{5}{|c|}{ Evaluación final (9 junio) } \\
\hline & Insuficiente & Regular & Buena & Muy buena & Excelente & Insuficiente & Regular & Buena & Muy buena & Excelente & Insuficiente & Regular & Buena & Muy buena & Excelente \\
\hline Efectividac & & & & & 3 & & & & p & 1 & & & & $\Gamma$ & 4 \\
\hline Alumno 1 & & & & 3 & 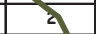 & & & & 4 & & & & & & \\
\hline Alumno 2 & & & & 4 & 1 & & & & 4 & 1 & & & & & 5 \\
\hline Alumno 3 & & & & 1 & 4 & & & & 3 & 2 & & & & & 5 \\
\hline Alumno 4 & & & & 3 & 2 & & & & 4 & 1 & & & & & 5 \\
\hline Alumno 5 & & & & 2 & & & & & 4 & 1 & & & & & 5 \\
\hline
\end{tabular}

Fig. 1. Evaluación con tendencia "No critica"

En la Fig. 2 se muestran los resultados de uno de los grupos con tendencia "CRÍTICA con cambios". En este caso y, al igual que el caso anterior, los alumnos se evalúan inicialmente de forma muy positiva. Sin embargo, en la evaluación intermedia se detectan dos compañeros que se desmarcan de la tendencia del grupo. Posteriormente, en la evaluación final uno de ellos obtiene una peor evaluación de sus compañeros lo que se podría considerar como alumno "manta", mientras que el otro vuelve a la tendencia global del grupo. Estos resultados se reafirman a partir de las observaciones realizadas por las profesoras siguiendo los ítems de la rúbrica.

\begin{tabular}{|c|c|c|c|c|c|c|c|c|c|c|c|c|c|c|c|}
\hline & \multicolumn{5}{|c|}{ Evaluación inicial (17-21 Febrero) } & \multicolumn{5}{|c|}{ Evaluación intermedia (3-7 Marzo) } & \multicolumn{5}{|c|}{ Evaluación final (9 junio) } \\
\hline GRUPO L & Insuficiente & Regular & Buena & Muy buena & Excelente & Insuficiente & Regular & Buena & Muy buena & Excelente & Insuficiente & Regular & Buena & Muy buena & Excelente \\
\hline Efectividad del grupo & & & & 5 & & & & $2 \mid$ & 2 & & & & & 3 & \\
\hline Alumno 1 & & & & 4 & & & & & 3 & $1)$ & & & 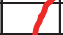 & 2 & 1 \\
\hline Alumno 2 & & & & 4 & & & & & 3 & 1 & & & & 2 & 1 \\
\hline Alumno 3 & & & & 4 & & & & $2 /$ & 1 & 1 & 1 & 2 & & & \\
\hline Alumno 4 & & & & 4 & & & & 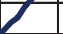 & 3 & 1 & & & & & \\
\hline
\end{tabular}

Fig. 2. Evaluación con tendencia "Critica con cambios"

(cc)) EY-NC-ND 2014, Universitat Politècnica de València

I Jornadas IN-RED (2014) 
¿Se puede evaluar el trabajo en grupo de forma individual?. Experiencia piloto en una asignatura experimental.

En la Fig. 3 se muestran los resultados de uno de los grupos con tendencia "CRÍTICA sin cambios". A primera vista se puede observar que la base de la campana de Gaus es en los tres tiempos muy amplia, lo que implica opiniones muy dispares entre los miembros del grupo desde el principio. Así, y a diferencia de los casos anteriores, se parte de una baja cohesión en el grupo donde las evaluaciones varían desde insuficiente hasta excelente. En la evaluación intermedia, ligeramente mejora la percepción de buen trabajo entre compañeros a excepción de uno de sus miembros que empeora. En la evaluación final, se sigue observando la disparidad de opiniones entre las que cabe destacar la confirmación del alumno 2 y posiblemente el alumno 3 como alumnos "manta". Además, se puede observar como el número de compañeros implicados en el proceso de evaluación se va reduciendo hasta la mitad.

Sin embargo, esta tendencia no es común entre el resto de grupos. En este caso, se pueden justificar los resultados si se tiene en cuenta que los miembros de este grupo no se eligieron entre sí, a diferencia del resto de grupos los cuales ya estaban formados.

Además, estos resultados se corroboran también con las observaciones de las profesoras a través de la rúbrica. En este grupo en concreto, se detectó la falta de motivación lo que se tradujo en un trabajo menos riguroso tanto dentro como fuera de laboratorio.

\begin{tabular}{|c|c|c|c|c|c|c|c|c|c|c|c|c|c|c|c|}
\hline \multirow[b]{2}{*}{ GRUPOV } & \multicolumn{5}{|c|}{ Evaluación inicial (17-21 Febrero) } & \multicolumn{5}{|c|}{ Evaluación intermedia (3-7 Marzo) } & \multicolumn{5}{|c|}{ Evaluación final (9 junio) } \\
\hline & Insuficiente & Regular & Buena & Muy buena & Excelente & Insuficiente & Regular & Buena & Muy buena & Excelente & Insuficiente & Regular & Buena & Muy buena & Excelente \\
\hline Efectivida & & 4 & & & & & & & & & & & 2 & & \\
\hline Alumno 1 & 1 & 1 & 2 & & & & 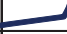 & 2 & & 1 & & & & 1 & 1 \\
\hline Alumno 2 & & 2 & 2 & & & 2 & 1 & & & & 2 & & & & \\
\hline Alumno 3 & & 2 & 1 & & 1 & & & 2 & 1 & & & 1 & & 1 & \\
\hline Alumno 4 & & 1 & 2 & & 1 & & & 1 & 2 & & & & & 2 & \\
\hline
\end{tabular}

Fig. 3. Evaluación con tendencia "Critica sin cambios"

En general, las puntuaciones obtenidas a través de la "rúbrica de evaluación" han incrementado mayoritariamente la "nota de prácticas" excepto en el ejemplo citado en la Fig. 3 donde la nota correspondiente a esta parte ha descendido ligeramente de 7,0 a 6,5. 


\section{Conclusiones}

- La metodología de evaluación continua aplicada al trabajo en grupo en una asignatura $100 \%$ experimental ha permitido conocer mejor el grado de implicación de cada uno de los miembros del grupo.

- Se han observado diferentes tendencias de evaluación "NO CRÍTICA", "CRÍTICA con cambios" y "CRÍTICA sin cambios" siendo las más común la "CRÍTICA con cambios".

- En general, los alumnos son autocríticos y coevalúan adecuadamente de forma que identifican a los alumnos "manta".

- A pesar del elevado número de profesores que comparten la asignatura, las puntuaciones dadas en la "rúbrica de evaluación" a todos los grupos fueron bastante similares entre ellas.

- Esta metodología aplicada evidencia que los alumnos que mejor trabajan en grupo logran los mejores resultados en la asignatura.

\section{Referencias}

GARCÍA-CARBONELL A. y WATTS F. (2013). Evaluación de trabajo en grupo. Curso ICE, Universitat Politècnica de València. Valencia-España.

WATTS F., GARCÍA-CARBONELL, A. Y LLORENS, J. A. (2006). La evaluación compartida: investigación multidisciplinar. Universidad Politécnica de Valencia.

GRUPO DE INNOVACIÓN EN LA EVALUACIÓN PARA LA MEJORA DEL APRENDIZAJE ACTIVE (IEMA).(2006). Evaluación compartida del trabajo: investigación multidisciplinar. Universitat Politècnica de València. Valencia: Editorial UPV.

(cc) EY-NC-ND 2014, Universitat Politècnica de València

I Jornadas IN-RED (2014) 


\title{
Adquisición de competencias realizando prácticas en la asignatura Gestión de la Empresa Audiovisual
}

\author{
Lourdes Canós-Darós ${ }^{a}$, Vicente Benlloch Aparisi ${ }^{b}$, Carlos Pons Morera ${ }^{c}$ y Cristina \\ Santandreu Mascarell ${ }^{\mathrm{c}}$ \\ ${ }^{a}$ ROGLE, Departamento de Organización de Empresas, Escuela Politécnica Superior de Gandia, \\ Universitat Politècnica de València, loucada@omp.upv.es, ${ }^{\mathrm{b}}$ Departamento de Organización de \\ Empresas, Escuela Politécnica Superior de Gandia, Universitat Politècnica de València, \\ vibenap@upvnet.upv.es y ${ }^{c}$ IGIC, Departamento de Organización de Empresas, Escuela Politécnica \\ Superior de Gandia, Universitat Politècnica de València, carponmo@upvnet.upv.es; \\ crisanma@omp.upv.es
}

\begin{abstract}
In this paper we present our experience on the practical activities of the subject Audiovisual Company Management belonging to the study plan of Bachelor Degree in Audiovisual Communication, taught in Gandia Campus, Universitat Politècnica de València. For this, we begin with a brief discussion of the concepts of transversal and specific competencies and their contextualization in the curricula of the new titles. Then, we develope the methodology for evaluating the work and the acquisition of competencial dimensions DC6 Teamwork and leadership, DC7 Ethics and professional responsibility and DC9 Critical thinking, as well as the specific competencies associated with them. We finish with the presentation of some general conclusions about practices in the subject Audiovisual Company Management.
\end{abstract}

Keywords: acquisition, competencies, audiovisual communication, critical thinking, practical work, ethical responsibility, teamwork.

\section{Resumen}

En este trabajo presentamos la experiencia que tenemos sobre la realización de las prácticas de la asignatura Gestión de la Empresa Audiovisual del Grado en Comunicación Audiovisual que se imparte en el Campus de 
Adquisición de competencias realizando prácticas en la asignatura Gestión de la Empresa Audiovisual

Gandia de la Universitat Politècnica de València. Con este fin, empezamos con una breve exposición de los conceptos de competencias transversales y específicas y su contextualización en los planes de estudios de los nuevos títulos. Posteriormente desarrollamos la metodología seguida para trabajar y evaluar la adquisición de las dimensiones competenciales DC6 Trabajo en equipo y liderazgo, DC7 Responsabilidad ética y profesional, y DC9 Pensamiento crítico, así como de las competencias específicas asociadas a las mismas. Finalizamos con la exposición de unas conclusiones generales acerca de la forma de trabajo seguida en las prácticas de la asignatura Gestión de la Empresa Audiovisual.

Palabras clave: adquisición, competencias, comunicación audiovisual, pensamiento crítico, prácticas, responsabilidad ética, trabajo en equipo.

\section{Introducción}

Entre los objetivos de la Unión Europea se encuentra la coordinación de las políticas y normas legislativas de sus estados miembros en cuestiones relacionadas no sólo con el desarrollo económico, sino también con el progreso y el bienestar social de los ciudadanos. Este objetivo se ha extendido en las últimas décadas al ámbito de la educación y, en particular, a la enseñanza superior, adoptándose medidas conducentes a la reforma de la estructura y organización de las enseñanzas universitarias en distintos países para favorecer la construcción del Espacio Europeo de Educación Superior.

En el Documento Marco sobre la Integración del Sistema Universitario Español en el Espacio Europeo de Educación Superior (Ministerio de Educación y Ciencia, 2003) se expone que "los objetivos formativos de las enseñanzas oficiales de nivel de grado tendrán, con carácter general, una orientación profesional, es decir, deberán proporcionar una formación universitaria en la que se integren armónicamente las competencias genéricas básicas, las competencias transversales relacionadas con la formación integral de las personas y las competencias más específicas que posibiliten una orientación profesional que permitan a los titulados una integración en el mercado de trabajo". De este modo, los contenidos de los programas (o guías docentes) deben estar orientados y garantizar el desarrollo de las competencias propias de un primer nivel de profesionalización, a nivel de grado, las cuales se clasificarán en competencias genéricas o transversales y específicas (Santandreu y Canós, 2011). Las competencias genéricas identifican elementos compartidos comunes a cualquier titulación y las competencias específicas son propias de cada disciplina o titulación, y permiten llevar a cabo el desarrollo de una profesión. 
En general, una competencia es el conjunto de conocimientos, actitudes y destrezas necesarias para desempeñar una función dada. La competencia incluye la capacidad de movilizar y aplicar correctamente estos recursos en un entorno determinado, para producir un resultado definido (Le Boterf, 2001). Según el Proyecto Tuning (2000), las competencias tienden a transmitir el significado de lo que la persona es capaz de ejecutar o es competente para realizar, así como del grado de preparación, suficiencia o responsabilidad para las tareas. La superación de las competencias engloba distintos aspectos de formación, tales como saber (conocimiento teórico), saber actuar (aplicación práctica del conocimiento en un determinado contexto) y saber ser (convivir con otras personas en un entorno social).

Tabla 1. Dimensiones competenciales en la Universitat Politècnica de València

\begin{tabular}{|r|l|}
\hline DC1 & Comprensión e integración \\
\hline DC2 & Aplicación del pensamiento práctico \\
\hline DC3 & Análisis y resolución de problemas \\
\hline DC4 & Innovación, creatividad y emprendimiento \\
\hline DC5 & Diseño y proyecto \\
\hline DC6 & Trabajo en equipo y liderazgo \\
\hline DC7 & Responsabilidad ética y profesional \\
\hline DC8 & Comunicación efectiva \\
\hline DC9 & Pensamiento crítico \\
\hline DC10 & Conocimiento de los problemas contemporáneos \\
\hline DC11 & Aprendizaje permanente \\
\hline DC12 & Planificación y gestión del tiempo \\
\hline DC13 & Instrumental específica \\
\hline
\end{tabular}

Las competencias genéricas o transversales han sido consideradas de diferentes formas en distintas universidades españolas. En la Universitat Politècnica de València se han definido 13 dimensiones competenciales (ver Tabla 1) que se relacionan con las competencias específicas de cada uno de los títulos definidas en los planes de estudios aprobados por la ANECA en el momento de implantación de los nuevos grados. En este trabajo nos remitimos particularmente a las DC6 Trabajo en equipo y liderazgo, DC7 Responsabilidad ética y profesional, y DC9 Pensamiento crítico, como se explica en los epígrafes siguientes.

\section{Objetivos}

El objetivo principal de este trabajo es la descripción de la metodología seguida en la asignatura Gestión de la Empresa Audiovisual del Grado en Comunicación Audiovisual, en el caso de la realización de prácticas, para la evaluación de algunas competencias del plan

\section{(c)) EY-NC-ND 2014, Universitat Politècnica de València}

I Jornadas IN-RED (2014) 
Adquisición de competencias realizando prácticas en la asignatura Gestión de la Empresa Audiovisual

de estudios relacionadas con las dimensiones competenciales de la Universitat Politècnica de València.

Para ello, explicamos el funcionamiento de las prácticas informáticas que se realizan en la asignatura y mostramos la consideración y evaluación de las dimensiones competenciales DC6 Trabajo en equipo y liderazgo, DC7 Responsabilidad ética y professional, y DC9 Pensamiento critico.

\section{Desarrollo de la innovación}

Gestión de la Empresa Audiovisual es una de las dos asignaturas obligatorias sobre Organización de Empresas que se imparten en el Grado en Comunicación Audiovisual del Campus de Gandia de la Universitat Politècnica de València.

En esta asignatura existe un núcleo de contenidos sobre estrategias empresariales, abarcando un amplio abanico de opciones como estrategias competitivas, de estabilidad y supervivencia, según sectores, fusion, absorción, adquisición, cooperación, internacionalización y diversificación. Un resumen de estos contenidos se puede ver en Canós et al. (2013a; 2013b). Estos conceptos se completan con la vision del empresario actual, la definición de empresa audiovisual (Canós et al. 2012b) y con el ajuste de los sistemas de información empresariales y los recursos humanos a la estrategia (Canós et al. 2012a).

Las prácticas, en las que los alumnos disponen de equipamiento informático pretenden cubrir las siguientes competencias específicas del plan de estudios:

- $\mathrm{CG05(G)} \mathrm{Fomentar} \mathrm{el} \mathrm{trabajo} \mathrm{en} \mathrm{equipo}$

- $\quad$ 08(E) Liderar un equipo audiovisual

- 09(E) Respetar la ética y la deontología profesional

Las dos primeras se corresponden claramente con la dimensión competencial DC6 Trabajo en equipo y liderazgo, mientras que la tercera se puede reflejar en DC7 Responsabilidad ética y profesional. Incluimos DC9 Pensamiento crítico en nuestro planteamiento porque en las prácticas proponemos, como mínimo, una pregunta de opinión personal razonada sobre los problemas y oportunidades que los estudiantes pueden encontrar según el tema tratado.

Las prácticas se realizan en una aula de informática preparada con ordenadores con conexión a Internet y, al final de cada práctica, los alumnos han de entregar un informe con su trabajo en el espacio compartido que cada uno tiene en PoliformaT. Para trabajar, los estudiantes forman equipos de dos o tres personas agrupadas libremente que pueden ser permanentes durante el semestre o cambiar en cada sesión. 
Los contenidos de las prácticas son los siguientes:

- P1.- Enseñanzas de cine. Sobre la base de un texto en el que se resumen los argumentos de algunas películas relacionadas con conceptos del mundo empresarial, los estudiantes han de identificar distintos conceptos empresariales y definirlos con sus propias palabras. En una última pregunta, ellos mismos han de pensar algunos ejemplos de series de TV o películas distintas a las del texto y realizar el mismo análisis. Esta práctica permite, por una parte, recordar lo básico aprendido en la asignatura del curso anterior (Organización de empresas) y, por otra, introducirse en la forma de trabajo que se seguirá durante todo el semestre (trabajo en equipo y realizar aportaciones propias).

- P2.- Grupos empresariales audiovisuales españoles. Utilizando un caso sobre Publicaciones Lonely Planet extraído de un libro académico los estudiantes han de responder a diferentes preguntas, algunas sobre el mismo texto y otras que se pueden responder con información extraida de la web de la editorial. Después, relacionamos la empresa con los grupos empresariales y los alumnos elaboran una tabla indicando las empresas que conforman los más importantes a nivel nacional (Atresmedia, Godó, Mediaset, Prisa, Unidad Editorial, Vocento), viendo su composición y las diferencias que existen entre ellos. Para obtener la información los alumnos han de descubrir por sí mismos cómo localizar y navegar por las páginas de los grupos empresariales.

- P3.- La industria audiovisual actual. Los estudiantes han de buscar datos (oferta y demanda) y ejemplos de empresas líderes para los dos últimos años sobre la edición de libros, la industria discográfica, la industria cinematográfica, la prensa diaria y periódica, la radio, la televisión y los videojuegos. Normalmente el ámbito de búsqueda es nacional, aunque en el caso de los videojuegos es lógico encontrar información a nivel internacional por ser un mercado globalizado. Para que los estudiantes no divaguen, se proponen una serie de ítems (no es obligatorio localizarlos todos) para cada industria. Así mismo, se les indica el interés de los informes del Estudio General de Medios y OJD que pueden encontrar en la web y que aglutinan datos de diferentes subsectores. Una vez tienen una visión panorámica de la industria audiovisual, han de responder si estas industrias son rentables o no y esgrimir sus argumentos. Con esta práctica los estudiantes aprenden a seleccionar datos, a sintetizarlos y a interpretarlos. Por supuesto, no se pretende obtener un análisis exhaustivo de cada industria, simplemente se pide una opinión justificada de cómo está el mercado en cada caso.

- P4.- La industria de la televisión. En esta práctica se profundiza en una de las industrias anteriores, en este caso, la televisión. Los estudiantes han de decidir antes que nada a qué nivel quieren hacer su análisis: local-regional, nacional o

\section{(c)) EY-NC-ND 2014, Universitat Politècnica de València}

I Jornadas IN-RED (2014) 
Adquisición de competencias realizando prácticas en la asignatura Gestión de la Empresa Audiovisual

internacional. Tomada esta decisión, se propone identificar quiénes son los principales agentes (productores, cadenas de televisión, competencia, espectadores, clientes y consumidores, etc.) y las principales características de esta industria (diferentes ofertas de televisión). Para ello, los estudiantes utilizan Internet. Igual que en el caso de la práctica anterior, se hace énfasis en la importancia de citar las fuentes consultadas, y en este informe, se exige como mínimo la consulta de 7 fuentes diferentes para que no obtengan sus resultados de una misma web. A la luz de los recientes acontecimientos ocurridos en la Comunidad Valenciana les preguntamos: ¿Cómo crees que afecta la desaparición del Grupo RTVV a la industria de la televisión valenciana? En su respuesta han de alegar al menos un aspecto negativo derivado de este suceso y otro positivo, de modo que usen el pensamiento crítico.

- P5.- Análisis de una empresa audiovisual. Consiste en realizar un informe sobre una empresa que eligen los estudiantes. Anteriormente han visto la conformación de la industria audiovisual y han tomado contacto con empresas que pueden ser de su interés; este es el momento de profundizar en una de ellas. El informe ha de ser estructurado en los siguientes apartados: Introducción; Análisis de las estrategias de programación o contenido (negocio de la empresa); Análisis de las estrategias implementadas en el tiempo (recordemos que este es el núcleo de la asignatura); Análisis de los recursos humanos; Conclusiones (opinar sobre los resultados anteriores). Sobre las referencias, han de usar al menos tres webs, aparte de la oficial de la empresa donde, obviamente, encuentran la mayor parte de la información, para contrastar la veracidad de la imagen que la empresa pretende transmitir.

En particular, esta última práctica se completa con una exposición oral ante toda la clase siguiendo la técnica elevator pitch. Con este método, la presentación la realiza un representante o todos los miembros del equipo (es decisión del grupo) en cinco minutos como máximo y consiste en contar al resto de compañeros las características más relevantes de la empresa (no hay que preparar transparencias ni material adicional) y las conclusiones obtenidas.

\section{Resultados}

La calificación de las prácticas de Gestión de la Empresa Audiovisual es, como máximo, el $30 \%$ sobre la nota final. Cada práctica y la exposición oral se evalúan sobre 0,5 puntos $(6 * 0,5=3)$. Para imponer la calificación, el profesor considera la calidad del informe y si está completo (responden a todas las preguntas planteadas). Además, se hace hincapié en la forma de citar información secundaria y en evitar el plagio, calificando ex profeso la 
inclusión de las referencias consultadas por Internet y la estructuración de la información. También se califica en la presentación oral la originalidad (los alumnos de Comunicación Audiovisual son muy creativos), la comunicación verbal y la no verbal. La calificación de cada práctica puede ser revisada por los alumnos si lo consideran oportuno, así como la calificación total.

En esta calificación se incluye la evaluación de las competencias específicas y las dimensiones competenciales de la Universidad. No se establece una calificación concreta puesto que todavía es pronto para conocer si a esta asignatura se le asigna un punto de control para alguna de las competencias tratadas, pero se tienen en cuenta para la calificación global de la práctica. La relación entre cada una de las prácticas y las competencias específicas y dimensiones competenciales asociadas puede verse en la Tabla 2 .

Tabla 2. Relación entre las prácticas de la asignatura, competencias específicas del Grado y dimensiones competenciales de la Universidad

\begin{tabular}{|c|c|c|}
\hline $\mathrm{P} 1$ & $\begin{array}{l}\text { CG05(G) Fomentar el trabajo en equipo } \\
\text { 08(E) Liderar un equipo audiovisual }\end{array}$ & DC6 Trabajo en equipo y liderazgo \\
\hline $\mathrm{P} 2$ & $\begin{array}{l}\text { CG05(G) Fomentar el trabajo en equipo } \\
\text { 08(E) Liderar un equipo audiovisual }\end{array}$ & DC6 Trabajo en equipo y liderazgo \\
\hline P3 & $\begin{array}{l}\text { CG05(G) Fomentar el trabajo en equipo } \\
\text { 08(E) Liderar un equipo audiovisual } \\
\text { 09(E) Respetar la ética y la deontología } \\
\text { profesional }\end{array}$ & $\begin{array}{l}\text { DC6 Trabajo en equipo y liderazgo } \\
\text { DC7 Responsabilidad ética y profesional } \\
\text { DC9 Pensamiento crítico }\end{array}$ \\
\hline $\mathrm{P} 4$ & $\begin{array}{l}\text { CG05(G) Fomentar el trabajo en equipo } \\
\text { 08(E) Liderar un equipo audiovisual } \\
\text { 09(E) Respetar la ética y la deontología } \\
\text { profesional }\end{array}$ & $\begin{array}{l}\text { DC6 Trabajo en equipo y liderazgo } \\
\text { DC7 Responsabilidad ética y profesional } \\
\text { DC9 Pensamiento crítico }\end{array}$ \\
\hline P5 & $\begin{array}{l}\text { CG05(G) Fomentar el trabajo en equipo } \\
\text { 08(E) Liderar un equipo audiovisual } \\
\text { 09(E) Respetar la ética y la deontología } \\
\text { profesional }\end{array}$ & $\begin{array}{l}\text { DC6 Trabajo en equipo y liderazgo } \\
\text { DC7 Responsabilidad ética y profesional } \\
\text { DC9 Pensamiento crítico }\end{array}$ \\
\hline
\end{tabular}

Podemos ver que en las dos primeras prácticas se introduce la forma de trabajo en equipo y liderago. La primera sirve de presentación y en la segunda se refuerza la dimensión competencial DC6, que seguirá con la misma dinámica hasta el final del semestre.

En la tercera práctica se introduce la DC7 Responsabilidad ética y profesional y DC9 Pensamiento crítico. Observamos si los estudiantes trabajan la DC7 a través del tratamiento de la información que hacen para presentar su trabajo y en la referencia de trabajos o webs utilizadas, pues la no citación de alguna fuente consultada puede ser considerada como un plagio y, máxime en la industria audiovisual en la que son importantes los derechos de

\section{(c)) EY-NC-ND 2014, Universitat Politècnica de València}

I Jornadas IN-RED (2014) 


\section{Adquisición de competencias realizando prácticas en la asignatura Gestión de la Empresa Audiovisual}

autor y la propiedad intelectual, los alumnos han de aprender a actuar correctamente. De este modo, el profesor al corregir la práctica comprueba si el contenido del informe de los alumnos está justificado con las citas y referencias que incluyen. Esta forma de trabajar se mantiene para las prácticas 4 y 5 , exigiendo en éstas un número específico de referencias o un tipo de referencias concretas en cada caso (ver una descripción más precisa en la definición de las prácticas).

Por otra parte, la DC9 Pensamiento crítico se fomenta con las preguntas de opinión que existen en las prácticas 3, 4 y 5. Los alumnos son absolutamente libres de contestar cualquier tipo de opinión, siempre que esté justificada y apoyada por la redacción del informe que entregan. Si esto se cumple y las ideas están expresadas correctamente, entendemos que los estudiantes del grupo han alcanzado la DC9 Pensamiento crítico.

En cualquier caso, la calificación de cada práctica incluye la consideración de las tres DC que se trabajan en la asignatura en cada nota particular, pues el desarrollo del propio trabajo y su corrección a través de los contenidos significa la adquisición de estas competencias. Queda por determinar si en el futuro se va a utilizar algún sistema de evaluación diferente (reglado o no) en el Grado en Comunicación Audiovisual, consensuado y coordinado con todos los profesores del título.

\section{Conclusiones}

Los resultados en general son positivos para los estudiantes, pues reconocen que la forma en la que se busca, identifica, selecciona y sintetizan la información en cada práctica les ayuda a saber como se organiza un informe. Hay que reconocer que al principio pueden resultar perdidos por no adaptarse a la metodología, pero con el paso de las semanas los propios alumnos son conscientes de que han aprendido una nueva forma de trabajar que es eficaz. También cabe destacar la libertad que tienen para realizar su informe. Aunque en las primeras prácticas preguntan qué tienen que escribir, dónde encontrar la información, qué datos buscar, etc., se acostumbran a pensar y a decidir de forma autónoma sobre los contenidos de su trabajo a medida que transcurre el semestre.

Otro resultado favorable proviene de la exposición usando la técnica elevator pitch. Sus esquemas se rompen cuando ven que no han de usar ningún tipo de apoyo audiovisual y que es imprescindible respetar el tiempo máximo de cinco minutos para contar su trabajo al resto de la clase. En la mayoría de asignaturas les enseñamos a hacer presentaciones orales usando un apoyo (power point, prezi, etc.), pero aquí se han de enfrentar a la audiencia desnudos, sólo con sus palabras y gestos. Para ellos es algo muy novedoso, de forma que aprenden una nueva forma de presentación de ideas. 
Esperamos recibir más retroalimentación de los alumnos sobre las prácticas realizadas al finalizar el semestre, cuando tengan una visión completa de lo que es la asignatura. En cursos anteriores la respuesta ha sido positiva y, aunque durante el desarrollo de las clases algunos alumnos han manifestado su disconformidad con respecto a la forma de realizar los informes finales porque les supone una novedad para la organización de su trabajo, al acabar el curso han comentado que esta metodología les resulta útil también para futuros trabajos, como el Trabajo Final de Grado. Algunos alumnos ya graduados de promociones anteriores han comentado que esta forma de enseñanza les ha ayudado en su vida laboral, pues han recordado las técnicas de búsqueda, redacción y presentación de la información que aprendieron en la asignatura.

\section{Agradecimientos}

PIME A16/12. Análisis comparativo de competencias en los nuevos grados. Universitat Politècnica de València.

\section{Referencias}

Canós Darós, L.; Pons Morera, C.; Santadreu Mascarell, C. (2013a). Estrategias de crecimiento y estrategias de cooperación en la empresa audiovisual. Riunet. < http://hdl.handle.net/10251/30059> [Consulta: 3 de junio de 2014].

Canós Darós, L.; Pons Morera, C.; Santadreu Mascarell, C. (2013b). Estrategias competitivas en la empresa audiovisual. Riunet. < http://hdl.handle.net/10251/30058> [Consulta: 13 de junio de 2014]

Canós Darós, L.; Santadreu Mascarell, C.; Maheut, J.P.D.; Valero Herrero, M. (2012a). Introducción a las políticas de gestión de recursos humanos. Riunet. < http://hdl.handle.net/10251/16495> [Consulta: 29 de mayo de 2014].

Canós Darós, L.; Santadreu Mascarell, C.; Pons Morera, C.; Maheut, J.P.D. (2012b). Funciones de los empresarios actuales y caracterización de la empresa. Riunet. < http://hdl.handle.net/10251/16501> [Consulta 10 de junio de 2014].

LE BOTERF, G. (2001). Ingeniería de las competencias. Barcelona: Gestión 2000.

MinISTERIO DE EDUCACIÓN Y CIENCIA (2003). La integración del sistema universitario español en el Espacio Europeo de Educación Superior (documento marco).

Santandreu Mascarell, C.; Canós Darós, L. (2011). "Las competencias profesionales en la docencia universitaria". Jornada de Innovación Docente ICE-UPV. Valencia.

\section{(c)) EY-NC-ND 2014, Universitat Politècnica de València}

I Jornadas IN-RED (2014) 


\title{
Innovación y su evaluación en la enseñanza universitaria
}

\author{
$\mathrm{M}^{\mathrm{a}}$ Ángeles Andreu-Andrés ${ }^{\mathrm{a}}$, Amparo García-Carbonell $^{\mathrm{b}}$ y Frances Watts
}

Dpto. de Lingüística Aplicada, Universitat Politècnica de València maandreu@idm.upv.es ${ }^{\mathrm{a}}$

Dpto. de Lingüística Aplicada, Universitat Politècnica de València agarciac@upvnet.upv.es ${ }^{\text {b }}$ Dpto. de Lingüística Aplicada, Universitat Politècnica de València fwatts@upv.es ${ }^{\mathrm{c}}$

\begin{abstract}
The changes that are taking place in higher education compel universities to provide students not only with knowledge, skills and attitudes but also with competences that can foster their professional success. The IEMA-UPV group, since it set forth on the complicated field of active learning assessment, has focused its interest on different aspects that merge into this type of learning and its assessment such as team working or innovation, central axis of the INCODE European project.

Once a teaching methodology is implemented, assessment must test whether the goals pursued have been achieved. This paper presents the steps followed during the first phase of construction of the scoring rubric or INCODE Barometer, intended to aid in the development and assessment of innovation competence.

This phase reaches the first five steps addressed by defining the innovation competence, identifying and describing behaviours that underline the construct, developing an initial instrument as well as piloting tests with the initial instrument in order to enhance its design and carry out new tests of the revised instrument.
\end{abstract}

Keywords: Innovation, competence, assessment, barometer, rubric, higher education 


\begin{abstract}
Resumen
Los cambios que se están llevando a cabo en la enseñanza superior obligan a las universidades a dotar a sus estudiantes no solo de conocimientos, destrezas y actitudes sino de competencias que favorezcan su éxito profesional. El grupo IEMA de la UPV, desde que emprendió su andadura en el intrincado terreno de la evaluación del aprendizaje activo, ha centrado su interés en diferentes aspectos que confluyen y derivan en dicho aprendizaje y su evaluación tales como el trabajo en grupo o la innovación, siendo esta última el eje central del proyecto europeo INCODE.
\end{abstract}

Una vez empleada una metodología se ha de comprobar a través de la evaluación si los logros perseguidos se han alcanzado y ratificar así el éxito de ésta. Este trabajo presenta los pasos seguidos en la primera fase de construcción del instrumento de evaluación o barómetro INCODE, diseñado con el objetivo de valorar la competencia de innovación y ayudar a fomentar su desarrollo.

Esta fase comprende las cinco primeras etapas en las que se define la competencia de innovación, se identifican y describen las pautas de comportamiento que son la base de tal competencia, seguido de un desarrollo inicial del instrumento, así como pruebas realizadas para alcanzar una mejora del diseño junto con nuevos tests del instrumento revisado.

Palabras clave: innovación, competencia, evaluación, barómetro, rúbrica, enseñanza universitaria

\title{
Introducción
}

Los cambios que se están llevando a cabo en la enseñanza superior dentro y fuera de nuestras fronteras obligan a las universidades a centrarse menos en un enfoque tradicional basado, fundamentalmente, en la transmisión de conocimiento a fin de dotar a sus estudiantes no solo de conocimientos, destrezas y actitudes sino también de competencias (Gillies y Howard, 2003). Unas competencias que las propias empresas empiezan a exigir a sus posibles empleados (García-Carbonell et al., en prensa) y que se pueden definir, según Villa y Poblete (2007:21), como "el buen desempeño en contextos diversos y auténticos basado en la integración y activación de conocimientos, normas, técnicas, procedimientos, habilidades y destrezas, actitudes y valores"; un saber hacer complejo resultado de la 
integración y adaptación de capacidades y destrezas a situaciones de características similares (Fernández-March, 2010; Lasnier, 2000) que permiten al individuo actuar por medio de una combinación eficaz de recursos internos y externos (Marin-García et al., 2013).

De igual modo, el interés empresarial por profesionales capaces de innovar está guiando a las universidades hacia un cambio de paradigma que tiene como retos no solo el perfilar los ingredientes de dichas competencias, sino una enseñanza-aprendizaje que permita su desarrollo y posterior evaluación en los futuros egresados. Un interés, la innovación, que lleva consigo significados diferentes para cada interlocutor y que puede definirse como la introducción de algo radicalmente nuevo, bien sea una idea, un método, un instrumento o una invención, o bien la mejora de algo existente, útil para las personas y las organizaciones que satisface sus necesidades (Watts et al., 2013).

De ese modo, entendemos que una educación superior, propia de una universidad politécnica, que proporciona conocimiento para ser aplicado de manera innovadora más tarde en la vida laboral, debe ir dejando paso a la pedagogía de la innovación. Se trata de una estrategia de enseñanza-aprendizaje, lanzada por la Universidad de Ciencias Aplicadas de Turku (TUAS) en Finlandia (Kettunen, 2011), capaz de ofrecer ambientes de aprendizaje activo en los que se combinan diferentes maneras de saber hacer que desemboquen en ideas, productos o servicios innovadores aplicables al mundo de la empresa. Está basada fundamentalmente en el pragmatismo de Dewey (1925), el aprendizaje experiencial de Kolb (1984), el modelo de adquisición de destrezas a través de la experiencia de Dreyfus (Dreyfus y Dreyfus, 1986) — con sus cinco etapas de desarrollo- y el aprendizaje a través del desarrollo de proyectos (Raij, 2007), entre otros. Su principal objetivo se centra en la creación de innovaciones reales durante el proceso de aprendizaje al tiempo que contribuye al desarrollo de destrezas innovadoras (KairistoMertanen, Kanerva-Lehto y Penttilä, 2009.)

El grupo IEMA (Innovación en la Evaluación para la Mejora del Aprendizaje Activo) de la Universitat Politècnica de València (UPV), desde que emprendió su andadura en el intrincado terreno de la evaluación del aprendizaje activo, ha centrado su interés en diferentes aspectos que confluyen y derivan en dicha enseñanza-aprendizaje y su evaluación tales como el trabajo en grupo o la innovación, siendo esta última el eje central del proyecto europeo INCODE (Desarrollo de Competencias de Innovación) ${ }^{1}$ en el que ha colaborado durante los últimos tres años con TUAS y otras dos universidades europeas para

1

Unión Europea 518132-LLP-1-2011-1-FI-ERASMUS-FEXI

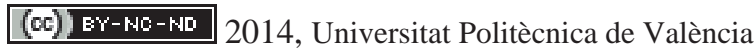

I Jornadas IN-RED (2014) 
definir y crear un instrumento de evaluación de competencias para la innovación: el Barómetro INCODE.

Una vez empleada una metodología se ha de comprobar a través de la evaluación si los logros perseguidos se han alcanzado y ratificar así el éxito de ésta. Este trabajo presenta los pasos seguidos en la primera fase de construcción del instrumento de evaluación o barómetro INCODE, diseñado con el objetivo de valorar la competencia de innovación y ayudar a fomentar su desarrollo, de acuerdo con las diez etapas descritas para el diseño por Onwuegbuzie et al. (2010).

\section{Hacía el barómetro}

De esas diez etapas de diseño, este trabajo recoge las cinco primeras; en ellas se define la competencia de innovación, se identifican y describen las pautas de comportamiento que son la base de tal competencia, seguido de un desarrollo inicial del instrumento, así como los tests realizados para alcanzar una mejora del diseño junto con nuevas pruebas del instrumento revisado. Con la finalidad de completar los cinco pasos restantes, los resultados obtenidos se completarán con los datos que se obtengan a través de la experimentación con estrategias, dentro de la pedagogía de la innovación, como son las Research Hatcheries (Kanerva-Lehto et al. 2011; Räsänen y Kyllönen, 2013) que combinan aprendizaje, innovación e investigación.

\subsection{Etapa primera}

Tras una pormenorizada revisión de la literatura a fin de identificar las posibles destrezas asociadas a las competencias de innovación y su importancia relativa al comportamiento innovador, éstas se agrupan según el modelo de Lehto et al. (2011), Penttilä and KairistoMertanene (2012) y Watts et al. (2012) de acuerdo con tres dimensiones: individual, interpersonal y red. Dicha revisión de la literatura se complementa con entrevistas en profundidad con tres directores de Recursos Humanos de tres compañías diferentes conocidas por su innovación.

La dimensión individual está directamente relacionada con la creatividad, la perseverancia, la asunción de riesgos y la actitud personal, aspectos relacionados con la innovación. La dimensión interpersonal gira en torno al liderazgo y la comunicación mientras que la de red está íntimamente relacionada con los valores éticos y la responsabilidad social además del trabajo colaborativo con personas de otras culturas y procedencias y la habilidad para crear una red de contactos. 


\subsection{Etapas segunda y tercera}

Para determinar y describir los comportamientos que subyacen en cada una de las dimensiones y desarrollar un instrumento inicial de evaluación o barómetro, en la segunda y tercera etapa dichos comportamientos se ampliaron tras el trabajo realizado en grupos de discusión con doce investigadores en el campo, teniendo en cuenta las once competencias genéricas definidas por la organización no gubernamental dedicada a la acreditación de programas de educación universitaria en ciencias aplicadas, de computación e ingenierías y tecnología ABET (Accreditation Board for Engineering and Technology); todas ellas adoptadas a iniciativa de la OCDE (Organización para la Cooperación y Desarrollo Económico) para la evaluación de los resultados de aprendizaje en la educación superior (AHELO) y descritas por múltiples autores como Passow (2012), Andreu-Andrés y GarcíaCasas (2014), Villa y Poblete (2007), Marin et al. (2011) o Montero-Fleta (2012).

\subsection{Etapas cuarta y quinta}

En la fase de pilotaje del instrumento inicial, cuarta etapa, un primer listado de treinta y nueve comportamientos fue analizado y revisado por veinte académicos con experiencia en evaluación y, posteriormente, comentado y filtrado por diecinueve evaluadores. Teniendo en cuenta la calidad y funcionalidad de los criterios, el listado fue reducido a veinticinco; de ellos doce correspondían a la dimensión individual, ocho a la interpersonal y cinco a la de red.

En la última etapa de esta primera fase, diecinueve evaluadores de diferentes campos y de manera simultánea participaron en la evaluación experimental de un vídeo en el que se mostraba el comportamiento de tres estudiantes que habían sido puestos ante una situación que requería una muestra de innovación para poder resolver un problema. Los evaluadores tenían tres opciones entre las que elegir en cada uno de los comportamientos: sí se ha observado el comportamiento, no se ha observado o no aplicable (n/a) si no se tenía evidencia de tal conducta. En esa evaluación se obtuvo un total de cincuenta y siete valoraciones. El análisis descriptivo de las puntuaciones y de aquellos comportamientos que se dejaron en blanco, y que se contabilizaron como ausentes, dio lugar a un filtrado tanto de evaluadores como de conductas.

Los análisis de correspondencia múltiple identificaron posibles agrupaciones de variables de acuerdo con su frecuencia; la técnica analiza las relaciones entre las diferentes categorías de variables y ofrece como resultado un diagrama de dos dimensiones en el que la posición de cada variable es esencial ya que la proximidad entre ellas indica relación o asociación entre categorías de variables, mientras que la distancia muestra una falta de relación o

(cc) EY-NC-ND 2014, Universitat Politècnica de València

I Jornadas IN-RED (2014) 
asociación. Para estudiar con detalle estos resultados se recomienda la lectura de Watts et al. (2012).

\section{Conclusiones}

De los resultados de los análisis realizados se desprende la existencia de diferencias entre las tres categorías, individual, interpersonal y de red, si bien en este estadio del estudio deben interpretarse con cautela al tratarse de una experiencia piloto con una única grabación. La falta de puntuaciones en algunos comportamientos y el hecho de que se recurra a la opción n/a muestra con claridad la necesidad de entrenar a los evaluadores antes de utilizar el barómetro.

Los siguientes pasos han de dirigirse hacia nuevas pruebas de campo tanto con estudiantes como con evaluadores de diferentes procedencias y lenguas a fin de poder completar la validación del instrumento.

Los resultados obtenidos en esta primera fase de la construcción del barómetro así como en la validación han de completarse en una última etapa con los datos que se obtengan para evaluar tanto el proceso como el producto a través de la experimentación en el aula por medio de la implementación de la metodología de enseñanza-aprendizaje acuñada como Research Hatchery.

\section{Referencias}

ANDREU-ANDRÉS, Ma Á. y García-Casas, M. (2014). Evaluación del pensamiento crítico en el trabajo en grupo. Revista de Investigación Educativa, 32(1), 203-222.

DEWEY, J. (1925). Experience and nature. LaSalle. IL: Open Court.

DREYFUS, H. L., y DREYFUS, S. E. (1986). Mind over machine: The power of human intuition and expertise in the age of the computer. Oxford: Basil Blackwell

FERNÁNDEZ-MARCH, A. (2010). La evaluación orientada al aprendizaje en un modelo de formación por competencias en la educación universitaria. Revista de Docencia Universitaria, $8(1), 11-34$.

GARCÍA-CARBONELL, A., ANDREU-ANDRÉS, Ma Á. y WATTS, F. (en prensa). "Simulation and Gaming as the future's language of languages for professional competences acquisition" en Back to the Future of Gaming.

GILLIES, A. y HOWARD, J. (2003), Managing change in process and people. TQM and Business Excellence, 14(7), 797-805. 
KAIRISTO-MERTANEN, L., KANERVA-LEHTO, H. y PENTTILÄ, T. (2009). Reports from Turku University of Applied Sciences 92. Turku: University of Applied Sciences.

KANERVA-LEHTO, H., LEHTONEN, J., JOLKKANEN, A. y RIIHIRANTA, J. (2011). "Research Hatchery. A concept for combining learning, developing and research" en Lehto. KairistoMertanen y Penttlilä, Towards Innovation Pedagogy. A New Approach to Teaching and Learning for Universities of Applied Sciences. Reports 100. Turku: University of Applied Sciences, 26-34. http://julkaisut.turkuamk.fi/isbn9789522161697.pdf [Consulta: 3 de junio de 2014].

KETTUNEN, J. (2011). "Innovation Pedagogy for Universities of Applied Sciences" en Creative Education, 2(1), 56-62.

KOLB, D. (1984). Experiential learning: experience as the source of learning and development. Englewood Cliffs, NJ: Prentice Hall. http://academic.regis.edu/ed205/kolb.pdf [Consulta: 31 de mayo de 2014].

LEHTO, A., KAIRISTO-MERTANENE, L. y PENTTILÄ, T. (2011). Towards Innovation Pedagogy. A New Approach to Teaching and Learning for Universities of Applied Sciences. Reports 100. Turku: University of Applied Sciences.

MARIN-GARCÍA, J. A., AZNAR-MAS, L. E. y GONZÁLEZ-LADRÓN-DE-GUEVARA, F. (2011). "Innovation types and talent management for innovation". Working Papers on Operations Management, 2(2), 25-31.

MARÍN-GARCÍA, J.A., PÉREZ-PEÑALVER, Ma J. y WATTS, F. (2013). "How to assess innovation competences in services: The case of university students". Dirección y Organización, 50, 48-62. http://www.revistadyo.com/index.php/dyo/article/view/431 [Consulta: 3 de junio de 2014].

MONTERO-FLETA, B. (2012). "Looking beyond linguistic outcomes: active learning and professional competencies in higher education”. Procedia-Social and Behavioral Sciences, 46, 1812-1819.

ONWUEGBUZIE, A. J., BUSTAMANTE, R. M., NELSON, J. A. (2010). "Mixed Research as a Tool for Developing Quantitative Instruments". Journal of Mixed Methods Research, 4(1), 56-78.

PASSOW, H. J. (2012). "Which ABET competencies do engineering graduates find most important in their work?" Journal of Engineering Education, 101(1), 95-118.

PENTTILÄ, T. y KAIRISTO-MERTANENE, L. (2012). "Innovation competence barometer ICB - a tool for assessing students' innovation competences as learning outcomes in higher education". INTED2012 Conference. 5-7 marzo 2012, 6347-6351.

RAIJ, K. (2007). Learning by developing. Laurea Publications, A 58. Helsinki: Edit Prima.

http://esdhweb.ucl.dk/133272.Learning\%20by\%20Developing,\%20artikel\%20Katarina\%20Raij.pdf [Consulta: 1 de junio de 2014].

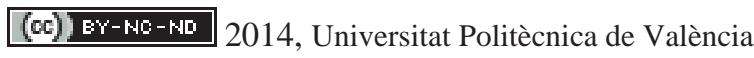

I Jornadas IN-RED (2014) 
RÄSÄNEN, M. y KYLLÖNEN, A. Eds. (2013). Research Hatchery as a Cradle for New Innovators. Handbook for Implementation. Turku: Turku University of Applied Sciences. http://julkaisut.turkuamk.fi/isbn9789522164223.pdf [Consulta: 6 de junio de 2014].

VILLA, A. y POBLETE, M. (2007). Aprendizaje basado en competencias. Una propuesta para la evaluación de las competencias genéricas. Bilbao: Universidad de Deusto.

WATTS, F., GARCÍA-CARBONELL, A. y ANDREU-ANDRÉS, Ma Á. (2013). Innovation Competencies Development. INCODE Barometer and User Guide. Turku: Turku University of Applied Sciences. http://julkaisut.turkuamk.fi/isbn9789522164254.pdf [Consulta: 1 de junio de 2014].

WATTS, F., MARIN-GARCIA, J. A., GARCIA-CARBONELL, A. y AZNAR-MAS, L. E. (2012). "Validation of a rubric to assess innovation competence". Working Papers on Operations Management, 3(1), 61-70. 
Jornadas In-Red 2014

UniversitatPolitècnica deValència

\title{
Dedicación del alumnado, utilidad y adecuación de las tareas no presenciales
}

Antonio Peña Cerdán ${ }^{a}$, Carmina Gisbert Doménech ${ }^{b}$, Eva Antonino Daviuc, Alberto Palomares Chust $^{d}$, José Vicente Ballester Server ${ }^{\mathrm{e}}$, Juan Carlos Ruiz García ${ }^{\mathrm{f}}$, David de Andres Martínez ${ }^{\mathrm{g}}$ y Carlos Villavieja Llorente ${ }^{\mathrm{h}}$

aPARA-UPV, anpecer2@pra.upv.es, $\quad{ }^{\mathrm{b}} \mathrm{BTC}-\mathrm{UPV}, \quad$ cgisbert@btc.upv.es, $\quad{ }^{\mathrm{c} D C O M-U P V}$, evanda@upvnet.upv.es, ${ }^{\mathrm{d}}$ DSIC-UPV, apalomares@dsic.upv.es, ${ }^{\mathrm{e}}$ Universitat de València (UV), jvballester@ pros.upv.es, ${ }^{\mathrm{f} D I S C A-U P V}$, jcruizg@disca.upv.es, ${ }^{\mathrm{g}}$ DISCA-UPV, ddandres@ disca.upv.es

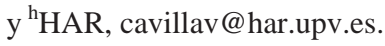

\begin{abstract}
In the framework of the Project for Innovation and Improvement in Education "Support for formative assessment by means of strategies for the collection of information and evidences about non-presential work" the EICE group TASCA studies different methodologies and tools for the collection of information about non-presential work carried out by the students with the purpose of improving the process of teaching and learning. This contribution discusses the importance achieved by non-presential work in the new plans of study, and presents the main goals and steps of the proposed innovation. Afterwards, details are provided about the tools designed for the collection of this information as well as the applied methodologies, and the derived results are analyzed. Finally, conclusions from the interpretation and reading of these analysis are presented.
\end{abstract}

Keywords: Non-presential work, tools, methodologies, feedback, formative assessment

\section{Resumen}

En el marco del Proyecto de Innovación y Mejora Educativa "Apoyo a la evaluación formativa mediante el uso de estrategias para la obtención de información y evidencias sobre el trabajo no presencial" el grupo EICE Tools and Strategies for Competences Assessment (TASCA) estudia distintas metodologías y herramientas para la obtención de información sobre el trabajo no presencial que realiza el alumno con el objeto de mejorar el

(c) BY-NC-ND 2014, UniversitatPolitècnica de València

I Jornadas In-Red (2014) 
proceso de enseñanza y aprendizaje. En esta contribución se describe el trabajo realizado en varios apartados. Primero, se describe y justifica la importancia que ha adquirido el trabajo no presencial en los nuevos planes de estudio, a continuación se explican los objetivos del proyecto planteado y las diferentes fases que se han seguido para su desarrollo, después se explican las herramientas diseñadas y las metodologías aplicadas según tipos de trabajos y actividades para conseguir esta información, analizando los resultados obtenidos. Por último, de la interpretación y lectura de dichos resultados se extraen unas conclusiones.

Palabras clave: trabajo no presencial, herramientas, dedicación, metodología, retroalimentación, evaluación formativa.

\section{Introducción}

Desde la entrada del Plan Bolonia como plan director de los estudios universitarios, el trabajo no presencial (fuera del aula) ha adquirido una importancia más relevante todavía en el proceso de enseñanza-aprendizaje. Sin embargo, esta aparente importancia parece que se ha traducido en muchas ocasiones en un rutinario y simple control cuantitativo, donde sólo se busca conocer el tiempo que el alumno dedica al trabajo fuera de clase, para saber si cumple con el tiempo asignado según el número de créditos de la asignatura. Por otra parte, con independencia del plan de estudios vigente, los trabajos no presenciales se han consolidado como una estrategia fundamental para la formación en competencias específicas y para el desarrollo de las capacidades de los alumnos, y por tanto, son un extraordinario instrumento para la evaluación continua y formativa (Mohanan, 2005).

Bajo el epígrafe general de "trabajo no presencial del alumno" se recogen demasiados parámetros con características muy diferentes que acaban perdiendo su singularidad e identidad y, por tanto, su valor específico. Así, este trabajo queda limitado a la presentación de determinados entregables evaluables y su control estadístico formalizado en el número de horas dedicadas. Sin embargo, el resto de parámetros intangibles no concretados en el entregable quedan perdidos en una especie de limbo del que no se tiene información ni evidencias y, por tanto, quedan fuera del proceso de control y evaluación.

Conocida la importancia del trabajo no presencial de los alumnos, resulta paradójico que exista tanta dificultad para conocer el trabajo no presencial real (no sólo el número de horas dedicadas) realizado por los alumnos, ya que en ocasiones no se dispone de suficientes evidencias que avalen dicho trabajo. En concreto, se plantean las incógnitas expuestas de forma esquemática en la Figura 1. 


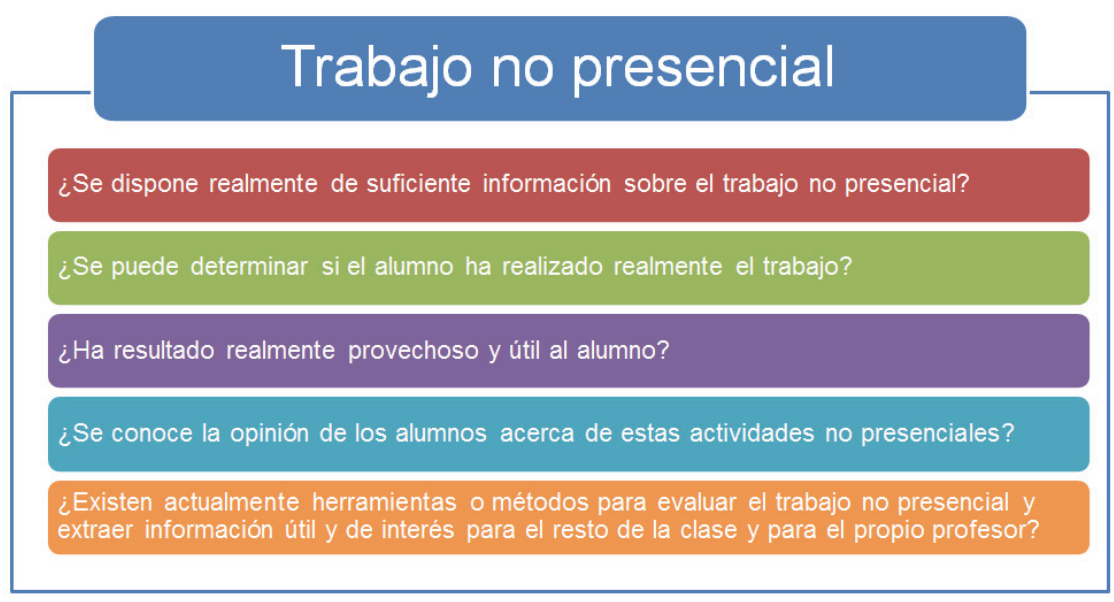

Fig. 1 Preguntas planteadas sobre el trabajo no presencial.

Obviamente, hay parte del trabajo no presencial que queda recogido en un documento, evidencia o resultado, el entregable a realizar. Sin embargo existe falta de información acerca de gran parte del trabajo no presencial más allá del resultado obtenido, como la organización y coordinación seguida (sobre todo si se trata de trabajo en equipo), la metodología utilizada para abordar la tarea (proceso), la dedicación del alumno para la consecución de la tarea, etc., de los que no existen pruebas físicas ni evidencias, pero que sería muy útil conocer para mejorar y completar el proceso de evaluación formativa y aumentar la retroalimentación proporcionada a los alumnos (Bain, 2005).

\section{Objetivos}

Uno de los objetivos iniciales de la innovación planteada es analizar la posibilidad de emplear diferentes herramientas tecnológicas existentes para obtener información y evidencias sobre el trabajo no presencial de los alumnos, y para guiar a los alumnos en la consecución de los objetivos docentes de la asignatura.

Con este objetivo en mente se ha realizado un estudio de las herramientas tecnológicas institucionales disponibles y de otras herramientas abiertas accesibles a través de Internet, que permitan recoger la mayor cantidad de información posible sobre el trabajo no presencial realizado, para así evaluarlo de una manera coherente y apropiada (Biggs, 2006). El conjunto de herramientas seleccionado debe tener como finalidad facilitar, recoger, analizar y gestionar las evidencias del trabajo no presencial:

- Pruebas concretas del trabajo no presencial, incluidas las que no se materializan en un entregable

- Estimación real y sincera del tiempo dedicado a este trabajo

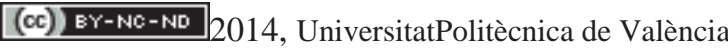

I Jornadas IN-RED (2014) 
- Análisis de la carga de trabajo de los alumnos

- Opinión de los alumnos sobre la actividad propuesta, grado de utilidad y satisfacción

- Información sobre el proceso de trabajo y no sólo del resultado obtenido

Con todo ello se intenta unificar y dotar de coherencia a todo el proceso de enseñanzaaprendizaje, eliminando la gran barrera existente entre la evaluación, seguimiento y retroalimentación del trabajo presencial y no presencial (Ramsdem, 1992). Los beneficios que esta aproximación puede proporcionar tanto a alumnos como profesores incluyen:

- Mayor retroalimentación para los alumnos acerca del trabajo realizado, incluyendo la organización y proceso, no solo el resultado.

- Retroalimentación para el profesor a través de las opiniones y sugerencias de los alumnos, lo que permitirá adaptar y mejorar las clases y el trabajo tanto presencial como no presencial.

- Estimulación del trabajo reflexivo y de la capacidad de análisis y crítica de los alumnos.

- Generación de un trabajo más activo, dinámico y participativo fuera del aula, que podría continuar de una forma muy natural y fluida dentro de la misma

- Aumento de la motivación del alumno.

El objetivo principal de la innovación, desde el punto de vista docente, consiste en el análisis, aplicación y posterior evaluación, de metodologías y estrategias docentes que, basadas en la evaluación continua y formativa, sean capaces de evaluar, en todas sus componentes, el trabajo no presencial realizado por los estudiantes. Así, será posible gestionar e incorporar la información y los resultados obtenidos de una manera natural a la dinámica de las clases presenciales, aumentando la motivación, la participación y la retroalimentación del alumnado, generando una mayor flexibilidad con el objeto de conseguir que los alumnos aprendan mediante el procedimiento que mejor funcione (Barr, 1995). Con toda la información generada:

- Se incorpora el trabajo no presencial a la dinámica general del curso.

- Se determina qué actividades han sido las más adecuadas para los diferentes objetivos docentes planteados.

- Se evalua el grado de consecución de los objetivos de aprendizaje por parte de los alumnos.

- Se conoce la motivación y satisfacción de los alumnos con el trabajo no presencial.

(cc) BY-NC-ND 2014, UniversitatPolitècnica de València 
- Se puede ajustar y modificar el ritmo en el aula y las actividades presenciales en función de la información obtenida (Melmer, 2008).

\section{Desarrollo de la innovación}

La innovación planteada se ha ido desarrollando en varias fases, que se enumeran a continucación:

Fase 1. Estado del arte: Se ha realizado una búsqueda de información y bibliografía que recogiera los aspectos más importantes que pudieran interesar para desarrollar y definir posteriormente el enfoque dado a la innovación, incluso para replantear los objetivos inicialmente propuestos. Fundamentalmente, la búsqueda de información y documentación se ha centrado en dos apartados, considerados prioritarios por ser objetivo principal del proyecto:

- Bibliografía sobre el trabajo no presencial y distintos tipos de herramientas y procesos pedagógicos para controlarlo y cuantificarlo.

- Búsqueda, análisis y selección de herramientas tecnológicas web que permitieran integrar la obtención de información sobre el trabajo no presencial con las tecnologías web habituales.

En un planteamiento inicial se pensó en el uso de herramientas similares a las que se utilizan en las empresas para el "control de tareas" de un proyecto. Existen herramientas que permiten dar de alta proyectos, tareas, asignar personas, imputar horas, validar horas, etc., que normalmente están integradas con las herramientas de Gestión de Proyectos. Muchas de estas herramientas son de pago, aunque también hay herramientas libres (TRAC, REDMINE, etc.) que se podrían emplear para la innovación. No obstante, estas herramientas suelen ser complejas de manejar y pueden dificultar mucho la recogida de la información, por lo que nos decantamos por usar herramientas más sencillas.

Fase 2. Diseño de herramientas pedagógicas. Para obtener y analizar la información sobre el trabajo no presencial se han elaborado modelos de cuestionarios y hojas Excel de control y seguimiento. Según los criterios establecidos por el profesor, la asignatura o el tipo de actividad o trabajo a realizar por el alumnado, estas herramientas se han ido adaptando y modificando en función de las diferentes aplicaciones que se han considerado oportunas. Se pueden clasificar en dos grupos:

- Cuestionarios incluidos en la propia actividad a realizar: que incluyen preguntas, opiniones y comentarios críticos sobre la actividad realizada, y donde se incluyen las preguntas sobre el tiempo y el esfuerzo dedicado a la actividad, su idoneidad y oportunidad y utilidad. Estos cuestionarios se entregan con la propia actividad, y

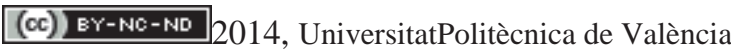

I Jornadas IN-RED (2014) 
se han aplicado tanto en actividades cortas (una semana), como en trabajos de prácticas de mayor duración (4-5 semanas).

- Hojas de cálculo tipo "Excel" para conocer la dedicación del alumno a la asignatura fuera de las horas de clase: Esta herramienta se ha utilizado en asignaturas cuatrimestrales para controlar el tiempo dedicado al trabajo no presencial durante 12-14 semanas por alumnos de las asignaturas de un mismo curso. Esta herramienta se ha aplicado creando una "tarea" en la plataforma de la UPV PoliformaT y se ha centrado en conocer y clasificar el tiempo de dedicación de los alumnos para: estudiar, hacer trabajos u otras actividades.

Fase 3. Aplicación de las herramientas pedagógicas. En la segunda parte del curso, se han empezado a aplicar los cuestionarios diseñados. Las baterías de preguntas se han ido adaptando al tipo de actividad realizada, según criterios docentes, debido a la interdisciplinareidad del equipo que ha desarrollado la innovación. Para ello, se ha realizado una adaptación de estos instrumentos a las diferentes asignaturas involucradas, teniendo en cuenta aspectos tales como la titulación en la que se imparte, el perfil del alumnado, las características intrínsecas de la asignatura o el tipo y duración del trabajo a realizar.

Se ha aplicado a asignaturas de distintas titulaciones, de Grado, de Máster, cuatrimestrales, anuales, incluso a "asignaturas verticales" (misma asignatura pero con tres niveles diferentes de alumnos en la misma clase).

Fase 4. Análisis de los resultados obtenidos. Los resultados obtenidos durante la fase de aplicación se han analizado, realizando una puesta en común entre los distintos tipos de actividades para validar la consecución de los diversos objetivos propuestos. En base a este análisis, se ha realizado un diagnóstico de errores comunes que se han repetido, y así, se han modificado algunas estrategias propuestas para adaptarlas y mejorarlas para intentar conseguir los objetivos propuestos.

\section{Herramientas utilizadas y Resultados}

Se han aplicado herramientas pedagógicas para la obtención de información en asignaturas y actividades de diversa índole y carácter, desde las más teóricas a las puramente prácticas.

Las asignaturas donde se han realizado estos instrumentos son las mostradas en la Fig. 2. 


\section{Proyectos arquitectónicos}

- Grado en Arquitectura

\section{Diseño de Arquitectura en VLSI y Diseńo de Sistemas}

\section{Digitales}

- Grado en Ingeniería Informática

- Máster Universitaria en Ingeniería de Computadores y Redes

Soluciones informáticas para dispositivos móviles

- Grado en Ingeniería Informática

Cultivo in vitro y Transformación Genética de Plantas

- Grado de Biotecnología

Aplicaciones del Cultivo in vitro a la Mejora Vegetal

- Máster de Mejora Genética Vegetal

Propagación

- Grado en Ingeniería de Telecomunicaciones, Sonido e Imagen

Nuevas tecnologias aplicadas al turismo

- Grado en Gestión Turística

Arquitectura de la Información en la Web

- Grado en Información y Documentación (UV)

Fig. 2 Listado de asignaturas y titulaciones donde se imparten.

Las distintas herramientas aplicadas se pueden agrupar en tres grupos diferentes:

\subsection{Herramientas de tipo "Cuestionario"}

Este tipo de herramienta se basa en la realización de una serie de preguntas generales, de tipo abierto, con el objetivo de recoger información y obtener feedback inmediato sobre un trabajo o actividad, de corta o media duración que se ha realizado en casa y que se entregan juntos, con la intención de obtener la información de la manera más natural y fluida posible.

A continuación, se presenta una tabla con el tipo de trabajo no presencial que ha realizado el alumno y el modelo de cuestionario que se ha realizado. Este tipo de pruebas se ha aplicado a todas las asignaturas antes mencionadas, excepto a "Nuevas Tecnologías Aplicadas al Turismo" y a "Soluciones informáticas para dispositivos móviles"

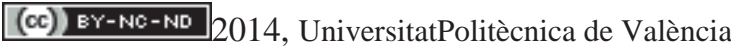

I Jornadas IN-RED (2014) 


\begin{tabular}{cl}
$\begin{array}{c}\text { Trabajo no-presencial a realizar } \\
\text { por el alumno }\end{array}$ & Forma de seguimiento del trabajo no presencial \\
\hline Lectura de un artículo científico & Cuestionario: \\
previo a la explicación de contenidos & ¿Cuál es la idea más interesante que has aprendido? \\
en clase & ¿Por qué? \\
& ¿Qué pregunta te gustaría que respondiéramos en la \\
& siguiente clase? ¿Por qué? \\
& ¿Qué es lo que te ha quedado menos claro del tema? \\
& ¿Por qué? \\
& ¿Qué parte del tema no precisa explicación después de \\
& leer el material? ¿Por qué? \\
& ¿Cuánto tiempo (en minutos) has necesitado para leerte \\
& el material y contestar a este cuestionario?
\end{tabular}

Actividad realizada tras una clase "teórica": Aplicación práctica de la teoría en el proyecto del alumno

Búsqueda de un artículo. Extracción de información cómo se trabaja en clase y preparación de la exposición que realizará a posteriori
Cuestionario:

$¿$ ¿Ha quedado claro el concepto fundamental de la clase? ¿Qué dudas tienes?

¿Has encontrado dificultad para aplicarlo en tu proyecto? ¿Por que?

¿Te ha servido el ejercicio para aclarar los conceptos teóricos explicados en clase?

¿Te han surgido nuevas preguntas o dudas después de realizar el ejercicio? ¿Cuáles son?

¿Cuánto tiempo (en minutos) has necesitado para

repasar la clase y realizar el ejercicio (incluyendo este cuestionario)?

Cuestionario:

¿Cuánto tiempo te ha costado encontrar y seleccionar el artículo?

¿Te ha resultado difícil la comprensión y extracción de la información? ¿Por qué?

¿Qué se concluye en el artículo trabajado?

$¿$ Te ha servido esta actividad para adquirir nuevos conocimientos /competencias?

¿Cuánto tiempo has dedicado a trabajar el artículo y preparar la presentación?

Cuestionario:

¿Cuánto tiempo (en horas) has necesitado aproximadamente para resolver el problema? ¿Te ha servido el problema para repasar y entender mejor los contenidos de los temas? 


\subsection{Herramientas web de la plataforma docente de la UPV: PoliformaT}

Otra herramienta utilizada para la recogida de información ha sido mediante la plataforma web docente de la Universitat Politècnica de València llamada PoliformaT: esta herramienta tecnológica se ha aplicado en dos asignaturas diferentes en la EPSG y se ha desarrollado utilizando la herramienta "tarea" de la plataforma docente con el mismo objetivo de recoger información sobre el trabajo en casa, pero diferencias entre ellas: se han utilizado metodologías distintas y su desarrollo en el tiempo ha sido diferente tambien. Se explican brevemente los dos métodos utilizados:

\subsubsection{Herramienta Hoja de cálculo Excel en PoliformaT}

La experiencia se ha aplicado en la asignatura "Nuevas Tecnologías Aplicadas al Turismo" (10128) y se ha desarrollado durante 12 semanas, es decir, ha durado casi un cuatrimestre completo. El procedimiento operativo ha sido el siguiente: se ha creado en Poliformat una tarea denominada "Control de Trabajo no Presencial, en la que se les ha explicado a los alumnos la importancia de realizar esta tarea, y las instrucciones para hacerla, además, los alumnos que han participado voluntariamente han recibido un punto extra al final del curso (10\% de la nota de la asignatura).

La tarea implica que todas las semanas los alumnos deben apuntar las horas "no presenciales" que dedican a cada asignatura (es decir sin contar clases y prácticas en las aulas), a diferencia de otro tipo de herramientas utilizadas (vistas anteriormente) que recogían información general directamente relacionada a algún trabajo o actividad concretos, este procedimiento recoge información referida únicamente a tiempo dedicado a trabajar en la asignatura, sin estar necesariamente asociada a trabajos o actividades específicos. También se ha aplicado a otras asignaturas del mismo curso.

La tarea incluye la Hoja de Cálculo que los alumnos tienen que completar. En la siguiente imagen podemos ver el diseño de esta hoja:

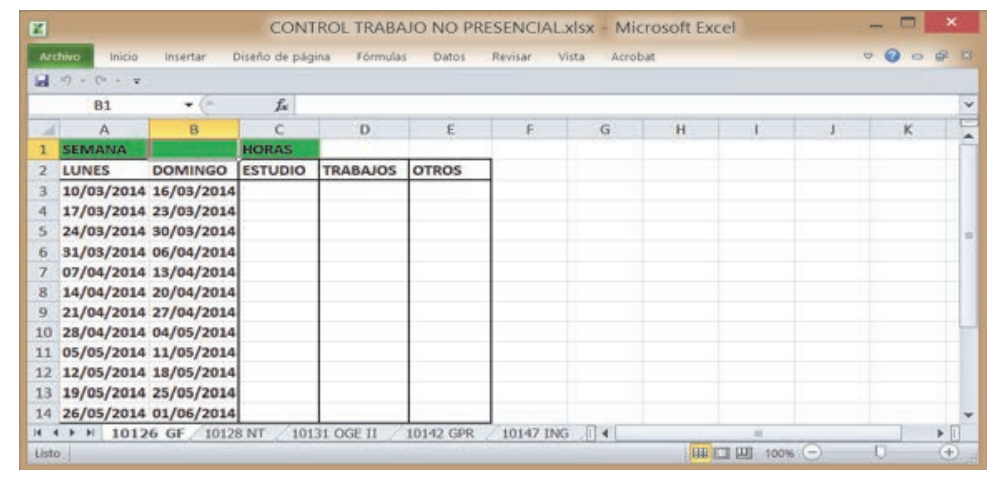

Fig. 3 Hoja de cálculo

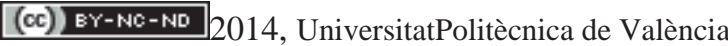

I Jornadas IN-RED (2014) 
El diseño es bastante sencillo y los alumnos simplemente tienen que apuntar las horas no presenciales que cada semana han dedicado a cada asignatura, desglosado en tres categorías: estudiar, trabajos y otros.

\subsubsection{Herramienta tipo "cuestionario" en PoliformaT}

La herramienta se ha aplicado en la asignatura "Propagación" (11278) de la titulación de Grado en Ingeniería de Sistemas de Telecomunicación, Sonido e Imagen, se ha procedido a realizar un breve cuestionario a través de PoliformaT tras la realización de una actividad no presencial.

La actividad consiste en la resolución por parte del alumno de un problema largo (5 apartados) y muy completo sobre los contenidos impartidos en los temas 1, 2 y 3 de la asignatura. Los alumnos disponen de 15 días para entregar el problema resuelto, y la entrega se realiza exclusivamente a través de la herramienta Tareas de PoliformaT.

A través de la Tarea de PoliformaT se les invita a contestar una pequeña encuesta (dos preguntas) relacionadas con la actividad realizada:

- ¿Cuánto tiempo (en horas) has necesitado aproximadamente para resolver el problema?

- ¿Te ha servido el problema para repasar y entender mejor los contenidos de los temas?

La encuesta la contestan justo en el momento de subir la tarea (ejercicio resuelto) a PoliformaT.

\subsection{Herramienta tipo "cuestionario" en herramientas web de acceso libre}

También se ha experimentado con una nueva metodología para recoger información sobre el trabajo no presencial, que se basa en la utilización conjunta y combinada de las herramientas de tipo cuestionario (preguntas rápidas y cortas) planteadas y propuestas mediante una herramienta web gratuita llamada Socrative (http://beta.socrative.com). Esta prueba se ha realizado en la asignatura de "Soluciones informáticas para dispositivos móviles" que se imparte en la ETS de Ingeniería Informática de la UPV; se ha planteado una estrategia consistente en, para cada tema, proponer un cuestionario que ayude a los alumnos a repasar los contenidos estudiados. Dicho cuestionario irá acompañado de un post-cuestionario que permita al alumno estimar la calidad del trabajo realizado, el tiempo empleado en dicha actividad, subrayar las bondades o defectos del cuestionario propuesto y proporcionar sugerenciasde mejora al mismo.

Cabe señalar que, aunque los cuestionarios varían de un tema a otro, el post-cuestionario es siempre el mismo. Por un lado, esto se ha hecho así para conseguir obtener el mismo tipo de información para todos los temas del curso. Por otro lado, la repetición del post- 
cuestionario tema tras tema hace que los alumnos estén muy familiarizados con las preguntas a responder, con lo que la dedicación exigida al alumno para completarlo es mínima. De esta forma se mitiga el efecto perverso de sobrecarga que se produciría al solicitar esta información de realimentación al alumno. Con este mismo propósito, se han limitado el número de preguntas a responder, reduciéndolas a 8: 4 de tipo verdadero/falso, 3 de selección de una alternativa entre varias propuestas y finalmente, una de respuesta abierta para el que el alumno aporte los comentarios, observaciones y sugerencias que estime necesarios.

A continuación se detallan las preguntas incluidas en el cuestionario:

1. ¿Cuanto tiempo has dedicado aproximadamente a responder al cuestionario del tema?
a. Menos de $30 \mathrm{~min}$
b. Entre $30 \mathrm{~min}$ y $1 \mathrm{~h}$
c. Entre $1 \mathrm{~h}$ y $1 \mathrm{~h} 30 \mathrm{~min}$
d. Entre $1 \mathrm{~h} 30$ y $2 \mathrm{~h}$
e. Másde2h

2. ¿Te han permitido las preguntas formuladas trabajar el contenido visto en clase?
a. True

b. False

3. ¿Con qué nivel de profundidad has trabajado dicho contenido?
a. Superficialmente
b. Adecuadamente
c. En profundidad

4. ¿Consideras que las preguntas planteadas te han hecho reflexionar sobre los visto en el tema?
a. True
b. False

5. Las reflexiones llevadas a cabo mientras contestabas a las preguntas y el trabajo de consulta realizado ¿te han permitido encontrar respuestas a tus dudas y clarificar aspectos que no tenías claros antes?

a. True

6. ¿Se han generado dudas que piensas que podrían requerir de una tutoría o de una reflexión grupal en clase?
a. True
b. False

7. ¿En qué medida consideras que el cuestionario de este tema te ha ayudado a estudiarlo?

a. Muy útil, de hecho me ha permitido revisar el material y plantearme dudas que me hecho reflexionar sobre el mismo y terminar conociéndolo mejor.

b. Útil, ya que me ha permitido revisar el material de teoría y saber qué tipo de preguntas van para examen.

c. Poco útil, lo he hecho por curiosidad, pero no he consultado el material de

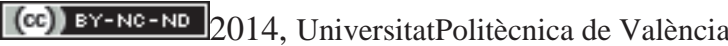

I Jornadas IN-RED (2014) 
teoría y me he limitado a ver las respuesta y a intentar aprender de las mismas.

d. Completamente inútil, no he aprendido nada que no supiera ya haciendo este cuestionario, con lo que lo considero una pérdida de tiempo.

8. Introduce a continuación cualquier comentario/observación/sugerencia que estimes pertinente para mejorar el cuestionario suministrado y su eficacia como soporte de estudio de los contenidos abordados en clase. Gracias por tu contribución. (Respuesta abierta)

Así al finalizar el curso, es posible obtener de una estimación promedia del tiempo dedicado por cada alumno a cada tema, así como de la calidad de los cuestionarios suministrados con el objetivo de ayudar al alumno a estudiar, asimilar y profundizar en los contenidos teórico-prácticos trabajados previamente en clase.

Para llevar a cabo el estudio se ha utilizado una herramienta web llamada Socrative (http://beta.socrative.com). Esta herramienta ofrece clases virtuales en las que los profesores pueden proponer a sus alumnos cuestionarios o preguntas rápidas vía web.

Tras introducir y plantear el cuestionario, el profesor puede obtener un informe de las respuestas suministradas por distintas vías: email, descarga de archivo (pdf y/o Excel), almacenamiento de resultados en Google Drive y Vista de resultados en el navegador web.

Si se opta por visualizar los datos vía web, la información suministrada es la siguiente (se muestra un extracto de 6 respuestas):

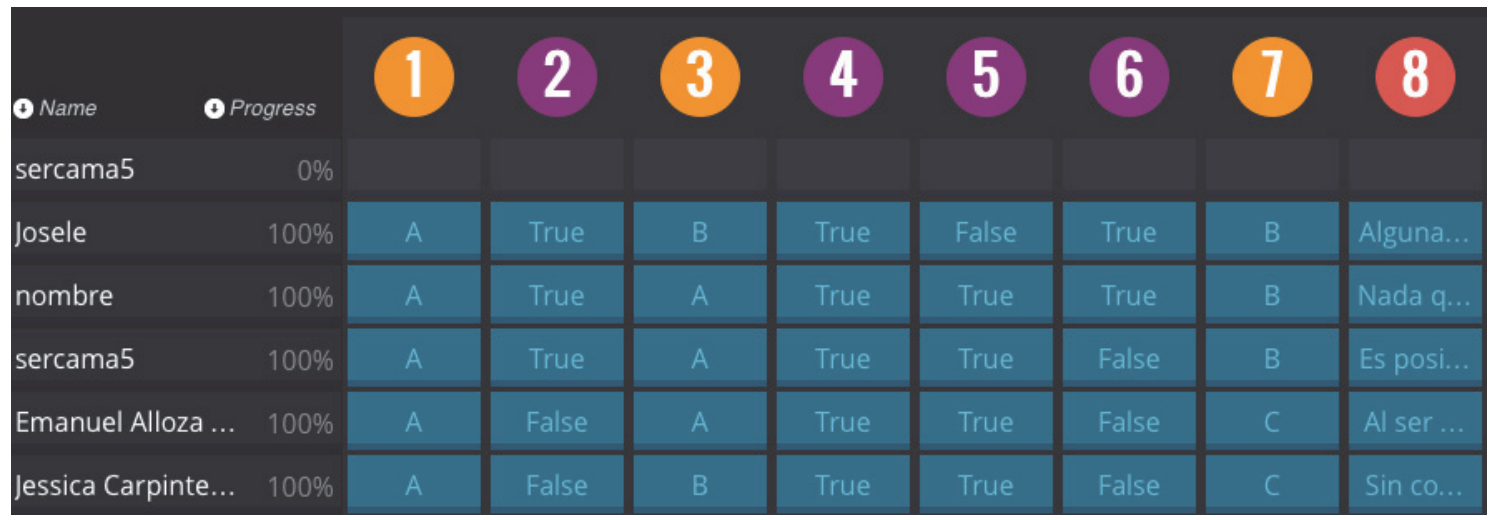

Fig. 4 Imagen de la información obtenida (6 alumnos) para las 8 cuestiones

\section{Resultados: Análisis e interpretación}

La heterogeneidad de asignaturas, de herramientas aplicadas, de tipos de cuestionarios, de tipos de actividades, trabajos o asignaturas, así como de su duración en el tiempo, han producido lo que cabría esperar, tanto una heterogeneidad de resultados como una riqueza de interpretaciones tan interesantes como prácticas. 
Para sintetizar esos resultados en un breve documento, conviene aclarar:

a) La participación del alumnado en este tipo de herramientas y experiencias varía mucho en función de las bonificaciones o "puntos extra" que el alumno consiga para su nota final. Esa es una realidad incuestionable que hay que asumir, de ahí que muchas de las herramientas utilizadas hayan valorado y premiado la participación en este tipo de innovaciones. Si el alumno no recibe recompensa por participar, no lo hará. Algunas de estas pruebas se habían intentado realizar con la participación voluntaria y no ha sido posible llevarla a cabo por el bajo número de alumnos involucrados.

b) Durante la realización de estas pruebas, con el fin de conseguir la mayor veracidad y sinceridad en la información obtenida, se ha determinado, tras encendidos debates, que el alumno es más fiable cuando realiza su cuestionario inmediatamente después de realizar la actividad o trabajo no presencial, es decir, se ha considerado fundamental que el alumno entregue la información requerida junto con el trabajo que debe entegar. Cuando se han realizado pruebas para determinar el tiempo de dedicación del alumno al trabajo en casa, sin estar asociado a ningun trabajo concreto, se ha realizado un control semanal; pensar que la información obtenida del alumno en plazos superiores a una semana puede ser fiable es cometer un error que invalida la metodología propuesta. Como estas herramientas funcionan en el mismo lapso de tiempo que la realización del propio trabajo, la información obtenida es muy creible, el alumno es sincero. Su trabajo ya está hecho y tiene una opinión muy clara sobre él, y muy reciente. Son datos muy útiles para conseguir feedback casi inmediato con el trabajo no presencial

c) La heterogeneidad de resultados obtenidos según actividades, asignaturas o trabajos, da lugar a múltiples lecturas, más o menos complejas, siempre interesantes ya que su análisis arrojará luz sobre la idoneidad y oportunidad de los trabajos, sobre la estimación de horas previstas por el profesor, sobre la marcha de la clase y su dedicación en casa, etc. A pesar de esta diversidad de información obtenida, se ha creido conveniente aportar al menos dos gráficos que reflejan la relación entre el número de horas dedicadas a la realización de la actividad (eje X) y el resultado obtenido en esa actividad (ejeY). Las gráficas responden a tipos de trabajos distintos en asignaturas distintas de titulaciones distintas y con duraciones distintas. Sin embargo, su aspecto es muy similar (obviando los valores numéricos) si atendemos a las formas y composiciones de los gráficos, en ninguno de los dos se observa una correlación clara entre el tiempo dedicado y la nota, se observa que las notas buenas (parte superior de los gráficos) se extienden muy horizontalmente, es decir, hay trabajos con buena nota y con tiempos de dedicación muy diferentes. En cualquier caso, la información obtenida para extraer interpretaciones de estos resultados es muy útil. Probablemente una pregunta en el cuestionario sobre el conocimiento previo del alumno en los temas tratados hubiera sido interesante.

(cc) BY-NC-ND 2014, UniversitatPolitècnica de València

I Jornadas IN-RED (2014) 
d) Otro resultado interesante que produce la lectura de los gráficos es que, a pesar de su heterogeneidad, siempre hay una "mancha" de mayor tamaño que indica que existe una mayoría de alumnos que dedica un tiempo parecido para obtener un determinado resultado. Este tipo de cuestionarios es muy útil para determinar el tiempo medio que se tarda en realizar esa actividad o trabajo. Cada alumno, según su capacidad, motivación o forma de trabajar, va a desarrollar la actividad en un tiempo concreto, no hay dos alumnos iguales, no habrá dos tiempos iguales, pero para el profesor disponer de esta información será muy práctico para plantear futuros trabajos y actividades y conocer el tiempo aproximado de dedicación y así ajustar la estimación previa que hace el profesor de la duración del trabajo no presencial que va a pedir en los próximos.

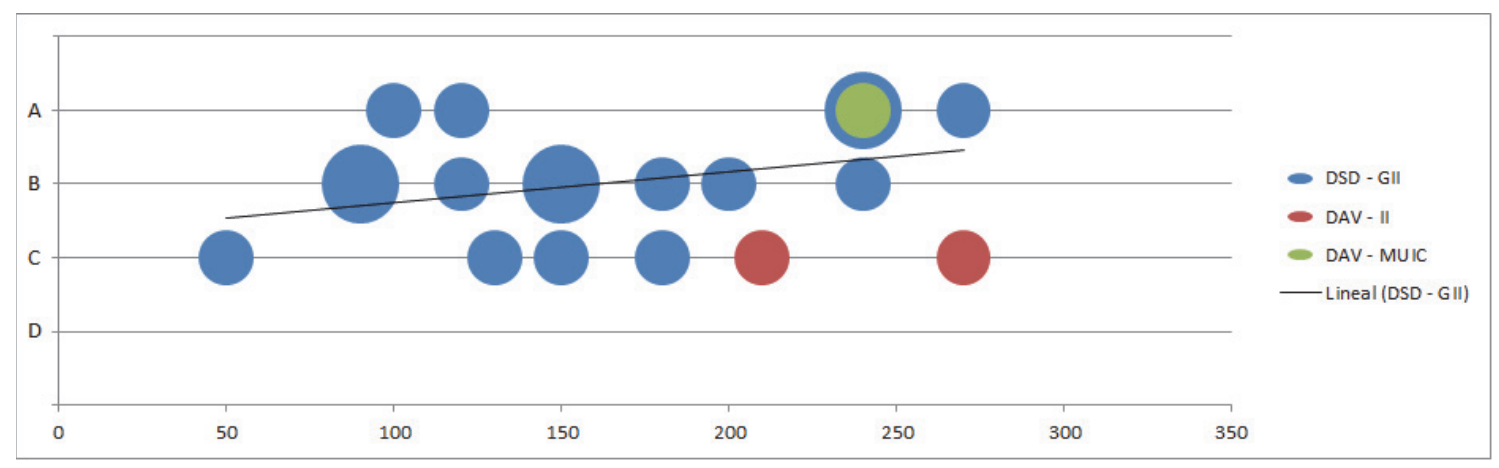

Fig. 5 Gráfico que relaciona las horas dedicadas a un trabajo con la evaluación obtenida

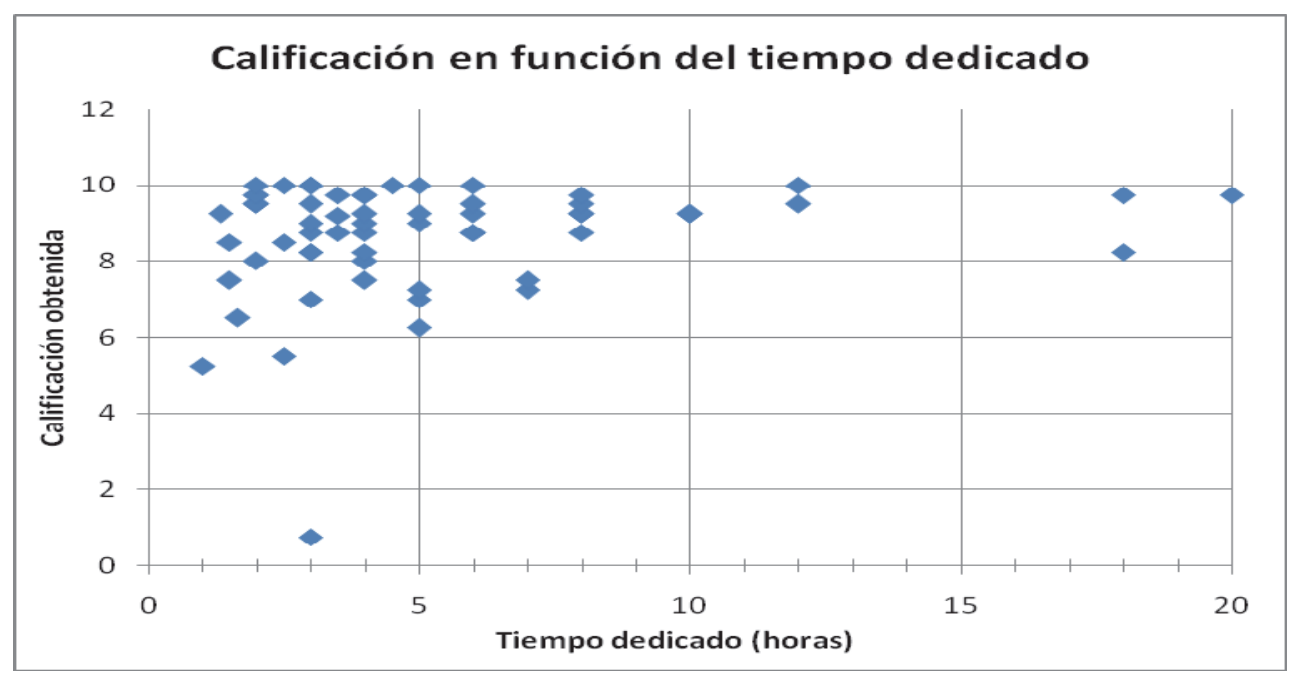

Fig. 6 Gráfico que relaciona las horas dedicadas a un trabajo con la evaluación obtenida 
Se ha considerado más oportuno reflejar los resultados en dos diagrams "tipo" para extaer conclusiones de los resultados, antes que incluir todos los resultados de las asignaturas entendiendo que lo más interesante es realizar una lectura crítica y racional de algunos más representativos.

\section{Conclusiones}

Una vez examinados y revisados los resultados, primero de una manera individualizada por cada profesor y después en una puesta en común entre los diferentes profesores con distintas asignaturas y titulaciones, se pueden extraer las siguientes conclusiones:

1. La primera conclusión evidente es que cuanta más información tengamos de los alumnos, más criterios y facilidades tendremos para mejorar nuestra docencia. Tener información de los alumnos es garantía de realizar una evaluación justa y objetiva, además de poder organizar y estructurar las clases según la información disponible. El famoso lema "Tener la información es tener el poder" es una verdad incuestionable, y si ese poder se canaliza en la mejora de la docencia, el proceso de aprendizaje y de enseñanza y los resultados de los alumnos mejorarán notablemente.

2. La información del tipo "juicio crítico, opinión, adecuación, oportunidad o conveniencia" es un feedback fundamental para completar el proceso de evaluación formativa de los alumnos. Normalmente, el profesor tiene información sobre resultados de los alumnos, incluso, durante la clase puede obtener retroalimentación, pero si este intercambio mutuo se lleva al trabajo no presencial, el profesor ya dispone de una completa información para detectar los aciertos y los errores del proceso de enseñanza aprendizaje. Determinar periódicamente el grado de satisfacción de los alumnos con la asignatura, las clases, los trabajos, es una valiosa información para modificar o recomponer el calendario y la organización de la asignatura y sus actividades o trabajos.

3. A pesar de la heterogeneidad de los datos obtenidos, la información sirve para realizar una estadistica y detectar problemas de aprendizaje. Cada alumno realizará el trabajo en un tiempo determinado, pero tanto como si ha dedicado mucho tiempo o poco tiempo, el resultado del trabajo será el que valide el proceso. No se debe olvidar que todas estas herramientas están diseñadas para favorecer y mejorar el proceso de enseñanza aprendizaje, en sí mismas no tienen más valor que la simple información, pero lo interesante es el manejo de esta información. Los buenos trabajos, si se hacen en poco tiempo, demuestran que el alumno es eficaz y se sabe organizar y planificar, si lo hace en mucho tiempo, tendrá que aprender a manejar los conceptos de organización y eficacia para rentabilizar mejor su esfuerzo. Los malos trabajos serán un problema a subsanar siempre, si han

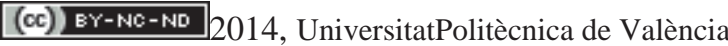

I Jornadas IN-RED (2014) 
Dedicación del alumnado, utilidad y adecuación de las tareas no presenciales

dedicado mucho tiempo, habrá que descubrir donde tiene ese alumno el problema (problemas de aprendizaje); si ha dedicado poco tiempo, lo normal es que esa sea la causa directa de su mal resultado. Con el grado de satisfacción del alumno ocurre exactamente lo mismo, tener su opinión y juicio crítico para validar o no el proceso de enseñanza es una información prioritaria.

\section{Referencias}

BAIN, K. (2005). Lo que hacen los mejores profesores universitarios. Valencia: Publicaciones de la Universitat de València.

BARR, R. y TAGG, J. (1995). "From teaching to learning" en A new Paradigm for Udergraduate Education, Change, Novembre/December, 27(6), p. 13-15.

BIGGS, J. (2006). Calidad del aprendizaje universitario. Madrid: Narcea Ed.

MELMER, R., BURMASTER, E y JAMES, T.K. (2008). Attributes of Effective Formative Assessment. Washington DC: Council of Chief State School Officers

MOHANAN, K-P. (2005). "Assessing Quality of Teaching in Higher Education. Centre for Development of Teaching and Learning"

RAMSDEM, P. (1992). Learning to teach in Higher Education. London: Routledge.

UNIVERSIDAD POLITÉCNICA DE VALENCIA (2014). <http://www.poliformat.upv.es> [Consulta: 10 de junio de 2014]

[sinautoríareconocida]

Student Response System <http://beta.socrative.com/ >

TRAC. The Trac Open Source Project. <http://trac.edgewall.org/>

REDMINE. Redmine project management web application. 〈http://www.redmine.org/> 


\title{
Objetivos de aprendizaje para grado y máster de la competencia genérica de innovación, creatividad y emprendimiento
}

\author{
Marta Fernández-Diego ${ }^{a}$, Leonor Ruiz ${ }^{b}$, MariLuz Gordo ${ }^{c}$, M.M.E. Alemany ${ }^{d}$, Andrés \\ Boza $^{\mathrm{e}}$, Llanos Cuenca ${ }^{\mathrm{f}}$ \\ a,b,c,e,f Departamento de Organización de Empresas. Escuela Técnica Superior de Informática \\ Aplicada. Universtat Politècnica de València (marferdi@omp.upv.es, lruiz@omp.upv.es, \\ magormon@upvnet.upv.es, 1lcuenca@omp.upv.es), ${ }^{\mathrm{d}}$ Departamento de Organización de Empresas. \\ Escuela Técnica Superior de Ingeniería Industrial. Universtat Politècnica de València \\ (mareva@omp.upv.es)
}

\begin{abstract}
The context of permanent change forces innovation to become a crucial value for the survival and development of the organizations. Therefore promoting the acquisition of innovation competence is one of the aspects to be solved. Learning objectives should be established to acquire competences. The objective of this work is the identification of the learning objectives associated to the innovation, creativity, entrepreneurship competence, which is the base for their assessment. The proposal takes into account the learning objecives associated to bachelor and master degree.
\end{abstract}

Keywords: competence, learning objective, learning object, innovation, creativity, entrepreneurship

\footnotetext{
Resumen

El context de cambio permanente, ha forzado que la innovación sea un valor crucial para la supervivencia de las organizaciones. Promover la adquisición de la competencia de innovación es uno de los aspectos que debe ser resuelto. Los objetivos de aprendizajes deben ser establecidos para la adquisición de la competencia. El objetivo de este trabajo es la indentificación de los objetivos de aprendizaje asociados a la competencia de innovación, creatividad y emprendimiento, la cual será la base para su posterior evaluación. La propuesta tiene en cuenta los objetivos asociados tanto a grado como a máster.
}

\section{(c) EY-NC-ND 2014, UniversitatPolitècnica de València}

I Jornadas In-Red (2014) 
Objetivos de aprendizaje para grado y máster de la competencia genérica de innovación, creatividad y emprendimiento

Palabras clave: competencia, objetivos de aprendizaje, objetos de aprendizaje, innovación, creatividad y emprendimiento

\section{Introducción}

La innovación se está convirtiendo en un requisito para la ventaja competitiva de las organizaciones, por lo que se ha convertido en un aspecto cada más importante y demandado. Favorecer la adquisición de la competencia en innovación es uno de los aspectos a resolver. La tendencia actual en la educación superior busca que los alumnos sean creativos y mejoren el pensamiento individual, para acercarles al mundo que les rodea y enfrentarlos a problemas complejos. Las titulaciones de la UPV tienen una estructura basada en módulos y materias. Las materias incluyen el listado de asignaturas. Las dimensiones competenciales UPV (DC) pretenden sintetizar el perfil competencial que adquieren los alumnos de la UPV, garantizando además cubrir el marco de referencia de algunas titulaciones con regulaciones o recomendaciones específicas.

Se han definido un total de 13 dimensiones competenciales. DC1-Comprensión e integración; DC2-Aplicación del pensamiento práctico; DC3-Análisis y resolución de problemas; DC4-Innovación, creatividad y emprendimiento; DC5-Diseño y proyecto; DC6Trabajo en equipo y liderazgo; DC7-Responsabilidad ética y profesional; DC8Comunicación efectiva; DC9-Pensamiento crítico; DC10-Conocimiento de los problemas contemporáneos; DC11-Aprendizaje permanente; DC12-Planificación y gestión del tiempo; DC13-Instrumental específica.

El Anexo I del R.D. 1393/2007 precisa que debe ser incluido el diseño de cada una de las materias especificando el sistema de evaluación de la adquisición de competencias y sistema de calificaciones. En el diseño de los nuevos planes de estudio deberán quedar reflejadas las evidencias de que se adquieren las competencias fijadas en la memoria de solicitud de títulos oficiales. Para ello, en el diseño de las materias se relacionarán dichas competencias y su procedimiento de evaluación.

En este sentido la Escuela Técnica Superior de Ingeniería Informática ha redactado un documento que recoge las directrices para la impartición del Grado en Ingeniería Informática, el cual incluye:

1) Directrices para el sistema de evaluación: El sistema de evaluación debe procurar una evaluación continua del alcance de los resultados de aprendizaje y de las competencias previstas en la asignatura o la materia objeto de evaluación.

Es un objetivo del centro transformar el proceso de enseñanza-aprendizaje para hacer del alumno su principal protagonista $y$, en este sentido, es necesario orientar las programaciones y metodologías docentes de las asignaturas centrándolas en el aprendizaje de los estudiantes y no exclusivamente en las horas lectivas. La clave está en plantear el 
Marta Fernández-Diego, Leonor Ruiz, MariLuz Gordo , M.M.E. Alemany, Andrés Boza, Llanos Cuenca

programa de cada asignatura como un conjunto de actividades que aseguren el aprendizaje del alumno e introducir los mecanismos necesarios para motivar al alumno a realizarlas.

2) Directrices para el seguimiento de las actividades presenciales: El conjunto de actividades de la asignatura se debe diseñar de forma que comprometa al alumno a la participación activa en clase con el objetivo de favorecer su progreso. Por tanto, se recomienda que se fomente la asistencia al aula.

3) Directrices para los contratos programa: La utilización de metodologías activas donde el alumno debe participar con trabajos individuales o en grupo, realización de problemas o ejercicios evaluables, pruebas al finalizar las sesiones de laboratorio, one-minute paper, actividades de coevaluación y autoevaluación, etc. Para la valoración significativa del trabajo del alumno en el aula y/o en el laboratorio deben seguirse las recomendaciones expresadas en el punto anterior.

Sin embargo, todo esto resulta difícil en la mayoría de los casos. De acuerdo al marco UPV de definición y evaluación de adquisición de competencias, actualmente con los programas de grado y máster nos encontramos con:

- Extensos listados de competencias definidas.

- Múltiples fuentes de competencias con enfoques diferentes en su definición: RD861/MECES, normas CIN, referentes internacionales REFLEX, ABET, EURACE, NAAB...

- No se han sistematizado mecanismos de evaluación que garanticen la adquisición de competencias.

- Es necesaria plantear una formación específica y el acceso a referentes que faciliten evaluación a los equipos de profesores.

La competencia describe lo que los participantes de la formación deberán ser capaces de hacer al finalizar dicha formación. Para la adquisición de las competencias se establecen unos determinados objetivos de aprendizaje que deben ser alcanzados. La manera que en que transmiten los conocimientos para la consecución de los objetivos de aprendizaje es a través de objetos de aprendizaje.

El cómo favorecer o propiciar el ambiente idóneo para el desarrollo y consecución de dichos objetivos de aprendizaje deberá ser abordado a través de dichos objetos de aprendizaje proporcionados a los alumnos. Estos objetos de aprendizaje se darán en forma de lección magistral, prácticas, casos de estudio, etc. Los objetos de aprendizaje pueden ser utilizados para favorecer la consecución de uno o más objetivos de aprendizaje.

Tras esta introducción, el presente trabajo se estructura de la siguiente forma: El siguiente apartado expone los objetivos del mismo. A continuación se describe la metodología seguida para la identificación de los objetos de aprendizaje asociados a la competencia de

\section{(c) EY-NC-ND 2014, UniversitatPolitècnica de València}

I Jornadas IN-RED (2014) 
Objetivos de aprendizaje para grado y máster de la competencia genérica de innovación, creatividad y emprendimiento

innovación para grado y máster. Y finalmente tras el análisis de resultados, se presentan las conclusiones en una última sección.

\section{Objetivos}

La actividad desarrollada se centra en el marco del proyecto de innovación y mejora educativa RECICRE - Rúbricas para la Evaluación de la Competencia Innovación, Creatividad y Emprendimiento.La motivación que lleva a la propuesta de este proyecto es contribuir a sistematizar mecanismos de evaluación que garanticen la adquisición de la dimensión competencial DC4-Innovación, creatividad y emprendimiento.

El objetivo de este trabajo coincide con el primer objetivo de proyecto RECICRE, que consiste en identificar la lista de objetivos de aprendizaje asociados a la competencia de innovación, lo que servirá de base para su posterior evaluación. Se trata de identificar los componentes, responsabilidades y destrezas asociadas a la innovación y el espíritu emprendedor, concretándolas en objetivos de aprendizaje para grado y máster por separado. Esta identificación es necesaria para saber qué aspectos son los que deberán ser medidos de manera que permitan conocer el grado de consecución y alcance de la competencia.

\section{Metodología}

La metodología de investigación seguida se basa en el proceso de revisión de literatura que permita identificar los objetivos de aprendizaje asociados a la competencia de innovación para grado y máster. Tomando como base la lista preliminar de objetivos de aprendizaje del Instituto de Ciencias de la Educación (ICE, 2014), se han analizado un total de ocho artículos publicados entre los años 2005 y 2013,con el objetivo de identificar una lista definitiva.

Por otra lado, se han tenido en cuenta también las mejores prácticas de las instituciones de educación superior de la UE y su ampliación con la cultura de la investigación y la innovación de la academia israelí identificada en el proyecto IDEA Tempus (IDEA; 2014). La aplicación de estas mejores prácticas ha ayudado a completar la lista de objetivos de aprendizaje.

\section{Resultados}

La revisión de la literatura ha permitido establecer una correspondencia entre la propuesta inicial del ICE y los nuevos objetivos de aprendizaje identificados.

Los resultados quedan reflejados en dos tablas de equivalencias entre los objetivos de aprendizaje del ICE y los identificados tras el análisis de los artículos revisados. La Tabla 1 presenta las equivalencias de objetivos de aprendizaje de grado.

(cc) EY-NC-ND 2014, UniversitatPolitècnica de València

I Jornadas IN-RED (2014) 
Marta Fernández-Diego, Leonor Ruiz, MariLuz Gordo , M.M.E. Alemany, Andrés Boza, Llanos Cuenca

Tabla 1 Equivalencias de objetivos de aprendizaje de grado

\begin{tabular}{|c|c|c|}
\hline Referencia & OA identificado & OA ICE equivalente \\
\hline \multirow[t]{4}{*}{$\begin{array}{l}\text { Kairisto et } \\
\text { al., } 2012 \\
\text { Bapta et al., } \\
2014\end{array}$} & $\begin{array}{lllll}\text { Acciones tenaces } & y & \text { orientadas a } \\
\text { objetivos } & & & & \end{array}$ & $\begin{array}{l}\text { Introducir nuevos procedimientos y } \\
\text { acciones en el propio proceso de trabajo } \\
\text { para responder mejor a las limitaciones y } \\
\text { problemas detectados }\end{array}$ \\
\hline & $\begin{array}{l}\text { Solución creativa de problemas y el } \\
\text { desarrollo de métodos de trabajo }\end{array}$ & $\begin{array}{l}\text { Proponer ideas y soluciones innovadoras } \\
\text { tanto en cuanto al contenido, como al } \\
\text { proceso para llevarlas a cabo }\end{array}$ \\
\hline & & $\begin{array}{l}\text { Buscar nuevos procedimientos y métodos } \\
\text { para hacer las cosas }\end{array}$ \\
\hline & $\begin{array}{l}\text { Capacidad para trabajar en proyectos de } \\
\text { investigación y desarrollo mediante la } \\
\text { aplicación y la combinación de los } \\
\text { conocimientos y métodos de los } \\
\text { diferentes campos }\end{array}$ & $\begin{array}{l}\text { Integrar conocimientos de varias } \\
\text { disciplinas, fuentes o ámbitos para generar } \\
\text { ideas novedosas a situaciones conocidas o } \\
\text { desconocidas }\end{array}$ \\
\hline \multirow{6}{*}{$\begin{array}{l}\text { Watts et al } \\
2012 \\
\text { Bapat et al., } \\
2014 \\
\text { Marin- } \\
\text { García } 2013\end{array}$} & $\begin{array}{l}\text { Aportar sugerencias a las ideas, } \\
\text { situaciones, casos o problemas que se } \\
\text { plantean. }\end{array}$ & $\begin{array}{l}\text { Propone sugerencias y alternativas } \\
\text { adecuadas a las necesidades de la tarea }\end{array}$ \\
\hline & $\begin{array}{l}\text { Expresar a otro las nuevas ideas que se } \\
\text { han generado. }\end{array}$ & $\begin{array}{l}\text { Transmite sus ideas con coherencia y } \\
\text { eficacia }\end{array}$ \\
\hline & $\begin{array}{l}\text { Aportar sugerencias propias de calidad } \\
\text { antes situaciones o problemas que se } \\
\text { presentan. } \\
\text { Utilizar técnicas de creatividad para } \\
\text { proponer y defender ideas de calidad, } \\
\text { originales o poco convencionales. }\end{array}$ & $\begin{array}{l}\text { Aporta ideas originales en cuanto a } \\
\text { contenido } \\
\text { Aporta ideas originales en cuanto a la } \\
\text { forma de materializarse }\end{array}$ \\
\hline & $\begin{array}{l}\text { Reconocer las limitaciones y puntos } \\
\text { débiles en sus procesos y métodos de } \\
\text { trabajo. }\end{array}$ & $\begin{array}{l}\text { Evalúa de forma crítica los fundamentos de } \\
\text { las ideas y las acciones }\end{array}$ \\
\hline & $\begin{array}{l}\text { Buscar nuevos procedimientos y } \\
\text { métodos para hacer las cosas. }\end{array}$ & $\begin{array}{l}\text { Ataca la tarea desde diferentes puntos de } \\
\text { vista }\end{array}$ \\
\hline & $\begin{array}{l}\text { Analizar riesgos y beneficios de la } \\
\text { innovación. }\end{array}$ & Asume riesgos con inteligencia \\
\hline
\end{tabular}

(c) EY-NC-ND 2014, UniversitatPolitècnica de València

I Jornadas IN-RED (2014) 
Objetivos de aprendizaje para grado y máster de la competencia genérica de innovación, creatividad y emprendimiento

La Tabla 2 presenta las equivalencias de objetivos de aprendizaje de máster.

Tabla 2 Equivalencias de objetivos de aprendizaje de máster

\begin{tabular}{|c|c|c|}
\hline Referencia & OA identificado & OA ICE equivalente \\
\hline $\begin{array}{l}\text { Kairisto et al., } \\
2012\end{array}$ & $\begin{array}{l}\text { Pensamiento y toma de } \\
\text { decisiones independientes }\end{array}$ & $\begin{array}{l}\text { Adoptar actitudes abiertas a la generación de } \\
\text { nuevos pensamientos }\end{array}$ \\
\hline \multirow[t]{2}{*}{$\begin{array}{l}\text { Bapat et al., } \\
2014\end{array}$} & & $\begin{array}{l}\text { Adoptar un punto de vista crítico y autónomo } \\
\text { respecto al conocimiento relativo a su propia } \\
\text { disciplina }\end{array}$ \\
\hline & $\begin{array}{l}\text { Capacidad de tomar la iniciativa } \\
\text { y trabajar de manera } \\
\text { responsable de acuerdo con los } \\
\text { objetivos de la comunidad }\end{array}$ & $\begin{array}{l}\text { Realizar proyectos por iniciativa propia, } \\
\text { comprometiendo determinados recursos con el } \\
\text { fin de explotar una oportunidad y asumiendo el } \\
\text { riesgo que ello acarrea }\end{array}$ \\
\hline $\begin{array}{l}\text { Watts et al } \\
2012 \\
\text { Marin-García } \\
2013\end{array}$ & $\begin{array}{l}\text { Tomar iniciativas contando con } \\
\text { otros, haciéndoles partícipes de } \\
\text { su visión de futuro y sus } \\
\text { proyectos. }\end{array}$ & Colabora activamente \\
\hline $\begin{array}{l}\text { Bapat et al., } \\
2014\end{array}$ & $\begin{array}{l}\text { Emprender proyectos } \\
\text { ambiciosos (complejos y } \\
\text { desafiantes), que implican una } \\
\text { decisión social. }\end{array}$ & $\begin{array}{l}\text { Establece relaciones constructivas en base al } \\
\text { diálogo }\end{array}$ \\
\hline
\end{tabular}

Por último, merecen especial atención aquellos objetivos identificados que no han encontrado correspondencia con los del ICE. Estos objetivos de aprendizaje nuevos se listan en la Tabla 3.

Tabla 3 Objetivos de aprendizaje a incorporar

\begin{tabular}{l|l}
\hline \multicolumn{1}{c|}{ Referencia } & \multicolumn{1}{c}{ Objetivo de Aprendizaje } \\
\hline $\begin{array}{l}\text { Kairisto et al., } \\
2012 \\
\text { Watts et al } 2012 \\
\text { Marin-García } \\
2013 b\end{array}$ & $\begin{array}{l}\text { Afronta los problemas de forma constructiva con el fin de alcanzar un } \\
\text { consenso } \\
\text { Autoevaluación y el desarrollo de habilidades y métodos de aprendizaje } \\
\text { Capacidad de anticipar el desarrollo y las consecuencias de las } \\
2014 \\
\text { Bapat et aluaciones. } \\
2014 \\
\text { Capacidad de comunicarse e interactuar en un entorno internacional } \\
\text { Capacidad de cooperar en un entorno multidisciplina y multicultural } \\
\text { Capacidad de cooperar en un equipo diversificado } \\
\text { Capacidad de crear y mantener conexiones de trabajo } \\
\text { Capacidad de trabajar según los principios de la ética y la }\end{array}$ \\
\hline
\end{tabular}


Marta Fernández-Diego, Leonor Ruiz, MariLuz Gordo, M.M.E. Alemany, Andrés Boza, Llanos Cuenca

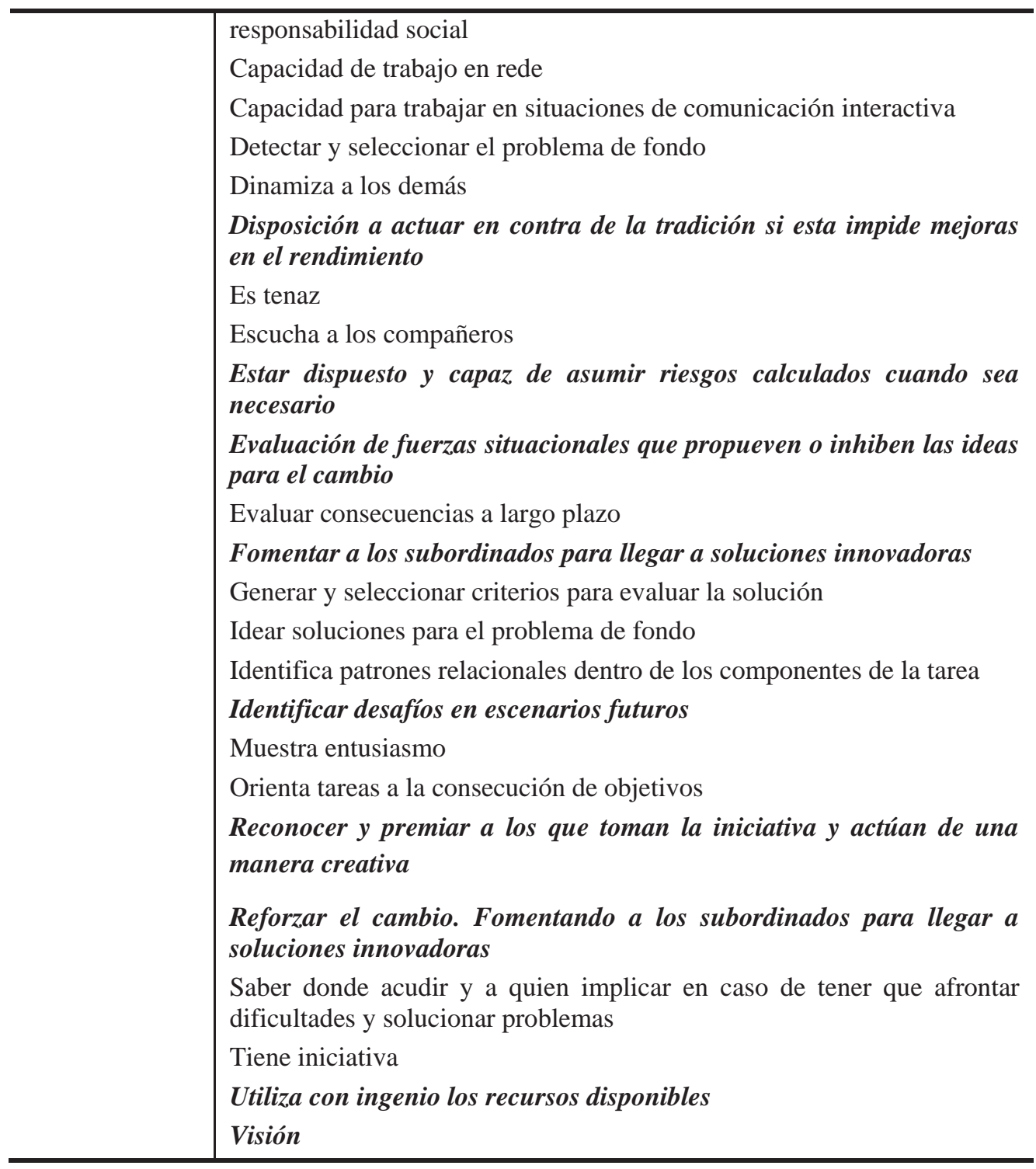

Se han resaltado en la tabla aquellos objetivos de aprendizaje que se considera forman parte directa de la competencia que analizamos. El resto se podrían solapar con otras competencias como trabajo en equipo, solución de problemas, responsabilidad social-ética entre otras, por lo que no serán incluidos en la lista final.

Otro aspecto a considerado a partir de la propuesta de Bapat(2014) es agrupar las competencias por grupos, según lo que tratan de medir. Esto permitirá dar más flexibilidad

\section{(c)) EY-NC-ND 2014, UniversitatPolitècnica de València}

I Jornadas IN-RED (2014) 
Objetivos de aprendizaje para grado y máster de la competencia genérica de innovación, creatividad y emprendimiento

a la gestión de los objetivos de aprendizaje y a su posterior evaluación. Los grupos o perspectivas son: creatividad, emprendimiento, integración, previsión y gestión del cambio.

Basándonos en dichos aspectos los objetivos de aprendizaje identificados se clasificaron de la siguiente forma:

Table 10.1 Clasificación de los objetivos de aprendizaje para grado

\begin{tabular}{|c|c|}
\hline Perspectiva & Objetivo de aprendizaje \\
\hline Creatividad & $\begin{array}{l}\text { Actuar de manera creativa en el desarrollo de métodos de trabajo } \\
\text { Actuar de manera creativa en la solución de problemas } \\
\text { Aportar ideas originales en cuanto a contenido } \\
\text { Aportar ideas originales en cuanto a la forma de materializarse } \\
\text { Aportar sugerencias a las ideas, situaciones, casos o problemas que se plantean. } \\
\text { Atacar la tarea desde diferentes puntos de vista } \\
\text { Cuestionarse la realidad en la que se plantea la innovación. } \\
\text { Encontrar nuevos métodos y procesos para hacer las cosas. } \\
\text { Evaluar de forma crítica los fundamentos de las ideas y las acciones } \\
\text { Experimentar con procedimientos nuevos. } \\
\text { Familiarizarse con los instrumentos y técnicas de generación de ideas: } \\
\text { Generar ideas originales y de calidad, que se pueden plasmar de una manera } \\
\text { formal y defenderlas en situaciones conocidas y desconocidas. } \\
\text { Generar y transmitir nuevas ideas o generar alternativas innovadoras a las } \\
\text { situaciones o problemas conocidos que se plantean. } \\
\text { Introducir nuevos procedimientos y acciones en el propio proceso de trabajo para } \\
\text { responder mejor a las limitaciones y problemas detectados } \\
\text { Plasmar de manera formal las ideas que se han generado. } \\
\text { Proponer ideas y soluciones innovadoras tanto en cuanto al contenido, como al } \\
\text { proceso para llevarlas a cabo. } \\
\text { Proponer sugerencias y alternativas adecuadas a las necesidades de la tarea } \\
\text { Reflexionar sobre nuevas formas de hacer las cosas. } \\
\text { Responder con detalle e integridad de respuestas } \\
\text { Responder con flexibilidad (variabilidad de ideas en las respuestas) } \\
\text { Responder con fluidez. Número de respuestas contestadas (fluidez) } \\
\text { Responder con originalidad (rareza de la respuesta) } \\
\text { Transmitir sus ideas con coherencia y eficacia } \\
\text { Utilizar técnicas de creatividad para proponer y defender ideas de calidad, } \\
\text { originales o poco convencionales. }\end{array}$ \\
\hline Emprendimiento & $\begin{array}{l}\text { Analizar una situación dada e identificar aspectos de mejora. } \\
\text { Aportar sugerencias propias de calidad ante situaciones o problemas que se } \\
\text { presentan. } \\
\text { Buscar nuevos procedimientos y métodos para hacer las cosas. } \\
\text { Buscar y proponer nuevos métodos y soluciones ante situaciones problemáticas } \\
\text { reales o hipotéticas. } \\
\text { Identificar los resultados de la innovación. }\end{array}$ \\
\hline $\begin{array}{l}\text { Gestión } \\
\text { cambio }\end{array}$ & $\begin{array}{l}\text { Analizar riesgos y beneficios de la innovación } \\
\text { Asumir riesgos con inteligencia } \\
\text { Reconocer las limitaciones y puntos débiles en sus procesos y métodos de } \\
\text { trabajo. }\end{array}$ \\
\hline
\end{tabular}

2014, UniversitatPolitècnica de València 
Marta Fernández-Diego, Leonor Ruiz, MariLuz Gordo , M.M.E. Alemany, Andrés Boza, Llanos Cuenca

\begin{tabular}{l|l} 
Integración & $\begin{array}{l}\text { Expresar a otro las nuevas ideas que se han generado. } \\
\text { Integrar conocimientos de varias disciplinas, fuentes o ámbitos para generar ideas } \\
\text { novedosas a situaciones conocidas o desconocidas } \\
\text { Tener en cuenta a quién y cómo afecta la innovación. }\end{array}$
\end{tabular}

Table 10.2 Clasificación de los objetivos de aprendizaje para máster

\begin{tabular}{|c|c|}
\hline Perspectiva & Objetivo de aprendizaje \\
\hline Creatividad & $\begin{array}{l}\text { Adoptar actitudes abiertas a la generación de nuevos pensamientos } \\
\text { Adoptar enfoques creativos en relación al contenido propio de la situación y } \\
\text { al modo de realización. } \\
\text { Evaluar críticamente los datos y sacar conclusiones. } \\
\text { Identificar necesidades de mejora en situaciones y contextos complejos. } \\
\text { Introducir soluciones singulares o punteras que mejoran varios aspectos o } \\
\text { ámbitos de actuación. } \\
\text { Obtener resultados con la innovación. } \\
\text { Responder con detalle e integridad de respuestas } \\
\text { Responder con flexibilidad (variabilidad de ideas en las respuestas) } \\
\text { Responder con fluidez. Número de respuestas contestadas (fluidez) } \\
\text { Responder con originalidad (rareza de la respuesta) } \\
\text { Utilizar métodos específicos para mejorar la creatividad. } \\
\text { Utilizar métodos y soluciones adecuadas a la innovación. } \\
\text { Diseñar y realizar experimentos adecuados, interpretar los datos y sacar } \\
\text { conclusiones. } \\
\text { Diseñar y aplicar procesos innovadores en la organización, que conducen a } \\
\text { la obtención de mejores resultados ante situaciones y/o proyectos reales. } \\
\text { Encontrar nuevos métodos de hacer las cosas de otra manera. }\end{array}$ \\
\hline Emprendimiento & $\begin{array}{l}\text { Realizar búsquedas de literatura técnica utilizando bases de datos y otras } \\
\text { fuentes de información. } \\
\text { Identificar, localizar y obtener los datos requeridos. } \\
\text { Investigar la aplicación de tecnologías nuevas y emergentes en su rama de la } \\
\text { ingeniería. } \\
\text { Pensar y tomar decisiones independientes } \\
\text { Realizar proyectos por iniciativa propia, comprometiendo determinados } \\
\text { recursos con el fin de explotar una oportunidad } \\
\text { Reflexionar sobre las causas y fines de la innovación. } \\
\text { Tomar la iniciativa y trabajar de manera responsable de acuerdo con los } \\
\text { objetivos de la comunidad } \\
\text { Afrontar la realidad con iniciativa } \\
\text { Diseñar y llevar a cabo investigaciones analíticas, de modelado y } \\
\text { experimentales. }\end{array}$ \\
\hline Gestión del cambio & $\begin{array}{l}\text { Afrontar la realidad sopesando riesgos y oportunidades y asumiendo las } \\
\text { consecuencias. } \\
\text { Emprender proyectos ambiciosos (complejos y desafiantes), que implican } \\
\text { una decisión social. } \\
\text { Estar dispuesto y capaz de asumir riesgos calculados cuando sea necesario } \\
\text { Evaluar fuerzas situacionales que promueven o inhiben las ideas para el } \\
\text { cambio } \\
\text { Ofrecer disposición a actuar en contra de la tradición si esta impide mejoras }\end{array}$ \\
\hline
\end{tabular}

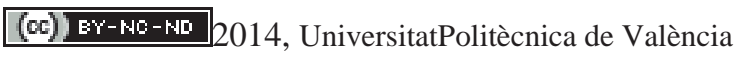

I Jornadas IN-RED (2014) 
Objetivos de aprendizaje para grado y máster de la competencia genérica de innovación, creatividad y emprendimiento

\begin{tabular}{l|l} 
Integración & $\begin{array}{l}\text { en el rendimiento } \\
\text { Reforzar el cambio. Fomentando a los subordinados para llegar a soluciones } \\
\text { innovadoras } \\
\text { Analizar riesgos y beneficios. } \\
\text { Adoptar un punto de vista crítico y autónomo respecto al conocimiento } \\
\text { relativo a su propia disciplina } \\
\text { Aportar ideas y soluciones de amplia originalidad, prácticas y aplicables, } \\
\text { flexibles y complejas, que afectan tanto a uno mismo y a los procesos en los } \\
\text { que está implicado, como a las personas y procesos cercanos. } \\
\text { Establecer relaciones constructivas en base al diálogo } \\
\text { Fomentar a los subordinados para llegar a soluciones innovadoras } \\
\text { Tomar iniciativas contando con otros, haciéndoles partícipes de su visión de } \\
\text { futuro y sus proyectos. } \\
\text { Construir el conocimiento científico acerca de los problemas (proyectos) de } \\
\text { ingeniería, con el propósito de solucionar eficientemente los problemas en el } \\
\text { contexto determinado. }\end{array}$
\end{tabular}

\section{Conclusiones}

El presente artículo recoge la lista de objetivos de aprendizaje asociados a la competencia de innovación en grado y máster. El análisis de la literatura ha permitido obtener los objetivos de aprendizaje asociados a dicha competencia y clasificarlos en distintas perspectivas, creatividad, emprendimiento, integración, previsión y gestión del cambio.

Los objetivos de aprendizaje identificados para grado y máster son prácticamente los mismos en cuanto a número, 35 de grado frente a los 37 de máster. Sin embargo la clasificación asignada si varía más significativamente. Los primeros (grado) se dividen en 24 objetivos de aprendizaje asociados a creativity, 5 para enterprising, 3 para innovation, ninguno para forecasting y tres para gestión del camio. En máster, disminuye el número de objetivos de aprendizaje asociados a creatividad a 15 , entendiendo que han sido adquiridos en grado, pero por el contrario aumentan en el resto de áreas, 9 enterprising, 5 integration, uno forecasting y 7 gestión del cambio. De lo que se desprende que la orientación en máster debe tener una visión más amplia y a más largo plazo, incluyendo aspectos relacionados a la previsión, integración y gestión del cambio.

Una vez definidos los objetivos de aprendizaje ser estará en disposición de abordar su evaluación. Se propone como línea futura, en la que se ha empezado a trabajar, siguiendo la línea del proyecto de investigación en el que se emparca este trabajo, la definición de una rúbrica que permita dividir el nivel de alcance de los objetivos y por tanto de la competencia.

Una segunda línea futura será diseñar cuales serán los objetos de aprendizaje que favorezcan la consecución de los objetivos de aprendizaje. 
Marta Fernández-Diego, Leonor Ruiz, MariLuz Gordo , M.M.E. Alemany, Andrés Boza, Llanos Cuenca

\section{Referencias}

Adams K., 2005 The source of Innovation and Creativity. A paper commissioned by the national center on education and the economy for the new commission on the skills of the American workforce.

Bapat et al., 2014 Technical Report. http://www.chsbs.cmich.edu/leader_model/assess.htm

Black, P. and D. Wiliam (1998), "Assessment and Classroom Learning”, Assessment in Education: Principles, Policy and Practice, Vol. 5, No. 1, pp. 7-74

Braun H., Kanjee A., Bettinger E., and Michael Kremer Improving Education Through Assessment, Innovation, and Evaluation. ISBN: 0-87724-058-2 by the American Academy of Arts and Sciences

Bruin, T. De., M. Rosemann, R. Freeze, U. Kulkarni, Understanding the main phases of developing a maturity assessment model, in: Proceedings of the 16th Australasian Conference on Information Systems, Sydney, Australia, 2005, pp. 1-10.

Cuenca L., Boza A., Alemany MME, Trienekens J.. (2013) Structural elements of coordination mechanisms in collaborative planning processes and their assessment through maturity models: Application to a ceramic tile company. Computers in Industry 64 (2013) 898-911

Gomez P.; Aguirre M.P.; Posso, F. y García G. (2002). Matriz de Valoración. EDUTEKA. http://www.eduteka.org/MatrizValoracion.php3

Goodrich H. (1997). Understanding Rubrics. Educational Leadership, 54(4), 14-17

Ice 2014; Dimensiones Competenciales UPV Report Interno. ICE-Universitat Politècnica de València.

Idea Tempus, 2014 Inter Disciplinary Education Agenda http://tempus-idea.org.il/idea_wp/

Incode, 2012 Innovation competencies development as integral part of higher education. http://www.incode-eu.eu/en/

Kairisto-

Mertanen,L.;Penttilä,T.Nuotio,J.(2011). On the definition of innovation competencies,in In novations forCompetence Management, Conference proceedings. eds. Torniainen; Ilona, M ahlamäki-

Kultanen, Seija, Nokelainen Petri \& Paul Ilsley; Series C, reports and other current pu blications, part 83, Lahti University of Applied Sciences, Esa print Oy.

Keeves, 1997; Keeves, J. P., ed. 1997. Educational Research, Methodology and Measurement: An International Handbook, 2nd ed. New York: Pergamon.

UNESCO, 2000 UNESCO 2000b. Status and Trends 2000: Assessing learning achievement. Paris:

(c)) EY-NC-ND 2014, UniversitatPolitècnica de València

I Jornadas IN-RED (2014) 
Objetivos de aprendizaje para grado y máster de la competencia genérica de innovación, creatividad y emprendimiento

Lonely, 2009 Looney, J. W. (2009), “Assessment and Innovation in Education”, OECD Education Working Papers, No. 24, OECD Publishing. http://dx.doi.org/10.1787/222814543073

Lopez J.L. (2002). Uso de rúbricas generalizadas para evaluar conocimientos en la técnica didáctica Aprendizaje Basado en Problemas. Documento en internet www.mty.itesm.mx/rectoria/dda/rieee/html/2002.htm [

Marin-Garcia J.A., Pérez-Peñalver M.J., Watts F.(2013) How to assess innovation competence in services: The case of university students. Dirección y Organización 50 (2013) 48-62

Markwell et al, 2003 Improving teaching and learning in universities. Business/Higher education round table, issue 18, 2003

Navarro J.P; Ortells M.J,; Martí M. Las rúbricas de evaluación como instrumento de aprendizaje entre pares. giac.upc.es/JAC10/09/Doc_69.pdf

NCME, 1990 American Federation of Teachers (AFT), National Council on Measurement in Education (NCME), and National Education Association (NEA). 1990. Standards for Teacher Competence in Educational Assessment of Students.Washington, DC: American Federation of Teachers.

Watts F., Marin-Garcia J.A., García Carbonell A., Aznar-Mas L. Validaton of a rubric to assess innovation competence. Working Papers on Operations Management. Vol 3, $\mathrm{N}^{\mathrm{o}} 1$ (61-70) ISSN: 1989-9068

\section{Agradecimientos}

Esta investigacón ha sido llevada a cabo en el marco del proyecto de innovación y mejora educativa 'RECICRE - Rúbricas para la Evaluación de la Competencia Innovación, Creatividad y Emprendimiento" subvencionado por la Universitat Politècnica de València y la Escuela Técnica Superior de Informática Aplicada. 
Jornadas In-Red 2014

Universitat Politècnica de València

\title{
La introducción de la responsabilidad profesional en los estudios de Grado en Ingeniería en Obras Públicas.
}

Ester Giménez ${ }^{\mathrm{a}}$,Amalia Sanz ${ }^{\mathrm{b}}$, Alicia Lozano ${ }^{c}$, J. R. Martí-Vargas ${ }^{\mathrm{d}}$, Julian Alcaláe, Joaquín Cataláf ${ }^{\text {, Rafael Cortés }}{ }^{\mathrm{g}}$ y J. Felix Lozano ${ }^{\mathrm{h}}$.

a ETSICCyP de la UPV, esgimen@cst.upv.es, ${ }^{b}$ ETSICCyP de la UPV, asanz@cst.upv.es, ${ }^{c}$ ETSICCyP de la UPV, allotor@upv.es, ${ }^{\text {d} E T S I C C y P ~ d e ~ l a ~ U P V, ~ j r m a r t i @ c s t . u p v . e s, ~}{ }^{\mathrm{e}} \mathrm{ETSICCyP}$ de la UPV, jualgon@upv.es, ${ }^{\mathrm{f}} \mathrm{ETSICCyP}$ de la UPV, jcatala@cst.upv.es, ${ }^{\mathrm{g}} \mathrm{ETSICCyP}$ de la UPV, rcortes@trr.upv.es, hETSII de la UPV, jlozan@dpi.upv.es.

\begin{abstract}
The paper presents the Innovation and Improvement Education Project (PIME) entitled "The introduction of professional responsibility in the studies of Civil Engineering degree (GIOP) " developed during 2013-2014 in the School of Civil Engineering of the UPV. The aforementioned PIME aims to get students of the GIOP, understand and assume the ethical and professional responsibility of the activity of the Civil Engineer.

The project explains how to introduce this competence in the GIOP, as well as how to evaluate the acquisition of such competence. This will work in several core subjects of the curriculum situated along the last three years of the degree, pose moral dilemmas related to the subject in which there are scheduled and then, the students complete a questionnaire to assess their work.

Based on the results will be discussed if this methodology is appropriate to introduce competence Professional Responsibility, or whether other actions are necessary to achieve the objective.
\end{abstract}

Keywords: Professional responsibilities, competence, transversal, ethics.

\section{Resumen}

El trabajo presenta el Proyecto de Innovación y Mejora Educativa (PIME) titulado "La introducción de la responsabilidad profesional en los estudios de Grado en Ingeniería en Obras Públicas" desarrollado durante el curso 
La introducción de la responsabilidad profesional en los estudios de Grado en Ingeniería en Obras Públicas.

2013-214 en la Escuela Técnica Superior de Ingenieros de Caminos, Canales y Puertos de la UPV. El objetivo del citado PIME es conseguir que los alumnos del GIOP, comprendan y asuman la responsabilidad ética y profesional de la actividad del Ingeniero Civil.

El proyecto explica un modo de introducir dicha competencia en el GIOP, así como el modo de evaluar la adquisición de dicha competencia. Para ello se trabajará en varias asignaturas obligatorias del plan de estudios situadas a lo largo de los tres últimos cursos, planteando dilemas morales relacionados con la asignatura en la que se programan y posteriormente los alumnos rellenaran un cuestionario para evaluar el trabajo realizado.

A partir de los resultados se discutirá si esta metodología es la adecuada para introducir la competencia Responsabilidad Profesional, o si son necesarias otras acciones para conseguir el objetivo.

Palabras clave: Responsabilida profesional, competencia, transversal, ética.

\section{Introducción}

La reciente implementación en nuestro país del Espacio Europeo de Educación Superior (EEES) a partir de la Declaración de Bolonia, ha sido una oportunidad para revisar y actualizar las titulaciones ofertadas por las universidades españolas que han debido adaptarse a los objetivos del EEES, esto es:

- Adopción de un sistema fácilmente legible y comparable de titulaciones

- Adopción de un sistema basado en tres ciclos (grado, master y doctorado)

- Establecimiento de un sistema internacional de créditos (ECTS European Credit Transfer System)

- Promoción de la movilidad de estudiantes, profesores e investigadores y personal de administración y servicios

- Promoción de la cooperación europea para garantizar la calidad de la educación superior

- Promoción de una dimensión europea de la educación superior

En el campo de las ingenierías, este cambio ha motivado la desaparición de los estudios tradicionales de ingeniero técnico e ingeniero superior, y de manera generalizada, se han dado atribuciones profesionales similares a las de los ingenieros Técnicos a los estudiantes que completen sus estudios de grado.

Paralelamente el Consejo Europeo y el Parlamento europeo aprobaron la creación del Marco Europeo de Cualificaciones para el aprendizaje permanente (EQF-MEC) que 
pretende ser una herramienta para homogeneizar las calificaciones obtenidas en los distintos estudios (desde la educación escolar hasta el doctorado) en los países miembros del EEES. Para realizar la correcta cualificación divide los aprendizajes en tres categorías: Conocimientos, Destrezas y Competencias.

Si observamos la evolución del sistema universitario español anterior a la declaración de Bolonia, se puede observar que el tipo de aprendizaje que más habitualmente se ha calificado, el que tiene mayor tradición, ha sido los que entrarían en la categoría de Conocimientos, ya fueran estos teóricos, fácticos, hechos, procesos, principios, etc. En esos momentos la critica que se hacía a la Universidad era fundamentalmente que se trataba de un mero lugar de trasmisión del conocimiento, pero sin desarrollar o potenciar Destrezas indispensables para alcanzar la excelencia.

En ese momento se empezaron a introducir dinámicas de trabajo en grupo en las aulas y se empezaron a plantear los aprendizajes de manera que los alumnos adquirieran Destrezas, descritas estas como cognitivas (uso del pensamiento lógico, intuitivo y creativo) y prácticas (fundadas en la destreza manual y en el uso de métodos, materiales, herramientas e instrumentos).

Llegados a este punto se estableció que también era importante que el alumno, a lo largo de su vida como estudiante adquiriera Competencias descritas en términos de responsabilidad y autonomía. No hay que olvidar que en el caso de las enseñanzas técnicas una vez finalizados los estudios de grados, estar en posesión de este título les da directamente atribuciones profesionales que les permite firmar proyectos no exentos de responsabilidad con la sociedad.

Todo esto queda reflejado en el EQF-MEC, sin establecer jerarquía de importancia de un grupo frente a otro.

Ahora bien, tenemos muy claro cómo evaluar los Conocimientos de nuestros alumnos (exámenes de pruebas teóricas, objetivas, etc.), y también sabemos cómo evaluar Destrezas (exámenes con resolución de problemas, estudio de casos, etc.), pero ¿Cómo introducimos en los planes de estudio las Competencias? ¿Cómo evaluamos las Competencias de los estudiantes? ¿Cómo podemos saber si un alumno ha adquirido la responsabilidad y la autonomía necesarias para el buen desarrollo de sus funciones profesionales?"

Por otra parte en la reciente publicación "La Visión para la Ingeniería Civil en 2025" preparada por el Comité directivo de la ASCE (Sociedad Americana de Ingenieros Civiles) para planificar una cumbre sobre el Futuro de la Profesión de la Ingeniería Civil en 2025 también se alerta de la importancia de la profesión y de la tendencia a tomar un papel más activo en el proceso de toma de decisiones de política. Para este propósito es imprescindible

\section{(c)) EY-NC-ND 2014, Universitat Politècnica de València}

I Jornadas IN-RED (2014) 
La introducción de la responsabilidad profesional en los estudios de Grado en Ingeniería en Obras Públicas.

que nuestros estudiantes adquieran la Competencia de ética y responsabilidad profesional que les permita realizar está tarea.

\section{Objetivos}

La llegada del Espacio Europeo de Educación Superior, obligó a rediseñar las titulaciones universitarias españolas para equipararlas a las características en cuanto a duración (número de créditos) y contenidos de las impartidas en el resto del EEES. En el año 2003 el Ministerio de Educación y Ciencia publicó diversos informes en los que se habla de "proporcionar una formación universitaria en la que se integren armónicamente las competencias genéricas básicas, las competencias transversales relacionadas con la formación integral de las personas y las competencias más específicas que posibiliten una orientación profesional que permita a los titulados una integración en el mercado de trabajo"

A partir de estos informes las Escuelas empezaron a redactar los planes de estudios de los distintos grados incorporando las competencias que debían adquirir los alumnos. En la figura 1 se detallan algunas de las competencias que debe tener un estudiante al completar los estudios de Grado en Ingeniería de Obras Públicas en la UPV (datos publicados en la web de la Escuela de Caminos, Canales y Puertos de la Universitat Politecnica de Valencia).

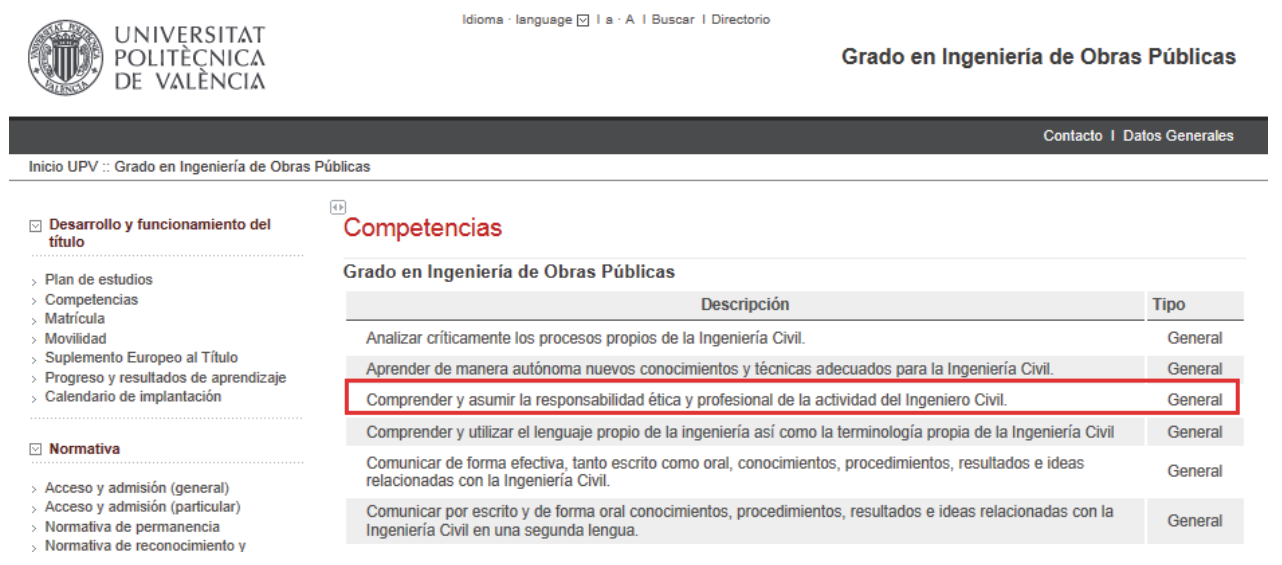

Fig. 1 Competencias en los estudios de Grado en Obras Publicas de la UPV

Como se observa, la tercera competencia enunciada dice: "Comprender y asumir la responsabilidad ética y profesional de la actividad del Ingeniero Civil”, sin embargo si observamos el plan de estudios que siguen los estudiantes (disponible en 
http://www.upv.es/titulaciones/GIOP/indexc.html) no se vislumbra ninguna asignatura en cuyo contenido se trate de manera directa esta competencia. ¿Cómo va a adquirirla el alumno?.

El objetivo de presente proyecto es conseguir que los alumnos del Grado en Ingeniería de Obras Públicas, comprendan y asuman la responsabilidad ética y profesional de la actividad del Ingeniero Civil. Se pretende que los alumnos egresados hayan adquirido la competencia Responsabilidad Profesional.

\section{Desarrollo de la Innovación}

Para la implantación del PIME se han previsto dos tipos de acciones a desarrollar para ofrecer a los estudiantes la adquisición de la competencia Responsabilidad Profesional.

La primera acción consiste en concienciar a los estudiantes, a lo largo del desarrollo de las asignaturas implicadas en el proyecto, de la responsabilidad profesional que van a asumir al finalizar sus estudios de grado. Esta acción ya se lleva a cabo en la actualidad por parte de varios profesores que imparten docencia en el grado. Esto se realiza mediante la explicación en el aula de experiencias reales y de decisiones tomadas en el ámbito profesional.

La segunda acción es el planteamiento de prácticas de aula en que se trabajen dilemas morales relacionados con las asignaturas, se expongan ejemplos reales de buenas y malas prácticas profesionales y sus consecuencias (ética profesional) o bien se presenten temas/noticias de actualidad para inciar un debate y que los estudiantes reflexionen y tomen alguna decisión simulando que se encuentran en pleno ejercicio de la profesión.

Está previsto que la competencia responsabilidad profesional se adquiera durante los estudios de Grado en Ingeniera de Obras Públicas. Por esta razón se han seleccionado dos asignaturas obligatorias de segundo, tercer y cuarto curso de manera que al terminar la carrera los alumnos sean conscientes de la responsabilidad que tienen al ejercer su profesión. Es decir, que estén mejor preparados ya que "La profesión debe ser vivida como responsabilidad: ante sí mismo, por la obra bien hecha (profesionalidad), por las consecuencias de la obra bien hecha (servicio a los intereses comunes) y en el marco institucional" (Etxeberria, 2002).

\subsection{Progreso de las prácticas de aula}

En el curso 2013-14, se han seleccionado dilemas morales preparados por el Grupo de Innovación Educativa en Eduacion en Valores (GREVOL), de la UPV. En este curso se ha priorizado que los dilemas estén relacionados con las asignaturas en que se imparten, sin

\section{(c) EY-NC-ND 2014, Universitat Politècnica de València}

I Jornadas IN-RED (2014) 
La introducción de la responsabilidad profesional en los estudios de Grado en Ingeniería en Obras Públicas.

tener en cuenta el grado de desarrollo de los alumnos. Es decir, no hay evolución en la dificultad del trabajo planteado. Esta dificultad dependerá exclusivamente de la experiencia que aporte cada estudiante. Esto implica que la evaluación de la competencia no se ha podido hacer de manera evolutiva. Por otra parte, al ser el primer curso en que se planteaba este tipo de trabajo de manera coordinada, a priori, los estudiantes no han trabajado esta competencia de manera concreta anteriormente.

El trabajo en el aula consiste en plantear los dilemas morales en equipos (el numero de estudiantes depende del tamaño del grupo), seguido de un debate y posteriormente cada alumno de manera individual rellena un cuestionario que entrega al profesor. El trabajo se puede evaluar con la ayuda de rúbricas

\subsection{Evaluación de la competencia Responsabilidad Profesional}

La evaluación de la competencia Responsabilidad Profesional presenta una gran dificultad y se ha diseñado una rúbrica para facilitar la tarea.

La rúbrica debe apreciar la capacidad (de manera cualitativa) del alumno de:

- En el ámbito cognitivo; deliberación, enjuiciamiento de las propias acciones, análisis de las consecuencias de las acciones y comprensión de que las propias acciones repercuten en el mundo de las personas actuales y en el mundo posterior.

- En el ámbito del comportamiento; realizar las acciones que se han decidido y articular de modo eficaz los medios con las metas que se desean alcanzar

- En el ámbito afectivo; autonomía para tomar decisiones y fortaleza para resistir presiones externas o internas.

Teniendo en cuenta estos aspectos se ha diseñado la rúbrica que aparece en la tabla 1. Nuestra experiencia en la aplicación de esta rúbrica es limitada por lo que probablemente en los próximos cursos será necesario su mejora y ajuste.

Con esta rúbrica se pretende evaluar si al al finalizar sus estudios un estudiante egresado es capaz de:

- Responder por las propias acciones ante los otros y ante uno mismo.

- Adquirir una obligación y tener autonomía.

- Contestar a las siguientes preguntas (ante la resolución de un problema o una actuación profesional); ¿De qué somos responsables? ¿Ante quién? ¿En virtud de qué?

- Elegir. Se debe ser capaz de discernir si debemos o no implicarnos en una determinada institución o proyecto. 
Tabla 1. Propuesta de rúbrica para evaluar la competencia Responsabilidad Profesional

\begin{tabular}{|c|c|c|c|c|}
\hline & Mal & Regular & Bien & Muy Bien \\
\hline $\begin{array}{l}\text { Toma una postura } \\
\text { respecto a la acción } \\
\text { del personaje }\end{array}$ & $\begin{array}{c}\text { No expresa su } \\
\text { opinión }\end{array}$ & $\begin{array}{c}\text { Expresa de manera } \\
\text { vaga su postura (no } \\
\text { queda clara) }\end{array}$ & $\begin{array}{c}\text { Expresa } \\
\text { claramente su } \\
\text { postura }\end{array}$ & $\begin{array}{c}\text { Expresa claramente } \\
\text { su postura (incluso } \\
\text { hace cambiar de } \\
\text { opinión a algunos } \\
\text { compañeros) }\end{array}$ \\
\hline $\begin{array}{c}\text { Cantidad de } \\
\text { argumentos para } \\
\text { expresar su opinión }\end{array}$ & $\begin{array}{c}\text { Ningún } \\
\text { argumento }\end{array}$ & $\begin{array}{c}\text { Muestra un argumento } \\
\text { no sólido }\end{array}$ & $\begin{array}{c}\text { Muestra de } 1 \text { a } 3 \\
\text { argumentos } \\
\text { sólidos }\end{array}$ & $\begin{array}{l}\text { Muestra una gran } \\
\text { cantidad de } \\
\text { argumentos sólidos } \\
\text { para ratificar su } \\
\text { postura }\end{array}$ \\
\hline $\begin{array}{c}\text { Calidad de la } \\
\text { argumentación }\end{array}$ & No argumenta & $\begin{array}{c}\text { Se expresa con } \\
\text { confusión, } \\
\text { contradicción, pero } \\
\text { logra comentar ideas } \\
\text { acerca del dilema }\end{array}$ & $\begin{array}{c}\text { Se expresa } \\
\text { claramente } \\
\text { manteniendo su } \\
\text { postura con ideas } \\
\text { completas y } \\
\text { pertinentes }\end{array}$ & $\begin{array}{c}\text { Propone ideas } \\
\text { claras y completas, } \\
\text { y basa su } \\
\text { argumentación en } \\
\text { referentes teóricos, } \\
\text { científicos, legales, } \\
\text { etc }\end{array}$ \\
\hline $\begin{array}{c}\text { Capacidad de } \\
\text { relacionar todos los } \\
\text { agentes implicados } \\
\text { en el dilema }\end{array}$ & $\begin{array}{l}\text { Ningún } \\
\text { aspecto de } \\
\text { análisis }\end{array}$ & $\begin{array}{c}\text { Es capaz de identificar } \\
\text { o relacionar } 1 \text { o } 2 \\
\text { aspectos del análisis }\end{array}$ & $\begin{array}{l}\text { Es capaz de } \\
\text { relacionar al } \\
\text { menos } 3 \text { de los } \\
\text { aspectos del } \\
\text { análisis }\end{array}$ & $\begin{array}{c}\text { Es capaz de } \\
\text { relacionar todos los } \\
\text { agentes implicados } \\
\text { en el dilema }\end{array}$ \\
\hline
\end{tabular}

\section{Resultados}

El proyecto en la actualidad tiene un recorrido muy corto, para obtener resultados acerca de la adquision de la competencia responsabilidad profesional.

Debido al carácter innovador del proyecto, además de evaluar la compencia, se preguntaba a los estudiantes su opinión acerca de la necesidad de introducir este tipo de trabajo durante sus estudios de grado (preguntas 4 y 5 del cuestionario mostradas en la figura 2) y de manera mayoritaria se opina que en los planes de estudio de GIOP se debería trabajar la ética y la responsabilidad profesional en mayor medida (respuesta d, de la pregunta 4).

También cabe destacar que la respuesta mayoritaria a la pregunta 5 ha sido la c. Es decir los alumnos piensan que necesitan experiencia profesional para poder resolver problemas éticos. Esta respuesta es muy interesante ya que nos indican que los alumnos no se llegan a plantear si las decisiones tomadas son ética o moralmente correctas, sino que pretenden

\section{(c)) EY-NC-ND 2014, Universitat Politècnica de València}

I Jornadas IN-RED (2014) 
La introducción de la responsabilidad profesional en los estudios de Grado en Ingeniería en Obras Públicas.

conocer cual es la práctica profesional (¿es esto cierto? ¿qué grado de ética/moralidad/responsabilidad profesional y personal tiene la sociedad actual?)

4. Piensas que el tipo de trabajo que has realizado hoy en el aula (discusión de un dilema moral)

a. No es interesante

b. Ha sido interesante, he reflexionado sobre temas nuevos para mí

c. Ha sido interesante, creo que se deberían plantear con más frecuencia

d. Ha sido muy interesante, creo que en los planes de estudio de GIOP se debería trabajar la ética y la responsabilidad profesional en mayor medida.

e. Otra respuesta

furmación (en el colegio, instituto, universidad ) chas recibido suficientes enseñanzas que te permitan afrontar este tipo de situaciones con suficiente confianza en tu criterio?

a. No me siento preparado para abordar este tipo de problemas.

b. No, he echado de menos formación ética a lo largo de mi vida de estudiante.

c. No, creo que me falta unos años de experiencia profesional para abordar este tipo de problemas.

d. Si estoy preparado, aunque sé que no siempre tomaré la decisión correcta.

e. Otra respuesta

Fig. 2 Parte del cuestionario de Evaluación de un dilema moral.

\section{Conclusiones}

Como se ha comentado en el apartado anterior, el proyecto es demasiado reciente para poder evaluar la adquisición de la competencia Responsabilidad Profesional por parte de los estudiantes.

Una dificultad observada durante el desarrollo del proyecto, y que es común a todas las competencias que se introducen de manera trasversal en asignaturas de contenido técnico, es que en caso de no poder completar el programa, se sacrifican las tareas para introducir competencias transversales en favor de los conocimientos técnicos (ambos igual de necesarios), con lo cuál " la materia en cuestión se escapa entre los dedos de la presunta transversalidad” (Cortina 2013).

(c) EY-NC-ND 2014, Universitat Politècnica de València

I Jornadas IN-RED (2014) 
En el contexto de la sociedad actual es indispensable que en los estudios de grado se intruduzcan de manera inminente la competencia responsabilidad/ética profesional. No se puede asegurar que la introducción de esta competencia de manera transversal sea la mas correcta. Expertos en la materia sostienen que "una sociedad demuestra que una materia le parece indispensable para la formación de un profesional cuando la incluye explícitamente en su plan de estudios" (Cortina 2013).

Por otra parte, el trabajo desarrollado ha servido para reflexionar sobre que tipo de formación estamos proporcionando a nuestros estudiantes y que tipo de profesional nos demanda la sociedad. Este debate es antiguo, y en 1952 Albert Einstein publicó las siguientes palabras "No basta con enseñar a un hombre una especialidad. Aunque esto pueda convertirle en una especie de máquina útil, no tendrá una personalidad armoniosamente desarrollada. Es esencial que el estudiante adquiera una comprensión de los valores y una profunda afinidad hacia ellos. Debe adquirir un vigoroso sentimiento de lo bello y de lo moralmente bueno." (Einstein 1952)

\section{Agradecimientos}

Los autores quieren agradacer al Vicerectorado de Estudios, Calidad y Acreditación, a la Escuela Técnica Superior de Ingenieros de Caminos, Canales y Puertos y al Instituto de Ciencias de la Educación de la Universidad Politécnica de Valencia el apoyo recibido para desarrollar el proyecto presentado.

\section{Referencias}

BONI A. et al. (2005). La educación en valores en la Universidad: los dilemas morales como herramienta de trabajo en los estudios científicos-técnicos. Valencia: Publicaciones de la UPV.

COMISION EUROPEA. (2009). El Marco Europeo de Cualificaciones para el aprendizaje permanente (EQF-MEC). Luxemburgo: Oficina de Publicaciones Oficiales de las Comunidades Europeas.

CORTINA A. (1998). "Ética de las profesiones“ en El País. Opinión del 20 de febrero de 1998.

CORTINA A. (2013). “¿Qué es ser ético" en El País. Opinión del 15 de diciembre de 2013.

EINSTEIN A. (1952). Entrevista sobre educación en New York Times, otoño 1952

ESCUELA TECNICA SUPERIOR DE INGENIEROS DE CAMINOS CANALES Y PUERTOS (2014). Grado en Ingeniería en Obras Públicas. < http://www.upv.es/titulaciones/GIOP/indexc.html> [Consulta: 20 de junio de 2013]

(c)) EY-NC-ND 2014, Universitat Politècnica de València

I Jornadas IN-RED (2014) 
La introducción de la responsabilidad profesional en los estudios de Grado en Ingeniería en Obras Públicas.

España. Orden CIN/307/2009, de 9 de febrero, de por la que se establecen los requisitos para la verificación de los títulos universitarios oficiales que habiliten para el ejercicio de la profesión de Ingeniero Técnico de Obras Públicas. BOE, 18 de febrero de 2009, núm. 42, p. 17166-17170

España. Real Decreto 1393/2007, de 29 de octubre, por el que se establece la ordenación de las enseñanzas universitarias oficiales. BOE, 30 de octubre de 2007, núm. 260, p. 44037-44048

ETXEBERRIA X. (2002) Temas básicos. Colección Etica de las Profesiones. Bilbao, Desclee

Portal oficial de la Conferencia de Rectores de las Universidades Españolas. <http://www.crue.org/espacioeuropeo> [Consulta: 20 de junio de 2013]

RÚA E. et al. (2004). Libro Blanco Título de Grado en Ingeniería Civil. Madrid: Agencia Nacional de Evaluación de la Calidad y Acreditación.

(c)) EY-NC-ND 2014, Universitat Politècnica de València 


\title{
Evaluación de las exposiciones orales por alumnos y profesorado: experiencia en "Obtención, Selección, Procesado y Utilización de los Materiales"
}

\section{M.J. Muñoz-Portero}

Departamento de Ingeniería Química y Nuclear, Universitat Politècnica de València, Camino de Vera s/n, 46022, Valencia (SPAIN), mjmunoz@iqn.upv.es, Equipo de Innovación y Calidad Educativa sobre Técnicas de Evaluación Continua Formativa (TECOF)

\begin{abstract}
The aim of the educational innovation proposed is the application of teaching-learning methodologies based in oral expositions, so that more active learning of the student is gotten and permit to the lecturer to apply alternative tools of evaluation. The educational innovation has been applied since 2009/2010 to 2012/2013 course in the subject of "Obtaining, Selection, Processing, and Use of Materials", imparted in the Material Engineer degree in the Higher Technical School of Industrial Engineering. Such educational innovation consists in the realization of an oral exposition in group, which is evaluated with a $10 \%$ of the global score of the subject. The oral exposition is evaluated both the lecturer and the others companions (evaluation between equals) using a rubric. The evaluation of the educational innovation proposed is realized by the scores of the students, the polls of the students, and the autoevaluation of the lecturer. The results show the high scores obtained by the students in the oral expositions and the high grade of satisfaction of the students after applying the educational innovation. Besides, the oral expositions permit that the students acquire new learning strategies, and develop linguistic competences.
\end{abstract}

Keywords: competence, evaluation, oral exposition, teaching-learning methodology. 
Evaluación de las exposiciones orales por alumnos y profesorado: experiencia en "Obtención, Selección, Procesado y Utilización de los Materiales"

\begin{abstract}
Resumen
El objetivo de la innovación educativa propuesta es la aplicación de metodologías de enseñanza-aprendizaje basadas en las exposiciones orales, de forma que se consiga un aprendizaje más activo del alumno y permita al profesorado aplicar herramientas alternativas de evaluación. La innovación educativa se ha aplicado desde el curso 2009/2010 hasta el curso 2012/2013 en la asignatura de "Obtención, Selección, Procesado y Utilización de los Materiales", impartida en la titulación de Ingeniero de Materiales en la Escuela Técnica Superior de Ingenieros Industriales. Dicha innovación educativa consiste en la realización de una exposición oral en grupo, que es evaluada con un $10 \%$ de la nota final de la asignatura. La exposición oral es evaluada tanto por la profesora como por el resto de compañeros (evaluación entre iguales) utilizando una rúbrica. La valoración de la innovación educativa propuesta se realiza mediante las calificaciones de los alumnos, las encuestas de los alumnos y la autoevaluación de la profesora. Los resultados muestran las altas calificaciones obtenidas por los alumnos en las exposiciones orales y el alto grado de satisfacción de los alumnos tras aplicar la innovación educativa. Además, las exposiciones orales permiten que el alumno adquiera nuevas estrategias de aprendizaje y desarrolle competencias lingüísticas.
\end{abstract}

Palabras clave: competencia, evaluación, exposición oral, metodología de enseñanza-aprendizaje.

\title{
1. Introducción
}

La adaptación de la universidad al Espacio Europeo de Educación Superior (EEES) implica el cambio y/o transformación de las metodologías tradicionales con el objetivo de favorecer el aprendizaje del alumno. Para ello es necesario que el profesorado añada a su metodología nuevos usos de los recursos didácticos e integre en ella los procedimientos de evaluación, tanto formativa como sumativa. Una metodología docente muy útil en este caso es la realización de exposiciones orales.

Una exposición oral representa una oportunidad para comunicar de manera clara nuestras ideas, además de un medio para evaluar los conocimientos del que expone un tema. Las exposiciones orales implican una serie de ventajas tanto para el alumno como para el profesorado. En el caso del alumno, las exposiciones orales permiten:

- Comprender mejor el tema (aprendizaje significativo).

- Aprender a planificar, producir y transmitir el conocimiento.

(cc) EY-NC-ND 2014, Universitat Politècnica de València

I Jornadas IN-RED (2014) 
- Adquirir una formación más completa (integral) de cara a su futura inserción profesional.

- Implicarse e interesarse por la materia.

En el caso del profesorado, las exposiciones orales conducen a:

- Clases más participativas, dinámicas y entretenidas.

- Evaluación más formativa y completa: 1) evaluar mejor y preguntar in situ, 2) comprobar la profundidad en la comprensión, 3) evaluar la capacidad de relacionar diversas materias, etc.

Las exposiciones orales permiten que el alumno adquiera nuevas estrategias de aprendizaje y desarrolle, por tanto, competencias genéricas comunes a cualquier titulación. De acuerdo con el proyecto "Tuning Educational Structures in Europe, 2003" (Instituto de Ciencias de la Educación, 2006), la competencia instrumental a desarrollar es "comunicación oral y escrita en la lengua nativa" (competencia lingüística).

En el Informe del Parlamento Europeo (Diario Oficial de la Unión Europea, 2006), la comunicación en la lengua nativa se define como "la habilidad para expresar e interpretar conceptos, pensamientos, sentimientos, hechos y opiniones de forma oral y escrita (escuchar, hablar, leer y escribir), y para interactuar lingüísticamente de una manera adecuada y creativa en todos los posibles contextos sociales y culturales, como la educación y la formación, la vida privada y profesional, y el ocio". Las personas deben poseer las capacidades necesarias para comunicarse de forma oral y escrita en múltiples situaciones comunicativas y para controlar y adaptar su propia comunicación a los requisitos de la situación. Esta competencia incluye, asimismo, las habilidades que permiten distinguir y utilizar distintos tipos de textos, buscar, recopilar y procesar información, utilizar herramientas de ayuda y formular y expresar los propios argumentos orales y escritos de una manera convincente y adecuada al contexto.

Emplear metodologías activas en el aula implica el desarrollo de nuevas actividades en clase para hacerlas más participativas y aumentar la carga de trabajo autónomo de los alumnos, lo cual por lo general hace necesario disminuir los contenidos que se imparten en las clases presenciales. Por ello es muy importante seleccionar los contenidos que es imprescindible tratar en clase y proponer que los alumnos trabajen el resto de forma autónoma, aunque guiada. Una herramienta muy útil en este caso es la realización de trabajos en grupo por parte de los alumnos y la posterior exposición oral de los contenidos más relevantes de los mismos en clase al resto de sus compañeros (UNIVERSITY OF TECHNOLOGY).

(cc) EY-NC-ND 2014, Universitat Politècnica de València

I Jornadas IN-RED (2014) 
Evaluación de las exposiciones orales por alumnos y profesorado: experiencia en "Obtención, Selección, Procesado y Utilización de los Materiales"

\section{Objetivos}

El objetivo de la innovación educativa es aplicar metodologías de enseñanza-aprendizaje basadas en las exposiciones orales, de forma que se consiga un aprendizaje más activo del alumno y permita al profesorado aplicar herramientas alternativas de evaluación.

\section{Desarrollo de la innovación}

\subsection{Contexto}

El ámbito de aplicación de la innovación educativa propuesta corresponde a la asignatura de "Obtención, Selección, Procesado y Utilización de los Materiales (OSPUM)", impartida en el $1^{\circ}$ curso de la titulación de Ingeniero de Materiales ( $2^{\circ}$ ciclo) en la Escuela Técnica Superior de Ingenieros Industriales (ETSII) de la Universidad Politécnica de Valencia (UPV). Se trata de una asignatura troncal de 15 créditos impartida por dos departamentos: Ingeniería Química y Nuclear (DIQN), el cual imparte 1/3 de la asignatura e Ingeniería Mecánica y de Materiales (DIMM), el cual imparte 2/3 de la asignatura. La innovación educativa se aplica en la parte de la asignatura impartida por el DIQN, la cual se imparte en el $1^{\circ}$ cuatrimestre del curso y consta de 5 créditos (2,5 créditos de teoría y 2,5 créditos de prácticas). El número de alumnos matriculados en los últimos cursos académicos es reducido, oscilando entre 8 y 12, lo que facilita el desarrollo y evaluación de innovaciones educativas. Además, soy la única profesora que imparte esta parte de la asignatura, por lo que tengo más margen de libertad para realizar innovaciones educativas. La asistencia a clase es alta (un $75 \%$ de los alumnos matriculados). La mayoría de los alumnos matriculados tiene experiencia profesional.

\subsection{Diseño de la innovación educativa}

Una de las metodologías activas aplicada en la asignatura es la realización de una actividad de trabajo autónomo basada en un trabajo en grupo sobre contaminación medioambiental y reciclado de materiales. Dicho temario no es impartido en clase. Hasta el curso académico 2008/2009 la evaluación del trabajo en grupo se realizaba solo mediante la entrega de un informe. Sin embargo, a partir del curso académico 2009/2010 se optó por realizar también una exposición oral, de forma que el informe representaba $2 / 3$ de la nota del trabajo en grupo y la exposición oral representaba $1 / 3$ de la nota del trabajo en grupo. La innovación educativa propuesta consiste en la realización de una exposición oral en grupo al final del cuatrimestre sobre los conceptos tratados en el trabajo en grupo.

\subsection{Organización de la exposición oral}

La exposición oral se realiza de forma grupal. El número de alumnos por grupo es de 2-3. La exposición oral es obligatoria para todos los alumnos que realizan el trabajo en grupo. 
En cuanto a la elección del tema, los alumnos deben realizar un trabajo en grupo sobre la contaminación medioambiental y reciclado de materiales. La profesora propone diferentes temas y la asignación a cada grupo se realiza por sorteo. Los temas propuestos son: 1) contaminación atmosférica, 2) contaminación de aguas, 3) residuos sólidos y peligrosos, 4) reciclado de plásticos y 5) reciclado de vidrio y metales. Algunos de los alumnos tienen conocimientos previos sobre el tema de contaminación medioambiental y reciclado de materiales. Junto con el tema del trabajo, la profesora proporciona un guión con los puntos básicos a tratar.

En cuanto a los recursos necesarios, es obligatorio realizar la exposición oral apoyándose en una presentación en Power Point. De forma opcional, los alumnos pueden enviar previamente a la profesora la presentación en Power Point. De esa forma, la profesora puede corregir la presentación y comentarla con los alumnos antes del día de la exposición oral.

En cuanto a la planificación, la exposición oral se realiza la última semana de clase del cuatrimestre. Así los alumnos disponen de mayor tiempo durante el cuatrimestre para la preparación tanto de la exposición oral como del informe del trabajo en grupo. La exposición oral se realiza dos semanas después de la entrega del informe del trabajo en grupo, de forma que la profesora puede corregir previamente el informe del trabajo y así comentar con los alumnos los posibles errores detectados antes de la exposición oral.

Finalmente, en cuanto al seguimiento por parte de la profesora, los alumnos pueden acudir a tutorías durante todo el cuatrimestre para resolver las dudas que puedan surgir tanto en la preparación de la exposición oral como en el informe del trabajo en grupo. Se realiza una tutoría obligatoria a mitad del cuatrimestre para comprobar como están enfocando el trabajo y poderles orientar en la mejora del mismo. Los alumnos reciben formación sobre la realización de exposiciones orales.

\subsection{Normas para la exposición oral (presentación)}

El tiempo máximo para la realización de la exposición oral es de 20 minutos. La exposición oral la realizan todos los miembros del grupo. Antes de la exposición la profesora realiza un sorteo para determinar en que orden van a intervenir cada miembro del grupo. No existe un guión-modelo para la presentación, pero si se les proporcionan indicaciones de cómo deben realizarse las exposiciones orales. Al final de la exposición, la profesora realiza preguntas sobre aquellos aspectos que no han quedado claros. También se invita al resto de compañeros a que realicen preguntas a los alumnos que han realizado la exposición oral.

\subsection{Evaluación de la exposición oral}

La nota del trabajo en grupo representa un $30 \%$ de la nota final de la asignatura: $20 \%$ el informe y $10 \%$ la exposición oral. La exposición oral es evaluada tanto por la profesora

\section{(cc) BY-NC-ND 2014, Universitat Politècnica de València}

I Jornadas IN-RED (2014) 
Evaluación de las exposiciones orales por alumnos y profesorado: experiencia en "Obtención, Selección, Procesado y Utilización de los Materiales"

como por el resto de compañeros (evaluación entre iguales) utilizando la rúbrica mostrada en la Fig. 1. Dicha rúbrica es colgada en la herramienta de "recursos" de la plataforma de elearning PoliformaT previamente a la exposición oral para que el alumno conozca cuáles son los indicadores que van a ser tenidos en cuenta en su evaluación. En total se evalúan 15 ítems, los cuales se agrupan en tres categorías: exposición, contenido y lengua.

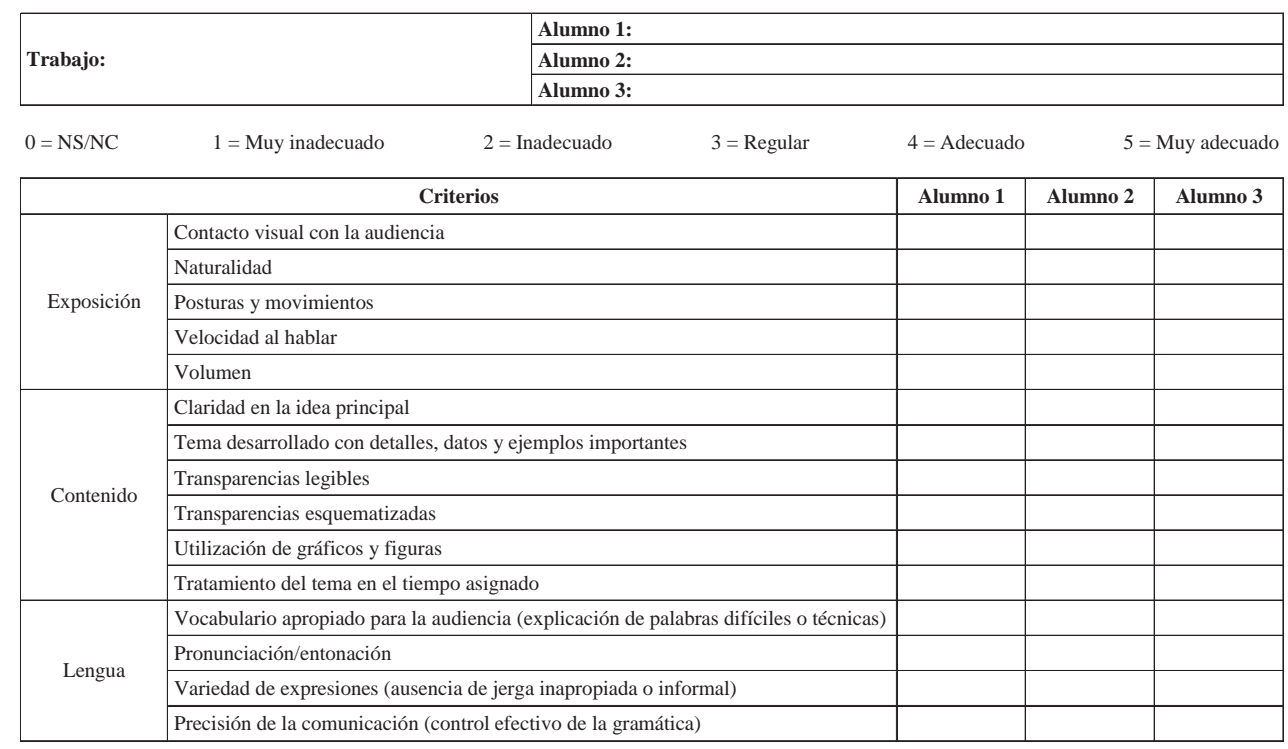

OBSERVACIONES:

Fig. 1. Rúbrica para la evaluación de la exposición oral.

La categoría de exposición incluye 5 ítems (33,3\% de los ítems a evaluar): 1) contacto visual con la audiencia, 2) naturalidad, 3) posturas y movimientos, 4) velocidad al hablar y 5) volumen.

La categoría de contenido incluye 6 ítems (40\% de los ítems a evaluar): 1) claridad en la idea principal, 2) tema desarrollado con detalles, datos y ejemplos importantes, 3) transparencias legibles, 4) transparencias esquematizadas, 5) utilización de gráficos y figuras y 6) tratamiento del tema en el tiempo asignado.

Por último, la categoría de lengua incluye 4 ítems (26,7 \% de los ítems a evaluar): 1) vocabulario apropiado para la audiencia (explicación de palabras difíciles o técnicas), 2) pronunciación/entonación, 3) variedad de expresiones (ausencia de jerga inapropiada o informal) y 4) precisión de la comunicación (control efectivo de la gramática). 
Los criterios de evaluación en la rúbrica se establecen en una escala de 0 a 5: no sabe/no contesta (0), muy inadecuado (1), inadecuado (2), regular (3), adecuado (4) y muy adecuado (5). La nota de cada alumno en la exposición oral es el promedio de la nota de la profesora y la media del resto de compañeros. Se realiza feedback de la exposición oral.

\section{Resultados}

\subsection{Calificaciones de los alumnos}

En la Tabla 1 se muestran las calificaciones obtenidas por los alumnos en las exposiciones orales evaluadas mediante rúbricas en la asignatura de OSPUM desde el curso académico 2009/2010 hasta el curso académico 2012/2013. En dicha tabla se incluye para cada curso académico el número de alumnos que ha realizado la exposición oral, junto con las calificaciones promedio para cada categoría de la exposición oral (exposición, contenido y lengua) obtenidas en una escala de 0 a 5: nota de la exposición oral que evalúa la profesora (Oral-profesora), media de las notas que evalúan los alumnos a las exposiciones de sus compañeros (Oral-compañeros) y nota media entre la nota de la profesora y la de los compañeros para la exposición oral (Oral-media). También se muestra los valores mínimo, máximo y el total obtenidos en la exposición oral. Al final de la Tabla se muestra la media global de los cuatro cursos académicos.

En la Fig. 2 se muestra una comparativa de las notas obtenidas por los alumnos en las exposiciones orales en la asignatura de OSPUM para los diferentes cursos académicos. También se muestra la media global de los cuatro cursos académicos.

Los resultados de la Tabla 1 y la Fig. 2 muestran que los alumnos obtienen calificaciones medias por encima de 4 sobre 5 en la exposición oral en todos los cursos académicos, siendo los valores de 4,14 en el curso académico 2009/2010, 4,48 en el curso académico 2010/2011, 4,33 en el curso académico 2011/2012 y 4,41 en el curso académico 2012/2013. La nota media global de los cuatro cursos académicos para la exposición oral es de 4,34.

Para todos los cursos académicos la categoría de contenido es la que presenta las calificaciones máximas, con valores medios entre 4,29 y 4,59, siendo la media global de los cuatro cursos académicos de 4,50. La categoría de lengua es la que presenta las calificaciones mínimas con valores medios entre 3,99 y 4,40 para todos los cursos académicos, excepto para el curso académico 2012/2013 donde la calificación mínima la obtiene la categoría de exposición con un valor medio de 4,28 (muy cercano al valor medio de 4,30 obtenido en la categoría de lengua). La nota media global de los cuatro cursos académicos para categoría de lengua es de 4,21, mientras que para la categoría de exposición es de 4,26.

\section{(cc) BY-NC-ND 2014, Universitat Politècnica de València}

I Jornadas IN-RED (2014) 
Evaluación de las exposiciones orales por alumnos y profesorado: experiencia en "Obtención, Selección, Procesado y Utilización de los Materiales"

Tabla 1. Notas obtenidas por los alumnos en las exposiciones orales en la asignatura de OSPUM.

\begin{tabular}{|c|c|c|c|}
\hline \multicolumn{4}{|c|}{ Curso 2009/2010 (8 alumnos) } \\
\hline Criterios & Oral-profesora & Oral-compañeros & Oral-media \\
\hline Exposición & 4,05 & 4,12 & 4,09 \\
\hline Contenido & 4,42 & 4,17 & 4,29 \\
\hline Lengua & 4,00 & 3,99 & 3,99 \\
\hline Mínimo-curso 2009/2010 & 4,00 & 3,99 & 3,99 \\
\hline Máximo-curso 2009/2010 & 4,42 & 4,17 & 4,29 \\
\hline Total-curso 2009/2010 & 4,19 & 4,10 & 4,14 \\
\hline \multicolumn{4}{|c|}{ Curso 2010/2011 (6 alumnos) } \\
\hline Criterios & Oral-profesora & Oral-compañeros & Oral-media \\
\hline Exposición & 4,10 & 4,74 & 4,42 \\
\hline Contenido & 4,44 & 4,73 & 4,59 \\
\hline Lengua & 4,00 & 4,80 & 4,40 \\
\hline Mínimo-curso 2010/2011 & 4,00 & 4,73 & 4,40 \\
\hline Máximo-curso 2010/2011 & 4,44 & 4,80 & 4,59 \\
\hline Total-curso 2010/2011 & 4,21 & 4,75 & 4,48 \\
\hline \multicolumn{4}{|c|}{ Curso 2011/2012 (9 alumnos) } \\
\hline Criterios & Oral-profesora & Oral-compañeros & Oral-media \\
\hline Exposición & 4,13 & 4,40 & 4,27 \\
\hline Contenido & 4,63 & 4,38 & 4,51 \\
\hline Lengua & 4,00 & 4,28 & 4,14 \\
\hline Mínimo-curso 2011/2012 & 4,00 & 4,28 & 4,14 \\
\hline Máximo-curso 2011/2012 & 4,63 & 4,40 & 4,51 \\
\hline Total-curso 2011/2012 & 4,30 & 4,36 & 4,33 \\
\hline \multicolumn{4}{|c|}{ Curso 2012/2013 (6 alumnos) } \\
\hline Criterios & Oral-profesora & Oral-compañeros & Oral-media \\
\hline Exposición & 3,97 & 4,59 & 4,28 \\
\hline Contenido & 4,53 & 4,65 & 4,59 \\
\hline Lengua & 4,00 & 4,60 & 4,30 \\
\hline Mínimo-curso 2012/2013 & 4,00 & 4,59 & 4,28 \\
\hline Máximo-curso 2012/2013 & 4,53 & 4,65 & 4,59 \\
\hline Total-curso 2012/2013 & 4,20 & 4,62 & 4,41 \\
\hline \multicolumn{4}{|c|}{ Media global } \\
\hline Criterios & Oral-profesora & Oral-compañeros & Oral-media \\
\hline Exposición & 4,06 & 4,46 & 4,26 \\
\hline Contenido & 4,51 & 4,48 & 4,50 \\
\hline Lengua & 4,00 & 4,42 & 4,21 \\
\hline Mínimo-media global & 4,00 & $\mathbf{4 , 4 2}$ & 4,21 \\
\hline Máximo-media global & 4,51 & $\mathbf{4 , 4 8}$ & 4,50 \\
\hline Total-media global & 4,23 & 4,46 & $\mathbf{4 , 3 4}$ \\
\hline
\end{tabular}




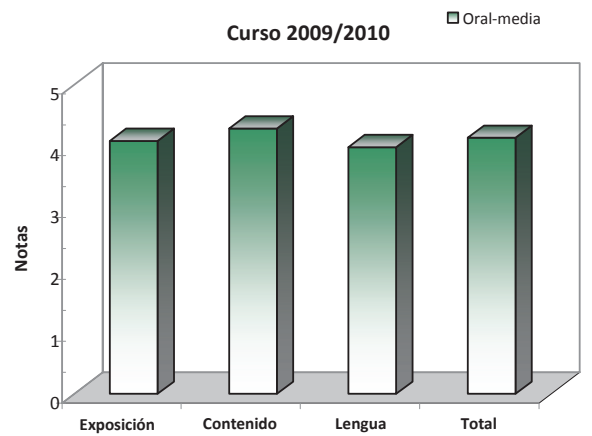

(a)

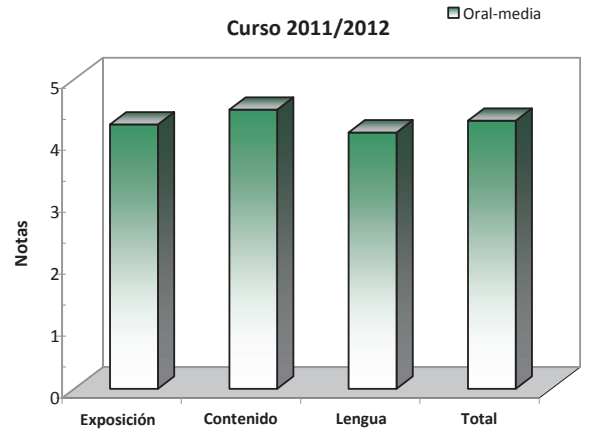

(c)

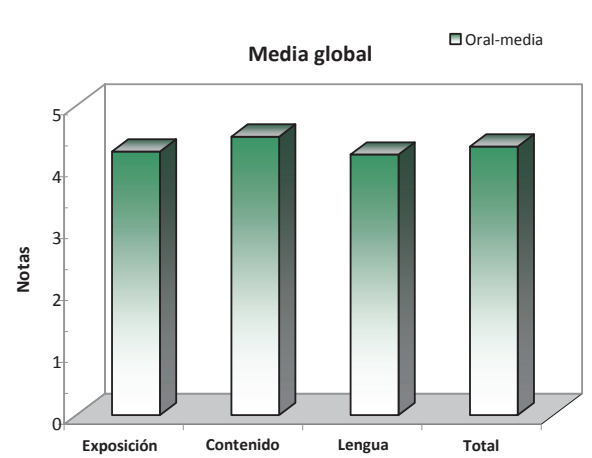

(e)

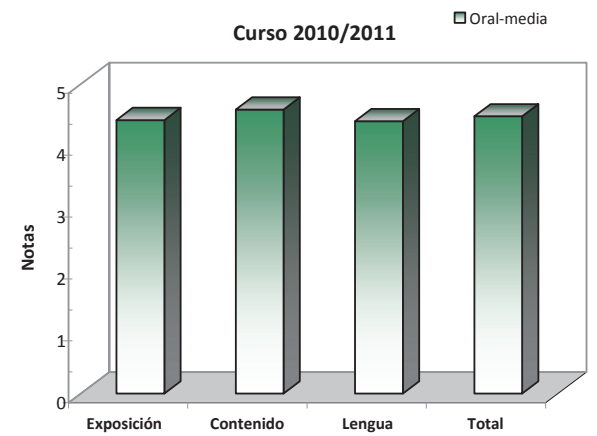

(b)

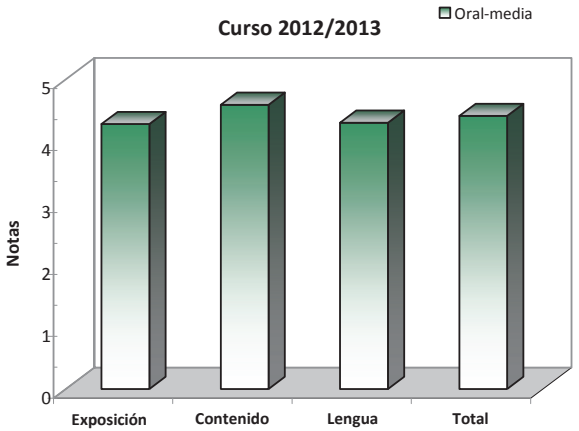

(d)

Fig. 2. Comparación de las notas obtenidas por los alumnos en las exposiciones orales en la asignatura de OSPUM en los cursos académicos (a) 2009/2010, (b) 2010/2011, (c) 2011/2012, (d) 2012/2013 y (e) media global.

(cc) BY-NC-ND 2014, Universitat Politècnica de València

I Jornadas IN-RED (2014) 
Evaluación de las exposiciones orales por alumnos y profesorado: experiencia en "Obtención, Selección, Procesado y Utilización de los Materiales"

En las Fig. 3 a 6 se muestra una comparación entre la evaluación realizada por la profesora y la realizada por el resto de compañeros en los cursos académicos desde 2009/2010 hasta 2012/2013 en cada una de las categorías de la exposición oral: exposición (Fig. 3), contenido (Fig. 4), lengua (Fig. 5) y total (Fig. 6). En cada gráfico se muestra también la media global de los cuatro cursos académicos.

Respecto a la categoría de exposición (Fig. 3), las notas obtenidas en la evaluación por compañeros son superiores a las obtenidas en la evaluación realizada por la profesora para todos los cursos académicos. La nota media global de los cuatro cursos académicos para la categoría de exposición evaluada por los compañeros es de 4,46, mientras que para la categoría de exposición evaluada por la profesora es de 4,06.

La Fig. 4 muestra que las notas obtenidas en la evaluación por la profesora de la categoría de contenido son superiores a las obtenidas en la evaluación realizada por los compañeros para los cursos académicos 2009/2010 y 2011/2012, mientras que para los cursos académicos 2010/2011 y 2012/2013 ocurre lo contrario. La nota media global de los cuatro cursos académicos para la categoría de contenido evaluada por la profesora es de 4,51, mientras que para la categoría de contenido evaluada por los compañeros es de 4,48.

Respecto a la categoría de lengua (Fig. 5), las notas obtenidas en la evaluación por compañeros son superiores a las obtenidas en la evaluación realizada por la profesora para todos los cursos académicos. La nota media global de los cuatro cursos académicos para la categoría de lengua evaluada por los compañeros es de 4,42, mientras que para la categoría de lengua evaluada por la profesora es de 4,00.

Respecto a la evaluación total de la exposición oral (Fig. 6), las notas obtenidas en la evaluación de la exposición oral por compañeros son superiores a las obtenidas en la evaluación de la exposición oral realizada por la profesora para todos los cursos académicos, excepto para el curso académico 2009/2010 donde la evaluación realizada por la profesora presenta notas superiores con una valor medio de 4,19 (cercano al valor de 4,10 correspondiente a la evaluación realizada por los compañeros). La nota media global de los cuatro cursos académicos para la exposición oral evaluada por los compañeros es de 4,46, mientras que para la exposición oral evaluada por la profesora es de 4,23.

Finalmente, hay que destacar que las calificaciones obtenidas por los alumnos en todas las categorías de la exposición oral evaluadas tanto por la profesora como por los compañeros presentan valores medios entre 4 (adecuado) y 5 (muy adecuado), por lo que se puede considerar que los alumnos han superado los resultados de aprendizaje que se pretenden conseguir con las exposiciones orales. Las exposiciones orales ayudan al alumno a adquirir destrezas y habilidades relacionadas con las competencia lingüísticas que les serán de utilidad durante su futura vida profesional. 


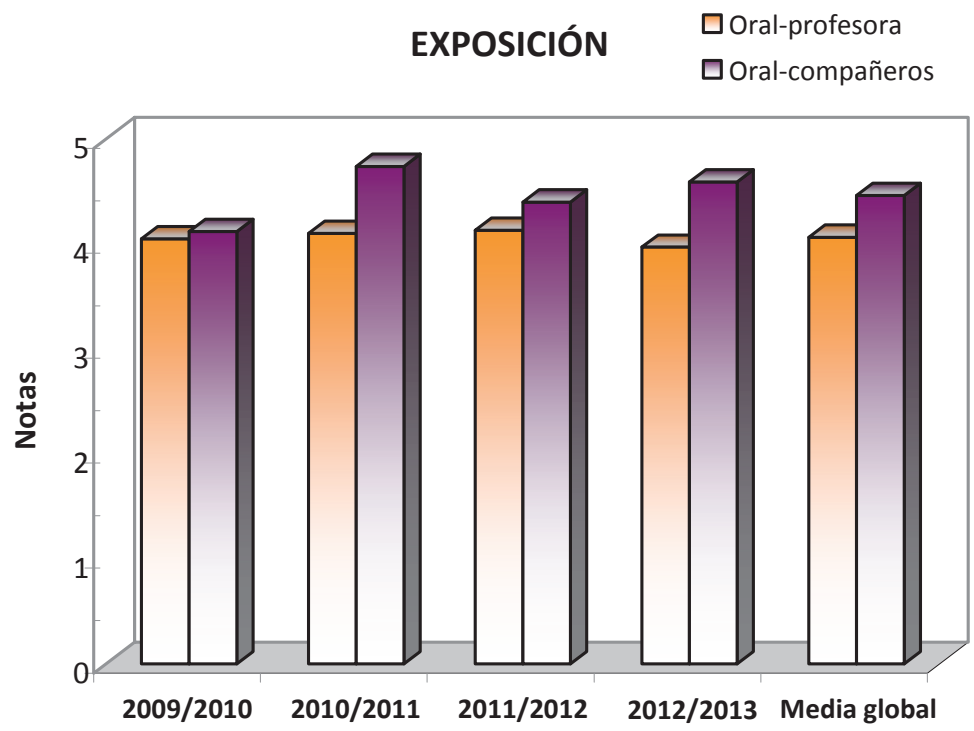

Fig. 3. Notas obtenidas por los alumnos en la categoría de exposición dentro de las exposiciones orales en la asignatura de OSPUM.

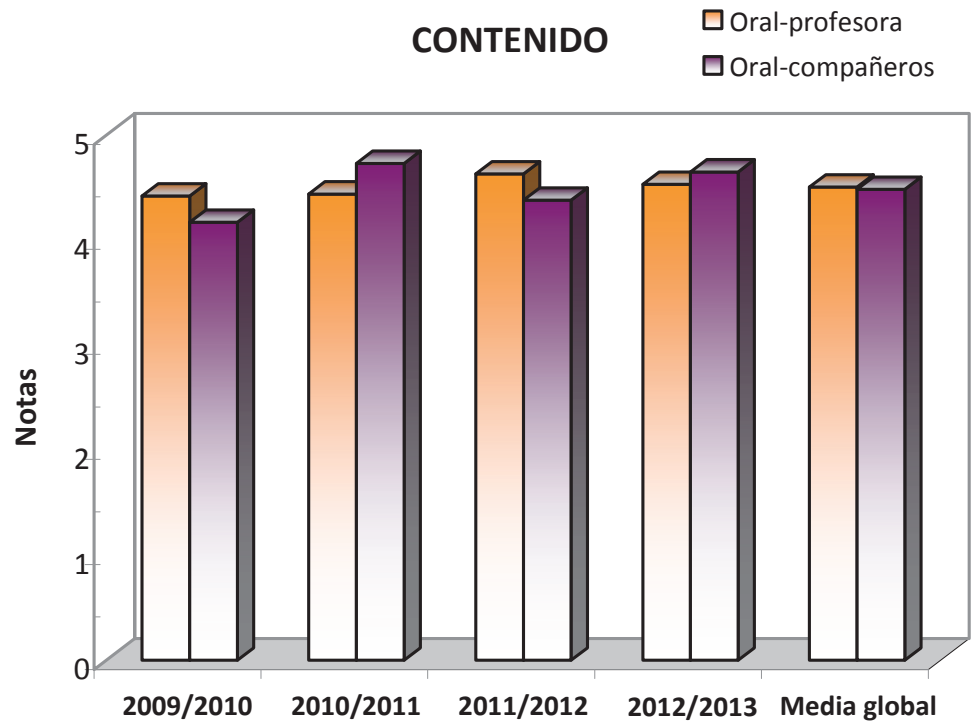

Fig. 4. Notas obtenidas por los alumnos en la categoría de contenido dentro de las exposiciones orales en la asignatura de OSPUM.

(cc) BY-NC-ND 2014, Universitat Politècnica de València

I Jornadas IN-RED (2014) 
Evaluación de las exposiciones orales por alumnos y profesorado: experiencia en "Obtención, Selección, Procesado y Utilización de los Materiales"

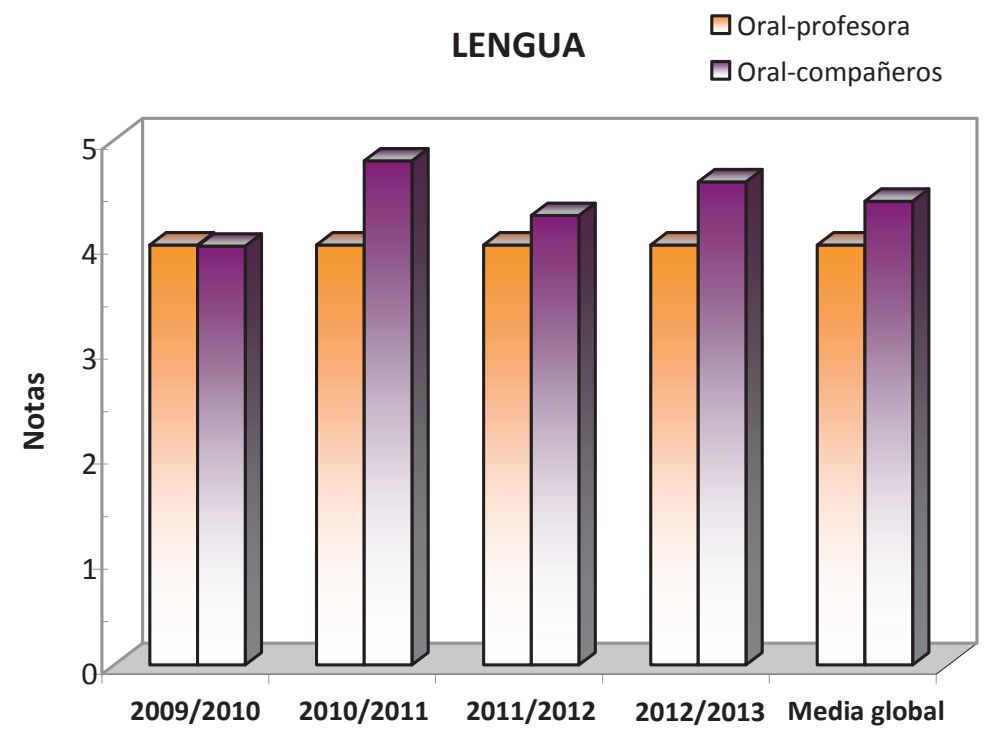

Fig. 5. Notas obtenidas por los alumnos en la categoría de lengua dentro de las exposiciones orales en la asignatura de OSPUM.

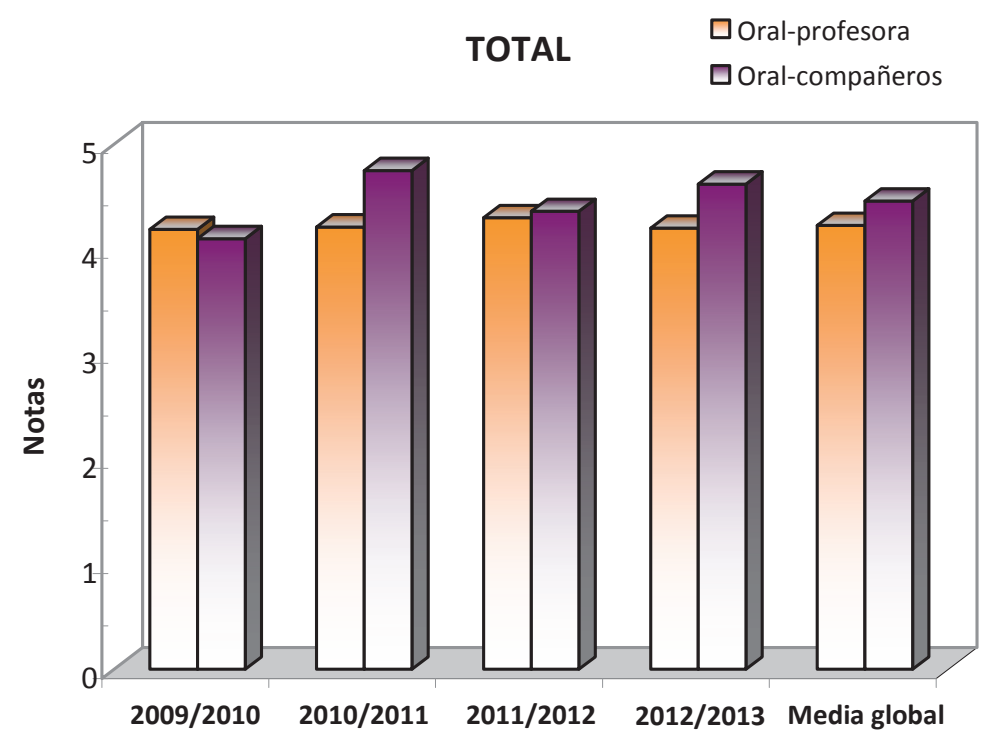

Fig. 6. Notas totales obtenidas por los alumnos en las exposiciones orales en la asignatura de OSPUM.

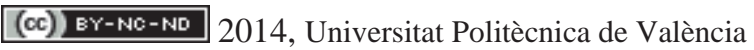
I Jornadas IN-RED (2014) 


\subsection{Encuestas de los alumnos}

El último día de clase los alumnos rellenan una encuesta de la asignatura de forma anónima. La finalidad de dicha encuesta es conocer la opinión de los alumnos de forma inmediata y así poder establecer iniciativas de mejora, ya que los resultados de las encuestas oficiales de los alumnos se obtienen al inicio del curso académico siguiente. En la encuesta los alumnos deben evaluar un total de 14 ítems, entre los cuales se encuentran las exposiciones orales, en una escala de 0 a 10 puntos: no sabe/no contesta ( 0 puntos), muy deficiente/muy bajo/muy inadecuado (0 puntos), deficiente/bajo/inadecuado (2,5 puntos), regular (5), bueno/alto/adecuado (7,5 puntos) y muy bueno/muy alto/muy adecuado (10 puntos). Al final de la encuesta hay un apartado de observaciones, donde los alumnos pueden expresar sus opiniones libremente.

En la Tabla 2 se muestran los resultados de la encuesta de opinión de los alumnos respecto al ítem de las exposiciones orales en la asignatura de OSPUM desde el curso académico 2009/2010 hasta el curso académico 2012/2013.

Tabla 2. Resultados de las encuestas de opinión de los alumnos respecto a la exposición oral realizada en la asignatura de OSPUM.

\begin{tabular}{|c|c|c|c|c|}
\hline $\begin{array}{c}\text { Curso } \\
\text { académico }\end{array}$ & $\begin{array}{c}\mathbf{N}^{0} \text { alumnos } \\
\text { matriculados }\end{array}$ & $\begin{array}{c}\mathbf{N}^{\mathbf{0}} \text { encuestas } \\
\text { procesadas }\end{array}$ & Media & $\begin{array}{c}\text { Desviación } \\
\text { típica }\end{array}$ \\
\hline $2009 / 2010$ & 12 & 8 & 6,56 & 1,21 \\
\hline $2010 / 2011$ & 8 & 6 & 8,33 & 1,86 \\
\hline $2011 / 2012$ & 12 & 7 & 7,50 & 0,00 \\
\hline $2012 / 2013$ & 8 & 6 & 8,33 & 1,86 \\
\hline
\end{tabular}

Los resultados de las encuestas muestran que los alumnos evalúan las exposiciones orales realizadas con puntuaciones medias entre 6,56 y 8,33 en los cuatro cursos académicos, siendo la media global de los cuatro cursos de 7,68. Por tanto, se puede considerar que los alumnos valoran favorablemente las exposiciones orales como metodología de enseñanzaaprendizaje.

\subsection{Autoevaluación de la innovación educativa}

Considero que la experiencia de realizar exposiciones orales con los alumnos ha resultado muy positiva, pues los alumnos han aprendido a defender un tema delante de sus compañeros. Esto ha quedado demostrado en las altas calificaciones obtenidas por los alumnos en las exposiciones orales y en el alto grado de satisfacción de los alumnos tras aplicar la innovación educativa. Considero que es importante que los alumnos aprendan a realizar exposiciones orales en clase, pues en su futuro profesional tendrán que hablar en público, exponer informes, etc. Además, el uso de exposiciones orales como metodología de enseñanza-aprendizaje me ha permitido realizar una evaluación más formativa y

\section{(cc) EY-NC-ND 2014, Universitat Politècnica de València}

I Jornadas IN-RED (2014) 
Evaluación de las exposiciones orales por alumnos y profesorado: experiencia en "Obtención, Selección, Procesado y Utilización de los Materiales"

completa del alumno. Dicha metodología se ha aplicado también con éxito en otra asignatura del área de Ingeniería Química, tal como se describe en un trabajo previo (Muñoz, 2011).

Una de las observaciones realizadas es que los alumnos no hacen preguntas a sus compañeros después de la exposición oral. Por ello, una de las propuestas de mejora de cara a próximos cursos sería que los alumnos entregaran de forma obligatoria la presentación previamente a la exposición oral, para que de esa forma tanto la profesora como el resto de compañeros la puedan mirar y así el día de la exposición oral puedan hacer preguntas sobre aquellos aspectos que no han quedado claros.

\section{Conclusiones}

Los resultados obtenidos tras la aplicación de las exposiciones orales como metodología de enseñanza-aprendizaje muestran que:

- Los alumnos obtienen altas calificaciones en las exposiciones orales, por lo que se puede considerar que los alumnos han superado los resultados de aprendizaje que se pretenden conseguir. La categoría de contenido es la que presenta las calificaciones máximas, mientras que la categoría de lengua es la que presenta las calificaciones mínimas.

- Respecto a la evaluación realizada por la profesora y la realizada por el resto de compañeros, las notas obtenidas en la evaluación por compañeros son superiores a las obtenidas en la evaluación realizada por la profesora en las categorías de exposición y de lengua, mientras que en la categoría de contenido son muy similares.

- El uso de exposiciones orales como metodología de enseñanza-aprendizaje permite al profesorado realizar una evaluación más formativa y completa del alumno.

- Las exposiciones orales permiten que el alumno adquiera nuevas estrategias de aprendizaje y desarrolle competencias lingüísticas.

Una de las propuestas de mejora de la innovación educativa de cara a próximos cursos académicos es:

- Disponer de la presentación de cada exposición oral previamente, tanto la profesora como por el resto de compañeros, para facilitar la realización de preguntas después de cada exposición. 


\section{Referencias}

España. Recomendación del Parlamento Europeo y del Consejo de 18 de Diciembre de 2006 sobre las competencias clave para el aprendizaje permanente (2006/962/CE). Diario Oficial de la Unión Europea, 30 de diciembre de 2006, L 394, p. 10-18.

INSTITUTO DE CIENCIAS DE LA EDUCACIÓN (2006). Plan de Acciones para la Convergencia Europea (PACE). Guía docente de la UPV: criterios para su elaboración. Valencia: Universidad Politécnica de Valencia.

MUÑOZ-PORTERO (2011). "Uso de las exposiciones orales en Técnicas Analíticas del Medio Ambiente". Jornadas de Innovación Docente ICE-UPV. Valencia: Editorial UPV. ISBN: 978-848363-763-0.

UNIVERSITY OF TECHNOLOGY, SYDNEY. Institute for Interactive Media and Learning (en Assessment, Assessing Group Work). 〈http://www.iml.uts.edu.au〉 [Consulta: 5 de Junio de 2014].

(cc)) EY-NC-ND 2014, Universitat Politècnica de València

I Jornadas IN-RED (2014) 


\section{Comunicación efectiva: Un enfoque para distintas asignaturas de la UPV}

A. J. Bañón-Gomis ${ }^{a}$, M. Clemente-Císcar ${ }^{b}$, L. Cortés ${ }^{c}$, N. Lajara-Camilleri ${ }^{\mathrm{d}}$, J. M. Montalváe, A. Rovira ${ }^{f^{*}}$, A. Trinidad ${ }^{\mathrm{g}}$, J.J. Tuset ${ }^{\mathrm{h}}$, J.F. Villanueva ${ }^{\mathrm{i}}$

${ }^{a}$ Dpto. de Organización de Empresas. Universitat Politècnica de València, albaogo@upvnet.upv.es, ${ }^{b}$ Centro de Gestión de la Calidad y del Cambio, Dpto. de Estadística e Investigación Operativa Aplicadas y Calidad. Universitat Politècnica de València, mclemen@eio.upv.es, ${ }^{\circ}$ Dpto. de Construcciones Arquitectónicas. Universitat Politècnica de València, luicorme@csa.upv.es, ${ }^{\mathrm{d} D p t o . ~ d e ~}$ Economía y Ciencias Sociales. CEGEA. Universitat Politècnica de València, nalade@cegea.upv.es, ${ }^{e}$ Dpto. de Ingeniería de la Constr. y de Proyectos de Ingeniería Civil. Universitat Politècnica de València, jmonsu@cst.upv.es, ${ }^{\text {f* }}$ CITV, Dpto. de Ingeniería Mecánica y de Materiales. Universitat Politècnica de València, arovira@mcm.upv.es, ${ }^{g}$ Dpto. de Urbanismo. Universitat Politècnica de València, antritor@urb.upv.es, ${ }^{\mathrm{h}}$ Dpto. de Proyectos Arquitectónicos. Universitat Politècnica de València, jjtuset@pra.upv.es, ${ }^{i}$ Dpto. de Estadística e Investigación Operativa. Universitat Politècnica de València, jovillo0@upvnet.upv.es.

\footnotetext{
Abstract

To proceed to the accreditation of its degrees, the UPV has developed the concept of competency dimensions in order to group the different academic profiles. This concept allows to homogenize the generic competencies acquired in its degrees, compare and simplify the assessment process to provide adapted tools.

In this context, the work presented in this paper is twofold: firstly, it proposes a method for obtaining disaggregated grades for the different competencies in each subject; and, secondly, it develops materials and tools to work with and evaluate different generic competencies associated with the competency dimension of effective communication.

Diverse experiences of subjects taught at the UPV are presented in the text, where the approach, materials, and the results achieved in the academic year 2013-2014 are shown. This work was performed under an Educational Improvement and Innovation Project.
}

(c) EY-NC-ND 2014, Universitat Politècnica de València

I Jornadas In-Red (2014) 
Comunicación efectiva: Un enfoque para distintas asignaturas de la UPV

Keywords: EHEA, assessment of competencies, UPV competency dimensions, effective communication

\section{Resumen}

Para proceder a la acreditación de sus titulaciones, la UPV ha desarrollado el concepto de dimensiones competenciales con el objeto de agrupar los distintos perfiles formativos. Este concepto permite homogeneizar las competencias genéricas que se adquieren en sus títulos, compararlos y simplificar el proceso de evaluación al poder proporcionar herramientas adaptadas.

En este contexto, el trabajo presentado en este artículo tiene un doble objetivo: en primer lugar, propone un procedimiento para obtener una calificación desagregada de las distintas competencias que se trabajan en cada asignatura; $y$, en segundo lugar, desarrolla materiales e instrumentos para trabajar y evaluar las distintas competencias genéricas asociadas a la dimensión competencial de comunicación efectiva.

En el texto se presentan diversas experiencias de asignaturas impartidas en la UPV donde se muestran el planteamiento, los materiales y los resultados conseguidos en el curso académico 2013-2014. Este trabajo se ha realizado bajo un Proyecto de Innovación y Mejora Educativa (PIME).

Palabras clave: EEES, evaluación de competencias, dimensiones competenciales UPV, comunicación efectiva.

\section{Introducción}

En el marco de formación en competencias del EEES, las competencias que conforman cada titulación pueden desglosarse en competencias genéricas y específicas. Las competencias genéricas identifican aspectos comunes a cualquier titulación, mientras que las competencias específicas son propias de la titulación en cuestión. Tradicionalmente cada asignatura ha trabajado unas competencias específicas a través de unos contenidos coherentes con los resultados de aprendizaje. En cambio, con el nuevo modelo del EEES, se deben incorporar además las competencias genéricas al diseño de cada asignatura (Rovira, 2013). Este aspecto implica, en primer lugar, trabajar las competencias y, en segundo lugar, evaluarlas.

El presente trabajo pretende introducir la evaluación por competencias dentro de las distintas asignaturas involucradas. Para ello, en primer lugar, se propone un procedimiento para el diseño de las pruebas de evaluación que permita obtener las puntuaciones obtenidas, asociadas a cada una de las competencias. De esta forma, se conseguirá cuantificar de 
forma desagregada el grado de adquisición de cada una de las competencias trabajadas en la asignatura. Este procedimiento debe ser válido para cualquier asignatura de la UPV.

En segundo lugar, se presenta la metodología para la evaluación de la comunicación efectiva. En este apartado se define la dimensión competencial de comunicación efectiva a través de los resultados de aprendizaje asociados y se acota en ámbito en el que se ha utilizado en el presente trabajo. Además, se presentan los instrumentos utilizados para la evaluación de la competencia y diversos ejemplos de materiales creados ad hoc para trabajar la competencia en las asignaturas involucradas.

Posteriormente, se presentan resultados obtenidos en las asignaturas sobre la evaluación de la comunicación efectiva y sobre la acreditación de las competencias trabajadas en las asignaturas. Finalmente se presentan las conclusiones de este trabajo.

\section{Objetivos}

Los objetivos del presente trabajo son:

- Presentar el procedimiento desarrollado para el diseño de las pruebas de evaluación y el algoritmo para calcular la calificación de la asignatura, desagregada por competencias.

- Mostrar el instrumento de evaluación de la comunicación efectiva utilizado, así como las distintas variantes introducidas en las asignaturas.

- Exponer algunos resultados obtenidos en las asignaturas involucradas, en cuanto a la acreditación del nivel de adquisición de competencias y en relación a la evaluación de la comunicación efectiva.

\section{Desarrollo de la innovación}

Este apartado se estructura en dos bloques: en primer lugar se explica el procedimiento para crear las pruebas de evaluación para valorar el progreso y acreditación de competencias, así como el algoritmo empleado para calcular la calificación de la asignatura, desagregada en competencias. En segundo lugar, se presenta la metodología para la evaluación de la comunicación efectiva.

\subsection{Evaluación y acreditación de competencias en una asignatura}

Para poder evaluar cada una de las competencias asociadas a una asignatura, se deben seguir los siguientes pasos:

- Realizar un análisis de las competencias trabajadas en la asignatura. A partir de las competencias, desglosar los resultados de aprendizaje evaluados.

- Trabajar las competencias.

- Diseñar las pruebas de evaluación para valorar el progreso de las competencias.

(c)) EY-NC-ND 2014, Universitat Politècnica de València

I Jornadas IN-RED (2014) 


\subsubsection{Análisis de las competencias}

En este primer paso se debe realizar un análisis de las competencias trabajadas en la asignatura y la definición de los objetivos de aprendizaje asociados. Se deben considerar tanto las competencias específicas o propias de la titulación, como las genéricas o transversales. Estas competencias se toman de la lista de competencias que conforman la titulación a la que pertenece la asignatura.

La Tabla 1 muestra, como ejemplo, las competencias asociadas a la asignatura Vibraciones Mecánicas perteneciente a la titulación de Grado en Ingeniería Mecánica. En esta asignatura, se trabajan dos competencias específicas, asociadas al módulo de especialidad mecánica, y una competencia genérica, asociada a la dimensión competencial UPV de la comunicación efectiva.

Estas competencias, para cada asignatura o materia, se desglosan en resultados de aprendizaje. Con el fin de conseguir un alineamiento docente (Biggs, 2003), las distintas pruebas de evaluación deben hacer referencia a los resultados de aprendizaje.

Tabla 1. Competencias asociadas a la asignatura Vibraciones Mecánicas. Adaptado de UPV (2013b).

\begin{tabular}{clcc}
\hline \multicolumn{1}{c}{ Competencias } & Tipo & Nivel \\
\hline 1 & $\begin{array}{l}\text { Calcular, diseñar y ensayar máquinas según los conceptos } \\
\text { asociados a la ingeniería mecánica y de materiales }\end{array}$ & Específica & Necesaria (3) \\
\hline 2 & $\begin{array}{l}\text { Resolución de problemas en el campo de la ingeniería a } \\
\text { partir de la aplicación de materias básicas y tecnológicas. }\end{array}$ & Específica & Necesaria (3) \\
\hline 3 & $\begin{array}{l}\text { Comunicar y transmitir conocimientos, habilidades y } \\
\text { destrezas en el campo de la ingeniería industrial }\end{array}$ & Genérica & Necesaria (3) \\
\hline
\end{tabular}

\subsubsection{Trabajo de las competencias}

Para poder evaluar las competencias, éstas se deben trabajar en las distintas actividades presenciales y no presenciales de la asignatura. Por una parte se distinguen las competencias específicas de las competencias genéricas. Las competencias genéricas se trabajan mediante ejercicios basados en casos prácticos de la asignatura. Por otro lado, en el caso de las competencias genéricas, éstas se deberán trabajar en la asignatura con actividades diseñadas ad hoc.

En el punto 2.2 se muestran diversos ejemplos de los materiales generados para trabajar la competencia asociada a la comunicación efectiva. 


\subsubsection{Diseño de las pruebas de evaluación y cálculo de la calificación por competencias}

Un diseño correcto de las pruebas de evaluación debe incluir diversos ejercicios que hagan referencia a las distintas competencias (a través de los resultados de aprendizaje correspondientes). Este diseño se explica con mayor detalle en Rovira (2014).

Para calcular la calificación de una competencia en la asignatura, se aplica la siguiente expresión:

$$
C_{j}^{C}=\frac{\sum_{i=1}^{m} \bar{p}_{i} c_{i, j}}{\sum_{i=1}^{m} \bar{p}_{i} \delta_{i, j}}
$$

siendo $C_{j}^{C}$ la calificación final asociada a la competencia $j, m$, el número de pruebas de evaluación, $\bar{p}_{i}$, el peso normalizado de cada una de las pruebas de evaluación $i, c_{i, j}$, la calificación de la competencia $j$ en la prueba de evaluación $i$ y $\delta_{i, j}$, una constante que vale 1 si la competencia $j$ se evalúa en la prueba de evaluación $i$ y 0 en caso contrario

Si $\bar{w}_{j}$ es el valor normalizado de los pesos de las competencias en la asignatura, a partir de la nota desagregada en competencias según la ecuación (1), se puede obtener la calificación final de la asignatura como:

$$
\sum_{j=1}^{n} \bar{w}_{j} C_{j}^{C}
$$

\subsection{Metodología para la evaluación de la comunicación efectiva}

En este punto se presenta la metodología usada en el proyecto de innovación y mejora educativa, para la evaluación de la comunicación efectiva. En primer lugar se define qué se entiende por "comunicación efectiva" a través de los resultados de aprendizaje asociados y se presentan las asignaturas involucradas en el proyecto que trabajan distintas competencias genéricas englobadas dentro de la dimensión competencial de comunicación efectiva. Finalmente, se muestran algunos ejemplos de los materiales docentes generados en las distintas asignaturas.

\subsubsection{Implantación de la dimensión competencial "comunicación efectiva"}

La comunicación es una competencia necesaria para el ingeniero, tanto en la redacción de informes, como en la presentación de proyectos o resultados (Villanueva, 2014). Esta competencia forma parte del perfil de un ingeniero incluso en los planes de estudio anteriores al EEES. Tal y como señala Reyzábal (2012), el hecho de considerar esta

\section{(c)) EY-NC-ND 2014, Universitat Politècnica de València}

I Jornadas IN-RED (2014) 
competencia de forma explícita permite hacer visible las capacidades que deben adquirir los alumnos.

De Miguel (2006) distingue los siguientes resultados de aprendizaje para la competencia de la comunicación: "hacerse entender", "presentar en público", "redactar documentos"; además, añade la característica de si los distintos resultados de aprendizaje se demuestran en lengua propia o en idiomas extranjeros. Estos resultados de aprendizaje hacen referencia tanto la comunicación oral, como la comunicación por escrito. En la UPV (2013a) se toman estos resultados de aprendizaje y se añaden "escuchar atentamente y responder adecuadamente" y "organizar y expresar correctamente ideas", además de incluir la característica de que el texto tenga "un contenido coherente de la especialidad". Además, según esta última clasificación, los resultados de aprendizaje se escalonan en función se trate para los niveles de grado o máster.

La Tabla 2 sintetiza los resultados de aprendizaje asociados a la comunicación efectiva según los criterios de la UPV. En el presente artículo, se trabajan los resultados de aprendizaje en la comunicación escrita y en lengua propia.

Tabla 2. Resultados de aprendizaje asociados a la comunicación efectiva. Elaborado a partir de UPV (2013a).

\begin{tabular}{|c|c|c|}
\hline & Comunicación escrita & Comunicación oral \\
\hline $\begin{array}{c}\text { Lengua } \\
\text { propia }\end{array}$ & $\begin{array}{l}\text { - Redactar textos y documentos con un } \\
\text { contenido coherente de la especialidad. } \\
\text { - Nivel básico de corrección ortográfica } \\
\text { y gramatical } \\
\text { - Estructura y estilo adecuados. }\end{array}$ & $\begin{array}{l}\text { - Escuchar atentamente y responder } \\
\text { adecuadamente. } \\
\text { - Organizar y expresar correctamente } \\
\text { ideas y conocimientos. }\end{array}$ \\
\hline $\begin{array}{c}\text { Lengua } \\
\text { extranjera }\end{array}$ & $\begin{array}{l}\text { - Redactar textos y documentos con un } \\
\text { contenido coherente de la especialidad. } \\
\text { - Nivel básico de corrección ortográfica } \\
\text { y gramatical } \\
\text { - Estructura y estilo adecuados }\end{array}$ & $\begin{array}{l}\text { - Escuchar atentamente y responder } \\
\text { adecuadamente. } \\
\text { - Organizar y expresar correctamente } \\
\text { ideas y conocimientos. }\end{array}$ \\
\hline
\end{tabular}

La Tabla 3 muestra una lista de las asignaturas involucradas en el presente trabajo; estas asignaturas pertenecen a distintas titulaciones impartidas en las UPV. Estas asignaturas trabajan distintas competencias genéricas asociadas a la dimensión competencial de la comunicación efectiva (Tabla 4). 
A. J. Bañón-Gomis, M. Clemente-Císcar, L. Cortés, N. Lajara-Camilleri, J. M. Montalvá, A. Rovira, A. Trinidad, J.J. Tuset, J.F. Villanueva

Tabla 3. Asignaturas involucradas.

\begin{tabular}{|c|c|c|c|c|}
\hline Cód. & Asignatura & Titulación & Carácter & ECTS \\
\hline 10593 & $\begin{array}{l}\text { Derecho Administrativo } \\
\text { (DA) }\end{array}$ & $\begin{array}{c}\text { Grado en Gestión de } \\
\text { Administración Pública }\end{array}$ & $\begin{array}{c}\text { Formación } \\
\text { básica. }\end{array}$ & 6,0 \\
\hline 11137 & $\begin{array}{l}\text { Economía de la } \\
\text { Empresa Biotecnológica } \\
(\mathrm{EEB})\end{array}$ & Grado en Biotecnología & Obligatorio. & 6,0 \\
\hline 12559 & Estadística (E) & Grado en Ingeniería Mecánica & $\begin{array}{c}\text { Formación } \\
\text { básica }\end{array}$ & 6,0 \\
\hline 10681 & $\begin{array}{l}\text { Iniciación al Proyecto } \\
\text { (IP) }\end{array}$ & Grado en Arquitectura & $\begin{array}{c}\text { Formación } \\
\text { básica }\end{array}$ & 6,0 \\
\hline 12577 & $\begin{array}{l}\text { Vibraciones Mecánicas } \\
(\mathrm{VM})\end{array}$ & Grado en Ingeniería Mecánica & Obligatorio. & 4,5 \\
\hline
\end{tabular}

Tabla 4. Competencias trabajadas en las asignaturas involucradas asociadas a la dimensión competencial de comunciación efectiva.

\begin{tabular}{|c|c|c|}
\hline Cód. & Asignatura & Competencia \\
\hline 10593 & $\begin{array}{l}\text { Derecho Administrativo } \\
\text { (DA) }\end{array}$ & Comunicarse de forma oral y escrita en su lengua nativa. \\
\hline 11137 & $\begin{array}{l}\text { Economía de la } \\
\text { Empresa Biotecnológica } \\
\text { (EEB) }\end{array}$ & Dirigir, redactar y ejecutar procesos y servicios. \\
\hline 12559 & Estadística (E) & $\begin{array}{c}\text { Capacidad de comunicar y transmitir conocimientos, } \\
\text { habilidades y destrezas en el campo de la Ingeniería } \\
\text { Industrial. }\end{array}$ \\
\hline 10681 & $\begin{array}{l}\text { Iniciación al Proyecto } \\
\text { (IP) }\end{array}$ & $\begin{array}{l}\text { Capacidad de comunicación en lenguajes formales, gráficos } \\
\text { y simbólicos. }\end{array}$ \\
\hline 12577 & $\begin{array}{l}\text { Vibraciones Mecánicas } \\
\text { (VM) }\end{array}$ & $\begin{array}{c}\text { Capacidad de comunicar y transmitir conocimientos, } \\
\text { habilidades y destrezas en el campo de la Ingeniería } \\
\text { Industrial. }\end{array}$ \\
\hline
\end{tabular}

\subsubsection{Instrumentos para la evaluación de la comunicación efectiva}

Para la medida de la competencia genérica asociada a la comunicación efectiva (comunicación escrita y en lengua propia) se ha diseñado un instrumento de evaluación que cumple las siguientes características:

- Transversal: debe poder utilizarse para cualquier asignatura.

- Eficiente: su aplicación debe realizarse con un bajo coste temporal. Para ello debe ser sencillo, de tal modo que su aplicación no implique un mayor tiempo de corrección para el profesorado.

\section{(c) EY-NC-ND 2014, Universitat Politècnica de València}

I Jornadas IN-RED (2014) 
Además, como cualquier instrumento de evaluación, permite no sólo calificar los ejercicios, sino también ofrece a los alumnos unas directrices de cómo deben enfocar la respuesta.

Según estos requisitos, se ha optado por una lista de control (Tabla 5). Este tipo de instrumento de evaluación se compone de distintas categorías que consisten en los aspectos a evaluar. La evaluación de cada una de estas categorías suele ser de todo/nada, de tal forma que resulta de una aplicación muy rápida.

Tabla 5. Lista de control para la evaluación de la comunicación efectiva. Adaptado de Rovira (2014)

\begin{tabular}{|c|c|}
\hline $\begin{array}{c}\text { Categoría } \\
\text { (peso) }\end{array}$ & Descripción \\
\hline $\begin{array}{l}\text { Contenido* } \\
(25 \%)\end{array}$ & $\begin{array}{l}\text { Se evalúa el contenido de la respuesta. Debe proporcionar una respuesta } \\
\text { semánticamente correcta y adecuada a lo que se pregunta. Para conseguir la } \\
\text { máxima puntuación en este apartado, debe contestarse exactamente a lo que se } \\
\text { pide, utilizando el léxico correspondiente, con concreción y sin lugar a ningún } \\
\text { tipo de ambigüedades. En este apartado se penaliza el añadir información no } \\
\text { relevante. }\end{array}$ \\
\hline $\begin{array}{c}\text { Estructura } \\
(25 \%)\end{array}$ & $\begin{array}{l}\text { El texto presentado, debe seguir un cierto orden. Por ejemplo, se puede partir de } \\
\text { lo general a lo particular, hacer la descripción de izquierda a derecha, siguiendo } \\
\text { un orden cronológico, un orden creciente en frecuencia, etc. }\end{array}$ \\
\hline $\begin{array}{l}\text { Corrección } \\
\text { ortográfica y } \\
\text { gramatical } \\
(25 \%)\end{array}$ & $\begin{array}{l}\text { El texto debe estar escrito de forma correcta, tanto ortográficamente, como las } \\
\text { estructuras gramaticales. Si se tiene un error, se obtiene la mitad de la puntuación } \\
\text { en este apartado; con dos errores, se obtiene un cero. }\end{array}$ \\
\hline $\begin{array}{c}\text { Concisión } \\
(25 \%)\end{array}$ & $\begin{array}{l}\text { Los textos deben ser cortos (menos de } 100 \text { palabras). Se tiene un cero en este } \\
\text { apartado si la respuesta tiene una longitud de una página. Se evalúa la capacidad } \\
\text { de síntesis de la respuesta. }\end{array}$ \\
\hline
\end{tabular}

${ }^{*}$ Si la respuesta no tiene ninguna relación con lo que se pide, la puntuación total es cero.

La lista de control de la Tabla 5 se ha utilizado en la asignatura Vibraciones Mecánicas (VM). En Villanueva (2014) se presentan los resultados del uso de esta lista de control, así como sus limitaciones y aspectos a mejorar. Como resumen, cabría destacar como aspecto positivo el hacer explícita la característica de "corrección ortográfica y gramatical”, ya que hace que los alumnos cuiden más la forma del texto; además analizando las cuatro categorías, se podría eliminar la de "concisión", ya que los textos en general se adecúan bastante bien a lo que se pide en este sentido. Finalmente, es interesante mencionar que es, en general, difícil separar por un lado la evaluación de la competencia genérica de la comunicación efectiva de la evaluación de competencias específicas de la asignatura.

Adicionalmente, tomando como partida este diseño y la experiencia en la asignatura VM, se han diseñado otros instrumentos de evaluación para las asignaturas de Derecho 
Administrativo (DA), Economía de la Empresa Biotecnológica (EEB), Estadística e Introducción al Proyecto (IP).

En las asignaturas DA y EEB se han utilizado también listas de control, mientras que en Estadística e IP se ha optado por expandir la lista de control y elaborar una rúbrica; este instrumento de evaluación se compone de diversas categorías y de distintos niveles de implicación para cada una de éstas. De esta forma, se pueden asignar valores intermedios para cada una de las categorías, según cumplan uno u otro nivel de implicación.La rúbrica, por un lado permite evaluar con mayor precisión los ejercicios pero, por otro lado, tiene más coste temporal en su utilización. La principal característica para optar al uso de una rúbrica frente a una lista de control es disponer de menor número de alumnos o tener que evaluar menor número de ejercicios, lo que permite hacer una evaluación más detallada de cada ejercicio. En Clemente-Císcar (2014) se muestra el diseño de la misma, usada en la asignatura Estadística.

\subsubsection{Materiales docentes}

En la presente sección se muestran ejemplos de los materiales docentes preparados para trabajar y evaluar la competencia de comunicación efectiva a través de ejercicios. Estos ejercicios serán propios de cada asignatura y se basarán en tareas auténticas (Vygotsky, 1934/2010). Éstas requieren usar lo que se está aprendiendo en cada asignatura, para los mismos tipos de aplicaciones que se encontrarán en la vida los futuros egresados. De esta forma se entiende la comunicación efectiva como una herramienta del profesional para poder expresar sus conocimientos, redactar informes o presentar conclusiones sobre sus trabajos.

Pregunta. Dada la primera notificación de una multa imponiendo una sanción de 200 euros en la que se otorga un plazo de 15 días para alegaciones. Indica de forma detallada de qué clase de acto administrativo se trata, recorriendo todas y cada una de las clasificaciones de actos explicadas en clase, describiéndolas y justificando la razón por la que se ajusta o no a cada una de ellas.

Respuesta propuesta. Se trata de un acto de gravamen ya que el procedimiento va dirigido a la posible imposición de una sanción económica para el particular. Es un acto singular, puesto que va dirigido a una persona en concreto en este caso, al conductor que ha cometido la infracción administrativa. Un acto expreso ya que se formaliza por escrito. Reglado, dado que la Administración no tiene margen de decisión en la adopción de la resolución del procedimiento. De trámite, porque se da un plazo de alegaciones y aún no se ha tomado una decisión definitiva por parte de la Administración. No agota la vía administrativa ya que sólo lo pueden hacer los actos definitivos, nunca los de trámite. Por último, no es firme puesto que en todo caso sería susceptible de recurso indirecto contra la resolución que cierre el procedimiento administrativo.

Fig. 1 Ejercicio propuesto para la asignatura Derecho Administrativo (DA).

La Fig. 1 muestra el ejemplo de un ejercicio propuesto en la asignatura DA, para evaluar la competencia de comunicación efectiva. Se trata de un ejercicio de aplicación del concepto

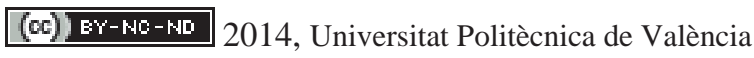

I Jornadas IN-RED (2014) 
de "acto administrativo", correspondiente al tema 2. Se puede comprobar la necesidad de utilización del vocabulario jurídico para concretar la respuesta.

Por otro lado, la Fig. 2 muestra un ejemplo de un ejercicio propuesto para evaluar la comunicación efectiva en la asignatura IP. Se trata de un trabajo académico que deben realizar los alumnos como actividad no presencial.

\begin{abstract}
Pregunta. A partir de las notas tomadas en la investigación personal sobre el artista/cliente se tiene redactar una carta al arquitecto describiendo las pretensiones del encargo.

Se recomienda hacer un escrito creativo sobre los deseos y aspiraciones del artista con su nueva casa en el mar Mediterráneo. Se valorará la creatividad, imaginación y la relación entre las reflexiones planteadas y las sugerencias planteadas

La extensión máxima de la carta es un A4. Aunque es preferible hacer un texto corto, bien elaborado y fundamentado [...]. Para ello es suficiente escribir un texto con una extensión de un A5 (medio folio). Fig. 2 Ejercicio propuesto para la asignatura Iniciación al Proyecto (IP).
\end{abstract}

Finalmente, la Fig. 3 muestra un ejemplo utilizado en la asignatura VM. Este ejercicio debe resolverse, entre otros, en la memoria de prácticas. Se trata del primer ejercicio de este tipo, por lo que se ofrece la solución propuesta por el profesor y se comenta ésta en relación al instrumento de evaluación empleado en la asignatura.

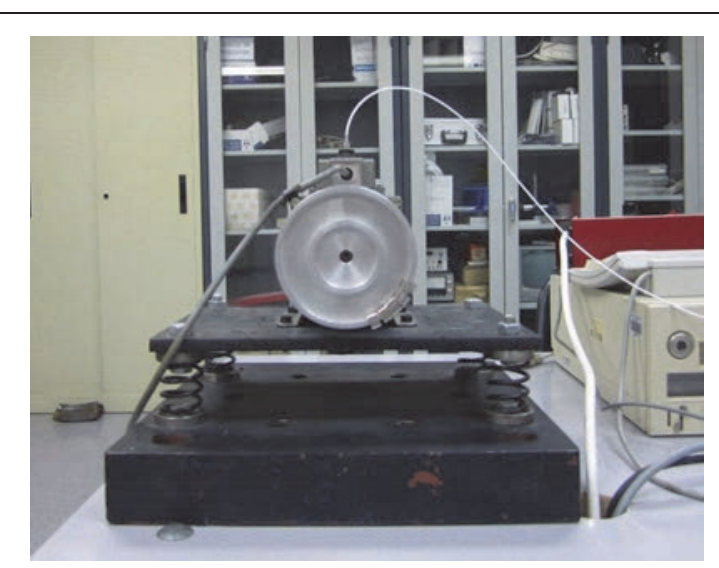

Pregunta. Describe el montaje utilizado en la práctica (ver fotografía anexa). Identificar los elementos masa, rigidez y amortiguamiento $y$ señalar la excitación del sistema.

Respuesta propuesta.

El sistema mecánico está compuesto por una base, supuesta fija, y una masa suspendida. La masa está formada por una plancha de acero y un motor unido a ésta. La suspensión está compuesta por cuatro muelles helicoidales de acero, montados en paralelo y situados cada uno de los cuatro extremos de la plancha.

Para obtener el modelo analítico, la suspensión se modela por una rigidez equivalente y un amortiguador viscoso en paralelo que tiene en cuenta las pérdidas por histéresis en el material del muelle. El sistema se excita por un rótor desequilibrado. El desequilibrio se consigue con unas pequeñas masas colocadas en dos discos unidos uno a cada extremo del rótor. De este modo, cuando aparece un giro en el rótor, se genera una fuerza de excitación.

Fig. 3 Ejercicio propuesto para la asignatura Vibraciones Mecánicas (VM). 


\section{Resultados}

En este apartado se presentan dos tipos de resultados. En primer lugar, se presentan las calificaciones finales de un grupo de alumnos de la asignatura Vibraciones Mecánicas, desagregados por las competencias trabajadas en la asignatura y calculados según la fórmula (1). En segundo lugar, se muestran los resultados de evaluación de la comunicación efectiva para la asignatura Iniciación al Proyecto, según los instrumentos de evaluación utilizados.

\subsection{Calificaciones desagregadas por competencias}

En este segundo conjunto de resultados se presentan las calificaciones de la asignatura desagregadas según las competencias que se trabajan en ésta. Para ello se sigue el procedimiento brevemente descrito en el punto 2.1.3 del presente trabajo. Este procedimiento se ha aplicado únicamente en la asignatura Vibraciones Mecánicas. Para el cálculo de las calificaciones, se ha implementado el algoritmo en MATLAB®.

La Fig. 4 muestra las calificaciones, desagregadas por competencias, para los alumnos de un grupo, considerando las prácticas de laboratorio. Las competencias 1, 2 y 3 son las que se muestran en la Tabla 1. La comunicación efectiva está representada en la competencia 3.

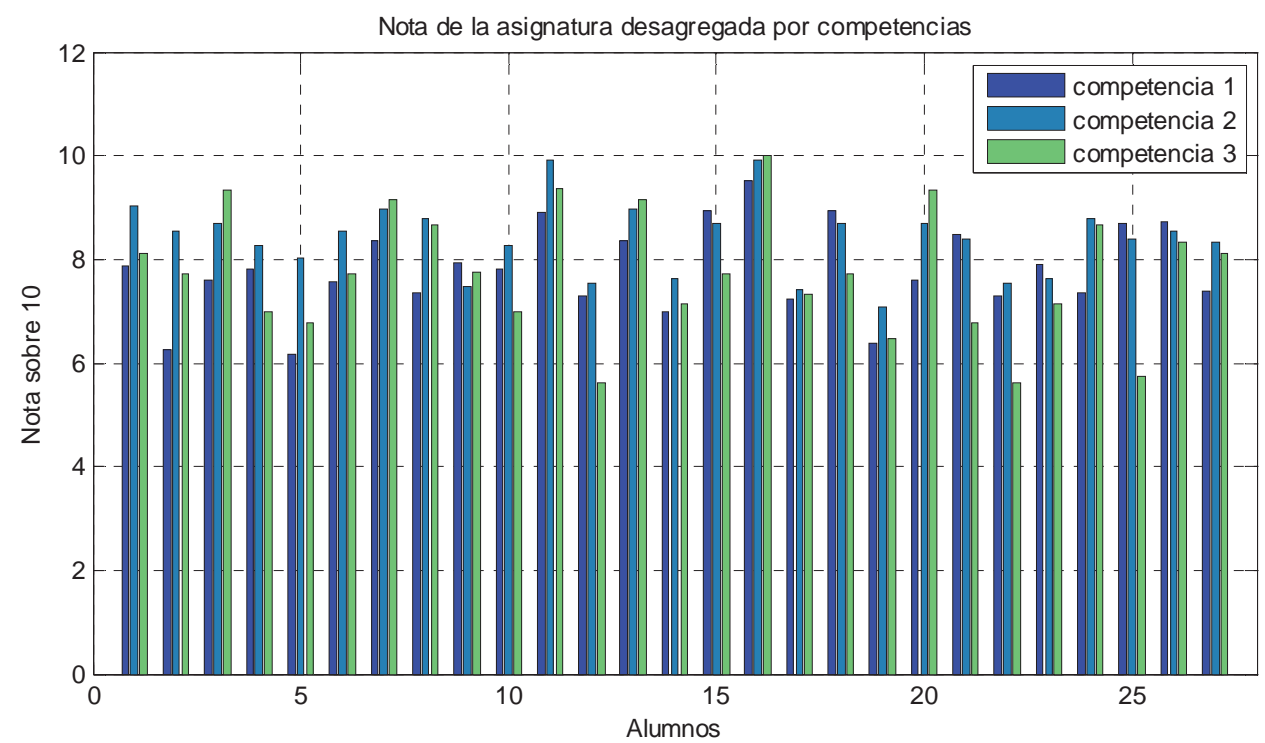

Fig. 4 Calificaciones finales de los alumnos, desagregadas por competencias.

Las calificaciones presentadas en la Fig. 4 representan una valiosa información para incorporar en el currículum del estudiante, ya que proporciona el grado de adquisición de cada competencia en la asignatura. Si esta metodología se aplicase a todas las asignaturas 
de la titulación, se podría obtener en el expediente del alumno una nota media por competencias, además de la que ya se obtiene de nota media por asignaturas.

Como inconveniente cabe señalar dos aspectos: en primer lugar, implica mayor carga de trabajo para los profesores ya que se deben diseñar de cierta forma las pruebas de evaluación y se deben introducir las notas individualmente en la aplicación de gestión de notas. En segundo lugar, el procesado de los datos resulta completo y no es posible realizarlo con la aplicación corporativa de gestión de notas de la UPV (programa Padrino2).

\subsection{Resultados de evaluación de la comunicación efectiva}

En este punto se presentan resultados de la evaluación de la comunicación efectiva para la asignatura Iniciación al Proyecto. Las Figs. 5 y 6 muestran las notas promedio para los alumnos y para el grupo estudiado junto a los valores de dispersión, respectivamente, según las cuatro categorías consideradas en el instrumento de evaluación.
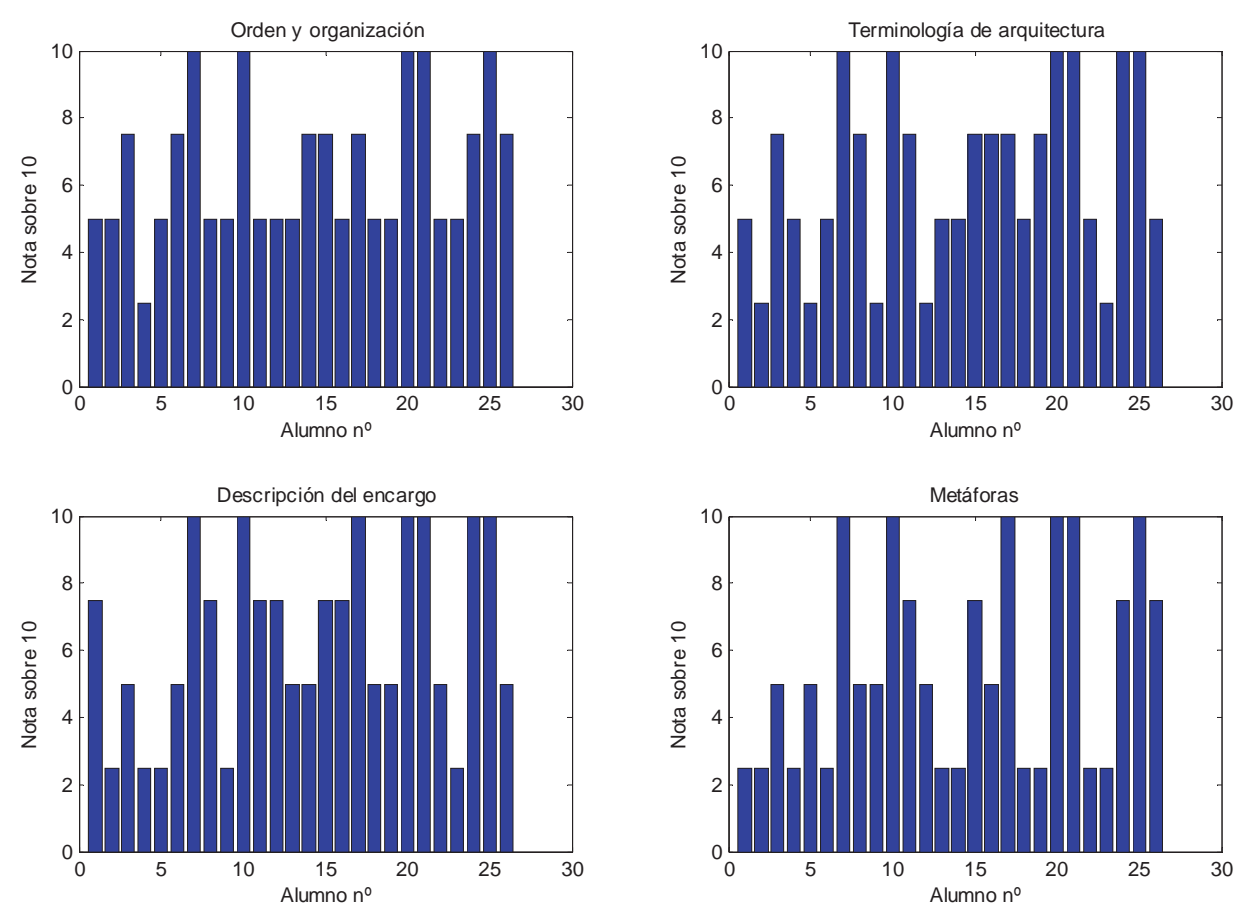

Fig. 5 Notas medias obtenidas por los alumnos en la asignatura Iniciación al Proyecto según las categorías consideradas.

Existen diferencias entre las calificaciones de los distintos alumnos, con notas que van desde un valor mínimo igual a 2,5 puntos hasta 10 puntos, sobre una escala de 10. En la Fig. 6 se muestran los valores medios para el grupo junto a los valores de dispersión, para cada una de las categorías. Las notas medias están entre 5,5 y 6,5 puntos; la dispersión 
(desviación típica) varía entre 2 y 3 puntos. La categoría de orden y organización es la que tiene una puntuación mayor y una menor dispersión; en el otro extremo se encuentra la categoría de "metáforas", con la nota más baja y la mayor dispersión. Aunque estas diferencias son pequeñas, sí que se puede extraer que los alumnos han tenido mayor dificultad a la hora de conseguir la puntuación máxima en esta última categoría.

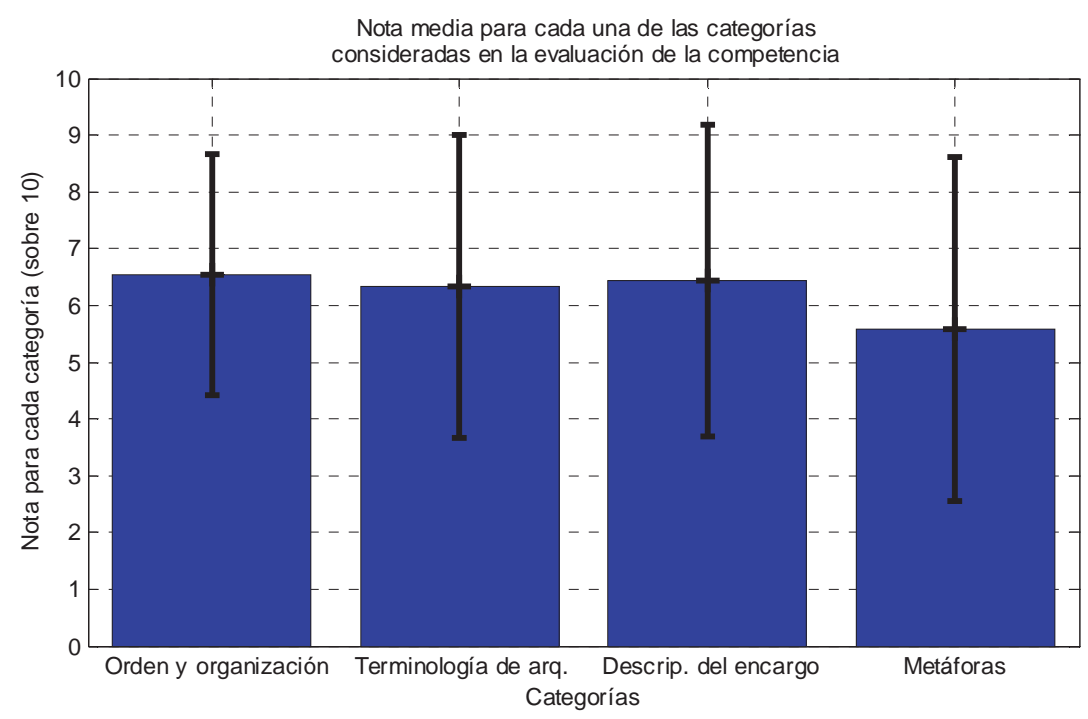

Fig. 6 Notas medias y valores de dispersión obtenidos por el grupo estudiado en la asignatura Iniciación al Proyecto, para las cuatro categorías consideradas.

Los resultados de evaluación de la competencia genérica de comunicación efectiva en la asignatura Vibraciones Mecánicas se han presentado en Villanueva (2014).

Considerando los resultados de ambas asignaturas, se pueden destacar un par de aspectos. En primer lugar, el hecho de hacer explícitas las categorías que se van a evaluar, hace que los alumnos construyan la respuesta teniendo en cuenta estos aspectos. En segundo lugar, es difícil evaluar una competencia de forma independiente del resto, porque aparecen relacionadas.

\section{Conclusiones}

En este trabajo se presenta, por un lado, el trabajo realizado para incluir la evaluación por competencias dentro de las asignaturas. Por otro lado, se muestran las distintas estrategias usadas en diversas asignaturas para trabajar y evaluar la comunicación efectiva.

Se ha desarrollado un procedimiento para crear las pruebas de evaluación de tal forma que se pueda evaluar el grado de adquisición de competencias, tanto específicas como

\section{(cc) EY-NC-ND 2014, Universitat Politècnica de València}

I Jornadas IN-RED (2014) 
genéricas. Además, se ha implementado el algoritmo en MATLAB® para el cálculo de las calificaciones desagregadas para cada una de las competencias trabajadas en la asignatura.

En cuanto a las competencias genéricas, se han estudiado las competencias asociadas a la dimensión competencial de la comunicación efectiva, según la clasificación propuesta en la UPV. Para poder medir el grado de adquisición de estas competencias se han desarrollado instrumentos de evaluación que se han utilizado en las asignaturas involucradas.

Para trabajar las competencias asociadas a la comunicación efectiva se han creado materiales en las distintas asignaturas. Estos materiales están formados por ejercicios basados en tareas auténticas, con el fin de proporcionar a los alumnos problemas que tratarán en su vida profesional.

Posteriormente, se muestran resultados de las notas obtenidas por los alumnos. Por un lado se muestran las notas obtenidas según el grado de adquisición de la competencia asociada a la comunicación efectiva. Por otro lado, se presentan las calificaciones desagregadas por competencias, calculadas según el algoritmo propuesto.

En cuanto a la evaluación de la comunicación efectiva, los profesores coincidimos que el hecho de hacer explícita esta competencia y los elementos de evaluación que se van a utilizar, hace que los alumnos presten atención a estos aspectos y construyan una mejor respuesta.

En cuanto a la obtención de las calificaciones desagregadas por competencias para cada uno de los alumnos, este aspecto representa una importante herramienta para configurar el expediente de los alumnos. Si el método propuesto se aplicase en todas las asignaturas de la titulación, los alumnos podrían disponer en su expediente del grado de adquisición de las competencias de la titulación, al igual que ahora tienen las calificaciones de las distintas asignaturas. Sin embargo, el aplicar este procedimiento implica una mayor carga del profesorado, mayor aún que la que ya supone la docencia en el nuevo EEES. Además, el programa de gestión de notas de la UPV no permite procesar las notas según el algoritmo propuesto, por lo que las notas se han procesado con un programa implementado en MATLAB®.

\section{Agradecimientos}

Los autores del trabajo agradecen la ayuda prestada por los técnicos del ICE de la Universitat Politècnica de València (UPV). Este trabajo ha sido financiado por el Vicerrectorado de Estudios, Calidad y Acreditación y la Escuela Técnica Superior de Ingeniería del Diseño (ETSID) a través de la convocatoria de ayudas para PIME 2013-2014 de la UPV, con el proyecto código B15/13. 


\section{Referencias}

BIGGS, J. (2003). "The teaching for quality learning at university: what the student does". Buckingham: Open University Press/Society for Research into Higher Education ( $2^{\text {nd }}$ edition).

DE MIGUEL DÍAZ, M. (2006). "Metodologías de enseñanza y aprendizaje para el desarrollo de competencias. Orientaciones para el profesorado universitario ante el Espacio Europeo de Educación Superior", Alianza D.L., Madrid.

CLEMENTE-CÍSCAR, M., ROVIRA, A., TRINIDAD, A., BAÑÓN-GOMIS, A.J. (2014). "Grado de adquisición de competencias específicas y transversales en la asignatura de Estadística: diferencias en los métodos de evaluación” En INNODOCT, International Conference on Innovation, Documentation and Teaching Technologies. Valencia (Spain). Pendiente de publicación en actas.

REYZÁBAL, M.V. (2012). "Las competencias comunicativas y lingüísticas, clave para la calidad educativa”. Revista Iberoamericana sobre Calidad, Eficacia y Cambio en Educación, Vol. 10, núm. 4.

ROVIRA, A., BOLUMAR, C., TUSET, J.J., MONTALVÁ, J.M., TRINIDAD-TORNEL, A. (2013). "Diseño de la asignatura Vibraciones Mecánicas para el nuevo plan de estudios del Grado en Ingeniería Mecánica en el marco del EEES" En XX1 CUIEET, XXI Congreso Universitario de Innovación Educativa en las Enseñanzas Técnicas. Valencia (Spain): Editorial UPV. 288-299.

ROVIRA, A., CLEMENTE-CÍSCAR, M., LAJARA-CAMILLERI, N., VILLANUEVA, J.F. (2014). "Creación de pruebas de evaluación para valorar el progreso y acreditación de competencias en la asignatura Vibraciones Mecánicas" En INNODOCT, International Conference on Innovation, Documentation and Teaching Technologies. Valencia (Spain). Pendiente de publicación en actas.

UPV (2013). “Dimensiones Competenciales UPV”, Borrador de trabajo, Valencia.

UPV (2013). "Guía Docente de la asignatura Vibraciones Mecánicas (12577)”. Competencias. Valencia (2013). Disponible en línea en

http://www.upv.es/pls/oalu/sic_gdoc.get_content?P_OCW=\&P_ASI=12577\&P_CACA=2013 (accedido 9-junio-2014).

VILlANUEVA, J.F., CLEMENTE-CÍSCAR, M., ROVIRA, A., BAÑÓN-GOMIS, A.J. (2014). "Instrumentos para la evaluación de la comunicación efectiva en la UPV" En CUIEET, XXII Congreso Universitario de Innovación Educativa en las Enseñanzas Técnicas. Almadén (Spain). Pendiente de publicación en actas.

VYGOTSKY, L. (1934/2010). Pensamiento y lenguaje, Paidós Ibérica, Barcelona. 


\title{
Adaptación de la docencia impartida en una asignatura experimental del plan extinguido de Ingeniero Químico a la nueva estructura de asignaturas del Grado de Ingeniería Química
}

\author{
José Miguel Arnal ${ }^{\mathrm{a}}$, María Sancho y Beatriz García-Fayos ${ }^{\mathrm{a}}$
}

${ }^{a}$ Dpto. Ingeniería Química y Nuclear, Universitat Politècnica València, Camino Vera s/n, 46022 Valencia, e-mails: jarnala@iqn.upv.es, msanchof@iqn.upv.es, beagarfa@iqn.upv.es

\begin{abstract}
The adaptation of curricula to the structure of new degrees, involves the modification of the contenst and methodologies to the structure of degree courses. In the previous plan of Chemical Engineering, there was taught an experimental core course in 4th year, in which, through students learnt by project oriented method. Through this methodology, students were formed in some disciplines essential to their practice as industrial safety, waste management and design of industrial plants. On the other hand, "roleplaying" methodology was also applied to encourage the development of professional skills. All these methodologies allowed to supplement the training of students in transversal contents such as: group work, written reports, oral presentation, and search for information.

In the structure of the new degree of Chemical Engineering, core experimental credits have been substantially reduced, as the mentioned $4^{\text {th }}$ year course has dissapeared. Since we consider essential both the content and the methodology taught in that course, we have tried to move them to the new structure of subjects in which we teach in years $3^{\text {rd }}$ and $4^{\text {th }}$ of Chemical engineering degree.

This work describes the adaptation of the teaching given above in the experimental subject of $4^{\text {th }}$ year to the new structure of degree subjects. We analyze the difficulties encountered in this adaptation and future performance measures for teaching improvement.
\end{abstract}

Keywords: Degrees, adaptation, project oriented learning, role-playing, transversal content 


\begin{abstract}
Resumen
La adaptación de los planes de estudio a la nueva estructura de grados, conlleva la modificación de contenidos y metodologías del plan antiguo a la estructura de asignaturas de grado. En el plan anterior de Ingeniería Química, se impartía en $4^{\circ}$ curso una asignatura troncal experimental, en la que, a través del Aprendizaje Orientado a Proyectos, los alumnos se formaban en algunas disciplinas esenciales para su práctica profesional como la seguridad industrial, la gestión de residuos y el diseño de instalaciones. Por otra parte, se aplicaba también la metodología "roleplaying" para fomentar el desarrollo de ciertas habilidades profesionales. Todo ello permitía complementar la formación de los estudiantes en contenidos transversales como: trabajo en grupo, presentación de informes escritos, exposición oral, y búsqueda de información.

En la estructura del nuevo Grado de Ingeniería Química (GIQ), los créditos experimentales troncales se han visto sustancialmente reducidos, habiendo desaparecido la asignatura mencionada. Dado que consideramos esenciales tanto los contenidos impartidos como la metodología aplicada en dicha asignatura, hemos intentado trasladarlos a la nueva estructura de asignaturas en las que impartimos docencia en los cursos $3^{\circ}$ y $4^{\circ}$ de GIQ.

En este trabajo se describe la adaptación de la docencia impartida anteriormente en una asignatura experimental de $4^{\circ}$ curso a la nueva estructura de asignaturas de GIQ. Se analizan las dificultades encontradas en dicha adaptación y se proponen medidas de actuación futuras para la mejora de la docencia.
\end{abstract}

Palabras clave: Grados, adaptación, aprendizaje orientado a proyectos, role-playing, contenidos transversales

\title{
1. Introducción
}

La convergencia de los planes de estudio hacia el Espacio Europeo de Educación Superior ha supuesto la creación y modificación de las distintas asignaturas dentro de las titulaciones. Esto supone, por un lado, la necesidad de adaptar los conocimientos y habilidades trabajados anteriormente al nuevo enfoque de competencias. Y, por otro lado, la adaptación de la docencia a las nuevas características del contexto en el que se desarrolla la docencia: número de alumnos, tipo de créditos impartidos, troncalidad u optatividad de la asignatura, calendario de evaluación, etc.

(cc) EY-NC-ND 2014, Universitat Politècnica de València

I Jornadas IN-RED (2014) 
En este trabajo se pretende describir cómo se ha realizado la adaptación de los contenidos y metodologías desarrollados en una asignatura experimental del plan antiguo, al nuevo grado correspondiente. Para ello, se comenzará describiendo la situación de partida, en dicha asignatura, para luego describir la situación actual de desarrollo docente en el grado.

\subsection{La docencia en la asignatura del plan 97 de Ingeniero Químico}

En el plan de estudios ya extinguido de Ingeniero Químico de la Universitat Politècnica de València (UPV), existían varias asignaturas troncales de carácter experimental que se impartían desde el $2^{\circ}$ cuatrimestre de $2^{\circ}$ curso hasta el $2^{\circ}$ cuatrimestre de $4^{\circ}$ curso. La secuencia y carga docente de dichas asignaturas, así como el profesorado implicado, pueden observarse en la Tabla 1. Estas asignaturas englobaban las prácticas de laboratorio de las principales asignaturas troncales impartidas en dichos cursos. A lo largo de las cuatro asignaturas, los alumnos iban completando su formación teórica en sintonía con la experimentación en el laboratorio, e iban adquiriendo progresivamente ciertas habilidades y actitudes relacionadas con el trabajo y la formación de ingeniería química.

Tabla 1. Asignaturas experimentales en el plan 97 de Ingeniero Químico

\begin{tabular}{|l|c|c|c|c|}
\hline Asignatura & Curso & Semestre & No $^{\circ}$ profesores & No créditos \\
\hline Experimentación en Ingeniería Química I & 2 & B & 4 & 4.5 \\
\hline Experimentación en Ingeniería Química II & 3 & A & 6 & 7.5 \\
\hline Experimentación en Plantas Piloto & 3 & B & 6 & 4.5 \\
\hline Experimentación Avanzada & 4 & A y B & 3 & 7.5 \\
\hline \multicolumn{7}{|c|}{ Total créditos experimentales } & 24 \\
\hline
\end{tabular}

La última de las cuatro asignaturas experimentales ("Experimentación Avanzada”), era una asignatura anual impartida a lo largo de los dos cuatrimestres de $4^{\circ}$ curso.

Tradicionalmente, en las cuatro asignaturas experimentales se seguía una metodología de trabajo similar, que consistía en la realización de prácticas en el laboratorio, en grupos de 45 alumnos, y la elaboración posterior de una memoria por práctica. El sistema de evaluación contemplaba la calificación obtenida en el conjunto de memorias con un peso del $40 \%$ en la nota final, y el restante $60 \%$ correspondía a la nota obtenida en el examen final escrito.

En un momento determinado, los profesores de "Experimentación Avanzada" decidimos modificar la metodología de la asignatura para dotarla de un carácter más multidisciplinar y acercar a los alumnos a su realidad profesional (Arnal, 2011). Tras varios años de cambios, tanto en los contenidos desarrollados como en la metodología aplicada, la asignatura se impartió durante 10 años de la forma que se describe a continuación.

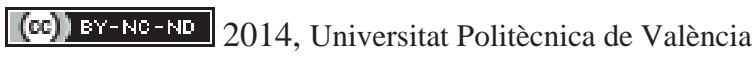

I Jornadas IN-RED (2014) 
Adaptación de la docencia impartida en una asignatura experimental del plan extinguido de Ingeniero Químico a la nueva estructura de asignaturas del Grado de Ingeniería Química

\subsubsection{Contenidos desarrollados}

El eje principal de los contenidos desarrollados en la asignatura se materializaba en el diseño de una instalación industrial. Este diseño se complementaba con contenidos más específicos (Fig. 1), poco desarrollados a lo largo de la titulación, pero de gran importancia en la futura labor profesional de los ingenieros químicos: gestión de residuos, seguridad industrial y selección de materiales. Todo ello en consonancia con la legislación en vigor y la normativa aplicable.

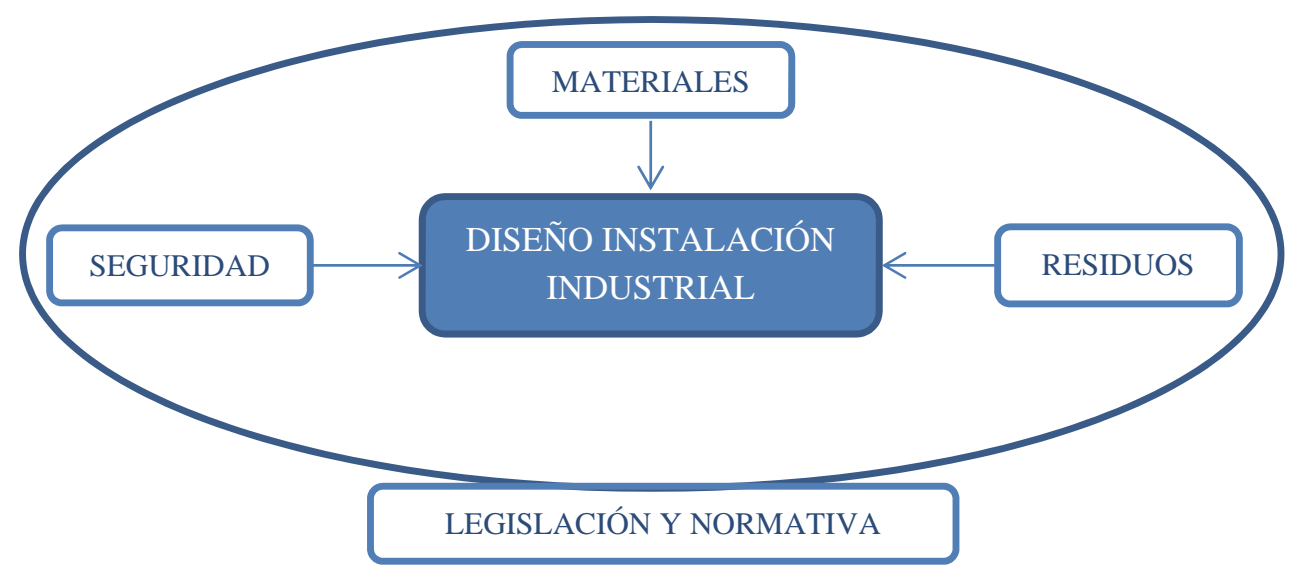

Fig. 1 Contenidos desarrollados en la asignatura del plan 97

\subsubsection{Metodologías aplicadas}

La asignatura tenía ciertas características ( $4^{\circ}$ curso, anual, media de alumnos entre 40-50) que la hacía idónea para la aplicación de metodologías activas de trabajo multidisciplinar en grupo. Por ello, se optó por aplicar el Aprendizaje Orientado a Proyectos, un método de enseñanza-aprendizaje que consiste en realizar un proyecto multidisciplinar, que permite desarrollar, entre otras, competencias como: análisis, síntesis, desarrollo y profundización de conocimientos y habilidades técnicas, investigación e innovación de soluciones técnicas, transferencia de conocimientos y procedimientos a situaciones prácticas, pensamiento crítico, manejo de información, expresión oral y escrita, trabajo en equipo, iniciativa, responsabilidad y respeto (De Miguel, 2006).

Entre las numerosas ventajas del Aprendizaje Orientado a Proyectos podrían destacarse las siguientes (Fernández, 2006): 
- Los estudiantes aprenden a tomar sus propias decisiones y a actuar de forma independiente.

- Mejora la motivación para aprender porque se apoya en la experiencia.

- Permite aplicar conocimientos, habilidades y actitudes a situaciones concretas.

- Se genera un producto final, el proyecto, en el que los alumnos ven reflejados los resultados de las competencias adquiridas, incluyendo el trabajo en grupo.

La aplicación de esta metología en "Experimentación Avanzada" se esquematiza en la Fig. 2. Concretamente, los alumnos debían extrapolar las prácticas realizadas a escala de laboratorio al diseño industrial de una instalación. En las distintas sesiones de laboratorio los estudiantes debían identificar todas las variables del proceso productivo y plasmarlas en un "Informe diario". Este informe, se entregaba al profesor al final de cada sesión de laboratorio, y se devolvía corregido para su aplicación en la elaboración del proyecto.

El proyecto se elaboraba de forma progresiva a lo largo de cada cuatrimestre y requiería una labor de tutoría importante por parte del profesorado de la asignatura . Para facilitar esta labor, cada uno de los profesores se encargaba del seguimiento de una parte del proyecto final (Arnal, 2012a). Al final del cuatrimestre, cada grupo de alumnos debía presentar el proyecto final escrito y realizar una presentación oral del mismo. Finalmente, se realizaba un examen escrito, mediante el que se evalúaba de forma individual los conocimientos relativos a las prácticas de laboratorio.

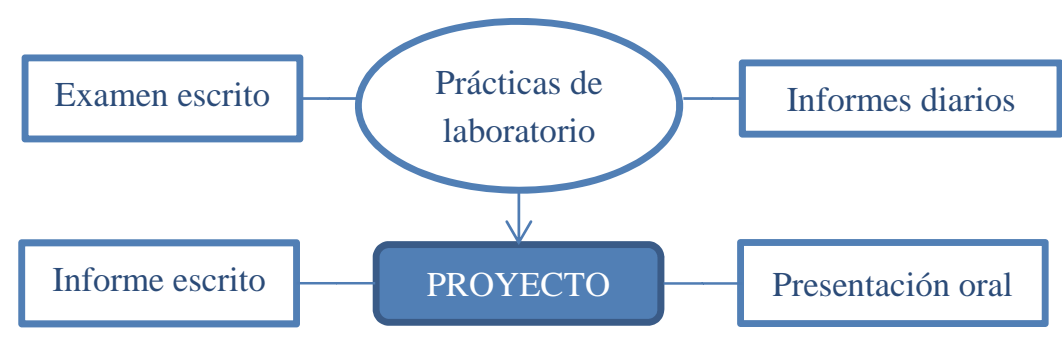

Fig. 2 Estructura del Aprendizaje Orientado a Proyectos aplicado en la asignatura del plan 97

En los últimos años de la asignatura se decidió incorporar una nueva actividad en el segundo cuatrimestre, consistente en la asignación de roles ("Role-playing") dentro del grupo, tanto durante la realización de la práctica como durante el desarrollo del proyecto,. Los objetivos principales de esta asignación de roles fueron, por un lado, favorecer y mejorar el aprendizaje de algunas disciplinas (como la seguridad y la gestión de residuos) en el laboratorio, a través de la implicación más directa del alumnado, así como su aplicación posterior en el proyecto a realizar. Por otro lado, la asignación de roles permite trabajar determinadas competencias muy importantes a nivel laboral como la

\section{(c)) EY-NC-ND 2014, Universitat Politècnica de València}

I Jornadas IN-RED (2014) 
Adaptación de la docencia impartida en una asignatura experimental del plan extinguido de Ingeniero Químico a la nueva estructura de asignaturas del Grado de Ingeniería Química

responsabilidad y el cumplimiento de protocolos (Graells, 2007). Así, en el laboratorio se asignaron los siguientes roles, que iban cambiando de estudiante en cada práctica:

-Responsable de Seguridad: encargado de comprobar y asegurar que se adoptan las medidas de protección oportunas durante la realización de la práctica.

-Responsable de Medioambiente: encargado de identificar y gestionar adecuadamente los residuos generados durante la práctica de laboratorio.

Por otra parte, y durante todo el cuatrimestre, el Responsable de Organización y Recursos

Humanos, se encargaba de distribuir las tareas a realizar, asignarlas a los miembros del grupo y verificar su realización y adecuación a los plazos establecidos.

Las tareas de los distintos responsables se registraban en unas fichas de comprobación, elaboradas de forma similar a lo que marca la normativa en la disciplina correspondiente (Gracía-Fayos, 2012).

\subsubsection{Resultados obtenidos}

A lo largo de los más de 10 años de aplicación del Aprendizaje Orientado a Proyectos en la asignatura se han obtenido excelentes resultados académicos de los alumnos. Las tasas de presentados ha rondado el 100\% todos los años (sólo han dejado de presentarse al examen los alumnos matriculados que se encontraban de estancia en otras universidades). Además, de los alumnos que han seguido la asignatura, el 100\% la ha superado, y con calificaciones iguales o superiores al notable (Arnal, 2011).

Por otra parte, en los últimos cursos desarrollamos encuestas de satisfacción para los alumnos en las que se les solicitaba evaluar distintos ítems relacionados con los contenidos de la asignatura cursada, la metodología y el grado de aprendizaje. En todos los cursos se obtuvieron valoraciones muy positivas de los estudiantes, destacando la alta valoración en la aplicabilidad de la asignatura a su futuro profesional (Arnal, 2012b).

Respecto a la metodología "role-playing", también fue evaluada por los alumnos a través de una encuesta. Los resultados pusieron de manifiesto que los estudiantes valoraban muy positivamente la asignación de los roles en el laboratorio (seguridad y medioambiente), bastante por encima que el rol de responsable de organización, que les resultaba más complicado de aplicar. En cualquier caso, el pensamiento que prevalecía de forma general era que su aprendizaje mejoraba con la asignación de roles, y que les permitía un mayor acercamiento a la realidad profesional (García-Fayos, 2014).

\subsection{Estructura de asignaturas en el Grado de Ingeniería Química}


En el nuevo Grado de Ingeniería Química, la asignatura "Experimentación Avanzada" ha desaparecido de $4^{\circ}$ curso. La estructura de asignatura sexperimentales, agrupadas dentro de una misma materia, queda actualmente como se presenta en la Tabla 2.

Como se puede observar, las tres asignaturas experimentales actuales aportan un total de 13.5 créditos, lo que supone una reducción de 10.5 créditos (aproximadamente el 45\%) respecto al plan anterior. Además, cabe destacar que ninguna de las asignaturas actuales es anual, finalizando la formación experimental obligatoria en $3^{\text {er }}$ curso.

Por otra parte, cabe señalar que el número de profesores de las asignaturas ha tenido que incrementarse debido a la dificultad de compaginar los horarios de éstas con otras asignaturas impartidas por los mismos. Ello redunda, en principio, en una mayor dificultad a la hora de coordinar cualquier metodología e impartición de contenidos.

Tabla 2. Asignaturas experimentales en el Grado de Ingeniería Química

\begin{tabular}{|c|c|c|c|c|}
\hline Asignatura & Curso & Semestre & $\mathrm{N}^{\mathrm{o}}$ profesores & $\mathrm{N}^{\mathrm{o}}$ créditos \\
\hline Experimentación en Ingeniería Química I & 2 & $\mathrm{~B}$ & 5 & 4.5 \\
\hline Experimentación en Ingeniería Química II & 3 & A & 7 & 4.5 \\
\hline Experimentación en Ingeniería Química III & 3 & B & 7 & 4.5 \\
\hline \multicolumn{4}{|c|}{ Total créditos experimentales } & 13.5 \\
\hline
\end{tabular}

\section{Objetivos}

En este trabajo se describe la adaptación de los contenidos impartidos y de la metodología aplicada, de una asignatura troncal experimental del plan antiguo de Ingeniero Químico, a la nueva secuencia y estructura de asignaturas del Grado en Ingeniería Química.

Tras la implementación de los cuatro cursos que componen el nuevo Grado, se identifican los puntos susceptibles de mejora y se proponen acciones futuras para ello.

\section{Desarrollo de la adaptación}

En los apartados siguientes se describe cómo se ha llevado a cabo la adaptación de la asignatura "Experimentación Avanzada" del plan antiguo a la nueva estructura de asignaturas experimentales. Cabe señalar que dada la reducción de créditos experimentales en el nuevo grado, se ha optado por ampliar la adaptación a otras asignaturas (troncales u optativas) impartidas en la titulación por el mismo profesorado. En la Tabla 3 se muestran las asignaturas implicadas en dicha adaptación.

Concretamente, la adaptación se ha ampliado a la asignatura "Procesos Industriales en Ingeniería Química", una asignatura troncal impartida en el primer cuatrimestre de $4^{\circ}$ curso; y a las asignaturas optativas: "Laboratorio Integrado en Ingeniería Química" y "Seguridad Industrial", ambas impartidas durante el $2^{\circ}$ cuatrimestre de $4^{\circ}$ curso.

\section{(c)) EY-NC-ND 2014, Universitat Politècnica de València}

I Jornadas IN-RED (2014) 
Adaptación de la docencia impartida en una asignatura experimental del plan extinguido de Ingeniero Químico a la nueva estructura de asignaturas del Grado de Ingeniería Química

Tabla 3. Asignaturas del Grado implicadas en la adaptación

\begin{tabular}{|c|c|l|c|}
\hline Curso & Cuatrimestre & Asignatura & Tipo asignatura \\
\hline $2^{\circ}$ & $\mathrm{A}$ & Experimentación en Ingeniería Química I & Troncal \\
\hline \multirow{2}{*}{$3^{\circ}$} & $\mathrm{A}$ & Experimentación en Ingeniería Química II & Troncal \\
\cline { 2 - 4 } & $\mathrm{B}$ & Experimentación en Ingeniería Química III & Troncal \\
\hline \multirow{2}{*}{$4^{\circ}$} & $\mathrm{A}$ & Procesos Industriales en Ingeniería Química & Troncal \\
\cline { 2 - 4 } & \multirow{2}{*}{$\mathrm{B}$} & Laboratorio Integrado en Ingeniería Química & Optativa \\
\cline { 2 - 4 } & & Seguridad Industrial & Optativa \\
\hline
\end{tabular}

\subsection{Adaptación de los contenidos específicos}

La reducción de créditos experimentales de 24 a 13.5 ha obligado a reducir los contenidos desarrollados en las nuevas experimentaciones. Entre los contenidos impartidos anteriormente, se decidió mantener una introducción al diseño industrial, por ser una competencia básica de la titulación. Y del resto de contenidos se decidió mantener y seguir trabajando la seguridad industrial, por considerarla una disciplina fundamental en la profesión de ingeniero químico (Arnal, 2013). En la Tabla 4 se muestra de manera resumida la adaptación de los principales contenidos trabajados anteriormente en "Experimentación Avanzada".

De esta forma, la adaptación de los contenidos ha quedado como se describe a continuación:

- Diseño industrial. Dentro de las asignaturas experimentales troncales el diseño se sigue trabajando en "Experimentación en Ingeniería Química III”, pero sólo a nivel de diagrama de bloques. En esta asignatura no hay tiempo suficiente para desarrollar el diagrama de flujo, ya que se debn desarrollar otros contenidos, y por el aumento del número de alumnos, que dificulta el seguimiento del trabajo realizado. Actualmente, el diseño a nivel de diagrama de flujo se ha podido desarrollar en la asignatura "Procesos Industriales en Ingeniería Química", a través de la realización de un portafolio elaborado en las sesiones de práctica de aula. Por último, se completa a un nivel similar al del $1^{\text {er }}$ cuatrimestre de "Experimentación Avanzada" en la asignatura "Laboratorio Integrado en Ingeniería Química". Sin embargo, ésta es una asignatura optativa que no cursan todos los alumnos (este curso 19 de aproximadamente 50 alumnos matriculados en $4^{\circ}$ curso). 
- $\quad$ Seguridad industrial. Este contenido, considerado fundamental en la formación de los ingenieros químicos, se desarrolla progresivamente a lo largo de todas las asignaturas experimentales, comenzando por la búsqueda y manejo de Fichas de Datos de Seguridad (FDS), hasta concluir con la selección e interpretación de la información de la FDS. Todo ello se ha materializado en un Proyecto de Innovación y Mejora Docente, concedido por el Vicerrrectorado de la UPV, cuyo resultado principal fue precisamente la integración de este contenido en el bloque experimental de GIQ (Arnal, 2012c). Por otra parte, los contenidos en materia de seguridad se refuerzan y amplían en la asignatura "Procesos Industriales en Ingeniería Química", con la inclusión de ciertas medidas preventivas fundamentales en los procesos químicos. Además, los alumnos que cursan el "Laboratorio Integrado en Ingeniería Química" profundizan en la disciplina incorporándola al diseño industrial, y trabajando la identificación de riesgos y la propuesta de medidas preventivas en cada una de las sesiones de laboratorio. Por último, los alumnos que escogen como optativa la asignatura "Seguridad Industrial" han podido adquirir una formación mucho más completa en la materia. Sin embargo, este curso sólo han sido 4 los alumnos que han escogido la asignatura, por lo que el grueso de los graduados no contarán con una formación completa, y creemos que necesaria, en esta disciplina.

Tabla 4. Adaptación de los contenidos a las nuevas asignaturas del Grado

\begin{tabular}{|l|l|l|}
\hline \multicolumn{1}{|c|}{ Contenido } & \multicolumn{1}{|c|}{ Asignatura implicada } & \multicolumn{1}{c|}{ Adaptación } \\
\hline \multirow{3}{*}{ Diseño industrial } & Exp. en Ing. Química III & $\begin{array}{l}\text { Diagrama de Bloques } \\
\text { tutorizado }\end{array}$ \\
\cline { 2 - 3 } & Procesos Industriales Ing. Química & $\begin{array}{l}\text { Diagrama de Flujo } \\
\text { (Portafolio en sesiones de } \\
\text { práctica de aula) }\end{array}$ \\
\cline { 2 - 4 } Seguridad & Laboratorio Integrado Ing. Química & Proyecto de diseño \\
\hline Exp. en Ing. Química I, II y III & $\begin{array}{l}\text { Proyecto de Mejora e } \\
\text { Innovación Docente } \\
\text { (Arnal, 2012c) }\end{array}$ \\
\cline { 2 - 3 } & Laboratorio Integrado Ing. Química & $\begin{array}{l}\text { Identificación de riesgos en } \\
\text { informes diarios } \\
\text { Apartado seguridad en } \\
\text { Proyecto en otras }\end{array}$ \\
\hline \multirow{2}{*}{ Residuos } & ------------- & $\begin{array}{l}\text { Realizado en } \\
\text { asignaturas no implicadas } \\
\text { en la adaptación }\end{array}$ \\
\hline
\end{tabular}

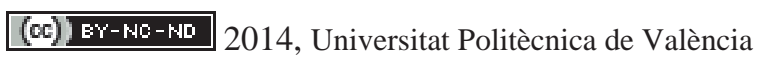

I Jornadas IN-RED (2014) 
Adaptación de la docencia impartida en una asignatura experimental del plan extinguido de Ingeniero Químico a la nueva estructura de asignaturas del Grado de Ingeniería Química

\begin{tabular}{|l|l|l|}
\hline Materiales & $\begin{array}{l}\text { No se tiene conocimiento } \\
\text { de que se realice en otras } \\
\text { asignaturas }\end{array}$ \\
\hline
\end{tabular}

- Gestión de residuos. En el nuevo plan la gestión de residuos se desarrolla en otra asignatura, por lo que se ha eliminado en "Experimentación en Ingeniería Química III". Sin embargo, consideramos que es una posible línea de trabajo a incorporar en el "Laboratorio Integrado en Ingeniería Química" para complementar el diseño realizado, como se hacía anteriormente en "Experimentación Avanzada".

- Selección de materiales. Este ha sido otro de los contenidos eliminados por falta de tiempo para su desarrollo, debido a la reducción de créditos ocurrida.

\subsection{Adaptación de las metodologías}

El Aprendizaje Orientado a Proyectos (AOP) no se aplica completo en ninguna de las nuevas asignaturas, fundamentalmente por una cuestión del tiempo disponible por los alumnos para realizar el proyecto, y por el tiempo disponible por los profesores para el seguimiento del trabajo en tutorías. Sin embargo, sí se aplican algunas metodologías similares al AOP, o algunas tareas que pretenden realizar un acercamiento a dicha metodología, como puede verse reflejado en la Tabla 5.

Tabla 5. Adaptación de la metodología a las nuevas asignaturas del Grado

\begin{tabular}{|c|l|l|}
\hline Metodología & \multicolumn{1}{|c|}{ Asignatura implicada } & \multicolumn{1}{c|}{ Adaptación } \\
\hline $\begin{array}{c}\text { Aprendizaje } \\
\text { Orientado a } \\
\text { Proyectos }\end{array}$ & Exp. en Ing. Química III & $\begin{array}{l}\text { Informes diarios } \\
\text { Seguimiento en tutorías del } \\
\text { diagrama de bloques }\end{array}$ \\
\cline { 2 - 3 } & Laboratorio Integrado Ing. Química & Proyecto de diseño \\
\hline Role-playing & Seguridad Industrial & $\begin{array}{l}\text { "Inspectores de seguridad" } \\
\text { en Exp. en Ing. Química III }\end{array}$ \\
\hline
\end{tabular}

En "Experimentación en Ingeniería Química III" se realizan informes diarios en algunas de las sesiones de laboratorio (no en todas como antes), que se aplican luego al diseño que está basado en dichas prácticas. De hecho, esta metodología se sigue únicamente en un tercio de la asignatura. Esto perjudica al trabajo en grupo, que sí se realiza en las sesiones de laboratorio implicadas, pero que en muchos casos se convierte en un simple reparto de tareas al realizar el proyecto. 
En el "Laboratorio Integrado en Ingeniería Química" el diseño sí se aplica a todas las prácticas de laboratorio, por lo que el Proyecto es más completo. Al mismo tiempo, al ser menos alumnos, se puede realizar un mayor seguimiento en tutorías. Pero como el periodo de docencia que nos corresponde es sólo de 4 semanas, no da tiempo de desarrollar todos los contenidos de antes (de ahí la eliminación de los residuos y los materiales). Cabe señalar que en esta asignatura los alumnos trabajan en grupo de forma más adecuada y similar a "Experimentación Avanzada", pero no les da tiempo de trabajar de forma tan independiente ni de tomar iniciativa para proponer ideas y materializarlas.

Es importante señalar que en ninguna de las asignaturas implicadas en la adaptación se realiza presentación oral del trabajo material, lo cual pensamos que es una deficiencia a subsanar en el futuro. Como propuesta de mejora podría plantearse como acto de evaluación alternativo o complementario de los actuales.

Por otra parte, el role-playing sólo se ha aplicado en "Seguridad Industrial", por tener menos alumnos y con una formación en seguridad suficiente. Un aspecto interesante a destacar es la interrelación que ha habido con la asignatura "Experimentación en Ingeniería Química III", ya que al impartirse simultáneamente, los alumnos de "Seguridad Industrial" ( $4^{\circ}$ curso) han acudido como "inspectores de seguridad" a supervisar una de las prácticas de laboratorio de sus compañeros de $3^{\circ}$. Esto ha resultado muy motivador para los estudiantes de la asignatura de $4^{\circ}$, pero también para los de $3^{\circ}$ que han tomado mayor conciencia de la importancia de la seguridad, a la vez que se han mostrado interesados en la asignatura optativa. Habrá que analizar si ello aumenta el número de alumnos que escogen dicha asignatura optativa en el futuro.

\subsection{Adaptación de los contenidos transversales}

Los contenidos transversales desarrollados anteriormente en la asignatura del plan antiguo también han resultado parcialmente reducidos por la disminución de créditos experimentales. El desarrollo de este tipo de créditos se realiza actualmente como se describe a continuación, y como se resume en la Tabla 6 , que incluye la valoración del nivel de adquisición tras la adaptación:

- Realización de informes escritos. Consideramos que éste es de los contenidos transversales que más se trabaja actualmente, ya que los alumnos siguen elaborando informes en todas las asignaturas experimentales.

- Presentación oral. Este contenido transversal, que actualmente no se aplica, debería incorporarse en alguna o varias de las asignaturas implicadas en la adaptación, dada la importancia que tiene en el futuro profesional de nuestros estudiantes. Además, en el corto plazo, los alumnos deben defender oralmente su Trabajo Final de Grado y no tienen experiencia suficiente. El practicarlo con anterioridad les ayhudaría a afrontarlo con mayor seguridad.

- Búsqueda de información. Aunque en menor medida que anteriormente, la búsqueda de información se sigue trabajando en todas las asignaturas señaladas.

- Trabajo en grupo. Aunque en muchas asignaturas los estudiantes realizan trabajos en grupo, pensamos que el tiempo de dedicación y el tiempo de seguimiento en

\section{(c)) EY-NC-ND 2014, Universitat Politècnica de València}

I Jornadas IN-RED (2014) 
Adaptación de la docencia impartida en una asignatura experimental del plan extinguido de Ingeniero Químico a la nueva estructura de asignaturas del Grado de Ingeniería Química

tutorías no permite desarrollar un nivel de trabajo en grupo como se alcanzaba antes en "Experimentación Avanzada".

Tabla 6. Adaptación de los contenidos transversales a las nuevas asignaturas del Grado

\begin{tabular}{|l|l|l|}
\hline Contenido Transversal & Asignaturas & Nivel de adaptación \\
\hline Informes escritos & $\begin{array}{l}\text { Exp. en Ing. Química I, II y III } \\
\text { Laboratorio Integrado Ing. Química }\end{array}$ & Adecuado \\
\hline Presentación oral & -------------- & $\begin{array}{l}\text { Totalmente } \\
\text { inadecuado }\end{array}$ \\
\hline Búsqueda de información & Todas las asignaturas implicadas & Mejorable \\
\hline Trabajo en grupo & $\begin{array}{l}\text { Exp. en Ing. Química I, II y III } \\
\text { Laboratorio Integrado Ing. Química }\end{array}$ & Insuficiente \\
\hline
\end{tabular}

\section{Resultados de la adaptación}

En este apartado se analizan los resultados de la adaptación tras este curso (2013-14) en el que se han implementado ya los cuatro cursos del nuevo grado. El análisis que se presenta corresponde a las impresiones recogidas e intercambiadas por los profesores implicados en las distintas asignaturas. Cabe señalar que en el futuro próximo sería conveniente incorporar estrategias para la recogida de resultados a través de encuestas o similares, para contar con datos cuantitativos con los que poder extraer conclusiones más objetivas.

A modo general, como impresión principal cabe destacar que la reducción de créditos experimentales ha redundado en una formación de los estudiantes en estos cuatro cursos menos completa en los siguientes aspectos:

- Algunos contenidos específicos han tenido que eliminarse por falta de tiempo y créditos suficientes. Dado que el Grado en Ingeniería Química tiene continuidad en el Máster de Ingeniero Químico, sería deseable poder trabajar y profundizar en dichos contenidos eliminados, en las asignaturas de continuación.

- Las habilidades de los estudiantes en el manejo de sustancias y equipos en el laboratorio también se ha visto mermada, dado que las horas impartidas en el laboratorio se han visto significativamente reducidas. Sería importante estudiar la posibilidad de aumentar la experimentabilidad de los estudiantes en el grado, para adquirir la destreza en el laboratorio que corresponde a las competencias de la titulación.

- La metodología Aprendizaje Orientado a Proyectos sólo puede aplicarse de forma casi completa en asignaturas optativas que cuentan con menos alumnos y que permiten un 
mayor seguimiento de la elaboración del Proyecto. En cualquier caso, el nivel de los proyectos presentados en este curso no son comparables a los de los Proyectos presentados en la asignatura del plan antiguo. En la asignatura desaparecida, el nivel de los contenidos desarrollados era mayor, así como el grado de implicación de los estudiante que contaban con un seguimiento muy exhaustivo por parte del profesorado.

- La presentación oral no se ha incluído por el momento en ninguna de las asignaturas implicadas en la adaptación. Sin embargo, resulta imprescindible incluirla como acto de evaluación alternativo o complementario. Por un lado, por la importancia en la futura labor profesional de los estudiantes; y, de forma más inmediata, por su aplicación en la defensa del TFG.

Por otra parte, consideramos que la adaptación ha dado como resultado algunos puntos positivos que merece la pena destacar, y seguir trabajando en el futuro:

- La aplicación del PIME mencionado anteriormente ha permitido obtener muy buenos resultados de aprendizaje de los estudiantes en materia de seguridad. A través de diversos puntos de control al inicio y fin de las distintas asignaturas, se ha podido constatar que el grado de avance de los estudiantes ha sido muy satisfactorio (dichos resultados están siendo recopilados y analizados en la actualidad). Por lo tanto, se debe seguir trabajando en la línea establecida en el curso actual.

- Aunque la metodología role-playing no se ha aplicado en ninguna asignatura troncal, creemos muy conveniente seguirla aplicando en la asignatura optativa con el enfoque que se le ha dado este curso. Como ya se ha comentado, la interrelación de los alumnos de $4^{\circ}$ curso en una asignatura de $3^{\text {er }}$ curso, resulta motivadora para los estudiantes de ambos cursos y permite asimilar de forma más adecuada la importancia de la disciplina trabajada.

\section{Conclusiones}

En este trabajo se ha analizado la adaptación de la docencia en las asignaturas experimentales del plan antiguo de Ingeniero Químico, a la nueva estructura de asignaturas del Grado en Ingeniería Química. Tras la implementación de los cuatro curso del Grado, cabe señalar los siguientes aspectos a mejorar:

- La reducción de créditos experimentales en GIQ redunda especialmente en una menor destreza de los estudiantes en el trabajo práctico en el laboratorio, que no se corresponde con las habilidades que deberían alcanzar en dicha competencia.

- El número de alumnos de las asignaturas experimentales troncales dificulta la aplicación de metodologías como el Aprendizaje Orientado a Proyectos, debido a la complicación de horarios y falta de disponibilidad para llevar a cabo el seguimiento del trabajo realizado por los estudiantes.

- Debería incluirse la presentación oral como método de evaluación complementario a los existentes, para que los alumnos practicaran de cara a la defensa de su TFG.

Como principal aspecto a destacar resulta la integración conseguida de la materia de seguridad a través de las distintas asignaturas experimentales. En este aspecto se ha

\section{(c)) EY-NC-ND 2014, Universitat Politècnica de València}

I Jornadas IN-RED (2014) 
Adaptación de la docencia impartida en una asignatura experimental del plan extinguido de Ingeniero Químico a la nueva estructura de asignaturas del Grado de Ingeniería Química

conseguido una formación progresiva de los estudiantes, en la que se debe seguir trabajando en los cursos futuros.

\section{Referencias}

ARNAL, J.M., SANCHO, M., GARCÍA-FAYOS, B., SANTAFÉ, A. y CUARTAS, B. (2011) "Análisis de los resultados académicos tras la implantación del Aprendizaje Basado en Proyectos en una asignatura experimental”. En: Jornadas de Innovación Docente ICE - UPV 2011 (15/07/2011 Valencia).

ARNAL, J.M., GARCÍA-FAYOS, B. y SANCHO, M. (2012a) "Evaluation of tutoring in an experimental subject of chemical engineering based on project oriented learning". En: International Technology, Education and Development Conference-INTED12 (05/03/2012 Valencia).

ARNAL, J.M., SANCHO, M. y GARCÍA-FAYOS, B. (2012b) "Evaluation by the students of the implementation of project oriented learning in an experimental subject of chemical engineering". En: International Technology, Education and Development Conference-INTED12 (05/03/2012 Valencia).

ARNAL, J.M. et al. (2012c) "Integración de la higiene y seguridad industrial en las asignaturas experimentales del grado en Ingeniería Química” Proyecto de Innovación y Mejora Educativa, Universitat Politècnica de València.

ARNAL, J.M., SANCHO, M. y GARCÍA-FAYOS, B. (2013) "Integration of industrial hygiene and safety in experimental subjects of chemical engineering degree”. En: International Technology, Education and Development Conference-INTED13 (06/03/2013 Valencia).

BADIA, A. y GARCÍA, C. (2006) "Incorporación de las TIC en la enseñanza y el aprendizaje basados en la elaboración colaborativa de proyectos". Revista de Universidad y Sociedad del Conocimiento. vol. $3, \mathrm{n}^{\circ}$ 2, p. $42-53$.

DE MIGUEL, M. (2006) "Modalidades de enseñanza centradas en el desarrollo de competencias". Universidad de Oviedo.

FERNÁNDEZ, A. (2006) "Metodologías activas para la formación de competencias". Educatio siglo XXI. vol. 24, p. 35-36.

GARCÍA-FAYOS, B., ARNAL, J.M. y SANCHO, M. (2012) "Análisis de la implantación de la metodología de "Role-playing" en una asignatura experimental de Ingeniería Química". En: Jornadas de Innovación Docente ICE - UPV 2012 (13/07/2012 Valencia).

GARCÍA-FAYOS, B., SANCHO, M. y ARNAL, J.M. (2014) "A role playing approach to teach safety, environment and organization skills in a chemical engineering course". En: International Technology, Education and Development Conference-INTED14 (10/03/2014 Valencia).

GRAELLS, M. y PÉREZ-MOYA, M. (2007) "Projecte PEEEQ: Planificació estratégica de les asignatures d'Experimentació en Enginyeria Química de l'Escola Universitària d'Enginyeria Tècnica Industrial de Barcelona". Universitat Politécnica de Catalunya. 


\title{
INCORPORACION DE LOS ÚLTIMOS AVANCES DE INVESTIGACIÓN EN EL APRENDIZAJE DE LOS ALUMNOS.
}

\author{
Amparo Quiles ${ }^{\mathrm{a}}$; Ana Puig ${ }^{\mathrm{a}}$.; Isabel Hernando ${ }^{\mathrm{a}}$
}

${ }^{a}$ Departamento de Tecnología de Alimentos. Universidad Politécnica de Valencia

\begin{abstract}
The content of university subjects must be consistent with the highest level of scientific knowledge; therefore it has to be updated to incorporate the latest trends, achievements and progress made by the scientific community. The aim of this work is to help the studenst to be autonomous in the task of updating the content and skills of the subjects studied in their university so they can continually shelf-recycle their knowledge, which will have a significant impact on their careers. In order to do this, students must familiarize with highimpact scientific papers in the field of food technology. In this context, the students have to carry out an active scientific literature search in three subjects in food technology area, selecting the papers and extracting the relevant information on the topics and contents of the subject. This task is evaluated with a work they have to write down and present to the class, so the rest of the students participate in that knowledge. The results show that students who carried out this type of work increased the interest in the scientific world and obtained higher academic level than those that which did not participated in this experience.
\end{abstract}

Keywords: research, tools, skills, knowledge updating, questionnaire,

university teaching, autonomy.

\section{Resumen}

El contenido de las asignaturas universitarias debe de estar en consonancia con el más alto nivel del conocimiento científico por lo que debe actualizarse incorporando las últimas tendencias, logros y avances obtenidos por la comunidad científica. Se plantea como objetivo que el alumno sea autónomo en la tarea de actualizar los contenidos teóricos y prácticos de las asignaturas estudiadas en su etapa universitaria de manera que pueda autoreciclarse continuamente, lo que tendrá una relevante repercusión en su vida profesional. Para ello el alumno debe familiarizarse con textos científicos de alto impacto en el campo de la tecnología de alimentos. En este contexto se propone en 3 asignaturas de esta área que los alumnos realicen búsquedas bibliográficas científicas activas, seleccionando textos y extractando la información de interés sobre los temas y contenidos de la asignatura. Esta tarea es evaluada mediante la realización de un trabajo escrito que se expone oralmente para hacer a toda la clase partícipe de los conocimientos adquiridos. Los

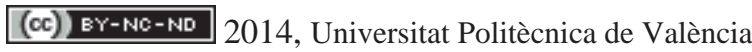

I Jornadas In-Red (2014) 
resultados muestran que aquellos alumnos que han realizado este tipo de trabajos presentan mayor interés por el mundo científico y mayor nivel académico que los no han participado en esta experiencia.

Palabras clave: investigación, herramientas, capacidades, actualización del conocimiento, evaluación, cuestionario, docencia, autonomía.

\section{Introducción}

El profesor de universidad, debe impartir información actual, novedosa, contrastada, enriquecida, y respaldada por su experiencia investigadora. Esta información que está en el linde del conocimiento debe ser recibida y asimilada por el alumno, el cual la empleará en su carrera profesional. El continuo conocimiento que se genera en la comunidad científica produce una evolución de la información. Así, cuando el alumno acaba sus estudios universitarios debe tener en su haber una información totalmente actual que puede quedar obsoleta a la hora de ponerla en práctica en su carrera profesional. Es importante proporcionar al alumno herramientas que le permitan adquirir capacidades para poder actualizar los conocimientos recibidos en su etapa universitaria. En este sentido, buenas herramientas podrían ser el uso de Internet donde se puede encontrar respuestas y soluciones a casi todas las preguntas que se nos puedan ocurrir, y la utilización de las Tecnologías de la Información y Comunicación (TIC). La búsqueda y recuperación de la información científica a través de Internet ha experimentado una gran revolución gracias al desarrollo del movimiento de acceso abierto. La información científica ya no está sólo accesible para aquellos que pagan suscripciones a revistas sino que ahora es posible acceder a gran cantidad de recursos gracias a repositorios institucionales, revistas y libros en acceso abierto y nuevas herramientas como las redes virtuales de investigación y los programas para la gestión de los contenidos recuperados. Las TIC nos acercan a nuevas posibilidades de comunicación, colaboración, distribución de conocimientos y adquisición de información, pudiendo además favorecer el aprendizaje constructivista y colaborativo (Delialioglu \& Yildirim, 2007; García-Sánchez \& Martínez-Segura, 2009; Shapiro \& Shelley, 2009). Esta herramienta nos ayuda a que el estudiante realice, de modo continuado, un ejercicio de metacognición, ofreciéndole un acceso a la documentación necesaria para la construcción del aprendizaje (Sanchez-López et al., 2012) que debe redundar en la adquisición de capacidades que permitan la actualización del conocimiento.

Lo que se pretende con este trabajo es que el alumno sea autónomo en la tarea de actualizar los contenidos teóricos y prácticos de las asignaturas estudiadas en su etapa universitaria, de manera que pueda autoreciclar de forma continua la información recibida en su momento. Esto puede resultar imprescindible durante el desarrollo de su vida profesional. Dado que en el mundo científico-tecnológico la información está en inglés, el alumno 
deberá enfrentarse a los documentos y textos científicos en este idioma. Para ello se propone en diferentes asignaturas que los alumnos realicen una revisión de temas muy concretos, para que manejen un número limitado de textos científicos, mediante el uso de herramientas adecuadas y desarrollen capacidades necesarias que les permitan extraer y sintetizar la información novedosa para la actualización de su conocimiento cuando ello sea necesario.

\section{Objetivo}

El objetivo de este trabajo es estudiar el efecto que tiene la impartición de asignaturas universitarias, con un contenido docente estructurado de forma que haya interacción entre los conocimientos teóricos y la investigación más actual, sobre los resultados en la evaluación de los alumnos. Al plantear esta docencia se pretende que el alumno consiga las capacidades necesarias y maneje las herramientas adecuadas para que pueda actualizar de forma autónoma, y en cualquier etapa de su vida los contenidos teóricos y prácticos de las asignaturas estudiadas en su etapa universitaria. Poder autoreciclar de forma continua la información recibida en su momento, tendrá una relevante repercusión en su vida profesional.

\section{Desarrollo de la Innovación}

\subsection{Descripción y evaluación de las asignaturas}

Las asignaturas que se describen a continuación han sido impartidas por profesoras de un mismo grupo docente y de investigación. Todas las profesoras del grupo siguieron los mismos criterios en la impartición de la docencia y en su evaluación.

\subsubsection{Tecnología y Química de los Alimentos}

Tecnología y Química de Alimentos (4085) es una asignatura optativa que se imparte en el $2^{\circ}$ semestre del $5^{\circ}$ curso de la titulación de Ingeniero Químico, en la Universidad Politécnica de Valencia (UPV). En esta asignatura se estudian los principales componentes químicos de los alimentos y las transformaciones químicas que sufren durante el procesado y almacenamiento de los alimentos. Se pretende que el alumno utilice herramientas (bases de datos, monografías, revistas especializadas, páginas web, redes virtuales, libros) que le permitan analizar, sintetizar y extractar información relevante en el ámbito de la química de alimentos y de esta forma desarrollar capacidades en la búsqueda de información científica.

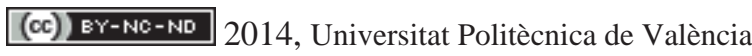

I Jornadas IN-RED (2014) 
La asignatura tiene 2 créditos de teoría de aula, 1.9 créditos de prácticas de aula y 1.2 créditos de prácticas de laboratorio. La asignatura se estructura en 1 unidad didáctica teórica que comprende 6 temas, 2 prácticas de laboratorio e incluye la realización de un trabajo individual y dirigido, en el que el alumno ha de buscar información científica actual y novedosa en publicaciones recientes. Esa información se contrasta con el profesor responsable y se incorpora en los apuntes teóricos de la asignatura. Para ello deben utilizar herramientas como internet y las TICS.

Con el método de evaluación establecido para esta asignatura se pretendió mantener un nivel adecuado de trabajo del alumno a lo largo del curso, y al mismo tiempo realizar una verificación continua del mismo. La evaluación se distribuyó de la siguiente manera: el $50 \%$ de la nota final correspondió a la teoría, evaluada de forma continua mediante prueba escrita de desarrollo, el $40 \%$ correspondió a la calidad del trabajo realizado, a la búsqueda de la información, y exposición y el 10\% a la nota obtenida en el laboratorio que se evaluó mediante la elaboración de informes. Los alumnos que no superaron la asignatura mediante una evaluación continua y aquellos que quisieron subir nota, tuvieron la opción de presentarse a un examen final. En el examen final realizaron una prueba escrita de respuesta abierta de todo lo visto en la parte teórica de la asignatura y un trabajo en la que debían actualizar un tema de los vistos en teoría.

\subsubsection{Propiedades Químicas de los Alimentos}

Propiedades Químicas de los Alimentos (5142) es una asignatura optativa que se imparte en el $2^{\circ}$ semestre del $4^{\circ}$ curso de la licenciatura de Ciencia y Tecnología de Alimentos, en la UPV. Esta asignatura refuerza y amplia los contenidos estudiados en otras asignaturas troncales de la licenciatura. En ella se estudian las principales modificaciones químicas, bioquímicas y estructurales que los alimentos sufren durante el procesado y almacenamiento, y cuál es su repercusión tecnológica. Igual que en la asignatura anteriormente descrita, el alumno realiza un trabajo mediante el uso de herramientas (bases de datos, monografías, revistas especializadas, páginas web, redes virtuales, libros) que les permitan desarrollar habilidades para analizar, sintetizar y extractar información relevante en el ámbito de la química de alimentos y desarrollar capacidades en la búsqueda de información científica.

La asignatura tiene 1.5 créditos de teoría de aula y 3 créditos de prácticas de laboratorio. Está estructurada en 1 unidad didáctica teórica que incluye diversos temas y 12 prácticas de laboratorio. Los alumnos tienen que realizar un trabajo individual y dirigido, mediante el uso de herramientas como internet y las TICS, en el que han de buscar información 
científica actual y novedosa en publicaciones recientes, contrastarla con el profesor responsable e incorporarla a los apuntes teóricos de la asignatura.

$\mathrm{Al}$ igual que en la anterior asignatura para mantener un nivel adecuado de trabajo del alumno a lo largo del curso, la evaluación se distribuyó de la siguiente manera: el 40\% de la nota final correspondió a la teoría, evaluada de forma continua mediante prueba escrita de desarrollo, el $20 \%$ correspondió a la calidad del trabajo realizado, a la búsqueda de la información, y a su exposición, y el $40 \%$ a la nota obtenida en el laboratorio que se evaluó mediante la elaboración de informes. Los alumnos que no superaron la asignatura mediante una evaluación continua y aquellos que quisieron subir nota, tuvieron la opción de presentarse a un examen final. En el examen final se realizó una prueba escrita de respuesta abierta de todo lo visto en la parte teórica y práctica de la asignatura y un trabajo en el que debían actualizar un tema de los vistos en teoría.

\subsubsection{Enzimología de Alimentos}

Enzimología de Alimentos (5123) es una asignatura optativa que se imparte en el $2^{\circ}$ semestre del $5^{\circ}$ curso de la licenciatura en Ciencia y Tecnología de Alimentos, en la UPV. La asignatura pone en contacto al alumno con las principales enzimas de aplicación industrial en el campo de la tecnología de los alimentos. Además se hace hincapié en las enzimas relacionadas con el deterioro y la pérdida de calidad de los alimentos y se explica cómo disminuir esa pérdida de calidad.

La asignatura tiene 1.5 créditos de teoría de aula y 3 créditos de prácticas de laboratorio. Está estructurada en 1 unidad didáctica teórica que incluye 10 temas, 10 prácticas de laboratorio y además los alumnos tienen la opción de realizar un trabajo de investigación como el que se ha expuesto en las otras dos asignaturas.

Esta asignatura se evaluó igual que Propiedades Química de los Alimentos, pero en Enzimología de Alimentos, la realización del trabajo fue optativa.

\subsubsection{Cuestionario de satisfacción}

Al finalizar el curso, en las tres asignaturas presentadas en este trabajo, se realizó una encuesta anónima, en la que se les pedía que evaluaran mediante una escala de 9 puntos ( 9 $=$ totalmente de acuerdo y $1=$ totalmente en desacuerdo) aspectos relativos al grado de satisfacción que habían tenido con la realización del trabajo, el grado de aplicación en su carrera profesional, el grado de desarrollo de capacidades, etc. Los ítems que se les pasó a los alumnos fueron exactamente los siguientes:

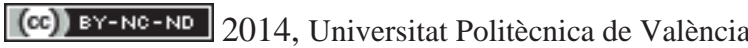

I Jornadas IN-RED (2014) 
- El trabajo desarrollado ha sido satisfactorio y ha aumentado mi interés por el mundo científico (Q1).

- Con la realización del trabajo he desarrollado capacidades que serán útiles en mi etapa profesional (Q2).

- Con la realización del trabajo he aprendido a manejar herramientas que me permitirán mantener mis conocimientos universitarios actualizados (Q3).

- Con la realización del trabajo he desarrollo capacidades de análisis, síntesis, extracción de información, etc...,(Q4).

Los datos del apartado resultados corresponden con el curso académico 2012-13.

\section{Resultados}

En la tabla 1 se muestran los resultados, del curso 2012-2013, de la evaluación de las tres asignaturas presentadas en este trabajo, Tecnología y Química de Alimentos (4085), Propiedades Químicas de los Alimentos (5142) y Enzimología de Alimentos (5123).

Tabla 1. Resultados de las evaluaciones del Curso Académico 2012-13.

\begin{tabular}{lccccccc}
\hline Asignatura & $\begin{array}{c}\text { Alumnos } \\
\text { matriculados }\end{array}$ & $\begin{array}{c}\text { Matricula } \\
\text { Honor }\end{array}$ & Sobresaliente & Notable & Aprobado & Suspenso & $\begin{array}{c}\text { No } \\
\text { presentado }\end{array}$ \\
\hline $\begin{array}{l}\text { Tecnología y } \\
\text { Química de }\end{array}$ & 27 & 1 & 19 & 6 & 0 & 0 & 1 \\
$\begin{array}{l}\text { Alimentos } \\
\text { Propiedades }\end{array}$ & 24 & 1 & 11 & 9 & 0 & 0 & 3 \\
$\begin{array}{l}\text { Químicas de } \\
\text { los Alimentos }\end{array}$ & & & & & & & \\
$\begin{array}{l}\text { Enzimología } \\
\text { de Alimentos }\end{array}$ & 30 & 0 & 4 & 17 & 8 & 0 & 1 \\
\hline
\end{tabular}

Como se puede observar en la tabla 1, en las asignaturas en las que la elaboración del trabajo fue obligatoria, Tecnología y Química de Alimentos y Propiedades Química de Alimentos, las calificaciones obtenidas mostraron una mayoría de sobresalientes. En Tecnología y Química de Alimentos el 77\% de los alumnos obtuvieron una calificación de sobresaliente, el resto (23\%) obtuvieron notable y no hubo ningún aprobado ni suspenso. En Propiedades Químicas el 57\% de los alumnos matriculados obtuvo una calificación de sobresaliente y el $45 \%$ de notable. No hubo calificaciones inferiores.

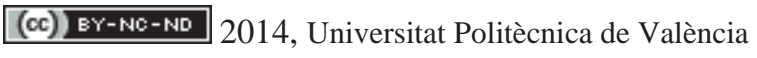

I Jornadas IN-RED (2014) 
En la asignatura Enzimología de Alimentos, la realización del trabajo de investigación fue optativa. El trabajo fue realizado por 12 alumnos. Los alumnos que decidieron hacer el trabajo obtuvieron las mejores calificaciones. Cuatro de estos alumnos (el 33.3\% de los que hicieron el trabajo) obtuvieron calificación de sobresaliente y 8 (el $66.6 \%$ de los que realizaron el trabajo) obtuvieron notable.

Los resultados del cuestionario de satisfacción que se les realizó a los alumnos de las tres asignaturas (tabla 2), permitió recabar información importante para el profesor de cara a la planificación de la docencia en las asignaturas universitarias.

En cuanto al ítem "El trabajo desarrollado ha sido satisfactorio y ha aumentado mi interés por el mundo científico" (Q1), los resultados mostraron que la realización del trabajo había sido muy satisfactorio en las tres asignaturas estudiadas. Los alumnos descubrieron y mostraron interés por el mundo científico. Los ítems Q2 y Q3 consiguieron la máxima puntuación. Prácticamente todos los alumnos opinaron que con la realización del trabajo habían desarrollado capacidades útiles para su etapa profesional y que habían aprendido a manejar herramientas que les permitirían mantener sus conocimientos universitarios actualizados. Además todos desarrollaron capacidades de análisis, síntesis y extracción de información (Q4). No hubo ninguna opinión negativa en los resultados del cuestionario.

Tabla 2. Resultados del cuestionario de satisfacción del Curso Académico 2012-13.

\begin{tabular}{|c|c|c|c|c|c|}
\hline Asignatura & & Q1 & Q2 & Q3 & Q4 \\
\hline $\begin{array}{l}\text { Tecnología } \\
\text { Química } \\
\text { Alimentos }\end{array}$ & $\begin{array}{r}\mathrm{y} \\
\mathrm{de}\end{array}$ & $8.7(0.4)$ & $9.0(0.0)$ & $9.0(0.0)$ & $8.8(0.4)$ \\
\hline $\begin{array}{l}\text { Propiedades } \\
\text { Químicas de } \\
\text { Alimentos }\end{array}$ & los & $8.8(0.4)$ & $9.0(0.0)$ & $9.0(0.0)$ & $8.9(0.3)$ \\
\hline $\begin{array}{l}\text { Enzimología } \\
\text { Alimentos }\end{array}$ & de & $8.7(0.4)$ & $8.9(0.2)$ & $8.9(0.2)$ & $8.9(0.3)$ \\
\hline
\end{tabular}

\section{Conclusiones}

La realización del trabajo de investigación autónomo durante el transcurso de la asignatura permitió a los alumnos un mayor grado de comprensión de los conocimientos teóricos de la asignatura y esto se tradujo en resultados excelentes en sus calificaciones.

La realización del trabajo de investigación permitió a los alumnos conocer herramientas y desarrollar capacidades importantes tanto para su etapa universitaria como profesional.

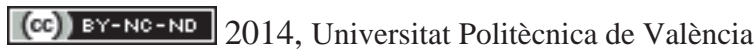

I Jornadas IN-RED (2014) 
Los alumnos que realizaron el trabajo vieron favorecido su nivel de análisis, extracción y síntesis de información.

\section{Referencias}

DELIALIOGLU, O., \& YILDIRIM, Z. (2007). Students' Perceptions on Effective Dimensions of interactive Learning in a Blended Learning Environment. Educational Technology \& Society, 10 (2), 133-146.

GARCÍA SÁNZ, M.P., GARCÍA SÁNCHEZ, F.A., MAQUILÓN, F.J., VALLEJO, M., DORADO, M.A., Y COLS. (2009). Adaptación al EEES del primer curso de la Titulación de Pedagogía” (pp. 257-280). En Arnaiz, P., Hernández Abenza, L. y García Sanz, M.P. (Coords.). Experiencias de Innovación Educativa en la Universidad de Murcia (2008). Murcia: EDITUM.

SHAPIRO, J.J., SHELLEY, K.H. (2009). The Challenges of Culture and Community in On-Line Academic Environments" in Kjell Rudestam and Judith Schoenholtz-Read (eds.), Handbook of Online Learning: Innovations in Higher Education and Corporate Training, 2d edition. Thousand Oaks: SAGE Publications, 2009.

SÁNCHEZ-LÓPEZ, C., GARCÍA-SÁNCHEZ, F.A., MARTÍNEZ-SEGURA, M.J., MIRETE-RUIZ, A. (2012). Approach to the evaluation that students make in Regards to online resources used in university teaching. Píxel-Bit. Revista de Medios y Educación, 40:35-45. 


\title{
Experiencias docentes en la UPV en torno a la competencia transversal "trabajo en equipo y liderazgo"
}

\begin{abstract}
Alexis J. Bañón-Gomis ${ }^{1}$, Mónica Clemente Ciscar $^{2}$, Luis Cortés-Meseguer ${ }^{3}$, Natalia LajaraCamilleri $^{4}$, Marta Pérez de los Cobos $^{5}$, Ángeles Rodrigo ${ }^{6}$, Andrés Rovira ${ }^{7}$, Ángel Trinidad ${ }^{8}$, José F. Villanueva9

${ }^{I}$ Dpto. de Organización de Empresas. Universitat Politècnica de València (SPAIN) albaogo@upvnet.upv.es. ${ }^{2}$ Dpto. de Estadística e Investigación Operativa. Universitat Politècnica de València (SPAIN) mclement@eio.upv.es. ${ }^{3}$ Dpto. de Construcciones Arquitectónicas. Universitat Politècnica de València (SPAIN) luicorme@csa.upv.es. ${ }^{4}$ Dpto. de Economía y Ciencias Sociales. CEGEA. Universitat Politècnica de València (SPAIN) nalade@cegea.upv.es. ${ }^{5}$ Dpto. de Expresión Gráfica Arquitectónica. Instituto Universitario de Restauración del Patrimonio. Universitat Politècnica de València (SPAIN) mperezdeloscobos@ega.upv.es. ${ }^{6}$ Dpto. de Expresión Gráfica Arquitectónica. Universitat Politècnica de València (SPAIN) arodrigo@ega.upv.es. ${ }^{7}$ CITV, dpto. de Ingeniería Mecánica y de Materiales. Universitat Politècnica de València (SPAIN) anrocar@mcm.upv.es. ${ }^{8}$ Dpto. de Urbanismo. Universitat Politècnica de València (SPAIN) antritor@urb.upv.es. ${ }^{9}$ Dpto. de Estadística e Investigación Operativa. Universitat Politècnica de València (SPAIN) jovillo0@iqn.upv.es.
\end{abstract}

\begin{abstract}
Finished the studies of the first promotions under the EHEA, it is time to evaluate experiences in order to carry out the necessary adjustments. One of the first obstacles that have been pointed out froom its implementation is the way to approach generic skills.

Additionally internacional accreditations through certifications such as $A B E T$, highlight the need to work in generic skills in coordination and the necessity of developing tools to assess and to quantify the degree of acquisition of such skills by the students. These evidences are key to certify that the students have reached at least the standards included in the Curriculum of the degree.

This paper sets out proposals for the development and assessment of the competency "Teamwork and leadership", which is the competency dimension $n^{\circ} 8$ of the Universitat Politécnica de València. Educational experiences included in this text can be easily extrapolated to other courses.
\end{abstract}

(c) EY-NC-ND 2014, Universitat Politècnica de València

I Jornadas In-Red (2014) 
Experiencias docentes en la UPV en torno a la competencia transversal "trabajo en equipo y liderazgo"

This work is part of the results of the PIME B14/13 of the UPV, entitled "Development of methods for the acquisition and assessment of the competency teamwork and leadership”.

Keywords: best practices, peer-assessment, self-assessment, EHEA, rubric.

\section{Resumen}

Finalizadas las primeras promociones de estudiantes que han desarrollado sus estudios bajo el Espacio Europeo de Educación Superior (EEES), llega el momento de evaluar las experiencias para poder llevar a cabo los ajustes necesarios. Uno de los primeros escollos que se vienen señalando desde su implantación es la forma de abordar las competencias transversales.

Adicionalmente la acreditación internacional a través de certificaciones como ABET (Accreditation Board for Engineering and Technology), pone de manifiesto la necesidad de trabajar de forma coordinada las competencias genéricas y de desarrollar herramientas que permitan evaluar y cuantificar el grado de adquisición de dichas competencias por parte de los estudiantes para certificar la consecución de los niveles mínimos recogidos en la titulación de Grado.

Esta comunicación expone propuestas de desarrollo y evaluación de la competencia "liderazgo y trabajo en equipo", que constituye la dimensión competencial $n^{\circ} 8$ de la Universitat Politècnica de València. Se recogen experiencias docentes que por su enfoque generalista pueden ser fácilmente extrapolables a otras titulaciones.

El trabajo expuesto forma parte de los resultados obtenidos en el PIME B14/13 de la convocatoria 2013-2014 de la UPV, titulado "Desarrollo de metodologías de adquisición y evaluación de la competencia "trabajo en equipo y liderazgo".

Palabras clave: buenas prácticas, coevaluación, autoevaluación, EEES, rúbrica. 


\section{Introducción}

Estamos inmersos en una sociedad de cambio constante y la Universidad no permanece ajena a esta situación. La revolución que supuso la implantación del Proceso de Bolonia modificando no sólo la estructura de la oferta de educación superior sino también la metodología de enseñanza-aprendizaje tiene su próximo hito en la cercana revisión de los primeros planes de estudios aprobados dentro del marco del EEES.

Es por ello momento de reflexión y de autocrítica, es también una oportunidad para incorporar las cuestiones que, por la magnitud de la tarea encomendada en su momento, no pudieron abordarse en aquellos primeros planes. Nos referimos a las siempre nombradas pero en cierta forma "eternamente postergadas" competencias transversales o, tal como se han recogido recientemente en la UPV, dimensiones competenciales.

El papel de la Universidad no puede limitarse a ejercer de mero transmisor de contenidos, formamos personas y profesionales y por tanto debemos trabajar no sólo los conocimientos formales de los estudiantes sino también sus aptitudes y habilidades.

Si bien existe una opinión unánime acerca de la relevancia de estas cuestiones en la posterior incorporación al mundo laboral y de las ventajas que confieren al alumno para el ejercicio profesional, el fomento activo de estos elementos es tradicionalmente motivo de cierto escepticismo y rechazo por parte del profesorado, quizá en parte por falta de formación.

Los intentos más "modernos" se han traducido frecuentemente en trabajos en grupo o bien presentaciones orales en clase, normalmente sin que existiera un trabajo real de desarrollo de la competencia y con evaluaciones escasas de los resultados obtenidos ya que mayoritamente se trabajaba de forma muy secundaria.

El escenario actual presenta oportunidades claras para la mejora. La motivación que suponen las acreditaciones internacionales como ABET suponen un acicate para avanzar en la integración plena de las competencias transversales en las aulas.

Este trabajo es consecuencia de un proyecto de innovación y mejora educativa con título "Desarrollo de metodologías de adquisición y evaluación de la competencia trabajo en equipo y liderazgo", formado por un grupo de profesores de distintas disciplinas de la Universitat Politècnica de València (UPV). Pretende aportar muestras aplicadas de cómo desarrollar y evaluar una de las dimensiones competenciales definidas en la UPV. Son propuestas desarrolladas con un espítiru generalista, con el propósito de que sean aplicables a prácticamente cualquier materia, de forma que puedan ser fácilmente traspuestas por los docentes.

\section{(c) EY-NC-ND 2014, Universitat Politècnica de València}


Experiencias docentes en la UPV en torno a la competencia transversal "trabajo en equipo y liderazgo"

\section{Objetivos}

Este trabajo se centra en un doble objetivo:

- Identificar recursos para el desarrollo de la dimensión competencial "trabajo en equipo y liderazgo" en el aula.

- Aportar herramientas para la evaluación de la dimensión competencial "trabajo en equipo y liderazgo".

\section{Propuestas de trabajo y evaluación}

La competencia de "trabajo en equipo y liderazgo" es definida por Villa y Poblete (2007) como la integración y colaboración de forma activa en la consecuencia de objetivos comunes con otras personas, áreas y organizaciones, influyendo sobre las personas y/o grupos, anticipándose al futuro y contribuyendo al desarrollo personal y profesional. De acuerdo con estos autores se trata de una de las competencias clave (core competence), pues suponen pensar analítica y sistemáticamente, administrar el tiempo de trabajo, participar en toma de decisiones y en gestión de objetivos y proyectos.

La evaluación de estas competencias debería ser llevada a cabo por tanto, no sólo por el profesor sino que también debe de incluir una autoevaluación y una evaluación de pares como complemento, puesto que son ellos quienes mejor conocen el funcionamiento del grupo. Los instrumentos clásicos utilizados son las entrevistas y sesiones de seguimiento, la planificación de objetivos, las hojas de rutas y plantillas de evaluación (rúbricas) (Blanco y Alba, 2009). Sin embargo otros autores como Golobardes et al (2009) sostienen la dificultad de establecer un sistema de rúbricas eficiente y enuncian una serie de indicadores objetivos tales como homogeneidad de calificaciones, diferencias entre la nota de grupo y las individuales, calidad de las notas obtenidas y presencialidad.

Por lo tanto, según lo expuesto, parece necesario no sólo desarrollar instrumentos que nos faciliten la evaluación de las competencias, y por tanto trasladar progresivamente nuestro sistema a una "evaluación POR competencias", sino que también resulta imprescindible integrar dichas competencias en las asignaturas, plasmándolas en actividades. No podemos plantearnos llevar a cabo la evaluación sin previamente haber enseñado el objeto de lo que va a ser evaluado.

Por ello en primer lugar expondremos recursos utilizados para trabajar la competencia con los alumnos: una actividad basada en los roles de los miembros del equipo, una guía de buenas prácticas y una actividad de resolución de problemas en grupo. A continuación se presenta una propuesta de evaluación mediante el sistema rúbricas y evaluación por pares. 


\subsection{Desarrollo del "trabajo en equipo y liderazgo"}

Tras una revisión de la literatura existente, se seleccionaron para el curso 13/14 tres actividades a realizar con el objetivo de fomentar esta competencia. Estas sesiones son independientes entre sí y pueden ser aplicadas de forma aislada en función del grupo, asignatura, etc.

\subsubsection{Resolución de un problema en equipo}

Basado en la actividad del Obelisco Zin de Francis y Young (1979). Se trata de proporcionar una serie de datos que contienen información relevante y no relevante a los miembros de un equipo. Deberán responder a una pregunta formulada y para ello es necesario que ordenen la información recibida y trabajen con ella.

La actividad ofrece múltiples posibilidades: desde realizar el juego original hasta hacer una adaptación de un caso específico de la asignatura. En Anexos se encuentra el material utilizado en la sesión, con la adaptación hecha para una asignatura de Economía.

\subsubsection{Identificación de roles en el equipo}

Esta actividad se basa en un cuestionario que los miembros del equipo deben cumplimentar segñun si actitud en el trabajo en grupo. A través de las preguntas llegan a identificar el rol que desempeñan en ese grupo. Posteriormente se hace una puesta en común intra-grupo donde se pone de manifiesto cómo normalmente aparecen distintos roles en el grupo que es lo que realmente hace que éste funcione.

En Anexos se puede consultar el cuestionario y la resolución de la actividad.

\subsubsection{Guía de buenas prácticas}

La guía de buenas prácticas para el trabajo en equipo es un documento breve que se ha elaborado en el marco del Proyecto de Innovación y Mejora Docente con el fin de proporcionar a los alumnos información concisa sobre aspectos clave del trabajo en equipo.

La guía puede ser utilizada como documento preliminar a una actividad o bien ponerlo a disposición de los alumnos a través de PoliformaT.

La guía se puede consultar en los Anexos de este trabajo.

\section{(c) EY-NC-ND 2014, Universitat Politècnica de València}

I Jornadas IN-RED (2014) 
Experiencias docentes en la UPV en torno a la competencia transversal "trabajo en equipo y liderazgo"

\subsection{Evaluación de la competencia "trabajo en equipo y liderazgo"}

Siguiendo la máxima de "lo que no se mide, no existe", se deben evaluar y calificar todas las actividades realizadas. Caer en el error de no calificarlo o incluso peor aún no evaluarlo, da a entender al alumno que se trata de un elemento secundario en su formación, por detrás de los contenidos formales de la sesión. Es por tanto un mensaje no coherente con las acciones que hemos llevado a cabo e impediría la consecución de los objetivos fijados.

No obstante es evidente que existe una dificultad clara en el hecho de evaluar y calificar una actividad a la que no tenemos acceso como profesores, es por ello que nuestra propuesta reside en delegar esta tarea a los propios alumnos, haciéndoles responsables tanto de su propia calificación como la de los compañeros de su grupo. La propuesta concreta que se realiza es que el profesor evalúa y califica el resultado presentado por el grupo, asignando una nota numérica. Dicha nota será multiplicada por el número de miembros del grupo y serán ellos mismos los que deberán repartir dichos puntos entre ellos. De esta forma existe la posibilidad de que lleguen a una solución de compromiso en la que todos reciben la misma nota o es posible que decidan reconocer el trabajo de quienes han contribuido en mayor medida a alcanzar los objetivos y decidan un reparto individualizado.

Partimos de la hipótesis de que posiblemente en las primeras experiencias bajo este sistema de evaluación los alumnos tenderán a evitar el conflicto, asumiendo todos la misma nota pero que con el tiempo y la experiencia -hay que recordar que esta competencia se trabaja a lo largo de toda la titulación- atenderán a criterios objetivos a la hora de realizar el reparto.

Para facilitar la toma de decisiones por parte del alumno, se les proporciona una rúbrica de autoevaluación basada en seis criterios, con cuatro niveles de desarrollo (desde pobre hasta excelente). La rúbrica utilizada es una adaptación de Chica (2011) y puede consultarse en Anexos.

\section{Conclusiones}

Es una realidad que el EEES ya está implantado en el sistema de educación superior en España, ha supuesto un considerable esfuerzo para todos los estamentos de la universidad y sin embargo todavía adolece de ciertas carencias. Entre ellas queda la cuestión del tratamiento de las competencias genéricas, la coordinación para su desarrollo a lo largo del Grado y la acreditación del grado de consecución, la evaluación.

Este trabajo pretende contribuir con propuestas docentes en este aspecto, abordando una competencia que ha sido definida como "dimensión competencial" en la UPV y que razonablemente estará integrada también en la mayoría de los planes de estudio de las diversas titulaciones. 
No obstante creemos que debe incrementarse el conocimiento sobre este tipo de experiencias, que nos enriquecen profesionalmente, mejoran nuestra actividad, refuerzan nuestro compromiso docente y nos animan a continuar en la mejora de las metodologías de aprendizaje.

\section{Agradecimientos}

Los autores del trabajo agradecen la ayuda prestada por los técnicos del ICE de la Universitat Politècnica de València (UPV). Este trabajo ha sido financiado por el Vicerrectorado de Estudios, Calidad y Acreditación y la Escuela Técnica Superior de Ingeniería Agronómica y del Medio Natural (ETSIAMN) a través de la convocatoria de ayudas para PIME 2013-2014 de la UPV, con el proyecto código B14/13.

\section{Referencias}

- $\quad$ BLANCO, A.; ALBA, E. (2009). "La participación de los estudiantes y el trabajo en equipo" en Desarrollo y evaluación de competencias en Educación Superior. Narcea de Ediciones. Madrid.

- CHICA, E. (2011). Una propuesta de evaluación para el trabajo en grupo mediante rúbrica. Escuela abierta, 14, 67-81.

- $\quad$ FRANCIS, D.; YOUNG, D. (1992). “Improving work groups”. Pfeiffer \& Company.

- GOLOBARDES, E. (2009). Guía para la evaluación de competencias en el área de ingeniería y arquitectura. Agència per a la Qualitat del Sistema Universitari de Catalunya. Barcelona.

- VIllA, A.; POBLETE, M. (2007). Aprendizaje basado en competencias. Una propuesta para la evaluación de las competencias genéricas. Ed Mensaje. Universidad de Deusto. Bilbao.

\section{(c) EY-NC-ND 2014, Universitat Politècnica de València}

I Jornadas IN-RED (2014) 
Experiencias docentes en la UPV en torno a la competencia transversal "trabajo en equipo y liderazgo"

\section{Anexo 1. Adaptación del Obelisco Zin (Francis y Young, 1979).}

SEMINARIO 1-ECONOMIA DE LA EMPRESA BIOTECNO LÓGICA

\author{
Guía para el profesor
}

El objetivo de la sesión es explicar a los alumnos parte de los conceptos de Administración incluidos en el tema 3 de la asignatura y real izar una actividad práctica en grupo sobre ellos.

\section{Recursos:}

Parte teórica (45 minutos-1h):

- Para la exposición del tema se utilizar el archivo: 3 . La dirección de la empresa y sus funciones pptx En esta sesión el cortenido a ver es desde la diapositiva 1 hasta la 32 (incluida), aunque algunas de ellas están ocultas y además las diapositivas 17, 18 y 19 se pueden resumir a grandes ræagos, sin detenernos demasiado en ellas.

Los alumnos cuentan con un resumen del material teórico: Seminario 1.docx

Parte práctica (45 min de trabajo en grupo+10-15 min de puesta en común)

- Los alumnos trabajarán en grupos sobre un caso de organización. La información a repartir a los alumnos -en forma de tarjetas. se encuentra en el documento Tarjetas caso seminariol.doox

- El enunciado completo del caso y la solución se pueden consultar en Caso seminario1.doc

- Para la resolución del ejercicio se puede usar la presentación Solución del caso seminario 1.pptx que incluye los organigramas que forman parte de la resolución.

\section{Observaciones:}

Las tarjetas incluyen toda la información relacionace con el caso, el profesor únicamente debe indicar al inicio de la actividad que las tarjetas contienen información sobre la organización y situación de una empresa, así como de los problemas que se le plantean actualmente como consecuencia de su estructura. La tarea de los alumnos consiste en identificar el organigrama actual de la empresa, estudiar los problemas que señala su presidente, atender a las sugerencias de mejora y con esa información, etbborar una propuesta de organigrama que solventela situación.

Cabe tener en cuenta que en las tarjetas los alumnos encontrarán tanto información relevante como no relevante.

\begin{tabular}{|c|c|}
\hline $\begin{array}{l}\text { Jaime vega es el director comercial de la empresa. El } \\
\text { departamen to se responsabiliza de la gestión } \\
\text { directa de las ventas y la distribución de productos, } \\
\text { de las relaciones púbicas y el trato con agencias de } \\
\text { publicidad. } \\
\text { Los operarios del departamento de producción } \\
\text { poseen la preparación necesaria para llevar a cabo } \\
\text { la transformación de las matterias primas. }\end{array}$ & 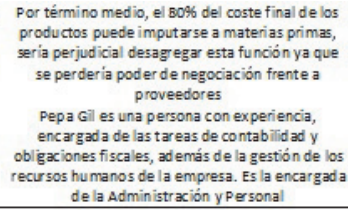 \\
\hline $\begin{array}{l}\text { Los puestos de los operarios de producción han sido } \\
\text { definidos con la flexibilidad suficiente para que } \\
\text { puedan ocuparse de cada uno de los flujos de } \\
\text { trabajo necesarios }\end{array}$ & $\begin{array}{l}\text { El personal de Compras, Finanzas y } \\
\text { sdministración y Personal posee autonomía } \\
\text { suficiente para tomar y ejecutar decisiones en } \\
\text { cada uno de sus campos respectivos. }\end{array}$ \\
\hline $\begin{array}{l}\text { Raimundo Siles es el jefe del depart amento de } \\
\text { Producción. }\end{array}$ & $\begin{array}{l}\text { Los téćcnicos de Mantenimiento encargados de la } \\
\text { maquinaria del núcleo operativo son los que } \\
\text { deciden cualquier cambio o mejora relacionado } \\
\text { con ésta }\end{array}$ \\
\hline $\begin{array}{l}\text { Abraham Callega es el jefe la unid ad de Investigación } \\
\text { de Mercados. }\end{array}$ & $\begin{array}{l}\text { El departamento de comercial ización toma } \\
\text { decisiones sobre las condiciones de venta } \\
\text { (precio, descuento, plazo de entregar, etc.). }\end{array}$ \\
\hline $\begin{array}{l}\text { La función del departamento de Investigación de } \\
\text { Mercados es desarroll ar lineas de productos al } \\
\text { objetto de acoplarse lo máximo pos ble a los } \\
\text { constantes cambios en gustos, preferencias y } \\
\text { necesidades de los clientes. }\end{array}$ & $\begin{array}{l}\text { El depart amento de comercia lización también } \\
\text { estudia y decide los objet ivos a alcanzar con cada } \\
\text { campaña de publicidad, pub lico objetivo y se } \\
\text { encargan de solucionar los problemas y quejas de } \\
\text { los clientes. }\end{array}$ \\
\hline $\begin{array}{l}\text { La complejid ad tecn ológica de congelación y, } \\
\text { precocinado hace imprescin dible la contr ibución } \\
\text { directa de los operarios de mantenimiento. }\end{array}$ & $\begin{array}{c}\text { Los operarios de Producción, además de realizar } \\
\text { las tareas de transformación, toman decisiones } \\
\text { relacionadas con ellas. }\end{array}$ \\
\hline $\begin{array}{c}\text { Carmelo Redondo, jefe de mantenimiento de la } \\
\text { empresa, es considerado un profesional capaz y muy } \\
\text { eficiente. }\end{array}$ & $\begin{array}{l}\text { Tomás Alonso, viendo que las ventas y el } \\
\text { rendimiento no aumentan al ritmo deseado, cree } \\
\text { necesario hacer un crambio organizativo } \\
\text { estructural. Tiene tres razones para ello }\end{array}$ \\
\hline $\begin{array}{l}\text { La empresa tiene un equipo de técnicos financieros } \\
\text { que realiza períodicamente detal lados análísis de } \\
\text { costes y complejos de ratios que suministran valiosa } \\
\text { información para la toma de decisiones. }\end{array}$ & $\begin{array}{l}\text { Tomás Alonso cree que con la estructura actual } \\
\text { es imposible identificar la contribución de cada } \\
\text { unidad organizativa al beneficio o pérdida de la } \\
\text { compañia. Es un hándicap para tomar medidas } \\
\text { correctoras. }\end{array}$ \\
\hline $\begin{array}{l}\text { El director financiero de la empresa es pedro } \\
\text { Ramirez, economista con más de } 20 \text { años de } \\
\text { experiencia en el sector. }\end{array}$ & $\begin{array}{l}\text { Tomás Alonso, dada la diversa naturaleza de los } \\
\text { productos, mercados yclientes, ha detect ado } \\
\text { que los técricos se senten inseguros en cuanto a } \\
\text { que el result ado final de sus decis ones sea el }\end{array}$ \\
\hline $\begin{array}{l}\text { El departamento de compras se encarga del } \\
\text { aprovisionamiento tanto de recursos para la } \\
\text { producción commo de material de oficina. }\end{array}$ & $\begin{array}{l}\text { más adecuado. } \\
\text { Tomás Alonso se ha dado cuenta de que la } \\
\text { dinámica del trab ajo hab itual de la empresa } \\
\text { provoca frecuentes necesidades de interrel ación } \\
\text { entre person as de distintos departament os que } \\
\text { no están contempladas en el diserio actual, } \\
\text { provocando problemas de coordinación. }\end{array}$ \\
\hline $\begin{array}{l}\text { Carmen Díaz es la directora del departamento de } \\
\text { Compras y dirige a un grupo de personas, } \\
\text { encargadas cada una de ellas de un tipo de compras, } \\
\text { con gran formación y experiencia para ello. }\end{array}$ & $\begin{array}{l}\text { Por término medio, el bo\% del coste final de los } \\
\text { productos puede imputarse a materias primas, } \\
\text { seria perjudicial desagregar esta función ya que } \\
\text { se perderia poder de negociación frente a } \\
\text { proveedores }\end{array}$ \\
\hline
\end{tabular}

(cc)) EY-NC-ND 2014, Universitat Politècnica de València

I Jornadas IN-RED (2014) 
Bañón-Gomis, Clemente, Cortés-Meseguer, Lajara-Camilleri, Pérez de los Cobos, Rodrigo, Rovira, Trinidad, Villanueva

Anexo 2. Cuestionario para determinar los roles en el equipo. Extraido de Francis y Young, 1979

Cuestionario para determinar los roles en el equipo

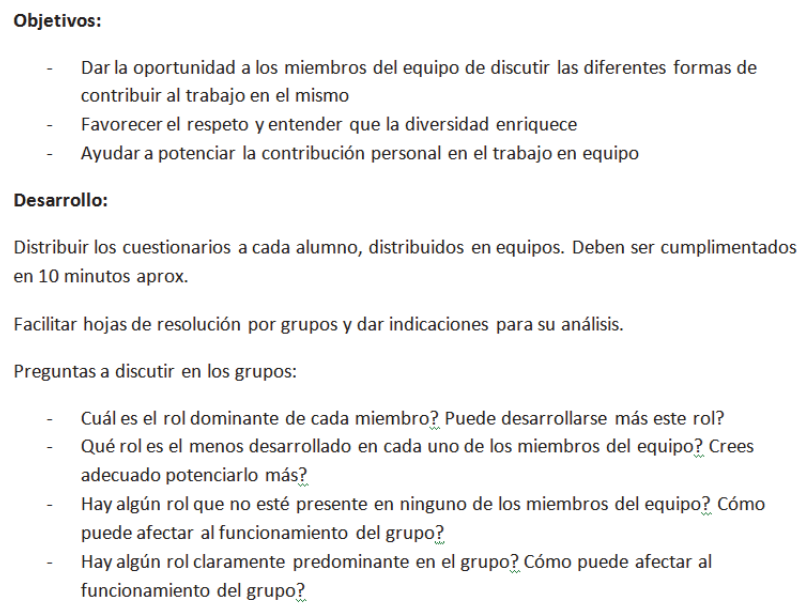

\section{Instrucciones:}

Este cuestionario te ayudará a determinar cuál es tu forma de actuar cuando trabajas en equipo.

El cuestionario tiene cinco secciones, cada una de ella se centra en un tipo de comportamiento distinto. En cada una de ellas tendrás que distribuir 10 puntos. La puntuación asignada a cada afirmación debe reflejar tu percepción sobre tu comportamiento actualmente. Cuanto más cercano a tu comportamiento sea el enunciado, mayor debe de ser el número de puntos asignado. Asegúrate de asignar un total de 10 puntos -ni más ni menos- en cada sección.

Responde considerando tu actitud y comportamiento cuando estás trabajando en grupo en general (sin particularizar en situaciones concretas).

\section{$\underline{\text { Sección 1: Toma de decisiones }}$}

Cuando se está tomando una decisión en equipo, yo...

\begin{tabular}{|c|c|}
\hline 1. Expongo mi opinión como especialista en mis áreas & \\
\hline 2. Exploro todas las implicaciones de todas las ideas expuestas & \\
\hline 3. Adopto un punto de vista independiente, considerando cada aspecto & \\
\hline 4. Evalúo el impacto de posibles decisiones en otros grupos & \\
\hline 5. Convenzo al equipo de aceptar mi punto de vista & \\
\hline 6. Intento que haya una actitud abierta para que todo el mundo pueda decir lo que piensan & \\
\hline 7. Ofrezco soluciones originales y creativas en las normalmente nadie ha pensado & \\
\hline 8. Intento estructurar la información para que todo el mundo entienda las opciones disponibles & \\
\hline 9. Me aseguro de que nos ceñimos al tiempo establecido para llevar a cabo la tarea & \\
\hline 10. Ayudo a otros a desarrollar sus ideas & \\
\hline
\end{tabular}

\section{(c)) EY-NC-ND 2014, Universitat Politècnica de València}

I Jornadas IN-RED (2014) 
Experiencias docentes en la UPV en torno a la competencia transversal "trabajo en equipo y liderazgo"

\section{Sección 2: Creatividad}

En un momento de brainstorming, yo..

\begin{tabular}{|l|l|}
\hline 11. Se puede confiar en que aportaré ideas sorprendentes & \\
\hline 12. Suelo comentar lo que otros aportan pero no tomo la iniciativa & \\
\hline $\begin{array}{l}\text { 13. Rápidamente elijo la que me parece la mejor idea y animo a los demás a compartir mi punto } \\
\text { de vista }\end{array}$ & \\
\hline 14. Contribuyo a la actividad si creo que realmente puedo aportar algo de valor & \\
\hline 15. Organizo el equipo para que el proceso de brainstorming funcione adecuadamente & \\
\hline 16. Desarrollo ideas sobre conceptos apuntados por otros & \\
\hline 17. Contribuyo con ideas relacionadas con mi formación o intereses & \\
\hline 18. Intento crear un clima de trabajo creativo y productivo & \\
\hline 19. Trato de traer ideas de fuera del grupo & \\
\hline $\begin{array}{l}\text { 20. Me aseguro de que el equipo lleva a cabo la tarea en el tiempo estipulado y de que la sesión } \\
\text { es productiva }\end{array}$ & \\
\hline
\end{tabular}

\section{Sección 3: Planificación}

Cuando el equipo está planificando lo que debe hacerse, yo...

\begin{tabular}{|l|l|}
\hline 21. Asigno acciones y prioridades en la tarea & \\
\hline 22. Considero las posibles implicaciones de nuestros planes con terceras personas & \\
\hline 23. Me aseguro de que estamos usando métodos efectivos de planificación & \\
\hline 24. Uno las propuestas y desarrollo planes que las incluyan & \\
\hline 25. Contribuyo con ideas relacionadas con áreas en las que me considero un experto & \\
\hline 26. Me aseguro de que se establece un calendario para las acciones a desarrollar & \\
\hline 27. Ayudo a motivar a mis compañeros & \\
\hline 28. Ayudo a mi equipo en todo lo que sea posible & \\
\hline 29. Considero cada aspecto del plan para asegurar que es realista y factible & \\
\hline 30. Invento formas originales de usar los recursos disponibles o conseguirlos & \\
\hline
\end{tabular}

\section{$\underline{\text { Sección 4: Efectividad del grupo }}$}

Cuando se considera la efectividad del grupo, yo...

\begin{tabular}{|l|l|}
\hline 31. Me aseguro de que se tienen en consideración las opiniones de todos & \\
\hline 32. Expongo mis opiniones e ideas cuando creo que pueden ser útiles & \\
\hline 33. Intento conseguir información sobre las opiniones de gente de fuera del grupo & \\
\hline 34. Pongo en duda la eficacia del equipo y sugiero cambios radicales & \\
\hline 35. Resumo todos los puntos de vista y trato de evaluar las fortalezas y debilidades del grupo & \\
\hline 36. Hago aportaciones como especialista & \\
\hline 37. Anoto todos las ideas útiles y establezco un plan de mejora & \\
\hline 38. Adopto una actitud imparcial para evaluar objetivamente al grupo & \\
\hline 39. Decido qué necesita hacerse y convenzo a los demás para que acepten mis propuestas & \\
\hline 40. Estimulo una comunicación abierta entre todos & \\
\hline
\end{tabular}


Bañón-Gomis, Clemente, Cortés-Meseguer, Lajara-Camilleri, Pérez de los Cobos, Rodrigo, Rovira, Trinidad, Villanueva

Sección 5: Valoración de contribuciones

Se valora mi trabajo en equipo porque...

\begin{tabular}{|l|l|}
\hline 41. Me esfuerzo en crear un clima positivo & \\
\hline 42. Tengo ideas innovadoras & \\
\hline 43. Soy flexible y me adapto bien & \\
\hline 44. Tengo conocimientos avanzados de las materias & \\
\hline 45. Me aseguro de que las cosas se hagan & \\
\hline 46. Establezco alianzas con otros equipos & \\
\hline 47. Ayudo a estructurar las reuniones del grupo & \\
\hline 48. Aporto liderazgo & \\
\hline 49. Ayudo a desarrollar las ideas que surgen en el grupo & \\
\hline 50. Evalúo de forma imparcial las actividades del grupo & \\
\hline
\end{tabular}

\section{Hoja de puntuación}

Transfiere las puntuaciones asignadas a los huecos correspondientes, suma las puntuaciones de cada fila y anótalas en el recuadro correspondiente.

\begin{tabular}{|l|l|l|l|l|l|l|}
\hline \multicolumn{3}{|l|}{ Items } & Total & Rol \\
\hline 8 & 15 & 23 & 31 & 47 & & Gestor de procesos \\
\hline 2 & 16 & 24 & 35 & 19 & & Desarrollador de conceptos \\
\hline 7 & 11 & 30 & 34 & 42 & & Radical \\
\hline 6 & 18 & 27 & 40 & 41 & & Armonizador \\
\hline 1 & 17 & 25 & 36 & 44 & & Técnico experto \\
\hline 9 & 20 & 26 & 37 & 45 & & Controlador del producto \\
\hline 3 & 12 & 29 & 38 & 50 & & Crítico \\
\hline 10 & 14 & 28 & 32 & 43 & & Cooperador \\
\hline 5 & 13 & 21 & 39 & 48 & & Político \\
\hline 4 & 19 & 22 & 33 & 46 & & Organizador \\
\hline
\end{tabular}

(c) EY-NC-ND 2014, Universitat Politècnica de València

I Jornadas IN-RED (2014) 
Experiencias docentes en la UPV en torno a la competencia transversal "trabajo en equipo y liderazgo"

Anexo 3.

BUENAS PRÁCTICAS EN EL TRABAJO EN EQUIPO

Trabajar en equipo es una forma de lograr metas que por nosotros mismos, individualmente, no podríamos alcanzar. Por supuesto, conseguiríamos hacer el mismo trabajo (o incluso mejor) pero con una inversión de recursos -fundamentalmente tiempo- mucho mayor.

El problema surge cuando hay ineficiencias en el grupo, eso produce desgaste en sus miembros y hace que los resultados sean inferiores a los deseados o bien que los recursos empleados sean mayores que los planificados inicialmente.

Es importante desarrollar una metodología de trabajo en equipo adecuada porque vivimos en sociedad. Tanto en el ámbito educativo como profesional y a nivel personal debemos saber adoptar las estrategias necesarias para tener éxito tanto si desarrollamos un trabajo individual como si lo hacemos en colaboración con otras personas.

En esta guía queremos daros algunos consejos y recomendaciones a tener en cuenta de cara a los trabajos en equipo.

¿Son importantes las personas con las que formo el equipo?

Son fundamentales. Tienen más probabilidades de éxito los equipos formados por personas que se complementan. Por ello, tanto si queremos montar una empresa como si vamos a preparar una presentación para una asignatura, tenemos que meditar bien con quién nos asociamos. Guiarse únicamente por la amistad es un error, hay que tener en cuenta todos los factores y aprender a trabajar con cualquier persona (es un tópico pero lo cierto es que en la vida profesional en la mayoría de las ocasiones no podremos elegir a nuestros compañeros).

¿Qué debo preparar antes de una primera reunión del equipo?

Cuando empezamos un trabajo tenemos que tener claros los resultados que queremos conseguir con el trabajo, nuestras capacidades y nuestra disponibilidad. Hay que ser honestos y en la primera puesta en común acordar el nivel de compromiso y los objetivos del grupo. Es una especie de "contrato" entre los miembros del grupo.

¿Cómo organizar el trabajo en equipo?

Los equipos toman decisiones y organizan tareas en las reuniones. Para ello hay que preparar con antelación las sesiones y llevar el material necesario. No todo el mundo tiene la misma disponibilidad de tiempo por lo que hay que intentar que las reuniones se hagan en el menor tiempo posible y estableciendo sólo aquellas que sean necesarias. Haremos un orden del día con los temas a tratar y tras la reunión haremos un acta sintética que contenga toda la información relevante (asistentes, temas tratados, decisiones adoptadas, tareas encargadas y responsables asignados). El acta debe permitir a un miembro que no ha asistido a la reunión tener una idea de lo hablado y acordado. 
Bañón-Gomis, Clemente, Cortés-Meseguer, Lajara-Camilleri, Pérez de los Cobos, Rodrigo, Rovira,

Trinidad, Villanueva

Recomendaciones para el día a día del trabajo en equipo

1. Cuando valores el trabajo de un compañero, sé concreto. Especialmente si tu crítica es para mejorar el resultado debes decir exactamente a qué te refieres. Obviamente hay que desterrar cualquier referencia personal.

\begin{tabular}{|l|l|}
\hline En lugar de... & Estaría mejor decir... \\
\hline Esto está fatal, no lo podemos entregar así & Deberíamos hacer un índice y darle formato antes de entregarlo \\
\hline No me gusta el PowerPoint & Deberíamos poner ejemplos/fotos... \\
\hline
\end{tabular}

2. Equivocarse está permitido, nos pasa a todos, tanto cuando trabajamos individualmente como en equipo. Hay que aceptar los fallos de los demás y no esconder los propios. Buscadle el valor positivo y la oportunidad que suponen.

3. Hay que ser realista con lo que asumimos que podemos hacer y responsable con los compromisos que adoptamos. Si no se va a poder hacer una tarea, es mejor decirlo y buscar la forma de compensarlo en otro momento. La falta de cumplimiento, aparte de retrasar, genera malestar e incomodidad en los equipos. La responsabilidad se plasma también en la puntualidad. Sed puntuales tanto en reuniones como en las entregas de tareas. Quien llega tarde a la reunión hace perder el tiempo a todos los que llegaron a la hora convenida, es una falta de respeto.

4. Desglosad el trabajo a realizar en tareas, asignadles responsables y poned fechas límite, es la forma de organizarse efectivamente.

5. Aprovechad la tecnología: usad Google Docs, Dropbox, etc para compartir archivos. En documentos de Office podéis utilizar el Control de cambios y Doodle es útil a la hora de encontrar huecos disponibles para hacer una reunión.

6. Los conflictos -que son inevitables- conviene atajarlos cuanto antes para que no se conviertan en verdaderos problemas. Hablad y negociad de forma que todos ganéis al final, en caso contrario no estará cerrado el tema.

7. Trabajando en equipo no tiene sentido la actitud de "yo lo sé todo y lo hago mejor que nadie". Escuchad a los demás atentamente, normalmente la mejor idea es la que se construye entre todos. Además no podemos imponer nuestros estándares de calidad sino que tendremos que asumir los que sean acordados por el grupo.

8. Favoreced la unidad y la participación de todos los miembros del equipo. Si hay alguien que tiene problemas para asumir algún aspecto del trabajo, el equipo debe ayudarle a superar la dificultad, bien sea asignándole otra tarea o bien echándole una mano.

9. Celebrad también los éxitos y compartidlos. Lo que consigue el equipo es mérito de todos.

10. Confía en tus compañeros, déjales hacer lo suyo y recurre a ellos en caso de necesitar ayuda. Si no confías en ellos, estarás constantemente desviando tu atención para vigilar las tareas de los demás. Con la confianza de que el trabajo está bien organizado y distribuido, podrás centrarte en tu parte y al final todo encajará a la perfección. La confianza también quiere decir que si necesitas ayuda, puedes pedirla.

\section{(c) EY-NC-ND 2014, Universitat Politècnica de València}

I Jornadas IN-RED (2014) 
Experiencias docentes en la UPV en torno a la competencia transversal "trabajo en equipo y liderazgo"

Anexo 4. Rúbrica de autoevaluación del trabajo en equipo y liderazgo (adaptación de Chica, 2011)

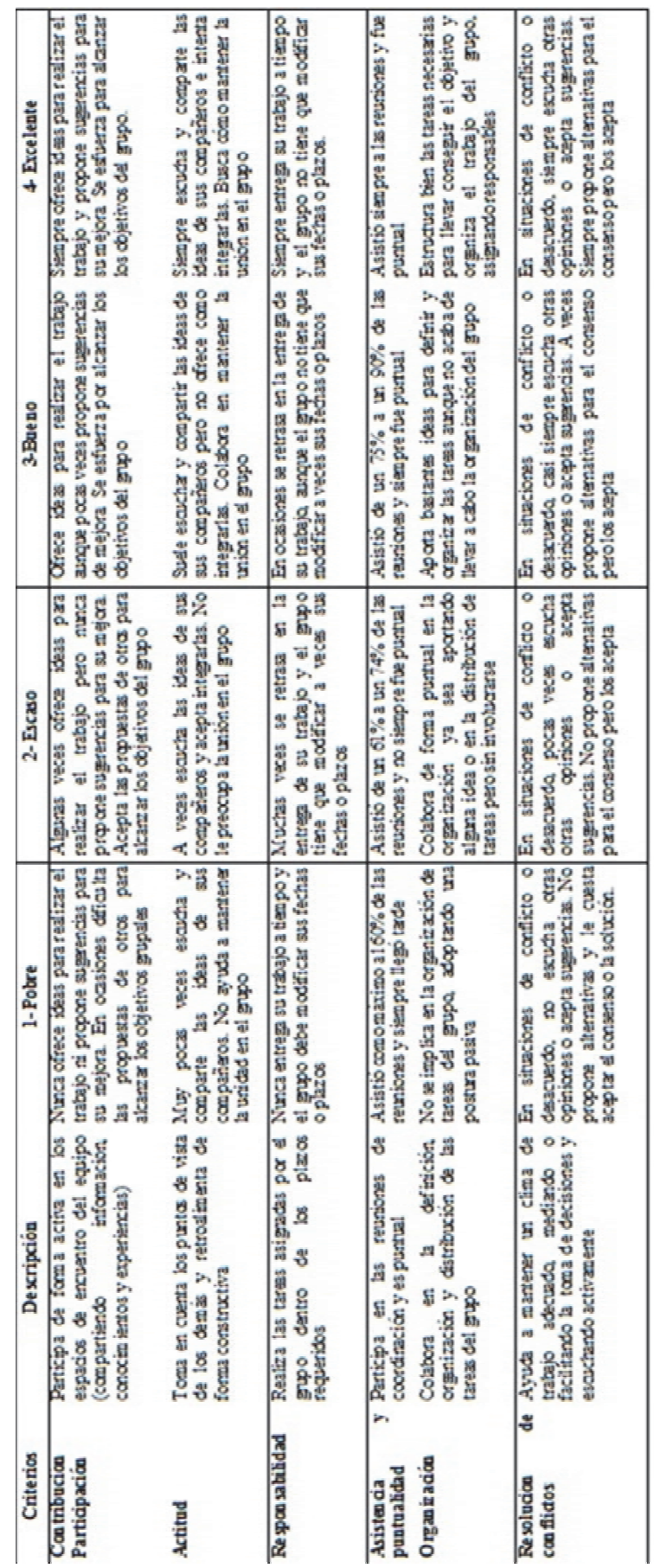

(c)) EY-NC-ND 2014, Universitat Politècnica de València I Jornadas IN-RED (2014) 


\title{
Experiencia en el uso de las TICs por parte de los alumnos de Ingeniería Industrial
}

\section{Joaquín Gracia Morán ${ }^{\mathrm{a}}$ Lenin G. Lemus Zúñiga ${ }^{\mathrm{c}}$}

${ }^{a}$ Escuela Técnica Superior de Ingeniería Informática, Dpto. de Informática de Sistemas y Computadores (DISCA), email: jgracia@disca.upv.es y ${ }^{c}$ Escuela Técnica Superior de Ingeniería Informática, Dpto. de Informática de Sistemas y Computadores (DISCA), email: lemus@upvnet.upv.es.

\begin{abstract}
This work describes the problems of the students of the Bachelor's Degree in Industrial Technologies Engineering when using ICT, such as: a) the lack of information when these students look for a job using Internet; and b) the low valuation that students have towards ICT to capitalize on Internet.

A problem detected with this experience is that the use and knowledge of Internet tools is not done from the beginning of the bachelor's degree, which prevents students to take a greater advantage of ICT and to be more productive.

With regard to the job search, it would be recommended that from the beginning of the bachelor's degree students were targeted to job opportunities related to the degree, so they can choose subjects really useful for him, based on their preferences, as well as to introduce different ways to become visible on Internet.
\end{abstract}

Finally, the initial apathy towards ICT was eliminated along the semester.

Keywords: ICT, motivation

\section{Resumen}

Este trabajo describe los problemas de los alumnos del Grado en Ingeniería en Tecnologías Industriales para utilizar las TIC, como puede ser: a) la falta de información que estos alumnos tienen para buscar trabajo utilizando 
Internet; y b) la baja valoración que los alumnos tienen hacia las TIC para sacar provecho de Internet.

Un problema detectado con esta experiencia es que el uso y conocimiento de las herramientas que proporciona Internet no se hace desde los inicios de la titulación, lo que impide que los alumnos saquen mayor provecho de las tecnologías de la información y sean más productivos.

En lo que respecta a la búsqueda de trabajo, también sería recomendable que desde el inicio de la titulación se les orientara en las salidas profesionales de la titulación, para que puedan elegir las asignaturas optativas que realmente les pueden ser útiles, en base a sus preferencias, así como presentarles diferentes formas de hacerse visibles en Internet.

Para terminar, cabe señalar que la apatía al inicio del curso hacia las TICs fue eliminada a lo largo del mismo.

Palabras clave: TIC, motivación.

\section{Introducción}

En los planes de estudio de las titulaciones de Grado, así como en el mundo empresarial, es necesario que los estudiantes posean competencias sólidas en las Tecnologías de la Información y la Comunicación (competencias TIC o competencias digitales) (Cebrián, 2000). De hecho, ésta es una de las competencias considerada como transversal -o genéricaen las universidades, y asimismo, en los títulos de grado que se están impartiendo.

Partiendo de este punto, los profesores encargados de impartir la docencia en la asignatura "Internet y Servicios de Red (ISR)" del Grado en Ingeniería en Tecnologías Industriales(GITI) desarrollamos el temario de la asignatura en base a los conocimientos básicos que todo ingeniero debe poseer hoy en día relacionados con las TIC.

Entre las habilidades que consideramos necesarias se encuentran:

- Búsqueda de trabajo en la red.

- Creación del currículo.

- Gestión de las redes sociales para profesionales.

- Gestión ficheros en la nube.

A continuación presentamos la forma de motivar a los alumnos para utilizar las TIC y la respuesta obtenida durante el curso. 


\section{Desarrollo de la innovación}

La asignatura ISR es una asignatura optativa que se imparte en el segundo semestre del cuarto curso del GITI (UPV, 2014). Se da la circunstancia que durante el curso escolar 2013/14 se ha puesto en marcha esta asignatura con alumnos de la primera promoción de esta titulación. El objetivo de la asignatura es presentar, desde un punto de vista conceptual, los principales servicios de red que se utilizan en las industrias. Con esta visión global, un Ing. Industrial adquiere las competencias para analizar y solicitar los servicios informáticos de una empresa en particular. Para ello, se presentará, en primer lugar, cuál es la estructura básica de Internet y los servicios comunes que se utilizan en una empresa, para a conmtinuación describir con más detalle dichos servicios. Se continua con las características básicas de la compartición de información en la nube, así como la descripción de los servicios de red social, finalizando con algunas medidas básicas de seguridad en redes. La asignatura consta de 4'5 ECTS (GITI, 2014), divididos en 3'6 de teoría y 0’9 de prácticas. La Tabla 1 muestra el temario de la asignatura.

Tabla 1. Temario de ISR

\begin{tabular}{|c|c|}
\hline Teoría & Prácticas \\
\hline Introducción & Práctica 1: Currículum Vitae. \\
\hline $\begin{array}{l}\text { Bloque I. Servicios comunes: } \\
\text { - UD1. Conceptos básicos. } \\
\text { - UD2. Servicios Web. } \\
\text { - UD3. Transferencia de ficheros. } \\
\text { - UD4. Servicios de correo electrónico. } \\
\text { - UD5. Servicios en una intranet. }\end{array}$ & Práctica 2: Cableado estructurado. \\
\hline $\begin{array}{l}\text { Bloque II. Compartir información en la nube: } \\
\text { - UD1. Servicios en la nube } \\
\text { UD2. Aspectos legales a tener en } \\
\text { cuenta } \\
\text { - UD3. Aplicaciones para compartir } \\
\text { información }\end{array}$ & $\begin{array}{l}\text { Práctica 3: Servidor XAMMP: } \\
\text { - Sesión 1. Instalación. } \\
\text { - Sesión 2. Servidor de correo. } \\
\text { WebDav. } \\
\text { - Sesión 3. Configuración FTP y } \\
\text { Clientes. }\end{array}$ \\
\hline $\begin{array}{l}\text { Bloque III. Servicio de red Social y Visibilidad: } \\
\text { - UD1. ¿Qué son las redes sociales? } \\
\text { Impacto de las redes en la ingeniería } \\
\text { - UD2. Servicios de red social } \\
\text { - UD3. Visibilidad del ingeniero }\end{array}$ & $\begin{array}{l}\text { Práctica 4. Google Drive. Compartición de } \\
\text { Archivos. }\end{array}$ \\
\hline $\begin{array}{l}\text { Bloque IV. Seguridad en Redes: } \\
\text { - UD1. Medidas básicas de prevención }\end{array}$ & Práctica 5. Antivirus/Cortafuegos. \\
\hline
\end{tabular}

(cc)) EY-NC-ND 2014, Universitat Politècnica de València

I Jornadas IN-RED (2014) 
El objetivo principal de ISR es el ayudar a mejorar las habilidades de los alumnos respecto a la utilización de las TIC en su desarrollo profesional. Por experiencia pasada de los profesores (Saiz, 2008), al impartir clases de informática a alumnos no informáticos, se constató que los alumnos no muestran interés por este área, a pesar de que en su vida cotidiana utilizan la informática ampliamente.

Con esta problemática en mente, los profesores encargados de impartir tanto la docencia como las prácticas de la asignatura intentamos que los alumnos adquiriesen de forma divertida y amena las habilidades siguientes:

- Búsqueda de trabajo en la red.

- Creación del currículo.

- Gestión de las redes sociales para profesionales.

- Gestión ficheros en la nube.

Para ello, desarrollamos actividades a medida. A continuación se describe cada una de estas actividades.

\subsection{Actividad uno: "Portales para búsqueda de empleo"}

Objetivo de la actividad: Fomentar en los alumnos el uso de los portales especializados para búsqueda de empleo.

Metodología:

1) Se determina si los alumnos conocen portales de búsqueda de empleo. Al ser alumnos del último año del grado, se puede suponer que sí los conocen, por lo que rellenan en la práctica el nombre de los portales que conocen.

2) Cada alumno define 5 palabras claves relacionadas con los ámbitos de trabajo de su especialidad.

3) A los alumnos se les proporciona un listado con portales para búsqueda de empleo.

4) Cada alumno debe buscar empleos teniendo en cuenta las palabras claves que eligió en sus aspiraciones personales.

5) En la práctica, se estudian los requisitos para obtener ese empleo.

6) Una vez terminada la búsqueda, cada alumno explica a sus compañeros los empleos que ha seleccionado.

7) El profesor hace un resumen de los salarios, los requisitos y directivas de cómo lograr ese puesto. 


\subsection{Actividad dos: "Uso de las redes sociales"}

Objetivo de la actividad: Indicar a los alumnos pautas de conducta en las redes sociales, es decir, lo que pueden y lo que no deben hacer.

Metodología:

1) Se determina si los alumnos tienen cuentas en redes sociales.

2) Se les pregunta de forma verbal si consideran apropiado subir a las redes sociales información personal comprometedora, como por ejemplo fotos graciosas.

3) Se pide a los alumnos que investiguen en Internet si se puede borrar información de los servidores de las redes sociales.

4) Se discute en clase qué problemas nos podría acarrear escribir comentarios a la ligera en las redes sociales, o subir fotos que en su momento pueden ser graciosas, pero que pueden dar una impresión errónea de la personalidad del autor.

\subsection{Actividad tres: "Uso de los servicios en la nube"}

Objetivo de la actividad: Conocer y utilizar las herramientas disponibles en la nube para facilitar nuestra vida diaria.

Metodología:

1) Se les pregunta a los alumnos si tienen cuenta en Google, en iCloud, DropBox, etcétera.

2) Se indaga para conocer el conocimiento de los alumnos acerca de la creación y gestión de calendarios.

3) Se indaga para conocer el conocimiento de los alumnos acerca de la creación y gestión de documentos.

4) Se indaga para conocer el conocimiento de los alumnos acerca de la creación y gestión de correo electrónico.

5) El profesor, con soporte de material escrito, explica las ventajas y desventajas de cada uno de estos servicios.

\subsection{Actividad cuatro: "Recopilación de datos"}

Objetivo de la actividad: Los alumnos deben rellenar un formulario de satisfacción con una serie de cuestiones relativas a las actividades realizadas. Este formulario se puede ver en el Anexo. 


\section{Resultados}

De cada una de las actividades anteriores, el profesor encargado de las sesiones de laboratorio obtuvo las siguientes conclusiones:

Actividad uno: "Portales para búsqueda de empleo"

- A pesar de estar en el último año del grado, ninguno de los alumnos matriculados se había preocupado por conocer ofertas de trabajo.

- El principal aliciente es obtener una buena remuneración, y a la gran mayoría les gustaría tener salarios de 60,000€ al año, ocupando puestos de alta dirección. Una sola persona se interesó por hacer carrera docente.

- Se les veía sorprendidos con los portales de empleo y daba la sensación de que los utilizarían en el futuro, no solo para buscar empleo sino para conocer qué tipos de trabajo hay en su carrera y los requisitos para obtener puestos con altas remuneraciones

Actividad dos: "Uso de las redes sociales"

- Al principio los alumnos estaban convencidos de que lo que se escriba o lo que se publique en las redes sociales no afecta en la vida profesional. Sin embargo, al final fueron conscientes acerca de los posibles obstáculos que les podría acarrear escribir de forma inconsciente.

- Jamás se habían preocupado por conocer las condiciones de uso de las redes sociales y del tratamiento de sus datos.

Actividad tres: "Uso de los servicios en la nube"

- A dos alumnos en concreto, que viven fuera de Valencia capital, les ha resultado chocante no haber conocido estos servicios antes, ya que les hubiesen sido muy útiles durante sus estudios universitarios, no solo para hacer trabajos, sino para gestionar su tiempo libre.

- Al igual que en el caso de las redes sociales, ninguno había investigado las condiciones de uso de los proveedores de servicios en la nube.

Actividad cuatro: "Recopilación de datos"

- Los comentarios finales de los alumnos estaban en concordancia con las ideas del profesor de laboratorio.

- 2 Alumnos consideraban que el tiempo dedicado para cada actividad (junto con el tiempo dedicado en clase y en laboratorio) fue excesivo.

- 6 Alumnos consideraban que el tiempo dedicado para cada actividad (junto con el tiempo dedicado en clase y en laboratorio) fue demasiado corto. 
- 4 Alumnos consideraban que el tiempo dedicado para cada actividad (junto con el tiempo dedicado en clase y en laboratorio) fue el apropiado.

\section{Conclusiones}

En este trabajo hemos presentado la experiencia realizada en la asignatura ISR, una asignatura opcional del segundo semestre del cuarto curso del GITI. Esta asignatura introduce conceptos informáticos a alumnos no informáticos. Uno de los principales problemas de este tipo de alumnos es el desconocimiento general sobre lo que puede aportar las TIC a su formación y futura vida profesional. Además, los alumnos ven a este tipo de asignaturas como algo no esencial en su futuro desempeño profesional. Un ejemplo de estos problemas es la poca información que estos alumnos tienen cuando buscan trabajo utilizando Internet.

Con el fin de motivar a los alumnos hacia las TIC, durante el curso 2013/2014 se han diseñado cuatro actividades a medida. El resultado ha sido en general satisfactorio. Los alumnos han visto la utilidad de las TIC en su futura vida profesional, así como han comprendido los riesgos de determinadas actitudes en Internet, como puede ser el descargarse archivos de cualquier sitio web o el escribir comentarios inadecuados en redes sociales.

\section{Referencias}

CEBRIÁN DE LA SERNA, M., RÍOS ARIZA, J.M. (2000). Nuevas tecnologías de la información y de la comunicación aplicadas a la educación. Ediciones Aljibe.

GRADO EN INGENIERÍA EN TECNOLOGÍAS INDUSRIALES (GITI). (2014). Internet $y$ Servicios en Red.〈http://www.upv.es/titulaciones/GITI/menu_813552c.html〉 [Consulta: 10 de junio de 2014].

SAIZ ADALID, L.J., GRACIA MORÁN, J. (2008) "La motivación del alumnado no informático hacia la Informática: mapas conceptuales" en $V$ Congreso Internacional de Docencia Universitaria e Innovación (V CIDUI). 100-111.

UNIVERSITAT POLITÈCNICA DE VALÈNCIA (UPV). (2014). Grado en Ingeniería en Tecnologías Industriales. <http://www.upv.es/titulaciones/GITI/indexc.html> [Consulta: 10 de junio de 2014].

\section{(c)) EY-NC-ND 2014, Universitat Politècnica de València}

I Jornadas IN-RED (2014) 


\section{Anexo: Cuestionario}

UNIVERSITAT

POLITÈCNICA

DE VALÈNCIA

Nombre:

Apellidos:

DNI:

Danos tu opinión acerca de los siguientes apartados:

1) El tiempo dedicado a la práctica. Si fue el correcto, o no, justificando tu respuesta.

2) Si te ha sido útil el contenido de la práctica para el desarrollo de tu profesión.

3) Si consideras que se podría omitir está práctica y por qué.

4) ¿Te interesaría reemplazar alguna práctica? En caso afirmativo, ¿en qué tema de la asignatura?

¿Qué opinas de la primera actividad?

1) Tiempo dedicado.

2) Utilidad del contenido de la actividad.

3) Se podría omitir está actividad y por qué.

4) ¿Reemplazarías está actividad? En caso afirmativo, ¿qué tema te sería interesante?

¿Qué opinas de la segunda actividad?

1) Tiempo dedicado.

2) Utilidad del contenido de la actividad.

3) Se podría omitir está actividad y por qué.

4) ¿Reemplazarías está actividad? En caso afirmativo, ¿qué tema te sería interesante?

¿Qué opinas de la tercera actividad?

1) Tiempo dedicado.

2) Utilidad del contenido de la actividad.

3) Se podría omitir está actividad y por qué.

4) ¿Reemplazarías está actividad? En caso afirmativo, ¿qué tema te sería interesante?

¿Qué opinas de la cuarta actividad?

1) Tiempo dedicado.

2) Utilidad del contenido de la actividad.

3) Se podría omitir está actividad y por qué.

4) ¿Reemplazarías está actividad? En caso afirmativo, ¿qué tema te sería interesante? 


\title{
Encontrando evidencias de la evaluación por competencias en el Grado de Ingeniería Informática
}

\author{
Jose-Luis Poza-Lujan, Silvia Terrasa, Alberto Conejero, Antonio Molina, Natividad \\ Prieto, Eduardo Vendrell y Julia Pérez \\ Escola Tècnica Superior d'Enginyeria Informàtica. Universitat Politècnica de València. Camino de \\ Vera s/n. 46022. Valencia (Spain). jopolu@disca.upv.es, sterrasa@disca.upv.es, aconejero@upv.es, \\ amolina@dsic.upv.es,nprieto@dsic.upv.es, even@upv.es, jperezl@upvnet.upv.es
}

\begin{abstract}
Nowadays, the design of a university degree is based on determining what students must learn in order to obtain a series of skills at the end of his studies. Due to the novelty of these regards, to define a syllabus based on competencies is a complex task. On the one hand, students are evaluated in order to demonstrate that they have acquired the competencies associated to a subject. On the other hand, the degrees must be certified in order to demonstrate that they meet their expected outcomes and to show that their students obtain the expected skills. This is essential to find the evidences of the competencies acquired in the grade subjects.

This article present an application called EVALÚA that support teachers, in the design of their subjects, to reflect the competencies acquired; and promotes the reformulation of the subjects in terms of learning outcomes witch are related with the competencies and the assessment method used.
\end{abstract}

Keywords: learning outcomes, evaluation of competencies, accreditation.

\section{Resumen}

Actualmente el diseño de los grados universitarios se basa en enunciar una serie de competencias que los estudiantes deben adquirir una vez finalizados sus estudios. Debido a la poca experiencia que se tiene a este respecto, diseñar e implantar un plan de estudios basado en competencias es una tarea compleja. Por una parte, los estudiantes cursan las asignaturas que se les proponen y son evaluados para cuantificar el grado de adquisición de las competencias asociadas. Por otra parte, las titulaciones deben ser certificadas para garantizar que cumplen sus objetivos, entre los cuales se

(c) EY-NC-ND 2014, Universitat Politècnica de València

I Jornadas In-Red (2014) 
encuentra el que sus estudiantes obtengan las destrezas esperadas. Para ello resulta imprescindible encontrar las evidencias de la evaluación por competencias a partir de las asignaturas del grado.

En este artículo se presenta la aplicación EVALÚA que permite recopilar estas evidencias promoviendo la reformulación de las asignaturas en términos de resultados de aprendizaje que se relacionan con las competencias y los sistemas de evaluación utilizados.

Palabras clave: resultados de aprendizaje, evaluación de competencias, acreditación.

\section{Introducción}

La integración del sistema universitario español dentro del Espacio Europeo de Educación Superior (EEES) iniciada en el 2003, ha supuesto una reforma de la docencia universitaria española, siendo quizás el aspecto más visible la introducción, de forma generalizada, de un modelo de formación centrado en el estudiante. Este modelo se ha desarrollado a través de la redefinición del sistema de créditos, estableciendo el Sistema Europeo de Transferencia de Créditos (ECTS) que mide el esfuerzo del alumno en el proceso de aprendizaje y en la redefinición de los planes de estudios de Grados y Posgrados que se plantean en términos de las competencias que los estudiantes deben desarrollar al completarlos, lo que el estudiante debe saber, entender y ser capaz de hacer [4] . También incluyen un listado de materias que desarrollan una o varias de estas competencias.

La Agencia Nacional de Evaluación de la Calidad y Acreditación (ANECA) establece un procedimiento de acreditación obligatorio (programa ACREDITA) [3] , en el que se comprueba "la adquisición de competencias por parte de los estudiantes y los mecanismos de valoración de la adquisición de las mismas que la universidad ha desarrollado para cada título, así como el análisis de la evolución de los resultados del mismo".

En este contexto, evidenciar los resultados académicos establece una cultura, en la actualidad no siempre asumida, de transparencia de la organización docente, tanto para las entidades responsables de organizar los títulos, como para el profesorado que imparte la docencia de las diferentes asignaturas. Se trata pues de establecer mecanismos que permitan a una entidad responsable de un título (grado o posgrado) garantizar la adquisición de competencias, su proceso de desarrollo y su evaluación, con el fin de cumplir con el requisito obligatorio de acreditación español y también optar a certificados de acreditación internacionales (ABET, EQANIE, etc.) [1] [8] , pero sobre todo con el objetivo de compromiso de análisis y mejora continua de la entidad.

La tarea puede parecer sencilla a priori, en principio bastaría con, para cada competencia, evidenciar y cuantificar la evaluación de las materias que, según el plan de estudios, la

(cc) EY-NC-ND 2014, Universitat Politècnica de València 
desarrollan. No obstante, analizando del listado de competencias del Grado en Ingeniería Informática [5] en particular, y del resto de grados en general, se observan varias cosas: por una parte que hay un número muy elevado de competencias presentando una gran diferencia de granularidad entre ellas, además hay muchas que son difíciles de leer para aquellos a los que van dirigidas, estudiantes, profesores, empleadores. Finalmente, es necesario resaltar que muchas de estas competencias son difícilmente cuantificables.

Por todo ello, siguiendo las directrices de ANECA [2] , resulta conveniente redefinir el plan de estudios describiendo cada una de las asignaturas que lo componen en términos de Resultados de Aprendizaje (Learning Outcomes). Los resultados de aprendizaje relacionan los contenidos de las asignaturas con las competencias a las que contribuyen. Esta redefinición facilitará la evaluación externa para asegurar la calidad universitaria, a nivel internacional, fomentará el reconocimiento, la movilidad y la transparencia entre distintos países, y permitirá realizar una coordinación entre las asignaturas de cara a cubrir todas las competencias.

En este contexto, la Escola Tècnica Superior d'Enginyeria Informàtica (ETSInf) de la Universitat Politècnica de València (UPV) ha desarrollado un procedimiento para evidenciar la obtención de los resultados académicos que pasa por pedir a los profesores que: (a) definan los resultados de aprendizaje de cada una de las asignaturas que forman el curriculum; se tendría así declaraciones específicas y concretas; (b) relacionen estos resultados de aprendizaje con las competencias (o resultados de aprendizaje globales) del programa y (c) expliciten la metodología de evaluación incorporando las evidencias que permitan cuantificar el alcance de los resultados obtenidos.

Para facilitar la tarea del profesor y el análisis de los datos obtenidos a la institución, se ha diseñado una aplicación llamada EVALÚA, que es la que se describe en los apartados 2 y 3 de este artículo. En las conclusiones del apartado 4 se muestran las reflexiones de esta primera experiencia de utilización de la aplicación EVALÚA para la reformulación de las asignaturas del Grado en Ingeniería Informática en términos de resultados de aprendizaje.

\section{Evidencias de la evaluación por competencias}

La ETSInf, como cualquier entidad responsable de título en el actual sistema universitario, se enfrenta al reto de comprobar en qué medida se desarrollan y evalúan las competencias establecidas en los planes de estudios de las titulaciones que tiene asignadas. Es un aspecto imprescindible e ineludible en su proceso de mejora continua de la calidad de las titulaciones que imparte y requisito para la acreditación, tanto a nivel nacional como internacional.

(cc) EY-NC-ND 2014, Universitat Politècnica de València

I Jornadas IN-RED (2014) 
El título de Grado en Ingeniería Informática que se imparte en la ETSInf se estructura en 39 materias, agrupadas en 10 módulos, con competencias asignadas de un conjunto de 72 , de las cuales 59 son específicas y 13 generales o transversales. En la actualidad hay unos 1500 alumnos matriculados en un total de 108 asignaturas impartidas por casi 250 profesores.

La complejidad del proceso de definir para cada asignatura sus resultados de aprendizaje, las relaciones de éstos con las competencias y las evidencias de la evaluación, sugieren la necesidad desarrollar una herramienta informática que facilite la captación de esta información de forma homogénea y la mantenga disponible para su análisis por parte de los responsables de la entidad responsable del título, en este caso la ETSInf.

Las funcionalidades de esta aplicación, denominada EVALÚA, a nivel de asignatura (FA) son las siguientes:

- Almacenar los resultados de aprendizaje y su vinculación con las competencias asignadas a la asignatura.

- Asociar el nivel objetivo que se espera que el alumno alcance por cada resultado de aprendizaje: niveles de conocimiento, comprensión, aplicación, síntesis y evaluación, que corresponden a la taxonomía de Bloom [6] .

- Almacenar los actos de evaluación y su vinculación con los resultados de aprendizaje, estableciendo el porcentaje de cada evaluación que corresponde a cada resultado.

- Posibilitar la revisión y actualización de la información relacionada con cada asignatura de forma periódica (típicamente de forma anual).

Por otra parte, las funcionalidades de la aplicación desde el punto de vista de la entidad responsable del título (FER) son las siguientes:

- Determinar el nivel de dedicación destinado en cada asignatura a cada una de las competencias del plan de estudios, para que un posterior análisis determine hasta qué punto éstas son cubiertas a lo largo del plan de estudios.

- Dotarse de una herramienta de gestión que permita acreditar la consecución y evaluación de cada una de las competencias del plan de estudios a partir de las evaluaciones hechas en el marco de las distintas asignaturas.

- Obtener información de cara a proponer recomendaciones que tengan que ver con el diseño y/o la organización docente del mismo: orientación de las asignaturas, asignación de créditos, redefinición o asignación de competencias, etc.

- Preparar solicitudes de la acreditación por distintos organismos y las principales agencias acreditadoras de la calidad: ANECA, EQANIE o ABET.

(c) BY-NC-ND 2014, Universitat Politècnica de València 


\section{Descripción de la herramienta EVALÚA}

La aplicación EVALÚA se ha desarrollado en la ETSInf como una aplicación Web desarrollada en PHP y utiliza el sistema de autenticación de la propia universidad para su acceso.

Este primer prototipo de la aplicación contempla tres tipos diferentes de perfiles: el del profesor responsable de asignatura, con acceso de lectura y escritura de la información que se solicita para la asignatura; el del resto de profesores, que pueden consultar la información introducida por los compañeros (sin posibilidad de modificación), y el de los responsables de la ETSInf, que pueden generar ciertos informes que a continuación se detallan.

Para los usuarios profesores responsables de asignatura, la aplicación presenta tres Menús: uno para gestionar los Resultados de Aprendizaje (MRA), otro para las Evaluaciones (MEV) y otro para visualizar información cruzada (MIC), que a continuación se describen:

- Menú MRA: Este menú despliega una ventana como la que se presenta en la figura 1. En la parte central se muestra el listado de competencias que tiene asociada la materia en la que se incluye la asignatura, información que se extrae directamente del plan de estudios. En la primera área de texto (200 caracteres) se escribe el resultado de aprendizaje; a continuación, se selecciona del desplegable el tipo de conocimiento que se espera que alcance el alumno para dicho resultado de aprendizaje (uno de los siguientes de la taxonomía de Bloom: conocimiento, comprensión, aplicación, análisis o síntesis). Además se marcan las competencias a las que contribuye dicho resultado.

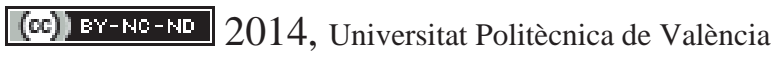

I Jornadas IN-RED (2014) 


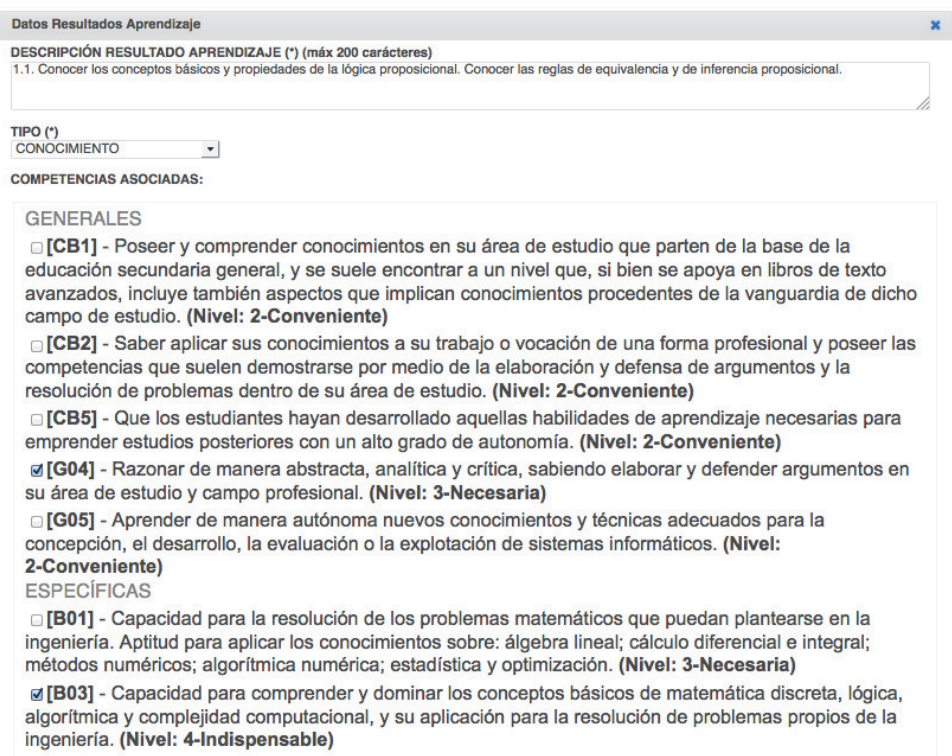

Fig. 1 Menú MRA: un ejemplo de resultado de aprendizaje, su tipo y las competencias a las que contribuye.

- Menú $M E V$ : Este menú despliega, para cada acto de evaluación, una ventana como la que se puede ver en la figura 2. A través de ella se introducen los siguientes campos: nombre del acto, tipo de acto (respuesta abierta, tipo test, trabajo académico, observación...), momento en el que se realiza (un mes determinado o a lo largo de todo el período de docencia) y porcentaje con el que este acto contribuye a la nota final de la asignatura. En la zona central de la pantalla se muestran todos los resultados de aprendizaje definidos para la asignatura y el profesor responsable debe marcar aquellos que son evaluados en este acto e indicar el porcentaje correspondiente. Como cada uno de los resultados de aprendizaje están asociados a competencias, la información introducida constituye una aproximación que permite valorar en qué medida se está evaluando la adquisición de las diferentes competencias.

- Menú MIC: permite el acceso a dos tablas resumen en las que se establecen la correspondencia entre los resultados de aprendizaje y las competencias, y la correspondencia entre evaluaciones y resultados de aprendizaje. En concreto, en la Figura 3 se muestra un ejemplo de la primera de ellas que permite observar qué resultados de aprendizaje cubren qué competencias (filas) y qué competencias están en mayor o menor grado cubiertas por resultados de aprendizaje (columnas). Estas tablas

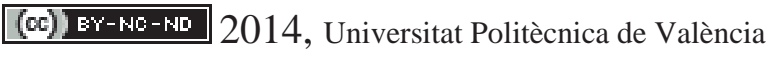

I Jornadas IN-RED (2014) 
permite detectar si se han definido resultados de aprendizaje que no cubren competencias suficientemente o si han quedado competencias que no están cubiertas por los resultados de aprendizaje definidos.

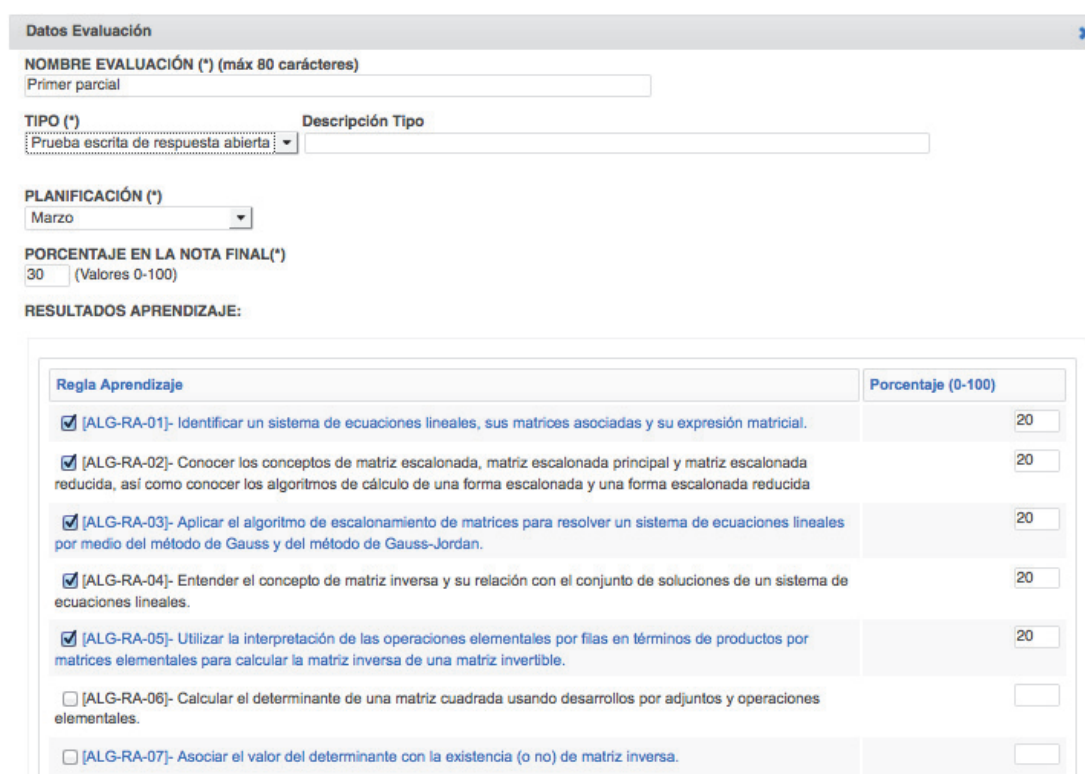

Fig. 2 Menú MEV: un ejemplo de acto de evaluación, tipo, planificación y resultados de aprendizaje evaluados..

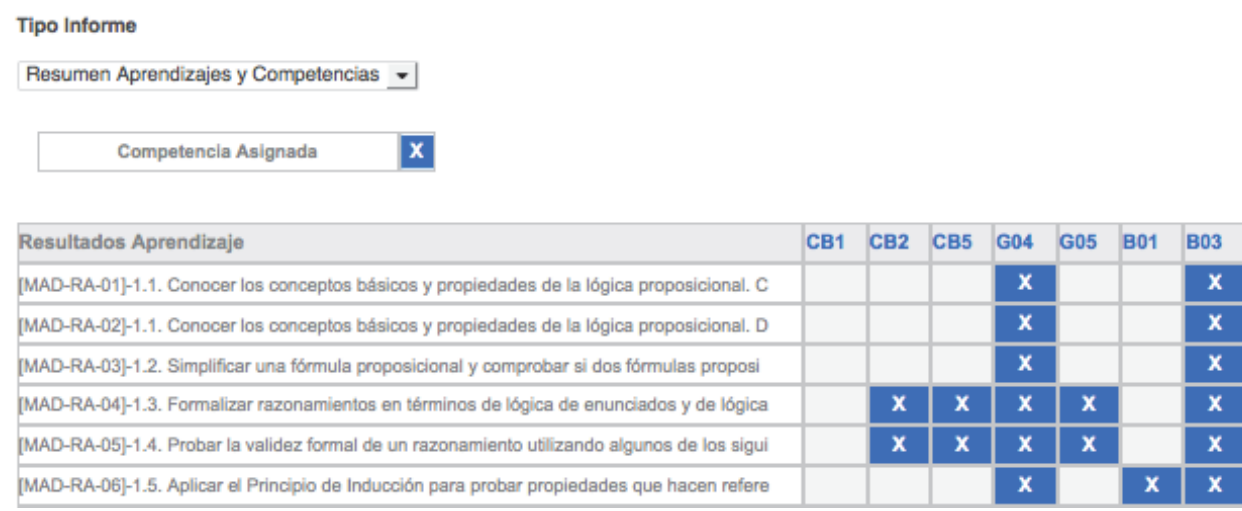

Fig. 3 Ejemplo de la tabla resumen que relaciona resultados de aprendizaje y competencias.

Cualquier profesor responsable de asignatura puede consultar toda la información relativa a cualquier asignatura: resultados de aprendizaje y evaluaciones. Para los usuarios responsables de la ETSinf, la aplicación permite además, para cada curso académico, generar informes para tener una visión global por asignatura, materia y módulo de cómo las

(cc) EY-NC-ND 2014, Universitat Politècnica de València

I Jornadas IN-RED (2014) 
competencias se están trabajando. En concreto, se pueden consultar la siguiente información cruzada:

1. Tabla de materias y competencias: para cada materia (fila) y para cada competencia (general o específica) definida por la guía docente se marca si realmente la competencia ha sido o no evaluada por la asignatura (ver figura 4).

2. Tabla de asignaturas y competencias: igual que la anterior pero por asignaturas en lugar de materias.

3. Listado en el que para cada competencia y materia se muestra la siguiente información relacionada con cada asignatura: resultado de aprendizaje, nivel y tipo de evaluación.

4. Listado en el que para cada materia se muestra las competencias asociadas y las asignaturas que las desarrollan detallando el tipo de evaluación y los resultados de aprendizaje asociados.

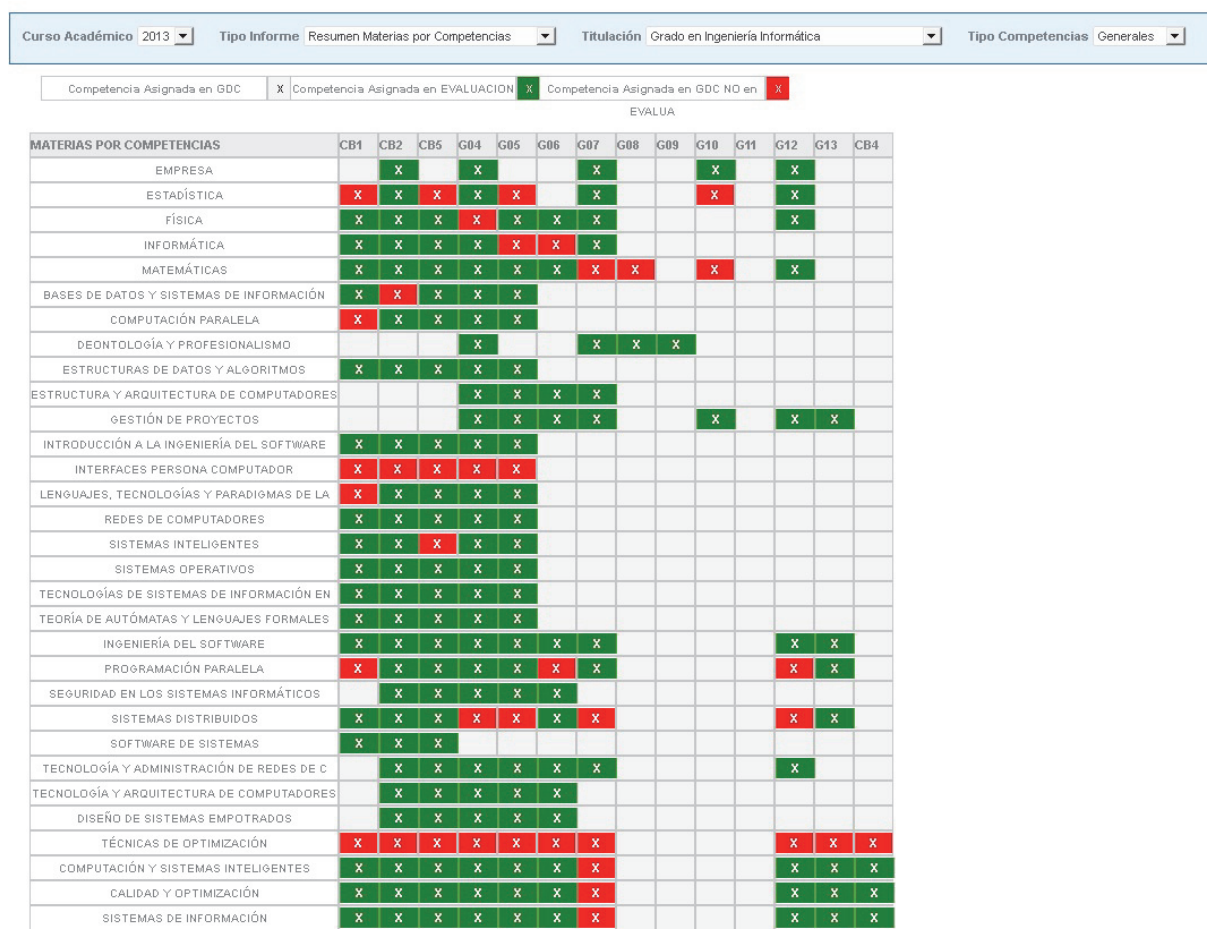

Fig. 4 Parte de la tabla de materias por competencias

Toda esta información resulta muy valiosa para realizar labores de coordinación, tanto horizontal como vertical, de las asignaturas que conforman la titulación. Por ejemplo, a partir de la planificación de los actos de evaluación explicitados por cada asignatura, se pueden hacer mapas de actividad que reflejen la carga real del alumno a lo largo de un

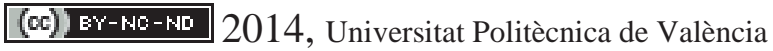


cuatrimestre, se pueden observar posibles duplicidades de contenidos, revisar las recomendaciones de prerrequisitos, etc.

\section{Utilización de EVALÚA: datos, valoración y desarrollos futuros.}

En marzo de 2014 se hizo un taller en la ETSInf en el que se presentó el prototipo de la herramienta a los profesores, explicándoles qué información se les pediría de la asignatura y como introducirla en EVALÚA. Se dieron las pautas para redactar los resultados de aprendizaje, siguiendo la definición y las normas recomendadas por la ANECA; se concretó la tipología de estos (conocimiento, comprensión, aplicación, análisis y síntesis) y el formato de los ficheros con los actos de evaluación.

Unos días después, y bajo la tutela de un grupo de profesores del centro, los profesores responsables de las 108 asignaturas fueron convocados para completar la información de sus asignaturas. En total se completaron 95 asignaturas (un $88 \%$ aproximadamente); se escribieron 1537 resultados de aprendizaje (un promedio de 16 por asignatura, siendo $3 \mathrm{el}$ mínimo y 54 el máximo) y se subieron 532 ficheros pdf con actos de evaluación.

El proceso continuó con la revisión, por parte de los responsables de la titulación en colaboración con un conjunto de profesores de la misma, de toda la información introducida. Lo más destacable de este proceso de revisión fueron los siguientes hechos:

(a) No todos los profesores redactaron los resultados de aprendizaje de la forma esperada "al finalizar este período de formación el alumno será capaz de...".

(b) Se observaban diferencias importantes en cuanto a la concreción de estos resultados. Nótese la gran variabilidad en el número de ellos (entre 3 y 54 ).

(c) La interpretación de los diferentes niveles de conocimiento de la taxonomía modificada de Bloom tampoco eran homogéneos, e incluso asignaturas que desarrollaban y evaluaban competencias transversales no habían incluido resultados de aprendizaje de este tipo.

(d) Además, se observó la dificultad del profesorado para asignar un peso a la evaluación de un resultado de aprendizaje, quizás por la forma de evaluación o por la redacción demasiado concreta o demasiado general que en ocasiones se hacía de los resultados.

Aunque la experiencia con el uso de la herramienta es positiva y la respuesta del profesorado también, todavía queda mucho trabajo por realizar. A nivel de aplicación y en breve plazo está previsto mejorar su usabilidad ofreciendo facilidades al usuario para la revisión de información y su actualización a lo largo de cursos sucesivos.

En cuanto a los objetivos perseguidos es necesario homogeneizar la redacción de los resultados de aprendizaje, sus niveles y, sobre todo incorporar los resultados y las evaluaciones que evidencien la integración efectiva de las competencias transversales.

(cc) EY-NC-ND 2014, Universitat Politècnica de València

I Jornadas IN-RED (2014) 
También es el momento de explotar toda la información recopilada al servicio de establecer mecanismos efectivos de coordinación entre los profesores de una misma asignatura, entre las asignaturas que conforman una materia o módulo y, a nivel global, de toda la titulación.

\section{Referencias}

[1] ABET. http://www.abet.org/ Última visita el 12 de junio de 2014.

[2] ANECA. Guía para la redacción y evaluación de los resultados del aprendizaje, Ed. ANECA, 2013.

[3] ANECA. Programa ACREDITA. http://www.aneca.es/Programas/ACREDITA Última visita el 12 de junio de 2014.

[4] Boletín Oficial del Estado. Real Decreto 1125/2003, de 5 de septiembre, por el que se establece el sistema europeo de créditos y el sistema de calificaciones en las titulaciones universitarias de carácter oficial y validez en todo el territorio nacional.

[5] Boletín Oficial del Estado. Resolución de 8 de junio de 2009, de la Secretaría General de Universidades, por la que se da publicidad al Acuerdo del Consejo de Universidades, por el que se establecen recomendaciones para la propuesta por las universidades de memorias de solicitud de títulos oficiales en los ámbitos de la Ingeniería Informática, Ingeniería Técnica Informática e Ingeniería Química.

[6] B.S. Bloom (Ed.) Taxonomy of Educational Objectives: The Classification of Educational Goals; pp. 201-207; David McKay Company, Inc. 1956.

[7] Bologna Working Group on Qualifications Frameworks. A Framework for Qualifi cations of the European Higher Education Area. Copenhague: Ministerio de Ciencia, Tecnología e Innovación. ISBN (internet) 87-31469-53-8. [Última versión realizada 8/12/2013. p. 29.

[8] EQANIE. http://www.eqanie.eu/ Última visita el 12 de junio de 2014.

(c) BY-NC-ND 2014, Universitat Politècnica de València 


\title{
Barómetro INCODE y guía de uso para la evaluación de competencias de innovación
}

Amparo García-Carbonell ${ }^{\mathrm{a}}$, Frances Watts ${ }^{\mathrm{b}}$ y $\mathrm{M}^{\mathrm{a}}$ Ángeles Andreu-Andrés

Dpto. de Lingüística Aplicada, Universitat Politècnica de València agarciac@ upvnet.upv.es

Dpto. de Lingüística Aplicada, Universitat Politècnica de València fwatts@idm.upv.es ${ }^{\text {b }}$

Dpto. de Lingüística Aplicada, Universitat Politècnica de València maandreu@idm.upv.es ${ }^{c}$

\begin{abstract}
Higher education is currently focused on objectives and learning outcomes of know-how and directs part of its attention to innovation and how it projects into the workplace. To innovate may not be the greatest difficulty; being able to define products, attitudes or innovation and, above all, its assessment is perhaps more complex.

In the European Project INCODE, Group IEMA of the UPV has developed an instrument for assessing innovation competencies: Innovation Competencies Development. INCODE Barometer and User Guide. It is a tool that can be used in self-assessment to train through learner reflection. It is also applicable to peer assessment, favoring collaborative learning and helping learners to give and receive information on achievement or acquisition. It can also be a tool for assessment by the teacher.

The rubrics included in the INCODE Barometer comprise three dimensions of capacities: Individual, interpersonal and networking skills. To help raters, the INCODE Barometer offers examples of different capacities and skills in context, which give raters a frame of reference for adapting the rubrics to their own context of use.
\end{abstract}

Keywords: innovation competence, self-assessment, peer assessment, teacher assessment, rubrics 


\begin{abstract}
Resumen
La enseñanza superior actual, centrada en objetivos y resultados de aprendizaje de saber hacer, reúne parte de su atención en la innovación y su proyección empresarial. Innovar no es tal vez la mayor dificultad, poder definir productos, actitudes o innovación y, sobre todo, su evaluación es quizás más complejo.

El grupo IEMA de la UPV, bajo el proyecto europeo INCODE, ha desarrollado un instrumento de evaluación de las competencias de innovación: Innovation Competencies Development. INCODE Barometer and User Guide. Es un instrumento que se puede utilizar en la autoevaluación, con fines formativos a través de la reflexión del aprendiz. También es aplicable en la evaluación entre pares, fomentando el aprendizaje colaborativo y ayudando al aprendiz a dar y recibir información sobre su desempeño o adquisición. Puede, de igual modo, ser una herramienta para la evaluación por el profesor.

Las rúbricas que incluye el barómetro INCODE engloban tres dimensiones de competencias o capacidades: la individual, la interpersonal y la de habilidades sociales o networking. Para ayudar al evaluador, el barómetro INCODE incluye ejemplos de las diferentes capacidades y destrezas a evaluar en contexto, que permiten al posible evaluador al posible evaluador un marco de referencia para adaptar las rúbricas a su propio contexto de uso.
\end{abstract}

Palabras clave: innovación competence, autoevaluación, evaluación entre pares, evaluación por profesor, rúbricas

\title{
Introducción
}

Innovar se puede definir de múltiples formas, pero quizás una de las más gráficas sea romper con los modelos establecidos y diseñar o reinventar nuevos modelos. Los modelos pueden hacer referencia a contenidos, prototipos, conductas, o cualquier conocimiento que la ciencia haya sido capaz de sistematizar, sin olvidar que la dimensión social ha de formar parte del argumento en su definición.

La actual política global en la educación superior centra su atención en objetivos y resultados de aprendizaje de saber hacer, potenciando la innovación y la proyección empresarial. Innovar no es tal vez la mayor dificultad, poder definir productos, actitudes o innovación y, sobre todo, su evaluación es quizás una tarea más compleja.

(c)) EY-NC-ND 2014, Universitat Politècnica de València

I Jornadas IN-RED (2014) 
El grupo de innovación IEMA de la UPV, centrado en la evaluación, bajo el proyecto europeo INCODE, ha desarrollado un instrumento de evaluación de las competencias de innovación: Innovation Competencies Development. INCODE Barometer and User Guide ${ }^{1}$. En su diseño y desarrollo se han seguido las etapas propuestas por Onwuegbuzie et al. (2010). La aportación Innovación y su evaluación en la Enseñanza Universitaria (AndreuAndres et al. (INRED 2014) se centra en las cinco primeras etapas, donde se definen la competencia de innovación, se identifican y describen las pautas de comportamiento que son la base de tal competencia, se hace un diseño inicial del instrumento y se llevan a cabo diferentes pruebas para alcanzar una mejora del diseño, junto con nuevas pruebas del instrumento revisado.

El presente trabajo se centra en describir el instrumento final y cómo utilizarlo. No obstante, más análisis cuantitativos y cualitativos para validar y evaluar el desarrollo del instrumento revisado son imprescindibles. Los resultados que se vayan obteniendo de la experimentación del barómetro INCODE, a través de la metodología de enseñanzaaprendizaje acuñada como Research Hatchery ${ }^{2}$ (Kanerva-Lehto et al. 2011; Räsänen y Kyllönen, 2013) o de experiencias de evaluación en diferentes contextos académicos, es la forma apropiada de hacer un seguimiento en la validación del instrumento.

No obstante, antes de adentrarnos en la presentación del barómetro INCODE y la guía de uso, es pertinente presentar alguno de los estudios que se han llevado a cabo para la elaboración del instrumento de evaluación y la guía del usuario. Un primer paso fue un estudio profundo de la literatura, con la revisión y análisis de alrededor de 200 referencias/casos de guías de evaluación, fundamentalmente de instituciones de educación; instituciones privadas; centros de formación y de empresas.

La figura 1 muestra los diferentes pilotajes del barómetro INCODE para el filtrado de obstáculos del barómetro y guía de uso. Para ello se utilizó el barómetro con 15 estudiantes del máster MUGESP, de la Facultad de Administración de Empresas (FADE), en una pre- y post-autoevaluación. Con el mismo grupo también se utilizó el barómetro en la evaluación por profesor y se utilizó el barómetro INCODE-BARS (Behavioral Anchor Rating Scale), una escala con descriptores y niveles de comportamiento en versión adaptada

Con un total de más de 200 alumnos de la asignatura Fundamentos de Organización de Empresa, Grado Ingeniero de Organización Industrial, de la Escuela Técnica Superior de Ingenieros Industriales (ETSII); de la asignatura Recursos Humanos, Grado Ingeniero de Organización Industrial de la ETSII; de (FADE) en una asignatura de GAP y de la

\footnotetext{
${ }^{1}$ http://julkaisut.turkuamk.fi/isbn9789522164254.pdf

${ }^{2}$ Research Hatchery as a Cradle for New Innovators http://julkaisut.turkuamk.fi/isbn9789522164223.pdf
}

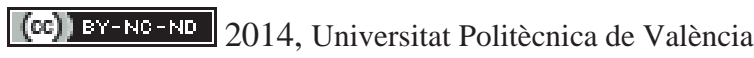

I Jornadas IN-RED (2014) 
asignatura Estrategia y Política de la Escuela Técnica Superior de Ingeniería de Diseño (ETSID) se utilizó el barómetro en una pre- y post-evaluación por profesor.

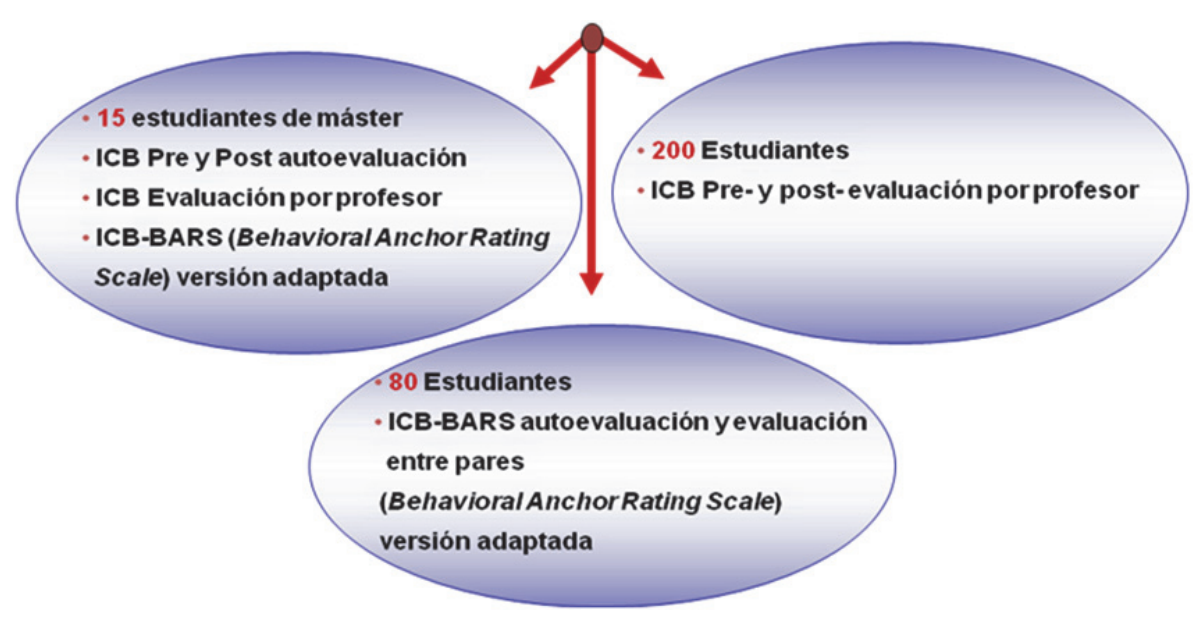

Fig. 1 Pilotajes del barómetro INCODE en la UPV

Finalmente, con 80 estudiantes del Grado Ingeniería Biomédica de la ETSII se utilizó el barómetro INCODE-BARS (Behavioral Anchor Rating Scale) para autoevaluación y evaluación entre pares.

Trabajos como el de Lehto et al. (2011), Towards Innovation Pedagogy. A New Approach to Teaching and Learning for Universities of Applied Sciences, presenta diferentes casos prácticos con nuevos enfoques de innovación. El estudio de Marín-García et al. (2013), How to assess innovation competence in services: The case of university students, presenta una definición de la capacidad de innovación de los estudiantes universitarios y propone el modelo de medida de las variables latentes, considerando la capacidad de innovación como un modelo de segundo orden formativo. Las escalas se han validado con una muestra de 332 estudiantes universitarios españoles. El análisis de Watts et al. (2013) Validation of a rubric to assess innovation, se centra en el desarrollo y validación de rúbricas, materiales y situaciones en la evaluación de la competencia de innovación. Assessment of innovation Competence, de Watts et al. (2013), centrado fundamentalmente en la formación para la evaluación de la innovación son una aportación más en el desarrollo y validación del barómetro INCODE.

Tras los diferentes estudios y pilotajes con el barómetro se pudo concluir que el barómetro y su guía de uso tenía que ser una herramienta sencilla y de fácil manejo, comprensible para 
el posible usuario, pero a la vez detallada y, finalmente, que la validez del barómetro se debía seguir midiendo con resultados procedentes de diferentes research hatcheries.

\section{Objetivos}

El Barómetro (INCODE) pretende ayudar en el desarrollo y la evaluación de la competencia de innovación en un entorno de educación superior. Es un instrumento que se puede utilizar en la autoevaluación con fines formativos, para involucrar a los estudiantes en su propio aprendizaje, a través de la reflexión sobre lo que implica la competencia de innovación. Del mismo modo, proporciona la oportunidad de la evaluación entre pares; en el proceso de aprendizaje en un curso fomenta el aprendizaje colaborativo ayudando a los estudiantes a aprender a dar y recibir realimentación o feedback. El Barómetro INCODE también se puede utilizar por el profesor, desde la fase de diseño de un curso hasta para las diferentes actividades de evaluación formativa a lo largo del mismo, y en la evaluación sumativa, en la que hay que tomar decisiones con respecto a la consecución de los objetivos de aprendizaje y la concesión de las calificaciones finales.

\section{Desarrollo de la innovación}

\subsection{Características del Barómetro INCODE}

De acuerdo con la definición de las competencias de innovación, el Barómetro INCODE es un modelo de rúbricas de puntuación que tiene en cuenta tres dimensiones de las capacidades y habilidades de innovación: la individual, la interpersonal y la de habilidades sociales o networking, siguiendo el modelo de Penttilä et al. (2012).

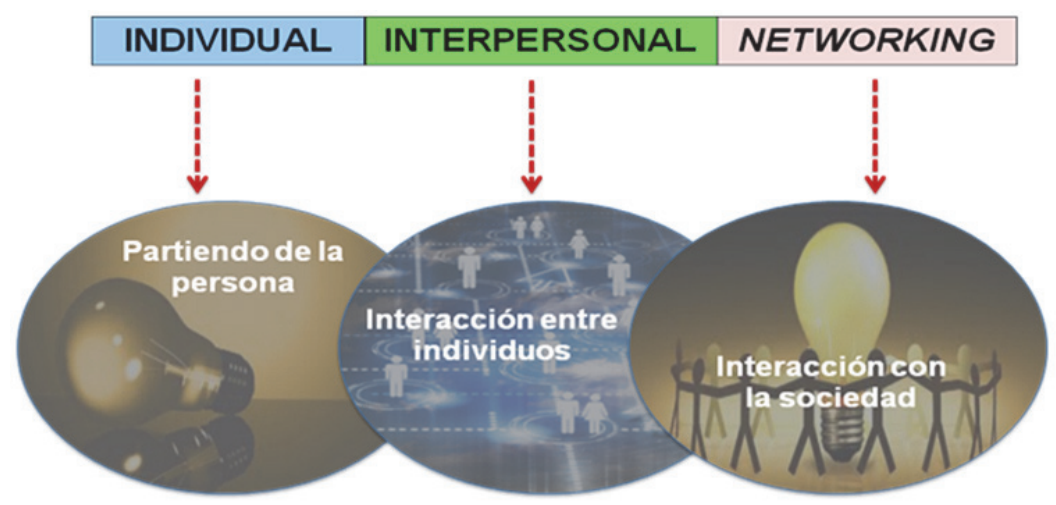

Fig. 1 Dimensiones de las capacidades y habilidades del barómetro INCODE

\section{(cc) EY-NC-ND 2014, Universitat Politècnica de València}

I Jornadas IN-RED (2014) 
La capacidad individual integra los comportamientos o habilidades que permiten a una persona innovar en la ejecución de las tareas personales. La capacidad interpersonal mejora la capacidad individual para innovar a través de la interacción con el grupo, y representa los comportamientos o habilidades que hacen que otros se dirijan hacia el objetivo. Las habilidades sociales o networking representa los comportamientos o habilidades que permiten a un grupo encontrar soluciones adecuadas en el proceso de completar tareas, en un entorno o contexto más amplio de lo habitual (Ver figura 1).

Cada una de las dimensiones contiene una serie de ítems relacionados que describen las pautas de comportamiento. El trabajo de Andreu et al. (presentado en INRED 2014) presenta en detalle las cinco primeras etapas que se han llevado a cabo para el diseño del barómetro INCODE, antes de resolver el producto final. Definir competencia de innovación; identificar pautas de comportamiento y desarrollo inicial del prototipo de barómetro; diferentes pruebas del barómetro por expertos para el filtrado de ítems; nuevas pruebas del barómetro y modificación del modelo y la experimentación del instrumento en research hatcheries conforman esas primeras etapas hacia el barómetro.

En los siguientes apartados presentaremos los resultados, describiendo los pasos seguidos hasta llegar a las dimensiones y los ítems correspondientes enmarcados en un contexto de uso; las diferentes rúbricas para diferentes tipos de evaluación y las recomendaciones de uso del barómetro. Finalmente, en el apartado cuatro se presentan las conclusiones.

\subsection{Dimensiones e ítems Barómetro INCODE}

Las dimensiones del barómetro que enmarcan los diferentes ítems de las capacidades y habilidades de innovación, como ya se mencionado en el apartado 2.1, son la individual, la interpersonal y la de habilidades sociales o networking. La capacidad individual, como su propio nombre indica, hace referencia a los comportamientos o habilidades para innovar a nivel individual. La capacidad interpersonal interrelaciona la mejora del individuo para innovar a través de la interacción con el grupo, y proyectar los comportamientos o habilidades de los demás hacia objetivos concretos. Las habilidades sociales o networking representan los comportamientos o habilidades que permiten a un grupo encontrar soluciones adecuadas en el proceso de completar tareas, en un entorno o contexto más amplio y global de lo habitual.

La tabla 1 presenta tres ejemplos de las tres dimensiones que se contemplan en el barómetro para evaluar la innovación. Los ítems 1,2 y 3 de la dimensión individual evalúan capacidades y destrezas de innovación personales del individuo, sin necesidad de que intervengan otras personas. 
García-Carbonell, A.; Watts, F. y Andreu-Andrés, M. A.

Tabla 1. Ítems de las dimensiones individual, interpersonal y networking

\begin{tabular}{|c|l|c|l|l|l|}
\cline { 2 - 5 } \multicolumn{1}{c|}{} & INDIVIDUAL & & INTERPERSONAL & & NETWORKING \\
\hline 1 & $\begin{array}{l}\text { Presenta ideas } \\
\text { adecuadas para } \\
\text { la tarea }\end{array}$ & 13 & $\begin{array}{l}\text { Transmite ideas } \\
\text { efectivamente }\end{array}$ & 21 & Aplica valores éticos \\
\hline 2 & $\begin{array}{l}\text { Presenta ideas } \\
\text { creativas }\end{array}$ & 14 & $\begin{array}{l}\text { Escucha a sus } \\
\text { compañeros de } \\
\text { equipo }\end{array}$ & 22 & $\begin{array}{l}\text { Toma en cuenta las } \\
\text { implicaciones de la } \\
\text { tarea en/para la } \\
\text { sociedad }\end{array}$ \\
\hline 3 & $\begin{array}{l}\text { Presenta nuevas } \\
\text { formas de } \\
\text { implementar } \\
\text { ideas }\end{array}$ & 15 & $\begin{array}{l}\text { Establece } \\
\text { relaciones de } \\
\text { grupo } \\
\text { constructivas a } \\
\text { través del diálogo }\end{array}$ & 23 & $\begin{array}{l}\text { Es capaz de trabajar } \\
\text { en entornos } \\
\text { multidisciplinares }\end{array}$ \\
\hline
\end{tabular}

Los ítems 13, 14 y 15 evalúan capacidades y destrezas de innovación del individuo cuando interactúa con el grupo. Finalmente, los ítems 21, 22 y 23 evalúan capacidades y destrezas de innovación del individuo y su proyección en contextos más amplios.

\subsection{Rúbricas del Barómetro INCODE}

El barómetro INCODE incluye tres rúbricas (rúbricas 1, 2 y 3) para la evaluación entre pares y evaluación por profesor y tres rúbricas para la autoevaluación (rúbricas 4, 5 y 6). Las rúbricas ofrecen una escala del 1 al 10; del 1 al 5 y del 1 al 3, y las categorías van en función de las escalas.

Tabla 2. Rúbrica 1: Evaluación de la competencia de innovación (escala del 1 al 10)

\begin{tabular}{|c|c|c|c|c|c|c|c|c|c|c|c|c|}
\hline \multirow{2}{*}{\multicolumn{2}{|c|}{ Nombre del estudiante }} & \multirow{4}{*}{$\begin{array}{c}\text { No } \\
\text { mostrado/ } \\
\text { observado }\end{array}$} & \multirow{3}{*}{\multicolumn{2}{|c|}{$\begin{array}{l}\text { Muy } \\
\text { pobre }\end{array}$}} & \multirow{3}{*}{\multicolumn{2}{|c|}{$\begin{array}{l}\text { Necesita } \\
\text { mejora }\end{array}$}} & \multirow{3}{*}{\multicolumn{2}{|c|}{ Apto }} & \multirow{3}{*}{\multicolumn{2}{|c|}{ Bueno }} & \multirow{3}{*}{\multicolumn{2}{|c|}{ Excelente }} \\
\hline & & & & & & & & & & & & \\
\hline \multicolumn{2}{|c|}{$\begin{array}{l}\text { El estudiante en las } \\
\text { actividades de clase: }\end{array}$} & & & & & & & & & & & \\
\hline & & & 1 & 2 & 3 & 4 & 5 & 6 & 7 & 8 & 9 & 10 \\
\hline & INDIVIDUAL & & & & & & & & & & & \\
\hline \multirow[t]{2}{*}{1} & $\begin{array}{l}\text { Presenta ideas } \\
\text { adecuadas para la tarea }\end{array}$ & & & & & & & & & & & \\
\hline & INTERPERSONAL & & & & & & & & & & & \\
\hline \multirow[t]{2}{*}{13} & $\begin{array}{l}\text { Transmite ideas } \\
\text { efectivamente }\end{array}$ & & & & & & & & & & & \\
\hline & NETWORKING & & & & & & & & & & & \\
\hline 23 & Aplica valores éticos & & & & & & & & & & & \\
\hline
\end{tabular}

\section{(cc) EY-NC-ND 2014, Universitat Politècnica de València}

I Jornadas IN-RED (2014) 
La tabla 2 muestra un ejemplo de la rúbrica 1 para evaluación entre pares y por el profesor, con una escala que va del 1 al 10. Las categorías son: no mostrado/observado; muy pobre; necesita mejora; apto; bueno y excelente.

Tabla 3. Rúbrica 2: Evaluación de la competencia de innovación (escala del 1 al 5)

\begin{tabular}{|c|c|c|c|c|c|c|c|}
\hline \multicolumn{2}{|c|}{ Nombre del estudiante } & \multirow{2}{*}{$\begin{array}{c}\text { No } \\
\text { mostrado/ } \\
\text { observado }\end{array}$} & \multirow[b]{2}{*}{$\begin{array}{l}\text { Muy } \\
\text { pobre }\end{array}$} & \multirow[b]{2}{*}{$\begin{array}{l}\text { Necesita } \\
\text { mejora }\end{array}$} & \multirow[b]{2}{*}{ Apto } & \multirow[b]{2}{*}{ Bueno } & \multirow[b]{2}{*}{ Excelente } \\
\hline & $\begin{array}{l}\text { tudiante en las } \\
\text { idades de clase: }\end{array}$ & & & & & & \\
\hline & & 0 & 1 & 2 & 3 & 4 & 5 \\
\hline & INDIVIDUAL & & & & & & \\
\hline \multirow[t]{2}{*}{1} & $\begin{array}{l}\text { Presenta ideas adecuadas } \\
\text { para la tarea }\end{array}$ & & & & & & \\
\hline & INTERPERSONAL & & & & & & \\
\hline \multirow[t]{2}{*}{13} & $\begin{array}{l}\text { Transmite ideas } \\
\text { efectivamente }\end{array}$ & & & & & & \\
\hline & NETWORKING & & & & & & \\
\hline 21 & Aplica valores éticos & & & & & & \\
\hline
\end{tabular}

La tabla 3 muestra un ejemplo de la rúbrica 2 para evaluación entre pares y por el profesor con una escala que va del 1 al 5. Las categorías son: no mostrado/observado; muy pobre; necesita mejora; apto; bueno y excelente.

Tabla 4. Rúbrica 3: Evaluación de la competencia de innovación (escala del 1 al 3)

\begin{tabular}{|l|l|c|c|c|c|}
\hline \multicolumn{2}{|l|}{ Nombre del estudiante } & $\begin{array}{c}\text { No } \\
\text { mostrado/ } \\
\text { observado }\end{array}$ & Insuficiente & Satisfactorio & Excelente \\
\hline \multicolumn{2}{|c|}{ El estudiante en las actividades de clase: } & 0 & $\mathbf{1}$ & $\mathbf{2}$ & $\mathbf{3}$ \\
\hline 1 & INDIVIDUAL & & & & \\
\hline & INTERPERSONAL & & & & \\
\hline 13 & Transmite ideas efectivamente & & & & \\
\hline 21 & NETWORKING & & & & Watts et al. eds. (2013) \\
\hline
\end{tabular}

La tabla 4 muestra un ejemplo de la rúbrica 3 para evaluación entre pares y por el profesor, con una escala que va del 1 al 3. Las categorías son: no mostrado/observado; insuficiente; satisfactorio y excelente.

Seguidamente se presenta un ejemplo de las rúbricas 4, 5 y 6 del barómetro INCODE para la autoevaluación. 
García-Carbonell, A.; Watts, F. y Andreu-Andrés, M. A.

Tabla 5. Rubrica 4: Autoevaluación de la competencia de innovación (escala del 1 al 10)

\begin{tabular}{|c|c|c|c|c|c|c|c|c|c|c|c|c|}
\hline \multicolumn{2}{|c|}{ Nombre del estudiante } & \multirow{3}{*}{$\begin{array}{c}\text { No } \\
\text { mostrado/ } \\
\text { observado }\end{array}$} & \multirow{3}{*}{\multicolumn{2}{|c|}{$\begin{array}{l}\text { Muy } \\
\text { pobre }\end{array}$}} & \multirow{3}{*}{\multicolumn{2}{|c|}{$\begin{array}{l}\text { Necesito } \\
\text { mejora }\end{array}$}} & \multirow{3}{*}{\multicolumn{2}{|c|}{ Apto }} & \multirow{3}{*}{\multicolumn{2}{|c|}{ Bueno }} & \multirow{3}{*}{\multicolumn{2}{|c|}{ Excelente }} \\
\hline & & & & & & & & & & & & \\
\hline \multicolumn{2}{|c|}{$\begin{array}{l}\text { El estudiante en las } \\
\text { actividades de clase: }\end{array}$} & & & & & & & & & & & \\
\hline & & 0 & 1 & 2 & 3 & 4 & 5 & 6 & 7 & 8 & 9 & 10 \\
\hline & INDIVIDUAL & & & & & & & & & & & \\
\hline \multirow[t]{2}{*}{1} & $\begin{array}{l}\text { Presento ideas } \\
\text { adecuadas para la tarea }\end{array}$ & & & & & & & & & & & \\
\hline & INTERPERSONAL & & & & & & & & & & & \\
\hline \multirow[t]{2}{*}{13} & $\begin{array}{l}\text { Transmito ideas } \\
\text { efectivamente }\end{array}$ & & & & & & & & & & & \\
\hline & NETWORKING & & & & & & & & & & & \\
\hline 23 & Aplico valores éticos & & & & & & & & & & & \\
\hline
\end{tabular}

La tabla 5 muestra un ejemplo de la rúbrica 4 para la autoevaluación, con una escala que va del 1 al 10. Las categorías son: no mostrado/observado; muy pobre; necesito mejora; apto; bueno y excelente.

Tabla 6. Rúbrica 5: Autoevaluación de la competencia de innovación (escala del 1 al 5)

\begin{tabular}{|c|c|c|c|c|c|c|c|}
\hline \multicolumn{2}{|c|}{ Nombre del estudiante } & \multirow{3}{*}{$\begin{array}{c}\text { No } \\
\text { mostrado/ } \\
\text { observado }\end{array}$} & \multirow{3}{*}{$\begin{array}{c}\begin{array}{c}\text { Muy } \\
\text { pobre }\end{array} \\
1\end{array}$} & \multirow{3}{*}{$\begin{array}{c}\begin{array}{c}\text { Necesito } \\
\text { mejora }\end{array} \\
2\end{array}$} & \multirow{3}{*}{$\begin{array}{c}\text { Apto } \\
3 \\
\end{array}$} & \multirow{3}{*}{$\begin{array}{c}\text { Bueno } \\
4\end{array}$} & \multirow{3}{*}{$\begin{array}{c}\text { Excelente } \\
5\end{array}$} \\
\hline \multicolumn{2}{|c|}{$\begin{array}{l}\text { El estudiante en las } \\
\text { actividades de clase: }\end{array}$} & & & & & & \\
\hline & & & & & & & \\
\hline & INDIVIDUAL & & & & & & \\
\hline \multirow[t]{2}{*}{1} & $\begin{array}{l}\text { Presento ideas adecuadas } \\
\text { para la tarea }\end{array}$ & & & & & & \\
\hline & INTERPERSONAL & & & & & & \\
\hline \multirow[t]{2}{*}{13} & $\begin{array}{l}\text { Transmito ideas } \\
\text { efectivamente }\end{array}$ & & & & & & \\
\hline & NETWORKING & & & & & & \\
\hline 21 & Aplico valores éticos & & & & & & \\
\hline
\end{tabular}

Watts et al. eds. (2013)

La tabla 6 muestra un ejemplo de la rúbrica 5 para la autoevaluación, con una escala que va del 1 al 5. Las categorías son: no mostrado/observado; muy pobre; necesito mejora; apto; bueno y excelente.

\section{(cc) EY-NC-ND 2014, Universitat Politècnica de València}

I Jornadas IN-RED (2014) 
Barómetro INCODE y guía de uso para la evaluación de competencias de innovación

Tabla 7. Rúbrica 6: Autoevaluación de la competencia de innovación (escala del 1 al 3)

\begin{tabular}{|c|c|c|c|c|c|}
\hline \multicolumn{2}{|c|}{ Nombre del estudiante } & \multirow{2}{*}{$\begin{array}{c}\text { No } \\
\text { mostrado/ } \\
\text { observado }\end{array}$} & \multirow{2}{*}{ Insuficiente } & \multirow{2}{*}{ Satisfactorio } & \multirow{2}{*}{ Excelente } \\
\hline \multicolumn{2}{|c|}{$\begin{array}{l}\text { El estudiante en las actividades de } \\
\text { clase: }\end{array}$} & & & & \\
\hline & & 0 & 1 & 2 & 3 \\
\hline & INDIVIDUAL & & & & \\
\hline \multirow[t]{2}{*}{1} & Presento ideas adecuadas para la tarea & & & & \\
\hline & INTERPERSONAL & & & & \\
\hline \multirow[t]{2}{*}{13} & Transmito ideas efectivamente & & & & \\
\hline & NETWORKING & & & & \\
\hline 21 & Aplico valores éticos & & & & \\
\hline
\end{tabular}

La tabla 7 muestra un ejemplo de la rúbrica 6 para la autoevaluación con una escala que va del 1 al 3. Las categorías son: no mostrado/observado; insuficientes; satisfactorio y excelente.

Para ayudar al posible usuario del barómetro INCODE, la guía de uso también presenta tres ejemplos de uso de las rúbricas en contexto. El primer ejemplo de contexto de uso está relacionado con el tema de la malnutrición en las residencias de ancianos, el segundo ejemplo de uso en contexto está relacionado con el proyecto del uso de bicicletas entre campus universitarios y el último ejemplo está relacionado con el proyecto TMO (The Making $O f)$.

A continuación se presenta un ejemplo de uso de las rúbricas en el contexto relacionado con el proyecto de uso de las bicicletas entre diferentes campus. Este proyecto se centra en el interés de la universidad por alentar a su personal a utilizar bicicletas entre los distintos campus. Para algunas personas el uso de las bicicletas no es una opción, ya que no la utilizan para ir al trabajo. La universidad ha decidido comprar tres bicicletas y se ha puesto en marcha una research hutchery (incubadora de investigación o combinación de aprendizaje, innovación e investigación) con la tarea fundamental de adquirir y preparar las bicicletas para su uso. El Proyecto Campus Bike está dirigido por estudiantes.

La tabla 8 muestra un ejemplo de un ítem de cada dimensión en contexto. El apartado POSIBLE CONDUCTA explica al evaluador como ha de aplicar cada uno de los ítems en ese contexto determinado. 
García-Carbonell, A.; Watts, F. y Andreu-Andrés, M. A.

Tabla 8. Ejemplo de un ítem de cada dimensión en contexto

\begin{tabular}{|c|l|l|}
\hline & INDIVIDUAL & POSIBLE CONDUCTA \\
\hline 1 & $\begin{array}{l}\text { Presenta ideas adecuadas para la } \\
\text { tarea }\end{array}$ & $\begin{array}{l}\text { Presenta ideas para la aplicación de una la encuesta } \\
\text { al grupo al comienzo del Proyecto Campus Bike (por } \\
\text { ejemplo, un cuestionario, entrevista, encuesta en } \\
\text { línea, entre otros). }\end{array}$ \\
\hline 13 & INTERPERSONAL & POSIBLE CONDUCTA \\
\hline 21 & Transmite ideas efectivamente & $\begin{array}{l}\text { Se asegura de que todos los miembros del grupo } \\
\text { entienden sus tareas después de la división de } \\
\text { tareas en una reunión de grupo. Utiliza un canal de } \\
\text { comunicación común (por ejemplo, un grupo de } \\
\text { Facebook) para comunicarse con el grupo. }\end{array}$ \\
\hline & NETWORKING & $\begin{array}{l}\text { Mantiene una actitud respetuosa para que nadie se } \\
\text { sienta ofendido por razones de sexo, creencias, etc. } \\
\text { (Por ejemplo, el grupo de proyecto Campus Bike se } \\
\text { compone principalmente de tos estudiantes varones). }\end{array}$ \\
\hline
\end{tabular}

Watts et al. eds. (2013)

La guía incluye ejemplos de uso contextualizados para ayudar al potencial usuario a alinear los ítems del barómetro INCODE con su situación o contexto particular.

\subsection{Recomendaciones de uso}

La última sección del barómetro INCODE y guía de uso presenta unas recomendaciones de cómo implementar la evaluación por profesor, entre pares y la autoevaluación. Las recomendaciones se dividen en tres bloques. La fase de información tiene por objetivo familiarizar al posible usuario con el uso de barómetro INCODE. La fase práctica se centra en cómo implementar la evaluación. Por último, la fase de reflexión analiza la experiencia de evaluación.

Las diferentes fases recogen las siguientes recomendaciones:

Fase de información

- Explorar los supuestos y principios que subyacen a la práctica de la evaluación de la innovación en lo que respecta a los contextos específicos de cada disciplina.

- Conocer a los alumnos y conversar con ellos acerca de la evaluación antes de la introducción de las prácticas de evaluación.

- Involucrar a los estudiantes en la determinación de los criterios para juzgarse a sí mismos y para juzgar el trabajo de sus pares.

(cc) EY-NC-ND 2014, Universitat Politècnica de València

I Jornadas IN-RED (2014) 
- Introducir las muestras de listas de verificación o rúbricas con criterios al principio del proceso de aprendizaje.

Fase práctica

- Usar una combinación de la evaluación entre pares, autoevaluación y/o evaluación por profesor.

- Asegurar que la evaluación entre pares y la autoevaluación son una parte de las actividades de aprendizaje. Permitir a los estudiantes la oportunidad de reconocer el progreso propio y de sus pares en relación con los resultados de aprendizaje que se han definido para el curso.

- Incluir una explicación clara de la finalidad de la actividad de evaluación y de cuál será el procedimiento a seguir. Asegurarse de que los estudiantes entienden lo que se espera de ellos.

- Formar a los estudiantes con las muestras de rendimiento adaptadas a los criterios de evaluación.

- Utilizar evaluación entre pares y/o autoevaluación en diferentes momentos durante el proceso de aprendizaje. Por ejemplo, al principio, una vez o varias veces en el medio y al final.

- Establecer un ambiente de confianza en el aula. Incitar a los estudiantes a ser honestos en la evaluación.

- Proporcionar realimentación del profesor o del grupo para apoyar la evaluación entre pares, la autoevaluación o la evaluación por profesor.

Fase de reflexión

- Animar a los estudiantes a mirar hacia atrás y analizar su progreso en la competencia de innovación y en la evaluación a los compañeros y/o autoevaluación.

- Ayudar a los estudiantes, mediante el uso de ejemplos de rendimiento utilizados en el entrenamiento recibido para la evaluación, a que reflejen lo que realmente ocurrió en la fase práctica.

- Invitar a los estudiantes a usar su nueva experiencia para mejorar el proceso y el instrumento de evaluación.

El barómetro INCODE y la guía completa de uso se puede consultar en http://julkaisut.turkuamk.fi/isbn9789522164254.pdf 
García-Carbonell, A.; Watts, F. y Andreu-Andrés, M. A.

\section{Conclusiones}

El barómetro INCODE y su guía de uso pretende ser un instrumento de fácil manejo que, bajo las dimensiones de individual, interpersonal y networking, presenta un total de 25 ítems para evaluar las capacidades y destrezas que conforman la competencia de innovación. Aunque los diferentes estudios y filtrados del instrumento no garantizan que sea un instrumento adecuado para todos los contextos de aprendizaje, como cualquier herramienta de aprendizaje-evaluación el usuario ha de adaptarla a los objetivos de aprendizaje concretos de la materia y del contexto.

El ámbito de aplicación actual del barómetro INCODE es la educación superior, fundamentalmente en evaluación formativa. No obstante, para llegar a cumplir con el objetivo final de preparar a individuos para ser innovadores en el mundo laboral, todavía resta pilotar el barómetro en contextos de empresa, donde el tiempo para la formación es más escaso y restringido que en la universidad. Para el pilotaje en empresas se prevé que será necesario hacer ajustes en el barómetro para agilizar su uso.

\section{Referencias}

KANERVA-LEHTO, H., LEHTONEN, J., JOLKKANEN, A. y RIIHIRANTA, J. (2011). "Research Hatchery. A concept for combining learning, developing and research" en Lehto. KairistoMertanen y Penttlilä, Towards Innovation Pedagogy. A New Approach to Teaching and Learning for Universities of Applied Sciences. Reports 100. Turku: University of Applied Sciences, 26-34. http://julkaisut.turkuamk.fi/isbn9789522161697.pdf [Consulta: 12 de junio de 2014].

Lehto, A., Kairisto-Mertanene, L. y Penttilä, T. (2011). Towards Innovation Pedagogy. A New Approach to Teaching and Learning for Universities of Applied Sciences. Reports 100. Turku: University of Applied Sciences.

Marín-García, J.A., Pérez-Peñalver, Ma J. Y Watts, F. (2013). "How to assess innovation competences in services: The case of university students". Dirección y Organización, 50, 48-62. http://www.revistadyo.com/index.php/dyo/article/view/431 [Consulta: 12 de junio de 2014].

Onwuegbuzie, A. J., Bustamante, R. M., Nelson, J. A. (2010). "Mixed Research as a Tool for Developing Quantitative Instruments". Journal of Mixed Methods Research, 4(1), 56-78.

PentTilä, T. y KAiRISTO-Mertanene, L. (2012). "Innovation competence barometer ICB - a tool for assessing students' innovation competences as learning outcomes in higher education" en INTED2012 Conference. 5-7 marzo 2012, 6347-6351.

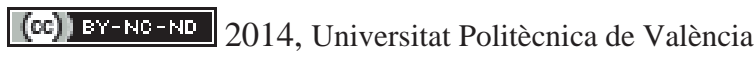

I Jornadas IN-RED (2014) 
RÄSÄNEN, M. Y KYLLÖNEN, A. EDS. (2013). Research Hatchery as a Cradle for New Innovators. Handbook for Implementation. Turku: Turku University of Applied Sciences. http://julkaisut.turkuamk.fi/isbn9789522164223.pdf [Consulta: 10 de junio de 2014].

Watts, F., García-CARbonell, A. y Andreu-Andrés, Mª́. (2013). Innovation Competencies Development. INCODE Barometer and User Guide. Turku: TUAS. http://julkaisut.turkuamk.fi/isbn9789522164254.pdf [Consulta: 13 de junio de 2014].

Watts, F.; García-Carbonell, A.; Andreu-Andrés, Ma Á.; Stange, C. y Helker, H. (2013). "Assessment of innovation Competence" en Anttoni Lehto y Taru Penttilä (eds) Pedagogical views on innovation competences and entrepreneurship. Turku: TUAS, 44-56. 



\section{Sesión 4}

\section{Otro tipo de innovación educativa}




\title{
Proyecto de implantación de SAP University Alliances en la Universitat Politècnica de València
}

Sabina Asensio-Cuesta ${ }^{\text {a }}$

${ }^{a}$ Departamento de Proyectos de Ingeniería. Universitat Politècnica de València. Camino de Vera, s/n. 46022 Valencia. Tel. +34963877007-85689. e-mail: sasensio@dpi.upv.es

\begin{abstract}
SAP University Alliances (SAP UA) is a cooperative program to help the integration of SAP Enterprise Resourcing Planning in formal education in universities and colleges. The integration of SAP UA at the Universitat Politècnica de València (SAP UA UPV) has been promoted by the Vicerectorate for the Development of ITC Technologies. Currently, SAP UA UPV Project involves 34 lecturers from five Departments: Engineering Projects, Business Organization, Economics and Social Sciences, Communications, IT and Computer Systems. As a logical consequence of the inter-departmental and multi-disciplinary framework of SAP UA UPV Project, a cross relationship between Schools and Degrees has been established. In order to provide SAP UA UPV with a formal and structured educational framework an inter-departmental collaborative and coordinated working group has been created. The group's aim is SAP-based learning experiences support and prevents potential concurrency data problems on UPV SAP system.

This article describes the SAP UA UPV Project from its coordination point of view. Likewise, results obtained in the first year of its implementation, and future lines of work are presented.
\end{abstract}

Keywords: SAP, ERP, multi-disciplinary project, inter-departmental project, SAP University Alliances, training, coordination 


\begin{abstract}
Resumen
SAP University Alliances (SAP UA) es un programa cooperativo dirigido a universidades y escuelas superiores cuyo objetivo es facilitar la integración del Sistema de Gestión Empresarial SAP en la enseñanza oficial. El Proyecto de implantación de SAP UA en la Universitat Politècnica de València (SAP UA UPV) ha sido impulsado por el Vicerrectorado de Tecnologías de la Información y de las Comunicaciones. Actualmente el Proyecto SAP UA UPV integra a 34 profesores de cinco Departamentos: Proyectos de Ingeniería, Organización de empresa, Economía y Ciencias sociales, Comunicaciones, Sistemas Informáticos y Computación. Como consecuencia lógica del marco inter-departamental y multi-disciplinar del proyecto SAP UA UPV, se establece una relación transversal entre Escuelas y Titulaciones.

Con el objetivo de dotar al Proyecto SAP UA UPV de un marco docente formal y estructurado, se ha creado un grupo de trabajo inter-departamental colaborativo y coordinado. El objetivo del grupo es la puesta en marcha de experiencias docentes basadas en SAP, así como minimizar potenciales problemas de concurrencia sobre la información en el sistema SAP.

El presente artículo describe el Proyecto SAP UA UPV desde la perspectiva de la coordinación, los resultados obtenidos en el primer año de su implantación, así como las líneas futuras de trabajo.
\end{abstract}

Palabras clave: SAP, ERP, proyecto multi-disciplinar, proyecto interdepartamental, SAP University Alliances, formación, coordinación

\title{
1. Introducción
}

Un sistema ERP es un software que permite gestionar todos los procesos de una empresa basándose en una única base de datos centralizada (Gómez, 2009). Dicha integración de procesos permite a los usuarios obtener una visión global y transversal de la empresa.

Estudios realizados sobre el empleo de sistemas ERP en la formación práctica de los alumnos han puesto de relieve su utilidad para mejorar la comprensión de éstos sobre los procesos de negocio de las empresas, la interrelación de los procesos de negocio, así como de los conceptos teóricos sobre sistemas de información (Scholtz et. al., 2012).

Actualmente existe una gran variedad de sistemas ERP disponibles en el mercado (Openbravo, MS Dyamics-AX, MS Dyamics-NAV, Oracle ERP, SAP, etc.), siendo SAP el sistema líder de mercado (Hestermann et al, 2010). SAP está implantado en numerosas 
empresas de gran tamaño, tales como: Ford, BMW, Bayer, Vodafone, etc. SAP es un ERP ampliamente utilizado tanto en el ámbito empresarial como académico. Se trata de un sistema complejo, con una curva de aprendizaje pronunciada, y un elevado coste de licencias, implantación y configuración. Todo ello dificulta el acceso a SAP a la mayoría de los docentes interesados en integrarlo en su docencia (Wang, 2011). No obstante, son numerosas las experiencias de incorporación de SAP en la docencia universitaria (Davis et al., 2004; Pellerin et al., 2006; Wang, 2011).

Debido a su carácter trasversal, existe un amplio número de asignaturas de titulaciones diversas, tanto de Grado como de Master, que incluyen el estudio de los Sistemas ERP en sus temarios. Si embargo, numerosos docentes han expresado en repetidas ocasiones su dificultad de acceso a estos sistemas debido, principalmente, al elevado coste de sus licencias y a la complejidad de su configuración. En respuesta a la problemática citada, en 1988 en Alemania surge el programa SAP University Alliances (SAP UA). Actualmente, el programa SAP UA, con presencia global, ofrece a más de 260.000 estudiantes en más de 1.300 universidades y escuelas miembro la oportunidad de adquirir conocimientos y experiencia en el software ERP de SAP (SAP Community Network, 2014).

En 2013 el Vicerrectorado de Tecnologías de la Información y de las Comunicaciones (VTIC) decide impulsar en la Universitat Politècnica de València el programa SAP University Alliances bajo la forma de el Proyecto denominado SAP UA UPV. Dicho proyecto cuenta con el soporte de SAP de University Alliances Iberia, así como con la asistencia técnica, formativa y de hosting del SAP-University Competence Center (Department of Informatics, Chair for Information Systems, Technische Universität München).

El sistema SAP disponible en la UPV implica la concurrencia de usuarios (profesores y alumnos) sobre una única Base de Datos, en la que se implementa una única Empresa, la cual es actualizada por los diferentes procesos de negocio lanzados en el sistema (Fig. 1). Con el objetivo de poder gestionar adecuadamente dicha concurrencia, y como tarea fundamental del Proyecto SAP UA UPV, se ha creado un grupo de trabajo denominado "SAP UA UPV Working Group", así como la figura del "Coordinador del Proyecto SAP UA UPV" (Fig. 2). 


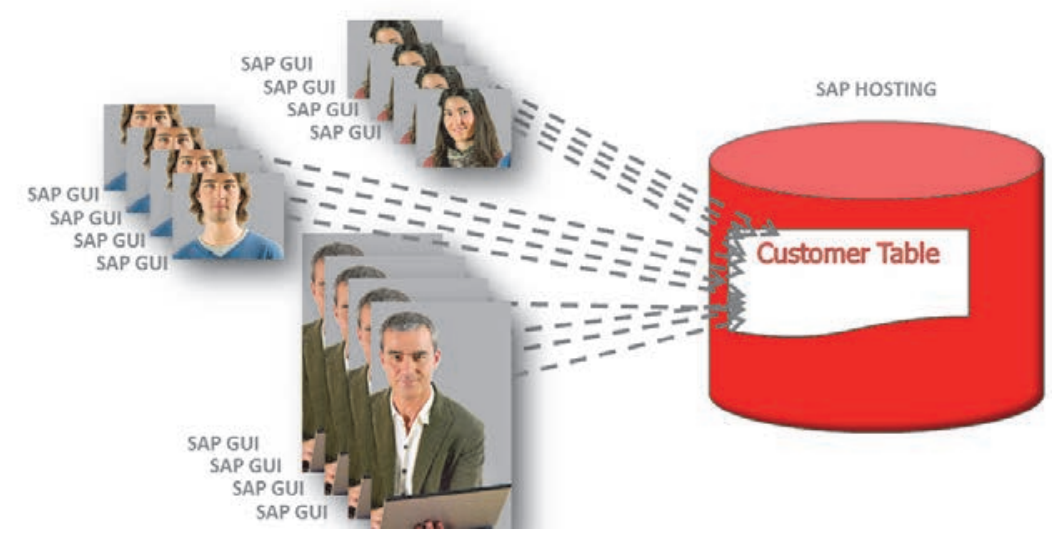

Fig. 1 Problemas de interferencias por concurrencia en una única Base de Datos

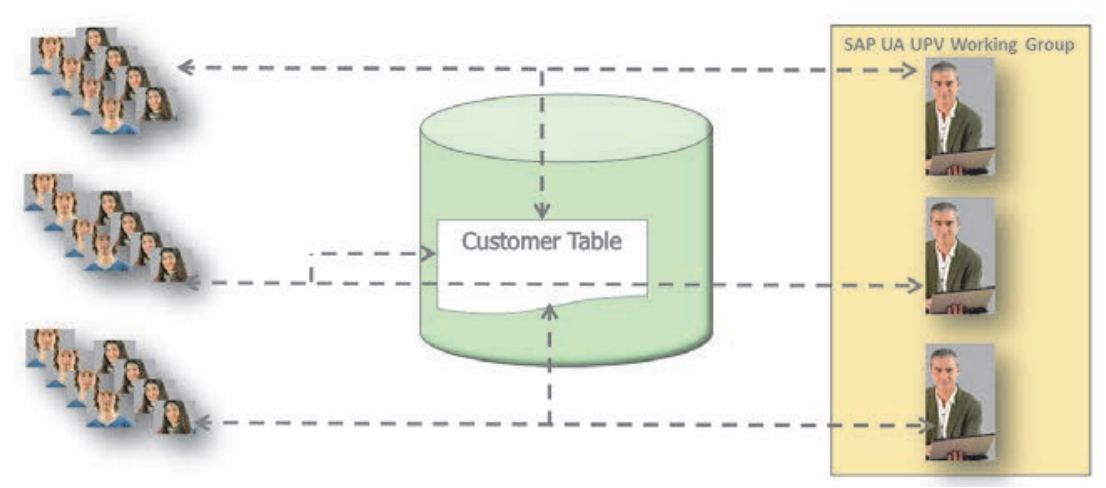

Fig. 2 Esquema de trabajo coordinado de concurrencia en el sistema SAP UA UPV

Actualmente, en el Proyecto SAP UA UPV participan 34 profesores de cinco Departamentos: Proyectos de Ingeniería, Organización de empresa, Economía y Ciencias sociales, Comunicaciones, Sistemas Informáticos y Computación. Siendo la coordinación realizada por Sabina Asensio (Departamento de Proyectos de Ingeniería). Por otra parte, y como consecuencia lógica del marco inter-departamental y multi-disciplinar del proyecto SAP UA UPV, se establece una relación transversal entre Escuelas y Titulaciones, siendo las Escuelas actualmente implicadas en el proyecto: la Escuela Técnica Superior de Ingenieros Industriales (ETSII), la Escuela Técnica Superior de Ingeniería Informática (ETSINF) y Facultad de Administración y Dirección de Empresas (FADE).

Para finalizar cabe señalar que las licencias del sistema SAP en la UPV acordadas en el convenio firmado con la Technische Universität München (TUM) son de carácter anual. Dicha circunstancia obliga a un seguimiento continuo del avance del proyecto que 
justifique la inversión realizada por el VTIC en términos de beneficios docentes, tanto desde la perspectiva de los profesores como de los alumnos .

\section{Objetivos}

Los objetivos del proyecto SAP UA UPV se han estructurado en forma de fases o hitos. La Fig. 3 muestra la planificación de dichos objetivos. Entre los objetivos planteados, en primer lugar, se marcó la "Difusión del proyecto en la UPV" para posteriormente llevar a cabo la "Creación del SAP UA UPV Working Group". A continuación se realizó la formación en el sistema SAP, a través del curso "SAP Introduction Week" de los miembros del grupo. Una vez formado el profesorado se procedió a la explotación del sistema SAP en diversas asignaturas, con asistencia técnica a los profesores. Y como objetivo transversal del proyecto SAP UA UPV cabe señalar la actividad de "Coordinación Docente" permanente.

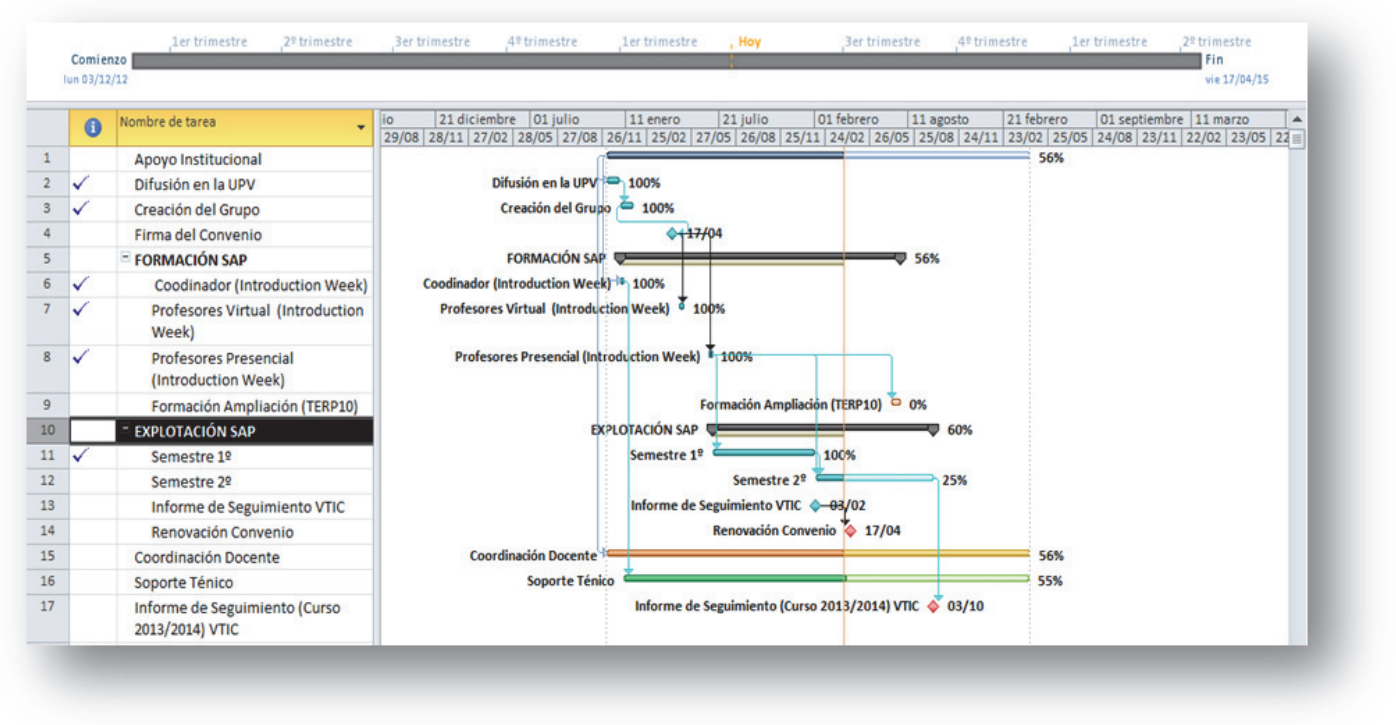

Fig. 3 Fases del Proyecto SAP UA UPV 2012 a 2014.

\section{Desarrollo de la innovación}

En el presente apartado se desarrolla la innovación llevada a cabo, diferenciando las acciones realizadas para cada uno de los semestres del curso 2013-2014.

\section{(c) EY-NC-ND 2014, Universitat Politècnica de València}

I Jornadas IN-RED (2014) 


\subsection{Balance de integración de SAP: Primer semestre 2013-2014}

En el grupo de trabajo inicialmente creado tras la difusión del proyecto SAP UA UPV se integraron 26 profesores, un total de 22 de ellos recibieron la formación inicial en el Curso "SAP Introduction Week" (Julio 2013). Se considera importante mencionar que de dicho grupo sólo 2 de ellos disponían de conocimientos previos del sistema SAP. Por otra parte, aproximadamente la mitad de los profesores participantes en la formación inicial tenían experiencia profesional y docente con otros Sistemas ERPs, tales como: Microsoft Dynamics-Ax, Microsoft Dynamics-Nav y Openbravo. Del grupo con formación, 5 profesores utilizaron SAP en el primer semestre del curso 2013-2014. En total, se explotó SAP en 2 Escuelas (ETSII y ETSINF), en 3 Titulaciones: Máster Universitario en Dirección y Gestión de Proyectos, Grado en Ingeniería Informática y Organización Industrial ( $2 \mathrm{n}$ cicle). Y 84 alumnos tuvieron acceso al sistema SAP.

La Tabla 1 muestra las asignaturas, titulaciones y escuelas que realizaron un uso efectivo de las licencias SAP en el primer semestre del curso 2013-2014:

\begin{tabular}{|c|c|c|c|c|}
\hline Asignatura/Tesina/PFC & Titulación & Escuela & Carácter & Departamento \\
\hline 30491- Planificación Empresarial (ERP's) & $\begin{array}{l}\text { Máster Universitario } \\
\text { en Dirección y } \\
\text { Gestión } \\
\text { Proyectos }\end{array}$ & ETSII & Obligatoria & $\begin{array}{l}\text { Proyectos de } \\
\text { Ingeniería (DPI) }\end{array}$ \\
\hline $\begin{array}{l}\text { 11603-Sistemas Integrados de Información } \\
\text { en las Organizaciones }\end{array}$ & $\begin{array}{l}\text { Grado en Ingeniería } \\
\text { Informática }\end{array}$ & ETSINF & Optativa & $\begin{array}{l}\text { Organización de } \\
\text { Empresas (DOE) }\end{array}$ \\
\hline $\begin{array}{l}\text { Tesina: Análisis de herramientas } \\
\text { informáticas ERP y de herramientas de } \\
\text { gestión de Proyectos para el sector de } \\
\text { pequeña y mediana empresa }\end{array}$ & $\begin{array}{l}\text { Máster Universitario } \\
\text { en Dirección y } \\
\text { Gestión } \\
\text { Proyectos }\end{array}$ & ETSII & Obligatoria & $\begin{array}{l}\text { Proyectos de } \\
\text { Ingeniería (DPI) }\end{array}$ \\
\hline $\begin{array}{l}\text { 7124-Gestión Integrada de } \quad \text { Sistemas } \\
\text { Industriales }\end{array}$ & $\begin{array}{l}\text { Organización } \\
\text { Industrial ( } 2 \mathrm{n} \text { cicle })\end{array}$ & ETSII & Optativa & $\begin{array}{l}\text { Organización de } \\
\text { Empresas (DOE) }\end{array}$ \\
\hline
\end{tabular}

Tabla 1: Integración de SAP en la UPV (primer semestre 2013-2014)

Además de la integración de SAP en las asignaturas y trabajos de fin de master nombrados, cabe indicar otras iniciativas llevadas a cabo desde la coordinación del proyecto SAP UA UPV en el primer semestre:

- Creación de Imagen Corporativa del proyecto SAP UA en la UPV y unificación de formatos.

- Gestión del Curso Virtual de "Introduction Week" impartido por Tecnológico de Monterrey (Mejico). 
Participantes: Universidad Politècnica València, Universidad Pública de Navarra, Universidad Politècnica Cataluña, Universidad de Vigo, Instituto Mackenzie (Brasil), Tecnológico de Monterrey (Mejico), Universidad Pública de Navarra, Universidad Castilla la Mancha, Universidad Católica Andres Bello (Venezuela), Universidad Católica Argentina (Argentina ), Universidad Autonoma de Coahuila, Universidad de Almería, CPA -Comissão Própria de Autoavalação (Brasil), Universidad de Vigo, Universidad Cesyt (Argentina ), University Alliances (Peru), Universidad Industrial de Santander (Colombia, Alemania)

- Gestión del curso de "SAP Introduction Week" a través del Centro de Formación Permanente de la UPV. Impartido por SAP UA a través del partner SAP Grupo Sothis.

- Descripción del curso: El curso introductorio está diseñado para las escuelas que se integran al programa de Alianzas Universitarias de SAP, así como para académicos que deseen utilizar SAP en sus clases. Proporciona a los participantes un plan completo de cursos disponibles. Desde la navegación básica hasta una visión general de cada una de las áreas de proceso de SAP ERP. Este curso introductorio explica las estructuras organizacionales y procesos de negocio bajo el esquema de SAP. Todos los profesores nuevos que se integran al programa de Alianzas Universitarias deberán completar la capacitación introductoria.

- Extensión del curso en la UPV a otras universidades española y de Sudamérica mediante su edición online. Universidades participantes: Universitat Politècnica de València (España), Universidad Pública de Navarra (España), Universidad Politècnica Cataluña (España) , Universidad Castilla la Mancha (España), Universidad de Almería (España), Universidad de Vigo (España), Instituto Mackenzie (Brasil), Tecnológico de Monterrey (Méjico), Universidad Católica Andrés Bello (Caracas-Venezuela), Universidad Católica Argentina (Argentina),

\section{(c) EY-NC-ND 2014, Universitat Politècnica de València}


Universidad Autónoma de Coahuila (Méjico)

- Gestión del reconocimiento de la formación de SAP, curso "SAP Introduction Week", por el Instituto de Ciencias de la Educación de la UPV (ICE) como formación docente del profesorado.

- Asistencia técnica al profesorado: actualización de periodos contables (mensual), gestión de grupos de usuarios por profesor/ámbito, gestión de activación de usuarios de SAP, asistencia técnica en la instalación SAP GUI a profesores y técnicos de aula.

- Creación y gestión del espacio común de compartición de documentación y comunicación para el proyecto en PoliformaT: $\underline{\text { SAP UNIVERSITY ALLIANCES }}$ - UPV.

- Utilización de las redes sociales para la difusión de noticias relacionadas con el proyecto:

○ Creación de la cuenta de Twitter @SAP_UA_UPV: https://twitter.com/SAP_UA_UPV.

- Creación de un portal web corporativo del proyecto: http://sapuniversityalliancesupv.dpi.upv.es.

- Elaboración de material docente y de apoyo a nuevas incorporaciones de profesores y alumnos al programa en la UPV:

- Elaboración de una Guía para nuevas incorporaciones a SAP UA UPV.

- Elaboración de 9 tutoriales audiovisuales publicados en Politube de introducción a los módulos de: Navegación, Ventas, Compras, Proyectos, Finanzas, Costes y Producción.

- Elaboración de documentación de ayuda a la conexión al sistema mediante SAP GUI en la UPV.

- Elaboración de plantillas corporativas del proyecto SAP UA UPV para la creación de nuevos casos de estudio con formato unificado.

(c)) EY-NC-ND 2014, Universitat Politècnica de València 


\subsection{Balance de integración de SAP: Segundo semestre 2013-2014}

En el periodo correspondiente al segundo semestre del curso 2013-2014, un total de 11 profesores han integrado SAP en diferentes asignaturas y/o temáticas de tesinas. Los departamentos implicados son: Proyectos de Ingeniería (DPI), Departamento de Organización de empresas (DOE) y Economía y Ciencias sociales (DECS). En cuanto a las Escuelas involucradas se encuentran: la Escuela Técnica Superior de Ingenieros Industriales (ETSII), la Escuela Técnica Superior de Ingeniería Informática (ETSINF) y la Facultad de Administración y Dirección de Empresas (FADE).

La Tabla 2 contiene las asignaturas, titulaciones y escuelas que ha realizado un uso efectivo de las licencias SAP en el segundo semestre del curso 2013-2014:

\begin{tabular}{|c|c|c|c|c|}
\hline Asignatura/Tesina/PFC & Titulación & Escuela & Carácter & Departamento \\
\hline $\begin{array}{l}\text { 11753- Investigación comercial y } \\
\text { Dirección Comercial }\end{array}$ & $\begin{array}{lr}\text { Grado en } \\
\text { Administración y } \\
\text { Dirección de Empresas }\end{array}$ & FADE & Obligatoria & Proyectos de Ingeniería (DPI) \\
\hline 3 Tesinas & $\begin{array}{l}\text { Grado en Ingeniería } \\
\text { Informática }\end{array}$ & ETSINF & Obligatoria & $\begin{array}{l}\text { Organización de Empresas (DOE) } \\
\text { / Proyectos de ingeniería (DPI) } \\
\text { *Codirección inter-departamenta }\end{array}$ \\
\hline Tesina & $\begin{array}{l}\text { Grado en Ingeniería } \\
\text { Informática }\end{array}$ & ETSINF & Obligatoria & Organización de Empresas (DOE) \\
\hline Proyectos & $\begin{array}{l}\text { Grado en Ingeniería en } \\
\text { Tecnologías Industriales } \\
\text { (GITI) }\end{array}$ & ETSII & Optativa & Proyectos de ingeniería (DPI)) \\
\hline Proyectos & $\begin{array}{l}\text { Ingeniería en } \\
\text { Organización Industrial }\end{array}$ & ETSII & Obligatoria & Proyectos de ingeniería (DPI) \\
\hline $\begin{array}{l}11495 \text { - Análisis de costes y } \\
\text { selección de inversiones } \\
\text { industriales }\end{array}$ & $\begin{array}{l}\text { Grado en Ingeniería de } \\
\text { Organización Industrial }\end{array}$ & ETSII & Obligatoria & Organización de Empresas (DOE) \\
\hline $\begin{array}{l}\text { Dirección de Un Proyecto de } \\
\text { Producción }\end{array}$ & Ingeniería Industrial & ETSII & Obligatoria & Proyectos de ingeniería (DPI) \\
\hline
\end{tabular}

Tabla 2: Integración de SAP en la UPV (primer semestre 2013-2014)

Además se han registrado 6 nuevas incorporaciones de docentes al proyecto, dos de ellos integrados en dos departamentos nuevos en el proyecto: Comunicaciones y Sistemas Informaticos y Computacion.

Cabe remarcar la capacidad del Proyecto SAP UA UPV para promover la colaboración inter-departamental, por ejemplo en la codirección de tesinas (ver Tabla 2).

\section{(cc) EY-NC-ND 2014, Universitat Politècnica de València}

I Jornadas IN-RED (2014) 


\section{Resultados}

Con el objetivo de obtener evidencias sobre los resultados del Proyecto SAP UA UPV se han realizado encuestas al profesorado integrado en el proyecto y a alumnos de una de las asignatura piloto (30491- Planificación Empresarial (ERP's) ver detalles en Tala 1).

\subsection{Encuestas de opinión profesorado}

Los resultados de la encuesta realizada al profesorado d el Proyecto SAP UA UPV a fecha 03/04/2014 en base a 11 respuestas permiten afirmar que la mayoría de los profesores desean seguir ampliando su formación en el sistema SAP para mejorar su docencia. La experiencia de incluir SAP en la docencia es calificada positivamente por todos los profesores encuestados que, además, desean seguir con la experiencia SAP en el próximo curso. De los profesores encuestados el 36\% integró SAP en el primer semestre del curso 2013-2014 mientras que la mayoría, 73\%, lo hizo en el segundo semestre del mismo curso (ver Fig. 4).

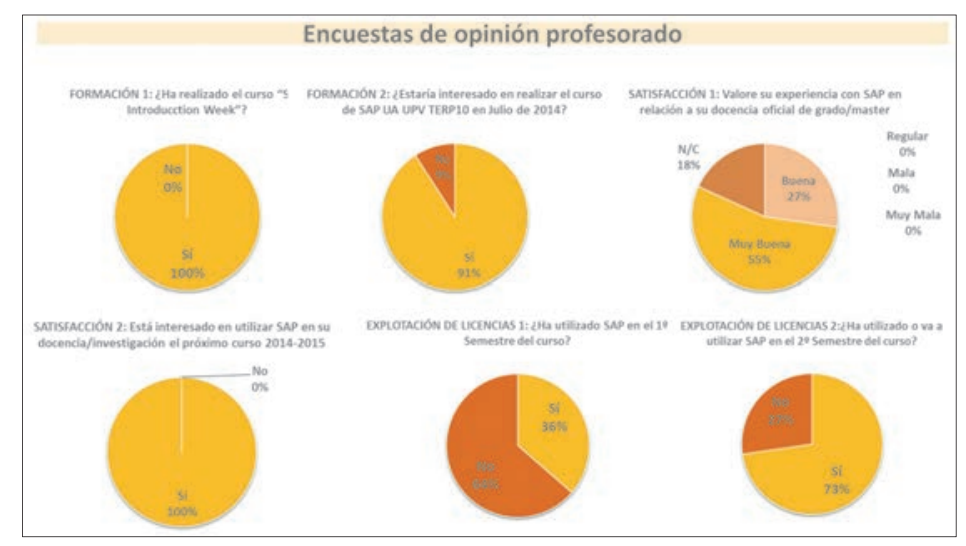

Fig.4 Encuestas de opinión profesorado integrado en SAP UA UPV (I). (03/04/2014, 11 respuestas).

Por otra parte, las licencias de SAP se utilizaron principalmente para docencia en grado, seguida de realización de Proyectos Fin de Carrera. Si bien cabe remarcar el empleo de las licencias también en el ámbito de la investigación así como el carácter multidisciplinar de las investigaciones realizadas (ver Fig. 5). 


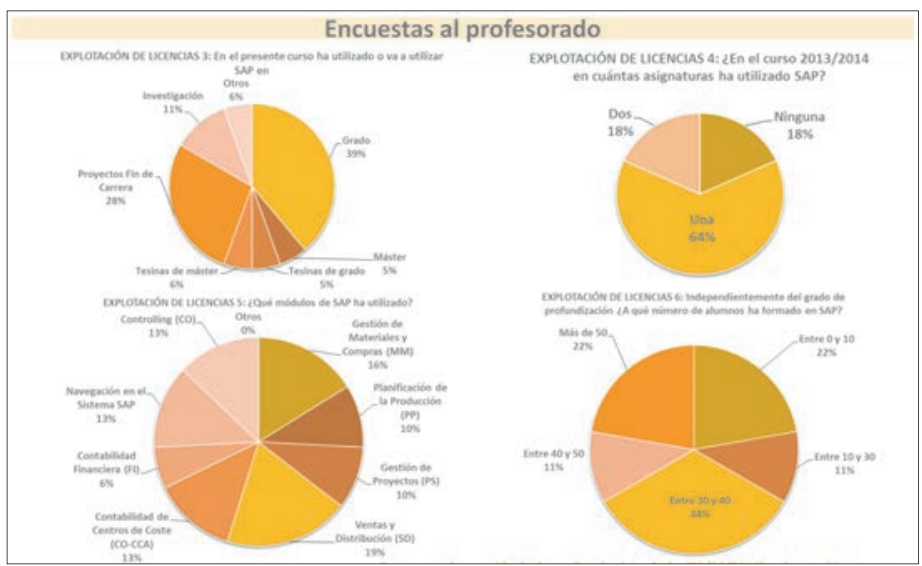

Fig.5 Encuestas de opinión profesorado integrado en SAP UA UPV (II). (03/04/2014, 11 respuestas).

Para finalizar, los resultados de las encuestas ponen de relieve el carácter multidisciplinar del sistema SAP, ya que tal y como se muestra en al Fig.5 prácticamente todos los módulos disponibles en el sistema (Finanzas, Navegación, Materiales, etc.) han sido utilizados en la misma proporción. En relación al número de alumnos que han sido formados en SAP la mayoría de los encuestados indicaron la formación a entre 30 y 40 alumnos, o a más de 50.

\subsection{Encuestas de opinión alumnado}

Las encuestas al alumnado disponibles corresponden a la asignatura "30491- Planificación Empresarial (ERP's)" del Máster Universitario en Dirección y Gestión de Proyectos, con un total de 28 alumnos matriculados en el presente curso 2013-2014, de los cuales cumplimentaron la encuesta 13 .

En base a los resultados obtenidos de la consulta realizada (ver Fig. 6) es posible afirmar que más de la mitad de los alumnos conocían el sistema SAP, si bien ninguno de ellos había tenido acceso a él previamente. Además prácticamente la totalidad de los encuestados consideran que las prácticas realizadas con SAP les han ayudado a entender mejor la asignatura. 


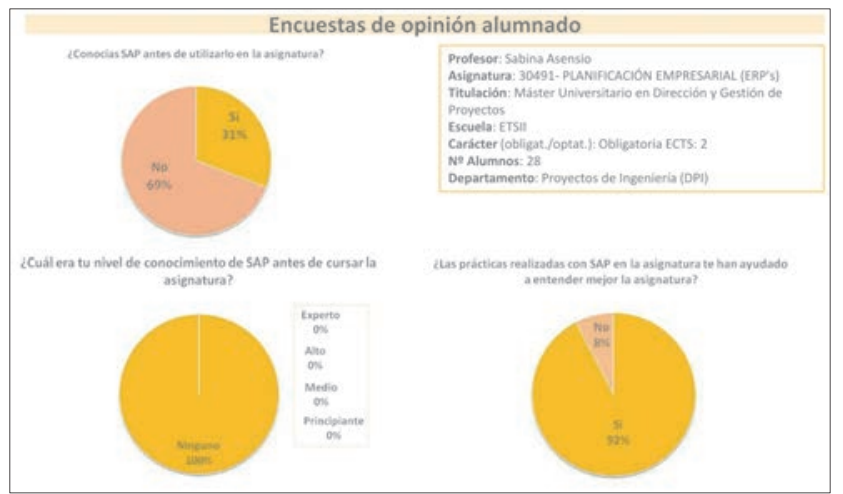

Fig.6 Encuestas de opinión alumnado (I). (03/04/2014, 13 respuestas).

Por otra parte, la gran mayoría de los alumnos (92\%) valoran la docencia de SAP en la asignatura positivamente y la recomiendan para cursos futuros (92\%). Los alumnos también consideran mayoritariamente que el material utilizado es bueno, dicho material corresponde al proporcionado por SAP University Alliances en el curso "SAP Introduction Week"

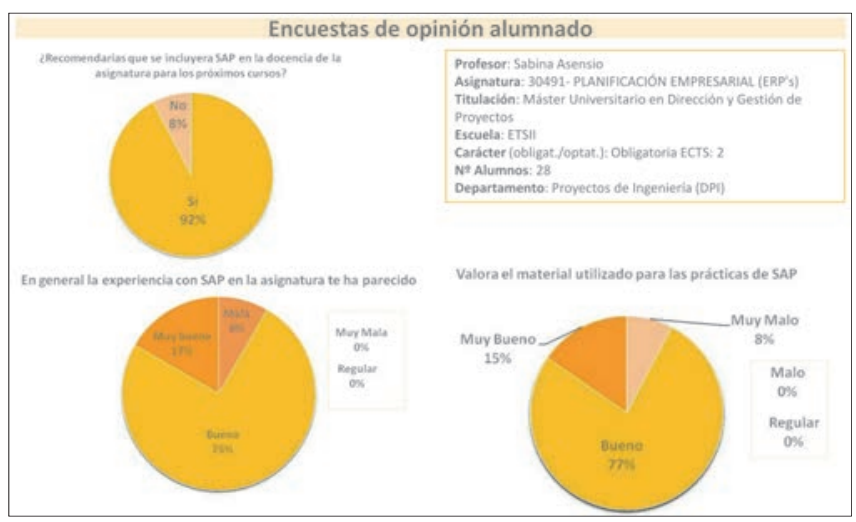

Fig.7 Encuestas de opinión alumnado (II). (03/04/2014, 13 respuestas)

En relación al ámbito laboral, casi la totalidad de los alumnos encuestados señalan que estarían interesados en seguir formándose en SAP después de la asignatura, y consideran que lo aprendido sobre SAP les puede ayudar en a la búsqueda de empleo, por lo cual lo han incluido en sus currículums profesionales. 


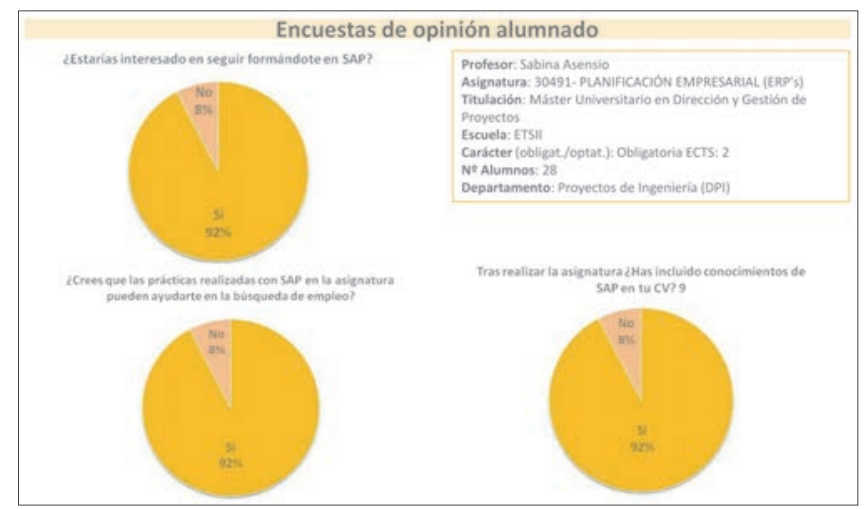

Fig.8 Encuestas de opinión alumnado (III). (03/04/2014, 13 respuestas)

\subsection{Líneas futuras planteadas}

Como acciones futuras del proyecto SAP UA UPV a destacar se encuentran la ampliación de la formación en el sistema SAP del profesorado mediante un curso intensivo TERP10 para formación de profesores (80 horas, Julio 2014). Hasta la fecha se han matriculado un total de 18 profesores pertenecientes a SAP UA UPV.

Además, se pretende continuar tanto con la difusión del proyecto como con la recogida de evidencias en forma de encuestas al profesorado y al alumnado para todas las asignaturas implicadas.

Por otra parte se han iniciado los primero pasos para la realización en Julio de 2015 del " $1^{\text {st }}$ Sap University Alliances UPV Conference".

\section{Conclusiones}

En base a las evidencias recogidas es posible afirmar que el proyecto SAP UA UPV ha resultado una experiencia positiva para el curso 2013-2014, tanto para los docentes como para los alumnos. A lo largo del curso se han logrado nuevas incorporaciones de docentes al proyecto, al tiempo que los profesores ya integrados han expresado mayoritariamente su satisfacción con la experiencia su intención de continuar en el futuro. Además elproyecto ha favorecido y potenciado la colaboración inter-departamental y el desarrollo de experiencias multi-disciplinares.

Desde la perspectiva de los alumnos se ha puesto de relieve la utilidad de la experiencia con SAP tanto para consolidar los conocimientos teóricos adquiridos en las asignaturas como en relación a la beneficio de lo aprendido para su futuro laboral.

\section{(c) EY-NC-ND 2014, Universitat Politècnica de València}

I Jornadas IN-RED (2014) 
Por último, cabe señalar que SAP University Alliances Iberia fomenta el modelo de implantación del sistema SAP en la UPV, al considerarlo exitoso y de referencia para otras instituciones que deseen integrarse en SAP UA. A este respecto desde la coordinación se han realizada diversos seminarios para exponer el modo de organización del profesorado a otras universidad interesadas en la misma iniciativa SAP University Alliances (AsensioCuesta, 2014).

\section{Referencias}

ASENSIO-CUESTA, S. (2013). "La integración de SAP University Alliances en la formación oficial de grado y postgrado: Experiencia en la Universitat Politècnica de València". Worksop About SAP University Alliances. Facultad de Económicas. Universidad de Málaga.

ASENSIO-CUESTA, S. (2014). "Guía para nuevas incorporaciones a SAP UA UPV”. En <http://sapuniversityalliancesupv.dpi.upv.es/> [Consulta: 16 de junio de 2014].

CHARLES, D., COMEAU, J. (2004) "Enterprise Integration in Business Education: Design and Outcomes of a Capstone ERP-based Undergraduate e-Business Management Course", Journal of Information Systems Education, vol.15, issue 3, p. 287-99.

GOMEZ VIEITES, A. (2009). Herramientas Practicas para la Gestión. España: Ra-ma.

HESTERMANN, C. Y PANG, C. (2010) "Magic Quadrant for Midmarket and Tier 2-Oriented ERP for Product-Centric Companies" en Gartner RAS Core Research Note G00205542, p. 5-30

PELLERIN, R. Y HADAYA, P. (2006) "An innovative framework for terracing reengineering and ERP implementation concepts”. Innovation Monograph II: Enterprise resource planning: Teaching and research, p. 13-20.

SAP COMMUNITY NETWORK. SAP University Alliances en América Latina y España <http://scn.sap.com/docs/DOC-31177> [Consulta: 16 de junio de 2014].

SAP UA UPV. ¿Cómo se integra SAP University Alliances en la UPV? <http://sapuniversityalliancesupv.dpi.upv.es/> [Consulta: 16 de junio de 2014].

SCHOltZ, B., CILliERS, C., CALITZ, A. (2012). "A Comprehensive, Competency-Based Education Framework Using Medium-Sized ERP Systems” en Academic journal article from Journal of Information Systems Education, vol. 23, issue 4.

WANG, M. (2011). "Integrating SAP to Information Systems Curriculum: Design and Delivery", Information Systems Education Journal. vol.9, issue 5, p.97-104 


\title{
Buenas y malas prácticas docentes según el punto de vista de los alumnos de grado
}

Juan A. Marin-Garcia ${ }^{a}$, Lorena Atarés

${ }^{a}$ ROGLE. Dpto. de Organización de Empresas. Universidad Politécnica de Valencia. Camino de Vera S/N 46022 Valencia. jamarin@omp.upv.es.

${ }^{\mathrm{b}}$ Departamento de Tecnología de Alimentos. Universidad Politécnica de Valencia. Camino de Vera S/N 46022 Valencia. loathue@tal.upv.es.

\begin{abstract}
In this paper we present a list of good and bad practices of teachers bases on students' perceptions in the subjects of the first half semester in Degree of Industrial Engineering of a Spanish university. The data were obtained through group meetings with students and delegates, as well as the open'responses to an on-line survey. We conducted one meeting with delegates from students and a separate meeting with the students in each course. The on-line survey has 87 students responses. We applied a qualitative methodology based on Grounded thoery to code and summarize the information. The data were processed using the ATLAS.ti program, as a measure of reliability, we tested the agreement between coders. The results allow us to identify the aspects that have bothered most to studentsduring the first semester of 2013-14.
\end{abstract}

Keywords: best teaching practices; positive aspects; areas for improvement; Industrial Engineering; Higher Education; qualitative.

\section{Resumen}

En este artículo presentamos un listado de buenas y malas prácticas docentes a partir de las percepciones de los alumnos de las asignaturas del primer semestre de las asignaturas del Grado de Ingeniería de Organizacion Industrial de una universidad española. Los datos se han obtenido a través de reuniones en grupo con los alumnos y sus delegados, así como de las repuestas abiertas a una encuesta on-line. Hemos realizado 5 reuniones con los alumnos. Una con los delegados de los cursos $1^{o}$ a $4^{o}$ y una reunión 
diferente con los alumno de cada curso. La encuesta on-line la han respondido 87 alumnos. Hemos aplicado una metodología cualitativa basada en Grounded thoery para codificar y resumir la información contenida en las actas de las reuniones y las preguntas abiertas. Los datos han sido procesados con el programa Atlas.Ti y, como medida de fiabilidad, hemos comprobado el acuerdo entre los codificadores. Los resultados nos permiten identificar los aspectos que más han valorado y más han molestado a los estudiantes durante el primer semestre del curso 2013-14.

Palabras clave: buenas prácticas docentes; aspectos positivos; aspectos a mejorar; docencia de grado; ingeniería de organización industrial; cualitativo.

\section{Introducción}

La satisfacción del alumnado es que es un concepto fundamental en la educación puesto que condiciona la motivación para aprender, los resultados que se obtienen e incluso, la permanencia en el centro de estudio (Alves y Raposo, 2009; Elliott y Shin, 2002; GiraldoO'Meara et al., 2014; Harvey, 1995; Young et al., 2007).

Existe cierta información acerca de los factores que están relacionados con la satisfacción de los estudiantes. Es decir, las cosas que les suelen gustar de las asiganturas que cursan y las cosas que no. Aunque mucha de esta investigación está centrada en experiencias de grupos muy reducidos de estudiantes, normalmente provenientes de universidades del mundo anglosajón sin una replicación de los estudios en otras culturas o contextos que permitan su generalización.

Así, por ejemplo, suelen valorar positivamente la aplicación práctica de los contenidos en contextos relevantes (Ali et al., 2009; Burke et al., 2005; Lima et al., 2007; Nafalski et al., 2001), que los profesores les den feedback acerca de su progresión en el aprendizaje (Drew, 2001; Kan Ma et al., 2013; Weaver, 2006) o que la actitud de los profesores muestre interés hacia la persona del alumno y su aprendizaje (Gremler y McCollough, 2002).

Por otra parte, suelen considerar muy negativamente que la distribución de la carga de trabajo no esté repartida adecuadamente durante el semestre o que diferentes asignaturas no se coordinen y soliciten entregas o tareas que se solapan en el tiempo con las encargadas por otros profesores (Dee, 2007; Kember, 2004). O que los procedimientos de evaluación no se adecúen a los contenidos, normas o niveles de docencia impartida (Gijbels y Dochy, 2006; Knight, 2004; Kniveton, 1996; Struyven et al., 2005). 
Sin embargo, no está claro que todos los alumnos tengan una visión compartida acerca del tipo de participación o implicación deseada en la organización de su aprendizaje (Oliver et al., 2008; Weaver y Jiang, 2005), del uso de metodologías activas (Gijbels et al., 2008; Machemer y Crawford, 2007; Nijhuis et al., 2008) o del uso de recursos tecnológicos para el aprendizaje (Neo y Neo, 2009; Tang y Austin, 2009).

\section{Objetivos}

Con este trabajo pretendemos identificar los aspectos que más gustan y más disgustan a los alumnos respecto a la docencia de las asignaturas en las que han participado durante un semestre de su formación universitaria. De este modo podemos comprobar si los alumnos sólo se fijan en aspectos negativos o si, por el contrario, también son capaces de evocar aspectos positivos en su experiencia durante el periodo lectivo. Por otra parte, resumir estos puntos de vista del alumno, permitirá a los profesores comprender mejor el modo de pensar y de sentir de los estudiantes. De este modo, pueden identificar si algo de lo que vamos a exponer afecta a su docencia y reflexionar sobre si les interesa introducir alguna modificación en su práctica diaria. Bien para evitar/reducir situaciones que parecen ser fuente clara de insatisfacción en los estudiantes, o bien para potenciar aquellos aspectos que parecen satisfacer o entusiasmar a los estudiantes.

\section{Desarrollo de la innovación}

Los datos provienen de los alumnos del Grado de Ingeniería de Organización Industrial (ETSII) de la Universidad Politécnica de Valencia. La toma de datos se realizó en febrero de 2014, pidiendo su opinión sobre las asignaturas del primer semestre del curso académico. El Grado tiene 351 alumnos matriculados en el curso 2013-14. A todos ellos se les mandó por correo electrónico un enlace a una encuesta on-line anónima, sin posibilidad de recordatorio personalizado a los alumnos que no la rellenaban. Se mandó un correo de recordatorio a los 10 días del primero. En total han respondido 87 alumnos a la encuesta (25\%). La encuesta tenía 3 preguntas de clasificación de los alumnos y dos preguntas abiertas que son el objeto de análisis de esta comunicación:

- $\quad$ "Comenta aspectos positivos del primer semestre 2013-14. Sé lo más explícito que puedas, indicando los motivos o "'evidencias"" por los que lo valoras así"

- Comenta cosas a mejorar en el grado del primer semestre 2013-14. Sé lo más explícito que puedas, indicando los motivos o ""evidencias"" por los que lo valoras así"

Estas preguntas están basadas en la técnica de incidentes críticos (Critical Incident Technique), que es usada con frecuencia en investigaciones sobre calidad de servicios o en evaluación del desempeño de recursos humanos (Bryman y Bell, 2011; Gremler, 2004).

\section{(c)) EY-NC-ND 2014, Universitat Politècnica de València}

I Jornadas IN-RED (2014) 
Esta técnica consiste en preguntar a los encuestados que describan con detalle conductas humanas observables donde las consecuencias son suficientemente claras para delimitar tanto la conducta como sus consecuencias. Una de sus variantes de aplicación consiste en pedir a las personas participantes que digan los aspectos que más les han hecho sentir bien o mal durante su trabajo, o su experiencia como clientes de un servicio concreto. En nuestro caso, les solicitábamos que se centraran en las asignaturas que habían cursado en el semestre que acababa de terminar.

Las contestaciones a los 87 cuestionarios han creado un corpus de 4251 palabras que hemos codificado con el siguiente proceso (Charmaz, 2006; Cutcliffe, 2005; Gremler, 2004): en primer lugar hemos usado una codificación de texto libre, identificando fragmentos de texto y etiquetándolos con una o dos palabras identificativas (codificación inicial). En el proceso hemos intervenido los dos autores de la comunicación de manera independiente. En total hemos identificado 286 citas (fragmentos de texto codificados). 125 por un autor y 161 por otro. A continuación hemos puesto en común los códigos y hemos resuelto los sinónimos (aquellos que representaban la misma idea) verbalizando qué cosas etiquetábamos cuando usábamos esos códigos (depuración de categorías). Del total de 45 códigos identificados, 28 han sido usados por ambos codificadores. Mientras realizábamos la codificación inicial y la depuración de categorías anotábamos las relaciones entre códigos que emergían de las opiniones de los encuestados o de la proximidad manifiesta entre una causa y su efecto. Todo el proceso ha sido apoyado con el uso del software Atlas-Ti vers 7.

Para comprobar la fiabilidad entre codificadores hemos exportado los datos a la plataforma Coding Analysis Toolkit (http://cat.ucsur.pitt.edu/). El Alfa de Kripendorf media de los 28 códigos comunes fue de 0,64 y el índice Kapa promedio de 0,40.

Adicionalmente se realizaron 5 reuniones con los alumnos para contrastar los resultados de la encuesta on-line y contrastar si las opiniones eran minoritarias o compartidas por un número elevado de alumnos. Una de las reuniones fue con los delegados de los cursos $1^{\circ} \mathrm{a}$ $4^{\mathrm{o}}$ y las otras, una reunión diferente con los alumno de cada curso.

\section{Resultados}

A continuación resumimos los principales resultados obtenidos tras analizar el conjunto de datos recogidos.

\subsection{Malas prácticas}

La tabla 1 muestra la lista de códigos utilizada para etiquetar los comentarios negativos de los alumnos, así como el número de veces (n) que aparece cada uno de estos códigos en el corpus trabajado. 
Tabla 1. Lista de códigos negativos y número de citas de cada uno (n)

\begin{tabular}{llll}
\hline Código & $n$ & Código & $n$ \\
\hline Baja motivación para el alumno & 16 & Impuntualidad & 3 \\
Calendario de exámenes & 1 & Masificación & 4 \\
Calidad del profesorado & 17 & Matrícula & 1 \\
Carga de trabajo & 6 & Metodología & 11 \\
Contenidos no interesantes & 2 & No se controla a los profesores & 5 \\
Desajuste explicado vs evaluado & 12 & Plan de estudios & 4 \\
Descoordinación & 7 & Poca aplicación práctica de contenidos & 7 \\
Desinterés del profesorado & $\mathbf{2 4}$ & Poner trabas & 2 \\
Desorientación & 2 & Recursos de aprendizaje. Baja calidad & 8 \\
Evaluación. Cumplir normativa & 7 & Recursos de aprendizaje. No disponibles & $\mathbf{2 4}$ \\
Evaluación. Método & 4 & Relación esfuerzo/resultado & 3 \\
Falta de respeto al alumno & 3 & Represalias & 1 \\
Horario no compactado & 1 & Resultados académicos & $\mathbf{2 4}$ \\
Impotencia & 4 & Silencio administrativo & 8 \\
\hline
\end{tabular}

Como puede observarse, los aspectos negativos que señalaron los alumnos cubrieron áreas muy diversas, tales como la actuación del profesorado (calidad, desinterés, impuntualidad, ...), los recursos de aprendizaje propuestos (calidad, disponibilidad), aspectos organizativos (carga de trabajo, masificación...), otros más personales (baja motivación, impotencia...), así como cuestiones administrativas y de funcionamiento (horarios, calendarios, matrículas...). Además, manifestaron repetidamente su insatisfacción en cuanto a sus resultados académicos y a la relación entre el esfuerzo invertido y el resultado obtenido.

Aunque en principio pueda resultar llamativo el gran número de citas del código "Desinterés del profesorado" es importante señalar que prácticamente todas ellas se relacionan con una única asignatura. Lo mismo ocurre para los códigos "Recursos de aprendizaje. No disponibles" y "Calidad del profesorado".

A modo de conclusión de la lista de códigos negativos y la frecuencia de los mismos, se puede afirmar que la inmensa mayoría de las quejas de los alumnos tuvieron relación con el funcionamiento de una asignatura en particular. Al margen de esto, los alumnos mostraron preocupación por la masificación en las aulas (sobre todo en las prácticas), la descoordinación (entre profesores de la misma asignatura, o bien entre prácticas y teoría) y

\section{(c)) EY-NC-ND 2014, Universitat Politècnica de València}

I Jornadas IN-RED (2014) 
la poca aplicación práctica de algunos contenidos (sobre todo, en alumnos de los últimos cursos).

En cuanto a la interrelación entre los códigos que indican las malas prácticas señaladas por los alumnos, la figura 1 muestra el mapa obtenido.

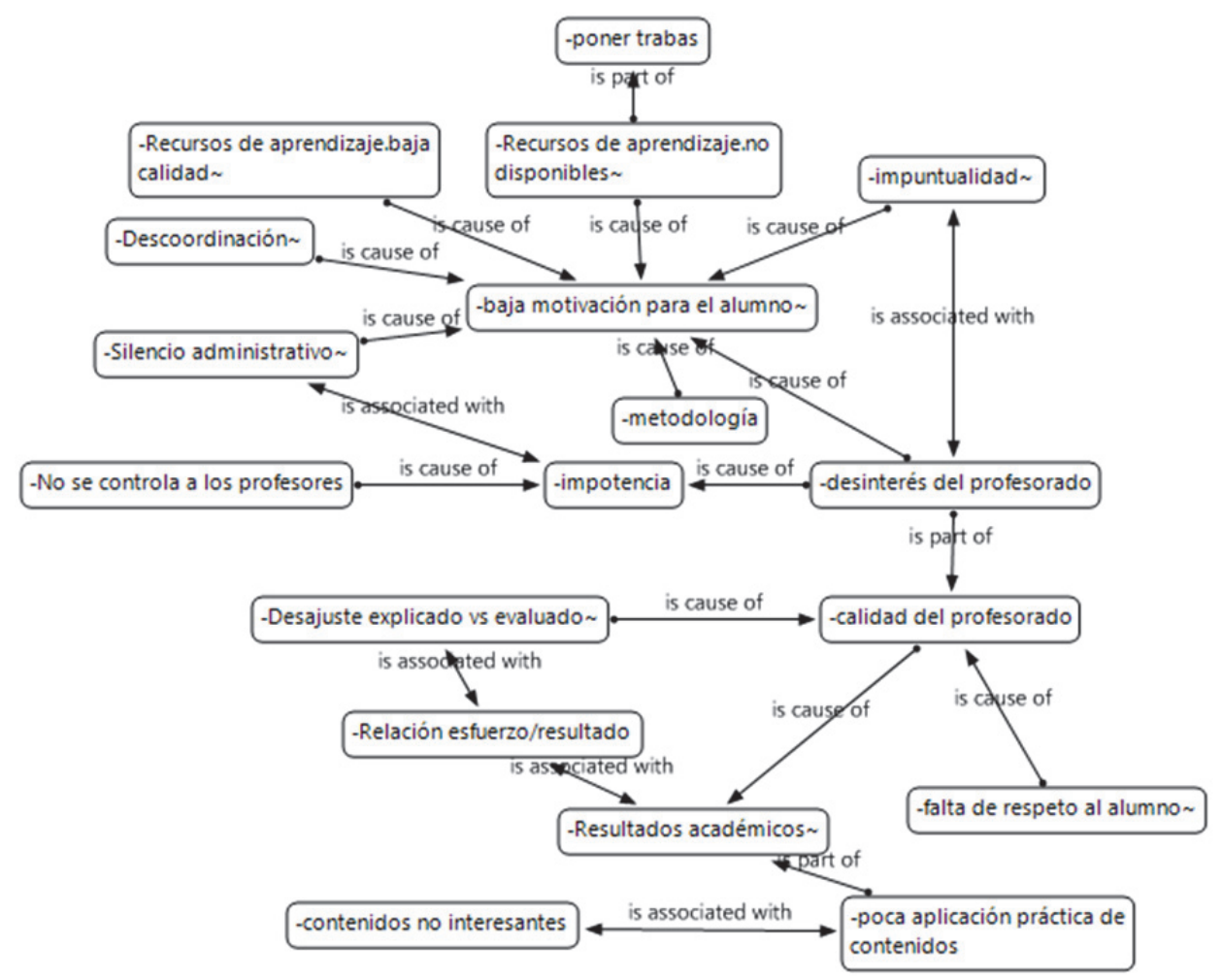

Fig. 1 Red de interrelación de las malas prácticas señaladas por los alumnos

El análisis de este mapa permite llegar a algunas reflexiones interesantes. Por una parte, se observa que diferentes causas influyen en la motivación de los alumnos de manera negativa. Estas causas están relacionadas con aspectos diversos del proceso de enseñanza aprendizaje, tales como los recursos de aprendizaje utilizados, la actuación del profesor o el silencio administrativo ante las quejas reiteradas por malas prácticas de un docente. Esto indica que mantener a un alumno motivado es un logro complejo que conlleva la implicación de diferentes actores, entre los cuales se encuentra, obviamente, el profesor. Así pues, la motivación del alumno se ve afectada por el desinterés del profesorado, que a su vez afecta a la calidad del mismo.

(c)) EY-NC-ND 2014, Universitat Politècnica de València

I Jornadas IN-RED (2014) 
Por otro lado, la incoherencia entre el contenido de las clases y la evaluación, y las faltas de respeto al alumnado también tendrían un impacto negativo sobre la calidad del profesorado. Ésta a su vez tiene consecuencias sobre los resultados académicos de los alumnos, además de aspectos negativos relacionados con los contenidos.

Por otra parte, hubo 10 códigos desvinculados de esta red: "represalias", "calendario de exámenes", "matricula", "evaluación incumplir normativa", "horario no compactado", "desorientación", "masificación”, "evaluación método", "carga de trabajo" y "plan de estudios".

\subsection{Buenas prácticas}

La tabla 2 muestra la lista de códigos utilizada para etiquetar los comentarios positivos de los alumnos, así como el número de citas (n) de cada uno de estos códigos.

Tabla 2. Lista de códigos positivos y número de citas de cada uno (n)

\begin{tabular}{llll}
\hline Código & $n$ & Código & $n$ \\
\hline Adaptación progresiva & 1 & Interés mostrado por el profesor & 5 \\
Aplicación práctica & $\mathbf{2 5}$ & Metodología & 3 \\
Buen ambiente & 2 & Motivación para el alumnado & 4 \\
Calidad del profesor & $\mathbf{1 7}$ & Organización & 5 \\
Contenido de prácticas & 2 & Plan de estudios & 7 \\
Contenido interesante & 12 & Resultados académicos & 6 \\
Distribución carga de trabajo & 8 & Satisfacción general & 1 \\
Escuchar al alumno & 1 & Tecnologías ayudan a aprender & 2 \\
Evaluación. Flexibilidad & 2 & & \\
\hline
\end{tabular}

Del mismo modo que para las malas prácticas, el nivel de satisfacción de los alumnos con su grado viene motivado por causas muy diversas relacionadas con diferentes aspectos. Éstos incluyen al profesorado, el plan de estudios, los resultados académicos, el ambiente universitario y los contenidos estudiados (que los alumnos describen como interesantes y aplicables).

En cuanto a las buenas prácticas indicadas por los alumnos, la figura 2 muestra el mapa obtenido.

\section{(cc) BY-NC-ND 2014, Universitat Politècnica de València}

I Jornadas IN-RED (2014) 


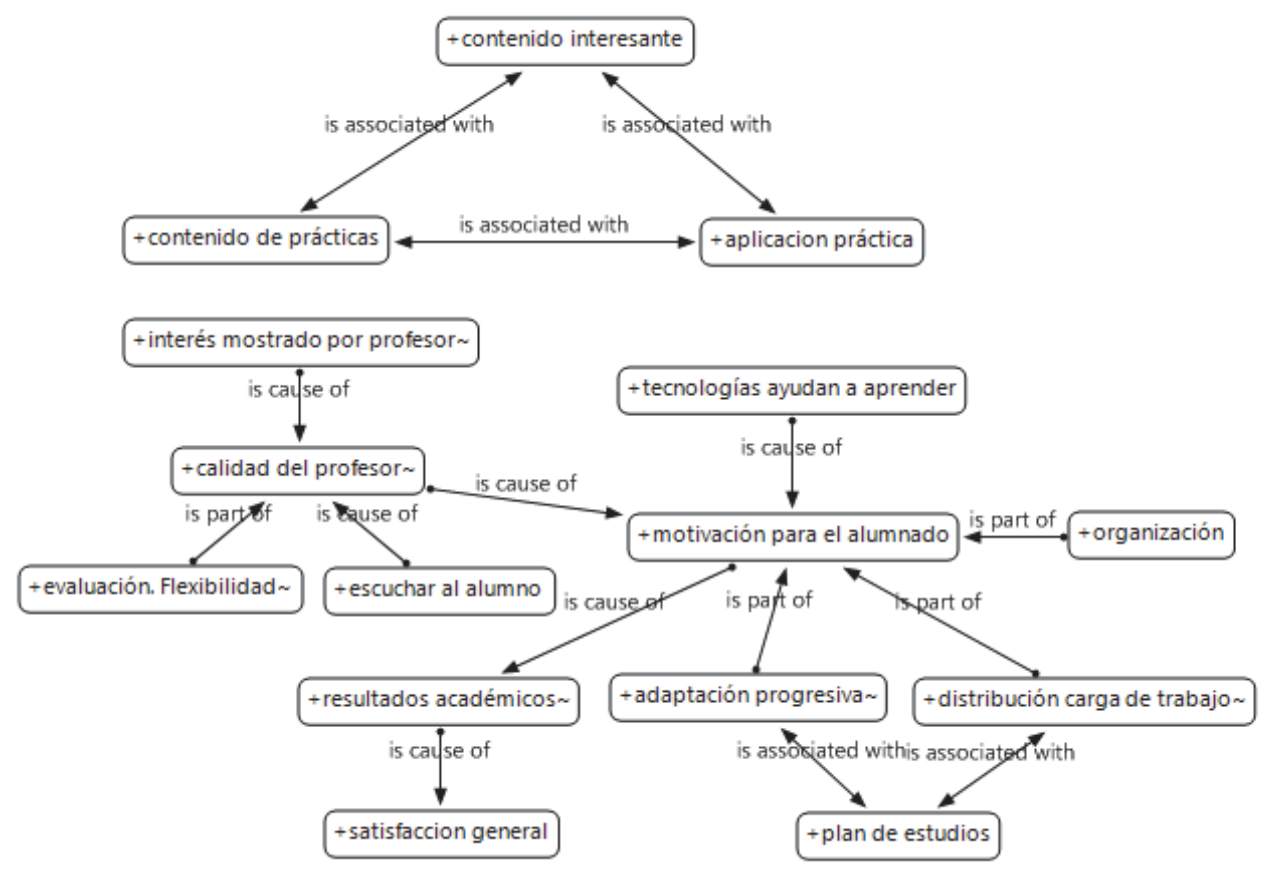

Fig. 2 Red de interrelación de las buenas prácticas señaladas por los alumnos

En este caso, los códigos relacionados con los contenidos impartidos (interés para el alumno, aplicabilidad) aparecieron desvinculados del resto y asociados con la aplicación práctica de los mismos.

Por otra parte se observó la interrelación entre el resto de códigos positivos. En este caso, vemos que la motivación del alumnado es de nuevo influida por los resultados académicos, las tecnologías que apoyan el aprendizaje, la organización etc. De nuevo continúa siendo relevante la actuación del profesor por su papel motivador para el alumno. Se valora que el profesor ofrezca opciones para subir nota (flexibilidad en la evaluación), que muestre interés y que escuche a sus alumnos.

Diferentes aspectos de organización del título son además positivamente valorados por los alumnos, entre los cuales se encuentra la adaptación progresiva de los contenidos y una buena distribución de la carga de trabajo.

Solamente dos códigos ("buen ambiente" y "metodología") quedan desvinculados del resto.

(c)) EY-NC-ND 2014, Universitat Politècnica de València

I Jornadas IN-RED (2014) 


\section{Conclusiones}

La utilización de una encuesta de opinión a los alumnos sirvió para recoger información general acerca del funcionamiento del Grado en Ingeniería de Organización Industrial. A través del planteamiento de preguntas abiertas a una muestra de alumnos se pudo obtener información acerca de su nivel de satisfacción y principales inquietudes relacionadas con sus estudios.

Atlas.ti supuso una herramienta útil para la codificación de las respuestas de los alumnos. Se utilizaron un total de 45 códigos, resultado de la fusión de dos análisis independientes. De ellos, 17 señalaban aspectos positivos y 28 aspectos negativos indicados por los alumnos. En algunos casos, se observó la necesidad de utilizar códigos paralelos para señalar aspectos positivos y negativos, como fue el caso de calidad del profesorado, Interés/desinterés del profesor, motivación/desmotivación para el alumno... En estos "códigos paralelos" se observó una mayor frecuencia de comentarios negativos frente a positivos. Tal es el caso de "Baja motivación para el alumno", con 16 citas, frente a las 4 de "Motivación para el alumnado". Este desequilibrio entre comentarios positivos y negativos no debe considerarse un indicador del descontento de los alumnos, puesto que el nivel de descontento necesario para emitir una queja es siempre menor que el nivel de satisfacción para emitir un halago. Además, bajo el supuesto de que "las cosas deberían funcionar bien", recoger información de un colectivo supone, sobre todo, tratar de identificar los aspectos mejorables, que tenderán a revelarse con mayor facilidad que todo aquello que ya funciona bien.

\section{Bibliografía}

ALI, A.; TARIQ, R. H.; TOPPING, J. (2009): Students' Perception of University Teaching Behaviours. Teaching in Higher Education, 14 (6): 631-647.

ALVES, H.; RAPOSO, M. (2009): The Measurement of the Construct Satisfaction in Higher Education. Service Industries Journal, 29 (2): 203-218.

BRYMAN, A.; BELL, E. (2011). Business Research Methods. USA: Oxford University Press.

BURKE, V.; JONES, I.; DOHERTY, M. (2005): Analysing Student Perceptions of Transferable Skills Via Undergraduate Degree Programmes. Active Learning in Higher Education, 6 (2): 132-144.

CHARMAZ, K. (2006). Constructing grounded theory. A practical guide through qualitative analysis. London: SAGE.

CUTCLIFFE, J. R. (2005): Adapt or Adopt: Developing and Transgressing the Methodological Boundaries of Grounded Theory. Journal of Advanced Nursing, 21 (4): 421. 
DEE, K. C. (2007): Student Perceptions of High Course Workloads Are Not Associated With Poor Student Evaluations of Instructor Performance. Journal of Engineering Education, 96 (1): 69-78.

DREW, S. (2001): Student Perceptions of What Helps Them Learn and Develop in Higher Education. Teaching in Higher Education, 6 (3): 309-331.

ELLIOTT, K. M.; SHIN, D. (2002): Student Satisfaction: an Alternative Approach to Assessing This Important Concept. Journal of Higher Education Policy \& Management, 24 (2): 197-209.

GIJBELS, D.; DOCHY, F. (2006): Students' Assessment Preferences and Approaches to Learning: Can Formative Assessment Make a Difference? Educational Studies, 32 (4): 399409.

GIJBELS, D.; SEGERS, M.; STRUYF, E. (2008): Constructivist Learning Environments and the (Im)Possibility to Change Students' Perceptions of Assessment Demands and Approaches to Learning. Instructional Science, 36 (5-6): 431-443.

GIRALDO-O'MEARA, M.; MARIN-GARCIA, J. A.; MARTÍNEZ-GÓMEZ, M. (2014): Validation of the JDS Satisfaction Scales Applied to Educational University Environments. Journal of Industrial Engineering and Management, 7 (1): 72-99.

GREMLER, D. D. (2004): The Critical Incident Technique in Service Research. Journal of Service Research, 7 (1): 65-89.

GREMLER, D. D.; MCCOLlOUGH, M. A. (2002): Student Satisfaction Guarantees: An Empirical Examination of Attitudes, Antecedents, and Consequences. Journal of Marketing Education, 24 (2): 150-160.

HARVEY, L. (1995): Student Satisfaction. The New Review of Academic Librarianship, 1: $161-173$.

KAN MA, H.; MIN, C.; NEVILLE, A.; EVA, K. (2013): How Good Is Good? Students and Assessors' Perceptions of Qualitative Markers of Performance. Teaching and Learning in Medicine, 25 (1): 15-23.

KEMBER, D. (2004): Interpreting Student Workload and the Factors Which Shape Students' Perceptions of Their Workload. Studies in Higher Education, 29 (2): 165-184.

KNIGHT, J. (2004): Comparison of Student Perception and Performance in Individual and Group Assessments in Practical Classes. Journal of Geography in Higher Education, 28 (1): 63-81.

KNIVETON, B. H. (1996): Student Perceptions of Assessment Methods. Assessment \& Evaluation in Higher Education, 21 (3): 229-237.

LIMA, R. M.; CARVALHO, D.; FLORES, M. A.; VAN HATTUM-JANSSEN, N. (2007): A Case Study on Project Led Education in Engineering: Students' and Teachers' Perceptions. European Journal of Engineering Education, 32 (3): 337-347.

MACHEMER, P. L.; CRAWFORD, P. (2007): Student Perceptions of Active Learning in a Large Cross-Disciplinary Classroom. Active Learning in Higher Education, 8 (1): 9-30.

NAFALSKI, A.; MCDERMOTT, K. J.; GÖL, Ö. (2001): Innovation in Engineering Education at the University of South Australia. Global Journal of Engineering Education, JAM-PDF (1): 87-98.

NEO, M.; NEO, T. K. (2009): Engaging Students in Multimedia-Mediated Constructivist Learning - Students' Perceptions. Educational Technology \& Society, 12 (2): 254-266.

NIJHUIS, J.; SEGERS, M.; GIJSELAERS, W. (2008): The Extent of Variability in Learning Strategies and Students' Perceptions of the Learning Environment. Learning and Instruction, 18 (2): 121-134. 
OLIVER, B.; TUCKER, B.; GUPTA, R.; YEO, S. (2008): EVALUate: an Evaluation Instrument for Measuring Students' Perceptions of Their Engagement and Learning Outcomes. Assessment \& Evaluation in Higher Education, 33 (6): 619-630.

STRUYVEN, K.; DOCHY, F.; JANSSENS, S. (2005): Students' Perceptions About Evaluation and Assessment in Higher Education: a Review. Assessment \& Evaluation in Higher Education, 30 (4): 325-342.

TANG, T. L. P.; AUSTIN, M. J. (2009): Students' Perceptions of Teaching Technologies, Application of Technologies, and Academic Performance. Computers \& Education, 53 (4): 1241-1255.

WEAVER, M. (2006): Do Students Value Feedback? Student Perceptions of Tutors' Written Responses. Assessment \& Evaluation in Higher Education, 31 (3): 379-394.

WEAVER, R.; JIANG, Q. (2005): Classroom Organization and Participation: College Student's Perceptions. The Journal of Higher Education, 76 (5): 570-601.

YOUNG, P.; GLOGOWSKA, M.; LOCKYER, L. (2007): Conceptions of Early Leaving: a Comparison of the Views of Teaching Staff and Students. Active Learning in Higher Education, 8 (3): 275-287.

\section{(c) EY-NC-ND 2014, Universitat Politècnica de València}

I Jornadas IN-RED (2014) 


\title{
Evaluación y valoración de nuevos contenidos docentes para la adaptación al EEES
}

\section{Maite Cháfer}

${ }^{a}$ Universitat Politècnica de Valencia, Instituto de Ingeniería de Alimentos para el Desarrollo. mtchafer@tal.upv.es

\begin{abstract}
In this paper how to address agroecological contents applied to food industry in a new university subject are shown. Internal students surveys were conducted to evaluate and assess the degree of acceptance and satisfaction with subject. The questionnaire takes into account the following aspects of the course: previous knowledge of the students, satisfaction with the participation of experts, knowledge acquired and applicability. The participation of students in this survey was anonymous and voluntary, and $70 \%$ was achieved. The results showed that most of students had no prior knowledge about this topic. The content of the course and how it had been addressed were well evaluated and the contribution from the experts was found to be very satisfactory. Around 93\% of the enrolled students obtained a mark higher than 7 (out of 10), and the 43\%, over 9; thus being a good indicator of the degree of learning achieved by the students.
\end{abstract}

Keywords: organic, surveys, ratings, competencies, methodology, evaluation

\footnotetext{
Resumen

En el presente trabajo se plantea la forma de abordar contenidos agroecológicos aplicados a la industria alimentaria en una asignatura nueva en el ámbito universitario. Se realizaron encuestas internas a los estudiantes matriculados para evaluar y valorar el grado de aceptación y satisfacción en cuanto a los contenidos tratados y la forma de abordarlos. El cuestionario trataba de valorar los siguientes aspectos sobre los contenidos de la asignatura: conocimientos previos de los estudiantes, satisfacción entorno a
}

(cc) EY-NC-ND 2014, Universitat Politècnica de València

I Jornadas In-Red (2014) 
la participación de expertos, conocimientos adquiridos con los contenidos tratados y aplicabilidad de los contenidos fuera del ámbito universitario y en la búsqueda de empleo. La participación de los alumnos en este proceso fue anónima, voluntaria y alcanzó el 70\%. La mayoría de los estudiantes que rellenaron el cuestionario no tenían conocimientos previos sobre los contenidos. En general, valoraron mayoritariamente y de forma muy positiva tanto los contenidos como la forma de abordarlos, destacando su gran interés por la participación de los expertos externos. Un 93\% de los matriculados en la asignatura han obtenido una nota global mayor a 7 (sobre 10) y un 43\% por encima de 9 (sobre 10), lo que es un buen indicador del grado de aprendizaje alcanzado por los estudiantes.

Palabras clave: ecológico, encuestas, calificaciones competencias, metodología, evaluación

\section{Introducción}

España es el primer país europeo en producción ecológica y uno de los primeros a nivel mundial. Pese al gran auge y potencial de este sector, los sistemas de producción en campo han sido los más analizados y estudiados, mientras que la industrialización de esta materia prima no se ha desarrollado al mismo nivel. La formación especializada e investigación específicas, especialmente en el ámbito universitario, pueden ser una de las claves para el adecuado desarrollo de este sector en nuestro país (Cháfer, M.). Además, permitirá mejorar nuestra adaptación al Espacio Europeo de Educación Superior (EEES). Como señala Tricio (2012) "Las universidades, como instituciones orientadas a la investigación, la formación para el mundo laboral y la generación de conciencia crítica, tienen una gran responsabilidad ante los problemas ambientales y como son uno de los motores más potentes de cambio social su ejemplo debe adelantarse a la sociedad para promover el necesario y urgente giro hacia la sostenibilidad ambiental". Para ello, se deben planificar y desarrollar programas de formación con este enfoque. En el presente trabajo se plantea la forma de abordar contenidos agroecológicos en una asignatura nueva en el ámbito universitario y a impartir en un Master del área de Tecnología de Alimentos. Se pretende que el alumno-a adquiera competencias y habilidades entorno a la producción de alimentos transformados desde una concepción integral de los procesos, garantizando la máxima calidad y seguridad alimentaria, y que esto permita una formación diferenciada del alumno-a en cuanto a producción ecológica para que sea lo más aplicada a la realidad del mercado y fomentando el trabajo autónomo del alumno. 


\section{Objetivo}

El objetivo de este trabajo fue conocer la valoración de los alumnos-as acerca de los contenidos tratados en la asignatura y la forma en la que se abordaron, y así poder implantar mejoras en la misma que estén lo más adaptadas posible a las necesidades del alumno-a.

\section{Desarrollo de la innovación}

Los contenidos del curso se organizaron, teniendo en cuenta como principios tratar unos contenidos teóricos mínimos y fortalecer los mismos con experiencias prácticas variadas.

- Sesiones de laboratorio sobre el control de calidad de los productos ecológicos de una industria concreta

- Trabajos prácticos por grupos sobre un tipo de industria específica en la que se van a aplicar los conceptos teóricos abordados en la asignatura

- Seminarios con expertos de la producción ecológica, industria y otros como asesoramiento, promoción y certificación

- Visitas a industrias relacionadas

Se realizaron encuestas, en las que el alumno-a valoró de 1 a 3 (1 nivel bajo, 2 nivel medio y 3 nivel alto) acerca de cuestiones agrupadas en los siguientes bloques de información:

Bloque I. Conocimientos previos generales y específicos del alumno-a acerca de la materia de estudio.

Bloque II. Valoración de los contenidos teóricos y prácticos abordados, y si estos han servido para ampliar los conocimientos previos del alumno-a.

Bloque III. Satisfacción del alumno-a con la participación de expertos agrupados en los sectores básicos (industria, calidad y certificación)

Bloque IV. Aplicabilidad de los contenidos vistos al mercado laboral.

Además se contempló un apartado opcional de comentarios y sugerencias para cada uno de los aspectos valorados.

\section{Resultados de la innovación}

\subsection{Conocimientos previos}

(cc) EY-NC-ND 2014, Universitat Politècnica de València

I Jornadas IN-RED (2014) 
En la figura 1 se muestran los resultados obtenidos de la encuesta de opinión realizada a los estudiantes para las cuestiones del bloque I. El $60 \%$ de los alumnos-as tenían un conocimiento bajo de aspectos generales relacionados con la materia y un $40 \%$ tenía un conocimiento de nivel medio. En cuanto a los conocimientos específicos, el nivel bajo aumenta a un $80 \%$ y sólo un $20 \%$ tenían conocimientos de nivel medio. Estos conocimientos habían sido adquiridos fuera de la universidad, lo que pone de manifiesto la novedad de los contenidos en este ámbito. Esta situación además es generalizada en la mayoría de las CCAA de nuestro país. Sólo se han encontrado 3 ejemplos de formación universitaria relacionada con la materia en títulos de master, pero ningún ejemplo de formación específica en la que se aborden los contenidos previstos de la asignatura.

(a)

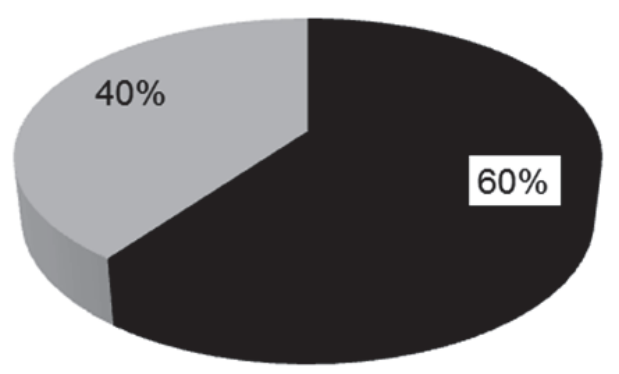

- Bajo

Medio (b)

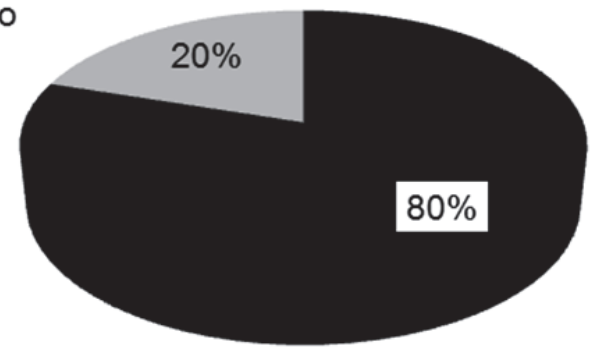

Figura 1. Nivel de conocimientos previos de los estudiantes en la materia: generales (a) y específicos (b).

\subsection{Valoración de contenidos}

La valoración de los contenidos teóricos (Figuras 2) fue en general buena y sólo un 10\% de los encuestados lo valoraron con un nivel bajo. Las sugerencias realizadas para este apartado, se resumen en general en la necesidad de:

- Dedicar más tiempo a unos temas específicos (certificación y aditivos)

- Aportar más bibliografía complementaria

En cuanto a los contenidos prácticos (Figuras 3), fueron en general, bien valorados y en especial los seminarios de expertos y las visitas a industrias del sector. Los alumnos-as sugirieron intentar incrementar el tiempo que se dedica a estas actividades por la gran oportunidad e interés que tienen. También obtuvo una buena valoración el trabajo por grupos, pese a la gran dificultad en la realización y a la gran inversión de tiempo que 
comentaron que representó para ellos-as. De esta actividad destacaron la gran aplicabilidad e interés. La actividad menos valorada fueron las sesiones de laboratorio. En este sentido, destacaron poco interés en el tipo de prácticas diseñadas para la materia y sugirieron algunas alternativas, que se contemplarán en las próximas ediciones.

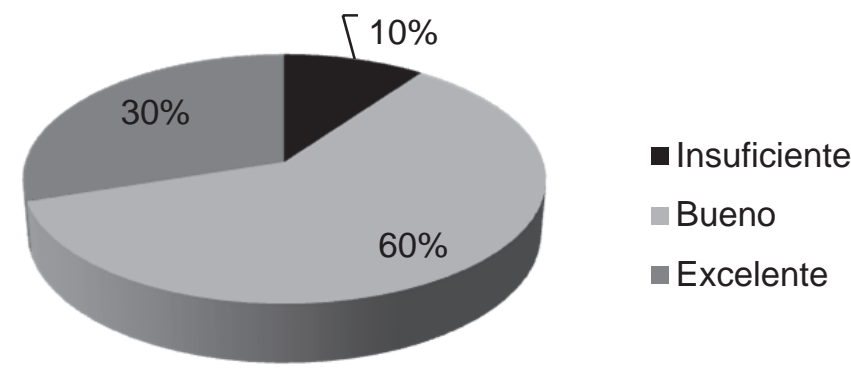

Figura 2. Valoración de los estudiantes de los contenidos teóricos del curso.

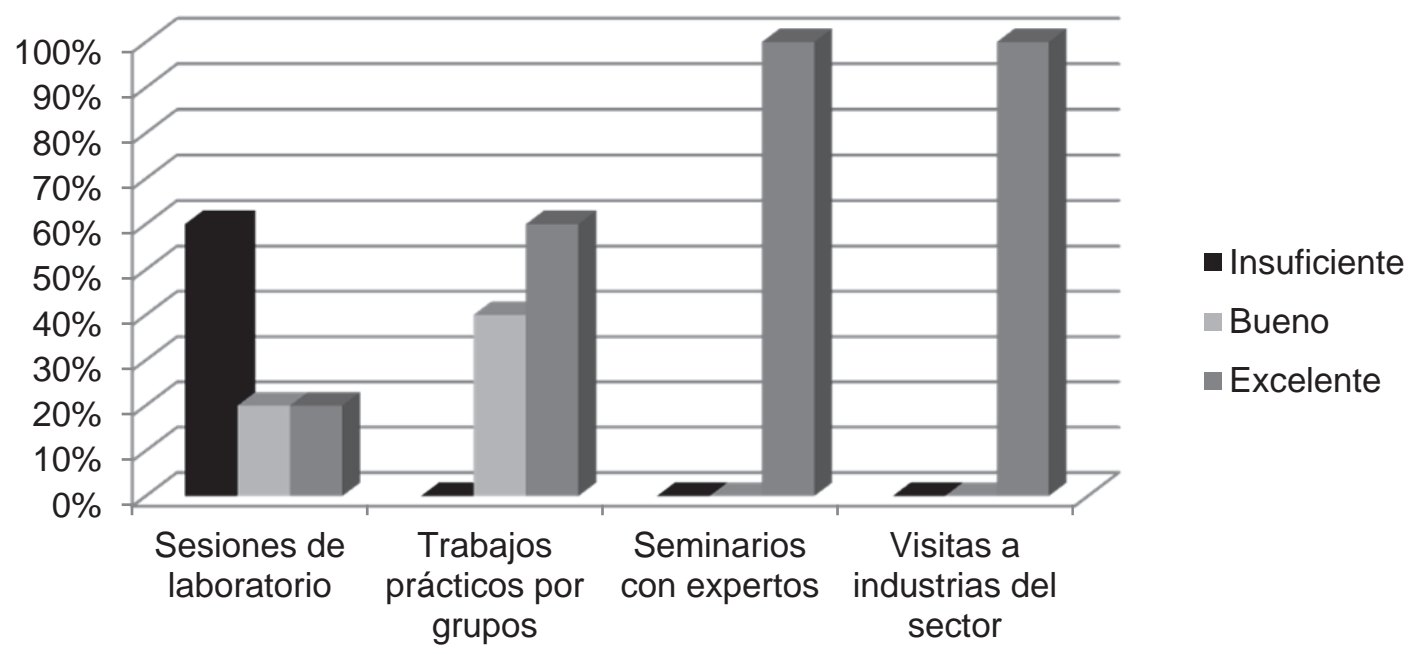

Figura 3. Valoración de los estudiantes de los contenidos prácticos del curso.

\section{(c)) EY-NC-ND 2014, Universitat Politècnica de València}

I Jornadas IN-RED (2014) 
En todos los casos, los alumnos-as consideraron que los contenidos abordados permitieron ampliar los conocimientos específicos previos que tenían de la materia con un buen nivel (40\%) y excelente $(60 \%)$.

\subsection{Participación de expertos}

Todos alumnos-as valoraron con el máximo nivel (3) la participación de los expertos elegidos para esta primera edición del curso. Los comentarios realizados por los estudiantes indicaron que para los alumnos-as fue la actividad más satisfactoria y provechosa, además de motivante. Por tanto, se mantendrá la estructura (industria, calidad y certificación) y perfil del tipo de expertos a participar en próximas ediciones.

\subsection{Aplicabilidad de contenidos}

Todos los encuestados-as opinaron que los contenidos abordados en la materia pueden resultarles de aplicabilidad en la búsqueda de empleo. Un $10 \%$ opinaron que esta aplicabilidad podía ser buena y un $90 \%$ alta. En este sentido, comentaron que se trataba de conocimientos que no habían visto en asignaturas previas y pensaban de gran actualidad en el mercado de trabajo de su área de conocimiento.

Por último, comentar los resultados de las notas obtenidas por los alumnos-as en la evaluación del curso. Todos los estudiantes aprobaron la asignatura, y entorno a una $93 \%$ de las calificaciones fueron notable o sobresaliente. Esto demuestra además, el alto grado de aprendizaje alcanzado por los estudiantes.

\section{Conclusiones}

Los resultados del estudio permitieron valorar aspectos esenciales para la mejora de la calidad del método docente y del proceso de aprendizaje del alumno-a. En general, los estudiantes valoraron muy positivamente la novedad de los contenidos en el ámbito universitario y la forma eminentemente práctica de abordarlos. En especial, destacaron su gran interés por conocer la realidad del sector industrial a través de las experiencias trasmitidas en los seminarios con expertos. En general, los estudiantes percibieron una gran aplicabilidad de los contenidos tratados para mejora sus competencias y habilidad en vistas a encontrar trabajo. 
Cháfer, $M$.

\section{Referencias}

Cháfer, M. (2012). La industria agroalimentaria ecológica en España tiene un enorme potencial. Revista AE (vol.7): pp. 44.. Cattarroja: SEAE.

Tricio, V. (2012). Sostenibilidad ambiental en la enseñanza universitaria: experiencia docente y otras iniciativas. En: Actas del III congresos internacional y VIII nacional de investigación en educación, pedagodía y formación docente. Bogotá: Grijalbo, Consejo Nacional para la Cultura y las Artes. pp 214-229.

(cc) EY-NC-ND 2014, Universitat Politècnica de València

I Jornadas IN-RED (2014) 


\title{
Hacia un calendario académico diseñado para promover y facilitar el aprendizaje del alumno
}

\section{Carlos R. Sánchez Carrataláa y José Casanova Colón}

Departamento de Mecánica de los Medios Continuos y Teoría de Estructuras, Universitat Politècnica de Valéncia.

acsanchez@mes.upv.es, ${ }^{\text {bicasanova@mes.upv.es }}$

\begin{abstract}
With the main objective of estimating the actual workload that the adaptation to the European Higher Education Area means for a student, this paper discusses the regulatory framework which transposes the European credit system to the Spanish university system, as well as its implementation in the Technical University of Valencia, materialized through both the academic calendar of the university and the educational organization that, based on it, several of its faculties carry out. It is found that the constraints imposed by the regulatory framework, together with the not very ambitious academic calendar of the university and its inefficient application by the faculties, leads to a completely unacceptable average working time for the student, that can rise to 50 hours per week, even for the minimum workload of 25 hours per ECTS, well above the working time established by the labor law for an employee. Also, various measures easy to implement are proposed to solve the serious problem identified, with which it would be possible to adjust the student workload to a reasonable level, without giving up a demanding and quality training.
\end{abstract}

Keywords: academic calendar, educational organization, continuous evaluation, adaptation to the EHEA, ECTS, workload, class period, exam period, second-chance exams

\section{Resumen}

Con el objetivo principal de estimar la carga de trabajo real que la adaptación al Espacio Europeo de Educación Superior supone para un alumno, en este artículo se analiza el marco normativo que transpone el sistema europeo de créditos al sistema universitario español, así como su

(cc) EY-NC-ND 2014, Universitat Politècnica de Valéncia

I Jornadas In-Red (2014) 
implementación en la Universidad Politécnica de Valencia, concretada a través tanto del calendario académico de la universidad como de la organización docente que, con base en él, realizan varios de sus centros. Se comprueba que las limitaciones impuestas por el marco normativo, unidas a lo poco ambicioso del calendario académico de la universidad y a su aplicación poco eficiente por parte de los centros, conduce a una jornada promedio para el estudiante completamente inaceptable, que puede llegar a las 50 horas semanales, incluso para la carga de trabajo mínima de 25 horas por ECTS, muy por encima de la jornada establecida por la legislación laboral para un trabajador por cuenta ajena. Asimismo, se propone diversas medidas de fácil implementación para la resolución del grave problema identificado, con las que sería posible ajustar la carga de trabajo del alumno a un nivel razonable, sin renunciar a una formación exigente y de calidad.

Palabras clave: calendario académico, organización docente, evaluación continua, adaptación al EEES, ECTS, carga de trabajo, período de clases, período de exámenes, exámenes de recuperación

\section{Introducción}

Con la entrada en vigor de los nuevos planes de estudio adaptados al Espacio Europeo de Educación Superior, se ha generalizado la adopción de metodologías de enseñanzaaprendizaje que priman el trabajo (dirigido, supervisado y controlado) del estudiante y que requieren un proceso continuo de evaluación. El éxito de tales metodologías está condicionado por dos premisas: que los alumnos perciban que el trabajo a realizar es útil para el aprendizaje y necesario para superar la materia; y que dispongan del tiempo suficiente para llevarlo a cabo, no sólo en su cómputo global, sino también por lo que se refiere a su distribución racional y suficientemente homogénea a lo largo del curso.

Las universidades españolas han planteado, en ocasiones, calendarios académicos que vienen a limitar la capacidad organizativa de los centros docentes para implementar, con suficiente flexibilidad, sus planes de estudio dentro de los márgenes establecidos en el marco normativo. Por su parte, los centros docentes, carentes de experiencia en la aplicación masiva de metodologías activas, han propuesto organizaciones docentes en las que, por una parte, los exámenes se concentran o se dispersan, y, por otra, se permiten o no las recuperaciones. La diversidad entre los modelos de organización docente adoptados es una muestra de que no existe uno que resuelva todos los problemas, o al menos de que aún no se ha encontrado. Sin embargo, todos tienen algo en común: dan más importancia al examen convencional que a cualquier otra actividad relacionada con el aprendizaje de los estudiantes, y por ello procuran que haya bastante tiempo para tales pruebas, sobre todo,

(cc)) EY-NC-ND 2014, Universitat Politècnica de Valéncia

I Jornadas In-Red (2014) 
para que los alumnos puedan concentrar su trabajo en el período inmediatamente anterior a los exámenes. Además, los calendarios académicos y las organizaciones docentes no parecen prestar mucha atención a los principios básicos del proceso de Bolonia, cuya principal aportación ha sido la de centrar la atención en el trabajo del alumno y no en la dedicación de profesorado o en las necesidades de los centros. Casanova et al. (2013) realizan una interesante comparativa, desde ese punto de vista, de los calendarios académicos implantados en diversas universidades españolas.

Por otra parte, los exámenes conviven con una gran variedad de instrumentos de evaluación adicionales (entregas de ejercicios, memorias de prácticas, exposiciones de trabajos, etc.) que, de forma natural, tienden a acumularse en determinados momentos durante el semestre, y que, por ello, compiten entre sí y con los exámenes por el tiempo del alumno. La regulación por parte de los centros de tales entregas o exposiciones, si existe, tiende a primar la sencillez de la norma por encima de su adecuación para facilitar un uso racional del tiempo de los estudiantes.

En esta ponencia se analizan las implicaciones del marco normativo que regula la carga de trabajo del estudiante, así como la forma en que dicha legislación ha sido implementada en la Universidad Politécnica de Valencia, mediante un estudio detallado del calendario académico general de la universidad y de las organizaciones docentes adoptadas en varios de sus centros, analizando sus ventajas e inconvenientes. Como conclusión, se propone una serie de medidas con las que sería posible ajustar la carga de trabajo del alumno a un nivel razonable, sin renunciar a una formación exigente y de calidad. El criterio fundamental para todo ello consiste en valorar el tiempo realmente disponible y la dedicación exigible al alumno de acuerdo con el sistema europeo de créditos, procurando evitar tanto la falta de continuidad en el trabajo, como la excesiva concentración temporal del mismo implícita en muchos de los modelos de calendario implementados a raíz de la puesta en marcha de los nuevos planes de estudio.

\section{El marco legal de las titulaciones universitarias}

El Real Decreto 1125/2003, de 5 de septiembre, por el que se establece el sistema europeo de créditos y el sistema de calificaciones en las titulaciones universitarias de carácter oficial y validez en todo el territorio nacional (España, 2003) (en adelante, RD 1125/2003), prescribe en su artículo 4 los criterios generales para determinar la carga de trabajo de un alumno. En concreto, el número de créditos ECTS correspondiente a un curso académico se fija en 60, pudiendo variar el número de horas de trabajo académico por crédito entre un mínimo de 25 y un máximo de 30 . Es decir, que el número de horas de dedicación del estudiante debe estar entre $60 \times 25=1.500$ y $60 \times 30=1.800$ h/curso. Según el mismo Real Decreto, dicha asignación de créditos y la estimación de su correspondiente número de

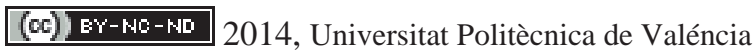

I Jornadas In-Red (2014) 
horas, se entiende referida a un estudiante dedicado a tiempo completo durante un mínimo de 36 y un máximo de 40 semanas por curso académico.

La idea que subyace en estas cifras es que el trabajo de un estudiante sea homologable al de un trabajador por cuenta ajena a tiempo completo, que viene a tener una jornada anual comprendida entre unas 1.650 y $1.800 \mathrm{~h} /$ año, dependiendo del convenio colectivo. El problema surge al fijar el número de semanas lectivas en un curso académico. Como referencia, según el artículo 38.1 del Real Decreto Legislativo 1/1995, de 24 de marzo, por el que se aprueba el texto refundido de la Ley del Estatuto de los Trabajadores (España, 1995; Ministerio de Empleo y Seguridad Social, 2014) (en adelante, Estatuto de los Trabajadores), un trabajador por cuenta ajena tiene un mínimo de 30 días naturales de vacaciones anuales retribuidas, es decir, 30/7 =4,3 sem/año. Aparte de ello, de acuerdo con el artículo 37.2 de esa misma norma, el número máximo de días festivos anuales retribuidos es de 14, entre nacionales, regionales y locales; suponiendo que todos ellos cayeran en día laborable y fuera del período de vacaciones, y que los días laborables de la semana sean 5 (aunque la legislación laboral admite otras posibilidades), estaríamos hablando de un máximo de $14 / 5=2,8$ sem/año. Un año no bisiesto tiene 365/7=52,1 sem/año, lo cual implica que un trabajador medio viene a tener una jornada anual efectiva de unas 52,1-4,3$2,8=45,0 \mathrm{sem} / a n ̃ o$. De esta forma es fácil deducir que su jornada semanal promedio es, como máximo, de unas $1.800 / 45=40 \mathrm{~h} / \mathrm{sem}$, tal y como se especifica en el artículo $34.1 \mathrm{del}$ Estatuto de los Trabajadores.

Tomando, por una parte, el número mínimo de horas por crédito con el número máximo de semanas por curso y, por otra, el número máximo de horas por crédito con el número mínimo de semanas por curso, las cifras especificadas en el RD 1125/2003 implicarían que la carga de trabajo del estudiante puede variar, respectivamente, entre un mínimo de $60 \times 25 / 40=37,5 \mathrm{~h} / \mathrm{sem}$ y un máximo de $60 \times 30 / 36=50 \mathrm{~h} / \mathrm{sem}$. El mínimo de 37,5 h/sem entra dentro de las $40 \mathrm{~h} / \mathrm{sem}$ fijadas como promedio máximo en el Estatuto de los Trabajadores, pero el máximo de $50 \mathrm{~h} / \mathrm{sem}$ lo supera en un 25\%. Además, contando con 5 días laborables por semana (de lunes a viernes), el máximo anterior implicaría una jornada diaria de 50/5=10 h/día, que también supera el tope de las 9 h/día establecido en el artículo 34.3 del Estatuto de los Trabajadores. Incluso añadiendo los sábados por la mañana (5,5 días laborables por semana) se seguiría excediendo dicho tope. Está claro que ésa no pudo ser la intención del RD 1125/2003.

Por ello, resulta más lógico considerar que hay una correspondencia entre los máximos de las dos variables (número de horas por crédito y número de semanas por curso académico), con lo que se tiene que la carga de trabajo máxima prevista sería de $60 \times 30 / 40=45 \mathrm{~h} / \mathrm{sem}$. Incluso haciendo las cuentas de esta forma, y por muy sorprendente que parezca, se constata que el legislador no tuvo en cuenta lo excesivo de la jornada semanal promedio resultante, y todo ello por el simple hecho de reducir arbitrariamente el curso académico a 
un máximo de $40 \mathrm{sem} /$ curso, cuando, según hemos visto, un trabajador normal por cuenta ajena realiza un tiempo de trabajo similar, pero repartido en unas $45 \mathrm{sem} / \mathrm{año.} \mathrm{Con} \mathrm{el} \mathrm{límite}$ de las $40 \mathrm{sem} /$ curso es evidente que el número de horas de trabajo por crédito no debería superar las $40 \times 40 / 60=26,6 \mathrm{~h} / \mathrm{ECTS}$. Sin duda, ésta es una de las razones por las que las universidades, con carácter general, han tendido a considerar que el crédito europeo equivale al mínimo de 25 horas dentro del rango previsto en el RD 1125/2003, desaprovechando así una oportunidad de mejorar la formación.

Con todo lo anterior, queda claro que se parte de un marco legal mal planteado, que ha impedido en la práctica el que las universidades puedan ajustar la carga de trabajo de los estudiantes a las necesidades formativas reales. Esto ha resultado especialmente negativo en titulaciones que habilitan para el ejercicio de profesiones reguladas - como es el caso de las ingenierías y la arquitectura-, al imponer que el tiempo de trabajo por crédito apenas pueda superar el mínimo previsto en el propio RD 1125/2003. La solución de este problema consistiría en modificar el RD 1125/2003, de forma que la duración del curso académico se pueda ampliar hasta las $60 \times 30 / 40=45 \mathrm{sem} / \mathrm{curso}$, a fin de no tener que superar las $40 \mathrm{~h} / \mathrm{sem}$ cuando el crédito se computa al máximo de $30 \mathrm{~h} / \mathrm{ECTS}$. Como alternativa, si se desea mantener el límite de las $40 \mathrm{sem} /$ curso, el RD 1125/2003 debería aclarar de forma explícita que la jornada semanal promedio de un estudiante puede alcanzar las $60 \times 30 / 40=45 \mathrm{~h} / \mathrm{sem}$.

\section{El calendario académico de la universidad}

El calendario académico universitario varía inevitablemente de curso en curso debido a la propia configuración del calendario gregoriano, a la existencia de períodos festivos cuya fecha varía de año en año y a diversas circunstancias organizativas. No obstante, analizando los calendarios académicos de la Universidad Politécnica de Valencia (en adelante, UPV) de los tres últimos cursos, correspondientes a las titulaciones de grado, y teniendo en cuenta cómo afectan las vacaciones y fiestas de todo tipo a las semanas lectivas (consideradas de lunes a viernes), se puede estimar el tiempo realmente disponible a efectos académicos. Yendo de septiembre a agosto y redondeando a múltiplos de medias semanas (precisión suficiente a estos efectos), los períodos no lectivos vienen a suponer lo siguiente:

- Las vacaciones correspondientes a Navidad duran unas 2,0 semanas.

- Los días festivos de Fallas vienen a representar unas 0,5 semanas.

- Las vacaciones de Semana Santa, incluida la Pascua de Resurrección, suponen unas 1,5 semanas.

- El período no lectivo de junio es aproximadamente de 1,0 semana.

- El mes de julio se considera inexistente a efectos docentes, lo que añade otras 4,5 semanas de inactividad.

- Las vacaciones estivales de agosto suponen 4,5 semanas.

\section{(cc) EY-NC-ND 2014, Universitat Politècnica de Valéncia}

I Jornadas In-Red (2014) 
- Los días festivos sueltos a lo largo del curso, no vinculados a los anteriores, suelen representar en torno a 1,0 semana más.

Es decir, que la duración de las vacaciones y días festivos a lo largo del año alcanza un monto total de unas 15,0 semanas, lo que, redondeando también la duración del año a múltiplos de medias semanas, reduce el período lectivo efectivo a tan sólo 52,0-15,0=37,0 sem/curso. Como se puede comprobar, dentro de los márgenes establecidos en el RD 1125/2003 para la duración del curso académico, la UPV ha optado por una cifra cerca del mínimo de 36 semanas. A falta de otras consideraciones, la cifra obtenida ya resulta preocupante, pues significa que con el calendario académico establecido por la UPV apenas si se dispone del período lectivo necesario para acometer un curso con la carga de trabajo mínima de 25 horas por crédito. De hecho, para conseguirlo sería precisa una jornada semanal de $60 \times 25 / 37,0=40,5 \mathrm{~h} / \mathrm{sem}$, ligeramente por encima del tope de las $40 \mathrm{~h} / \mathrm{sem}$ prescrito en el Estatuto de los Trabajadores, aunque ello no sería mayor problema. Como todo, también esta situación es susceptible de empeorar, y para ello basta con echar un vistazo a la organización docente realizada por los centros dentro del apretado calendario académico fijado por la universidad, a lo que se dedica el siguiente apartado.

\section{La organización docente de los centros}

\subsection{Consideraciones generales}

Para empezar, hay que señalar que los centros suelen empezar el curso en septiembre dos o tres días más tarde de la fecha mínima marcada por la universidad, probablemente para evitar problemas relacionados con la puesta en marcha de la pesada maquinaria administrativa tras el parón de las vacaciones de agosto. Algunos centros aumentan el retraso hasta una semana completa en todos los cursos, aprovechando la flexibilidad que permite el calendario académico de la universidad para planificar unas jornadas de acogida para alumnos de nuevo ingreso. Aparte de ello hay que añadir un día festivo adicional dedicado al Patrón del centro. Algunos centros extienden los días no lectivos, por ejemplo en Fallas. Otros no programan nada los últimos días de ambos semestres. Esto hace, redondeando, que se pierdan de 1,5 a 2,5 semanas más de período lectivo, lo que nos deja en cifras de entre unas 34,5 y 35,5 sem/curso. Con esta duración nominal del curso está claro que ya no es posible llegar al mínimo de $25 \mathrm{~h} /$ ECTS. O dicho de otro modo: como los programas de las asignaturas sí que están diseñados para alcanzar ese mínimo, la realidad es que la pérdida adicional de período lectivo obligaría a los alumnos a jornadas semanales promedio de entre $60 \times 25 / 35,5=42,3$ y $60 \times 25 / 34,5=43,5 \mathrm{~h} / \mathrm{sem}$. Ésta es la realidad que esconden las cifras generales, pero que parece que nadie quiere ver. Con todo, si la situación descrita hasta aquí ya parece algo apurada para el alumno, vamos a ver 
seguidamente que, en realidad, es todavía peor cuando se analiza a qué dedican los centros las escasas semanas aún disponibles.

Las actividades docentes universitarias son de muy diverso tipo, pudiendo tener carácter presencial o no presencial. Lo que se conoce habitualmente como organización docente hace referencia sólo a la parte de las actividades presenciales para las que el centro debe garantizar la disponibilidad de un espacio concreto (aula, sala, laboratorio) durante un tiempo determinado (horario) para que la actividad pueda llevarse a cabo en condiciones adecuadas. Sin ánimo de ser exhaustivos, las actividades de carácter presencial pueden ser desglosadas como sigue:

- Teoría: teoría de aula, teoría de seminario, teoría tutorizada.

- Práctica: práctica de aula, práctica de laboratorio, práctica informática, práctica de campo, práctica tutorizada.

- Trabajo: trabajo final de grado, trabajo tutorizado.

- Examen: examen parcial, examen final; examen ordinario, examen extraordinario.

Como se puede comprobar, en el epígrafe examen sólo se incluyen lo que podríamos llamar exámenes "reglados", excluyendo explícitamente otras actividades de evaluación continua (exámenes realizados en horas de clase, test electrónicos, controles en clase, entrega de problemas resueltos en el aula, etc.) que no responden a dicho concepto. Definir lo que es un examen "reglado" implica que los centros deben contar con una normativa específica que defina los tipos de examen a realizar y su cuantía, para poder reservar espacios y distribuirlos temporalmente de forma razonable.

Las actividades tutorizadas (incluyendo entre ellas el trabajo final de grado) no suelen ser objeto de total concreción en la organización docente, pues, en su parte presencial, se entiende que se realizan mayormente en despachos de profesores, en salas de las unidades docentes o en aulas reservadas al efecto. Además, las actividades cuyo objeto es la realización de algún tipo de trabajo suelen tener una parte no presencial importante, que lógicamente no precisa ser considerada en la organización docente.

En consecuencia, la organización docente de un curso se suele agrupar, fundamentalmente, en los siguientes períodos:

- Período de clases: es el período durante el cual se llevan a cabo las actividades enumeradas bajo los epígrafes de teoría y práctica, salvo las tutorizadas en su caso. Un resultado característico de la concreción del período de clases es saber de cuántas semanas y de cuántos días de la semana de cada tipo (lunes, martes, etc.) se dispone realmente para impartir clase. A fin de compensar los desequilibrios creados por el calendario académico variable, la universidad y/o los centros suelen cambiar algunos días concretos a efectos de horarios para conseguir que, aproximadamente, haya el

\section{(c) EY-NC-ND 2014, Universitat Politècnica de Valéncia}

I Jornadas In-Red (2014) 
mismo número de días de la semana de cada tipo. Los horarios de clases publicados por el centro detallan dónde (aula, laboratorio, etc.) y cuándo (día de la semana, franja horaria) se impartirán las clases de las asignaturas. En los grados, el período de clases se divide en dos semestres que abarcan, aproximadamente, de septiembre a enero y de febrero a junio. Cruzando el período de clases con el horario de clases, el profesor ya puede realizar la programación completa de una asignatura concreta.

- Período de exámenes: es el período reservado para realizar los exámenes definidos como reglados. Los horarios de exámenes publicados por el centro detallan dónde (aula, laboratorio, etc.) y cuándo (fecha concreta, franja horaria) se realizarán los exámenes de las asignaturas.

\subsection{Centros analizados}

Para poder estudiar distintas posibilidades de organización docente y analizar sus diferencias, se ha tomado una muestra de algunas Escuelas de la UPV caracterizadas por haber impartido titulaciones de ingeniería superior desde su creación, con la condición de que en la actualidad impartan titulaciones de grado que forman parte de programas integrados (grado + máster) habilitantes para una profesión regulada. En el caso de que una Escuela imparta más de un grado, se ha seleccionado el grado de referencia que conduce a un máster habilitante. Las Escuelas seleccionadas han sido las siguientes, en orden alfabético: Escuela Técnica Superior de Ingeniería Agronómica y del Medio Natural (ETSIAMN), con su Grado en Ingeniería Agroalimentaria y del Medio Rural (GIAMR); Escuela Técnica Superior de Ingenieros de Caminos, Canales y Puertos (ETSICCP), con su Grado en Ingeniería Civil (GIC); Escuela Técnica Superior de Ingenieros Industriales (ETSII), con su Grado en Ingeniería de Tecnologías Industriales (GITI); y Escuela Técnica Superior de Ingenieros de Telecomunicación (ETSIT), con su Grado en Ingeniería de Tecnologías y Servicios de Telecomunicación (GITST).

Debe señalarse que, en un principio, se pretendió incluir también en este estudio a la Escuela Técnica Superior de Arquitectura (ETSA) con su actual Grado de Arquitectura (GA), pero la singular organización docente del mismo, que no permite diferenciar con nitidez los períodos de exámenes ordinarios y extraordinarios, hizo que se desechara para no tener que introducir elementos interpretativos en el análisis.

En algunos grados, la organización docente es notoriamente distinta entre los tres primeros cursos, por una parte, y el cuarto, por otra, debido a la necesidad de incorporar en la planificación la realización del trabajo final de grado. En esos casos, se ha tomado como referencia el horario estándar de los tres primeros cursos. 
El análisis a realizar se limita a la organización docente del curso 2013-14, con lo que se evita la complejidad que introduciría el considerar los notables cambios de organización habidos durante los últimos cursos en algunas Escuelas. Esto no supone ninguna limitación para el objetivo de nuestro estudio, pues la diversidad introducida al analizar varias Escuelas en un mismo curso es suficiente para incorporar la variabilidad atribuible a varios sistemas de organización docente dentro de la misma universidad. La información necesaria para el análisis que se pretende se ha obtenido por dos vías. En primer lugar, se ha recopilado la información existente en el sitio electrónico de la UPV (UPV, 2014; ETSIAMN, 2014; ETSICCP, 2014; ETSII, 2014; ETSIT, 2014). En segundo lugar, la información anterior se ha corroborado, completado o matizado mediante un cuestionario sobre los aspectos de interés, enviado a profesores que imparten docencia en dichas Escuelas.

El período de exámenes suele diferenciarse en los grados en dos tipos: período de exámenes ordinarios (llamado, según Escuelas, período de parciales o período de evaluación) y período de exámenes extraordinarios (llamado, según Escuelas, período de finales, período de recuperación o período de evaluación complementaria). Todas las Escuelas analizadas tienen exámenes de los dos tipos, salvo la ETSIT, que en el curso 2013-14 ha optado por no hacer exámenes de recuperación.

Algunas Escuelas incluyen explícitamente en la organización docente otras actividades de evaluación distintas a los exámenes reglados (generalmente entregas de problemas o de trabajos), al objeto de asegurar una distribución razonable de la carga de trabajo a lo largo del curso, sin concentraciones excesivas.

\subsection{Determinación de la carga de trabajo}

El período de exámenes ordinarios claramente forma parte de la carga de trabajo prevista en el sistema europeo de créditos, pero no así el período de recuperaciones. El sistema de Bolonia está basado en que un curso adecuadamente diseñado debe permitir superar todas las asignaturas a un "alumno promedio" que dedique el tiempo necesario a cada una de ellas (tiempo que debe ser medido según la carga de trabajo correspondiente a su número de créditos ECTS). El período dedicado a las recuperaciones es un tiempo que, si el alumno debe hacer uso de él, es porque antes no lo había dedicado. De lo contrario, se estaría penalizando al alumno que aprueba las asignaturas en los exámenes ordinarios, pues se le estaría obligando a hacer el trabajo correspondiente a los créditos del curso en menos semanas que los demás. Así pues, el período de recuperaciones, de haberlo, no debe computar en la organización básica del curso por lo que debe programarse sin reducir el número de semanas lectivas útiles. Por ello, en lo que sigue distinguiremos entre el período

(c)) EY-NC-ND 2014, Universitat Politècnica de Valéncia

I Jornadas In-Red (2014) 
Tabla 1. Duración del período de clases

\begin{tabular}{ccccc}
\hline \multirow{2}{*}{ ESCUELA } & \multirow{2}{*}{ GRADO } & \multicolumn{3}{c}{$\begin{array}{c}\text { PERÍODO DE CLASES } \\
\text { (días) }\end{array}$} \\
\cline { 3 - 5 } & & S1 & S2 & Total \\
\cline { 3 - 5 } & GIAMN & $14+13+14+13+13=67$ & $13+13+14+13+13=66$ & 133 \\
ETSIAMN $^{*}$ ETSICCP $^{(1)(2)}$ & GIC & $15+15+15+16+3=64$ & $15+15+15+15+3=63$ & 127 \\
ETSII & GITI & $12+12+12+12+12=60$ & $12+12+12+12+12=60$ & 120 \\
ETSIT & GITST & $14+14+14+14+14=70$ & $14+14+15+14+14=71$ & 141 \\
\hline
\end{tabular}

(1) Los viernes no se imparte clase, pues se reservan para exámenes ordinarios, salvo las 2-3 primeras semanas de cada semestre, que por ello tienen un horario especial.

(2) Se pone lo reflejado en la organización docente, aunque el período real de clases es algo menor, pues se acumulan horas de clase en el primer mes.

lectivo total (que incluye el período de exámenes extraordinarios) y el período lectivo útil (que lo excluye).

Lo que es un alumno promedio podría ser objeto de matices, pero una base mínima de consenso sería definirlo como un alumno de capacidad intelectual media y con una formación previa ajustada al currículo oficial. Sin embargo, dicha definición no es suficiente. De acuerdo con la teoría de las inteligencias múltiples de Gardner (1993, 2000) todas las personas disponen de ocho tipos de inteligencia, a saber: lingüístico-verbal, lógico-matemática, visual-espacial, rítmico-musical, corporal-cinestésica, intrapersonal, interpersonal y naturalista. Más recientemente se ha propuesto una novena denominada inteligencia espiritual-religiosa o existencial. Dependiendo de las habilidades en cada una de ellas, la persona dispondrá de una mayor o menor capacidad para amoldarse a las distintas circunstancias vitales y ámbitos de actividad en los que debe desenvolverse.

En las titulaciones de ingeniería y arquitectura, y por lo que se refiere al aspecto más técnico de la profesión, es obvio que resultan de especial relevancia las inteligencias lógicomatemática y visual-espacial, sin que pueda faltar una dosis apreciable de las inteligencias lingüístico-verbal y naturalista, ya que el buen técnico debe saber comunicar con claridad y relacionarse de forma crítica, ponderada y respetuosa con el entorno sobre el que actúa. Evidentemente, los otros tipos de inteligencia son también necesarios en la medida adecuada, especialmente si consideramos las dimensiones individual y social del estudiante y futuro profesional. Como no todos los alumnos son iguales, los habrá con mejores capacidades naturales y que, por lo tanto, podrían dedicar algo menos de tiempo en su formación, pero también los habrá menos dotados que deberán realizar un mayor esfuerzo. El sistema de ECTS hace referencia al alumno promedio, al que se supone una distribución de inteligencias razonablemente ajustada a la titulación elegida. En este contexto, es 
Tabla 2. Duración del período de exámenes

\begin{tabular}{|c|c|c|c|c|c|c|}
\hline \multirow{3}{*}{ ESCUELA } & \multirow{3}{*}{ GRADO } & \multicolumn{5}{|c|}{$\begin{array}{c}\text { PERÍODO DE EXÁMENES } \\
\text { (días) }\end{array}$} \\
\hline & & \multicolumn{2}{|c|}{ Ordinarios } & \multicolumn{2}{|c|}{ Extraordinarios } & \multirow{2}{*}{ Total } \\
\hline & & S1 & $\mathrm{S} 2$ & S1 & $\mathrm{S} 2$ & \\
\hline ETSIAMN & GIAMN & 8 & 10 & 13 & 9 & 40 \\
\hline $\mathrm{ETSICCP}^{(1)(2)}$ & GIC & 11 & 12 & 13 & 10 & 46 \\
\hline ETSII & GITI & $9+11=20$ & $8+10=18$ & 12 & 10 & 60 \\
\hline ETSIT & GITST & $6+6+6=18$ & $6+6+6=18$ & - & - & 36 \\
\hline
\end{tabular}

(1) Los viernes no se imparte clase, pues se reservan para exámenes ordinarios, salvo las 2-3 primeras semanas de cada semestre, que por ello tienen un horario especial.

(2) Se pone lo reflejado en la organización docente, aunque el período real de exámenes ordinarios es algo mayor, pues se acumulan horas de clase en el primer mes.

importante recordar que la inteligencia no es algo estático, sino que la formación y el propio individuo pueden actuar sobre ella, potenciando fortalezas y minorando debilidades.

En la Tabla 1 se indica, para cada una de las Escuelas analizadas, la duración del período de clases, dividido en los dos semestres del curso (S1 y S2), mientras que en la Tabla 2 se da la duración del período de exámenes ordinarios y extraordinarios, también por semestres. En la Tabla 3 se resume la duración del período lectivo real en cada Escuela, como suma del período de clases más el período de exámenes, obteniendo tanto el período lectivo total como el período lectivo útil. Como los números se hacen por días laborables, dividiendo por 5 se obtiene la duración equivalente en semanas. Se llega a la conclusión de que el período lectivo que se le ofrece al estudiante para aprobar en los exámenes ordinarios es de tan sólo 30,0 a 31,6 sem/curso, cuando también se programan exámenes extraordinarios. Considerando la carga de trabajo asociada al crédito (entre 25 y 30 horas), se puede calcular la jornada semanal promedio correspondiente. Las cifras son demoledoras, pues en todos los casos superan el máximo de $40 \mathrm{~h} / \mathrm{sem}$ contemplado en la legislación laboral, llegando hasta unas 47,5 a 50,0 h/sem para $25 \mathrm{~h} /$ ECTS y hasta unas 57,0 a 60,0 h/sem para 30 h/ECTS. Algo inaceptable, salvo que se pretenda que el estudiante lleve hoy en día el ritmo de locura que exigían, en algunos períodos del curso, los planes de estudios de ingeniería y arquitectura de hace tres o cuatro décadas, en los que se formaron bastantes de los profesores actuales más veteranos.

Al respecto de la necesidad o no de programar un período de recuperaciones, es opinión firme de los autores que la universidad debería establecer como obligación a los centros la necesidad de incluir en la programación un período de exámenes extraordinarios, por escueto que sea. Un sistema de evaluación coherente y justo debe permitir al estudiante el acceso a una segunda oportunidad, ante las múltiples circunstancias adversas que pueden

\section{(cc) EY-NC-ND 2014, Universitat Politècnica de Valéncia}

I Jornadas In-Red (2014) 
Tabla 3. Duración real del período lectivo y jornada semanal promedio exigida al estudiante

\begin{tabular}{|c|c|c|c|c|c|}
\hline \multirow{2}{*}{ ESCUELA } & \multirow{2}{*}{ GRADO } & \multicolumn{2}{|c|}{ PERÍODO LECTIVO REAL } & \multicolumn{2}{|c|}{$\begin{array}{l}\text { JORNADA SEMANAL } \\
\text { PROMEDIO } \\
\text { (h/sem) }\end{array}$} \\
\hline & & $\begin{array}{c}\text { Total } \\
\text { (días / sem) }\end{array}$ & $\begin{array}{c}\text { Útil } \\
\text { (días / sem) }\end{array}$ & $25 \mathrm{~h} / \mathrm{ECTS}$ & $30 \mathrm{~h} / \mathrm{ECTS}$ \\
\hline ETSIAMN & GIAMN & $173 / 34,6$ & $151 / 30,2$ & 49,7 & 59,6 \\
\hline ETSICCP & GIC & $173 / 34,6$ & $150 / 30,0$ & 50,0 & 60,0 \\
\hline ETSII & GITI & $180 / 36,0$ & $158 / 31,6$ & 47,5 & 57,0 \\
\hline ETSIT $^{(1)}$ & GITST & $177 / 35,4$ & $177 / 35,4$ & 42,4 & 50,8 \\
\hline
\end{tabular}

(1) Las cifras de la ETSIT marcadas en cursiva no son comparables con las de las restantes Escuelas, pues se han obtenido sin considerar un período de exámenes extraordinarios. En opinión de los autores, dicho período es imprescindible en un sistema de evaluación que se pretenda coherente y justo.

acaecer a lo largo del curso académico: período de baja por enfermedad, problemas personales, incidencias familiares, nervios en un examen, mala planificación, apreciación incorrecta del trabajo necesario, equivocaciones con la agenda, etc.

Los resultados obtenidos en el análisis realizado no son relevantes por los números concretos - que, de hecho, podrían variar ligeramente en otro curso, o que alguien podría considerar asumibles-, como porque evidencian algo de lo que muchos profesores son conscientes: que el calendario académico de la universidad resulta escaso, y que la organización docente implantada en los centros entroniza el examen por encima de otros medios de evaluación, transmite un mensaje subliminal erróneo —es necesario concentrar el estudio justo antes del examen- y parece estar hecha pensando en el estudiante mediocre o en las labores administrativas. Ello no sería un inconveniente, si no fuera porque se hace a costa de someter al buen estudiante a una carga de trabajo excesiva o, posiblemente, obligando al profesorado a reducir en la práctica la carga de trabajo de las asignaturas bastante por debajo de lo legalmente exigido, en detrimento del nivel formativo.

\section{Propuestas de solución}

Una vez identificados los problemas derivados tanto del calendario académico de la universidad como de las organizaciones docentes diseñadas en distintos centros, vamos a tratar de apuntar posibles vías de solución que permitan mejorar la situación actual. Anunciamos que dichas vías transcurren por caminos más próximos a las necesidades reales del estudiante que a los condicionantes de la maquinaria administrativa o a cualquier otra cuestión ajena a la misión formativa que la sociedad tiene encomendada a la universidad. 
Para empezar, debe decirse que carece de sentido que el calendario académico de la UPV no permita disponer del máximo tiempo posible, llegando a las 40 semanas de período lectivo fijadas por el RD 1125/2003. Bastaría para ello con prolongar el período lectivo hasta mediados de julio, lo que permitiría añadir 3 semanas a las 37 disponibles en la actualidad. Se argumenta, algunas veces, las necesidades administrativas como motivo para no hacerlo, pero en la era de las TIC esto es perfectamente posible. Además, lo normal sería que la universidad funcionara como muchos otros organismos públicos, manteniendo unos servicios administrativos mínimos durante todo el año.

Por otra parte, debería exigirse a los centros que realicen la organización docente pensando en la carga de trabajo del alumno correspondiente al número de créditos del curso completo. Esto implicaría el no retrasar el comienzo del curso, no prolongar artificialmente los períodos festivos y no desaprovechar parte del calendario académico de la universidad, programando para ello actividades presenciales en toda su extensión, incluidas las de evaluación ordinaria. Los centros deberían incorporar también dentro de la organización docente una regulación sensata y suficientemente flexible del conjunto de entregas y actividades complementarias de evaluación, que proporcione a los alumnos el tiempo necesario para llevar a cabo las actividades de aprendizaje y ordene un curso menos agobiante para los estudiantes responsables.

Los períodos de exámenes extraordinarios deberían reducirse a un mínimo, pues, como su propio nombre indica, son extraordinarios, es decir, una segunda oportunidad para el estudiante que ha tenido alguna dificultad puntual, no una nueva prueba a la que acude prácticamente todo el alumnado. Visto desde esta óptica, entendemos que carece de sentido dedicarles más allá de los 5 días laborables por semestre. Los exámenes de recuperación podrían hacerse al final de cada semestre o, posiblemente mejor, concentrarlos todos al final del segundo semestre, lo que permitiría trasladar de forma más clara al alumno la idea unitaria de curso, actualmente difuminada al no haber prácticamente asignaturas anuales.

En resumen, con sólo alargar el calendario académico de la universidad hasta mediados de julio, estaríamos hablando de conseguir un período lectivo total de unas 40 semanas por curso, que dividido en un período lectivo útil de unas 38 semanas y unas 2 semanas adicionales para exámenes extraordinarios permitiría garantizar realmente el mínimo por crédito de 25 horas sin superar la jornada promedio de 40 horas semanales establecida en la legislación laboral.

\section{Conclusiones}

La duración máxima de 40 semanas por curso académico fijada por el Real Decreto 1125/2003, aplicada a una carga de trabajo de 30 horas por crédito, conllevaría exigir al

\section{(cc) EY-NC-ND 2014, Universitat Politècnica de Valéncia}


estudiante una jornada semanal promedio de 45 horas, superior al límite de 40 horas fijado en el Estatuto de los Trabajadores. Con el máximo de 40 semanas por curso académico no es posible superar las 26,6 horas por crédito, salvo que se acepte que el estudiante debe dedicar a su "profesión" una jornada semanal superior a la de un trabajador por cuenta ajena. Ésta es, posiblemente, una de las principales razones por las que las universidades han acabado aplicando, con carácter general, el mínimo de 25 horas por crédito.

Debido a los períodos de vacaciones y días fiestas, el calendario académico de la UPV limita el período lectivo disponible a un máximo de unas 37 semanas, cerca del mínimo de 36 semanas previsto en el RD 1125/2003. Con este tope institucional, la jornada semanal mínima se eleva ya a las 40,5 horas por semana para la carga mínima de trabajo de las 25 horas por crédito. Se diría que el calendario universitario viene a ser un reflejo del calendario escolar utilizado en la educación primaria y secundaria, lo cual resulta poco comprensible, pues a la educación universitaria acceden de forma voluntaria personas que son legalmente mayores de edad y en edad de trabajar.

La organización docente general de los centros hace que se pierdan de 1,5 a 2,5 semanas más de período lectivo por retrasos en el comienzo del curso, ampliación de períodos festivos, o falta de programación de actividades presenciales en algunos períodos, lo que nos deja en períodos lectivos de entre unas 34,5 y 35,5 semanas por curso. Con esto se aumenta de nuevo la jornada semanal mínima del estudiante hasta alcanzar unas 42,3 a 43,5 horas por semana, y ello haciendo de nuevo las cuentas para el mínimo de 25 horas por crédito.

Cuando se estudian en detalle las organizaciones docentes de los distintos centros analizados —desglosando las actividades presenciales programadas en un período de clases, otro de exámenes ordinarios y un tercero de exámenes extraordinarios-, se descubre que el período lectivo útil, que es aquél en el que el estudiante promedio debería de ser capaz de superar todas las asignaturas de un curso, se reduce hasta la irrisoria cifra de unas 30,0 a 31,2 semanas por curso, cuando, como es lógico y deseable, se ofrece al estudiante la posibilidad de recuperar algún examen o acto de evaluación que no le fue bien. De esta manera, la jornada semanal mínima para el crédito de 25 horas se dispara hasta unas 47,5 a 50,0 horas por semana, que no parece razonable aceptar como promedio de trabajo en un curso académico. Si se tomara el valor máximo de 30 horas por crédito, la jornada llegaría incluso hasta la cifra de 60,0 horas por semana.

Se ha propuesto una serie de medidas para conseguir ajustar el calendario académico de la universidad y la organización docente de los centros a las necesidades del estudiante, demostrando que, aun dentro del corsé impuesto por el RD 1125/2003, es posible conseguir que la carga de trabajo del estudiante alcance realmente el mínimo por crédito de 25 horas sin superar la jornada promedio de 40 horas semanales establecida en la legislación laboral. 


\section{Referencias}

Casanova, J., Sánchez-Carratalá, C.R. y Pallarés, F.J. (2013). "Propuestas de mejora en la aplicación práctica del marco normativo de Bolonia para facilitar el aprendizaje", en Actas III Jornadas Internacionales de Enseñanza de la Ingeniería Estructural. Madrid: ACHE. [CD-ROM]

Escuela TÉCNiCA Superior de Ingeniería AgronómiCa y del Medio Natural (2014). Calendario académico ETSIAMN Grados - Cursos $1^{\circ}, 2^{\circ}$ y $3^{\circ}$. Curso 2013-14.

〈http://www.etsiamn.upv.es/Docencia/Calendario/calendario.académico.GRADO.13.14..pdf〉> [Consulta: 10 de junio de 2014]

Escuela Técnica Superior de Ingenieros de CAminos, CANALES y Puertos (2014). Calendario académico ETSICCP Grados - Cursos $1^{\circ}, 2^{\circ}$ y $3^{\circ}$. Curso 2013-14.

<http://www.iccp.upv.es/new/expl.aspx?id=1HYsVMMa6Fr9\%2b6Wj6FucaYmBFZWv\%2fB7wYZf bNytE2YBhHdyB64JTS\%2fI3\%2fPnbmNgz> [Consulta: 10 de junio de 2014]

EsCuEla TÉCNICA SUPERIOR DE INGENIEROS DE TELECOMUNICACIÓN (2014). Programación de actividades académicas del GITSC. Curso 2013-14.

<http://nueva.etsit.upv.es/media/content/category/docencia/estudios_de_grado/planificacion_academi ca/pat_grado_13_14.pdf> [Consulta: 10 de junio de 2014]

ESCUELA TÉCNICA SUPERIOR DE INGENIEROS INDUSTRIALES (2014). Calendario académico ETSII Grados - Cursos $1^{\circ}, 2^{\circ}$ y $3^{\circ}$. Curso 2013-14.

<http://www.etsii.upv.es/horario/documentos/Calen_Grados_1-2-3_2013-14.pdf> [Consulta: 10 de junio de 2014]

EsPaña. Ministerio de EduCACión, Cultura y Deporte (2003). Real Decreto 1125/2003, de 5 de septiembre, por el que se establece el sistema europeo de créditos y el sistema de calificaciones en las titulaciones universitarias de carácter oficial y validez en todo el territorio nacional. Boletín Oficial del Estado, núm. 224, 18 de septiembre de 2003, pp. 34355-34356.

España. Ministerio de Trabajo y Seguridad Social (1995). Real Decreto Legislativo 1/1995, de 24 marzo de 1995, por el que se aprueba el texto refundido de la Ley del Estatuto de los Trabajadores. Boletín Oficial del Estado, núm. 75, 29 de marzo de 1995, pp. 9654-9688.

GARDNER, H. (1993). Multiple intelligences: The theory in practice. New York, NY: Basic Books.

GARDNER, H. (2000). Intelligence reframed: Multiple intelligences for the 21st century. New York, NY: Basic Books.

Ministerio de Empleo y Seguridad Social (2014). Guía Laboral - Jornada laboral. Permisos y vacaciones. 〈http://www.empleo.gob.es/es/Guia/texto/guia_6/contenidos/guia_6_14_0.htm> [Consulta: 10 de junio de 2014]

Universidad Politécnica de VAlencia (2014). Calendario académico UPV. Curso 2013-14. 〈http://www.upv.es/entidades/EDOCTORADO/info/Calendario_Academico_2013_2014.pdf> [Consulta: 10 de junio de 2014]

(cc)) EY-NC-ND 2014, Universitat Politècnica de Valéncia

I Jornadas In-Red (2014) 


\title{
Diseño e implementación del protocolo de coordinación para la evaluación de las competencias en el Máster de Transportes, Territorio y Urbanismo de la ETSICCP. Fase I.
}

\author{
M. Salomé Moreno Navarro ${ }^{a}$, Mercedes Trenor Galindo ${ }^{b}$, Vicent Jesús Altur Grau ${ }^{c}$ y \\ José luís Miralles i García ${ }^{\text {. }}$ \\ a'Departament d'Urbanisme, Universitat Politècnica de València, smoreno@upvnet.upv.es, \\ ${ }^{b}$ Departament d'Urbanisme, Universitat Politècnica de València, mtrenor@urb.upv.es, ${ }^{\mathrm{c} D e p a r t a m e n t}$ \\ d'Urbanisme, Universitat Politècnica de València, vialgr@upvnet.upv.es y ${ }^{\mathrm{d}}$ Departament \\ d'Urbanisme, Universitat Politècnica de València, jlmirall@urb.upv.es.
}

\begin{abstract}
This paper summarizes the project developed over the course 2012/2013 which the aim of proposing the first phase to design and implement a working protocol to ensure the acquisition of title's competences by graduates in the Master's Degree in Transport Planning and Urban Development. The work aims to unify the meaning of each of the skills in the context of the degree, and to establish their relationship both with teaching and assessment methods and with learning outcomes in order to obtain the weight and magnitude of participation of each of the subjects included, to guarantee the achievement of competencies by students.
\end{abstract}

Keywords: Competency assessment, higher education, teaching methods, learning outcomes

\begin{abstract}
Resumen
Este trabajo resume el proyecto de innovación desarrollado a lo largo del curso 2012/2013 que plantea la primera fase para el diseño $e$ implementación de un protocolo de trabajo que permita asegurar que los egresados del Título de Máster de Transportes Territorio y Urbanismo han adquirido las competencias definidas en el título. El trabajo pretende la unificación del significado de cada una de las competencias en el contexto del título, así como su relación con las distintas metodologías docentes, resultados de aprendizaje y métodos de evaluación utilizados. El objetivo es
\end{abstract}

(c)) EY-NC-ND 2014, Universitat Politècnica de València

I Jornadas In-Red (2014) 
Diseño e implementación del protocolo de coordinación para la evaluación de las competencias en el Máster de Transportes, Territorio y Urbanismo de la ETSICCP

poder ponderar el peso y la magnitud de participación de cada una de las asignaturas y la aseguración de la consecución de las competencias por parte de los de los alumnos.

Palabras clave: Competencias, evaluación, educación superior, metodologías docentes, resultados de aprendizaje

\section{Introducción}

Las escuelas superiores y facultades del futuro, si quieren diferenciarse y ser competitivas, deberán estar en situación de garantizar la calidad de los títulos que imparten. Así, los futuros procesos de acreditación van a estar cada vez más enfocados a verificar la consecución del perfil de formación que los títulos proponen.

La incorporación de las universidades españolas al EEES supone una reforma en profundidad que afecta al ámbito estructural, curricular y organizativo (Mateo, 2000), donde el modelo educativo introducido está centrado en el aprendizaje de competencias por parte del estudiante, de manera que todos los aspectos curriculares y organizativos se definen en torno a las competencias que tiene que adquirir el alumno (Biggs, 2004). Por lo tanto se sustituye el tradicional paradigma de la enseñanza, centrada en la mera transmisión de conocimientos (en el que fundamentalmente éstos han de acumularse, memorizarse y después reproducirse en un examen), y conlleva el hecho de que el profesorado universitario ha de replantearse su actuación como docente. Éste, a la hora de abordar el nuevo modelo necesitara de una formación específica que le permita seguir en la dirección adecuada para la implantación de la docencia en Grados y Postgrados, y de esta manera guiar al estudiante hacia el desarrollo de sus competencias académicas y profesionales (Rodriguez Espinar 2003; Perrenoud 2004; Galan 2007; Zabala 2007; Garcia Garcia 2010).

A partir de la definición del concepto de competencia surgen catalogaciones de las mismas: competencias específicas, vinculadas a cada área de estudio; competencias genéricas, transversales a las titulaciones, y relacionadas con la formación integral de la persona. Desde la década de los noventa, el EEES se ha hecho eco de diferentes estudios realizados (encuesta Cheers, proyecto Tunning, Reflex, UEConverge, etc.) en los que, a través de amplias encuestas realizadas entre graduados y empleadores, se ha puesto de manifiesto la importancia que las denominadas competencias transversales o genéricas tienen en el desempeño académico y profesional de los titulados universitarios. Por ello, los nuevos títulos de grado y posgrado adaptados al Espacio Europeo de Educación Superior (EEES) incorporan la exigencia de que los estudiantes sean formados en esas denominadas 
competencias transversales, o genéricas, además de en las tradicionales competencias específicas, y su logro debe ser constatado, es decir, evaluado.

El aprendizaje basado en competencias pretende asegurar que los estudiantes adquieran aquellos conocimientos, habilidades y actitudes importantes, tanto con relación a lo que se está estudiando como a las transiciones para las que se preparan en el futuro (transición laboral, preparación para másters académicos, etc.).

Los últimos trabajos realizados sobre el aprendizaje basado en competencias tienden a concretar cómo han de definirse y trabajarse en cada una de las disciplinas en las cuales dicha competencia se encuentra inmersa (Jiménez Rodríguez, 2011), es por ejemplo ésta la línea seguida por la Agència per a la Qualitat del Sistema Universitari de Catalunya en la serie de guías de apoyo al profesorado, elaboradas por áreas temáticas, para la evaluación de competencias en sus títulos. En la guía del ärea de Ingeniería y Arquitectura (AQU Catalunya 2009) se describe cómo el aprendizaje basado en competencias implica el desarrollo de cuatro componentes diferentes pero interactivos:

- Descripción de la competencia.

- Descripción de las actividades donde se manifestará la competencia.

- Instrumentos o medios para evaluar la competencia.

- Estándares o criterios por los que se juzga si alguien es o no competente

es decir, hay que establecer sobre esos cuatro parámetros la estrategia a seguir que nos permita trabajar en la educación superior para garantizar el aprendizaje basado en competencias.

Es por esto, que el proyecto de innovación que proponemos se sustenta sobre una doble motivación. Por un lado, todos los títulos adaptados al Espacio Europeo de Educación Superior han de disponer de un perfil de formación en competencias, es decir, se ha formulado qué se espera de los graduados en términos de competencias específicas y transversales, pero no se especifica de qué manera, desde el punto de vista organizacional, estos alumnos habrán de alcanzar esas competencias.

Por otro lado, los estándares europeos de garantía de calidad (ENQA, 2005) establecen que los estudiantes han de estar claramente informados sobre los métodos de valoración a los que estarán sujetos, sobre qué se espera de ellos y sobre qué criterios se aplicarán para valorar su rendimiento. Todo esto implica que el reto que ahora tiene el profesorado de nuestras universidades consiste en encontrar cómo desarrollar y cómo evaluar de forma coherente las competencias asumidas al perfil de formación.

Por otra parte, en un contexto en el que prima la autonomía en el diseño de los títulos, así como en los procesos para desarrollarlos, se hace absolutamente necesario conocer cuál es el nivel de certificación de los títulos que se ponen en marcha en nuestra universidad, sobre

\section{(c)) EY-NC-ND 2014, UniversitatPolitècnica de València}

I Jornadas IN-RED (2014) 
Diseño e implementación del protocolo de coordinación para la evaluación de las competencias en el Máster de Transportes, Territorio y Urbanismo de la ETSICCP

todo teniendo en cuenta que las repercusiones de esa certificación lo son a escala internacional.

De este modo, es de esperar que los futuros procesos de acreditación estén cada vez más enfocados a verificar la consecución del perfil de formación. Por lo que la coordinación entre docentes que imparten la misma asignatura, materia y título junto con la evaluación de los aprendizajes, son la herramienta que nos permitirá constatar esa consecución por parte de los estudiantes.

Por último, la evaluación de las competencias no se puede entender desde un punto de vista generalista. Se ha escrito abundantemente sobre el hecho de que ni siquiera la propia definición del término competencia es un asunto pacífico, y las propuestas sobre cómo se han de trabajar y evaluar esas competencias han de surgir de propuestas que pueden ser diferentes, según los ámbitos disciplinarios en los que se vayan a aplicar, aunque la metodología de trabajo para que alumnos y profesorado participen en el procedimiento de verificación pueda ser común, en mayor o menor medida, a otras titulaciones y/o disciplinas.

\section{Objetivos}

El diseño metodológico del proyecto propone un sistema de relación entre las "competencias del título", la "metodología de enseñanza aprendizaje", "los sistemas de evaluación" y los "resultados de aprendizaje", centrándose por lo tanto en los siguientes objetivos:

- Objetivo 1: Contextualizar y caracterizar el conjunto de competencias que definen el título del Máster de Transportes, Territorio y Urbanismo en orden a concretar y establecer su relación con los resultados de aprendizaje que garantizarán la consecución de cada una de las competencias definidas en el título.

- Objetivo 2: Analizar, identificar estrategias de trabajo, llevar a la práctica y evaluar las competencias del Máster de Transportes, Territorio y Urbanismo.

- Objetivo 3: Definir la colaboración de cada una de las asignaturas que componen el título a la consecución de las competencias que lo definen.

En esta fase que se presenta se ha trabajado sobre el primero de los objetivos descritos.

\section{Desarrollo de la innovación}

Durante el segundo semestre del curso 2011-2012 en el Departamento de Urbanismo se realizó una investigación sobre evaluación de las competencias genéricas en el Máster de Transportes, Territorio y Urbanismo. A este trabajo, junto con la experiencia sobre 
certificación académica y evaluación de las competencias que se ha adquirido por parte de los profesores de la Escuela Técnica Superior de Ingenieros de Caminos Canales y Puertos, que desde enero de 2011 han trabajado en el proceso de acreditación llevado a cabo por la comisión de ingeniería ABET, y que ha culminado con la acreditación internacional del Título de Ingeniero de Caminos, Canales y Puertos, ha puesto en evidencia la necesidad de regular en los títulos que se imparten en esa escuela el aseguramiento de la adquisición de competencias por parte de sus egresados.

De este modo, la Escuela Técnica Superior de Caminos Canales y Puertos se conciencia de que es imprescindible el planteamiento de una nueva metodología de trabajo que facilite, coordine y evalúe la adquisición de competencias genéricas y específicas que definen el Título del Máster de transportes, Territorio y Urbanismo.

Evidentemente es necesario este cambio, porque dentro del nuevo Espacio Europeo de la Educación Superior la realización de un máster de calidad con certificaciones internacionales extracomunitarias, proporciona a la universidad que lo imparte el salto cualitativo necesario que diferencia, y al mismo tiempo distingue del resto, el Título que imparte la UPV, lo que ciertamente ha elevado la competitividad de esta universidad.

Si bien el proyecto se encuentra estructurado con una duración de dos años, a la finalización del primer año se han obtenido resultados que han conllevado modificaciones de las correspondientes guías docentes y la necesidad de implementar los cambios en el curso siguiente. Es por eso que en principio, se planteó la descripción del plan de trabajo en una programación bianual que garantizase el seguimiento de los cambios introducidos a la finalización de la primera anualidad y que permitiría contrastar si los cambios introducidos operan el efecto perseguido.

Así, en su totalidad se plantea la realización del proyecto en cuatro fases diferenciadas por semestres, donde cada fase comprende diversas actuaciones y que en el trabajo que ahora se presenta se ha abordado la primera de ellas y parte de la segunda que pasamos a describir:

Fase 1.1: Toma de datos y análisis de la documentación de partida. (Primer semestre del curso 2012-2013)

En esta fase se ha trabajado con la información oficial actual correspondiente al título y a las diferentes asignaturas que lo componen, durante el primer semestre, se ha hecho un análisis en profundidad de la totalidad de las guías docentes que componen las asignaturas troncales del título del Máster de Transportes, Territorio y Urbanismo, de las competencias que se trabajan en cada una de ellas, la metodología docente y la evaluación y resultados de aprendizaje. 
Diseño e implementación del protocolo de coordinación para la evaluación de las competencias en el Máster de Transportes, Territorio y Urbanismo de la ETSICCP

\begin{tabular}{|c|c|c|}
\hline \multicolumn{3}{|c|}{ Máster Universitario en Transporte, Territorio y Urbanismo } \\
\hline Competencia & Descripción de las Competencias & Tipo \\
\hline $\mathrm{C} 1$ & $\begin{array}{l}\text { Que los estudiantes comprendan y asuman la responsabilidad ética y profesional de la } \\
\text { actividad del Ingeniero de Transportes y del Especialista en Territorio y Urbanismo. }\end{array}$ & General \\
\hline $\mathrm{C2}$ & $\begin{array}{l}\text { Que los estudiantes comprendan y sepan utilizar el lenguaje propio y la terminologia } \\
\text { técnica de la ingenieria de Transportes, del Urbanismo y de la Ordenación del Territorio. }\end{array}$ & General \\
\hline $\mathrm{C}_{3}$ & $\begin{array}{l}\text { Que los estudiantes sepan comunicar de forma clara y sin ambiguedades, tanto verbal } \\
\text { como escrita, conccimientos, procedimientos, resultados e ideas relativos a la ingenieria } \\
\text { del transporte, el urbanismo y la ordenación del territorio. }\end{array}$ & General \\
\hline $\mathrm{C}_{4}$ & $\begin{array}{l}\text { Que los estudiantes conozcan los fundamentos fisicos y matemáticos necesarios para } \\
\text { interpretar, seleccionar y valorar la aplicación de nuevos conceptos y desarrollos } \\
\text { cientificos y tecnológicos relacionados con la ingenieria de Transportes }\end{array}$ & General \\
\hline Cs & $\begin{array}{l}\text { Que los estudiantes sepan elaborar estudios de impacto ambiental y estudios de paisaje } \\
\text { del planeamiento urbanistico }\end{array}$ & General \\
\hline C6 & $\begin{array}{l}\text { Que los estudiantes sepan aplicar los conocimientos adquiridos y su capacidad de } \\
\text { resolución de problemas en entornos nuevos o poco conocidos dentro de contextos más } \\
\text { amplios (o multidisciplinares) }\end{array}$ & General \\
\hline C7 & \begin{tabular}{|l|} 
Que los estudiantes sean capaces de integrar conocimientos y enfrentarse a la \\
complejidad de formular juicios a partir de una información que siendo incompleta o \\
limitada, incluya reflexiones sobre las responsabilidades sociales y èticas vinculada
\end{tabular} & General \\
\hline $\mathrm{C} 8$ & $\begin{array}{l}\text { Que los estudiantes sepan comunicar sus conclusiones (y los conocimientos y razones } \\
\text { últimas que las sustentan) a públicos especializados y no especializados de un modo claro } \\
\text { y sin ambiguedades }\end{array}$ & General \\
\hline $\mathrm{cg}$ & $\begin{array}{l}\text { Que los estudiantes posean las habilidades de aprendizaje que les permitan continuar } \\
\text { estudiando de un modo que habrá de ser en gran medida autodirigido o autónomo }\end{array}$ & General \\
\hline $\mathrm{C} 10$ & $\begin{array}{l}\text { Que los estudiantes sepan analizar criticamente los procesos propios de la ingenieria de } \\
\text { Transportes, tanto en los aspectos de planificación y gestión como en el diseño y } \\
\text { construoción de infraestructuras. }\end{array}$ & Especifica \\
\hline C11 & $\begin{array}{l}\text { Que los estudiantes conozcan y comprendan las tecnologias que se utilizan para la } \\
\text { planificación, proyecto, construcción y explotación de las infraestructuras del transporte y } \\
\text { la planificación y gestión de la ciudad y el territorio. }\end{array}$ & Especifica \\
\hline $\mathrm{C} 12$ & $\begin{array}{l}\text { Que los estudiantes sepan dirigir y coordinar grupos de trabajo, proponiendo métodos de } \\
\text { trabajo y herramientas eficientes y actuales. }\end{array}$ & Especifica \\
\hline $\mathrm{C} 13$ & $\begin{array}{l}\text { Que los estudiantes sepan evaluar y corregir los efectos negativos medioambientales } \\
\text { producidos por las infraestructuras de transporte y promover la aplicación de los } \\
\text { principios de sostenibilidad. }\end{array}$ & Especifica \\
\hline C 14 & $\begin{array}{l}\text { Que los estudiantes conozcan las tecnologias a utilizar para el diseño, el cálculo, la } \\
\text { construoción, la evaluación, la rehabilitación, la reparación y el desmantelamiento de las } \\
\text { infraestructuras de transporte. }\end{array}$ & Especifica \\
\hline C15 & $\begin{array}{l}\text { Que los estudiantes conozcan las tecnologías para la planificación, gestión, explotación y } \\
\text { optimización de infraestructuras territoriales. }\end{array}$ & Especifica \\
\hline C16 & $\begin{array}{l}\text { Que los estudiantes sean capaces de supervisar y dirigir equipos personales en adecuadas } \\
\text { condiciones de seguridad y salud laboral }\end{array}$ & Especifica \\
\hline C17 & $\begin{array}{l}\text { Que los estudiantes sean capaces de elaborar estudios de impacto ambiental y estudios y } \\
\text { adecuaciones medioambientales en zonas litorales. }\end{array}$ & Especifica \\
\hline C 18 & $\begin{array}{l}\text { Que los estudiantes conozcan el procedimiento y los contenidos de la documentación } \\
\text { para la evaluación estratégica ambiental de planes y programas de transporte, } \\
\text { urbanisticos y territoriales }\end{array}$ & Espedifica \\
\hline C19 & $\begin{array}{l}\text { Que los estudiantes posean habilidades para integrarse en equipos multidisciplinares } \\
\text { creados para la redacción de planeamiento urbanistico y territorial }\end{array}$ & Especifica \\
\hline $\mathrm{C} 20$ & $\begin{array}{l}\text { Que los estudiantes sean capaces de analizar y comprender los planes urbanisticos y } \\
\text { territoriales para su ejecución y desarrollo }\end{array}$ & Especifica \\
\hline $\mathrm{C} 21$ & $\begin{array}{l}\text { Que los estudiantes tengan habilidades para integrarse en equipos multidisciplinares } \\
\text { para la elaboración y gestión de programas de actuación de desarrollo urbano }\end{array}$ & Especifica \\
\hline $\mathrm{C} 22$ & Que los estudiantes comprendan y sepan realizar valoraciones urbanisticas. & Especifica \\
\hline $\mathrm{C} 23$ & $\begin{array}{l}\text { Que los estudiantes sepan integrar las infraestructuras de transporte en el planeamiento } \\
\text { urbanistico bajo la perspectiva de proyecto de paisaje }\end{array}$ & Especifica \\
\hline $\mathrm{C} 24$ & $\begin{array}{l}\text { Que los estudiantes tengan aptitudes y habilidades para organizar y gestionar técnica, } \\
\text { económica y administrativamente los distintos medios de producción proplos de la } \\
\text { Ingenieria de Transportes }\end{array}$ & Especifica \\
\hline
\end{tabular}

Fig. 1 Identificación, definición y carácter de las competencias del título.

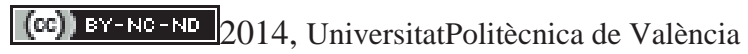

I Jornadas IN-RED (2014) 
El proceso a seguido a lo largo de esta fase ha sido el siguiente:

- Delimitación de las Competencias del Máster de Transportes, Territorio y Urbanismo (Fig. 1).

- Análisis de las Guías Docentes de las asignaturas del Máster de Transportes, Territorio y Urbanismo. Verificación del estado y distribución de las competencias.

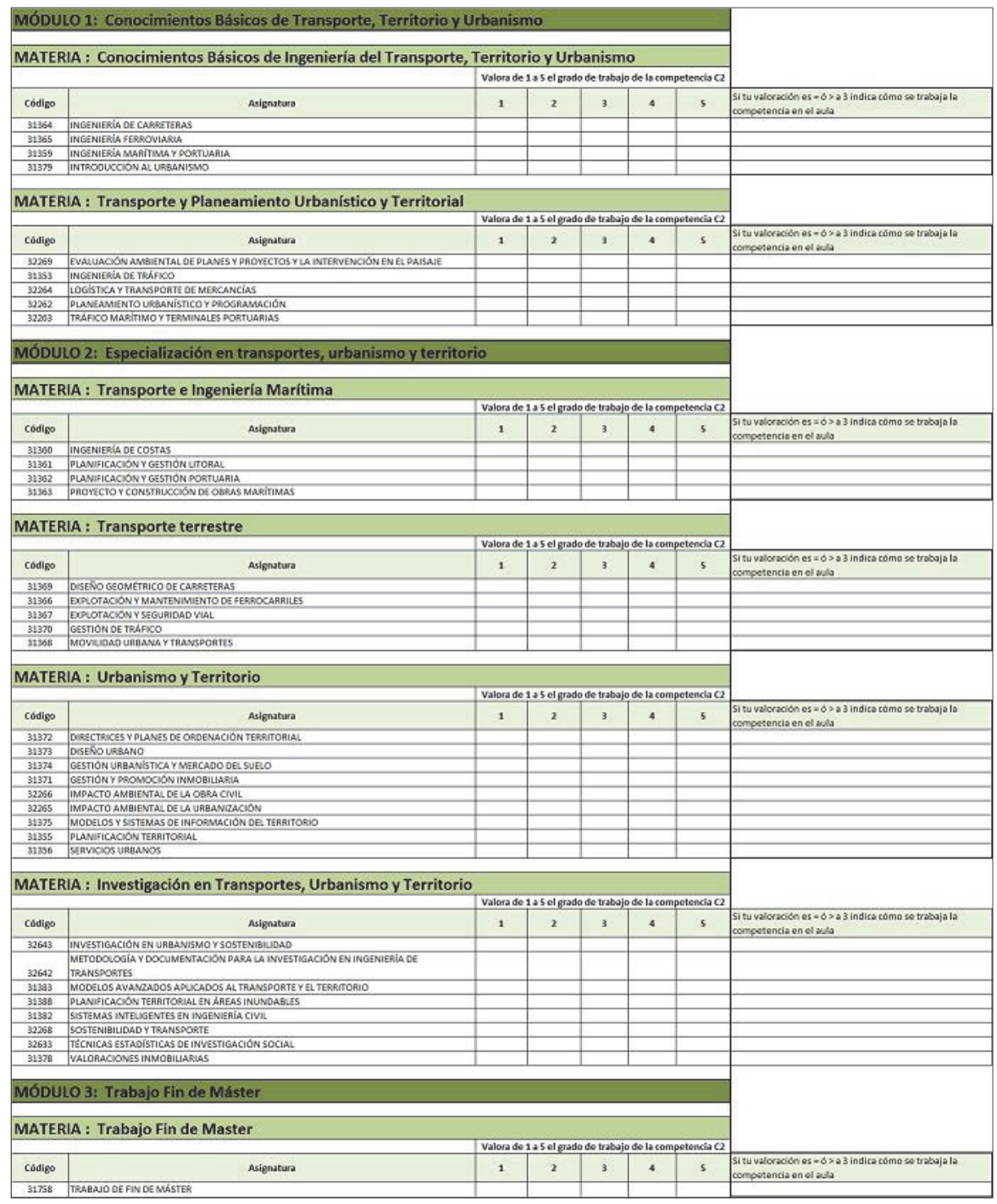

Fig.2. Diselño del cuestionario pasado a los alumnos.

(c) EY-NC-ND 2014, UniversitatPolitècnica de València

I Jornadas IN-RED (2014) 
Diseño e implementación del protocolo de coordinación para la evaluación de las competencias en el Máster de Transportes, Territorio y Urbanismo de la ETSICCP

Fase 1.2: En esta fase se ha realizado un trabajo de análisis exhaustivo sobre cómo trabaja el alumno lo que las diferentes guías docentes proponen en las asignaturas obligatorias del Máster (Segundo semestre del curso 2012-2013)

- Elaboración y pase de cuestionarios a antiguos alumnos del Máster de Transportes, Territorio y Urbanismo (2 promociones), a partir de los resultados obtenidos en la fase I (Fig. 2).

- Análisis de los cuestionarios (Fig.3).

- Como complemento del estudio, se ha pasado a los alumnos durante el curso 2012-2013 y 2013-2014 los test (CEVEAPEU y CEVAPU) al alumnado sobre estrategias, actitudes y enfoques de aprendizaje al inicio de cada semestre.

- Conclusiones

- A la vista de los resultados detectados se ha realizado una acción formativa en competencias dirigida a los profesores responsables de asignaturas en colaboración con el ICE.

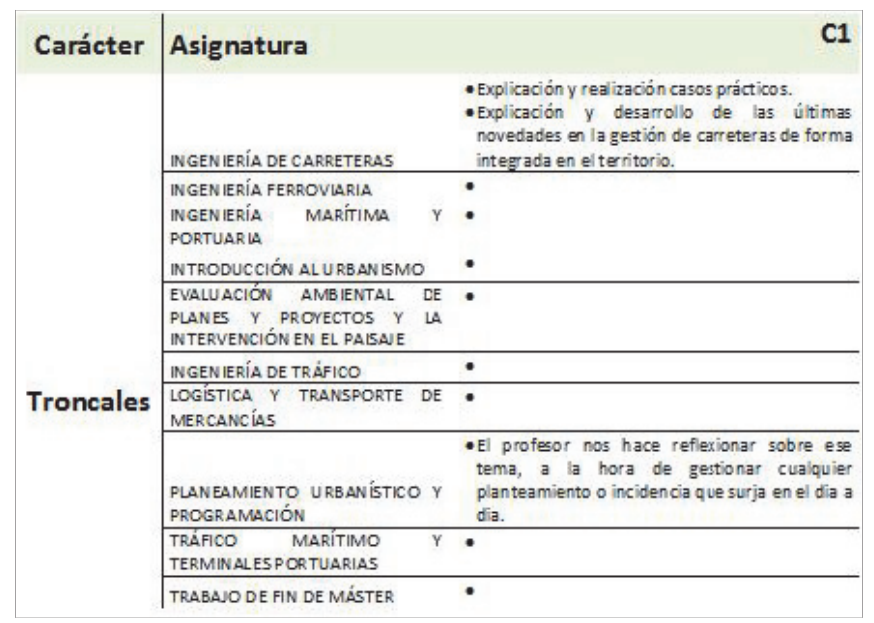

Fig.3. Diselño del cuestionario pasado a los alumnos.

\section{Resultados}

Se ha planteado un sistema de trabajo que, partiendo de la realización de una importante tarea de coordinación entre los docentes que imparten la misma asignatura, materia y título, consiga la unificación del significado de cada una de las competencias en el contexto del título y su relación con las distintas metodologías docentes, resultados de aprendizaje y

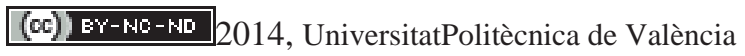


métodos de evaluación utilizados. En este trabajo de investigación se ha realizado un análisis preliminar de las competencias genéricas comprendidas en el título del Máster de Transportes, Territorio y Urbanismo que revela la necesidad de definir y concretar de manera más específica cuáles son y qué significan las competencias que el título propone. Así como qué se pretende conseguir al trabajarlas durante el curso.

En segundo lugar se ha detectado que la clasificación que se propone en las guía docentes en dos grupos: "General" y "Específica", nos lleva a confusión. Esta clasificación sigue un modelo que no se corresponde con lo que se entiende por por "Competencia Genérica" y "Específica" en el EEES (Fig. 1).

Así, se ha realizado un análisis preliminar de las competencias genéricas y específicas comprendidas en el título del Máster de Transportes, Territorio y Urbanismo que revela la necesidad de definir y concretar su significado, y qué se pretende conseguir al trabajarlas durante el curso.

Del análisis de la totalidad de las guías docentes y su relación con las competencias del título se desprende lo siguiente:

1. De manera sistemática en la mayoría de las guías docentes de las asignaturas, como competencias a trabajar durante el curso, se seleccionan de manera indiscriminada casi todas las competencias del título (en la mayoría de los casos todas).

2. Esta selección de competencias no tiene correspondencia ni con las metodologías, ni con la evaluación, ni con los resultados de aprendizaje reflejados en cada una de las guías docentes.

3. Hay competencias del título que formalmente no trabaja ninguna asignatura.

Del análisis del cuestionario pasado a los alumnos (Fig. 2):

1. Existen grandes incongruencias entre lo analizado en las guías docentes y lo que de manera efectiva dicen los alumnos que trabajan en lo que se refiere a competencias, metodología, evaluación y resultados de aprendizaje.

2. Los resultados de los Test (CEVEAPEU y CEVAPU) al alumnado en estos momentos se encuentran en fase de explotación por el Departamento de Teoría de la Educación de la Universitat de València.

Por último, y a la vista de los resultados detectados se ha realizado una acción formativa en competencias, con la colaboración del ICE, dirigida a los profesores responsables de asignaturas durante el segundo semestre de la anualidad. 
Diseño e implementación del protocolo de coordinación para la evaluación de las competencias en el Máster de Transportes, Territorio y Urbanismo de la ETSICCP

\section{Conclusiones}

Las conclusiones que se han extraído de la experiencia confirman la necesidad de plantear un sistema de aseguramiento, que debe ir desde el propio inicio del diseño de los títulos, que garantice la consecución del perfil de formación y adquisición de competencias que dichos títulos proponen.

En este sentido se pone de manifiesto la necesidad de realizar una importante tarea de coordinación entre los docentes que imparten la misma asignatura, materia y título, para unificar el significado de cada una de las competencias en el contexto del título y su relación con las distintas metodologías docentes, resultados de aprendizaje y métodos de evaluación utilizados.

El proyecto que ha comenzado a desarrollarse plantea un diseño metodológico y su implementación en un caso concreto, el Máster de Transportes Territorio y Urbanismo, relacionando las "competencias del título", la "metodología de enseñanza aprendizaje", "los sistemas de evaluación" y los "resultados de aprendizaje", se ha venido desarrollando de forma bastante ajustada a la planificada, por lo que se estima que el procedimiento diseñado es adecuado.

Como consecuencia de la implantación del nuevo título oficial de Máster en Ingeniería de Caminos Canales y Puertos en la ETSICCP, y a la vista de la viabilidad como metodología de trabajo demostrada por el proyecto de investigación original, éste se ha convertido en un proyecto mucho más ambicioso, el rediseño de un título de Master, visto desde la perspectiva de coordinación con los nuevos grados implantados en 2010 y con el Máster en Ingeniería de Caminos Canales y Puertos que previsiblemente se iniciará en el curso 20142015, por lo que la propuesta de futuro es la de poner en práctica una metodología para el diseño del nuevo título partiendo de los resultados obtenidos en la fase de análisis realizada, y siguiendo las pautas definidas en el modelo del proyecto de investigación original, que hasta este momento se ha mostrado como adecuada.

\section{Referencias}

ANECA (2004). Libro blanco del título de grado en Ingeniería Civil. Agencia Nacional de Evaluación de la Calidad y Acreditación. Madrid: Universidad Politécnica de Madrid.

AQU CATALUNYA (2009). Guía para la evaluación de competencias en el área de ingeniería y arquitectura. Barcelona: Agència per a la Qualitat del Sistema Universitari de Catalunya .

BIGGS, J. (2004). Calidad del aprendizaje universitario. Madrid: Narcea.

(c)) EY-NC-ND 2014, UniversitatPolitècnica de València

I Jornadas IN-RED (2014) 
ENQUA (2005): Criterios y Directrices para la Garantía de Calidad en el Espacio Europeo de Educación Superior. Helsinki: European Association for Quality Assurance in Higher Education.

GALÁN, A. (2007). El perfil del profesor universitario. Situación actual y retos de futuro. Madrid: Ediciones Encuentro.

GARCÍA GARCÍA, E. (2010). Competencias éticas del profesor y calidad de la educación. Revista electrónica interuniversitaria de formación del profesorado (REIFOP), Vol. 2010, 13 (4), pp. 29-41.

JIMENEZ RODRIGUEZ M.A. (2011). Como diseñar y desarrollar el currículo por competencias. Madrid: PPC editorial.

MATEO, J. (2000). La evaluación educativa, su práctica y otras metáforas. Barcelona: ICE Universitat de Barcelona.

PERRENOUD, P. (2004). Diez nuevas competencias para enseñar. Barcelona: Graó.

RODRÍGUEZ ESPINAR, S. (2003). Nuevos retos y enfoques en la formación del profesorado universitario. Revista de Educación, Vol. 2003 (331) pp. 67-99.

ZABALA, A. y ARNAU, L. (2007). 11 ideas clave. Cómo aprender y enseñar competencias. Barcelona: Graó.

ENCUESTA CHEERS <http://www.uni-kassel.de/incher/cheers/> [Consulta: 13 de junio 2012]

REFLEX. Informe ejecutivo.

<http://www.aneca.es/estudios/docs/InformeejecutivoANECA_jornadasREFLEXV20.pdf> [Consulta: 15 de mayo 2012]

RAUDENBUSH, S.W. \& BRYK, A.S. (2002). Hieracrhical Linear Models: Applications and data analysis methods. Newbury Park. CA: Sage.

TUNNING PROJECT. General Brochure.

<http://tuning.unideusto.org/tuningeu/images/stories/template/General_Brochure_Spanish_ version.pdf $>$ [Consulta: 12 de mayo 2012]

UE-CONVERGE. < http://ueconverge.com.mialias.net/actions/public/index.inc.php> [Consulta: 25 de mayo 2012] 


\title{
Integración del EPS en los títulos de grado de la ETSID
}

\author{
Isabel Gasch ${ }^{\mathrm{a}}$, Pedro Fuentes-Durá ${ }^{\mathrm{b}}$, Leopoldo Armesto ${ }^{\mathrm{c}}$, David Perry ${ }^{\mathrm{d}}$, Marina \\ Puyuelo $^{\mathrm{e}}$ y Gabriel Songel ${ }^{\mathrm{f}}$
}

${ }^{a}$ Universitat Politècnica de València, igasch@mes.upv.es, ${ }^{b}$ Universitat Politècnica de València, pfuentes@iqn.upv.es, ${ }^{c}$ Universitat Politècnica de València, larmesto@idf.upv.es, ${ }^{\mathrm{d}}$ Universitat Politècnica de València, daper@idm.upv.es, ${ }^{\mathrm{e} U n i v e r s i t a t ~ P o l i t e ̀ c n i c a ~ d e ~ V a l e ̀ n c i a, ~}$ mapuca@ega.upv.es y ${ }^{\mathrm{f}}$ Universitat Politècnica de València, gsongel@upv.es.

\begin{abstract}
The Escuela Técnica Superior de Ingeniería del Diseño (ETSID) strives for continuous improvement of its study plans and curricula, especially in relation to teaching methodologies that promote active learning and learning opportunities that facilitate the achievement of the most important skills. Among other actions to achieve these objectives, in 2005 the ETSID introduced the European Project Semester (EPS), a training package in which international teams working in multidisciplinary projects develop their subject-matter knowledge as well as their intercultural communication and teamwork skills. EPS is currently taught at 14 universities in 11 European countries.

EPS contributes directly to the aims of both the UPV in general, and to those of the ETSID in particular, through its positive impact on a large number of students and its contribution to the professional development of professors. It also contributes indirectly by making the subjects on offer to foreign students more attractive. Here we describe the protocol analysis and redesign of the EPS so that it can form part of the curricula of the various degrees of the ETSID.
\end{abstract}

Keywords: EPS, internationalization, multidisciplinary

\section{Resumen}

La Escuela Técnica Superior de Ingeniería del Diseño (ETSID) tiene como fundamento de su funcionamiento la mejora continua de sus titulaciones, especialmente en lo referente a metodologías docentes que fomenten el

(c) EY-NC-ND 2014, Universitat Politècnica de València

I Jornadas In-Red (2014) 
aprendizaje activo y las oportunidades de aprendizaje que faciliten el logro de las competencias más importantes.

Entre otras actuaciones para alcanzar estos objetivos, en 2005, la ETSID implantó el European Project Semester (EPS), un paquete formativo en el que equipos internacionales trabajan en proyectos multidisciplinares, para desarrollar sus capacidades, así como sus habilidades de comunicación intercultural y el trabajo en equipo. Actualmente se imparte en 14 universidades de 11 países europeos.

Utilizando como herramienta básica el EPS, se pretende contribuir de manera positiva a las intenciones de la UPV en general y de la ETSID en particular mediante el impacto directo en un número importante de estudiantes $e$, indirectamente, al hacer más atractiva la oferta para los estudiantes extranjeros y al contribuir al desarrollo profesional de los profesores.

Se establece un protocolo de análisis, información y rediseño del EPS para que este pueda formar parte de los planes de estudio de los distintos títulos de grado de la ETSID.

Palabras clave: EPS, títulos de grado, internacionalización, multidisciplinar

\section{Introducción}

\subsection{El escenario}

La Educación Superior trata de adaptarse al entorno, anticiparse a los cambios y rediseñarse al gusto de sus usuarios. Esto incluye su relación con el entorno económico, la utilidad de su actividad educativa y la evolución de su propia comunidad universitaria.

La globalización y sus consecuencias en los mercados internacionales influyen en el sector de la educación superior, constituyendo nuevos retos para los planes de estudio y para los graduados en ingeniería. Las universidades politécnicas tienen que responder a la siguiente pregunta básica (Vest, 2012): En el futuro los ingenieros ¿qué harán, dónde lo harán, por qué lo harán y que implica esto para la enseñanza de la ingeniería?

La dirección del cambio no es fácilmente predecible por lo que la única manera razonable de diseñar unos planes de estudio es ayudando a los estudiantes a ser "lifelong learners", de modo que sepan cómo encontrar y manejar información para resolver problemas complejos, 
cómo realizar inmersiones en nuevos campos de estudio y cómo cambiar y desarrollarse adaptándose a su medio ambiente que, a buen seguro, mutará.

Los ingenieros han de ser capaces de trabajar en ambientes internacionales, debido al intenso intercambio actual de personas, ideas y productos, acompañado de la omnipresencia de las empresas multinacionales. Estos conllevan, de manera inherente, diversidad de culturas, sistemas, formaciones, valores, perspectivas y expectativas, lo que convierte en necesidad equipar a los jóvenes con las habilidades para comunicarse de forma eficiente y trabajar colaborativamente en estos ambientes complejos.

Otro importante punto de vista es la necesidad de disponer capital humano bien preparado, creativo e innovador para ser competitivo. Hace falta una sólida base técnica y profesional al tiempo que una actitud visionaria, atrevida y abierta, ya que los problemas reales requieren metodologías y soluciones multidisciplinares e integradoras que se consiguen con el trabajo de equipos complejos.

Respecto a la utilidad de su actividad educativa, podemos encontrar referencias acerca de las competencias que deben desarrollar los ingenieros al concluir sus estudios tanto a escala global (ABET, 2014) como europea (Teichler y Schonburg, 2004) o estatal, por ejemplo, la orden CIN/351/2009, de 9 de febrero, por la que se establecen los requisitos para la verificación de los títulos universitarios oficiales que habiliten para el ejercicio de la profesión de Ingeniero Técnico Industrial.

En el marco de la Universitat Politècnica de València (UPV) se está trabajando en la revisión de la definición de las competencias (fundamentalmente las transversales) de los títulos actuales para tratar de garantizar y medir la adquisición de las mismas.

En lo concerniente a la evolución de las comunidades universitarias, vemos cómo cambian las condiciones humanas, materiales y financieras, lo que hace evolucionar los recursos educativos que se emplean (Heinrich, 2007) y las interacciones estudiante-profesor que se producen (Mina y Gerdes, 2006). El tiempo empleado en cursar un grado es del orden del $10 \%$ de la vida laboral de un graduado. ¿Qué debe hacerse en ese tiempo? ¿Y que no sea obsoleto en pocos años? ¿Y que no se olvide una vez hecho el examen?

\subsection{European Project Semester}

Harrison (2002) sugirió que el propósito de una educación superior moderna debe ser el mostrar a los estudiantes cómo resolver problemas y proporcionar las herramientas básicas para resolver esos problemas. Pero, ¿cuáles son esas herramientas fundamentales y cómo deben ser "enseñadas"?

\section{(c)) EY-NC-ND 2014, Universitat Politècnica de València}

I Jornadas IN-RED (2014) 
Los empleadores (Crossman y Clarke, 2010) identifican claramente experiencia internacional y empleabilidad de un graduado, debido a la experiencia, los contactos, los idiomas y el desarrollo de "soft skills" relacionados con la multiculturalidad, las características personales y las formas de pensar.

Hace más de 20 años, en Dinamarca, Andersen (1997) ya combinó las ideas expresadas en los dos párrafos anteriores con el reconocimiento cosechado por el éxito de la metodología "Project Based Learning", especialmente "The Aalborg PBL Model" (Barge, 2010). Y decidió impulsar un enfoque basado en proyectos multidisciplinares realizados en equipos internacionales: el EPS.

El EPS fue sido diseñado para preparar a los estudiantes con las habilidades necesarias para afrontar los retos de la economía mundial actual. Equipos de estudiantes internacionales trabajan en proyectos multidisciplinares, donde pueden desarrollar sus capacidades, así como sus habilidades de comunicación intercultural y el trabajo en equipo.

El European Project Semester es un paquete formativo ofertado en este momento por 14 universidades en 11 países europeos donde se combina PBL con un conjunto de microcursos, seminarios y actividades de soporte. En él participan estudiantes de diferentes titulaciones y trabajan equipos multinivel, multidisciplinares y multiculturales. Está orientado a la adquisición de las competencias demandadas por la globalización y el rápido cambio actual (EPS, 2014).

\subsection{Escuela Técnica Superior de Ingeniería del Diseño}

La ETSID pretende mejorar continuamente sus titulaciones, especialmente en lo referente a metodologías docentes que mejoren el aprendizaje activo y las oportunidades de aprendizaje que faciliten el logro de las competencias asociadas a las mismas (Ballester et al, 2012).

Como recoge en su propia visión: "La visión estratégica de la ETSID es constituirse en referente nacional e internacional por la formación permanente de ciudadanos comprometidos y profesionales altamente cualificados, las vinculaciones con las empresas y organizaciones, la cultura emprendedora, la calidad y la innovación, la colaboración y liderazgo en redes universitarias del ámbito de las ingenierías y un claro compromiso con la búsqueda de soluciones que contribuyan a un desarrollo sostenible" (ETSID, 2014).

En el curso 2014/2015 se impartirá en la ETSID un total de 5 grados de ingeniería, 6 masters universitarios, 4 masters propios y el programa de Doctorado en Diseño, Fabricación y Gestión de Proyectos Industriales. Todos ellos con una perspectiva de adaptación europea (Ballester, 2012). Los títulos se diseñaron alrededor de un catálogo de competencias, cuyo alcance es la meta formativa de la titulación. Para validar este grado de 
alcance disponemos de experiencia en el caso de las competencias específicas; sin embargo, en el caso de las competencias transversales la experiencia es mucho menor. A este problema se suma el hecho de que las competencias transversales suelen validarse a través de varias asignaturas, apareciendo un nuevo reto evaluativo. Uno de los principales objetivos de la UPV para el curso 2014/2015 es la evaluación de las competencias transversales, que afectará a todas las asignaturas de los nuevos planes.

La ETSID recibe más de 200 estudiantes de intercambio al año desde 2003, con un promedio de 271 anuales en los últimos 5 años. Esto exige una oferta académica con valor añadido para los estudiantes extranjeros.

En los últimos 10 años, 1899 alumnos de la ETSID han disfrutado de un periodo en otra Universidad. Pese a ser una cifra espectacular, significa que muchos egresados no lo han hecho. Por ello, la ETSID considera la internacionalización en casa un elemento inexcusable en su actividad.

Entre otras actuaciones para alcanzar estos objetivos, en 2005, la ETSID implantó el European Project Semester (Gasch et al, 2012), que constituye un banco de pruebas de contenidos transversales. Actualmente se encuentra bajo estudio su impacto en las Dimensiones Competenciales de la UPV.

\section{Objetivos}

De acuerdo con lo anteriormente expuesto, un equipo de profesores de la ETSID, involucrados en el European Project Semester (EPS), presentó un Proyecto de Innovación y Mejora Educativa (PIME) llamado "Integración, comunicación y trabajo en equipo". Este proyecto, concedido por la UPV, utilizando como herramienta básica el EPS, pretende contribuir de manera positiva a las intenciones de la UPV en general y de la ETSID en particular. Directamente, mediante el impacto en un número importante de estudiantes e, indirectamente, al hacer más atractiva la oferta para los estudiantes extranjeros y al contribuir al desarrollo profesional de los profesores.

La herramienta básica del mencionado proyecto es el EPS, cuya implantación se llevó a cabo con una doble finalidad: mejorar las "soft skills" de los graduados de la ETSID y crear un ambiente excelente para la recepción de alumnos de intercambio.

Los objetivos de este PIME son:

- Establecer un protocolo de análisis, información y rediseño del EPS para que este pueda formar parte de los planes de estudio de los distintos títulos de grado de la ETSID. Esto beneficiaría tanto a los alumnos extranjeros como a los propios de la Escuela que podrían cursar el EPS en la propia Universidad.

\section{(c) EY-NC-ND 2014, Universitat Politècnica de València}

I Jornadas IN-RED (2014) 
- Evaluar el impacto del EPS en las Dimensiones Competenciales de la UPV, especialmente DC1, DC5, DC6 y DC8. En la tabla 1 se muestra el significado de cada una de estas dimensiones seleccionadas entre un total de trece.

- Contribuir al desarrollo profesional de los profesores de la ETSID en el campo de la innovación educativa, con especial referencia a la multiculturalidad, la multidisciplinariedad, la comunicación y el trabajo en equipo.

Tabla 1. Explicación de las cuatro Dimensionales Competenciales UPV seleccionadas

\begin{tabular}{|c|c|l|}
\hline Clave & Denominación & \multicolumn{1}{c|}{ Descripción } \\
\hline DC1 & $\begin{array}{c}\text { Comprensión e } \\
\text { integración }\end{array}$ & $\begin{array}{l}\text { Demostrar la comprensión e integración del conocimiento tanto de la } \\
\text { propia especialización como en otros contextos más amplios. }\end{array}$ \\
\hline DC5 & $\begin{array}{c}\text { Diseño y } \\
\text { proyecto }\end{array}$ & $\begin{array}{l}\text { Diseñar, dirigir y evaluar una idea de manera eficaz hasta concretarla en } \\
\text { un proyecto. }\end{array}$ \\
\hline DC6 & $\begin{array}{c}\text { Trabajo en } \\
\text { equipo y } \\
\text { liderazgo }\end{array}$ & $\begin{array}{l}\text { Trabajar y liderar equipos de forma efectiva para la consecución de } \\
\text { objetivos comunes, contribuyendo al desarrollo personal y profesional de } \\
\text { los mismos. }\end{array}$ \\
\hline DC8 & $\begin{array}{c}\text { Comunicación } \\
\text { efectiva }\end{array}$ & $\begin{array}{l}\text { Comunicarse de manera efectiva, tanto de forma oral como escrita, } \\
\text { utilizando adecuadamente los recursos necesarios y adaptándose a las } \\
\text { características de la situación y la audiencia. }\end{array}$ \\
\hline
\end{tabular}

\section{Desarrollo de la Innovación}

El EPS se comenzó a impartir en la Escuela Técnica Superior de Ingeniería del Diseño de la UPV en 2005 y hasta el momento han participado como supervisores de los estudiantes 14 profesores de 9 departamentos diferentes de la UPV en colaboración con diversas empresas. Este esfuerzo multidisciplinar y complejo se lleva a cabo para generar valor añadido a los periodos de intercambio, creando un ambiente excelente para la recepción de estudiantes y abriendo el abanico de oportunidades para los estudiantes de grado. Tanto los estudiantes como los profesores realizan encuestas de satisfacción y de innovación abierta con el fin de soportar su continua evolución y mejora.

Las titulaciones oficiales involucradas en este proyecto son:

- Grado en Ingeniería Aeroespacial

- Grado en Ingeniería en Diseño Industrial y Desarrollo de Productos

- Grado en Ingeniería Eléctrica

- Grado en Ingeniería Electrónica Industrial y Automática

- Grado en Ingeniería Mecánica 
El proyecto se coordina por el responsable del proyecto gracias a la compartición en BOX de la documentación (borradores, datos, etc.) y a través de reuniones a demanda que, como mínimo, habrán de suceder una vez al mes. El calendario se adaptará a las posibilidades reales de las personas involucradas y a la publicación definitiva de fechas académicas, congresos, etc.

El Grado en Ingeniería en Diseño Industrial y Desarrollo de Productos (GIDIDP) es el elegido como piloto debido a sus características intrínsecas así como al perfil del profesorado y el alumnado del mismo (Puyuelo et al, 2013; Ballester et al, 2012) .

El proyecto empezó durante el primer semestre del curso 2013/2014 y está prevista su conclusión en septiembre de 2015. Se espera haber comenzado ya en ese momento con nuevas acciones que se desarrollarán simultáneamente. De tal forma que lo logrado con el GIDIDP sea transferido al resto de grados impartidos en la ETSID en el curso 2015/2016.

La actividad del grupo de profesores busca establecer un círculo virtuoso: investigación, información, rediseño, difusión, implementación, análisis y transferencia (Fuentes-Durá et al, 2012). Este proyecto comprende gran parte de ese círculo.

Para su desarrollo se llevan a cabo diversas tareas que podemos agrupar en cuatro grandes bloques:

- RECOGIDA de información sobre la actividades desarrolladas. Análisis de la información y elaboración de propuestas adaptadas al Grado en Ingeniería en Diseño Industrial y Desarrollo de Productos (GIDIDP).

- INFORMACION a las Comisiones Académicas de Título (CATs) y profesores de la ETSID y búsqueda de una solución conjunta a través de Metaplán y posterior Delphi. Elaboración de formatos específicos para la asignatura 10329. Especificación de protocolos, participantes y calendarios.

- DIFUSION a diferentes escalas, local, nacional e internacional, mediante presentaciones y reuniones en diferentes ámbitos y actividades de innovación educativa.

- EVALUACION según las evidencias e indicadores definidos.

La tabla 2 muestra la matriz de responsabilidad del equipo de profesores del proyecto indicando las tareas, los responsables $(\mathrm{R})$ de cada una de ellas y las personas que actuarán de soporte (S) para dichas tareas.

\section{(c) EY-NC-ND 2014, Universitat Politècnica de València}

I Jornadas IN-RED (2014) 
Tabla 2. Matriz de responsabilidad del PIME

\begin{tabular}{|l|c|c|c|c|c|c|}
\hline \multicolumn{1}{|c|}{ Tarea/Responsabilidad } & D & G & I & L & M & P \\
\hline $\begin{array}{l}\text { Recogida de información sobre las actividades } \\
\text { desarrolladas }\end{array}$ & & & R & S & & S \\
\hline $\begin{array}{l}\text { Análisis de la información y elaboración de propuestas } \\
\text { adaptadas al GIDIDP }\end{array}$ & S & $\mathbf{R}$ & & & & S \\
\hline Información a las CAT y profesores de la ETSID & & $\mathrm{S}$ & & & $\mathbf{R}$ & $\mathrm{S}$ \\
\hline Metaplán/Delphi & & & & & $\mathrm{S}$ & $\mathbf{R}$ \\
\hline $\begin{array}{l}\text { Elaboración de formatos específicos. Especificación } \\
\text { de protocolos, participantes y calendarios }\end{array}$ & $\mathbf{R}$ & & & & $\mathrm{S}$ & $\mathrm{S}$ \\
\hline Difusión a escala local & & & $\mathrm{S}$ & & $\mathrm{S}$ & $\mathbf{R}$ \\
\hline Difusión a escala nacional & & $\mathrm{S}$ & $\mathbf{R}$ & & $\mathrm{S}$ & $\mathrm{S}$ \\
\hline Difusión a escala internacional & $\mathrm{S}$ & & & $\mathrm{S}$ & & $\mathbf{R}$ \\
\hline Evaluación según los indicadores definidos & & & & $\mathbf{R}$ & & $\mathrm{S}$ \\
\hline
\end{tabular}

\section{Resultados}

En este apartado vamos a indicar, en primer lugar, una lista de documentos en lo que se está trabajando junto a ciertas acciones que se están llevando a cabo. Posteriormente se citarán los principales indicadores de cumplimiento del proyecto e indicaciones acerca de su difusión. Finalmente incluiremos una serie de resultados obtenidos por la red de proveedores de EPS y otros resultados obtenidos en la ETSID, teniendo en cuenta que son parciales puesto que el proyecto se encuentra en desarrollo.

Actualmente se está trabajando para obtener los siguientes documentos:

- Aprobación de la Comisión Académica de Título del Grado en Ingeniería en Diseño Industrial y Desarrollo de Productos de la actividad European Project Semester como equivalente de la asignatura Intercambio para los estudiantes que realizan una periodo de movilidad en la ETSID.

- Aprobación de la Comisión Académica de Título del Grado en Ingeniería en Diseño Industrial y Desarrollo de Productos de la actividad European Project Semester como equivalente de la asignatura Intercambio para los estudiantes a tiempo completo de la ETSID.

- Compromiso de las comisiones académicas del resto de Títulos de Grado de valorar la actividad European Project Semester como equivalente de la asignatura Intercambio o Programa de Intercambio, según corresponda. 
Por otro lado se están llevando a cabo las siguientes acciones:

- Creación de materiales base adaptados a los diferentes grados.

- Análisis de encuestas de satisfacción y de innovación abierta a los alumnos participantes.

- Análisis de encuestas de satisfacción y de innovación abierta a los profesores participantes.

- Análisis de innovación abierta a observadores.

- Análisis prospectivo a potenciales participantes.

- Análisis de encuestas de satisfacción y de innovación abierta a participantes en EPS en otros centros universitarios de la red.

Como indicadores se busca:

- Un 100\% de rendimiento académico en el EPS.

- Un 90\% de satisfacción de los estudiantes participantes en EPS.

- Un 100\% de satisfacción de los profesores participantes en EPS.

- Una lista de al menos 10 profesores dispuestos a participar en futuros cursos.

- Contribuciones críticas de al menos 30 profesores.

- La implantación de EPS (o equivalente) en la asignatura 10329 el curso $2014 / 2015$.

Está previsto difundir los resultados a tres niveles:

- En primer lugar, a escala local. Mediante presentaciones y reuniones con el profesorado de la ETSID y mediante las actividades de difusión de innovación educativa que se organizasen en la UPV durante 2014, en este caso las Jornadas de Innovación Educativa y Docencia en Red.

- A escala nacional, a través del Congreso Universitario de Innovación Educativa en las Enseñanzas Técnicas, que se celebrará en Almadén en septiembre2014 y alguna actividad pendiente de decidir.

- Y, por último, a escala internacional, con la asistencia a la reunión anual de proveedores de EPS en St Polten, Austria en diciembre de 2013, la reunión anual de proveedores de EPS en Delft, Holanda, en octubre de 2014 y Valencia Global 2014. Está también previsto el envío de una publicación al European Journal of Engineering Education.

Como resultados obtenidos por EPS en su conjunto podemos citar:

- Actualmente, más de 3000 estudiantes han participado en EPS.

- El número de HEIs en los que se imparte EPS no ha parado de crecer en más de una década como puede verse en la figura 1.

(c)) EY-NC-ND 2014, Universitat Politècnica de València

I Jornadas IN-RED (2014) 
- Los proyectos son innovadores (Hanzel et al., 2014).

- Han participado estudiantes de más de 50 nacionalidades.

- Numerosas universidades lo consideran un ejemplo de buenas prácticas (Abata et al., 2013).

- El modelo se ha transferido a otras disciplinas, como por ejemplo el International Business Semester que se imparte en la Danmarks Tekniske Universitet (DTU, 2014) o el International Design Project Semester, que se imparte en la Universitat Politécnica de Catalunya (UPC, 2014).

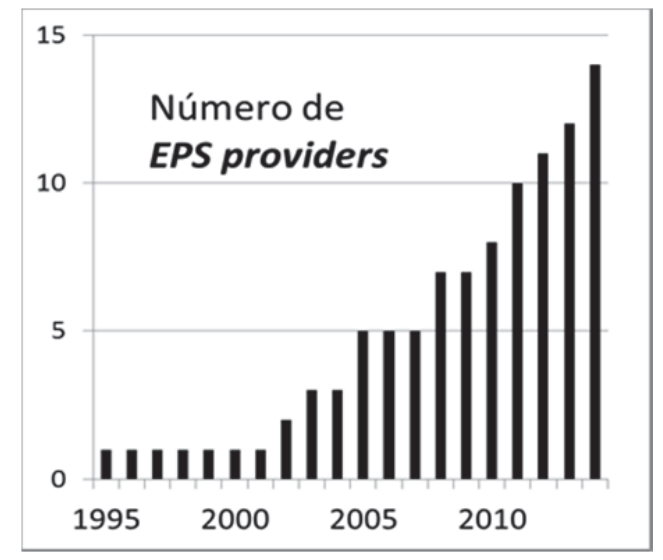

Fig. 1 Número de HEIs impartiendo EPS

Como resultados obtenidos por EPS en ETSID-UPV podemos citar:

- Actualmente, más de 300 estudiantes han participado en EPS. En la figura 2 puede verse esta información en base anual.

- $\quad$ El rendimiento académico es $100 \%$.

- $\quad$ El 97\% de los participantes recomendarían EPS. De hecho, en el último curso, más del $60 \%$ de los participantes habían recibido una recomendación directamente de un antiguo estudiante.

- $\quad$ El 100\% de los profesores están satisfechos con su participación.

- Hay más de 10 profesores dispuestos a participar en futuras ediciones.

- Los resultados de los proyectos son explotables (Fuentes-Durá y Songel, 2009; Vento et al, 2011). 


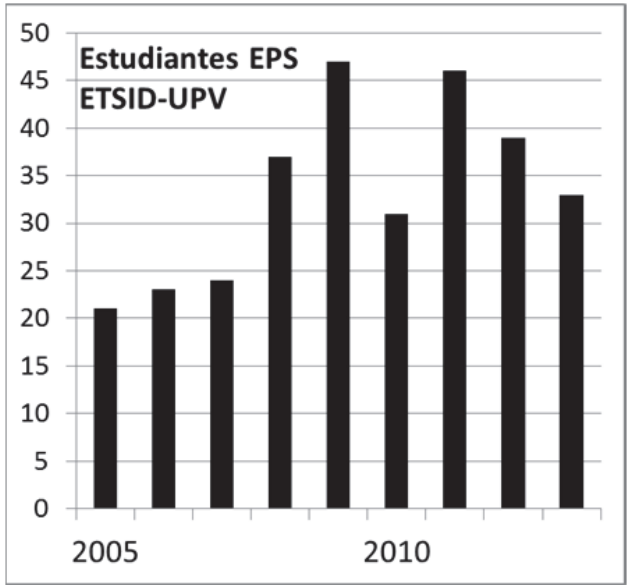

Fig. 2 Número de estudiantes EPS en la ETSID-UPV

\section{Conclusiones}

EPS está en línea con Education and Training 2020 (UE, 2009) y 2011 EU modernisation Agenda (UE, 2011), disminuyendo la brecha de conocimientos y habilidades entre los deseos de los empleadores y la realidad de los graduados y ayudando al desarrollo de las competencias del siglo XXI.

Los proveedores de EPS pretenden rediseñar este paquete de aprendizaje complejo, promoviendo el desarrollo profesional de la comunidad universitaria en las TIC e innovación, creando un conjunto de buenas prácticas y OER, estableciendo puentes sólidos entre los diferentes actores de la educación superior y difundiendo EPS a un público más amplio

A corto plazo, los proveedores de EPS esperan lograr:

- Unos vínculos aún más fuertes entre los miembros de la red, para lograr una red consistente y sostenible de universidades.

- Una correcta difusión del EPS tanto dentro como fuera de la red. Para establecer unos puentes sólidos entre los diferentes actores de la educación superior y aumentar la movilidad de estudiantes y profesores.

- La creación de valor añadido a escala de la Unión Europea gracias al desarrollo de un paquete formativo llevado a cabo en diferentes países y fácilmente implementable por toda la Unión.

- La creación de un conjunto de buenas prácticas y documentos disponibles para todo el mundo.

(cc)) EY-NC-ND 2014, Universitat Politècnica de València

I Jornadas IN-RED (2014) 
En la ETSID, tras casi 10 años desarrollando EPS en el marco de las Ingenierías Técnicas Industriales y la Ingeniería en Organización Industrial, ha llegado el momento de una transición irreversible hacia su contextualización en los nuevos Grados en Ingeniería.

Actualmente, la recogida de información y análisis de las actividades desarrolladas arroja un balance muy positivo, que recomienda la continuidad del EPS. Los participantes están satisfechos, existe un interés internacional (alumnos potenciales, universidades socias y empresas multinacionales) y las partes interesadas dentro del colectivo del centro (Dirección, CATs y profesores involucrados) están apoyando decididamente la integración del EPS en los títulos de grado de la ETSID.

La evaluación del impacto del EPS en las citadas Dimensiones Competenciales seleccionadas puede contribuir a uno de los temas pendientes en la UPV tras la implantación de los nuevos títulos universitarios: la evaluación de las competencias transversales, que piden las Agencias de acreditación (ABET, EUR-ACE, etc.) con evidencias constatables de que los alumnos adquieren las citadas competencias. La UPV está realizando durante el verano de 2014 una serie de reuniones informativas con el fin de conocer y preparar las acciones a realizar el próximo curso.

La participación de los profesores en EPS contribuye a su desarrollo en el campo de la innovación educativa, con especial referencia a la multiculturalidad, la multidisciplinariedad, la comunicación y el trabajo en equipo.

\section{Referencias}

ABATA, D.L., ANDERSEN, A. Y KRAUSE, W.B. (2013). "Transatlantic Interaction with European Project Semester" en 2013 American Society Engineering Education Annual Conference Program. Georgia, Atlanta, USA: ASEE.

ACCREDITATION BOARD FOR ENGINEERING AND TECHNOLOGY (ABET). "Criteria for Accrediting Engineering Programs. 2014-2015”. <http://www.abet.org/eac-criteria-20142015> [Consulta: 5 de mayo de 2014]

ANDERSEN, A. (1997). International Teamwork with Perspectives. European Project Semester (EPS). Roskilde University Conference Papers Vol. 1.

BALLESTER, E., GASCH, M., CONTAT, L., GASCH, I., NAVARRO, M. D. Y SÁNCHEZ, L.M. (2012). "Bologna VS non-Bologna academic outcome in BEng Mechanical Engineering within EHEA" en 42th Annual Frontiers in Education (FIE) Conference. IEEE. 780 - 784.

BALLESTER, E., GASCH, M., CONTAT, L., GASCH, I., NAVARRO, M. D. Y SÁNCHEZ, L.M. (2012). "Implementation of a new teaching-learning system in the BEng degree in Mechanical Engineering towards its EHEA adaptation" en ICEE International Conference on Engineering Education. Turku, Finlandia: Turku University of Applied Sciences. 870 - 875. 
BALlESTER, E., PUYUELO, M., CONTAT-RODRIGO, L., GASCH-SALVADOR, M. Y SÁNCHEZ-RUIZ, L. (2012). "Analyzing students' performance in an EHEA BEng Industrial Design Engineering degree" en 42th Annual Frontiers in Education. Seattle, Washington, USA: SEATTLE UNIVERSITY. 785-788.

BARGE, S. (2010). Principles of Problem and Project Based Learning. The Aalborg PBL Model.

CROSSMAN, J.E. y CLARKE, M. (2010). International experience and graduate employability: stakeholder perceptions on the connection. High Education, 59:599-613.

DTU. International-Business-Semester. <http://www.dtu.dk/english/Education/Gueststudents/Exchange/BEng/International-Business-Semester>. [Consulta: 5 de mayo de 2014]

ESCUELA TECNICA SUPERIOR DE INGENIERIA DEL DISEÑO. <http://novapaginaetsid.webs.upv.es/?page_id=2> [Consulta: 5 de mayo de 2014]

ESPAÑA. Orden CIN/351/2009, de 9 de febrero, por la que se establecen los requisitos para la verificación de los títulos universitarios oficiales que habiliten para el ejercicio de la profesión de Ingeniero Técnico Industrial. BOE, 20 de febrero de 2009, núm. 44, p. 18145-18149.

EUROPEAN PROJECT SEMESTER. <http://www.europeanprojectsemester.eu> [Consulta: 5 de mayo de 2014]

FUENTES-DURÁ, P. ARMESTO, A.L. Y PERRY, D. (2012). "Multidisciplinary Projects: Critical Points and Perceptions" en Innovation and Quality in Engineering Education. Valladolid: EII-UVA. 315-331.

FUENTES-DURÁ, P. Y SONGEL, G. (2009). "Multidisciplinar PBL: Innovation in Leisure and Amusement Products and Services" en Innovation and Assessment of Engineering. Valladolid: EIIUVA. 273-284.

GASCH, I., FUENTES-DURÁ, P. Y PERRY, D. (2012). “European Project Semester” en Jornadas de Innovación Educativa 2012. Valencia: UPV. 132 - 136.

HANZEL, M., MLYNARCZYK, A.,TESSIER A., MUNOZ. M.M., MICIECES Y NOIRE, F., (2014). Smart City - a Quest for Innovation within the EPS framework. Ed. Shrenk, M.Popovich V. V., Zeile, P. Elisei, P., Vienna, Austria, Real Corp, 563-571.

HARRISON,J.C (2002). On Scope and Assessment in Modern Engineering Education. Int. J. Engineering Education, 18, 301-306.

HEINRICH, E., BHATTACHARYA, M. Y RAYUDU R. (2007). Preparation for lifelong learning using ePortfolios. European J. Engineering Education, 32, 653-663.

MINA, M. AND GERDES, R.M (2006), "The pedantic 21st century freshman engineering student", European J. Engineering Education, 5, 509-516.

PUYUELO CAZORLA, M., BALLESTER SARRIAS, E., ALCAIDE MARZAL, J.E., BRUSOLA SIMÓN, F., MARCH LEUBA, M.E. Y MONSORIU SERRA J.A. (2013). "El Grado de Ingeniería en Diseño Industrial y Desarrollo de Productos de la ETSID en el marco de las enseñanzas técnicas: Acciones, Oportunidades y Limitaciones" en XXI Congreso Universitario de Innovación Educativa en las Enseñanzas Técnicas. Valencia: ETSID. 457-459.

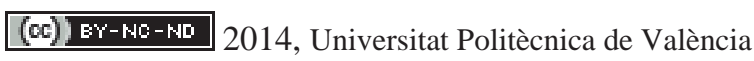

I Jornadas IN-RED (2014) 
TEICHLER, U. \& SCHONBURG, H. (Eds.), (2004). Comparative Perspectives on Higher Education and Graduate Employment and Work - Experiences from Twelve Countries. Kluwer Pub.

UE. Communication from the commission to the European parliament, the council, the European economic and social committee and the committee of the regions Supporting growth and jobs - an agenda for the modernisation of Europe's higher education systems. COM/2011/0567.

UE. Conclusiones del Consejo de 12 de mayo de 2009 sobre un marco estratégico para la cooperación europea en el ámbito de la educación y la formación («ET 2020»). DOUE. 2009/C 119/02.

UNIVERSITAT POLITÉCNICA DE VALENCIA. Dimensiones Competenciales UPV. <http://www.upv.es/contenidos/ICEP/info/DimensionesCompetenciales.pdf> [Consulta: 5 de mayo de 2014]

UPC. International Design Project Semester. <http://www.epsevg.upc.edu/idps> [Consulta: 5 de mayo de 2014]

VENTO, E., PUYUELO, M. Y FUENTES-DURÁ, P. (2011). "What a Waste, a project to engage companies and public/users in green design" en DPPI 11 Designing Pleasurable Products And Interfaces. Milán, Italia: Politecnico Di Milano. 105-112.

VEST, CH. Educating Engineers for 2020 and Beyond. National Academy of Engineering. Washington DC. <http://www.engineeringchallenges.org/cms/7126/7639.aspx, 2012>. [Consulta: 5 de mayo de 2014] 


\title{
Estudio conjunto de la geometría analítica y descriptiva de las superficies arquitectónicas
}

\section{Daniel Martín Fuentes ${ }^{\mathrm{a}}$, Alfred Peris Manguillot ${ }^{\mathrm{b}}$}

${ }^{a}$ Departamento Expresión Gráfica Arquitectónica, Profesor Asociado en la Escuela Técnica Superior de Arquitectura de Valencia, dmartin@ega.upv.es; 'bUMPA, Universitat Politécnica de València, aperis@mat.upv.es

\begin{abstract}
Archietctural surfaces, even the most complex ones that can be designed thanks to digital tools nowadays, have a mathematical basis that characterizes them and that cannot be eluded. Having a truly belief in transversality as a catalyser for the acquisition of competences and skills, in Descriptive Geometry and Mathematics I-II we aim to implement an innovative educational procedure combining the work developed in the two courses.
\end{abstract}

Keywords: Descriptive Geometry, Mathematics, Transversality, Motivation, Interdisciplinary Work.

\begin{abstract}
Resumen
Las superficies arquitectónicas, incluidas las más complejas que hoy se pueden diseñar gracias a las herramientas digitales, tienen ineludiblemente una base matemática que las caracteriza. Desde el convencimiento de que la transversalidad mejora la adquisición de competencias y aptitudes, se plantea como innovación docente una colaboración entre asignaturas que tratan este tema desde los diferentes puntos de vista: Geometría Descriptiva y Matemáticas I-II.
\end{abstract}

Palabras clave: Geometría Descriptiva, Matemáticas, Transversalidad, Motivación, Trabajo Interdisciplinar.

(cc) EY-NC-ND 2014, Universitat Politècnica de València

I Jornadas In-Red (2014) 


\section{Introducción}

Los docentes universitarios nos vemos inmersos en la actualidad en un proceso de cambio continuo en el que intentamos adaptarnos a los nuevos modelos de Educación Universitaria. En ellos se establecen desafíos fundamentales que se deben alcanzar (Fernández, 2014): el desarrollo de una práctica reflexiva, sustituir el individualismo por trabajo en grupo, pasar de enseñar información al aprendizaje de competencias y todo ello teniendo en cuenta la componente ética de la función docente. No son objetivos factibles en el corto plazo, aún más si tenemos en cuenta la inercia de las grandes instituciones, pero como profesionales de la docencia podemos ir dando pequeños pasos en la dirección adecuada.

El proceso de Bolonia supuso una reestructuración del mapa de titulaciones, pero además comportaba una decidida apuesta por la renovación de contenidos y métodos de enseñanzaaprendizaje (Vázquez, 2011). Además de buscar la homologación de un Espacio Europeo de Educación Superior, en el fondo de la cuestión se pretendía resolver uno de los retos a los que se enfrenta la universidad contemporánea: preparar a los estudiantes para enfrentarse con éxito al mundo globalizado, formando profesionales con un perfil creativo, innovador y con capacidad de adaptación y desarrollo.

El mismo concepto, tratado desde un enfoque holístico, según escritos realizados por la UNILATINA (2001), se concreta en que la formación de un profesional óptimo significa haber adquirido la información de su área suficiente, pero siempre con una óptica inter y transdisciplinaria.

En esa línea y desde el convencimiento de que la transversalidad mejora la adquisición de conocimientos y competencias se plantea la presente actividad de colaboración entre asignaturas de la Escuela Superior de Arquitectura de Valencia, Geometría Descriptiva y Matemáticas II que se pretende plasmar en un futuro Proyecto de Innovación y Mejora Educativa para el próximo curso 2014/2015.

Por otro lado, si nos centramos en ver qué es pertinente para la formación de profesionales de la Arquitectura, en relación a las materias tratadas, Verner y Maor (2006), implantaron un curso de cálculo basado en acercar las Matemáticas a la realidad de la actuación del arquitecto y Rossi (2006), basó la enseñanza de la Geometría en la comprensión de esquemas geométricos regulares pertenecientes a objetos orgánicos convirtiendo el dibujo y la representación científica, en una síntesis arquitectónica formal.

Todas estas experiencias no hacen más que atestiguar algo que ya sabemos. La educación es un ámbito en el que el conocimiento especializado sobre cualquier materia, no se adquiere, exclusivamente, mediante contenidos teóricos, sino que su adquisición es una combinación entre el aprendizaje experiencial (Kolb, 1984) y la contrastación con la teoría. 
Parece entonces necesario analizar esta experiencia de coordinación interdisciplinar y de integración de recursos tecnológicos, en busca de una mejora de la práctica docente que apoye los objetivos generales que señalábamos: mejorar el proceso enseñanza-aprendizaje y formar mejores profesionales.

\section{Análisis de la situación actual}

En el plan de estudios de 2010 del Grado en Arquitectura, las asignaturas de Geometría Descriptiva y Matemáticas II pertenecen al módulo 1 de Formación Propedéutica y tienen las características que se indican en la tabla 1.

Tabla 1. Características asignaturas

\begin{tabular}{lcccccc}
\hline ASIGNATURA & TIPO & CURSO & SEMESTRE & C.T. & C.P. & ECTS \\
\hline Geometría Descriptiva & Básica & 1 & A + B & 4,5 & 4,5 & 9 \\
Matemáticas II & Básica & 1 & B & 3,5 & 3,5 & 7 \\
\hline
\end{tabular}

La docencia es coincidente sólo en el segundo semestre y los temarios, aunque son muy distintos en cuanto a organización tal y como se observa en la tabla 2, son coincidentes conceptualmente en algunos puntos importantes.

Tabla 2. Temario asignaturas

\begin{tabular}{|c|c|c|c|}
\hline \multicolumn{2}{|r|}{ GEOMETRÍA DESCRIPTIVA } & \multicolumn{2}{|r|}{ MATEMÁTICAS II } \\
\hline 2.1 & $\begin{array}{l}\text { - Concepto de Superficie. } \\
\text { Generación y Clasificación }\end{array}$ & T. 1 & $\begin{array}{l}\text { - Autovalores y autovectores de una } \\
\text { matriz cuadrada. Diagonalización y }\end{array}$ \\
\hline 2.2 & - Superficies poliédricas & & aplicaciones al tensor de inercia. \\
\hline 2.3 & - Superficies Radiadas: cónicas y & & Cónicas y cuádricas \\
\hline & cilíndricas & T. 2 & - Funciones de varias variables. \\
\hline 2.4 & - La esfera y sus aplicaciones & & Cálculo de extremos \\
\hline 2.5 & arquitectónicas & T. 3 & - Integración múltiple. Aplicaciones al \\
\hline 2.6 & - Superficies de Revolución & & cálculo de áreas planas, volúmenes y \\
\hline 2.7 & - Superficies regladas alabeadas & & geometría de masas \\
\hline 2.8 & - Intersección de superficies. & T. 4 & - Integrales de línea y de superficie. \\
\hline 2.9 & $\begin{array}{l}\text { Aplicaciones arquitectónicas } \\
\text { - Asoleo Geométrico }\end{array}$ & & $\begin{array}{l}\text { Aplicaciones al cálculo de áreas de } \\
\text { superficies 3D }\end{array}$ \\
\hline
\end{tabular}

Bajo denominaciones o clasificaciones distintas, principalmente las superficies arquitectónicas que se estudian son coincidentes, así como sus características. La manera en

\section{(cc)) EY-NC-ND 2014, Universitat Politècnica de València}

I Jornadas IN-RED (2014) 
la que se proyectan en los diferentes sistemas de representación (temática básica en Geometría Descriptiva) o incluso su comportamiento estructural dependen en gran medida de su geometría y también de las leyes matemáticas que la definen -concepto en realidad análogo.

Las cuádricas (superficies enmarcadas en naranja en la tabla 3) de entre todas las superficies estudiadas, forman un grupo importante sobre el que se basa la actividad que proponemos. Hasta el momento nunca se ha realizado un trabajo conjunto de las asignaturas y parece algo lógico puesto que muchos de los conceptos son idénticos pero expresados con lenguajes diferentes.

Adicionalmente, hemos detectado que la mayoría de alumnos no establecen por sí mismos esa correlación y eso se traduce en que no entienden la justificación de estudiar algunos conceptos matemáticos y físicos.

Tabla 3. Clasificación se superficies

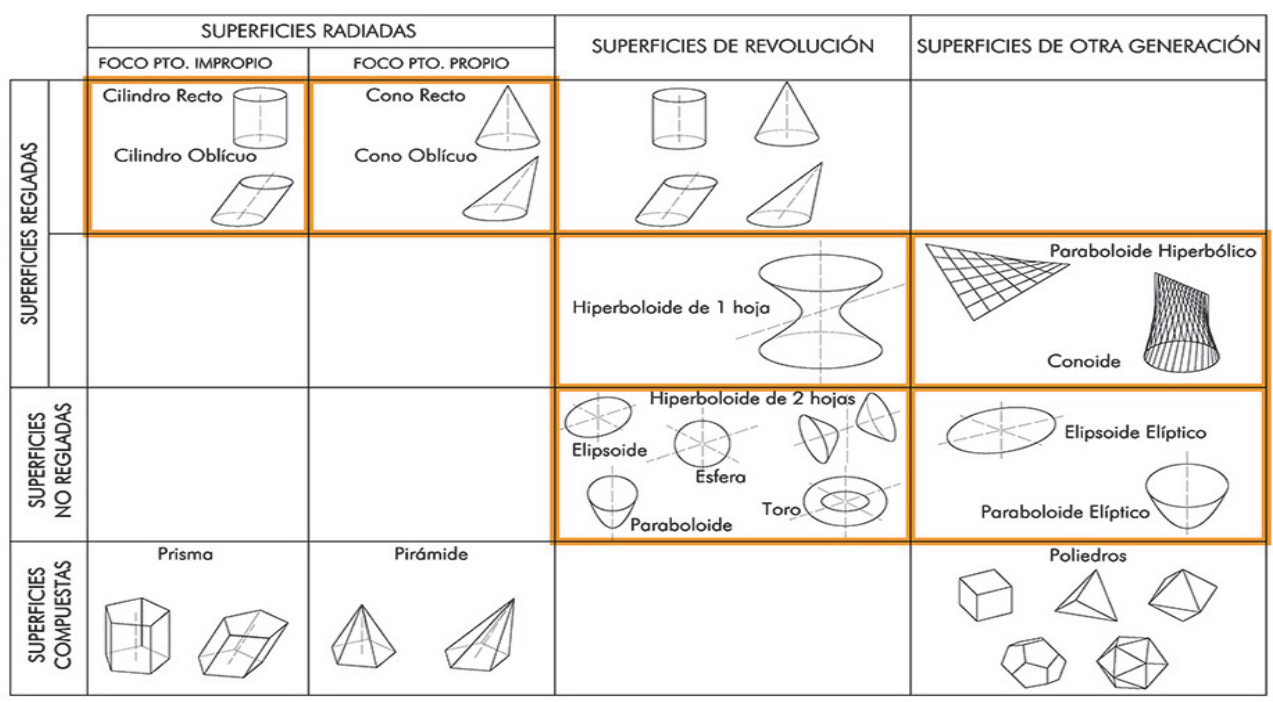

Elaboración propia

\section{Objetivos}

Los objetivos perseguidos se centran en dos aspectos no poco ambiciosos, por un lado la comprensión holística de conceptos, lo que se traduce en una mejor preparación profesional e intelectual; y por otro lado la reducción perceptiva de duplicidades, buscando eficiencia en las horas de dedicación. 


\subsection{Objetivo 1: Comprensión Holística}

Las competencias se definen como: "un saber actuar complejo que se apoya en la movilización y la combinación eficaz de una variedad de recursos internos y externos dentro de una familia de situaciones" (Tardif, 2006, p. 22).

Por tanto, una competencia tiene como característica ser integradora, combinatoria, en desarrollo, contextual y evolutiva. Como la competencia integra diversos recursos de naturaleza variada, hace también referencia a la complejidad del saber actuar (Fernández, 2014) y justo a esto nos referimos con alcanzar una comprensión holística.

Aproximarse a un concepto desde diferentes vertientes favorece el entendimiento por parte de todos los perfiles de individuos (Gardner, 1995) y favorece el entendimiento de ese concepto gracias a su posicionamiento dentro de una red lógica, mallada según las experiencias y necesidades de cada uno, trasladando el aprendizaje desde el modelo memorístico hasta el significativo, mucho más acorde con un aprendizaje real y con las necesidades y exigencias de un fututo profesional de la Arquitectura.

\subsection{Objetivo 2: Eficiencia y motivación}

Existen ciertas asignaturas en el Grado de Arquitectura en las que los profesores presentan una cierta preocupación por el escaso grado de motivación por parte de sus alumnos. Las encuestas de satisfacción del alumnado año tras año siempre reflejan en las preguntas relacionadas con este tema, puntuaciones inferiores al resto, incluso en los profesores que obtienen muy buenas calificaciones. Sin ánimo de realizar un análisis en profundidad en este tema -algo que por otro lado sería interesante de tratar- parece que este problema está relacionado con la abstracción de las materias tratadas. Cuando el alumno no observa una clara relación entre la asignatura y lo que él concibe como formación de un Arquitecto, la motivación desciende drásticamente.

Al respecto, los profesores tenemos que tomar medidas en dos niveles. Primero, es necesario que los alumnos entiendan el por qué de la existencia de la asignatura en el plan de estudios y segundo debemos diseñar y programar actividades de aprendizaje que el alumno considere valiosas y en las que se sienta con posibilidad de alcanzar buenos niveles de competencia.

Sin olvidar que en un contexto de logro como el universitario es necesario que el alumno tenga una percepción de progreso hacia metas personales que deben ser viables pero de cierta exigencia para ir alcanzando el nivel de conocimiento, desempeño y competencia adecuados con su titulación.

\section{(c) EY-NC-ND 2014, Universitat Politècnica de València}

I Jornadas IN-RED (2014) 


\subsection{Previsión de cumplimiento de objetivos}

En este apartado es necesario indicar como surge la propuesta de colaboración.

En el pasado curso 2012/2013, de manera casual una de las prácticas que los alumnos realizaban en la asignatura de Matemáticas II era igual que una realizada en Geometría Descriptiva unas semanas antes. Este hecho despertó gran interés por parte del alumnado que comunicó de manera abierta al profesorado su entusiasmo.

En base a esta situación fortuita que produjo gran motivación y resultados excelentes, se estableció la voluntad de organizar una actividad conjunta, pensada y planificada que alcanzase los logros observados de manera óptima.

\section{Planificación actividad conjunta}

En las asignaturas se plantea el trabajo con una base teórica necesaria pero que rápidamente se traslada a la práctica. Desde diferentes programas informáticos los alumnos modelan las superficies y así, debido entre otras cosas a la interactividad, comprenden más fácilmente de manera visual-espacial y conceptual su construcción, comportamiento y características. El software utilizado es en Matemáticas I y II, el MATHEMATICA y en Geometría Descriptiva, AUTOCAD y 3DSMAX.

Cada uno de los programas presenta diferentes peculiaridades y requiere de una utilización conceptualmente distinta para llegar a un resultado común -por ejemplo el modelado de un paraboloide hiperbólico, fig. 1.

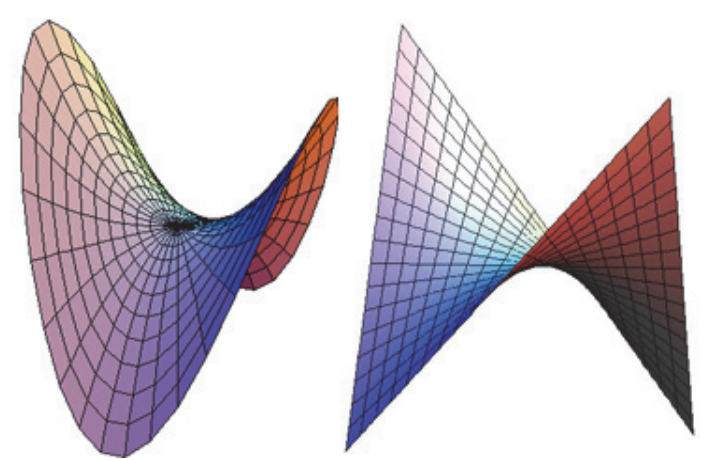

Fig. 1 Dos representaciones de la superficie Paraboloide Hiperbólico

Además hay operaciones que son posibles en alguno de ellos y en los otros no, por lo que su uso se complementa. Adicionalmente, los ficheros generados se pueden exportar/importar de un programa a otro. En definitiva, el alumno comprende que los 
programas son herramientas que están a su disposición y que le pueden facilitar el trabajo, pero que no deben sustituir su comprensión y concepción propias que deseablemente deben estar por encima de las limitaciones instrumentales.

En términos prácticos, la experiencia se concreta en la realización de prácticas comunes a las dos asignaturas en base al estudio de casos. Se modelan edificios o proyectos singulares que contengan superficies interesantes, estudiándolas desde la geometría analítica y desde la geometría descriptiva.

\subsection{Organización de las prácticas}

Las prácticas se estructuran en base al TRABAJO DE CASOS:

\section{- $1^{\text {a }}$ sesión: GEOMETRÍA DESCRIPTIVA}

1.- Presentación de un caso. (10 min) El profesor hará una introducción en la que contextualiza un edificio que puede estar construido o ser un proyecto y que contiene alguna de las superficies arquitectónicas estudiadas. La información proyectada se habrá colgado el día de antes en PoliformaT de manera que los alumnos pueden haberla descargado con anterioridad o en el mismo momento de clase.

En las primeras sesiones la introducción encaminará el trabajo de los alumnos y poco a poco se irá reduciendo la cantidad de información contada por el profesor.

2.- Análisis del tipo de superficie y de la documentación. (40 min) Los alumnos deben de analizar el dosier entregado para ir seleccionando los planos e imágenes que les aportan información en un tiempo determinado. Conforme avanzan las sesiones, la documentación y los edificios aumentan en complejidad, pero el tiempo dedicado en clase no, de manera que se hará necesaria una preparación previa en casa por parte del alumno. Así se fomenta la gestión del tiempo y la necesidad del trabajo autónomo.

3.- Extraer información relevante y utilizarla para el modelado. (40 min) Los alumnos comenzarán el modelado de la superficie con los programas informáticos utilizados en la asignatura con la información relevante que está recogida en el dosier entregado y lo finalizarán de manera autónoma.

- 2 $2^{\mathrm{a}}$ sesión: MATEMÁTICAS II

1.- Introducción teórica. (45 min) El profesor realizará una explicación teórica en la que se presentará la formulación matemática de la superficie y los cálculos de sus características principales (máximos, mínimos, absolutos y relativos, puntos de inflexión, superficie, volumen, etc.) todo ello mediante derivadas, integrales y diagonalización de matrices.

\section{(c)) EY-NC-ND 2014, Universitat Politècnica de València}

I Jornadas IN-RED (2014) 
2.- Modelado. (45 min) Mediante el programa MATHEMATICA los alumnos modelarán la misma superficie que se ha modelado en la sesión anterior de Geometría Descriptiva construyéndola y posicionándola con parámetros matemáticos y no gráficos.

\section{- 3ª sesión: GEOMETRÍA DESCRIPTIVA+MATEMÁTICAS II}

Esta sesión se plantea de forma conjunta y en función del desarrollo del curso y de las prácticas se establecerá en el horario de Geometría Descriptiva o de Matemáticas. Esta sesión no es correlativa con las dos anteriores si no que se realiza cuando se han realizado varias prácticas. En ella los profesores de ambas asignaturas presentarán los resultados de las prácticas hechas y entregadas anteriormente por los alumnos y evidenciarán la correlación unívoca existente entre la formulación y operaciones matemáticas y las características gráficas y dimensionales de las superficies y volúmenes estudiados.

\subsection{Ejemplos}

Para la realización de prácticas y organización de la materia a impartir se han realizado comparativas de las diferentes superficies obtenidas por cada programa informático. Se recogen algunos ejemplos más interesantes por la operativa.

\subsubsection{Obtención de Cónicas}

Las cónicas son curvas planas que se obtienen por sección de cuádricas. La superficie cuádrica que permite obtener todas las cónicas y que da nombre a estas curvas es el cono. La intersección de un cono con un plano que no pase por su vértice, en diferentes posiciones relativas nos permite obtener las cuatro curvas cónicas recogidas en la fig. 2.
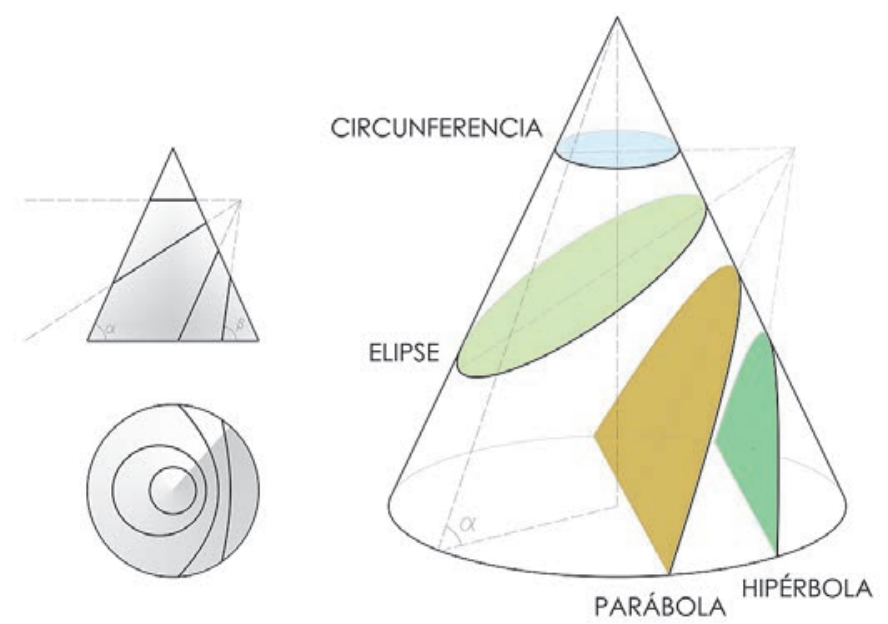

Fig. 2 Curvas cónicas por sección plana de un cono 
El modelado de dichas curvas se realiza en cada asignatura de diferentes maneras en función del programa utilizado. Con AUTOCAD, circunferencia y elipse se pueden modelar directamente en base a sus datos geométricos, pero la parábola y la hipérbola sólo pueden obtenerse mediante la sección plana de un cono. MATHEMATICA nos permite el modelado de dichas curvas directamente mediante su función o también como secciones planas del cono. Adicionalmente 3DS MAX que admite los modelados de los dos programas nos permite generar imágenes con una calidad gráfica mucho mayor, para presentaciones. Fig. 3 , 4 y 5 .

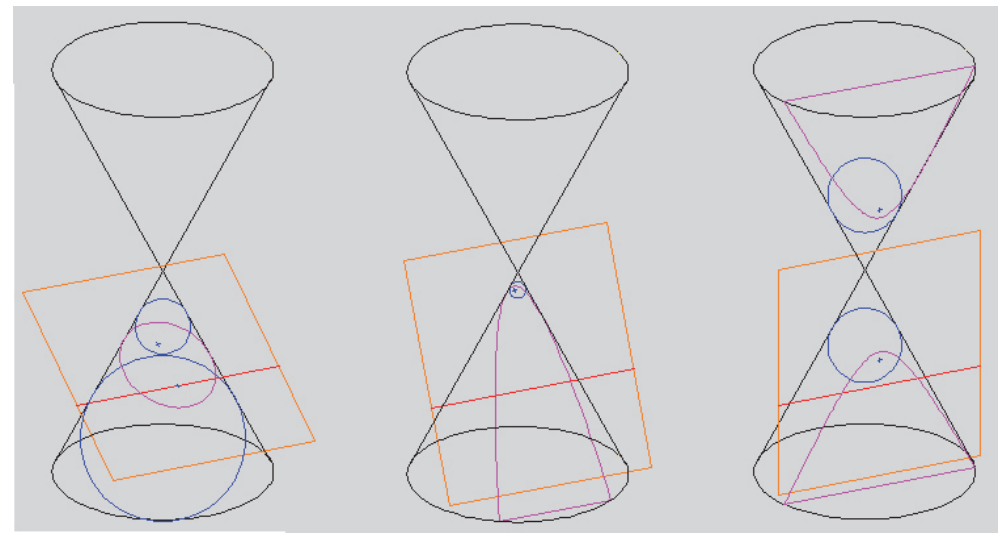

Fig. 3 Curvas cónicas por sección plana de un cono. Obtención con AUTOCAD
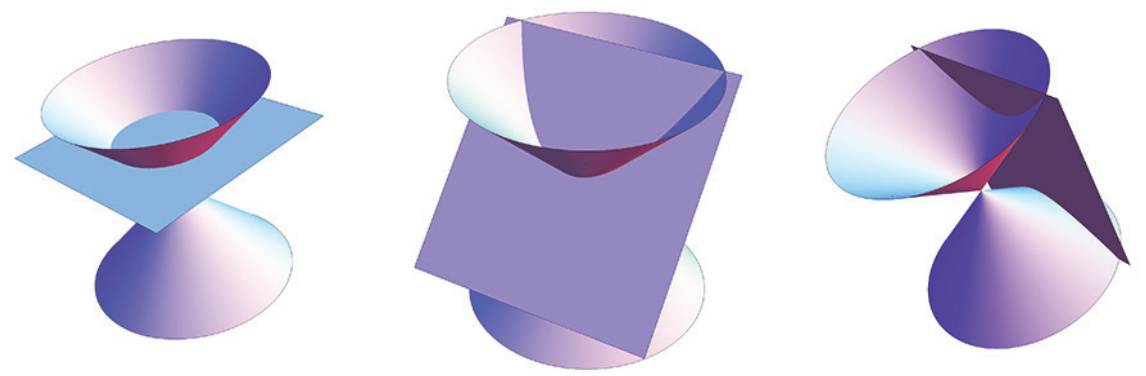

Fig. 4 Curvas cónicas por sección plana de un cono. Obtención con MATHEMATICA

\section{(c)) EY-NC-ND 2014, Universitat Politècnica de València}

I Jornadas IN-RED (2014) 

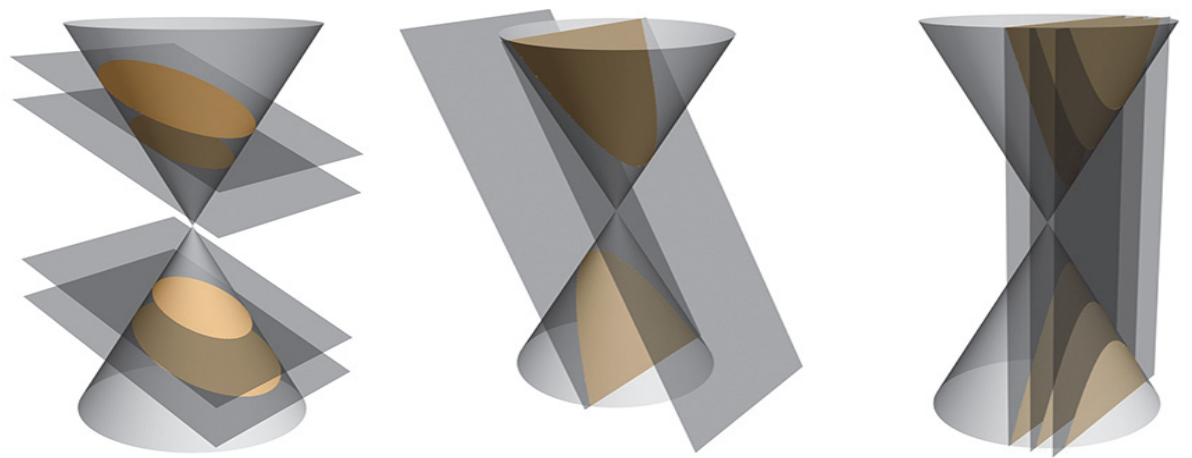

Fig. 5 Curvas cónicas por sección plana de un cono. Representación con 3DSMAX

\subsubsection{Obtención de superficies no características}

Las posibilidades de modelado y presentación cuando se dominan las herramientas son múltiples. AUTOCAD es un programa en el que no es fácil el modelado de superficies no características, como por ejemplo las denominadas superficies de Bézier, MATHEMATICA por el contrario, si conocemos la función que las define, es capaz de modelar de manera automática cualquier superficie. Como ejemplo de esta situación en la figura 6 observamos una superficie que se autointersecta pero con una definición matemática sencilla. Exportando el modelo con extensión 3DS e importándolo en 3DS MAX, podemos añadir colores, materiales, luces que proyecten sombras para entender mejor la volumetría y además podemos realizar vistas diédricas, axonométricas y perspectivas cónicas.
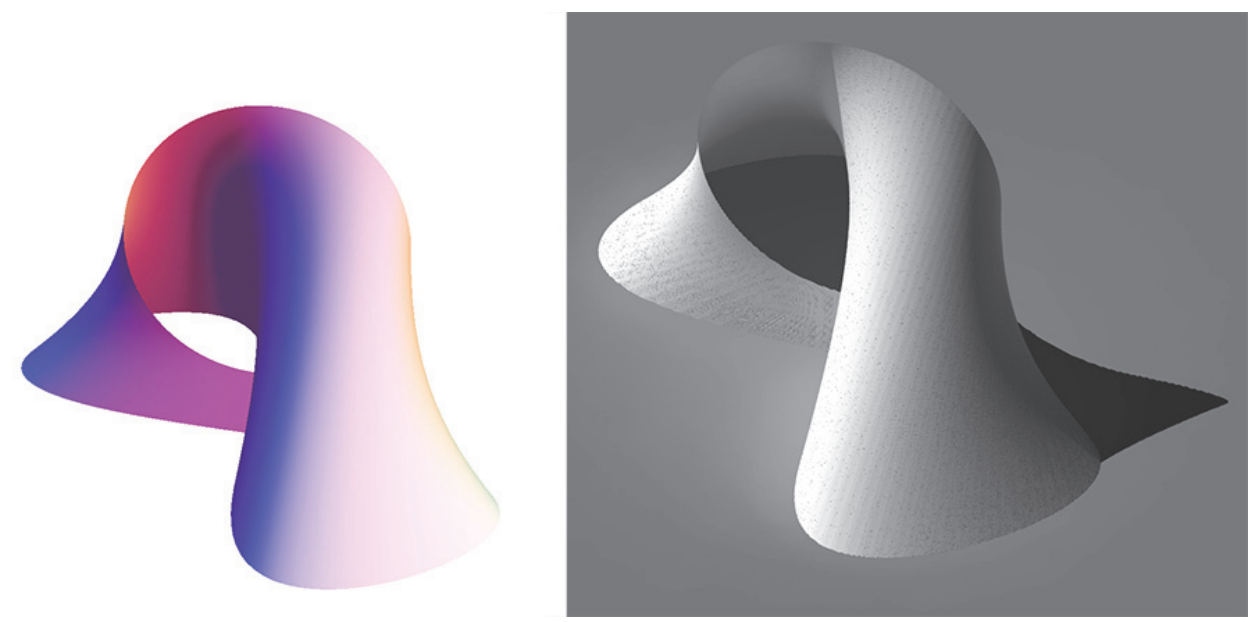

Fig. 6 Representación de superficie con MATHEMATICA y con 3DSMAX

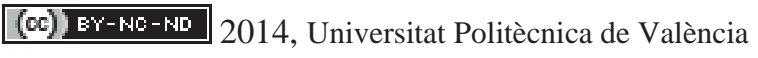

I Jornadas IN-RED (2014) 


\subsubsection{Modelado de edificios o proyectos que contienen superficies a estudiar}

El estudio de casos detallado en el apartado 3.1. en base a edificios permite conocer las herramientas geométricas y matemáticas proyectuales que arquitectos o ingenieros han utilizado para su diseño.

El Atomium una estructura de 102 metros de altura construida con ocasión de la Feria Mundial de 1958, celebrada en Bruselas, es un buen ejemplo de las posibilidades docentes de este tipo de recurso. Representa un cristal de hierro ampliado 165 mil millones de veces, está formado por nueve esferas de acero de 18 metros de diámetro que se unen mediante cilindros de 3 metros de diámetro y longitud aproximada de 81,30 metros. La estructura, diseñada por el arquitecto André Waterkeyn, fue planeada para permanecer seis meses; sin embargo rápidamente se convirtió en una atracción turística y se ha mantenido hasta la actualidad. Entre marzo de 2004 y febrero de 2006, se llevó a cabo un proceso de renovación, incluyendo en su interior un elevador que lleva a la cima a una velocidad de 5 $\mathrm{m} / \mathrm{s}$.

Tres de las cuatro esferas superiores carecen de soporte vertical y por lo tanto no están abiertas al público por razones de seguridad. El diseño original contemplaba el átomo sin soportes verticales, pero las pruebas en túnel de viento demostraron que la estructura se habría derrumbado con $80 \mathrm{~km} / \mathrm{h}$ de viento (se han registrado vientos de $140 \mathrm{~km} / \mathrm{h}$ en Bélgica) y por tanto fue necesario añadir 3 soportes verticales.

Para el modelado se obvian los soportes verticales y se dibujan únicamente las esferas y cilindros que componen el edificio. La geometría global de la estructura es sencilla puesto que la posición relativa de las esferas se obtiene situándolas en los vértices y centro geométrico de un cubo para posteriormente unirlas con cilindros.

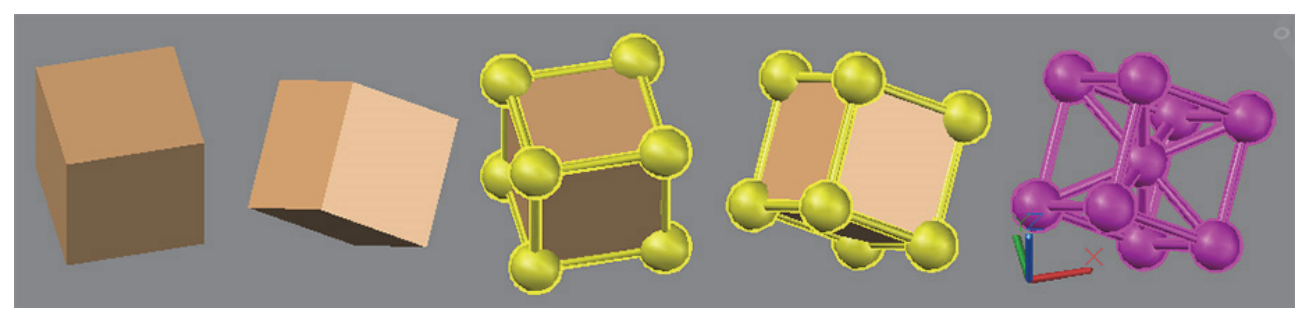

Fig. 8 Proceso resumido de construcción del modelo con AUTOCAD

En este caso debido a que las superficies son todas ellas características, se pueden modelar con AUTOCAD y también con MATHEMATICA. La diferencia conceptual entre ambos,

\section{(c)) EY-NC-ND 2014, Universitat Politècnica de València}

I Jornadas IN-RED (2014) 
es que en el primero el modelado de las superficies es sencillo en una posición de cubo apoyado por su cara y el ejercicio de desarrollo de visión espacial requiere definir un giro en tres dimensiones que coloque el cubo apoyado sobre un vértice, Fig. 7. En el segundo hay que conocer la función que define una esfera y un cilindro y definir los parámetros de estas funciones que les darán las dimensiones y posición espacial correctos. Así se va construyendo elemento a elemento y finalmente se visualizan todos en conjunto, Fig. 8.

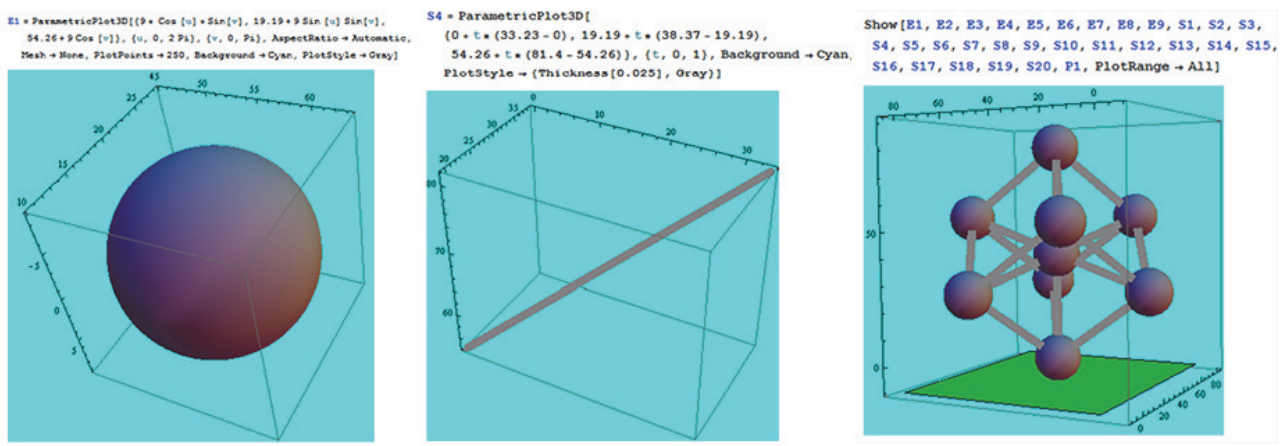

Fig. 8 Proceso resumido de construcción del modelo y vista del conjunto con MATHEMATICA

Para el estudio de los diferentes tipos de proyección, del asoleamiento geométrico y proyección de sombras, 3DS MAX es la herramienta utilizada, ya que permite iluminar el objeto con luces cilíndricas y obtener de un mismo modelo diferentes proyecciones a las que se le han aplicado materiales, Fig. 9.

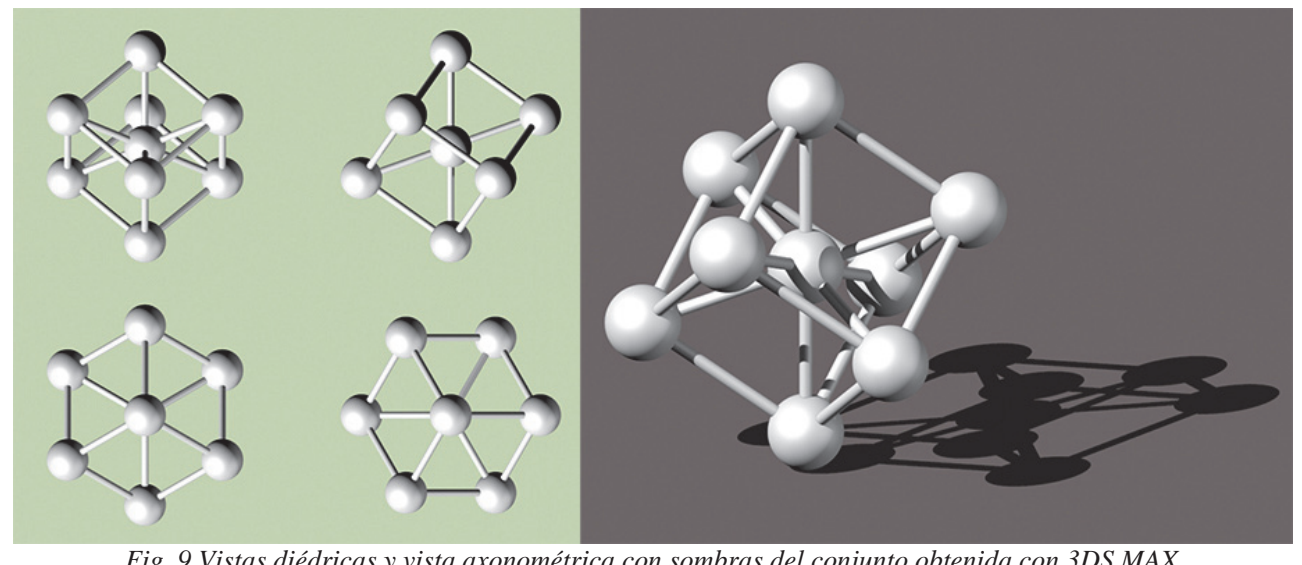

Fig. 9 Vistas diédricas y vista axonométrica con sombras del conjunto obtenida con 3DS MAX 
Y las posibilidades de representación son múltiples una vez obtenido el modelo. Los alumnos Carlos Maeso de Vicente y Antonio Martínez Rosiñol, yendo más allá de lo estrictamente exigido en la asignatura, lo demuestran con una imagen en la que insertan el modelo virtual, Fig. 10.

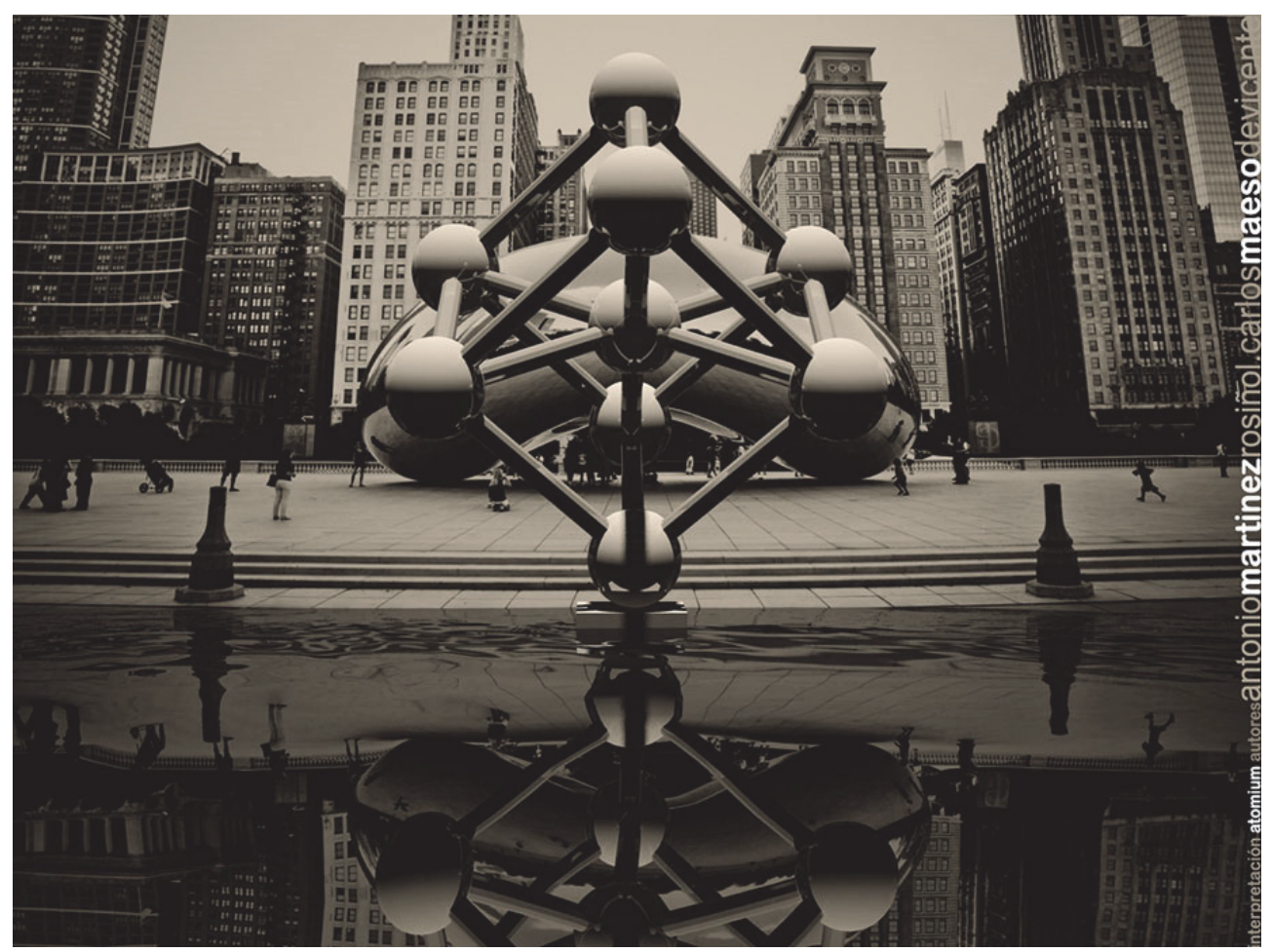

Fig. 10 Fotomontaje realizado con renderizado de 3DS MAX sobre imagen fotográfica

\section{Conclusiones}

Debido a que la realización de prácticas definidas en este proyecto se ha empezado a realizar como experiencia piloto en un grupo de este año, de manera casi intuitiva, se pretende que los alumnos expresen su opinión por comparativa entre las prácticas realizadas de manera independiente por las asignaturas y las prácticas conjuntas.

Para evidenciar este hecho se plantearán dos herramientas:

- Encuestas cualitativas, en las que se evidenciará si mejoran los niveles de motivación.

- Encuestas cuantitativas centradas en las horas de dedicación a las diferentes asignaturas. Así se podrá observar si tal como se pretende se reducen las horas de dedicación para ajustarse a los parámetros de los ECTS, al menos en percepción de los alumnos.

\section{(c)) EY-NC-ND 2014, Universitat Politècnica de València}

I Jornadas IN-RED (2014) 
Está en la voluntad de los profesores de estas dos asignaturas tan interrelacionadas, enfrentarse a este desafío que supone el salto de la cultura egocéntrica y competitiva propia de las tribus académicas a una cultura de compromiso compartido, tal y como afirma McDonnald (2001). Buscando así, la excelencia personal como profesionales pero principalmente la excelencia profesional futura de nuestros alumnos.

\section{Referencias}

FERNÁNDEZ MARCH, A. (2014). Evaluación y mejora de la enseñanza:Portafolio Docente. Valencia: apuntes EUPU

GARDNER, H. (2005). Las cinco mentes del futuro: Un ensayo educativo. Madrid: Paidos educativo

KOLB, D.A. (1984): Experiential learning: experience as the source of learning and development. New Jersey: Prentice-Hall Inc.

ROSSI, M. (2006). Natural Architecture and constructed forms: structure and surfaces from idea to drawing. Nexus Network Journal 8(1), 112-122.

TARDIF, J. (2006). L'évaluation des compétences. Documenter le parcours de développement [La evaluación de las competencias. Documentar el trayecto de desarrollo]. Montréal : Chenelière Éducation.

UNILATINA (2001). Modelo holístico para la Educación Superior. Obtenido el 3 de Junio, 2014, de http://www.unilatina.edu.co/filosofía.mth

VÁZQUEZ GARCÍA, J.A. (2011). Los caminos de Bolonia. Revista de Docencia Universitaria. REDU. Monográfico: El espacio europeo de educación superior. Hacia dónde va la Universidad Europea. 9 (3), 29-38.

VERNER, I. M. \& Maor, S. (2006). Mathematical mode of thought in architectural design education: a case study.Nexus Network Journal 8(1), 93-106. 
Jornadas In-Red 2014

Universitat Politècnica de València

\title{
Experiencias en la impartición del curso "on-line" para alumnos de doctorado de la UPV "Estadística y Métodos Matemáticos para la Investigación: Introducción a las Técnicas Estadísticas para la Investigación”.
}

Suitberto Cabrera García ${ }^{a}$, Andres Carrión García ${ }^{b}$, Elena Vázquez Barrachina ${ }^{c}$, Ana Isabel Sánchez Galdón ${ }^{\mathrm{d}}$, Ana Maria Debón Aucejo ${ }^{\mathrm{e}}$, José Manuel Soler Torro ${ }^{\mathrm{f}}$, Andrea Conchado Peiróg ${ }^{\mathrm{g}}$, Félix Francés García ${ }^{\mathrm{h}}$

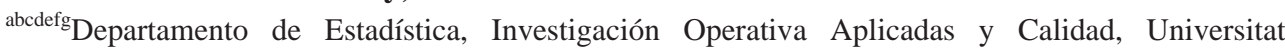
Politécnica de Valéncia, ${ }^{a}$ suicabga@eio.upv.es, b daisanche@eio.upv.es, ${ }^{\mathrm{e}} \underline{\text { andeau @eio.upv.es, }}{ }^{\mathrm{f}} \mathrm{jmsoler@eio.upv.es,}{ }^{\mathrm{g}}$ anconpei@eio.upv.es, ${ }^{\mathrm{f}}$ Instituto Universitario de Investigación de Ingeniería del Agua y Medio Ambiente, Universitat Politècnica de València, ffrances@upv.es.

\begin{abstract}
Students enrolled in PhD programs, as well as early career researchers, are usually expected to analyse data from different sources of information, obtained as a result of their research projects. Their needs are mainly based on the identification of the more appropriate statistical techniques, depending on the nature of their data and the relationships they intend to study through the analysis. With the aim of offering training specially designed to cover these requirements, an online course has been developed and given during this academic course, as a part of the studies offered by the recently created Doctoral School of the UPV. This course provides an introduction and description at a glance of the main statistical techniques researchers may use to test their hypothesis in different knowledge areas where
\end{abstract}

(c) $\mathbf{\text { EY-NC-ND }}$ 2014, Universitat Politècnica de València

I Jornadas In-Red (2014) 
Experiencias en la impartición del curso on-line para alumnos de doctorado de la UPV: Estadística y Métodos Matemáticos para la Investigación: Introducción a las Técnicas Estadísticas para la Investigación

data analysis is required: social sciences, economics, engineering, life sciences, etc. This paper presents the teaching programme of this course, includying competencies, learning outcomes, modes of teaching and learning and system of assessment, taken as a reference point during the course. Subsequently, academic performance of students is examined, in order to identify strong and weak points and recommend improvement strategies for next editions.

Keywords: On-line course, Transverse Course, Doctorate, Statistics.

\begin{abstract}
Resumen
Los alumnos de doctorado, futuros investigadores, requieren con frecuencia analizar datos de distinto tipo recogidos en el desarrollo de su investigación. Necesitan identificar aquellas técnicas estadísticas que deben de utilizar, en función del tipo de dato y del objetivo perseguido con su análisis. Con el objeto de cubrir estas necesidades, se ha elaborado e implementado un curso de doctorado transversal, el cual brinda una panorámica de las diferentes herramientas estadísticas existentes, sus fines, los problemas que resuelven y su utilidad para el desarrollo de investigaciones en todos los ámbitos en lo que se deban analizar datos: ciencias sociales, economía, ingeniería, ciencias de la tierra, etc. En este trabajo se expone el Proyecto Docente (competencias, objetivos de aprendizaje, metodología, sistema de evaluación) que ha servido de base para la impartición del curso "on-line" basado en la plataforma Poliformat y se analizan los resultados obtenidos, detectando los puntos fuertes y débiles que permitan llevar a cabo acciones de mejora para próximas ediciones.
\end{abstract}

Palabras clave: doctorado, formación transversal "on-line", métodos estadísticos, proyecto docente, metodología, evaluación.

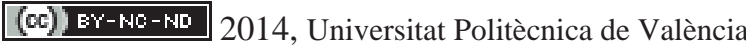

I Jornadas IN-RED (2014) 
Suitberto Cabrera García, Andres Carrión García, Elena Barrachina Vázquez, Ana Isabel Sánchez Galdón, Ana Maria Debón Aucejo, Felix Ramón Frances García, Andrea Conchado Peiró y José Manuel Soler Torro

\section{Introducción}

Los alumnos de doctorado se enfrentan al reto de realizar una investigación compleja y en este proceso será necesario utilizar una muy amplia y variada información. Esta información significará el manejo de una gran cantidad de datos estadísticos. La calidad del proceso de toma y procesamiento de esta información influye en la calidad de los resultados, incluso en la confiabilidad de los mismos. Es imposible obtener resultados validos sin la correcta aplicación de los diferentes métodos estadisticos que existen. Actualmente se dispone de un gran numero de programas informaticos que permiten "fácilmente" aplicar los métodos existentes. Por lo tanto se trata, al desarrollar una investigación y en dependencia de muchos factores, poder determinar qué métodos estadísticos necesitamos aplicar, profundizar en el conocimiento de los mismos, si no los conocemos ya, proceder a la correcta aplicación de los mismos y al correcto análisis de los resultados obtenidos.

Adicionalmente, el desarrollo de las nuevas tecnologías en el contexto docente, tales como la plataforma PoliformaT y los contenidos multimedia facilitan hoy día el prceso enseñanze-aprendizaje no presencial.

Los objetivos del presente trabajo consisten en:

- Exponer las experiencias en la docencia, por primera vez en la Universitat Politécnica de Valencia, de un curso "on-line" dirigido a los alumnos de doctorado para apoyarlos en la identificación y aplicación de los métodos estadísticos que necesitan en sus temas de investigación.

- En base al analisis de los resultados, centrados en el proyecto docente de la asignatura y las particularidades del desarrollo de la primera versión del curso, llegar a conclusiones, que permitan la mejora de la docencia en las futuras versiones.

\section{Desarrollo}

El curso fue previsto como un curso de formación transversal para alumnos de doctorado de la Universitat Politécnica de Valencia. El colectivo de profesores de la asignatura realizó una propuesta de contenidos principales. La Escuela de Doctorado confeccionó una oferta de cursos y los estudiantes expresaron sus preferencias de matricula. Al curso de "Estadística y Métodos Matemáticos para la Investigación: Introducción a las Técnicas Estadísticas para la Investigación" se matricularon 169 alumnos.

El curso se ha realizado en dos ediciones, la primera desde febrero a abril de 2014 y la segunda desde abril a junio de 2014. En el primer grupo se matricularon 81 alumnos, mientras que en el segundo la matricula fue de 88 alumnos.

\section{(cc)) EY-NC-ND 2014, Universitat Politècnica de València}

I Jornadas IN-RED (2014) 
Experiencias en la impartición del curso on-line para alumnos de doctorado de la UPV: Estadística y Métodos Matemáticos para la Investigación: Introducción a las Técnicas Estadísticas para la Investigación

El colectivo docente está integrado por 8 profesores con amplia experiencia en la docencia, en primer lugar de los métodos estadísticos ofertados y en segundo lugar de la enseñanza "on-line".

\subsection{Objetivos de la asignatura - Resultados del aprendizaje}

Los objetivos de aprendizaje planteados son lograr que el alumno sea capaz de:

- Diseñar experimentos, gestionar y procesar datos, así como aprender, identificar y comparar herramientas para un correcto análisis estadístico de éstos.

- Conocer los conceptos estadísticos básicos sobre teoría de probabilidad, distribuciones e inferencia.

- Analizar críticamente y evaluar los propios resultados obtenidos así como también los obtenidos por otros investigadores.

- Elaborar hipótesis, plantear objetivos y definir protocolos basados en el método científico.

- Identificar "la importancia" de cada método en el quehacer científico de los alumnos de doctorado, para poder brindar apoyo, en su caso, en la profundización del aprendizaje de los mismos.

\subsection{Unidades didácticas}

Para la obtención de los objetivos planteados, se consideró estructurar el curso en las siguientes Unidades Didacticas:

1. Obtención de información y datos

1. Técnicas de muestreo

2. Diseño de experimentos.

2. Sofware estadístico para la investigación

1. Paquetes comerciales: SPSS y Statgraphics

2. Software libre: $\mathrm{R}$

3. Descripción y análisis básico de datos

1. Técnicas de descripción numéricas

2. Técnicas de descripción gráficas

3. Pruebas estadísticas básicas

4. ANOVA y Regresión

1. Introducción

2. ANOVA de un factor. Test de Kruskal-Wallis

3. Regresión lineal simple. Modelo, hipótesis y diagnóstico

4. Introducción a la regresión lineal múltiple. 
Suitberto Cabrera García, Andres Carrión García, Elena Barrachina Vázquez, Ana Isabel Sánchez Galdón, Ana Maria Debón Aucejo, Felix Ramón Frances García, Andrea Conchado Peiró y José Manuel Soler Torro

5. Técnicas de clasificación

1. Introducción

2. Regresión logística

3. Análisis discriminante

4. Análisis cluster

6. Análisis Factorial

1. Introducción

2. Objetivos

3. ¿Qué es un factor?

4. Desenmascarando los factores: análisis preliminar y adecuación

5. Extracción de los factores: Métodos. Valores propios. Comunalidades. Gráfico de Sedimentación. Cargas y puntuaciones factoriales

6. Interpretando el significado de los factores: rotación

7. Consideraciones finales.

7. Análisis de Series Temporales.

1. Introducción

2. Modelos ARIMA

3. Metodología Box-Jenkins

8. Estadística de valores extremos

1. Conceptos fundamentales en estadística paramétrica

2. Teoría básica de valores extremos

3. Métodos de estimación de parámetros

4. Selección del modelo paramétrico

5. Análisis de incertidumbre

\subsection{Método de enseñanza aprendizaje.}

El curso es "on-line", en el cual se estima un total de 6,5 horas de trabajo del alumno por cada tema, de las cuales 0,5 horas corresponden a la evaluación presencial. Para un total de 52 horas de trabajo del alumno en todo el curso.

Dado el carácter no presencial del curso, el material docente fundamental del curso se elaboró mediante la herramienta Contenidos de POliformaT y con apoyo de herramientas de creación de material multimedia (Polimedia)

Adicionalmente, en el apartado Recursos de PoliformaT fue creada una carpeta para cada tema, donde cada profesor depositó el material complementario que consideró pertinente y. usado diferentes formatos para el material docente: Word, pdf, ficheros de datos, etc.

En el desarrollo de los materiales utilizados ha sido tenida en cuenta la experiencia de los docentes del curso (Cabrera, 2013, 2012 y 2010).

(cc) EY-NC-ND 2014, Universitat Politècnica de València

I Jornadas IN-RED (2014) 
Experiencias en la impartición del curso on-line para alumnos de doctorado de la UPV: Estadística y Métodos Matemáticos para la Investigación: Introducción a las Técnicas Estadísticas para la Investigación

Se publicó un calendario y las aclaraciones, comentarios e indicaciones para realizar el curso, también usando las herramientas disponibles en PoliformaT como Anuncios, Correo interno y foros de discusión.

Inicialmente se usó la herramienta de chat, incluida en Poliformat $\mathrm{T}$ para aclarar dudas de carácter general y posterioremente se habilitaron, en la misma aplicación, foros de discusión, uno por cada tema. Los alumnos disponen de los correos electrónicos de los profesores para realizar las consultas pertinentes. Tambié se utilizó el apartado estadística, que permite obtener información sobre la interacción de los alumnos con la plataforma (Vázquez, 2011). Entre otras estadísticas importantes, 1 numero de correos enviados ha oscilado entre los 25 y los 159 por profesor, mientras que en el chat fueron escritos 435 mensajes.

\subsection{Evaluación}

La evaluación consta de dos actos de evaluación:

Al finalizar el curso una prueba objetiva tipo test a realizar mediante Poliformat con un peso total del $60 \%$ de la nota de la asignatura.

Durante el curso, la realización de cuatro tareas o trabajos individuales, a escoger entre ocho ofertas (una sobre cada tema) y que suponen el $40 \%$ restante de la nota. Se recomiendó al alumno escoger aquellas tareas vinculadas a los temas que le son de mayor importancia en su trabajo de investigación, con el objetivo de que se sienta más motivado en su realización y pueda profundizar en los mismos.

En concreto, los estudiantes de las titulaciones de la UPV utilizan la plataforma PoliformaT. PoliformaT es el campus virtual de la Universidad Politécnica de Valencia (https://poliformat.upv.es/portal). Pero también es una nueva plataforma de e-learning que ofrece una amplia variedad de herramientas de apoyo a la docencia presencial y "on-line". En este sentido, la mayoría de las instituciones universitarias están apostando por el uso de plataformas de teleformación o campus virtuales, como una vía para poder realizar prácticas educativas venciendo las limitaciones espacio-temporales (Carril, 2009)

Estudios previos en el uso de la herramienta de exámenes de Poliformat por parte de otros profesores de la Universidad Politécnica de Valencia, avalan la conveniencia de su uso (Cabrera 2013; Tolosa-Igualada 2011; Portillo 2009).

\section{Resultados.}

Se analizan los resultados del primer grupo matriculado a la asignatura, ya que el segundo grupo realiza en la actualidad el curso.

Realizaron las dos evaluaciones exigidas 49 alumnos, para un 60,5\% de los alumnos matriculados, si bien es cierto que las tareas en su totalidad o parcialmente fueron entregadas por 64 alumnos (un $79,0 \%$ de los matriculados), solicitando el resto 
autorización para presentarse al examen final en la segunda edición del mismo, alegando en la mayoría de los casos problemas de tiempo y estancias de investigación fuera de la UPV.

Es importante tener en cuenta que no para todos los alumnos la realización del curso tiene carácter obligatorio. Sólo los inscritos en los programas recogidos en la legislación actual tienen la obligación de cursar estos cursos transversales, mientras que lo alumnos procedentes de legislaciones anteriores lo tienen como optativo. Esto ha hecho que algunos alumnos que se matricularon sin obligación, hayan posteriormente cambiado de idea conforme los cursos avanzaban y el volumen de trabajo crecía.

De los 49 alumnos que realizaron el examen final, solo uno no aprobó el curso en la primera convocatoria. La distribución de las notas finales se representa en la Tabla 1 y en la Figura 1. Como se observa aproximadamente el $36 \%$ de los alumnos obtuvo evaluación de notable y/o exelente.

Tabla1. Tabla de Frecuencias para NOTA FINAL

\begin{tabular}{|l|c|c|c|c|c|c|}
\hline & Limite & Limite & & Frecuencia & Frecuencia & Frecuencia \\
\hline Clase & Inferior & Superior & Frecuencia & Relativa & Acumulada & Rel. Acum. \\
\hline & menor o igual & 4 & 0 & 0,0000 & 0 & 0,0000 \\
\hline 1 & 4,0 & 5,0 & 1 & 0,0204 & 1 & 0,0204 \\
\hline 2 & 5,0 & 6,0 & 4 & 0,0816 & 5 & 0,1020 \\
\hline 3 & 6,0 & 7,0 & 13 & 0,2653 & 18 & 0,3673 \\
\hline 4 & 7,0 & 8,0 & 13 & 0,2653 & 31 & 0,6327 \\
\hline 5 & 8,0 & 9,0 & 15 & 0,3061 & 46 & 0,9388 \\
\hline 6 & 9,0 & 10,0 & 3 & 0,0612 & 49 & 1,0000 \\
\hline
\end{tabular}

Media $=7,38$ Desviación Estándar $=1,22019$

\section{Histograma}

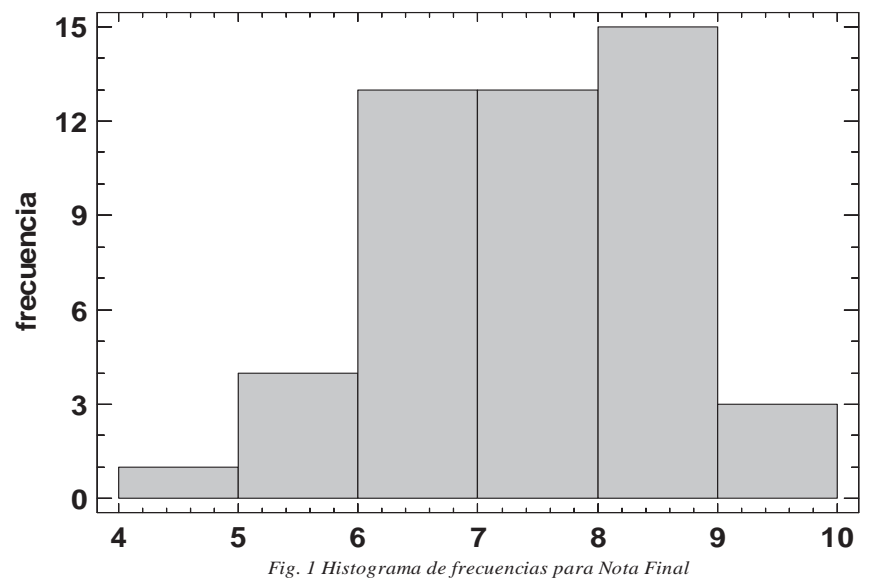

(c)) EY-NC-ND 2014, Universitat Politècnica de València

I Jornadas IN-RED (2014) 
Experiencias en la impartición del curso on-line para alumnos de doctorado de la UPV: Estadística y Métodos Matemáticos para la Investigación: Introducción a las Técnicas Estadísticas para la Investigación

Vale la pena analizar los resultados de las tareas entregadas por los alumnos. Como se señaló en la introducción el objetivo fundamental que persigue el curso, es que los alumnos “identifiquen y puedan profundizar" en aquellos métodos estadísticos que "necesitan" en su tema de investigación, es por ello precisamente que se incluyen los contenidos desarrollados en el curso. En base a la experiencia de los profesores participantes los temas incluidos son los mas utilizados en el desarrollo de trabajos de investigación de doctorado en la UPV.

La selección de 4 de los métodos desarrollados en el curso para entregar las 4 tareas puede tomarse como un indicador "de las necesidades" de los estudiantes de doctorado. En la Tabla 2 se analiza cuales fueron las temas de las tareas realizadas con mas frecuencia tanto en relación al numero total de tareas, como al numero de alumnos que entregaron las tareas. Es necesario, no obstante, señalar que los resultados presentados en la Tabla 2 pueden haber estado influidos, además, por el orden de las tareas en el desarrollo del temario o por la disponibilidad de tiempo de los alumnos, si bien es cierto que siempre se ha insistido en que el curso va dirigido a detectar y conocer las necesidades de métodos estadísticos en el trabajo individual de cada cual para poder profundizar en los mismos y aplicarlos adecuadamente.

Tabla 2. Número de Tareas por Temas entregadas.

\begin{tabular}{|l|c|c|c|}
\hline Tarea & Número & $\%$ Tareas & $\%$ Alumnos \\
\hline T1. Obtención de información y datos. & 59,0 & 23,89 & 92,19 \\
\hline T2. Sofware estadístico para la investigación. & 28,0 & 11,34 & 43,75 \\
\hline T3. Descripción y análisis básico de datos. & 54,0 & 21,86 & 84,38 \\
\hline T4. ANOVA y Regresión & 42,0 & 17,00 & 65,63 \\
\hline T5. Técnicas de clasificación. & 33,0 & 13,36 & 51,56 \\
\hline T6. Análisis Factorial & 21,0 & 8,50 & 32,81 \\
\hline T7. Análisis de Series Temporales. & 8,0 & 3,24 & 12,50 \\
\hline T8. Estadística de valores extremos & 2,0 & 0,81 & 03,13 \\
\hline Total de Tareas entregadas & 247,0 & 100,00 & - \\
\hline Total de alumnos & 64,0 & - & 100,00 \\
\hline
\end{tabular}

No obstante lo anterior, los resultados expresan que las tareas 1 y 3 fueron las mas realizadas. Estas tareas tienen que ver con métodos de obtención y descripción de datos, aspectos estos que están presentes en prácticamente todas las investigaciones. Luego el tema mas desarrollado es el de Anova y Regresión, métodos estos muy utilizados en la investigación. Mientras que temas como la estadística de valores extremos o el análisis de series temporales han sido menos utilizados. También la ubicación de cada tema en el programa puede haber influido en la mayor o menor selección de la tarea correspondiente.

No todos los alumnos entregaron solo las 4 tareas exigidas, un 23\% entregaron mas de las 4 tareas, como se observa en la Tabla 3 , lo cual puede estar vinculado a alumnos que están aun definiendo el método de investigación y no tienen claro los métodos que tendrán que 
Suitberto Cabrera García, Andres Carrión García, Elena Barrachina Vázquez, Ana Isabel Sánchez Galdón, Ana

Maria Debón Aucejo, Felix Ramón Frances García, Andrea Conchado Peiró y José Manuel Soler Torro

utilizar o bien a que entienden la realización de las tareas como una oportunidad de profundizar en el manejo de diferentes ténicas estadísticas.

Tabla 3. Número de Tareas totales entregadas.

\begin{tabular}{|l|c|c|c|c|}
\hline Cantidad & Frecuencia & Frecuencia & Frecuencia & Frecuencia \\
\hline Tareas & & Relativa & Acumulada & Rel. acum. \\
\hline 1 & 8 & 0,1250 & 8 & 0,1250 \\
\hline 2 & 6 & 0,0938 & 14 & 0,2188 \\
\hline 3 & 7 & 0,1094 & 21 & 0,3281 \\
\hline 4 & 22 & 0,3438 & 43 & 0,6719 \\
\hline 5 & 12 & 0,1875 & 55 & 0,8594 \\
\hline 6 & 7 & 0,1094 & 62 & 0,9688 \\
\hline 7 & 2 & 0,0313 & 64 & 1,0000 \\
\hline
\end{tabular}

En la tabla 4 y Figura 2 se muestra la distribución de la evaluación obtenida sobre las tareas entregadas. Se observa la calidad de los trabajos presentados, aproximadamente un $64 \%$ de ellos obtuvo calificaciones de 9 y 10 puntos.

Tabla 4. Tabla de Frecuencias para Notas de Tareas

\begin{tabular}{|l|c|c|c|c|c|c|}
\hline & Limite & Limite & & Frecuencia & Frecuencia & Frecuencia \\
\hline Clase & Inferior & Superior & Frecuencia & Relativa & Acumulada & Rel. Acum. \\
\hline 1 & 0 & 3,0 & 0 & 0,0000 & 0 & 0,0000 \\
\hline 2 & 3,0 & 4,0 & 8 & 0,1250 & 8 & 0,1250 \\
\hline 3 & 4,0 & 5,0 & 2 & 0,0313 & 10 & 0,1563 \\
\hline 4 & 5,0 & 6,0 & 6 & 0,0938 & 16 & 0,2500 \\
\hline 5 & 6,0 & 7,0 & 5 & 0,0781 & 21 & 0,3281 \\
\hline 6 & 7,0 & 8,0 & 2 & 0,0313 & 23 & 0,3594 \\
\hline 7 & 8,0 & 9,0 & 18 & 0,2813 & 41 & 0,6406 \\
\hline 8 & 9,0 & 10,0 & 23 & 0,3594 & 64 & 1,0000 \\
\hline
\end{tabular}

Media $=7,83969$ Desviación Estándar $=2,1497$

\section{(cc) EY-NC-ND 2014, Universitat Politècnica de València}

I Jornadas IN-RED (2014) 
Experiencias en la impartición del curso on-line para alumnos de doctorado de la UPV: Estadística y Métodos Matemáticos para la Investigación: Introducción a las Técnicas Estadísticas para la Investigación

\section{Histograma}

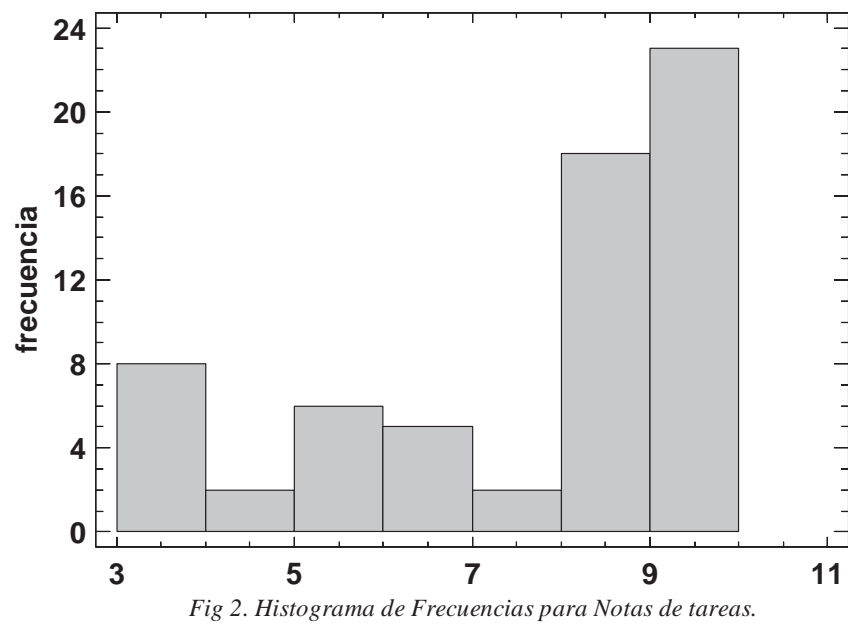

\section{Dificultades detectadas durante la primera versión del curso.}

Las principales dificultades han estado relacionadas con el carácter "on-line" del curso. Ha existido una cierta dificultad inicial en que a los alumnos les quedara clara la forma de entrega de las tareas, la forma de evaluación, etc. Precisamente cerca de una tercera parte de las preguntas y dudas estuvieron enfocadas hacia los aspectos organizativos.

En este sentido cabe destacar que se trata de una primera edición y que es la primera vez que la UPV ofrece un curso de doctorado "on-line".

Como anécdota señalar que el examen final puesto a través del Poliformat, una vez realizado, presentó dificultades informaticas con la conservación de las notas en una de las preguntas, lo cual conllevó a un trabajo adicional de revisión.

Estas dificultadas fueron analizadas por el colectivo docente del curso y fueron tomadas las medidas para solucionarlas en las segunda edición del curso, en la que se ha realizado un importante esfuerzo de clarificación y comunicación de normas y prodecimiento para la realización del curso.

Es importante añadir que los métodos estadísticos que se incluyen en el curso son técnicas complejas y se dispone de pocos créditos. 
Suitberto Cabrera García, Andres Carrión García, Elena Barrachina Vázquez, Ana Isabel Sánchez Galdón, Ana Maria Debón Aucejo, Felix Ramón Frances García, Andrea Conchado Peiró y José Manuel Soler Torro

\section{Conclusiones}

Ha quedado claro, por la amplia matricula del curso, la necesidad expresada por los alumnos de doctorado en la identificación y profundización de los métodos estadísticos en sus temas de investigación.

El curso ha cumplido con los objetivos planteados en su desarrollo y la calidad del proceso docente ha sido buena.

Los contenidos señalados por los alumnos como los mas frecuentes en sus temas de investigación han sido los relacionados con los métodos de obtención y descripción de datos, Anova y Regresión.

Han existido dificultades organizativas en el desarrollo de la primera edición del curso que han sido tenidas en cuenta para la segunda edición que actualmente se desarrolla.

\section{Referencias.}

CABRERA GARCIA, S., DEBON AUCEJO, A., CLEMENTE CISCAR, M., MARTINEZ ALZAMORA, N. y CABRERA ULLOA, A.(2013) "Evaluacion de la estadística en un entorno virtual”. XXI Congreso Universitario de Innovación Educativa en las Enseñanzas Técnicas. (06. 2010. Valencia).

<http://dx.doi.org/10.1186/1687-1499-2013-111> [Consulta: 5 de junio de 2013]

CABRERA GARCIA ,S., DEBON AUCEJO, A., y MARTINEZ ALZAMORA, N.(2011). "La enseñanza de métodos estadísticos en la ETSID”. IV Jornada de Innovación Docente JIDINF'1, Escuela Técnica Superior de Ingeniería Informática, UPV. Valencia.

<http://jidinf11.webs.upv.es/posters/Cabrera\%20S,\%20Martinez\%20N,\%20Deb\%C3\%B3n\%20A\%2 0-\%20Metodos\%20estad\%C3\%ADsticos\%20en\%20la\%20ETSID.pdf> [Consulta: 5 de junio de 2014]

CABRERA GARCIA ,S., MARTINEZ ALZAMORA, N.,TORRENT MARTÍ D. (2011). “La Docencia de Estadística y su Adaptación al EEES en la Titulación de Grado en Ingeniería en Diseño Industrial y Desarrollo de Productos de la Universidad Politécnica de Valencia”. XIX Congreso Universitario de Innovación Educativa en las Enseñanzas Técnicas. ( 07 2011.Barcelona)

CABRERA GARCIA ,S.,CARRION GARCIA A. (2010). "El análisis de datos en la formación de los nuevos especialistas". XVIII Congreso Universitario de Innovación Educativa en las Enseñanzas Técnicas. ( 06 2010.Santander).

CARRIL, P. C. M., M. G. SANMAMED. (2009), Plataformas de teleformación y herramientas telemáticas, Editorial UOC, España.

TOLOSA IGUALADA M., .(2011). La evaluación de la evolución formativa de los estudiantes de interpretación de la Universidad de Alicante a través de la Plataforma multimedia para la docencia virtual, presencial y semipresencial, IX Jornadas Redes de Investigación en Docencia Universitaria, Alicante (España)

\section{(cc)) EY-NC-ND 2014, Universitat Politècnica de València}

I Jornadas IN-RED (2014) 
Experiencias en la impartición del curso on-line para alumnos de doctorado de la UPV: Estadística y Métodos Matemáticos para la Investigación: Introducción a las Técnicas Estadísticas para la Investigación

Portillo-Poblador N., S. Vidal-Puig, A. Montesinos-Guillot, J. Martín-Marín. E-learning in teaching statistics: an application in civil engineering, EDULEARN09 proceedings, p. 265, Barcelona (España).(2009).

VÁZQUEZ BARRACHINA, E., CONCHADO PEIRÓ, A., y ALCOVER ARÁNDIGA, R.(2011). "Estudio exploratorio del uso de PoliformaT en la asignatura de Estadística del grado en Ingeniería Informática”. IV Jornada de Innovación Docente JIDINF'1, Escuela Técnica Superior de Ingeniería Informática, UPV. Valencia. 


\title{
¿Cómo perciben la ética contable los estudiantes de ADE?: valoraciones generales e impacto de las asignaturas de ética cursadas, el género y la edad
}

\section{Guillermina Tormo-Carbó ${ }^{\text {a }}$, Elies Seguí-Mas ${ }^{\text {b }}$ y Víctor Oltra Comorera ${ }^{c}$}

${ }^{a}$ CEGEA - Universitat Politènica de València (gtormo@omp.upv.es), ${ }^{b}$ CEGEA - Universitat Politènica de València (esegui@cegea.upv.es) y ${ }^{\mathrm{c}}$ Departamento de Dirección de Empresas Universitat de València (Victor.Oltra@uv.es).

\begin{abstract}
The aim of this paper is twofold. First, consider the general perception that business students have of business ethics, and specifically his views on the importance and objectives of accounting ethics. Second, analyze the extent to which differences in these perceptions depend on having previously studied subjects of ethics, as well as gender and age of the students.

In recent years, in close connection with financial scandals, the public debate on business ethics has intensified both locally and internationally. Consequently, there is a growing concern for the formal introduction of business ethics in university curricula. The purpose of this is to improve the ethical behavior of future entrepreneurs and managers, and in particular accounting professionals. In this study, we investigated the perceptions of students about the importance of accounting ethics, from a sample of 551 business students of the Technical University of Valencia. For this, several statistical techniques are used for testing the research hypotheses.

The results indicate that those students who have previously taken courses in ethics are especially prone to think that accounting education should include ethical considerations, and also show a greater interest in further study of this subject. Also, our results show significant differences in perceptions of the importance of accounting ethics by gender and age of the students (women and older students show higher ethical inclinations, respectively).
\end{abstract}

Keywords: Business ethics, accounting ethics, Business students, ethics subjects. 
¿Cómo perciben la ética contable los estudiantes de ADE?: valoraciones generales e impacto de las asignaturas de ética cursadas, el género y la edad

\begin{abstract}
Resumen
El objetivo de este trabajo es doble. En primer lugar, examinar la percepción general que los estudiantes de ADE tienen de la ética empresarial y, específicamente, sus puntos de vista sobre la importancia y objetivos de la ética contable. En segundo lugar, analizar en qué medida las posibles diferencias en dichas percepciones dependen de haber cursado previamente asignaturas de ética, así como del género y la edad de los estudiantes.

En los últimos años, en estrecha conexión con escándalos financieros, el debate público sobre la ética empresarial se ha intensificado tanto a nivel local como internacional. En consecuencia, existe una creciente preocupación por la introducción formal de la ética empresarial en los planes de estudios universitarios. El propósito de ello es mejorar el comportamiento ético de los futuros empresarios y directivos, y en particular de los profesionales de la contabilidad. En este estudio, se investigan las percepciones del alumnado acerca de la importancia de la ética contable, a partir de una muestra de 551 estudiantes de ADE de la Universitat Politècnica de València. Para ello, se utilizan diversas técnicas estadísticas para realizar análisis descriptivos y se contrastan varias hipótesis.
\end{abstract}

Los resultados del estudio empírico indican que aquéllos estudiantes que han cursado previamente asignaturas de ética son especialmente proclives a pensar que la educación contable debería incluir consideraciones éticas, y además muestran un mayor interés en profundizar en el estudio de esta materia. Así mismo, nuestros resultados arrojan diferencias significativas en las percepciones de la importancia de la ética contable en función del género y de la edad de los estudiantes. En la línea de anteriores investigaciones, las mujeres y los estudiantes de mayor edad muestran mayores inclinaciones éticas que, respectivamente, los hombres y los estudiantes más jóvenes.

Palabras clave: Ética empresarial, ética contable, estudiantes de ADE, asignaturas de ética. 


\section{Introducción}

La formación ética en la información financiera es una materia que ha contado con una amplia audiencia entre los docentes en contabilidad (Mayhew y Murphy, 2009; Gaa y Thorne, 2004). Sin embargo, la proporción de literatura académica en el área de economía financiera dedicada a temas éticos es reducida (Bampton y Cowton, 2012), siendo todavía un campo relativamente joven donde investigar (Uysal, 2010).

Dentro de los distintos debates existentes actualmente en el ámbito docente se manifiesta de forma destacada la discusión acerca de cómo impartir eficazmente ética a los estudiantes de contabilidad (Williams y Raymond, 2010; Dellaportas, Cooper y Leung, 2006). Otra cuestión candente es saber si impartir ética en los planes de estudio deber ser un contenido transversal que impregne todas las asignaturas de contabilidad o bien debe estructurarse a partir de una asignatura diferenciada y singular. En este sentido, resultaría relevante demostrar si una asignatura diferenciada tiene algún efecto a largo plazo sobre el razonamiento moral de los estudiantes o si los beneficios -si existen- resultan meramente transitorios (Loeb, 1999). Por otra parte, parece evidente que la educación moral de los estudiantes de contabilidad es un factor clave para influir en el futuro de la profesión contable (Bampton y Cowton, 2012). De hecho, la inclusión de la conciencia ética como una habilidad adicional para la empleabilidad podría tener enormes beneficios a largo plazo en el conjunto de la economía, si ésta ayudara a reducir la probabilidad de que se produjeran malas prácticas financieras (Graham, 2012).

El trabajo se organiza a través de una introducción y cuatro secciones. La segunda sección ofrece una panorámica general de la investigación previa sobre la ética en la contabilidad. A continuación, la tercera sección describe la metodología de la investigación y la cuarta sección presenta los resultados. Por último, la sección quinta resume las conclusiones del estudio, sus limitaciones potenciales y sus implicaciones respecto a la docencia de la ética en la contabilidad.

\section{Objetivos}

El objetivo de este trabajo es doble. En primer lugar, examinar la percepción general que los estudiantes de ADE tienen de la ética empresarial y, específicamente, sus puntos de vista sobre la importancia y objetivos de la ética contable. En segundo lugar, analizar en qué medida las posibles diferencias en dichas percepciones dependen de haber cursado previame nte asignaturas de ética, así como del género y la edad de los estudiantes

\subsection{Participantes y características de la muestra.}

\section{(c) EY-NC-ND 2014, Universitat Politècnica de València}


¿Cómo perciben la ética contable los estudiantes de ADE?: valoraciones generales e impacto de las asignaturas de ética cursadas, el género y la edad

La recogida de datos se realizó a partir de una encuesta dirigida a 1.825 estudiantes de la licenciatura en Administración y Dirección de Empresas (cinco cursos) en una universidad española, y se llevó a cabo durante el primer cuatrimestre del curso académico 2010-2011. $\mathrm{Su}$ objetivo fue evaluar la percepción de los estudiantes sobre cuestiones éticas en contabilidad. Finalmente, se obtuvieron 551 respuestas válidas, lo que implica una tasa de respuesta del $31,28 \%$.

La muestra está compuesta por más mujeres que hombres, $339(61,5 \%)$ frente a 209 $(37,9 \%)$, respectivamente. La edad media es de 21,23 años (desv. típica $=3,58)$. Los estudiantes que más han respondido al cuestionario son los pertenecientes a quinto $(26,0 \%)$ y segundo curso $(21,6 \%)$ de la licenciatura, y los estudiantes han superado con éxito una media de 1,57 asignaturas de contabilidad (desviación típica $=1,47$ ). El reparto de la muestra entre los dos campus donde se imparte la titulación es $27,6 \%$ (EPSA) y 72,4\% (FADE). Las características de la muestra se pueden observar en la tabla 1:

\subsection{Medidas}

El cuestionario fue administrado a los estudiantes durante el horario lectivo y el tiempo medio para completarlo fue de unos quince minutos. Así mismo, se explicó que la participación era voluntaria y anónima. El cuestionario constó de tres partes. En la primera sección, los estudiantes respondían a las preguntas relativas a las materias sobre ética en la universidad. Esta sección del cuestionario se basó en la encuesta de Adkins y Radtke (2004) (adaptada del estudio anterior de Cohen y Pant, 1989). En la segunda sección, los alumnos evaluaron la importancia percibida de la ética en las áreas generales, la comunidad empresarial, las asignaturas de administración de empresas, las decisiones personales y en el lugar de trabajo y, también, se solicitó a los estudiantes que calificaran la importancia de siete posibles objetivos de la educación ética en contabilidad. Estos objetivos se adaptaron de los estudios de Graham (2012) y de Adkins y Radtke (2004), que a su vez había sido adaptado de los estudios anteriores de Callahan (1980) y Loeb (1988). El cuestionario utilizó una escala Likert de siete estados, donde el 1 significaba "importante" y el 7 "sin importancia".

\section{Desarrollo de la innovación}

La ética constituye el sistema de creencias que apoya una particular forma de moralidad (Stedham, Yamamura y Beekun, 2007). Por su parte, el desarrollo de la ética individual ha sido ampliamente investigado, siendo uno de los marcos más utilizados para explicarlo el modelo de Rest (1986). Este considera cuatro elementos principales: la consciencia, el juicio moral, la motivación y el carácter moral. Posteriormente, Thorne (1999) integró estos cuatro elementos en dos. Los dos primeros componentes son de naturaleza cognitiva, 
mientras que los dos últimos son función de la personalidad y moral individual (e implican acciones en vez de cognición).

Hooker (2003) consideró la ética como un campo de aprendizaje, que tiene que estar alineado con la consciencia y los juicios morales. Sin embargo, el carácter y la motivación los consideró aparte puesto que están relacionados con los rasgos personales. Hooker (2003) también argumentó que si una persona está motivada para ser buena, entonces la enseñanza en aspectos éticos le ayuda a cómo serlo. Concretamente subrayó que la educación en ética puede ayudar al comportamiento ético de los estudiantes, proporcionándoles conciencia sobre las consecuencias de sus acciones, lenguaje y modelos conceptuales para poder pensar y actuar sobre temas éticos. Esta teoría les ayudaría a definir argumentaciones éticas, desarrollar habilidades para distinguir entre alternativas y evitar falacias, así como facilitar la oportunidad de reflexión sobre ello.

En el aprendizaje de la ética en los negocios Bampton y Maclagan (2005) consideraron que era importante tener en cuenta el punto de vista de los tres grupos implicados en el mismo: los académicos, los profesionales en contabilidad y los estudiantes.

Históricamente han existido numerosos enfoques de investigación sobre la percepción de los docentes hacia la pedagogía de la ética y su eficacia. Sin embargo, se ha realizado poca investigación adoptando un enfoque que tuviera en cuenta las preferencias de los estudiantes respecto al aprendizaje de la ética. En ese sentido, comprender la perspectiva del estudiante podría ayudar al proceso de aprendizaje (Duff, 2004).

Entre los antecedentes relacionados con nuestra investigación se desprende que los estudiantes de contabilidad y administración de empresas consideran importante la enseñanza de la ética (Graham, 2012; Adkins y Radtke, 2004; Crane, 2004). En particular, Crane (2004) encontró que los estudiantes parecen ser receptivos a la información y al aprendizaje en ética empresarial y que éstos sentían que se podía mejorar a través de la educación.

Por otro lado, Adkins y Radtke (2004) encontraron que los estudiantes valoran esta educación y estudiaron la existencia de una "brecha de expectativas" entre los estudiantes y los académicos, surgida de las diferencias percibidas sobre la importancia, los valores y las metas de la ética en contabilidad. En este sentido, Graham (2012) evaluó los objetivos y la eficacia de la docencia de la ética en los estudiantes universitarios de contabilidad, pero teniendo en cuenta su opinión.

Siguiendo ese enfoque, este trabajo también considera la opinión de los estudiantes sobre los objetivos de la docencia de la ética, aunque focalizando la atención en los estudiantes que han asistido anteriormente a cursos de ética. El motivo es ofrecer un punto de vista más realista (basado en su propia experiencia) ya que la opinión de estos estudiantes podía estar

\section{(cc) BY-NC-ND 2014, Universitat Politècnica de València}


¿Cómo perciben la ética contable los estudiantes de ADE?: valoraciones generales e impacto de las asignaturas de ética cursadas, el género y la edad

influenciada por la forma en que se les había impartido la materia y podían evaluar mejor la eficacia de las asignaturas de ética en términos de objetivos y metodologías.

Cabe por último contextualizar la docencia de la ética en la universidad española. Así, con motivo de la adaptación de la enseñanza superior al espacio de Bolonia, la ANECA publicó en 2005 el Libro Blanco del Grado en Economía y Empresa donde la ética es considerada como una materia relevante según la opinión de académicos y profesionales respecto a la adecuación de los estudios en ADE para la inserción laboral (especialmente para los perfiles de dirección general/gerencia, dirección administrativo-financiera y analista financiero y de inversiones). De este modo, la ética se identifica-dentro del área de sociología- como una materia específica en la propuesta de plan de estudios para ADE. En relación al sistema europeo de competencias, ésta asignatura se clasifica como una asignaturas que aporta competencias transversales de carácter personal. Respecto a la tipología de la asignatura (obligatoria u optativa) se recomienda considerar dentro de la troncalidad aquéllas materias que poseen una mayor valoración. En ese sentido, cabe señalar que la mayoría de universidades (también la del caso-estudio analizado en este trabajo) han introducido la asignatura de ética como una materia optativa.

\subsection{Hipótesis de investigación}

El estudio del comportamiento ético es más complejo de estudiar que los enjuiciamientos o las intenciones (Dalton y Ortegren, 2011). Es por ello que muchos estudios previos se han centrado en las intenciones en lugar de en los comportamientos (O'Fallon y Butterfield, 2005).

El presente estudio se basará en las conductas entendiendo que aquellos alumnos que libremente han elegido cursar una asignatura de ética (puesto que en la universidad objeto de estudio se trata de una asignatura de libre elección, no obligatoria) es porque manifiestan explícitamente su interés en esta materia. Adicionalmente, hay que tener en cuenta que resulta más fácil para las personas decir que ellos desempeñarían una acción deseable que realmente hacerla (Mayhew y Murphy, 2009). Por ello, y con el fin de evitar la deseabilidad social, en este estudio se ha estudiado la diferencia entre aquellos alumnos que han cursado alguna asignatura de ética frente a los que no. De este modo, la primera hipótesis de investigación es:

H1: los alumnos que han cursado un curso de ética percibirán la ética en contabilidad como más importante que los que no.

Una de las variables más frecuentemente estudiadas en la literatura sobre la ética en los negocios es el género (O'Fallon y Butterfield, 2005; Loe, Ferrell y Mansfield, 2000). Los estudios previos que han analizado el efecto del género en las decisiones éticas han arrojado resultados poco claros (Loe et al., 2000; Jaffe y Hyde, 2000). Sin embargo, cuando se han

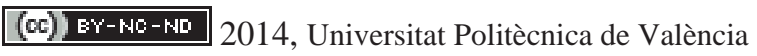

I Jornadas IN-RED (2014) 
encontrado diferencias significativas, lo habitual es que las mujeres den respuestas más éticas que los hombres (O'Fallon y Butterfield, 2005). Muchos estudios muestras que las mujeres tiene más intenciones (Dalton y Ortegren, 2011; Stedham et al., 2007), razonamientos (Christie, Kwon, Stoeberl y Baumhart, 2003) y más comportamientos éticos (Ros y Robertson, 2003, citado por Dalton y Ortegren, 2011).

La teoría del rol social de Eagley (1987) apoya la idea de que los hombres y las mujeres se comportan conforme a los estereotipos que socialmente se espera que ellos ocupen. Por su parte, la teoría de la socialización del género sostiene que las mujeres están socializadas en principios más comunitarios (altruismo, etc.) y que -en general- tienen una preocupación mayor por el bienestar de los demás. Por su parte, los hombres están más socializados en principios que tienen más que ver con el éxito competitivo y el crecimiento personal, por lo que -en ocasiones- son más proclives a implicarse en comportamientos no éticos (Loo, 2003).

La evidencia empírica en aquellos estudios basados también en estudiantes de administración y dirección de empresas muestra que las mujeres son más éticas que los hombres (Adkins y Radtke, 2004; Knott et al, 2000). Más concretamente, en la literatura sobre contabilidad Cohen et al (1998) investigaron el efecto del género en la evaluación ética y en la intención y orientación en la selección de potenciales contables públicos, encontrando que las mujeres son menos capaces de realizar acciones poco éticas que los hombres. Por lo tanto y debido a que la mayoría de estudios previos han encontrado evidencias de que las mujeres son más éticas que los hombres, la segunda hipótesis de investigación es:

H2: Las mujeres percibirán la ética en contabilidad más importante que los hombres.

Otra variable de interés para los investigadores ha sido tradicionalmente la edad de los individuos. Algunos estudios previos con estudiantes encontraron que los estudiantes mayores toman decisiones más éticas que los más jóvenes. Además, Kohlberg (1969) indicó que a medida que nos hacemos mayores, nos importan más y estamos más conscientes de los aspectos éticos en general. En esta misma línea, Bernardi y Bean (2000) o Rest (1994) encontraron que el razonamiento ético se incrementaba con la edad y que había elevadas correlaciones entre edad y razonamiento ético. Por ello la tercera hipótesis que plantea el trabajo es:

H3: los estudiantes mayores percibirán la ética en la educación en contabilidad más importante que los más jóvenes.

\section{(c) EY-NC-ND 2014, Universitat Politècnica de València}

I Jornadas IN-RED (2014) 
¿Cómo perciben la ética contable los estudiantes de ADE?: valoraciones generales e impacto de las asignaturas de ética cursadas, el género y la edad

\section{Resultados}

En relación a la primera sección del cuestionario (donde los alumnos responden a las preguntas relativas a los cursos de educación ética en su universidad) los datos fueron analizados usando estadísticos descriptivos básicos y tablas de contingencia (tabla 1).

Tabla 1. Respuesta a las preguntas previas

\begin{tabular}{lccc}
\hline \multicolumn{1}{c}{ Preguntas } & \multicolumn{3}{c}{ Respuestas } \\
& Si & No estoy & $\begin{array}{c}\text { seguro } \\
\text { EC1: Cursado asignatura ética }\end{array}$ \\
(n=551) & 116 & 399 & 36 \\
EC2: Asignatura fue eficaz & $(21.1 \%)$ & $(72.4 \%)$ & $(6.5 \%)$ \\
(n=114) & 89 & 25 & \\
EC3: Universidad ofrece asignaturas ética & 337 & 83 & 101 \\
(n=521) & $(64.7 \%)$ & $(15.9 \%)$ & $(19.4 \%)$ \\
EC4: Asignatura necesaria plan estudios & 126 & 235 & 81 \\
n=442 & $(28.5 \%)$ & $(53.2 \%)$ & $(18.3 \%)$ \\
EC5: Matricularía & 223 & 141 & 181 \\
(n=545) & $(40.9 \%)$ & $(25.9 \%)$ & $(33.2 \%)$ \\
EC6: Conviene asignatura ética facultad & 356 & 89 & 102 \\
(n=547) & $(65.1 \%)$ & $(16.3 \%)$ & $(18.6 \%)$ \\
EC7: Ayuda a resolver cuestiones éticas & 293 & 105 & 150 \\
(n=548) & $(53.5 \%)$ & $(19.2 \%)$ & $(27.3 \%)$ \\
\hline
\end{tabular}

Como muestra la tabla 1, sólo 116 estudiantes (el 21,1\% de la muestra) habían cursado una asignatura sobre ética en la universidad. Cabe destacar que, de entre estos estudiantes, el $78,1 \%$ piensan que la asignatura de ética estaba bien diseñada y era efectiva. Por otro lado, la mayoría de los estudiantes encuestados (337; el 64,7\%) indicaron conocer que su universidad ofertaba asignaturas sobre ética, mientras que el 40,9\% (223) declaraban que se matricularían de una asignatura sobre ética si fuera ofrecida como optativa. 
Las tablas de contingencia y el test $\chi^{2}$ nos permitieron evaluar si habían diferencias significativas entre los estudiantes que habían cursado alguna asignatura sobre ética (curso ética) y aquellos estudiantes que no lo habían cursado ( no curso ética).

Los resultados de dichos análisis, mostraron que había diferencias significativas entre los estudiantes con curso de ética y no curso de ética respecto a EC5 " se matricularía en una asignatura sobre ética" $\chi 2(4)=51,77 \mathrm{p}<.01(\mathrm{Phi}=, 314)$, EC4 "asignatura necesaria en su plan de estudios" $\chi 2(4)=24,016 \mathrm{p}<.01(\mathrm{Phi}=, 239)$ y EC6 “ conveniencia de tener asignaturas de ética en la facultad" $\chi 2(4)=48,8$ p <.01 (Phi =,308). En concreto, el 69,3\% de los alumnos que ya habían cursado una asignatura de ética en contabilidad, se matricularían otra vez frente al 32,8\% de los alumnos que no lo habían cursado.

Además, el 92\% de los alumnos que habían cursado alguna asignatura en materia de ética, conocían mejor la oferta formativa de sus facultades que los alumnos que no la habían cursado $(55,8 \%)$. Ello puede indicar que a pesar de la motivación y el interés personal de cada estudiante hacia la ética, la importancia de la institución, en este caso la universidad y la facultad, como elemento de socialización es fundamental. Por ello, sería necesario que se enfatizara la necesidad de la ética y la importancia de las decisiones éticas a través de una mejor información a sus estudiantes (tal y como sugirieron Mayhew y Murphy, 2008).

Al igual que en investigaciones previas (Hurtt y Thomas, 2008), los alumnos de contabilidad consideran positivo tener cursos de ética en asignaturas específicas, pero en general consideran que un curso puede no ser suficiente (de ahí la voluntad de matricularse en otros cursos). Estos resultados son consistentes con los obtenidos (por ejemplo, por Swanson, 2005), dónde se pone de manifiesto que un único curso no sería suficiente.

Los estudiantes que habían asistido a una asignatura sobre ética (44,2\%) son más favorables a incluir una asignatura sobre ética en el plan de estudios que aquellos que no lo habían hecho $(22,9 \%)$. En el mismo sentido, los estudiantes que habían asistido a una asignatura sobre ética $(89,7 \%)$ consideran más apropiado tener una asignatura en la facultad que los estudiantes actuales que no han recibido la materia $(58,8 \%)$.

Sin embargo, no existen diferencias estadísticamente significativas en relación a la pregunta EC7 "¿Cree que tener una asignatura de ética en la universidad le ayudaría a resolver las cuestiones éticas y morales a que se enfrenta la profesión contable y la comunidad empresarial en general? “ $\chi 2(2)=5,758$ p >,05 (Phi =,106), lo cual indica que la mayoría de estudiantes (356; un $65,1 \%$ de la muestra) creen que es apropiado contar con una asignatura sobre ética en el plan de estudios y que ello ayudaría a los estudiantes a resolver conflictos morales y éticos a la hora de afrontar su carrera profesional. Este resultado confirma los hallazgos de aquellos autores que demostraron que los estudiantes reconocen la docencia de la ética como una parte necesaria de la formación empresarial (Graham, 2012; Adkins y Radtke, 2004; Crane, 2004).

\section{(cc) EY-NC-ND 2014, Universitat Politècnica de València}

I Jornadas IN-RED (2014) 
¿Cómo perciben la ética contable los estudiantes de ADE?: valoraciones generales e impacto de las asignaturas de ética cursadas, el género y la edad

Los estudiantes evaluaron la importancia percibida por ellos de la ética en áspectos generales (en la comunidad empresarial, en la formación empresarial, en las decisiones personales y en las decisiones en el puesto de trabajo) y también calificaron la relevancia de los posibles objetivos de la educación ética en contabilidad.

El análisis de datos exploratorio de la segunda parte del cuestionario identificó la existencia de una severa falta de normalidad en la distribución de todas las variables.

Consecuentemente, se decidió usar técnicas estadísticas no paramétricas sobre los datos para testar diferencias grupales. Así, para testear las diferencias entre la percepción de los estudiantes que habían cursado una asignatura de ética frente a los que no lo habían hecho, se utilizó el test Mann-Whitney.

La tabla 2 muestra los resultados del test de Mann-Whitney para evaluar si existían diferencias significativas entre los estudiantes que habían asistido a una asignatura de ética y los que no.

Tabla 2: Test de Mann-Whitney para aspectos generales

\begin{tabular}{|c|c|c|c|c|}
\hline Objetivos generales & $\begin{array}{c}\text { Md } \\
\text { Curso } \\
\text { ética }\end{array}$ & $\begin{array}{c}\text { Md } \\
\text { No curso } \\
\text { ética }\end{array}$ & $\begin{array}{c}\text { Mann-Whitney } \\
\text { test }\end{array}$ & $\underset{\text { valor }}{\mathbf{p}}$ \\
\hline GE1: Ética en comunidad empresarial & $\begin{array}{c}2 \\
n=116\end{array}$ & $\begin{array}{c}2 \\
n=399\end{array}$ & 20423.5 & 0.047 \\
\hline GE2: Ética en la formación empresarial & $\begin{array}{c}2 \\
n=116\end{array}$ & $\begin{array}{c}2 \\
n=399\end{array}$ & 19220.5 & 0.05 \\
\hline GE3: Ética en decisiones personales & $\begin{array}{c}2 \\
n=116\end{array}$ & $\begin{array}{c}2 \\
\mathrm{n}=399\end{array}$ & 22046.6 & 0.413 \\
\hline GE4: Ética en decisiones del trabajo & $\begin{array}{c}2 \\
\mathrm{n}=116\end{array}$ & $\begin{array}{c}2 \\
\mathrm{n}=399\end{array}$ & 17942.5 & 0.006 \\
\hline
\end{tabular}

Md: Mediana

Curso ética: alumnos que han cursado alguna asignatura ética

No curso étcia: Aumnos que nunca han cursado asignatura ética

En términos relativos, lo más importante para ambos grupos es la ética en las decisiones personales. Las diferencias en las respuestas de los dos grupos de estudiantes son significativas respecto a la relevancia de la ética entre la comunidad empresarial, en la formación empresarial y en las decisiones en el puesto de trabajo, lo que indica que los estudiantes que habían cursado anteriormente asignaturas de ética percibían estas cuestiones como más importantes que los estudiantes que no lo habían hecho. Estos 
resultados pueden ser indicativos de la creencia de los estudiantes de que necesitan aprender más sobre ética empresarial con el fin de aplicarla en sus decisiones en el puesto de trabajo.

Este hallazgo muestra diferencias en los niveles de desarrollo moral después de cursar una asignatura de ética, lo que puede indicar que los cursos de ética pueden ser eficaces en algunos casos dependiendo de la naturaleza de la intervención (Bampton y Maclagan, 2005). Por el contrario, no se identifican diferencias significativas en el nivel de las decisiones personales después de la intervención ética, lo cual sugieren que el razonamiento moral puede ser definido por otros factores como las influencias ambientales (y no por la intervención realizada) (Bampton y Maclagan, 2005).

Los resultados del test de Mann-Whitney sobre la relevancia de diversos objetivos específicos de la educación ética en contabilidad se describen en la tabla 3.

Tabla 3: Test de Mann-Whitney para objetivos específicos

\begin{tabular}{|c|c|c|c|c|}
\hline Objetivos específicos & $\begin{array}{c}\text { Md } \\
\text { Curso } \\
\text { ética }\end{array}$ & $\begin{array}{l}\text { Md No } \\
\text { curso } \\
\text { ética }\end{array}$ & $\begin{array}{c}\text { Mann-Whitney } \\
\text { test }\end{array}$ & $\begin{array}{c}\mathbf{p} \\
\text { valor }\end{array}$ \\
\hline OE1:Relacionar temas morales & $\begin{array}{c}3 \\
\mathrm{n}=116\end{array}$ & $\begin{array}{c}3 \\
\mathrm{n}=396\end{array}$ & 20076.5 & 0.035 \\
\hline OE2: Reconocer implicaciones éticas & $\begin{array}{c}3 \\
\mathrm{n}=116\end{array}$ & $\begin{array}{c}3 \\
\mathrm{n}=398\end{array}$ & 20542 & 0.063 \\
\hline OE3: Desarrollar sentido responsabilidad & $\underset{n=116}{2}$ & $\begin{array}{c}2 \\
\mathrm{n}=399\end{array}$ & 21397 & 0.202 \\
\hline OE4:Desarrollar capacidad trata conflictos & $\begin{array}{c}2 \\
\mathrm{n}=116\end{array}$ & $\begin{array}{c}2 \\
\mathrm{n}=398\end{array}$ & 20419.5 & 0.051 \\
\hline OE5:Aprender a tratar incertidumbres & $\begin{array}{c}2 \\
\mathrm{n}=116\end{array}$ & $\begin{array}{c}2 \\
n=397\end{array}$ & 22688.5 & 0.804 \\
\hline OE6: Establecer cambio comportamiento ético & $\begin{array}{c}3 \\
\mathrm{n}=115\end{array}$ & $\begin{array}{c}3 \\
n=399\end{array}$ & 19333.5 & 0.008 \\
\hline OE7: Entender aspectos de la ética & $\begin{array}{c}3 \\
\mathrm{n}=115\end{array}$ & $\begin{array}{c}3 \\
n=399\end{array}$ & 22319 & 0.648 \\
\hline
\end{tabular}

Md: Mediana

Curso ética: alumnos que han cursado alguna asignatura ética

No curso étcia: Aumnos que nunca han cursado asignatura ética

El test de Mann-Whitney evalúa las diferencias entre los dos grupos, identificándose en este caso dos diferencias estadísticamente significativas (tabla 3) entre los estudiantes que habían asistido a un curso de ética y los que no. Así, "relacionar la educación en

(c)) EY-NC-ND 2014, Universitat Politècnica de València

I Jornadas IN-RED (2014) 
¿Cómo perciben la ética contable los estudiantes de ADE?: valoraciones generales e impacto de las asignaturas de ética cursadas, el género y la edad

contabilidad con temas morales" ( $\mathrm{p}=, 035)$ y "establecer las bases para un cambio en el comportamiento ético $(\mathrm{p}=, 008)$ eran objetivos más importantes para los alumnos que habían asistido a un curso de ética que para los que no habían asistido.

Para analizar la influencia de las distintas variables se ha realizado un análisis multivariante, en concreto, se han ejecutado regresiones lineales para cada una de las 11 preguntas sobre la importancia de la ética en la contabilidad (ver tablas 4 y 5)

Las variables explicativas incluidas en el análisis han sido las de grupo (estudiantes que sí habían cursado una asignatura de ética respecto a los que no), género y edad. Los resultados de la regresión se muestran en las tablas 4 y 5.

Tabla 4: Regresión múltiple para objetivos generales

Preguntas

GE1: Ética en comunidad empresarial $\mathrm{n}=464 \mathrm{R}^{2}=.032 * \mathrm{p}<.01 * \mathrm{p}<.05$

$B$
SBE

$\beta$

GE2: Ética en la formación empresarial $\mathrm{n}=463 \mathrm{R}^{2}=.053 * * \mathrm{p}<.01 * \mathrm{p}<.05$

B

$\beta$

GE3: Ética en decisiones personales

$$
\begin{gathered}
\mathrm{n}=464 \quad \mathrm{R}^{2}=.038 \quad * * \mathrm{p}<.01 * \mathrm{p}<.05 \\
\mathrm{~B} \\
\mathrm{SBE} \\
\beta
\end{gathered}
$$

GE4: Ética en decisiones del trabajo

$$
\begin{gathered}
\mathrm{n}=452 \quad \mathrm{R}^{2}=.073 * * \mathrm{p}<.01 * \mathrm{p}<.05 \\
\mathrm{~B} \\
\mathrm{SBE} \\
\beta
\end{gathered}
$$

Constante Grupo Género Edad

$\begin{array}{cccc}3.861 & .194 & -.403 & -.032 \\ .663 & .156 & .135 & .020 \\ & .058 & -.139 * * & -.074\end{array}$

$\begin{array}{cccc}3.901 & .308 & -.418 & -.047 \\ .610 & .144 & .124 & .019 \\ & .099 * & -.155^{* *} & -.116^{*}\end{array}$

$\begin{array}{cccc}3.558 & .108 & -.371 & -.033 \\ .571 & .138 & .116 & .018 \\ & .038 & -.148 * * & -.088\end{array}$

\begin{tabular}{cccc}
4.309 & .209 & -.434 & -.048 \\
.575 & .137 & .117 & .018 \\
& .072 & $-.171 * *$ & $-.127 * *$ \\
\hline
\end{tabular}


Los resultados que se muestran en la tabla 4 sugieren que sólo hay diferencias significativas respecto a la importancia que tiene la "ética en la formación empresarial" (GE2) en relación a los alumnos que han cursado y los que no alguna asignatura de ética.

En todos los casos se aprecian diferencias significativas entre las mujeres y los hombres, manifestándose más importantes las cuestiones éticas para las primeras que para los segundos.

Además, se puede observar que a mayor edad se considera que es más importante la ética en la formación empresarial y también en las decisiones en el puesto de trabajo.

Para los aspectos generales sobre la importancia de la ética contable, tal y como se ha visto las hipótesis 1 y 3 se cumplen parcialmente y sólo la hipótesis 2 se aceptaría totalmente.

A continuación, se ha seguido el mismo procedimiento pero para los objetivos que debería cumplir la docencia en ética contable. En la tabla 5 se muestran los resultados:

Tabla 5: Regresión múltiple para objetivos específico en la educación ética contable

\section{Preguntas}

OE1:Relacionar temas morales

$\mathrm{n}=462 \quad \mathrm{R}^{2}=.055 * * \mathrm{p}<.01 * \mathrm{p}<.05$

B

SBE

$\beta$

OE2: Reconocer implicaciones éticas

$$
\mathrm{n}=463 \quad \mathrm{R}^{2}=.062 * \mathrm{p}<.01 * \mathrm{p}<.05
$$

B

SBE

$\beta$

OE3: Desarrollar sentido responsabilidad

$$
\mathrm{n}=464 \mathrm{R}^{2}=.037 * * \mathrm{p}<.01 * \mathrm{p}<.05
$$

B

SBE

$\beta$

OE4:Desarrollar capacidad trata conflictos

$$
\begin{gathered}
\mathrm{n}=463 \quad \mathrm{R}^{2}=.040 * * \mathrm{p}<.01 * \mathrm{p}<.05 \\
\mathrm{~B} \\
\mathrm{SBE} \\
\beta
\end{gathered}
$$

\section{Constante Grupo Género Edad}

$\begin{array}{cccc}5.331 & .250 & -.295 & -.075 \\ .656 & .155 & .134 & .020 \\ & .075 & -.102 * & -.173 * *\end{array}$

$\begin{array}{cccc}5.381 & .105 & -.375 & -.083 \\ .599 & .141 & .122 & .018 \\ & .034 & -.141 * * & -.209 * *\end{array}$

$\begin{array}{cccc}4.361 & .077 & -.341 & -.057 \\ .601 & .141 & .122 & .018 \\ & .025 & -.130 * * & -.144 * *\end{array}$

$\begin{array}{cccc}3.863 & .174 & -.417 & -.047 \\ .601 & .141 & .122 & .018 \\ & .057 & -.158 * * & -.120 * *\end{array}$

(c)) EY-NC-ND 2014, Universitat Politècnica de València

I Jornadas IN-RED (2014) 
¿Cómo perciben la ética contable los estudiantes de ADE?: valoraciones generales e impacto de las asignaturas de ética cursadas, el género y la edad

OE5:Aprender a tratar incertidumbres

$$
\mathrm{n}=462 \mathrm{R}^{2}=.021 * * \mathrm{p}<.01 * \mathrm{p}<.05
$$

$\begin{array}{cccc}3.743 & -.035 & -.344 & -.028 \\ .584 & .137 & .199 & .018 \\ & -.012 & -.136 * * & -.073\end{array}$

OE6: Establecer cambio comportamiento ético

$$
\begin{gathered}
\mathrm{n}=463 \mathrm{R}^{2}=.144 * \mathrm{p}<.01 * \mathrm{p}<.05 \\
\mathrm{~B} \\
\mathrm{SBE} \\
\beta
\end{gathered}
$$

$\begin{array}{cccc}5.589 & .276 & -.632 & -.083 \\ .574 & .135 & .116 & .018 \\ & .092 * & -.241 * * & -.212 * *\end{array}$

OE7: Entender aspectos de la ética

$$
\begin{gathered}
\mathrm{n}=463 \mathrm{R}^{2}=.036 * * \mathrm{p}<.01 * \mathrm{p}<.05 \\
\mathrm{~B} \\
\mathrm{SBE} \\
\beta
\end{gathered}
$$$$
5.564 \quad-.071 \quad-.431 \quad-.049
$$$$
.648
$$$$
.153 \quad .131 \quad .020
$$$$
-.022-.152 * *-.115^{*}
$$

Tal y como se esperaba es más importante la ética en contabilidad para los que han hecho algún curso de ética que para los que no, en concreto, que los objetivos de la formación ética en contabilidad estén orientados fundamentalmente a "establecer las bases para un cambio en el comportamiento ético"

Además, para todos los objetivos, la importancia es mayor en el caso de las mujeres que en los hombres. De forma análoga ocurre con la edad: a mayor edad más importancia se le da a todos los objetivos excepto el de "aprender a lidiar con las incertidumbres de la profesión contable".

La hipótesis 1 se puede rechazar, mientras que se aceptarían las hipótesis 2 y 3.

Nuestros resultados muestran que sí existe relación entre la edad y la importancia de los objetivos de la ética en la contabilidad, resultados que están en la línea de los que obtuvieron Adkins y Radke (2004).

\section{Conclusiones}

A partir de los resultados obtenidos en este estudio pueden establecerse las siguientes conclusiones. En primer lugar, los estudiantes son generalmente receptivos a la docencia de la ética. Este resultado confirma las conclusiones obtenidas por investigaciones previas (Graham, 2012; Adkins y Radtke, 2004; Crane, 2004), con diferentes estudiantes 
(diferentes facultades, titulaciones y graduados y postgradudos y en diferentes países (EE.UU., Reino Unido entre otros).

En segundo lugar, los estudiantes también señalaron la importancia del aprendizaje en ética en sus planes de estudio cara a prepararles en los potenciales dilemas éticos y las decisiones que tendrán que tomar en sus futuros puestos de trabajo. Consecuentemente, la pedagogía y las metodologías para el aprendizaje de la ética necesitarían ser adaptadas para reconocer esta necesidad.

Por otro lado, los estudiantes piensan que la ética en la contabilidad es importante en su educación. En consecuencia, parece necesario que las universidades oferten asignaturas y que las incluyan en su formación.

Los alumnos en general creen que son útiles todos los objetivos que se plantean en la formación en ética, pero aquellos alumnos que han cursado esta asignatura anteriormente entienden que estos objetivos deberían estar orientados fundamentalmente a establecer las bases necesarias para un cambio en el comportamiento ético.

En general, los estudiantes (tanto los que han cursado anteriormente una asignatura de ética como los que no) consideran que la educación en ética en contabilidad es apropiada, que tiene que estar integrada en el plan de estudios y que, además, tiene que impartirse en las universidades porque es deseable y valorada. Además, en el caso que nos ocupa, la mayoría de los alumnos que han cursado la asignatura de ética consideran que ésta estuvo bien diseñada y que les ha sido útil, lo que indica que en la UPV esta asignatura está bien valorada por los alumnos. Este hecho puede derivarse del hecho que el profesorado que imparte esta asignatura sea profesional y que -además- esté comprometido con la materia. En estos casos, el profesor adopta un rol activo en el proceso de aprendizaje de los alumnos, preparando la asignatura, los materiales y diseñando la metodología que considera más adecuada para conseguir los objetivos que se quieren alcanzar. Al tratarse de una asignatura optativa, tanto el profesorado que la imparte como los alumnos que asisten están más interesados, comprometidos y motivados en esta materia.

Los resultados de este estudio parten de la percepción de los estudiantes. De este modo, la mayoría de los estudiantes tienen una firme expectativa de los objetivos de la docencia de la ética en contabilidad. Sin embargo, los estudiantes que han asistido anteriormente a una asignatura de ética consideran más importante focalizar la atención en los objetivos primero y sexto propuestos por Adkins y Radtke (2004). Es decir, en relacionar la educación de la contabilidad con cuestiones morales y en establecer las bases para un cambio en el comportamiento ético.

En este sentido, Dellaportas et al. (2006) afirmaron que una intervención discreta que enfatizara el dilema ético tiene un efecto positive y significativo sobre el razonamiento

\section{(c)) EY-NC-ND 2014, Universitat Politècnica de València}

I Jornadas IN-RED (2014) 
¿Cómo perciben la ética contable los estudiantes de ADE?: valoraciones generales e impacto de las asignaturas de ética cursadas, el género y la edad

moral y el desarrollo de los estudiantes. Por su parte, Swanson (2005) proponía un enfoque holístico donde las cuestiones éticas estuvieran integradas en las diferentes asignaturas.

Además, la mayor parte de los estudiantes que habían asistido a clases de ética manifestaron que el curso había sido bien diseñado y que era efectivo. Por lo tanto, para ellos, no era necesario asistir a más asignaturas de ática. En sentido contrario se manifestaron los docentes y las instituciones académicas en el estudio de Adkins y Radtke (2004), ya que estos eran favorables a un enfoque de la docencia de la ética integrado transversalmente en varias asignaturas.

Respecto a las limitaciones del estudio cabe hacer referencia a las características de la muestra de estudiantes. En primer lugar la muestra corresponde a estudiantes de administración y dirección de empresas de una universidad valenciana, por lo que los resultados podrían no ser generalizables a otros estudiantes de administración y dirección de empresas, y a estudiantes de otras universidades. Otra limitación subyace en el hecho que las respuestas de los estudiantes podrían sufrir de deseabilidad social, tal y como se observa de los valores de sus respuestas, la mayoría de ellos están más cerca del extremo 1 (importante) que del extremo 7 (no importante). De este modo, los estudiantes pueden estar respondiendo que la ética es importante porque eso es lo que ellos piensan que el investigador quiere escuchar y no querrían ser etiquetados como 'no éticos'. Adicionalmente, otra limitación es el carácter transversal de la investigación.

\section{Referencias}

ADKINS, N. y RADTKE, R.R. (2004). "Students' and faculty members' perceptions of the importance of business ethics and accounting ethics education: Is there an expectations gap?" en Journal of Business Ethics, 51(3), 279-300.

BAMPTON, R. y COWTON, C. (2012). "Taking stock of accounting ethics scholarship: A review of the journal literature" en Journal of Business Ethics, , 1-15.

BAMPTON, R., y MACLAGAN, P. (2005). "Why teach ethics to accounting students? A response to the sceptics" en Business Ethics: A European Review, 14(3), 290-300.

CHRISTIE, P. M., KWON, I., STOEBERL, P., y BAUMHART, R. (2003). “A crosscultural comparison of ethical attitudes of business managers: India, Korea and the United States" en Journal of Business Ethics, 46(3), 263-287.

CHUNG, J. y MONROE, G. (2003). "Exploring social desirability bias" en Journal of Business Ethics, 44(4), 291-302.

COOPER, B. y DELLAPORTAS, S. (2009). "Business ethics and the accounting profession” en Deakin Business Review, 2(2), 4-9. 
DALTON, D. y ORTEGREN, M. (2011). "Gender differences in ethics research: The importance of controlling for the social desirability response bias" en Journal of Business Ethics, 103(1), 73-93.

DELLAPORTAS, S., COOPER, B. J., y LEUNG, P. (2006). "Measuring moral judgement and the implications of cooperative education and rule-based learning" en Accounting \& Finance, 46(1), 53-70.

DUFF, A. (2004). "The role of cognitive learning styles in accounting education: Developing learning competencies" en Journal of Accounting Education, 22(1), 29-52.

EAGLY, A.H. (1987). Sex differences in social behavior: A social-role interpretation. Lawrence Erlbaum Associates, Inc.

EAGLY, A.H., WOOD, W., y DIEKMAN, A.B. (2000). "Social role theory of sex differences and similarities: A current appraisal" en The developmental social psychology of gender, 123-174

GAA, J.C., y THORNE, L. (2004). "An introduction to the special issue on professionalism and ethics in accounting education" en Issues in Accounting Education, 19(1), 1-6.

GRAHAM, A. (2012). "The teaching of ethics in undergraduate accounting programmes: The students' perspective" en Accounting Education, 21(6), 599-613.

HURTT, R.K., Y THOMAS, C.W. (2008). "Implementing a required ethics class for students in accounting: The texas experience" en Issues in Accounting Education, 23(1), $31-51$.

KOHLBERG, L. (1969). Stage and sequence: The cognitive-developmental approach to socialization (pp. 347-480). Rand McNally.

LOE, T., FERRELL, L. y MANSFIELD, P. (2000). "A review of empirical studies assessing ethical decision making in business" en Journal of Business Ethics, 25(3), 185204.

LOEB, S. E. (1999). "Accounting ethics research" en Journal of Accounting and Public Policy, 18(4-5), 333-334.

LOO, R. (2003). "Are women more ethical than men? Findings from three independent studies". Women in Management Review, 18(4), 169-181.

MAYHEW, B. W. y MURPHY, P.R. (2009). "The impact of ethics education on reporting behaviour" en Journal of Business Ethics, 86(3), 397-416.

O'FALLON, M.J. y BUTTERFIELD, K.D. (2005). "A review of the empirical ethical decision-making literature: 1996-2003" en Journal of Business Ethics, 59(4)

STEDHAM, Y., YAMAMURA, J.H. y BEEKUN, R.I. (2007). "Gender differences in business ethics: Justice and relativist perspectives" en Business Ethics: A European Review, 16(2), 163-174.

SWANSON, D.L. (2005). "Business ethics education at bay: Addressing a crisis of legitimacy" en Issues in Accounting Education, 20(3), 247-253.

(c)) EY-NC-ND 2014, Universitat Politècnica de València

I Jornadas IN-RED (2014) 
¿Cómo perciben la ética contable los estudiantes de ADE?: valoraciones generales e impacto de las asignaturas de ética cursadas, el género y la edad

THORNE, L. (1999). "An analysis of the association of demographic variables with the cognitive moral development of Canadian accounting students: An examination of the applicability of american-based findings to the Canadian context" en Journal of Accounting Education, 17(2-3), 157-174.

UYSAL, O.O. (2010). "Business ethics research with an accounting focus: A bibliometric analysis from 1988 to 2007" en Journal of Business Ethics, 93(1), 137-160.

WILLIAMS, J. y ELSON, R.J. (2010). "The challenges and opportunities of incorporating accounting ethics into the accounting curriculum" en Journal of Legal, Ethical \& Regulatory Issues, 13(1), 105-115. 


\title{
Adecuación progresiva y análisis permanente de la metodología docente hacia una evaluación continua.
}

Juan Andrés González ${ }^{\mathrm{a}}$ y Jesús Mengual ${ }^{\mathrm{b}}$

Universitat Politècnica de València ( ${ }^{a}$ juagonr1@hma.upv.es, b jemencu@hma.upv.es)

\begin{abstract}
Continuous evaluation is the main evaluation system used into the new European Space for Higher Education. This paper describes the continuous evaluation applied to the course "Fundamentals of Environmental Engineering" and presents a comparative analysis of the impact that this methodological change has resulted in academic performance. This comparison shows an improvement of academic performance with the use of continuous evaluation. Also, an analysis of the review process is made to proceed with a progressive adjustment of continuous evaluation system. Previous experience and curricular planning are showed important factors for its implementation, as well as analysis of educational context. Finally, the main advantages and disadvantages observed in the application of this methodology during last years are discussed.
\end{abstract}

\section{Keywords:}

Continuous Evaluation, Review Process, Active Teaching Methodologies, Academic Performance, Progressive Adaptation. 
Adecuación progresiva y análisis permanente de la metodología docente hacia una evaluación continua

\section{Introducción}

La adquisición por parte de los estudiantes de una serie de competencias constituye uno de los principales objetivos del actual escenario correspondiente al Espacio Europeo de Educación Superior (EEES). Tanto la metodología docente como el sistema de evaluación utilizados en el proceso de aprendizaje desempeñan un papel importante para alcanzar una consecución real de las competencias. Tradicionalmente, se ha enfocado el proceso de evaluación a la etapa final del aprendizaje, descuidando el resto del proceso. Este sistema de evaluación no permite incidir en la mejora del aprendizaje y fomenta en el estudiante un enfoque del aprendizaje orientado, principalmente, a la superación de la prueba final. Por ello, dicho sistema no resulta adecuado en el escenario del EEES (Brown y Glasner, 2003). En este sentido, la utilización de sistemas de evaluación continua puede constituir un mejor método para evaluar el correcto desarrollo de las competencias (Delgado y Oliver, 2006).

La evaluación continua se caracteriza por su realización durante el proceso de aprendizaje, por lo que es capaz de proporcionar información a lo largo de este. Esta retroalimentación de información aporta ciertas ventajas a los alumnos, ya que es capaz de valorar su ritmo de aprendizaje y reorientarlo, constituye una forma más gradual de adquisición de los contenidos o competencias y está más familiarizado y adaptado a los criterios de la evaluación. Todo ello constituye una mayor garantía de éxito. Por su parte, el profesor percibe una información que le permite identificar los progresos y las dificultades de los estudiantes que posibilita informar y reorientar el proceso de aprendizaje.

El diseño de la evaluación continua debe considerar tres aspectos clave como la planificación, la información al alumno y el diseño de las actividades de evaluación (Delgado y Oliver, 2006). Sin embargo, durante su implantación pueden existir factores imprevistos, o insuficientemente planificados, que dificulten alcanzar los objetivos propuestos. Por ello, la revisión permanente del propio sistema de evaluación debe servir para su reorientación y adaptación al entorno.

\section{Objetivos}

El escenario del EEES ha propiciado un importante revulsivo en los procesos de reflexión del profesorado acerca de las metodologías docentes y sistemas de evaluación. Esta reflexión se ha traducido en un esfuerzo del profesorado por mejorar la calidad docente, principalmente, a través de cambios metodológicos. En este sentido, el objetivo principal de este trabajo es analizar el proceso de cambio implementado durante los últimos ocho cursos en el sistema de evaluación de una asignatura obligatoria de segundo curso del Grado en Ciencias Ambientales, así como analizar la evolución de los resultados académicos obtenidos a lo largo de este período. 


\section{Desarrollo de la innovación}

La innovación educativa analizada se ha desarrollado bajo el siguiente contexto y diseño metodológico.

\subsection{Contexto}

La asignatura Fundamentos de Ingeniería Ambiental (4.5 ECTS) se imparte con carácter obligatorio en el segundo curso del Grado en Ciencias Ambientales de la Universidad Politécnica de Valencia. Con anterioridad a la adaptación al EEES, en el segundo curso de la Licenciatura en Ciencias Ambientales se impartía la asignatura Bases de la Ingeniería Ambiental (6 créditos), con un contenido curricular similar. Fundamentalmente, sus objetivos se centran en el manejo de los conceptos básicos propios del ámbito de la ingeniería ambiental, los cuales están fundamentados en aspectos matemáticos, físicos y químicos. Además, constituye la primera asignatura del ámbito de la ingeniería que los estudiantes cursan en esta titulación de la rama de ciencias.

Los resultados académicos alcanzados en la asignatura Bases de la Ingeniería Ambiental han sido, generalmente, poco satisfactorios. Si bien ello no puede atribuirse a una única causa, estos resultados eran comparables a los rendimientos académicos de las asignaturas fundamentales en las que se sustenta (Matemáticas, Física y Química). Por todo ello, y en vías a la adaptación al EEES, se propuso una transformación progresiva del sistema de evaluación a efectos de mejorar el rendimiento académico en la asignatura.

\subsection{Metodología}

El cambio en el sistema de evaluación utilizado en la asignatura se empezó a ensayar en el curso 2008/2009, en la Licenciatura, y se implantó definitivamente en el curso 2010/2011, en el Grado. Sin embargo, desde la primera aproximación en el curso 2008/2009 hasta el curso actual, se ha venido detectando una serie de condicionantes que han exigido una revisión de la metodología y del sistema de evaluación en la asignatura, a efecto de corregir la evolución de los resultados académicos. Así, durante los últimos seis cursos, tanto la reorientación metodológica como el propio proceso evaluativo se ha convertido en una acción permanente a lo largo de este período.

Hasta el curso 2006/2007, inclusive, el sistema de evaluación utilizado en la signatura era la evaluación final, tal y como se muestra en la Tabla 1. Este sistema de evaluación contemplaba una convocatoria ordinaria y otra extraordinaria, en las que poder obtener el total de la nota. No obstante, en la convocatoria extraordinaria quedaban exentos, de la 
Adecuación progresiva y análisis permanente de la metodología docente hacia una evaluación continua

evaluación de alguna de las partes, aquellos alumnos que ya las hubiesen superado previamente en la convocatoria ordinaria.

Tabla 1. Características del sistema de evaluación final (curso 2006/2007)

\begin{tabular}{|c|c|c|c|c|}
\hline Actividad docente & Tipo de actividad de evaluación & $\begin{array}{l}\mathrm{N}^{0} \text { de } \\
\text { actos }\end{array}$ & Temporización & $\begin{array}{l}\text { Peso en } \\
\text { la nota }\end{array}$ \\
\hline $\begin{array}{l}\text { Teoría de aula } \\
\text { Práctica de aula }\end{array}$ & $\begin{array}{l}\text { Preguntas de desarrollo } \\
\text { Resolución de problemas }\end{array}$ & 1 & $\begin{array}{l}\text { Período de exámenes } \\
\text { Convocatoria ordinaria }\end{array}$ & $80 \%$ \\
\hline Práctica de laboratorio & Elaboración de informes & 2 & $\begin{array}{l}\text { Período de exámenes } \\
\text { Convocatoria ordinaria }\end{array}$ & $20 \%$ \\
\hline $\begin{array}{c}\text { Recuperación } \\
\text { de Teoría y Práctica. } \\
\text { (Exentos los alumnos con estas } \\
\text { partes superadas) }\end{array}$ & $\begin{array}{c}\text { Preguntas de desarrollo } \\
\text { Resolución de problemas } \\
\text { Prueba práctica de laboratorio }\end{array}$ & 1 & $\begin{array}{c}\text { Período de exámenes } \\
\text { Convocatoria } \\
\text { extraordinaria }\end{array}$ & $\begin{array}{c}\text { Hasta el } \\
100 \%\end{array}$ \\
\hline
\end{tabular}

Los cambios metodológicos se iniciaron en el curso 2007-2008 a través de la introducción de tareas y actividades, de carácter voluntario, que eran realizadas por los alumnos a lo largo del curso y corregidas por el profesor, permitiendo al alumno distribuir su tiempo de estudio de una forma más uniforme. Los primeros cambios en el sistema de evaluación se implementaron en el curso 2008-2009 con la incorporación de varias pruebas parciales que eliminaban materia de la prueba final. Sin embargo, debido a su carácter voluntario, únicamente el $28 \%$ de los alumnos optó por esta vía. La normativa de la UPV vigente garantizaba el derecho del alumno a la realización de una prueba final, por lo que en el curso 2009-2010 se planteó la evaluación a través de dos sistemas alternativos, continua y final. Así, este curso el 49\% de los alumnos optó por la propuesta de evaluación continua, teniendo acceso a una evaluación final en caso de no superar la asignatura por evaluación continua. En el curso 2010-2011 se impartió por primera vez la asignatura en el título de Grado, ya bajo el actual marco normativo de la UPV que contempla una única convocatoria y la consideración de diferentes actos de evaluación realizados a lo largo del curso. En consecuencia, este curso se consideró un único sistema de evaluación (continua) obligatorio para todos los alumnos. Hasta la actualidad, se ha venido reorientando las características de la evaluación continua utilizada. La Tabla 2 muestra el sistema utilizado en el curso 20132014. El sistema de evaluación continua incluye, durante el curso, la realización de diversas pruebas parciales de carácter teórico y otras de carácter aplicado basadas en la resolución de problemas. Además, se incorpora el análisis y resolución de casos de estudio, con carácter práctico, abordados mediante técnicas de trabajo en equipo. Durante los últimos cuatro cursos se han realizado cambios que afectan al número de actividades de evaluación, a la tipología, a la duración y a la temporización de estos.

(cc) EY-NC-ND 2014, UniversitatPolitècnica de València

I Jornadas IN-RED (2014) 
Tabla 2. Características del sistema de evaluación continua (curso 2013/2014)

\begin{tabular}{ccccc}
\hline Actividad docente & Tipo de actividad de evaluación & $\begin{array}{c}\mathbf{N}^{\mathbf{0}} \text { de } \\
\text { actos }\end{array}$ & Temporización & $\begin{array}{c}\text { Peso en } \\
\text { la nota }\end{array}$ \\
\hline Teoría de aula & Preguntas tipo test y cuestiones & 3 & Semanas 6, 11 y 15 & $30 \%$ \\
Práctica de aula & Resolución de problemas & 2 & Semanas 6 y 11 & $30 \%$ \\
Seminario & Casos prácticos & 4 & Semanas 4, 7, 10 y 13 & $20 \%$ \\
Práctica de laboratorio & Elaboración de informes & 2 & Semanas 10 y 14 & $20 \%$ \\
\hline $\begin{array}{c}\text { Recuperación } \\
\text { de Teoría y Práctica de aula. } \\
\text { (Exentos los alumnos con estas } \\
\text { partes superadas) }\end{array}$ & Preguntas tipo test y cuestiones & Resolución de problemas & Período de exámenes & Hasta el \\
\hline
\end{tabular}

\section{Resultados}

Tanto los resultados académicos como los derivados del proceso de la evaluación y revisión continuada del proceso han sido objeto de un análisis. A continuación, se discuten los principales resultados obtenidos.

\subsection{Análisis de la evolución de los resultados académicos.}

En la Figura 1 se presenta, por curso académico, los resultados del porcentaje de alumnos presentados sobre matriculados (tasa de presentados), de alumnos aprobados sobre presentados (tasa de éxito) y de alumnos aprobados sobre matriculados (tasa de rendimiento), así como los resultados promedios de los períodos de aplicación de la evaluación final (2005-2009) y continua (2010-2014). En este sentido, el curso 2009-2010 constituye un caso particular, ya que el 51\% del alumnado había optado por una evaluación final, mientras que el $49 \%$ restante lo hizo inicialmente por una evaluación continua, de los que una pequeña parte finalmente abandonó acogiéndose a la evaluación final. Durante la Licenciatura, en el período 2005-2009 la tasa de presentados si situaba en el 59\%, lo que combinado con una tasa de éxito del $69 \%$ daba lugar a un rendimiento promedio del $40 \%$. Si bien, las mejoras introducidas en el curso 2008-2009 no conllevaron una mejora de los resultados globales, en parte por ser seguidas por un bajo porcentaje de los alumnos. No obstante, sí que se apreció un incremento en la tasa de éxito de la convocatoria ordinaria que se situó en un $70 \%$, sensiblemente superior al $40 \%$, aproximadamente, obtenido en los cursos anteriores. En el curso 2009-2010, donde la mitad de los alumnos adoptó el sistema de evaluación continua la tasa de rendimiento mostró un incremento notable, del $40 \%$ al $61 \%$, respecto al período anterior. En el período 2010-2014, ya en el Grado, todos los indicadores se han incrementado. Así, el promedio de la tasa de presentados se sitúa en el

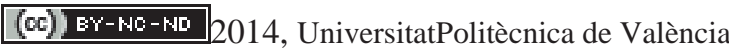

I Jornadas IN-RED (2014) 
Adecuación progresiva y análisis permanente de la metodología docente hacia una evaluación continua

$89 \%$, la de éxito en el $83 \%$ y la de rendimiento en el $73 \%$, constituyendo una significativa mejora respecto a la Licenciatura. Una de las principales mejoras radica en la reducción del número de alumnos no presentados a las actividades de evaluación. En parte, debido a que la evaluación continua supone un mayor control del esfuerzo del alumno y un incentivo para su presentación a los actos de evaluación. A ello cabe añadir la diferencia existente entre el número de alumnos de los últimos cursos de Licenciatura (94) en comparación con el número de alumnos existente los primeros cursos del Grado (50), que facilita al profesor la implantación de estas metodologías.
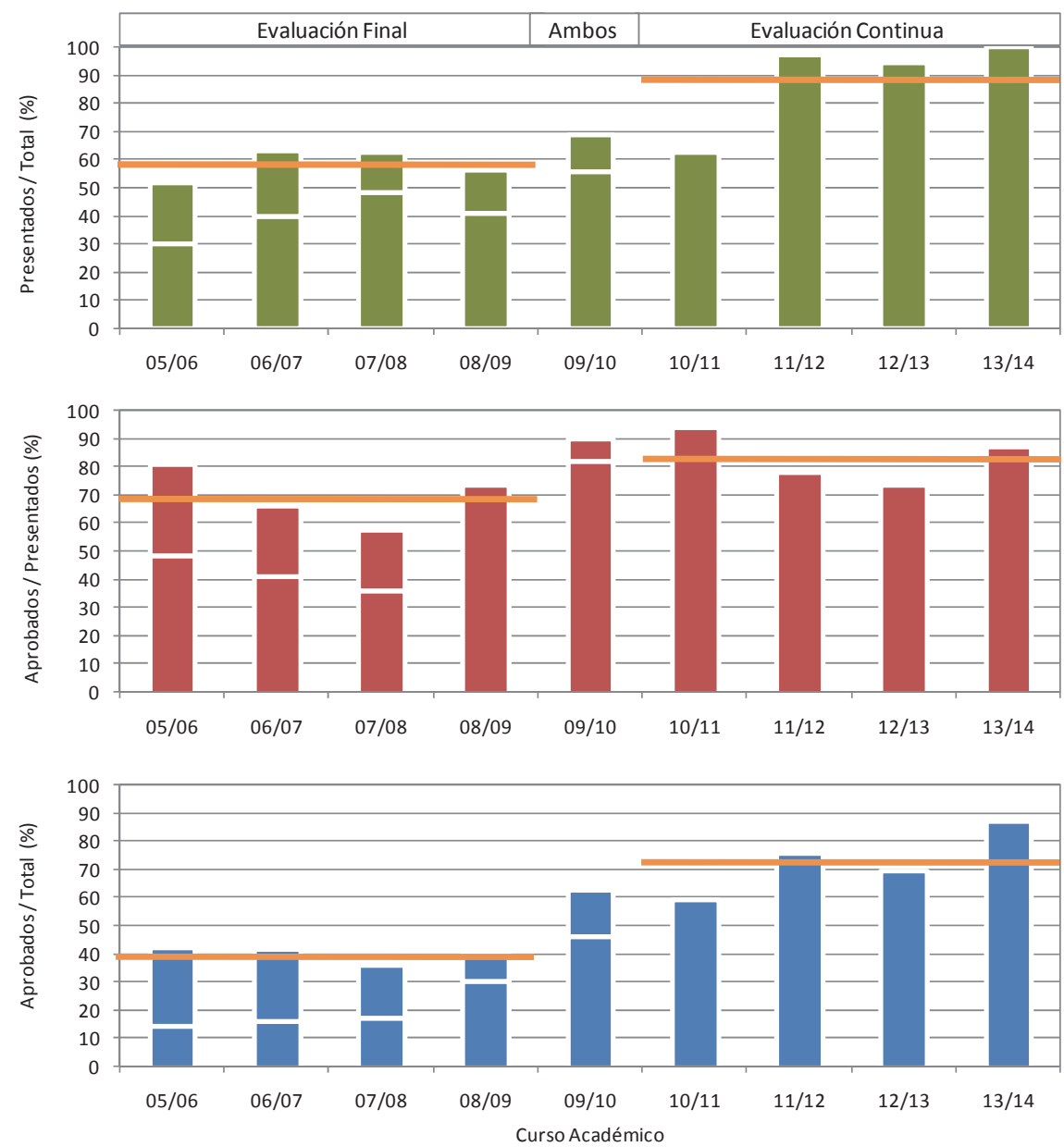

Fig. 1 Resultados académicos por curso académico. La línea naranja señala el valor promedio en los periodos de evaluación final y continua. La línea blanca señala el resultado parcial tras la convocatoria ordinaria. 
Por otra parte, la Figura 2 muestra el análisis de las calificaciones finales obtenidas por los alumnos en cada curso académico (clasificadas en no presentado, suspendido, aprobado, notable y sobresaliente). Puede observarse un descenso significativo en la categoría de alumnos no presentados con el uso del nuevo sistema de evaluación, así como un incremento de alumnos que superan la asignatura. Las calificaciones más altas, notables y sobresalientes, presentan también un ligero incremento, pasando de representar un valor en la Licenciatura del $8 \%$, respecto a los alumnos que han superado la asignatura, a constituir el $18 \%$ en el Grado.

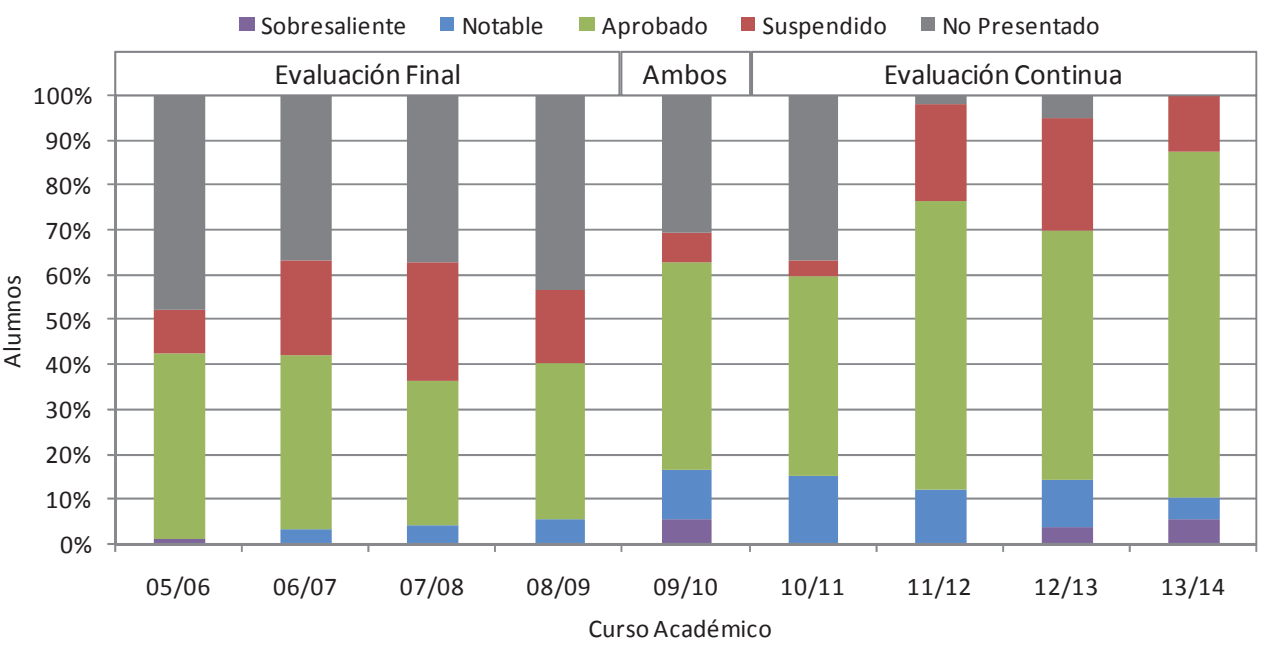

Fig. 2 Distribución relativa de las calificaciones por curso académico.

En relación a la nota obtenida por el conjunto de alumnos presentados, ésta ha incrementado su valor promedio desde un 4.5 en el período 2005-2009 (Licenciatura) hasta un 5.5 en el período 2010-2014 (Grado), tal y como se muestra en la Figura 3. Por su parte, para el conjunto de alumnos que han logrado superar la asignatura, la calificación promedio muestra un ligero incremento cuando se consideran estos períodos, en concreto desde el 5.5 hasta el 5.9. No obstante, al considerar cada uno de los cursos académicos, no es posible identificar una evidente incidencia de la evaluación continua en la calificación promedio del conjunto de alumnos que superan la asignatura, tal y como se ha observado en estudios similares realizados sobre asignaturas de otros ámbitos académicos (Sancho et al., 2013).

(cc) EY-NC-ND 2014, UniversitatPolitècnica de València

I Jornadas IN-RED (2014) 
Adecuación progresiva y análisis permanente de la metodología docente hacia una evaluación continua

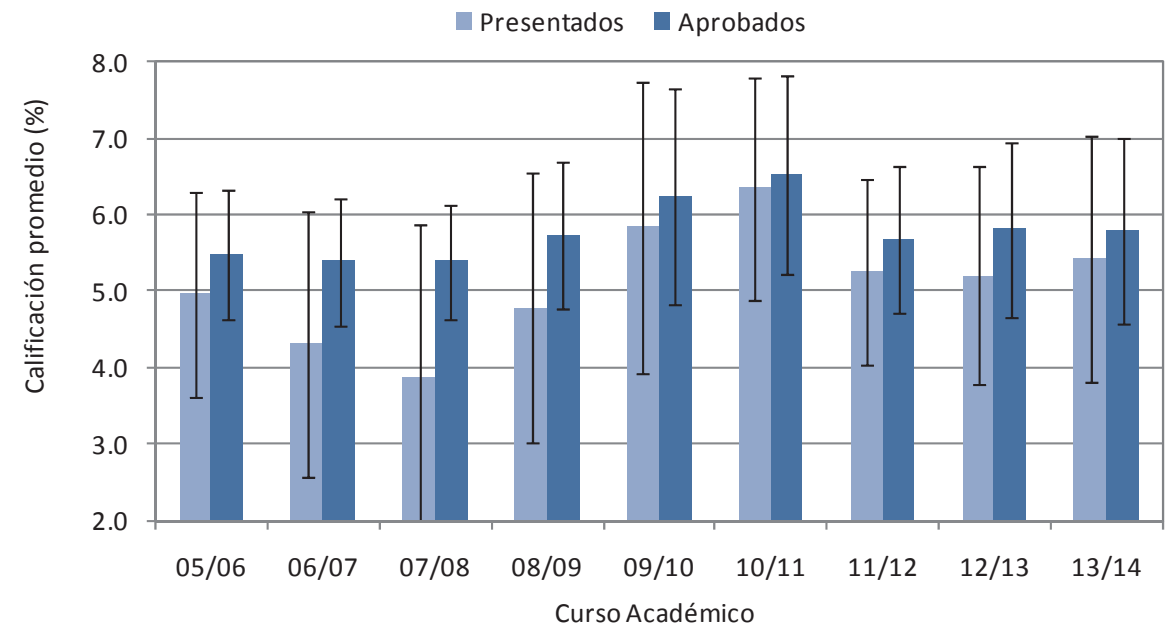

Fig. 3 Notas promedio de los alumnos presentados y aprobados por curso académico.

\subsection{Análisis del proceso de revisión permanente}

La implantación de este tipo de procesos puede requerir cierto tiempo. En ocasiones, la inexperiencia, el contexto o una escasa planificación pueden conllevar limitaciones en la aplicabilidad del proceso y la no consecución de los objetivos perseguidos. Además, como apunta Allen (2000), para enseñar bien no sólo hay que conocer el programa de estudios y las metodologías didácticas, sino también a los alumnos. Por ello, su desarrollo debe ajustarse curso a curso (López, 2006).

Así, por una parte, las actividades de evaluación deben estar adecuadamente planificadas (Delgado et al., 2005). Ello implica un diseño de las actividades acorde a los objetivos de la asignatura y competencias a desarrollar, así como una estimación del esfuerzo a realizar por el estudiante y el profesor en dicho proceso. Esta tarea puede no resultar fácil de pronosticar, especialmente, cuando no se dispone de suficiente experiencia previa o cuando se ignoran cambios en el contexto del proceso evaluativo o de aprendizaje. En este sentido, la tarea de revisión, análisis o evaluación del proceso resulta necesaria a efectos de corregir las desviaciones del sistema.

En la Tabla 3 se muestran los principales cambios realizados en esta asignatura desde sus primeras aproximaciones a la evaluación continua hasta el curso actual. Así, la incorporación de pruebas parciales en el curso 2008-2009 resultó en un mejor resultado académico de los alumnos que las realizaron. No obstante, el número de alumnos que optó por esta vía fue reducido pero mejoró sensiblemente la tasa de éxito en la convocatoria ordinaria, en relación a cursos anteriores. El curso siguiente, se incrementó el número de actos de evaluación y el grupo de alumnos que la siguió obtuvo un rendimiento académico 
del 91\%. Este hecho, motivó que el curso 2010-2011 se incrementase el seguimiento y control a través de la adición de nuevas actividades de evaluación. Sin embargo, el resultado fue contrario al esperado al obtenerse un significativo descenso en la tasa de presentados. Este hecho denota que un exceso de actos de evaluación provoca un efecto contraproducente. Además, junto a la mayor carga de trabajo en la propia asignatura, la implantación del Grado ha generalizado el sistema de evaluación continua provocando, en este caso un exceso de carga de trabajo para el estudiante y un mayor número o una concentración de pruebas parciales insuficientemente coordinadas. Por ello, los siguientes cursos se ha tratado de reducir el número de actividades de evaluación y pruebas parciales y adecuarlas al contexto. Estos cambios han permitido una mejora en el rendimiento académico de estos últimos cursos. Por último, en el curso 2013-2014 se ha iniciado un proceso de rediseño de las actividades de evaluación con el objetivo de lograr un aprendizaje más significativo. No obstante, como se ha discutido anteriormente, se debería continuar profundizando en este sentido.

Tabla 3. Evolución de las modificaciones del sistema de evaluación

\begin{tabular}{|c|c|c|c|}
\hline Curso & $\begin{array}{l}\mathrm{N}^{\mathbf{o}} \text { de } \\
\text { actos }\end{array}$ & Modificación en el sistema de evaluación & Motivación \\
\hline $07 / 08$ & 3 & $\begin{array}{l}\text { Prueba final teórico-práctica (1) y de laboratorio } \\
\text { (2) }\end{array}$ & Evaluación final \\
\hline 08/09 & 7 & $\begin{array}{l}\text { Incorporación pruebas parciales teórica }(+1) \text { y } \\
\text { prácticas }(+3)\end{array}$ & $\begin{array}{l}\text { Primera aproximación a la evaluación } \\
\text { continua }\end{array}$ \\
\hline $09 / 10$ & 13 & $\begin{array}{l}\text { Incorporación pruebas parciales teórica }(+2) \text { y } \\
\text { casos de estudio para trabajo autónomo }(+5) \\
\text { Eliminación de la prueba final a alumnos } \\
\text { aprobados }(-1)\end{array}$ & $\begin{array}{l}\text { Evaluación continua alternativa a la } \\
\text { evaluación final }\end{array}$ \\
\hline $10 / 11$ & 18 & $\begin{array}{l}\text { Incorporación pruebas parciales teórica }(+1) \text { y } \\
\text { práctica }(+1) \text {, y casos de estudio no presenciales } \\
\text { voluntarios }(+3)\end{array}$ & $\begin{array}{l}\text { Implantación del Grado } \\
\text { Evaluación continua obligatoria }\end{array}$ \\
\hline $11 / 12$ & 14 & Eliminación de casos de estudio (-4) & $\begin{array}{l}\text { Exceso en la carga de trabajo no } \\
\text { presencial del alumno }\end{array}$ \\
\hline $12 / 13$ & 12 & $\begin{array}{l}\text { Reducción de pruebas parciales teórica (-1) y } \\
\text { práctica (-1). } \\
\text { Rediseño de las pruebas parciales con nuevas } \\
\text { tipologías de actividades de evaluación y } \\
\text { adecuación de la temporización. }\end{array}$ & $\begin{array}{l}\text { Exceso del número de pruebas de } \\
\text { evaluación en la titulación }\end{array}$ \\
\hline $13 / 14$ & 11 & $\begin{array}{l}\text { Reducción de prueba parcial práctica (-1) } \\
\text { Rediseño de los casos de estudio para su } \\
\text { realización en aula }\end{array}$ & $\begin{array}{l}\text { Refuerzo de las acciones de tutorización } \\
\text { y seguimiento }\end{array}$ \\
\hline
\end{tabular}

Por último, atendiendo a los resultados de la encuesta realizada a los estudiantes durante los últimos cursos, la percepción que el estudiante muestra en relación a la influencia que el uso de esta metodología docente presenta sobre su aprendizaje es ligeramente favorable según se observa en la Figura 4. Sin embargo, la alta desviación estándar muestra una distinta percepción en determinados grupos de estudiantes. Así, mientras algunos alumnos

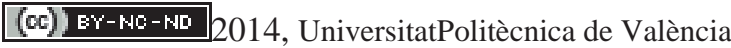

I Jornadas IN-RED (2014) 
Adecuación progresiva y análisis permanente de la metodología docente hacia una evaluación continua

valoran positivamente la metodología y atribuyen a ésta una oportunidad para la superación de la asignatura, otros alumnos se muestran indiferentes o la valoran negativamente al considerar que les genera un exceso de carga de trabajo, especialmente, cuando se cursan simultáneamente distintas asignaturas con un similar sistema metodológico y de evaluación.

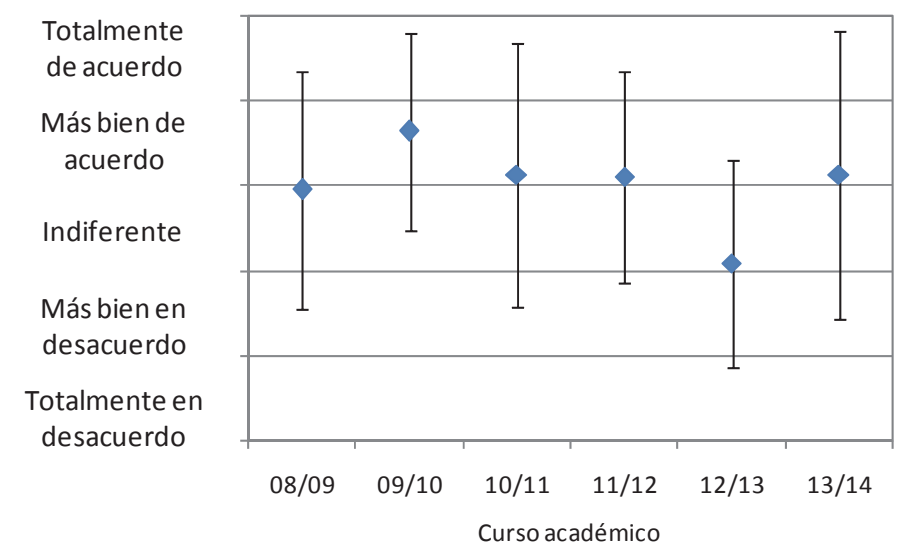

Fig. 4 Valoración del alumnado a la cuestión “ ¿La metodología docente empleada ayuda en el aprendizaje?”

\section{Conclusiones}

La experiencia continuada de la aplicación de la evaluación continua, en la asignatura Fundamentos de Ingeniería Ambiental, ha permitido constatar una serie de ventajas e inconvenientes de la metodología. En este sentido, como aspecto más favorable, se ha observado que se incrementa notablemente el rendimiento académico del alumnado. Fundamentalmente, porque permite una mayor distribución temporal del esfuerzo del estudiante, permite el ajuste de los procesos de aprendizaje gracias a una mayor interacción profesor-alumno y aumenta la implicación y autonomía del alumno hacia el aprendizaje.

No obstante, también se ha observado una serie de puntos débiles. En este sentido, la inexperiencia genera dificultades las primeras veces que es aplicado, requiriéndose un ajuste curso a curso. La implantación precisa una planificación muy meditada del proceso que no debe despreciar algunos aspectos externos a la propia asignatura, como la coordinación e interferencias entre las asignaturas de un mismo curso. Además, la carga de trabajo excesiva, tanto para el estudiante como para el profesor, puede provocar un efecto de rechazo o abandono. Por último, la selección y diseño de las actividades evaluativas deberían orientarse hacia la obtención de un aprendizaje significativo, sin que ello resulte en una programación inflexible que dificulte su adaptación al nuevo contexto. 
Todo esto conlleva que la planificación de las actividades de evaluación deba ser revisada y, generalmente, adaptada al contexto cada nuevo curso, por lo que tanto la revisión como el análisis permanente del sistema metodológico debería constituirse como parte dinámica del proceso.

\section{Referencias}

ALLEN, D. (2000). "La evaluación del aprendizaje de los estudiantes: una herramienta para el desarrollo profesional de los docentes”. Madrid: Síntesis.

BROWN, S., y GLASNER, A. (2003). "Evaluar en la Universidad. Problemas y nuevos enfoques". Madrid: Narcea.

DELGADO, A.M. et al. (2005): "Competencias y diseño de la evaluación continua y final en el Espacio Europeo de Educación Superior". Dirección General de Universidades. MEC.

DELGADO, A. M. y OLIVER, R. (2006). "La evaluación continua en un nuevo escenario docente". Revista de Universidad y Sociedad del Conocimiento (RUSC). Vol. 3, n. ${ }^{\circ} 1$. UOC. <http://www.uoc.edu/rusc/3/1/dt/esp/delgado_oliver.pdf>[Fecha de consulta: 04/06/14].

LOPEZ, V. M. (2006). "El papel de la evaluación formativa en el proceso de convergencia hacia el E.E.E.S. Análisis del estado de la cuestión y presentación de un sistema de intervención". Revista Interuniversitaria de Formación del Profesorado, 20(3), 93-119.

SANCHO, F.J. et al. (2013). “Análisis comparativo de la evaluación docente de "Investigación Comercial" entre Grado y Licenciatura: Impacto del nuevo EEES". En: XI Jornadas de Redes de Investigación en Docencia Universitaria. Alicante: Universidad de Alicante. 1858-1872. 


\section{Índice de autores}

$\begin{array}{llll}\text { Alarcón, F. } & 753 & \text { Cuartas Uribe, B. } & 1114 \\ \text { Albors Garrigós, J. } & 624 & \text { De la Poza, E. } & 856 \\ \text { Andreu Andrés, M.A. } & 1130 & \text { del Rey Tormos, R. } & 704 \\ \text { Aragón Revuelta, P. } & 771 & \text { Escrivà, D. } & 412 \\ \text { Ardid Ramírez, M. } & 786 & \text { Estelles Miguel, S. } & 630 \\ \text { Asensi, E. } & 538 & \text { Fernández Diego, M. } & 1154 \\ \text { Asensio Cuesta, S. } & 1276 & \text { Fernández Plazaola, I. } & 665 \\ \text { Asunción, J. } & 80 & \text { Ferrando Bataller, M. } & 14 \\ \text { Bañón Gomis, A.J. } & 1191 & \text { Ferrando, V. } & 986 \\ \text { Bañón Gomis, A.J. } & 1228 & \text { García Carbonell, A. } & 1260 \\ \text { Bautista, I. } & 802 & \text { García García, A. } & 514 \\ \text { Baydal, E. } & 905 & \text { García Martínez, E. } & 423 \\ \text { Belda, R.M. } & 1028 & \text { García Puchades, W. } & 652 \\ \text { Benlloch Dualde, J.V. } & 499 & \text { Gasch, I. } & 866 \\ \text { Blanes, S. } & 974 & \text { Gasch, I. } & 1334 \\ \text { Boigues, F.J. } & 741 & \text { Giménez, E. } & 1166 \\ \text { Cabrera García, S. } & 1362 & \text { Giménez, F. } & 601 \\ \text { Calduch, A. } & 553 & \text { Giménez, F. } & 954 \\ \text { Candelas Valiente, P. } & 377 & \text { Gimeno Sanz, A. } & 26 \\ \text { Canós Darós, L. } & 1121 & \text { Gómez Sacristán, A. } & 195 \\ \text { Casanova Colón, J. } & 209 & \text { Gómez Tejedor, J.A. } & 299 \\ \text { Castelló, M.L. } & 251 & \text { Gómez, C. } & 88 \\ \text { Cervelló Royo, R. } & 1037 & \text { González, J.A. } & 1392 \\ \text { Cháfer, M. } & 1301 & \text { Gracia Morán, J. } & 1242 \\ \text { Conchado, A. } & 458 & \text { Guirao, A.J. } & 288 \\ \text { Corbatón Báguena, M.J. } & 1065 & \text { Hernández Franco, C. } & 398\end{array}$




$\begin{array}{llll}\text { Hernández Franco, C. } & 846 & \text { Page, A. } & 1089 \\ \text { Iborra Clar, M.I. } & 835 & \text { Part Escriva, M.C. } & 762 \\ \text { Izquierdo, J. } & 474 & \text { Payá Zaforteza, I. } & 714 \\ \text { Jordán Lluch, C. } & 310 & \text { Payá Zaforteza, I. } & 721 \\ \text { Llinares Millán, J. } & 943 & \text { Payá, J. } & 878 \\ \text { Llorens Molina, J. A. } & 116 & \text { Payria, B. } & 181 \\ \text { Llorente, R. } & 565 & \text { Peña Cerdán, A. } & 1138 \\ \text { López Mateu, V. } & 964 & \text { Pons Martí, A. } & 1005 \\ \text { Marín García, J.A. } & 1074 & \text { Porres de la Haza, M.J. } & 897 \\ \text { Marín García, J.A. } & 1290 & \text { Poza Luján, J.L. } & 1250 \\ \text { Martí Campoy, A. } & 815 & \text { Prósper Ribes, J. } & 140 \\ \text { Martín de Madrid, P.S. } & 728 & \text { Quiles, A. } & 1220 \\ \text { Martín Fuentes, D. } & 1348 & \text { Quintanilla, I. } & 610 \\ \text { Martínez Gómez, V. } & 343 & \text { Ramón Fernández, F. } & 130 \\ \text { Martínez Navarrete, N. } & 1103 & \text { Rodríguez, A. } & 1012 \\ \text { Martínez Román, J. } & 365 & \text { Ruiz García, J.C. } & 353 \\ \text { Mengual Cuquerella, J. } & 529 & \text { Sahuquillo, O. } & 487 \\ \text { Miguel Arnal, J. } & 1206 & \text { Sanabria Codesal, E. } & 1050 \\ \text { Moll, S.E. } & 680 & \text { Sánchez Carratalá, C.R. } & 1308 \\ \text { Moltó, G. } & 54 & \text { Santafé Moros, A. } & 324 \\ \text { Moltó, G. } & 151 & \text { Segarra García, M. } & 913 \\ \text { Moltó, G. } & 166 & \text { Sendra, S. } & 576 \\ \text { Monfort i Signes, J. } & 102 & \text { Soriano, J. } & 432 \\ \text { Montañés, M.T. } & 640 & \text { Tormo Carbó, G. } & 1374 \\ \text { Moraño Fernández, J.A. } & 887 & \text { Val Fiel, M. } & 279 \\ \text { Moreno Navarro, M.S. } & 929 & \text { Valor Miró, J.D. } & 272 \\ \text { Moreno Navarro, M.S. } & 993 & \text { Vargas Colás, M.D. } & 388 \\ \text { Moreno Navarro, M.S. } & 1323 & \text { Vázquez, E. } & 443 \\ \text { Morera, I. } & 239 & \text { Vidal Meló, A. } & 689 \\ \text { Muñoz Portero, M.J. } & 1176 & \text { Vidaurre, A. } & 224 \\ \text { Navarro Jover, J.M. } & 69 & & 39 \\ \text { Noguera, P. } & 260 & & 591\end{array}$

